JOINT INTERNATIONAL CONGRESS
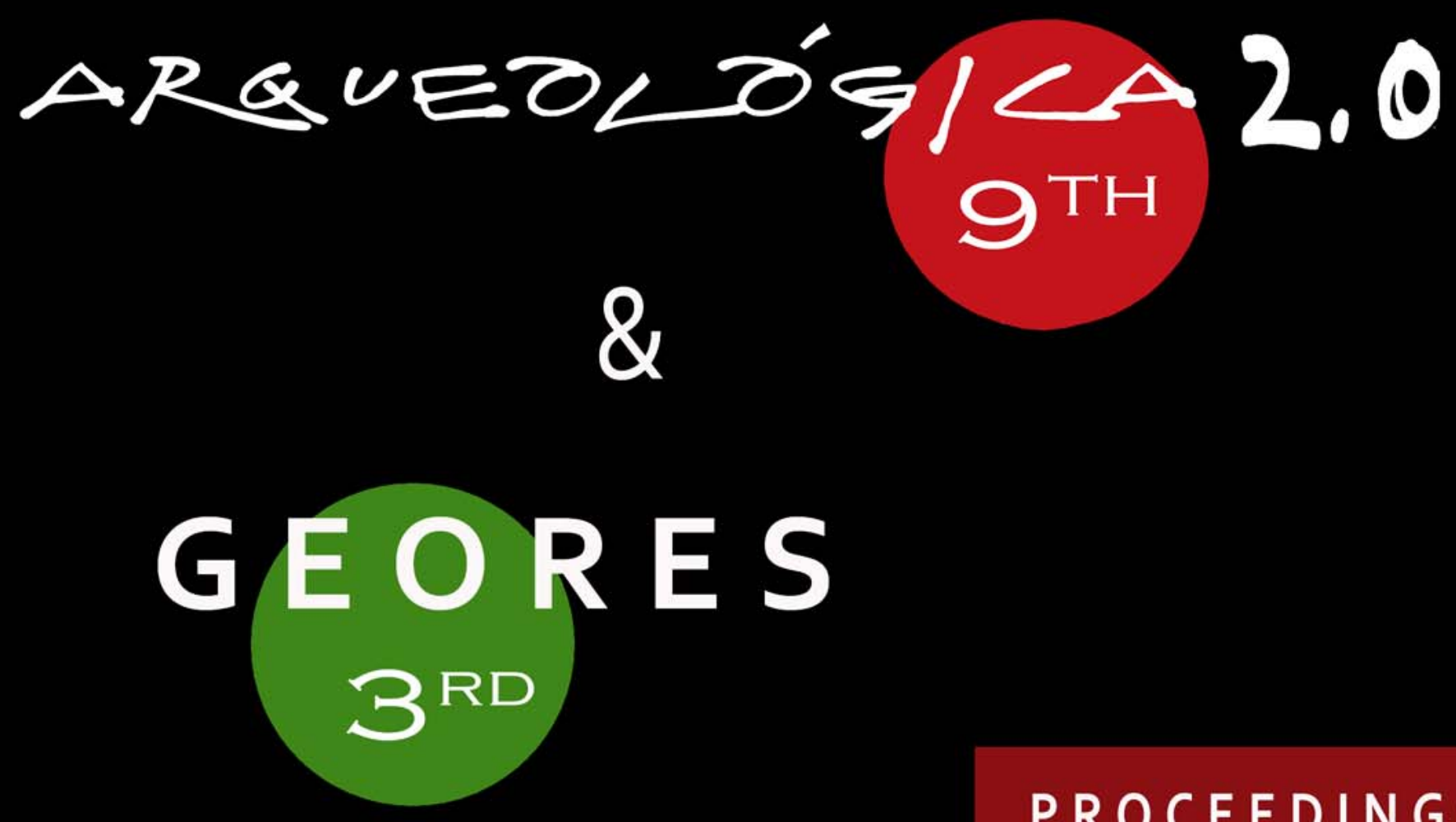

PROCEEDINGS

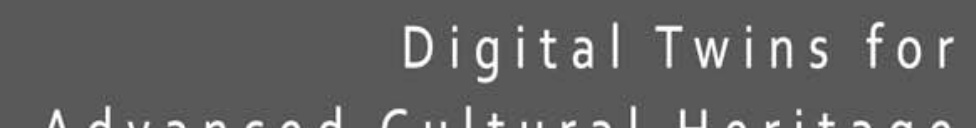
Advanced Cultural Heritage Semantic Digitization

Online - Valencia 26-28 April 2021 


\section{Congress UPV}

Proceedings of the ARQUEOLÓGICA 2.0 - 9th International Congress \& 3rd GEORES - GEOmatics and pREServation Lemma: Digital Twins for Advanced Cultural Heritage Semantic Digitization.

ARQUEOLÓGICA 2.0 - 9th International Congress on Archaeology, Computer Graphics, Cultural Heritage and Innovation.

GEORES - 3rd GEOmatics and pREServation.

The contents of this publication have been evaluated by the Scientific Committee which it relates and the procedure set out http://ocs.editorial.upv.es/index.php/arqueologica20/arqueologica9/about/organizingTeam

\section{Scientific Editors}

\section{J. L. Lerma}

M. Cabrelles

(c) of the texts: authors

(c) 2021, Editorial Universitat Politècnica de València www.lalibreria.upv.es / Ref.: 6589_01_01_01

ISBN: 978-84-9048-872-0 (print version)

Print on-demand

DOI: https: //doi.org/10.4995/arqueologica9.2021.13259

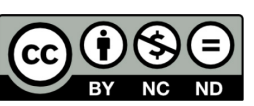

Proceedings of the ARQUEOLÓGICA 2.0 - 9th International Congress \& 3rd GEORES - GEOmatics and pREServation This book is licensed under a Creative Commons Atribution-NonCommercial-NonDetivates-4.0 International license Editorial Universitat Politècnica de València http://ocs.editorial.upv.es/index.php/arqueologica20/arqueologica9 


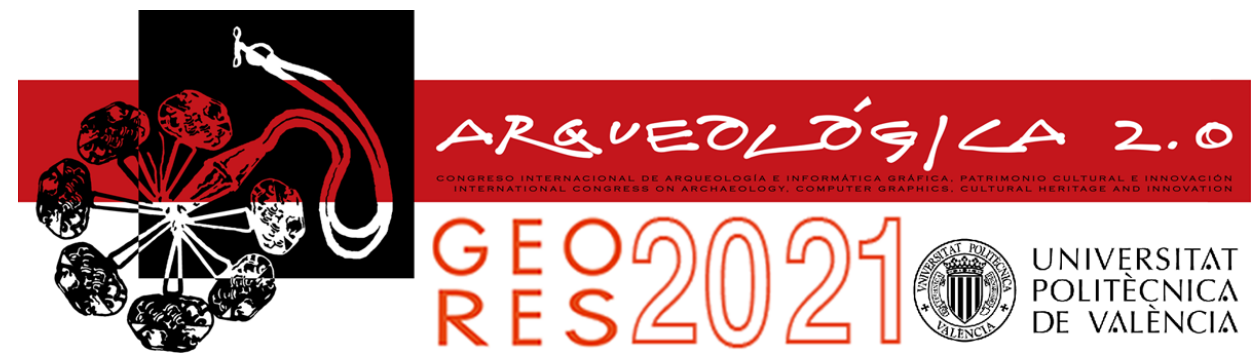

Proceedings of the joint international event $9^{\text {th }}$ ARQUEOLÓGICA $2.0 \& 3^{r d}$ GEORES Valencia (Spain) 26-28 April 2021

\section{Conference Committee}

\section{Congress Co-Chairs:}

$\checkmark$ José Luis Lerma (UPV)

$\checkmark$ Grazia Tucci (UNIFI)

$\checkmark$ Raffaella Brumana (POLIMI)

$\checkmark \quad$ Víctor M. López-Menchero (Global Digital Heritage)

\section{Organising Committee:}

$\checkmark \quad$ Ana Belén Anquela (Dir. ETSIGCT/UPV)

$$
\begin{array}{ll}
\checkmark & \text { Lourdes García (SEAV) } \\
\checkmark & \text { José Luis Lerma (UPV) } \\
\checkmark & \text { Ángel Marqués (DICGF/UPV) } \\
\checkmark & \text { Jordi Padín (Dir. DICGF/UPV) } \\
\checkmark & \text { Erica Parisi (UNIFI) }
\end{array}
$$

$\checkmark$ Matilde Balaguer (DICGF/UPV)

\begin{tabular}{|c|c|c|c|c|c|}
\hline$\checkmark$ & Athos Agapiou & Cyprus & $\checkmark$ & Minna Lonnqvist & Finland \\
\hline$\checkmark$ & Ana Almagro & Spain & $\checkmark$ & Eva Malinverni & Italy \\
\hline$\checkmark$ & Julia Armesto & Spain & $\checkmark$ & Andrea Masiero & Italy \\
\hline$\checkmark$ & Juan Antonio Barceló & Spain & $\checkmark$ & Camilla Mileto & Spain \\
\hline & Gabriele Bitelli & Italy & $\checkmark$ & Gaspar Mora-Navarro & Spain \\
\hline & Valentina Bonora & Italy & $\checkmark$ & Maurice Murphy & Ireland \\
\hline$\checkmark$ & Rosario Cebrián & Spain & $\checkmark$ & Ma Amparo Núñez & Spain \\
\hline & Filiberto Chiabrando & Italy & $\checkmark$ & Roberto Pierdicca & Italy \\
\hline & Arivaldo Leao de Amorim & Brazil & $\checkmark$ & Mattia Previtali & Italy \\
\hline & Donatella Dominici & Italy & $\checkmark$ & Fulvio Rinaudo & Italy \\
\hline & Salim A. Elwazani & USA & $\checkmark$ & José Ignacio Rojas-Sola & Spain \\
\hline & Steven Fai & Canada & $\checkmark$ & Riccardo Roncella & Italy \\
\hline & Francesco Fassi & Italy & $\checkmark$ & Mario Santana & Canadó \\
\hline$\checkmark$ & Oreto García & Spain & $\checkmark$ & Jin Shang & China \\
\hline$\checkmark$ & Andreas Georgopoulos & Greece & $\checkmark$ & Nannina Spanò & Italy \\
\hline & Pierre Grussenmeyer & France & $\checkmark$ & Grazia Tucci & Italy \\
\hline$\checkmark$ & Luis Hernández & Spain & $\checkmark$ & Fernando Vegas & Spain \\
\hline$\checkmark$ & David Hernández-López & Spain & $\checkmark$ & Geert Verhoeven & Austria \\
\hline 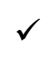 & José Luis Jiménez & Spain & $\checkmark$ & Ona Vileikis & UK \\
\hline & José Luis Lerma & Spain & $\checkmark$ & Alex Yen & China \\
\hline
\end{tabular}

$\checkmark$ Fabrizio Banfi (POLIMI)

$\checkmark$ Inés Barbero (GIFLE/UPV)

$\checkmark$ Miriam Cabrelles (GIFLE/UPV)

\section{Scientific committee:}




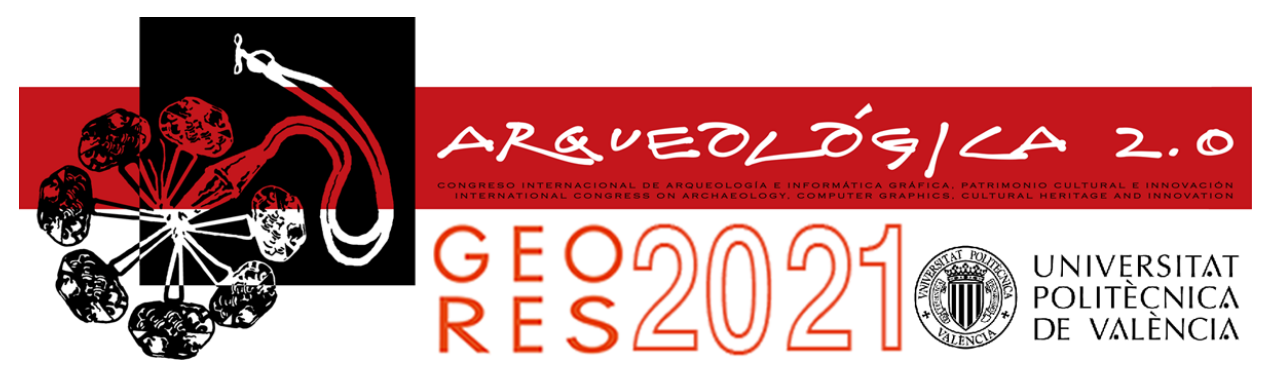

Proceedings of the joint international event $9^{\text {th }}$ ARQUEOLÓGICA $2.0 \& 3^{\text {rd }}$ GEORES Valencia (Spain) 26-28 April 2021

\section{Supporters:}

$\checkmark$ Universitat Politècnica de València

\section{Collaborators:}

$\checkmark$ CIPA Heritage Documentation

$\checkmark$ Spanish Society of Virtual Archaeology (SEAV)

$\checkmark$ Virtual Archaeology International Network (INNOVA)

$\checkmark$ Virtual Archaeology Review (VAR)

$\checkmark$ School of Engineering in Geodesy, Cartography and Surveying

$\checkmark$ Dept. of Cartographic Engineering, Geodesy and Photogrammetry

$\checkmark$ Photogrammetry \& Laser Scanning Research Group (GIFLE) 


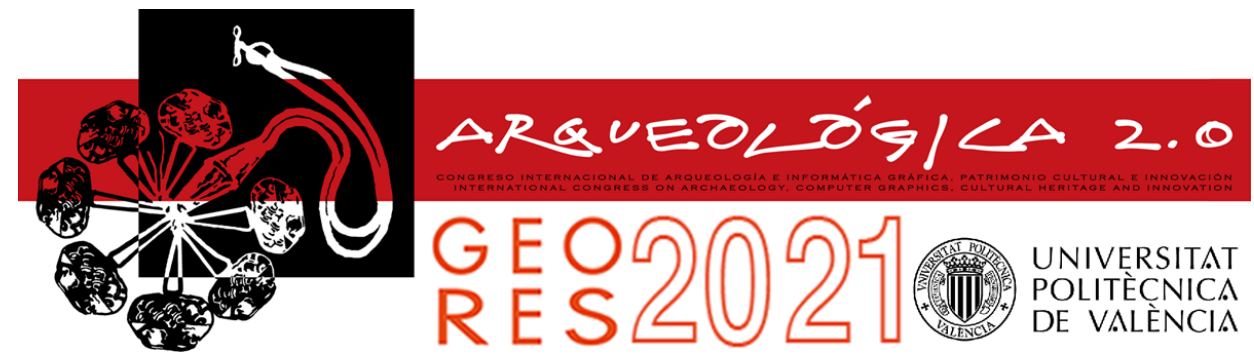

Proceedings of the joint international event $9^{\text {th }}$ ARQUEOLÓGICA $2.0 \& 3^{\text {rd }}$ GEORES Valencia (Spain) 26-28 April 2021

\section{Preface}

More than 10 years have passed since the first edition of ARQUEOLÓGICA 2.0 (International Congress on Archaeology, Computer Graphics, Cultural Heritage and Innovation) was held, in 2009. At that time, its promoter, Dr. Alfredo Grande, dreamed of creating a meeting place for all researchers and professionals who were experimenting with the application of new technologies in the field of archaeology. They were years of change and resistance, since part of the academic community considered these new lines of research as something secondary and residual, without connection to true scientific knowledge. People who worked in the field of virtual archaeology did so as isolated units, scattered across different regions and countries and with very little connection to each other. Although in the first decade of the $21^{\text {st }}$ century the number of researchers working in this field had grown exponentially, there was a lack of spaces that would make it possible to make visible what was being done. Thus ARQUEOLÓGICA 2.0 was born, to fill those spaces for the Spanish case but with an international vocation. An open and inclusive congress where it was possible to know what other researchers from different countries were doing but also to forge new contacts and relationships to foster not only the virtual archaeology field but also the widening field of cultural heritage with collateral resources. A congress that favoured the emergence of new collaborations and projects. A congress to know that we were not working alone, encouraging new researchers to join the field of virtual archaeology.

In these years, this congress has evolved at the same time as the scientific discipline that today we call virtual archaeology. During this time, ARQUEOLÓGICA 2.0 has established itself as a meeting forum for professionals from different branches of knowledge. The congress has served to build in Spain and the rest of the world, a link between the latest technological developments and archaeological science. It has promoted the creation of the International Principles of Virtual Archeology (Seville Principles) that were ratified by ICOMOS in 2017. It has served as the basis for creating a scientific journal, Virtual Archaeology Review (VAR), which in 10 years has been positioned as one of the most important archaeology journals in the world, and which has allowed, and continues to allow, researchers from around the world to share their progress with the international scientific community in an open and free format.

ARQUEOLÓGICA 2.0 has also demonstrated its commitment internationally and in some editions, Marseille 2013 and Granada 2015, it has joined other similar congresses. This year, ARQUEOLÓGICA 2.0 once again demonstrates its ability to join forces, in this case with the close friendship of the GEORES (GEOmatics and pREServation) community. The previous two editions of GEORES in Italy capture the innovative spirit of the cultural heritage community. In the present edition of the virtual joint international event, the $9^{\text {th }}$ ARQUEOLÓGICA 2.0 \& $3^{\text {rd }}$ GEORES 2021, deal with topics related to data acquisition, virtual archaeology, virtual architecture, conservation, cultural heritage, high-end digitization, advanced geomatics, preservation and restoration, through the event lemma, Digital Twins for Advanced Cultural Heritage Semantic Digitization. The power of technology, combined with deep understanding of heritage will definitely contribute to increase the scientific level of state-of-the-art technologies applied to safeguarding our heritage, trying to be useful to our society. 


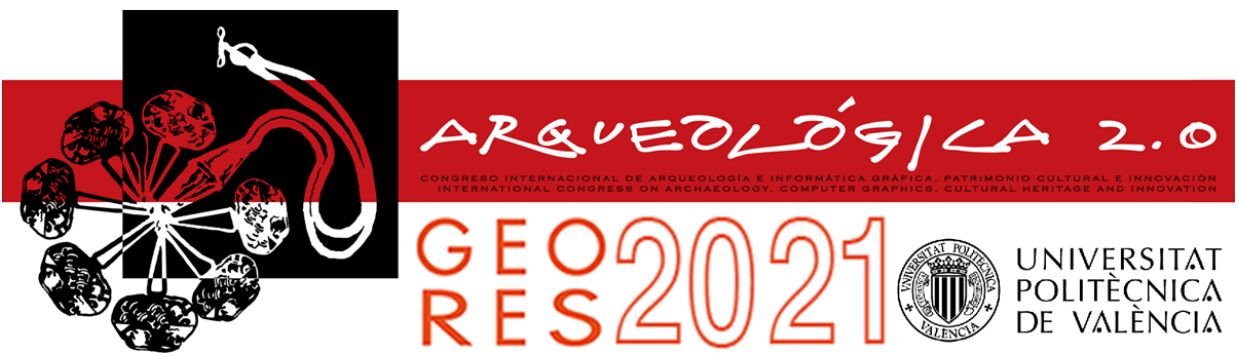

Proceedings of the joint international event $9^{\text {th }}$ ARQUEOLÓGICA $2.0 \& 3^{\text {rd }}$ GEORES Valencia (Spain) 26-28 April 2021

The proceedings report about 87 contributions that have been peer-reviewed by an international scientific committee fully compromised with the advancement of technology. We would like to express our gratitude to the PhD Forum co-chairs, Nannina Spanò (POLITO), Giulia Sammartano (POLITO), Valentina Bonora (UNIFI), Mattia Previtali (POLIMI) \& Roberto Pierdicca (UNIVPM), for their active compromise and excellent undertakings in this congress.

We want to express our gratitude to both the Organising Committee and the Scientific Committee for their compromise in the success of this virtual event during the COVID-19 pandemic era. Hopefully, the next editions will be in a face-to-face format. Last but not least, our gratitude to all the researchers and participants for their positive input that have allowed us to gather this excellent manuscript.

Prof. José Luis Lerma (UPV), Prof. Grazia Tucci (UNIFI), Prof. Raffaella Brumana (POLIMI) \& Dr. Víctor M. López-Menchero (Global Digital Heritage) Congress Co-Chairs 


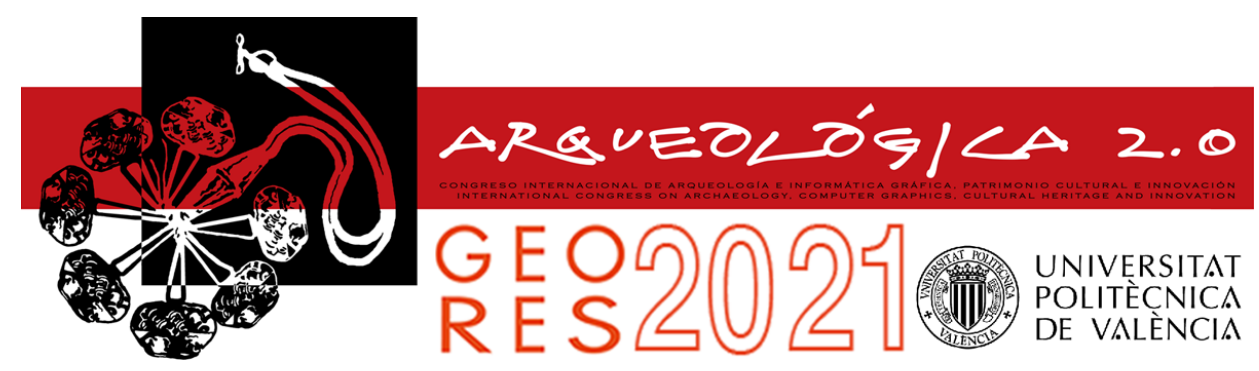

Proceedings of the joint international event $9^{\text {th }}$ ARQUEOLÓGICA $2.0 \& 3^{\text {rd }}$ GEORES, Valencia (Spain). 26-28 April 2021

\section{Contents}

\section{Long scientific papers}

THE DIGITAL TRANSFORMATION OF THE MUSEO EGIZIO

D. Mezzino, F. V. L. Lori

YEDI KULE - MONUMENT ROAD RACE: THE CONSTRUCTION OF THE 3D MAPPING ANIMATION OF THE

OLD CITY OF THESSALONIKI, GREECE.

E. S. Georgiou, N. Lambrinos

THE ETRUSCAN CITY GATES OF PERUGIA: GEOMATIC TECHNIQUES FOR THE DOCUMENTATION AND

STUDY OF AN URBAN HISTORY HERITAGE 15

F. Radicioni, P. Matracchi, A. Stoppini, G. Tosi, L. Marconi

HBIM FOR RESTORATION WORK AND MONITORING OF COMPLEX ARCHITECTURES: THE FAMILY

CHAPEL OF RAMÓN PERES Y ROVIRA IN CASTELLÓN DE LA PLANA (SPAIN).

G. Bertacchi, F. Juan-Vidal, L. Cipriani

AN INTERACTIVE 3D APPLICATION OF A HOUSE FROM THE XVI CENTURY IN SAN CRISTÓBAL DE

LAGUNA AS A CASE STUDY FOR THE DISSEMINATION OF CULTURAL HERITAGE

I. Sánchez-Berriel, A. González-González, F. Pérez-Nava, C. Meier, J. Pérez-

Morera, C. R. Hernández-Alberto

DIGITAL CULTURE, UMWELT AND ALETHEIA AN ONTOLOGICAL INTRODUCTION

A. Pasqui

AN INTEGRATED APPROACH AIMED AT THE PROTECTION OF CULTURAL HERITAGE: FROM THE GEOMATIC SURVEY TO HBIM AND AR REPRESENTATION OF VILLA PISANI (STRA, ITALY) .....

M. Monego, S. Maioli, M. Salvalaggio

BIM DESIGN LEAD FOR RESTORATION OF SHIPWRECK MUSEUM IN KYRENIA CASTLE IN CYPRUS 63

C. Biagini, F. Capparelli, G. Verdiani

CRITERIA AND TOOLS TO CATALOGUE BRICK-MASONRY VAULTS. THE GIS-DATABASE OF FRAME, A

FASCE AND PLANTERIAN VAULTS BETWEEN THE 16TH AND 18TH CENTURY IN NORTHERN ITALY.

C. Stanga

VOCABULARY ALIGNMENT FOR SHARING ARCHITECTURAL CONSERVATION DATA 79

M. Acierno, D. Fiorani, A. Velios

VIRTUAL TERRESTRIAL LASER SCANNER SIMULATOR IN DIGITAL TWIN ENVIRONMENT

D. Popovas, M. Chizhova, D. Gorkovchuk, J. Gorkovchuk, M. Hess, T. Luhmann

CONSIDERATIONS AND QUESTIONS DERIVED FROM THE APPLICATION OF A SCAN-TO-BIM MODELING

PROCESS OF A HISTORICAL PUBLIC BUILDING

F. Guzzetti, K. L. N. Anyabolu, F. Biolo, L. D’Ambrosio

THREE-DIMENSIONAL SURVEY AND MATERIAL CHARACTERIZATION OF THE TEMPIO-MASSERIA DEL

GIGANTE IN CUMAE

R. Amore, F. Carandente 


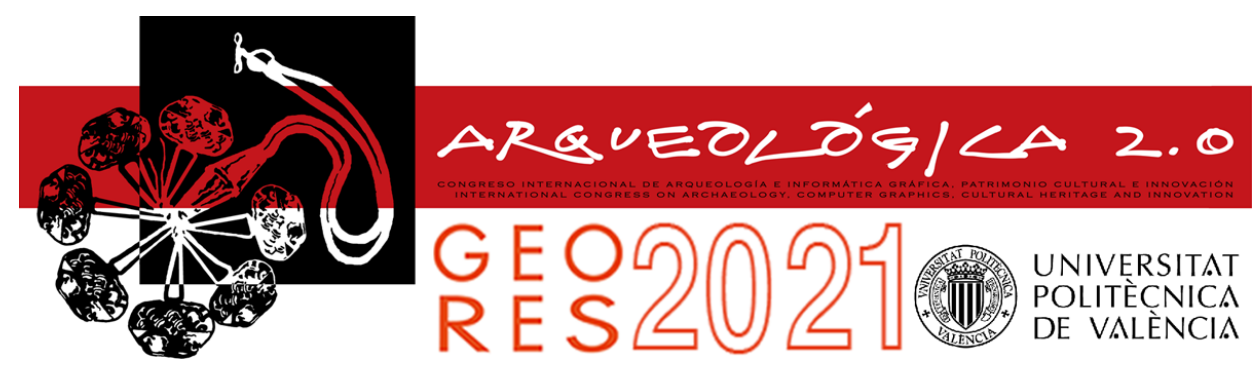

Proceedings of the joint international event $9^{\text {th }}$ ARQUEOLÓGICA $2.0 \& 3^{\text {rd }}$ GEORES, Valencia (Spain) 26-28 April 2021

AN INTEGRATION OF NON-DESTRUCTIVE TECHNIQUES (SFM-GPR-TLS) AS A VIRTUAL TOOL FOR ARCHAEOLOGICAL STRATEGY: THE CASE OF THE ROMAN SITE OF THE PLAZA DE LA MORERÍA IN SAGUNTO (SPAIN).

F. Buchón-Moragues, J. Benedito, F. García, J. M. Melchor

COMPARISON OF THE PHOTOGRAPHY, RADIOGRAPHY AND PROCESSED IMAGES IN THE STUDY OF METALLIC PIECES FROM ARCHAEOLOGICAL SITES

J. A. Madrid, E. Yahaghi, J. M. Melchor, A. Movafeghi

INFORMATIVE MODELS OF CULTURAL HERITAGE. THE "UNFINISHED” CHURCH OF BRENDOLA 127

E. Sorbo, G. Spironelli

GENERATIVE NETWORKS FOR POINT CLOUD GENERATION IN CULTURAL HERITAGE

R. Pierdicca, M. Paolanti, R. Quattrini, M. Martini, E. S. Malinverni, E. Frontoni

QANATS AS AN ENDANGERED TRADITIONAL HYDRAULIC HERITAGE. AN INTEGRATED METHODOLOGY

FOR DOCUMENTING, RESTORING AND REUSING AN ANCIENT IRANIAN QANAT

P. Branduini, F. Zaina, F. Zavvari, Y. Nabati Mazloumi

BIM INTEROPERABILITY: OPEN BIM-BASED WORKFLOW FOR HERITAGE BUILDING INFORMATION MODELLING (HBIM). A MULTIDISCIPLINARY APPROACH BASED ON ADVANCED 3D TOOLS AND EXCHANGE FORMATS

J. A. Bonini, A. Mandelli, S. M. de Gennaro, F. Banfi

THE RECONSTRUCTION OF A DYNAMIC INVENTORY MODEL TOWARD SHARED HBIM LIBRARIES FOR VAULTED SYSTEMS

A. Turrina, D. Attico

DOCUMENTATION OF A COMPLEX CULTURAL HERITAGE ASSET WITH INTEGRATED GEOMATIC SURVEY: THE MONTANARO BELL TOWER

L. Teppati Losè, F. Chiabrando, F. Novelli, G. Patrucco, S. Perri

AN INFORMATIVE TOOL FOR THE PRESERVATION OF THE WOODEN ENCIRCLING TIE ROD OF THE DOME OF SANTA MARIA DEL FIORE, IN FLORENCE

S. Celli, F. Ottoni

THE ROLE OF EXTENDED REALITIES IN HERITAGE BUILDINGS REPRESENTATION 193

A. Khalil, S. Stravoravdis

STUDY ON QUALITY IN 3D DIGITISATION OF TANGIBLE CULTURAL HERITAGE

D. Pritchard, T. Rigauts, F. Ripanti, M. Ioannides, R. Brumana, R. Davies, E. Avouri, H. Cliffen,

N. Joncic, G. Osti, M. Toumpouri

DETECTING AND MAPPING FLASH FLOODING WITH SYNTHETIC APERTURE RADAR (SAR) SATELLITE DATA: THE METAPONTO PLAIN CULTURAL LANDSCAPE CASE STUDY

M. Gabriele

CANOSSA CASTLE: THE IMPORTANCE OF A CRITIC AND AWARE PLAN OF INTERVENTIONS FOR CONSERVATION AND PREVENTION OF CULTURAL HERITAGE

M. Catellani, L. Ferrari, E. Zanazzi

INTEGRATION OF COMPLEX 3D MODELS INTO VR ENVIRONMENTS: CASE STUDIES FROM ARCHAEOLOGY.

J. Gorkovchuk, D. Gorkovchuk, T. Luhmann 


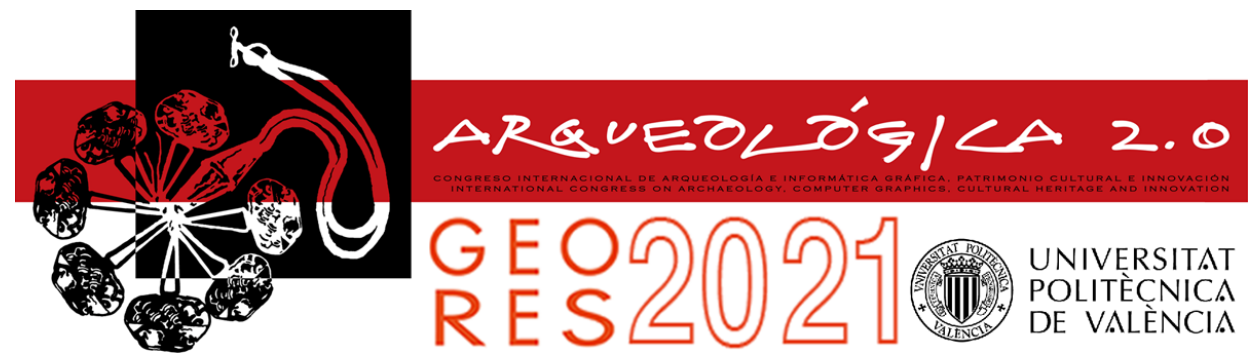

Proceedings of the joint international event $9^{\text {th }}$ ARQUEOLÓGICA $2.0 \& 3^{\text {rd }}$ GEORES Valencia (Spain) 26-28 April 2021

MENSIOCHRONOLOGICAL TECHNIQUES FOR TIMBER ELEMENTS: LIMITS AND SPECIFICITIES

THROUGH A CASE STUDY

A. Grimoldi, A. G. Landi, E. Zamperini

DEVELOPMENT OF AN INTEGRATED BIM-GIS MANAGEMENT TOOL FOR MAINTENANCE PLAN OF HISTORICAL HERITAGE.

I. Bonfanti, E. Colucci, V. De Ruvoa M. Del Giudice, S. Fasana, E. lacono, A. M. Lingua,

F. Matrone, G. M. Ventura, M. Zerbinatti

3D GIS FOR A SMART MANAGEMENT SYSTEM APPLIED TO HISTORICAL VILLAGES DAMAGED BY EARTHQUAKE

A. Gorreja, F. Di Stefano, F. Piccinini, R. Pierdicca, E. S. Malinverni

THE LAST DECADE DEVELOPMENT OF PROJECT DATA MANAGEMENT THROUGH THE BIM..... 261

F. Di Stefano

TECHNIQUES OF GEOMATICS AND SOFT COMPUTING FOR THE MONITORING OF UNSAFE BUILDINGS ........ 267

E. Bernardo, G. Bilotta

DIGITAL TWINS: COMBINED SURVEYING PRAXIS FOR MODELLING. 275

C. M. Bolognesi, M. Signorini

A HYBRID MODEL FOR THE REVERSE ENGINEERING OF THE MILAN CATHEDRAL. CHALLENGES AND LESSON LEARNT

F. Spettu, S. Teruggi, F. Canali, C. Achille, F. Fassi

ENHANCING AND MANAGING DATA AND DIGITAL COMPETENCIES FOR ARCHITECTURE TEACHING AND

TRAINING IN THE FIELD OF PROTECTION OF HERITAGE

N. Lombardini, C. Achille, C. Tommasi, E. Fioretto

PARAMETRIC PARADIGMA: EXCEPTIONAL COFFERED CEILING ARCHITECTURE VS HBIM. 300

O. Rosignoli, B. Scala, D. Treccani, A. Adami, L. Taffurelli, S. Scandurra, L. Fregonese

TLS AND IMAGE-BASED ACQUISITION GEOMETRY FOR EVALUATING SURFACE CHARACTERIZATION 307

G. Patrucco, S. Perri, A. Spanò

MULTI-SCALE AND MULTI-DOMAIN APPROACHES FOR CULTURAL TERRACED LANDSCAPES 317

E. I. Parisi, J. Tyc

MONITORING LANDSCAPE DEGRADATION IN MEDITERRANEAN AREAS INTEGRATING MEDALUS AND REMOTE SENSING FOR FRAGILE ARCHEOLANDSCAPE PLANNING: THE BASILICATA CASE STUDY 325

M. Gabriele, R. Brumana, M. Previtali, A. Cazzani

ACCESSIBILITY TO UNDERWATER CULTURAL HERITAGE: THE INTERACTIVE WEB NAVIGATION OF THE ROMAN SUBMERSED VESSEL OF CALA MINNOLA.

A. Scianna, G. F. Gaglio, M. La Guardia

GEOMATICS ADVANCED IMAGE-BASED TECHNIQUES FLANKING ARCHAEOLOGICAL RESEARCH. A NOTEWORTHY AREA IN THE NORTHERN NECROPOLIS OF HIERAPOLIS OF FRIGIA (TK) 343

L. Teppati Losè, A. Spanò, A. Anguissola

COMPARATIVE INVESTIGATION OF THE 3D REPRESENTATIONS OF THE HOLY AEDICULE OF THE TOMB

OF CHRIST 354

N. Tentoma, A. Georgopoulos, G. Tucci 


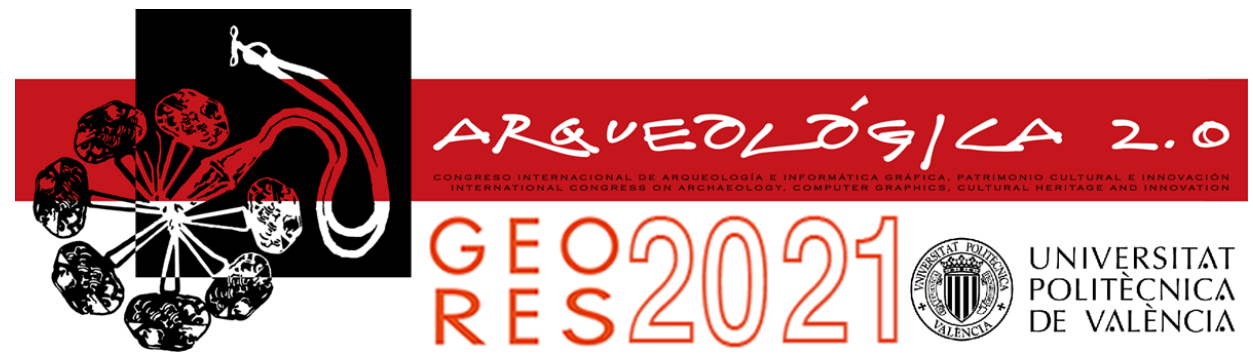

Proceedings of the joint international event $9^{\text {th }}$ ARQUEOLÓGICA $2.0 \& 3^{\text {rd }}$ GEORES Valencia (Spain) 26-28 April 2021

READING INTEGRITY IN THE LANDSCAPE: METHODS' COMPARISON ON TICINO AREA 363

P. Branduini, M. Previtali, E. Spinelli, M. Tagliabue

PARAMETRIC GENERATION IN HBIM WORKFLOWS FOR SLAM-BASED DATA: DISCUSSING EXPECTATIONS ON SUITABILITY AND ACCURACY 374

G. Sammartano, M. Previtali, F. Banfi

TOWARDS AN INTEGRATED DESIGN METHODOLOGY FOR H-BIM 389

E. Pellis, A. Masiero, G. Tucci, M. Betti, P. Grussenmeyer

RESTORATION, REPRESENTATION, PROJECT: A DIALOGUE-LIKE APPROACH FOR THE COMPSA

PALIMPSEST

B. G. Marino, R. Catuogno, R. Marena

THE COMPLEX OF SANTA CROCE IN RAVENNA AS A CASE STUDY: INTEGRATION OF 3D TECHNIQUES FOR SURVEYING AND MONITORING OF A HISTORICAL SITE 408

G. Bitelli, E. Barbieri, V. A. Girelli, A. Lambertini, E. Mandanici, E. Melandri, D. S. Roggio,

A. Santangelo, M. A. Tini, S. Tondelli, A. Ugolini

CARE OF ANCIENT HUMAN REMAINS. CONSERVATION AND MANAGEMENT WITH 3D MODELING AND DBMS 414

E. Dellù, A. Sciatti

THE TAORMINA THEATER: THE DIGITAL SURVEY SYSTEM OF KNOWLEDGE OPEN IN TIME 427 G. Di Gregorio

HOW WERE THE TAPESTRIES IN THE SALA DI SATURNO OF PITTI PALACE ARRANGED? GEOMATICS AND VIRTUAL REALITY FOR ART CURATORS

G. Tucci, V. Bonora, A. Conti, L. Fiorini

INTEGRATING LASER SCANNING AND GEO-MECHANICAL SURVEY IN CONSERVATIVE RESTORATION;

THE CASE OF FIRST WORLD WAR'S CIMA GRAPPA MILITARY SHRINE, ITALY

F. Mugnai, P. Farina, G. Tucci

FRESCO PHOTOGRAMMETRY: DOCUMENTING THE IMPERIAL CULT CHAMBER AT LUXOR TEMPLE 449

O. Murray

COPERNICUS EARTH OBSERVATION FOR CULTURAL HERITAGE 459

A. Agapiou, V. Lysandrou, B. Cuca

SPACE-BASED APPLICATIONS FOR BUILT CULTURAL HERITAGE: EXPERIENCE OF COPERNICUS4REGIONS PUBLICATION

B. Cuca, R. Brumana

SANTA MARIA NOVA (VIA APPIA ANTICA, ROME), II - XX A.D. ARCHAEOLOGY OF ARCHITECTURE OF A LONGLIFE BUILDING

L. Oliva, F. R. Paolillo, S. Roascio 


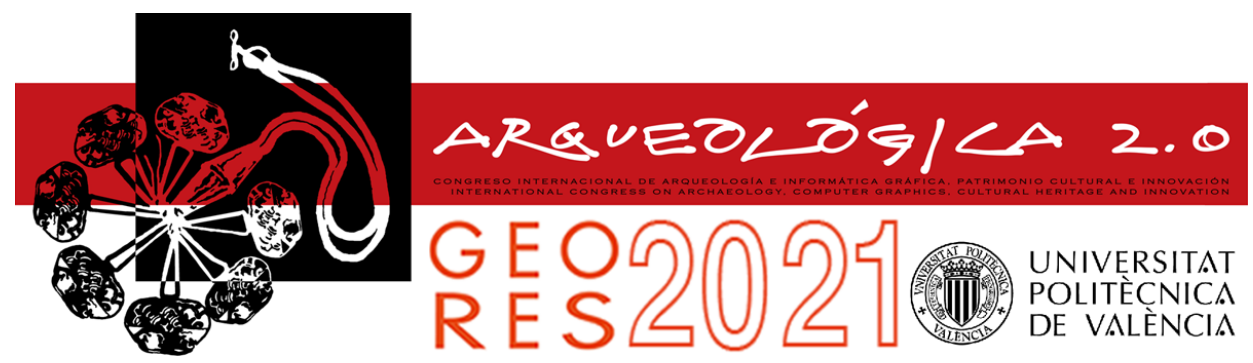

Proceedings of the joint international event $9^{\text {th }}$ ARQUEOLÓGICA $2.0 \& 3^{\text {rd }}$ GEORES, Valencia (Spain). 26-28 April 2021

\section{Works in progress}

DOCUMENT MANAGEMENT FOR ARCHITECTURAL HERITAGE RESTORATION AND ITS APPLICATION IN

THE MONASTERY OF SAN MILLÁN DE LA COGOLLA (LA RIOJA)...

J. Korro, P. Acosta, F. Pinto, J. M. Valle, A. Zornoza-Indart

TOWARDS ONLINE 3D ARCHIVE OF HISTORICAL SITE: THE TURIN 1911 WORLD'S FAIR 487

A. Spreafico, C. Della Coletta

CLOUD DATA SHARING AND EXCHANGE OF HBIM PROJECTS FOR ARCHAEOLOGY: POSSIBLE

SOLUTIONS AND PROPOSALS

F. Diara, F. Rinaudo

ARTIFICIAL INTELLIGENCE APPLIED TO MULTISPECTRAL IMAGERY FOR FLUVIAL MACROPLASTICS

DETECTION

I. Cortesi

ENGINEERING THE ARCHAEOLOGICAL RESEARCH: SUBMILLIMETRIC CT SCAN OF ANCIENT EGYPTIAN

ARTIFACTS.

S. Galli

ANALYSIS OF HISTORICAL EVOLUTION AND PRESENT STATE OF CONSERVATION OF REGIO VII, INSULA 14 IN POMPEII...

A. Capobianco, S. Gagliolo, S. Pallecchi, D. Sguerso

3D TECHNOLOGIES IN CYPRIOT PREHISTORIC ARCHAEOLOGY AND HERITAGE: THE ERIMI USER

EXPERIENCE

F. Dolcetti, L. Bombardieri

ALGORITHMIC MODELLING PROCESSES IN SCAN-TO-BIM WORKFLOWS 508

R. Argiolas

PRE- AND SELF-CALIBRATION OF UNDERWATER CAMERAS FOR PHOTOGRAMMETRIC DOCUMENTATION OF ARCHAEOLOGICAL SITES

A. Calantropio, D. Rissolo, E. Kovacs

MYTHOPOIESIS AND COLLECTIVE IMAGINATION IN VIDEOGAMES

A. Piano, E. Ilardi, A. Ceccherelli

POINT CLOUD PROCESSING FOR URBAN ACCESSIBILITY MANAGEMENT IN HISTORIC CONTEXT.

D. Treccani, A. Adami, L. Díaz-Vilariño

THE ARCH OF AUGUSTUS IN AOSTA: DATA AND ANALYSIS REUSE FOR A CONSERVATION PROJECT

A. Adami, L. Appolonia, B. Scala

MANAGEMENT OF ARCHAEOLOGICAL HERITAGE THROUGH TICS IN MUSEUMS. THE CASE OF THE ARCHAEOLOGICAL MUSEUM OF BURRIANA (CASTELLÓN)

J. M. Melchor-Monserrat, J. Martínez-Uso, J. Alcaide-Marzal

FROM THE DOCUMENT'S LIFE CYCLE TO THE MONUMENT'S LIFE CYCLE: THE CASE OF THE DE MURTAS BARRACK IN CAGLIARI

A. Agus, D. R. Fiorino

USE OF A NOVEL, LOW-COST 3D CT-SCAN VIEWER BY THE HOYO NEGRO PROJECT, QUINTANA ROO,

MEXICO

J. C. Chatters, W. O. Adams Jr, D. Arano Recio, D. Rissolo, H. Barba Meineke 


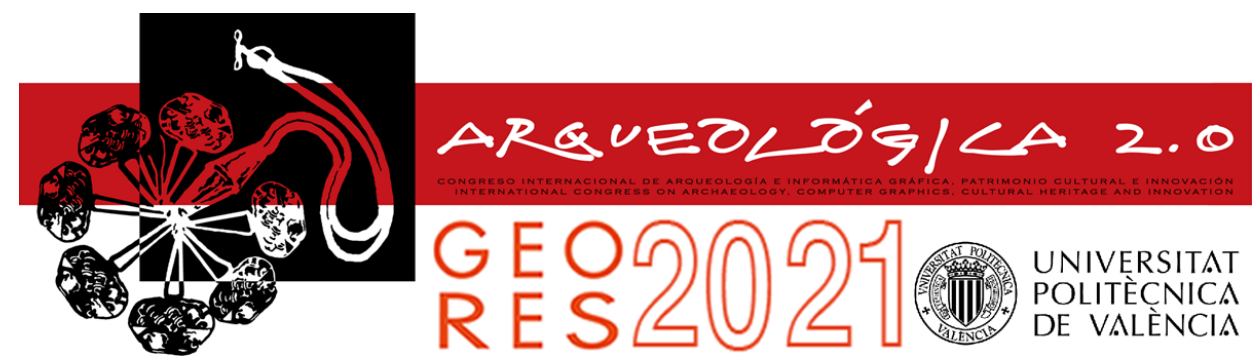

Proceedings of the joint international event $9^{\text {th }}$ ARQUEOLÓGICA $2.0 \& 3^{\text {rd }}$ GEORES Valencia (Spain) 26-28 April 2021

MIXED REALITY FOR THE MONUMENTAL HERITAGE. A FIRST TEST 538

S. Teruggi, F. Fassi

AN EXPERIMENTAL WORKFLOW FOR THE VIRTUAL RECONSTRUCTION OF ANCIENT STATUES 542

L. Fazio, M. Lo Brutto

INTEGRATION OF DIGITAL ACQUISITION TECHNIQUES FOR THE MANAGEMENT OF CULTURAL

HERITAGE: THE ARCHAEOLOGICAL PARK OF THE VIA LATINA AND VIA APPIA ANTICA TOMBS 546

S. A. Cugno, F. Fantini, F. Juan-Vidal, S. Rinaldi

DIGITIZING TO RE-DISCOVER: THE CASE STUDY OF THE ROMAN CITY-GATE IN ALTINUM, ITALY..... 550

C. Balletti, E. Delpozzo

MAPPING MONUMENTS' STONE WEATHERING USING LOW-COST MULTISPECTRAL TECHNOLOGIES

AND IMAGE PROCESSING 555

E. Adamopoulos, F. Rinaudo

HBIM AND WORKSITE SIMULATION: FIRST EXPERIMENTS 558

O. Rosignoli

A HERITAGE INFORMATION SYSTEM FOR MULTISCALE ANALYSIS FOR THE WORLD HERITAGE SITE OF CUENCA, ECUADOR 562

V. Heras, P. Ochoa, A. Delgado

CANTÓN NABÓN CULTURAL HERITAGE GEOPORTAL IMPLEMENTATION: FIRST STEPS 566

A. Collado, G. Mora-Navarro, P. Rodas, V. Heras, J. L. Lerma

DIGITAL SURVEY AND RECEPTION STRUCTURES FOR A VIRTUAL FRUITION: THE CASE STUDY OF THE HYPOGEUM OF CALAFORNO (RAGUSA).... 569

G. D’Agostino, M. Figuera, G. Rodonò

\section{Extended Abstracts}

SIMULATION OF PAST PROCESSES THROUGH LINEAR PROGRAMMING. THE CASE OF THE DISTRIBUTION OF SUPPLIES DURING THE SIEGE OF BILBAO IN 1874

Á. Rodríguez Miranda, P. Ferreira-Lopes, G. Martín, J. Korro

A WEB APPLICATION TO GEOLOCATE THE CURRENT CITY OF SAN CRISTOBAL DE LA LAGUNA IN A XVI CENTURY MAP

F. Pérez-Nava, I. Sánchez-Berriel, A. Pérez-Nava, V. Gutiérrez-Rodríguez, J. Pérez-Morera

PARAMETRIC APPROACH TO THE RECONSTRUCTION OF TIMBER STRUCTURES IN CAMPANIAN ROMAN HOUSES

L. Sbrogiò

DOCUMENTATION AND ENHANCEMENT OF A ROMAN WATERMILL WITH ALL ITS STRUCTURAL

ELEMENTS

J. García-León, J. A. González-García, P. E. Collado-Espejo

DIGITAL EARTHQUAKE-DAMAGED BUILDING USING HBIM, COMMON DATA ENVIRONMENT(CDE) AND EXTENDED REALITY (XR): THE CHURCH OF SAN FRANCESCO IN ARQUATA DEL TRONTO

F. Banfi, R. Brumana, A. G. Landi, M. Previtali, F. Roncoroni, C. Stanga 


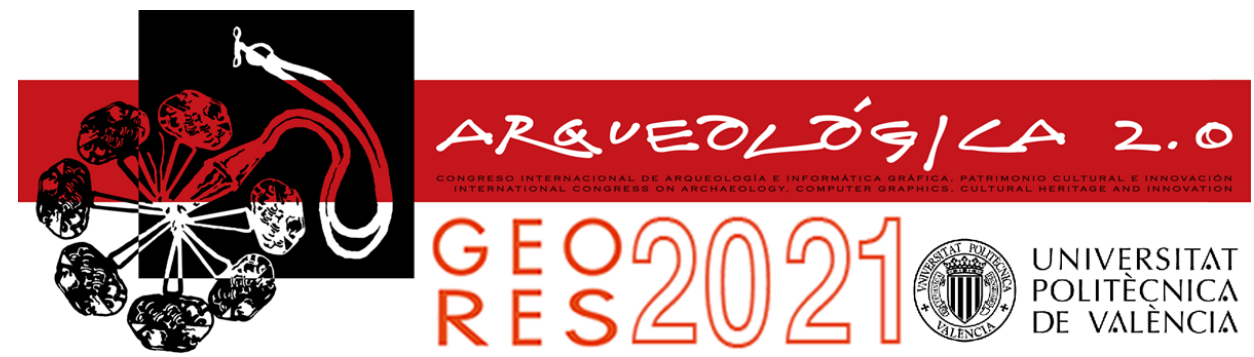

Proceedings of the joint international event $9^{\text {th }}$ ARQUEOLÓGICA $2.0 \& 3^{\text {rd }}$ GEORES Valencia (Spain) 26-28 April 2021

AUTOMATIC MASKS GENERATION FOR THE DIGITIZATION OF A WOODEN COLLECTION OF MAQUETTES USING DEEP LEARNING.

G. Patrucco, F. Setragno

FINE TUNING AND DATA AUGMENTATION TECHNIQUES FOR SEMANTIC SEGMENTATION OF HERITAGE POINT CLOUDS 580

F. Matrone, M. Martini

LOST GEOMETRIES - A METHODOLOGY FOR THE DIGITAL RECONSTRUCTION OF HISTORIC ARCHITECTURAL RUINS 581

S. Fallica, R. Garozzo, C. Santagati 


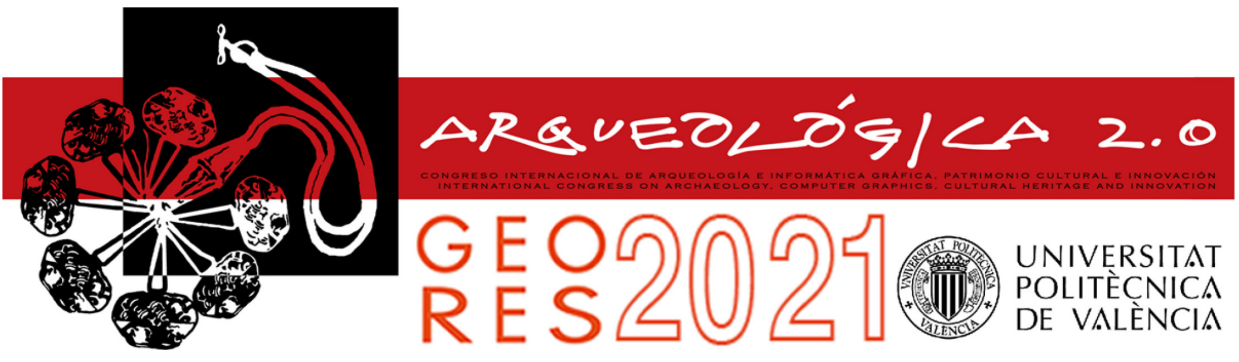

Proceedings of the joint international event $9^{\text {th }}$ ARQUEOLÓGICA $2.0 \& 3^{\text {rd }}$ GEORES, Valencia (Spain). 26-28 April 2021

\section{Long scientific papers}




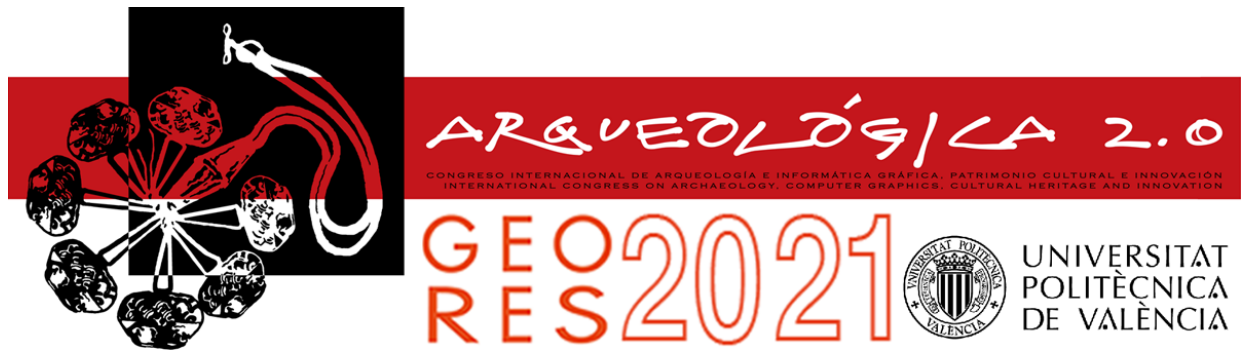

Proceedings of the joint international event $9^{\text {th }}$ ARQUEOLÓGICA

$2.0 \& 3^{\text {rd }}$ GEORES

Valencia (Spain).

26-28 April 2021

Received: 15/10/2020

Accepted: 25/03/2021

DOI: https://doi.org/10.4995/Arqueologica9.2021.12041

\title{
THE DIGITAL TRANSFORMATION OF THE MUSEO EGIZIO
}

\author{
Davide Mezzinoa,", Francesca Valentina Luisa Lori ${ }^{b}$ \\ ${ }^{a}$ Department Development and European Funds, Fondazione Museo delle Antichità Egizie di Torino, Via Accademia delle Scienze 6 , \\ 10123 Torino, Italy. davide.mezzino@museoegizio.it \\ ${ }^{\mathrm{b}}$ Department of Architecture, Built Environment and Construction Engineering, Politecnico di Milano, Via Giuseppe Ponzio 31, 20133 \\ Milano, Italy. francy.lori@gmail.com
}

\begin{abstract}
:
The project of the digital transformation of Museo Egizio di Torino started in response to the rapid change of its structure and needs. The project is centred on the integration of heterogeneous information and data to implement collection management, conservation and research workflows. This paper presents the concept and design of a management system, called SiME (Sistema Museo Egizio) that the Museum conceived in collaboration with Politecnico di Milano. The project is intended not only as a mere acquisition of technological tools, but rather as the construction of an integrated system that facilitates dialogue and connections between all museum activities, from daily management to research, from the design of installations to the generation of multiple possible narratives. Considering the pace of technological innovation a solid methodological approach has been adopted to ensure the longevity of the designed solutions from a long-term perspective.
\end{abstract}

Keywords: digital innovation strategy, collection management, archaeological data, workflows management, museum

\section{Introduction: the cultural and socio- economic framework}

Museums aim at preserving cultural identity and collective memory as well as interpreting and communicating their meanings to wide and heterogeneous audiences. By their nature, they are open and dynamic places that encourage, promote and host the interaction between objects, researchers and audiences.

The Museo Egizio di Torino, a bicentennial institution profoundly renewed in 2015 , is an archaeological museum and research centre focused on socio-cultural topics.

To support the development of the Museo Egizio, the elaboration of a digital innovation strategy has been identified as necessary. It is intended not only as a mere acquisition of technological tools, but rather as the construction of an integrated system that facilitates dialogue and connections between all museum activities, from daily management to research, from the design of museum installations to the generation of multiple possible narratives.

Therefore, the switch provided by the digital transformation would significantly act on two main aspects:

a) The possibility to overcome the de-contextualization of the collection's objects (typical problematic issue of archaeological museums) through innovative ways of managing and visualizing data and information.

b) The implementation of the interaction strategies with the public.

The proposed project, in line with the general mission of the Museum, aims to replace all outdated software and to fully exploit the capabilities of the tools already in use to address the heterogeneous needs of the Museum.

Furthermore, the current socio-economic context makes the project even more relevant. The global Coronavirus crisis has had an unprecedented impact on cultural institutions and, specifically, museums all over the world. Most museums around the globe are now closed $(93 \%)$ and report a considerable loss of income of $75-80 \%$, with larger museums and the museums in tourist areas losing between 10.000 and 600.000 Euros per week, depending on their dimension (NEMO, 2020).

Regardless, the current crisis may represent the chance to re-design the relationship between material and immaterial culture: museums will need a more flexible interplay of the onsite/online public engagement by harmonizing digital and material experience of cultural heritage as complementary phases of the same dissemination process. This means, in practice, connecting a large mass of data and information: in this respect, the proposed digital transformation of the Museum will play a crucial role (Fig. 1).

"Corresponding Author: Davide Mezzino, davide.mezzino@museoegizio.it 


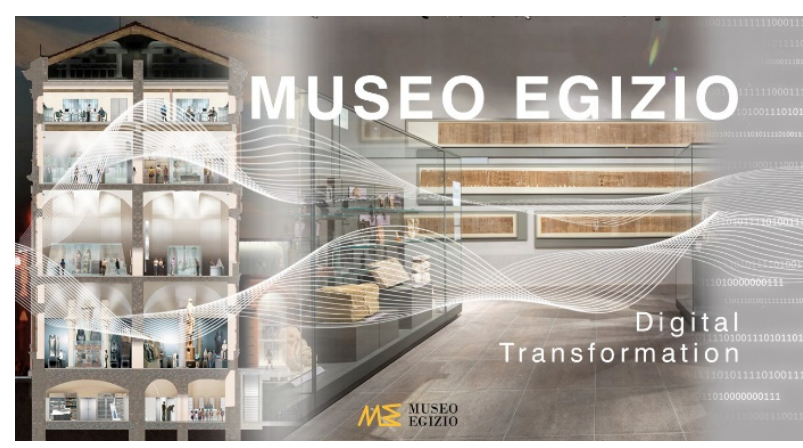

Figure 1: The metaphoric depiction of the digital transformation of the Museo Egizio involving collection, workflows and building management. Image source: Authors.

\section{Planning the Digital Transformation}

\subsection{The as is analysis and the Museum needs}

The digital transformation of Museo Egizio di Torino is necessary to fill the gap between the available software equipment and the Museum's needs. On the one hand the rapid increase in the number of employees requires new tools to coordinate their tasks as well as new tools to manage the growing material produced by the Museum research activities. On the other hand, technological development offers a growing number of tools to be potentially used to enhance both the collection and the work that is being carried out on it in a coordinated and organic manner.

The digital transformation process started by identifying three main needs of the Museum:

a) Improve the Collection Data Management;

b) Facilitate the coordination between departments;

c) Guarantee the security of the data over time.

Regarding the improvement of Collection Data Management, the following needs have been identified:

1) Simplify and make access to data more user-friendly;

2) Collect, connect and consult the new material produced (i.e. photogrammetric data, data relating to the logistics of the museum objects, digital material resulting from conservation work and physicalchemical analysis);

3) Prevent employees from wasting time on unnecessary paperwork;

4) Online access to the Collection data;

5) Encourage smart working activities (a latent necessity that exploded during the Covid19 pandemic);

6) Promote the sharing of the research results among researchers from other museums and academia;

7) Avoid loss of money and efforts in the development of non-interoperable applications;

8) Improve Museum attractiveness towards a younger audience;

9) Increase the digital skills of employees to seize the opportunities provided by new technologies and spread the culture of innovation.
About the coordination between employees of the Museo Egizio, the project aims at promoting dialogue and collaboration between Museum departments.

Finally, concerning data security, Museo Egizio di Torino needs to:

1) Limit as much as possible the risk of loss of digital material;

2) Comply with the most up-to-date security criteria regarding data sharing.

\subsection{The goals of the digital transformation project}

To implement the proposal, the needs listed above have been translated into a list of measurable goals, which include:

1) designate a technological partner capable of supporting the museum in digital choices and of helping it to foresee future trends and to focus all efforts in a consistent strategy;

2) collect and catalogue the huge amount of multimedia data into a new Collection Management System, strictly web based; in which almost every paperwork could find a place and be transformed into a digital online procedure;

3) implement an IT infrastructure capable of supporting smart working;

4) plan a "cold" backup for all the data owned by Museo Egizio on cloud infrastructure;

5) schedule training courses to push collection managers and curators to the use of digital systems.

\subsection{Actions needed}

The project of digital transformation requires the completion of various actions on the fronts of the archive, of the shared tools and of the IT infrastructure (Fig. 2). The actions will directly involve all sectors of Museo Egizio.

Concerning the development of the Collection Management System of SiME, the following actions are envisaged:

1) Review the cataloguing method of the museum collection, starting from a study on the ontology;

2) Map workflows and multimedia material that employees want to manage within the new Collection Management System;

3) Develop an ad hoc document system that is more in line with the needs of emerging professionals and that allows the archiving of the large (and growing) amount of data resulting from their research activities;

4) Develop simple Application Programming Interface (API) protocols to allow third-party applications to use the collection's data;

5) Create an open interoperable section in the Management System accessible to researchers and scholars. 


\section{WBS}

DIGITAL TRANSFORMATION PLAN

\section{SiME and Cloud infrastructure}

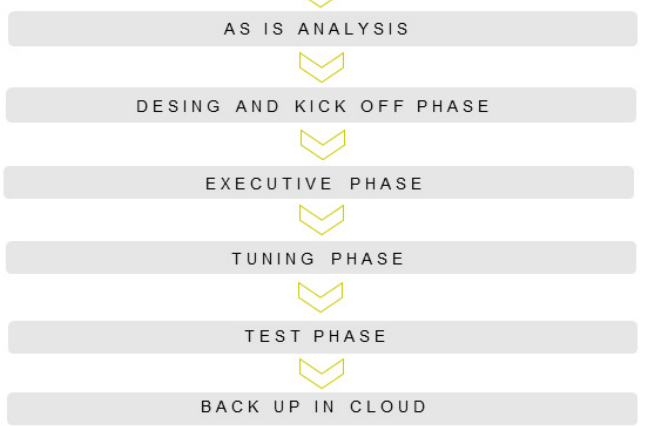

Figure 2: Diagram of the Work Breakdown Structure (WBS) for the SiME development. Image source: Authors.

Concerning the Cloud infrastructure, the following operation is envisaged:

1) Purchase and set a cloud backup service for all collected data. The service should complement the backup that already takes place on the servers in situ;

2) Build a solid IT infrastructure to host SiME.

\section{Methods and approaches}

Considering the pace of technological innovation a solid methodological approach has been adopted to ensure the longevity of the designed solutions in a long-term perspective. The identified methodological approach allows reducing the risk of developing incoherent solutions and tools without a holistic vision. Below is a detailed list of the methods and approaches that have been adopted.

\subsection{Bottom-up approaches for knowledge and critical analysis of the as-is situation}

The needs of the different departments of the Museo Egizio di Torino were identified thanks to a survey conducted through targeted interviews with 32 employees (out of 54).

\subsection{Digital transformation approach}

Museo Egizio charged Politecnico di Milano to support the Museum in the digital transformation process.

In the very first steps of the project, the team of Politecnico di Milano carried out focus group and individual interviews identifying and collecting all the needs and requirements to later translate them into concrete objectives.

Then, the team of Politecnico di Milano supported the Museum in the definition of the most appropriate and customized technological solutions to be developed by a technological partner.

\subsection{Technological partner selection}

The partner has been identified in the Piedmont area, thus reducing assistance times and costs. The selection criteria considered the following strengths: small and medium digital agencies with great skills in developing high-tech IT solutions, designing visual experiences, strong forecasting capabilities on digital trends and proactivity in solving current or upcoming problems.

\subsection{Innovative approach for the implementation of the SiME Collection Management System}

\subsubsection{Analysis of the archiving system in use}

The organization of the data in the old management system will not be completely replaced. At the time of writing this article, the old management software is being studied to understand how the fields were used and what were the problems encountered during the data entry. To carry out this study, the team of Politecnico di Milano is working closely with the curators and collection managers of the Museo Egizio.

\subsubsection{Collaborative approach for the study of ontologies}

In this project, it was necessary to select some categories and subcategories among all the others to cluster the objects and to simplify the search within the database. Therefore, a shared effort will be required from all editors to produce a table of relationships among the input fields. This will allow the software engineer to add alerts and controls at the same time as the data entry in the management system.

This operation will be carried out by the entire team of curators coordinated by a professional with extensive skills in archiving.

\subsubsection{Testing approach}

Professionals not directly involved in the digital transformation project will be selected for each department to complete some activities on the Collection Management System among those carried out daily. The testers will then be asked to comment on the aspects that they would like to change or that they do not find intuitive or immediate.

\section{Workflow interested by the SiME development}

The main challenge in the project development is the integration of most of the processes including their checkpoints as well as the integration of data.

Below are reported the processes that will be most affected by SiME:

- Conservation and restoration of the collection objects;

- Design and schedule temporary exhibition;

- Chemical-physical analysis on the Museum collection;

- Visual query builder; 
- Organization of multimedia and photographic material;

- Interdepartmental digital communication.

\subsection{Conservation and restoration of the collection object}

Concerning the conservation issues, the project acts on two main aspects: the condition reporting and the archival of digital files produced by objects' analysis. Both aspects are relevant for both managing conservation actions and insurance issues

SiME will implement the semi-automatic production of the condition report and legal documents needed to loan collection objects (i.e. in case of temporary exhibitions) or to move them outside the Museum (i.e. in case of conservation works).

\subsection{Design and schedule temporary exhibition}

The workflow needed to plan and design temporary exhibitions will benefit from the objects' calendar interconnection that will define in real-time position, planned loans, state of conservation and restorations planned. This will avoid the overlap of loans allowing at the same time to gain useful information for the exhibition design according to the conservation conditions of each object.

\subsection{Chemical-physical analysis on Museum collection}

Non-destructive analysis and sample analysis will benefit from a standardization of the data entry process.

It will be possible to keep track of all the material sampling interventions made on each object with an indication of the type of analysis carried out. This approach will avoid overlapping analysis.

\subsection{Visual query builder}

SiME will implement a complex query builder system for the consultation of the information in a simple visual way. A visual query system will allow users to interrogate the digitized objects interactively.

\subsection{Organization of multimedia and photographic material}

The development of SiME will radically change the data research and retrieval process. SiME will allow the storage and management of $3 \mathrm{D}$ data such as point cloud, geometric 3D models, 3D animation, video, VR, AR and $\mathrm{XR}$ products. This will affect the collection management department, the curators' department as well as the communication and marketing department actions (i.e. in the ADV online and offline activities, the social media communication, press and digital visual communication).

\subsection{Interdepartmental digital communication}

The creation of a single interconnected system (SiME) will allow both to speed up and facilitate individual processes and to connect the workflows of each department.

\section{SiME's modularity and the Satellite applications strategy}

The modularity of the SiME system will be guaranteed by its internal structure, which will allow the expansion of the platform through satellite applications, thus extending its functionality and display methods. Also, the flexibility of SiME will allow future changes according to the new needs of each department of the Museum (Fig. 3).

All satellite applications will refer, for data exchanging, to a centralized database, shared with SiME. All these applications could only be released once the development of SiME will be completed, the end of the works is expected by November 2021.

An example of a satellite application is CURA, which will integrate different tools to carry on conservation processes including the condition report tool (that will register the conditions of each museum's object) and the conservation tool (that will allow to record all the multimedia files acquired for documentation and conservation purposes).

\section{Technical solutions adopted}

The technological solutions provided concern both hardware and software equipment.

\subsection{Cloud infrastructure}

\subsubsection{Hosting on external virtual machines}

Concerning the hosting of the SiME, the aim is to move to an external cloud infrastructure to delegate the maintenance and performance control operations outside. The advantage of this solution is the scalability of the hosting of SiME.

At its fullest potential, SiME will involve three virtual machine services dedicated respectively to the following applications:

- $\quad$ Core software;

- Frontend software;

- Database.

\subsubsection{Backup in cloud}

The Museo Egizio selected a 'cold' hybrid cloud backup solution integrated with a 'hot' backup solution, already in use. This solution will be implemented through the Microsoft Azure Blob archive service.

\subsection{SiME collection management software solution}

Concerning the collection documents, recently there has been a change of direction in the software market for Saas (Software as a service). The strong competition between large software houses such as Microsoft and Google led to the development of software applications that can be easily integrated with custom software solutions. This condition has given new impetus to the creation of ad hoc software that meets the needs of customization, maintenance and reliability of the software over time. 
With this in mind, we have chosen to develop an ad hoc system for the collection's documents which includes the software solutions described below.

\subsubsection{Web-based}

It allows consultation through any remote browser instead of inconvenient installations of limited software licenses.

\subsubsection{Query builder}

It allows users to query the database in a user-friendly mode and save the outputs of complex searches.

\subsubsection{Image navigator and real-time collaboration}

It allows the exploration of very high-resolution images with Google Maps like algorithm through the zoom function.

It also allows real-time collaboration through tags and comments that can be placed directly on the image of interest. Multiple researchers can remotely work on the same file by sharing their comments to speed up the study and research activities.

\subsubsection{JSesh library}

The integration of JSesh allows the editing of hieroglyphic texts as a sequence of symbols in .png format and transliteration into digital text according to the Manuel de Codage standard. The Turin Papyrus Open Platform (TPOP), the platform dedicated to Papyri, is already using the JSesh engine for transliteration and the creation of glyphs in image format.

\subsection{Management of permissions and users}

SiME administrators will be able to create users with different profiles for accessing the database, this will allow curators to manage external users' permissions.

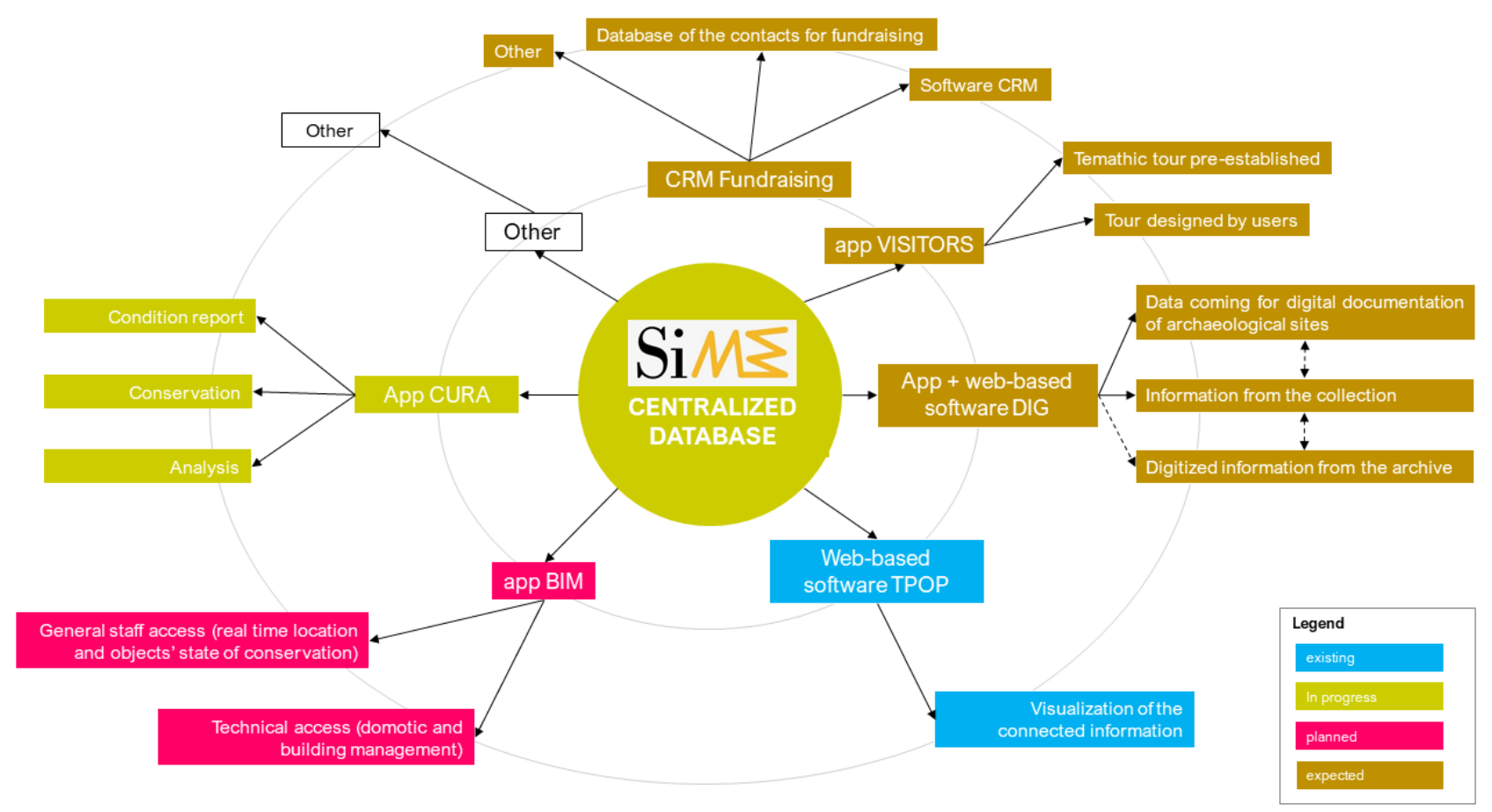

Figure 3: The figure illustrates the satellite applications connected to the SiME system. Image source: Authors.

\section{Expected deliverables}

The deliverables expected by the digital transformation, in a temporal framework of 15 months, are the following, classified into two macro-area of interest.

\subsection{Cloud infrastructure: Hosting of SiME}

a) Provision of hosting services for SiME: 3 virtual machines (software that emulates a physical machine but more flexible) dedicated respectively to frontend, backend and database instances;

b) Acquisition of the Microsoft Blob Azure service for "cold" backup of the whole data.

\subsection{SiME outputs}

The deliverables of the SiME project include software solutions as well as services, such as:

- Documentation regarding the study of ontology and objects classification;

- Export software - expected date: April 1, 2021;

- $\quad$ SiME platform - expected date: December 1, 2021;

- Automatic data import and semi-automatic data entry;

- The application CURA - expected date: April 1, 2022;

- Capacity-building activities. 


\section{Monitoring phase}

To monitor the effectiveness of the proposed solution, Key Performance Indicator (KPI) have been identified to measure the project performances.

\subsection{Specific goal}

Organization of $60 \%$ of digital material in SiME and consequent sharing of data from the Museum's collection to facilitate collaborative maintenance, research, promotion and communication activities, by June 2023 .

\subsection{Key performance indicator (KPI)}

The KPI measure the capability of the Museum to increase research on its collection and improve the management of its tangible and intangible heritage.

\subsubsection{KPI measurement}

The indicators to measure the achievement of the specific goal are:

1) The number of user interactions with the archive;

2) The number of satellite apps developed in dialogue with SIME.

\subsection{Verification sources}

To verify the results of the first measurable KPI, the log file (recording users' activity) of the new platform will be compared with the one currently in use.

To test the second KPI measurement, the number of applications in use will be compared with the number of satellite applications that will be developed.

\section{Capacity-building activities}

According to the project objectives, the training approach involves the collaboration of all the Museum staff. Based on the professional profile and competencies the training activities have been differentiated for two teams.

The team with technical and IT competencies will deal with data and information security, cloud infrastructure management and problem-solving in response to system alerts.

The second team composed of most of the Museum staff with a basic and medium knowledge of IT system will deal with data editing and consulting of the System SiME, task managing and multimedia data archiving and cataloging procedure.

More specifically, capacity-building activities for both teams will include two courses of three meetings each to be repeated for the first two years.

\section{Conclusions and future perspectives}

The working activities briefly described in this contribution are the first step of the digital transformation of the Museum.

The digital transformation is a cross-process to all the museum's departments involving all the staff's workflows.
More specifically, the planned actions concerning the data collection management affect the monitoring and conservation processes as well as exhibition design and research activities.

The project output consisting of a tailor-made database will enable more immediate access to collection data and collaborative workflows. The effectiveness of this approach has been already tested in the TPOP platform which was awarded by the prestigious Heritage Prize Europa Nostra 2020 Awards in the research category.

In a long-term perspective, the logic of a central database and satellite application can develop new processes such as virtual tour of the collections.

Further, the development of Application Programming Interface (API) software allows the interoperability with third-party applications with SiME thus not depending on a single service provider.

The implementation of an integrated system will amplify the awareness of the museum activities by the different departments in real-time as well as cross-department collaboration.

The proposed project generates a digital environment integrating the existing hardware resources (when possible), developing tailor-made solutions based on the consolidated experiences of the Museum staff that oriented the development of SiME in the design thinking phase as well as in the tuning phase.

Future perspectives also include the development of an HBIM (Lo Turco \& Calvano, 2019) of the building to be configured as a satellite application connected with SiME. This structure enables the development of an integrated HBIM-CIM model for an overall documentation and stewardship of the Museum intended as building (container) and its archaeological collection (content) (Lo Turco \& Spallone, 2019; Lo Turco, Giovannini, \& Manfrici, 2020).

\section{Acknowledgements}

This research is a cumulative work that had the fundamental support of two institutions: Fondazione Museo delle Antichità Egizie di Torino and the Politecnico di Milano. Without the efforts and collaboration of these two institutions, this research would have not been possible.

First and foremost, we would like to thank Christian Greco, Director of the Fondazione Museo delle Antichità Egizie di Torino and all the dedicated staff that contributed to the feasibility study of the project. All the staff members shared their thorough knowledge and generously offering us access to the Museum resources, thus giving us the opportunity of improving the technical skills that have been fundamental to this research.

A special thanks goes to Corinna Rossi, Professor of Egyptology at the Politecnico di Milano. She generously shared with us her intellectual, social and professional capital. This research was conceived and completed thanks to their guidance, wisdom and confidence. This work was partially supported by the project LIFE, funded by the European Research Council (ERC) under the European Union's Horizon 2020 research and innovation programme (grant agreement 681673). 


\section{References}

Banfi, F. (2020). HBIM, 3D drawing and virtual reality for archaeological sites and ancient ruins. Virtual Archaeology Review, 11(23), 16-33. https://doi.org/10.4995/var.2020.12416

CHCfE Consortium. (2015). Cultural Heritage Counts for Europe. Full report. Retrieved May 12, 2020, from http://blogs.encatc.org/culturalheritagecountsforeurope/outcomes/

Jan, J. F. (2018). Application of open-source software in community heritage resources management. ISPRS International Journal of Geo-Information, 7(11), 426. https://doi.org/10.3390/ijgi7110426

Lo Turco, M., Giovannini, E. C., \& Manfrici, (2020). Digital \& Documentation. Digital Strategies for Cultural Heritage. Pavia University Press, Pavia.

Lo Turco, M., \& Spallone, R. (2019). Piattaforme digitali integrate per i Beni Culturali. Alcune esperienze della Scuola di Architettura del Politecnico di Torino. In Paesaggio Urbano, 1, 52-65. https://www.architetti.com/paesaggio-urbano$1-2019$

Lo Turco, M., \& Calvano, M. (2019). Digital Museums, Digitized Museums. The case of the Egyptian Museum in Turin. In Proceedings of the 1st International and Interdisciplinary Conference on Digital Environments for Education, Arts and Heritage. EARTH 2018. Advances in Intelligent Systems and Computing, 387-398. http://dx.doi.org/10.1007/978-3-030-12240-9_41

NEMO The Network of European Museum Organisations, (2020). Survey on the impact of the COVID-19 situation on museums in Europe: Final Report. Retrieved May 12, 2020, from https://www.nemo.org/fileadmin/Dateien/public/NEMO_documents/NEMO_COVID19_Report_12.05.2020.pdf 


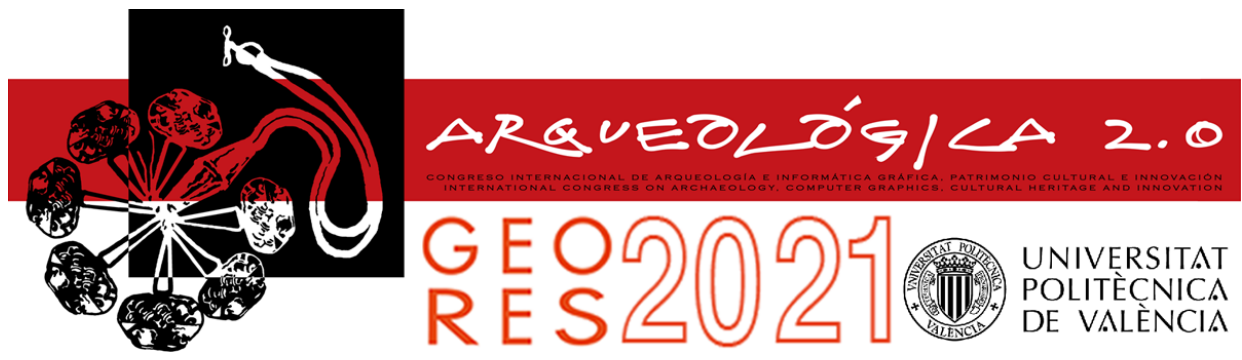

Proceedings of the joint international event $9^{\text {th }}$ ARQUEOLÓGICA

$2.0 \& 3^{\text {rd }}$ GEORES

Valencia (Spain).

26-28 April 2021

\title{
YEDI KULE - MONUMENT ROAD RACE: THE CONSTRUCTION OF THE 3D MAPPING ANIMATION OF THE OLD CITY OF THESSALONIKI, GREECE
}

\author{
Efthymios-Spyridon Georgiou ${ }^{\mathrm{a}}$, Nikos Lambrinos ${ }^{\mathrm{b},{ }^{*}}$ \\ a Master Integrated School Spatial Planning and Development, Department Engineering, Aristotle University of Thessaloniki, \\ Thessaloniki GR-54124, Greece. efthimios_georgiou@yahoo.gr \\ ${ }^{b}$ Department of Primary Education, School of Education, Aristotle University of Thessaloniki, Thessaloniki GR-54124, Greece. \\ labrinos@eled.auth.gr
}

\begin{abstract}
:
This project refers to the construction of a 3D map of Thessaloniki's historical route. The Yedi Kule Conquest - Monument Road Race took place in the old city of Thessaloniki, which was built during the Byzantine and Ottoman period. The purpose of this project is to make a digital recording of the castles, the monuments, the old churches, the traditional buildings, and the squares that the contestant encounters during the route so he/she can be aware of the characteristic points he/she will meet during the race. The methodology of the project is based on the implementation of online software Google Earth Studio and Adobe Premiere Pro which were used for the digitization, rendering, and building process of the animation. With this methodology, the authors achieved the documentation of land use and the architectural landscape. The animation is a credible graphic index of the historical background of Thessaloniki. The Yedi Kule area constitutes a cultural mosaic made during the Ancient Greek/Roman, Byzantine, and Ottoman Empire historic periods. The responsibility of the governmental politics and of every citizen of Thessaloniki is to promote and preserve the historic background of the city. The final product offers a good opportunity for the digital storage of Thessaloniki's old city. The animation creates an interactive environment that portrays the current image of the transition from the old to a modern city.
\end{abstract}

Keywords: 3D mapping, animation, cultural landscape, Thessaloniki, Greece

\section{One City Many Cultures}

Thessaloniki city was founded in 315 B.C. by Kassandros, General of Alexander the Great. Its main history starts in the Hellenistic period (321 - 31 B.C.) and reaches until today, without losing its urban-metropolitan and multicultural character. It presents over 2,000 years of continuous uninterrupted urban life. Its history is constantly marked by intense discontinuities and ruptures. (Mazower, 2006).

Due to its geographical location, has a very important role in Greek and Balkan history, was a crossroads of people and cultures, but also a major commercial centre. For this reason, various conquerors claimed it and tried to occupy it.

Thessaloniki, the "metropolis of Macedonia" according to Strabo, the "first after the first" or the "ruling" city of Byzantine sources, took her name after the wife of Kassandros. Thessaloniki was the daughter of Philip II and Nikisipolis from Ferres, Thessaly (Central Greece). The new city formed after the clustering of 26 settlements located in the area. (Strabon, 1992).
Byzantine Thessaloniki managed to maintain its vitality and dynamism, despite the successive and repeated sieges (and sometimes outbursts) it experienced from various invaders (Goths, Avars, Slavs, Saracens, Bulgarians, Arabs, Catalans, Dutch, Catalans).

According to Mazower (2006), Thessaloniki has already started to become a melting pot of peoples, traditions, and cultures since Byzantine times.

In Roman times, Thessaloniki became the capital of an extensive administrative district, the Province of Macedonia (Provincia Macedonia). It was the most important city along the Egnatia Highway, the famous military road that started from Durres and ended in Evros (today Greek Turkish borders), connecting the west with the Asia Minor possessions of the Roman Empire. On March 29, 1430, Thessaloniki was finally conquered by the Ottomans and a new chapter opened in its history. Thessaloniki during the Ottoman occupation was a city that could be characterized as multinational. (Vakalopoulos, 1983).

During the Ottoman period and mainly from the $15^{\text {th }}$ century onwards, Thessaloniki began to host very large 
numbers of refugees, who settled there. The arrival of approximately 20000 expelled Jews from Spain in 1492 who in fact will baptize Thessaloniki "Mother of Israel", will be one of the most decisive factors in shaping its multicultural profile and will pave the way for customs. (Benbassa, Rodrigue, \& Jewry, 2000).

Mazower (2006) characteristically states that in the mid$16^{\text {th }}$ century the merchants of the Egyptian market, mainly a food market, spoke eleven languages: Greek, Turkish, Italian, French, Spanish, Vlach, Russian, Latin, Arabic, Albanian and Bulgarian. Nowadays the same place is called "Ladadika" and served as a food market until 1990 and now is a recreational area full of tavernas and bars.

Especially after the fire of 1620, the spatial rearrangements that took place were maintained until 1850. Specifically, the neighbourhoods were a nationreligiously separated: Muslims lived in Ano Poli, Orthodox lived in various areas along the Egnatia Road, around the Valtada Monastery, Vardari, and the Diocese, Jews lived near the sea below the Egnatia Road, while the area around the church of Agios Minas - due to the establishment of consulates and European traders - was named "Frangomahalas" (Gerolympou-Karadimos, 1995).

The establishment of the French consulate in Thessaloniki in 1685, underlines the intense trade relations with the Franks, while indicative of the prosperity of the city is the testimonies of travellers of the time. A typical example is the testimony of the priest and writings of Jozefdela Portoopoios in 1737 stating that Thessaloniki numbered 48 mosques, 30 Greek churches, and 36 Jewish synagogues (Gregoriou, \& Hekimoglou, 2008).

According to historical documents, the multicultural element of Thessaloniki continued to be dominant even after the liberation of the city from the Ottomans.

In addition, according to historical sources, in the 1915 parliamentary elections $14204(37 \%)$ Israelis, 13353 (35\%) Greek Orthodox, 8900 (23.11\%) Muslims, 700 $(1.8 \%)$ Armenians and $969(2.5 \%)$ of other ethnicities were registered to vote (Anastasiadis, 2011).

Thessaloniki joined the Greek state with the Treaty of Bucharest of August 10, 1913. Despite guarantees of economic and social protection, a large number of Jews, 800 merchants and capitalists, and about 500 craftsmen left Thessaloniki (Pierron, 2004).

An important event in the modern history of Thessaloniki was the fire that broke out in August 1917 starting from a house in the Muslim quarter on the outskirts of Ano Poli, which spread rapidly due to strong wind, wooden structures, paving, and lack of proper infrastructure for to deal with it, at a time when General Saray had refused to give up the barracks' reserves to water (Machaira, 2002). The fire was devastating for most of the historic city centre: 3.900 shops and 14,200 houses were burned, while 73.448 residents were left homeless, 52.000 of whom were Jews. (Machaira, 2002).

The arrival of the refugees was the starting point of the spatial and social transformation of Thessaloniki. During the period 1922-1928, the population of the urban area of Thessaloniki (Fig. 1) increased by $37.50 \%$ (Giannakou, 2015).

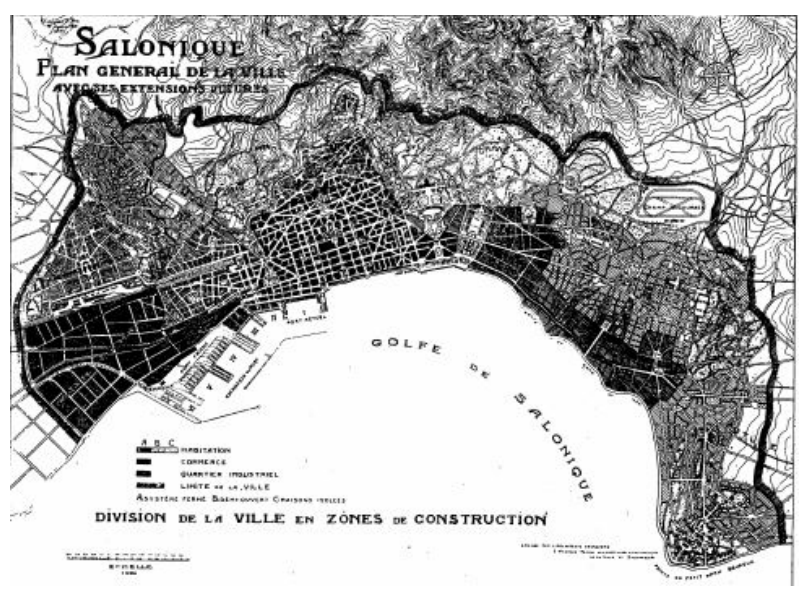

Figure 1: The plan for Thessaloniki by E. Hébrard, 1918 (from Hastaoglou-Martinidis, 1997).

At the dawn of the $21^{\text {st }}$ century, the Macedonian capital, responding and adapting to situations and conditions that are constantly differentiating, is moving towards the future, but its past is evident thanks to the number of monuments that are scattered within the current urban fabric: Hellenistic and Roman antiquities, Byzantine churches with mosaics and frescoes, imposing architectures such as walls, towers, and fortresses, Ottoman mosques, and baths, stand out among multistory apartment buildings, represent the timeless.

The historical site of Ano Poli transformed during the previous centuries. Despite this urban phenomenon, the area keeps the traditional architecture and the memories of the mosaic of urbanism from the ancient/roman, Byzantine, Ottoman period. Nowadays, Ano Poli is a tourist attraction and a place with many elements of the historical background of Thessaloniki. In fact, the modernization of the city shaped the "travel in the history", when the inhabitants, tourists and other people visited Ano Poli.

\subsection{Historical background of the race}

A sports and cultural celebration takes place every year in the Upper City of Thessaloniki. The $5.6 \mathrm{~km}$ road race. Yedi Kule Conquest is organized by SFENDAMOS with co-organizer the Thessaloniki Tourism Organization. The route of the struggle has the peculiarity of highlighting eight monuments of Thessaloniki and specifically: Eptapyrgio, Vlatada Monastery, Saint David, Byzantine Baths, Agios Nikolaos ton Orfanon, Islahane, Pasha Gardens, Tower of Chain.

This sporting cultural route gives life and content to the monuments of the city and turns them into institutions of sustainable development and ambassadors of the history of nature and culture (Diazoma, 2018). The goal of the organizers, in this historical retrospect of centuries, crossing the historical alleys, is the promotion of Ano Poli, with its historical monuments and rich cultural heritage as a tourist destination.

The route starts from the acropolis of Thessaloniki, the Eptapyrgio (Yedi Kule) (Fig. 2), which is identical to the history of the city. It is a very important historical monument, which consists of a polygonal fortress on the northeastern side of the Acropolis and owes its name to its seven rectangular towers. Together with the central 
tower of the entrance, they create a P-shape. It has a total of ten fortification towers while its original layout is placed in the post-Byzantine years. A similar fortress was built in Istanbul at the same time. Following our route, we meet the patriarchal Monastery of Vlatada, also known as Tsaous Monastery, which is one of the most important Byzantine monuments of the city.

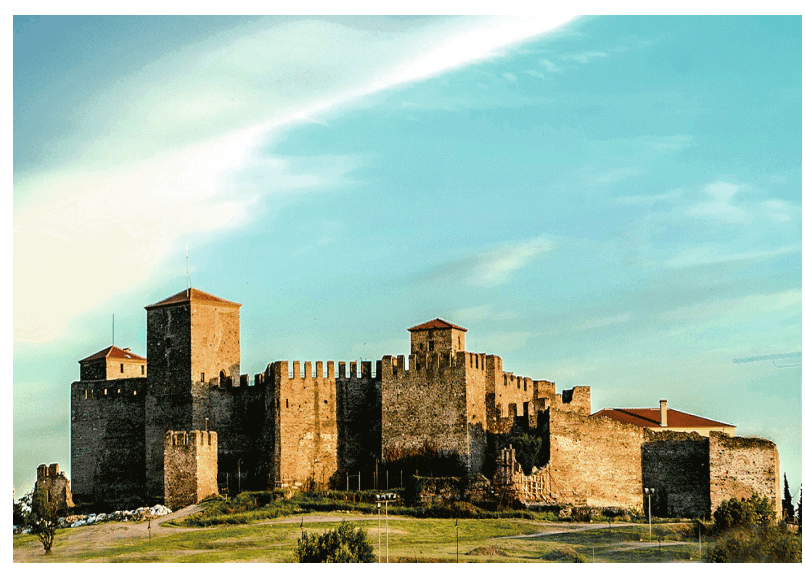

Figure 2: Heptapyrgion- Yedi-Kule: (Thessaloniki tourism Organization, 2020).

On our trip we meet the Temple of Saint David, it is an early Christian monument of great archaeological value, both for its antiquity and the precursor architectural style of the temple (cruciform with a dome), as well as for its interior decoration. (Unesco World Heritage Site, 2020)

The Byzantine baths the Byzantine Bath of Ano Poli is the only Byzantine Bath that survives from the mid-Byzantine or late Byzantine period in Greece and one of the few surviving secular buildings of that time. Its value as a monument is great and its urban position holds important.

Of unparalleled value and beauty is the Church of Agios Nikolaos of Orfanos is an old Byzantine monastery of Thessaloniki and a World Heritage Site, built in the early $14^{\text {th }}$ century. It is located in the northeast corner of Ano Poli, within the walls, between Herodotou and Apostolou Pavlou streets.

In the middle of the eastern walls of the city, near the New Golden Gate, dominates the School of Arts and Professions Hamidie, or Islahane of Thessaloniki, or otherwise Polytechnic Midat Pasha. It is the first complex of an orphanage - technical school in the city during the last period of Ottoman rule in Thessaloniki, an illustrative example of the reforms undertaken by the Ottoman Empire during the Tanzimat period (1839-1876), but also of the wider modernizing educational trends of the time.

A sample of Fantastic Architecture from the era of eclecticism, we enjoy in the Gardens of Pasha. It is a fenced park that occupies an area of about 1000 sqm. On the northeast side of the walls of Ano Poli is one of the most important historical, morphological and architectural monuments of Thessaloniki, it is the Tower of Chain or the Belted Tower.

And this is probably due to the stone decorative strip, which surrounds the trunk of the Tower like a chain. It was built to strengthen the fortification of Thessaloniki. The runner of Yedi Kule Conquest followed the material and intangible traces of Ano Poli of Thessaloniki and breathed the air of 2,500 years of history and culture through a modern integrated cultural-sports route.

\subsection{The Coronavirus pandemic crisis as a factor of delay}

The rapidly spreading of Coronavirus caused the Greek government to take measures against it. The most serious measure was the lockdown from March 2020 until May 2020. During that period the University was closed and everything was in online progress. That was also the case for this research, which faced a big delay due to unpredictable circumstances.

There were online meetings and the data processing took more time than it was scheduled. Even transportations were suspended and the research team could not visit the places where the race is going to take place. Nevertheless, people have the "privilege" to live in the first global crisis of the digital world and it looks like they have more tools to overcome the crisis than our ancestors had when facing health crisis or other crisis in their day. Talking about "tools", our communities use social media which can inform (either in a positive or negative way) people. Health crisis gave motive to a unique and global research, part of which concluded that civilians started to support public authorities more than before (Merkley et al, 2020; Harell, 2020; Bol, Giani, Blais, \& Loweven, 2020). Research showed that lockdowns had a positive effect on support for democracy (Bol, Giani, Blais, \& Loweven, 2020). The same think (political support) has been observed after a major crisis such as a terrorist attack (Hetherington, \& Nelson, 2003; Balcells \& TorratsEspinosa, 2018).

In our case, what we expect is that the restrictions imposed by the health crisis and the government, which include among others, social distancing and less audience (people attending the race) will have an impact on the monitoring of the race (under the framework of the, so-called, political support). People will try to follow the instructions for attending the race virtually. In order to overcome the problem, we decided to build the trace of the race onto a $3 \mathrm{D}$ image of the area.

\section{Introduction in Google Earth Studio}

Google Earth Studio is one of the most popular Google Earth and virtual globe applications that offer most of the planet free access to high-resolution imagery. According to scientific indexes, Google Earth (GE) has been downloaded more than 1 billion times on desktop and mobile clients since the introduction of the Google Earth software in 2005 (Guo et al., 2020).

Google Earth Studio is a browser-based animation platform for Google Earth 3D and satellite imagery that is unique and distinct. From large-scale geological features to individual city buildings, Google Earth has a vast store of $2 \mathrm{D}$ and $3 \mathrm{D}$ Earth data. The best way to utilize this imagery for still and animated material is with Google Earth Studio.

We based Google Earth Studio on industry-standard animation software, so it can be picked up by motion professionals and started to animate immediately. Helpful tools like Quick Starts make it possible, extremely quickly, for anyone to create beautiful animations. This documentation includes a detailed overview of the 
features of Earth Studio, as well as tips on how to use the product to produce the best-looking results quickly (Google Earth Studio, 2020).

Google Earth (GE) is a software developed by Google for the virtual world. On a three-dimensional model of the earth, it arranges satellite images, aerial photographs, and GIS.

\section{Methodology}

\subsection{Main steps}

The working group used Google Earth Studio in order to proceed with the project. Initially, a license was requested by the company, so the online software could be used for scientific purposes and more specifically, for the construction of the three-dimensional map. The design of the project followed these steps:

- Draw the race route in the GIS GRASS software.

- Connect the digitized race route to Google Earth Studio software.

- Delimitation of the study area with appropriate location of the camera station.

- Draw the map with successive overlaid images.

- Place labels in every point of historical and cultural interest.

- Render of the successive images.

The result is a three-dimensional video map, which highlights the architectural and urban planning ensembles of the study area. The importance of the sporting event, which is organized under the auspices of the municipality of Thessaloniki, contributes to the promotion of the history of the study area.

\subsection{Camera Targeting}

The camera is located to a steady place and the view angle changes respectively in accordance to/and following the route of the race from the start to the middle and up to the end of it.

A major challenge the working group had to face was the relationship that occurs between the point where the camera was located and the points of the route because the distance between each of these points and the camera was constantly changing, Eq. 1 :

$X+d_{1} \neq X+d_{2}$

For each $d(1,2,3 \ldots \mathrm{n})$

For each $P(1,2.3 \ldots . n), P \in N$

where

$$
\begin{aligned}
& X=\text { the location of the camera } \\
& d=\text { the distance between } X \text { and } P \\
& P=\text { the projected point of the camera onto the }
\end{aligned}
$$

map

The distance, in parallel to the height of the buildings, raised problems as for the high definition of the video. The working group solved this problem by adding:

- The camera in the middle of the circular route of the race and
- After a number of tests, a limited range was chosen between the lower and upper viewing angle of the animation of the race.

Finally, the video analysis has the following characteristics relative to the quality of the project (Table 1).

Table 1: The characteristics of the animation

\begin{tabular}{c|c} 
Setting of video & Size \\
\hline Length & $00: 04: 12$ \\
Frame width & 1000 \\
Frame height & 562 \\
Data rate & $6421 \mathrm{kbps}$ \\
Total bitrate & $6738 \mathrm{kbps}$ \\
Frame rate & $29.97 \mathrm{FPS}$
\end{tabular}

\subsection{The analysis of methodology}

The three-dimensional video aims at the digital documentation and recording of the historical monuments and buildings in the area. It is a way of digital representation and storage of the sporting event and the cultural wealth of the traditional quarter of Thessaloniki (Fig. 3):

1) The design of the route with GRASS, is important for the race route delimitation. The construction of the route was under World Geodetic System (WGS84) in order to be compatible with Google Earth Studio. The race route was digitized on-screen with a distinct colour to stand out on the map.

2) The first step of the design process was to upload the race route into Google Earth Studio. The coordinate system must be the same to get a successful connection of the race route to the background of the map. The digitization of the route was done to limit the study area.

3) The next step was the installation of the camera station. It was crucial for the camera placement to be installed both in a conspicuous position from the points of interest and in the middle of the circular race route for two reasons:

- The final product should be attractive with the simplicity and clarity of information.

- The cultural points of interest should be wellpresented.

4) The design of the three-dimensional map was based on the successive overlaid photos. Both the overlay between two consecutive photos and the subsequent one must be large enough. This created a better synthesis between images for the next step of rendering. Also, the creation of images was done with small consecutive tracks of the camera, which were timed sequentially (Fig. 4). 


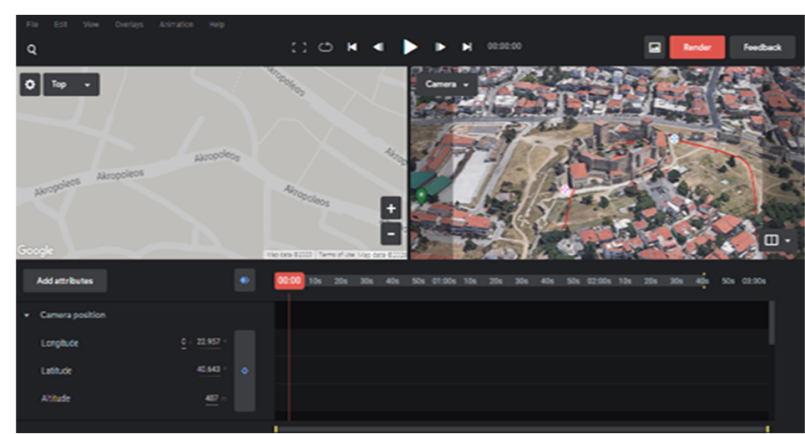

Figure 3: Transition from 2D to 3D (snapshot from the Google Earth Studio).

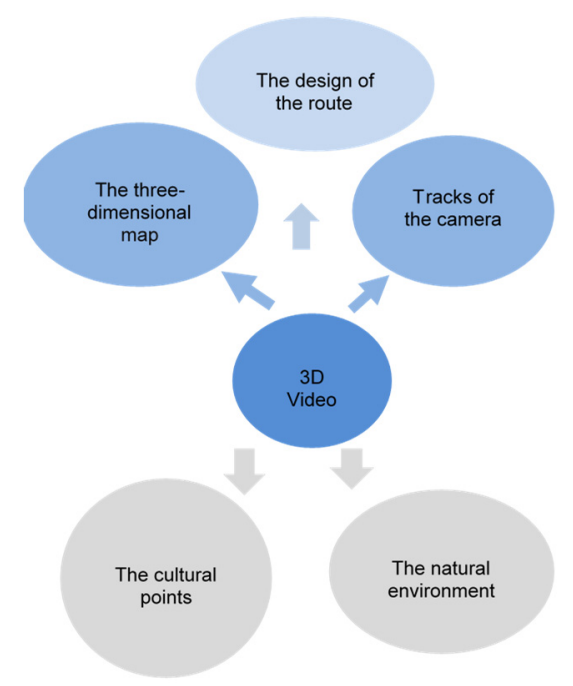

Figure 4: Technical sets for the 3D video and sites of interest.

One challenge faced by the working group was the clarity of all points. The main factor that contributed to the sharpness was the fixed camera located in the middle of the map of the study area. Besides that, the angle of shooting was slightly shifted, without changing the orientation of the map.

The route of the race was circular, resulting in the 60 degree angles, which was the biggest problem for the presentation of the area. Finally, putting labels on the historical sites was an important task for making the map more attractive.

\section{Results}

\subsection{Summary of the project}

The purpose of this paper is interdisciplinary. Initially, the work generates data, which are capable of recording cultural heritage. In addition, 3D video preserves the cultural value of the architectural landscape, monuments and natural environment in 3D geospatial representation (Landes, Grussenmeyer, Voegtle, \& Ringle, 2007).

The final video transforms the $2 \mathrm{D}$ track into $3 \mathrm{D}$ panoramic viewing. The advantages are the speed in the rotation of the video, the panoramic viewing of the area, the capture angles and the focus on points of cultural and architectural interest. (Emmanuel \& Grussenmeyer, 2012). Finally, the virtual tour was created during the pandemic without on-site recording.
The 3D mapping animation for the race purposes is innovative, because it is a multi-factor result of the following indexes:

1) Records part of the outdoor area.

2) Designs the route of the race.

3) Promotes the historic sites of Thessaloniki city.

4) Analyzes the historical background of the old - city.

5) The methodology uses a wide - range software with low - cost construction.

6) Human vision is made for a $3 D$ world and thus can easily deal with the relative position of natural and man-made characteristics when shown in an animation. Even more so when the animation is 3D.

The procedure started with the delimitation of the route of the race. For this purpose, we used GRASS GIS for the construction of a shapefile under WGS84 coordinate system. This system is the same that Google Earth Studio uses and helps the layer to overlay correctly on Google's imagery. Then, the transformation from $2 D$ images to $3 D$ with successive and overlapping snapshots was designed and the rendering process for the union of successive images resulted to the final product of a $3 D$ animated map.

\subsection{Photograph's Snapshots of the 3D Mapping}

The photos show snapshots from the video. They are from the beginning of the race (Fig. 5) and follow the route to the finish (Fig. 6), through the transition zone of Old and modern City (Fig. 7) and the border between the Old and modern City (Fig. 8). The route is of very significant cultural value, with monuments, landfills, administration buildings, green spaces (Fig. 9). The route bridges the history of three civilizations with modern elements for example urban regeneration, and hiking.

Finally, the athletes and the visitors of the race play in a creative way knowing the history, the culture of the area. The innovation of the Municipality of Thessaloniki promotes participation, fair play, and the noble rivalry between the athletes.

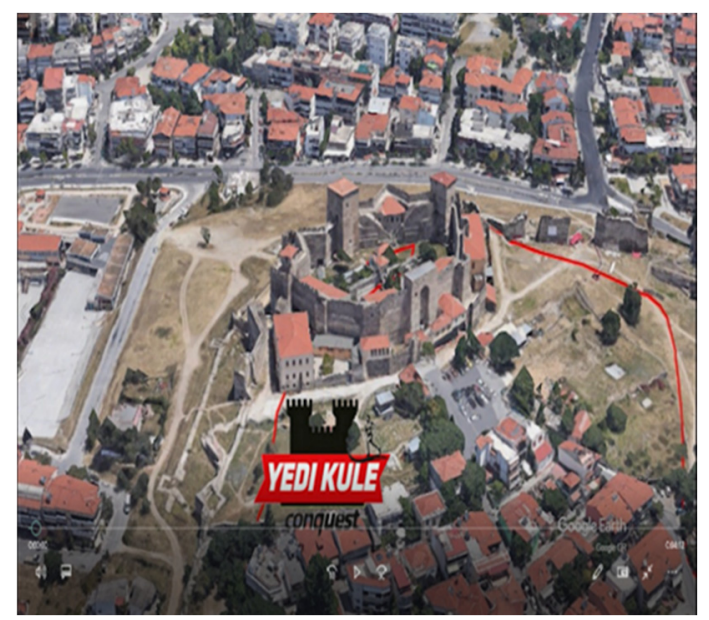

Figure 5: The beginning of 3D Mapping (snapshot from Google Earth Studio) 


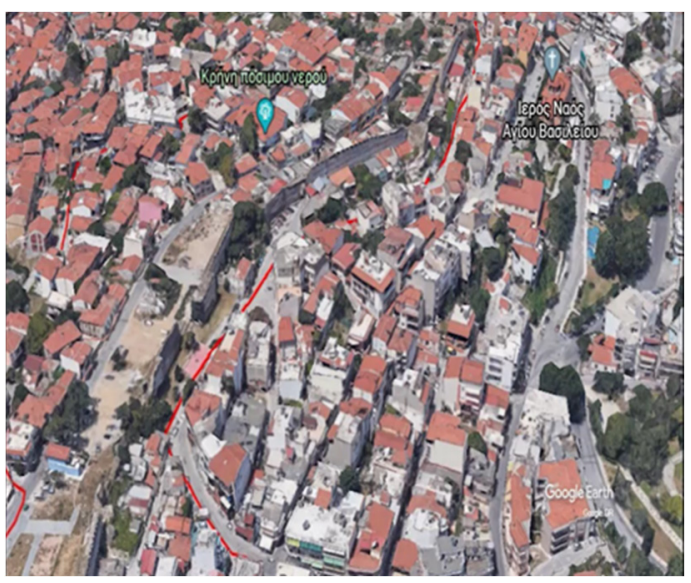

Figure 6: At the middle of the route (snapshot from Google Earth Studio).

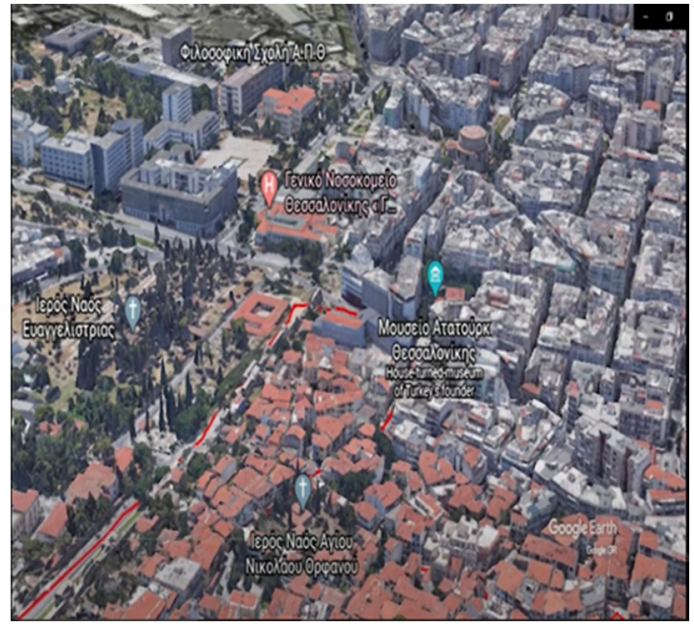

Figure 7: The lower location of the race (snapshot from Google Earth Studio).

\section{Conclusion}

Documentation is a specific component of the preservation chain since it contains all the details required to clarify the item in question and contributes to the implementation of the best safeguarding practices. Some form of protection of cultural heritage is assured through documentation. It also acts as an instrument for practitioners and experts, public bodies and the general public to interact and raise awareness (Stylianidis, 2019). The application of the Google Earth Studio covers the gap between the construction of the 3D Mapping in the online environment and the animation of the digital map. The result is based on the right use of the scientific methodology of the Google Earth Studio and also the scientific documentation about the history of the area and city history. This way, the 3D animation enhances the digital representation of the cultural route and all the monuments and important sites found on the race route.

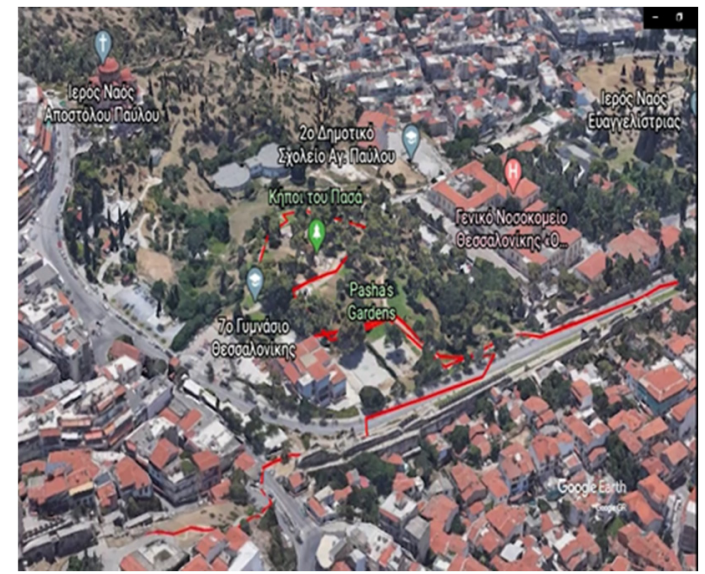

Figure 8: The castle and the green space (snapshot from Google Earth Studio).

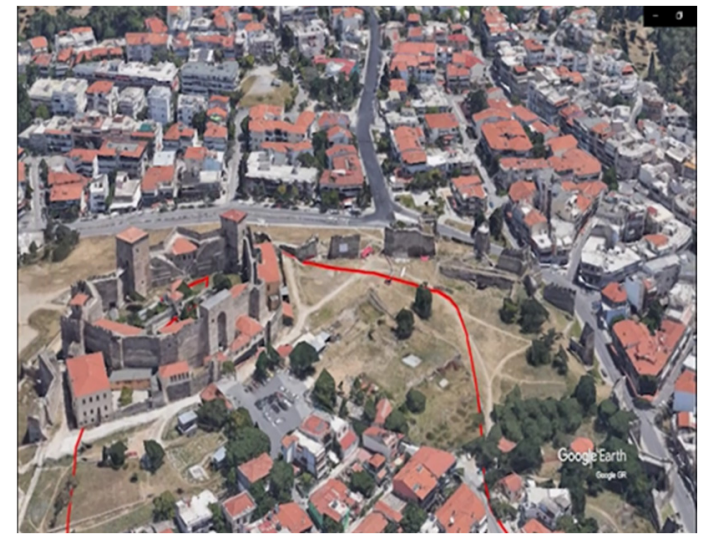

Figure 9: The end of the race (snapshot from Google Earth Studio).

\section{References}

Anastasiadis, G. (2011). Chronologio of Thessaloniki Part II. Thessaloniki on Polis, March 2011, p. 13.

Benbassa, E., Rodrigue, A., \& Jewry, S., (2000). A History of the Judeo-Spanish Community, $14^{\text {th }}-20^{\text {th }}$ Centuries. University of California Press, Los Angeles.

Balcells, L., \& Torrats-Espinosa, G. (2018). The electoral consequences of terrorism: Evidence from a natural experiment. Proceedings of the National Academy of Sciences 115(42), 10624-10629.

Bol, D., Giani, M., Blais, A., \& Loweven, J. P., (2020). The effect of COVID-19 lockdowns on political support: Some good news for democracy? European Journal of Political Research. https://doi.org/10.1111/1475-6765.12401

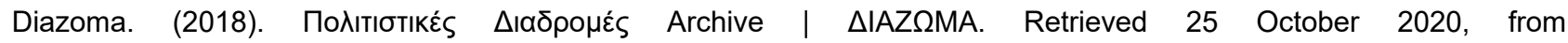
https://www.diazoma.gr/cultural-routes/

Emmanuel, A., \& Grussenmeyer, P. (2012). From point cloud to 3D model, modelling methods based on architectural knowledge applied to fortress of Chatel-sur-moselle (FRANCE). International Archives of the Photogrammetry, Remote Sensing and Spatial Information Sciences, XXXIX-B5. https://doi.org/10.5194/isprsarchives-XXXIX-B5-75- 
2012

Gerolympou-Karadimos, A. (1995). The reconstruction of Thessaloniki after the fire of 1917, Thessaloniki Ed. University Studio Press.

Giannakou, A. (2015). Land policy programs in Thessaloniki from the interwar to the 1960s: The transition to a modern metropolitan area. In: D. Kiridis (Ed.), Thessaloniki: a city in transition 1912-2012. Thessaloniki: Epicenter A.E, pp. 487-488.

Google Earth Studio. (2020). Introducción - Google Earth Studio. Retrieved 28 October 2020, from https://earth.google.com/studio/docs/

Gregoriou, A. X., \& Hekimoglou, E. (2008). Thessaloniki of travelers 1430-1930: choices of texts and testimonies. Athens. Miletus and Society of Macedonian studies.

Guo, J., Zhang, J. X., Zhao, H. T., Li, C., Zhou, J., Tu, H. J., \& Zhao, Y. (2020). Horizontal accuracy assessment of Google Earth data over typical regions of Asia. Int. Arch. Photogramm. Remote Sens. Spatial Inf. Sci., XLIII-B3-2020, 13331338. https://doi.org/10.5194/isprs-archives-XLIII-B3-2020-1333-2020

Harell, A. (2020). How Canada's pandemic is shifting political views. Report for the Institute for Research on Public Policy. Retrieved May, 19, 2020 from https://policyoptions.irpp.org/fr/magazines/avril-2020/how-canadaspandemicresponse-is-shifting-political-views/

Hastaoglou-Martinidis, V. (1997). A Mediterranean City in Transition: Thessaloniki between the Two World Wars. Facta Universitatis, Ser. Architecture and Civil Engineering., 1(4), 493-507.

Hetherington, M.J., \& Nelson, M. (2003). Anatomy of a rally effect: George W. Bush and the war on terrorism. PS: Tania

Landes, T., Grussenmeyer, P., Voegtle, T,. \& Ringle, K. (2007). Combination of Terrestrial Recording Techniques for 3D Object Modelling regarding topographic constraints. Example of the Castle of Haut-Andlau, Alsace, France.. XXIth CIPA International Symposium, Oct 2007, Athenes, Greece. pp.435-440. halshs-00264855 Political Science \& Politics, 36(1), 37-42.

Mazower, M. (2006). Thessaloniki, city of ghosts: Christians, Muslims and Jews, 1430-1950. 1st Ed. Athens. Alexandria.

Machaira, A. (2002). Thessaloniki of the interwar period. History of Greece of the $20^{\text {th }}$ century, 1922-1940. In: X. Hatziosif (Ed.), The Interwar. Athens. Bibliorama, pp.107-131.

Merkley, E., Bridgeman, A., Loewen, P.J., Owen, T., Ruths, D., \& Zhilin, O. (2020). A rare moment of cross-partisan consensus: Elite and public response to the COVID-19 pandemic in Canada. Canadian Journal of Political Science, First View.

Pierron. (2004). Jews and Christians of modern Greece. History of intercommunity relations from 1821 to 1945. Polis.

Strabon. (1992). Geographia 7. Kaktos Publ., Athens (in Greek).

Stylianidis, E. (2019). CIPA - Heritage Documentation: 50 Years: Looking Backwards, Int. Arch. Photogramm. Remote Sens. Spatial Inf. Sci., XLII-2/W14, 1-130. https://doi.org/10.5194/isprs-archives-XLII-2-W14-1-2019

Thessaloniki tourism Organization (2020). Thessaloniki Tourism - Heptapyrgion - Yedi Kule. Retrieved 30 September 2020 , from https://www.thessalonikitourism.gr/index.php/en/component/k2/item/107-heptapyrgion-yedi-kule

Unesco World Heritage Site. (2020). Paleochristian and Byzantine Monuments of Thessalonika - UNESCO World Heritage Centre. Retrieved 20 October 2020, from http://whc.unesco.org/en/list/456/

Vakalopoulos, A. (1983). History of Thessaloniki 316 P.X -1983. Thessaloniki. Altintzis Publications. 


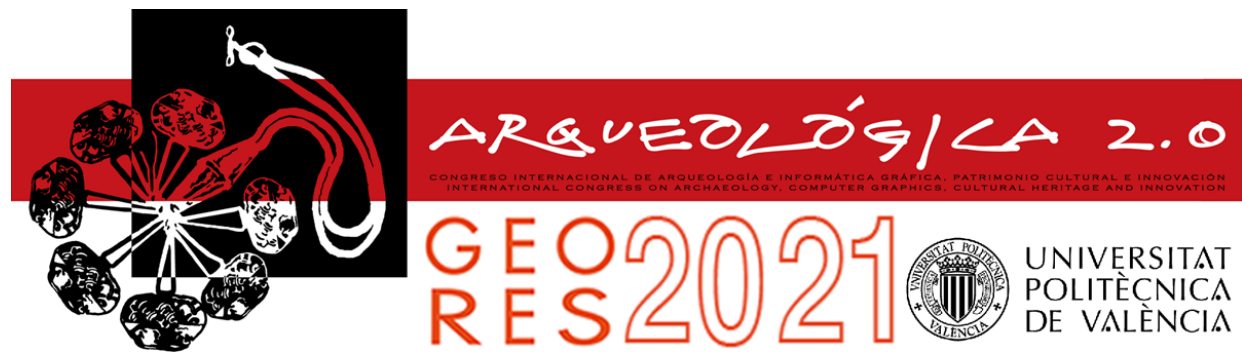

Proceedings of the joint international event $9^{\text {th }}$ ARQUEOLÓGICA

$2.0 \& 3^{\text {rd }}$ GEORES

Valencia (Spain).

26-28 April 2021

\title{
THE ETRUSCAN CITY GATES OF PERUGIA: GEOMATIC TECHNIQUES FOR THE DOCUMENTATION AND STUDY OF AN URBAN HISTORY HERITAGE
}

\author{
Fabio Radicionia, ${ }^{*}$, Pietro Matracchi ${ }^{b}$, Aurelio Stoppinia ${ }^{a}$, Grazia Tosia $^{\mathrm{a}}$, Laura Marconi ${ }^{\mathrm{a}}$ \\ a Department of Engineering, University of Perugia, Via G. Duranti 93, 06125 Perugia, Italy. fabio.radicioni@unipg.it; \\ aurelio.stoppini@unipg.it; grazia.tosi@unipg.it; laura.marconi@collaboratori.unipg.it \\ b Department of Architecture, University of Firenze, Via della Mattonaia 8, 50121 Firenze, Italy. pietro.matracchi@unifi.it
}

\begin{abstract}
:
The Engineering Department of the University of Perugia and the Architecture Department of the University of Florence have started a research project on the ancient city gates of Perugia, belonging to the Etruscan city, dating between the third and second centuries B.C., and to the subsequent city wall completed in the twelfth century. In this paper, focus is placed on three Etruscan gates - Porta Eburnea (also called Porta della Mandorla), Porta Cornea and Porta Trasimena which have in common profound Middle Age transformations and further significant context changes following the loss of function as defensive walls. Due to the decommissioning of this urban infrastructure, the gates have assumed a marginal role; nowadays they are almost completely absorbed by residential buildings, almost losing the memory of their origins and of the important Etruscan remains that are still preserved in the gates. Geomatic surveys on the three Etruscan gates were carried out by the Geomatics Laboratory of Perugia University in the frame of a research project financed by the Cassa di Risparmio di Perugia Foundation. The survey was carried out by means of a coordinated use of more Geomatic techniques: GNSS, Total Station, Terrestrial LIDAR and Digital Photogrammetry. From LIDAR and photogrammetry were derived dense point clouds, beside CAD plans, sections and elevations. The information acquired with these detailed surveys provide a completely new and accurate documentary evidence of the gates' consistency, allowing to identify the actions and interventions that have changed their structure over time.
\end{abstract}

Keywords: cultural heritage, 3D reconstruction, laser scanning, digital photogrammetry, restoration, Etruscan walls

\section{Introduction}

The research project concerned the urban gates of Perugia, belonging to the first walls of the Etruscan city, which can be dated between the $3^{\text {rd }}$ and $2^{\text {nd }}$ centuries B.C., and the subsequent wall circle erected to protect the urban development of the medieval era and substantially completed in the $12^{\text {th }}$ century (Begni, 1956; Fiocca, 1918).

In this paper, the focus was placed on three Etruscan gates - Porta Eburnea or della Mandorla, Porta Cornea and Porta Trasimena - united by profound transformations from the Middle Ages and further incisive changes in context that followed the loss of the defensive function of the walls. The decommissioning of this urban infrastructure has placed the gates in a marginal role; today they are almost completely engulfed by residential buildings, making them almost lose the memory of the origins and the important Etruscan remains that are still preserved in them (Calderoni, 1977).

The studies on the gates to date have been limited to the observation of partial architectural aspects and considerations carried out on an urban scale that link the gates to the history of the city of Perugia (Bilancia 2015; Fiocca, 1926).

The purpose of this research is to document the gates with detailed surveys that highlight their architectural peculiarities and their state of conservation. In particular, the laser scanner surveys here presented have been carried out for the first time with such technique on the three gates. The Perugia gates are monumental and complex historical manufacts, characterized by a remarkable height compared to the narrow internal and external adjacent spaces.

The study of the gates presented in this paper, in addition to highlight the traces left by complex construction events, such as the inscriptions engraved in the reused ashlars, has deepened the knowledge on the further relevant transformations that the Etruscan structure of the Eburnea, Cornea and Trasimena gates have undergone over time.

The original remains, the reused materials, the vast medieval reconstructions and the still subsequent $19^{\text {th }}$

`Corresponding Author: Fabio Radicioni, fabio.radicioni@unipg.it 
century contributions of these architectural artefacts, have been identified, highlighting the effects of the subsequent restoration interventions.

For decades now, Geomatics, thanks to its increasingly advanced and powerful survey techniques, has played a fundamental role in the documentation of cultural heritage all over the world (Balletti, Costa, Guerra, Martinello, \& Vernier, 2018; Hatzopoulos et al., 2017; Radicioni et al., 2017; Tucci, Bonora, Fiorini, \& Conti, 2016; Grussenmeyer, Landes, Voegtle, \& Ringle, 2008).

The present survey on three Etruscan gates was performed by a coordinated integration of the following techniques of applied Geomatics:

- GNSS positioning, for a general georefencing of the gates and the surrounding areas and buildings in a global datum (the European datum ETRF2000);

- Three-dimensional (planimetric-altimetric) local networks measured with terrestrial methods, for the accurate georeferencing of targets (to be used for LIDAR point clouds registration) and architectural details of the manufacts;

- $\quad$ Terrestrial LIDAR, for the detailed survey and 3D reconstruction of all external surfaces and most of the internal spaces;

- Digital photogrammetry, for an integration and/or an alternative to the LIDAR survey.

From LIDAR and photogrammetry were derived dense point clouds, accurately describing the external and internal geometry of the manufacts. Data provided by the point clouds were then processed in order to obtain detailed plans, sections and elevations with CAD software.

The information acquired with these detailed surveys provide documentary evidence of the doors consistency for the first time, allowing identifying the actions and interventions that have changed their structure over time.

\section{The Etruscan Wall and its gates}

The first Etruscan urban settlement characterized by a strong urban connotation, dating back to the $8^{\text {th }}$ century B.C., is certified by an extended masonry now incorporated in the hypogeum spaces of the Capitular Museum of the Cathedral of San Lorenzo. It was an extensive embankment where the acropolis of Perugia developed.

The Etruscan city wall, dated between the third and the early $2^{\text {nd }}$ century B.C., developed for over $3 \mathrm{~km}$ on the edge of two hills, Colle Sole and Colle Landone, with a path that followed the slopes orography (Nicolini, 1986; Defosse, 1980). The city wall was built with square travertine blocks placed on fairly regular rows, dry-walled, without mortar (Giambi, 2004; Amorini, 1996).

The siege led by Octavian in the winter of $41-40$ B.C. caused the fall of the city and its consequent raid and damage. With the reconstruction, the city took the name of "Augusta Perusia" and the city power was entrusted to the most powerful family, the Vibi. In the $3^{\text {rd }}$ century B.C., Emperor Vibio Treboniano Gallo, born in Perugia, reigned from 251 to 253 B.C. (Cotana, 2012).
The study of the city gates, in addition to examining some traces left by these events, such as the inscriptions engraved in the ashlars, investigated the further significant transformations that the Etruscan layout of the gates underwent over time. The original remains, the materials reused, the extended medieval transformations and the still subsequent contributions (perhaps made by restorers) of these architectural artifacts, characterized by modest size but very complex in terms of the incurred modifications, have been identified (Fig. 1).

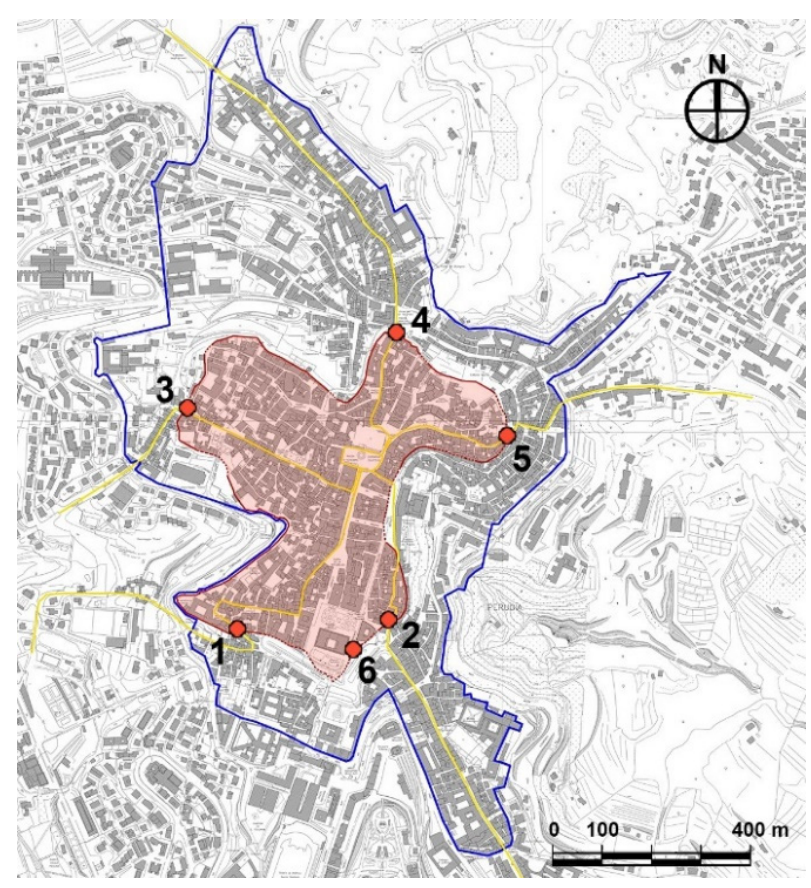

Figure 1: Map of Perugia city with the layout of the Etruscan and Medieval walls and collocation of their gates: 1. Porta Eburnea; 2. Porta Cornea; 3. Porta Trasimena; 4. Porta Augusta; 5. Arco dei Gigli; 6. Porta Marzia.

\subsection{Knowledge and interpretation}

The new surveys of the wall facings and the 3D models, which had never been realized before for these city gates, made possible an accurate analysis and study of their construction features. It was possible to highlight many relevant aspects and themes thanks to the particular technical characteristics of the survey, which combines an accurate three-dimensional description of the geometry with a high definition in the representation of the surface textures.

The materials, the state of conservation, the different stone workmanship, the way the rows were laid, the homogeneity and inconsistency in the masonry techniques were carefully identified. All these information highlighted aspects that can be attributed to various worksite practices. This led to the interpretation of the gates' current structure as a palimpsest of interventions from different periods.

The main phases identified concern the remains of the Etruscan walls and the medieval modifications, which were achieved in some cases with the reuse of Etruscan stone material. In more recent times, at the top of the walls some adaptations to everyday living have been made, e.g. by creating small terraces connected to the adjacent houses. Some portions of the walls, apparently belonging 
to the original structure, can be identified as restoration works.

\subsection{Porta Eburnea (or Arco della Mandorla)}

Porta Eburnea shows great part of the Etruscan walls on the side that corresponded to the outside of the city.

The masonry consists of large squared ashlars laid in continuous rows, from about 55 to $62 \mathrm{~cm}$ high. An additional wall parallel to the road that crosses the door is connected to the gate wall.

In the first section of this masonry, ashlars of similar size to those of the gate were used; in the following part, ashlars of lower height overlap forming a retaining wall. These walls are probably attributable to the Etruscan period. However, also due to the discontinuities that characterize the foundations, the retaining wall seems to be placed in a different construction phase.

The large ashlars facing in the vaulted gateway is interrupted to then be present again on the inner side of the city walls; the interrupted part corresponds to the internal corner of the gate which was subsequently rebuilt. Anyway, the remaining Etruscan wall on three sides outlines the original overall dimensions of the sidewalls of the gate.

A further important evidence shows on the most unaltered side of the Etruscan gate. In the highest part, the ashlars are set back from those below; they are interrupted in each row by tracing a curved line profile, which corresponded to the extrados of the original arch that adorned the side of the entrance to the city. Assuming the primitive arch was a semicircle, the remaining extrados curve would suggest a greater width Etruscan gate than the current one (Fig. 2).

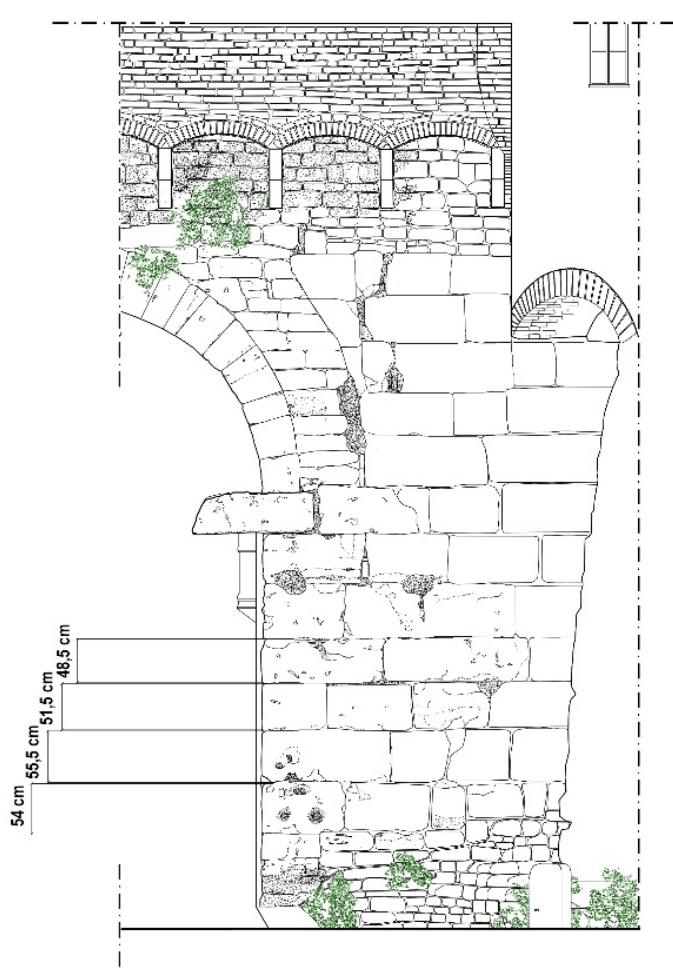

Figure 2: Detail of the gate side with the trace of the original arch and the size of the ashlars in different rows.
The present context does not explain the different state of conservation between the two Etruscan walls sides, of which the internal one is considerably worse (Fig. 3). This is probably due to particular conditions which existed in the past and which have changed over time.

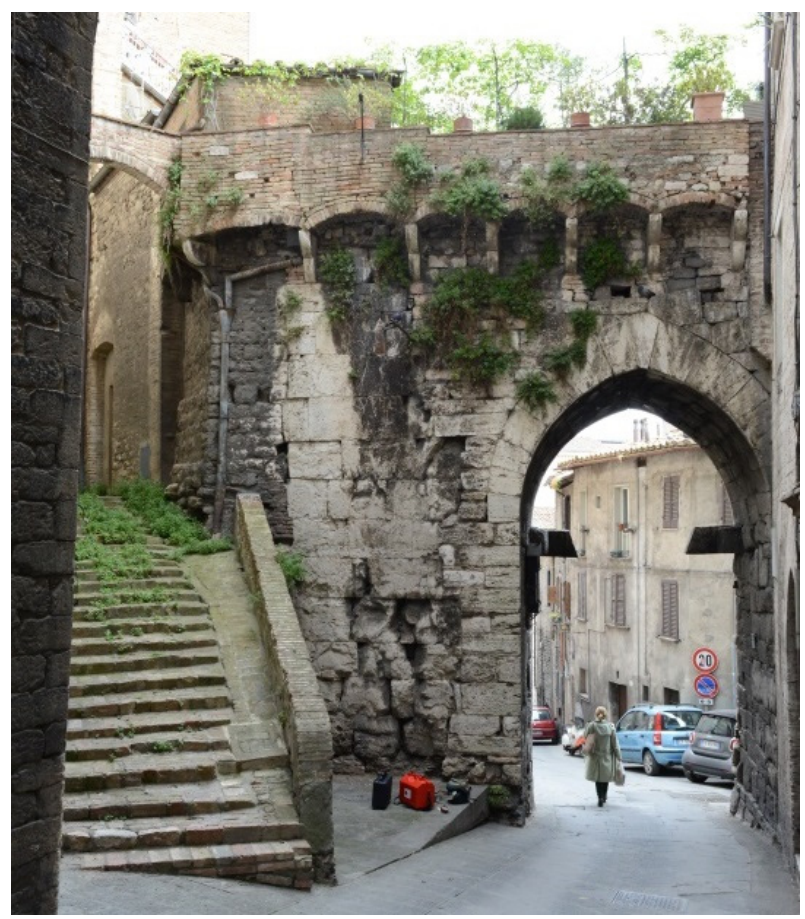

Figure 3: Porta Eburnea, internal side.

In the best-preserved parts, the facing shows a refined thin joints working. Sometimes the vertical joints have a slight incline, perhaps in order to obtain a jack arch effect helping to create connections between adjacent ashlars of the same row.

The inner side of the remaining gate abutment was completely absorbed by the expanded urban area, aligned today with the vaulted gateway.

The sides below the arch and outside the walls are all visible. In this case the masonry is heterogeneous, with variable-sized ashlars and discontinuous rows. On the external side in particular, the larger ashlars are in the lower part and near the gate arch; the remaining part is more homogeneous for the use of small ashlars on more regular courses.

Some of the larger ashlars are probably reused materials from the pre-existing Etruscan gate. This is particularly evidenced by the ashlars with engraved letters. "VIB" is engraved in an ashlar probably referring to the word "COLONIA VIBA". In an ashlar, an "S" engraving preceded by the trace of a further letter, probably a "U", would suggest letters belonging to one of the two words writing "AUGUSTA PERUSIA". These signs are recurring in the Etruscan wall gates, such as the Etruscan Arch or Porta Marzia (Gigliarelli, 2016; Marcaccioli, 2014).

The gate is also characterized by a Florentine pointed arch with two very protruding ashlars with diagonal termination at the external side impost, on which a further ashlar was to rest forming a jack arch lintel. Close to this lintel there is a stone hinge on each side, with a horizontal hook, in which the wooden doors that closed the gate could rotate, leaning on the architrave itself. 
The Etruscan period was then followed by a deep reconstruction during the Middle Ages, with a consequent reduction of the original gate width and the re-use of part of the travertine ashlars. The Etruscan remains of the Porta Eburnea and the exposed foundations of the Etruscan walls continuing outside on Via San Giacomo, would suggest that the Etruscan layout was maintained during the gate medieval reconstruction, but at the same time the Etruscan walking levels had to be lowered (Fig. 4).

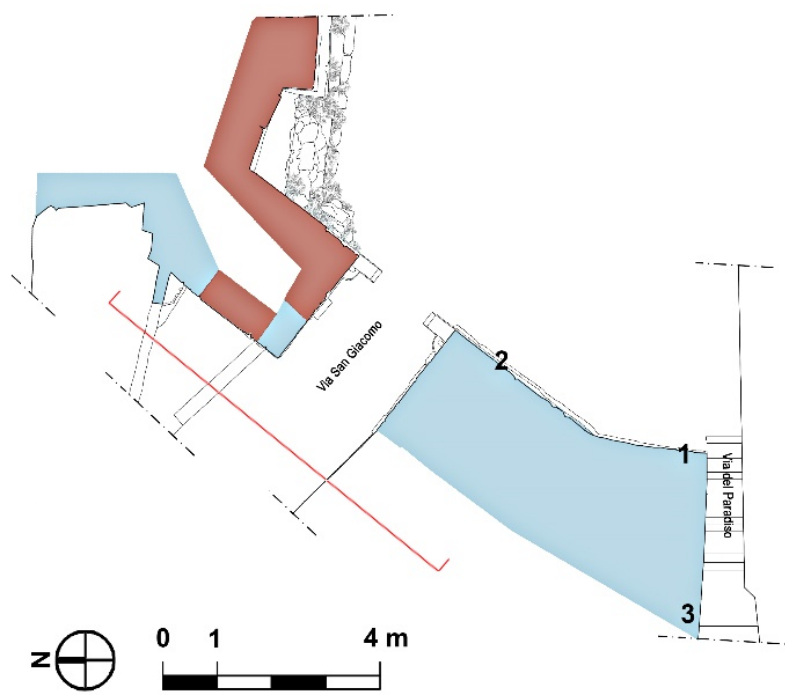

Figure 4: Plan of Porta Eburnea with the original Etruscan parts in red. 1, 2, 3 Etruscan ashlars with epigraphs reused during medieval period (light blue).

The gate corbelled crowning, with double quarter-circle stone corbel on which segmental arches and brick parapets rest, are to be considered a later intervention. The corbels are perhaps due to a restoration; while the construction of a connection or a terrace for private residential use on the gate crowning could still be later, as the final act of a long urban development process, almost completely absorbing the Porta Eburnea (Fig. 5).

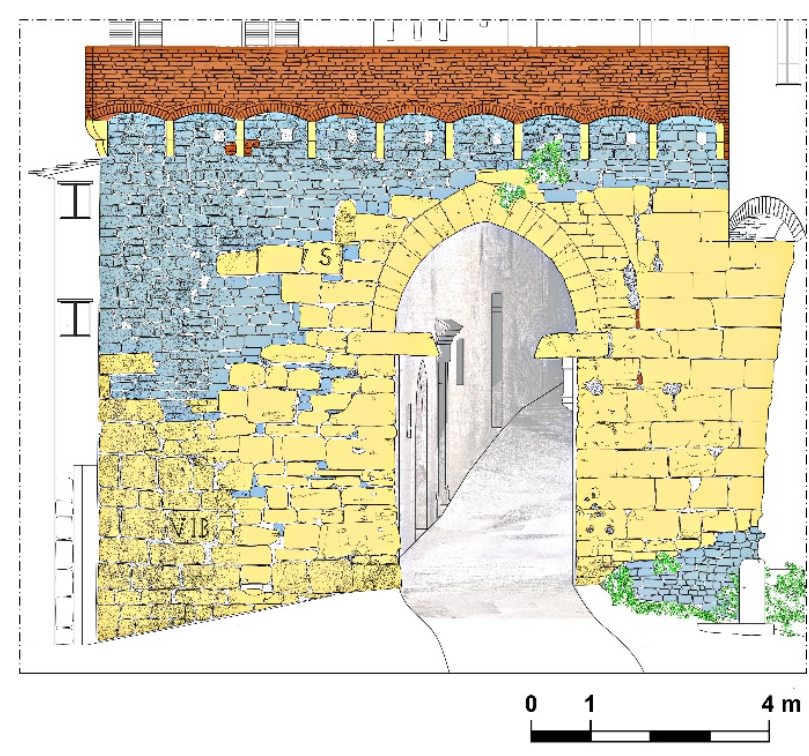

Figure 5: External front of the gate with highlighted the ashlars in travertine (yellow), limestone (blue) and the brick parts (red).

\subsection{Porta Cornea}

In via Sant'Ercolano, near the homonymous church, there is Porta Cornea, also known as Arco di Sant'Ercolano, Porta Berarda or Comitoli (Marcaccioli, 2015).

One abutment of the gate is almost completely incorporated by the progressive extension of the buildings; the side below the arch and a small section of the side towards Sant'Ercolano church are still visible. The other abutment of the gate emerges from the surrounding building for a short distance about 1 meter deep. On this same side, above the small building that leans against the external side of the gate, a portion of the walls with large travertine ashlars survives, dating back to the Etruscan period (Fig. 6).

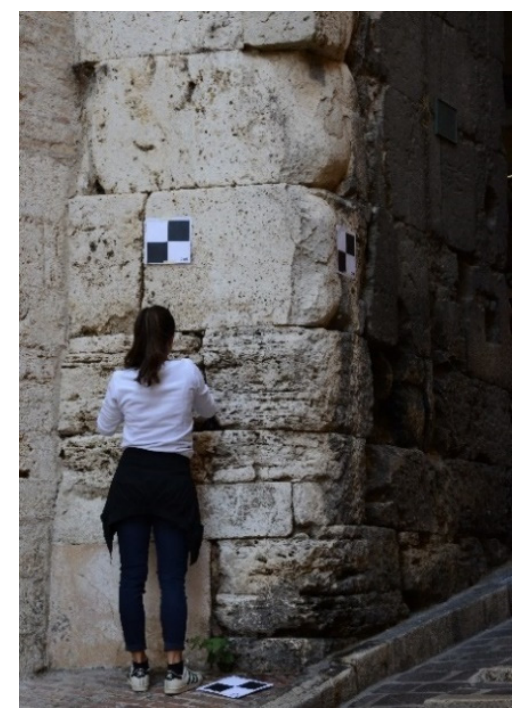

Figure 6: Porta Cornea, detail of the large ashlars.

This section of the wall shows a rotation with respect to the position of the gate. The abutment on the same side does not have a rectangular but slightly slanted plan. The gate opening has a mostly unvaried width.

However, the two sides of the gate differ in one important aspect. The almost completely incorporated abutment has the external side with an evident retaining wall profile in the upper part, created by the retreat of each row with respect to the one below. This feature is missing in the lower part due to the alterations related to the creation of ground floor access of the adjacent building (Fig. 7).

The other wall of the gate does not present this feature in an equally marked way; it has an apparently smooth profile, with undetectable projections between one row and another, but recorded by the laser scanner survey. However, both sides share the use of masonry with large well-squared travertine ashlars.

Considering that Porta Cornea has a width (about $3.40 \mathrm{~m}$ ) similar to that of Porta Eburnea (about $3.24 \mathrm{~m}$ ), it could be hypothesized that the abutment where the retaining wall is not noticed is a medieval reconstruction performed with Etruscan ashlars.

The medieval reconstruction with a gate opening narrower than the pre-existing Etruscan gate could be confirmed by a wall trace that can be observed on the internal side of the reconstructed abutment. Just above the arch shutter and close to the adjacent building, there 
are three ashlars with radial joints that could testify to the position of the primordial Etruscan arch. However, only a part of these ashlars is visible, which moreover is now covered by a thick black patina (Fig. 8). In order to define with certainty if they are actually residual ashlars of a preexisting arch or erratic pieces of reuse, it would be necessary to closely analyse these elements, possibly after having cleaned the surface.

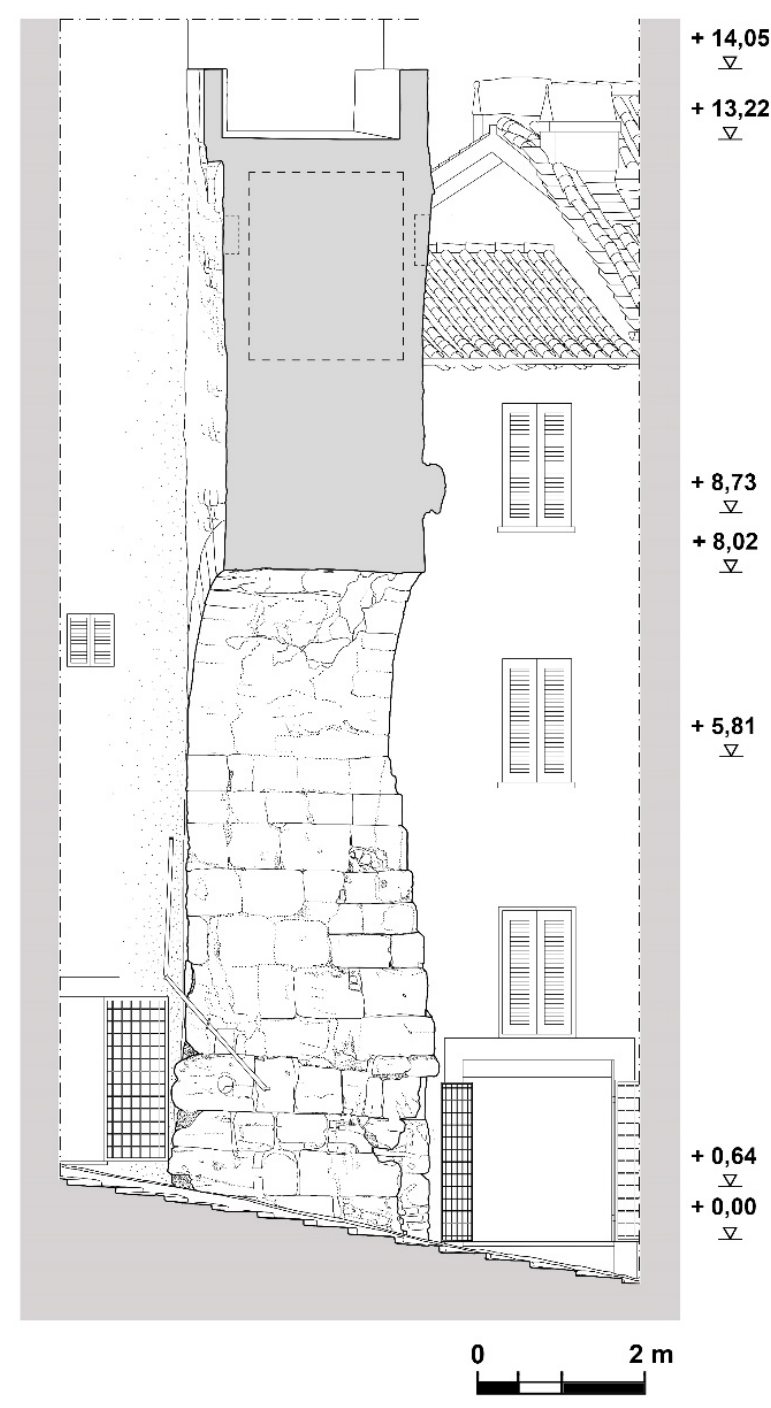

Figure 7: Section of Porta Cornea, with highlighted the retaining wall profile of one side (right).

The medieval reconstruction is evident from the springer of the doorway arch, with the Florentine arch flanked and surmounted by rows of limestone ashlars much smaller than the Etruscan ones.

On the inner side of the gate, at the still visible medieval arch shutter, you can appreciate the refined solution of keeping the vertical plane of the arch front backward from the abutment below. Thus, the wall above the arch assumes a recessed position with respect to the edge of the wall which probably corresponded to the Etruscan facing.

A brick crowing is superimposed on Porta Cornea, dating back to the period after the medieval reconstruction, of a residential character, with which a volume and a terrace were created at the top (Fig. 9).

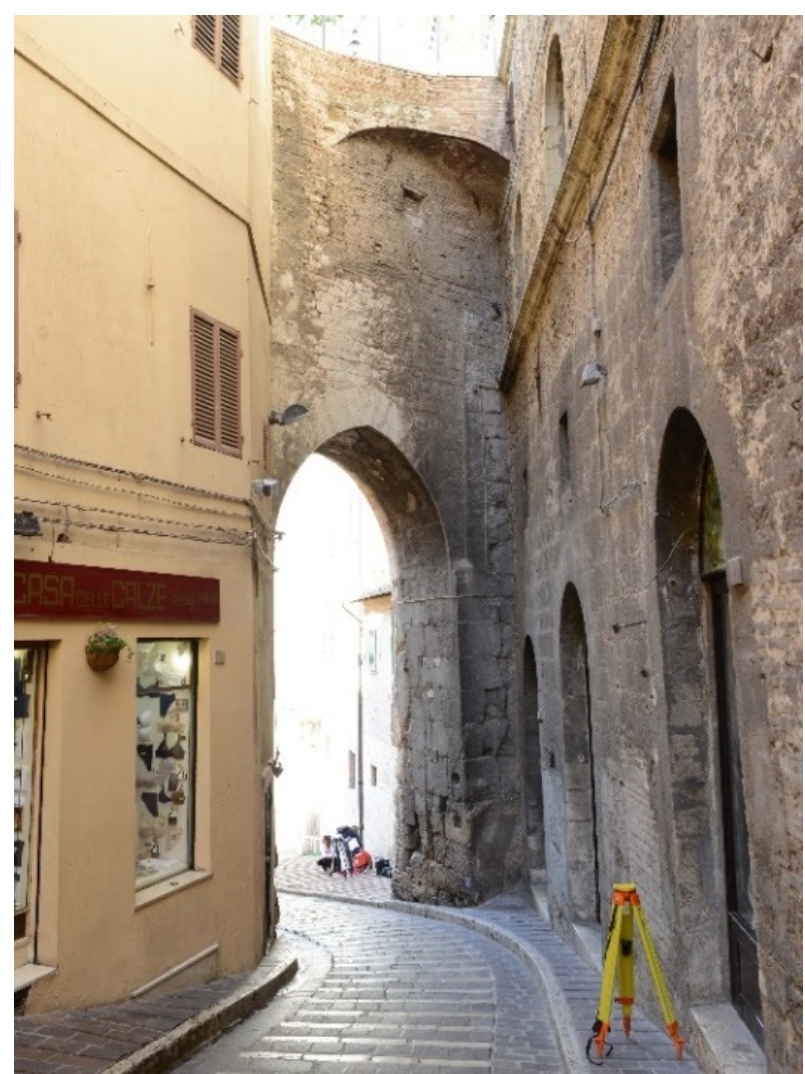

Figure 8: Internal side of Porta Cornea.

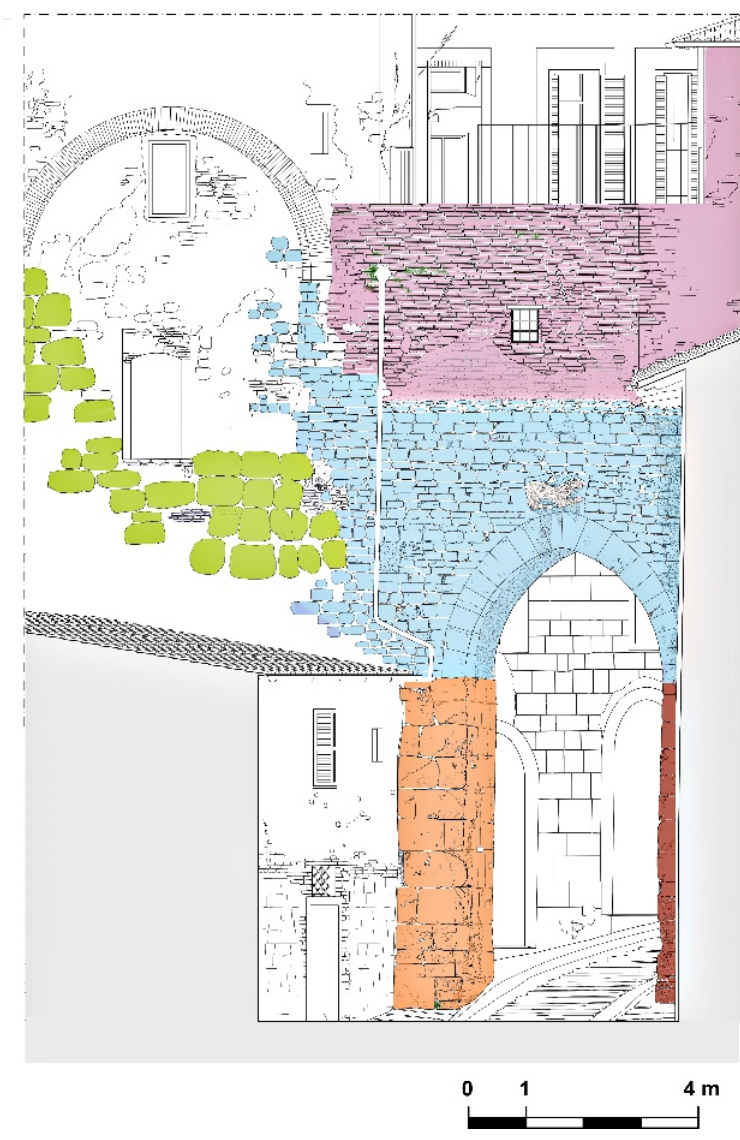

Figure 9: External front of the gate: the remains of the Etruscan walls (green) rise almost to pass Porta Cornea, divided into three materials zones, travertine (orange and red), limestone (blue), brick (purple), introduced in different periods. 


\subsection{Porta Trasimena}

It is also known as Porta di S. Luca and Madonna della Luce due to its proximity to the churches of the same name, or Porta della Luna having a half moon carved above the arch (Gigliarelli, 2016). It is oriented in the direction of Lake Trasimeno from which it takes its name (Marcaccioli, 2015).

On the external side, an abutment of the gate is flanked on one side by an extended stretch of the Etruscan walls (Fig. 10), while near the other abutment the visible portion of the walls is limited by the presence of the service areas of the Madonna della Luce church. The internal side of the gate is limited only to the vaulted passage, closed between the residential buildings and a side of the Madonna della Luce church.

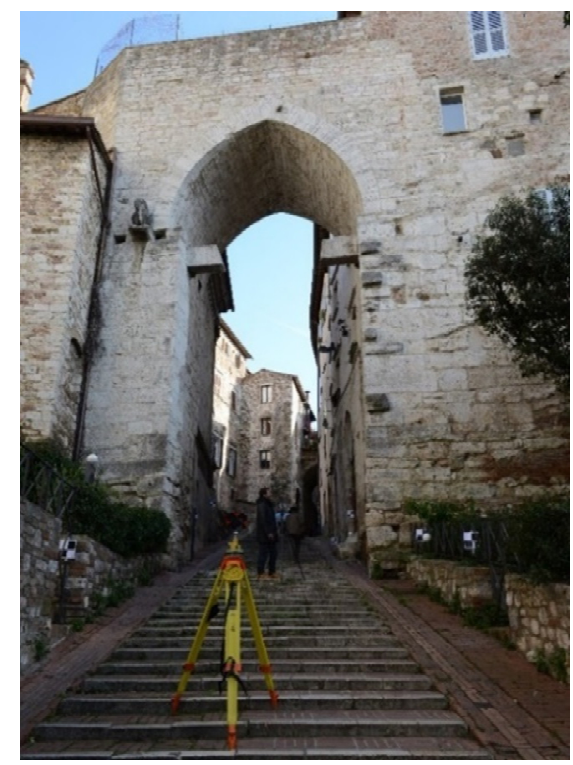

Figure 10: Porta Trasimena, external side.

Porta Trasimena highlight even more complex interpretative problems than Porta Eburnea and Porta Cornea, where the masonry facing differentiation of the successive transformation phases are more evident.

In order to formulate a proposal to differentiate the original Etruscan construction from the medieval contribution, it is useful to focus on some aspects. The first one concerns the arch with the surrounding masonry, all elements to be considered from the medieval phase, which, compared to the underlying abutment, form a wall slightly set backward, creating a recess. An additional fact to underline is that the internal sides of the gate opening have, in the lower part, brick refacing and a generally rather confused masonry (Fig. 11).

In this regard, the external jambs of the gate, which protrude from the internal sides of the passage, are instead characterized by a homogeneous masonry up to the floor. Still speaking of these jambs, it should be added that the overhanging stone corbels are inserted into them, creating a flat lintel with the central piece missing.

Next to the lintel there are stone hook hinges (completely similar to those of the Porta Eburnea) and below, at a higher level of 'via dei Priori' , a masonry connected to the jambst one was created: the stone hinge and the underlying support made up the anchoring and rotation system for the wooden shutter of the gate (Fig. 12). Furthermore, of the two external jambs, one is characterized by singular ashlars.

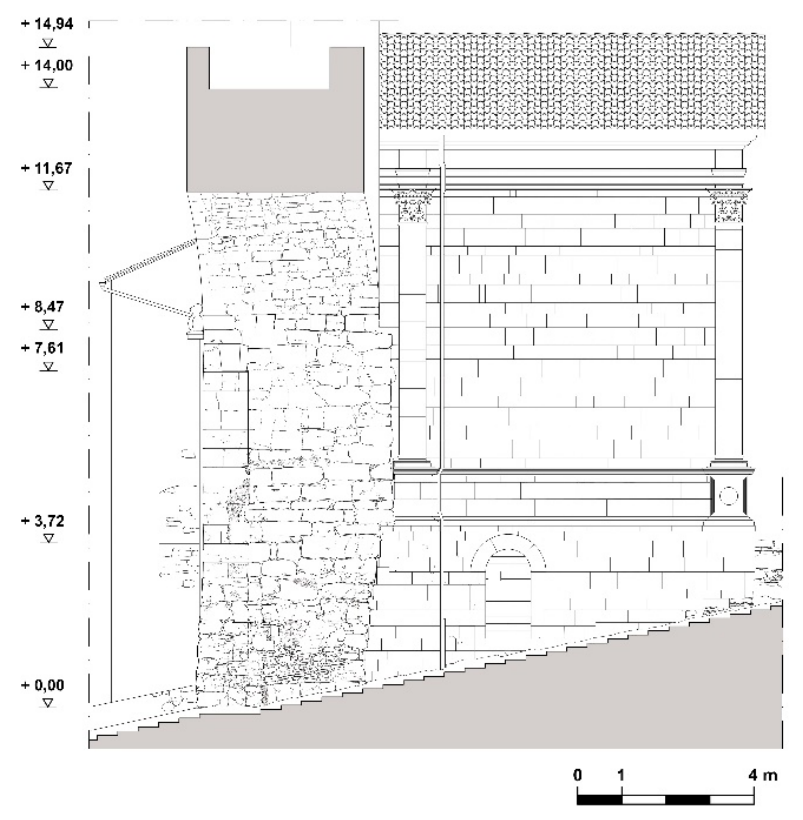

Figure 11: Section of the gate with the side of the Madonna dei Lumi church.

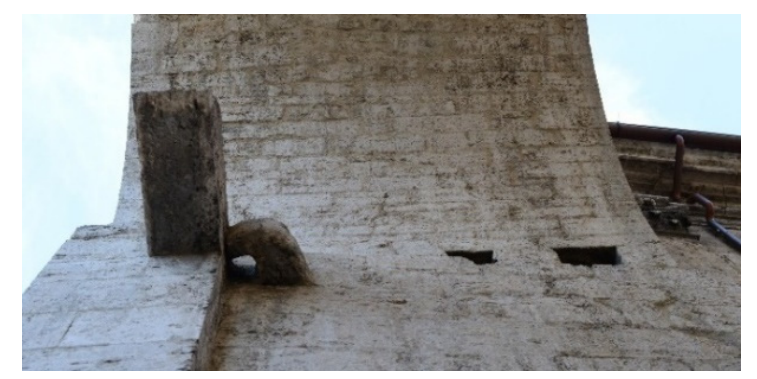

Figure 12: Detail of the stone corbel, belonging to a lintel, and of a stone hinge.

The totality of these evidences supports the hypothesis that the overall structure of the abutments of the gate is the Etruscan one and that in medieval times the gate was rebuilt from the arch springer, adding the jambs of the external side with the stone lintel and hinge system. The highest part of the shoulders shows ashlars with an excellent state of conservation; this also seems to support the contribution of restoration interventions.

A further element that could support this interpretation on the Etruscan remains is given by the greater width of the gate, equal to about $4.80 \mathrm{~m}$, compared to Porta Eburnea and Porta Cornea. At the springer level of the barrel vault of the gateway, an overturned ashlar can be seen with engraved letters that are not easily readable, but they would seem an "ER" preceded by a part of the "P"; in this case it could be an erratic ashlar that was part of the writing "AUGUSTA PERUSIA".

The sections of the Etruscan walls near the gate have been the object of extensive dismantlement works over time. The plan shows that some parts of the Madonna della Luce church, such as the main altar, a spiral staircase and part of the service areas, were created right on the wall layout, dismantling them almost completely. On 
the opposite side, inside a small opening adjacent to the stone corbel, a brick infill was found which supports demolition interventions similar to those carried out during the construction of the church (Fig. 13).

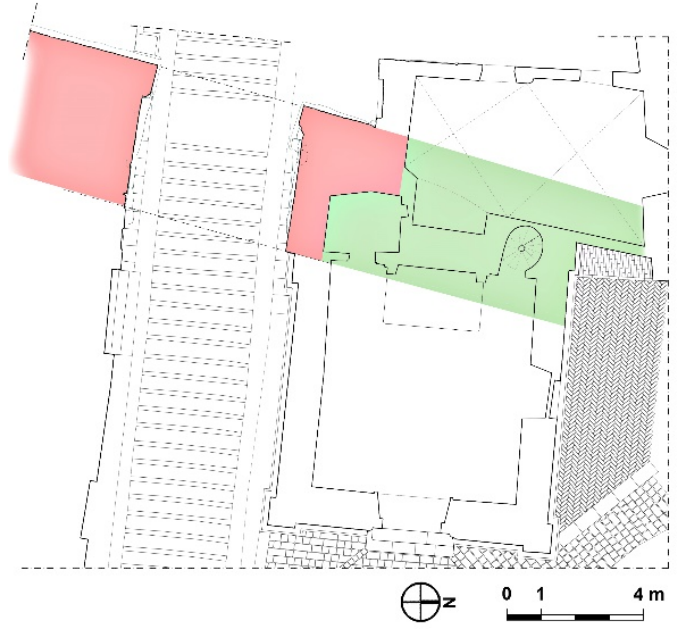

Figure 13: Plan of the gate and the adjacent Madonna dei Lumi church with highlighted the section of walls almost completely dismantled (green) to build the church.

A strong reduction in the passageway width of the medieval structure of the gate was also implemented. It was a passage created between the jambs and outlined by an entrance arch with a subsequent section of barrel vault. On one side of the gate, halfway up the jambs, the springer ashlar of this arch survives and, still above, the chiselling of some ashlars where it continued. Next to the springer ashlar there is a metal hinge and a further hinge lower; on the adjacent wall, a horizontal chiselling section indicates the springer of a barrel vault (Fig. 14).

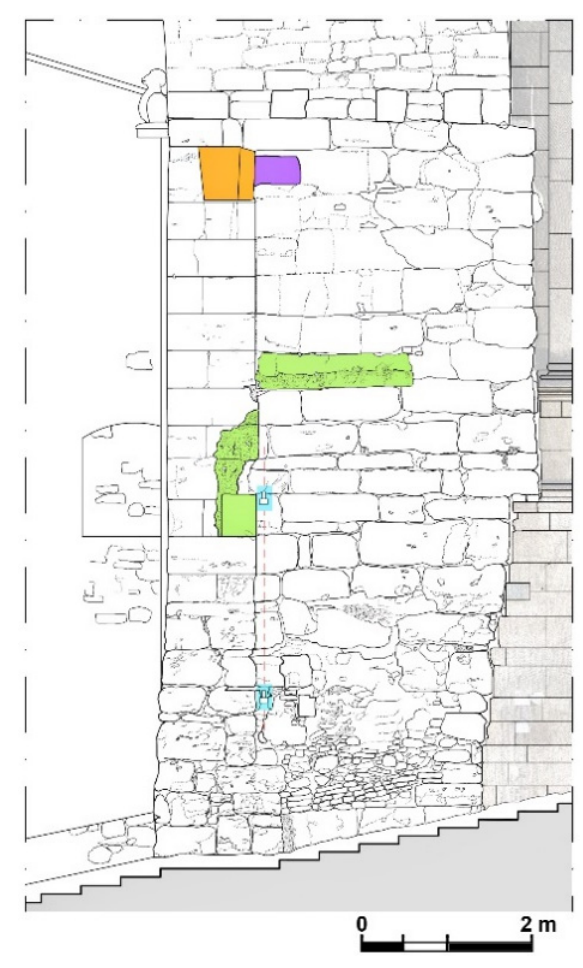

Figure 14: Detail of the gate section with the stone corbel and hinge (respectively in orange and purple), the arch springer and a barrel vault section springer (in green) of a passage much smaller than the current one.
On the other side of the gate there are no such traces; it could be supposed that they have been deleted by restorations, but it seems more likely that, in addition to reducing the height of the medieval gate, its width was also reduced by infilling it for a stretch on the edge of the reduced passageway.

\section{Survey and modelling tools and methodologies}

The development of modern innovative techniques allows a more efficient integration of Geomatics with restoration activities, creating a common and shared language useful in the cultural heritage interest (Radicioni, Stoppini, Tosi, \& Marconi, 2020; Hassani, 2015; Hoffmeister et al., 2014; Petrelli et al., 2013).

$3 \mathrm{D}$ models created by laser scanning or photogrammetry permit to carry out detailed investigations supporting the sustainable preservation and documentation of historical buildings for restoration purposes, in addition to metrical and structural studies (Balletti, Bertellini, Gottardi, \& Guerra, 2019; Matracchi, Radicioni, Stoppini, \& Tosi, 2019; Bernat, Janowski, Rzepa, Sobieraj, \& Szulwic, 2014; Armesto-González, Riveiro-Rodríguez, GonzálezAguilera, \& Rivas-Brea, 2010). All data acquired can be stored in digital databases easily available for further analysis, and can be used to create virtual spaces contributing to cultural divulgation and awareness extending them to wider audiences (Scandurra et al., 2018; Napolitano, Douglas, Garlock, \& Glisic 2017; Núñez, Buill, Regot, \& de Mesa, 2012).

In order to carry out a centimetre accuracy 3D survey of the three Perugia city gates for restoration analysis and graphic representation, some of the most advanced and efficient geomatics techniques and instruments were utilised, as briefly mentioned in the introduction:

- $\quad$ GNSS positioning;

- Optical - electronic total station;

- Terrestrial Laser Scanning laser (TLS);

- Digital Photogrammetry with cameras mounted on high tripods and telescopic bars.

Such techniques complement with each other creating an integrated survey system that led to a complete and detailed 3D geometric description of three Etruscan Perugia gates.

\subsection{GNSS positioning}

The survey had two distinct purposes:

a) accurate geometric description of each civic gate and adjacent buildings in a local coordinate system: thus, a local network was realised for each gate and measured with a total station (see next paragraph);

b) georeferencing of all civic gates in a unique global datum: for such purpose, the GNSS technique was used, in the ETRF2000 datum officially adopted by the Italian state.

Topcon Legacy GGD-E geodetic receivers with LegAnt antennas and Topcon GR-5 receivers (Fig. 15) were utilised for the survey, acquiring GPS and GLONASS 
signals in all available frequencies and modulations. More GNSS methodologies were used:

- $\quad$ post-processed static relative positioning;

- real-time kinematic survey in two modalities: RTK base-rover and Network RTK (NRTK).
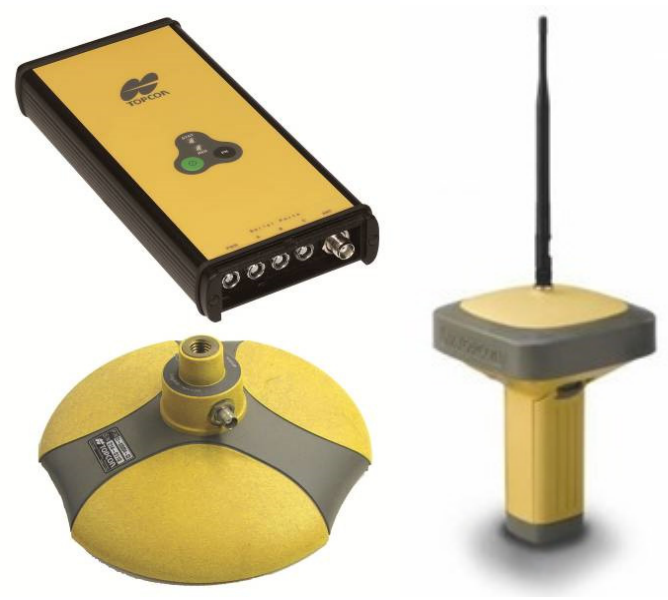

Figure 15: Topcon Legacy GNSS receiver with external LegAnt antenna (left) and Topcon GR-5 receiver with internal antenna (right).

The results are characterized by a planimetric-altimetric accuracy of about $1-2 \mathrm{~cm}$ in the absolute coordinates.

For the purpose of global datum georeferencing, the measurements connect the local network points with GNSS vertices known in the ETRF2000 system. Some permanent stations of the GPSUMBRIA GNSS network (developed since 2005 by Perugia University and Umbria Region - see Radicioni, \& Stoppini, 2019) were selected as reference points.

The local points were materialized by means of topographic nails or permanent signals on the floor, providing a geometric reference for the subsequent surveys with a minimum environmental impact.

\subsection{Total Station}

The GNSS technique, depending on satellites visibility, provides optimal results in open spaces without obstructions and obstacles such as buildings, protruding roofs and balconies, arcades and other planimetric discontinuities (Cina, 2014). In this case, as satellite visibility is limited by the gates themselves and by the other buildings facing the street, a Leica TS06 opticalelectronic total station (accuracy of about 2" on angles and $2 \mathrm{~mm}$ on distances) was used to create local reference networks (one for each surveyed gate).

Thanks to two laser pointers (one for marker centering and another for collimation purpose) and a diagonal eyepiece the TS06 permits to carry out the survey in poorly lit environments such as the inside spaces of the gates; the laser pointer also allow to perform collimations with great inclination from a lower position on considerable height buildings or manufacts. The accuracy of these local networks on vertices and targets has been estimated at about $1 \mathrm{~cm}$ for planimetry and height in the local coordinate systems.
Through the total station, the framing networks were also connected to the external points measured with the GNSS technique to the vertices and targets placed inside or near the city gates (Fig. 16).

After data processing, all points measured by total station resulted georeferenced in two ways:

a) in the local coordinate system (one for each gate);

b) in the global ETRF2000 datum.
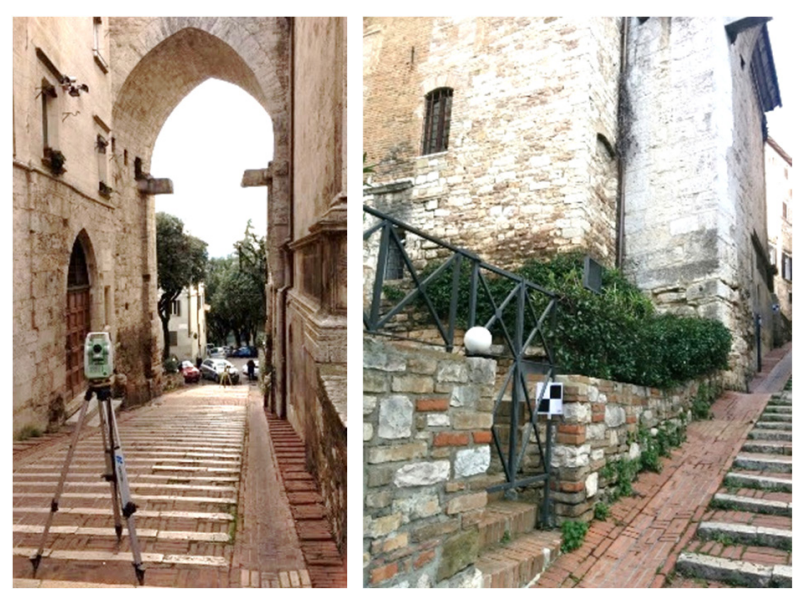

Figure 16: Total station survey, with checkerboard targets and reference spheres on the left.

\subsection{Terrestrial Laser Scanning (TLS)}

LIDAR (also referable with the acronym TLS) is one of the most powerful 3D survey tools in Geomatics. Unlike the total station, which allows to detect a limited number of points in time, the laser scanner measures a large quantity of distances and angles in very short times, thus performing a three-dimensional scan of objects, terrain and architectural artifacts (Wei, Chin, Majid, \& Setan, 2010; Abmayr, Härtl, Reinköster, \& Fröhlich, 2005).

For the city gates survey a FARO FOCUS 3D X130 laser scanner was employed, whose main feature is a speed acquisition up to 976,000 points/second. It is a very fast and accurate "phase measurement" laser scanner, particularly suitable for surveying architectures from relatively short distances and in particular for internal spaces, thanks to its small size and weight. The scans have been taken with an acquisition time of about $5-10$ minutes each (depending on distance and resolution), setting a resolution between scanned points of $10-15 \mathrm{~mm}$ at $10 \mathrm{~m}$ (Fig. 17).

After a scan is completed, the scanner also shots a $360^{\circ}$ digital photo series over the entire scanned area, thanks to an integrated coaxial 70 MPixel digital camera. This allows to obtain the so called "coloured point clouds" where the brightness and colour information of the digital images is associated to the geometric data, obtaining a realistic visualization of the scan.

Each scan produces a point cloud, consisting in an extremely high number of 3D points whose geometry refers to the instrument center (Fig. 18).

The single point clouds were acquired so that each one partially covers $40-50 \%$ of the adjacent scans, and were aligned and merged each other during processing by carrying out a relative orientation. For this purpose, two 
types of recognizable markers were used, both identifiable with great accuracy by the scanner:

- $\quad$ checkerboard pattern square plate targets;

- $\quad$ calibrated spheres with a diameter of about 15 $\mathrm{cm}$, made of synthetic resin.

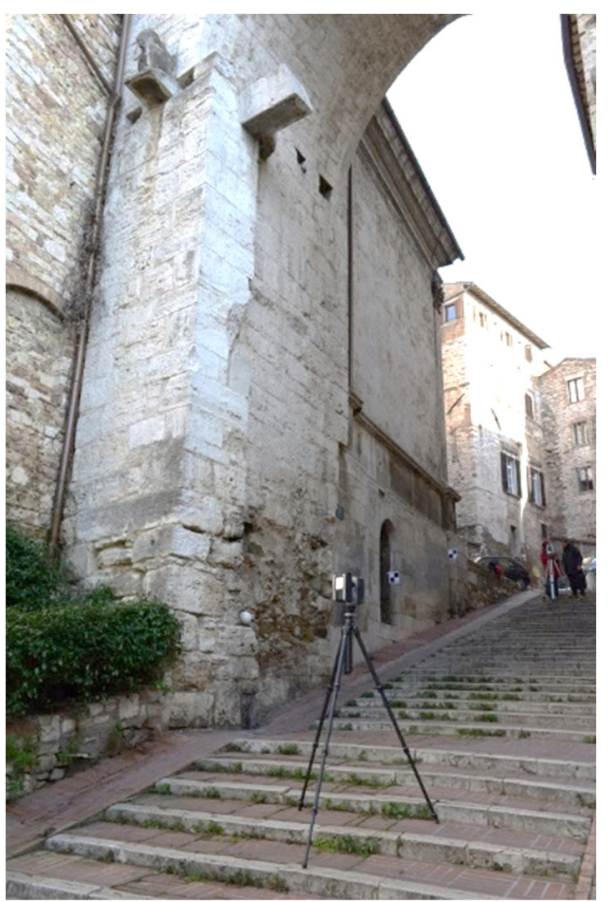

Figure 17: TLS survey.

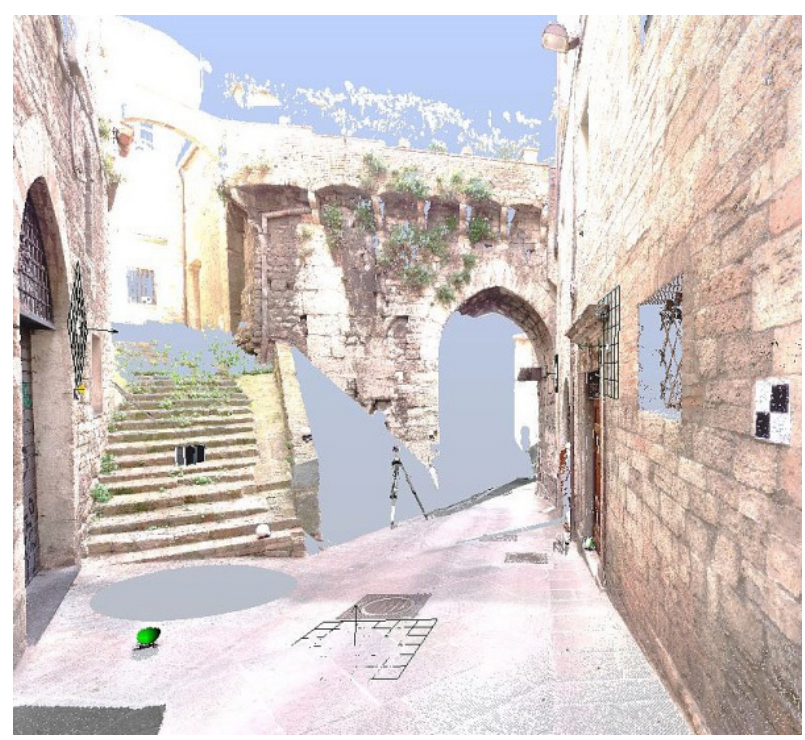

Figure 18: Coloured point cloud derived by a single scan

The processing software identifies both of them and determines their center coordinates. An adequate common number of targets (at least 4) and spheres between adjacent scans are required for a good point cloud alignment.

The advantage of the spheres with respect to the targets is that their geometry and center are absolutely defined from each position. In this way during the processing, the relative alignment point cloud error is reduced.
The relative orientation of the scans is followed by an absolute orientation (overall georeferencing of the assembled point cloud). This orientation is possible thanks to the checkerboard pattern targets, whose coordinates had been previously determined by means of total station measurements.

Given the two distinct georeference modes of the framing networks (local and global), the point cloud coordinates were also determined in the local coordinate systems of each gate and in the global ETRF2000 datum.

\section{Survey results and products}

The CAM2 Scene software (Faro CAM2, 2020) was used for processing and managing the FARO point clouds. This software performs a spatial rototranslation of the scans. Through the roto-translation algorithms the scans are aligned with each other, thus the final result is a unique point cloud georeferenced in a local system (that of a single scan assumed as reference).

"Normalized tension" is the parameter which statistically evaluates the success of the registration. In our project, the "normal tension" parameter corresponds to the "point distance", that represents the mean value of reference points residuals (Faro CAM2, 2020). A normal tension of about $2 \mathrm{~mm}$ has been obtained.

The next step is the application of a filtering to reduce the point cloud noise and an editing/cleaning process to remove all unnecessary data such double points, vegetation etc.

The models were successively processed through Leica Cyclone software (Leica Geosystems, 2020) for a registration of the point clouds on the target coordinates previously measured. At the end of the process, the residuals on known points show an average value of about $1 \mathrm{~cm}$.

The final result of the TLS survey for each gate is an overall coloured point cloud (Fig. 19), composed of millions of points, describing the three-dimensional geometry of the gate and surrounding buildings.

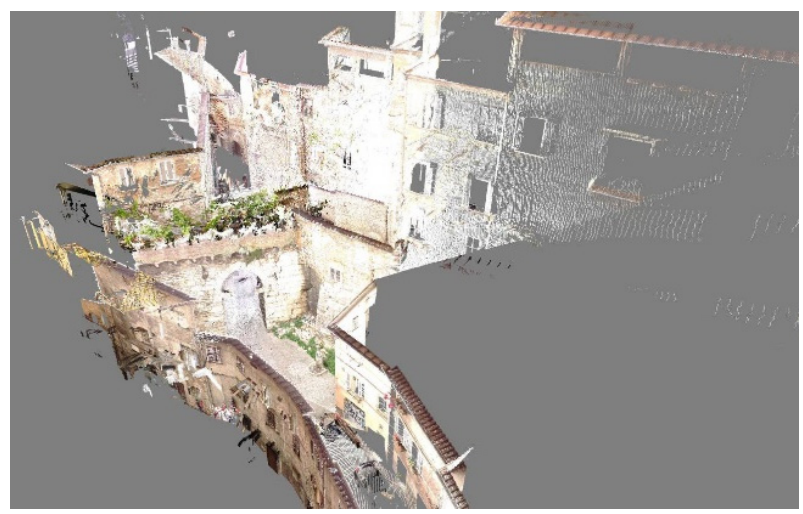

Figure 19: Assembled point cloud.

The overall point clouds for each gate (with colours and textures acquired from the digital images) were subsequently exported in the digital format JSV. These files can be distributed and viewed through the free Leica Jetstream Viewer software. With this software it is possible to measure distances, areas, volumes directly on 
the model and perform detailed analyses on a video terminal.

\section{Digital Photogrammetry}

In addition to the TLS survey, a detailed threedimensional modelling for Porta Eburnea and Porta Trasimena has been also obtained from high-resolution digital images. The photogrammetric models allow to integrate the laser scanner information especially for the unreachable or shaded areas not directly scanned by the instrument (Yastikli, 2007; Alshawabkeh, \& Haala, 2004; Kadobayashi, Kochi, Otani, \& Furukawa, 2004).

The digital images were obtained with the following photographic equipment:

- a Nikon D800E camera (36 megapixels fullframe reflex digital camera equipped with a $24 \times 36 \mathrm{~mm}$ sensor), using Nikon lenses with a fixed focal length of $14 \mathrm{~mm}, 28 \mathrm{~mm}, 50 \mathrm{~mm}$ and $85 \mathrm{~mm}$;

- a Panasonic Lumix DMC-GH4 EG-K camera (16 Megapixel mirrorless digital camera with $4 / 3$ sensor), smaller in size and weight than the previous one, with a compact and lightweight 14 $\mathrm{mm}$ focal lens (wide angle).

Both cameras were used freehand or mounted on a tripod, depending on the shutter speed.

To survey the upper parts of the manufacts, a $10 \mathrm{~m}$ carbon fiber telescopic rod with a DJI OSMO+ digital camera was used in order to shoot from a high position (Fig. 20). The DJI OSMO+ camera, very light and adjustable by means of a built-in gimbal, is remotely controlled using an Android device thanks to a support application. It represents a good solution for shooting from a high position, performing results similar to a UAV but avoiding the associated risk and authorization needs, difficult to obtain in historical centers, on artifacts limited by the Superintendence of Cultural Heritage opinion (Fig. 21).

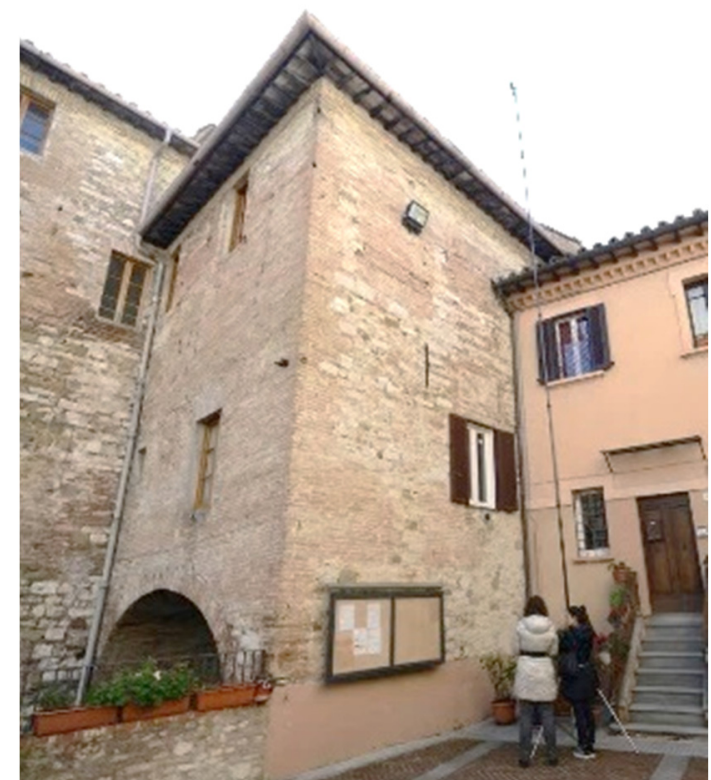

Figure 20: DJI OSMO+ digital camera mounted on a telescopic rod.

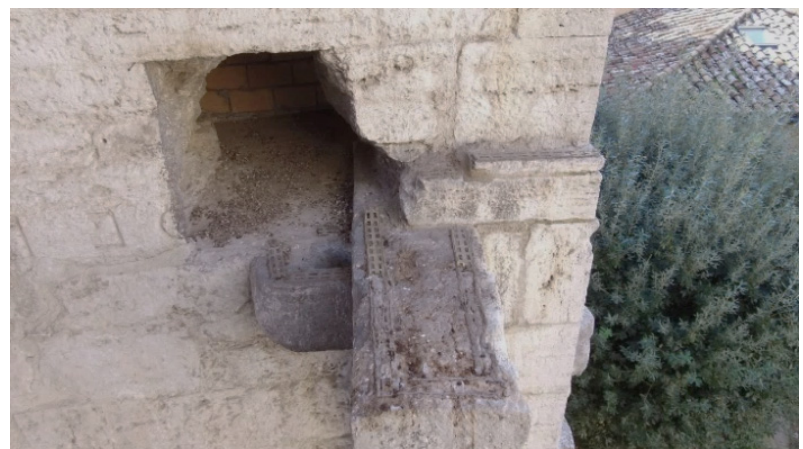

Figure 21: Particular of Porta Trasimena shot with DJI OSMO+ camera from telescopic rod.

The photogrammetric processing of the high-resolution digital images was performed by Agisoft Photoscan Professional software version 1.4.5, which uses imagebased modelling and SfM (Structure from Motion) techniques, producing 3D point cloud similar to laser scanning one (Tucci, Bonora, Conti, \& Fiorini, 2017; Kwiatek, \& Tokarczyk, 2015; Remondino, 2011).

After aligning the hundred photos taken with the two cameras and inserting the markers previously surveyed with total station and GNSS positioning, dense point clouds were obtained, consisting of million points (Fig. 22).

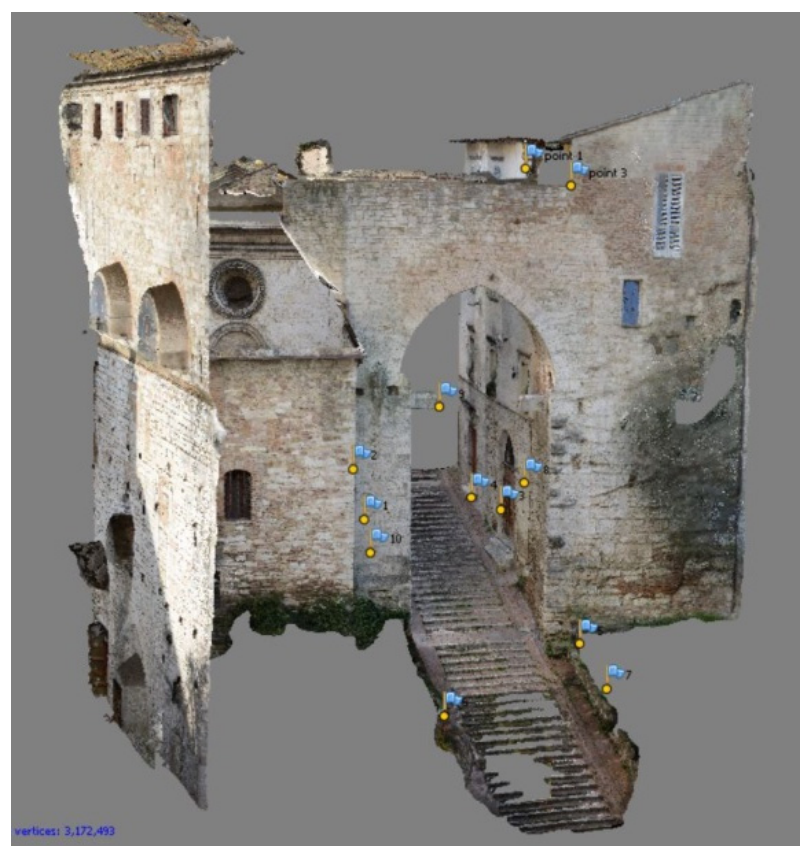

Figure 22: Porta Trasimena point cloud with markers made with Agisoft Photoscan software.

From the georeferencing, a total error of about 0.5 pixels was obtained, equal to about $5-10 \mathrm{~cm}$ in relation to distance. Thanks to the presence of the targets it was possible to use the photogrammetric point clouds to integrate the models obtained by the laser, in particular for those areas where the instrument was not able to correctly detect the points (high areas, blind spots).

From these clouds, high-definition textured mesh models were obtained (Fig. 23), from which the ortho-images were exported for material and degradation surface analysis. 


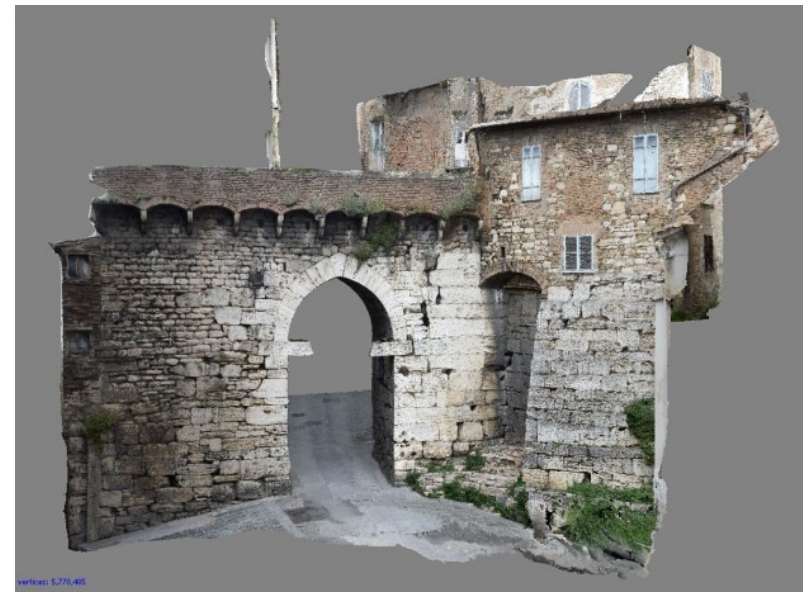

Figure 23: Porta Eburnea texturized mesh.

\section{Graphic representation and material/surface analysis}

From the 3D models, using the solution georeferenced in the local coordinate system of each gate, a series of detailed CAD vectorial drawings have been obtained, consisting of plans, sections and elevations of all the city gates surveyed.

Orthoimage files in .tif format were exported from Cyclone software, by choosing appropriate cutting planes so that it's possible to obtain sections of the $3 D$ model. CAD drawings are more traditional elaborates with respect to 3D modelling, and result easier to use in technical field without the need of special software for 3D models viewing. The advantage of these graphic data is that it's possible to print scaled drawings, which increases their accessibility even in other fields (e.g. humanities) not equipped with software which often require high hardware requirements (Fig. 24).

From the high detailed 3D model, additional 2D vectorial drawings were obtained in order to highlight the materials that characterize monuments surfaces and their state of preservation. From the graphic drawings (but also directly from the RGB point clouds) it is possible to acquire information about the state of preservation and vulnerability of the structures, crack patterns if present, and singularities of the original construction or induced by modification over time.

\section{Conclusions}

The deep transformations of the Perugia Etruscan gates leave us great importance evidence of such architecture. On Porta Eburnea and Porta Cornea, an abutment with original walls has survived which in the case of the first rise above the springer of the medieval arch, leaving an extended trace of the intrados of the original Etruscan arch. In Porta Cornea it is possible perhaps to identify the remains of three ashlars starting from the springer. If this interpretation were confirmed by further investigations, taking into account the position of the remaining arch and of the original abutment on the opposite side, we could identify the width of the original passageway, which would have had a span of about $4.30 \mathrm{~m}$, that is a dimension close to that of Porta Trasimena, where both abutments are from the Etruscan age.

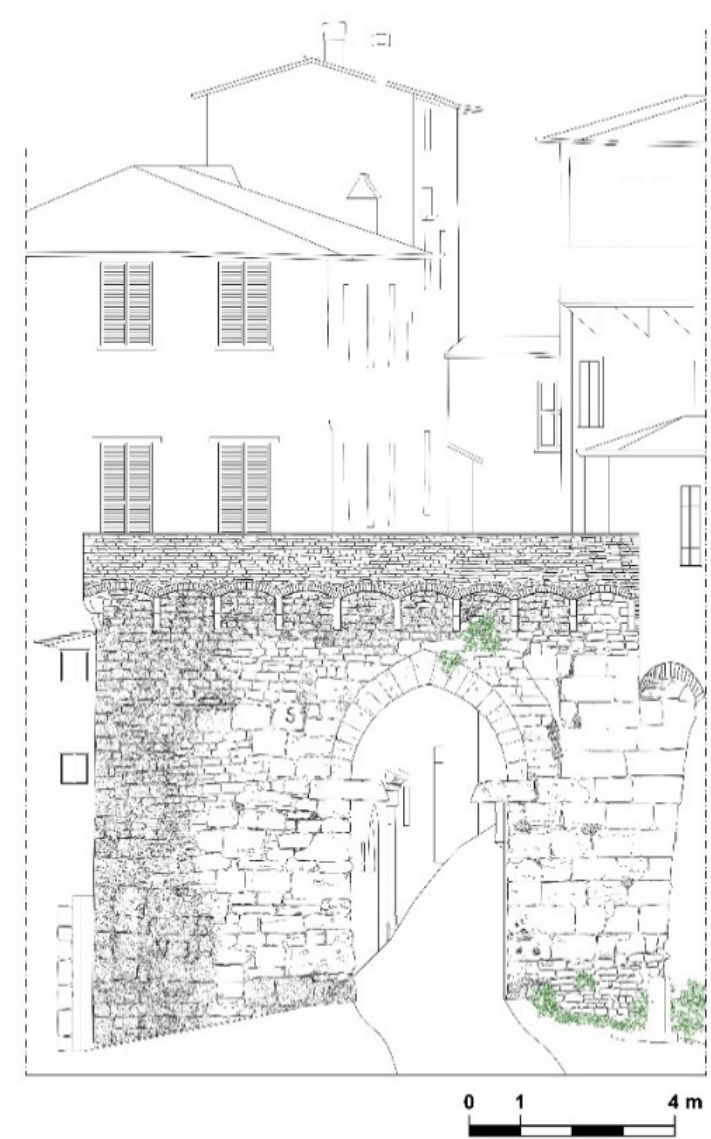

Figure 24: Example of CAD drawing (vertical section) obtained by a scan cutting plane.

The remains allow us to verify the thickness of the Etruscan walls near the gates. Those of Porta Eburnea and Porta Cornea are similar, respectively of $2.80 \mathrm{~m}$ and $2.60 \mathrm{~m}$, while the one in Porta Trasimena of $4.20 \mathrm{~m}$ is much more conspicuous. Where it is possible to check at least part of the plan of the abutments, as in Porta Eburnea and Porta Trasimena, the perpendicularity between internal facings of the gates and external facings is verified.

The most refined Etruscan masonry structures are found in Porta Eburnea and Porta Cornea where there are rows with ashlars up to $61 \mathrm{~cm}$ high, laid with thin joints. The construction technique is particularly refined in the wall sections where vertical joints orthogonal to the row are alternated with inclined vertical joints; in this way greater cohesion was ensured between adjacent ashlars of the same row, creating a jack arch between the ashlars.

A further relevant aspect is the reuse of Etruscan remains in medieval times. It is plausible that the Etruscan gates were in a state of ruin, not only due to the very long period of abandon following the loss of their military function, but also following a progressive dismantlement activity for the reuse of building material. In other words, the walls were probably considered as a kind of "quarry" from which to extract precious material, as it was already worked and available directly in the city.

The reuse of material was particularly extended in Porta Eburnea and Porta Cornea. In the first it includes ashlars with engraved letters related to the inscription "COLONIA VIBIA" and "AUGUSTA PERUSIA"; also, in Porta 
Trasimena some letters engraved in a stone may have been part of the inscription "COLONIA VIBIA". The latter is believed to have been commissioned by the Roman emperor Vibio Treboniano Gallo, originated of Perugia. The inscription "AUGUSTA PERUSIA" may have been engraved after Octavian Augustus conquered the city in 41-40 B.C. (Gigliarelli, 2016). Today these epigraphs can be read entirely in Porta Marzia and in the most famous Arco Etrusco (Cenciaioli, Mariani, \& Timpani, 2019; Di Massimo, 2019).

The use of ashlars with engraved letters would suggest to be, rather than elements left abandoned for centuries at the edge of the city gates, like stone materials available after the complete dismantlement of the Etruscan gates, in this case Porta Eburnea and Porta Trasimena, which probably occurred in medieval times. At the same time, the pointed barrel vaults were built, ended laterally by Florentine arches, which made the three gates examined in this contribution uniform.

It should be note that the medieval walls, much larger than the Etruscan one, except for a short stretch where they coincide, gave the rebuilt Etruscan gates a non-prominent defence role, at most a second defence of the most central city core. But the hypothesis that the reconstruction of the Etruscan gates wanted mainly to demonstrate how ancient the origins of the city of Perugia were can also be taken into consideration. Moreover, the closing system with wooden doors rotating on stone hinges leaning on three-pieces stone jack arches does not seem to have a military connotation that made it difficult to assault.
Today the three gates wall faces are not very visible in some parts due to the surfaces blackening, which would require further specific laboratory diagnostic investigations in order to develop the correct cleaning and conservation works.

However, the wall structures analysed through advanced survey techniques have allowed to highlight the complex urban history of Perugia still witnessed by these architectural constructions, despite having been largely incorporated by the expansion of the residential building, and are still today diminished by the lack of attention towards their high cultural significance.

The advanced techniques of Geomatics adopted for this survey (GNSS, Total Station, LIDAR and Digital Photogrammetry), effectively integrated with each other, have been confirmed as a fundamental tool for the threedimensional reconstruction at a high level of detail of cultural heritage, providing a complete and accurate documentation which constituted a solid support for the analyses performed on the ancient artefacts described in this article. The documentation acquired is however available for further studies and future developments.

\section{Acknowledgements}

This work was supported by the Cassa di Risparmio di Perugia Foundation under Grant number 2015.021.0311.

A special thanks goes to the graduate Giulia Anastasi who processed the data from the 3D model acquired by laser scanner survey, with the coordination of the authors, in order to process vectorial plants, sections and elevations represented in this article.

\section{References}

Abmayr, T., Härtl, F., Reinköster, M., \& Fröhlich, C. (2005). Terrestrial laser scanning - Applications in cultural heritage conservation and civil engineering. Proceedings of the ISPRS Working Group V/4, XXXVI-5/W17. 3D-ARCH 2005: Virtual Reconstruction and Visualization of Complex Architectures, 22-24 August, 2005, Mestre-Venice, Italy.

Alshawabkeh, Y., \& Haala, N. (2004). Integration of digital photogrammetry and laser scanning for heritage documentation. International Archives of Photogrammetry, Remote Sensing and Spatial Information Sciences, 35-B5, 424-429.

Amorini, E. (1996). Le mura etrusche della città di Perugia: percorso-guida lungo la cinta della città vecchia. Perugia, IT: Benucci.

Núñez, A., Buill, F., Regot, J., \& de Mesa A. (2012). Generation of virtual models of cultural heritage. Journal of Cultural Heritage, 13(1), 103-106. https://doi.org/10.1016/j.culher.2011.06.004

Armesto-González, J., Riveiro-Rodríguez, B., González-Aguilera, D., \& Rivas-Brea, M. T. (2010). Terrestrial laser scanning intensity data applied to damage detection for historical buildings. Journal of Archaeological Science, 37(12), 30373047. https://doi.org/10.1016/j.jas.2010.06.031

Balletti, C., Costa, M., Guerra, F., Martinello, F., \& Vernier, P. (2018). Modern and contemporary Cultural Heritage documentation and knowledge by surveying and its representation. The International Archives of the Photogrammetry, Remote Sensing and Spatial Information Sciences, XLII-2, 63-67. ISPRS TC II Mid-term Symposium "Towards Photogrammetry 2020", 4-7 June 2018, Riva del Garda, Italy. https://doi.org/10.5194/isprsarchives-XLII-2-63-2018

Balletti, C., Bertellini, B., Gottardi, C., \& Guerra, F. (2019). Geomatics techniques for the enhancement and preservation of Cultural Heritage. The International Archives of the Photogrammetry, Remote Sensing and Spatial Information Sciences, XLII-2/W11, 133-140. GEORES 2019 - 2nd International Conference of Geomatics and Restoration, 810 May 2019, Milan, Italy. https://doi.org/10.5194/isprs-archives-XLII-2-W11-133-2019

Begni Perina, G. (1956). La datazione delle antiche mura di Perugia. In Atti della Accademia di San Luca, N.S. 2.1953/56 (pp. 99-101). Roma, IT.

Bernat, M., Janowski, A., Rzepa, S., Sobieraj, A., \& Szulwic, J. (2014). Studies on the use of terrestrial laser scanning in the maintenance of buildings belonging to the cultural heritage. SGEM2014 Conference Proceedings, 2(3), 307-318. 
14th International Multidisciplinary Scientific GeoConference SGEM 2014, June 19-25, 2014, Albena, Bulgaria. https://doi.org/10.5593/SGEM2014/B23/S10.039

Bilancia, M. (2015). II muro nascosto: alla scoperta delle mura antiche di Perugia nel decennale della prima pubblicazione. Perugia, IT: Francesco Tozzuolo editore. ISBN: 978-88-95229-53-9

Calderoni, A. (1977). Evoluzione del Centro di Perugia dal periodo etrusco ad oggi. Marcaccioli E. (Ed).

Cenciaioli, L., Mariani, M., \& Timpani, M. C. (Eds.). (2019). L'Arco Etrusco di Perugia: storia e restauro. Perugia, IT: Volumnia Editrice. ISBN: 9788889024928

Cina, A. (2014). Dal GPS al GNSS (Global Navigation Satellite System). Per la geomatica. Torino, IT: Celid.

Cotana, F. (2012). L'imperatore Gaio Vibio Treboniano Gallo. Da Monte Vibiano. Perugia, IT: Morlacchi Editore. ISBN: 9788860745729

Defosse, P. (1980). Les remparts de Pérouse : contribution à l'histoire de l'urbanisme préromain. Mélanges de l'École française de Rome. Antiquité MEFRA, 92(2), 725-820. https://doi.org/10.3406/mefr.1980.1256

Di Massimo, G. (2019). Elenco delle specie vegetali presenti sulle mura dell'Arco Etrusco. In L. Cenciaioli, M. Mariani, \& M. C. Timpani (Eds.), L'Arco Etrusco di Perugia: storia e restauro (pp. 275-277).

Faro CAM2. (2020). Scene software. Retrieved March 15, 2021, from https://insights.faro.com/scene/techsheet-faro-scene and https://faro.app.box.com/s/7v2xdi8j6id4wf9g5jlledha18s9506b/file/601434891703

Fiocca, L. (1918). Le porte etrusche in Perugia. Perugia, IT: Unione Tipografica Cooperativa.

Fiocca, L. (1926). Perugia, sua origine. Cinta delle Mura e Porte. Perugia, IT: Tipografia Guerriero Guerra Editrice.

Giambi, A. (2004). Metodologie innovative per l'archeometria del travertino utilizzato nella costruzione delle "mura etrusche" di Perugia. Dissertation, supervisor Prof. Poli Giampiero, University of Perugia, Department of Physics and Geology.

Gigliarelli, R. (2016). Perugia antica e Perugia moderna. Indicazioni storico topografiche. Perugia, IT: Francesco Tozzuolo editore.

Grussenmeyer, P., Landes, T., Voegtle, T., \& Ringle, K. (2008). Comparison methods of terrestrial laser scanning, photogrammetry and tacheometry data for recording of cultural heritage buildings. The International Archives of the Photogrammetry, Remote Sensing and Spatial Information Sciences, XXXVII-B5, 213-218.

Hassani, F. (2015). Documentation of cultural heritage techniques, potentials and constraints. The International Archives of the Photogrammetry, Remote Sensing and Spatial Information Sciences, XL-5/W7, 207-214. 25th International CIPA Symposium 2015, 31 August - 04 September 2015, Taipei, Taiwan. https://doi.org/10.5194/isprsarchives-XL5-W7-207-2015

Hatzopoulos, J. N., Stefanakis, D., Georgopoulos, A., Tapinaki, S., Pantelis, V., \& Liritzis, I. (2017). Use of various surveying technologies to 3D digital mapping and modelling of cultural heritage structures for maintenance and restoration purposes: the Tholos in Delphi, Greece. Mediterranean Archaeology \& Archaeometry, 17(3), 311-336. https://doi.org/10.5281/zenodo.1048937

Hoffmeister, D., Zellmann, S., Kindermann, K., Pastoors, A., Lang, U., Bubenzer, O., Weniger, G., \& Bareth, G. (2014). Geoarchaeological site documentation and analysis of 3D data derived by terrestrial laser scanning. ISPRS Annals of the Photogrammetry, Remote Sensing and Spatial Information Sciences, II-5, 173-179. ISPRS Technical Commission V Symposium, 23-25 June 2014, Riva del Garda, Italy. https://doi.org/10.5194/isprsannals-II-5-1732014

Kadobayashi, R., Kochi, N., Otani, H., \& Furukawa, R. (2004). Comparison and evaluation of laser scanning and photogrammetry and their combined use for digital recording of Cultural Heritage. The International Archives of Photogrammetry, Remote Sensing and Spatial Information Sciences, 35(5), 401-406. XX ISPRS Congress, 12-23 July 2004 , Istanbul, Turkey.

Kwiatek, K., \& Tokarczyk, R. (2015). Immersive Photogrammetry in 3D Modelling. Geomatics and Environmental Engineering, 9(2), 51-62. https://doi.org/10.7494/geom.2015.9.2.51

Leica Geosystems. (2020). Cyclone software. Retrieved March 15, 2021, from https://leica-geosystems.com/enin/products/laser-scanners/software/leica-cyclone.

Marcaccioli, E. (2014). Porta Eburnea. Caserta e le fonti di Veggio. Perugia, IT: Futura.

Marcaccioli, E. (2015). I/ «Palmo». Visioni della terra vecchia. Perugia, IT: Futura.

Matracchi, P., Radicioni, F., Stoppini, A., \& Tosi, G. (2019). The Cathedral of s. Lorenzo in Perugia and the hypogeal spaces. Geomatic techniques for spatial investigations aimed at the knowledge and interpretation of the origin of the transept. The International Archives of the Photogrammetry, Remote Sensing and Spatial Information Sciences, XLII-2/W11, 849-856. GEORES 2019 - 2nd International Conference of Geomatics and Restoration, 8-10 May 2019, Milan, Italy. https://doi.org/10.5194/isprs-archives-XLII-2-W11-849-2019 
Napolitano, R. K., Douglas, I. P., Garlock, M. E., \& Glisic, B. (2017). Virtual Tour Environment of Cuba's National School of Art, The International Archives of the Photogrammetry, Remote Sensing and Spatial Information Sciences, XLII2/W5, 547-551. 26th International CIPA Symposium, 28 August-01 September 2017, Ottawa, Canada. https://doi.org/10.5194/isprs-archives-XLII-2-W5-547-2017

Nicolini, U. (1986). Reformationes Comunis Perusii quae extant anni MCCLXII. Deputazione di Storia Patria per I'Umbria. Fonti per la storia dell'Umbria, 5, Città di Castello, Perugia, Italy.

Petrelli, D., Ciolfi, L., Van Dick, D., Horneker, E., Not, E., \& Schmidt, A. (2013). Integrating material and digital: a new way for cultural heritage. Interactions, 20(4), 58-63. https://doi.org/10.1145/2486227.2486239

Radicioni, F., Matracchi, P., Brigante, R., Brozzi, A., Cecconi, M., Stoppini, A., \& Tosi, G. (2017). The Tempio della Consolazione in Todi: integrated geomatic techniques for a monument description including structural damage evolution in time. The International Archives of the Photogrammetry, Remote Sensing and Spatial Information Sciences, XLII-5/W1, 433-440. GEOMATICS \& RESTORATION - Conservation of Cultural Heritage in the Digital Era, 22-24 May 2017, Florence, Italy. https://doi.org/10.5194/isprs-archives-XLII-5-W1-433-2017

Radicioni, F., \& Stoppini, A. (2019). Umbria's new multi-constellation GNSS network. GEOmedia, 23(4), 6-11.

Radicioni, F., Stoppini, A., Tosi G., \& Marconi L. (2020). Necropolis of Palazzone in Perugia: integrated geomatic techniques for a geomorphological analysis. In M. Alvioli, I. Marchesini, L. Melelli \& P. Guth (Eds.), Proceedings of the Geomorphometry 2020 Conference, CNR Edizioni, Perugia, Italy. https://doi.org/10.30437/GEOMORPHOMETRY2020_18

Remondino, F. (2011). Heritage recording and 3D modeling with photogrammetry and 3D scanning. Remote sensing, 3(6), 1104-1138. https://doi.org/10.3390/rs3061104

Scandurra, S., Pulcrano, M., Cirillo, V., Campi, M., di Luggo, A., \& Zerlenga, O. (2018). Integrated survey procedures for the virtual reading and fruition of historical buildings. The International Archives of the Photogrammetry, Remote Sensing and Spatial Information Sciences, XLII-2, 1037-1044. ISPRS TC II Mid-term Symposium "Towards Photogrammetry 2020", 4-7 June 2018, Riva del Garda, Italy. https://doi.org/10.5194/isprs-archives-XLII-2-10372018

Tucci, G., Bonora, V., Fiorini, L., \& Conti, A. (2016). The Florence Baptistery: 3-D survey as a knowledge tool for historical and structural investigations. The International Archives of the Photogrammetry, Remote Sensing and Spatial Information Sciences, XLI-B5, 977-984. XXIII ISPRS Congress, 12-19 July 2016, Prague, Czech Republic. https://doi.org/10.5194/isprs-archives-XLI-B5-977-2016

Tucci, G., Bonora, V., Conti, A., \& Fiorini, L. (2017). High-quality 3D models and their use in a Cultural Heritage conservation project. The International Archives of the Photogrammetry, Remote Sensing and Spatial Information Sciences, XLII-2/W5, 687-693. 26th International CIPA Symposium, 28 August-01 September 2017, Ottawa, Canada. https://doi.org/10.5194/isprs-archives-XLII-2-W5-687-2017

Wei, O. C., Chin, C. S., Majid, Z., \& Setan, H. (2010). 3D documentation and preservation of historical monument using terrestrial laser scanning. Geoinformation Science Journal, 10(1), 73-90.

Yastikli, N. (2007). Documentation of cultural heritage using digital photogrammetry and laser scanning. Journal of Cultural heritage, 8(4), 423-427. https://doi.org/10.1016/j.culher.2007.06.003 


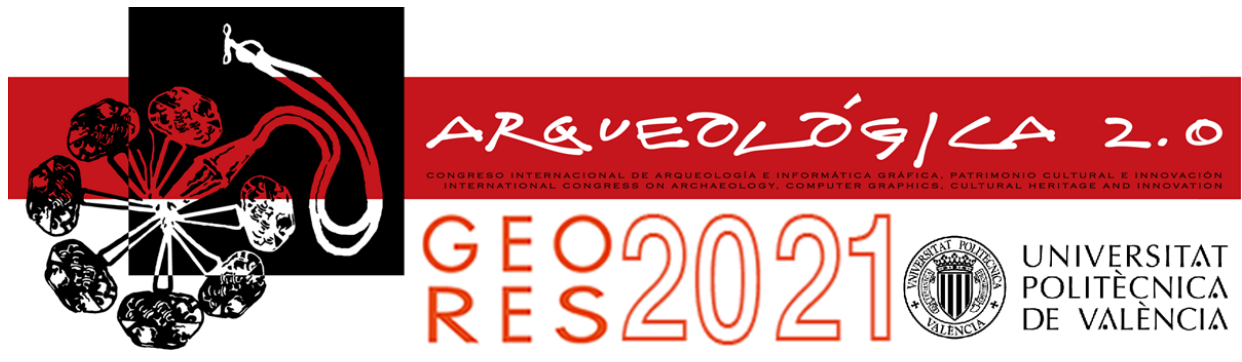

Proceedings of the joint international event $9^{\text {th }}$ ARQUEOLÓGICA

$2.0 \& 3^{\text {rd }}$ GEORES

Valencia (Spain).

26-28 April 2021

\title{
HBIM FOR RESTORATION WORK AND MONITORING OF COMPLEX ARCHITECTURES: THE FAMILY CHAPEL OF RAMÓN PERES Y ROVIRA IN CASTELLÓN DE LA PLANA (SPAIN)
}

\author{
Gianna Bertacchia, ${ }^{*}$, Francisco Juan-Vidal $^{\mathrm{b}}$, Luca Cipriania \\ a Department of Architecture, University of Bologna, Viale del Risorgimento 2, 40136 Bologna, Italy. gianna.bertacchi2@unibo.it; \\ luca.cipriani@unibo.it \\ ${ }^{\mathrm{b}}$ Department of Graphic Expression in Architecture, Instituto de Restauración del Patrimonio, Universitat Politècnica de València, \\ Camino de Vera, s/n, 46022 Valencia, Spain. fjuan@ega.upv.es
}

\begin{abstract}
:
The paper analyses the procedure to create a 3D model of a neogothic family chapel situated in Castellón de la Plana (Spain). The characteristics of the case study make it an emblematic case of Building Information Modeling (BIM) applied to Cultural Heritage (Historic BIM). The paper explores the workflow used to create the model and how the difficulties encountered have been addressed. The key motivations for this research project are: (i) local authority needs and objectives (restoration works for the conservation of architecture; necessity to monitor the asset after restoration); (ii) the intrinsic peculiarities of the small building (vast diversity of materials, richness and diversity of decorative elements); (iii) the creation of a pilot project for future applications in similar architectures. The chosen workflow tries to tackle the principal issues shared by the academic world with respect to 3D and HBIM models, e.g. the difficulty in reconstructing complex architectures without time-consuming processes, the reliability and high detail in the rendering of colours and textures, the insertion of detailed information for each element. The experiments carried out have made this case study interesting because of its complexity despite its reduced dimensions.
\end{abstract}

Keywords: HBIM, restoration works, neogothic architecture, family chapel, 3D reconstruction, Cultural Heritage

\section{Introduction}

In the field of Cultural Heritage $(\mathrm{CH})$ documentation, the last decades have been characterised by a huge increase in digital documentation with the use of active and passive sensors, in particular Terrestrial Laser Scanners (TLS) and digital photogrammetry. The latest research in the field of digital heritage documentation now focuses on the application of the Building Information Modeling (BIM) process to cultural assets (some recent experiments are cited in the reviews by Dore \& Murphy, 2017; López, Lerones, Llamas, Gómez-García-Bermejo, \& Zalama, 2018; Pocobelli, Boehm, Bryan, Still, \& Grau-Bové, 2018; Salvador-García, García-Valldecabres, \& Viñals-Blasco, 2018). This field of research is known today as Historic BIM (HBIM), as defined by Dore \& Murphy (2012). Since BIM is a modelling method created for the modelling and management of new buildings, its application to historical buildings generates evident critical issues that we can divide into three areas: (i) modelling criticalities; (ii) standardisation criticalities; (iii) criticalities related to the texture and final appearance of the model. The paper tries to address mainly points (i) and (ii) in a BIM environment, while point (iii) is addressed using digital photogrammetry and different 3D modelling software.

The modelling criticalities (i) derive mainly from the very characteristics of BIM software, created to be used with newly designed and constructed buildings, generally characterised by simple and rectified shapes and standardised elements. BIM software houses have therefore focused on providing basic modelling tools, that can be easily applied for the creation of simple models. These tools, limited and rigid, are poorly adaptable to replicate the geometric characteristics of the heterogeneous elements that constitute $\mathrm{CH}$. Moreover, the management of raw survey data (e.g. TLS point clouds or digital photogrammetry) in BIM environment is still limited and not very fluid. Since point clouds are generally the base for a $3 \mathrm{D}$ reconstruction of the cultural asset, their fluid use in BIM would provide a reliable tool for the scan-to-BIM methodology. For example, the inability to easily relate the outer and inner part of the same element, such as a wall, from a point cloud to a BIM component, causes difficulties in this time-consuming modelling phase. This problem could be implemented by software houses by improving mesh import and 
decimation, either directly from the point cloud or from mesh models already made.

Modelling problems are generally solved with the following approaches: (a) modelling in software external to BIM model management software (Massafra, Prati, Predari, \& Gulli, 2020); (b) development of ad hoc plugins and workflows for the management, modelling or import of mesh models in BIM environment (Bolognesi \& Caffi, 2019); (c) development of algorithms for automatic segmentation and classification of point clouds (Grilli \& Remondino, 2019; Pierdicca et al., 2020); (d) parametric modelling of complex components using Dynamo in Autodesk Revit (Massafra, Prati, Predari, \& Gulli, 2020; Jiang et al., 2020). Sometimes, these techniques are not completely conclusive and lead to partial results or where the loss of detail makes the model unusable for certain types of analysis. In addition, the developed workflows have considerable criticality in terms of time consumption and data loss when switching from one software to another; moreover, they generally require user-specific skills in the use of multiple modelling software and data interchange.

The most recent experiments try to solve the critical issues highlighted, for example by developing a workflow with software from the same software house, so as to avoid problems generated in the transition from one to the other, or with open source software and interchange formats (Diara \& Rinaudo, 2018). The same software houses are moving in the direction of developing new tools for mesh creation within the same program, trying to facilitate the onerous process of model generation. Our contribution tries to follow the latter workflow for the creation of the BIM model: external 3D modelling software are not used for the creation and import of elements into the BIM environment, but are only used to produce realitybased 3D models with a focus on texture appearance and model optimisation (as shown in previous works and experiments, such as in Cipriani \& Fantini, 2018; Bertacchi, Bertacchi \& Cipriani, 2021).

The modelling issue is related to the second one, i.e. the standardization (ii). As is well known, $\mathrm{CH}$ is characterised by elements with different geometric and conservative characteristics, even if they belong to the same category (e.g. the wooden beams of a ceiling or the columns of a portico). It is clear that each project must be preceded by the definition of the level of detail required for the work to be carried out, avoiding long-lasting modelling procedures. In this sense, since there is no specific international regulation, some scholars are trying to formalize the representation scales applicable to HBIM, deriving from the levels used to define BIM models (Biagini \& Donato, 2016; Castellano-Román \& PintoPuerto, 2019; Banfi, 2017; Banfi, 2020). As a basic concept, the necessary level of detail will be derived from the use of the information and the model in the restoration project, as it is for the representation scales of the traditional 2D drawings (Brumana, Banfi, Cantini, Previtali, \& Della Torre, 2019).

The complexity of finding universal standards for the creation of HBIM models leads to an inevitable simplification and the impossibility of creating libraries of elements with the same characteristics for subsequent reuse. This mainly leads to a lengthening of modelling times and the consequent impossibility of using families of elements already modelled, one of the most advantageous aspects of BIM software. Despite these current problems, HBIM remains one of the most expanding fields, precisely because of the advantages that a BIM model, once completed, offers in terms of managing not only a single restoration, but also the entire life cycle of the building (Mol, Cabaleiro, Sousa, \& Branco, 2020) and the information that can be included in it for a collaborative approach to the project (Heesom et al., 2020). However, it is necessary to assess on a case-bycase basis whether the expenditure of energy and economic resources involved in implementing an HBIM model is really justified by the needs in terms of restoration, monitoring and management of the asset, or whether it would be more convenient to choose another type of method that is more congenial and effective for the type of object being worked on.

Since the projects and technical drawings of the restoration work are based precisely on the possibility of interacting with the complexity and variability that characterises historic buildings, excessive standardisation can lead to an unusable result for restoration users, who therefore resort to classic 2D drawings, nullifying the potential of the BIM model.

Finally, the critical issues related to the texture of elements with complex geometry (iii) determine a final visualization of the model that often does not meet the needs of a restorer (e.g. for mapping pathologies directly on the 3D model). This problem is generally solved with the introduction of high quality orthoimages as an attachment to the specific element or part of the artifact, or with the support of other systems parallel to the model for texture visualization (Tsilimantou, Delegou, Nikitakos, Ioannidis, \& Moropoulou, 2020). Some experiments concern the use of adaptive components in Revit's BIM environment, that are used as elements to perform pathologies mapping (Chiabrando, Lo Turco, \& Rinaudo, 2017); in Sun, Xie, Zhang, \& Cao (2019) Revit's components are used for detail modelling ("brick-bybrick"), which provides the possibility to link attributes to the individual brick. For complex geometries, previous experiences have focused on other types of workflows (Adembri et al., 2016; Apollonio, Gaiani, \& Bertacchi, 2019; Cipriani, Bertacchi, \& Bertacchi, 2019; Cipriani \& Fantini, 2018). In these cases, information systems are developed centred on a reality-based 3D model with multi-scale and multi-user visualization. The strengths of this type of methodology are the high quality of the texture and the ease of use of the online platform even by nonexpert users, through an interface that allows direct mapping to the 3D model, also providing other useful data for restoration operations (such as the total surface affected by a given pathology, etc.). The critical points of this workflow, however, lie in the need for computer skills for the creation of the platform much more specific than those required for the use of BIM or other 3D modelling software.

Summing up, despite the multiplication in the last period of experiments in this field trying to solve the most emerging problems and the simultaneous development of dedicated software tools, these issues related to HBIM are still open.

This contribution is part of this framework as an experiment in the creation of an HBIM model of a complex architecture. The case study is a small oratory chapel for which restoration work will be undertaken (Fig. 1). The 
small building is characterised by the coexistence of many different materials and an important decorative apparatus in terracotta elements, which determines the complexity of the transposition into the BIM environment. As part of the restoration project, the research group decided to go beyond a "classic" digital documentation with TLS sensors and digital photogrammetry, proceeding with the creation of a BIM model with the following aims: (1) support to restoration work; (2) post-restoration monitoring; (3) pilot model for the restoration of stylistically and historically similar buildings; (4) creation of a library of standardized decorative elements present in similar buildings of the same period; (5) enhancement of $\mathrm{CH}$ with the use of the 3D model for educational purposes. However, beyond the BIM model, the research project maintains a parallel experimentation on high-detail models, especially of those decorative elements for which physical reproduction is necessary. This can be achieved with 3D printing operations, both positively and negatively for the prototyping of reusable formwork.

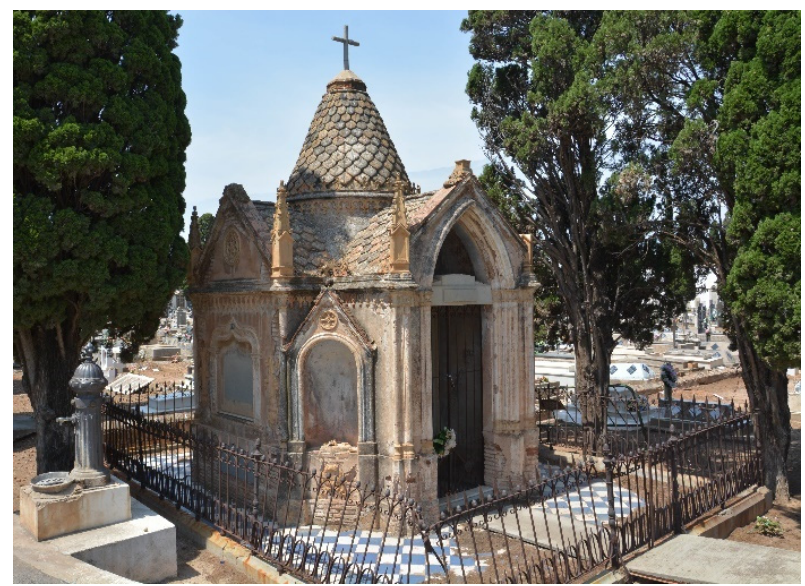

Figure 1: External view of the family chapel of Ramón Peres y Rovira.

The contribution makes an in-depth analysis of point (1), describing in detail the creation of the BIM model used support restoration work. The restoration work has not yet started, so the BIM model was used in the design phase of the restoration. Points (3), (4) and (5) are also explained but referring to the restoration project. Point (2) will be deepened after the restoration work, and it is analysed here in his design phase. In other words, we describe how the BIM model has been imagined to be used as a tool in every phase of the restoration work, present and future.

The article is divided as follows: in section 1 the project is inserted in the areas of research that make up the current HBIM panorama; in section 2 the case study and the surveying campaigns are described, highlighting the motivations that led to the development of the HBIM model; in section 3 the methodology followed for the implementation of the BIM model is defined, reporting some examples of the creation of families; in section 4 the possible future developments of the project and the conclusions deriving from the research are described.

\section{Case study}

This contribution reports an experimentation of the HBIM workflow applied to the family chapel (panteón) of Ramón Peres y Rovira, located in Sant Josep cemetery of
Castellón de la Plana (Comunitat Valenciana, Spain). The Municipality of Castellón decided to undertake restoration work on the chapel, which now suffers some serious pathologies, affecting both the decorative apparatus and the structure (Fig. 2).

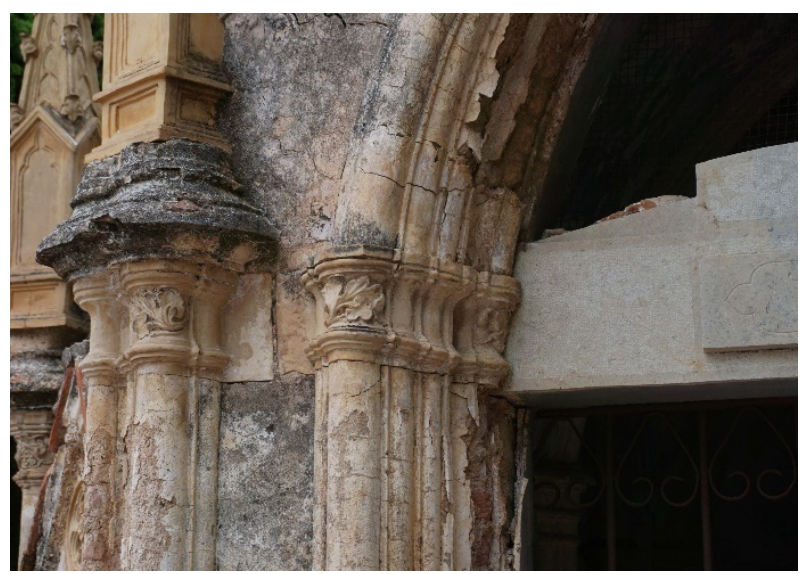

Figure 2: Some of the pathologies affecting the interior and exterior walls of the chapel.

The diversity of materials and pathologies found during the first inspections made it necessary to bring together a group of restorers specialised in different sectors of the Instituto de Restauración del Patrimonio (Institute for the Heritage Restoration) of the Universitat Politècnica de Valencia, responsible for the presentation of the preliminary project.

In order to provide the documentation underlying the preliminary restoration proposal, the documentation was created using TLS sensors and digital photogrammetry (see paragraph 2.2). This preliminary study served to identify the characteristics and problems of the small building.

In fact, as already mentioned in the introduction, the panteón has some characteristics that make its restoration and monitoring complex. First of all, (1) the presence of very different materials involves the interaction of professionals specialised in specific fields, such as the restoration of metals, glazed ceramics, terracotta, stone elements, plasters. Subsequently, (2) the presence of many decorative terracotta elements (Fig. 3 ) that can be found in similar buildings, led to think of standardized elements, probably made in series, following catalogues, by the factories in the area (famous for their ceramic production). In the chapel there are also some elements with a structural or complementary function that also have a decorative function (3) and therefore must be catalogued in the same way as decorative elements. This is the case of terracotta tiles, which have a particular petal shape, at least three different sizes and two different paste colours, arranged to form geometric patterns with alternating rhombuses (Fig. 4).

All these characteristics led to a cataloguing prior to the creation of the HBIM model, in order to establish the totality of the chapel components and decide for each component what information should be included in the BIM model. The cataloguing procedure is described in paragraph 3.1. 


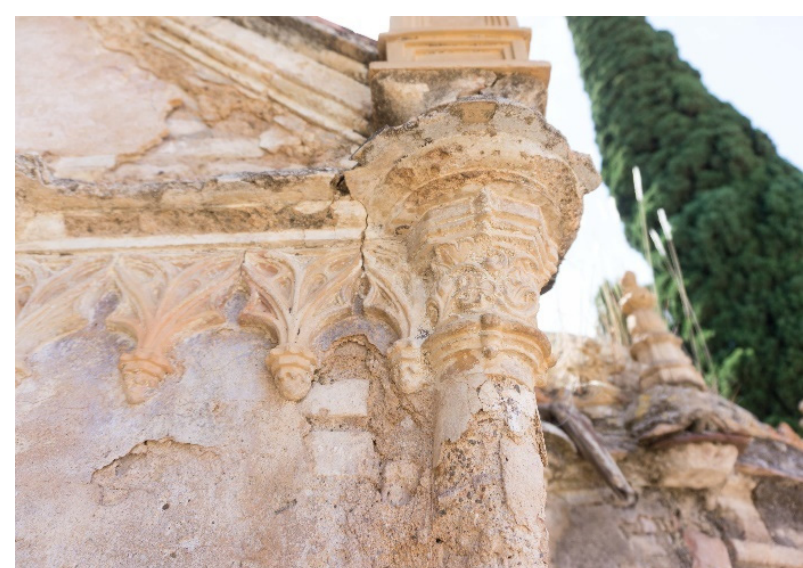

Figure 3: The decoration of the upper part of the outer wall.

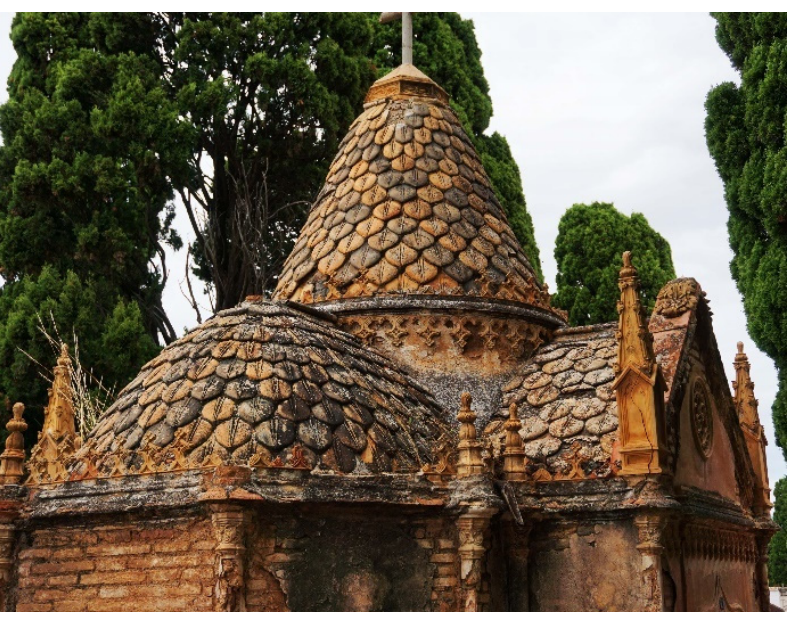

Figure 4: Terracotta roof tiles: the two different colours that form a geometric pattern are still visible despite the decay of the surface.

\subsection{Historical introduction}

The chapel of Ramón Peres y Rovira is a small building located in the centre of the old part of the cemetery of Sant Josep in Castellón de la Plana, in the province of València (Spain). The panteón is defined "oratory", since inside it has a small altar, two seats and a stoup, allowing to celebrate Mass in honour of the family members buried there. Little is known about its construction: we know that his wife was given the land for the construction of the chapel in 1866, a few years after the inauguration of the cemetery in 1861 (Molina Coronado, 2017). We can therefore deduce that the panteón was one of the first buildings in the cemetery. Unfortunately, at the time of writing this article we have no further information about the designer architect or construction companies; furthermore, the current period of restrictions for the COVID-19 pandemic makes it difficult to find further information in the local archives.

On the basis of a comparative stylistic analysis, we can say that the style of construction and decoration is neogothic and presents decorative elements common to chapels and buildings of the same period and in the same area. This detail is very useful to plan an in-depth analysis of the ceramic pieces. These in fact characterise the neogothic architecture of the provinces of Valencia and Barcelona and generally follow standardised profiles and shapes. Moreover, the Castellón area is both historically and currently an important centre of ceramic production (today it represents $90 \%$ of Spanish production). The first industrial production dates back to the $18^{\text {th }}$ century with the creation of the Real Fábrica de Loza y Porcelana de Alcora, and especially in the $19^{\text {th }}$ and $20^{\text {th }}$ centuries with the installation of many terracotta, ceramic and porcelain factories in Castellón and its surroundings (Ortells Chabrera, 2005). The analysis of ceramics can therefore be traced back to the production plant and its specific catalogues. This would allow, at best, to find in the catalogue of the time more information on the decorative pieces, especially those currently partial or missing (which can be glimpsed in the only historical photo in our possession). The search for similar elements and catalogues relating to the period of production of the decorations would also be a perfect basis for the creation of a library of three-dimensional models that could be adapted and reused in similar monuments in the same area.

Now the chapel is suffering from a deterioration that in recent years has been aggravated by a lack of maintenance. The close presence of three large cypress trees leads to the accumulation of organic material on the roof and in the enclosure, with consequent humidity present both outside and inside. The detachment of the plasters is widespread both internally and externally. In addition, some events that have occurred over the years have created serious damage to the metal fence (Fig. 5) and the south side of the building (the probable fall of the statue of the angel, that once crowned the central dome, caused the breakage of the decoration on the south side).

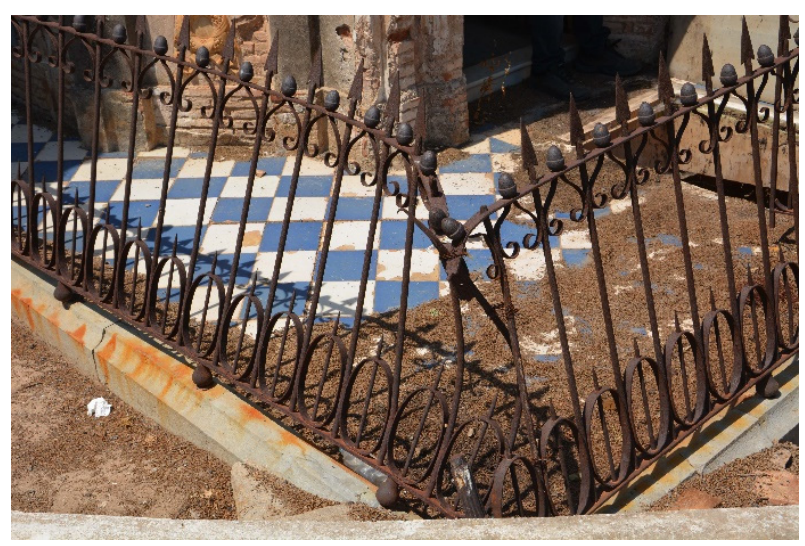

Figure 5: The northeast side of the iron enclosure with its deformation.

\subsection{Survey and preliminary data processing}

The panteón data were collected in three different survey campaigns conducted in February, March and June 2020 (due to the restrictions caused by COVID-2019 emergency, the campaigns were limited). The collection of external and internal data was carried out simultaneously with Terrestrial Laser Scanner (TLS) and digital photogrammetry. Fourteen scans were performed with a Trimble TX6 time-of-flight scanner. About 400 photos were processed with the Agisoft Metashape software, 1.5 .1 build 7618 (64 bit) in different chunks, joined by the coordinates obtained from the TLS point cloud. The final model is the result of the union of exterior, interior and roof. Other photos have been used for the realization of detail models, in particular the decorative elements present. 
Despite the small size of the artefact, the complexity of the decoration and the presence of trees near the building, led to some shortcomings in the digital reconstruction by photogrammetry, which were integrated with the mesh model created by the laser scanner point cloud (Fig. 6).

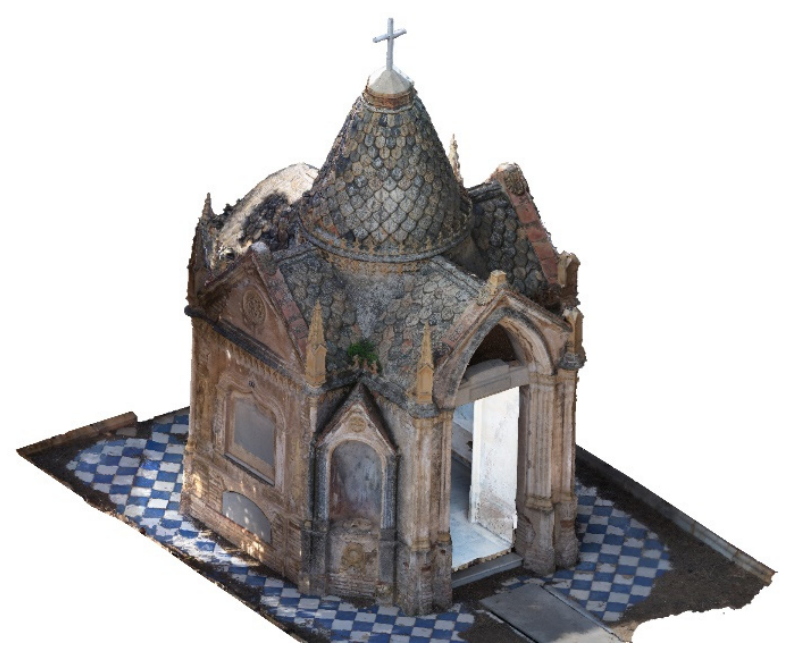

Figure 6: The mesh model produced with Agisoft Metashape.

Once the preliminary model was completed, it was possible to extract detail sections for the production of 2D drawings and corresponding orthoimages. Plans and sections were then inserted into the BIM environment to create the basic model.

\section{Methodology for the creation of the HBIM model}

As already described in section 2.2, some preliminary elaborations were carried out with CAD methods, prior to the realization of the model in a BIM environment (a detailed report of survey and data processing can be found in Bertacchi, Juan-Vidal, Cipriani, \& Molina Sánchez, 2020).

In addition, the building point cloud has been inserted in the BIM file, in the same position of the previously set origin, to serve as a reference for subsequent modelling. The context was modelled by creating a topography and a building pad corresponding to the enclosure. The floors were created from the lines extrapolated from the point cloud, using the corresponding family. For the walls, which have a very articulated shape, an "In-place component" was created by extruding successive sections derived from the point cloud. For roofs, a mass was modelled which was then used as the basis for the "Roof by surface" tool. To this model were added all the specific elements that assemble the building (Fig. 7).

At the basis of the preparation of the BIM model some general observations were made for its correct execution. On the basis of the physical and geometrical characteristics of the building, the needs of the restorers were taken into consideration in order to create a tool that can be effectively used in the restoration project and at the same time keep open the possibilities of further development and processing of the raw material, both inside and outside the BIM environment (3D printing, enhancement of the heritage through the publication on online platforms for the visualization of the 3D model...).
An essential phase for the correct setting of the model was the cataloguing of all the elements that make up the building, in order to have a global control of the operations before the restoration. The concepts underlying the cataloguing are described below.

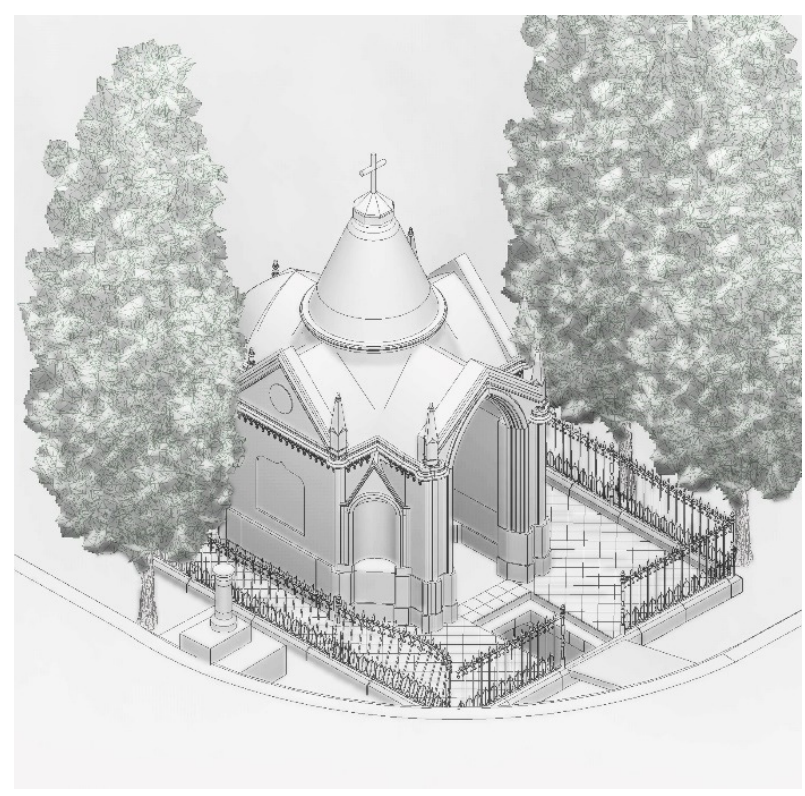

Figure 7: The BIM model in Autodesk Revit.

\subsection{Preliminary cataloguing}

The initial inspections revealed the need to have precise control over every element that makes up the panteón. For each type of element, it was necessary to be able to provide the restorers with detailed information, for example on the size, number of elements and state of conservation.

The cataloguing before the creation of the model was then used to define: the type of elements based on intrinsic physical characteristics such as material and dimensions; the number of elements for each type; the state of conservation. This information then determined the subsequent creation of the element families in Autodesk Revit v2019. In fact, for each family the characteristics and the information that it would have to report in order to meet the specific requirements of the restorers were clear a priori. The creation of the families will be further investigated by reporting some specific examples in section 3.2.

In order to insert in the BIM model the detailed models of the decorative elements with all this information, it was considered necessary to carry out a preventive cataloguing to facilitate the subsequent creation of the BIM families, so that restorers and maintainers can have a real advantage from the use of the model. The cataloguing therefore served as a basis to avoid errors in the design of the families. Being a completely manual and time-consuming phase and subject to possible compilation errors, it is considered necessary to try to avoid this phase in the future development of the project, when the creation of a library of common elements and the repetition of the workflow applied to this first case study will have solved this initial lack.

For the compilation of the catalogue, the panteón was previously divided into levels, each of which was 
interpreted with an acronym and with the addition of an " $\mathrm{i}$ " for internal and "e" for external. Each element was then assigned a code starting from an abbreviation of the name, a letter corresponding to the cardinal point of the side in which it is located and finally a progressive number of the element for each side of the building (Fig. 8). The code of each element makes it easy to understand its position in the building. Additional information on the type of material and state of conservation has been provided for each element in order to facilitate the preliminary assessment of the restoration operations to be carried out. The same approach to the assignment of the codes was also followed for the elements not currently present, but which were part of the original composition. The information in this case comes from a photo of the early twentieth century and it has been combined with the seriality of the presence of the same decorations. For each element it is therefore possible to proceed with the realization of the missing pieces, with the exception of a type of pinnacle, of which no exemplar remains, and the statue of an angel that originally crowned the central dome, of which only the photo and a piece of wing found on the roof remain.

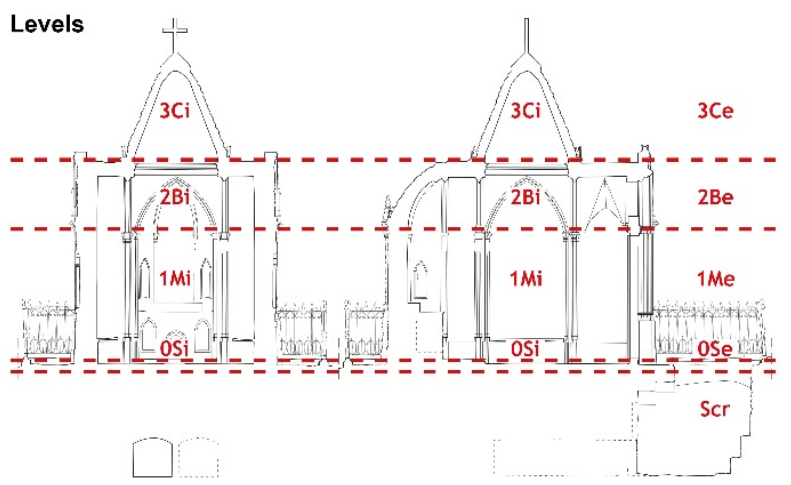

Figure 8: Level division in the catalogue.

Assigning a code to each element thus facilitates the creation of the families and makes it possible to create a phase of the model in which the original state of the chapel is reproduced.

\subsection{The HBIM model: creation of families}

To describe the methodology used, we report 4 specific cases that have been developed for the completion of the HBIM model. Each case is a reference to a typology of elements present in the panteón, so it can be applied to similar cases in different contexts.

First, the creation of the stone kerb that is part of the railing surrounding the building. The kerb is in limestone, with a particular section profile. Each single element has a different length and those at the corners have an $L$ shape. The main pathologies affecting the kerb are: damage with the detachment of substantial parts, mainly due to the expansion of the oxidised metal supports of the railing inserted in the stone; a high percentage of the surface covered by rust stains; some small cracks; the displacement of some elements from their original position (Fig. 9).

The restorers needed information on the total number of pieces, the length of each piece, the total surface area and the pathologies related to each element.
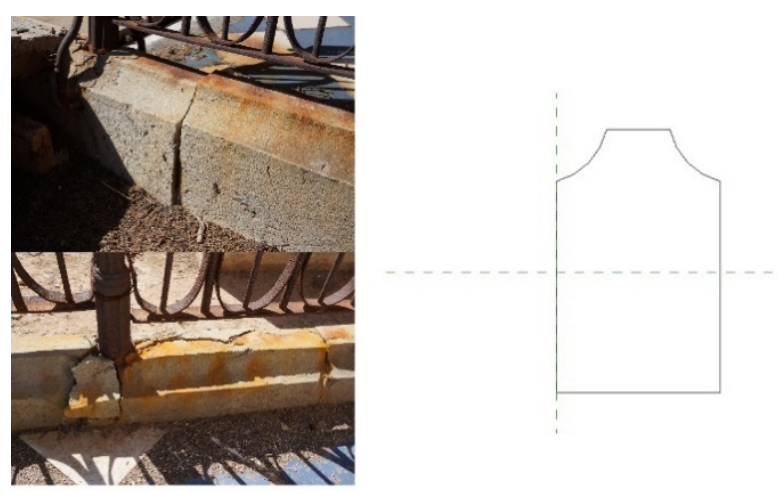

Figure 9: Some photos of the stone kerb and the profile in the Revit family editor.

The family created is a railing based one, with only the baluster active. The section profile obtained by the point cloud has simply been inserted into the family editor in a convenient position for subsequent insertion into the model (the origin corresponds to the reference level). A "limestone" material has been added to the family type. The kerb was inserted following the reference of the point cloud and separating each element from another as in the real condition. Then, in the "Mark" section the code established in the catalogue has been inserted and in the "Comments" the state of conservation has been provided, as a simple textual description.

All the information that has been linked to each element is easily accessible through the automatic schedule tool, which also offers the possibility of listing and counting the elements by Length or Comments or Code, as required (Fig. 10).

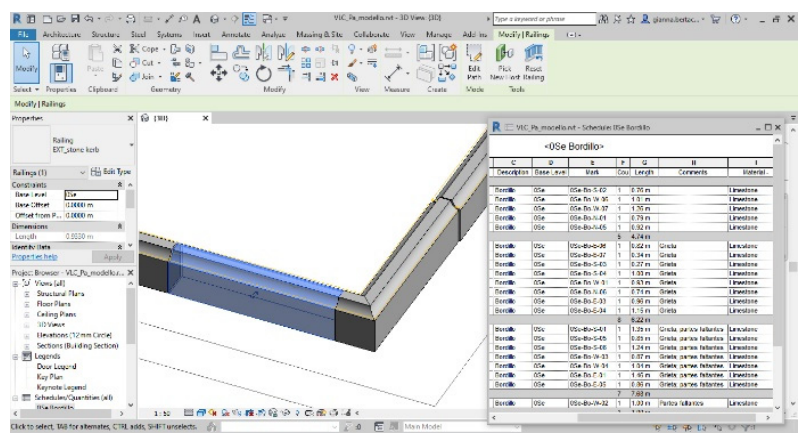

Figure 10: The stone kerb type in the model and the schedule with all the listed information and features.

The iron railing that leans on the kerb has been divided into sectors corresponding to those formed by the posts. Each sector of the railing consists of two horizontal bars and a variable number of modules. A single module consists of an arrow shaped bar and some decorative elements (Fig. 11).

Here, too, the restorers needed precise information on the number and condition of each individual element. In addition, some areas of the railing suffered damage that caused the loss of supports, verticality and shape (particularly in the northeast corner).

For these reasons it was important to recreate the railing following its current shape (to provide information on where and how to intervene and restore the original condition) and to recreate the division into modules (to add status information on broken or missing elements). 

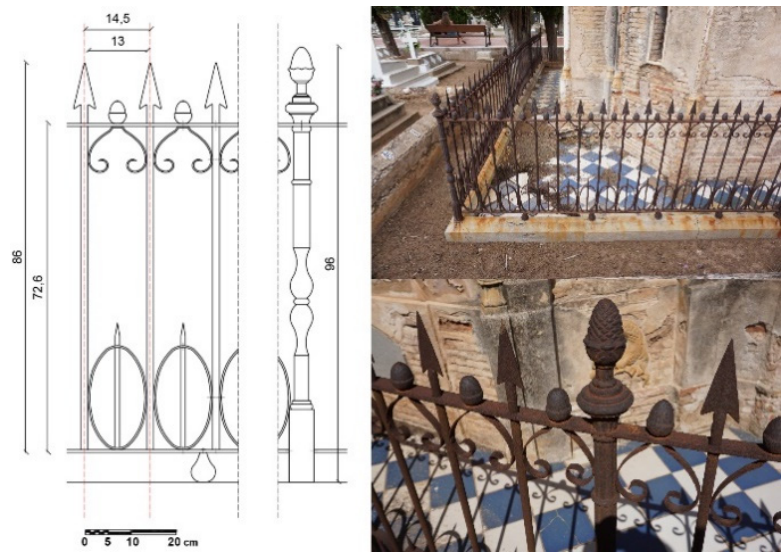

Figure 11: $C A D$ drawing of the railing module and some railing details.

The methodology undertaken began with the creation of surfaces (as "in-site mass") that followed the point cloud data. Then, for each sector a surface was created and automatically divided into the number of modules. This subdivision was then used to position the family types corresponding to each railing element.

Four different adaptive models were created from CADdrawn profiles, with extrusion or rotation commands. The different types of railing family can be easily positioned on the mass that forms each sector. Then, all the elements appear in the schedule, so they can be easily counted and report all the information added (Fig. 12).

Another procedure was used for the external floor. This is composed of alternately white and blue square ceramic tiles. For the floor it was necessary to know the total tile count for each different colour, size (if the tile was complete or cut) and condition of the material, to decide whether to replace or restore it.

In order to have the possibility to quickly list all the elements according to these specific parameters, we decided to divide the floor into parts. Once the floor had been set, with the "Create parts" tool and the use of the $C A D$ drawing, the floor was divided according to the position of the tiles. Then, some specific parameters were added to the category (type of parameter Yes/No): Broken, Lack of varnish, Serious lack of varnish, Lack of material, Absent, No information. These parameters appear in the properties of each tile and can be easily selected if present (Fig. 13). Then they are listed and counted in the Schedule view, providing the necessary information for restoration work. For example, it is possible to know how many white tiles have a serious lack of varnish or are broken and therefore probably need to be replaced instead of being restored. The schedule analysis shows that blue tiles are in better condition than white ones.

Certainly, this subdivision is useful not only during the restoration phase, but also to add information about the restored or replaced parts during the monitoring phase.

Finally, the last example describes the process used for a ceramic decorative element that forms a frame at the top of the wall. This is probably one of the standard elements produced during the construction period of the chapel. The model was made in two versions: the first, a highly detailed model derived from the curves extrapolated from the photogrammetric model, and the second, a simplified geometry recreated in a line-based family. The component can then be added directly following the wall sectors on which it appears (Fig. 14).

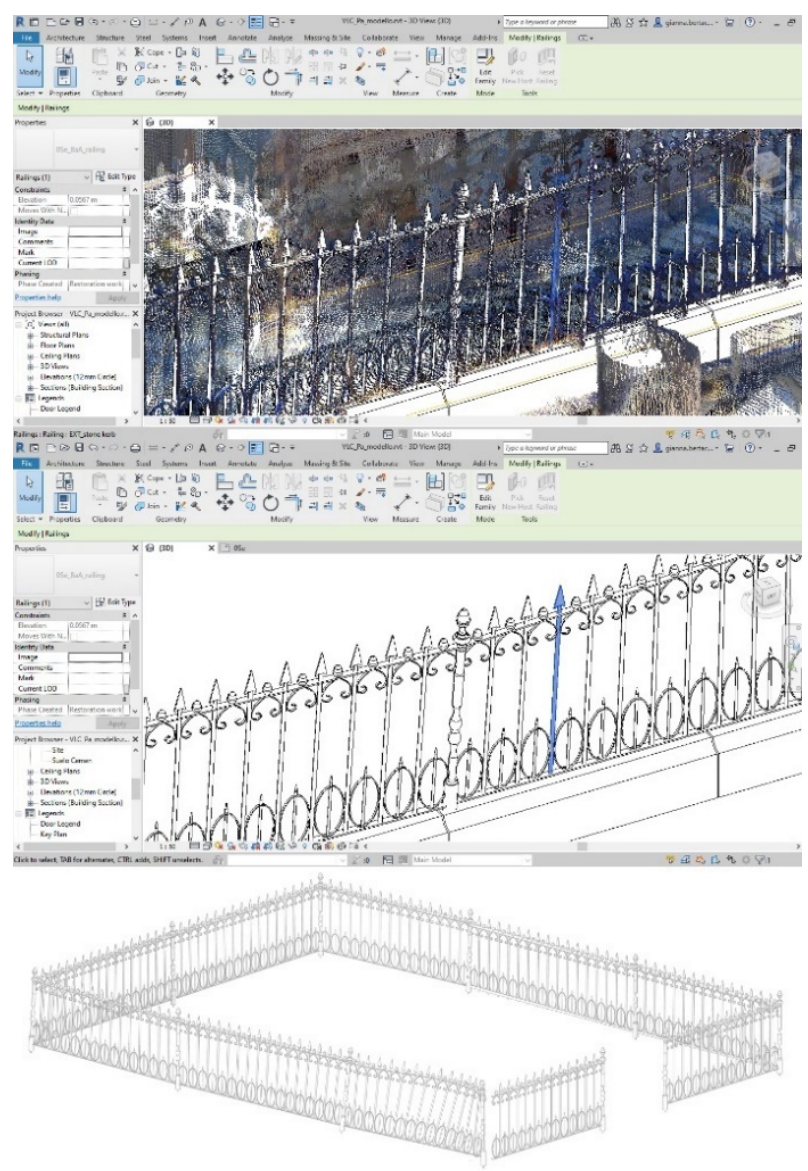

Figure 12: The subdivision of the surface into modules and its correspondence with the point cloud. In the final railing the possibility to select a single element of a module and add specific information is active.

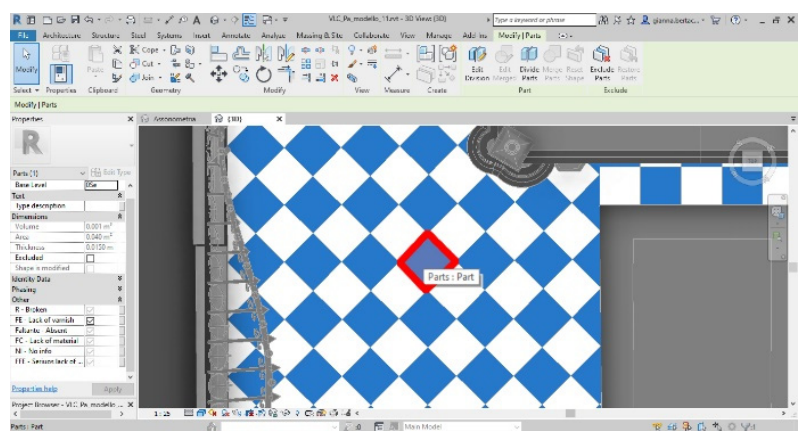

Figure 13: The parts that form the floor: each one is selectable, and all the necessary information can be added.

As with the other examples, the characteristics and information of each element can be listed automatically with the schedule view.

\section{Future developments and conclusions}

This document describes the methodology adopted to create an HBIM model of a particular cultural asset. As indicated in the introduction on the state of the art, HBIM experiments clash with some practical and theoretical problems. The main ones concern the modelling phase 
(all actions needed to transform raw data into BIM elements), and the design phase (to understand the best solution for creating an element that provides what end users need).

Given the technological development, some problems of the first category are being solved, although there are not yet tools as easy to use as in software like McNeel Rhinoceros. Given the peculiarities of the heritage assets, for now experimentation and differentiation of workflows according to each element is still predominant, and the scarce modelling tools slow down the workflow and make it rigid.

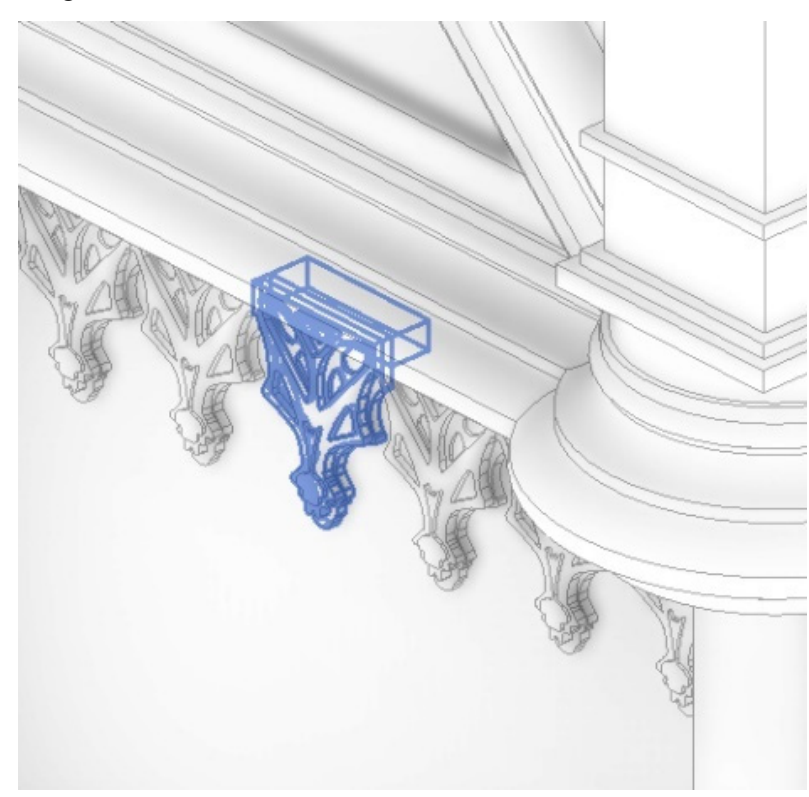

Figure 14: The decoration added on the upper part of the outer wall.

On the other hand, after the initial effort, what can be achieved with the BIM models created, in terms of fast counting and adding information, is the real saving in terms of time, and also opens up to different possibilities and users (static analysis, energy studies, etc.).

The paper presents some specific examples of the modelling workflow carried out on a small but complex building, which in itself contains peculiarities that have allowed diversified experiments on the elements. Each of the workflows presented derives not only from the initial intrinsic conditions of the single element, but from the combination of the physical parameters (shape, material, arrangement...) with the characteristics of the BIM software (families, parameters, links to external objects...) and with the needs of use (counting, mapping, volume, area, state of conservation...). The interaction and combination of these parameters are essential for the correct creation of families and types to be inserted in the model. Moreover, the variety of typologies analysed and their flexibility allows their application to objects at different scales and in different contexts.
Therefore, the approach that has been maintained in the case of such a complex building is one of maximum flexibility, not only in the BIM model creation phase, but also in the raw data processing phase for the parallel creation of models with different details and for different purposes, which can always be added to the BIM model as a link to a database. This partially solves the still existing difficulty in processing the huge amounts of data that generally characterise the documentation of the built heritage. Moreover, the bases are prepared for different uses of three-dimensional models at different treatment levels (think of the potential of automatic segmentation or automatic recognition of pathologies for surface mapping or 3D printing of missing or to be replaced elements). The $3 \mathrm{D}$ reality-based models therefore play a complementary role to the HBIM model in documentation and restoration work and are prepared for specific uses, such as high detail texture visualisation, 3D printing, heritage dissemination via online platforms.

In conclusion, the most unresolved issues concern modelling and model setting problems.

While the first can be solved by looking for the workflow that best suits each type of element, the second depends on the setting of the whole project. In this sense, the examples presented in detail in section 3.2 are the result of a previous reasoning which, thanks to manual cataloguing and in-depth study of the construction and architectural characteristics of the chapel, made it possible to logically execute the parts created and the model. In essence, the creation of the BIM model did not occur by juxtaposition of parts, but by following the construction logic, combined with the potential offered by the software to satisfy specific requests. These requests were mainly highlighted by the restorers of the Instituto de Restauración del Patrimonio themselves, in order to really obtain from the model the information necessary for the restoration work.

The flexible approach to project components lays the foundations for future developments and applications in similar projects, for which the BIM model can be set up following the guidelines of this pilot project. Those families created can also be reused or easily adapted in other similar projects (as better described in section 2).

The creation of a library of standardised elements belonging to neogothic architectures stylistically and historically linked to the Castellón chapel, together with the continuous experimentation of specific workflows for the creation of families in a similar context, are the main aspects in continuous development.

\section{Acknowledgements}

Authors would like to thank: the municipality of Castellón de la Plana, the Instituto de Restauración del Patrimonio of the Universitat Politècnica de València, professors José Herráez Boquera and José Luís Denia Ríos for facilitating access to the laser scanner and Susana Molina Sánchez for the help provided during the survey operations.

\section{References}

Adembri, B., Alonso-Durá, A., Juan-Vidal, F., Bertacchi, G., Bertacchi, S., Cipriani, L., Fantini, F., \& Soriano-Estevalis, B. (2016). Modelli digitali 3D per documentare, conoscere ed analizzare l'architettura e la costruzione nel mondo antico: 
l'esempio della Sala Ottagonale delle Piccole Terme di Villa Adriana. Archeologia e Calcolatori, XXVII, 291-316.

Apollonio, F. I., Gaiani, M., \& Bertacchi, S. (2019). Managing Cultural Heritage with integrated services platform. Int Arch Photogramm Remote Sens Spatial Inf Sci, XLII-2/W11, 91-98. https://doi.org/10.5194/isprs-archives-XLII-2-W11-912019

Banfi, F. (2017). BIM Orientation: Grades of Generation and Information for Different Type of Analysis and Management Process. Int Arch Photogramm Remote Sens Spatial Inf Sci XLII-2/W5, 57-64. https://doi.org/10.5194/isprs-archivesXLII-2-W5-57-2017

Banfi, F. (2020). HBIM, 3D drawing and virtual reality for archaeological sites and ancient ruins. Virtual Archaeology Review, 11(23), 16-33. https://doi.org/10.4995/var.2020.12416

Bertacchi, S., Bertacchi, G. \& Cipriani, L. (2021). Chiuro laboratory: integration of workflows from digital survey to optimised 3D urban models for interactive exploration. Appl. Geomat. https://doi.org/10.1007/s12518-020-00352-1

Bertacchi, G., Juan-Vidal, F., Cipriani, L., \& Molina Sánchez, S. (2020). Levantamiento digital del Panteón de Ramón Peres y Rovira en el cementerio de Castellón de la Plana (Valencia, España). Arché, 13 - 14 - 15, $171-180$. http://hdl.handle.net/10251/156576

Biagini, C., \& Donato, V. (2016). Levels of development for historic building information modeling: towards building simulation. UID2016 - XXXVIII Convegno internazionale dei Docenti delle Discipline della Rappresentazione, XIII Congresso della Unione Italiana del Disegno - Le ragioni del disegno - pensiero, forme e modello nella gestione della complessità, Florence, Italy. 1045-1050.

Bolognesi, C., \& Caffi, V. (2019). Extraction of primitives and objects from HSHAPES, Int. Arch. Photogramm. Remote Sens. Spatial Inf. Sci., XLII-2/W9, 151-156. https://doi.org/10.5194/isprs-archives-XLII-2-W9-151-2019

Brumana, R., Banfi, F., Cantini, L., Previtali, M., \& Della Torre, S. (2019). HBIM Level of Detail-Geometry-Accuracy and survey analysis for architectural preservation. Int. Arch. Photogramm. Remote Sens. Spatial Inf. Sci., XLII-2/W11, 293-299. https://doi.org/10.5194/isprs-archives-XLII-2-W11-293-2019

Castellano-Román, M. \& Pinto-Puerto, F. (2019). Dimensions and Levels of Knowledge in Heritage Building Information Modelling, HBIM: The model of the Charterhouse of Jerez (Cádiz, Spain). Digital Applications in Archaeology and Cultural Heritage, 14. https://doi.org/10.1016/j.daach.2019.e00110

Cipriani, L., Bertacchi, S., \& Bertacchi, G. (2019). An optimised workflow for the interactive experience with Cultural Heritage through reality-based 3D models: cases study in archaeological and urban complexes. Int Arch Photogramm Remote Sens Spatial Inf Sci XLII-2/W11, 427-434. https://doi.org/10.5194/isprs-archives-XLII-2-W11427-2019

Cipriani, L. \& Fantini, F. (2018). Integration of Pipelines and Open Issues in Heritage Digitisation. In: Remondino, F., Georgopoulos, A., González-Aguilera, D. \& P. Agrafiotis (Eds) Latest Developments in Reality-Based 3D Surveying and Modelling. Basel (CH), MDPI, 171-191. https://doi.org/10.3390/books978-3-03842-685-1-8

Chiabrando, F., Lo Turco, M., and Rinaudo, F. (2017). Modeling the decay in an HBIM starting from 3D point clouds. A followed approach for Cultural Heritage knowledge. ISPRS - International Archives of the Photogrammetry, Remote Sensing and Spatial Information Sciences, 62, 605-612, 2017. https://doi.org/10.5194/isprs-archives-XLII-2-W5-6052017

Diara, F., \& Rinaudo, F. (2018). Open source HBIM for Cultural Heritage: a project proposal. Int. Arch. Photogramm. Remote Sens. Spatial Inf. Sci., XLII-2, 303-309. https://doi.org/10.5194/isprs-archives-XLII-2-303-2018

Dore, C., \& Murphy, M. (2012). Integration of Historic Building Information Modeling and 3D GIS for Recording and Managing Cultural Heritage Sites. $18^{\text {th }}$ International Conference on Virtual Systems and Multimedia: "Virtual Systems in the Information Society", 2-5 September. 2012, Milan, Italy. 369-376.

Dore, C., \& Murphy, M. (2017). Current state of the art Historic Building Information Modelling. ISPRS - International Archives of the Photogrammetry, Remote Sensing and Spatial Information Sciences, XLII-2/W5, $185-192$. https://doi.org/10.5194/isprs-archives-XLII-2-W5-185-2017

Grilli, E., \& Remondino, F. (2019). Classification of 3D Digital Heritage. Remote Sens., $11,847$. https://doi.org/10.3390/rs11070847

Heesom, D., Boden, P., Hatfield, A., Rooble, S., Andrews, K. \& Berwari, H. (2020). Developing a collaborative HBIM to integrate tangible and intangible cultural heritage. Int. J. Building Pathology and Adaptation, 2020. https://doi.org/10.1108/IJBPA-04-2019-0036

Jiang, Y., Li, A., Xie, L., Hou, M., Qi, Y., \& Liu, H. (2020). Development and Application of an Intelligent Modeling Method for Ancient Wooden Architecture. ISPRS Int. J. Geo-Inf., 9, 167. https://doi.org/10.3390/ijgi9030167

López, F.J., Lerones, P.M., Llamas, J., Gómez-García-Bermejo, J., \& Zalama, E. (2018). A Review of Heritage Building Information Modeling (H-BIM). Multimodal Technologies Interact 2(2), 21. https://doi.org/10.3390/mti2020021

Massafra, A., Prati, D., Predari, G., \& Gulli, R. (2020). Wooden Truss Analysis, Preservation Strategies, and Digital Documentation through Parametric 3D Modeling and HBIM Workflow. Sustainability, 12, 4975. 
https://doi.org/10.3390/su12124975

Molina Coronado, E. (2017) La historia de Castellón llama a la puerta y reclama derecho a la memoria el 1 de noviembre. Memoria histórica del Cementerio de San José de Castellón | Castellón Información. Retrieved March 15, 2021, from http://www.castelloninformacion.com/memoria-historica-del-cementerio-de-san-jose-de-castellon/

Mol, A., Cabaleiro, M., Sousa, H. S., \& Branco, J. M. (2020). HBIM for storing life-cycle data regarding decay and damage in existing timber structures. Automation in Construction, 117, 1032622. https://doi.org/10.1016/j.autcon.2020.103262

Ortells Chabrera, V. (2005). La indústria ceràmica a la Plana de Castelló. Tradició històrica i mundialització actual. Treballs de la Societat Catalana de Geografia, 58, 35-66.

Pierdicca, R., Paolanti, M., Matrone, F., Martini, M., Morbidoni, C., Malinverni, E. S., Frontoni, E., \& Lingua, A. M. (2020). Point Cloud Semantic Segmentation Using a Deep Learning Framework for Cultural Heritage. Remote Sens., 12, 1005. https://doi.org/10.3390/rs12061005

Pocobelli, D. P., Boehm, J., Bryan, P., Still, J., \& Grau-Bové, J. (2018). BIM for heritage science: a review. Heritage Science 6:30. https://doi.org/10.1186/s40494-018-0191-4

Salvador-García, E., García-Valldecabres, J., \& Viñals-Blasco, M. J. (2018). The use of HBIM models as a tool for dissemination and public use management of historical architecture: a review. International Journal of Sustainable Development and Planning. 13(1), 96-107. https://doi.org/10.2495/SDP-V13-N1-96-107

Sun, Z., Xie, J., Zhang, Y., \& Cao, Y. (2019). As-Built BIM for a Fifteenth-Century Chinese Brick Structure at Various LoDs. ISPRS Int. J. Geo-Inf., 8. 577. https://doi.org/10.3390/ijgi8120577

Tsilimantou, E., Delegou, E. T., Nikitakos, I. A., loannidis, C., \& Moropoulou, A. (2020). GIS and BIM as Integrated Digital Environments for Modeling and Monitoring of Historic Buildings. Appl. Sci., 10, 1078. https://doi.org/10.3390/app10031078 


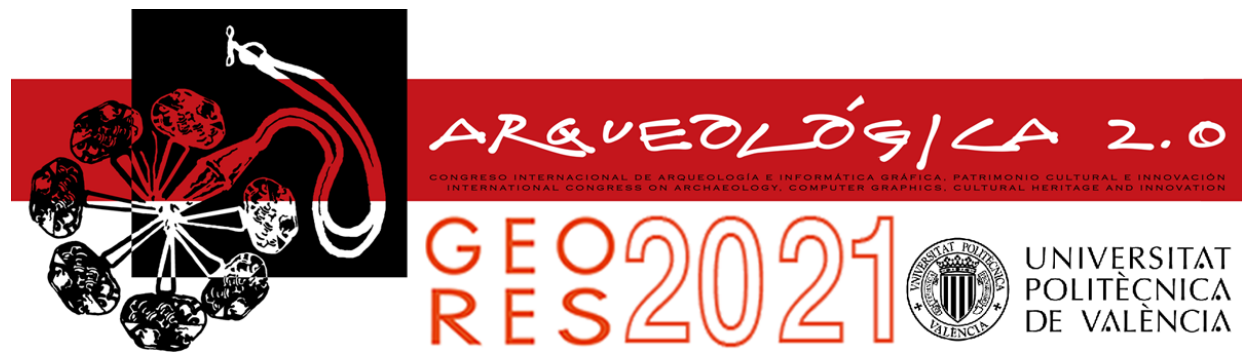

Proceedings of the joint international event $9^{\text {th }}$ ARQUEOLÓGICA

$2.0 \& 3^{\text {rd }}$ GEORES

Valencia (Spain).

26-28 April 2021

\title{
AN INTERACTIVE 3D APPLICATION OF A HOUSE FROM THE XVI CENTURY IN SAN CRISTÓBAL DE LAGUNA AS A CASE STUDY FOR THE DISSEMINATION OF CULTURAL HERITAGE
}

\author{
Isabel Sánchez-Berrie|a, ${ }^{a}$, Alejandro González-Gonzáleza ${ }^{a}$, Fernando Pérez-Navaa ${ }^{a}$ Cecile Meier ${ }^{b}$, \\ Jesús Pérez-Morerac ${ }^{c}$, Carmen Rosa Hernández-Alberto ${ }^{d}$ \\ ${ }^{a}$ Departamento de Ingeniería Informática y Sistemas, Escuela Superior de Ingeniería y Tecnología, Camino San Francisco de Paula \\ s/n, 38200 La Laguna, Spain. isanchez@ull.edu.es; fdoperez@ull.edu.es; esit@ull.edu.es \\ ${ }^{b}$ Departamento de Bellas Artes, Facultad de Bellas Artes, C/ Prof. José Luis Moreno Becerra s/n, 38200 La Laguna, Spain. \\ cemeier@ull.es
}

c Departamento de Historia del Arte y Filosofía, Facultad de Humanidades, C/ Prof. José Luis Moreno Becerra s/n, 38200 La Laguna, Spain.jperezmo@ull.edu.es

${ }^{d}$ Ayuntamiento de San Cristóbal de La Laguna, C/ Obispo Rey Redondo 1, 38201 La Laguna, Spain. rheralb@lalaguna.es

\begin{abstract}
:
At the end of the XVI century, the historic centre of San Cristóbal de La Laguna was definitively configured as we know it today, as can be seen in the first preserved map of the city, drawn in 1588 by the engineer Leonardo Torriani. It is the first non-fortified Spanish colonial city and its plan has provided a model for the colonial cities of America, making it a UNESCO World Heritage site. The dissemination of this legacy is a task of great importance. A tool of increasing importance for the dissemination and preservation of history and cultural heritage are reconstructions and virtual recreations in 3D. This paper presents a case of the use of these tools for the dissemination of the city's heritage. The 3D modelling of one of the most characteristic types of housing in San Cristóbal de La Laguna in the $16^{\text {th }}$ century is carried out along with the 3D modelling of human virtual characters all based on the historical documentation of that time. With these elements, a WebGL application has been implemented in which a user can visit the virtually reconstructed house and receive information on the construction systems and architecture in the city in the XVI century.
\end{abstract}

Keywords: virtual reality (VR), 3D modelling, 3D visualization, virtual characters, cultural heritage

\section{Introduction}

Three-dimensional reconstructions and virtual recreations have become useful tool for the dissemination and preservation of history and cultural heritage. The recent advances and ease of access in multimedia technologies have generated a growing development of attractive experiences for learning (Bostanci, Kanwal \& Clark, 2015). Among these technologies, we highlight Virtual Reality (VR) as a support for the creation of sensory experiences that contribute to a better understanding and dissemination of cultural heritage. VR constitutes one of the most attractive and promising tools in this field since it offers the possibility for users to perceive heritage through their senses and to even manipulate and act on the objects of study (Bekele, Pierdicca, Frontoni, Malinverni, \& Gain, 2018). In this way, a more natural and instinctive way of learning is achieved, compared to symbol-based learning (Carrozzino, Bergamasco, 2010). Besides this, in learning applications, recreations of cultural elements located in spatial locations at determined temporal instants can be provided that would not be possible otherwise (Vincent, Defanti, Schulze, Kuester, \& Levy, 2013).

An increasing number of entities are taking advantage of this technology to illustrate the reconstructions of buildings at different times in the past. These reconstructions include in recent years virtual human characters in VR applications given the degree of maturity of the technology. The characters are mainly used as virtual teachers to obtain a more user-friendly and attractive application. It should be noted that in this type of recreation it is considered that the introduction of characters helps us to contextualize and better understand the reconstruction (Machidon, Duguleană \& Carrozzino, 2018).

In this paper we present an application belonging to a research project that aims to develop an immersive experience of the city of San Cristóbal de La Laguna

‘Corresponding Author: Isabel Sánchez-Berriel, isanchez@ull.edu.es 
(commonly called La Laguna) in the $16^{\text {th }}$ century. This work focuses on the virtual reconstruction of a domestic house in La Laguna from the XVI century. The advantages outlined before on the use of technologies for the dissemination of cultural heritage are used to show the house features and customs of that time. In the application, virtual human characters are introduced and their clothes reproduce those that could be found at that century, creating empathy with the context in which the user is immersed. These characters are part of the virtual recreation and will allow the user to understand the uses and cultural significance of the reconstructed environment. By means of these elements, it is intended that the Virtual Reality application promotes the general interest towards the patrimonial and cultural heritage of the city.

\section{Architecture of San Cristóbal de La Laguna in the XVI century}

\subsection{La Laguna in the XVI century}

In 1496, the island of Tenerife became part of the Crown of Castile, the year in which the city of San Cristóbal de La Laguna was also founded (Abreu, 1977). After the conquest of the island, the distribution of land and repopulation began with new inhabitants from the Kingdom of Castile (from the regions of Andalusia, Extremadura, Galicia ...) and also from Portugal, the Netherlands and Genoa. The first settlement of the city took place in the area where the church of La Concepción stands today (Cioranescu, 1965; Aznar, 2008). The first houses and a small chapel dedicated to the Virgin of La Concepción were built in the so-called Upper Town. Towards 1500 the configuration of the city changed, promoted by the King's delegate: el Adelantado, moving the new buildings to what would be the Lower Town. The Island Government: el Cabildo agreed to draw an expansion plan in a southerly direction, establishing a grid (checkerboard plan) of ordered streets, according to the taste that prevailed in the European Renaissance at that time. In this way, the historical centre of the city was definitely configured as we know it today at the end of the $16^{\text {th }}$ century, as observed in the map drawn in 1588 by the military engineer Leonardo Torriani as shown in Figure 1.

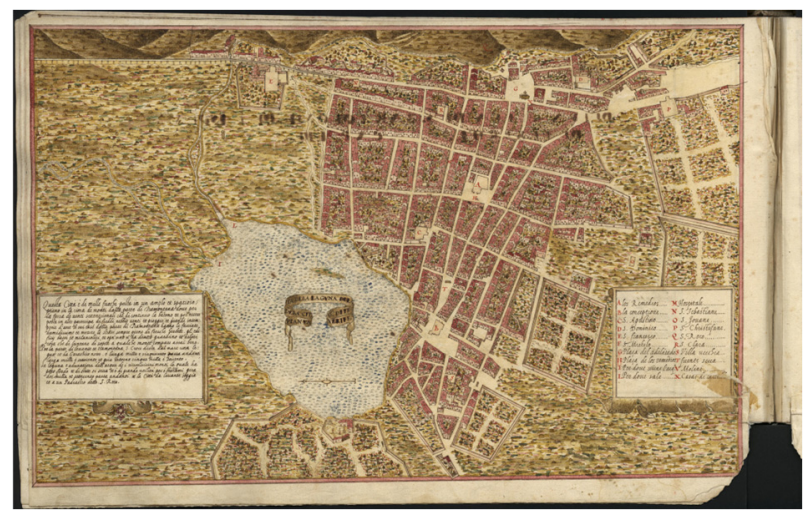

Figure 1: Torriani's map of La Laguna. (source: Library of the University of Coimbra).

The coexistence between the old houses of Mudejar tradition, the old convents, the eclectic architecture, and the new urban plans characterize the most contemporary stage. However, there have been no substantive changes in its urban layout since then, an issue that has been key to obtain on December 2, 1999, the title of World Heritage Site.

\subsection{Constructive features in the houses in La Laguna in the XVI century}

The style of construction that is imposed in the city is Mudejar, highlighting 5 functional types: armoury house, barn house, commercial house, low house or casa terrera and high house or casa sobradada (Navarro, 1999; Navarro, Perera, \& Pérez, 2018). Large extensions of lime masonry are used, combined with corners, facades and stone towers. In the facades, the carpentry is distributed in frames, windows and balconies. The houses are structured in three parts that occupy the plot, with the built-up area facing the street and with a facade parallel to it. Following the house, there is a yard and in the last section the garden for self-consumption. In the city of La Laguna, the houses conform to the casa-corral type, which refers to a house with a garden and space for raising animals, this part of the site was fenced and is what is called the corral. The documents in which el Adelantado registered the plot concessions of the island of Tenerife between conquerors and settlers at the end of the conquest (datas) refer to their use for both house and garden.

The plots are rectangular, sometimes squared, resulting from the perfect division of the land (Larraz, 2009). The front of the plot faced the street and is usually the main facade of the house. The sides were called bottoms and the occupancy ratios of the house with respect to the plot were usually: 1 to 1.5 or 1 to 2 . The plots were fully occupied, even by building a wall on its perimeter (Fig. 2). The construction system used is simple; the design of the Andalusian house-room is simplified, due to the shortage of construction craftsmen and the difficulty to obtain the materials.

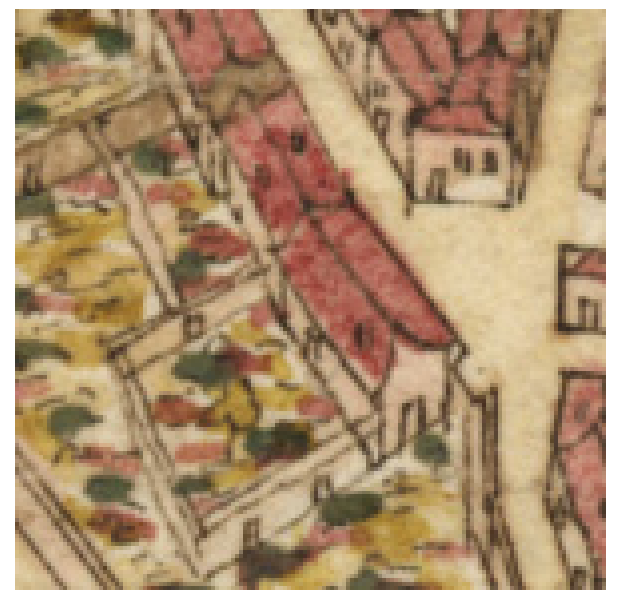

Figure 2: Houses with a yard and garden. Detail from Torriani's map of La Laguna.

In the city, houses had two types of roofs: straw or ceramic tiles (Larraz, 2009). Although the construction of thatched roofs was forbidden, it was common to find thatched houses, in which the roof was made of intertwined straw. These houses could be found of two types: adobe and straw and stone and straw. In rural areas, their structure is simpler, but in the city, they usually had the same dimensions and construction 
system as the tiled ones. They were usually of a quadrangular plant, the inner part was divided by means of partitions of adobe walls, dry stone or masonry walls. It was common for thatched houses to have a single room, but if they had more than one it was because of the existence of several terraced houses. The rooms were not connected to each other, in case several of them existed, the communication was made through the yard.

The second type of housing is tile houses; in these the construction systems are more complex. They are usually of two floors and compartments are made more frequently. Stone walls are used to build the house and the stonework is incorporated for the carved corners and the compartments.

The high houses (sobradada or sobrada) refer to those that have more than one floor (Navarro, 1999; Larraz, 2009). The staircase to access the second floor used to be attached to the outside. The first section corresponded to a stone staircase, which gives access to a wooden staircase that ends at the access door. In higher category houses, it can be found inside, starting either from the lobby or from the main room.

\subsection{Morphology of the sobrada house}

It has been chosen to reproduce a tiled sobrada house that was mainly present in the Lower Town, so below we detail the morphology and features of this type of housing that have been included in the 3D model.

The sobrada house usually had two floors: one at the street level and the sobrado floor over it (Navarro, 1999; Larraz, 2009). The sobrado floor was usually used as a barn with the intention of preserving crops from moisture. Due to the simplicity of the constructions, they did not usually have many compartments in the structure, so it was common for the rooms to have a window to the street and a door to the yard, acting as a connecting link between the rooms. Besides the yard, there was a garden with fruit trees, vineyards and crops. Some space was also reserved for animals.

The access to the house was made through the main door that lead to the living-dining room or main room and in opposite direction directly to the yard's access in the simplest houses. When housing extensions were built, the yard was the growth zone. The kitchen was usually set up as an extension in the yard, located in an area protected from the wind. In the kitchens a worktop or poyo made of stone and mud to the back is constructed, a fireplace or hogar is located in the upper part that in the humblest houses is formed with 3 rocks or teniques (Pérez, 1967). An earthen or ditch floor is common, and 3 tiles were placed in the form of a pyramid, that in conjunction with the open door facilitated the exit of the smoke. Inside or outside the kitchen was an oven. When the kitchen is on the sobrado floor, it had its own fireplace. Finally, a well could also be found in the yard to provide water to the house.

\section{Modelling the house}

A two-floor house is designed with open-source software for 3D modelling (Blender, 2020). A simplified model has been chosen to be used in a web browser but retaining the main characteristics of the house. The model takes into account features such as measurements, proportions, floors, distribution of rooms, materials, etc. described in studies on the type of housing of the $\mathrm{s}$. XVI in San Cristóbal de La Laguna. More complex architectural details are not considered due to the performance limitations on the platform chosen for display. The house is in the range for the measurements at the time for a casa sobrada (Larraz, 2009). The front, which faces the street, is about 14 meters and the back of the house is about 10 meters. The height of the houses is not found in the bibliography and has been estimated at 9.5 meters (Fig. 3).

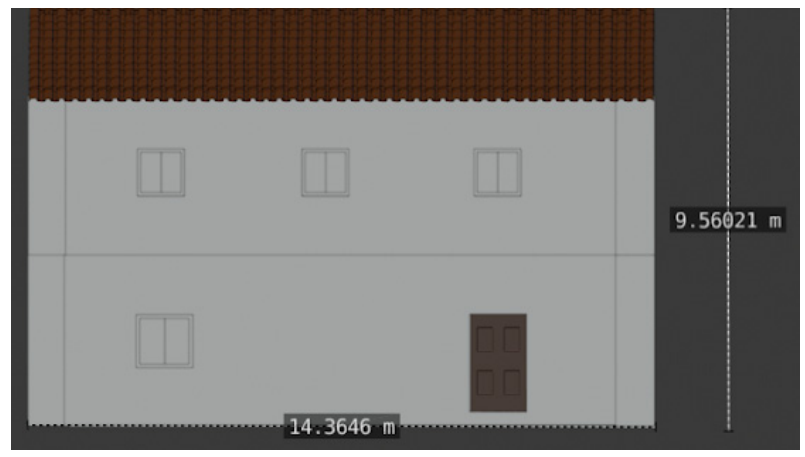

Figure 3: Front view of the house without textures.

The building site dimensions have been determined using a proportion house-plot around 1:3 (Larraz, 2009) as can be seen of Figure 4.

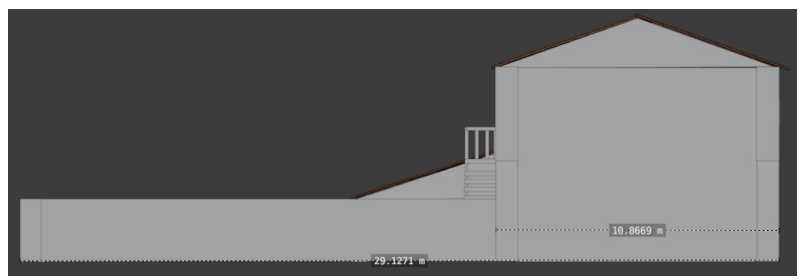

Figure 4: House and land measures.

The interior of the house is modelled by dividing the space into different rooms. On the ground floor, we find a living room and a bedroom, while the upper part is assigned the function of a barn. The living room was the space in which daily life took place; its furniture consists of some chairs and tables, cushions, stools or trunks. The access door to the house is located on the front and the access to the yard has been placed in front of it. A view of the living room is shown in Figure 5.

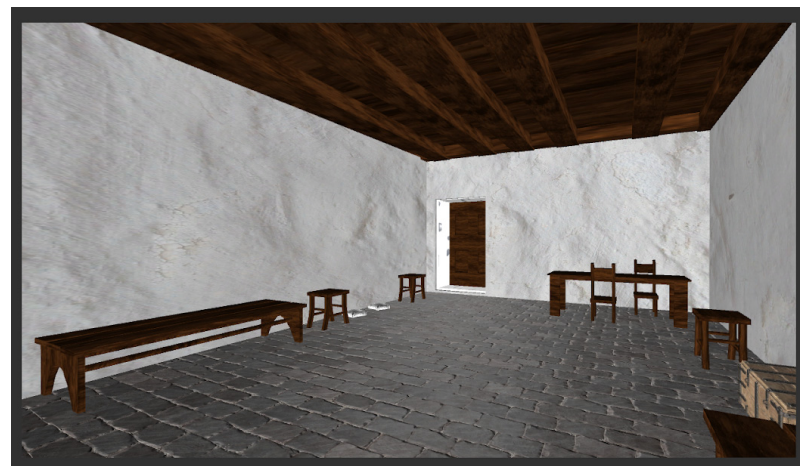

Figure 5: View of the living room. 
Room measures at the ground floor are both around 6 meters, and the barn measures 12 meters approximately, as they are shown in Figure 6.

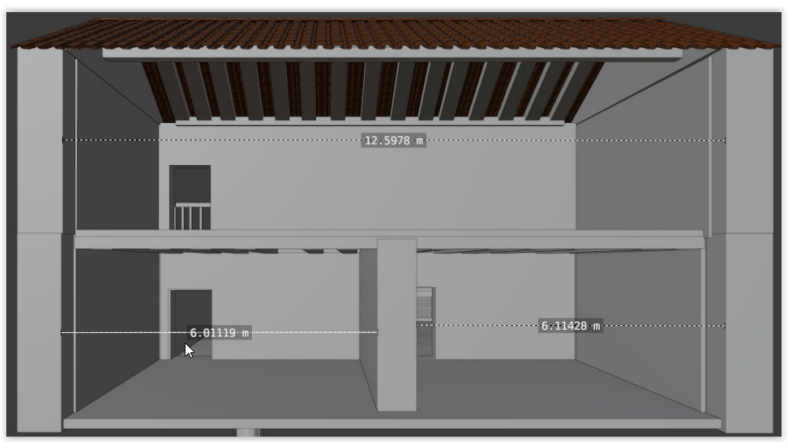

Figure 6: Room measures.

Simple furniture has been arranged in the bedroom room. It is composed of beds, trunks to store clothes and buckets. The room has a window to the street and also access through a door to the yard (Fig. 7).

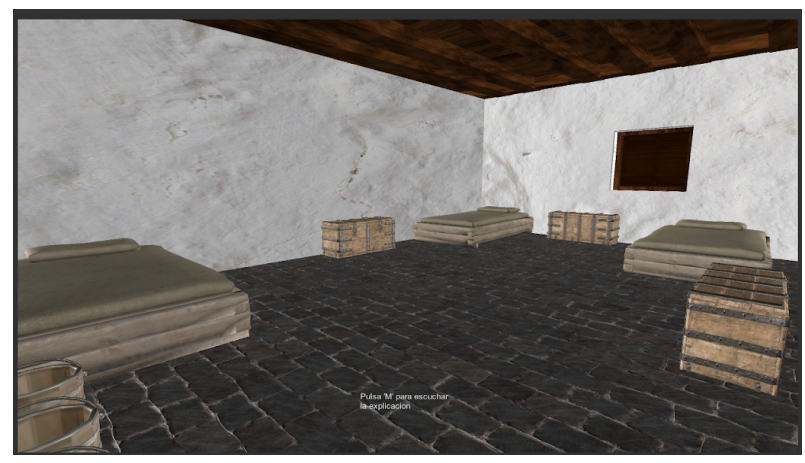

Figure 7: View of the bedroom.

The kitchen has been located in the yard, sharing a wall with the house. It has a stone kitchen top on where the fireplace is located. A cupboard has been added to keep the dishes along with a wooden table with some chairs (Fig. 8). Furthermore, an oven has been attached to the kitchen and some poultry pens have also been added to the model in the garden area (Fig. 9).

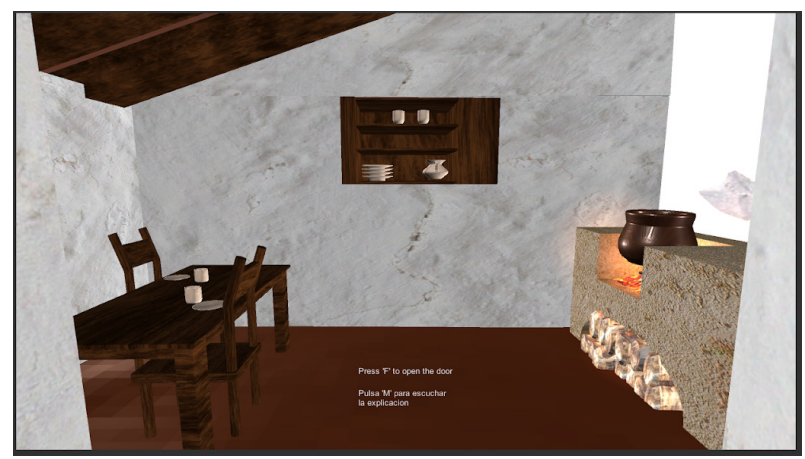

Figure 8: Inside view of the kitchen.

In the barn some sacks have been included along with some grain and wine casks. Some trunks to store household items such as blankets or farm equipment can also be seen (Fig. 10).

Both furniture and crops are assets that were acquired to develop the project. Six vineyard lines and wheat furrows were included in the garden. In the poultry pens some chickens and rabbits were included.

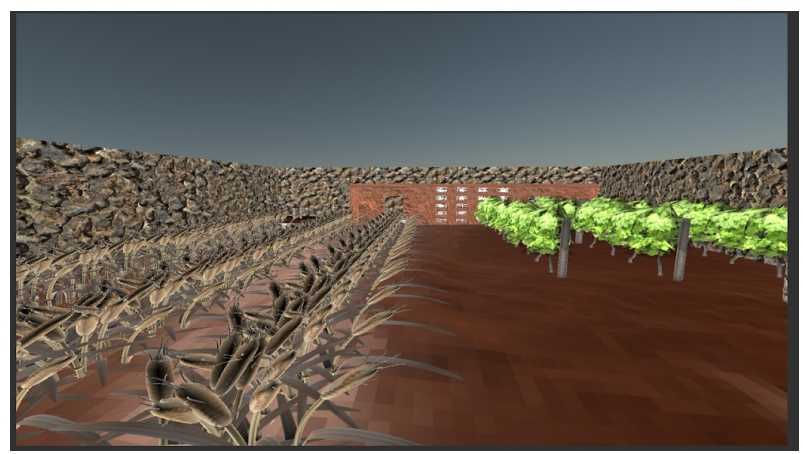

Figure 9: View of the garden and poultry pens.

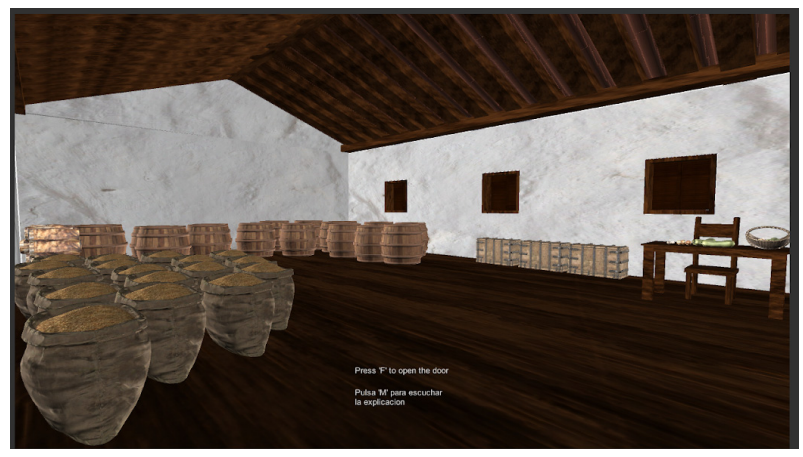

Figure 10: View of the barn.

\subsection{Materials}

In a 3D application, textures are essential for obtaining scenes with realism, for this reason they were carefully selected to obtain an aspect of the objects similar to those of the period. Most of the furniture models were acquired with their textures, however, to give them more verisimilitude, physically based rendering (PBR) textures for wood, stone and wool were obtained. They were applied to doors, walls and blankets respectively. Various materials were created for the exterior of the house. Images of stonework were chosen for the corners and for the interior, dry stone for the partitions, while for the ceiling, second floor and the doors of the house, pitchpine wood was used. Finally, brown tiles were used for the roof. The final result for Figure 6 is shown in Figure 11.

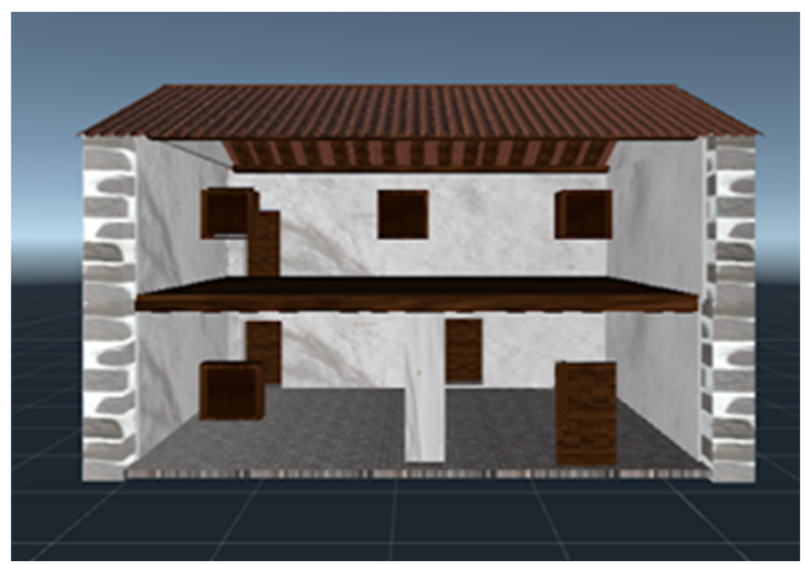

Figure 11: View of the house with textures. 


\section{Virtual Humans character design}

Advances in VR techniques now make it possible to recreate historical characters in great detail and bring them to life. By using people dressed in historical costumes, the recreation is more faithful, and it becomes an immersive experience of excellent quality. The recreation of historical characters allows the user to interact with them, see what they used to do and how they lived, and we can even join them in the daily life of the time. A fundamental part of the recreation of characters is the recreation of their clothing. In our case, it was necessary to study the type of clothing of the different social classes that lived together in the $16^{\text {th }}$ century in La Laguna. The type of clothing worn at that time is similar throughout Spain. To study how they dressed at that time, we have used as a basis the book entitled Geometria y traça perteneciente al oficio de sastres (De la Rocha, 1618). This book contains studies, patterns, types of fabric and very complete samples of all the clothing that a tailor must have known how to make at that time. However, this book is too complex to be used by someone without knowledge of historical tailoring. Fortunately, in the book El traje y los tipos sociales en el Quijote (Bernis, 2001) the information is collected in a more legible way and the patterns of the clothing are shown in a much clearer way. In addition, it includes drawings associated with the tailoring of that time (Fig. 12).

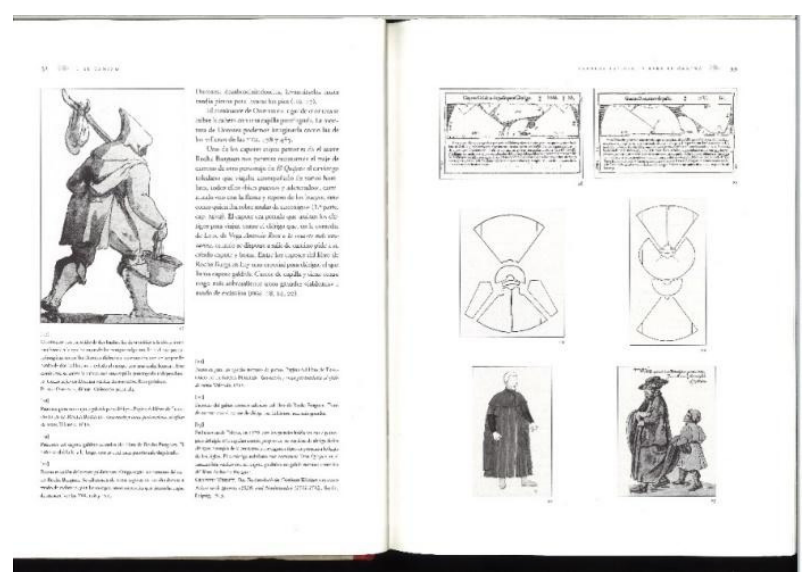

Figure 12: Book: El traje y los tipos sociales en el quijote (Bernis, 2001).

In addition, other sources were consulted such as $17^{\text {th }}$ century men's dress patterns 1600-1630 (Braun, Costigliolo, North, Thorton, \& Tiramani, 2016) and web resources where historical dress patterns are provided (Vogue Fabrics, 2020). For the other details of the clothing, we consulted pictorial works from the period in which a character with the studied clothing appears.

Several techniques can be used to create $3 D$ models of $16^{\text {th }}$-century people with the appropriate clothing. The first option is to model the clothes with generic programs such as Blender, 3D Studio Max, ZBrush, etc. However, the use of generic $3 D$ modelling programs makes it very complex to create all the clothing in addition to the corresponding animations (Liu, Zhang, \& Yuen, 2010). A second option is to use a specific program to model the characters clothing (Frâncu \& Moldoveanu, 2015). Finally, the last option is the $3 \mathrm{D}$ scanning of clothing recreations of the period. This technique offers a 3D model in a short time with enough detail; however a single
3D mesh is obtained and a complex post-processing step is necessary to divide the different pieces of clothing of the character, beside having to incorporate the animation.

In this work we have chosen the second option and we have used a specific program to create all clothing. The selected program is Marvelous Designer (CLO Virtual Fashion Inc, 2020) widely used in the fashion design industry as well as in entertainment. The program creates the clothing almost automatically from the drawing of a pattern (Spahiu, Shehi, \& Piperi, 2014). It works with already incorporated characters (avatars) although they can be edited and customized. The learning curve of this program is very fast and basic garments can be made in a short time without prior advanced knowledge of 3D modeling or sewing. It is also easy and fast to make variants of the clothing in shape, color and texture or to add details such as buttons, cuts, different lengths, etc. However, its use becomes more complicated with complex clothing when more details are incorporated. Marvelous Designer creates an automatic animation of the clothes when the character moves, since it incorporates into the cloth design the characteristics of the fabrics, such as weight, grammage, movement of clothes when walking, elasticity, etc.

The results of the program are shown below for simple clothes like a priest's suit (Fig. $13 \mathrm{a}$ and b) and a peasant girl's dress (Fig. $13 \mathrm{c}$ and d). These garments are composed of six pieces.

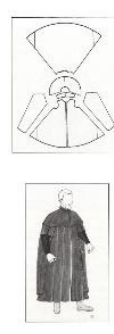

(a)

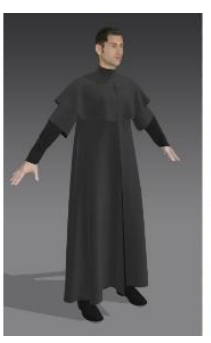

(b)

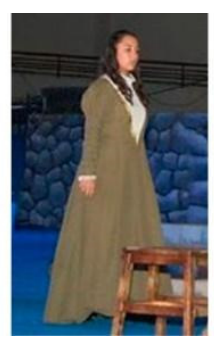

(c)

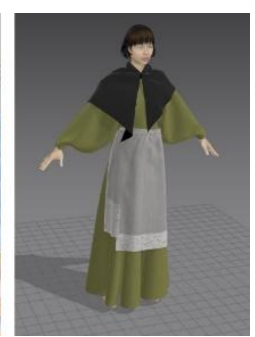

(d)
Figure 13: Results of the program Marvelous Designer: a) Dress patterns of a priest from the book (Bernis, 2001); b) Result; c) Study of the dress of a countrywoman (theater); d) Result.

The process taken for the creation of characters has been the following, first the pattern of the clothes is imported as a reference in the program (Fig. $14 \mathrm{a}$ ). This pattern is used to draw over the main pieces of clothing. Once the book patterns have been redrawn in one of the windows of the Marvelous Designer program (Fig. 14 b), the measurements are corrected and adjusted to the proportions of the avatar (3D model of the character without clothes). Then the different parts of the pattern are placed in the $3 D$ window in the right place above the avatar, the pieces are virtually sewn and finally adjusted using program options (Fig. $14 \mathrm{c}$ ).

For the dressing of the social strata of the nobility, an exhaustive study of the clothes to be designed is required (Fig. 15 a) because the clothing of the $16^{\text {th }}$ century is complex and the patterns are described with terms that are not commonly used today. When many details are added, the program needs more and more resources to animate the design. Likewise, once the design is exported to incorporate the figures into the VR application, it 
requires too many computer resources. This is why we have chosen to simplify the clothing as much as possible, avoiding the creation of details and non-essential extras. We have solved the colour changes in the fabric, the seams of different materials, buttons, etc. by drawing directly on the fabric. To do this, a flat image has been taken from the pattern once all the measurements and details have been adjusted. For this pattern, a texture image has been created using an editing program like Adobe Photoshop adding there all the details, embroideries, fabric changes, seams, etc. (Fig. 15 b). By adding the details with the texture as a drawing over the fabric, a result very similar to the original has been achieved (Fig. $15 \mathrm{c}$ ).

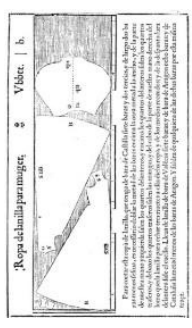

(a)

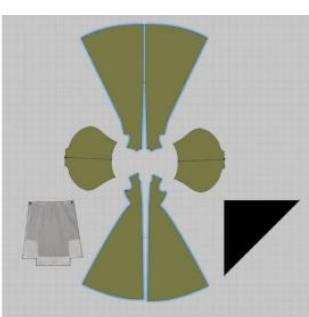

(b)

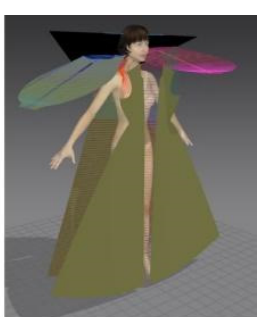

(c)
Figure 14: Process taken for the creation of characters: a) Detail of the pattern book reference image (Bernis, 2001); b) Pattern redrawn in Marvelous Designer; c) Placement in 3D space and virtual sewing.

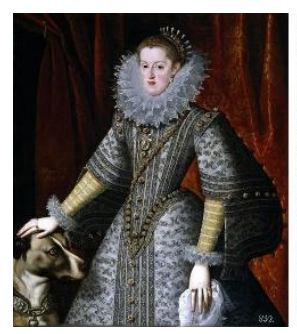

(a)

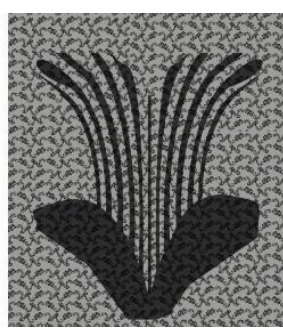

(b)

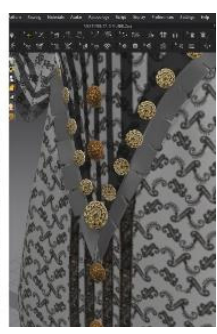

(c)
Figure 15: Study of the dress of the nobility a) Queen Marguerite of Austria, 1609, Author: Gonzalez, Bartholomew; b) One single texture to avoid many pieces of different fabrics; c) Result in Marvelous Designer.

For this type of complex clothing, the use of specific programs such as Marvelous Designer is a wise decision since these designs require modelling tools not present in generic programs such as Blender.

\section{Development of the interactive 3D application}

\subsection{Implementation}

An application has been implemented in (Unity Technologies, 2020) designed for VR devices that is currently in a web version, so the mechanics correspond to a first-person application. The user moves through the scene and decides which place to visit, starting the visit on the street facing the house. The visit has been designed similar to a museum visit with an audio guide. In this way when entering each room or accessing the yard the relevant characteristics recreated in each location are described. The mechanics implemented include the control of the user's movements for navigation through the house, the yard and the exterior street, as well as the automatic opening of doors when entering an area of influence.

\subsection{Integration of characters}

The human virtual characters are located static in the scene. They are able to reproduce the audios with fragments of the books of agreements of the Cabildo and also protocols of different notaries that serve as reinforcement to the explanations reproduced. Table 1 includes the texts reproduced by the characters, corresponding to notes in (Larraz, 2009) referred to collections of Agreements of the Cabildo and Protocolos Notariales in the Fontes Rerum Canarium collection of the Instituto de Estudios Canarios, In this case, scripts have also been implemented to facilitate the playback of the audio when the user enters in the character's action area.

A crucial aspect to give realism to the characters is the physical simulation of the costumes. Marvelous Designer has a powerful physics simulation engine that responds to clothing behaviour. The properties of the fabrics are configurable, there are some types already preestablished like wool, cotton, and silk or define our own fabrics. Although the simulation is generated with Marvelous Designer software, it is necessary to export the model in a format that supports the transfer of this information to Unity. By using Blender as an intermediate step this purpose can be achieved through the Alembic format. This open format condenses information from animated scenes into a set of pre-calculated results on geometry. This process is analogous to texture baking. Today it has become a common format for transferring complex animated models between development teams.

Since the VR application will be accessed through the web the generated meshes must be optimized, for which Blender is used again. In the process of optimizing meshes, the geometric elements of the garment mesh are ordered, since mesh aberrations may appear from an automatic export and very complex meshes may be obtained. The optimized model in Alembic format can be integrated into a Unity3D scene using the AlembicForUnity package. Some characters in the living room and the kitchen are shown in Figures 16 and 17 respectively.

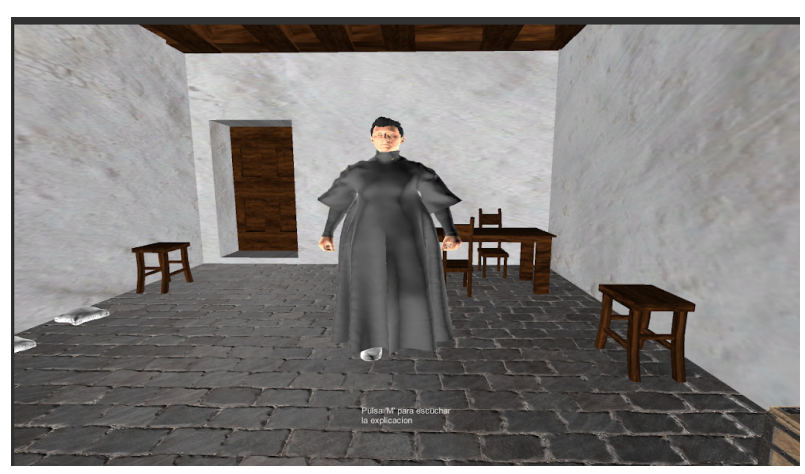

Figure 16: Priest character in the room.

\subsection{Optimization}

The application has been optimized for smooth execution on the necessary hardware resources. For this purpose, the ogg format has been used for the audios since it 
preserves the sound quality and has a lower weight than others such as mp3 or m4a. This decision made a great improvement in the time to load the application. Moreover, the application uses the Unity3D Static Batching mode that reduces the call draws of objects of any size. This option is best for geometric objects that share material and do not move. Given the characteristics of the scene, both requirements are met in the housing model. Finally, in the WebGL version the options for the player have been configured in background execution, so that if the browser's containing window is not the main window, the application will continue to run even if it loses focus.

Table 1: Ancient texts from the $16^{\text {th }}$ century used as audios.

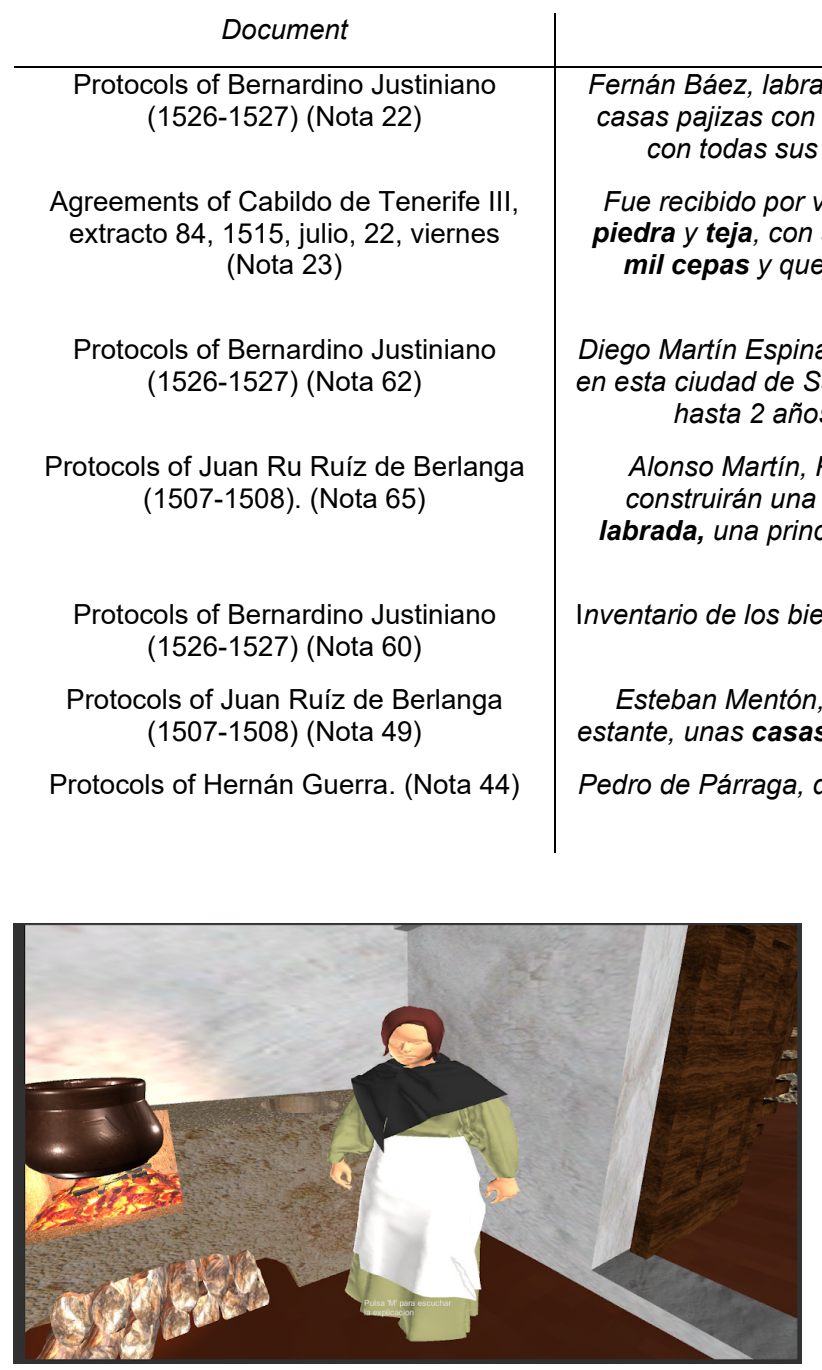

Figure 17: Cook character next to the kitchen stove.

\section{Conclusions}

Nowadays there is a large amount of historical documentation of the Canary Islands including documents that provide information about what the houses and customs of society were like in the $16^{\text {th }}$ century. A tool of increasing importance for the dissemination and preservation of history and cultural heritage are reconstructions and virtual recreations in 3D. This paper presents a case of use of these tools for the dissemination of the city's heritage.

A 3D environment with a high level of detail has been designed for a sobrada house in San Cristóbal de La Laguna in the $16^{\text {th }}$ century along with its yard and garden. Human virtual characters were incorporated with clothing of that age. They were designed using the Marvelous Designer program. The use of textures to imitate details such as fabric changes, stitching, buttons, etc. has made
Text-Audio

venden a Sancho Caballero mercader, vecino, unas
y su mujer, venden a Sancho Caballero mercader, vecino, unas s puertas a la calle real, con sus corrales, horno, medio pozo y Antonio Font con tal que haga una casa de sesenta pies, de
sobrado y que la edifique nueva y que haga una viña de cinco en cinco años y que en dos años la plante y fabrique. arrienda a Juan Descano, un sobrado de las casas de su morada
Cristóbal. Lo arrienda desde el día de San Juan de junio venidero umplidos, cada año por el precio de 1 cahíz de buen trigo.

Cristóbal y Juan Álvarez, portugueses, pedreros y albañiles a Fernando Llerena, que llevará tres portadas de cantería escalera para entrar en la cámara.
escalle, otra en la sala y

Marcos Franco, mercader difunto: primeramente en un sobrado

un montón de trigo de unas 150 fanegas.

serrador, portugués, con su corral y pozo, situadas en la calle que va a San Francisco.

da a renta a Fernán Alonso Galíndez y a Antón Galíndez unas casas con corral y un horno que tiene en esta villa.

it possible to create light models. In addition, by changing the $2 \mathrm{D}$ image of the fabric texture, several variants of the garment are achieved without having to change the entire 3D model.

The 3D environment and the characters have been integrated in a VR application developed with Unity where the user has absolute control of movement and can receive historical information about the house both visually and audibly. Various mechanics have also been applied so that the user can interact with the application without tools other than the keyboard of their computer.

The application has been developed for a web platform, and certain optimizations have been considered to make the performance of the application as smooth as possible. The application has been hosted on a website where Unity developers upload their projects.

An application like this contributes to the dissemination of the cultural and architectural heritage of the city of San Cristobal de La Laguna. It can be very instructive not only for visitors who want to know more about the history of the city but also to be used in training activities in schools, so that children can learn and understand in a more visual way how life was at that time using an attractive media support for the historic content.

\section{Acknowledgements}

This work was supported by the Fundación CajaCanarias and Fundación Bancaria La Caixa under Patrimonio Cultural en Canarias: del legado aborigen a la nueva sociedad canaria. 


\section{References}

Abreu Galindo, J. [1632] (1977). Historia de la conquista de las siete islas de Canaria. Introducción y notas de A. Cioranescu. Goya Ediciones, Santa Cruz de Tenerife.

Aznar Vallejo, E. (2008). La Época Fundacional y su influjo en el patrimonio histórico de san Cristóbal de La Laguna. Anuario de Estudios Atlánticos, 54-1, Madrid-Las Palmas, España, pp. 169-205.

Bernis, C. (2001). El traje y los tipos sociales en el Quijote. Madrid: Ediciones El Viso.

Bekele, M. K., Pierdicca, R., Frontoni, E., Malinverni, E. S., \& Gain, J. (2018). A survey of augmented, virtual, and mixed reality for cultural heritage. Journal on Computing and Cultural Heritage (JOCCH), 11(2), 1-36. https://doi.org/10.1145/3145534

Blender Foundation. (2018). Blender - a 3D modelling and rendering package. Stichting Blender Foundation, Amsterdam. Retrieved September 28, 2020, from http://www.blender.org

Bostanci, E., Kanwal, N., \& Clark, A. F. (2015). Augmented reality applications for cultural heritage using Kinect. Humancentric Computing and Information Sciences, 5(1), 1-18. https://doi.org/10.1186/s13673-015-0040-3

Braun, M., Costigliolo, L., North, S., Thorton, C., \& Tiramani, J. (2016). 17 th-Century men's dress patterns 1600-1630. London: Victoria \& Albert Museum Thames \& Hudson.

Carrozzino, M., \& Bergamasco, M. (2010). Beyond virtual museums: Experiencing immersive virtual reality in real museums. Journal of Cultural Heritage, 11(4), 452-458. https://doi.org/10.1016/j.culher.2010.04.001

Cioranescu, A., 1965. La Laguna: Guía Histórica y Monumental. Ayuntamiento de San Cristobal de la Laguna.

De la Rocha Burguen, F. (1618). Geometria y traça perteneciente al oficio de sastres. Valencia.

Frâncu, M., \& Moldoveanu, F. (2015). Virtual try on systems for clothes: Issues and solutions. UPB Sci. Bull., 77(4), 3144.

Larraz Mora, A. (2009). A vista de oficiales y a su contento. Tipología sistemas constructivos de la vivienda de La Laguna y Tenerife a raíz de la conquista. Ed. Instituto de Estudios Canarios, año 2009. ISBN: 978-84-88366-68-9.

Liu, Y. J., Zhang, D. L., \& Yuen, M. M. (2010). A survey on CAD methods in 3D garment design. Computers in Industry, 61(6), 576-593. https://doi.org/10.1016/j.compind.2010.03.007

Machidon, O., Duguleană, M., \& Carrozzino, M. (2018). Virtual humans in cultural heritage ICT applications: A review. Journal of Cultural Heritage, 33, 249-260. https://doi.org/10.1016/j.culher.2018.01.007

CLO Virtual Fashion Inc. (2020). Marvelous Designer. Retrieved September 28, 2020, from https://www.marvelousdesigner.com/

Navarro Segura, M. I. (1999). La Laguna 1500: la ciudad-república. Una utopía insular según las leyes de Platón. La Laguna (Spain): Excmo. Ayuntamiento de San Cristóbal de La Laguna.

Navarro Segura, M., Perera, F., \& Pérez, D. (2018). Arquitectura en La Laguna: El concepto vernáculo. Criterios de protección y el papel del dibujo. Revista de Historia Canaria. 155-176.

Pérez Vidal, J. (1967). La vivienda canaria. Datos para su estudio. Anuario de Estudios Atlánticos, 12, 41-113.

Spahiu, T., Shehi, E., \& Piperi, E. (2014). Advanced CAD/CAM systems for garment design and simulation. $6^{\text {th }}$ International conference of textile, (págs. 1-6). Tirana, Albania.

Unity Technologies. (2020). Unity Real-Time Development Platform | 3D, 2D VR \& AR Engine. Retrieved September 28, 2020, from https://www.unity.com/

Vincent, M., DeFanti, T., Schulze, J., Kuester, F., \& Levy, T. (2013). Stereo panorama photography in archaeology: Bringing the past into the present through CAVEcams and immersive virtual environments. In 2013 Digital Heritage International Congress (DigitalHeritage), $\quad 1, \quad$ pp. $455-455 . \quad$ IEEE. https://doi.org/10.1109/DigitalHeritage.2013.6743783

Vogue Fabrics. (2020). Reconstructing History Pattern \#RH206 - Men's 1570-1600 Breeches or Trunkhose. Retrieved September 28, 2020, from https://www.voguefabricsstore.com/reconstructing-history-pattern-men-s-1570-1600breeches-or-trunkhose.html 


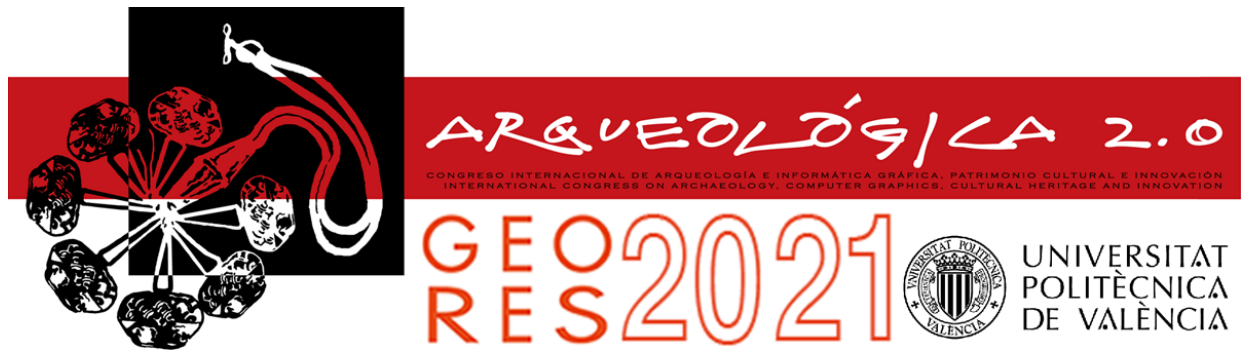

Proceedings of the joint international event $9^{\text {th }}$ ARQUEOLÓGICA

$2.0 \& 3^{\text {rd }}$ GEORES

Valencia (Spain).

26-28 April 2021

\title{
DIGITAL CULTURE, UMWELT AND ALETHEIA AN ONTOLOGICAL INTRODUCTION
}

\author{
Andrea Pasqui \\ Department of Architecture, Built environment and Construction engineering (ABC), Politecnico di Milano, Via Ponzio 31, Milano, Italy. \\ andrea.pasqui@polimi.it
}

\begin{abstract}
:
The paper presented here focuses on the idea of interpreting the digital culture as an image of the material culture rather than a mere copy of it. First of all, we should ask ourselves what an image really is; it is in investigating its deep meaning, which is often devalued due to the enormous dissemination of void images, that we can overcome the superficial concept of the digital as a digitalised copy. The description of an archaeological artifact cannot prescind from its physical and material appearance, but has to go further towards its profound nature and meaning. Considering the so-called aura of archaeological and artistic objects as an engagement between the hic et nunc of the object and the hic et nunc of the observer it will be possible to go beyond in the comprehension of the agency of the objects. Moreover, it is necessary to consider technology as a way through which objects could reveal themselves in a process of $\alpha \dot{\lambda} \eta \dot{\theta \varepsilon} \alpha$ and not just a tool with the only scope of showing itself and its capacities. Considering digital copies as images could yield compelling challenges: every archaeological object, at any scale from the very little to the very big, has its own lost Umwelt: a way of being entangled in the world in which it was created. Probably, no answer will be provided within this paper, but suggestions to move towards an ontology of digital objects and their relationship with virtual realm.
\end{abstract}

Keywords: virtual archaeology, landscape, recontextualisation, image, digital culture, material culture

\section{Expanding images}

In recent years we witnessed the spread of a sheer amount of digital material consisting most often in different types of photographs. The risk, in this case, is to become immunized to the power of images which are getting every day voider and mere exhibition of their superficial charm. As Wim Wenders (2015, p.41) stated during an interview with his Italian editor, 'La saturazione di immagini è tale che le immagini che ci circondano sono diventate irrilevanti: sono talmente tante che finiscono per diventare arbitrarie, per non rappresentare più nulla. Trasmettono solo se stesse, o un'idea completamente vuota' As the aim of this research is to go further in the comprehension of the value of digital culture as an image of the material, the first step is to give back to images their former prominence of 'cultural objectivations' (Assmann, 2010, p.109). As illustrated in the following sections, while staring at a wonderful archaeological find in a museum, we are already facing an image of the former object.

What is an image? First of all, it has to be said that an image is not a picture. At best, a picture can contain an image. Above all, an image is something that is created primarily in our mind or at least is in our mind that reaches its complete form. Greek mythology is full of examples: Euripides, for example, tells us that the entire war of Troy has been fought for a ghost and not for the true Helen, hence just for an image of Helen. This concept of image as a "double" of the reality recurs often in Homer too: in
Iliad, Achilles tries to embrace his friend Patroclus in dreamtime and is shocked when his image vanishes between his arms. Similarly in the Odyssey, Odysseus is upset when he fails embracing his mother in Hades (Valditara, 2007). Later on Plato referrers to inner imagery as something in a way more "positive": in the Theaetetus $(191, \mathrm{c}, \mathrm{d})$ he conceives memory as a wax tablet in which, through our perceptions, images are inscribed. Something similar is mentioned in Philebus $(39, b, c)$ where he speaks about a metaphorical painter who create mental images of what we physically perceive.

Briefly, an image, is the inner reproduction of what we perceive through five senses, but at the same time it could be something completely detached from physical perception and existing a priori in our mind produced by the cultural influence that society has. It has to be noted that not only the sense of sight concurs to the creation of images, but it cooperates with all others in a phenomenological scenario. As we shall see later on, cultural background is crucial in the process of imagination. It is for this reason that when we stare at an archaeological find inside a showcase, the image of that object could not be the same as the one people that made it used to have: just because our "mind" is born and raised in a completely different environment (Ingold, 1993), hence it has developed different kind of approaches to manufact or ancient buildings which we could find "beautiful" without being touched - or culturally activated - by them. 


\section{Concerning the aura}

What makes an archaeological object unique is its agency, its aura. But what exactly is the so-called aura?

We can consider it as an engagement between two different hic et nunc (Benjamin, 1935). First of all, the hic et nunc properly pertaining to the object comprehending the core elements which form its being. We can summarize them all in three categories: environment, material and shape (Fig. 1). We can assert that these elements form the thing regarding just its physical side. But creating an object does not imply just tangible elements: the human factor is crucial. Nevertheless, this should not be seen only by the side of the human interaction with primary products, the manipulation of raw materials, but we have to consider the way in which humans simultaneously create and are created by their artifacts. Self-awareness and, broadly speaking, culture, is possible only by creating the other (Assmann, 2010; Greco, 2019; Hodder, 2012). This mutual interference between subject and object could be explained under different point of view. On the one hand, as Leroi-Gourhan (1964) states, the shape of the amygdala, one on the first tools created by humans, spawned by, let's say, a crystallisation of their gesture. From this point of view the amygdala is conceived as a sort of natural prolongation of human body and gestures. On the other hand, trying to avoid an hylomorphic perspective, Tim Ingold argues that the actual shape of the tool unfolds thanks to the interaction of human gesture and the developmentpotential intrinsically pertaining to the material itself (Ingold, 2013). Despite this opposition, that could be easily overcome considering mental imagery not as rigid schemes entirely existing a priori but as fluid and dynamic interaction between perception and knowledge (Freud, 1954), what appears clear is that assimilation requires reelaboration. It is not enough to see - or to hear something - to "grasp it". A true perception requires action, and it is in this mutual engagement between the object of our perception, our pre-existing concepts and our actions that knowledge and self-awareness emerge. There is a widely known example that could clarify the essential relationship between subject and object. As MerleauPonty suggests, we are led to ask ourselves where do the self of a blind man begin: at his hand or at the end of his white stick?

As many scholars state, human mind and body do not halt at the physical end of our body, neither on our fingertips nor at the top of the head, but continue in the man-made objects (Renefrew, Frith, \& Malafouris, 2009; Greco, 2019). In the light of recent studies (Freedberg \& Gallese, 2007) we can assert that perception of a work of art or, more in general, of an object or even of the landscape, has precisely material basis in the physical conformation of human brain. What appears clear is that the way we see and experience a man-made object is influenced both by our culture and our neurological system which provokes an embodied simulation of what we are seeing based on a concept of empathy. This does not mean that cultural background plays a secondary or in a way minor role (Assmann, 2010). Quite the contrary. Culture and neurological response are reciprocal influenced.

In this regard, adherents of phenomenological archaeology argue that an embodied experience of monuments or landscape could help us understanding the way in which ancient civilisation used to perceive their world (Hodder, 2012; Tilley, 1994). As will be examined below, reconstructing ancient world is quite hardly probable, at least from the physical side: but the virtual realm could help us in creating meaningful recontextualisation and virtual reconstruction of how the world used to looks like for ancient people. Recontextualisation that won't be aimed to simulate the past, but whose purpose will rather be narrate and recount stories which should raise active and transformative engagement with the observer. In a word, recontextualisation that will become fertile image of the past.

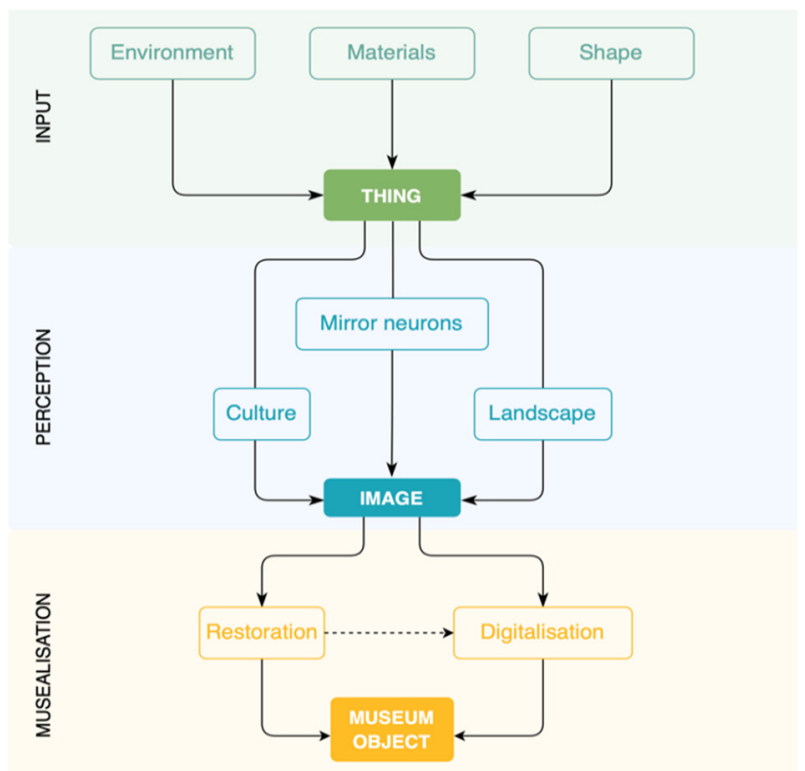

Figure 1: Diagram enhancing relationships between an object and its former components. A thing is transformed into an image through the cultural conception of it. Flowchart by the author.

In the framework of this one-to-one relationship between thing and human, we must consider three further layers which contribute to the identity of the object - hence of the subject. What transform a "inert object" into a cultural objectivation, or image, is the union of three elements: the culture that makes the object itself (Benjamin, 1935; Hodder, 1984); the landscape - which differs from the environment, mostly intended as merely natural elements (López, 1986; Casey, 1997; Brück, 2005); and the way in which humans perceive the object (Fig. 1).

Let's talk about some examples. In Museo Egizio of Turin a reconstruction of the tomb of Iti and Neferu, discovered by Schiaparelli in Geblein in 1911, is shown. The layout of wall paintings here exhibited is coherent with the former shape of the tomb itself. It could be useful to think about the former tomb keeping in mind the diagram of Figure 1. Obviously, the address of our attention is the tomb, here regarded as the "thing". Considering it from the physical side its main former element is the environment, which provides some kinds of raw materials which for their part require and suggest one or more possible shape. Being a rock-cut saff tomb (Snape, 2011), this tomb is primarily built with mudbricks provided by surrounding environment, and the stone in which is dug into. This tomb consists of 11 chambers arranged in a row facing a pillared corridor overlooking the Nile. The wall was covered with paintings. The substrate of this paintings, as 
we can see in Museo Egizio, is made out of easily findable material - clay and straw. We should now focus on one of this painting, located in the northern corner of the tomb (Fig. 2). The scene represents workers transporting grain to the silos. As western observer we could note some unusual and not so easily comprehensible element such as the fact that the bag upon mule's back is represented upside down. The cause of this lack of "communication" between us, as observer, and the painting is due to the gap that exist between our perception of the object and the way ancient Egyptian perceived it. Ancient Egyptian used to see it not only as a thing, but as an image arisen from their particular way of relating with the thing itself. As mentioned above, to transform a thing into a "cultural objectivation", is necessary the mediation of at least two elements: culture and landscape. Ancient Egyptian culture used to consider paintings and hieroglyphs as something magical. A depiction should be as clearer as possible in order to represent the subject without any kind of possible misunderstanding (Gay, 1994): the mule aforementioned is carrying two bags, and two bags should be depicted. The only way to represent them both is to draw the back one reversed upside down. The theoretical background of Egyptian iconography lies on the fact that, of a picture, exist what is evident.

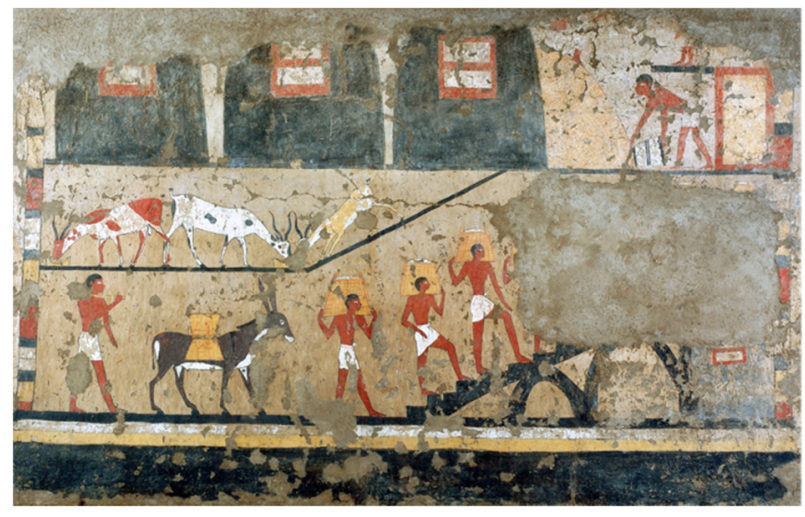

Figure 2: Wall painting from the tomb of Iti and Neferu, in Museo Egizio, Turin. Photo by Nicola Dell'Aquila and Federico Taverni/Museo Egizio.

Furthermore, another element which could help us to come closer to ancient Egyptian way of considering this tomb is "looking to" the Nile. As well shown in Museo Egizio, this tomb was facing the Nile. This feature, which for modern-era-people could be considered just as part of the environment, was otherwise conceived as crucial for ancient Egyptian. It was the source of life, Egypt itself was

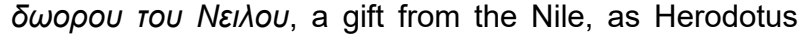
said. Recontextualise ancient manufacts or buildings means, in short, wave the manufacts together and within its loci, the latter not to be intended just as geographical environment.

Thus, the power of images is becoming clearer. While looking at an archaeological find, we are moved towards it, culturally and physically. But what has to be repeated is that we are not looking at it as the people who made it millennia ago were doing. While looking at the sarcophagus of Butehamon in Museo Egizio di Torino, we are facing a wonderful manufact dating back to Third Intermediate Period, but, no matter how specialised and accurate our knowledge may be, we could never give it the same significance and value ancient Egyptians used to. In this sense, we are already in front of another image of the home for the eternity of Egyptian. It is crucial to grasp this gap between the former object created by the ancients and the museum object we are in front of.

We could find four causes for the former object: 1) causa materialis, namely the wood used for the coffin, plaster and colours; 2) Causa formalis, which is the shape and the manner of the sarcophagus; 3) Causa finalis, meaning the purpose and the intention of the manufact to provide the scribe Butehamon his home for the eternity, and finally; 4) causa efficiens, the artisans who made it with their knowledge (Heidegger, 1954; Hui, 2016).

Now what makes the sarcophagus of Butehamon the real sarcophagus of Butehamon is the third cause or causa finalis (Heidegger 1954), hence the ritual and

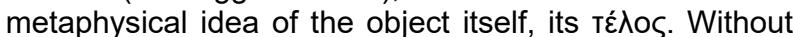
this specific causa finalis, it would be just a coffin. Grasping the gap between former object and museum object means realising that what we are standing in front of is something, let's say, constructed by the mind: in fact, it is an image.

Said this, we can underline the principle which stands at the basis of the value of archaeological finds: what makes an historical artifact noteworthy (leaving aside the concept of quality) does not lie only in its materiality, and that's quite obvious, but neither in its own and mere cultural background. The agency of an object displayed in a museum necessarily resides in that engagement produced between the hic et nunc of the object and that of the observer. We could define the hic et nunc as the peculiar way in which every subject perceives an object and at the same time gain self-awareness. This way of perceiving is influenced - and broadly speaking produced - by the society in which he lives and the landscape in which he is nested - which in a way generate the society itself (Fig. 1). The manufact displayed inside a showcase has a new life; it is not, or at least not only, the object conceived and created centuries or millennia before.

It is for this reasons that digital objects should not be considered on a lower level than physical object. It could be easier to gain self-awareness inter-acting with a virtual reconstruction than with some "scattered pieces".

\section{Virtualisation and actualisation}

Despite living in a world embedded in smart devices and computers, the "virtual" realm is still largely debated. If the aim of this work is to underline the theoretical principles for an effective involvement of digital culture in the archaeology field, it is necessary to draw up a theoretical environment in which clarify, first of all, what a digital object is, and then which are its potentials and limits. Insofar digital objects have to be taken for granted nowadays, they need an ontological framework.

Virtual and digital, although they broadly refer to the same thing, carry deep differences in their original meaning. The term "digital" refers to a notion of computing, deriving from "digit" - for its part being derived from Latin digitalis - to be considered as numerical issue. Different matter for "virtual", traceable to a question of potentially-being. No better definition of what is virtual has been given than the one by Pierre Lévy: 'The virtual is by no means the opposite of the real. On the contrary, it is a fecund and powerful mode of being that expands the process of creation, opens up future, injects a core of meaning 
beneath the platitude of immediate physical presence.' (Lévy, 1999). The first thing that needs to be underlined is that "virtual" is not something opposed to the real. This aspect is crucial while considering the relationship between material and digital culture. A digital object is not a surrogate of the "real". Digital culture is not displayed just when a display of material objects is not possible, or at least not only. Clearly, in this time of pandemic, digital culture seems to be the only way to access to museums and collections but is desirable - and likely probable - that a serious effort in order to include digital culture in museums' agendas will be done even when pandemic will be over.

As suggested by Lévy (1999) "physical absence" opens up to several chance of, let's say, creation. The term virtual should be compared to "actual" instead of "real". In such a case, the notion of virtual would undergo a deep enlargement of meaning: virtual would not be by no means something un-real, rather than a re-presentation of something possible. If some scholar legitimately criticise the term "reconstruction" referred to digital models of archaeological buildings, since a reconstruction would entail a high level of confidence regarding the original shape of the manufact (Clark, 2010), this matter should not even arise being aware of the specific meaning of the term "virtual". A virtual reconstruction is, as intrinsic in its etymology, a possible answer to some questions. It is not something "certain". Actually, the term "simulation" suggested by Clark would be more misleading, implying an idea of "imitation" or fake. A virtual reconstruction, or to avoid any conflict, a virtual recontextualisation, is far from being an imitation: it is an actualisation of one possible layout. Being buildings or object from the distant past the focus of these kind of studies, a complete level of confidence regarding their original appearance will evidently be just a chimera. Exactly for this reason, for the uncertainty embedded in the archaeological discipline, a virtual recontextualisation is a unique tool which allows scholars to ask specific questions to the manufact and deliver ad hoc representations of specific problematic situations (Lévy, 1999).

To further explain the identity of virtual, we can think about the process of actualisation, by means of which "virtual" becomes "actual". Thanks to this process, something possibly-being becomes in-being and the initial state of things undergoes a transformation. Let's take an example: the above-mentioned amygdala, as the others tool invented by humans, went through the concept of virtual in its making process. Human strength was conceived as virtual, extrapolated by the actual context, made an abstract entity. Human movements needed to de-flesh animals' skins, to chop vegetable or to work ropes were transformed into "problematic entities", virtual indeed. After that, a possible actualisation of the virtual strength was transformed into actual in the shape of the amygdala.

\section{Digital objects as images}

Defining digital objects' ontology is not immediate, just as much as putting them into a precise category. Hui (2016) legitimately put them in their own discrete category as subset of technical objects. It has to be noted that technology is something that have always characterised human species and not something directly related to digital development. In this perspective, human's life has been depending on a close relation with technology and its evolution since the stealing of fire at the hand of Prometheus.

One of the more pressing issue about digital objects is if they are worth a definition of object "in itself" or just as representation of a material objects. I will dare to propose that digital objects are worthy of the value of real object since they possess several qualities of their material counterpart. First of all, and here is the focus of this work, they are, exactly as material objects, images of the former artifacts. As we ventured to state above, a museum object ceases to be its former, becoming a new entity: an image of the original and ancient object, since no one could see it as the civilisation that conceived and created it. Obviously, this does not mean that it is not worth displaying it into a museum, quite the contrary. But it has to be clear that museum objects are something other: as stated above, an image is something that primarily arise in our mind, influenced by our way of perceiving the world.

Nevertheless, notion of digital as a copy of the material, should be considered with great attention, starting from the idea itself of copy. It is appropriate to begin this argument with a Chinese saying: 'Under normal conditions we adhere to the rules of convention, but in times of change we use quan' (Han, 2011). Quan stands for law, although representing an idea of law completely different from the absolute European one, being quan the moveable and adjusting sliding weight on a scale.

The quintessential combination of the notions of copy and that of recontextualisation consists of the case of Veronese's Nozze di Cana. The painting was conceived to merge with Palladio's architecture at Isola di San Giorgio, Venice, in order to give Benedictine Monks' refectory a tromp l'oeil effect of depth. In 1797 Napoleon send it, cut into strips, to Paris, where is still displayed in Mona Lisa's room. It can be asserted that here the painting is completely de-contextualised, displayed in a place absolutely different - in its dimension, lighting condition, height, presence of frame and son on - from the former one. For this reason, in 2006 Factum Arte started working on a 1:1 high definition "threedimensional" copy of Nozze di Cana (Fig. 3) in order to re-place it in Venice, in its original landscape.

Would it be reasonable to say that the aura of the painting has migrated from Paris, where the ancient painting is displayed, to Venice, where a "copy" has returned in its original for which it has been painted and devised? Let's say yes. As above mentioned, aura lies, in a way, in the engagement between the object and the observer. It should not be just a question of "age" of the artifact - in this case we could not consider Roman statues copies of Greek insofar they are thousands-year-old - but, in the value of cultural activator value that artifact from the past do have. We should not visit museum just because the display ancient objects. In the aforementioned example, the hic et nunc of Nozze di Cana has nothing to do with Paris and Louvre, rather than its origins are in Venice. Moving away from a certain fetish view of works of art as "untouchable reliquiae", how could an observer be touched by Nozze di Cana's aura, if he/she could neither observe its details - due to disproportioned quantity of people crowding the room (Latour \& Lowe, 2010)? 


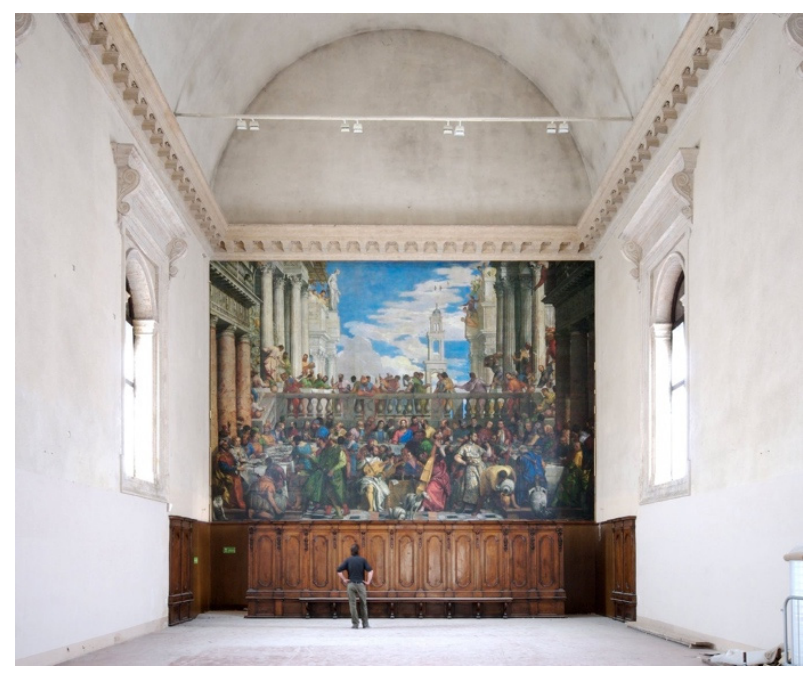

Figure 3: Nozze di Cana fac-simile in its original landscape. Source: Adrian Lowe, Factum Arte's head.

Why copies are considered so evil, nowadays - at least in Western world? Accordingly to Latour \& Lowe (2010) the focus should not be the existence of copies, rather than on their quality. The high quality of Nozze di Cana fac-simile makes it absolutely worth observing it and considering it qualitatively equal to the original. Technology, which as we will further see, has the power to act as a means of unveiling of hidden issues and features. A skilful use of it allowed Factum Arte to realise a copy of Nozze di Cana in pigment on a canvas coated with gesso, just like the one created by Veronese. A copy which actually has more of that auratic quality the original one in Louvre seems to have lost.

It could help to consider the Chinese word for original: zhen $j i$ literally means "authentic trace", giving a clear idea of the Eastern notion of originality. It tells us about a process instead of a permanent quality of Being (Han, 2011). Conceiving the entire world as something in process instead of a static essence, the work of art ceases to have a "date of birth". Considering the reality as something in perpetual change and evolution, there could not be any kind of attack to the concept of originality of an archaeological building or painting. For example, the famous Ise shrine, the well-known sanctuary in Shinto, Japan, is considered 1.300 years old, despite being reconstructed from scratch every twenty years.

Something not-so-different - despite apparently opposite - happens in the Western world. An ancient building, painting or artifact, is constantly monitored, protected and conserved by means of focused intervention. In historical building restoration, for example, great attention is paid to enhance the "signs of aging", treating its "aged aspect" as reliquiae. Something slightly different happens to moveable artifacts, which undergo a process of restoration and conservation inside museums. Let's stress that a museum object, or a musealised building, is not its former, it has become an image of itself by means of the many processes of re-production it has undergone along its life.

Insofar every museum object or archaeological site can be considered as an image of itself, in fact something like a replica, why should we consider digital objects on a lower level, treating them as mere copies?

\section{Surveying the Umwelt}

As already mentioned, every object, living being or ancient building is entangled in a thick system of relations with the natural environment and the society, hence with the landscape. Paradoxically, in order to adopt a meaningful approach to the realm of virtual, is necessary to step back to the environment. If, as affirmed above, the term "recontextualisation" is preferred to "reconstruction" since the latter entails a certain degree of confidence regarding the original shape of the building under consideration, great attention must be paid to the - as far as possible - original context. Relationships gather and create, but at the same time it is this gathering that creates objects. For example, let's consider Heidegger's jug. It 'takes what is poured into it, and then pours the liquid out. The water and wine come from a rock spring or from rain or from the grape growing in the earth. The pouring out can quench thirst for humans or be a libation to the gods. So the jug connects humans, gods, earth and sky. It is this "gathering" that makes the jug a thing.' (Hodder, 2012). From a more pragmatic point of view, let's think about commercial route in ancient Egypt. Caravans used to link cities in the Nile valley with oasis in the desert carrying supplies and raw materials connecting distant places and, in a way, giving them existence. Nowadays these connections are far wider and more obvious, while being at the same time more striking. Let's think about a smartphone, designed in the Silicon Valley, produced in China with raw materials and semifinished ones from all over the world and used by a European customer. The net of relationship entangles almost the whole world, transforming the environment of modern-days men in a virtually unlimited one. For ancient civilisation, fortunately, world was not so wide, giving scholars the chance of understanding and theoretically reconstruct it.

In order to undertake a progressive process towards an effective virtualisation of archaeology, is necessary to adopt an ecological approach to the reality, or better yet, to the actual. Ecology, deriving from Greek oíkos and \óyos, literally means the study of the "dwelling place". The term Umwelt suggest the idea of environment in which every living creature dwells. According to Uexküll, humans can have different umwelten despite living in the same environment (Agamben, 2002): this idea is crucial for understanding the centrality of Umwelt in archaeology. As much as two humans share an environment, their "personal environments", made of the whole system of relations they weave, could be not exactly the same. This fact entails the complexity of archaeological matter which has to keep together data from different subjects and fields: archaeobotany, philology, architecture, art history and so on. Moreover, a strong gap exists between the quantity and quality of data collected and disseminated, being the latter often more fragmented, making quite difficult an homogeneous and complete comprehension of the site (Forte, 2009). All these different features contribute, and are essential, to the comprehension of objects' umwelten.

The first step towards the comprehension of Umwelt is in the understanding of the centrality of the landscape: the cover of Casey's The Fate of Place (1997) - in its paperback edition - well represents the richness of what is landscape. Moving away from the idea that a map could represent a place in its essence, the illustration joins a photograph, a topographical map and an aerial photo of 
the same loci. In its symbolical meaning this illustration is striking. Furthermore, Tim Ingold states that 'The landscape itself is a reticulate maze of criss-crossing lines of ancestral travel, with the most significant localities at its nodal points. Localities identified by particular landscape features - hills, rocks, gullies, waterholes, and so on embody the ancestors' powers of creativity and movement in a congealed form.' (Ingold, 2000, p. 141). Being the landscape so deeply tied to human's life and development it should be itself intended as the Umwelt much more than a mere background or naturalistic concept of environment.

It has been stated that one of the major difficulty scholars have to face is the complexity of data collected and their subsequent dissemination. In this paper is suggested that the best way to put them in an effective relation is through digital objects and their virtual Umwelt: considering a virtual recontextualisation as a palimpsest is possible to manage data collected along different phases of the digging process, as well as data from different fields. In a unique model, for example, it would be possible to join and display - data regarding the actual condition of the artifact, the context in which it has been found and its possible former aspect along with results of the most varied biological, chemical, physical - but also artistic, philological, philosophical - exams and surveys, allowing for a true engagement between observer and object.

\section{Technology as means of aletheia}

Key role in this research is evidently played by technology. Overcoming the dichotomy between scientific and humanistic disciplines (Greco, 2019; Rossi, 2019) it is necessary to weave an interdisciplinary work which comprehend anthropology, archaeology, philosophy and architecture as well as specific expertise regarding digital field. Nowadays it would be foolish and counterproductive to ignore the potential of digital tools but at the same time great attention must be paid in order to employ technology productively, without using it as a manifesto of itself. At a time of daily achievements and new discoveries in digital field, the employment of technology does not have to be necessarily aimed to obtain the most innovative product, rather than the most useful and compelling regarding the ongoing research (Rossi, 2019).

In order to take advantage of technology enhancing its value of moínб/s, we have to consider it as a means by which revealing of hidden information and characteristics of the case study is possible and accomplished. It has to be noted, above all, that working with digital culture does not mean digitalizing collections. Digital culture does not consist of photographs on a museum website, or at least, not only (Meehan, 2020). A digital object should be intended both as a tool for surveying the material object and an image of the object itself with the power of creating active and transformative engagement with the observer (Hogsden \& Poulter 2012).

While working on the advanced survey of the coffin on Butehamon carried on by 3D Survey Group of Politecnico di Milano, (Mandelli et al., 2019), the 3D model created from sub-millimetric survey and the information obtained through non-invasive analysis, serves as a way of acting of $\alpha \dot{\lambda} \hat{\theta} \theta \varepsilon / \alpha$ (disclosure), being a tool by which investigate actually non-visible elements - such as the fact that the sarcophagus had been reused joining parts of pre- existing coffins -, and at the same time - and at different phases of the work - as an image of the former sarcophagus, as shown in the temporary exhibition Archeologia Invisibile held at Museo Egizio di Torino last year. The advanced sub-millimetric survey allowed the creation of a 1:1 3D printed model for the focal installation of Archeologia Invisibile (Fig. 4) which acted as support for re-projecting images onto the coffin's surface becoming the quintessence of an archaeological object's image: in fact, it serves for the projecting of different analysis results (Fig. 5) such as radiometric and colourimetric studies showing at the same time the object itself and its formerly undisclosed features, now disclosed thanks to the technology potential of being means of $\alpha \dot{\lambda} \eta \dot{\theta \varepsilon ı}$.

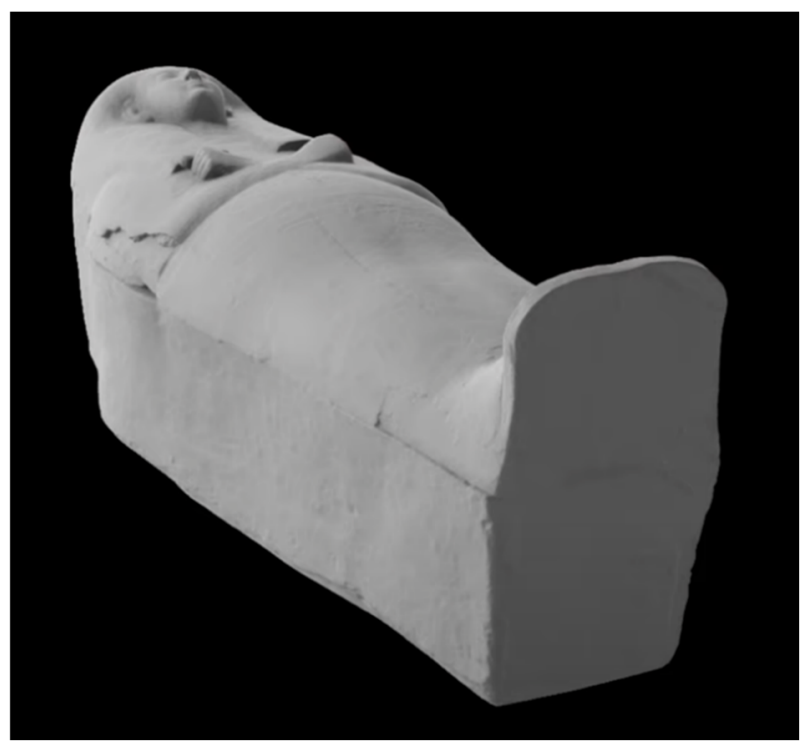

Figure 4: Video capture of Butehamon's sarcophagus 3D printed model before details projection. Source: Museo Egizio's YouTube channel.

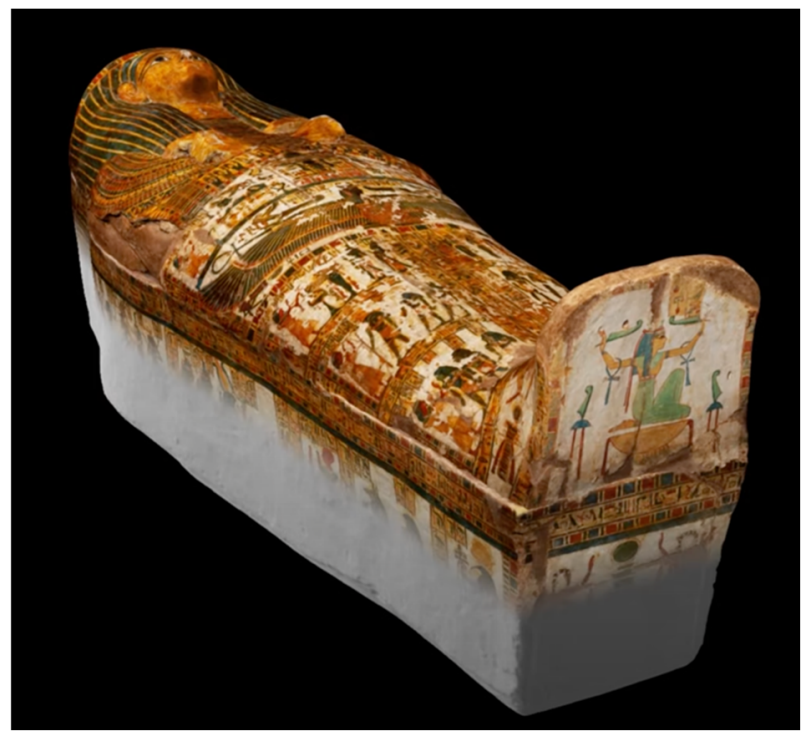

Figure 5: Video capture of Butehamon's sarcophagus 3D printed model during details projection. Source: Museo Egizio's YouTube channel.

Thanks to the features of advanced survey techniques and $3 \mathrm{D}$ modelling, scholars from different disciplines 
cooperate in order to reconstruct the Umwelt of archaeological finds suggesting a virtual recontextualization without overlooking at the new Umwelt that every object has in its new life as a museum object. All these elements contribute to the biography of the objects (Greco, 2019) and are crucial in the close dialogue that occurs between them and the observer (Meehan, 2020). For this reason, re-contextualisation is compelling and culturally challenging: successful recontextualisation would entail a deep comprehension of how the artifact looked like at the eyes of ancient people and will be possible only if carried out in a multidisciplinary environment in which dissemination and study purposes will go together.

Modern survey techniques are essential especially since they allow a - virtually - simultaneous work of data collection, elaboration and dissemination. A crucial aspect of modern archaeology is the study of the complex stratigraphy of a site which conceals features and important information that could get lost if not properly surveyed. As shown in Archeologia Invisibile, photogrammetrical surveying allows this type of elaboration since it enables surveyor to collect a large amount of data in relatively short time. Elaboration of this data, furthermore, provides a virtual landscape in which coexistence of dataset from different disciplines is possible and easily achievable.

\section{Conclusions}

In conclusion, every object has its Umwelt, its own specific cultural landscape in which it is deeply entangled. A landscape made by a substrate of geographical elements combined with a sheer number of cultural connotations. For humans, creating an object means objectifying cultural memory making it durable and crosstemporal (Assmann, 2010). An object could - and perhaps should - never be just a "thing". Studying artifacts dating back to millennia ago could entail great difficulties in investigating their lost Umwelt. Digital tools - and digital objects to be considered as medium of $\alpha \dot{\alpha} \lambda \dot{\theta \varepsilon l \alpha}$ and as images - could reveal their potentialities in working through these difficulties, creating a multidisciplinary environment aimed at a deep comprehension of the artifacts from the past and, at the same time, to find new and more efficient ways to display archaeological finds and remains and contribute to an effective dissemination of knowledge.

\section{Acknowledgements}

My gratitude goes to Prof. Corinna Rossi (Department $A B C$, Politecnico di Milano) for her extraordinary guidance and continuous support during the different phases of this work, and to Prof. Stefano Natrella (Accademia di Belle Arti di Brera) for our extremely fruitful discussions regarding, among others, the concept of image. Finally, thanks to Prof. Todd Shimoda for his brilliant support. This paper represents an outcome of the project LIFE (Living In a Fringe Environment) funded by the ERC CoGrant 681673.

\section{References}

Agamben, G. (2002). L'aperto: l'uomo e l'animale. Torino, IT: Bollati Boringhieri.

Assmann, J. (2010). Communicative and cultural memory. In A. Erll, \& A. Nünning (Eds.), Cultural memory studies: An international and interdisciplinary handbook (pp. 109-118). Berlin, Germany: Walter de Gruyter.

Benjamin, W. (1935). Das Kunstwerk im Zeitalter seiner technischen Reproduzierbarkeit. Frankfurt/Main, DE:Suhrkamp.

Brück, J. (2005). Experiencing the past? The development of a phenomenological archaeology in British prehistory. Archaeological Dialogues 12(1),45-72. https://doi.org/10.1017/S1380203805001583

Casey, E. S. (1997). The fate of place. Berkeley, USA: University of California Press.

Clark, J. T. (2010). The fallacy of reconstruction. In M. Forte (ed), Cyber-Archaeology (pp. 63-73). Oxford, UK: Archaeopress.

Forte, M., (2009). Cyber-Archaeology: Notes on the simulation of the past. Virtual Archaeology Review, 2(4), 7-18. https://doi.org/10.4995/var.2011.4543

Freedberg, D., \& Gallese, V. (2007). Motion, emotion and empathy in esthetic experience. Trends in Cognitive Sciences, 11(5), 197-203. https://doi.org/10.1016/j.tics.2007.02.003

Freud, S. (1954). The origins of Psychoanalysis: Letters to Wilhelm Fliess. New York, USA: Basic.

Gay, R. (1994). Proportion and Style in Ancient Egypt. London, UK: Thames \& Hudson.

Greco, C. (2019). Keynote: The biography of objects. Int. Arch. Photogramm. Remote Sens. Spatial Inf. Sci., XLII-2/W11, 5-10, https://doi.org/10.5194/isprs-archives-XLII-2-W11-5-2019

Heidegger, M. (1954). Die Frage nach der technik; Wissenschaft un Besinnung. In M. Heidegger, Vorträge und Aufsätze. Pfullingen, DE: Günther Neske.

Hodder, I. (1984). Archaeology in 1984. Antiquity, 58(222),25-32. https://doi.org/10.1017/S0003598X00055940

Hodder, I. (2012). Entangled. An archaeology of the relationships between humans and things. Oxford, UK: John Wiley and Sons, Inc.

Hogsden, C., \& Poulter, E. K. (2012). The real other? Museum objects in digital contact networks. Journal of Material 
Culture, 17(3), 265-286. https://doi.org/10.1177/1359183512453809

Han, B. (2011). Shanzhai: Dekonstruktion auf Chinesisch. Berlin, DE: Merve Verlag.

Hui, Y. (2016). On the existence of digital objects. Minneapolis, MN: University Of Minnesota Press.

Ingold, T. (1993). The Temporality of the Landscape. World Archaeology, 25(2),152-174.

Ingold, T. (2000). The perception of the Environment. Essays in livelihood, dwelling and skill. London, UK: Routledge.

Ingold, T. (2013). Making: Anthropology, Archaeology, Art and Architecture. London, UK: Routledge.

Latour, B., \& Lowe, A. (2010). The migration of the aura or how to explore the original through its fac similes. Switching Codes, 108, 275-297.

Leroi-Gourhan, A. (1964). Il gesto e la parola. Tr. It. 1977. Torino, IT: Einaudi.

Lévy, P. (1999). Becoming virtual: reality in the Digital Age. New York, USA: Plenum Trade.

López, B. (1986). Arctic Dreams. Imagination and desire in a northern landscape. New York, USA: Simon \& Schuster.

Mandelli, A., Perfetti, L., Fiorillo, F., Fassi, F., Rossi, C., \& Greco, C. (2019). The Digitalization of ancient Egyptian coffins: a discussion over different techniques for recording fine details. Int. Arch. Photogramm. Remote Sens. Spatial Inf. Sci., XLII-2/W15,743-750. https://doi.org/10.5194/isprs-archives-XLII-2-W15-743-2019

Meehan, N. (2020). Digital Museum Objects and Memory: Postdigital Materiality, Aura and Value. Curator: The Museum Journal. https://doi.org/10.1111/cura.12361

Renefrew, C., Frith, C., \& Malafouris, L. (2009). The sapient mind. Archaeology meets neuroscience. Oxford, UK: Oxford University Press.

Rossi, C. (2019). Aristotle's Mirror: combining digital and material culture. Int. Arch. Photogramm. Remote Sens. Spatial Inf. Sci., XLII-2/W11, 1025-1029, https://doi.org/10.5194/isprs-archives-XLII-2-W11-1025-2019

Snape, S. (2011). Ancient Egyptian Tombs. Chichester, UK: Wiley Blackwell.

Tilley, C. (1994). A Phenomenology of Landscape: Places, Paths and Monuments. London, UK: Berg.

Valditara, L. M. (2007). Platone e le 'ragioni' dell'immagine. Percorsi filosofici e deviazioni tra metafore e miti. Milano, IT: Vita e Pensiero.

Wenders, W. (2015). Una volta. Roma, IT: Contrasto. 


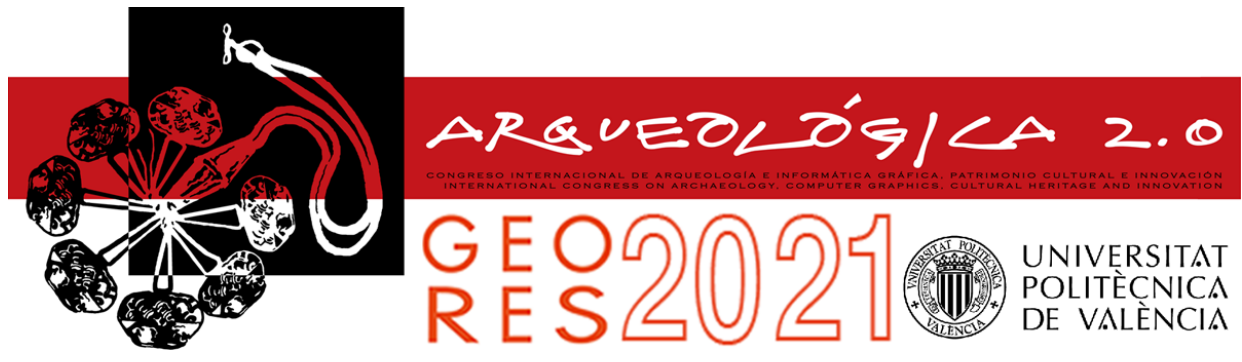

Proceedings of the joint international event $9^{\text {th }}$ ARQUEOLÓGICA

$2.0 \& 3^{\text {rd }}$ GEORES

Valencia (Spain).

26-28 April 2021

\title{
AN INTEGRATED APPROACH AIMED AT THE PROTECTION OF CULTURAL HERITAGE: FROM THE GEOMATIC SURVEY TO HBIM AND AR REPRESENTATION OF VILLA PISANI (STRA, ITALY)
}

\author{
Michele Monego ${ }^{a, b}$, Simone Maiolic ${ }^{c}$ Matteo Salvalaggio ${ }^{a,{ }^{*}}$ \\ a Department of Cultural Heritage, University of Padova, Piazza Capitaniato 7, 35139 Padova, Italy. michele.monego@unipd.it; \\ matteo.salvalaggio@unipd.it \\ b Department of Civil, Environmental and Architectural Engineering, Via Marzolo 9, 35131 Padova, Italy. michele.monego@unipd.it \\ c School of Engineering, University of Padova, Via Marzolo 9, Padova 35131, Italy. simone.maioli@studenti.unipd.it
}

\begin{abstract}
:
The topic of Cultural Heritage preservation has gained increasing attention during the last decades. The protection of such complex and delicate manufactures require the intervention of experts from a different field (e.g. archaeology, restoration, survey, 3D modeller, structural engineering, architecture), addressed towards an integrated and multidisciplinary scientific approach. Recently, technology advancements have involved many scientific disciplines, affecting both investigation tools and data computing. In this paper, an approach aimed at assessing the health status and preserving a heritage building is presented and applied to a case study, exploiting the most effective tools nowadays available. Based on the so-called knowledge path, the study started from the analysis of historical data, through the collection of in-situ measures and towards the construction of a 3D digital model where the information is stored. In particular, a set of images taken by drone and processed by the photogrammetric technique of Structure from Motion, were used to produce detailed point clouds, mesh model, DEM and orthophotos that collect accurate geometrical documentation, useful to analyse the conservation status and the crack pattern. Based on the detailed model from geomatic survey and drawings, a Heritage Building Information Modelling (HBIM) database was collected with the possibility of managing historical, geometric, structural and health status information. In the end, the study focused on the availability of the information collected for non-professional users or professionals from different fields, who do not have access to data kept in a commercial database. Partly, this resulted in the elaboration of the augmented reality (AR) model, accessible by common mobile applications. The case study is Villa Pisani in Stra (Venice, Italy), a well-known example of Venetian villa built in the XVIII century which hosted many protagonists of European contemporary history.
\end{abstract}

Keywords: cultural heritage, health monitoring, geomatic survey, HBIM, drone, augmented reality

\section{Introduction}

The protection of Cultural and Architectural Heritage is a mission that assumes prominent importance in a country such as Italy, with plenty of extraordinary buildings and manufactures. Among these is Villa Pisani in Stra (Venice), an XVIII-century Venetian villa.

The study presented in this paper is moved by the necessity to detect the health and conservation status of Villa Pisani, but not limited to it. Since the building is part of the architectural heritage it is also protected by specific conservation laws, which rule the investigations and survey procedure. The appearance of the building cannot be altered, and destructive tests are neglected. These limits became the occasion to apply an integrated approach, based on state-of-art geomatic survey techniques and 3D modelling methods.
The main aims of the study here presented are:

- Detection of the conservation status of Villa Pisani;

- Validation of a multidisciplinary approach, based on the integration of survey data with historical information and the recollection into a 3D HBIM;

- Availability and accesibility of the HBIM database to a wide range of professional and non-professional users, taking advantage of opensource tools.

\subsection{Villa Pisani}

Villa Pisani in Stra, Italy (Fig. 1) is an extraordinary example of a Venetian villa, which aroused in the XVIII

*Corresponding Author: Matteo Salvalaggio, matteo.salvalaggio@unipd.it 
century as a summer residence for the wealthy Pisani family.

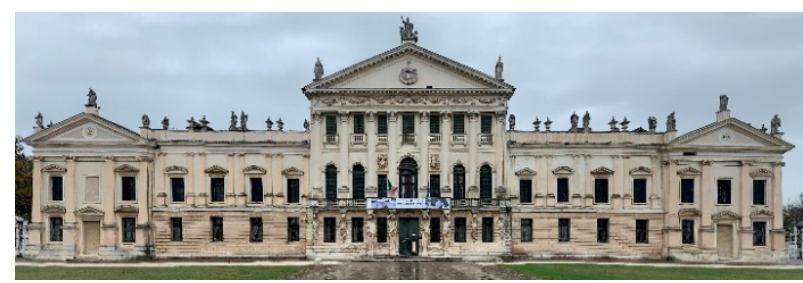

Figure 1: Main façade of Villa Pisani (Stra, Italy).

Francesco Maria Preti was the architect of the building project, whose layout has remained unchanged during centuries (Favaro Fabris, 1954). The structure is inscribed in a square $80 \times 55 \mathrm{~m}$, composed of thick clay brick masonry walls with timber floors and roof. A magnificent garden was designed adjacent to it, with annexes and outbuildings for leisure (e.g. greenhouse, guardian house, labyrinth).

In 1806, the French occupation of Venice resulted in the weakening of Pisani family, which sold the complex to Napoleon for the use of the viceroy Eugene of Beauharnais, until 1815. In those years, some structural arrangements were done, as the creation of two apartments with the introduction of new floors and bathroom, including the well-known Napoleon bathtub.

Passed through the Austrian occupancy of the Venetian region, the villa remains basically unchanged. After the end of foreign domination in 1866, the residential use of Villa Pisani ended too.

In the first years of the $X X$ century, the University of Padova managed the complex as Hydro technology Institute and introduced the huge water basin in the garden (Ferrari \& Rallo, 2011). After the emergency use as a military hospital during the First World War and a general abandonment, in the 80 s a renewed interest towards the complex aroused, with the restoration of the Tiepolo fresco in the magnificent ballroom (Rallo \& Monti, 2000).

Nowadays, the Villa Pisani system is a National Museum itself, which need to be protected and maintained through visitor's fruition and the frequent monitoring of its structures health.

\section{Materials and methods}

The methodology followed the well-known knowledge path (Binda, Cardani, Saisi, Modena, \& Valluzzi, 2004; Valluzzi et al., 2019; EN 1998-3, 2005), which comprehends the historical analysis, the collection of onsite data, the critical interpretation of decay status and crack pattern, the management and analysis of results. The data could be implemented later in the structural assessment of the building, similarly to the procedure reported in Sbrogiò, Salvalaggio, \& Valluzzi (2020).

Once the historical phases have been reconstructed, the in-situ operations have been addressed to the collection of geometrical, architectural and conservation data.

The data presented in this paper have been collected through totally non-destructive techniques, which involved direct measures of objects, photogrammetry reconstructions through professional cameras and the collection of aerial images through drone flights. This permitted to generate a point cloud of the building external surfaces (i.e. façades and roofs).

The processing of the data brought to the validation of the geometrical survey, the creation of a photographic survey and the editing of a critical survey, made through a detailed analysis of the non-structural materials deterioration processes and the mapping of the decay status (i.e. masonry cracks, wall inclination, roof depressions) which affects the structures.

This amount of data has been following implemented in a 3D HBIM model into the Autodesk Revit environment, where structural, geometric and conservation information are managed.

In the end, the accessibility issue of commercial software from non-specialized users has been overcome through the creation of an AR model in the Unity environment, accessible through a mobile application within Android and iOS operating systems.

In the following, the main materials and technologies adopted are described.

\subsection{Geomatic survey}

The improvement of the architectural knowledge about Villa Pisani was supported, in the first phase, by a campaign of geomatic survey.

Geomatic techniques, in the last years, have shown a crucial increasing in efficiency due to the development of sensors and software that improve the quality of the data and the user-friendliness of the devices. Thanks to that, in many cases the main aims can be focused on producing the proper and most adequate documentation oriented by multidisciplinary requirements (Sammartano \& Spanò, 2017).

In this case, the choice of a "light" approach seemed to be an adequate solution in an optic of non-invasive presence in a particular protected site and considering the relation between time of surveying and obtained results (Carraro et al., 2019). An aerial photogrammetric survey with a lightweight drone (Fig. 2a) and a set of GNSS measurements were chosen for the imagery acquisition and the measurements of the control points. The main aim of the survey was the coverage of the roof in order to produce a detailed orthophoto, useful in the visual detection of roof degradation. This inspection through the orthophoto, for instance, could support the Superintendence in the monitoring of damages in the roof tiles.

For scaling and georeferencing the survey 20 planar targets (Fig. 2b) were positioned on the ground around the building and measured by GNSS acquisition with RTK technic. The distribution of the GCPs only on the ground (and not on the façades or roof) represents a clear limit for an optimal control of the resulting model. However, it is not possible to access the roof area with a reasonable safety margin if not with a considerable use of means and time.

It has to be stated that the aero-photogrammetry was primarily aimed at the creation of an orthophoto of the roof and, only later, the good results in the vertical surfaces of the building brought to use the model also in support of HBIM modeling. 
A future flight, focused on the façades and with new GCPs could be a further step in the digital documentation and study of the building. The images were processed by SfM technic using the software Agisoft Metashape while the further data extracted from the models were produced through 3DReshaper and JRC Reconstructor.

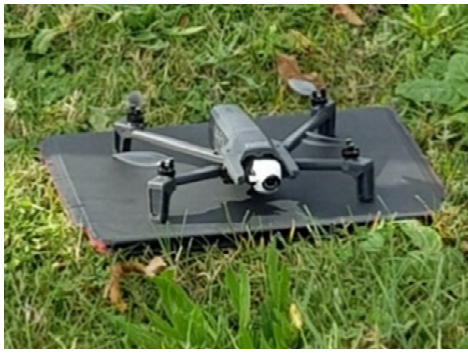

(a)

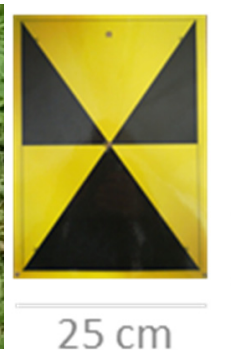

(b)
Figure 2: Aerial photogrammetric survey: a) Parrot Anafi drone; b) control point

\subsection{HBIM approach}

The use of HBIM approach for historical buildings and fields such as AR/VR has not been fully investigated yet. One of the main reasons is the difficulty in representing detailed elements of $\mathrm{CH}$ such as irregular walls, decay phenomena and ancient traces of structures corrupted by time, which require a high level of knowledge of the artefact (Banfi, 2016). For this reason, in particular, HBIM models should become more beneficial for historical buildings as they offer access to both geometric and historical information, allowing to use this information for its maintenance (Chiabrando, Lo Turco, \& Rinaudo, 2017), which a traditional approach cannot offer. The BIM creation process can be differentiated for i) new and ii) existing buildings, due to variation in building information quality, information availability and functionality requirements (Brumana et al., 2020). In the case study, the support of photogrammetry facilitated the HBIM modelling process, making it possible to compare the model with the geometric information of the point cloud. It was possible to update the 2-D geometric survey by a cross-checking procedure with the point cloud, refining, among the others, the dimensions of the façade elements, the inclination of the pitch and the height of the floor. Furthermore, it allowed collecting data about the storeys heights (i.e., to produce geometric sections). Other types of analysis were permitted, such as checking the orthogonality of the perimeter walls or highlighting overhanging elements. From an operational point of view, the process of creating the HBIM model was divided into three phases: i) data collection, ii) processing and iii) integration of the collected data (Fig. 3).

The first step involved the collection of all existing knowledge, studying historical sources, archival documents, drawings, descriptions of the techniques and materials used. The second step consisted in the reelaboration of the collected data with the survey data in order to obtain a reality-based model. By mapping, for example, demolition and new construction parameters on the masonry through the phases, structural functions on the wooden carpentry and decay on the façades. Finally, all the information was implemented in 2-D and 3-D reports, producing the necessary documentation for the scheduled maintenance interventions, as well as carrying out all the essential queries to plan the required actions.

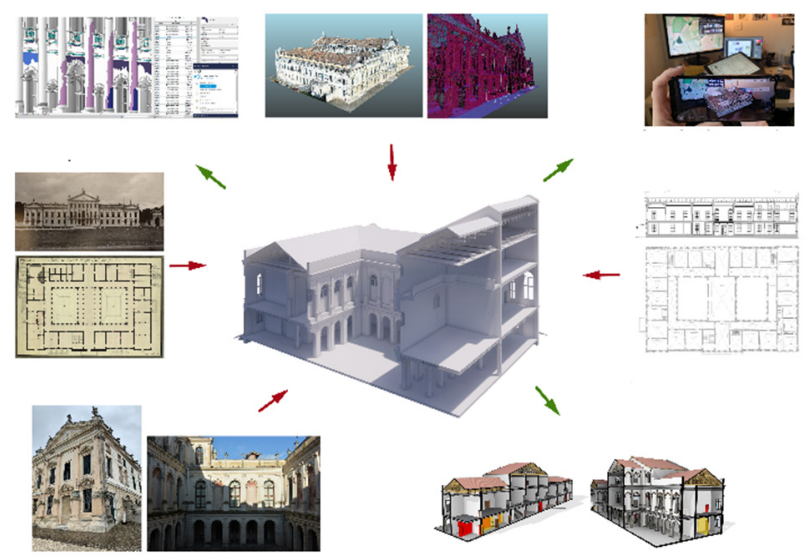

Figure 3: HBIM model input and output.

\subsection{From HBIM to $A R$}

Aiming at the accessibility of the model and the results to professionals and a wider audience, an augmented reality (AR) application for mobile devices was developed. In this way it was made possible to share information about Villa Pisani through graphic visualization, improving the communicative strength of the contents. The application of these innovative tools in the field of cultural heritage and the historical building has to be considered a fundamental opportunity (Cabrelles, Blanco-Pons, Carrión-Ruiz, \& Lerma, 2018). The use of an application improves the user experience because virtual elements are superimposed based on a real world, enriching it with information that is not easily available, and leading to virtual involvement.

This was possible thanks to the union of the BIM world with object-oriented programming and software like Unity. Importing a BIM model by fbx format into Unity involves the recognition of the geometry through the name of the type / family (entered in the modelling environment) and the recognition of the ID linked to each instance. This dependency has facilitated the app creation process (Lai, Hu, Cui, Sun, \& Dai, 2018).

Vuforia was used for the development of the apps, an advanced AR building engine that inside Unity provides an intuitive platform for creating augmented reality apps for Android and iOS platforms (Fig. 4). In practice, the Augmented Reality (AR) application permits, through the camera of a compatible device and the recognition of a predetermined target, to view the model of the Villa in correspondence of the target surface. In addition to visualization, the app makes possible to interact with the model.

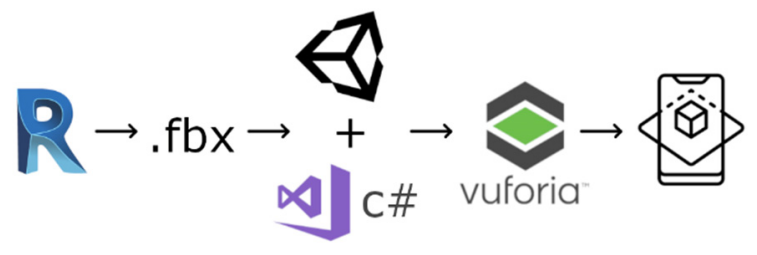

Figure 4: AR app development process. 


\section{Results and discussion}

In this section, the results of the work are presented and discussed.

\subsection{D model from survey}

A set of 782 aerial images was taken with a Parrot Anafi drone (Table 1), using inclinations of $90^{\circ}$ and $70^{\circ}$ in 3 different flight plans, at a mean altitude from the ground of $33 \mathrm{~m}$ and with a resulting Ground Sample Distance (GSD) of $6 \mathrm{~mm}$.

Table 1: Technical specifications on aerial imagery acquisition with Parrot Anafi drone.

\begin{tabular}{c|c} 
Setting & Value \\
\hline Sensor & $1 / 2.4 " 21$ MP CMOS Sony \\
Image size & $5344 \times 4016$ pix \\
Fly height (mean) & $33 \mathrm{~m}$ \\
GSD (mean) & $6 \mathrm{~mm}$
\end{tabular}

The processing of the 782 images started with the aerotriangulation phase and brought to the extraction of a sparse cloud consisting of 747,631 tie points (Fig. 5a). A more specific area around the building was selected for the further processing that produced a dense cloud of $114,948,462$ points and a triangular mesh model of $26,183,087$ (Fig. 5b). The high density of points is a necessary feature to get an adequate model, which can be used for the detection, for example, of small anomalies in the roof surface. In order to validate the geometrical accuracy of the result, a set of GCP (Ground Control Points) have been measured and introduced in the processing phase. These targets provided the georeferencing of the data and the error evaluation. The coordinate reference system is the Italian national projection system Gauss-Boaga (west fuse), classified with code EPSG: 3003 - Monte Mario Italy (zone 1).
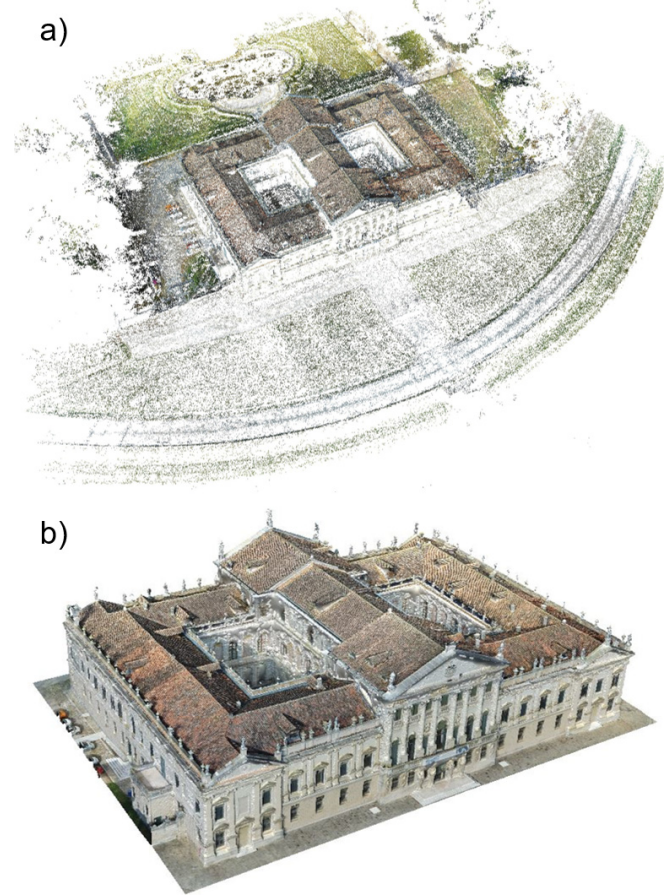

Figure 5: Processing of images (Agisoft Metashape): a) Sparse cloud of Villa Pisani from SfM; b) Textured mesh surface model.
The choice of this reference system is motivated by the need for uniformity with the existing archival data.

In this case the GCP are divided in Control Points, the targets that were used also for scaling and georeferencing the model, and Check Points that are the markers used only for the error verification. The RMSE values are shown in Table 2 while the graphical representation can be observed in Figure 6.

Table 2: Control points and check points RMSE.

\begin{tabular}{c|c|c} 
Setting & Control Points & Check Points \\
\hline Number of points & 13 & 3 \\
X error $(\mathrm{cm})$ & 1.0 & 1.3 \\
Y error $(\mathrm{cm})$ & 1.1 & 1.9 \\
Z error $(\mathrm{cm})$ & 2.0 & 0.3 \\
XY error $(\mathrm{cm})$ & 1.5 & 2.3 \\
Total error $(\mathrm{cm})$ & 2.5 & 2.3
\end{tabular}

Considering the objectives and the methodology, the global accuracy of the survey is good, and the model can be used as a reliable base of data both for BIM and architectural or structural analysis.

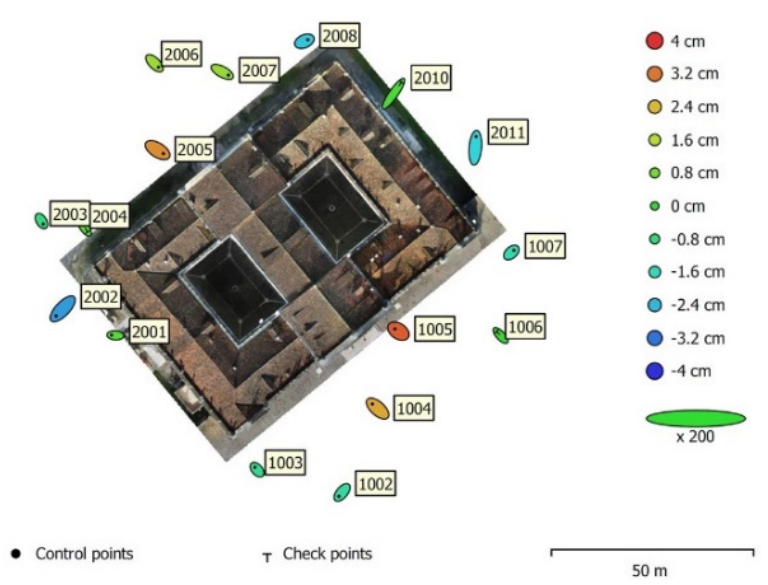

Figure 6: GCP locations and error estimates.

A further product extracted from the 3D model was a DEM $(1.2 \mathrm{~cm} / \mathrm{pix})$ that allowed some observations focused on the health status of the roof coverage. While the inspection of the conservation status of the tiles could be done through a visual check of the single high-resolution images taken by the drone, a deeper view of the structure was made possible by morphological analysis. First, a height map was created for the DEM searching for a customized colour scale with a customized palette that permits highlighting the geometry of the roof pitches as shown in Figure $7 a$.

Besides this, a set of contour lines with interval of $10 \mathrm{~cm}$ and $1 \mathrm{~m}$ was produced from the DEM and so the capacity of detecting the morphological anomalies was improved (Fig. 7b). In some parts of the roof small differences in the continuity of the colour or the lines were evident and could be considered as surface displacement caused by underlying deformations. Of course, the age, the materials and a physiological adjustment of the structure must be considered as factors in the global evaluations. The area that was identified as possibly subject to 
problems will be directly investigated with site inspections and targeted diagnostics on the roof beam structure.
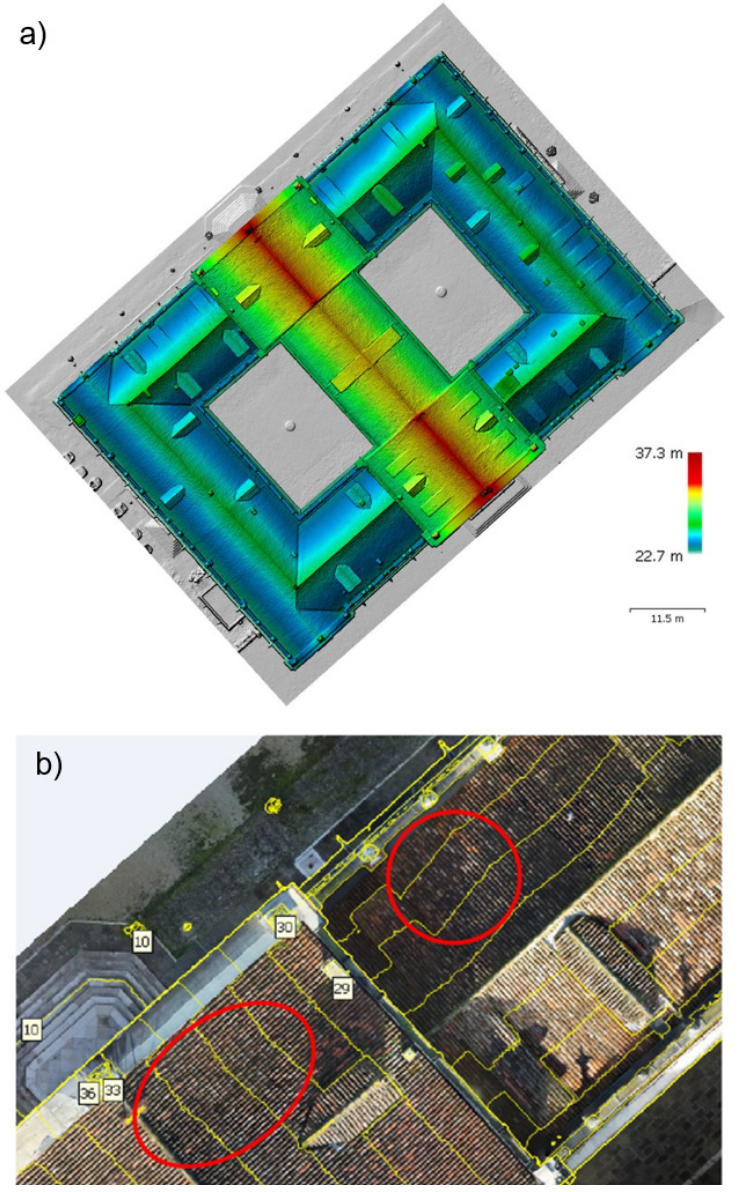

Figure 7: Products extracted from the 3D model: a) DEM with height colour scale of the roof part; b) Orthophoto with contour lines (interval of $1 \mathrm{~m}$ ) with an example of two anomalies that could imply more detailed in-site inspections.

\subsection{Conservation status analysis}

The large amount of data elaborated provided the base for the performance of a detailed analysis of Villa Pisani external surfaces. First, a map of the decay phenomena and crack patterns was prepared, which revealed the effects of weathering. Plaster and stone covers, in some cases, are powdered leaving the underneath structural masonry vulnerable to deterioration (Fig. 8a), especially near the foundations. Some deposits of vegetal and inorganic patina were detected, as well as black spot and pouring, due to stagnating water and humidity.

Furthermore, the processing of on-site data allowed to perform a primary detection of the displacements and strains occurred and occurring in the main structural parts (e.g. walls and roofs). In particular, the analysis of Figure 7 permitted to assess the health of timber roof systems, made of truss beams and purlins. The anomalies detected provided the focus of the investigation plan on that parts, whose timber components are being investigated (Fig. $8 b)$.

\subsection{HBIM and data enrichment}

The digital reconstruction of the artefact, through its modelling, made possible to integrate the data relate to historical variations using the "phases" tool of the Revit software. The operation carried out was to implement the information about variations undergone over time associating a date with it, and subsequently creating a historical phase within the software for each of the dates with details about the construction and/or demolition of the architectural elements. In this way, 8 historical phases from the original state to the current one have been obtained. The last step was to associate each element with its construction or demolition phase, then extrapolate views for each comparative date where the elements are displayed in red (built) or yellow (demolished).

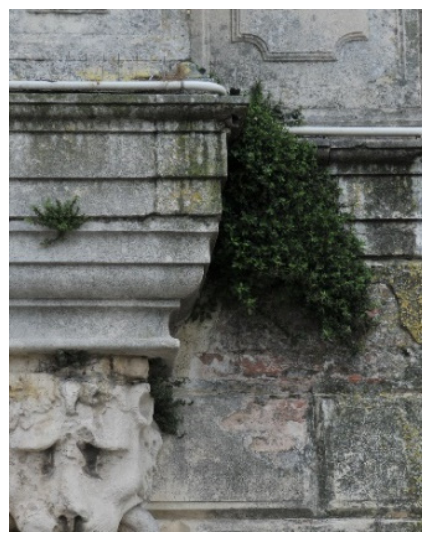

(a)

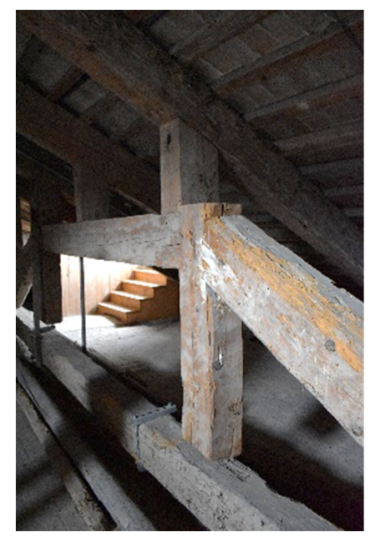

(b)
Figure 8: Detailed analysis of Villa Pisani external surfaces: a) Southern façade decay detail; b) roof system detail.

Again, referring to the information provided by the Superintendence of Cultural Heritage of the Veneto, it was possible to identify both the structural types of floors and roofs and previous consolidation interventions, validated by the historical and documentary information found. Once all this information has been entered into the digital model, it was possible to classify the different elements by type, size and material, finally extrapolating the schedules that uniquely identified the different types of structural system, facilitating identification and possible calculation (Fig. 9).

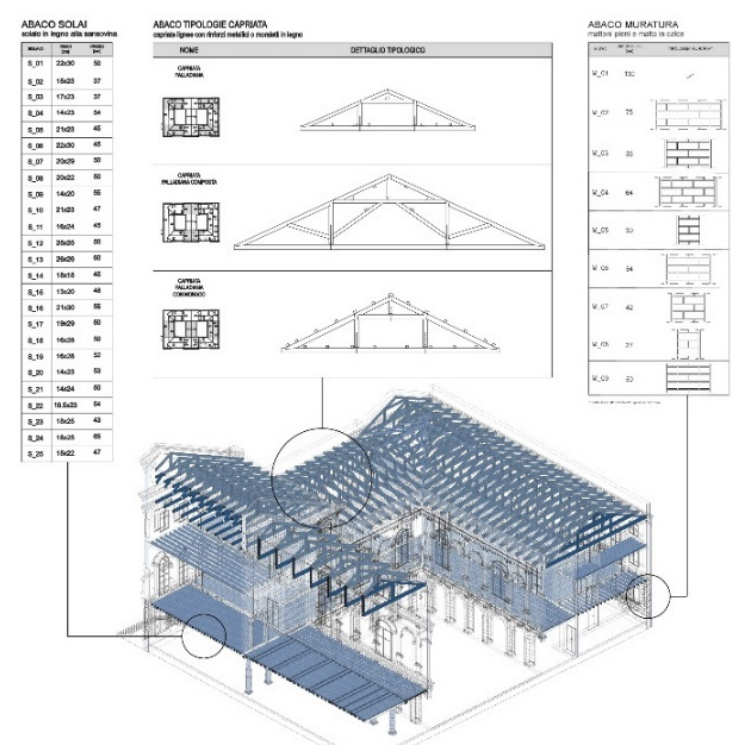

Figure 9: HBIM structural 3D view with related schemes. 
In the field of BIM modelling, however, being able to effectively mapping degradation required an important research and application effort. The objectives set included the geometric representation of degradation in the model, the position and, above all, the quantification and classification of the degradation phenomena.

In the Revit environment, it is not easy to manage these operations and thus it was necessary to use the tool Dynamo visual programming, integrated within the program. First, through the observation of the building 3$\mathrm{D}$ configuration and the photographic documentation, the state of conservation was investigated, detecting the different forms of degradation and mapping them into $\mathrm{CAD}$ environment as closed areas. Following, the areas were imported into the Revit software. These were converted into real BIM objects thanks to the use of a script developed in Dynamo (Fig. 10). The script first proceeds by asking the user to select the surface on which the degrade should be placed and the thickness to assign to it. After that, it is necessary to select the closed areas (consisting of model lines) that correspond to a specific type of deterioration. Given these input values, the selected area is extruded until its intersection with the surface. This creates a geometry and a subsequent generic family.

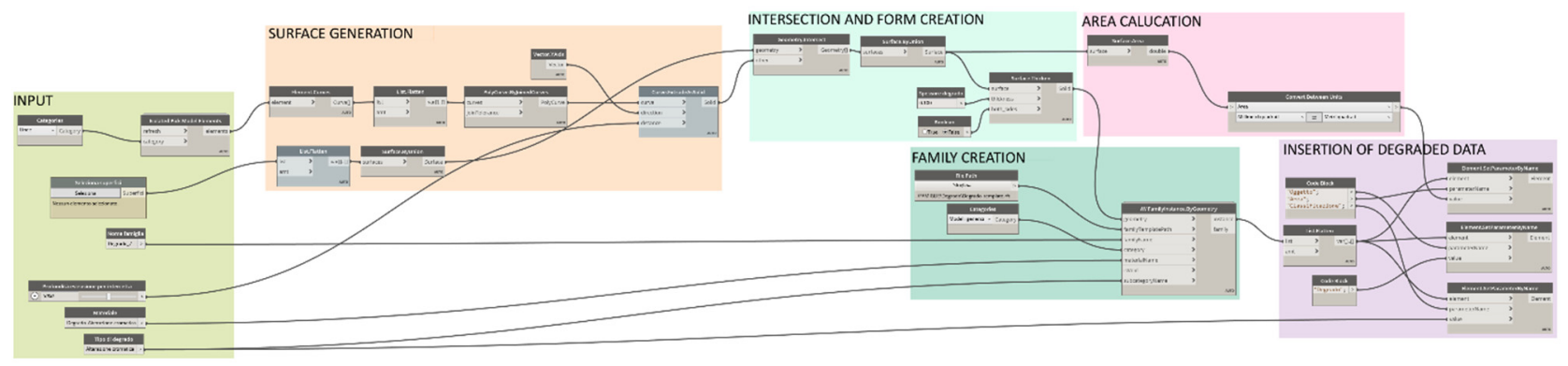

Figure 10: Dynamo code for the execution of the degradation mapping in Revit.

Once the generated geometry has been inserted into the model, other operations are performed to insert further data, as follows:

- Type of degradation (defined by the user as input);

- Fill according to Raccomandazioni NorMaL 1/88 (CNR-ICR, 1990) and UNI 11182 (2006) (application of a material to the geometry created);

- $\quad$ Surface area (calculated using the same script).

Once the degradation modelling and related information have been obtained, it will be possible to create the schedule including all the information necessary for adequate description and quantification (Fig. 11).

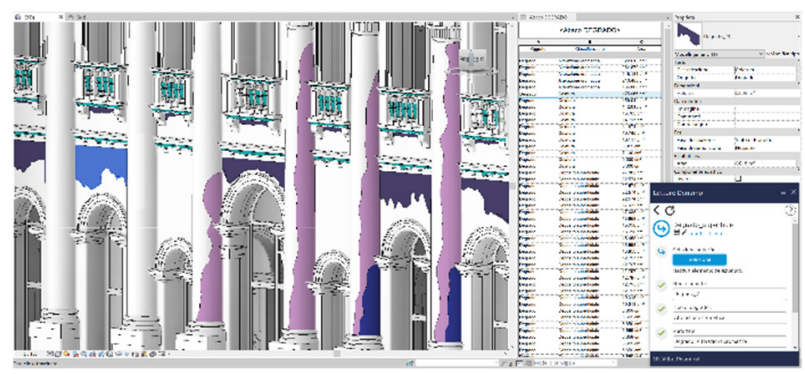

Figure 11: Mapped decay in the Revit environment.

\section{4. $\quad$ AR for information sharing}

The ability to recognize and track arbitrary images is a powerful boost to AR applications as it avoids the requirement of creating and distributing custom markers paired with specific apps. In this case, the plan of the villa first floor is the target to be pointed through the mobile camera, in order to make its use more intuitive. The interaction with the model by means of the application occurs through virtual buttons. It is possible to change the visualization in order to select and highlight separately the 3D architectural or structural components (Fig. 12). In this way, professionals in the field such as architects and engineers can use the app as an open-source dissemination tool and integration to paper documents.

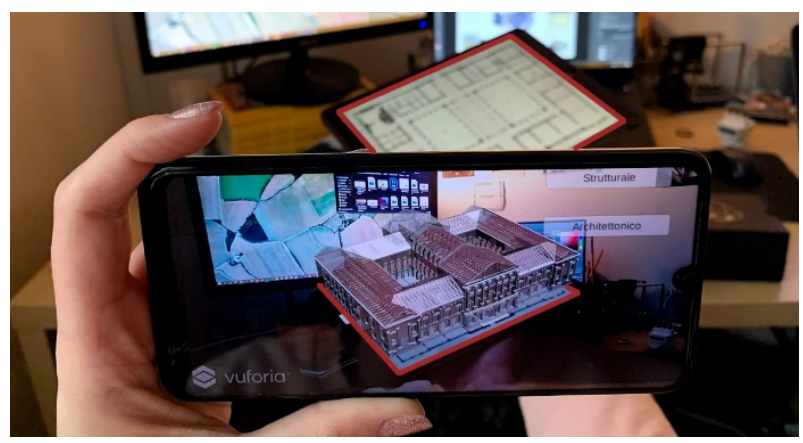

Figure 12: A view of the structural model through the AR app.

Actually, its use is not bound to any software or specific skills. One can use the app to search for spatial information through the phone. Additionally, museum users gain virtual access to parts of the villa they would not otherwise be able to, and browse through the building in an intuitive and fun way. At last, aiming at advertising the site among cultural heritage media, the app can be shared through Superintendence of Cultural Heritage to cultural institutions concerned.

\section{Conclusions}

The reported study shows a part of the results that the application of a multidisciplinary approach could produce in the field of the conservation of cultural and architectural heritage.

Two main lines, aimed at the protection of the building, were followed. The first consists on the assessment of the health of the structure through survey and site activities. 
The second line regards the collection, management and analysis of the data, in an optic of sharing information to make them available for consulting by professional and non-professional users.

Furthermore, the promotion and stimulation of tourism, to keep Villa Pisani a territory monument worthy of investment, come also from the spreading of historical and architectural knowledge through common usage tools.

Besides, the application of well-known methodologies and the extraction of reliable data is important to make this data useful and productive, not only as pure documentation.

Fruitful dialogue between the disciplines was fundamental to choose the better strategies of intervention in the site. In this way, the integration of competences of geomatics, architecture, engineering and 3D modelling provided a workflow that aimed to be as efficient as possible.

Geomatic methods such as SfM and GNSS provided an accurate set of $3 D$ data in form of point clouds, mesh models, DEM and orthophotos. These constituted solid metric support for analysis of the conservation status, above all in a not accessible area like the roof.

An HBIM model, based on drawings and survey data, collected all the information, and permits the querying and the management of the different types of data. It could be consulted by professional operators, both in the technical and cultural field, with the common aim of $\mathrm{CH}$ preservation and valorisation.
At last, an AR model was developed as an example of possible fruition for common users, trying to disseminate the knowledge of the historical building and promote tourism, also through easy tools within everyone's reach.

\section{Acknowledgements}

The work was carried out in the frame of a multidisciplinary collaboration between the Department of Cultural Heritage - dBC and the Department of Civil, Environmental and Architectural Engineering - DICEA of the University of Padova under the leading of Prof. Maria Rosa Valluzzi.

The authors wish to thank the A.Y. 2019/20 students of the Restoration course in Architectural Engineering (Marta Angeletti, Filippo Baldan, Marco Baratto, Jorge Garcia Hernanze, Martina Giorio, Arianna Mazzocchin, Giorgia Saltarin, Martino Zadra) and the teaching assistants for the support in the collection and elaboration of on-site data.

The authors would like also to thank Prof. Vladimiro Achilli for the availability of instruments and software of the Laboratory of Survey and Geomatics - LRG and Prof. Andrea Menin for the GNSS survey.

The authors wish to thank Arch. Loretta Zega, Director of the National Museum of Villa Pisani, for the possibility to access and study this magnificent building.

\section{References}

Banfi, F. (2016). Building Information Modelling-A novel parametric modeling approach based on 3D surveys ofhistoric architecture. In Euro-Mediterranean Conference, 116-127. Cham: Springer. https://doi.org/10.1007/978-3-31948496-9_10

Binda, L., Cardani, G., Saisi, A., Modena, C., \& Valluzzi, M. R. (2004). Multilevel approach to the analysis of the historical buildings: application to four centers in seismic area finalised to the evaluation of the repair and strengthened techniques. In: Proceedings of the 13th International Brick and Block Masonry Conference, Amsterdam, July 4-7 2004.

Brumana, R., Oreni, D., Barazzetti, L., Cuca, B., Previtali, M., \& Banfi, F. (2020). Survey and scan to BIM model for the knowledge of built heritage and the management of conservation activities. Digital Transformation of the Design, Construction and Management Processes of the Built Environment, 391-400, Springer International Publishing. https://doi.org/10.1007/978-3-030-33570-0_35

Cabrelles, M., Blanco-Pons, S., Carrión-Ruiz, B., \& Lerma, J. L. (2018). From multispectral 3D recording and documentation to development of mobile apps for dissemination of cultural heritage. In T. Levy, I. Jones (Eds.), Cyber-Archaeology and Grand Narratives, 67-90. Cham: Springer. https://doi.org/10.1007/978-3-319-65693-9_5

Carraro, F., Monego, M., Callegaro, C., Mazzariol, A., Perticarini, M., Menin, A., Achilli V., Bonetto J., \& Giordano, A. (2019). The 3D survey of the roman bridge of San Lorenzo in Padova (Italy): a comparison between SfM and TLS methodologies applied to the arch structure. Int. Arch. Photogramm. Remote Sens. Spatial Inf. Sci., XLII-2/W15, 255-262. https://doi.org/10.5194/isprs-archives-XLII-2-W15-255-2019

Chiabrando, F., Lo Turco, M., \& Rinaudo, F. (2017). Modeling the decay in an HBIM starting from 3D point clouds. A followed approach for cultural heritage knowledge. The International Archives of the Photogrammetry, Remote Sensing and Spatial Information Sciences, XLII-2/W5, 605-612. https://doi.org/10.5194/isprs-archives-XLII-2-W5$605-2017$

CNR-ICR. (1990). Raccomandazioni NorMaL - 1/88. Alterazioni macroscopiche dei materiali lapidei: lessico.

EN 1998-3. (2005). Eurocode 8: Design of structures or earthquake resistance, Part 3: Strengthening and repair of buildings.

Favaro Fabris, M. (1954). L'architetto Francesco Maria Preti di Castelfranco Veneto 1701-1774. Treviso, Italy: Tipografia Editrice Trevigiana 
Ferrari, S., \& Rallo, G. (2011). Venezia, Italia. Villa Pisani da villeggiatura di corte a museo degli Italiani. Venice, Italy: Medoacus Edizioni.

Lai, Z., Hu, Y. C., Cui, Y., Sun, L., \& Dai, N. (2017). Furion: Engineering high-quality immersive virtual reality on today's mobile devices. Proceedings of the 23rd Annual International Conference on Mobile Computing and Networking, 409-421. Snowbird, Utah, USA. https://doi.org/10.1145/3117811.3117815

Rallo , G., \& Monti, G. (2000). Opere di restauro e valorizzazione di Villa Pisani a Stra. Padova, Italy: II Prato.

Sammartano, G., \& Spanò, A. (2017). High scale 3d modelling and orthophoto of curved masonries for a multipurpose representation, analysis and assessment. The International Archives of the Photogrammetry, Remote Sensing and Spatial Information Sciences, XLII-5/W1, 245-252. https://doi.org/10.5194/isprs-archives-XLII-5-W1-245-2017

Sbrogiò, L., Salvalaggio, M., \& Valluzzi, M. R. (2020). Local mechanism analysis in unreinforced masonry buildings according to a new procedure based on floor spectra evaluation. In J. Kubica, A. Kwiecien \& L. Bednarz (Eds.), Brick and Block Masonry - From Historical to Sustainable Masonry, Proceedings of the 17th International Brick/Block Masonry Conference, July 5-8, 2020, Kraków, Poland. https://doi.org/10.1201/9781003098508.

UNI 11182. (2006). Beni culturali -Materiali lapidei naturali ed artificiali -Descrizione della forma di alterazione -Termini e definizioni.

Valluzzi, M.R., Marson, C., Taffarel, S., Salvalaggio, M., Deiana, R., \& Boaga, J. (2019). Structural investigations and modelling of seismic behaviour on ruins in the monumental area of Hierapolis of Phrygia. In: Aguilar R., Torrealva D., Moreira S., Pando M.A., Ramos L.F. (eds) Structural Analysis of Historical Constructions. An Interdisciplinary Approach. RILEM Bookseries, 18, 1849-1857, Springer, Cham. https://doi.org/10.1007/978-3-319-99441-3_198. 


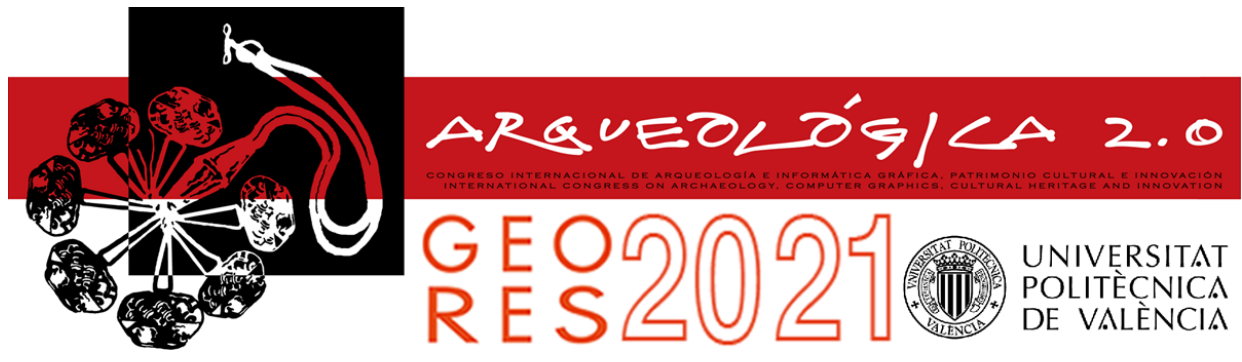

Proceedings of the joint international event $9^{\text {th }}$ ARQUEOLÓGICA

$2.0 \& 3^{\text {rd }}$ GEORES

Valencia (Spain).

26-28 April 2021

\title{
BIM DESIGN LEAD FOR RESTORATION OF SHIPWRECK MUSEUM IN KYRENIA CASTLE IN CYPRUS
}

\author{
Carlo Biagini", Francesco Capparelli, Giorgio Verdiani \\ Department of Architecture, University of Florence, Via della Mattonaia 14, 50121 Firenze, Italy. carlo.biagini@unifi.it; \\ francesco.capparelli94@gmail.com; giorgio.verdiani@unifi.it
}

\begin{abstract}
:
The paper deals with the application of Building Information Modelling (BIM) to the documentation and preservation of Archaeological Heritage, illustrating the implementation process to a case study. The work process started from the historical analysis together with the geometric capturing of the built morphology. A 3D model was created by combining laser scans and a digital photogrammetric survey. To make all 3D data sets interoperable, it was developed a BIM project execution plan focused on the restoration of Shipwreck Museum in the Kyrenia Castle in Cyprus. The HBIM approach not only allows to represent of the existing historic fabric with an effective visualization but also to lead a complex analysis of designed interventions in various scenarios. BIM objects were modelled and managed parametrically for a synthetic definition of the individual elements. All the additional information besides the geometrical data were stored into the HBIM able to document the maintenance and to help the future works. It will be illustrated the procedure and the methodology by presenting the outcomes of the research.
\end{abstract}

Keywords: Kyrenia Castle, H-BIM for archaeology, digital survey, Cyprus, fortifications, built heritage

\section{Introduction}

The collection of data and information on the historicalarchitectural heritage, aimed at producing accurate and complete documentation in the context of diagnosis, restoration, digital integration, design, and museum enhancement, has recently become possible even with a rather reduced available budget (Banti, 2020). Digital detection solutions based on latest generation instruments, which use active as well as passive systems, today offer versatile opportunities for interventions on historical architecture, without worrying about the size of the building: identification of objectives and correct planning of activities are essential to proceed effectively and continuously in a digital survey operation.

The network of fortifications across the Mediterranean, with its specific balance between "heritage buildings at risk" and "high-quality landscapes/historical landmarks" (Verdiani, 2016), is one of the most interesting themes that may benefit from such an approach. In the case of Kyrenia Castle on the island of Cyprus (Fig. 1), a combination of terrestrial and aerial photogrammetry on the one hand and terrestrial lasergrammetry, on the other hand, took place in 2018 at an academic workshop organized by Girne American University with the participation of a unit from the Department of Architecture, University of Florence (Camiz, Verdiani, \& Ceylanli, 2018). Kyrenia Castle is a large medieval fortification laid out in an almost square plan with sides of about 150 meters long and walls of up to about 30 meters high. On the occasion of the laboratory, opened for a week in May 2018, the first (partial) digital model of this great heritage building was produced. Following the best practices of a digital survey, the operative group, together with the management unit of the castle museum, performed a detailed investigation, from the study of the morphology of the castle to its stratigraphy and from the restoration problems of the museum to the exhibition aspects, including the production of multimedia content for the general and/or the more technical public. Such an accurate data set is the ideal basis for developing a more "evolved" digital twin of the castle, or at least of some of its "strategic" parts, such as the museum complex. Although it welcomes one of the fundamental discoveries of underwater archaeology, such as the Kyrenia Shipwreck (Steffy, 1985), the need for an overall redesign in line with contemporary museum strategies is strongly felt. The creation of a parametric model of the museum area developed in the Autodesk Revit $^{\odot}$ environment was thus an opportunity to experiment with an H-BIM approach in the study of a relevant example of a historical-archaeological heritage building (Capparelli, 2019) (Fig. 2).

\section{BIM design lead for restoration}

The digitization of building information processes has long since extended to the cultural heritage sector too, for which the use of Building Information Modelling

`Corresponding Author: Carlo Biagini, carlo.biagini@unifi.it 
technologies has opened up new scenarios in the management of historical-architectural heritage (Murphy, McGovern, \& Pavia, 2013). However, the transfer of information modelling approaches effectively tested in new constructions raises issues that are still not completely resolved in the context of existing buildings (Antonopoulou, 2017).

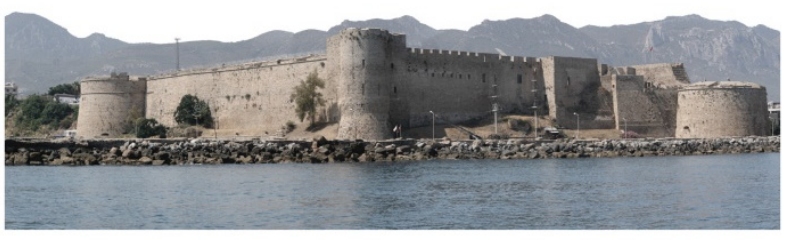

Figure 1: A view of Kyrenia Castle in Cyprus.
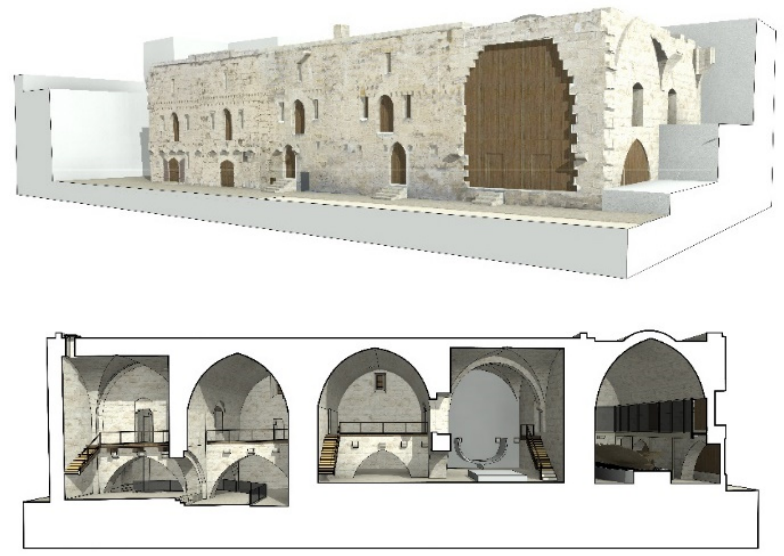

Figure 2: H-BIM model of the Kyrenia Shipwreck Museum.

On the one hand, the advances obtained in recent years by Geomatics in terms of portability, ease of use, speed and precision of measuring instruments, have not been matched by an adequate improvement in the automation tools for the implementation of information models. Indeed, the "Existing condition modelling" processes are highly asymmetrical in scan-to-BIM procedures between the phase of massive acquisition of geo-spatial data and the creation of parametric models (Quattrini, Clini, Nespeca, \& Ruggeri, 2016). On the other hand, in a broader perspective of an asset life cycle, the information management of historic buildings requires a more comprehensive redefinition of delivery and operational phases, regulated not only by design information requirements but by a specific conservation philosophy (Biagini, Donato, Capone, \& Facchini, 2016).

In particular, the information management of the historical heritage must be able to hold new information classes related to the asset management strategies of the employer (owner/manager), and other important items such as shared cultural values and recognized meanings in built heritage; conservation criteria informed to the most advanced theories and restoration techniques; needs of architectural survey and instrumental testing campaigns required for the various specialist investigations; identification of rehabilitation, functional adaptation, maintenance and conservation interventions (Brumana et al., 2017).

On the first issue, there are now many studies and research, which have tried to propose information management procedures on specific objectives; they were aimed at implementing parametric models of built heritage, focusing mainly on the levels of accuracy and geometric detail achievable in the modelling of historical building elements, starting from an assigned granularity of the captured geometric data (Biagini \& Donato, 2014).

However, the production of "BIM-ready" models, without a clear identification of objectives of use, always constitutes a partial response to the information requirements of asset management set by an employer, and often the premise of further heavy processing phases. That is especially in cases where the morphological complexity of the historical building requires advanced customization of the parametric objects, abandoning the ordinary modelling of the software's native objects of BIM authoring (Volk, Stengel, \& Schultmann, 2014), hybrid solutions, in which geospatial data sets coexist with parametric objects, limiting the modelling to the new conservationmaintenance-restoration interventions, certainly represent interesting alternatives at low cost and quick to implement (Brookes, 2017). However, they strongly reduce the potential use of the BIM model. The need to identify an information vehicle, able to integrate the different dimensions of the building project (graphics, documents, multimedia), shifts attention to the management of the database underlying the parametric model, and to the multiplicity of data that the historical built heritage has inherited from a more or less recent past (archival documents, reliefs, photos, surveys, etc.). This is a problem that configures a new idea of information model no longer virtualized in the simple digital transposition of the building semantics but moreover identified with the same data-sharing environment (CDE common data environment), which can be interrogated through data-mining procedures.

This recent proposal is working in this perspective, aimed to change the information development standard of models and objects in the restoration setting (UNI 113374,2017 ), which provides for overcoming the rigid double articulation of the current Levels Of Development (LOD) in the two items, Level Of Geometry (LOG) and Level Of Information (LOI), towards a more complex articulation of graphic models and document systems, which is expressed through a new "Level Of Information Need" (LOIN) (Brumana, Banfi, Cantini, Previtali, \& Della Torre, 2019).

\section{Modelling methodology and solutions}

Some techniques of parametric modelling applied to the historical heritage have been experimented with in the survey of the Kyrenia Castle, affecting one of the most significant parts of the fortified complex, the Shipwreck Museum (Fig. 3). With a BIM model, it was carried out an effective tool for the evaluation of design choices aimed at the enhancement of the museum rooms, which are devoid of a uniform layout and adequate lighting technology, despite the presence of a naval archaeological find of considerable value dated between IV and III sec. B.C. 


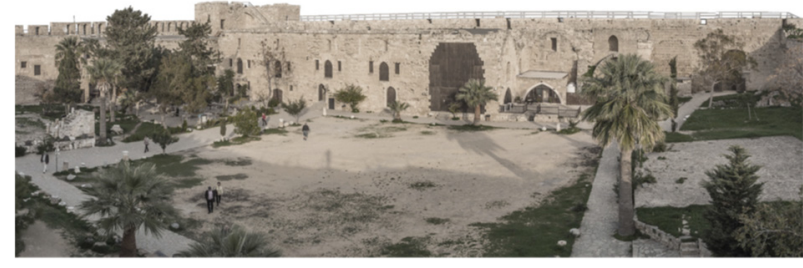

Figure 3: A view of the central courtyard and Shipwrek Museum

The Kyrenia Castle represents three distinct periods of architectural development, as the techniques of warfare advanced from bows and arrows to the invention of gunpowder and cannons (Camiz, Khalil, Cansu Demir, \& Nafa, 2016). It is an excellent example of tracing the evolution of medieval military castles in that area with a specific reference to other European models from the same period (Cathcart King, 2019). The periods of the fortifications are: First phase, Byzantine (330-1192); second phase, Lusignan (1192-1472); third phase, Venetian (1472-1570). The "Kyrenia shipwreck", the common name used to indicate the important finding of a ship from the IVth century BC in the waters in front of Kyrenia (Katzev, 1981), also supports the idea about the presence of an important port town. However, there is no evidence of a Roman military castle. The hull remains of the ship are preserved inside the castle museum (Katzev, 2008). The castle has round towers, solid curtain walls, gun ports and ramparts, all typical elements of the Venetian military architecture. Inside there are wellpreserved cells, accommodations, and water cisterns to be used in case of a siege. The drawbridge over a moat was the only way to access the castle. The North East tower of the Kyrenia castle is a Lusignan "horseshoeshaped" tower with angled footing and loopholes for firing longbows. The Lusignan Donjon is today still partially visible. The Kyrenia town was a fortified town with its towers acting as part of the castle fortification which was further enhanced by the Venetians and went out of use during the Ottoman period (Petre, 2010). In facts, the castle did not resist to the Ottoman expansion, in 1571, the Kyrenia castle surrendered without firing a single shot.

\subsection{Digital Survey of the Castle}

All the digital survey operations were done during the workshop in Kyrenia in May 2018. The 3d laser scanner in use for this survey was a Zöller-Froelich Z+F Imager $5006 \mathrm{~h}$ a phase-shift unit capable of gathering points at a distance up to 80 metres with an accuracy of about two millimetres on a standard reflective material (Fig. 4). For all the scans it was preferred to use settings with a density of points in "middle" mode (in this survey work this setting created point clouds defined up to nine million points) or "high" mode (this setting allow the creation of point clouds up to 19 million points) and with an accuracy mostly set to "high" for the scans done in full light and open spaces (with redundancy of five measurements for each point) and "medium" in interiors and low light situations (with redundancy of three measurements for each point). In this way, each scan station asked about three to six minutes, plus the positioning times. Because of the high level of details and the possibility to have articulated shapes with well recognizable characteristics, the use of targets for supporting the alignment procedures was reduced to a minimal, using mostly classic "black and white" paper checkerboard targets in strategic situations. A logic of "reduction" of the occlusion spaces (Bini, \& Bertocci, 2012) and of "support" to the following automatisms in point cloud alignments (Pomerleau, Colas, \& Siegwart, 2015), guided the planning of the survey strategy. In this way, it was possible to have short post-processing times and fully descriptive results. The lasergrammetry survey covered the part of the castle from the entrance up to the central court along the main passage and from there to the museum areas, the inner part of the northern tower, all the higher passages and the area of the Church. In five days, 257 scan stations were completed, gathering about 2.5 billion points.

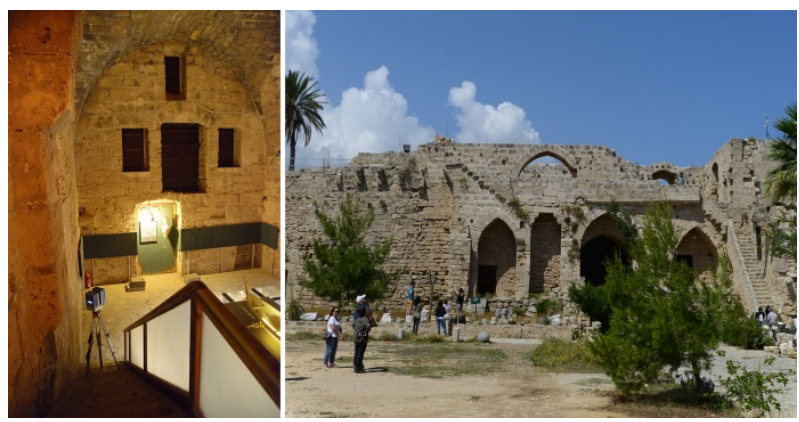

Figure 4: The 3D Laser Scanner Unit inside the Museum Area. Ground view of the central courtyard towards East.

The first phase of a BIM planning process involves the identification of BIM Uses. In this case, an attempt has been made to provide an informative basis for the restoration and conservation, using the "modelling of existing conditions". Based on the construction characteristics of the manufacture, particular attention has been paid to the collection of data and information relating to walls and masonry surfaces, which were then implemented in the model. Besides, it was necessary to conduct in-depth studies of the various archival and bibliographical sources available for the modelling of the historical sequence of the construction phases.

\subsection{Geometric modelling}

The geospatial data-set acquisition of the building was developed using the base reference coming from the digital survey campaign, exploiting the over 250 collected scans produced with the Zoller+Fröhlich Imager 5006h 3D laser scanner, the 1.900 aerial shots taken by the UAV unit (Barba, Barbarella, Di Benedetto, Fiani, \& Limongiello, 2019) and the over 30.000 terrestrial photographs taken using a set of high-resolution digital cameras. The creation of the BIM model was brought on within Autodesk $\operatorname{Revit}^{\odot}$. This was subjected to a preliminary process of decimating and cleaning of the redundant data, segmenting the global point cloud into parts to avoid excessive slowdowns in the workflow, before importing the point cloud in the BIM authoring software. These operations were carried out through Autodesk Recap@, fully interoperable with Autodesk Revit@ (Figs. 5 \& 6). In the modelling of parametric objects, it was possible to experience the potential of Revit $^{\odot}$ in the creation of complex shapes, such as those of the walls and vaults of the Shipwreck Museum rooms. The level of accuracy of a BIM model depends significantly on the degree of simplification applied to the modelling of objects, which may in some cases not be 
commensurate with the needs of the subsequent design phases of the restoration (Eastman, Teicholz, Sacks, \& Liston, 2011).

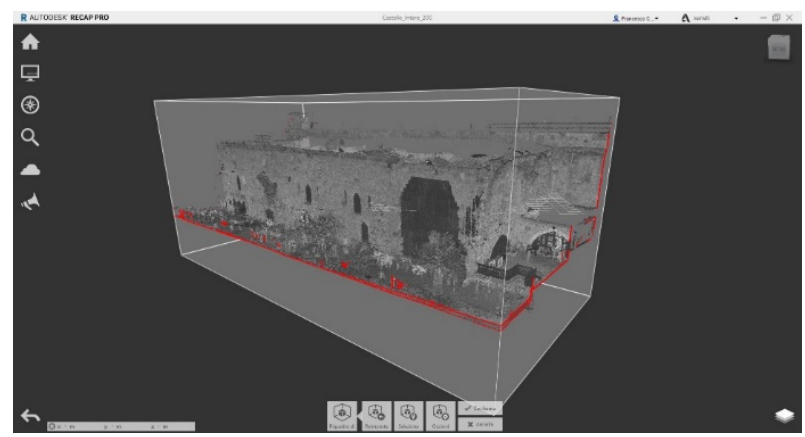

Figure 5: Cut part of the point cloud in Autodesk Recap ${ }^{\odot}$.

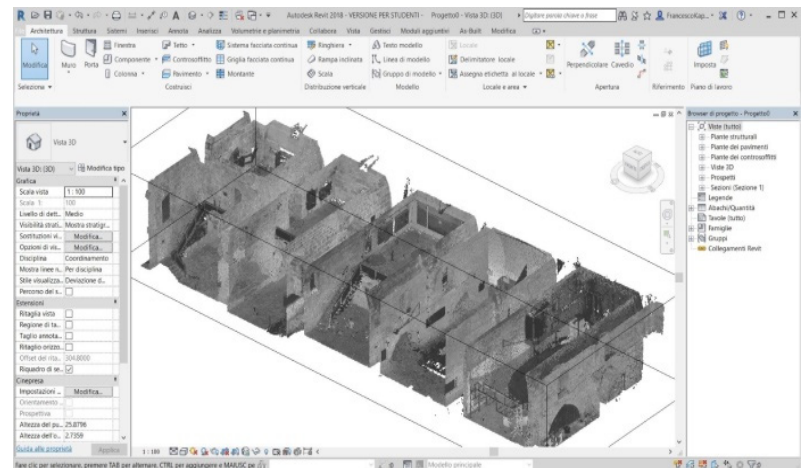

Figure 6: Point cloud imported in Revit ${ }^{\odot}$.

For this reason, it has been made wide use of objects modelled "in-place", having to renounce to the fastest automatic procedures of the software that is to the use of "system families". Irregular shapes and non-standard geometries can be created through the local modelling tools and inserted in specific categories, to allow management through the definition of schedules. However, they do not enjoy the parametric properties of standard objects. So, each wall was modelled considering it individually, thus being able to obtain a model more adherent to the point cloud and close to the real object. A similar modelling process was used in the creation of the vaults, all characterized by a high irregularity (Fig. 7). For this "adaptive metric families" were used: "adaptive" points have been set to be positioned manually within the model in addition to the usual control parameters, allowing to match a regular basic geometry to a specific conformation.

The doors and the windows modelling were made in two different ways according to the complexity (Fig.8):

a) Through the creation of parametric families using the dimensional indications obtained from the point cloud and quoting plant, façades, and sections for each type.

b) Through the creation of "in-place" geometries, in cases where the geometry and/or the wall shape did not allow the insertion "clean" of a family, it was preferred to proceed with in-place modelling of subtraction solids to be applied on the geometry of the masonry.
In this work, it was also experimented the Revit plug-in FARO As-built, by modelling some components of the museum rooms. The plugin has advantageous modelling capabilities, which allow you to maintain a remarkable correspondence with the point cloud. However, sometimes the results have not been satisfactory, such as in the modelling of masonry with inclined surfaces relative to the vertical plane.
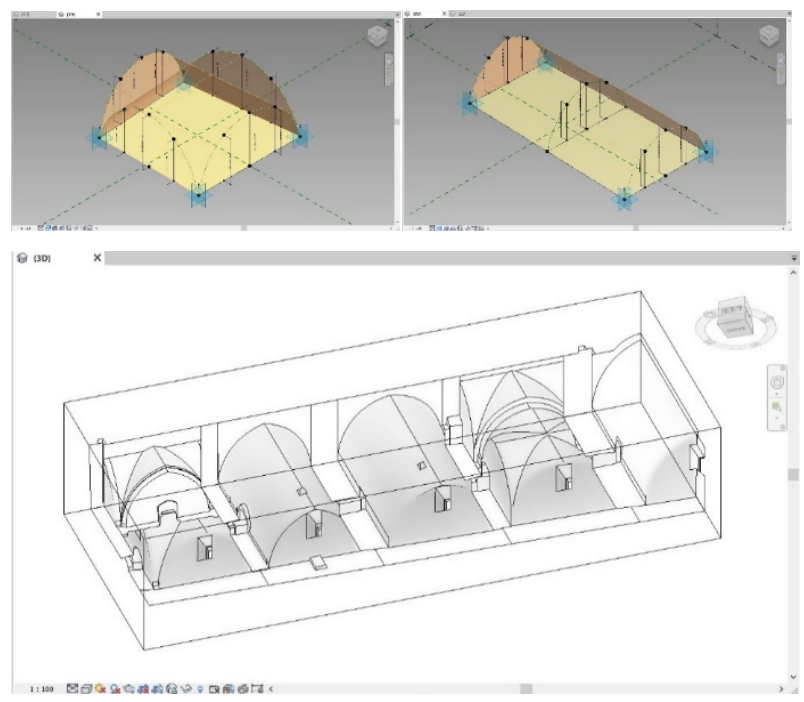

Figure 7: The adaptive vaults imported into the model.

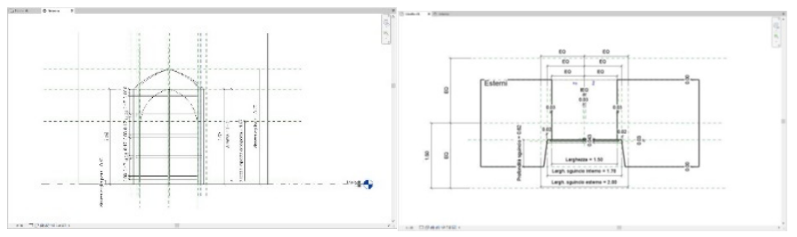

Figure 8: Example of a door parametrically modelled.

The transformation of the Kyrenia ship's point cloud into a polygonal network (mesh) took very complex modelling (Fig. 9). As a first step, the point cloud was imported in Raindrop Geomagic Studio, using this software to "clean up" the dataset and then turn it into a mesh. Before importing it in Revit, a simplification of the mesh was needed. It was done using the function named "mesh Doctor" in Geomagic Studio. This allowed to reduce and optimize the triangles avoiding possible slowing down in the following processing. Then the mesh has been imported into Autocad, its scale was checked back according to the original measurements and then export it into DXF file format to make it compliant with Revit. The Kyrenia ship's mesh has been imported in the Revit model as an "in-place" mass, allowing to create and insert new parameters within it, for example, identification code, description, location, historical phase, materials, references, and conservation status.

A specific task allowed to verify the accuracy of the model concerning the points cloud after its completion. There are inevitably differences between the point cloud and the BIM model because it remains an approximation of the real object. Also, in this case, FARO As-built was used to quantitatively verify this correspondence, capable of measuring the deviation of the surfaces/mesh of the model concerning the point cloud. The plugin automatically aligns the $3 \mathrm{D}$ model and the point cloud 
according to specific cutting planes. It has been found that the mean deviation error is less than $3-4 \mathrm{~cm}$, which is more than acceptable about the geometric characteristics of the artefact analyzed.

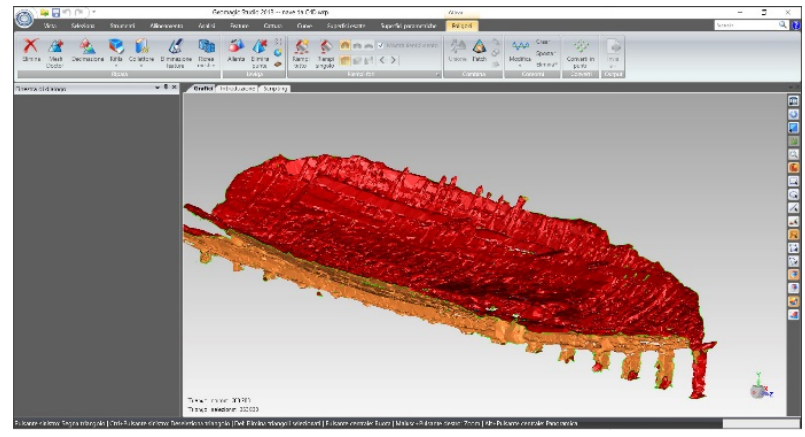

Figure 9: The Kyrenia ship mesh model converted from the point cloud.

\subsection{Information modelling}

The information collecting activity due to implement in the HBIM model is a very complex phase of its creation process and not yet fully evaluated in its implications. It is a matter of developing not only in-depth research of the documentary direct and indirect sources available on the building, but of proceeding with a careful selection based on the type of collected document, which can be computing structured or not, and fixed on digital support or not. For example, in the digital transformation of original paper documents, the data resolution requirements must be carefully evaluated to avoid unnecessary waste of resources and management difficulties. Therefore, it is fundamental the information management strategy in the various phases of the life asset cycle, which is to be implemented.

Each component and space of the model has indeed a predefined set of alpha-numeric parameters, which can be suitably implemented to collect all the information related to the specific objectives of the model and the expected BIM uses. Furthermore, any type of external digital file can be associated with the model through appropriate links to its elements: product specifications, user and maintenance manuals, multimedia documents, etc. The linked files can also be used through external applications. The information modelling phase of the Kyrenia Shipwreck Museum involved the insertion of alpha-numerical information relating to materials, decay, and construction techniques of the different architectural components within the 3D geometries. In particular, the following sets of information contents have been identified:

1) Cadastral documentation and historic and existing drawings of the building.

2) Geometric survey of the building.

3) Thematic survey on the conditions of materials and structures decay.

4) Investigation of the historical characteristics of the building components.

5) Details of construction techniques.

The information entered in the model can be managed, filtered, and appropriately selected through shared parameters, and collected in schedules of homogeneous elements, referred to as the component's families. Each element was associated with an alphanumeric identification code, a name, a brief description, the historical phase of reference, the construction technique, and the constituent material.

The information management relating to the material decay of the wall faces is carried out by viewing the photoplanes suitably geo-referenced on the surface of the corresponding wall component (Fig. 10). Through external links inserted in some shared parameters, it is possible to recall the decay sheets associated with that specific wall (Fig. 11). After completing the model about the existing condition of the Kyrenia Shipwreck Museum and a careful evaluation of the current problems of the museum complex, a project has been proposed to redevelop and enhance the exhibition rooms, exploiting parametric modelling tools to manage the design phase and to plan the stages of the project interventions.

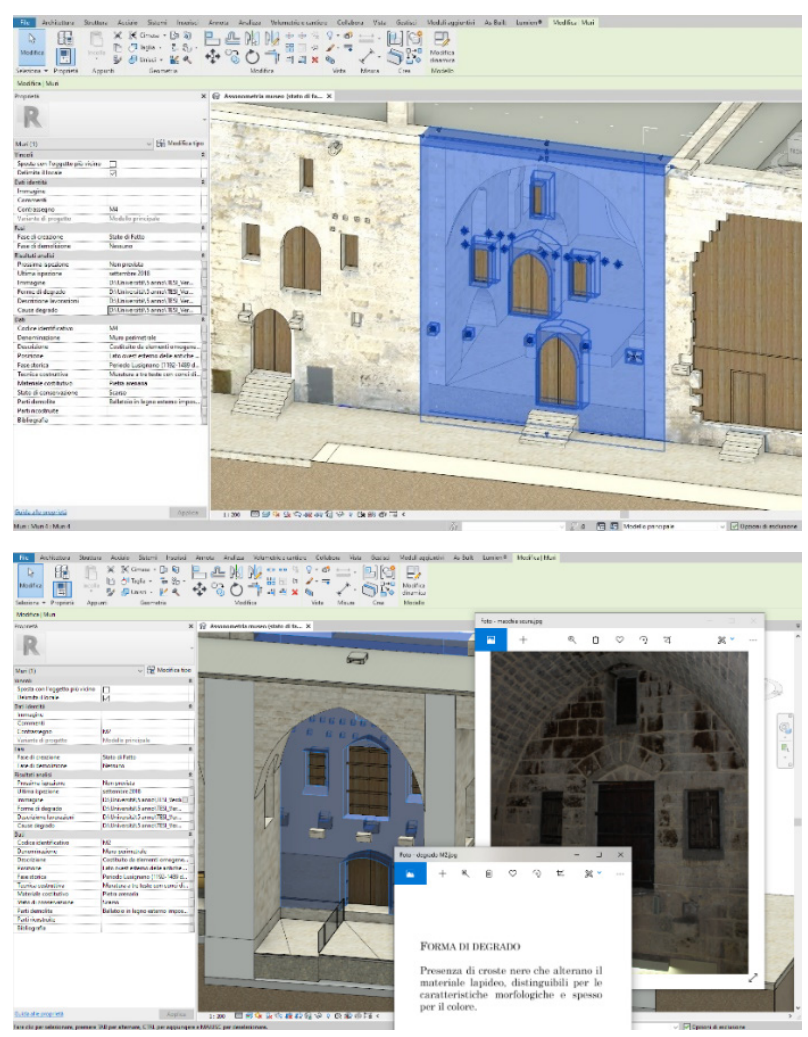

Figure 10: Examples of parameters inserted in walls.

\section{Outcomes}

At the end of the BIM modelling, a database was obtained containing all the information relating to the historical asset to document its state of conservation, making it a potential tool for managing cultural heritage and a resource for studies and future research.

The model also allows extrapolating schedules in a simple and fast way through a filtering system made available by the $\mathrm{Revit}^{\odot}$ software, based on the family's classes and the parameters contained in the single objects.

The following identification fields have been associated with each parametric object: identification code, naming, description, position, historical phase, construction technique, constituent material, state of conservation, demolished parts, reconstructed parts, and the bibliographic references of the single component. Other 
included fields concern the survey results for the restoration: next and last inspection, photos, forms of decay, decay causes, description of works. All of these fields can be filled in within Revit $^{\odot}$, automatically appearing within the schedules, or associated with external links, which refer to JPG, PDF or XLSX documents achieved in the data-sharing environment (CDE). In this way, it will be possible for the museum manager himself to update the information stored in the model every time the building is carried out for maintenance /conservation /restoration activities (Ceylanlı, Özen, Çiçek, \& Arslan, 2019). This approach will make it possible to have complete and reliable information within a few years (technical information, maintenance, installation date, etc.) to guarantee efficient operational management of the asset (Günçe \& Misirlisoy, 2014) (Fig. 12).

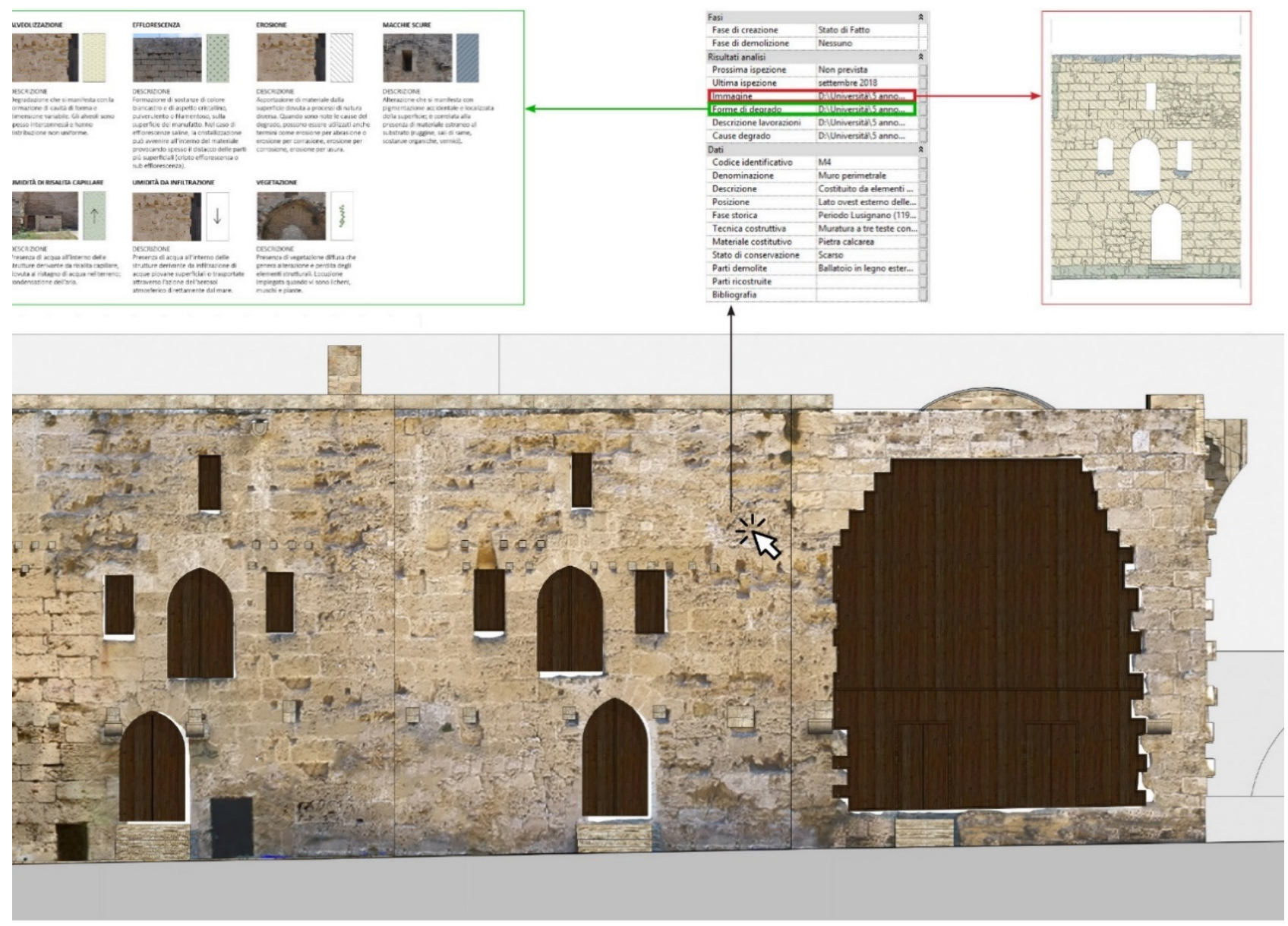

Figure 11: Information management of the material decay.

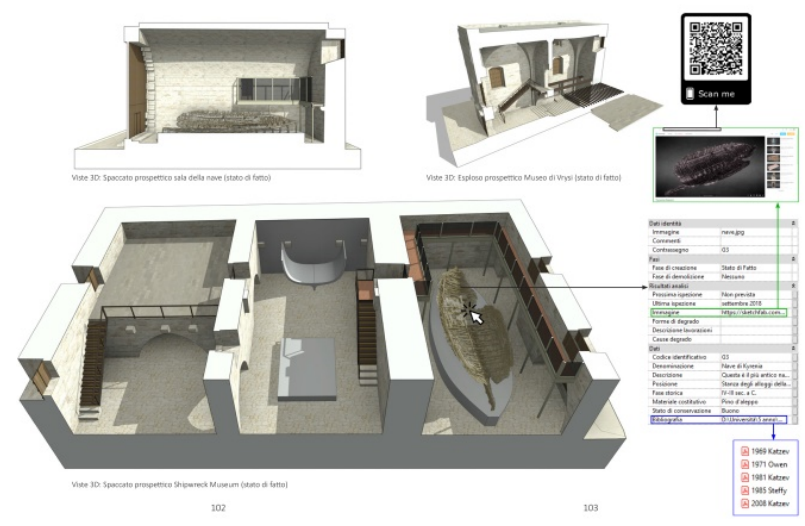

Figure 12: Information management of research references.

\section{Conclusions}

The present study has highlighted the potential and limits of BIM applications to historical built heritage. There are still many difficulties to overcome in reproducing an architectural object through parametric modelling, which moves away from regular geometric patterns. In the archaeological field, this problem is even more relevant, having to abandon any automated modelling technique and proceed to customized production of the parametric objects. Although some Revit ${ }^{\odot}$ plugins exist on the market bringing simplifications in the modelling of components based on point cloud datasets, they are not yet completely available in meeting all the modelling needs of such a complex artefact like the Kyrenia Castle. The complete implementation of similar HBIM models would require the development of specific libraries created with adaptive parametric objects, capable of conforming to the conditions of uniqueness that characterize the corresponding real objects.

The achieved results show that H-BIM modelling is progressively overcoming the initial critical issues related to the standardized creation of objects and that the solutions available for their customization, although still not completely satisfactory, already suggest probable advances in terms of efficiency and reliability. The final BIM model included the production of the analysis 
drawings of the historical building and the project of the museum restoration. $2 \mathrm{D}$ and $3 \mathrm{D}$ views are also extracted from the model (axonometry, plans, sections, elevations, and details) and displayed in an appropriately chosen graphic style with notes, photos, and details (Fig. 13).

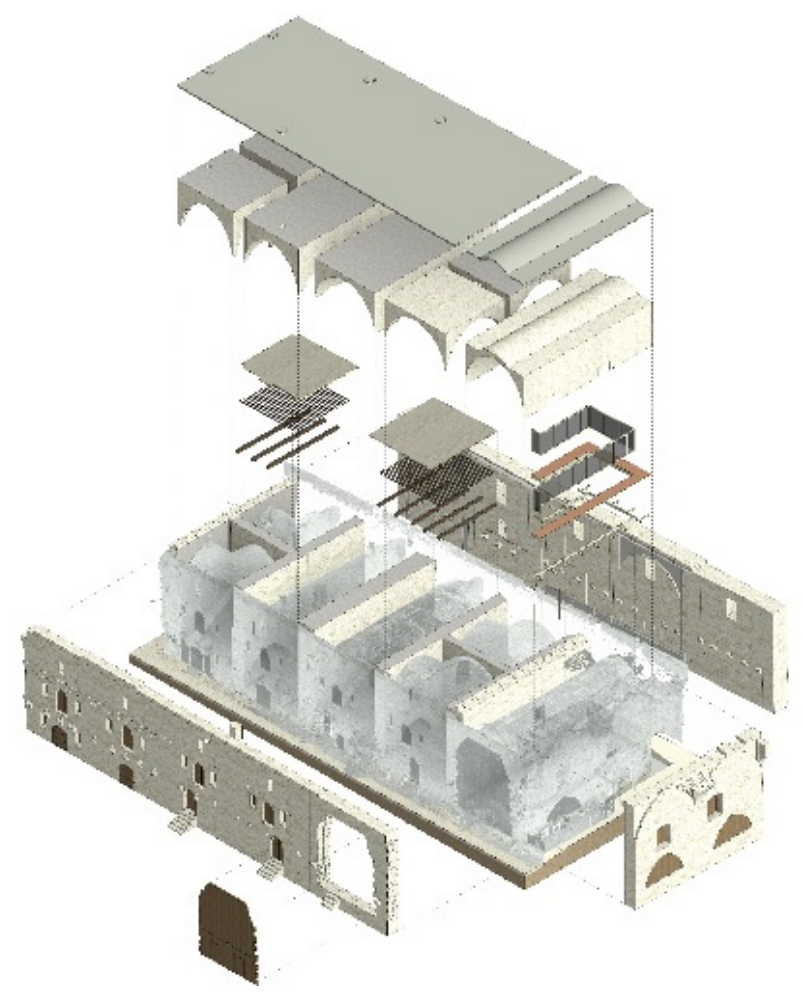

\section{Acknowledgements}

The study presented here is based on the survey produced during the workshop "Reading and Designing the Kyrenia Castle", 6th-13th May 2018, organized by the Girne American University (Department of Interior Architecture), with the Department of Architecture of the University of Florence and the Department of Interior Architecture of the Özyeğin University, Istanbul. The authors would like to thank all the members of the scientific committee and in particular Alessandro Camiz, Stefano Bertocci, Zeynep Ceylanli, Giovanni Carbonara, Roberto Secchi, Kutsal Öztürk, Orhan Hacıhasanoğlu, Carlo Bianchini and Daniela Esposito, for their collaborative support. Within the organizing committee, a special acknowledgement must be given to Pembe Özen and the entire Department of Antiquities and Museums for constant participation.

Figure 13: Exploded Isometric view of the 3D model.

\section{References}

Antonopoulou, S. (2017). BIM for Heritage: Developing a Historic Building Information Model. Swindon. Historic England.

Banti, F. (2020). HBIM, 3D drawing and virtual reality for archaeological sites and ancient ruins. Virtual Archaeology Review, 11(23), 16-33.

Barba, S., Barbarella, M., Di Benedetto, A., Fiani, M., \& Limongiello, M. (2019). Quality assessment of UAV photogrammetric archaeological survey. International Archives of the Photogrammetry, Remote Sensing \& Spatial Information Sciences, XLII-2/W9, 93-100.

Biagini, C., \& Donato, V. (2014). Building Object Models (BOMS) for the documentation of Historical Building Heritage. In proceedings of the $V$ Congreso Egrafia, 142-9. Rosario, Argentina.

Biagini, C., Capone, P., Donato, V., \& Facchini, N. (2016). Towards the BIM implementation for historical building restoration site. In Automation in Construction, Elsevier, 71, 74-86.

Bini, M., \& Bertocci, S. (2012). Manuale di rilievo architettonico e urbano, CittàStudi, Torino, Italia.

Brookes, C. (2017). The Application of Buiiding Information Modelling (BIM) within a Heritage Science Context. Ramboll. Historic England.

Brumana, R., Banfi, F., Cantini L., Previtali, M., \& Della Torre, S. (2019). HBIM Level of Detail-Geometry-Accuracy and Survey Analysis for Architectural Preservation. In Proceedings of the Geores conference 2019, 293-99, Milan, Italy.

Brumana, R., Della Torre, S., Oreni, D., Previtali, D., Cantini, L., Barazzetti, L., Franchi, L., \& Banfi A. (2017). HBIM challenge among the paradigm of complexity, tools and preservation: the basilica di Collemaggio 8 years after the earthquake (L'Aquila). In proceedings of the XXVI CIPA Symposium, 97-104. Ottawa, Canada.

Camiz, A., Verdiani, G., \& Ceylanli, Z. (2018). International workshop: reading and designing the Kyrenia castle. In Symposium of Representation Scientific Area for Development of Multidisciplinary International Programs, 264-298, Florence, Italy.

Camiz, A., Khalil, S., Cansu, Demir, S., \& Nafa, H. (2016). The Venetian defense of the Mediterranean: the Kyrenia Castle, Cyprus (1540-1544). In Verdiani G. (Eds.) Defensive architecture of the Mediterranean. XV to XVIII centuries, 3, 
DIDApress. 371-8. Florence, Italy.

Ceylanlı, Z., Özen, P., Çiçek, E., \& Arslan, P. (2019). Evolving from castle to virtual space: the case of Kyrenia Shipwreck Museum, in Proceedings of the CHNTNH Conference, Museen der Stadt Wien, Stadtarchäologie, Vienna, Austria.

Capparelli, F. (2019). BIM solutions for the architecture and archaeology: the case of the Kyrenia Shipwreck Museum, a 25 centuries long path. (Master thesis) University of Florence, Italy.

Cathcart King, D. J. (2019). The Castle in England and Wales: an Interpretive History. Routledge, United Kingdom.

Eastman, C., Teicholz, P., Sacks, R., \& Liston, K. (2011). BIM Handbook. A Guide to Building Information Modelling for Owners, Managers, Designers, Engineers and Contractors. Hoboken, New Jersey, Wiley\&Sons Inc.

Günçe, K., \& Mısırlısoy, D., (2014). Adaptive reuse of military establishments as museums: conservation vs. museography, in *WITTransactions on The Built Environment*, 143, WIT Press, 125-132.

Katzev, M. L. (1981). The Reconstruction of the Kyrenia Ship, 1972-1975. In National Geographic Society Research Reports, 13, 315-28, Washington D.C..

Katzev, S. (2008). The Kyrenia Ship: Her Recent Journey. In Near Eastern Archaeology, 71(1/2), 76-81, The American Schools of Oriental Research.

Steffy, J.R. (1985). The Kyrenia Ship: An Interim Report on Its Hull Construction. In American Journal of Archaeology, 89(1), 71-101, Archaeological Institute of America.

Murphy, M., McGovern, E., \& Pavia, S. (2013). Historic building information modelling-Adding intelligence to laser and image based surveys of European classical architecture. In ISPRS Journal of Photogrammetry and Remote Sensing, 76, 89-102.

Petre, J. (2010). Crusader Castles of Cyprus, the fortifications of Cyprus under the Lusignans: 1191-1489. Microform Edition ProQuest LLC, 789 East Eisenhower Parkway.

Pomerleau, F., Colas, F., \& Siegwart, R. (2015). A Review of Point Cloud Registration Algorithms for Mobile Robotics. In Foundations and Trends $₫$ in Robotics, 4(1), pp 1-104, Now Publisher, USA.

Quattrini, R., Clini, P., Nespeca, R., \& Ruggeri, L. (2016). Measurement and Historical Information Building: chalenges and opportunities in the representation of semantically structured 3D content. In DisegnareCon, 9(16), 1-11.

UNI 11337-4 (2017). Construction and civil engineering works - Digital management of information processes of construction. Level of development (LOD).

Verdiani, G. (Ed.) (2016). Defensive Architecture of the Mediterranean. XV to XVIII centuries, 3, DIDAPress. Florence, Italy.

Volk, R., Stengel, J., \& Schultmann, F. (2014). Building information modeling (BIM) for existing buildings - Literature review and future needs. In Automation in Construction, Elsevier, 38, 109-127. 


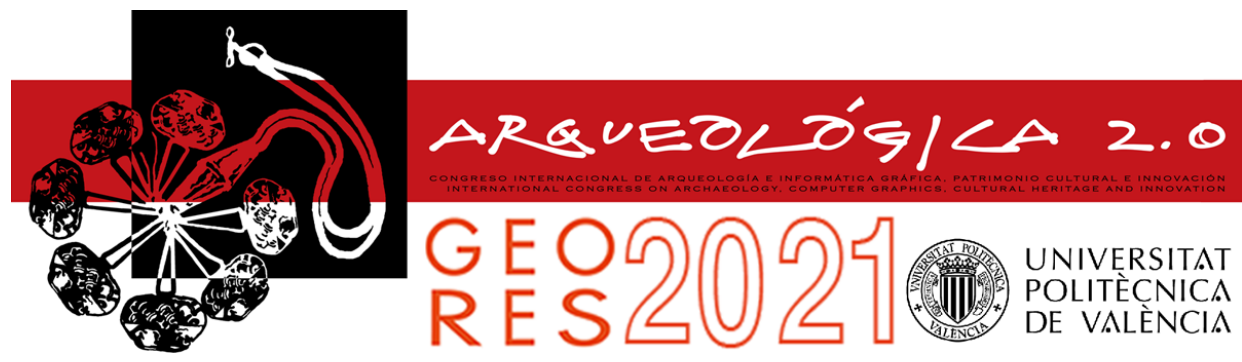

Proceedings of the joint international event $9^{\text {th }}$ ARQUEOLÓGICA

$2.0 \& 3^{\text {rd }}$ GEORES

Valencia (Spain).

26-28 April 2021

\title{
CRITERIA AND TOOLS TO CATALOGUE BRICK-MASONRY VAULTS. THE GIS-DATABASE OF FRAME, A FASCE AND PLANTERIAN VAULTS BETWEEN THE $16^{\text {TH }}$ AND $18^{\text {TH }}$ CENTURY IN NORTHERN ITALY
}

\author{
Chiara Stanga \\ Department of Architecture and Urban Studies (DAStU), Politecnico di Milano, Via Bonardi 9, 20133 Milan, Italy. chiara.stanga@polimi.it
}

\begin{abstract}
:
The paper describes a proposal for criteria and tools to catalogue brick-masonry vaulted systems in Northern Italy between the $16^{\text {th }}$ and $18^{\text {th }}$ centuries. Along with the standard geometric typologies, three novel parameters (maitresses voûtes, voûte sur le plan d'une autre voûte, constructive features) are proposed to include the constructive features in the vault taxonomy. The novel parameters help catalogue three vaulting types that can be considered the metamorphosis of cloister vaults: frame, a fasce, and planterian vaults. The database was realized in MS Access and then imported into QGIS 3.10. Database and GIS have been operative tools to form hypotheses on vault disseminations, highlighting the recurrences and specificities across time and space of some peculiar construction techniques. The database collects the acquired information on each vault (building type, geolocation, building date, vaulting type, vault dimensions and description and, whenever possible, photogrammetric survey, 3D modelling, and thermographic survey). In the future, the database should be published online, making the data available and building a broader dataset to share the information.
\end{abstract}

Keywords: vaulted systems, $16^{\text {th }}-18^{\text {th }}$ century, Northern Italy, Guarino Guarini, database, GIS

\section{Introduction}

For a long time, vaulted systems have represented a field to experiment with shapes and constructions for architects and craftsmen. An intriguing challenge - formal and constructive - that involved creativity, materials, structure - think about the huge vaults with the complex rib systems that covered gothic cathedrals or the refined stereotomy vaults, such as the well-known Town Hall in Arles, designed by Francois Mansart (1598-1666) in 1676.

Although the incredible variations of vaulting types, the traditional classification is based on geometric-typology shapes. If individual studies are going beyond a simple and superficial analysis - i.e., correlating the intrados geometry to the extrados or understating how the brick or stone arrangement affects the structural behavior of vaults - it is still missing an approach to the classification of vaulted systems depending on shapes and construction techniques, even considering a limited timeframe and geographical area.

The paper describes the need to go beyond the standard vault typology classification to understand vault design and constructive genesis. By doing this, it will be possible to understand how the construction techniques are the most diverse, even if considering one type of vault, showing what can be called "the metamorphosis" of vaulting.
Along with the standard vault typology classification (cloister vault, cross vault, etc.), novel criteria and tools are needed. This paper proposes a methodology to classify the vaults, which helps to understand even the hybrid ones and to represent and study their dissemination. The case studies are three cloister-vaultconstruction techniques variations (frame, a fasce, planterian vaults) in Northern Italy between the $16^{\text {th }}$ and $18^{\text {th }}$ century. The new parameters (maittresses voûtes, voûte sur le plan d'un autre voûte, constructive features) include vaults constructive features and refer to historical architectural treatises to understand how architects and craftsmen designed and constructed vaults. The methodology could be applied to other typologies. In that case, the parameter "constructive feature" should be adjusted to the specificity of the vault typologies.

Once the criteria were fixed, the vaults were classified with a GIS-based catalogue that collects the information (vault description and dimension, drawings, thermography, 3D model, orthophoto, and bibliographical references) about each vault example. The GIS-based catalogue is meant to be an operational tool for the onfield research of case studies. On the other hand, by implementing the GIS-based catalogue on an online platform, it will be possible to share the data, possibly allowing other scholars to populate the database, increasing the research.

The author is carrying out the in-depth study of the three vaults families in Northern Italy (construction techniques, history, and dissemination) in her Ph.D. research at the 
Politecnico di Milano (DAStU Department, Preservation of the Architectural Heritage, supervisor: prof. Alberto Grimoldi). However, the vault-GIS-based database is part of a wider project about vaulted systems catalogue, including Northern Italy and European case studies.

The paper structure is the following: paragraph 2 explains the research objectives; paragraph 3 presents a brief literature review on vaulted systems catalogues; paragraph 4 describes the previous works on vault database; paragraph 5 proposes three new parameters for vault classification that goes along the traditional typology; paragraph 6 explains the work carried out for the vault catalogue and the GIS database; paragraph 7 is about the potential of the database for future works and the conclusion.

\section{Research objectives, method, and tools}

The research proposes a novel approach for studying the vaulted system to be combined with the standard typology classification. The approach wants to help the analysis of design, constructive and structural features of vaulted systems.

The research is based on analyzing "the metamorphosis" of cloister brick-masonry vaults, but the same methodology could be applied to other vault typologies. It concerns the classification criteria of three-cloister-vault variations (frame, a fasce, and planterian vaults), mainly disseminated in Northern Italy (firstly Piedmont and Lombardy, secondly Veneto and Emilia-Romagna) between the $16^{\text {th }}$ and $18^{\text {th }}$ centuries.

The goal is to realize a sort of raisonné catalogue of vaulted systems founded on the shape-typology classification and vaults constructive features. Other parameters, rather than geometric shapes, were included to set up a more flexible and "open" vault taxonomy. The research proposes three novel parameters, borrowed from the stone stereotomy vault construction and the $18^{\text {th }}$. century architectural treatises, especially the Architettura Civile (1737) by Guarino Guarini: maîtresses voûtes, voûte sur le plan d'une autre voûte and constructive figure (described in paragraph 5). They help describe hybrid vaulted solutions: vaults that do not match the standard vault typology or vaults that seem to belong to a standard vault typology, but which structure belongs to another kind of typology. For example, the vault covering the staircase of Palazzo Magio Grasselli in Cremona, renovated around the $18^{\text {th }}$ century, is a combination of a cloister vault and a cupola (Brumana et al., 2018).

The research has oscillated between inductive and deductive methods. In the first instance, the identification of vault examples made it possible to highlight recurring features, which led to an investigation that was as extensive as possible, collecting the largest number of examples for each cloister-vault variation, examining the data using spreadsheets and GIS. It allowed to picture an overview of the variants, the construction figures, and the diffusion of construction techniques, forming first considerations. The approach then moved towards a deductive method, testing the hypotheses by searching for additional vault examples (from general or specific architectural literature) that could support or reject the first conjectures.
The phase includes collecting direct and indirect sources on each vault that would become part of the catalogue. First, it was necessary to review the existing literature. Those types of vaulting have not yet been the subject of systematic studies. Frame and a fasce vaults are usually called "compartimenti" or "modiglioni" vaults (Piccoli, 2001); while planterian vaults are usually associated with the ceiling structures built by architect Gian Giacomo Plantery (1680-1756) in Piedmont (Cavallari Murat, 1957), including some frame vaults (Spallone \& Vitali, 2017). Secondly, general catalogues on villas and buildings in Northern Italy have been checked and, whenever it was possible, a monograph on specific palaces. From time to time, articles on vault construction techniques have been found. The literature review was accompanied by an on-site photographic survey in some selected cities and surroundings (Turin, Casale Monferrato, Alessandria, Brescia, Cremona, Milan, Bologna), getting an overview of the real dissemination in each territory. Then, starting from the catalogue first draft, some examples for each vault variation were selected and documented through on-site observation, photogrammetry, direct and laser scanner survey, 3D modeling, and thermography. In many cases, only the intrados was analyzed because the extrados was not accessible. The intrados and extrados analysis allows observations on the vault typology and highlights how some structures are not easy to "classify". It could be possible to distinguish between a "formal" typology of the vault, visible at the intrados, and a "structural" typology, visible at the extrados. The thermographic survey was useful for studying the brick arrangement when the extrados was not accessible and understanding how the bricks interlock the intrados and extrados.

Since the research is carried out in Italian, the terminology is based on the Italian language. For this paper, some terms have been translated, according to previous studies. However, vocabulary and technical terms are fundamental issues when dealing with online databases. Especially if one wants to extend the research to a broader audience, it could be recommended to publish it in English. Then, it will be necessary to consider each Italian technical term, finding the correspondent English ones, if possible.

\section{Literature review on vaulted system studies and catalogues in Europe}

The paragraph reports a short literature review on vaulted systems catalogues to understand criteria and methods of classification. Starting from French and Spain stereotomy studies, the paragraph describes the works on vaults carried out in recent years in Italy and United Kingdom, specifically focusing on the ones that have developed a database.

French and Spain studies mainly focused on stereotomy and the art of building stone vaults. Stereotomy has provided effective classification criteria thanks to constructive figures, such as the maîtresses voûtes, trompes, arrière-voussure, etc., representing a technique to build vaults or part of them. Thanks to the Renaissance stereotomy treatises, such as Philibert De L'Orme (1567) and Francois Derand (1643), it is possible to link stereotomy constructive figures to examples disseminated in the buildings across the territory. Stereotomy constructive figures help correlate the 
technical literature to vaults tangible examples, specifically to correlate the trait (drawings of the vault and each stone) to its real construction application.

From the deep-rooted French stereotomy tradition, Pérouse de Montclos (2013) derives a robust vocabulary that allows him to draw a coherent and significant picture of the Modern Age vaulted systems in France common national roots and regional particularities. Modern-AgeFrench vaults main features are the variations of shapes and patterns, which define an incredible diversity of structures. By doing this, vaults do not match the rigid grid of typology. Vault shape and stone pattern, together with the intrados design, the arrangement of the lunettes, the connection between different vaulted surfaces become the constructive criteria for analyzing the vaults. The stereotomic vocabulary is supported by the corresponding constructive drawing (trait) derived from architectural treatises and examples disseminated throughout the territory. An attempt is made to understand the cultural and constructive meaning of vaults, and the catalogue is not just a repertoire of examples.

In Spain, Palacios (1990) creates a catalogue of vaulted systems that includes the models reported by Alonso de Vandelvira, author of the well-known Libro de las traças de cortes de Piedra, compiled between 1575 and 1590 . Palacios gives an overall description for each maîtresse voûte and the method of making the trait for each variant, referring to Vandelvira. Then he reports some examples of each type of vaulting. However, there is no interest in tracing a constructive history of these maîtresses voûtes, nor even their dissemination, unlike the French case. In their research on late gothic rib vaults, SenentDomínguez, López-Mozo, Martín-Talaverano, Pérez-delos-Ríos, \& Rabasa-Díaz (2015) have already pointed out the need to go beyond formal and stylistic criteria, focusing on vaults constructive features. They proposed a database finalized to collect vaults depending on keyaspects, not to develop an extensive repertoire of examples. The key-aspects regard specific research topics to create categories that help the search. Since the database would be open to an international audience, the terminology issue is a central aspect. The authors point out that considering countries with a robust technical vocabulary, it is sometimes difficult to translate into English specific terms.

In Italy, the well-known Manuali del Recupero of historical town-centers is more an operational tool for conservation activities than an in-depth knowledge of the historical building. Manuali includes the main information on construction techniques, materials, and geometricdimensional data of each historical architectural element, but it is not easy to derive reproducible criteria and methods. Thanks to the research funding, "iDome Invisible |Accessible. Masonry Domes of the $15^{\text {th }}$ and $16^{\text {th }}$ Centuries in Campania. Innovative Strategies for the Interpretation and the Multi-thematic Inclusive Fruition of Vulnerable Architectures" (iDome, scientific coordinator Valentina Russo), the Federico II University in Naples has developed an online website about domes disseminated in Campania with the demonstration case of the dome of the church of Santa Caterina in Formiello (Russo, 2018).

In the United Kingdom, studies are focused on Gothic Architecture, mainly on the vaulted systems of cathedrals. Howard (1911) and Leedy (1980) focused their research on the fan vault: origin and cultural significance, construction technique, geometric design, and geographical dissemination, in order to highlight regional particularities, together with an apparatus illustrative and a catalogue of vaults starting from 1540. A more comprehensive approach is provided by Lancaster (2015). She examines six vaulting types (opus caementicium, brick barrel vaults, complex brick vault forms, vaulting tubes, hollow voussoirs, armchair voussoir) throughout the Roman Empire, especially in its provinces. By doing this, she tries to unravel some of the threads that affected their creation and dissemination: the exchange of ideas (and constructive techniques) between the capital and other cities, the different craftsmanship, the availability of construction materials, the contextual conditions. The vault database was imported into GIS, which helps form hypotheses that could explain the dissemination of the six vaulting types.

\section{Previous work on vault catalogues and databases}

This paper is part of a wider project that has been developed on vaulted systems catalogues and databases since 2017 (Brumana, Condoleo, Grimoldi, \& Landi Brumana, 2017).

In the previous research, the starting point was the HBIM (Historic Building Information Model). HBIMs of vaulted systems is a punctual analysis - a node of information in the knowledge chain - of an architectural element of a building. However, there is no circulation of such data, which could implement the sharing of information. The increasing availability of HBIMs could allow access to these nodes in cross-sectorial studies (Brumana, loannides, \& Previtali, 2019).

Databases and cloud-based platforms might represent a way to disseminate the acquired data stored into HBIMs, taking into account the privacy and authorship issues. The result is a virtual space where it is possible to connect information. In this regard, Virtual Hubs could be used as information systems that support the life cycle of vaults open data: publishing, discovery, and access (Mazzetti et al., 2015).

To build the project, it became necessary to set up: 1) criteria for vault classifications; 2) database model; 3) connection with a Geographic server; 4) online publishing. A database has been developed that takes into account the standard vault typology but also considers the hybrid solutions and the construction techniques. Particular attention is given to the geometric survey detail and scale/tolerance to aware the users of the kind of output they could use. The database structure is as follows: 1) main information: 1.1) Building information (name, address, country, regions, province, city, geographical coordinates, building typology); 1.2) Macro typology: horizontal (vault, slab, roof, etc.) and vertical elements (walls, windows, etc.). 2) Vault survey: 2.1) Typology: "Vault" including the standard vault typologies, and the hybrid ones, i.e., cloister vault turned to cupola; 2.2) Subcomponents: reinforced structural arches, frenelli, tie rods (intrados or extrados), trompe, etc.; 2.3) Brick or stone arrangement (along the directrix, along the generatrix, diagonal, herringbone, etc.) and description; 2.4) Materials: brick-block, tile brick, stone, clay pipes, etc.; 2.5) Texture: soldier laid, in foglio, etc.; 2.6) Sub texture (single or double texturing) and 
description. 3) Sources: 3.1) Indirect: Bibliography; 3.2) Direct: Laser scanner, 3D photogrammetry, IRT, etc. Output (2D drawings, 3D model, orthophoto 3D, BIM Library, 3D PDF, etc.), scale/tolerance, and format.

So far, it has been populated with examples from Italy. The goal is to make the database crowdsourced, following a bottom-up methodology. The HBIM of the vault examples is realized with different levels of detail. Sometimes only the intrados geometry is modeled, and sometimes even the brick pattern. It makes understanding the interlocking between the intrados and the extrados. The brick pattern was modeled in the case of Sala Manfredini vault of Palazzo Magio Grasselli in Cremona (Brumana et al., 2018).

A further step was developed through an ontology-based vault database, which uses a set of ontologies to effectively combine data and information from multiple heterogeneous sources (Previtali, Brumana, Stanga, \& Banfi, 2020).

\section{New parameters for a more inclusive taxonomy of vaulted system}

The typology is based on the idea that the vaulted structures derive from abstract geometric operations: for example, the cross vault is the interpenetration of two barrel vaults. While this is true in many cases, it becomes misleading because the intrados shape is affected by the construction technique. Some vaulted systems are made without centerings, and this changes their geometry because it creates double-curved structures. Even the construction technique and the way the bricks are laid modify the geometry: to obtain a more continuous structure in the corner, an arrangement of concentric circular bricks is adopted instead of a herringbone pattern. For these reasons, the intrados geometry can often be misleading to conduct a structural analysis because it not necessarily mirrors the geometry derived from the construction technique. Moreover, the geometry of the intrados can be altered by decorative partitions or plaster finishing. Furthermore, structural problems, such as settlements (that can happen during the centerings removal or the building life cycle), can alter the intrados shape.

Three novel parameters are proposed to include the construction technique in vault classification. The first and the second were borrowed from stereotomy: maitresses voûtes and voûte sur le plan d'une autre voûte, which can be found in the well-known treatises of Philibert de L'Orme or Francois Derand. The concept of maitresses voûtes is similar to the typology-geometric shapes: barrel vaults, cross vaults, cloister vaults, etc. The maitresses voûtes, however, are also stone vaults "constructive principles". It means that they represent basic techniques for solving common "problems" within the stereotomy construction, from which it is necessary to start to solve more complex problems of solid interpenetration.

In stereotomy, the variations of stone arrangements are expressed through the concept of voûte sur le plan d'une autre voûte. It means that the vault is not realized on the plan usually adopted for its typology. For this reason, we found a cross vault on a circular plan (voûte spherique faisant le plan d'un voûte d'arestes quarrée), where usually the cross vault covers a square or rectangular plan. It implies a different geometric construction of each stone. This principle is that the same type of vaulting could correspond to a different stone pattern (arrangement). This construction method is also used for brick-masonry vaults. It means that if from the intrados I could classify one vault as a cloister vault, this would not necessarily mean that the vault is geometrically and constructively generated as a standard cloister vault. The parallel with stereotomy is only on a geometric basis and does not include the construction process, which is very different. Stereotomy provides, through the art du trait, the design, and construction of each stone, skilfully shaped to be placed in a precise spatial configuration; the masonry construction is based on the use of brick, an element made in series that can be shaped for specific purposes, but which is usually cut and adapted according to need.

The third parameter is the constructive figures, which characterize the vaulted structures both at a formal and a constructive level (Fig. 1). They were derived from the architectural treatises of the baroque period, such as the ones by Vincenzo Scamozzi (Dell'idea dell'architettura universale, 1615), Guarino Guarini (L'Architettura Civile, 1737), and Bernardo Vittone (Istruzioni elementari, 1760). Among them, Guarini seems to summarize the constructive features in his treatise better, although on a geometric level: these are the "fasce" (like arches), used in the construction of the frame and a fasce vaults; the pointed and arched lunettes, which lead towards the three-dimensional arches of the planterian vaults; the half cones, which allow the cloister vault to be connected to the four corners of the room.

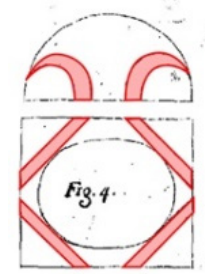

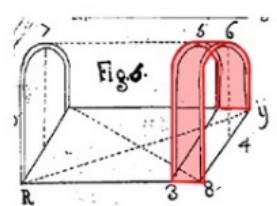

fasce
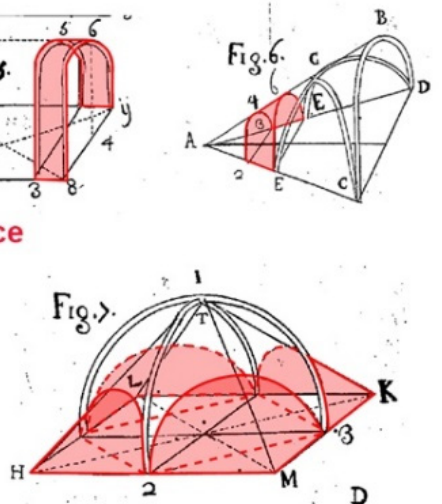

half cone

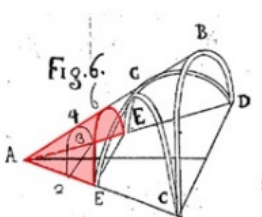

B

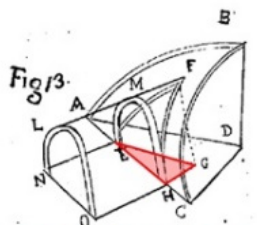

pointed lunettes

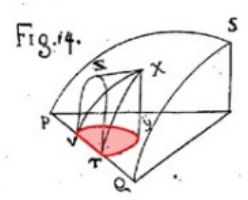

arched lunettes/3D arches
Figure 1: The constructive figures, after Guarino Guarini, plate XIX and XX (Guarini, 1737).

The "fasce" are stiffening elements that, if placed at the level of the intrados, divide the vaulted surface into various compartments. They can have both decorative and structural roles. They can also be realized only at the extrados for a structural function. In this case, the intrados is continuous. Fasce is the main constructive feature of the frame and a fasce vaults. 
In this research, "pointed lunettes" means the lunettes that have a projection onto the plan made of two straight lines that meet at one point. "Arched lunettes" refer to the lunettes with a semi-circular or semi-oval plan projection.

The three-dimensional arch is a lunette whose projection onto the plan is a half-circle or an oval. It is different from the arched lunettes because it derives from the interpenetration of two solids of rotation (cylinders or spheroids) of different diameters, for example, a horizontal half-cylinder (barrel vault) and a perpendicular vertical half-cylinder. Mathematically, it generates a fourth-degree skewed algebraic curve, whose points lie on different planes. These are projecting curves whose inflection points, where curvature change occurs, generate those winding lines that characterize the planterian vaults.

Half cones can be used to realize the vault. Guarini shows a sail vault, rotated by $45^{\circ}$ on a square or rectangular plan, connected to the four corners of the room by half cones.

\section{The GIS-based catalogue of frame vaults, a fasce vaults, and planterian vaults}

The study focuses on three typologies of cloister vaults characterized by three constructive figures: the frame vaults and a fasce vaults, based on fasce constructive figures, and the planterian vault based on the threedimensional arches (Figs. 2 and 3). The other constructive figures (half cone, pointed lunettes, and arched lunettes) are sometimes combined in the three typologies.

\begin{tabular}{|c|c|c|c|}
\hline $\begin{array}{l}\text { Vault } \\
\text { Family }\end{array}$ & $\begin{array}{c}\text { Vault } \\
\text { Description }\end{array}$ & $\begin{array}{l}\text { Constructive } \\
\text { figures }\end{array}$ & $\begin{array}{c}\text { Architectural } \\
\text { treatises }\end{array}$ \\
\hline $\begin{array}{c}\text { Frame } \\
\text { vault }\end{array}$ & $\begin{array}{l}\text { The room is } \\
\text { divided by arches } \\
\text { parallel/orthogona } \\
\text { //oblique to the } \\
\text { wall and the } \\
\text { space between } \\
\text { them is covered } \\
\text { by different } \\
\text { vaulting types }\end{array}$ & arches (fasce) & 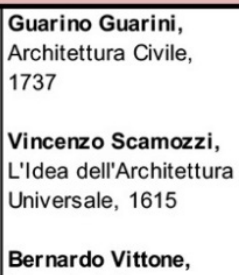 \\
\hline $\begin{array}{l}\text { A fasce } \\
\text { vault }\end{array}$ & $\begin{array}{l}\text { Sail vault rotate } \\
\text { of } 45^{\circ} \text { on a } \\
\text { rectangular/squar } \\
\text { e room }\end{array}$ & arches (fasce) & $\begin{array}{l}\text { Istruzioni diverse, } \\
1760\end{array}$ \\
\hline $\begin{array}{l}\text { Planterian } \\
\text { vault }\end{array}$ & $\begin{array}{l}\text { Cloister vault with } \\
\text { 3D arches }\end{array}$ & 3D arches & \\
\hline
\end{tabular}

Figure 2: Cloister vaults metamorphosis: frame, a fasce, and planterian vaults.

The research carried out so far has allowed finding a corpus of examples of frame, a fasce, and planterian vaults disseminated mainly in Lombardy, Piedmont, Emilia-Romagna, Veneto, Sardinia, Abruzzi, and the Czech Republic.

The recored examples (195) are witnesses of peculiar construction practices (in a broader sense) of the cloister vaults:

- Frame vaults: 142 examples, 102 from literature (of which 19 geometric surveys), 33 from on-field research (photos by the author), 7 geometric surveys by the author (laser scanner or photogrammetry or thermography).

- A fasce vaults: 16 examples, 13 from literature (of which 3 geometric surveys), 3 geometric surveys by the author.

- Planterian vaults: 40 examples, 36 from literature (of which 25 geometric surveys), 1 from on-field research (photo by the author), 3 geometric surveys by the author.

In the first instance, the case studies that were gradually being identified, with the related information, coming from the existing literature on the subject, direct surveys or inspections, were inserted in sheet work for cataloguing (in MSWord). The sheet work, named after the building with the vault, gives information on the palace location, the period of construction, the vault description, and the bibliographic references. The sheet work includes the onfield research data, such as thermographic and geometric survey (vault dimensions), photos, 3D modelling. The box with keywords highlights the elements that can help make cross-queries among the typologies. Keywords are related to the novel parameters, such as maitresses voûtes, brick or stone arrangement, and constructive figure. The sheet work (Fig. 4) was the first level of data collection. A database was then set up (MSAccess) to store the information and to georeference them in GIS. The database is the first step into the sharing of the collected data. Along with the sheet work, the GIS seemed the appropriate tool to visualize a map of the dissemination and concentration of the three types of vaults, although the research is still on-going and opened to additional information coming from future studies.

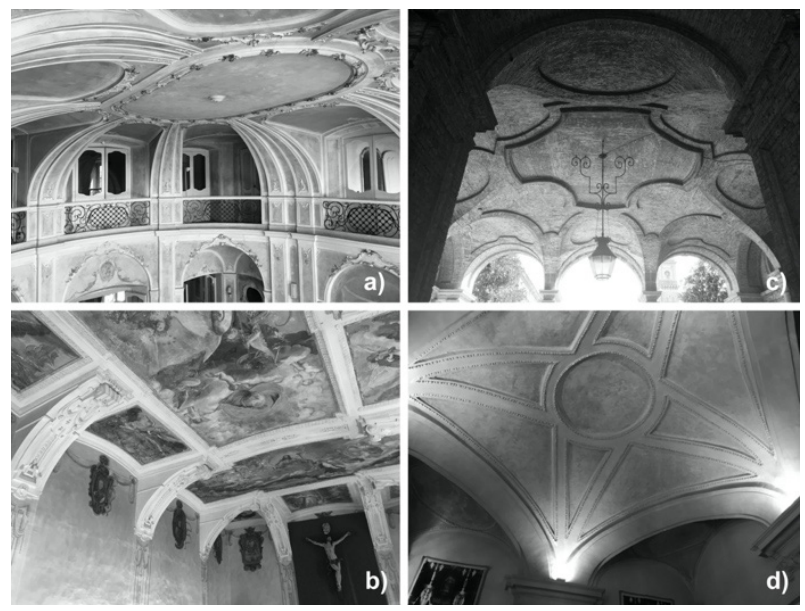

Figure 3: Study of typologies of cloister vaults: a) frame vault of Villa d'Adda-Borromeo, arch. F. Croce (ca. 1765), Cassano d'Adda; b) frame vault of St. Sigismondo refectory (ca. 1758), Cremona; c) planterian vault, Palazzo Ghilini, arch. B. Alfieri

(1732), Alessandria; d) a fasce vault, St. Lorenzo church sacresty, arch. G. Guarini (ca. 1680). 
BS. T. 57. Abbazia olivetana di S. Nicola, Rodengo Saiano

Localizzazione: via Brescia 83, Rodengo
Saiano (Brescia).
Cronologia: ante 1560.
Dimensioni della struttura voltata: in
pianta 9,70x7,60m; altezza in chiave
$5,76 \mathrm{~m}$; altezza della cornice $3,95 \mathrm{~m}$.
Descrizione della volta: la volta copre lo
spazio antistante il refettorio dell'abbazia.
Ė costituita da tre coppie di mensole,
impostate su una cornice in rilievo sui lati
lunghi, e da due coppie di mensole sui lati
corti. Gli stuchi, realizzati nel 1560 , sono
opera del mastro Francesco Oselli, di
Mantova, mentre i dipinti, datati al 1561,
sono opera di Lattanzio Gambara.
Riferimenti bibliografici: VoLTA 2002, p. 182.

KEYWORDS: XVI secolo; Rodengo Saiano (Brescia); solaio ligneo; mensole; maestranze mantovane.

Figura BS. T. 57. Dall'alto verso il basso: la volta dell'anti-refettorio; pianta e sezione con ortofoto del refettorio; ripresa (Stanga, 2020)
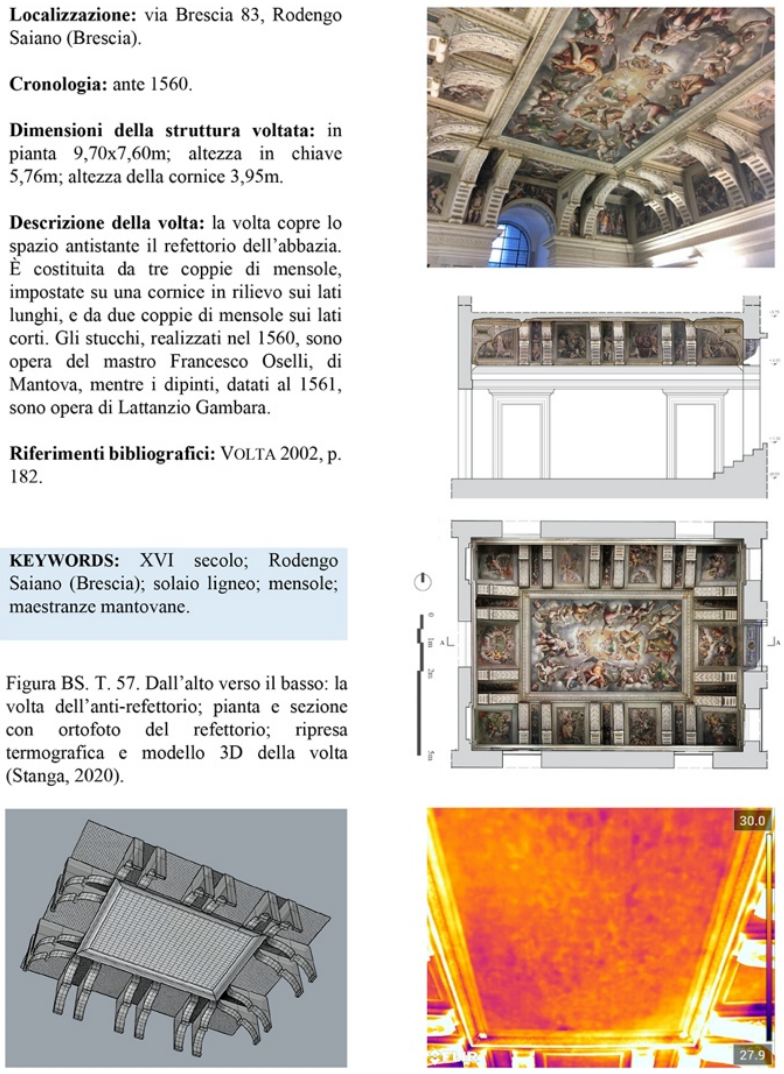

Figure 4: An example of vault sheet work (frame vault of St. Nicola Abbey, ca. 1561, frescos by Lattanzio Gambara,

Rodengo-Saiano, Brescia). Each vault has a code (BS.T.57),

the building name, the building address, vault dimensions and description, bibliographical references, photos, drawings,

thermo camera photo, 3D model (whenever possible). The keywords in the box are the elements that can help in the cross queries, in this case: $16^{\text {th }}$ century; Rodengo-Saiano; wooden ceilings; brackets (fasce/arches); Mantuan craftsmen.

One crucial step was realizing the database structure: it was necessary to think about the categories at play, realizing a functional tool regarding the research objectives (Fig. 5). The database is made of different tables:

- Building. To which belongs the table Building types (Palaces or churches); Description (name of the building); Dates (construction phase if possible); City, Address and X, Y coordinates to georeferenced the building.

- Regions, Provinces and Cities. Regions, Provinces and cities belonging to the study were added. Regions: Abruzzi; Emilia-Romagna; Lombardy; Piedmont; Sardinia; Veneto. Provinces: Alessandria; Asti; Bergamo; Bologna; Brescia; Cagliari; Cremona; Cuneo; Mantova; Milano; Oristano; Pescara; Piacenza; Reggio Emilia; Sassari; Torino; Verbano Cusio Ossola; Verona. 65 Cities.

- Vaults. To which belongs vaults ID; buildings ID; Vault type (Vault; frame; a fasce; planterian); Vault material (Brick; in foglio brick; voussoires; mortared rubble; wooden centerings);
Constructive figures intrados (Fasce; pointed lunettes; arched lunettes; 3D arches; tie rods); Constructive figures extrados (half cone; frenelli - brick masonry walls; ribs; tie rods); Arrangement (Brick or stone arrangement can be parallel to the transversal wall; parallel to the longitudinal walls; herringbone pattern, concentric rectangular pattern, concentric circle pattern); Type of sources (direct or indirect); link to the photos; link to the $3 \mathrm{D}$ model on a360 (whenever possible).

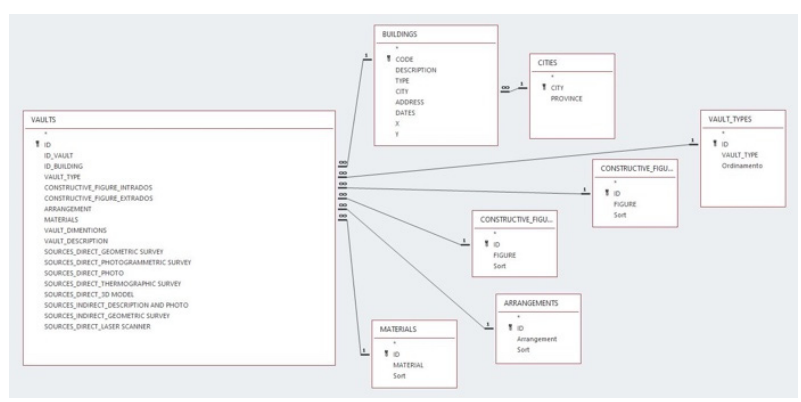

Figure 5: Vault database schema.

The database was populated by the 195 vaults that were studied for the research. Thanks to the database, it was possible to make queries highlighting the recurrence, in space and time, of specific construction techniques or vaulting types. The query was structured to make it possible to sort the vault depending on the city, or the province, the building date, the vaulting type, the constructive vault figures (intrados and extrados), the vault arrangement, the vault material, and the type of sources (direct or indirect) (Fig. 6).

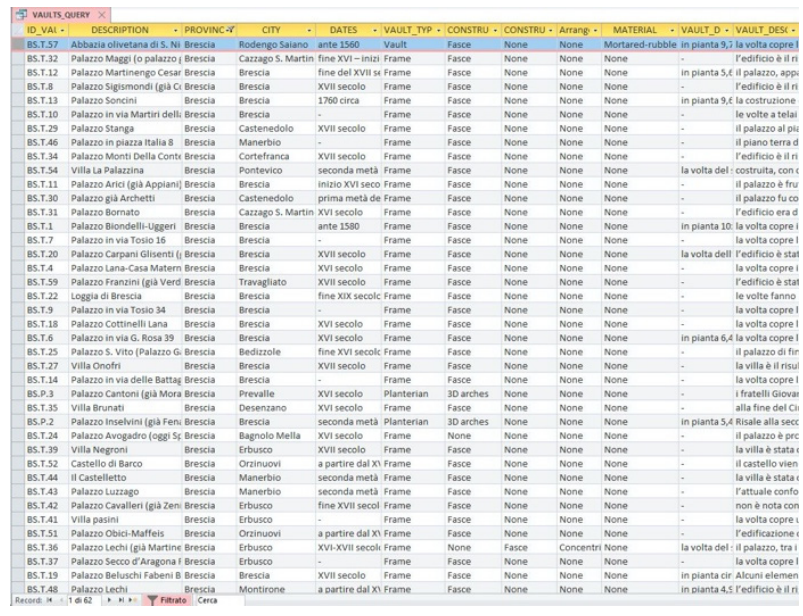

Figure 6: DB query: vaults that can be found in the Province of Brescia with Rodengo Saiano highlighted.

The idea to create a specific voice for intrados and extrados constructive figures is meant to allow more flexible research: if a vault is hybrid (for example, not just a frame vaults but a combination of frame and other constructive figures), one can search for "vault" and "constructive figures intrados" so the vault, which was stored with these features, shows up (Fig. 7). 


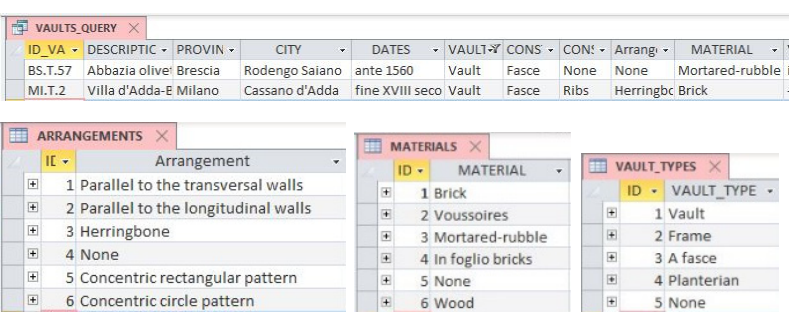

Figure 7: DB query: vaults that have the same constructive figures but different materials: BS.T.57 (BS=Brescia, T=Frame vault, n.57) St. Nicola Abbey in Rodengo Saiano; MI.T.2

$$
\text { (Ml=Milano, n.2). }
$$

Particular attention was devoted to the type of sources: 1) indirect sources: description and photos from literature; geometrical survey from literature; 2) direct sources: a geometrical survey (hand measurement); laser scanner survey; photogrammetric survey; thermographic survey; photos. The indirect and direct sources were subdivided to highlight each information specificity. If thinking about sharing the database on a broader scale, the subdivision makes the researchers aware of the information provenance.

The database was then imported into QGIS 3.10 to visualize the map of vaults dissemination and concentration, even if the research is still on-going and the map does not mirror the real dissemination of the vaulting types. Because the database path is saved in QGIS, it is automatically updated in the GIS (Fig. 8). When clicking on one of the points representing a vault, the information is visible on the right side (Fig. 9).

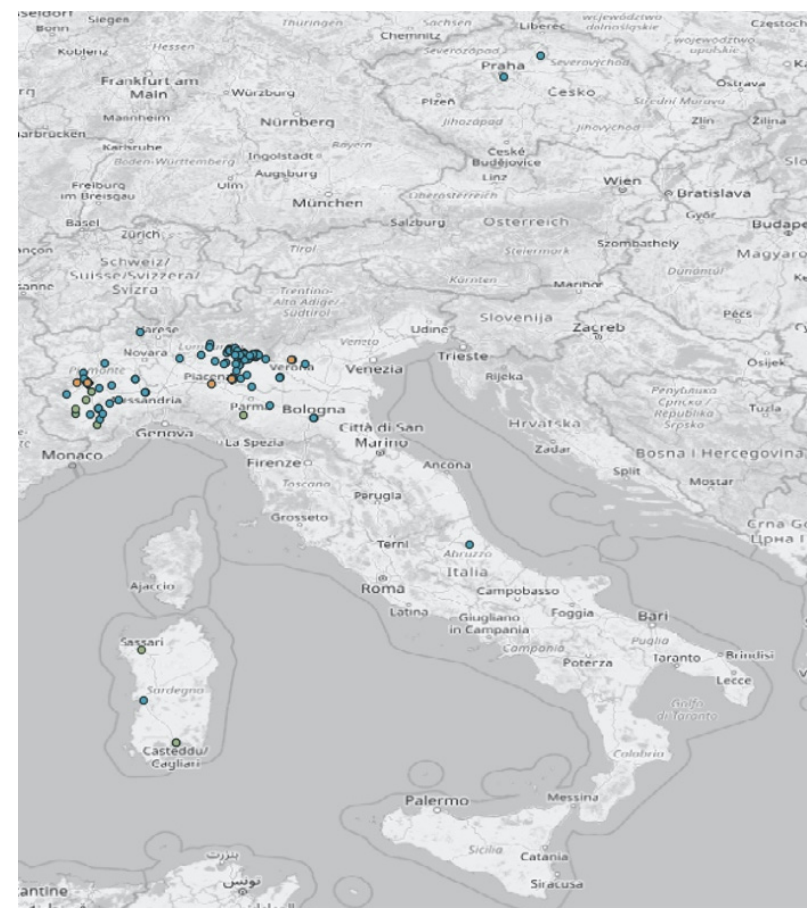

Figure 8: Map of the dissemination of frame (blue), a fasce (orange), and planterian vaults (green) (GIS). The main concentration in Northern Italy is due to the broader research carried out in this area. It is possible to notice frame and planterian vaults in Sardinia, Abruzzi, and Prague. More studies could shed further light on these vault typologies in other nations or regions.

\section{Conclusions}

In this research, the database and the GIS are tools to collect vaulting types and information. They also help form hypotheses about the technology transfer of a particular type of construction technique.

The frame, a fasce, and planterian vaults dissemination depend on many factors, such as the availability of materials, the architectural traditions, the network of clients, architects, and craftsmen. The next steps will be to understand the distributive principles underlying the geographical and temporal diffusion in Northern Italy of the three families of vaulted structures.

The dissemination could involve other regions, even in Europe. It seems proven by previous research that shows the dissemination of frame vaults in the Czech Republic, such as the ones of the Klementinum Baroque Library and Italian Cultural Institute in Prague, and the Abbey in Broumov (Stanga, Hasníková, Brumana, Grimoldi, \& Banfi, 2019). The presence of frame vaults in the Czech Republic can find an explanation in the work of Italian architects and craftsmen who traveled from the Lake Areas (Lugano, Lecco, Como) to work outside Italy (Della Torre, Mannoni, \& Pracchi, 1997).

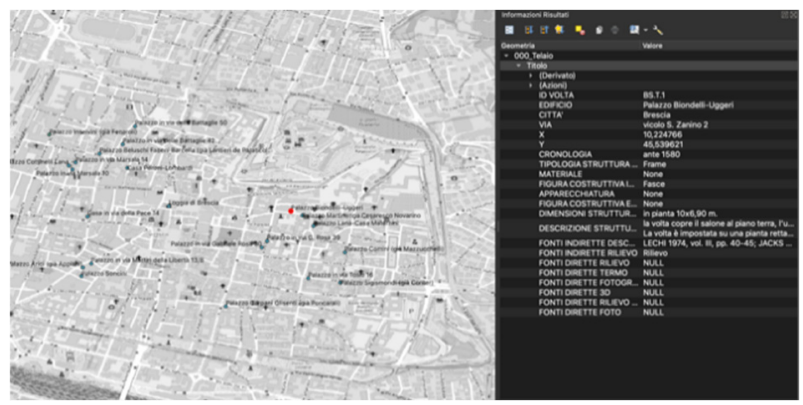

Figure 9: GIS map, close up to Brescia city, BS.T.1, Palazzo Biondelli Uggeri as selected entity.

The GIS-based catalogue opens towards sharing the data to a broader audience, scholars, experts, and nonexperts. It could help to show and make people aware of the exchange of ideas about vault design and construction techniques between the $16^{\text {th }}$ and $18^{\text {th }}$ centuries. Since the work is part of a more comprehensive project, it will be implemented to make it available on an online platform, making it possible to work in a Common Geospatial Environment, where scholars could add their vault examples. In addition to the challenge of making the database available online, it will be necessary to think about a shared vocabulary of terminology by starting from the robust one settled up by the Getty Institute.

\section{Acknowledgements}

The author thanks prof. A. Grimoldi (Politecnico di Milano) for his Ph.D. supervision and valuable suggestions; prof.ssa R. Brumana (Politecnico di Milano) for the support during the laser scanner and photogrammetric survey; arch. Luca Valisi (LADC, Politecnico di Milano) for the thermographic survey. 


\section{References}

Brumana, R., Condoleo, P, Grimoldi, A, \& Landi, A. G. (2017). Shape and construction of brick vaults. Criteria, methods and tools for a possible catalogue. Int. Arch. Photogramm. Remote Sens. Spatial Inf. Sci., XLII-5/W1, 137-143. https://doi.org/10.5194/isprs-archives-XLII-5-W1-137-2017

Brumana, R., Condoleo, P., Grimoldi, A., Landi, A. G., Attico, D., Turrina, A., Banfi, F., \& Previtali, M. (2018). HBIM Feeding Open Access Vault Inventory Through GeoDB HUB. In: Ioannides M. et al. (eds) Digital Heritage. Progress in Cultural Heritage: Documentation, Preservation, and Protection. EuroMed 2018. Lecture Notes in Computer Science, vol 11196. Springer, Cham. https://doi.org/10.1007/978-3-030-01762-0_3

Brumana, R., loannides, M., \& Previtali, M. (2019). Holistic Heritage Building Information Modelling (HHBIM): from nodes to HUB networking, vocabularies and repositories. Int. Arch. Photogramm. Remote Sens. Spatial Inf. Sci., XLII2/W11, 309-316. https://doi.org/10.5194/isprs-archives-XLII-2-W11-309-2019

Cavallari Murat, A. (1957). Gian Giacomo Plantery, architetto barocco. Atti e rassegna tecnica della Società degli ingegneri e degli architetti in Torino 11(7), 313-346.

De L'Orme, P. (1567). Premier tome de l'architecture. Paris: Fédéric Morel.

Della Torre, S., Mannoni, T., \& Pracchi, V. (1997). Magistri d'Europa. Como: Nodo Libri

Derand, F. (1643). L'Architecture des voûtes. Paris: S. Cramoisy

Howard, F. E. (1911). Fan-vaults. London: Hunt, Barnard \& co. Limited

Guarini, G. (1737). L’Architettura Civile. Turin: Gianfrancesco Mairesse

Lancaster, L. C. (2015). Innovative vaulting in the architecture of the Roman Empire. $1^{\text {st }}$ to $4^{\text {th }}$ centuries CE. New York: Cambridge University Press

Leedy, W. C. (1980). Fan Vaulting: A Study of Form, Technology and Meaning. London: Scolar Press

Mazzetti, P., Latre, M. Á., Ernst, J., Brumana, R., Brauman, S., \& Nativi, S. (2015). Virtual hubs for facilitating access to open data. EGU General Assembly Conference ,17.

Palacios, J. C. (1990). Trazas y cortes de cantería en el Renacimiento español. Madrid: Ministerio de cultura, Instituto de conservación y restauración de bienes culturales.

Pérouse de Montclos, J. M. (2013). L'architecture à la française: du milieu du 15. siècle à la fin du 18. Siècle. Paris: Picard (third edition).

Piccoli, E. (2001). Le strutture voltate nell'architettura civile a Torino (1660-1720). G. Dardanello (eds.), Sperimentare l'architettura: Guarini, Juvarra, Alfieri, Borra e Vittone. Turin: Fondazione CRT, 38-96.

Previtali, P., Brumana, R., Stanga, C., \& Banfi, F. (2020). An ontology-based representation of vaulted system for HBIM. Applied Sciences, 10, 1377. https://doi.org/10.3390/app10041377

Russo, V. (2018). iDome Invisible | Accessible. Masonry Domes of the $15^{\text {th }}$ and $16^{\text {th }}$ Centuries in Campania. Innovative Strategies for the Interpretation and the Multi-thematic Inclusive Fruition of Vulnerable Architectures. Retrieved March 15, 2021, from https://idome.site

Senent-Domínguez, R., López-Mozo, A., Martín-Talaverano, R., Pérez-de-los-Ríos, C., \& Rabasa-Díaz, E. (2015). Late gothic ribbed vaults. basis for cataloging. Proceedings of the Fifth International Congress on Construction History, Chicago.

Scamozzi, V. (1615). Dell'idea della architettura universale : Scamozzi, Vincenzo, 1552-1616 : Free Download, Borrow, and Streaming : Internet Archive. Retrieved March 15, 2021, from https://archive.org/details/dellideadellaarc00scam/page/n13/mode/2up

Spallone, R., \& Vitali, M. (2017). Volte stellari e planteriane negli atri barocchi in Torino. Roma: Aracne editrice (Disegno e sistemi voltati, 1$)$.

Stanga, C., Hasníková, H., Brumana, R., Grimoldi, A., \& Banfi, F. (2019). Geometric primitives assessing italian-czech vault construction techniuqes in baroque period. Int. Arch. Photogramm. Remote Sens. Spatial Inf. Sci., XLII-2/W11, 1081-1088. https://doi.org/10.5194/isprs-archives-XLII-2-W11-1081-2019

Vittone, B. (1760). Istruzioni elementari. Lugano: Agnelli. Biblioteca Salita dei Frati, Lugano / Istruzioni elementari... Retrieved March 15, 2021, from https://www.e-rara.ch/lg1/content/pageview/3877489 


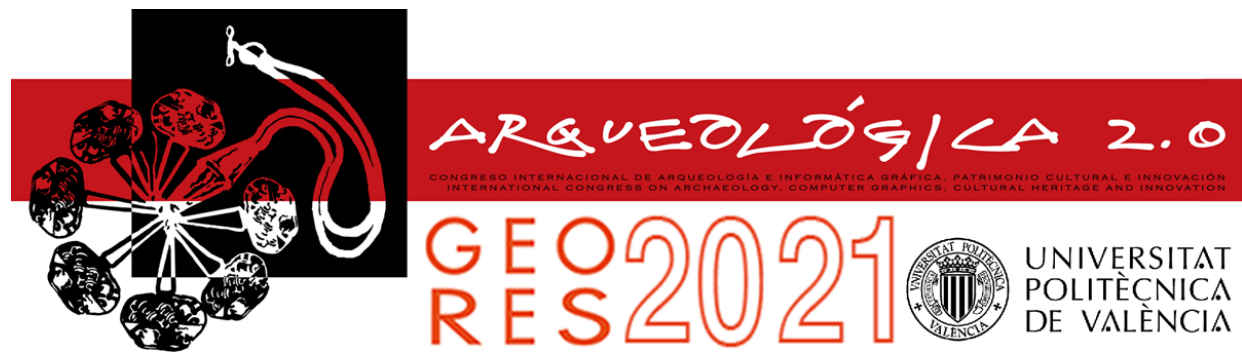

Proceedings of the joint international event $9^{\text {th }}$ ARQUEOLÓGICA

$2.0 \& 3^{\text {rd }}$ GEORES

Valencia (Spain).

26-28 April 2021

Received: 26/11/2020

Accepted: $17 / 03 / 2021$

DOI: https://doi.org/10.4995/Arqueologica9.2021.12090

\title{
VOCABULARY ALIGNMENT FOR SHARING ARCHITECTURAL CONSERVATION DATA
}

\author{
Marta Acierno a, ${ }^{a}$, Donatella Fiorani ${ }^{a}$, Athanasios Velios ${ }^{b}$ \\ a Dipartimento di Storia, Disegno e Restauro dell'Architettura, Sapienza University of Rome, Piazza Borghese 9, 00186 Roma, Italy. \\ marta.acierno@uniroma1.it; donatella.fiorani@uniroma1.it \\ b Ligatus, Chelsea College of Arts, University of the Arts London, 16 John Islip Street London, SW1P 4JU, UK. a.velios@arts.ac.uk
}

\begin{abstract}
:
In the domain of heritage conservation, much of the decision making relies on assessing risk and planning in advance. This is particularly important for built heritage where environmental conditions cannot be controlled easily and a broader range of risks must be taken into account. Risk assessment requires detailed surveys of built heritage which produce a wealth of data around the vulnerability of a building using domain expert terminology. It also requires information about the environmental condition and the dangerousness of the area that the building is situated. Integrating these data within systems is essential. Further sharing this data with external audiences such as emergency services is also important. In this paper guidelines developed for the Linked Conservation Data project are considered in relation to a risk assessment system: Risk Map of the Italian Ministry of Culture. The guidelines explain how terminology data can be integrated to ensure a common language across systems or system components. Terminology alignment with the Getty Arts \& Architecture Thesaurus is considered and specific terms from the built heritage domain are explored as well as the challenges posed by their use in different contexts.
\end{abstract}

Keywords: integration, risk assessment, cultural heritage, documentation, conservation

\section{Integration of data}

The value of documentation in heritage conservation is emphasised through codes of ethics and international charters. Documentation captures information about the production (materials and techniques), condition and treatment activity of heritage objects and sites. This allows monitoring the development of deterioration processes and assessing past conservation treatments. Built heritage data is a subset of conservation data. It is more complex due to scale and dependency on topology and structure while including mobile objects located in buildings.

Documentation records in conservation are often considered on a per item basis and are produced using free text to be read as part of reviewing a single object or site. Extra value is added to documentation records when they can be summarised at collection level and integrated at cross-collection level. For example, more representative samples of observations on materials and techniques outline the history of technology for objects. Combined observations from the results of conservation treatment allow better assessment of treatment techniques and materials. Monitoring deterioration at scale allows conclusions about deterioration patterns to emerge both in connection to geography and to material type. Systematic sharing of environmental monitoring data combined with condition survey data can assess environmental control and establish causality for damage. These benefits show that integration of conservation records is a pivotal activity for the development of the profession.

This is also true for built heritage with the additional complexity of considering each case individually and therefore more difficult to integrate (i.e., it is difficult to identify categories for a common approach). While complete integration of data for built heritage may be achieved in the future, at the moment the focus is on integrating data for risk assessments to evaluate the possibility of losing historic architecture (Fig. 1) considering buildings and the areas where they are located.

We are introducing a description of risk data here followed by a methodology for integration offered by the Linked Conservation Data (LCD) consortium and its application to Risk Map - a project from the Italian Ministry of Heritage - with particular interest in terminology. 


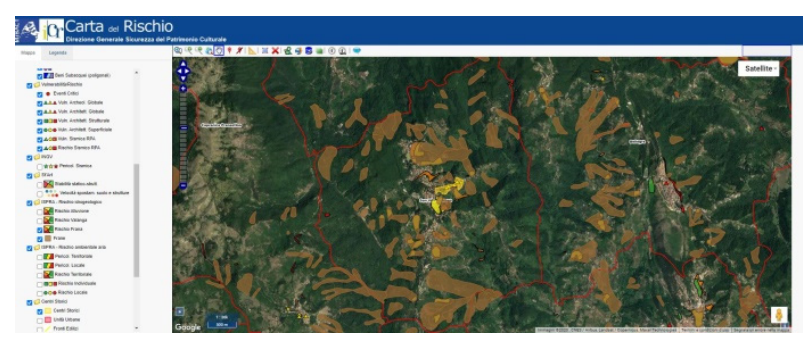

Figure 1: Risk Map of MIBACT, the historic centre of San Vito Romano (Rome) georeferred with the evidence of landslides.

\subsection{Risk assessment for historical architecture}

Risk is calculated based on territorial dangerousness (area factors) and object vulnerability. We consider three types of territorial dangerousness: a) physical: i.e. landslides, floods, earthquakes, etc., b) environmental/air: i.e. pollution and c) human-related: i.e. depopulation. Vulnerability can be related to structural weakness (for example a design error or a transformation), material decay, bad craftsmanship and inadequate restoration.

Data for risk assessment of built heritage is gathered in different platforms, often in Geographic Information Systems (GIS) where it can be georeferenced, so the vulnerability of a single building and its contents can be related to the dangerousness of the territory that hosts it.

We can collect data about groups of buildings and their components and we can monitor that over time to allow minimal conservation interventions when necessary. We can also compare with observations on similar buildings located nearby and provide a scientific basis for developing conservation strategies.

\subsection{Linked Conservation Data}

Recognising the importance of integrating records, the LCD consortium investigates the steps required for sharing conservation data and for making integration practical for conservators and conservation departments. The consortium currently examines the use of Linked Data technologies to achieve integration. Different working groups are undertaking work into two main areas: modelling and terminology.

Modelling describes the process of aligning local schemas to enable data comparisons. An efficient way of aligning schemas is through a generic ontology. In LCD we are currently examining the suitability of the CIDOCCRM ontology (CIDOC, 2020) alongside its extensions for modelling conservation data. Work on modelling risk with the CRM ontology is in progress and will be reported separately. This paper is only concerned with the second area of activity in LCD which is the terminology (Velios, \& St.John, 2020).

\section{Terminology for integrating heritage data}

The CIDOC-CRM ontology is a generic ontology. As such it does not feature domain-specific classes. The additional granularity needed for describing conservation data is provided through the CRM 'E55 Type' class, i.e. every vocabulary term is matched to 'E55 Type'. Integration at schema level is possible through CRM classes and properties, but if one requires the granularity of domainspecific terminology then vocabulary entries also need to be aligned.

Within the realm of Linked Data there is a dominant standard for encoding and sharing vocabularies known as the Simple Knowledge Organisation System (see SKOS, 2012). SKOS features properties that can assist integration. It allows synonyms for each entry and it features properties that match entries across different vocabularies. These include: skos:exactMatch, skos:closeMatch, skos:broadMatch (and skos:narrowMatch). Using the property skos:exactMatch indicates that two entries from different vocabularies describe the same idea, in practical terms the two entries can be used interchangeably. The property skos:closeMatch indicates semantic overlap useful for retrieval purposes. The property skos:broadMatch (and its inverse skos:narrowMatch) indicate that one vocabulary lacks the detail included in the other but that there is a possible hierarchical connection between terms. There is relatively clear expectation on how skos:exactMatch and skos:closeMatch would be interpreted in implementations for cross-database retrieval systems where a user would enter one word in a search box using their own vocabulary and results with records from matched terms in other vocabularies would appear. Similarly, the skos:broadMatch indicates hierarchical relationships so it would be expected to be utilised when browsing hierarchical vocabularies with terms from one vocabulary appearing as child-terms of another.

The LCD consortium has identified the Getty Arts \& Architecture Thesaurus (see Getty Research Institute, 2017) as a vocabulary with enough coverage in conservation to act as a matching hub. Vocabulary maintainers are encouraged to match to the Getty AAT before any other vocabulary to enforce the hub role and minimise the amount of matching needed across vocabularies.

Examples from risk assessment follow after we introduce the Risk Map system in the next section.

\section{The Risk Map of the Italian Ministry of Heritage: use and data organisation}

Risk Map (Fig. 2) is one of the GIS platforms of the Italian Ministry of Culture (Ministero della Cultura - MiC). It is interoperable with other GIS platforms in the Ministry, such as Sigecweb, from the Central Institute of Catalogue and Documentation (ICCD). Risk Map expresses the vulnerability of buildings or building complexes (i.e. a town's historic centre) in relation to territorial dangerousness. The former being data collected of buildings and the latter data from specific thematic maps (Cacace, 2007).

Risk Map is used in case of local disasters - such as earthquakes or floods - because it allows quick identification of heritage at risk. Applications of the system exist for areas of Italy, including Abruzzo, Marche, Sicily and Calabria (Cacace, \& Fiorani, 2008; Donatelli, 2010; Acierno, Cacace, \& Giovagnoli, 2014).

Risk Map collects data using documentation forms that depend on the type of object or conservation task (i.e. 
mobile objects, buildings, historic centres, archaeological remains, archaeological sites, underwater archaeological remains etc). Risk Map extends ICCD to produce these documentation forms. The ICCD provides references, such as a registry and part of the thesaurus for Risk Map which acts as an integration platform. In this paper, we consider how it can further be integrated by sharing records with other systems.

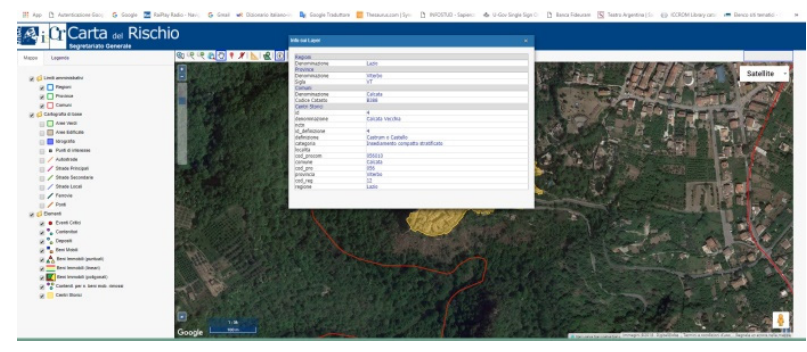

Figure 2: Risk Map of MIBACT, the historic centre of Calcata (Viterbo) georeferred with the info on the selected area.

Like in many other cases, the system of the ICCD is based on historic paper records and therefore inherits legacy data. As such, there is no provision for global identifiers in the system and therefore any linking is done based on internal identifiers or labels. Any attempt to share records from this system would require matching local identifiers and labels with global identifiers possibly provided by well-recognised authority files.

As part of this work, a contribution to Risk Map is made related to the description of historic centres through the creation of six new information forms that correspond to different urban scales. This required the employment of a vocabulary to manage historic centres which reference existing thesauri in ICCD (which are also based on SKOS) (ICCD, 2020) but also adding some new terms.

\section{Case study: Risk Map for historic centres}

The Risk Map vocabularies reflect the nature of the risk assessment records covering generic terms about built heritage and more specific ones deriving from conservation. Comparisons on words only are avoided and instead the use of the word is considered to identify its meaning. The task was to formalise the Risk Map vocabularies and publish them as SKOS Linked Data. This included five steps:

1) Creation of global identifier and URI. The Risk Map system only allows local identifiers for the vocabulary terms. Therefore, unique identifiers and unambiguous reference points within a global scope were produced outside the system. We use https://w3id.org, whose purpose is to provide persistent re-direction services, namespace is proposed alongside providing a subdirectory 'mibactsapienza', followed by a number (for example: https://w3id.org/mibact-sapienza/1). The w3id consortium requires that the URIs are resolvable to serve content and as Risk Map is not currently offering such functionality changes to the w3id domain yet have not been committed yet.
2) Creation of a scope note to describe the vocabulary term. This allows clarifying the meaning of a term based on its use and is required to control synonyms and equivalent terms.

3) Establishing the hierarchical position of the term in the vocabulary. To allow browsing the vocabulary, relationships across terms can be built. Associative relationships are between concepts that are relevant using the property skos:related. Hierarchical relationships are between parent and child terms using the properties skos:broader and skos:narrower indicating that the part term is more general than the child term.

4) Aligning to target thesauri. To enable integration with datasets built with different vocabularies the AAT is used as a hub thesaurus as expressed by the LCD guidelines. This allows maintaining the Risk Map vocabulary locally while enabling retrieval of data using the AAT. The use of each Risk Map term has been checked against relevant scope notes in the AAT. When semantic relevance was identified, the term was marked as skos:exactMatch. skos:closeMatch was used for terms which diverted slightly from the AAT scope note but were close enough to justify retrieval. More rarely skos:broadMatch or skos:narrowMatch was used when the hierarchical relationship across vocabularies could be established. In other cases, corresponding terms could not be identified and a plan for submitting new terms to the AAT has been made. Note that matching properties are actually described in the official SKOS documentation that specifies that "A skos:closeMatch link indicates that two concepts are sufficiently similar that they can be used interchangeably in some information retrieval applications. A skos:exactMatch link indicates a high degree of confidence that two concepts can be used interchangeably across a wide range of information retrieval applications.

5) SKOS publishing. The resulting data was encoded in a spreadsheet and converted to SKOS and validated using the popular SKOS Play tools (Francart, 2020). A sample of that encoding can be seen in the Appendix (see Section 6).

\subsection{Terms relation and matches}

The hierarchy based on Risk Map entries for 'historic centres' is highlighted here. Scope notes were developed after defining the cultural context of built heritage in Italy (Fiorani, 2018, 94-95) based on relevant bibliography which was also the prism under which AAT entries were considered.

The concept 'historic centres' is defined within Risk Map as the "Ensemble of historic buildings within an urban agglomeration formed by World War I (1919). The definition of 'historic centre' is one of the most discussed issue in literature and the choices made for the Risk Map have already been discussed (Fiorani 2018, pp. 88-96). This chronological threshold normally identifies a part - 
generally central - of the town, but the contemporary city can also include several historic districts that are in fact disjoint. This centre is marked by a perimeter that can sometimes coincide with the boundary of the city walls when they still exist or when they can be identified on the basis of historical records, material evidence, or on natural limits (streams, strong slopes, etc.). The chronological threshold can sometimes result from the evident constructive mutation of the building, verified by the comparison with the available cartographic and historical graphic documentation and direct feedback." Considering the specificity of the term, conceived in a particular geographical context (Italy) and for a particular purpose (Risk Map), an exact match on AAT was not expected. Instead the anticipation was the use of a broader match. The temporal limitation was introduced to identify only those parts of the town constructed with traditional building techniques, since the method for calculating vulnerability within Risk Map is defined upon mathematical models that represent masonry buildings and not reinforced concrete or steel structures. Searching the AAT showed no exact matches.

More thorough investigation indicated three close matches: 'historic district', 'historic quarters' and 'downtown'. The first two disregarded the quality of the buildings and mainly focussed on the administrative role in the designation of the historical value, while the third was mainly focusing on the geographical understanding of the concept. The four scope notes (the three from AAT and the one from our definition of 'historic centres') are different but involve a common core concept which is substantially expressed by the concept 'historic quarters'.

Note that 'historic district' is defined as "Former administrative or electoral districts that have been designated by a modern governing body as being culturally or historically significant, or embodying distinctive characteristics of a period, method of construction, or inhabitants. For historic areas of a city or town, use "historic quarters."; the third as "Core or central areas of cities or towns that are either the oldest areas of the city or the core business areas. The term is thought to derive from these areas, as the oldest areas, having the lowest street numbers; alternatively, term may derive from the development of New York City, where the oldest section is in the south, at the bottom of a map".

The term 'historic centres' declares a whole made of different parts, two of which are defined as 'urban unitsaggregates' and 'urban units-residential or special isolated buildings'. The 'urban units-aggregates' contain further parts which are described with 'building units'. Parts of 'building units' and urban units-residential or special isolated buildings are 'building fronts'. Another part of 'historic centres' is considered as 'urban spaces'. The partitive relationships among these terms do not indicate relevance in terms of characteristics of the things described. For example a facade ('building fronts') is not a building itself ('building unit'), but only part of it. While SKOS does not provide a specific way to express partitive relationships, guidelines indicate that extensions of the SKOS model should be used instead (W3C, 2020). The adoption of a new relationship (Icd:broaderPartitive) within the wider LCD project is considered as shown in our encoding example in the Appendix.

'Urban units' manifest as at least 'urban units-aggregates' and 'urban units-residential or special isolated buildings' and in both cases these are more specific types (specialisations) of 'urban units' where the broader relationship (skos:broader) can be used.

Associative relationships (skos:related) are used to indicate the connection between 'building units' and 'urban units-residential or special isolated buildings' as neither the partitive relationship nor the specialisation is valid.

The term 'urban spaces' is defined within Risk Map as "an open space inside the historic centre bordered by several 'urban fronts' and characterized by the presence of specific elements (gardens, furnishings, flooring, etc.). In theory, all streets and squares contained within the centre are urban spaces." Such definition is broader to AAT 'open space' which is conceived only for pedestrians. Finally, it is interesting to refer to the exact matches that resulted for the concepts 'urban units - aggregates', 'building units' and 'building fronts' whose scope notes exactly match those in AAT 'complexes (buildings and sites)', 'single built works (built environment)' and 'fronts (architectural)'. Conversely, it was impossible to identify an exact match for 'urban units-residential or special isolated buildings' which although scale-wise occupy an urban unit, they are single buildings (not aggregates) and therefore different to AAT 'complexes'.

\section{Conclusions}

The exploration of the subject is ongoing and further experience is gained from matching the local vocabulary of Risk Map to AAT. The advantage of maintaining a local vocabulary is that the local preferences on composite entries and hierarchical arrangements of terms can be preserved thus without requiring modifications to the Risk Map system. To enable interoperability with other datasets alignment of our vocabulary to the AAT is underway. This will allow external users to search our records without having to observe the peculiarities of our local vocabulary. Searching through a well-known vocabulary such as the AAT allows broader exposure of records.

The proposal to encode Risk Map vocabularies intends to amplify the scenario of the digital platform of the Italian Ministry MIC through the alignment with other international thesauri. Collaboration with ICCD experts is initiated to resolve technical issues including those on global identifiers. More generally, the work has to be considered within ongoing research frameworks that aims to integrating conservation data in different institutional contexts in a wider global environment. The work on terminology developed intends to assist the research on conceptual modelling that has focussed on historic centres issue representation (Acierno, \& Fiorani, 2019).

The LCD efforts and conceptual modelling open the application of Risk Map to a completely new dimension connecting operational needs of digital instruments for conservation planning and emergency planning with a wider strategy of globally sharing conservation data. 


\section{Appendix}

\subsection{Term relations}

Broader relationships (skos:broaderlsA)

urban units

$\rightarrow \quad$ urban units-aggregates

$\rightarrow \quad$ urban units-residential or special isolated buildings

Broader partitive relationships (Icd:broaderPartitive)

historic centres

$\rightarrow \quad$ urban units-aggregates

$\rightarrow \quad \rightarrow \quad$ building units

$\rightarrow \quad \rightarrow \quad \rightarrow \quad$ building fronts

$\rightarrow \quad$ urban units-residential or special isolated

buildings

$\rightarrow \quad \rightarrow \quad$ building fronts

$\rightarrow \quad$ urban spaces

Associative relationships (skos:related)

building units ---- urban units-residential or special isolated buildings

\subsection{Encoding examples}

\subsubsection{SKOS concepts and scope notes}

mbs:4 a skos:Concept;

skos:broader mbs:3;

skos:inScheme <https://w3id.org/mibact-sapienza/>;

skos:narrower mbs:6;

skos:prefLabel "Unità urbana-aggregato"@it, "urban units-aggregates"@en;

skos:scopeNote "It is a type of 'urban unit' and is understood as a continuous set of structurally connected but distinguishable building units as organisms that are architecturally coherent. It is bordered by urban spaces with which it communicates through accesses to the ground floor and may contain within it places relevant to one or more building units. It overlooks on urban spaces through fronts that result from the succession of the individual facades of the building units."@en;

Icd:broaderPartitive mbs: 1 .

mbs:5 a skos:Concept;

skos:broader mbs:3;

skos:inScheme <https://w3id.org/mibact-sapienza/>;

skos:prefLabel "unità urbana-edilizia puntuale residenziale o specialistica"@it, "urban units-residential or special isolated buildings"@en;

skos:related mbs:6;

skos:scopeNote "It is a type of 'urban unit' and is understood as a homogeneous and autonomous unitary element. It is bordered by urban spaces with whom it communicates through accesses to the ground floor and can contain open places inside. It overlooks urban spaces through a variable number of fronts generally figuratively and constructively coherent with each other. 'Residential punctual building units' are buildings such as villas or cottages, while 'Specialist punctual building units' include hospitals or schools."@en;

Icd:broaderPartitive mbs: 1 .

mbs:6 a skos:Concept;

skos:broader mbs:4;

skos:inScheme <https://w3id.org/mibact-sapienza/>; skos:prefLabel "building units"@en, "unità edilizia"@it; skos:related mbs:5;

skos:scopeNote "It is a coherent architectural organism, consisting in a single construction phase or by the merging/recasting of several pre-existing building units. This organism is characterized by the presence of one or more functional units (residential and non-residential) connected to each other through common distribution elements and served by access at the road level; it is bordered by external facades with a generally continuous eaves line and a unitary or composite roof composed of flat and/or inclined parts consistent with all fronts."@en.

mbs:7 a skos:Concept;

skos:inScheme <https://w3id.org/mibact-sapienza/>;

skos:prefLabel "building fronts"@en, "fronte edilizio"@it;

skos:scopeNote "It corresponds to the façade of the single 'building unit' overlooking on an urban space or, more generally, on a street or a town square but also on the natural margin of the town (maritime, river, lake coast, prmonatory limit, etc.)."@en;

skos:topConceptOf

$<$ https://w3id.org/mibactsapienza/>;

Icd:broaderPartitive mbs:5, mbs:6.

\subsubsection{Alignment with AAT}

mbs:2 a skos:Concept;

skos:inScheme <https://w3id.org/mibact-sapienza/>; skos:narrowMatch aat:300008072;

skos:prefLabel "urban spaces"@en;

skos:topConceptOf <https://w3id.org/mibact-sapienza/> mbs:3 a skos:Concept;

skos:inScheme <https://w3id.org/mibact-sapienza/>; skos:narrowMatch aat:300264550;

skos:prefLabel "urban units"@en;

skos:topConceptOf <https://w3id.org/mibact-sapienza/> mbs:4 a skos:Concept;

skos:exactMatch aat:300000202;

skos:inScheme <https://w3id.org/mibact-sapienza/>;

skos:prefLabel "urban units-aggregates"@en;

skos:topConceptOf <https://w3id.org/mibact-sapienza/> 


\section{References}

Acierno, M., Cacace, C., \& Giovagnoli, A. M. (2014). La Carta del Rischio: un approccio possibile alla manutenzione programmata. Il caso di Ancona, Materiali e Strutture. Problemi di conservazione. 3(5-6), 81-106.

Acierno, M., \& Fiorani, D. (2019). Innovative Tools for Managing Historical Buildings: the Use of Geographic Information System and Ontologies for Historical Centers. ISPRS. International Archives of the Photogrammetry, Remote Sensing and Spatial Information Sciences., XLII, 2019, 21-27. https://doi.org/10.5194/isprs-archives-XLII-2-W11-212019

Cacace, C. (2007). Risk Map Methodology. In R. Varoli-Piazza (ed.), Sharing Conservation Data, Rome, Italy: Iccrom.

Cacace, C., \& Fiorani, D. (2008). Sistema informativo territoriale della Carta del Rischio, schedatura di chiese dell'Abruzzo e del Molise e calcolo della loro vulnerabilità. In 12a Conferenza Nazionale della Federazione italiana delle Associazioni Scientifiche per le Informazioni Territoriali e Ambientali, (L'Aquila, 21-24 ottobre 2008), L'Aquila, Italy: ASITA, 569-574.

CIDOC. (2020). CIDOC Conceptual Reference Model (CRM). Retrieved November 12, 2020, from http://www.cidoccrm.org/

Donatelli, A. (2010). Terremoto e architettura storica. Prevenire l'emergenza. Roma: Gangemi, 199-214.

Fiorani, D. (2018). Il futuro dei centri storici. Digitalizzazione e strategia conservativa. Roma:Quasar.

Francart, T. (2020). SKOS Play! - Thesaurus \& Taxonomies (sparna.fr). Retrieved November 12, 2020, from https://skosplay.sparna.fr/play/

Getty Research Institute. (2017). Art \& Architecture Thesaurus. Retrieved November 12, 2020, from https://www.getty.edu/research/tools/vocabularies/aat/

ICCD. (2020). Home - ICCD - Istituto Centrale per il Catalogo e la Documentazione (beniculturali.it). Retrieved November 12, 2020, from http://www.iccd.beniculturali.it/it/percondividere/interoperabilita

SKOS. (2012). SKOS Simple Knowledge Organization System - home page (w3.org). Retrieved November 12, 2020, from https://www.w3.org/2004/02/skos/

Velios, A., \& St.John, K. (2020). Linked Conservation Data terminology guidelines. Retrieved November 12, 2020, from https://www.ligatus.org.uk/lcd/sites/ligatus.org.uk.lcd/files/attachments/193/terminology-working-groupguidelines.pdf

W3C. (2020). W3C Wiki. Retrieved November $12, \quad$ 2020, from https://www.w3.org/wiki/SkosCoreGuideToc/SectionExtending /SemanticRelations 


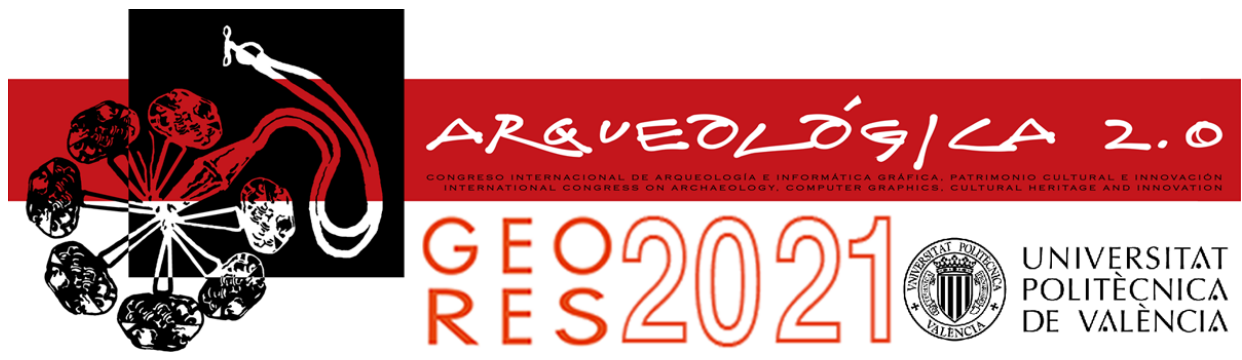

Proceedings of the joint international event $9^{\text {th }}$ ARQUEOLÓGICA

$2.0 \& 3^{\text {rd }}$ GEORES

Valencia (Spain).

26-28 April 2021

Received: 26/11/2020

Accepted: 08/04/2021

DOI: https://doi.org/10.4995/Arqueologica9.2021.12091

\title{
VIRTUAL TERRESTRIAL LASER SCANNER SIMULATOR IN DIGITAL TWIN ENVIRONMENT
}

\author{
Darius Popovas ${ }^{\mathrm{a}, \mathrm{b},{ }^{*},}$ Maria Chizhovac, Denys Gorkovchuk ${ }^{\mathrm{d}, \mathrm{e}}$, Julia Gorkovchuk ${ }^{\mathrm{d}}$, Mona Hess ${ }^{\mathrm{c}}$, \\ Thomas Luhmann ${ }^{a}$ \\ ${ }^{a}$ Institute for Applied Photogrammetry and Geoinformatics, Jade University of Applied Sciences, Ofener Straße 16/19, D-26121 \\ Oldenburg, Germany. darius.popovas@jade-hs.de; luhmann@jade-hs.de \\ ${ }^{\mathrm{b}}$ Faculty of Environmental Engineering, Department of Geodesy and Cadastre, Vilnius Gediminas Technical University, Sauletekio al. \\ 11, 10223 Vilnius, Lithuania. darius.popovas@vgtu.It \\ ${ }^{c}$ Institute of Archaeology, Heritage Sciences and Art History, University of Bamberg, Digital Technologies in Heritage Conservation, Am \\ Zwinger 4, D-96047 Bamberg, Germany.maria.chizhova@uni-bamberg.de; mona.hess@uni-bamberg.de \\ ${ }^{\mathrm{d}}$ Department of Geoinformatics and Photogrammetry, Kyiv National University for Construction and Architecture, Kyiv, Ukraine. \\ denys.gorkovchuk@spm3d.com; gorkovchukjulia@gmail.com \\ e SPM3D LLC, Martyrosyana str., 16/14, Kyiv, Ukraine. denys.gorkovchuk@spm3d.com
}

\begin{abstract}
:
We are presenting a Terrestrial Laser Scanner simulator - a software device which could be a valuable educational tool for geomatics and engineering students. The main goal of the VirScan3D project is to cover engineering digitisation and will be solved through the development of a virtual system that allows users to create realistic data in the absence of a real measuring device in a modelled real-life environment (digital twin). The prototype implementation of the virtual laser scanner is realised within a game engine, which allows for fast and easy 3D visualisation and navigation. Real-life objects can be digitised, modelled and integrated into the simulator, thus creating a digital copy of a real-world environment. Within this environment, the user can freely navigate and define suitable scanning positions/stations. At each scanning station, a simulated scan is performed which is adapted to the technical specifications of a real scanner. The mathematical solution is based on 3D line intersection with the virtual 3D surface including noise and colour as well as an intensity simulation. As a result, 3D point clouds for each station are generated, which will be further processed for registration and modelling using standard software packages.
\end{abstract}

Keywords: simulator, laser scanning, point cloud, virtual scanner, digital twin, game engine

\section{Introduction}

\subsection{Digital Twin in heritage conservation}

In heritage education and heritage conservation, the production of as-built surveys in plan and section in representational scales from an overview of 1:100 up to a detail of $1: 10$ is still a subject that is classically taught in courses across Europe. The strategically set and annotated 2D plans and sections are a stand-in for the real building and its information about materiality and construction. The $2 \mathrm{D}$ representations allow a holistic understanding of a historic building, foster the opportunity to display a building research project, apply condition and damage mapping as a further layer and serve as a basis for efficient planning of rehabilitation measures and building monitoring. The use of hand-drawing and total stations in heritage buildings and cultural heritage environments, such as archaeology, is now extended to the production of digital 3D surveys by terrestrial laser scanning and photogrammetry with the same intentions.

$3 \mathrm{D}$ imaging can be used as a teaching tool, to work with models that represent the reality and must, of course, respect the same requirements and appropriateness for accuracy, resolution and information as the existing formats of the 2D as-built surveying described above (Kravchenko, Luhmann, \& Shults, 2016). Here the idea is much likened to the use of digital surrogates or the function of a 'Digital Twin' in 3D.

In industry 4.0, the goal of a Digital Twin is the simulation of functionality processes of machines and sensors and reproduction of these functionalities in a virtual world in order to ensure a flawless accelerated production environment with equivalent reactions and within thresholds for quality control (Gómez-Cabrera, Paez, \& Alvarado, 2016; Peruzzini, Pellicciari, \& Bil, 2018). 
These goals for a Digital Twin are seen quite differently from the perspective of preservation and management of immobile heritage (Jouan \& Hallot, 2020). The creation of digitised 3D survey products with added information can now be seen as the Digital Twin of the tangible heritage, which can be connected with rich semantic information and real-time on-site sensors for monitoring to support the life-cycle of heritage buildings and management in line with the sustainable preservation of our built cultural heritage. This is supported by the new way of representing 3D survey models as the database in H-BIM (Historic Building Information Modelling after Dore \& Murphy, 2012). Further steps in the connection of survey, $\mathrm{H}$-BIM and heritage management have already taken place (Jouan \& Hallot, 2019) and are more and more established in heritage authorities (Bryan, 2017).

In a time, and especially at the time of writing during the Covid-19 pandemic, where e-learning tools have gained an essential significance, and where students are ever more familiar with virtual gaming environments, the teaching of practical capabilities in relation to heritage conservation for as-built survey can take advantage of the opportunity of digitalisation of the activity of teaching (Vlachopoulos \& Makri, 2017). The proficiency of the next generation of practitioners in heritage and geomatics in $3 \mathrm{D}$ imaging is an educational goal that needs to be included in curricula, such as in the new M.Sc. Digital Technologies in Heritage Conservation in Bamberg university (Hess et al., 2019). Here, a step into a simulator for teaching and learning with the appropriate delivery in reality-like application, resolution and quality outcome is desirable for heritage practitioners.

\subsection{VirScan 3D scanning simulator as an educational tool}

In the areas of environmental planning, building construction, infrastructure maintenance or cultural heritage conservation, the use of digital geospatial information has significantly grown during the last decade, for instance in the field of building information modelling (BIM). Location-based data and geoinformation, in general, are nowadays also a key factor in the economy such as logistics, energy, communication or internet business. Specifically, new instruments for digital recording and processing tools are increasingly established in those application areas.

Since digitalisation is one of the major worldwide trends, the teaching curricula, related to digitisation in engineering practice (e.g. geo-information sciences, cadastral mapping, geodesy) should educate their students according to current needs and demands from the professional market and industry. State-of-the-art technologies in these fields (e.g. 3D laser scanning, photogrammetry, UAVs) lead to large amounts of digital data and are difficult to process, analyse and transform into useful information. For this purpose, appropriate tools and workflows have to be provided, otherwise, neither teachers nor students have realistic chances to adapt to new methods in due time, and they will not be able to contribute to further developments.

However, this objective is hard to achieve, since there is a lack of knowledge among many teachers, out-of-date equipment (hardware and software), insufficient ICT infrastructure and insufficient finances for necessary investments, especially in developing countries. Furthermore, the development of recording instruments has a rapid change cycle of ca. five years. For instance, expensive terrestrial laser scanners are very rare in higher education institutions of those countries. In addition, a strong interdisciplinary approach should be followed since these technologies are relevant in many other subjects such as civil engineering, machine construction, cultural heritage or informatics (Hess, Garside, Nelson, Robson, \& Weyrich, 2017).

We are presenting a concept and initial results of a terrestrial laser scanner simulator - a tool, which could be a valuable educational tool for geomatics and engineering students with the aim of experiential learning strategies (Falloon, 2019; Dib, Adamo-Villani, \& Garver, 2014).

\subsection{Objectives for VirScan 3D scanning simulator}

The project group of VirScan3D project consists of two German universities and one Ukrainian university based on long-term cooperation that has started in 2002.

The virtual scanner simulates commercially available tools with realistic user interfaces and creates 3D point clouds according to individual specifications and settings in a digital real-world environment. Any digital 3D model (such as a cultural or technical building) that is virtually scanned in a digital environment can be used as a training object. With this system, teachers and students will be able to learn how to manage such systems, generate realistic big data and complete the entire data processing chain. In order to make learning processes more immersive, it is possible to simulate scanning in a virtual twin environment.

A virtual learning environment will solve the problem of providing high-precision (and highly-priced) devices in accordance with professional standards. Especially in geospatial sciences, the simulation in virtual environments can be used for the virtual reconstruction of natural scenes like cultural heritage objects or 3D cities (Kersten \& Edler, 2020). It is relevant for the specialists in the fields of geodesy, photogrammetry, GIS and land management as well as neighbouring disciplines (architecture and cultural heritage digitalization, computer vision, mathematics etc.).

\section{Simulator description}

As mentioned before, VirScan3D is developed for students of geodetic and other higher education departments with limited access to laser scanning equipment. It allows simulating of all processes of the fieldwork phase of terrestrial laser scanning and generates results that are very close to data generated with real physical scanners on-site. Moreover, the digital environment can simulate real-world objects, i.e. buildings or sites. These results can be used for further processing in scanning software in the office work phase.

The project is developed using readily available resources and tools and it is designed to run on Windows platforms.

The product functionality includes the following features:

- Selecting the scanner type which will be simulated; 
- Laser scanning process simulation with visualisation to obtain point clouds with intensity and noise values according to scanner specifications (noise and intensity not fully implemented yet);

- Scan station management which allows to specify settings for each scan station, create and delete stations:

- Target management which allows placing and removing targets of different types;

- Project management which allows to save the project as a user and to continue work later;

- Batch scanning;

- Real-time visualisation of generated point clouds;

- Exporting the point cloud.

The simulator offers two scenarios of work:

1) The user is navigating within the virtual environment and selects target positions as in real life. Then the scanner position and scan settings are specified and the scanning process of the virtual device is started. This is visualised in real-time. When the scanning is finished the user avatar 'goes' to the next station.

2) The user navigates within the virtual environment and selects positions for all targets and all scan stations. Subsequently, scan settings are specified for all stations or for each station separately. Finally, the scanning simulation is started for all stations one by one.

The result of the simulation is a structured $3 \mathrm{D}$ point cloud in ASCIl format for import in further software. For each scan station, a single point cloud is generated, hence similar to reality no registration is provided. It is also possible to export target coordinates to use it in registration software for cloud referencing.

VirScan3D is developed within Unreal Engine (a wellknown gaming engine); therefore, user's computers should satisfy its minimum requirements (Unreal, 2020). However, the speed of scan simulation directly depends on computer performance. Therefore, to obtain the speed of simulation no slower than scanning in the real world, the following specifications are recommended:

- OS: Windows 10 64-bit.

- Processor: Quad-core Intel or AMD, $2.5 \mathrm{GHz}$ or faster.

- RAM: 8 GB RAM.

- Video Card/DirectX Version: DirectX 11 or DirectX 12 compatible graphics card.

Main functions are programmed with Blueprint Visual Scripting system of Unreal Engine. It allows making the system very flexible and modifying software modules without recompiling the whole code. Some specific modules were programmed in $\mathrm{C}++$ due to Blueprint limitations.

Implementation of advanced features in future versions of software might need the use of additional external software, e.g. Blender (2020).

\section{Digital twin environment integration}

In order to create a real-world replica/digital twin within the simulator environment, the existing building should be recreated as a 3D model and integrated. It was decided to use the "Scan to BIM" approach, i.e. perform the 3D scanning of the desired object and model it using Autodesk Revit software. This BIM model can be integrated into Unreal Engine environment using the Datasmith importer plugin, which allows to convert 3D data from a variety of industry-standard design applications into Unreal assets.

\subsection{Test objects}

Initially, the simulator testing was intended to be carried out as part of a summer school for project participants. Thus, the campus buildings of the University of Bamberg have been selected as test objects. The buildings form an ensemble and are the individual monuments in the centre of the UNESCO world heritage in Bamberg.

The building complex with the address 'An der Universität $2^{\prime}$ begins its history in the $17^{\text {th }}$ century as a Carmelite monastery, which is reflected in its three-storey baroque architecture with a courtyard surrounded by three-storey buildings and a church (Fig. 1). After a construction period of almost 50 years, the building was completed in 1742 with the establishment of the theological library (Wied, 2007). In the following, this building will be referred to as 'Baroque building'.

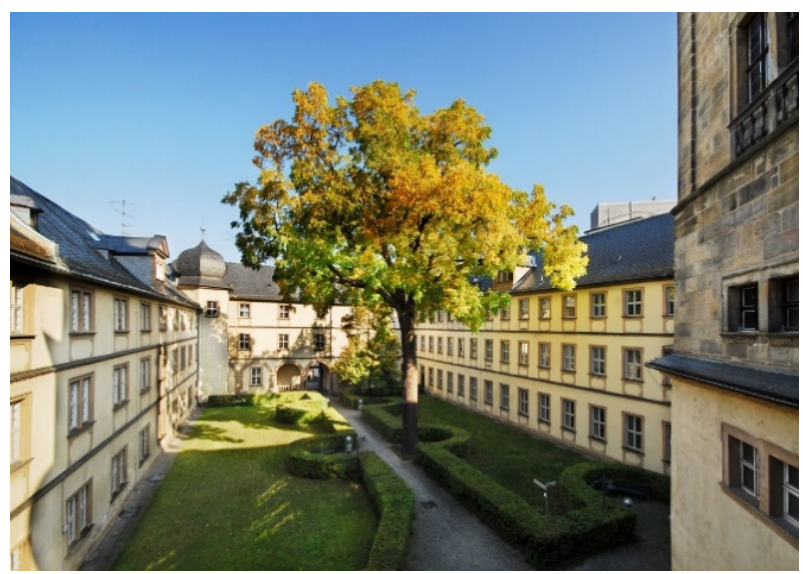

Figure 1: Baroque building complex 'An der Universität 2' (Photo: Jürgen Schabel @ Universität Bamberg).

Another building - 'An der Universität 9' - integrates a former tower of the ancient city wall with its characteristic late medieval sandstone stone blocks and octagonal roof. It has received building extensions and numerous alterations in the $17^{\text {th }}$ and $19^{\text {th }}$ century, which can also be seen in the appearance of the building (Fig. 2). In the following, this building will be referred to as 'university office building'.

\subsection{Data acquisition}

The objects have been scanned with high resolution in their real-world environment using Leica BLK360 and Faro Focus 3D scanners. Both trial cases include the elements of different materials, such as sandstone, building stone, tiled roof, glass and steel structures with glass (e.g. the modern library corridor). The details also 
differ in their colours (Fig. 3a). This has been reflected in the resulting point cloud (Fig. $3 b$ ).

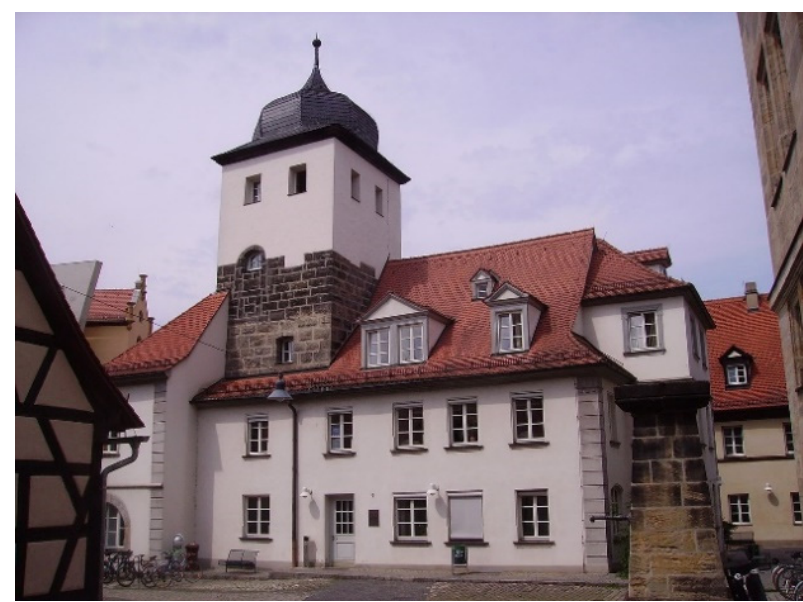

Figure 2: University office building 'An der Universität 9' (Photo: Immanuel Giel).

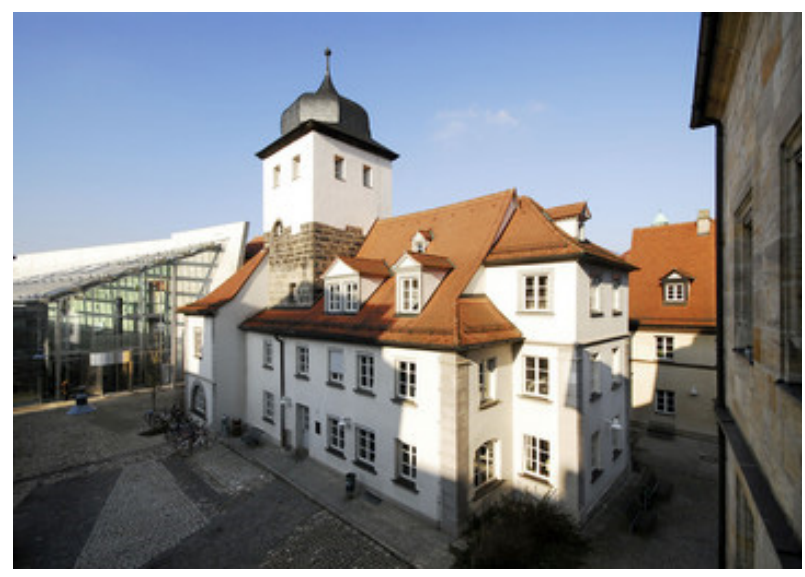

(a)

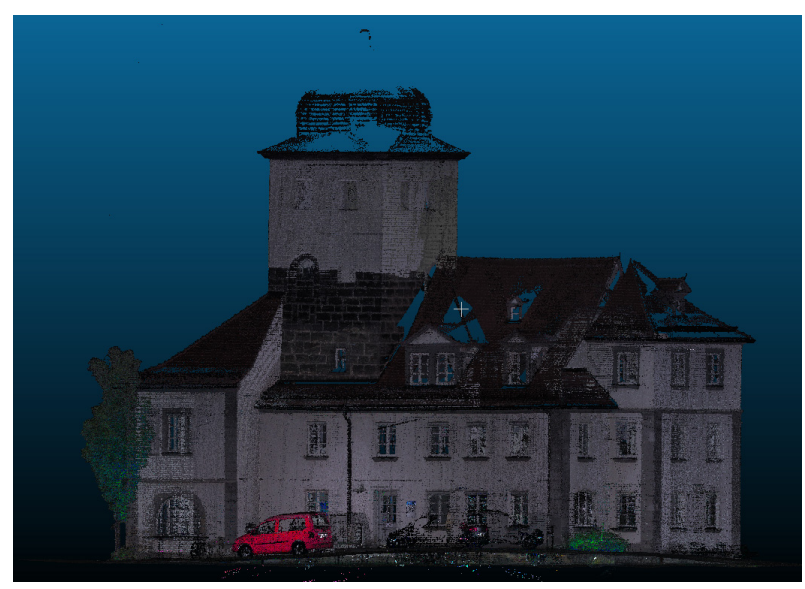

(b)

Figure 3: University office building: a) different material types on the objects; b) resulting point cloud.

In the resulting point cloud, the geometries were recorded with a resolution of $1 \mathrm{~cm}$ which allows detailing fine elements and decoration in later modelling. Due to the material properties and object colours, different intensity values were obtained. Sometimes the individual elements could not be captured due to over radiation or penetration, which consequently led to the gaps in the point cloud.

\subsection{Modelling}

In the simulator, the object material was represented as an object colour. In the future, the specific material properties will be analysed and integrated into the software (reflection intensity and noise according to specific element material).

In order to generate $3 \mathrm{D}$ test objects that are compatible with the simulator software, the recorded buildings have been modelled in Autodesk Revit BIM software. This involves object geometry modelling and assigning materials to object elements. The pre-modelled components available in the Revit library also consist of material properties. This mostly concerns standard Revit elements, such as glass windows and facades, walls and roof materials. For new and unique geometries modelled by the user, the materials were configured manually.

According to the simulator software requirements, the optimal number of model polygons should not exceed 30000 elements.

In addition to the main geometries of objects, the individual elements such as window and door decorations are presented in detail in this case study (Fig. 4).

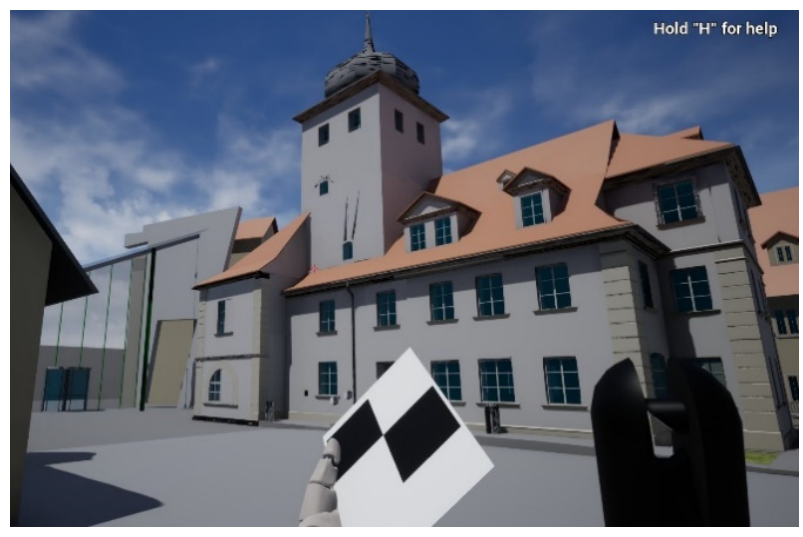

(a)
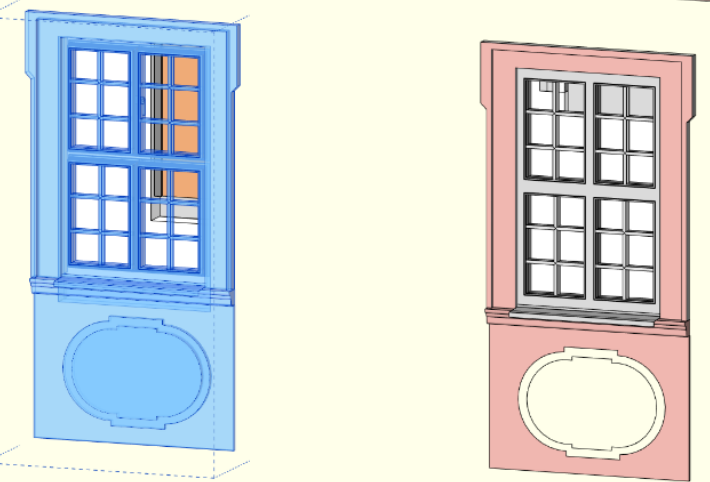

(b)

Figure 4: University office building: a) 3D model integrated with the simulation software; b) detailed decoration modelling on the example of a baroque building complex in the VirScan3D simulator. 
In combination with geometry and object property representation, the level of detail of generated models is equal to LoD 300 according to AIA E202 (Document E202, 2008). The detail precision varies within $+/-5 \mathrm{~cm}$. For the realistic representation, the surrounding objects were also modelled, but their level of detail is much lower (LoD200, Fig. 5). All models have been stored in a Revit format (.rvt) and additionally in IFC format for further import by the Datasmith plugin.

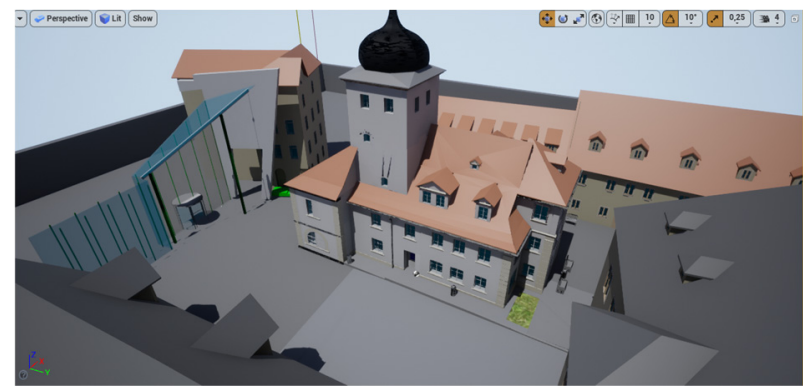

Figure 5: Revit model integrated into simulator environment.

\subsection{Data integration}

As rendering in Unreal Engine is made in real-time several aspects need to be considered during the integration of 3D data:

- High-polygonal models cause a significant drop in performance;

- $\quad$ Large textures require a high amount of graphic memory;

- Large coordinate numbers might cause a loss in coordinate precision;

- Collision generation needs to be considered for correct navigation within the model.

The BIM modelling approach was chosen to solve these problems:

- LOD300 modelling (which is typical for the Scanto-BIM approach) does not consider deformations, so the model remains of lowpolygon count;

- Most BIM software is optimized for small-size textures;

- Large coordinates in BIM systems are implemented as "local coordinates + global shift", which simplifies export to game engines;

- A highly structured BIM model generates each building element as a separate object with simple collision.

In addition, BIM models include information about the material of elements which is important for intensity generation functions.

Figure 5 shows the model of the building with its surroundings integrated into the simulator.

Unique elements of the object might be modelled with the "Model-in-place" feature. However, the same structured approach has to be implemented to consider the correct calculation of collisions.

\section{Experiment - working example of the VirScan3d software}

As a prototype for the terrestrial 3D scanners (TLS) that can be chosen in the VirScan3D simulator, we used the Leica BLK 360 laser scanner and an integrated BIM model of one of the historical buildings, the office building described in Section 3.1., in the city of Bamberg. The current simulator version offers four integrated scanner models (Faro X330, Leica Scanstation P40, Leica RTC360 and Leica BLK). In the future, other common laser scanner brands and models on the market will be simulated to extend the training variety.

The process starts with the placing of numbered targets and positioning of scanner stations (Fig. 6). The user can choose either checkboard targets and/or spheres that can be attached to walls and surfaces like in real life.

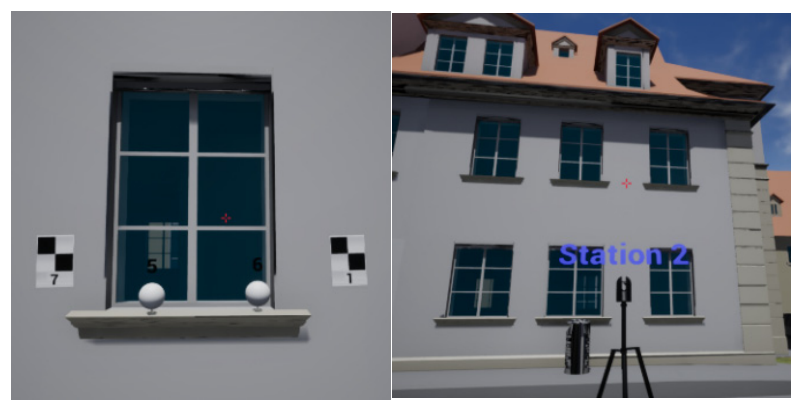

Figure 6: Target placing and laser scanner positioning in VirScan3D software around the university office building.

By picking a point in the 3D model the user specifies a scan position. Then the system checks if the station is correct, and saves it.

There are some functional requirements to be noted:

- A station is incorrect if it is too close $(20 \mathrm{~cm})$ to other objects or inside of other objects;

- A station is incorrect if it is located on vertical $\left( \pm 30^{\circ}\right)$ surfaces.

The access to scanner settings is implemented through realistic interfaces of the selected scanner model (example in Fig. 7). The user can select scanning parameters and set the instrument height (height is set to $1.60 \mathrm{~m}$ by default). It is possible to change the scanning position or remove a station.

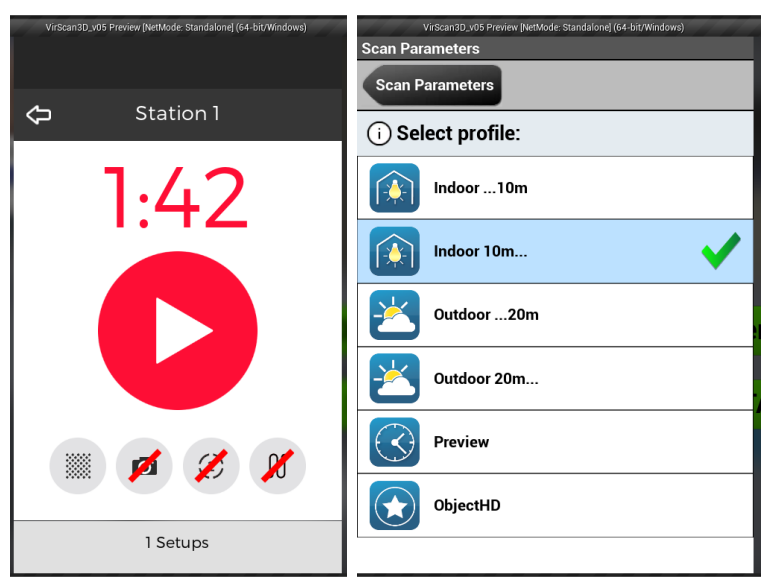

Figure 7: Simulated TLS interfaces; left: RTC360 interface; right: Faro X330 interface. 
After the simulated scanning, a 3D point cloud is generated in Cartesian coordinates (X, Y, Z). According to the station settings, an angular grid of rays is projected from the station point. The intersection of the ray with the first surface gives a discrete point, and its $X Y Z$ coordinates are stored in a text file. The origin of the coordinate system has been set to the station point. The maximum range of surface search is limited to the scanner specifications.

Figure 8 represents an example of a single point cloud, generated by the simulator. It can be seen that point intensities are not fully simulated with the current version of the software; i.e. the material reflectance dependent part of intensity is not implemented yet.

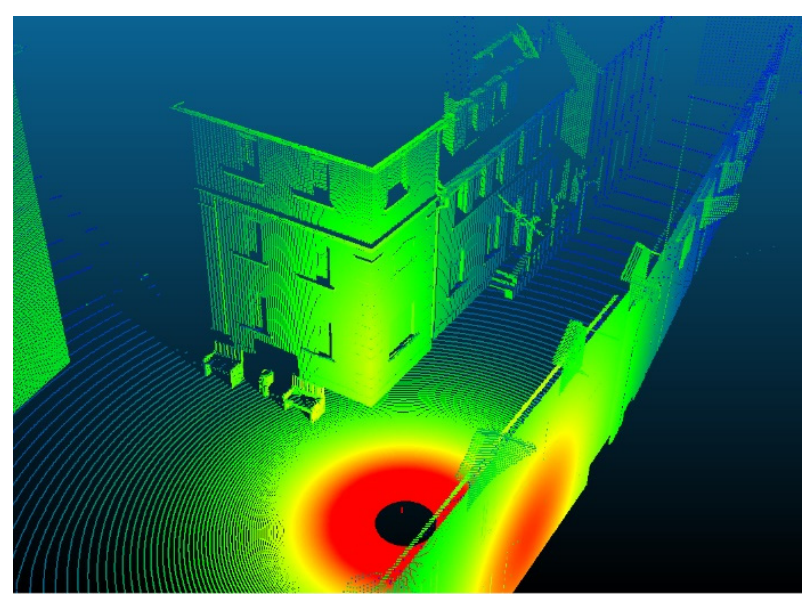

Figure 8: Example of a point cloud of the university office building generated by the simulator

As mentioned above, the current prototype version consists of four terrestrial laser scanner models and one $3 \mathrm{D}$ environment for simulation. It is expected that release versions of the software will have more models of scanners implemented and a possibility to configure custom scanners. A highly detailed and precise $3 \mathrm{D}$ model of the real environment of the University of Bamberg, based on real laser scanning data, was used as a reference environment (see Section 3.1). In future releases, more 3D environments will be accessible. The functionality to place targets is already implemented, which allows users to register resulting point clouds by a target-to-target approach. Also, it is expected that future versions of the simulator will be able to fully simulate intensity and noise.

Since the reference environment shows a realistic and quite complicated example, it is necessary to occupy several scanning locations in order to cover the building surface geometry completely. As in a real-life situation, the roof is the most difficult part to capture in simulation, because of the occlusions and narrow streets surrounding the object of interest. For this reason, some scanning locations were selected at longer distances from the university office building, allowing to scan the roof details as much as possible. During the simulation, 18 stations were selected in order to record the building. The distribution of the simulated scan stations is shown in Figure 9 below.

After the simulation, the 18 scans were exported/saved in a typical industry-standard text file format containing coordinates, intensities and RGB values. At this stage, the simulation part of the fieldwork phase of terrestrial laser scanning is completed and further processing (cleaning, registration, modelling) could be done using any available laser scanning software. In the presented case we used Leica Cyclone software. The 18 simulated datasets were imported and registered by a cloud-to-cloud approach, using the "visual registration" tool for initial alignment. The mean absolute error for enabled constraints results to $0.001 \mathrm{~m}$; while registration errors for individual clouds not exceeding $0.004 \mathrm{~m}$. The error histogram for cloud constraint between stations 10 and 11 is shown in Figure 10.

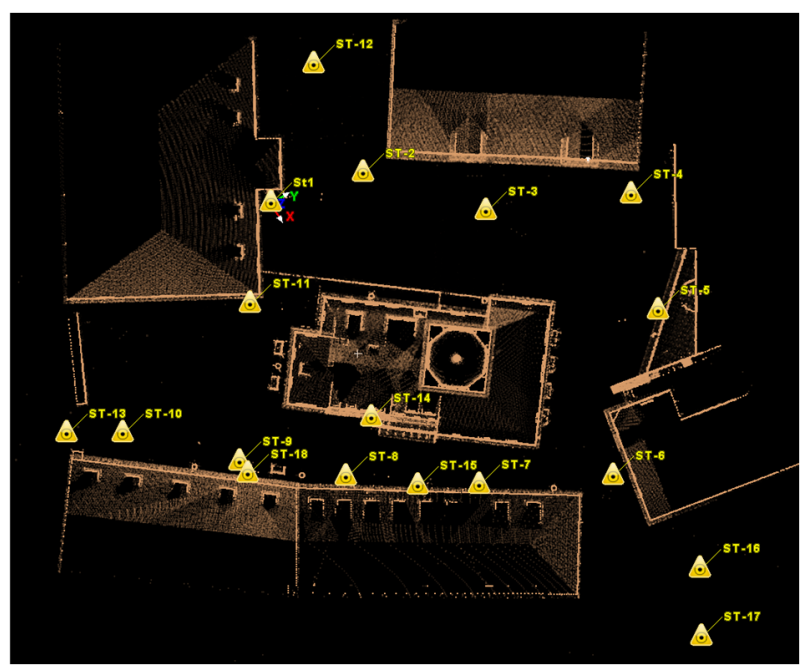

Figure 9: Distribution of simulated scan stations around the university office building.

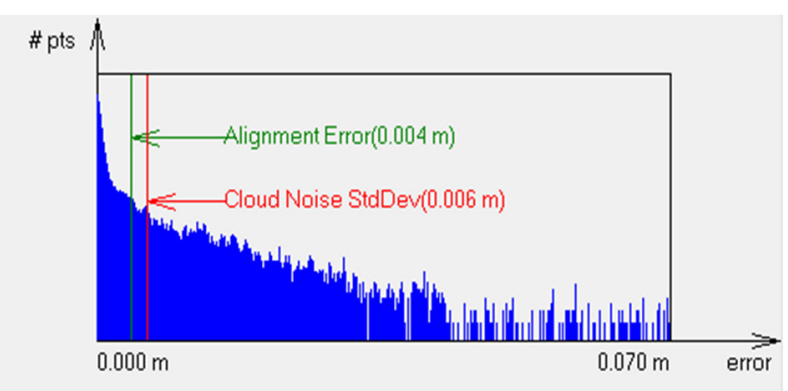

Figure 10: Error histogram for cloud constraint of the simulated point cloud registration (stations 10 and 11).

The registration statistics show slightly better results than one can expect from real scanning and cloud-to-cloud registration. One possible explanation could be that simulated data is free of noise, since noise simulation is not implemented yet in the current prototype version of the VirScan3D simulator.

The final registered point cloud was cleaned and exported as (.pts) file. The unusual intensity values are the result of not fully implemented intensity simulation (Fig. 11).

This chapter has shown that the whole sequence of scanning could be simulated in a digital twin environment, thus generating realistic scanning data which later can be processed, registered and used in the entire data processing chain.

The comparison with real data will be conducted during the future 'summer school' application weeks planned for 2021. 


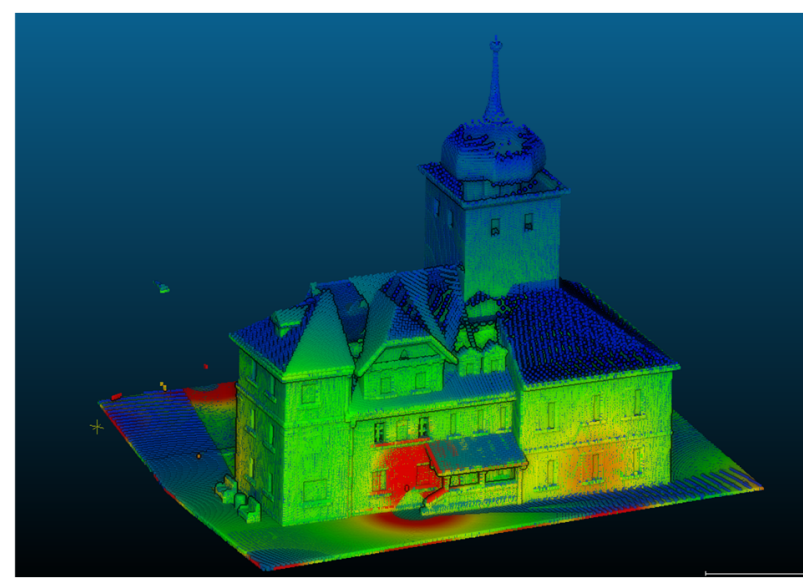

Figure 11: Result of the registered simulated point clouds of the university office building with intricate architectural details of the entrance.

\section{Discussion}

The recent Covid-19 pandemic has demonstrated that digitalization of teaching is necessary, even in those academic programs where classroom teaching is unavoidable, for example, in practical courses with surveying equipment. VirScan3D, as a new virtual instrument for digitised teaching of terrestrial laser scanning, can be used to create 3D point clouds from different stations including strategic target placement; in a further step, these 3D point clouds have to be registered (and if needed geo-referenced) and processed to higherlevel information such as 3D models, architectural drawings or maps. The virtual 3D scanner emulates commercially available instruments with realistic user interfaces and creates 3D point clouds in a virtual simulation according to individual specifications and settings. Highly detailed and accurate BIM models, which represent real-world objects, can be used as training objects within this environment. With such a virtual system, tutors, as well as students, can learn and prepare to operate those devices, generate close-to-reality large $3 \mathrm{D}$ data sets and perform the complete chain of data processing.

\section{Conclusion}

We would like to summarise the work presented here by an evaluation and an outlook for further work on the Virscan3D system.

\subsection{Evaluation}

The developed software tool for the simulation of $3 D$ terrestrial laser scanning allows users to reproduce the sequence of actions at the stage of fieldwork and create realistic 3D scanning data in the absence of a real measuring device. Users can plan their fieldwork in the virtual environment, i.e. specify 3D scanner type and target positions or change scanner settings. In addition, users can observe the process of virtual scanning and analyse the results, e.g. check the density of the point cloud and surface coverage of the recorded object.
Summarizing the simulator features, we state that VirScan3D:

- Gives a good 3D laser scanning visualisation for a hands-on process explanation to use a terrestrial laser scanning device;

- Helps to learn basic terrestrial laser scanning parameters and interface usage, useful for planning of an individual workflow;

- Allows the generation of scanning results comparable with real data;

- Replaces real equipment for practical exercises in case of lacking financing of expensive equipment;

- And is a useful tool for distance learning courses, e-learning and online teaching.

\subsection{Simulator optimization and further work}

Future work will consist of a more realistic simulation of laser intensity based on:

- Material-dependent reflection functions resulting as intensity/RGB values;

- Estimated beam diameter for the area where the laser beam hits a surface element (laser spot).

Point cloud noise simulation functions are also to be implemented:

- Deviations due to distance and angular measurement accuracy;

- Range error due to surface reflectivity;

- Advanced noise functions for surfaces with specific reflectance (water, glass, mirror etc).

Integration of more scanner models with reality-like user interfaces and specifications, and a variety of laser scanning settings specifying such parameters as that can be defined for each scan station:

- Station name;

- Field of view;

- Resolution;

- Quality, etc.

It is also desired that users can load their own 3D model into the virtual environment, which is, however, currently not supported by Unreal Engine.

\section{Acknowledgements}

The project is funded by DAAD (German Academic Exchange Service) from 2019 to 2021 within a program for 'Supporting the internationalisation of Ukrainian universities - shaping the digital future together: GermanUkrainian higher education institution collaborations'.

The financial support and opportunity for this collaboration between three universities, two in Germany and one in Ukraine, is gratefully acknowledged.

\section{References}

Blender. (2020). Home of the Blender project - Free and Open 3D Creation Software. Retrieved October 20, 2020, from 
https://www.blender.org/

Bryan, P. (2017). 3D Recording, Documentation and Management of Cultural Heritage. Conservation and Management of Archaeological Sites, 19(2), 144-146. https://doi.org/10.1080/13505033.2017.1321364

Dib, H., Adamo-Villani, N., \& Garver, S. (2014). Advances in Engineering Education An interactive Virtual Environment for Learning Differential Leveling: Development and initial Findings. Advances in Engineering Education, 4(1), 1-17.

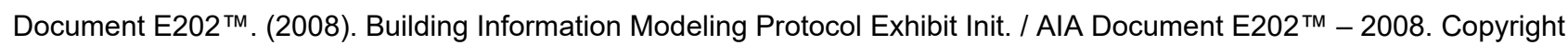
(C) 2008 by The American Institute of Architects.

Dore, C., \& Murphy, M. (2012). Integration of Historic Building Information Modeling (HBIM) and 3D GIS for recording and managing cultural heritage sites. Proceedings of the 2012 18th International Conference on Virtual Systems and Multimedia, VSMM 2012: Virtual Systems in the Information Society, 369-376. https://doi.org/10.1109/VSMM.2012.6365947

Falloon, G. (2019). Using simulations to teach young students science concepts: An Experiential Learning theoretical analysis. Computers and Education, 135, 138-159. https://doi.org/10.1016/j.compedu.2019.03.001

Gómez-Cabrera, A., Paez, H., \& Alvarado, Y. (2016). Digital simulation as a tool for transforming the construction industry. Proceedings of the VII ELAGEC Conference, 577-587.

Hess, M., Garside, D., Nelson, T., Robson, S., \& Weyrich, T. (2017). Object-based teaching and learning for a critical assessment of digital technologies in arts and cultural heritage. International Archives of the Photogrammetry, Remote Sensing and Spatial Information Sciences (ISPRS), 42(2), 349-354.

Hess, M., Schlieder, C., Troi, A., Huth, O., Jagfeld, M., Hindmarch, J., \& Henrich, A. (2019). Digital Technologies in Heritage Conservation. Methods of Teaching and Learning This M.Sc. Degree, Unique in Germany (pp. 53-63). https://doi.org/10.1007/978-3-030-12240-9_7

Jouan, P., \& Hallot, P. (2019). Digital Twin: A HBIM-based methodology to support preventive conservation of historic assets through heritage significance awareness. ISPRS - International Archives of the Photogrammetry, Remote Sensing and Spatial Information Sciences, XLII-2NW15, 609-615. https://doi.org/10.5194/isprs-archives-XLII-2-W15609-2019

Jouan, P., \& Hallot, P. (2020). Digital Twin: Research Framework to Support Preventive Conservation Policies. ISPRS International Journal of Geo-Information, 9(4), 228. https://doi.org/10.3390/ijgi9040228

Kersten, T. P., \& Edler, D. (2020). Special Issue "Methods and Applications of Virtual and Augmented Reality in GeoInformation Sciences." PFG - Journal of Photogrammetry, Remote Sensing and Geoinformation Science, 88(2), 119-120. https://doi.org/10.1007/s41064-020-00109-w

Kravchenko, I., Luhmann, T., \& Shults, R. (2016). Concept and practice of teaching technical university students to modern technologies of 3D data acquisition and processing: A case study of close-range photogrammetry and terrestrial laserscanning. ISPRS - International Archives of the Photogrammetry, Remote Sensing and Spatial Information Sciences, XLI-B6, 65-69. https://doi.org/10.5194/isprs-archives-XLI-B6-65-2016

Peruzzini, M., Pellicciari, M., \& Bil, C. (2018). Transdisciplinary Engineering Methods for Social Innovation of Industry 4.0: Proceedings of the 25th ISPE Inc. International Conference on Transdisciplinary Engineering. 00007 (August), 1250.

Unreal. (2020): The game engine. Retrieved October 14, 2020, from https://www.unrealengine.com

Vlachopoulos, D., \& Makri, A. (2017). The effect of games and simulations on higher education: a systematic literature review. International Journal of Educational Technology in Higher Education, 14(1). https://doi.org/10.1186/s41239017-0062-1

Wied, C. (2007). UNIChron: Geschichte und Geschichten der Gebäude der Otto-Friedrich-Universität Bamberg. Ed. Lehrstuhl für Kommunikationswissenschaft der Otto-Friedrich-Universität Bamberg. Bamberg: Universitäts-Verlag 


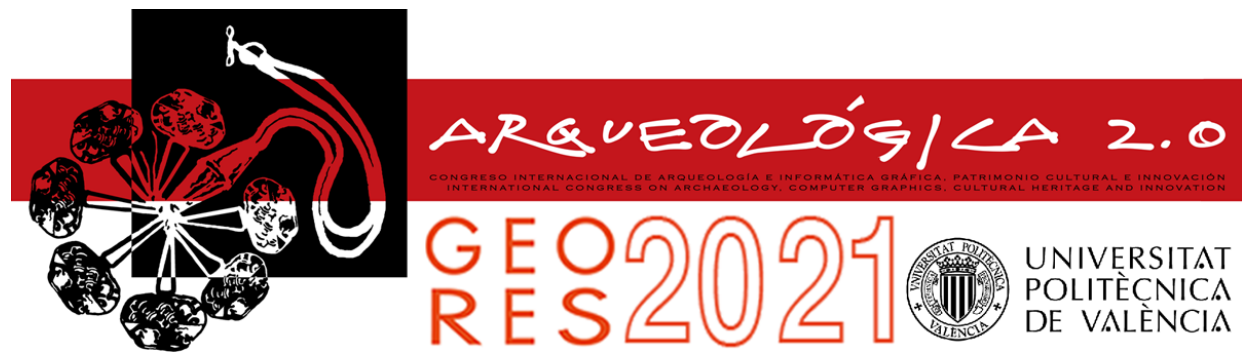

Proceedings of the joint international event $9^{\text {th }}$ ARQUEOLÓGICA

$2.0 \& 3^{\text {rd }}$ GEORES

Valencia (Spain).

26-28 April 2021

\title{
CONSIDERATIONS AND QUESTIONS DERIVED FROM THE APPLICATION OF A SCAN-TO-BIM MODELING PROCESS OF A HISTORICAL PUBLIC BUILDING
}

\author{
Franco Guzzetti", Karen L. N. Anyabolu, Francesca Biolo, Lara D’Ambrosio
}

Department of Architecture, Built Environment and Construction Engineering, Politecnico di Milano, Via Ponzio 31, 20133 Milan, Italy. franco.guzzetti@polimi.it; karenlara.anyabolu@polimi.it; francesca.biolo@polimi.it; lara.dambrosio@polimi.it

\begin{abstract}
:
According to the new Italian regulation (DM 560-17), every building project has to present a BIM model. The purpose of this new attitude is to better manage every single part of the building process, until the maintenance in the years. With these terms, public administrations should have guidelines to collect different data projects in a standard way for an optimal organization. The importance of standards is even more felt with HBIM, so when the subjects are historical buildings and Architectural Heritage. Analysis of the case study and its digitization process has brought to light many problems, some of them directly regarding the software, others are critical issues discussed in the following paper. The teamwork highlights the modelling phase's criticalities for irregular and complex elements, a central feature for historical buildings but also an important limit for today's BIM software. Secondly, this work regards essential data integrated to complete historical BIM. Lastly, the theme of the digital-twin, that is meant as a complete, and as-is model. The main issue is to understand if this unique detailed model - with the same BIM's LOD of new buildings - is enough to aggregate all the information or is it better to create multiple 3D models based on different aims: structure, history, maintenance, and so on. Some examples of critical points are exposed and discussed, referring to a hypothetic conservation project.
\end{abstract}

Keywords: scan-to-BIM, HBIM, historical building, public administration, BIM modelling

\section{Introduction}

\subsection{Legislative framework and public administration}

In the last years, the regulation of public tender has changed following the development of new technology. One of the main aims is to use the BIM methodology in the design and construction phases. The introduction of this tool represents an international reform, which has led to various results in different countries in term of standardization. The BIM presence is already deeply rooted in the same states like Germany, the United Kingdom and other countries of Northern Europe. Instead, the deadline for Italy is in 2025 . For that period, every project (new, restoration, enlargement, infrastructures) should be presented in BIM (Ministry of Infrastructure and Transport, Ministerial Decree, 1-122017, n. 560).

Furthermore, respecting the no soil consumption's purpose, many regional and municipal funding is arisen to restore buildings in the old town and abandoned constructions, especially for public schools.
In this period, projects on existing constructions have augmented rapidly, and most of the time, buildings are historically significant and they show the result of years of changing. To create BIM, it is necessary to start with an adequate survey phase (Osello, Lucibello, \& Morgagni, 2018; Tommasi, Fiorillo, Jiménez Fernàndez-Palacios, \& Achille, 2019) that allows us to obtain all the information to model the building; then, it is possible to proceed with the project, construction, and maintenance. Considering the entire life cycle of a structure, from public tender to facility management in the years, is one of the principal innovations with a BIM, Building Information Model.

This kind of process has a higher level of complexity in an existing building than in a new one due to irregularity of geometries, particular elements, difficulties obtaining information, and lack of software commands (Guzzetti, Anyabolu, D'Ambrosio, Marchetti, \& Sarrecchia, 2018).

The experience of teamwork aims to explain different issues individuated. The interaction between laser scanner survey, historical investigations, and BIM standards allow creating of a model suitable for a hypothetic conservation and renovation project. The potentiality of digitization in every sector is crucial, especially for Smart Cities and all the loT applications for the built (Angelidou, Angelidou, Karachaliou, \&

“Corresponding Author: Franco Guzzetti, franco.guzzetti@polimi.it 
Stylianidis, 2017; Bie et al., 2018; Atta \& Talamo, 2019; Lerario \& Varesano, 2020).

In this case, the Scan-to-BIM method is focused on framing a historical BIM into guidelines that are necessary for the municipal technical office to manage its immovable properties. The challenge is to keep together an official regulation for Facility Management and generic quantification of spaces in the municipality and maintain features, details, and structural and historical information fundamental in an ancient building.

\subsection{Condition for exploiting the potential of BIM}

Creating a BIM has an extreme value in the management view; it permits working with a long-term vision on a building. It is possible to compute construction costs and defining strategy for the next years, calculating the price of a restructuring or maintenance, quantifying changes in the energetic building class considering the substitution of several elements. For instance, the shell with fine quality materials allowed to save a considerable amount of money in the years, and with a BIM, a direct and fast comparison is feasible.

Furthermore, this kind of analysis is suited to choose adequate materials considering CAM (Criteri Ambientali Minimi - Minimum Environmental Criteria): the Italian regulation for better building recycling management.

All things considered, the model should follow official rules to be aligned to municipal documentation and respect criteria of calls for public funding, usually concerning structural analysis, landscape, and contest evaluation, historical information and consideration, maintenance of relevant historical-architectural elements. Another important theme is the valorization of the building that is difficult to show and explain through BIM if the model tends to become too simplified according to the guidelines. How can BIM maintain together all the requirements? Is it possible to have an actual digital twin referring to a historical building?

Nowadays, many different H-BIM approaches are analyzed (Lopez, Lerones, Llamas, Gomez-GarciaBermejo, \& Zalama, 2018): creating mesh and using NURBS are appropriate solutions to follow the realistic shape of the irregular and complex building (Barazzetti, Banfi, Brumana, \& Previtali, 2015) visible in a point cloud. Still, models do not have standard elements, of course. Different LOD can be defined in modelling (BIMForum, 2018), or GoG referring to NURBS (Banfi, 2017), but it is necessary to consider a high level of detail to obtain correct BIM, both from a geometrical and informative point of view. It is interesting comparing a new building model and an existing building model. For the first one, it is usually feasible to reach LOD 500 (LOD F for Italian scales) the same LOD of the as-built (Mirarchi, Lupica Spagnolo, Daniotti, \& Pavan, 2020) owing to all the data present in the design phase (until technology node and detailed stratigraphy). It is more difficult for the second one to obtain this high LOD level due to the lack of information on the construction phase (materials, facilities, dimensions); the available documentation is not often enough. To gain the correct information and create detailed BIM is necessary to consider teamwork to integrate different knowledge and investigations
(Tommasi, Fiorillo, Jiménez Fernàndez-Palacios, \& Achille, 2019).

\section{Case study: Palazzo Trivulzio's model}

\subsection{Historical building and survey phase}

The building analyzed for this research is Palazzo Trivulzio, situated in the old town of Melzo, $20 \mathrm{~km}$ east of Milan. The construction has great importance in the history of the entire city; it results from numerous overlays, enlargement, and changes of use destinations over eight centuries that lead to today's complex building.

In the first place, there was the castle of which today is possible to recognize the XIII century tower and the internal facade of the west wing facing the courtyard, with pointed arches. Between 400 and 500, the building consisted of three courts, and now only one of them is visible. In 1600 it became a representative villa of the local landlord, and on this occasion, various chambers were enriched with frescoes, and different spaces were modified. Unfortunately, two centuries after this period, a change of ownership was made, which leads to a period of decline.

In the middle of 1800 , the municipality acquired the palace (precisely in 1866) to host a public school. In the last century, in the first decades, a movie theater was realized that is still in function (north part), while, since 1980, the south-west sector was restored to host public library and communal halls and spaces. With the inauguration of a new library in 2014, its communal part is currently little used.

Together with other 23 buildings, property of the Municipality of Melzo, Palazzo Trivulzio is considered inside a massive pluriannual project that aims to digitized public buildings creating BIM to improve facility management. For this reason, the modeling phase involves the use of specific guidelines (Di Giuda et al., 2020) defined by BIMGroup, a Politecnico di Milano's team in the Department of Architecture, Built Environment and Construction Engineering. The team work in the construction field, primarily to obtain informative models for building maintenance over time. Simultaneously, as said before, the BIM should contain the information for conservation and design phases.

The geometrical survey has been conducted by Digitarca s.r.l.s. using a static laser scanner; in three days on the field: it has been carried out 300 scans for both exterior path and interior rooms, and in total, $5.400 \mathrm{~m}^{2}$ of plot and $20.100 \mathrm{~m}^{3}$ of the building are investigated (Fig. 1).

The complete point cloud (after a cleaning step) has a size of 23,7 GB; the product is indispensable to modelling but not by itself: it is necessary an accurate and careful analyzing phase to generate a usable model or to extract the information needed.

\subsection{Modelling settings}

The geometrical modelling phase is conducted with Revit Autodesk software to follow inputs defined by the Municipality of Melzo in collaboration with BIMGroup. To work correctly is fundamental to choose in advance the level of detail and level of accuracy, in agreement with the ultimate goal of the model as happens for typical $2 \mathrm{D}$ 
drawings. Considering the graphics error at a medium scale of 1:50, the model permits a tolerance of $+/-2 \mathrm{~cm}$, except for particular elements with more close attention to details described in the official guidelines.

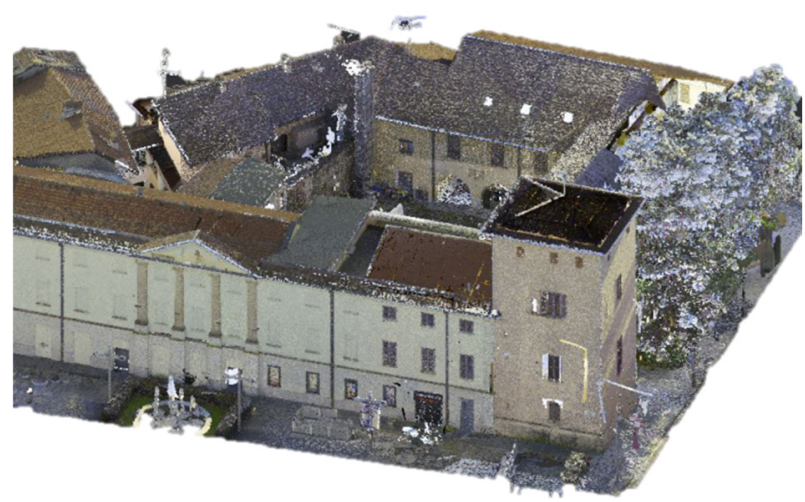

Figure 1: View of point cloud generated from the laser scanner survey

Despite this correct process to define tolerance, in the case study, the geometric irregularities generate considerable problems in the modelling phase (Osello, Lucibello, \& Morgagni, 2018; Stanga et al., 2017; Tommasi, Fiorillo, Jiménez Fernàndez-Palacios, \& Achille, 2019, Banfi, 2020): the aim of Facility Management, in some cases, leads to excessive simplification of geometries, and this out-of-tolerance may invalidate some metric calculations, for instance, the number of finishes. This topic will be discussed in the following chapters. Anyway, the shared rules are useful to determine standards and a methodology for the classification and creation of elements.

It is known that BIM software is thought and set for new constructions, and in the case of historical buildings, many obstacles are shown. Modelling is intricate and complex. It is necessary to create numerous specific families and elements different from the standards ones or particular shapes of walls and floors; consequently, even the name categorization is more arduous to define.

Among the various issues, in the following pages, problems concerning wall modelling and settings are analyzed; the experience also shows that the same issues could be found in other irregular existing buildings because of the lack of the starting information.

\subsection{Geometrical modelling criticality in irregular elements: the creation of a wall on Revit}

In order to follow the guidelines defined by the Municipality, Autodesk Revit has been the best tool to model the building due to the creation of families with specific attributes and parameters. The aim of the regulatory documents is to set an adequate protocol for every type of building. The project is incredibly challenging because the examined building shows numerous particularities that could be better modelled exploiting other smart solutions and the integration among different software, as the use of NURBS (Barazzetti, Banfi, Brumana, \& Previtali, 2015). An example is the creation of an irregular wall.
In a new building, modelling is facilitated thanks to the detailed information of stratigraphy, features, technical data are defined in project phases and they are reported in relevant parameters. In the case of existing constructions, many precise details are missing, and the geometry of elements are not standard. Historical buildings present irregularities due to physical deterioration, structural failures, substitutions, and replacements carried out over time (Osello, Lucibello, \& Morgagni, 2018); but also because, in the past, the constructions were built differently from the standard way of today. The global deviation between the modelled element on Revit and the point cloud profile is bigger than the initially imposed $2 \mathrm{~cm}$ tolerance. The simplification in this software is necessary to create a model following standard rules, useful to manage a typical system. Still, in some cases, this method cannot solve the problems presented.

1) Variable thickness. A first example is related to the walls with a variable thickness both in plan and in section, with a regular course. The simplest solution is to create a local component because it is easier to modify considering shape and dimensions, but the element is hard to categorize. For this reason, in the project, it has been decided to choose a standard type of wall and then cut it with void elements (Fig. 2 ). In this way, the wall features are considered, but other problems arise: voids deleted part of the wall material, so the cut eliminates the finish and eventually interior layers. It is necessary utilizing a command to paint the wall in cut parts (Fig. 3). Furthermore, thick wall classification is wrong because of the voids that modified the wall geometry.

2) Elements of the junction. Another problematic case is the junction between not orthogonal elements, significantly more than two walls. This problem is exclusively a software lack because the automated solutions lead to different junction node conformations but it is hard to intervene manually (Fig. 4).

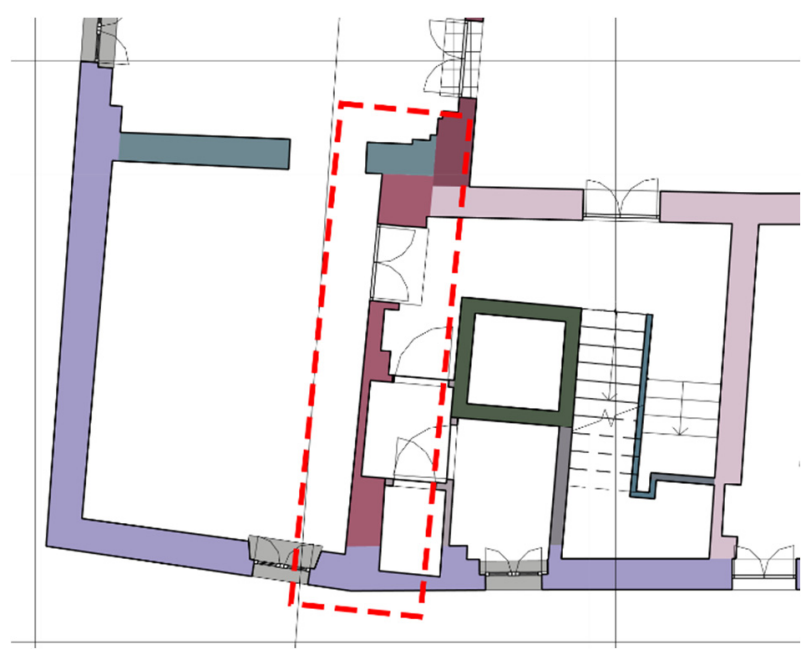

Figure 2: Masonry consisting of one type of wall with the application of voids. 


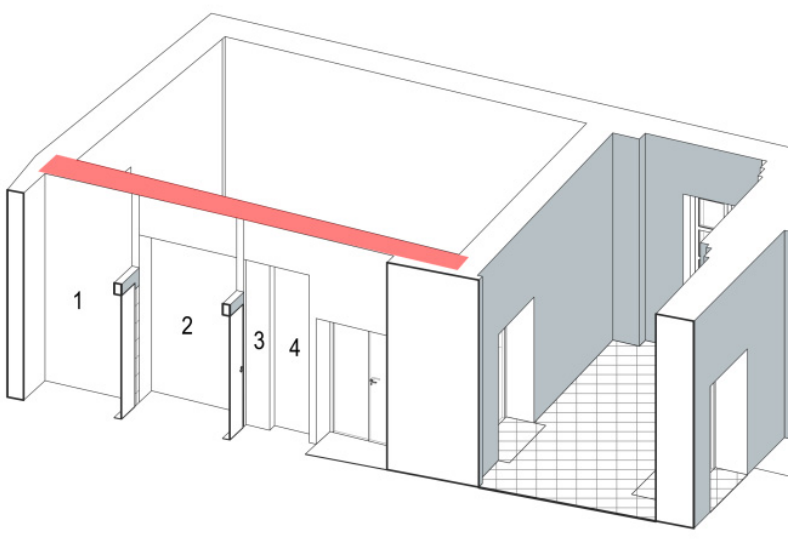

Figure 3: Numbers indicate different finish material in the same Revit type wall.

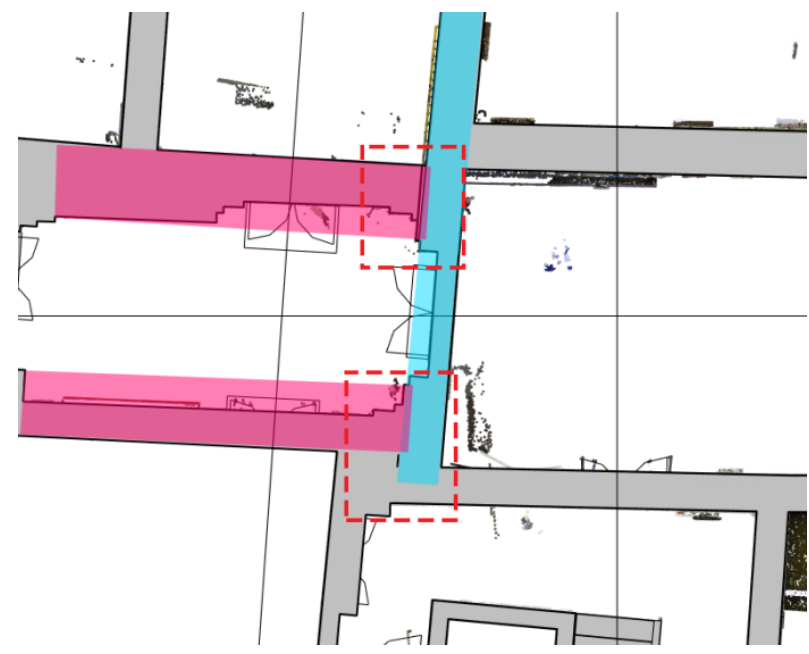

Figure 4: The overlay of not orthogonal walls may cause errors in the count of quantities.

In many cases, not orthogonal (and irregular) walls create critical points that remain unsolved. The element's position will be out of tolerance and may cause a problem in the next phases

3) Missing data. In Revit, to create a wall, it is necessary defining at least one material in the stratigraphy section. Considering that, in an existing building, the only way to precisely know the walls' characteristics is through coring or others not destructive investigations, walls are always described as "generic wall", a default element with unknown features. During point cloud analysis, it has been individuated different points where the material is undefined, but also geometry is unclear (Qiuchen \& Sanghoon, 2017). It might be interesting to distinguish between default material and non surveyed element.

As it happens in typical 2D drawings, in many cases is useful to individuate parts of building not known to understand which parts can be further investigated. Instead, in a BIM, every object is modeled with a determinate geometry. It is common to use the model as a complete and correct base for projects due to the higher technological level reached, and the model is derived from a high-precise laser scanner survey. It is crucial to annotate the lack of information and make them visible in the virtual model. The problem recurs in several constructive elements, i.e. vaults and slabs (Fig. 5) (Fig.6).

4) Partitions of a unique element. The next example analyzes an integral wall that, in the modeling phase, has to represent in different separated parts. The figure, constructively and visually, can be referred to as a unique wall with particular features. As mentioned, it is a single element; it was made simultaneously and with the same technology indeed. However, it presents narrowings because of the realization of some niches, and there is a change of parietal finish, for example, in sanitary facilities.

Ideally, in the 3D model, the wall should have a continuous development throughout its length with additional and editable elements, such as the change of finish or subtractions for the creation of voids (Fig. 7). Instead, working with Autodesk Revit, the wall results from the juxtaposition of as many walls as there are sections with different characteristics. The wall with the smaller thick will be a separate element from the bigger ones. The change of finish defines the creation of another type of masonry with slightly different characteristics. The software settings bring the user to this approach, according to the features of the wall family. However, considering, for example, this wall as a bearing one, such modelling would not be correct. Indeed, it would include attributes that are not relevant for constructing the building (such as finishes), and it invalidates the main characteristic of the element (the structural one).

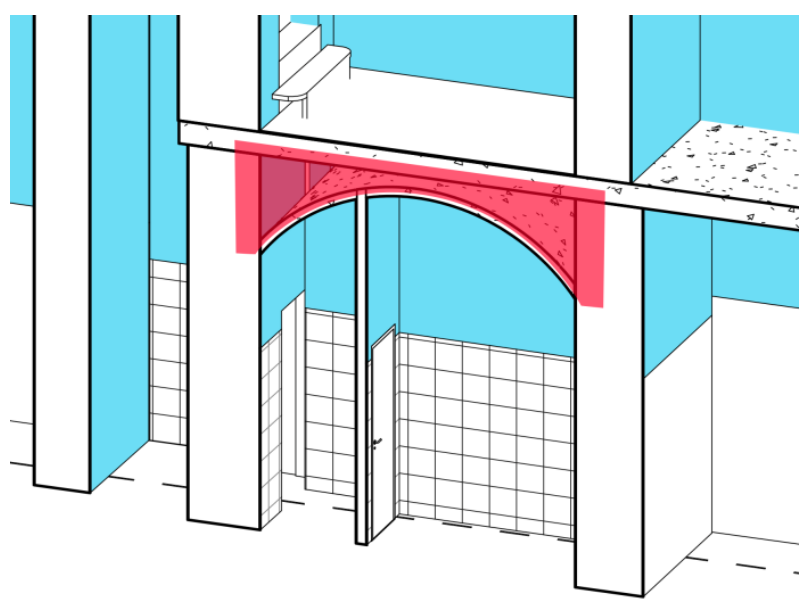

Figure 5: The not surveyed part between floor and intrados is highlighted. In this case, it was not possible to define correct thicknesses and stratifications.

The stratification of several historical phases and corresponding architectural elements is another aspect of masonry (extendable to other parts) (Stanga et al., 2017; Banfi, Stanga, \& Brumana, 2018). In historical buildings, the articulation of some objects and the processes that generated them are not often known. They are unique and not standard elements, and they are often unsolved points of the cognitive phase. In these situations, what is the more correct line to follow? Consider a junction point of two parts of the same building, built at different times. Observing the abnormal thickness and the various surface trends could be viewed as consisting of two juxtaposed structures. All this could result from the combination of two elements with a cavity, or even of a single wall with two layers of external finish. The latter 
solution is less logical but possible, according to the BIM scheme. The modeling of these three options has different consequences during the design and material cubic meter estimation or structural analysis (Fig. 8).

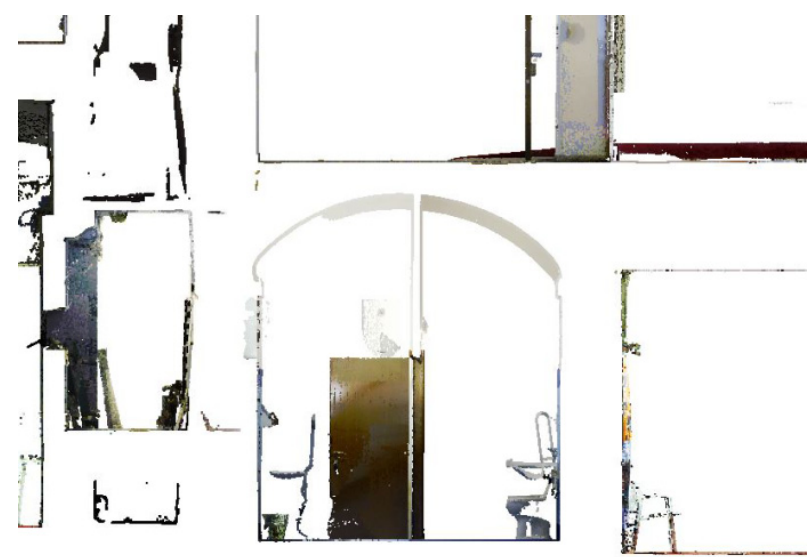

Figure 6: A point cloud section shows the thickness of the structures where is impossible to understand stratifications and nodes with certainty.

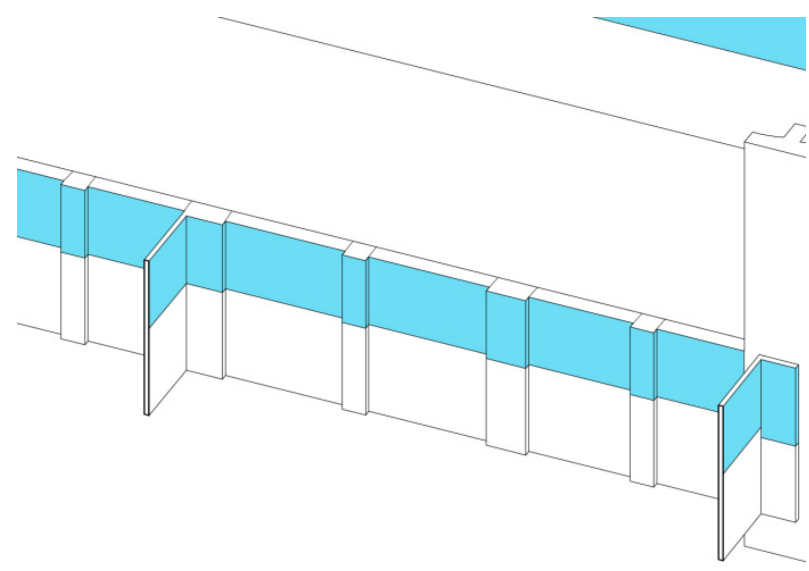

Figure 7: Partition of a wall owing to the difference in thickness of different parts.

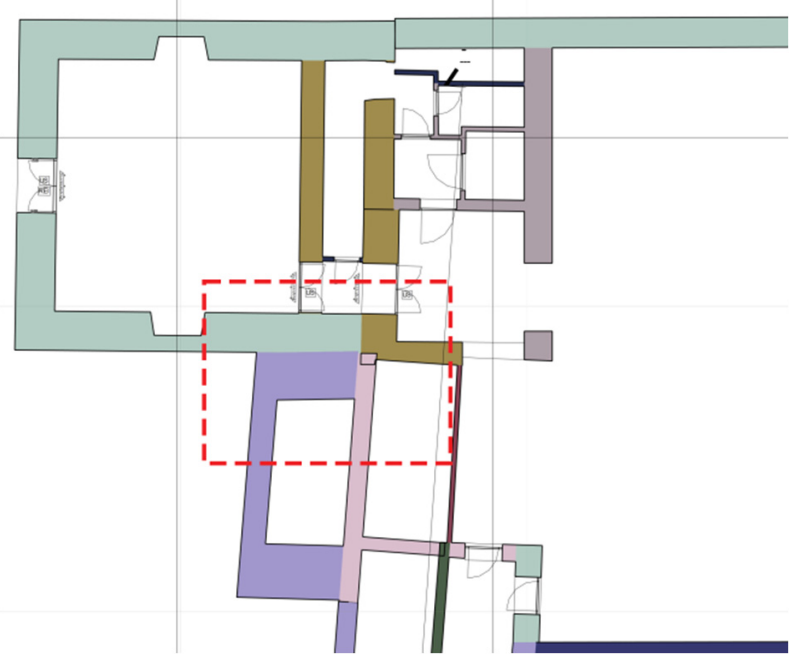

Figure 8: Junction of blocks built in different historical periods is created with different types of wall.

In the chance of a further development of the software, it would be helpful to add the feature of creating a new annotation for the element not surveyed, as explained in the following chapter.

\section{Considerations arising from the case study}

\subsection{Functionality of the BIM for historical buildings}

Setting up a BIM model of a preexistence requires a high level of knowledge of the structure itself, including as much information as possible. Historical buildings, therefore, imply a particular geometric and historical survey, typical of the conservation sector. A BIM system peculiarity is to reduce significantly, during the construction phase, the in-process variations. All this, thanks to its ability to manage information at every stage and part of the project. Precisely the in-process variations are one of the weaknesses in the construction sector, especially for public buildings due to the massive changes in the project costs, almost always adverse, and the difficulties in terms of consequences and operations managing. Designing, with this type of technology, to avoid variants as much as possible, is strategic. Therefore, this process has to be possible also for existing buildings that are often involved in complex redevelopment projects. But it will be possible only if the state of fact, with which the construction site then faces, is accurately detected (and modelled) and if software precisely responds to all the singularities found in an existing building. Otherwise, the BIM model needs to be reviewed during the work, with evidence manifestation. Standardizations in the modelling phase are understandable in new building construction, converting to an industrial approach (construction 4.0). However, they are not always acceptable in realizing a preexistence state of fact because they often involve massive adaptations of the project in modelling.

In many cases, BIM aims to be a digital twin of the built starts from the state of fact. If this could not be possible, it would be difficult to design and model MEP systems, structures, and other parts that need a precise model. The work of the various figures involved could not be organized, as indicated by the UNI 11337 legislation (Building and civil engineering works - Digital management of the informative processes, UNI11337:2017). The initial investment is necessary in order to model the different parts of the existing in an accurate way, and to collect data; this will allow the BIM to function properly in the long run. The problems above, are not affecting only the architectural model. BIM must be able to generate as directly as possible the structural resistance. Furthermore, BIM should support interaction with sub-services, urban areas development and related infrastructures and urban technological installations (Guzzetti, Anyabolu, D’Ambrosio, \& Marchetti, 2019).

Considering another point of view, it could be extremely interesting and useful a BIM for Facility Management (FM) as mentioned before (Di Giuda et al., 2020). But what are the problems, considering work in a BIM system aimed at Facility Management?

In order to obtain and visualize all the information needed for the management of a building, the idea of a precise and perfect digital twin could be really different. Despite creating a more schematic model, it is possible to relate 
all the information and parameters to a specific Autodesk Revit family. The element contains the correct data, it is computable, it has a particular positioning inside the model, therefore in an FM concept the precision of geometry is not essential. It is certain that some problem arises anyway, due to the software settings, but the scope of the model is reached. Following the guidelines, one of the most evident problem is the correct counting of the surfaces.

Considering a room, there is the necessity to count square meters of a specific type of finish, for instance, plaster. The irregular geometry of masonry it is defined using a void: in this way the finish of the wall is cutted out and the quantity of finishing change. In this case study, in order to follow as much as possible the point cloud, it is necessary to modify and trim numerous walls and this method invalidates the actual count. The solution described before is a procedure for in-place modelling. Therefore, the final result is correct but it is not among the standard attributes of the element.

\subsection{Possible parameters integration for a historical building}

Autodesk Revit defines the wall typologies organization. This software does not create a generic wall element to assign parameters that describe and complete it. In contrast, for each feature change, Autodesk Revit creates a new element in the library. In this way, the result is an endless list of walls with different and combined characteristics. This problem occurs not only with masonries but also with other building components, e.g., windows. All this, rapidly becomes challenging and limiting, working on a historical building.

Other parameters to explore:

- Element dating. Knowing the building's age leads to greater awareness in the design and maintenance phases. It can be better understood the needs of the building.

- Deterioration phenomena and information transmission. Always referring to the building, primarily to manage the design phase in a BIM environment, it is increasingly important to model this sort of data. But how can this information be inserted into a model? How can we make them easily readable and immediately noticeable? In Palazzo Trivulzio model, it has been created notes connected to the elements. This methodology is proving uncomfortable because it is not possible to query and to visualize these annotations automatically. Knowledge of the elements on this particular topic is a laborious and not immediate process. Revit should be able to manage new objects tool related to pathology and deterioration analyses and representation. The purpose is to obtain a BIM model aimed to facility management. In this context, it would be more useful to interact with this information and make them an integral part of the modeled objects. It is essential for promoting more performing interventions and actions closer to structure needs. For this reason, it is necessary to know these phenomena and their effects on the building system.

- Points of attention. As already mentioned before, it is not always possible to obtain all the necessary information relating to every element of a pre-existence and even more of a historical building. Questions are as many as the wall compositions, not visible structures or particular surveyed geometries hypothesis. It might be useful to add an extra phase dedicated to these uncertainties to highlight them and clarify the further possible interventions for cognitive purposes. It could be a layer where to insert all those elements on which there is not full knowledge. Therefore, they are points of attention in the intervention phase. This solution could be useful during the design phase as a knowledge indicator of building and starting point for further investigation activities.

During the work, it is resulted that is extremely difficult to create a definitive library in Autdodesk Revit, especially working with existing buildings because of their unique and non-standard elements. The list rapidly increases every time a new building is added. These derive not only from irregularities and object peculiarities but also from the settings of the software used. Therefore, is it conceivable imaging changes to software and operating standards to obtain a more organized and flexible system?

It has been analyzed a comparison with the GIS environment. As an example, in the DBT documentation (the CISIS Topography DataBase for Regione Lombardia), the classification "layer, theme, class" never cites geometric characteristics because the geometries are modelled or defined in the drawing. The geometric information is not explicit in the name of the element and it is not a distinctive attribute in the model: this allows the creation of a more orderly classification system. The experience with this different logical scheme leads to classifying elements in a more flexible way. The structure would be easily implementable with the use of codes. Moreover, the shapefiles can be punctual, linear or areal and the same organization could be used for deterioration mapping mentioned before.

\section{Conclusions}

Several critical issues have been highlighted during the modelling of Palazzo Trivulzio. All things considered, for a complex existing building, it could be necessary to have multiple digital models, everyone for a given function but related one to each other.

The structural model (Tucci et al., 2018), which tends to simplify, will define the main elements without precise geometric accuracy but considering the future purpose of the model itself and the structural verifications it might will used for. Based on the accuracy decided a priori, the architectural model will have to describe specifically the elements and potentially also the historical phases, which allow understanding the actual building shape. Finally, the 
facility management model, which manages the building as a whole, deals with spaces, and the estimation of surfaces could be more streamlined.

Therefore, the BIM can hardly be a real and precise digital twin of the building. The model does not match perfectly with the survey point cloud despite the set tolerances (based on the chosen model type and its features) and the analysis of the available informative materials. The important thing is to define the adequate accuracy for the model, that is related to the construction on site and to the executive project. If, for a new construction, it is a consequence of project phase, for an existing building, it is essential to specify before starting the modelling phase. Furthermore, it is relevant for choosing the appropriate methodology for the survey phase in order to avoid unnecessary work. In this case, the laser scanner survey generated an extremely precise point cloud that allowed to analyze the building in its complexity and understand nodes that would not be caught by direct analysis and theodolite survey.

In order to better understand the modelling problem in Autodesk Revit, it is interesting to consider that in the facility management field often is not necessary to work with a precise model: software analyzes data and quantities and the actual shape is less significant for this kind of studies.

To summarize, it could be interesting to think about different models (with different simplification) and even manage the database related to the model as a precious item to further analyze in other software.

Talking about pre-existences and especially historical buildings, it is necessary to create elements with irregular geometries. This requirement is not always supported by Autodesk Revit, and it is indispensable to intervene with different software. This observation is supported by the constant current demand for a BIM model for any intervention on any type of building, new and existing. As described above, assuming to work with different models, BIM with simplified geometries is undoubtedly a useful and usable tool for various activities. Still, it is not adequate for detailed modelling of the built.

One thing is certain: if the world of construction and its standards are increasingly moving towards the BIM world, the evolution of the modelling of the preexistences is necessary. It is expected an update and a development of various BIM software in order to enhance the modelling of heritage buildings (irregulars and complexes). If that does not happen, it will be necessary to find a different method to intervene on this type of buildings because, especially in Italy, there is an elevated number of preexistence to valorize and to renovate. The effective solutions that involved different software and skills are adequate but the aim is to define a unique system that can be used by public administrations in order to respect the next deadline legislation.

\section{References}

Angelidou, M., Angelidou, T., Karachaliou, E., \& Stylianidis, E. (2017). Cultural heritage in smart city environments. Int. Arch. Photogramm, Remote Sens. Spatial Inf. Sci., XLII-2/W5, 27-32. https://doi.org/10.5194/isprs-archives-XLII-2W5-27-2017

Atta, N., \& Talamo, C. (2019). Digital transformation in facility management (FM). loT and big data for service innovation. In: Daniotti, B., Gianinetto, M., Della Torre, S. (ed) Digital Transformation of the Design, Construction and Management Processes of the Built Environment. Research for Development. Springer, Heidelberg, $267-278$. https://doi.org/10.1007/978-3-030-33570-0_24

Banfi, F. (2017). BIM orientation: grades of generation and information for different type of analysis and management process. Int. Arch. Photogramm, Remote Sens. Spatial Inf. Sci., XLII-2/W5, 57-64. https://doi.org/10.5194/isprsarchives-XLII-2-W5-57-2017

Banfi, F. (2020). HBIM, 3D drawing and virtual reality for archaeological sites and ancient ruins. Virtual Archaeology Review, 11(23), 16-33. https://doi.org/10.4995/var.2020.12416

Banfi, F., Stanga, C., \& Brumana, R. (2018). A Digital Workflow for Built Heritage: From SCAN-to-BIM process to the VRTour of the Basilica of Sant'Ambrogio in Milan. 7th International Conference, EuroMed 2018, Nicosia, Cyprus, October 29- November 3, 2018, Proceedings, Part I

Barazzetti, L., Banfi, F., Brumana, R., \& Previtali, M. (2015). Creation of Parametric BIM Objects from Point Cloud using NURBS. The Photogrammetric Record, 30(152), 339-362. https://doi.org/10.1111/phor.12122

Bie, R., Bocchi, Y., Genooud, D., Jara, A.J., Song, H., \& Sun, Y. (2015). Internet of things for cultural heritage of smart cities and smart regions. 29th International Conference on Advanced Information Networking and Applications Workshops, Gwangiu, South Korea, 2015, 668-675. https://doi.org/10.1109/WAINA.2015.169

BIMForum. (2018). Level of development specification.

Di Giuda, G. M., Paleari, F., Schievano, M., Seghezzi, E., Locatelli, M., Pattini, G., Pellegrini, L., Campi, S., \& Tucci, A. (2020). Linee guida Melzo BIM 1 - Modellazione informativa di interventi di nuova costruzione.

Di Giuda, G. M., Paleari, F., Schievano, M., Seghezzi, E., Locatelli, M., Pattini, G., Pellegrini, L., Campi, S., \& Tucci, A. (2020). Linee guida Melzo BIM 2 - Modellazione informativa di interventi su edifici esistenti.

Di Giuda, G. M., Paleari, F., Schievano, M., Seghezzi, E., Locatelli, M., Pattini, G., Pellegrini, L., Campi, S., \& Tucci, A. (2020). Linee guida Melzo BIM 3 - Modellazione informativa di interventi di manutenzione ordinaria e straordinaria.

Guzzetti, F., Anyabolu, K. L. N., D’Ambrosio, L., Marchetti, G., \& Sarrecchia, S. (2018). Dal rilievo al modello BIM di una 
piazza. XXII Conferenza Nazionale ASITA, 27-29 novembre 2018, Bolzano, 577-584

Guzzetti, F., Anyabolu, K. L. N., D’Ambrosio, L., \& Marchetti Guerrini, G. (2019). Built environment: modelling the Urban Space. Int. Arch. Photogramm. Remote Sens. Spatial Inf. Sci., XLII-2/W11, 595-600. https://doi.org/10.5194/isprsarchives-XLII-2-W11-595-2019

Lerario, A., \& Varesano, A. (2020). An loT smart infrastructure for S. Domenico church in Matera's "Sassi": a multiscale perspective to built heritage conservation. Sustainability, 12(16). https://doi.org/10.3390/su12166553

Lopez, F. J., Lerones, P. M., Llamas, J., Gomez-Garcia-Bermejo, J., \& Zalama, E. (2018). A review of Heritage Building Information Modeling (H-BIM). Multimedial Technologes and Interact, 2(21). https://doi.org/10.3390/mti2020021

Ministerial Decree, (2017). Ministerial Decree, 1-12-2017, n. 560, Ministry of Infrastructure and Transport, Italy

Mirarchi, C., Lupica Spagnolo, S., Daniotti, B., \& Pavan, A. (2020). Structuring General Information Specifications for Contracts in Accordance with the UNI 11337:2017 Standard. In: Daniotti B, Gianinetto M, Della Torre (Eds.) Digital Transformation of the Design, Construction and Management Process of the Built environmrnt. Research for Development. Springer, Cham. https://doi.org/10.1007/978-3-030-33570-0_10

Osello, A., Lucibello, G., \& Morgagni, F. (2018). HBIM and virtual tools: a new chance to preserve architectural heritage. Techne, 13, 21-26. https://doi.org/10.3390/buildings8010012

Qiuchen, L., \& Sanghoon, L. (2017). Image-based technologies for constructing as-is building information models for existing buildings. Journal of Computing in Civil Engineering, 31(4). https://doi.org/10.1061/(ASCE)CP.19435487.0000652

Stanga, C., Spinelli, C., Brumana, R., Oreni, D., Valente, R., \& Banfi, F. (2017). A N-D virtual notebook about the Basilica of S. Ambrogio in Milan: information modeling for the communication of historical phases subtraction process. Int. Arch. Photogramm, Remote Sens. Spatial Inf. Sci., XLII/W5, 653-660. https://doi.org/10.5194/isprs-archives-XLII-2W5-653-2017

Tommasi, C., Fiorillo, F., Jiménez Fernàndez-Palacios, B., \& Achille, C. (2019). Access and web-sharing of 3D digital documentation of environmental and architectural heritage. Int. Arch. Photogramm, Remote Sens. Spatial Inf. Sci., XLII-2/W9, 707-714. https://doi.org/10.5194/isprs-archives-XLII-2-W9-707-2019

Tucci, G., Bartoli, G., Betti, M., Bonora, V., Korumaz, M., \& Korumaz, A. G. (2018). Advanced procedure for documenting and assessment of Cultural Heritage: from Laser Scanning to Finite Element. IOP Conf. Series: Materials Science and Engineering, 364. https://doi.org/10.1088/1757-899X/364/1/012085

UNI (2017). UNI 11337:2017 - Building and civil engineering works - Digital management of the informative processes 


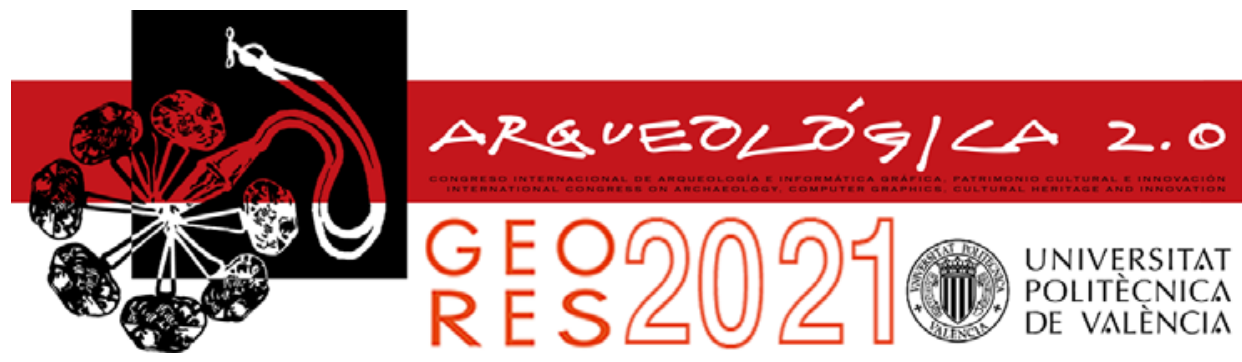

Proceedings of the joint international event $9^{\text {th }}$ ARQUEOLÓGICA

$2.0 \& 3^{\text {rd }}$ GEORES

Valencia (Spain).

26-28 April 2021

\title{
THREE-DIMENSIONAL SURVEY AND MATERIAL CHARACTERIZATION OF THE TEMPIO-MASSERIA DEL GIGANTE IN CUMAE
}

\author{
Raffaele Amore ${ }^{\mathrm{a},{ }^{*}}$, Federica Carandente ${ }^{\mathrm{b}}$ \\ a Department of Architecture, University Federico II of Naples, Viale Giacchino Rossini 33, 80055 Portici, Naples, Italy. \\ raffaeleamore@unina.it \\ ${ }^{\mathrm{b}}$ Department of Architecture, University Federico II of Naples, Via Antonio de Curtis 16, 80078 Pozzuoli, Naples, Italy. \\ fe.carandente@studenti.unina.it
}

\begin{abstract}
:
The following paper describes the work carried out from a University exercise of the Restoration Lab of the Architecture Department of the University of Naples Federico II. The work reflects the results of a Three-dimensional survey and metric characterisation of the 'Tempio-Masseria del Gigante', in Cumae, in the Naples province, to elaborate an architectural restoration project. This is a rural building from the XVIII century, built and extended by incorporating the rests of the cell of an ancient temple from the Flavian Age, located at the eastern border of Cumae lower city's Foro, that was called 'del Gigante' (of the Giant), since a large Jupiter's bust was found in its proximities. Well known in the world of antiquarian dealers, it was pictured in many drawings and landscape paintings since the end of the XVII century and the first half of the XVIII, the Masseria Temple is taken into exam had been acquired by the public domain only at the end of 1990 , so only after this period, the first archaeological investigations were made. Afterwards, between 1996 and 2002, conspicuous restoration and securing works were made. Today the structure is used as a temporary deposit for archaeological findings and it's among the buildings included in a wider restoration and re-functionalization project that has been proposed by the Campi Flegrei Archaeological Park and that is now about to start. The research work proposed is part of the preparatory analysis phase for the design of restoration work and has consisted of survey made with photo-modelling techniques with direct survey operations and it aimed to identify the construction methodologies and the degrading phenomena in place, with special regards to the identification of the ancient parts of the Temple, of those pertaining the conversion in a farmhouse and, lastly, those realised during the restoration works. The constant reference between the results of the threedimensional survey performed and those of the comparative analysis of historical iconography and the graphs and photos examined, has allowed reconstructing the history of the ancient and recent transformations of the building in order to define an integrated knowledge framework, necessary for the definition of suitable conservative strategies.
\end{abstract}

Keywords: cultural heritage, restoration, 3D reconstruction

\section{Introduction}

During the last century, the archaeological excavation operations made in Cumae's lower city were focused in the Foro's eastern sector, that brought to light the Capitolium, the Thermal Baths, the ruins of the southern buildings and of the so-called Temple with the Portico (Maiuri, 1927; Maiuri, 1958; Barrella, 2019). The Masseria del Gigante Temple wasn't involved in systematic archaeological research until 1994. Since that date, thanks to the Kyme project of the Federico II University, essays and surveys have been made, allowing the identification of the number of ancient structures of the Temple, without removing those of the more recent farmhouse (Gasparri \& Greco, 2007; Gasparri \& Greco, 2009). Following this investigation, restoration and securing works were made between 1995 and 2003. Unfortunately, these haven't been followed by a suitable re-functionalization of the complex, with the result that today only a few areas are used as a deposit of archaeological findings and the overall preservation of the building is mediocre. Recently the Campi Flegrei Archaeological Park has started a public call for projects called Restoration, securing and enhancement of the archaeological sites of Cumae's lower city, which is currently being awarded and that implies, among many actions, the re-functionalization of the Tempio-Masseria del Gigante. Taking this into account, the following paper, elaborated during the activities of the Restoration Lab of the Architecture Department of the University of Naples Federico II, after a historical framing, illustrates the results from the survey made at the Tempio-Masseria del Gigante, done with photo-modelling techniques integrated with direct measurements. The work has been designed with a precise objective: identifying the surviving parts of the ancient temple, those pertaining the 
conversion in a farmhouse and those realised during the restoration works made recently, always relying on previous studies on the matter. All this to recreate the scheme of the material documents and traces that today characterise this important and multi-layered monument and its decaying state.

The survey and documentary research carried out, in a logic of continuous integration and osmosis, have made it possible to highlight and consider the infinite diversity of the elements that make up the masonry of the TempleMasseria and to record the traces that history has imprinted on its subject; an interweaving of knowledge that is indispensable to direct the restoration project in an effectively conservative vision, able to preserve the material authenticity of what remains, also taking due account of the needs of material integration to ensure its stability and use.

\section{Cumae Archaeological Park}

The Archaeological evidence of Cumae are among the most ancient between those known in the Campi Flegrei area (Caputo, Morichi, Pane, \& Rispoli, 1996; Valenti, 2016). The Euboic column of Kyme was founded in the second quarter of the VIII century BC, within an area where the primitive Oscan town existed, made of nuclear residential settlements spread on the Cumaean plain and at the Acropolis' foothill. Modelled on the greek city structure, it was relevant during the Early Archaic age, extending its hegemony from the Licola plain to Miseno. Similarly, to Pithekoussai, on the Island of Ischia. Kyme had a central role in the maritime trade. In $421 \mathrm{BC}$ it was conquered by the Samnites, who dominated it for about a century, until $334 \mathrm{BC}$ when it became colonia sine suffragio of Rome. Following the transformations from the Samnites Era, further alterations were made during the Roman domination. The sacred buildings and the walls were largely transformed: the area of the ancient agorà was transformed in the city Foro, that would suffer several transformations during the centuries. In its shape, traceable back to the Imperial Age, it was characterised by the presence of a large rectangular and colonnaded square, paved with limestone and on which all the main monuments of the city were facing, such as the Tempio con Portico and the Capitolium, the tabernae and the commercial spaces. The colonnade was articulated on two levels, with a first-order supported by Doric columns and a second one with lonic columns.

Later, Octavian Augustus commissioned important engineering works to Agrippa and Cocceio Aucto in order to enhance the military role of the whole area of the Campi Flegrei: were so realised the Roman Crypta, the Cocceio Cave and the Sibilla Cave, that linked the portal area of Cumae to the Avernum and from there to the Portus lulius in Lucrino. During the Flavian Age the road Domitiana and the majority of the city structures were built. Following the Fall of the Roman Empire, years of decadence and neglect ensued. Since the III century AD until the Middle Age, a series of flooding's radically changed the consistence of Cumae's lower city that after the following raising of the walking surfaces was transformed into a productive area destined to artisanal activities and for the processing of glass and metal. (Gasparri \& Greco, 2007; Gasparri \& Greco, 2009). During the Byzantian era a cocciopiesto road was built, to cross the foro's square horizontally, in order to reach the Northern side of the
Capitolium. In those same years several calcare (limestone klin) were made: the most majestic one was located near the foro, including part of the so-called 'sillana room'. During the late ancient era the lime production became a very profitable activity thanks to the great amount of raw materials that were taken from the marble coatings and statues, still present in the Foro. During the same time, the main temples of the Acropolis from the Greek era were transformed into Paleochristians basilicas; the Roman Crypta and the Sybilla Cave were used to establish places of worship and burials (Maiuri, 1934).

\section{The archaeological structures and the hypotheses on its original articulation}

The analysis of the ancient structures found, partly incorporated and reused in the rooms of the Masseria, partly re-emerged during excavation campaigns carried out at the beginning of the $21^{\text {st }}$ century, and integrated with that of the marble finds recognized as belonging to the same complex, have allowed the archaeologist Flavia Coraggio to elaborate a hypothesis for the reconstruction of the temple and its decorative part. According to the reconstruction of the aforementioned scholar, it is a temple located within a sacred enclosure consisting of a three-armed portico, probably dedicated to Vespasian. The internal scanning of the space responds - according to the model of the Forum of Augustus - to an accurate tripartition distributed on the longitudinal axis, that is a large vestibule accessible from three entrances, the uncovered courtyard and, finally, the sacred building raised on a podium (Coraggio, 2007; Coraggio, 2013).

The temple was oriented along the east-west axis and was divided into a hexastyle pronaos with two columns on the sides, accessible by a flight of eleven steps; the last two steps are interrupted by the foundation plinths of the colonnade. Since the width of the cell exceeded that of the pronaos, Coraggio hypothesized that they were made up of two disjoint bodies, also treated differently from the point of view of the surface covering (Figs. 1, 2, \& 3). The podium was covered with marble, while the external volume of the peribulum was finished with a layer of cocciopesto; in elevation, the pronaos was covered in marble, while the walls of temple cell were covered in plaster. The three porticoed arms enclosed only the pronaos, leaving the outside temple cell at the peribulum. On the opposite side of the portico there were the three entrances that allowed access. The columns stood on composite attic bases and was made of smooth stems of cipollino marble, whose rhythm is documented by the trachyte foundation blocks, surmounted by composite capitals. The entire monumental complex is built in mixed masonry consisting of opus reticulatum and opus latericium. The cell of the temple, in particular, was characterized by the presence of opus reticulatum with toothing of latericium, as well as by walls in opus vittatum mixtum with alternating applications of parallelepiped blocks and bricks. Horizontal bands of opus latericium run along the walls, without a precise design (Coraggio, 2013). 


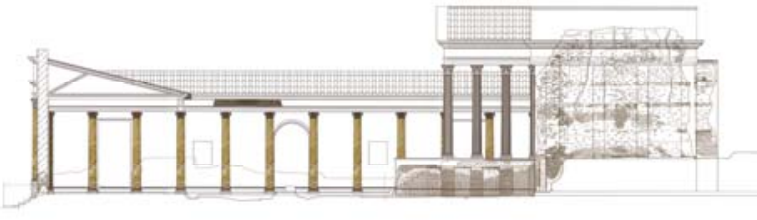

Figure 1: Tempio-Masseria del Gigante, Cuma. Longitudinal section according to the reconstructive hypothesis of $\mathrm{F}$. Coraggio, in Coraggio (2007), annexe L.

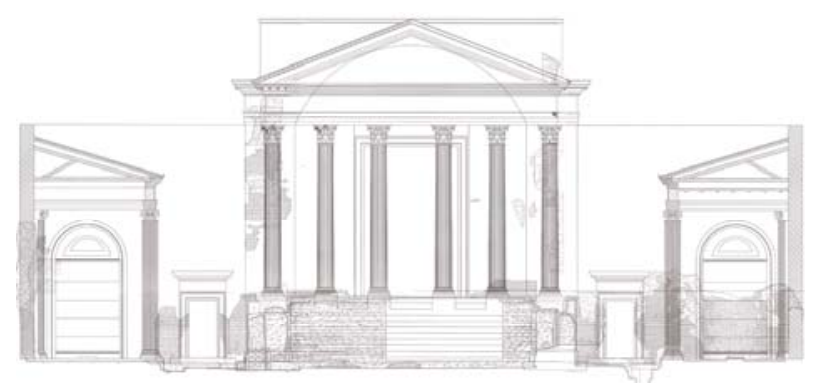

Figure 2: Tempio-Masseria del Gigante, Cuma. Pronaos prospectus according to the reconstructive hypothesis of $F$. Coraggio, in Coraggio (2007), annexe I.

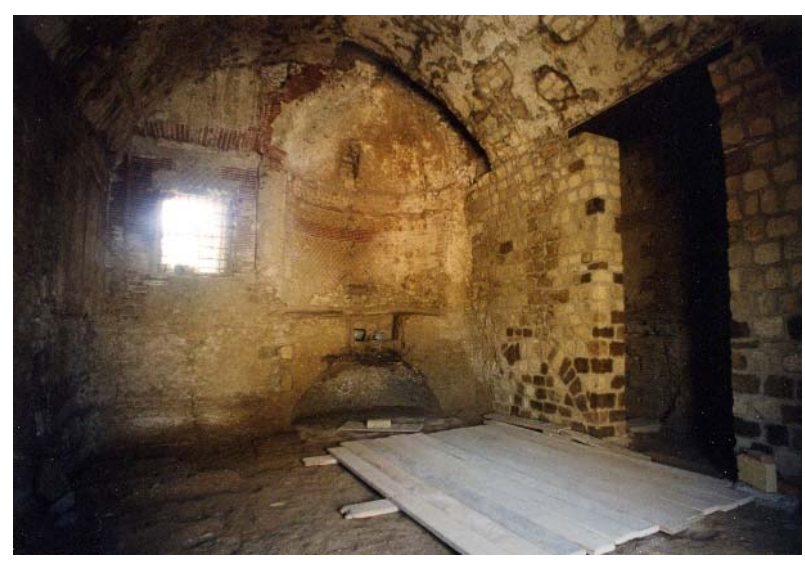

Figure 3: Tempio-Masseria del Gigante, Cuma. The apse before the restoration work 1994, photos by R. Morichi.

\section{The Temple-Masseria dei Giganti}

Literary sources testify that statuary and epigraphic material was found in the ancient settlement of Cuma as early as the Middle Ages (De Filippis, 1996a; 1996b). However, only from the beginning of the seventeenth century were undertaken specific excavation activities, with the aim of recovering valuable ancient materials. The Tempio-Masseria owes its name to the discovery in its vicinity of the so-called 'Giant' of the Palace: the torso of the colossal acrolithic statue of Jupiter, which was originally located in the nearby Capitolium. Among the many rural buildings built in the area on partially emerging ancient ruins (Caputo, 2015), the Tempio-Masseria del Gigante has been for centuries a significant architectural emergence and an immediate topographical point of reference for the entire area of ancient Cuma, represented in many paintings and performances of travellers and scholarly.

As the view by Filippo Morghen showed, at least until 1740 , the barrel vault of the cell was perfectly preserved, as well as the lacunars: only a few years later, probably following a fire, it collapsed (Figs. 4, 5).

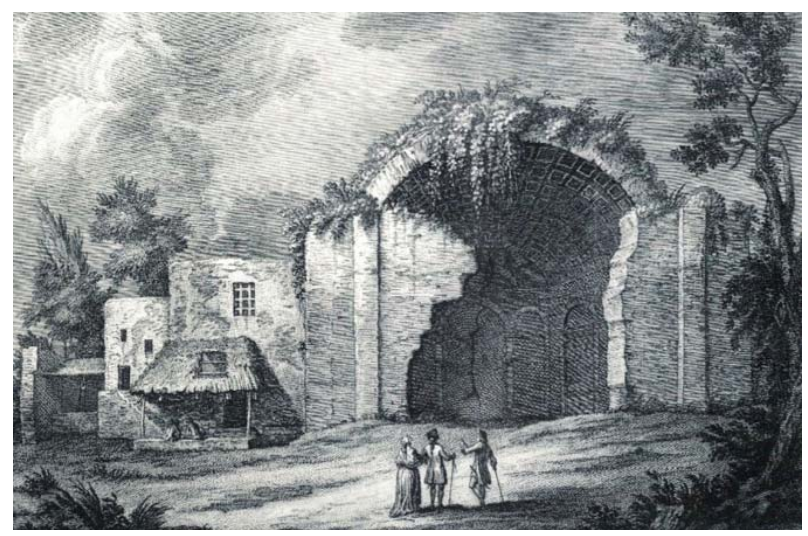

Figure 4: Morghen F, Parete anteriore del precedente Tempio di Giove nella via di Cuma. In Morghen 1814, tav. 28.

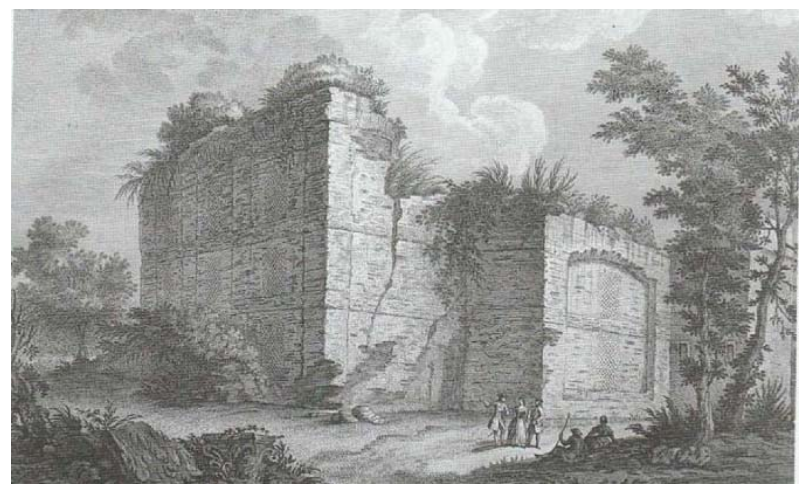

Figure 5: Morghen F., Parte posteriore d'un tempio nella via dell'antica Cuma: da molti creduto sacro a Giove. In Morghen 1814, tav. 27.

Then it was realized a new vault. It was set on the original wall to the north and on a new wall parallel to the original one, to the south, since the ancient one was no longer considered safe. This led to a significant reduction of the ancient volume. Throughout the eighteenth and nineteenth centuries, there were many discoveries and thefts of precious marble from the area of the forum: we will have to wait for Prince Leopoldo Borbone, Count of Syracuse, who was the first one on showing interest in recording the first systematic archaeological searches. They started right from the Temple- Masseria, of which part of the structures of the enclosures and its entrances were brought to light. Subsequently, and throughout the twentieth century, the Tempio-Masseria was volumetrically enlarged by the owners and actually nobody really cared about studying it. The interest of the scientific community of the time was entirely directed to the major excavations in the western sector of the Forum (Figs. 6, 7).

\section{The three-dimensional survey}

After completing the necessary historical documentary investigations, synthetically described here, the work carried out consisted of surveying the complex with the photo modelling technique, integrated with direct measurements of the construction details. The threedimensional survey carried out benefited from preexisting topographic measurements which made it 
possible to verify the degree of accuracy that was very high. 233 photographic shots from drone have been used, georeferenced by GPS antenna. These photos were taken according to three distinct shooting plans at different heights, made all around the building and then subsequently treated with a three-dimensional photo modelling program. Once aligned with the photos, there was a first cloud of the rough points that we proceeded to clean up manually. Subsequently, a dense cloud was generated and, from this, a three-dimensional polygon mesh from which the orthophotos of the elevations were extracted. From the three-dimensional model (Figs. 8, 9, 10 , \& 11), various section plans were obtained and exported to additional computer-assisted drawing programs, to elaborate plans and sections. For the completion of these graphs, a series of direct surveys have been carried out, room by room. In particular, the survey of many construction details and individual masonry parts of the interior rooms and some sample areas outside was carried out, also to verify the correctness of the photo modelling process.

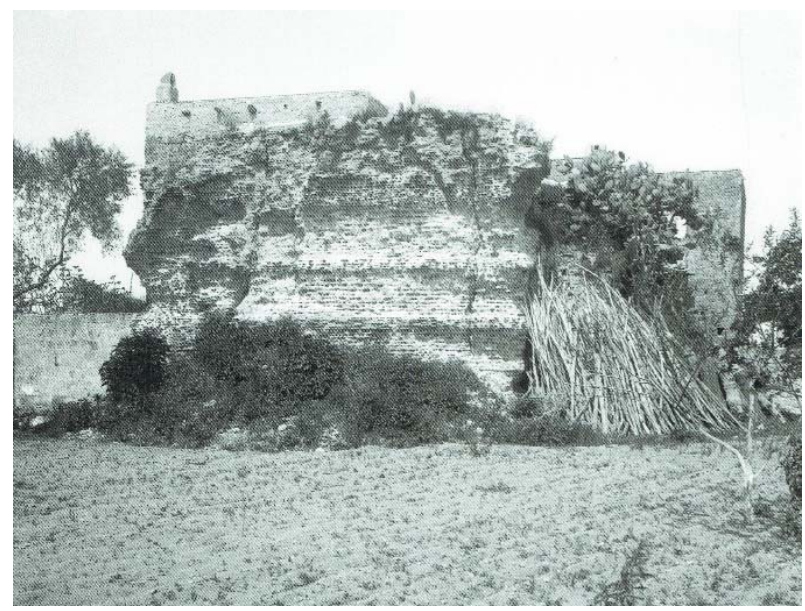

Figure 6: Tempio-Masseria del Gigante, Cuma. Archivio fotografico Mann, 3073, ex C165, 1938 in Valenti 2016, p.108.

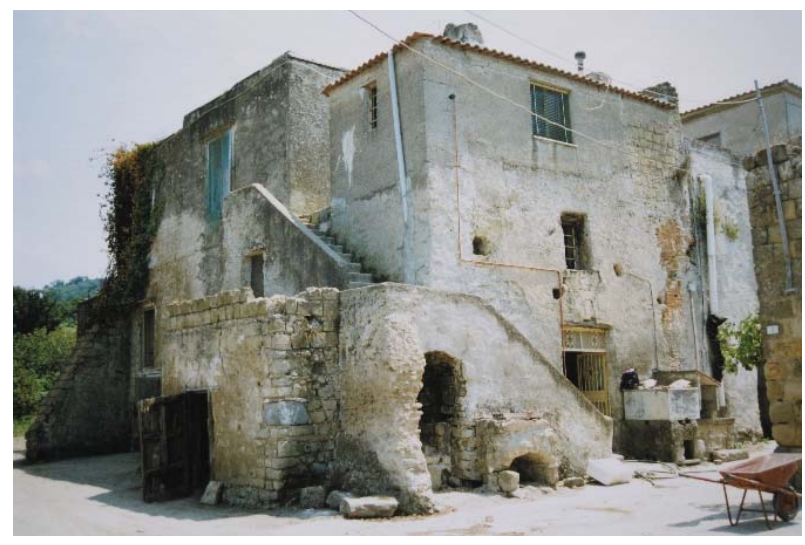

Figure 7: Tempio-Masseria del Gigante, Cuma. View of the north-west corner before the restoration work 1994, photos by

$$
\text { R. Di Re. }
$$

The graphic and photographic documentation produced was subsequently compared with the pre-existing one, made before the restoration works implemented. We proceeded, therefore, to identify the effective consistency of the consolidation and integration works completed and to evaluate their impact on the overall conservation of the archaeological artefact.

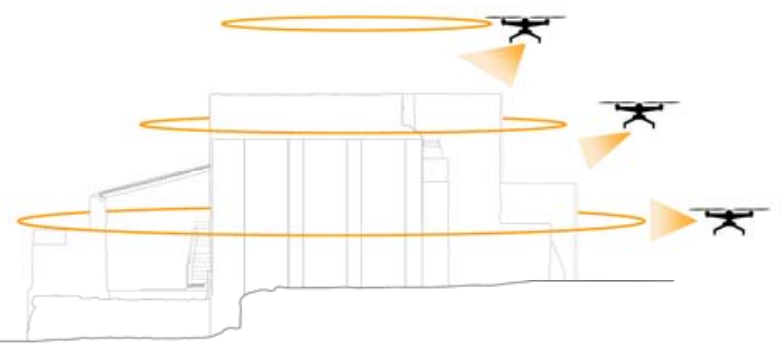

Figure 8: Tempio-Masseria del Gigante, Cuma. 3D model. The flight phases of the drone.

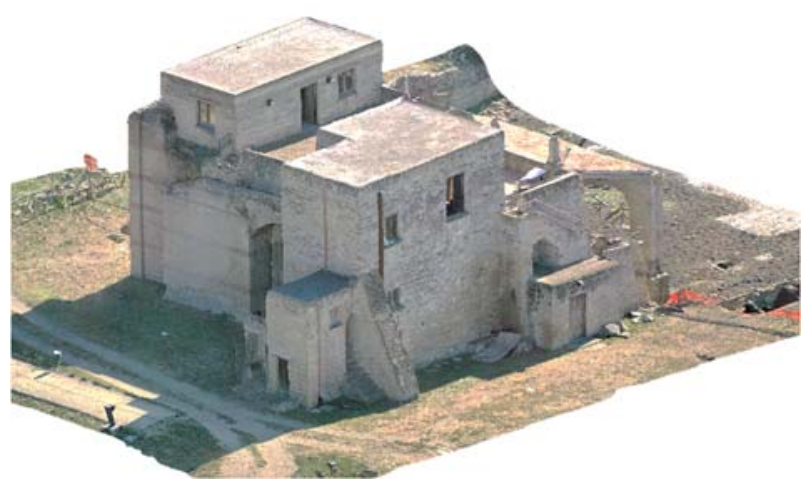

Figure 9: Tempio-Masseria del Gigante, Cuma. 3D model. View from the northeast.

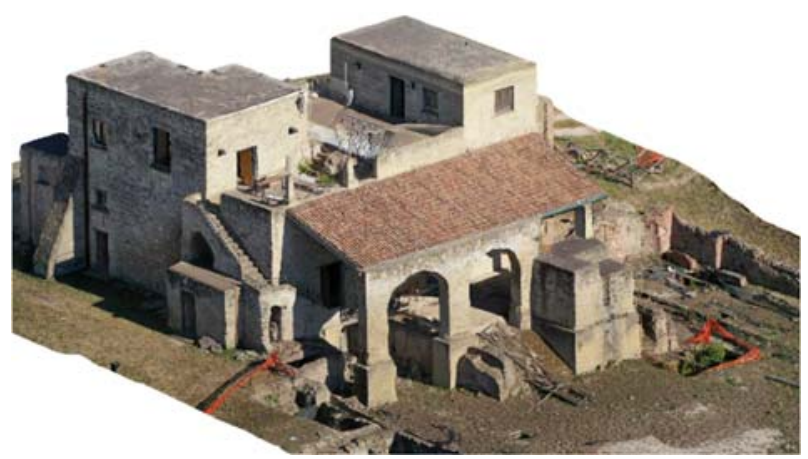

Figure 10: Tempio-Masseria del Gigante, Cuma. 3D model. View from the northwest.

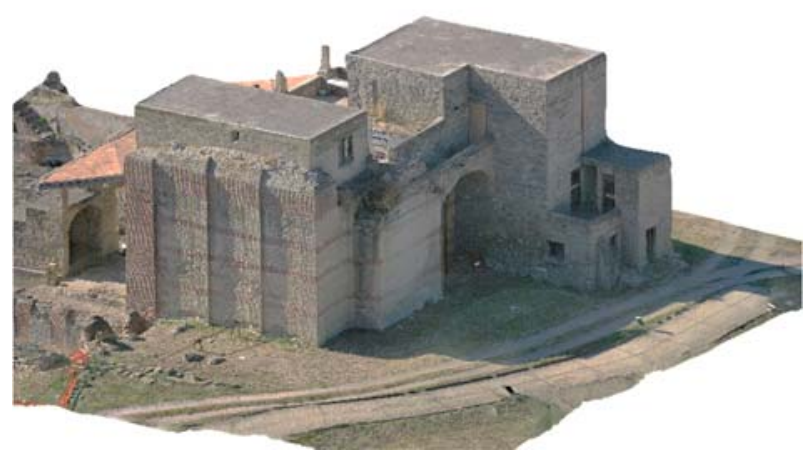

Figure 11: Tempio-Masseria del Gigante, Cuma. 3D model. View from the southeast. 


\section{Some considerations on recent restoration work}

That said, the comparison between the current state of The Temple-Masseria and the one prior to its restoration - that was possible to obtain by the historical-iconographic investigation, the three-dimensional surveys and the direct observation of the monument - leads to a series of critical observations on what has been accomplished. That is, about the nature and the number of wall integrations carried out and about the quality of the additions of new structural and functional elements, both in architectural terms and in terms of durability. The wall integrations performed, for example, were excessive (Figs. 12, 13, \& 14). Let's take for example what was done to consolidate the remains of the southern wall of temple cell. Probably due to structural necessity, the whole original wall was covered by a new wall structure: that was, by a physically-mechanical standpoint, a 'distinguished' and 'compatible' integration, but at the same point also irreversible and invasive.

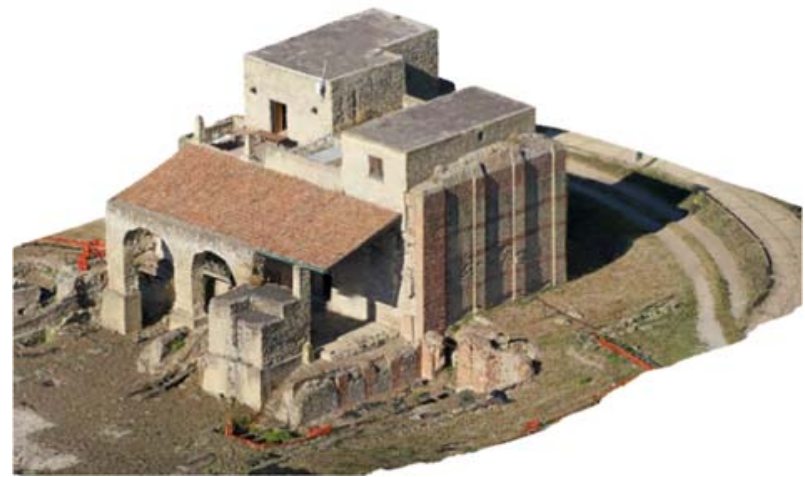

Figure 12: Tempio-Masseria del Gigante, Cuma. 3D model. View from the southwest.

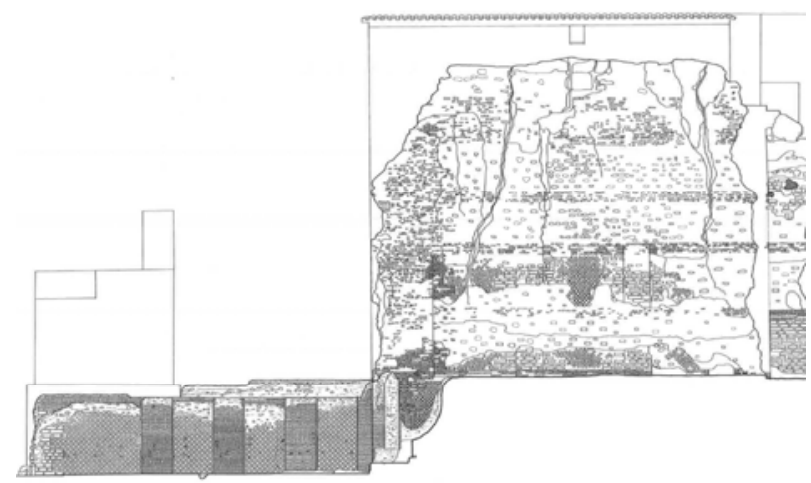

Figure 13: Tempio-Masseria del Gigante, Cuma. South prospectus, before restoration work, in Coraggio (2007), annex $\mathrm{F}$.

The typologies of consolidation of the vaults and wooden floors cannot be fully shared, because of the techniques based on reinforced concrete that do not guarantee instead the complete physical-mechanical compatibility of the additions with the existing structures (Fig. 15). Unfortunately, the rigour of the archaeological explorations and the richness of the revealed schedule has not been followed by consolidation and integration works that respect the authentic consistency of the complex. At this point, it seems legitimate to ask if it could have been possible to have adopted alternative solutions, in order to give more regard to the ruins of the walls and their stratifications or, at least, of being less invasive. Other misgivings are about the choices related to the finishing works (Figs. 16, 17, \& 18). Fixtures, handrails, railings, gratings, walls and so on have been made in ways and shapes that only respond to functional needs, renouncing any attempt to make a connection between the ancient and contemporary element. This was, in our opinion, an incomprehensible choice, which assumes the belief that in the archaeological field what needs to be added must be anonymous and devoid of all those qualities that are not so strictly related to the functionality. This point is flatly denied by the fact that, a little less than twenty years after their realization, these elements are the ones that more than the others have suffered a rapid degradation process. Furthermore, we can't ignore that the lack of a clear purpose of the use of the complex has led to a general 'aging' of all the parts, old and new, due to lack of maintenance.

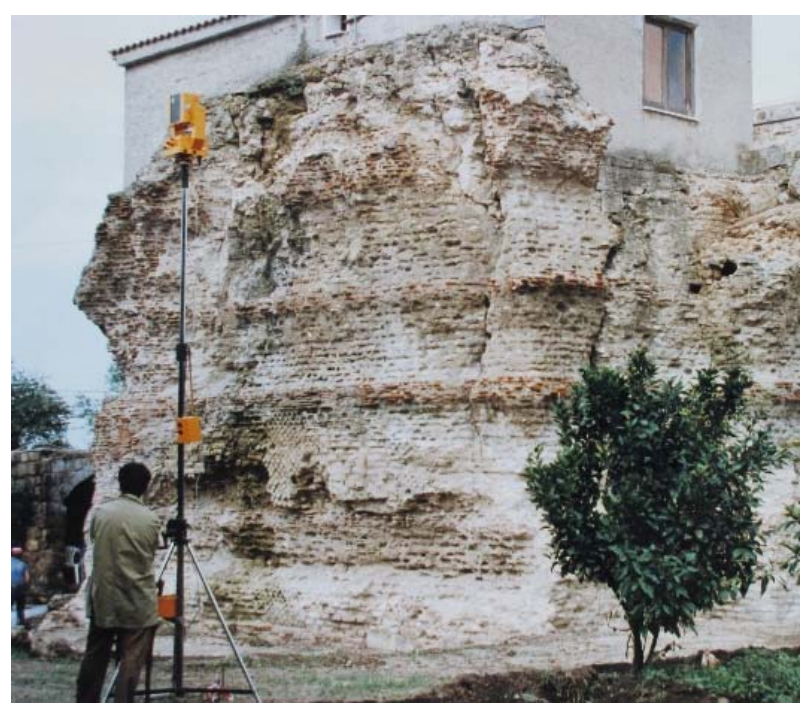

Figure 14: Tempio-Masseria del Gigante, Cuma. South prospectus, before restoration work 1994, photos by R. Di Re.

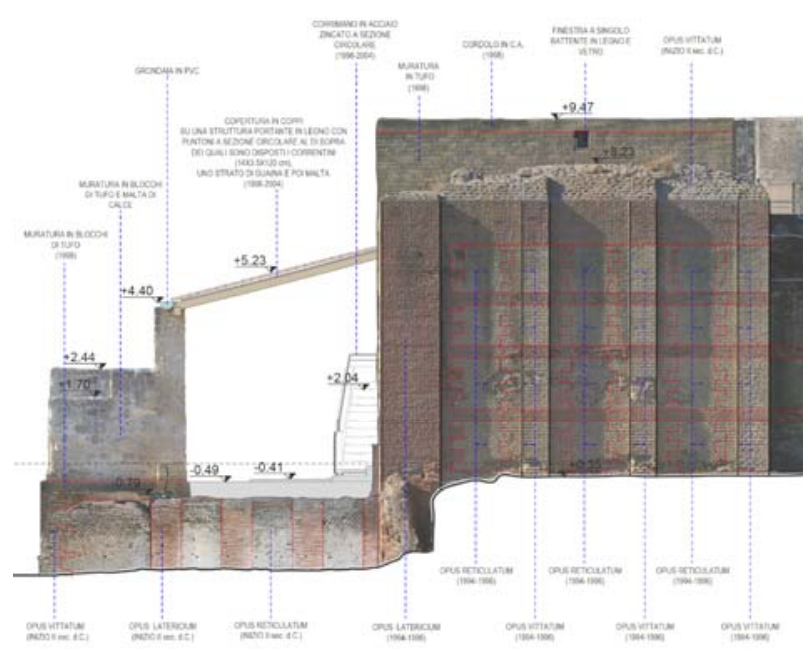

Figure 15: Tempio-Masseria del Gigante. South facade. Classification of the masonry typologies. 


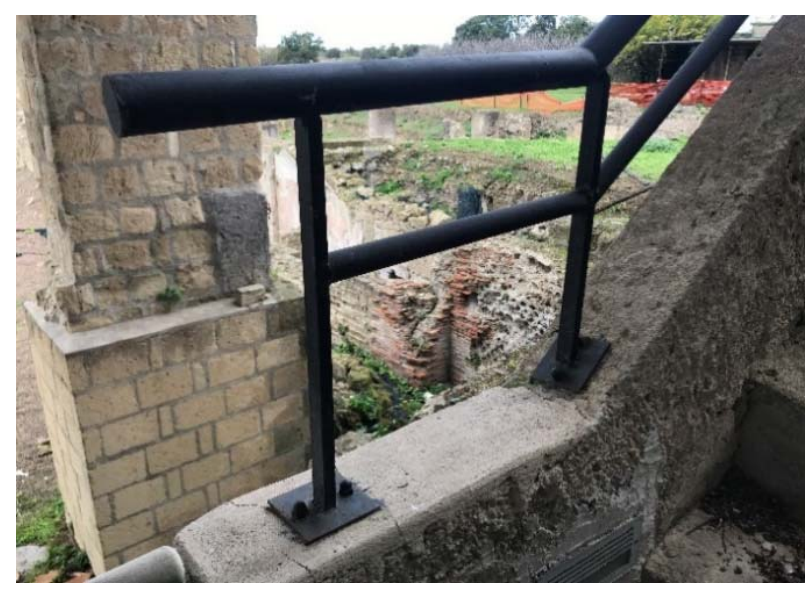

Figure 16: Tempio-Masseria del Gigante. The metal handrail of the staircase.

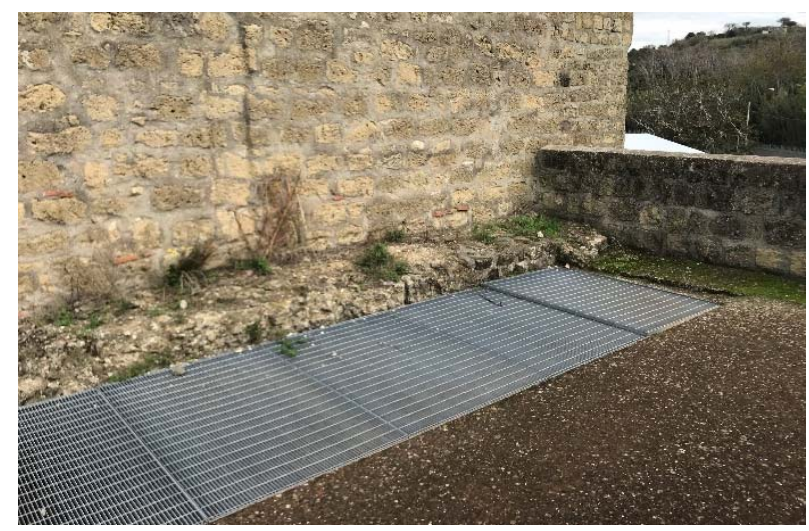

Figure 17: Tempio-Masseria del Gigante, Cuma. The grid for collecting rainwater on the terrace.

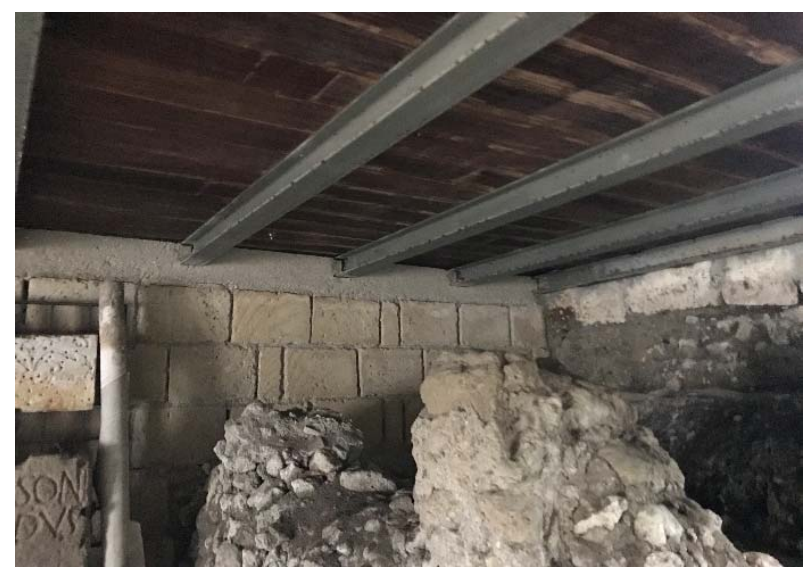

Figure 18: Tempio-Masseria del Gigante, Cuma. The floor in putrelles and wood.

\section{Conclusions}

The essays, studies, and archaeological surveys of such stratified monuments as the one in question allow us to reveal complex and articulated palimpsests, which tell us about millenary events through the overlapping and integration of the walls. However, it is an extremely fragile palinsesto: ensuring its safeguarding requires that immediately after the archaeological studies, we proceed - with the same care and attention - to identifying suitable restoration interventions necessary to guarantee its conservation and protection. Therefore, to the structural and conservative fragility of archaeological structures it must be answered with recognizable and limited additions "to the minimum that will be necessary to guarantee the conservation of the monument and restore the continuity of its forms" (art. 15 Charter of Venice). From here the need to operate in a synergistic and multidisciplinary manner. All the skills of the archaeologist must put beside those of the restorer architect and of all the specialists who - within a clear framework of skills and roles - may be able to provide useful information to achieve the aforementioned objectives

The resulting design and executive choices, in addition to being distinguishable and limited, in order to do not irremediably alter the authenticity and the flagrance of the archaeological data, must also be characterized by effective durability over time, otherwise, they would be useless. To these, which are prerogatives that are generally found for all maintenance and restoration interventions in archaeological areas, for structures such as the Tempio-Masseria del Gigante in Cuma, it is also necessary to add formal and functional integration operations, to ensure them an appropriate and conscious use and a respectful consideration of the stratifications detected. In these cases, in addition to revealing all the layers (strata), reading their sedimentations and recognizing their structures, their age and their consistency, it is also necessary to design all the additions necessary for their use and their formal reconfiguration, if necessary. And this, not to the detriment of this or other structures, but with the aim of making it readable as much as possible, in the full awareness that each design act that will be carried out will represent another text that will be added to the existing ones, inevitably determining a new order.

Within these methodological premises, the investigation and research carried out for the realization of this work reinforce the conviction that only an interdisciplinary approach is the tool to increase the fertile hermeneutic circle necessary to guarantee authentic conservation of historical materials and to define conservative strategies and enhancement of cultural heritage both in the architectural historical and archaeological fields. Threedimensional photomodelling techniques represent, in this framework of investigations, an extraordinarily useful and fast tool of knowledge that, when engaged in a broader process of cognitive deepening, can provide results of great importance to reveal the complexity of the values kept in the ancient masonry of archaeological monuments.

\section{References}

Barrella, N. (2019). Amedeo Maiuri e "l'invenzione" del parco archeologico di Cuma. Opportunismo e opportunità di un funzionario statale durante il Ventennio/Amedeo Maiuri and the" invention" of the archaeological park of Cuma. Opportunism and opportunity of a state official during Fascism. IL CAPITALE CULTURALE. Studies on the Value of Cultural Heritage, (9), 199-233. http://dx.doi.org/10.13138/2039-2362/2184 
Caputo, P., Morichi, R., Pane, R., \& Rispoli, P (1996). Cuma e il suo parco archeologico. Un territorio e le sue testimonianze. Scienze e Lettere, Roma.

Caputo, P. (2015). Masserie e paesaggio storico-archeologico dei Campi Flegrei. Tutela, conservazione e valorizzazione. In I Campi flegrei. L'architettura per i paesaggi archeologici, P. Miano, F. Izzo, L. Pagano, Eds. Quodlibet, Macerata.

Coraggio, F. (2007). La Masseria del Gigante. In Studi Cumani, 1. Cuma. Il foro. Scavi dell'Università di Napoli Federico II, 2000-2001. Atti della Giornata di studi, Naples, 22 June 2002 (Eds). C. Gasparri, G. Greco. Naus editoria, Napoli.

Coraggio, F. (2013). II tempio della Masseria del Gigante a Cuma. Quaderni del Centro Studi Magna Grecia 17, Studi Cumani 4. Naus editoria, Pozzuoli.

De Filippis, A. (1996a). Gli scavi dal XVII secolo alla Raccolta Cumana del Conte di Siracusa. In I Greci in Occidente, La Magna Grecia nelle Collezioni del Museo Archeologico di Napoli. Electa Napoli. Napoli, pp. 215-222.

De Filippis, A. (1996b). Gli scavi cumani di Emilio Stevens e la collezione Stevens. In I Greci in Occidente, La Magna Grecia nelle Collezioni del Museo Archeologico di Napoli. Electa Napoli. Napoli, pp. 233-240

Gasparri, C., \& Greco, G. (2007). Studi Cumani, 1. Cuma. II foro. Scavi dell'Università di Napoli Federico II, $2000-2001$. Atti della Giornata di studi, Naples, 22 June 2002. Quaderni del Centro Studi Magna Grecia. Naus editoria, Napoli.

Gasparri, C., \& Greco, G. (2009). Studi Cumani, 2. Cuma. Indagini archeologiche e nuove scoperte. Atti della Giornata di studi, Naples, 12 december 2007. Quaderni del Centro Studi Magna Grecia. Naus editoria, Pozzuoli.

Maiuri, A. (1927). Gli ultimi scavi di Cuma e l'epopea virgiliana. In Nuova antologia, 16, 489-199.

Maiuri, A. (1934). Monumenti cristiani di Cuma. In Atti del II Congresso Internazionale Archeologia Cristiana (Ravenna 2530 settembre 1932). Pontificio istituto di archeologia cristiana, Roma, pp. 217-231.

Maiuri, A. (1958). I Campi Flegrei. Dal Sepolcro di Virgilio all'antro di Cuma, Libreria dello Stato, Roma.

Valenti, R. (2016). I Campi Flegrei oltre il visibile. Artstudiopaparo, Napoli. 


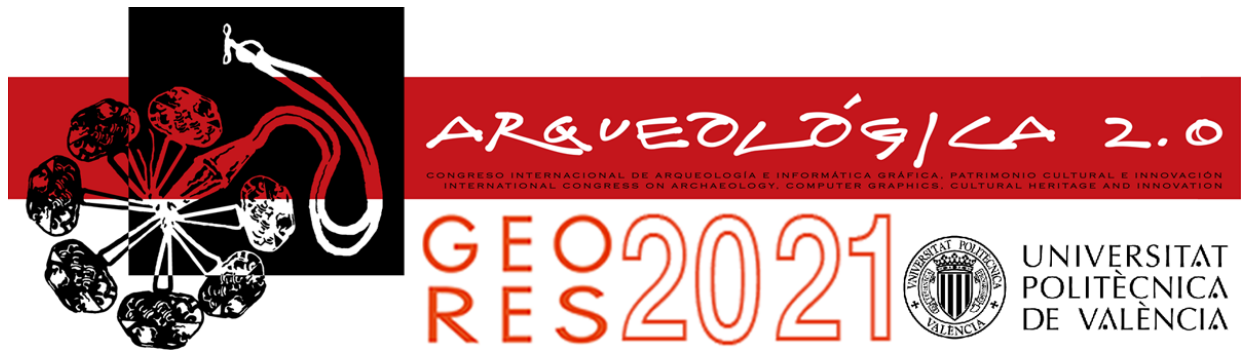

Proceedings of the joint international event $9^{\text {th }}$ ARQUEOLÓGICA

$2.0 \& 3^{\text {rd }}$ GEORES

Valencia (Spain).

26-28 April 2021

\title{
AN INTEGRATION OF NON-DESTRUCTIVE TECHNIQUES (SFM-GPR- TLS) AS A VIRTUAL TOOL FOR ARCHAEOLOGICAL STRATEGY: THE CASE OF THE ROMAN SITE OF THE PLAZA DE LA MORERÍA IN SAGUNTO (SPAIN)
}

\author{
Fernando Buchón-Moraguesa ${ }^{\mathrm{a}}$, Josep Beneditob, Francisco García ${ }^{\mathrm{a},{ }^{*},}$, José Manuel Melchor ${ }^{\mathrm{c}}$ \\ ${ }^{a}$ Department of Cartographic Engineering, Geodesy and Photogrammetry, Universitat Politècnica de València, Camino de Vera s/n, \\ 46022 Valencia, Spain. fbuchon@upv.es; fgarciag@upv.es \\ ${ }^{b}$ Department of History, Geography and Art - Ancient History, Universitat Jaume I, Av. Vicent Sos Baynat s/n, 12071 Castellón de la \\ Plana, Spain. jbenedit@uji.es \\ ${ }^{c}$ Municipal Archaeological Museum, Burriana City Council, Plaza de la Merced s/n, 12530 Burriana, Spain. arqueologo@burriana.es
}

\begin{abstract}
:
In this article, we present a methodology involving a combination of structure from motion (SFM) photogrammetry, ground penetrating radar (GPR) and terrestrial laser scanner (TLS), georeferenced on the same reference frame defined by topographic methods. We show that this simultaneous integration of non-destructive techniques (NDTs) and analysis of archaeological data constitutes a highly effective approach for archaeological research strategies. As an example of the applicability of this framework, we discuss in detail the archaeological research (1991, 2002 and 2018 campaigns) at a Roman site, the Plaza de la Morería, located in the urban area of the city of Sagunto (eastern Spain). The goal of this research was to design a strategy to recover a pre-1 ${ }^{\text {st }}$ century AD Roman funerary space, and to assess whether to remove a $3^{\text {rd }}$ century AD domus pavement covering the funerary remains. We found that our methodology was able to provide an adaptable and flexible design at each phase of the project. The high resolution of 2D and 3D virtual visualisation features of the GPR technique made it possible to pinpoint and map the existence of Roman overlapped horizons and buried structures in the study zone. Therefore, this framework is able to provide a deep understanding of the spatial organisation and stratigraphic potential, allowing informed decisions about which levels to excavate and which ones to remove. This feature is extremely significant for the inherent decision-making process in every archaeological research project, thus opening new perspectives in interventions of location, study, management, conservation and planning in archaeological heritage research.
\end{abstract}

Keywords: virtual-digital archaeology, photogrammetry, structure from motion (SFM), terrestrial scanner laser (TLS), ground penetrating radar (GPR), Roman period, archaeological strategy, 3D virtual visualisation, digital twin

\section{Introduction}

The archaeological site in our study lies in the urban centre of the city of Sagunto (eastern Spain) within a completely urbanised area. The entire urban nucleus of Sagunto is archaeologically protected by urban laws. Specifically, since 2002 various excavation campaigns have been carried out on the site located between Alorco and Huertos streets and Plaza Morería in the city of Sagunto, which is known as the Roman site of Plaza de la Morería (Fig. 1). Archaeological interventions have documented notable construction activity during the Early Roman Empire, with a majority of monumental buildings. These discoveries comprise temple foundations several mausoleums, a Roman road, five domus and the remains of an honorific arch, together with the discovery of sculptural and epigraphic fragments. The site of Plaza de la Morería has recognized importance as it offers a series of stratigraphic and material information that allows confirming the existence of a continuous occupation in this place since the Late Republican period.

Archaeological findings, as has been proven in other Hispanic cities, undoubtedly offer a renewed vision of the evolution and transformation of the city in the transition from the Early Empire to the Late Roman Empire and Late Antiquity (Kulikowski, 2004; Ferrer, Oliver \& Benendito, 2016; Ferrer, Benedito \& Melchor, 2018; Ferrer, Benedito $\&$ Melchor 2020). At the same time, the arrangement of some buildings, the projection of public squares and contemporary terraces has hindered advancements in archaeological research for many years. These conditions, therefore, force us to use methods capable of 
evaluating the potentiality of remains in the subsurface and, as far as possible, technology able to obtain the necessary information without digging up or altering the actual surface. Crucial decisions for the archaeological and historical knowledge of the city of Sagunto may depend on these results.

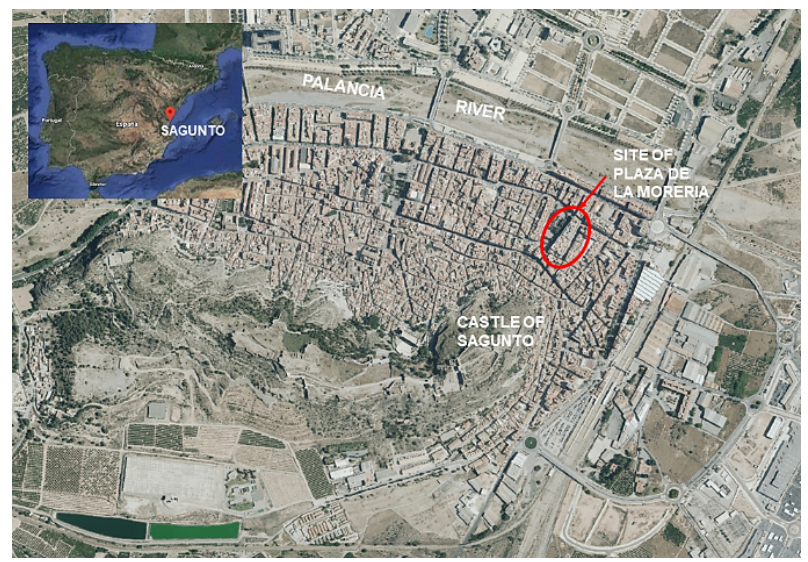

Figure 1: Location of the archaeological site of Plaza de la Morería in the urban area of the city of Sagunto (eastern Spain near the Mediterranean coast).

Archaeological strategy requires accurate techniques for mapping, surface modelling and detecting buried structures in urban areas. Non-destructive techniques (NDTs) integration offers multiple decision making options in archaeological exploration (Puente, Solla, Lagüela, \& Sanjurjo-Pinto, 2018; Malfitana et al., 2015; Horsley, Wright, \& Barrier, 2014; Stal et al., 2014; Lerma, Navarro, Cabrelles, \& Villaverde, 2010).

Because of the results of a previous 2002 site excavation, the existence of funerary remains of the Roman necropolis, still unexcavated, was very likely. The aim of our archaeological research was to recover a section of this pre- $1^{\text {st }}$ century AD Roman funerary space placed under 2 nd and $3^{\text {rd }}$ centuries $A D$ levels. Therefore, a decision-making process of whether to remove the Roman pavement of opus caementicium from an excavated domus from the $3^{\text {rd }}$ century $A D$ covering this funerary space in the eastern part of the site, was necessary. A multidisciplinary approach, involving the integration of several NDT results, was chosen in order to evaluate the existence of pre-1 $1^{\text {st }}$ century $A D$ Roman remains and burial pavement below the Roman pavement of opus caementicium.

A methodology for acquiring three-dimensional data faster, cheaper and more accurate is the photogrammetric correlation (SFM) from terrestrial photographic images (Muñumer, \& Lerma, 2015). This methodology makes it possible to analyse the topographic data of the study area, assess the possible archaeological potential horizon and identify areas of interest.

Geophysics is widely employed for non-invasive studies of underground structures and geological and cultural levels. In the last years, the ground-penetrating radar (GPR) geophysical method has gained increasing importance as the preferred non-invasive method for Cultural Heritage study, due to its high resolution subsurface imagery and 3D data representation, high productivity in collection and recording field data, suitability for high-resolution subsurface imaging. GPR is also remarkable for its accuracy in pinpointing subsurface structures and defining their geometry. These features make the GPR method a more effective means of studying buried structures than other geophysical techniques in archaeological studies (Urban, Murray, Vella, \& Lahikainen, 2015; Conyers, 2013; Leucci \& Negri, 2006; Leckebusch, 2003; Pérez-Gracia et al., 2000). Therefore, the GPR method was proposed to pinpoint Roman underground structures and layers for this study.

The use of the terrestrial laser scanner (TLS) (Kościuk, 2012; Yastikli, 2007) was chosen to document the 2018 archaeological campaign, which was carried out based on SFM photogrammetry and GPR results. A cloud of points was obtained over which the results of the excavation were georeferenced and exposed.

The main objective of this study was to pinpoint the continuity and existence of Roman burial structures and pavement (pre- $1^{\text {st }}$ century AD funerary space) underneath the Roman pavement of opus caementicium from the $3^{\text {rd }}$ century $A D$ in the eastern part of the site. Our study was non-invasive, integrating three-dimensional photogrammetric correlation techniques (SFM), terrestrial laser scanner mapping (TLS) and 3D visualisation of GPR data. Therefore, a suitable archaeological strategy for the recovery of the pre- $1^{\text {st }}$ century $A D$ Roman funerary space was determined, based on the results obtained in the integration of NDTs. A complex and delicate decision had to be made about whether to remove a Roman pavement from the $3^{\text {rd }}$ century $A D$ in order to recover a pre- $1^{\text {st }}$ century AD Roman funerary space.

\section{Sagunto: Historical context in Roman times}

The history of Sagunto is linked to the Iberian oppidum of Arse, located on the hill of Sagunto Castle, on the southern slope of the last foothill of the Sierra Calderona. The first archaeological pieces of evidence of the Iberian population have been located in the western peak in the $6^{\text {th }}$ century $\mathrm{BC}$, but until the end of the $5^{\text {th }}$ century or the first decades of the $4^{\text {th }} \mathrm{BC}$ the construction of the wall on the southern slope is not attested. For its part, the easternmost peak is located in the middle of the coastal plain and from there the control of the passage of the Via Heraclea, the later Via Augusta, as well as the route that runs into the valley of the Palancia River and of the coastline that would practically cover the territory of the Edetana region. In the first half of the $4^{\text {th }}$ century BC Sagunto was a great city on which the coastal settlement of Grau Vell depended. In the following century, the findings have revealed an occupation outside the walls, as indicated by the Iberian ceramics that came to light in the excavation of the site of Plaza de la Morería (Ferrer, Oliver, \& Benendito, 2016; Ferrer, Benedito, \& Melchor, 2018). Roman rule over this enclave intensified since 226 BC. The Ebro Treaty between Carthage and Rome came into force. The classic texts mention the city because it is the scene of confrontations that occurred within the framework of the warlike conflict since $218 \mathrm{BC}$, which ended with the fall of the city the following year. For its part, the news provided on the evolution and transformation of the city has undergone a notable change thanks to the remains that have come to light in the excavations of the Plaza de la Morería. We know that, during the Late Empire, the characteristic urbanism of the 
Roman civitas is in a phase of decline to make way for a new urban model. In this sense, the interventions have made it possible to prove that there is a singular transformation of the buildings that stood out for their public and monumental representation and that the city had built since the Augustus government, that is, some temples, public squares, roads, etc. (Ferrer, Benedito, \& Melchor, 2018). However, written sources, as well as archaeological investigations, provide data that today are insufficient to undertake the complete analysis of the renovation process that affected the city of Sagunto and its territory in Late Antiquity. For this reason, it is not easy to assess the true importance that said city had during the last centuries of Roman domination and the effective control of the Visigoths over the Peninsula, that is, between the middle of the $5^{\text {th }}$ century and the first decades of the $8^{\text {th }}$ century.

The preferential attention in the archaeological investigation of the city of Sagunto for many years was focused on the theatre and the Roman circus. To this must be added the different archaeological interventions that have been carried out in recent years and that have documented a remarkable construction activity. According to the information provided by the excavations, it can be affirmed that Sagunto was organized through various routes that ran through the population to include the Palancia River to the north.

\subsection{Roman site description: Plaza de la Morería}

The excavations carried out on the site of the Plaza de la Moreria in the 2002 campaigns confirmed the existence of levels of occupation since the end of the Republican period and ceramic finds from the Iberian period. On the other hand, remains ascribed to funeral constructions related to cremation burials have been documented, whose grave goods have been dated to the JulioClaudian period (Melchor, Benedito, \& Ferrer, 2015). The next construction phase dates back to the end of the $1^{\text {st }}$ century, among whose remains stand out the foundations of a temple, the arcaded road and the bases of an honorific arch (Ferrer, Benedito \& Melchor, 2018).

The archaeological intervention carried out in the Plaza de la Morería, in 2002, revealed the main road axis of communication with the interior of the city, with a northsouth orientation. It is a paved and road's portico, while several funerary monuments were built on its eastern flank. This road completes another paved street, this time with an east-west direction, located a few meters away (Fig. 2).

During the Late Empire, the characteristic urbanism of the Roman civitas gave way to a new urban model, where the public buildings that had been erected in the city since Augustus was being distorted. The domus followed new residential models, while the provision of new constructions led to the transformation of urban planning from the Early Roman Empire.

In the $3^{\text {rd }}$ century, five domus were built next to the road which paid off the cemetery area and part of the structures built in the $2^{\text {nd }}$ century. The extension of the area for housing meant the opening of new drains, the construction of fountains, the closing of the portico and the occupation of the sidewalk to use the scarce surface available. The location of these environments, then barely known in Sagunto, opened a new vision of the processes of change that manifested in the urban environment in Roman times (Melchor, 2013) (Fig. 3).

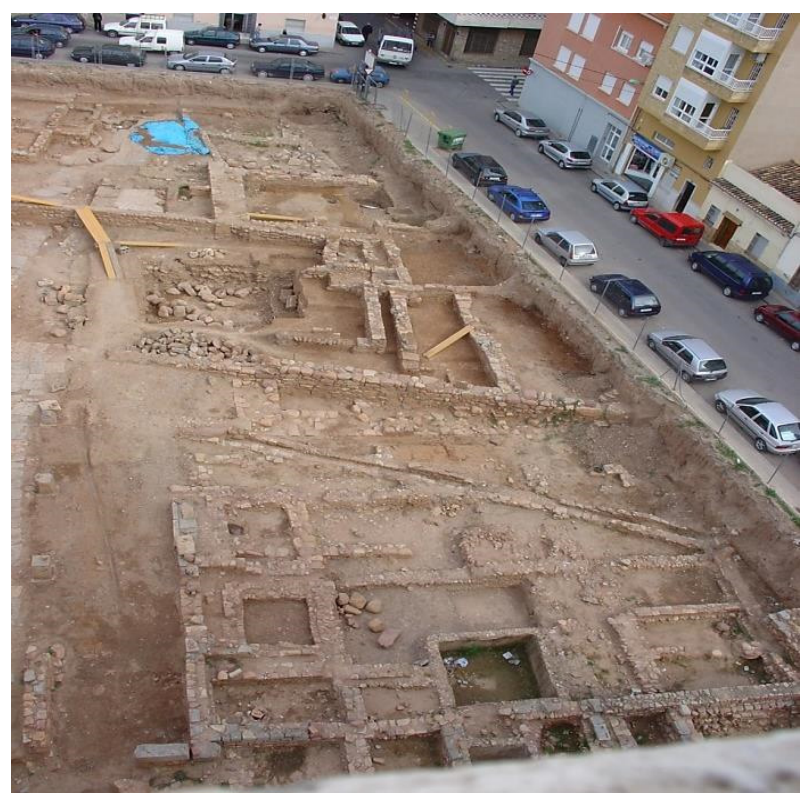

Figure 2: A photograph showing the Roman structures excavated at the Plaza de la Morería site from the 1991 and 2002 archaeological campaigns.

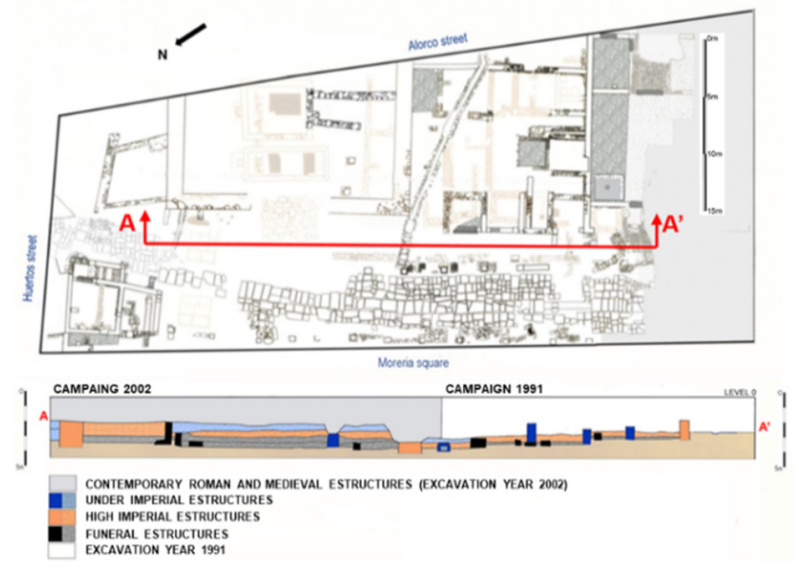

Figure 3: A section view A-A' of the excavation in the Plaza de la Morería site.

Since Late Antiquity, the city has offered a decadent image, a circumstance that can be seen in a decline in urban development. Some of the roads were disabled, the domus located outside the walls were abandoned and, finally, the habited area was contracted. In the $5^{\text {th }}$ century, looting phenomena of Roman structures and extensive levels of collapse appeared covering practically the whole surface occupied by the domus, a process that culminated in the use of part of the sewer as a burial necropolis. This new urban scheme would leave almost the entire old residential area in the lower part of Sagunto uninhabited and including the Plaza de la Morería site. 


\section{Non-destructive techniques}

\subsection{Structure from motion (SFM) photogrammetry}

In order to have a first topographical approximation of the study area, the SFM (Structure from Motion) photogrammetry was chosen to obtain a threedimensional model of the study area environment, using photographic images supported by surveying points measured on the ground.

The camera used for the photogrammetric survey was the Canon EOS-1Ds Mark III, with a focal length of $35 \mathrm{~mm}$, a resolution of $5,616 \times 3,744$ pixels and a pixel size of $6.41 \times 6.41$ microns. And a SOUTH NTS-330 total station was used for the surveying measurements. A local system of coordinates was defined from the surveying measurements, on which all the subsequent work will be georeferenced.

Prior to taking the photographic images, a total of $6 \mathrm{~B} / \mathrm{W}$ objectives were placed on the pillars of the building, in whose basement the ruins under study are located, and they were given three-dimensional coordinates using a topographic total station. The distribution of terrestrial photographic shots was made in a random way given the difficulty of making linear passes through the characteristics of the terrain, at all times the principles of photogrammetry were maintained in terms of overlap between consecutive photographs. Each photograph taken had a high percentage of overlap with the previous and subsequent photograph and the route of the photographic shots was carried out in a perimeter way to the study area, densifying the number of photographs in those areas that suggested greater interest. Figure 4 shows the distribution of the 189 photographs taken.

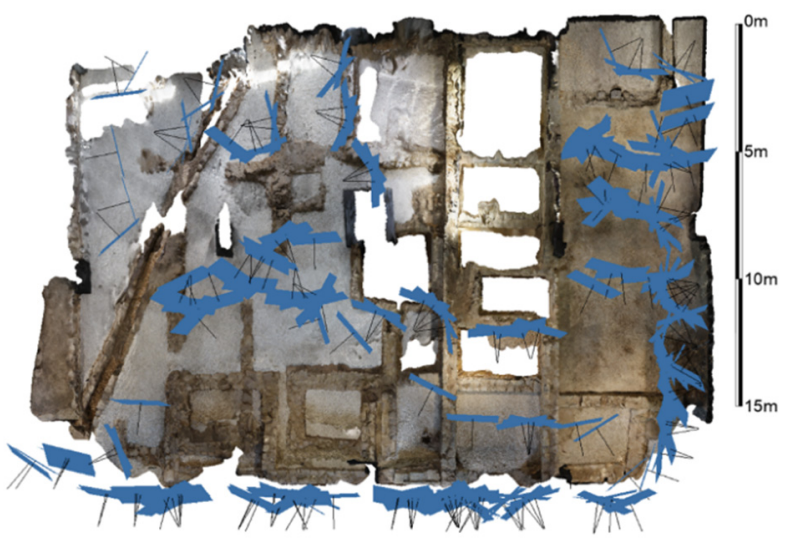

Figure 4: Distribution of each of the positions (blue) and orientations (black lines) of the photographic shots.

The calculation of the three-dimensional point cloud and its texturing was executed with the Agisoft Metashape Professional program and its georeferencing was carried out from the $6 \mathrm{~B} / \mathrm{W}$ targets distributed in some of the pillars of the work area and of which its topographic coordinates are known. The error obtained in the absolute orientation of the model was $0.016 \mathrm{~m}$. The number of three-dimensional points obtained was $24,371,568$, which have been used to construct a digital model of the terrain with $1,610,380$ triangles and a point density of 9.69 points per square centimetre.
The archaeological site three-dimensional model purpose (Fig. 5) was to check the levels in each of the enclosures defined by the wall uprights. In this way, two burial sites were identified with heights of $9.85 \mathrm{~m}$ and $10.37 \mathrm{~m}$ according to our local reference system (AA') and the height of the opus caementicium pavement of the $3^{\text {rd }}$ century $A D$ which is $10.65 \mathrm{~m}\left(\mathrm{BB}^{\prime}\right)$. Figure 6 identifies these levels on the orthophoto of the site and the section made by the areas of interest, clearly showing that the $3^{\text {rd }}$ century $A D$ pavement is $0.28 \mathrm{~m}$ and $0.85 \mathrm{~m}$ above the identified burial sites. This led us to consider the existence of a potential archaeological horizon under the $3^{\text {rd }}$ century $A D$ pavement which should be analysed with the GPR technique.

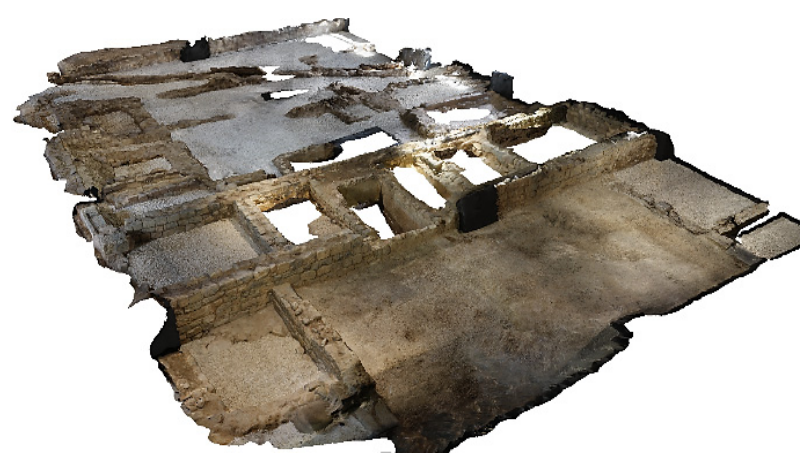

Figure 5: Textured 3D model obtained from the archaeological site of Plaza de la Morería by photogrammetry (SFM).

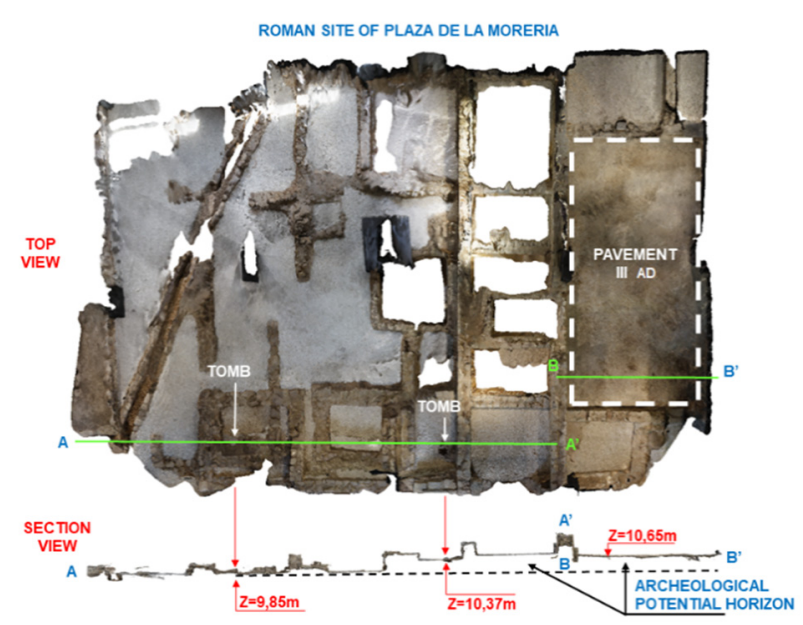

Figure 6: Orthophoto of the site plan and the section made where the existence of a potential archaeological horizon is inferred under the pavement of opus caementicium from the $3^{\text {rd }}$ century AD.

\subsection{GPR technique}

\subsubsection{Field data acquisition}

Data collection was required for the whole of the Roman pavement of opus caementicium under study. Threedimensional (3D) GPR methodology was carried out to pinpoint and define the continuity and existence of pre- $1^{\text {st }}$ century $A D$ Roman burial structures and pavement, according to the results from depth analysis of the archaeological layers in the cross section obtained by SFM. A rectangular grid $(10.50 \times 5 \mathrm{~m}$ size $)$, with equidistant orthogonal 2D lines, spaced every $0.50 \mathrm{~m}$, was designed for the data acquisition on the Roman pavement of opus caementicium. This rectangular grid was topographically 
georeferenced to the local system previously defined with the SOUTH NTS-330 total station. Each beginning and end of the profiles were marked with chalk on the ground. Once marked, an elastic tape was extended between the beginning and end chalk marks of each 2D GPR profile in order to follow precisely the corresponding line. The GPR data were collected with a GSSI SIR-3000 device. Considering that the average depth of study for pre-1 $1^{\text {st }}$ century AD Roman funerary space was around $2 \mathrm{~m}$, a nominal $400 \mathrm{MHz}$ centre frequency antenna was used. The data acquisition was carried out in the continuous mode with trace-interval of $0.02 \mathrm{~m}$, a total time window (range) of 60 ns and defined by 512 samples per trace for a total of 33 profiles (22 transversal and 11 longitudinal profiles), as shown in Figure 7. A survey wheel (encoder) was attached to the side of the GPR antenna. Thus, it was possible to record GRP profiles $0.15 \mathrm{~m}$ from the perimeter walls that framed the studied pavement. Due to the fact that the Roman pavement of opus caementicium was flat with no unevenness or slopes, the survey wheel tracked the distance travelled and allowed consistent scan spacing in order to calculate trace-interval distance.

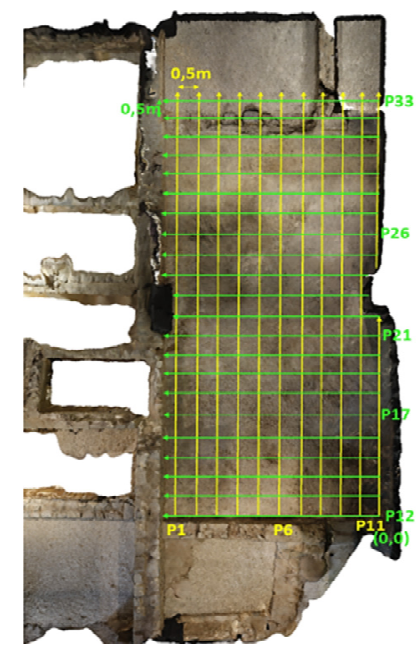

Figure 7: Layout of the GPR profiles in a grid $0.50 \times 0.50 \mathrm{~m} \mathrm{(22}$ transversal and 11 longitudinal profiles) on the Roman pavement of opus caementicium of $3^{\text {rd }}$ century AD.

The GPR reflection data were acquired on the same day. Therefore, the subsurface moisture conditions of this investigated sector could be considered almost constant for the investigated depth during the acquisition of GPR field data. This velocity estimation assumption was made for the proposed objective of locating the Roman burial structures and pavement underneath the Roman opus caementicium pavement from the $3^{\text {rd }}$ century $A D$, with consideration to the fact that possible changes in the subsurface conditions could cause velocity variations which that would affect velocity-to-depth conversions. The average velocity of the GPR wave was determined by using the hyperbola fitting method in a set of hyperbolas recorded in different profiles, obtaining an average velocity value $8.5 \mathrm{~cm} / \mathrm{ns}$. The dielectric permittivity was calculated to be 12.5 , according to the following Eq. (1) (Conyers, 2013):

$$
\varepsilon=\left(\frac{c}{v}\right)^{2}
$$

where

$$
\begin{aligned}
\varepsilon & =\text { dielectric permittivity } \\
v & =\text { electromagnetic wave velocity } \\
c & =\text { velocity of light in free space }(c \approx 29.97 \mathrm{~cm} / \mathrm{s})
\end{aligned}
$$

Windows were converted to depth using the same dielectric permittivity at all times. This value was applied for calculation of the processed depths in the investigated sector. This average velocity was also used in Kirchhoff migration for the processing of the 2D GPR data.

\subsubsection{Data processing}

Prior to the construction of a rendered three-dimensional image with all reflection profiles in a grid, post-acquisition processing procedures are required for application to the GPR raw field data set. There are several post-acquisition radar signal processing techniques that can potentially be used for GPR datasets depending on their objectives. In this study, a basic data processing procedure was applied to the raw data set using the RADAN software developed by Geophysical Survey Systems, Inc. (GSSI), due to the fact that good signal penetration in the reflection profiles.

As a first step, the zero-time correction, background removal and gain function were also applied to amplify the received signal and improve the reflection identifications. Raw 2D data was also processed by applying filters such as the Kirchhoff migration filter using average velocity for diffraction removal. A GPR-3D model of the subsurface was obtained by aligning processed $2 \mathrm{D}$ profiles to accurately locate the burial structures and evidence of pavement underneath the sector studied. In addition, a transparent visualisation of the 3D GPR data set was carried out to reveal the main structures of the subsurface.

\subsubsection{Results}

The 2D radar profiles provide an overview of the area under the study of the archaeological site. These radar profiles illustrate the dissimilarities of the subsurface. The profiles show main anomalies of interest (Roman structures) from meters 0 to 7.50 and from meters 8.70 to 10.50 at depths from meters from 0.27 to 0.85 . Besides, deeper anomalies observe from meters 0 to 7.50 and from meters 8.70 to 10.50 at depths from meters from 0.88 to 2.20 (Iberian structures), as shown in Figure 8a. These anomalies reveal the presence of Roman and Iberian structures in the studied volumetric space. Additionally, the existence of strong linear reflector is observed at depth $0.80-0.88 \mathrm{~m}$ that corresponds to pre- $1^{\text {st }}$ century $A D$ burial pavement. These GPR results correspond to the results of the 2002 archaeological campaign and the cross-analysis of the depths of archaeological layers obtained by SFM.

Determining geometrical and dimensional features of Roman structures derived from GPR 2D data is timeconsuming and requires an individual analysis of every radar profile. 3D GPR visualisation techniques overcome this drawback by defining the buried remain features for the entire studied underground volume, as shown in Figure 8b.

Further, the isosurface rendering technique allowed displaying surfaces of equal amplitude in the studied volume. Specifically, this 3D GPR data visualisation 
reproduces and highlights the geometric characteristics of the reflections, derived from archaeological remains, with a strong contrast to the surrounding environment of the analysed volume. This isosurface image was coloured purple-magenta to show these amplitude values, while others were made transparent to better represent only the archaeological remains and simplify their detection and interpretation of the data. The transparent visualisation of the 3D GPR data set was conducted in order to reveal the main anomalies of interest (Roman structures and layers) in the studied volume. The obtained isosurface image allowed the three-dimensional visualisation of the most relevant Roman structures and layers defined in the volume from 0.20 to $0.88 \mathrm{~m}$ depth and also the Iberian remains in the volume from 0.88 to $2.20 \mathrm{~m}$ depth, as shown in Figure 8c.

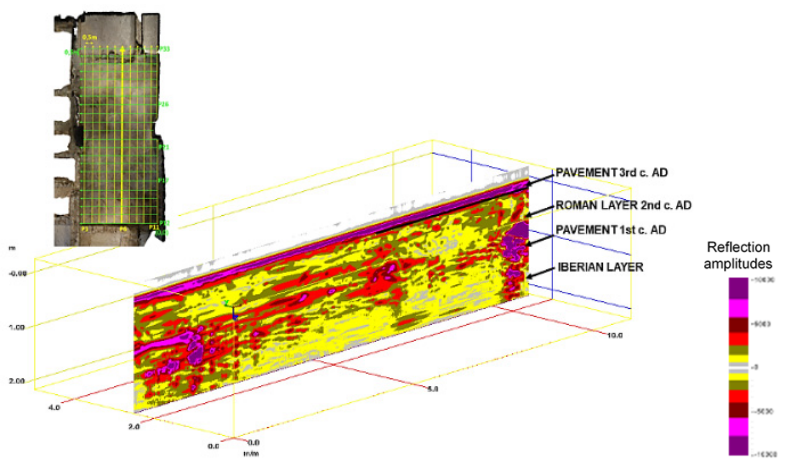

(a)

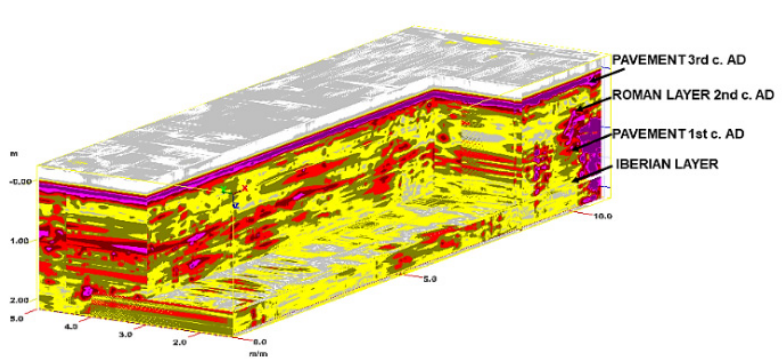

(b)

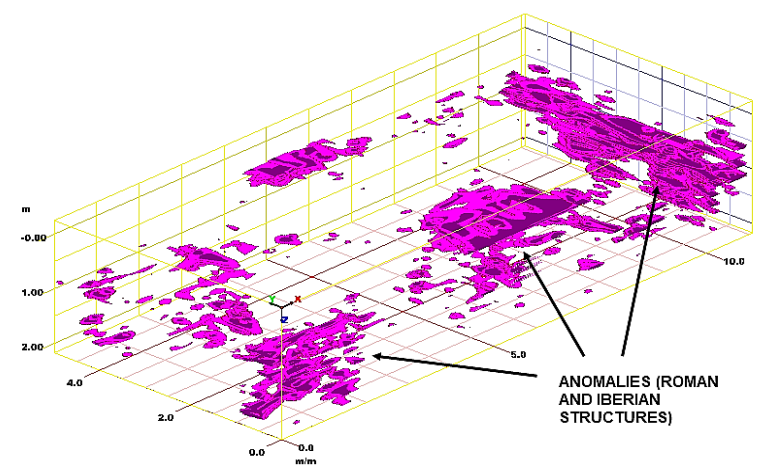

(c)

Figure 8: Overview of the area under the study of the archaeological site: a) P6 reflection profile; b) 3D radar section images after processing the raw data, showing strong underground evidence of Roman and Iberian structures and layers; c) Isosurface image in the volume under study, showing the main anomalies (Roman and Iberian structures) detected and other reflection points.
As seen in Figure 8, the main recorded anomalies (Roman and Iberian structures) are concentrated in the southern, central and northern areas of the volumetric space under study.

It should be noted that the evidence of the continuity of the pre- $1^{\text {st }}$ century $A D$ burial pavement had been pinpointed at a depth of $0.85 \mathrm{~m}$. This information was crucial for determining which archaeological strategy was required in order to recover the Roman funerary space at the Plaza de la Morería site.

\subsection{Integration of SFM photogrammetry and GPR techniques}

Because the origin and final coordinates of each of the profiles made with the GPR are known, it is straightforward to integrate these profiles into the terrain's photogrammetric correlation digital model. The 3D photogrammetric model data integration with the 2D GPR profiles and the 3D GPR mode was carried out using AutoCAD software. Figure 9 shows the representation of the longitudinal profile P6 in its exact position, as in the area of the pavement studied (opus caementicium from the $3^{\text {rd }}$ century $A D$ ), it can be seen that the thickness is continuously $0.20 \mathrm{~m}$, the existence of anomalies between $0.88 \mathrm{~m}$ and $2.20 \mathrm{~m}$ can also be seen in the initial zone of the profile and in the final part of the profile it can be seen how the surface wall presents a response in depth which reaches $2.10 \mathrm{~m}$

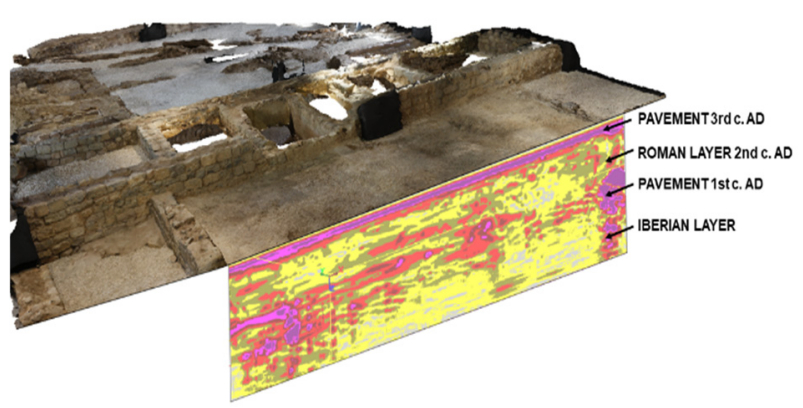

Figure 9: $\mathrm{P} 6$ reflection profile georeferenced in the digital model of the terrain of the Plaza de la Morería site, which shows underground evidence of Roman and Iberian structures and layers along the profile.

Using the same methodology, the profiles have been integrated into the digital model of the terrain in order to have a better interpretation of the GPR three-dimensional data in the volume studied. The superposition result is presented in Figure 10, where the thickness of $0.20 \mathrm{~m}$ of the pavement from the $3^{\text {rd }}$ century $A D$ and the continuity of the pre- $1^{\text {st }}$ century $A D$ funerary pavement is apparent.

\section{Archaeological strategy}

It was conjectured, by results obtained in 2002 in the excavation of a different $2^{\text {nd }}$ century AD building within the site previously excavated in 1991, that it was likely that archaeological strata existed below the excavated remains, similar to those documented on the north flank of the site where the base of a temple came to light, as shown in Figure 11. Therefore, in the process of defining an archaeological strategy to recover the funerary space that existed until the $1^{\text {st }}$ century $A D$ at the Plaza de la Morería, it was essential to determine the extent and entity of the archaeological remains located in the 
subsurface, in order to be able to relate them to the findings already excavated in the 1991 and 2002 campaigns.

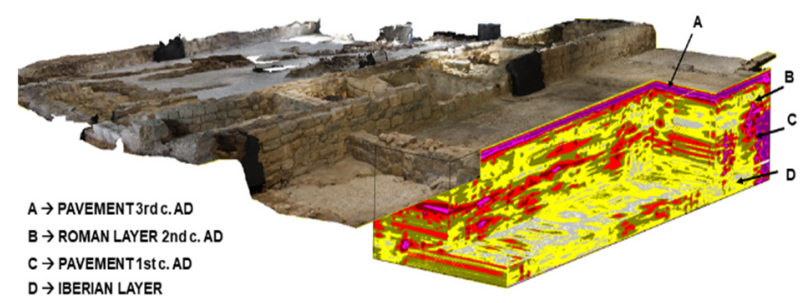

Figure 10: 3D GPR model georeferenced in the digital model of the terrain obtained in the Plaza de la Morería site, which shows underground evidence of Roman and Iberian structures and layers in the volumetric space studied under the Roman pavement of opus caementicium from the $3^{\text {rd }}$ century $A D$.

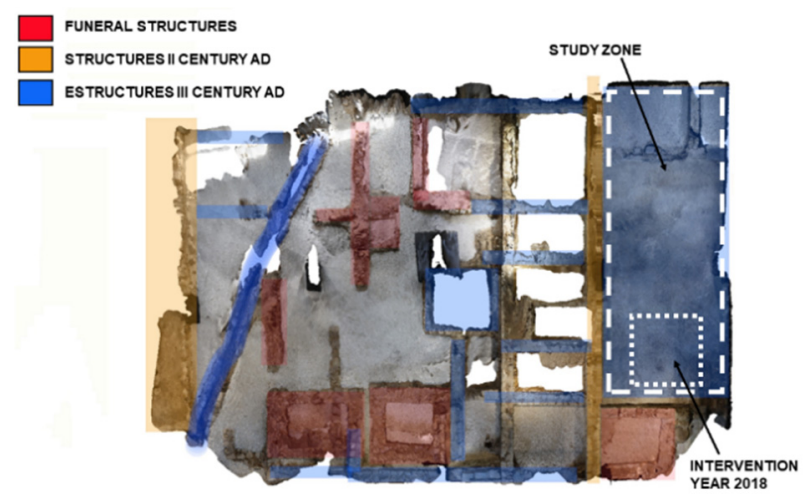

Figure 11: Archaeological intervention area in the 2018 campaign (white dotted line) following the decision made based on the results obtained in the SFM photogrammetry and GPR in the study area (white dashed line).

The integration of data from non-destructive SFM and GPR techniques, combined with archaeological data represent an important potential in archaeological research project strategies where the overlap of cultural levels is present, especially in urban areas that may continue in the subsurface.

The integration of SMF and GPR allowed determining the main area (concentration of Roman structures and the presence of the funerary pavement) with the greatest stratigraphic power. This integration specified that part of the structures from the Roman period, such as the roads and monumental buildings, had continuity in the immediate space. In addition, it was detected that the walls of the domus were on other previous structures that had the same arrangement. The existence of other structures sub posed to the funerary levels within the site was also recorded, therefore it was very likely that the structures could have a Late Republican or Iberian chronology.

Consequently, it was possible to demonstrate that there were pre- $1^{\text {st }}$ century AD Roman funerary remains below the $2^{\text {nd }}$ century building. These remains were covered by a $3^{\text {rd }}$ century opus caementicium pavement, corresponding to a floor of the domus using part of the structure of the monumental building.

After analysis and evaluation of the integrated SFM and GPR results, the decision was made to recover the pre$1^{\text {st }}$ century $A D$ Roman funerary space by removing the paving of a $3^{\text {rd }}$ century $A D$ domus and the Roman structures from the $2^{\text {nd }}$ century that covered it. As a result, a new archaeological intervention was proposed specifically in the southern area of the $3^{\text {rd }}$ century $A D$ pavement.

\subsection{Archaeological intervention}

The new archaeological campaign was carried out in January 2018. Work was carried out on the excavation of the stratigraphy in an archaeological survey of approximately $3 \times 3 \mathrm{~m}$ where a greater presence of archaeological structures and a possible funerary pavement had previously been detected by GPR (Fig. 11).

First, the opus caementicium paving covering this space was removed. The soil was composed of a $0.06 \mathrm{~m}$ layer of lime mortar, sand and gravel and a pebble preparation that was $0.14 \mathrm{~m}$ thick. From this pavement, some fragments of common pottery and tegulae mixed with the caementicium were recovered. Below the pavement, a layer of $0.22 \mathrm{~m}$ of depth was registered, formed by the earth of a clay composition of beige colour, very compact, and little ceramic and bone material. Among the materials, the presence of very small fragments of limestone with a blackish hue stood out above all, which due to their characteristics could correspond to the remains of the carving of the stones that were part of the walls of the building linked to the caementicium pavement. It could be a level of compaction and levelling of said soil. The next layer had an archaeological power of $0.43 \mathrm{~m}$ and corresponded to a stirred level. Many large stones and bowls, other small and medium-sized stones, abundant fragments of stone and ceramic material were documented. Among the ceramics, the presence of amphora, dolia and tegulae fragments stands out. Only next to the south cut of the excavation did there appear caked edges with a certain orderly arrangement, which could indicate the presence of a wall. During the excavation process of this level, it was observed that it amortized a large pebble wall of which $0.45 \mathrm{~m}$ in height was preserved. This was under the structures of the superimposed building and had attached the remains of a pavement preparation, which was composed of a layer of lime and a compacted level of clay soil and gravel. This unit had a thickness of $0.08 \mathrm{~m}$. Likewise, this pavement appeared associated with a small circular pit. In the eastern sector of the table, a $0.28 \mathrm{~m}$ diameter pit affected its conservation.

Finally a $0.40 \mathrm{~m}$ strip was excavated in the section where the pavement was not preserved, in the southern part of the excavation, which allowed reaching a stratum of sandy composition and $0.30 \mathrm{~m}$ of stratigraphic power, with few ceramic materials from the Iberian period.

\subsection{Results of the archaeological intervention 2018}

The excavation revealed that the caementicium pavement covered a mixed level, in which the remains of various foundations appeared: very roughly carved pebbles and stones, squared stone fragments and slab fragments that were probably part of a pavement that was not preserved (Fig. 12). We also recorded abundant ceramic material, especially brick material, fragments of amphorae and Iberian ceramics, and to a lesser quantity 
of sigillata and thin-walled pottery. The chronology of this material varies between the $2^{\text {nd }}$ century $B C$ (fragments of Iberian pottery, Greco-Italian and Punic pottery) to the $1^{\text {st }}$ century AD (Roman thin-walled pottery, Italic and South Gaulish terra sigillata). This chronology could indicate that, at this time, a remarkable transformation of the terrain took place that undoubtedly affected the basal structures. In this sense, the works brought to light the preparation of a floor, fragments of stone slabs with lime mortar residue and a small circular pit, which might be a hole for a roof support post. This pavement was attached to a wall beneath the $2^{\text {nd }}$ century AD structures, coinciding with the closure of a structure excavated in 1991. The pavement was located below the structures of the 2 nd and $3^{\text {rd }}$ centuries $A D$, next to the road. It is, therefore, a structure dating from before the $2^{\text {nd }}$ century $A D$, which can be related to the funerary levels of the site. The fact that many stone fragments from opus vittatum walls appeared in the filling that amortized this structure, may suggest that the funerary level is inside the $2^{\text {nd }}$ century structure.

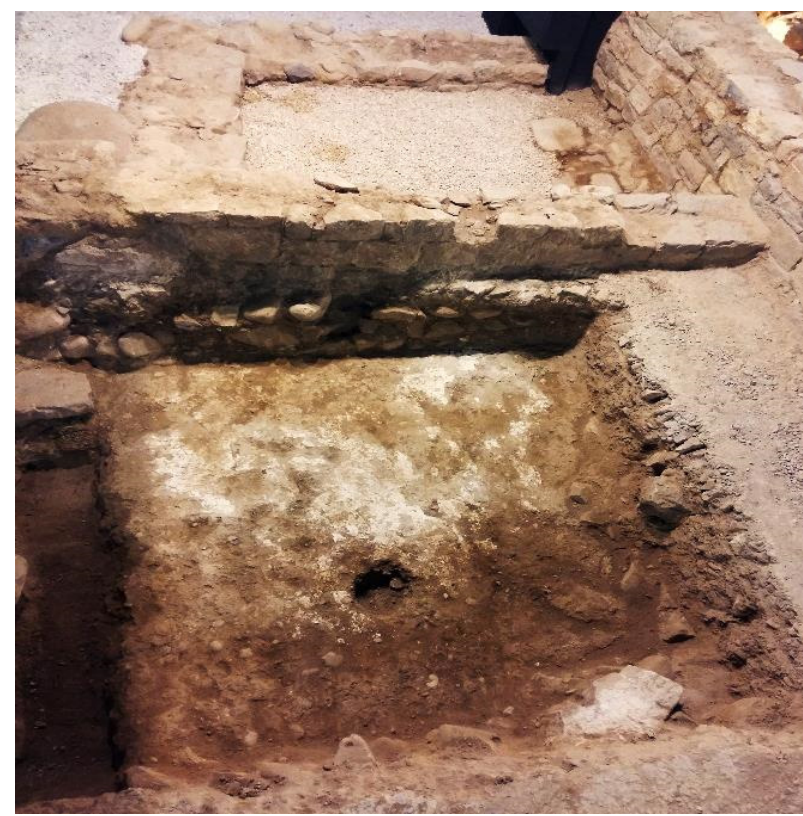

Figure 12: A photograph of the entire plan of the funerary space after the 2018 archaeological intervention, showing the pre- $1^{\text {st }}$ century AD funerary pavement and the circular pit previously detected in the GPR geophysical survey.

\section{Digital documentation: terrestrial laser scanner (TLS)}

Documentation of the results of the 2018 archaeological campaign was completed with a topographical survey of the final state of the prospection using a terrestrial laser scanner (TLS). The instrument used was the TRIMBLE TX-6.

The main reason for using a terrestrial laser scanner (TLS) for digitally documenting the results is that the TLS was also used in a previous 2018 campaign to digitize the interior and exterior of the archaeological site area. Thus, the corresponding digital documentation data obtained in this study could be combined with those of the previous campaign.

The point cloud obtained was georeferenced on the local system of coordinates used in the studies prior to the tasting. Measurements were also made on targets outside of which the coordinates are known in UTM projection, datum ETRS-89, zone 30, orthometric height, in order to be able to materialise all the three-dimensional metric products made in this work on an absolute coordinate system.

The main advantage of working with laser scanners is that the three-dimensional model generated is incorporated into the final file, and at any time afterwards, the necessary measurements can be obtained. However, the stratigraphy obtained because of the 2018 intervention was incorporated into the archaeological dossier, as shown in Figure 13.

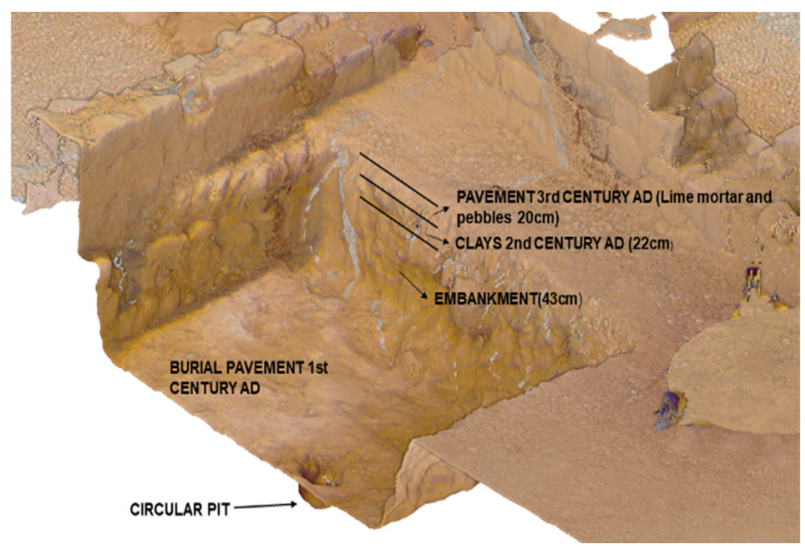

Figure 13: Stratigraphy obtained because of the 2018 archaeological intervention georeferenced in the 3D laser scanner model of the Plaza de la Morería site.

\section{Conclusions}

The archaeological interventions that were carried out on this site in 1991 and 2002 proved the existence of very interesting structures from the early imperial period. The original plan was rectangular, with opus vittatum walls, while in the $3^{\text {rd }}$ century AD the foundations of a domus were attached to the northern wall. Inside, a caementicum floor was documented, three rooms on the west façade and another on the east façade, facing the road.

The GPR and SFM results first indicated, and then revealed, the existence of structures below the pavement. These results were later corroborated by the remains documented in the archaeological excavation of 2018 without appreciable deviations. Furthermore, a laser scan inventory was carried out of the funerary space of the Plaza de la Morería site, the only one preserved so far in the city. This laser scan inventory cleared the way for relating the funerary remains from the 2018 excavation with those of the previous campaigns present on the site at a topographic and spatial level, through the stratigraphic correlation and orientation of various monuments.

As a consequence of this multidisciplinary intervention, the 2018 archaeological campaign has recovered the floor plan of a funerary monument from the High-Imperial period, the loculus, and the remains of the pavement of the possible pre-1 ${ }^{\text {st }}$ century access area. At the time of this publication, this is the only funerary monument from the Early Roman Empire period visible in the city of Sagunto. This funerary complex was masked by structures from a later period, specifically from the 2nd and $3^{\text {rd }}$ centuries AD. Currently, after delimitation and excavation, it serves as an example not only for the 
understanding and interpretation of the other funerary monuments in Plaza de la Morería, but also for the general mapping of the necropolis and its interaction with the other levels and period. This funerary complex also opens the door to further research into the pre-Roman levels and strata (Iberian horizons) underneath this Roman funerary complex.

In summary, we have shown that our methodology of detection, documentation, mapping and $3 D$ restitution, based on the integration of SFM photogrammetry, GPR and TLS, is an efficient virtual tool in the decision-making process and other decisions made in phases of archaeological prospecting and intervention (both excavation and conservation). In addition, due to its flexibility and capacity to obtain information for analysis, digital mapping and 3D surface and subsurface virtual visualisation, this methodology can serve as a model for other sites with different geographical characteristics and chronologies, both in urban and rural areas.

\section{Acknowledgements}

The authors are grateful to Sagunto Town Council for funding the archaeological excavation work in 2018.

\section{References}

Conyers, L. B. (2013). Ground-Penetrating Radar for Archaeology. Third edition. Altamira Press, Walnut Creek, California.

Ferrer, J. J., Benedito, J., \& Melchor, J. M. (2018). A New Impression of the Roman City of Saguntum (Spain) Based on Recent Findings. Archeologia Classica, 69, 357-72. https://doi.org/10.1400/267461

Ferrer, J. J., Benedito, J. \& Melchor, J. M. (2020). Saguntum: The Remains of an Honorary Arch and Urban Planning Outside the City Walls. European Journal of Archaeology, 23(1), 43-63. https://doi.org/10.1017/eaa.2019.43

Ferrer, J. J., Oliver, A., \& Benedito, J. (2016). Saguntum y La Plana. Una ciudad romana y su territorio. Publicacions Diputació de Castelló, Castellón.

Horsley T., Wright A., \& Barrier C. (2014). Prospecting for New Questions: Integrating Geophysics to Define Anthropological Research Objectives and Inform Excavation Strategies at Monumental Sites. Archaeological Prospection, 21, 75-86. https://doi.org/10.1002/arp.1476

Kościuk, J. (2012). Modern 3D scanning in modelling, documentation and conservation of architectural heritage. Wiadomości Konserwatorskie, 82-88.

Kulikowski, M. (2004). Late Roman Spain and its Cities. Baltimore et Londres. Johns Hopkins University Press.

Leckebusch, J. (2003). Ground-penetrating Radar: A Modern Three-dimensional Prospection Method. Archaeological Prospection, 10, 213-240. https://doi.org/10.1002/arp.211

Lerma, J. L., Navarro, S., Cabrelles, M., \& Villaverde, V. (2010). Terrestrial laser scanning and closerange photogrammetry for 3D archaeological documentation: The Upper Palaeolithic Cave of Parpalló as a case study. Journal of Archaeological. Science, 37, 499-507. https://doi.org/10.1016/j.jas.2009.10.011

Leucci, G., \& Negri, S. (2006). Use of ground penetrating radar to map subsurface archaeological features in an urban área. Journal of Archaeological Science, 33, 502-512. https://doi.org/10.1016/j.jas.2005.09.006

Malfitana, D., Leucci, G., Fragalà, G., Masini, N., Scardozzi, G., Cacciaguerra, G., Santagati, C., \& Shehi, E. (2015). The potential of integrated GPR survey and aerial photographic analysis of historic urban areas: A case study and digital reconstruction of a Late Roman villa in Durrës (Albania). Journal of Archaeological Science: Reports, 4, $276-284$. https://doi.org/10.1016/j.jasrep.2015.09.018

Melchor, J. M. (2013). El poblamiento romano en Saguntum y su territorium: organización urbana y explotación agrícola. Tesis Doctoral inédita. Castellón: Universitat Jaume I.

Melchor, J. M., Benedito, J., \& Ferrer, J. J. (2015). Una nueva necrópolis augústea en Sagunto. Los monumentos funerarios de la plaza de la Morería. In J. López-Vilar (Ed.), Tarraco Biennal. 2 Congrés internacional d'arqueologia i món antic (pp. 239-245).

Muñumer, E., \& Lerma, J. L. (2015). Fusion of 3D data from different image-based and range-based sources for efficient heritage recording. Digital Heritage, 1, 83-86. IEEE. https://doi.org/10.1109/DigitalHeritage.2015.7413840

Pérez-Gracia, V., Canas, J. A., Pujades, L. G.; Clapés, J., Caselles, O., García, F., \& Osorio, R. (2000). GPR survey to confirm the location of ancient structures under the Valencian Cathedral (Spain). Journal of Applied Geophysics, 43, 167-174. https://doi.org/10.1016/S0926-9851(99)00056-7

Puente, I., Solla, M., Lagüela, S. \& Sanjurjo-Pinto, J. (2018). Reconstructing the Roman Site "Aquis Querquennis" (Bande, Spain) from GPR, T-LiDAR and IRT Data Fusion. Remote Sensing, 10(3), 379. https://doi.org/10.3390/rs10030379

Stal, C., Van Liefferinge, K., De Reu, J., Docter, R., Dierkens, G., De Maeyer, P., Mortier, S., Nuttens, T., Pieters, T., van den Eijnde, F., van de Put, W., \& De Wulf, A. (2014). Integrating geomatics in archaeological research at the site of Thorikos (Greece). Journal of Archaeological Science, 45, 112-125. https://doi.org/10.1016/j.jas.2014.02.018

Urban, T. M., Murray, C. A., Vella, C., \& Lahikainen, A. (2015). Ground-penetrating radar survey on the island of Pantelleria (Italy) reveals an ancient architectural complex with likely Punic and Roman components. Journal of Applied Geophysics, 123, 164-169. https://doi.org/10.1016/j.jappgeo.2015.10.012 
Yastikli, N. (2007). Documentation of cultural heritage using digital photogrammetry and laser scanning. Journal of Cultural Heritage, 8, 423-427. https://doi.org/10.1016/j.culher.2007.06.003 


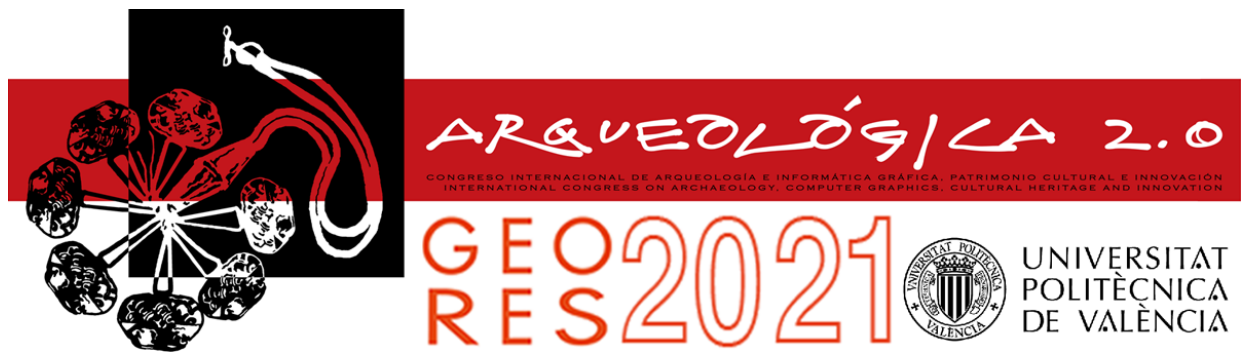

Proceedings of the joint international event $9^{\text {th }}$ ARQUEOLÓGICA

$2.0 \& 3^{\text {rd }}$ GEORES

Valencia (Spain).

26-28 April 2021

\title{
COMPARISON OF THE PHOTOGRAPHY, RADIOGRAPHY AND PROCESSED IMAGES IN THE STUDY OF METALLIC PIECES FROM ARCHAEOLOGICAL SITES
}

\author{
Jose A. Madrida, ${ }^{,}$, Effat Yahaghib, Jose M. Melchor ${ }^{c}$, Amir Movafeghid $^{\mathrm{b}}$ \\ a Instituto Universitario para la Restauración del Patrimonio, Universitat Politècnica de València, Camino de Vera s/n, 46022 Valencia, \\ Spain.jmadrid@crbc.upv.es \\ b Department of Physics, Imam Khomeini International University, Qazvin, Iran. yahaghi@sci.ikiu.ac.ir
}

c Museo Arqueológico, Ayuntamiento de Burriana, Plaza de la Merced s/n, 12530 Burriana, Spain. arqueologo@burriana.es

${ }^{d}$ Nuclear Science and Technology Research Institute (NSTRI), Tehran, Iran. amovafeghi@aeoi.org.ir

\begin{abstract}
:
Archaeologists and conservators face different challenges when inspecting metal pieces extracted from the archaeological sites including their high quantity and the complexity of the materials and their shapes and often the pieces are covered by oxidized layers. Non-destructive analysis techniques such as digital radiography imaging are used to efficiently detect and classify the pieces. Furthermore, the shape of pieces, the state of their metalcore is assessed to inform the required handling, investigation, and intervention technique. However, for thicker metal pieces, the acquired X-ray images are often foggy and lack the required quality making the effective assessment of the piece difficult. Without further tools at the disposal of the non-radiologically-trained archaeologists and conservators, extraction of accurate information from unprocessed radiographs showing the internal hidden structures, the level of oxidation, and the presence of cracks is not possible. To complement the visual examination and original radiograph of the piece, an effective solution for improving the contrast of pertinent features of the $x$-ray image is implementing a digital imaging processing algorithm to enhance the quality of the radiographs. This study has used the "Fast 2D Gaussian convolution first-order infinite impulsive response" (IIR) to extract greater detail for better interpretation of the radiological images. The archaeological metal pieces to which the complementary technique was applied were from two important Iberian-Roman sites located on the coast of the municipality of Burriana (Castellón), i.e. Sant Gregori and Torre d'Onda. The pieces were the property of the archaeological museum of Burriana, Spain, and were investigated using X-ray imaging. The complexity of the task necessitated close interaction between the multidisciplinary team involved in this study. The study has found that the combination of visual inspection/photograph, the original radiograph, and processed X-ray image is a powerful inspection tool especially in the hands of the non-radiologically trained archaeological experts and conservators. The complementary technique of using processed X-ray images was also found to be highly effective for quantification of the location, geometry, and extent of the pertinent features of the studied items as confirmed by the experts involved in this study.
\end{abstract}

Keywords: digital radiography, metal pieces, archaeology, conservation, Sant Gregori, Torre d'Onda, The Archaeological Museum of Burriana

\section{Introduction}

As a non-destruction method, Radiography testing (RT) offers several advantages for examining metal archaeological pieces. Such items are usually covered in earth and have extensive surface oxidation limiting effective visual inspection. RT is often the technique of choice therefore for the examination of such items with digital RT offering further data analysis and processing possibilities (Fell, Mould, \& White, 2006; Nicoll \& Hook, 2008; Madrid \& Ramírez, 2011; Madrid, 2014a; Lang \& Middleton, 2016).
Flemish Institute for the Archaeological Heritage reports that with conventional tools it would take about 24 years to clean the total of 25,000 pieces of iron from an archaeological site; the process was reduced to two and a half years with the aid of RT.

Cleeren (2006) report that using RT they could focus on two-thirds of items that were partial "diagnostically cleaned". Caple and Garlick (2018) however reported that that reliance only on a digital comparison of RT images was found to be too subjective for the assessment of the object. 
The archaeological site of Sant Gregori was excavated for the first time in 1987. At the time of the initial archaeological survey, little was known about the site; for example, unlike similar villa sites in the same vicinity, the new site had been built with luxurious characteristics.

Further recent excavation effort was commissioned as a result of a new urbanization project in the area. The area of the settlement was delimited and later a series of surveys were carried out at specific locations to reveal the state of conservation of the remains and their characteristics.

Later a series of archaeological campaigns were undertaken which revealed that the town had two distinct phases of settlement. Relating to the initial settlement phase, the excavation revealed the presence of a funerary monument, a peristyle with a large rectangular pond, around which a series of rooms and thermal baths are arranged.

The second phase dated from the $2^{\text {nd }}$ century AD. It was characterized by the reform and reuse of part of the existing structures. The funerary monument had been razed, the existing rooms were compartmentalized and new flats were built with smaller walls. The second phase of settlement was generally a period of less wealth (Ferrer, Melchor, \& Benedito 2013).

With the selection of pieces from the site of the Roman Villa of Sant Gregori (Díaz, 2014), 66 radiographs were produced, which revealed the interior of 278 metal fragments, of which 149 were nails according to the classification by typologies where Manrique (1980) makes on the nails found in a deposit in Numancia (Soria) constituting about $53 \%$ of the items. The rest of the pieces were staples, rings, or knife fragments. On that occasion, the study provided information on the contours of the pieces, the distinction of their morphology, and facilitated the cleaning work to which the pieces were subjected.

The study of the pieces from the Torre D'Onda site was poorly documented as it was greatly affected by the construction of numerous houses and the promenade. The restricted nature of the excavated area only allowed broad confirmation of the existence of a first enclave from the $6^{\text {th }}$ or $7^{\text {th }}$ century B.C., perhaps associated with the end of the Iron Age.

The most important settlement was from the IberianRoman era, specifically from the $3^{\text {rd }}$ century B.C., where very homogeneous levels were documented that included large containers such as amphorae, kalathoi, pots, jars, small vessels, remains of elements of iron, lead, fauna, etc. Abundant ceramics were excavated from Campania where only large foundation structures were found. The fragments analyzed here were recovered during archaeological campaigns carried out between 1977 and 2007.

This settlement is thought to be related to the coastal trade in Iberian and Roman-Republican times, practically disappearing at the beginning of the imperial era due to the large Roman owners with interests in the viticulture of Hispania Citerior, who altered the commercial circuits and the system of exploitation of the territory (Melchor, 2013).

On this occasion, 32 radiographs were obtained relating to 193 objects (Aznar, 2020). Making the same typological discrimination as the previous case (Manrique, 1980), 54 nails were revealed which constituted about $29 \%$ of the objects. The sets were spikes or hooks.

The two sets of items share some common archaeological characteristics since they come from wide strata of occupation and present a post-depositional mixture of various periods or cultural stages. Neither of the sets has previously been subjected to any conservation or restoration processes.

\section{Objectives}

In this study, enhanced radiography has been used to make a detailed and quantitative assessment of the objects' state of conservation, especially of their metallic core.

Radiography enhancement has been achieved through the application of image processing based on Fast 2D Gaussian convolution first-order infinite impulsive response (IIR) to improve both the contrast and the contouring on the Database Administration System (DBAS).

\section{Methodology}

Photographic and radiographic images were analyzed for each item and the processed image was used to provide further complimentary information. The multi-disciplinary team included the Laboratory of Documentation and Registration at the University Institute for the Restoration of the Patrimony (IRP) of the Universitat Politècnica de València (UPV) for the acquisition of documentary and radiographic registration of information and the Imam Khomeini International University (Qazvin, Iran) for enhanced processing of the X-ray images.

\subsection{Photographic and radiological experiments}

The initial step of the study involved the systematic documentation of information for all the pieces. Pieces were grouped and assemble mounted on rigid plates ready for deployment of the radiographic plate. The plates had a scale system and signage references (Fig. 1). The mounting system allowed reproducible geometric set-up for the pieces. The photographic image was taken in the visible light spectrum on a Kaiser $\AA$ RS10 Copy Stand Using a reflex-type camera, Canon® EOS 15 (Fig. 2).

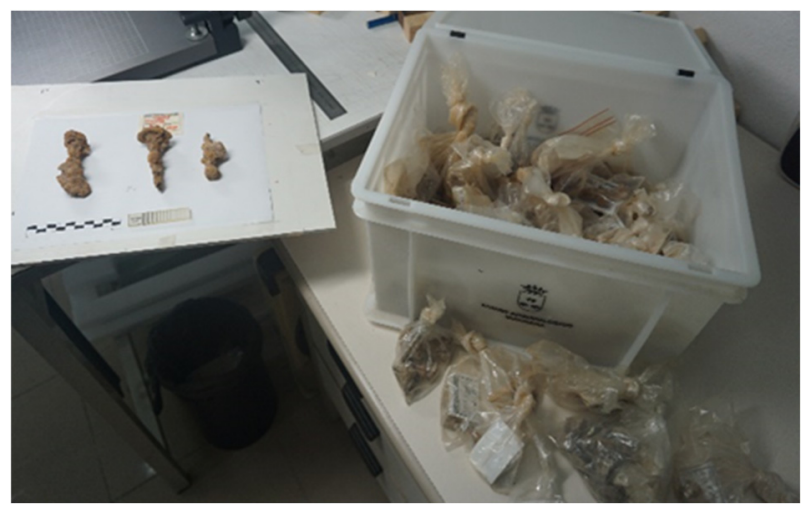

Figure 1: A Set of studied objects. 


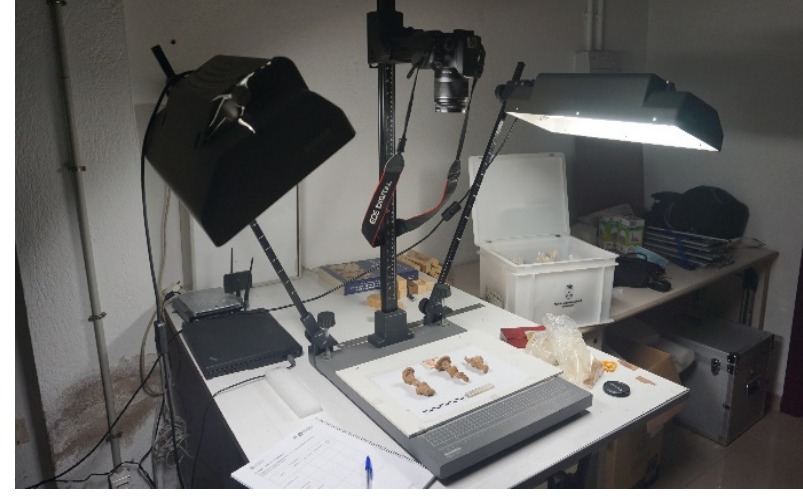

Figure 2: Photography process on a table type Kaiser ${ }^{\circledR}$ RS10 Copy Stand.

The X-ray unit was the TRANSXPORTIX 50 from the General Electric $₫$ company which had a $3 \mathrm{~kW}$ X-ray tube, a $2.3 \mathrm{~mm}$ focal spot size with a total filtration of $2 \mathrm{~mm}$ of aluminum (Fig. 3). The equipment allowed the acquisition of images between $20 \mathrm{kV}$ and $110 \mathrm{kV}$ (Madrid, 2014b). The Tube current was set to 10 or $20 \mathrm{~mA}$ depending on the thickness of the item.

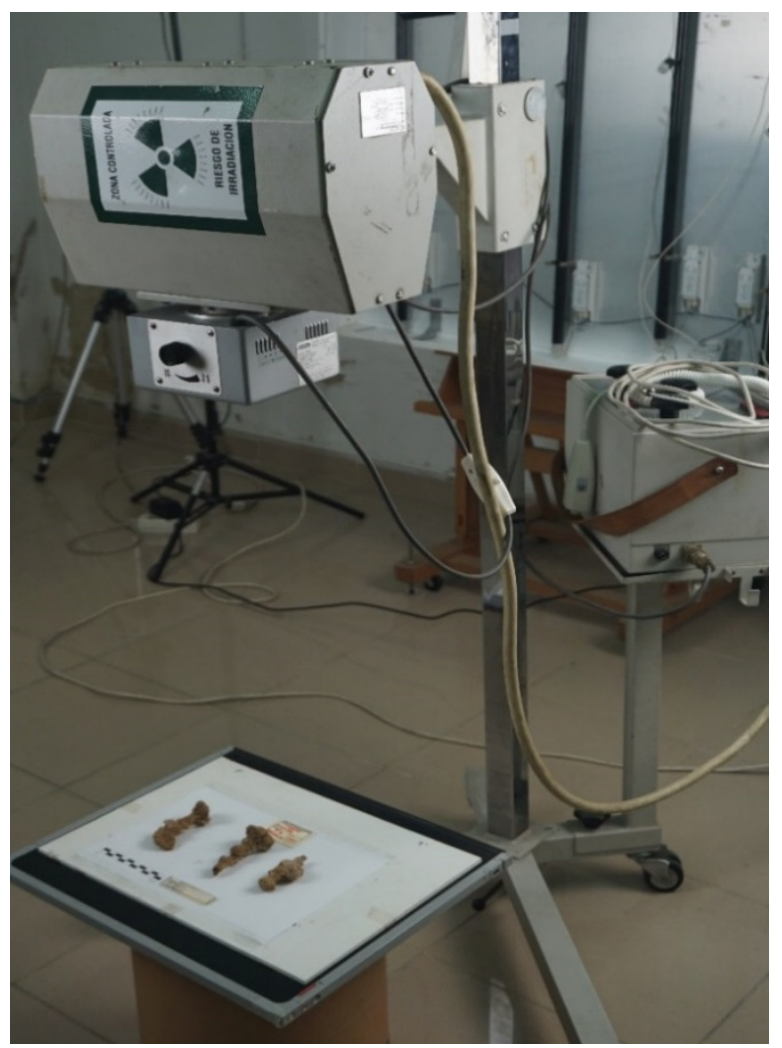

Figure 3: X-ray imaging set up.

The system for centering and locating the imaging area was achieved using visible light collimation. The system also had a duplex-type Image Quality Indicator (IQI) compliant with ISO 19232-5 standard supplied by Kowotest $₫$. The CR MDT4.0T chassis, from AGFA®, was adjusted to $35 \mathrm{~cm}$ by $43 \mathrm{~cm}$ format and a $3480 \times 4248$ pixel matrix was set for the radiographic images.

Nine pieces from both the Sant Gregori (ref_303, ref_308, ref_310,ref_321 and ref_325) and Torre d'Ōnda (ref_894, ref_895, ref_906 and ref_910) sites were selected for radiography as refrenced in Table 1.
Table 1: Parameters used in radiography

\begin{tabular}{c|c|c|c} 
Ref.-Rx & $\begin{array}{c}\text { Voltage } \\
(\mathrm{kV})\end{array}$ & $\begin{array}{c}\text { Intensity } \\
(\mathrm{mA})\end{array}$ & $\begin{array}{c}\text { Exposure } \\
(\mathrm{sec} .)\end{array}$ \\
\hline ref_303 & 72 & 20 & 3 \\
ref_308 & 72 & 20 & 3 \\
ref_310 & 74 & 20 & 3 \\
ref_321 & 60 & 20 & 3 \\
ref_325 & 60 & 20 & 3 \\
ref_894 & 75 & 20 & 3 \\
ref_895 & 75 & 20 & 3 \\
ref_906 & 75 & 20 & 3 \\
ref_910 & 75 & 20 & 3
\end{tabular}

The $\mathrm{kV}$ was varied as necessary but the current was set to $20 \mathrm{~mA}$ with a time maintained at $3 \mathrm{sec}$. and the source to the detector was set to $100 \mathrm{~cm}$ for all exposures.

For items ref 303 to ref 310 , the tube voltage was set to $72 \mathrm{kV}$ but for items ref_321 and ref_325, this was reduced to drop to $60 \mathrm{kV}$ since the corrosion layer was small in the former and excess soil had adhered to the latter item. For items ef 894 to ref 910 , the tube voltage was set to 75 $\mathrm{kV}$.

The CR plate was processed using a computerized radiography workstation for indirect radiography with $\mathrm{CR}$ 30-X digitizer, from AGFA®. The procedure was controlled by $A G F A \AA N X$ quality control and image identification program.

This working protocol allowed comparison between both image records, where the scale values were kept constant for all radiographic acquisition, see Figures $4 a$ and $4 b$.
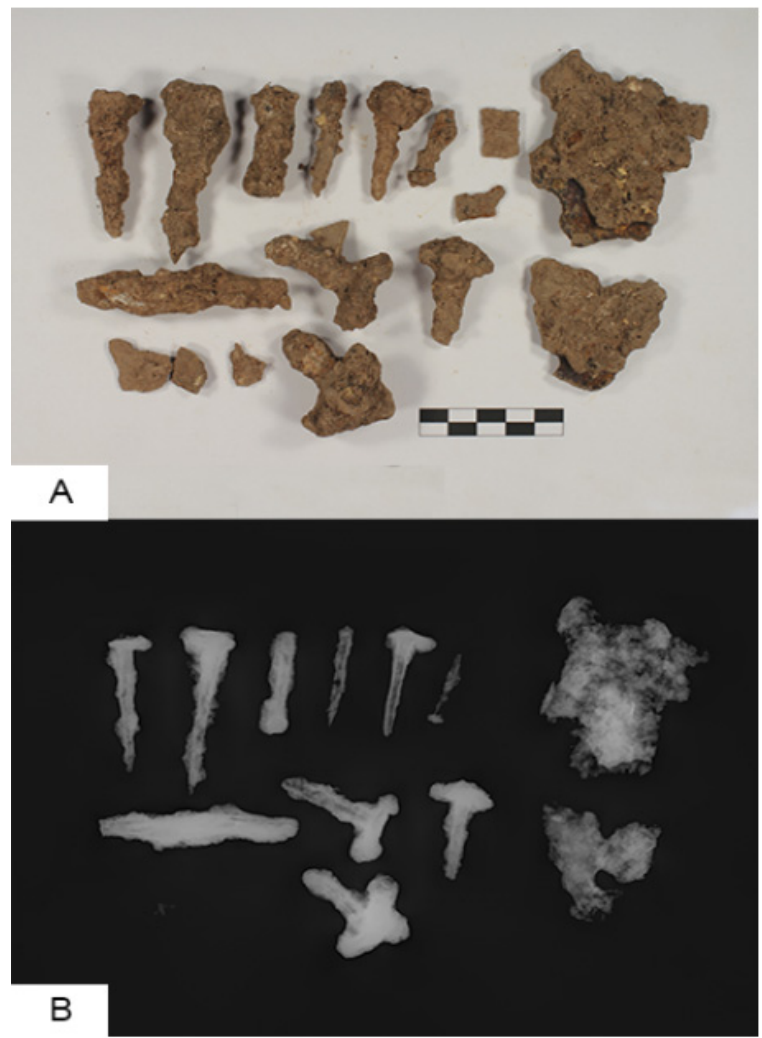

Figure 4: Comparison between photographic and radiographic images at ref 895: a) Photographs; b) radiographs. 
The criteria used for the selected pieces that were applied to the image enhancement process were determined by the characteristics of the items, mainly their topological complexity, Table 2.

Table 2: Provisional description of objects.

\begin{tabular}{|c|c|}
\hline Ref.-Rx & $\begin{array}{c}\text { Provisional description and reason for } \\
\text { selection }\end{array}$ \\
\hline ref_303_y4_1 & $\begin{array}{l}\text { Fibula bridge fragment; The piece has a } \\
\text { "T" shape that makes it unusual }\end{array}$ \\
\hline ref_303_y4_2 & $\begin{array}{l}\text { Fibula bridge fragment; The piece has a } \\
\text { cross shape that makes it unusual }\end{array}$ \\
\hline ref_308_y8_1 & $\begin{array}{l}\text { Handle; Its shape would indicate that it is } \\
\text { part of a larger and more complex artifact }\end{array}$ \\
\hline ref_310_y10_1 & $\begin{array}{l}\text { Decorative rivet; A priori, it looked like a } \\
\text { rivet or nail, but the hemispherical shape } \\
\text { of the head is very rare at the site }\end{array}$ \\
\hline ref_321_y21 & $\begin{array}{l}\text { A possible part of a bolt; The shape of its } \\
\text { circular tip indicates that it would be an } \\
\text { instrument of complex shape }\end{array}$ \\
\hline ref_325_y25 & $\begin{array}{l}\text { Linear element possibly disabled by } \\
\text { twisting; It was a very complex form of } \\
\text { indeterminate interests due to its unique } \\
\text { appearance }\end{array}$ \\
\hline ref_894_1 & $\begin{array}{c}\text { Fragment of a large square or rectangular } \\
\text { plate with possible rivets; It is the largest } \\
\text { iron fragment recovered in the } \\
\text { archaeological site }\end{array}$ \\
\hline ref_895_4 & $\begin{array}{l}\text { Iron tape with other metal rivets, possible } \\
\text { decorative element; This is the best- } \\
\text { preserved piece with apparent rivets on } \\
\text { the site }\end{array}$ \\
\hline ref_906_1 & $\begin{array}{l}\text { Element with the tip for the sleeve, } \\
\text { possible projectile or punch; It was one of } \\
\text { the few fragments of unknown shape that } \\
\text { had to be identified }\end{array}$ \\
\hline ref_910_1 & $\begin{array}{l}\text { Elbow-shaped element; It was one of the } \\
\text { few fragments of unknown shape that has } \\
\text { to be identified }\end{array}$ \\
\hline
\end{tabular}

The output of the CR scanning system was in DICOM standard but needed to be changed to enable data handling in the processing software. Considering that the proposal is a proof of concept of the system used, the file characteristics were set to yield high compatibility. The final images were $800 \times 600$ pixels and in SRGB color system with a color depth of 8 bits.

\subsection{Fast 2D Gaussian convolution}

In this study, Fast 2D Gaussian convolution first-order infinite impulsive response (IIR) approximation was used to enhance the contrast and edges of the images using shock filters (Weickert, 2003) and anisotropic diffusion (Perona \& Malik, 1990). In simpler format the 2-D image; I(i,j); discrete Gaussian convolution can be written as (Álvarez \& Mazorra, 1994) Eq. (1):

$$
u(i, j)=h_{\sigma}(i, j) * I(i, j)=\sum_{k} \sum_{l} h(i-k, j-l)(I(k, l)
$$

where '*' denotes convolution operator and $h_{\sigma}(i . j)$ denotes the Gaussian mask or kernel with $\sigma$ standard deviation and defined as follows in Eq. (2):

$$
h_{\sigma}(i, j)=\frac{1}{\left(2 \pi \sigma^{2}\right)^{\frac{m}{2}}} e^{\left(-\frac{i^{2}+j^{2}}{2 \sigma^{2}}\right)}
$$

Since the m-dimensional kernel $h_{\sigma}(i . j)$ has a 'bell-shaped curve' and drops-off rapidly to infinity, one can use discrete Gaussian convolution with the sampled and normalized kernel. Algorithm 1 shows the procedure of the general Gaussian-based convolution used in this study.

Algorithm 1: Gaussian-based convolution.

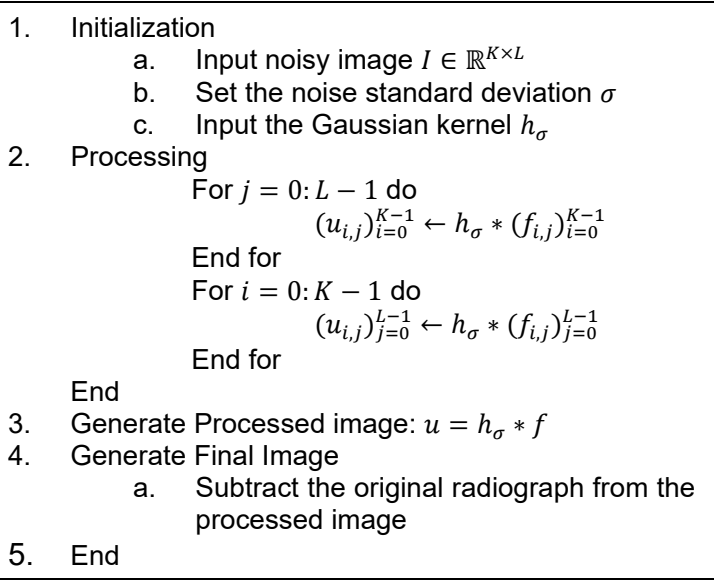

In Algorithm 1, the 2-D Gaussian convolution is considered a tensor product of 1-D convolution. These algorithms convolve data with an approximation of a Gaussian with a standard deviation sigma and the number of steps. The routine used the fast Gaussian convolution algorithm of Álvarez and Mazorra (1994), where the Gaussian has been approximated by a cascade of first-order infinite impulsive response (IIR) filters according to the heat equation. The calculated filters were applied along with columns and rows in each step.

The boundaries were handled with a half-sample symmetric extension. Using more steps increased the accuracy but also prolonged the computation time. Increasing the $\sigma$ will make the output images smoother for the proposed convolution algorithms. Finding the optimal value of $\sigma$ was difficult due to the different levels of the fogginess of each radiograph. Therefore, the foggy components were subtracted from the original images to yield the sharpened images.

The algorithms were run in the Matlab 2016 software with an Intel囚 Core-i7 based computer (MathWorks, 2021).

\section{Results and discussion}

In this study, some metallic pieces from the archaeological sites have been investigated for estimating the metal core and the corrosion layer of oxidation. For this purpose, the X-ray imaging method was used to reveal the hidden layer without any damage to pieces. Then, the Fast 2D Gaussian convolution firstorder infinite impulsive response (IIR) is implemented to the radiography images for improving the contrast and better information extraction.

Figures $5 a, 5 b$, and $5 c$ show the photograph, radiograph, and the reconstructed image for item ref_303_y4_1 
respectively. The images are annotated with the arrow to indicate the location of the piece's advanced corrosion.
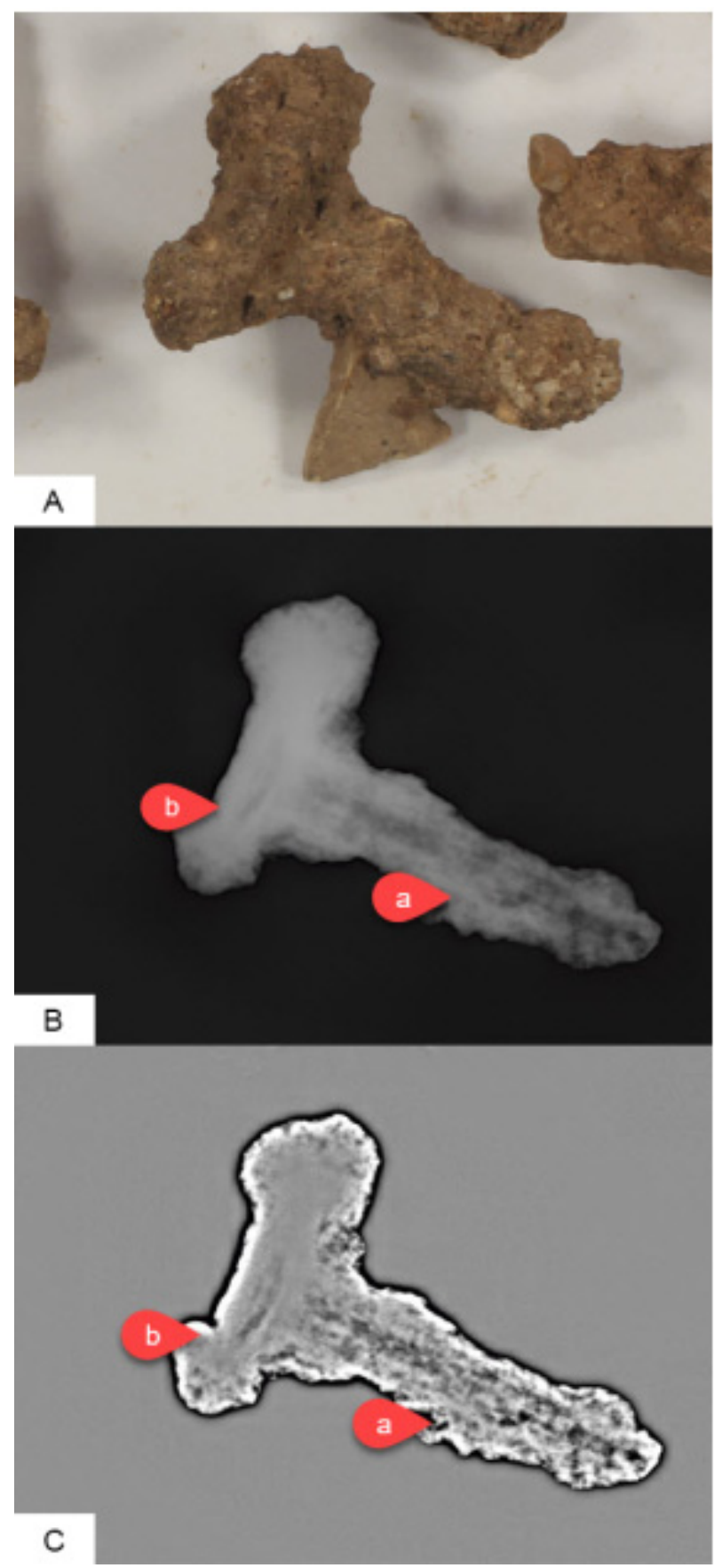

Figure 5: Study of metallic pieces: a) photograph image; b) radiographic image; c) processed image of ref_303_y4_1.

Items ref_303_y4_2, Figure 6a, and ref_906_1, Figure $7 a$, exhibit severe loss of metallic core as shown on the processed images Figures $6 \mathrm{~b}$ and $7 \mathrm{~b}$, where layers of corrosion have led to partial disintegration of the items as indicated on the images.

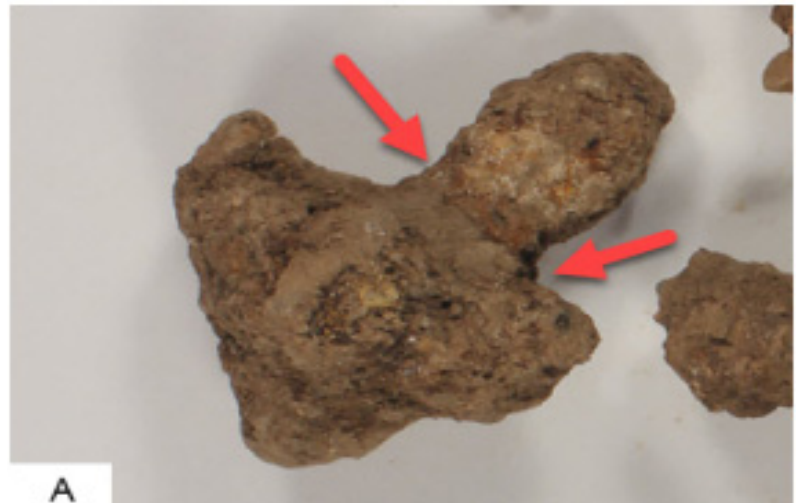

A

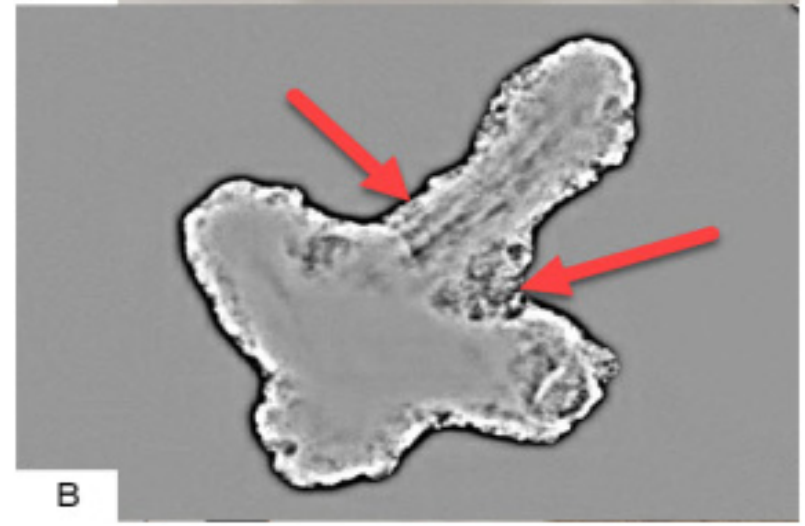

Figure 6: Study of metallic pieces: a) Photograph image; b) processed image of ref_303_y4_2.

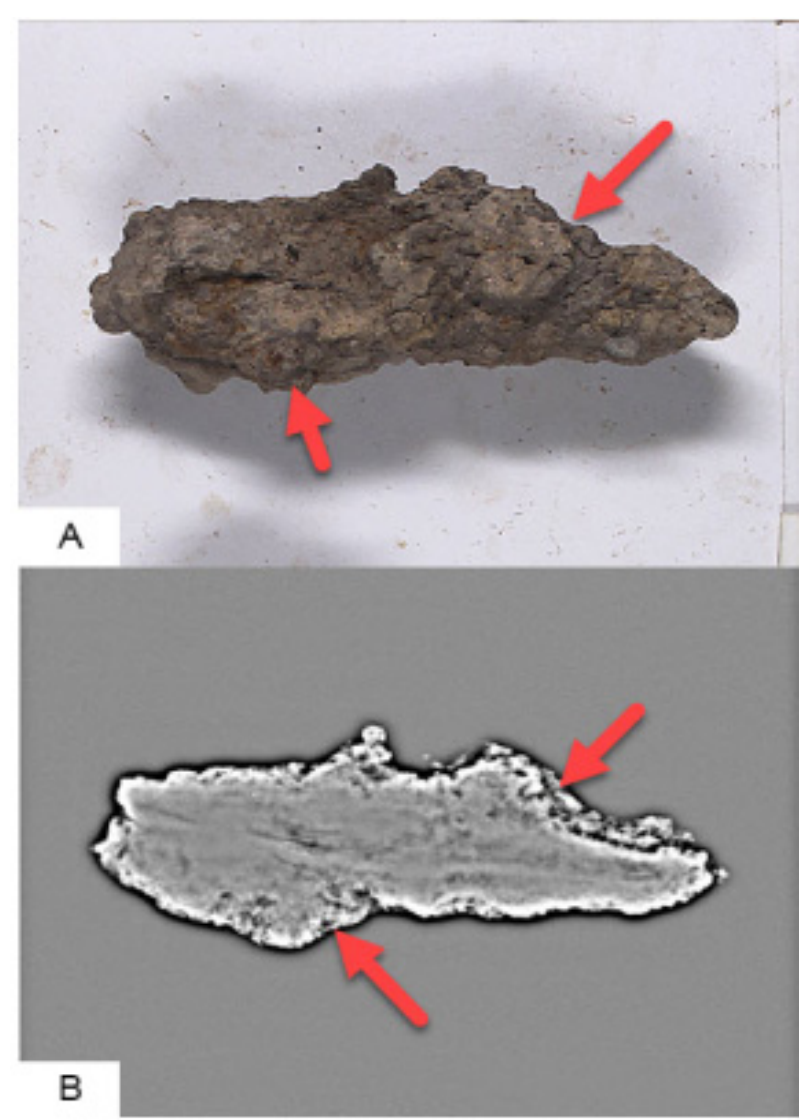

Figure 7: Study of metallic pieces: a) Photograph image; b) processed image of ref_906_1. 
Similarly, Figure $8 a, 8 b$, and $8 c$ relate to item ref_308_y8_1. The extent of oxidation with the fracture lines are better visualized in the processed image such as those shown in comparison to the original radiograph; for example, marker 'a' shows the edge has fractured along the piece, and marker 'b' shows the state of exfoliation in its midsection.

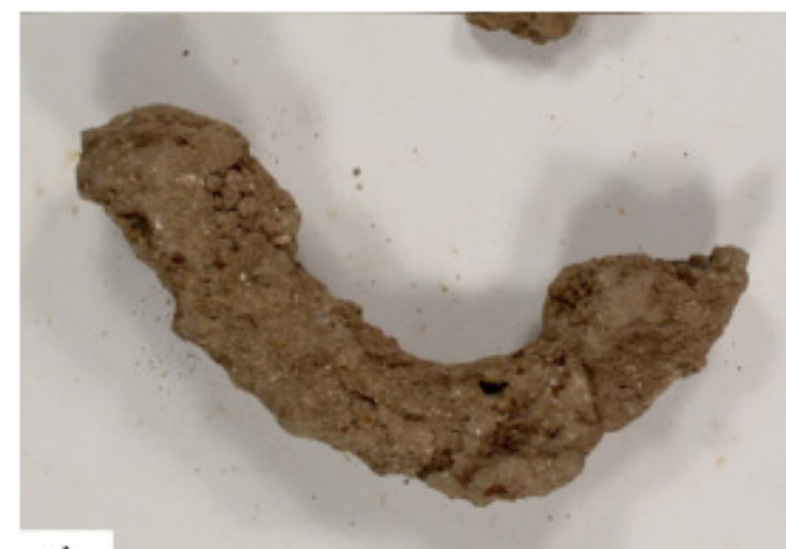

\section{A}

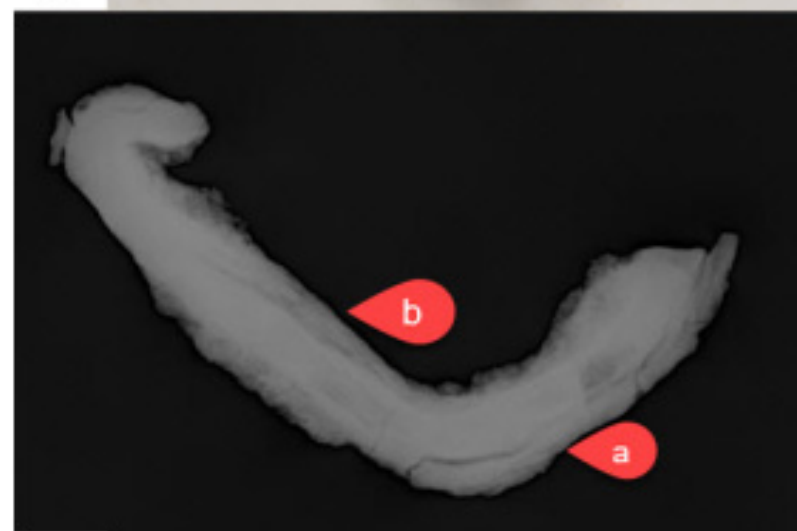

B

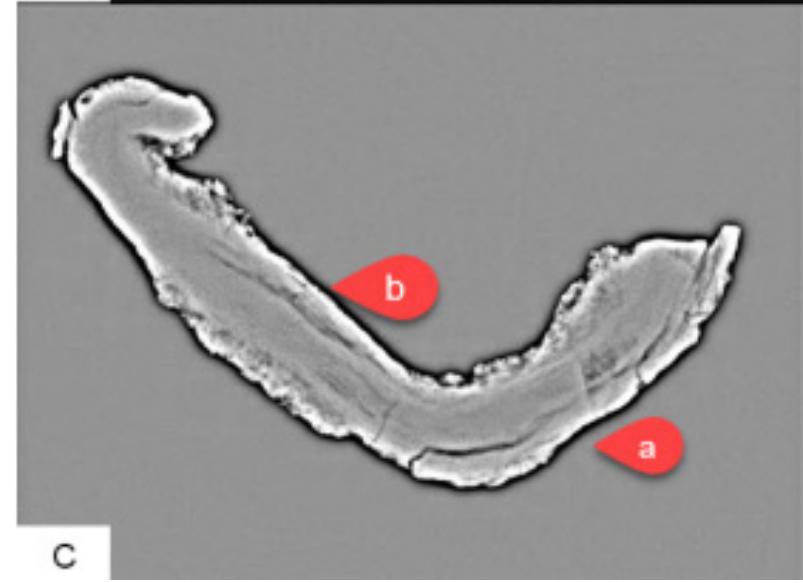

Figure 8: Study of metallic pieces: a) Photograph image; b) radiographic image; c) processed image of ref_308_y8_1.

The enhancement of image contrast in the processed image is invaluable to the radiographically untrained eyes so the archaeologist can focus on the areas of most interest through the elimination of noise/fog and nonpertinent information content. The level of the fissure and the degree of exfoliation are decisive data in intervention works for correct storage.
Figure $9 \mathrm{~b}$ and $9 \mathrm{c}$ show similar images for the decorative rivet ref_310_y10_1. Simultaneous review of the three images by the operator whilst working on the piece would help inform the choice of the cleaning method e.g. to use a mechanical versus chemical method. In this example, the radiograph is foggier due to the greater thickness of the core metal. Image processing has helped remove much of the fogginess to yield enhanced contrast in the regions of interest.

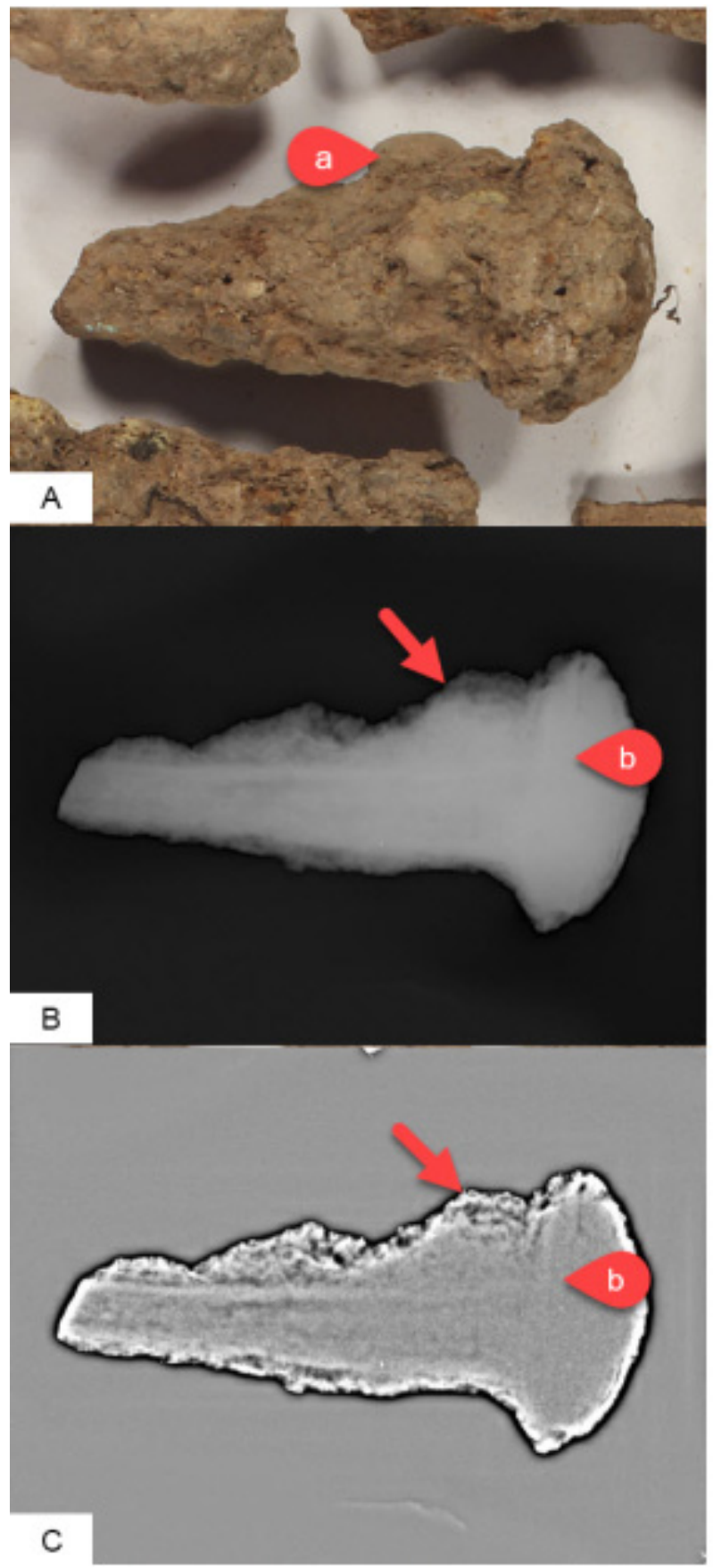

Figure 9: Study of metallic pieces: a) Photograph image; b) radiographic image; c) processed image of ref_310_y10_1.

A statement that we can see better again in ref_910_1 (Fig. 10). The unknown region of the piece is marked $\bar{b} y$ archaeologists (Fig.10a). The radiograph (Fig 10b) showed an elbow-shaped element in good condition. The processed image (Fig.10c) certified this information. A 
comparison of the three images showed that both fragments belong to the same object.
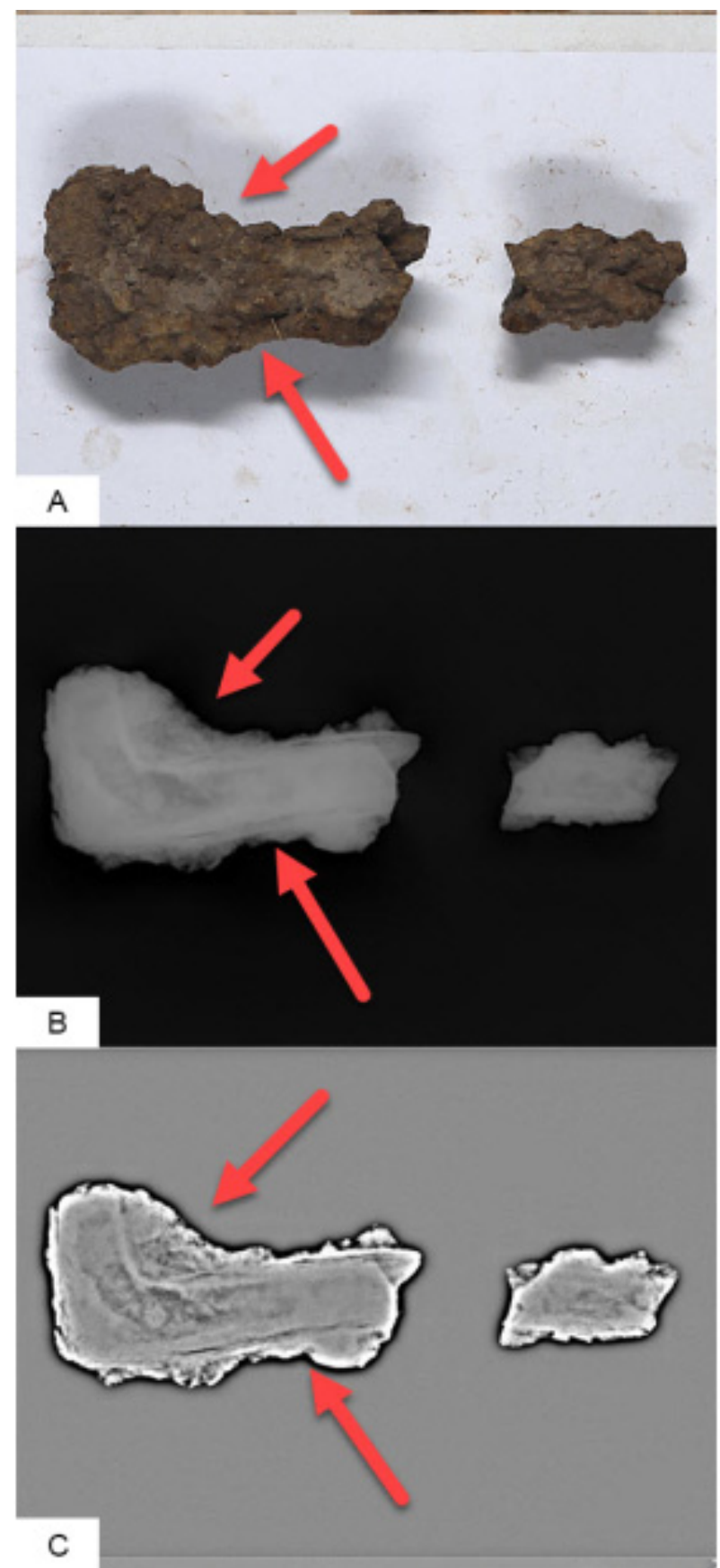

Figure 10: Study of metallic pieces: a) Photograph image; b) radiographic image; c) processed image of la ref_910_1.

The processed image offers higher contrast in regions such as the boundary between concretion and the state of the metallic core, or the internal exfoliation regions. Figures $11 \mathrm{a}$ and $11 \mathrm{~b}$ show the bolt fragment of item ref_321_y21 where the two pieces have become fused over time. Similarly, it can be seen that item ref_325_y25 has lost all its shape by torsion, Figures $12 \mathrm{a}$ and $12 \mathrm{~b}$.
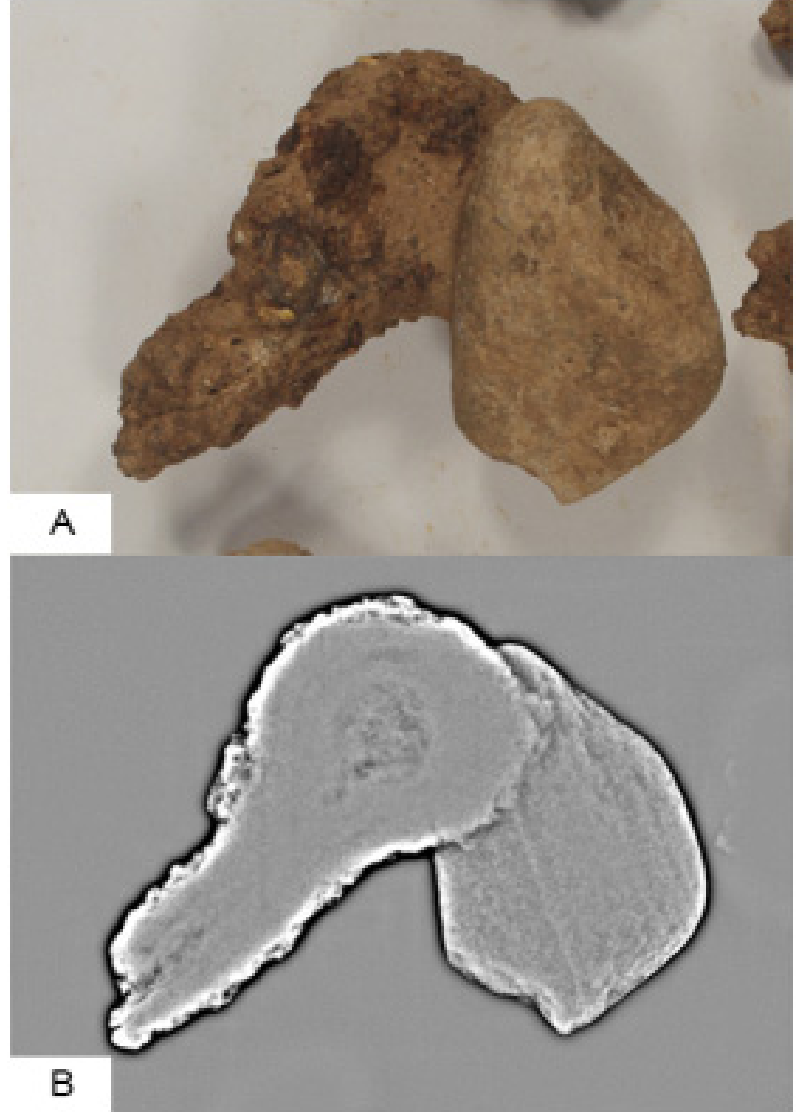

Figure 11: Study of metallic pieces: a) Photograph; b) processed image of ref_321_y21.

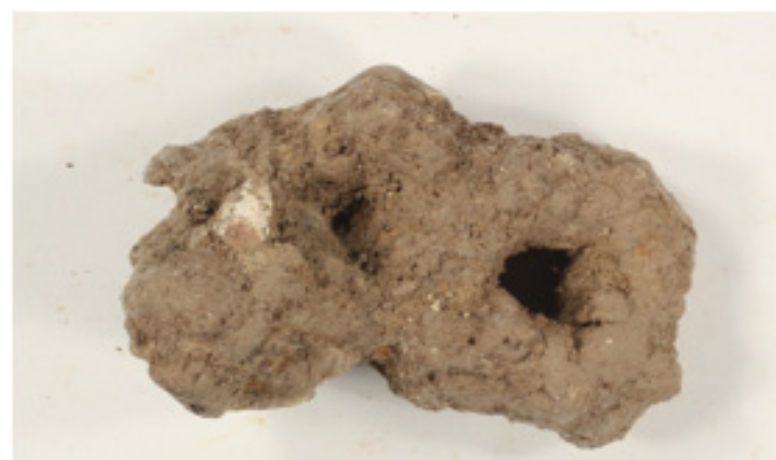

A

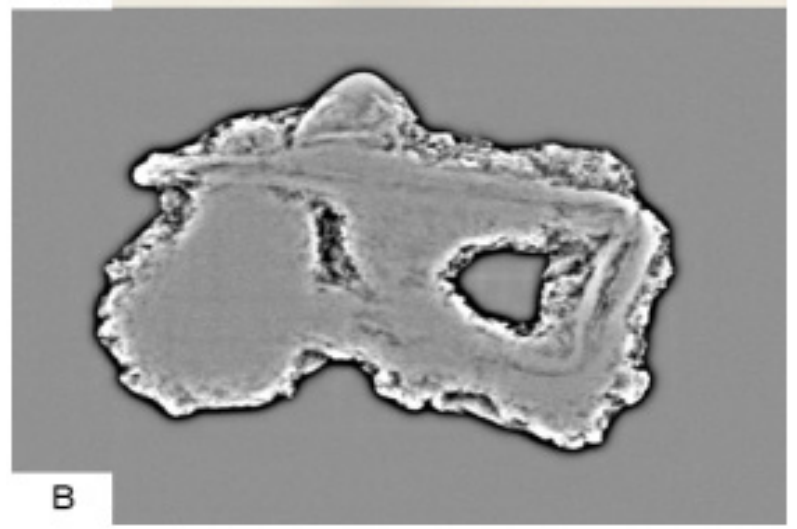

Figure 12: Study of metallic pieces: a) Photograph image; b) radiographic image; c) processed image ref_325_y25. 
Also, of potential significance is the enhanced results offered by the processed image of the items internal texture and porosity which informs the investigator of the manufacturing processes (Lang \& Middleton, 2016; Yahaghi, Madrid, \& Movafeghi, 2020), see Figures 13a and $13 \mathrm{~b}$ relate to the metal fragment ref_894_1 where the processed image focuses on the internal granulometry of the fragment.
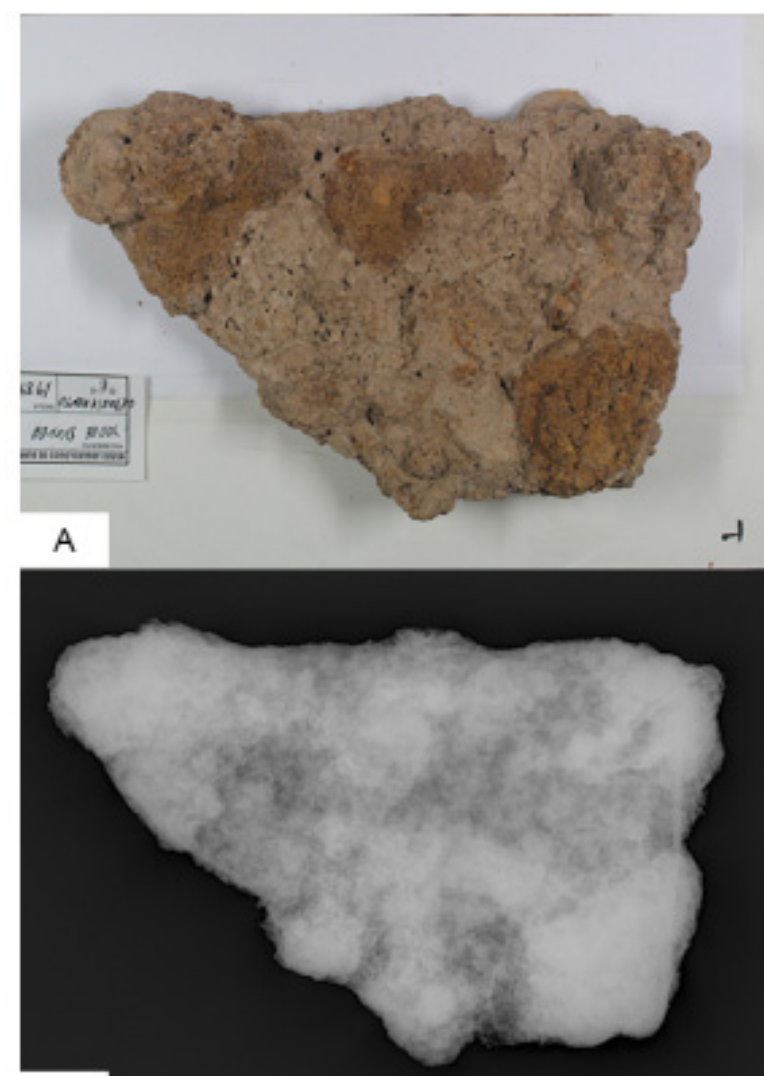

B

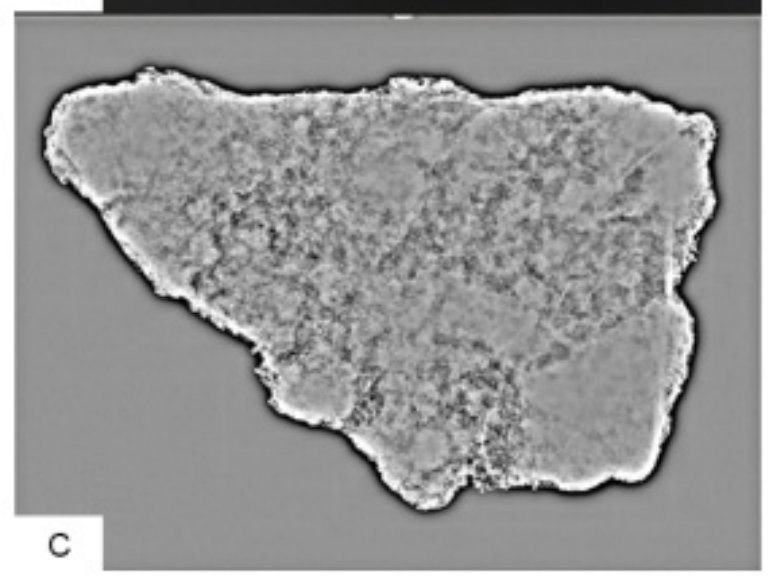

Figure 13: Study of metallic pieces: a) Photograph image; b) radiographic image; c) processed image of ref_894_1.

Similarly, for item ref_895_4, which corresponds to an iron tape with metal rivets which is thought to be from a decorative element, Figure 14a. The processed image shown in Figure 14b marks the perimeter of the piece that would otherwise be blurred out due to its advanced state of oxidation.

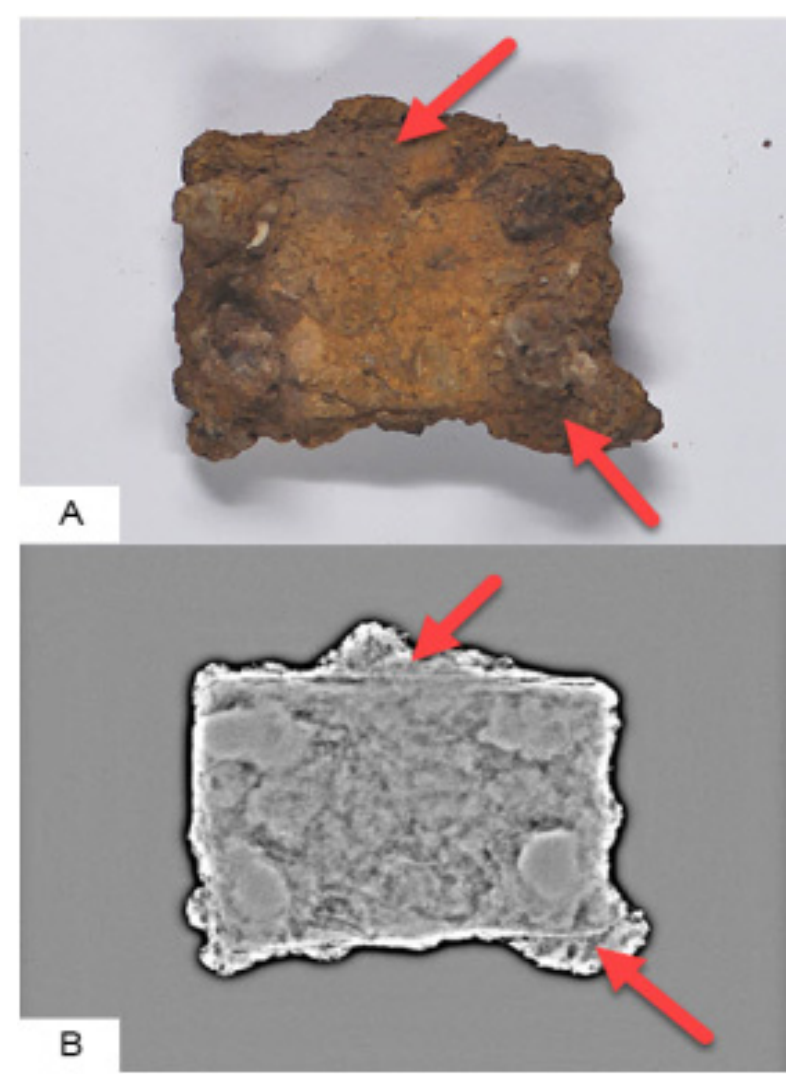

Figure 14: Study of metallic pieces: a) Photograph image; b) processed image of ref_895_4.

\section{Conclusion}

This study has found that the combination of visual inspection/photograph, the original radiograph, and tool than the photograph plus the radiograph alone. They complement each other and allow the operator to focus on the pertinent imaging data to better inform the intervention processes.

Furthermore, the pertinent information including the internal state of the piece, the metal core, and level of its oxidation and disintegration, the presence of exfoliated in inner layers, maybe better quantified in terms of the location, geometry and extent of the feature when the processed X-ray image is deployed as confirmed by the archaeological experts involved in this study.

With effective protocols, the extracted information can be used by the experts to direct the archaeological intervention where the maximum benefit would result whilst shielding the piece from unnecessary damage during the process and ensuring.

\section{Acknowledgements}

We are grateful to all the institutions involved in this multidisciplinary work, including the archaeological museum of Burriana (Spain), the Laboratory of Documentation and Registration in the University Institute for the Restoration of the Patrimony (IRP) of the Universitat Politècnica de València (UPV) and Imam Khomeini International University (Qazvin, Iran), who have made available to us both the means and the archaeological pieces. 


\section{References}

Álvarez, L., \& Mazorra, L. (1994). Signal and Image Restoration using Shock Filters and Anisotropic Diffusion. SIAM J. on Numerical Analysis, 31(2), 590-605. https://doi.org/10.1137/0731032

Aznar, C. (2020). Valoración global de objetos metálicos arqueológicos a través de los rayos x. Estudios previos de los materiales metálicos de Torre d'Onda (Burriana, Castellón). Trabajo fin de Máster. Universitat Politècnica de València. http://hdl.handle.net/10251/150821

Caple, C., \& Garlick, V. (2018). Identification and valuation of archaeological artifacts: developments using digital Xradiography. Journal of the Institute of Conservation, 41(2), $128-141$. https://doi.org/10.1080/19455224.2018.1464487

Cleeren, N. (2006). Oudenburg: conservatie is (gefundeerde) keuzes maken, Conservering van objecten versus de conservering van hun wetenschappelijke inhoud. Journée d'archéologie romaine. Gent: Flemish Institute for the Archaeological Heritage, pp.140-145.

Díaz, T. (2014). Propuesta metodológica en el estudio previo de los materiales férreos de la Villa romana de Sant Gregori (Burriana, Castellón). Aplicación de la técnica radiográfica digital en las fases previas al proceso de restauración. Trabajo fin de Máster. Universitat Politècnica de València. http://hdl.handle.net/10251/39213

Fell, V., Mould, Q., \& White, R. (2006). Guidelines on the X-radiography of Archeological Metalwork. Swindon: English Heritage.

Ferrer, J. J., Melchor, J. M., \& Benedito, J. (2013). Sant Gregori. Un complejo arquitectónico de época romana en la costa de Burriana (España). Millars: espai i història; 36, 201-225. http://dx.doi.org/10.6035/Millars

Lang, J., \& Middleton, A. (2016). Radiography of Cultural Material. Londres, Reino Unido: $2^{\text {nd }}$ ed, Elsevier ButterworthHeinemann.

Madrid, J. A. (2014a). Catálogo radiográfico del Servicio de Rayos X del Laboratorio de Documentación y Registro. Arché, 8, 87-98. http://hdl.handle.net/10251/85227

Madrid, J. A. (2014b). Dos décadas de inspección radiográfica en España: retrospectiva y horizontes futuros en un contexto de cambio tecnológico. Intervención. Revista Internacional de Conservación, Restauración y Museología, Escuela Nacional de Conservación, Restauración y Museografía-INAH, 10, 87-95.

Madrid, J. A., \& Ramírez, A. (2011). Radiografía digital en el estudio de piezas cerámicas. Estudio e interpretación de cerámica medieval procedentes del Museo Arqueológico Municipal de Burriana. En J. M. Melchor, J. Benedito, T. Pasies (Eds.), La arqueología de la Buriyyana islámica a la Borrianacristiana, (pp. 153-172). Valencia, España: Conselleria de Governació de la Generalitat Valenciana.

Manrique, M. (1980). Instrumentos de hierro de Numancia conservados en el Museo Numantino (Soria). Madrid, España: Ministerio de Cultura.

MathWorks. (2021). MATLAB - El lenguaje del cálculo técnico - MATLAB \& Simulink (mathworks.com). Retrieved March 15, 2021, from https://es.mathworks.com/products/matlab.html

Melchor, J. M. (2013). Diez años del Servicio Arqueológico Municipal de Burriana (2003-2013). Burriana, España: Ayuntamiento de Burriana.

Nicoll, D., \& Hook, A. (2008). Saracen Strongholds AD 630-1050: The Middle East and Central Asia. Oxford, Reino Unido: Osprey Publishing.

Perona, P. \& Malik, J. (1990). Scale-space and edge detection using anisotropic difusión. IEEE Transactions on Pattern Analysis and Machine Intelligence, 12(7), 629-639.

Weickert, J. (2003) Coherence-Enhancing Shock Filters. In: Michaelis B., Krell G. (eds) Pattern Recognition. DAGM 2003. Lecture Notes in Computer Science, 2781. Springer, Berlin, Heidelberg. https://doi.org/10.1007/978-3-540-45243$0 \_1$

Yahaghi, E., Madrid, J. A., \& Movafeghi. A. (2020). Fracture and internal structure detection of ceramic objects using improved digital radiography images. Journal of Cultural Heritage, 44, $152-162$. https://doi.org/10.1016/j.culher.2020.02.003 


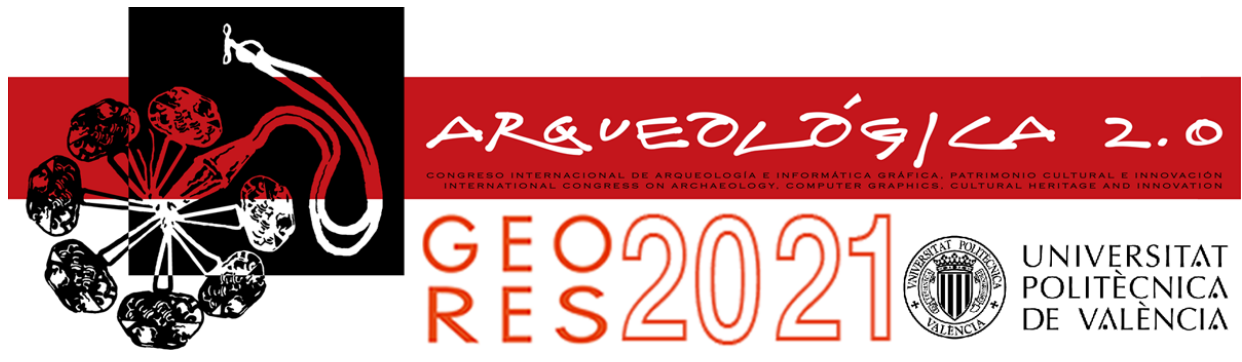

Proceedings of the joint international event $9^{\text {th }}$ ARQUEOLÓGICA

$2.0 \& 3^{\text {rd }}$ GEORES

Valencia (Spain).

26-28 April 2021

\title{
INFORMATIVE MODELS OF CULTURAL HERITAGE. THE “UNFINISHED” CHURCH OF BRENDOLA
}

\author{
Emanuela Sorbo*, Gianluca Spironelli \\ Dipartimento di Culture del Progetto, Università luav di Venezia, Palazzo Badoer, San Polo 2468, 30125 Venice, Italy. esorbo@iuav.it; \\ gspironelli@iuav.it
}

\begin{abstract}
:
The paper is an initial form of dissemination of the research activities carried out by the Università luav di Venezia working group which, on behalf of the Municipal administration of Brendola, seeks to delineate the application of a methodology for the study and analysis of the architectural and landscape heritage of significant cultural interest that is in a state of abandonment. The case study application is the church of San Michele Arcangelo in Brendola (Vicenza), known as the "Incompiuta" ("Unfinished"). The case study proposed is an interesting exemplar of ecclesiastical architecture, designed by engineer-architect Fausto Franco, in which its characteristics of being unfinished and in a state of ruin contribute to redefining the image of a work that fits in a historical context of architectural and technical experimentation, where the reference to historical architecture is mediated by contemporary forms and by the use of modern building materials, among which, the use of reinforced bricks is noteworthy. The research activity, which is taking place in the context of the COVID19 health emergency, aims at putting a series of strategies and operational practices based on the digitisation of data to the test, so as to allow increased interoperability and sharing through the building of an online open data repository addressed to the actors involved in the conservation process and to the community. In the processes of conservation and valorisation, in-depth knowledge and documentation of the materials and construction techniques involves multidisciplinary areas; effectively organising them in a system that regulates their collection, cataloguing, processing and archiving according to shared procedures, therefore becomes a fundamental prerequisite for the development of operational planning of the valorisation strategies. All the instruments that make it possible to collect data and reach a true knowledge of the object therefore become indispensable. From this point of view, the push towards the digitisation of the data that emerged during the pandemic phase plays a fundamental role in the range of application possibilities, from the survey to the mechanisms for the conservation and management of the cultural heritage.
\end{abstract}

Keywords: cultural heritage, unfinished architecture, interoperable digital documentation, HBIM database, experimental techniques, open knowledge

\section{Introduction}

The research activity is based on the following Memorandum of Understanding: "Il limite della Rovina. Procedure di conoscenza, analisi e valutazione dello stato conservativo della Chiesa 'Incompiuta' di Brendola" (The Limit of the Ruin. Procedures of knowledge, analysis and evaluation of the state of conservation of the 'Unfinished' Church of Brendola), stipulated between the Università luav di Venezia and the Municipality of Brendola through a funded research contract (file. no. 772020 prot. no. 1476 of $20 / 01 / 2020$ ). The memorandum of understanding promotes the identification of a study and analysis methodology for the architectural and landscape heritage of significant cultural interest found in a state of abandonment. The applied case study is the "Unfinished" Church of Brendola (Fig. 1). The aim of the research is to attain the creation of a system of knowledge concerning the building's state of conservation that allows the identification of conservation and valorisation strategies that can be shared with the bodies that are responsible for its protection as well as with the community of Brendola, acting as a possible reference for the development of operational guidelines in the best practice of the discipline of restoration.

\section{Case Study: The "Unfinished" Church of Brendola}

The earliest information found concerning the construction of the church dates back to 1904 . Historical events and construction report are collected in the writings of Don Francesco Cecchini (1937), Archpriest of Brendola, reference figure and promoter of the construction of the building. Dedicated to the city's patron saint, Michael the Archangel, the church rises isolated at the summit of Cerro Hill, in a barycentric position with respect to the nearby communities. As the Archipriest's

`Corresponding Author: Emanuela Sorbo, esorbo@iuav.it 
writings of 1915 clearly express, the temple "which responds to long-standing desires", was to have been built "out of concordant will and generosity", "in a place that is convenient to all", cementing "the scattered districts together in unity of faith and in piety of actions". The study of the project for the new church "which responds to the noblest ecclesiastical traditions" was entrusted on 10 January 1928 to the young engineer-architect Fausto Franco (1899-1968) who had recently obtained his second degree in architecture. Born in Vicenza on June 19,1899 , in 1922, at the age of twenty-two, he graduated in engineering at the University of Padova. In 1927, at the age of twenty-eight, he obtained his second degree in architecture at the Royal School of Architecture in Rome. (Ministero per i beni e le attività culturali et. al, 2011 and Gazzola, 1968).

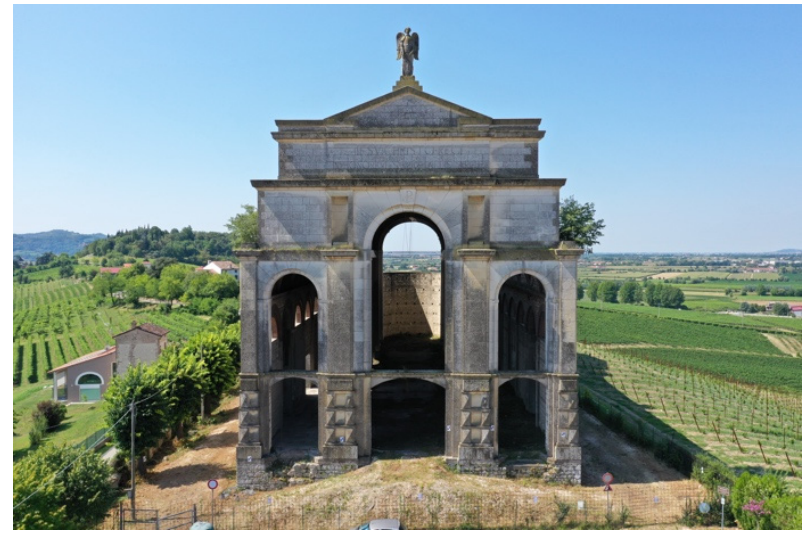

Figure 1: General view of the "Unfinished" church of Brendola.

A scholar of the ancient civilisations of the Middle East, starting from 1929, Franco was a student of the Archaeological School of Rome and Athens, taking part in numerous excavation and restoration campaigns with Professor Carlo Anti. In 1930 he was appointed Honorary Royal Inspector of the Monuments of Vicenza, where, in parallel with his archaeological activities, he began to study the work of Andrea Palladio. In 1933 he became part of the Antiquities and Fine Arts Department and was assigned to the Superintendence of Medieval and Modern Art of Milan, and soon after, to that of Venice; in 1939 he became Director of the Superintendence of Antiquities and Art of Venezia Giulia and of Friuli, where he remained until 1952. In parallel with his professional activity, in 1936 he obtained the qualification of professorship in History and Styles of Architecture (1936) and in Stylistic and Building Characteristics of Monuments (1937) at the University Institute of Architecture in Venice (1937-67). Observing the original project (Fig. 2), it is possible to see how the church is characterised by a typological layout that can be traced back to a Latin cross plan in Romanesque style, delineated by a rectangle measuring $53.5 \mathrm{~m} \times 22.5 \mathrm{~m}$, punctuated by three symmetrical barrelvaulted naves ending in semicircular apses. The central nave, which is twice as wide as the lateral ones, is defined by columns on pedestals ( 9 on each side) made of reinforced concrete and clad in pietra di Vicenza stone, connected by a series of round arches. The masonry structure is constituted of core-and-veneer masonry with concrete recesses and is punctuated by the presence of four semicircular chapels that flank the building's exterior and characterise its composition together with lunette openings located in the upper part of the facing walls.
In the Church of San Michele Arcangelo, Franco manages to combine the architectural language with an experimental use of mixed construction techniques, characterised by the juxtaposition of different materials and techniques; the use of reinforced brick elements in the roof structures is noteworthy.

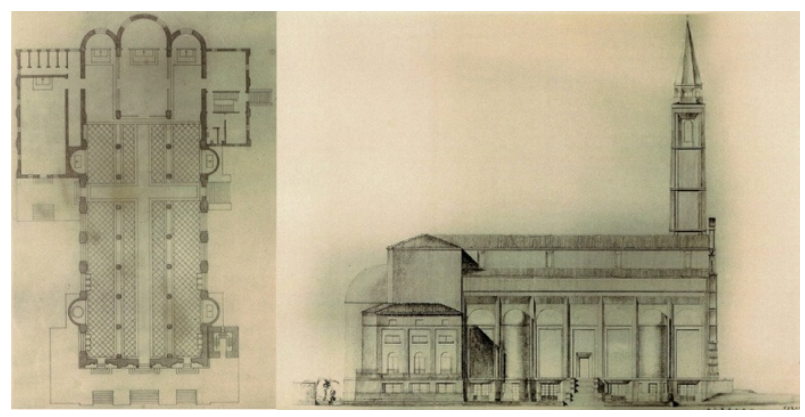

Figure 2: Original drawings made by Fausto Franco.

The inclusion of the project in the landscape was the object of evaluation, on 2nd October 1931, by the artistic commission composed of important figures in the national panorama of conservation such as Ferdinando Forlati (1882-1975 one of the protagonist of the post-war reconstruction of monuments after the First and Second World Wars) of the Royal Superintendence of Monuments of Venice, Luigi Ongaro, Vice President of the Provincial Monuments Commission and Director of the Civic Museum of Vicenza, and Giuseppe Stocchiero, Commissioner of Sacred Artworks for the diocese of Vicenza, all of whom were called to "consider the project and the orientation of the church in relation to the landscape requirements". The construction officially began on 3rd October 1931, with the blessing of the foundation stone by Bishop Ferdinando Rodolfi and continued as planned until 1934, a year that marked a turning point, characterised by the suspension of the construction site due to the Archpriest's replacement for reasons of health. On 20th March 1939 the Bishop authorised the resumption of the construction works at Cerro, but with limited resources, insufficient for the completion of the work. In 1940, in support of the continuation of the work, Fausto Franco intervened and, addressing the Bishop, pointed out the critical issues that the interruption of the construction works would have entailed, stressing how the failure to build the roof would have rendered futile the work completed up to that point. Notwithstanding the economic difficulties, in October 1940 , permission was granted for the roofing of the building, which was completed in 1941. The impossibility of receiving new funding and the death of Father Cecchini on 18th May 1949 brought the construction site to a standstill, leaving the sacristy area, a chapel and the bell tower unfinished. Following its abandonment, the church was purchased by the Municipal administration of Brendola in 1997, with the commitment of using the building for social or cultural purposes of public utility. Since 22nd June 2009, the church has been under the protection of Legislative Decree no. 42 of 2004, which defines it as "the only evidence of the activity of an architect with an original and eclectic personality, fully integrated into the Italian culture of the 1930s and, in particular, in the architectural debate that was emerging following the great archaeological campaigns in Africa and Asia". 


\section{Method}

The fields of investigation of the research activity have entailed a first phase of historical-critical investigation aimed at identifying the information useful for developing a critical knowledge of the cultural property, together with a campaign of inspections aimed at carrying out the geometric survey of the building and the analysis and cataloguing of the vulnerable elements and the mechanisms of deterioration. This first phase involving the gathering of information makes it possible to compare and interpret the data obtained and to reach different levels of knowledge, making it possible to delineate strategies for the valorisation of the cultural property through the use of digital technologies for data sharing and dissemination by building an online repository and an HBIM database. The collection of documents involves the gathering of elements belonging to different contexts; given the above, it has been decided to orient the structure of the database towards an architectural study aimed at identifying those documents that can retrace the construction phases of the building and that can bear witness to its architectural value. For each of the documents scanned and catalogued, wherever possible, optical character recognition has been performed in order to make the contents searchable by means of computer devices.

\subsection{Field acquisitions}

The data acquisition and processing campaign, led by the CIRCE photogrammetry laboratory of the Università luav di Venezia, was conducted with the use of different types of surveys related to specific theoretical and operational procedures. The necessary instrumental and methodological apparatus was evaluated, in relation to the complexity of the building and to the scale of representation required for the subsequent multidisciplinary analyses. The survey operations were carried out through the implementation of topographic, laser scanner and photogrammetric surveys (Castagnetti et. al. 2016), programmed according to an effective data acquisition campaign that made it possible to complete the acquisition operations in a single day. The first operation carried out concerned the design of the polygonal structure, leading to the definition of six cornerstones upon which to position the full station. The conformation of the church and the presence of natural obstacles made it impossible to make some of the points of the polygonal structure visible from several points of the station. In order to overcome the problem and to allow a good stiffening of the grid, it was decided to place some passage points on the building in positions visible from several station points. Once the structure of the grid was defined, the cornerstones were materialised in the field and 87 support points were marked with special paper targets (checkerboard) applied to the building. The support points positioned, together with architectural points identified on the building, facilitated the orientation of the photogrammetric survey and the various scans carried out by means of the laser scanner. The topographic observations of the detail points were collected by irradiation with a Leica TCR 1103 full station with $\mathrm{Hz}$ and $\mathrm{V}$ precision of $1 \mathrm{mgon}$ and $3 \mathrm{~mm} \pm 3 \mathrm{ppm}$ in distance measurement.

The photogrammetric survey was carried out using digital cameras and software based on Structure from Motion
(SFM) and Multi View 3D Reconstruction algorithms, using the commercial reference software: Agisoft Metashape Pro. The photogrammetric images were recorded using Nikon D800 type digital terrestrial cameras with a focal length of $20 \mathrm{~mm}$ and 36 megapixel full frame CMOS sensor, and aerial cameras using DJI Mavick 2 Pro type RPAS (Remotely Piloted Aircraft Systems) equipped with Hasselblad L1D-20c camera with $35 \mathrm{~mm}$ focal length equivalent to $28 \mathrm{~mm}$ and 1" 20 megapixel CMOS sensor, and DJI Phantom 4 Pro equipped with FC6310S camera with $35 \mathrm{~mm}$ focal length equivalent to $24 \mathrm{~mm}$ and 1" 20 megapixel CMOS sensor. The imaging positions were divided into two macrogroups, one dedicated to the survey of the internal façades and one dedicated to the external ones; each macro-group was then divided into sets with different imaging modes and distances: the farthest sets made it possible to identify an overall view, while those closer to the object made it possible to acquire data with a higher resolution for the detailed representation of the façades. Overall, the operations led to the recording of 1,533 images. As far as the laser scanner survey is concerned, the acquisition operations were carried out using two phase-measurement instruments, Faro Focus 3D S120 and Focus $S 150$, which are characterised by their high precision and the speed of their data acquisition (up to 976,000 points per second). The scans, 34 in all, have been acquired by positioning the instrument in such a way as to minimise the formation of shadow cones as much as possible and to ensure an adequate overlap with the previous scans. The individual scans were orientated in the local reference system thanks to the previously positioned targets. The distance between the instrument and the object of the survey was evaluated in order to guarantee a density of about one point every centimetre at a distance of 10 metres.

\subsection{Materials analyses}

The building of the church of San Michele Arcangelo is characterised by a strong presence of modern construction techniques juxtaposed with traditional techniques (Fig. 3). Among the historical documents related to the construction of the church, it is possible to find descriptions of the building materials used, including those of the stone elements, which can be traced back to the use of "pieta bianca di san Gottardo" (white San Gottardo stone), "pietra gialla dei Berici" (yellow Berici stone) and "Trachite Euganea".

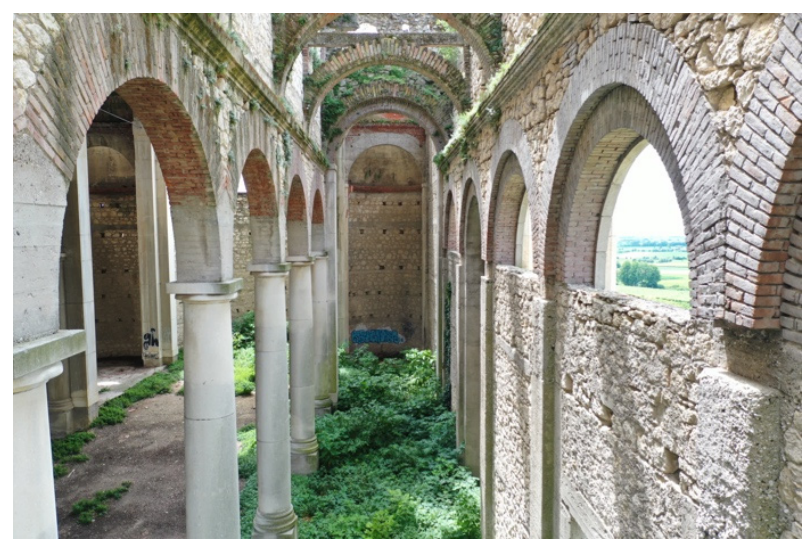

Figure 3: View of the interior spaces of the church after the abandonment. 
An element that opens an interesting field of investigation in the understanding of the vulnerabilities found in the masonry is represented not so much by the quality of the stones used, mainly due to the use of "pietra di Vicenza" (Vicenza stone), but rather by the quality of the mortars and the stone cladding. In this sense, the subsequent phases of characterisation of the masonry will be oriented where, through assays and laboratory analyses, the quality of the mortars and the relative critical points that may have influenced the behaviour of the masonry over time will be identified, also in relation to the presence of different construction techniques.

\section{Results obtained}

The use of laser scanner and photogrammetric survey methods has allowed a considerable reduction in acquisition times and has lessened the possibility of operator error. The laser scanner survey has been the most effective methodology for the survey of the architecture in its complexity, thanks to its high acquisition speed and the considerable amount of information it was able to collect. The photogrammetric survey, on the other hand, made it possible to integrate the portions of the building not directly accessible from the ground, such as the roof structures, and at the same time, made it possible to acquire data with a high photographic resolution useful for the detailed representation of the façades by means of orthophotos generated by the three-dimensional model obtained. The local reference system generated by the topographic survey made it possible to orient and join together, thanks to the topographic support points, the point cloud obtained by joining the different laser scans with the point clouds obtained by means of photogrammetry.

From the point of view of the precision obtained, the processing of the laser scans led to a difference of about $0.5 \mathrm{~cm}$ while, as far as the point cloud obtained by photogrammetry is concerned, a precision in the region of one centimetre was reached, perfectly in line with the expected scale of representation. An experimental element introduced in the processing of the large number of images is the use of a cloud processing service. This has made it possible to drastically reduce processing times, making post-processing and rendering operations possible on a normal computer. The processing of the point cloud (Fig. 4) will make it possible to evaluate the actual geometry of the components of the structure, identifying possible deviations from the plane of the facing walls or of subsidence, described by a continuity of points and not by a discretisation operation carried out by the surveyor. The point clouds obtained, together with the analysis carried out on the building, established the basis (Bruno et. al. 2013) for the development of the informative model of the church that collects its identity data and its vulnerabilities, configuring itself as a useful project tool for the delineation of hypothetical guidelines for a conservative design project.

\subsection{HBIM Database}

Through the critical analysis of sources and data collected, the in-depth study of cultural heritage allows looking at these cultural assets as fragments of stratified memory (Augé, 2004) that meet the criterion of uniqueness. Associate the construction of BIM models to the cultural heritage means to weave different knowledge composed by material and immaterial values that sometimes hardly fall within the concept of standardization and parameterization that is usually associated with the construction of informative models for architecture (Attenni, 2019). In the construction of informative models for the cultural heritage, every object, even if defined by characteristics common to other elements, is configured as a unicum defined by a rigorous semantics.

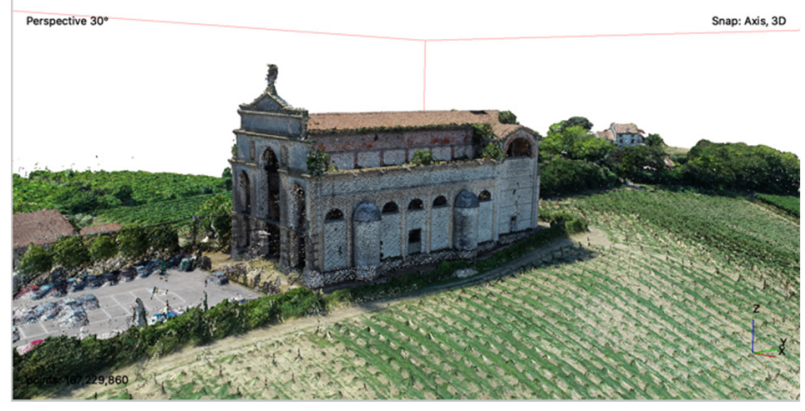

Figure 4: Final point cloud.

The construction of HBIM models, as in the case of the unfinished church of Brendola (Fig. 5), deals with managing a large amount of data. The collection of this data presupposes a philological reconstruction of the information that allows reconstructing of the archival and bibliographic sources used in the association of the data to the geometric model.

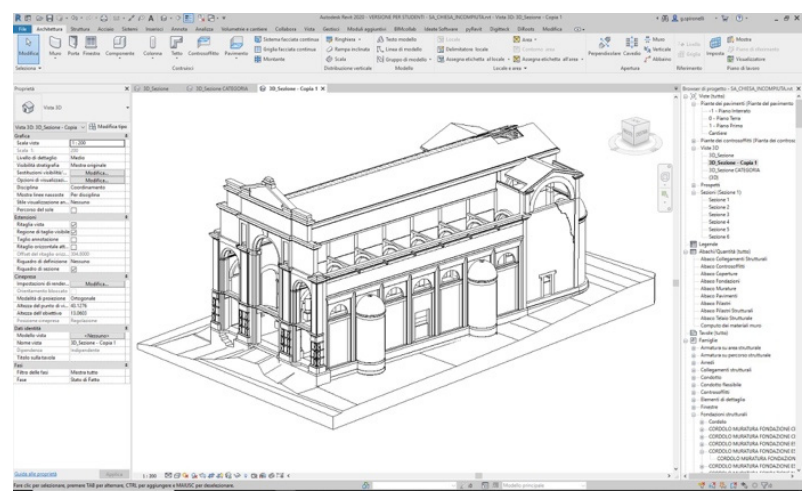

Figure 5: View of the HBIM model of the "Unfinished" church of Brendola.

This method of comparative study, which embraces technique and cultural humanism, was the basis of the decision to structure the information in databases (Fig. 6) that would act as a system for an archival and constructive investigation (Acierno, Cursi, Simeone, \& Fiorani, 2017) of the architectural elements in parallel with the assessment of the state of conservation and the design choices. This assumption was the base to develop an HBIM model connected to a repository that can be consulted and implemented (even by non-specialized personnel). The analyses carried out, within the archival documents, are associated with each architectural element. This tool wants to be the key to a multi-level interaction of knowledge and data sharing structures over time, being a vehicle for historical investigation and design.

The digital model's construction took place within the Autodesk Revit 2020 work environment, one of the sector's leading reference software. The choice of 
constructing the church's HBIM model within a commercial software is dictated by the fact that (currently) there are no valid open-source alternatives that allow managing an informative model with the same effectiveness.

While on one hand the modelling of architectural elements and the association of information content passes through the use of commercial software, on the other hand, the setting given to the model guarantees a high possibility of access and modification (Diara, \& Rinaudo 2018) thanks to the IFC (Industry Foundation Classes) scheme.

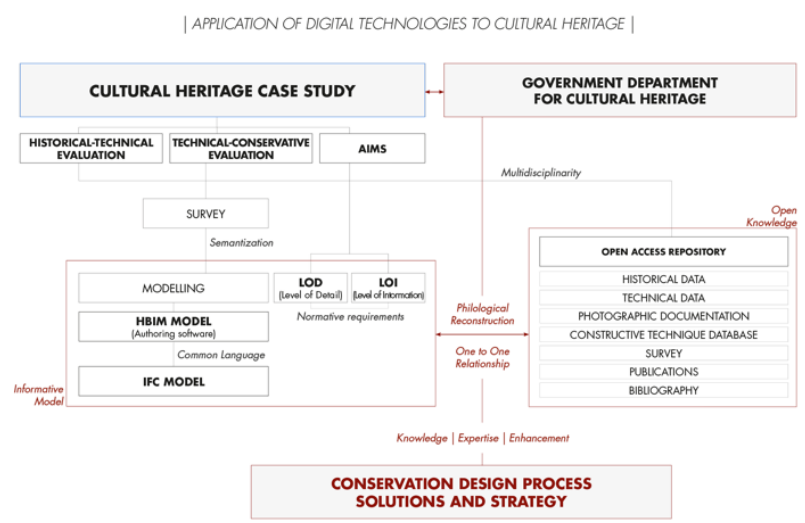

Figure 6: Schema of the workflow of the research activities.

The research activity's final objective is to achieve the definition of a system of knowledge of the church. A digital model of the architecture developed according to the IFC scheme allows obtaining a one-to-one correspondence between the model and the repository information. The diriment element in the system's construction is represented by choice to collect within the digital model the information collected in the phases of historical-critical investigation and knowledge of architecture through synthetic attributes (Fig. 7). The use of synthetics attribute allows to directly interrogate the model by using query (Fig. 8). Additional value is given by using dynamic links to specific directories of the repository where the data are collected.

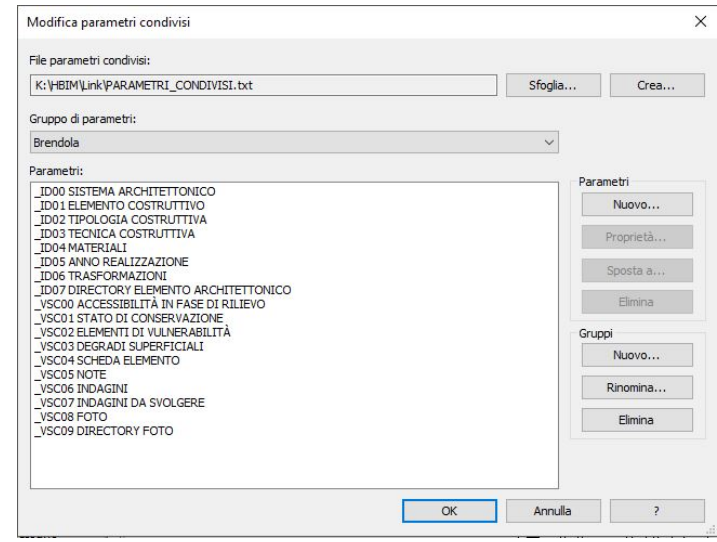

Figure 7: List of attributes coded according to shared parameters used to describe the identity data of the construction elements and their evaluation of the state of conservation. In order of appearance: Architectural System, Building Element, Construction Typology, Materials, Year of Construction, Transformations, Architectural Element Directory, Survey Accessibility, State of Conservation, Vulnerability, Decay Process, Element Data Sheet, Notes, Investigations, Investigations to be Carried Out, Photos, Photos Directory.
In this sense, the model becomes a tool with which it is possible to relate different access levels to the architecture's knowledge (Nazarena \& Roncella 2019 and Quattrini, Pierdicca, \& Morbidoni, 2017).

The construction of digital models for cultural heritage passes through the need to represent complex geometry, often difficult to reproduce except with specific software. It is well known how the main BIM applications' essential modelling tools can represent a limit in describing complex shapes (Murphy, McGovern, \& Pavia, 2009). Its definition passes through simplifications that do not respect the elements' real morphology, often defined by construction irregularities and the patina of time. During the semantization phase of the field's acquired data, the characterisation of the constructive elements (Brusaporci, Maiezza, \& Tata, 2018) passes through the notion of LOD (Level of Detail) and LOI (Level of Information), themes treated by two milestones normative requirements, the American Institute of Architects (AIA) with the AIA G202 Protocol, and the Italian UNI 11337

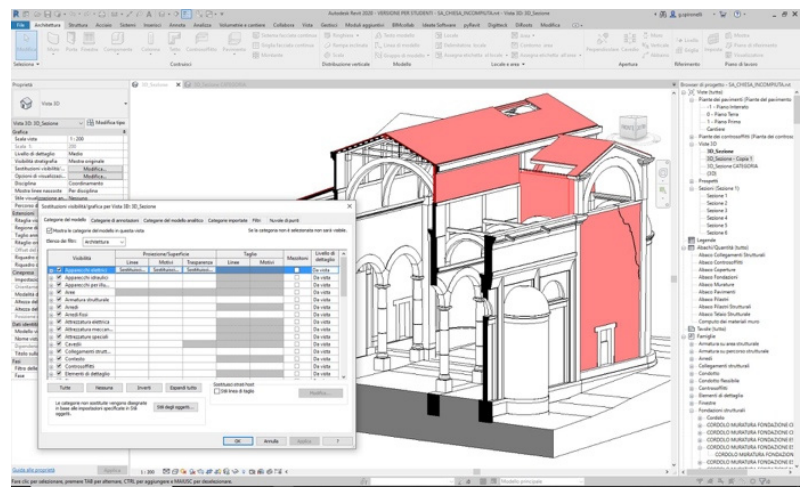

Figure 8: Example of a query created within the Autodesk Revit 2020 authoring software. Through a filter applied to the view, it is possible to highlight all the constructive elements with a severe state of conservation.

The church's informative model's construction was conceived following the criteria used during the construction site phases (Brumana, Georgopoulos, Oreni, Raimondi, \& Bregianni, 2013). From this point of view, the church's digital model's construction was carried out using the native instruments available on the software, basing the modelling of complex geometry on the "model in place" asset.

The use of local models is a powerful modelling tool that, in most cases, avoid the use of external resources (Tommasi, Achille, \& Fassi 2016) and give access to a series of advanced modelling tools that allow reproducing complex architectural elements faithfully. Compared to the point cloud obtained instrumentally, the modelling operations' accuracy led to an average deviation of the model of about two centimetres.

The association of information contents within geometric models referred to cultural heritage open up a wide field of investigation into the methods and shared procedures (Del Giudice \& Osello 2013) in which the data have to be associated with the digital model. Although in the field of cultural heritage an open-bim standard for collecting the information has not yet been delineated by the non-profit organisation "buildingSMART", the research group's goal is to identify the possible features that, through the IFC scheme may define their characterisation and their 
conservation status. (Fig. 9). As reported in Baldwin (2019), IFC is not an exchange format but a hierarchical structure that provide the organisation and the transportation of digital data. In this schema each object is defined and described by relationship and property.

The operation resulted in the search for the identity information necessary to describe the architectural element observed and its conservation status encoding them in a series of synthetic attributes associated with the model elements by introducing a series of "shared parameters" linked with the different categories of the model. This operation made it possible to combine the attributes, commonly available in the software, with specific features that refer to the heritage data.

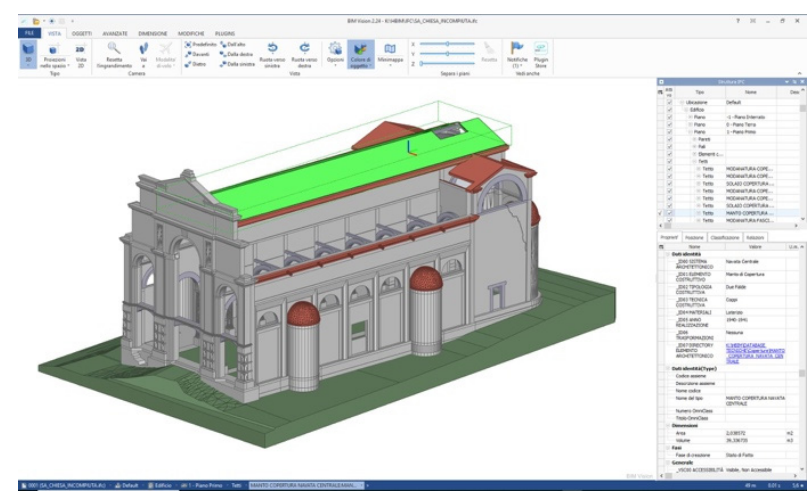

Figure 9: Example of the visualization of the data contained in the HBIM model within the open-source BIM Vision application.

The use of "shared parameters" has made it possible to collect information within specific schedules referring to the different architectural systems, ensuring high interoperability and allowing for the possibility of one-toone modification between model and schedule. The interoperability is ensured by the open-source plugin SheetLink (2020) developed by "DiRoots" company, which enables the export of the information in the form of spreadsheets with the possibility of being modified, also by non-specialized persons, in any application that supports its editing. This operation will allow a progressive advancement of knowledge linked to the asset and the possibility of managing the aspects related to conservation.

\section{Conclusions}

The studies carried out so far on the church show how the acquisition and processing of three-dimensional models supported by high-resolution digital images, together with the use of CAD tools and HBIM methodology, contribute to providing valuable support to the preliminary knowledge of the building. This instrumental premise interfaces with the theoretical and methodological assumption of recovering and enhancing the intangible value of the abandonment and the state of ruin of the Church, as well as its being an unfinished fragment (Augé, \& Meneguzzo, 2013), crossing the balance of the relationship between material traces and collective memory in an attempt to grasp the limits and opportunities of transmission.

\section{Acknowledgements}

We would like to thank: the Municipal Administration of Brendola for the great helpfulness it has shown us; the CIRCE Photogrammetry Laboratory for its willingness to carry out the activities and for having made the laboratory equipment available to us; the Superintendence of Archaeology, Fine Arts and Landscape for the provinces of Verona, Rovigo and Vicenza in the person of Silvia Dandria for the continuous support in the acquisition of data and the evaluation of conservation strategies; and Professors Mauro Marzo, Ettore Muneratti and Claudio Bertocco for their advice. Finally, we would like to thank Architect Gaetano Cecchini and Martino Albiero, for providing us with some of the historical data on the Church.

\section{References}

Acierno, M., Cursi, S., Simeone, D., \& Fiorani, D. (2017). Architectural heritage knowledge modelling: An ontology-based framework for conservation process. Journal of Cultural Heritage, 24, 124-133. https://doi.org/10.1016/j.culher.2016.09.010

AIA. (2013). AIA Contract Documents. G202-2013 Project BIM Protocol (aiacontracts.org). Retrieved March 15, 2021, from https://www.aiacontracts.org/contract-documents/19016-project-bim-protocol

Attenni, M. (2019). Informative Models for Architectural Heritage. Heritage, 3, 2067-2089. https://doi.org/10.3390/heritage2030125

Augé, M. (2004). Rovine e macerie. Il senso del tempo. (Ruins and rubble. The sense of time) Bollati Boringhieri.

Augé, M., \& Meneguzzo, M. (2013). Non-finito, infinito. Paolo Delle Monache film di Benoit Felici. (Unfinished, infinite. Paolo Delle Monache film by Benoit Felici). Mondadori Electa.

Baldwin, M. (2019). The BIM-Manager: A Practical Guide for BIM Project Management. Beuth Innovation.

Brumana, R., Georgopoulos, A., Oreni, D., Raimondi, A., \& Bregianni, A. (2013). HBIM for Documentation, Dissemination and Management of Built Heritage. The Case Study of St. Maria in Scaria d'Intelvi. In International Journal of Heritage in the Digital Era, 2(3), 433-451. https://doi.org/10.1260/2047-4970.2.3.433

Bruno, N., \& Roncella, R. (2018). A restoration oriented HBIM system for cultural heritage documentation: the case study of parma cathedral. Int. Arch. Photogramm. Remote Sens. Spatial Inf. Sci., XLII-2, 171-178. https://doi.org/10.5194/isprs-archives-XLII-2-171-2018

Brusaporci, S., Maiezza, P., \& Tata, A. (2018). A framework for architectural heritage hbim semantization and development. In ISPRS - International Archives of the Photogrammetry, Remote Sensing and Spatial Information Sciences, XLII- 
2, 179-184. https://doi.org/10.5194/isprs-archives-XLII-2-179-2018

buildingSMART. (2021). buildingSMART - The Home of BIM. Retrieved March 15, 2021, from https://www.buildingsmart.org

Castagnetti, C., Dubbini, M., Ricci, P.C., Rivola, R., Giannini, M., \& Capra, A., (2016), Critical issues and key points from the survey to the creation of the historical building information model: The case of Santo Stefano Basilica. International Archives of the Photogrammetry, Remote Sensing and Spatial Information Sciences, XLII-5/W1, 467474. https://doi.org/10.5194/isprs-archives-XLII-5-W1-467-2017

Cecchin, F. (1937). Il giubileo arcipretale nella parrocchia di San Michele arcangelo in Brendola: 19 Maggio 1912 - 19 Maggio 1937 (The archpriest's jubilee in the parish of San Michele Arcangelo in Brendola: 19th May 1912 - 19 th May 1937). Tipografia commerciale.

Del Giudice, M. \& Osello, A. (2013), BIM FOR CULTURAL HERITAGE. Int. Arch. Photogramm. Remote Sens. Spatial Inf. Sci., XL-5/W2, 225-229. https://doi.org/10.5194/isprsarchives-XL-5-W2-225-2013

Diara, F., \& Rinaudo, F., (2018) Open source hbim for cultural heritage: a project proposal, in The International Archives of the Photogrammetry. International Archives of the Photogrammetry, Remote Sensing and Spatial Information Sciences, XLII-2, 303-309. https://doi.org/10.5194/isprs-archives-XLII-2-303-2018

Gazzola, P. (1968). In Memoriam. Per Fausto Franco: 1899-1968. Arte Veneta, XXII, 217-218.

Murphy, M., McGovern, E., \& Pavia, S. (2009). Historic building information modelling (HBIM). Structural Survey, 27(4), 311-327. https://doi.org/10.1108/02630800910985108

Nazarena, B., \& Roncella, R. (2019), HBIM for Conservation: A New Proposal for Information Modeling. Remote Sens., 11, 1751. https://doi.org/10.3390/rs11151751

Quattrini, R., Pierdicca, R.;ç, \& Morbidoni, C. (2017). Knowledge-based data enrichment for HBIM: Exploring high-quality models using the semantic-web. Journal of Cultural Heritage, 28, 129-139. https://doi.org/10.1016/j.culher.2017.05.004

Sheetlink (1.2.2). (2020). [Free Revit plugin that allows you to sync the model data back and forth between Revit and Excel]. DiRoots. Retrieved March 15, 2021, from https://diroots.com/plugins/sheetlink-revit-to-excel

Tommasi, C., Achille, C., \& Fassi, F., (2016) From point cloud to BIM: A modelling challenge in the Cultural Heritage field. In ISPRS - International Archives of the Photogrammetry, Remote Sensing and Spatial Information Sciences, XLIB5, 429-436. https://doi.org/10.5194/isprs-archives-XLI-B5-429-2016

UNI - Ente Italiano di Normazione. (2017). UNI 11337-4:2017. Https://Www.Uni.Com. Retrieved March 15, 2021, from http://store.uni.com/catalogo/index.php/uni-11337-4-2017.html 


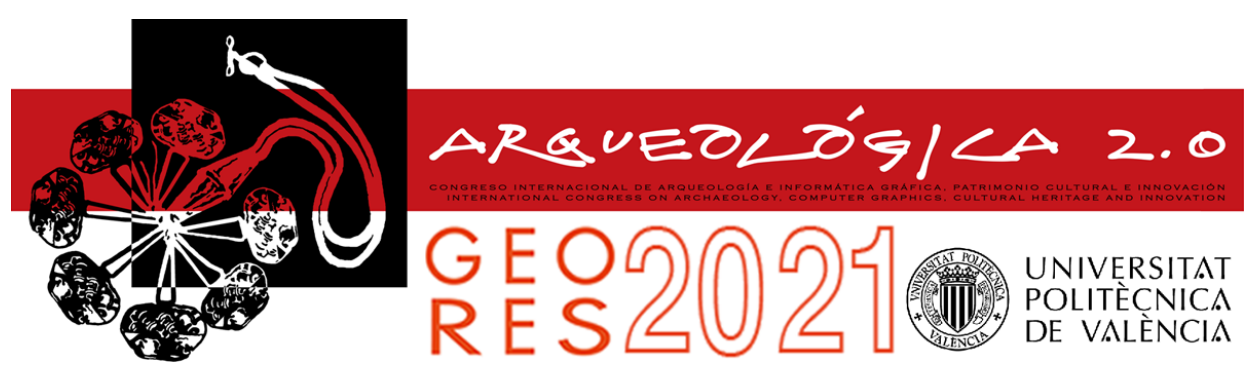

Proceedings of the joint international event $9^{\text {th }}$ ARQUEOLÓGICA

$2.0 \& 3^{\text {rd }}$ GEORES

Valencia (Spain).

26-28 April 2021

Received: 27/11/2020

Accepted: 25/03/2021

DOI: https://doi.org/10.4995/Arqueologica9.2021.12101

\title{
GENERATIVE NETWORKS FOR POINT CLOUD GENERATION IN CULTURAL HERITAGE
}

\author{
Roberto Pierdiccaa, ${ }^{a}$, Marina Paolantib, Ramona Quattrinia, Massimo Martinib ${ }^{b}$ Eva Savina \\ Malinvernia ${ }^{a}$ Emanuele Frontoni ${ }^{b}$ \\ ${ }^{a}$ Dipartimento di Ingegneria Civile, Edile e dell'Architettura, Università Politecnica delle Marche, Via Brecce Bianche 1, 60131 Ancona, \\ Italy.r.pierdicca@univpm.it; r.quattrini@univpm.it; e.s.malinverni@univpm.it

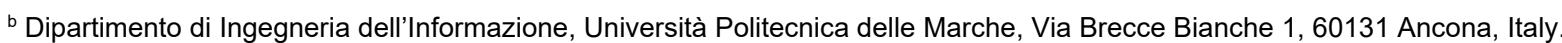 \\ m.paolanti@univpm.it; m.martini@pm.univpm.it; e.frontoni@univpm.it
}

\begin{abstract}
:
In the Cultural Heritage $(\mathrm{CH})$ domain, the semantic segmentation of 3D point clouds with Deep Learning (DL) techniques allows to recognize historical architectural elements, at a suitable level of detail, and hence expedite the process of modelling historical buildings for the development of BIM models from survey data. However, it is more difficult to collect a balanced dataset of labelled architectural elements for training a network. In fact, the $\mathrm{CH}$ objects are unique, and it is challenging for the network to recognize this kind of data. In recent years, Generative Networks have proven to be proper for generating new data. Starting from such premises, in this paper Generative Networks have been used for augmenting a $\mathrm{CH}$ dataset. In particular, the performances of three state-of-art Generative Networks such as PointGrow, PointFLow and PointGMM have been compared in terms of Jensen-Shannon Divergence (JSD), the Minimum Matching DistanceChamfer Distance (MMD-CD) and the Minimum Matching Distance-Earth Mover's Distance (MMD-EMD). The objects generated have been used for augmenting two classes of $\mathrm{ArCH}$ dataset, which are columns and windows. Then a DGCNNMod network was trained and tested for the semantic segmentation task, comparing the performance in the case of the $\mathrm{ArCH}$ dataset without and with augmentation.
\end{abstract}

Keywords: virtual archaeology, digital archaeology, cyber-archaeology, cultural heritage, documentation, 3D reconstruction

\section{Introduction}

The restoration, conservation, valorisation and cataloguing of architectural, archaeological and Cultural Heritage $(\mathrm{CH})$ goods necessitate as preliminary operation the survey that allows analysing several characteristics of the object of study. With the survey, it is possible to identify, analyze and highlight the shape, structure, single elements, composition, relationships between the parts and the whole, material, state of conservation and any critical situations, historical evidence, temporal and spatial evolution.

The methodological operation of the traditional survey consists of a series of actions for which the final purpose is the reproduction of the object studied using a graphic representation. This representation must respond to certain aims, depending on the purpose of the survey, since there are several areas of investigation for an object as a historical or artistic document.

Traditionally, due to time and costs, to obtain a result suitable for the purposes of the survey, a preliminary phase was anticipated to the measurement phase in which it was decided which data to acquire, thus making a selection on which all the final results would have depended.

The significant convenience introduced by the detection methodology using new high-resolution technologies is that of having principles of objectivity and identifying a procedure that allows the acquisition of all possible data of the existing elements, considering successively the subjective phase.

The articulated shapes, often characterized by curved, concave and convex elements, rotated parts, whose position is often determined by innumerable alterations, as well as by the loss of finishes, have suggested the use of the laser scanner technology, to overcome the difficulties of a traditional survey with all the uncertainties and imprecisions deriving from the morphological conformation.

Lasers scanner allow acquiring information about the shape of an object through the points cloud which returns images from arbitrary points of view and in arbitrary light conditions (Blais, 2004). 
The use of 3D point clouds in the field of $\mathrm{CH}$ have demonstrated considerable advantages, since the representation of $\mathrm{CH}$ artifacts through $3 \mathrm{D}$ data allows to perform several tasks. In fact, their rich informative virtual representation makes morphological analysis, map degradation and data enrichment. So, the management of cultural heritage goods is important to understand this data and to develop the available conservation strategy (Pierdicca et al., 2020).

Traditional methods are used in literature to deal with 3D point clouds using manual and time-consuming operations (Murtiyoso \& Grussenmeyer, 2019; Grilli, Özdemir \& Remondino, 2019; Spina, Debattista, Bugeja, \& Chalmers 2011). However, most recent applications based on deep learning (DL) approaches have demonstrated high performance and more efficient ways to elaborate this data (Qi, Su, Mo, \& Guibas 2017; Qi, Yi, $\mathrm{Su}, \&$ Guibas 2017). Some examples are also in $\mathrm{CH}$ field where deep learning algorithms are used to semantically segment 3D point clouds to recognize historical architectural elements at an appropriate detail level (Pierdicca et al., 2020). The semantic segmentation task that classifies different parts associating to each part a label, is an approach most used in the cultural heritage field (Barsanti, Guidi \& De Luca, 2017; Llamas, Lerones, Medina, Zalama, \& Gómez-García-Bermejo, 2017; Grilli \& Remondino, 2019).

The problem is that the training of deep learning networks requires a great amount of data mainly considering $\mathrm{CH}$ dataset with unique and unrepeatable elements. Moreover, the dataset has unbalanced classes and then the networks are not able to correctly recognize the objects (e.g. wall, roof, column, vault, etc.) due to the lack of data (Pierdicca et al., 2020).

For this reason, mainly in the last years, the use of Generative Networks have filled this gap since they are able to generate novel suitable data as well as learn (Arshad \& Beksi, 2020).

In this context, the aim of this paper is to propose a framework based on DL that synthetically generates additional architectural elements to increase segmentation accuracy. To generate novel scenes, we use three different generative networks: PointGrow (Sun, Wang, Liu, Siegel, \& Sarma, 2020), PointFlow (Yang et al., 2019), and PointGMM (Hertz, Hanocka, Giryes, \& Cohen-Or, 2020). Moreover, to compare the best performances we train a novel Deep Neural Network, namely DGCNN-Mod that classifies the synthetically generate scenes (Pierdicca et al., 2020). The experiments have been performed to $\mathrm{ArCH}$ dataset described in (Matrone et al., 2020a). In contrast to many existing datasets, it has been manually labelled by domain experts, thus providing a more precise dataset.

The main contributions of this paper can be summarized as follows:

1) Generation of $\mathrm{CH}$ point clouds, useful for $3 \mathrm{D}$ documentation of documents and sites.

2) A generative based approach adapted to this domain.

3) A new set of synthetically generated architectural elements that is useful for data augmentation.
The paper is organized as follows. Section 2 provides a description of the approaches that were adopted for Point Clouds generations. Section 3 describes our approach to present the Point Clouds generation and a new challenging dataset for the $\mathrm{CH}$ domain. Section 4 offers an extensive comparative evaluation and a detailed analysis of our approach. Finally, Section 5 draws conclusions and discuss future directions for this field of research.

\section{Related works}

Synthetic data are used in several application fields. One of the pioneer works is proposed by Myers (1999) that demonstrates that the use of simulated data has significant advantages. This work introduces a simulator that describes and stochastically generates a sequence of DNA with different repeated structures.

Most recent work is proposed by that Fan, Su \& Guibas (2017) that produces synthetic point clouds departing from a single 2D-dimensional image and reconstructing the 3D geometry of the complete object. To do this task they use an algorithm based on deep learning.

A 3D point cloud is automatically generated in the work of $\mathrm{Li}$ et al. (2016) and used to train a traditional random forest network. This approach is based on supervised learning to classify $3 \mathrm{D}$ real urban scenes.

The work of (Wu, Zhou, Zhao, Yue, \& Keutzer, 2019) extracts synthetic point clouds of urban scenes (road scene) from the Grand Theft Auto famous videogame to augment a standard benchmark dataset (KITTI). This approach has the aim to increase the semantic segmentation task based on Convolutional Neural Networks.

Street scenes are also dealt in the work of (Wang, Zhuang, Gu, \& Hu, 2019) where virtual LiDAR sensors are used to acquire synthetic point clouds. The work simulates several point clouds acquisition tools.

The urban context is also the object of the work proposed by Griffiths \& Boehm (2019), where there is a need of a great amount of data to train a deep neural network to classify a 3D point cloud. The authors create a synthetic dataset and intend to demonstrate that the network trained with the dataset is able to generalize correctly the points cloud.

In the work of Chu, Sung, \& Cho (2018) the authors propose a GAN to generate 3D points cloud departing from RGB-D images and corresponding to a single red, green, blue image. The method involves two phases. In the first phase, a generative adversarial network generates a depth image estimation from a single RGB image. In the second the 3D point cloud is calculated from the depth image. During the experimental phase, they demonstrate that the method provides high-quality 3D point clouds from single 2D images.

The work of Arshad \& Beksi (2020) proposes a novel GAN that creates in an unsupervised way dense coloured 3D point clouds of various classes of objects. They propose a point transformer that using a graph convolution to increase in progress of the network, this to overcome the problem to acquire complex details with high resolution. The aim of the paper is to create a network able to 
produce coloured point clouds with fine details at multiple resolutions.

In the context of cultural heritage interesting is the work of Egiazarian et al. (2019) where they propose a model that combines the latent-space GAN and Laplacian GAN architectures to form a multi-scale model capable of generating 3D point clouds at augmenting levels of detail. During the experimental phase they demonstrate that the method is better than other object of comparison.

The work of Martínek, Lenc, \& Král (2019) shows different training approaches with the task to classify optical character in historical documents. To solve the problem to have a great amount of annotated data, they summarize several methods to create a synthetic dataset.
Moreover, they train a convolutional recurrent neural network using input a synthetic dataset and validate the approach using a real annotated dataset.

\section{Materials and Methods}

This section introduces the framework as well as the dataset used for the evaluation. The framework, as said in the introduction section, is depicted in Figure 1. The purpose of the proposed method is to improve the semantic segmentation of point clouds of an unbalanced dataset, generating new objects through generative approaches. Three generative networks have been trained for point cloud generation in $\mathrm{CH}$ Domain.

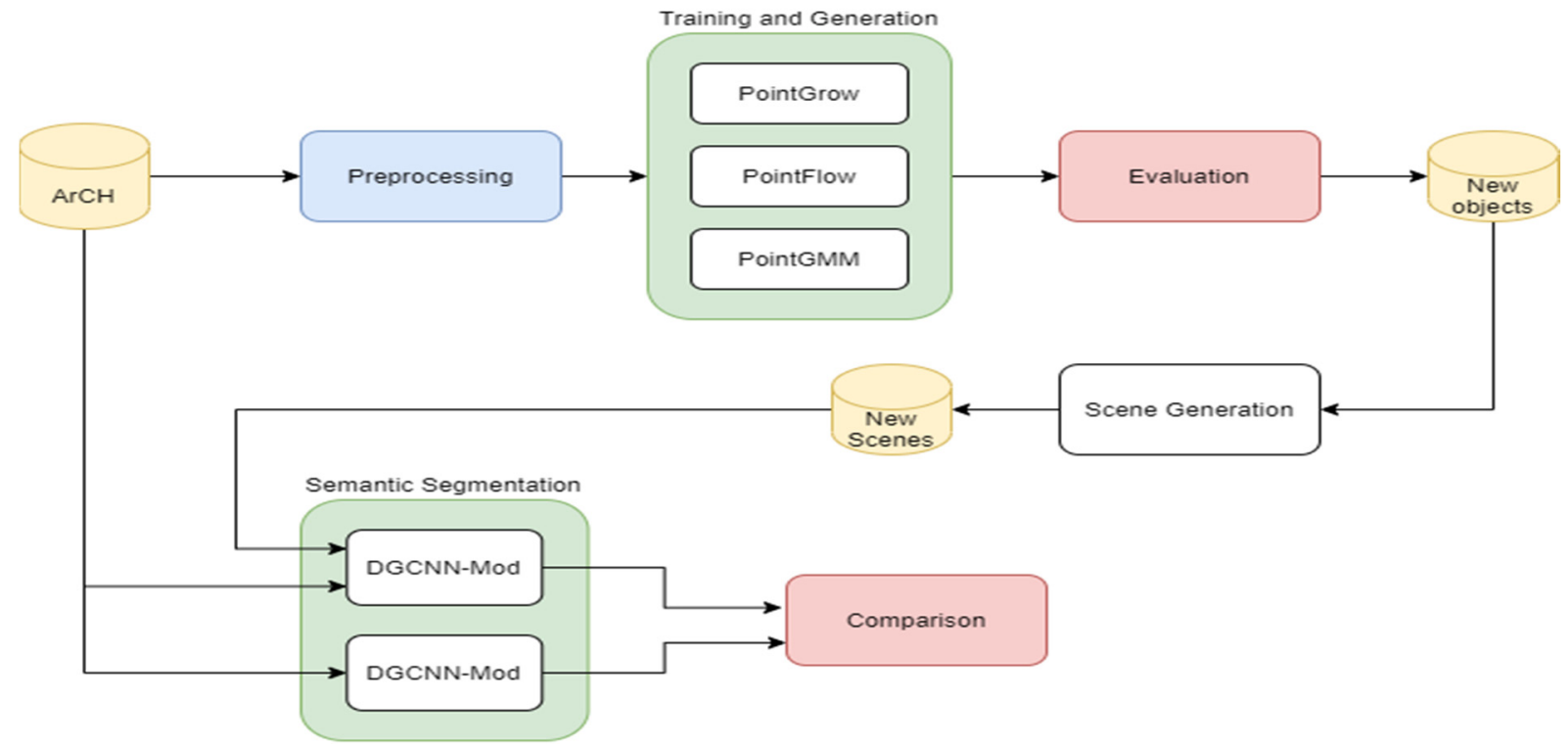

Figure 1: Workflow of the proposed approach.

An initial pre-processing phase is also introduced, to give in input proper objects to the networks, and a final phase for the comparison of two different pieces of training for the semantic segmentation of point clouds.

Further details are given in the following subsections. The framework is comprehensively evaluated on $\mathrm{ArCH}$, a publicly available dataset.

\subsection{ArCH Dataset}

The experiment section are based on the scenes of the $\mathrm{ArCH}$ benchmark (Matrone et al. 2020b), a group of architectural point clouds collected by several research groups and universities, with the purpose of sharing and labelling a large dataset of point clouds for training and testing learning approaches.

In literature, there are several benchmarks and datasets for point clouds classification and semantic segmentation, but the $\mathrm{ArCH}$ dataset is the only one specifically focused on the $\mathrm{CH}$ domain and with a higher level of detail.

The dataset is composed of 17 point clouds of architectural scenarios, divided into 15 scene for the training and 2 scenes for the final test.

This work is based on the tests carried out in (Matrone et al., 2020a), specifically the experiment of the Trompone's scene is reproduced using only the coordinates as a feature. Figure 2 shows this particular scene, representing original features and the relative ground truth.

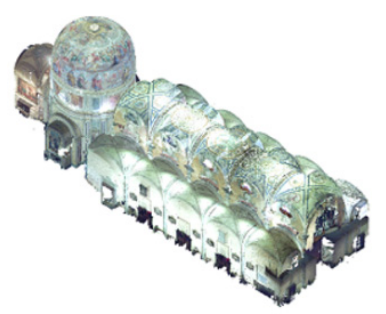

(a)

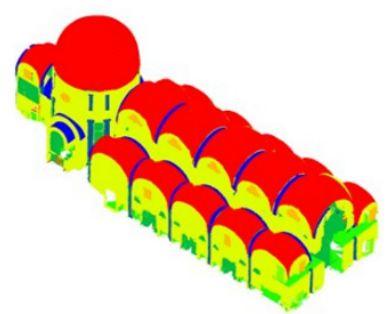

(b)
Figure 2: Trompone's scene from $\mathrm{ArCH}$ dataset: a) shows the scene features; b) shows the ground truth.

The objects of this dataset are given as input to generative approaches, in order to generate new objects and counterbalance the dataset.

However, this dataset does not provide labels of the instances but only for the classes. Then, every single object has been manually divided. ArCH dataset provides the ground truth for 10 classes, but only the classes that are more difficult to recognize has been selected, as indicated in (Matrone et al., 2020a). For this reason, only 
the objects regarding Column and Window classes have extrapolated from all scenes.

The dataset used to train generative approaches comprises:

- 234 columns;

- 390 windows.

In the last phase of the workflow, $\mathrm{ArCH}$ dataset is used to compare two different trainings: the first one using the original dataset and the last one using the increased dataset through the generated objects.

\subsection{Generative Approaches for Point Cloud Generation}

This subsection describes the generative approaches used to generate new $\mathrm{ArCH}$ dataset objects and counterbalance those classes that have only few instances.

Before the training of the networks, a pre-processing phase is performed on the data, consisting of 2 steps: subsampling and data normalization.

These networks can only take in input objects of 1024 points, so a random subsampling has been done for each instance of the dataset. Then, the objects are spatially centred at the $(0,0,0)$ point and normalized to obtain values in the range of 0 and 1 .

The pre-processed data are then used to train three different generative networks: PointGrow (Sun, Wang, Liu, Siegel, \& Sarma, 2020), PointFlow (Yang et al., 2019), and PointGMM (Hertz, Hanocka, Giryes, \& CohenOr, 2020).

These networks have been chosen because they are very recent state of the art approaches and have very good performance in point clouds generation, which are then used to improve related tasks such as classification and segmentation.

The first tested approach is PointGrow (Sun, Wang, Liu, Siegel, \& Sarma, 2020), an autoregressive method for generating recurrently every point. This network estimates a conditional distribution of the point by considering all its preceding points. Taking into account the irregularity of the point clouds, the authors of this paper propose two point cloud-based self-attention modules for dynamically aggregating long-range dependencies from the other points. There are several ways to train these networks: in this work, the Unconditional PointGrow approach is used. To facilitate the generation process, training points are sorted according to their $z$ coordinates; in this way, the shape should be encouraged to be generated mainly along its primary axis during the test phase.

The second network of our framework is called PointFlow (Yang et al., 2019). It is a variational auto-encoders (VAE) based approach, it is composed by three modules:

- An Encoder, that encodes a point cloud into a shape representation $z$;

- A Prior Module $\mathrm{P}(\mathrm{z})$ over shape representations Z;

- $\quad$ A Decoder $P(X \mid z)$ that models the distribution of points given the shape representation.
This particular network learns a two-level hierarchy of distributions: the first one is the distribution of shapes and the second one is the distribution of points given a shape. A continuous normalizing flow is used to learn these particular levels of distributions.

The third network, PointGMM (Hertz, Hanocka, Giryes, \& Cohen-Or, 2020), is also composed of encoders and decoders: the first receives point clouds as input and generates a features map as an output, the second build a GMM representation from the previous latent vector. GMM is a Gaussian mixture model, usually used as an alternative representation for $3 D$ objects. This approach learns a hierarchical GMM (hGMM), performing coarseto-fine learning to improve performance, instead of a common single scale GMM.

All three approaches take the input data from the preprocessing phase, generate new objects, and then are compared according to appropriate metrics

\subsection{Performance Evaluation}

To evaluate the performance of the generative networks the following metrics have been adopted: Minimum Matching Distance based on Chamfer Distance (MMDCD), Minimum Matching Distance based on Earth Mover's Distance (MMD-EMD) and Jensen-Shannon Divergence (JSD) (Achlioptas, Diamanti, Mitliagkas, \& Guibas, 2018).

First of all, Chamfer Distance (CD) and the Earth Mover's Distance (EMD) should be introduced: they are two symmetric distance metrics to measure the distance between two points clouds. In our case, the two points clouds are the original and the generated ones.

Given two points clouds, S1 and S2, CD metric measures the squared distance between each point in S1 to its nearest neighbour in S2. So, the Chamfer Distance between $S 1$ and $S 2$ is defined in Eqs. (1) and (2):

$d_{C D}\left(S_{1}, S_{2}\right)=\sum_{x \in S_{1}} \min _{y \in S_{2}}\|x-y\|_{2}^{2}+\sum_{y \in S_{2}} \min _{x \in S_{1}}\|x-y\|_{2}^{2}$

Instead, the EMD is defined as

$d_{E M D}\left(S_{1}, S_{2}\right)=\min _{\varphi: S_{1} \rightarrow S_{2}} \sum_{x \in S_{1}}\|x-\varphi(x)\|_{2}$

where

$$
\varphi=\text { bijection between } \mathrm{S} 1 \text { and } \mathrm{S} 2
$$

Then, a method to measure the similarity of $A$ (set of generated point clouds) with respect to $B$ (set of original point clouds) is needed. To this end, every point in $B$ is matched with the closer one in $A$, by using minimum distance (MMD) and reporting the average of distances in the matching. $C D$ and EMD metrics can be used as pointset distance for MMD, yielding MMD-CD and MMDEMD (Achlioptas, Diamanti, Mitliagkas, \& Guibas, 2018).

The last comparison metric is JSD, which measures if point clouds of $A$ tend to occupy similar spaces as those of $B$, and the degree of this similarity. Given the empirical distributions $\left(P_{A}, P_{B}\right)$, JSD metric is described as follow in Eq. (3):

$J S D\left(P_{A} \| P_{B}\right)=\frac{1}{2} D\left(P_{A} \| M\right)+\frac{1}{2} D\left(P_{B} \| M\right)$

where 
$\mathrm{M}=\frac{1}{2}\left(P_{A}+P_{B}\right)$ and $D(\|)$ the $\mathrm{KL}$-divergence between the two distributions

Another state of the art method to evaluate the quality of the generated points clouds is to use PointNet (Qi, Su, Mo, \& Guibas 2017) as a shape classifier (Sun, Wang, Liu, Siegel, \& Sarma, 2020). In fact, if the generated objects will have very discriminating features for their relative class, it means that a classification model trained on the original objects should have good performance in classifying those generated, and vice-versa.

In this work, after generating 100 points clouds per category, two classification activities are conducted:

1) Training on original data and testing on generated shapes:

2) Training on generated shapes and testing on original data.

\section{Results and Discussions}

This section describes the configuration for network training and discusses the results of the various experiments.

The three generative networks were trained using Window and Column objects from the $\mathrm{ArCH}$ dataset. As described in Chapter 3.2, the objects were sub-sampled at 1024 points, then centred with respect to the point (0.0.0) and normalized with values between 0 and 1 .

The training was done by splitting the dataset as follows:

- $80 \%$ of the objects for training;

- $20 \%$ of the objects for the final test.

A part of the training was used as the validation set.

The networks have been trained using the hyperparameters configuration described in the related papers.

The first experiment performed concerns the training of generative networks. Table 1 shows the comparison of the approaches in terms of JSD, MMD-CD and MMCEMD metrics. The most satisfactory results are those obtained with PointFlow, which is the best approach for the generation of columns object, by obtaining lower JSD. Mand both MMD values. However, regarding windows objects, the two best methods for their generations seem to be PointGrow and PointGMM.

Table 1: Results of the generative approaches.

\begin{tabular}{|c|c|c|c|c|}
\hline Class & Model & $J S D$ & $M M D-C D$ & $M M D-E M D$ \\
\hline \multirow{3}{*}{ Column } & PointGrow & 0.1941 & 0.0090 & 0.1352 \\
\hline & PointFlow & 0.0820 & 0.0078 & 0.1228 \\
\hline & PointGMM & 0.0929 & 0.0080 & 0.1421 \\
\hline \multirow{3}{*}{ Window } & PointGrow & 0.2588 & 0.0061 & 0.1030 \\
\hline & PointFlow & 0.3014 & 0.0292 & 0.1613 \\
\hline & PointGMM & 0.1704 & 0.0079 & 0.1052 \\
\hline
\end{tabular}

The second experiment regards the classification performed with PointNet. The results are shown in Table 2: even in this case, PointFlow approach turns out to be the best generative method, as the classification accuracy for both SG and GS tests remain congruent.
Table 2: Classification accuracy using PointNet. SG: Training on $\mathrm{ArCH}$ Dataset and testing on generated shapes; GS: Training on generated shapes and testing on $\mathrm{ArCH}$ Dataset.

\begin{tabular}{c|c|c} 
Model & SG & GS \\
\hline PointGrow & 0.5733 & 0.9350 \\
PointFlow & 0.7143 & 0.7150 \\
PointGMM & 0.6900 & 0.9200
\end{tabular}

From the results obtained, the PointFlow network has been chosen to generate column objects, while the PointGrow network has been used to generate Window objects.

Using CloudCompare software, it was possible to build 3 scenes containing these objects. To make the scene more realistic, portions of the wall were also added, so that the objects could be positioned consistently. Figure 3 shows the scenes created with the generated objects.

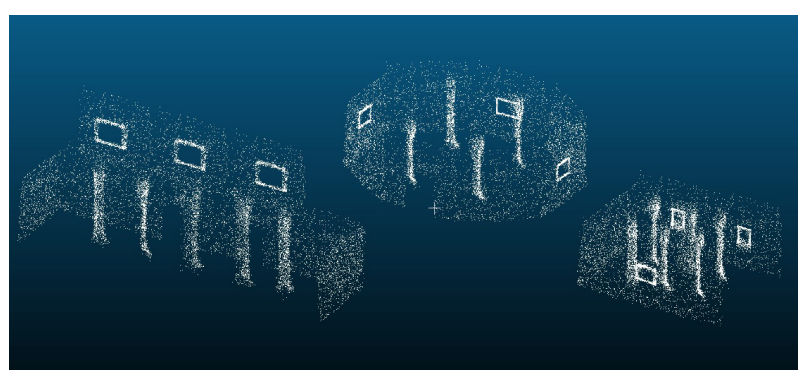

Figure 3: Scenes created by using generated objects.

Finally, these scenes are used to improve the training of the DGCNN-Mod network, for the semantic segmentation task on $\mathrm{ArCH}$ dataset. As said previously, experiments are conducted on the Trompone's scene.

Two different experiments are performed: the first regards the training by using original dataset, while the last regards the training with the $\mathrm{ArCh}$ dataset augmented by the generated scenes.

Table 3 and Table 4 show the results in terms of Precision, Recall and F1-Score, for every class of the Arch dataset. Performance of the DGCNN-Mod semantic segmentation on $\mathrm{ArCH}$ Dataset without the generated scenes are represented in Table 3. On the other hand, the performance of the DGCNN-Mod trained with the augmented dataset is shown in Table.

Table 3: Results of the DGCNN-Mod semantic segmentation on $\mathrm{ArCH}$ Dataset without the generated scenes.

\begin{tabular}{c|c|c|c} 
Object & Precision & Recall & F1-Score \\
\hline Arc & 0.2904 & 0.1268 & 0.1765 \\
Column & $\mathbf{0 . 9 9 0 6}$ & $\mathbf{0 . 0 8 5 6}$ & $\mathbf{0 . 1 5 7 6}$ \\
Molding & 0.5074 & 0.1465 & 0.2273 \\
Floor & 0.9485 & 0.9051 & 0.9263 \\
Door-Win & $\mathbf{0 . 0 9 7 4}$ & $\mathbf{0 . 0 4 6 7}$ & $\mathbf{0 . 0 6 3 1}$ \\
Wall & 0.5867 & 0.2339 & 0.3344 \\
Stairs & 0.0424 & 0.0006 & 0.0011 \\
Vault & 0.9177 & 0.7408 & 0.8198 \\
Forniture & 0.3484 & 0.9241 & 0.5060
\end{tabular}


These experiments show that semantic segmentation performance regarding column class are improved. However, window segmentation has decreased. This is probably due to the fact that in the $\mathrm{ArCH}$ dataset windows are included in the same class as doors, because they are the classes with fewer elements. By increasing the number of windows, the network probably has more difficulty in classifying door points.

These findings deserve a more detailed explanation. First, looking at the column class, it is worth noting that despite the precision value is higher "without" than "with" the generated scenes, F1-score and Recall increase in this latter case (see the comparison between Tables 3 and 4); such values provide comforting insights from our experiments, since they are meaningful and opens to future generalizations of the method. This is not true for the class Door-Win, but the reason shall is that this class is merged among two objects (namely doors and windows), while in the benchmark dataset such classes were considered separately.

Table 4: Results of the DGCNN-Mod semantic segmentation on $\mathrm{ArCH}$ Dataset with the generated scenes.

\begin{tabular}{c|c|c|c} 
Object & Precision & Recall & F1-Score \\
\hline Arc & 0.2284 & 0.4445 & 0.3018 \\
Column & $\mathbf{0 . 6 6 9 2}$ & $\mathbf{0 . 2 1 3 1}$ & $\mathbf{0 . 3 2 3 2}$ \\
Molding & 0.4460 & 0.2488 & 0.3194 \\
Floor & 0.9159 & 0.9808 & 0.9473 \\
Door-Win & $\mathbf{0 . 1 2 0 7}$ & $\mathbf{0 . 0 3 5 4}$ & $\mathbf{0 . 0 5 4 7}$ \\
Wall & 0.6646 & 0.5773 & 0.6179 \\
Stairs & 0.3583 & 0.1789 & 0.2386 \\
Vault & 0.9380 & 0.7460 & 0.8310 \\
Forniture & 0.5556 & 0.8286 & 0.6652
\end{tabular}

It is possible to obtain a further comparison through the graph of Figure 4. In this graph, the comparison of metrics for the entire dataset is shown. The results show that the accuracy of semantic segmentation has also improved thanks to the inclusion of these new generated scenes. It is fairly straightforward to deduce the motivation behind this increase in accuracy; data generation has been performed for those classes with a lower number of points available, that is to say unbalanced classes. Consequently, by balancing the dataset, the overall performances yield better results.

To the sake of completeness, the latest discussion is devoted to the generative model. The PointFlow model will be the one to design future experiments, as it gains stability for both SG and GS values. This means that the generator is able to reproduce the object regardless of the type of training-test method (see Table 2).

\section{Conclusions and Future Works}

The aim of this paper is to propose a framework based on $\mathrm{DL}$ methods able to semantically segment $3 \mathrm{D}$ points clouds of $\mathrm{CH}$ domain. Since the dataset is unbalanced, we used generative adversarial networks to increase the performance of the semantic segmentation. Experimental results demonstrated that augmenting the dataset, the rate of recognition of each element increases. In this paper, we worked with three generative networks, PointGrow, PointFlow and PointGMM for the generation of point clouds related to the cultural heritage domain. The main purpose was to obtain new scenes to improve the semantic segmentation task of the DGCNN-Mod network. The generated scenes provided good performance for the column segmentation task.

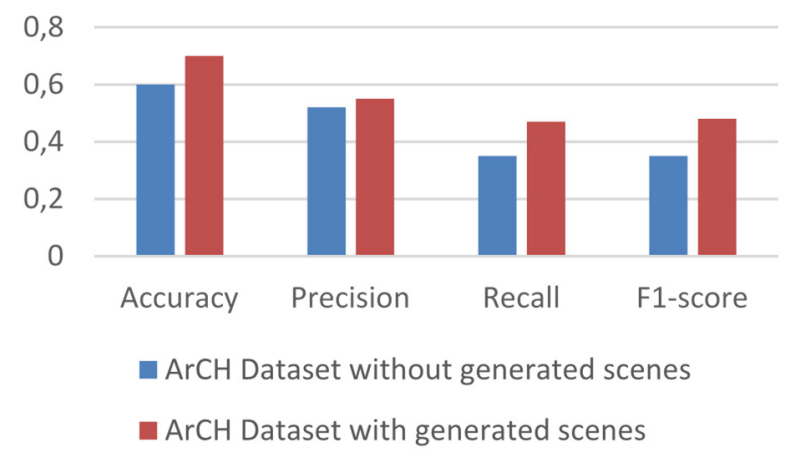

Figure 4: Comparison of metrics considering $\mathrm{ArCH}$ dataset without and with generated.

The automatic generation of 3D class object can revolutionize the cultural heritage domain in several aspects. (H)BIM, given the uniqueness of $\mathrm{CH}$ objects, requires time-consuming parametrization that are nowadays completely entrusted to human operation; our method opens up to great opportunities in terms of automatization. Moreover, as demonstrated by the literature, one of the main bottlenecks towards the full exploitation of DL methods for semantic segmentation is the lack of available and annotated datasets. Again, our method proves to be a robust alternative to manual and time consuming manual labelling.

A possible future development is to increase the points clouds, both for the training phase and to obtain more defined shapes. Another possible future development is to improve the fine-tuning technique on PointFlow freezing the first layers of the network. Moreover, another possible future development could be to implement additional features such as colours to make realistic the generated point clouds.

\section{References}

Achlioptas, P., Diamanti, O., Mitliagkas, I., \& Guibas, L. (2018). Learning representations and generative models for 3d point clouds. In International conference on machine learning (pp. 40-49). PMLR.

Arshad, M., \& Beksi, W. J. (2020). A Progressive Conditional Generative Adversarial Network for Generating Dense and Colored 3D Point Clouds. ArXiv, abs/2010.05391.

Barsanti, S. G., Guidi, G., \& De Luca, L. (2017). Segmentation of 3D models for cultural heritage structural analysis-some critical issues. ISPRS Annals of the Photogrammetry, Remote Sensing and Spatial Information Sciences, 4, 115. 
https://doi.org/10.5194/isprs-annals-IV-2-W2-115-2017

Blais, F. (2004). Review of 20 years of range sensor development. Journal of electronic imaging, 13(1), $231-243$. https://doi.org/10.1117/12.473116

Chu, P. M., Sung, Y., \& Cho, K. (2018). Generative adversarial network-based method for transforming single RGB image into 3D point cloud. IEEE Access, 7, 1021-1029. https://doi.org/10.1109/ACCESS.2018.2886213

Egiazarian, V., Ignatyev, S., Artemov, A., Voynov, O., Kravchenko, A., Zheng, Y., \& Burnaev, E. (2019). Latent-Space Laplacian Pyramids for Adversarial Representation Learning with 3D Point Clouds. arXiv preprint arXiv:1912.06466.

Fan, H., Su, H., \& Guibas, L. J. (2017). A point set generation network for 3d object reconstruction from a single image. In Proceedings of the IEEE conference on computer vision and pattern recognition (pp. 605-613).

Griffiths, D., \& Boehm, J. (2019). SynthCity: A large scale synthetic point cloud. arXiv preprint arXiv:1907.04758.

Grilli, E., Özdemir, E., \& Remondino, F. (2019). Application of machine and deep learning strategies for the classification of heritage point clouds. International Archives of the Photogrammetry, Remote Sensing \& Spatial Information Sciences. https://doi.org/10.5194/isprs-archives-XLII-4-W18-447-2019.

Grilli, E., \& Remondino, F. (2019). Classification of 3D digital heritage. Remote Sensing, $11(7), 847$. https://doi.org/10.3390/rs11070847.

Hertz, A., Hanocka, R., Giryes, R., \& Cohen-Or, D. (2020). PointGMM: a Neural GMM Network for Point Clouds. In Proceedings of the IEEE/CVF Conference on Computer Vision and Pattern Recognition (pp. 12054-12063). https://doi.org/10.1109/CVPR42600.2020.01207

Llamas, J., M Lerones, P., Medina, R., Zalama, E., \& Gómez-García-Bermejo, J. (2017). Classification of architectural heritage images using deep learning techniques. Applied Sciences, 7(10), 992. https://doi.org/10.3390/app7100992.

Li, Z., Zhang, L., Zhong, R., Fang, T., Zhang, L., \& Zhang, Z. (2016). Classification of urban point clouds: A robust supervised approach with automatically generating training data. IEEE Journal of Selected Topics in Applied Earth Observations and Remote Sensing, 10(3), 1207-1220. https://doi.org/10.1109/JSTARS.2016.2628399

Martínek, J., Lenc, L., \& Král, P. (2019). Training Strategies for OCR Systems for Historical Documents. In IFIP International Conference on Artificial Intelligence Applications and Innovations (pp. 362-373). Springer, Cham

Matrone, F., Grilli, E., Martini, M., Paolanti, M., Pierdicca, R., \& Remondino, F. (2020a). Comparing Machine and Deep Matrone Learning Methods for Large 3D Heritage Semantic Segmentation. ISPRS International Journal of GeoInformation, 9(9), 535. https://doi.org/10.3390/ijgi9090535

Matrone, F., Lingua, A., Pierdicca, R., Malinverni, E. S., Paolanti, M., Grilli, E., Remondino, F. Murtiyoso \& Landes, T. (2020b). A Benchmark for Large-Scale Heritage Point Cloud Semantic Segmentation. International Archives of the Photogrammetry, Remote Sensing and Spatial Information Sciences, 43, 1419-1426. https://doi.org/10.5194/isprsarchives-XLIII-B2-2020-1419-2020

Myers, G. (1999). A dataset generator for whole genome shotgun sequencing. In ISMB (pp. 202-210).

Murtiyoso, A., \& Grussenmeyer, P. (2019). Automatic heritage building point cloud segmentation and classification using geometrical rules. International Archives of the Photogrammetry, Remote Sensing \& Spatial Information Sciences. https://doi.org/10.5194/isprs-archives-XLII-2-W15-821-2019

Pierdicca, R., Paolanti, M., Matrone, F., Martini, M., Morbidoni, C., Malinverni, E. S., E. Frontoni \& Lingua, A. M. (2020). Point Cloud Semantic Segmentation Using a Deep Learning Framework for Cultural Heritage. Remote Sensing, 12(6), 1005. https://doi.org/10.3390/rs12061005

Qi, C. R., Su, H., Mo, K., \& Guibas, L. J. (2017). Pointnet: Deep learning on point sets for 3d classification and segmentation. In Proceedings of the IEEE conference on computer vision and pattern recognition (pp. 652-660). https://doi.org/10.1109/CVPR.2017.16

Qi, C. R., Yi, L., Su, H., \& Guibas, L. J. (2017). Pointnet++: Deep hierarchical feature learning on point sets in a metric space. In Advances in neural information processing systems, 5099-5108.

Spina, S., Debattista, K., Bugeja, K., \& Chalmers, A. (2011). Point cloud segmentation for cultural heritage sites. In Proceedings of the 12th International conference on Virtual Reality, Archaeology and Cultural Heritage (pp. 41-48). http://dx.doi.org/10.2312/VAST/VAST11/041-048

Sun, Y., Wang, Y., Liu, Z., Siegel, J., \& Sarma, S. (2020). Pointgrow: Autoregressively learned point cloud generation with self-attention. In The IEEE Winter Conference on Applications of Computer Vision (pp. 61-70). https://doi.org/10.1109/WACV45572.2020.9093430

Wang, F., Zhuang, Y., Gu, H., \& Hu, H. (2019). Automatic generation of synthetic LiDAR point clouds for 3-d data analysis. IEEE Transactions on Instrumentation and Measurement, 68(7), 2671-2673. https://doi.org/10.1109/TIM.2019.2906416

Wu, B., Zhou, X., Zhao, S., Yue, X., \& Keutzer, K. (2019). Squeezesegv2: Improved model structure and unsupervised 
domain adaptation for road-object segmentation from a lidar point cloud. In 2019 International Conference on Robotics and Automation (ICRA) (pp. 4376-4382). IEEE. https://doi.org/10.1109/ICRA.2019.8793495

Yang, G., Huang, X., Hao, Z., Liu, M. Y., Belongie, S., \& Hariharan, B. (2019). Pointflow: 3d point cloud generation with continuous normalizing flows. In Proceedings of the IEEE International Conference on Computer Vision (pp. 45414550). https://doi.org/10.1109/ICCV.2019.00464 


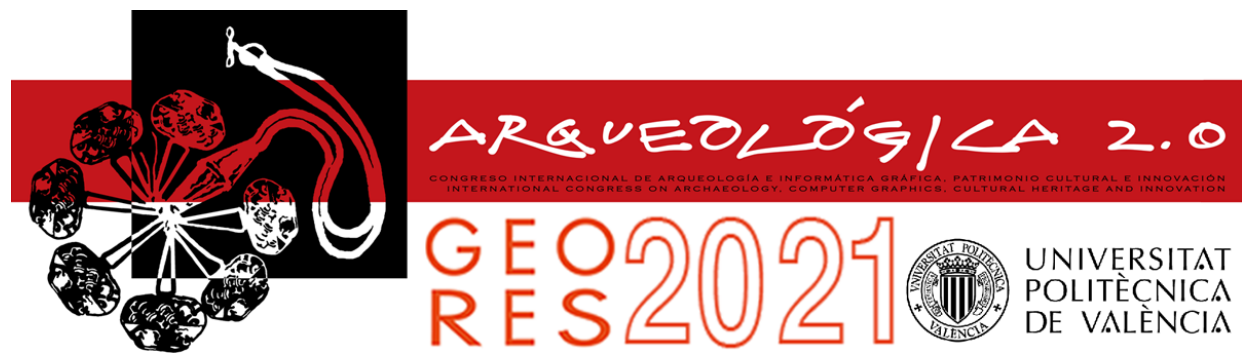

\title{
QANATS AS AN ENDANGERED TRADITIONAL HYDRAULIC HERITAGE. AN INTEGRATED METHODOLOGY FOR DOCUMENTING, RESTORING AND REUSING AN ANCIENT IRANIAN QANAT
}

\author{
Paola Branduinia, ${ }^{a}$, Federico Zainab, ${ }^{b}$ Fereshteh Zavvaria, Yasaman Nabati Mazloumi ${ }^{b}$ \\ ${ }^{a}$ Department of Architecture, Built Environment and Construction Engineering, Polytechnic University of Milan, P.zza Leonardo Da Vinci \\ 3, 20133 Milano, Italy. paola.branduini@polimi.it; fereshteh.zavvari@mail.polimi.it \\ ${ }^{\mathrm{b}}$ Department of History and Cultures, University of Bologna, P.zza San Giovanni in Monte 4, 40124 Bologna, Italy. \\ federico.zaina@unibo.it; yasaman.nabati@studio.unibo.com
}

\begin{abstract}
:
Qanats represented a major technological solution for water supply in arid and semi-arid regions for millennia. Thanks to their multiple social and economic benefits, qanat-like systems spread from Iran through the Middle East in most of the arid and semi-arid regions of the world. In recent years, this valuable traditional hydraulic technology has been neglected in the preservation and reuse due to the lack of management as well as the lack of legal support. This precious heritage and sustainable water supply system according to their sustainable structural features has been replaced by modern water collection and management systems such as dams and other hydroelectric infrastructures along with new pumping technologies. Nevertheless, there is a growing consensus on the number of short, medium and long-term issues emerging from these systems including pollution and other environmental damages, regional conflicts, political pressures as well as their limited lifetime and structural instability. The purpose of this paper is to show qanats as an example of endangered heritage which could also represent a sustainable and clean technology. To do so, we apply a multi-disciplinary perspective integrating archaeological, architectural, sociological and conservation methodologies on a specific case study from the Tabriz region in Northwest Iran: the "No-Ras" qanat.
\end{abstract}

Keywords: Iran, qanat, urban-rural communities, traditional hydraulic technology, remote-sensing, endangered heritage, community perception, restoration and repairing

\section{Introduction}

Qanats have represented a major technological advance and solution for water supply in arid and semi-arid regions for millennia (Goblot, 1979; Yazdi and Khaneiki, 2017; Khaneiki, 2019) and their history is entangled with the emergence of several civilizations over time.

Archaeological research recognized two main areas of the Middle East as the cradle of qanats system (Wilkinson \& Rayne, 2010): the Zagros mountain in the west of Iran (Lightfoot, 1997; Ur, 2005) and southeast Arabia (Al Tikriti, 2002; Lightfoot, 2000; Wikander, 2000). The former location is also supported by textual evidence provided by the Neo-Assyrian chronicles of King Sennacherib (Dalley, 2013; Salvini, 2001) which brought specialized artisans to Assyria for replicating the system to provide water to the main cities of the empire.

Thanks to their multiple social and economic benefits, qanat-like systems spread throughout the Middle East and beyond in most of the arid and semi-arid regions of the world, from the Mediterranean (Gerrard \& Gutiérrez,
2018; Lofrano et al., 2013) to Central and South America (Beekman, Weigand, Pint, Zotz, \& Pin, 1996), and from China and the Far East (Hu, Zhang, \& Liu 2012; Luo et al., 2014) to Africa (Briant, 2001; Lightfoot, 1997). Although it might be argued that there was a major decline in the construction of qanats after their heyday during the Sasanian and Islamic periods, historical sources suggest that they continued to be built and used until at least the 19th century CE (Hütteroth, 1990; Wilkinson \& Rayne, 2010). Today, qanats are documented in 34 countries around the world (Mostafaeipour, 2010). In terms of quantity and dimensions, Iran represents the richest country with almost 24,000 qanats mostly clustered in the arid and semi-arid dry steppe areas in the Yazd, Fars and Isfahan provinces (Fig. 1). Several thousand are also attested in the Alborz and Zagros upland areas along with other traditional hydraulic facilities.

Nowadays, an increasing number of qanats are being replaced by modern water collection and management systems such as dams and other hydroelectric infrastructures along with new pumping technologies (Bensi, 2020). However, there is a growing consensus on 
the multiple, often irreversible, issues inherent or caused by most of these modern systems including pollution and other environmental damages, regional conflicts, political pressures as well as their limited lifetime and structural instability (Shoup, 2006; Strzepek, Yohe, Tol, \& Rosegrant, 2008; White, 1988; Wieland \& Mueller, 2009). The considerable negative impact on the planet of these water infrastructures has also recently led various scholars to include them among the global trends of the Anthropocene (Steffen, Broadgate, Deutsch, Gaffney, \& Ludwig, 2015).

Currently, we continue to witness the gradual abandonment of many qanats partly due to the lack of awareness of local populations and the loss of skilled personnel, management and maintenance. Additionally, human-induced activities such as urban sprawl and growing agricultural fields are threatening these ancient water systems worldwide (Khaneiki, 2019; Saberi, 2016). In this regard, over the last decade, an increasing number of studies underlined how the conservation and use of qanats integrated with modern clean methodologies, can play a key role from an economic, environmental, social and cultural point of view (Jomehpour, 2009; Khaneiki, 2019; Yazdi \& Khaneiki, 2017).

The purpose of this paper is to show qanats as an example of endangered heritage which could also represent a sustainable and clean technology. To do so, we apply a multi-disciplinary perspective integrating archaeological, architectural, and sociological and conservation methodologies on a specific case study from the Tabriz region in Northwest Iran: the "No-Ras" qanat.

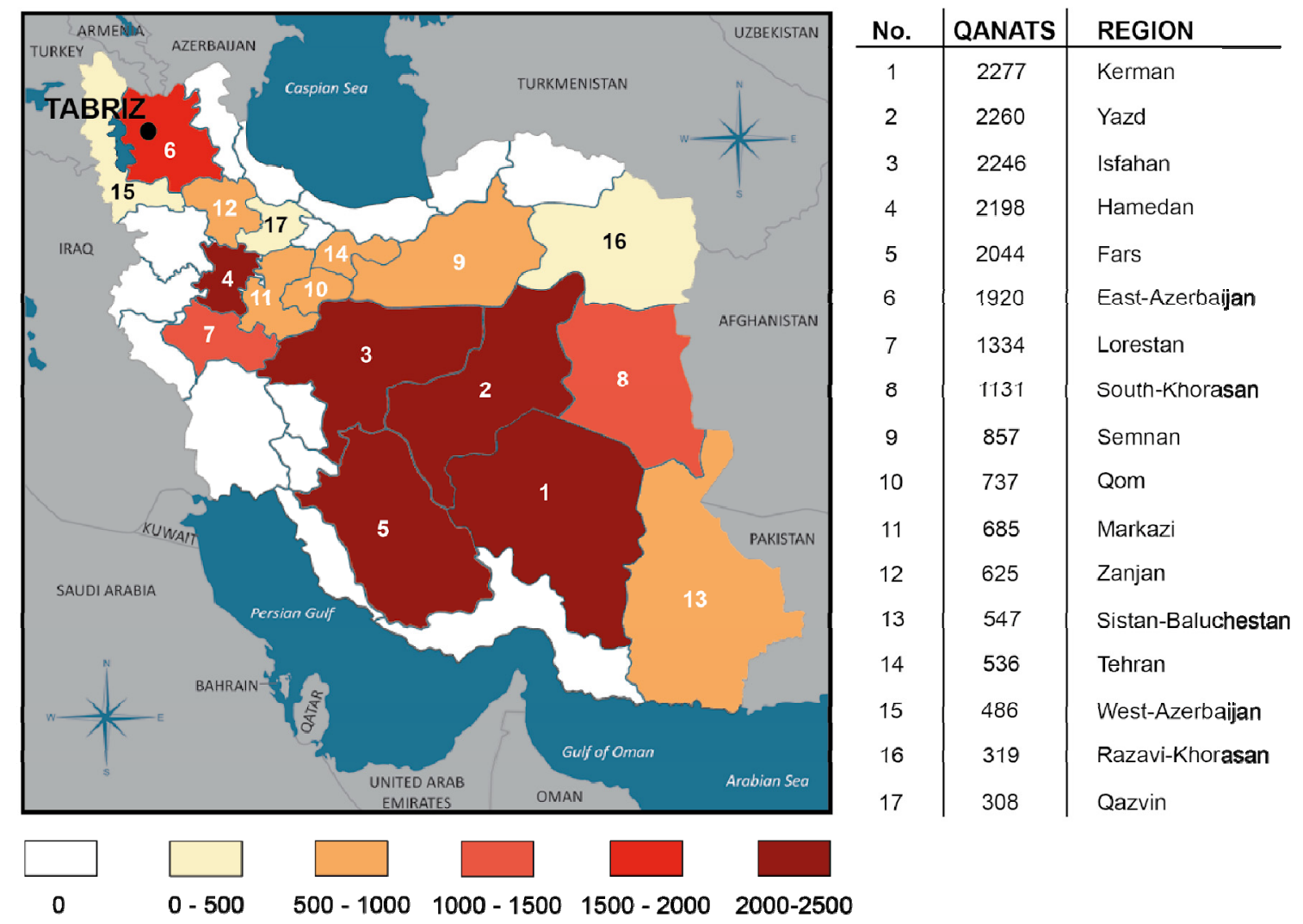

Figure 1: Approximate distribution of qanats in Iran by region and the location of Tabriz (modified after Maleki \& Khorsandiaqaei, 2016).

\section{Current issues}

The current state-of-the-art highlighted five intertwined key-issues revolving around qanats in Iran.

\subsection{Water shortage}

The most pressing issue regards the water shortage. Indeed, arid and semi-arid regions in Iran and beyond are facing severe water scarcity due to natural and anthropogenic factors (Hosseini et al., 2010; Weingartner, 2007). While representing a sustainable and clean solution to solve such a major issue, during the last 20 years the Iranian Ministry of Energy (2005) gradually excluded qanats from the national water supply system investments which led to a dramatic drop in their use. Alternatively, modern hydraulic infrastructures such as dams and other facilities came to force. However, while providing substantial economic benefits, these infrastructures require regular maintenance and have a finite lifespan (Wieland \& Muller, 2009). Furthermore, the construction of dams causes the dislocation of thousands of people, permanent loss of soil fertility and widespread destruction of cultural and natural heritage (Marchetti et al., 2019; Marchetti, Bitelli, Franci, \& Zaina 2020).

\subsection{Mismanagement and lack of documentation}

One of the main causes of water shortage (2.1) in Iran is the mismanagement and lack of control of the hydraulic resources throughout the country. In the case of the qanats, to date, a complete documentation (both in use and abandoned) is missing (Maleki \& Khorsandi aqaei, 2016). Although scattered initiatives provided glimpses on their distribution and the state of preservation in different 
provinces such as Tehran (Ebadati \& Hosseini, 2018), Mashhad (Hosseini et al., 2010) or Sabzevar (Estaji \& Raith, 2016), such a huge endeavour could be accomplished only through a wider project promoted or in collaboration with national bodies such as the Ministry of Energy.

\subsection{Loss of knowledge and technical skills}

The lack of control and mismanagement (2.2) result in a decrease in the use of qanats. This is strictly connected with the loss of specific technical skills and the in-depth topographic and geomorphologic knowledge needed to build the major hydraulic feature. This phenomenon is particularly apparent outside the most popular areas such as Yazd, where the gradual abandonment of qanats in favour of wells backed by diesel pumps, resulted in the decrease of skilled artisans (Mostafaeipour, 2010).

\subsection{Lack of awareness}

The lack of control and mismanagement (2.2), along with the loss of specific personnel in charge of building qanats (2.3) lead to the low or total absence of awareness toward this traditional water infrastructure among local communities throughout Iran (Balali, Keulartz, \& Korthals, 2009). According to De Chatel (2005), this lack of awareness is also tightly related to the idea that the modern hydraulic infrastructures will provide endless water supply, thus concealing the reality of water shortage.

\subsection{Underestimation of qanats as cultural heritage}

Lack of awareness (2.4) also means a drop in the people's perception of the qanats as an integral part of their culture, society and economy. Qanats represent the oldest, most widespread and monumental traditional technology still in use in Iran. These factors contributed to recognize their outstanding value and to inscribe a small number of qanats (11) within the UNESCO World Heritage List (WHL). However, this is a fraction of the 24,000 in the country, many of which are as important and monumental as those within the WHL. Qanats are also protected by Iranian law (Iranian Dept. of Environment, arts. 1 and 12).

However, recent research (Hosseini et al., 2010) highlighted the widespread disrespect for the current legislation often in favour of unregulated urban expansion, or the conversion of land for more profitable uses.

\section{Aims and methods}

Despite these issues, qanat still represents a clean and sustainable traditional hydraulic technology having the potential to 1. Replace modern polluting water-related infrastructures (dams etc.), 2. Be recognized as an important part of the national heritage (beyond the already well-recognized areas).

Therefore, in this paper by analyzing the No-Ras qanat as a case study, located in the Tabriz region, we investigate the twofold potential of qanats to contribute solving the above-mentioned issues. In particular, our research is underpinned by the following research questions:
1) How did the territory of the Tabriz area change through time? What is its relation with the No-Ras qanat?

2) What kind of issues and threats affected the No-Ras qanat during the last decades?

3) How did the perception of the local communities towards the No-Ras qanat change through time?

4) What kinds of recommendations can be proposed to fulfil the twofold potential of the qanats?

The first group of research questions will allow tackling issue 2.1, the second one will address issues 2.2 and 2.3, while research question three will allow tackling issues 2.4 and 2.5. The last research question has been designed to provide solutions and to foster the potential of qanats as a useful traditional hydraulic infrastructure and an important part of the country's heritage. The methodology applied to answer these questions integrates established approaches taken from archaeology and landscape architecture: 1) Territorial and land-use analysis (3.1); 2) Multi-temporal remote sensing analysis of the damages $(3.2)$; 3) Structural analysis of the qanat $(3.3)$; 4) Perception and awareness analysis (3.4).

These types of analysis allow a comprehensive study of the qanat as a traditional hydraulic technology useful for addressing the aforementioned five issues illustrated (section 2). We have applied a multi-scalar methodology, consisting in the analysis of the whole geographic context related to qanat, starting from the regional and urban one (analysis 1), to the area of qanat (analysis 2), moving to the qanat itself (analysis 3 ) and eventually to the relationship between qanat and local communities (analysis 4).

\subsection{Territorial and local land-use analysis}

Popular perceptions as well as the majority of scientific research, usually associate qanats to the arid and semiarid highlands of central Iran. However, as shown in Figure 1, several thousand others are also found in the more temperate valleys and uplands of the north and north-western parts of the country. While in the past, these qanats integrated the water flow provided by the numerous rivers, in recent years the maintenance costs together with the emergence of new hydraulic technologies caused their gradual abandonment and slow structural decay. Among those, the No-Ras qanat, located in the south-eastern outskirts of Tabriz, represented an important water supply system for the city (Afshar, 1971). Despite the efforts of the local farmers to preserve it, during the last twenty years, urban and regional development projects severely damaged the overall structure including many wells, part of the gallery and the outlet.

To better understand the changes in the No-Ras qanat area, territorial and land-use analysis will be carried out. This type of analysis allow to identify the transformation of agricultural lands into residential areas in the qanat buffer zone and the growth of unconventional semiindustrial land-uses as well as to integrate the results of the multi-temporal analysis. The former consists of the analysis of the key environmental and urban elements influencing the development of Tabriz and the surrounding area. The land-use analysis will be conducted using satellite imagery and governmental 
sources as well as the region observation to understand the current use of the area within the qanat buffer zone.

\subsection{Multi-temporal remote sensing analysis of the damages}

In order to answer the second research question, we applied a multi-temporal remote sensing analysis of the damages to the case study. The identification of damages to the No-Ras qanat was conducted for the last 20 years taking into account four-time frames: 2003, 2008, 2013, 2020. These periods have been selected for three reasons:

1) High-quality open-access satellite imagery of the region has become available from 2003 onwards.

2) From the early 2000s onwards, Tabriz and its periphery experienced a vast and unregulated urban sprawl which also affected the No-Ras qanat.

3) Within the considered chronological time span, the four periods selected correspond to the main phases of upheavals and disturbance.

Remote sensing and satellite imagery has become a key methodology in the wider field of cultural heritage management (Lasaponara \& Masini 2012). Sources for remote sensing analysis may include different spatial datasets of historical aerial and satellite imagery, often available through open-access or on-purchase online platforms and websites (Zaina, 2019). The application of remote sensing to cultural heritage risk assessment has recently become popular in the Middle East (Agapiou, Lysandrou, \& Hadjimitsis 2017; Agapiou, Lysandrou, \& Hadjimitsis 2020; Cunliffe, 2014; 2016; Hammer, Seifried, Franklin, \& Lauricella 2018; Lauricella, Cannon, Branting, \& Hammer 2017; Marchetti et al., 2019; Marchetti, Bitelli, Franci, \& Zaina 2020; Richardson, 2011; Zaina, 2019). However, no attempts have been done so far for documenting and monitoring the state of preservation of qanats through time. The multi-temporal remote sensing analysis conducted consists of three steps: 1. Data collection, 2. Data processing; 3. Results.

Data collection: For the first step, spatial data related to the No-Ras qanat and geographic data (satellite imagery) have been collected from hardcopy publications and online platforms and then organized in a QGIS environment. Hardcopy publications (Haeri, 2007; Hosseini et al, 2010; Jomepour, 2009; Kabir, 2008; 2010; Shahabadi \& Olfati, 2009; Tabatabaei \& Khazimeh Nejad, 2019) allowed to obtain spatial information such as the location of the No-Ras qanat, the position and dimension of the wells and its path in the outskirt of Tabriz, and to generate an attribute table with non-spatial data including the types of damages and their extension. The official buffer zone of the qanat, available through the hardcopy guidelines issued by the Ministry of Energy (2018), provided the limit of the area of the No-Ras qanat under analysis. This ranges between 1 and $1.5 \mathrm{Km}$ based on the geomorphology of the area and the flow rate of the mother well. In the case of the No-Ras qanat, the buffer zone is 1 $\mathrm{Km}$. Geographic data, consisting of high-resolution openaccess satellite imagery of the four different periods, were collected from Google Earth Pro $®$ and the USGS platform (Table 1). The highest quality images (in terms of resolution and visibility) were selected to identify the types of damages considering also the seasonal changes which can greatly influence their identification. It must be pointed out that $30 \%$ of 2003 satellite imagery of the No-Ras qanat did not provide accurate data, thus slightly affecting the damage assessment. For example, we have excluded images that presented visibility problems caused by atmospheric agents (i.e. clouds).

Table 1: Detailed description of the satellite images.

\begin{tabular}{|c|c|c|c|}
\hline Dates & Satellite & Resolution & Source \\
\hline $\begin{array}{l}5-11-2020 \text { to } \\
9-21-2020\end{array}$ & $\begin{array}{l}\text { Maxar® } \\
\text { satellites }\end{array}$ & $0.3-15 \mathrm{~m}$ & $\begin{array}{l}\text { Google Earth } \\
\text { Pro® } \\
\text { USGS Earth } \\
\text { Explorer }\end{array}$ \\
\hline $\begin{array}{l}3-15-2013 \text { to } \\
9-1-2013\end{array}$ & $\begin{array}{c}\text { Maxar® } \\
\text { satellites } \\
\text { CNES } \\
\text { Airbus }\end{array}$ & $0.3-15 \mathrm{~m}$ & $\begin{array}{c}\text { Google Earth } \\
\text { Pro } \AA\end{array}$ \\
\hline $\begin{array}{c}6-2-2008 \text { to } \\
6-7-2008\end{array}$ & $\begin{array}{l}\text { Maxar® } \\
\text { satellites }\end{array}$ & $0.3-15 \mathrm{~m}$ & $\begin{array}{c}\text { Google Earth } \\
\text { Pro }{ }^{\circledR}\end{array}$ \\
\hline $8-8-2003$ & $\begin{array}{l}\text { Maxar® } \\
\text { satellites }\end{array}$ & $0.3-15 \mathrm{~m}$ & $\begin{array}{c}\text { Google Earth } \\
\text { Pro® }\end{array}$ \\
\hline
\end{tabular}

Data processing: We conducted a semi-automatic classification of the different types of damages and their development over the last 20 years cross-correlating the spatial and geographic data in QGIS. The first part consisted of the visual detection of the risks and damages within the buffer zone area. Then we automatically calculated the area through QGIS.

Results: The last step consisted of the analysis of the results of the damages to the No-Ras qanat. These results allowed us to develop an ad hoc framework of the different types of damages to the No-Ras qanat and the factors triggering each type of damage (see below).

A kind of groundwater extraction, a qanat consists of an underground gallery which conveys water to the surface, and several vertical shaft-wells to bring the water for diverse uses. Soils excavated from the shafts are piled around their collar thus creating a line of short mounds (Abbasnejad, Abbasnejad, Derakhshani, \& Hemmati Sarapardeh, 2016; Bensi, 2020; Khaneiki, 2019; Yazdi \& Khaneiki, 2017). Unlike an aqueduct, a qanat is a dynamic system which cuts through the soil and advances into the saturated area underground (Yazdi \& Khaneiki, 2017). The critical issue in conducting a risk assessment of qanats is that only the piles around the vertical shafts (showing the direction of the qanat on the ground) are visible from above. This fact made necessary to develop a proper framework to ensure a comprehensive classification of risks and damages.

Recent studies have tried to develop several types of classification of risks and damages to the cultural heritage focusing on the triggering factors, types of risks and actions (ICCROM, 2016; ICOMOS, 2000; Lopez, 2016; Palumbo, 2000; Stovel, 1998; UNESCO, 2010; Zaina, 2019). Our framework has been designed by integrating and enriching the structure of the previous examples provided by Zaina (2019), Lopez (2016) and ICCROM (2016). We developed a tailor-made framework focusing on qanats (while previous studies were designed around general cultural heritage) including a double-factor scheme divided between human-induced and naturalinduced factors (Fig. 2). Each of these factors may be 
related to different drivers meaning a condition, a necessity or a decision causing one or more subsequent processes (in our case the threats). Threats are defined as one or more risks generally related to one specific driver, even though often possibly connected to more than one, and eventually generating a specific set of physically dangerous actions (Zaina, 2019). For our risk assessment, we identified threats such as construction, agriculture and abandonment, erosion and earthquake (Fig. 2). The next tier of the risks typology is represented by the physical actions which are any kind of activities jeopardizing the qanats. For example buildings, roads, canals and levelling activities are the types of actions related to the construction threat. Each action or more interrelated actions may put the qanat in danger causing a specific impact leading to its total of partial destruction. Impacts are the influence of the situation in which they can strongly affect a site as a direct result of an action (ICCROM, 2016). Buildings as an action resulted by human-induced drivers and threats can result in vegetation loss of the area which can be one of the main reasons in qanat destructions (Abbasnejad, Abbasnejad, Derakhshani, \& Hemmati Sarapardeh, 2016; Khaneiki, 2019; Saberi, 2006).

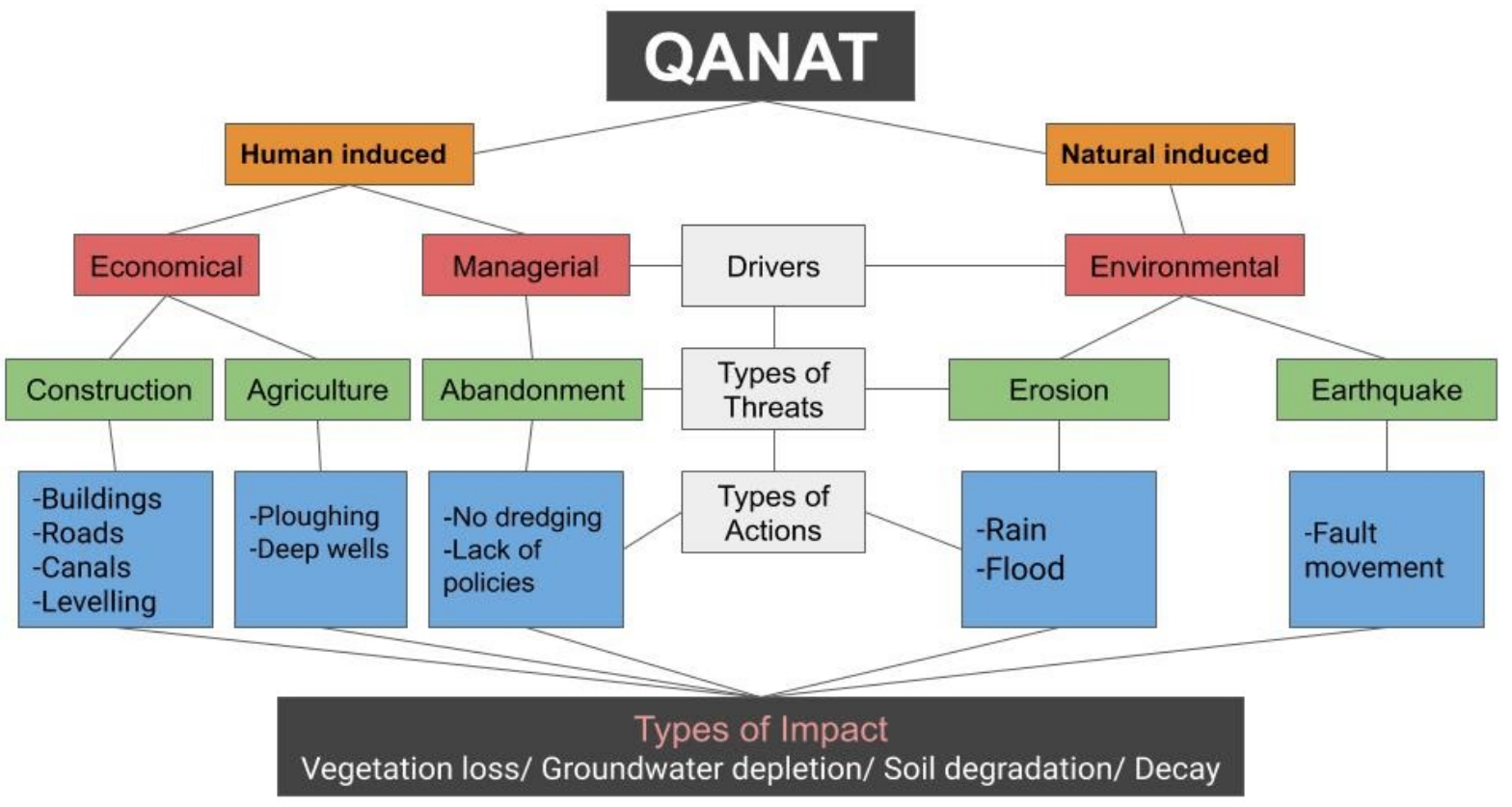

Figure 2: The Double-factor framework of risks and damages to qanats, modified after Zaina, 2019.

\subsection{Structural analysis}

As a sustainable water supply structure, any changes or damages in the qanat structure affect its water flowing rate. The structure consists of three main parts (gallery, shaft-wells, and outlet). These extend from the qanat starting point, the mother-well to the structure's endpoint, the outlet, corresponding to about $3.5 \mathrm{~km}$.

The land-use changes along the No-Ras qanat route area are directly or indirectly responsible for major changes in the No-Ras qanat structure. However, compared to the last ten years, the amount of water production has been significantly reduced. For instance, the northern area of FathAbad garden's is challenging with a water shortage based on the interviews. Therefore a structural analysis conducted through ground-truthing activities between 2019 and 2020 allowed to map the state of preservation of each part of the No-Ras qanat (gallery, shaft-wells, and outlet) and to propose solutions for restoration and maintenance.

\subsection{Perception and awareness analysis}

Perception and awareness analysis is crucial for answering the third research question. For centuries, since the qanat was one of the main methods of supplying water, and human life depended on it, people were fully aware of this structure's value and worked to maintain it.
Therefore, people's awareness and knowledge about the qanat as sustainable water supplying structure plays an essential role in the restoration, maintenance, and reconstruction of the qanats. Specifically, in the case of the No-Ras qanat, we deal with an area the economy of which was based on agriculture and animal husbandry and the water supplied through the qanats and seasonal rivers. Therefore local communities were fully aware of the value of this structure and took care of its maintenance. In the last decades, after migration of native population and expansion of Tabriz, this area has been included among its suburbs. New local people are slowly forgetting the relevance of qanats for many intertwined reasons. The region also experienced new semi-industrial land-uses in the last decade, which have turned its rural face.

The analysis of the social fabric of the regional population allowed to identify five groups of people: local farmers, old immigrant farmers, new immigrants, factories employees, new owners. The perception and awareness of these five groups have been analyzed using semi-structured interviews.

\section{The case-study: No-Ras qanat}

The earliest evidence of the presence of qanat in the Tabriz area can be traced back to the 13th century CE (AI 
Kashani, 1968). The historical text of "History of Al-Jaito", dating to this period, testified the numerous hydraulic activities carried out by Khajeh Rashid Al-Din Fazlullah during the Mongolian rule over the region. In Al Kashani's (1968) words "In the past, the region of FathAbad was just dry mountains, but now every part of it is a paradise adorned with all kinds of trees and the rivers and the green meadows". Rashid al-Din Fazlullah's plan included the improvement of water supply in the region. To do so, he brought farmers and "moqanni" (Artisan specialized in the digging, cleaning, and repairs of qanats) from Yazd (in central Iran). In addition, due to the lack of local rural population, he entrusted foreigners with the creation of gardens, ploughing fields and other water-related infrastructures (Petrushevsky, 1978). "Rabe-e Rashidi" endowment letter provides a detailed explanation of the conditions of the qanats that flowed to the villages (Minovi
\& Afshar, 1972). This document highlights how the construction of the qanat was the result of his comprehensive geological knowledge of the region and the skills of the moqannis in building qanats (Al Khashani, 1968). The overall plan fostered the economic and social development of FathAbad region which became a prosperous rural residential area, with facilities and extended cultivated lands (Afshar, 1971). While the political situation in the region remarkably changed through time, the hydraulic system developed by Rashid Al-Din Fazlullah, including the No-Ras qanat, was maintained for almost seven centuries.

The "No-Ras" qanat length is about $3.5 \mathrm{~km}$ and runs from the slope of Sahand Mountain near the village of Chavan to the outlet located in the FathAbad garden (Fig. 3).

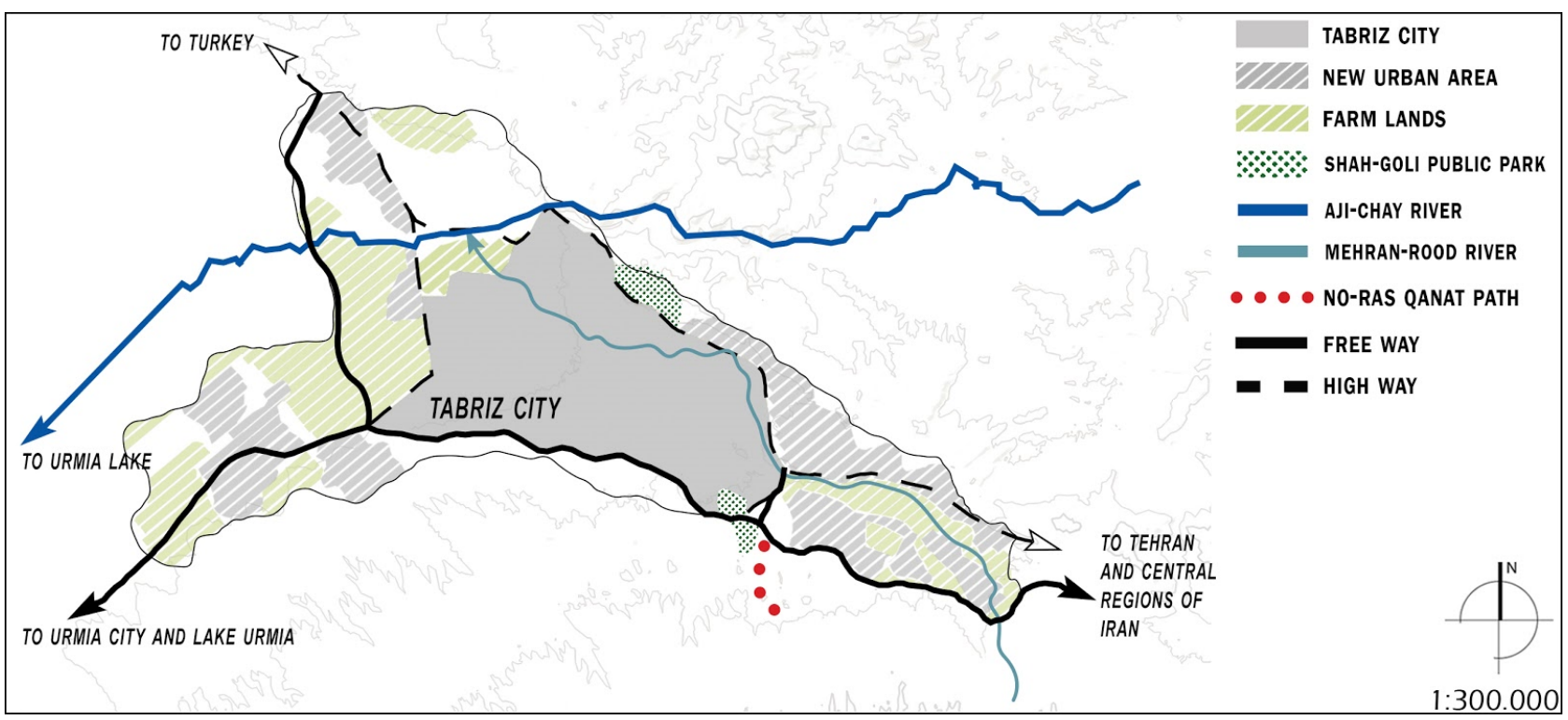

Figure 3: The Tabriz area and the No-Ras qanat.
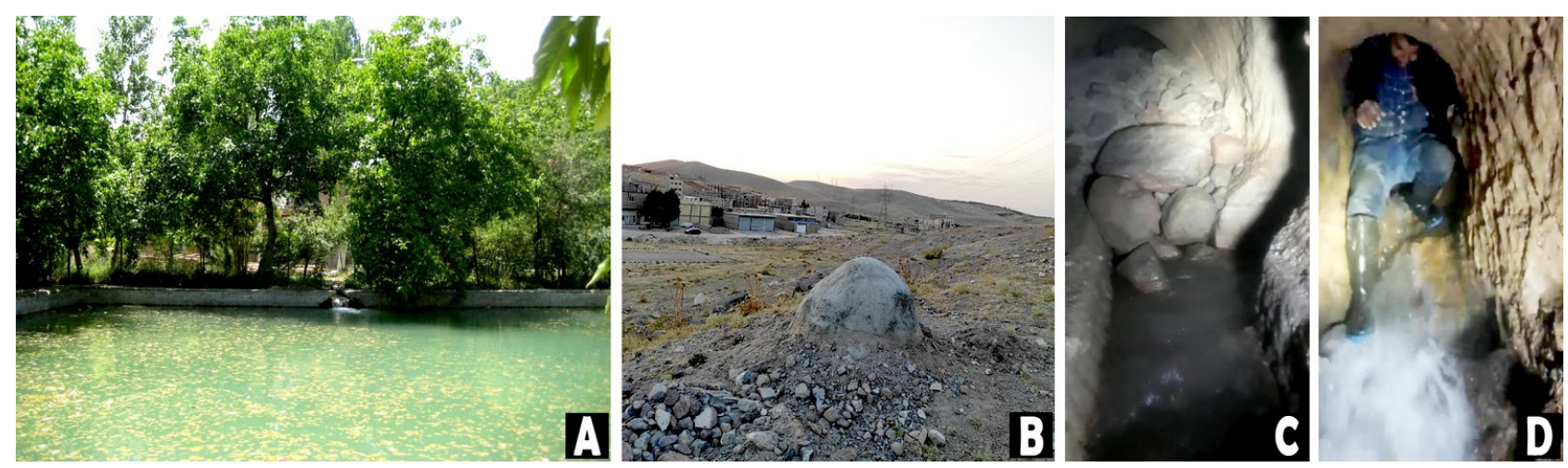

Figure 4: "No-Ras" Qanat. 4A. One of the water pools of the No-Ras qanat outside the garden for agricultural use; 4B. One of the blocked shaft-wells (photo taken in September 2020 by F. Zavvari); 4C. Part of the qanat canal that was destroyed by seasonal flood; $4 \mathrm{D}$. The uneven surface of the qanat channel (Photo taken in 2019 by the manager of the garden and the moqanni).

From the pool located inside the garden (Fig. 4a), the qanat water flow through the FathAbad village and the surrounding cultivated lands. The No-Ras qanat has 54 shafts (wells) including the mother well, located at a relatively regular distance of about $60 \mathrm{~m}$ (Fig. 4b). Only 11 of these wells can be recognized, and just four of them are accessible and open, while the rest are blocked with cement or concrete (Fig. 4b). Several shafts (wells) were destroyed by seasonal floods, which also affected part of the qanat gallery (Fig. 4c), while others were blocked by new owners or fenced within private buildings. The deepest shaft is the "Mother-well" which is about $49 \mathrm{~m}$. Due to the highly irregular morphology of the terrain, several more shaft-wells were dug to the same depth of the Mother-well to reach the underground gallery (Fig. 4d). 


\section{Results}

\subsection{Territorial and land-use analysis}

Tabriz is the capital and main centre of the East Azerbaijan province and the fifth most populous city of Iran. The urban centre is distributed over a large area ranging between $1200 \mathrm{~m}$ and $3800 \mathrm{~m}$ a.s.l. resulting in annual precipitations of about $230 \mathrm{~mm}$, with a maximum of $48.2 \mathrm{~mm}$ in winter and a minimum of $4 \mathrm{~mm}$ in spring and summer seasons. The average annual temperature in the study area is about $12.5^{\circ} \mathrm{C}$. The temperature often reaches $30{ }^{\circ} \mathrm{C}$ in summer and drops to $-0.5{ }^{\circ} \mathrm{C}$ in winter (De Martonne, 1941).

The No-Ras qanat is part of a complex environmental and urban system that centred on the city of Tabriz, the Zagros Mountains and Lake Urmia. These elements play a key role in shaping and modifying land-use in the region. With an area of more than $700 \mathrm{~km}^{2}$, Tabriz province is extended from the eastern limit of Tabriz city to Urmia Lake to the west. It is surrounded by the southern slopes of Mishow and Morow to the west, the Garadug Mountains to the north, and the northern slopes of Sahand Mountain to the south.

The environmental system of Tabriz province is characterized by natural elements such as rivers and mountains as well as human/natural made ecological green corridors. The riverine system is characterized by two main streams (Fig. 5a): 1) The Aji-Chay River, the most important river in the area, enters from the east and flows towards the west, and eventually discharges to the Urmia Lake; 2) The Mehran-Rood River passes inside the Tabriz city, from east to west, and then joins the AjiChay River at the city's western end. The mountain system occupies large parts of the city including (Fig. 5a) the Eynali Mount to the north and the Sahand Mountain range to the south. The topographic distribution of these mountains shaped Tabriz to a linear and longitudinal development. They played a prominent role as a natural landmark in the city's visual structure. Ecological green corridors (Fig. 5a) consist of regular or irregular open spaces. Natural or human-made vegetation has ecological and social efficiency.

The city of Tabriz is located in a strategic position that contributed to shaping its urban system (Fig. 5b). Since its foundation, it was placed at the cross-road between Azerbaijan, Turkey, and Iraq and it represented a gateway to the Ottoman Empire, Russia, and Europe for Iran and central and eastern Asian countries. Moreover, the city has been located along the "Silk Road" connecting Far East to Europe. The linear development of the urban layout of Tabriz brought it to include most of the surrounding villages and to turn much of the cultivated land into residential areas over time (Fig. 5b). Tabriz environmental and urban system highly influenced the overall organization of the city and land-use through time. At the south-eastern end of the city, 14 small towns and villages have been slowly incorporated into its urban system.

Farmlands, new residential neighbourhoods, industrial areas and a large university campus filled most of the empty areas and have been connected to the city centre through a web of roads, free-ways and high-ways (Fig. 6). Such major changes in the land-use also affected the area around the No-Ras qanat (Fig. 7). In particular, the units have been constructed throughout its path. Moreover, close to the FathAbad garden area, previously unoccupied lands within the buffer zone have been turned into sand and gravel mine, while both the gas pipeline and railway (to be completed in 2025) cut through the last stretch of the qanat. Other major changes include the development of the Tabriz-FathAbad and the TabrizChavan roads from earth paths to asphalt roads. The garden itself has been heavily affected by the construction of the freeway passing through it.

\subsection{Multi-temporal remote sensing analysis}

This framework resulted from the multi-temporal analysis conducted to identify the damages that occurred to the No-Ras qanat between 2003 and 2020. This analysis was performed by overlaying satellite imagery in four-time frames of 2003, 2008, 2013, 2020. Figure 8 shows the distribution of the risks and damages in the No-Ras qanat over time. In general, the analysis showed a gradual increase in damages between 2003 and 2020. Building construction represents the major physical action damaging the qanat and its buffer zone with a boost from 6.24 ha in 2003 to 19.89 ha in 2008 . The same trend has been observed for roads. Indeed, while 2.69 ha of the case study area was occupied by roads in 2003, this number has doubled twice, first in 2008 (4.49 ha), and then in 2013 (13.17 ha) eventually reaching 15.36 ha in 2020 . Although the presence of these infrastructures may not cause direct destruction of the qanat, the overall widespread urban sprawl in the proximity of the qanat resulted in vegetation loss and soil degradation, both having a direct impact on the buffer zone of qanat by jeopardizing the soil density around it and contributing to the collapse of the shaft-wells. The second most pervasive damage is levelling. While the steady increase of levelling activities in the area passed from 14 ha in 2003 and raised to 19.8 ha in 2008, it sharply increased to 29.95 ha in 2013 and jumped to 51.57 ha in 2020 . The entanglement of the physical actions is confirmed by the fact that almost all the areas levelled between 2003 and 2008, turned into roads or buildings between 2013 and 2020. While levelling caused vegetation loss within the buffer zone, the heavy machinery put pressure on the walls of the qanat gallery. A similar trend has been identified for ploughing. From having little impact in 2003, with no more than 5 ha in cultivated fields, the ploughed area has grown exponentially in almost twenty years reaching 45.66 ha in 2020 . As we mentioned before, soil degradation and vegetation loss can be the direct impact of ploughing and agricultural activity. Deep or semi-deep wells drilling can only be identified from 2003 to 2008 over an approximate area of 0.45 ha. Despite their seemingly small impact, these kinds of actions, mostly carried out for agricultural purposes, can cause substantial damages to the structure of the qanat.

Overall, the multi-temporal analysis demonstrated an increasing trend in all of the physical actions throughout the No-Ras qanat and its buffer zone. Currently, 201.39 ha out of 685 ha of the entire buffer zone have been damaged.

\subsection{Structural analysis}

The changes in the land-use heavily affected the structure of the qanat including the wells, the gallery and the outlet. At the regional level, a substantial reduction of the water 
flow from underground water including the No-Ras qanat has been observed. Locally, each of the abovementioned land-use changes caused major disturbances and damage to the qanat structure (Fig. 9). For example, the construction of the gas pipeline destroyed a $100 \mathrm{~m}$ long stretch of the qanat close to the outlet (Fig. 9b and 9c). Instead of repairing the damages, an artificial pipe was used to transfer the water to the outlet. Moreover, the heavy trucks and cargo vehicles passing close to the wells together with the digging the large and deep holes to collect sand and gravel highly affected the structural stability of the wells and the gallery (Fig. 9b and 9c). The same effect is caused by the widespread construction of residential and industrial buildings (often illegally) within the buffer zone and often close to the wells (Fig. 9b and 9c). Another major issue is the illegal drilling of deep or semi-deep wells which are used both to obtain freshwater and as for sewage discharge.

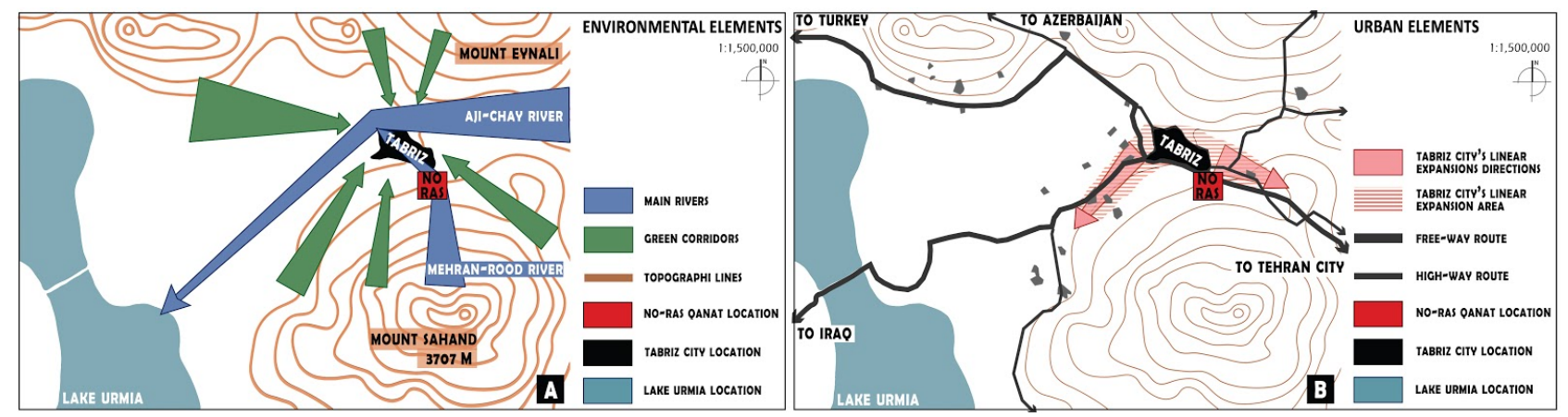

Figure 5: Tabriz province analysis in terms of affective environmental and urban elements.

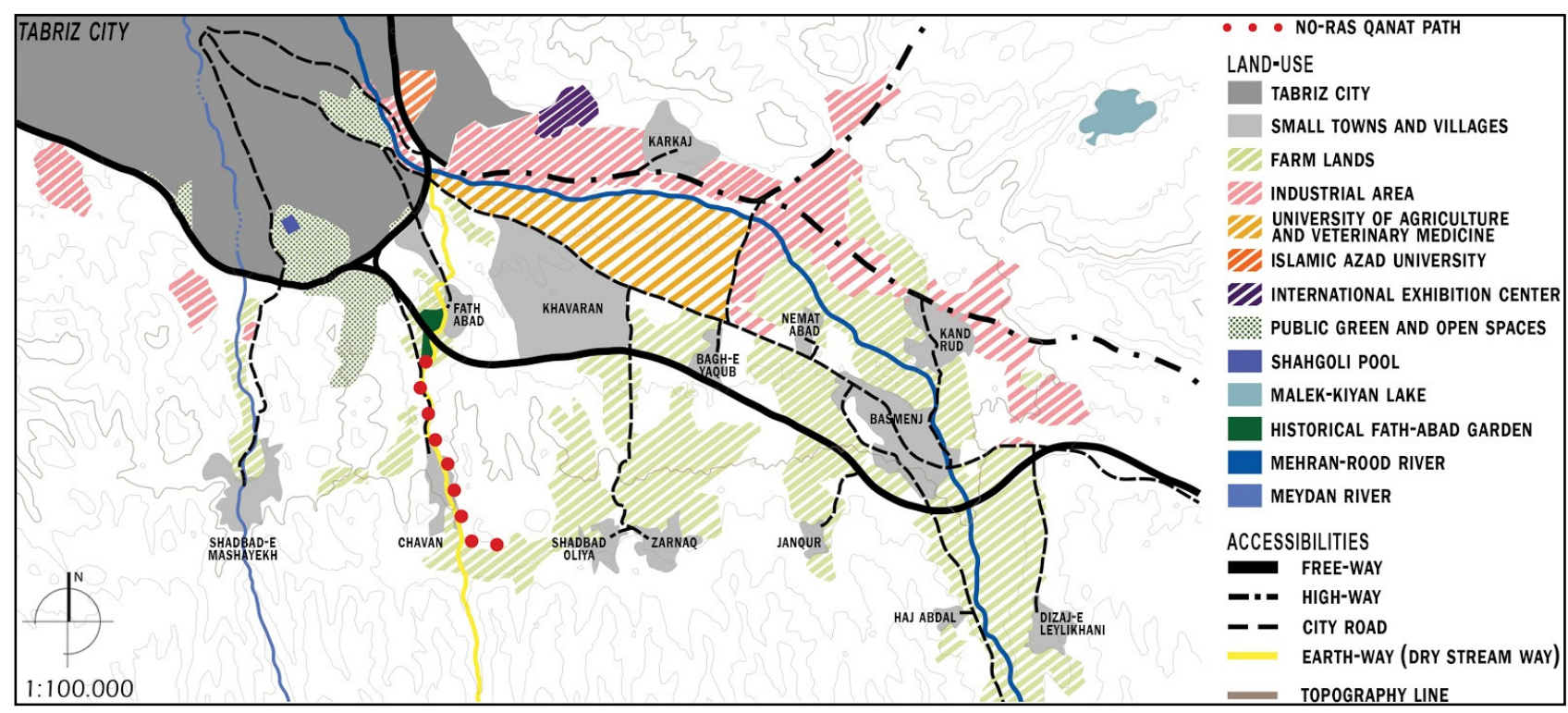

Figure 6: Current land-use of the area of the No-Ras qanat and its neighbourhood.

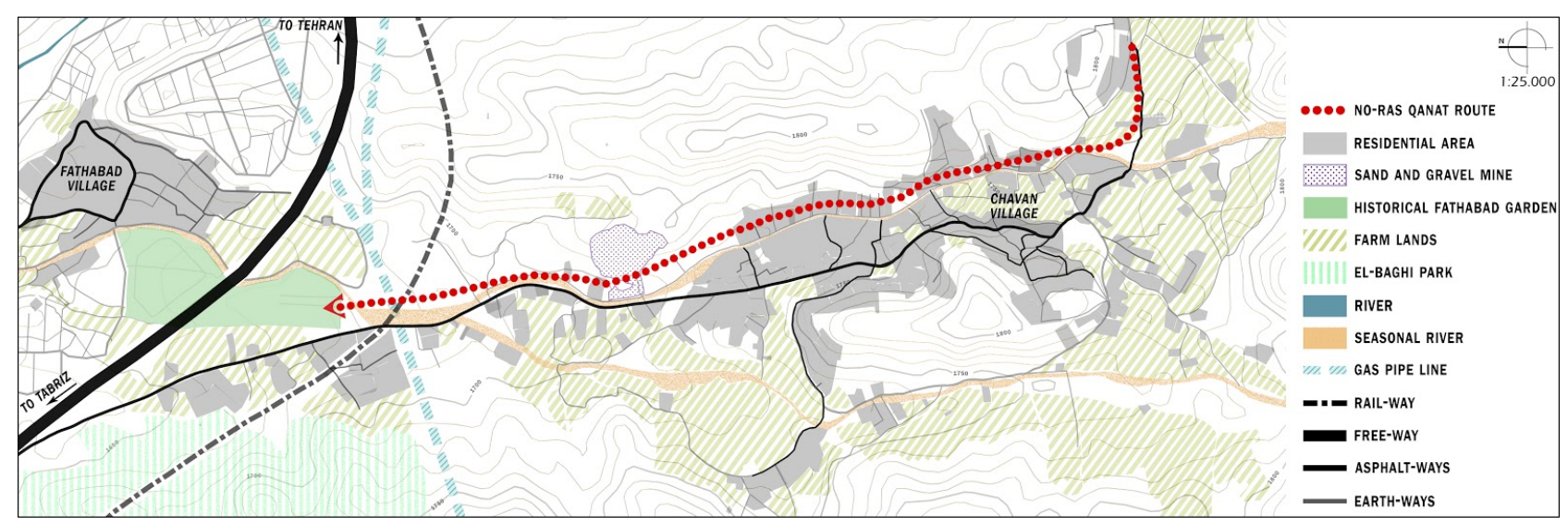

Figure 7: Current land-use of the area of the No-Ras qanat. 
The ground-truthing conducted in 2019 also indicates that both the height and the width of the No-Ras gallery have decreased dramatically during the last 30 years. The main reason for this is the deposition of sediments over time. Generally, some accessible parts of the qanat gallery are inspected two times a year by the moqanni and his team, and when necessary cleaning and dredging need to be done.

Both the gradual loss of skilled artisans and the lack of accessibility to the wells are making these activities barely impossible to be done.

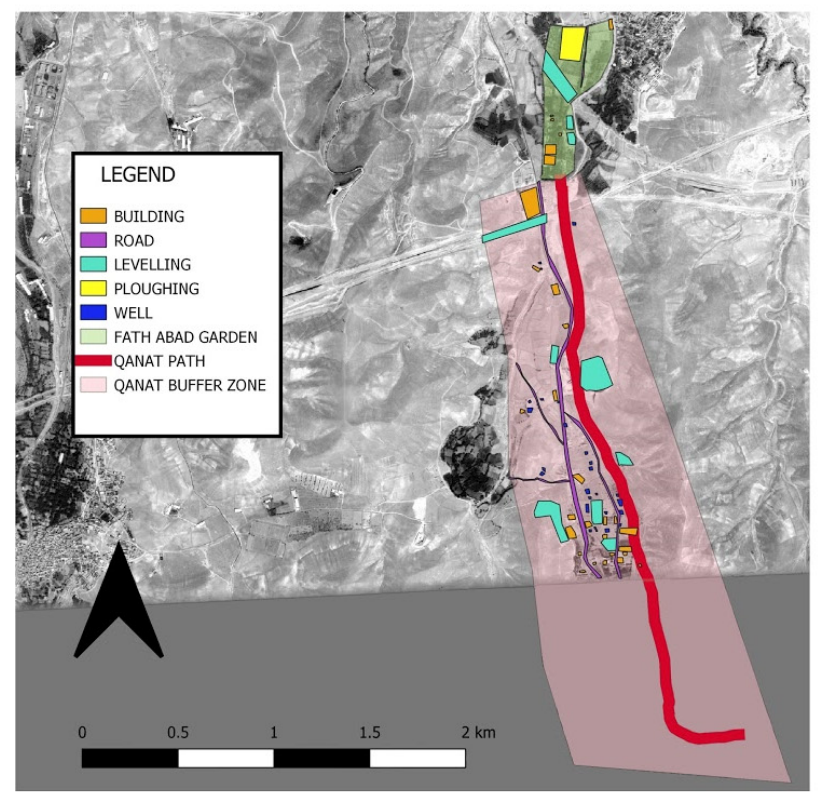

2003

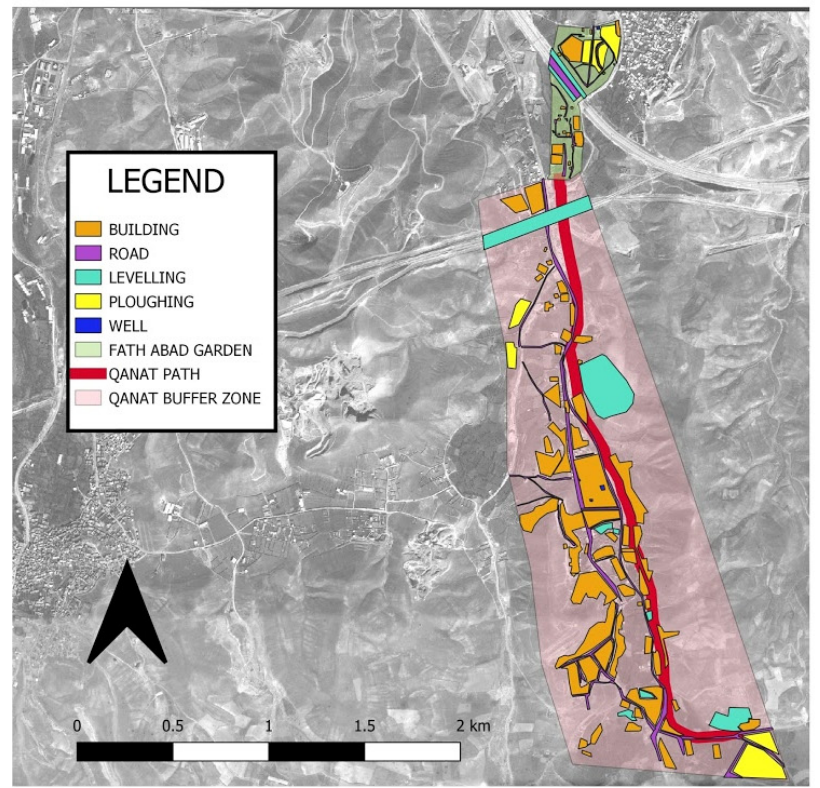

2013
With regard to the conservation and promotion of the NoRas qanat, as an element of heritage, following the registration of the FathAbad garden in the Iran National Heritage List in 1996, the Historical Garden Mansion (Fig. $10 \mathrm{a}$ and $10 \mathrm{~b}$ ) along with part of its surrounding garden have been restored (Fig. 10c). The restorations took place in a non-invasive way, respecting the architectural layout and the original decorations.

Some restorations, however, were conducted in an invasive manner, modifying the original layout of the FathAbad Garden (Fig. 11).
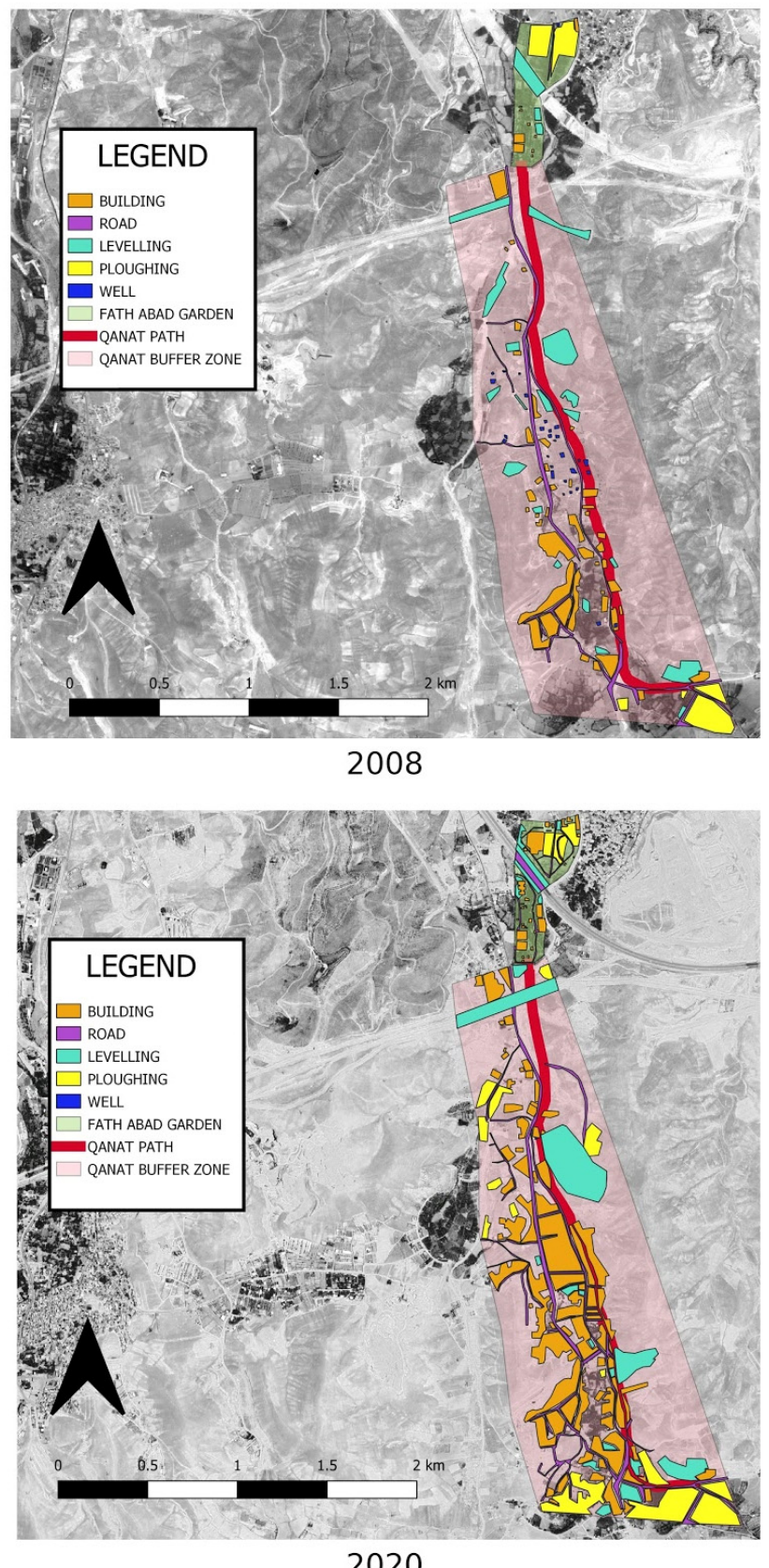

2020

Figure 8: Multi-temporal development of the damages to the No-Ras qanat and its buffer zone.

In particular, the main path leading to the mansion was mostly characterized by a long meadow, flanked on both sides by trees and with a water channel in the centre interspersed with fountains (Fig. 11a). Following the registration of the FathAbad Garden in the National Heritage List major restoration works had been undertaken including the replacement of the meadow with a self-locking pavement, the creation of small walls at 
both sides of the water channel and the construction of wooden fences (Fig. 11b and 11c).

\subsection{Perception and awareness analysis}

We first analyzed the multi-faceted population living within the No-Ras buffer zone or close to it. Five main groups have been identified based on the economic and social factors:

1) LOCAL FARMERS. The native people of the area consist of old farmers. Their number has gradually reduced due to their migration to large cities such as Tabriz. Until the early 2000s, their lands were not connected to the municipal water system and their subsistence relied upon the use and maintenance of qanats. This makes them among the most informed group of the importance of the preservation of the qanats.

2) OLD IMMIGRANTS FARMERS. This group represents the majority of the population in the region, especially in the village of Chavan. They include old immigrants whose main jobs are agriculture, gardening, and animal husbandry. They also have a good understanding of the value of qanats which they have extensively used for the irrigation of cultivated lands and gardens as well as the supply of water for their livestock.

3) NEW IMMIGRANTS. This group includes people who have migrated from Tabriz and other major cities to Chavan and FathAbad areas in the last ten years due to the advantages of these areas, the lower cost of land and the greater space. Although they live in these areas, most of these people have kept their jobs in Tabriz and therefore, they have no direct relationship and interest in the issues related to the qanat. The majority of them have no information about qanats in general.

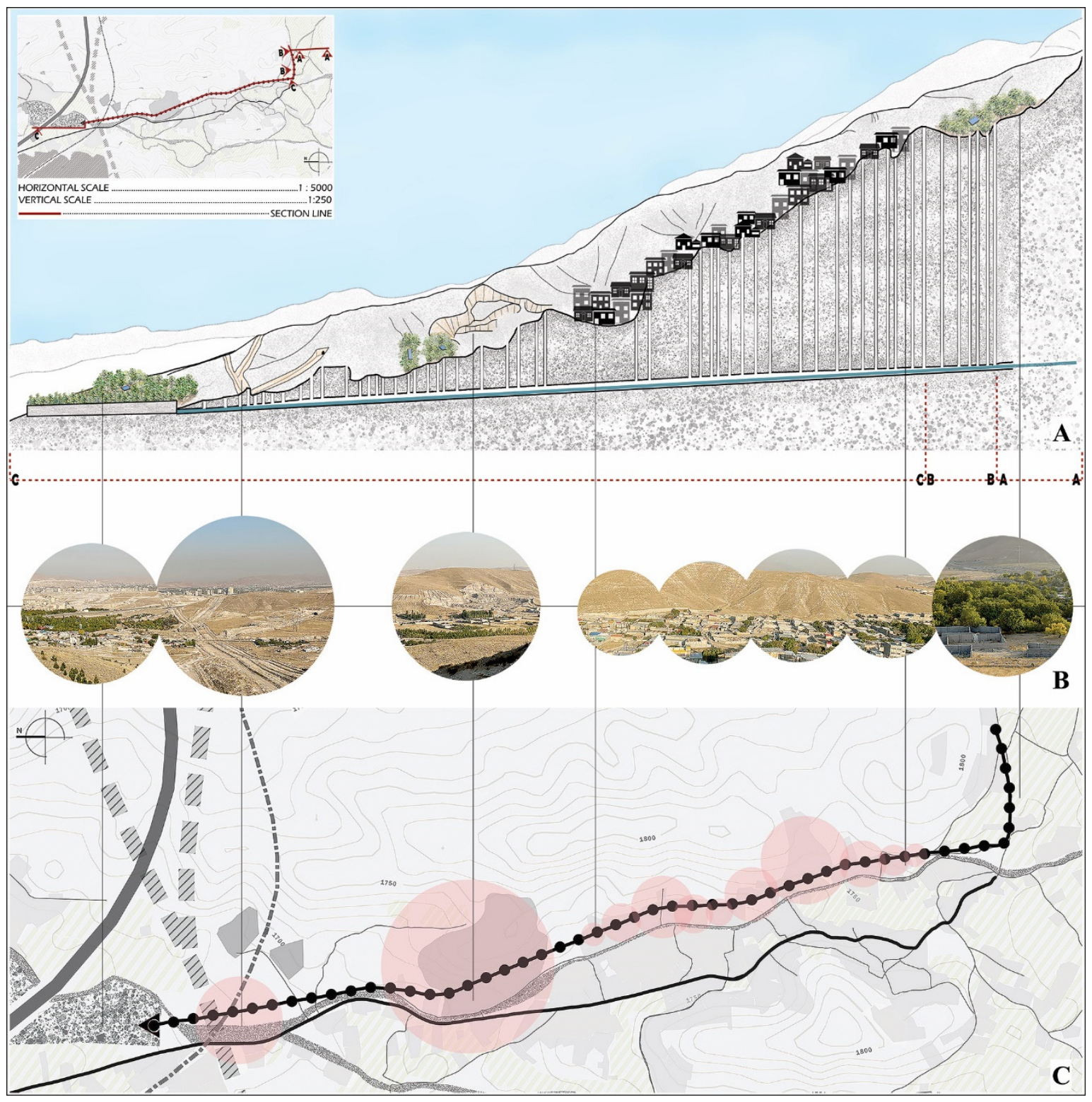

Figure 9: Current damages and structural failures along the No-Ras qanat. 

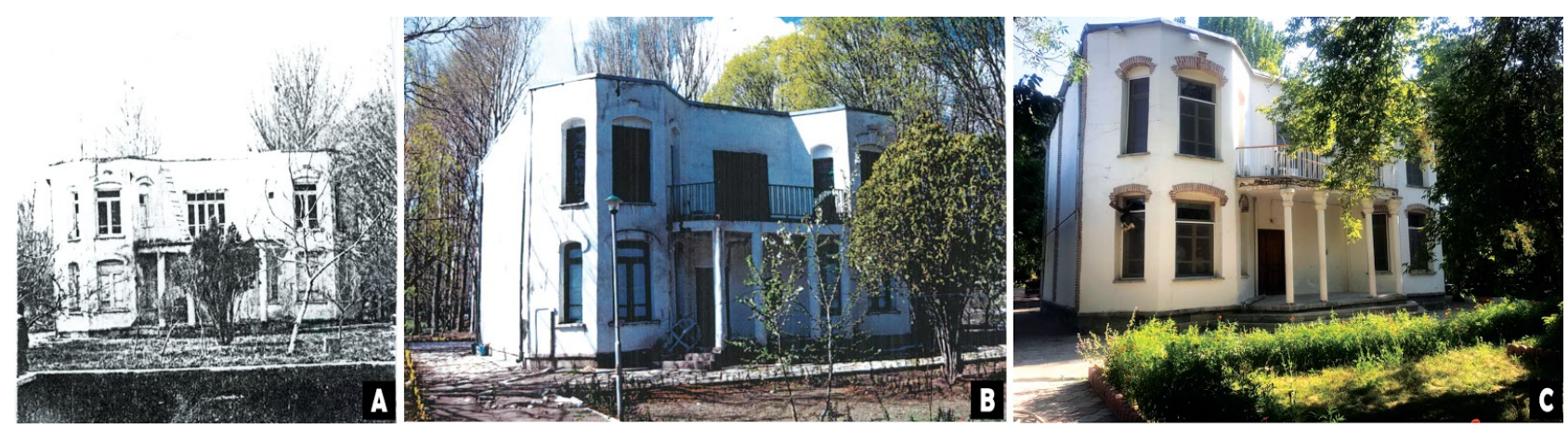

Figure 10: FathAbad Historical Garden Mansion. 10A) The mansion in 1972; 10B) The mansion at the time of the registration of the FathAbad Garden in the list of National Monuments in 1996 (FathAbad garden's national monuments registration document, 2001); 10C) The mansion after the restoration (photo taken in September 2020 by F. Zavvari).
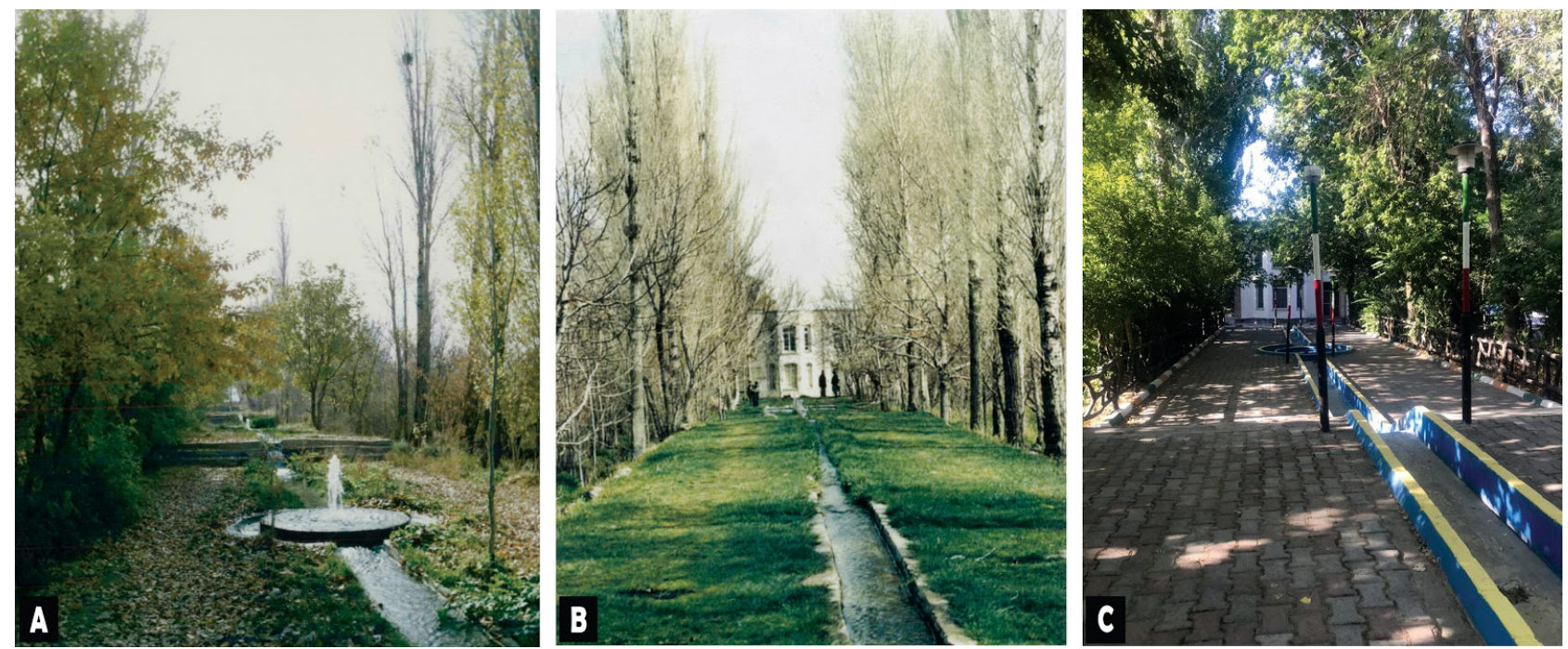

Figure 11: FathAbad Historical Garden main path. 11A) The garden before restoration in 1994 (FathAbad garden's national monuments document, 2001); 11B) The garden at the time of its registration within the list of National Monuments (FathAbad garden's national monuments document, 2001); 11C) After the restoration (photo taken in September 2020 by F. Zavvari).

4) FACTORIES EMPLOYEES. This group includes people employed in small factories such as stone cutting, construction, warehouses, sand and gravel mines etc. Most of these people are commuter workers. The importance of this group for our research lies in the fact that through their work (deep excavations, unloading industrial waste, the passage of heavy vehicles, etc.) they modify and damage the structure of the qanat.

5) NEW OWNERS. These people purchased lands within the qanat buffer zone during the last ten years, to build private villas. Given their remarkable size, part of these lands was also turned to small agricultural fields and fruit planting for personal use, as well as leisure facilities such as swimming pools. What makes this group relevant for the research is that each owner has one or two deep or semi-deep wells in their lands which are often part of the qanat structure or have been illegally dug to get the water from the qanat gallery. Moreover, the construction of the villas and related structures near the wells triggered major stability issues, while the use of the wells for sewage discharge may pollute the qanat water.
The interviews revealed two main interpretations of the qanats among the five groups. Group 1 (Local farmers) and group 2 (Old immigrant farmers), which primarily benefit from the water supply of the qanat, have in-depth knowledge of the function, maintenance as well as some historical information. Their commitment towards the preservation of the qanat is so strong that many of them organized protests (together with the FathAbad garden owner) against the heavy damages caused by the sand and gravel mine (which unfortunately were ignored).

Although far from the monumental qanat of central Iran, groups 1 and 2 perceive No-Ras as a cultural asset that is part of the region's history. They also recognize how modern technologies together with climate change strongly affect the abandonment and destruction of these hydraulic infrastructures. They also believe that specific actions, including in compliance with the laws in force, are carried out to preserve the qanat.

Groups 3 (New immigrants), 4 (Factories employees) and 5 (New owners) have a completely different view. Most of them have poor or no information on the overall function, economic benefits and history of qanats. The few who have the information about the No-Ras and other qanats, consider them an obsolete technology, unsuitable for modern economic and social challenges. Some interviewee (Group 3) stressed the fact that the existence 
of the No-Ras and other qanats represents a barrier for the urban development of the region. While acknowledging in a few cases, the relevance of some qanats (mainly from the Yazd region) as national cultural heritage, none of them recognize the No-Ras as such.

This analysis highlighted that there is still a part of the population that recognizes both the economic and cultural value of the No-Ras qanat (Groups 1 and 2). These people can be important drivers in communicating the importance of qanats to the remaining groups and in mitigating the current destructive processes. Indeed, as for the remaining groups, the main issue is the lack of knowledge towards the function, economic benefits and history of qanats. In addition, most of them also ignore the negative impact of some of the technologies used to replace them (such as dams).

\section{Discussion}

The territorial and land-use analysis offered a detailed picture of the changes in the Tabriz region and their impact on the No-Ras qanat, thus allowing us to answer the first research question. The gradual shifts in territorial occupation and land-use are a direct indicator of widespread anthropization. Among others, human activities included farmlands expansion, the sharp increase of the residential complexes and industrial areas, as well as the growing network of roads and highways. Altogether, these had a profound impact on the environmental, social and economic systems of Tabriz and the No-Ras qanat.

This regional scale was then integrated, following a multiscalar approach, with a detailed multi-temporal damage assessment and structural analysis of the No-Ras qanat. These allowed us to tackle the second research question regarding the issues and threats that affected the massive hydraulic structure during the recent past. Figure 8 showed the dramatic boost in the damages to the No-Ras qanat due to the heavy anthropization between 2003 and 2020. Buildings and roads represent the major actions damaging the qanat and its buffer zone in this period, although other threats such as ploughing and levelling must be considered.

Our analysis confirmed that economic development in the region over the last 20 years had the greatest effect in terms of threats and damages to the area of the No-Ras qanat and the surrounding environment. The more people move out from the cities to the peripheries, the more land is converted to buildings and roads. The gradual increase of damages to the qanat and its buffer zone, also heavily affected the internal structure of the qanat including the wells, the gallery and the outlet. Construction of roads and the passing the heavy trucks and cargo vehicles put pressure on the internal structure of the qanat. Therefore both the gallery and the walls would fall off and block the water flow. Moreover, while the residents' need to access water made them drill wells, in our case study, it led to water shortage of the No-Ras qanat which is one of the impacts of being abandoned.

The emerging issue of the abandonment of the No-Ras qanat was tackled by the third research question by means of interviews with the different communities living in the area. This last analysis highlighted a clear-cut division between local farmers living in, with and for the land and other groups such as immigrants and new owners. The deep understanding of the current issues specifically the water reduction in the qanat is mostly relevant to human conduct that directly influences their cultivations. As well as the strong commitment towards the safeguarding of the farmlands as their economical resources make the first group the most suitable to convey the importance of the No-Ras qanat as a traditional hydraulic tool and local heritage. To be fully efficient, this group needs to be supported by institutions and organizations.

In the conclusive section, we provide tailor-made recommendations (fourth research question) to foster collaborations and preserve and re-use the No-Ras qanat.

\section{Conclusion and recommendations}

The Qanat is a multifaceted structure in which cities and villages' stability and consistency depend on its existence both in the past and now.

The multifaceted nature of the Qanat refers to its essential function, which is supplying water. However, while always considered as a valuable thing, the meaning of water is more understandable when it becomes hard to reach.

In this conclusive section, we answer the fourth research question by offering recommendations to mitigate the issues raised at the beginning of the paper, based on the results provided by the integrated methodology. These recommendations are addressed to different target groups including national and local authorities, NGOs, the local community (i.e. the five groups identified) and the local, national and international research community and other private stakeholders such as cultural heritage organizations and agricultural organizations.

\subsection{Recommendations for mitigating water shortage (Issue 1)}

Our multidisciplinary approach has shown (see 5.1 and 5.2) a substantial change in the land-use over the entire Tabriz area, both in the form of population growth and urban sprawl, an increase of ploughed areas, alongside the growing interest in drilling deep and semi-deep wells. This phenomenon resulted in an increasing water shortage, which was mitigated by the local institutions through the construction of modern water supply systems. However, their mitigation effects will decrease in the medium and long-term as confirmed by numerous studies (Marchetti, Bitelli, Franci, \& Zaina 2020; Wieland \& Muller, 2009), bringing back the issue of water shortage to the fore. Moreover, most of these hydraulic infrastructures are already providing substantial environmental and social problems, such as loss of biodiversity, pollution or soil degradation. The millennial history of qanat demonstrates its long-term use. Also, qanats represent a clean and perennial water supply system. While a detailed analysis of the cost and the water flow compared to that of the existing hydraulic infrastructures will better frame the benefits of qanats, their low environmental impact, the cultural value and the great efficiency are reason to consider them as a traditional system to mitigate water shortage and at least partially replace modern infrastructures.

In this regard, the Regional Water Company and the Agricultural Jihad Organization should conduct/promote 
detailed assessments to compare the cost/benefits of current hydraulic infrastructure and qanat (including the No-Ras), in the region. If they will result in a successful water supply method, a collaborative and sustainable water management protocol should be developed involving national and local authorities as well as farmers and other stakeholders.

\subsection{Recommendations for mitigating mismanagement and lack of documentation (Issue 2)}

This paper revealed a substantial lack of management and documentation of qanats by official bodies in the Tabriz region. Recommendations for mitigating these shortcomings should be addressed to two major stakeholders meaning governmental bodies and local institutions. Management strategies of Iranian qanats at the institutional level remained poorly developed until 2011 due to the higher interest in modern water supply systems (dams, water pumping etc.). Despite the formal protection provided by the national law, this lack of interest caused the gradual abandonment and destruction of qanats throughout the country.

Since 2011, the growing issue of water shortage and the recognized cultural value of some of the qanats, fostered the collaboration between the Ministry of Cultural Heritage, Tourism and Handicrafts, and the Agricultural Jihad Ministry, to improve the documentation and management of several qanats in central Iran.

This successful collaboration should be also extended to the rest of the country. In addition, the analysis provided in this paper should be also applied to other qanats to have a clear assessment of the state of preservation of each qanat. These assessments may be critical for future policy-makers to improve current legislation as well as to better orient investments. Public calls funded by national or regional bodies may foster the participation and involvement of different public and private research institutes in this kind of studies.

\subsection{Recommendations for mitigating loss of technical skills (Issue 3)}

The integrated analysis showed that during the last 20 years, there has been a substantial land-use change in the No-Ras qanat area connected with a slow decrease of local farmers and craftsmen specialized in the construction and maintenance of qanat (moqanni and others). In particular, being a moqanni is a kind of job usually inherited from father to son or continued among family members. The territorial, land-use and demographic changes in the region highly affected this historical and social process. As highlighted by the perception and awareness analysis some farmers still keep partial technical skills. Moreover, local organizations such as the Regional centre of Agriculture Jihad work to support farmers and landowners in the maintenance and use of qanat also integrating modern clean and noninvasive techniques. The joint collaboration of these two groups has proved to be a best practice in other regions of the country including Yazd, Isfahan, and Semnan and could be successfully applied also in the Tabriz region. In addition, specific funds could be allocated both at the national and regional level for training courses for Moqannis.

\subsection{Recommendations for improving the lack of awareness (Issue 4)}

A large part of the current local residents showed a remarkably low level of awareness towards the qanats as both an important hydraulic system and part of the national heritage. This fact, coupled with the lack of NGOs or other groups promoting and communicating the importance of qanats will lead to a steady drop in the people's perception and commitment toward their preservation and use over the next decades. This situation is further complicated by poor communication between academia and society. This is demonstrated by the low impact of numerous academic research on the subject, together with the inscription of Yazd qanats on the UNESCO WHL, on the population.

As already suggested in the discussion, also in this case it is the local farmers who play a pivotal role. Therefore, we suggest increasing the synergy between universities and local farmers, possibly with the support of the government, in creating projects and associations for the protection and communication of the importance of qanat. In this regard, capacity-building projects such as those promoted by the Erasmus+ KA2 scheme of the European Union represent a well known and successful strategy to start this kind of collaboration. Field visits, meetings, training, production and distribution of videos, brochures and booklets to explain the relevance of qanat and compare them with other water supply sources such as deep wells and dams to learn their advantages and disadvantages could be among the activities to be carried out.

\subsection{Recommendations to increase the perception of qanat as cultural heritage (Issue 5)}

The perception and awareness analysis (5.4) allowed us to detect a considerable difference in the perception of qanats as heritage amongst the five identified groups. According to the semi-structured interviews, only two groups (who directly benefit from the qanat) perceived the No-Ras qanat as a heritage worth preserving, while other groups, not having any or enough information, see the qanat as an obstacle for urban development.

The results of this study have several practical implications on the necessity to equip local residences with sufficient and up-to-date information about their heritage. The cultural heritage value of qanat should be first recognized, accepted and protected by the society to which they belong. Raising awareness and promoting qanat as cultural heritage can be done by involving several stakeholders including the government, NGOs, universities and research centres, local communities and private entrepreneurs. In the case of No-Ras qanat, we suggest a stronger collaboration between the regional Jihad Agricultural Organization and the regional organization of cultural heritage, tourism, and handicraft, local universities and communities through activities and projects. Collecting the oral history and historical documents (photos, documents etc.) about the No-Ras qanat, setting up of tailor-made communication strategy through videos, ad-hoc websites, brochures and booklets are amongst them. Moreover, we propose the educational sectors introduce cultural heritage and its importance to the young generation by engaging them in site visiting, 
lectures and workshops not only to promote awareness, even to encourage them to participate in heritage conservation.

\section{Future Perspectives}

While the present research mostly provided assessments on the land-use, state of preservation of the No-Ras qanat, and community awareness and engagement, future researches and projects should move to the "next step", meaning designing and conducting fieldwork projects keeping in mind the recommendations proposed in this paper. These projects should integrate two different types of approaches:

1) Bottom-up. By applying community-based researches involving local farmers, future projects should promote a wide range of activities aiming at raising awareness toward the importance of qanat as a shared economic resource and local heritage as well as for enhancing social cohesion and cultural identity.

2) Top-down. Future projects should not avoid the involvement of local and national authorities. For example, consultation between policy-makers and local stakeholders will be crucial to improve the current legislation for the protection and maintenance of qanats at the national level.

In this regard, best practices on the integration of bottomup and top-down approaches have been already successfully tested for other traditional hydraulic systems in England (Cook \& Williamson, 2007; Historic England, 2017), Spain (Civantos \& Garcia 2015) and Italy (Bove, Branduini, \& Molina, 2020; Branduini, 2020).

Besides the practical application, future studies must also frame the preservation and reuse of qanats within larger debates including climate change. Indeed, qanats may play an important role in the mitigation of hazards caused by both climate change and modern human-made infrastructures such as dams.

\section{Acknowledgements}

The authors wish to acknowledge the manager of the FathAbad Garden and the moqanni of the No-Ras qanat for their help and support during the fieldwork and the numerous information provided, including photos and videos.

\section{References}

Abbasnejad, A., Abbasnejad, B., Derakhshani, R., \& Hemmati Sarapardeh, A. (2016). Qanat hazard in Iranian urban areas: explanation and remedies. Environmental Earth Sciences, 75, 1-14. https://doi.org/10.1007/s12665-016-6067-6

Al-Kashani, A. (1968). History of Al-Jaito. Tehran: Mahin Mohbeli. https://doi.org/10.1163/1875-9831_isla_com_0125

Afshar, I. (1971). Rashid Al-Din Fazlullah and Yazd. Tehran: University Press. https://doi.org/10.2307/600182

Agapiou, A., Lysandrou, V. \& Hadjimitsis, D. G. (2017). Optical Remote Sensing Potentials for Looting Detection. Geosciences, 7, 1-18. https://doi.org/10.3390/geosciences7040098

Agapiou, A., Lysandrou, V., \& Hadjimitsis, D. G. (2020). Earth Observation Contribution to Cultural Heritage Disaster Risk Management: Case Study of Eastern Mediterranean Open Air Archaeological Monuments and Sites. Remote Sensing, 12(1330), 1-12. https://doi.org/10.3390/rs12081330

Al Tikriti, W. Y. A. (2002). The South-East Arabian Origin of the Falaj System. Proceedings of the Seminar for Arabian Studies (Vol. 32), 117-138. Turnout: Brepols.

Balali, M. R., Keulartz, J., \& Korthals, M. (2009). Reflexive water management in arid regions: the case of Iran. Environmental Values, 20, 91-112. https://doi.org/10.3197/096327109X404807

Beekman, C. S., Weigand, P., Pint, J. J., Zotz, G. E., \& Pin, S. (1996). El qanat de La Venta: sistemas hidráulicos de la época colonial en el centro de Jalisco. Jalisco: Secretaría de Cultura Gobierno del Estado de Jalisco.

Bensi, N. S. (2020). The Qanat System: A Reflection on the Heritage of the Extraction of Hidden Waters. In C. Hein (ed.) Adaptive Strategies for Water Heritage, 40-57. Berlin: Springer.

Bove M., Branduini P. \& Molina G. (2020). La Marcita. Storia di un'antica invenzione contadina che parla di futuro all'agricoltura italiana. Magenta. Retrieved November 25, 2020, from http://ticinobiosource.it/wpcontent/uploads/2018/12/Pubblicazione-Marcite-WEB.pdf

Branduini, P. (2020). Engagement, participation and governance of urban agricultural heritage. In L. Scazzosi \& P. Branduini, (Eds), AgriCultura. Urban agriculture and the heritage potential of agrarian landscape, 45-62. Berlin: Springer. https://doi.org/10.1007/978-3-030-49012-6

Briant, P. (2001). Irrigation et drainage dans l'Antiquité, qanats et canalisations souterraines en Iran, en Égypte et en Grèce. Paris: Thotm Éditions.

Civantos, J.M. \& Garcia, M.T. (2015). MEMOLA project. Mediterranean Mountainous Landscapes: an historical approach to cultural heritage based on traditional agrosystems. Post-Classical Archaeologies, 5, 347-356. https://memolaproject.eu/node/1873.

Cook, H. \& Williamson T. (eds) (2007). Water Meadows: History, Ecology and Conservation, Windgather Press. Retrieved November 25, 2020, from https://historicengland.org.uk/images-books/publications/conserving-historic-watermeadows/heag176-conserving-water-meadows/ 
Cunliffe, E. (2014). Archaeological Site Damage in the Cycle of War and Peace: A Syrian Case Study. Journal of Eastern Mediterranean Archaeology and Heritage Studies, 2, 229-247. https://doi.org/10.5325/jeasmedarcherstu.2.3.0229

Cunliffe, E. (2016). Sixty Years of Site Damage in the Carchemish Region. In T.J., Wilkinson, E. Peltenburg \& E.B. Wilkinson (Eds.), Carchemish in Context, 203-214. Oxford: Oxbow.

Dalley, S. (2013). The mystery of the Hanging Garden of Babylon: an Elusive World Wonder Traced. Oxford: OUP.

De Martonne, E. (1941). Nouvelle carte mondiale de l'indice d'aridité. Annales de géographie, 288, 3-20.

De Chatel, F. (2005). Water of the Prophets. Amsterdam: Uitgeverij Contact.

Ebadati, N., \& Hosseini, A. H. (2018). Quality assessment of qanat water for drinking and agricultural uses in Tehran. International Journal of Hydrology, 2(2), 198-203. https://doi.org/10.15406/ijh.2018.02.00069.

Estaji, H., \& Raith, K. (2016). The role of Qanat and irrigation networks in the process of city formation and evolution in the central Plateau of Iran, the Case of Sabzevar. In F.F. Arefian \& S.H. Moeini (Eds.), Urban change in Iran, 9-189. Berlin: Springer. https://doi.org/10.1007/978-3-319-26115-7_2

FathAbad Garden National Registration File in the List of National Monuments of Iran (2001). Tehran, Library and Documentation Center of the Cultural Heritage. Tabriz: Tourism and Handicrafts Organization of East Azerbaijan.

Gerrard, C., \& Gutiérrez, A. (2018). The Qanat in Spain: Archaeology and Environment. In J. Berking (ed.), Water Management in Ancient Civilizations, 197-226. Berlin: Humboldt. https://doi.org/10.17171/3-53

Goblot, H. (1979). Les Qanats, une technique d'acquisition de l'eau. Paris-La Haye: Ecole des hautes sciences sociales.

Haeri, M. (2007). Qanat in Iran. Tehran: Institute of cultural research.

Hammer, E., Seifried, R., Franklin, K. \& Lauricella, A., (2018). Remote assessments of the archaeological heritage situation in Afghanistan. Journal of Cultural Heritage, 33, 125-144. https://doi.org/10.1016/j.culher.2017.12.008

Hosseini, S. A., Shahraki, S. Z., Farhudi, R., Hosseini, S. M., Salari, M., \& Pourahmad, A. (2010). Effect of urban sprawl on a traditional water system (Qanat) in the City of Mashhad, NE Iran. Urban Water Journal, 7(5), 309-320. https://doi.org/10.1080/1573062X.2010.484497

Historic England (2017). Conserving Historic Water Meadows. Swindon: Historic England.

Hu, W., Zhang, J., \& Liu, Y. (2012). The qanats of Xinjiang: historical development, characteristics and modern implications for environmental protection. Arid Land, 4(2), 211-220. https://doi.org/10.3724/SP.J.1227.2012.00211

Hütteroth, W. (1990). Villages and tribes of the Gézire under the early Ottoman administration (16th century). A preliminary report. Berytus, 28, 179-184.

ICCROM, (2016). A Guide to Risk Management of Cultural Heritage. Ottawa: Canadian Conservation Institute.

ICOMOS, (2000). Heritage at Risk: ICOMOS World Report 2000 on Monuments and Sites in Danger. Paris: ICOMOS.

Jomehpour, M. (2009). Qanat irrigation systems as important and ingenious agricultural heritage: case study of the qanats of Kashan, Iran. International Journal of Environmental Studies, 66(3), $297-315$. https://doi.org/10.1080/00207230902752629

Kabir, M. (2008). Interaction of design and nature in Fath Abad Garden of Tabriz. Golestan-e Honar, 11, 48-54

Kabir, M. (2010). Rereading the original evolution plan of Fath Abad village in Tabriz. Maskan va Mohite, 140, 39-50.

Khaneiki, M. (2019). Territorial Water Cooperation in the Central Plateau of Iran. Berlin: Springer. https://doi.org/ 10.1007/978-3-030-01494-0

Lasaponara, R., \& Masini, N. (2012) Remote sensing in archaeology: from visual data interpretation to digital data manipulation. In R. Lasaponara \& N. Masini (Eds.), Satellite Remote Sensing: A New Tool for Archaeology, 17-63. Berlin: Springer. https://doi.org/ 10.1007/978-90-481-8801-7

Lauricella, A., Cannon, J., Branting, S., \& Hammer, E. (2017). Semi-automated detection of looting in Afghanistan using multispectral imagery and principal component analysis. Antiquity, 91, 1344-1355. https://doi.org/ 10.15184/aqy.2017.90

Lightfoot, D. R. (1997). Qanats in the Levant: hydraulic technology at the periphery of early empires. Technology and Culture, 38(2), 432-434. https://doi.org/10.2307/3107129

Lightfoot, D. R. (2000). The origin and diffusion of qanats in Arabia: new evidence from the northern and southern peninsula. Geographical Journal, 166(3), 215-226. https://doi.rog/10.1111/j.1475-4959.2000.tb00021.x

Lofrano, G., Carotenuto, M., Maffettone, R., Todar, P., Sammataro, S., \& Kalavrouziotis, K. (2013). Water collection and distribution systems in the Palermo plain during the middle ages. Water, 5(4), 1662-1676. https://doi.org/10.3390/w5041662

Lopez, P.J.M. (2016). Integrated Risk Assessment for Cultural Heritage Sites: a Holistic Support Tool for Decision-making. 
Unpublished PhD thesis. IMT School for Advanced Studies, Lucca. http://e-theses.imtlucca.it/195/

Luo, L., Wang, X., Guo, H., Liu, C., Liu, J., Li, L., \& Qian, G. (2014). Automated extraction of the archaeological tops of qanat shafts from VHR imagery in Google Earth. Remote Sensing, 6(12), 11956-11976. https://doi.org/10.3390/rs61211956

Maleki, A., \& Khorsandi aqaei, A. (2016). Qanat in Iran (the case study of Tehran qanats), urban processing and planning company, Tehran: University Press. https://doi.org/10.4000/abstractairanica.11302

Marchetti, N., Bitelli, G., Franci, F., \& Zaina, F., (2020). Archaeology and Dams in South-eastern Turkey: Post-Flooding Damage Assessment and Safeguarding Strategies on Cultural Heritage. Journal of Mediterranean Archaeology, 33, 29-54. https://doi.org/10.1558/jma.42345

Marchetti, N., Curci, A., Gatto, M.C., Muhl, S., Nicolini, S., \& Zaina, F. (2019). A multi-scalar approach for assessing the impact of dams on the cultural heritage in the Middle East and North Africa. Journal of Cultural Heritage, 37, 17-28. https://doi.org/10.1016/j.culher.2018.10.007

Ministry of Energy (2005). The reserves of Iran water recourse. Tehran: Ministry of Energy.

Ministry of Energy (2018). Guideline for determining the core and buffer zones of the wells and qanats. Tehran: Ministry of Energy.

Minovi, M., \& Afshar, I. (1972). Rashid-al-Din Fazl-Allah, Waqf-nāma-ye Rab -e rašidi, Tehran: University Press.

Mostafaeipour, A. (2010). Historical background, productivity and technical issues of qanats. Water history, 2(1), 61-80. https://doi.org/10.1007/s12685-010-0018-z

Palumbo, G., (2000). Threats and Challenges to the Archaeological Heritage in the Mediterranean. In J.M., Teutonico \& G. Palumbo (Eds.), Management Planning for Archaeological Sites, 3-13. Los Angeles: The Getty Conservation Institute.

Petrushevsky, P. (1978). Agriculture and agrarian relations in Mongol Mongol Empire, Iran, Tehran: Nil Press.

Richardson, B. F. (2011). Techniques of Detecting and Delineating Archaeological Site Destruction Using High Resolution Satellite Imagery: An Iraq Case Study. Paper presented at the ASPRS 2011 Annual Conference Milwaukee, Wisconsin. May 1-5, 2011.

Saberi, R. (2016). Environmental, economic and social consequences of the destruction of qanats. Geography, 75, $42-57$.

Salvini, M. (2001). Pas de Qanat en Urartu. In P. Briant (ed.), Irrigation et drainage dans l'antiquité, qanats et canalisations souterraines en Iran, Egypte et en Grèce, 190-210, Paris: Thotm éditions. https://doi.org/10.4000/etudesrurales.126

Shahabadi, A. \& Olfati, S. (2009). Qanats in Ecology. Geography, 3, 28-39.

Shoup, D. (2006). Can Archaeology Build a Dam? Sites and Politics in Turkey's Southeast Anatolia Project. Journal of Mediterranean Archaeology, 19(2), 231-258. https://doi.org/10.1558/jmea.2006.v19i2.231

Steffen, W., Broadgate, W., Deutsch, L., Gaffney, O., \& Ludwig, C. (2015). The trajectory of the Anthropocene: the great acceleration. The Anthropocene Review, 2(1), 81-98. https://doi.org/10.1177/2053019614564785

Stovel, H. (1998). Risk Preparedness: A Management Manual for World Cultural Heritage. Rome: ICCROM.

Strzepek, K. M., Yohe, G. W., Tol, R.S.J. \& Rosegrant, M. W. (2008). The value of the High Aswan dam to the Egyptian economy. Ecological Economics, 66, 117-26. https://doi.org/10.1016/j.ecolecon.2007.08.019

Tabatabaei, M. \& Khazimeh Nejad, H. (2019). Evaluation of protection methods and increase of qanat flow rate in Iran. Abkhan va Qanat, 2(1), 17- 28.

UNESCO, (2010). Managing Disaster Risks for World Heritage, World Heritage Resource Manual. Paris: UNESCO.

Ur, J. (2005). Sennacherib's northern Assyrian canals: new insights from satellite imagery and aerial photography, Iraq, 67(1), 317-345. https://doi.org/ 10.1017/S0021088900001418

Weingartner, H. (2007). Water supply by qanats: a contribution to water shortage in Mediterranean areas. In Proceedings of the 10th International Conference on Environmental Science and Technology, Kos island, Greece (Vol. $57,15551561)$.

White, G.F. (1988). The environmental effects of the high dam at Aswan. Environment: Science and Policy for Sustainable Development, 30, 4-40. https://doi.org/10.1080/00139157.1988.9930898

Wieland, M. \& Mueller, R. (2009). Dam Safety, Emergency Action Plans and Water Alarm System. International Water Power and Dams Construction, 61, 34-38.

Wikander, Ö. (2000). Handbook of Ancient Water Technology. Leiden: Brill.

Wilkinson, T.J., \& Rayne, L. (2010). Hydraulic landscapes and imperial power in the Near East. Water History, 2(2), 115144. https://doi.org/10.1007/s12685-010-0024-1 
Yazdi, A., \& Khaneiki, M. (2017). Qanat Knowledge: construction and maintenance. Berlin: Springer. https://doi.org/ 10.1007/978-94-024-0957-4

Zaina, F. (2019). A Risk Assessment for Cultural Heritage in Southern Iraq: Framing Drivers, Threats and Actions Affecting Archaeological Sites. Conservation and Management of Archaeological Sites, 21, 184-206. https://doi.org/10.1080/13505033.2019.1662653 


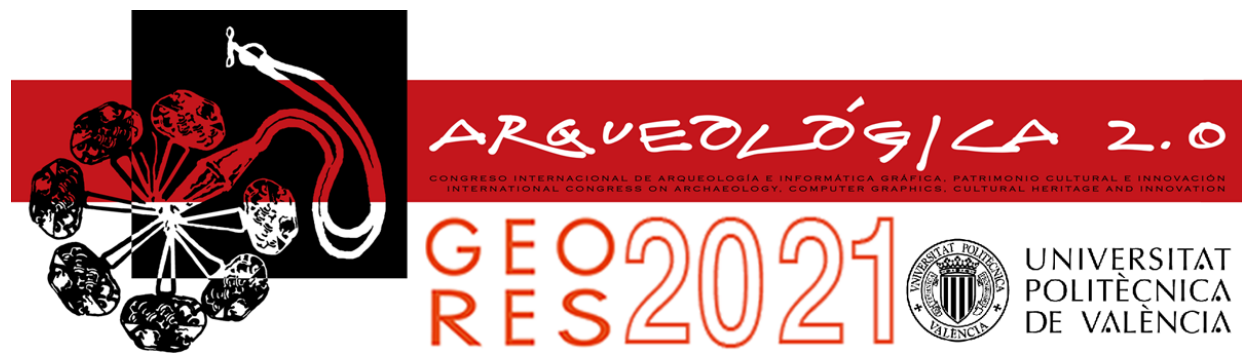

Proceedings of the joint international event $9^{\text {th }}$ ARQUEOLÓGICA

$2.0 \& 3^{\text {rd }}$ GEORES

Valencia (Spain).

26-28 April 2021

\title{
BIM INTEROPERABILITY: OPEN BIM-BASED WORKFLOW FOR HERITAGE BUILDING INFORMATION MODELLING (HBIM). A MULTIDISCIPLINARY APPROACH BASED ON ADVANCED 3D TOOLS AND EXCHANGE FORMATS
}

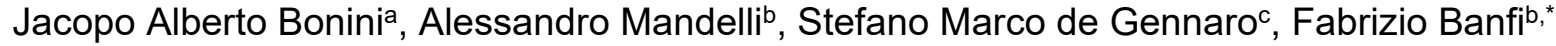 \\ ${ }^{a}$ AB Studio Archiettura, 20156 Milan, Italy. j.bonini@abstudioarchitettura.it \\ ${ }^{\mathrm{b}}$ Department of Architecture, Built Environment and Construction Engineering (DABC), Politecnico di Milano, Piazza Leonardo da Vinci \\ 32, 20133 Milan, Italy. fabrizio.banfi@polimi.it; alessandro.mandelli@polimi.it \\ c Politecnico di Milano, Piazza Leonardo da Vinci 32, 20133 Milan, Italy. stefanomarco.degennaro@mail.polimi.it
}

\begin{abstract}
:
In recent years we have witnessed how technology applied to built heritage has exponentially changed the daily practices of the various experts involved in the life cycle of buildings. The techniques of representation of historical architecture have been able to make use of new 3D survey tools as well as research methods capable of managing a large amount of data while improving the level of information (LOI) and accuracy of the surveyed artefacts. On the other hand, professionals still must make use of many exchange formats to share their digital representations (3D, 2D) and analysis. For this reason, this paper describes the research approach followed to obtain "standard" architectural representations of a heritage building in the Cultural Heritage domain. The word "standard" is used in its original meaning: "something established by authority, custom, or general consent as a model or example" (Collins Dictionary). In this context, 3D models have a primary role in the workflow because their position is in-between the 3D survey techniques that come first and the restoration/maintenance activities. The authors' thought is that the workflow should be as smooth and sustainable as possible to have an effective standardization and collaboration among disciplines, sectors and technicians working in the different study areas.
\end{abstract}

Keywords: interoperability, Building Information Modelling (BIM), exchange formats, IFC, 3D reconstruction, laser-scanner survey, photogrammetry

\section{The era of standardization and BIM interoperability}

In the last decades, there was an increasing use of 3D instruments and technologies to survey, model and spread any kind of 3D real object, from artefacts, artworks, buildings, and landscapes. At the same time, government bodies have implemented, and where possible made mandatory, new standards capable of communicating the levels of development, detail (LOD) and information (LOI) of digital models. Many nations have encouraged and subsequently adopted new supranational standards such as the ISO and CEN to guarantee the quality of those new types of digital representations (Luedy, Couto, Silva \& Hormigo, 2020). As we well know, in December 2018, ISO 19650 was adopted, which through the mechanism of direct adoption of the Vienna Agreement became a European (EN) and national standard for each member state in 2019. Accordingly, the standard should therefore represent the state of the art, practice and science shared by all stakeholders (private and public), concerning a specific process, service, or product. In this context, interesting studies have identified the main shortcomings of these guidelines oriented to new buildings and proposed their methods able to improve HBIM projects (Banfi, 2020; Tommasi \& Achille, 2017).

Furthermore, for most of the member states of the European Union where BIM is not yet mandatory, there is an urgent need to integrate the scan-to-BIM process into guidelines and standards to improve and better specify LODs and LOls of built heritage. Historical buildings are characterized by complex and unique elements of their kind, difficult to obtain from a customization process of object libraries already included in BIM platforms such as Autodesk Revit and Graphisoft Archicad.

The added value of these methods was the integration of survey tools capable of improving the three-dimensional representation of digital models moving from simple

"Corresponding Author: Fabrizio Banfi, fabrizio.banfi@polimi.it 
points to accurate informative models. Thanks to in-depth analysis and study of application cases that have obtained tangible feedbacks (Brumana et al., 2018; Cabrelles, Blanco-Pons, Carrión-Ruiz, \& Lerma, 2018; Tucci et al., 2019), it emerged that the correct creation of complex models mainly depended on four factors:

1) accurate digital surveys based on the most modern 3D survey tools and historical documentation (data collection);

2) an appropriate three-dimensional representation of the buildings surveyed (model generation - scan-toBIM process);

3) information mapping and parameter definition of BIM objects;

4) sharing of information previously mapped in the BIM models.

Nevertheless, often the results and outcomes of these works are caged in their proprietary formats and the results are editable, visible, updatable, and upgradable only if users have the software that produced that files. Moreover, there is the risk of the obsolesce of the files, it happens that the software is discontinued or no more compatible with new operative systems. Last, in collaborative projects between different actors and disciplines, there is often the possibility that the files are not compatible between different application, i.e., structural or energy software may not correctly read the proprieties of the model generated using the $3^{\text {rd }}$ program.

In this scenario, in 2013 the IFC was ISO certified. Even if IFC is commonly referred to as an exchange format, it is a schema. IFC was developed by buildingSMART which is a worldwide industry body driving the digital transformation or the built asset industry buildingSMART is committed to delivering improvement by the creation and adoption of open, international standards and solutions for infrastructure and buildings. buildingSMART is the community for visionaries working to transform the design, construction, operation, and maintenance of built assets. buildingSMART is an open, neutral, and international not-for-profit organization. (buildingSMART, 2020). IFC born mainly for designing, planning, and building new constructions; a typical workflow with IFC is the following: an architect designs its project and export in IFC, the engineer imports the IFC in its software where he can design all the systems (electrical, hydraulic, ventilation, etc.), he can perform structural and energy analyses, he can manage the timesheet of the works. The IFC transport enough information for the simulation software to read and analyse the IFC spaces in the referenced model. If a change is needed, the engineer should not modify the IFC, but he needs to ask who designed the building to make the changes and deliver again the IFC

If this is true for the new construction, this is not always possible if we are dealing with Cultural Heritage, where the objects already exist. In this field, the geometries involved in the modelling phase are quite complex and often they are not classifiable into predefined architectonical classes managed by 3D modelling BIM software (Tommasi, Achille, \& Fassi, 2016). In this case, it is fundamental to manage the whole process verifying and testing the interoperability between applications, starting from the survey until the management of the final
3D model (Banfi, 2017). In the case study here presented, the applications involved in the process are Leica Cyclone, Agisoft Metashape, Autodesk Recap Pro, McNeel Rhinoceros, Autodesk Revit, Unreal Engine, and a BIM-based cloud platform. The integration between these domains and the complementary nature of the information provided by each technology could, therefore, lead to having a new data flow and a highly detailed and holistic picture of a project (Colucci, De Ruvo, Lingua, Matrone, \& Rizzo, 2020; Goulding, Rahimian \& Wang 2014).

\section{The Senate Building in Milan and research objectives}

The case study is represented by the Senate building in Milan currently home to the State Archives. The method described in the article regards the most representative part of the construction, i.e., the main façade designed by Francesco Maria Richini in 1632 among the major protagonist of the seventeenth-century Milanese architectural scene (Fig. 1). The façade is about $50 \mathrm{~m}$ long and $18 \mathrm{~m}$ high built in the baroque style. The central part, where the main access is, has a semi-elliptical shape, the windows are on two rows decorated with curved and triangular tympanums.

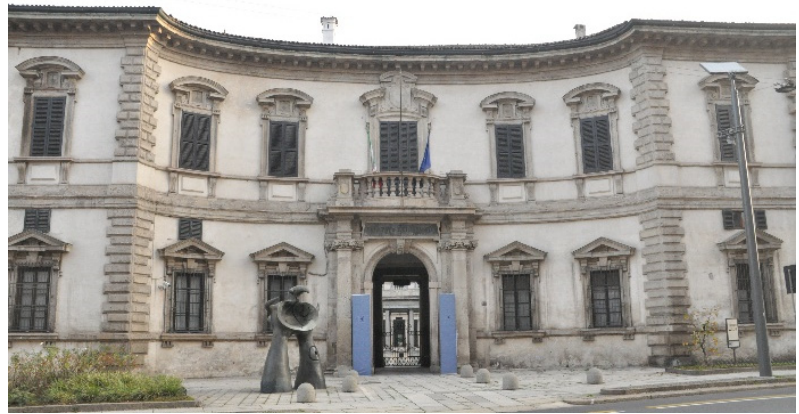

(a)

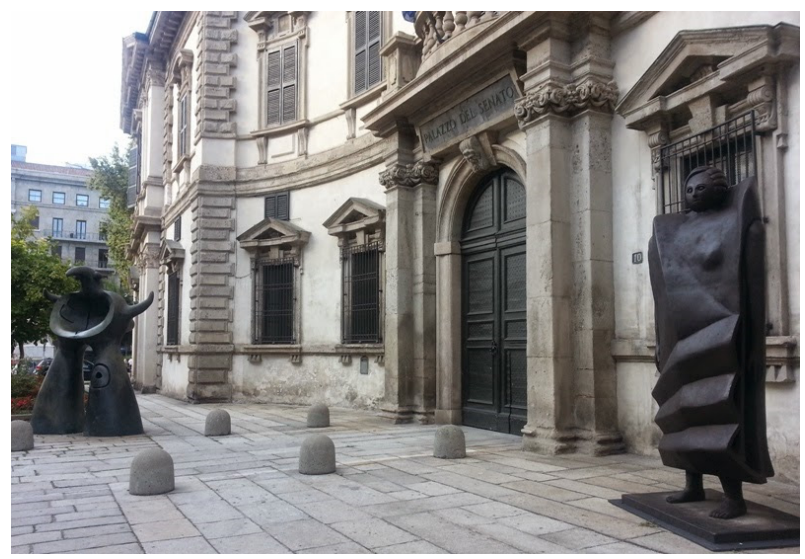

(b)

Figure 1: The main façade of Senate building (a), via Senato 10 , Milan and the architectural details of the entrance (b).

The building was built starting in 1608 by the will of Archbishop Carlo Borromeo as the seat of the Helvetic College, an institution he founded in Milan in 1579 to train the Swiss clergy engaged in the fight against the Protestant reform. It originally overlooked the internal canal that ran along the current route of the ring road 
known as the "circle of canals", buried since 1929. The bronze statue that can be seen in front of the entrance is one of the last works of Mirò, the memory of the Mirò Milano exhibition in 1981. Over the decades, the project was assigned to different foremen including Cesare Arano, Aurelio Trezzi, Fabio Mangone (master builder of the Milan Cathedral) and then resumed around by Francesco Maria Richini in 1632. Richini had to deal with a problem that was not easy to solve: if the façade had been aligned with the internal courtyards, it would not have been parallel to the Naviglio, while the façade of the church was. The original solution found by the architect was that of the concave façade (Fig. 2), devoid of architectural orders, which "partially hides the lack of alignment with the court" (Onida, 1997). Since the Litta coat of arms can be seen on the façade, it can be said that this was not completed until after 1652 during the episcopate of Alfonso Litta.

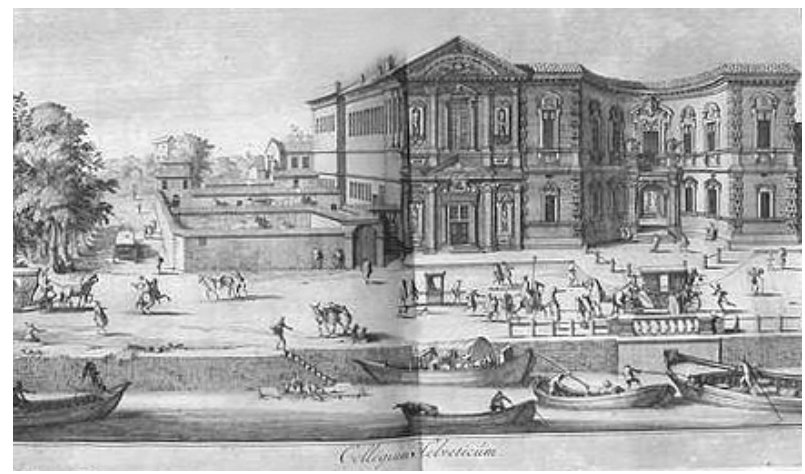

Figure 2: The main façade of the building. Civica Raccolta delle Stampe Achille Bertarelli.

Over the centuries the building had a troubled historychanging often function and became the seat in 1786 of the Supreme Governing Council, the seat of the Lower Chamber (Consiglio de' Juniori) of the new-born Cisalpine Republic in 1797, the seat of the Ministry of the Italian Republic first in 1802, and then of the Kingdom of Italy. From 1809 to 1814 it was used as Palazzo del Senato (hence the name by which the building is known) and from 1817 to 1859 it was the seat of the State Accounting. It should also be remembered, in 1329 Azzone Visconti promoted the strengthening of the city walls and had the moats dredged, thus creating the Cerchia dei Navigli and making Milan a very rich city, thanks to the trade made possible by these waterways. The relationship between canals and the buildings remained unchanged over the centuries, representing a real asset for its representative functions and essential services for the city of Milan (Fig. $3)$.

Thanks to a long work that ended in 1886, all the archives previously deposited in various city locations were transferred to the building and the current State Archives of Milan was born. Between 12 and 13 July 1943, the Senate building was affected by the bombings of the Second World War (Fig. 4). In August 1943, during the devastating bombings on Milan, the building suffered extensive damage both in the wall structure and in the preserved documentation. Regarding the first and related reconstruction works "the criterion of saving the façade and the courtyards and of reconstructing the rear buildings according to utilitarian criteria was followed" (Onida, 1997).

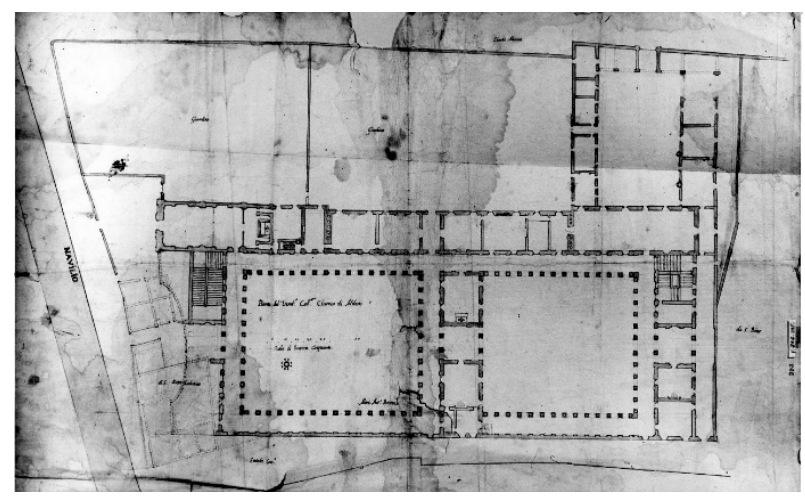

Figure 3: Historical drawings by Marcantonio Banuci: Ground plan of the Collegio Elvetico with the canal marked on the left side. Inventory-Catalogue of the Drawings in the Biblioteca Ambrosiana.

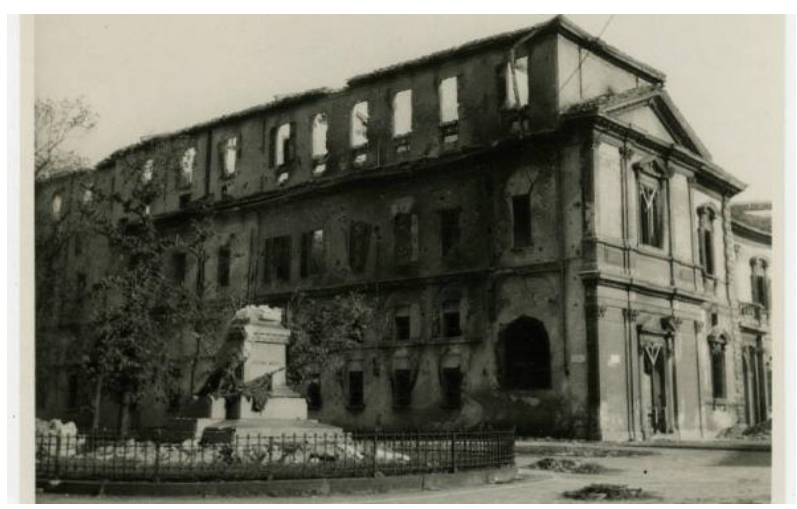

Figure 4: Bombings 1943 - Outside at the corner of via Senato and via Marina. S.A. Dotti \& Bernini.

As shown in Figure 5, the building was severely hit in the raid of the night from 14 to 15 August 1943 by four bombs. Starting from the end of the war, the building underwent an architectural reconstruction that lasted for most of the 1950s and was entrusted to the Superintendency. In March 2008, a vast campaign of stratigraphic investigations was conducted in some rooms of the former offices of the Superintendence for archival assets. The analyses that highlighted the most interesting results are those that were carried out in the internal rooms. In the latter, a vaulted brick structure was found entirely decorated with ornaments on an ochre background. Below this decoration in lean tempera, analyses have brought to light an even older decoration, again with motifs, painted with lime on a blue-blue background. Following the findings, it was decided to proceed in 2009 with the urgent restoration of the ancient pictorial finishes dating back to the mid-century XVII by the Superintendence for Architectural Heritage of Milan and D\&A Communication SRL of Rome (Paola Villa, ND).

Today the façade of the building arrives at us in fair condition. Its historical and cultural heritage represents one of the main architectural assets of the city of Milan.

In recent years, the author's scientific research activity has shown how different methods and technologies of the latest generation oriented to heritage documentation can support 3D survey, digital architectural representation and restoration and maintenance activities. For those reasons, this study proposes a multidisciplinary approach based on the use of the most advanced $3 D$ tools and 
exchange formats (proprietary and open) oriented to represent and share the tangible and intangible values of the built heritage. In particular, the proposed method aims to lay the foundations for a holistic approach based on the integration of different survey tools, software applications, research methods, architectural representations and above all characterized by high levels of interoperability.

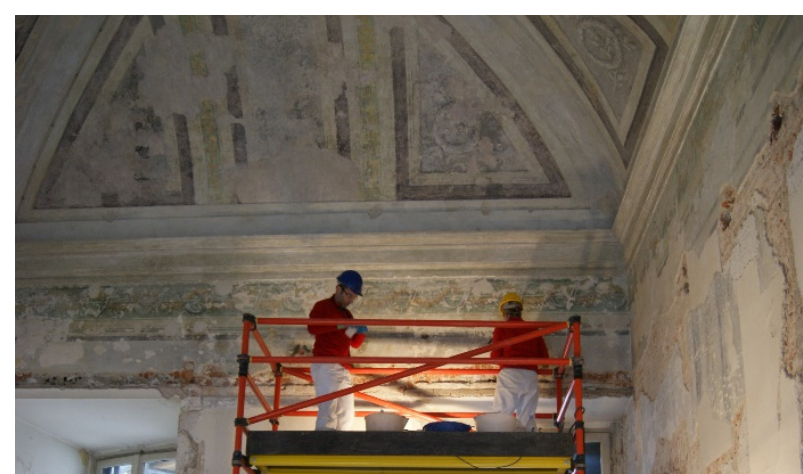

Figure 5: Conservative restoration performed on the decorative apparatus of the "room of frescoes". Source: "Milano nei cantieri dell'arte". Photographs by Alberto Favara / Villa Archive.

Figure 6 shows the high number that a professional must be able to convert and above all optimize to create an appropriate scan-to-BIM process. As briefly anticipated, the large number of formats and software leads to a high loss of information both of a geometric and descriptive/informative nature. For this reason, one of the main results of this study is also to define a data flow that is as sustainable as possible, proposing:

1) the most updated version regarding the interoperability of exchange formats for the generation of HBIM models;

2) transform information and point clouds from proprietary formats to open BIM models.

\section{3) 3D geometrical survey of the Senate building}

As widely discussed, (Achille et al., 2019) nowadays in standard conditions the use of photogrammetry or laser scanner to get the 3D information is almost the same. This is true both for simple and complex objects. Nevertheless, several factors influence the choice of one technique or the other.

In the professional activity, the first parameter that rules the choice is the cost of the instrument, even if the gap between camera plus lenses and terrestrial laser scanners is getting smaller year after year.

Nowadays, also the portability of the instruments is almost the same. In some cases, the laser scanners are more compact than cameras, such as the Leica RTC or Leica BLK360.

Today, the real difference between the use of photogrammetry or laser scanner lies in the elaboration phase and the needs of the project manager. On one hand, both the use of the laser scanner on the field and the following data elaboration is almost straightforward. With the latest technologies, theoretically, the use of the markers is no more needed for the registration of the clouds. A very accurate pre-registration is automatically done during the survey campaign. During the data elaboration, the operator must check the preliminary result of the alignment and locally correct the possible misalignments.

\section{IMPORT/EXPORT POINTCLOUD FORMATS}

Faro, Scene:

Import: XYZ, CVS, COR

Export: PTC, PTX, PST, XYZ, DXF, IGES, VRML, E57 Autodesk, ReCap:

Import: ASC, CL3, CLR, E57, FLS, FWS, ISPROJ, LAS, PCG, PTG,

PTS, PTX, RDS, TXT, XYB, XYZ, ZFS, ZFPRJ, DXF, DWG

Export: RCS, RCP, PCG, PTS, E57, DXF, DWG Bentley, Pointools:

Import: POD, OBJ, SHP, DXF, DWG, ESRI, E57, ZFS, LAZ, LAS,

FLS, FWS, XYZ, PTS, PTX, PTZ, TXT, LWO, CL3, BIN, RSP, 3DD Export: POD, PTS, XYZ

Capturing Reality, RealityCapture

Import: JPG, PNG, PTX, E57

Export: OBJ, PLY, XYZ, DSM

Leica, Cyclone:

Import: XYZ, PTS, PTX, LAS, E57, ZFS, DP, LSPROJ, BLK

Export: XYZ, PTS, PTX, E57, DXF, PCI/CWF, DBX, XML, RCP, RCS Trimble, Realworks

Import: XYZ, E57, LAS, LAZ, ZFS, RSP, FLS, DP, PTX, PTS Export: E57, ASC, LAS 1.2, LAS 1.4, LAZ,

POD, PTS, PTX, TZF, BSF, KMZ, DWG, DXF, DGN, FBX, OBJ Agisoft Metashape

Import: JPG, PNG, OBJ, PLY, LAS, LAZ, E57, PTS, PTX, PCD

Export: OBJ, PLY, TXT, LAS, LAZ, E57, CL3, PTS, DXF, U3D, OC3

\section{D EXCHANGE FORMATS}

3DM, 3DS, ASM, CAM360, CATPART, CATPRODUCT, CGR, DAE, DLV3, DWF, DWFX, DWG, DWT, EXP, F3D, FBX, GBXML, IAM,

IDW, IFC, IGE, IGES, IGS, IPT, JT, MODEL, NEU, NWC, NWD, OBJ, PRT, RVT, SAB, SAT, SESSION, SKP, SLDASM, SLDPRT, SMB, SMT, STE, STEP, STL, STLA, STLB, STP, WIRE, X B, X T, XAS, XPR

Figure 6: The huge number of exchange formats that a professional must consider approaching a scan-to-BIM project.

On the other hand, the photogrammetric approach requires skilled operators both in the acquisition phase and the elaboration too. The images must be as much as possible sharp, not blurred, possibly with the same illumination without strong shadows. The geometry of acquisition must follow precise rules of position and overlap (Grussenmeyer, Hanke, \& Streilein, 2002). The use of known points, i.e., high precisely measured markers, or architectonic points is mandatory to get the correct result in the elaboration phase.

The choice of using photogrammetry is usually due to the need for high-resolution textures, to produce orthophotos. This is possible also with laser scanners since some of them have an integrated camera, but the quality is not comparable with cameras, in terms of resolution. Another option is to use ad hoc cameras or supports for professional cameras, that placed in the same position of each scanner station, which gives the possibility to reproject the colours and textures on the laser scanners point clouds and meshes.

In the case study here presented, having at disposal both a Leica BLK360 and a consumer camera, it was chosen to use both techniques to have both the precision given by the laser survey and the high-quality textures coming from photogrammetry.

The acquisition of the geometries was performed by using Leica instruments, namely the total station TS12 to 
measure the topographic network and some architectonic points, and the BLK 360 to get the dense point cloud. The architectonic points were useful to double-check in Cyclone the automatic alignment performed via tablet during the survey campaign.

\subsection{Laser scanner survey}

The laser was placed on its tripod at a horizontal distance of $10 \mathrm{~m}$ from the façade, it was necessary to acquire the data from three different stations to get the geometry of the building. One of these scans was acquired from a farther point go get also the slope of the roof (Fig. 7).

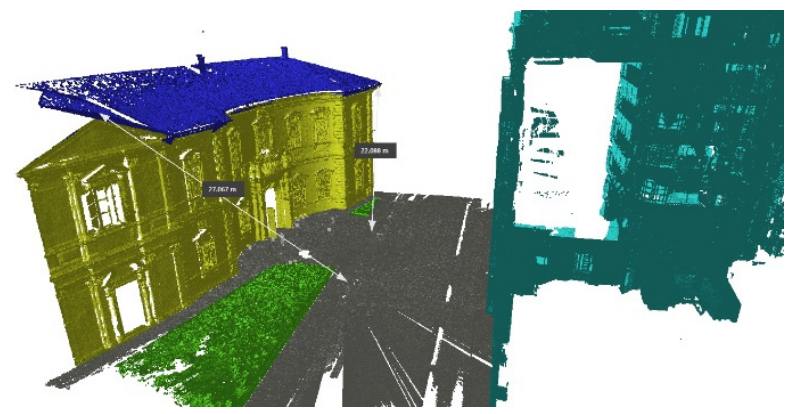

Figure 7: Laser scanner survey layout. Max. distance between the scanner head and the top of the building equal to $22 \mathrm{~m}$.

The scans were performed at the maximum resolution of $5 \mathrm{~mm} @ 10 \mathrm{~m}$ of distance, together with a precision of 4 $\mathrm{mm} @ 10 \mathrm{~m} / 7 \mathrm{~mm} @ 20 \mathrm{~m}$. The final point cloud is about 197 million points with a mean accuracy of $1 \mathrm{~cm}$, due to the distance between the head of the scanner and the farthest points at the top of the building (Fig. 8). Even if the BLK 360 has an integrated camera sensor, it was preferred to perform a fast-photogrammetric survey to get high-resolution textures to be used with the final 3D model.

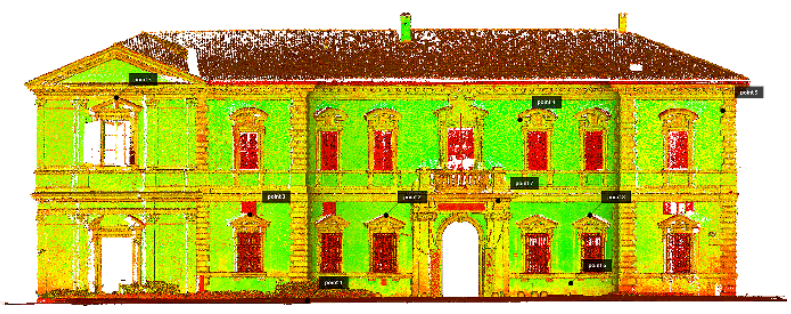

Figure 8: Laser scanner point cloud of the main façade.

\subsection{Photogrammetric survey}

The photogrammetric survey followed the CIPA recommendation adopting the $3 \times 3$ practical rules for simple photogrammetric documentation of architecture (Waldhäusl, Ogleby, Lerma, \& Georgopoulos, 2013).

As mentioned before, the photogrammetric survey was performed mainly to integrate the texture information. Even if the laser point cloud is coloured, the details are not enough to get proper textures to be used in the 3D model mapping. The images were acquired using an entry-level reflex camera, namely the Nikon D90 coupled with an 18-200 mm lens.

As suggested by the CIPA recommendation the camera was set to get the images in RAW format at the maximum resolution of 4.288 pixel * 2.848 pixels. Considering the sensor dimensions of $23,6 \mathrm{~mm} * 15,8 \mathrm{~mm}$, the pixel size of the sensor is equal to $5,5 \mu \mathrm{m}$. The photogrammetric project is composed of 142 images organised in three strips parallel to the façade plus some extra images distributed around the modern statue facing the left part of the building. The overlap of the images is more or less of $80 \%$ with some convergent images where the façade changes its shape, from linear to elliptical. These images and the farthest ones permit to have a more rigid photogrammetric block (Fig. 9).

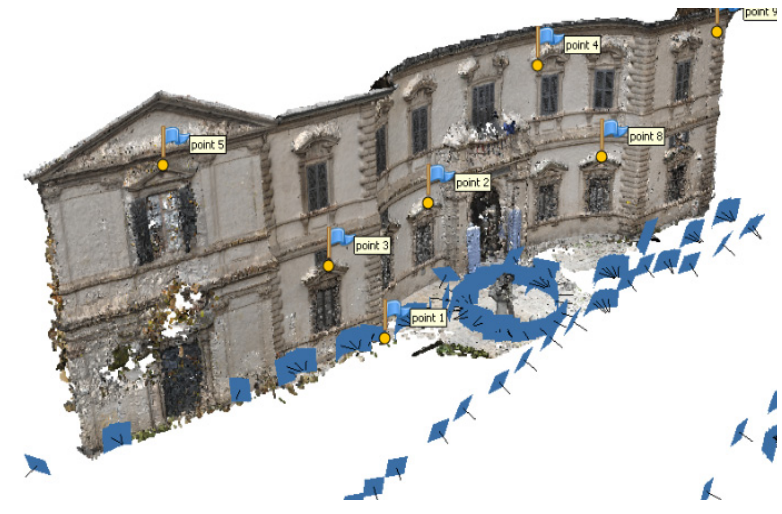

Figure 9: Photogrammetric schema acquisition. The mean distance between the images and the building equal to $10 \mathrm{~m}$.

The acquisition design described above was planned with the goal to get 3D data coherent with the TLS survey. A GSD of $3 \mathrm{~mm}$ was reached fixing with a tape the focal to $18 \mathrm{~mm}$ and maintaining a mean distance of 10 meters prof the façade.

The elaboration phase was performed using Agisoft Metashape following the proven rigid photogrammetric pipeline (Rahaman \& Champion, 2019). First, the alignment phase was concluded with all the images aligned, this suggests that the acquisition geometry was correct without missing overlaps. Also, the score of the images confirmed that all of them was suitable to be used in the following elaborations, i.e., there are no blurry, overexposed, or underexposed photos.

Then the natural points measured with the total station were placed utilizing virtual markers on the images. A mean of 20 reprojections for each measured points was considered. This phase permitted to optimise of the alignment by calculating the internal parameters of the camera and estimating the accuracy of the photogrammetric survey, which resulted in equal to $1 \mathrm{~cm}$. Moreover, constraining the position of the natural points permitted to scale and georeference of the photogrammetric survey concerning the TLS survey. This condition permitted to continue with the elaboration trusting the correctness of the measurements. The construction of the dense point cloud was performed using the "high" resolution, i.e., downscaling the images by a factor of 4 compared to the original size. Then, the dense point cloud was sampled to obtain several points as much as closer to the laser scanner point cloud. Lastly, the mesh construction and the texturing stage were performed to conclude the elaboration and to get the textures to be applied to the final 3D model.

As a final check, the laser scanner point cloud and the mesh model were imported in Geomagic Design $X$ to calculate the mesh deviation from the source point cloud 
(Mandelli, Fassi, Perfetti, \& Polari, 2017). There was no need to apply any transformation since the two 3D elaborations share the same coordinates system measured with the total station. The coloured map obtained after the comparison confirms that all the values of the distance between the mesh and the point cloud are inside the interval $\pm 1 \mathrm{~cm}$. This value confirms that the photogrammetric survey is accurate till the 1:50 rendering scale, and the texture can be used to map the 3D model that will be extracted from the laser point cloud (Fig. 10).

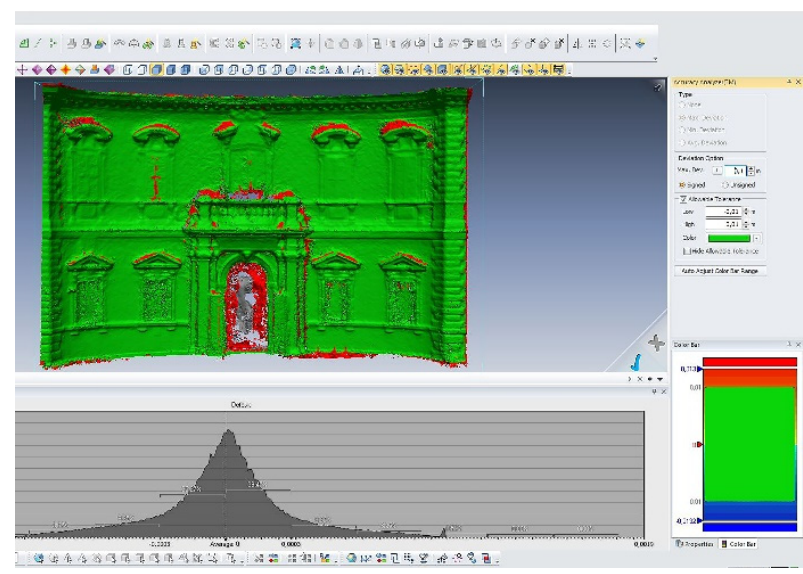

Figure 10: Cloud to mesh compute distances.

\subsection{The value of the measure: the growing need to have an appropriate basis for generating HBIM projects}

Dealing with the 3D survey of complex objects belonging to the Cultural Heritage field and their 3D representations in an HBIM system raises some questions about the value of the measure. Today it is possible to get very detailed 3D surveys, pushing the instruments (cameras a TLS) to their maximum performances. With reverse engineering software it is possible to get extremely detailed digital models interpolating almost each point of the source data (point clouds). But what is the limit? Is it useful to get these results? Are BIM software capable to manage this complexity? Firstly, the purpose of the work should be clear and consequently, it is possible to define the parameters to judge a model accurate enough to satisfy the requests. In Mandelli, Achille, Tommasi, \& Fassi (2017), had been investigated, discussed and related the plotting error $(0,2 \mathrm{~mm})$ typical of the $2 \mathrm{D}$ domain, with its corresponding value in the $3 \mathrm{D}$ domain. They were defined three parameters to evaluate if a $3 D$ model fits or not a determined representation scale. These values are the density of the raw survey data, the precision on measured reference points and the deviation between the final 3D model and the reference surveyed data. The density must be equal to or higher than the plotting error $(0,2 \mathrm{~mm})$ of the chosen representation scale. The residual error on measured points and the standard deviation must be lower compared to the representation scale. Usually, in the architectonic field and dealing with restoration activities, the representation scale adopted is 1:50. This means that, for such projects, the distance between two adjacent points, the maximum error on measured points and the standard deviation must not exceed $4 \mathrm{~mm}$. The first two parameters are intrinsic to the instruments and the design of the survey. The last one depends on the 3D model construction and the flexibility of the BIM software to adapt its modelling elements to complex shapes.
Measurements should be always consistent with the goal of the HBIM projects. Poor data coming from survey drive to models unable to meets the requirements of the work, preventing the use of them as the basis for further analyses. On the other hand, proper data collection leads to virtuous examples as described in the following paragraphs.

\section{Toward a Scan-to-HBIM process: from point clouds to accurate informative models}

In recent years, interesting studies proposed digital workflows able to manage the richness of heritage buildings through very detailed HBIM projects. Unlike digital representations of newly built buildings, HBIM was useful for investigating new types of analyses such as material analyzes (Brumana et al., 2018), construction site conservation projects (Fai, \& Rafeiro, 2014), work breakdown structures (WBS) (Putra Lim, \& Latief, 2020), mixed reality and archaeological sites (Banfi, 2020), infrastructures (Boykov, Skvortsov, \& Gurev, 2020), and finite element analysis (FEA) (Fabozzi et al., 2020). In this context, thanks to specific exchange formats have been possible to transform geometric entities such as solids, surfaces, and primitives for different types of BIM-based analyses. Consequently, the professional in charge of generating and managing the scan-to-BIM model must possess knowledge that goes far beyond those related to the construction sector of new buildings. For this reason, today the figure of architects and engineers who address these issues must also possess advanced skills in computer programming. In 2016, the Social Sciences and Humanities Research Council (SSHRC) financed the research activity of any authors through the New Paradigm/New Tools for Architectural Heritage training program (NPNT, 2020) at Carleton Immersive Media Studio (CIMS) research centres Lab - Carleton University in Ottawa and at Autodesk Research Toronto, Ontario (Canada). Thanks to this collaboration, it was possible to undertake a line of IT development capable of proposing new solutions for the management of built heritage in the following years. As shown in the next paragraphs, through the case study of the Senate building in Milan, it was possible to identify the GOGs, LOls, exchange formats, platforms, and APIs useful for improving the Scan-toHBIM process, passing from simple points (point clouds) to information models capable of going far beyond simple two-dimensional representations.

\subsection{The value of scan-to-BIM process: application of the Grades of Generation (GOG) and descriptive geometry for heritage building}

After one year of experience in the CIMS lab and Autodesk Research Toronto, one of the authors proposed new scan-to-BIM modelling requirements, known as grades of generation (GOG) (Banfi, 2017). GOGs are based on a geometric representation of point clouds capable of connecting various types of information. It is known that BIM platforms were developed for the management of new buildings. This aspect nowadays leads BIM users to deal with a limited number of commands (GOG 1 to 8 ), designed for buildings composed of regular objects compared to those that characterize heritage buildings. For this reason, two new GOGs (9 \& 10) have been defined as able to exploit 
NURBS algorithms for the generation of complex models, and consequently, once imported into Autodesk Revit, automatically generate HBIM objects with high grades of accuracy (GOA). On the other hand, however, it should be noted that one of the main difficulties of the scan-toBIM process is the simultaneous use of different modelling software. In fact, applications have many inequalities such as the constructive logic of the model, interface, primitives, modelling tools and exchange formats. For this reason, this study compares these limits related to these software differences, which in many cases, despite having the same input data (point clouds), can generate different outputs, especially in the field of HBIM. Consequently, thanks to the application of different GOGs it was possible to carry out the case study of the façade of the Senate building which is characterized by many complex historical architectural elements. Besides, as shown in Fig. 11, GOGs made it possible to identify the exchange formats necessary to improve the dialogue between NURBS modelling applications such as McNeel Rhinoceros and BIM software such as Revit and Archicad.

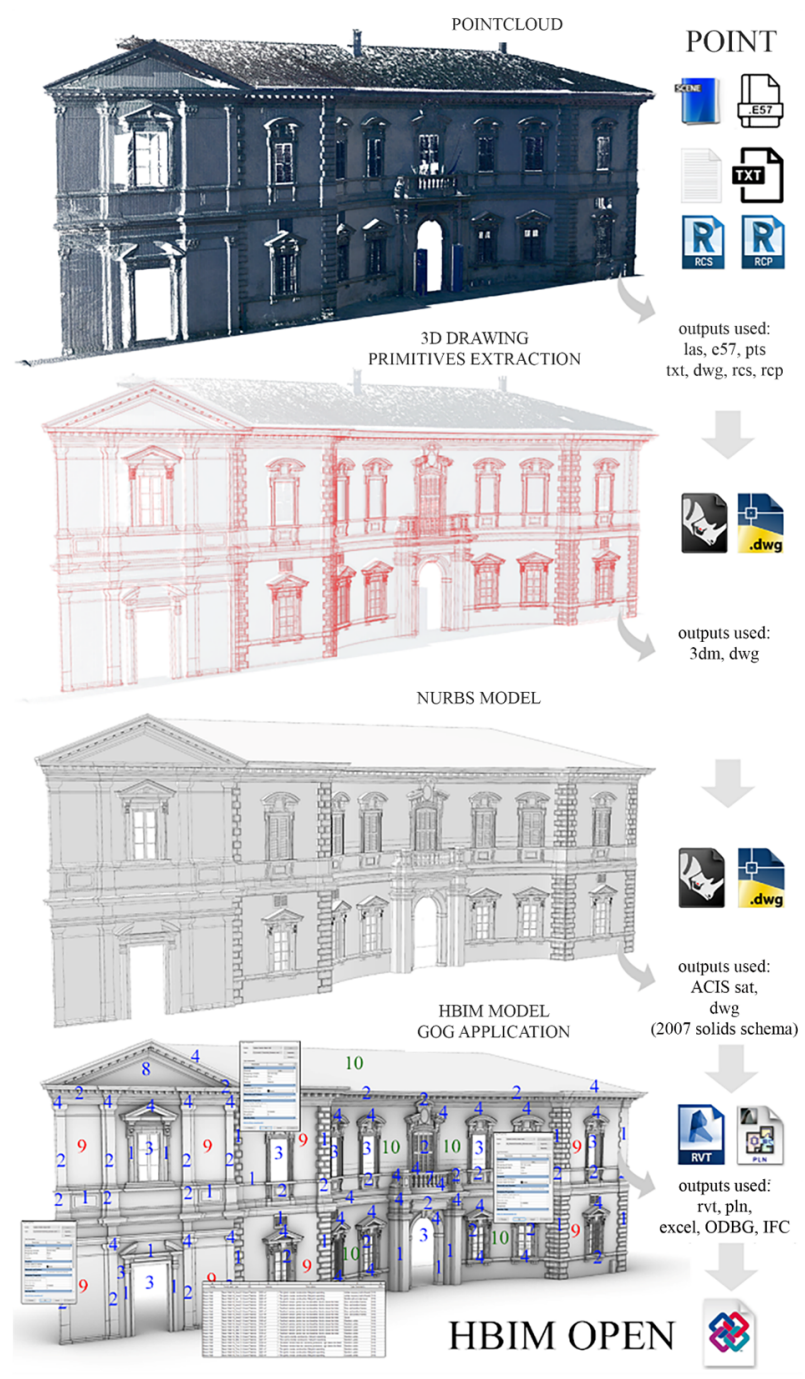

Figure 11: Open HBIM-based workflow for heritage buildings: from simple points to complex models. The exchange formats used for the model generation and ten Grades of Generations (GOG) applied to the scan-to-BIM steps.
In particular, the proposed research approach is based on the following steps and exchange formats:

- $\quad$ Laser scanning outputs used: las, e57, pts;

- Photogrammetry outputs used: pts, jpg, png;

- AutoCad and Recap Pro outputs used: dxf, dwg, rcs, rcp;

- NURBS model generation outputs used: $3 \mathrm{dm}$, dwg (2007 solids schema), ACIS sat;

- HBIM generations outputs used: rvt, ifc, excel, ODBC.

Through this selection, it was possible to transform simple points into complex HBIM objects capable of communicating different types of information in an open language. It was found that the format and the best scheme to be able to dialogue between NURBS modellers and BIM software is the DWG format. It should, however, be emphasized that the DWG format, in turn, must be based on a specific export scheme that can transform primitives, surfaces and solids into entities recognizable by the BIM application. The final step consists of the automatic or semiautomatic transformation of geometric assets into BIM objects capable of being linked to alphanumeric information and new HBIM parameters. Figure 12 shows the export scheme used to transform automatic NURBS models into entities that can be recognized by BIM applications such as Autodesk Revit and Graphisoft Archicad.

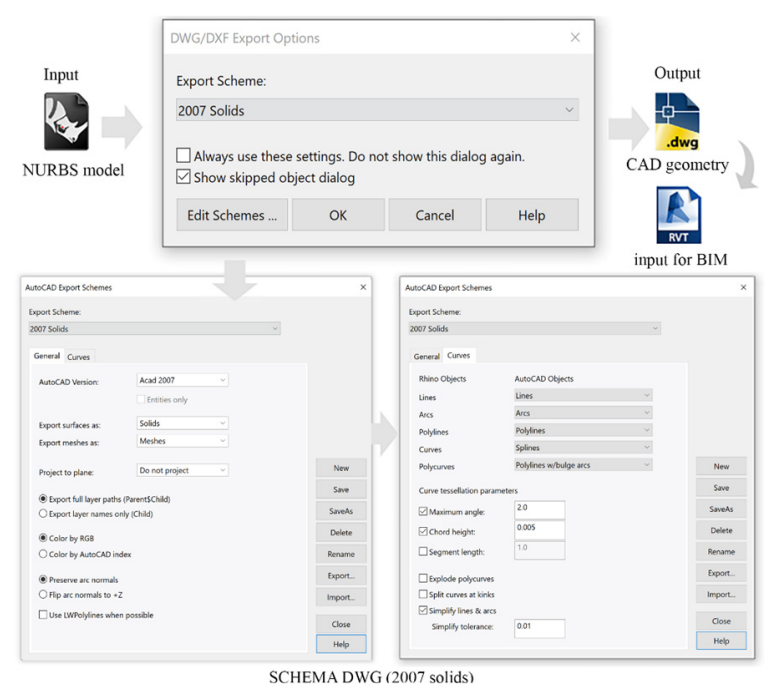

Figure 12: Open HBIM-based workflow is based on the schema definition of the DWG format.

\subsection{Information mapping: semantic enrichment of the model and the development of new HBIM parameters}

The 80 s and 90 s were characterized by a sudden change in the main techniques of representation. Mainly Autodesk with its flagship software (AutoCad) has allowed professionals to reduce exponentially the time dedicated to the realization of drawings able to represent buildings following ISO and UNI standards, passing from manual drawing (on paper) to digital one. On the other hand, in recent years we have seen how BIM has made it possible to link parameters and information to 2D and 3D representations. Thanks to a two-way relationship between information and objects created, it is possible to 
increase the communicative value of each element. Where before in the CAD software we had simple lines, now in the BIM platforms we have parametric elements corresponding to the architectural, structural, and mechanical, electrical, and plumbing (MEP) components of the buildings. In the domain of built heritage, GOGs and the scan-to-BIM process, in general, made it possible to generate unique HBIM objects such as vaults, walls with variable sections, damaged walls and many other elements capable of communicating new information and parameters, unlike new buildings. Therefore, to support the information value of each element, parameters capable of accommodating alphanumeric values have been implemented for the façade of the Senate building. Figure 13 shows the process applied to develop new parameters for different types of HBIM objects to communicate information of a historical, material, physical and mechanical nature. In addition to these types of information, BIM parameters have been developed which in turn can collect the values deriving from the analysis of the automatic verification system (AVS), the grade of accuracy (GOA), standard deviation and GOG used. Consequently, through schedules, databases linked to the objects, it was possible to communicate to the future users the reliability of the model also in numerical terms.

\section{Information sharing and the Common data environment (CDE) of the research project: novel strategies to share digital HBIM models and information}

As briefly described in the previous paragraphs, one of the main objectives of this approach is to identify exchange formats and methods capable of increasing the communicative value of digital models for historic buildings and favouring the sharing of different types of information connected to the model at the same time. To do this, it was necessary to investigate new computer development languages and test many shared application programming interfaces (APIs) through the main online repositories such as Autodesk Revit API and Autodesk Forge. Thanks to the project "HOMeBIM liveAPP: Development of a multi-user Live APP of $4 D$ virtual reality for the improvement of comfort-efficiency costs, from a cloud platform that controls the BIM-sensor flow over time - ID 379270 funded by Regione Lombardia" - it was possible to develop a BIM-based cloud platform able to welcome and share any type of HBIM model and format. Thanks to the use of the IFC it has been possible to convert the information connected to them as well as the BIM objects, such as the parameters described in the previous paragraph, the numerical values associated with the physical and mechanical features and the descriptive fields created to deepen the material and historical characteristics of historical elements at the same time. Figure 14 shows the developed interface and how the geometric model is closely linked to functions capable of communicating alphanumeric contents. Therefore, it was possible to implement the information sharing phase which for the most part is characterized by a serious loss of information between the various users involved in the process. Finally, thanks to the sharing of the model in the platform, all users involved (experts and non-experts) can investigate the various levels of information and in turn, share any type of format.
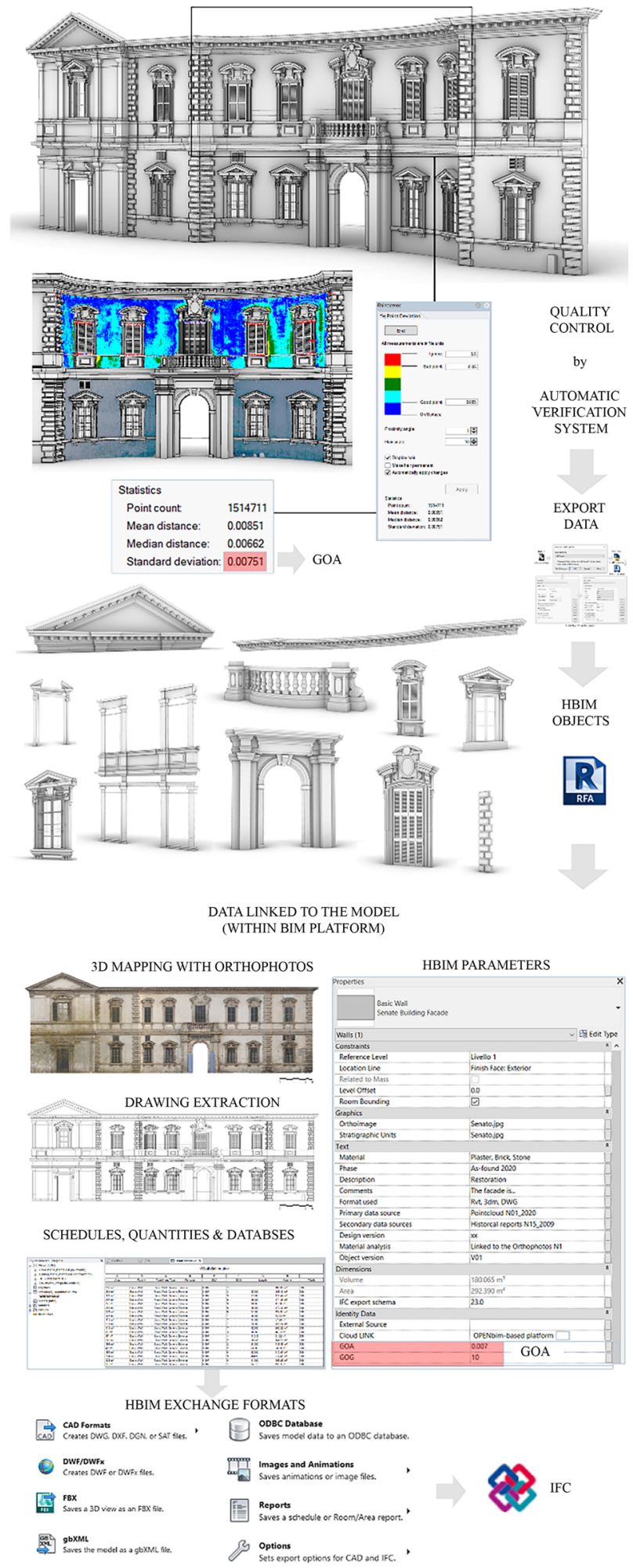

Figure 13: From 2D drawings and historical objects to BIM parameters, schedules, and databases for heritage buildings.

\section{Discussion and Results: from simple points to open exchange formats and vice-versa}

As demonstrated in the previous paragraphs, each element that makes up a complex HBIM model can achieve high LODs and LOIs at the same time. Thanks to the bidirectional relationship between object and 
information, for the case study of the Senate building, new information fields have been implemented.

Unlike pure modellers, it is known that BIM applications are used to involve as much as possible many experts, operating in turn in different application fields and with different software. For this reason, according to the project objectives, Figure 15 also shows the identification of descriptive fields developed for heritage elements, which can accommodate and connect external data sources, with the goal of expanding the information value of all the elements investigated at a geometric level.

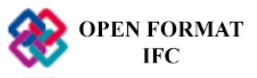

OPEN BIM BASED CLOUD PLATFORM

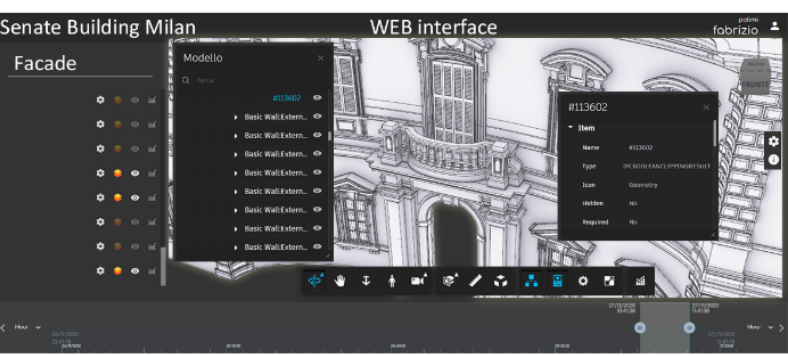

Accepted File Formats for Uploads in cloud (in addition to 3D formats)

Media file formats

3G2, 3GP, ASF, AVX, AVI, BMP, DIVX, DV, DVI, F4V, FLI, FLC, FLV, GIF, JPE, JPEG, JPG, MOV, MOVIE, MP4, MPE, MPG, MPEG, MPV2, OGG, PNG, PPM, QT, RM, TIF, TIFF, WEBM, WMV

Office file formats

CSV, DOC, DOCM, DOCX, ODP, ODS, ODT, PDF, PS, POT, POTM, POTX, PPT, PPTX, RTF, TXT, XLS, XLSX

Figure 14: The BIM-based cloud platform able to share any types of formats.

\section{IMPORT/EXPORT POINTCLOUD FORMATS}

Faro, Scene:

Import: $\mathrm{XYZ}, \mathrm{CVS}, \mathrm{COR}$

Export: E57

Autodesk, ReCap:

Import: E57, ISPROJ, LAS

PTS, DXF, DWG

Export: RCS, RCP, PCG, PTS, E57, DXF, DWG Leica, Cyclone:

Import: E57, LSPROJ, BLK

Export: E57,RCP, RCS

Agisoft Metashape

Import: JPG, PNG, E57, PTS

Export: E57, PTS

3D EXCHANGE FORMATS

3DM, DWG, FBX, IFC, RVT

Figure 15: The selection of exchange formats for the proposed scan-to-HBIM process. IFC is considered the result to share informative models in an open way.

It was found that the modelling and the descriptive geometry made it possible to reach different LODs depending on the project needs. As regards the LOls, it was found that they are strictly linked to the generation of a three-dimensional element: the information can be linked if a "container" has previously been created. In this case and in the field of BIM in general, the ability to accommodate different types of information depends solely on "how" the professional in charge of creating and managing the model digitally enables all these fields (BIM parameters). For this reason, the value of the measure and the descriptive geometry in support of the scan-toBIM process are crucial and certainly not left to chance.

In this context, open formats are reachable and usable for open BIM cloud platforms only if objects have previously been created in BIM logic. The IFC format must be considered as one more possibility to share information related to geometric elements which in turn correspond to architectural, structural, and plant elements. For the heritage documentation sector, on the other hand, elements such as vaults, walls, arches, capitals, and classical columns cannot be represented by IFC categories aimed at historic buildings. For this reason, the following study proposes a workflow capable of transforming historical objects both in proprietary and open formats such as IFC according to the project needs.

In the specific case of the Senate building, the wall BIM family has made it possible to maintain the bidirectional relationship between IFC formats (easily usable even by non-experts) and BIM software. Besides, it should be emphasized that in recent years the exchange formats and schemes based on CAD formats have also been improved. It has been found that working simultaneously in both McNeel Rhinoceros and Autodesk Revit through GOG 9 \& 10 allows experts to complete complex models also from an informative point of view. Consequently, it was considered essential for the research case study to also test the proposed workflow in reverse to evaluate pros and cons in a more digital and IT perspective.

In fact, the reverse process (from information to points) based on three main steps, is immediately blocked by the IFC format. Once the BIM model has been exported to IFC, its geometries are frozen and once re-imported into the BIM platforms it is no longer possible to consider them as real parametric objects.

By bypassing this aspect and moving backwards (from BIM platforms to NURBS modellers), we found the "new" possibility of migrating BIM objects by categories to pure modellers such as Autodesk 3D Studio Max and McNeel Rhinoceros. In the DWG format (ACIS sat scheme) it is possible to switch from Autodesk Revit to McNeel Rhinoceros object categories such as walls, floors, windows, roofs, etc. The latter, once imported into the pure modeller, is recognized in layers, and automatically renamed in specific categories.

Finally, again in a geometric context, the transition from NURBS models to points is based on the extraction of the latter directly from solids, poly-surfaces, surfaces, and curves. Thanks to NURBS algorithms it is possible to automatically recover the primitives from which the whole process proposed this study started.

\section{Conclusion}

When we talk about interoperability in the field of HBIM it is essential to consider and use the exchange formats (proprietary and open) appropriately. Thanks to specific 3D schemes and model transformations it has been possible to improve the communication between software and users. When the Cultural Heritage sector has become digital and computable, the world of making as-found drawing and 3D architectural representations are changed forever. In recent years we are witnesses a leap 
forward driven by advanced digital tools and maturing methods that are opening new sectors and disciplines based on the use of detailed HBIM models.

For this reason, this article proposes a digital workflow aimed at transforming simple points (3D survey data) into digital contents (informative models), which in turn are connected to models based on a scan-to-BIM process. In this context, the authors investigated and applied a real case study that has characterized the history and culture of the city of Milan, different techniques and methods of $3 \mathrm{D}$ survey and digital representation to achieve high levels of information sharing.

Visiting the frontlines of development in the heritage documentation field, authors combine disciplines such as geomatics, 3D modelling, BIM, and digital clouds to improve the level of details (LOD), and the grade of accuracy (GOA) of heritage buildings.

Accordingly, the values of measurement and representation have been investigated and applied to architectural and complex elements both from a geometric and descriptive point of view.
BIM parameters have been developed to improve the ability of each HBIM objects that made up the buildings, communicating material and historical information of each individual element created. Preservation and restoration projects can now benefit from these new tools and exchange format to improve the design, restoration, preservation, maintenance, and many other forms of activities aimed to support the life cycle of heritage buildings openly and sustainably.

\section{Acknowledgements}

The research leading to the results of this paper is partially funded by Regione Lombardia - Bando "Smart Living: integrazione fra produzione servizi e tecnologia nella filiera costruzioni-legno-arredo-casa" approvato con d.d.u.o. n.11672 del 15 novembre 2016 per la presentazione di progetti di sviluppo sperimentale e innovazione (S\&I) a favore della filiera dello "Smart Living" e nell'ambito del progetto "HOMeBIM liveAPP: Sviluppo di una Live APP multi-utente della realtà virtuale abitativa 4D per il miglioramento di comfort-efficienza-costi, da una piattaforma cloud che controlla nel tempo il flusso BIMsensori - ID 379270".

\section{References}

Banfi, F. (2017). BIM orientation: grades of generation and information for different type of analysis and management process. International Archives of the Photogrammetry, Remote Sensing and Spatial Information Sciences, 42(2/W5), 57-64. https://10.5194/isprs-archives-XLII-2-W5-57-2017

Banfi, F. (2020). HBIM, 3D drawing and virtual reality for archaeological sites and ancient ruins. Virtual Archaeology Review, 11(23), 16-33. https://doi.org/10.4995/var.2020.12416

Boykov, V. N., Skvortsov, A. V., \& Gurev, V. A. (2020). InfraBIM Open paradigm as the driver of informatization of the road sector in Russia. In IOP Conference Series: Materials Science and Engineering, 832, 012045. IOP Publishing.

Brumana, R., Della Torre, S., Previtali, M., Barazzetti, L., Cantini, L., Oreni, D., \& Banfi, F. (2018). Generative HBIM modelling to embody complexity (LOD, LOG, LOA, LOI): surveying, preservation, site intervention-the Basilica di Collemaggio (L’Aquila). Applied geomatics, 10(4), 545-567. https://doi.org/10.1007/s12518-018-0233-3

Cabrelles, M., Blanco-Pons, S., Carrión-Ruiz, B., \& Lerma, J. L. (2018). From Multispectral 3D Recording and Documentation to Development of Mobile Apps for Dissemination of Cultural Heritage. In T. E. Levy \& I. W. N. Jones (Eds.), Cyber-Archaeology and Grand Narratives: Digital Technology and Deep-Time Perspectives on Culture Change in the Middle East (pp. 67-90). https://doi.org/10.1007/978-3-319-65693-9

Fabozzi, S., Cipolletta, G., Capano, E., Asprone, D., Dell'Acqua, G., \& Bilotta, E. (2020). BIM-FEM interoperability for the modelling of a traditional excavated tunnel. Tunnels and Underground Cities: Engineering and Innovation Meet Archaeology, Architecture and Art: Volume 3: Geological and Geotechnical Knowledge and Requirements for Project Implementation, 785.

Tucci, G., Conti, A., Fiorini, L., Corongiu, M., Valdambrini, N., \& Matta, C. (2019). M-BIM: a new tool for the Galleria dell'Accademia di Firenze. Virtual Archaeology Review, 10(21), 40-55. https://doi.org/10.4995/var.2019.11943

Onida, N. (1997). Architetture milanesi. Collegio Elvetico, centro per l'architettura di Milano.

Villa, P. (ND). Technical report. Milano ex Collegio Elvetico Palazzo del Senato Archivio di Stato Restauro conservativo eseguito sull'apparato decorativo della "sala degli affreschi" ed altri ambienti al primo piano 2009/2012. Milano nei cantieri dell'arte. Available at: http://www2.milanoneicantieridellarte.it/cms/wpcontent/files_flutter/1334326361Reltec.pdf

Achille, C., Fassi, F., Mandelli, A., Perfetti, L., Rechichi, F., \& Teruggi, S. (2019). From a Traditional to a Digital Site: 20082019. The History of Milan Cathedral Surveys. Digital Transformation of the Design, Construction and Management Processes of the Built Environment. Springer International Publishing, 331-341.

buildingSMART. (2020). buildingSMART - The Home of BIM. Retrieved March 15, 2021, from https://www.buildingsmart.org

Colucci, E., De Ruvo, V., Lingua, A., Matrone, F., \& Rizzo, G. (2020). HBIM-GIS Integration: From IFC to CityGML Standard for Damaged Cultural Heritage in a Multiscale 3D GIS. Applied Sciences, 10(4), 1356. https://doi.org/10.3390/app10041356 
Grussenmeyer, P., Hanke, K., \& Streilein, A. (2002). Architectural photogrammetry. In M. KASSER and Y. EGELS, Taylor \& Francis (Eds.), Digital Photogrammetry (pp. 300-339)

Fai, S., \& Rafeiro, J. (2014). Establishing an appropriate level of detail (LoD) for a building information model (BIM)-West Block, Parliament Hill, Ottawa, Canada. ISPRS Annals of the Photogrammetry, Remote Sensing and Spatial Information Sciences, 2(5), 123. https://doi:10.5194/isprsannals-II-5-123-2014

Goulding, J. S., Rahimian, F. P., \& Wang, X. (2014). Virtual reality-based cloud BIM platform for integrated AEC projects. Journal of Information Technology in Construction, 19, 308-325.

Luedy, L., Couto, P., Silva, M. J. F., \& Hormigo, J. (2020). Information Requirements to BIM Models. In Sustainability and Automation in Smart Constructions (pp. 29-35). Springer, Cham.

Mandelli, A., Achille, C., Tommasi, C., \& Fassi, F. (2017). Integration of 3D models and diagnostic analyses through a conservation-oriented information system. Int. Arch. Photogramm. Remote Sens. Spatial Inf. Sci., XLII-2/W5, 497504. https://doi.org/10.5194/isprs-archives-XLII-2-W5-497-2017

Mandelli, A., Fassi, F., Perfetti, L., \& Polari, C. (2017). Testing different survey techniques to model architectonic narrow spaces. Int. Arch. Photogramm. Remote Sens. Spatial Inf. Sci., XLII-2/W5, 505-511, 2017. https://doi.org/10.5194/isprs-archives-XLII-2-W5-505-2017

NPNT. (2020). New Paradigm / New Tools for Architectural Heritage in Canada. March 15, 2021, from http://npnt.ca/\#/home

Putra Lim, A. W., \& Latief, Y. (2020). The Development of Safety Plan Using Work Breakdown Structure (WBS) for Building Information Modelling (BIM)-Based Building Structure Work. Journal of Computational and Theoretical Nanoscience, 17(2-3), 1402-1413. https://doi.org/10.1166/jctn.2020.8818

Rahaman, H., \& Champion, E. (2019). To 3D or Not 3D: Choosing a Photogrammetry Workflow for Cultural Heritage Groups. Heritage, 2, 1835-1851. https://doi.org/10.3390/heritage2030112

Tommasi, C., \& Achille, C. (2017). Interoperability matter: levels of data sharing, starting from a 3d information modelling. Int. Arch. Photogramm. Remote Sens. Spatial Inf. Sci., XLII-2/W3, 623-630, 2017. https://doi.org/10.5194/isprsarchives-XLII-2-W3-623-2017

Tommasi, C., Achille, C., \& Fassi, F. (2016). From point cloud to BIM: a modelling challenge in the cultural heritage field. Int. Arch. Photogramm. Remote Sens. Spatial Inf. Sci., XLI-B5, 429-436, 2016. https://doi.org/10.5194/isprsarchives-XLI-B5-429-2016

Waldhäusl, P., Ogleby, C. L., Lerma, J. L., \& Georgopoulos, A. (2013). 3 x 3 Rules for Simple Photogrammetric Documentation of Architecture. Available at: https://www.cipaheritagedocumentation.org/wpcontent/uploads/2017/02/CIPA_3x3_rules_20131018.pdf 


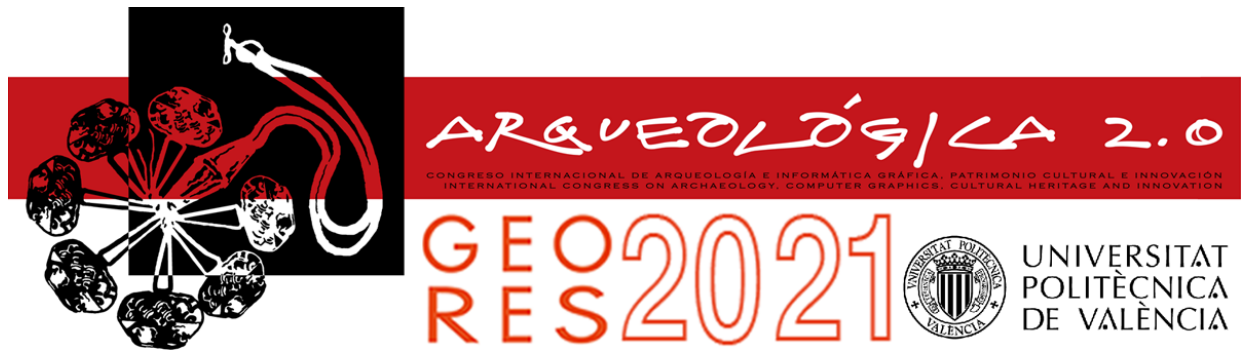

\title{
THE RECONSTRUCTION OF A DYNAMIC INVENTORY MODEL TOWARD SHARED HBIM LIBRARIES FOR VAULTED SYSTEMS
}

\author{
Anna Turrina*, Dario Attico \\ Department of Architecture, Built Environment and Construction (DABC), Polytechnic of Milan, Via Ponzio 31, 20133 Milan, Italy. \\ anna.turrina@polimi.it; dario.attico@polimi.it
}

\section{Abstract: THE RECONSTRUCTION OF A DYNAMIC INVENTORY MODEL TOWARD SHARED HBIM LIBRARIES FOR VAULTED SYSTEMS}

The complexity and variety of solutions in the domain of cultural heritage are the results of a heterogeneous network of social and historical factors generating them. Each individual architectural object, including not only notorious typologies but little-known construction systems such as brick vaults, are generated by a specific social and physical framework. The richness of vaulted systems stresses the need for an in-depth investigation supported by informative models connected in a single geospatial platform. The paper describes a methodological workflow starting from an abacus of vaults, based on different Levels of Detail and Information, to populate a geo-spatial database. Focusing on the acquisition of an open and shared database of historical elements, the definition of an HBIM targeted Library, integrating different types of data in one dynamic model, requires the management of different Levels of Detail and guidelines to establish a correct hierarchy of information. The proposed study can be considered a modern approach to the traditional practice of Répertoires, to set up a methodology that could be applied indifferently and widely, regardless of how the model is built. The diverse vaulted systems of Palazzo Magio Grasselli provide the possibility to build an inventory model as a result of multiple informative models coming from different geographical backgrounds to solve critical issues such as data loss and to enhance knowledge dissemination.

Keywords: HBIM, vault, LOD, digitization, database, cultural heritage

\section{Introduction}

The study of cultural heritage still moves its steps among unsolved issues related to the complexity and variety of solutions in time and space. The presence of a large stock of historical buildings, with variable connotations in different Italian regions, makes it necessary to adopt a systematic approach to gather the information.

The suggested study can be considered a modern approach to the traditional practice of Repertoires, to set up a methodology that could be applied indifferently and widely, regardless of how the model is built. Each individual architectural object, including not only notorious typologies but little-known construction systems such as brick vaults, are generated by a specific social and physical framework. The richness of vaulted systems stresses the need for an in-depth investigation supported by informative models grouped in a single geo-spatial database to allow a geographical reconstruction.

\section{Following the logic of a modern Répertoire}

In order to create a database aimed to organize the construction elements, an important reference can be found in the concept of Répertoire formed within the French culture.

Towards the end of the twentieth century, the topic of vaulted systems returned to the center of architectural culture and became particularly interesting among scholars and historians after an eclipse of almost a hundred years (Brumana et al., 2018a).

Important cases of stereotomy, made between the sixteenth and nineteenth centuries, that is from the late Gothic to the Baroque époque, have been subject of studies to reconstruct a new historical perspective.

This phenomenon affected Europe as a whole, in France thanks Jean Marie Pérouse de Montclos (2000) in 1964 it took up the idea of inventory by recording a significant number of cases of stereotomic treatment, attributing a typological vocabulary to each individual example. We can therefore speak of a revival of the French répertoires and a reimagining of the treatise of De l'Orme, where the technical vocabulary of architecture is associated with a lexicon through the illustration of the different cases.

In the following years, other studies were performed less systematically in Spain (Palacios, 1990), England (Willis, 1842 ) and Germany. In Italy, treaties - with the exception

‘Corresponding Author: Anna Turrina, anna.turrina@polimi.it 
of Guarini (Piccoli, 2001) - were often elementary and repetitive. From the seventeenth century, there is a direct reference to the notions of French literature. At the same time, the presence of the recovery manuals of the individual cities began to spread, but with a limit, that is, the treatment of typically local customs and techniques. This fragmented framework makes it difficult to recognize a way of building linked to a specific region, because the same skilled workers often operate by moving geographically from one border to another. If Piedmont is known for offering a large number of examples of brick vaults, it is not possible to attribute authorship to the region. The famous thin vaults, for example, are often traced back to Piedmonts architecture for their massive use in the $19^{\text {th }}$ century but the "Piedmonts" attribute is incorrect because their real location has much wider geographical boundaries.

This eighteenth-century practice must be sought in different ways and times. Only this example shows the vastness of the theme and the uncertainty of relationships. Currently, there is only one heterogeneous picture spread over time and space that needs a repertoire model suitable for containing the infinite variables. From the beginning, in fact, the final aim is to concentrate every action of the process - from detection to redesign - towards an information model containing a series of transmissible data, as accurate as possible.

The need is not only to not lose the complexity of the data but also to make this complexity as accessible as possible to an external user who wants to approach these issues. The use of BIM platforms could be the solution for creating a library with these features.

\section{A short overview of data integration and HBIM models}

Authors can include illustrations related to the accompanying text. It is the responsibility of authors to insert figures, graphics and images in the right place.

\subsection{Introduction to HBIM}

The introduction of BIM (Building Information Model) in the sector of AEC (Architecture, Engineering, Construction) is intended to integrate different types of information and allow collaboration and exchange of shared 3D models and structured data attached to them. This logic of data organization in one cohesive platform aims to allow collaboration between the architectural and construction fields. Updated heritage documentation techniques are the result of the increasing use of HBIM models for the management and digitization of cultural heritage assets (Dore, \& Murphy, 2017). Nowadays, HBIM models are overcoming the role of emerging practice, turning into a widespread process in constant growth, supported by new survey technologies and digitization practices that allow the reconstruction of parametric models (Banfi, Chow, Reina Ortiz, Ouimet, \& Fai, 2018). The complexity of cultural heritage entails the adoption of new solutions to support data storage and visualization and system management to avoid the loss of information between different models and projects. However, in most cases, due to different software interoperability or projects set up for different purposes, a traditional approach persists and generally, the information does not intersect correctly. The risk is that individual studies stay unconnected, depriving them of a potential historical connection, in time and space, which instead, if inserted in a shared platform, would get added evidential value. This study moves from the general idea of a geospatial database, integrating HBIM and GIS to promote and allow a broader dialogue between similar objects. That said, the still unexplored topic of brick vaults and their construction helps to identify the priority issues for a shared catalogue. The HBIM informative models can be accessed as HBIM libraries, as in the case of the product catalogue in the construction industry, or as Open Access format, to create an inventory model made by the built HBIMs coming from the punctual diverse case studies, and using them to feed a geographic database (GeoDB) (Brumana et al., 2018b).

\subsection{Data Integration and Interoperability}

The continuous evolution of BIM emerging software and its application in the cultural heritage leads to limitations about data transferring such as loss of information or incorrect translation. The use of a HBIM approach for modelling historical architectures/features introduces several further issues related to geometry complexity, level of detail, data organization, structural components classification and consequently new limits for a data exchange purpose.

It has to be said that, when we talk about BIM, defined as a semantically enriched model for knowledge, a growing and still ongoing issue concerns the creation of a catalogue of data and its consequent exchange between different platforms. If HBIM models, by themselves, can be considered a visual library and a solution for managing and storing information coming from different sources, including tangible and intangible data, multiple geometric information, photogrammetry and laser scanning measurements assimilated as different datasets (Chow \& Fai, 2017). However, it is necessary to understand how they can be properly integrated in the one inventory platform that overcomes that individual case-study with a view to a geospatial database. Information-sharing indeed should allow different inventory models to talk to each other.

\subsection{HBIM and geo-spatial DB}

The review of the recent literature evidences different tests to export HBIM models structure into GIS environment. Most of them show different applications to explore the limits due to interoperability issues between architectural and structural models and to overcome the gaps between the complexity of a heritage model and the software collaboration.

The main issue is how to transfer the logic of an objectbased software into the GIS database, considering data conversion and different kinds of information at different Levels of Details. The interoperability performance is hindered by inadequate communication between two different datasets, designed for different scaled objects. If GIS includes four types of Level of Detail (LOD), starting from the landscape scale, the more detailed one never reaches the complexity of BIM models. So as to make communication possible, it is necessary to identify what kind of semantic and geometry can be imported into a geospatial platform (Arroyo et al., 2017). All this is not about how to manage the geometry itself, but the data 
related to it, such as shared and family parameters, geographical coordinates and different Level of Information (LOI). BIM approach differs from the GIS approach because 3D data maintain their threedimensional output without being flattened to a vector image or a raster (Reina et al., 2019). Recently to closest studies (Matrone, Colucci, De Ruvo, Lingua, \& Spanò, 2019; Vacca, Quaquero, Pili, \& Brandolini, 2018) suggested two similar workflows visualise 3D objects into an Open Source GIS software where different architectural elements, modelled at a LOD300, successfully populate the DB where geometries and attributes are connected to each other.

\section{HBIM for vaulted systems}

\subsection{The evolution of the modelling workflow}

The BIM standards are insufficient for developing a parametric model that follows the complexity and deformation of a historical building that presents irregularities due to the movement of the structures, to inaccuracies or adjustments during the construction phase, but also to geometries that are too complex to be returned by just one software.
The virtual reconstruction of historical elements requires a modelling methodology (Fig. 1) that avoids arbitrary preselection of information and an excessive simplification of the shape (Oreni, Brumana, Georgopoulos, \& Cuca, 2014).

The methodology establishes guidelines to define correct LOD and LOA (Brumana, Banfi, Cantini, Previtali, \& Della Torre, 2019) and correct geometry interpretation. For this reason, it is essential to interact simultaneously with different modelling software, each one with a specific task to perform, defining a workflow that starts from slicing the point cloud (Autocad), to the reconstruction of surfaces (Rhinoceros) and finally to the creation of parametric solids (Revit). Therefore, the surfaces are imported into the BIM software and then it's possible to use a tool for generating three-dimensional elements from surfaces maintaining their complexity (Chow et al., 2019).

The case of the vaults (Fig. 2) falls into that category of elements that are too complex geometrically to be managed only by the BIM program. The survey of these structures shows that all of them are off by a few inches from the ideal geometrical vision of Architecture.

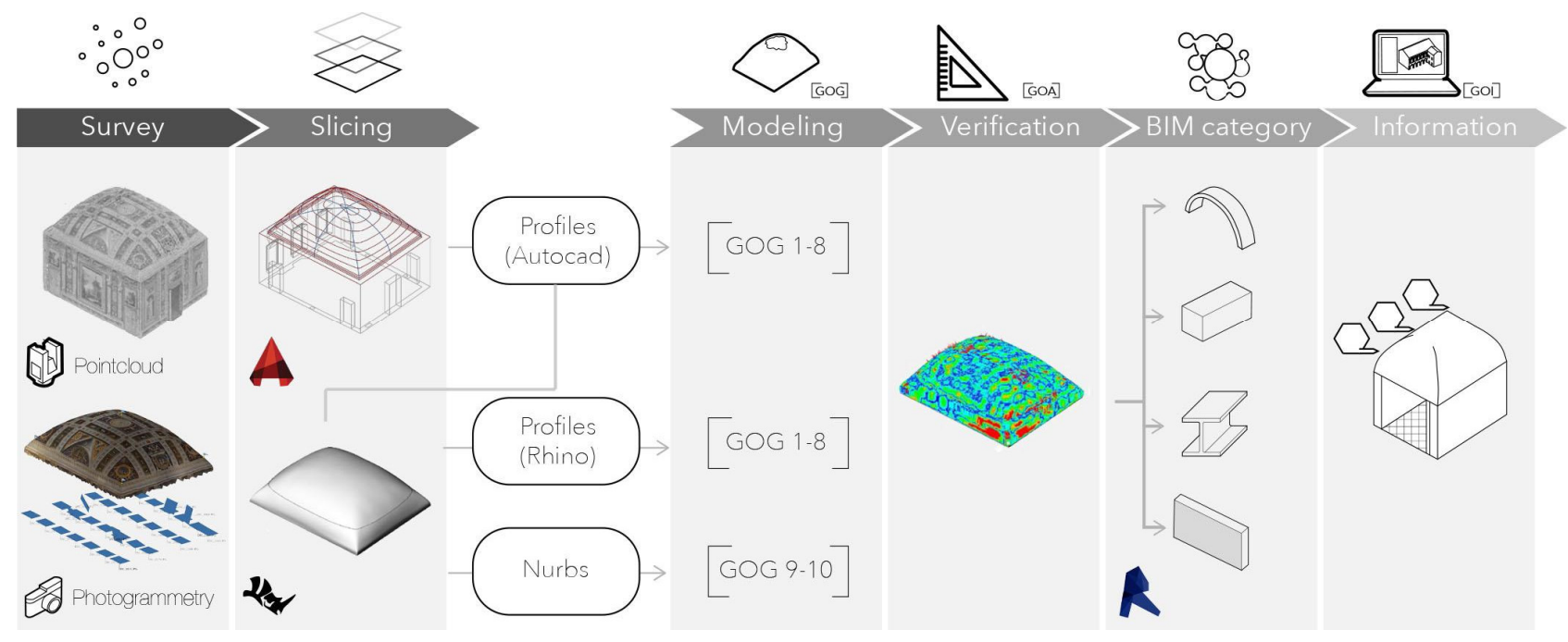

Figure 1: The vaulted systems are modelled following a dynamic interpretative workflow to avoid arbitrary preselection of information and geometry simplification.

The challenge focuses on a modelling practice to get a complex geometry in Revit and the definition of an accurate result in terms of geometrical deviations/anomalies. Different Level of Detail, Geometry and Information, acquired in Cremona palaces, provide an example when dealing with adaptive components. Considering vertical and horizontal sections cannot be used as generative profiles for all the vaults, because they are not enough to extrapolate the information needed, the translation of survey points into linear dimensional parameters within a family can drive the geometry.

Survey points and spring points in the case of springer vaults for example. Vault modelling, however, does not consist only in the generation of the main volume of the vault's body itself, but it is necessary to add all those elements that contribute to the formation of the complex structure. Reinforcement arches, frenelli, tie rods are all elements that cannot be ignored, and which therefore must be rebuilt digitally. These elements do not find a modern consideration and the BIM software is not able to generate them automatically, but it will be necessary to proceed through alternative ways by associating these structures, as done with vaults body, with categories that allow their modelling and assignment of the information that can characterize them.

The first step toward the definition of an HBIM library of vaulted systems toward a shared DB can be summarized in the definition of macro-families (ceiling, slabs, floors) and sub-components (as adaptive ones: structural, no structural elements, decorative layers). Finally, the geometry is related to a historical phase in Revit and its constructive technique and material. 


\subsection{Palazzo Magio Grasselli: a rich abacus of solutions}

Palazzo Magio has a great deal of heterogeneous information (Fig. 3) attributed to it deriving from years of analysis (Landi, 2011) aimed at the restoration that is affecting it. The organization of these data not only leads to correct their management such as to avoid data loss, but through the use of a coherent archiving method, new awareness can arise.

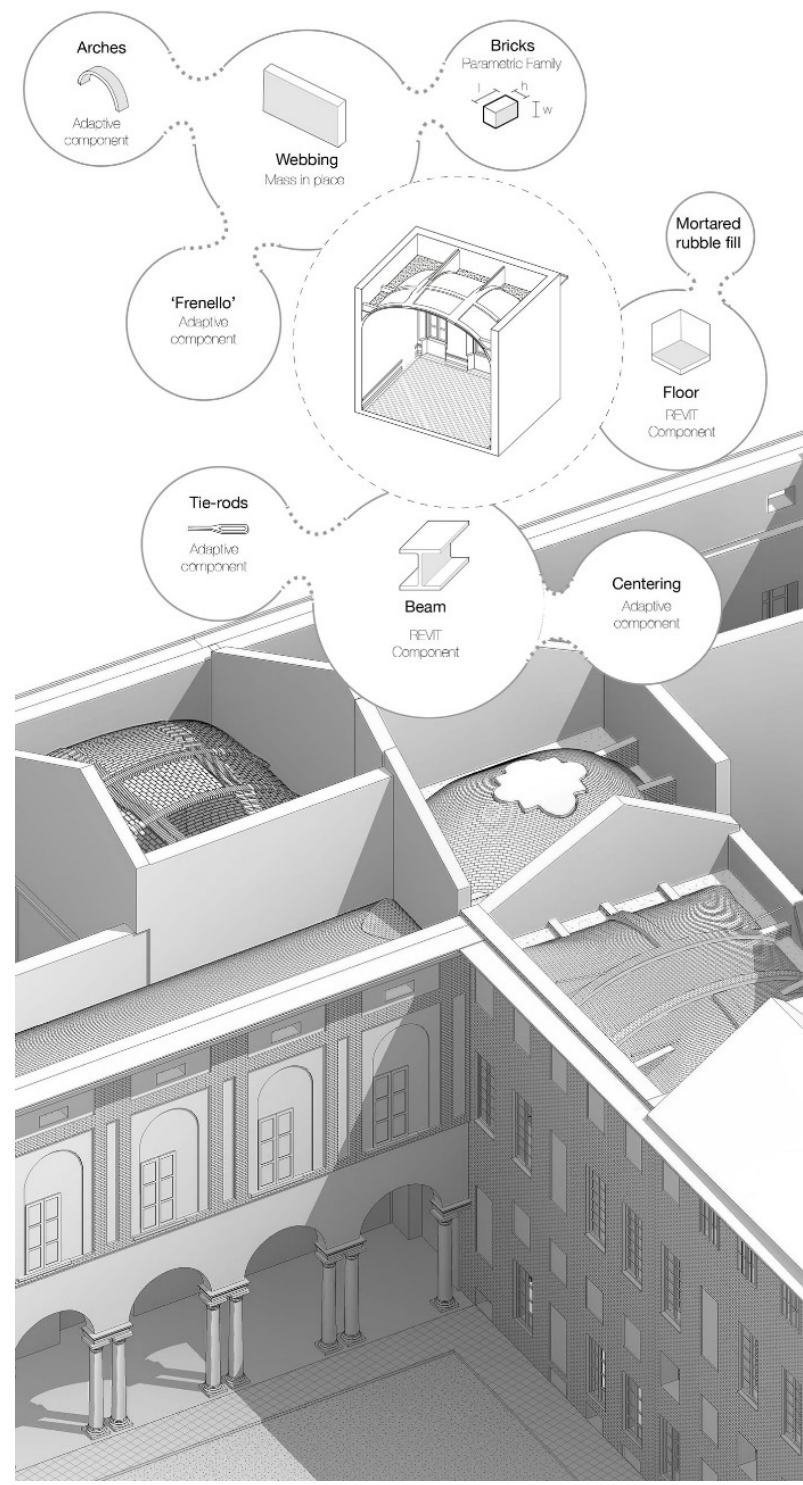

Figure 2: The HBIM of Palazzo Magio Grasselli. Highlighted are the main brick vaults built between the XVII and the XVIII centuries. The modelling process provides for the definition of macro-elements (Revit families) and sub-elements as adaptive components (structural, no structural elements, decorative layers).

The HBIM model of the palace is a valuable tool to store the data coming from the survey and archival sources within the modelled elements.

The knowledge of these elements, however, reaches a further degree of development when the information concerning the single units of the system is associated with it. If the solid model of the vault is able to define its real thickness, this will not be enough if the bricks are fundamental to understand how the vault was built.

To achieve this, the BIM model of the three main vaults of the building is integrated through the three-dimensional modelling of the previously reconstructed texture. The modelling, in this case, is quite heavy due to the numerous limitations provided by the software standards, related to the absence of specific families for complex elements and difficulty in reading the modelled elements.

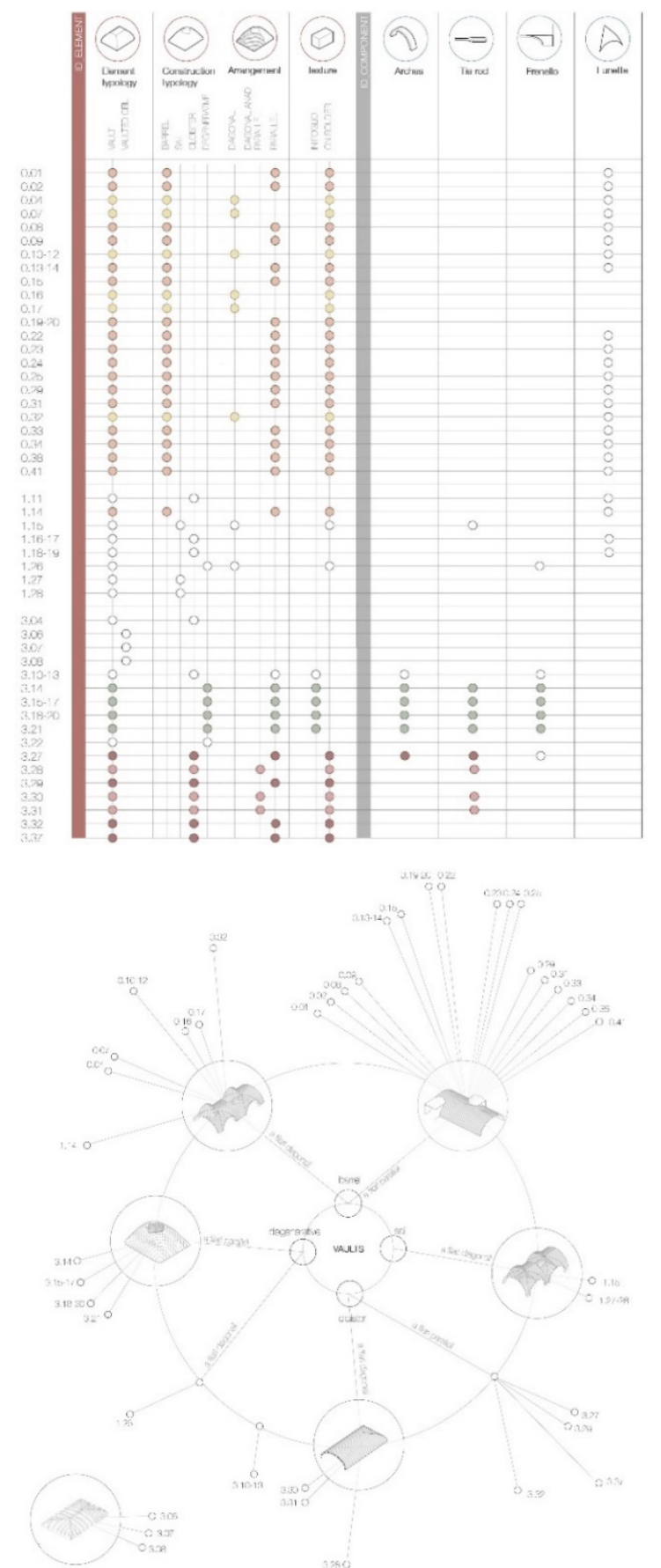

Figure 3: The classification of the vaults is the first step toward the definition of a HBIM targeted library.

This occurs through the creation of the single brick as an external family subsequently inserted within the main project and positioned individually on the surface of the vault. 
Moreover, according to the workflow, it is necessary to create specific families not only for the type of brick considered, but also for the face they show along with the ceiling. The type of family that best allows the modelling of the overall vault and in general, most complex heritage elements, is the metric generic model.

However, the HBIM environment can be considered an inventory model but not a complete database due to limitations of the software itself which can be summarized in two fundamental points: 1). lack of the possibility of subordination of the objects and of the aggregation of the individual objects to contribute to the formation of a complex object; 2). lack of adequate categories for some elements found in the historical building, which entails the adaptation of these objects into partially improper categories which lead to irregularities in the assignment of new data fields.

\section{Towards the genesis of a database}

In order to build a database aimed to accomplish the purpose for what has been conceived, it's necessary to organize sequentially the actions for the data collection and elements analysis.

The Road Map summarizes the main phases of the workflow starting from the identification of the case study, which involves the context where the same building is placed.

The preliminary actions concern the collection of data correlating two methods, the bibliographic research for the recovery of historical information and the digital survey through the use of emerging available techniques.

The information is subsequently analysed and linked to a three-dimensional BIM model. The role of the catalogue comes ex post, at the end of the analysis and synthesis of the work, turning into a tool for managing the model and the collected data (Fig. 4).

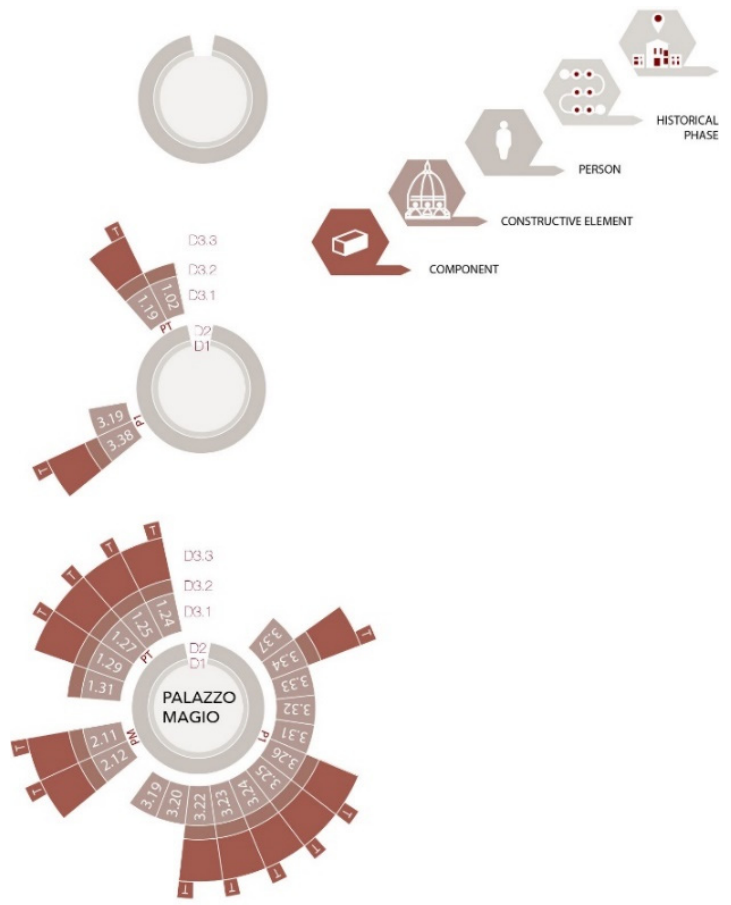

Figure 4: The generation of a shared DB gathering vaults containing different LOD.
Therefore, to avoid the system malfunction, first of all, indications are provided for each entry in the database so that it is easy to read for anyone, a sort of vocabulary, and at a later time, for those who, in addition to the consultation, wish to make changes or insert data to the database, a sort of filter element that checks every information before its insertion.

Clearly, it cannot be expected that any information included in the catalogue is the result of strong analysis. The feedback tool allows users to keep control of data that is not supported by a high level of knowledge and confirmed by strong sources.

The generation of the catalogue coincides with the need to re-order and establish a hierarchy within the data. In order to be functional, an open-access database must allow the population of new data by different users while preserving its linearity, doing so data integration won't involve modifications to the structure.

Given that the case study of Palazzo Magio contains, in addition to the presence of the BIM model, a considerable amount of information as a result of different survey techniques, the difficulty lies in not limiting the cataloguing to the types of vaults found in this building.

Taking into account the question of how to build a database and how can be feed with the collected data, there is a noticeable lack of information related to many aspects: the scarcity of historical documents regarding the vaults elements, the spread of stereotomic knowledge, the workers and their specific way of building, but also the absence of a study that collects all the possible bibliographic documentation, clearly extended outside Cremona, mapping all possible buildings.

Considering that this kind of work cannot lead to a result of absolute completeness, it is decided to overturn the reasoning.

We, therefore, abandon the idea of an inventory that adopts the logic of the greatest possible bibliographic extension by exploiting every single information present in the books and inserting all the indications of a certain type of physical context.

The approach chosen is to set up a construction model that develops an optimal form, a sort of matrix, accepting the incompleteness of the information collected and considering that even non-datable cases can re-enter it. We then proceed to the construction of a correct "matrix form" on Palazzo Magio (Fig. 5), being the case we are dealing with using the greatest accuracy. The genesis of this database is made by populating it with any reliable information by leaving the non-completable fields empty, understanding if these "gaps" are lack of information or more conceptual, which should therefore be fixed in the Magio starting box. For this reason, the precision of setting the starting form is essential to ensure that the insertion of one case does not continually call into question the previous one. It is not necessary for the database to extend infinitely, since the goal as previously stated, is not to create an extensive inventory, however at the same time we can't accept an arbitrary data insertion, based on the randomness of an extraneous bibliography. 

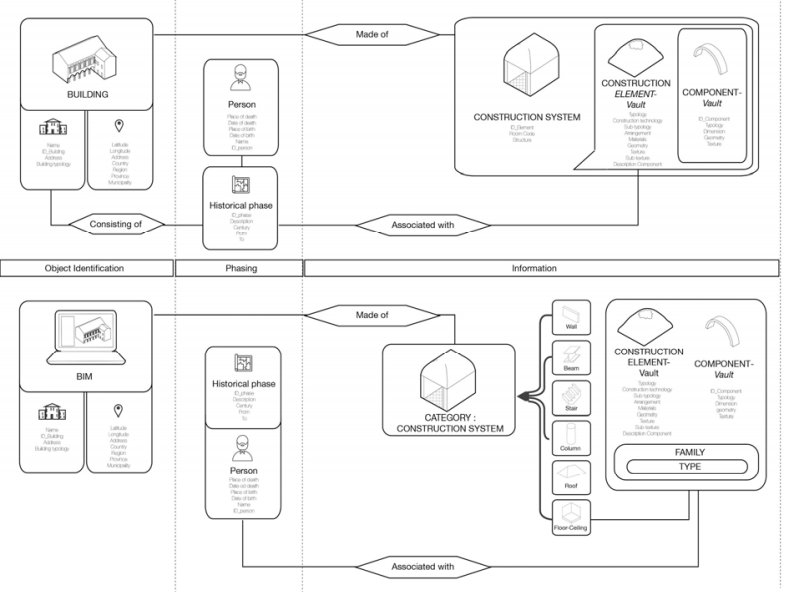

Figure 5: Logical model of the database vs. BIM library.

\section{Conclusion}

The model of Palazzo Magio is the result of a mapping process from a diverse set of remotely sensed survey data to generate a geometric framework that combines a digital model and a data information system. The generation of a highly accurate comprehensive digital model was supported by the point cloud and photogrammetry as primary sources and by archival documents as well as hand measurements taken on site for cross-referencing.

To sum up, it is necessary to understand how to make the database interact with the BIM model by overcoming limits due to data integration and modelling standards. The connection between the main geospatial inventory model and BIM libraries can take place through some precautions in setting up the creation of new information fields.

Following the logic of a bottom-up process, the database has a hierarchical structure in which every single component contributes to the reconstruction of an entire construction system, placing itself in a geographic (Fig. 6) context for knowledge dissemination.

If within a single platform one can proceed in a relatively serene manner, this does not happen if one has to imagine interoperability with other software with which connections have yet to be invented.

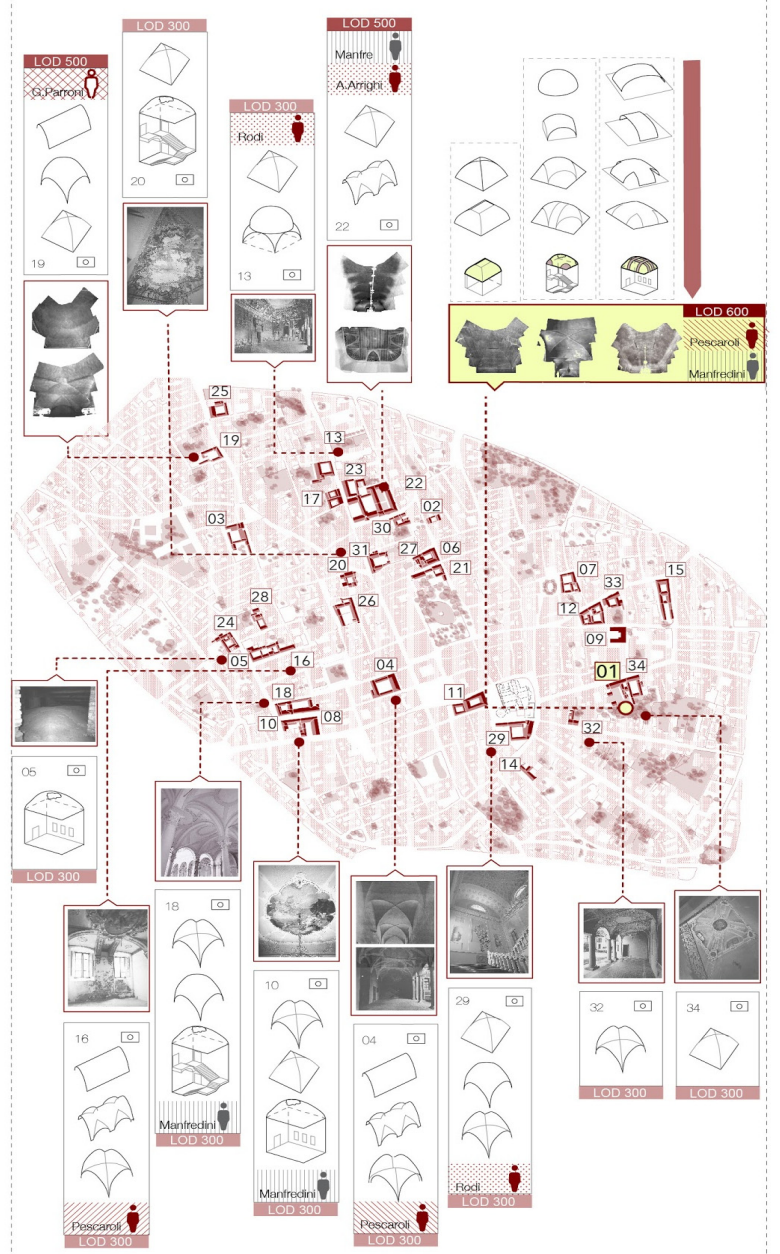

Figure 6: Mapping of main vaulted systems and their related information in Cremona.

\section{Acknowledgements}

The authors would like to thank Professors Raffaella Brumana and Fabrizio Banfi for the opportunity to explore a different modelling approach and to publish this punctual research following the latest studies on this topic in collaboration with the Gicarus Lab (DABC) at Polytechnic of Milan.

\section{References}

Arroyo Ohori, K., Biljecki, F., Diakité, A., Krijnen, T., Ledoux, H., \& Stoter, J. (2017). Towards an integration of GIS and BIM Data: what are the geometric and topological issues?. ISPRS Ann. Photogramm. Remote Sens. Spatial Inf. Sci., IV-4/W5, 1-8. https://doi.org/10.5194/isprs-annals-IV-4-W5-1-2017

Banfi, F., Chow, L., Reina Ortiz, M., Ouimet, C., \& Fai, S. (2018). Building Information Modeling for Cultural Heritage: The Management of Generative Process for Complex Historical Buildings. In: loannides M. (eds) Digital Cultural Heritage. Lecture Notes in Computer Science, 10605. Springer, Cham. https://doi.org/10.1007/978-3-319-75826-8_10

Brumana, R., Condoleo, P., Grimoldi, A., Banfi, F., Landi, A. G., \& Previtali, M. (2018a). HR LOD based HBIM to detect influences on geometry and shape by stereotomic construction techniques of brick vaults. Applied Geomatics, Special Issue GEORES2017. Geomatics and Restoration: Conservation of Cultural Heritage in the Digital Era. https://doi.org/10.1007/s12518-018-0209-3

Brumana, R., Condoleo, P., Grimoldi, A., Landi, A. G., Attico, D., Turrina, A., Banfi, F., \& Previtali, M. (2018b). HBIM Feeding Open Access Vault Inventory Through GeoDB HUB. In: Ioannides M. et al. (eds) Digital Heritage. Progress in Cultural Heritage: Documentation, Preservation, and Protection. EuroMed 2018. Lecture Notes in Computer Science, 11196. Springer, Cham. https://doi.org/10.1007/978-3-030-01762-0_3 
Brumana, R., Banfi, F., Cantini, L., Previtali, M., \& Della Torre, S. (2019). HBIM Level Of Detail - geometry - accuracy and survey analysis for architectural preservation. Int. Arch. Photogramm. Remote Sens. Spatial Inf. Sci. XLII-2/W11, 293-299. https://doi.org/10.5194/isprs-archives-XLII-2-W11-293-2019

Chow, L., \& Fai, S. (2017). Developing verification systems for building information models of heritage buildings with heterogeneous datasets. Int. Arch. Photogramm. Remote Sens. Spatial Inf. Sci., 42, $125-128$. https://doi.org/10.5194/isprs-archives-XLII-2-W5-125-2017

Chow, L., Graham, K., Grunt, T., Gallant, M., Rafeiro, J., \& Fai, S. (2019). The evolution of modelling practices on Canada's Parliament Hill: an analysis of three significant heritage building information models (HBIM). Int. Arch. Photogramm. Remote Sens. Spatial Inf. Sci. XLII-2N111, 419-426. https://doi.org/10.5194/isprs-archives-XLII-2-W11-419-2019

Dore, C., \& Murphy, M. (2017). Current State of the Art Historic Building Information Modelling. In International Archives of the Photogrammetry, Remote Sensing and Spatial Information Sciences - ISPRS Archives, 42, $185-92$. https://doi.org/10.5194/isprs-archives-XLII-2-W5-185-2017

Landi, A. G. (2011). Patrizi, notabili, costruzione della città. Fabbrica e tutela di palazzo Magio Grasselli a Cremona, 243.

Matrone, F., Colucci, E., De Ruvo, V., Lingua, A., \& Spanò, A. (2019). HBIM in a semantic 3d gis database. Int. Arch. Photogramm. Remote Sens. Spatial Inf. Sci. XLII-2/W11, 857-865. https://doi.org/10.5194/isprs-archives-XLII-2W11-857-2019

Oreni, D., Brumana, R., Georgopoulos, A., \& Cuca, B. (2014). HBIM library objects for conservation and management of built heritage. International Journal of Heritage in the Digital Era, 3(2), 321-334. https://doi.org/10.1260/20474970.3.2.32

Palacios Gonzalo, J. C. (1990). Trazas y cortes de cantería en el Renacimiento español. Ministerio de cultura, Instituto de conservacion y restauracion de bienes culturales, Madrid.

Pérouse de Montclos, J. M. (2000). Philibert De l'Orme architecte du roi (1514-1570). Paris, Mengè.

Piccoli, E. (2001). Le strutture voltate nell'architettura civile a Torino, 1660-1720. In: Dardanello, G. (ed.) Sperimentare l'architettura. Guarini, Juvarra, Alfieri, Borra e Vittone, pp. 38-96. Fondazione CRT, Torino.

Reina Ortiz, M., Yang, C., Weigert, A., Dhanda, A., Min, A., Gyi, M., Su, S., Fai, S., \& Santana Quintero, M. (2019). Integrating heterogeneous datasets in HBIM of decorated surfaces. Int. Arch. Photogramm. Remote Sens. Spatial Inf. Sci. XLII-2/W15, 981-988. https://doi.org/10.5194/isprs-archives-XLII-2-W15-981-2019

Vacca, G., Quaquero, E., Pili, D., \& Brandolini, M. (2018). GIS-HBIM integration for the management of historical buildings. Int. Arch. Photogramm. Remote Sens. Spatial Inf. Sci. XLII-2,1129-1135. https://doi.org/10.5194/isprs-archives-XLII2-1129-2018

Willis, R. (1842). On the construction of the vaults of the middle ages. Transactions of the Royal Institute of British Architects, 1(2), 1-61. Longman, Brown, Green and Longmans, London. 


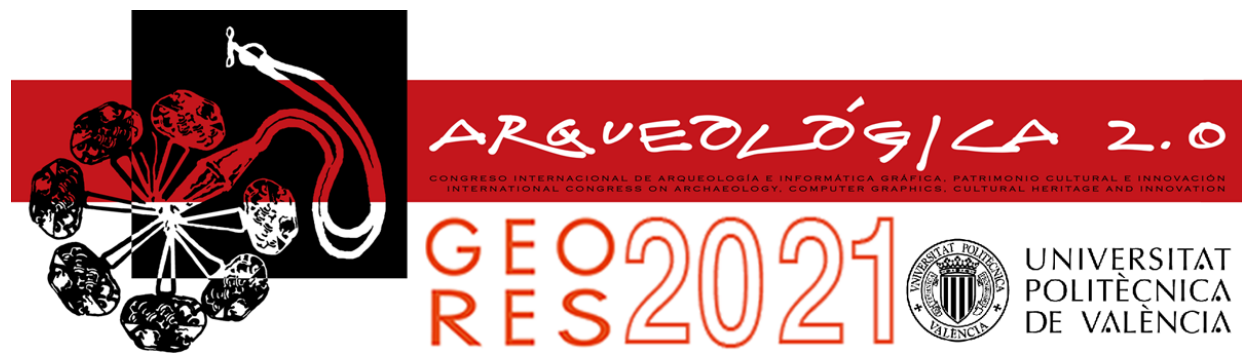

Proceedings of the joint international event $9^{\text {th }}$ ARQUEOLÓGICA

$2.0 \& 3^{\text {rd }}$ GEORES

Valencia (Spain).

26-28 April 2021

\title{
DOCUMENTATION OF A COMPLEX CULTURAL HERITAGE ASSET WITH INTEGRATED GEOMATIC SURVEY: THE MONTANARO BELL TOWER
}

\author{
Lorenzo Teppati Losè ${ }^{a,},{ }^{,}$Filiberto Chiabrando ${ }^{a}$, Francesco Novelli ${ }^{b}$, Giacomo Patrucco ${ }^{a}$, Stefano \\ Perria \\ a Laboratory of Geomatics for Cultural Heritage. Department of Architecture and Design (DAD), Politecnico di Torino, Viale Mattioli 39, \\ 10125 Torino, Italy. Iorenzo.teppati@polito.it; filiberto.chiabrando@polito.it; giacomo.patrucco@polito.it; stefano.perri@polito.it \\ b Department of Architecture and Design (DAD), Politecnico di Torino, Viale Mattioli 39, 10125 Torino, Italy. francesco.novelli@polito.it
}

\begin{abstract}
:
The research activities presented in this manuscript are focused on the documentation of a valuable built heritage asset: the Santa Marta bell tower (1769-1772), designed by the Italian architect Bernardo Antonio Vittone and located in the municipality of Montanaro (30 km North-East of Turin, Italy). The documentation of this complex palimpsest was designed to meet the requirements of the decay analysis and to provide a reference for the future restoration and valorisation project. To achieve these objectives a multi-scale and multi-sensor survey was designed and carried out exploiting several geomatics techniques (both range and image-based). The fieldwork activities were firstly dedicated to the creation and measurement of a reference topographic network to be used as a common local reference system for all the acquisitions as well as a series of control points (both inside and outside the bell tower) to be used for data orientation and accuracy assessment. Secondly, the exterior of the bell tower and its surroundings were imaged by means of an Unmanned Aerial Vehicle (UAV) and a set of Terrestrial Laser Scanning (TLS) acquisitions. The interior of the bell tower was acquired with two different rapid mapping approaches: using a handheld laser scanner based on the Simultaneous Localisation And Mapping (SLAM) technology and two different $360^{\circ}$ cameras. All the acquired data were processed following both consolidated and experimental approaches and then integrated to generate traditional 2D architectural drawings supported by added value metric products. Of particular interest are the tests connected with the processing of the SLAM data and $360^{\circ}$ images using a spherical photogrammetric approach that delivered preliminary encouraging results.
\end{abstract}

Keywords: built heritage, SfM, spherical photogrammetry, SLAM, multi-sensor, multi-scale

\section{Introduction and historical background}

Geomatics techniques are nowadays able to create threedimensional (3D) models in order to document extensive complexes or specific objects at a different scale. A 3D model in form of a point cloud or mesh could provide a useful base on which other products and further analyses can be extracted and carried out in the cultural heritage domain especially when different actors are involved (historian, restorers etc). In this scenario, the range-based and image-based techniques integrated with traditional topographic measurements could be considered as consolidated methodologies that can provide all the geometric information useful for architectural documentation. In the last years, two interesting new approaches related to the aforementioned techniques are even more employed for architectural surveys in complex environments (narrow areas or articulated spaces). These instruments are the handled laser scanner based on SLAM algorithms and $360^{\circ}$ cameras. Those sensors have been employed and integrated with UAV photogrammetry and TLS for the 3D survey of a very challenging structure: the municipality bell tower of Montanaro, a little village close to Torino in Piedmont (Italy). The bell tower, the old town hall, the brotherhood of S. Marta and the parish church form an indivisible whole in Montanaro, which well expresses the ideal integration between the secular community and the sacred space in a small eighteenth-century 'civic center' (Fig. 1). The fulcrum of the composition is the bell tower, about $48 \mathrm{~m}$ high. Built together with the municipal house between 1769 and 1772, on a project by Bernardo Antonio Vittone, it was the result of a complicated survey, in which the architect examined five different possible arrangements for the tower, in the space of a few tens of meters (Battaglio, 2000)

The lightening of the building towards the top and the decorative progression characterize the work, which becomes slender and jagged towards the top. A stone spiral staircase develops inside. The tower was built under the guidance of Mario Ludovico Quarini, who inherited the site after Vittone's death in 1770. 


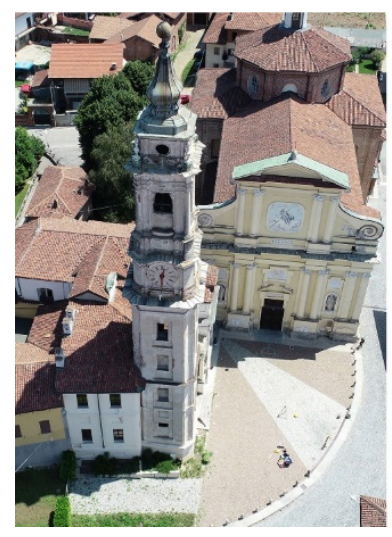

(a)

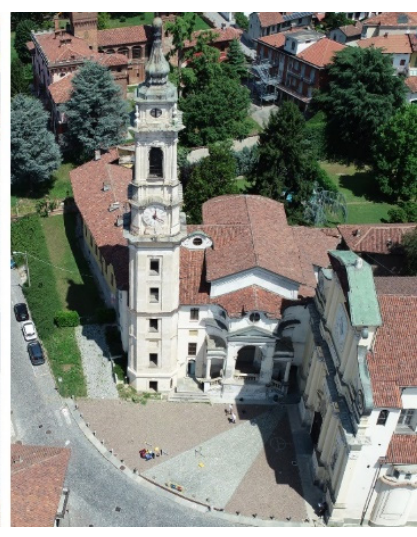

(b)
Figure 1: Aerial views of the bell tower and the complex of buildings around: a) west view; b) south view.

The bell tower is an ambitious work, which makes use of models and experiences accumulated over a lifetime of work (Canavesio, 2005; Portoghesi, 1966). Already prefigured in the projects designed in Rome in the 1730s, the Montanaro tower is indebted to similar projects by Juvarra, but also takes into account the experiences of Benedetto Alfieri. The latter, in fact, had set up very tall bell towers in Novara and Carignano a few years earlier. The construction is documented by a rare set of original drawings still preserved in Montanaro, which include plans, sections, elevations, and several 1:1 scale drawings of the main mouldings (two examples are shown in Figure 2). An original drawing for the Montanaro bell tower is also kept in Berlin, in the collections of the Art Library.

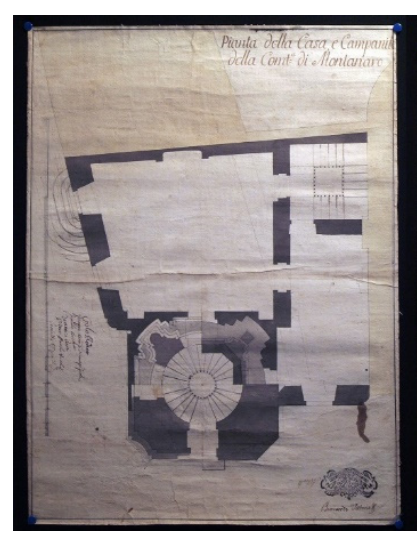

(a)

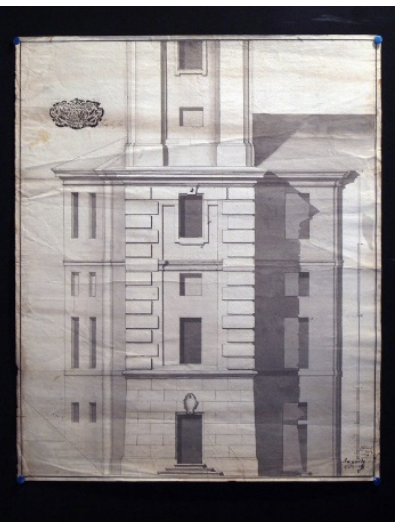

(b)
Figure 2: Two images of the drawings (Historical Archive of Montanaro) carried out by B. A. Vittone: a) the bell tower plan (27th of August 1769- left); b) the main façade (1769-1772).

\section{The documentation project and field acquisitions}

Due to the high complexity of the heritage asset to be surveyed, it was necessary to carefully design all the phases of the documentation project to achieve a 1:100 nominal map scale (accuracy for a 1:100 nominal scale should be under $0.02 \mathrm{~m}$ with a tolerance of $0.04 \mathrm{~m}$ ). This necessity was fulfilled through a preliminary on-site visit and a study of the already existing materials (e.g. drawings, images, etc.) available for the bell tower and a careful design of the survey operations and techniques adopted.

The first task was the setup and measurement of the topographic network to create a common reference network referenced to a global coordinate system with a 3D accuracy of few millimeters, fitting the requirements of a 1:100 nominal map scale. A total of five vertices were created and measured on the area in front of the tower and three additional vertices were materialized on some of the intermediate floors of the tower, to guarantee the possibility of measuring control points also on the interior spiral stairway (an architectural and structural element that highly characterize the tower). Besides, two of the ground vertices were measured also with Global Navigation Satellite System (GNSS) static technique, to georeference the reference network with respect to WGS84 Datum (UTM Zone 32N coordinates). Some of the measurement phases are shown in Figure 3. The choice of using only two vertices for georeferencing the topographic network was conditioned by the urban conformation of the area that does not allow to reach a good intervisibility between the interior part of the tower and the surrounding area. Moreover, due to the proximity between buildings in this area few locations were suitable to offer good satellite visibility. However, the data from the Continuously Operating Reference Stations (CORS) network available near this area were used to strengthen the network geometry and its computation.

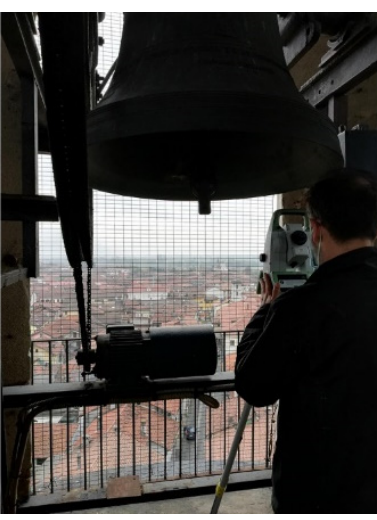

(a)

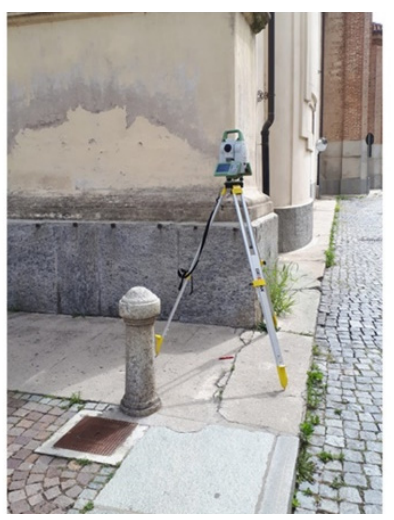

(b)
Figure 3: Some of the topographic measurements during fieldwork: a) from the belltower; b) from the area underneath

The second step of fieldwork consisted in the measurement of a set of control points with centimeter accuracy on the overall external surfaces of the tower to support the subsequent phases of data processing and accuracy assessment of the metric survey. A set of control points was also measured on the internal section of the tower to be used for the acquisitions performed in the spiral stairway; 98 control points were measured both outdoor and indoor.

During the phases of topographic measurement, several other geospatial data were acquired: UAVs photogrammetric flights, TLS acquisition, SLAM based acquisition and finally $360^{\circ}$ acquisitions.

UAVs acquisitions were performed with manual flights, due to the object structure and its location in the centre of a dense urban area. A total of 543 images, both nadiral and oblique, was acquired with the DJI Phantom 4 Pro, 
with a flight scheme parallel to each one of the tower facades and maintaining an average sensor - object distance of $5 / 6$ meters with the goal to have an average GSD of $0.003 \mathrm{~m}$. The acquisition scheme adopted during the flights is shown in Figure 4 while the main specifications of the Phantom 4 Pro camera are reported in Table 1. The flight plans were designed following consolidated approaches of the authors' research group, well documented in the literature (e.g. Achille et al., 2015; Calantropio, Chiabrando, Rinaudo, \& Teppati Losè, 2018; Murtiyoso, Grussenmeyer, \& Freville, 2017).

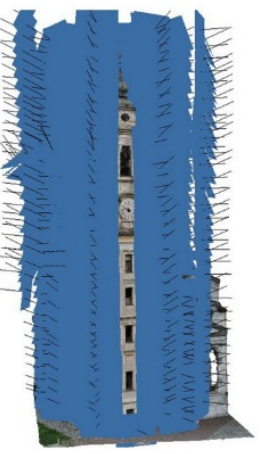

(a)

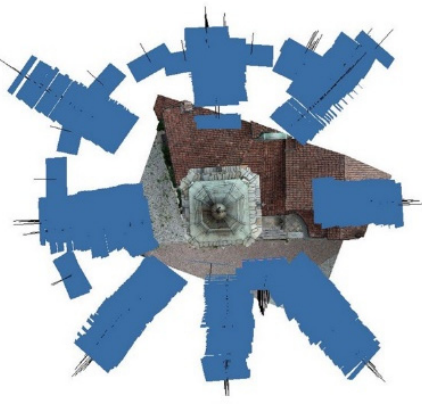

(b)
Figure 4: Acquisition scheme for the UAV flights (blue polygons are the scaled sensor frame, black lines the sensor position and attitude): a) Side view; b) top view.

Table 1: Main specifications of the DJI Phantom 4 Pro.

\begin{tabular}{c|c|c|c} 
Sensor & $\begin{array}{c}\text { Size } \\
(\mathrm{MP})\end{array}$ & $\begin{array}{c}\text { Focal length } \\
(\mathrm{mm})\end{array}$ & $\begin{array}{c}\text { Max image } \\
\text { dimension (pix) }\end{array}$ \\
\hline CMOS 1" & 20 & $24(35 \mathrm{eq})$ & $4864 \times 3648$
\end{tabular}

Traditional TLS acquisitions were completed using a Faro Focus $^{3 \mathrm{D}}$ X330. Scans positions and acquisition parameters were designed to cover the external square and part of the interior of the tower with eleven scans. Seven indoor scans were intended as a further ground truth element to validate the accuracies of other datasets and of the traditional 2D drawings, especially the horizontal and vertical cross-sections. Scan positions are shown in Figure 5 while the main specifications of the Focus $^{3 \mathrm{D}}$ X330 TLS are reported in Table 2. Due to accessibility and other operational constraints, it was not possible to perform a complete acquisition of the interior part of the tower, however, the data collected on the field are sufficient to work as ground truth reference, thanks also to the homogenous distribution of the control points.

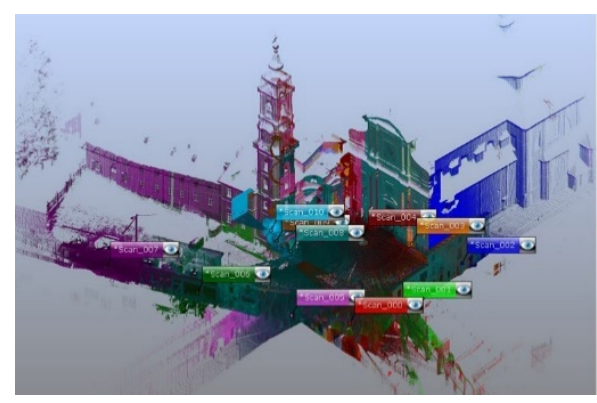

(a)

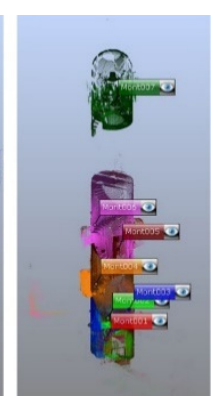

(b)
Figure 5: Scan position of the scans acquired on the field: a) bird's eye view; b) view of the interior of the tower.
Table 2: Main specifications of the Faro Focus X330.

\begin{tabular}{c|c|c|c} 
Range $(m)$ & $\begin{array}{c}\text { Measurement } \\
\text { Speed (pps) }\end{array}$ & $\begin{array}{c}\text { Ranging } \\
\text { error }(\mathrm{mm})\end{array}$ & Field of View \\
\hline $0.6-330$ & 976,000 & \pm 2 & $300 / 360^{\circ}$
\end{tabular}

Other range-based acquisitions were completed using the Zeb Revo RT system that is based on the SLAM technology. This relatively new technology has proven its efficiency also in the field of cultural heritage documentation as reported for example in (Chiabrando, Della Coletta, Sammartano, Spanò, \& Spreafico, 2018; Otero, Lagüela, Garrido, \& Arias, 2020; Tucci, Visintini, Bonora, \& Parisi, 2018). Four different acquisitions were carried out performing closed-loop, as suggested by the best practices for using this system (Riisgaard \& Blas, 2004) and testing different paths starting outdoor and covering indoor up to the higher accessible area. An example of two different scans performed with the Zeb Revo is shown in Figure 6 while the main specifications of the system are reported in Table 3.

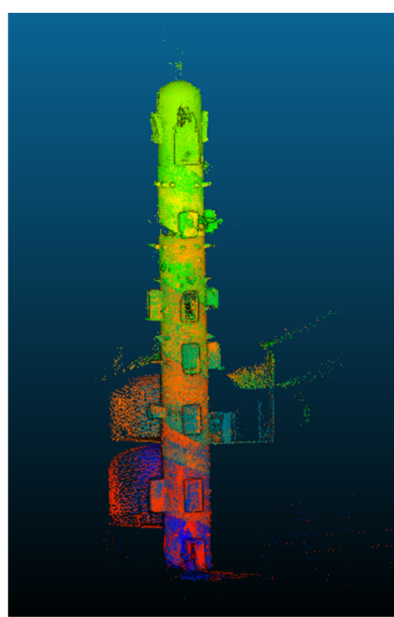

(a)

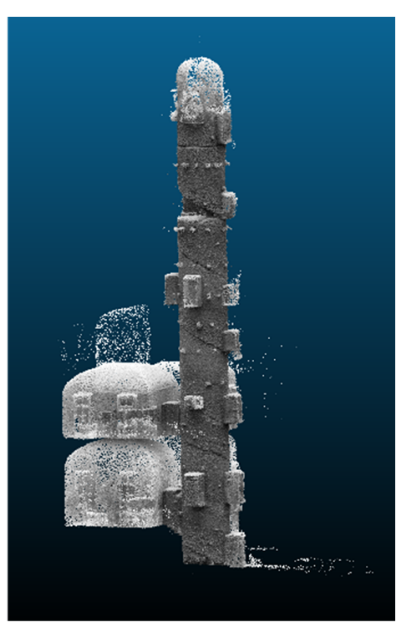

(b)
Figure 6: Example of two different scans completed with the Zeb Revo system: a) south view; b) west view.

Table 3: Zeb Revo main specifications.

\begin{tabular}{c|c|c|c} 
Range $(m)$ & $\begin{array}{c}\text { Measurement } \\
\text { Speed (pps) }\end{array}$ & $\begin{array}{c}\text { Relative } \\
\text { accuracy } \\
(\mathrm{cm})\end{array}$ & $\begin{array}{c}\text { Field of } \\
\text { View }\end{array}$ \\
\hline $15-30$ & $\sim 43,200$ & $1-3$ & $270^{\circ} / 100^{\circ}$
\end{tabular}

For the $360^{\circ}$ acquisition two different cameras were tested: the GoPro Fusion and the Kandao Qoocam 8k. The two cameras have similar specifications, except for the maximum resolution achievable: $5.2 \mathrm{k}$ for the GoPro and $8 \mathrm{k}$ for the Kandao. The same acquisition path was adopted for both cameras: a round-trip walk from outside the tower up to the highest accessible area, the bell chamber. For each camera a video at maximum resolution was recorder with an average duration of 7 minutes. An example of a spherical images acquired with the GoPro Fusion is shown in Figure 7 while the main specifications of the two cameras are reported in Table 4. After its first development (D'Annibale \& Fangi, 2009; Fangi, 2007; Fangi \& Nardinocchi, 2013) spherical photogrammetry is facing a second development phase thanks to the enhancement of the Structure from Motion (SfM) approaches, as demonstrated by recent literature (Abate, Toschi, Sturdy-Colls, \& Remondino, 2017; 
Barazzetti, Previtali, \& Roncoroni, 2018; Fangi, Pierdicca, Sturari, \& Malinverni, 2018; Gottardi \& Guerra, 2018; Teppati Losè, Chiabrando, \& Spanò, 2018).

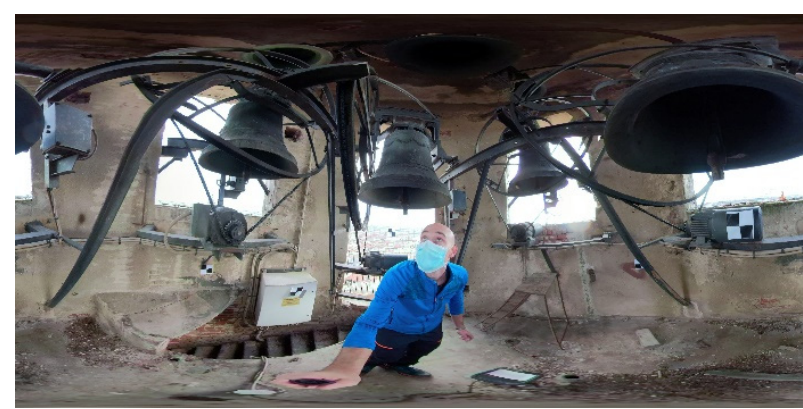

Figure 7: Example of spherical images (equirectangular projection) acquired in the bell tower with the GoPro Fusion.

Table 4: Main specifications of the two $360^{\circ}$ cameras used in the documentation project.

\begin{tabular}{c|c|c} 
Camera & Sensor & Max video resolution \\
\hline GoPro Fusion & CMOS & $5.2 \mathrm{~K} \mathrm{(5228^{ \star } 2 6 2 4 -}$ \\
& $1 / 2.3 "$ & $30 \mathrm{fps})$ \\
Kandao Qoocam 8k & CMOS & $8 \mathrm{~K}\left(7680^{\star} 3840-30 \mathrm{fps}\right)$ \\
& $1 / 2.3 "$ &
\end{tabular}

\section{Data processing and results}

The acquired data were processed following consolidated workflows that will be briefly described in the following section. UAVs collected images were processed in a wellknown SfM software (Agisoft Metashape) following the standard pipeline: image matching and tie points extraction, Bundle Block Adjustment (BBA), densification and generation of added value products such as Digital Surface Model (DSM) and orthophoto. The results of the photogrammetric processing are reported in Table 5; a small portion of the derived 3D model is shown in Figure 8 , demonstrating the very high level of detail.

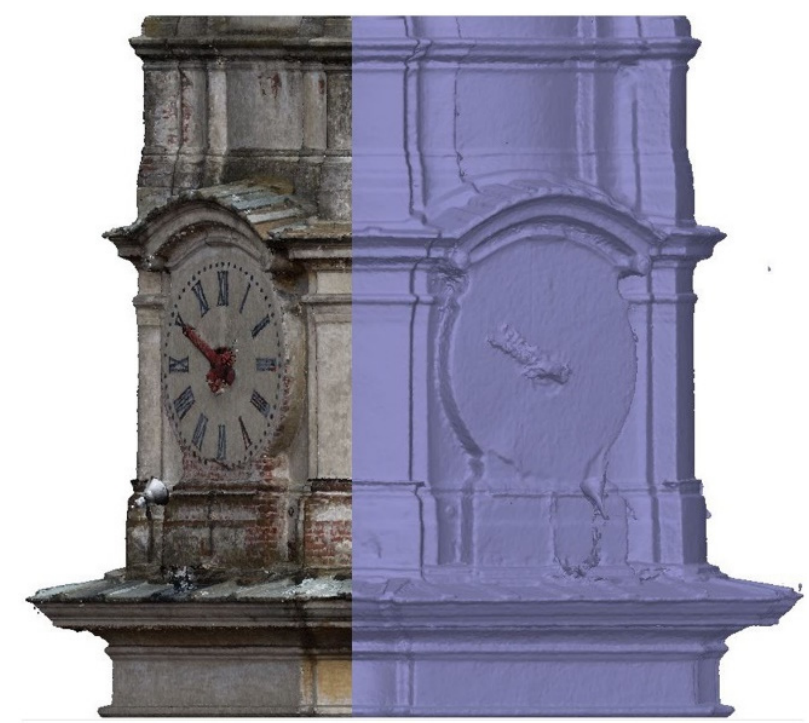

Figure 8: Portion of the 3D model derived from the UAVs dataset processing: point cloud (left with RGB value) and mesh model (right in violet).
Table 5: UAVs photogrammetric processing main results.

\begin{tabular}{c|c|c|c|c|c} 
Images & \multicolumn{2}{|c|}{ GCPSs } & \multicolumn{2}{|c|}{ CPS } & $\begin{array}{c}\text { GSD } \\
(\mathrm{m})\end{array}$ \\
& $N^{\circ}$ & $\begin{array}{c}3 D \text { RMSe } \\
(\mathrm{m})\end{array}$ & $N^{\circ}$ & $\begin{array}{c}3 D \text { RMSe } \\
(\mathrm{m})\end{array}$ & \\
\hline 543 & 27 & 0.009 & 8 & 0.008 & 0.003
\end{tabular}

The TLS dataset was processed inside the software Faro SCENE and two different approaches were followed for the outdoor and indoor dataset, as reported in (Chiabrando, Spanò, Sammartano, \& Teppati Losè, 2017). The outdoor scans were firstly registered using an Iterative Closest Points (ICP) algorithm and then georeferenced using the available control points measured. For the indoor dataset, the control points were used for both the registration and georeferencing phase, due to the different and more complex geometry of the scan positions influenced by the environmental constraints. The results of the processing of the two datasets are reported in Table 6.

Table 6: TLS dataset processing main results.

\begin{tabular}{c|c|c|c}
$\begin{array}{c}\text { Scan } \\
\text { Group }\end{array}$ & $\begin{array}{c}\text { Number } \\
\text { of scans }\end{array}$ & $\begin{array}{c}\text { Mean scan points } \\
\text { tension }(\mathrm{m})\end{array}$ & $\begin{array}{c}\text { Mean Target } \\
\text { tension }(\mathrm{m})\end{array}$ \\
\hline Outdoor & 11 & 0.002 & 0.013 \\
Indoor & 7 & n.a. & 0.004
\end{tabular}

As regards the scans acquired with the ZEB Revo RT through the use of SLAM-based algorithms, an optimization of the four-point clouds is required (before proceeding with the registration of the point clouds in the same reference system adopted for the other data collected during the survey).

During the data processing phase, the data derived from the ZEB Revo RT were processed using the GeoSLAM Hub platform following the standard workflow.

After a preliminary procedure during which the different point clouds have been roughly manually aligned, the four acquisitions have been processed with the "merge" function of the GeoSLAM Hub platform. This process allows us to join the different scans in the same relative reference system; besides, an optimization of the point cloud is performed in order to improve the quality of the finals results. The "merge" function allows fixing the possible misalignments and the drifts errors affecting the raw scan, which are, in many cases, not detectable through a simple visual inspection. In fact, besides the high complexity of the surveyed tower, one of the reasons why different point clouds have been acquired characterized by a high reciprocal overlapping - is due to the possibility to optimize each of the acquired point clouds. During this phase, following the standard processing strategy adopted ZEB Revo RT, a coregistration between scans is performed by non-rigid transformation. For every scan involved in the merge reprocessing, the SLAM algorithm is recomputed, mutually using the features of the adjacent cloud, in order to solve the aforementioned misalignment issues.

At the end of these optimization procedures, the data was then registered using as reference the indoor LiDAR scans, to align the point cloud acquired with the ZEB Revo $\mathrm{RT}$ in the reference system of the point clouds generated using the other sensors. An ICP registration has been performed using the open-source platform CloudCompare (Fig. 9a). The RMSE (Root mean square 
error) observable at the end of the ICP registration is approximately around $4 \mathrm{~cm}$. In order to check the final accuracy of the acquired data, a distance analysis has been carried out between the two datasets (LIDAR and ZEB) in the considered area of overlapping. As observed in Figure 9b, it is possible to see that the discrepancies are lower than $5 \mathrm{~cm}$ in approximately $85 \%$ of the SLAM dataset).

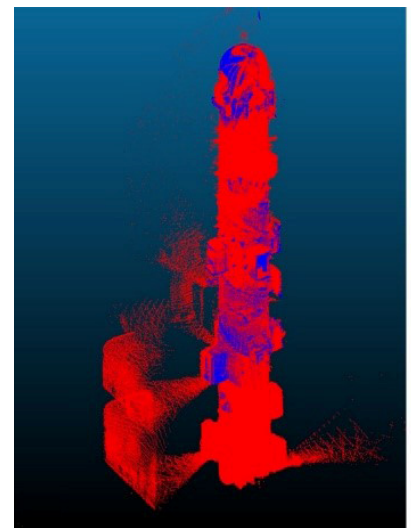

(a)

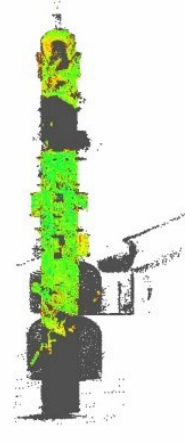

(b)
Figure 9: C2C: a) ICP registration between LiDAR point cloud (ground truth reference, blue point cloud) and data derived from ZEB Revo RT (aligned scan, red point cloud); b) Discrepancies between the LiDAR point cloud and the registered ZEB Revo RT scan.

Lastly, the processing of the $360^{\circ}$ dataset required a less consolidated approach, due to the recent new developments of spherical photogrammetry. The first step consisted in the extraction of a series of frames from the $360^{\circ}$ videos (one out of 30 , i.e. around 1 frame/second considering the data were acquired at $30 \mathrm{fps}$ ) that were then processed inside Agisoft Metashape. Spherical photogrammetry is nowadays challenging under several aspects and despite tailored tests are still ongoing, the first outcomes are encouraging. The main parameters of the processing of spherical data are reported in Table 7 while an extract of the acquisition geometry is shown in Figure 10. For the purposes of this contribute only the dataset derived from the GoPro Fusion is reported and discussed. Tests and analyses on the dataset acquired with the Qoocam $8 \mathrm{~K}$ are still under development and will be part of a wider research on the accuracy assessment and best practices on the use of $360^{\circ}$ cameras for the documentation of cultural heritage.

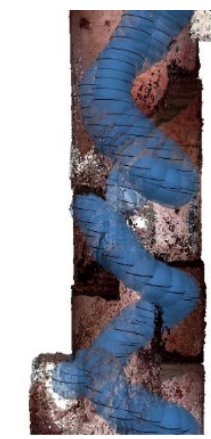

Figure 10: Extract of the acquisition geometry of the $360^{\circ}$ dataset (blue spheres represent camera position, black letters are the name of the single images).
Table 7: Spherical photogrammetry processing main results.

\begin{tabular}{c|c|c|c|c|c} 
Images & \multicolumn{2}{|c|}{ GCPSs } & \multicolumn{2}{c|}{ CPS } & $\begin{array}{c}\text { Average } \\
\text { GSD } \\
(\mathrm{m})\end{array}$ \\
\hline 319 & 17 & 0.048 & 5 & 0.054 & 0.002 \\
& $N^{\circ}$ & $\begin{array}{c}3 D \\
(\mathrm{~m})\end{array}$ & $N^{\circ}$ & $\begin{array}{c}3 D \mathrm{RMSe} \\
(\mathrm{m})\end{array}$ &
\end{tabular}

However, some preliminary analyses were conducted on the point cloud derived from the GoPro Fusion spherical images photogrammetric processing to start evaluating its accuracy and validating its use in this specific documentation project. A first analysis of the $360^{\circ}$ point cloud was performed with the 3D Reshaper software: a Cloud to Cloud (C2C) distance analysis was carried out using the TLS point cloud as reference. This analysis was performed only on a small portion of the point clouds: a graphical representation of the point cloud distances is shown in Figure 11, while the percentages of the points that are included in different ranges of distances are reported in Table 8.

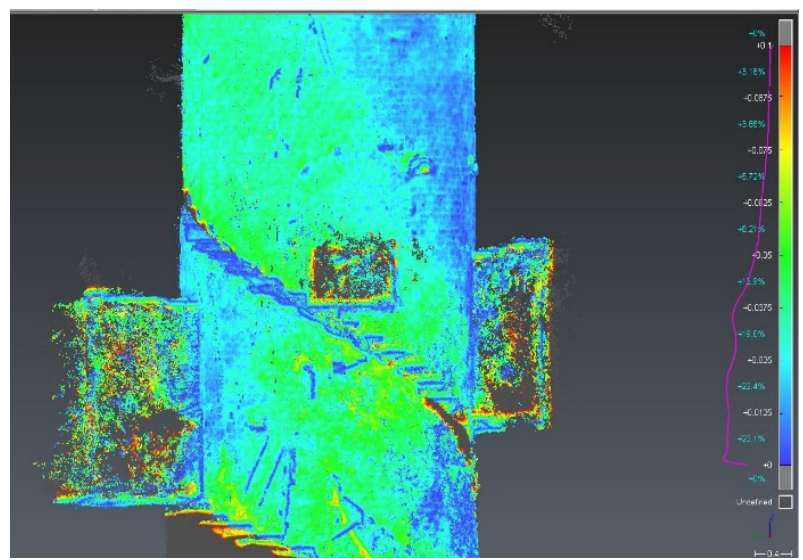

Figure 11: C2C distance analysis between the TLS and $360^{\circ}$ derived point cloud.

Table 8: C2C comparison between TLS and spherical point clouds.

\begin{tabular}{c|c} 
Ranges of distances $(m)$ & Percentages of the points \\
\hline $0.00-0.02$ & $37 \%$ \\
$0.02-0.04$ & $32 \%$ \\
$0.04-0.06$ & $17 \%$ \\
$0.06-0.10$ & $14 \%$
\end{tabular}

It is interesting to notice that, at least for the portion of the $360^{\circ}$ point cloud considered in this analysis, almost $70 \%$ of points presents a deviation from the TLS point cloud that is less than $0.04 \mathrm{~m}$, confirming the accuracy of the photogrammetric processing that was already declared for the GCPS RMSE in Table 7.

Another type of analysis was performed on the 2D polyline derived from a thin horizontal section of the different point clouds and was aimed to verify the geometrical accuracy of the two rapid mapping approaches tested for the documentation of the bell tower. For this analysis, the same thin horizontal section (0.007 $\mathrm{m}$ width) was replicated in three different point clouds: TLS, SLAM and $360^{\circ}$ derived using the PointCab software. From these sections, three different horizontal profiles were drawn in a CAD environment (the subjectivity introduced by the human intervention shall be taken into account in these analyses) and then compared 
inside the 3D Reshaper software. Also for this analysis, the TLS data was used as a reference and it was then possible to compare the other two datasets with the TLS. The plot of the distances between different horizontal profiles as shown in Figure 12.

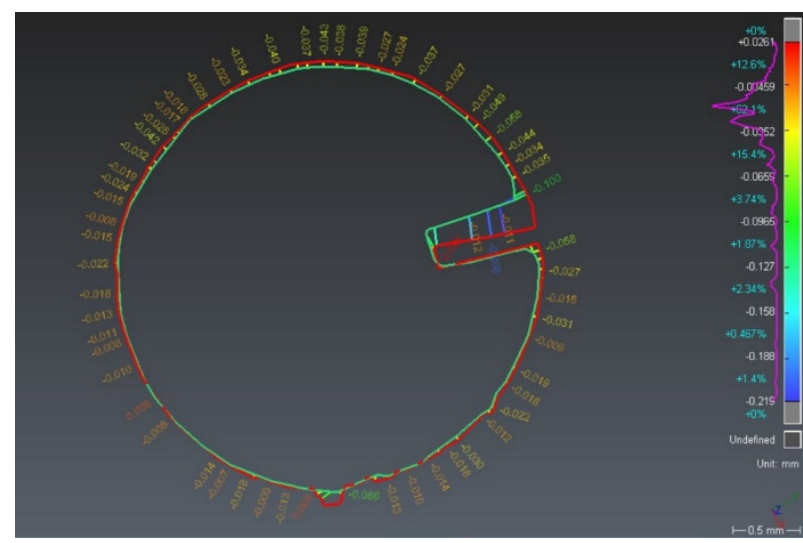

(a)

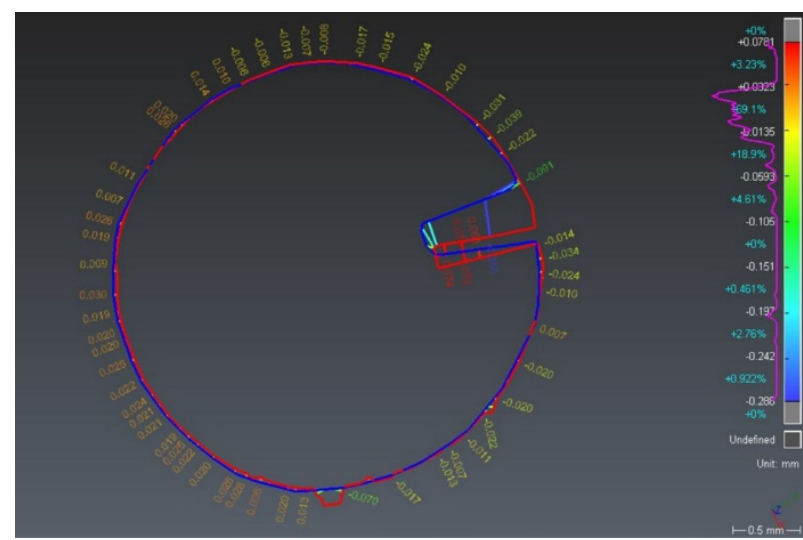

(b)

Figure 12: Distance analyses between 2D horizontal profiles derived from thin sections of the different point clouds. Red lines are extracted from the TLS dataset, green line (a) is extracted from $360^{\circ}$ dataset while the blue one (b) is extracted from the SLAM dataset)

\section{Generation of the required metric products}

One of the deliverables planned for the documentation project is the generation of traditional $2 \mathrm{D}$ architectural drawings to support further decay analyses and future restoration projects. This work is generally a timeconsuming operation that requires a large effort from the involved operators. In the presented experience it was made more difficult from the structure of the tower and its morphological complexity. Overall, this step was successfully completed in a reasonable amount of time thanks to the integration between the different datasets acquired and processed that allowed representing all the architectonical features and principal characteristics of the bell tower. Moreover, the availability of the $360^{\circ}$ videos allowed a visual immersive inspection of the tower enabling a virtual survey to visually inspect the area of interest and solving any possible interpretation doubt in the architectural drawing phase. Several drawings were then realized, enriched also from the radiometric content of the orthoimagery, as shown in Figure 13. Despite the delivery of the aforementioned products in a GeoPDF format enables end-user to perform additional spatial analysis (e.g. 3D measures) or to fine-tune how to display the architectural drawings (e.g. switching layers on and off), further experimentations are under development to test different solution for an easier and more effective exploitation of the added value products from the enduser perspective (i.e. restorers in this case). This goal can be achieved by taking advantage of different web applications, which deployment will be better described in a future contribute, and that allows to share different types of contents such as 3D models or spherical images/videos.

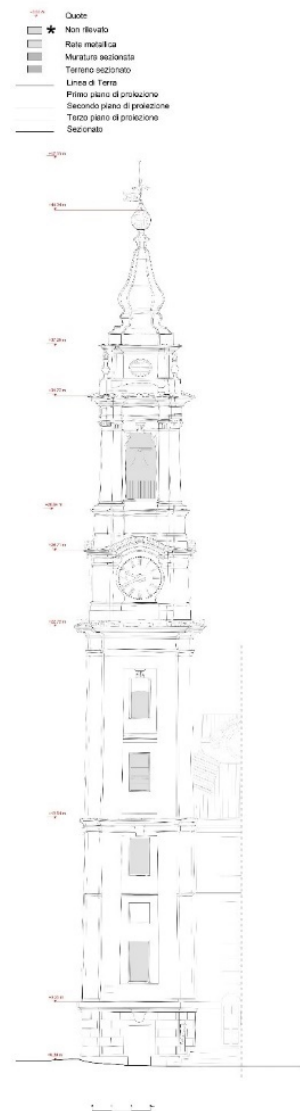

(a)

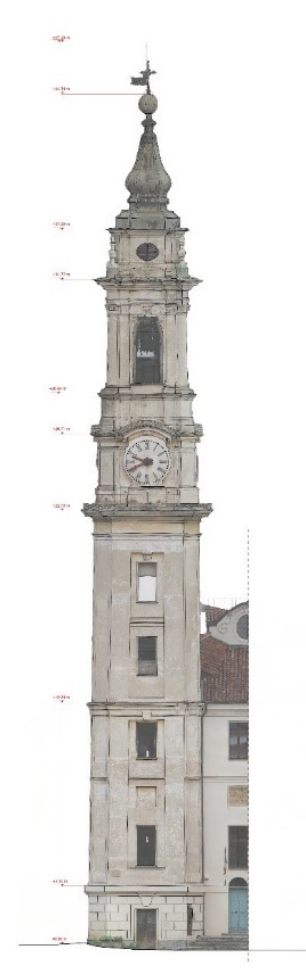

(b)
Figure 13: Example of one of the 2D architectural drawing (south facade): a) based on the $3 \mathrm{D}$ integrated survey; b) overlayed with the orthoimage.

\section{Conclusions and further perspectives}

The documentation project of the Montanaro bell tower represents a good opportunity to showcase the crucial role of geomatics in supporting the restoration domain thanks to an interdisciplinary approach.

Geomatics experts can design the proper 3D survey only by means of effective interaction with the restoration experts, understanding the specific requirements especially in terms of accuracy, level of detail and final products.

In this specific case study, the peculiar conformation of the bell tower, especially the indoor spiral stairway, and its value as heritage assets, represented the perfect test 
field to adopt and test cutting edge 3D survey approaches.

The two more consolidated approaches, UAV and TLS acquisitions, have been successfully deployed for the acquisition of geospatial data and the generation of added value products with the proper 3D accuracy level. In parallel, they have been flanked by two additional experimental approaches: handheld laser based on the SLAM technology and spherical photogrammetry.

Mobile Mapping Systems are more developed if compared with spherical photogrammetry, however, their deployment in the field is still characterized by some issues (e.g. the georeferencing of the acquired data, the association of RGB values to the SLAM point cloud, the metrical and geometrical accuracy) that need to be further analysed, especially if connected with the documentation of cultural heritage.

Spherical photogrammetry has raised new interest in the geomatics community in the last few years thanks to the latest development of SfM algorithms that allowed to effectively process also this category of images. The accuracy and robustness of these approaches still need to be validated, as well as the most efficient strategies to adopt for their processing. In the planned development of this research project, the difference between the two tested $360^{\circ}$ cameras will be evaluated; different processing solutions will be tested (stitched or single images) and the results will be further compared with more consolidated techniques adopted as ground truth.

Lastly, it has to be remarked that a streamlined sharing and remote access to survey-based 3D data is a trending topic of high interest for several application domains and research communities, also due to the movement limitations imposed by the Covid-19 pandemic emergency in 2020.

\section{Acknowledgements}

The authors would like to acknowledge the Montanaro Municipality for its availability and support in all the fieldwork phases. The authors would also like to thank Prof. Fabio Giulio Tonolo for the support during the field activities and the review of the draft manuscript.

\section{References}

Abate, D., Toschi, I., Sturdy-Colls, C., \& Remondino, F. (2017). A low-cost panoramic camera for the 3d documentation of contaminated crime scenes. International Archives of the Photogrammetry, Remote Sensing and Spatial Information Sciences - ISPRS Archives, 42(2W8), 1-8. https://doi.org/10.5194/isprs-archives-XLII-2-W8-1-2017

Achille, C., Adami, A., Chiarini, S., Cremonesi, S., Fassi, F., Fregonese, L., \& Taffurelli, L. (2015). UAV-Based Photogrammetry and Integrated Technologies for Architectural Applications-Methodological Strategies for the After-Quake Survey of Vertical Structures in Mantua (Italy). Sensors, 15(7), 15520-15539. https://doi.org/10.3390/s150715520

Barazzetti, L., Previtali, M., \& Roncoroni, F. (2018). Can we use low-cost 360 degree cameras to create accurate 3D models? In International Archives of the Photogrammetry, Remote Sensing and Spatial Information Sciences ISPRS Archives, 42, 69-75. https://doi.org/10.5194/isprs-archives-XLII-2-69-2018

Battaglio, M. (2000). L'ultimo Vittone. Il campanile di Montanaro nuovi rilievi e fonti d'archivio. Edizioni Litoart, Torino 2000.

Calantropio, A., Chiabrando, F., Rinaudo, F., \& Teppati Losè, L. (2018). Use and evaluation of a short range small quadcopter and a portable imaging laser for built heritage 3D documentation. In International Archives of the Photogrammetry, Remote Sensing and Spatial Information Sciences - ISPRS Archives, 42, 71-78. https://doi.org/10.5194/isprs-archives-XLII-1-71-2018

Canavesio, W. (2005). Il voluttuoso genio dell'occhio. Nuovi studi su Bernardo Antonio Vittone. Ages Arti Grafiche, Torino 2005.

Chiabrando, F., Della Coletta, C., Sammartano, G., Spanò, A. T., \& Spreafico, A. (2018). "TORINO 1911" project: A contribution of a SLAM-based survey to extensive 3D heritage modeling. In International Archives of the Photogrammetry, Remote Sensing and Spatial Information Sciences - ISPRS Archives, 42, $225-234$. https://doi.org/10.5194/isprs-archives-XLII-2-225-2018

Chiabrando, F., Spanò, A. T., Sammartano, G., \& Teppati Losè, L. (2017). UAV oblique photogrammetry and LiDAR data acquisition for 3D documentation of the Hercules Fountain. Virtual Archaeology Review, 8(16), 83. https://doi.org/10.4995/var.2017.5961

D’Annibale, E., \& Fangi, G. (2009). Interactive Modelling by Projection of Oriented Spherical Panorama -- Ad Deir, Petra, Jordan. In 3D-ARCH 2009: $3 D$ Virtual Reconstruction and Visualization of Complex Architectures XXXVIII. https://doi.org/10.1007/s00421-007-0565-x

Fangi, G. (2007). The Multi-image spherical Panoramas as a tool for Architectural Survey. XXI International CIPA Symposium, (October), 0256--1840.

Fangi, G., \& Nardinocchi, C. (2013). Photogrammetric processing of spherical panoramas. Photogrammetric Record, 28(143), 293-311. https://doi.org/10.1111/phor.12031

Fangi, G., Pierdicca, R., Sturari, M., \& Malinverni, E. S. (2018). Improving spherical photogrammetry using $360^{\circ} \mathrm{OMNI-}$ Cameras: Use cases and new applications. In International Archives of the Photogrammetry, Remote Sensing and Spatial Information Sciences - ISPRS Archives, 42, 331-337). https://doi.org/10.5194/isprs-archives-XLII-2-3312018 
Gottardi, C., \& Guerra, F. (2018). Spherical images for cultural heritage: Survey and documentation with the NIKON KM360. In International Archives of the Photogrammetry, Remote Sensing and Spatial Information Sciences - ISPRS Archives, 42, 385-390. https://doi.org/10.5194/isprs-archives-XLII-2-385-2018

Murtiyoso, A., Grussenmeyer, P., \& Freville, T. (2017). Close range uav accurate recording and modeling of St-Pierre-LeJeune Neo-Romanesque church in Strasbourg (France). International Archives of the Photogrammetry, Remote Sensing and Spatial Information Sciences - ISPRS Archives, 42(2W3), 519-526. https://doi.org/10.5194/isprsarchives-XLII-2-W3-519-2017

Otero, R., Lagüela, S., Garrido, I., \& Arias, P. (2020). Mobile indoor mapping technologies: A review. Automation in Construction. Elsevier B.V. https://doi.org/10.1016/j.autcon.2020.103399

Portoghesi, P. (1966). Bernardo Vittone. Un architetto tra Illuminismo e Rococò, Ed. dell'Elefante, Roma, 1966.

Riisgaard, S., \& Blas, M. R. (2004). SLAM for Dummies. Massachusetts Institute OfTechnology Projects, 1-127.

Teppati Losè, L., Chiabrando, F., \& Spanò, A. (2018). Preliminary evaluation of a commercial 360 multi-camera RIG for photogrammetric purposes. In International Archives of the Photogrammetry, Remote Sensing and Spatial Information Sciences - ISPRS Archives , 42, 1113-1120). https://doi.org/10.5194/isprs-archives-XLII-2-1113-2018

Tucci, G., Visintini, D., Bonora, V., \& Parisi, E. (2018). Examination of Indoor Mobile Mapping Systems in a Diversified Internal/External Test Field. Applied Sciences, 8(3), 401. https://doi.org/10.3390/app8030401 


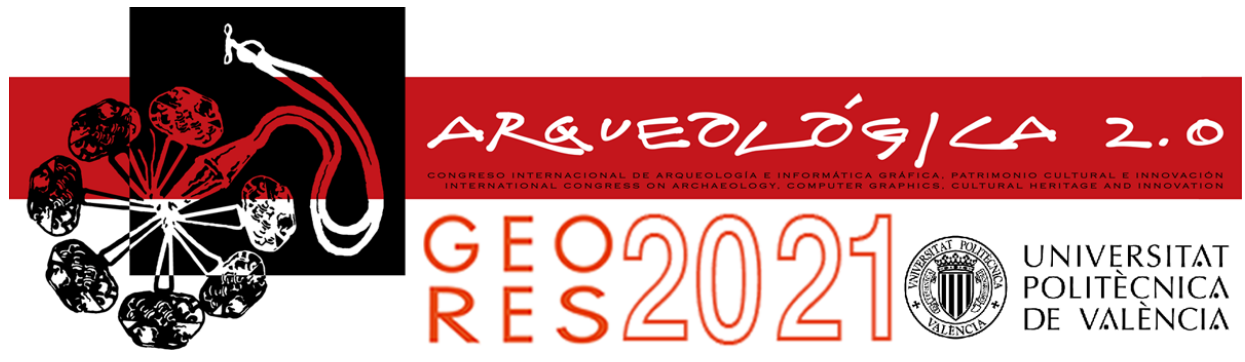

\title{
AN INFORMATIVE TOOL FOR THE PRESERVATION OF THE WOODEN ENCIRCLING TIE ROD OF THE DOME OF SANTA MARIA DEL FIORE, IN FLORENCE
}

\author{
Sofia Celli*, Federica Ottoni \\ Department of Engineering and Architecture, Università di Parma, Viale Parco Area delle Scienze 181/A, 43124 Parma, Italy. \\ sofia.celli@unipr.it; federica.ottoni@unipr.it
}

\begin{abstract}
:
Proceeding under the assumption that restorers need to become more involved in the definition of the most advanced management tools for historic buildings, this paper aims to offer a contribution to the "informative" feature of the H-BIM methodology. Indeed, over the past few years, the issues addressed by scholars mostly concerned surveying and modelling techniques, whereas the organization of external data within the virtual model has rarely been considered. The necessity of defining a new operative tool for the maintenance of the wooden chain encircling the dome of Santa Maria del Fiore represented an occasion to develop an informative model that attempts to confer centrality to the knowledge process as a whole. Attention was thus focused on the articulation of the informative apparatus to be associated to the 3D model, as well as to its practical implications in terms of conservation.
\end{abstract}

Keywords: informative model, planned preventive conservation, Santa Maria del Fiore's dome, wooden hooping tie rod

\section{Introduction}

The continuous enhancement of surveying and modelling technologies has been the focal point of the research concerning the relationship between geomatics and restoration over the past few years (Brumana et al., 2018; Banfi, Fai, \& Brumana, 2017; Castagnetti et al., 2017; Tommasi, Achille, \& Fassi 2016). However, in order for the H-BIM methodology to further improve its efficacy as a tool to support conservation activities, it seems opportune to start focusing also on the informative apparatus to be associated with the 3D model (Bruno \& Roncella, 2019). In particular, it might be useful to identify which data are the most useful in terms of conservation and how they could most effectively be organized to help planning and performing inspections and maintenance.

Clearly, given the intrinsic specificity of historical heritage, it will not be possible to develop a fixed system to be slavishly applied to any case study. The definition of a few guidelines might however help to structure operative and conservation-driven information models.

The wooden hooping tie-rod encircling the dome of Santa Maria del Fiore, hence became the occasion to develop an informative model which, focusing on data organization, aims at validly supporting all those conservation activities that are fundamental to ensure the preservation of this famous monumental complex.

\section{The wooden hooping tie rod of Brunelleschi's dome}

As well known, when the construction of the Florentine cathedral's dome started in 1420, masons followed the detailed instructions provided by the work program outlined by Filippo Brunelleschi and Lorenzo Ghiberti. Among other directives, the two architects pointed out the necessity of encircling the dome with a complex system of hoops comprising several orders of stone, wood and iron tie rods (Ottoni \& Blasi, 2015). Although not expressly declared, the aim of such expedients was to absorb the physiological horizontal thrust of the masonry dome that, at the time, had already been empirically acknowledged as the main cause of collapse of this type of structures (Como, Iori, \& Ottoni, 2019; Ottoni \& Blasi, 2016). While the four stone chains - partly visible - have been widely analyzed and the actual presence of iron hoops is yet to be verified (Corazzi \& Conti, 2011), little attention has been paid to the wooden ring located at the base of the dome (Figs. 1-3).

Composed of twenty-four chestnut beams connected by means of metallic joints, the hoop - installed between 1423 and 1424 - was supposed to be the first of four, but it ended up being the only one. Indeed, the amendments made to the original construction program in 1426 resulted in the dismissal of any further wooden tie (Mainstone, 1970), which would have however proven

‘Corresponding Author: Sofia Celli, sofia.celli@unipr.it 
somehow superfluous, considering that the maximum stress is recorded in the proximity of the vault's springer.

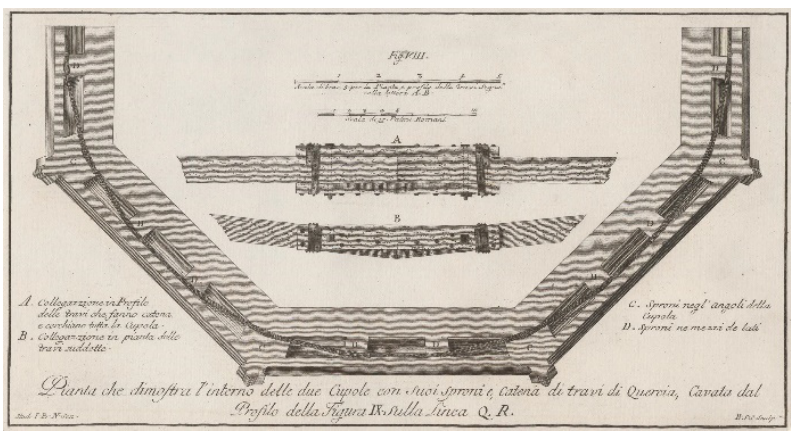

Figure 1: The wooden tie as represented by Giovan Battista Nelli at the end of the XVII century (Sgrilli, 1733 - tav. VII).

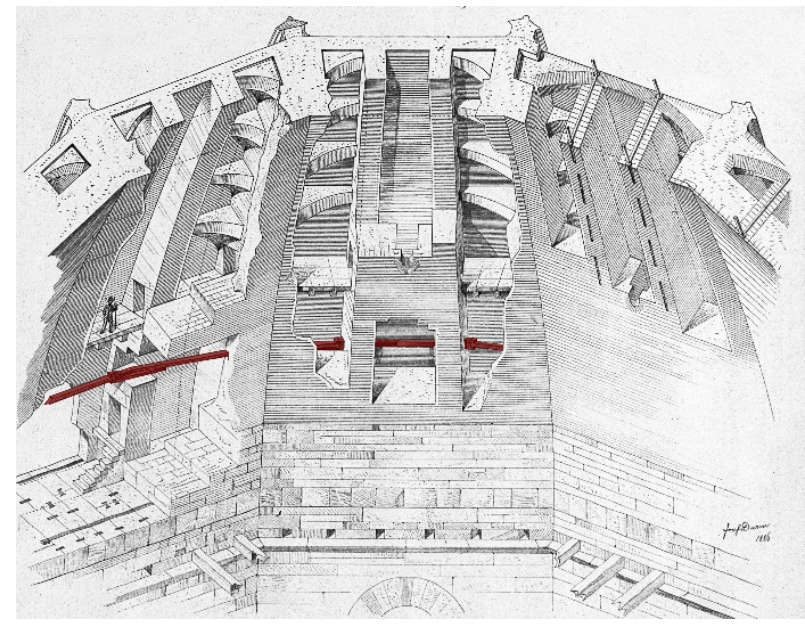

Figure 2: The structural arrangement of Santa Maria del Fiore's dome in Josef Durm representation. Marked in red the wooden hooping tie rod (Durm, 1887).

Ever since its construction, the wooden chain surrounding Santa Maria del Fiore's dome has thus been the subject of an intense debate due both to the fact that only one out of the four foreseen hoops was actually built and to the material choice (wood), which does not seem particularly fitting for an element designed to last in time. Responsible for causing significant disagreements between Brunelleschi and Ghiberti as soon as the time of its installation (Manetti, 1976), this device has kept arousing the interest of scholars who, over the centuries, have provided the most diverse interpretations regarding its function and its contribution to the Dome in terms of stability. As a matter of fact, although many have resolutely recognized the wooden structure to be an element designed to counteract the horizontal thrusts resulting from hoop tension (Fontana, 1696; Saalman, 1980; Tampone, 1996; Blasi, Ottoni, Coïsson, \& Tedeschi, 2017), many others claim that it was a device built exclusively to gain greater control of the building site or even useless (Prager \& Scaglia, 1970; Sanpaolesi, 1977; Rossi, 1982). The shifting of opinions on this regard reflected on the preservation of this artifact which has alternatively undergone periods of constant care and periods of substantial neglect. For instance, in the 1900s, the persuasion that the static contribution of the wood ring to the global equilibrium of the dome was close to none (Sanpaolesi, 1977) led to minimal repairs to the device. Luckily enough the punctual maintenance of all the surrounding elements - with particular reference to the external cap and its tile covering, which forbade water infiltration - has guaranteed the conservation of the wooden tie. Although today renewed attention is being paid to this ancient encircling device, its peculiar nature calls for the reinstatement of those good practices that ensured its permanence throughout the centuries.

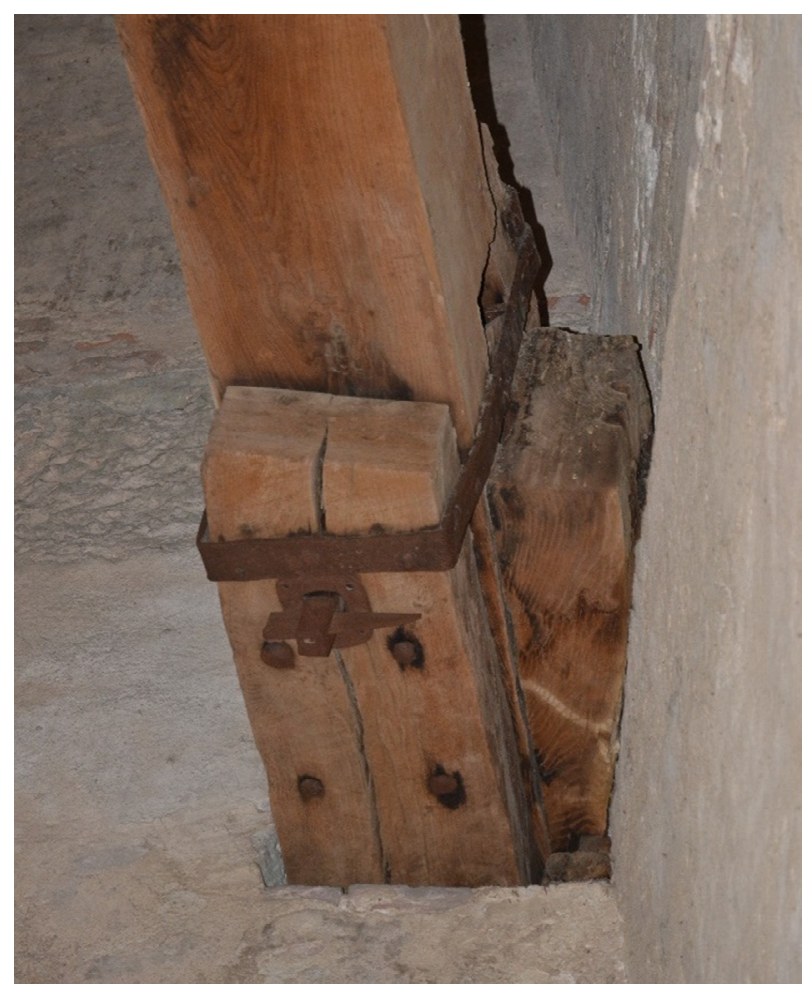

Figure 3: One of the metallic joints connecting the beams of the chestnut chain (photograph taken by the authors).

The need to develop a brand-new preservation strategy for Santa Maria del Fiore's chestnut chain made it the ideal case study to attempt to define a modus operandi that could be diffusely applied to the built heritage. Thus, starting from the canonical data retrieval, the present research explores the potential of an informative model aimed both at supporting the planning and completion of conservation activities and at boosting the knowledge process.

\section{The archival research}

Despite the great amount of writings and publications that, especially since the late nineteenth century, has led to clarify many aspects of the constructive system of Brunelleschi's dome, so far only few scholars have focused their attention on the wooden hooping tie (Blasi, Ottoni, Coïsson, \& Tedeschi, 2017; Ottoni \& Blasi, 2016; CNR-IVALSA, 2014; Tampone, 1996; Ricci, 1989). None of them has however conducted a systematic study aimed at better understanding its construction process, pinpointing the events and maintenance works that shaped it over time, making it what we get to see today.

As noted by Gennaro Tampone: «there is quite a lot of work yet to be done in order to obtain a complete and meticulous survey of the whole chain and its joints, to distinguish the authentic parts from the ones that were added later on, and, above all, to define with greater 
discernment the role, functioning and efficacy of the device in terms of both its individual components and as a whole. It is also important to analyze the state of repair of wooden elements, as well as the efficiency of their connections». The need for an accurate study that, based on reliable data, could help dispel at least some of the centuries-old doubts concerning the wooden chain, appears therefore clear.

To this purpose, also taking into account the relevance of historical investigation within the conservation process (De Fusco, 1980), the first activity that was carried out was a thorough bibliographic and archival research. After the analysis of published materials (Guasti, 1857; Haines, 2015) - which helped to isolate some significant dates, mostly related to catastrophic events such as earthquakes and lightening - the study turned to the massive documentation stored at the historical archive of the Opera of Santa Maria del Fiore. While books and journals have been extremely useful to piece together a sort of anthology of opinions on what the original function of the chain was supposed to be, historic papers proved essential to investigate its construction and maintenance history. Pieces of information emerged from archival documentation - integrated with geometrical data retrieved from the most recent laser scanner survey (conducted by Studio Scaletti e Studio Comes in 2018 upon request of the Opera di Santa Maria del Fiore) allowed to spatially locate the repairs described by the ancient craftsmen (mostly blacksmiths and woodworkers), and hence to set a date to most of the elements composing the hoop tie rod.

\section{Towards a planned preventive conservation}

Citing Bellini, we can say that: «if the primary scope is conservation, the first aim of ad hoc historical investigation is the examination of the circumstances that materially produced and modified the building" (Bellini, 1980). Knowledge acquired through historical investigation ought to find operative implications in restoration activities, as stated by the so called "planned conservation" (Della Torre, 2003). Indeed, such strategy proposes a conceptual shift from major interventions to constant and preventive care, conferring great importance to inspections and minor maintenance activities. The reiteration of these actions keeps generating new information that will help calibrate further steps, thus feeding into a virtuous cycle of knowledge. This is especially relevant in the field of cultural heritage since there are no certain predictions concerning the lifespan of the individual elements composing each building. Conservation activities are hence planned on the basis of empirical observations and recurring monitoring. In this respect, historical data are a precious resource, as they increase the overall acquaintance with the object while possibly highlighting causal relationships that can significantly improve the conservation activities planning. (Cecchi \& Gasparoli, 2010).

However, in order to satisfactorily fulfil this purpose, it is necessary to address the still open issue of data managing, which could be summarized as the identification of the most fitting procedure to critically select, organize and file information to make it easily accessible support for the preservation process. The proposed solution, tested on the wooden hooping tie of
Santa Maria del Fiore's dome, is an informative model that aims at making data available to all the actors involved in the conservation process, facilitating the planning and completion of different activities, but also fostering better communication between the various professional figures involved.

Although experimentally implemented only for the chestnut chain, the tool should be further developed to gather information concerning the whole dome, in order to supply the technicians with a unified and integrated model which would simplify the global management of the entire monumental complex.

\section{The 3D model}

The first step in the definition of the informative tool of Santa Maria del Fiore in Florence, has been the setting up of a simplified 3D model, based on consistent geometrical regularization (Fig. 4).

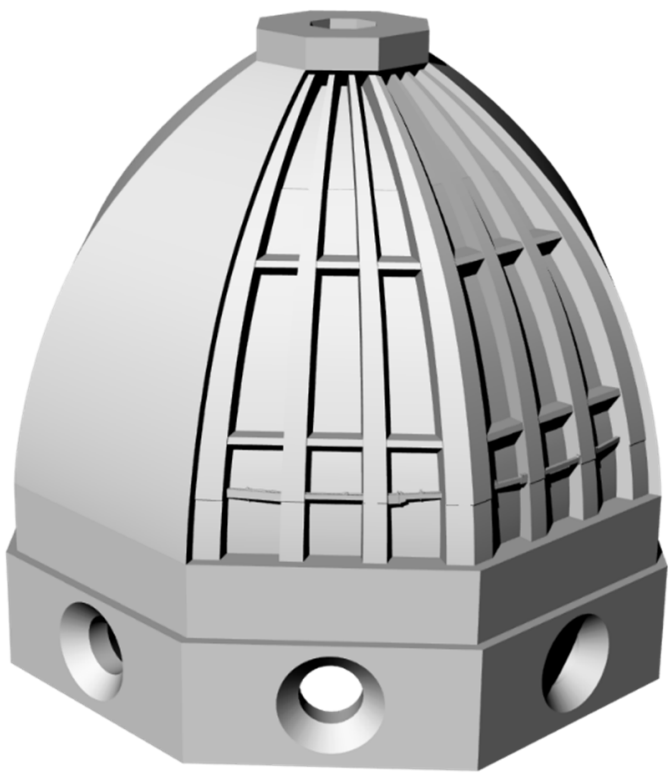

Figure 4: The 3D model of the dome of Santa Maria del Fiore inclusive of all its main construction elements.

In fact, the difficulties connected to the modelling of complex shapes are widely acknowledged and constitutes one of the main challenges in the application of BIM methodology to historic heritage (Brumana et al., 2018; Banfi, Fai, \& Brumana, 2017; Tommasi, Achille, \& Fassi 2016).

Since the idea of a Historic or Heritage BIM came to life (Murphy, McGovern, \& Pavia 2009), studies have mainly focused on geomatics, working on improving the existing survey technologies as well as the following data processing and modelling (Brumana et al, 2020). Indeed, one of the most peculiar features of historic buildings is their irregularity. Traditional craftsmanship in manufacturing, traumatic events, transformations in use, as well as the mere passage of time, resulted in stratifications, deformations, disarray, unique marks of the inevitable changeableness of existence (Bellini, 1996). Such specificities are however difficult to manage in terms of both survey and modelling, mostly because of the need to find the right balance between geometric 
accuracy, input resources (time and money), and outcome manageability (file size).

Moreover, most BIM software uses parametric modelling, which is extremely useful when operating on new buildings, but rather inadequate for cultural heritage. A possible way to overcome this problem is, of course, to turn to $3 \mathrm{D}$ modelling software. Despite this solution guarantees more freedom in the development of complex shapes, interoperability issues might arise when importing the model into the BIM software with the risk of losing part of the data or properties. This topic, partly dealt with in recent years, should be further explored as a pivotal point. In fact, "research on the so-called "historic BIM" should avoid the risk of being limited to the representation of historic architecture. Instead, it should exploit the potentials of electronic interoperable tools for the regularization of conservation phases» (Della Torre, 2020).

Starting from these assumptions, and given the main objective of the research, a simplified model was considered suitable for the task. Indeed, the level of detail - as well as the level of information - should be defined according to the final purpose. In the specific case, a conceptual model appeared to be the best solution in order to provide quick access to a large amount of information required to support conservation activities. Within the case study, metric accuracy was hence moved to the background in favour of other aspects pointing towards an improved preservation strategy. The soundness of this approach has been pointed out by several scholars (Ottoni, Zerbi, \& Freddi, 2017) who underlined how higher accuracy is not necessarily the answer to the problem, whereas geometric precision should always be calibrated considering the target.

The 3D model of the dome of Santa Maria del Fiore has hence been shaped based on the photogrammetric survey conducted by F.O.A.R.T. (Dalla Negra, 2004), which was schematized in consideration of the study of the original proportions of the dome as emerged from the 1420 construction program. As for the wood ring, geometrical information was taken from the recent laser scanner survey of 2018.

The model comprises all the main construction elements of the dome, such as the two caps - external and internal, both divided into eight webs -, the 24 ribs, the walkways delimiting the three levels of the structure, and finally the wooden chain. The latter is further subdivided into beams and joints, so that it will be possible to associate information to both wooden and metallic elements.

As a matter of fact, even though the geometrical accuracy is rather low, each object is immediately recognizable, guaranteeing an intuitive retrieval of the georeferenced data. However, in order not to lose precious data, the informative tool has been arranged so that it will be possible to associate further and more precise geometrical information to the model, such as detailed 2D/3D representations or even the original point clouds. The possibility to withdraw firsthand data will allow both to verify the reliability of possible previous studies and to carry out further analysis that might require higher geometrical definition.

\section{The informative tool}

As previously mentioned, although the 3D model represents the whole dome, the informative structure has so far only been implemented with regard to the wooden tie-rod, the main concern of the presented research (Fig. 5).

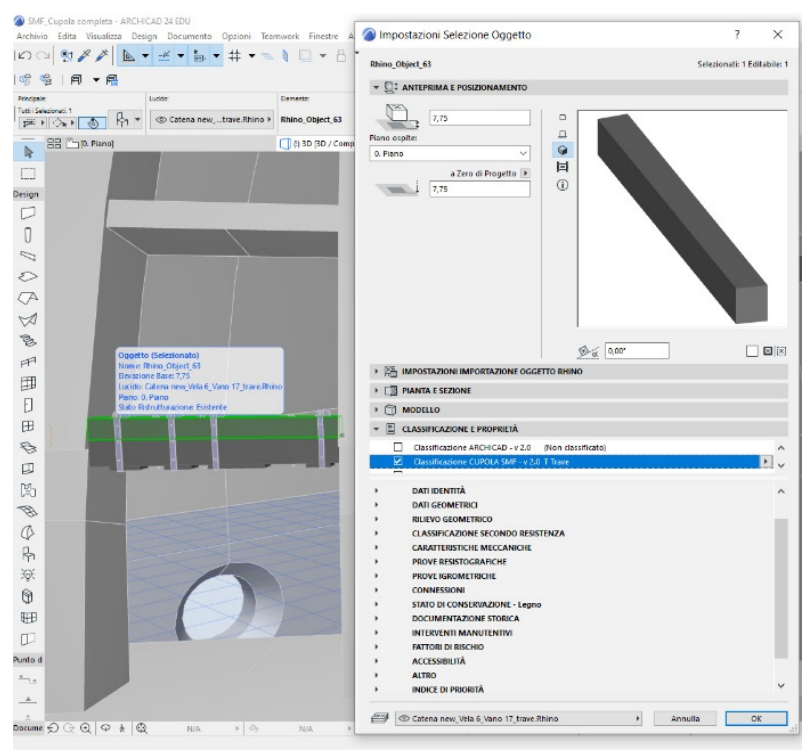

Figure 5: A screenshot of the informative model.

Before actually start organizing data, it appeared necessary to clearly state the purposes of the information model, in order to be able to develop it accordingly. In particular, four focal points were identified:

- Create a repository to store available information concerning the dome's wooden hoop (and possibly the global structure of the dome) in an orderly system;

- Supply the technical office of the Opera of Santa Maria del Fiore with an operational tool suited to simplify the conservation and general management process;

- Foster coherent interventions by favouring a more efficient dialogue among the actors involved throughout the conservation process;

- Ensure large-scale accessibility and userfriendliness of the proposed instrument.

Once set the objectives, the informative tool was structured as briefly described in the following paragraphs.

\subsection{An operational support}

The most basic function of the model is that of collecting heterogeneous data and sort them in an intelligible way, in order to be easily retrievable when needed. Information is gathered together depending on their nature to create thematic groups, such as identity data, geometric data, mechanical properties, and so forth. The idea is that of offering the most comprehensive description of each element, providing restorers with the knowledge that should lead any intervention on cultural heritage. However, as aforementioned, the ambition is higher, as 
the proposed tool wishes to become operational support to preservation activities.

Working towards improved management of the asset, sets of information have been outlined following the guidance offered by the Italian standard UNI 11257:2007, which reports the main criteria for the drafting of a conservation plan (both for existing and underconstruction buildings).

Attention was especially focused on more efficient planning of inspective and maintenance activities. In this regard, looking beyond the mere description of the single analyzed objects, the aim is to provide information to help define a numerical index expressing an overall and concise assessment of their current condition. Such value will thus determine the priority of intervention, with positive repercussions on the scheduling of conservation interventions.

The proposal is that of a priority index that takes into account three main features, namely: historical and architectural value, damage conditions, and risk conditions (Fig. 6).

\begin{tabular}{|c|c|c|}
\hline 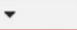 & INDICE DI PRIORITÀ & \\
\hline 5 & Indice di priorità & 13 \\
\hline 5 & VALORE STORICO-ARCHITETTONICO & 4 \\
\hline 河 & Datazione & 5 \\
\hline 河 & Qualità di lavorazione & 3 \\
\hline 河 & CONDIZIONI DI DANNO & 5 \\
\hline 河 & Degrado materico & 5 \\
\hline 河 & Perdita di efficacia & 5 \\
\hline 河 & CONDIZIONI DI RISCHIO & 4 \\
\hline 宫 & Periodo di ispezione & 5 \\
\hline 四 & Criticità & 2 \\
\hline
\end{tabular}

Figure 6: The priority index information set.

Each one of the three entries will be assigned a number from 0 to 5 , being 0 the highest score (excellent) and 5 the lowest one (extremely bad). Such a number will represent the average of the scores (from 0 to 5 ) appointed to the respective subitems. In particular, the historical-architectural value will result from dating and quality of workmanship; damage condition from the state of repair and loss of efficacy; and risk condition from inspection period and criticalities. The priority index will be obtained by adding up the three scores, and it will hence range from 0 to 15 , where 15 will represent maximum urgency and 0 minimum urgency. Each score will descend from throughout examinations of the collected data, which will be displayed in the corresponding sets of information (Ottoni, Coïsson, \& Brignoli, 2014).

\subsubsection{Historical and architectural value}

The historical-architectural value is determined by the dating of the analyzed element and its quality of workmanship. As for the former, 5 points will be assigned in case the object in question is original (thus dating back to the $15^{\text {th }}$ century), whereas 0 points will be given to the most recent additions (from the $21^{\text {st }}$ century onwards).

On the other hand, the latter is a quality assessment, and should be expressed in relation to the technical knowledge of the period of construction. Five points will indicate a very fine and technically advanced work, while zero points will stand for extremely poor technique and realization.

\subsubsection{Damage conditions}

\subsubsection{State of repair}

An essential evaluation to be done in order to assess the conditions of the element in question regards the state of repair (Fig. 7). Indeed, if unresolved, material decay may lead to material loss causing irreversible damages in terms of authenticity and value.

In order to homogenize terminology and facilitate a univocal understanding of the information, items included in this set of data were named following existing standards. For instance, when considering wooden beams, decay pathologies were deduced from the Italian standard UNI 11130:2004.

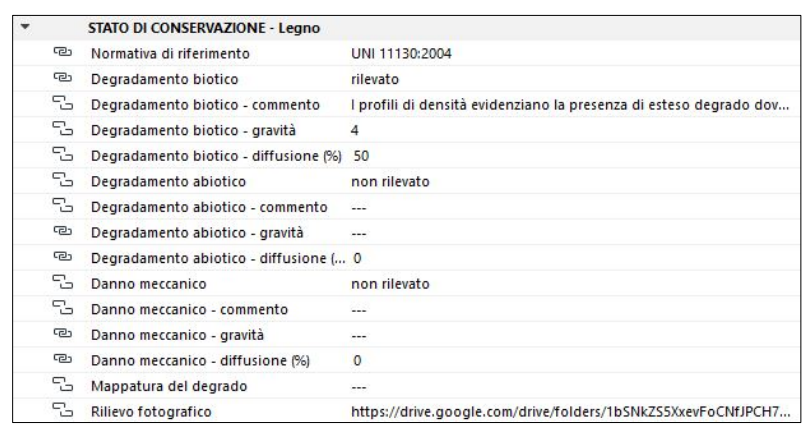

Figure 7: The set of information to describe the state of repair of wooden elements.

Each identified pathology is described through four entries, derived from the 2003 guidelines for the drafting of maintenance plans (Della Torre, 2003). The first one simply indicates whether the specific kind of decay has been detected or not; the second one textually describes the ongoing phenomenon; the third one offers an evaluation (1 to 5 ) concerning the seriousness of the situation; the fourth one quantifies the extent of the damage in percentual.

Complementary data and descriptive files (such as photographs or $2 \mathrm{D}$ thematic maps) can also be added as external hyperlinks.

\subsubsection{Loss of efficacy}

Another aspect to carefully consider when defining intervention priority is mechanical properties. This is particularly true since the wooden chain plays an (although minimal) structural role. It is hence important to establish whether the device is still able to fulfil its task or needs strengthening.

Information can be sourced alternatively from regulations providing average values (in the specific case, for wooden beams the reference was to UNI 11035-2), from standardized visual inspection procedures (as described in UNI 11119:2004 for wooden elements) or from on-site instrumental tests.

Although the first option could supply a plausible suggestion, in order to correctly evaluate residual properties - and consequently set a representative priority index - the second and third options are preferable, as they somehow measure the object itself. 
A precompiled set of information has also been arranged for wooden beams according to UNI 11119:2004 to guide operators during visual inspection procedures.

A last appraisal should regard the efficacy of the strengthening interventions conducted on the wooden ring throughout the centuries. In fact, as emerged from historical investigation, several repairs were done on the wooden chain, often improving the joints' efficiency and installing additional metallic tie-rods.

Such evaluations are complementary to those concerning mechanical properties, as both these aspects condition the structural performance of the encircling device.

\subsubsection{Risk conditions}

\subsubsection{Inspection period}

The date of the latest inspection or intervention should also be considered, as it reflects on the reliability of all the other data. Clearly, if the last inspection dates many years back, information collected on that occasion might not be truthful anymore, as the situation has probably evolved and possibly worsened. It is therefore obvious that the longer time has passed since the latest inspection, the higher the priority to schedule a new one.

In this regard, the informative model presents a set of information designed to record the chronology of interventions (date and nature). The table includes an entry where to signal the possible presence of monitoring systems (either instrumental or visual) and a further field for notes.

\subsubsection{Criticalities}

In addition to the information related to previous inspections, a set of data has been arranged in order to assess risks, highlighting the main criticalities detected and thus the major aspects to keep under control. The dedicated table will include insights concerning interactions with other elements and possible solutions to address risks and better manage the global situation.

Useful suggestions for future conservation activities are also offered by the accessibility section, which provides details about the ease of inspection of the specific object, expressing evaluations in terms of lighting, visibility and possibility to physically reach the element in question. In both cases, it is possible to add further textual advice (e.g. equipment needed, preliminary activities to carry out before the inspections etc.).

\subsection{Sharing of information}

The advantages of the informative tool also concern the interaction between the actors involved in the conservation process. Indeed, while the need for an integrated approach within the field of restoration is by now widely acknowledged, it is still difficult to orchestrate the numerous activities carried out by different professionals. In this regard, the opportunity to provide each one of them with the same all-encompassing model, will reduce materials exchange, resulting in an increased coherence among the proposed designs and solutions. Moreover, the fact that every actor will have access to information in its totality, should encourage and facilitate dialogue, keeping everyone up to speed on the most recent events.

Finally, the possibility of accessing the informative tool by means of an application available for mobile devices will have positive effects on the quality of all conservation activities. Operators will be able to consult the database right on the spot, making comparisons, dispelling possible doubts and acquiring an overall deeper knowledge of the element in question.

\section{Conclusions}

The proposed tool - which currently only gathers data related to the wooden chain - could be implemented by inserting information concerning the whole dome structure, allowing to correlate the different construction elements composing the dome. This would result in further improvements in the overall conservation process of the asset, with positive implication in terms of resources management.

As noted, the informative model primarily represents an instrument to support conservation activities. At the same time, however, it outlines a possible methodology to be exported within the cultural heritage environment, with the hope that, in the next future, restorers will become more involved in the articulation of the new powerful technologies at their disposal.

\section{Acknowledgements}

The presented research has been made possible thanks to the Opera del Duomo di Firenze which promoted the most recent studies concerning the wooden chain of Santa Maria del Fiore. A sincere thank also goes to the archivists of the Opera's historical archive who guided our steps through the archive collection, as well as to Studio Scaletti and Studio Comes (Prof. Carlo Blasi) who provided the latest geometric survey of the chain in question.

\section{References}

Banfi, F., Fai, S., \& Brumana, R. (2017). BIM automation: advanced modeling generative process for complex structures. ISPRS Annals of Photogrammetry, Remote Sensing and Spatial Information Sciences, IV-2/W2, 9-16. https://doi.org/10.5194/isprs-annals-IV-2-W2-9-2017

Bellini, A. (1980). Ricchi apparati e povere idee, Restauro, 51.

Bellini, A. (1996). A proposito di alcuni equivoci sulla conservazione. TeMA, 1, 2-3.

Blasi, C., Ottoni, F., Coïsson, E., \& Tedeschi, C. (2017). Battistero di San Giovanni in Firenze. Note su dissesti, lesioni e catene. In F. Gurrieri (ed.), II Battistero di San Giovanni. Conoscenza, diagnostica, conservazione (pp. 119-133). Firenze, Italy: Mandragora. 
Brumana, R., Della Torre, S., Previtali, M., Barazzetti, L., Cantini, L., Oreni, D., \& Banfi, F. (2018). Generative HBIMmodeling to embody complexity. Surveying, preservation, site intervention. The Basilica di Collemaggio (L'Aquila), Applied Geomatics 10(4), 545-567. https://doi.org/10.1007/s12518-018-0233-3

Brumana, R., Oreni, D., Barazzetti, L., Cuca, B., Previtali, M., \& Banfi, F. (2020). Survey and Scan to BIM Model for the Knowledge of Built Heritage and the Management of Conservation Activities. In B. Daniotti, M. Gianinetto, S. Della Torre (Eds.), Digital Transformation of the Design, Construction and Management Process of the Built Environment (pp. 391-400). https://doi.org/10.1007/978-3-030-33570-0_35

Bruno, N. (2018). From survey to analysis for Cultural Heritage management: a new proposal for database design in BIM, Doctoral Thesis (Supervisor: R. Roncella), Scuola di Dottorato in Ingegneria Civile e Architettura, Università di Parma.

Bruno, N., \& Roncella, R. (2019). HBIM for conservation: a new proposal for information modeling, Remote Sensing, 11(15), 1751. https://doi.org/10.3390/rs11151751

Castagnetti, C., Dubbini, M., Ricci, P.C., Rivola, R., Giannini, M., \& Capra, A. (2017). Critical issues and key points from the survey to the creation of the historical building information model: the case of Santo Stefano Basilica. International Archives of Photogrammetry, Remote Sensing and Spatial Information Sciences, XLII-5/W1, 467-474. https://doi.org/10.5194/isprs-archives-XLII-5-W1-467-2017

Cecchi, R., \& Gasparoli, P. (2010). Prevenzione e manutenzione per i beni culturali edificati. Procedimenti scientifici per lo sviluppo delle attività ispettive, Cesena, Italy: Alinea Editrice.

CNR-IVALSA. (2014). Relazione preliminare sullo stato di conservazione e tensionale di alcuni elementi lignei della cupola di Santa Maria del Fiore in Firenze.

Como, M., Iori, I., \& Ottoni, F. (2019). Scientia abscondita. Arte e scienza del costruire nelle architetture del passato, Venice, Italy: Marsilio.

Corazzi, R., \& Conti, G. (2011). I/ segreto della cupola del Brunelleschi, Firenze, Italy: Pontecorboli.

Dalla Negra, F. (2004). La Cupola di Santa Maria del Fiore. Il rilievo fotogrammetrico. Livorno, Italy: Sillabe.

De Fusco, R. (1980). II restauro architettonico: ricchi apparati e povere idee. Op. cit., 49.

Della Torre, S. (2003). La conservazione programmata del patrimonio storico architettonico. Milan, Italy: Guerrini e Associati.

Della Torre, S. (2020). Italian perspective on the planned preventive conservation. Frontiers of Architectural Research. https://doi.org/10.1016/j.foar.2020.07.008

Durm, J. (1887). Die domkuppel in Florenz und die kuppel der Peterskirche in Rom, Berlin, Germany: Verlag Von Ernst \& Korn.

Fontana, F. (1696). Relazione dell'ultima visita del Cav. Francesco Fontana. Archivio dell'Opera di Santa Maria del Fiore (AOSMF) III.1.19, fasc. 305.

Guasti, C. (1857). La Cupola di Santa Maria del Fiore illustrata con i documenti dell'Archivio dell'Opera secolare, Florence, Italy: Barbèra, Bianchi e Comp.

Haines, M. (2015). Gli Anni della Cupola. Archivio digitale delle fonti dell'Opera di Santa Maria del Fiore, 1417-1436, Opera di Santa Maria del Fiore. Retrieved March 15, 2021, from https://duomo.mpiwg-berlin.mpg.de

Mainstone, R.J. (1969). Brunelleschi's Dome of Santa Maria del Fiore and some related structures. Transaction of the Newcomen Society, 42(1), 107-126. https://doi.org/10.1179/tns.1969.006

Manetti, A. (1976). Vita di Filippo Brunelleschi, Milan, Italy: II Polifilo.

Murphy, M., McGovern, E., \& Pavia, S. (2009). Historic Building Information Modelling (HBIM). Structural Survey, 27(4), 311-327. https://doi.org/10.1108/02630800910985108

Nelli, C. (1753). Discorsi di Architettura del senatore Giovan Batista Nelli. Florence, Italy: Per gli Eredi Paperini.

Ottoni, F., Coïsson, E., \& Brignoli, A. (2014). Edifici storici in zona sismica: per una programmazione degli interventi, tra economia e sicurezza. In Safe Monuments 2014. Tra conservazione e sicurezza di edifici monumentali e del costruito storico, Florence, Italy: Edizioni Collegio degli Ingegneri della Toscana.

Ottoni, F., \& Blasi, C. (2015). Results of 60 years-monitoring system on Santa Maria del Fiore dome, in Florence. International Journal of Architectural Heritage, 9(1), 7-24. http://dx.doi.org/10.1080/15583058.2013.815291

Ottoni, F., \& Blasi, C. (2016). Hooping as an Ancient Remedy for Conservation of Large Masonry Domes. International Journal of Architectural Heritage, 10(2-3), 164-181. https://doi.org/10.1080/15583058.2015.1113335

Ottoni, F., Zerbi, A., \& Freddi, F. (2017). Dalla realtà al modello, e ritorno. Riflessioni sul rilievo e astrazione per la conservazione del patrimonio culturale, ANANKE speciale GEORES 2017, 70-75.

Prager, F. D., \& Scaglia, G. (1970). Brunelleschi. Studies of his technology and inventions. New York, USA: Dover 
Publications Inc.

Ricci, M. (1989). La catena de' castagni della cupola di S. Maria del Fiore. In G. Tampone (Ed.), Legno e restauro. Ricerche e restauri su architetture e manufatti lignei (pp.89-93).

Rossi, P. A. (1982). Le cupole del Brunelleschi. Bologna, Italy: Edizioni Calderini.

Saalman, H. (1980). Filippo Brunelleschi. The Cupola of Santa Maria del Fiore. London, UK: A. Zwemmer Ltd.

Sanpaolesi, P. (1977). La Cupola di S. Maria del Fiore. Il progetto. La costruzione. Florence, Italy: Editrice EDAM.

Sgrilli, B. S. (1733). Descrizione e studi dell'insigne fabbrica di S. Maria del Fiore metropolitana fiorentina, Florence, Italy: Per Bernardo Paperini.

Tampone, G. (1996). Il restauro delle strutture di legno. Milan, Italy: Hoepli Editore.

Tommasi, C., Achille, C., \& Fassi, F. (2016). From point cloud to BIM: a modelling challenge in the cultural heritage field, International Archives of Photogrammetry, Remote Sensing and Spatial Information Sciences, XLI-B5, 429-436. https://doi.org/10.5194/isprs-archives-XLI-B5-429-2016 


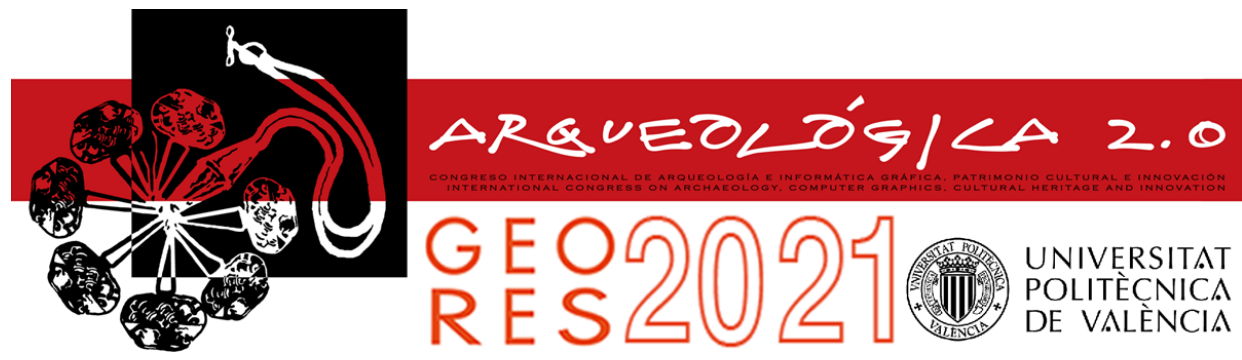

Proceedings of the joint international event $9^{\text {th }}$ ARQUEOLÓGICA

$2.0 \& 3^{\text {rd }}$ GEORES

Valencia (Spain).

26-28 April 2021

\title{
THE ROLE OF EXTENDED REALITIES IN HERITAGE BUILDINGS REPRESENTATION
}

\author{
Ahmed Khalila, ${ }^{*}$, Spyridon Stravoravdis ${ }^{b}$ \\ a School of Design, Faculty of Liberal Arts \& Sciences, University of Greenwich, London, UK. A.Khalil@greenwich.ac.uk \\ b School of Architecture, University of Liverpool, L69 7ZN London, UK. S.Stravoravdis@liverpool.ac.uk
}

\begin{abstract}
:
Architectural visualisation has been developing over the year to improve the representation of buildings and their contexts to the public. It achieved a long journey from manual drawings to photography to digital 2D and 3D representation, until it reached the era of extended realities $(X R)$, which allowed unprecedented immersive and interactive engagement. Extended reality applications represent a unique opportunity for the visualisation of heritage buildings on many stages; from the early design phase, through the construction and facility management phases, to the education and cultural tourism applications. This paper aims to explore the wide range of state of the art XR applications, investigate their aspects and variations, and study their potentials, challenges, and limitations for the built heritage sector.
\end{abstract}

Keywords: heritage buildings, visualisation, extended reality, virtual reality, augmented reality, mixed reality, HBIM

\section{Background on Historical Building Representation}

Architectural visualisation has been developing for a long time. It aims to present the building to a wider audience than its direct users. It can even represent the building in an iconic way, thus creating and exporting a symbolic image of a building, its context, culture, or place, even for audiences who have never visited the building itself. Historically, heritage documentation mainly relied on human interpretation such as hand drawings, on-site measurement, sculptures, and paintings, which was timeconsuming and less precise (Albourae, Armenakis, \& Kyan, 2017). The invention of photography in the early nineteenth century represented a revolutionary way to produce fast and realistic representations of buildings, as well as documenting their context and real-life view. Architectural representation, also, witnessed a revolution that transformed the manual analogue representation to the digital representation as a consequence of the introduction of CAD (Computer Aided Design) during the third industrial revolution in the 1980s (Techopedia, 2021; Banfi, 2019), which facilitated the transition into a digital 2D environment. This is shortly followed by the development of 3D visualisation software. The introduction of BIM (Building Information Modelling) tools further developed the ways of architectural representation in that it introduced an environment that can link several forms of buildings digital representation such as 2D drawings, 3D models, parametric information, photographic representation, and many other forms of data (Khalil, Stravoravdis, \& Backes, 2020). Later, the introduction of extended reality applications and their rapid development paved the way towards a new era of immersive and interactive visual communication. It also helped to integrate more sensual and informative useroriented experiences that can reach a much larger audience (Fig. 1).

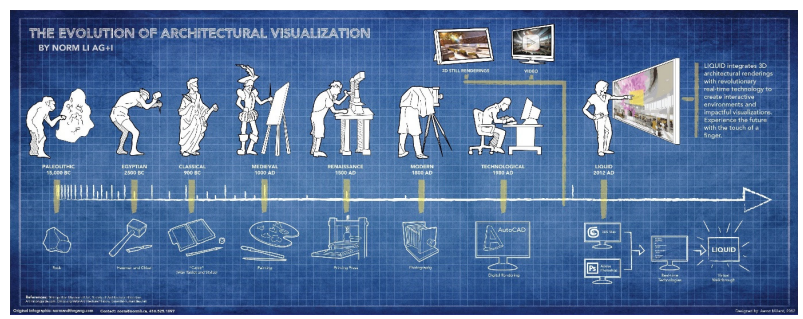

Figure 1: Evolution of architectural visualisation (Albourae, Armenakis, \& Kyan, 2017).

\section{Historical building representation in extended realities}

Digital visualisation of heritage buildings and sites can represent a contribution for several aspects. it can help in planning preservation and conservation works by modelling and visualising the current status of the building and its historic view. It can assist in the process of adaptive reuse and retrofitting projects through better communication and visualisation through the design and construction phases. It can be a useful tool in real estate markets by marketing the building image for wider clients (Felli, Liu, Ullah, \& Sepasgozar, 2018), which even gained 
more momentum due to the COVID-19 pandemic and its consequential social distancing strategies that shifted many markets towards the online digital environment. Also, digital visualisation plays a role in analytical researches concerning the building's history by modelling its various changes over time, as well as predictions of its potential future development (Fig. 2) (RodríguezGonzálvez et al., 2017). Visualisation can also represent a revolutionary development in the fields of education, public dissemination, virtual museums and cultural tourism (Albourae, Armenakis, \& Kyan, 2017)

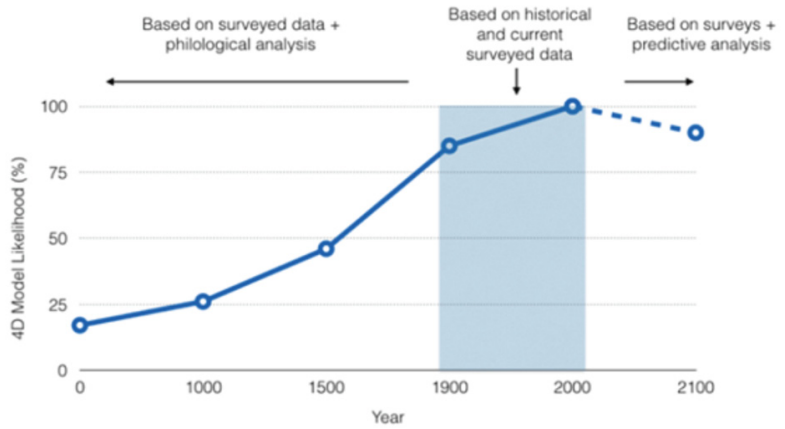

Figure 2: Representation of timeline in $4 \mathrm{D}$ visualisation (Rodríguez-Gonzálvez et al., 2017).

Digital visualisation of heritage buildings consists of many concepts involving the merging of physical real environment with digital virtual environment. It can be achieved through various levels of immersion and interactivity.

\subsection{Reality/Virtuality}

Visualisation and representation comprise of a wide spectrum of concepts, technologies and applications. The continuum containing all these applications is referred to as the reality/virtuality continuum, suggested by (Milgram, Takemura, Utsumi, \& Fumio, 1995). It represents both the real world and the virtual environment on its two contrasting poles, while representing the different applications as levels of merging between them (Fig. 3). Following this classification, augmented reality (AR) is merging virtual objects into the real environment, mixed reality (MR) is half-way between real and virtual environments, while augmented virtuality (AV) merges real elements within the virtual environment, and virtual reality (VR) totally excludes the real world.

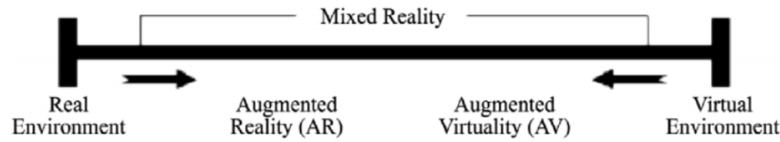

Figure 3: Milgram, Takemura, Utsumi, \& Fumio (1995) RealityVirtuality Continuum. The reality-virtuality continuum consists of environments ranging from real to virtual and all possible variations and compositions of real and virtual objects in these environments.

An umbrella term that is used to represent the whole spectrum including $A R, M R, A V, V R$ and everything in between, is referred to as (XR) "Extended Reality" (Andrade \& Bastos, 2019; Storchi, 2018) or "Cross Reality" (Davies, Miller, \& Allison, 2013; Reilly et al., 2010; Paradiso \& Landay, 2009), while Bekele, Pierdicca, Frontoni, Malinverni, \& Gain (2018) used the term "Immersive Reality".
Bekele and Champion (2019b) argue that common definitions of Augmented Reality (AR), Augmented Virtuality (AV), Virtual Reality (VR) and Mixed Reality (MR) in current literature are based on outdated display technologies, and a relationship between virtuality and reality, without consideration to the importance of the users necessarily complicit sense of immersion. They conclude that existing definitions focus is technological, rather than experiential. Hence they redefined the realityvirtuality continuum according to the relation of different application to both the real world and the user experience (Fig. 4). Consequently, they classified the different visualisation approaches according to their level of fusion between real and virtual, the user interaction, the realityvirtuality interaction, and the level of immersion (Fig. 5).

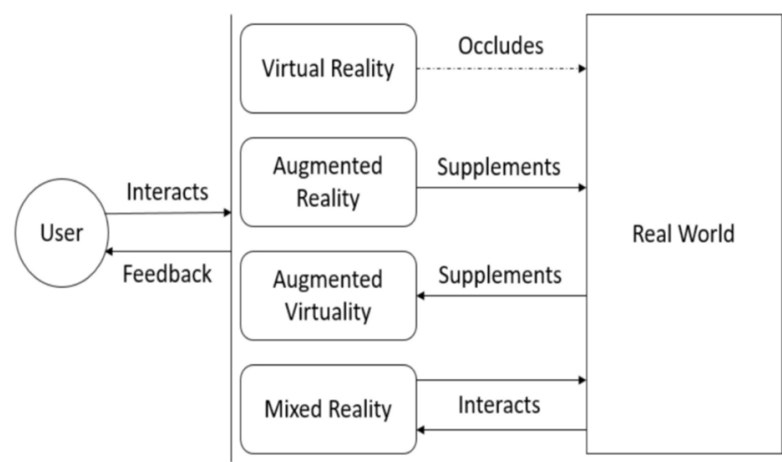

Figure 4: User-Reality-Virtuality (URV) Interaction: (Bekele \& Champion, 2019b)

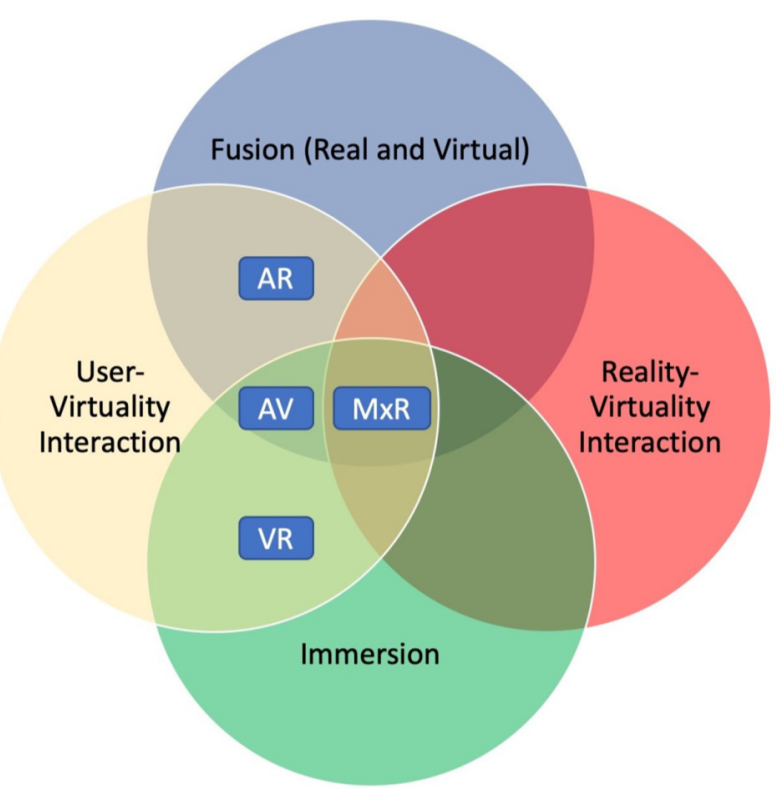

Figure 5: Classification of the different visualisation approaches according to (Bekele \& Champion, 2019b).

\subsection{Virtual Reality VR}

Virtual Reality (VR) is defined as a segment of the realityvirtuality continuum that transports users into a computergenerated virtual world, where users are expected to experience a high level of immersion in the virtual environment (Carmigniani et al., 2011). VR is characterised by the fact that it immerses users in a synthetic world without any means to see or interact with the real world, except through computer-generated representations. the term "virtual reality" was first 
introduced in 1989 (Bekele, Pierdicca, Frontoni, Malinverni, \& Gain, 2018). Immersion and interaction are key aspects of a VR experience. According to Carrozzino \& Bergamasco (2010), VR is a complex technology that creates a digital environment with which users may interact and which they feel completely immersed within. This immersion can also include a simulation of visual perception, acoustic, haptic, smell, taste, and motion senses, A perfect virtual reality experience affects all of human senses and allows the user to interact with the virtual environment naturally as they would with the real environment (Bekele, Pierdicca, Frontoni, Malinverni, \& Gain, 2018; Zhao, 2009).

$\mathrm{VR}$, in conjunction with data capture technologies, provides many applications that are used for a variety of cultural heritage purposes, such as virtual museums, virtual reconstruction, virtual exploration, and Cultural Heritage education (Haydar, Roussel, Maïdi, Otmane, \& Mallem, 2011; Gonizzi Barsanti, Caruso, Micoli, Covarrubias Rodriguez, \& Guidi, 2015; Pietroni, Pagano, \& Rufa 2013). VR can benefit from the development of $360^{\circ}$ photography and videography to create virtual tours that can be useful especially in the field of real estate (Felli, Liu, Ullah, \& Sepasgozar, 2018). VR also has the potential to simulate imaginative and existing physical environments along with their processes and environmental parameters (Bekele \& Champion, 2019a).

Virtual reality can be presented in a 3DoF (Three Degrees of Freedom) or 6DoF (Six Degrees of Freedom) systems. In a 3DoF VR system, the user's head movements (rotation) are tracked, known as 'passive VR'; where the user can look but cannot control their physical movements in the space. In a 6DoF VR system, also known as 'active VR', the user's head and body movements are tracked (rotation and translation) (Dhanda et al., 2019). Slater \& Wilbur (1997) stated that the correlation between user movements and the virtual movements is a crucial factor that affects how a user feels presence in a virtual space (Dhanda et al., 2019).

Photogrammetry and physically based rendering (PBR, a way of rendering that accurately represents how light interacts with materials and surfaces) can be used in modelling and representing VR (Dhanda et al., 2019).

Dhanda et al. (2019) have an interesting case study where they modelled the Myin-pya-gu temple in Bagan, Myanmar, which is no longer open the public due to its condition (Fig. 6). They used photogrammetry and laser scanning to capture the temple. Then a high poly mesh was created including 44 million polygons, which is too large to render in a real-time environment. Therefore, they reduced it to low poly mesh of 60 thousand polygons. They added mesh maps in order to enable the low poly mesh to realistically resemble the high poly mesh. Five types of maps are used in the PBR (physically based rendering); The texture map (holds all the colour information for the mesh), the normal map (use RGB values to encode surface normal directions.), the ambient occlusion map (approximates the inner shadows of objects when they are under diffuse lighting), the roughness map identifies the irregularities in a surface that cause light to scatter diffusely, and the metallic map (defines what part of the material are metal). Finally, the VR of Myin-pya-gu was put together in the Unreal Engine by Epic Games (Dhanda et al., 2019) (Fig. 7)
The main challenge facing VR applications to heritage buildings is in the modelling process and how to ensure the production of a photorealistic result with the least possible complicated model, in order to reduce rendering demands.

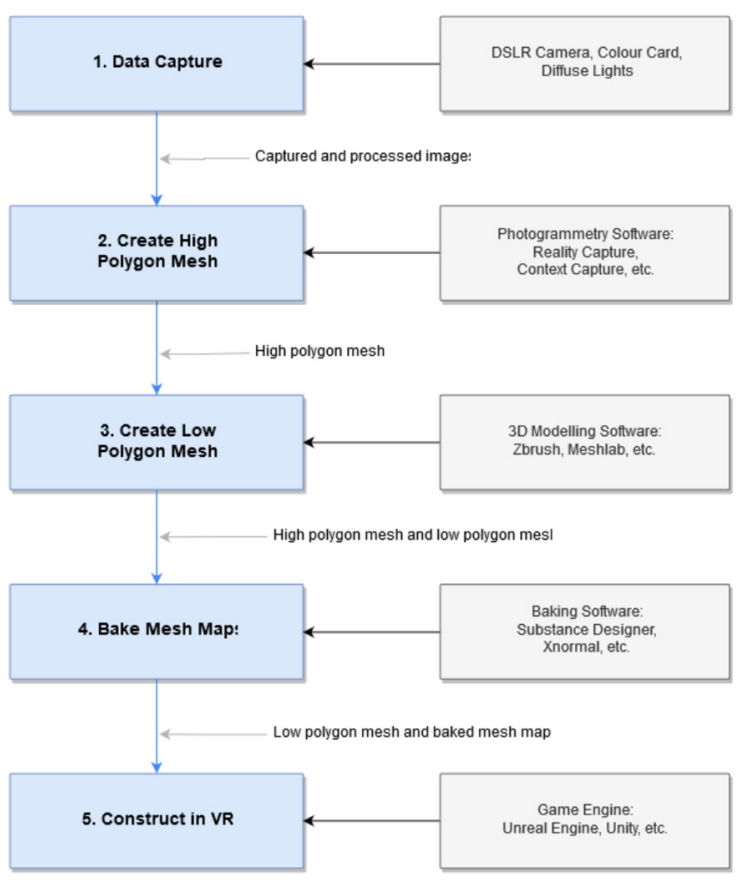

Figure 6: Workflow of the modelling of Myin-pya-gu temple (Dhanda et al., 2019).

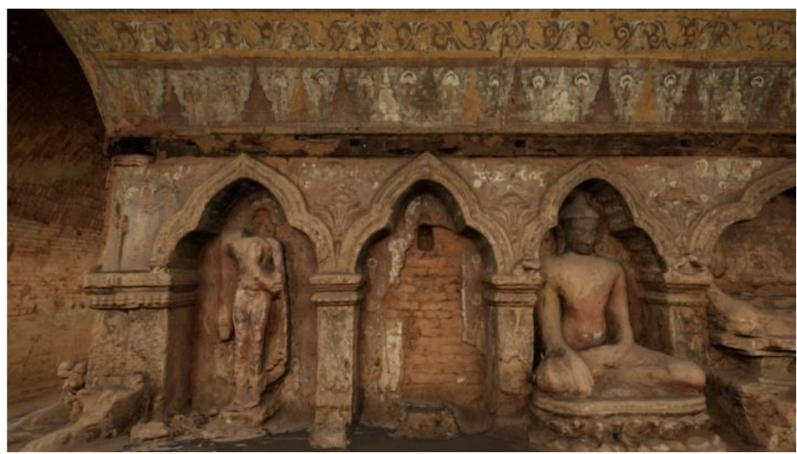

Figure 7: VR model of Myin-pya-gu temple (Dhanda et al. 2019).

Another challenge facing virtual reality is Motion Sickness (MS) due to the high level of immersion, which causes general discomfort, apathy, drowsiness, headache, disorientation or fatigue users might feel during or after a VR experience. To induce motion sickness effects, complete surround environment with depth perception, spatialised audio, and natural gestures and movements should be achieved (Andrade \& Bastos, 2019).

An interesting VR application is the reconstruction of the St Andrews cathedral in Second-Life platform by Davies, Miller, \& Allison (2013). The reconstruction was used for viewing the original cathedral in a walking tour within the site of its ruins.

The 3D virtual environment was implemented using the Second Life/Open Simulator (SL/OpenSim) platform. A walking route around the St Andrews cathedral ruins, akin to the route that an individual visitor or school group might 
take, was planned and then walked with a laptop connected with GPS unit as well as a smartphone. Then real-world positions were translated as latitude and longitude pairs, into corresponding Open-Sim (X,Y). Information from the tablet's magnetometer and accelerometer were translated as joystick movement in the Second-Life platform to control the camera direction. Users can view the reconstruction of the cathedral following the defined route and point of interest (Fig. 8).

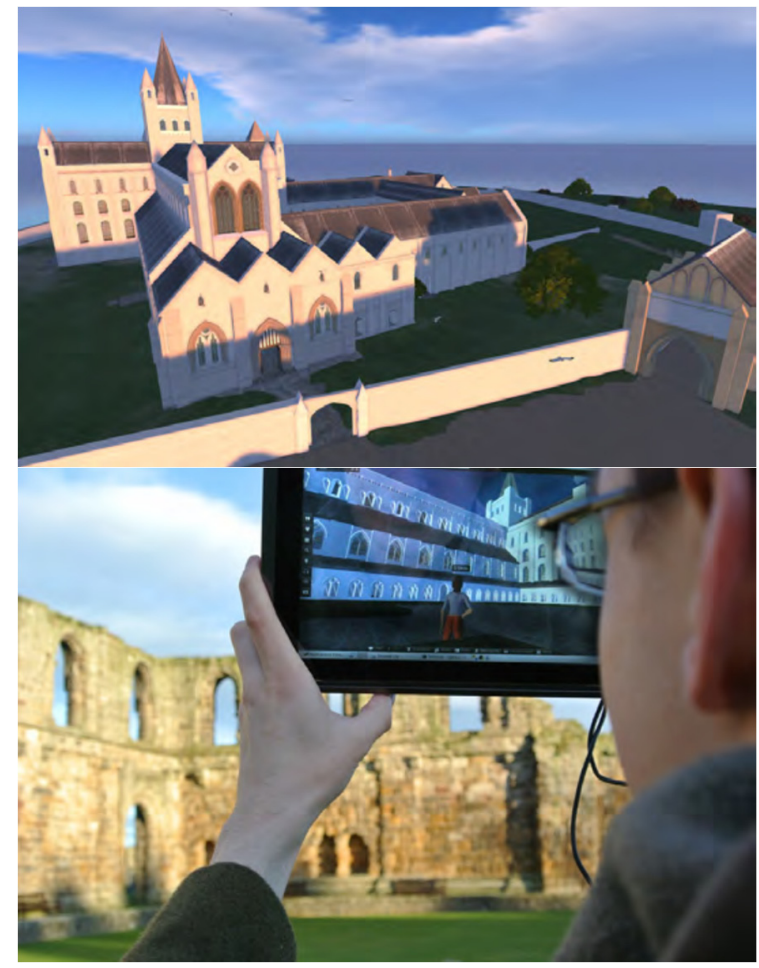

Figure 8: VR reconstruction of St Andrews Cathedral (Davies, Miller, \& Allison, 2013).

In the context of historical buildings and VR, it is still a challenge to capture a building with high levels of detail and reproduce the experience in VR. It is technically possible, but normally experts from various disciplines are needed, such as 3D data capture, data processing and appropriate setup for VR which often involves programming in a game engine. All this can be costly and time consuming and as a result it is not easily scalable to be used for all buildings of historical significance. Low cost solutions such as the employment of inexpensive 360 degree cameras, the footage of which can be used directly in VR can provide an easy to employ, scalable solution for historical building VR experiences and digital presentation, but the current state of the art in this field lacks the level of detail needed. Recent technological updates to tablets and smart phones with Lidar sensors, show promise of an ability to easily capture and recreate environments in VR. This is a low cost, scalable solution, which is in the right direction, but its capabilities in the field are yet to be proven.

\subsection{Augmented Reality AR}

Augmented Reality (AR) is defined as a system that combines real and virtual contents. It provides a real-time interactive environment, and registers virtual objects in 3D to enhance the understanding of the physical environment (Azuma, 1997). According to (Milgram,
Takemura, Utsumi, \& Fumio, 1995), AR completes reality without completely replacing it. It aims to enhance the perception and understanding of the real world by superimposing virtual information on top of the real world view (Bekele \& Champion, 2019a). Augmented reality is a collection of interactive technologies that merge these two elements; virtual and real, in real-time, providing accurate registration in three dimensions (Azuma, 1997). An AR system's typical characteristics are:

- It combines real-world and virtual objects.

- It runs in real time.

- It allows interaction between users and virtual objects (Azuma et al., 2001; Bekele, Pierdicca, Frontoni, Malinverni, \& Gain, 2018).

The first AR device created was optical see-through, a Head-Mounted Display by Sutherland in 1968 (Marto \& Gonçalves, 2019). In the cultural heritage applications, AR was adopted as early as 2001 with the ARCHEOGUIDE project (Vlahakis et al., 2001). AR allows the visualisation of no longer existing elements destroyed by human action or natural disasters, or, on the contrary, to hide successive addition revealing the original appearance of the investigated item (Leach et al., 2018; Sernani, Angeloni, Dragoni, Quattrini, \& Clini, 2019). From the user's perspective, an AR experience overlays virtual information over their surrounding real environment. In order to fulfil this experience, the user should carry a technological device which allows to perceive virtual information, while seeing the real environment at the same time (Bae et al., 2016; Marto \& Gonçalves, 2019). This can be used in three major application areas: enhancing visitors' experience, heritage reconstruction, and heritage data management and exploration (Bekele, Pierdicca, Frontoni, Malinverni, \& Gain, 2018).

AR can serve in enhancing the visitors experience of heritage places by experiencing reconstructions of the building and its context at different historical periods, such as in the case of the project of $5 \mathrm{G}$ Smart tourism trial at the Roman baths in Bath, where over 100 visitors experienced reconstructions of the baths at key moments in history, on a mobile AR app. High-quality 360 video was streamed over the project's network, that included the first UK deployment of a $60 \mathrm{GHz}$ mesh network. (Fig. 9) (BBC R\&D, 2021).

Outdoor AR experiences which attempt to embed 3D content into an environment are more complex than AR experiences inside buildings. Potential solutions are complicated by real world complexities such as dynamic environments (e.g. people and traffic movement and lighting changes) and solving the occlusion problem, i.e. showing a 3D model with some parts in front of and some parts behind different buildings. Specialist hardware, with depth cameras, can help, as can remote server power, but real-time SLAM (simultaneous localisation and mapping) is beyond consumer mobile phones for outdoor AR (Leach et al., 2018).

Augmented reality, while sharing with VR the need for high-end realistic, yet less computing capabilities demanding models, the main challenge is in the registration, alignment, and tracking process to produce seamless connection between the real world and the added virtual objects. This challenge not only relies on the 
modelling process but also on the viewing devices capabilities and tracking sensors.

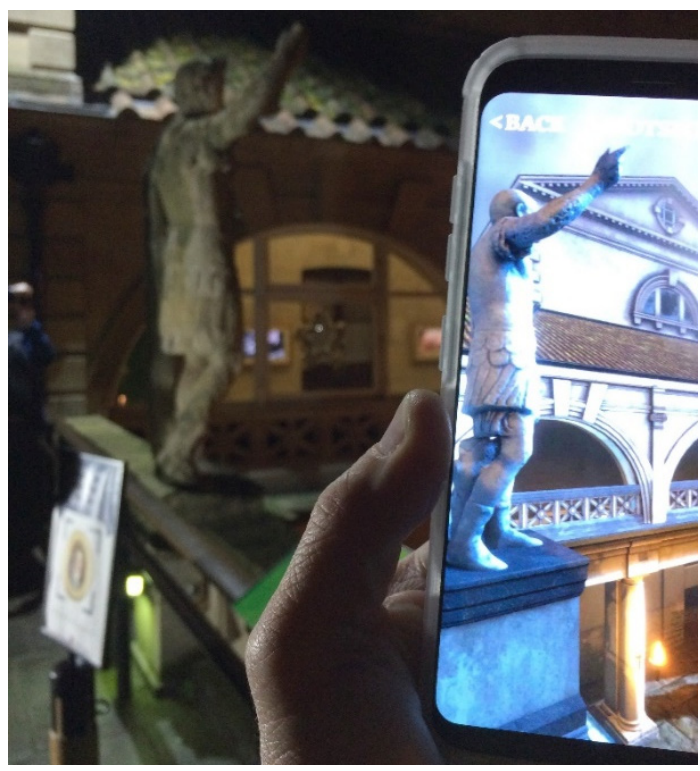

Figure 9: AR view of the Roman Baths in Bath in different historic periods (BBC R\&D, 2021).

A case of AR application is the work of Leach et al. (2018) as they visualised Sheffield's medieval castle, destroyed during the English Civil War in the mid-seventeenth century, within its current location. They used outdoor AR system that run on android phones (Fig. 10). The process begins with the user alignment process to align virtual 3D model of the area containing various 'landmark buildings' with the real-world view, with the help of the smartphone the GPS and compass sensors (Fig. 11). Next is the viewing stage, where the castle is seen in situ using $A R$, correctly aligned and positioned relative to the user (Fig. 12). They are also considering modelling proposed future development of the area, so the users can view both the future building plans and the site's cultural heritage.

\begin{tabular}{ll}
$\begin{array}{l}\text { Program Flow } \\
\text { (User Processes) }\end{array}$ & Data/Hardware Requirements \\
\hline \hline App Start & - User Interface Icons \\
(Press Continue) & \\
\hline Alignment Screen & - GPS location \\
(User lines up virtual landmark & - Landmark building photos \\
buildings with real world scene) & - Known locations for landmark buildings \\
(Press Aligned) & - Gyroscope data \\
& - Accelerometer data
\end{tabular}

Figure 10: An overview of the components of the system (Leach et al., 2018).

The main limitation observed by the researchers was some drift issues over time, that can affect especially the depth masking process. although it can be rectified by user re-alignment, it could be more time consuming and interrupting experience for the user (Leach et al., 2018).

A project that combined VR and AR applications is in the work of Barazzetti \& Banfi (2017) on the Castel Masegra, a castle located in the city of Sondrio (Lombardy region, Italy). A detailed and accurate HBIM was generated from laser scanning and photogrammetry, which provided a point cloud made up of 7.5 billion points. The different structural elements were modelled following their logic of construction as well as chronological, material, and stratigraphic aspects. The model was then simplified and exported into different file formats to try out different mobile applications for both professional operators and "casual" users interested in digital tourism.

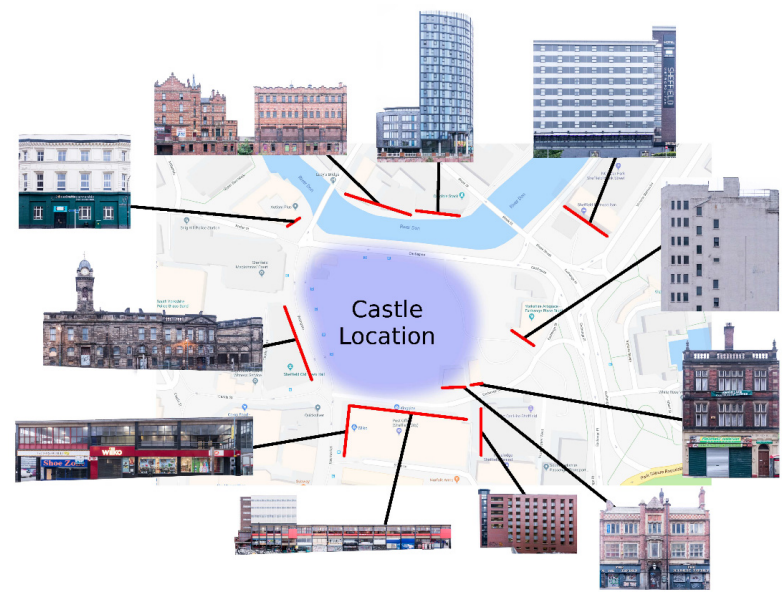

Figure 11: The various landmark buildings and their locations, which they used as markers for the AR mode tracking (Leach et al., 2018).
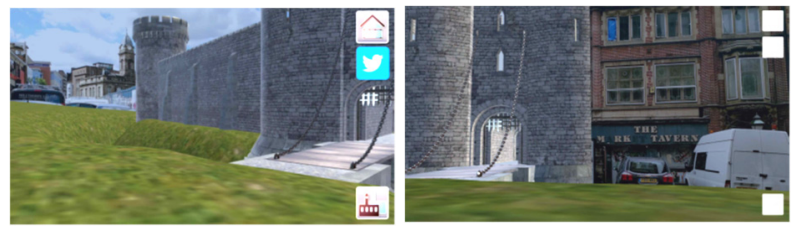

Figure 12: AR of the Sheffield castle with real surrounding buildings, modelled in front of the real Old Town Hall (left), and masked behind the real Market Tavern (right) (Leach et al., 2018).

The HBIM project of Castel Masegra (Autodesk Revit file format) was saved with the .dwf file format to preserve object information during the creation of the mobile version, so that the HBIM database remains available also in smartphones and tablets. A virtual tour of the castle was produced from the BIM model using iVisit 3D, which is based on the rendering engine Artlantis. AR visualisation on mobile phones was produced by ARmedia application using markers in a brochure of the castle (Fig. 13). The main problem was in the transformation of BIM files into different formats for the visualisation that results in information loss.

Sernani, Angeloni, Dragoni, Quattrini, \& Clini (2019) proposed the development of an AR app integrating image targets and SLAM to support and guide a visitor in the fruition of the "Studiolo" inside the "Palazzo Ducale" in Urbino, Italy. image targets are used to recognize the Points of Interest (POIs) and the SLAM to perform the object tracking and achieve a reliable immersive userexperience. SLAM can be used to anchor suggestions about different POls into specific positions inside the "Studiolo", guiding the users' orientation during the visit. POls were identified in the "Studiolo" to depict messages to the visitor that could not get many of them due to the high complexity of the scene and the need of a deep knowledge of Renaissance History, Literature, Philosophy and Policy. Then A linear storytelling was 
developed, from the entrance to the exit of the room, connecting all these elements.
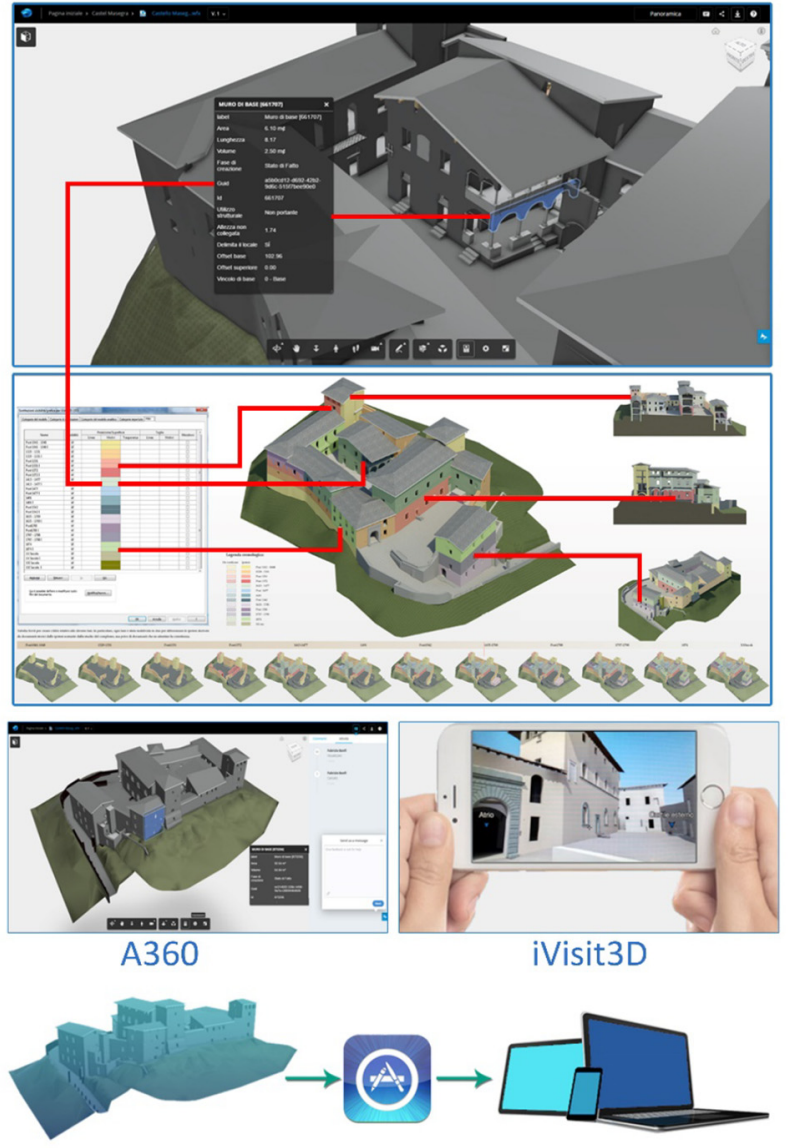

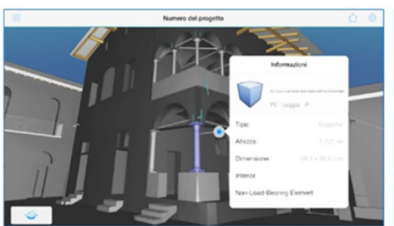

$\mathrm{BIMx}$

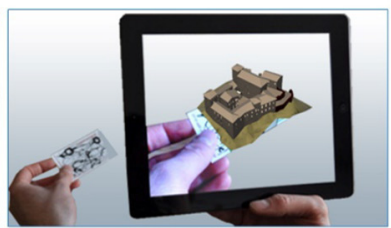

AUGMENTED 3D
Figure 13: BIM model of the Castel Masegra depicting chronological phases of the building that was used for mobile VR and AR applications (Barazzetti \& Banfi, 2017).

When the image target is acquired in the AR, i.e. the POI is recognized, the app automatically switches to SLAM mode to perform instant tracking, assigning the visual elements related to the suggestion of other POls to a virtual ground plane (Figs. 14 and 15).

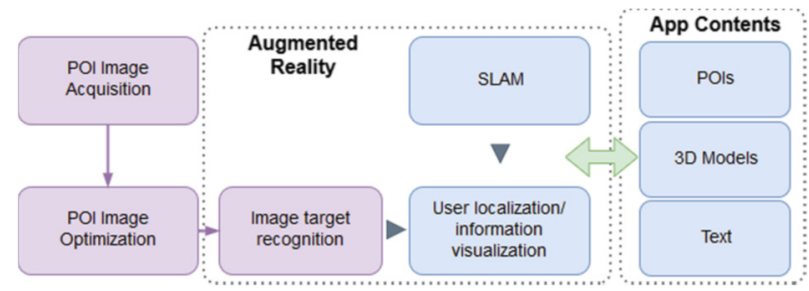

Figure 14: AR workflow of the "Studiolo" at "Palazzo Ducale" in Urbino, Italy (Sernani, Angeloni, Dragoni, Quattrini, \& Clini, 2019).
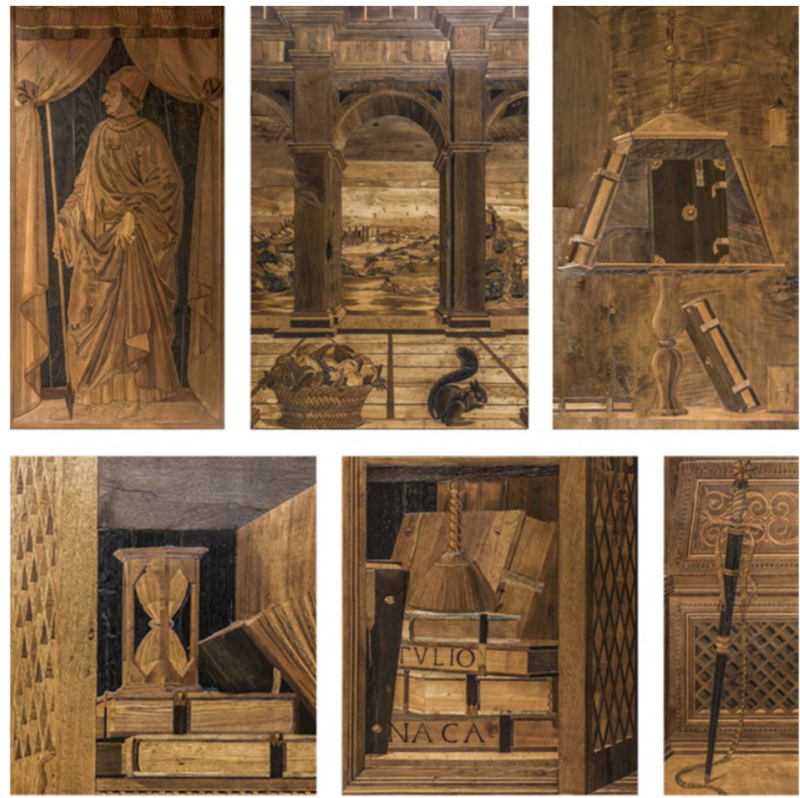

Figure 15: Orthoimages of the POls to be used as image targets for the AR app (Sernani, Angeloni, Dragoni, Quattrini, \& Clini, 2019).

Limitation can occur in some challenging cases such as the change in ambient lighting, as well as the computational needs of SLAM that can stresses the mobile devices.

\subsection{Augmented Virtuality AV}

Augmented Virtuality (AV) aims to augment virtual environments with live scenes to enhance our understanding of the underlying virtual environment. This contrasts with VR's aim to transport users to a completely virtual world. AV is closely aligned to $A R$ in terms of purpose, in the sense that both aim at enhancing the environment they are applied to (Bekele \& Champion, 2019a). However, AV applications to the built heritage are rather limited to date.

Gheorghiu \& Stefan (2018) tried to implement AV to a visualisation of two Greco-Roman sites in Romania. They achieved it by adding architectural fragments reconstructed in reality (as experimental archaeology) and 3D-scanning of real characters dressed in epoch costumes into 3D models of the sites in order to enhance the users experience by adding information about activities and daily life technologies, in a living, engaging way (Fig. 16).

\subsection{Mixed Reality MR}

Milgram, Takemura, Utsumi, \& Fumio (1995) defined Mixed Reality (MR) as "...a particular subclass of VR related technologies that involve the merging of real and virtual worlds.". MR involves the blending of real and virtual worlds somewhere along the reality-virtuality continuum which connects completely real environments to completely virtual ones (Bekele \& Champion, 2019a). According to Bekele, Pierdicca, Frontoni, Malinverni, \& Gain (2018), Mixed reality is an environment where real and virtual content coexist and interact in real time. The aspects of augmented and virtual reality merge to achieve this. It is not just an alternative to augmented or virtual 
reality, rather, it is a unique perspective that enriches human perception of both real and virtual environments, where flexibility, immersion, interaction, coexistence, and enhancement are the essential aspects of a mixed reality experience. MR combines some properties from both segments, interactivity from $A R$ and immersion from VR (Bekele \& Champion, 2019a).

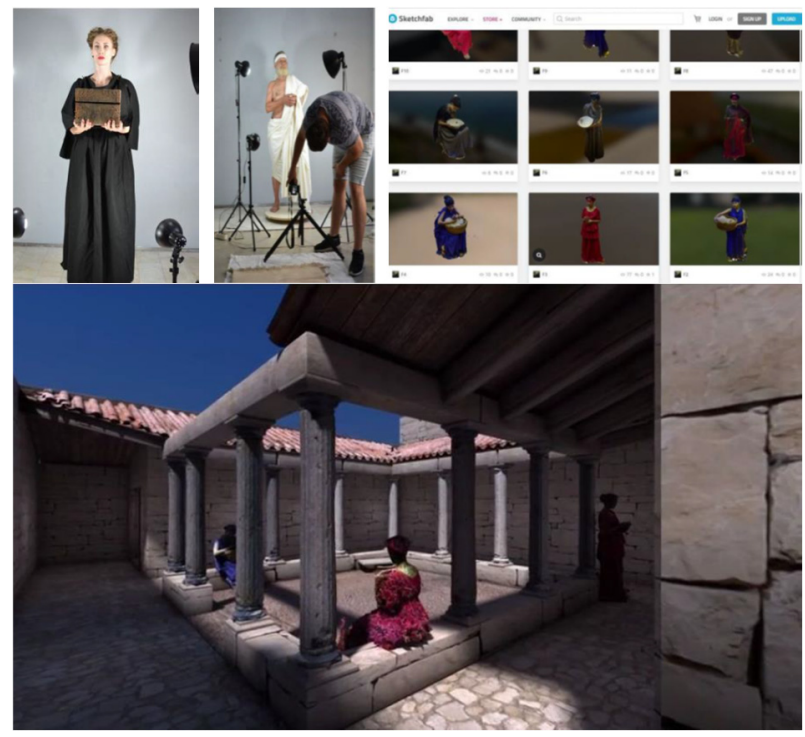

Figure 16: Adding real characters dressed in epoch costumes into virtual scenes (Gheorghiu \& Stefan, 2018).

In contrast with MR, the academic literature has noted that $A R$ has a limited visual and spatial immersion (Leach et al., 2018). MR, on the other hand, combines interactivity and immersion from $A R$ and $V R$, respectively, to bring immersive-interactive experiences to our view of the real-virtual word (Bekele \& Champion, 2019a).

MR applications for the built environment and specifically heritage buildings have been rare due to the lack of devices with robust real-time tracking, 3D registration, realistic virtual environments, natural interaction interfaces, and presentation devices for vivid experiences (Bekele, Pierdicca, Frontoni, Malinverni, \& Gain, 2018). Over the past two years more and more MR devices are appearing in the market, such as Microsoft Hololens 2 (the first generation was released in March 2016 and the second generation in November 2019) (Microsoft, 2020) and Magic leap 1 (released in August 2018) (Magic leap, 2020). This is coupled with more built environment related applications. However, the focus is more towards the early design stage of buildings, but examples exist for building representation only. MR for heritage buildings has a lot of potential, but it is still not a straightforward process on how an existing heritage building can be meaningfully interacted with in MR, or how a digitally.

An interesting heritage related MR application is in the work of Pollalis et al., (2018) as they produced an MR visualisation and interaction with ancient Egyptian sculptures using the HoloLens 1 headset, 3D model viewing website (SketchFab), and plastic extrusion 3D prints (Fig. 17).

An example of MR application in facility management is in the "HeritageCARE" project by Fonnet, Alves, Sousa, Guevara, \& Magalhães, (2017). The project is aiming to help facility management inspectors to inspect heritage buildings using Microsoft HoloLens. The idea is to impose a BIM model of the building on the real site in order to inspect and report any new problem (Fig. 18).
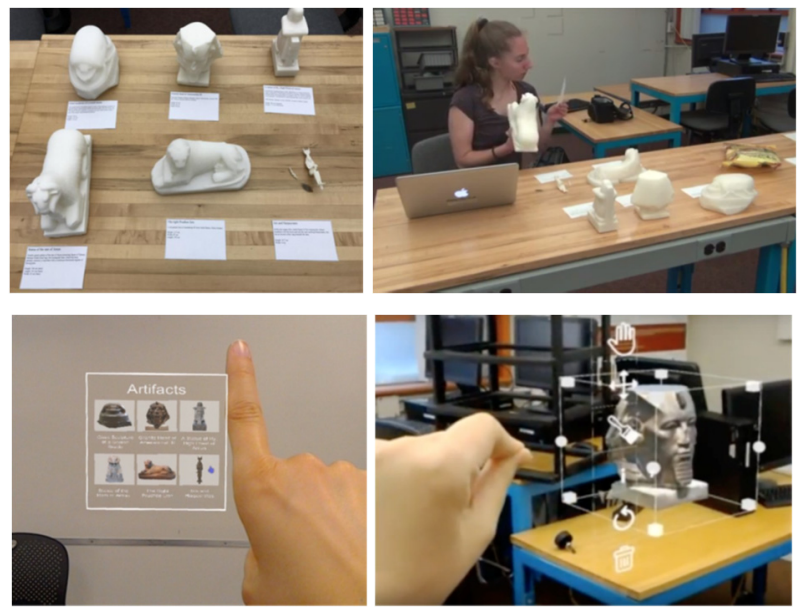

Figure 17: The 3D printed artefact inventory and Holographic artefact inventory used in MR visualisation by (Pollalis et al., 2018).

Drawbacks of the system are in the limited capacity of the HoloLens battery that is limited to 150 minutes. Another problem is in the text input from the inspectors, as the HoloLens only allows a virtual keyboard which is not practical, so they rely on recording audio notes that require further time to translate into text notes.

Bekele (2019) suggested a framework for a walkable MR map that can allow users to interact with virtual objects via maps that are virtually projected on the floor and viewable through MR devices. The projected maps are room-scale and walkable with a potential global scalability. Besides movement-based interaction, users can interact with virtual objects, multimedia content and 3D models using Microsoft HoloLens's standard gesture, gaze and voice interaction methods (Fig. 19).
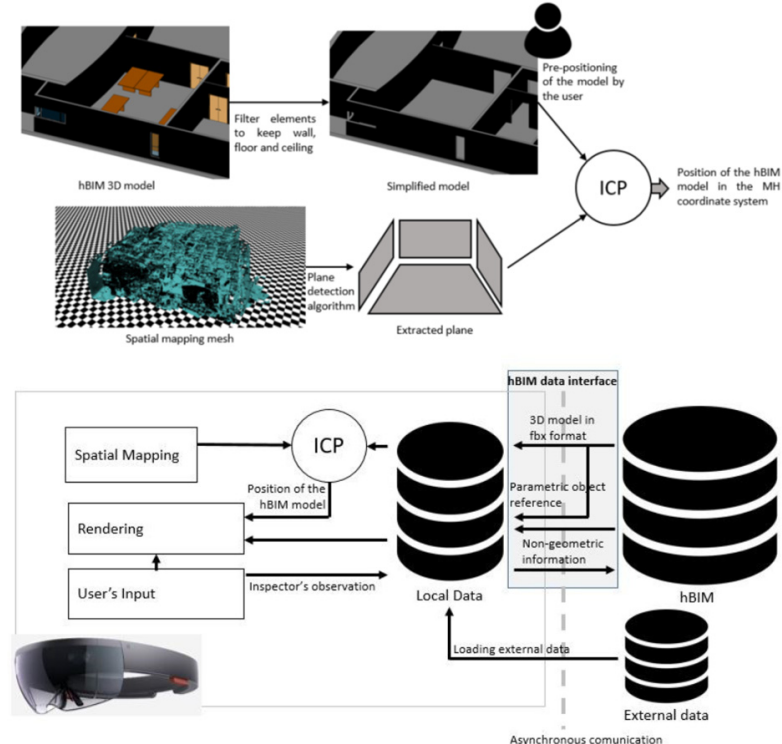

Figure 18: H-BIM model positioning steps and the architecture of the mixed reality application (Fonnet, Alves, Sousa, Guevara, \& Magalhães, 2017). 


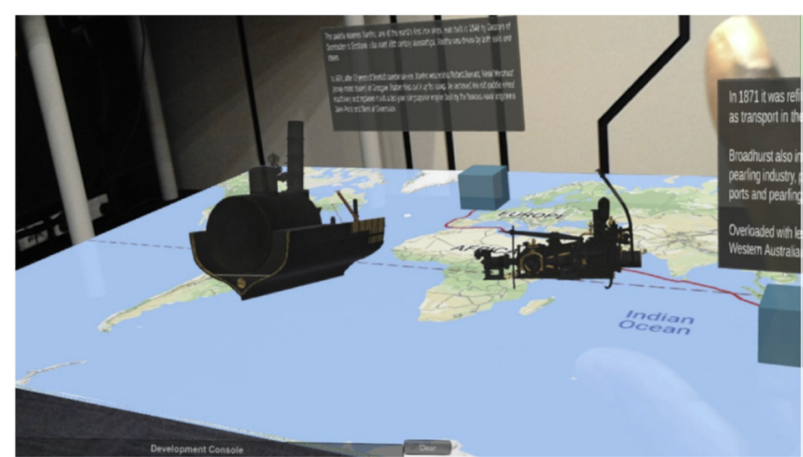

Figure 19: User moving round the map projected on the floor and interacting with 3D models placed on the map (Bekele, 2019).

The system consists of Head Mounted Display (HMD), Geospatial Information and Event Cue, Interaction Inputs and Mixed Reality Framework, Event and Spatial Query Handler, and Cultural Dataset containing historical and cultural context (3D models, multimedia content and event spatiotemporal information) (Fig. 20).

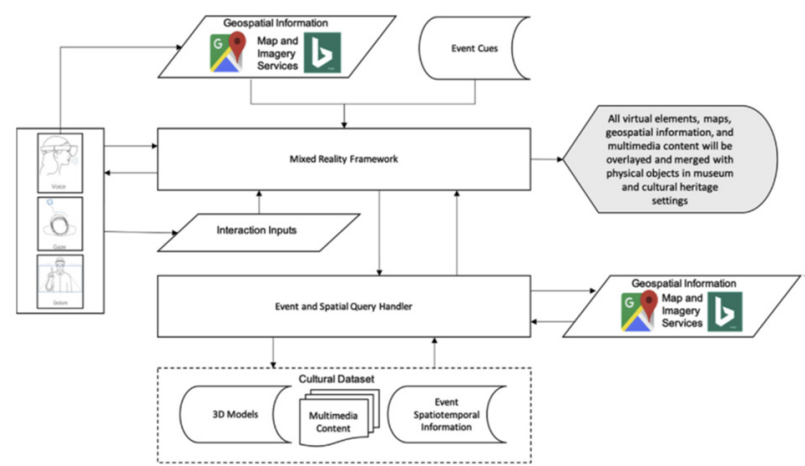

Figure 20: System architecture of the walkable mixed reality map (Bekele, 2019).

The map loads at the initial scene of that will be launched based on users' request. Once users start interacting with the virtual environment, a series of maps and 3D models and cultural context will be revealed to the user.

Limitations lay in the rapid development of software such as MRTK that are still going through rapid and frequent changes, which can cause some incompatibility issues with existing implementations and requires extra effort to port older version codes to latest version development framework. Another challenge is that rendering highly detailed 3D models in HoloLens is problematic, thus, the models had to be decimated to collapse the models to a less detailed and simplified geometry. Also, occlusion between physical and virtual objects can lead to some performance degradation, especially when there are moving objects continually detected by the environmental understanding cameras of the device. As a result, some lags were introduced when rendering frames.

\subsection{Comparison}

Different $X R$ applications, while sharing the basic concept of visual representation of the building, can vary in many aspects. Figure 21 summarises the main aspects and their variations between the different extended realities, and explores their potential applications for the built heritage. Every aspect is represented in three levels (high, medium or low value). Every XR application for heritage buildings is represented in three levels (high potential, medium potential or low potential), this is based on how likely the specific application could benefit from each XR tool.

\begin{tabular}{|c|c|c|c|c|c|}
\hline & & AR & MR & AV & VR \\
\hline \multicolumn{2}{|c|}{ Immersiveness } & $\bullet$ & $\bullet$ & 0 & 0 \\
\hline \multicolumn{2}{|c|}{ Photorealism } & 0 & 0 & $\bullet$ & $\bullet$ \\
\hline \multicolumn{2}{|c|}{ Interaction } & $\bullet$ & 0 & - & $\bullet$ \\
\hline \multicolumn{2}{|c|}{$\begin{array}{l}\text { Accessibilityl } \\
\text { Ease of use }\end{array}$} & $\bullet$ & $\bullet$ & $\bullet$ & 0 \\
\hline \multicolumn{2}{|c|}{ Technology } & $\bullet$ & 0 & $\bullet$ & $\bullet$ \\
\hline \multirow{7}{*}{ 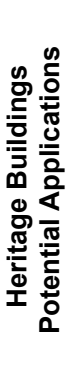 } & Design & $\bullet$ & $\bullet$ & $\bullet$ & 0 \\
\hline & Construction & 0 & $\bullet$ & $\bullet$ & $\bullet$ \\
\hline & $\begin{array}{c}\text { Facility } \\
\text { management }\end{array}$ & O & $\bullet$ & $\bullet$ & $\bullet$ \\
\hline & Real estate & $\bullet$ & $\bullet$ & $\bullet$ & 0 \\
\hline & Education & $\bullet$ & $\bullet$ & $\bullet$ & 0 \\
\hline & $\begin{array}{l}\text { Cultural } \\
\text { tourism }\end{array}$ & ○ & ○ & $\bullet$ & $\bullet$ \\
\hline & $\begin{array}{l}\text { Virtual } \\
\text { museums }\end{array}$ & $\bullet$ & $\bullet$ & $\bullet$ & 0 \\
\hline \multicolumn{6}{|c|}{ High value / high potential. } \\
\hline \multicolumn{6}{|c|}{ ? } \\
\hline
\end{tabular}

Figure 21: Aspects of extended realities and their potential applications for heritage buildings.

Immersiveness represents how much the user feels included in the virtual environment. Naturally, it is more observed in VR as the user is totally engulfed by the virtual environment and excluded from the real environment.

Photorealism, on the other hand, represents how realistic is the visualisation to the user experience. This is particularly harder to achieve in VR, as it depends entirely on the modelled virtual environment, in contrast with AR that basically uses the real environment as the main visualisation with virtual elements integrated.

Photorealism is defined by Ferwerda (2003) as one aspect of realism as they distinguished three different varieties of realism:

- Physical realism, where the virtual objects provide the same visual simulation as the real scene;

- Photorealism, where the image produces the same visual response as the scene;

- Functional realism, in which the image provides the same visual information as the scene.

It is argued that the non-photorealistic rendering (NPR) approach can also be used in AR to describe abstract information that is not representable, or in case of a required focus on a special detail (Haller, 2004). According to Fernando \& Kilgard (2003) objects in wireframe, flat shading or NPR shading are easily discernible, and can focus the user's attention to augmented objects. Durand (2002) states that the border between photorealism and non-photorealism can be 
fuzzy and the notion of realism itself is very complex. He argues that the virtual world has to be interpreted as more convincing rather than realistic. The same idea is also elaborated by Roussou \& Drettakis (2003).

Although, in the heritage sector, fine details are usually in need to be elaborated and models need to be rendered as realistic as possible with seamless integration of the virtual objects into the real world, In some cases nonphotorealism could be of good use to differentiate different aspects, for example, to contrast different phases of the construction of the building using simplified models.

Interaction between the user and the visualisation environment and between the real and virtual environments is another aspect that varies between different extended reality applications. Mixed reality is considered as the ultimate interaction potential as it merges between real and virtual environments and enables users to interact with both environments and sometimes with other users through the virtual environment. Followed by the augmented reality that enables users to fully interact with their real surroundings and integrated virtual objects. VR, on the other hand, allows the user to interact only with the virtual environment. It includes, as well, two levels of interaction: 3 DoF VR has very limited interaction as the user can only explore the virtual model, while 6DoF VR allows much more interaction as the user's movements are tracked and translated into the virtual environment.

Accessibility and ease of use favour VR applications as it requires only a medium of the display to view the visualisation and sometimes sensors for movement tracking without requiring the user to be in a specific location (i.e. the site of a heritage building) or to use an initial alignment and registration steps like in $A R, M R$, and AV.

The technology level required for visualisation varies as well. While VR is less complicated, AR needs more advanced technology to capture the real environment and align the virtual model within it using cameras and sensors for place, orientation, and movement registration and tracking. MR is even more technologically demanding as it requires interaction between the users and both real and virtual environment, it can also require fast communication technology to facilitate virtual interaction between different users in different places.

Extended reality can be used in a range of use cases that require specific applications. Visualisation in the design phase, for instance, can benefit from VR to visualise the proposed new design or alternative models. AR and MR can be used as well to view the new design within its actual location.

In the construction and facility management phases, AR is more appropriate as it visualises the building model and its different systems on the actual building. MR can potentially be useful in communication between different teams in the construction process.

In real estate marketing VR is the most useful tool as it can represent real $360^{\circ}$ photos of the building as immersive virtual tours that are more appealing and informative to potential clients than photos and videos.

$\mathrm{VR}$ is also more likely as a potential tool for education, public dissemination and virtual museums to view heritage buildings in their different stages with linked information. MR and AV can also be helpful in education and virtual classrooms to facilitate communication between the presenter and audience with enhanced virtual and real merging.

Cultural tourism, on the other hand, has its ultimate potentials in AR and MR applications as models of lost buildings can be viewed within their actual places, also different changes and previous states can be viewed on the building's current status as well as linking useful information within the real view of the building.

\section{H-BIM and extended reality in heritage buildings representation}

HBIM tools represent a crucial development in the heritage buildings sector. It facilitates the integration of different stakeholders into a unified platform that can combine the various data about heritage buildings (Khalil, Stravoravdis, \& Backes, 2020). HBIM can incorporate both quantitative assets (intelligent objects, performance data) and qualitative assets (historic photographs, oral histories, music) (Fai, Graham, Duckworth, Wood, \& Attar, 2011), as well as historic texts, archaeological figures, architectural information, administrative data and past drawings, sketches, photos, etc. (Cheng, Yang, Bin, \& Yen, 2015). HBIM offers a process of digitally documenting all the features that are made or incorporated into the heritage building over its life-span, therefore offers unique opportunities for information preservation (Albourae, Armenakis, \& Kyan, 2017). HBIM is also useful to disseminate the building and its historic development for the wider audience through modelling the different phases of the building's history.

Extended reality applications can greatly benefit from HBIM environment as it already contains a detailed 3D model of the heritage building, enhanced with a multitude of data about the building. These 3D models can represent a base for different visualisation applications. Recent developments of visualisation engines such as Unity 3D engine and Unreal engine can link with BIM software to facilitate the transition from a BIM model to XR visualisation (Unity, 2021; Engine, 2020).

A recent development in the field of modelling and geometry capture is the introduction of applications for modern smartphones equipped with LIDAR sensors that can facilitate $3 \mathrm{D}$ geometric capture and upload it to create BIM models (Fig. 22) (Canvas, 2020). Although this approach is still in development and the accuracy of these models is still questionable, it has the potential to dramatically reduce the cost and time of geometry capture of heritage buildings and allows non-experts to perform a $3 \mathrm{D}$ capture of heritage buildings. This in turn can help to capture in 3D more heritage buildings with less cost and labour.

A similar approach is seen in the development of several online platforms that allow creating virtual tours and 3D photogrammetric models from lower end $360^{\circ}$ cameras, such as Cupix (2018) and Matterport (2021) (Fig. 23).

These technologies can facilitate the introduction of VR and AR solutions for the heritage sector that can be beneficial in a wide range of uses from project collaboration to education to virtual museums to real estate. The significance of it is further emphasised in the 
situation of the current COVID-19 pandemic and the great shift from physical interaction to online interaction. Such technologies are removing barriers to the digital documentation of heritage buildings and provide new paradigms. It is easy to imagine a step by step approach that can be adopted by facility managers and other stakeholders in heritage buildings by 3D capturing one room at a time, as needed and as budgets allow without having to go through long procurement routes.
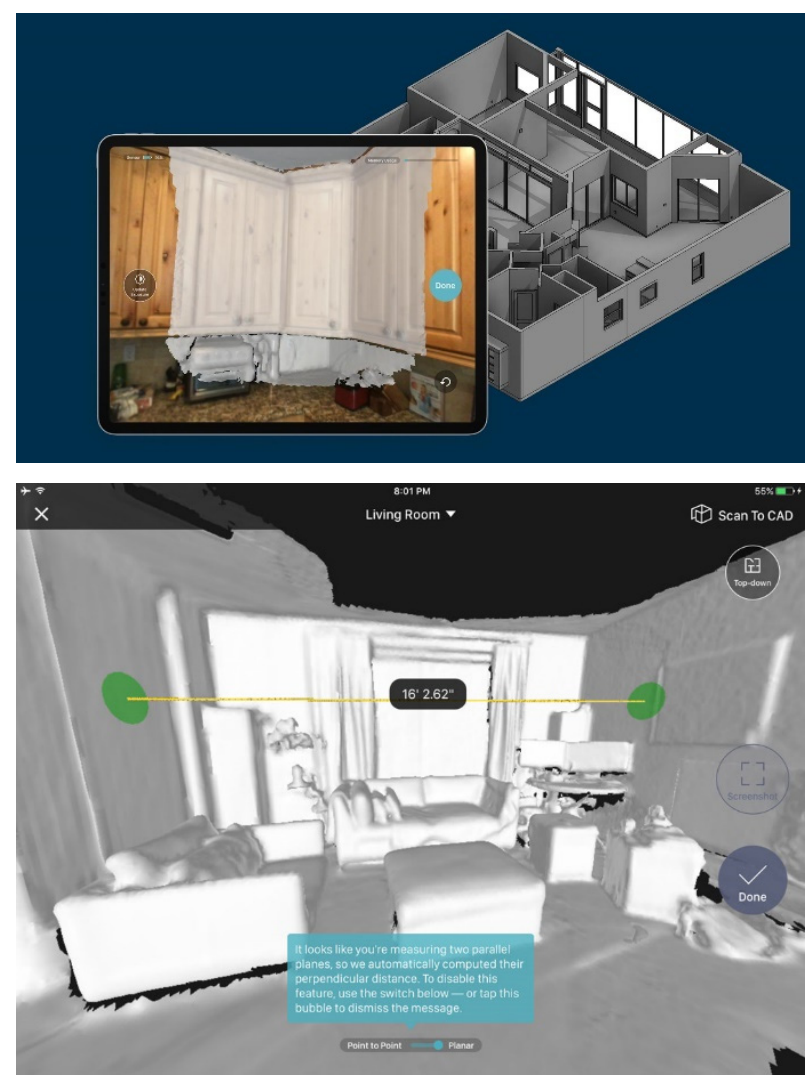

Figure 22: Canvas workflow that allows as built scanning using mobile devices equipped with LIDAR to create a BIM model

(Canvas, 2020).

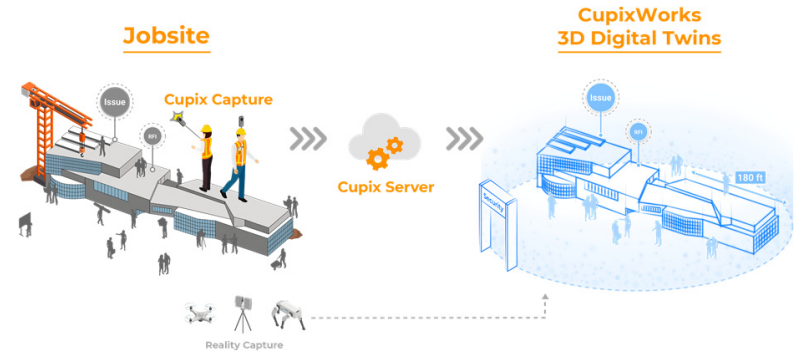

Figure 23: Cupix cloud-based workflow using $360^{\circ}$ photography to create as-built photogrammetric models (Cupix, 2018).

\section{Conclusion}

Heritage buildings digital visualisation is an area that witnessed a revolution in architectural representation through extended reality applications. It can facilitate faster and more reliable communication between project's stakeholders, as well as creating more immersive and interactive public engagement and education about built heritage.
Extended reality $(X R)$ is represented in a spectrum that merges real environment and virtual environment. It contains, augmented reality (AR), mixed reality (MR), augmented virtuality (AV), and virtual reality (VR). They differ in their respective level of immersiveness, photorealism, interaction, ease of use and technology.

$\mathrm{VR}$, as the most basic form, totally excludes the real world and represent the most immersive experience. It can be used to present buildings that could be lost, damaged, or not accessible. The major challenge in VR is how realistically the building can be modelled to enhance the immersion of the user. The great potentials in VR are in the straightforward user experience (with no requirement of registration and alignment), it can be viewed on a wide range of devices and can be experienced in any place. Even the higher-end VR devices are in constant development and rapid drop in cost, which can contribute towards more public accessibility.

$A R$, on the other hand, aims to represent a building, element, or information within the real world. It can also present planned works within its actual real environment. It can represent lost historical elements or buildings within their actual site or show how the building looked in previous times. Beyond the modelling challenges, AR faces the registration and tracking challenges, to keep the modelled part aligned within the real view, where many sensors can be used to achieve it. This means that, although it can be accessed on average smartphones, it requires a high level of sensor responsiveness and computing capacity. Potential mobile devices with some kind of SLAM technology (simulations location and mapping) could be of great benefit in AR applications for heritage buildings.

In the same way, AV is where the virtual environment is augmented with real elements, however, its application is rather limited in the built heritage.

Whereas, MR is the ultimate merging between real and virtual environments. it depends on the fast advancement of communication and display technologies. It is still an area in development; however, it promises the most interactive and engaging experience, which can be an added value for the representation of heritage buildings.

Extended reality applications represent valuable potentials for the heritage sector. It can enhance the visual representation in the design process. AR and MR applications can also serve as a communication tool between different teams in the construction phase to better monitor progress and conflicts on the real building, as well as helping in helping in the facility management process.

Virtual reality can be used in real estate marketing, education, and virtual museums application. While augmented reality can be a very useful tool in cultural tourism to add valuable information to real-life views as well as viewing the past status of the building and its context.

Limitations of the extended reality applications are mainly represented on its dependability on high-end technologies, sophisticated devices, reliable software, fast communication systems, and complicated workflows, which makes it harder to achieve, especially to produce photorealistic, low-latency, immersive user experience. Although constant development in technology is leading 
the way towards wider XR applications with better results, it can mean also that older models can no longer be accessed with newer technologies, which is a challenging aspect in the heritage sector that ideally requires visual models to live longer and be viewed for long times. Adding to that, that the heritage building sector is typically more expensive to run and less in revenue than other projects, as a result, the financial capabilities for extended reality application could be limited, especially to update models every few years or even months to follow up with the endlessly developing technologies, software, and viewing devices.

\section{References}

Albourae, A. T., Armenakis, C., \& Kyan, M. (2017). Architectural heritage visualization using interactive technologies. International Archives of the Photogrammetry, Remote Sensing and Spatial Information Sciences - ISPRS Archives, 42(2W5), 7-13. https://doi.org/10.5194/isprs-archives-XLII-2-W5-7-2017

Andrade, T., \& Bastos, D. (2019). Extended reality in iot scenarios: Concepts, applications and future trends. Proceedings of the 2019 5th Experiment at International Conference, Exp.at 2019, $107-112$. https://doi.org/10.1109/EXPAT.2019.8876559

Azuma, R., Baillot, Y., Behringer, R., Feiner, S., Julier, S., \& Maclntyre, B. (2001). Recent advances in augmented reality. IEEE Computer Graphics and Applications, 21(6), 34-47. https://doi.org/10.1109/38.963459

Azuma, R. T. (1997). A Survey of Augmented Reality. Presence: Teleoperators and Virtual Environments, 6(4), 355-385. https://doi.org/10.1162/pres.1997.6.4.355

Bae, H., Walker, M., White, J., Pan, Y., Sun, Y., \& Golparvar-Fard, M. (2016). Fast and scalable structure-from-motion based localization for high-precision mobile augmented reality systems. MUX: The Journal of Mobile User Experience, 5(1). https://doi.org/10.1186/s13678-016-0005-0

Banfi, F. (2019). The integration of a scan-to-hbim process in BIM application: the development of an add-in to guide users in autodesk revit. ISPRS - International Archives of the Photogrammetry, Remote Sensing and Spatial Information Sciences, XLII-2(2/W11), 141-148. https://doi.org/10.5194/isprs-archives-XLII-2-W11-141-2019

Barazzetti, L., \& Banfi, F. (2017). Historic BIM for Mobile VR/AR Applications. In: Ioannides M., Magnenat-Thalmann N., Papagiannakis G. (eds) Mixed Reality and Gamification for Cultural Heritage. Springer, Cham. https://doi.org/10.1007/978-3-319-49607-8_10

BBC R\&D. (2021). 5G Smart Tourism Trial at the Roman Baths - BBC R\&D. Retrieved November 25, 2020, from https://www.bbc.co.uk/rd/blog/2019-02-5g-mobile-augmented-reality-bath

Bekele, M. K. (2019). Walkable Mixed Reality Map as interaction interface for Virtual Heritage. Digital Applications in Archaeology and Cultural Heritage, 15(August), e00127. https://doi.org/10.1016/j.daach.2019.e00127

Bekele, M. K., \& Champion, E. (2019a). A Comparison of Immersive Realities and Interaction Methods: Cultural Learning in Virtual Heritage. Frontiers in Robotics and Al, 6(September). https://doi.org/10.3389/frobt.2019.00091

Bekele, M. K., \& Champion, E. (2019b). Redefining mixed reality: User-reality-virtuality and virtual heritage perspectives. Intelligent and Informed - Proceedings of the 24th International Conference on Computer-Aided Architectural Design Research in Asia, CAADRIA 2019, 2(April), 675-684.

Bekele, M. K., Pierdicca, R., Frontoni, E., Malinverni, E. S., \& Gain, J. (2018). A survey of augmented, virtual, and mixed reality for cultural heritage. Journal on Computing and Cultural Heritage. Association for Computing Machinery. https://doi.org/10.1145/3145534

Canvas. (2020). Blazing-Fast Mobile 3D Capture | Canvas. Retrieved March 4, 2021, from https://canvas.io/

Carmigniani, J., Furht, B., Anisetti, M., Ceravolo, P., Damiani, E., \& Ivkovic, M. (2011). Augmented reality technologies, systems and applications. Multimedia Tools and Applications, 51(1), 341-377. https://doi.org/10.1007/s11042-0100660-6

Carrozzino, M., \& Bergamasco, M. (2010). Beyond virtual museums: Experiencing immersive virtual reality in real museums. Journal of Cultural Heritage, 11(4), 452-458. https://doi.org/10.1016/j.culher.2010.04.001

Cheng, H. M., Yang, W. Bin, \& Yen, Y. N. (2015). BIM applied in historical building documentation and refurbishing. International Archives of the Photogrammetry, Remote Sensing and Spatial Information Sciences - ISPRS Archives, 40(5W7), 85-90. https://doi.org/10.5194/isprsarchives-XL-5-W7-85-2015

Cupix. (2018). Cupix: Software to Transform 360 Photos into a 3D Virtual Space. Retrieved March 4, 2021, from https://www.cupix.com/

Davies, C., Miller, A., \& Allison, C. (2013). Mobile Cross Reality for cultural heritage. Proceedings of the DigitalHeritage 2013 - Federating the 19th Int'l VSMM, 10th Eurographics GCH, and 2nd UNESCO Memory of the World Conferences, Plus Special Sessions FromCAA, Arqueológica 2.0 et Al., 1(October), 331-338. https://doi.org/10.1109/DigitalHeritage.2013.6743757

Dhanda, A., Reina Ortiz, M., Weigert, A., Paladini, A., Min, A., Gyi, M., Su, S., Fai, s., Santana Quintero, M. (2019). 
RECREATING CULTURAL HERITAGE ENVIRONMENTS for VR USING PHOTOGRAMMETRY. ISPRS Annals of the Photogrammetry, Remote Sensing and Spatial Information Sciences, 42(2/W9), 305-310. https://doi.org/10.5194/isprs-archives-XLII-2-W9-305-2019

Durand, F. (2002). An invitation to discuss computer depiction. In Proceedings of the 2nd international symposium on Nonphotorealistic animation and rendering (pp. 111-124).

Engine, U. (2020). Datasmith - Unreal Engine. Retrieved November 25, 2020, from https://www.unrealengine.com/enUS/datasmith

Fai, S., Graham, K., Duckworth, T., Wood, N., \& Attar, R. (2011). Building Information Modelling and Heritage Documentation. Proceedings of the 23rd International Symposium, International Scientific Committee for Documentation of Cultural Heritage (CIPA), Prague, Czech Republic (pp. 12-16).

Felli, F., Liu, C., Ullah, F., \& Sepasgozar, S. M. E. (2018). Implementation of 360 videos and mobile laser measurement technologies for immersive visualisation of real estate \& properties. In Proceedings of the 42nd AUBEA Conference, Singapore, 1.

Fernando, R., \& Kilgard, M. (2003). The Cg Tutorial: The definitive guide to programmable real-time graphics. Addison Wesley Professional.

Ferwerda, J. A. (2003). Three varieties of realism in computer graphics. In Proc.SPIE, 5007. https://doi.org/10.1117/12.473899

Fonnet, A., Alves, N., Sousa, N., Guevara, M., \& Magalhães, L. (2017). Heritage BIM integration with mixed reality for building preventive maintenance. EPCGI 2017 - 24th Encontro Portugues de Computacao Grafica e Interacao, January, 1-7. https://doi.org/10.1109/EPCGI.2017.8124304

Gheorghiu, D., \& Stefan, L. (2018). Augmented Virtuality as an Instrument for a Better Learning of History. Proceedings of the 13Th International Conference on Virtual Learning, Icvl, 2(2), 299-305.

Gonizzi Barsanti, S., Caruso, G., Micoli, L. L., Covarrubias Rodriguez, M., \& Guidi, G. (2015). 3D visualization of cultural heritage artefacts with virtual reality devices. International Archives of the Photogrammetry, Remote Sensing and Spatial Information Sciences - ISPRS Archives, 40(5W7), 165-172. https://doi.org/10.5194/isprsarchives-XL-5-W7$165-2015$

Haller, M. (2004). Photorealism or/and non-photorealism in Augmented Reality. Proceedings VRCAI 2004 - ACM SIGGRAPH International Conference on Virtual Reality Continuum and Its Applications in Industry, $189-196$. https://doi.org/10.1145/1044588.1044627

Haydar, M., Roussel, D., Maïdi, M., Otmane, S., \& Mallem, M. (2011). Virtual and augmented reality for cultural computing and heritage: A case study of virtual exploration of underwater archaeological sites (preprint). Virtual Reality, 15(4), 311-327. https://doi.org/10.1007/s10055-010-0176-4

Khalil, A., Stravoravdis, S., \& Backes, D. (2020). Categorisation of building data in the digital documentation of heritage buildings. Applied Geomatics 1(26). https://doi.org/10.1007/s12518-020-00322-7

Leach, M., Maddock, S., Hadley, D., Butterworth, C., Moreland, J., Dean, G., Mackinder, R., Pach, K., Bax, N., Mckone, M., Fleetwood, D. (2018). Recreating sheffield's medieval castle in situ using outdoor augmented reality. In: Bourdot P., Cobb S., Interrante V., kato H., Stricker D. (eds) Virtual Reality and Augmented Reality. EuroVR 2018. Lecture Notes in Computer Science, 11162. Springer, Cham. https://doi.org/10.1007/978-3-030-01790-3_13

Magic leap. (2020). Spatial Computing for Enterprise | Magic Leap. Retrieved November 27, 2020, from https://www.magicleap.com/en-us

Marto, A., \& Gonçalves, A. (2019). Mobile AR: User evaluation in a cultural heritage context. Applied Sciences (Switzerland), 9(24). https://doi.org/10.3390/app9245454

Matterport. (2021). Capture, share, and collaborate the built world in immersive 3D. Retrieved March 4, 2021, from https://matterport.com/en-gb

Microsoft. (2020). Microsoft HoloLens | Mixed Reality Technology for Business. Retrieved November 27, 2020, from https://www.microsoft.com/en-us/hololens

Milgram, P., Takemura, H., Utsumi, A., \& Fumio, K. (1995). Augmented reality: a class of displays on the reality-virtuality continuum. In Proc. SPIE 2351, Telemanipulator and Telepresence Technologies, Boston, MA, United States. https://doi.org/https://doi.org/10.1117/12.197321

Paradiso, J. A., \& Landay, J. A. (2009). Guest Editors' Introduction: Cross reality environments. IEEE Pervasive Computing, 8(3), 14-15. https://doi.org/10.1109/MPRV.2009.47

Pietroni, E., Pagano, A., \& Rufa, C. (2013). The Etruscanning Project: Gesture-based interaction and user experience in the virtual reconstruction of the Regolini-Galassi tomb. 2013 Digital Heritage International Congress (DigitalHeritage), Marseille, France, pp. 653-660. https://doi.org/10.1109/DigitalHeritage.2013.6744832.

Pollalis, C., Minor, E. J., Westendorf, L., Fahnbulleh, W., Virgilio, I., Kun, A. L., \& Shaer, O. (2018). Evaluating Learning 
with Tangible and Virtual Representations of Archaeological Artifacts. Proceedings of the Twelfth International Conference on Tangible, Embedded, and Embodied Interaction, pp. 626-637. Stockholm, Sweden. https://doi.org/10.1145/3173225.3173260

Reilly, D. F., Rouzati, H., Wu, A., Hwang, J. Y., Brudvik, J., \& Edwards, W. K. (2010). TwinSpace: An infrastructure for cross-reality team spaces. UIST 2010 - 23rd ACM Symposium on User Interface Software and Technology, (December 2013), 119-128. https://doi.org/10.1145/1866029.1866050

Rodríguez-Gonzálvez, P., Muñoz-Nieto, A. L., DelPozo, S., Sanchez-Aparicio, L. J., Gonzalez-Aguilera, D., Micoli, L., Gonizzi Barsanti, S., Guidi, G., Mills, J., Fieber, K., Haynes, I., \& Hejmanowska, B. (2017). 4D reconstruction and visualization of cultural heritage: Analyzing our legacy through time. Int. Arch. Photogramm. Remote Sens. Spatial Inf. Sci., XLII-2/W3, 609-616. https://doi.org/10.5194/isprs-archives-XLII-2-W3-609-2017

Roussou, M., \& Drettakis, G. (2003). Photorealism and non-photorealism in virtual heritage representation. In First Eurographics Workshop on Graphics and Cultural Heritage (p. 10). Eurographics. http://dx.doi.org/10.2312/VAST/VAST03/051-060

Sernani, P., Angeloni, R., Dragoni, A. F., Quattrini, R., \& Clini, P. (2019). Combining Image Targets and SLAM for ARBased Cultural Heritage Fruition. Lecture Notes in Computer Science (including subseries Lecture Notes in Artificial Intelligence and Lecture Notes in Bioinformatics), 11614 LNCS. Springer International Publishing. https://doi.org/10.1007/978-3-030-25999-0_17

Slater, M., \& Wilbur, S. (1997). A Framework for Immersive Virtual Environments (FIVE): Speculations on the Role of Presence in Virtual Environments. Presence: Teleoperators and Virtual Environments, 6(6), 603-616. https://doi.org/10.1162/pres.1997.6.6.603

Storchi, A. (2018). Extended Realities: insights from the next, (August), 0-18. https://doi.org/10.13140/RG.2.2.11144.06405

Techopedia. (2021). What is the Digital Revolution? - Definition from Techopedia. Retrieved December 10, 2019, from https://www.techopedia.com/definition/23371/digital-revolution

Unity. (2021). 3D Software for Architecture, Engineering \& Construction | Unity. Retrieved November 25, 2020, from https://unity.com/solutions/architecture-engineering-construction

Vlahakis, V., Karigiannis, J., Tsotros, M., Gounaris, M., Almeida, L., Stricker, D., Gleue, T., Christou, I. T., Carlucci, R., \& loannidis, N. (2001). Archeoguide: first results of an augmented reality, mobile computing system in cultural heritage sites. Virtual Reality, Archeology, and Cultural Heritage, 9(10.1145), 584993-585015. https://doi.org/10.1145/584993.585015

Zhao, Q. (2009). A survey on virtual reality. Science in China, Series F: Information Sciences, 52, 348-400. https://doi.org/10.1007/s11432-009-0066-0 


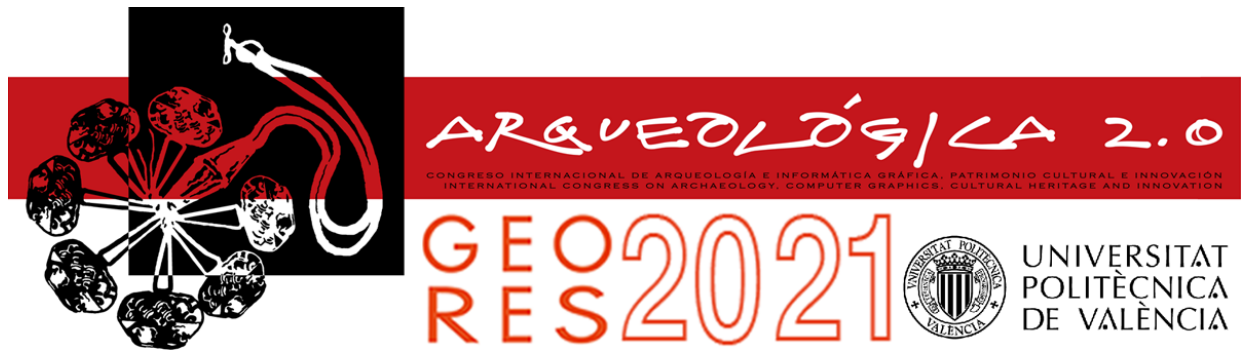

Proceedings of the joint international event $9^{\text {th }}$ ARQUEOLÓGICA

$2.0 \& 3^{\text {rd }}$ GEORES

Valencia (Spain).

26-28 April 2021

\title{
STUDY ON QUALITY IN 3D DIGITISATION OF TANGIBLE CULTURAL HERITAGE
}

\author{
Douglas Pritcharda, ${ }^{*}$, Thomas Rigauts ${ }^{a}$, Francesco Ripantia, Marinos loannides ${ }^{a}$, Raffaella \\ Brumana $^{\text {b }}$, Robert Davies ${ }^{a}$, Eleanna Avouria, Harriet Cliffena, Nenad Joncic ${ }^{a}$, Giulia Ostia, Marina \\ Toumpouria

\begin{abstract}
${ }^{a}$ Digital Heritage Research Laboratory, Department of Electrical Engineering, Computer Engineering and Informatics, Cyprus University of Technology, Arch. Kyprianou 31, CY 3036 Limassol, Cyprus. douglas.pritchard@cut.ac.cy; thomas.rigauts@cut.ac.cy; francesco.ripanti@cut.ac.cy; marinos.ioannides@cut.ac.cy; robert.davies@cut.ac.cy; eleni.avouri@cut.ac.cy; harriet.cliffen@cut.ac.cy;
\end{abstract} \\ nenad.joncic@cut.ac.cy; giulia.osti@cut.ac.cy; marina.toumpouri@cut.ac.cy \\ b Dipartimento Architettura, Ingegneria delle Costruzioni e Ambiente Costruito (ABC), Politecnico di Milano, Via Ponzio 31, 20133 Milan,
} Italy. raffaella.brumana@polimi.it

\begin{abstract}
:
Following the implementation of the Virtual Multimodal Museum (ViMM) project, which finished in March 2019, the European Commission issued a Declaration on Cooperation on Advancing Digitisation of Cultural Heritage during the Digital Day in April 2019. One year later, in April 2020, the European Commission (EC) launched a commercial call for tenders to develop a Study on quality in 3D digitisation of tangible cultural heritage (the study). The tender theme is to acknowledge the increasing demand for internationally recognised standards for the holistic 3D documentation of Europe's rich cultural heritage $(\mathrm{CH})$ and address the lack of standards. The study aims to map parameters, formats, standards, benchmarks, methodologies, and guidelines relating to 3D digitisation of tangible cultural heritage, the different potential purposes or uses, by type of tangible cultural heritage, and the degree of complexity of tangible cultural heritage. A team of researchers at the Cyprus University of Technology (CUT) leads a consortium of partners from industry and academia across Europe to conduct this unique study. This work in progress paper introduces the research's objectives and methodology and presents some of its first results.
\end{abstract}

Keywords: tangible cultural heritage, documentation, 3D digitisation, international documentation standards, digital heritage

\section{Introduction}

The digital documentation and virtual representation of artefacts, monuments, and sites are essential for the conservation, management, scientific documentation, and cultural heritage analysis. At present, there are a vast array of technologies, recording methods, software solutions and post-processing techniques to address this issue. Despite the ever-increasing demand for these systems and procedures, there are few internationally recognised standards or methodologies for 'the comprehensive, holistic 3D documentation of European cultural heritage assets.' As the value of 3D digitisation technologies in cultural heritage is growing steadily, the need for standards becomes ever more urgent.

In 2019, 27 Member States of the European Union had committed to the importance of these digital technologies by signing the Declaration of Cooperation on advancing the digitisation of cultural heritage on Digital Day (April 2019). By doing so, they endorsed the call for common standards, methodologies and guidelines for the holistic 3D documentation of European Cultural Heritage (European Commission, 2019).

In April 2020, the European Commission launched a call for tenders to carry out for the first time a Study on quality in 3D digitisation of tangible cultural heritage (VIGIE 2020/654). The purpose of the call is to map parameters, formats, standards, benchmarks, methodologies and guidelines, relating to the $3 \mathrm{D}$ digitisation of tangible cultural heritage. Addressing the different potential purposes or uses, by type of tangible cultural heritage, and the degree of complexity of tangible cultural heritage (European Commission, 2020b).

As illustrated in Figure 1, the Cyprus University of Technology (2020a), which holds the UNESCO and ERA Chairs on Digital Cultural Heritage, is leading a consortium of partners from the industry and academia across Europe to conduct this unique study (European Commission, 2020c). 


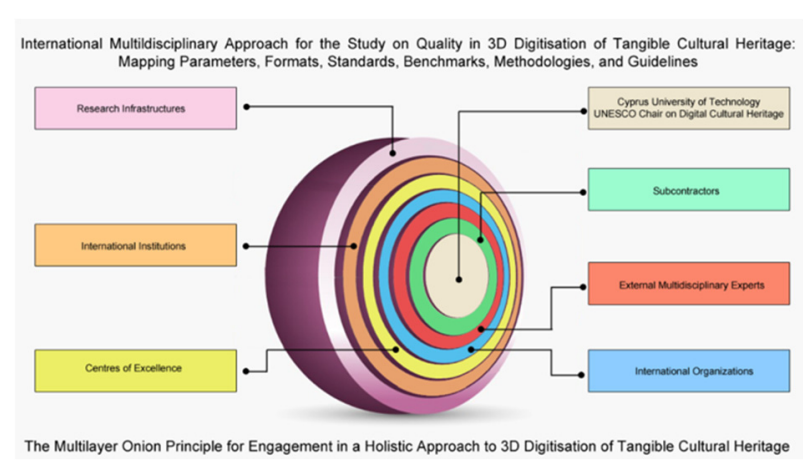

Figure 1: Consortium of experts and external partners for the Study.

\section{The study}

The ongoing VIGIE 2020/654 Study draws upon existing analysis and information sources, comprising a large amount of prior knowledge represented by the in-house team, supplemented by preliminary research. These emanate from a variety of relevant sources, including literature reviews, scientific publications and technological surveys, and information from scientific organisations, cultural heritage institutions, SME's, industry, and government. Previous efforts to develop guidelines for cultural heritage documentation include Historic England (2017; 2018), Historic Environment Scotland (2018) and the European Commission (2020a). The Study also incorporates a wide range of External Experts, which forms part of the study team and will be extended through the subsequent investigation throughout the Study (see Fig. 1).

The digital representation of cultural heritage objects, architectural structures and environments is an essential tool for analysis, conservation, interpretation and exhibition. However, selecting the most effective recording technology and efficient production workflow for the $3 \mathrm{D}$ digitisation of tangible cultural heritage is a complicated procedure requiring careful consideration.

As identified by the European Commission there is no generally accepted framework for specifying the level of detail and accuracy in $\mathrm{CH}$ digitisation. Documentation projects are typically determined on a case-by-case basis, using the many available methods, and often require significant interdisciplinary cooperation. In addition to the cost of hardware and associated software, there is also a considerable investment in knowledgeable staff and time dedicated to specialised training (European Commission 2020).

The purpose of the VIGIE 2020/654 Study is to investigate the parameters, formats, standards, benchmarks, methodologies and guidelines, relating to the 3D digitisation of tangible cultural heritage. The Study is intended to be exceptionally comprehensive and will address topics such as:

- recording hardware, for example, LiDAR scanning, photogrammetry etc.;

- types of data, formats, standards, benchmarks, methodologies and guidelines;

- defined digitisation process stages and attention to the importance of a structured approach to managing $3 \mathrm{D}$ digitisation projects;
- quality parameters;

- degrees of complexity;

- purposes, audiences and use;

- formats, standards, benchmarks, methodologies and guidelines;

- equipment;

- $\quad$ past or ongoing digitisation projects and 3D models and data sets that can serve as benchmarks and future technological advances.

The Study's unique idea is to develop a framework of standardised best-practices and methods concerning the recording, processing, production, long-term preservation and reuse of $3 \mathrm{D}$ objects and associated metadata. According to the terms of the original EC tender, the Study addresses two broad areas of tangible cultural heritage. One refers to 'immovable' tangible cultural heritage including buildings, monuments, sites, and maritime archaeology. The other looks at 'movable' tangible cultural heritage, such as museum objects, archaeological finds and other artefacts.

Of particular importance in the 3D documentation process is that the VIGIE 2020/654 Study must address surface or geometrical complexity as a general classification. For example, "low complexity refers to tangible cultural heritage with few and straightforward features. At the other end, tangible cultural heritage with a very high degree of complexity is very detailed and has a large number of complicated features that require considerably more effort to capture."

Defining the degree of complexity in a 3D documentation project is essential as it typically prescribes the necessary production effort. Complexity in architecture or sites can be determined by various factors such as geometrical exuberance, height, accessibility and surface quality. For example, a High Gothic church's documentation such as the Cologne Cathedral would take considerably longer than an office building constructed in the 1950s, even if they have the same dimensional footprint.

\section{Preliminary results}

\subsection{Complexity and quality}

As cultural heritage is highly diverse, and the resulting 3D models are often quite complex, it can be challenging to achieve a certain level of quality in 3D digitisation. There are many parameters involved at the various stages of the $3 \mathrm{D}$ documentation process. They can vary by the purpose of the Study, user, equipment used and methodology, as illustrated in Figure 2.

The term quality is highly subjective and easily open to misinterpretation. Formulating a clear, precise definition concerning $3 \mathrm{D}$ digitisation is a challenge. The study's initial data quality indicators include accuracy, precision, resolution, and the acceptable margin of data error. Further considerations, as expressed in a recent report by the Expert Group on Digital Cultural Heritage and Europeana (2020), are also taken into consideration in this Study: "Quality in 3D digitisation of cultural heritage is not only about capture accuracy and resolution, but also about other key aspects such as historical accuracy, range of data and metadata generated and collected, and fitness for purpose." 


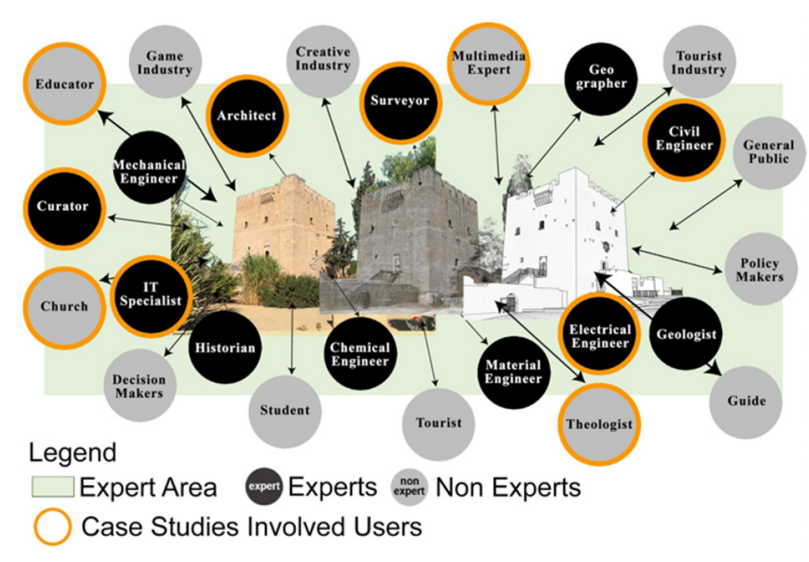

Figure 2: Cultural Heritage Documentation according to the needs of multidisciplinary users.

Another factor to consider is the degree of complexity of the cultural heritage object to be digitised. The complexity of an artefact or building can refer to its size, geometry, interior/exterior, surface and many other parameters that may impact the challenges in capturing the object in $3 D$, as illustrated in Figure 3.

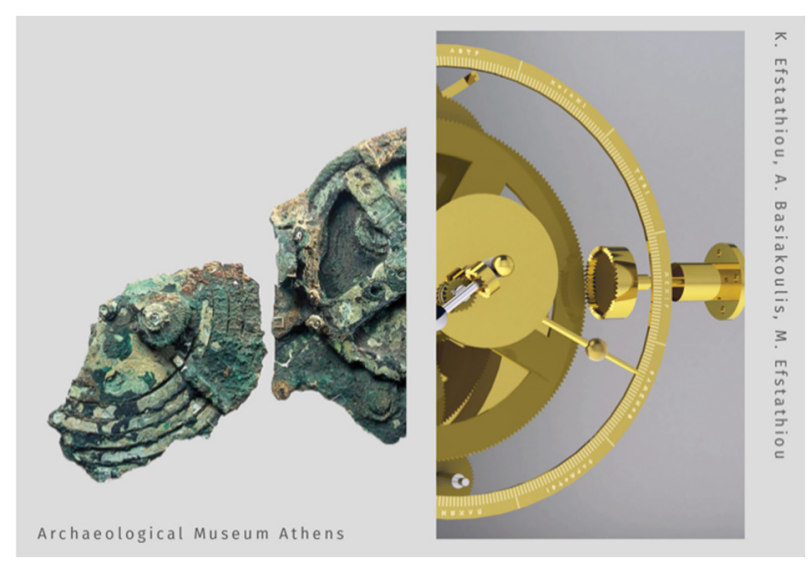

Figure 3: Complexity of an artefact, the Antikythera Mechanism, (interior/exterior).

Establishing a definition of the degrees of complexity of tangible cultural heritage and identifying the parameters that determine quality in 3D digitisation of cultural heritage has been the Study's initial focus. CUT has consulted with a consortium of experts to provide input on these questions during the Study's first months. The budget of a documentation project, physical and environmental conditions, technology, and equipment influenced complexity and quality, as highlighted by these experts. The consortium is now compiling the information into a comprehensive report on the technical parameters that determine the quality and complexity of $3 \mathrm{D}$ digitisation.

\subsection{D quality models and HBIM opportunities}

$3 \mathrm{D}$ models have the opportunity to become core digital gears leveraging knowledge, interpretation and understanding. They are tools through which it is possible to decode cultural heritage's complexity, extract contents, and integrate them within multidisciplinary processes.

Complexity is related to several issues which need to be taken into account with an overall approach: methods of surveying and digitisation require to be addressed within a holistic framework, where models are related to information. Despite the BIM limitations when applied to the HBIM, the world of Heritage Building Information Modelling could help orient 3D quality models (Brumana, Banfi, Cantini, Previtali, \& Della Torre, 2019; Brumana et al., 2018).

$3 \mathrm{D}$ quality models are required to support the digitisation of state of the art (SofA) as resulting from:

- $\quad$ past stratified layers across the centuries and transformation phases with its materials, techniques and geometry;

- the fragility coming from the state of decay and deformation occurred throughout the centuries. Conditions that can be detected through the geometric analysis together with the knowledge of the processes involving the materials and their construction techniques, with the help of NonDestructive Techniques and other diagnostics;

- fragility as impacted by current hazards and pressures (i.e., climate change, earthquakes, flooding, flash water bombs, landslide, hydrogeological risks) within the context of the built environment.

The common element is that the geometry cannot be considered a standalone issue, but requires integration with the materials. These materials are intended to extend the understanding of construction techniques within a multiscale concept.

The scale concept inherited from the cartographic domain in surveying specifications can be applied to the models to help define the need and drive transparent data sharing. One parameter for determining the quality of 3D models is dimensional accuracy, which encompasses tolerance and details incorporated. The richness of the information collected in the digitisation process represents the second pillar of the knowledge process.

The concept of HBIM Level of Development (the combination of the Level of Geometry and Level of Detail) can be integrated to enrich the quality of $3 D$ models during the phases of the modelling and preservation process. To this aim, a new definition of LOD is proposed by the contributors to the VIGIE project, which differs from the BIM building construction process logic. This can vary from LOD100 up to LOD600 depending on the information embedded in the 3D BIM model.

Therefore, the quality of $3 \mathrm{D}$ models needs to match the following requirements:

a) to reflect the exact geometry and any other anomalies available on the surface of the artefact/monument (such as corrosion, cracks, etc.);

b) to support information enrichment with materials properties and construction techniques analysis;

c) to support the assessment and the data interpretation (structural behaviour);

d) to drive the preservation plans starting from understanding and interpreting state of the art up to supporting the design and decision-making process; 
e) to prevent future damages fostering planned preservation (Long Life Cycle Management);

f) to deploy knowledge transfer of enriched models among different operators;

g) to promote the use and re-use for dissemination purposes (MR/VR/AR).

\subsection{Awareness and Dissemination}

The Study was presented to a broad audience of heritage professionals, students and culture enthusiasts at the 8th International EuroMed Conference on Digital Cultural Heritage (Cyprus, 2-5 November 2020 , www.euromed2020.eu). It was organised online this year due to the global pandemic, it attracted over one thousand participants from more than seventy different countries (EuroMed, 2020).

The first workshop of EuroMed 2020 (2 November 2020), organised by the Digital Heritage Research lab and was specifically dedicated to the Study, featuring speakers from all subcontracted expert organisations and institutions, such as:

- Historic Environment Scotland.

- Zoller \& Fröhlich GmbH.

- National Technical University of Athens.

- ArcTron 3D GmbH.

- $\quad$ Aristotle University of Thessaloniki.

- Bene Construere.

- Politecnico di Milano.

- Time Machine Organisation.

- ICOMOS.

The workshop also invited speakers from beyond the network of experts involved in the Study, including:

- Getty Research Institute.

- Global Digital Heritage.

- Smithsonian Institution.

- IIIF 3D Community Group.

- Cambridge University.

- Mnemoscene.

- Duke University.

- Cultural Heritage Imaging.

- Uppsala University.

The keynote speakers were all asked to present their experiences on the different degrees of tangible cultural heritage from the 3D documentation process and the parameters that determine quality in $3 D$ digitisation of tangible cultural heritage. In this way, their presentations directly contributed to the requirements of the Study. The workshop outcomes are currently being processed and will feature in the Study's final output report in June 2021.

\subsection{Online Survey}

The main objective of the questionnaire entitled "Survey on quality in the digitisation of tangible cultural heritage" is to support the study by collecting from multidisciplinary experts in the domain of digital acquisition data about the use of acquisition technologies, metadata, paradata, and the definitions of quality and complexity for 3D (Cyprus University of Technology, 2020b). The survey is currently running digitally on the platform LimeSurvey, and the plan is to collect responses in the period $21 / 10-31 / 12 / 2020$. It is advertised through the DHRLab social network profiles (Facebook, Instagram) and the consortium.

The questionnaire consists of 40 questions, grouped into four sections:

- General information and demographics.

- Overview of the used technologies - where data about the most popular acquisition technologies are collected.

- Description of the project.

- Final questions.

The questionnaire requires a minimum of 15 minutes to be filled and is also scalable: respondents have the option to describe up to three digitisation projects, answering the same set of questions three times.

The demographic section asked respondents about, among other things, provenience, professional background, years of experience and affiliation to relevant organisations. In the overview of the used technologies section, data about the most popular acquisition technologies are collected. The section regarding the description of the project requires each respondent for information on a successful digitisation project on immovable and movable objects and for specifics about the used technology, metadata, paradata, limitations and problems.

The data is intended to enrich the information collected from the core subcontractors about quality and complexity and support the study in showcasing the best-practice projects in the digitisation domain. More than 200 completed responses have been collected from more than 40 countries worldwide after the first month.

As indicated in Figures 4, 5, 6 and 7, the data collected so far comes from a wide range of experts in digitising both monuments and sites and museum objects worldwide and will be processed in early 2021.

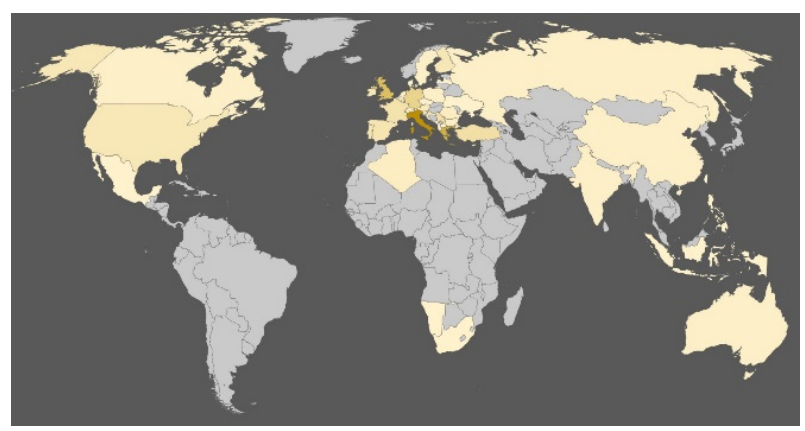

Figure 4: The map shows the geographical provenance of the respondents $(n=235)$. 


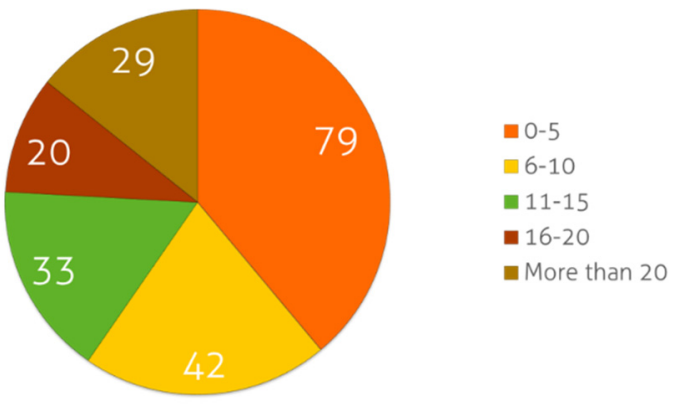

Figure 5: The graph reports the answers to the question "How many years of experience do you have in the digitisation area?" $(n=203)$.

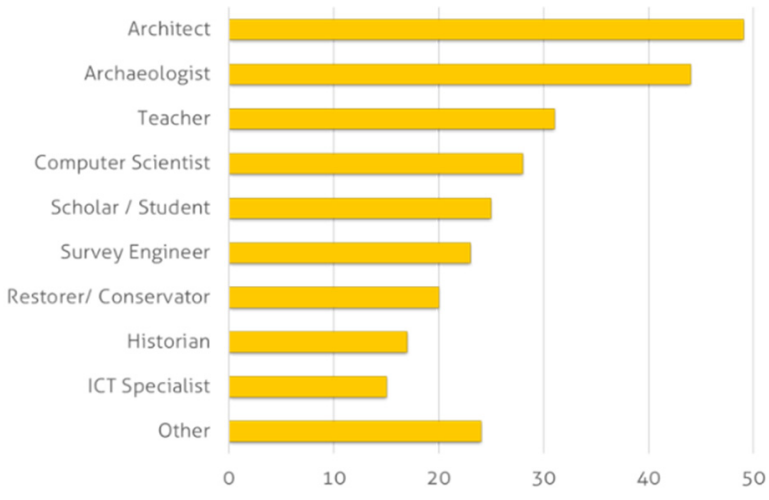

Figure 6: The graph reports the answers to the question "What is your professional background?

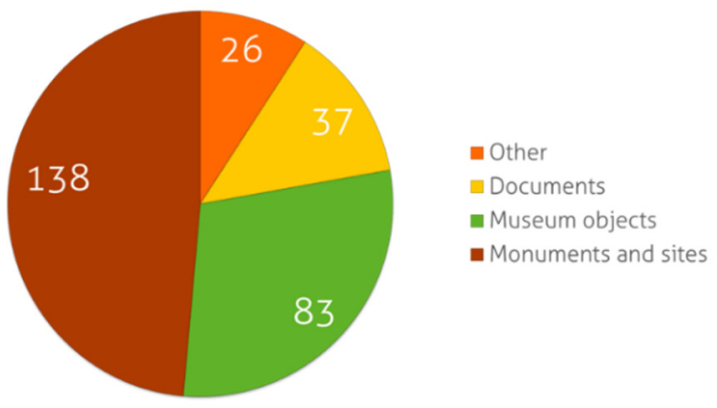

Figure 7: The graph reports the answer to the question "In which area of digitisation are you an expert?" $(n=296)$.

\section{Conclusion}

The Study consortium has collected data from different experts in digital cultural heritage regarding the significance and applications of quality and complexity in the 3D digitisation of tangible cultural heritage. The team will now focus on compiling this data and supplement it with the information coming from the online survey.

In parallel, the consortium has begun identifying existing formats, standards, benchmarks, methodologies, and guidelines relevant for 3D digitisation of tangible cultural heritage, including metadata and paradata (Task 3 ). The first results of these activities will be presented and discussed during the study's online mid-term workshop in March 2021.

\section{Acknowledgements}

Study at the request of and financed by the European Commission, Directorate-General of Communications Networks, Content \& Technology under contract no. LC01549024

\section{References}

Brumana, R., Banfi, F., Cantini, L., Previtali, M., \& Della Torre, S. (2019). HBIM level of detail-geometry-Accuracy and survey analysis for architectural preservation. ISPRS Annals of the Photogrammetry, Remote Sensing and Spatial Information Sciences, 42(2/W11), 293-299. Copernicus GmbH. https://doi.org/10.5194/isprs-Archives-XLII-2-W11293-2019

Brumana, R., Della Torre, S., Previtali, M., Barazzetti, L., Cantini, L., Oreni, D., \& Banfi, F. (2018). Generative HBIM modelling to embody complexity (LOD, LOG, LOA, LOI): surveying, preservation, site intervention-the Basilica di Collemaggio (L’Aquila). Applied Geomatics, 10(4), 545-567. https://doi.org/10.1007/s12518-018-0233-3

Cyprus University of Technology. (2020a). Home Page. Retrieved March 12, 2021, from https://www.cut.ac.cy/

Cyprus University of Technology. (2020b). Survey on quality in digitisation of tangible cultural heritage - LimeSurvey. Retrieved March 12, 2021, from https://web.cut.ac.cy/survey-expired/121155.html?lang=en

EuroMed. (2020). Workshops - EuroMed 2020. Retrieved March 12, 2021, from http://www.euromed2020.eu/workshops

European Commission. (2019). EU Member States sign up to cooperate on digitising cultural heritage. Retrieved March 12, 2021, from https://ec.europa.eu/digital-single-market/en/news/eu-member-states-sign-cooperate-digitisingcultural-heritage

European Commission. (2020a). Basic principles and tips for 3D digitisation of cultural heritage. Retrieved March 12, 2021, from https://ec.europa.eu/digital-single-market/en/news/basic-principles-and-tips-3d-digitisation-cultural-heritage

European Commission. (2020b). Study on quality in 3D digitisation of tangible cultural heritage. Retrieved March 12, 2021 , from https://ec.europa.eu/digital-single-market/en/news/study-quality-3d-digitisation-tangible-cultural-heritage

European Commission. (2020c). The European Commission launches a unique study on 3D digitisation of tangible cultural heritage. Retrieved March 12, 2021, from https://ec.europa.eu/digital-single-market/en/news/european-commissionlaunches-unique-study-3d-digitisation-tangible-cultural-heritage 
Europeana. (2020). Home Page. Retrieved March 12, 2021, from https://www.europeana.eu/en

Historic England. (2017). Photogrammetric Applications for Cultural Heritage. Retrieved March 12, 2021, from https://historicengland.org.uk/advice/technical-advice/recording-heritage/

Historic England. (2018). 3D Laser Scanning for Heritage. Retrieved March 12, 2021, from https://historicengland.org.uk/images-books/publications/3d-laser-scanning-heritage/

Historic Environment Scotland. (2018). Short Guide: Applied Digital Documentation in the Historic Environment. Retrieved March 12, 2021, from https://www.historicenvironment.scot/archives-andresearch/publications/publication/?publicationld=9b35b799-4221-46fa-80d6-a8a8009d802d 


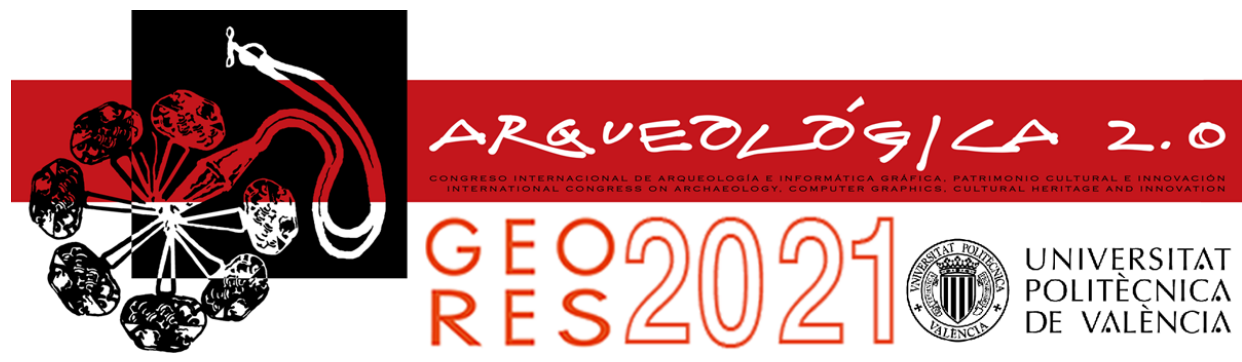

\title{
DETECTING AND MAPPING FLASH FLOODING WITH SYNTHETIC APERTURE RADAR (SAR) SATELLITE DATA: THE METAPONTO PLAIN CULTURAL LANDSCAPE CASE STUDY
}

\author{
Marzia Gabriele \\ Department of Architecture, Built Environment and Construction Engineering (ABC), Politecnico di Milano, Via Giuseppe Ponzio 31 , \\ 20133 Milano, Italy. marzia.gabriele@polimi.it
}

\begin{abstract}
:
Due to Climate change, unpredictable and uncertain weather conditions increase the likelihood of natural disasters, which correlates to major impacts on Cultural Landscapes and Heritage sites. Thanks to SAR sensors, continuous and rapid information can be collected with satellite data. When a sensor generates a directed beam of pulses, terrain returns highresolution radar-frequency reflected energy, enabling a first effective data implementation, helping to quickly localize where damage occurred during a flash-flood event. This could facilitate after-disaster response through rapid delivery and coordination of rescue operations. Synthetic Aperture Radar (SAR) data is capable of passing through clouds and weather phenomena and continuously monitor a flooding event by plotting its patterns for a cost-effective flood mapping. Free availability of SAR data through the European Space Agency's (ESA) Sentinel-1 SAR mission created a major opportunity for flood extent monitoring. The chosen case study is the area of the Metaponto Plain in Basilicata, southern Italy, which recently earned a candidacy as UNESCO site. In the effort of protecting cultural landscape and archaeological heritage, local authorities have to face multiple challenges coming from climate change and the impact of human activity. The object of this study is the flash-flooding event occurred on the $12^{\text {th }}$ of November 2019, which was reported to be an extreme hydrological event, causing important damages to the agricultural landscapes and cultural heritage sites. The Metaponto area exemplifies multiple pressures deriving from climate change and human activity, thus having to cohabit within an important cultural landscape and archeological heritage. The workflow here presented can be quickly implemented to extract information through simple and effortless algorithms, providing mid-regional scale event maps with a good resolution, and it is formally aimed at user-end Control Centres for putting in place rapid risk mitigation actions.
\end{abstract}

Keywords: climate change, hazard mapping, cultural landscapes, flash-flooding, cultural heritage, SAR

\section{Introduction}

Emergencies happen, and it is essential for government institutions to respond as soon as possible, estimate damage rapidly, and administer support payments in a short space of time (NEREUS, 2018). Timely and continuous information about flood dynamics are fundamental to ensure effective implementation of the relief and rescue operations (Lacava et al., 2019). The flood risk management cycle is comprehensive of different intricate phases (i.e. mitigation, preparedness, response, recovery), moreover, it is important to stress the crucial intake given by the flood monitoring and mapping activities. Flood mapping is the starting point and the solid base of the rest of the risk management process (Sanyal \& Lu, 2004; Ward et al., 2018). Mapping the flood during or after a flooding event helps to monitor water expansion and regression and to delineate what are the areas which, in different time threshold, have been invested by the hazard, and so where to concentrate further investments for monitoring flood hazards and land vulnerability overtime (Sanyal \& Lu, 2004; Franci, Mandanici, \& Bitelli, 2015). These products can be used for flood-prone area delineation in order to prevent future floods, providing crucial information to identify appropriate protection measures and strategies for risk mitigation and producing efficient response plans (Lacava et al., 2019; Dasgupta et al., 2018).

Nowadays, the availability of multiple satellite data can be used as an effective alternative to monitor the flood situation and extent in the particular area (Brivio, Colombo, Maggi, \& Tomasoni 2002; Rahman \& Thakur, 2018). Bad weather conditions during and after food events can represent a strong constraint to the utilization of optical remotely sensed data. For this reason, spaceborne radar systems, because of their exclusive cloud penetration capacity, offers a primary tool for realtime assessment of flooded areas, specifically synthetic aperture radar (SAR) data. The introduction of SAR sensors has shown great potential for flood mapping due to their independence from solar illumination and very low dependency on atmospheric conditions (Greifeneder, Wagner, Sabel, \& Naeimi, 2014; Uddin, Matin, \& Meyer, 2019) as in fact, due to the penetration capacity of synthetic aperture radar (SAR) data through clouds and hazy atmospheric circumstances like fog, smog, light rain, 
mist etc., it has the ability to the continuous observation of flood events for producing accurate, rapid and costeffective flood mapping (Rahman \& Thakur, 2018). SAR sensors are able to detect flooding because flat surfaces reflect (acts as a specular reflector) the signal away from the sensor, decreasing the amount of returned radiation (Gan, Zunic, Kuo, \& Strobl, 2012; Rahman \& Thakur, 2018). This causes relatively dark pixels in radar data for water areas which contrast with non-water areas (Rahman \& Thakur, 2018). The disadvantages of the use of radar sensors lie in the difficult classification of the acquired signal because of the influence of complex ground and system variables (Brivio, Colombo, Maggi, \& Tomasoni 2002). To improve this situation, multi-temporal techniques based on detection of changes between radar images acquired before and after the inundation event are usually recommended (Badji et al. 1994; Brivio, Colombo, Maggi, \& Tomasoni 2002; Wang, Koopmans, \& Pohl, 1995; Profeti \& Macintosh 1997; Rahman \& Thakur, 2018; Takeuchi, Konishi, Suga, \& Kishi, 1999). Today, spaceborne synthetic aperture radar (SAR) systems are the most preferred option for monitoring flood condition. Studies have demonstrated that SAR images are useful for determining flood extent during a disaster (Ajmar et al., 2017; Ohki et al., 2016; Uddin, Matin, \& Meyer, 2019; Voormansik, Praks, Antropov, Jagomägi, \& Zalite, 2013).

This research aimed at evaluating the flooded areas using Sentinel-1A and Sentinel-1B SAR data during an emergency flash-flood event. The specific objectives were as: (i) flood inundation mapping using multi-temporal Sentinel-1A and Sentinel-1B SAR images; (ii) map the flood-prone areas at risk in a territorial context of cultural heritage and cultural landscapes (iii) rapid flash-flood analysis using multi-date flood maps.

The Sentinel data are available as part of the Copernicus program. Formerly Global Monitoring for Environment and Security (GMES), it is nowadays a major space development program launched by the European Commission (EC) in partnership with the European Space Agency (ESA) in 2014. Its main purpose is to ensure Europe's sustainable development, enhance international competitiveness, security and realize real-time dynamic monitoring of the environment by coordinating, managing and integrating the observation data of existing and future European and non-European (third-party) satellites. Users of Copernicus services are policymakers and public authorities who need the information to develop environmental legislation and policies or to take critical decisions in the event of an emergency, such as a natural disaster or a humanitarian crisis but also for more sustainable everyday life (Guo, Fu, \& Liu, 2019).

\section{The study area}

Mediterranean Basin's lands are of a very long history of intensive use by man, apparently longer and more intensive than that of the other Mediterranean regions of the world. This feature confers unique adaptations to several components of the Basin's biodiversity, and some characteristic features to the structure and function of its ecosystems, especially with respect to their responses to human impact, including grazing, cultivation and fires (Naveh, 1990). Furthermore, meteorological studies suggest that the land-use changes in the Mediterranean Basin, accumulated over historical time and much accelerated during the last 30 years may have induced climatic change expressed in intensified winter rains and floods (Millán et al., 2005).

The Metaponto Plain is situated on the lonian coast of the Basilicata region, Southern Italy. The Site was founded by a Greek colony in the seventh century BC. Metaponto was a rich and flourishing centre of Magna Graecia and it was also the town where Pythagoras was born. Its archaeological area hosts the Palatine Tables, which are the remains of a hexastyle peripteral Greek temple of the sixth century BC, dedicated to the goddess Hera. Among the ruins of the ancient city, there are also the ruins of the Doric temple of Apollo Licio, with large monolithic columns and the ruins of a theatre dating back to the fourth century BC. The archaeological ruins of both Greek and Roman ancient civilizations located in this area made possible the proposal of the Metaponto plain as a UNESCO World Heritage Site. The Metaponto saw its historical evolution from the Bronze Age to the advent of the Romans, passing through the Greek colonization between the mouths of the Bradano and Basento rivers. The Greek colonization was mainly a conquest for the region's cultivated lands from which to extract agricultural and commercial profit. Greek immigration was sporadic at first, but then more and more massive. Between the seventh and third centuries $\mathrm{BC}$, the area was subjected to an intense and extensive agricultural organization, demonstrated by the dense subdivision still observable in the terraces, as well as in the numerous farms scattered throughout the territory. That was the moment where the parcellation, and the formal organization of land was formally set. The Greek agricultural grid is still seen nowadays as one of the fundamental valuable elements of the regional agricultural (and Cultural) landscape to be preserved together with all the other elements that add complexity to both traditional and contemporary landscapes, urban and rural, tangible and intangible, both archaeological remains and modern monuments (Council of Europe, 2000).

Referring to the concept of Landscape and Cultural Heritage preservation, it is strictly necessary to mention that the whole study area is an "area di notevole interesse pubblico" (area of remarkable Public Interest) protected and administrated by the State and the Region within the Art. 136 of the DIgs 42/2004 Codice dei Beni Culturali e del Paesaggio (Cultural Heritage and Landscape Law) (Figs. 1 and 2).

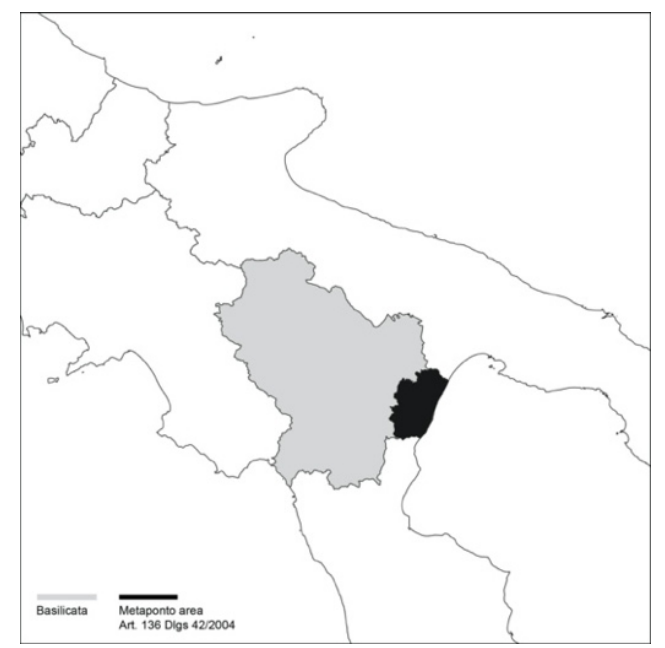

Figure 1: The localization of the Study Area in the context of Southern Italy and Basilicata region. 


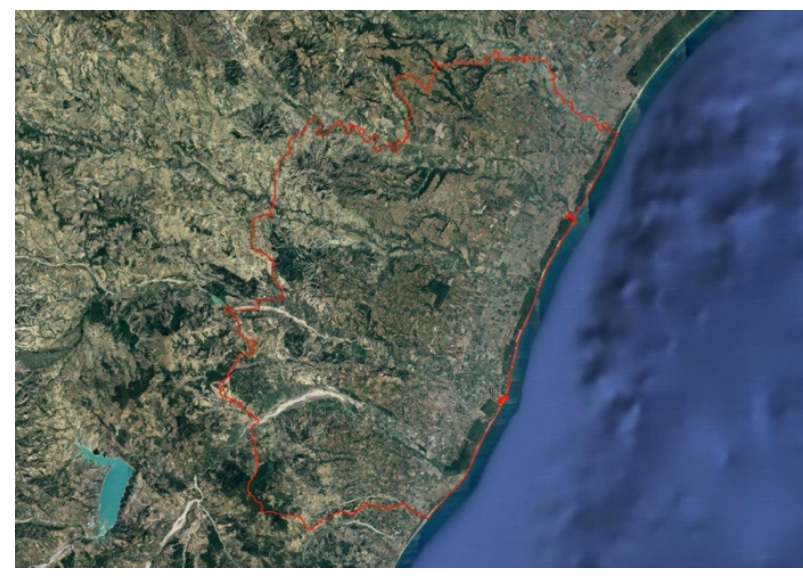

Figure 2: Metaponto Plain via Google Earth, 2020.

Apart from its Cultural value, the Plain itself is also a productive landscape, as it is one of the most important Italy's fruits and vegetable productions, with specialization in intensive cultivation of early species (strawberries, apricots, nectarine peaches), favoured by climatic and pedological conditions, characterized by a tendentially dry and mild climate in the periods of flowering of the fruit trees, and in those of ripening. This huge production was progressively achieved during the decades through the reclamation of the marsh areas and the channelling/filling of secondary channels. The Metaponto Plain area historically fell into the territories affected by the 1950 reform in Southern Italy, together with all the possible implications related to the pressure of its water bodies, as in fact the complete realization of the irrigation works triggered that specialization process towards an intense irrigated agriculture with a higher rate of profitability, thus triggering a higher hydrogeological risk. After this rapid overview, it is clear that the Ionian coast of the Basilicata region, southern Italy, is characterized by a remarkable archaeological heritage, valuable crops, and national and international tourism, contributing significantly to the regional economy. Unfortunately, from a geomorphological point of view, the Metaponto plain is particularly prone to suffer flooding (Bentivenga, Giano, \& Piccarreta, 2020; De Musso et al., 2018; Lacava et al., 2019). In the last two decades, the area has been affected by the heavy recurrence of flooding events, which caused significant damage to agriculture, tourist infrastructure, and archaeological heritage.

A huge number of river flooding happened because of persistent thunderstorms for extended periods. Among these, an important number of phenomena can be referred to flash floods, due to extreme rainfall occurred in few hours. In some cases, relatively shallow minor flooding due to the accumulation of excessive surface runoff has also been recorded (Bentivenga, Giano, \& Piccarreta, 2020).

A study carrying an accurate meteorological analysis on data from the National Civil Protection revealed that 23 extreme hydrological events occurred from 1921 to 1999 in the Ionian belt, whilst only 19 events have been recorded from 2000 to the present day (Bentivenga, Giano, \& Piccarreta, 2020). The recurrent flash floods caused huge economic damages in the studied area, such as the flood events of autumn 2013 that produced about 45 million euros of damages, involving farms damages in the Metapontino area for at least 27 million euros (Bentivenga, Giano, \& Piccarreta, 2020).

Furthermore, the last flood of November 2019, which is the one investigated for this study, caused damages up to 46 million euros in the area (Bentivenga, Giano, \& Piccarreta, 2020). Of course, the plain is prone to climaterelated flash flooding events, but it is still important to quote the human impact.

As aforementioned, during the past centuries, the Metaponto plain was an important part of a land reclamation project mainly consisting in the creation of an extensive channelling network, that aimed at providing assets for land cultivation, fast access to the beaches and archaeological heritage protection. Human impact related to the absence of channel cleaning has proved to be the most relevant factor that greatly amplified the effects of low-intensity rainfall events, thus triggering flooding events (Bentivenga, Giano, \& Piccarreta, 2020).

\section{Materials and method}

\subsection{Data used}

For flashfloods mapping and analysis, Sentinel-1A SAR and Sentinel-1B SAR data were used. SAR data was acquired for the date of $6^{\text {th }}$ and $12^{\text {th }}$ November 2019 (Sentinel-1A SAR $6^{\text {th }}$ November 2019 pre flashflood event and Sentinel-1B SAR 12 ${ }^{\text {th }}$ November 2019 after the event). The reference image was selected to be the 6 th of November, before the flash-flood event, because as previously mentioned multi-temporal techniques based on detection of changes between radar images acquired before and after the inundation event are usually recommended (Badji et al. 1994; Brivio, Colombo, Maggi, \& Tomasoni 2002; Wang, Koopmans, \& Pohl, 1995; Profeti \& Macintosh 1997; Rahman \& Thakur, 2018; Takeuchi, Konishi, Suga, \& Kishi, 1999). SENTINEL-1 carries a single C-band synthetic aperture radar instrument operating at a centre frequency of $5.405 \mathrm{GHz}$. It includes a right-looking active phased array antenna providing fast scanning in elevation and azimuth, data storage capacity of $1410 \mathrm{~Gb}$ and $520 \mathrm{Mbit} / \mathrm{s}$ X-band downlink capacity. The C-SAR instrument supports operation in dual polarisation $(\mathrm{HH}+\mathrm{HV}, \mathrm{VV}+\mathrm{VH})$ implemented through one transmit chain (switchable to $\mathrm{H}$ or $\mathrm{V}$ ) and two parallel receive chains for $\mathrm{H}$ and $\mathrm{V}$ polarisation. The presented study was entirely performed using VV polarized images. According to (Touzi, Deschamps, \& Rother, 2009; Twele, Cao, Plank, \& Martinis, 2016; Zhang, Li, Tian, Zhou, \& Tang, 2016; Zhang, Chen, Liang, Tian, \& Yang, 2020) it is much easier to detect flood water and avoid misclassifications with VV polarized images than $\mathrm{VH}$ polarized ones when the area is a low altitude vegetated plain with an agricultural vocation. There was no possibility to collect field data or to achieve a field validation immediately after the event, it is however reasonable to mention that this is an aspect that should be further implemented in the research for future investigations, carrying an in-situ validation of the methodology accuracy during the post-flooding events (e.g. (i) detailed after event field survey of the affected areas' perimeter by using the GPS system; (ii) UAV (Unmanned Aerial Vehicles) survey; (iii) in-situ flood marks field photographs, geographic coordinates of the damaged area and severity of the event information from 
local citizens (Singh, Dhote, Thakur, Chouksey, \& Aggarwal,2020).

\subsection{Methodology}

The methods used for this study are presented in (Fig. 3). Specifically, Sentinel-1 image classification for flood mapping, with initial pre-processing carried out to mitigate the SAR-typical speckle-noise signatures from the images. During the pre-processing step, the radiometric and geometric distortions were rectified due to the characteristics of the imaging system and imaging conditions and radiometric corrections (Radiometric Calibration, Radiometric Terrain correction) were performed to improve visualization and interpretation for flood mapping. The pre-processing steps, including data import, multilooking, radiometric calibration, speckle filtering, radiometric terrain correction, linear-tobackscattering coefficient decibel scaling (dB) transformation, were implemented using ESA's Sentinel Application Platform (SNAP). The open-access SNAP toolbox is capable of reading, pre-processing, and visualizing Sentinel-1 SAR images. The input is a calibrated Sentinel-1 GRD product $(10 \mathrm{~m}$ spatial resolution). After creating the subset of the area of interest (AOI) to investigate and after the Radiometric Calibration is applied, the image is firstly treated with a Radiometric Terrain Correction (RTC). RTC corrects geometric distortions that lead to geolocation errors.

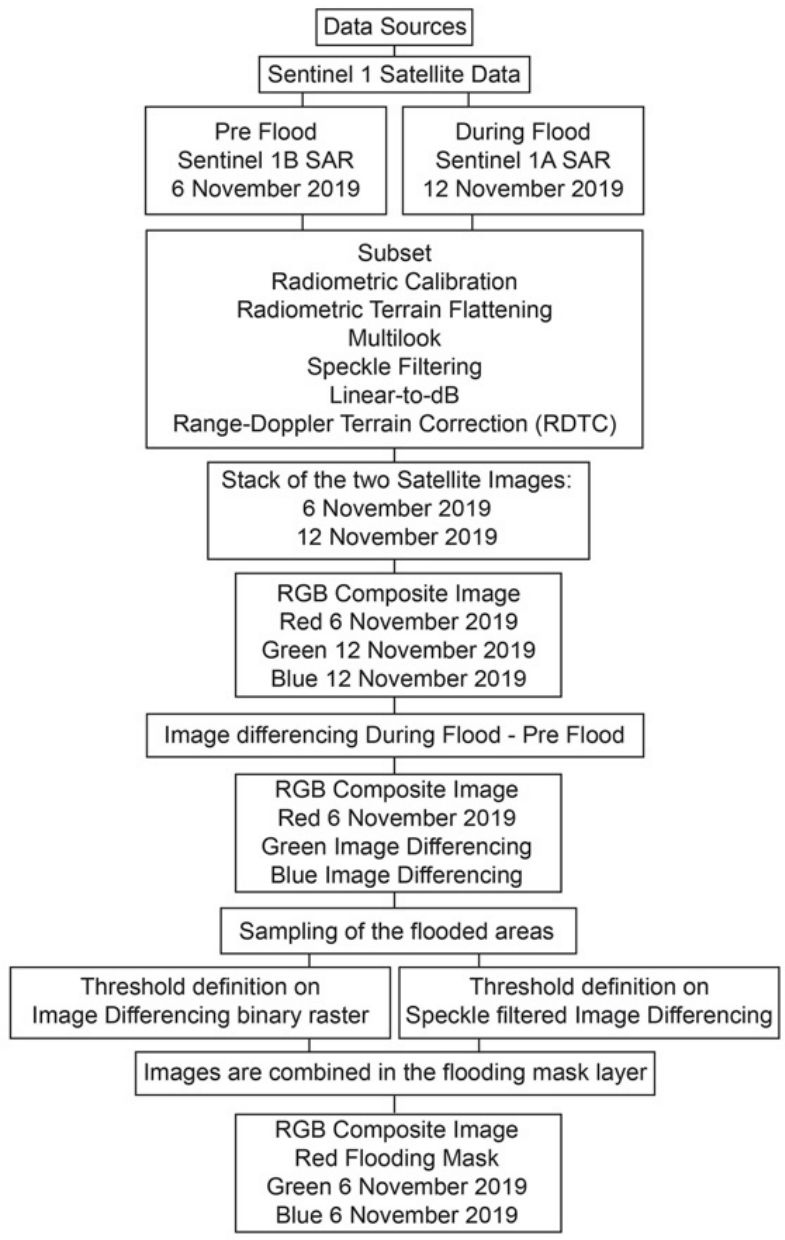

Figure 3: Workflow of the methodology presented in the study.
RTC (right) moves pixels to stretch the mountains and adjusts pixel values to subtract the effect of slopes on brightness, avoiding the distortions induced by sidelooking (rather than straight-down looking or nadir) that are compounded by rugged terrain. After RTC, the image is treated with a moderate single image multilook $(3 \times 3)$ in order to reduce speckle without degrading excessively the image resolution that passes from 10 to $30 \mathrm{~m}$. The fundamental characteristic recorded on a radar image is the backscattering coefficient, which may vary from surface to surface. The strength of the returned signal from the surface is influenced by the combined system and ground parameters, including the average surface roughness and soil dielectric properties. Horizontal smooth surfaces, such as water bodies, reflect nearly all incident radiation away from the sensor and the weak return signal is represented by dark tonality on radar images with the result that standing water areas are easily recognizable. This specular reflection can be decreased by bad weather conditions and/or the presence of vegetation, roughening the surface and making the detection of flooded areas more difficult (Brivio, Colombo, Maggi, \& Tomasoni 2002; Laugier et al. 1997). Moreover, SAR data are subject to speckle, a multiplicative random noise that considerably reduces the interpretability of the images and limits classification techniques, and SAR images have to be filtered in order to increase the signalto-noise ratio (Brivio, Colombo, Maggi, \& Tomasoni 2002). For these reasons, a Speckle Filtering was implemented in order to lower the backscattering noise and avoid a "salt and pepper" effect in the following passages. It is necessary to mention that: (i) the following passages were run parallelly on both the Speckle filtered and the no Speckle filtered images; (ii) the goal was to maintain the level of detail of the initial image with the no Speckle filtered image and to have the noises removed with the Speckle filtered image.

Then a decibel $(D b)$ conversion is applied to the image, which betters the comparison of two satellite images and permits to go from digital numbers to a physical quantity, which in this case is from Sigma Nought $\left(\sigma_{0}\right)$ backscatter to Sigma Nought Decibel ( $\left.\sigma_{0} D b\right)$ (Figs. 4 and 5); $\sigma_{0}$ is the backscatter returned to the antenna from a unit area on the ground. It is corrected for the local incidence angle and is thus in the realm of ground range. Sigma Nought $\left(\sigma_{0}\right)$ is the usual measure used to evaluate the reflectivity conditions of the surface, independent from geometric effects. This is often used in the scientific interpretation of SAR imagery. As the pixel values are absolutely calibrated, different SAR images in Sigma Nought $\left(\sigma_{0}\right)$ notation can easily be compared. When using Sigma Nought $\left(\sigma_{0}\right)$ in the SAR analysis workflow, it can be noticed that in the image-related histogram most of the pixels have a very low backscatter value, and there are a few pixels with a very high backscatter value. When converting the pixels from a linear scale to a nonlinear logarithmic scale, and so converting the images to decibel $\left(\sigma_{0} D b\right)$, the information related to the backscatter information performs a distribution histogram over the given colour range. This is due to the fact that in $\sigma_{0} D b$ the data is logarithmized (the conversion to $\mathrm{dB}$ transforms data into the logarithmic scale), distributing the SAR values evenly over the black/white colour range. This leads to a higher presence of grey pixels and less extreme values. It is not a compulsory prerequisite but helps visual interpretation and also statistical evaluation. Additionally, it increases the contrast, performing a much clearer 
distinction between black water and bright land pixels. The radiometric conversion from a linear scale to a $d B$ scale conducted is expressed using the following Eq. (1):

$\sigma_{0}(d B)=10 \cdot \log _{10} \sigma_{0}$

where

$$
\begin{aligned}
& \sigma_{0}(d B)=\text { backscattering image in } d B \\
& \sigma_{0}=\text { Sigma Nought image }
\end{aligned}
$$
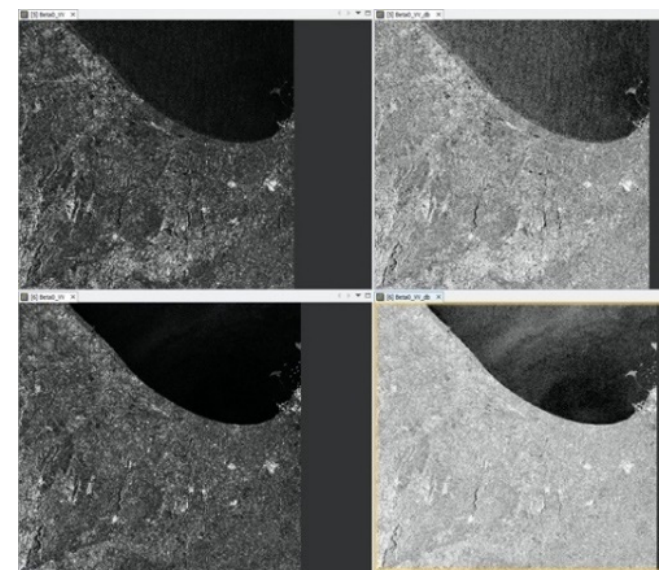

Figure 4: General From upper left, $12^{\text {th }}$ Nov. $\sigma_{0}$ without Speckle filtering; $12^{\text {th }}$ Nov. without Speckle filtering $\sigma_{0} d B ; 6^{\text {th }}$ Nov. $\sigma_{0}$ without Speckle filtering; $6^{\text {th }}$ Nov. without Speckle filtering $\sigma_{0} d B$.

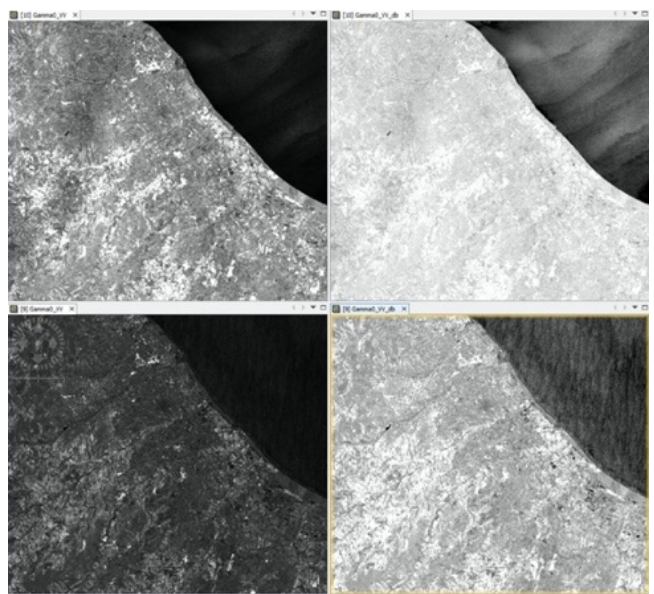

Figure 5: From upper left, $6^{\text {th }}$ Nov. $\sigma 0$ with Speckle filtering; $6^{\text {th }}$ Nov. with Speckle filtering $\sigma_{0} d B ; 12^{\text {th }}$ Nov. $\sigma_{0}$ with Speckle filtering; $12^{\text {th }}$ Nov. with Speckle filtering $\sigma o d B$.

The histogram shows two peaks, one peak corresponds to the pixels over land and the smaller peak corresponds to the pixels over water (Figs. 6-9).

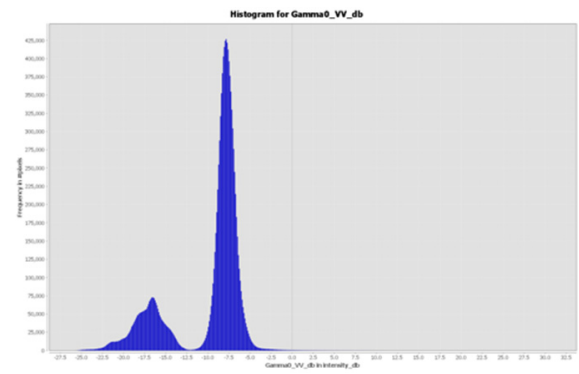

Figure 6: $6^{\text {th }}$ November $\mathrm{dB}$ scale Histogram with Speckle filtering.

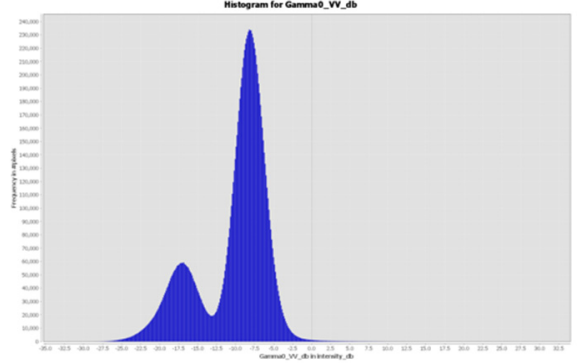

Figure 7: $6^{\text {th }}$ November $\mathrm{dB}$ scale Histogram without Speckle filtering.

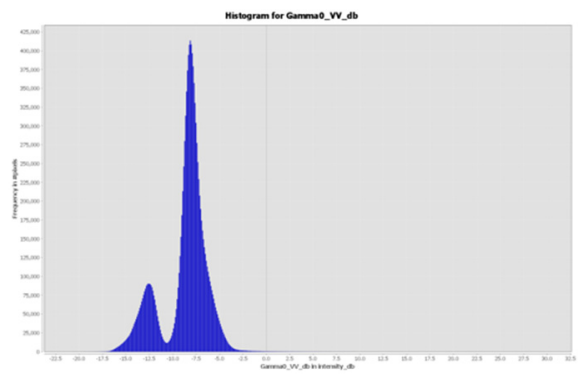

Figure 8: $12^{\text {th }}$ November $d B$ scale Histogram with Speckle filtering.

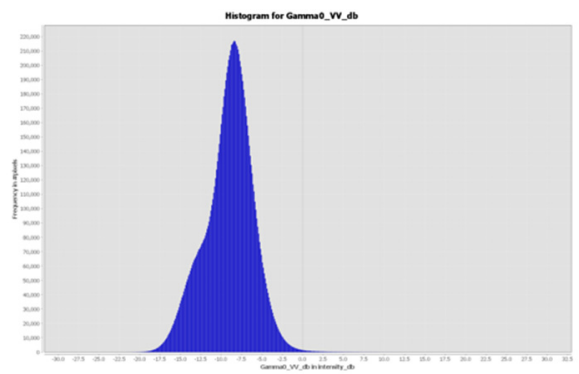

Figure 9: $12^{\text {th }}$ November $d B$ scale Histogram without Speckle filtering.

Finally, a terrain correction in order to project the pixels onto a map system and also correct the distortion over the areas of the terrain is made with a Range-Doppler terrain correction (RDTC). RDTC coordinate reference system (CRS) is World Geodetic System 1984 (Geodetic datum) with Geographic Lat/Long (WGS 84) for the projection.

The Range Doppler Terrain Correction (RDTC) operator implements the Range Doppler orthorectification method (Small \& Schubert, 2008) for geocoding SAR imagery from a single $2 \mathrm{D}$ of raster radar geometry. It uses available orbit state vector information in the metadata, the radar timing annotations, the slant to ground range conversion parameters together with the reference DEM data to derive the precise geolocation information (Bayanudin \& Jatmiko, 2016). Detail algorithm of this method can be found in (Small \& Schubert, 2008). The first step is the input/output parameter, using the imported SAR data as an input in orthorectification and choose the directory output for saving the orthorectified image. Input and output data are saved in one project file. The second step is defining the parameters and band amplitude VV which will be processed using SRTM 3 Sec as inputs to the DEM data, it will be automatically downloaded, both DEM and Image Resampling use bilinear interpolation method. Define a pixel spacing of $30 \mathrm{~m}$, thus this size will fit both to the orthorectified SAR data size in the GLS- 
2000 and the map projection that is used, UTM (Universal Transfer Mercator) and also the datum, WGS (World Geodetic System) 1984. After defining the parameters, then the process will be running automatically (Bayanudin \& Jatmiko, 2016).

Two couples of false-colour RGB band composites were performed in order to smoothly achieve a clear distinction of the areas invested by flash-flooding; it is important to mention that for carrying the whole workflow, the falsecolour RGB band composites were implemented for both speckle and not-speckle filtered images, this is the reason why they come in couples. The first couple of RGB composite allowed to achieve a first raw distinction between the flooded/not flooded areas; flooded areas were the ones having a high response on the red channel and derived from the combination of: (i) $12^{\text {th }}$ Nov. 2019 (green channel; blue channel), (ii) $6^{\text {th }}$ November 2019 (red channel). The second couple of RGB composite images was driven by the aim of having an image precisely detecting the inundated areas, to use as a reference for sampling the flooding wavelength and so define a threshold for it; this was possible to achieve using: (i) an image calculated from the differencing between the $12^{\text {th }}$ November 2019 flash flood event and the $6^{\text {th }}$ November 2019 reference image (green channel, blue channel), (ii) $6^{\text {th }}$ November 2019 (red channel).

To further express the abovementioned workflow, hereafter is explained the extended methodology. The first couple of RGB band composite was processed selecting the archive image for the red band $\left(6^{\text {th }}\right.$ November 2019) and the flooding crisis image for the green and the blue bands (12 ${ }^{\text {th }}$ November 2019). Radar response appears to have a high backscatter return in the archive image where flooded areas are not expected to be, and therefore, flooded areas appear to have a low backscatter return.

The flooded areas in the false colour RGB composite clearly have a high response in the red channel and a low response in the green and blue channels, whereas permanent water bodies have tones of grey as the backscatter (Fig. 10). After framing within the first rough RGB band composite what were the areas invested by the phenomenon (the ones having a high response in the red channel), the second phase of extracting the mapping of flooded areas using SAR data, involved (i) computing a band differencing to highlight the changes between the flooded and no-flooded areas; (ii) classify SAR images into water and non-water areas with a fixed threshold; (iii) create a flooding mask.

Firstly, for highlighting the changes in time between the flooded and not flooded areas, was computed a difference between the image acquired during the flash flood event and the reference image. In this way, it could be achieved a better evidence of the changes detected during pre and post event (Fig. 11).

Then, another false colour RBG composite was defined, deriving from the combination of (i) image differencing $\left(12^{\text {th }}\right.$ November 2019 flash flood event and the $6^{\text {th }}$ November 2019 reference image) in both the green channel and blue channel, (ii) $6^{\text {th }}$ November 2019 in the red channel. RGB helped to visually understand if the image differencing effectively achieved the goal of reaching a better precision in detecting changes. This is confirmed by the visible interdependencies between the darker zones (low reflection areas) of the image differencing, which are respectively present in the high response areas registered in the red channel of the RGB image (detecting inundated areas) (Fig.12).

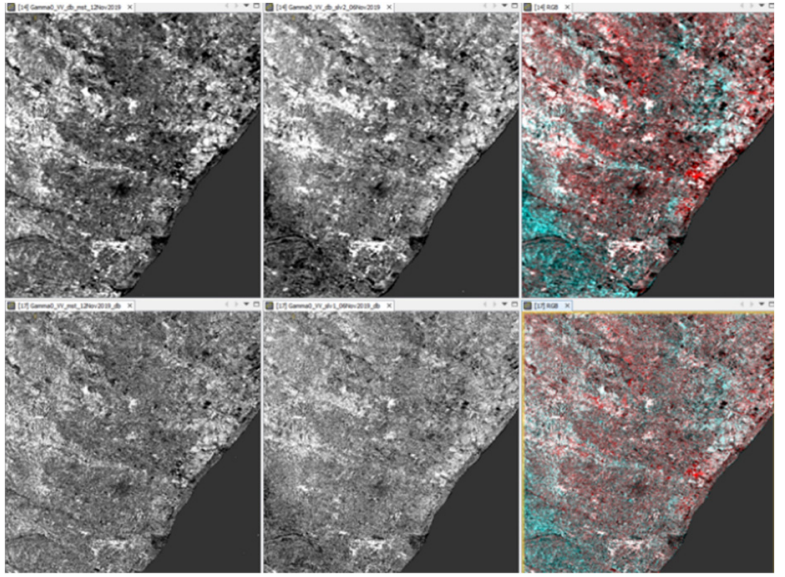

Figure 10: In the first row from the left: speckle filtered image of $12^{\text {th }}$ Nov. 2019, speckle filtered image of $6^{\text {th }}$ Nov. 2019, the RGB composite obtained; in the second row from the left: no speckle filtered image of $12^{\text {th }}$ Nov. 2019, no speckle filtered image of $6^{\text {th }}$ Nov. 2019, the obtained RGB composite.

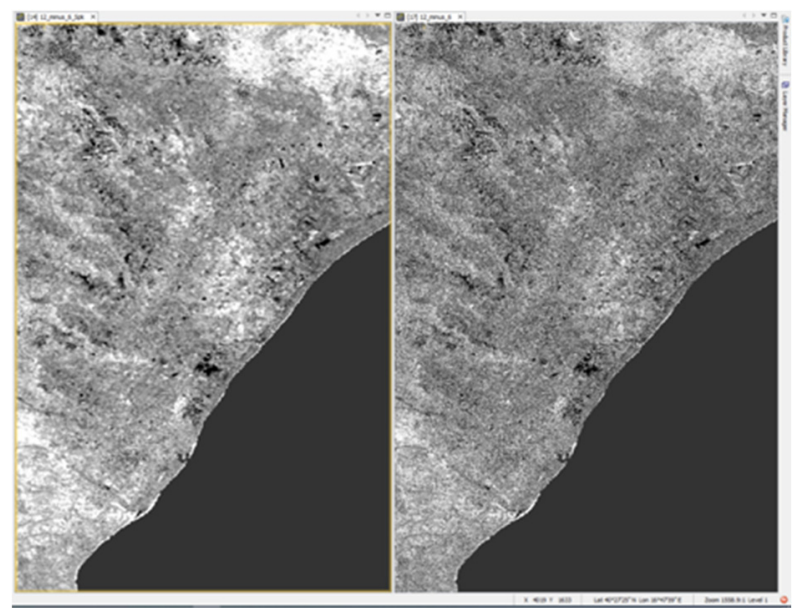

Figure 11: On the left, image differencing with speckle filter; on the right: image differencing without speckle filtering.

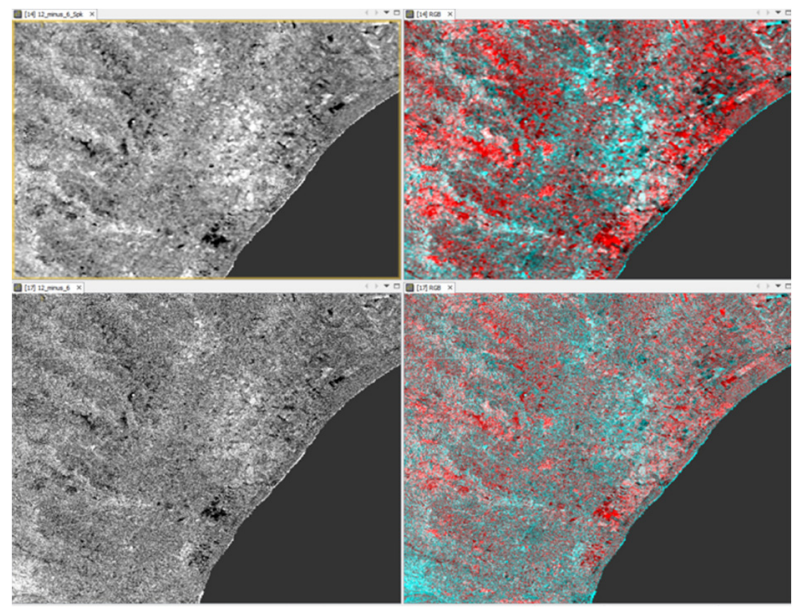

Figure 12: On the left, image differencing (up) with speckle filter (down) without speckle filtering; on the right RGB with image differencing on the Red channel (up) with speckle filter (down) without speckle filtering. 
The mapping of the inundated area was then extracted from the SAR images using the threshold method (Sheng, Gong, \& Xiao, 2001; Rahman \& Thakur, 2018). In SAR image inundated areas appear in a dark tone, which can be clearly delineated from the non-inundated areas due to the surface roughness of water and land (Rahman \& Thakur, 2018). The speckle filtered image differencing (SpkID) (calculated from the differencing between the $12^{\text {th }}$ November 2019 flash flood event and the $6^{\text {th }}$ November 2019 reference image) was the one taken as a sampling reference in order to investigate the flooded areas within the change detection framework. This due to the fact that the SpkID is the one having the lowest backscattering noise and so, allows a clearer interpretation of the phenomenon.

To determine an appropriate threshold value, manual sampling of representative flooded areas was carried out, based on the direct observation of the inundated zones, appearing as the areas with low reflection in the abovementioned speckle filtered image differencing (SpkID). In the threshold method, water areas are identified as the ones if SpkID $\leq T_{W}$, where SpkID is the speckle filtered image differencing applied to the SAR image and $T_{w}$ is the threshold value for water.

The threshold sampled values can be referred to as the histogram distribution of the image differencing pixel (Fig.13). From the location of the collected samples, it is clearly visible that the low reflection areas are concentrating in the negative region of the histogram, which is where the $T_{w}$ was set.

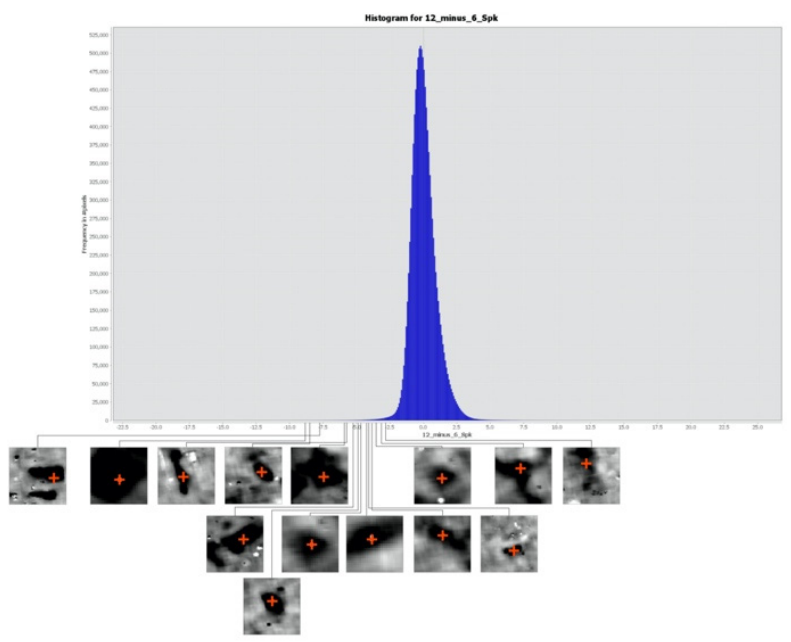

Figure 13: Extract of the sampled values referred to the histogram distribution of the image differencing pixels performed for the Speckle filtered image.

To create a flooding mask the two different layers were combined: (i) a binary map obtained by thresholding the image filtered with the speckle filter and (ii) the binary original threshold difference layer without the speckle filter (Fig. 14). The not speckled-filtered binary raster (iii) presents a high "salt and pepper" effect, but at the same time (iv) preserves the level of detail $(30 \times 30 \mathrm{~m})$; the speckle filtered image (v) does not present the "salt and pepper" effect but (vi) has a lower level of detail. After these considerations, it is reasonable to say that the final mask had to be computed as the one for which both conditions (iv) and (v) are satisfied. The final flood mask layer deriving from the combination of both speckle and not-speckle has the following advantages: (i) removes noise connected with the speckle effect and (ii) preserves the level of detail of the initial images (Fig. 15).

Finally, the last RGB composite was defined in order to see the flooded areas. RGB composite used the Flooding Mask on the red channel and the archive image $\left(6^{\text {th }}\right.$ November 2019 reference image) on the green and blue channels (Fig. 16). The area invested by flash-flooding on the day of 12 November 2019 covered $9,865 \mathrm{~km}^{2}$ of a total area of $819,814 \mathrm{~km}^{2}$

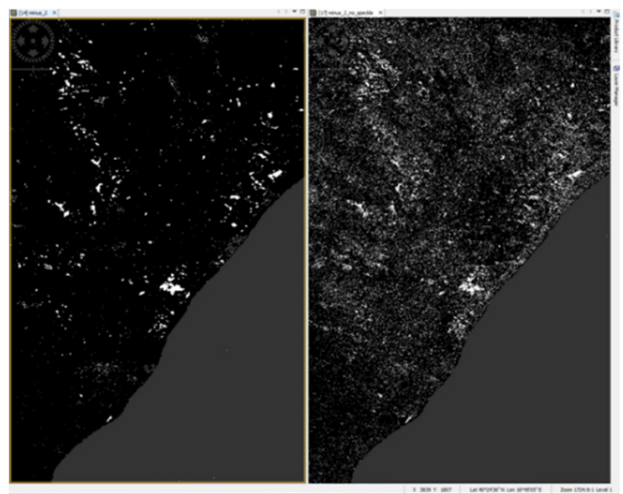

Figure 14: Threshold images, left: speckle filter; right: binary original threshold difference layer.

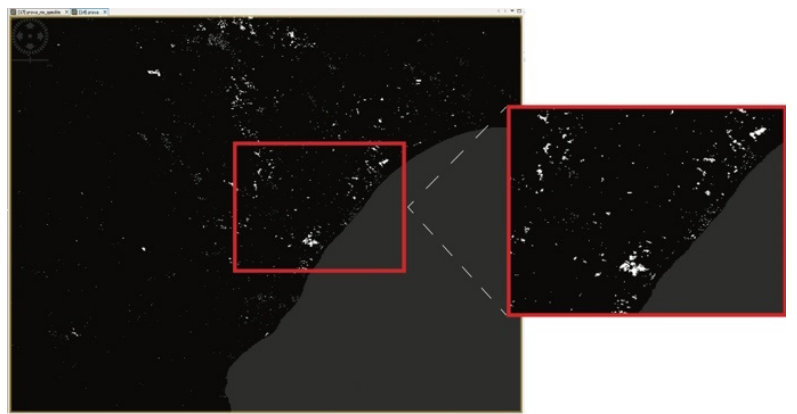

Figure 15: Flooding mask derived from the combination of the two threshold images.
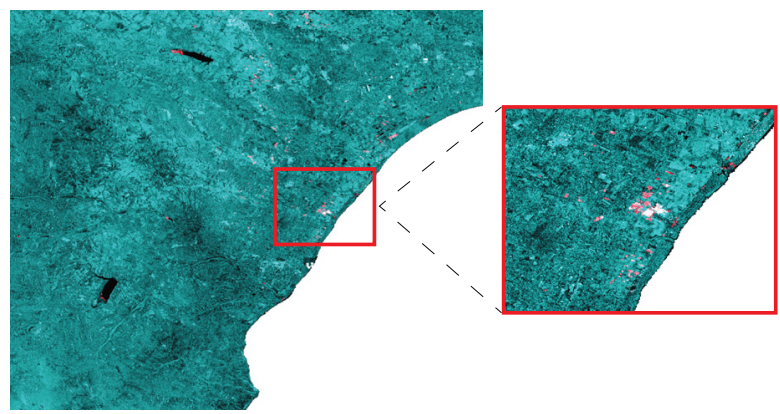

Figure 16: The RGB Composite deriving from using the Flooding mask on the red channel.

\section{Results and discussion}

To better understand and spatially locate the flooded areas in the Cultural Landscape and its Heritage, the mask layer was transferred to a QGIS environment and vectorized. The following layers extracted from both the MIBACT (The Ministry of Cultural Heritage and Activities) Open Database and Basilicata Open Data WebGIS were added to the final map, contextualizing the high Cultural value of the area (Fig.17): 
- Beni di Interesse Archeologico (Archeological Cultural assets) Art.10 Dlgs 42/2004. Cultural assets are immovable and movable things belonging to the State, to the regions, to other territorial public bodies, as well as to any other public body and institution and to private nonprofit legal persons, including civilly recognized ecclesiastical bodies, which are of artistic, historical, archaeological or ethnoanthropological interest.

- Beni Paesaggistici (Landscape Heritage) art. 142c Dlgs 42/2004. Rivers, streams, watercourses registered in the lists provided for by the consolidated text of the provisions of the law on water and electrical systems, approved by royal decree 11 December 1933, n. 1775, and the relative sides or feet of the embankments for a band of 150 meters each;

- Beni Paesaggistici (Landscape Heritage) art. 142c1 lettera a Dlgs 42/2004. These are the coastal territories included in a strip of the depth of 300 meters from the shoreline, also comprising the elevated lands on the sea;

- $\quad$ MIBACT (The Ministry of Cultural Heritage and Activities-Ministero per i Beni e le Attività culturali e per il Turismo), Open Data on Cultural Assets both Archeological and Architectonical.

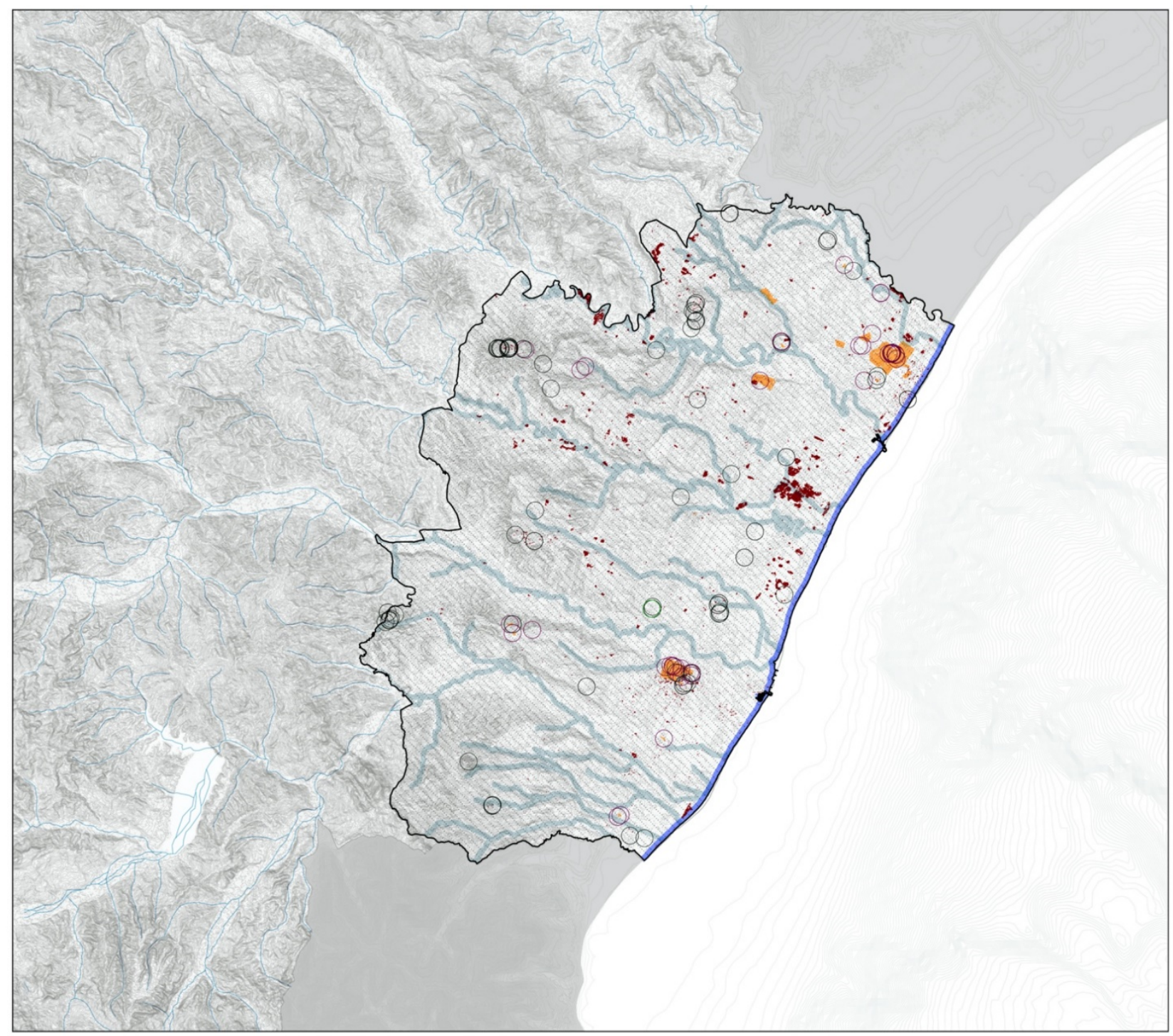

$\underline{0}$

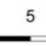

$\underline{10}$

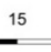

20

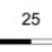

30 $40 \mathrm{~km}$

A
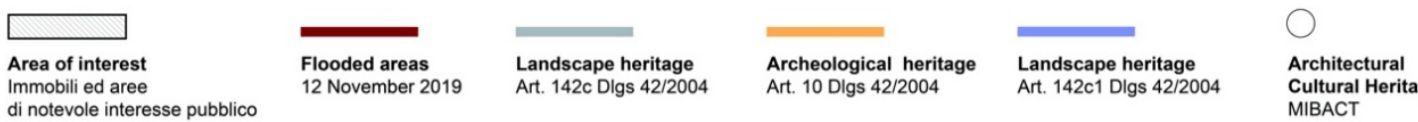

Architectural
Cultural Heritag MIBACT

Figure 17: The flooded areas and the Cultural, Archaeological, Architectonical and Landscape assets. 
As aforementioned in the introduction to the study area, we are dealing with a Heritage itself, which is the Metaponto Plain area, protected within the Dlgs 42/2004 (Codice dei Beni Culturali e del Paesaggio -Cultural Heritage and Landscape Code), in the Art. 136, as an "area of remarkable public interest".

"Acknowledging that the landscape is an important part of the quality of life for people everywhere: in urban areas and in the countryside, in degraded areas as well as in areas of high quality, in areas recognized as being of outstanding beauty as well as everyday areas (Council of Europe, 2000)". This is an extract of the European Landscape Convention, and perfectly fits in the organic idea of "protection" (the Italian tutela) as it shouldn't be something literally guided by the formal Landscape and Cultural assets, that rigidly design formal bounds of protection on the land.

As in fact, the Landscape as described in the European Landscape Convention is not only a list of aesthetic excellences where the recognition of historical-cultural value merges with the iconographic stasis of the "beautiful view" but is the result of a complex system of relationships that stratifies and evolves with the natural processes and the life of populations inhabiting it. Landscape and its assets are constantly evolving, as living things do.

The main aim of the protection from flash-flooding and extreme events, that progressively attacks the Heritage due to the unpredictable changing climate, should be constantly monitoring the whole, in order to act precisely and prompt when needed in time 0 and so avoid losses and irreplaceable damages.

The idea itself of the Metaponto Plain, which is formally invested by a protection law in its total area, it's the perfect example that if we don't take care of the whole, letting it undergo damages, we also lose part of the total significance of that one single element in it, even the one that maybe it is not considered "formally" remarkable, but still, is a fundamental part of the territorial entity and foremost of its Cultural identity.

\section{Conclusions}

Cultural Landscapes and Heritage sites are constantly facing risks deriving from unpredictable changes in the climate, resulting in a need for specific attention regardless of the formal existing legal constraints that yet protect them. The availability of Copernicus Sentinels Synthetic-Aperture Radar (SAR) data helps to achieve the mapping of disasters caused by flashfloods and extremely heavy rainfalls. Radar backscatter signal on the water is much different than the one on vegetated areas, allowing flood mapping with SAR radar to be almost undeniable. The idea behind the study is to demonstrate that monitoring Heritage at risk is achievable with a low-cost effective approach. The research presents a methodology based on the extraction of a food mask from SAR data by a series of simple algorithms that reach a $30 \times 30 \mathrm{mt}$ resolution with low "salt and pepper" noise disturbances. The presented analysis should have been further implemented with an after-event in-situ survey for validation in order to assess the overall accuracy. It is however important to stress the goal of rapidly individuating the flood-prone areas during a disaster, in order to frame the portions of land where to concentrate resources and further investigations in the subsequent phase of flooding management. The rapid response to flooding events in Heritage sites and Cultural Landscapes contexts is a key part of Heritage management, as it formally aims to avoid damages and thus, permanent losses.

\section{References}

Ajmar, A., Boccardo, P., Broglia, M., Kucera, J., Giulio-Tonolo, F., \& Wania, A. (2017). Response to flood events: The role of satellite-based emergency mapping and the experience of the Copernicus emergency management service. Flood Damage Surv. Assess. New Insights Res. Pract, 228, 213-228.

Badji, M. (1994). ERS-1 SAR imagery applied to rural basins hydrological studies: Flood inundation mapping and monitoring. European Space Agency-Publications-ESA SP, 365, 117-117.

Bayanudin, A. A., \& Jatmiko, R. H. (2016). Orthorectification of Sentinel-1 SAR (Synthetic Aperture Radar) Data in Some Parts of South-eastern Sulawesi Using Sentinel-1 Toolbox. In IOP Conference Series: Earth and Environmental Science (Vol. 47, No. 1, p. 012007). IOP Publishing. https://doi.org/10.1088/1755-1315/47/1/012007

Bentivenga, M., Giano, S. I., \& Piccarreta, M. (2020). Recent Increase of Flood Frequency in the lonian Belt of Basilicata Region, Southern Italy: Human or Climatic Changes?. Water, 12(7), 2062. https://doi.org/10.3390/w12072062

Brivio, P. A., Colombo, R., Maggi, M., \& Tomasoni, R. (2002). Integration of remote sensing data and GIS for accurate mapping of flooded areas. International Journal of Remote Sensing, 23(3), $429-441$. https://doi.org/10.1080/01431160010014729

COUNCIL, O. E. (2000). European landscape convention. US/ICOMOS Scientific Journal, 2, 88-92.

Dasgupta, A., Grimaldi, S., Ramsankaran, R. A. A. J., Pauwels, V. R., Walker, J. P., Chini, M., \& Matgen, P. (2018). Flood mapping using synthetic aperture radar sensors from local to global scales. Global Flood Hazard: Applications in Modeling, Mapping, and Forecasting, 55-77. https://doi.org/10.1002/9781119217886.ch4

De Musso, N. M., Capolongo, D., Refice, A., Lovergine, F. P., D’Addabbo, A., \& Pennetta, L. (2018). Spatial evolution of the December 2013 Metaponto plain (Basilicata, Italy) flood event using multi-source and high-resolution remotely sensed data. Journal of Maps, 14(2), 219-229. https://doi.org/10.1080/17445647.2018.1454349

Franci, F., Mandanici, E., \& Bitelli, G. (2015). Remote sensing analysis for flood risk management in urban sprawl contexts. Geomatics, Natural Hazards and Risk, 6(5-7), 583-599. https://doi.org/10.1080/19475705.2014.913695 
Gan, T. Y., Zunic, F., Kuo, C. C., \& Strobl, T. (2012). Flood mapping of Danube River at Romania using single and multidate ERS2-SAR images. International Journal of Applied Earth Observation and Geoinformation, $18,69-81$. https://doi.org/10.1016/j.jag.2012.01.012

Greifeneder, F., Wagner, W., Sabel, D., \& Naeimi, V. (2014). Suitability of SAR imagery for automatic flood mapping in the Lower Mekong Basin. International journal of remote sensing, 35(8), $2857-2874$. https://doi.org/10.1080/01431161.2014.890299

Guo, H., Fu, W., \& Liu, G. (2019). Scientific Satellite and Moon-Based Earth Observation for Global Change. Springer Singapore.

Lacava, T., Ciancia, E., Faruolo, M., Pergola, N., Satriano, V., \& Tramutoli, V. (2018). Analyzing the December 2013 Metaponto Plain (Southern Italy) Flood Event by Integrating Optical Sensors Satellite Data. Hydrology, 5(3), 43. https://doi.org/10.3390/hydrology5030043

Lacava, T., Ciancia, E., Faruolo, M., Pergola, N., Satriano, V., \& Tramutoli, V. (2019). On the potential of RST-FLOOD on visible infrared imaging radiometer suite data for flooded areas detection. Remote Sensing, 11(5), 598. https://doi.org/10.3390/rs11050598

Millán, M. M., Estrela, M. J., Sanz, M. J., Mantilla, E., Martín, M., Pastor, F., \& Versino, B. (2005). Climatic feedbacks and desertification: the Mediterranean model. Journal of Climate, 18(5), 684-701. https://doi.org/10.1175/JCLI-3283.1

Naveh, Z. (1990). Ancient man's impact on the Mediterranean landscape in Israel-ecological and evolutionary perspectives. Man's role in the shaping of the eastern Mediterranean landscape. Balkema, Rotterdam, 43-50.

NEREUS, European Space Agency and European Commission. (2018). "The Ever-Growing use of Copernicus across Europe's Regions: a selection of 99 user stories by local and regional authorities", 1-277.

Ohki, M.; Watanabe, M.; Natsuaki, R.; Motohka, T.; Nagai, H.; Tadono, T.; Suzuki, S.; Ishii, K.; Itoh, T.; \& Yamanokuchi, T. (2016). "Flood Area Detection Using ALOS-2 PALSAR-2 Data for the 2015Heavy Rainfall Disaster in the Kanto and Tohoku Area, Japan." Journal of The Remote Sensing Society of Japan 36, no. 4 (2016): 348-359. https://doi.org/10.11440/rssj.36.348

Profeti, G., \& Macintosh, H. (1997). Flood management through Landsat TM and ERS SAR data: a case study. Hydrological Processes, 11(10), 1397-1408. https://doi.org/10.1002/(SICl)10991085(199708)11:10<1397::AID-HYP530>3.0.CO;2-Y

Rahman, M. R., \& Thakur, P. K. (2018). Detecting, mapping and analysing of flood water propagation using synthetic aperture radar (SAR) satellite data and GIS: A case study from the Kendrapara District of Orissa State of India. The Egyptian Journal of Remote Sensing and Space Science, 21, S37-S41. https://doi.org/10.1016/j.ejrs.2017.10.002

Sanyal, J., \& Lu, X. X. (2004). Application of remote sensing in flood management with special reference to monsoon Asia: a review. Natural Hazards, 33(2), 283-301. https://doi.org/10.1023/B:NHAZ.0000037035.65105.95

Sheng, Y., Gong, P., \& Xiao, Q. (2001). Quantitative dynamic flood monitoring with NOAA AVHRR. International Journal of Remote Sensing, 22(9), 1709-1724. https://doi.org/10.1080/01431160118481

Singh, S., Dhote, P. R., Thakur, P. K., Chouksey, A., \& Aggarwal, S. P. (2021). Identification of flash-floods-prone river reaches in Beas river basin using GIS-based multi-criteria technique: validation using field and satellite observations. Natural Hazards, 105(3), 2431-2453. https://doi.org/10.1007/s11069-020-04406-w

Small, D., \& Schubert, A. (2008). Guide to ASAR geocoding. ESA-ESRIN Technical Note RSL-ASAR-GC-AD, 1, 36.

Takeuchi, S., Konishi, T., Suga, Y., \& Kishi, S. (1999). Comparative study for flood detection using JERS-1 SAR and Landsat TM data. In IEEE 1999 International Geoscience and Remote Sensing Symposium. IGARSS'99 (Cat. No. 99CH36293) (Vol. 2, pp. 873-875). IEEE. https://doi.org/10.1109/IGARSS.1999.774470.

Touzi, R., Deschamps, A., \& Rother, G. (2009). Phase of target scattering for wetland characterization using polarimetric C-band SAR. IEEE Transactions on Geoscience and Remote Sensing, 47(9), 3241-3261. https://doi.org/10.1109/TGRS.2009.2018626.

Twele, A., Cao, W., Plank, S., \& Martinis, S. (2016). Sentinel-1-based flood mapping: a fully automated processing chain. International Journal of Remote $\quad$ Sensing, 37(13), https://doi.org/10.1080/01431161.2016.1192304

Uddin, K., Matin, M. A., \& Meyer, F. J. (2019). Operational flood mapping using multi-temporal sentinel-1 SAR images: a case study from Bangladesh. Remote Sensing, 11(13), 1581. https://doi.org/10.3390/rs11131581

Voormansik, K., Praks, J., Antropov, O., Jagomägi, J., \& Zalite, K. (2013). Flood mapping with TerraSAR-X in forested regions in Estonia. IEEE Journal of Selected Topics in Applied Earth Observations and Remote Sensing, 7(2), 562577. https://doi.org/10.1109/JSTARS.2013.2283340.

Wang, F., Koopmans, B. N., \& Pohl, C. (1996). The 1995 Flood in the Netherlands monitored from Space-a multisensor approach. European Space Agency-Publications-ESA SP, 383, 469-472.

Ward, P. J., De Perez, E. C., Dottori, F., Jongman, B., Luo, T., Safaie, S., \& Uhlemann-Elmer, S. (2018). The need for 
mapping, modeling, and predicting flood hazard and risk at the global scale. Global flood hazard: Applications in modeling, mapping, and forecasting, 1-15. https://doi.org/10.1002/9781119217886.ch1

Zhang, M., Chen, F., Liang, D., Tian, B., \& Yang, A. (2020). Use of Sentinel-1 GRD SAR images to delineate flood extent in Pakistan. Sustainability, 12(14), 5784. https://doi.org/10.3390/su12145784

Zhang, M., Li, Z., Tian, B., Zhou, J., \& Tang, P. (2016). The backscattering characteristics of wetland vegetation and waterlevel changes detection using multi-mode SAR: A case study. International Journal of Applied Earth Observation and Geoinformation, 45, 1-13. https://doi.org/10.1016/j.jag.2015.10.001 


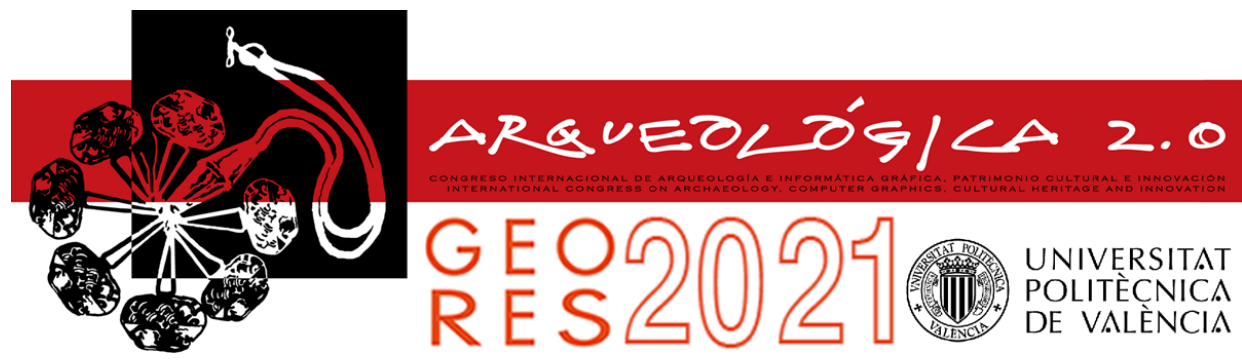

Proceedings of the joint international event $9^{\text {th }}$ ARQUEOLÓGICA

$2.0 \& 3^{\text {rd }}$ GEORES

Valencia (Spain).

26-28 April 2021

\title{
CANOSSA CASTLE: THE IMPORTANCE OF A CRITIC AND AWARE PLAN OF INTERVENTIONS FOR CONSERVATION AND PREVENTION OF CULTURAL HERITAGE
}

\author{
Marco Catellani, Lia Ferrari ${ }^{\star}$, Elena Zanazzi \\ Department of Engineering and Architecture, University of Parma, Viale delle Scienze 181/A, 43124 Parma, Italy. \\ marco.catellani3@studenti.unipr.it; lia.ferrari@unipr.it; elena.zanazzi@unipr.it
}

\begin{abstract}
:
Fortified architecture is a widespread and peculiar typology in Italy as it represents an identifying element for communities and a reference point in the landscape. An imposing system of castles, dating back to the $11^{\text {th }}$ century, characterises the area of Reggio Emilia, in the Emilia Romagna Region. Among these fortifications, Canossa Castle is an important and distinctive fortress. Built on the top of an isolated cliff, a particularly strategic and defensive point, it played a central role in medieval European history. For instance, it was the scene of the well-known reconciliation between Henry IV and Pope Gregory VII, which ended the Investiture Controversy in 1077. The current state of ruins of this fortress is due to both centuries of neglect and to recent incongruent interventions. Therefore, archival research, in-situ inspections and photogrammetric techniques were carried out on the case study of Canossa Castle, in order to analyse the numerous restoration yards that have followed one another on the fortress in the last century. Firstly, the lack of coordination between the different interventions emerged. Furthermore, it has been observed that the principles of restoration have been disregarded several times, with consequent damage to the archaeological remains. Therefore, the present study aims to underline the importance of a critical and aware intervention plan for the conservation and damage prevention of cultural heritage, considering the possible support of HBIM tools.
\end{abstract}

Keywords: castles, ruins, cultural heritage preservation, architectural survey, archival research, in situ investigations

\section{Introduction}

The continuous loss or damage of monuments observed worldwide is caused by several reasons, both natural and man-induced. Among the natural phenomena, the occurrence of ground movements (landslides, subsidence) and seismic activity (earthquakes) are the most common causes. In general slow landslides are extremely sensitive to climate changes: extreme natural phenomena increase the effects of deformation and degradation processes. Then, seismic actions ultimately affect the stability of the architectural heritage. The consequences of these effects, combined with the insufficient and decreasing budgets for the conservation of monuments, are proving to be catastrophic for the Italian Cultural Heritage, as evidenced by the effects of the recent earthquakes (2012 in the Po valley and $2016 / 17$ in Central Italy). In this scenario, authorities in charge of preserving cultural heritage have a strong need for systematic, effective, usable and affordable tools and services to forecast and monitor degradation processes and to enable preventive maintenance.

In this perspective, in 2018 , with the aim of defining tools for the prevention of seismic damage on cultural heritage, a research project was launched, within the collaboration between the University of Parma and the Agency for Reconstruction of the Emilia Romagna Region. The research focuses on fortified architecture, which proved to be highly vulnerable to earthquakes, as shown by the damage that occurred after the 2012 Emilia seismic event. The study is analysing recurrent seismic damages and defining the seismic behaviour of these historic buildings, using the so-called phenomenological approach. This method relies on the observation and classification of the actual damage to recognize and classify recurring vulnerabilities (Coïsson, Ferretti \& Lenticchia, 2017).

In order to manage large numbers of buildings, this analysis is supported by the use of GIS (Geographic Information System), a tool that is becoming widespread in the field of architectural restoration (Bartolomucci, 2008). As a matter of fact, this software is a useful support for the management of conservation strategies on cultural heritage. It allows planning maintenance programs and preventive interventions, leading to more effective seismic improvements and reducing emergency interventions, which so far has guided the restoration works on the architectural heritage in response to

•Corresponding Author: Lia Ferrari, lia.ferrari@unipr.it 
earthquakes. Moreover, for a better distribution of the limited resources available, the definition of a priority list based on damage mechanisms rather than entire buildings (Cattari et al., 2014; Bartolomucci, 2012), as usually happens, would allow focusing the intervention on the most vulnerable elements. As a result, more buildings can be retrofitted. With this aim, further development of the aforementioned research would be the elaboration of experimental vulnerability curves. In this way, a low-cost tool is provided for the identification of vulnerabilities, in relation to the features of the building and local seismicity.

This kind of approach is fundamental for the preservation of fortified architecture, a peculiar typology that is widespread not only in Italy but also all over Europe. For centuries, fortresses have been a landmark, as well as an identifying symbol for communities. Starting from the encastellation phenomenon, this structure spread widely during the Middle Ages. Since then, the fortified structures have undergone several modifications and adaptations, but they have always remained important elements of the landscape and of the people's cultural identity.

An impressive system of castles, dating back to the $11^{\text {th }}$ century, characterises the area of Reggio Emilia (Fig. 1), in the Emilia Romagna Region (Manenti Valli, 1987). Among these fortifications, Canossa Castle is an important and distinctive fortress. Built on the top of an isolated cliff, a particularly strategic and defensive point, it played a central role in medieval European history. The Countess Matilde of Canossa placed there the political and military centre of a feud that extended from Lombardy to Tuscany.

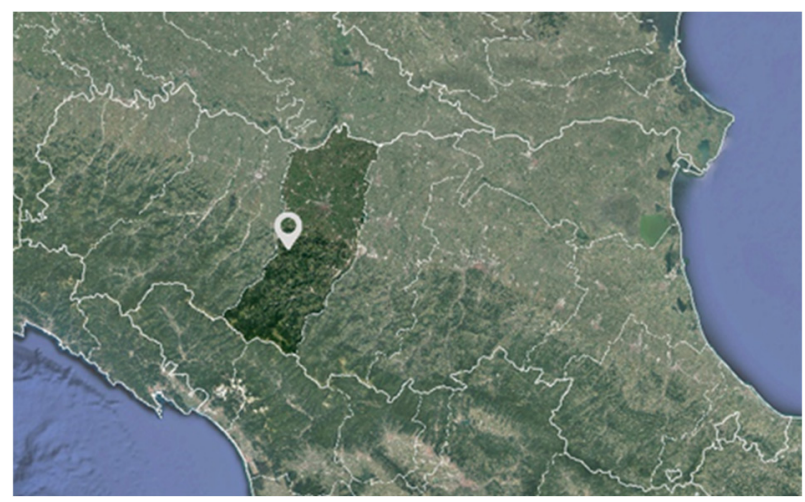

Figure 1: Canossa Fortress is located on the hills of the province of Reggio Emilia, in northern Italy.

\section{Canossa: from fortress to ruin}

The first evidence of a fortified system on the top of Canossa cliff dates back to the beginning of the $10^{\text {th }}$ century (Manenti Valli, 2002). This historical period was characterised by political and social instability due to internal conflicts and barbaric invasions. For this reason, the Bishop of Reggio built a defensive system to protect the local community. Later, considering the strategic importance of the area, the first Count of Canossa, Atto Adalberto (939 - 988 A.D.) decided to improve the existent fortified system with the construction of an imposing fortress. Thus, Canossa Castle, whose construction period is uncertain, probably stood on the bishop's original establishment (Settia, 2015). Under the rule of Canossa Family (Atto 939 - Matilde 1115) the castle has undergone several modifications and adaptations, from the improvement of the defensive configuration to the transformation into a magnificent fortified palace. The Castle became one of the safest places in Europe, giving protection to important historical figures and playing a relevant role in European medieval history (Franceschi,1999; Piccinini \& Raffaelli, 2010). In the specific, in 1077, during the reign of Matilde, the castle became the set of a relevant episode in European history, the so-called "Walk to Canossa", which lead to the reconciliation between Emperor Henry IV and Pope Gregory VII, ending the Investiture Controversy thanks to the mediation of the countess (Bedogni \& Grasselli, 2007; Bedogni \& Grasselli, 2010).

After the end of Canossa's reign, the fortress and its surrounding changed owner several times and suffered relevant damages due to local conflicts. Various parts of the Castle were thus restructured or re-built. The last important conflict dates back to 1557, when Ottavio Farnese, Duke of Parma, attacked Ercole II, Duke of Ferrara and owner of the castle (Fig. 2). The conflict between the two families severely damaged the fortress (Grignano, 2006). In the following years, the castle was thus restored and its defensive system improved.

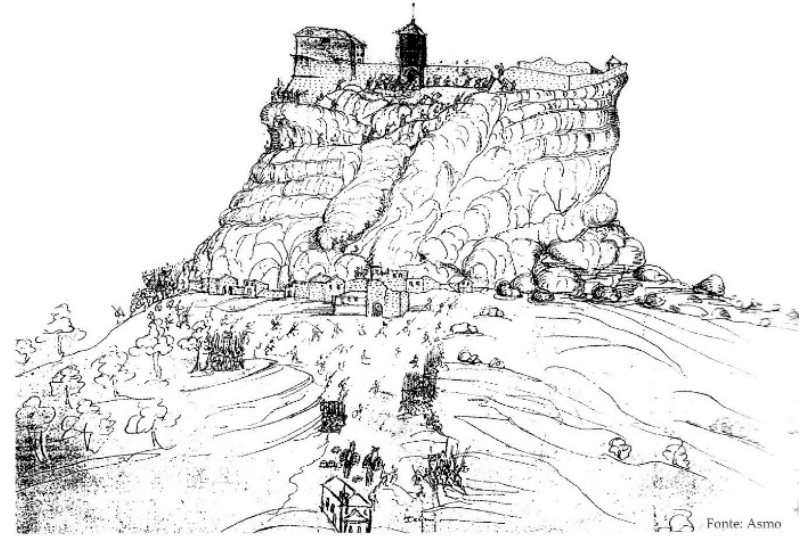

Figure 2: Illustration of the siege of Canossa Fortress during the attack moved by Ottavio Farnese to the Duke of Ferrara (1557), ASMO, Fund "Città", folder 142/3.

Then, Count Bonifazio Ruggieri definitely modified the defensive structure into a noble residence. In 1642, Francesco I, Duke of Modena, designed the knight Paolo Valentini as the owner of Canossa. From the beginning of the $19^{\text {th }}$ century, the fortress has fallen into a state of neglect, probably due to the dispossess made by the Napoleonic Edit.

The Castle remained the property of Valentini Family until 1881, the year in which the Italian State decided to purchase the monument. The negotiation between the previous owner and the State, represented by the palaeologist Don Gaetano Chierici (1819-1886), lasted several years.

In this period, the archaeological site (Fig. 3) was investigated through several excavation campaigns, directed by Chierici himself. During the first campaign (1877-1879) large quantities of debris (rubbles and earth) was removed, bringing to light the crypt and the adjacent rooms. Further excavation campaigns were carried out until 1892, discovering artefacts that helped to better understand the history of the monument (Spagni \& Ferrari, 1877;Campanini \& Ghirandini, 1984; Patroncini, 1997) Patroncini, 1997). In the first decade of the $20^{\text {th }}$ 
century, the archaeological site needed first aid interventions to secure the excavated areas and to allow access to the public: the monument became a national museum.

The two World Wars interrupted the restoration, resumed in the second half of the $20^{\text {th }}$ century. Between the 1960 s and 1980 s, new interventions concerned the stability of the cliff, affected by landslide. In the past 40 years, several invasive interventions have tried to strengthen the structure, deeply modifying the nature of the monument (Fig. 4).

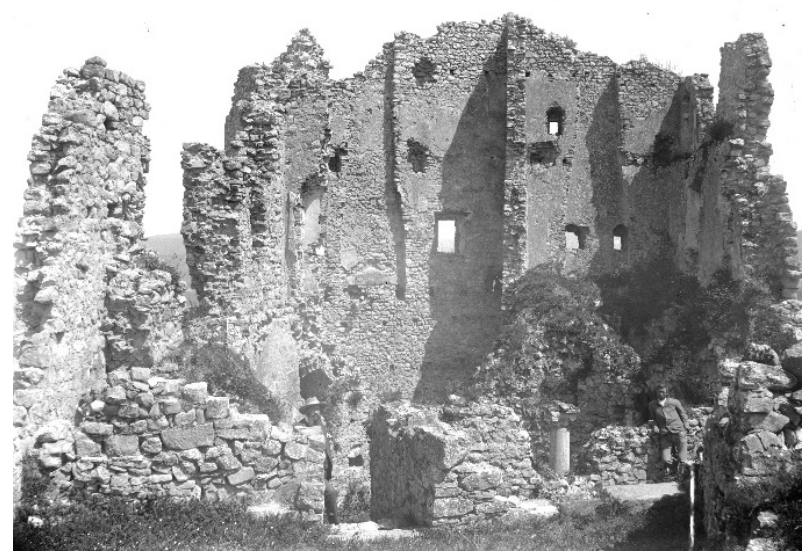

Figure 3: Picture of the second half of the $19^{\text {th }}$ century, representing the ruins of the Fortress before the interventions of the $20^{\text {th }}$ century.

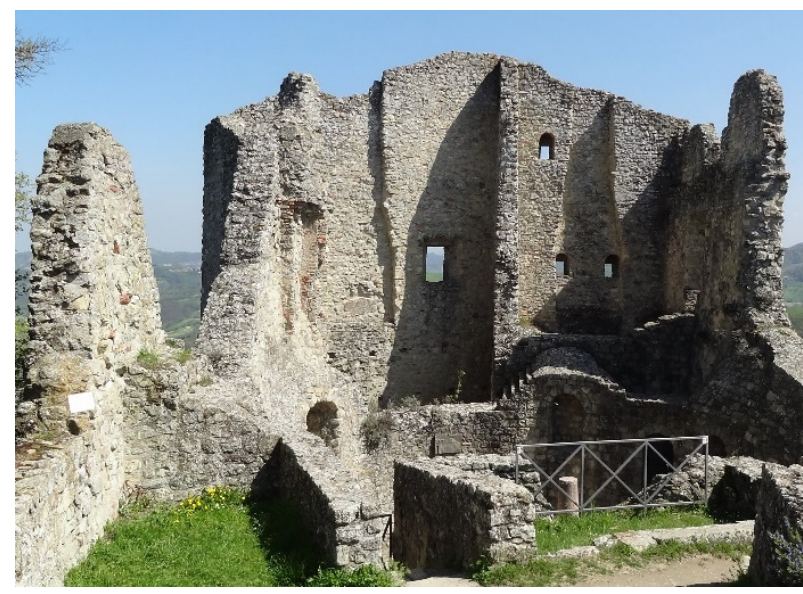

Figure 4: The ruins of Fortress today after the interventions of the last 40 years.

The current state of ruins is therefore the result of damaging conflicts (from the $12^{\text {th }}$ to $16^{\text {th }}$ century), abandonment (18 ${ }^{\text {th }}$ century) and recent incongruent interventions $\left(20^{\text {th }}\right.$ century). Moreover, the harsh environment and seismic events caused the collapse of most of the structures. Archival research, in-situ inspections and photogrammetric techniques were carried out on Canossa Castle, in order to analyse the current state of conservation and underline the importance of a critical and aware intervention plan for the conservation and the prevention of damage of this important fortified system.

\section{Interventions: the fortress in the last $\mathbf{4 0}$ years}

The study presented in this paper focuses on the strengthening interventions carried out on the fortress in the last 40 years, of which we have evidence from archival research (Ministero per i Beni e le Attività culturali, 2019a; Ministero per i Beni e le attività Culturali, 2019b). The historical documentation allows identifying the main reinforcement interventions even if some inaccuracies prevent a complete and precise definition of the complex intervention system developed over the last decades. The documentation relating to the interventions carried out in the 1980s, in fact, is rather generic, not very technical and sometimes lacking graphics and detailed descriptions. Consequently, it was difficult to identify the accurate area of intervention, as well as to find information on the materials and techniques used in the restoration yards. Moreover, the terminology adopted in the archival documents is different from the current technical vocabulary, giving rise to misunderstandings. For instance, the term "mortar grout injections" is often used to refer to the technique of injected reinforcing bars. The reports of the interventions carried out in the 1990s are instead more complete and detailed. However, even in this case, information regarding the localisation of interventions, is usually not accurate. Graphic drawings, when available, simplify the castle shapes with regular geometries. Furthermore, the proportions are often not respected, making it even more difficult to identify the precise areas of intervention (Fig. 5).

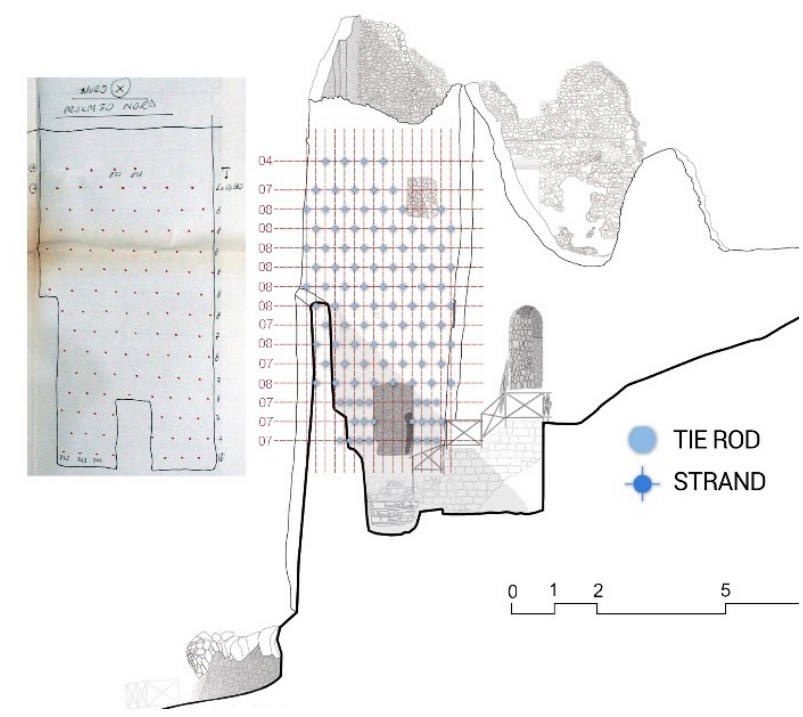

Figure 5: On the right, graphic representation of the position of the reinforcing bars on the northern front (intervention carried out in 1979). This reconstruction is made difficult by the evident simplification of geometries in the drawings of the archive documentation, on the left.

The first interventions analysed date back to the years 1979-1980. In this phase, foundation micro-piles were installed in correspondence with the eastern elevation. Other interventions were carried out to strengthen the masonry walls which were in a precarious state of conservation, because of the presence of vegetation. The documents refer to the insertion of reinforcing bars into the wall thickness, in order to reconnect the external layers with the central core. In-situ investigations show that these cement mortar injections concerned all three 
elevations. Overall, this strengthening intervention is rather invasive and ill-conceived: in the following years, cement mortars, in contact with humidity, created efflorescence, which caused the detachment of the surface layers, worsening the degradation of the original materials. Moreover, the anchorages were hidden under masonry, requiring the demolition of a portion of the original material. The metal plates were sometimes covered with a salvaged stone, other times with stones similar to the original ones, making it difficult to recognise their authenticity. Moreover, the frequency of installation of these elements suggests a complete renewal of the east and south façade and part of the north façade, losing its original image and its historicity.

The following consolidation project, dating back to 1983, shows an improvement in the level of knowledge of the architectural organism. The operations are more targeted and calibrated according to the area under investigation. In this phase of intervention, a water drainage system was created and a so-called "crodolo" (ring beam) were installed in correspondence with the two horizontal floors. Thanks to the in-situ investigation (presented in paragraph 4) it has been possible to understand that the term actually refers to metal tie-rods. The purpose of the two-level tie-rods system was to avoid dangerous overturning mechanisms, restoring the box-like behaviour of the structure. Furthermore, the base of the most vulnerable fronts, the southern and the eastern one, has been strengthened again through the insertions of reinforcing bars. As will be explained in paragraph 4, the in-situ investigation has shown that this additional system of reinforcing bars integrates, without overlapping, the one created in the previous interventions (1979-1980).

In 1985, the consolidation and restoration of the crypt began. The interventions concerned the central portion of the walls, which goes from the entrance vault on the north side to the access to the adjacent rooms on the south side. In the same year, the Ceramic Center of Bologna carried out chemical analysis on the reinforced masonries. The purpose was to identify the state of conservation of the materials. The analysis showed the presence of degradation in the masonry walls due to different factors. First of all, it has been highlighted an excessive accumulation of water inside the walls: the excessive exposure to atmospheric agents favoured the penetration of water inside the masonry, whereas the binders used for the finishes and the cement-based injections prevented its evaporation. In addition, the presence of ettringitis was also detected: the formation of this dangerous salt has been increased by the reaction between the injected cement and the lime sulphates, present in large quantities. Ettringitis, by increasing its volume, creates compressive stresses inside the masonry layers, causing swelling, fractures and detachment phenomena. The previous injections of cement mortars (1979-1980), of which the monument is studded, have thus contributed to worsening the crack pattern, showing fractures even in recently restored parts and in areas previously unrelated to crack phenomena. Therefore, this study has been essential to understanding the ineffectiveness and the inadequacy of the interventions performed until then. In 1986, once the results of the chemical tests were obtained, the restoration yard was immediately interrupted.
The following years, other interventions for restoring portions of degraded masonry started over. These parts were demolished and rebuilt with salvage stones or new ones, according to the availability. Once again, mixture of hydraulic lime and cement type 425 were used, even if the results of the chemical analyses have advised against the use of such type of binder. The same approach was used for the local dismantling and reconstructions that concerned the south-east corner in 1987. Consequently, a few years later, in 1988, the detachment between masonry layers seriously worsened, giving rise to a widespread crack pattern. The intervention carried out to repair this situation replaced the original stone material of the masonry core, completely disregarding the preservation of the original features of the monument.

It is therefore possible to note that, at least until the 1990s, the interventions did not conform to the principles of restoration (reversibility, recognisability, minimum intervention). The strengthening techniques have been carried out with unsuitable materials (e.g. cement-based mortars) which, in some cases, worsened the situation, giving rise to new crack patterns and degradation of the material.

In 1991 interventions focused mainly on the northern front and on the crypt, with rather invasive procedures. In particular, the upper part of the front undergone demolition and reconstruction operations within the wall thickness, in order to reinforce the masonry faces. The interventions in the crypt were aimed at removing the cement mortars trying to remedy the incongruent past consolidations. Although the purpose was good, the adoption of sandblasting to remove the mortar joints has erased the historical patina, that characterised the original stones. This aggressive technique not only brought the monument to a state of conservation that perhaps it had never had before, but also it has weakened the masonry.

Hence, these latest interventions still denote insufficient awareness and lack of respect for the historical construction (e.g. sandblasting), even if the previous reports and studies have provided a deeper knowledge of the monument. Furthermore, looking at the historical background in which these interventions took places, guidelines already existed, that suggested the principles for a respectful and conscious restoration, aimed at transferring the cultural and historical value of the monument to future generations (Brandi, 1977). The importance of the so-called "path of knowledge", the preservation of building historicity and the compatibility between reinforcing materials and existing structures was already recognized as fundamental.

It was only in the early 2000 s that interventions began to be more aware of the preservation issues of the architectural heritage. In 2005, fourteen tie rods were installed on the southern front of the fortress. In the meantime the techniques have improved becoming less invasive: the tie rods were made of steel strands with a diameter of $15 \mathrm{~mm}$ and required small holes to be placed. These holes were drilled by rotation, without hammering effects in order to avoid damaging the walls. Actually, this new intervention has concerned a portion of the fortress, which was already undergone a similar strengthening. Indeed, this tie-rods system implemented the previous one, inserted a few decades earlier (1983). This may be a sign both of the worsening of the structural condition of the castle and of the loss of effectiveness of the existent 
tie-rods, perhaps due to chemical reactions between the cement mortars and the humidity in the masonry (Fig. 6).

Today, it is difficult to distinguish the different interventions and the original historical material from the new products used in the interventions described above. These strengthening operations, even if aimed at the conservation and protection of the monument, proved to be invasive, ineffective and sometimes harmful. Furthermore, the archival documentation shows that many of the consolidation interventions seem to overlap with others strengthening tools previously inserted in the same area. Further analysis is therefore required to investigate the correspondence between the historical documentation and the actual state of the monument in order to verify whether all the aforementioned interventions have been realized. For this reason, in-situ investigations were carried out to identify the presence of past interventions, their extension and the actual technique.

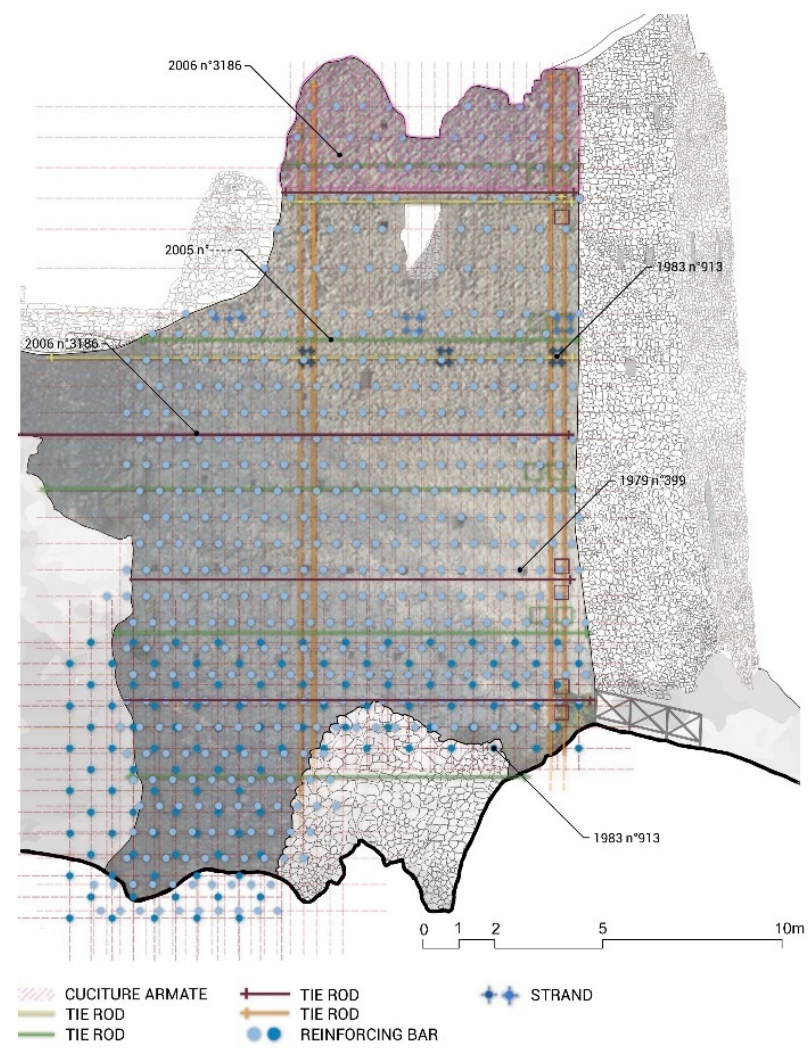

Figure 6: Graphic representation of the strengthening interventions carried out on the southern front: tie rods placed in 1983 (yellow) and in 2005 (green) are in a similar position. It may be a symptom of the inefficiency of the first intervention.

\section{Instrumental analyses}

Some interventions, mentioned in the archive reports, appear difficult to identify both in terms of consolidation technique and in terms of extension, which sometimes seems unreliable. Indeed, in the reports and in the metric computation, some interventions are described with technical terminology that, today, has a completely different meaning compared to the one attributed in the historical period of the reports. As a consequence, also in consideration of the operative practices of the period (last 20 years of $20^{\text {th }}$ century), it is assumed that the description presented in the archival documents could not completely fit with the actual interventions carried out on the fortress.

However, another reason may explain the overlapping of several chronologically successive interventions in the same portion of the monument. For instance, this overlapping could be due to representation inaccuracies. The manual drawing, indeed, required a very long time for the elaboration of the projects, especially in buildings characterized by a high level of complexity, such as Canossa Castle. It could happen that the few tables representing the monument, belonging to previous projects, have been used to indicate the new interventions, even if placed at a different level than the one represented. In the case of Canossa fortress, drawings belonging to different reports present the same graphic representations in plan, sections and elevations. These similarities have therefore suggested the abovementioned approach, which implies inaccuracies in the location of the intervention areas. In addition, there is a possibility that past interventions were not considered during the most recent design phases. However, in this case, the existence of a past intervention should have emerged during the construction phase, leading to three possible choices:

1. the removal and replacement of the previous intervention with the new one;

2. the reassessment of the design choices (not always supported by documents), with consequent relocation of the new consolidation elements, if the existing intervention was deemed not sufficient to ensure the stability of the structure;

3 . renunciation of carrying out the new intervention.

In light of these considerations, the direct investigation of the monument is fundamental to better understand the interventions realized in the past in order to identify the actual vulnerabilities, still present. The monument was thus investigated with in-situ inspections, both visual and instrumental.

First of all, this analysis were aimed at identifying the interventions carried out around the 1980s which, more than others, generated the serious cracking pattern that still affects the fortress today. In 1985, indeed, chemical analysis showed that these interventions, made with cement mortars (incompatible with the historic masonry of the fortress), were one of the main causes of the crack pattern that occurred on the monument in the periods immediately following their fitting.

Through the use of specific instrumentation (metal detector Bosch DMF 10 ZOOM Professional and concrete rebar scanner Hilti Ferroscan rv 10) the presence of iron elements under the surface of the masonry was investigated in the areas where the reports of 1979 and 1983 indicated the presence of "grout injections". Indeed, despite the terminology, the description of the interventions suggested the presence of reinforcing bars. The aim was to assess the actual presence of the reinforcing bars injected into the masonry, their extension and the possible overlapping of the consolidations described in both the reports (1979 and 1983). The scans carried out with Ferroscan (rebar scanner) were limited to two precise points of the castle, both in the crypt, in order to verify two elements placed in 1983. A grid with dimensions of $80 \times 80 \mathrm{~cm}$, divided into 4 horizontal and 
vertical bands of $20 \mathrm{~cm}$ each, was used for scanning. Once the grid was positioned on the chosen surface, the scan was performed from left to right, starting from the upper band and continuing with the same methodology in the bands below. The same procedure is then repeated, but scanning the bands from top to bottom. The data collected has been processed with the software provided by the manufacturer (Hilti ferroscan v4.0), in order to obtain more information about the characteristics, location, depth and shape of the elements investigated. The largest number of reinforcing bars were found on the eastern front. Moreover, the inspection showed the presence of two distinct systems of reinforcing bars that intersect without overlapping (Fig. 7).

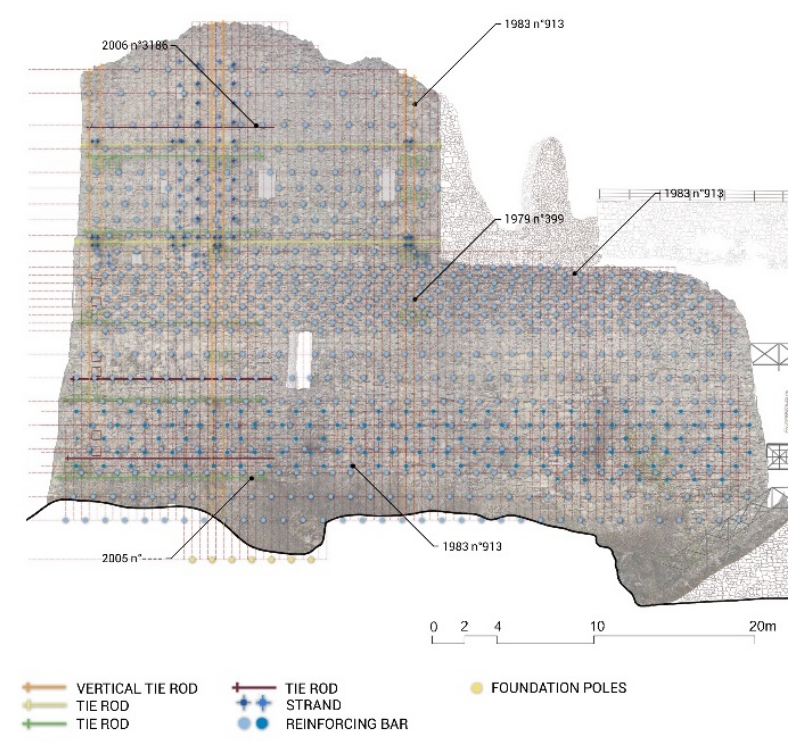

Figure 7: Graphic representation of the strengthening interventions carried out on the eastern front: it is possible to identify two distinct texture that intersects without overlapping: the reinforcing bars placed in 1979 (blue) and 1983 (light blue).

With these data it is possible to define the reliability of the aforementioned reports, whose interventions with the reinforcing bars have actually been placed not overlapped, but with a slight translation of the two reinforcing bars systems.

Similar investigations were performed to analyse another intervention mentioned in the 1983 report, which indicated the construction of ring beams ("cordoli" is the Italian word in the report), inside the masonry, arranged on several levels connecting the eastern front with the thick walls of the crypt in order to create a "frame". Therefore, the additional part at the top of the fronts of the monument and the perimeter walls of the crypt were investigated. The analysis performed with the metal detector initially highlighted the presence of a metal element, which was then further investigated through the use of Ferroscan. However, the investigations have excluded the presence of a beam, showing instead the presence of a circular anchor plate with reinforcing stiffeners, inside the masonry (Fig. 8).

From this, it can be deduced that the intervention of 1983 consisted of the insertion of tie rods. Probably the term "cordolo" was used improperly to indicate the frame made once the tied-rods system was installed. As can be seen from the image, the elements that make up the extreme portion of the tie rod are rather eroded, probably due to a large amount of moisture present inside its walls.

\section{Photogrammetric survey: geometric and environmental complexity}

The survey of the Canossa Castle was a fundamental support for the analysis of the aforementioned interventions. Nevertheless, several difficulties emerged during the survey campaign, mainly, due to the geometrical complexity and morphological irregularity of the object (Fig. 9), as well as to the difference in height of the cliff peak.

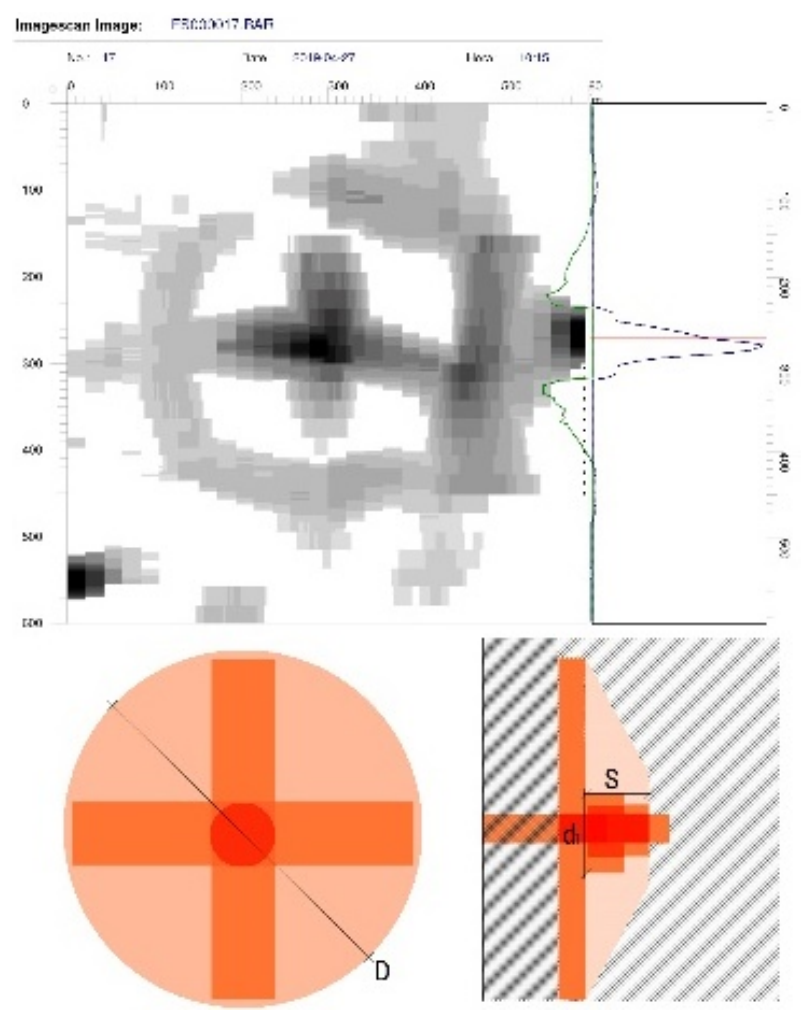

Figure 8: Scan with rebar detector of an anchor plate inside the masonry and graphical representation.

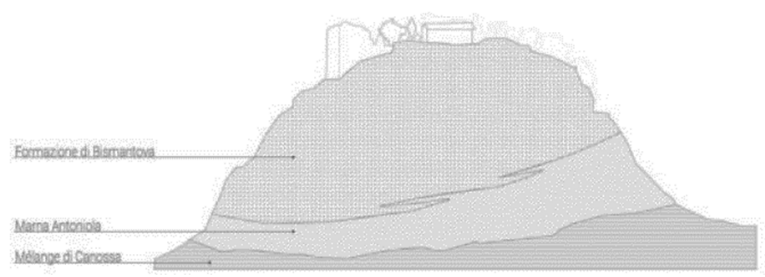

Figure 9: The complex orography of the area, not only caused part of the crack pattern of the fortress, but also made it difficult to survey the external façades.

To overcome these difficulties, different survey techniques were used (Pane et al, 2020). With the collaboration of the University of Cesena, a survey was first carried out with the aid of laser scanner technology. The instrument was located at several points to scan the main portions of the ruins and specific archaeological artefacts. However, the morphology of the cliff and the tight spaces of the ruins made it impossible to reach all surfaces of the monument using the instrument with a tripod. The final result, a dense point cloud, was thus 
incomplete of most of the external surfaces, located on the cliff edge. For the purpose of this study, a complete model of all surfaces of the monument was required.

Therefore, in order to survey all the surfaces arranged along the ridge, it was decided to carry out a photogrammetric survey performed by a drone. The photogrammetric model (Fig. 10) of the external façade was scaled thanks to the common part available in both point clouds (the laser scanner point cloud and the photogrammetric one). Furthermore the geo-localization of the two models made the interpolation between the two clouds possible.

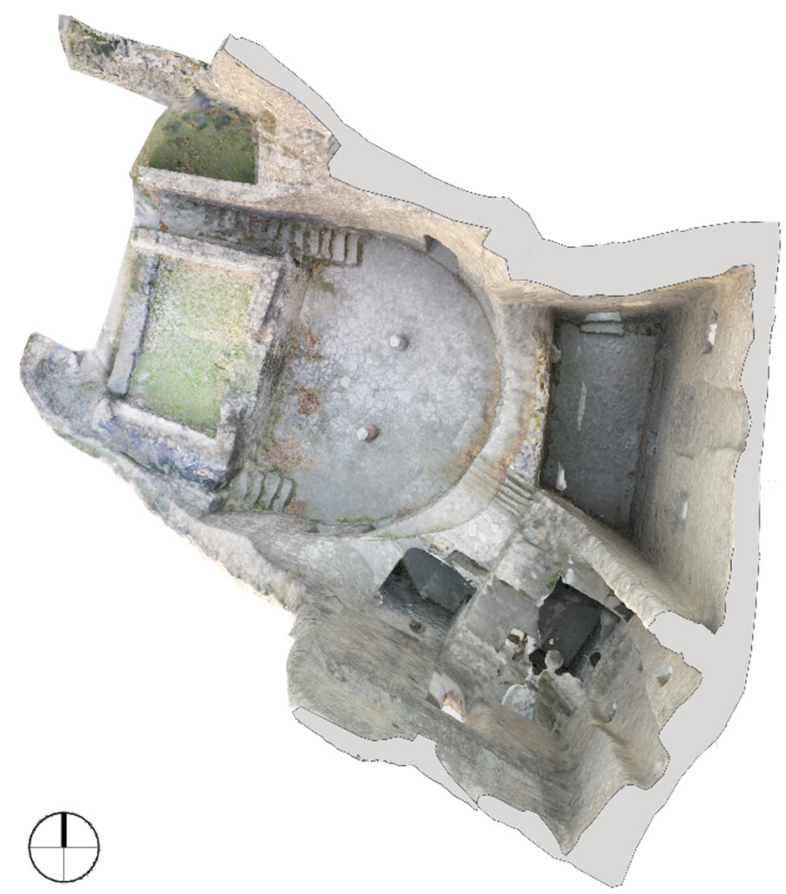

Figure 10: Top view of the fortress obtained from the photogrammetric model.

The point cloud obtained from this interpolation was uploaded into the BIM software (Building Information Modelling), in order to create an accurate parametric approximation of the monument in which to insert the data on the materials and the interventions realized during the $20^{\text {th }}$ century on the fortress. The aim was to ensure a global overview of the previous works and to point out the area where possible structural problems could arise because of both excess and lack of strengthening. Unfortunately, once again, the geometric complexity of the ground and ruins, as well as the irregularities in thickness and in height of the masonry walls, have caused difficulties in using the BIM software (Archicad and Revit). Specifically, the main problems in the use of Revit concerned the approximation of geometries and the nonintuitive insertion of elements placed at different heights from predetermined levels and not orthogonal to the model. The model and its elements were easier to manage in Archicad, even for non-experts users, but, on the other hand, the accuracy remains unsatisfying.

Therefore, the BIM models thus obtained were inaccurate in several respects due to the lack of flexibility of the BIM towards particular construction types, characterized by significant geometrical irregularities. It was therefore preferred to proceed with the use of the photogrammetric survey, which allowed us to achieve a much more precise result. Photogrammetric software, Agisoft PhotoScan (Agisoft Metashape, 2020), and CAD software made it possible to recreate accurate plans, sections and all the façades of the monument by freely choosing the cutting plans of the point cloud. However, the photogrammetric model does not have the same potential as the BIM one: the choice of these tools reduced the global vision of the monument and the possibility of an immediate consideration and perception of all the works realized on the monument.

To solve this problem, the solid mesh of the monument could be imported into a modelling program. This possible solution allows to have a global view of the monument and the possibility to insert all the restoration and strengthening interventions carried out during the last century, but without the possibility provided by BIM software.

\section{Conclusion}

The research on the case study of Canossa Castle has shown that the recent interventions carried out on the fortress have slowly transfigured the image of the monument we see today. Some of these interventions, disregarding the principles of restoration, have used incompatible materials that have compromised the historicity and the appearance of the fortress. Several reinforcing interventions have also proved to be ineffective leading to the need to strengthen the same part several times, thus becoming excessive and invasive. In general, most of the restorations carried out in the last decades of the $20^{\text {th }}$ century, lacking a historical analysis and a deep knowledge of the building, have generated dangerous effects for the conservation of the monument.

Furthermore the archival documentation relating to these interventions is inaccurate and lacking in information, preventing the understanding of the current state of the monument from being achieved. In-situ investigation for defining the actual strengthening techniques used in past intervention and their localisation were therefore required to define a clear picture of the architectural object to be conserved.

To this aim, significance, knowledge, conservation and management should be brought together, considering many aspects: historical data, philological approach, degradation mapping, structural analysis, multidisciplinary modelling, conservation plan guidelines, code checking, structural health monitoring.

In this regard, the use of BIM models would make it possible to organise all the information collected on Canossa Castle, laying the basis for any future conservation activities on this archaeological site. In particular, these tools could prove to be very useful as a database of past interventions and to plan future ones, in order to define a long-term maintenance program of the asset. This strategy could have positive results not only from an economic point of view, but also (and even more important) from the point of view of conservation, avoiding unnecessary interventions and respecting the value of the cultural heritage.

However, in this case, the difficulties in processing complex geometries with BIM software (Revit and Archicad) prevented the elaboration of a parametric 
model by non-expert users. Instead, CAD software (Autocad 3D) combined with photogrammetric software (PhotoScan), proved to be a more flexible tool, allowing a wider range of users to describe complex and irregular morphologies, typical of ruins. However, the mesh developed with this type of software cannot become an information or monitoring database as the BIM model.

Nonetheless, photogrammetric software is increasingly developing becoming more and more automated, accurate and easy to use, helping even non expert-users to survey complex buildings such as fortified architecture. On the other hand, the risk is to generate an overproduction of data, difficult to manage and actually useless for the survey, the interventions and, in general, the conservation plan.
It is therefore important to underline that, despite the growing automation of this software, the architect should continue to play the main role in the preservation process because of its competence to produce a survey that is not only correct but also the result of a critical interpretation of data (Fallavollita \& Ugolini, 2017). This critical analysis is even more important in the case of the survey of archaeological ruins, whose geometries are anything but regular and easy to interpret and where the edge between architecture and rubbles is often blurred (Ugolini, 2010). Moreover, the survey of these ruined monuments assumes considerable documentary importance in those ruins whose decline we are called to slow down as much as possible but which may ultimately be unavoidable.

\section{References}

Agisoft Metashape, (2020). User Manual Professional Edition, Version 1.6. Retrieved November 25, 2020, from https://www.agisoft.com/downloads/user-manuals/

Bartolomucci, C. (2008). I GIS per la conservazione dell'architettura storica. MondoGIS 66/67, 13-17 (ISSN 1128-8175).

Bartolomucci, C. (2012). II terremoto sui beni archeologici: una casistica dei danni. II patrimonio culturale dopo il terremoto del 6 aprile del 2009. Siti archeologici nell'Aquilano, 385-389.

Bedogni, B. J., \& Grasselli, G. (2007). Matilde di Canossa: Una regina cento castelli. Montecchio Emilia (RE), Cipsa Soc. Coop. Sociale.

Bedogni, B. J., \& Grasselli, G. (2010). Matilde di Canossa: la storia in immagini. CIPSA. Montecchio Emilia.

Brandi, C. (1977). Teoria del Restauro. Einaudi Editore.Torino.

Campanini, N., \& Ghirandini, L. (Eds) (1984). Canossa guida storico illustrata. Editrice Bizzocchi. Reggio Emilia.

Cattari, S., Degli Abbati, S., Ferretti, D., Lagomarsino, S., Ottonelli, D., \& Tralli, A. (2014). Damage assessment of fortresses after the 2012 Emilia earthquake (Italy). Bulletin of earthquake engineering, 12(5), $2333-2365$. https://doi.org/10.1007/s10518-013-9520-x

Coïsson, E., Ferretti, D., \& Lenticchia, E. (2017). Analysis of damage mechanisms suffered by Italian fortified buildings hit by earthquakes in the last 40 years. Bulletin of Earthquake Engineering, 15, 5139-5166. https://doi.org/10.1007/s10518-017-0172-0

Fallavollita, F., \& Ugolini, A. (2017). New methodologies for the documentation of fortified architecture in the state of ruins. Int. Arch. Photogramm. Remote Sens. Spatial Inf. Sci., XLII-5/W1, 411-418. https://doi.org/10.5194/isprs-archivesXLII-5-W1-411-2017

Franceschi, E. (Eds.) (1999). Castelli reggiani: castelli rocche fortilizi feudi feudatari del territorio reggiano. Finale Emilia.

Grignano, M. (2006). L'incastellamento matildico nell'Appenino Reggiano. Ricerche storiche e analisi della stratigrafia muraria. Degree course in Archaeology and Conservation of Archaeological Heritage, University Cà Foscari of Venice. Tutor Gelichi S., Co -Tutor Librenti M.

Manenti Valli, F. (1987). Architettura di castelli nell'appennino reggiano. Edizioni Aedes Muratoriana.

Manenti Valli, F.(Eds.) (2002). Architettura fortificata un problema interpretativo e operativo il sistema castellano matildico: atti del convegno nazionale degli studi castellogici. Istituto italiano dei castelli, Roma.

Ministero per i Beni e le Attività Culturali (2019a). Soprintendenza Archeologia, Belle Arti e Paesaggio per la città metropolitana di Bologna e le province di Modena, Ferrara e Reggio Emilia. Reports $n^{\circ} 399$ of 1979; $n^{\circ} 913$ of 1983; $n^{\circ} 1437$ of $1988 ; n^{\circ} 1873$ of $1991 ; n^{\circ} 3165$ of 2005; $n^{\circ} 3186$ of 2006. Retrieved November 25, 2020, from http://www.sbapbo.beniculturali.it/

Ministero per i Beni e le Attività Culturali (2019b). Soprintendenza Archeologia, Belle Arti e Paesaggio per la città metropolitana di Bologna e le province di Modena, Ferrara e Reggio Emilia. Cronologia di Canossa. Folder 01; REM_5 (1982/1905). Retrieved November 25, 2020, from http://www.sbapbo.beniculturali.it/

Pane, A., Catuogno, R., Facchini, M., \& Morano, L. (2020). A Fortress Between Artifice and Nature: the Laser Scanning Survey of the Castle of Pescopagano as AN Instrument of Knowledge, Conservation and Enhancement. Int. Arch. Photogramm. Remote Sens. Spatial Inf. Sci., XLIV-M-1-2020, 405-412. https://doi.org/10.5194/isprs-archives-XLIVM-1-2020-405-2020

Patroncini, L. (1997). Canossa: ricerche sulla struttura castrense. Quaderni d'Archeologia Reggiana. Edizioni Italgraf. 
Piccinini, D., \& Raffaelli, F. (2010). Castelli, dimore storiche e rocche dell'Emilia Romagna. Alberto Perdisa Editore

Settia, A. (2015). Canossa: Segno di Simbolo e Storia: atti e memorie del V convegno di studi Matildici. Deputazione di storia e Patria per le antiche province modenesi, Sezione di Reggio Emilia. Aedes Muratoriana. Modena.

Spagni, E., \& Ferrari, G. (1877). Relazione delle gite fatte a Canossa dai soci del Club Alpino. Sezione dell'Enza nei giorni 31 maggio e 10 giugno 1877 e proposta scavi. Editore Calderini. Reggio Emilia.

Ugolini, A. (Eds.) (2010). Ricomporre la rovina. Alinea Editrice 


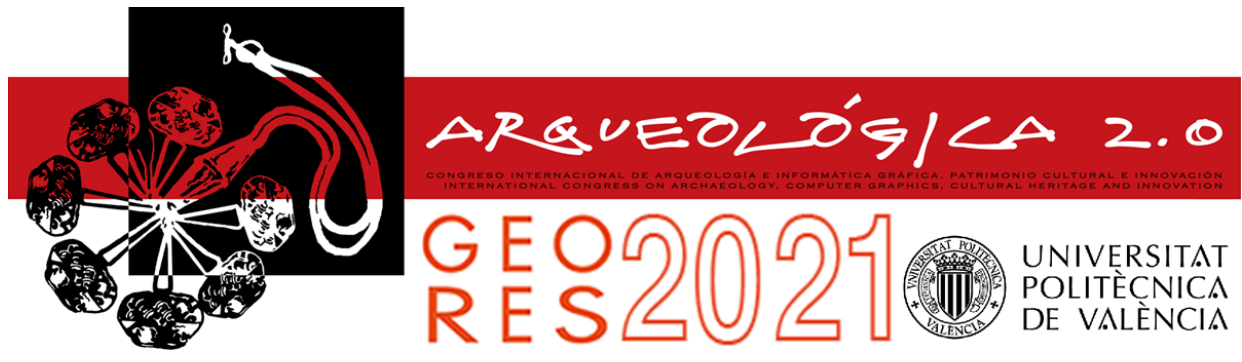

Proceedings of the joint international event $9^{\text {th }}$ ARQUEOLÓGICA

$2.0 \& 3^{\text {rd }}$ GEORES

Valencia (Spain).

26-28 April 2021

\title{
INTEGRATION OF COMPLEX 3D MODELS INTO VR ENVIRONMENTS: CASE STUDIES FROM ARCHAEOLOGY
}

\author{
Julia Gorkovchuka, ${ }^{a}$, Denys Gorkovchuka,b, Thomas Luhmann ${ }^{c}$ \\ ${ }^{a}$ Kiev National University for Construction and Architecture, Kyiv, Ukraine. gorkovchukjulia@gmail.com \\ b SPM3D LLC, Kyiv, Ukraine. denys.gorkovchuk@spm3d.com \\ ${ }^{\mathrm{c}}$ Institute for Applied Photogrammetry and Geoinformatics, Jade University of Applied Sciences, 26121 Oldenburg, Germany. \\ luhmann@jade-hs.de
}

\begin{abstract}
:
Recently, virtual reality technologies are increasingly being introduced into our lives. The focus of their use is shifting from the entertainment industry to design, healthcare, tourism, architecture, education and more. The advantages of virtual reality technology are especially noticeable in the field of archaeology, as many historical objects have not survived to our time, and their appearance can be reproduced only on the basis of historical sources and archaeological excavations. Most platforms for implementing virtual reality programs are based on game engines that can provide the required level of performance for VR. Such platforms show very good results for architectural objects, which often have many similar elements of simple shapes. Integrating complex objects with unique shapes is usually a problem. In this article, we consider the use of photogrammetric methods to create 3D models of historical objects and the aspects of their integration into a virtual environment based on a game engine. Specifically, aspects such as object resolution and suitable level of detail are discussed. As a case study, such a virtual environment was created for the ancient Trypillia settlement in the territory of Ukraine.
\end{abstract}

Keywords: archaeology, photogrammetry, 3d modelling, historical reconstruction, virtual reality, immersive technologies

\section{Introduction}

\subsection{Historical reconstruction in virtual reality}

To cover the history of mankind on the basis of artefacts that lie at the depth of cultural and geological layers can be referred to as the main task of the ancient science of archaeology which today, due to scientific progress, has received state-of-the-art tools and research methods (Terpylovsky, 2008).

The purpose of the reconstruction of historical and cultural heritage sites is, first of all, their preservation and rational use, the formation of protected areas, historical areas of settlements and historical environment. It is important to create investment-attractive conditions for the rehabilitation, reconstruction and use of buildings and structures that have a certain historical, cultural or architectural and artistic value as carriers of the traditional nature of the environment.

This paper deals with historical reconstruction as a method of restoring the appearance and construction of an object, based on its preserved fragments, remains and available historical information. The solution to this problem is realized by immersive technologies: a term that defines the technology of human interaction with space, information, content in the real and virtual worlds. The modelling of the historical environment by these technologies has a number of advantages:

- clarity: in the virtual space you can consider in detail any process or object;

- accuracy: not limited by the technical capabilities of the physical embodiment of objects;

- maximum involvement: the ability to fully control and change the scenario of events;

- safety: no risks to humans and the environment;

- cost: no costs for logistics, materials, etc.

\subsection{The current state of use of immersive technologies in virtual reality}

Nowadays, immersive technologies are used in almost all areas of activity from school education to artificial intelligence. Considering different levels of user involvement, they can be classified into: 
- VR (virtual reality): require a special headset which immerse a person in a fictional or recreated environment;

- $\quad$ AR (augmented reality): literally supplements the existing environment with virtual images, animations, visual effects;

- $\quad \mathrm{RR}$ (real reality): a real-world which is not virtual or augmented;

- MR (mixed reality): similar in meaning to augmented, but instead of "embedding" images or text over the reality, it creates virtual objects or elements, which co-exist and interact with real-world objects;

- $\quad$ XR (cross reality): a combination of VR, AR and $M R$, which allows to bring digital objects into the physical world and bring physical world objects into the digital world.

Immersive technologies are often used to present objects with difficult or dangerous access to the public. As example, detailed models created with laser scanning are integrated into VR environment which allows to walk inside of the caves (Büyüksalih, et al., 2020).

One of the options for improving the quality of VR models is the integration of panoramic images into the virtual $3 D$ model. It allows to significantly improve the level of details for 3D models (Kersten \& Walmsley, 2020a).

$3 \mathrm{D}$ models of historical objects can be used in learning processes for knowledge transfer in virtual environments (Kersten, Trau, \& Tschirschwitz, 2020).

Virtual reality is also being applied for the reconstruction of ancient cities. Typically, traditional surveying methods (laser scanning or photogrammetry) are used to build 3D model of the city territory and ancient maps are used as a basis for 3D reconstruction (Kersten \& Walmsley, 2020b).

It is worth mentioning that currently immersive technologies in archaeological research are illustrative and concern with the reproduction of artefacts in virtual reality. For example, modelling archaeological findings in 3D and publishing them on online platforms (e.g. Sketchfab) (Historical Truth, 2019). No additional software or hardware is required to view such models.

The Lithodomos VR project gives a nice example for the implementation of full virtual reality for archaeology is the development of Spanish archaeologist Lith - a special application for virtual reality devices that will bring users to the ancient world of reconstructed historical sites, including Ancient Greek Olympia, Jerusalem and others (Ancient Worlds, 2020).

Several projects in digitizing of historical objects and creating 3D models were conducted in Ukraine. They were aimed at the development of AR touristic guidebooks and the creation of physical scaled copies of these objects to interact with blind people (Rudyi, 2019).

One of the most progressive uses of virtual reality for archaeological purposes is creating fully virtual archaeological sites with the integration of historical maps, architectural plans and other information in one place to organize teamwork of researchers within one complete virtual environment (Paradis, et al., 2019).

\subsection{Objectives}

The aim of the following project is the integration of complex 3D models into a virtual environment for realtime visualization of an ancient city.

\section{Modelling approach}

\subsection{Object description}

The state historical and cultural reserve "Trypillya culture" is currently the only Ukrainian museum institution of one archaeological culture, which includes 11 Trypillia settlements located in the Cherkasy region, Ukraine. Most famous are "Talyanki" (Fig. 1), "Maidanets", "Dobrovody", "Kosenivka": the largest Eneolithic settlements in the world in the IV millennium BC.

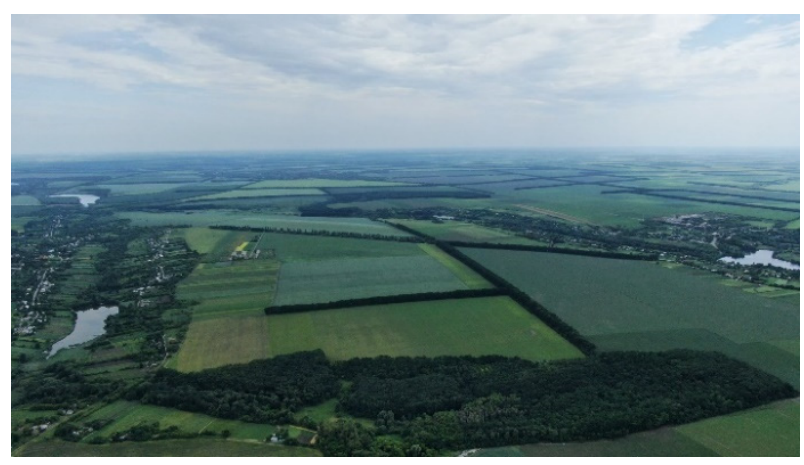

Figure 1: Overview of the "Talyanki" settlement territory.

The Talyanki settlement was chosen as a modelling object for this work. It comprises an area of 450 hectares and can be dated back to the first half of the IV millennium $\mathrm{BC}$.

General dimensions and outlines of the settlement have been established according to extracted data from aerial imagery of 1966. Later in 1983-1986 a geomagnetic survey showed that the settlement consisted of about 1,500 to 2,800 buildings located in concentric circles. In 2011-2012 the geomagnetic survey was repeated with modern equipment which made it possible to determine not only the exact location of buildings, but also their size.

Around 30 objects in that area were studied by archaeological excavations, mostly addressed to the remains of burned houses. As a part of experimental archaeological studies, two of such buildings were reconstructed using old technologies in the territory of "Trypillya culture" museum in Lehedzyne, Cherkasy region, Ukraine.

The Northern part of the settlement (200 hectares) was chosen for the modelling in this research project.

\subsection{Data acquisition and modelling}

Data collection was conducted with photogrammetric methods.

As a first step, the territory of the settlement was surveyed with a DJI Mavic 2 Pro UAV. 350 images with a ground resolution of around $8 \mathrm{~cm}$ were taken (Fig. 2). 


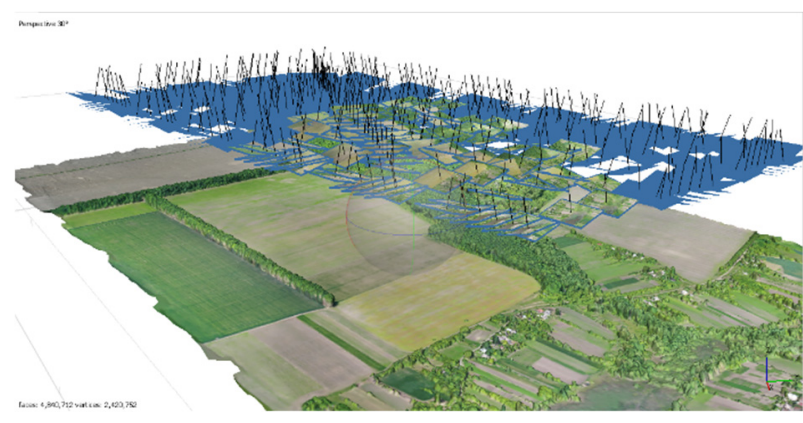

Figure 2: UAV camera positions and 3D model of the settlement territory.

An orthophoto, a DSM and a DEM of the territory were generated (Fig. 3). They were used as a basis for the integration of all further data.

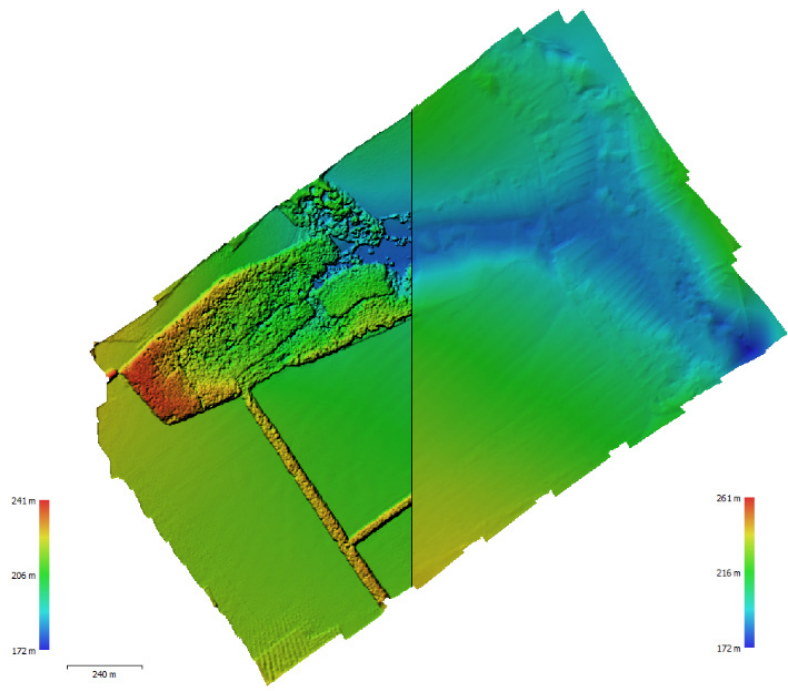

Figure 3: Left: DSM; Right: DEM of the territory.

The results of geomagnetic survey, conducted in 2011 2012, were superimposed to the created model of the territory (Fig. 4). Black spots represent the remains of burned clay which was used as floor for Trypillya houses. They have a clear rectangular shape that allows to determine the size of the building. Distribution of these buildings allows to discover the locations of streets in an ancient city.

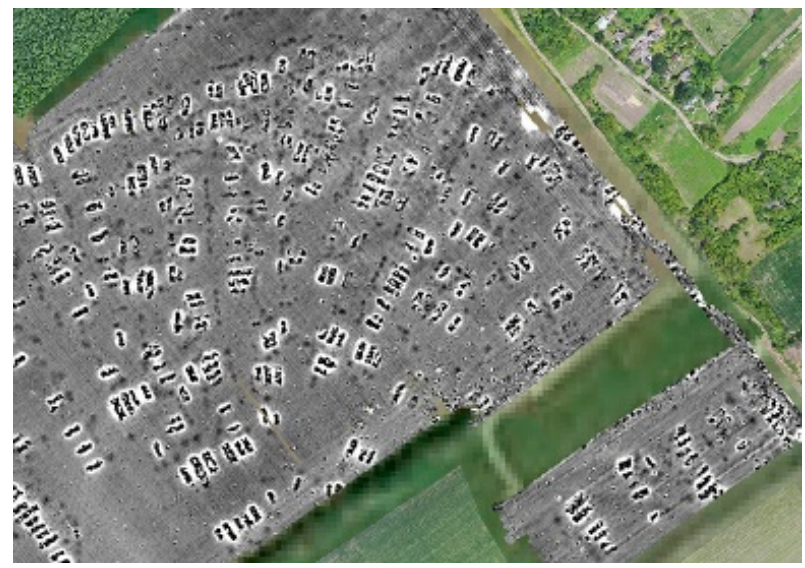

Figure 4: Orthophoto of the territory with superimposed geomagnetic survey.
The second step of data acquisition was the capturing of Trypillya buildings which were reconstructed in the territory of the museum. The buildings have $6 \times 13$ meters footprint and $8 \mathrm{~m}$ height. Again, photogrammetric methods have been applied for this purpose. The same DJI Mavic 2 Pro was used to capture the roof part and a Nikon D3200 DSLR camera was used for taking terrestrial images. 1100 images were captured in total (Fig. 5).

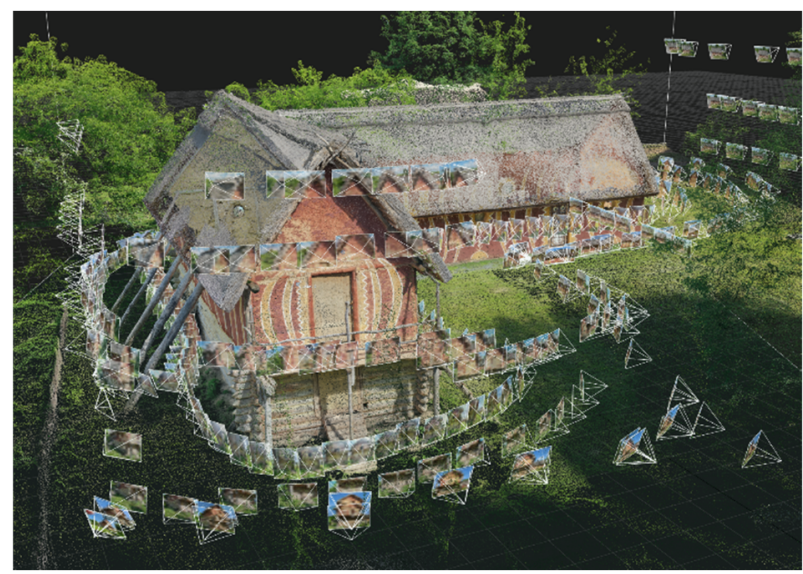

Figure 5: Camera positions and 3D model of the reconstructed Trypillya buildings.

Processing was conducted in RealityCapture software. Due to high overlap, good textures, absence of shiny and reflective surfaces, all of the photos were aligned with a mean reprojection error of 0.6 pixels. Several reference distances were measured for scaling the model and accuracy estimation. The maximum distance error was 10 $\mathrm{mm}$. The cleaned reconstructed mesh model of two buildings consists of about 45 million polygons.

\subsection{Modelling for VR}

Traditionally models generated by photogrammetric methods have millions of polygons and require very powerful workstations and specific software. High quality rendering of such models is usually not possible in real time.

Virtual reality applications require very fast system response (not lower than 60 frames per second) in order to make the interaction with the user comfortable and not stressful. For this purpose, photogrammetric models need to be modified.

The DTM model has been subsampled to $1.0 \mathrm{~m}$ resolution which didn't affect the accuracy significantly, as most of the territory is flat.

To get acceptable performance for building model visualization it has to be simplified to around $50 \mathrm{k}$ polygons. Such significant reduction of polygons $(0.001 \%$ from the full data) results in a loss of quality. To preserve realistic visualization of such simplified model, the simplification process has to be done adaptively - more points remain in complex areas, whereas simple areas are treated in a higher grade of reduction. After reducing the number of polygons the new simplified model is texturized with the original images, hence small elements remain as texture. There is no noticeable difference between texturized models for 20 million and 50k polygon models (Figs. 6 and 7) 


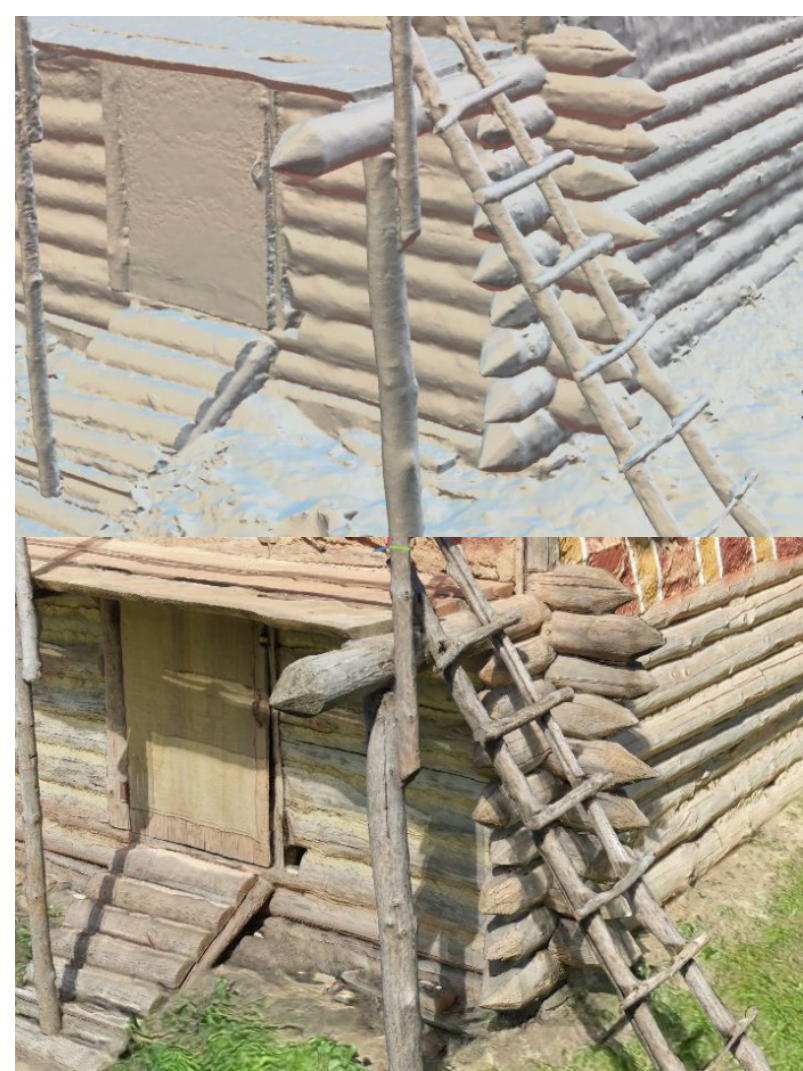

Figure 6: Top: 20 million polygon model without textures; bottom: same model with textures.

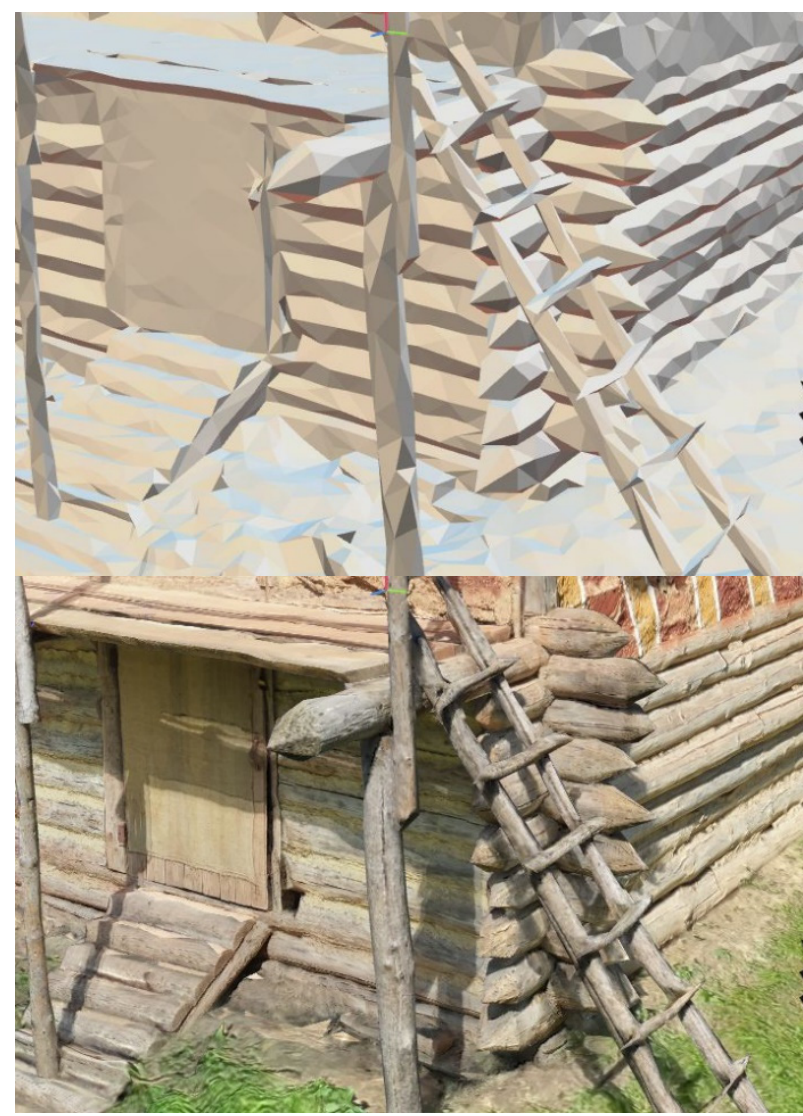

Figure 7: Top: 50k polygon model without textures; bottom: same model with textures.

\section{Virtual reality creation}

\subsection{Description of chosen VR platform}

The reconstruction of settlement in VR was done in Twinmotion software. It is a real-time 3D-immersion software designed mostly for architectural visualizations. It is based on the Unreal Engine, which is used typically for game development.

Twinmotion has a library of different environment elements (trees, grass, stones etc.) and realistic materials which can be used for photorealistic reconstruction.

It also supports the import of digital terrain models and textured 3D models of objects.

\subsection{Data import and modelling aspects}

Twinmotion (same as most game engines) supports only importing several "game-ready" 3D formats.

A terrain model is the base for the virtual reconstruction of the city and has to be implemented at the first stage. The terrain model is critical for correct navigation within the virtual environment (to avoid falling under or flying above the ground) and need to be prepared in a special format, which guarantees a correct collision generation. It is represented as a $2.5 \mathrm{D}$ terrain model, similar to GIS raster formats. However, traditional formats (e.g. GeoTIFF) are not supported directly.

The generated terrain model was exported as GeoTIFF with $1 \mathrm{~m}$ resolution and converted to a grayscale 16-bit PNG image using GRASS GIS software. This allows importing the DEM into the game engine.

Importing of orthophotos is also not supported directly. The results of the geomagnetic survey given as an orthophoto were projected onto the DEM model and imported as a 3D textured model. It allows integrating building locations into Twinmotion. Subsequently, after the modelling of buildings is finished, this model will be removed.

3D textured models of buildings obtained from photogrammetry can be converted to OBJ-format and easily imported into the software.

The next stage is "building" a city with imported models and existing libraries. Building locations and orientations are obtained from geomagnetic survey. Other elements (roads, natural objects) are modelled based on archaeological assumptions.

\subsection{Results}

The use of game engines for generation of virtual environments allows to create a realistic reconstruction of historical objects with very high level of detail. The combination of optimized textured photogrammetric models with highly detailed environment elements (grass, bushes, trees) and visual effects (shadows, sun and cloud movement) an gives impressive photorealistic visualisation in real time (Fig. 8). 


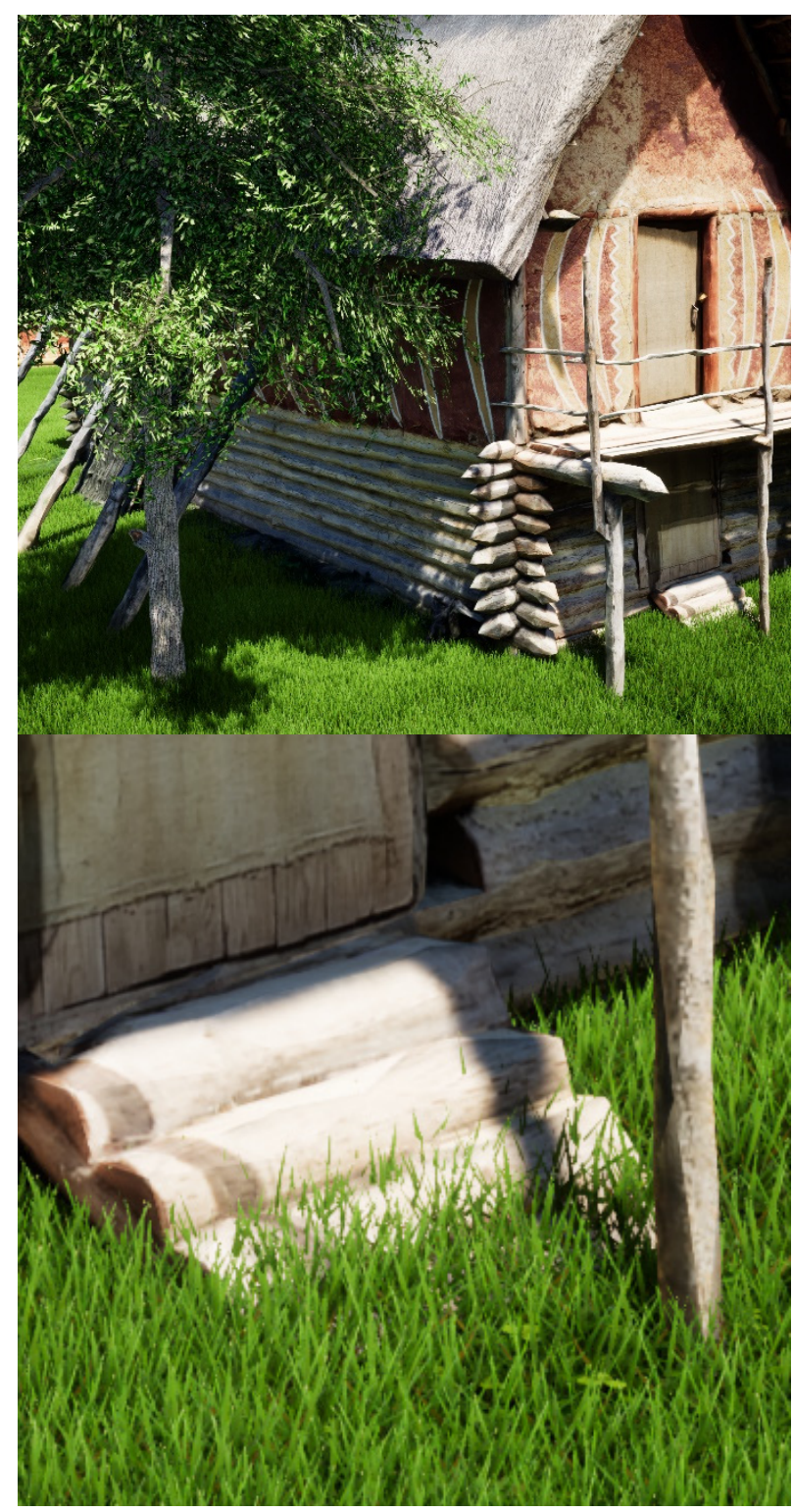

Figure 8: Level of detail for real-time photorealistic visualization in Twinmotion.

Photogrammetry enables the creation of realistic models for such virtual environments. The ability to render them in real-time provides an immersive experience to the user.

The whole project can be exported in different formats such as image renderings, 360-degree and 3D videos or as a standalone VR application, where the user is able to walk and overview the virtual environment by himself.

The most important advantage of using a "game engine approach" in historical virtualization is the simplified workflow for the user, who does not require a big team of different specialists (visual effect artists, modellers) for creating realistic renderings.

However, there are still some difficulties with the direct implementation of geodetic survey results (3D models, DEMs, geomagnetic surveys etc.) into game engine environments:

- 3D model modifications needed;

- no support of common GIS-formats:

- $\quad$ problems with large coordinates.
Another problem arises for the modelling of large territories. To maintain the high speed of visualization, game engines reduce the level of detail when many objects are present in the scene. Figure 9 illustrates the visualization of a complete city with reduced quality: small objects (e.g. grass, bushes and some trees) are not rendered, some objects have missing shadows, textures are simplified.

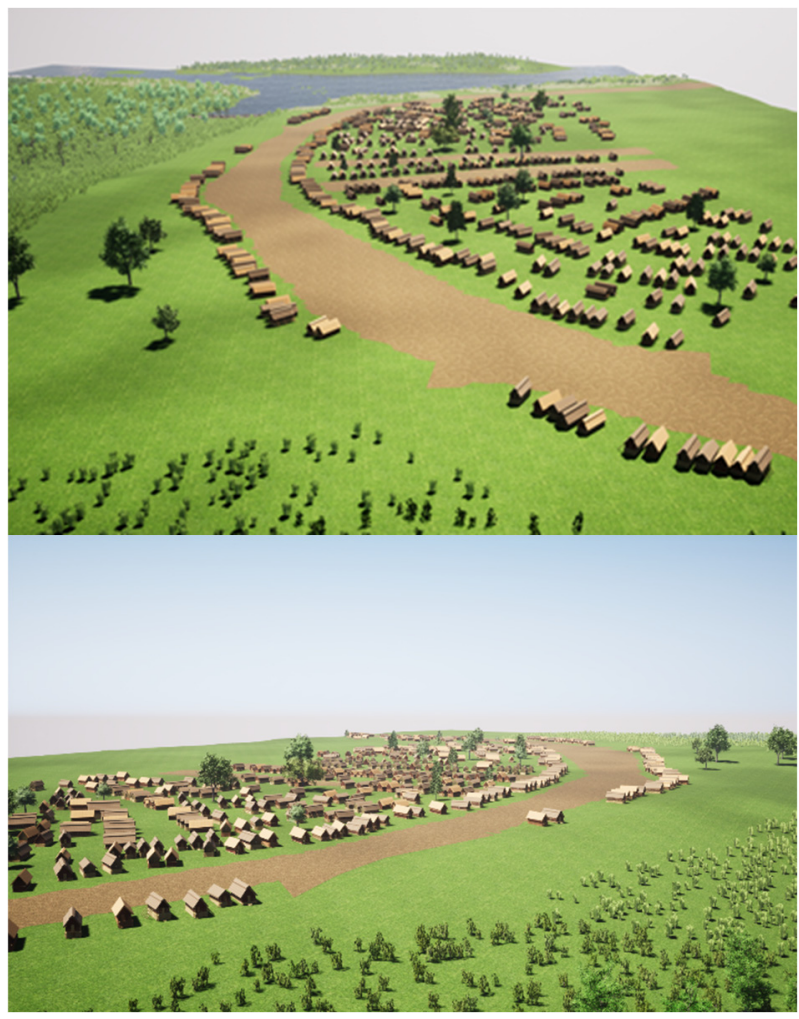

Figure 9: Reduced level of detail for complete settlement visualization.

This is due to specific properties of Twinmotion software, which is not designated for modelling of large spaces. One of the possible solutions of this problem is creating models with several levels of detail (LOD), which are similar to raster-pyramids in GIS. In this case, when the distance from the object to the camera is increasing, a more detailed model will be removed from memory and replaced with a simpler one. This approach allows to use very detailed (up to millimetre resolution) 3D models in game engine environment.

\section{Discussion}

Virtual reality technologies are becoming widespread in many areas and historical reconstruction is one of the most suitable for it. Modern game engines allow you to reproduce in real time a virtual environment of photorealistic quality. Photogrammetry provides an efficient workflow for fast creating of highly detailed 3D models for integrating into such virtual environments.

\section{Conclusion}

Summarizing the results of the study we can draw the following conclusions: 
- $\quad$ photogrammetric methods allow to reconstruct 3D models of unique historic buildings with a high level of detail and low cost;

- modern game engines have proven themselves as a good basis for integrating architectural models into a virtual reality environment, however, integrating models of complex objects with unique shapes into the game engine environment requires additional pre-processing of such models.

- The scope of virtual reconstruction significantly affects the quality of visualization and requires additional configuration of the virtual environment to display objects with different levels of detail.

\section{Further research}

Further research of this project is designated to advanced 3D modelling approaches that allow for the generation of "game-ready" models, with better-optimized textures and LODs. Such models help to avoid simplification problems and allow to render larger areas without a loss of quality.

Another aspect of further research is the use of the "raw" game engine environment, which allows to configure much more parameters and generate results for different platforms, including VR headsets.

\section{References}

Ancient Worlds. (2020). Ancient World - LithodomosVR. Retrieved March 15, 2021, from https://www.lithodomosvr.com/ancient-world/

Büyüksalih, G., Kan, T., Enç, G. Ö., Müge, M., Isın, L., \& Kersten, T. P. (2020). Preserving the Knowledge of the Past Through Virtual Visits: From 3D Laser Scanning to Virtual Reality Visualisation at the Istanbul Çatalca İnceğiz Caves. Journal of Photogrammetry, Remote Sensing and Geoinformation Science volume, 133-146. https://doi.org/10.1007/s41064-020-00091-3

Historical Truth. (2019). 3D-archeology: what the findings of Lviv archaeologists look like. Retrieved March 15, 2021, from https://www.istpravda.com.ua/short/2019/08/2/156028/

Kersten, T. P., Trau, D., \& Tschirschwitz, F. (2020). The four-masted barque peking in virtual reality as a new form of knowledge transfer. ISPRS Ann. Photogramm. Remote Sens. Spatial Inf. Sci., V-4-2020, $155-162$. https://doi.org/10.5194/isprs-annals-V-4-2020-155-2020

Kersten, T., \& Walmsley, A. (2020a). The Imperial Cathedral in Königslutter (Germany) as an Immersive Experience in Virtual Reality with Integrated 360。 Panoramic Photography. Applied Sciences, $10,1517$. https://doi.org/10.3390/app10041517

Kersten, T. P., \& Walmsley, A. P. (2020b). Entwicklung einer interaktiven, immersiven Virtual-RealityApplikation des historischen Stadtmodells Stade 1620. Conference: Publikationen der Deutschen Gesellschaft für Photogrammetrie, Fernerkundung und Geoinformation e.V., Band 29, Tagungsband der 40. Wissenschaftlich-Technischen Jahrestagung der DGPF, 4.-6. März 2020 in Stuttgart, pp. 99-113.

Paradis, M. A., Nicolas, T., Gaugne, R., Barreau, J. B., Auger, R., \& Gouranton, V. (2019). Making virtual archeology great again (without scientific compromise). Int. Arch. Photogramm. Remote Sens. Spatial Inf. Sci., XLII-2/W15,, 879-886. https://doi.org/10.5194/isprs-archives-XLII-2-W15-879-2019

Rudyi, V. (2019). How IT helps preserve and restore architectural landmarks. Retrieved March 15, 2021, from https://nachasi.com/2019/04/16/technologies-architecture/

Terpylovsky, R. (2008). Archeology. Special historical disciplines. Kyiv, Ukraine: Lybid. 


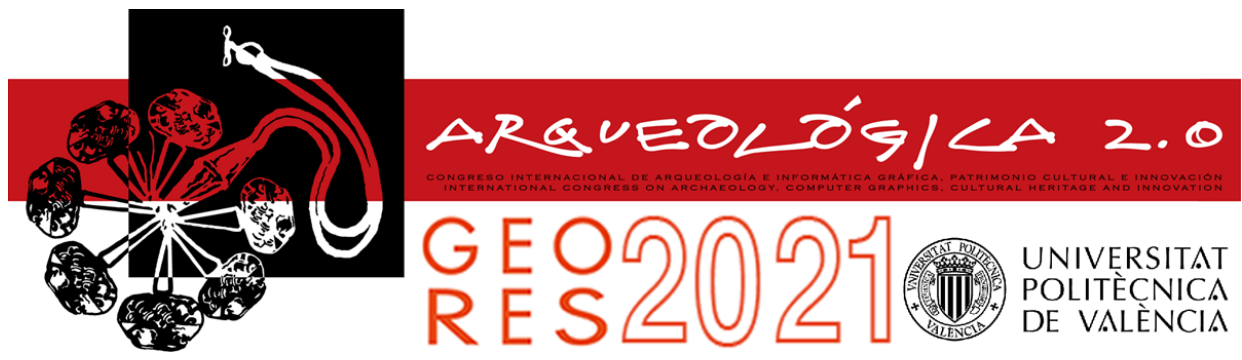

Proceedings of the joint international event $9^{\text {th }}$ ARQUEOLÓGICA

$2.0 \& 3^{\text {rd }}$ GEORES

Valencia (Spain).

26-28 April 2021

\title{
MENSIOCHRONOLOGICAL TECHNIQUES FOR TIMBER ELEMENTS: LIMITS AND SPECIFICITIES THROUGH A CASE STUDY
}

\author{
Alberto Grimoldi, Angelo Giuseppe Landi, Emanuele Zamperini* \\ Department of Architecture and Urban Studies, Politecnico di Milano, Via Bonardi 3, 20133 Milan, Italy. alberto.grimoldi@polimi.it; \\ angelogiuseppe.landi@polimi.it; emanuele.zamperini@polimi.it
}

\begin{abstract}
:
In Italy, studies on wooden structural elements in masonry buildings, from the Middle Ages throughout the Modern Age to the twentieth century, are few in number compared to other European countries and present a less systematic approach. It is necessary to carry out progressively, but systematically, highly-detailed surveys and to correlate them with the existing discontinuous documentation. Diachronic comparisons - referring to significant geographical areas in which evident constructive constants are recognizable - would highlight the variation over time of the models and their diffusion, while the comparison, especially synchronic, between solutions evidently different or apparently similar, would allow to better understand both the constructive choices and their static behaviour. The application of mensiochronological techniques to the analysis of timber structures, especially floors, is an interesting and promising field of research. The significant measures for dating are various: dimensions and centre distances of beams and joists, width and thickness of the boards, the dimension of the accessory elements (e.g. joint laths), but the variety of construction techniques often makes it difficult to identify comparable measures. In addition, the working processes and tree species have a decisive impact on the measures of the artefacts. Mensiochronological techniques usually detect slow but evident variations; however, a centuries' old constancy is equally significant. More general information about the context is useful, in particular which choices are not determined by mere technical reasons. A better historical knowledge serves to understand the qualities and limitations of existing structures, and the features - including decay - in which they appear. The floors of Palazzo Magio in Cremona, dating from the fifteenth century to the end of the eighteenth century, allow reflecting on how and what to examine.
\end{abstract}

Keywords: timber floors, historic construction techniques, mensiochronological analysis, Palazzo Magio in Cremona

\section{From bricks to timber: limits of mensiochronological techniques}

Mensiochronology is an analytical technique aimed at correlating the dimensions of a given element to its absolute dating. This technique has developed since the 1970s, focusing especially on brick elements, for which for some time it was already known that the measures had varied over centuries, following the transformations of the technique, of the production methods, and of the social relations underlying them (Mannoni \& Milanese, 1988; Pittaluga, 2009). After the first enthusiasm, the idea of creating a mensiochronological "curve" - similar in many respects to the dendrochronological curves - necessarily had to deal with individual places and individual historical circumstances (Landi, 2013).

Timber also has recurring measures, linked to its specific characteristics, and the practice of re-use is widely documented, as for bricks. Therefore, we can ask ourselves if, in what way, and within what limits, the metric data of the various artefacts - in particular of the wooden floors - can at least partially flank dendrochronology in dating.
In particular, for which time intervals the measures of wooden elements did not undergo significant variations? The constancy of measures over long periods - as often happens also for bricks - isn't less significant than a relatively frequent variation, which intuitively allows easier dating.

More so than bricks, wooden artefacts have their own particularities. As in dendrochronology, the species is relevant, since it affects the size and shape of the elements. However it is also essential to take into account the entire production process, from cutting and trading of logs and sawn timber, to their processing before and during construction site operations.

As a consequence, another question arises: which measures are significant, and how to acquire and record them? In the study of the floors, the measures that can be considered as significant quantities for dating are various: dimensions and centre distances of girders and joists, width and thickness of the boards, the dimension of the accessory elements (e.g. joint covering laths).

An attempt at an answer also involves direct verifications and case studies. 


\section{Studies on timber floors}

The bibliography on timber floors in masonry buildings is extensive, even if systematic studies are lacking, especially in Italy. Most of the research focuses on technological and typological features of timber floors of a specific geographic area and are often limited to analyzing the proportions of the elements and their centre distances. The topic of dimensions is generally treated only marginally, with generic references to the commercial measures of timber elements and often providing very wide and, therefore, not very significant dimensional ranges. Among some research, that of Emilien Bouticourt is particularly significant, because it follows the genesis of carpentry from the cutting of the timber and the woodworking, to the realization of the structure, floor or roof, highlighting all the conditions that influence it (Bouticourt, 2016); in particular, he analyzes nine examples of floors made in an interval of 100 years, reporting the average section and centre distance of the joists. Instead, no research deals systematically with the measurements of the wooden floors to evaluate the possibility of using them for dating the analyzed artefacts.

\section{Cremona and its timber structures: a short season between the $15^{\text {th }}$ and the $17^{\text {th }}$ centuries}

Cremona is famous for some of its wooden artefacts, not only for its luthier production - from the $16^{\text {th }}$ century to the early $18^{\text {th }}$ century, disappeared and restarted in the last half-century - but also for its wooden sculpture. Timber roof structures and floors, partly surviving, are also of great interest, albeit little known. The recurring wood is oak, as happens in the heart of the Po Valley, going up the river Po from Cremona; downstream, the floating of the logs and the large market in Verona make conifer wood from the Adige valley easily available (Dandria, 2010).

However, only the best-finished artefacts can show significant dimensional recurrences, since, in the works of lesser quality, builders used what was easily available; even the choice of timber could vary, using less dense and resistant species, like poplar and alder.

The only existing studies - Floriana Petracco's doctoral thesis (Petracco, 1998) - also report imports, when demand cannot be satisfied by local production. However, the inflow does not appear to be constant or systematic.

The wood comes from Emilia via river, or from Brescia, a city to which the road was already vehicle accessible at the end of the $15^{\text {th }}$ century, from which spruce wood was imported (Petracco, 2011). However, it seems that the use of coniferous wood was limited to boards, since the mining industry - with its demand for both coal and firewood - was a formidable competitor.

The Palazzo Magio (Landi, 2011) - where the surveys that inspire these considerations were carried out - is a sort of sample case of the most common timber floors in the city (Grimoldi, Landi, \& Facchi 2019; Figs. 1-3). The building is the result of the unification of four pre-existing houses into a large patrician residence, of which decorative and structural elements have often been preserved. On the ground floor, in the west wing there is a very elaborate double frame floor - datable to the late $15^{\text {th }}$ century - with girders and joists on corbels, and double bussole (small boards) flat and vertical between the joists and concave - typical of the city and of the countryside of Cremona - between the corbels (Figs. 4 and 5). Upstairs, in the corresponding rooms, only the sequence of the main beams remains from the same phase. Joists and planking were integrated and reassembled or replaced in the second half of the $17^{\text {th }}$ century or in the first decades of the following, when Giuseppe Natali (Biffi, 1988) painted the decoration of the room (Baroni \& Travaglio, 2011) (Figs. 6 and 7).

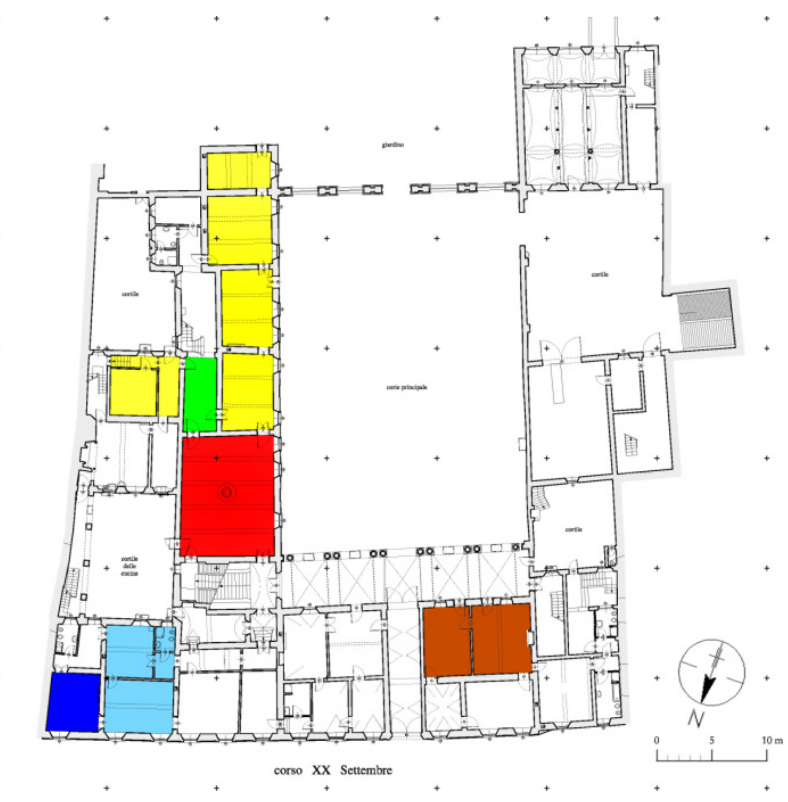

Figure 1: Ground floor plan of Palazzo Magio. In brown it's evidenced the floor from the late $15^{\text {th }}$ century; in cyan the floor decorated by Natali; in blue the floor hidden by a painted canvas ceiling; in red the floor with walnut joists; in yellow and green the reassembled floors, in green that with joists only.

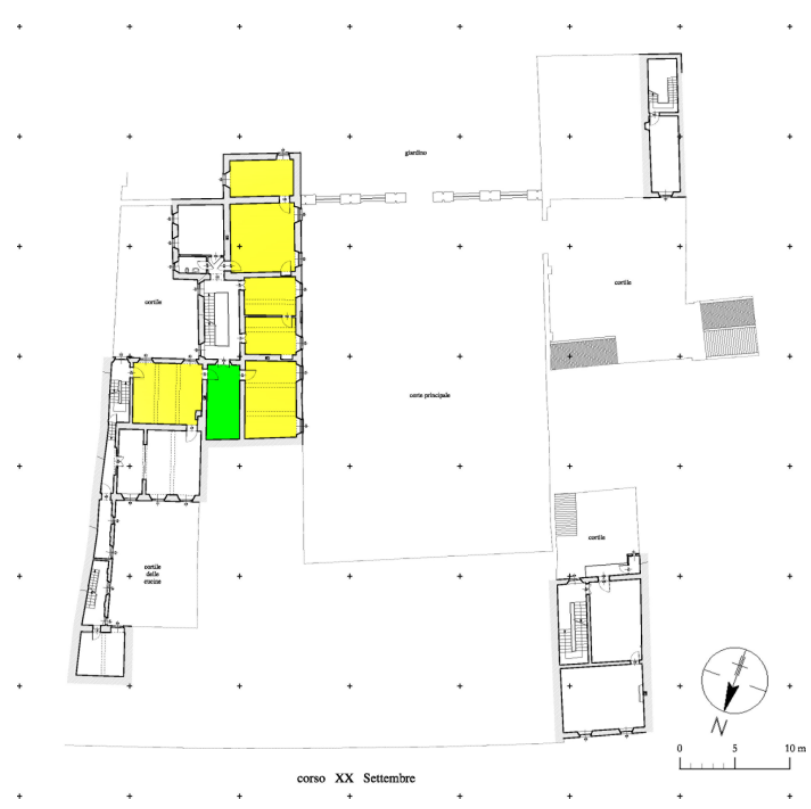

Figure 2: Mezzanine floor plan of Palazzo Magio. In yellow it's evidenced and green the reassembled floors, in green that with joists only. 


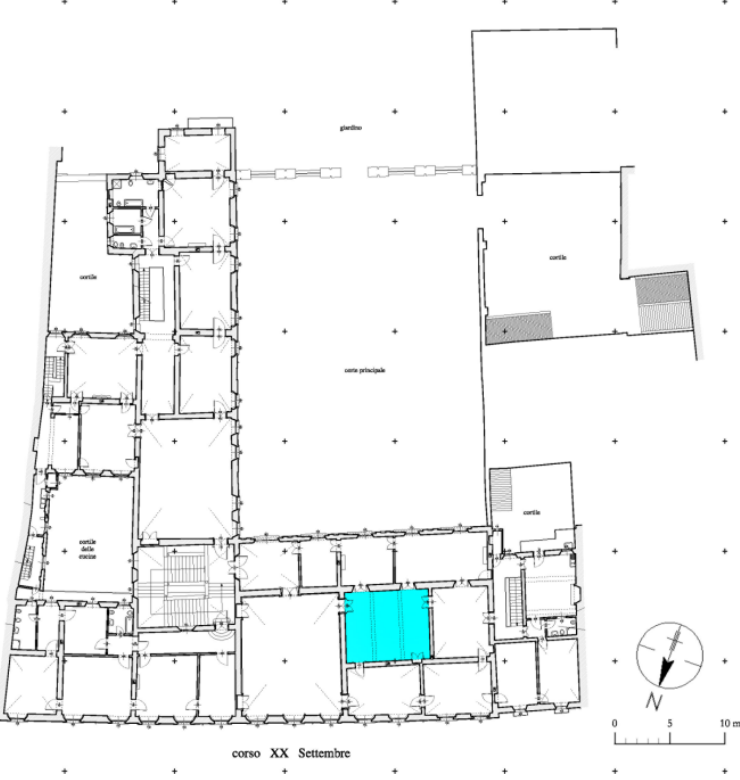

Figure 3: Main floor plan of Palazzo Magio. In cyan it's evidenced the floor with joists and planking renewed in the late $17^{\text {th }}$-early $18^{\text {th }}$ centuries.

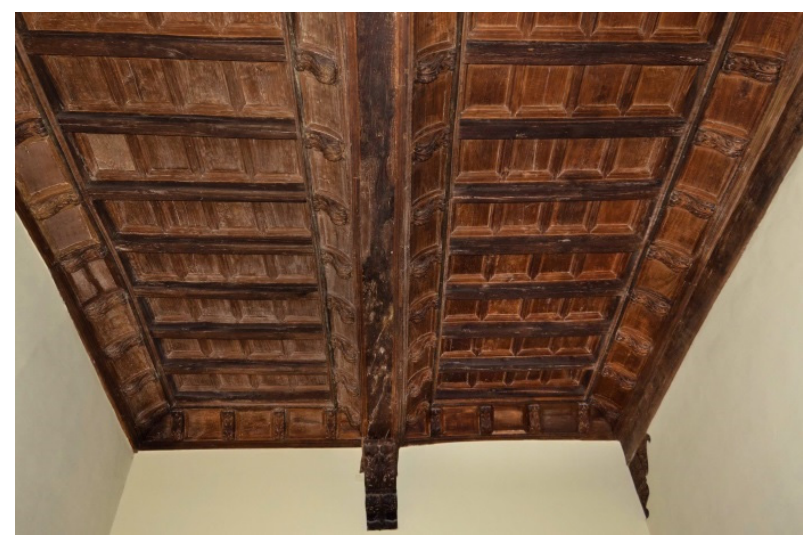

Figure 4: Timber floor from the late $15^{\text {th }}$ century, with corbels under the joists and concave bussole (photo by Giuliano Regis).

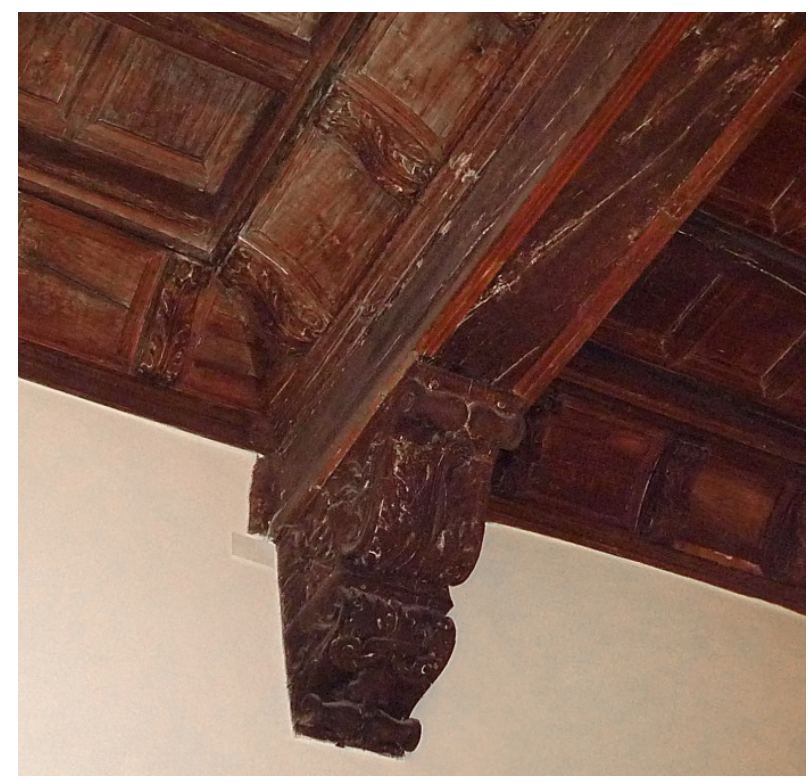

Figure 5: Detail of the floor in fig. 4.

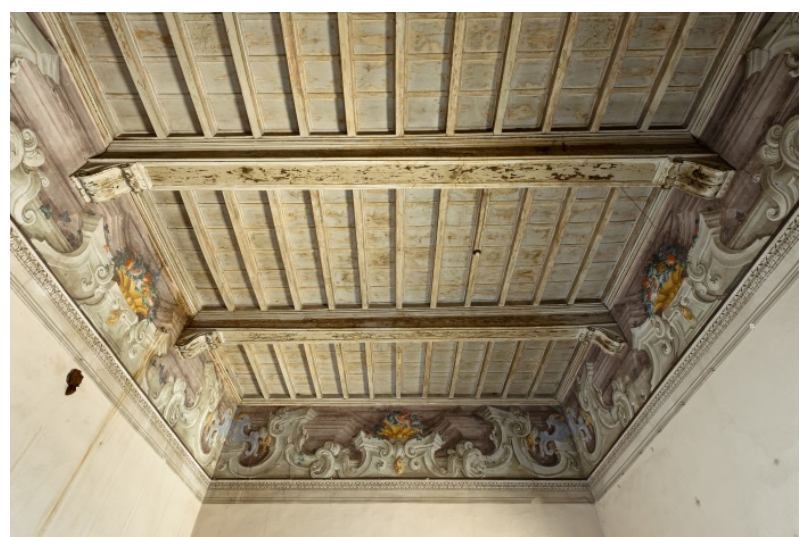

Figure 6: Timber floor with old girders; joists and planking were renewed between the late $17^{\text {th }}$ and the early $18^{\text {th }}$ centuries.

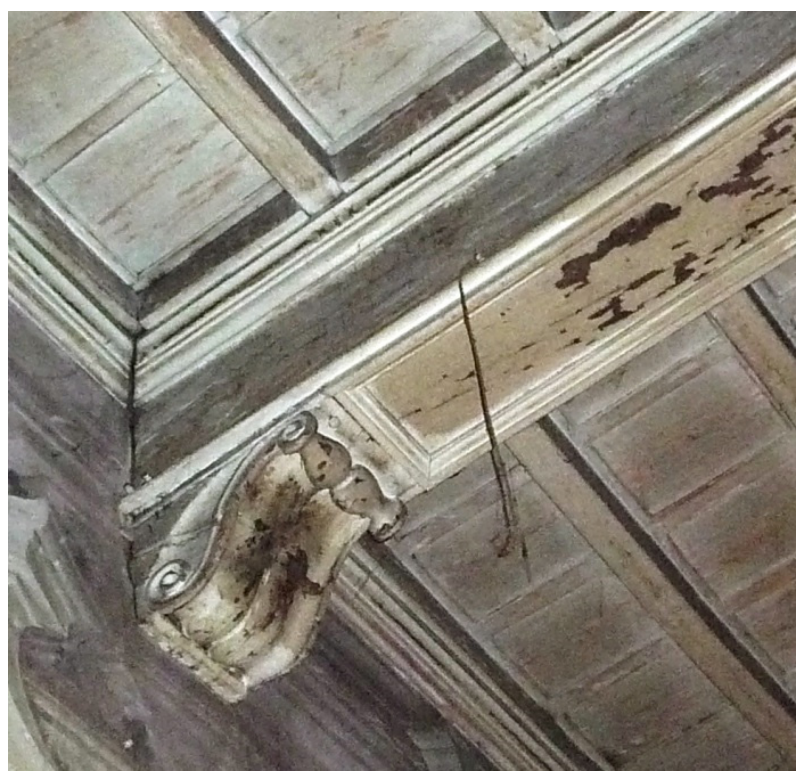

Figure 7: Detail of the floor in fig. 6.

In the east wing, another timber floor remains, it was decorated by Natali too, but three to four decades earlier, in the late $17^{\text {th }}$ century. In the adjoining room, only the two major beams are preserved, while joists and planking appear to have been replaced in an unspecified period, perhaps in the late $18^{\text {th }}$ century, much more likely in the late $19^{\text {th }}$ century, and the structure is covered by a painted canvas "ceiling" of the end from the $18^{\text {th }}$ century.

In the wing on the courtyard, instead, there is still a single large timber floor, of about $100 \mathrm{~m}^{2}$, with walnut joists and boards, which already existed in 1702 (Fig. 8).

In the other rooms on the ground and mezzanine levels, pre-existing floor structures - almost all of which have joists with the same dimensions as those in the other part of the building - have been reassembled, simplifying them, in particular without placing the bussole, so that the grooves aimed to house them are now in sight (Fig. 9). Perhaps they are those once present on the main floor in the wing along the street, towards the east, that were dismantled to build vaults, or perhaps the reused material comes from the older demolished buildings, that stood on the same area of the new building or in the main courtyard. The construction site takes place in two successive phases, a first around 1760 and a second 
within 1780. In the latter, a subfloor made with tavelle (flat bricks) replaces the wooden boards.

This sequence of transformations can be dated with certainty within a sufficiently limited time interval, the corresponding timber elements and their measures especially if compared with other examples of the same city - allow one to reconstruct accurately a single constructive event, but also to get a sense of more general dynamics for this type of artefacts.

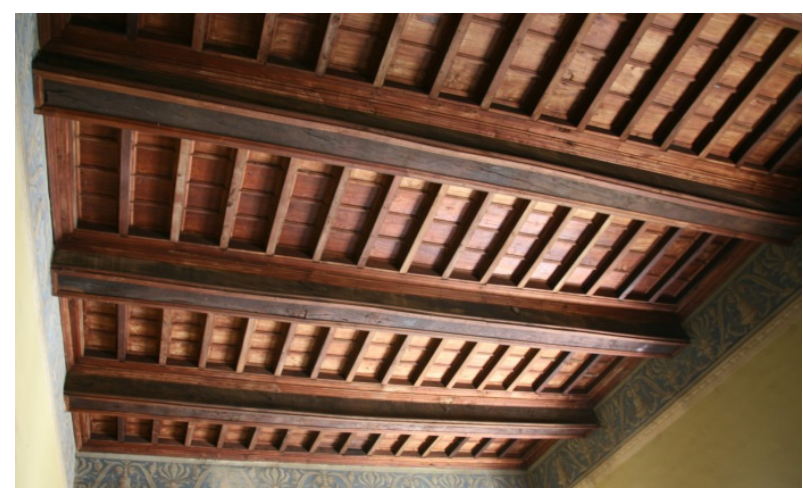

Figure 8: Floor from the late $17^{\text {th }}$ century.

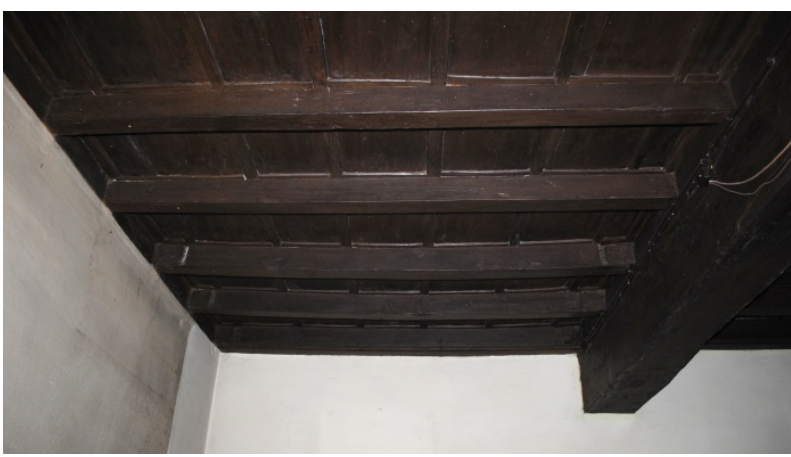

Figure 9: Floor rebuilt at the mezzanine in which the grooves for hosing the bussole are still visible.

To complete the diachronic repertoire of Cremonese timber floors, only the most elementary version is missing: the floor with concave bussole, that cover the whole height of joists and corbels, whose thickness is lower than in other types of floors (Figs. 10 and 11). Numerous examples of this type of floor still exist in the city, the oldest are preserved in civil and monastic buildings, and date back to about the mid- $15^{\text {th }}$ century.

The use of exposed timber floors on large rooms in which a high degree of finish was required lasts less than three centuries. From the second half of the $18^{\text {th }}$ century brick vaults were ordinarily used. If the building was not very modest and the rooms were not strictly utilitarian, when timber floors were still built, they were hidden by a ceiling made of reed mats and plaster, supported by a wooden frame, which often assumed a vaulted shape. This evolution is generalized in Italian civil construction, albeit in different times and ways between region and region, city and city. In Cremona the disappearance of the exposed timber floors also coincides with the lesser availability - at least in proportion to the demand - of the wood which ensured their quality, even the structural one: the local oak.

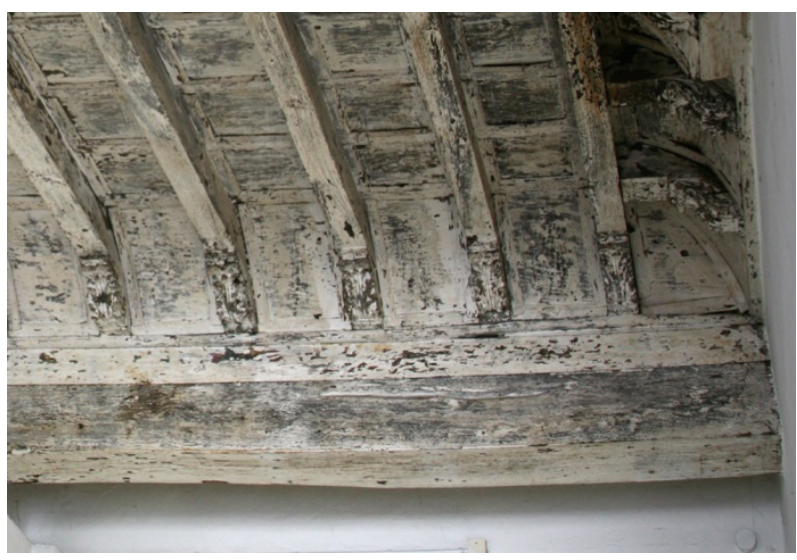

Figure 10: Floor with bussole covering joists and corbels from the late $15^{\text {th }}$ century (Palazzo Affaitati-Soldi).

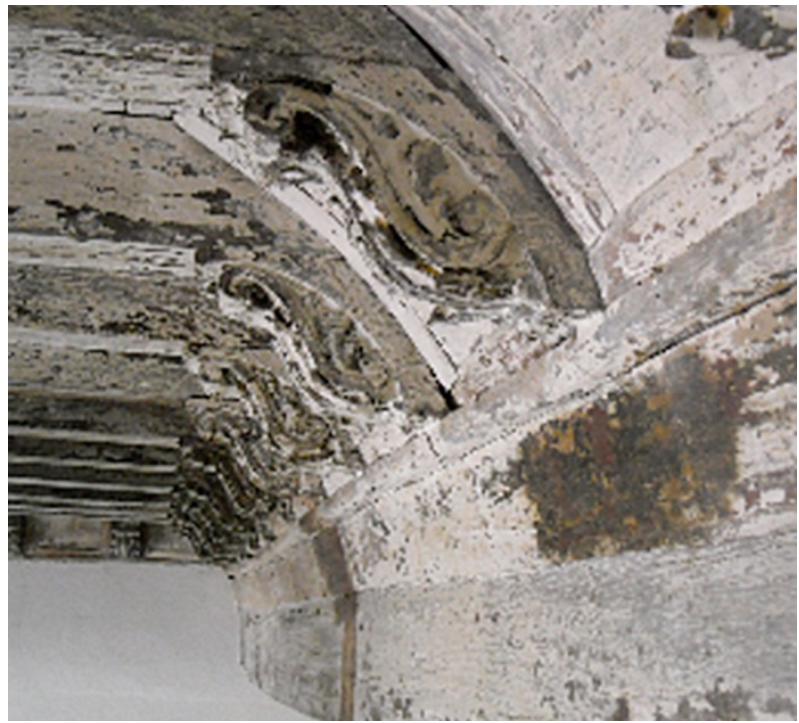

Figure 11: Detail of the floor in Fig. 9.

However, a direct cause and effect relationship cannot be identified: the checks made by Floriana Petracco (2011) show an increase in the wooded area between the Cadastre of Charles V (Jacopetti 1984), in the mid-16 ${ }^{\text {th }}$ century, and the Teresian Cadastre, in the first half of the $18^{\text {th }}$ century, but it is unlikely that the cultivation was directed towards the production of timber for structures, especially taking into account the time required for the growth of trees capable of providing the large trunks necessary for the girders.

\section{The literature and the institutional sources of the Modern Era}

Another circumstance is favourable: the Cremonese Alessandro Capra (circa 1610 - circa 1685), architect, military engineer, skilled machine builder (Dezzi Bardeschi, 1963; Olivato, 1976; Bellini, 1982), published - in various parts then collected in a single work - a sort of treatise, a collection in five "books" of the knowledge necessary for the activities of an engineer of his time, which extends from agriculture to construction, measurement techniques, geometry and machines (Capra, 1678), which enjoyed a fair amount of success even outside Cremona. The treatise is based on local 
construction practices and is quite detailed, even in metric terms.

The estimate of the existing trees in agricultural properties and the recommended dimensions in the buildings give a series of measures that find punctual correspondence in the preserved examples, starting from Palazzo Magio itself. In this way, we can overcome the shortcomings of another possible source, the Statutes of the city, which under the heading DCXLIX, of the 1578 edition, deal almost exclusively with the much more requested firewood (Statuta, 1578).

Capra describes the oaks as the only species suitable for beams for roofs and floors, while joists could also be made of the less expensive poplar, birch and mulberry timber. This subdivision was preserved over time and appears even more marked in the $19^{\text {th }}$ century documents analysed by Emanuela Carpani (2003), according to which in timber floors girders were almost always made with oak, joists and planking with poplar.

Capra almost never speaks of the length of the logs, but rather of their section: on average those from which boards must be obtained are long ten braccia (the Cremonese braccio - arm - is equal to about $48.35 \mathrm{~cm}$ and remained in use until 1781, when it was replaced by the Milanese braccio; Galosio, 1786), and have a net width between 10 and 15 ounces (i.e. from 40 to $60 \mathrm{~cm}$, being the ounce a twelfth part of the braccio) and a thickness of one ounce or two, and in this second case they are called tasselli. The height of the bordonali beams used for the roofs - is up to 8 ounces $(32 \mathrm{~cm})$ but their length would not exceed ten braccia, even if the logs are made from «big, straight and long» oaks. The sections of the joists are described in greater detail (3 ounces $\times 3.5$ or 4 ounces, $12 \mathrm{~cm} \times 14$ or $16 \mathrm{~cm}$ ) and it is said that they are obtained from the small oaks.

The measures indicated by Capra were probably those of the elements obtained squaring the logs by axing or sawing and then reducing them in four joists with the saw; it is, therefore, necessary to remember that - especially in the more refined floors, those for which, as already written, this type of study makes the most sense - the timber elements were further worked by planing the upper face to allow perfect support for the overlapping elements and usually even the bottom and sides to improve their appearance. The quantity of material subtracted by planing depended on various aspects (e.g. regularity of the previous woodworking); it is therefore not easy to define the dimensional loss connected to it. Given the processing techniques, what tolerance should be assumed in this case? The comparison between the measurements found in Palazzo Magio and the texts suggests an interval of about half an ounce, $2 \mathrm{~cm}$, which determines the increase or decrease of one unit.

Capra makes no mention of the import of timber, which would therefore be produced actually in the local countryside, not only for rural construction, but also for the limited city market. Perhaps, more simply, the substantial economic autonomy of large land properties is confirmed, as in the production of brick. An argued answer would require an accurate comparison between the vague indications of the Charles V Cadastre and the much more precise ones of the Teresian Cadastre, and, if possible, on the administration of a number of large agricultural estates.
In the building and demographic recovery that followed the plague of 1630 and the peace treaties of Westphalia (1648) and the Pyrenees (1659), the large exposed timber floors in monumental rooms were a rapidly declining practice, limited to cases in which it was justified by availability of spolia from demolished or renewed buildings, especially the less common and more expensive girders to be eventually integrated with new more easily available joists. Again, the substantial identity of size between the $15^{\text {th }}$ century and $17^{\text {th }}$ century elements suggests an analogy with bricks, which have not changed in size since the late Middle Ages (Landi, 2013). This uniformity facilitates re-use, and - even more than for brick - the measurements of the timber are a difficult balance between structural quality and rational use of the trunks of the same tree species.

These reasonable motivations are further supported by the fact that the share of self-consumption timber is probably high. Large landowners are also the major investors in the city and in documents the costs of building materials often emerge only indirectly and are quantified in the management or in the rental contracts of the rustic funds that provide them. Moreover, since they control the institutions they could act directly on the price, if they wanted to achieve a greater profit with the product that exceeds their needs. Even in the case of timber, there would therefore be no free market, no demand and supply capable of forming prices, but also of encouraging the modification of products, a real dialectic between producers and consumers, which either coincide or have highly unbalanced contractual powers. These summary considerations certainly have a reference time span, from the late sixteenth century to the early decades of the eighteenth century, a time interval that is actually not homogeneous, if not in the hegemony, both political and economic, of the citizen patriciate.

\section{Construction and reuse of timber floors from $17^{\text {th }}$ to $18^{\text {th }}$ century in a patrician palace}

In Palazzo Magio the surviving construction phases are distant in time, between the beginning of the $16^{\text {th }}$ century and the second half of the following century: the extremes - apogee and decline - of the use of timber floors. The centre distance of the beams and the dimensions of the elements (joists, moulds, bussole, corbels) that make up the $15^{\text {th }}$ century floor towards the loggia are similar to the other numerous examples known in the city. More checks would be needed, but the floors of Palazzo Affaitati, then Pallavicino di Busseto, Brumani - and subsequently Soldi - (Azzolini, 1996) are comparable with those of Palazzo Magio and referable to the dimensional indications given by Capra; in this palace, the joists have a width of 10.5 $\mathrm{cm}$ and a height of $12 \mathrm{~cm}$. In Palazzo Magio the span of the joists is $2.45 \mathrm{~m}$ (just over 5 braccia), but it becomes $1.90 \mathrm{~m}$ (4 braccia) if the corbels are taken into account; in Palazzo Affaitati-Soldi the span is $2.90 \mathrm{~m}$ ( 6 braccia), but becomes $2.20 \mathrm{~m} \mathrm{(4} \mathrm{1/2} \mathrm{braccia)} \mathrm{net} \mathrm{of} \mathrm{the} \mathrm{corbels} \mathrm{(Fig.} \mathrm{12).}$

The processing of the raw material imposes its logic, and tends to standardise. The transition between these floors and those of a century and a half later is hardly recognizable in the city, and the examples that can be dated with certainty to the end of the $16^{\text {th }}$ and early $17^{\text {th }}$ centuries appear as coffered ceilings of boards. They are rare and were expensive. According to Capra, who 
estimates eight different types of floors, they require twenty-four times more hours - two days for each quadretto (the square with the side of one braccio) - than the simpler floor, the one that has only cantinelle (i.e. trapezoidal laths) hiding from below the joints between the boards, which are simply placed on top of the joists, without realizing notches; twelve quadretti of this elementary floor could be made in a day. Another significant cost leap separates the floors framed with cantinelle from those framed with cornices (i.e. laths with cyma reversa mouldings); in this case laths are not only used to hide the joints between the boards, they are also put along the joists to complete the frame; we go from six quadretti to three quadretti per day. The floors on the ground floor of Palazzo Magio belong to this more expensive case. In reality, as it's clearly visible in the room whose ceilings are decorated with passasotto paintings (Fig. 13), the moulded laths are still very similar to those in the Renaissance floors and they contrast - much more than the simpler trapezoidal laths - with the continuous decoration of the planking, which spread at the end of the $17^{\text {th }}$ century.

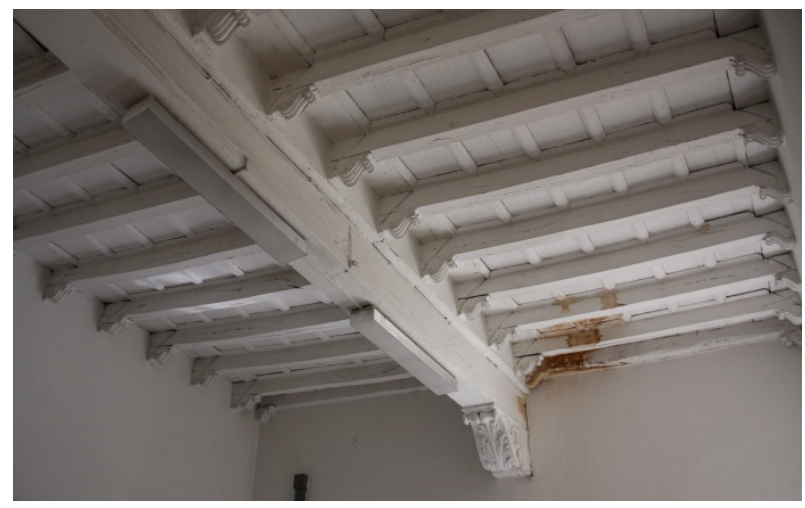

Figure 12: Timber floor in Palazzo Affaitati-Soldi.

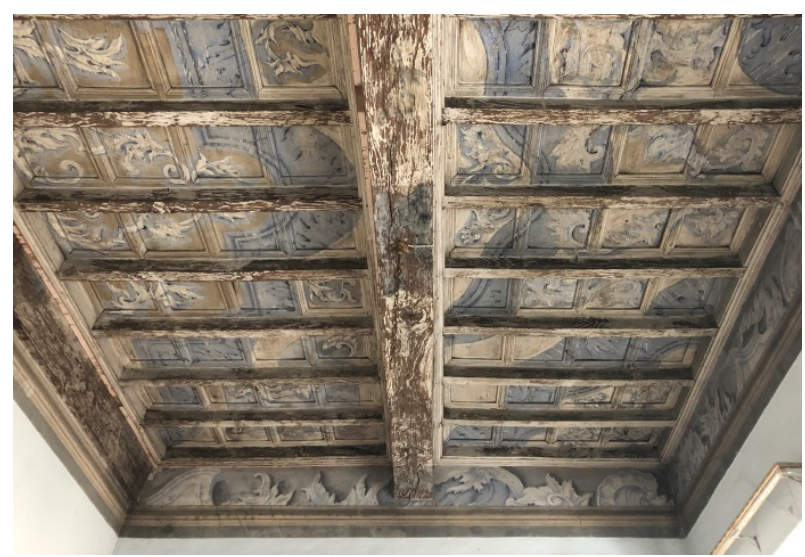

Figure 13: Timber floor in Palazzo Magio with passasotto painting.

This is perhaps the last step in a progressive simplification. Compared to the early $16^{\text {th }}$ century, the corbels under the girders and under the joists have disappeared, therefore the net spans increased. The double concave bussole have been replaced by a simple vertical board, also inserted from above into two grooves of decreasing depth made in the sides of the joists and by a horizontal board with moulding on the external side or by a simple moulded cornice, which runs along the walls and the beams just below the joists, to which it is nailed.
Other moulded cornices - the section of which is inscribed in an isosceles right-angled triangle, perhaps obtained from a solid wood the size of a joist - are inserted in the corners, connecting vertical and horizontal surfaces. The goal was to counter or hide the reciprocal movement between the elements, but at the same time, they wanted to convey an idea of coherence and order.

By simplifying, the floor is lightened, and at the same time, however, the admissible loads decrease: the sections of the joists do not change between the end of the $15^{\text {th }}$ century (ground floor towards the loggia) and the $17^{\text {th }}$ century (floor of the hall, always on the ground floor, towards the courtyard), however, the spacing (centre to centre distance) between the joists and their clear span change, since the spacing between the beams remains almost constant, but there are no longer the corbels. The span of the joists goes from about $1.90 \mathrm{~m}$ net of the corbels in the $15^{\text {th }}$ century floor to about $2.40 \mathrm{~m}$ in the large $17^{\text {th }}$ century floor with walnut joists, that is, from 4 to 5 braccia.

In this case, the actual spans are determined by the dimensions of the individual rooms (which are affected by the size of the lot) and, consequently, by the distances between the walls, as well as by the size of the available joists, to be obtained, according to Capra, from logs about $4.80 \mathrm{~m}$ long. Given this length, although it has not been possible to carry out direct investigations, we can hypothesize that the joists could be continuous on two spans. Despite referring to the use of "small" oaks, four joists already corresponded to a log of about $36-40 \mathrm{~cm}$ in diameter at its smaller end.

In the floors of Palazzo Magio, the depth/span ratio of the joists is always between $1 / 18$ and $1 / 23$, and it's $1 / 24$ in the analysed case of Palazzo Affaitati, as suggested by various authors over time (Scamozzi, 1615; Patte, 1777; Rondelet, 1810; Borgnis, 1823). In the floor with walnut joists, the elements have larger dimension than the others: the depth/span ratio is the biggest $(1 / 18)$, an aspect that leads us to hypothesize that the lower resistance of walnut wood compared to oak - in addition to the slightly greater spacing of the joists - was taken into account. Only in two floors with only joists and without beams, the span of the span is significantly greater $(3.20$ $\mathrm{m})$ : those that cover two overlapped rooms whose dimensions were predetermined by those of a medieval cellar and therefore, at least in part, by the persistence of the walls above ground. These floors were also dismantled and reassembled - as evidenced by the grooves of the bussole which are now visible since they were not put back in place - probably in the same rooms in which they were located, following the change in height of the storeys. These are the only floors in which oak joists have significantly different dimensions $(10 \mathrm{~cm} \times 14 \mathrm{~cm})$ and are probably obtained by planing the larger joists suggested by Capra ( 3 ounces $\times 4$ ounces, $12 \mathrm{~cm} \times 16$ $\mathrm{cm}$ ); the choice of using larger elements could have been determined by the fact that with joists of the size used in the other floors, the limit of $1 / 24$ would have been exceeded, reaching 1/27.

Observing what seems to be an almost perfect dimensional correspondence between the lengths of the reused elements and the dimensions of the rooms, it seems possible to propose the hypothesis that it was the size of the material available - coming from the demolitions - that provided the basis for determining the 
dimensions of the rooms built in the $18^{\text {th }}$ century. This hypothesis must not seem too odd, since even some treatise writers suggest defining the dimensions of the rooms according to those of the timber available (Valadier, 1831). This would better explain the unusual dimensional progression of the rooms towards the garden of Palazzo Magio, not bound by the common rule that the larger size of a room becomes the diagonal of the adjacent one.

The rooms of Palazzo Magio have sequences of between ten and sixteen joists. In the absence of a commercial circuit that would ensure an absolute homogeneity of the materials supplied, the adjustment in the construction site could be complex; the differences in spacing between the beams of the same floor can thus be more easily explained. The spacing between the joists also varies; the most accentuated difference can be seen in the case of the large $17^{\text {th }}$ century floor of the room overlooking the courtyard is probably connected to the wood species, not oak but walnut, joists and boards are made of; the latter also seem to have greater width, probably to keep a square shape to the framing of laths covering the joints of the boards and placed along the joists. This has probably been an occasional purchase, or availability in the Magio landholdings. Capra distinguishes walnut in some varieties, and identifies one intended for carriages or agricultural equipment, which required particular solidity, and therefore justifies this - in any case singular - use in construction.

Conversely, between the $15^{\text {th }}$ and late $17^{\text {th }}$-early $18^{\text {th }}$ centuries, the variation in the spacing of the laths covering the joints of the planking appears to be less significant and less systematic: necessarily the width of the boards had to be been more constant.

In theory, the increase in the spacing of the joists should always translate into a greater width of the boards, to keep a square shape to the laths framing; in reality, the numerous necessary adjustments determine a visible difference only when the distance between the joists is significantly increased, but these are then rough repairs of the full nineteenth century.

The floors reused at the end of the $18^{\text {th }}$ century require particular attention to reconstruct the extent of the adaptations undergone, and to trace their possible original late $17^{\text {th }}$ century construction. The most evident modification is that the boards between the joists - in which the grooves remain empty - have not been reassembled, as the underlying horizontal moulded boards or cornices. In fact, the most difficult parts to remove intact and to reassemble are missing.

Furthermore, there are no moulded, but simple trapezoidal laths. The lack of dendrochronological investigations, and of absolute dating of single wooden elements makes the measures and the traces of processing decisive for the comprehension of the construction events.

\section{Further development of the research}

The research presented is open to further development. These can be directed on the one hand towards a greater detail of the surveyed measurements and towards their correlation with the level of finish of the joists' surfaces, on the other hand towards the extension of the metric and construction surveys to a greater number of floors. A systematic analysis - also statistical - of the detected dimensions could allow estimating with good approximation the dimensional tolerance of the commercial timbers, the dimensional losses due to the planing operations and the final dimensions of the elements; the extension to a significant number of cases could also make it possible to detect an evolution over time of the various quantities obtained from the surveys or from the analyzes.

\section{Conclusions: recurrences and differences}

Generally, the usefulness of a detailed and precise survey of the individual elements has complex purposes. It has ancient measurements as a reference, recognizes the allowed tolerances, variations and presumable adjustments at the time of execution, thus allowing to reconstruct the details, the interaction between local availability and processing of the material and sizing of the elements to be made. A purely morphological analysis - even if it detects a dimensional identity - is of little significance, especially if we take into account that its most evident reference, the mouldings, are part of a vocabulary that has been substantially shared throughout Europe since the Renaissance. Cyma recta and reversa, fillet, cavetto, ovolo, etc. and their tracing are part of the notions of elementary design that all specialized craftsman owned, when the particularity of the case didn't justify the intervention of a professional, often also an entrepreneur, or of the commissioner with deeper artistic culture. Only this vast and generic common background makes it clear why the similarities that can be found in these details in different and distant regions since the $16^{\text {th }}$ century are very numerous. A "mensiochronology of wooden elements" - no less than their "chronotypology" becomes all the more uncertain and requires more sophisticated criteria for periods in which cultural exchanges increase and the ornamentation is codified by treatises, which the press makes more and more available.

However, a less sophisticated utility is not lacking: if we understand the sizing methods and tolerances, if we go back even to the less immediately visible construction nodes (as it is essential to establish the also metric correct representation of numerous details) real structural models can be established, obviously in well-defined times and contexts. Taking into account the tolerances, it is possible to establish validity ranges, including dimensional ones, of these models. Therefore significant dimensional discrepancies with respect to ordinary practice would allow us to understand the specificity of a given floor and encourage deepening the investigations to better understand the causes of this "anomaly" (Zamperini, 2013).

On the basis of some common peculiarities, individual cases can be traced back to these models and they can simplify and above all correctly orient each type of verification. The uncertainty and arbitrariness not only of the structural calculation, but also of the surveys that support it are too widespread; it is therefore necessary to counteract this superficiality - naturally, given the field of study - in a "constructive" way. 


\section{Acknowledgements}

This work was supported by Fondazione Cariplo ("Patrimonio culturale per lo sviluppo") in the framework of the action plan "Il Palazzo di Città: formazione, documentazione e innovazione per Cremona e il suo Distretto Culturale" (project no. 2016-2241), led by the Municipality of Cremona with the scientific partnership of Politecnico di Milano - Dipartimento di Architettura e Studi Urbani.

\section{References}

Azzolini, L. (1996). Palazzi del Cinquecento a Cremona. Cremona, Italy: Turris.

Baroni, S., \& Travaglio, P. (2011). Gli apparati decorativi di Palazzo Magio Grasselli a Cremona. In Landi, A.G. (Ed.), Patrizi, notabili, costruzione della città: fabbrica e tutela di palazzo Magio Grasselli a Cremona. Torino, Italy: Allemandi (pp.117-153).

Bellini, A. (1982). Alessandro Capra, ingegnere cremonese del '600 e trattatista di architettura civile. Cremona, Italy: Biblioteca Statale e Libreria Civica.

Biffi, G. B. (1988). Memorie per servire alla storia degli artisti cremonesi (L. Bandera Gregori Ed.). Annali della Biblioteca statale e libreria civica di Cremona, 39(2) Cremona, Italy: Linograf.

Borgnis, G. A. (1823). Traité élémentaire de construction appliquée à l'architecture civile. Paris, France: Bachelier.

Bouticourt, E. (2016). Charpentes méridionales. Construire autrement: le midi rhodanien à la fin du Moyen Age. Arles, France: Honoré Clair.

Capra, A. (1678). La nuova architettura famigliare. Bologna, Italy: Giacomo Monti.

Carpani, E. (2003). A fior d'arte. Il cantiere cremonese preindustriale. Milano, Italy: LED.

Dandria, S. (2010). Commercio del "legname da opera" nella valle dell'adige fra XIII e XVII secolo: assortimenti e impieghi in relazione alla diffusione delle travi composte. Doctoral thesis. Milano, Italy: Politecnico di Milano.

Dezzi Bardeschi, M. (1963). Su Alessandro Capra, ingegnere e architetto cremonese, e sul suo trattato d'architettura. Studi secenteschi, 4, 45-79.

Galosio, G. A. (1786). La perizia e l'agrimensura. Cremona, Italy: Francesco Gaetano Ferrari.

Grimoldi, A., Landi, A. G., \& Facchi, E. (2019). Re-employed, transformed or preserved. The wooden beam floors in palazzo Magio Grasselli in Cremona. In J. M. Branco, E. Poletti, \& H. S. Sousa (Eds) SHATiS'19 - 5th International conference on structural health assessment of timber structures, Guimarães, Portugal: University of Minho (pp. 189198).

Jacopetti, I. N. (1984). Il territorio agrario-forestale di Cremona nel catasto di Carlo V (1551-1561). Cremona, Italy: Biblioteca Statale e Libreria Civica - Camera di commercio, industria e agricoltura.

Landi, A. G. (2011). Riforme edilizie in una dimora aristocratica cremonese: palazzo Grasselli fra civitas e urbs. In Landi, A. G. (Ed.), Patrizi, notabili, costruzione della città: fabbrica e tutela di palazzo Magio Grasselli a Cremona. Torino, Italy: Allemandi (pp. 33-116).

Landi, A. G. (2013). I mercati del laterizio a Cremona tra età medievale e XIX secolo. Premesse all'avvio di un'indagine mensiocronologica. Materiali e strutture. N. S., 2 (4), 18-30.

Mannoni, T., \& Milanese, M. (1988). Mensiocronologia. In Archeologia e restauro dei monumenti, "Quaderni del Dipartimento di Archeologia e Storia delle Arti. Sezione Archeologica. Università di Siena", 12-13, Firenze, Italy: All'Insegna del Giglio (pp. 383-402).

Olivato, L. (1976). Alessandro Capra, In Dizionario Biografico degli Italiani, 19, Roma, Italy: Istituto della Enciclopedia italiana.

Patte, P. (1777). Cours d'architecture ou traité de la décoration, distribution \& construction des bâtiments commencé par feu J. F. Blondel [...] et continué par M. Patte [...]. Tome sixième. Paris, France: Chez la Veuve Desaint.

Petracco, F. (1998). L'arte del costruire a Cremona: maestranze, materiali e tecniche nei secoli 16-17. Tesi di dottorato, Milano, Italia: Politecnico di Milano.

Petracco, F. (2011). II legno a Cremona nei secoli XVI-XVIII: primi cenni sulla coltivazione, i formati e i suoi molteplici utilizzi. Liuteria Musica e cultura. N.S., 6(2), 35-45.

Pittaluga, D. (2009). La mensiocronologia dei mattoni. Genova, Italy: EClg.

Rondelet, J. (1810). Traité théorique et pratique de l'art de batir. Tome quatrieme. Première partie. Charpente. Paris, France: Chez l'auteur, Enclos du Panthéon.

Scamozzi, V. (1615). L'idea della architettura universale. Parte seconda. Venice, Italy.

Statuta, (1578). Statuta civitatis Cremonae. Cremona, Italy. 
Valadier, G. (1831). L'architettura pratica dettata nella scuola e cattedra dell'insigne Accademia di S. Luca. Tomo II. Roma, Italy: Rogrué e Catesi.

Zamperini, E. (2013). The study of timber structures base on in situ investigation. Advanced Materials Research. 778, 97104. https://doi.org/10.4028/www.scientific.net/AMR.778.97 


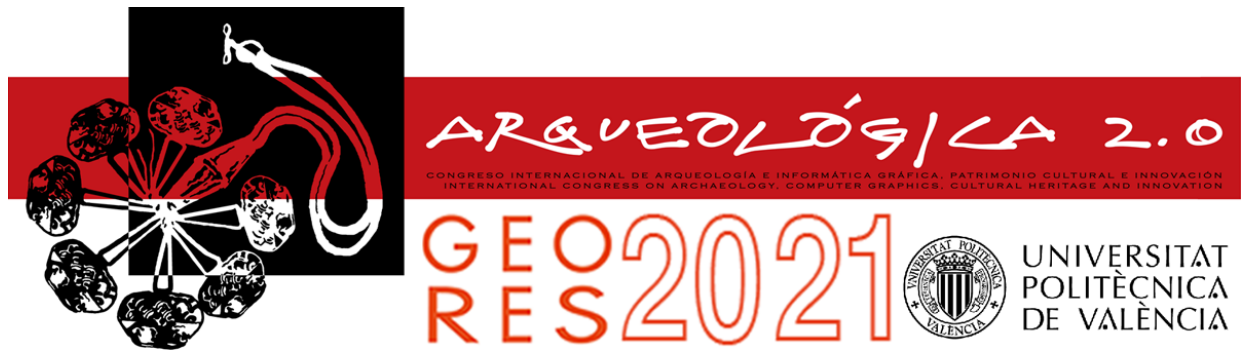

Proceedings of the joint international event $9^{\text {th }}$ ARQUEOLÓGICA

$2.0 \& 3^{\text {rd }}$ GEORES

Valencia (Spain).

26-28 April 2021

\title{
DEVELOPMENT OF AN INTEGRATED BIM-GIS MANAGEMENT TOOL FOR MAINTENANCE PLAN OF HISTORICAL HERITAGE
}

\author{
Ilaria Bonfantia, ${ }^{*}$, Elisabetta Coluccia, Valeria De Ruvo ${ }^{a}$, Matteo Del Giudice ${ }^{b}$, Sara Fasana ${ }^{b}$, \\ Emmanuele laconoc, Andrea Maria Lingua ${ }^{a}$, Francesca Matrone ${ }^{a}$, Gianvito Marino Ventura ${ }^{c}$, Marco \\ Zerbinatti ${ }^{b}$ \\ a Department of Environmental, Land and Infrastructure Engineering (DIATI), Politecnico di Torino, C.so Duca degli Abruzzi 24, 10129 \\ Torino, Italy. ilaria.bonfanti@polito.it; elisabetta.colucci@polito.it; valeria.deruvo@polito.it; andrea.lingua@polito.it; \\ francesca.matrone@polito.it

\footnotetext{
${ }^{\mathrm{b}}$ Department of Structurall, Building and Geotechnical Engineering (DISEG), Politecnico di Torino, C.so Duca degli Abruzzi 24, 10129

${ }^{\mathrm{c}}$ Department of Economics and Business Studies (DISEI), Università del Piemonte Orientale, Via Duomo 6, 13100 Vercelli, Italy. emmanuele.iacono@uniupo.it; gianvito.ventura@uniupo.it
} \\ Torino, Italy. matteo.delgiudice@polito.it; sara.fasana@polito.it; marco.zerbinatti@polito.it
}

\begin{abstract}
:
The planned maintenance of cultural heritage $(\mathrm{CH})$, in recent years, has been strongly supported by innovations in the digital field and, in particular, by digital models. In this framework, Main10ance, an INTERREG project, aims to implement a plan of maintenance and conservation of the historical cultural heritage. The case study is the system of the Sacri Monti of northern Italy and Switzerland, groups of chapels and other architectural artefacts. The design phases are divided into: survey of the historical architectural heritage present; data processing and realisation of three-dimensional models with the help of BIM software; integration of the same in the geographical context through GIS support; creation of a database (DB) which creates interoperability between the various domains and which collects information on the characteristics of the heritage for maintenance and conservation purposes; possibility to make the information associated with 3D models accessible through demonstrators that allow interrogation of the DB and the models themselves. The data have been entered (planned maintenance records, history of activities, etc.), convey them into the DB structured according to the INSPIRE Directive (2007/2/EC, Infrastructure for spatial information in Europe) and CityGML standard with its Level of Detail - LODs) for the GIS representation and IFC for the BIM. The Italian National Unification (UNI) norms have also been considered for the DB design.
\end{abstract}

Keywords: planned maintenance, built cultural and historical heritage, HBIM, cityGML LoD, spatial database, multiscale approach

\section{Introduction}

The growing use and development of increasingly efficient and accurate 3D surveying and modelling techniques in geomatics are leading to numerous applications in the cultural heritage $(\mathrm{CH})$ field, especially for architectural, built and urban heritage. In the presented project, the integrated 3D metric survey and objectoriented modelling are used to support an easier administration of the architectural assets.

In particular, the contribution outlines the main elements of the Main.10.ance project. This work in progress is part of an international research program created to improve and enhance the management tools of the existing maintenance plans for architectural complexes, nowadays experimentally used at the Sacro Monte di Varallo Sesia. Thanks to the proposed methodology, we aim at structuring a functional model useful for different territorial realities and adaptable not only for similar artefacts but also for all the widespread heritage of our Countries.

It is, therefore, necessary to systematise procedures and maintenance protocols that have already been tested, as well as information models and intervention management programs, considering the complexity of the context and the diversity of information.

The information to be integrated derives not only from metric surveys and the geometries of the threedimensional models but also from glossaries ad hoc created to allow the use of a common language; historical and diagnostic investigations; reports of construction techniques; archival and iconographic sources; previous maintenance activities, with their diachronic periodicity,

`Corresponding Author: Ilaria Bonfanti, ilaria.bonfanti@polito.it 
and so on. Not least, glossaries ad hoc created to allow the use of a common language. Therefore, adequately addressing semantic aspects' management is crucial for setting up a valuable and dynamic tool.

\subsection{The Main.10.ance project}

Main10ance is a three-year research project (Interreg Italy-Switzerland "MAIN.10.ANCE", 2019-2021) and has as objective the creation of a tool to support the planned maintenance of the Italian and Swiss Sacri Monti. One of the aims is to develop the complete database structure for scheduled maintenance, conduct campaigns of integrated metric surveys, thereby developing 3D models, and harmonise technical terminology with specific glossaries. The present paper will explain this process.

The search for adequate applications able to manage an elaborate maintenance plan of Cultural Heritage led to the choice of adopting the BIM methodology (and the Historical Building Information Modelling - HBIM accordingly) for the architectural scale, integrating it in a GIS structure capable of providing more adequate tools for territorial and multiscale analysis. These tools and methods have, in fact, great relevance in the interpretative phase and for the "physical" knowledge of the asset. However, they can also provide a decisive contribution to the completion of the mere geometric models, making them even semantic and informative, thus proper for 360 degree planning of the maintenance of the historic architectural heritage.

Therefore, the database is divided into different Levels of Detail (LoD) to allow the development of simple and "scalable" tools, agile and useful for maintenance. The database is interoperable as it is based on international standards and is suitable and queryable by different users, from specialised maintenance technicians to restorers and tourists. This database forms an everyday basis for the HBIM models and the GIS environment and is managed by open source software (PostgreSQL).

Information of the geographical and territorial context is combined with geometric, morphological, material and interventions data on the site's chapels.

The project focuses on the dialogue of the two BIM and GIS domains, creating a demonstrator able to unify the different types of information at different levels of detail.

\section{The case study}

The object of the project is the system of the Sacri Monti of northern Italy and Switzerland, groups of chapels and other architectural artefacts, such as statues, like frescoes, wall painting and terracotta sculptures, erected mainly between the $\mathrm{XVI}$ and $\mathrm{XVII}$ century.

These are architectural complexes of high value, inserted in mountain landscapes and environmental contexts and declared part of the UNESCO World Heritage List in 2003 (Piedmont and Lombardy). The system consists of 7 Piedmontese, 2 Lombard and 2 Swiss sites (Fig. 1) and experienced their most excellent development during the Catholic Reformation, after the Council of Trento (15451563).

They were conceived and organised to bring the populations who lived along the subalpine arc closer to the Catholic faith, especially those near those penetrated by the Protestant Reformation. Therefore, they became places where, through the creation of works of art and the depiction of the life of Christ or the Saints, also illiterate people could have a clear understanding of the Christian message. Precisely for this reason, it is possible to find statues, frescoes and iconographic elements inside each chapel, thus complicating the overall management and maintenance.

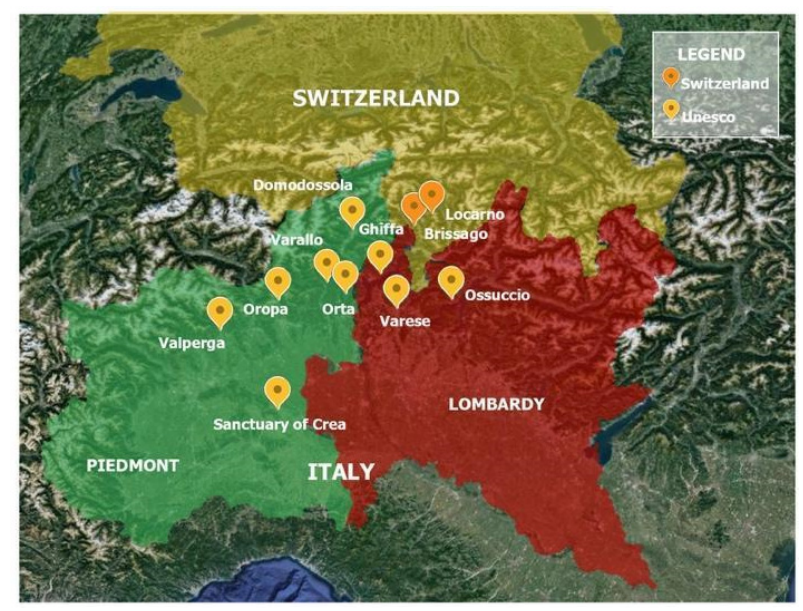

Figure 1: The system of "Sacri Monti" across Italy (Lombardy and Piedmont) and Switzerland.

\subsection{Survey Campaigns}

The survey campaigns for some complexes of the Sacri Monti have been conducted since 2015 and are still ongoing. In particular, to date, data of some buildings of the "Sacro Monte di Ghiffa" and a large part of the "Sacro Monte di Varallo" have been acquired with an integrated metric survey (Fig. 2).

The methods involved are:

- Integrated 3D metric survey. A planimetric network with static GPS/GNSS has been surveyed, with the integration of Real-Time Kinematic and topographic techniques. A Terrestrial Laser Scanner (FARO Focus) has been used for the data acquisition of indoor and outdoor parts. In contrast, a photogrammetric survey with UAVs (Unmanned Aerial Vehicles) has been conducted for the roofing.

- Rapid techniques. High cost (Stencil Kaarta) and low-cost sensors (smartphones, GoPro) have been tested (Calantropio, Matrone, \& Lingua, 2019).

For details on data acquisition and processing, refer to (Zerbinatti, Matrone, \& Lingua, 2020; Matrone, 2018; Lingua, Noardo, Spanò, Sanna, \& Matrone, 2017).

\section{Related Works}

Planned maintenance and the safeguarding of cultural and architectural heritage must take into account several factors. First, as mentioned above, the integration and management of different types of data and their easy handling by managers or users (Tommasi, Achille, Fanzini, \& Fassi, 2019). In this sense, the HBIM methodology offers an excellent support tool for the 
management of built heritage (Brumana, Georgopoulos, Oreni, Raimondi, \& Bregianni, 2013; GarcíaValldecabres, Pellicer, \& Jordan-Palomar, 2016; Brumana, Oreni, Raimondi, Georgopoulos, \& Bregianni, 2016; García, García-Valldecabres, \& Blasco, 2018; Bruno \& Roncella, 2019). Despite the still substantial limitations in the modelling of complex structures or decorative apparatuses, to which a solution can be found thanks to external modelling software and the use of NURBS (Oreni et al., 2014; Brumana et al., 2018; Diara \& Rinaudo, 2020), the ease of data management and its visualisation and the simplicity of updating, provides a reason why this methodology is increasingly used (Logothetis, Delinasiou, \& Stylianidis, 2015; Yang et al., 2020).

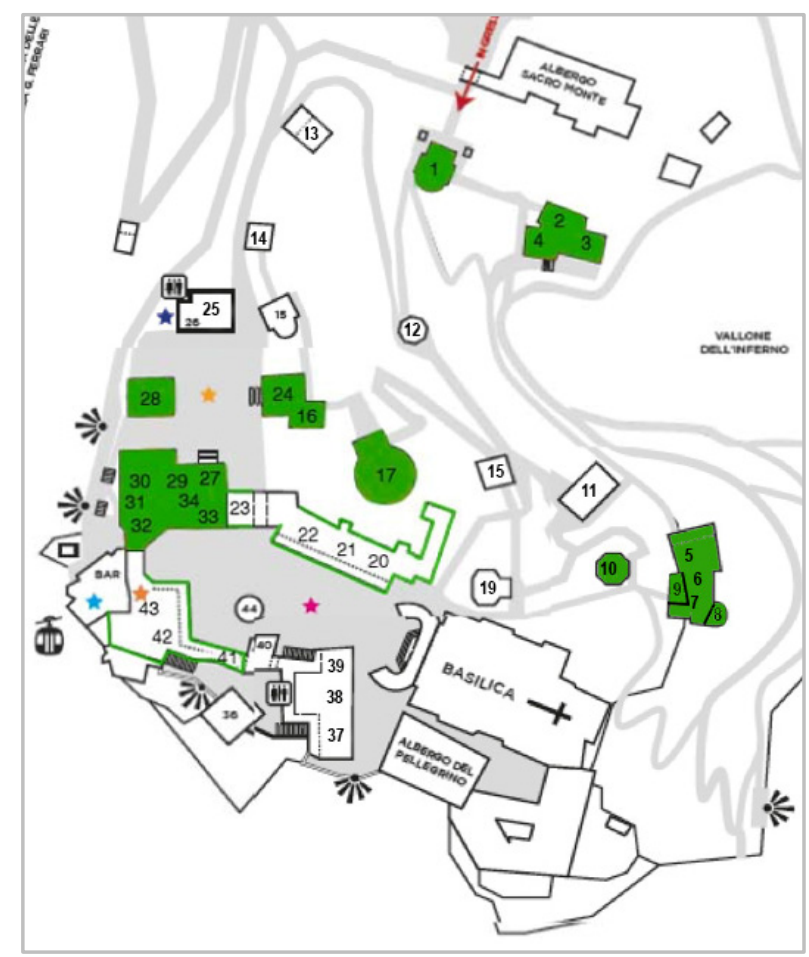

Figure 2: Plan of the Sacro Monte di Varallo. Starting from a complete photogrammetric survey of the whole complex integrated with laser scans, 21 chapels have been modelled with BIM methodology (green). For those with a green border the HBIM modelling is ongoing.

Furthermore, there is also an increasing interest in inserting HBIM models in their urban-environmental context, thus allowing more articulated, complex and complete analyses (Vacca, Quaquero, Pili, \& Brandolini, 2018; Matrone, Colucci, De Ruvo, Lingua, \& Spanò, 2019; Bruno et al., 2020; Colucci, De Ruvo, Lingua, Matrone, \& Rizzo, 2020; Tsilimantou, Delegou, Nikitakos, Ioannidis, \& Moropoulou, 2020). In some of these cases, however, there is no unique interoperable database capable of containing both data from the BIM and GIS domains. The management of these two domains usually occurs by importing the HBIM model into the GIS environment, not taking into account the full integration of the data structure and sources, instead verifying only the actual reading of the semantic component of the model. The methodology proposed here, instead, seeks to build a common database and create a demonstrator able to manage both the IFC (Industry Foundation Classes) structure and the data (geometries and attributes) coming from the GIS.
Furthermore, even within the same BIM domain, an additional element is added here compared to other research works. Since there are 11 sites with many chapels inside each one (only the Sacro Monte di Varallo has 45 chapels), it is not enough to manage a single HBIM model into the GIS environment. Still, it is necessary to create federated models for each site. There is, therefore, the definition of a LoD for the statues, decorations and so on, to then move to the architectural one of the individual chapels, then to the urban one of each complex, the regional one of the Italian Sacri Monti and finally the supra-national one with the integration of the Swiss Sacri Monti.

\section{Methodology}

This study aims to create a simple to use tool, scalable to different case studies, interoperable for other domains and easily accessible by multiple types of users. The interoperability of the database between the GIS domain and the BIM domain is made possible thanks to the use of international standards; this allows to extend the applicability of this methodology in contexts with similar characteristics (widespread historical architectural heritage). The realisation of integrated three-dimensional visualisation tools and management of a single database must allow different users to have access and be able to modify and manage information belonging to the different levels of detail of the Sacri Monti. The maintenance technician shall have access to all levels of detail for scheduled maintenance, and the simple tourist must have access to information relating to the topography of the place and then the spatial data for guidance and knowledge of the architectural and artistic works of the Sacri Monti.

\subsection{Tools and Interoperability}

The research highlights the need to enhance the interoperability between different domains, data models and software; for this reason, many national and international standards have been studied and considered. They allow geometric, semantic, and technical interoperability among different environments such as BIM, GIS, existing documentation, etc.

Among these, it is possible to identify: standards in the BIM domain (1), geographic representation data models (2) and standards for architectural and built heritage documentation (3).

Depending on the software used and, therefore, the types of information stored, different international standards have been taken into account:

- $\quad I F C$, Industrial Foundation Classes, is an open data format to facilitate interoperability between different operators. It allows the interchange of an information model without loss or distortion of data or information (https://technical.buildingsmart.org/standards/ifc ).

- UNI 11337-5:2017, for Construction and civil engineering works, Digital management of building information processes, Part 5, information flows in digitised processes. It defines the roles, rules and flows necessary for 
the production, management and transmission of information in the digitalised construction processes

(https://www.uni.com/index.php?option=com_c ontent\&view=article\&id=5753\%3Agestione-

digitale-dei-processi-informativi-delle-

costruzioni-pubblicate-le-parti-1-4-e-5-della-uni11337).

For as regard the GIS environment the standards adopted are:

- INSPIRE, Infrastructure for Spatial Information in Europe (https://inspire.ec.europa.eu/). It aims at the representation of homogeneous data to support environmental analysis in Europe.

- Open Geospatial Consortium (OGC) CityGML, (https://www.ogc.org/standards/citygml). It is an exchange format to store digital 3D models of cities and landscapes. It defines different standard levels of detail (LoDs) for the 3D objects, which allows the representation of objects for different applications and objectives.

- $\quad$ BDTRE, Base Territoriale di Riferimento degli Enti,

(https://www.geoportale.piemonte.it/cms/bdtre/b dtre-2). It is the Piedmont Region Geoportal, INSPIRE compliant (Technical Regional Map).

Then, for architectural and cultural heritage representation, it is possible to select:

- $\quad$ The Getty Vocabulary, specifically The Getty Art and Architecture Thesaurus (AAT), (https://www.getty.edu/research/tools/vocabular ies/aat/). It is a structured vocabulary, including terms, descriptions, and other metadata for generic concepts related to art, architecture, conservation, archaeology, and other cultural heritage. Included are work types, styles, materials, techniques, and others (https://www.getty.edu/research/tools/vocabular ies/).

- $\quad$ CIDOC-CRM, the Conceptual Reference Model is the core ontology for cultural heritage. It can help researchers, administrators and the public explore complex questions regarding our past across diverse and dispersed datasets (http://www.cidoc-crm.org/).

- UNI 11182:2006, Cultural heritage, Natural and artificial stone materials, Description of alteration form, Terms and definitions.

\subsection{The Glossary}

The "Illustrated Glossary" contains the terms used to describe the constituent materials, previous interventions and degradation phenomena related to stone materials and decorated surfaces of architecture (wall paintings, graphite, plaster). Based on the general terms (alteration, degradation and damage), we classify the phenomena of decay of materials, the executive technique (characteristics of each element and how it was realised) and previous interventions. From this information, it is possible to define the state of conservation of the material and the level of urgency of intervention that are important for the planning of the maintenance.

\subsection{The database design}

The design of Sacri Monti DB aims to start from a complex world, represented by perceived reality, reaching its implementation in a language comprehensible to the computer. It is a database organised according to different levels of detail, as defined by the CityGML standard, further deepened up to a Lod 5, regarding the aspects related to maintenance.

Firstly, the objects for which to store information in the data model were chosen. Therefore, it has been defined as the so-called "external model", made up of the entities with which to simplify the complex reality. These entities were selected from among the geographical data shared by the BDTRE standard; the INSPIRE standard has been chosen for raster data, the IFC one for BIM objects and a glossary drew up based on UNI 11182:2006 has been used. The next stage of DB design involves the definition of a "conceptual model", which represents a formal description of the "external model", based on well-defined and straightforward rules. It represents the model "entity relationships", in which the various entities are distinguished. The aim is to record information in the form of "attributes" for each entity. In this phase the relations between two entities have been defined, specifying the "cardinalities", which represent the minimum and the maximum number of possible occurrences.

The "conceptual model" (Fig. 3) has been subsequently schematised in the "logical" one, through which a structure of data has been expressed in a useful form to the computer. Precisely, it is a "relational model" based on the storage of data expressed in the form of numbers, strings and identifiers. At this stage, both the modalities with which to store the data and the modalities to connect two entities through a common field have been defined.

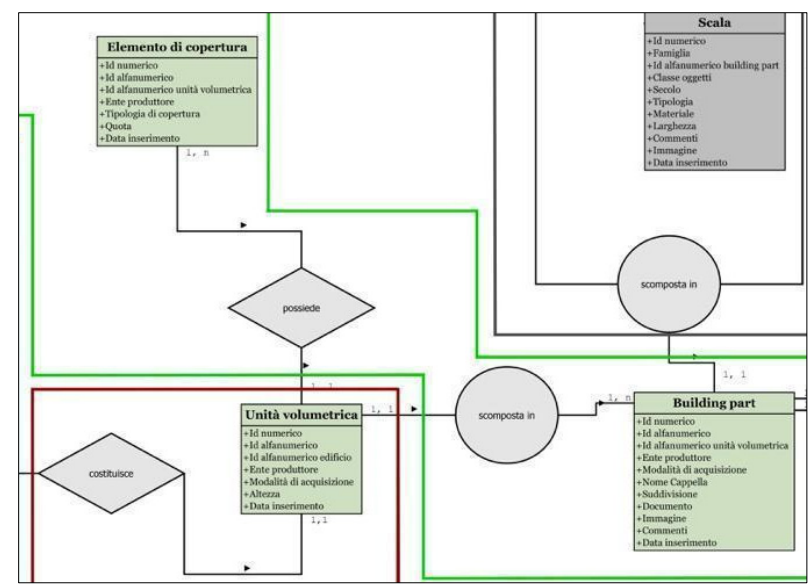

Figure 3: Excerpt of the Conceptual model with the links between "Roofing element", "Volumetric units", Building part, "Staircase").

The final design phase concerns the realisation of the "logical model" (Fig. 4) in the "internal" one, which represents the implementation of a database in a language comprehensible to the computer, so that the 
creation, manipulation and efficient query of data can be carried out.

The open-source object-relational database system PostgreSQL (https://www.postgresql.org/) was chosen for the implementation of the DB, for the possibility through the PostGIS extension to perform geospatial queries on the database and for its compatibility with all major operating systems. PgAdmin has been adopted as a graphical client for the DB Postgresql's simplified administration, allowing the creation of tables and their population. To enable the GIS connection, the PostGIS extension has been added.

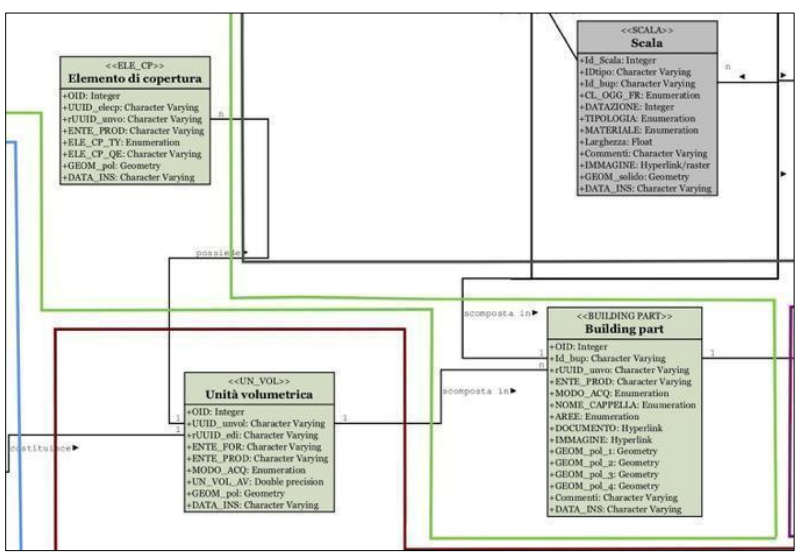

Figure 4: Excerpt of the Logical model with the links between "Roofing element", "Volumetric units", Building part, "Staircase").

Hence, this process's outcome is the creation of a GIS, in which the DB is connected, allowing its population with vector and raster data. For the geometries visualisation and querying the open-source software QGIS has been used (https://www.qgis.org/en/site/). Through PostgreSQL the relationships between the data have been created to make them questionable.

Each created table corresponds to the different entities represented in the logical model. It has been defined fields, data type, primary key, and any existing constraints for each one of them. In the case of $n: m$ relation type, it was necessary to create additional tables, all indicated with the prefix "nm", followed by the names of the two related tables. In the case of "enumeration" data, socalled "types" were also created and "labels" were defined for each of them. Everything has been embedded in a scheme, created explicitly for this project.

The subdivision in LOD makes different available levels of scale of information that correspond to different target users. The more general information about the geographical and topographical context in the LODO (digital soil model, roads, woods, watercourse areas, significant locations, etc.) is implemented by other more specific information about the building, to its volume, to the inner secondary roads to the Sacro Monte, in LOD1. The LOD2 contains three-dimensional information of the soil and the masses of the individual chapels of the Sacri Monti (covering elements, topography and soil surface model, building part, etc.). The first levels of detail are based on national and international standards, BDTRE (regional standard), INSPIRE (for raster data) and IFC (Industry Foundation Classes) only for the entity Building part, that is the mass of the individual chapels of Sacro
Monte. The geometric and data information of the individual structural and architectural elements (floor, roof, wall, staircase, etc.) is connected directly to the Building entity part of the chapels' individual masses. This is the LOD3 that represents the level of scale connected to the BIM domain and $3 \mathrm{D}$ modelling, and refers to the international IFC standard. Level of detail 4 collects the entities related to the decorative elements present inside the chapels (painting, mosaic, mural painting, etc.). The additional level of detail (LOD5), created ad-hoc for the present project, is characterised by alphanumeric information related to maintenance planning and programming. The characteristic entities (risk, control, damage, degradation, etc.) and those of LOD4, are subject to a hierarchical coding of an illustrated Glossary containing the terms used to describe the constituent materials, previous interventions and degradation phenomena related to stone materials and decorated surfaces of architecture.

\section{First Results}

This work aims to show the first project results developed in the first year of the research.

Thanks to the continued collaboration among all the partners, it was possible to achieve different valuable results.

Firstly, creating an interoperable spatial database structured following existing and international standards, then the DB population with geometries and attributes deriving from the Glossario and many suggestions of administrative and management parts of Sacri Monti.

Finally, the creation of the BIM models thanks to the 3D metric survey data.

All these outcomes will be helpful in the next steps of the project aimed at the BIM-GIS integration and the DB query and implementation with new parameters by technicians.

\subsection{Database population in PostgreSQL, DB connection in GIS and LODs visualisation}

After the creation of the internal model and its entities, the first LODs have been populated with attributes and geometries deriving from different standards above mentioned (such as Geoportals vector data and INSPIRE raster entities).

Georeferenced spatial data was returned via the open Quantum GIS software. Information on the territory, the mapping and topography of the area, the green, the urban furnishings, and all the geometric and alphanumeric information necessary for the maintenance plan's construction were added.

Firstly, the connection to the PostgreSQL database was created, configuring a series of parameters (e.g. database name, IP address, port on which the DB is exposed). Then, thanks to the "Data Source Manager" tool, all the layers corresponding to the tables built in the $\mathrm{DB}$, were added on map. These are still in lack of information, both geometric and semantic.

As regards the territorial scale data, corresponding to LoD0, LoD1 and LoD2, the shapefiles available on the Geoportal of Piedmont region and organised according to the BDTRE standard, have been used and their attribute 
tables have been copied into the appropriate ones created in the database Postgres.

By saving the QGIS project changes and refreshing the database connection, everything can be easily viewed on the PgAdmin client. This means that database tables now contain all the desired geometric and semantic information (Fig. 5).

\subsection{BIM tools}

HBIM methodology, an effective system to reconstruct intelligent 3D models of historic buildings, to manage information useful for cultural heritage interventions, was used to complete the higher levels of detail of the database. The modelling of the individual buildings making up the Sacri Monti was carried out through the use of the Autodesk Revit software, through a reverse engineering process with which all the architectural elements were created, integrated with all the information necessary for planned maintenance at this scale. These made it possible to create virtual representations associated with information previously determined in the database's logical structure.

The processing of a large number of three-dimensional data collected during the digital survey has generated a series of georeferenced point clouds, allowing to work on separate models with the ability to reassemble each Sacri Monti's models through subsequent federation, thanks to the possibilities offered by the options of connection between models within the software used. This will allow end-users to view the entire complex or a single chapel based on their tasks and, therefore, access the information.

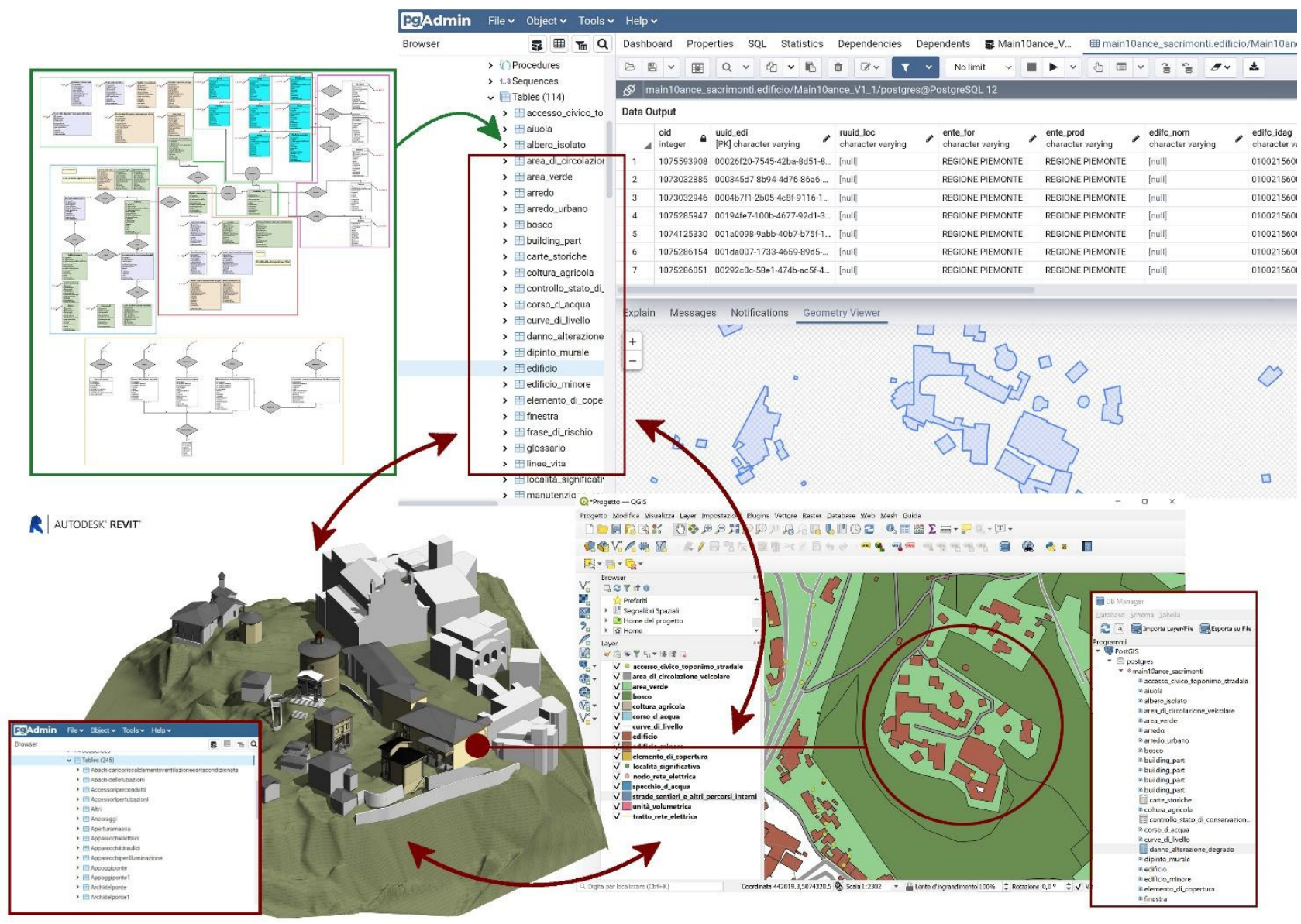

Figure 5: Connection between Main10ance DB with geometric and semantic data on PostgreSQL, QGIS DB and Revit-BIM DB (Sacro Monte of Varallo).

To model optimally and efficiently, the point clouds were divided into sections and subsections to facilitate operations and ease the software's computing load. In order to create the various elements making up the buildings of the Sacri Monti, a series of Revit families were created and subsequently parameterised, belonging to multiple categories (doors, windows, parapets, stairs, columns, etc.). This process of creating and parameterising families allows collecting, at the end of the modelling operations, a series of parametric objects which, gathered together, form a sort of database of historical BIM architectural elements, thus generating an additional project output that can be reused in future similar applications.

Finally, a script was created with Dynamo, a Visual Programming Language (VPL) tool, to test the possibility of creating a two-way information bridge between the modelling software and PostgreSQL. This made it possible to export not the entire BIM database as Revit DBLink would usually do, but to filter only the necessary geometric and alphanumeric information, populating the database attributes. These tests confirmed the possibility of achieving the final goal, the integration of GIS and BIM domains, combining data from different LODs from the 
territorial to the architectural scale, and also the bidirectionality of the data flow for a continuous updating of the models, all according to international standards (UNI 11337, ISO 19650).

\section{Discussions and Conclusions}

Built, historical and architectural heritage are values to be safeguarded and protected. For this reason, the design of a suitable tool that allows to manage and program maintenance activities is nowadays indispensable. Despite the known interoperability issues of BIM-GIS integration, this work aims to present a complete tool able to support maintenance plans of historical heritage. The database platform, developed with open source software, wants to be accessible and guarantee a user-friendly system to store, edit, and update $\mathrm{CH}$.

The interoperability of a database structure is essential for defining a complete instrument to operate at various scales of knowledge representation.
Finally, the ongoing research focuses on creating new controls, including a valuable dashboard for an immediate understanding of complex and multiscale data through graphs or charts and the option to modify only specific parameters according to the login type. This element lets the specialised user, authorised for the access, modify and record new data to be sent to the database.

\section{Acknowledgements}

For the present study, the authors would like to thank the director of management of the Sacri Monti and all the staff members for their support during all the project phases and the Department of the University of Italian Switzerland (SUPSI - Professional University School of Italian Switzerland) for the help and consultancy in the database design.

\section{References}

Brumana, R., Della Torre, S., Previtali, M., Barazzetti, L., Cantini, L., Oreni, D., \& Banfi, F. (2018). Generative HBIM modelling to embody complexity (LOD, LOG, LOA, LOI): surveying, preservation, site intervention-the Basilica di Collemaggio (L’Aquila). Applied geomatics, 10(4), 545-567.

Brumana, R., Georgopoulos, A., Oreni, D., Raimondi, A., \& Bregianni, A. (2013). HBIM for documentation, dissemination and management of built heritage. The case study of St. Maria in Scaria d'Intelvi. International journal of heritage in the digital era, 2(3), 433-451.

Brumana, R., Oreni, D., Raimondi, A., Georgopoulos, A., \& Bregianni, A. (2016). From survey to HBIM for documentation, dissemination and management of built heritage: The case study of St. Maria in Scaria d'Intelvi. In 2013 Digital Heritage International Congress (DigitalHeritage) (Vol. 1, pp. 497-504). IEEE.

Bruno, N., Rechichi, F., Achille, C., Zerbi, A., Roncella, R., \& Fassi, F.( 2020). Integration of historical GIS data in a HBIM system, Int. Arch. Photogramm. Remote Sens. Spatial Inf. Sci., XLIII-B4-2020, $427-434$. https://doi.org/10.5194/isprs-archives-XLIII-B4-2020-427-2020

Bruno, N., \& Roncella, R. (2019). HBIM for conservation: A new proposal for information modelling. Remote Sensing, 11(15), 1751

Calantropio A., Matrone, F., \& Lingua, A.(2019). Data integration of photogrammetric and laser-visual-inertial odometry based sensors in the metric survey of cultural heritage. Proceeding of R3 in GEOMATICS: Research, Results and Review, Naples 10-11 October.

Colucci, E., De Ruvo, V., Lingua, A., Matrone, F., \& Rizzo, G. (2020). HBIM-GIS integration: From IFC to cityGML standard for damaged cultural heritage in a multiscale 3D GIS. Applied Sciences, 10(4), 1356.

Diara, F., \& Rinaudo, F. (2020). Building Archaeology Documentation and Analysis Through Open Source Hbim Solutions via Nurbs Modelling. The International Archives of Photogrammetry, Remote Sensing and Spatial Information Sciences, 43, 1381-1388.

García, E. S., García-Valldecabres, J., \& Blasco, M. J. V. (2018). The use of HBIM models as a tool for dissemination and public use management of historical architecture: A review. Building Information Systems in the Construction Industry, 101.

García-Valldecabres, J., Pellicer, E., \& Jordan-Palomar, I. (2016). BIM scientific literature review for existing buildings and a theoretical method: proposal for heritage data management using HBIM. In Construction Research Congress 2016 (pp. 2228-2238).

Lingua, A., Noardo, F., Spanò, A., Sanna, S., \& Matrone, F. (2017).3D model generation using oblique images acquired by UAV. Int. Arch. Photogramm. Remote Sens. Spatial Inf. Sci., XLII-4/W2, 107-115. https://doi.org/10.5194/isprsarchives-XLII-4-W2-107-2017

Logothetis, S., Delinasiou, A., \& Stylianidis, E. (2015). Building information modelling for cultural heritage: a review. ISPRS Annals of the Photogrammetry, Remote Sensing and Spatial Information Sciences, 2(5), 177.

Matrone, F. (2018). Modelli HBIM da nuvola di punti: la verifica metrica dei dati e la valutazione dei risultati / Matrone, Francesca. - In: Bollettino della società italiana di fotogrammetria e topografia. - ISSN 1721-971X. - 2, pp. 1-9.

Matrone, F., Colucci, E., De Ruvo, V., Lingua, A., \& Spanò, A. (2019). HBIM in a semantic 3D GIS database. International 
Archives of the Photogrammetry, Remote Sensing \& Spatial Information Sciences.

Oreni, D., Brumana, R., Banfi, F., Bertola, L., Barazzetti, L., Cuca, B., \& Roncoroni, F. (2014). Beyond crude 3D models: from point clouds to historical building information modelling via NURBS. In Euro-Mediterranean Conference (pp. 166-175). Springer, Cham.

Tommasi, C., Achille, C., Fanzini, D., \& Fassi, F. (2020). Advanced Digital Technologies for the Conservation and Valorisation of the UNESCO Sacri Monti. In Digital Transformation of the Design, Construction and Management Processes of the Built Environment (pp. 379-389). Springer, Cham.

Tsilimantou, E., Delegou, E. T., Nikitakos, I. A., Ioannidis, C., \& Moropoulou, A. (2020). GIS and BIM as Integrated Digital Environments for Modelling and Monitoring of Historic Buildings. Applied Sciences, 10(3), 1078.

Vacca, G., Quaquero, E., Pili, D., \& Brandolini, M. (2018). GIS-HBIM INTEGRATION FOR THE MANAGEMENT OF HISTORICAL BUILDINGS. International Archives of the Photogrammetry, Remote Sensing \& Spatial Information Sciences, 42(2).

Yang, X., Grussenmeyer, P., Koehl, M., Macher, H., Murtiyoso, A., \& Landes, T. (2020). Review of built heritage modelling: Integration of HBIM and other information techniques. Journal of Cultural Heritage.

Zerbinatti, M., Matrone, F., \& Lingua, A. (2020). Planned maintenance for architectural heritage. experiences in progress from 3D survey to intervention programmes through HBIM. In: TEMA Technologies, Engineering, Materials, Architecture. 


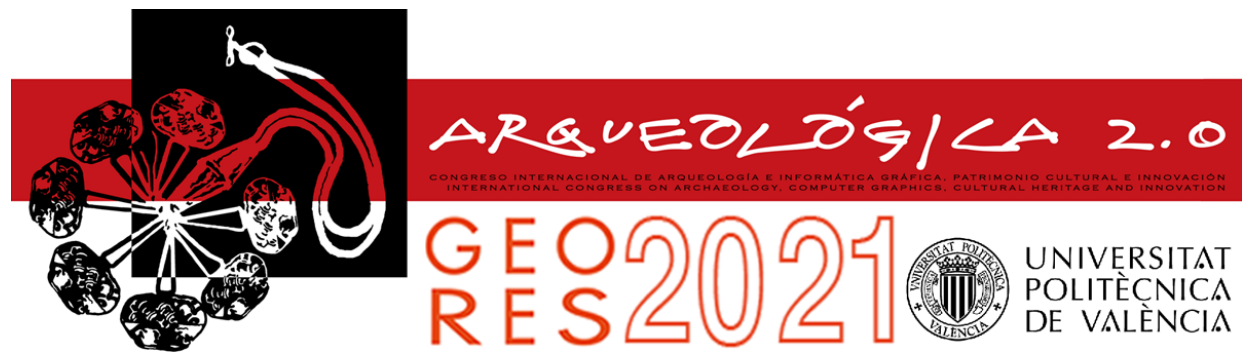

Proceedings of the joint international event $9^{\text {th }}$ ARQUEOLÓGICA

$2.0 \& 3^{\text {rd }}$ GEORES

Valencia (Spain).

26-28 April 2021

Received: 27/11/2020

Accepted: $13 / 03 / 2021$

DOI: https://doi.org/10.4995/Arqueologica9.2021.12132

\title{
3D GIS FOR A SMART MANAGEMENT SYSTEM APPLIED TO HISTORICAL VILLAGES DAMAGED BY EARTHQUAKE
}

\author{
Alban Gorreja*, Francesco Di Stefano, Fabio Piccinini, Roberto Pierdicca, Eva Savina Malinverni \\ Dipartimento di Ingegneria Civile, Edile e Architettura (DICEA), Università Politecnica delle Marche, Via Brecce Bianche 12, 60131 \\ Ancona, Italy. a.gorreja@pm.univpm.it; f.distefano@pm.univpm.it; f.piccinini@pm.univpm.it, r.pierdicca@staff.univpm.it; \\ e.s.malinverni@staff.univpm.it
}

\begin{abstract}
:
Historic villages are included in the category of cultural heritage to be safeguarded and preserved. Accidental events, such as earthquakes, represent a threat to their vulnerability. Usually, the analyses of damaged buildings, which are part of these villages, are then carried out singularly, not fostering instead the constitution of mapping at the urban scale that allows a more complete knowledge of the state of damage and risk of adjacent buildings and of the entire area. An information system such as 3D GIS is a suitable solution for this purpose. The aim of this research is to develop a SMART management system for preservation activities of historical villages through the management of heterogeneous types of data, from the survey to the technical documentation. The workflow is structured as follows: (i) Data acquisition: the survey of a small village was carried out by combining geomatic techniques necessary to produce a complete point cloud; (ii) 3D modelling: data extrapolation from the post-processed point cloud and subsequent generation of a GIS-based on 3D model thanks to the creation of DTM and DSM of the area of interest; (iii) Knowledge modelling: a geospatial information model is necessary to put in order and together all the information collected for the whole village and each building composing it; (iv) SMART management modelling: improvement of the information management system that guarantees the possibility to enrich and update data at any time. This research paves the way to develop a web platform where GIS data would be imported for a digital twin approach.
\end{abstract}

Keywords: historical village, GIS, knowledge modelling, SMART information management system, earthquake

\section{Introduction}

In recent years the use of three-dimensional (3D) modelling software and open-source platforms for SMART data management of urban and building projects has become increasingly frequent. The constantly updated regulations suggest and, in some cases, enforce the adoption of new sustainable, advanced and more accessible digital information systems. (Nam \& Pardo, 2011; Vinodkumar, 2016). This SMART approach is not only intended to represent optimal management of the data of one or more projects after a seismic event, but it also serves to define preventive measures (real-time data visualisation, disasters prediction, etc) that can be taken to deal with this type of emergency.

As a case study for this research project, one of the many villages damaged by the seismic events that hit central Italy in 2016 is chosen. Villages that represent a fullfledged historical and cultural heritage. Among these, there is a small village called "Gabbiano", located in the municipality of Pieve Torina, in the Marche region in Italy. It is characterized by a historic centre with a limited number of buildings that have suffered damage as a result of the earthquake that has affected this area. The aim of this research activity is to create a robust information system for the management of various types of data, from the survey to the technical documentation up to the following phases of the project through an information system such as GIS. The first step is to create a 3D model obtained through a combination of geomatic techniques. The entities composing the 3D geometric model become the object features of an organized knowledge modelling in order to have a precise connection with geometries, defined by a semantic representation following the CityGML schema. This leads to a SMART approach to the information management system that collects not only spatial data but also topological and not-geometrical data. The enriched knowledge modelling linked to the 3D object may represent a starting point for the digital twin approach, useful to manage the monitoring and restoration activities (Ketzler et al., 2020). This solution can be replicated in other similar case studies to safeguard these small villages that risk losing their historical, architectural, urban and social identity as a result of these accidental events. 


\section{State of the art}

The GIS platform is well suited for data management at the urban scale in a given geographical area. Moreover, 3D GIS software gives a three-dimensional model of the topographic representation of the terrain with the geolocalization of the buildings in the form of volumes at the various LODs (Level of Details) (Almeida, Gonçalves, Falcão, \& Ildefonso, 2016). It incorporates 3D territorial and buildings information giving a stronger, richer and clearer visual impact compared with a simple twodimensional GIS mapping. A 3D GIS can be used as a reference 3D map for any urban planning management activities and among them also in case of seismic emergency (Lenticchia \& Coïsson, 2017). In particular, GIS is suggested as a suitable tool for the risk mapping or better the spatial extent of risk in which document the effects of hazard situations, according to the ISO/IEC 31010:2009 and the Recommendations for National Risk Assessment (Poljanšek et al., 2019). An example of risk assessment in GIS was implemented for the data management of expected seismic scenario analysing a building complex in Lisbona (llic, Bento, \& Cattari, 2020). Other case studies to assess and manage the seismic damages and vulnerability in GIS were adopted for Scarperia (Cardinali et al., 2020) or to monitor the recovery plan after earthquake in L'Aquila (Contreras Blaschke, Tiede, \& Jilge, 2016).

It's possible to convert the 3D GIS modelling in an open data system thanks to the CityGML standard (OGC, 2020). CityGML is a common semantic information model for the representation of $3 \mathrm{D}$ urban objects that can be shared over different applications. It is an open-source data model and eXtendible Markup Language (XML)based format for the creation of city models (Gröger, Kolbe, Nagel, \& Häfele, 2012). CityGML is widely used in GIS city modelling and represents an open recognized standard and well-defined ontology. The hierarchical structure of data is provided by CityGML that thanks to its schema allows having a semantic representation that defines relationships between the various entities composing the 3D city model (Malinverni et al., 2020). CityGML-based approach that leads to defining a knowledge modelling where not only spatial but also external information, like topological, architectonical, technical data, is managed (Agugiaro, 2016). The benefits of using a centralized GIS-based information system, developed in CityGML environment, may guarantee an efficient, well-structured and SMART city management system (Banerjee, Chakraborty \& Das, 2020). This open-source GIS tool allows to map the damages and support the emergency planning for risk and hazard scenario like an earthquake (Pollino et al., 2012; Francini, Artese, Gaudio, Palermo, \& Viapiana, 2018).

\section{Methodology}

Following the data processing of the data acquired through the geomatic survey, which allowed the creation of mesh of the terrain, the volumes of the buildings in a 3D GIS environment can be generated. In parallel to the geometric modelling is defined a CityGML schema identifying the entities, such as roads, buildings and their features, composing the 3D model of the village and their relationships. This knowledge model will represent the starting point for a SMART management modelling of the entire village promoting advanced data management ensuring access by different figures as project experts and private clients who can constantly update with new data at any time.

The workflow shown in Figure 1 will be described below.

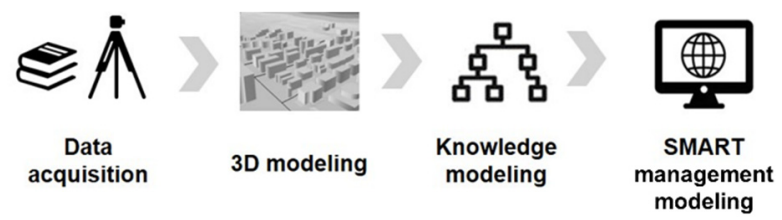

Figure 1: The research workflow.

\subsection{Data acquisition}

The survey of the small village "Gabbiano" was carried out by integrating three geomatic techniques: GNSS (Global Navigation Satellite System), terrestrial LIDAR (Light Detection And Ranging) and aerial photogrammetry from UAV (Unmanned Aerial Vehicle). The aim was to obtain the most comprehensive point cloud possible from which to create a complete $3 \mathrm{D}$ model. In fact, the terrestrial LIDAR is very useful to detect building facades facing the narrow alleys of the village, the aerial photogrammetry to complete the survey in detecting roofs and the GNSS to collect the coordinates of specific points through which georeferencing the whole generated point cloud. The terrestrial LIDAR scans registration process has led to a point cloud with a total network RMSE (Root Mean Square Error) of $6.82 \mathrm{~cm}$, while using $10 \mathrm{GCP}$ (Ground Control Points) for the photogrammetric processing of aerial images, a reconstruction with RMSE of $4.82 \mathrm{~cm}$ was achieved. These two have been merged into one unified point cloud (Fig. 2).

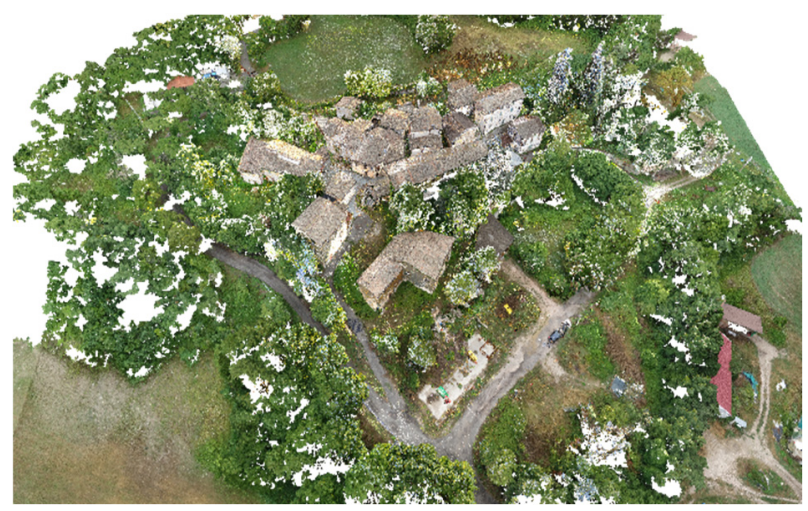

Figure 2: Unified point cloud.

\subsection{D modelling}

The availability of a numerical mapping at $1: 10.000$ scale by the Marche region, where the equidistance between contour lines is 10 meters, couldn't give a detailed 3D model of the small village. Therefore, the absence of an open-data platform that provides GIS data has led us to obtain the 3D model through the generation of mesh from the processed point cloud.

The extrapolation of data from point is useful for 3D modelling and can be conducted through an open-source 3D model management software. In this context CloudCompare (2021) was chosen, in order to ensure that the required data, such as the buildings base plan and their height above ground, are precisely calculated, 
taking into account the non-constant morphological distribution of the terrain. The "Rasterize" command allows to generate DTM (Digital Terrain Model) and DSM (Digital Surface Model) raster images. The latter is obtained using the entire point cloud and considering the maximum height of the points in each cell of the grid. For the former instead only the ground points must be used, which can be extracted thanks to the Cloth Simulation Filter (CSF) (Zhang et al., 2016), considering the average height of the points for each cell. In the empty cells, the height is interpolated. Importing the DTM in raster format in GIS it is easy to reproduce the TIN (Triangulated Irregular Network) model of the terrain on which the volumes of buildings are placed.

In order to obtain a correct map of the buildings, it has been drawn in CAD software using the point cloud as reference. Then we imported it as a vector layer of polygons in GIS to enrich the data in its attribute table. The mean height values from DTM and DSM on the area of each building is extracted thanks to the "Zonal Statistic" function, while the difference between them can be easily obtained using the field calculator. The latter constitute the extrusion height to use on each polygon to build up the 3D entities with good volumetric representation. In this case LOD 1 (Level of Detail - OGC, 2020) has been reached (Fig. 3). This level will increase once other useful information will be added to enrich the 3D modelling.

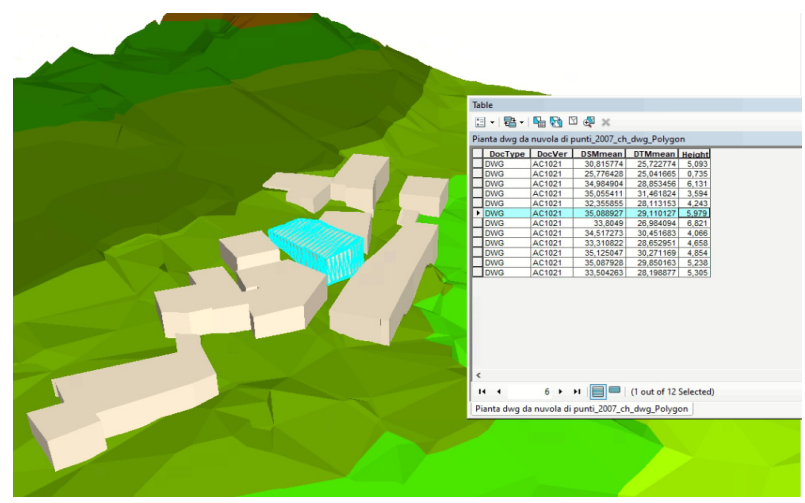

Figure 3: 3D GIS model (LOD 1).

\subsection{Knowledge modelling}

The 2016 seismic events made the analysis of the current state of the small village a priority for an adequate and rapid preservation project that would also takes into account the safety works carried out in the aftermath of the earthquake. For this study, the possibility to collect all these data into an information system enriching a 3D model represents a fundamental knowledge step for planning forthcoming interventions. An example of a detailed description of the damage state of these buildings in Italy is outlined on the technical data sheets called AeDES, whose acronym stands for "building operability and damage in post-earthquake emergency" (Baggio et al., 2007), recorded by the Italian Civil Protection. Through GIS it will be possible to create a link to these documents for each building and try to describe the state of damage by enriching the 3D model with thematic mappings of the decay (Malinverni, Giuliano, \& Mariano, 2018; Tsilimantou, Delegou, Nikitakos, Ioannidis, \& Moropoulou, 2020). Once collected the AeDES data sheets, the operation adopted is to store such files in a webserver and link each file with its building in the model. Using any GIS software, it can be done manually by adding to the table of attributes of the project a new column containing the reference path to where the information is stored. For large and complex models, it's not handy doing this for every building manually, an automatic process is suggested.

Since the 3D GIS model was converted into a CityGML model, many modifications, such as further data enrichment or even changes to the elements as well as the topography, can be done. In this step, corresponding between GIS and CityGML is possible to automatize the process of enriching information, such as AeDES sheets. A geospatial information model has been created with the aim to reach a common $3 \mathrm{D}$ city model allowing the reuse of data in other application fields of city management. These features make CityGML the best choice to follow. A new 3D model means a new ontological schema, necessary to put in order and together all the information collected for the entire village. In short, each building is represented by a CityObject of the village. Information related to each building are linked to the _CityObject with other features (subclass) thanks to the CityGML schema. The externalReference, already provided by CityGML, allows to link other types of data to the project object, for example technical documents (Fig. 4).

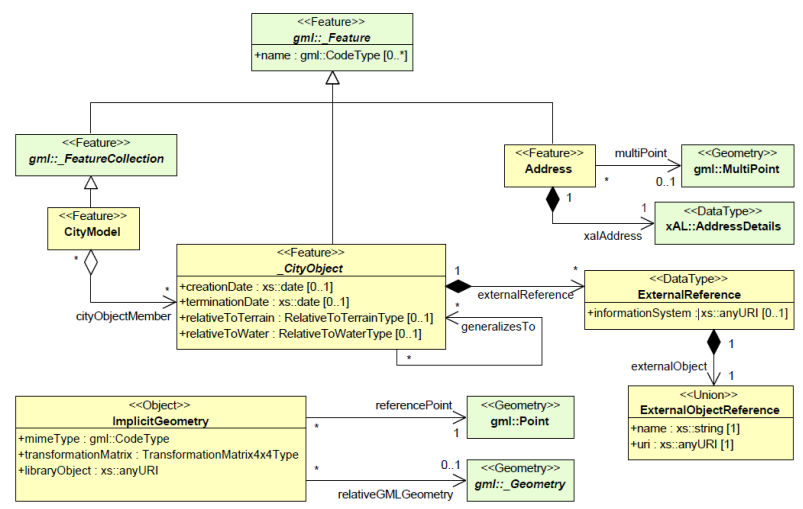

Figure 4: CityGML schema (OGC).

As just outlined, it is necessary to create a relationship between the 3D city object and external documents, but externalReference allows to link these data to the whole 3D city model, not for each single object composing the city model. A solution that can be adopted consists of using another element of the CityGML schema. The Address can be filled with different data for each building. Through FME (Feature Manipulation Engine) software it is possible to create a workflow of transformation tools that can modify the structure of the model itself. FME is a data integration and transformation platform. Leaving an empty column of an attribute within the GIS model, it is possible to fill it with information through FME (2019). It can be done automatically if the data are previously stored in XML format. FME allows redirecting the information stored in the XML to each building using the Address (Fig.5).

This means that the software will get a hypothetic address, write it in the empty attribute previously created. At this point, the attributes of each building in the CityGML model will show a link to the webserver (or local host, depending on where the data is stored) (Fig. 6). This ontological approach represents a valuable solution to link information to the 3D GIS model. 


\subsection{SMART management modelling}

A parametric navigable "virtual" model is very different from the previous systems where the information was limited to something graphic. Today, the advent of new technologies makes it possible to create information systems where information can not only be visualised in real-time in a navigable $3 \mathrm{D}$ environment, but can also be entered in real-time, processed and read by a user. In addition, given the complexity of the territory and cities, the information related to them may come from different sources and refer to different fields of application. A system designed in this way is a structure that represents the dual reality for which it is called a 'digital twin'. One of the aims of this research is to address this challenge by providing features and data from a GIS information system that will form part of, or better still define the basis for a digital twin model. Therefore, a working process as explained in the previous paragraph can help to move towards a detailed representation of reality. Generating a workflow where information is updated in a very short time can be a further development of the information management of an urban area. It may also save time and resources, both in the research project and for figures working in the AEC (Architecture, Engineering and
Construction) field and public institutions. The involvement of several figures within the planning of a recovery project such as the reconstruction of a village hit by an earthquake also allows common and optimal choices and decisions to be taken in a short time thanks to this open data platform (Artese \& Achilli, 2019).

These innovative aspects that allow an improvement of data management through an information system like GIS give it a development of the knowledge modelling towards SMART management modelling.
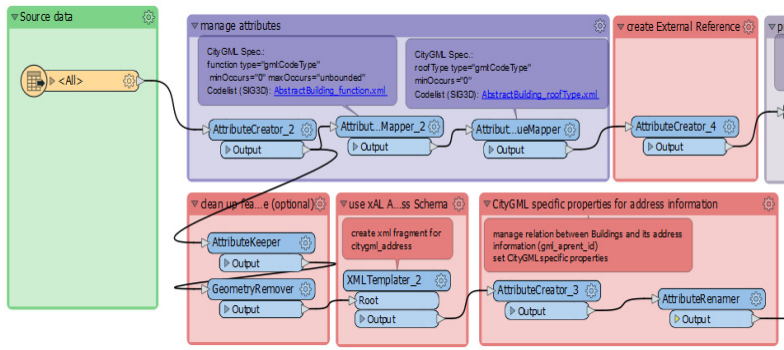

Figure 5: FME workflow showing address and external reference data enrichment.

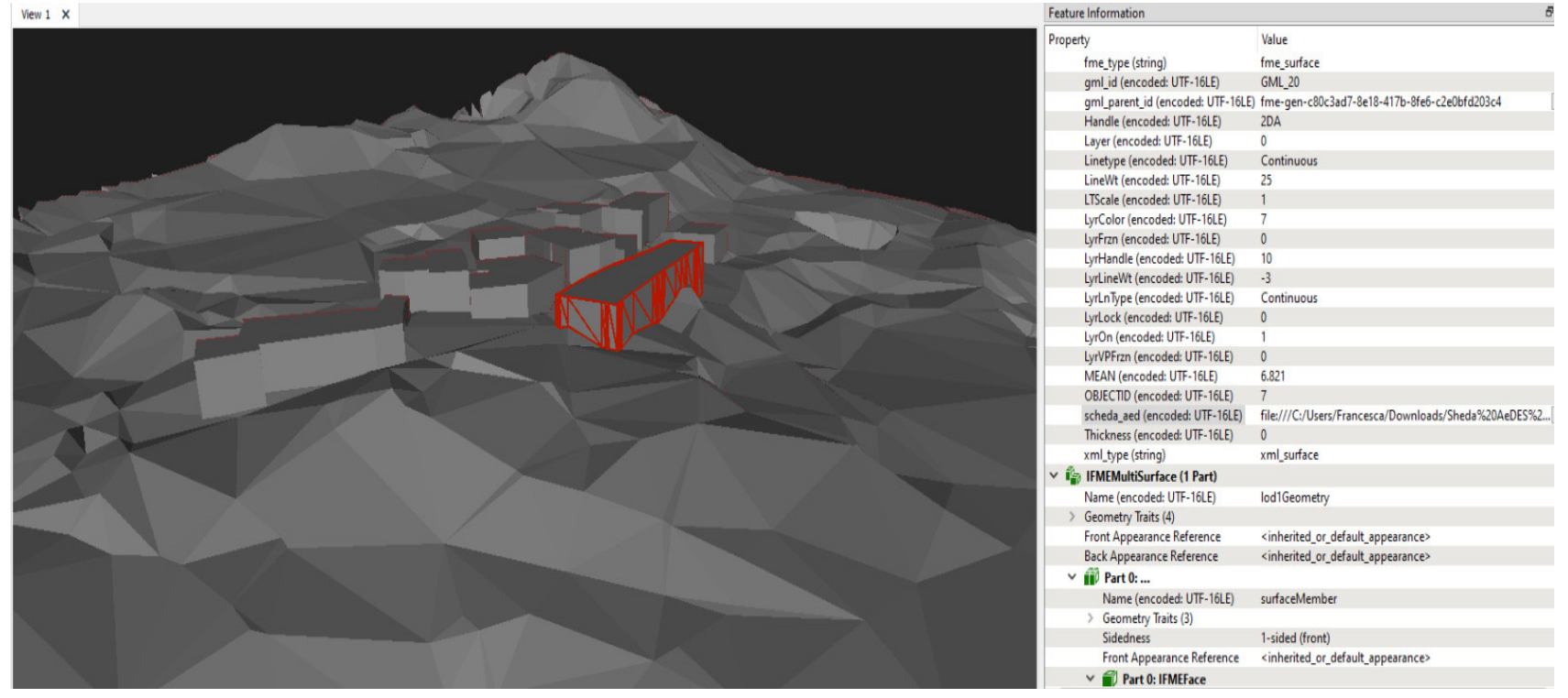

Figure 6: 3D CityGML: model and related attributes to the selected building.

\section{Conclusions and future works}

This is an ongoing project, there are only preliminary results of this research activity such as the creation of the 3D GIS model following the processing of the survey data and the definition of CityGML knowledge modelling for information management. The next step will be to perform this knowledge modelling adopting a SMART approach to the management system in order to ensure sustainability, accessibility, including the time factor needed to define the lifecycle of the interventions to be carried out. Phase also characterized by the constant data enrichment or updating of the information at any time.

In case of small villages, a large scale is required, which means that the information, associated with it, are significant. While a BIM model offers a great opportunity to represent a high level of detail on an architectural scale, it cannot guarantee this for an entire village. A 3D GIS model will be more appropriate, where the information contained is not only a 3D representation at a low LOD but contains all the information linked to the related model but also makes relationships between the different entities composing the village, from the terrain to the buildings themselves. But it's not excluded that, after a process of data standardization using CityGML or graph databases and data conversion into an exchange format (Malinverni et al, 2020), it will ensure a possible integration of GIS data with any BIM data of each building (Ma \& Ren, 2017), guaranteeing a sort of interoperability within a CDE (Common Data Environment) that will facilitate the archiving, sharing and dissemination of information. 


\section{Acknowledgements}

This work is part of the project "RICOSTRUZIONE SMART DEI BORGHI STORICI", which has been financed by the "PROGRAMMA OPERATIVO REGIONALE DEL FONDO EUROPEO DI SVILUPPO REGIONALE POR MARCHE FESR 2014/2020".

\section{References}

Agugiaro, G. (2016). First steps towards an integrated CityGML-based 3d model of Vienna. ISPRS Annals of Photogrammetry, Remote Sensing \& Spatial Information Sciences, 3(4). https://doi.org/10.5194/isprsannals-III-4139-2016

Almeida, A., Gonçalves, L., Falcão, A., \& Ildefonso, S. (2016). 3D-GIS Heritage City Model: Case study of the Historical City of Leiria. Proceedings of the 19th AGILE International Conference on Geographic Information Science, Helsinki, June 14-17.

Artese, S., \& Achilli, V. (2019). A GIS tool for the management of seismic emergencies in historical centers: how to choose the optimal routes for civil protection interventions. Int. Arch. Photogramm. Remote Sens. Spatial Inf. Sci., XLII2/W11, 99-106. https://doi.org/10.5194/isprs-archives-XLII-2-W11-99-2019

Baggio, C., Bernardini, A., Colozza, R., Corazza, L., Della Bella, M., Di Pasquale, G., Dolce, M., Goretti, A., Martinelli, A., Orsini, G., Papa, F., \& Zuccaro, G. (2007). Field Manual for post-earthquake damage and safety assessment and short-term countermeasures (AeDES). JRC Scientific and Thechnical Reports.

Banerjee, S., Chakraborty, C., \& Das, D. (2020). An Approach towards GIS Application in Smart City Urban Planning. Internet of Things and Secure Smart Environments: Successes and Pitfalls, 71.

Cardinali, V., Cristofaro, M. T., Ferrini, M., Nudo, R., Paoletti, B., \& Tanganelli, M. (2020). An Interdisciplinary Approach for the Seismic Vulnerability Assessment of Historical Centres in Masonry Building Aggregates: Application to the City of Scarperia, Italy. The International Archives of Photogrammetry, Remote Sensing and Spatial Information Sciences, 44, 667-674. https://doi.org/10.5194/isprs-archives-XLIV-M-1-2020-667-2020

CloudCompare. (2021). CloudCompare - Latest stable release (2.11.3 Anoia). Retrieved November 12, 2020, from https://www.danielgm.net/cc/

Contreras, D., Blaschke, T., Tiede, D., \& Jilge, M. (2016). Monitoring recovery after earthquakes through the integration of remote sensing, GIS, and ground observations: the case of L'Aquila (Italy). Cartography and Geographic Information Science, 43(2), 115-133. https://doi.org/10.1080/15230406.2015.1029520

FME. (2019). FME Workbench 2019.2. Retrieved November 12, 2020, from https://www.safe.com/

Francini, M., Artese, S., Gaudio, S., Palermo, A., \& Viapiana, M. F. (2018). To support urban emergency planning: A GIS instrument for the choice of optimal routes based on seismic hazards. International Journal of Disaster Risk Reduction, 31, 121-134. https://doi.org/10.1016/j.ijdrr.2018.04.020

Gröger, G., Kolbe, T. H., Nagel, C., \& Häfele, K. H. (2012). Open Geospatial Consortium OGC City Geography Markup Language (CityGML) Encoding standard.

Ilic, J. M., Bento, R., \& Cattari, S. (2020). 3DGIS representation for supporting seismic mitigation policies at urban scale: The case study of Lisbon. Journal of Cultural Heritage, 45, 265-278. https://doi.org/10.1016/j.culher.2020.04.001

ISO 31000:2009, Risk management - Principles and guidelines

IEC 31010:2009, Risk management - Risk assessment techniques

Ketzler, B., Naserentin, V., Latino, F., Zangelidis, C., Thuvander, L., \& Logg, A. (2020). Digital Twins for Cities: A State of the Art Review. Built Environment, 46(4), 547-573. https://doi.org/10.2148/benv.46.4.547

Lenticchia, E. \& Coïsson, E. (2017). The use of GIS for the application of the phenomenological approach to the seismic risk analysis: the case of the Italian fortified architecture. International Archives of the Photogrammetry. Remote Sens Spat Inf Sci, 42, 39-46. https://doi.org/10.5194/isprs-archives-XLII-5-W1-39-2017

Ma, Z., \& Ren, Y. (2017). Integrated application of BIM and GIS: an overview. Procedia Engineering, 196, $1072-1079$. https://doi.org/10.1016/j.proeng.2017.08.064

Malinverni, E. S., Giuliano, A. A., \& Mariano, F. (2018). 3D information management system for the conservation of an old deserted military site. In 2018 Metrology for Archaeology and Cultural Heritage (MetroArchaeo) (pp. 188-192). IEEE. https://doi.org/10.1109/MetroArchaeo43810.2018.13618

Malinverni, E. S., Naticchia, B., Lerma, J. L., Gorreja, A., Uriarte, J. L., \& Di Stefano, F. (2020). A semantic graph database for the interoperability of 3D GIS data. Applied Geomatics, 1-14. https://doi.org/10.1007/s12518-020-00334-3

Nam, T., \& Pardo, T. A. (2011). Smart city as urban innovation: Focusing on management, policy, and context. In 
Proceedings of the 5th international conference on theory and practice of electronic governance, 185-194. https://doi.org/10.1145/2072069.2072100

OGC. (2020). Open Geospatial Consortium - CityGML. Retrieved November 12, 2020, from https://www.ogc.org/standards/citygml

Poljanšek, K., Casajus Valles, A., Marin Ferrer, M., De Jager, A., Dottori, F., Galbusera, L., Garcia Puerta, B., Giannopoulos, G., Girgin, S., Hernandez Ceballos, M., Iurlaro, G., Karlos, V., Krausmann, E., Larcher, M., Lequarre, A., Theocharidou, M., Montero Prieto, M., Naumann, G., Necci, A., Salamon, P., Sangiorgi, M., Sousa, M. L, Trueba Alonso, C., Tsionis, G., Vogt, J., \& Wood, M. (2019). Recommendations for National Risk Assessment for Disaster Risk Management in EU, EUR 29557 EN, Publications Office of the European Union, Luxembourg, 2019, ISBN 97892-79-98366-5 (online). https://doi.org/10.2760/084707 (online), JRC114650.

Pollino, M., Della Rocca, A. B., Fattoruso, G., La Porta, L., Lo Curzio, S., Arolchi, A., James, V., \& Pascale, C. (2012). Open source GIS Tools to Map Earthquake Damage Scenarios and to Support Emergency. GEOProcessing 2012: The Fourth International Conference on Advanced Geographic Information Systems, Applications, and Services.

Tsilimantou, E., Delegou, E. T., Nikitakos, I. A., loannidis, C., \& Moropoulou, A. (2020). GIS and BIM as Integrated Digital Environments for Modeling and Monitoring of Historic Buildings. Applied Sciences, 10(3), 1078. https://doi.org/10.3390/app10031078

Vinodkumar, T. M. (2016). Geographic information system for smart cities. Copal Publishing Group

Zhang, W., Qi, J., Wan, P., Wang, H., Xie, D., Wang, X., \& Yan, G. (2016). An easy-to-use airborne LiDAR data filtering method based on cloth simulation. Remote Sensing, 8(6), 501. https://doi.org/10.3390/rs8060501 


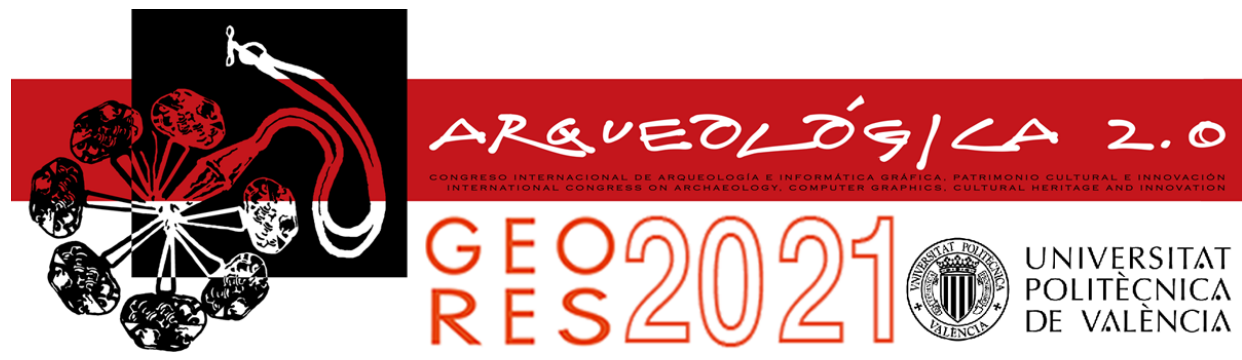

Proceedings of the joint international event $9^{\text {th }}$ ARQUEOLÓGICA

$2.0 \& 3^{\text {rd }}$ GEORES

Valencia (Spain).

26-28 April 2021

Received: 27/11/2020

Accepted: $17 / 03 / 2021$

DOI: https://doi.org/10.4995/Arqueologica9.2021.12133

\title{
THE LAST DECADE DEVELOPMENT OF PROJECT DATA MANAGEMENT THROUGH THE BIM
}

\author{
Francesco Di Stefano \\ Dipartimento di Ingegneria Civile, Edile e Architettura (DICEA), Università Politecnica delle Marche, Via Brecce Bianche 12, 60131 \\ Ancona, Italy. f.distefano@pm.univpm.it
}

\begin{abstract}
:
In the last decade, the management of data through information systems has become more widespread in the field of AEC. BIM represents a complete and integrated methodological approach based on a new process of modelling and interpreting reality into an information system. Starting from the data acquisition and collection, an initial geometric 3D model of the building can be designed. The lack of a direct connection between different information systems (e.g. BIM and GIS) for the same object forces to determine a common domain through the definition of an ontology. This semantic ontology will represent the basis of this knowledge model based on data coming from different information systems allowing data standardization and data enrichment operations. Thanks to the ontology, the threshold of interoperability between BIM and other information systems in a semantic web environment can be overcome. After a process of data conversion in exchange data format, a graph database can be built which collects all the heterogeneous data of the whole project. Ensuring access to anyone to the web graph database, it is possible to formulate a query for information recognition.
\end{abstract}

Keywords: geomatics, data management, BIM, ontology, interoperability, semantic web

\section{Introduction}

In the last decade, the management of data through information systems has become more widespread in the field of AEC (Architecture, Engineering and Construction) industry. Building Information Modelling (BIM) today represents a complete and integrated methodological approach based on a new process of modelling and interpreting reality into an information system. In short, BIM applications make it possible to: insert, in addition to 3D dimensional data, additional information useful for evaluating and analysing the project/model; manage and organise model objects parametrically; automatically update the relational database all the information about the building and the flow of data exchange between the actors involved in the construction process.

The advanced 3D model consists of individual building elements represented by 'intelligent' objects, i. e. objects that 'know' what they are and are associated with information describing their properties in relation to other objects. In several countries characterised by the progress of information technology, ad hoc regulations have been issued concerning and encouraging the use of such multi-data, multi-user and multi-purpose management platforms as BIM (Bradley, Li, Lark, \& Dunn, 2016).

While the use of parametric modelling for new buildings is becoming a stable reality, the paradigm of parametric modelling on historic buildings is slow to become established. There are several reasons for this, mainly related to the intrinsic characteristics of a historic building and the lack of a life-cycle concept.

HBIM (Murphy, McGovern \& Pavia, 2009) is a new way of modelling historic or existing building structures using a BIM process. HBIM is therefore a process that greatly increases the potential of the BIM method, because it also expands its use to the creation of models of existing buildings, and not only as their digital and geometric restitution in 3D, but as intelligent models rich in information, in which all the parts that compose them are objects with well-defined semantics. With HBIM, a kind of 'reverse engineering' is applied because, while modelling the building, the processes that led to the construction of that particular building organism are studied (López, Lerones, Llamas, Gómez-García-Bermejo \& Zalama, 2018).

Nowadays, there are several established geomatic techniques available, but for analysing historical assets, not all methodologies are always suitable. In particular, there are several factors to take into account, such as the accuracy and reliability of the survey, the adherence of the model to reality, the time and management of the historical data and so on.

Once initial parametric modelling of the components that make up the existing building been carried out, the challenge is to understand how to structure the data from a semantic point of view and to adopt a technique for standardization of the data. It is therefore necessary to define domains that help to determine a semantic hierarchy of the various entities and the relationships 
between them and the attributes associated with them. This introduces the concept of ontology, which is an innovative element that promotes data interoperability between a BIM platform and other information systems. For example, a building stands on terrain, so it has its own geolocation, but BIM software does not have the right tools to represent the terrain and define the buildingterrain relationship. The support of a geographic information system (GIS) becomes necessary in order to have a more complete representation of the context of this existing building. In this case, the ontology plays a decisive role in ensuring that there is a correspondence of the same data represented in different information systems that are characterised by a different semantic structure.

Interoperability between different information systems can be ensured with web-based tools. This will make it possible to produce information that can be made accessible by any user, thus defining so-called open data.

Concerning the interoperability between BIM and GIS, information systems are taken as an example for this research, it can be said that there are already software manufacturers such as ESRI and Autodesk that are implementing an integrated BIM-GIS platform (ESRI, 1969 ) but it is necessary to understand the dynamics that allow to operate in this extended platform and to improve this dual interoperability.

\section{Objectives of the research}

In this perspective, the objectives of the research project, on which it focuses most in order to highlight the innovative aspects linked to the development of the data management system using BIM, are as follows:

- Optimization of survey data through advanced geomatics techniques for 3D modelling;

- Semantic ontology as a common domain between BIM and other information management systems;

- Interoperability and data exchange between BIM and other information management systems.

\section{Critical literature review}

The integration of geomatics techniques is particularly relevant for accelerating spatial data collection from existing buildings (Gómez-García-Bermejo, Zalama \& Feliz, 2013). The accuracy can be ensured after a data optimization process (Akbarnezhad, Ong \& Chandra, 2014). Some research projects have been focused on optimizing modelling times (Biagini, Capone, Donato \& Facchini, 2016), combining data from the geomatic survey into BIM by the creation of parametric objects directly from the 3D point cloud, defining the most suitable levels of accuracy of the parametric model and characterizing it with data related to materials and construction techniques (Garagnani \& Manferdini, 2013; Spallone, Piano, A. \& Piano, S., 2016).

BIM software describes 3D geometry and identifies semantic relationships between building components basing on the hierarchical structure given by the software used. Some limitations of BIM software on data management, in comparison to other information systems, are linked to a lack of a defined LOD (Level of
Detail) structure. It needs to provide first an external wellstructured database, but it is often not easy to import it into BIM, especially for existing buildings. An example of scheme characterized by a semantic structure based on LOD can be offered by GIS (or better CityGML) (OGC, 1994). GIS is another information system that is well suited for cataloguing building data, but not only that, it also allows the building to be related to the terrain on which it stands. This is a further advantage over BIM.

Having said that, there are some dissimilarities between BIM and GIS, such as spatial scale, level of representation of geometric models and structure of database. In computer science, ontologies are adopted as domains providing a formal structure for sharing and managing data defining objects (taxonomies) and their relationships (El-Diraby, Lima \& Feis, 2005).

Ontologies are used to overcome the barriers to heterogeneous semantic data sharing (Hor, 2015). The definition of a semantic ontology as a common domain, for sharing and managing data coming from different information system, represents a valuable solution promoting a multidirectional approach between BIM and other information systems, such as GIS (Deng, Cheng \& Anumba, 2016).

The integration of data coming from different information modelling environment represents an efficient way for defining a smarter, more sustainable and resilient project. It gives the possibilities to combine heterogeneous data: geometric shapes, quantitative analysis, enrichment of semantic knowledge, application of different technologies and multi-scale management (Ma \& Ren 2017; Fosu, Suprabhas, Rathore \& Cory, 2015).

Data exchange between BIM and other information systems is ensured through interoperability, which is only possible through the web environment. While, syntactic interoperability refers to the use common data format to exchange information between BIM and GIS systems, using a domain of one of the information systems, a bidirectional approach is ensured (Deng, Cheng \& Anumba, 2016) through dual semantic interoperability between information systems. Examples of syntactic interoperability are systems that combine building data with landscape maps, data formats of BIM object on GIS environment, and solutions to convert BIM data from IFC (Industry Foundation Class) to CityGML (Kolbe, Gröger \& Plümer, 2005; Karimi \& Akinci, 2009; De Laat \& Van Berlo, 2011). The highest level of interoperability is guaranteed by the semantic aspect of data integration. The key point of semantic interoperability is to make sure that the features and relations between information management systems are maintained during data conversion (Peachavanish, Karimi, Akinci, \& Boukamp, 2006).

The semantic web technology represents new efficient online platform to make possible this kind of interoperability. The web ontology language (OWL) expresses the data in terms of classes. A collection of these classes, their attributes and relations can be stored as RDF triples describing each individual object, its properties and features, which can be understood as a graph-based on nodes (entities) and vertices (relationships) (Karan \& Irizarry, 2015; Hor, Jadidi \& Sohn, 2016). Taking this approach into account, it becomes possible to move forward a graph database 
direction, useful also for a BIM data interaction providing so a complete interoperability in the web environment and so allowing an eventually bidirectional way of data transfer between information systems.

\section{Materials and methods}

Starting from the data acquisition and collection, an initial geometric 3D model of the building can be designed, but first, some considerations must be taken into account. It needs to understand on which scale of detail to represent the various elements that make up the building structure according to the BIM scheme, how non-geometrical attributes can be linked to the 3D model and then how the building can be connected to the terrain where it stands.

First, a conceptual model is developed, which is then converted into a relational database to represent the basis of the semantic structure adopted for the BIM project. On the other hand, with the elaboration of a 3D model of the terrain in GIS environment, one tries to establish which LOD to operate at the building scale in order to find elements in common with those modelled in BIM.

The lack of a direct connection between these two information systems forces us to determine a common domain through the definition of an ontology.

This semantic ontology will represent the basis of this knowledge model based on data coming from different information systems allowing data standardization and data enrichment operations.

Thanks to the ontology, the threshold of interoperability between BIM and other information system in a semantic web environment can be overcome.

After a process of data conversion in exchange data format, a graph database can be built which collects all the heterogeneous data of the whole project. Ensuring access to anyone to the web graph database, also nonexperts, it is possible to formulate a query for the information recognition. A further step could be the link to a digital twin model.

The following flowchart summarizes the methodology of the research project (Fig. 1).

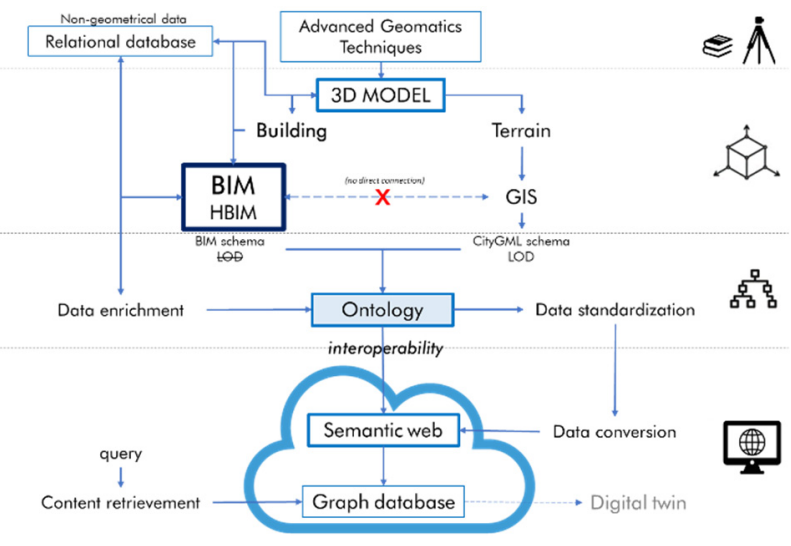

Figure 1: Workflow of the research project.

For the purpose of this research, existing, historical buildings or newly built artefacts, building complexes and small villages were taken as case studies. Not only the buildings are considered, but also their location, such as the ground on which they stand, in order to define relationships not only between elements of the same building but also with other buildings and the environment in which they are located.

\section{Partial results}

\subsection{Advanced geomatics techniques}

The improvement in technical skills with geomatics instruments by the PhD Student, led him to assess the data acquisition in different type of built environments. In particular, Mobile Laser Scanning (MLS), Mobile Mapping System (MMS) and devices with SLAM technology integrated to other geomatics techniques, when they occurred, has been carried out in different environments: structured outdoor environment (Di Stefano, Chiappini, Piccinini, \& Pierdicca, 2019), indoor cluttered environment (Paolanti et al., 2019) and tight underground environment. During the data processing phase, when the data obtained from different acquisition techniques are combined, the assessment of the final resolution is evaluated, just to ensure the higher accuracy of the final point cloud (Fig. 2) useful for the following 3D model design.

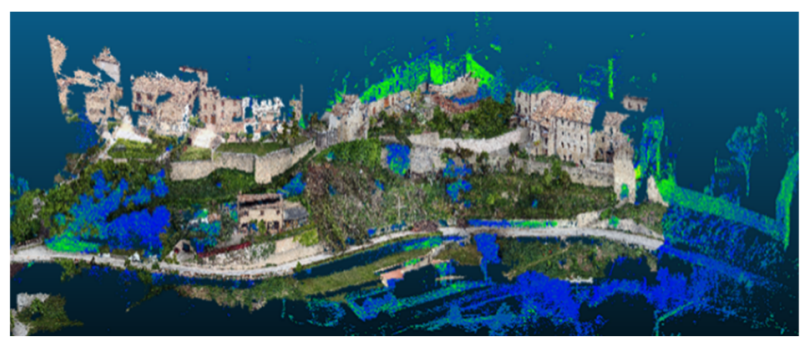

Figure 2: Example of integration and assessment of advanced geomatics technologies (city wall of San Ginesio, Italy).

The objective of this first part of the research activity is not to create a detailed 3D geometrical model, for example for the definition of parametric surfaces, but only to represents the volume of $3 \mathrm{D}$ objects for the management of information linked to them. In addition to modelling the buildings, the terrain is also modelled in GIS by obtaining DTM (or DSM) from the survey data (Fig. 3).

\subsection{Semantic ontology}

For each case study analysed, a conceptual model was drafted to identify the objects that would be created in the BIM modelling phase and to define the initial relationships between the objects and their components. Some BIM software does not allow each object to be named, so an identification system (ID-code) is created externally to classify it in the database within the software and make it easy to recognise (Di Stefano, Malinverni, Pierdicca, Fangi \& Ejupi, 2019).

In order to develop a strategy for building knowledge modelling to actively support the project process, it proposes a dual approach: one ontology-based to represent the semantic contents, especially nongeometrical information, one in BIM environment to represent the logic of the construction, above all geometrical-constructive aspects (Di Stefano, Gorreja, Malinverni \& Mariotti, 2020).

Some limitations of BIM, as parametric software, don't allow a direct importing of semantic ontology scheme, 
from an external tool. The structure of BIM software not based on a well-defined LOD (e.g. family-type-instance of Autodesk Revit) make it hard to find a correspondence with the ontological scheme. Before re-define this tripartite ontological structure in BIM software, it occurs to identify the domains that compose it. Taking as an example the case study of a historic building the ontological scheme, useful for a preservation and restoration management project, is characterized by four main domains such as artefact, investigation process, actors and lifecycle (Fig. 3a). This empirical representation (ontology) combined with the visual and descriptive 3D model provides a knowledge modelling of the historical artefact (Fiorani \& Acierno, 2017). The BIM model can be also enriched with thematic mapping that represents an adding information to the surfaces of the 3D object itself (e.g. decay mapping) (Malinverni, Mariano, Di Stefano, Petetta, \& Onori, 2019) (Fig. CityGML 3b). Then, through specific plug-in tools of BIM software, non-geometrical information, such as the glossaries of building regulations (e.g. decay glossaries), can be imported (Di Stefano, Gorreja, Malinverni \& Mariotti, 2020) (Fig. 3c).

The loading of digital libraries into BIM software allows rapid conversion of data into an interchange format. IFC (BuildingSMART, 2005) is the basic component of openBIM, the online BIM data management platform.

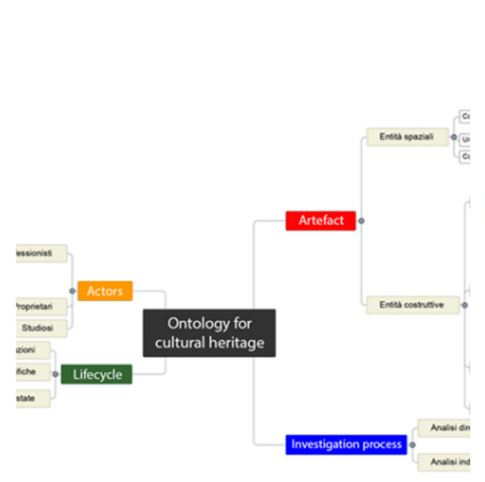

(a)

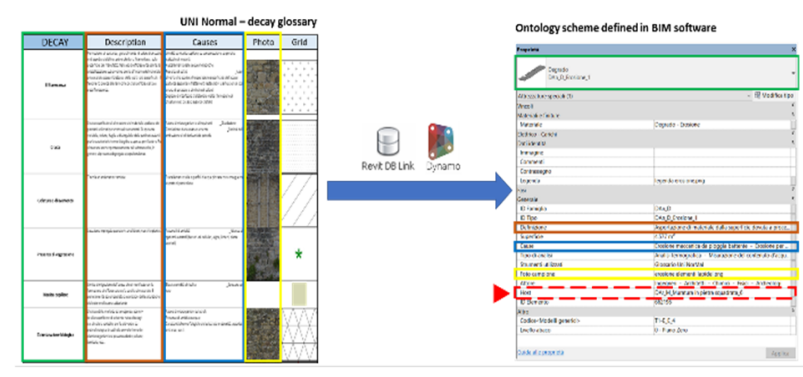

(c)

Figure 3: Management of information linked to 3D objects: a) A semantic ontology for a historical building; b) Thematic mapping on a BIM model (e.g. decay mapping); c) Conversion of a glossary into ontological scheme in BIM software.

\subsection{Interoperability and data exchange}

Up to now, it has been talking about BIM dealing with the management of data about a building, now the aim is to relate the building itself to the terrain on which it stands. GIS is the information system that best processes spatial data, allowing 3D models to be created at different scales of detail. The fictitious volume of the same building analysed in BIM is also created on the DTM (Fig.4), so as to have a common element that can link information from different information systems.

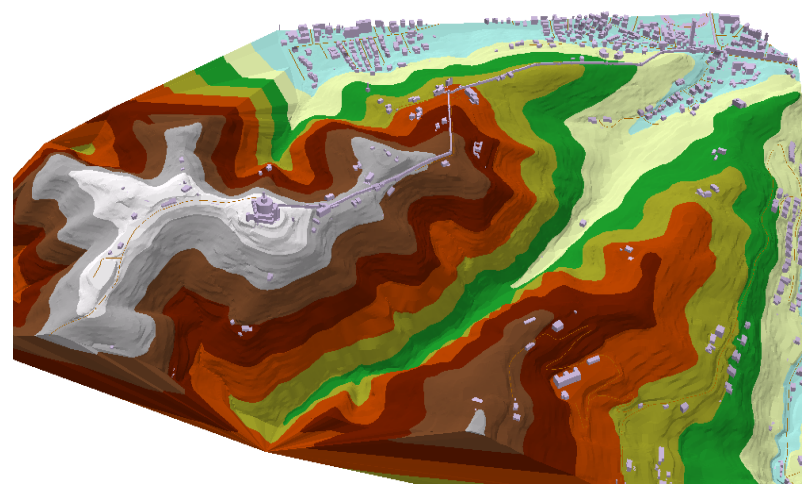

Figure 4: DTM with buildings (LOD 1).

But the lack of a direct connection between information systems like BIM and GIS does not allow to ensure the right information exchange. The solution is to adapt the ontology also for GIS data, enriching it, finding correspondences and creating relationships with BIM elements. The GIS ontology can be developed basing on CityGML scheme (OGC, 1994).

The creation of 3D GIS model of the same object analysed on BIM environment and its transformation in online format, CityGML, has been executed (Fig. 4). This process allowed to make a comparison between the CityGML scheme based on LOD and the BIM one based only on the tripartition structure, as previously mentioned. A process of data standardisation is necessary in order to identify common elements and determine correspondences. This leads to the creation of an integrated BIM-GIS ontology scheme (Fig. 5).

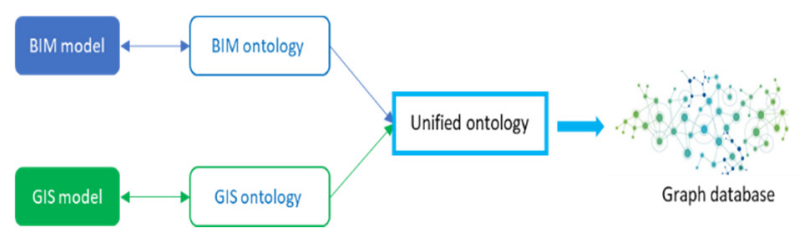

Figure 5: BIM-GIS ontology integration.

This unified ontological schema overcomes the threshold of interoperability between BIM and GIS through the definition of nodes that form the basis of the graph database created in the semantic web environment. This requires the conversion of BIM and GIS data into RDF triples. While BIM is already provided with digital libraries where IFC data are easily to convert to RDF format, transforming CityGML data in the same format required a longer process. According to the file formats supported by some graph databases, CityGML data has been converted into GeoJSON (OGC, 1994; Malinverni \& al., 2020).

Finally, obtained all data into lightweight interchange format, the ontological scheme can be directly transformed into a graph database. Graph databases belong to NoSQL databases, useful to store unstructured information. After comparing several graph database 
examples, ArangoDB was chosen for this research project (Fernandes \& Bernardino, 2018).

ArangoDB (ArangoDB, 2011) is a graph database based on documents and edges. The former store information, whereas the latter define relationships between data (Fig. $6)$.

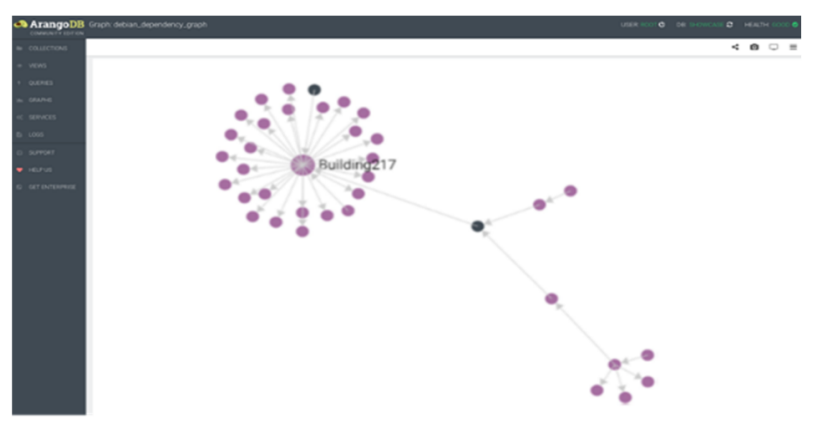

Figure 6: Example of a graph database created in the semantic web environment (Arango DB).

\section{Conclusions and future works}

Information management systems, related to building and urban planning, represent today a fundamental tool in both working and research fields. However, the exchange of data between information systems is still a huge challenge, while, if possible, it could bring enormous benefits. To guarantee the interoperability of data between BIM and other information systems (such as
GIS) it needs to use tools already standardized and accessible to everyone, which means basing on defined and known schemes and ontologies. Semantic web technology is used to get interpretable transferred data by both BIM and GIS environment.

The current main achievements of this research project are listed as follow:

- Assessment of the accuracy of acquired data after integration of different advanced geomatics technologies;

- Definition of semantic ontology for a building project;

- Overcoming of the limitations of BIM software to import an ontological scheme;

- 3D modelling in GIS environment defining the connection building-terrain;

- Definition of an integrated BIM-GIS ontology;

- GIS data conversion in RDF format through FME;

- A first attempt at graph database creation based on RDF triples obtained from GIS data.

In order to complete the PhD research, the planned activities are: check of the dual interoperability BIM-GIS through the graph database and testing the query formulation for content retrievement. Finally, a tentative approach to the digital twin model will be made.

\section{References}

Akbarnezhad, A., Ong, K. C. G., \& Chandra, L. R. (2014). Economic and environmental assessment of deconstruction strategies using building information modeling. Automation in Construction, 37, $131-144$. https://doi.org/10.1016/j.autcon.2013.10.017

ArangoDB. (2011). Arango DB Oasis. Retrieved July 15, 2019, from https://www.arangodb.com/

Biagini, C., Capone, P., Donato, V., \& Facchini, N. (2016). Towards the BIM implementation for historical building restoration sites. Automation in Construction, 71, 74-86. https://doi.org/10.1016/j.autcon.2016.03.003

Bradley, A., Li, H., Lark, R., \& Dunn, S. (2016). BIM for infrastructure: An overall review and constructor perspective. Automation in Construction, 71, 139-152. https://doi.org/10.1016/j.autcon.2016.08.019

BuildingSMART. (2005). Industry Foundation Classes (IFC). Retrieved July 15, 2019, from https://www.buildingsmartitalia.org/standard/standard-bs/industry-foundation-classes-ifc/

Deng, Y., Cheng, J.C. \& Anumba, C. (2016). Mapping between BIM and 3D GIS in different levels of detail using schema mediation and instance comparison. Automation in Construction, 67, 1-21 https://doi.org/10.1016/j.autcon.2016.03.006

De Laat, R., \& Van Berlo, L. (2011). Integration of BIM and GIS: The development of the CityGML GeoBIM extension. In Advances in 3D geo-information sciences (pp. 211-225). Springer, Berlin, Heidelberg. https://doi.org/10.1007/9783-642-12670-3_13

Di Stefano, F., Chiappini, S., Piccinini, F., \& Pierdicca, R. (2019). Integration and Assessment Between 3D Data from Different Geomatics Techniques. Case Study: The Ancient City Walls of San Ginesio (Italy). In International Workshop on R3 in Geomatics: Research, Results and Review (pp. 186-197). Springer, Cham. https://doi.org/10.1007/978-3-030-62800-0_15

Di Stefano, F., Malinverni, E. S., Pierdicca, R., Fangi, G., \& Ejupi, S. (2019). HBIM implementation for an ottoman mosque. Case of study: Sultan Mehmet Fatih ii mosque in Kosovo. International Archives of the Photogrammetry, Remote Sensing \& Spatial Information Sciences, 42, 429-436. https://doi.org/10.5194/isprs-archives-XLII-2-W15-429-2019

Di Stefano, F., Gorreja, A., Malinverni, E. S., \& Mariotti, C. (2020). Knowledge modeling for heritage conservation process: from survey to HBIM implementation. The International Archives of Photogrammetry, Remote Sensing and Spatial Information Sciences, 44, 19-26. https://doi.org/10.5194/isprs-archives-XLIV-4-W1-2020-19-2020

El-Diraby, T. A., Lima, C., \& Feis, B. (2005). Domain taxonomy for construction concepts: toward a formal ontology for construction knowledge. Journal of computing in civil engineering, 19(4), $394-406$. 
https://doi.org/10.1061/(ASCE)CO.1943-7862.0000646

ESRI (1969). Autodesk \& Esri - Collaboration Connects GIS and BIM. Retrieved March 11, 2019, from https://www.esri.com/en-us/about/esri-partner-network/our-partners/global-alliances/autodesk-esri

Fiorani, D., \& Acierno, M. (2017). Conservation process model (CPM): a twofold scientific research scope in the information modelling for cultural heritage. International Archives of the Photogrammetry, Remote Sensing \& Spatial Information Sciences, 42, 283-290. https://doi.org/10.5194/isprs-archives-XLII-5-W1-283-2017.

Fernandes, D., \& Bernardino, J. (2018). Graph Databases Comparison: AllegroGraph, ArangoDB, InfiniteGraph, Neo4J, and OrientDB. In DATA (pp. 373-380). https://doi.org/10.5220/0006910203730380

Fosu, R., Suprabhas, K., Rathore, Z., \& Cory, C. (2015). Integration of Building Information Modeling (BIM) and Geographic Information Systems (GIS)-a literature review and future needs. In Proceedings of the 32nd CIB W78 Conference, Eindhoven, The Netherlands (pp. 27-29).

Garagnani, S., \& Manferdini, A. M. (2013). Parametric accuracy: building information modeling process applied to the cultural heritage preservation. International Archives of the Photogrammetry, Remote Sensing and Spatial Information Sciences, 5(1), 87-92. https://doi.org/10.5194/isprsarchives-XL-5-W1-87-2013

Gómez-García-Bermejo, J., Zalama, E., \& Feliz, R. (2013). Automated registration of 3D scans using geometric features and normalized color data. Computer-Aided Civil and Infrastructure Engineering, 28(2), 98-111. https://doi.org/10.1111/j.1467-8667.2012.00785.x

Hor, A. H. (2015). A semantic Web platform for BIM-GIS integration. https://doi.org/10.13140/RG.2.1.4176.6643

Hor, A. H., Jadidi, A., \& Sohn, G. (2016). BIM-GIS integrated geospatial information model using semantic web and RDF graphs. ISPRS Ann. Photogramm. Remote Sens. Spat. Inf. Sci, 3(4), 73-79. https://doi.org/10.5194/isprs-annals-III4-73-2016

Karan, E. P., \& Irizarry, J. (2015). Extending BIM interoperability to preconstruction operations using geospatial analyses and semantic web services. Automation in Construction, 53, 1-12. https://doi.org/10.1016/j.autcon.2015.02.012

Karimi, H. A., \& Akinci, B. (2009). CAD and GIS integration. CRC Press.

Kolbe, T. H., Gröger, G., \& Plümer, L. (2005). CityGML: Interoperable access to 3D city models. In Geo-information for disaster management (pp. 883-899). Springer, Berlin, Heidelberg. https://doi.org/10.1007/3-540-27468-5_63

López, F. J., Lerones, P. M., Llamas, J., Gómez-García-Bermejo, J., \& Zalama, E. (2018). A review of heritage building information modeling (H-BIM). Multimodal Technologies and Interaction, 2(2), 21. https://doi.org/10.3390/mti2020021

Ma, Z., \& Ren, Y. (2017). Integrated application of BIM and GIS: an overview. Procedia Engineering, 196, $1072-1079$. https://doi.org/10.1016/j.proeng.2017.08.064

Malinverni, E. S., Mariano, F., Di Stefano, F., Petetta, L., \& Onori, F. (2019). Modelling in HBIM to document materials decay by a thematic mapping to manage the cultural heritage: the case of "Chiesa della Pietà" in Fermo. International Archives of the Photogrammetry, Remote Sensing \& Spatial Information Sciences. https://doi.org/10.5194/isprsarchives-XLII-2-W11-777-2019

Malinverni, E. S., Naticchia, B., Garcia, J. L. L., Gorreja, A., Uriarte, J. L., \& Di Stefano, F. (2020). A semantic graph database for the interoperability of 3D GIS data. Applied Geomatics, 1-14. https://doi.org/10.1007/s12518-02000334-37

Murphy, M., McGovern, E., \& Pavia, S. (2009). Historic building information modelling (HBIM). Structural Survey, $311-327$. https://doi.org/10.1108/02630800910985108

OGC. (1994). Open Geospatial Consortium. Retrieved July 15, 2019, from https://www.opengeospatial.org/standards/citygml

Paolanti, M., Pierdicca, R., Martini, M., Di Stefano, F., Morbidoni, C., Mancini, A., Christian Morbidoni, C., Malinverni, E.S., Frontoni, E., \& Zingaretti, P. (2019). Semantic 3D object maps for everyday robotic retail inspection. In International Conference on Image Analysis and Processing (pp. 263-274). Springer, Cham. https://doi.org/10.1007/978-3-03030754-7_27

Peachavanish, R., Karimi, H. A., Akinci, B., \& Boukamp, F. (2006). An ontological engineering approach for integrating $\mathrm{CAD}$ and GIS in support of infrastructure management. Advanced Engineering Informatics, 20(1), 71-88. https://doi.org/10.1016/j.aei.2005.06.001

Spallone, R., Piano, A., \& Piano, S. (2016). BIM and cultural heritage: multi-scalar and multi-dimensional analysis and representation of an historical settlement. DisegnareCON, 9(16), 13-1. 


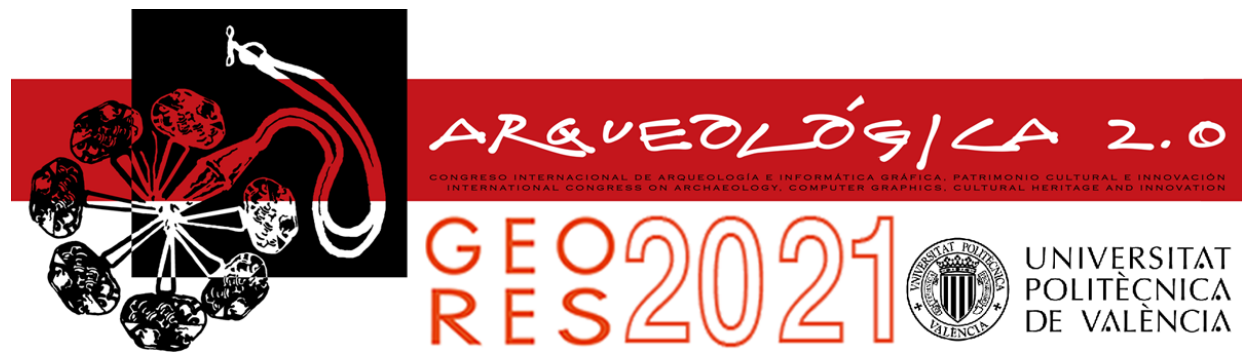

Proceedings of the joint international event $9^{\text {th }}$ ARQUEOLÓGICA

$2.0 \& 3^{\text {rd }}$ GEORES

Valencia (Spain).

26-28 April 2021

\title{
TECHNIQUES OF GEOMATICS AND SOFT COMPUTING FOR THE MONITORING OF UNSAFE BUILDINGS
}

\author{
Ernesto Bernardo a, ${ }^{,}$, Giuliana Bilottab \\ ${ }^{a}$ Department of Civil Engineering, Energy, Environment and Materials (DICEAM), Mediterranea University of Reggio Calabria, Via \\ Graziella Feo di Vito, 89124 Reggio Calabria, Italy. ernesto.bernardo@unirc.it \\ ${ }^{\text {b }}$ Department of Planning, University IUAV of Venice, Santa Croce 191 Tolentini, 30135 Venice, Italy. giuliana.bilotta@iuav.it
}

\begin{abstract}
:
The proposed research activity is part of the conservation of cultural heritage and is based on the study and development of advanced techniques for monitoring, inspecting and mapping building cracks in order to obtain and constantly update the safety status of building through a GIS platform. Data collection (initial and periodic) is one of the most important phases of the monitoring process and allows to obtain information about the integrity of the buildings, essential to plan future design and intervention choices. This can be carried out both through traditional tools (3D laser scanners, GNSS receivers, motorized total station) and innovative tools (such as remote sensing or UAVs). The goal of the research was the design and construction of an innovative automated system for monitoring and continuous data acquisition (big data). Furthermore, we implemented algorithms dedicated to the management of the amount of georeferenced data (big data) acquired. We optimized their representation on GIS (Geographic Information System) platforms in order to obtain an "open and updatable" thematic cartography, and set up a sort of Cadastre of unsafe buildings in the village of Casalvecchio Siculo (possibly extended to other villages in the future). This is intended (in our application) as an updatable IT tool for archiving, viewing, querying and managing all the data that the municipality and the regions have on their own villages. In it, it will be possible to represent the elements inherent to the geometric characteristics of the buildings, their relevance, the state of the cracks, the interventions carried out in the most important historical buildings and the systems created, having databases available that allow quick selective searches by topics.
\end{abstract}

Keywords: UAV, big data, virtual archaeology, digital archaeology, cultural heritage, 3D reconstruction

\section{Introduction}

This note refers to a series of activities developed by the Geomatics Laboratory of the Mediterranean University of Reggio Calabria in the context of Cultural Heritage (Bernardo, Musolino, \& Maesano, 2021) with particular reference to the monitoring, diffusion, dissemination of small villages. In particular, attention is focused on the development of a complex innovative and automated system capable of acquiring, processing and managing images by treating them with soft computing techniques in order to extract significant details of the area object of the image, transposing the results automatically into a GIS. These activities are experiments currently in progress within a PhD thesis that is part of the update of the Road Cadastre entitled: "Geomatics and soft computing techniques for monitoring infrastructure and managing big data".

For several decades, the introduction of electronic computers has led to a substantial revolution in the ability to analyze and collect data, a field that until now perhaps has not fully benefited from the latest technological advances of the digital age (Postorino, Barrile, \& Cotroneo, 2006). In practice, what used to be acquired in the field manually with punctual campaigns and consequently with relatively high time and cost, perhaps while leveraging advanced technologies, can now be made available through a growing number of devices such as sensors, actuators and cameras, characterized by ever-increasing automation (also in terms of the possibility of a subsequent integrated and dynamic analysis of the data) and increasingly reduced costs (Barrile, Bernardo, \& Fotia, 2020).

Among the many types of sensors that can be used in the monitoring of the building are already today consolidated examples of hardware systems aimed at quantifying virtually real-time, or almost, state of the crack, geometric elements of a building (for example, point clouds by laser scanning), etc (Shan \& Toth, 2018; Chen, Truong-Hong, Laefer, \& Mangina, 2018; Florkova, Duris, Veselovsky, Sedivý, \& Kovalova, 2018).

It will be possible to carry out visual inspections of the state of a building in a continuous and automatic way by drones, ground and air, using for the analysis of the 
collected data (in the form of instrumental measurements, but also images) of artificial intelligence, overcoming in this the intrinsic limits of a human operator in terms of fallibility and ability to compare a large amount of data variable over time.

The first effect of this evolution is the increase in the amount of building information that can be stored in databases, whose availability and number for stakeholders is growing at an exponential rate, also introducing the new aspect of dynamic data over time. At the same time, even traditional analytics and management systems are beginning to be insufficient to process such a large amount of big data (Bernardo, Barrile, \& Fotia, 2020). The archives of the managing bodies also contain the register of works, the history of maintenance interventions with the relative costs and all information related to the safety of important buildings. Therefore, one of the main elements of building network management becomes the punctual and predictive query and analysis system used to manage the database in order to arrive at informed decisions on the interventions to be carried out, also implementing decisions in the most real-time possible.

Although the amount of data can be considered a distinctive character, the heterogeneity and structure of the information strongly characterize this type of data and, even more so, it becomes essential to be able to rely on effective methods and as automated as possible, which enhance only the information useful for analysis, discarding unnecessary information to avoid overburdening the system, but without the risk of incurring in oversimplification or amplification of errors.

The biggest challenge of big data management lies in the development of methods capable of predicting future observations, optimize the information available, and at the same time find correlations between the information collected (Bernardo, Barrile, Fotia, \& Bilotta 2020). In this regard (management and use of the large amount of data acquired for building monitoring), the application reported in this note can be particularly useful. In fact, the aim of the research will be the design and implementation of an innovative system of measurement sensors and components to be equipped on technological data acquisition systems.

The research also consists of the implementation of algorithms dedicated to the management of the amount of georeferenced data obtained and their representation on GIS (Geographic Information System) platforms as "open and updatable" thematic cartography. These activities are in experimentation for a PhD thesis. This developed system is therefore an open GIS to be considered as a valid tool also for updating the Cadastre of unsafe Buildings; once completed and implemented it can be proposed to the Authorities responsible for its use.

\section{Materials and methods}

\subsection{Study Area}

We decided to test the experimental methodology on the town of Castelvecchio Siculo, an Italian municipality in the metropolitan city of Messina, one of the largest in eastern Sicily. The town, located at $420 \mathrm{~m}$. above sea level, on the slopes of Mount Sant'Elia, dominates the Valle d'Agrò and represents a reference point for cultural, artistic, architectural and naturalistic tourism. According to an Aragonese deed of 1351, the original Greek-Byzantine name of the town was "Palachorion" (Old Casale), a name which, over time, was translated into the Latin language "Rus Vetus", "Casale Vetus" and the current Casalvecchio. From the beginning of the Norman age until the eighteenth century it was under the jurisdiction of Savoca, from 1928 until 1939 a hamlet of Santa Teresa di Riva, finally an autonomous municipality (Fig. 1). There are numerous historical buildings of high quality.

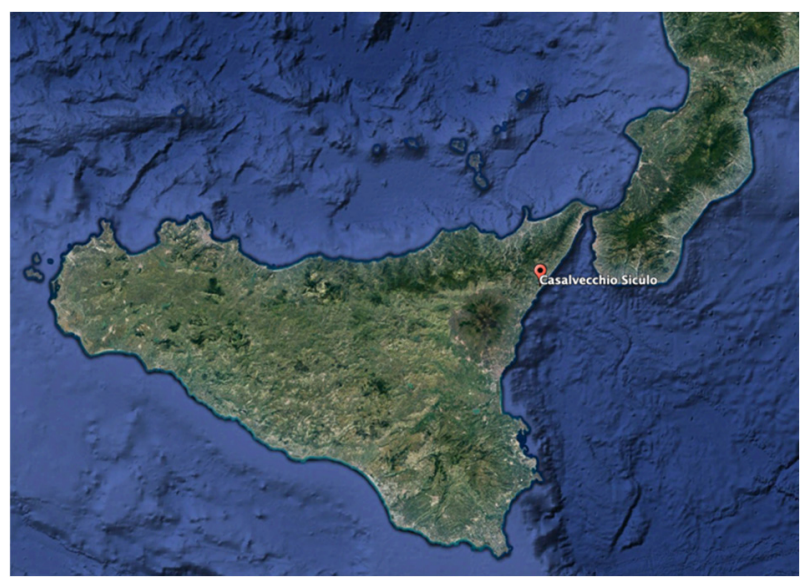

Figure 1: Casalvecchio Siculo, (ME), Sicily, Italy.

\subsection{Cadastre of unsafe buildings and proposed automatic update methodology}

The system we propose provides a fleet of drones that in fully automatic mode takes off and acquires images of the buildings to be monitored, then the images of the buildings are processed in order to highlight any damage present, also obtaining a 3D model of the same. The 3D models are transferred into an updatable GIS to obtain the safety level of the buildings according to the detected cracks. Keeping in mind the possible evolution of the cracks over time, the proposed system will allow the updating of 3D models by also implementing additional useful information characteristic of the building. These 3D models will be updated from time to time by implementing other useful information (architectural details of particular value, interior plans, links to view or download the BIM model). In particular, in this paper, we will focus on the experimental methodology used for the identification of cracks and therefore for the level of safety in the GIS by updating the attributes of the vector file with the results obtained from the elaboration of the methodology produced (Barrile \& Cotroneo, 2006).

The Cadastre of unsafe buildings of the village could have as its first objective to represent all the elements inherent to the geometric characteristics of the buildings, their relevance, the state of the cracks, the interventions carried out in the most important historic buildings and the systems created having databases available that allow fast selective searches by subjects.

The segmented attributes of elements could be grouped into homogeneous entities. Among these, the most significant could be: (1) cracks; (2) presence of exposed iron; (3) presence of humidity; (4) plaster damage; (5) construction type.

In this case, we experimented with an innovative procedure that involves the use of a properly designed 
fleet of drones that, proceeding from point $a$ to point $b$, allows the acquisition of images of the object of study. Subsequently, the images are processed by appropriate automated algorithms aimed at the identification of cracks, and their subsequent visualization and updating through base cartography on the GIS system (Barrile, Bernardo, Fotia, Candela, \& Bilotta, 2020). The acquired data are therefore high resolution images with high spatial sampling rates.

In this research activity, we focused specifically on the analysis of the attributes in the database that can be identified through the classification and segmentation of the images acquired by the proposed system in order to detect the presence of deterioration in the masonry.

\subsection{Innovative measurement system}

We used a fleet of automated drones connected to the cloud (or to a local network) that automatically recharge via special charging stations located at pre-established points (Fig. 2).

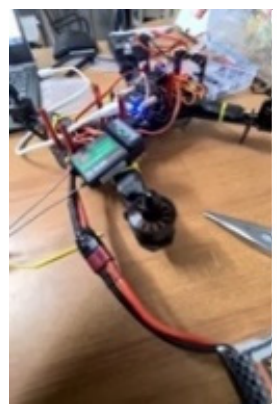

(a)

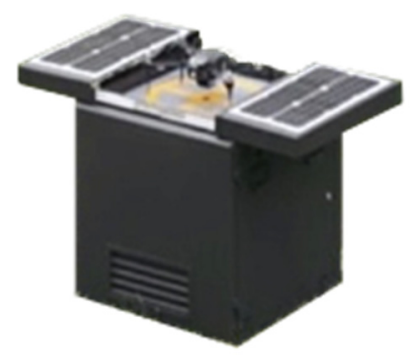

(b)
Figure 2: Automated drones: a) System components; b) Input/output wireless charging base.

The drone fleet sends real time data to the cloud platform, which is then processed by the algorithms to select the images.

The data acquisition system provides for the installation of different platforms along the path to be monitored to allow the drone battery to be recharged and the data necessary for subsequent processing to be transferred.

We have built an innovative monitoring system including drones, intelligent multi-landing and charging pads, automatically governed that communicate at short range with nearby drones and indicate the status of the station.

1) When a drone in flight detects that the battery is running low, it looks for the nearest charging station, the latter communicates to the drone if there is a free pitch and a charged battery available.

2) Having obtained the ok to land, the drone, knowing the GPS coordinates of the station, approaches and, moving vertically, lands on the assigned stand.

3) Once landed, a subsystem recharges the onboard battery or swaps it, automatically replacing the discharged battery with a charged one. During the replacement, the drone is still powered through a special connector in order not to lose communications and to allow the automatic procedure with the exchange of information. After recharging, take-off takes place.

The wireless charging station is made up of an "intelligent" induction plate which, when the drone lands, determines the type of batteries supplied to the aircraft, and thus establishes the correct charging parameters.

This is made possible thanks to a small device on board the drone consisting of a microcircuit with a data transmission system, weighing a few tens of grams and dimensions contained in the order of a few centimeters, such that it can be installed not only on large professional drones but also on smaller commercial ones.

These stations are totally waterproof and weatherproof and also serve as a temporary shelter for appliances. In particular, the process of this first experimentation is divided into three automated phases, schematized in the flow diagram in Figure 3, which include:

1) Definition of the flight plan, in terms of Ground Sampling Distance (GDS), overlapping of images and waypoints.

2) Image analysis: preprocessing - segmentation classification.

3) In order to improve the precision of the image processing and the identification of the investigated element, the use of different cascading algorithms was experimented which involve the combination of different methodologies (segregation; edge detector; Canny filter; Gaussian filter; Support Vector Machine - SVM).

4) Geo-localization of data on the GIS platform.

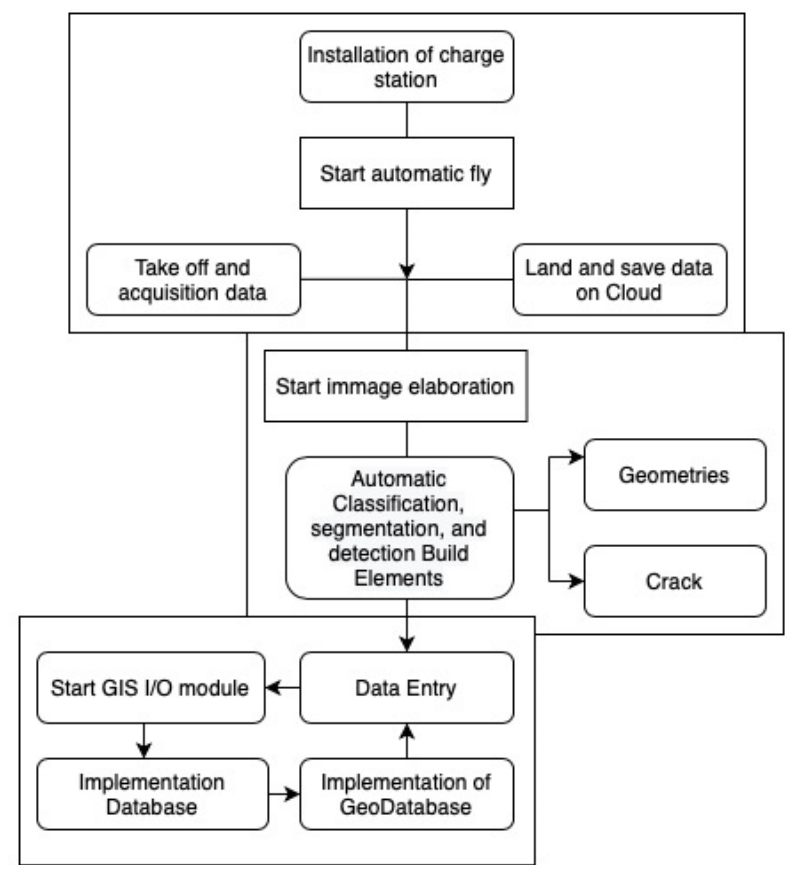

Figure 3: Workflow automatic system GIS integration.

Figure 4 shows the 3D restitution of the village of Casalvecchio Siculo from the study activities carried out by the Geomatics Laboratory as part of the Cultural Heritage (Bernardo \& Bilotta, 2021). By way of example, an image acquired by the system relating to the identification of cracks is shown (Fig. 5). 


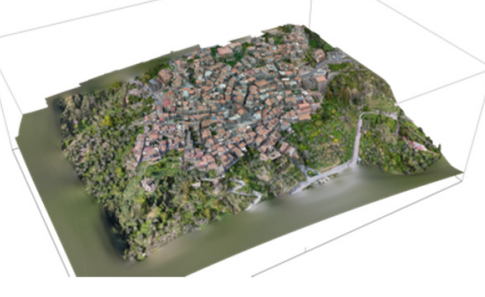

Figure 4: 3D model created.

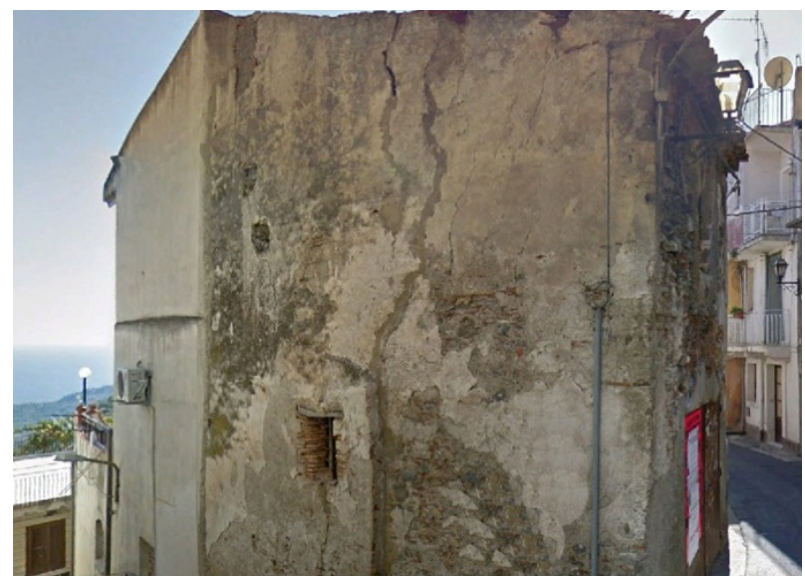

Figure 5: Image acquired by the drone relating to the identification of cracks.

\section{Result and discussion}

\subsection{Image acquisition and processing}

In order to populate the database we have suitably processed the images acquired through the described acquisition system, extracting the geometric characteristics of the buildings, the presence of decay in the walls. To better explain the procedure, an example of methodology applied to the classification of a single type of building crack is reported (Fig. 6).

The acquired images (Fig. 6a) were automatically subjected to a pre-processing and enhancement process (Sobel operator and Prewit), then they were segmented (edge detector, Canny filter, Gaussian filter) and classified (Support Vector Machine) to be able to extrapolate the information we need (Fig. 6b) (Grüen \& Li, 1997; Serna \& Marcotegui, 2014; Ameri, Dadrass Javan, \& Zarrinpanjeh, 2019; Dadrasjavan, Zarrinpanjeh, \& Ameri, 2019). In particular, the SVM classification was carried out in two phases:

1) SVM Training.

2) Performance testing.

In the first phase, the geometric characteristics of the linked components assigned for SVM training were initially calculated. Then, these features were normalized to a range. Kernel with radial base function (RBF) was chosen as a kernel trick, because the number of instances (connected regions) was not very large, and the size of the space transformed with RBF is infinite.
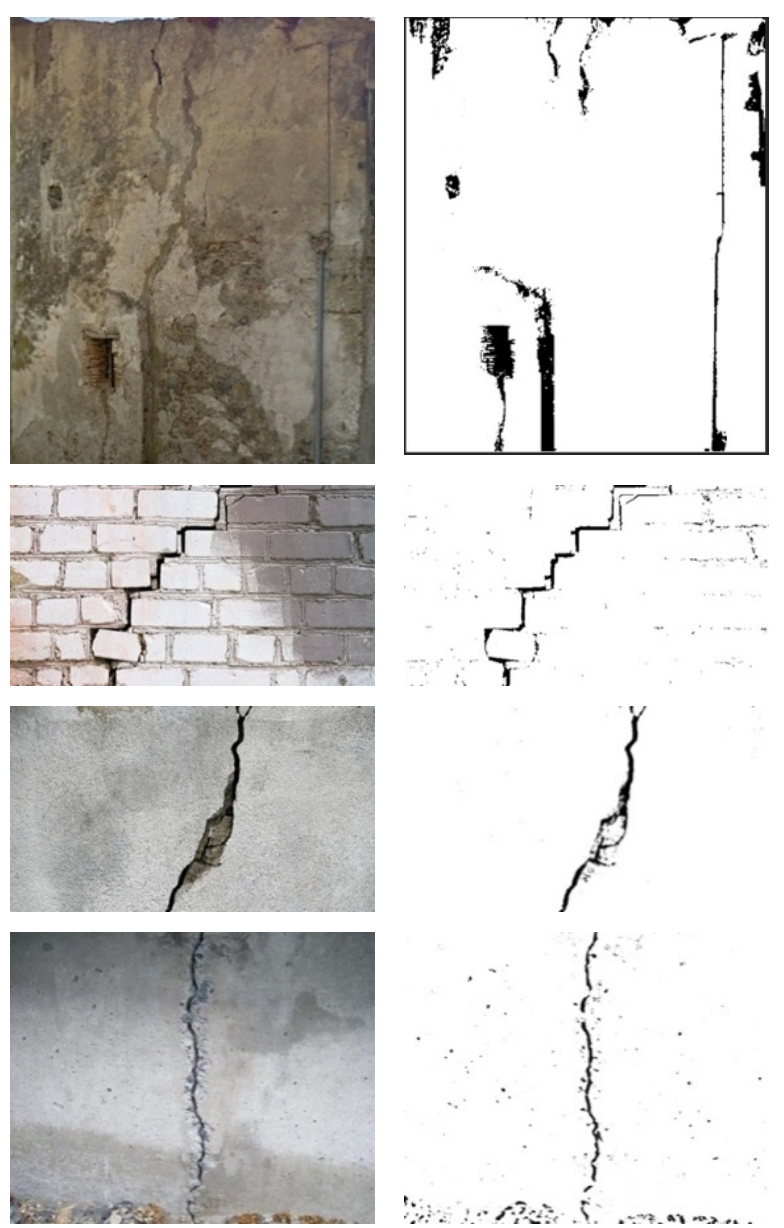

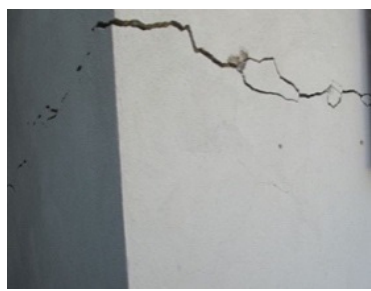

(a)

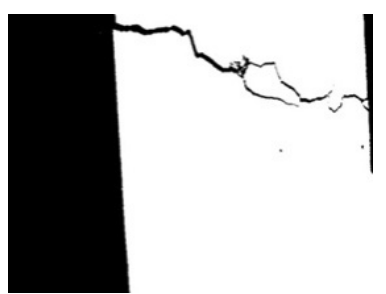

(b)
Figure 6: methodology applied to the classification of a single type of building crack is reported: a) Input Images; b) Crack detection.

The optimal training parameters for the SVM were found using grid search. During this operation, triple crossvalidation was performed to correctly learn the different types of cracks. In this triple cross-validation, the training set was divided into three equal subsets. To ensure proper learning, a subset was tested using the trained classifier on the remaining two subsets. The goal was to identify good parameters so that the classifier can predict test data effectively. After learning that the parameters had been determined, SVM was trained with the "One Against All" approach using the MATLAB LIBSVM library.

In the second phase, connected regions were tested that were not used during SVM training (Grüen \& Li, 1997; Hoang \& Nguyen 2019; Mancini, Malinverni, Frontoni, \& Zingaretti, 2013; Ogawa, Matsushima, \& Takahashi, 2019; Sari, Prakoso, \& Baskara, 2020; Sari, Prakoso, \& Baskara, 2019; Sekeroglu \& Tuncal, K. 2020; Tonkin \& Midgley, 2016). 


\subsection{Big data treatment}

The real value associated with the great availability of data lies not only in the quantity, but in the ability to use them to process, analyze and find objective evidence and correlations between various sectors, in the specific example in favour of the monitoring, inspection and mapping of building cracks at the in order to obtain and constantly update the safety status of buildings through a GIS platform.

Big Data, therefore, means the range of opportunities for analyzing the correlations on the data associated with this aspect, to be used for research, management and conservation applications of cultural heritage. To manage large amounts of data, basic technologies and specific technologies are required.

In this article, we want to describe a solution capable of correlating the large amount of data acquired thanks to the implementation of big data management algorithms. Specifically, these algorithms subsequently reprocess the previously processed images and the acquired data in order to identify if over time there has been an evolution of the crack, otherwise, they are discarded. Algorithms we have used for the treatment of big data (Gopalakrishnan, Gholami, Vidyadharan, Choudhary, \& Agrawal, 2018; Agrawal \& Choudhary, 2016; Bai, 2017; Deng et al., 2009):

- Linear regression (identifies the correlation between the input data and the output data).

- Logistic regression (it is used to give definitive answers: eg. Is the building worthy of attention yes or no?).

- Regression Trees (it is a decision-making system linked to several variables; it allows making a decision for the classification of data relating to different input variables).

- K-nearest neighbours and Kmeans clustering, the first has been used only partially because it is very expensive at the computational level and is affected by both the nature and the type of data to be processed. The second is a fairly fast algorithm at the computation level and presents as well as an easy implementation also an easy training phase, however, it turns out to be very sensitive to anomalous values.

\subsection{Database and Geodatabase}

As is well known, the data in a Geographic Information System are traditionally divided into "graphs" and "attribute". Graphs are organized in vector or raster structures while the attribute data are made up of tables connected to the graphical data and connectable to each other through the rules of the relational databases (through the application of SQL commands on the table structures appropriately). Vector graphic structures are those that mostly use SQL commands for the connection between attribute tables ("select" and "join" commands). Generally, in this way, the thematic cartography is produced, often as an integral part of extensive and indepth territorial studies. In these studies, the term "database" is sometimes used improperly, in the sense that the set of tables connected to graphic layers is defined as a database, very often not connected to each other in any way. A relational database, on the other hand, is a completely different thing or an archive of integrated and shared digital data, through the relationships created by the various keys in the fields of the tables. Storing a multitude of tables connected to graphic layers on a hard disk does not mean building a relational database.

We can define a database as a digital data store. Generally, a software called DBMS (Database Management System) manages databases. The management of a database consists of a whole series of operations for its operation, including data storage, deletion, display (access to the database), updating, processing. As for the data, these are stored only through tables (generally non-square matrices). Tables are made up of columns (fields) and rows (records). The data of a database must be integrated and shared. This feature is of fundamental importance for the correct and efficient functioning of the database.

As mentioned above, integration means avoiding the duplication of a data item in the archive. Integration ensures that information is managed efficiently (for example, updates are faster) and is a good premise to avoid errors within the archive. Data integration is achieved by relating the different tables that populate the database. Relationships are achieved through the equality of common fields ("key" fields).

If geometric components are also stored in the database tables, we can speak of spatial databases or geodatabases. In this way, the database structure acquires additional potential, linked to the spatial analyses (often also very advanced) made available. The management software becomes a "Spatial DBMS", able to perform spatial queries and geographical elaborations of the data obtained from them (Gustavsson, Seijmonsbergen, \& Kolstrup, 2008). Specifically, the database was built with:

- The trajectory graphic subsystem (in ASCII format containing trajectory information), Table 1.

- $\quad$ Photo capture units of the drone (JPEG image folders related to photographic capture, ASCII files containing the connection information between the trajectory data and the images,) Table 2

- What was indicated in the previous paragraph (JPEG image folders related to elaboration, ASCII files containing the connection information between the trajectory data and the elaborated images).

Since there are a multitude of these elements, it is necessary to put them in connection with each other by populating for each of them a table also containing a reference to an element of the upper level. Therefore, the data structure used consists of a set of the integrated relational tables some auxiliary tables that contain the source data and the information processed in progress (Monteiro, Costa, Pina, Santos, \& Ferrão, 2018).

In order to relate the data described above, initial processing is carried out which consists of the population of the table, with the grids and the placement of the 
images within folders with the same name assigned to the measurement session. Copies of the Trajectories table, exported in XML format, and the folders containing the images are then delivered to operators to make observations on frames. For the construction of the Geodatabase, we proceeded by creating and naming the database on pgAdmin and inside it the PostGIS spatial extension was inserted. A connection to the database was built on QGIS in pgAdmin and through the "DB manager" plugin, PostGIS was chosen among the available spatial extensions (thus ensuring the connection between the database and the layers); thus, creating the database tables with spatial component. The experimental system in operation, using the aforementioned automations, was tested on the reference area by acquiring a number of frames equal to 200 , transferred to the cloud and processed. In the post-processing phase, the entities detected automatically were georeferenced and shown on the screen (Fig. 7).

Table 1: Trajectories table.

Trajectories (contains survey data and association with photograms)

Id (primary key)

Id Session (unique identifier assigned to the survey session, and the name of folders containing the image files)

Time (numeric, instant of the measure)

Distance (numeric, odometric distance detected)

Latitude (numeric, latitude)

Longitude (numeric, longitude)

Altitude (numeric)

Heading (numeric)

Frame (string, measure associated file name)

Table 2: Table frame.

Frame (contains the pixel observations performed on the frames, the flat coordinates of the points in the map system and the classification of observations)

$$
\text { Id (primary key) }
$$

Id Session (foreign key to the Trajectories table)

Photogram (foreign key to the Trajectories table)

Typology (main classification numeric code)

Collocation (bin code to the axis [+, -, NULL])

Segmentation (Segment end marking [Start, End, NULL])

Element (numeric, elements road code)

Figure 7 shows the GIS capable of displaying the map of the buildings, the trajectories of the drones, the buildings where the cracks are present (highlighted in yellow). In particular, by clicking on the trajectory we can see all the images acquired, by clicking on the building we are able to identify the crack and the valuable elements.

We realized a first updated map showing the building network updated by the data collected by the proposed experimental system. The buildings are clearly visible from the images and both the presence of signs or artefacts and the conditions of the building surface can be determined. The images acquired by drone clearly show the details of the cracks, and the data can be acquired regularly, without the aid of operators, thus facilitating operations and reducing costs and times.

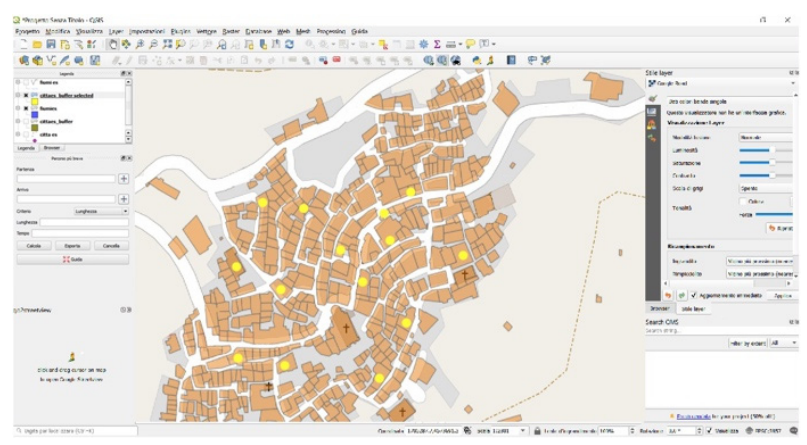

Figure 7: GIS elaboration.

The buildings can then be monitored and consequently facilitate the scheduled maintenance process. A building network geodatabase has been generated. The database shows the coordinate of the buildings identified in the study area, their types and conditions, etc. The study attests to the fact that UAV images can capture more information on the buildings than field investigations and can help in a variety of situations (Barbaro, Fiamma, Barrile, Foti, \& lelo, 2017).

In addition, work is underway on how to make the system usable in accordance with the new EASA regulations.

Moreover, other implementations and therefore additional information can be inserted into the Cadastre of unsafe Buildings. As for the Information System that we are implementing to propose to the municipality of Casalvecchio Siculo, we have populated the dataset with other additional information: census of the segmented attributes of buildings, crack monitoring data. In order to highlight the regions within the study area, that are more distressed from this point of view and then go to assess which are the most appropriate interventions to solve the problem (inserting noise barriers or traffic diversion interventions for example).

In addition, a basic function has been implemented for the planning of maintenance of various aspects such as the state of the masonry, the systems built and the complementary works.

For this purpose, in addition to the geometric and identifying information of the censused elements, the conservative and functional state must also be indicated, thus integrating the information entered in the Cadastre.

\section{Conclusions}

From an economic point of view, the system we created in order to obtain a Cadastre of unsafe buildings is very expensive; however, if implemented with safety, prevention and maintenance functions, it can be an excellent tool for public administrations, which can then plan interventions based on the indications contained within the GIS.

In fact, the Cadastre of buildings can be used with the sole purpose of taking a census of the existing building heritage of the villages. However, based on the acquired data, we could extend the knowledge to elements more aimed at planning maintenance activities such as the 
identification of buildings with a high level of danger (due to the presence of dangerous cracks) and the planning of interventions to increase safety. The databases were then enriched with a series of possible additional information useful for this purpose. It was therefore decided to analyze how to implement the cadastre of buildings in order to be able to use it for planning maintenance and restoration interventions.

Future developments will be aimed at the implementation of automation systems.

\section{Acknowledgements}

We thank the Geomatics laboratory of the Mediterranean University of Reggio Calabria in the person of Prof. Eng. Vincenzo Barrile (scientific and technical manager of the laboratory) and Eng. Antonino Fotia, for support in the complex and different phases of the entire process covered by the $\mathrm{PhD}$ thesis of one of the authors of the article.

\section{References}

Agrawal, A., \& Choudhary, A. (2016). Perspective: Materials informatics and big data: Realization of the "fourth paradigm" of science in materials science. APL Materials 4(5), 1-9. https://doi.org/10.1063/1.4946894

Ameri, A., Dadrass Javan, F., \& Zarrinpanjeh, N. (2019). Automatic Pavement Crack Detection Based on Aerial Imagery. Journal of Geomatics Science and Technology, 9(1), 145-160

Bai, S. (2017). Growing random forest on deep convolutional neural networks for scene categorization. Expert Systems with Applications, 71. 279-287

Barbaro, G., Fiamma, V., Barrile, V., Foti, G., \& lelo, G. (2017). Analysis of the shoreline changes of Reggio Calabria (Italy). International Journal of Civil Engineering and Technology, 8(10), 1777-1791.

Barrile, B., Bernardo, E., \& Fotia, A. (2020). GPS/GIS system for updating capable faults in the Calabrian territory through the use of soft computing techniques. European Association of Geoscientists \& Engineers. Conference Proceedings, International Conference of Young Professionals «GeoTerrace-2020», 2020 (1), p.1-5. https://doi.org/10.3997/22144609.20205710

Barrile, V., Bernardo, E., Fotia, A., Candela, G., \& Bilotta, G. (2020). Road safety: Road degradation survey through images by UAV. WSEAS Transactions on Environment and Development, 16, 649-659, ISSN: $2224-3496$. https://doi.org/10.37394/232015.2020.16.67

Barrile, V., \& Cotroneo, F. (2006) A software for the automatic update of the road cadastre in the GIS environment. Bulletin of the Italian society of photogrammetry and topography.

Bernardo, E., Barrile, V., \& Fotia, A., (2020). Innovative UAV methods for intelligent landslide monitoring. European Association of Geoscientists \& Engineers Conference Proceedings, International Conference of Young Professionals «GeoTerrace-2020», 2020 (1), 1 - 5. https://doi.org/10.3997/2214-4609.20205713. issn: 2214-4609

Bernardo, E., Barrile, V., Fotia, A., \& Bilotta, G. (2020). Landslide susceptibility mapping with fuzzy methodology. European Association of Geoscientists \& Engineers, Conference Proceedings, International Conference of Young Professionals «GeoTerrace-2020», 2020 (1), 1-5. https://doi.org/10.3997/2214-4609.20205712. issn: 2214-4609

Bernardo, E., \& Bilotta, G. (2021). Monumental Arc 3D Model Reconstruction Through BIM Technology. In: Bevilacqua C., Calabrò F., Della Spina L. (eds) New Metropolitan Perspectives. NMP 2020. Smart Innovation, Systems and Technologies, 178. Springer, Cham. https://doi.org/10.1007/978-3-030-48279-4_148

Bernardo, E., Musolino, M., \& Maesano, M. (2021). San Pietro di Deca: From Knowledge to Restoration. Studies and Geomatics Investigations for Conservation, Redevelopment and Promotion. In: Bevilacqua C., Calabrò F., Della Spina L. (eds) New Metropolitan Perspectives. NMP 2020. Smart Innovation, Systems and Technologies, 178. Springer, Cham. https://doi.org/10.1007/978-3-030-48279-4_147

Chen, C., Seo, H. S., Zhao, Y., Chen, B., Kim, J. W., Choi, Y., \& Bang, M. (2019). Automatic Pavement Crack Detection Based on Image Recognition. International Conference on Smart Infrastructure and Construction, (ICSIC), 361-369. https://doi.org/10.1680/icsic.64669.361

Chen, S., Truong-Hong, L., Laefer, D. F., \& Mangina, E., (2018). Automated Bridge Deck Evaluation through UAV Derived Point Cloud. CERI-ITRN2018, Dublin, Ireland, 735-740.

Dadrasjavan, F., Zarrinpanjeh, N., \& Ameri, A. (2019). Automatic Crack Detection of Road Pavement Based on Aerial UAV Imagery. Preprints, 2019070009. https://doi.org/10.20944/preprints201907.0009.v1

Deng, J., Dong, W., Socher, R., Li, L., Li, K., Fei-fei, L., (2009). Imagenet: A large-scale hierarchical image database. In Proceedings of the 2009 IEEE Conference on Computer Vision and Pattern Recognition (CVPR), $248-255$. https://doi.org/10.1109 / CVPR.2009.5206848

Florkova, Z., Duris, L, Veselovsky, M., Sedivý, S., \& Kovalova, D. (2018). Three-dimensional mobile mapping system and its use in road engineering. MATEC Web Conf., 196(04082). https://doi.org/10.1051/matecconf/201819604082

Gopalakrishnan, K., Gholami, H., Vidyadharan, A., Choudhary, A., \& Agrawal, A. (2018). Crack damage detection in unmanned aerial vehicle images of civil infrastructure using pre-trained deep learning model. International Journal 
for Traffic and Transport Engineering, 8(1), 1-14. http://dx.doi.org/10.7708/ijtte.2018.8(1).01

Gustavsson, M., Seijmonsbergen, A., \& Kolstrup, E, (2008). Structure and contents of a new geomorphological GIS database linked to a geomorphological map - With an example from Liden, central Sweden. Geomorphology, 95(34), 335-349. https://doi.org/10.1016/j.geomorph.2007.06.014

Grüen, A., \& Li, H. (1997). Linear feature extraction with 3-D LSB-snakes. Automatic Extraction of Man-Made Objects from Aerial and Space Images, 2, 287-298.

Hoang, N., \& Nguyen, Q. (2019). A novel method for asphalt pavement crack classification based on image processing and machine learning. Engineering with Computers, 35, 487-498. https://doi.org/10.1007/s00366-018-0611-9

Mancini, A., Malinverni, E. S., Frontoni, E., \& Zingaretti, P. (2013). Road pavement crack automatic detection by MMS images. 21st Mediterranean Conference on Control and Automation, Chania, 1589-1596. https://doi.org/10.1109/MED.2013.6608934

Monteiro, C., Costa, C., Pina, A., Santos, M., \& Ferrão, P. (2018). An urban building database (UBD) supporting a smart city information system. Energy and Buildings, 158, 244-260. https://doi.org/10.1016/j.enbuild.2017.10.009

Ogawa, S., Matsushima, K., \& Takahashi, O. (2019). Efficient Pavement Crack Area Classification Using Gaussian Mixture Model Based Features. International Conference on Mechatronics, Robotics and Systems Engineering (MoRSE), Bali, Indonesia, 75-80. https://doi.org/10.1109/MoRSE48060.2019.8998713

Postorino, M.N., Barrile, V., \& Cotroneo, F. (2006). Surface movement ground control by means of a GPS-GIS system. Journal of Air Transport Management, 12(6), 375-381. https://doi.org/10.1016/j.jairtraman.2006.09.003

Sari, Y., Prakoso, P. B., \& Baskara, A. R. (2020). Application of neural network method for road crack detection. TELKOMNIKA, Telecommunication, Computing, Electronics and Control, 18(4), 1962-1967. https://doi.org/10.12928/TELKOMNIKA.v18i4.14825

Sari, Y., Prakoso P. B., \& Baskara, A. R. (2019). Road Crack Detection using Support Vector Machine (SVM) and OTSU Algorithm. $6^{\text {th }}$ International Conference on Electric Vehicular Technology (ICEVT), Bali, Indonesia, $349-354$. https://doi.org/10.1109/ICEVT48285.2019.8993969

Sekeroglu, B., \& Tuncal, K. (2020). Image Processing in Unmanned Aerial Vehicles. Al-Turjman F. (eds) Unmanned Aerial Vehicles in Smart Cities. Unmanned System Technologies, Springer, Cham, 167-179. https://doi.org/10.1007/9783-030-38712-9_10

Serna, A., \& Marcotegui, B. (2014). Detection, segmentation and classification of 3D urban objects using mathematical morphology and supervised learning. ISPRS J. Photogrammetry Remote Sens. 93, 243-255.

Shan, J., \& Toth, C. K. (2018). Topographic Laser Ranging and Scanning: Principles and Processing. Second Edition. CRC Press, Taylor \& Francis Group.

Tonkin, T. N., \& Midgley, N. G. (2016). Ground-Control Networks for Image Based Surface Reconstruction: An Investigation of Optimum Survey Designs Using UAV Derived Imagery and Structure-from-Motion Photogrammetry. Remote Sens., 8(9), 786. https://doi.org/10.3390/rs8090786 


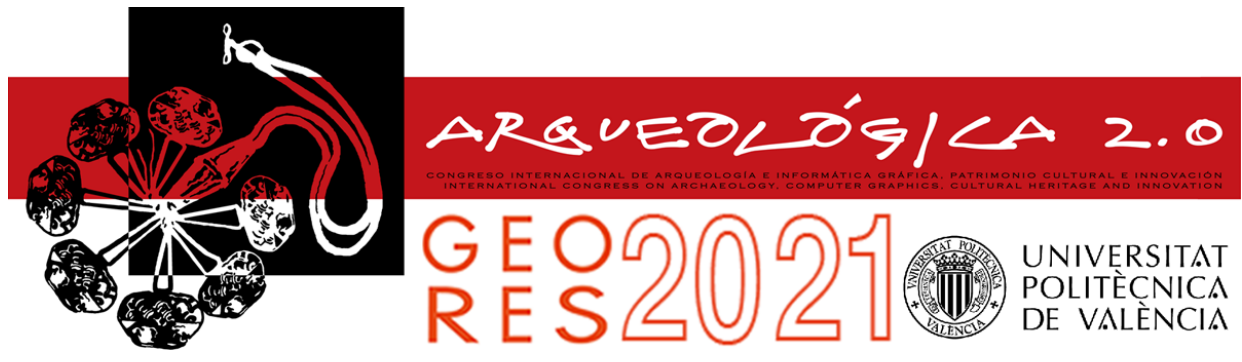

Proceedings of the joint international event $9^{\text {th }}$ ARQUEOLÓGICA

$2.0 \& 3^{\text {rd }}$ GEORES

Valencia (Spain).

26-28 April 2021

\title{
DIGITAL TWINS: COMBINED SURVEYING PRAXIS FOR MODELLING
}

\author{
Cecilia Maria Bolognesi", Martina Signorini \\ Department of Architecture, Built Environment and Construction Engineering, Politecnico di Milano, Via G. Ponzio 31, 20133 Milan, Italy. \\ cecilia.bolognesi@polimi.it; martina.signorini@polimi.it
}

\begin{abstract}
:
While the construction sector embraces the digitalization, new technologies are spreading and are generating benefits. The need of creating a 3D model of the reality, in particular of the built asset, is not new. The Building Information Modelling, a process that gives a great contribution in improving project quality, reducing errors, avoiding uncertainties and enhancing collaboration, allows a virtual representation of the existing asset enriching its geometry with precious and significant information related to its properties. Despite BIM benefits, BIM models do not take into account the real-time component and do not report the real-time behaviour of the building. Digital twin, the virtual copy of an object, instead creates a realtime virtual twin of the physical asset considering this ingredient and reproducing how the building behaves. The paper starts right from the investigation of the Digital Twin concepts and its main features and proceeds with an analysis of several technologies and instruments exploited till now for the surveying and positioning of existing buildings. In addition, a new toolkit based on AR and coupled with sensors and visualisation tool developed by BIM4EEB, an ongoing H2020 project, is presented to show its main advantages when it comes to representing the virtual copy of an existing building.
\end{abstract}

Keywords: digital twin, virtual reality, BIM, digitalization, survey

\section{Introduction}

Nowadays the AEC (Architecture, Engineering and Construction) sector is fully involved in the digitalization focusing on the management of data and the interconnection between machines-objects-people and processes. Information in real environments, data management (big data and $\mathrm{Al}$ ), digital collaboration and intelligent objects (IoT) are the keywords of this revolution (Daniotti et al., 2020).

With BIM, a widely used concept in the literature and implemented in real-world construction projects around the globe, the construction sector has had the chance to improve productivity and quality in building but also in infrastructure projects, reducing both design and construction errors and financial losses, avoiding uncertainties thanks to the interoperability among all stakeholders and ICT tools. Despite BIM potentialities and although BIM uses cover lifecycle management of built asset, BIM models don't consider how people interact with the built environment and they don't reproduce real-time behaviour of the asset in service or in use (Matarneh, Danso-Amoako, Al-Bizri, Gaterell, \& Matarneh 2019). Sensors and IoT devices would perform the function of enhancing the information set of high-fidelity BIM models by providing real-time data streaming with a consequent improvement in construction and operational effectiveness. However, BIM and loT integration are still in progress (Tang, Shelden, Eastman, Pishdad-Bozorgi, \& Gao, 2019).

Digital Twin - whose first adoption dates back to 2010 when NASA used it in technology roadmaps and proposals for exploration of sustainable space (Caruso, Dumbacher, \& Grieves, 2010; National Research Council, 2012) and then in fighter aircrafts and NASA vehicles (Glaessgen \& Stargel, 2012; Tuegel, Ingraffea, Eason, \& Spottswood, 2011) - tries to achieve what BIM models have not delivered. Based on the idea that a digital informational construct about a physical asset could be created as an entity on its own and linked with that physical system through its whole life cycle, the digital representation should include all information (Burnett et al., 2019) concerning the system asset that could be potentially obtained from its thorough inspection in the real world (Grieves \& Vickers, 2016).

Although there is the lack of a universal definition about what a Digital Twin is for application to a construction or infrastructure asset, it is possible to outline its main features and potentialities.

From the definition of Grieves according to which the Digital Twin is defined as "a set of virtual information constructs that fully describes a potential or actual physical manufactured product from the micro atomic level to the macro geometrical level" (Grieves \& Vickers, 2016) to another significant definition highlighting the importance of Digital Twin over BIM by Stojanovic

"Corresponding Author: Cecilia Maria Bolognesi, cecilia.bolognesi@polimi.it 
(Stojanovic, Trapp, Richter, Hagedorn, \& Döllner, 2018) stating that "a Digital Twin (DT) is a digital duplicate of the physical environment, states and processes. While a BIM model contains as-is and historical data, a DT can be used to assess the current state, and to potentially forecast the future state", it is clear what digital twin represents.

Following the approach of Grieves, the Digital Twin concept model is composed by three main parts:

a) physical product;

b) virtual product;

c) data and information that provides the connections between the virtual and the real.

The connection among the virtual product and the physical product is provided by data in different forms. The Physical collects and store real time data that are sent to virtual copy for processing. Vice versa, the Virtual applies its imbedded engineering models and $\mathrm{Al}$ subjecting data to transformations and processing information (Fig. 1) (Grieves, 2015).

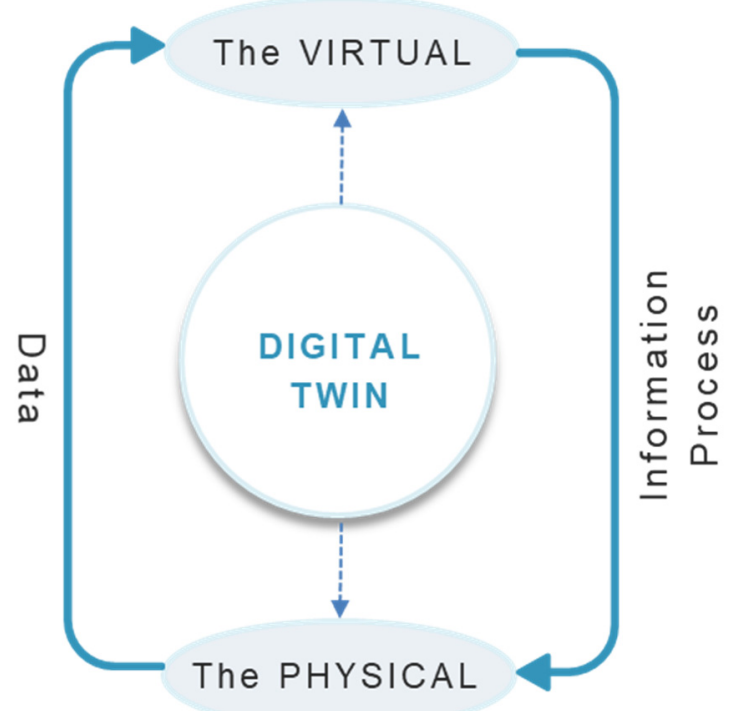

Figure 1: The Digital twin concept.

It is fundamental to underline the strong interconnection among the Physical and the Virtual: in fact, the digital twin is not only the copy of the real asset, but it is also strictly connected to it by specific relationships.

The supporting technologies for the DT development are: wireless sensor networks, installed in buildings to collect data about temperature, humidity, lighting, occupancy, etc. and data analytics, a broad term including the artificial intelligence A.I. and machine learning concepts (Khajavi, Motlagh, Jaribion, Werner, \& Holmstrom, 2019).

The virtual copy can be visualized in a $3 \mathrm{D}$ model, but thanks to the use of various sensor networks a real-time view of the built asset is created (Fig. 2). The dynamic view allows for real-time analysis, building efficiency and comfort enhancement and informed decision-making (Khajavi, Motlagh, Jaribion, Werner, \& Holmstrom, 2019).

Concerning the level of development, the twin could vary from a simple component, moving to a building or even country such as the one implemented by the UK National
Digital Twin programme (Centre for Digital Built Britain, 2020).

Proceeding towards the digitalization of the construction sector, embracing the digital twin technology and applying it to the existing construction means a series of benefits such as construction and operating costs reduction, productivity and collaboration enhancement, safety improvement, asset performance and sustainability optimization.

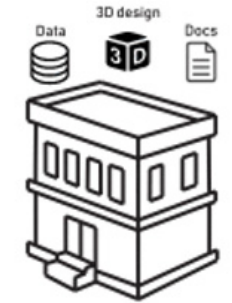

$$
\text { Required Data Components from }
$$<smiles>[CH]</smiles>
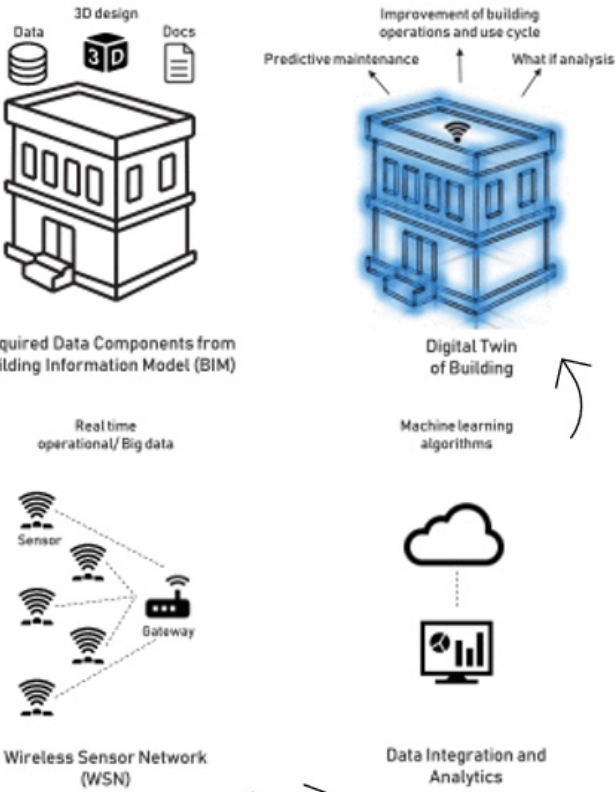

Data Integration and Analytics
Figure 2: Components to create a digital twin of building and comparison with BIM (Khajavi, Motlagh, Jaribion, Werner, \& Holmstrom, 2019).

This paper investigates how a virtual copy, named a digital twin, of an existing building can be reproduced, analysing which are the main used tools among the existing ones and outlining the features of the AR-toolkit developed by the $\mathrm{H} 2020$ ongoing project BIM4EEB.

The paper is organized as follows. After an introduction dealing with the concept of digital twin, section 2 focuses on the common instruments for the surveying and positiong of the model, section 3 introduces a new tool based on Augemented Reality coupled with sensors developed by the BIM4EEB project. Section 4 summarises the outcomes and the future developments.

\section{Surveying and positioning}

The construction of a digital model of an existing or historical building (Dore, \& Murphy, 2017) brings with it the need for a phase of accurate survey, that is to say of real importance; the technological evolution that has followed over the last twenty years has led in the first instance to the development of various hardware, software and devices for the measurement and acquisition of the existing building and immediately afterwards to the translation of the information into what is defined a BIM model (Osello, Lucibello, \& Morgagni, 2018). The measurement themes focus on the conversion of the different units according to the instrument used, the translation of the information into the model on the difficulty of spatial positioning of the information. 


\subsection{Surveying}

Among the existing tools for surveying, technologies are multiplying, specialising in relationship with the size of surveying objects and their visibility inside the building also. What can be precisely detected on a surface by one tool can be ignored by another; on the contrary, what is inserted inside a masonry is ignored for example by a laser or photogrammetric techniques. Depending on the peculiarities of each one a survey of the building could have to do with:

- $\quad$ Lidar technologies (Light Detection and Ranging or Laser Imaging Detection and Ranging) that allow to reconstruct three-dimensional models through the recording of single or multiple scans determining the distance of an object or surface using a laser pulse, based on the time of flight (the time it takes for the laser beam to travel to the target and reflect back) (Cardaci, Mirabella Roberti, \& Versaci, 2019);

- Photogrammetry, a passive detection system, time consuming in terms of post processing but with undoubted economic advantages and increasingly faster considering the development of the latest modeling software algorithms (Remondino, Nocerino, Toschi, \& Menna, 2017);

- Infrared thermometers as well as heat cameras where thermal mappings give different information about the building such as objects behind others with uniform temperature, find heat leaks, or detect faulty electric cabling and which can rarely be associated with model geometries except with the intervention of the operator (González-Jorge, Lagüela, MartínezSánchez, 2012);

- Radar which uses electromagnetic radiation in the microwave band (UHF/VHF frequencies) of the radio spectrum, and detects the reflected signals from subsurface structures;

- Magnetic or x-ray sensors but also capacitors or voltage or stud detectors as well as $\mathrm{x}$-rays or

- ultrasounds where ultrasonic range sensors produce a beam of ultrasound that is sent out and reflects back from the object, allowing the sensor to measure distances but different density of a wall as well. This technology is the same used in medicine application to create multidimensional images of the human body, detecting different densities.

Considering the different structure and nature of data acquisition it is natural to read in digital twin the only possibility to collect them, assuming the model as the unique container and the digital replica of what we have investigated. Therefore, in addition to the difficulties derived from the different previous measurements, there are also those derived from the need to position the measurement we are performing.

\subsection{Positioning}

After surveying the main task to organize the digital replica could be concerning both the spatial positioning of the model within a Coordinate System and an Internal Positioning System of the surveys carried out. In the case of heat cameras for example this association can be done manually. In the case of some laser scanners the connected applications allow the automatic recording of the user's movements from one scan to another for prerecording in the field without manual intervention but also the acquisition of associated images in HDR (High Dynamic Range) (Pavan et al., 2020). However, in the case of more precise detection positioning, it may be necessary to scale down the indoor positioning down to 1:50 detail, with tolerances of just a few $\mathrm{mm}$.

Almost all indoor positioning systems also lack external reference systems due to their nature and are anchored to temporary positioning systems that should be linked to more general systems. In fact, while for the outdoor environment, the GPS geolocation system is particularly effective, inside buildings or in heavily urbanized areas, the GPS easily loses operation, and it is necessary to play hard to find other alternatives.

Among the most used technologies for indoor positioning, we consider with different funcionalities:

- Beacon as other technologies or app for mobile devices have found wide use both in maintenance and in areas more related to Cultural Heritage as tracking tools. Specifically beacons are hardware devices thanks to which bluetooth technology is used to send and receive signals within short distances. They are used nearby as access-points to calculate where the device is located.

- Glasses: Hololens, HTC Vive, Oculus Rift. They are different in functionality with respect to which they have been designed but all three disposals contain positioning capabilities with respect to indoor environments. Hololens, designed for AR for the vision of holograms superimposed on environments, includes several sensors, to measure inertia also, a light sensor and four cameras for environmental analysis. The tool measures the time of flight for IR light and creates a $3 d$ image of the room. The accuracy is about $3 \mathrm{~cm}$. HTC vive uses an IR-flash, little microchips with a photocell that are tuned to listen to infrared light, followed by sweeping IRline lasers horizontal and vertical. It is a passive sensor sensing on headset, handles and trackers. Positioning is then determined by detecting the pulses of a photo led. The time between the initial pulse and the pulse generated by the line laser helps the positioning with a $2 \mathrm{~mm}$ accuracy with a $30 \mathrm{~Hz}$ update time. There are some limitations in the dimension of the spaces that must be related to the sensor's possibility of detection. Set up considers both PC and Headset. Oculus rift uses LED markers on the headset, handles and trackers and then uses 
cameras to track their position. The cameras are both fitted in the headset as well as the on stands in the room. The accuracy of this system is around 3.5 to $12 \mathrm{~mm}$ but just as with the HTC vive errors increase on distance to the cameras.

- QR codes attached to objects is the most traditional tool we can use but still one of the most accurate. A simple camera tracks objects with a camera. If the $Q R$ code is attached to a fixed object as a reference point geographically that position will be known for a camera. The orientation, angle and the position of the camera can be calculated by register the symmetry and size of the QR-code in the image. Image recognition is used in AR-tools and this allows to anchor/position a virtual CAD to the real world so that they match each other.

\section{The BIM4EEBproject}

BIM4EEM is a wide $\mathrm{H} 2020$ project coordinated by Politecnico of Milan with the participation of fifteen partners spread all over Europe. The aim of the project is to foster the renovation industry by developing an attractive and powerful BIM-based toolset able to support designers in the design and planning phase, construction companies to efficiently carry out the work and service companies to provide attractive solutions for building retrofitting. A principal tool eases decision making and asset management, thanks, among all, to the exploitation of augmented reality.

Through the BIM management system linked data and a set of tools increases semantic interoperability between software and stakeholders involved along the overall renovation process (design, planning, construction, performance assessment and management).

The renovation project within the project is carried out according to the expectations and requests of the renovation market; the project considers two public administrations, and two general contractor companies will validate the toolset in a social housing setting and private residential buildings in Italy, Poland and Finland.

In this field a tool has been developed to facilitate the creation of digital twins starting from the existing construction and for which the detection operations would meet parameters of accuracy, speed, transfer within an interoperable data management system.

\subsection{The fast mapping toolkit}

The aim of the digital renovation process deepens how to get knowledge about the building and create a useful model for a more efficient and safe renovation process.

With the experimentation the partners wish to make up for the shortcomings of many devices where a wide abundance of sensor technologies available lacks interfaces and interoperability for collecting the data measured or lack shareable positioning systems.

The BIM4EEB project includes developing of tools to implement the mapping of buildings; the aim is to reach a faster workflow that includes the detection of hidden installations and materials in the wall that will help the renovation process both in recent than more ancient building. The approach followed has been to be able to use devices and solutions starting from tools and software already available on the market but which, in new couplings, can meet the needs of speed, accuracy and survey of hidden parts (Fig. 3).

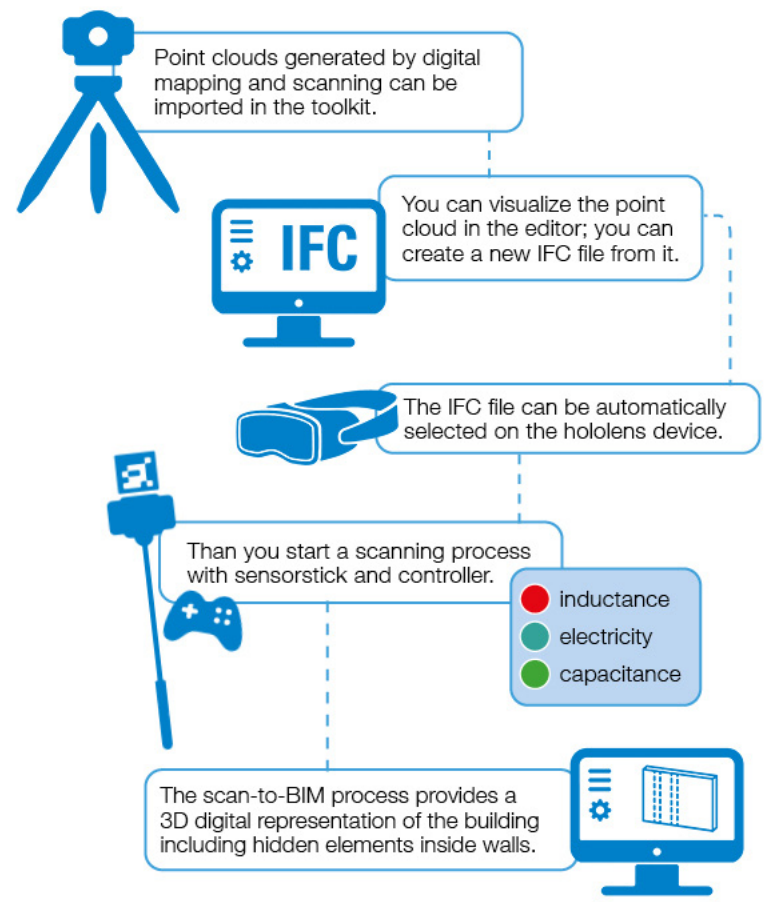

Figure 3: The figure shows the workflow from scanning and mapping to visualize objects behind hidden surfaces in buildings.

From one side mapping tools as previously seen, from the other 3D-laser scanning that measure the geometry, are the beginning of the workflow that deals with collected data to be stored and translated by a BIM-platform into a 3D-model and visualized for the user.

The aims to process and transform the whole data into a BIM model, saving time, mapping process with quality, and storing data easily, works on IFC-format as a requirement of the whole process.

The experimentation uses a combination of market available laser scanning techniques with a HoloLens device and a prototype sensor array consisting of heat sensor, stud detectors and more as mapping equipment. The so called -sensor stick- measure capacitance, temperature, inductance, voltage and position so that it's possible to visualize the room with its hidden installations.

Preparation and equipment for setup includes the positioning system and markers when needed.

The sensor dialogues through a sensor stick with several functions for detecting installations inside walls with Hololens combining input data directly into the point cloud previously surveyed. But both mapping data are converted in a 3D model in Unity environment to dialogue and be transformed into an IFC-file.Through the HoloLens the user can see the physical environment around as well as a digital representation of the scanned data. At the beginning of the process a calibration procedure needs to be done for the HoloLens view to align with the 3D laser 
scan and the sensor stick (Fig. 4). During the process different spaces can be added one after the other while the building data is mapped in a hierarchy, defining different parts such as floors, walls.

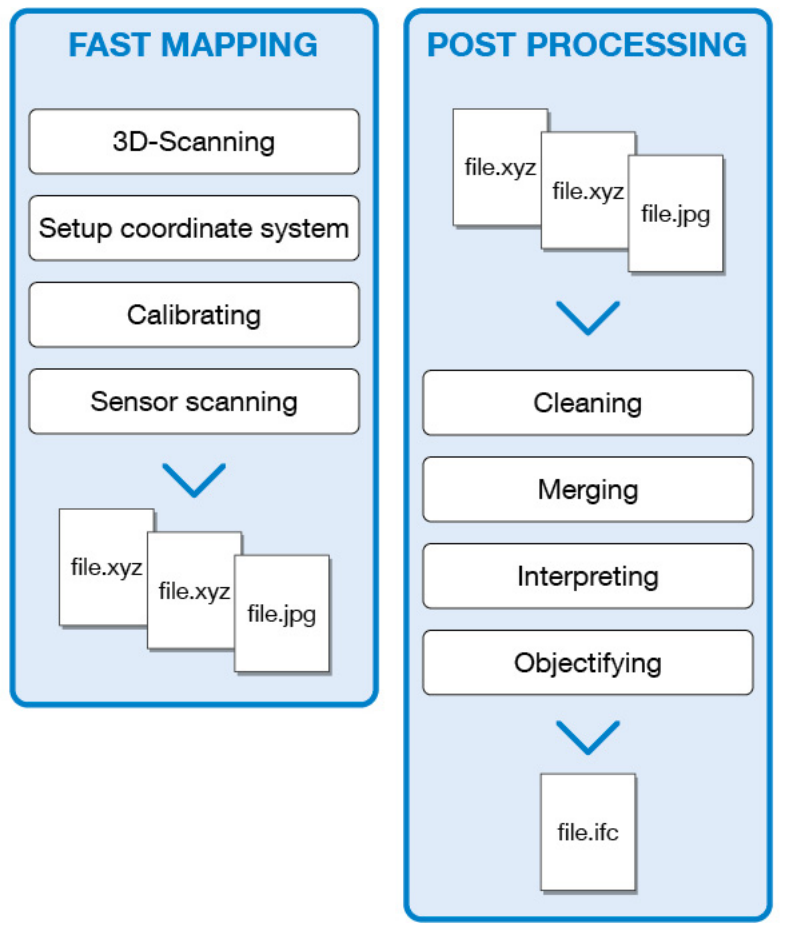

Figure 4: Survey with the new set of fast mapping and post processing operation.

The view of the point cloud in the headset obliges to optimize the point cloud whose import would result impossible in the Hololens device. For this reason, the point cloud is streamed and not imported, even if this approach is under investigation now. One service has been organized for streaming point cloud data, the other for altering IFC-files and to provide a visualization model for the AR-device. A dedicated app has been developed for managing and converting point clouds and provide a visualization.

\section{Future developments}

As briefly outlined in this paper, the presence of increasingly sophisticated hardware is fundamental for the collection of data useful for the creation of a digital twin. The experience of the Fast Mapping Toolkit developed in BIM4EEB project is an example of this and indicates several possibilities of deepening and optimizing workflows. There are some topics that will become the object of future developments that will have to answer typical questions related the surveying process in order to elaborate a clear digital replica such as: the size of the data bases of the surveys, the translation into interoperable languages, the possibility of integration between different surveying units, the portability of the tools, the cost-effectiveness of the system.

These and other topics will be developed in the next steps of the projects.

\section{Acknowledgements}

This paper deals with one specific part of the BIM4EEB project, $x x x$, responding to the Call for proposals LC-EEB02-2018 Building information modelling adapted to efficient renovation. The project has received funding from European Union's H2020 research and innovation programme under grant agreement $\mathrm{N}$. GA $\mathrm{N}$. $82066030 / 06 / 2020$. The content of this document reflects only the author's view only and the Commission is not responsible for any use that may be made of the information it contains.

The development of the Sensor stick has been led mainly by RISE and CGI Sweden partner; and in the final project deliverable, confidential still, by Deliverable 5.3.

\section{References}

Burnett, D., Thorp, J., Richards, D., Gorkovenko, K., \& Murray-Rust, D. (2019). Digital twins as a resource for design research. Proceedings - Pervasive Displays 2019 - 8th ACM International Symposium on Pervasive Displays, PerDis 2019, 6-7. https://doi.org/10.1145/3321335.3329685

Caruso, P. W., Dumbacher, D. L., \& Grieves, M. W. (2010). Product Lifecycle Management and the quest for sustainable space exploration. AIAA SPACE Conference and Exposition 2010, 1-12. https://doi.org/10.2514/6.2010-8628

Cardaci, A., Mirabella Roberti, G., \& Versaci, A. (2019).The integrated 3D survy for planned conservation: the former church and convent of sant'Agostino in Bergamo. Int. Arch. Photogramm. Remote Sens. Spatial Inf. Sci., XLII-2/W9. (pp. 235-242). https://doi.org/10.5194/isprs-archives-XLII-2-W9-235-2019

Centre for Digital Built Britain. (2020). National Digital Twin programme (NDTp). Retrieved March 15, 2021, from https://www.cdbb.cam.ac.uk/what-we-do/national-digital-twin-programme

Daniotti, B., Pavan, A., Lupica Spagnolo, S., Caffi, V., Pasini, D., \& Mirarchi, C. (2020). Collaborative Working in a BIM Environment (BIM Platform). In BIM-Based Collaborative Building Process Management (pp. 71-102). Springer International Publishing. https://doi.org/10.1007/978-3-030-32889-4

Glaessgen, E. H., \& Stargel, D. S. (2012). The digital twin paradigm for future NASA and U.S. Air force vehicles. Collection of Technical Papers - AIAA/ASME/ASCE/AHS/ASC Structures, Structural Dynamics and Materials Conference, April. https://doi.org/10.2514/6.2012-1818

González-Jorge, H., Lagüela, S., Martínez-Sánchez, J. (2012).Single image rectification of thermal images for geometric studies in façade inspections. Infrared Physics and Technology. https://doi.org/ 10.1016/j.infrared.2012.05.003

Grieves, M. (2015). Digital Twin: Manufacturing Excellence through Virtual Factory Replication. White Paper, March. available 
https://www.researchgate.net/publication/275211047_Digital_Twin_Manufacturing_Excellence_through_Virtual_Fa ctory_Replication

Grieves, M., \& Vickers, J. (2016). Digital Twin: Mitigating Unpredictable, Undesirable Emergent Behavior in Complex Systems. In F.-J. Kahlen, S. Flumerfelt, \& A. Alves (Eds.), Transdisciplinary Perspectives on Complex Systems (pp. 85-113). Springer. https://doi.org/https://doi.org/10.1007/978-3-319-38756-7_4

Khajavi, S. H., Motlagh, N. H., Jaribion, A., Werner, L. C., \& Holmstrom, J. (2019). Digital Twin: Vision, benefits, boundaries, and creation for buildings. IEEE Access, 7, 147406-147419. https://doi.org/10.1109/ACCESS.2019.2946515

Matarneh, S. T., Danso-Amoako, M., Al-Bizri, S., Gaterell, M., \& Matarneh, R. (2019). Building information modeling for facilities management: A literature review and future research directions. Journal of Building Engineering, 24(January), 100755. https://doi.org/10.1016/j.jobe.2019.100755

Dore, C., \& Murphy, M.(2017). Current state of the art historic building information modelling. Int. Arch. Photogramm. Remote Sens. Spatial Inf. Sci., XLII-2/W5. (pp.185-192), https://doi.org/10.5194/isprs-archives-XLII-2-W5-1852017.

National Research Council. (2012). Technology Area 12: Materials, Structures, Mechanical Systems, and Manufacturing Road Map. Available at: https://www.nap.edu/read/13354/chapter/22\#296

Osello, A., Lucibello, G., \& Morgagni, F.(2018). HBIM and Virtual Tools: A New Chance to Preserve Architectural Heritage. Buildings (pp. 8-12). https://doi.org/10.3390/buildings8010012

Pavan, A., Bolognesi, C., Guzzetti, F., Sattanino, E., Pozzoli, E., D’Abrosio, L., Mirarchi, C., \& Mancini, M (2020) BIM Digital Platform for First Aid: Firefighters, Police, Red Cross. In: Daniotti B., Gianinetto M., Della Torre S. (eds) Digital Transformation of the Design, Construction and Management Processes of the Built Environment. Research for Development. Springer, Cham. https://doi.org/10.1007/978-3-030-33570-0_25

Remondino, F., Nocerino, E., Toschi, I., \& Menna, F.(2017). Acritical review of automated photogrammetric processing of large dataset. Int. Arch. Photogramm. Remote Sens. Spatial Inf. Sci., XLII-2/W5. (pp. 591-599) https://doi.org/10.5194/isprs-archives-XLII-2-W5-591-2017

Stojanovic, V., Trapp, M., Richter, R., Hagedorn, B., \& Döllner, J. (2018). Towards the generation of digital twins for facility management based on 3D point clouds. Proceeding of the $34^{\text {th }}$ Annual ARCOM Conference, ARCOM 2018, June, 270-279.

Tang, S., Shelden, D. R., Eastman, C. M., Pishdad-Bozorgi, P., \& Gao, X. (2019). A review of building information modeling (BIM) and the internet of things (IoT) devices integration: Present status and future trends. Automation in Construction, 101(January), 127-139. https://doi.org/10.1016/j.autcon.2019.01.020

Tuegel, E. J., Ingraffea, A. R., Eason, T. G., \& Spottswood, S. M. (2011). Reengineering aircraft structural life prediction using a digital twin. International Journal of Aerospace Engineering. https://doi.org/10.1155/2011/154798 


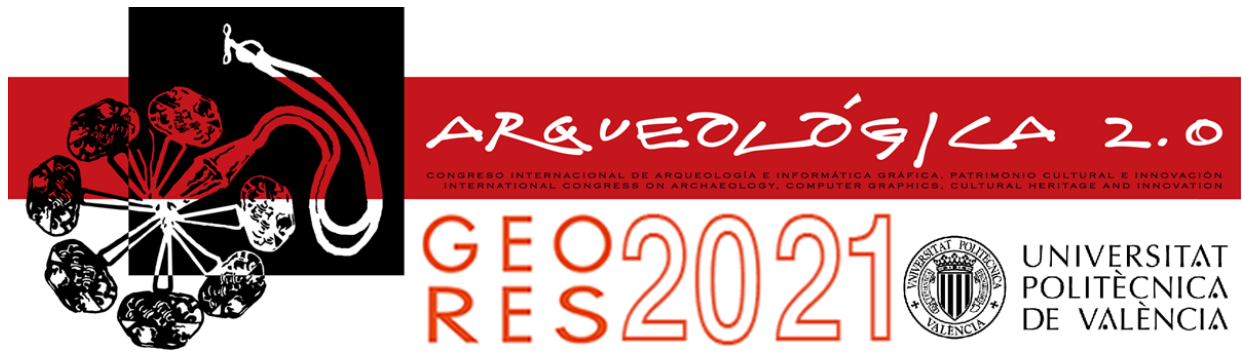

Proceedings of the joint international event $9^{\text {th }}$ ARQUEOLÓGICA

$2.0 \& 3^{\text {rd }}$ GEORES

Valencia (Spain).

26-28 April 2021

\title{
A HYBRID MODEL FOR THE REVERSE ENGINEERING OF THE MILAN CATHEDRAL. CHALLENGES AND LESSON LEARNT
}

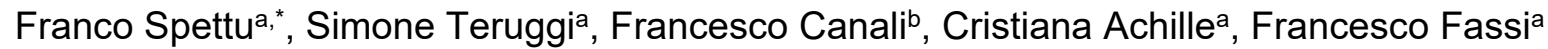 \\ a 3D Survey Group, ABC Lab, Politecnico di Milano, Via Ponzio 31, 20133 Milano, Italy. franco.spettu@polimi.it; \\ simone.teruggi@polimi.it; cristiana.achille@polimi.it; francesco.fassi@polimi.it \\ b Veneranda Fabbrica del Duomo di Milano, Via Carlo Maria Martini 1, 20122 Milano, Italy. dl.cantieri@duomomilano.it
}

\begin{abstract}
:
Cultural Heritage $(\mathrm{CH}) 3 \mathrm{D}$ digitisation is getting increasing attention and importance. Advanced survey techniques provide as output a 3D point cloud, a complete and accurate description even of the most complex architectural geometries with a priori established accuracy. These 3D point models are generally used as the base for the realisation of 2D technical drawings and 3D advanced representations. During the last 12 years, the 3DSurveyGroup (3DSG, Politecnico di Milano) conduced an omni-comprehensive, multi-technique survey, obtaining the complete point cloud of Milan Cathedral, from which were produced the 2D technical drawings and the 3D model of the Main Spire used by the Veneranda Fabbrica del Duomo di Milano (VFD) to plan its periodic maintenance and inspection activities on the Cathedral. Using the survey product directly to plan VFD activities would help to skip a long-lasting, uneconomical and manual process of $2 \mathrm{D}$ and $3 \mathrm{D}$ technical elaboration extraction. In order to do so, the unstructured point cloud data must be enriched with semantics, providing a hierarchical structure that can communicate with a powerful, flexible information system able to effectively manage both point clouds and 3D geometries as hybrid models. For this purpose, the point cloud was segmented using a machine-learning algorithm with a multi-level multi-resolution (MLMR) approach in order to obtain a manageable, reliable and repeatable dataset. This reverse engineering process allowed to identify directly on the point cloud the main architectonic elements that are then re-organised in a logical structure inserted inside the informative system built inside the 3DExperience environment, developed by Dassault Systémes.
\end{abstract}

Keywords: cultural heritage, classification, reverse engineering, point cloud, machine learning, BIM

\section{Introduction}

The Veneranda Fabbrica del Duomo di Milano (VFD, 2021 ) is the organisation responsible of the construction, maintenance and development of Milan Cathedral since the very beginning of its history, in 1387 ; through more than six centuries the VFD operated using the techniques of the time and collecting records and documents of all the operations.

Nowadays the archives host a prosperous deposit of information, derived from the VFD activities, that should be made entirely consultable and kept up to date with new entries from the present and future operations.

There is a significant and evident awareness that the only feasible way to obtain an efficient and organised system for the study and fruition of the archived data can only rely on the digital form. However, it is also clear that lots of questions should find answer before taking the first step in this direction.

The rapid acceleration given to our society and activities by the digitisation process requires to have at disposal a large amount of information available in real-time, organized in such a way that it is possible to manage them in an efficient and intuitive way. The interaction between end-users and data repositories design should be inspired by immediate usability and a reduced learning phase.

Professionals working in the Cultural Heritage field (as conservators, archivists, restorers, designers, project managers...) that take care of grand historical architectures are today thoroughly evaluating the advantages of a full digital transition of their internal processes and archives, which brings to the crucial question of how to proceed in this transition and how to face the proficient management of huge data set.

The VFD is nowadays confronting with this topic and questioning itself about the most suitable way to proceed, exploring some solutions together with Politecnico di Milano.

Should the robust logical structures that have been adopted by the curators of the Historical Archives be reproduced inside an articulated database? Which

`Corresponding Author: Franco Spettu, franco.spettu@polimi.it 
digitisation strategy for the existing architecture can be pursued in order to construct a reliable three-dimensional basis, a digital twin of the Cathedral, in order to extract useful information and provide a support for knowledge and dissemination? How to secure a long-term investment that should be profitable for many years, considering the speed at which technological tools evolve and become obsolete nowadays? It is possible to adopt a lean approach that can focus on specific parts according to the present needs of the VFD? Which strategy can provide significative results in a short time, relying on the already present data and carrying on the already open projects?

The activities that VFD and Politecnico di Milano conducted together over the last ten years (Achille et al., 2020) represented a significant experience on the topic of digitisation of Cultural Heritage and an occasion to encounter both well-known and unexpected problems in the management and proficient use of such extended dataset. The complete point cloud of the Cathedral, obtained as final product of the survey activities and data elaboration, proved itself as a promising candidate to be the three-dimensional basis for the realisation of the digital twin of the monument, providing an adequate answer to some of the questions that, as previously described, VFD was posing to itself.

The awareness of the possibilities offered by the point cloud of the Cathedral grew as the survey went on: it started as a data-gathering campaign, experiencing considerable difficulties due to the extension of the monument that needed a thorough design of the operations, for the realisation of $2 \mathrm{D}$ updated technical drawings, according to the needs of the restoration yard at that time. The step that followed was to imagine what else could be derived from such complete data, and several 3D models were realised.

Nowadays, the main topic regards what the whole point cloud can be transformed into without losing its metrological accuracy, and how to integrate it with all the previously produced material and data.

Such a heterogeneous repository of knowledge could be effectively organised and used inside a Heritage Building Information Model (HBIM) environment, but the overall complexity of the monument and the need for metrologically accurate data inevitably pose questions about the most appropriate and efficient way to pursue this goal. The experience gathered in the past years showed that "modelling-time" and "yard-time" usually do not correspond, as the strict schedule of the restoration yard could not wait for models to be accomplished in order to extract the measurements and data needed for the operations: a compromise between speeded up digitisation and accuracy of the shape should be found. In this sense, the point cloud can be a resource to be directly used, if enriched with semantics, with the recognition of the specific architectural objects and structured inside an informative system with all the related and useful data.

The very recent and experimental applications that the research group is developing on the Cathedral point cloud showed encouraging results in terms of categorisation and recognition of the constitutive elements of the architecture, using automatic machine-learning algorithms.
The considered solution allows building a semantic model of the architecture avoiding the time-consuming traditional modelling activity (direct or parametric-based), which can bring to uncertain results depending on the ability of the operator. Moreover, starting from the segmented point cloud, also the real-based modelling operation can be accelerated and benefit of a direct reference for metrological comparison of the shapes.

The model obtained could act as a support for the archive of the remarkable amount of data gathered about the Cathedral during the centuries, linking the information to the architectural elements it refers to. The user experience can indeed benefit from a visual navigation tool founded on the real shape of the architecture for the retrieving of the restoration data, while the pre-existent structure of the archive should be preserved and carefully implemented in the new system.

The archiving is linked to the physical evidence of the architectures, consequentially very intuitive and userfriendly while ensuring respect for the structure and complexity of any archival system that is to be made available and accessible through the model itself and the appropriate relational links. Moreover, as required or necessary, the classified point cloud can facilitate and speed up also the modelling process in the most classic sense.

This paper, presenting the current research activities and their up-to-date results, aims to provide possible answers, encouraging solutions and feasible strategies to some of the question here exposed.

\section{The Reverse Engineering of Cultural Heritage}

For Reverse Engineering of Cultural Heritage is here intended a digitisation strategy for the historical architecture, which is based on three-dimensional survey and semantics, a complete virtual reconstruction of an existing object (Fassi \& Parri, 2012). This implies not only the accurate digital reconstruction of the shape of the architectural elements (De Luca, Veron, \& Florenzano, 2006; Dore \& Murphy, 2013) but also the deep understanding of the architecture-system and the identification of its components and their mutual interrelationships in order to create a representation of the system itself (Chikofsky \& Cross, 1990; Rekoff, 1985).

It produces a $3 \mathrm{D}$ informative model to extract knowledge from the Monument, as a support for the maintenance activities and, also, as a repository of historical and geometrical data. The digitisation is conducted following a metrological approach: it starts with the complete 3D survey of the architecture with established accuracy and precision, which represents the best, basic geometrical knowledge of architecture in the form of an undifferentiated point cloud.

With "semantics" is here intended the act of giving a structure to the elements of the model, namely identifying them as separated objects through a label (Grilli, Farella, Torresani \& Remondino, 2019) according to their architectural features and role. This structure organises the whole model and allows to navigate in it.

It is essential to define the minimum intervention object of the structure according to the maintenance needs and in 
general to the use of the model. Higher levels of the structure are then defined as macro-aggregation of "unbreakable elements" according to the chosen criteria.

\section{A new approach to a metrological model for Duomo maintenance}

The aim of this work is to conduct a preliminary test on the possibility of using the digital tools belonging to the manufacturing industry field for the digitisation of Cultural Heritage and as a support to the maintenance practices, taking a further step in the informative modelling process for Milan Cathedral, started in 2011 with the realisation of the Main Spire model (Fassi, Achille, \& Fregonese, 2011).

\subsection{General system requirements}

The followed metrological approach guarantees that the model is precise and accurate, and that should be suitable for a 1:50 and 1:20 representation scale, with a $2 \mathrm{~cm}$ and $1 \mathrm{~cm}$ tolerance. According to this value all elements, including the decorative apparatus (when needed), are modelled.

The final element of the semantic structure has to be the marble block, which should be automatically computed the volume and the area of the external surface. This means that for marble bocks the modelling phase cannot be avoided, and inside the established internal model tolerances, the CAD objects representing the marble blocks must be closed (watertight) in order to be recognised as a solid. To achieve the required precision, modelling activities should be based on point cloud objects, that have to be importable and manageable inside the software. In particular, it should be possible to visualise the point clouds correctly, to cut cross-sections in order to obtain modelling profiles and perform deviation analysis to evaluate in quantitative terms if the modelled geometry is adequate for the established precision.

During the past years, several feasibility tests have been conducted in order to find which software (or software combination) could provide useful modelling tools able to reach the required metrological accuracy and how to manage the informative part related to the $3 \mathrm{D}$ geometries (Lo Furno, Pietrucci, Tommasi, \& Mandelli, 2016; Tommasi \& Achille, 2017).

The leading BIM software are generally designed to cover the needs of the new constructions, in which architectural elements and procedures are usually standardised: consequently, the modelling tools embedded in BIM software can be unsuitable to the elaborated and complex geometries that are typical in the Cultural Heritage field. On the other hand, 3D modelling software as Rhinoceros offer tools able to reach considerable precision and complexity in modelling, but they may lack the point cloud support and could need external resources in order to manage the informative part and attached documents (Tommasi \& Achille, 2017). As an example of how the Cultural Heritage field has specific needs in terms of flexibility, both in modelling and data management, is here mentioned the case of Parma Cathedral, which used Autodesk Revit (Autodesk, 2020) as a general model manager, but integrated with an external software for the management of the data repository and the user interface for restorers (Bruno \& Roncella, 2018; Bruno \& Roncella, 2019).
In terms of data management, the objects should be enriched with the information related to their condition and the maintenance operations, also with the possibility to attach external data; a more advanced requirement would be the ability to manage the informative part directly on the point cloud, which will become in this way an object of the model and not only a geometrical reference.

The previously and future-realised models should be importable and managed inside the software in order to ensure the continuity of data and work.

The needs and requirements here expressed were addressed through a proficient answer with the BIM3DSG system (Fassi, Achille, Mandelli, Rechichi, \& Parri, 2015), a device to manage and store the complex and huge amount of data built through the years, to enrich it with information though specifically created attributes and to visualise geometries on the internet, with no application needed but a web-browser (Rechichi, Mandelli, Achille, \& Fassi, 2016). The system is based on open-source libraries; it manages both NURBS and mesh objects, and automatically adapts visualisation performances according to the device. It was designed to be fully adaptable: among the others, it is used in Saint Mark Basilica in Venice (Fregonese, Adami, 2020) in Sacri Monti of Piedmont and Lombardy (Tommasi, Fiorillo, Jiménez Fernández-Palacios, \& Achille, 2019) and even for sculpture, as the Michelangelo's Pietà Rondanini (Mandelli, Achille, Tommasi, \& Fassi, 2017) case. The system is structured in two different macro-entities: Back and Front Office (Fassi \& Parri, 2012): Back Office represents the authoring part: it comprehends the modelling part of geometry performed inside Rhinoceros (2021), which is linked to the online database through a plugin, and has privileges of reading and writing for all the data; the Front Office is the web-based interactive part for users, which can be passive (only consultation of data) or active, being allowed to modify attributes and nongeometrical data, like photographs. The BIM3DSG system is optimised for touch screen and mobile devices in order to be used directly in the restoration yard as a tool for locating the blocks and update information on the field: it is at the same time an operational tool and a logbook of the Monument's management through time, and its latest development, Chimera, provides support and integrates GIS data inside the HBIM environment (Bruno et al., 2020; Rechichi, 2020) (Fig. 1).

Considered all the gained experience about the digitisation of Milan Cathedral and the needs and the modus operandi of its restoration yard as previously described, the intention nowadays is to search for an integrated system, as a software platform, in which perform all the operations that may derive from the processed and segmented point cloud. The idea is to find a powerful digital tool suitable to build the digital twin of the Cathedral and daily support of the activities of the Veneranda Fabbrica all inside the same common environment, without data duplication and effort and energy dissipation.

The quest for this kind of digital tool was directed to the mechanical and manufacturing sector, in which the operational needs can be comparable: metric modelling up to precise tolerances and consequently the need of embedded tools to perform geometrical verifications, the management of complex and articulated CAD models, the guarantee of rigorous topology for the $3 D$ modelled 
elements and the integration and management of different information systems at different level of usability.

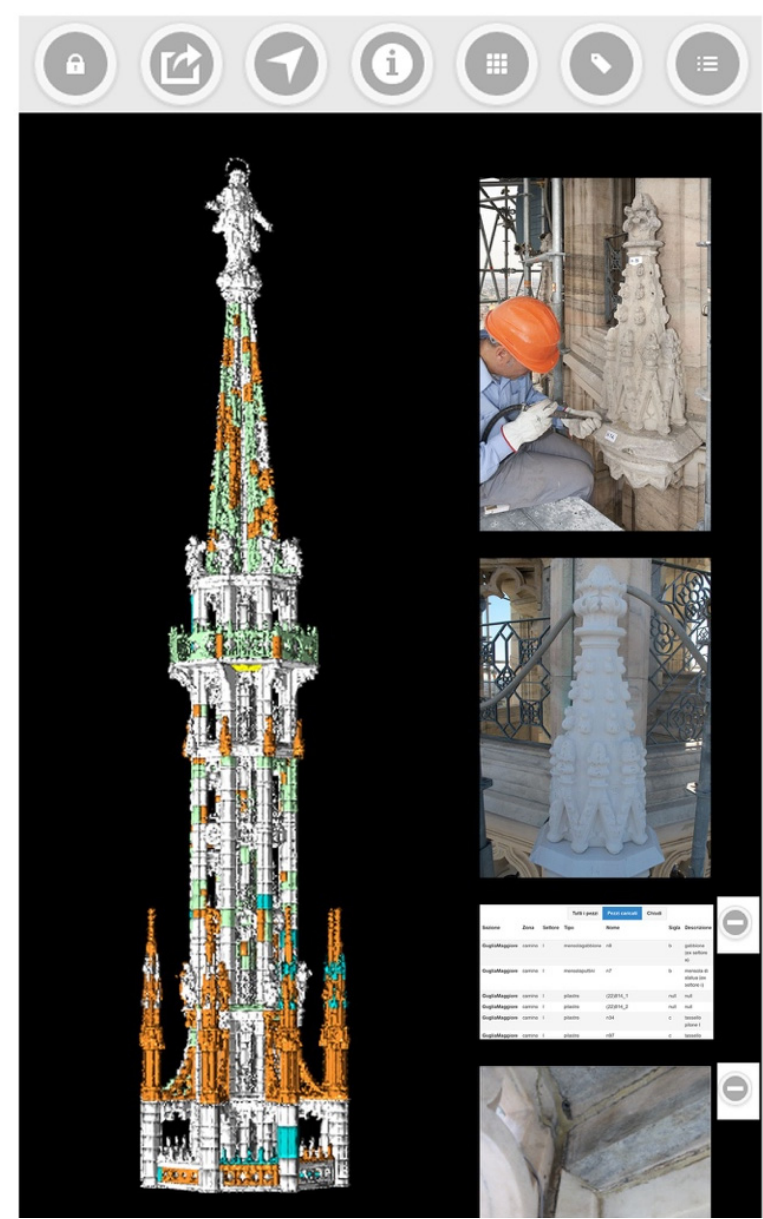

Figure 1: The BIM3DSG web system, showing the entire model of the Main Spire, coloured according to the maintenance status and the attached information of a decorative element (Achille et al., 2020).

\subsection{The 3DExperience platform}

The tested solution is the 3DExperience platform developed by Dassault Systèmes (Dassault Systèmes, 2020). It is an ensemble of different software engines for 3D modelling, computational simulation, product management and manufacturing, among the others, able to work in symbiosis sharing the same data, which are stored in a common online database.

The fields of application span from the manufacturing sector to the mining and biomedical ones: wherever it is necessary to model, manage complex geometries and run simulations; the main application is as Product Lifecycle Management (PLM) software in the manufacturing context, as the platform is able to manage all the phases of the product lifecycle, from the first mockups and design sketches to the assembly line and even the dismantling at the end of the lifecycle of the product. Each software engine has several development environments (also called "apps") designed to accomplish a task, which can be very general, like solid or surface modelling, or very specific, like to design the reinforcement of carbon fibre panels or to optimise the product packaging.
The 3DExperience is web-based and accessible through a common web browser; the primary interface acts as a launchpad and consents to run the needed application and accomplish some tasks with the dashboard system, a customisable user interface based on the composition of "app" windows on the web page.

The cloud-based system ensures that, virtually, the services and the data are synchronised and available from everywhere and from every device. Users have an assigned role that determines their access privileges and their ability to modify or create new objects or contents, keeping every user inside its pre-established competence field, following and expanding the already consolidated logic of Front and Back Office on which the BIM3DSG was based and developed.

The 3DExperience is an integrated system in which all the operations are performed in the same environment and where the interoperability problems among different software are virtually solved, gathering together inside common platform features and roles that are usually scattered. Every operation will be conducted inside the 3DExperience, from modelling to dissemination and visualisation.

A non-trivial aspect to be considered is the one of the long-term support of the software and general reliability matter: a solution developed for the manufacturing industry and adopted mainly in the business, should guarantee stability, availability and support for all the loaded data for a long time, roughly estimated in 25 years: it is compatible with the typical lifecycle of some industrial projects, as in the aerospace field, and consequently is the usually guaranteed lifespan of backward compatibility of the dedicated software tools.

\section{The structure of the model}

\subsection{A multi-source, multi-scale model}

The realised model is constituted by the segmented point cloud, by the consolidated data deriving from previous modelling experiences inside the Rhinoceros software and by new models, fully realised inside CATIA. The imported data were originally made for the 1:20 scale and present the block subdivision; in this category are included all the Main Spire, the dome cladding and the dome itself, with the remarkable exception of the Madonnina statue in the top of the Main Spire, in 1:5 scale. The new data were realised in 1:50 scale and did not present the block subdivision, to be accomplished in a second phase; was modelled the interior part of the cross, namely the four pillars and the drum, on which the dome rises (Fig. 2).

The breakdown structure of the informative model is the principle upon which all the data is organised. It represents the logical but also spatial relations between the different elements. Throughout this structure, it is possible to visually navigate the model and have access to all the information stored in the database.

The adopted structure was defined starting from the one that was established developing the Main Spire project (Fassi, Achille, Gaudio, \& Fregonese, 2012; Fassi, Achille, Mandelli, Rechichi \& Parri, 2015) and that is currently used for its on-going restoration. Some modifications and few changes were made to cover all the 
possible "object" contained in the Cathedral. Nowadays, on the same idea and principle is going to be defined as the spatial-reference interface for the digitised historical archive of the Veneranda Fabbrica.

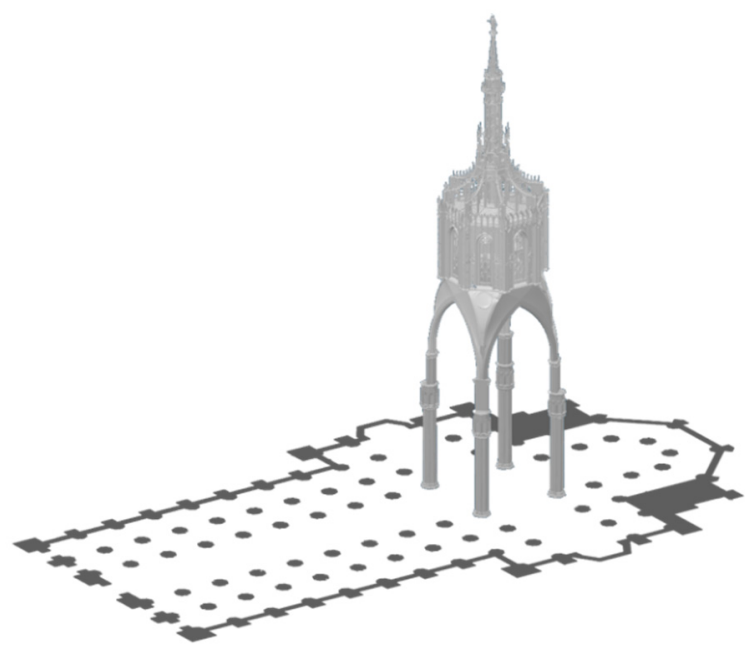

Figure 2: The position of the model inside the Cathedral, at the intersection between the main nave and the transept.

The result is an implemented breakdown structure centred on the marble block, the final element and the focus of the restoration activities, that provides five overall levels related with a logical, progressive architectural subdivision, suitable also for the yard operations, defined as follows (Figs. 3 and 4 ):

1) Zone: a portion of the Monument presenting similar intervention practices.

2) Area: position inside the zone according to architectural features.

3) Sector: specific location inside the area, as a bay for the nave.

4) Architectural element: a recognisable object with specific architectural function and features.

5) Block: final element with no possible further subdivision.

\subsection{Level of Development of the model}

Building Information Modelling (BIM) is nowadays a wellknown and established method in the field of Architecture and Building Construction. The sector of the Cultural Heritage can indeed benefit from the tools and methods of the BIM initially developed for the new architectures. However, particular care should be used in the direct translation and application of some concepts and methodologies in the $\mathrm{CH}$ field, as "this might not be the most appropriate way of approaching HBIM for existing buildings" (Edwards, 2017).

This is the case of the LOD concept (here to be intended as "Level of Development") (American Institute Architects, 2008; UNI, 2017) that defines the reached level of informative evolution of a digital object (Pavan, Mirarchi, \& Giani, 2017). Being developed for the field of contemporary architecture, it takes into account the informative requirements (which information should be integrated into the model) and the normal development (that follows a pre-established pipeline among all the actors of the process) of the information modelling for the new construction (Pavan, Mirarchi, \& Giani, 2017). In this work, it has been decided to take the central concept of LOD and to apply it in the specific context of the model for Milan Cathedral restoration.

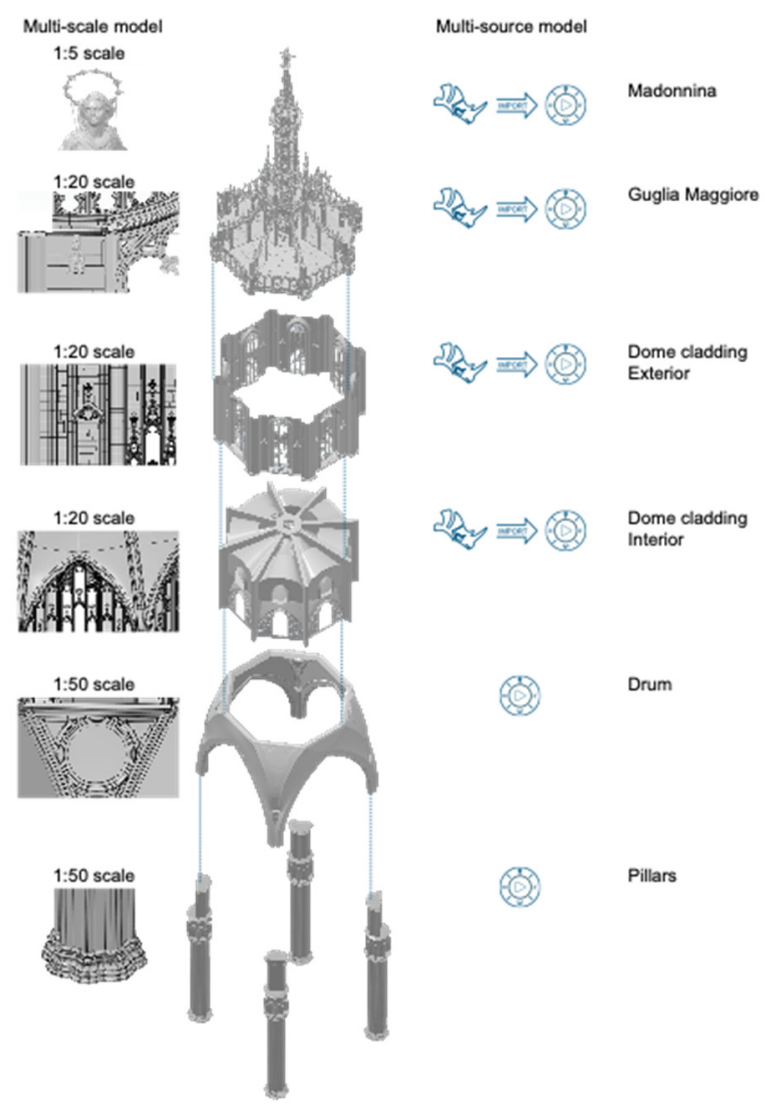

Figure 3: A schematic representation of the model with its scale and source of the objects.

As previously stated, the realised model comprehends objects at different representation scale and different resolution in terms of breakdown structure: in fact, the imported elements present the subdivision in blocks, while the new modelled ones, at 1:50 scale, do not present further subdivision than the architectural element, the fourth level in the structure. Since all the modelling of Milan Cathedral elements has always been performed on a real-based approach, they are modelled at the maximum possible accuracy offered by the point cloud, which is the product of a survey designed for that scale and to produce digital representation at the established accuracy. Any increment in the geometric level of detail is possible if a new survey is carried out at a suitable geometric accuracy. Objects are modelled "in place" at the level of the architectural element (the same in which the point cloud was segmented) and then, when needed by the restoration activities, are subdivided through a splitting operation into their constitutive blocks in order to reach the higher informative level of detail in the established structure. With this operation, the reverse engineering of the part of the Cathedral should be considered complete as the final, constitutive element of its architectural system has been reached and defined. Since the splitting operation is carried out manually and it ends to be a very time and resource-consuming, it is realised when needed by the planned activities of the restoration yard. 


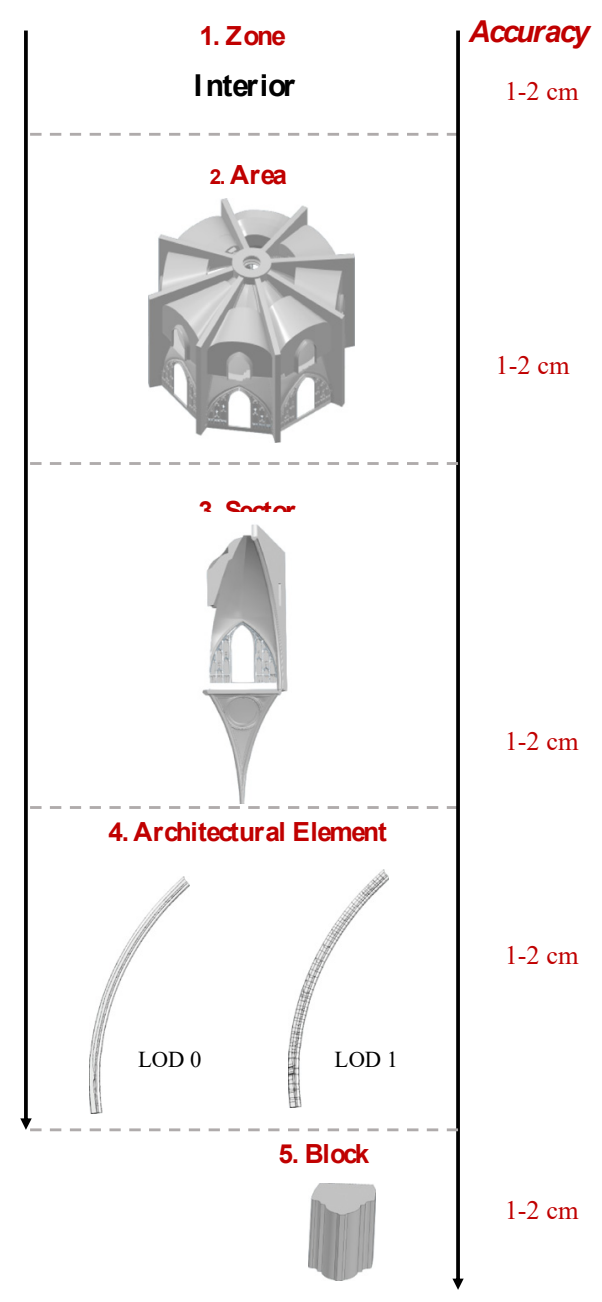

Figure 4: A schematic representation of the logic of the breakdown structure.

In order to take into account, this progressive and localised development of the informative content of the model as the maintenance of the Cathedral proceeds, namely if the block subdivision is available for a determined architectural object, the concept of Level of Development (LOD) has been adopted: objects at LODO level are modelled as architectural elements and do not present further subdivision, while objects at LOD1 had been modelled as architectural elements but after were subdivided into the constitutive marble blocks. Between the two LODs there is no difference in terms of geometrical accuracy since all the model has been realised in order to comply with the representation scale, and consequently the metrological accuracy, of the reference point cloud.

\section{The Digitised Cathedral}

\subsection{Preliminary operation: Point Cloud segmentation}

The point cloud data on which the operator bases his modelling actions must be set up for the task. The raw data coming from the survey is a set of $x, y, z$ points together with radiometric or colour information (depending on the instrument used for the acquisition).
These data are rich in metric content and describe completely the 3D geometry of the object that is surveyed but lack semantics and hierarchy among parts.

Computational requirements and the complexity inherent in such an extended dataset, like that of Milan Cathedral, make the semantic structuring of the point cloud a fundamental step preceding the modelling phase itself. Up until now, this process has been done mainly manually, with an expert operator visually interpreting and segmenting the dataset. Recent advancements in the Artificial Intelligence (AI) field made possible to develop semi-automatic Deep Learning (DL) and Machine Learning (ML) procedure that speed up the process which, otherwise, would have been as time-consuming as the modelling phase itself.

Due to the difficulties of finding a wide, enough labelled dataset to train a Neural Network for a DL approach and to ML better performance (Matrone et al., 2020), a supervised ML approach based on Grilli, Farella, Torresani \& Remondino (2019) has been used to classify Milan Cathedral dataset. The authors train a Random Forest (RF) classifier manually annotating a small portion of the dataset together with geometric features designed for the architecture (Grilli, Farella, Torresani \& Remondino, 2019). The size of Milan Cathedral point cloud makes it difficult to perform classification on the whole dataset. Its requirements in computational capacity make it a real challenge to manage the whole set of points. Furthermore, the necessity to distinguish among such a high number of semantic classes introduce a high degree of uncertainty leading to classification errors.

In Teruggi, Grilli, Russo, Fassi, \& Remondino (2020) the method has been improved using a Multi-level Multiresolution approach. The classification process is divided into different stages (Fig. 5).

At first, the full resolution dataset is subsampled, and the architectural macro-elements are classified by training a specific RF classifier on a $5 \mathrm{~cm}$ resolution point cloud. The result is interpolated on a higher resolution version of the point cloud $(2 \mathrm{~cm})$ so that each macro element can be further subdivided. The process is iterated until each element of the architecture is classified with increasing detail directly related to point cloud resolution and until the initial resolution is reached $(5 \mathrm{~mm})$.

Each step requires a new $\mathrm{RF}$ to be trained on its relative manually annotated portion (Fig. 6), but the small amount of required labelled data and the speed of the training and classification process make the methodology a success. Performance have been assessed with standard ML metrics (Precision, Recall and F1 score) and results are satisfactory at each classification level (Level 1: 94.7\%, 95\%, 93\%; Level 2: 99\%, 98\%,99.3\%; Level 3: 92\%, $88.5 \%, 91.8 \%$ respectively) (Teruggi, Grilli, Russo, Fassi \& Remondino, 2020).

Figure 7 shows Milan Cathedral $5 \mathrm{~cm}$ resolution point cloud classified at level 1 in its constituting macroelements.

At the end of the elaboration, the whole point cloud is entirely composed of the sub-recognised point cloud portion that semantically describes the Duomo shape. From macro to micro-scale every element is correctly recognised and classified, like a 3D puzzle, it is possible to "disassemble" and "re-assemble" Duomo. The visual 
recognition of the elements makes it easier to consult the point cloud and solves the problems of ambiguity that can be created in reading the unstructured cloud. Also, for people that have not familiarity whit this type of data is easy to consult it, they take advantage from the coloured view of the architectural object and related vocabulary (altar, floor, pillar, vault, roof).

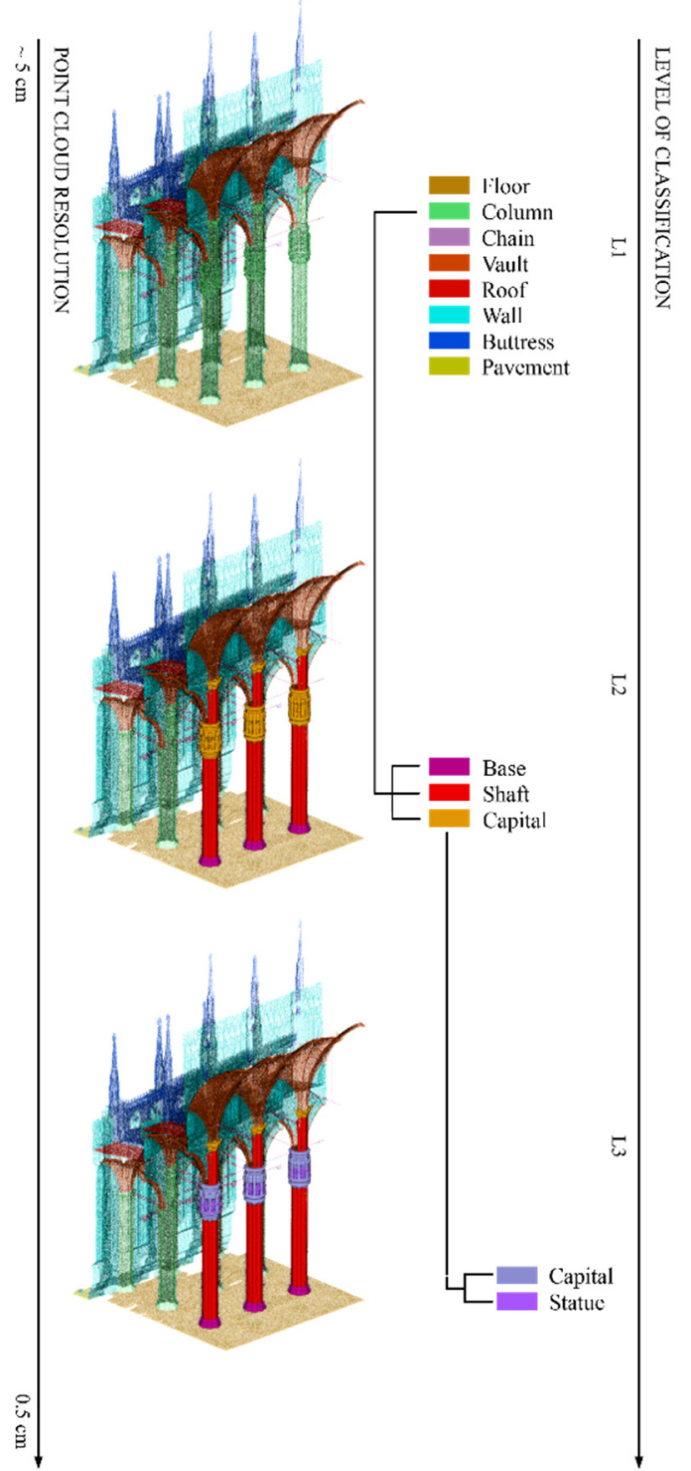

Figure 5: MLMR classification results and semantic classes. The subdivision starts from architectural macroelements, proceed to architectural element, and reach full resolution point cloud $(5 \mathrm{~mm})$ for object subdivision (statues, decorations). Point cloud resolution changes according to the dimensions of elements to be recognised.

The first immediate use of this data regards the possibility to take dimensional information. Using simple tools (ruler) the user, having selected and visualised the element, is able to measure it. The second way regards the possibility to use it as a starting point to create a solid model. When it is necessary, the structured point cloud can be uploaded in different modelling software as a "base" to build the 3D shape. The entire step of point cloud contour is outdone, the modeller starts directly from the single set (single selected point cloud object). This means much time saved and avoiding subjective interpretation of the point cloud data. This second application was tested using the sophisticated modelling tools provided by the 3DExperience platform.

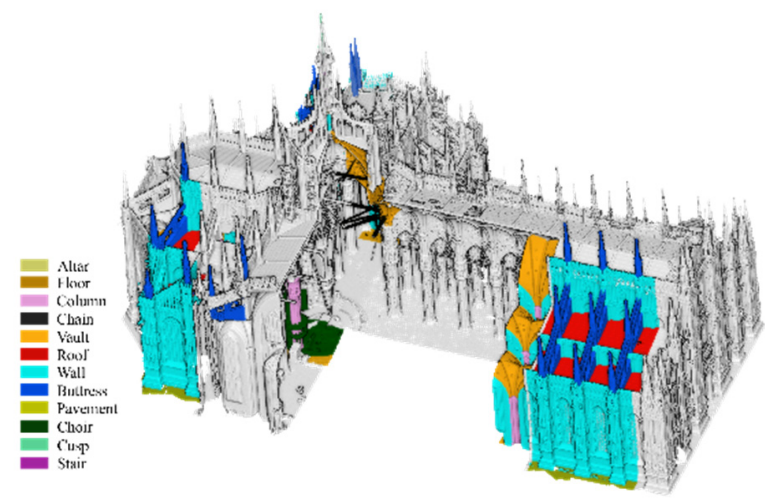

Figure 6: Manually annotated training set for classification level.

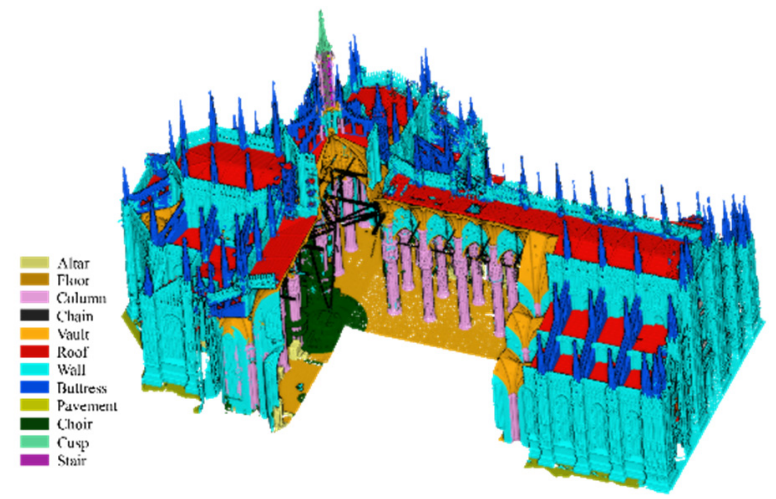

Figure 7: Architectonic macro-elements classified at level 1 on a $5 \mathrm{~cm}$ resolution point cloud.

\subsection{The adopted modelling pipeline}

The chosen approach was to model "in-place" starting from the already segmented point cloud, extracting the most significative cross-sections and profiles to be used as generative geometries for the modelling algorithms of the software.

The modelling engine of the 3DExperience platform is called CATIA (Computer-Aided Three-Dimensional Interactive Application) and is composed of different development environments, according to the task to be accomplished and the type of geometries to be modelled. The first step was to import the point cloud, appropriately segmented and filtered in dedicated software, usually Cloud Compare (CloudCompare, 2020), inside the Digitized Shape environment, that allows the user to import and process non-NURBS geometrical data, like point clouds and meshes and perform the preliminary operations of modelling. Inside this module, it is possible to manually select and extract cross-sections and profiles as subgroups of the complete point cloud, to be used in the subsequent modelling phase. These profiles are then drawn inside the dedicated environment to 2D restitution, called Sketcher, able to create bi-dimensional drawing entities on a reference plane previously established, which can be integrated with $3 \mathrm{D}$ splines that connect particular points, acting as guides for the modelling algorithms that will be used in the following phase. The 
result of these preliminary operations is a wireframe model (Fig. 8) built by the representative profiles, crosssections, guides and reference planes. It has to be noticed that the quality of the final model relies mainly on the ability of the operator during this phase, which is also the most time consuming, having to arbitrary decide how many and which profiles are the best solution in order to describe the considered geometry, also taking into account the available time and resources for this operation.

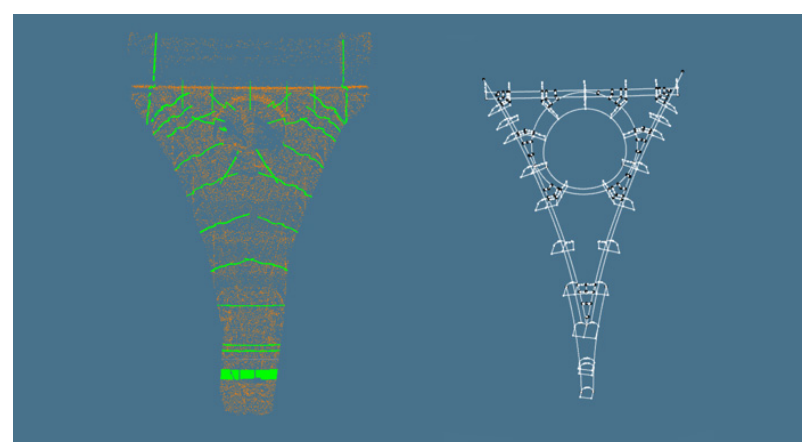

Figure 8: The extracted sections and profiles (left) and the obtained wireframe model of a pendentive (right).

The proper modelling phase, intended as the production of surface and solid 3D geometry, was conducted inside the "Part Design" and the "Generative Shape Design" environments. It can be considered partially automatised since a suitable choice of guides and profiles speed up considerably the geometry production.

CATIA provides several powerful tools based on "multisection" input: they can build surfaces or solids interpolating between the provided sections and guides, performing in the background several single modelling operations as extrusions and sweeps based on the input geometry.

The skills and experience of the operator in this phase are expressed by its ability to split the modelling task into subtasks and, if needed, modify the input profiles inside the tolerances in order to help the modelling algorithms in the processing phase. Again, it has to be noticed that the final result (Fig. 9) depends on the ability of the operator to act as a mediator between the needed accuracy of the model, the possibilities of the software to build the desired geometries and the available resources, especially time.

The final step in this pipeline is the most critical in terms of reality-based modelling at an established representation scale: in order to verify that the finalised model was built inside the dimensional tolerances from the point cloud, a deviation analysis has to be performed. It gives a visual and quantitative idea of how much, and in which parts, the model respects the input geometry according to the tolerances chosen with the representation scale, as a final validation of all the choices made by the operator, as previously described (Fig. 10). It has to be noticed that this operation is easy to be carried out directly inside the "Digitised Shape" environment of CATIA, allowing modellers to perform fast work-inprogress accuracy controls and more refined final checks without the need to export the data to other software environments, representing a significative saving of time and resources if compared to the operations needed to accomplish the same task at the time in which the model of the Main Spire was realised (Fassi \& Parri, 2012).

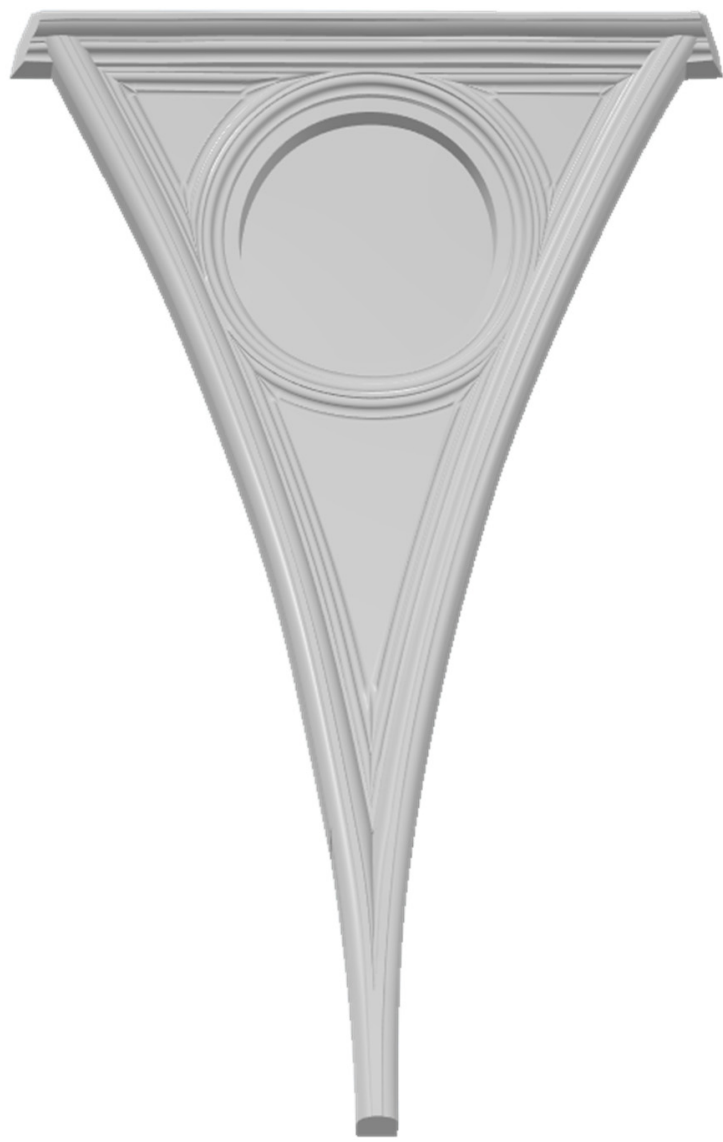

Figure 9: The final modelled element, a pendentive of the dome, scale 1:50.

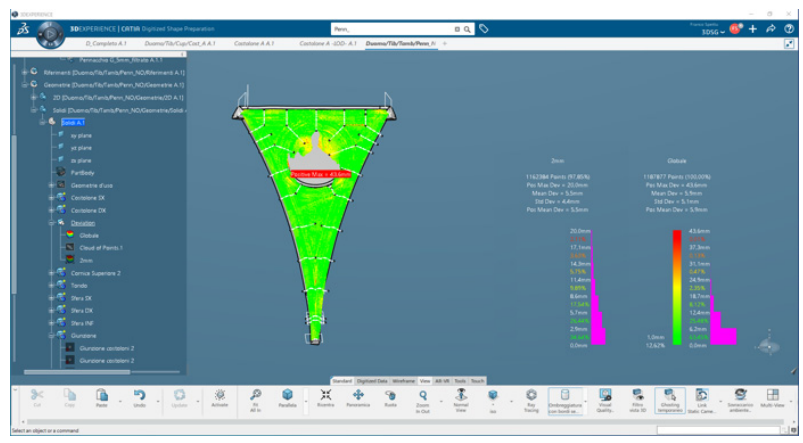

Figure 10: The dimensional verification performed inside the modelling environment.

\subsection{Hybrid Modelling}

For "hybrid model" (Brookes, 2017) is here intended an informative model that is constituted both by point clouds and solid and surface geometries. This kind of approach uses the point cloud as a self-standing object and not only as a reference for the profile extraction, being possible to manage information and attachments directly on the cloud object. The main advantage of this approach is that, once the global point cloud is accurately elaborated and segmented into the elements of the implemented structure, is possible to skip the time-consuming modelling phase, relying on the possible more accurate data representing the architecture, which is the point 
cloud, instead of producing geometries that approximate the reality through selected profiles and software interpolation.

In the presented example, the hybrid modelling was applied to the statues of a capital (Fig. 11): a decorative element that is very difficult to be modelled and, on the side of the restoration yard, is managed as a whole. Each statue is a separated point cloud and has its own dedicated, informative sheet about status, condition and maintenance operations, as shown in the previous example in Section 4.4.

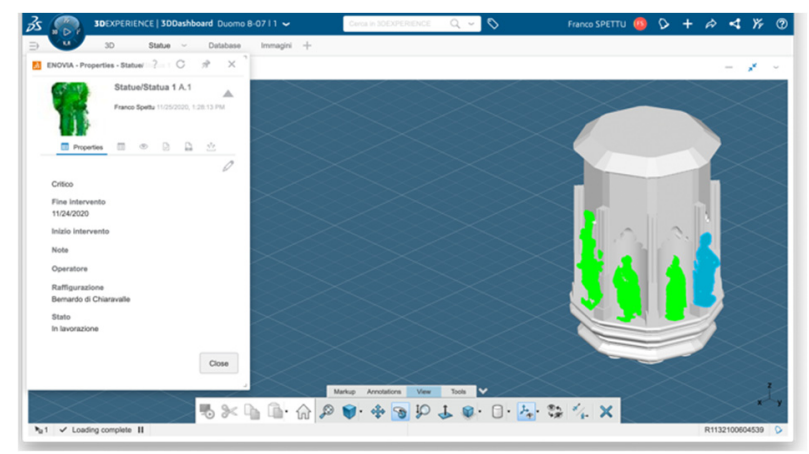

Figure 11: Example of how the point cloud was integrated with the solid models and how it is possible to enrich it with information.

The possibility of modelling when needed, when this operation adds value and information to the whole model, is believed as the most promising and encouraging aspect of the conducted test on the 3DExperience platform. It consents to focus the initial efforts and resources on the post-production of the survey data and in its general classification and segmentation in the established structure, being possible to subsequently integrate the whole model with solid and surface geometries, as an example, obtaining the marble block subdivision. This kind of adaptability is believed to be particularly useful in the field of Cultural Heritage.

\subsection{Database creation}

One of the most critical operations to be accomplished is to set the structure of the database and to populate it with the modelled three-dimensional objects, representing in a certain way the idea of translating all the data, knowledge, maintenance history and practices into an informative system able to gather such different and consistent information and to be proficiently used by the archivists, yard directors and operators.

The 3DExperience embodies a specific tool to accomplish this task, called "IP Classification", accessible through a web browser and with a textual interface that consents to build the database and manage the objects without visualising or render any geometry. The root of the database is named "Library" and can host an arbitrary number of nested subcategories, according to the needs. Each subcategory represents a level of the Cathedral subdivision as previously discussed.

This system acts as a central repository of all the information available for the Cathedral and consents to navigate through the monument structure and manage all the data: from the geometries and information attributes to the attached documents (Fig. 11). Every object, also documents, has its lifecycle and all its versions are stored and available to the consultation: in this sense, the database allows the user to navigate inside the digitised knowledge of the Cathedral in spatial and chronological terms.

\subsection{The user interface: front office}

As "front office" (Fassi \& Parri, 2012) is here intended the user-friendly interface created as a support for the maintenance operations in Milan Cathedral, used by the workers of the restoration yard to interact with the model for visualisation purposes and work on the informative part as the inspection and restoration activities are performed. This interface is intended to be used by notspecialised users and also on the restoration yard: it has to be easy to access and ensure usability even from portable devices.

The solution implemented as a feasibility test inside the 3DExperience platform is web-based and accessible through browser: every user has an account with specific permission and with a personalised interface, managed through dashboards and widgets. Dashboards are customisable panels that can be freely populated with widgets, specific applications for visualising, searching and modifying the data loaded in the platform. Once logged in, the user finds among his available dashboards the one suitable to his tasks and needs.

From the fruition interface, the user can visualise and navigate the 3D model or a portion of it, in order to identify the objects, as the blocks, on which he should intervene. The system allows to visualise the geometries, query the database and modify the data related to the objects inside the limits assigned to the user profile and make graphic and textual annotations on the shown geometries (Fig. 12).

\section{Conclusion and future works}

The long process of digitization of the Milan Cathedral began more than 10 years ago, starting from the knowledge and maintenance needs expressed by the VF. Comply with these needs means designing and implementing both on-site surveys and the processing and use of the data so that they are an effective support for the restoration office and yard. This implies using all the investigation techniques, keeping up with their evolution, and all the innovative and unconventional solutions, in the belief that the Milan Cathedral due to its history, its dimensions, and the uninterrupted operation of the maintenance yard, represents a unique challenge for the research in the field of digitisation in favour of built heritage.

The aim of this research is to experiment and consolidate various documentation techniques and test tools in order to create systems of knowledge, management, and use. "Documenting" and "managing" take on a very specific meaning. The documentation of the shape is necessary for the planning of maintenance activities, therefore suitable resolution and accuracy must be guaranteed. To manage the information that gravitates around the maintenance yard means dealing with an impressive amount of data that embodies a significant historical value: therefore, it is necessary to respond with a "time perspective" that does not only search for a solution to the immediate problems, but works to provide answers to 
relevant questions. The management of Cultural Heritage as Milan Cathedral requires designing a flexible, customizable, and above all to build a long-lasting model (3D geometries and information) and data archiving system.

On the survey side, during the 10 years of work on Milan Cathedral, the frontier of research has moved from the acquisition of the data on the field to the processing and semantisation, with the significant contribution of $\mathrm{Al}$ and the derivative $\mathrm{DL}$ and $\mathrm{ML}$ procedures which have allowed data to be processed in significantly shorter times than what would have been possible doing it manually. Furthermore, the process eliminates the uncertainty linked to the interpretation of the data by the operator.

These first results suggest possible and unforeseen chances of using the data. The point models classified by the ML processes have been effectively employed with the Dassault system. The modelling tools that the platform offers are very effective, and the ability to create hybrid models and manage the life cycle of each object within the same environment makes the system extremely promising for an ambitious task as the complete reverse engineering of the Cathedral.

The close collaboration together with the technical office of the VFD has always stimulated the research activities and led to optimal and shared solutions to the encountered problems. An informative system for the entire Cathedral able to embody the data produced in recent years, to avoid duplicating the operations already done, to create connections between the different archives would act as a "hinge" around with the future operations and discussions will move.

\section{Acknowledgements}

The authors would like to thank all the colleagues who have participated in the past and are now collaborating in the Milan Cathedral project. Thanks to Dassault Systémes for the possibility to test the 3D Experience platform and for their availability and support.

\section{References}

Achille, C., Fassi, F., Mandelli, A., Perfetti, L., Rechichi, F., \& Teruggi, S. (2020). From a Traditional to a Digital Site: 20082019. The History of Milan Cathedral Surveys. In B. Daniotti, M. Gianinetto, \& S. Della Torre (Eds.), Digital Transformation of the Design, Construction and Management Processes of the Built Environment (pp. 331-341). https://doi.org/10.1007/978-3-030-33570-0_30

American Institute Architects. (2008). AIA Document E202 - 2008 Building Information Modeling Protocol Exhibit.

Autodesk. (2020). Revit Software | Get Prices \& Buy Official Revit 2022 | Autodesk. Retrieved November 24, 2020, from https://www.autodesk.com/products/revit/overview

Brookes, C. (2017). The application of building information modelling (BIM) within a heritage science context. Discovery Innovation and Science in the Historic Environment. Historic England Research Project Report, (7351).

Bruno, N., Rechichi, F., Achille, C., Zerbi, A., Roncella, R., \& Fassi, F. (2020). Integration of historical gis data in a HBIM system. ISPRS - International Archives of the Photogrammetry, Remote Sensing and Spatial Information Sciences, XLIII-B4-2, 427-434. https://doi.org/10.5194/isprs-archives-XLIII-B4-2020-427-2020

Bruno, N., \& Roncella, R. (2018). A restoration oriented HBIM system for Cultural Heritage documentation: the case study of Parma Cathedral. ISPRS - International Archives of the Photogrammetry, Remote Sensing and Spatial Information Sciences, XLII-2, 171-178. https://doi.org/10.5194/isprs-archives-XLII-2-171-2018

Bruno, N., \& Roncella, R. (2019). HBIM for Conservation: A New Proposal for Information Modeling. Remote Sensing, 11, 1751. https://doi.org/10.3390/rs11151751

Chikofsky, E. J., \& Cross, J. H. I. I. (1990). Reverse engineering and design recovery: a taxonomy. IEEE Software, 7(1), 13-17. https://doi.org/10.1109/52.43044

CloudCompare. (2020). CloudCompare official website. Retrieved November 24, 2020, from https://www.cloudcompare.org

Dassault Systèmes. (2020). Dassault Système official website. Retrieved November 24, 2020, from https://www.3ds.com/3dexperience

De Luca, L., Veron, P., \& Florenzano, M. (2006). Reverse engineering of architectural buildings based on a hybrid modeling approach. Computers \& Graphics, 30(2), 160-176. https://doi.org/10.1016/j.cag.2006.01.020

Dore, C., \& Murphy, M. (2013). Semi-automatic modelling of building façades with shape grammars using Historic Building Information Modelling. ISPRS - International Archives of the Photogrammetry, Remote Sensing and Spatial Information Sciences. https://doi.org/10.5194/isprsarchives-xl-5-w1-57-2013

Edwards, J. (2017). It's BIM - but not as we know it! In Y. Arayici, J. Counsell, L. Mahdjoubi, G. Nagy, S. Z. Hawwās, \& K. Dweidar (Eds.), Heritage building information modelling (I). New York: Routledge/Taylor \& Francis Group.

Fassi, F., Achille, C., Gaudio, F., \& Fregonese, L. (2012). Integrated strategies for the modeling very large and complex architectures. ISPRS - International Archives of the Photogrammetry, Remote Sensing and Spatial Information Sciences, XXXVIII-5/ W16, 105-112. https://doi.org/10.5194/isprsarchives-XXXVIII-5-W16-105-2011

Fassi, F., Achille, C., \& Fregonese, L. (2011). Surveying and modelling the main spire of Milan Cathedral using multiple 
data sources. The Photogrammetric Record, 26(136), 462-487. https://doi.org/10.1111/j.1477-9730.2011.00658.x

Fassi, F., Achille, C., Mandelli, A., Rechichi, F., \& Parri, S. (2015). A New idea of bim system for visualization, web sharing and using huge complex $3 \mathrm{~d}$ models for facility management. International Archives of the Photogrammetry, Remote Sensing and Spatial Information Sciences - ISPRS Archives. https://doi.org/10.5194/isprsarchives-XL-5-W4-3592015

Fassi, F., \& Parri, S. (2012). Complex Architecture in 3D: From Survey to Web. International Journal of Heritage in the Digital Era, 1(3), 379-398. https://doi.org/10.1260/2047-4970.1.3.379

Fregonese, L., Adami, A., (2020). The 3D Model of St. Mark's Basilica in Venice. In B. Daniotti, M. Gianinetto, \& S. Della Torre (Eds.), Digital Transformation of the Design, Construction and Management Processes of the Built Environment (pp. 343-354). https://doi.org/10.1007/978-3-030-33570-0_31

Grilli, E., Farella, E. M., Torresani, A., \& Remondino, F. (2019). Geometric Features Analysis for the Classification of Cultural Heritage Point Clouds. International Archives of the Photogrammetry, Remote Sensing and Spatial Information Sciences - ISPRS Archives, 42(2/W15), 541-548. https://doi.org/10.5194/isprs-archives-XLII-2-W15$541-2019$

Lo Furno, F., Pietrucci, F., Tommasi, C., \& Mandelli, A. (2016). Un modello informativo parametrico per il Duomo di Milano. In Archeomatica 4-2016 (pp. 22-25).

Mandelli, A., Achille, C., Tommasi, C., \& Fassi, F. (2017). Integration of 3D models and diagnostic analyses through a conservation-oriented information system. International Archives of the Photogrammetry, Remote Sensing and Spatial Information Sciences - ISPRS Archives. https://doi.org/10.5194/isprs-archives-XLII-2-W5-497-2017

Matrone, F., Grilli, E., Martini, M., Paolanti, M., Pierdicca, R., \& Remondino, F. (2020). Comparing machine and deep learning methods for large 3D heritage semantic segmentation. ISPRS International Journal of Geo-Information, 9(9). https://doi.org/10.3390/ijgi9090535

Pavan, A., Mirarchi, C., \& Giani, M. (2017). BIM: Metodi e Strumenti. Progettare, costruire e gestire nell'era digitale. Milano: Tecniche Nuove.

Rechichi, F. (2020). Chimera: a BIM+GIS system for cultural heritage. ISPRS - International Archives of the Photogrammetry, Remote Sensing and Spatial Information Sciences, XLIII-B4-2, 493-500. https://doi.org/10.5194/isprs-archives-XLIII-B4-2020-493-2020

Rechichi, F., Mandelli, A., Achille, C., \& Fassi, F. (2016). Sharing high-resolution models and information on web: The web module of bim3dsg system. International Archives of the Photogrammetry, Remote Sensing and Spatial Information Sciences - ISPRS Archives. https://doi.org/10.5194/isprsarchives-XLI-B5-703-2016

Rekoff, M. G. (1985). On reverse engineering. IEEE Transactions on Systems, Man, and Cybernetics, SMC-15(2), 244252. https://doi.org/10.1109/TSMC.1985.6313354

Rhinoceros. (2021). Rhinoceros Offical website. Retrieved March 5, 2021, from https://www.rhino3d.com/

Teruggi, S., Grilli, E., Russo, M., Fassi, F., \& Remondino, F. (2020). A hierarchical machine learning approach for multilevel and multi-resolution 3d point cloud classification. Remote Sensing, 12(16), 2598. https://doi.org/10.3390/RS12162598

Tommasi, C., \& Achille, C. (2017). Interoperability matter: Levels of data sharing, starting from a 3D information modelling. International Archives of the Photogrammetry, Remote Sensing and Spatial Information Sciences - ISPRS Archives. https://doi.org/10.5194/isprs-archives-XLII-2-W3-623-2017

Tommasi, C., Fiorillo, F., Jiménez Fernández-Palacios, B., \& Achille, C. (2019). Access and web-sharing of 3D digital documentation of environmental and architectural heritage. ISPRS Annals of the Photogrammetry, Remote Sensing and Spatial Information Sciences, 42, 707-714. https://doi.org/10.5194/isprs-archives-XLII-2-W9-707-2019

UNI. (2017). Italian regulation 11337-4:2017.

VFD. (2021). Veneranda Fabbrica del Duomo Official webside. Retrieved March 5, 2021, from https://www.duomomilano.it/en/ 


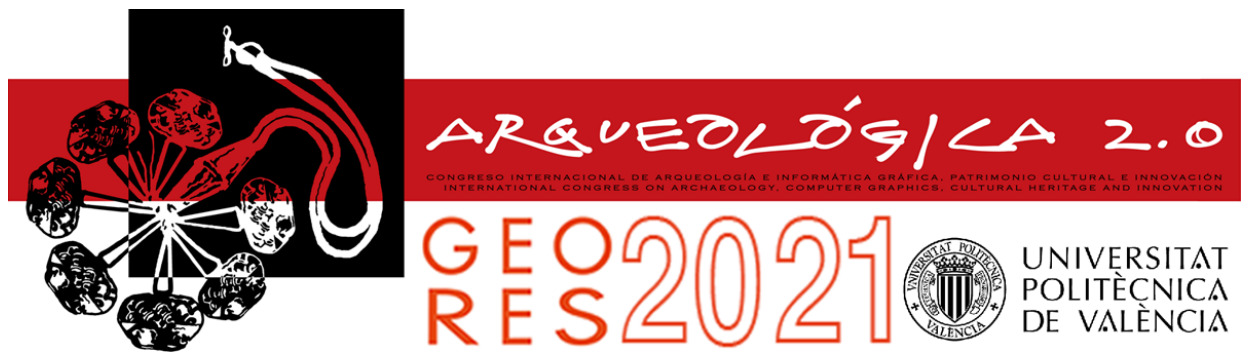

Proceedings of the joint international event $9^{\text {th }}$ ARQUEOLÓGICA

$2.0 \& 3^{\text {rd }}$ GEORES

Valencia (Spain).

26-28 April 2021

\title{
ENHANCING AND MANAGING DATA AND DIGITAL COMPETENCIES FOR ARCHITECTURE TEACHING AND TRAINING IN THE FIELD OF PROTECTION OF HERITAGE
}

\author{
Nora Lombardini ${ }^{a}$, Cristiana Achille ${ }^{b}$, Cinzia Tommasi ${ }^{b}$, Elena Fioretto ${ }^{a,{ }^{*}}$ \\ ${ }^{a}$ Department of Architecture, Built Environment and Construction Engineering (ABC), Politecnico di Milano, Via Ponzio 31, 20133 \\ Milano, Italy. nora.lombardini@polimi.it; elena.fioretto@polimi.it \\ b 3D Survey Group, ABC Lab, Department of Architecture, Built Environment and Construction Engineering (ABC), Politecnico di Milano, \\ Via Ponzio 31, 20133 Milano, Italy. cristiana.achille@polimi.it; cinzia.tommasi@polimi.it
}

\begin{abstract}
:
Given the growing relevance, at national and international levels, of restoration and conservation interventions on existing buildings, the universities have developed degree courses with specific addresses in "Conservation of Architectural and Environmental Heritage". The students that attend this course become a graduate with specific, extensive, and updated skills in the field of knowledge, protection, conservation, reuse and enhancement of architectural and environmental heritage. The complexity of the intervention is faced through the contribution of the various disciplines that contribute to the training of the architect, at the same time they studied modern instruments and tools for collecting and managing data, from on-field survey to sharing projects and ideas. The goal is to learn to manage, in its entirety, the project and the range of possible interventions with deep conservative sensitivity, with skills ranging from maintenance to restoration and redevelopment, both in the dimension of the single building and the urban and landscape scale.
\end{abstract}

Keywords: cultural heritage, digital competences, conservation, learning, HBIM

\section{Education in the protection of heritage}

According to the Italian school of Architecture, the architects must be trained in the field of conservation of architectural heritage (Di Stefano, 1975). The reason for this need is rooted in the Italian laws of 1925 under which only the architects, immediately after the master's degree, State examination and professional qualification, can work on the "monuments" of the national list. For this reason, architects must be able, right from the beginning of their work experience, to interact with the offices in charge of controlling the works on the heritage, such as the Soprintendenza Archeologia, Belle Arti e Paesaggio, the special Commissions of the Roman Catholic Church (in charge for the control of the safeguarding of the artistic and religious value of the churches) and the municipal, provincial and regional authorities of the Italian government. Nowadays, considering the adoption of the sustainable approach in the urban development, the attention is mostly devoted to the recovery of the existing urban structures and, especially, the existing buildings, in order to enhance, as the Brundtland Report/Our Common Future states (Brundtland Commission, 1987), a sustainable growth. The new attention to the existing buildings (not only architectural heritage) is strictly connected with the special economic/social Italian situation. It is imposing the needs both to improve the training on the analyses and the understanding of what is already built, pushing on the needs to use all the training and educational approaches in order to improve the ability of the future architects to grasp the existing structures, using advanced technologies. Moreover, it is useful to remember the introduction of new rules in the public procurement applications, imposing the need to use the BIM process for the submission of projects on existing structures and existing buildings (UNI 11337, 2017). The necessity of BIM in the management of existing buildings is well recognized today. What is already and not definitively solved is what kind of implementation needs the BIM procedure on the existing structures. What are the parameters useful to describe the process is one of the main questions to be solved. This research must be developed at different levels, concerning the contents and the methods to share the knowledge at local and international levels. This is both because it is necessary to improve the involvement of local communities in the participation of the management phase, and because, for the professionals, the labour market is day by day more widespread, and not only restricted within national borders. What is very urgent, furthermore, is the internationalisation of the classrooms and, consequently, the backgrounds of the students. The sharing of knowledge is the priority at several levels described and 
it is one of the aims of the educational strategy (UN 17 goals, quality education and EU roles - Bologna Process). Considering the growing importance assumed in the international framework by interventions on buildings, universities have developed degree courses with specific addresses in 'Conservation of Architectural and Environmental Heritage' (Di Biase \& Albani, 2019). These courses of study aim at training students with specific, indepth, and up-to-date skills in the field of knowledge, protection, conservation, reuse, and enhancement of architectural heritage and environment. The specific issues are faced through the contribution of the various disciplines as an addiction to the training of the architect. Particular attention is paid to the history of protection and restoration, to the methods of investigation, diagnosis and evaluation of the building, to the selection criteria between conservation and transformative approaches (Musso, 2008). The goal is to manage each phase of the project and the range of possible interventions with a deep conservation sensitivity: from maintenance to restoration, renovation, and addition, both in the size of the single building, and at the scale of urban contexts and landscape.

One of the stronger points of the conservation approach (at training and professional level) was, until quite recently, the possibility to "touch" the building. Several different boundary conditions, such as the restrictions imposed by the governments during the lockdown due by Covid-19, have shown that it is necessary to define different approaches able to decrease the necessity, for the students, to have direct access to the case of study. First of all, what it is necessary to do in order to avoid this gap, is to collect, arrange and use all the available sources and data connected with the cases of study (Achille, Lombardini \& Valentini, 2012). Starting from the point that often we have an excess of data, the management of the existing ones can represent the training starting point. The second issue is to bypass the involvement of the students, directly, in the phase of collecting data, offering them a materials' package, introduced and explained by professors, that they have to understand, manage, imputing, improve and disseminate. This approach requests the necessity to arrange the existing data by trainers and institutions. Also, for this reason, it is very urgent the optimisation of the knowledge, in order to create a database useful for its sharing. This gap in the data organisation represents the weakness in the data processing, both in the higher institution training and, also, in the control and supervision that the public administration must exercise for the cultural heritage supervision and dissemination.

\section{Competences on conservation project data and methodologies}

The Learning Conservation Practices (LCPP) are based on the study of the building (or/and the built environment) in its authentic dimension (ICOMOS, 1994).

Each object constitutes a singularity that even the use of new digital technologies and related skills are able to grasp. The determination of this singularity requires a precise study of the history of its construction phases, of construction techniques and of materials. Decays, alterations and failures are detected and analysed to proceed with the conservation project which, through the identification of the urban, social, economic characteristics of the context, requires that its use ought to be confirmed or renewed.

The project is developed considering both the structural and energy efficiency of the building.

It is therefore evident that the information necessary for the preparation of a conservation project, which involves all the most up-to-date restoration techniques, must combine digital skills and the necessary information for the building knowledge. The description of the existing building, especially the old one, is not based on standardized data. The protocols concern not the data (as happens today with the new buildings), but the procedures for detecting data (UNI 11182, 2006).

\subsection{Digital and theoretical competencies}

Today, thanks to the digital tools at disposal, it is possible to partially compensate for the inability to go to the site (Covid 19). When data have been already recorded, the students are able to do a 'digital survey' exploring point clouds and use them with images to check in a deep way the object characteristics. Data acquisition is a consolidated process, workflow and techniques are well established (Remondino, 2011; loannides, Fellner, Georgopoulos \& Hadjimitsis, 2010; Bianchi et al., 2016; Fassi, Fregonese, Ackermann, \& De Troia Fassi, 2013).

Today the main techniques available include total station and GNSS surveying, terrestrial laser scanning (TLS) and photogrammetry (close range and UAV).

The geometric survey is generally done through an integrated survey, in this way it is possible to obtain different products (point clouds, orthophoto, precise measures) and compensate for the eventual limitations of a single technique.

The combination of different techniques permits a sensible on-site time reduction, simultaneously the acquired data is multiscale and multi-functional.

The survey must be as complete and exhaustive as possible, it must return the shape and position of the elements to the selected scale, thus guaranteeing the appropriate level of resolution, as described in the international guidelines (Bryan, Blake, Bedford, Barber \& Mills, 2009; ICOMOS, 2003; Historic England, 2018, Heritage Association of South Africa, 2019). The difficulties lie not so much in the use of the survey tools, but in the subsequent data processing. The process is known as scan-to-BIM and provides progressively construction of 3D objects (as elements windows, decoration, walls, foundations, roofs, vaults, ceilings and their construction, as the core of masonry construction: brickworks, stone works that make the building). Conservation projects are based on the collection, analysis and interpretation of a significant amount of heterogeneous data to develop a good project from the structural, efficient energy and adaptive re-use point of view (Achille, Lombardini \& Tommasi, 2016).

BIM process applied to Historical building becomes HBIM (Murphy, McGovern \& Pavia, 2009; Murphy, McGovern \& Pavia, 2011), and it represents an information system at the architectural scale and makes it possible to manage semantically enriched 3D models, sustaining a study and the analysis of historical buildings. 
The increasing ability to manage and process data by the HBIM software and its progressive customization levels have, in fact, made them an interesting alternative for the collaborative management of information and projects. The three-dimensional modelling phase mainly focuses on how to parameterize complex elements and how to model structural deformations and irregularities typical of the existing architecture (Tommasi \& Achille, 2017). Until now, no BIM software has proved adequate to directly model the shapes of the existing building from data in a point cloud format. The standard object libraries do not fully satisfy the needs of the representation of the existing building, especially when the scale of the drawing shows a high level of detail. For this reason, the research explores different strategies for recognizing, modelling and managing data, from the creation of a library of parametric architectural elements (Dore, \& Murphy, 2013) to the segmentation of raw data (Teruggi, Grilli, Russo, Fassi \& Remondino, 2020). The goal is always to 'recognise' the architectural elements and the construction of the building so that it can be effectively managed by the HBIM process. The final model is the best compromise between architectural analysis (recognition of the element according to the vocabulary) and tools and software used (Fai, \& Rafeiro, 2014; Bruno \& Roncella, 2019). The students training must develop a critical capability to identify and build the model of the object, finalizing the aim of the project.

The survey with advanced tools such as laser scanner, after the processing and the elaboration of the data, represents the object as-built and the envelope as it is. The aim of the modelling phase of the object is to link to the envelope the necessary information to describe the object in relation to the conservation project's aim.

The 3D model has to collect the data required to evaluate the building for its conservation.

That is why the BIM process seems the best way to do it, the structure of the software (parametric and objectoriented) lets to connect the 3D objects to specific information obtaining in this way an 'information system of the building'.

This kind of association is not possible with other modelling techniques, even if the BIM process can present some limits when the building is an existing one (Achille, Lombardini, \& Tommasi, 2018). In fact, the nonstandard materials and the class of information required for the conservation, make it hard to match the BIM process functionalities with these kinds of needs.

The level of detail (LOD) of the 3D model should be appropriate to the survey data acquired. It is important that the building is modelled in each of its components because the information refers not to the entire building, but to the single objects. The Italian standard defines 7 LOD degrees, indicated with letters A to G. Each level refers to a specific maturity of the object (UNI 11337, 2017; Lombardini, Achille \& Valentini, 2017). This classification introduces the LOD $\mathrm{G}$, intended as a life cycle LOD. This LOD, representing the evolution of the object during its lifetime and the transformation that occurred, it is a further in-depth level (Fig. 1).

The LOD $G$ represents a novelty in the international regulatory framework. All the interventions of management, maintenance, replacement, and all the material and decay description in time have to be included in the LOD G.

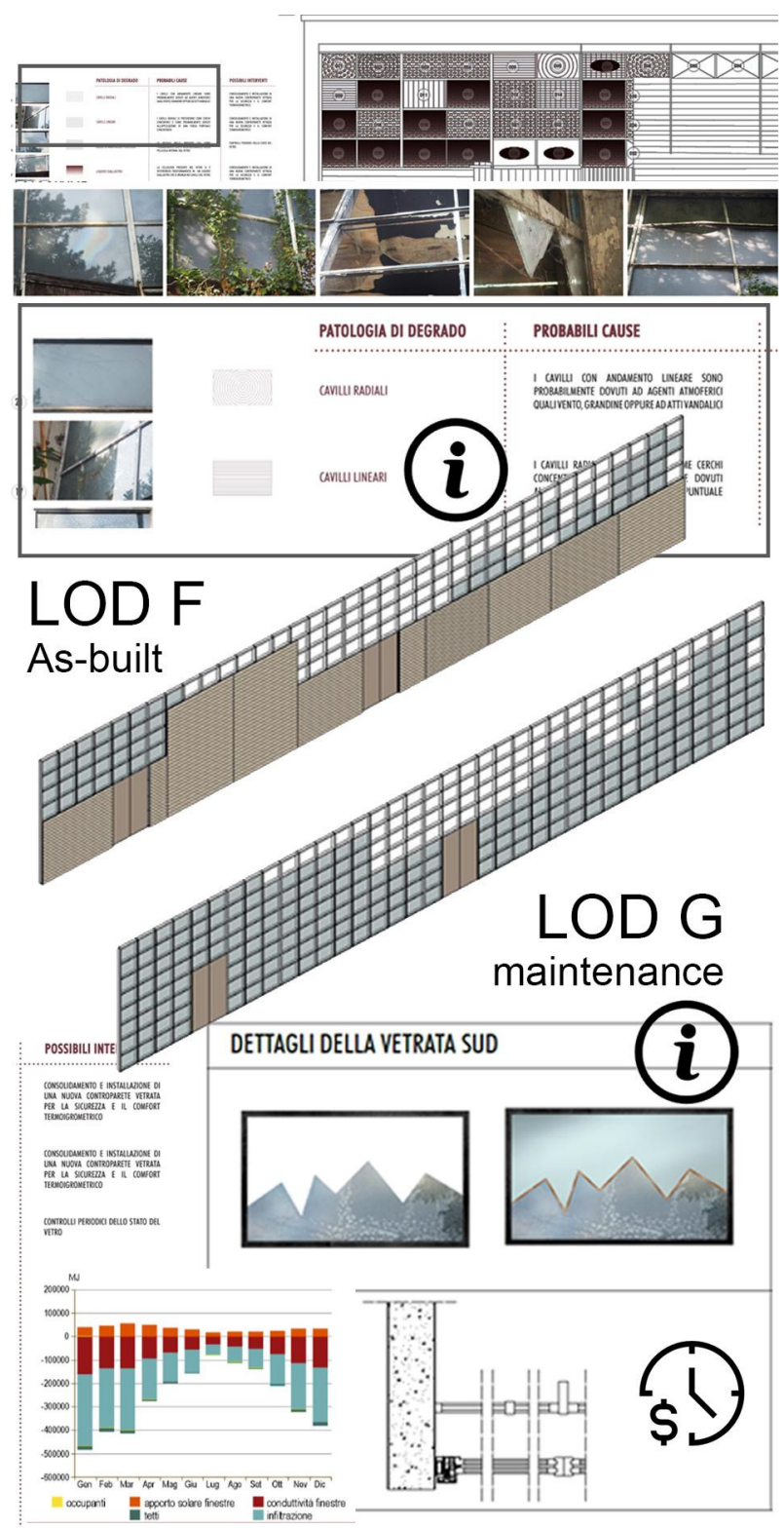

Figure 1: Differences between the LOD for Restoration according to UNI 11337:4. Top line: LOD G has to represent the as-built phase, and for this reason, it contains all the information about the existing building, such as decay and material

analysis. LOD F, instead, represents the maintenance and conservation program, showing the ordinary and extra-ordinary interventions.

The localisation in the 3D model of the analyses and the state of decay relating to materials in the HBIM platform contributes to enrich the database itself, with data that can be effectively used to design interventions (Chiabrando, Lo Turco \& Rinaudo, 2017). The issue of collecting historical qualitative data is a delicate one and is often not sufficiently evaluated. Historical semantic data (photographs, historical archives, original drawings, texts, ...) are frequently discussed in disciplinary fields other than those that directly involve the BIM and HBIM process. These data are also often presented in paper form and must be digitized before being inserted into a relational database. 
There are no guidelines or other references that indicate which and how much data should be digitized and organized through HBIM.

It is, therefore, essential that during the degree course students are 'trained' to recognize, choose, digitize, and organize the data necessary for the success of the project. Good knowledge of software tools must be accompanied by critical and data selection skills; this skill must allow evaluating when the tools already present in the software are sufficient or when it is necessary to create ad hoc databases connected to HBIM models. All necessary information must not be lost and need to be properly filed. In this way, it is possible to associate the modelled objects with both the selected info and parameters that describe the history and state of conservation of the building and the description of the interventions necessary for the restoration. The purpose for selecting the HBIM process is the potentialities that it offers to connect the 3D representation with an information database and the predisposition of managing the whole life cycle of the building, especially the maintenance, following national and international legislation (UNI 11337, 2017; EUPPD, 2014). The data inserted in the database strictly depend on the value that the architect assigns to them. Training, both theoretical ones and practical on-site, plays a fundamental role.

\subsection{HBIM conservation project}

At the end of the elaboration, each student group has at disposal the 'digital twin' (Raghunathan \& Barma, 2019; Farsi, Daneshkhah, Hosseinian-Far \& Jahankhani, 2020), with the data useful to manage the building, 3D model, and metadata about the state of art are the basis for the conservation project. In this phase, the target is to build capacity for the 'virtual design' of interventions based on the collected data. In this phase, the target is to build capacity for the 'virtual design' of interventions based on the collected data. The design process for conservation managed by BIM-based systems contemplates numerous temporal and managerial advantages. The process shares quickly the information among the actors: project proposals can be immediately analysed; errors identified, in order to choose the best solution. The careful design makes performance measurable of the intervention, the specialist contribution of all the actors involved is enhanced. The so-called 'facility management' takes advantage of the information stored in the database and uses it to evaluate the life cycle of the planned activities (Eastman, Teicholz, Sacks \& Liston, 2016). The HBIM process encourages and supports teamwork. Working in the architectural field, by its nature, requires teamwork. It is necessary to learn to work together, encouraging multidisciplinary cooperation and dynamic interchange among the students/teachers and professional people.

HBIM can be an efficient method to handle and manage a building, including costs, energy simulation, construction and production data. The scientific literature shows (Bruno \& Roncella, 2019, Dore et al., 2015; Fai, Graham, Duckworth, Wood \& Attar, 2011; Fassi, Achille, Mandelli, Rechichi \& Parri, 2015; Fregonese et al., 2016) that the use of digital models and HBIM process provides a lot of advantages: the building can be documented over time cataloguing material and decay state, it is easy to recognise the different construction phase keeping track of all intervention and support maintenance plan, all data are collected in a unique database, structural and energetic analysis is supported, BIM process support web sharing, hypothesis virtual reconstruction, and Augmented Reality. The use of HBIM-type software aims to improve the effectiveness of data management processes among stakeholders, to ensure more reasonable conservation of the existing built heritage, and to reduce the costs associated with conservation and enhancement projects (Jouan \& Hallot, 2019).

The students at the end of the training path are obliged to show the technical and digital competencies acquired during the course. The assessment is to create new and original work starting from the technical drawings and 3D models. The first step is to visualise their workflow representing it in large boards: from survey to 3D model, the HBIM potentialities (Fig. 2). From there, they can build their project enhancing the protection of the heritage through digital technologies, and its valorisation through the reuse of the spaces for social and community purposes.

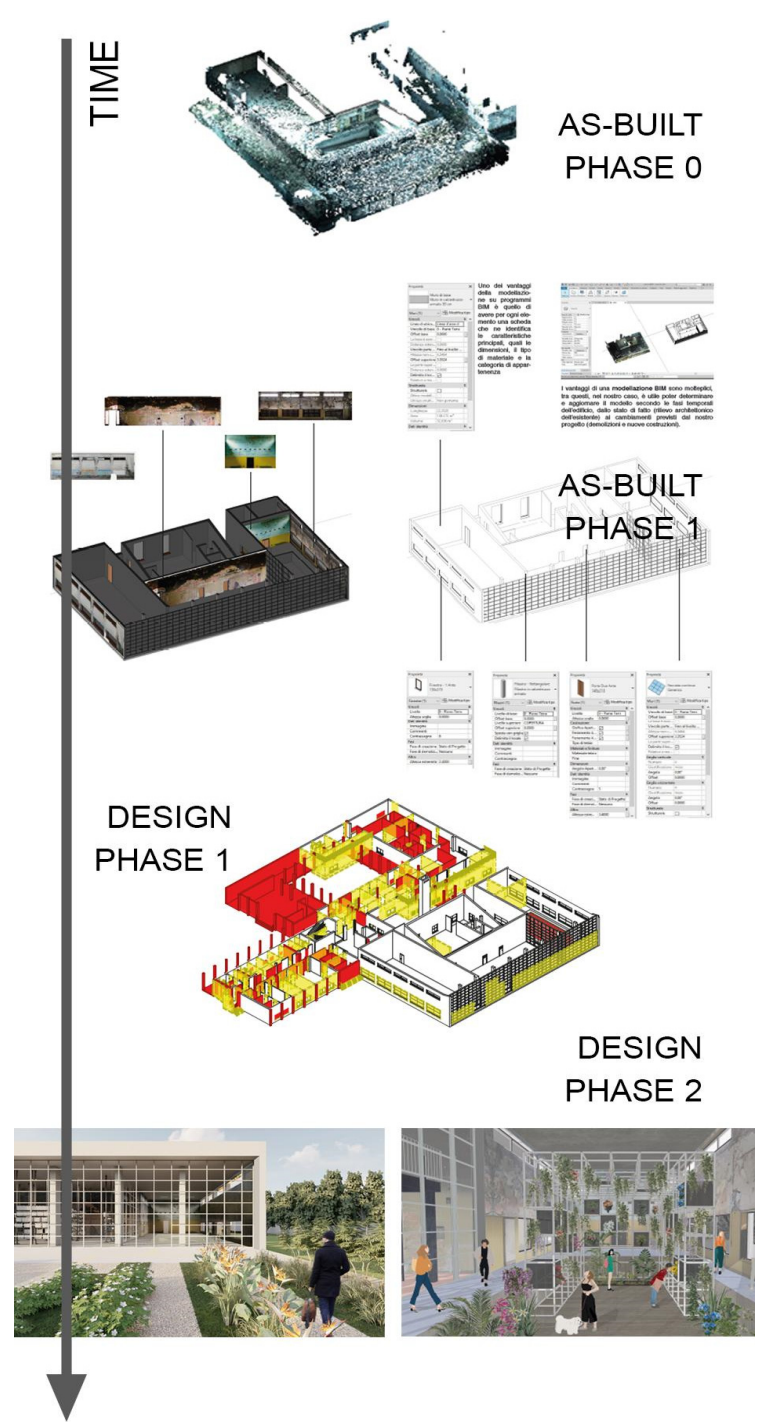

Figure 2: General The phases of the conservation process that the students have to face: from the as-built assets, point cloud and HBIM model with maintenance and restoration information, to the design assets, studying the phases of the project, and the re-use of the building. 


\subsection{Sharing data}

Sharing the project and the final product is an important step for learning how to disseminate the work between other kinds of targets, which can include nonprofessionals, or people from other fields. Today, a project accessed only by expert users is out of date and without a future as much as its effectiveness is measured in terms of social and cultural impact on society (Tommasi, Achille, Fanzini \& Fassi, 2020).

The education and learning areas give the possibility to create participation and involvement, enriching personal knowledge and awareness for the process of conservation. Its efficiency and continuity depend on the development of new research and design competencies, also through specific training paths. Today it is necessary to overpass the "traditional" idea of the training course: good technical skills are not enough anymore, but it is mandatory to combine technological expertise with the social impact of the data collected, where education is related to access and participation, conservation, and sustainability (Tommasi, Achille, Fanzini \& Fassi, 2020).

The integrated and suitable planning and management of heritage should be based on the mediation amongst institutions, businesses and universities, as well as the other cross-sectional elements connecting these three main protagonists of the valorisation project (Fanzini, Casoni, \& Bergamini, 2014):

- Conservation, concerning the growth and the diffusion of knowledge related to heritage, its features and particularities and terms of the promotion of new strategies and supply chains aimed at restoration and valorisation.

- Usage, as a lever of social and economic sustainability of conservation and precondition for the effective re-appropriation of cultural, environmental and landscape heritage.

- Development, through promoting creative activities and innovation process relying on culture to create new values and new heritage (an increase of cultural capital, development of cultural tourism, enhancement of real estate values, entrepreneurial growth in the areas of conservation and craftsmanship, etc.).

This approach helps to handle the requests also from the professional field, helping to reduce the gap between academia and work.

Moreover, the soft skills developed during this sharing phase as the project's communication and collaborative design in teams, can be spent in both real life and digital environments.

\section{Conclusion and future developments}

The digital management of information on architectural heritage is a problem not yet completely solved, as an object of architectural heritage requires an integrated representation of various types of information in order to develop appropriate conservation strategies.

The ability to use digital tools must be accompanied by a profound critical ability to analyse and manage data:
HBIM models must allow evaluating data beyond the data themselves.

The progressive transition from 2D drawings-3D modelsHBIM models is not only the transition from twodimensional representations to volumetric objects but it is a more complex operation. Conservation professionals don't need a model 'only' to navigate documents but also to perform spatial and temporal analyses and multicriteria queries in a virtual $3 D$ environment, to support design choices.

Restoration training in higher education aims to develop the framework of criteria, procedures and tools oriented towards the conservation of cultural heritage, satisfying the key theme of Responsible Research and Innovation (RRI) about "Science and Education". The demand for highly qualified people in the European Union is expected to rise significantly in the coming years. Improved science teaching could promote research as a career and provide citizens with the knowledge and skills they need to take part in discussions and decisions on research and innovation (European Union, 2016).

This approach and the goals require a multidisciplinary teaching team, able to provide different approaches and interpretative keys thanks to skills and experience in the fields of conservation, restoration and enhancement, cultural design and digital technologies and communication for cultural heritage (Lombardini, 2011).

With these assumptions as a starting point, the training path of Restoration Studio is organized into the following principal phases of investigation and experimentation (Fig. 3):

1) The first phase deals with the development of the theoretical framework and the creation of rules for data collection, information processing and knowledge management. The quali/quantitative analysis of data through innovative applications will allow for the recognition and connection of the case study assets. The result of this phase will be the development of an investigation map/model/drawings - based on a set of data and criteria and processing procedures - for identifying and describing the territories and their cultural assets suitable for enhancement.

2) The second phase proposes a set of innovative strategies, tools, educational programs, and experiences for the enhancement of case study heritage assets. The project developed on the case study allows for the application and testing of the theoretical framework and proposed model for involving various categories of stakeholders, to assess the possible interconnected impacts on the building.

3) The communication and dissemination of the outcomes of the research will not only enable knowledge sharing, but also the collection of more data and the improvement of the theoretical framework and the model.

In this training path, new technologies offer spaces for improvement for the students, especially in this time that requires the adoption of digital learning. 
These benefits, however, require a structured approach of management and use of the hardware and software tools at disposal, and the attitude to learn and test new solutions. Restoration studio in this framework can represent a "best practice" sustaining the laboratorial digitalisation (remotisation) and teaching stuff with multidisciplinary skills and competencies. But, during this time, it is necessary to think about how is it possible to make the training path more effective? How can it be more engaging when the fruition is almost $100 \%$ online?

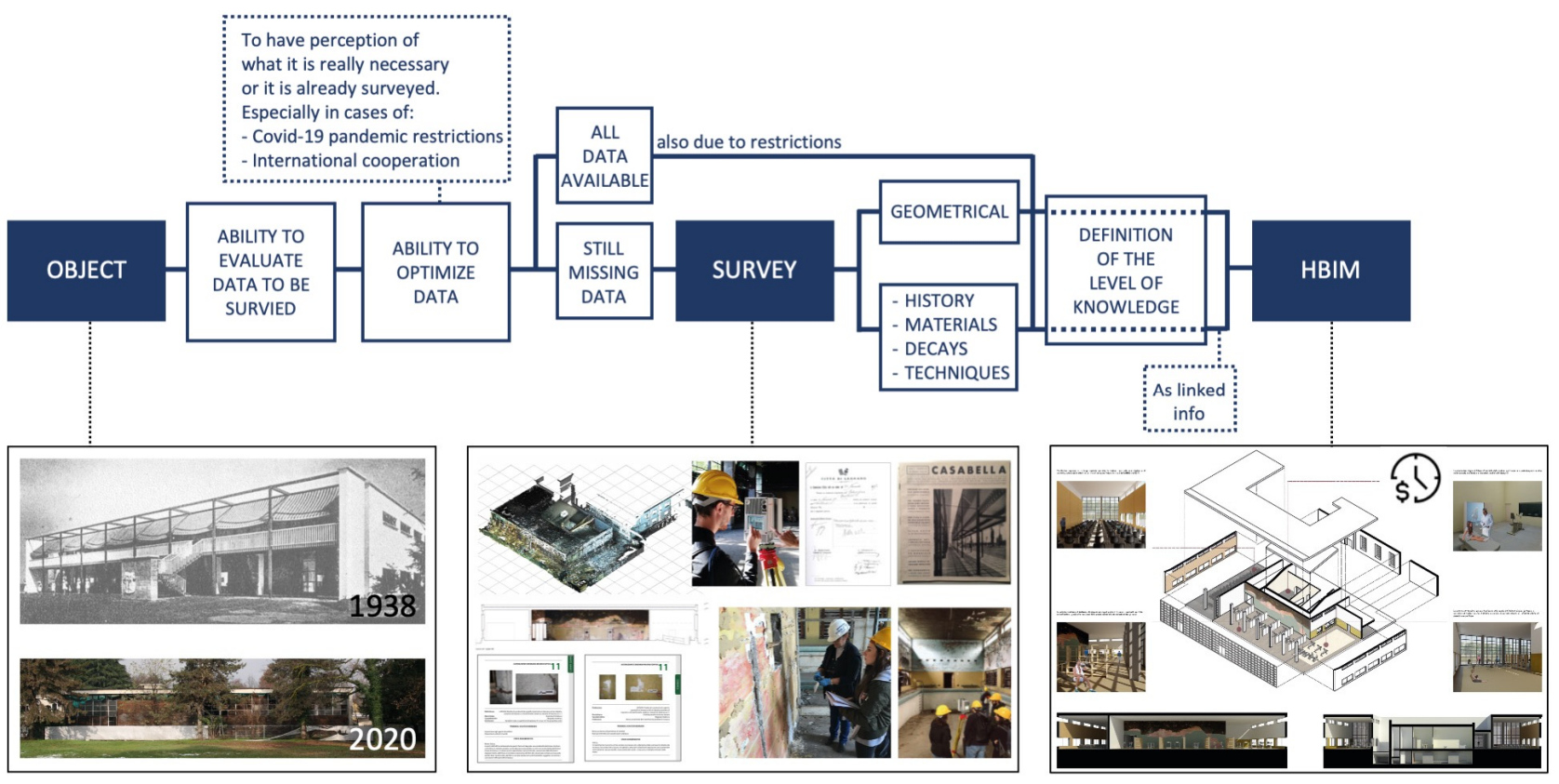

Figure 3: "Best practice" of the workflow and training path for learning about conservation processes. The path considers two different scenarios: one "linear" where there is the possibility to go on the field to perform surveys and analyses, and the second where, maybe also due to restrictions (e.g., COVID-19), there is no possibility to go on the field to collect data, and where the students receive a pack of data already acquired.

The Covid-19 pandemic accelerated the digitalisation processes already in progress and highlighted the structural, organisational, and social limits of the entire school system (Agasisti, 2020). For this reason, it is necessary to think about not a passive adaptation of the courses in the emergency time, but preventive planning of the learning path in a digital way. In this way, it will be possible to turn a critical issue into a transformation of the education projected towards the future.

\section{References}

Achille, C., Lombardini, N., \& Valentini, M. (2012). Aree archeologiche e sistemi di protezione: modelli di valutazione di compatibilità. Scienza e beni culturali XVIII, 268-279, Bressanone, Italy.

Achille, C., Lombardini, N., \& Tommasi, C. (2016). BIM and Cultural Heritage: Compatibility Tests in an Archaeological Site. International Journal of 3-D Information Modeling (IJ3DIM), 5(1), 29-44. https://doi.org/10.4018 / IJ3DIM.2016010103

Achille, C., Lombardini, N., \& Tommasi, C. (2018). BIM and Cultural Heritage: compatibility tests on existing buildings. In B. Kumar (Eds.), Contemporary Strategies and Approaches in 3-D Information Modeling (pp. 1-26). https://doi.org/10.5194/isprs-archives-XLII-2-W5-497-2017

Agasisti, T. (2020). Opportunità, limiti e paradossi della didattica a distanza. Quotidiano Politecnico 1863, 9.

Bianchi, G., Bruno, N., Dall'Asta, E., Forlani, G., Re, C., Roncella, R., Santise, M., Vernizzi, C., \& Zerbi, A. (2016). Integrated survey for architectural restoration: a methodological comparison of two case studies. The International Archives of the Photogrammetry, Remote Sensing and Spatial Information Sciences, XLI (B5). https://doi.org/10.5194/isprsarchives-XLI-B5-175-2016

Brundtland Commission (1987). Our Common Future. Oxford University Press.

Bruno, N., \& Roncella, R. (2019). HBIM for Conservation: A New Proposal for Information Modeling. Remote Sensing, 11(15), 1751. https://doi.org/10.3390/rs11151751

Bruno N., \& Roncella, R. (2019). A restoration oriented HBIM system for cultural heritage documentation: the case study of Parma cathedral. The International Archives of the Photogrammetry, Remote Sensing and Spatial Information Sciences. https://doi.org/10.5194/isprs-archives-XLII-2-171-2018

Bryan, P., Blake, B., Bedford, J., Barber, D., \& Mills, J. (2009). Metric Survey Specifications for Cultural Heritage. Andrews Ed.; English Heritage Swindon, UK. 
Chiabrando, F., LoTurco, M., \& Rinaudo, F. (2017). Modeling the decay in an HBIM starting from 3d point clouds a followed approach for cultural heritage knowledge. ISPRS - International Archives of the Photogrammetry, Remote Sensing and Spatial Information Sciences. XLII-2/W5, 605-612. https://doi.org/10.5194/isprs-archives-XLII-2-W5-605-2017

Di Biase, C. \& Albani, F. (2019). The Teaching of Restoration at the Architecture School of the Politecnico di Milano. Traditions and Perspectives. In Di Biase, C., Albani, F., The Teaching of Architectural Conservation in Europe, (pp. 17-75), Santarcangelo di Romagna (IT): Maggioli Editore.

Di Stefano, R. (1975). La formazione dei restauratori in Italia e all'estero. Restauro, 4(20), 25-28.

Dore, C. \& Murphy, M. (2013). Semi-Automatic Modelling of Building Façades with Shape Grammars using Historic Building Information Modelling. ISPRS - International Archives of the Photogrammetry, Remote Sensing and Spatial Information Sciences. XL-5/W1, 57-64. https://doi.org/10.5194/isprsarchives-XL-5-W1-57-2013

Dore, C., Murphy, M., McCarthy, S., Brechin, F., Casidy, C. \& Dirix, E. (2015). Structural simulations and conservation analysis - historic building information model (HBIM). International Archives of Photogrammetry, Remote Sensing and Spatial Information Sciences, 40(5/W4). https://doi.org/10.5194/isprsarchives-XL-5-W4-351-2015

Eastman, C., Teicholz, P., Sacks, R., \& Liston, K. (2016). BIM Handbook: A Guide to Building Information Modeling for Owners, Designers, Engineers, Contractors, and Facility Managers. New Jersey (US): John Wiley \& Sons.

EUPPD. (2014). European Union Public Procurement Directive, 2014/24.

European Union. (). RRI Tools. A practical guide to Responsible Research and Innovation. Key Lessons from RRI Tools. Retrieved November 15, 2020, from: https://rri-tools.eu/-/rri-tools-a-practical-guide-to-responsible-research-andinnovation-key-lessons-from-rri-tools-\#

Fai, S., Graham, K., Duckworth, T., Wood, N. \& Attar, R. (2011). Building Information Modelling and heritage documentation. Proceedings XXIII International CIPA Symposium, Prague, Czech Republic.

Fai, S. \& Rafeiro, J. (2014). Establishing an Appropriate Level of Detail (LoD) for a Building Information Model (BIM) West Block, Parliament Hill, Ottawa, Canada. ISPRS Annals of Photogrammetry, Remote Sensing and Spatial Information Sciences, II-5, 123-130. https://doi.org/10.5194/isprsannals-II-5-123-2014

Fanzini, D., Casoni, G., \& Bergamini, I. (2014). Valorizzazione dei Beni Culturali \& Sviluppo Locale. Enhancement of Cultural Heritage and local development. Santarcangelo di Romagna (IT): Maggioli Editore.

Farsi, M., Daneshkhah. A., Hosseinian-Far. A. \& Jahankhani. H. (2020). Digital Twin Technologies and Smart Cities (Internet of Things). Springer International Publishing.

Fassi, F., Achille, C., Mandelli, A., Rechichi, F. \& Parri, S. (2015). A new idea of BIM system for visualization, web sharing and using huge complex 3D models for facility management. The International Archives of the Photogrammetry, Remote Sensing and Spatial Information Sciences, 40(5/W4), 359-366. https://doi.org/10.5194/isprsarchives-XL-5W4-359-2015

Fassi, F., Fregonese, L., Ackermann, S. \& De Troia, V. (2013). Comparison between laser scanning and automated 3D modelling techniques to reconstruct complex and extensive Cultural Heritage areas. ISPRS Workshop 3D-ARCH: $3 D$ virtual reconstruction and visualization of complex architectures, Trento, Italy.

Fregonese, L., Achille, C., Adami, A., Fassi, F., Spezzoni, A., \& Taffurelli, L. (2016). BIM: An integrated model for planned and preventive maintenance of architectural heritage. Digital Heritage, 77-80. Granada, Spain. https://doi.org/10.1109/DigitalHeritage.2015.7419456

Heritage Association of South Africa. (2019). Guide to conduct a heritage survey. Retrieved November 15, 2020, from: https://heritagesa.org/guide-to-conducting-a-heritage-survey/

Historic England. (2018). 3D Laser Scanning for Heritage. Advice and guidance on the use of laser scanning in architecture and archaeology. Retrieved November 15, 2020, from: https://historicengland.org.uk/images-books/publications/3dlaser-scanning-heritage/

ICOMOS. (1994). The Nara Document on Authenticity. Retrieved November 15, 2020, from: https://www.icomos.org/charters/nara-e.pdf.

ICOMOS. (2003). Icomos Charter. Principles for the analysis, conservation and structural restoration of architectural heritage. Retrieved November 15, 2020, from: https://www.icomos.org/en/about-the-centre/179-articles-enfrancais/ressources/charters-and-standards/165-icomos-charter-principles-for-the-analysis-conservation-andstructural-restoration-of-architectural-heritage

Ioannides, M., Fellner, D. Georgopoulos, \& A. Hadjimitsis, D. (2010). Digital Heritage. Third International Conference, EuroMed 2010. Lemessos, Cyprus. https://doi.org/10.1007/978-3-642-16873-4

Jouan, P., \& Hallot, P. (2019). Digital twin: a HBIM-based methodology to support preventive conservation of historic assets through heritage significance awareness. ISPRS - International Archives of the Photogrammetry, Remote Sensing and Spatial Information Sciences. XLII-2/W15, 609-615. https://doi.org/10.5194/isprs-archives-XLII-2-W15-6092019 
Lombardini, N. (2011). The necessity of knowing the different strategies of conservation for the inspiration of cultural progress. In Fioravanti, M. \& Mecca, S. (Eds.), The safeguard of cultural heritage. A challenge from the past for the Europe of tomorrow, pp. 304-305.

Lombardini N., Achille C. \& Valentini M. (2017). BIM e progetto di conservazione. In Della Torre, S. (Ed.), Reportage BHIMM - Built Heritage Information Modeling Management, pp. 1-11. Retrieved November 15, 2020, from: https://www.ingenio-web.it/Sfogliabile/ReportageBHIMM2017/index.html

Murphy, M., McGovern, E. \& Pavia, S. (2009). Historic Building Information Modelling (HBIM). Structural Survey, 27(4). https://doi.org/10.1108/02630800910985108

Murphy, M., McGovern E. \& Pavia, S. (2011). Historic Building Information Modelling - Adding Intelligence to Laser and Image Based Surveys, International Archives of the Photogrammetry, Remote Sensing and Spatial Information Sciences, 38 (5/W16). https://doi.org/10.1016/j.isprsjprs.2012.11.006

Musso, S. F. (2008). Teaching Conservation/Restoration: tendencies and emerging problems. In Musso, Stefano F., De Marco, L., Teaching Conservation/Restoration of the Architectural Heritage. Goals, Contents and Methods 1, pp. 1526, Leuven EAAE-European Ass. for Architectural Education.

Raghunathan, V., \& Barma, S. B. (2019). Digital Twin: A Complete Guide for The Complete Beginner.

“Regolamento per le professioni di ingegnere e di architetto", Art. n. 52, R.D. n.2537/1925 (1925) (Italy).

Remondino, F. (2011). Heritage recording and 3D modeling with photogrammetry and 3D scanning. Remote Sens. 3. https://doi.org/10.3390/rs3061104

Teruggi, S., Grilli, E., Russo, M., Fassi, F., \& Remondino, F. (2020). A Hierarchical Machine Learning Approach for MultiLevel and Multi-Resolution 3D Point Cloud Classification. Remote Sensing, 12(16), 2598. https://doi.org/10.3390/rs12162598

Tommasi, C. \& Achille, C. (2017). Interoperability matter: levels of data sharing, starting from a 3d information modelling. ISPRS - International Archives of the Photogrammetry, Remote Sensing and Spatial Information Sciences, XLII2/W3, 623-630. https://doi.org/10.5194/isprs-archives-XLII-2-W3-623-2017

Tommasi, C., Achille, C., Fanzini, D., \& Fassi, F. (2020). Advanced Digital Technologies for the Conservation and Valorisation of the UNESCO Sacri Monti. In: Daniotti B., Gianinetto M., Della Torre S. (Eds.) Digital Transformation of the Design, Construction and Management Processes of the Built Environment. Research for Development. Springer, Cham. https://doi.org/10.1007/978-3-030-33570-0_34

UNI 11182. (2006). Beni culturali, Materiali lapidei naturali ed artificiali Descrizione della forma di alterazione - Termini e definizioni.

UNI 11337I. (2017). Edilizia e opere di ingegneria civile - Gestione digitale dei processi informativi delle costruzioni - Parte 4: Evoluzione e sviluppo informativo di modelli, elaborati e oggetti. Retrieved November 15, 2020, from: http://store.uni.com/catalogo/index.php/uni-11337-4-2017.html 


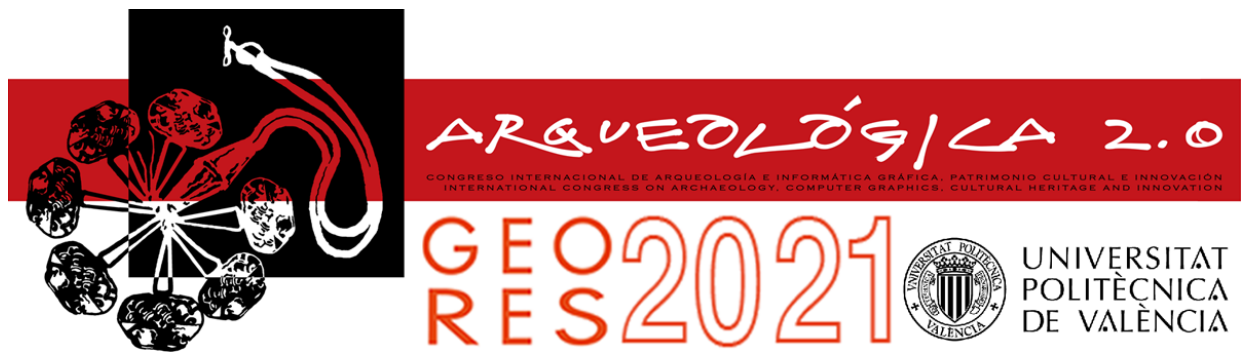

Proceedings of the joint international event $9^{\text {th }}$ ARQUEOLÓGICA

$2.0 \& 3^{\text {rd }}$ GEORES

Valencia (Spain).

26-28 April 2021

Received: 27/11/2020

Accepted: 18/03/2021

DOI: https://doi.org/10.4995/Arqueologica9.2021.12140

\title{
PARAMETRIC PARADIGMA: EXCEPTIONAL COFFERED CEILING ARCHITECTURE VS HBIM
}

\author{
Olga Rosignolia, ${ }^{\star}$, Barbara Scalab ${ }^{b}$ Daniele Treccani ${ }^{\mathrm{a}}$, Andrea Adamia $^{\mathrm{a}}$, Laura Taffurellia, Simona \\ Scandurra ${ }^{a}$, Luigi Fregonese ${ }^{a}$ \\ ${ }^{a}$ Department of Architecture, Built Environment and Construction Engineering (DABC), Politecnico di Milano, Piazza Leonardo da Vinci \\ 32, 20133 Milan, Italy. olga.rosignoli@polimi.it; daniele.treccani@polimi.it; andrea.adami@polimi.it; laura.taffurelli@polimi.it; \\ simona.scandurra@polimi.it; luigi.fregonese@polimi.it \\ ${ }^{b}$ Department of Civil, Environmental, Architectural Engineering and Mathematics (DICATAM), University of Brescia, Via Branze 43, \\ 25121 Brescia, Italy. barbara.scala@unibs.it
}

\begin{abstract}
:
The scientific community is confirming the advantages of using BIM in the processes of conservation, management, and intervention over architectural-historical heritage. However, many difficulties remain in the transcription process of elements of the built environment, especially when the objective of the model is to support decision-making processes in restoration operations. Even for apparently simple elements, the procedures are not trivial; the need to define the most adequate operational strategies remains. In the context of this study, a possible approach concerning the documentation of a coffered ceiling has been proposed, a case study which takes into consideration the need to discretize information (to make it effective, transmissible, and understandable) and the potential offered by the combined use of further software automatization.
\end{abstract}

Keywords: cultural heritage, digitization, 3D modelling, HBIM

\section{Introduction}

The parametric nature of BIM clashes greatly with the precision of the as-built acquired reality that is obtainable with nowadays digital survey techniques, especially where heritage artefacts are investigated, and the results are HBIM (Historic Building Information Modelling) products; it is almost always necessary to elaborate strategies that mediate this significant issue (Capone \& Lanzara, 2019). However, no matter how challenging the process, it is not advisable to construct an HBIM model without a precedent digital survey of the assets: the amount of knowledge obtainable with these products is indisputable, and the reason why point-clouds are the first step of the modelling process. After the survey, the socalled 'scan-to-BIM' phase follows, by means of drafting actions and modelling choices performed to recreate parametrically the geometric model from the point-cloud (Yang, Koehl, \& Grussenmeyer, 2018). This operation can be tackled differently in terms of approaches and software: methods range from automatic to semiautomatic and even manual (López, Lerones, Llamas, Gómez-García-Bermejo, \& Zalama, 2017).

Research is pushing towards reducing human manual involvement as much as possible whilst modelling heritage from digital surveys, by favouring the automatic methods. Nevertheless, the clash with the articulate and complex nature of heritage makes even this assignment challenging. Preparing a discretization of reality to be fed to automatisms is not an immediate nor an easy task itself; at the same time, excessive simplifications of the surveyed configuration, run the risk of rendering the model worthless. In between these two opposites, is possible to locate the example narrated in this paper, a case study that focuses on 3D modelling issues in HBIM practises: a $16^{\text {th }}$ century coffered ceiling.

The experience has value in that the exceptionality of the object modelled required a series of decisions that brought to the creation of an architectural 3D modelling 'paradigma': a parametric object enough coherent with the cloud as to recreate its original configuration but stripped of the geometric information related to damages and deformations.

Before narrating the experience, a few words regarding the context in which it is situated: the coffered ceiling is part of a larger HBIM project, the Duomo of Mantova: in 2018 the local Diocese required the realization of an experimental BIM model of one of its most valuable and articulated assets (the Duomo di San Pietro) for planned conservation purposes (Della Torre, 2003). The model (Fig. 1) was the result of an integrated survey (Adami et al., 2019) turned into a comprehensive digital replica, and 
the occasion on which to apply and test HBIM procedures acquired from literature.

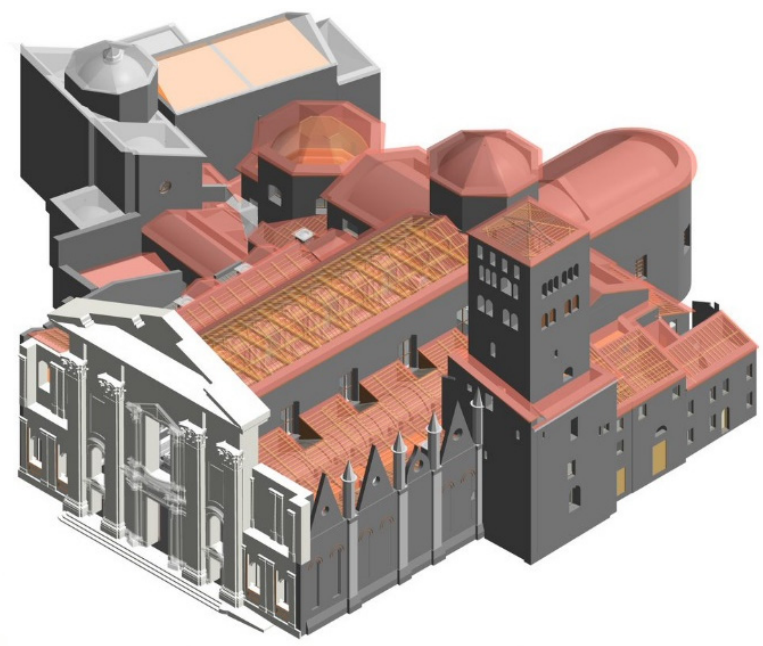

Figure 1: General outer view of the Duomo HBIM model.

The known requirements of planned conservation governed the modelling choices made (see Section 3): the presence of all the objects to schedule, their correct collocation in the three-dimensional space and their topology were the priority. Nevertheless, although some simplifications set might be considered excessive, good accuracy was obtained, given the extraordinary diversity of the Duomo (which made it impossible to have unique representation rules throughout the building). Furthermore, whenever geometry failed to describe objects adequately, informative modelling came into play to integrate what was missing as additional data.

Representation of both geometric and informative data, in an HBIM model, is rooted in the knowledge of the heritage itself (Adami et al., 2019), and its original design and functioning. This knowledge needs to be as complete as possible: archival research about the building, besides investigation about traditional techniques and materials, processes and tools used in the past for the production of artistic decorations and the training of artisans and artists, all need to come together to obtain valid description explanation of the asset.

In the Duomo, the parts that compose the coffer units were not identifiable on sight. The structural wooden pieces and the decorative wooden planks appeared as unique pieces: as it often happens for artefacts alike, the structure beneath the decorative elements had to forcibly have a different configuration from how it appeared to the naked eye as well as to the laser-scanner. With no further and more invasive analyses being planned, it was necessary to involve conservation experts which formulated hypotheses regarding the hidden technological parts. This passage was crucial, as it highlighted how the interpretation of point-clouds and survey products must be carried out by conservation experts and operators, who are the reliable sources of knowledge about historical building techniques and the devices used by artisans and artists in the past, knowledge that needs to be passed on to the model drafter.

Such knowledge is particularly important especially in cases alike: coffered ceilings, in fact, can have many different configurations, depending on the span they need to cover, the decoration required and the material available. In the case of the Duomo, the structure behaves as described in the following section.

\section{Acknowledging the exceptional technology}

The coffered ceiling was a solution technique widespread in the Mantuan cultural landscape (Introini \& Spinelli, 2018); it is also recorded that architect Giulio Romano worked at the Duomo refurbishment in the $16^{\text {th }}$ century (Piva, 1988). Other records testify the use of this technology on several churches in the area: S. Andrea Church and the Ostilia Sanctum Church are amongst the most famous. Research related to other similar cases, (even though never identical) has been used to understand thoroughly constructive functioning (Venturi, 1938; Giorgi, 2017; Antonucci, 2018).

Therefore, in the case of the coffered ceiling above the Duomo central nave, different types of knowledge, one coming from literature references (Breymann, 1884; Venturi 1938) and one provided by experts in construction techniques, were combined to the laser-scanner survey performed in the attics as well as the interior of the church (and visible in Figure 2) to understand an unprecedented artefact.

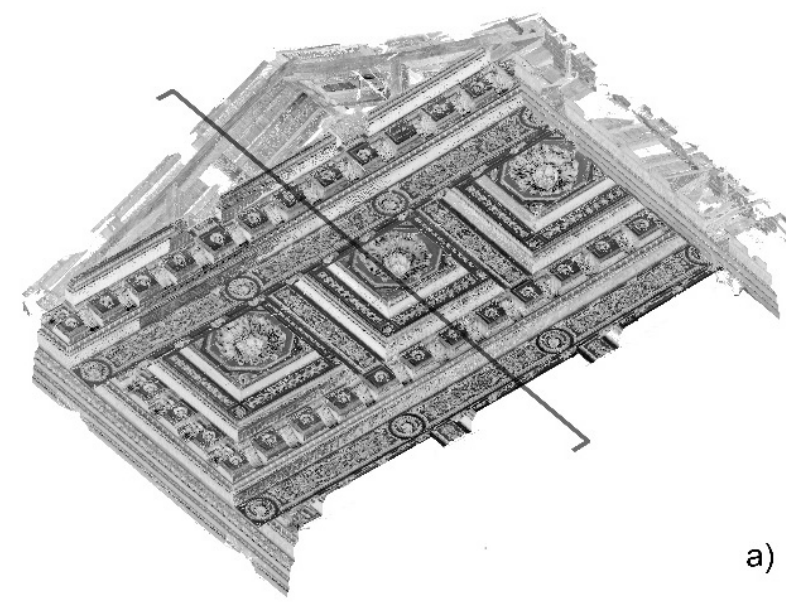

a)

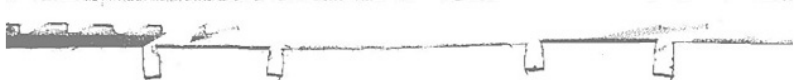

U

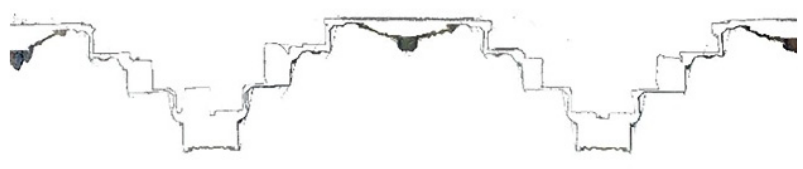

b)

Figure 2: Ceiling point-cloud. Detail of the coffer and the structure of the roof: a) axonometric view; b) longitudinal section.

During the process, it was discovered that the coffer units are hanging onto wooden trusses, which are arranged in a variable sequence. Such sequence can be described as successive pairs of trusses: some of them are of the 
Italian 'palladiana' type, whilst some others are regular trusses with additional posts (the two types are referenced as type a) or type b) in this article). The distance between the two trusses composing one pair is quite modest and occupied by smaller structural shelves (orthogonal to the truss tie beam) that themselves lean on another lower beam, situated beneath them, as visible in Figure 3.

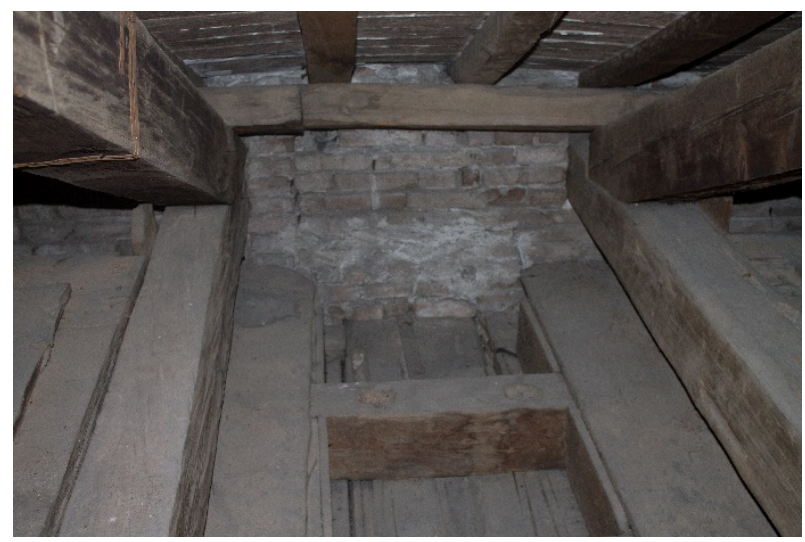

Figure 3: Photograph of the coupled trusses insertion in the perimetral walls and the shorter span between them; the upper part of the smaller structural shelves is visible.

When in the nave, it can be observed that these loadbearing elements appear as single highly decorated beams, of an unusual depth and width. The span they cover $(10 \mathrm{~m})$ guided towards adopting the hypothesis of a composite beam, fabricated of two or more jointed parts. The presence of decorated wooden planks boxes around the composite beam bottom, gives the illusion of a single element; because of that, they might be referred to as 'false beams', the Italian 'false travi' (Giorgi, 2017). To confirm this hypothesis, is the presence of metal tie rods (Fig. 4) which bear the decorative planks and are hooked to the roof purlins.

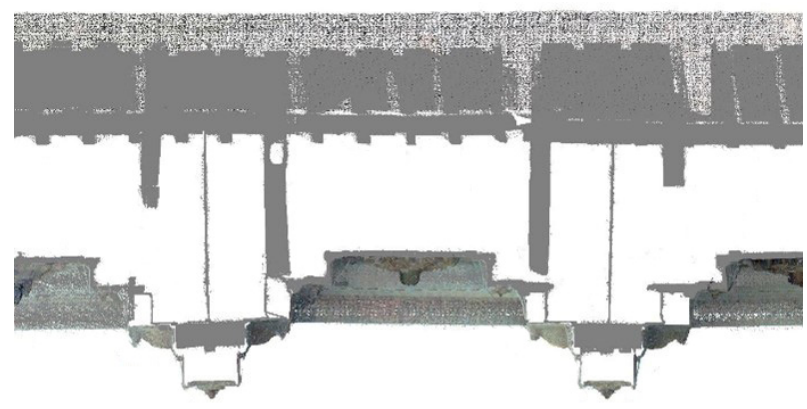

Figure 4: Longitudinal point-cloud section, the metal tie rods visible in the background.

The richness of detail visible from the nave, is the work of the ultimate layer added on to the wooden boxes, a layer composed of thinner and highly decorated planks, the socalled 'fodere'. Information from historical manuals was crucial to understand and hypothesize this detail.

The larger distance between each pair of trusses is occupied by the coffered ceiling units. Once the structural role of the beams and trusses was made clear, the technological solution used to complete the other parts of the coffers was studied. These elements are, similarly to the false beams, composed of wooden planks embedded together. Some of them encounter the trusses' tie beams perpendicularly and protrude over the nave below. Other wooden planks are positioned along the perimetral walls, visible from the nave itself but not from the attic. Their appearance is very similar to that of the composite beams described earlier.

The remaining planks, the ones holding the decorative central flower visible from the nave, have a particular spatial arrangement sequence, a stepped one. As stated before, those planks close the space between the two farther trusses pairs.

The global configuration of the technology, which is bare and discernible almost entirely when in the attic (Fig. 5), complete with the iron connections and all the devices invented by the workers to support the artistic interior decoration, is in strike contrast with the richness of the artisanal wooden work visible from the naves of the church (Fig. 6).

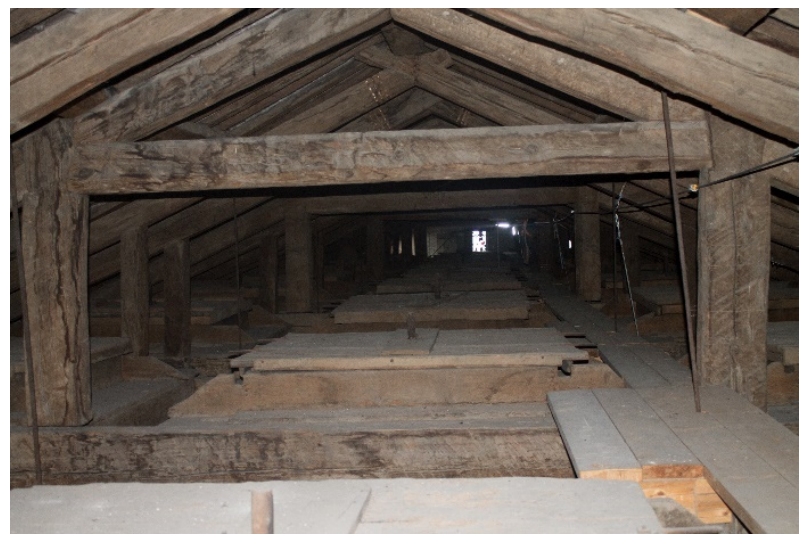

Figure 5: Photograph of the ceiling as seen from the attic; as is visible, the larger distance between the trusses is occupied by the coffer units.

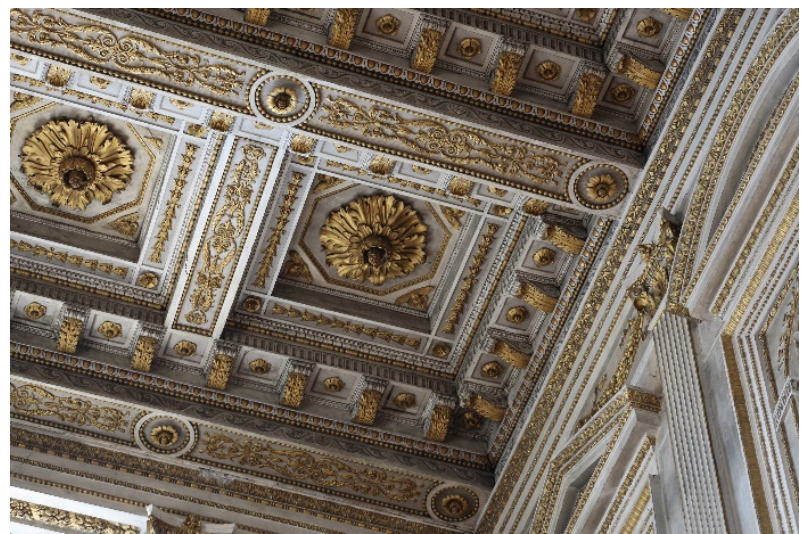

Figure 6: Photograph of the coffers as visible from the nave interior; the lower load-bearing beams are covered with decoration; the metal wire ends with the decorated circular button visible beneath the beams.

\section{Modelling choices}

The HBIM model of the Duomo was commissioned to support planned conservation activities. Given this objective and the diversity of the building (highly articulated and stratified), a general modelling rule was decided between the stakeholders: an error tolerance under $5 \mathrm{~cm}$. This rule has been tested sufficiently for what, at the beginning of the process, had been identified as a 'level of information need' in an informal way. 
The modelling process was executed with Autodesk Revit@ and Autodesk AutoCAD@.

\subsection{Semantic structure of the 3D model}

The elements of the ceiling (whose configuration is represented by the scheme in Figure 7) with structural functions, have been modelled as structural elements, to stay true to their nature and for possible further structural analysis. Given the configuration of the structure, several types of the beam are present: those composing the trusses, those at the first level (the composite beams), rafter, purlins, and the decorated planks.

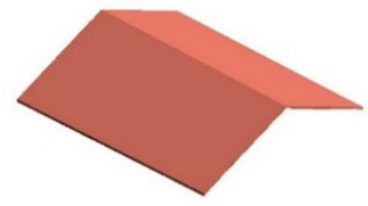

i)

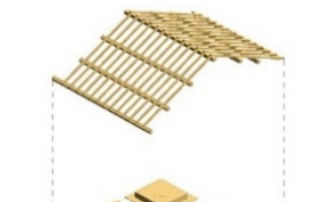

ii)

iii)

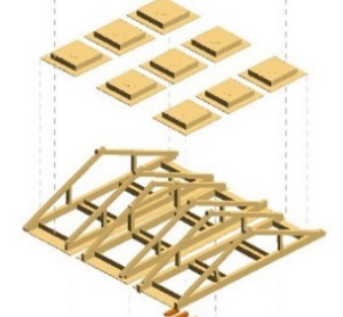

iv)
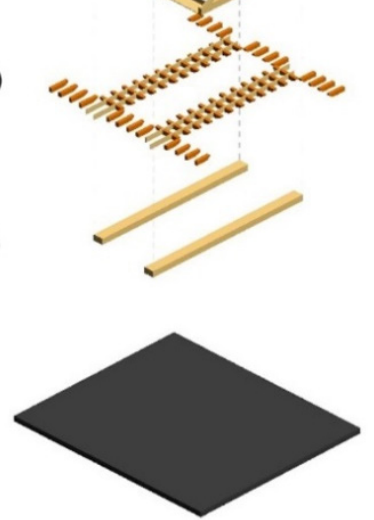

Figure 7: Model view with the ceiling parts put together from the top down: i) roof structure; ii) coffer units; iii) trusses and planks; iv) decorated shelves; v) load-bearing composite

$$
\text { beams. }
$$

The central nave coffer units are composed of numerous different planks of wood, as described in the previous section. One modelling possibility would have been to create a single element representing all the planks together; instead, when designing the object, it was preferred to draft singularly every plank element, for allowing the possibility to identify the conservative problems of the different wooden parts and of the metal wires, nails, and cramps.

These coffer units were created as 'generic' objects, as they could not be referred to any native BIM category. It is important to note that every object physically touches the others it is adjacent to. The level of decoration is significantly reduced in the model object, as it was considered not necessary to the project database (Fig. 8).
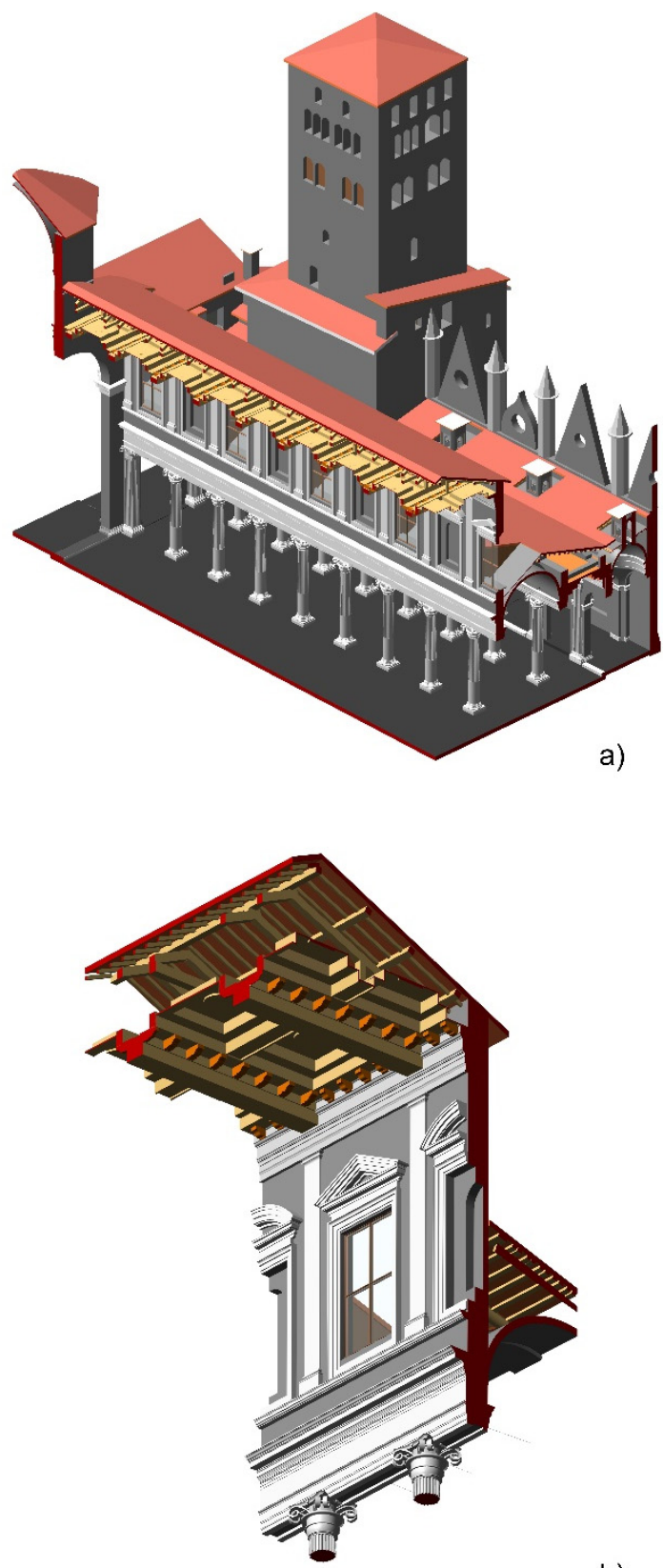

b)

Figure 8: Cut-away axonometric views of the model with the ceiling components together: a) entire ceiling; b) detail of a portion.

\subsection{Planar alignments}

Thus far, the elements used in the BIM model (except for the coffer units) were regular and functionally close to the original function (beams, rafters, purlins), therefore their category and the information included matched. At this stage, they also mainly were configured as simple regular axial extrusions. The planar layout followed strictly the information given by the point-cloud, following a nonorthogonal grid (Fig. 9). Coincidentally, the objects all laid on an ideal linear plane, including all the elements composing the trusses. 


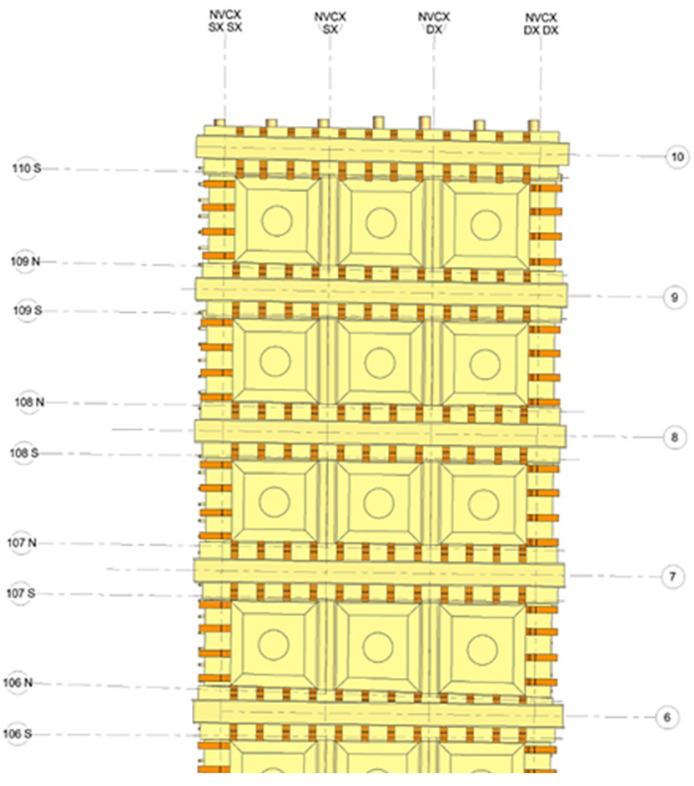

Figure 9: Planar course of the structural elements.

Other geometrical information given by the point-cloud had been harder to convey, when in elevation. The structural elements of the trusses and of the roof structure presented (as it often happens in these cases) a significative deflection at their midpoint (Fig. 10), thus determining a bended shape that influenced the dimensions of all the other components of the ceiling structure.
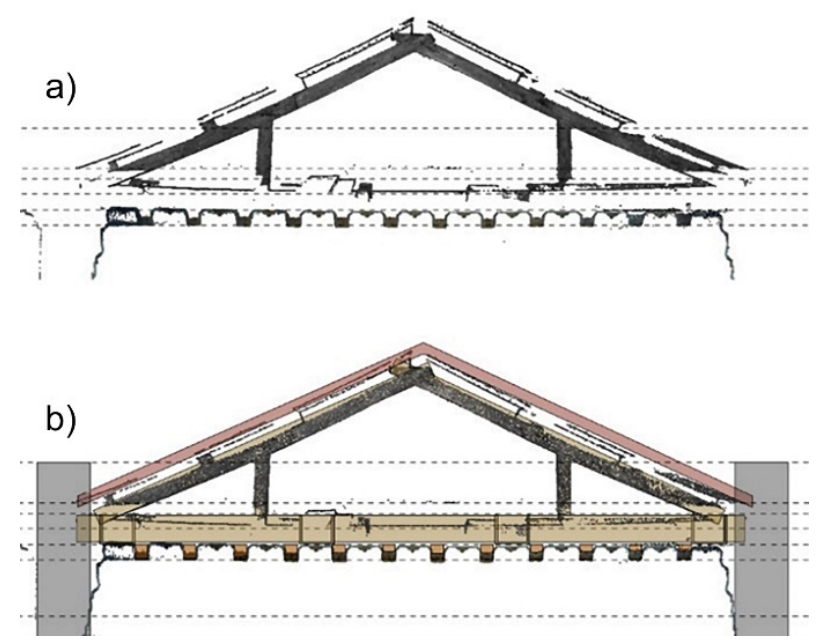

Figure 10: Example with a regular truss with additional posts ('type b' truss). Comparison between: a) point-cloud, with it is evident deflection; $b$ ) the regular objects of the model.

The deflection caused a concatenated series of other deformations: the vertical posts of type b) trusses rotated towards the exterior; the external coffers also rotated, lowering the side closer to the central axis of the nave. The central coffers do not rotate, rather lower equally on both sides; the shelves underneath the trusses tie beam also rotate around their longer axis towards the exterior.

After some observations, it was decided that the translation of these deformations in the model, could be obtained in the form of a value (namely a parameter, custom-made or default, associated to each object) more conveniently than in a geometric way, as in the example shown in Figure 11. The not equally effortless passage was the one necessary to determine the value of said parameters for each single object in the models. Manual effort would have been time-consuming; also, the quantity of the deformation parameters necessary, and their accuracy, could be defined only when different objectives, (besides the planned conservation ones) would be defined by the commission, and extremely dependent on them.

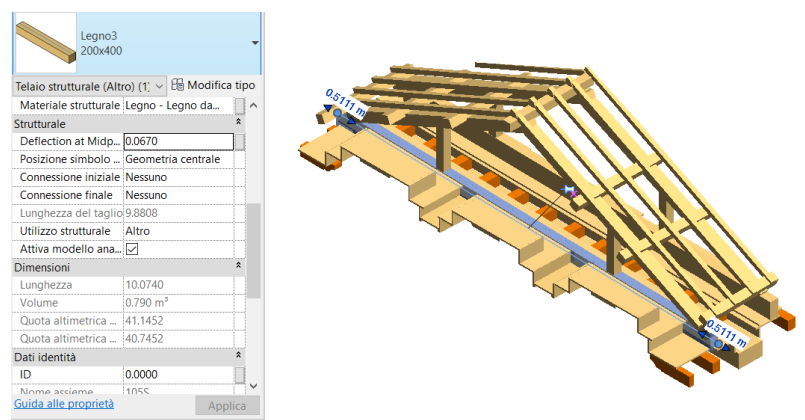

Figure 11: In the trusses there is a significant deflection at the midpoint; what could not be conveyed with the geometry was inserted as additional information, (parameter, see 'deflection at midpoint') to be compiled when necessary.

Eventually, such complexity was resolved by simplifying the geometry and not including the deformations in the model if not as addition textual values (parameters) to be compiled at a later time, as stated in the beginning. It is important to note that in the case of the trusses the deformation surpasses, in certain cases, the informal established tolerance of $5 \mathrm{~cm}$.

Therefore the HBIM model of the coffered ceiling is not as truthful to the as-built situation as the point-cloud is. It might be stated that the model, configured like this, represented the structure once it was newly built in the $16^{\text {th }}$ century, and before the loads caused the deformation of its components. This decided simplified version constitutes the 'paradigmatic' configuration of the coffered ceiling of the Duomo of Mantova.

\section{The 'paradigma' concept}

The latest research in historic architecture informative modelling displays a lot of promising possibilities that suggest the possibility of adapting geometries, even complex ones, to the very accurate data collectable in a comprehensive digital survey.

In the case of the coffered ceiling, as stated earlier, adapting the whole system to the data coming from the point-cloud elevation was challenging, even if only in determining how many deformation parameters were necessary. For the requirements of this project, geometric description of the deformations was kept aside in favour of additional parametrical information. But the premises for a future adaptation were settled by inserting some of these parameters in the model, ready to be edited when necessary. Interestingly, the recording of these value through time could also lay the groundwork for a historical record of their changes.

Once considered useful to the requirement of the project the adaptation can be performed as an additional second step. 
Otherwise, paradigmatic objects, such as the coffered ceiling in its 'static' configuration, are valuable for: documentation, simple static modelling, and even for a library of traditional architectural details. Mostly, objects alike are considered usable for future similar and therefore relatable cases (Prizeman, Pezzica, Taher, \& Boughanmi, 2020) and to possibly network the similar technologies used within the same cultural landscape.

\section{Conclusion and future works}

The exceptionality and complexity of the coffered ceiling of the Duomo (Fig. 12) highlighted an ever-present issue in the HBIM methodology process: how to and when to discretize the abundant information given by the digital survey. The manual intervention necessary to adapt or to perform adaptation automatically is an effort that is shown to be feasible: the possibility of automating operations in BIM environments arisen recently can speed up and automatize repetitive actions once executed manually (Yang, Koehl, \& Grussenmeyer, 2017). Research foresees for such tools to be used strategically to adapt complex structure in the direction of the as-built surveyed configuration. This requires a thorough knowledge of the programming languages as well as of the heritage.

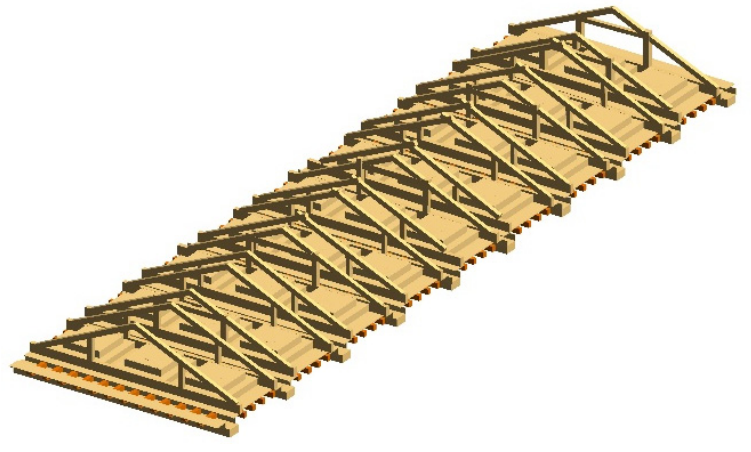

Figure 12: Axonometric view of the complete HBIM model of the coffered ceiling.

Since the routines, once performed, can be non-editable (Yang, Koehl, \& Grussenmeyer, 2018), having a paradigmatic object to which to refer to as a staple is an additional guarantee to avoid misinformation. Meanwhile, the simplified configuration ('paradigma') carries values itself: it can be easily replicated and networked, if necessary, within other buildings. Even, and more importantly, when the cases are not as exceptional.

\section{References}

Adami, A., Fregonese, L., Rosignoli, O., Scala, B., Taffurelli, L., \& Treccani, D. (2019). Geometric survey data and historical sources interpretation for HBIM process: the case of Mantua cathedral façade. ISPRS Annals of the Photogrammetry, Remote Sensing and Spatial Information Sciences, XLII-2/W11, 29-35. https://doi.org/10.5194/isprs-Archives-XLII-2-W11-29-2019

Antonucci, M. (2018). I soffitti lignei di palazzo Stati Cenci Maccarani a Roma. Opus Incertum, 3, $100-111$. https://doi.org/10.13128/opus-23054

Breymann, G. A. (1884). Costruzioni in legno. In: Trattato generale di costruzioni civili (tradotto da Carlo Valentini) 2 , Milano, Vallardi-Biblioteca Internazionale dell'Ingegnere.

Capone, M., \& Lanzara, E. (2019). Scan-to-BIM vs 3D ideal model HBIM: parametric tools to study domes geometry. ISPRS - International Archives of the Photogrammetry, Remote Sensing and Spatial Information Sciences, XLII2/W9, 219-226. https://doi.org/10.5194/isprs-archives-XLII-2-W9-219-2019

Della Torre, S. (Ed.). (2003). La conservazione programmata del patrimonio storico architettonico. Linee guida per il piano di manutenzione e consuntivo scientifico. Milano, Italy: Guerini e Associati.

Giorgi, L. (2017). I solai e i soffitti quattrocenteschi di Palazzo Vecchio, Rlcerca/REstauro, Sezione 2B: Conoscenza dell'edificio: casi-studio (Maurizio De Vita Ed.); I Convegno della Società Italiana per il Restauro dell'Architettura (SIRA), pp. 548-558. Roma, Italy: Edizioni Quasar.

Introini, M. Spinelli, L. (2018). Architettura a Mantova. Dal Palazzo Ducale alla Cartiera Burgo. Cinisello Balsamo, Italy: Silvana Editoriale.

López, F. J., Lerones, P. M., Llamas, J., Gómez-García-Bermejo, J., \& Zalama, E. (2017). A Framework for Using Point Cloud Data of Heritage Buildings Toward Geometry Modeling in A BIM Context: A Case Study on Santa Maria La Real De Mave Church. International Journal of Architectural Heritage, 11(7), 965-986. https://doi.org/10.1080/15583058.2017.1325541

Piva, P. (1988). L' "altro" Giulio Romano: il duomo di Mantova, La chiesa di Polirone e la dialettica col medioevo. Quistello, Italy, Officina Grafica Ceschi.

Prizeman, O., Pezzica, C., Taher, A., \& Boughanmi, M. (2020). Networking Historic Environmental Standards to Address Modern Challenges for Sustainable Conservation in HBIM. Applied Sciences, 10(4), 1283. https://doi.org/10.3390/app10041283

Venturi, A. (1938). Storia dell'Arte Italiana: vol XI, Architettura del Cinquecento, parte I. Milano, Italy: Edizioni Hoepli.

Yang, X., Koehl, M., \& Grussenmeyer, P. (2017). Parametric modelling of as-built beam framed structure in BIM environment. ISPRS - International Archives of the Photogrammetry, Remote Sensing and Spatial Information Sciences, XLII-2/W3, 651-657. https://doi.org/10.5194/isprs-archives-XLII-2-W3-651-2017

Yang, X., Koehl, M., \& Grussenmeyer, P. (2018). Mesh-to-bim: from segmented mesh elements to BIM model with limited 
parameters. ISPRS - International Archives of the Photogrammetry, Remote Sensing and Spatial Information Sciences, XLII-2, 1213-1218. https://doi.org/10.5194/isprs-archives-XLII-2-1213-2018 


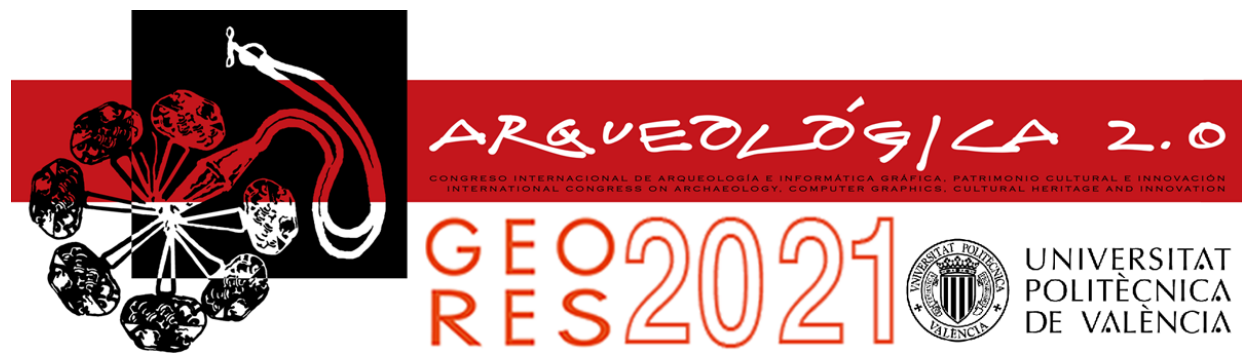

Proceedings of the joint international event $9^{\text {th }}$ ARQUEOLÓGICA

$2.0 \& 3^{\text {rd }}$ GEORES

Valencia (Spain).

26-28 April 2021

\title{
TLS AND IMAGE-BASED ACQUISITION GEOMETRY FOR EVALUATING SURFACE CHARACTERIZATION
}

\author{
Giacomo Patrucco*, Stefano Perri, Antonia Spanò \\ Department of Architecture and Design (DAD), Politecnico di Torino, Viale Mattioli 39, 10125 Torino, Italy. giacomo.patrucco@polito.it; \\ stefano.perri@polito.it; antonia.spano@polito.it
}

\begin{abstract}
:
In the framework of cultural heritage documentation projects, it is very frequent the use of dense and detailed 3D models derived from range-based or image-based techniques. These reality-based models represent an effective and powerful solution to document the geometries, the surfaces and the characteristic of heritage assets. In fact, these technologies allow us to accurately describe the level of detail and the surface characterization of the materials, and also to provide precious support for the evaluation of the conservation status of the surveyed structures. In particular, the object studied in the presented research experience is the Morano sul Po arch (Morano sul Po, AL, Piedmont, Italy), a valuable example of an industrial archaeology asset. For the knowledge process of the arch, both LiDAR systems and photogrammetric strategies have been used, in order to properly document the geometry, the consistency of the material and the decays. The specific aim of the research presented in this paper is the evaluation of the advantages and the critical issues of using a telescopic pneumatic pole to raise the position of the scans from the ground and decrease the angle of incidence of the laser beam on the surveyed object. For this reason, the study also takes into consideration the use of mini UAVs and their flexibility to effectively acquire vertical surfaces even at elevated heights, comparing the density and the roughness of the derived model with the data obtainable by using TLS systems.
\end{abstract}

Keywords: TLS, UAV photogrammetry, surface characterisation, multi-sensor, cultural heritage, 3D model

\section{Introduction}

The survey techniques aimed at cultural heritage documentation and the generation of dense and accurate 3D models have undergone an impressive evolution in the last few years. Nowadays, thanks to the availability of many tools, methods and strategies it is possible to effectively respond to very diversified needs connected to heritage documentation processes (Murtiyoso, Grussenmeyer, Suwardhi \& Awalludin, 2018; Chiabrando, Sammartano, Spanò \& Spreafico, 2019).

The use of topographic systems allows the developing of the entire workflow and the generation of the 3D models in a common reference system. In addition, it also provides valuable instruments to properly perform an accuracy check on the final results.

Among the most widespread trends in the field of multisensor techniques aimed at obtaining multi-scale and multi-resolution models, rapid mapping techniques are usually preferred, allowing rapid site occupation and increasing the survey sustainability.

Moreover, it should be underlined that advantages are evident in terms of efficiency and effectiveness derived from the automation of image-based techniques, the development of co-registration techniques as well as the
ICP algorithms - allowing to align point clouds of different nature and resolution. Due to these significant developments, the possibility to perform productive fusions and integrations among data from different sources and techniques is being strengthened in the heritage documentation sector. (Muñumer \& Lerma 2015; Ramos \& Remondino 2015; Georgopoulos et al., 2017; Güleç Korumaz, 2019).

Considering the aforementioned technological advances, the obtainable 3D models can be more and more addressed to users-oriented purposes, ensuring centimeter and sometimes even millimeter accuracies, depending on the purposes for which the 3D models are made. The aforementioned technologies and achievable results can provide valid support to the maintenance, conservation and restoration interventions planning, contributing to define materials decay or structural anomalies and pathologies. In the framework of dissemination and communication of the heritage, it is necessary to consider virtual applications or augmented reality navigation, moreover, replicas generations and the realisation of virtual museums can be achieved using these methods and strategies (Balletti \& Ballarin, 2019; Barbieri, Bruno \& Muzzupappa, 2018). 
In this contribution, the main aim is to highlight how the acquisition geometry - not only as regards the image collection for photogrammetric purposes, but also considering the TLS (Terrestrial Laser Scanning) sampling - can affect the accuracy of the 3D model and the possibility to properly document the characterisation and the roughness of the surveyed surfaces.

In the next sections, the effectiveness of a device able to change the point of view of the acquisition of the scans will be evaluated. Furthermore, it will be investigated how to ration the acquisition of the point clouds by modifying the distance between the TLS system and the object of interest during point clouds collection and the inclination of the laser beam with respect to the surveyed surfaces.

The results obtained are also compared with an imagebased 3D model, obtained through acquisitions performed using a mini UAV (Unmanned Aerial Vehicle) system. Nowadays this kind of technology seems particularly promising for documenting the heritage, since it allows to acquire hard to reach surfaces with a relatively high level of detail. In fact, it should be underlined that, due to the versatility and manageability of these systems, the acquisitions can be performed at very short distances from the surfaces of interest. (Adami et al. 2019; Xiang, Xia \& Zhang, 2019).

Since its inception, laser scanning technology has been represented as an object of interest for the community of measurements science and surveyors. The extraordinary potential of this technology has been immediately highlighted and the calibration issues of the various sensors and measurement systems (both time-of-flight and phase-shift scanners) have been deeply investigated (Boehler, Bordas Vicent, \& Marbs, 2003).

Many researchers operating in the fields of 3D survey and modelling of the built heritage focused their studies on this topic, and perhaps one of the most recognized advantages was the possibility of deriving true digital orthophotos from Dense Digital Surface Models (DDSM) (Balletti, Guerra, Lingua \& Rinaudo, 2003). That laid the foundations for close collaborative applications of both TLS and image-based techniques that characterize many cultural heritage documentation projects, ranging from the most important sites of cultural interest to artistic or archaeological heritage.

The quality assessment of TLS systems has been investigated (Vögtle, Schwab \& Landes, 2008), considering the influence of different materials in the measurements of the range of terrestrial scanners. In addition, intensity analyses have been considered. Other authors have studied the different results deriving from the direction of the laser beam intercepting the surface, and how the distance between the laser scanner and the surveyed object affect the quality of the acquired point cloud (Tucci, Bonora \& Guardini, 2013). Generally, these issues can be interpreted with calibration matters (Lichti \& Licht, 2006).

In the framework of point cloud acquisition, high accuracies and high level of detail are often required. In some cases, the shape of the surveyed object is not the only feature to be investigated, but also the surface characterization. For this reason, in order to study the effects that the distance and the incidence angle of the laser beam produce on the surfaces (featuring the local accuracy and noise of the point cloud), a comparison among 3D models derived from different scans planned positions have been investigated in the current paper.

The possibility to acquire scans by a device that raises the acquisition centre of the scanner from the ground has been also tested.

Tripods or telescopic pole are sometimes used in cultural heritage documentation, usually equipped with a camera, and as observed in various researches, the possible instability issues can be considered not significant (Bitelli, Dellapasqua, Girelli, Sanchini \& Tini, 2017).

In this framework, extension arms, telescopic poles and lift platforms are often used and they certainly require great attention even when the scale of the survey is the architectural one (Corso, Casals, Marco, López \& Garcia Almirall, 2018), but they need further assessments if the characterization of roughness materials is also considered and investigated, as proposed in the next sections.

\section{Case Study: the Morano sul Po arch}

The Morano sul Po arch (Morano sul Po, AL, Piedmont, Italy) (Fig. 1a) was built in the years of the economic boom, after World War II. It plays a symbolic role as a demonstration of the construction possibilities achieved with the experiments of structural engineering carried out in the 1930s and with the innovative materials produced by the cement industry. The arch was also functional to the production cycle as it allowed the passage of the raw material from the Coniolo quarry, on the other side of the Po river, to the Morano furnace. In fact, it protected the Trino-Morano-Casale provincial road from possible losses of material from the trolleys transported by the cableway (Fig. 1b). Now the arch has been subjected to a conservation project aimed at the dissemination of the socio-economic and cultural values coming from the cement industry together with its innovations in the constructive systems.

\section{Methodology}

\subsection{Instrumentation and data acquisition}

In December 2019, a 3D metric acquisition campaign has been carried out by a team from G4CH Lab of Politecnico di Torino with the aim of documenting the conservation status of the paraboloid arch of Morano in the framework of the planning of the aforementioned scheduled restoration works. A complete LiDAR survey and a series of photogrammetric acquisitions (both terrestrial and from UAV) have been performed in order to provide a multisensor three-dimensional documentation of the considered structure belonging to the valuable industrial heritage assets of the areas adjacent to Casale Monferrato, where the cement production activities have always played a key-role in the framework of the local economy.

As regards the TLS survey, 19 LiDAR point clouds have been acquired using 2 laser scanners: a Faro Focus ${ }^{3 D} X$ 330 and a Faro Focus ${ }^{3 D}$ S120 (Fig. 2). The acquisition scheme of the collected scans can be observed in Figure 3 . Since the main specifications of the two employed devices - which are reported in Table 1 - are equal, except for the operational acquisition range, the point 
clouds from both the laser scanners can be considered comparable in terms of density and noise.
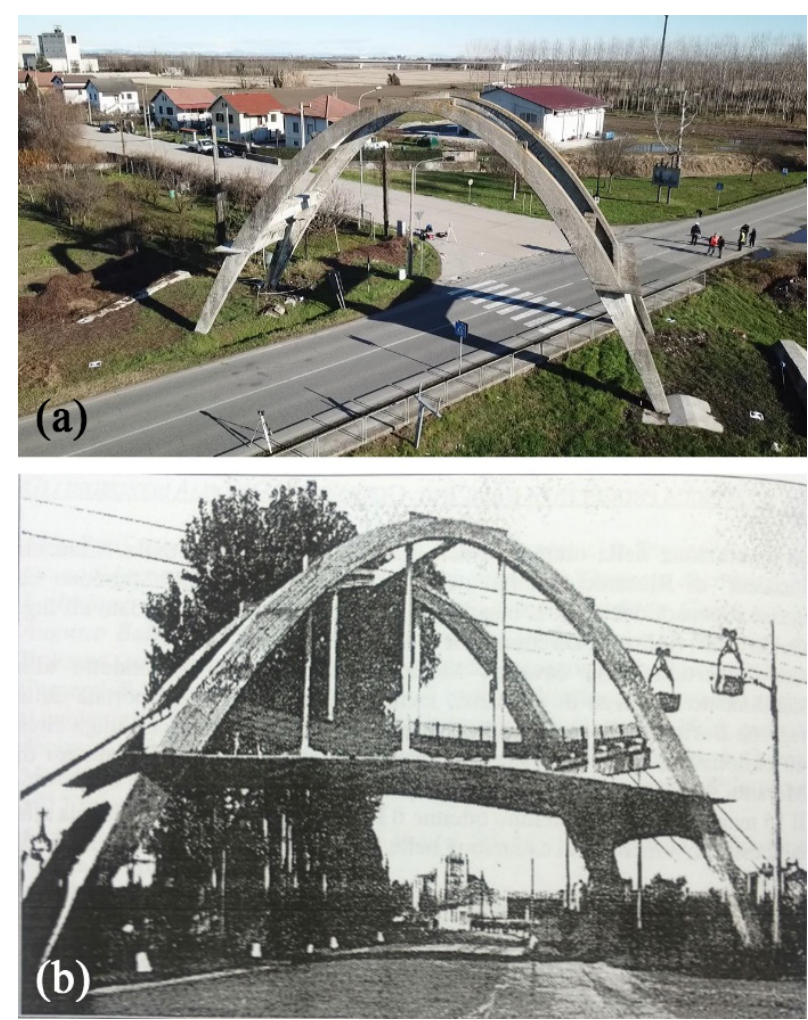

Figure 1: The paraboloid arch of Morano sul Po: a) Current image; b) Historical image (1955) of the arch, during the transport operations of raw material over the Trino-MoranoCasale provincial road.

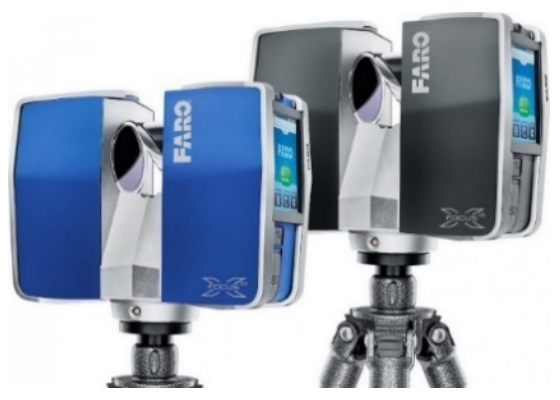

Figure 2: On the left, Faro Focus ${ }^{3 D} \times 330$. On the right, Faro Focus $^{3 \mathrm{D}} \mathrm{S} 120$.

Table 1: Main specifications of the used laser scanners (Faro Focus $^{3 D} \times 330$ and Faro Focus ${ }^{3 D}$ S120).

\begin{tabular}{c|c|c} 
Laser scanner & $\begin{array}{c}\text { Faro Focus } \\
330\end{array}$ & $\begin{array}{c}\text { Faro Focus } \\
\text { S120 }\end{array}$ \\
\hline $\begin{array}{c}\text { Distance Range } \\
\text { Horizontal and } \\
\text { vertical range }\end{array}$ & $0.6-330 \mathrm{~m}$ & $0.6-120 \mathrm{~m}$ \\
$\begin{array}{c}\text { Distance accuracy } \\
\text { Acquisition speed }\end{array}$ & $\begin{array}{c} \pm 2 \mathrm{~mm} @ 10 \mathrm{~m} \\
\text { up to } 976.000 \mathrm{pt} / \mathrm{s}\end{array}$ & $\begin{array}{c} \pm 2 \mathrm{~mm} @ 10 \mathrm{~m} \\
\text { up to } 976.000 \mathrm{pt} / \mathrm{s}\end{array}$
\end{tabular}

The TLS acquisition has been planned in order to homogeneously cover the maximum number of surfaces of the Arch, with the aim of providing an adequate overlapping between the adjacent scans to facilitate the successive registration operations. As concerns the resolution of the collected point clouds, the acquisitions have been performed using a resolution of $1 \mathrm{pt} / 6 \mathrm{~mm}$ at $10 \mathrm{~m}$ of distance.

On this occasion a pneumatic telescopic pole has been tested in order to raise the laser scanner and acquire a point cloud of the higher areas of the arch with a lower angle of incidence of the laser signal - the angle between the laser beam and the normal direction of the surveyed surface (Soudarissanane, Lindenbergh, Menenti \& Teunissen, 2009; Soudarissanane, Lindenbergh, Menenti \& Teunissen, 2011; Roca-Pardiñas, Argüelles-Fraga, de Asís López \& Ordóñez) - in comparison to the scans acquired from the ground level.

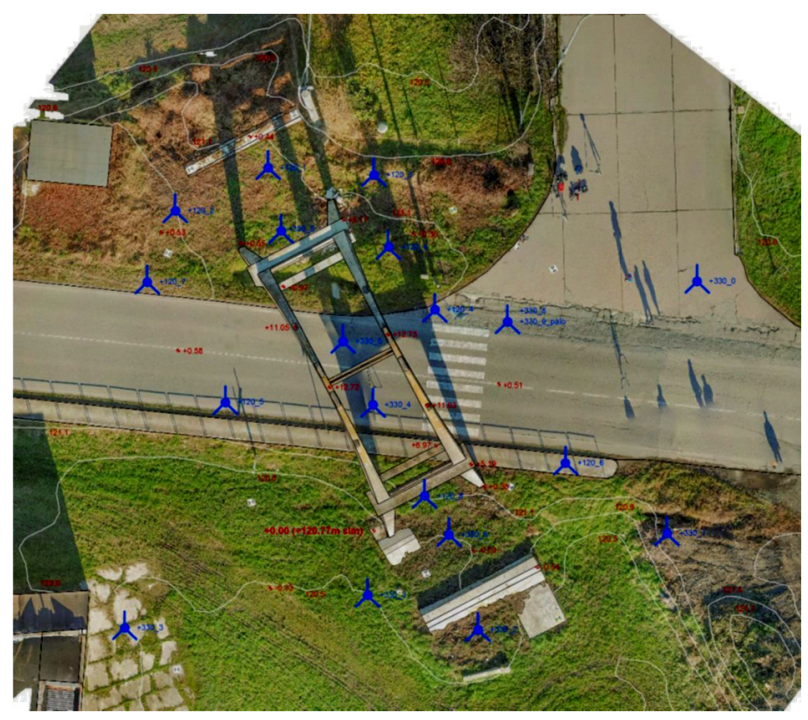

Figure 3: Position of the acquired scans.

These last aspects represent a key issue in the framework of heritage building documentation: in order to provide complete metric documentation of heritage buildings especially as regards the particularly high facades and the outdoor areas - there is often the need to acquire data from an elevated perspective.

As noted above, this is the reason why, in the last few years it was possible to observe an incremental increase of the use of UAV systems in many fields and disciplines - including heritage assets documentation (Bakirman et al., 2020; Chiabrando, Sammartano, Spanò \& Teppati, 2020) - for aerial monitoring and survey purposes. The flexibility, the efficiency and the rapidity of these kinds of solutions are the reasons why in recent years the use of drones has become a very popular and effective strategy to collect images from hard-to-reach perspectives, with a particular focus on the mini UAV solutions compliant to the needs and purposes of this research.

Also in the case presented a photogrammetric aerial survey has been carried out. The UAV system used for the aerial acquisitions is a commercial drone developed from DJI (model: DJI Mavic Pro, equipped with a digital camera FC220) (Fig. 4). The principal specifications of the employed drone can be observed in Table 2. Several flights have been performed with both nadir and oblique camera configuration (to effectively acquire the higher surfaces and the extrados of the Arch) and a planned overlapping between the images $\geq 80 \%$. In total 384 images (resolution $4000 \times 3000$ pixels) have been collected during these flights (mean shooting distance $\approx$ 
15-20 m) with a mean GSD (Ground Sample Distance) of $\approx 5 \mathrm{~mm}$.

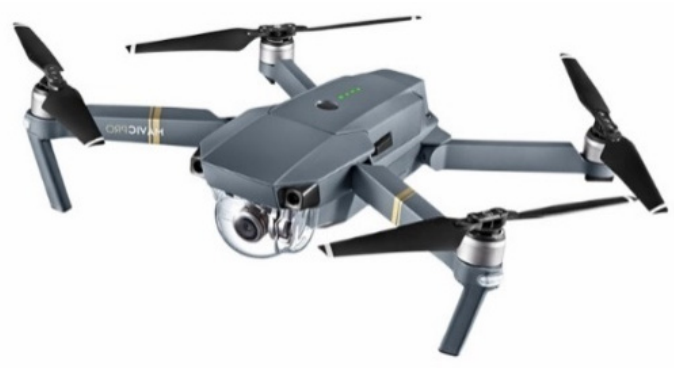

Figure 4: DJI Mavic Pro.

Table 2: Main specifications of DJI Mavic Pro.

\begin{tabular}{c|c} 
DJI Mavic Pro (FC220) & Camera specifications \\
\hline Sensor & CMOS 1/2.3" \\
Effective pixels & 12.35 Mpixels \\
Lens & FOV $78.8^{\circ} 5 \mathrm{~mm} \mathrm{f} / 2.2(26 \mathrm{~mm}$ \\
in $35 \mathrm{~mm}$ format equivalent $)$ \\
ISO Range & $100-1600$ \\
Shutter Speed & $8 \mathrm{~s}-1 / 8000 \mathrm{~s}$ \\
Max image size & $4000 \times 3000$ pixels \\
Photo format & JPG, DNG
\end{tabular}

In addition, 222 images (resolution: $8688 \times 5791$ pixels) have been collected using a DSLR (Digital Single Lens Reflex) camera (model: Canon EOS 5DSR) equipped with a $25 \mathrm{~mm}$ Zeiss lens (principal specifications in Table 3 ). In this case, the aim was to cover the lower areas of the concrete structure, in order to achieve a complete photogrammetric model of the Arch of Morano by integrating the UAV acquired images with the terrestrial ones.

Table 3: Main specifications of Canon EOS 5DSR.

\begin{tabular}{c|c} 
Canon EOS 5DSR & Camera specifications \\
\hline Sensor & CMOS 50.3 Mpixels \\
Sensor size & $36 \times 24 \mathrm{~mm}$ \\
Image size & $8688 \times 5792$ pixels \\
Lens & Zeiss ZE $/$ ZF.2 \\
Focal lenght & Distagon T*25 mm/ $2 / 2$ \\
& $25 \mathrm{~mm}$
\end{tabular}

With the aim of registering all the data acquired during the campaign in a common reference system, 34 topographic points have been measured (both artificial checkboard target and natural points) from two vertices, using a total station. The coordinates of the two vertices have been derived from a control network adjustment; measures were carried out using two GNSS receivers (static technique) in order to georeference the data derived from the survey.

\subsection{Data processing}

The 19 LiDAR scans have been processed using the Faro Scene software, following a consolidated registration strategy which consists of a preliminary alignment of the point clouds using an ICP (Iterative Closest Point) algorithm, and in a subsequent rigid rototraslation of the block composed by the registered scans using the coordinates of the measured markers. At the end of this procedure the observed accuracy on the control points is $\approx 6 \mathrm{~mm}$ (this value represents the mean $3 \mathrm{D}$ deviation between the coordinates observed on the target in the point cloud and the reference coordinates) (Lachat, Landes \& Grussenmeyer, 2018) (Fig. 5).

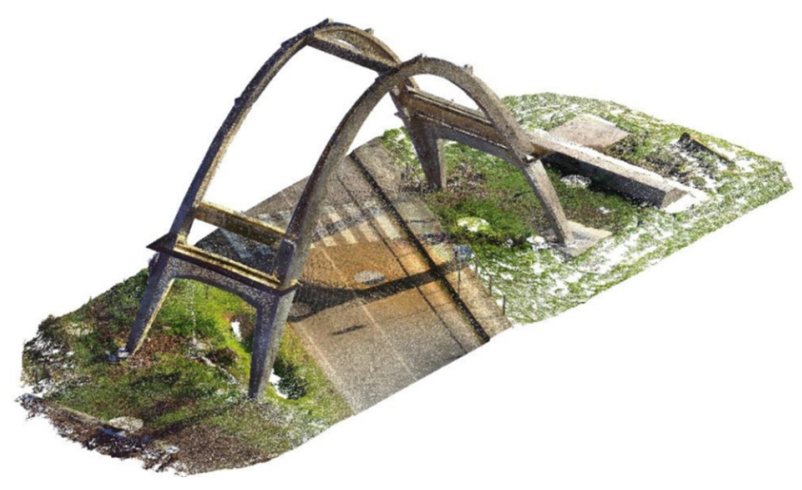

Figure 5: Lidar point cloud.

As regards the image-based approach, the 606 images acquired from both the UAV system and the DLSR camera have been processed (Figs. 6 and 7) using the SfM-based (Structure-from-Motion) software Agisoft Metashape, following the standard pipeline (images masking; relative orientation of the images and tie-points extraction; georeferencing and bundle adjustment using the acquired Ground Control Points; accuracy evaluation using both control points and check points; dense point cloud generation) (Ewertowski, Tomczyk, Evans, Roberts, \& Ewertowski, 2019). As concerns both the image alignment phase and the generation of the dense point cloud, the quality parameter has been set on "high" (which means that all the images have been processed at their original resolution without downscaling).

Of the 34 points measured with the total station, 28 have been used as GCPs (Ground Control Points) and 6 as CPs (Control Points) in order to perform an accuracy check on the final results. The RMSE (Root-Mean-Square Error) after the bundle block adjustment is reported in Table 4

Table 4: Main specifications of Canon EOS 5DSR.

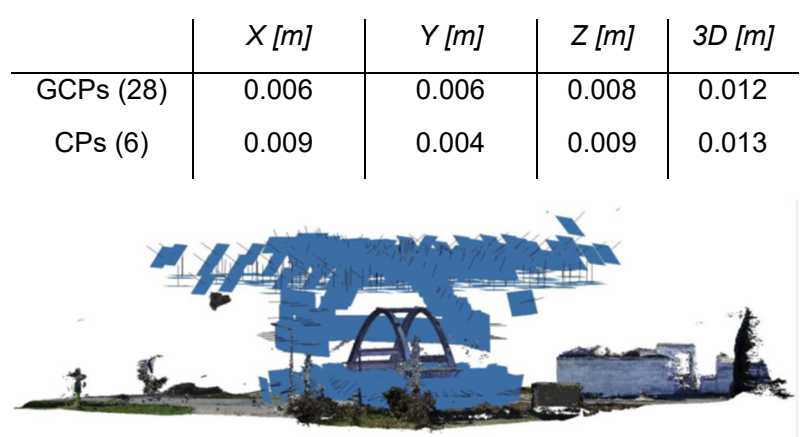

Figure 6: Image alignment and tie points generation. 


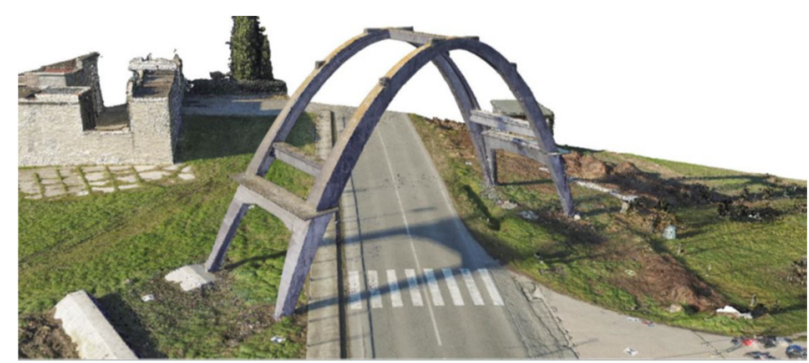

Figure 7: Photogrammetric point cloud.

\section{Results analysis}

As stated in the previous section, in this framework the use of a pneumatic telescopic pole to raise the laser scanner above the ground level (and therefore to acquire points on the elevated surfaces of the Arch façade with a low incidence angle) has been tested (Fig. 8).

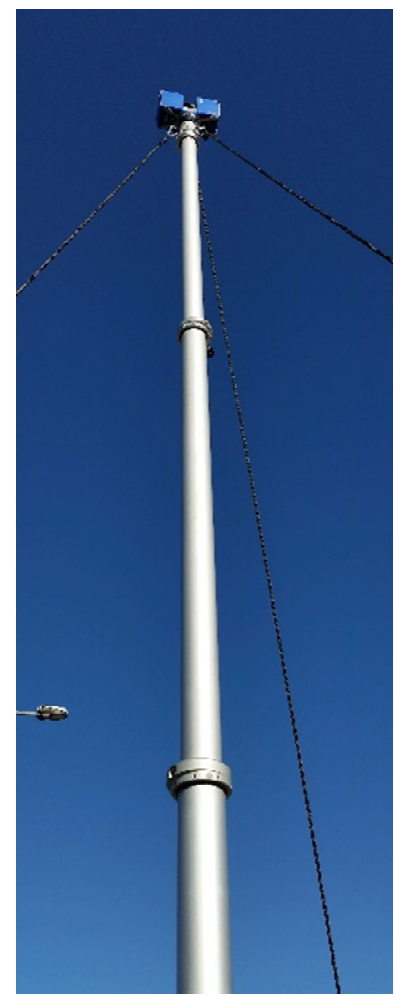

Figure 8: Telescopic pole equipping the Faro laser scanner during the case study 3D survey.

A set of focused analysis has been performed on the upper area of the east façade of the Arch, to compare both the scans acquired at different heights (thanks to the telescopic pole) and different distances.

For this comparison, among the 19 scans acquired during the TLS survey to achieve the complete model of the Arch, four have been selected according to the acquisition geometry (Fig. 9):

- 1 scan (Scan A) acquired raising the laser scanner by using a telescopic pneumatic pole. The acquisition distance is approximately $10 \mathrm{~m}$. The scan has been performed in calm wind conditions.
- 1 scan (Scan B) acquired at ground level. The acquisition distance is approximately the same of Scan A.

- 1 scan (Scan C) acquired at ground level. The acquisition distance is approximately $25 \mathrm{~m}$.

- 1 scan (Scan D) acquired very close to the Arch.
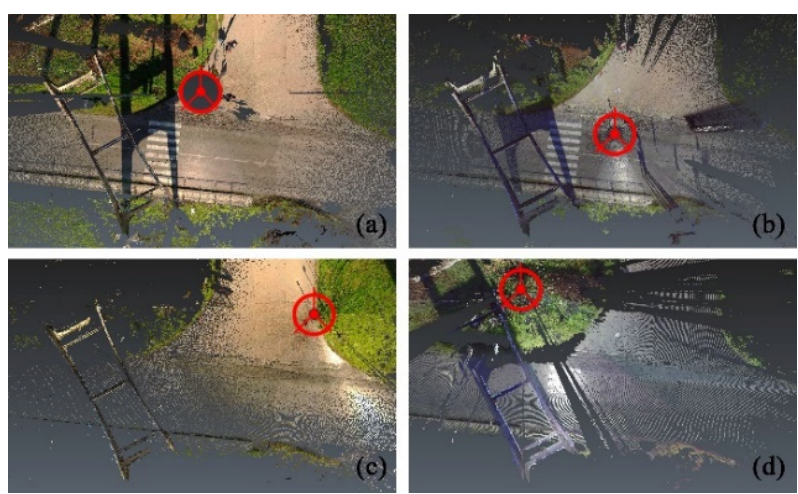

Figure 9: Acquisition scheme of each of the considered LiDAR scan (the position of the laser scanner is indicated by the red symbol): a) scanner on the pneumatic telescopic pole, acquisition from medium distance; b) scanner on ground level, acquisition from medium distance; c) scanner on ground level, acquisition from long distance); d) scanner on ground level, acquisition from short distance.

The photogrammetric point cloud has been considered too in the framework of these analyses, since - as reported in the previous sections - the UAV photogrammetry has proved itself as a very competitive and viable alternative. In this case, starting from the oriented block of 606 images, a dense point cloud has been generated enabling only the images collected with the camera in a forward camera configuration (Fig. 10).

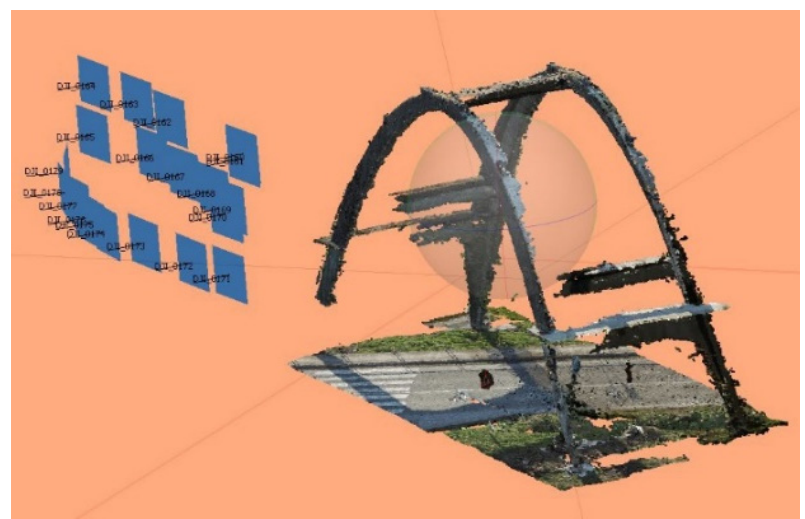

Figure 10: Photogrammetric point cloud generated from the images acquired with a forward camera asset.

For the analyses described in the following paragraphs, a portion located in the highest part of the arch façade has been considered (Fig. 11). Firstly, a density analysis has been carried out using the CloudCompare open-source platform (Fig. 12). For each point the number of neighbours has been estimated considering a sphere with a radius of $5 \mathrm{~cm}\left(\mathrm{n}^{\circ}\right.$ points/sphere $\left.r=5 \mathrm{~cm}\right)$. As predictable, the point cloud characterised by a higher density is the one acquired from the telescopic pole (Scan A) due to the lower distance of acquisition to the surveyed surface (in comparison to Scan B, where the scanner was placed at a greater distance, and Scan C, acquired from 
the ground level) and to the lower inclination of the laser signal. In fact, in the case of Scan D, the laser scanner is positioned very close to the Arch, but due to the very high incidence angle of the laser beam the density of the acquired point cloud is extremely low (a mean value of 30 pt./V. sphere $r=0.05 \mathrm{~cm}$ ).

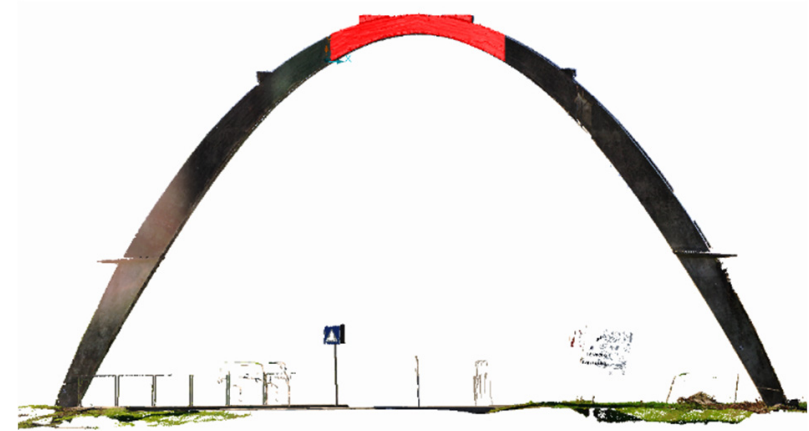

Figure 11: Portion of the arch (red points) considered for the analyses which have been carried out during this research.

However, as evidenced from the subsequent roughness analysis, the surface of the telescopic pole point cloud is affected by a topological error due to the vibrations transmitted from the laser scanner to the pole during the acquisition of the scan. The CloudCompare roughness analysis allows to evidence the points that deviate from the best fitting plane (computed between the neighbouring points in a sphere that in this case has been set with a radius of $5 \mathrm{~cm}$ ). In this case, the observed mean value is comparable for each of the considered point clouds, but as regards Scan $A$ the regular corrugation observable along its surface (Fig. 13a) begins to become more evident.

This last characteristics in extremely evident observing the mesh triangulated from each point cloud (Fig. 14). However, besides the corrugation issue, it is possible to notice that the mesh computed from Scan A is (as expected) the one with a higher resolution and level of detail. The only other point cloud showing a high degree of characterization of the surface which allows to adequately describe the consistency of the material of the scanned object, is Scan B; while in Scan C (acquired from a longer distance - $25 \mathrm{~m}$ - to the arch) and in Scan $D$ (characterised by a very high incidence angle of the laser beam to the surface due to the proximity to the concrete structure) it is possible to observe a low level of detail and material consistency interpretation (the two meshes are extremely smoothed).

After the detection of the regular corrugation due to the vibrations of the scanner, an investigation has been performed in order to evaluate how the metric accuracy of the acquired point cloud was affected by this topological error. With the aim of quantifying the dimension of the undulating deformation observed in Scan A, a best-fitting plane has been interpolated on a portion of the considered point cloud and a planarity analysis has been carried out with the 3DReshaper software using the extracted plane as reference. From this analysis, the topologically erroneous corrugation (previously detected on the roughness analysis and on the surface of the triangulated mesh) can be estimated with a maximum deviation of $\pm 1 \mathrm{~mm}$ (Fig. 15).
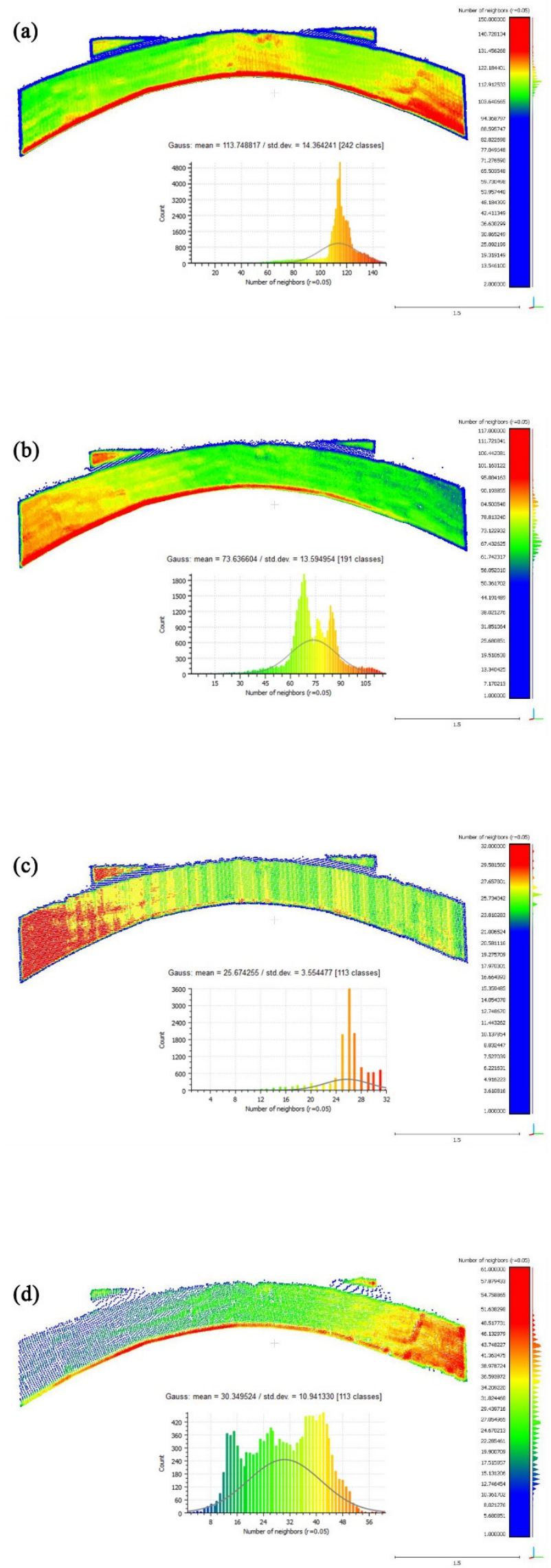

Figure 12: Density analysis of a portion of the upper part of the Arch façade, performed with CloudCompare: a) Scan A; b) Scan B; c) Scan C; d) Scan D. 

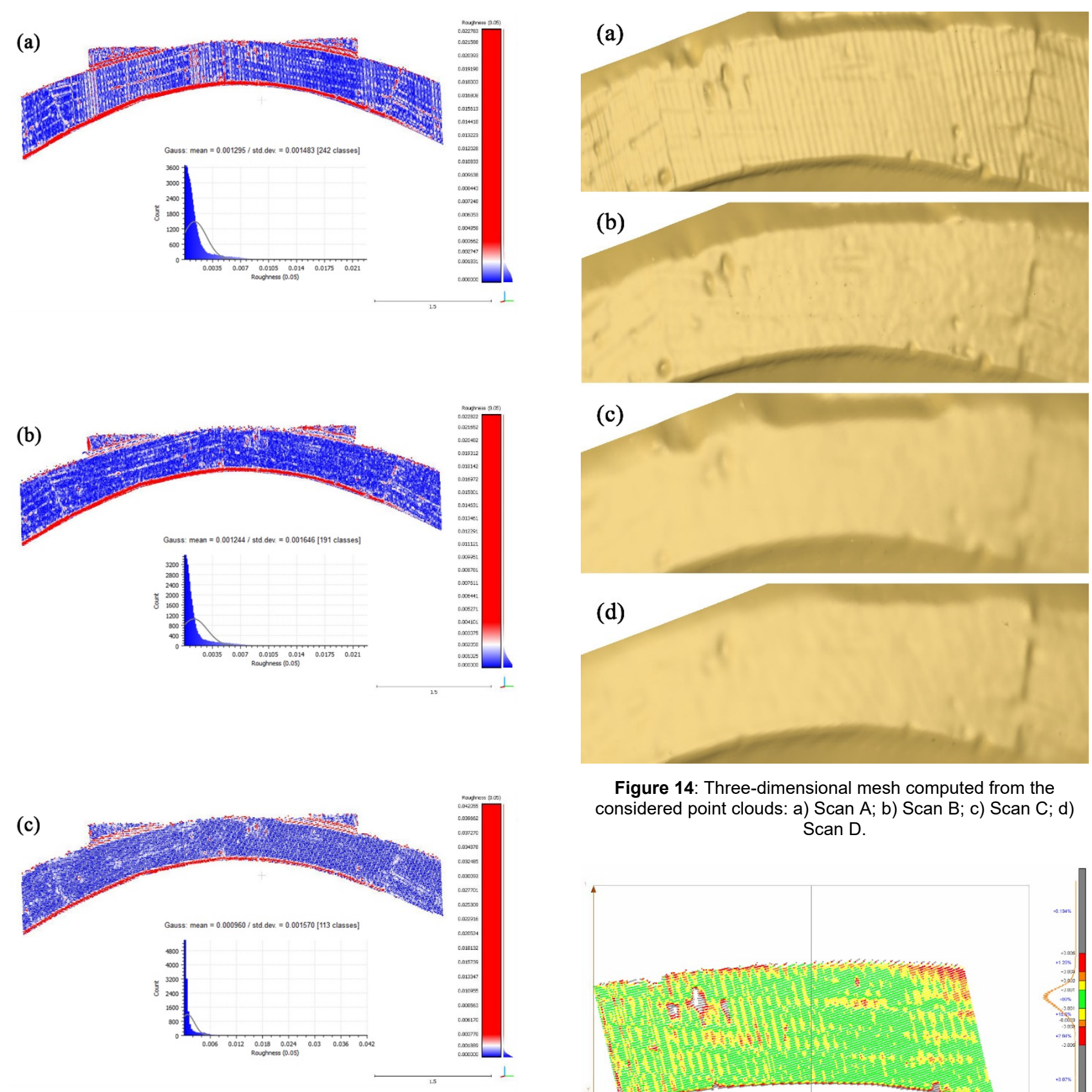

Figure 14: Three-dimensional mesh computed from the considered point clouds: a) Scan A; b) Scan B; c) Scan C; d) Scan D.

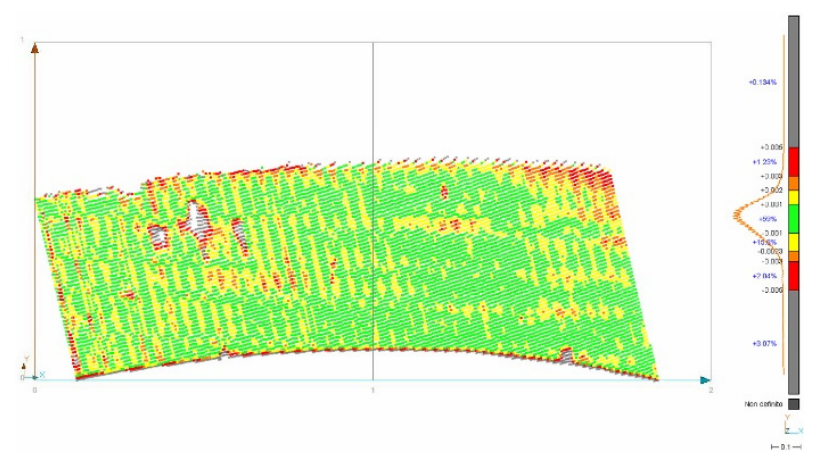

Figure 15: Planarity analysis carried out on a portion of the point cloud acquired from the telescopic pole.

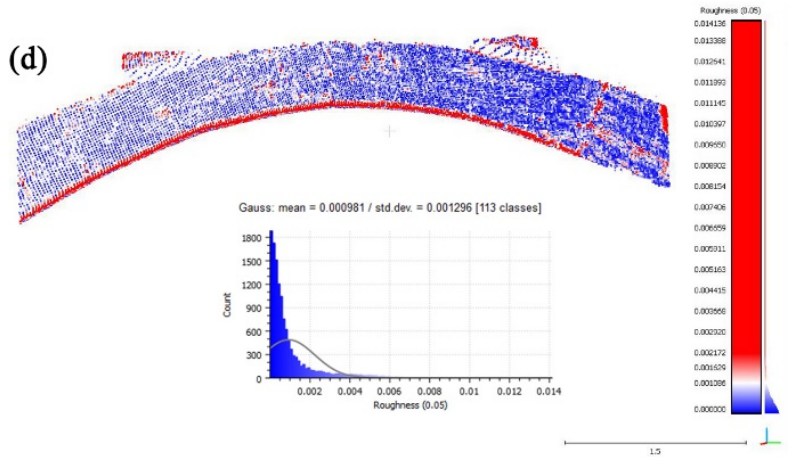

In order to perform a comparison between the products achievable using different strategies (LiDAR techniques or an image-based approach), the same analyses (density analysis; roughness analysis; 3D mesh computation) has been performed on the dense point cloud generated from UAV dataset using an SfM-based photogrammetric pipeline. As it is possible to observe in Figure $16 \mathrm{a}$, the data density is much smaller (mean value $\approx 24$ pt. $/ \mathrm{V}$. sphere $r=0.05 \mathrm{~cm}$ ) in comparison to Scan $A$ and Scan B.

Figure 13: Roughness analysis of a portion of the upper part of the Arch façade, performed with CloudCompare: a) Scan A; b) Scan B; c) Scan C; d) Scan D. 
(a)
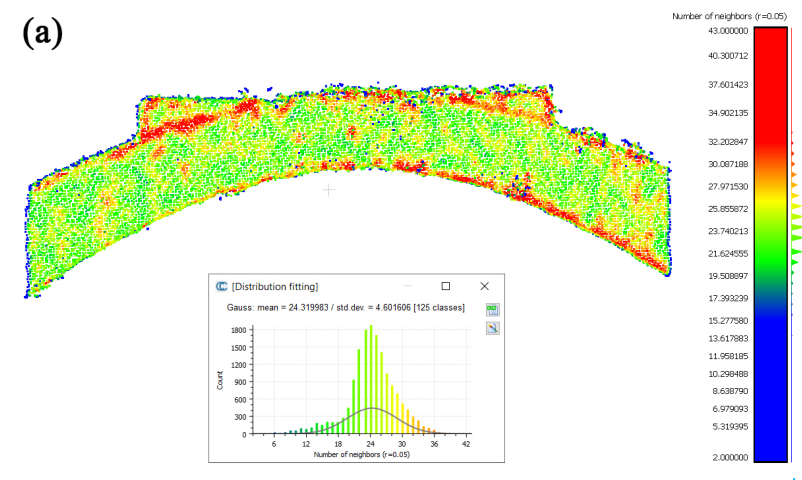

(b)

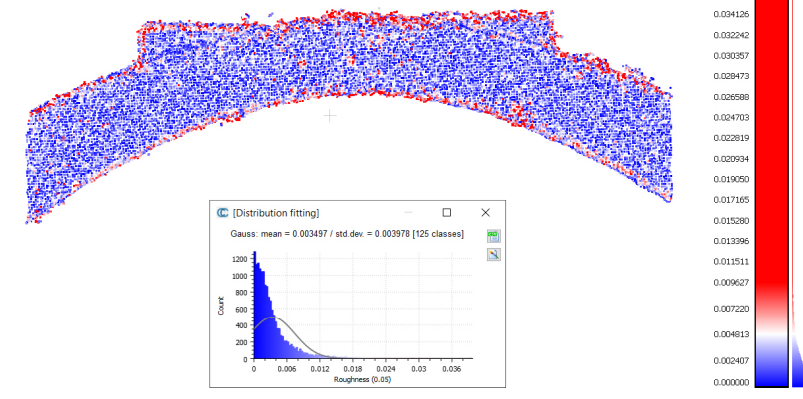

(c)

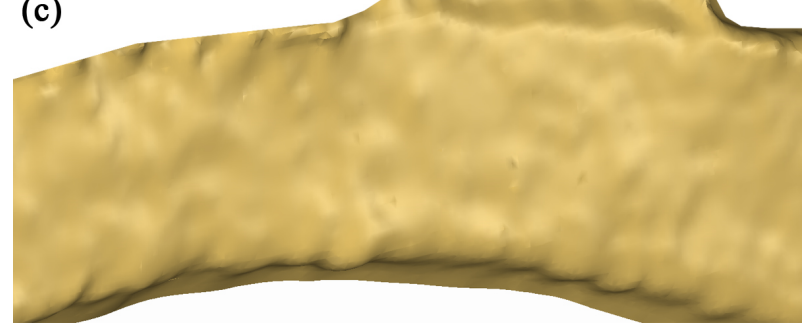

Figure 16: Analysis performed on UAV dataset: a) Density analysis; b) Roughness analysis; c) Triangulated mesh.

Furthermore, in the 3D reconstruction (Fig. 16c) a very high smoothness and a low 3D characterisation in terms of consistency of the material roughness are observable. However, it should be underlined that the image-based approach can provide, besides the geometric information, also the radiometric content of the object, through the production of a texturized 3D model or the generation of orthoimagery. As regards this particular aspect, the photogrammetric image-based approach is very competitive and preferable to the traditional LiDAR survey strategies. In fact, despite nowadays almost all of the commercial laser scanners are equipped with an embedded optical camera - or they have the possibility to equip an external one - the radiometric quality of the data derived from laser scanning technologies in generally lower in comparison to photogrammetric products.

\section{Discussion}

As observed in the previous section, starting from the performed analysis it is possible to confirm how the acquisition geometry during a LiDAR survey - and, in the specific, the position of the laser scanner - influences different aspects of the final point cloud. As expected and as evidenced by the results obtained with Scan B and Scan $C$ it is evident that the density of the data decrease with increasing distance or in correspondence of high incidence angles of the laser beam. Also the spatial resolution and the level of the detail are lower.

As regards this last aspect, the two best performing point clouds are certainly Scan A and Scan B. However, in the case of Scan $A$ the regular pattern corrugation generated from the vibrations and micro-movements transmitted to the pneumatic telescopic pole from the laser scanner rotation represents a heavy limit in the definition of a topological correct characterisation of the surveyed surface. In the framework of the current research experience, and if the aim is to accurately document the roughness of the concrete surface of the arch, Scan B represents the best compromise between density of the data and level of detail. However, it should be underlined that, in the case of a higher structure (the arch is approximately $13 \mathrm{~m}$ ) and/or a smaller space in front of the object of interest, this acquisition strategy it would not be possible.

In terms of completeness, the photogrammetric point cloud derived from mini UAV acquisitions is very competitive. In fact, following a LiDAR approach, even using the telescopic pole it was possible to acquire the surfaces of the extrados: to pursue this goal it would have been necessary to develop a further strategy to increase the acquisition height of the laser scanner (e.g. using a lift platform). However, the level of detail of the photogrammetric is extremely lower in comparison to the elevated surface characterisation observable in the LiDAR data (especially in the scans acquired from a low distance and where the incidence angle of the laser beam is not excessive). In connection to this issue, a solution can be represented by the use of UAV systems characterised by larger dimensions (specifically designed to lift heavier payloads) and equipped with more performing camera sensors. However, it would not be possible to exploit the specific advantages connected to mini UAV solutions (greater manoeuvrability; greater safety during acquisitions; lower cost; etc.).

Another effective solution in order to boost the quality of the final results and to reach a comparable level of detail is related to the shooting distance, which in this case should be drastically decreased. However, this is not always possible since a lower shooting distance corresponds to a greater number of acquired images to properly cover all the surfaces of the surveyed object, at the expenses of the data processing phase and file storage. In the case of the presented research, the acquisition distance has been planned in order to reach a fair compromise between the obtainable resolution of the final 3D model and the management of the data.

However, it must be recognised that thanks to the radiometric contents - and, consequently, metric products as 3D texturized mesh and orthoimagery achievable using the photogrammetric approach - it is nevertheless possible to obtain valuable information about the material and the consistency of the acquired surfaces (on the contrary to LiDAR data where the information is connected to the spatial resolution of the point clouds, since the poor radiometric resolution of the embedded camera). 


\section{Conclusion}

The presented analysis has allowed an evaluation of the advantages and critical issues connected with the use of a device to raise the centre of acquisition of a range scanner from the ground, comparing the achievable points model and derived mesh surface to another one generated by an image-based approach and using a mini UAV.

We can say that the topological description of the roughness and the characterisation of the surface is a very particular goal pursuable during the 3D metric documentation process. The acquisition strategies and the techniques to be used must be defined after an attentive critical analysis of the aims of the survey, considering the scale, the desired level of detail and the characteristics of the object of interest. It is often also necessary to consider the characteristics of the adjacent space, in order to effectively plan the geometry of the acquisitions.

On many occasions - like the one described in the current paper - a multi-sensor and multi-scale approach can provide the necessary flexibility to properly document a cultural heritage asset. In addition, the opportunity offered by the possibility to perform the fusion between data from different sources and to merge different information contents can contribute to reaching a more complete and deeper knowledge of the buildings belonging to our legacy.

\section{Acknowledgements}

The research is connected to a conservation and valorisation project that selected the Morano sul Po arch as the symbol of the cement industry, which provided in the past many innovations and socio-economic development in the area.

We would like to express our gratitude to "Il Cemento" Association for having asked for our cooperation in this cultural project.

Moreover, we would like to thank our colleague Lorenzo Teppati Losè for precious support in data acquisition.

\section{References}

Adami, A., Fregonese, L., Gallo, M., Helder, J., Pepe, M., \& Treccani, D. (2019). Ultra light UAV systems for the metrical documentation of Cultural Heritage: applications for architecture and archaeology. ISPRS - International Archives of the Photogrammetry, Remote Sensing and Spatial Information Sciences, XLII-2/W17, 15-21.

Bakirman, T., Bayram, B., Akpinar, B., Karabulut, M. F., Bayrak, O. C., Yigitoglu, A., \& Seker, D. Z. (2020). Implementation of ultra-light UAV systems for cultural heritage documentation. Journal of Cultural Heritage, 44, 174-184.

Balletti, C., \& Ballarin, M. (2019). An application of integrated 3D technologies for replicas in Cultural Heritage. International Journal of Geo-Information, 8(6), 285.

Balletti, C., Guerra, F., Lingua, A., \& Rinaudo, F. (2003). True digital orthophoto of the San Marco basilica in Venice. ISPRS - International Archives of the Photogrammetry, Remote Sensing and Spatial Information Sciences, XXXIV(5)MV12, 43-48.

Barbieri, L., Bruno, F., \& Muzzupappa, M. (2018). User-centered design of a virtual reality exhibit for archaeological museums. International Journal on Interactive Design and Manufacturing (IJIDeM), 12(2), 561-571.

Bitelli, G., Dellapasqua, M., Girelli, V. A., Sanchini, E., \& Tini, M. (2017). 3D Geomatics Techniques for an Integrated Approach to Cultural Heritage Knowledge: the case of San Michele in Acerboli's church in Santarcangelo di Romagna. ISPRS - International Archives of the Photogrammetry, Remote Sensing and Spatial Information Sciences, XLII-5/W1, 291-296.

Boehler, W., Bordas Vicent, M., \& Marbs, A. (2003). Investigating laser scanner accuracy. ISPRS - International Archives of the Photogrammetry, Remote Sensing and Spatial Information Sciences, XXXIV(5)/W15, 696-701.

Chiabrando, F., Sammartano, G., Spanò, A., Spreafico, A. (2019). Hybrid 3D Models: When Geomatics Innovations Meet Extensive Built Heritage Complexes. ISPRS International Journal of Geo-Information, 8(3), 124.

Chiabrando, F., Sammartano, G., Spanò, A., \& Teppati Losè, L. (2020). Very light UAV data and ranging methods for heritage documentation. In: Barba, S., Parrinello, S., Limongiello, M., Dell'Amico, A. (ed.), D-SITE Drones - Systems of Information on culTural hEritage. For a spatial and social investigation, Pavia University Press, Pavia, Italy, 5869 .

Corso, J., Casals, J., Marco, A., López, D., \& Garcia Almirall, P. (2018). Data taking and quality control for complex surveys: Case study Sagrada Familia. World heritage and knowledge: representation, restauration, redesign, resilience, 960970.

Ewertowski, M. W., Tomczyk, A. M., Evans, D. J. A., Roberts, D. H., \& Ewertowski, W. (2019). Operational Framework for Rapid, Very-high Resolution Mapping of Glacial Geomorphology Using Low-cost Unmanned Aerial Vehicles and Structure-from-Motion Approach. Remote Sensing, 11(1), 65.

Georgopoulos, A., Lambrou, E., Pantazis, G., Agrafiotis, P., Papadaki, A., Kotoula, L., Lampropoulos, K., Delegou, E., Apostolopoulou, M., Alexakis, M., \& Moropoulou, A. (2017). Merging geometric documentation with materials characterization and analysis of the history of the holy aedicule in the church of the holy sepulchre in Jerusalem. ISPRS - International Archives of the Photogrammetry, Remote Sensing and Spatial Information Sciences, XLII$5 / W 1,487-494$. 
Güleç Korumaz, S. A. (2019). Improved documentation of Cultural Heritage using digital photogrammetry with visible and thermal images from Unmanned Aerial Vehicles (UAV). Ph.D. Dissertation, University of Braunschweig - Institute of Technology and University of Florence. Thesis advisors: Niemeier, W., Tucci, G.

Lachat, E., Landes, T., \& Grussenmeyer, P. (2018). Comparison of point cloud registration algorithms for better result assessment - Towards an open-source solution. ISPRS - International Archives of the Photogrammetry, Remote Sensing and Spatial Information Sciences, XLII-2, 551-558.

Lichti, D., \& Licht, M. (2006). Experiences with Terrestrial Laser Scanner Modelling and Accuracy Assessment. ISPRS International Archives of the Photogrammetry, Remote Sensing and Spatial Information Sciences, XXXVI(5), 155160.

Muñumer, E., \& Lerma, J. L. (2015). Fusion of 3D data from different image-based and range-based sources for efficient heritage recording. 2015 Digital Heritage, 1, 83-86.

Murtiyoso, A., Grussenmeyer, P., Suwardhi, D., \& Awalludin, R. (2018). Multi-Scale and Multi-Sensor 3D Documentation of Heritage Complexes in Urban Areas. ISPRS International Journal of Geo-Information, 7(12), 483.

Ramos, M. M., \& Remondino, F. (2015). Data fusion in Cultural Heritage - A Review. ISPRS - International Archives of the Photogrammetry, Remote Sensing and Spatial Information Sciences, XL-5/W7, 359-363.

Roca-Pardiñas, J., Argüelles-Fraga, R., de Asís López, F., \& Ordóñez, C. (2014). Analysis of the influence of range and angle of incidence of terrestrial laser scanning measurements on tunnel inspection. Tunnelling and underground space technology, 43, 133-139.

Soudarissanane, S., Lindenbergh, R., Menenti, M., \& Teunissen, P. (2009). Incidence angle influence on the quality of terrestrial laser scanning points. Proceedings ISPRS Workshop Laserscanning 2009, Paris, France.

Soudarissanane, S., Lindenbergh, R., Menenti, M., \& Teunissen, P. (2011). Scanning geometry: influencing factor on the quality of terrestrial laser scanning points. ISPRS Journal of Photogrammetry and Remote Sensing, 66(4), 389-399.

Tucci, G., Bonora, V., \& Guardini, N. (2013). Analysis of the factors affecting 3D models resolution - Application to the recording of vaults in Sangallo's House. ISPRS - Annals of the Photogrammetry, Remote Sensing and Spatial Information Sciences, II-5/W1, 307-312.

Vögtle, T., Schwab, I., \& Landes, T. (2008). Influences of different materials on the measurements of a terrestrial laser scanner (TLS). ISPRS - International Archives of the Photogrammetry, Remote Sensing and Spatial Information Sciences, Vol. XXXVII-B5, 1061-1066.

Xiang, T. Z., Xia, G. S., \& Zhang, L. (2019). Mini-Unmanned Aerial Vehicle-based Remote Sensing: Techniques, applications, and prospectives. IEEE Geoscience and Remote Sensing Magazine, 7(3), 29-63. 


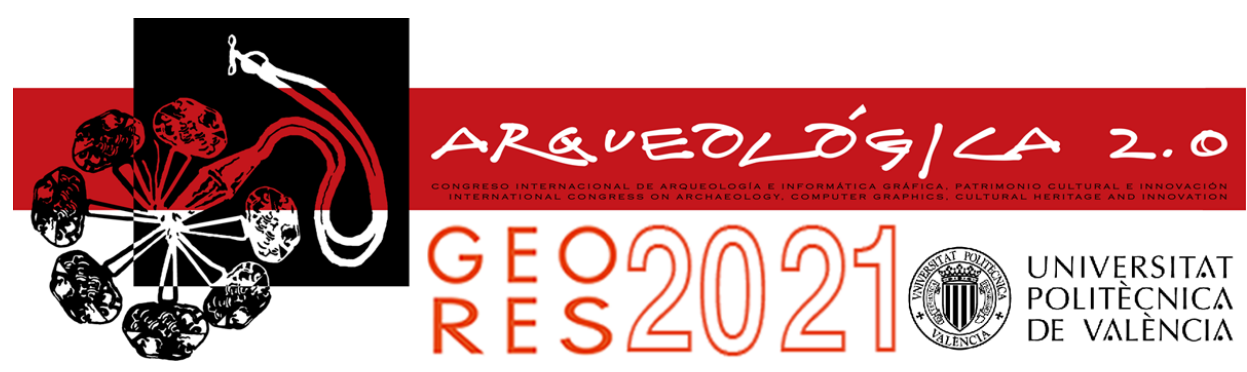

Proceedings of the joint international event $9^{\text {th }}$ ARQUEOLÓGICA

$2.0 \& 3^{\text {rd }}$ GEORES

Valencia (Spain).

26-28 April 2021

\title{
MULTI-SCALE AND MULTI-DOMAIN APPROACHES FOR CULTURAL TERRACED LANDSCAPES
}

\author{
Erica Isabella Parisia, ${ }^{a,}, J^{,}$Jakub Tyc ${ }^{b}$ \\ ${ }^{a}$ Laboratory of Geomatics for Environment and Conservation of Cultural Heritage (GeCo), Department of Civil and Environmental \\ Engineering, University of Florence, Via di S. Marta 3, 50139 Florence, Italy. ericaisabella.parisi@unifi.it \\ ${ }^{\mathrm{b}}$ Digital Architecture and Planning, Institute of Architectural Sciences, Vienna University of Technology, Karlsplatz 13, A-1040 Vienna, \\ Austria. jakub.tyc@tuwien.ac.at
}

\begin{abstract}
:
This contribution reports the activities aiming at multi-domain and multi-scale research applied to cultural terraced landscapes. Terracing and dry-stone walling have been internationally recognized as carriers of cultural values and traditional knowledge. Lamole in Chianti (Italy) has served as a primary case study of terraced vineyards, where interdisciplinary research has been converging for almost a decade. The evolution of multi-sensor data acquisition in different spectral ranges, data-driven modelling, and multi-scalar approaches performed over the years are mentioned, with specific attention to the evaluation of microclimate variations induced by dry-stone walls and how they affect plant growth, ripening, and production. The results already obtained from data processing and analysis are described, although the work is still progressing. The ongoing and planned future research are reported for developing methodologies to understand the parameters that are critical for the effective restoration and functioning of the dry-stone walled vineyards and construct performance-oriented design strategies to enable knowledge-based design processes.
\end{abstract}

Keywords: terracing, dry-stone walls, cultural landscapes, microclimate, thermal infrared, photogrammetry

\section{Terraced landscapes}

Terracing is considered one of the most evident anthropogenic footprints on the landscape. This traditional agro-hydraulic system represents a longstanding and intimate relationship between humankind and nature. Some of these "Cultural landscape" sites, with peculiar value, are protected by UNESCO and inscribed in the World Heritage List (UNESCO, 1979), from rice terraces in China and Philippines to the typical Italian terraced landscapes (Costiera Amalfitana and Portovenere, Cinque Terre). Another international recognition of the specific agricultural value of terraces has been given by FAO - Globally Important Agricultural Heritage Systems (GIAHS), for recovering traditional knowledge, farm resilience, food security, cultural identity, agrobiodiversity, and landscape peculiarity criteria. Amongst the overall protected agricultural areas, at least $17 / 50$ sites are terraced landscapes (Varotto, Bonardi, \& Tarolli, 2019), from Andean terraced agriculture (Peru) to the olive groves of the slopes between Assisi and Spoleto (Italy) (FAO-GIAHS, 2002).

Dry-stone walls are strictly connected to terraces since they represent structural elements and retaining slope systems. The "Art of dry-stone walling, knowledge and techniques" was inscribed in the UNESCO
Representative List of the Intangible Cultural Heritage of Humanity in 2018 (Intergovernmental Committee, 2018).

The combined presence of terraces and dry-stone walls strongly influences and shapes steep hillsides and the environment. The main functions of terraces (Agnoletti, Conti, Frezza, Monti, \& Santoro, 2015) are widely recognised as:

- Control of water runoff and storage.

- Prevention of erosion phenomena.

- Improvement of soil fertility and productivity.

- Increase food quality and security.

- Foster agrobiodiversity.

- Enhance landscape complexity.

- Face climate changes.

The natural hydrogeological processes, mitigated by these artificial systems, tend to reactivate because of the lack of active terracing conservation. The main issues triggering slope dynamics may be ascribed to land abandonment by the farmers, inappropriate maintenance of terraces, dry-stone walls and drainage systems, and to the lack of shared regulations for their management.

`Corresponding Author: Erica Isabella Parisi, ericaisabella.parisi@unifi.it 


\section{The case study of Lamole}

The Italian territory is made up for $77 \%$ by mountains and hills, thus terracing is the primary form of adaptation to the adverse environmental conditions for polyculture cultivation, mainly olive groves and vineyards (Agnoletti, Conti, Frezza, Monti, \& Santoro, 2015) The typical Tuscan landscape represents a complex resource, with a cultural, historical, environmental, social, and economic value, fundamental for rural areas' identity and development (Sereni, 1991).

The Chianti Classico area is characterized by a synergy of natural and anthropic structures, and it represents a remarkable example of terraced vineyards landscape. Lamole is an ancient site for wine production, dating back to Roman times and with a prestigious history related to the Medici family. Its position at a medium altitude of 600 m MSL (Mean Sea Level) has fostered the use of bench terraces to create horizontal surfaces that strongly reshaped the steep slopes of the hills for agriculture.

These traditional features have been progressively recognised, from a cultural, social, and economic, point of view, in recent years. In fact, in 2018 Lamole was included in the Rural Historic Landscape Catalogue of the Italian Ministry of Agricultural, Food, Forestry Policies (Ministerial Decree, 2018). Moreover, the Italian interministerial decree of June 2020 (Inter-ministerial Decree, 2020) defines and recognizes heroic and historical vineyards, as a further step in the valorisation of traditional and sustainable agricultural practices.

Over the years, both Lamole's terraces and dry-stone walls have been suffering abandonment, in favour of more industrial systems, and degradation processes such as deformations, bulging and collapses. Recently, a process of recovery and conservation of past traditions and ancient structures is being carried out by local farmers.

In particular, the terracing and dry-stone walls recovery, restoration and conservation activities performed by $\mathrm{Mr}$. Paolo Socci (Fattoria di Lamole) since 2003 have provided useful sites for the tests, thus allowing a productive and enduring collaboration throughout the years.

Four bench terraced vineyards have been surveyed and analysed since 2016: Grospoli I, Grospoli II (Fig. 1), Castello and a newly constructed vineyard. An overview of the Grospoli area is shown in Figure 2. Grospoli I and II vineyards are located at altitudes ranging from 550 to 630 meters on the west-facing slopes in near proximity to the centre of Lamole. The Castello vineyard is located at altitudes from 510 to 540 meters, mainly on the northeastfacing slope (see Fig. 3). The name of the vineyard comes from the adjacent settlement - Castello di Lamole (marked orange in Figure 3).

\section{Research on the field}

Lamole has been a suitable case study for multi-domain and multi-scale approaches, aiming to address practical problems, in strict collaboration with the local farmers, building up on their experience and responding to their needs.

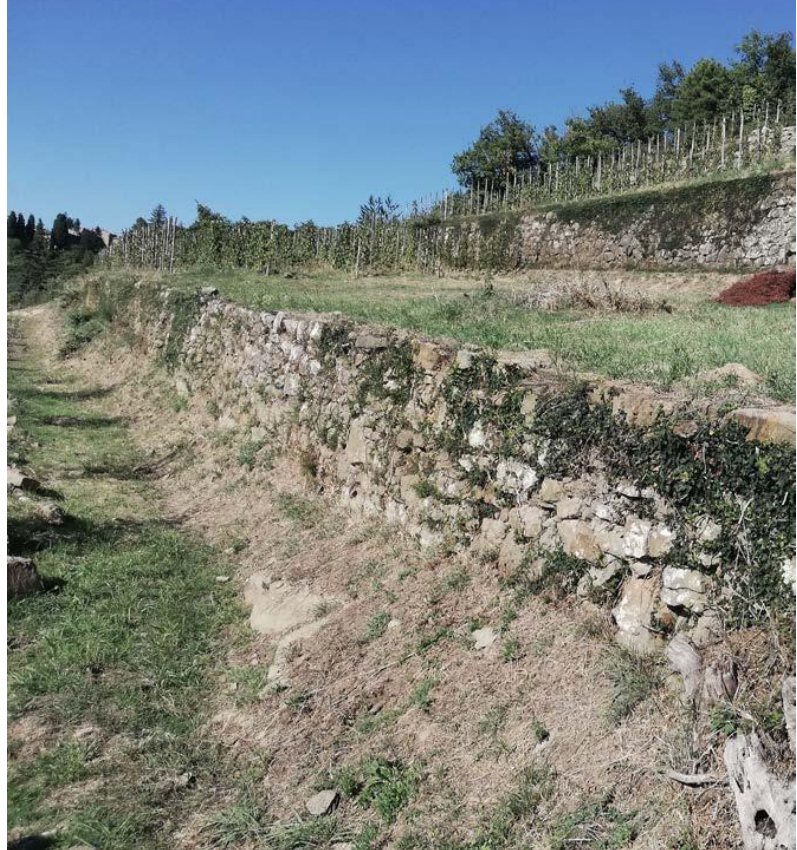

Figure 1: Dry-stone walls and terraces in the Grospoli II vineyard. Height of the dry-stone walls varies throughout the vineyard, as well as the distribution of the wine plants on each terrace.

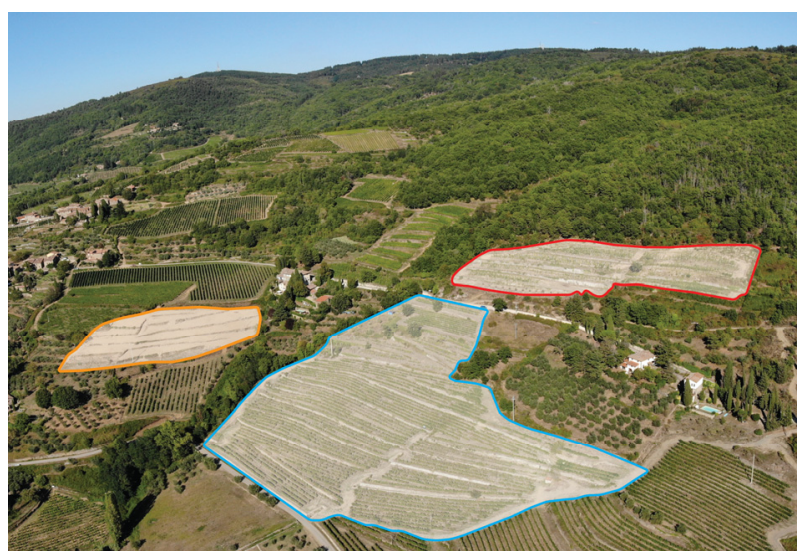

Figure 2: The Grospoli I vineyard (marked blue) was surveyed in 2017 (Tucci et al., 2019), Grospoli II vineyard (marked red) was analysed in 2019 as a part of a Master Thesis in

Architecture (Gambini, Nassi, \& Tesi, 2020) and surveyed in the TIR range in 2020 . The vineyard marked in orange was newly constructed in 2020; an initial survey was conducted at that time.

Several research groups, belonging to different disciplines, have been studying terraced-related phenomena for almost a decade in Lamole (Agnoletti, 2013). Experts in the field of agronomy, hydraulics, landscape architecture, civil and environmental engineering, and geomatics, have joined their efforts for the combined study of degradation mechanisms, like soil erosion, slope failure processes, water flows pathways, which can cause damage to retaining walls, terracing failures and trigger landslides (Preti, Tarolli, Dani, Calligaro, \& Prosdocimi, 2013; Tarolli, Preti, \& Romano, 2014; Tarolli et al., 2015; Preti, Errico, Caruso, Dani, \& Guastini, 2018; Preti, et al., 2018; Varotto, Bonardi, \& Tarolli, 2019; Socci, Errico, Castelli, Penna, \& Preti, 2019). 
One aspect that has been foregrounding since 2015 is the study of temperature variations induced by terraces and dry-stone walls and how these affects vine growth and ripening, influencing the final quality of the produced wine. Multi-sensor aerial and ground-based data acquisition have been performed to study the effect of microclimate on a local scale, and data-driven models have been constructed to accommodate the diverse disciplinary perspectives of the participants.

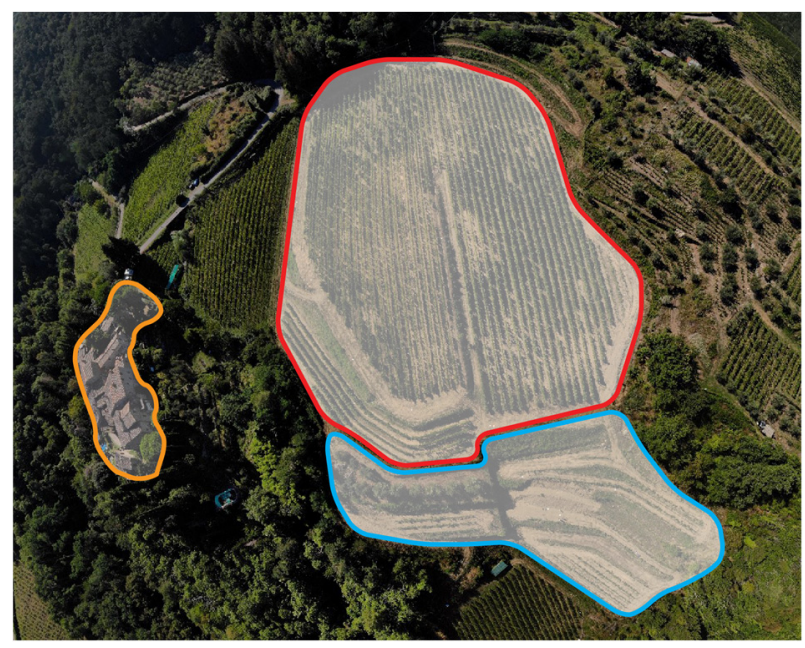

Figure 3: The Castello vineyard has been surveyed in September 2020. The terraced part (marked blue) is located at the lowest part of the vineyard and facing northeast. Nonterraced part (marked red) is constructed on a continuous, moderate slope facing north (rows of wine plants running in the north-south direction). In orange the Castello small hamlet.

\subsection{The adopted methodologies}

Different technologies and methodologies have been adopted for thermal behaviour evaluations. Details on the Unmanned Aerial Vehicles (UAV) and sensors specifics are extensively reported in Tables 1-3.

Tables 1-3 show specifications of methodologies, instruments, and sensors used for field-tests from 2017 to 2020. The subdivision is made by year and vineyard, describing the adopted methodologies (ground- or aerialbased), the UAV platforms, and the characteristics of the sensors. Also, radiometric, spatial, and temporal resolutions are reported for each survey. For spatial resolution GSD is considered for $3 D$ outputs and projections (orthomosaics); for thermal sensors IFOV (Instantaneous Field of View) at $1 \mathrm{~m}$ is used for comparison.

A first approach involved the use of fixed weather stations on the field for environmental parameter monitoring (like air temperature, relative humidity, wind speed, etc.). These sensors were installed and controlled by the Research Centre for Architecture and Tectonics (RCAT) of the Oslo School of Architecture and Design from 2016 to 2017.

A combination of ground-based and aerial-based data acquisition in the visible (VIS) and Thermal-InfraRed (TIR) ranges have being performed since 2017 . A methodology that combines aerial photogrammetry and multi-sensor imaging was tested in 2017, under the coordination of the University of Florence (Tucci et al., 2019; Parisi, Suma, Güleç Korumaz, Rosina, \& Tucci, 2019). The study allowed the production of $3 D$ models from aerial-based
(UAV) photogrammetry of the Grospoli I vineyard (marked blue in Fig. 2), both in the VIS and TIR spectral range.

Table 1: 2017 field test: Grospoli I.

\begin{tabular}{|c|c|c|}
\hline Methodology & Ground-based & Aerial-based \\
\hline Photogrammetry & & $\mathrm{x}$ \\
\hline Thermal imaging & & $\mathrm{x}$ \\
\hline Specifications & $R G B$ & TIR \\
\hline UAV & $\begin{array}{c}\text { DJI Phantom } 4 \\
\text { Pro }\end{array}$ & $\begin{array}{l}\text { customized } \\
\text { hexacopter }\end{array}$ \\
\hline Sensor & $\begin{array}{l}\text { DJI FC6310 1" } \\
\text { CMOS }\end{array}$ & $\begin{array}{l}\text { OPTRIS PI450 } \\
\text { FPA, uncooled }\end{array}$ \\
\hline $\begin{array}{l}\text { Optical resolution } \\
\text { (pix) }\end{array}$ & $5472 \times 3648$ & $382 \times 288$ \\
\hline $\begin{array}{l}\text { Thermal sensitivity } \\
\left(\text { at } 30^{\circ} \mathrm{C}\right)\end{array}$ & & $0.04^{\circ} \mathrm{C}$ \\
\hline Spectral range & Visible & $8-14 \mu m$ \\
\hline Temporal resolution & $\begin{array}{l}\text { Once/day on } \\
\text { Sept. 7, } 2017\end{array}$ & $\begin{array}{c}\text { Twice/day } \\
(08: 50 / 15: 00)\end{array}$ \\
\hline $\begin{array}{l}\text { Spatial resolution } \\
\text { (GSD) }\end{array}$ & $2 \mathrm{~cm} / \mathrm{pix}$ & $12 \mathrm{~cm} / \mathrm{pix}$ \\
\hline
\end{tabular}

Table 2: 2019 field test: Grospoli II.

\begin{tabular}{c|c|c} 
Methodology & Ground-based & Aerial-based \\
\hline Photogrammetry & $\mathrm{x}$ & $\mathrm{x}$ \\
Thermal imaging & $\mathrm{x}$ &
\end{tabular}

\begin{tabular}{|c|c|c|}
\hline Specifications & $R G B$ & TIR \\
\hline UAV & $\begin{array}{c}\text { DJI Phantom } 4 \\
\text { Pro }\end{array}$ & \\
\hline UAV sensor & $\begin{array}{l}\text { DJI FC6310 1" } \\
\text { CMOS }\end{array}$ & \\
\hline Ground sensors & $\begin{array}{l}\text { Nikon D3300 } \\
\text { CMOS }\end{array}$ & $\begin{array}{c}\text { FLIR B360 } \\
\text { FPA, uncooled }\end{array}$ \\
\hline $\begin{array}{l}\text { Optical resolution } \\
\text { UAV (pix) }\end{array}$ & $5472 \times 3648$ & \\
\hline $\begin{array}{l}\text { Optical resolution } \\
\text { Ground sensors } \\
\text { (pix) }\end{array}$ & $6000 \times 4000$ & $320 \times 240$ \\
\hline $\begin{array}{l}\text { Thermal sensitivity } \\
\quad\left(\text { at } 30^{\circ} \mathrm{C}\right)\end{array}$ & & $<0.05^{\circ} \mathrm{C}$ \\
\hline Spectral range & Visible & $7.5-13 \mu \mathrm{m}$ \\
\hline Temporal resolution & $\begin{array}{l}\text { Once/day on } \\
\text { Sept. 13, } 2019\end{array}$ & $\begin{array}{c}\text { Every } 2 \text { hours } \\
\text { /day }\end{array}$ \\
\hline UAV GSD & $1.5 \mathrm{~cm} / \mathrm{pix}$ & \\
\hline $\begin{array}{l}\text { Ground sensors } \\
\text { GSD/IFOV }\end{array}$ & $1 \mathrm{~mm} / \mathrm{pix}$ & $\begin{array}{l}\text { IFOV } 1.4 \mathrm{~mm}^{2} \\
\text { at } 1 \mathrm{~m}\end{array}$ \\
\hline
\end{tabular}

A common photogrammetry survey was performed to reconstruct the geometry of the vineyard with a DJI Phantom 4.0 Pro drone, equipped with an RGB digital camera (for further details see Tables 1-3). A customized aircraft was used for TIR radiometric survey, with two different flights (in the morning and in the afternoon). 
The main challenge was to set up a procedure for frame extraction from the thermal radiometric videos, maintaining the thermal information and obtaining suitable images for the photogrammetric process. The completed procedure is reported in Tucci et al. (2019). The produced orthomosaics were compared thanks to a common reference system provided by GNSS measurements of special targets, covered in aluminium foil, visible also in the TIR. The spatial resolution (given by Ground Sample Distance - GSD in Tables 1-3) of the orthomosaics was considerably different because of different sensors size for VIS and TIR.

Table 3: 2020 field test: Grospoli II / Castello.

\begin{tabular}{|c|c|c|}
\hline Methodology & $\begin{array}{l}\text { Ground- } \\
\text { based }\end{array}$ & Aerial-based \\
\hline Photogrammetry & & $x$ \\
\hline Thermal imaging & $x$ & $x$ \\
\hline Specifications & $R G B$ & $T I R$ \\
\hline UAV & \multicolumn{2}{|c|}{ DJI Mavic 2 Enterprise dual } \\
\hline UAV sensor & \multirow[t]{3}{*}{$\begin{array}{l}\text { M2ED 1/2.3" } \\
\text { CMOS }\end{array}$} & $\begin{array}{l}\text { M2ED FPA, } \\
\text { uncooled }\end{array}$ \\
\hline Thermal sensor & & FLIR SC620 \\
\hline & & $\begin{array}{l}\text { WIC } 336 \text { FPA, } \\
\text { uncooled }\end{array}$ \\
\hline $\begin{array}{l}\text { Optical resolution } \\
\text { UAV (pix) }\end{array}$ & \multirow[t]{6}{*}{$4056 \times 3040$} & $160 \times 120$ \\
\hline Optical resolution & & FLIR $640 \times 480$ \\
\hline $\begin{array}{l}\text { Thermal cameras } \\
\text { (pix) }\end{array}$ & & WIC $336 \times 256$ \\
\hline Thermal sensitivity & & $\mathrm{UAV}<0.05^{\circ} \mathrm{C}$ \\
\hline (at $\left.30^{\circ} \mathrm{C}\right)$ & & FLIR $0.04^{\circ} \mathrm{C}$ \\
\hline & & WIC $\leq 0.03^{\circ} \mathrm{C}$ \\
\hline Spectral range UAV & \multirow[t]{2}{*}{ Visible } & $8-14 \mu m$ \\
\hline $\begin{array}{l}\text { Spectral range } \\
\text { Thermal cameras }\end{array}$ & & $\begin{array}{c}\text { FLIR } 8-14 \mu \mathrm{m} \\
\text { WIC } 7.5-13.5 \mu \mathrm{m}\end{array}$ \\
\hline $\begin{array}{c}\text { Temporal resolution } \\
\text { UAV }\end{array}$ & \multicolumn{2}{|c|}{$\begin{array}{l}\text { Every } 3 \text { hours/day on Sept. 5-8, } \\
2020\end{array}$} \\
\hline $\begin{array}{l}\text { Temporal resolution } \\
\text { Thermal cameras }\end{array}$ & \multirow{3}{*}{$1 \mathrm{~cm} / \mathrm{px}$} & $\begin{array}{l}\text { FLIR } 10 \mathrm{~min} / \text { day } \\
\text { WIC } 5 \mathrm{~min} / \text { day }\end{array}$ \\
\hline UAV GSD & & N.A. \\
\hline $\begin{array}{l}\text { Ground sensors } \\
\text { GSD/IFOV }\end{array}$ & & $\begin{array}{l}\text { FLIR } 0.6 \mathrm{~mm}^{2} \text { at } 1 \mathrm{~m} \\
\text { WIC (IFOV) } 1.3 \mathrm{~mm}^{2} \\
\text { at } 1 \mathrm{~m}\end{array}$ \\
\hline
\end{tabular}

Evaluations on a different scale were performed in 2019, with a ground-based experimental setup to record the daily surface temperature variation of both sides of the closest grapevine rows to the wall. A new vineyard (Grospoli II, marked red in Figure 2) was used as case study and spatially reconstructed in $3 D$ by UAV photogrammetry. A new experiment with a ground thermal camera (FLIR B360) was set up for monitoring daily temperature variations of dry-stone walls and the closest vine rows with high spatial and temporal resolution (thermal images acquired every two hours for one day as reported in Table 2)). Ground-based photogrammetry was also applied for reconstructing a section of a drystone wall affected by bulging to assess its structural performances (GSD $1 \mathrm{~mm} / \mathrm{px}$ ).

The previous experience was useful to combine, in 2020 surveys, ground-based and aerial-based methodologies to produce spatial data in both VIS and TIR range. The Grospoli II and Castello vineyards were used for data collection. Castello vineyard was also surveyed with aerial photogrammetry to reproduce its georeferenced spatial geometry.

The aerial survey utilized a low-cost UAV (DJI Mavic 2 Enterprise Dual), which includes both RGB and nonradiometric TIR sensors in a stereo setup. Some of the best practices proposed by (Kelly et al., 2019) were applied to derive accurate temperature data with this UAV platform. In addition, the ground-based experimental setup was improved, by using two thermal radiometric cameras (FLIR SC620 and WIC 336) in fixed positions, framing the dry-stone wall and the vines in the closest proximity. Spatial and temporal resolutions (5-10 minutes/day) were further increased to have a more accurate daily monitoring of the thermal behaviour (Table 3 ). All the atmospheric parameters needed for absolute temperature evaluation in thermography, were provided by thermo-hygrometers placed close to the thermal cameras. A validation system was also considered, using contacts sensors (thermocouples) measures on special aluminium reference targets. This experimental setup is considered the last methodological evolution to deliver accurate temperature data in two different scales, from the single plant to entire vineyard.

\subsection{Obtained results}

The methodologies reported in section 4.1 allowed to collect multi-source data analysed with multi-domain approaches. This section mentions some of the results obtained in the past years.

The Research Centre for Architecture and Tectonics (RCAT) at the Oslo School of Architecture and Design applied the research by designing methodology based on the integration of data collected on the field. Master-level students developed speculative projects to learn how to design in highly sensitive environments while preserving the environmental conditions of the terraced vineyards. Weather data collected on-site over two years period was used in the micro-climate simulations, supplemented also by the results of the thermographic survey and by the expert knowledge on the requirements for the growth of vine plants. Such a process required the application of data-driven parametric design processes, incorporating both the datasets, uncommon for architecture and the interdisciplinary knowledge of the collaborators involved.

The tests carried out on the field in 2017 allowed to experiment new approaches for multi-spectral data collection and to set up new methods for data processing and analysis. In particular, the TIR radiometric sensor (OPTRIS PI450) mounted on the UAV was able to acquire only radiometric videos, thus a suitable procedure was created for extracting radiometric images to be used for the photogrammetric reconstruction. The results are two radiometric 3D models and thermal orthomosaics of the Grospoli I vineyard (morning and afternoon), which can be overlayed to the VIS orthophoto of the same area. The measured temperatures are to be considered as relative 
values since it was not possible to insert all the ambient and specific parameters (air temperature, relative humidity, distance, emissivity, reflected temperature) used for absolute readings. A visual interpretation of the thermal behaviour in Figure 4, already suggests that the closest vine rows in respect to the bottom of the dry-stone walls are colder in morning compared to all the other rows, while in the afternoon the thermal equilibrium is reached. Furthermore, a statistical analysis of the associated temperature values, were performed over all the plant rows of the vineyard through GIS to monitor their daily thermal behaviour, the possible influence of the drystone walls, and of solar exposition. The results, extensively reported in Tucci et al. (2019), showed that the main measurable effects on temperature variations are due to solar irradiation and shadowing, although some minor variations were detected. This preliminary research and its promising results drove to further experiments on the topic. The necessity of higher spatial and temporal resolution led then to a multi-scale approach, still ongoing, with ground-based tests coupled with aerial and UAV surveys, further reported in section 4.3.

The multi-scalar approach for studying the terraced landscape of Lamole, was also the research topic of a Master Thesis in Architecture, supervised by the GeCo Lab of the University of Florence in 2019 (Gambini, Nassi, \& Tesi, 2020). The analysis of 3D spatial data, obtained by photogrammetry, of a single dry-stone wall and of a vineyard (Grospoli II), was combined with an extensive study of the land-use changes over decades of the entire area, based on national and regional GIS systems. Abandonment, lack of knowledge on how to maintain and how to design for reconstruction and durability of the terraced vineyards were found to be the biggest threats for the preservation of the historic terraced vineyards. The study included the role of plants in the considered scales, from the changes in the forest coverage, through the analysis of the species distribution in the proximity of the vineyard and the presence of plants on the walls and its relation to the structural stability. The scope of the study was the analysis of the relations between the territory, the landscape, the single vineyard and the dry-stone walls, as inseparable elements that belong to the complexity of a terraced cultural landscape, with the final aim to produce and manage information to preserve such diffuse heritage (Fig. 5).

\subsection{Ongoing and future research}

In 2020, two new terraced vineyards were constructed in Lamole by two winemaker companies who decided to recover pre-existing structures or build new terraces. Supposedly, global climate change influences the ripening processes of the grapes, thus increasing the attractiveness of such high-altitude locations as Lamole. The abovementioned winemakers are looking back at the historic examples of the terraced vineyards to recover the knowledge on how to construct and maintain such agricultural systems. In some cases, historical orthophotographs of Lamole can provide insights on the structure of the terraced vineyards, yet the methods to efficiently support the multi-objective planning processes of the vineyard restoration are to be studied. Interdisciplinary-oriented restoration of the terraced vineyards allows to cultivate steep slopes and, due to enhanced slope stability, mitigates the risks of landslides and vineyard soil erosion. A preliminary photogrammetric survey of the first newly constructed vineyard was carried out in September 2020 (marked orange in Figure 2). This opens the possibility to observe the complete evolution of the terraced vineyard in the upcoming years of surveys.
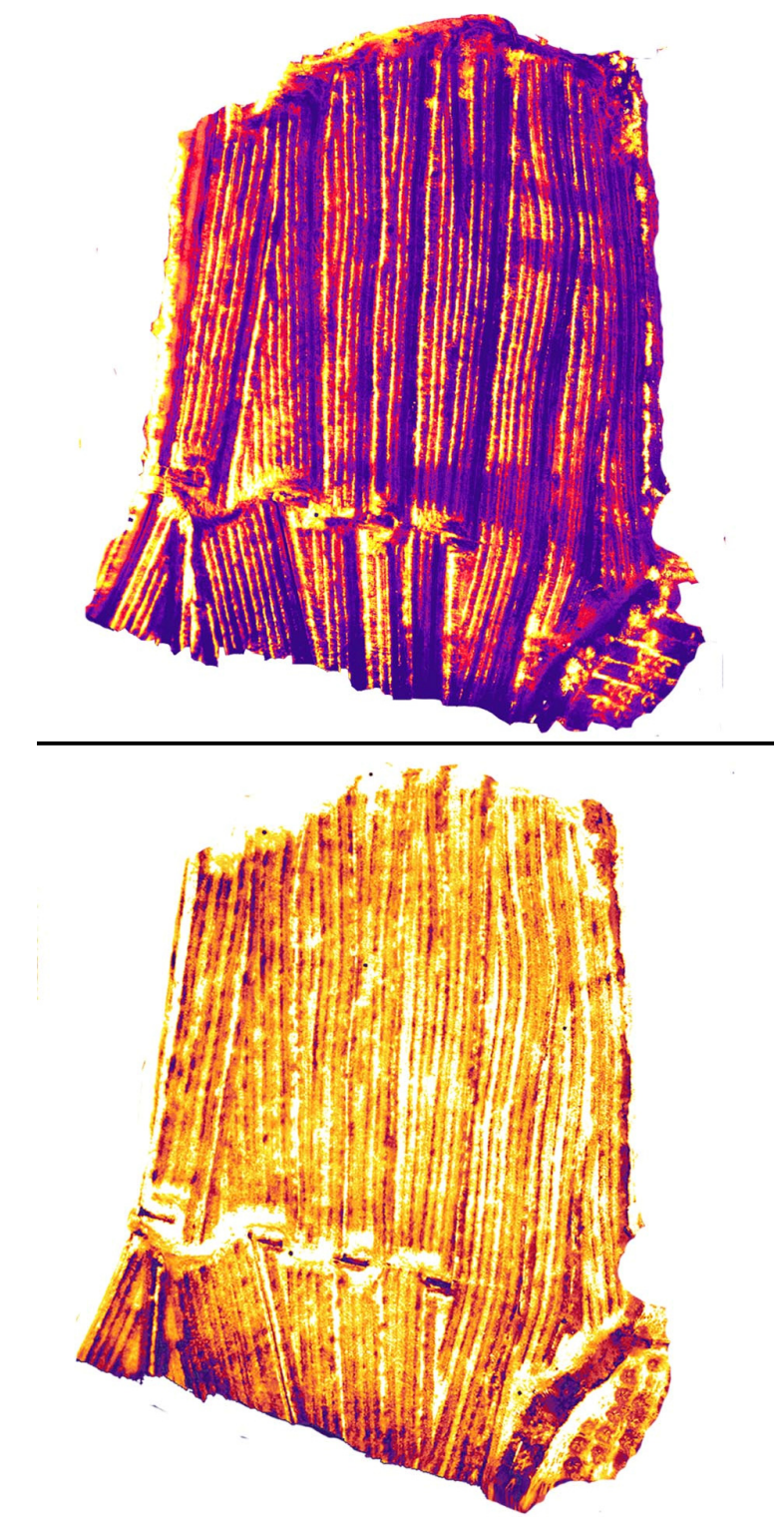

Figure 4: Thermal orthomosaics of the morning UAV photogrammetric flight (top) and of the afternoon (bottom). The daily temperature variation is clearly showed: in the morning (temperature relative range $14.8-18.3^{\circ} \mathrm{C}$ ) shadowing effects cause the dry-stone wall facing rows to be colder than the other rows; in the afternoon (temperature relative range $21-25^{\circ} \mathrm{C}$ ) solar insolation allowed to reach thermal equilibrium.

Acknowledging the importance of the terraced vineyards, this research is developing methodologies to understand the parameters that are critical for the effective restoration and functioning of the dry-stone walled vineyards on one hand, and construct performance-oriented design strategies to enable knowledge-based design processes on the other hand. Such methods are based on the use of the collected geospatial data, geoscientific analysis, and simulations, as well as iterative, multi-scalar design processes. Such approach was partially pursued in the aforementioned research and recently discussed in-depth in the context of 'ecological prototypes', which constitute a particular type of Green Constructions. The Lamole 
terraced vineyards are considered to provide diverse ecosystem services and help increase biodiversity. The conducted surveys will contribute to establishing the Key Performance Indicators for the design of ecological prototypes, aiming at the construction of multi-scale computational tools and methods, resulting in the definition of the design decision support system (Hensel \& Sørensen, 2019; Sunguroğlu Hensel, 2020).

In the upcoming years, understanding the contribution of plants from the multi-scalar perspective will be addressed. A study on the vine plant physiology in a wide time series would allow for the qualitative evaluation of the benefits that historical terraced vineyards provide for the resulting product. The role of the mosaicked land-use patterns visible in the historic terraced vineyards is believed to play an important role in creating diverse ecosystems, incorporating water collecting crevasses and forests surrounding the vineyards. Future activities will utilize the photogrammetric data collected during the past surveys and blend it with the airborne LiDAR data, acquired in July 2020 , to encompass the wide range of scales.

The thermographic study previously conducted on the Grospoli I vineyard presented temperature distribution patterns induced by the dry-stone walls on the vine rows. Limited time resolution, as well as spatial resolution of the resulting TIR point cloud was also mentioned. Preliminary results are promising, showing a strong correlation between the control measurements and the acquired data. Low-cost, integrated platform allowed for longer flight times, not constrained by the limited power supply of the TIR sensor used in the 2017 survey. Relatively short recharging intervals allowed to complete five UAV acquisitions of the whole Grospoli II vineyard in a day, extending the temporal scale of the acquired data. On the other hand, the quality of the resulting point cloud in both RGB and TIR spectrum is being currently evaluated. This study was conducted in the Grospoli II vineyard (Fig. 2), as well as in the Castello vineyard (Fig. 3).

A particular property of the Castello vineyard is that both the terraced and non-terraced parts are present in one vineyard. Photogrammetric data was collected in September 2020 with multiple UAVs flights with combined RGB and TIR acquisition, to include both terraced and non-terraced parts in the survey, documenting their geometry and thermal behaviour. Datasets collected in the different vineyards throughout the years are currently being analysed: it is still to be discovered to which degree such diverse data can be compared and effectively used to help understanding the environmental role of the historic dry-stone walls in the terraced vineyards. On one hand, a systematically constructed methodology would suggest that such direct comparison should be possible. On the other hand, the Grospoli vineyards and Castello are located on different altitudes and are facing different directions. Understanding how the different factors influence the role and functioning of the dry-wall terraces poses a challenge, but the understanding of the interdependencies would be an important step forward, allowing to construct an effective decision-support system.

In future research, given the availability of airborne LiDAR data of the entire valley (Fig. 6), photogrammetric and thermographic measurements taken in different vineyards will be correlated spatially. Also, the availability of data obtained from classification methodologies of the point cloud, such as LiDAR-based terrain and tree canopy models, will be used in the geospatial simulations to understand the significance of the historical terraced vineyards on the territorial scale.
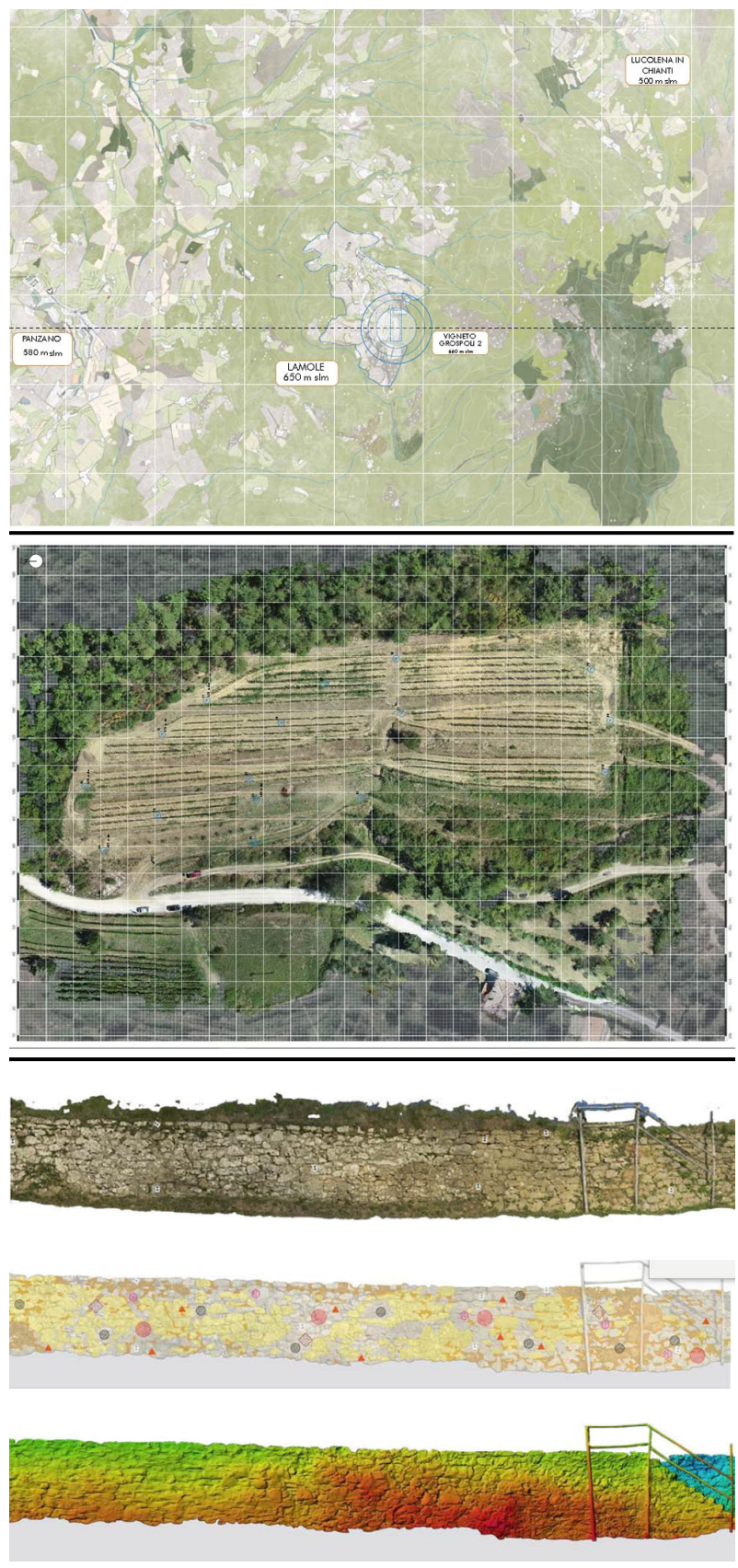

Figure 5: Example of multi-scalar analysis applied to the terraced landscape of Lamole (Gambini, Nassi, \& Tesi, 2020). Starting from the top: terrestrial scale analysis of the mosaicked land use, based on the regional GIS data; Grospoli II vineyard marked in blue. In the centre: orthophoto from the 3D model produced by UAV photogrammetry of the Grospoli II vineyard (GSD $1.5 \mathrm{~cm} / \mathrm{px}$ ). Last three illustrations: orthophoto of a single dry-stone wall (GSD $1 \mathrm{~mm} / \mathrm{px}$ ), characterized by bulging problems, thematic map of the material degradation, and DEM model to identify bulging and related structural problems.

These data represent a considerable source of information that can be used for several applications in different research field, as for example geological monitoring, for the study of induced-landslides due to terraces abandonment with innovative sensors (Mucchi et 
al., 2020). Moreover, the application of multispectral and hyperspectral sensors, active in other ranges of the electromagnetic spectrum, is considered in the near future, enabling the calculation of biophysical vegetation indices, which is widely applied in precision agriculture (Adão et al., 2017; Pastonchi, Di Gennaro, Toscano, \& Matese, 2020).

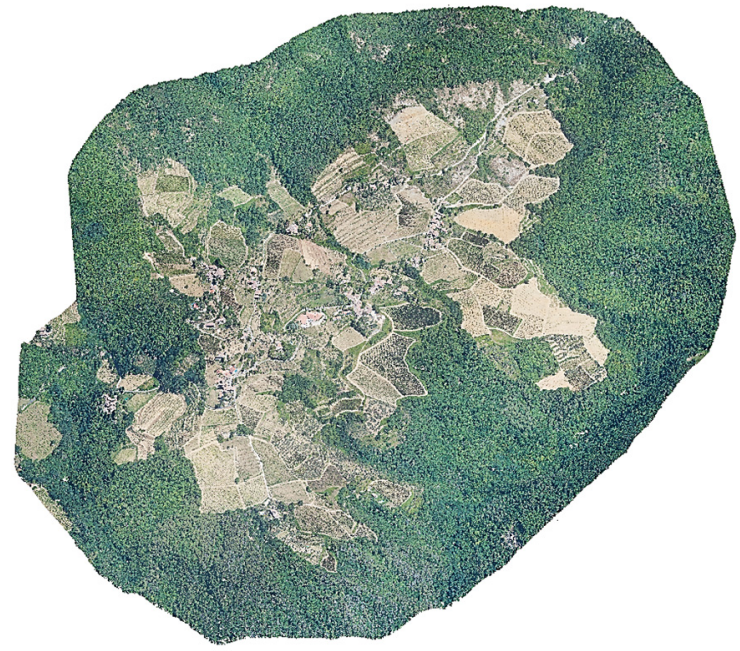

Figure 6: The airborne LiDAR data (point cloud) covering Lamole and the surrounding valley. All vineyards in the area are included in this dataset. Multiple returns acquired by the LiDAR sensor allow to properly model both tree canopies (DSM) and the underlying landform (DTM). This dataset is considered to help understanding the water regimes and related ecosystem functions. Complex relations between the form of the valley partially covered with forests and the terraced vineyards result

in the mosaicked land use pattern of small vineyards, interwoven with the water-diverting crevasses.

\section{Conclusions}

This contribution aims at presenting the research activities performed on terraced landscapes in Lamole.

Anthropic modification of the environment with terracing, as well as the recovery and conservation of traditional knowledge, has being increasingly recognized recently. Unique qualities of terraced landscapes, referred to as "Cultural landscapes" and "Heroic and historic vineyards" are acknowledged by UNESCO, FAO-GIAHS, and Italian governmental Bodies. "Art of dry-stone walling" refers to the knowledge related to construction and operation of the terraced vineyards and is considered as an Intangible Cultural Heritage of Humanity by UNESCO. Thus, terraced landscapes are clearly understood as carriers of social, cultural, and economical qualities.

The involvement of expertise from different research fields has converged over the years in Lamole. Peculiarities of the Chianti area and presence of wellestablished agricultural terraced systems resulted in Lamole being chosen as primary case study of the presented interdisciplinary research activities. The multidomain approach towards those unique landscape forms, allowed to study the impacts of such diffuse heritage under different levels. This, in turn uncovered new research directions that will be further addressed in future study cases in Tuscany, Italy, and worldwide.

In particular, the description of the evolution of the methodologies adopted for studying temperature variations induced by terraces and dry-stone walls in selected vineyards is reported. The first test on the field (in 2017) involved the use of UAV-mounted VIS and TIR sensors, for temperature evaluations of the entire vineyard. A suitable procedure for data extraction and the related information obtained have been studied. The promising results further led to increase the spatial and temporal resolution with experiments on the ground (2019) with thermal camera for the evaluation of surface temperatures of plants and walls, to finally combine the two methodologies for a multi-scalar approach in 2020. The currently available results and the research they have fostered, have been described in section 4.2. The data from the last surveys has currently being analyzed, although the trend of the future research has been mentioned in 4.3 section.

In the recent years, growing numbers of vineyards in Lamole have been captured photogrammetrically in both TIR and VIS ranges. Subsequent acquisitions of both historic and newly established vineyards will allow to monitor geometric changes and to address the questions of changing environmental conditions in the terraced vineyards. Inclusion of airborne LiDAR data and multispectral photogrammetric data in the future will allow to extend the scope of investigation.

\section{Acknowledgements}

Authors would like to acknowledge all the research group of the Geomatics for Environment and Conservation of Cultural Heritage Laboratory of the Department of Civil and Environmental Engineering at the University of Florence, directed and coordinated by Prof. Grazia Tucci for the constant involvement in Lamole surveys (data acquisition, processing and analysis); at the Department of Digital Architecture and Planning at Vienna University of Technology, Prof. Michael Hensel as well as Defne Sunguroglu Hensel for her numerous contributions foregrounding the prominent environmental role of the terraced vineyards; Mr. Paolo Socci, proprietor of Fattoria di Lamole, for his support, knowledge sharing and participation in all the activities. Special thanks go also to Filippo Fiaschi, DICEA flight operator for UAV flights. Finally, the authors wish to thank the students Sofia Gambini, Carolina Nassi, and Jessica Tesi, for their thesis work and for providing some of the image present in this contribution.

\section{References}

Adão, T., Hruška, J., Pádua, L., Bessa, J., Peres, E., Morais, R., \& Sousa, J. J. (2017). Hyperspectral imaging: A review on UAV-based sensors, data processing and applications for agriculture and forestry. Remote Sensing, 9(11). https://doi.org/10.3390/rs9111110

Agnoletti, M. (Ed.). (2013). Italian Historical Rural Landscapes. Environmental History (Vol. 1). Dordrecht: Springer Netherlands. https://doi.org/10.1007/978-94-007-5354-9 
Agnoletti, M., Conti, L., Frezza, L., Monti, M., \& Santoro, A. (2015). Features analysis of dry stone walls of Tuscany (Italy). Sustainability, 7(10), 13887-13903. https://doi.org/10.3390/su71013887

FAO-GIAHS (2002). Globally Important Agricultural Heritage Systems. Retrieved November 25, 2020, from http://www.fao.org/giahs/background/a-global-partnership/en/

Gambini, S., Nassi, C., \& Tesi, J. (2020). Aerial and terrestrial photogrammetry and GIS for multiscale reading of the terraced landscape of Lamole in Chianti. Master's Degree in Architecture, University of Florence. Tutor: Prof. G. Tucci, co-tutor: Prof. T. Matteini.

Hensel, M. U., \& Sørensen, S. S. (2019). Performance-oriented architecture and urban design. FormAkademisk Forskningstidsskrift for Design Og Designdidaktikk, 12(2). https://doi.org/10.7577/formakademisk.2963

Intergovernmental Committee. (2018). Decision of the Intergovernmental Committee: 13.COM 10.B.10. Retrieved November 25, 2020, from https://ich.unesco.org/en/decisions/13.COM/10.B.10

Inter-ministerial Decree. (2020). Safeguard of heroic and historical vineyards. Retrieved November 25, 2020, from https://www.politicheagricole.it/flex/cm/pages/ServeBLOB.php/L/IT/IDPagina/15621

Kelly, J., Kljun, N., Olsson, P. O., Mihai, L., Liljeblad, B., Weslien, P., Klemedtsson L., \& Eklundh, L. (2019). Challenges and best practices for deriving temperature data from an uncalibrated UAV thermal infrared camera. Remote Sensing, 11(5). https://doi.org/10.3390/rs11050567

Ministerial Decree (2018). Italian Ministerial Decree n. 6415 of 20 February 2018. Retrieved November 25, 2020, from https://www.reterurale.it/flex/cm/pages/ServeBLOB.php/L/IT/IDPagina/18073

Mucchi, L., Jayousi, S., Martinelli, A., Caputo, S., Intrieri, E., Gigli, G., Gracchi, T., Mugnai, F., Favalli, M., Fornaciai, A., \& Nannipieri, L. (2018). A Flexible Wireless Sensor Network Based on Ultra-Wide Band Technology for Ground Instability Monitoring. Sensors, 18, 2948. https://doi,org/10.3390/s18092948

Parisi, E. I., Suma, M., Güleç Korumaz, A., Rosina, E., \& Tucci, G. (2019). Aerial platforms (UAV) surveys in the VIS and TIR range. Applications on archaeology and agriculture. ISPRS Annals of the Photogrammetry, Remote Sensing and Spatial Information Sciences, 42(2/W11), 945-952. https://doi.org/10.5194/isprs-Archives-XLII-2-W11-9452019

Pastonchi, L., Di Gennaro, S. F., Toscano, P., \& Matese, A. (2020). Comparison between satellite and ground data with UAV-based information to analyse vineyard spatio-temporal variability. OENO One, 54(4), 919-934. https://doi.org/10.20870/oeno-one.2020.54.4.4028

Preti, F., Errico, A., Caruso, M., Dani, A., \& Guastini, E. (2018). Dry-stone wall terrace monitoring and modelling. Land Degradation and Development, 29(6), 1806-1818. https://doi.org/10.1002/ldr.2926

Preti, F., Guastini, E., Penna, D., Dani, A., Cassiani, G., Boaga, J., Deiana R., Romano N., Nasta P., Palladino M., Errico A., Giambastiani Y., Trucchi P., \& Tarolli, P. (2018). Conceptualization of Water Flow Pathways in Agricultural Terraced Landscapes. Land Degradation and Development, 29(3), 651-662. https://doi.org/10.1002/ldr.2764

Preti, F., Tarolli, P., Dani, A., Calligaro, S., \& Prosdocimi, M. (2013). LiDAR derived high resolution topography: the next challenge for the analysis of terraces stability and vineyard soil erosion. Journal of Agricultural Engineering, 44(2s). https://doi.org/10.4081/jae.2013.s2.e16

Sereni, E. (Ed.). (1991). Storia del paesaggio agrario italiano. Bari, Italia: Laterza. Retrieved November 25, 2020, from https://books.google.it/books?id=w6n-SQAACAAJ

Socci, P., Errico, A., Castelli, G., Penna, D., \& Preti, F., (2019). Terracing: From Agriculture to Multiple Ecosystem Services. In Oxford Research Encyclopedia of Environmental Science. https://doi.org/10.1093/acrefore/9780199389414.013.206

Sunguroğlu Hensel, D. (2020). Ecological prototypes: Initiating design innovation in green construction. Sustainability, 12(14). https://doi.org/10.3390/su12145865

Tarolli, P., Preti, F., \& Romano, N. (2014). Terraced landscapes: From an old best practice to a potential hazard for soil degradation due to land abandonment. Anthropocene, 6, 10-25. https://doi.org/10.1016/j.ancene.2014.03.002

Tarolli, P., So, G., Calligaro, S., Prosdocimi, M., Preti, F., \& Fontana, G. D. (2015). Vineyards in Terraced Landscapes: new opportunities from LiDAR data. Land Degradation \& Development, 102(26), 92-102. https://doi.org/10.1002/ldr.2311

Tucci, G., Parisi, E. I., Castelli, G., Errico, A., Corongiu, M., Sona, G., Viviani E., Bresci E., \& Preti, F. (2019). Multi-Sensor UAV Application for Thermal Analysis on a Dry-Stone Terraced Vineyard in Rural Tuscany Landscape. ISPRS International Journal of Geo-Information, 8(2), 87. https://doi.org/10.3390/ijgi8020087

UNESCO (1979). World Heritage List. Retrieved November 25, from https://whc.unesco.org/en/list/\&order=country

Varotto, M., Bonardi, L., \& Tarolli, P. (Eds.) (2019). World Terraced Landscapes: History, Environment, Quality of Life, 9. Cham: Springer International Publishing. https://doi.org/10.1007/978-3-319-96815-5 


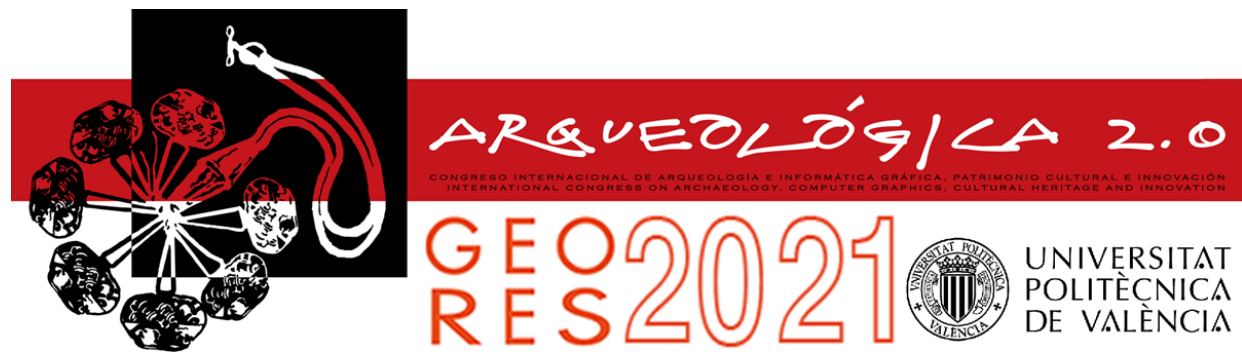

Proceedings of the joint international event $9^{\text {th }}$ ARQUEOLÓGICA

$2.0 \& 3^{\text {rd }}$ GEORES

Valencia (Spain).

26-28 April 2021

\title{
MONITORING LANDSCAPE DEGRADATION IN MEDITERRANEAN AREAS INTEGRATING MEDALUS AND REMOTE SENSING FOR FRAGILE ARCHEOLANDSCAPE PLANNING: THE BASILICATA CASE STUDY
}

\author{
Marzia Gabriele ${ }^{a},{ }^{,}$, Raffaella Brumana ${ }^{a}$, Mattia Previtalia ${ }^{a}$ Alberta Cazzanib \\ a Department of Architecture, Built Environment and Construction Engineering, Politecnico di Milano, Via Ponzio 31, 20133 Milan, Italy. \\ marzia.gabriele@polimi.it; raffaella.brumana@polimi.it; mattia.previtali@polimi.it \\ b Department of Architecture and Urban Studies, Politecnico di Milano, Piazza Leonardo da Vinci 26, 20133 Milan, Italy. \\ alberta.cazzani@polimi.it
}

\begin{abstract}
:
The main objective of the research was identifying the phenomena that generate land degradation (LD), in the Basilicata region's landscape (southern Italy), with a MEDALUS (Kosmas, Ferrara, Briasouli, \& Imeson, 1999) and RS approach, through the help of 6 main indicators (Soil Quality Index, Climate Quality Index, Vegetation Quality Index, Management Quality Index, Landslide Risk Index, Water Availability Index) and through NDVI differencing thresholds evaluation in time intervals, covering a 20 years' time span going from 2000 to 2020 . The Basilicata region saw this phenomenon increased in the past centuries, both because there has never been any monitoring of LD at the regional planning-level, and for the fact that historically the region suffered severe agricultural stress, with enormous deforestations that have led to soil degradation and consequently to the depopulation of the internal marginal areas. These elements caused a strong impact on the potential regional progress, both economic and social, leading to huge ecological damage. The methodology helped to outline the future LD predictions for the region, and consequentially its management possibilities and implications in relation to this critical issue, in order to maintain or restore the pre-existing values, thus integrating the study of Environmentally Sensitive Areas (ESAs) in a scientific validated Decision Support System (DSS), for new coherent and integrated landscape strategies in marginal territories. This objective derives from recognizing the landscape as defined in the European Convention (Council of Europe, 2000) as an important element for community interest, on the cultural, ecological, environmental and social point of view, and as a resource for economic development, pursued by enhancing the preservation of its fundamental component of cultural and natural heritage.
\end{abstract}

Keywords: desertification, soil degradation, remote sensing, archeo-agricultural landscape, landscape preservation, marginal areas

\section{Introduction}

The United Nations Convention to Combat Drought and Desertification (UNCCD) described desertification as the "land degradation (LD) in arid, semi-arid and dry subhumid areas, resulting from various factors, including climatic variations and human activities" (UNCCD 1996) (Fig. 1)

The Mediterranean-type ecosystem is recognized as one of the most imperilled as it is estimated to experience the greatest proportional change in biodiversity by 2100 owing to its sensitivity to land-use change and climate (Sala et al., 2000). The issues and the problems deriving from the study of LD in the Mediterranean ecosystem, must be referred to as the multi-faceted and multidisciplinary aspects of the desertification phenomenon itself. In the field of environmental sciences, having an adequate information base, in terms of consistency and soundness in identifying, defining and evaluating the relevant aggregates (both spatial and temporal), represents a fundamental prerequisite for the application of evaluation models. In addition, for the estimation of environmental vulnerability, this condition is obtained through a reliable and careful collection of the basic data. Knowledge of environmental changes and processes over time and the availability of a large amount of scientific data regarding vegetation, fauna, air, meteorology, hydrology, etc., would permit to distinguish between the forms of degradation caused by anthropic factors and those derived by natural processes (Trotta, Menegoni, Frattarelli, \& lannetta, 2015). Said this, in order to properly evaluate LD, desertification indicators are those which are the most complete for indicating the 
potential risk of desertification. A good indicator should be at a regional level and should be based on available international source materials, including remotely sensed images, topographic map data, climate, soil, and geologic data (Nicholson, Tucker, \& Ba, 1998; Thornes 1995); also, the integration between Geographic Information Systems (GIS) and remote sensing (RS) is the most complete methodology to estimate environmental hazards. On one hand, the GIS-driven reference methodology for the identification of areas vulnerable to desertification in this study is known as ESAs (Environmentally Sensitive Areas), and was developed by Kosmas, Ferrara, Briasouli, \& Imeson, (1999) within the MEDALUS (MEditerranean Desertification And Land USe) project of the European Union, and it provided, on a scale of 1:100000, the application of both biophysical and socio-economic indicators allowing to classify the areas under desertification pressures in critical, fragile and potential. The MEDALUS methodology had numerous applications, assuming the role of standard and uniformly shared methodology, while respecting the local peculiarities of the territory. The ESAs calculation is based on the geometric mean value of four quality indexes Soil Quality Index (SQI), Climate Quality Index (CQI), Vegetation Quality Index (VQI) that are used for the calculation of the environmental conditions and the Management Quality Index (MQI) used for assessing the environmental conditions due to the pressures of anthropogenic activities; in particular, for this case study of Basilicata (Southern Italy), the aim was to search for implementations in the current indexes developed in Gabriele and Previtali (2020) within the framework of the MEDALUS methodology in the aforementioned southItalian region; for this purpose, two new indexes were elaborated to achieve a fine-tuning of the previous study, focusing more on the local peculiarities of the region, namely both landslides and hydrographic network. On the other hand, an additional RS-driven methodology was accomplished in order to monitor the past 20-years evolution of the LD phenomenon at an infra-regional scale, specifically with NDVI differencing applied to change detection. This approach is important in relation to land management goals. Remote sensing is one of the tools of choice for desertification studies, monitoring the phenomenon both at a regional and global scale.

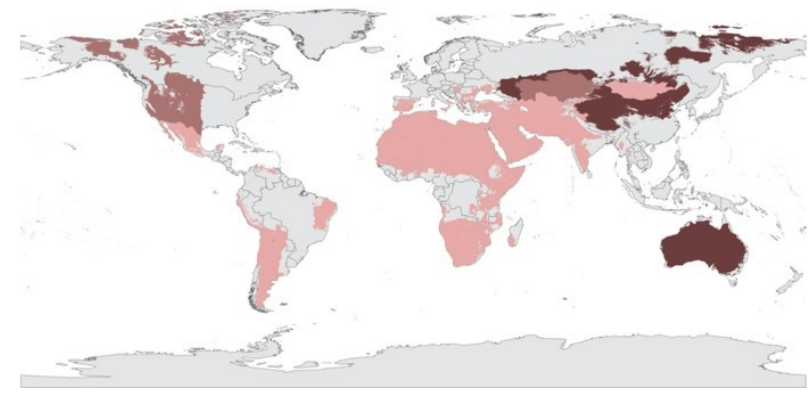

Figure 1: Patterns of aridity 1981-2010 The observed global distribution of the climate classes over the periods from 19511980 and 1981-2010 (Spinoni, Vogt, Naumann, Carrao, \& Barbosa, 2015).

\section{Literature review and related work}

The study of the LD was based on a first literature review aimed at finding a widespread methodology for assessing large scale desertification, that could be easily adapted to include the peculiarities of the places and at the same time have a scientific relevance; it was carried with a specific focus on the Mediterranean area, covering approximately 20 years of research, using widely accepted scientific repositories such as Google Scholar, Scopus, Web-of-Science, et al. For the keyword "sensitivity", "land degradation", "desertification" and "UNCCD", the MEDALUS (MEditerranean Desertification And Land Use) methodology, derived from the framework of MEDALUS projects, financed by the European Commission from 1991 to 1999 , was the most quoted one. This methodology becomes, during the years, one of the most used ones to monitor land sensitivity to degradation and desertification all over the world (Ferrara et al., 2020), based on the evaluation of 4 main Indexes: Climate Quality Index (CQI), Soil Quality Index (SQI), Vegetation Quality Index (VQI) and Management Quality Index (MQI) (Kosmas, Ferrara, Briasouli, \& Imeson, 1999). The review of the adjusted and innovated MEDALUS methodology applied to large scale analysis, with different scientifically valuable cases in Italy (Canora, D'Angella, \& Aiello, 2015; Colantoni, Ferrara, Perini, \& Salvati, 2015; Coluzzi et al., 2019; Ferrara, Mancino, Urbano, Coletta, \& Baffari, 2010; Ladisa, Todorovic, \& Liuzzi, 2012; Trotta, Menegoni, Frattarelli, \& lannetta, 2015; Salvati \& Bajocco, 2011; Salvati et al., 2013), in Asia (Lee et al., 2019), in the rest of Europe (Karamesouti, Panagos, \& Kosmas, 2018; Contador, Schnabel, Gutierrez, \& Fernandez, 2009), in northern Africa (Ait Lamqadem, Pradhan, Saber, \& Rahimi, 2018) and in the Middle east (Bakr, Weindorf, Bahnassy, \& El-Badawi, 2012), confirmed the worldwide efficiency and applicability of the ESA methodology even in the past 10 years, allowing for the harmonization of regional/countrylevel studies and applications, and the more efficient use of global level datasets (Ferrara et al., 2020). Then, a second literature review was carried out in order to find an indicator for evaluating the LD at a mid-regional scale, for a time span of twenty years (2000-2020). The studies found were mainly based on Remote Sensing techniques, showing that with the aggravation of desertification, the surface vegetation, observed through RS, appeared seriously damaged, causing the reduction of the coverage of the biomass, resulting in a lower Vegetation Index (VI) in the remote sensing image (Schlesinger et al., 1990; Zeng, Feng, \& Xiang, 2006; Pan \& Li, 2013; Becerril-Piña, Díaz-Delgado, Mastachi-Loza, \& González-Sosa, 2016). The use of multispectral remote sensing images to extract various indices constructing feature space for extraction and monitoring of ecological environment information currently represents an advanced method for remote sensing monitoring of the ecological environment (Ding, Zhao, Zheng, \& Jiang, 2014). However, up to date, there is no unified mathematical expression that defines all VIs due to the complexity of different light spectra combinations, instrumentation, platforms, and resolutions used. Among the VIs, the change detection through NDVI (Normalized Difference Vegetation Index) resulted in one of the most extensively applied for its sensitivity to the presence, density and condition of vegetation. It is of considerable value as an indicator of environmental change (Eastman, Sangermano, Machado, Rogan, \& Anyamba, 2013), as in fact, temporal analysis of satellitebased NDVI is one of the major remote sensing tools which can identify the depletion of vegetation cover (Kundu, Patel, Saha, \& Dutta, 2017). Change detection is a simple, but effective method for assessing LUCs, carried by comparing vegetation indices from Satellite 
data among different dates (Lyon, Yuan, Lunetta, \& Elvidge, 1998). This method has been documented widely in research, favoured for its accuracy, simplicity in computation, and ease in interpretation (Singh, 1986; Muchoney \& Haack, 1994; Green, Kempka, \& Lackey, 1994; Coppin \& Bauer, 1996; Macleod \& Congalton, 1998; Mancino, Nolè, Ripullone, \& Ferrara, 2014).

\section{A dynamic archaeolandscape: the Basilicata case study}

\subsection{Landscape as the result of the interaction between natural and cultural factors}

The "Built Environment" is progressively intended with an extended meaning, developing from single exceptional monuments to historic centres, urban areas, historical and archaeological sites, architectural objects, natural and cultural landscapes, as well as what we call "cultural heritage" artefacts with human and intangible values. It needs specific care and an integrated approach, in order to analyze and know it and then to process and to manage all the data needed for careful control and deeper understanding of its transformations across the time (past and future) under different challenging issues (human pressures, socio-economic modifications, climate changes, natural hazards) preserving the material authenticity and unicity, as a vehicle for the intangible values.

Referring to this "Built Environment" concept, we consider the landscape as a product of history, which operates on natural environmental pictures through man interventions.

A landscape is a space of various extension for a time of various duration. The lasting works of man, like structures and infrastructures necessary for his life, for his economic, cultural and spiritual actions, overlap the natural substrate and fit into a historical legacy in the process of progressive enrichment.

The complex of natural and cultural features must be analyzed to manage, valorize and rehabilitate outstanding and ordinary landscapes in their dynamic changing.

In this regard, it should be remembered that the European Landscape Convention (ELC, Florence, October 2000), redefines the concept of landscape highlighting the landscape value of the entire territory (including landscapes that might be considered outstanding as well as every day or degraded landscapes), the complex and pervasive meaning of the landscape values, and the necessary reference to perceptions and expectations of the populations (Council of Europe,2000). In this view, focus is not on the islands of excellence, that is on areas of exceptional value, but on the diffuse landscape heritage that represents the common heritage, the identity values (Gambino, 2010).

Landscape is not only construction or structural composition, but it also has an intangible element that reflects the man cultures that created it. Because the landscape is a cultural heritage that is living and dynamic, it is able to assimilate and integrate over time those elements that mark territorial changes, if those modifications are not too violent, too fast or of enormous impact. The problem is not the transformation of the landscape, but the type and means of the transformation. With few exceptions, industry, intensive farming, mass tourism and major contemporary infrastructure in our countries have not transformed the landscape but destroyed it or rendered it uniform. Also, climate and socio-economic changes caused the marginalization of areas that are now fragile and in decay.

Conserving the authenticity of a landscape does not mean maintaining it intact and fossilizing it. Landscape - as already mentioned - is dynamic in itself as it is the result of the constant tension and interaction between nature and man. Thus, it becomes a goal of conserving and valorising those specific and original components, taking into account its dynamic nature.

All this considered, we must also remember that landscape is an archaic complex layered system strongly linked to our archaeological heritage. It is therefore important to support the knowledge of cultural and traditional landscapes or - better - of our archaeolandscapes - considered as a tool to strengthen the identity of communities and to better valorize fragile and deteriorated areas.

\subsection{Basilicata landscape development}

The Basilicata Region has a rich and significant archaeolandscape. Basilicata has been inhabited since ancient times and its agricultural landscape was famous in Magna Graecia with extensive cereal crops on the plateaus, olive groves and vineyards on the hills, as well as vast pastures and woods in the mountain areas.

The landscape of Basilicata presents archaeological elements from the Paleolithic to the Roman age to which are added interesting evidence of the Medieval and Renaissance periods: the result is a complex system of historical sites linked with natural and environmental resources.

Today's Basilicata landscape is a result of the long- term human-environment-climate interactions that have driven the ecological dynamics throughout the Holocene. The agricultural landscape is in some areas still conserved: olive groves, vineyards and chestnut groves produce high quality and renowned products. The historic road system and water network are still readable and characterize the landscape layout. However, historical cartography between the $16^{\text {th }}$ and $18^{\text {th }}$ Centuries documents a much more complex and designed landscape with precious cultivations and vast wooden areas, undoubtedly closer to the ancient one than the current one that is the result of profound transformations of the $20^{\text {th }}$ century.

Basilicata is a region where animal breeding and pastoralism have a long tradition. It is believed that the name Lucania derived from the Latin noun lucus -which means woodland- that characterized the mountain and hilly landscape of the region. Azimonti (1909) in his parliamentary inquiry into the conditions of peasants in the southern provinces, notes that at the beginning of the 1800 s at least half of the region was covered in lush forests. The most emblematic intervention was represented by the consistent and uncontrolled campaign of deforestation and clearing of considerable portions of state property. These deforestation measures were focused on the internal area of the region subjected to a wider context of a systematic recovery operation of spaces that were meant to be converted to cereal crops. 
Moreover, the autarchic policies of the fascist period, known as the "wheat battle", led to a considerable expansion of the areas cultivated with cereals (registering from 1927 to 1930 an increase of 37.000 ha). Milone (1955) referring to the data of Quattrocchi on the wooded area in Italy of 1947, observes that Basilicata had become the poorest region in the wooded heritage (Quattrocchi, 1999). The substantial and massive reduction of the forest heritage had thus further marked the natural instability of the soils, exposing them to landslides and to the erosive activity of torrential rain flows in mountainous and hilly areas. From an economic point of view, the cultivation of these soils, initially registered higher yields than the soils already used for cereal crops, and then realigned it to the regional values.

The geography of soil degradation in today Basilicata sees the region to be one of the most under pressures. The degradation issues concerns (i) the macro- category of climatic factors and the geomorphological characteristics of the soils, responding to particular changes in climatic conditions or to the action of atmospheric agents, with the loss of soil characteristics; (ii) the pressure for the macro-category of the dynamics of social organization, in its most diverse articulations: agricultural, industrial, tourism, building activities. It can be assumed that the Basilicata region well summarizes many basic features of the biogeographic complexity characterizing Mediterranean countries. Both due to the logic and functioning of the agricultural world (abandonment of certain agricultural practices, deterioration of traditional construction heritage, intensification of breeding, depopulation, marginalization of the inner areas), and due to external agents (climate change, aridity, forest fires, etc.).

\section{Materials and methods}

\subsection{The Basilicata case study}

To have the Basilicata region as a paradigmatic case study gave the opportunity to analyse the aforementioned cross-sectoral characteristics that fostered land degradation and that are today vastly assimilated in the entire Lucan territory: (i) the degree of seismicity of the region, and the consequential soil instability and landslides, which have historically redesigned the forms of the settlement for several times; (ii) the soil itself and its intrinsic qualities, specifically, the dominance of clay and sandy soils, which gives the Lucanian territory low degrees of fertility as regards productivity, and a low degree of soil cohesion with strong exposure to the various forms of soil erosion, giving rise to the aforementioned constant landslides, which jeopardize the safety of the settlement and offer considerable difficulties to primary activity, especially in the innermost hilly areas, leading to marginalization; (iii) the methodologies of land management that have taken place in relation to the preservation of natural sites and water elements, both following EU and National laws (e.g.Dir 1992/43/CEE and D.Lgs 42/2004) (iii) the agricultural primary production and livestock density, that contributed to the redefinition of the settlement patterns of the population and to the agricultural activities, reshaping the territorializing processes from a functional and geographic point of view; (iv) vegetation loss patterns (poor biodiversity) that progressively decreased the protective effect on the soil, until the process became irreversible; in this case, unsustainable agronomic practices (deforestation for intensive agricultural purposes) have happened to aggravate the local conditions; (v) climate-topography interactions and trends, characterized by an unequal annual distribution of rainfall with more than $80 \%$ falling from October to March, often in the form of torrential rain leading to the flash-floods and slope erosion patterns, reflecting a negative incidence on the vegetation of the north-exposed slopes; (vi) the water resources and aquifer quality, that filter and regulate freshwater dynamics (both surface and groundwater), although Basilicata has a complex and structured groundwater network, this does not necessarily mean increased water availability, as in fact the region amply suffers from aridity and water scarcity.

The literature review evidenced the MEDALUS methodology as the one suitable to the study scope and application, as it harmonizes multisource databases mainly covering the climate, soil, vegetation and management aspects, whereas some indicators may be excluded and some other may be added into the framework, in order either to adapt the model to the specific environmental conditions, or to improve knowledge about some particular aspects of desertification (Ladisa, Todorovic, \& Liuzzi, 2012).

\subsection{The MEDALUS methodology}

The original MEDALUS method framework is based on four basic indicators specific to the original ESA procedure, i.e., Climate Quality Index (CQI), Soil Quality Index (SQI), Vegetation Quality Index (VQI) and Management Quality Index (MQI) (Kosmas, Ferrara, Briasouli, \& Imeson, 1999). These indicators, obtained by processing certain constituting and representative parameters (variables or sub-indicators) for each individual case capture the main environmental characteristics that are directly or indirectly responsible for land sensitivity to degradation in each territory, and which are determined by climate, soil and vegetation conditions, and by anthropogenic land management specificities. The classes assigned to each sub-indicator must be weighted with certain score values (ranging from 1 , which indicates a low land degradation sensitivity, to 2 , which indicates high sensitivity to degradation), which in the end are processed as a geometric mean for obtaining the main quality indicators. Subsequently, the weighted classes of the main quality indicators are processed using the same averaging procedure, resulting in the Environmentally Sensitive Areas Index (ESAI). In this case study, the weight factors were assigned and based, where possible, on the analysis of the previous literature (Kosmas et al., 2014, Prăvălie, Patriche, \& Bandoc, 2017, Salvati et al., 2013, Vieira et al., 2015; Tavares et al., 2015; Salvati \& Bajocco, 2011). Other parameters, depending on the quality and quantity of the input data and on the characteristics of the study area, were implemented and given a precise score calibrated on the local characteristics. As expressed in the introduction paragraph, one of the final goals of the work was to adjust and implement the previous ESAls presented in Gabriele \& Previtali (2020), which consisted in the evaluation of the three main environmental quality indicators (SQI, CQI, VQI) together with the management quality indicator (MQI), for doing so, there were taken into consideration other characteristics of the Basilicata region as Landslide 
Risk Index (LRI) and Water Availability Index (WAI), assessing in this way a more accurate land desertification sensitivity of the region, calibrated on its peculiarities. LRI defines one of the mainland degradation issues in the region, the landslides, that shaped Basilicata geomorphology, enhanced by the deforestation during centuries. WAl assesses the availability of water resources in a region that is formally characterized by long drought periods and a scarcity of groundwater supplies. By doing so, the MEDALUS method was implicitly implemented with new variables (in addition to the original MEDALUS procedure) reinforcing the basic indicators CQI, SQI, VQI and MQI, and attesting the methodology's adaptability and flexibility according to local and national conditions (Contador, Schnabel, Gutierrez, \& Fernandez, 2009; Bakr, Weindorf, Bahnassy, \& El-Badawi, 2012; Prăvălie, Patriche, \& Bandoc, 2017); the six indicators were then processed using GIS tools (QGIS 3.8 software) in order to obtain the final ESAI.

\subsection{MEDALUS methodology implementations}

The Water Availability Index (WAI) was implemented from the geometric average of four sub-indexes as: water density, groundwater bodies quality, flood risk and aquifer productivity, and calculated as in Eq. (1):

WAI $_{i j}=\left(\right.$ Water Density $_{i j} \times{\text { Groundwater Bodies } \text { Quality }_{i j} \times}$ Flood Risk ${ }_{i j} \times$ Aquifer Productivity $\left._{i j}\right)^{1 / 4}$

The major aquifers of regional importance are in the carbonate hydro structures, characterized by high permeability due to their fracturing and karst. An accurate review of both the National Management Plan of the Hydrographic District of the Southern Apennines and of the transboundary aquifers dataset from UNESCO International Hydrogeological Programme (IGRAC, 2015; Duscher et al., 2015) has shown that the hydrogeological structures and flat areas that fall close to the regional borders, whose aquifers are of national and regional importance, are characterized by high water potential. Therefore, they are a source of conspicuous withdrawals for drinking, irrigation and industrial use. Moreover, flood risk classes were extracted from the National Flood hazard maps and flood risk maps (directive 2007/60 / EC and Italian legislative decree 49/2010), of Distretto dell' Appennino Meridionale (Southern Apennine District) and then scored.

The Landslide Risk Index (LRI) was implemented from the geometric average of two sub-indexes as landslide risk and distance from faults, and calculated as the following Eq. (2):

$L R I_{i j}=\left(\text { Landslide Risk }_{i j} \times \text { Distance from Faults }_{i j}\right)^{1 / 2}$

The knowledge of the spatial distribution of landslide phenomena is crucial to investigate many issues of landscape evolution and its relationships with human activities and land management. Historically, Basilicata has been described as "the most degraded region of southern Italy" as a result of the widespread soil erosion and landslides that it experiences" (Kayser, 1958). The risk deriving from the landslide phenomena, was calculated from the current plan for the defence against hydrogeological risk (PAI Basilicata) and the relationships between the mapped landslide element and the potential elements of risk (loss of life, people injured, damage to properties and disruption of economic activities) falling within its perimeter. For the Distance from Faults subindex, the faults database from International Hydrogeological Map of Europe, (Duscher et al., 2015) was buffered with an interval of $10 \mathrm{mt}$ to $200 \mathrm{mt}$ and then scored.

ESAI Land sensitivity to degradation was defined as the final step in environment quality (soil quality, climate quality, vegetation quality), landslide risk, water availability and management quality assessment based on original methodology (Kosmas, Ferrara, Briasouli, \& Imeson, 1999) classifying the area into four main classes (not affected $(N)$, potentially affected $(P)$, fragile $(F)$ and critical (C)) and 8 sub-classes (N, P, F1, F2, F3; C1, C2, C3). ESAI (Environmentally Sensitive Areas Index), (Fig. 2 ), was obtained from the geometric average of four above mentioned layers using the Eq. (3):

$E S A I_{i j}=\left(S Q I_{i j} \times V Q I_{i j} \times C Q I_{i j} \times M Q I_{i j} \times L R I_{i j} \times W A I_{i j}\right)^{1 / 6}$

The spatial distribution of the ESAI defines $1317.560 \mathrm{~km} 2$ for the non-affected areas ( $\mathrm{N}$ sub-class); $2989.038 \mathrm{~km} 2$ for the potential areas ( $P$ sub-class); $2843.366 \mathrm{~km} 2$ for the first band fragile areas (F1) areas; $2016.629 \mathrm{~km} 2$ for the second band fragile areas (F2); $351.303 \mathrm{~km} 2$ for the third band fragile areas (F3); $24.104 \mathrm{~km} 2$ for the first band critical areas (C1); $1.589 \mathrm{~km} 2$ for the second band critical areas (C2); there are no third band critical areas (C3).

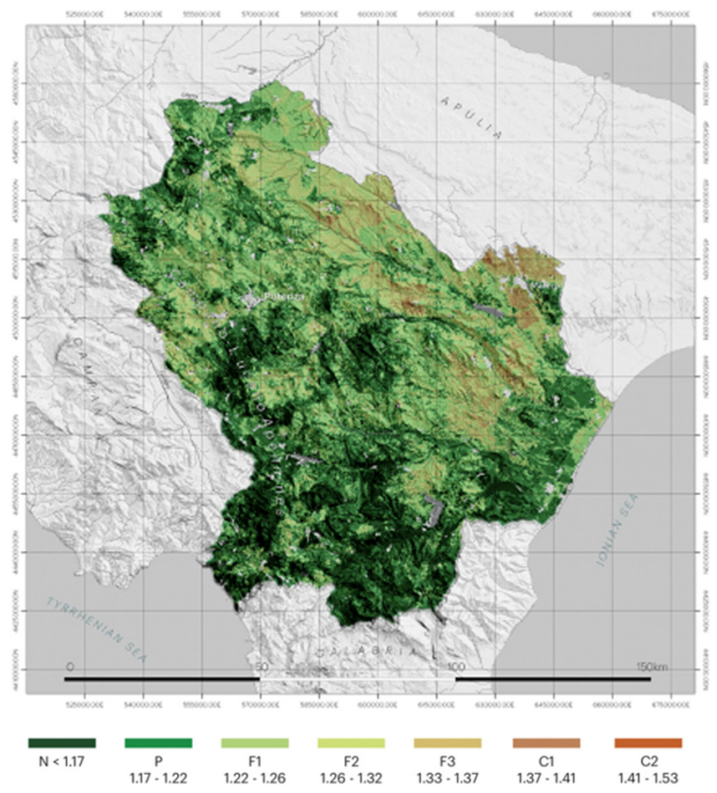

Figure 2: The spatial distribution of the Land Degradation (LD) phenomenon through the ESAI index.

\subsection{NDVI differencing threshold and vegetation change detection}

Image differencing is simply the subtraction of the pixel digital values of an image recorded at one date from the corresponding pixel values of the second date (Hayes \& Sader, 2001), the histogram of the resulting image depicts a range of pixel values from negative to positive numbers, where those clustered around zero represent no change and those at either tail represent reflectance changes from one image date to the next (Jensen, 1996); a threshold value based on the mean $(\mu)$ and standard 
deviation $(\sigma)$ of NDVI differencing image is required in determining real change occurrence Eq. (4):

$\triangle N D V I=\mu \pm n \cdot \sigma$

The threshold identifies three ranges in the normal distribution: (a) the left tail $(\triangle N D V I<\mu-\mathrm{n} \cdot \sigma)$; (b) the right tail $(\triangle N D V I>\mu+\mathrm{n} \cdot \sigma)$; and (c) the central region of the normal distribution $(\mu-\mathrm{n} \cdot \sigma<\Delta N D V I<\mu+\mathrm{n} \cdot \sigma)$. Pixels within the two tails of the distribution are characterized by significant vegetation changes, while pixels in the central region represent no change. The $n$ factor defines the range of dispersion around the mean. This study considered only the negative variation in vegetation cover defined as the area of probable land degradation. The chosen threshold value used for the NDVI image differencing classification was 1.5 and it is expressed with the following Eq. (5):

$$
\triangle N D V I<\mu-1.5 \cdot \sigma
$$

The chosen high-risk area for the study of NDVI differencing assessment is the Fossa Bradanica and a portion of Montagna Materana (Fig. 3). The area falls in the badland area of Basilicata region. Badlands are characterized by their steep, unvegetated slopes, high drainage densities, high rates of erosion and a tendency for the formation of a regolith profile with desiccation cracks in the top 1-5 cm, creating a 'popcorn' surface (Howard, 1994). For the NDVI image differencing, two Landsat TM cloud-free images (path 188, row 32) with 30 x $30 \mathrm{~m}$ spatial resolution were analyzed. The images were acquired during the period between: 13 June - 16 August, for the following years: 2000 and 2019. 12 randomly chosen areas were sampled from the $\Delta$ NDVI 2000-2019, spotting the effective changes in the landscape with a comparison of the National Orthophoto from 2000 and the Basilicata Orthophoto from 2017 (Fig. 4). These two orthophotos were chosen mainly for the fact that they were the closest in terms of time reference to the $\triangle \mathrm{NDVI}$ 2000-2019 and for the availability of data.

\section{Policy addressing}

\subsection{Integration of vulnerability studies in regional DDS}

Availability of trustful, reliable and updated information is of uttermost importance for any decision-making process. The method presented in Section 4 can be considered as a starting point for the construction of a Regional Decision Support System integrating several layers:

- Vulnerability studies to define areas that need specific attention in the planning and in the monitoring stages due to specific fragilities (climatic, orographic, anthropogenic, etc.),

- Risk analysis carried out considering different scenarios (e.g. landslide risk assessment and connected issues, wildfire, etc.)

- Earth Observation-based analysis that can be used for timely and monitoring of ongoing phenomena, identify anomalies with respect to a defined reference scenario and time evolution of specific trends.
The integration of such information into a unique framework can be used twofold. On the one side, it provides to decision-makers an overall view of complex and interlinked phenomena providing a digital twin solution (in this case a Twin Earth) for real-time analysis and simulations. On the other side, the availability of a platform for data communication can be used to raise awareness in citizens and local communities on the issues related to soil degradation and soil sealing. This awareness rising can also determine a more collaborative decision-making process by involving local stakeholders in planning activities by collecting requirements and feedbacks from citizens and local associations.

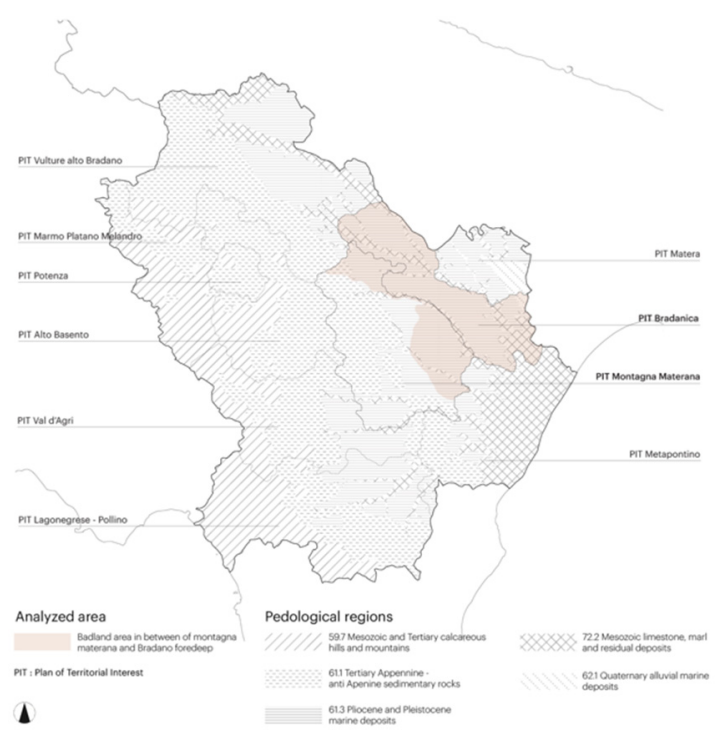

Figure 3: The chosen high-risk area (partially falling into the Montagna Materana and covering the whole Fossa Bradanica), evidenced in pink.

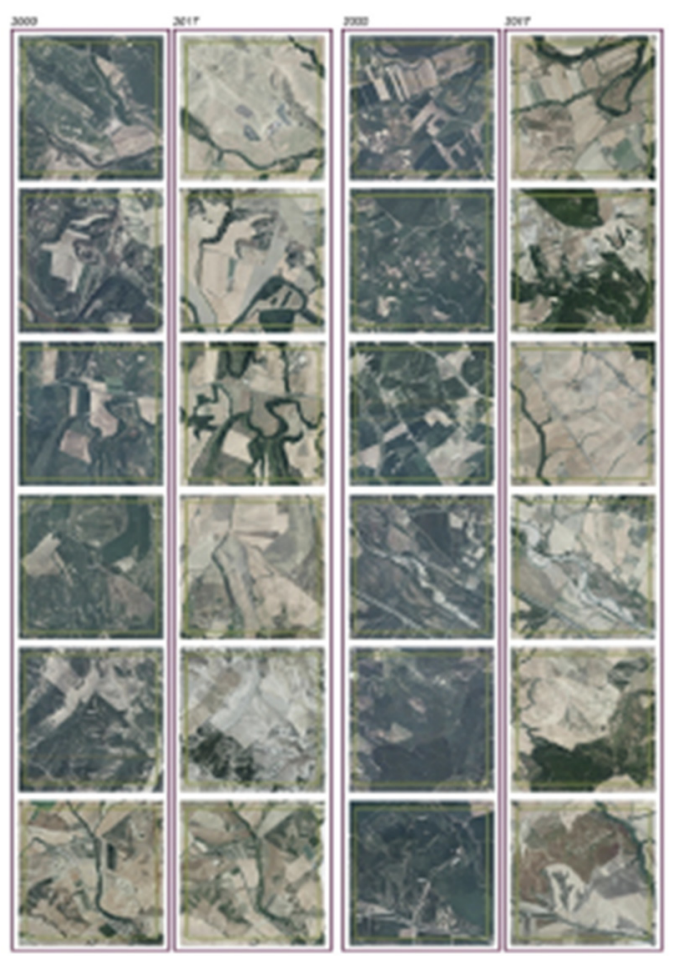

Figure 4: The 12 randomly chosen areas spotting the changes between the National Orthophoto from 2000 and the Basilicata Orthophoto from 2017. 


\subsection{Landscape preservation as an active planning tool}

From the evolution of the landscape concept, it is currently necessary to define methodologies to read and evaluate landscape typologies and features involving natural, historic, perceptive and constructive components, examining decay and transformation problems and understanding social needs and functional options.

The current landscape preservation aims to conserve the historic stratification and to define new compatible plans and uses, identifying the ways to mitigate alteration impacts, to requalificate degraded zones, to re-connect marginalized and fragile areas, to enhance natural, historic and cultural values, to improve documentary and educational options and to manage new projects and opportunities.

In this regard, the already mentioned European Landscape Convention (ELC, Florence, October 2000), underlines landscape policies and practices, listing conservation means and ways to maintain the peculiar features of a landscape, considering the natural and cultural value. It also details the possible actions to guarantee landscape management, considering and harmonizing the transformation caused by social, economic and environmental changes (Council of Europe, 2000).

Management must be dynamic and move towards improving landscape quality in accordance with local goals and with efforts to valorize, conserve or create landscapes. That landscape planning covers the surveying, analyzing, the understanding process in order to preserve the historic values and to design new compatible landscapes.

Therefore, the ELC is an innovative document that foregrounds how landscape preservation cannot be limited to exceptional sites, cannot be dealt with by a minority and cannot be imposed by law, but requires a broad strategy that encompasses the entire territory and the connected communities and activities.

It is important to highlight that the meaning of conservation is gradually changed during the last decades, both in the nature conservation field and in the cultural heritage conservation field. In both fields, it becomes clear that effective conservation of the values to be protected cannot be ensured by mere measures of limitation or prohibition (even if such measures are often absolutely essential). It requires active intervention. There cannot be authentic conservation without new values production, and indeed the conservation is, for the contemporary society, "the innovation privileged place".

In this perspective, landscape planning can play a particularly important role. A new landscape active preservation must target both the social enhancement of extraordinary landscapes (often already recognized and protected by national laws) and ordinary ones (almost always lacking such recognition). It is necessary to set cooperation between government bodies and communities so that active criteria can be drafted to manage the landscape as a place in which people live and as an asset to be transmit to future generations in a richer - and not impoverished- state (Gambino, 2010).
As noted, the landscape needs to be viewed as a dynamic organism and, in historical terms, it must be understood as the result of a series of temporal sequences created by the complex interrelations over time between man and nature. In this regard it is important to rise the knowledge integrating natural and anthropic elements of the interpretative analysis in order to define planning tools, considering the ecosystem approach to plan the landscape as a system of ecosystems (Ferrari \& Pezzi, 2013).

Consequently, landscape valorization strategies need to consider the multiple transformations that have taken place and analyze the effects on the landscape of the human and nature actions in order to define planning tools and management criteria capable of conserving and/or rehabilitating landscape meanings and values.

In order to make it possible, it is necessary to increase the integration between territorial and landscape planning tools and promote shared planning and landscape design at a Regional scale.

\section{Conclusions}

Land degradation is a major issue in many areas of the world. For this reason, the availability of methodologies to define the levels of vulnerability within a specific area should take into consideration two diverging requirements: i) the definition of a standardized approach to be used in various areas and ii) the specific characteristics and factors influencing the land degradation phenomenon that may vary from site to site. The presented approach tries to use a well-established and standardized framework (i.e., the MEDALUS methodology) customizing to take into the specific vulnerability aspects of the Basilicata region by adding two new indexes (WAI and LRI) to the original formulation. Starting from the identified vulnerable areas Earth Observation data were used to have the first map of areas under stress at the regional level. The derived results from this analysis can be considered as a starting point for further in-depth analysis. Indeed, the secretion of a unique threshold for the entire region is not taking into consideration localized phenomena connected to difference in vegetation activity and phenology as well as the difference in the land cover. The definition of a more robust multi-threshold analysis will be investigated in further works.

However, the integration of both evaluations contributed to achieving the final goal of the research, which mainly consisted in identifying the phenomena that generate degradation in the landscape, therefore outlining the future management possibilities and implications in relation to this critical issue, in order to maintain or restore the pre-existing values, or to support the creation of new coherent and integrated landscape strategies. This objective derives from recognizing the landscape as defined in the already mentioned European Landscape Convention Landscape. In fact, performs important functions of community interest, on the cultural, ecological, environmental and social point of view, and is also a resource for economic development, without forgetting that it is a fundamental component of archaeological, cultural and natural heritage too.

The final assumption is that each territory is constantly changing, so the landscape transformations are 
inevitable: the problem is to evaluate how these transformations contribute to modify the landscape. In fact, these must be consciously guided and managed by appropriate planning policies. In the case of degradation, the transformation of the landscape is the result of the evolution of centuries and of a series of extremely complex phenomena that it is impossible to consider reversible. This means that we can treat, in this situation, the landscape as a compromised landscape, that defines definitive loss of the characters, quality and values of a landscape, that determines the disappearance of its integrity from a perceptual and functional point of view and relationships and loss of the references through which the population attributes collective value and quality to the landscape. Degradation and alteration can deeply compromise the landscape, deleting the preexisting components and values: in this situation it is possible to add new functions and features in order to create new coherent and integrated landscape values, using correct planning and management policies. The European Landscape Convention reaffirms how, in the era of globalization, the problems relating to the protection and development of rural and often fragile areas are extremely relevant: protecting and enhancing the agricultural landscape and promoting eco-sustainable agriculture are not only necessities for economic and social development of those areas, but also for cultural and environmental ones.

\section{References}

Ait Lamqadem, A., Pradhan, B., Saber, H., \& Rahimi, A. (2018). Desertification sensitivity analysis using MEDALUS model and GIS: a case study of the Oases of Middle Draa Valley, Morocco. Sensors, 18(7), 2230. https://doi.org/10.3390/s18072230

Azimonti, E. (1909). IP, Basilicata. Relazione del delegato tecnico, Basilicata e Calabrie, tomo I, vol. V, $236-23$.

Bakr, N., Weindorf, D. C., Bahnassy, M. H., \& El-Badawi, M. M. (2012). Multi-temporal assessment of land sensitivity to desertification in a fragile agro-ecosystem: Environmental indicators. Ecological indicators, 15(1), $271-280$. https://doi.org/10.1016/j.ecolind.2011.09.034

Becerril-Piña, R., Díaz-Delgado, C., Mastachi-Loza, C. A., \& González-Sosa, E. (2016). Integration of remote sensing techniques for monitoring desertification in Mexico. Human and Ecological Risk Assessment: An International Journal, 22(6), 1323-1340. https://doi.org/10.1080/10807039.2016.1169914

Canora, F., D'Angella, A., \& Aiello, A. (2015). Quantitative assessment of the sensitivity to desertification in the Bradano River basin (Basilicata, southern Italy). Journal of Maps, 11(5), $745-759$. https://doi.org/10.1080/17445647.2014.980857

Colantoni, A., Ferrara, C., Perini, L., \& Salvati, L. (2015). Assessing trends in climate aridity and vulnerability to soil degradation in Italy. Ecological indicators, 48, 599-604. https://doi.org/10.1016/j.ecolind.2014.09.031

Coluzzi, R., D’Emilio, M., Imbrenda, V., Giorgio, G. A., Lanfredi, M., Macchiato, M., \& Telesca, V. (2019). Investigating climate variability and long-term vegetation activity across heterogeneous Basilicata agroecosystems. Geomatics, Natural Hazards and Risk, 10(1), 168-180. https://doi.org/10.1080/19475705.2018.1513872

Contador, J. L., Schnabel, S., Gutierrez, A. G., \& Fernandez, M. P. (2009). Mapping sensitivity to land degradation in Extremadura. SW Spain. Land Degradation \& Development, 20(2), 129-144. https://doi.org/10.1002/ldr.884

Council of Europe (2000). European landscape convention. US/ICOMOS Scientific Journal, 2, 88-92.

Coppin, P. R., \& Bauer, M. E. (1996). Digital change detection in forest ecosystems with remote sensing imagery. Remote sensing reviews, 13(3-4), 207-234. https://doi.org/10.1080/02757259609532305

Ding, Y., Zhao, K., Zheng, X., \& Jiang, T. (2014). Temporal dynamics of spatial heterogeneity over cropland quantified by time-series NDVI, near infrared and red reflectance of Landsat $8 \mathrm{OLI}$ imagery. International Journal of Applied Earth Observation and Geoinformation, 30, 139-145. https://doi.org/10.1016/j.jag.2014.01.009

Duscher, K., Günther, A., Richts, A., Clos, P., Philipp, U., \& Struckmeier, W. (2015). The GIS layers of the "International Hydrogeological Map of Europe 1: 1,500,000" in a vector format. Hydrogeology journal, 23(8), 1867-1875. https://doi.org/10.1007/s10040-015-1296-4

Eastman, J. R., Sangermano, F., Machado, E. A., Rogan, J., \& Anyamba, A. (2013). Global trends in seasonality of normalized difference vegetation index (NDVI), 1982-2011. Remote Sensing, 5(10), 4799-4818. https://doi.org/10.3390/rs5104799

Ferrara, A., Mancino, G., Urbano, V., Coletta, V., \& Baffari, P. (2010). Analisi delle potenzialità applicative del metodo ESA (Environmental Sensitive Areas) e aggiornamento della carta delle aree sensibili alla desertificazione della Basilicata. Forest@-Journal of Silviculture and Forest Ecology, 7(4), 133. https://doi.org/10.3832/efor0627-007

Ferrara, A., Kosmas, C., Salvati, L., Padula, A., Mancino, G., \& Nolè, A. (2020). Updating the MEDALUS-ESA Framework for Worldwide Land Degradation and Desertification Assessment. Land Degradation \& Development. https://doi.org/10.1002/ldr.3559

Ferrari, C., \& Pezzi, G. (2013). L'ecologia del paesaggio. Bologna, II Mulino.

Gabriele, M., \& Previtali, M. (2020). A GIS and Remote Sensing Approach for Desertification Sensitivity Assessment in 
Basilicata Region (Italy). In Proceedings of the 2020 3rd International Conference on Geoinformatics and Data Analysis (pp. 62-66).

Gambino, R. (2010). Parchi e paesaggi d'Europa. Un programma di ricerca territoriale. Ri-Vista, 14.

Green, K., Kempka, D., \& Lackey, L. (1994). Using remote sensing to detect and monitor land-cover and land-use change. Photogrammetric engineering and remote sensing, 60(3), 331-337.

Hayes, D. J., \& Sader, S. A. (2001). Comparison of change-detection techniques for monitoring tropical forest clearing and vegetation regrowth in a time series. Photogrammetric engineering and remote sensing, 67(9), 1067-1075.

Howard, A. D. (1994). Badlands. In Geomorphology of desert environments (pp. 213-242). Springer, Dordrecht. https://doi.org/10.1007/978-94-015-8254-4_9

IGRAC (International Groundwater Resources Assessment Centre), UNESCO-IHP (UNESCO International Hydrological Programme). (2015). Transboundary Aquifers of the World [map]. Edition 2015. Scale 1: 50000000. Delft, Netherlands: IGRAC, 2015.

Jensen, J. R. (1996). Introductory digital image processing: a remote sensing perspective (No. Ed. 2). Prentice-Hall Inc.

Karamesouti, M., Panagos, P., \& Kosmas, C. (2018). Model-based spatio-temporal analysis of land desertification risk in Greece. Catena, 167, 266-275. https://doi.org/10.1016/j.catena.2018.04.042

Kayser, B. (1958). Recherches sur les sols et l'érosion en Italie méridionale, Lucanie (Doctoral dissertation, Paris).

Kosmas, C., Ferrara, A., Briasouli, H., \& Imeson, A. (1999). Methodology for mapping environmentally sensitive areas (ESAs) to desertification. The medalus project Mediterranean desertification and land use. Manual on key indicators of desertification and mapping Environmentally Sensitive Areas to desertification, 31-47.

Kosmas, C., Kairis, O., Karavitis, C., Ritsema, C., Salvati, L., Acikalin, S., \& Belgacem, A. (2014). Evaluation and selection of indicators for land degradation and desertification monitoring: methodological approach. Environmental management, 54(5), 951-970.

Kundu, A., Patel, N. R., Saha, S. K., \& Dutta, D. (2017). Desertification in western Rajasthan (India): an assessment using remote sensing derived rain-use efficiency and residual trend methods. Natural Hazards, 86(1), 297-313.

Ladisa, G., Todorovic, M., \& Liuzzi, G. T. (2012). A GIS-based approach for desertification risk assessment in Apulia region, SE Italy. Physics and Chemistry of the Earth, Parts a/B/C, 49, 103-113. https://doi.org/10.1016/j.pce.2011.05.007

Lee, E. J., Piao, D., Song, C., Kim, J., Lim, C. H., Kim, E., \& Lee, W. K. (2019). Assessing environmentally sensitive land to desertification using MEDALUS method in Mongolia. Forest Science and Technology, 15(4), $210-220$. https://doi.org/10.1080/21580103.2019.1667880

Lyon, J. G., Yuan, D., Lunetta, R. S., \& Elvidge, C. D. (1998). A change detection experiment using vegetation indices. Photogrammetric engineering and remote sensing, 64(2), 143-150.

Macleod, R. D., \& Congalton, R. G. (1998). A quantitative comparison of change-detection algorithms for monitoring eelgrass from remotely sensed data. Photogrammetric engineering and remote sensing, 64(3), 207-216.

Mancino, G., Nolè, A., Ripullone, F., \& Ferrara, A. (2014). Landsat TM imagery and NDVI differencing to detect vegetation change: assessing natural forest expansion in Basilicata, southern Italy. Iforest-Biogeosciences and Forestry, 7(2), 75. https://doi.org/10.3832/ifor0909-007

Milone, F. (1955). L'Italia nell'economia delle sue regioni. Edizioni Scientifiche Einaudi, Torino.

Muchoney, D. M., \& Haack, B. N. (1994). Change detection for monitoring forest defoliation. Photogrammetric engineering and remote sensing, 60(10), 1243-1252.

Nicholson, S. E., Tucker, C. J., \& Ba, M. B. (1998). Desertification, drought, and surface vegetation: An example from the West African Sahel. Bulletin of the American Meteorological Society, 79(5), 815-830. https://doi.org/10.1175/15200477(1998)079<0815:DDASVA>2.0.CO;2

Pan, J., \& Li, T. (2013). Extracting desertification from Landsat TM imagery based on spectral mixture analysis and AlbedoVegetation feature space. Natural hazards, 68(2), 915-927.

Prăvălie, R., Patriche, C., \& Bandoc, G. (2017). Quantification of land degradation sensitivity areas in Southern and Central Southeastern Europe. New results based on improving DISMED methodology with new climate data. Catena, 158, 309-320. https://doi.org/10.1016/j.catena.2017.07.006

Quattrocchi, U. (1999). CRC World Dictionary of Plant Names: Common Names, Scientific Names, Eponyms. Synonyms, and Etymology (Vol. 4). CRC press.

Sala, O. E., Chapin, F. S., Armesto, J. J., Berlow, E., Bloomfield, J., Dirzo, R., \& Leemans, R. (2000). Global biodiversity scenarios for the year 2100. Science, 287(5459), 1770-1774. https://doi.org/10.1126/science.287.5459.1770

Salvati, L., \& Bajocco, S. (2011). Land sensitivity to desertification across Italy: past, present, and future. Applied Geography, 31(1), 223-231. https://doi.org/10.1016/j.apgeog.2010.04.006 
Salvati, L., Mancino, G., De Zuliani, E., Sateriano, A., Zitti, M., \& Ferrara, A. (2013). An expert system to evaluate environmental sensitivity: a local-scale approach to desertification risk. Applied ecology and environmental research, 11(4), 611-627.

Schlesinger, W. H., Reynolds, J. F., Cunningham, G. L., Huenneke, L. F., Jarrell, W. M., Virginia, R. A., \& Whitford, W. G. (1990). Biological feedbacks in global desertification. Science, 247(4946), 1043-1048. https://doi.org/10.1126/science.247.4946.1043

Singh, A. (1986). Change detection in the tropical forest environment of northeastern India using Landsat. Remote sensing and tropical land management, 44, 273-254.

Spinoni, J., Vogt, J., Naumann, G., Carrao, H., \& Barbosa, P. (2015). Towards identifying areas at climatological risk of desertification using the Köppen-Geiger classification and FAO aridity index. International Journal of Climatology, 35(9), 2210-2222. https://doi.org/10.1002/joc.4124

Tavares, J. D. P., Baptista, I., Ferreira, A. J., Amiotte-Suchet, P., Coelho, C., Gomes, S., \& Bentub, J. (2015). Assessment and mapping the sensitive areas to desertification in an insular Sahelian mountain region Case study of the Ribeira Seca Watershed, Santiago Island, Cabo Verde. Catena, 128, 214-223. https://doi.org/10.1016/j.catena.2014.10.005

Thornes, J. B. (1995). Mediterranean desertification and the vegetation cover. Mediterranean desertification and the vegetation cover., 169-194.

Trotta, C., Menegoni, P., Frattarelli, F. M. M., \& lannetta, M. (2015). Assessing desertification vulnerability on a local scale: the Castelporziano study case (central Italy). Rendiconti Lincei, 26(3), 421-450. https://doi.org/10.1007/s12210-0140362-5

United Nations Convention to Combat Desertification (Secretariat). (1999). United Nations Convention to Combat Desertification in Those Countries Experiencing Serious Drought And/or Desertification, Particulary in Africa. Secretariat of the United Nations Convention to Combat Desertification.

Vieira, R. D. S. P., Tomasella, J., Alvalá, R. C. S., Sestini, M. F., Affonso, A. G., Rodriguez, D. A., \& De Oliveira, S. B. P. (2015). Identifying areas susceptible to desertification in the Brazilian northeast. Solid Earth, 6(1), $347-360$. https://doi.org/10.5194/se-6-347-2015

Zeng, Y., Feng, Z., \& Xiang, N. (2006). Albedo-NDVI space and remote sensing synthesis index models for desertification monitoring. Scientia Geographica Sinica, 26(1), 75. 


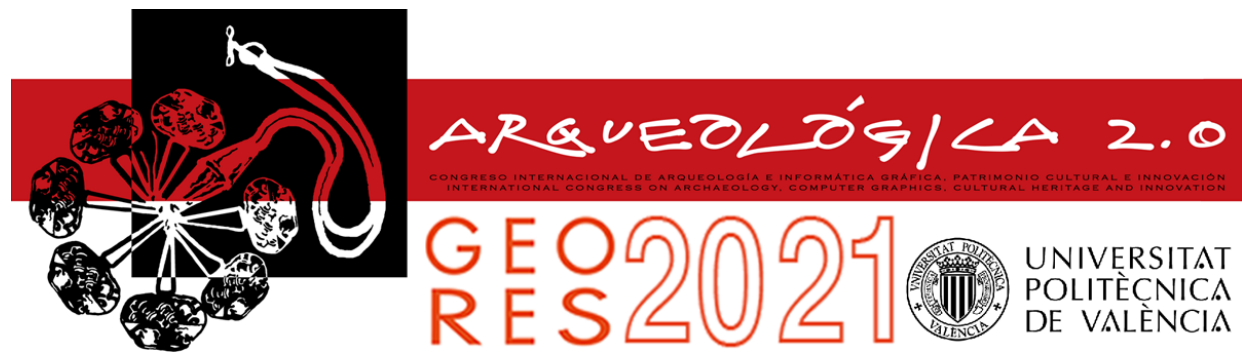

Proceedings of the joint international event $9^{\text {th }}$ ARQUEOLÓGICA

$2.0 \& 3^{\text {rd }}$ GEORES

Valencia (Spain).

26-28 April 2021

\title{
ACCESSIBILITY TO UNDERWATER CULTURAL HERITAGE: THE INTERACTIVE WEB NAVIGATION OF THE ROMAN SUBMERSED VESSEL OF CALA MINNOLA
}

\author{
Andrea Scianna a, ${ }^{a}$, Giuseppe Fulvio Gaglio ${ }^{a}$, Marcello La Guardiab \\ a ICAR-CNR (High Performance Computing and Networking Institute - National Research Council of Italy) at GISLab, via Ugo La Malfa \\ 153, 90146 Palermo, Italy. andrea.scianna@icar.cnr.it; gfulvio.gaglio@gmail.com \\ ${ }^{\mathrm{b}}$ Department of Engineering, Polytechnic School of University of Palermo, Viale delle Scienze, Edificio 10, 90128 Palermo, Italy. \\ marcellolaguardia87@libero.it
}

\begin{abstract}
:
The possibilities offered by photogrammetric reconstruction based on computer vision algorithms allowed in recent years to develop new interesting solutions for the spread and dissemination of knowledge on Cultural Heritage $(\mathrm{CH})$. In the same way, the recent technological development in the field of Virtual Reality (VR) has offered new possibilities for the creation of interactive virtual environments, which can be freely accessed via the browser using any type of device. These technologies acquire an additional relevance if applied to archaeological sites or monuments that are difficult to access, or even totally inaccessible, except by specialized personnel. In this case, the virtual fruition on the web becomes strategic for the valorization of $\mathrm{CH}$, as in the case of submerged archaeological sites, where the virtual tour represents in fact the only opportunity of diffuse accessibility. The present case shows the virtual reconstruction of the wreck area of the Roman ship found on the seabed of Cala Minnola on the island of Levanzo (TP, Italy). The model, obtained from a Structure from Motion (SfM) processing of a chunk of photos originally intended for a traditional photogrammetric survey, was edited and inserted into a specific template based on HTML5 and linked to Javascript libraries (Three.js) which allowed browsing on the web. Subsequently, the navigation model was suitability adapted to the purpose, in order to make the online virtualnavigation as intuitive as possible, considering the navigation with any type of device and using the most common browsers (Chrome, Safari, Firefox). This experimentation is a viable procedure for spreading the knowledge of a submerged archaeological site in a simple way, by web-browsing. This type of navigation models with the future development of $5 \mathrm{G}$ networks will find greater diffusion and application, with the possibility of including increasingly complex environments in the navigation.
\end{abstract}

Keywords: Survey, Cultural Heritage, 3D modelling, photogrammetry, WebGL, Virtual Reality

\section{Introduction}

The work reported in this article shows the potential and importance of online virtual fruition of inaccessible archaeological sites, in a period in which the enhancement of cultural heritage is particularly connected with the spread of knowledge regarding cultural goods (loannides et al., 2017). Advances in information technologies, applied in particular to survey and photogrammetric reconstruction techniques, now allow very realistic virtual reconstructions of real objects and environments (Banfi, 2020; Barrile, Fotia, Bilotta \& De Carlo, 2019; Scianna, Gaglio \& La Guardia, 2020; Masiero et al., 2019).

The importance of virtual visualization is now undisputed, as it allows visitors to observe, and, therefore, study objects of artistic and cultural value from new points of view. Moreover, thanks to it, it is possible to reach a much larger number of users, both for the entertainment character that distinguishes it, and because it allows access to visual and sensory information that is otherwise unreachable. The problem of accessibility to $\mathrm{CH}$, in fact, does not concern only those people with physical disabilities. In this regard, some archaeological sites, in fact, represent proper features that are not compliant with the accessibility to visitors, such as the presence of very fragile elements or parts that risk being easily altered. Furthermore, many sites are unreachable for most people, as they are located in particular, remote places, inside private property or because the paths to reach them make access to places too complicated (Dominici, Alicandro \& Massimi, 2017; Scianna \& La Guardia, 2019). This is the case, in particular, of submerged archaeological sites, which can only be reached in particular conditions and only by specialized personnel, and represents a challenging field for photogrammetric reconstructions (Skarlatos, Menna, Nocerino \& Agrafiotis, 
2019; Vlachos, Berger, Mathelier, Agrafiotis \& Skarlatos, 2019; Balletti, Beltrame, Costa, Guerra \& Vernier, 2015; Pacheco-Ruiz, Adams \& Pedrotti, 2018).

Therefore, the virtual model, in this case, represents a valid tool for the dissemination of knowledge (Skarlatos \& Agrafiotis, 2020; Liarokapis et al., 2017), as it is able to make users interact with three-dimensional contexts that represent real environments in other way not accessible. In this context, the aspect of sharing information on the network is a factor that today is becoming increasingly important due to the widespread use of mobile devices such as smartphones and tablets and the improvement of network connections. In our case, the possibilities offered by the WebGL JavaScript libraries, based on HTML5, allow showing three-dimensional contents in real-time and without the need to download client-side applications, making the sharing of cultural heritage easier and more immediate (Campanaro, Landeschi, Dell'Unto \& Touati, 2016; Scianna, La Guardia \& Scaduto, 2016; Mortara et al., 2014).

In the following sections of this article, a review of the advances in ITC technologies for $\mathrm{CH}$ will be initially shown, with particular reference to three-dimensional reconstructions and VR. Subsequently, the case study here presented, regards the reconstruction and dissemination on the network, with WebGL libraries, of the three-dimensional model of the underwater archaeological site of Cala Minnola, in Levanzo (TP, Italy). This model has been obtained from the photogrammetric reconstruction of a set of underwater images belonging to the Superintendence of the Sea of the Sicilian Region, originally intended for a traditional photogrammetric survey.

\section{Recent technological advances for $\mathrm{CH}$ sites (state of art)}

The use of virtual reality is now widespread in various fields, and in recent years, it has affected the world of Cultural Heritage. The digitization of Cultural Heritage is the basis of the new way of transmitting knowledge brought forward by new media technology (Bekele, Pierdicca, Frontoni, Malinverni \& Gain, 2018; Brovelli, Hogan, Minghini, \& Zamboni, 2013). This primary operation makes it possible to return information in different forms and for different purposes, satisfying the requirements of speed and immediacy and improving its usability. Applied to Cultural Heritage, Virtual Reality has in fact proved to be an interesting means for the reconstruction, preservation and safeguarding of works belonging to the past which have now been destroyed by time. The Digital Michelangelo project is an excellent example of the possibilities offered by this technique (Levoy et al., 2000). Great advantages have also been obtained in the digital reconstruction of damaged parts (Magnenat-Thalmann \& Papagiannakis, 2005) or in the support of restoration interventions, as in the case of Bamyan's Buddah (Grün, Remondino \& Zhang, 2004). Furthermore, the three-dimensionality and virtualization are capable of exploiting the emotions that images can arouse in the observer (Meschini, 2011). The immediate degree of understanding of images compared to language-based mediation alone has made these applications also very effective in the field of dissemination and cultural education (Carrozzino \& Bergamasco, 2010).
Archaeological sites, museums and art collections have long begun to rely on these technologies also to increase the involvement of the viewer and to offer more complete knowledge of what is observed. Interactive monitors, 3D printing, mobile applications, consoles with threedimensional reconstructions and augmented reality, therefore, aim to increase interest in culture in an innovative way (Ballarin, Balletti \& Vernier; 2018; Fernández-Palacios, Morabito \& Remondino, 2017; Becattini et al., 2016). These technologies have also allowed exhibiting objects from collections that cannot normally be shown due to fragility or limited space available. Making use of virtuality, therefore, offers the possibility of interacting with objects in the collection even at a distance, thus involving a greater number of users, including disabled people and students (Scianna \& Di Filippo, 2019; Walczak, Cellary \& White, 2006). The virtual movement to other places for temporary exhibitions is also possible, as in the case of the exhibition of the Vietnamese Treasury in Germany in 2016 (Kersten, 2018).

However, special equipment and space dedicated to them are often required, as in the case of the CINECA Virtual Theater (Farella, Brunelli, Benini, Ricco \& Bonfigli, 2005). VR applied to $\mathrm{CH}$ offers two possibilities of Virtual Museum reconstruction. In fact, it is possible to produce both virtual reconstructions of existing museums, including all the objects in the collection, and reconstructions of places that no longer exist, strongly deteriorated or difficult to access to allow the public to use them easily (Lepouras \& Vassilakis, 2005). The latter case is of particular importance precisely because of the precious possibility to share visual information of places that cannot be any longer visited in reality. In particular, virtuality has proved very useful in the reconstruction of submerged archaeological sites, considering their strong limitations of real accessibility. The remains from the ancient marine trade, a great testimony to the cultural exchange of peoples in the Mediterranean, are in fact unreachable by the vast majority of the public and the possibility of disseminating their knowledge on a large scale has always interested researchers in the sector. In this field, photogrammetric reconstruction techniques have been applied to nautical archaeology since the 1960s, when photography was used in submerged sites as a recording, documentation and cataloguing tool. The first photogrammetric surveys used a manual process of measuring and observing images in order to recreate models (Bass, 1966).

The development of computer science subsequently made it possible to speed up and automate most of the reconstruction operations. In this way, underwater photogrammetry has become both more powerful and accessible, as demonstrated by the reconstruction of the remains of Dolia in the Meloria Shoals (Canciani, Gambogi, Romano, Cannata \& Drap, 2003). To date, current software, using algorithms based on Structure from Motion (SfM), allow the three-dimensional automatic reconstruction of the detected environments, limiting the effect of the refraction of the sea and calculating the relative position of the cameras. Underwater photogrammetry, therefore, presents itself as a powerful tool capable of supporting archaeology, avoiding significant invasive strategies that could alter a site characterized by cultural relevance. Hence, this technology, in the context of the study of submerged 
historical finds, allows acquiring geometrical information necessary to share a relevant part of the Cultural Heritage not accessible for the majority of users (Menna, Agrafiotis, \& Georgopoulos, 2018; Yamafune, Torres \& Castro, 2017). The wreck of Cala Minnola, a case study presented in this article, was also the subject of experimentation within the VISAS project, dedicated to the enhancement and virtual use of underwater archaeological sites (Bruno et al., 2017). In fact, an application was created that allows you to navigate within a virtual environment, reproducing in detail the real conditions of the site. Navigation involves the use of 3D monitors, related glasses and a multi-touch tablet for movement. In this case, therefore, necessary to make use of special tools and to install the necessary required software.

Otherwise, the recent possibility of sharing virtual representations also on the web has offered the opportunity to create several applications, where it is possible to navigate within increasingly engaging 3D environments, using devices that are easily accessible to the majority of the public.

In fact, it is possible to follow pre-established routes inside a touristic path, or to customize the virtual visit by choosing individual preferences. The ARCO project allows, for example, managing virtual exhibitions with the contribution of Augmented Reality (AR) technology (White et al., 2004). Remote archaeological sites, excavation activities or lost collections can thus be explored easily by users, offering them a deep knowledge of the cultural goods (Bruno et al., 2010). Dissemination via a web browser represents a tool for broad information sharing in a period of great diffusion of portable devices. It is now increasingly simple and natural to access information on the web through portable devices like smartphones and tablets than through PCs, used almost only for longer and more complex operations. In particular, today, through the development of WebGL, specific JavaScript libraries based on HTML5 models, it is possible to develop effective solutions for the creation of virtual three-dimensional environments freely real-time navigable on the web in an interactive way (Scianna, La Guardia \& Scaduto, 2016). Solutions particularly followed in the development of video games, such as the firstperson interactive navigation of online virtual environments, have proved to be very effective in involving the user in the exploration of a cultural site (Scianna \& La Guardia, 2018). The use of these technologies results to be smart, because allows users to easily discover virtual 3D environments on the web without the need to install applications on the client-side.

These considerations led to the development of the model described in the following paragraphs. Through advanced photogrammetric reconstruction techniques, 3D modelling and web development, the online interactive virtual reconstruction of the underwater archaeological site of Cala Minnola was developed, making a part of Italian cultural heritage currently accessible only to specialized personnel perfectly navigable and virtually explorable in the first person.

\section{The experimentation}

The creation of the virtual navigation model of the submerged archaeological site located close to Cala
Minnola, in the Sicilian island of Levanzo, follows a complex procedure (Fig. 1), starting from the acquisition of historical documentation and ending with the porting of the virtual navigation model on different kind of devices.

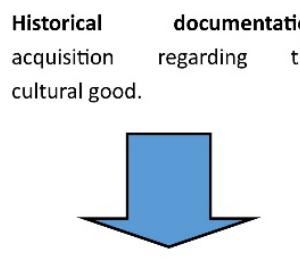

Survey operations based on images and Ground Control Points acquisition

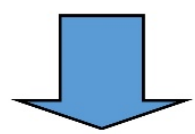

Digital Photogrammetric Reconstruction based on $\mathrm{SFM}$ algorithms

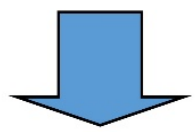

WebGL implementation of the 3D model inside a virtual environment, using proper lavascript strings inside the. $\mathrm{html}$ webpage.
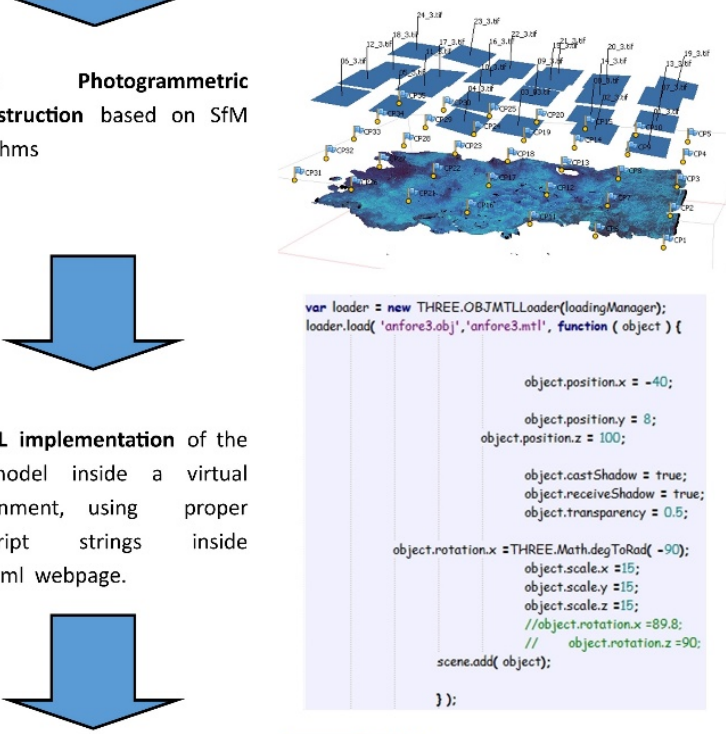

Oprtimization of the 3D environment navigation model, testing the web-browsing on different kind of devices.
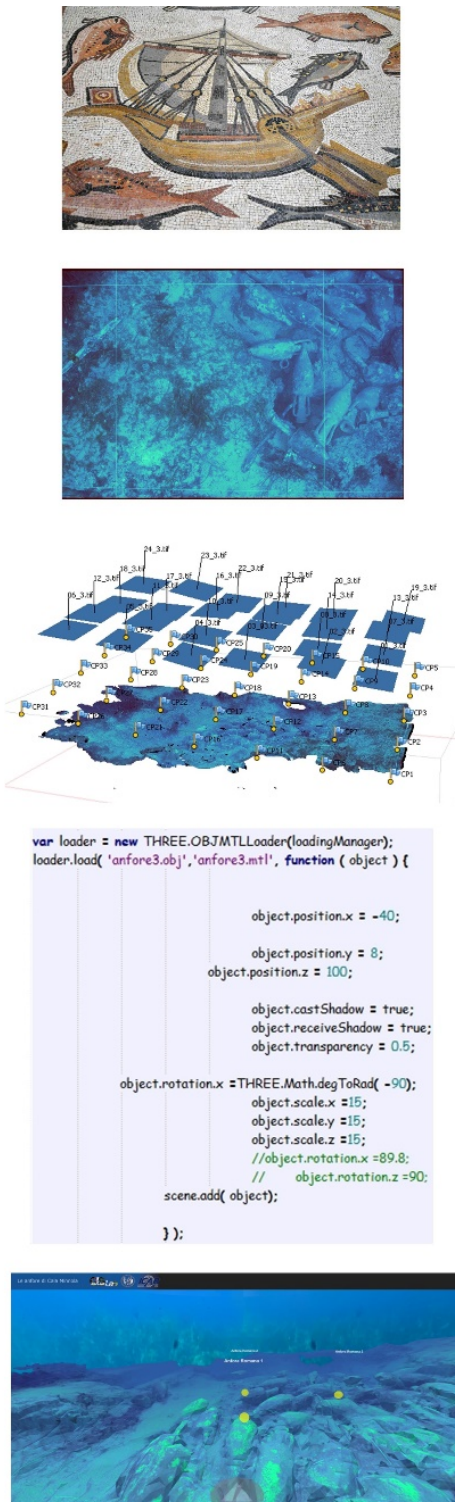

Figure 1: The workflow for the creation of the virtual interactive navigation model.

Firstly, the acquisition of historical background is the base of the research, because it gives the main information necessary for the development of the virtual navigation model and outlines the main archaeological finds to focus. The second phase that consists of survey operations, as affirmed before, was originally intended for a traditional photogrammetric survey. Anyway, the considered dataset contains the necessary information to test this methodology, allowing the digital photogrammetric reconstruction of the considered seabed. The next phase consists of the digital photogrammetric reconstruction of the model, considering a proper network of Ground Control Points (GCP). Once obtained the 3D model, the building of the virtual environment on the web represents the further step of the workflow, where the 3D model should be adapted for the web browsing and every component of the scene should be implemented into the 
webpage using WebGL JavaScript libraries. In the end, the final navigation model should be tested considering the most used browsers for mobile (tablets and smartphones) and PC devices. Every step of the workflow is described below in the following paragraphs.

\subsection{The wreck of Cala Minnola}

The wreck of Cala Minnola is located in front of the island of Levanzo (TP) (Fig. 2), in the archipelago of the Egadi Islands, in Sicily. Discovered around 1970, the site preserves the remains of an ancient Roman ship at a depth of about 30 meters. The wreck, dating back to the $1^{\text {st }}$ century B.C., represents what remains of a Roman ship transporting wine amphorae near Punta Altarella, where the ruins of a factory for the processing of Garum were found.

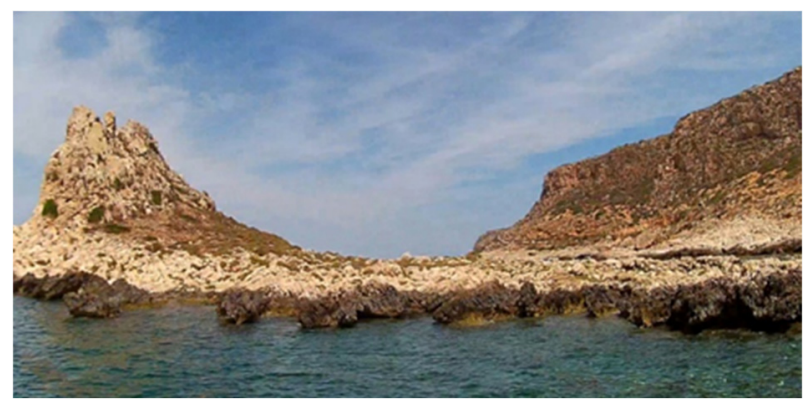

Figure 2: The Levanzo island (TP), Italy.

Further findings have occurred over the years during survey activities. In fact, about 50 amphorae and fragments of them were found, in addition to the wooden remains of the ship. The morphology of the site is quite particular, as it is surrounded by rather high rocks and largely covered with seagrass (Fig. 3).

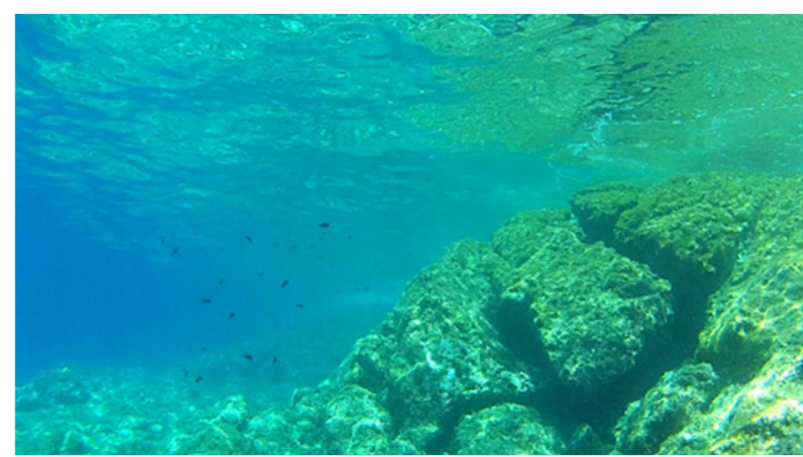

Figure 3: The composition of the seabed in the area of Cala Minnola.

\subsection{The photogrammetric reconstruction}

At the basis of the experimentation, images and measurements provided by a previous survey of the site were used, where the dataset available consisted of only 24 nadiral photos with a resolution of $3671 \times 2481$ pixels, covering a surface of about $96 \mathrm{~m}^{2}$. Each photo covered a specific area (Fig. 4) of the archaeological site of known size $(2 \mathrm{~m} \times 2 \mathrm{~m})$. The photos in question, despite being numerically reduced, were sufficient to reconstruct the archaeological area where the amphorae lie in three dimensions. Furthermore, the availability of a larger survey area would have been superfluous for the purposes of this experimentation, because the same procedure could be carried out with any dataset provided by a correct photogrammetric reconstruction. Otherwise, as explained below, the networking of $3 \mathrm{D}$ environments requires a strong simplification of the original model to optimize web navigation. Consequently, the acquisition of huge datasets of images covering is not ever useful for this aim.

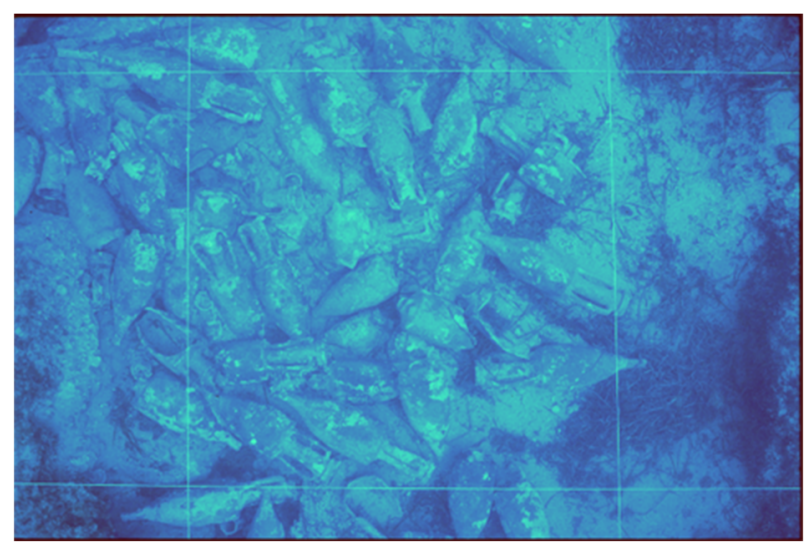

Figure 4: An example of the nadiral photos in the dataset.

The 3D reconstruction was performed using Agisoft Photoscan, a photogrammetric reconstruction software based on SfM algorithms, associating a network of 35 Ground Control Points (GCP) based on a local reference system of known targets (Fig. 5). The local coordinates of every target have been obtained considering the mutual position of the nodes of the $2 \mathrm{~m} \times 2 \mathrm{~m}$ grid used during survey operation. The digital photogrammetric reconstruction achieved a level of accuracy of $0,075 \mathrm{~m}$ (Table 1) of total error (the distance between source and estimated location for marker). This level of accuracy satisfies the requirements for the reconstruction of a $3 \mathrm{D}$ model finalized to the virtual fruition on web and for virtual dissemination of $\mathrm{CH}$, considering the dimensions of the dataset (24 images of 9 MP for $8 \mathrm{~m} \times 12 \mathrm{~m}$ surface) and the underwater conditions on 30 meters deep (problems of refraction and presence of suspensions in water). Furthermore, it's necessary to underline that the dataset wasn't originally obtained for digital photogrammetry reconstruction, but for a traditional photogrammetric survey.

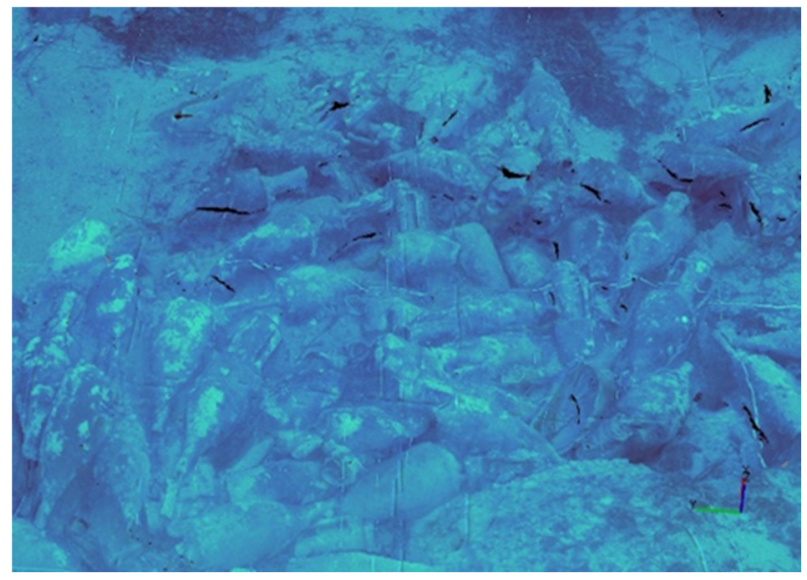

Figure 5: The result of the photogrammetric reconstruction of the site. 
Once generated the 3D reconstruction, the texture associated with the model has been corrected by calibrating the colours appropriately, in order to obtain a more realistic display during the web navigation.

Table 1: The positioning data and the errors found in the photogrammetric reconstruction phase.

\begin{tabular}{|c|c|c|c|c|}
\hline Markers & $X(m)$ & $Y(m)$ & $Z(m)$ & Error $(m)$ \\
\hline CP1 & 0.000 & 0.000 & 0.000 & 0.0761 \\
\hline CP2 & 2.000 & 0.000 & 0.000 & 0.0721 \\
\hline CP3 & 4.000 & 0.000 & 0.000 & 0.0726 \\
\hline CP4 & 6.000 & 0.000 & 0.000 & 0.1260 \\
\hline CP5 & 8.000 & 0.000 & 0.000 & 0.0852 \\
\hline CP6 & 0.000 & 2.000 & 0.000 & 0.0857 \\
\hline $\mathrm{CP} 7$ & 2.000 & 2.000 & 0.000 & 0.0565 \\
\hline CP8 & 4.000 & 2.000 & 0.000 & 0.0471 \\
\hline CP9 & 6.000 & 2.000 & 0.000 & 0.1042 \\
\hline CP10 & 8.000 & 2.000 & 0.000 & 0.0574 \\
\hline CP11 & 0.000 & 4.000 & 0.000 & 0.0893 \\
\hline CP12 & 2.000 & 4.000 & 0.000 & 0.0414 \\
\hline CP13 & 4.000 & 4.000 & 0.000 & 0.0445 \\
\hline CP14 & 6.000 & 4.000 & 0.000 & 0.0883 \\
\hline CP15 & 8.000 & 4.000 & 0.000 & 0.0832 \\
\hline CP16 & 0.000 & 6.000 & 0.000 & 0.1077 \\
\hline CP17 & 2.000 & 6.000 & 0.000 & 0.0248 \\
\hline CP18 & 4.000 & 6.000 & 0.000 & 0.0369 \\
\hline CP19 & 6.000 & 6.000 & 0.000 & 0.0843 \\
\hline CP20 & 8.000 & 6.000 & 0.000 & 0.1350 \\
\hline CP21 & 0.000 & 8.000 & 0.000 & 0.1181 \\
\hline CP22 & 2.000 & 8.000 & 0.000 & 0.0248 \\
\hline CP23 & 4.000 & 8.000 & 0.000 & 0.0415 \\
\hline CP24 & 6.000 & 8.000 & 0.000 & 0.0751 \\
\hline CP25 & 8.000 & 8.000 & 0.000 & 0.0842 \\
\hline CP26 & 0.000 & 10.000 & 0.000 & 0.1245 \\
\hline CP27 & 2.000 & 10.000 & 0.000 & 0.0460 \\
\hline CP28 & 4.000 & 10.000 & 0.000 & 0.0366 \\
\hline CP29 & 6.000 & 10.000 & 0.000 & 0.0666 \\
\hline CP30 & 8.000 & 10.000 & 0.000 & 0.0552 \\
\hline CP31 & 0.000 & 12.000 & 0.000 & 0.1001 \\
\hline CP32 & 2.000 & 12.000 & 0.000 & 0.0280 \\
\hline CP33 & 4.000 & 12.000 & 0.000 & 0.0642 \\
\hline CP34 & 6.000 & 12.000 & 0.000 & 0.0841 \\
\hline CP35 & 8.000 & 12.000 & 0.000 & 0.0461 \\
\hline Total Error & & & & 0.0758 \\
\hline
\end{tabular}

\subsection{The web visualization using WebGL libraries}

The 3D model, generated from the photogrammetric reconstruction, was properly simplified and adapted to web browsing, for the construction of the interactive navigation model. Virtual web navigation, in fact, requires the use of simplified 3D models, with the dimension not exceeding 10-15 MB, as seen in the data summary (Tables 2 and 3 ). More complex models, with a larger number of polygons, are not useful for web navigation, as they would crash the webpage. In light of this, the absence of the 3D model of the surrounding environment did not constitute a serious loss for navigation purposes, in fact, it would have been omitted to optimize performance during online viewing.

Table 2: Survey and Digital Photogrammetric reconstruction data. Summary of the process.

\begin{tabular}{c|c} 
Setting & Value \\
\hline Number of images & 24 \\
Image resolution & $3671 \times 2481$ pix \\
Surveyed area dimension & $8 \times 12 \mathrm{~m}$ \\
Number of GCP & 35 \\
$\begin{array}{c}\text { Level of Accuracy of } \\
\text { photogrammetric } \\
\text { reconstruction }\end{array}$ & $0-0.13 \mathrm{~m}$
\end{tabular}

Table 3: WebGL environment data. Summary of the process.

\begin{tabular}{c|c} 
Setting & Value \\
\hline Dimensions of the 3D mesh & $11.3 \mathrm{MB}$ \\
Texture resolution & $8192 \times 8192 \mathrm{pix}$ \\
$\begin{array}{c}\text { Background texture } \\
\text { resolution }\end{array}$ & $2672 \times 900$ pix
\end{tabular}

The surrounding environment, on the other hand, was reproduced by inserting a $360^{\circ}$ image of the underwater environment into the inner surface of a sphere. The spherical geometry contains the entire interior of the reconstructed model of the amphorae, so as to become the background displayed during web navigation (Fig. 6).

This solution offers a realistic visualization on the web, and, at the same time, doesn't oversize the dimension of the $3 \mathrm{D}$ model during the web-browsing with further geometric information of surrounding environments.

The spherical geometry and the reconstructed model generated inside Agisoft Photoscan software, were finally uploaded to the server in .obj format, and loaded into the main webpage, using the Javascript language and loading external WebGL libraries, necessary to visualize the environment online. Once the elements, to be displayed within the virtual environment, have been defined, it was necessary to study a simple and intuitive navigation system, for both desktop PCs and mobile devices (Fig. 7). Using the JavaScript WebGL libraries based on Three.js, a first-person navigation system was developed, which allowed the viewer to move freely along a horizontal plane, with the possibility of interacting through information popups along the way. The viewer is anchored to a sphere that can be pushed by the user by pressing the forward button. In this way, the sphere undergoes a force that moves the viewer in the direction 
chosen by the user along with an invisible horizontal plan with a proper coefficient of friction. Finally, effects were also included in the rendering phase, simulating the underwater environment to guarantee more realistic navigation.

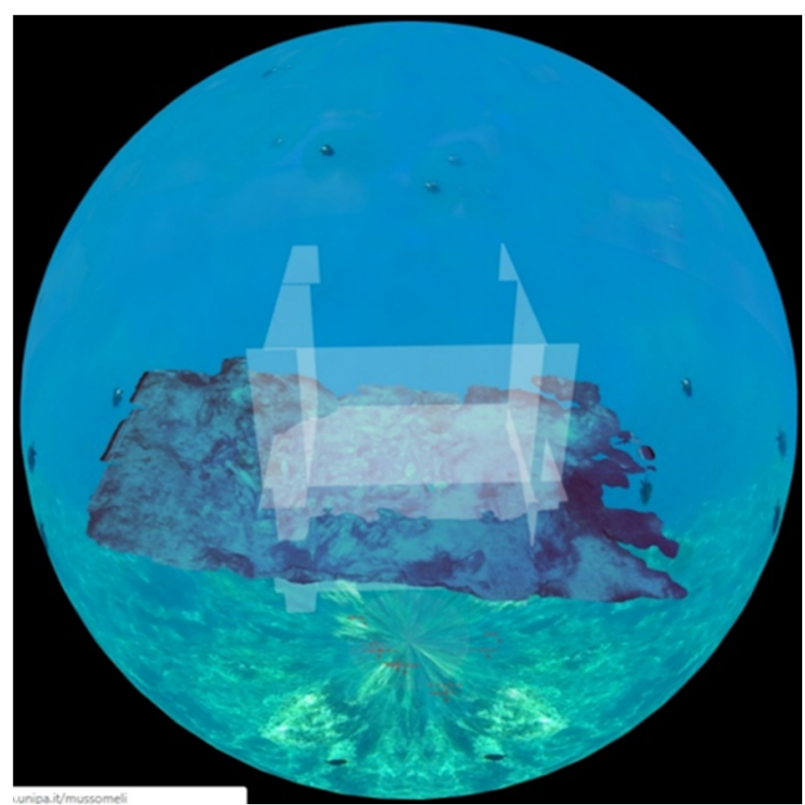

Figure 6: The architecture of the 3D environment. It's possible to notice the sphere that contains the entire environment and the transparent boundaries that limit navigation.

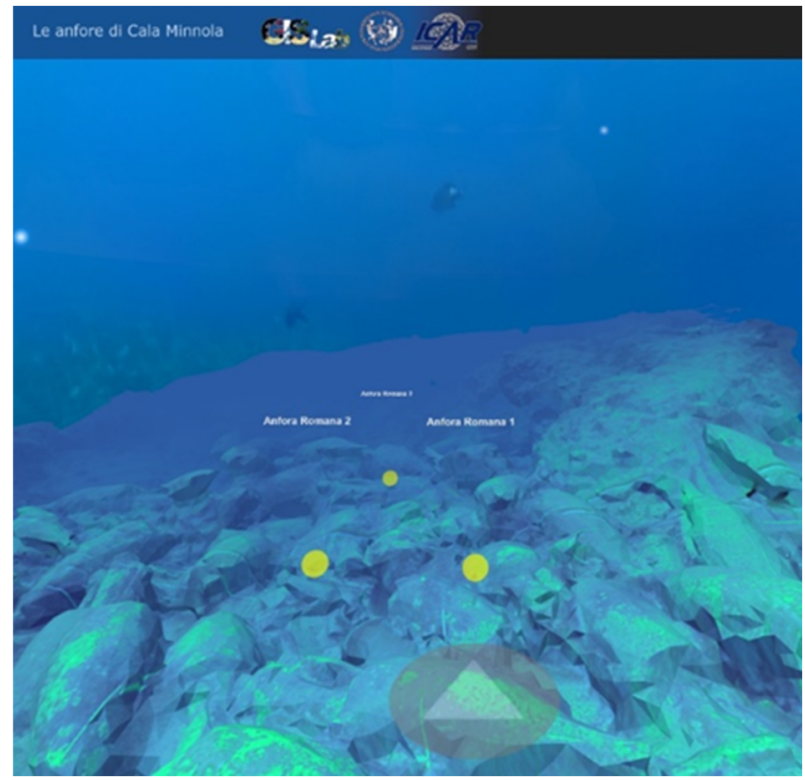

Figure 7: The online visualization of the interactive first-person navigation and the system of yellow popups along the path.

The structure of the $3 \mathrm{D}$ visualization and the navigation system have been implemented directly in the .html page, within links to external JavaScript libraries and JavaScript strings inside the same page. The system of popups placed along the 3D environments allowed users to click and open external html pages with further information about the site (Fig. 8).

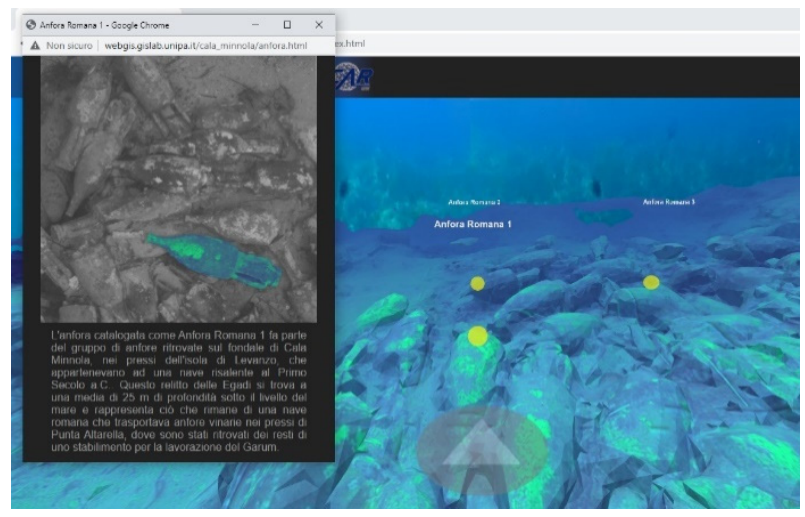

Figure 8: An example of the popups implemented in the web navigation model.

The web navigation model is freely online available, for both desktop PCs and mobile devices, on the GISLab Website using the following Link: http://webgis.gislab.unipa.it/cala_minnola/index.html.

\section{Conclusions and open scenarios}

The growing diffusion of devices, that allow access to information on the web from anywhere and at any time, has underlined the importance of sharing 3D models of cultural heritage and archaeological sites online, directly navigable, without the need to install any application. In this way, it is possible not only to facilitate disabled people to visit virtually an archaeological asset, but, in general, to offer anyone the opportunity to visit places that are otherwise difficult to access, enhancing their visibility. Although there are, still, some limitations mainly related to the size of the 3D models to be displayed, as highlighted by the case study, the use of the WebGL libraries constitutes a valid option for the online use of Cultural Heritage, as they allow you to discover virtual environments and 3D models directly through webbrowser. Obviously, virtual navigation cannot replace the real visit to the place of interest, but it certainly constitutes a powerful means of spreading knowledge and therefore arousing interest and curiosity. Therefore, online use is not, in any case, to be understood as a substitute factor for the real visit, but as an element of enhancement, which can act as a catalyst for the real use of the asset. In the future, the development of increasingly high-performance internet connections will broaden the possibilities already offered by the world of VR, allowing the insertion of increasingly complex and information-rich navigable environments.

\section{References}

Ballarin, M., Balletti, C., \& Vernier, P. (2018). Replicas In Cultural Heritage: 3d Printing And The Museum Experience. The International Archives of the Photogrammetry, Remote Sensing and Spatial Information Sciences, XLII-2, 55-62. https://doi.org/10.5194/isprs-archives-XLII-2-55-2018

Balletti, C., Beltrame, C., Costa, E., Guerra, F., \& Vernier, P. (2015). Underwater Photogrammetry And 3d Reconstruction Of Marble Cargos Shipwreck. The International Archives of the Photogrammetry, Remote Sensing and Spatial 
Information Sciences, XL-5/W5, 7-13. https://doi.org/10.5194/isprsarchives-XL-5-W5-7-2015

Banfi, F. (2020). HBIM, 3D drawing and virtual reality for archaeological sites and ancient ruins. Virtual Archaeology Review, 11(23), pp. 16-33. https://doi.org/10.4995/var.2020.12416

Barrile, V., Fotia, A., Bilotta, G., \& De Carlo, D. (2019). Integration of geomatics methodologies and creation of a cultural heritage app using augmented reality. Virtual Archaeology Review, 10(20), pp. 40-51. https://doi.org/10.4995/var.2019.10361

Bass, G. (1966). Archaeology under water. Bristol: Thames and Hudson.

Becattini, F., Ferracani, A., Landucci, L., Pezzatini, D., Uricchio, T., \& Del Bimbo, A. (2016). Imaging Novecento. A Mobile App for Automatic Recognition of Artworks and Transfer of Artistic Styles. loannides M. et al. (eds) Digital Heritage. Progress in Cultural Heritage: Documentation, Preservation, and Protection. EuroMed 2016. Lecture Notes in Computer Science, 10058. Springer, Cham. https://doi.org/10.1007/978-3-319-48496-9_62

Bekele, M. K., Pierdicca, R., Frontoni, E., Malinverni, E. S., \& Gain, J. (2018). A Survey of Augmented, Virtual, and Mixed Reality for Cultural Heritage. Journal on Computing and Cultural Heritage, 11(2). https://doi.org/10.1145/3145534

Brovelli, M. A., Hogan, P., Minghini, M., \& Zamboni, G. (2013). The power of Virtual Globes for valorising cultural heritage and enabling sustainable tourism: NASA World Wind applications. International Archives of the Photogrammetry, Remote Sensing and Spatial Information Sciences, XL-4/W2, 115-120. https://doi.org/10.5194/isprsarchives-XL-4W2-115-2013

Bruno, F., Bruno, S., De Sensi, G., Luchi, M.L., Mancuso, S., \& Muzzupappa, M. (2010). From 3D reconstruction to virtual reality: A complete methodology for digital archaeological exhibition. Journal of Cultural Heritage, 11, 42-49. https://doi.org/10.1016/j.culher.2009.02.006

Bruno, F., Lagudi, A., Barbieri, L., Muzzupappa, M., Mangeruga, M., Pupo, F., Cozza, M., Cozza, C., Ritacco, G., Peluso, R., \& Tusa, S. (2017). Virtual Diving In The Underwater Archaeological Site Of Cala Minnola. The International Archives of the Photogrammetry, Remote Sensing and Spatial Information Sciences, XLII-2/W3, $121-126$. https://doi.org/10.5194/isprs-archives-XLII-2-W3-121-2017

Campanaro, D. M., Landeschi, G., Dell'Unto, N., \& Touati, A. M. L. (2016). 3D GIS for cultural heritage restoration: A 'white box' workflow. Journal of Cultural Heritage, 18, pp. 321-332. https://doi.org/10.1016/j.culher.2015.09.006

Canciani, M., Gambogi, P., Romano, F., Cannata, G., \& Drap, P. (2003). Low cost digital photogrammetry for underwater archaeological site survey and artifact isertion. The case study of the Dolia wreck in Secche della Meloria-LivornoItalia. ISPRS Workshop Vision Tecniques for digital architectural and archaeological archives, Jul 2003, Portugal. 〈halshs-00271413〉

Carrozzino, M., \& Bergamasco, M. (2010). Beyond virtual museums: Experiencing immersive virtual reality in real museums. Journal of Cultural Heritage, 11(4), 452-458. https://doi.org/10.1016/j.culher.2010.04.001

Dominici, D., Alicandro, M. \& Massimi V. (2017). UAV photogrammetry in the post-earthquake scenario: case studies in L'Aquila. Geomatics, Natural Hazards and Risk, 8(1), 87-103. https://doi.org/10.1080/19475705.2016.1176605

Farella, E., Brunelli, D., Benini, L., Ricco B.\& Bonfigli, M. E. (2005). Pervasive computing for interactive virtual heritage. IEEE MultiMedia, 12(3), pp. 46-58, July-Sept. https://doi.org/10.1109/MMUL.2005.54

Fernández-Palacios, B. J., Morabito, D., Remondino, F. (2017). Access to complex reality-based 3D models using virtual reality solutions. Journal of Cultural Heritage, 23, 2017, pp. 40-48. https://doi.org/10.1016/j.culher.2016.09.003

Grün, A., Remondino, F., \& Zhang, L. (2004). Photogrammetric reconstruction of the great Buddha of Bamiyan, Afghanistan. The Photogrammetric Record, 19(107), 177-199. https://doi.org/10.1111/j.0031-868X.2004.00278.x

Ioannides, M., Davies, R., Chatzigrigoriou, P., Papageorgiou, E., Leventis, G., Nikolakopoulou, V., \& Athanasiou, V. (2017). 3D Digital Libraries and Their Contribution in the Documentation of the Past. Ioannides M., Magnenat-Thalmann N., Papagiannakis G. (Eds) Mixed Reality and Gamification for Cultural Heritage. Springer, Cham. https://doi.org/10.1007/978-3-319-49607-8_6

Kersten, T. P. (2018). 3D Models and Virtual Tours for a Museum Exhibition of Vietnamese Cultural Heritage Exhibits and Sites. Ioannides M. et al. (Eds) Digital Heritage. Progress in Cultural Heritage: Documentation, Preservation, and Protection. EuroMed 2018. Lecture Notes in Computer Science, 11196. Springer, Cham. https://doi.org/10.1007/9783-030-01762-0_46

Lepouras, G., \& Vassilakis, C. (2005). Virtual museums for all: employing game technology for edutainment. Virtual Reality 8(2), 96-106, ISSN 1359-4338

Levoy, M., Pulli, K., Curless, B., Rusinkiewicz, S., Koller, D., Pereira, L., Ginzton, M., Anderson, S., Davis, J., Ginsberg, J., Shade, J., \& Fulk, D. (2000). The digital Michelangelo project: 3D scanning of large statues. Proceedings of the 27th annual conference on Computer graphics and interactive techniques, pp. 131-144. ACM Press/Addison-Wesley Publishing Co. https://doi.org/10.1145/344779.344849

Liarokapis, F., Kouřil, P., Agrafiotis, P., Demesticha, S., Chmelík, J., \& Skarlatos, D. (2017). 3d Modelling And Mapping For Virtual Exploration Of Underwater Archaeology Assets. The International Archives of the Photogrammetry, 
Remote Sensing and Spatial Information Sciences, XLII-2/W3, 425-431. https://doi.org/10.5194/isprs-archives-XLII2-W3-425-2017

Magnenat-Thalmann, N., \& Papagiannakis, G. (2005). Virtual worlds and augmented reality in cultural heritage applications. Recording, modeling and visualization of cultural heritage, 419-430.

Masiero, A., Chiabrando, F., Lingua, A. M., Marino, B. G., Fissore, F., Guarnieri, A., \& Vettore, A. (2019). 3d Modeling Of Girifalco Fortress. The International Archives of the Photogrammetry, Remote Sensing and Spatial Information Sciences, XLII-2/W9, 473-478. https://doi.org/10.5194/isprs-archives-XLII-2-W9-473-2019

Meschini, A. (2011). Tecnologie digitali e comunicazione dei beni culturali. Stato dell'arte e prospettive di sviluppo. Disegnarecon, 4(8), 14-24. https://doi.org/10.6092/issn.1828-5961/2565

Menna, F., Agrafiotis, P., \& Georgopoulos, A. (2018). State of the art and applications in archaeological underwater 3D recording and mapping. Journal of Cultural Heritage, 33, 231-248. https://doi.org/10.1016/j.culher.2018.02.017

Mortara, M., Catalano, C. E., Bellotti, F., Fiucci, G., Houry-Panchetti, M., \& Petridis, P. (2014). Learning cultural heritage by serious games. Journal of Cultural Heritage, 15(3), 2014, pp. 318-325, https://doi.org/10.1016/j.culher.2013.04.004

Pacheco-Ruiz, R., Adams, J., \& Pedrotti, F. (2018). 4D modelling of low visibility Underwater Archaeological excavations using multi-source photogrammetry in the Bulgarian Black Sea. Journal of Archaeological Science, 100, $2018, \mathrm{pp}$. 120-129, ISSN 0305-4403. https://doi.org/10.1016/j.jas.2018.10.005

Scianna, A., Gaglio, G. F., \& La Guardia, M. (2020). Digital Photogrammetry, Tls Survey And 3d Modelling For Vr And Ar Applications In Ch. The International Archives of the Photogrammetry, Remote Sensing and Spatial Information Sciences, XLIII-B2-2020, 901-909. https://doi.org/10.5194/isprs-archives-XLIII-B2-2020-901-2020

Scianna, A., La Guardia, M. (2019). Survey and Photogrammetric Restitution of Monumental Complexes: Issues and Solutions-The Case of the Manfredonic Castle of Mussomeli. Heritage 2019, 2, 774-786. https://doi.org/10.3390/heritage2010050

Scianna, A., \& La Guardia, M. (2018). 3D Virtual CH Interactive Information Systems for a smart web browsing experience for desktop PCs and mobile devices. The International Archives of the Photogrammetry, Remote Sensing and Spatial Information Sciences, XLII-2, 1053-1059. https://doi.org/10.5194/isprs-archives-XLII-2-1053-2018.

Scianna A., La Guardia M., \& Scaduto M.L. (2016). Definition of a Workflow for Web Browsing of 3D Models in Archaeology. loannides M. et al. (eds) Digital Heritage. Progress in Cultural Heritage: Documentation, Preservation, and Protection. EuroMed 2016. Lecture Notes in Computer Science, vol 10059. Springer, Cham. https://doi.org/10.1007/978-3-319-48974-2_6

Skarlatos D., \& Agrafiotis P. (2020). Image-Based Underwater 3D Reconstruction for Cultural Heritage: From Image Collection to 3D. Critical Steps and Considerations. Liarokapis F., Voulodimos A., Doulamis N., Doulamis A. (eds) Visual Computing for Cultural Heritage. Springer Series on Cultural Computing. Springer, Cham. https://doi.org/10.1007/978-3-030-37191-3_8

Skarlatos, D., Menna, F., Nocerino, E., \& Agrafiotis, P. (2019). Precision Potential Of Underwater Networks For Archaeological Excavation Through Trilateration And Photogrammetry. The International Archives of the Photogrammetry, Remote Sensing and Spatial Information Sciences, XLII-2/W10, 175-180, https://doi.org/10.5194/isprs-archives-XLII-2-W10-175-2019

Vlachos, M., Berger, L., Mathelier, R., Agrafiotis, P., \& Skarlatos, D. (2019). Software Comparison For Underwater Archaeological Photogrammetric Applications. The International Archives of the Photogrammetry, Remote Sensing and Spatial Information Sciences, XLII-2/W15, 1195-1201. https://doi.org/10.5194/isprs-archives-XLII-2-W15-11952019

Walczak, K., Cellary, W., \& White, M. (2006). Virtual museum exbibitions. Computer, 39(3), 93-95. https://doi.org/10.1109/MC.2006.108

White, M., Mourkoussis, N., Darcy, J., Petridis, P., Liarokapis, F., Lister, P., Walczak, K., Wojciechowski, R., Cellary, W., Chmielewski, J., Stawniak, M., Wiza, W., Patel, M., Stevenson, J., Manley, J., Giorgini, F., Sayd, P. Gaspard, F. (2004). ARCO_An Architecture for Digitization, Management and Presentation of Virtual Exhibitions. Proceedings Computer Graphics International, 622-625. https://doi.org/10.1109/CGI.2004.1309277

Yamafune, K., Torres, R., \& Castro, F. (2017). Multi-Image Photogrammetry to Record and Reconstruct Underwater Shipwreck Sites. Journal of Archaeological Method and Theory, 24(3), 703-725. https://doi.org/10.1007/s10816-0169283-1 


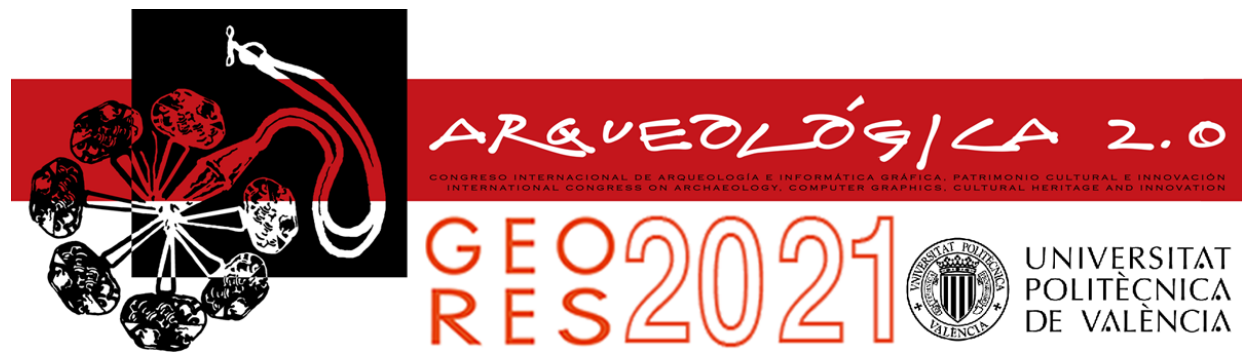

Proceedings of the joint international event $9^{\text {th }}$ ARQUEOLÓGICA

$2.0 \& 3^{\text {rd }}$ GEORES

Valencia (Spain).

26-28 April 2021

\title{
GEOMATICS ADVANCED IMAGE-BASED TECHNIQUES FLANKING ARCHAEOLOGICAL RESEARCH. A NOTEWORTHY AREA IN THE NORTHERN NECROPOLIS OF HIERAPOLIS OF FRIGIA (TK)
}

\author{
Lorenzo Teppati Losè ${ }^{a,},{ }^{,}$Antonia Spanòa, Anna Anguissola ${ }^{b}$ \\ ${ }^{a}$ Laboratory of Geomatics for Cultural Heritage $(\mathrm{G} 4 \mathrm{CH})$, Department of Architecture and Design (DAD), Politecnico di Torino, Viale \\ Mattioli 39, 10125 Torino, Italy. Iorenzo.teppati@polito.it; antonia.spano@polito.it \\ b Department of Civilizations and Forms of Knowledge, University of Pisa, Via dei Mille 19, 56126 Pisa, Italy. anna.anguissola@unipi.it
}

\begin{abstract}
:
The paper relates the studies aimed at experimenting with aerial and terrestrial methods of rapid mapping survey applied in an archaeological context, and at evaluating the effectiveness of their results in relation to the purposes of archaeological researches. Different UAV (Unmanned aerial vehicle) and $360^{\circ}$ camera data acquisition and processing strategies are reported and discussed. The integration and fusion approaches have been investigated taking advantages of coregistration approaches. Archaeologists from the University of Pisa have investigated areas of the northern necropolis at Hierapolis since 2017, exploring the arrangement and use of Roman sarcophagi in their architectural context. Thanks to a full review of the archaeological and epigraphic evidence from Tomb 159c, and thanks to the high detailed 3D models and high-resolution orthophotos derived with geomatics techniques, it has been possible to reconstruct patterns and changes in ownership, use, and movement in a significant section of the necropolis across three centuries.
\end{abstract}

Keywords: archaeological heritage, UAVs, SfM, spherical photogrammetry

\section{Introduction}

The research objectives were directed towards the study of the applicability of the rapid mapping survey approaches, within a complex archaeological context such as that of the city of Hierapolis of Phrygia. This methodological aspect was combined with the need for continuous documentation of the excavations and archaeological studies on the ancient city.

In relation to its size, the site of Hierapolis boasts one of the largest concentrations of graves known in the Roman world. Some 600 monumental tombs with a remarkable variety of architectural types have been identified north, east, and south of the ancient city, ranging from the $2^{\text {nd }}$ century BCE to Late Antiquity. Scattered between the monuments, marble and stone sarcophagi are almost everywhere, from the city limits to the top of the hills.

Researchers from the University of Pisa have been investigating the burial grounds of Hierapolis since 2008 (Anguissola, Bochicchio, Calabrò, \& Costa, 2012; 2013; 2014 ; 2016), aiming at a contextual study of both their funerary monuments and sarcophagi. In a broader perspective, this program aims at initiating a more articulate discussion on Roman funerary practices in light of individual, exceptionally informative case studies. During the 2017-2019 campaigns, attention focused on an area in the Northern necropolis where monuments and sarcophagi seem to have clustered for centuries, causing a series of changes both in the layout of the burial ground and in the road system across it.

In order to fully understand the layout and the history of this area, advanced survey techniques were required to assist in the archaeological, architectural, epigraphical, and art-historical investigations. Firstly, it seemed necessary to survey and map a larger area than direct, unassisted methods would allow. Secondly, the scope of the research called for highly detailed images and comprehensive data-sets, able to account for the features of the terrain (altitude, slopes, passages, staircases, terraces, aligned buildings which may indicate earlier road systems)

\section{Data acquisition. Consolidated and experimental approaches}

As presented in the introduction to this paper, survey campaigns in the Northern Necropolis of Hierapolis are part of a wider project of documentation developed thanks to different field campaigns completed during the last years in the Turkish archaeological site. A first approach to the documentation of this area was completed in 2015 by mean of a UAV fixed-wing platform (Chiabrando, D'Andria, Sammartano, \& Spanò, 2018). Only a small

`Corresponding Author: Lorenzo Teppati Losè, Iorenzo.teppati@polito.it 
portion of the Northern Necropolis was acquired in this first UAVs flight (the southern part). The flights performed were aimed at documenting a large area of the archaeological site with the accuracies and level of detail proper for an overview investigation (1:200/1:500 nominal scale).

The second step in the process of documentation was accomplished in the 2017 campaign. In this campaign, all the area of the Northern Necropolis was included in a dedicated UAVs medium-altitude acquisition (40-50 meters flight altitude), with a multi-rotor platform, to reach a higher level of details in comparison with the 2015 flight and with higher overall accuracy. Finally, part of the 2018 field campaign was devoted to the documentation of a smaller section of the necropolis, the area included between tomb 163 and 159d. It is in this area (highlighted in Figure 1, together with the area acquired in 2017) that archaeologists from the University of Pisa focused their investigation.

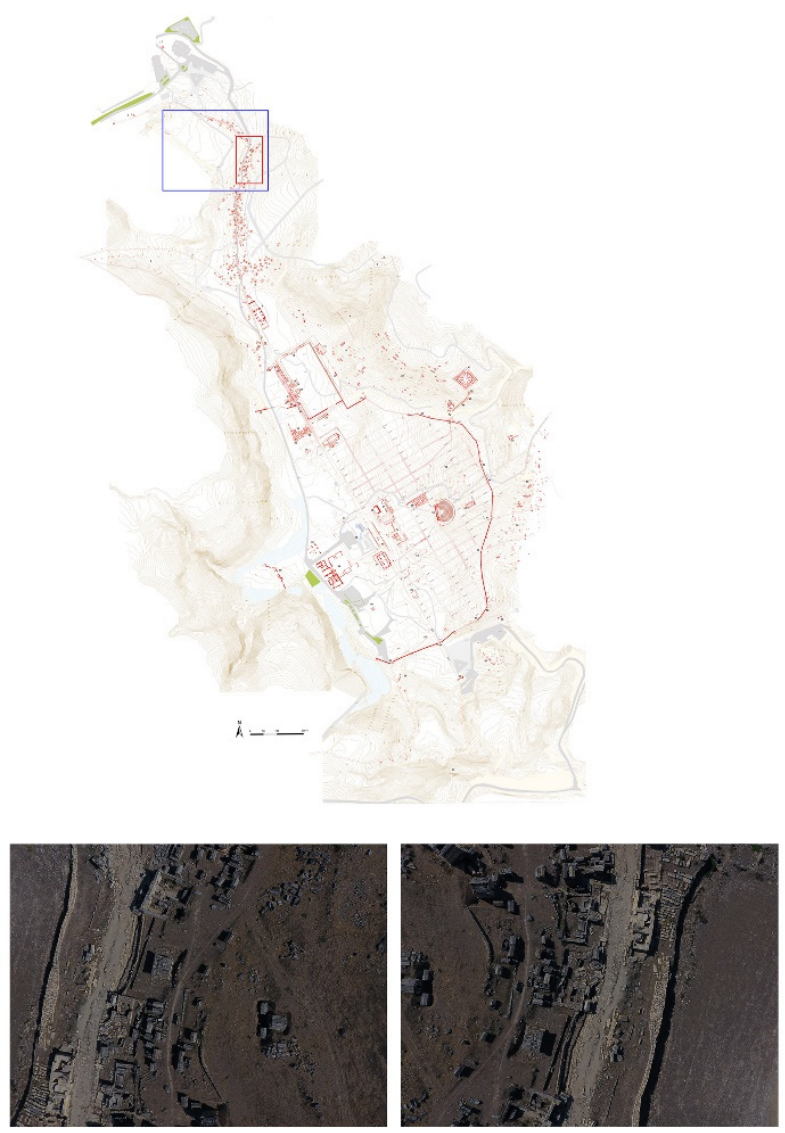

Figure 1: Northern Necropolis of Hierapolis, the area acquired in 2017 is highlighted in blue while the area acquired in 2018 is highlighted in red (from D'Andria, Scardozzi, \& Spanò, 2008). Below an example of two images acquired in 2017.

In the 2018 field campaign, different geomatic techniques were deployed to achieve a complete and high detail multi-scale and multi-sensor documentation of this area. Both consolidated and more experimental approaches were thus adopted in the field, with the aim of testing also rapid mapping approaches by mean of COTS (Commercial Off The Shelf) sensors in parallel with more established techniques. The area was firstly imaged with manually operated low altitude UAV flights; a series of TLS (Terrestrial Laser Scanner) acquisitions were completed and finally, acquisitions with a $360^{\circ}$ camera were performed as well (some acquisitions with a handheld laser scanner based on SLAM - Simultaneous Localization And Mapping technology were achieved, but they will not be referred to in the present paper).

In particular, the use of $360^{\circ}$ cameras for the documentation of cultural heritage has quite a long history in the geomatics community (D'Annibale, Piermattei, \& Fangi, 2011; Fangi \& Nardinocchi, 2013), however, thanks to the development of SfM (Structure from Motion) algorithms and the availability of new low-cost $360^{\circ}$ systems it has gained new interest in the last years (Fangi, Pierdicca, Sturari, \& Malinverni, 2018; Gottardi \& Guerra, 2018; Ramos \& Prieto, 2016), opening new research addresses.

It should be noted that in all the campaigns completed in the site of Hierapolis of Phrygia the metric control and the georeferencing of all the acquisitions in the same coordinate system was guaranteed thanks to the measurement of different sets of control points in the field by mean of traditional topographic techniques (e.g. total station and GNSS). This operation was made possible by the network of topographic vertices that had been created, measured, and integrated in the archaeological site during the past decades (D'Andria, Scardozzi, \& Spanò, 2008), and that has been useful also for topographical measurements performed by other teams (Scardozzi, 2015).

For the purposes of the research presented in this manuscript, the focus will be on medium-altitude UAV photogrammetric surveys and $360^{\circ}$ camera acquisitions, and on possible approaches to integrating them. Moreover, not all the employed and tested techniques will be discussed.

\subsection{The northern necropolis rapid mapping general documentation (2017 acquisitions)}

Part of the 2017 field campaigns was thus dedicated to integrating and updating the data collected on the Northern Necropolis in 2015. The main aim of these acquisitions was to achieve complete coverage of all the necropolis with UAVs flights at a medium altitude to generate metric products of this area at a large scale (1:100/1:200): namely 3D model, DSM (Digital Surface Model) and orthophoto. The experience gained in previous researches dedicated to the optimization of the flight planning phases for UAVs acquisition in archaeological and architectural contexts (Chiabrando, Lingua, Maschio, \& Teppati Losè, 2017; Chiabrando \& Teppati Losè, 2017) as well as other researches available in the literature (e.g. Hernández-Lopez, Felipe-Garcia, Gonzalez-Aguilera, \& Arias-Perez, 2013; Nex \& Remondino, 2014; Remondino, Barazzetti, Nex, Scaioni, \& Sarazzi, 2012) allowed to complete all the acquisition phases for the area of interest $\left(\approx 0.2 \mathrm{~km}^{2}\right)$ in few hours, including also the phase of control points positioning and measurement.

In 2017 a total number of five flights were performed on the area of the Northern Necropolis:

- Three nadiral flights were completed with an orientation of the flight lines that followed the main urban organization of buildings and its road network. These flights aimed also to include a 
wider part of the area around the necropolis' monuments to define the terrain and the environment in which the tombs insist.

- Two oblique acquisitions were integrated into the area where the concentration of monuments is higher, in order to achieve a higher detail in terms of completeness of the geometrical reconstruction. Flight lines of these flights were designed to be interconnected with the other three nadiral flights.

An overview of the flight plans completed in this area in 2017 is shown in Figure 2, while the main parameters of the five flights are reported in Table 1.
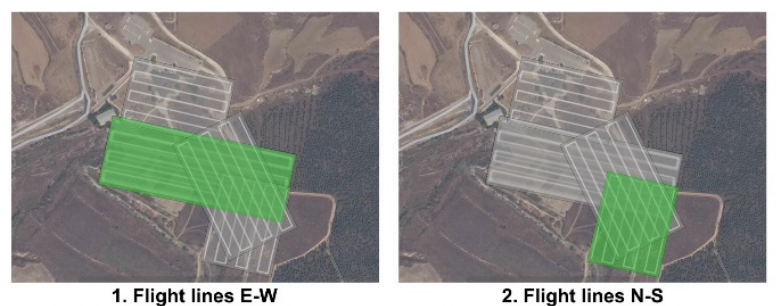

Nadrial configuration of camera

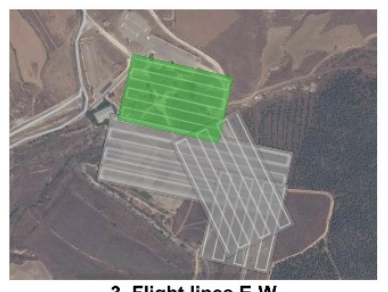

3. Flight lines E-W Nadrial configuration of camera
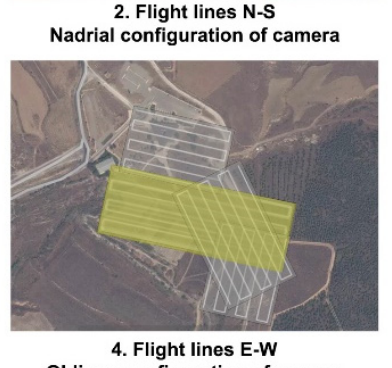

Oblique configuration of camera

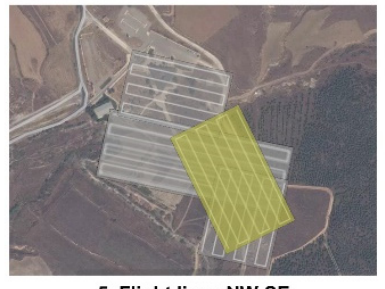

5. Flight lines NW-SE

Oblique configuration of camera

Figure 2: Northern Necropolis of Hierapolis. 2017 flight planning and camera orientation.

Table 1: Northern Necropolis of Hierapolis. 2017 flights main characteristics.

\begin{tabular}{c|c|c|c|c}
$I D$ & $\begin{array}{c}N^{\circ} \\
\text { Images }\end{array}$ & $\begin{array}{c}\text { Camera } \\
\text { configuration }\end{array}$ & $\begin{array}{c}\text { Flight time } \\
(\text { min })\end{array}$ & $\begin{array}{c}\text { Flight } \\
\text { altitude }(\mathrm{m})\end{array}$ \\
\hline 1 & 215 & Nadir & 10 & $40-50$ \\
2 & 115 & Nadir & 6 & $40-50$ \\
3 & 127 & Nadir & 6 & $40-50$ \\
4 & 159 & Oblique & 8 & $40-50$ \\
5 & 126 & Oblique & 6 & $40-50$
\end{tabular}

All the flights completed in 2017 in this area were performed with a DJI Phantom 4. This quadcopter is equipped with a $4 \mathrm{~K}$ camera (1/2.3" CMOS sensor, 12.4 MP), $20 \mathrm{~mm}$ ( $35 \mathrm{~mm}$ equivalent) with a focus on infinity. It weighs $1.38 \mathrm{~kg}$ and has a maximum flight time of 28 minutes.

\subsection{Focusing on the noteworthy area of $159 \mathrm{~b}$ tomb (2018 acquisitions)}

As previously reported, during the 2018 campaign particular attention was set on the documentation of a specific portion of the Northern Necropolis. The field activities were conducted in accordance with and in cooperation with the Italian archaeologists that were working in that area on the same days. A complete documentation project was thus designed and executed involving the deployment in the field of different instruments and techniques. After the setup and measurement of a set of control points, homogenously distributed in the area and measured by mean of a total station with the final accuracy achieved in the order of few millimetres, several acquisitions were performed.

\subsubsection{UAVs acquisitions}

Firstly, the total number of seven manual UAVs flights were performed in this area. The choice of performing manual flights instead of the automatic pre-programmed was dictated by different reasons: the increased presence of tourists at the time of the flight operations, the morphological conformation of the area that develops on different levels, the presence of unauthorized UAVs piloted from the visitors of the site and finally the low details of the satellite images database for the area of interest that did not allow to precisely plan a flight for the high detail desired.

In this case, the choice of performing manual flights was also supported by the main characteristics of the two platforms available on the field (DJI Mavic Pro and DJI Spark) and by the conformation of the area that presents a high density of archaeological pieces of evidence scattered on different levels.

However, despite being fully manually performed, the flights were completed following the same criteria adopted for the pre-programmed automatic flight plans: a grid of waypoints, corresponding with the image acquisition positions was executed (still images were acquired for each waypoint); different orientation of the camera angles were used, in relation with the conformation of the area and the architectural arrangement of the necropolis' structures. An average overlap $(75-85 \%)$ has been maintained both for the frontal and lateral side between stripes. The Mavic Pro is equipped with a $4 \mathrm{~K}$ camera mounted on a 3-axis mechanical gimbal. The camera acquires video with $4 \mathrm{~K}$ resolution and images at $12.7 \mathrm{MP}$ (26 mm focal length). On the other side, the Spark is a mini drone that weights only $300 \mathrm{~g}$ and is equipped with a 12 MP camera (CMOS sensor of 1/2.3"; $25 \mathrm{~mm}$ focal length). The camera acquires images in $4 \mathrm{~K}(4: 3)$ and videos in full HD (16:9). The mechanical gimbal is stabilized only on 2-axis and has a controllable range of pitch from $0^{\circ}$ to $-85^{\circ}$.

Considering that the sensors mounted on the two platforms have similar characteristics it was decided to test combined use of the two UAVs. This choice allowed also to optimize the overall flight time and batteries performances. A total number of four flights was completed using the Mavic Pro while the Spark was deployed for the other three flights. Moreover, to obtain the same GSD, it was planned to use the two systems at slightly different altitudes in order to compensate for the different resolutions: for the flights achieved with the 
Spark a lower altitude was used. The main characteristics of the flights are reported in Tables 2 and 3.

Table 2: Northern Necropolis of Hierapolis. 2018 flights main characteristics. Mavic Pro.

\begin{tabular}{|c|c|c|c|c|}
\hline$I D$ & $\begin{array}{c}N^{\circ} \\
\text { Images }\end{array}$ & $\begin{array}{c}\text { Camera } \\
\text { configuration }\end{array}$ & $\begin{array}{l}\text { Flight time } \\
\text { (min) }\end{array}$ & $\begin{array}{c}\text { Flight } \\
\text { altitude }(m)\end{array}$ \\
\hline 1 & 127 & $\begin{array}{l}\text { Nadiral. Flight } \\
\text { lines N-S }\end{array}$ & 11 & $\approx 25$ \\
\hline 2 & 91 & $\begin{array}{l}\text { Nadiral. Flight } \\
\text { lines N-S }\end{array}$ & 7 & $\approx 25$ \\
\hline 3 & 130 & $\begin{array}{l}\text { Oblique. Flight } \\
\text { lines N-S. } \\
\text { Camera } \\
\text { direction: E }\end{array}$ & 13 & $\approx 25$ \\
\hline 4 & 195 & $\begin{array}{l}\text { Oblique. Flight } \\
\text { lines N-S. } \\
\text { Camera } \\
\text { direction: W }\end{array}$ & 15 & $\approx 25$ \\
\hline
\end{tabular}

Table 3: Northern Necropolis of Hierapolis. 2018 flights main characteristics. Mavic Pro. Spark.

\begin{tabular}{c|c|c|c|c}
$I D$ & $\begin{array}{c}N^{\circ} \\
\text { Images }\end{array}$ & $\begin{array}{c}\text { Camera } \\
\text { configuration }\end{array}$ & $\begin{array}{c}\text { Flight time } \\
(\mathrm{min})\end{array}$ & $\begin{array}{c}\text { Flight } \\
\text { altitude }(\mathrm{m})\end{array}$ \\
\hline 5 & 86 & $\begin{array}{c}\text { Oblique. } \\
\text { Flight lines } \\
\text { W-E. Camera } \\
\text { direction: E } \\
\text { Oblique. } \\
\text { Flight lines } \\
\text { W-E. Camera } \\
\text { direction: W } \\
\text { Oblique. } \\
\text { Flight lines N- } \\
\text { S. Camera } \\
\text { direction: N } \\
\text { and S }\end{array}$ & 122 & $\approx 15$ \\
& 10 & $\approx 15$ \\
& &
\end{tabular}

\subsubsection{Acquisition with $360^{\circ}$ cameras}

Spherical cameras are designed to acquire all the environment around them so they may seem easy to use during the field phases, however, this impression can be tricky. As for the acquisitions with normal frame cameras different factors need to be considered and the acquisitions need to be completed respecting some basic principles. In a previous research work (Teppati Losè, 2019) the possibilities connected with the use of these systems for the development of terrestrial rapid mapping approaches in the field of built heritage documentation have been exploited and the acquisitions performed on the Northern Necropolis are part of this work as well. During the research performed in the previously cited work three different acquisition strategies were proposed and tested:

- $\quad$ Still images acquisition. This acquisition strategy requires the use of a tripod and the possibility of remotely control the camera. It is more effective in terms of quality of the acquired images but less efficient in terms of acquisition time due to the time needed to set up each single camera position.
- Time Lapse acquisition. This strategy takes advantage of the possibility of acquiring images at preselected intervals. Unlike the first strategy, it is possible to move the camera around the scene during the acquisition, however, movements should be quite slow and soft to preserve an acceptable quality of the acquired images.

- Video acquisition. This is the most efficient strategy in terms of acquisition time optimization thanks to two factors: the acquisition of a high number of frames, that can be downsampled and selected in post-processing, and the stabilization algorithms embedded in this kind of system for the video recording.

Considering all these issues, it is clear that also for $360^{\circ}$ cameras, the acquisition phase must be carefully designed and executed during the field activities especially when the last two acquisition modalities (timelapse and video) are adopted, and the operator is moving around the scene. It is thus important to previously design the acquisition path to follow in the field to maintain a constant sensor-object distance and a similar distance between camera positions. Different tests conducted showed that performing circular closed acquisition, with start and end point located in the same position, represents a good strategy to add constraints and improve the orientation phase. An example of circular acquisition performed in video mode is shown in Figure 3.

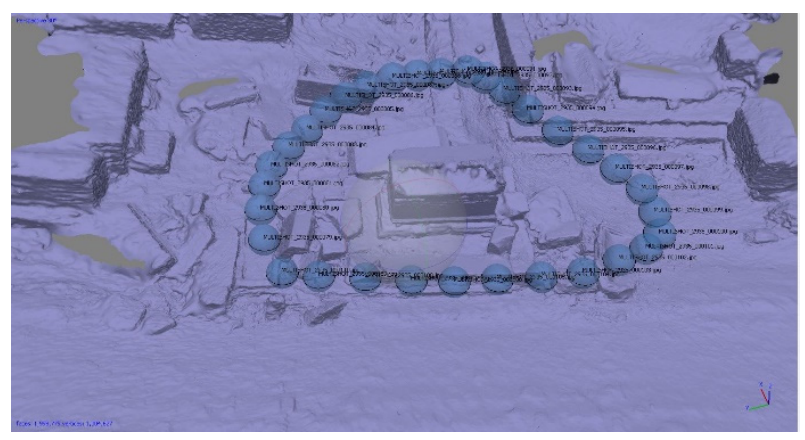

Figure 3: The 159b tomb area. Example of "circular" acquisition performed in video mode with a $360^{\circ}$ camera.

In the framework of 2018 activities, both time-lapse and video strategy were tested in the Northern Necropolis. The $360^{\circ}$ camera used was a GoPro Fusion: a small lightweight camera $(220 \mathrm{gr})$ that is equipped with two $1 / 2.3$ " CMOS sensor and can record video in $5.2 \mathrm{~K}$ and images with a max resolution of $18 \mathrm{MP}$. For both the acquisitions performed in this area a multipurpose tripod was used in order to let the operator freely move in the environment.

For the time lapse strategy, the shooting interval was set at 1 second and the path followed is reported in Figure $4 a$. The overall acquisition time was five minutes, during which 317 images were recorded and an area of $\approx 8.000$ $\mathrm{m}^{2}$ was covered. The mean acquisition distance from the camera to archaeological structures was between 3 and 5 meters. 

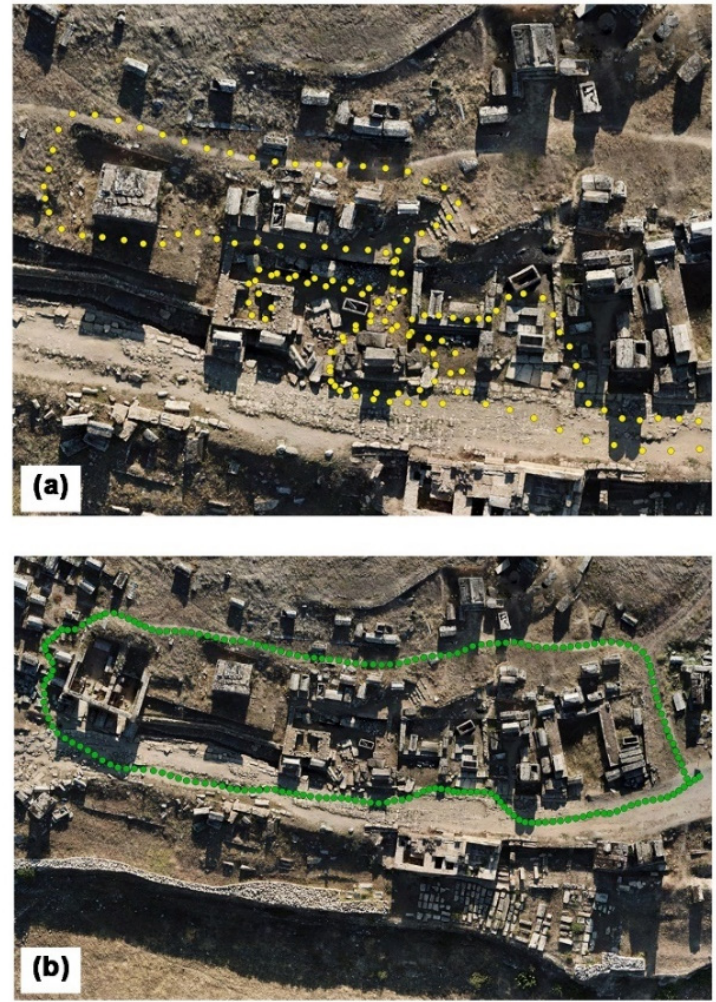

Figure 4: The $159 \mathrm{~b}$ tomb area. Acquisition schemes with the GoPro Fusion: a) Time lapse strategy; b) Video strategy.

For the video approach, the maximum video resolution was adopted $(5.2 \mathrm{~K}, 30 \mathrm{fps})$. The path completed through the area, Figure $4 \mathrm{~b}$, is similar to the one achieved in the time-lapse approach, slightly more peripheral. Also in this case the mean acquisition distance between camera and structures was between 3 and 5 meters. The acquisition was completed in three and a half minutes and an area of $\approx 9.000 \mathrm{~m}^{2}$ was covered.

\section{Data processing and validation}

In the following section, a brief overview of the processing of the data collected in the field campaigns will be reported. More specifically, the 2017 and 2018 UAVs dataset were processed following the standard SfM pipeline (image matching, tie point extraction, bundle block adjustment) and subsequent products generation (densification, DSM, and orthophoto) in the well-known commercial solution Agisoft Metashape. Spherical images were processed with a similar approach, but following specific criteria for a spherical photogrammetric approach (Fangi \& Nardinocchi, 2013; Fangi, Pierdicca, Sturari, \& Malinverni, 2018; Teppati Losè, Chiabrando, \& Spanò, 2018).

Finally, a co-registration approach was tested between the $2018 \mathrm{UAVs}$ and $360^{\circ}$ dataset to enhance the overall photogrammetric processing and reduce the time needed to complete it.

\subsection{UAV data processing}

The data collected in 2017 from the five UAVs flights were processed together in a single photogrammetric project.
In Table 4 the RMS (Root Mean Square) error on both GCPs (Ground Control Points) and CPs (Check Points) is reported, together with the main processing parameters.

Table 4: Northern Necropolis of Hierapolis. 2017 flights processing main characteristics.

\begin{tabular}{c|c|c|c|c}
$\begin{array}{c}N^{\circ} \\
\text { Images }\end{array}$ & $\begin{array}{c}\text { Reprojection } \\
\text { error (mean) }\end{array}$ & $\begin{array}{c}\text { GSD } \\
(\mathrm{cm} / \text { pix })\end{array}$ & $\begin{array}{c}\text { RMSe } \\
\text { GCPs } \\
(\mathrm{m})\end{array}$ & $\begin{array}{c}\text { RMSe } \\
\mathrm{CPS}(\mathrm{m})\end{array}$ \\
\hline 742 & 0.25 pix & 2.9 & 0.036 & 0.036
\end{tabular}

It should be noted that the processing results confirmed the possibility of deploying a COTS platform and covering a wide area of the site. The result achieved can guarantee a representational scale of 1:200. The 2018 manual flights were processed with the same approach and the main processing parameters are reported in Table 5.

Table 5: The 159b tomb area. 2018 flights processing main characteristics.

\begin{tabular}{c|c|c|c|c}
$N^{\circ}$ & $\begin{array}{c}\text { Reprojection } \\
\text { error (mean) }\end{array}$ & $\begin{array}{c}G S D \\
(\mathrm{~cm} / \text { pix })\end{array}$ & $\begin{array}{c}\text { RMSe } \\
\text { GCPs } \\
(\mathrm{m})\end{array}$ & $\begin{array}{c}\text { RMSe } \\
\mathrm{CPS}(\mathrm{m})\end{array}$ \\
\hline 829 & 1.08 pix & 0.07 & 0.007 & 0.008
\end{tabular}

In this case, thanks to the lower altitude of the flights, the higher overlap and the flight scheme adopted it was possible to guarantee the generation of metric products at a nominal scale of 1:50 or even greater.

\subsection{Spherical Photogrammetry}

The first dataset processed and validated is the one acquired with the time-lapse strategy.

After a preliminary stitching phase, that was completed in the software GoPro Fusion Studio, it was decided to downsample the dataset due to a redundant number of images available. A total number of 158 images was thus imported and processed in Metashape, the metric accuracy of the processing was evaluated thanks to 12 control points (6 used as GCPs and 6 as CPs); the main parameters of the processing are reported in Table 6.

Table 6: The $159 \mathrm{~b}$ tomb area. $360^{\circ}$ camera time-lapse approach processing main characteristics.

\begin{tabular}{c|c|c|c|c}
$N^{\circ}$ & $\begin{array}{c}\text { Reprojection } \\
\text { error (mean) }\end{array}$ & $\begin{array}{c}\text { GSD } \\
(\mathrm{cm} / \text { pix })\end{array}$ & $\begin{array}{c}\text { RMSe } \\
\text { GCPs } \\
(\mathrm{m})\end{array}$ & $\begin{array}{c}\text { RMSe } \\
\text { CPS }(\mathrm{m})\end{array}$ \\
\hline 158 & 0.82 pix & 0.47 & 0.021 & 0.024
\end{tabular}

The data contained in the table confirm the overall good performances of this approach: the RMSE on both GCPs and CPs can guarantee a representational scale of 1:100.

The dataset acquired with the video approach was in a first step stitched in the dedicated GoPro software and a spherical video of $\approx 15 \mathrm{~Gb}$ was obtained. Single frames were then extracted from the video (one frame each 30 1 frame per second) obtaining a total number of 202 frames. The main processing parameters of this dataset are reported in Table 7. 
Table 7: The $159 \mathrm{~b}$ tomb area. $360^{\circ}$ camera video approach processing main characteristics

\begin{tabular}{c|c|c|c|c}
$N^{\circ}$ & $\begin{array}{c}\text { Reprojection } \\
\text { error (mean) }\end{array}$ & $\begin{array}{c}G S D \\
(\mathrm{~cm} / \mathrm{pix})\end{array}$ & $\begin{array}{c}\text { RMSe } \\
\mathrm{GCPS} \\
(\mathrm{m})\end{array}$ & $\begin{array}{c}\text { RMSe } \\
\mathrm{CPS}(\mathrm{m})\end{array}$ \\
\hline 202 & 0.11 pix & 0.56 & 0.011 & 0.037
\end{tabular}

To further examine and validate the proposed approaches a TLS dataset was used as ground reference elements as usual in this kind of experimental text (Spanò, Chiabrando, Sammartano, Teppati Losè, 2018). The same area was selected and segmented in the three point clouds and further analyses were performed in CloudCompare software, exploiting the Cloud2Cloud distance tool. The results of these analyses are reported in Table 8.

Table 8: $\mathrm{C} 2 \mathrm{C}$ distance analysis on the $\mathrm{TLS} / 360^{\circ}$ datasets (maximum research distance set to $0,1 \mathrm{~m}$ ).

\begin{tabular}{c|c|c|c|c} 
Model & $\begin{array}{c}<0,03 \\
m\end{array}$ & $\begin{array}{c}<0,02 \\
m\end{array}$ & $\begin{array}{c}<0,01 \\
m\end{array}$ & $\begin{array}{c}<0,005 \\
m\end{array}$ \\
\hline TLS/TimeLapse & $78 \%$ & $65 \%$ & $40 \%$ & $22 \%$ \\
TLS/Video & $69 \%$ & $54 \%$ & $31 \%$ & $16 \%$
\end{tabular}

Considering the overall resolution and number of the images processed in the SfM approach, the overall deviations of the spherical datasets from the TLS one can be considered satisfying. However, it is important to underline the main issues of $360^{\circ}$ generated point clouds. Firstly, the low density of the point cloud if compared with other techniques and secondly the presence of a relatively diffused noise. These issues relate to the resolution of the 360 images used and the high distortion present in the stitched 360 images that influence the overall process. Finally, it should be noted that the video dataset is performing a little worse than the time lapse one. This issue is connected with the geometry of the acquisition and also with the little reduction of image quality due to the choice of recording video and not images.

\subsection{Co-registration approach}

To reduce the time needed for the processing of the $360^{\circ}$ dataset and especially the solution of the E.O. (Exterior Orientation) phase, a co-registration approach was tested and validated using the already processed UAVs dataset of 2018 and the $360^{\circ}$ dataset acquired in time lapse mode.

The UAVs dataset, acquired a few hours before the $360^{\circ}$, was processed in first instance in the standard photogrammetric pipeline; as already described and reported in Table 5 . The spherical images were thus imported into the UAVs processed dataset to use the aerial images as a rigid block to orient the terrestrial acquisition. To validate the overall accuracy of this approach two quality checks were performed:

- Coordinates of camera stations derived from the co-registration approach were compared with the ones derived from the standard processing (Table 6);

- Similar analyses were completed using a set of control points.
A view of the camera stations of the two datasets is reported in Figure 5.

The first analysis was performed after extracting the coordinates estimated for all the camera stations both from the traditional processing performed for the timelapse dataset, both for the processing performed with the co-registration approach. For this analysis deviations between the two sets were evaluated for $\mathrm{x}, \mathrm{y}$, and $\mathrm{z}$ components separately. The values derived from this analysis are reported in Table 9 with also the mean value of these deviations and the standard deviation for all the reported parameters analysed.
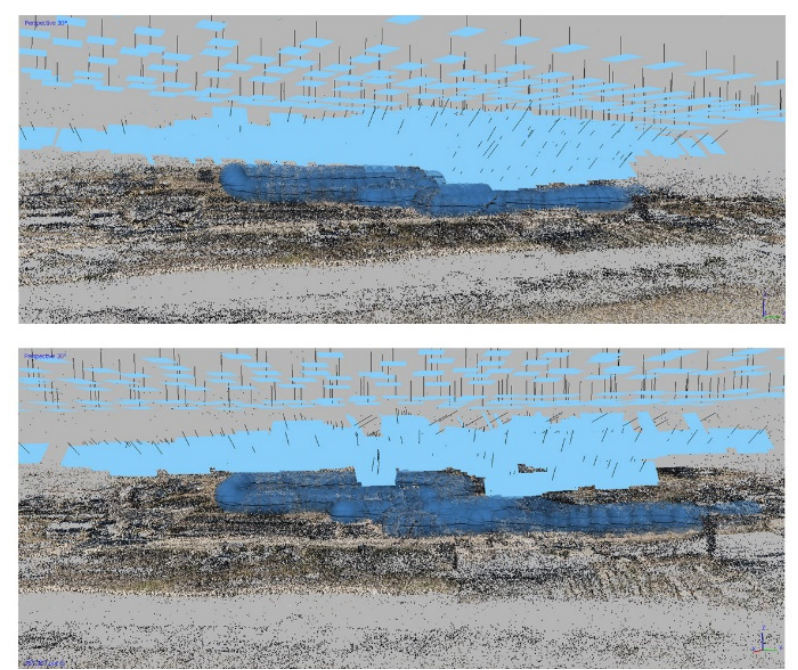

Figure 5: Hierapolis, the $159 \mathrm{~b}$ tomb area. Co-registration of $360^{\circ}$ dataset (dark blue) with the UAVs acquisition (light blue).

The data reported in the table shows that the estimation of camera stations coordinates adopting the coregistration approach is delivering good results in terms of accuracy. The mean value of the deviation is lower than $0,03 \mathrm{~m}$ for all the three components and there are no particular trends to underline, except for the standard deviation value of the $x$ component that presents a higher value and needs to be further investigated. This issue can be related with the direction of the flight lines, that is perpendicular in relation to the $x$ axis of the reference system, however further tests and analyses are needed to clarify this aspect. The data derived from this analysis were also represented in a gaussian distribution (Fig. 6).

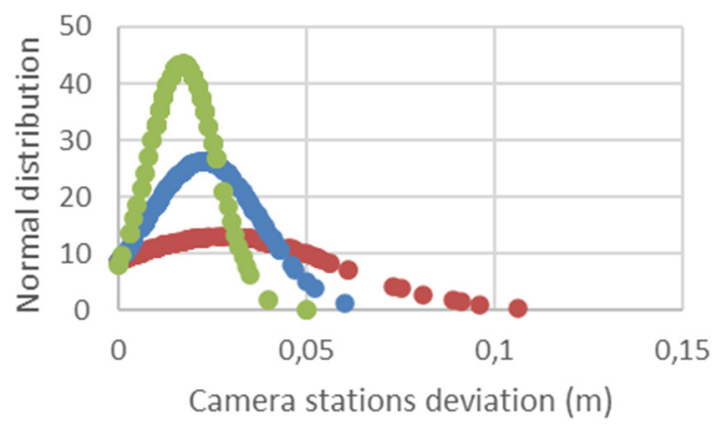

$\bullet X \bullet P Z$

Figure 6: Graphical representation of the normal distribution of the deviation in the three coordinates components between the camera positions estimated with the co-registration and the traditional approach. 
On the other hand, the second analysis was performed using as reference a set of control points measured in the field with a total station; after the co-registration approach, the coordinates of this set of points were estimated in the photogrammetric software (they were computed as manual Tie Points). The results of this analysis are reported in Table 10.

The second analysis, reported in the previous table, allowed to confirm the overall good accuracy of this approach, however, by mean of this analysis, it was possible to highlight an error on the deviation for the $z$ coordinate. This issue is probably derived from a wrong estimation of I.O. (Interior Orientation) parameters and a weak acquisition geometry. However, this is an issue that needs to be further investigated to identify which elements are causing it.

After the solution of the E.O. adopting the co-registration approach, the photogrammetric processing can be completed excluding the UAVs images.

Table 9: Co-registration approach, comparison on the coordinates of camera stations estimated with the co-registration approach and with the traditional approach.

\begin{tabular}{c|c|c|c|c|c|c|c|c}
$\begin{array}{c}N^{\circ} \\
\text { cameras }\end{array}$ & $\begin{array}{c}\Delta X \\
(m)\end{array}$ & $\begin{array}{c}\Delta Y \\
(m)\end{array}$ & $\begin{array}{c}\Delta Z \\
(m)\end{array}$ & $\begin{array}{c}\text { Mean } \Delta \\
(m)\end{array}$ & $\begin{array}{c}\text { Std. Dev. } \Delta X \\
(m)\end{array}$ & $\begin{array}{c}\text { Std. Dev. } \Delta Y \\
(m)\end{array}$ & $\begin{array}{c}\text { Std. Dev. } \Delta Z \\
(m)\end{array}$ & $\begin{array}{c}\text { Mean Std. Dev. } \Delta \\
(m)\end{array}$ \\
\hline 158 & 0.028 & 0.023 & 0.017 & 0.022 & 0.031 & 0.015 & 0.009 & 0.018
\end{tabular}

Table 10: Co-registration approach, comparison on the coordinates of control points derived from co-registration approach and topographic measured.

\begin{tabular}{c|c|c|c|c|c|c|c|c}
$\begin{array}{c}N^{\circ} \text { control } \\
\text { points }\end{array}$ & $\begin{array}{c}\Delta X \\
(m)\end{array}$ & $\begin{array}{c}\Delta Y \\
(m)\end{array}$ & $\begin{array}{c}\Delta Z \\
(m)\end{array}$ & $\begin{array}{c}\text { Mean } \Delta \\
(m)\end{array}$ & $\begin{array}{c}\text { Std. Dev. } \Delta X \\
(m)\end{array}$ & $\begin{array}{c}\text { Std. Dev. } \Delta Y \\
(m)\end{array}$ & $\begin{array}{c}\text { Std. Dev. } \Delta Z \\
(m)\end{array}$ & $\begin{array}{c}\text { Mean Std. Dev. } \Delta \\
(m)\end{array}$ \\
\hline 8 & 0.018 & 0.027 & 0.064 & 0.036 & 0.011 & 0.028 & 0.019 & 0.019
\end{tabular}

\subsection{Consideration in the generation of metric products suitable for the archaeological research}

Before moving to the phase of metric products generation in agreement with the archaeological needs for the studying of this area it was decided to perform some further analyses and comparisons between the different datasets available.

The first dataset investigated in this sense was the one derived from the different UAVs acquisitions. A first qualitative analysis was achieved on the DSMs generated from different scale surveys $(2017,2018)$, which is shown in Figure 7.

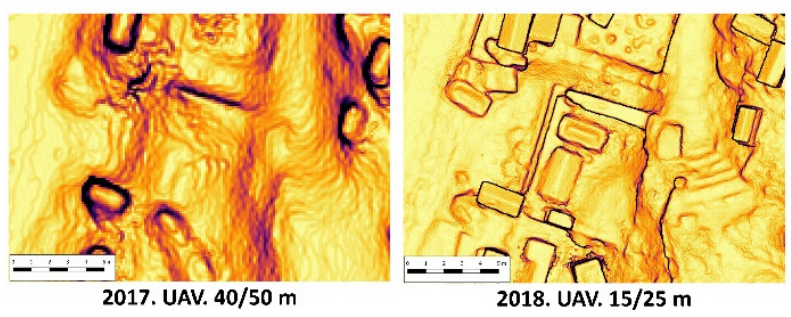

Figure 7: Hierapolis, the $159 \mathrm{~b}$ tomb area. DSMs generated from 2017 and 2018 UAVs datasets, generated from flights performed at different altitudes.

Another qualitative analysis was then achieved on the same datasets but on a different product: the orthophoto. An extract of the orthophotos generated from the two datasets is shown in Figure 8.

As is possible to notice from both the analyses on the DSM and orthophoto it is clear, as expected, that reducing the flight altitude is a crucial element to reach a higher level of detail. The 2017 dataset, which was perfect for general documentation of the area and its main features, was not sufficient to support the archaeological research in this area, a role that can be fulfilled with the 2018 dataset.

Another analysis was completed thanks to the qProf plugin developed for Qgis, which allows extracting height and slope profiles from the DSM, as shown in Figure 9; in this case, the analysis was replicated both in 2017 and 2018 datasets, to evaluate the different characteristics of the two datasets.

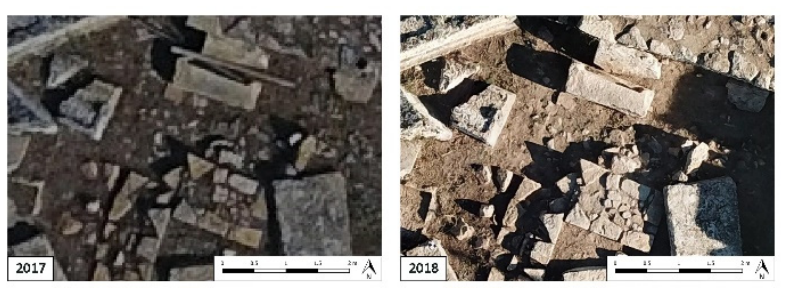

Figure 8: Hierapolis, the $159 \mathrm{~b}$ tomb area. Qualitative analysis between 2017 and 2018 orthophotos generated from flights performed at different altitudes.

It should be reported that the different resolutions of the two datasets are clearly impacting also the resolution of the details that can be extracted from the DSM.

As already underlined from the RMSE of the control points and as confirmed from the analyses presented in this section the 2017 dataset is able to guarantee a 1:200 scale, that suits the need for a general description of the area of interest at a territorial scale, while the 2018 dataset reach a 1:50 scale, that is perfect for the subsequent archaeological studies.

Similar analyses were also performed for the $360^{\circ}$ dataset. An extract of the DSM is reported in Figure 10.

It is interesting to compare this DSM with the UAVs one. The model generated from the $360^{\circ}$ dataset can be considered as completed as the UAV one in terms of the level of detail. As already reported, the 360 model is however characterized by a diffuse noise and this issue is 
clearly visible also on the DSM. However, despite this noise, the terrestrial DSM is as complete as the one generated from the UAVs dataset and also at a bigger scale.
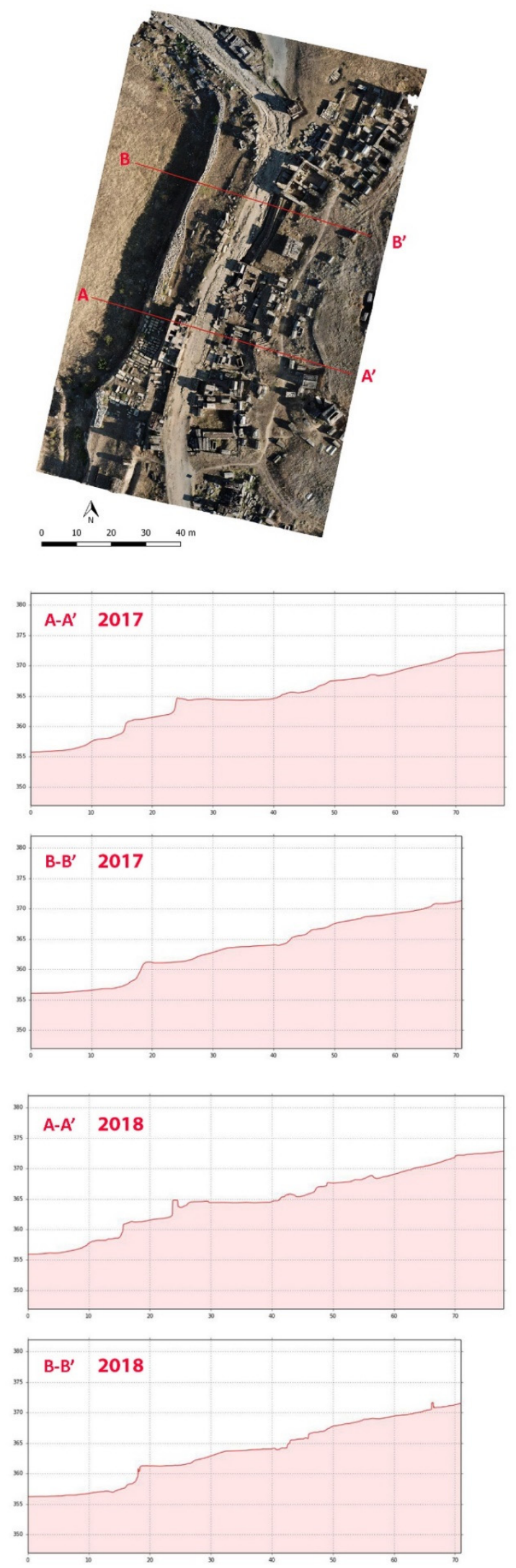

Figure 9: Terrain profiles generated with the qProf plugin, 2017 (top) and 2018 (down).

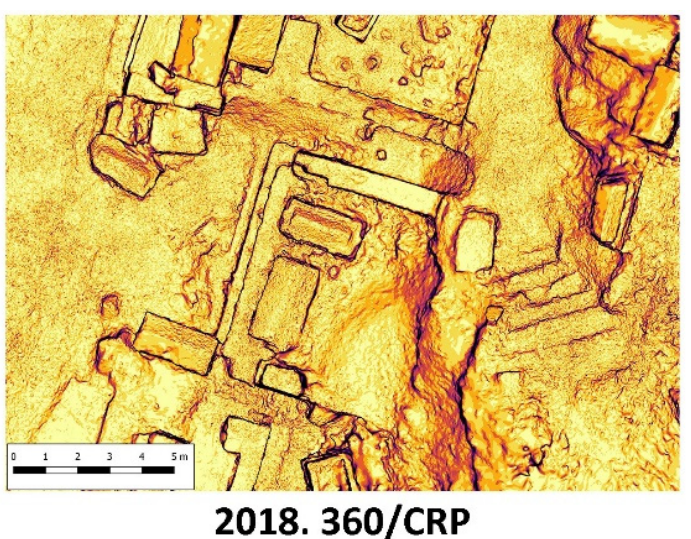

Figure 10: Hierapolis, the $159 \mathrm{~b}$ tomb area. Extract of the DSM generated from the 2018 spherical dataset.

Finally, the qProf plugin was used also to extract profiles from the $360^{\circ}$ model. Two examples of these profiles are shown in Figure 11. In this case the resolution of the dataset allowed to extract profiles also in a smaller area. Profile A-A' can be used to define the connection between the archaeological remains and the road that crosses the area, while profile B-B' can define the stone steps of a smaller route that connected different levels of the area.

\section{Use of the derived products in the archaeological research}

Archaeological investigations conducted by the University of Pisa between 2017 and 2019 resulted in a clearer understanding of the system of terraces and of the internal articulation in the area between Tombs $163 d$ and 159d (Anguissola, forthcoming; Anguissola, \& Costa, 2020). Thanks to the information provided by the 2018 campaign of images and data acquisition (see above), a number of crucial points with significant gradient have been detected and have received closer consideration (e.g., surface cleaning and close-up drawing of individual architectural features) (Fig. 12).

In particular, attention focused on Tomb 159c, a monumental grave that seems to have undergone several changes in layout and ownership.

Tomb 159c, surrounded by a funerary enclosure (for which several parallels exists in both the South-Western necropolis, e.g. Tomb S10, and the Nothern necropolis, e.g. Tombs A18, 2, 142, 156, 156a e 163b-g), occupies a large area along the main street leading towards Tripolis and the Meander Valley. Examination of the collapsed architectural elements belonging to the monument has allowed identifying a large inscribed limestone lintel bearing the name of $\Phi \lambda$. ФІ入ímmou ( $F l$. Philippou), probably the person who owned the tomb (or a part thereof) at some point in the $4^{\text {th }}$ century CE.

An imposing funerary chamber, originally covered by a barrel vault (see parallels in Tombs A20, A22, 45, 150a and $150 \mathrm{~b}$ in the Northern Necropolis, Tombs D16 and D33 in the South-Eastern necropolis, and Tomb E182 in the Eastern necropolis), stands at the north end of the area included in the enclosure. Two sarcophagi to the east of the enclosure bear lengthy Greek inscriptions, dating to the $3 \mathrm{rd}$ and the $4^{\text {th }}$ centuries CE respectively. They explain that an area of $15 \times 6$ cubiti, as well as some of the sarcophagi placed in the tomb and the heroon (i.e., 
an 'heroic', monumental grave) "to the left of those who enter the enclosure" belonged first to a man named Marcus Aurelius Rouphos Asklepianos, and later to the deacon Theodoros.
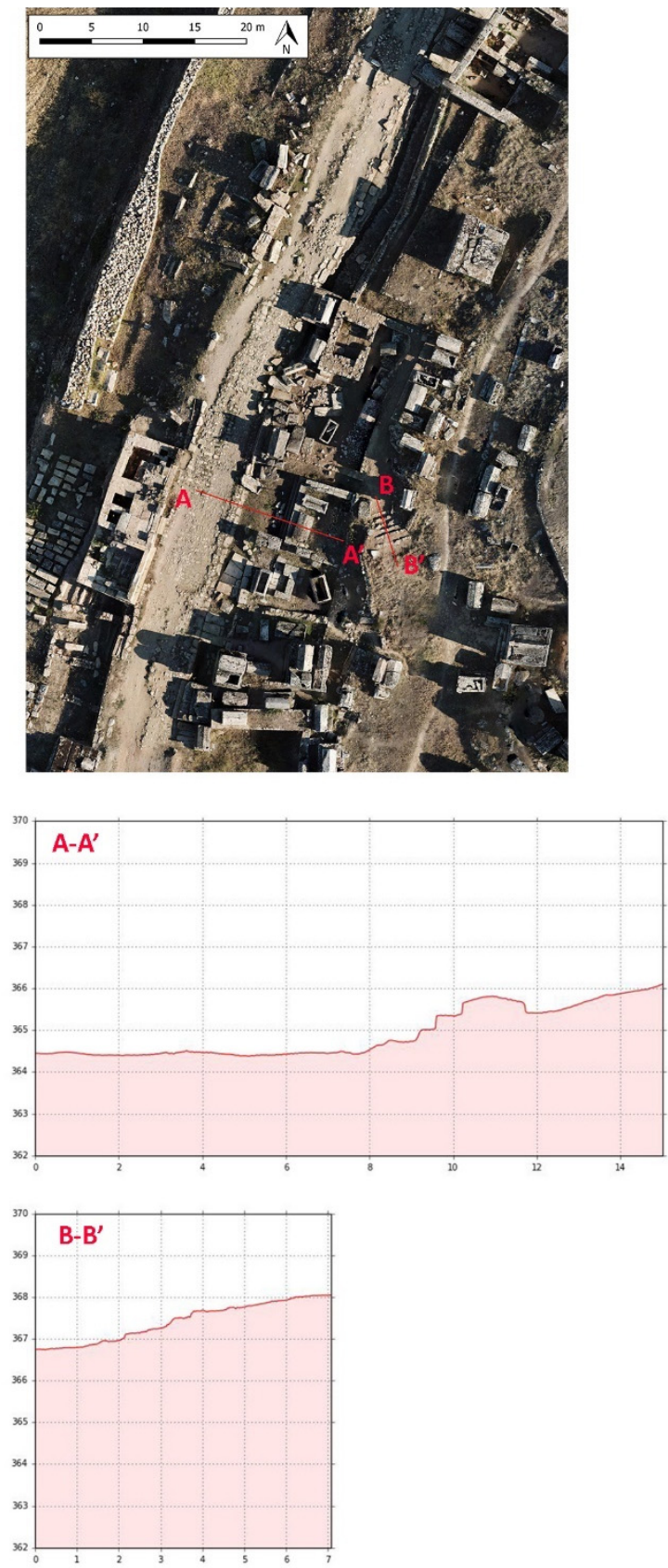

Figure 11: Terrain profiles generated with the qProf plugin from the 360 model.

The inscriptions' singular insistence on both the size of the area, smaller than the entire Tomb 159c, and the position of the heroon - which is likely identified with the monumental funerary chamber, "to the left of those who enter" - seemed to require further investigation. The orthophotos generated from the 2017 UAVs dataset (above, Figure 8) suggested a way to address this apparently enigmatic abundance in details. The orthophotos revealed the previously undetected remains of a second, smaller chamber that once stood in the southern part of the enclosure - that is, a much less stately building placed to the right for those entering the funerary area. The presence of a second, smaller chamber, which may have belonged to a different individual or family, would explain the need for both Marcus Aurelius Rouphos Asklepianos and Theodoros to describe explicitly the size and location of their grave. Perhaps, most of the open-air area and the smaller chamber belonged in the $4^{\text {th }}$ century CE to FI. Philippos, whose name was inscribed above the entrance.

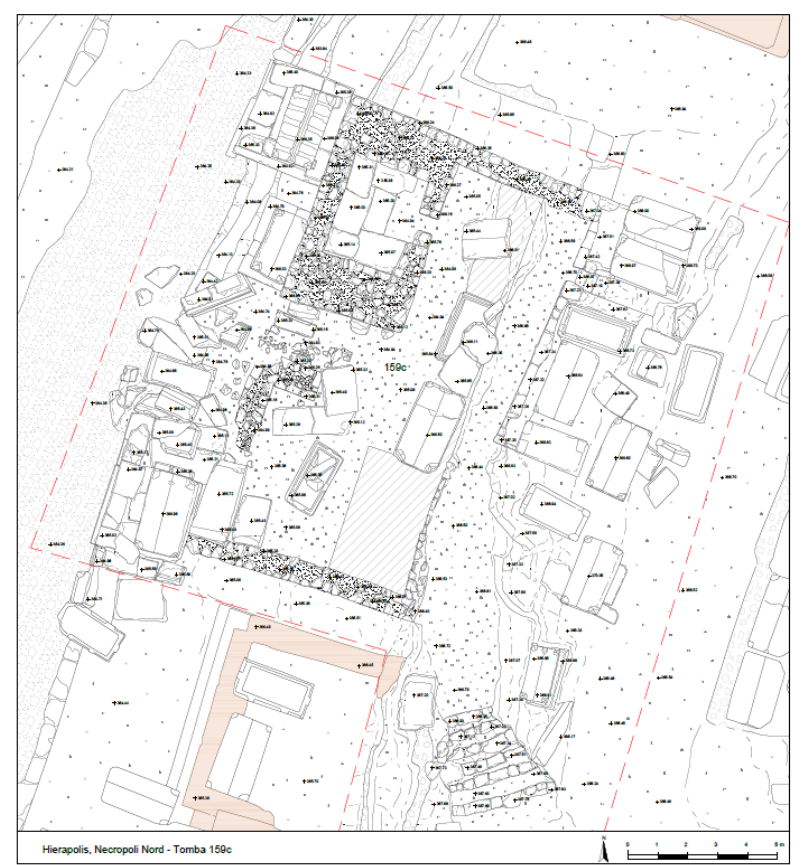

Figure 12: Hierapolis, Northern Necropolis. Tomb 159c and immediate surroundings, with indication of altitudes.

It is impossible to determine whether Tomb 159c was first built during the $3^{\text {rd }}$ century $C E$, when the earliest of the two inscribed sarcophagi must have been placed inside the enclosure. However, as is clear in the terrain profiles extracted in Qgis with the qProf plugin on the 360 acquisition (above, Figure 11), this large complex altered significantly the existing layout of the necropolis. Tomb $159 \mathrm{c}$ blocked direct circulation from the main street to the upper terrace of the necropolis, by destroying what must have been a rather large road leading upwards to a large staircase (above, Figure 11, profile B-B', and Figure 13, Left).
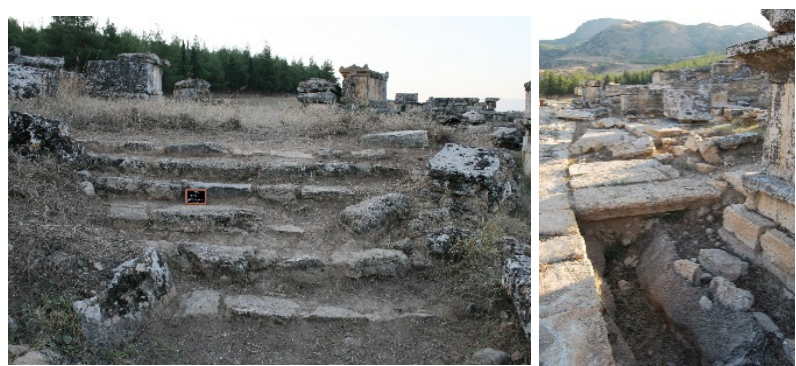

Figure 13: Hierapolis, Northern Necropolis. (Left) Stairs leading to the upper terrace from the South-West corner of Tomb 159c, 2018 (Right) Channel running along the main street.

A further, equally relevant moment in the life of Tomb $159 \mathrm{c}$ - and of the whole necropolis - is the progressive occupation of the public soil in front of the funerary buildings in the first row, thus concealing the channel 
along the main street (Figure 13, Right). The burial ground seems to have grown at an impressively fast pace, to the point that it became virtually impossible to enforce orderly

\section{Conclusions and further perspectives}

The research presented in this work was aimed at testing different approaches, both consolidated and more experimental, to flank the archaeological research in the area of the Northern Necropolis of Hierapolis. The potential of UAVs as a means for completing rapid mapping approaches were confirmed once again. Issues related to flight plan and acquisition distance have been investigated both during the field acquisition, the processing phase and the generation of the required products.

On the other hand, the first tests on the use of $360^{\circ}$ cameras delivered encouraging results as well as different issues that need to be further investigated in future research. Starting from the different modalities of acquisition that can be deployed in the field to an analysis of the different products generated from this kind of sensor several topics have been explored.

Moreover, the tests aimed to validate the possibility of integrating multi-sensor acquisitions, one terrestrial and one aerial, to enhance operations both in the field and in the processing. A co-registration approach would allow the operator to perform in the field the positioning and measuring of a single set of control points or to use datasets collected in different periods. Moreover, the two sensors were deployed adopting different acquisition distances and it is thus possible to perform also a multiscale approach. The tests performed on the coregistration approach underlined some issues in the estimation of the camera position of the co-registered dataset, an aspect that requires further tests to be better understood and validated.

Finally, the potential of an integrated approach, based on geomatics techniques - and in particular COTS methods - could be fully exploited by extending consideration to the whole Northern Necropolis of Hierapolis. A large-scale investigation could provide invaluable data to address issues of circulation, ownership, organization, and urban planning. One possible avenue of investigation includes surveying the features that attest to both existing and disrupted pathways (such as stairs, steps, and stone benches). These elements, seen in the light of the large body of funerary inscriptions available at Hierapolis, allow reconstructing the ancient landscape throughout a long period of time. In this perspective, a clearly defined set of 'connective' features could account for changes in layout which, in turn, mirror major transformations in the social and economic fabric of the town, as well as in the funerary practices of the Roman world (Anguissola, Costa, \& Monticolo, forthcoming).

In particular, mapping the roughly 170 stone benches and seats (according to a catalogue made in 2019) attached to monumental tombs or funerary precints from various periods (among which two semi-circular exedrae, Tombs 55 and 147a), may provide insightful clues about passageways, boundaries, the layout of terraces, and points of increased visibility throughout the entire life of the necropolis (Fig. 14).

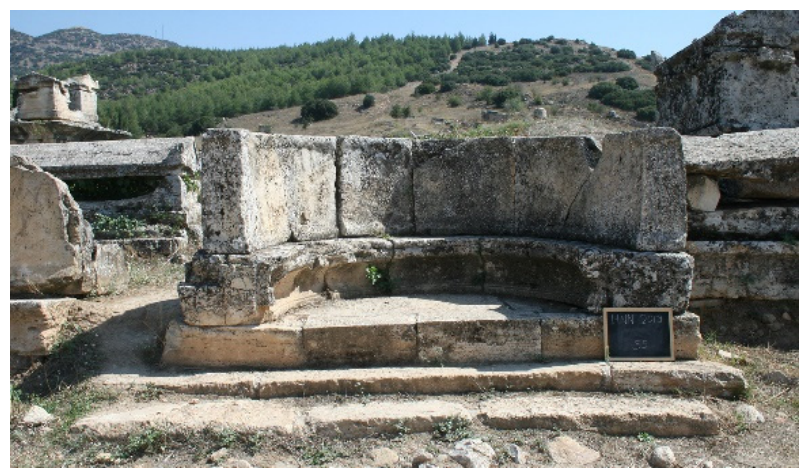

Figure 14: Hierapolis, Northern Necropolis. Tomb 55 (exedrashaped bench), 2019.

\section{Acknowledgements}

The present study was carried out within the PRIN project titled Archeologia dei paesaggi urbani in Asia Minore tra tardo ellenismo ed età bizantina. Approcci multidisciplinari allo studio di Hierapolis di Frigia., principal investigator G. Semeraro, resp for Geomatics unit A. Spanò, Resp. for acheologists equipe studying Hierapolis necropolis, A. Anguissola.

The authors would like to thank Giulia Sammartano, Silvana Costa and Antonio Monticolo, for geomatics data acquisition and archaeological studies respectively.

\section{References}

Anguissola, A. (forthcoming). Nuovi dati per la conoscenza dei paesaggi funerari di Hierapolis di Frigia. La Tomba 159c della Necropoli Nord. АГ $\Omega Г \mathrm{H}, 14-16$

Anguissola, A., Bochicchio, L., Calabrò, A., \& Costa, S. (2012). Challenging Local Traditions: The South-Western Necropolis at Hierapolis in Phrygia. 7ICAANE. Proceedings of the 7th International Congress on the Archaeology of the Ancient Near East (Harrassowitz Verlag, Ed.). Wiesbaden, 3, 417-435.

Anguissola, A., Bochicchio, L., Calabrò, A., \& Costa, S. (2013). Funerary architecture at Hierapolis in Phrygia: the southwestern necropolis. SOMA 2012. Identity and Connectivity (BAR International, Ed.). Oxford, 457-465.

Anguissola, A., Bochicchio, L., Calabrò, A., \& Costa, S. (2014). Research in the South-Western Necropolis at Hierapolis in Phrygia: the Tomb of the Dragons (S2). 8 ICAANE. Proceedings of the 8th International Congress on the Archaeology of the Ancient Near East (Harrassowitz Verlag, Ed.). Wiesbaden, 2, 619-629.

Anguissola, A., Bochicchio, L., Calabrò, A., \& Costa, S. (2016). La necropoli Sud-Ovest a Hierapolis di Frigia: lo scavo della tomba di Tiberius Claudius Thalamos (S10). Hierapolis di Frigia VIII. Le attività delle campagne di scavo e restauro, 2007-2011 (E. Yayinlari, Ed.). Istanbul, 2, 503-527.

Anguissola, A., \& Costa, S. (2020). I sarcofagi della Necropoli Nord di Hierapolis in contesto: due casi di studio, Studi 
Classici e Orientali, 66, 301-328

Anguissola, A., Costa, S., \& Monticolo, A. (forthcoming). Ricerche nella necropoli nord a Hierapolis di Frigia. Le campagne 2017-2019 nell'area delle Tombe 156-163. ArcheoLogica Data.

Chiabrando, F., D’Andria, F., Sammartano, G., \& Spanò, A. (2018). UAV photogrammetry for archaeological site survey. $3 \mathrm{~d}$ models at the hierapolis in Phrygia (Turkey). Virtual Archaeology Review, 9(18), $28-43$. https://doi.org/10.4995/var.2018.5958

Chiabrando, F., Lingua, A., Maschio, P., \& Teppati Losè, L. (2017). The influence of flight planning and camera orientation in UAVs photogrammetry. A test in the area of rocca San Silvestro (LI), Tuscany. In International Archives of the Photogrammetry, Remote Sensing and Spatial Information Sciences - ISPRS Archives, 42. https://doi.org/10.5194/isprs-archives-XLII-2-W3-163-2017

Chiabrando, F., \& Teppati Losè, L. (2017). Performance evaluation of COTS UAV for architectural heritage documentation. A test on s.giuliano Chapel in Savigliano (CN) - Italy. In International Archives of the Photogrammetry, Remote Sensing and Spatial Information Sciences - ISPRS Archives, 42, 77-84. https://doi.org/10.5194/isprs-archives-XLII2-W6-77-2017

D’Andria, F., Scardozzi, G., \& Spanò, A. (2008). Atlante di Hierapolis di Frigia. (E. Yayinlari, Ed.). Istanbul.

D'Annibale, E., Piermattei, L., \& Fangi, G. (2011). Spherical Photogrammetry As Emergency Photogrammetry. XXIII CIPA Symposium.

Fangi, G., \& Nardinocchi, C. (2013). Photogrammetric processing of spherical panoramas. Photogrammetric Record, 28(143), 293-311. https://doi.org/10.1111/phor.12031

Fangi, G., Pierdicca, R., Sturari, M., \& Malinverni, E. S. (2018). Improving spherical photogrammetry using $360^{\circ} \mathrm{OMNI-}$ Cameras: Use cases and new applications. In International Archives of the Photogrammetry, Remote Sensing and Spatial Information Sciences - ISPRS Archives, 42, 331-337). https://doi.org/10.5194/isprs-archives-XLII-2-3312018

Gottardi, C., \& Guerra, F. (2018). Spherical images for cultural heritage: Survey and documentation with the NIKON KM360. In International Archives of the Photogrammetry, Remote Sensing and Spatial Information Sciences - ISPRS Archives, 42, 385-390. https://doi.org/10.5194/isprs-archives-XLII-2-385-2018

Hernández-Lopez, D., Felipe-Garcia, B., Gonzalez-Aguilera, D., \& Arias-Perez, B. (2013). An automatic approach to UAV flight planning and control for photogrammetric applications: A test case in the asturias region (Spain). Photogrammetric Engineering and Remote Sensing, 79(1), 87-98. https://doi.org/10.14358/PERS.79.1.87

Nex, F., \& Remondino, F. (2014). UAV for 3D mapping applications: A review. Applied Geomatics, 6(1), 1-15. https://doi.org/10.1007/s12518-013-0120-x

Ramos, A. P., \& Prieto, G. R. (2016). Only image based for the 3D metric survey of gothic structures by using frame cameras and panoramic cameras. International Archives of the Photogrammetry, Remote Sensing and Spatial Information Sciences - ISPRS Archives, 41(July), 363-370. https://doi.org/10.5194/isprsarchives-XLI-B5-363-2016

Remondino, F., Barazzetti, L., Nex, F., Scaioni, M., \& Sarazzi, D. (2012). Uav Photogrammetry for Mapping and 3D Modeling - Current Status and Future Perspectives. ISPRS - International Archives of the Photogrammetry, Remote Sensing and Spatial Information Sciences, XXXVIII-1/(September), 25-31. https://doi.org/10.5194/isprsarchivesXXXVIII-1-C22-25-2011

Scardozzi, G. (2015). Nuovo Atlante di Hierapolis di Frigia. Cartografia archeologica della città e delle necropoli (E. Yayinlari, Ed.). Istanbul.

Spanò, A., Chiabrando, F., Sammartano, G., Teppati Losè, L. (2018). Integrated imaging approaches supporting the excavation activities. multi-scale geospatial documentation in Hierapolis (TK)", in International Archives of the Photogrammetry, Remote Sensing and Spatial Information Sciences, XLII-2.

Teppati Lose', L. (2019). Geomatics support to the metric documentation of the archaeological heritage. Tests and validations on the use of low-cost, rapid, image-based sensors and systems. Italy. Retrieved from https://iris.polito.it/handle/11583/2735515\#.X0_6n8gzZEY

Teppati Losè, L., Chiabrando, F., \& Spanò, A. (2018). Preliminary evaluation of a commercial 360 multi-camera RIG for photogrammetric purposes. In International Archives of the Photogrammetry, Remote Sensing and Spatial Information Sciences - ISPRS Archives 42, 1113-1120. https://doi.org/10.5194/isprs-archives-XLII-2-1113-2018 


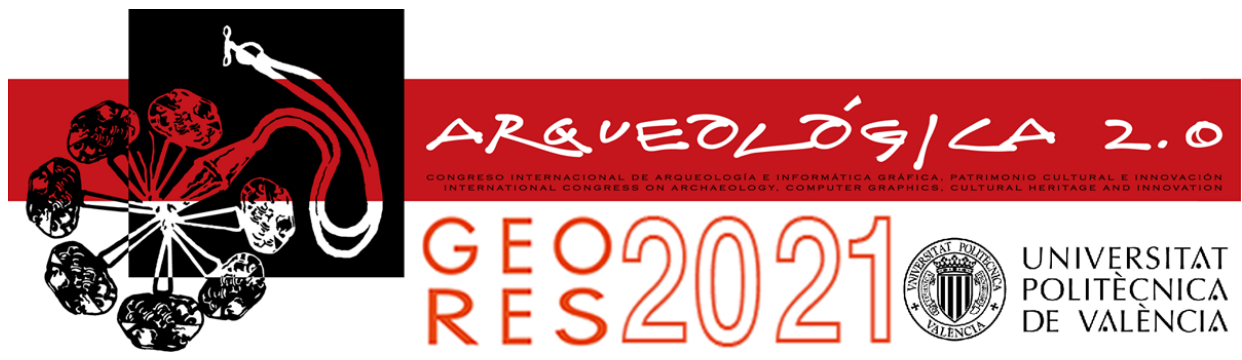

Proceedings of the joint international event $9^{\text {th }}$ ARQUEOLÓGICA

$2.0 \& 3^{\text {rd }}$ GEORES

Valencia (Spain).

26-28 April 2021

\title{
COMPARATIVE INVESTIGATION OF THE 3D REPRESENTATIONS OF THE HOLY AEDICULE OF THE TOMB OF CHRIST
}

\author{
Nefeli Tentomaa, ${ }^{a}$, Andreas Georgopoulos ${ }^{a}$, Grazia Tuccib \\ ${ }^{a}$ Laboratory of Photogrammetry, School of Rural and Surveying Engineering, National Technical University of Athens, Heroon \\ Polytechniou 9, 15780 Zografou, Athens, Greece.nefelitentom@gmail.com; drag@cental.ntua.gr \\ ${ }^{\mathrm{b}}$ GECO, Geomatics for Environment and Conservation of Cultural Heritage Laboratory, Department of Civil and Environmental \\ Engineering, University of Florence, Via S. Marta 3, 50121 Florence, Italy. grazia.tucci@unifi.it
}

\begin{abstract}
:
The significance of preservation of cultural heritage is undeniable, which is why both their geometric documentation and the creation of their digital "twins", i.e., reconstructions and replicas at any scale, are essential procedures. A special category of cultural heritage is sacred sites which combine historical, spiritual and religious values. The most sacred monument of Christianity is the Holy Aedicule covering the Tomb of Christ in the Church of the Holy Sepulchre in Jerusalem. This paper aims to investigate and compare the various three-dimensional representations of the Holy Aedicule of the Tomb of Christ, which exist both in physical and in digital form. Initially, the main structural phases of the Aedicule are presented, including its destructions and restorations. Moreover, the different categories of the three-dimensional representations of the monument are defined. With reference to the replicas, both the reasons of their construction and their list in the form of a dataset table are presented. More specifically, in the context of this research, the three-dimensional representations of the Aedicule are divided into two major categories: the replicas constructed worldwide and the geometric documentations of the monument's condition through the years. Regarding the replicas, a list of the discovered representations is created, and this database is visualized and depicted in an online web map along with essential information with the use of an open-source Geographic Information System (GIS). Based on this visualization an online web map has been created. Furthermore, the previous geometric documentations and surveys of the Holy Aedicule of the Tomb of Christ are presented. A comparison is conducted between the 3D models of the Aedicule, which were created by the University of Florence in 2007-8 and the National Technical University of Athens in 2015-17. The impact of the Holy Aedicule across the world is examined through statistics based on the type, date of construction and location of the replicas. The possible deformations of the monument's structure are detected from the assessment of the results from both the processing and the comparison of the 3D models. In conclusion, future works are suggested focusing on the discovery of the total number of replicas worldwide and the monitoring of the condition of the Aedicule.
\end{abstract}

Keywords: cultural heritage, geometric documentation, three-dimensional representations, online webmap, digital photogrammetry, 3D reconstruction

\section{Introduction}

Sacred sites are considered to have a major impact on the various religious communities across the world. The vast number of the existing shrines, which can be detected globally, is strong evidence of both the devotion and the veneration of the faithful. Moreover, they constitute a symbol of the spiritual beliefs and values that are inherited from previous generations (Alexopoulos, 2014). Consequently, sacred sites differ from other forms of cultural heritage and represent a unique category, which demands a particular approach as far as their conservation and preservation are concerned.

Among all the sacred sites of Christianity, there is one which is acknowledged as the most important monument, because it proves the authenticity of the Christian belief. This is the Tomb of Christ located in the Church of the Holy Sepulchre in Jerusalem, which verifies the entombment and the resurrection of Christ in the eyes of the Christians. The Holy Aedicule, a small edifice surrounding the tomb, was erected in order to protect this valuable shrine. As a result, the documentation of the Aedicule's condition and its preservation is vital and should be a priority.

Focusing on the practices for the documentation of religious cultural heritage, such as the Aedicule of the Tomb of Christ, the most appropriate methods will accurately represent the monument without causing any damage to the original. Special treatment and sensitivity are required (Alexopoulos, 2014). 3D modelling with the implementation of laser scanning and digital 
photogrammetry are non-destructive techniques that offer new perspectives for three-dimensional cultural heritage recording, with precise and representative outcomes.

The main purpose of this paper is the research on the three-dimensional representations of the Aedicule of the Tomb of Christ, which consist of the replicas and the geometric documentations. The main structural phases of the Holy Aedicule, from the day of its erection until the present day, are presented to better perceive the evolution of the form of the monument.

Regarding the three-dimensional representations of the Aedicule and more specifically the replicas, their locations around the world are detected and archived, with the aim of creating a list with their name, type, date of construction and image. Afterwards, this database is visualized and digitized with the use of an open-source Geographic Information System (GIS). The final goal is the creation of an online interactive web map, which depicts all the spatial and attribute data related to the replicas.

Furthermore, the various geometric documentations of this significant edifice are highlighted and some of their data are further processed. From the analogue data which were acquired by the National Technical University of Athens during a metric survey on the monument in 1995, an attempt is made in order to construct a new 3D model through digital photogrammetry. Additionally, a comparison is carried out between the two 3D models of the Aedicule created by the University of Florence in 2007 and the National Technical University of Athens in 2015. In this way, both the alterations and the deformations of the shape of the edifice through time are detected, with the creation of $2 \mathrm{D}$ drawings and the application of the multiscale Model to Model Cloud Comparison (M3C2) algorithm, which computes the local distances between two point clouds.

\section{Structural Phases of the Holy Aedicule}

Many cities in the world are characterized by great religious significance because they are places where either an incident of a saint's life had been recorded or many sacred sites are located. Jerusalem is a historic city that attracts numerous pilgrims not only from different parts of the globe but also from different religions. Its uniqueness derives from the multiculturality and the fact that it is identified as the Holy Land for three major religions: Christianity, Judaism and Islam.

Jerusalem is one of the most famous pilgrimage sites, especially for the Christian community, since it is the Holy City where the scenes of Christ's crucifixion, burial and resurrection took place. The Holy Rock of Golgotha (Calvary), the Tomb of Christ and the spot that parts of the Holy Cross were discovered are enclosed within the Church of the Anastasis (Resurrection) or the Church of the Holy Sepulchre, which is located inside the walls of the Old City of Jerusalem (Fig.1).

Many Christian Communities coexist within the Church of the Holy Sepulchre. The Greek Orthodox, the Roman Catholic Franciscans, the Armenian Apostolics, the Copts, the Ethiopians and the Syrians represent the Christian Communities that are all active and each one "owns" different sections of the monument. The respectful sharing of common areas for religious ceremonies is achievable due to the Status Quo of the Holy Sepulchre, which defines the ownership, the rights and the privileges of each community (Georgopoulos et al., 2017). The most vital religious shrine that all Christian Communities are devoted to and attract thousands of pilgrims from around the world is the Tomb of Christ.

\section{Jerusalem Old City}

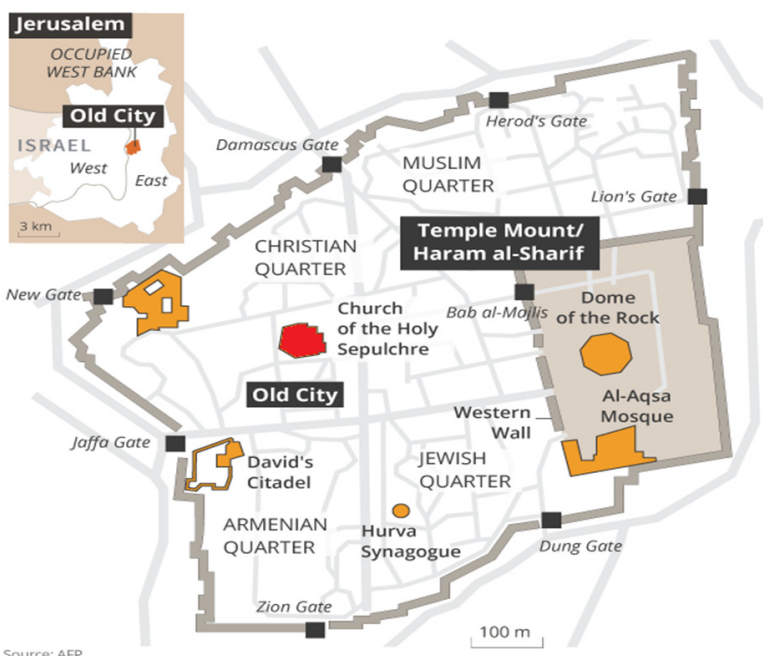

Figure 1: The Church of the Holy Sepulchre in the Old City of Jerusalem @ Middle East Eye 2020.

The Tomb of Christ reflects the belief in the miracle of the Resurrection and reinforces the Christian faith because it is evidence of the events described in the Gospels. The rock-cut tomb, where it is believed that Christ was temporarily entombed after his crucifixion, is enclosed within a small edifice called the Holy Aedicule or

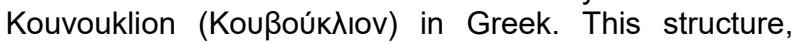
which is protecting the holiest monument of Christianity, is located at the western side of the Church of the Holy Sepulchre, underneath a tall cylindrical building called the Rotunda. The Aedicule has undergone multiple structural alterations through the years due to successive destructions, damages, earthquakes, fires and attempts of reconstructions.

The first Aedicule was erected by the Roman Emperor Constantine the Great in 326 AD, whose mother, Empress Helena, discovered Christ's Tomb. The main characteristics of its structure were a porch which consisted of four columns and a gable roof leading to the Tomb chamber at the western side. The burial chamber was surrounded by five decorative columns and had a conical roof (Fig. 2) (Biddle, 1999).

The first destruction of the monument occurred during the Persian invasion, led by emperor Chosroes II in 614 AD. Both the Church of the Holy Sepulchre and the Holy Aedicule were damaged to a great extent (Jeffery, 1919). An attempt for their reconstruction was carried out in 629 AD by Abbot Modestos. Although in 1009 AD Khalif AlHakim Bi-Amr-Allah ordered the complete demolition of the Church of the Resurrection, the Tomb of Christ was possibly injured but eventually it was not destroyed (Macpherson, 1892). The following years the Byzantines undertook a restoration to the whole complex. Concerning the Aedicule, its form was preserved and was similar to the initial edifice built by Emperor Constantine. 
In 1009 AD Jerusalem was again under the control of Christians until 1187. During this period, slow progress of reconstruction had begun. The form of the Holy Aedicule was modified with the adjustment of four additional elements which were never significantly altered until the present day. More specifically, these features are an eastern room fully integrated with the rounded western structure (now the Chapel of the Angel), a cupola over the burial chamber, a chapel attached to the west end of the Aedicule (now the Coptic Chapel) and two benches, which were placed at the entrance on the sides of the door of the Aedicule (Fig. 2) (Biddle, 1999).

The state of the Aedicule as time passed was deteriorated and decayed and the rehabilitation of the edifice was crucial. In 1555, restoration was carried out by the Franciscan custodian, Bonifacio of Ragusa (Fig. 2). Even though Bonifacio had claimed that the reconstruction was from the foundation, there is a possibility that only the cupola was restored, and some parts of the structure were repositioned (Moropoulou et al., 2019).

The Church of the Holy Sepulchre was once again extensively damaged by a fire that broke out in 1808. The roof of the Rotunda collapsed on to the Aedicule and as a result, the outer parts and the cupola of the edifice were mainly damaged. The structural condition of the Aedicule was in urgent need of restoration. In 1810 this goal was accomplished by Kalfa Komnenos, who rebuilt the edifice in a new style (Fig. 2), apart from the marble slabs of the Tomb Chamber, the base of the structure's exterior and the Coptic chapel. The Chapel of the Angel, the dome over the Tomb Chamber, the exterior walls and the cupola were entirely altered (Biddle, 1999).

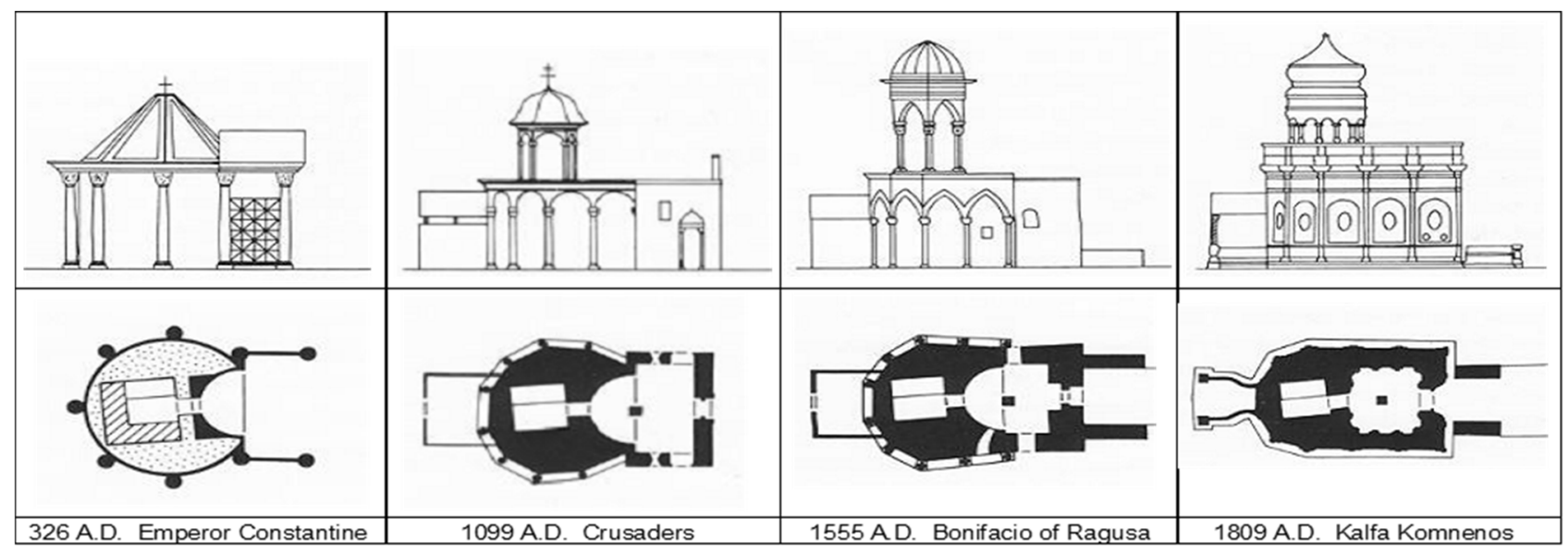

Figure 2: South view of the Aedicule through time (Up), and plan of the Aedicule through time $\odot$ Martin Biddle 1999 (Down).

The Aedicule was damaged once more by an earthquake in 1927. An external iron frame was installed by the Public Works Department of the British Mandatory Government of Palestine in March 1947, as a temporary solution, in order to prevent the collapse of the Aedicule. After many years of decay, a rehabilitation project was carried out by the National Technical University of Athens, which would intend to restore the monument. The project was successfully completed in March 2017 and the main goal of the specific restoration, which was the assurance of the sustainability of the Aedicule, was finally achieved (Moropoulou et al., 2019).

\section{Development of Web Database}

\subsection{List of the Replicas}

An alternative way of $3 D$ representation and therefore of documentation of the Aedicule is by its replicas which exist in physical form. The majority of these reconstructions were created by pilgrims who took measurements of the dimensions of the original monument when they visited Jerusalem. The significance of this sacred site is highlighted through these structures which exist worldwide. Each replica corresponds also to a structural phase of the Aedicule, thus the study of these representations result in a better understanding of its form through the years.

The Church of the Holy Sepulchre, as a building complex, had also an impact on the architecture of both churches and monasteries globally. The Rotunda in particular, the tall circular structure surrounding the Holy Aedicule, influenced the construction of round medieval churches which is an unusual architectural phenomenon for the specific period.

Churches, tombs, burial sites, calvaries, monasteries, relics and religious items comprise the main examples of the replicas. This paper is aiming to give prominence to the sphere of influence of the Aedicule and the Holy Sepulchre through the detection of their threedimensional physical representations. Eventually, the amount of the discovered replicas was 109 in total and they consist of different types, which were divided into various categories:

- True-to-scale replicas of the Aedicule (23 of them), which have the dimensions of the monument and most of them have similar or even identical form

- Edifices of the Aedicule (9 of them), which are composed of structures that represent the shrine, but they are not identical replicas of the original.

- Miniature Models of the Aedicule (15 of them), which exist on a smaller scale and were usually used as reliquaries. 
- Calvaries (45 of them), which consist of many chapels recreating the Stations of the Cross, including the burial chapel.

- Buildings inspired by the Holy Sepulchre (17 of them), which represent some architectural features of the Church of the Holy Sepulchre.

In this way, a database was created with the total amount of the detected replicas worldwide, along with additional information for each one such as name, type, location, date of construction and an image if possible.

\subsection{Creation of Interactive Web Map}

The subsequent step was the development of an online database that would be accessible by all the users of the internet. This could be accomplished with the production of a web map of the replicas and the implementation of a Geographic Information System (GIS). The characteristic advantage of GIS software is the combination of spatial data that are geographically corresponding to the real world and of attribute data that provide additional information about each of the spatial features. In this way, the user is available to both have access to a wide range of information and display them in any such away in order to create a desired visual outcome (Research Guides, 2019). The QGIS (Quantum GIS) (QGIS, 2020) software was eventually selected for the depiction and the visualization of the places where replicas of the Aedicule and the Holy Sepulchre are located.

Based on the list presented previously and taking advantage of the tools provided by QGIS, a map was produced for the digitization and visualization of the replicas' locations. The structures were classified into five different categories (layers) depending on their type (trueto-scale, edifices, miniature models, calvaries and buildings inspired by the Holy Sepulchre) and new fields were added to the attribute table of each category according to the information from the dataset (name, type, location, date of construction and image). The Open Street Map was used as a basemap and the vector data, which describe geographic data in terms of points for this project, were placed at the location of each copy. Finally, a new 'action' was created in QGIS. Actions happen when the user clicks on a feature, allowing the retrieval of additional information (Esri, 2020). It was called "Show Image" and it would enable the appearance of an image by picking the replica that it represented.

When the visualization and the map of the Replicas of the Aedicule and the Holy Sepulchre were completed, it was possible to create a web map. A web map is the presentation of a map online, which was initially created with a Geographic Information System (GIS), and the user is able to interact through different tools, such as pop-up windows with additional information for the visualized data, continuous pan and zoom and measurements of distances on the map (Esri, 2020). The map should be converted to a form which is compatible with a browser and for this reason the Qgis2web plugin was installed. The specific plugin generates a web map from the current QGIS project, either as OpenLayers or Leaflet form. Qgis2web creates the final web map by replicating as many aspects of the project as possible, including layers and styles, and converting them into HTML, Javascript, and CSS files, that can be viewed from the browser (QGIS plugins, 2020).
With the aim of creating a web map for the project of the replicas of the Aedicule and the Holy Sepulchre, the parameters of the web map were defined, which consist of the data layers, the overall appearance and the way that the web map will be exported. First of all, the Leaflet form was thought to be the best choice, due to its simplicity and the user-friendly environment. Moreover, all the layers of the project and their fields would be depicted on the web map. Regarding the appearance, the different layers would be presented at the upper right corner of the web map, pop-up windows with the additional information of the attribute table of each layer were enabled and the highlighting of every aspect that will be picked by the user was also selected. Some tools were added, such as the geolocation of the user, the metric measure tool for distances and areas (units: meters) and the research tool. The web map would be depicted in full-screen, with an extent which would fit to the layers and with maximum zoom level 28 and minimum zoom. The title of the web map was not available through the Qgis2web plugin, but it was added through the tab 'Project' > 'Properties' > 'Project Title'.

In order to upload the specific web map to the internet, a web hosting account was required. For the presentation of the web map the web server of the National Technical University of Athens was used, which provides to the members of the university the ability to create a personal website. When the personal website has been activated, access to the personal website for modifications is available through the link: ftp://username@users.ntua.grl and the use of FTP software, such as FileZilla (FileZilla, 2020). The user must enter the link of the web directory and the passwords in order to log in through the FileZilla software. When access is permitted, there are two separate windows depicting the files of the desktop computer and the files in the web directory. The user decides which files will be transferred to the web directory. Thus, the 'index.html' file and the folders with associated Javascript and CSS files which were exported from the Qgis2web plugin were uploaded to the web directory.

The web map of the replicas of the Aedicule and the Holy Sepulchre was finally online and accessible through the internet (Fig. 3), through the website: http://aediculereplicas.rf.gd/?i=3\#3/25.02/-16.16

\section{Methodology for Point Cloud Evaluation}

\subsection{Geometric documentations of the Aedicule}

Through the years several scientific researches have been conducted in order to geometrically document the state of the Aedicule. The first metric survey of the monument was carried out by a Franciscan monk named Father Virgilio Corbo (1960-1973), who documented the holy shrine and created accurate drawings of its condition (Custodia Terrae Sanctae, 2020). The first documentation of the monument was performed by Martin Biddle (19891992 ) in cooperation with a team of British experts, with the implementation of photogrammetry and 3D modelling (Biddle, 1999). In the years 1993-1999, the National Technical University of Athens in collaboration with the University of Athens undertook the task of documenting the whole complex of the Church of the Holy Sepulchre. 
Drawings of the Aedicule were created with the combination of geodetic measurements and photogrammetry (Balodimos \& Georgopoulos, 2019). A survey on the seismic risk of the structures of the Holy Sepulchre was conducted by the University of Florence from 2007 until 2011. The technique of terrestrial laser scanning (TLS) was implemented for the first time regarding the three-dimensional representation of the
Aedicule (Tucci \& Bonora, 2011). In May 2015 the works for the diagnostic study of the Aedicule of the Tomb of Christ was initiated by the National Technical University of Athens. Data acquisition included geodetic measurements, digital image acquisition and terrestrial laser scanning (TLS) around and inside the monument (Moropoulou et al., 2019).

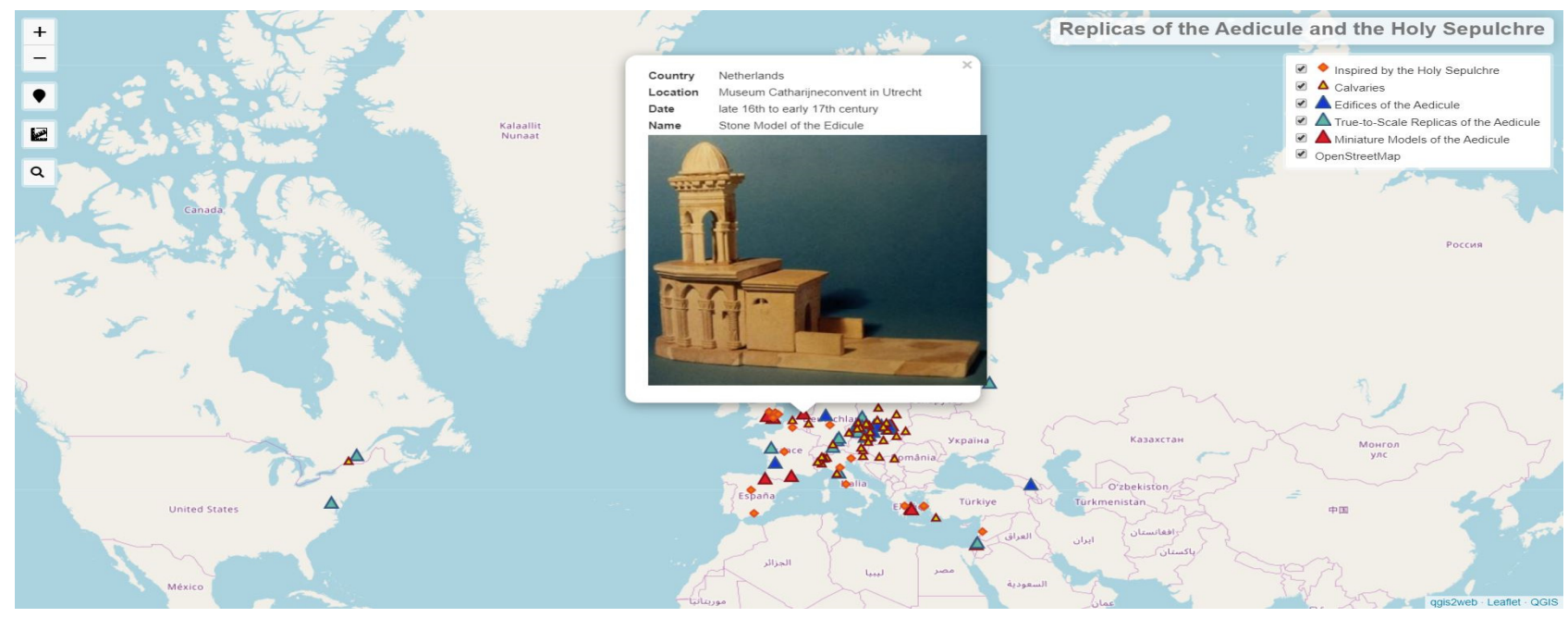

Figure 3: The online web map of the replicas of the Aedicule and the Holy Sepulche $\odot$ Author 2020.

\subsection{Point Cloud from Analogue Data}

An attempt was made for the construction of a threedimensional model using part of the analogue imagery data acquired during the National Technical University of Athens survey in 1995.The specific photographs were captured with classical stereoscopic processing in mind and concerned the Rotunda and not the Aedicule itself. Printed photographs, films and slides were acquired with various analogue cameras, either coloured or grayscale. In the end, four sets of data were formed:

1) Hasselblad $6 \times 6$ colour slides with $50 \mathrm{~mm}$ focal length (29 of them)

2) Canon $A E-135 \mathrm{~mm}$ SLRB\&W negatives with $50 \mathrm{~mm}$ focal length (15 of them)

3) WILD P31 metric camera B\&W negatives $(10 \times 12.50$ $\mathrm{cm}^{2}$ ) with 45,21 $\mathrm{mm}$ focal length (7 of them)

4) Printed colour photographs from an unknown camera (14 of them)

All the analogue images were scanned in order to be digitized, with a resolution of 1200 dpi. Every scanned photograph had distinct dimensions and size, so they were cropped according to the group that they were classified. The parameters of the interior orientation were necessary to be attached to every image. Therefore, the EXIF (Exchangeable Image File format) file of the scanned photographs and slides was edited in Zoner Photo Studio X (Zoner Photo Studio, 2019) and information such as the focal length, the maker and the model of the camera were added. Eventually, the photographs were imported into the photogrammetric software Metashape (Agisoft Metashape, 2019) and they were divided into separate camera groups so that they could be processed correctly.
The construction of a 3D model of the Aedicule was initially attempted using only the colour images. First step was the categorization of the photographs in various groups (chunks) according to which part of the Aedicule they were depicting. Afterwards, the alignment of each group was performed, for the computation of the camera position, orientation for each photo and the creation of the sparse point cloud. The results of every alignment were inspected, and incorrectly positioned photos were removed or realigned. In some cases, markers were added or removed depending on their effect to the total error of the alignment.

After adjusting the volume bounding box by resizing or rotating the region and removing from the sparse point cloud all the spots or areas that appear as displayed imperfections in the image (noise) (IGI Global, 2020), the preferred reconstruction parameters for this procedure were selected. As a result, the dense point cloud of each chunk was generated and visualized (Fig. 4). It is obvious that the dense point cloud is very incomplete and that the image coverage is not adequate.

A second attempt was carried out with the aim of processing the B\&W photographs. Taking into consideration that this kind of photographs were very few, the colour photographs were converted to greyscale images in Photoshop (Adobe Photoshop, 2019) so that they could be combined all together. Moreover, since the negatives were scanned in order to create digital images, some photographs that were in grayscale had to be edited as well and converted into photo positive. Then, the images were imported into Metashape again and separated into several chunks. Subsequently, the dense point clouds representing different parts of the Aedicule were created, following the same processing as previously (Fig. 5). It is again observed that the result is rather unsatisfactory. 


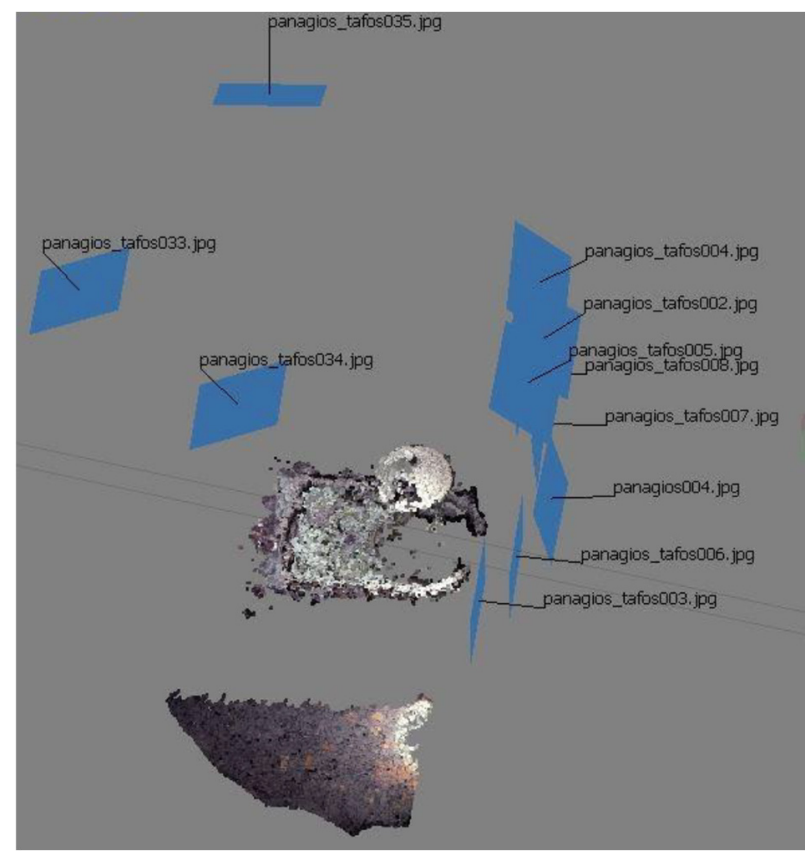

Figure 4: The dense point cloud of the top view of the Aedicule from colour photographs (c) Author 2020.

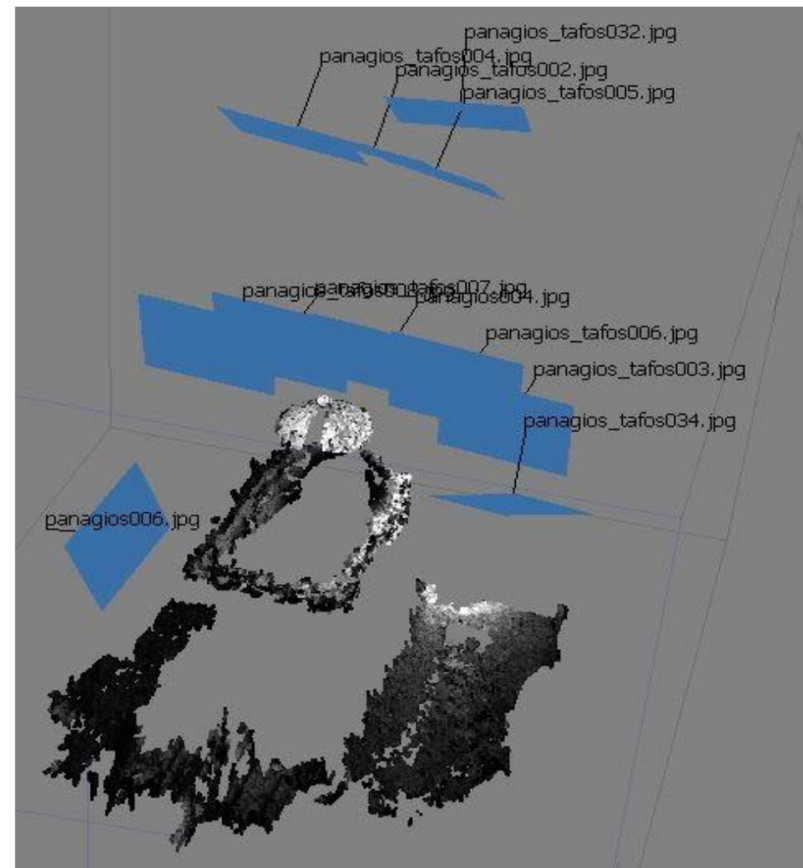

Figure 5: The dense point cloud of the top view of the Aedicule from grayscale photographs (c) Author 2020.

Even though more photographs were aligned, 40 in this case, as opposed to 31 colour photographs, the result of the dense point cloud based on the grayscale photographs was not better or more precise than the dense point cloud from the color photographs. It is obvious that the results are not correct from a metric point of view. One is only able to obtain an idea of the shape and the form of the edifice.

The specific photographs have many drawbacks concerning the photogrammetric procedures. First of all, a major obstacle was the absence of sufficient overlap between the photographs, which is the main essential condition for photogrammetry. What is more, most of the photographs were not of high resolution. Furthermore, the lack of Ground Control Points (GCP) or of a measured distance of the Aedicule affects both the geometry and the scale of the final constructed point cloud. It is also important that the camera-to-object relative positioning varied even if the same camera model or the same focal length was used. Additionally, the fact that the photographs were not taken from different viewpoints, the bad lighting conditions and the continuous population hiding the monument resulted in the loss of information. Unfortunately, a better outcome could not be achieved by processing only these photographs which were apparently not suitable for reconstructing the Aedicule, since the geometry of the dense point clouds was not identical to the geometry of the edifice.

\subsection{Point Cloud Comparison}

During the two last surveys that took place in Jerusalem and focused on the geometric documentation of the Aedicule of the Tomb of the Christ, three-dimensional models were constructed through terrestrial laser scanning (TLS). The specific method constitutes an effective technique for Cultural Heritage Digitization, because of the high acquisition rate, the relatively high accuracy and the high spatial density (Lichti, Gordon, Stewart, Franke, \& Tsakiri, 2002). Therefore, both of the three-dimensional models depict precisely the state of the Aedicule. The GECO Laboratory of the University of Florence visited the monument in 2007 and performed the first survey with the application of a laser scanner. Some years later in 2015 the National Technical University of Athens with the collaboration of the Laboratory of Photogrammetry produced several 3D models of the Aedicule during the different stages of the restoration again with measurements that were acquired with the same method.

Both the Italian point cloud and the Greek point cloud, which was constructed before the restoration of the monument, are accurate representations of the Aedicule in different time periods. Therefore, their comparison and the assessment of its outcome could provide important information about the condition of the structure through these years. The same resolution and reference system are essential for a precise comparison between the two 3D models. As a result, the Greek point cloud was decimated. Also, a rigid body transformation, which preserves the size and the shape, was applied. This kind of transformation typically consists of a translation and a rotation in 3D space.

Regarding the rigid body transformation, the Greek point cloud was selected to be the reference and the Italian point cloud would be transformed. Only two common points in both reference systems with known coordinates were detected. Consequently, it was assumed that three translations and one rotation angle around the Z-axis were required for the transformation. The parameters were calculated, and the Italian point cloud was transformed. The Global Registration, which uses the ICP algorithm, was applied for the improvement of the outcome. As a result, the point clouds were registered, and their comparison was possible through the creation of sections and the implementation of the $\mathrm{M} 3 \mathrm{C} 2$ algorithm. It should be noted that the comparison concerns the relative differences of the two-point clouds 
and not their deviations from any ground truth, as there was no such data available.

\subsubsection{Creation of Sections}

Four sections were created for each point cloud: a horizontal section with 1.60 meters elevation, a transverse section at the Chapel of the Angel, a longitudinal section and a longitudinal section with the orientation of the Tomb Chamber. The purpose of the production of these sections was the comparison of the main dimensions of the Aedicule through the measurements of relative distances. From every pair of sections ten (10) measurements of common distances in different parts of the Aedicule were performed. An approximation of the deviation of the data was estimated by calculating the RMS error for each pair of sections. The formula of the error is presented below in Eq. (1):

$R M S E=\sqrt{\frac{\sum_{1}^{10}\left(d_{i}-d_{j}\right)^{2}}{N-1}}=\sqrt{\frac{\sum_{1}^{10}\left(d_{i}-d_{j}\right)^{2}}{9}}$

where

$$
\begin{aligned}
& d_{i}=\text { Italian measurements } \\
& d_{j}=\text { Greek measurements }
\end{aligned}
$$

Eventually, four RMSE values were estimated (Fig. 6), one for each type of section, namely that of (i) the horizontal section error $(0.0040 \mathrm{~m})$, (ii) the transverse section error $(0.0064 \mathrm{~m})$, (iii) the longitudinal section error $(0.0173 \mathrm{~m})$ and (iv) the longitudinal section error with the tomb chamber orientation $(0.0164 \mathrm{~m})$.

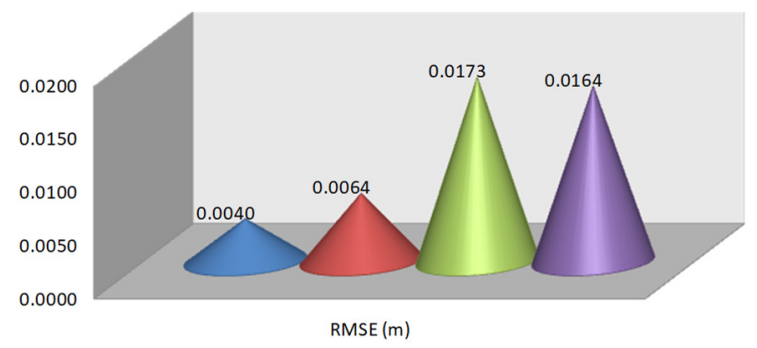

घorizontal Section $\quad$ Transverse Section $\square$ Longitudinal Section $\quad$ Longitudinal Tomb

Figure 6: Values of the RMS error in meters @ Author 2020.

It was noticed that the deviation of the measurements had larger values for the two longitudinal sections than for both the horizontal and the transverse section. A possible cause for this outcome could be the specific part of the Aedicule that these measurements refer to. Most of the dimensions in the longitudinal sections belonged to the interior of the structure, while most of the dimensions in the horizontal and transverse section referred to the exterior. Therefore, two additional errors were estimated, which would define the deviations of the interior (average of the errors of the longitudinal sections, Eq. (2)) and the exterior (average of the errors of the horizontal and transverse section, Eq. (3)) of the structure:

$$
\begin{aligned}
& R M S E_{\text {interior }}=\frac{(0.0173+0.0164)}{2}=0.0168 \mathrm{~m} \\
& R M S E_{\text {exterior }}=\frac{(0.0040+0.0064)}{2}=0.0052 \mathrm{~m}
\end{aligned}
$$

The total error derived from the average of the overall deviation errors and is equal to Eq. (4):

$$
R M S E_{\text {total }}=\frac{(0.004+0.0064+0.0173+0.0164)}{4}=0.0110 \mathrm{~m}
$$

All things considered, the result of the estimated total deviation error could be justified due to the combination of both the uncertainty of the previous processing stages of the point clouds and the state of the Aedicule through the eight years that had passed from the earliest to the latest survey (2007-2015).

Moreover, during the survey of the National Technical University of Athens in 2015 deformations were noticed at the external lower part of the southern side of the Aedicule. In order to investigate if these deformations existed in 2007 or they were formed later due to decaying, two new horizontal sections were created with 0.80 meters elevation (Fig. 7). From the comparison of these sections, it was obvious that the walls of the Aedicule generally did not have any differences. On the other hand, the columns seemed to have been deformed but it cannot be defined in which way exactly.

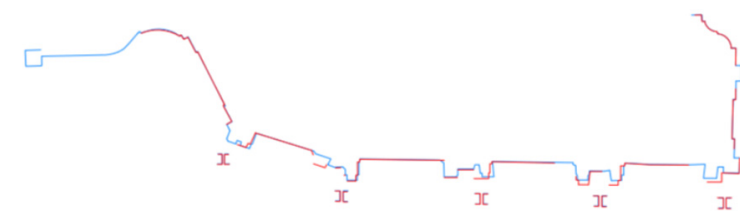

Figure 7: Comparison of the horizontal sections at +0.80 meters (C) Author 2020.

\subsubsection{M3C2 Algorithm}

When it comes to the comparison of point clouds that were constructed through laser scanning, the best method that is able to manage big data sets is the multiscale Model to Model Cloud Comparison (M3C2). The specific algorithm computes the local distances between two point clouds, for detecting 3D variations in surface orientation and estimates for each distance measurement a confidence interval depending on point cloud roughness and registration error (Lague, Brody \& Leroux, 2013). When there is no point correspondence there is also no distance computation. The units of the measured distances are equivalent to the units of the point cloud, which in this case are in meters (Barnhart \& Crosby, 2013). The Greek point cloud was chosen to be the reference cloud and the Italian point cloud the compare cloud. The outcome was a new coloured point cloud, with each colour representing a specific distance value (Fig. 8). The colour scale was chosen to present distances from 0.000 meters to 0.144 meters and the Nan points (no correspondence points) were invisible. The distance values ranging from $0-1.8 \mathrm{~cm}$ were depicted with green colour. The different shades of red, yellow and blue colour represent distance values from $1.8 \mathrm{~cm}-14 \mathrm{~cm}$. Hence, regarding the exterior of the Aedicule, the only parts with significant differences are the Coptic Chapel, the benches, the entrance above the door, which are justified due to decorations or unstable structures. Big distance values could be also noticed at the lower parts of the columns at the southern side of the edifice and at the decorative columns placed around the roof and the cupola, which might be proof of deformation.

A longitudinal section of the original $\mathrm{M} 3 \mathrm{C} 2$ distance point cloud was created in order to examine the results at the inner part of the Aedicule (Fig. 9). Apart from the Coptic Chapel, bigger distance values were detected at the Chapel of the Angel and the Tomb Chamber. Due to the 
existence of many decorations, oil-lamps and candles, there were big distance values at the wall above the passage and above the tomb's self. Many differences were also displayed at the domes of both chambers. Furthermore, the west part of the tomb was not depicted, which meant that the distance values were even bigger than $14 \mathrm{~cm}$. Further investigation proved that the Italian point cloud had some gaps at the specific areas and as a result the distance computation was not correct. These gaps were justified since none of the decorations were allowed to be removed during the data acquisition with the laser scanner. Therefore, these distance values should not be taken into account.

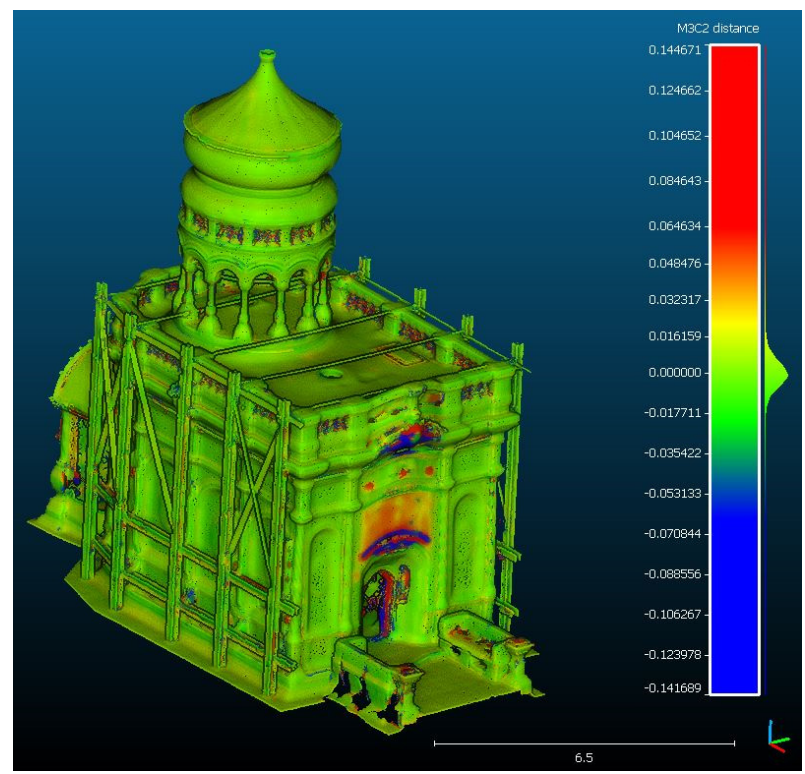

Figure 8: Result of the $\mathrm{M} 3 \mathrm{C} 2$ algorithm for the exterior of the Aedicule $\subset$ Author 2020

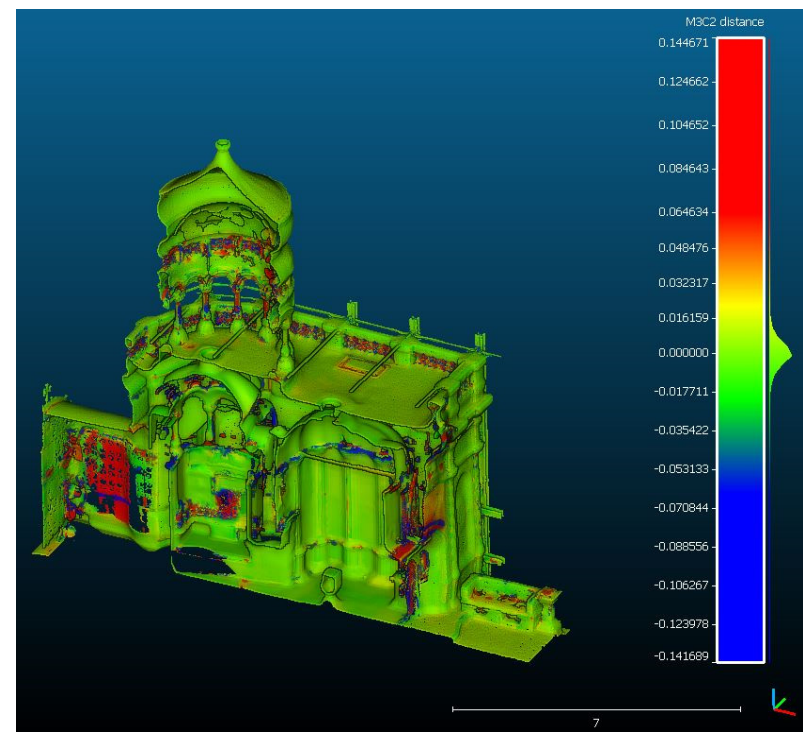

Figure 9: Result of the $\mathrm{M} 3 \mathrm{C} 2$ algorithm for the interior of the Aedicule (c) Author 2020.

\section{Discussion and Concluding Remarks}

The significance of the Aedicule of the Tomb of Christ can be identified through the numerous three-dimensional representations of this small edifice. Based on the research for the replicas of the monument, it was noticed that there was massive construction of certain types or its physical representations, such as the calvaries and the true-to-scale replicas. The edifices of the Aedicule are the type of replicas with the fewest reconstructions worldwide. Based on these results it is obvious that the number of replicas for each type depends on their similarity to the original. The better the correspondences, the more replicas of this type were constructed.

Most of them were created during the $16^{\text {th }}$ and $17^{\text {th }}$ century and can be detected in places either far away or close to Jerusalem. The countries where several replicas have been constructed are 23 in total and they are situated in Europe, Asia, North and South America. Those with the biggest number of replicas are Poland (22 replicas), Czech Republic (18 replicas), Italy (14 replicas) and England (10 replicas).

The online web map provides additional information for the types of replicas constructed in each region. For example, most of the true-to-scale copies are located in Czech Republic and in Germany. Also, the majority of the calvaries are detected in Poland and in Northern Italy. As a result, it is possible to obtain the global impact of the Holy Aedicule through the combination of the replicas dataset and their geographical relations with the visualization of a web map.

Apart from the replicas, there are digital threedimensional representations of the Aedicule of the Tomb of Christ. These forms of representations were mainly created for the geometric documentation of the monument and are characterized by high accuracy. One method for the construction of a 3D model, which is a form of digital documentation, is the photogrammetric processing of analogue photographs. For a precise outcome, several parameters should be taken into consideration. For example, the site of interest should be captured from different positions and angles. Moreover, sufficient overlap, high resolution and good lighting conditions are necessary. Also, GCP points or a known distance are essential for the correct scale and geometry of the 3D model.

An even more accurate technique that recent surveys have adapted is terrestrial laser scanning. The assessment of the comparison of the point clouds of the Aedicule indicates its deformations. Eventually, the outcome of the comparison computed by the algorithm is similar to the distance deviations which derived from the sections. The condition of the structure had remained in general the same from 2007 until 2015. The only major deformations which were detected are those of the columns at the southern side of the Aedicule and those of the small columns around the roof and the cupola.

\subsection{Future Work}

A suggestion for future work is the enrichment of the replicas' database through Crowdsourcing, which is the open call for online participation of a group of people in order to voluntarily undertake a task (Estellés-Arolas, González \& Guevara, 2012). For the specific case, religious communities, researchers or scholars related to the Aedicule could provide information. For this reason, the online web map should also be easily modified by the user, so that all the existed replicas could eventually be detected. 
Furthermore, the monitoring of the Aedicule would be possible through future geometric documentations of its condition and the comparison with the existed 3D model.
The evaluation of the results could provide information for its maintenance and potential restoration.

\section{References}

Adobe Photoshop. (2019). Make. Believe. Photoshop. Retrieved December 15, 2019, from https://www.adobe.com/gr_en/products/photoshop.html

Agisoft Metashape. (2019). Discover Intelligent Photogrammetry with Metashape. Retrieved December 15, 2019, from https://www.agisoft.com/

Alexopoulos, G. (2014) Sacred Site Conservation and Preservation. In: Smith C. (Eds) Encyclopedia of Global Archaeology. Springer, New York, NY. https://doi.org/10.1007/978-1-4419-0465-2_510

Balodimos, D. D., \& Georgopoulos, A. (2019). The survey of the Church of the Holy Sepulchre before the Digital Era, Chapter 2.1 in Tucci, G. (ed.). Jerusalem, The Holy Sepulchre. Research and Investigations 2007-2011. Altralineaedizioni, ISBN 978-88-94869-78-1, pp. 336.

Barnhart, T. B., \& Crosby, B. T. (2013). Comparing Two Methods of Surface Change Detection on an Evolving Thermokarst Using High-Temporal-Frequency Terrestrial Laser Scanning, Selawik River, Alaska. Remote Sensing, 5, $2813-2837$. https://doi.org/10.3390/rs5062813

Biddle, M. (1999). The Tomb of Christ. Editions of the Sutton Publishing Limited, ISBN 0-7509-1926-4, pp.142.

Custodia Terrae Sanctae. (2020). Father Corbo, the archaelogist friar of the Holy Sepulchre. Retrieved February 15, 2020, from: https://www.custodia.org/en/sanctuaries/holy-sepulchre

Esri. (2020). ArcGIS Dashboards-Actions. Retrieved January 15, 2020, from https://doc.arcgis.com/en/dashboards/createand-share/actions.htm

Estellés-Arolas, E., González L., \& Guevara, F. (2012). Towards an Integrated Crowdsourcing Definition. Journal of Information Science. 38. https://doi.org/10.1177/0165551512437638

FileZilla. (2020). FileZilla-The free FTP solution. Retrieved January 15, 2020, from https://filezilla-project.org/

Georgopoulos, A., Lambrou, E., Pantazis, G., Agrafiotis, P., Papadaki, A., Kotoula, L., Lampropoulos, K., Delegou, E., Apostolopoulou, M., Alexakis, M., \& Moropoulou, A. (2017). Merging geometric documentation with materials characterization and analysis of the history of the Holy Aedicule in the Church of the Holy Sepulchre in Jerusalem. The International Archives of the Photogrammetry, Remote Sensing and Spatial Information Sciences, Volume XLII5/W1, 2017 GEOMATICS \& RESTORATION - Conservation of Cultural Heritage in the Digital Era, 22-24 May 2017, Florence, Italy.

IGI Global. (2020). What is Noise in Photogrammetry Images. Retrieved December 15, 2019, from https://www.igiglobal.com/dictionary/noise-in-photogrammetry-images/59643

Jeffery, G. (1919). A Brief Description of the Holy Sepulchre Jerusalem and Other Christian Churches in the Holy City: With Some Account of the Mediaeval Copies of the Holy Sepulchre Surviving in Europe. Cambridge University Press, ISBN 9780511710926, pp. 264.

Lague, D., Brodu, N., \& Leroux, J. (2013). Accurate 3D comparison of complex topography with terrestrial laser scanner: Application to the Rangitikei canyon (N-Z). ISPRS Journal of Photogrammetry and Remote Sensing, 82, 10-26.

Lichti, D. D., Gordon, S. J., Stewart, M. P., Franke, J., \& Tsakiri, M. (2002). Comparison of Digital Photogrammetry and Laser Scanning. In Proc. International Society for Photogrammetry and Remote Sensing, 39-44.

Macpherson, J. (1892). The Church of the Resurrection, or of the Holy Sepulchre. The English Historical Review, 7(27), 417-436.

Moropoulou, A., Delegou, E., Apostolopoulou, M., Kolaiti, A., Papatrechas, C., Economou, G., \& Mavrogonatos, C. (2019). The White Marbles of the Tomb of Christ in Jerusalem: Characterization and Provenance. Sustainability, 11, 2495. https://doi.org/10.3390/su11092495

QGIS. (2020). A Free and Open Source Geographic Information System. Retrieved January 15, 2020, from https://www.qgis.org/en/site/

QGIS Python Plugins Repository. (2020). Qgis2web plugin. Retrieved January 15, 2020, from https://plugins.qgis.org/plugins/qgis2web/

Research Guides. (1999). Mapping and Geographic Information Systems (GIS). Retrieved January 15, 2020, from; https://researchguides.library.wisc.edu/GIS

Tucci, G., \& Bonora, V. (2011). Geomatic Techniques and 3D modeling for the survey of the Church of the Holy Sepulchre in Jerusalem. 23rd International CIPA Symposium. Prague,Czech Republic.

Zoner Photo Studio. (2019). Zoner Photo Studio X. Retrieved December 15, 2019, from https://www.zoner.com/ 


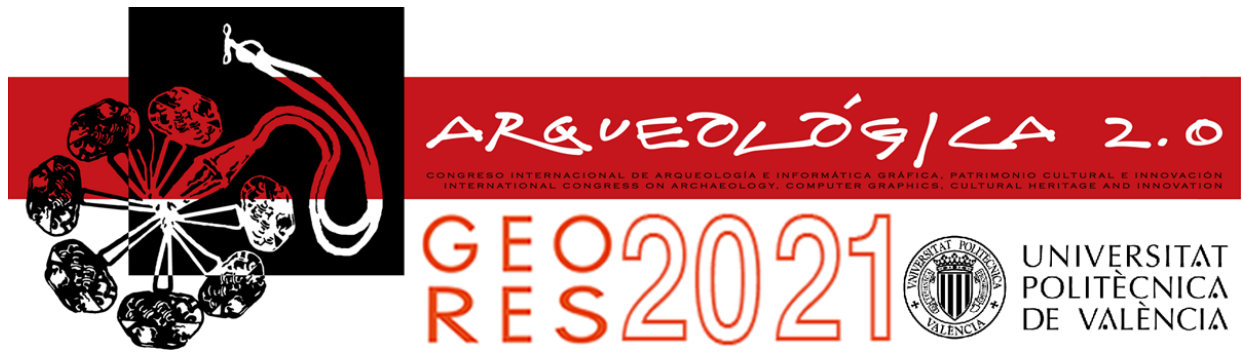

\title{
READING INTEGRITY IN THE LANDSCAPE: METHODS' COMPARISON ON TICINO AREA
}

\author{
Paola Branduinia ${ }^{a}$, Mattia Previtalia ${ }^{,}$, Eugenia Spinellia, Marco Tagliabue ${ }^{b}$ \\ ${ }^{a}$ Department of Architecture, Built Environment and Construction Engineering, Politecnico di Milano, Via Ponzio 31, 20133 Milan, Italy. \\ paola.branduini@polimi.it; mattia.previtali@polimi.it; eug.spinelli@gmail.com \\ b GPSBrianza, Parco del Ticino, Italy. mark.taglia@gmail.com
}

\begin{abstract}
:
The landscape is the system of both tangible and intangible heritage. A key element to evaluate a landscape is its integrity intended as the wholeness and intactness of natural and/or cultural heritage. The problem of identifying the integrity of a landscape is twofold: on one side it is necessary to identify the element that determines the intactness of a landscape and on the other side the methodology to study and quantify the integrity. Different methodologies have been developed in the literature to assess and measure landscape integrity: some of them are more quantitative, while others are more qualitative. This paper presents two different methods for landscape integrity evaluation: the Valutazione Storico Ambientale (VASA) and the Landscape System Historical Analysis (LaHSA) one. The comparison of the two methodologies is carried out in a portion of the Ticino river (North Italy) and more specifically in the municipality of Morimondo. The two methods are compared considering a set of elements taking into account both the understanding of tangible and intangible permanencies and data accessibility/accuracy to carry out the analysis.
\end{abstract}

Keywords: VASA methodology, historical rural landscape, integrity, historical analysis

\section{Introduction}

The landscape is a tangible and intangible heritage (ICOMOS, 2017; Scazzosi, 2018a). This connection is part of UNESCO's broader reflections on integrity that lead to a cultural landscape to be included in the World Heritage List (UNESCO, 1972). In Article 88 of the Guidelines for the implementation of the World Heritage Convention (2011), integrity is defined as "a measure of the wholeness and intactness of the natural and / or cultural heritage and its attributes". It "includes all elements necessary to express its outstanding universal value" and it has to have an "adequate size to ensure the complete representation of the features and processes which convey the property's significance". The attributes to assess integrity are indicated in the Operational Guidelines and are related to tangible permanence, namely form and design, material and substance, location and settings, and intangible permanence, namely tradition, techniques, language, spirit and feeling.

Therefore, in order to assess the integrity of a landscape, the question is twofold: on one hand, we should consider which elements and at which scale they should be taken into account, on the other hand, we should define which method/approach to use to evaluate the permanence of the previously listed attributes of the landscape. In this context, the availability of digital tools (Yang \& Han, 2020) can be of primary importance to evaluate, quantify and report the landscape integrity. In particular, this paper would like to offer a reflection on the evaluation of historical permanencies in a landscape through two different approaches relying on GIS tools.

We also assume to overcome the interpretation of the landscape reading as a simple sum of different elements and we move towards the concept of landscape system: "the landscape as a system comprehends its social and functional organization. It is not possible to explain the landscape system by reading its components separately. " (Scazzosi, 2018b; Branduini, Laviscio, L'Erario, \& Toso, 2019; Mitchell, 2008).

Talking about historical remains, the emerging problem is which historical documents and in particular maps and land use registers (mainly land registry) are useful and digitally available as fundamental references to assess integrity. Historical analysis requires not only map and registry availability but also their effective utilization. In particular, maps should be digitalized and georeferenced. Direct georeferencing, intended as a transformation between two coordinate systems where transformation parameters are known, is not always feasible and/or desirable. This may result in the need for georeferencing large set historical maps (Brovelli \& Minghini, 2012). 
Methodologies relying on historical analysis for reading and interpreting the landscape integrity are based both on mapping land use surfaces, tree or wall lines and buildings, attributing indices (quantitative method), and interpreting the relations among the landscape permanencies (qualitative method). Indeed, Gullino \& Larcher (2013) in their discussion about methodologies to evaluate integrity, state that "the scientific community agrees with a multidisciplinary and integrated approach to integrity, not one based on pure historical interpretation". Moreover, Scazzosi (2004) explains that the integrity concept is not limited to the definition, but it also relates to theoretical, methodological, and experimental work at different levels.

The purpose of this contribution is to compare two of these methodologies, one more quantitative, the Valutazione Storico Ambientale (VASA), the other more qualitative, the Landscape System Historical analysis (LASHA), both used to assess integrity on the Italian territory. In particular, the purpose of the comparison is to understand the pros and cons of each one of them and evaluate the two methodologies on the basis of contents and technical-practical criteria.

In order to carry out the presented comparison data availability is a key element. Indeed, both methodologies analyzed in this paper are taking advantage of historical maps and land register data available in archives. Availability of those data is a key issue of both presented methods.

\subsection{Case study}

We selected to conduct the study on Ticino Valley because part of the authors' team is working on the candidature of water meadows landscape along the Ticino valley for the Historical landscape National Register, promoted by the Ministry of Agricultural, Food and Forestry Policies. The methodology requested by the Ministry is the VASA, and during the application of the methodology, we encountered some problematic issues concerning data source selection and interpretation, notably with regards to the meadow identification in the GAI map requested. In fact, tree cultivation, like vineyards or olive trees, are easier to be identified in GAI maps; conversely, the distinction between arable land and meadows is really hard to perform. The two methodologies have been applied on a portion within the Milan district, with two macrozones divisible in the area within the Ticino river valley, and a second one outside to underline the differences between the two neighbouring regions. The two regions are so different in the land uses dynamics.

\section{Material and method}

\subsection{Tables VASA methodology}

The VASA methodology was born in the early 2000s. It takes up the Historical and Cultural Evaluation Approach (HCEA), conceived and used by the Department of Forest Sciences and Technologies of the University of Florence to monitor the state of the Tuscan landscape (Agnoletti, 2006). Today it is proposed in the National Register of Historic Rural Landscapes to understand the evolution of the landscape and to evaluate which areas meet the criteria issued by the Ministry of Agricultural, Food and
Forestry Policies in order to become part of the Register. In fact, the VASA analysis is regulated by strict ministerial directives.

The VASA evaluates the landscape with a historical approach. It aims to understand the evolutionary dynamics of the territory; to estimate the state of the landscape through the use of indices deriving from landscape ecology and to produce assessments of integrity, importance and vulnerability already used for the UNESCO World Heritage List (Agnoletti, 2007). Furthermore, it aims to consider and preserve the habitats deriving from human influence. For this purpose, it focuses on the land uses, considered as the basic tiles of the mosaic that forms the landscape.

The methodology is based on the photo interpretation: two aerial photos belonging to two different eras are analyzed and compared. The first is generally taken from the 1954 GAl flight, the last image of the whole Italian territory before the transformations that took place after the Second World War. The second is from the current era.

Once the images have been geo-referenced a land cover map is produced for each historical period in a GIS environment. The minimum mappable unit is $500 \mathrm{~m} 2$. In the case of particularly fragmented landscapes, a minimum unit of $250 \mathrm{~m} 2$ is accepted. Linear and point elements can be identified for further analysis, which may include: linear or scattered trees: hedges; monumental trees; plants showing traces of traditional cutting techniques; artifacts of historical rural construction; elements pertaining to historical, architectural, archaeological heritage; land arrangements such as terracing, verges (Agnoletti \& Tempesta, 2016). So, we proceed with the comparison of the data collected to know the evolutionary dynamics of the specific area. In particular, by overlapping the layers relating to land uses, a third information layer is obtained in which the portions of the territory are classified according to the following terms:

- Built up: loss of forests, crops or pastures, replaced by urbanized areas.

- Deforestation: loss of forested land, replaced by cultivated areas or pastures.

- Extensification: transition from intensive to extensive cultivation.

- Forestation: loss of cultivated areas or pastures, replaced by shrub or tree formations.

- Intensification: transition from extensive to intensive cultivation.

- Stable: land use has remained constant (Agnoletti, 2006).

To recognize these cases is facilitated by the creation of the Cross Tabulation, a graph that facilitates the choice of evolutionary dynamics for each change in land use that occurs in the area over time. Starting from the crosstabulation and related data, using a given formula, it is calculated the historical index that evaluates the risk of disappearance for each agricultural practice. Lastly, following the parameters provided by MIPAAF (Ministry of Agricultural, Food and Forestry Policies), the class of integrity to which the landscape under examination belongs is established. To complete the analysis, the 
following files are required: cartography that indicates the linear and punctual elements present in the landscape; the calculation and comparison of data relating to the fragmentation and extension of land uses; the charts and histograms necessary to explain each cartography data (Reterurale, 2021).

\subsection{LaSHA methodology}

The LASHA methodology is a way of interpreting the landscape, developed by research activities of the PaRID laboratory at the Politecnico di Milano: it is applied to different scales, from the territorial scale (city-country ratio) to the farm scale (farm, buildings and fields) and allows good control of the project in the landscape. It is based on the interpretation of the landscape as a system of material permanencies (waters, roads, rural buildings, vegetation - woods, rows, hedges - use of agricultural land and division of fields) linked by immaterial relationships (economic, social, cultural), evolving through time. This interpretation is in line with the studies of Marc Bloch and Fernand Braudel on material culture and with the Unesco concept of evolutionary landscape (Scazzosi, 2011). The "reading by systems" methodology is applied in order to understand the historical evolution of places: firstly, a diachronic analysis is done with the aim to read the transformations at the different historical thresholds, secondly a synchronic analysis is prepared in order to understand the tangible and intangible permanencies (of elements and relationships) still present today. This last interpretation responds to the need to understand only material and meaning pieces of evidence, avoiding the possibility of reconstructing elements that have no material permanence, in compliance with the principles of conservation (from the Venice Restoration Charter, 1964 to the of Krakow of 2000). Developed in Lombardy, the diachronic study analyzes the historical cadastral maps to depict an image "of the historical landscape at each century. Normally, the period from the $18^{\text {th }}$ century to the present is analyzed. In Lombardy for each period are available the respective materials that will be discussed in paragraph 2.3: for the '700 is used the Catasto Teresiano, for the ' 800 the cadastre Lombardo Veneto, for the ' 900 the IGM maps dated 1930 and for the current landcover map (DUSAF).

The cadastral maps are providing not only a detailed description of the landscape structure (roads, channels, etc.) but also a rich description of the different land uses and cultivation (e.g., water meadows, crop fields, etc.). Small scale maps (1:30.000) were used to analyse the structure of the landscape at a territorial scale providing a larger picture of the structure of the territory in terms of connection (road and water) as well as a general identification of the land uses. On the different maps, waters channel, roads, rural buildings, vegetation woods, rows, hedges - use of agricultural land and division of parcels are traced, and to each land use we assigned a color that can be associated with reality (so the cereal fields will be shades of yellow, the meadows green, dark green woods).

In particular, once historical maps are georeferenced the different land parcels, roads and water network are digitized in a GIS environment. The information concerning the land uses are derived from data coming from land registry archives. A research in the archive was carried out to link the land uses and the land parcels. The land use data are stored in a shapefile characterized with the following attribute table: "ID" identifying the parcel identifier reported in the maps, "Land use" reporting the land uses reported in the and registry archive and "toponym" reporting (if present) the toponym of the land parcel. Water networks are digitized making a specific distinction among the different levels of the hydrographic network (e.g., main river, secondary rivers, channels , "rogge", etc.). A similar distinction is done for the road network: main roads, secondary roads, pathways, etc. In this way, the diachronic maps belonging to the different historical periods chosen are obtained. The analysis of the results and their comparison takes place de visu. The analysis of the results and their comparison takes place de visu in order to understand which portions of the territory derive from which historical periods. The synchronic map is constructed by reporting on the current cartography (for example Google map or regional technical map) the permanences of previous epochs, attributing a colour to each historical period (usually decreasing from red to yellow) and attributing different graphic signs to the different elements of the landscape. The synchronic map allows you to know for each element of the landscape still present today when it was created. The identification of permanencies is done according to the criteria shown in Table 1.

Table 1: Criteria for identifying permanencies.

\begin{tabular}{c|c} 
Land use & Permanence \\
\hline Riparian woodlan & Forest \\
Futting forest & \\
Mixed coppic & \\
\hline Irrigated meadow & Pasture and meadow \\
Wet meadow & \\
Pasture & \\
\hline Arable land & Arable land \\
Arable land with vineyar & \\
\hline Chestnuts wood & Trees crop \\
\hline Trees crop & \\
\hline Irigated arable land & Irrigated arable land \\
\hline Rice field & Rice field \\
\hline Path & Path \\
\hline Water body & Water body \\
\hline
\end{tabular}

The interpretation of the permanences could be completed by the creation of a so-called "bloc-diagram" or axonometric section which, through the addition of textual labels, allows to explain the underlying economic and functional relationships between the cultivations and rural buildings: it can be created for each historical threshold, as well as for the current state (Scazzosi \& Branduini, 2014).

\subsection{Materials}

The two methods compared in this paper differ significantly for the materials used for the analysis of landscape integrity. 
The VASA methodology relies on the comparison of two different landuse maps. Generally, landuse maps are derived from photointerpretation of the photogrammetric aerial survey with panchromatic film black and white collected by the Istituto Geografico Militare Italiano (IGM) acquired in 1954/1955 by a specific group named "Gruppo Aereo Italiano" (G.A.I.). For this reason, the dataset is generally named as 1954 GAl Flight. The dataset has an average frame scale ranging from $1: 45,000$ in mountainous areas and 1:33,000 in lowland areas. The images were digitized with a scanning quality ranging between from 800 to 2500 DPI. Orthophotos derived from the 1954 GAI Flight are available at National and Regional level as already georeferenced products as well as a layer providing the land use derived from photointerpretation. The photointerpretation of the 1954 GAl Flight is a challenging task since there is no information about the date of the frame shoot used for the G.A.I mosaic, so it's not possible to associate a detailed specification of the kind of agricultural crop or lawn. For this reason, in the presented work we are using a different dataset. In particular, we used IGM maps at 1:25000 scale realized in the ' 30 s. The main advantages of using this dataset are: i) a larger scale compared to the 1954 GAI Flight, ii) a higher level of detail in the definition of land used with respect to those that can be derived from the interpretation of the 1954 GAl Flight, iii) IGM '30s maps were realized before the big urbanistic transformations that involved Italy after Second World War. The second data set used for the VASA analysis is the official land use map of the Lombardy region (named DUSAF) realized in 2018. DUSAF map was complemented by an in-situ survey to verify and possibly correct the land use map. Due to its original error, we used the corrected version of DUSAF for analysis. Verification focused on the Valley area, the nearest to the Ticino river. However, a more complete data assessment should be done also on the entire study area.

The LaSHA methodology relies on the comparison of several land use maps (one per century) to create synchronic and diachronic maps. In this work the map analyzed are the following ones:

- The "Teresian Cadastre" (1722) wanted by the Empress Maria Theresa of Austria to know and quantify value of the land on which she ruled, drawn up on a scale of approximately 1:2.000.

- The 1865 so-called "Lombardo Veneto Cadastre" commissioned by Charles VI, always on an approximate scale. Both land registers allow accurate mapping of land use parcel by parcel thanks to the indications reported on the map or in associated registers.

- IGM maps drawn up at a scale of 1: 10.000 or 1: 25.000 around the 1930s and subsequent updates. The latter, even if at a larger scale, are very accurate and the land uses are mapped as well as the presence of trees.

- For the current situation the regional technical map and landcover map (DUSAF) are used, cross checked with IGM maps and with the aerial photo.
The first step of the LaSHA method is the georeferencing of the historical maps of the Therian and the Lombardo Veneto cadaster (IGM maps and DUSAF are already georeferenced). The georeferencing is carried out without known parameters by (i) using as reference data set the current cartography, (ii) finding corresponding points, and (iii) applying an affine transformation method. In particular, the georeferencing of historical maps was carried out in a two-step way: (i) georeferencing of historical maps to a contemporary coordinate system and (ii) mosaicking of the individual map sheets into a unique map (Previtali \& Latre, 2018). To guarantee a good overlap between consecutive sheets we georeferenced each image separately first and then we used boundary points to stitch them together in a final map. The accuracy of maps georeferencing is mainly affected by two different aspects: (i) the period of the map production and (ii) the nominal scale of the original map. In the presented work cadastral maps of different epochs (XVIII and XIX centuries) are used. Both map series were designed for the scale 1:2000. However, the XVIII century maps georeferencing can be considered compatible for the scale $1: 5.000-1: 10.000$ (this is mainly due to the difficulty in determining corresponding points in agricultural areas), while the XVIII century maps are compatible for the scale 1:2.000-1:5.000. As previously highlighted one of the most important aspects concerning LaSHA methodology is the georeferencing of the historical maps. Georeferencing is carried out in a QGIS environment by using the Georeferencer Plugin. Georeferencing is performed without known parameters using the current cartography as the reference dataset, finding minimum of four corresponding GCP points, and applying a polynomial transformation method. Finally, an evaluation of the georeferencing accuracy was carried out by considering a set of Ground Control Points (GCPs) and evaluating the difference between their position in the georeferenced historical cadastre and their actual position. The results of this analysis are summarized in Table 2.

Table 2: Analysis of historic map georeferencing results.

\begin{tabular}{c|c|c|c} 
Cadastre & $\begin{array}{c}\text { Mean GCP } \\
\text { distance } \\
(m)\end{array}$ & $\begin{array}{c}25 \% \\
\text { percentile } \\
(m)\end{array}$ & $\begin{array}{c}75 \% \\
\text { percentile } \\
(m)\end{array}$ \\
\hline $\begin{array}{c}\text { Teresian } \\
\text { Cadastre 1722 }\end{array}$ & 10 & 8 & 19 \\
$\begin{array}{c}\text { Lombardo } \\
\text { Veneto } \\
\text { Cadastre 1865 }\end{array}$ & 8 & 5 & 17
\end{tabular}

\subsection{Criteria of comparison}

The two methodologies are compared following criteria that concern the ease to understand permanencies and the accessibility and availability of digital data.

Thus, the criteria selected for detecting permenencies are:

- Ease to identify tangible permanencies: form and design, material and substance, location and settings.

- Ease to recognise intangible permanencies: tradition, techniques, language, spirit and feelings. 
- Clarity in graphical representation: it comprehends colour selection, graphical signs and symbols associated to elements.

The criteria selected to assess availability and accessibility of data are:

- Data availability: it refers to the difficulty to access the basic data to be analyzed.

- Data interpretation facility: on the trial of extrapolating information from the basic data.

- Need for data integration: it relates to the need to acquire additional data to complete the analysis.

- Quality (type) and quantity (number) of analyzed data (as polygons and as linear elements).

- Data analysis complexity: it refers to the difficulty of processing data and generating information.

- Execution times.

\section{Results}

\subsection{The VASA analysis applied to Ticino - Morimondo case study}

The VASA methodology provides five main results:

- Maps that identify land uses (Fig. 1) and rows of trees (Fig. 2) in the different periods.

- Tables and histograms (Fig. 3) that show the percentage of different land uses within the analyzed area and it's strictly linked to the previous maps.

- A map that shows how the landscape changes in the two different periods (Fig. 4a). Pink shapes identify permanences, the yellows ones the intensification of crops kind, for example. the switch from meadows to generic arable field.

- Cross-tabulation tables and pie charts (Fig. 5) where identical or similar land uses have pink colour.

- Two indexes: the first one (Fig. 6) shows how much the landscape is fragmented, with the number of patches and their extension. It's useful to understand how much nowadays fields grow in extension for companies' needs. The second one is the Historic Index (HI) that is a value associated with different kinds of crops that show the land uses that don't change from time to time (Fig. 7). In the map (Fig. 8) remain just the fields which have exactly the same value in the two years of analysis.

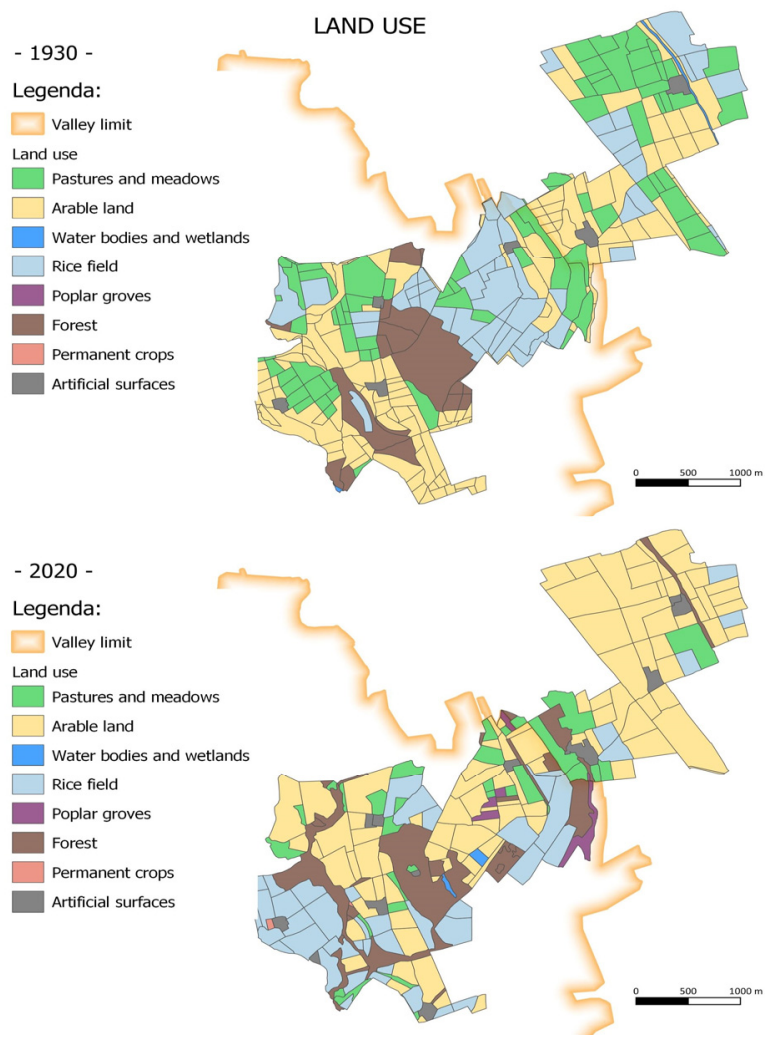

Figure 1: Land use maps of 1930 and 2020.

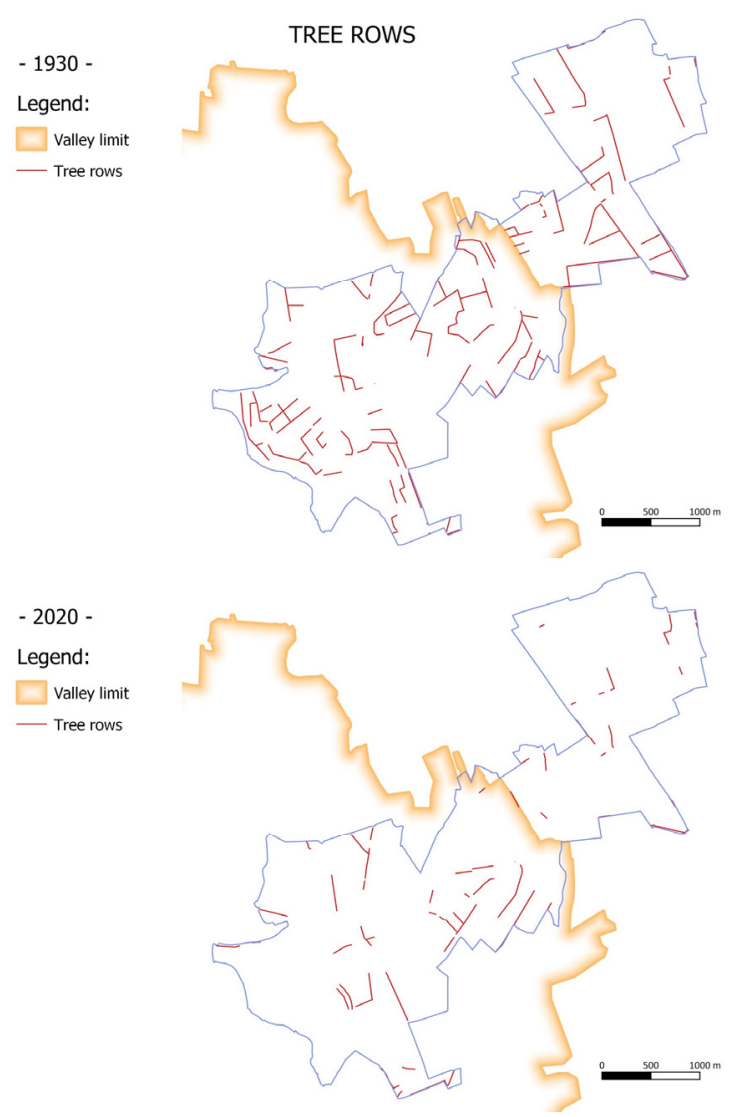

Figure 2: Rows of trees maps of 1930 and 2020. 

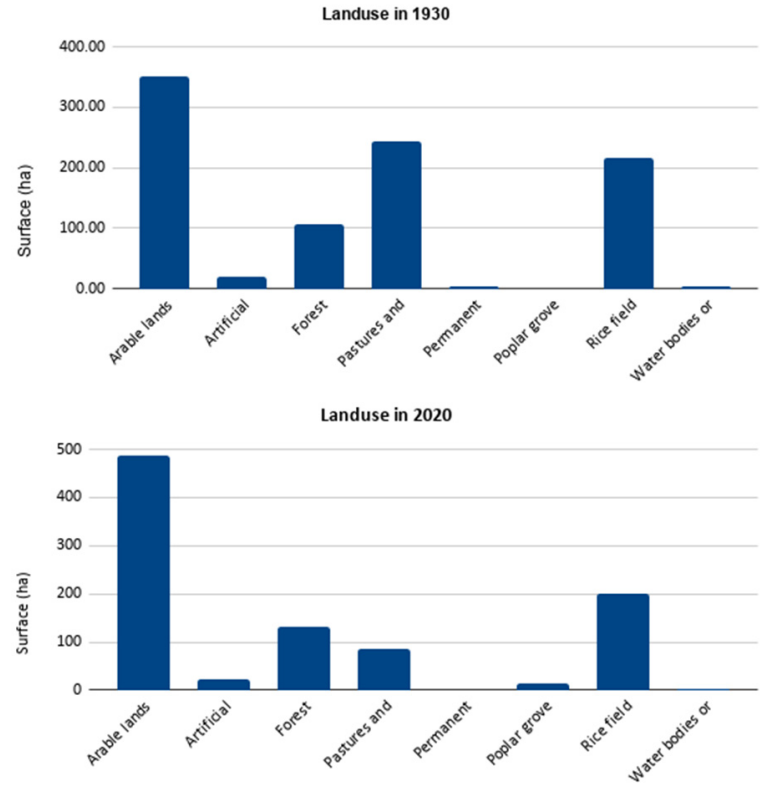

Figure 3: Land use histogram of 1930 and 2020.

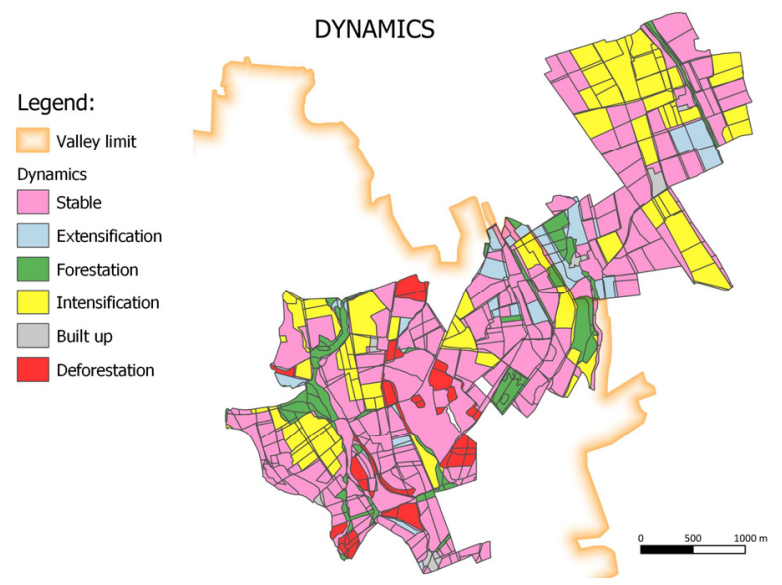

Figure 4: The map of land use changes between 1930 and 2020.

\subsection{The LaSHA analysis applied to Ticino - Morimondo case study}

The analysis shows a decrease in land uses, in particular the subsequent disappearance of promiscuous crops and woodland used for logging that have been rarefied since the $18^{\text {th }}$ century. Specifically, we note that forests underwent a strong decrease between ' 700 and ' 900 with a slight increase in 2020 . The canalizations have seen a thickening in the ' 800 and ' 900 and then remain stable, the same happens for the paths. Grazing disappears between ' 800 and ' 900 . While already in the ' 900 there is a decrease of irrigated arable land in favour of nonirrigated and in general a prevalence of rice fields on arable land.

Finally, between 1900 and 2020 there is a reduction in meadows and pastures. As far as permanence is concerned, it can be seen that the woodland visible today was already present in the 1700 s, while the percentage of irrigated and non-irrigated arable land datable to the 1700 s is very small. Most of the fields originate in the 1900s. There are few portions of land where land uses can be traced back to the 1800 s. On the other hand, we find a large part of irrigated and non-irrigated arable land dating back to the 1900 s and a good part of the rice fields. Thanks to the analysis carried out, we have been able to identify the periods of belonging of the individual portions of the territory and to define which of the canals and paths in the area can be traced back to which historical periods, highlighting also in this case the presence of traces in the landscape dating back to the ' 700 .

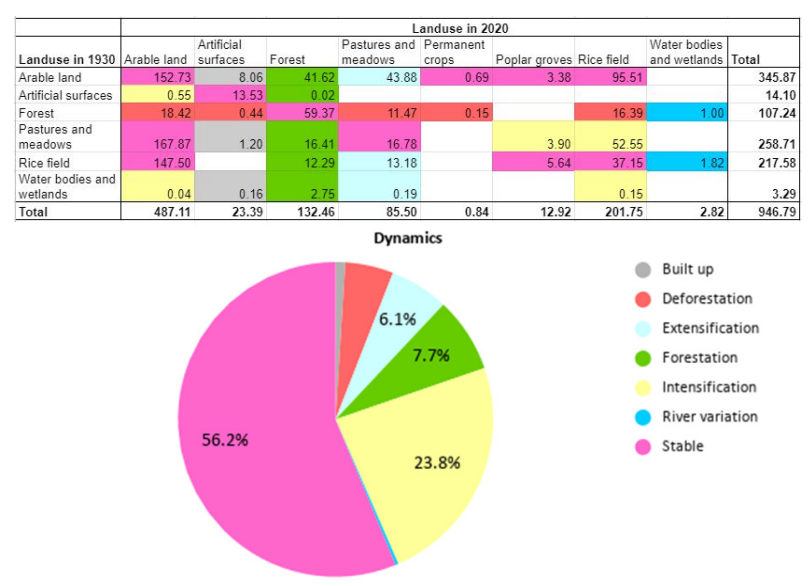

(a)

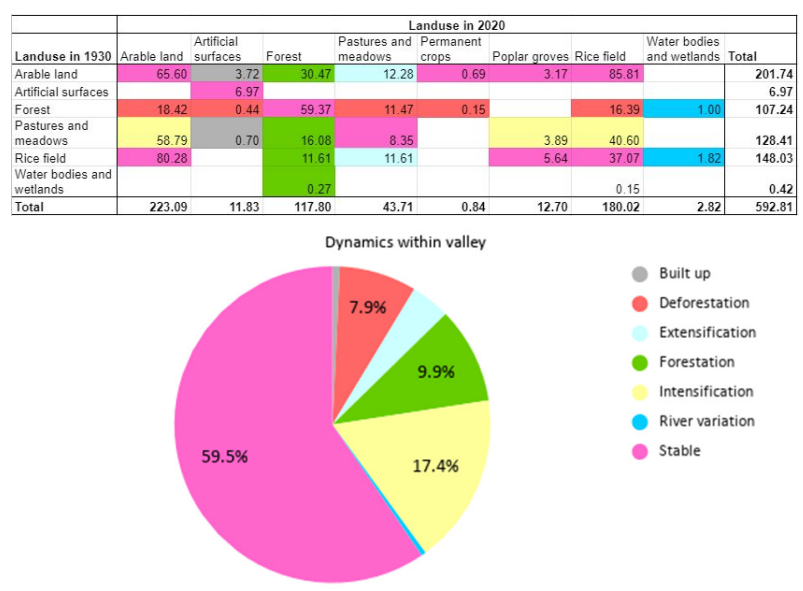

(b)

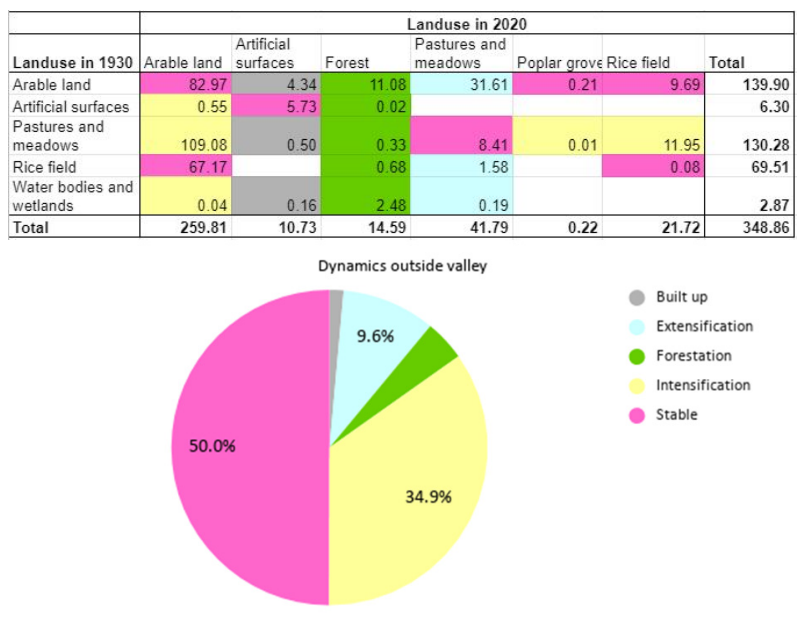

(c)

Figure 5: Cross-tabulation table and pie chart show the percentage of the changes, referred to the entire area (a), and details within (b) and outside (c) the Ticino Valley. 


\begin{tabular}{l|r|r} 
& 1930 & $\mathbf{2 0 2 0}$ \\
\hline Number of patch & 2227 & 2239 \\
\hline Medium surface (ha) & 3.16 & 4.32 \\
\hline Agricoltural medium surfa & 3.00 & 4.38 \\
\hline Number of landuses & 6 & 8
\end{tabular}

Figure 6: Historical index map showing the persistence of historical land uses.

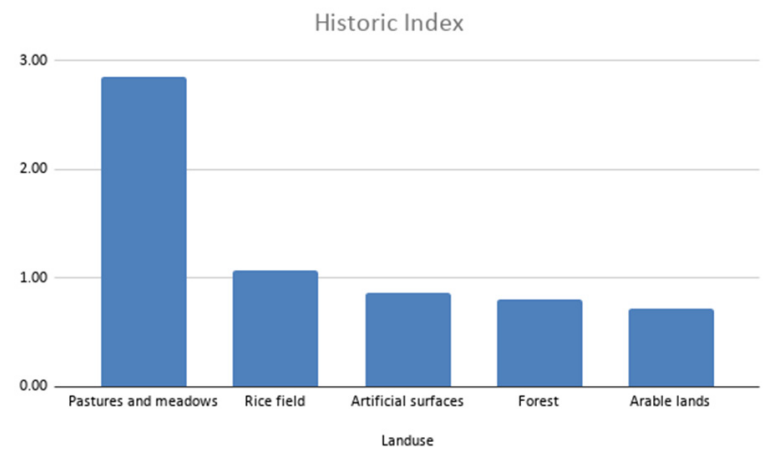

Figure 7: Histogram with historic index sorted decrescent.

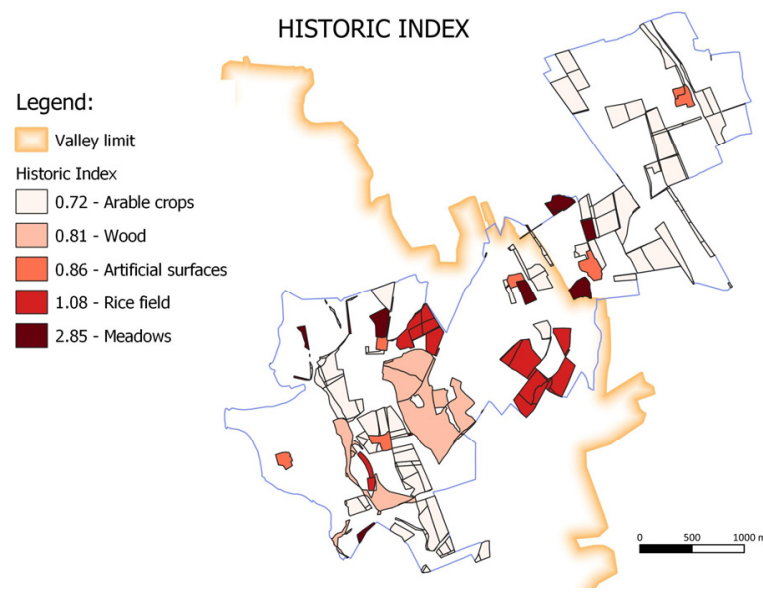

Figure 8: Historical index map showing the persistence of historical land uses.

Results of the proposed LaSHA analysis for the same area studied with the VASA are presented in Figures 912. Here the diachronic Landscape analysis is carried out for the following historical phases: i) 1722 - Theresian Cadastre, ii) 1866 - Lombardo Veneto Cadastre, iii) 1930 - Tavole IGM and iv) 2018- CTR Lombardia.

As can be observed (Fig. 11) the diachronic Landscape analysis for the same time period previously discussed is carried out. Figure 13 presents also an example of Synchronic Landscape Analysis: the permanences are represented on a current map attributing a colour to permanences for each historical period.
XVIII century - Teresian Cadastre 1722

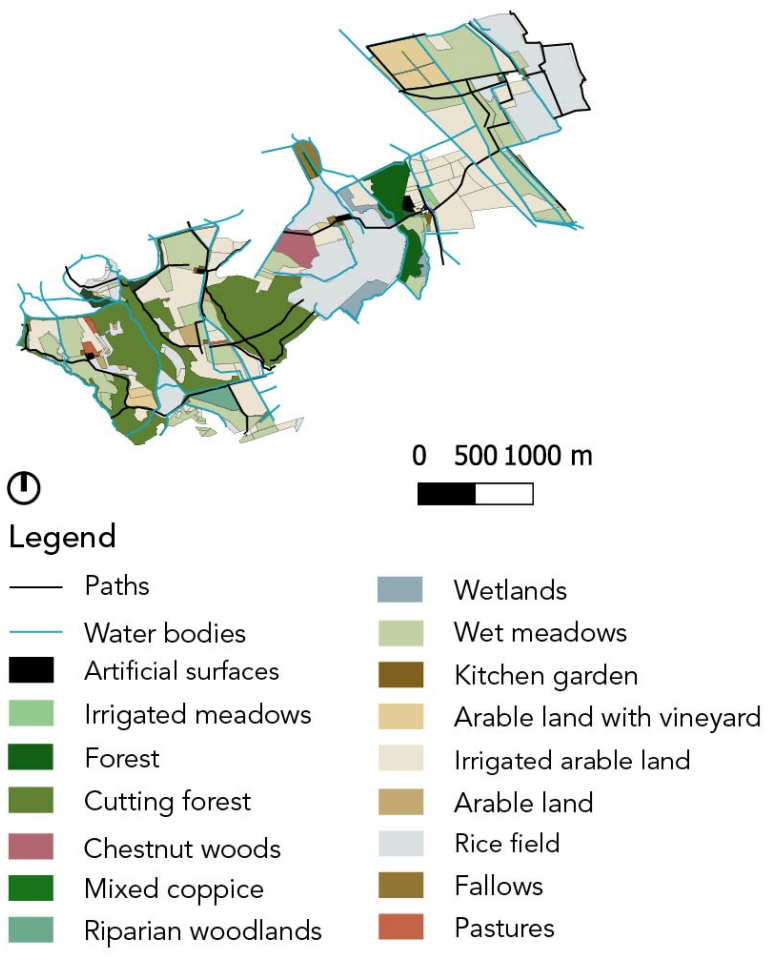

Figure 9: Diachronic Landscape Analysis: 1722 - Theresian Cadastre.

XIX century - Lombardo Veneto Cadastre 1866

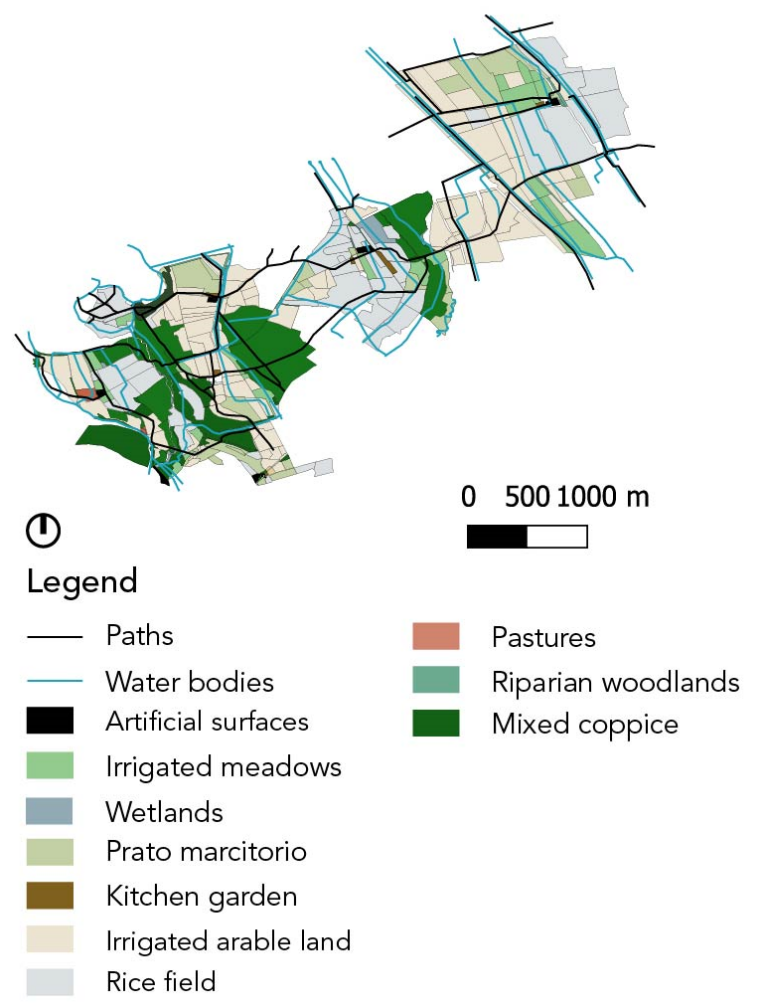

Figure 10: Diachronic Landscape Analysis: 1866 - Lombardo Veneto Cadastre. 


\section{XX century - IGM 1930}

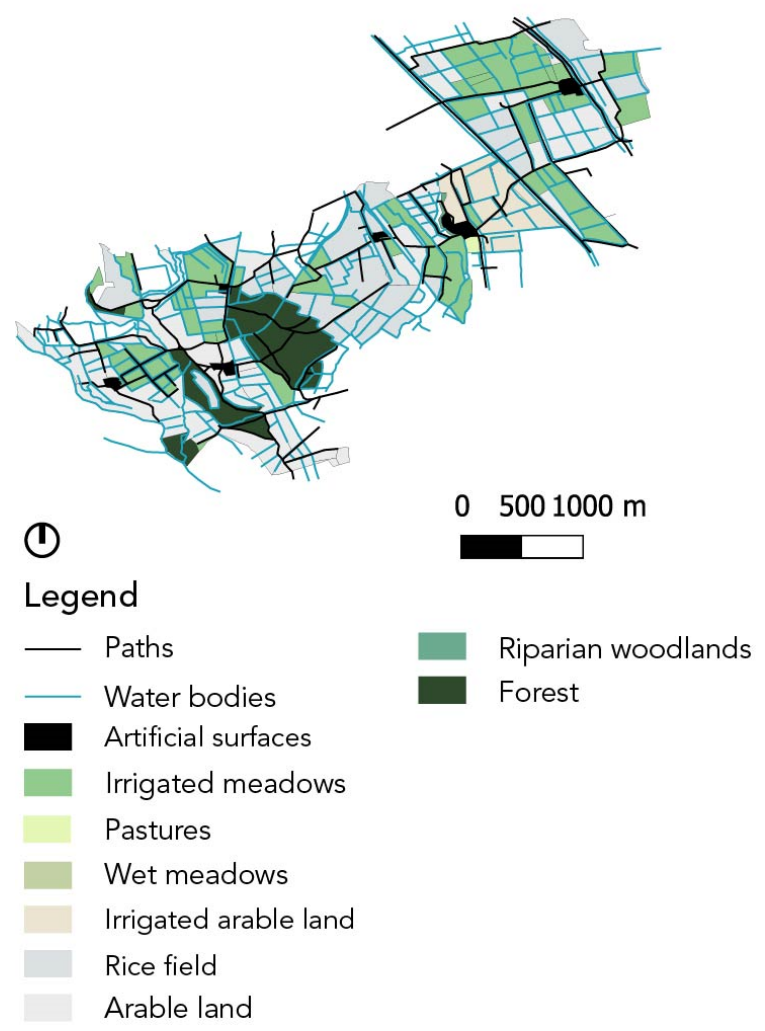

Figure 11: Diachronic Landscape Analysis: 1930 - Tavole IGM.

Current situation - CTR Lombardia 2020

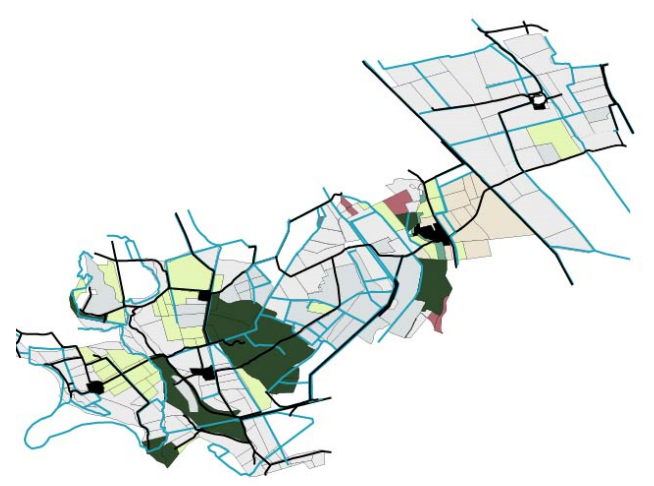

(1)

$0 \quad 5001000 \mathrm{~m}$

Legend

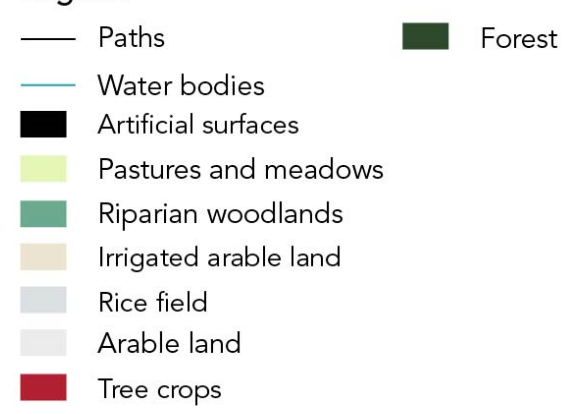

Figure 12: Diachronic Landscape Analysis: 2018- CTR Lombardia.

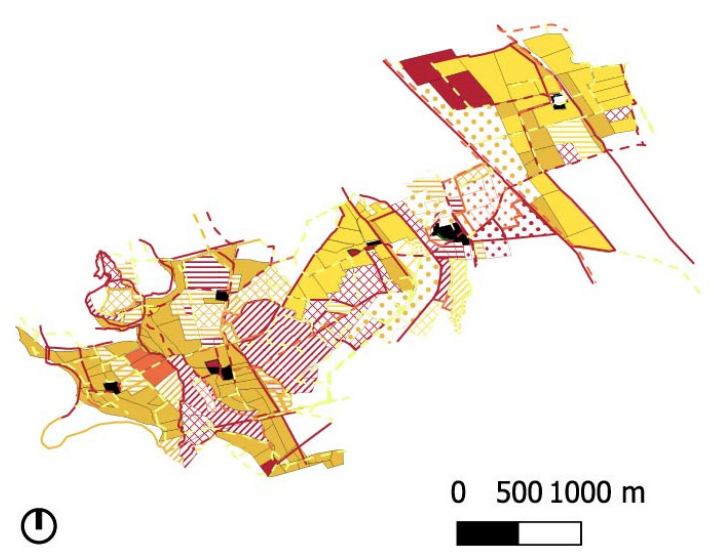

Legend

\begin{tabular}{|c|c|c|}
\hline$<\mathrm{XVIII}$ century & \multicolumn{2}{|c|}{$<\mathrm{XIX}$ century } \\
\hline --- Paths & --- & Paths \\
\hline Water bodies & 一 & Water bodies \\
\hline Irrigated arable land & 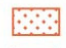 & Irrigated arable land \\
\hline Arable land & & Arable land \\
\hline Rice field & $x$ & Rice field \\
\hline Forest & एII & Forest \\
\hline Tree crops & $\because$ & Tree crops \\
\hline Pastures and meadows & 昰 & Pastures and meadows \\
\hline Artificial surfaces & & Artificial surfaces \\
\hline
\end{tabular}

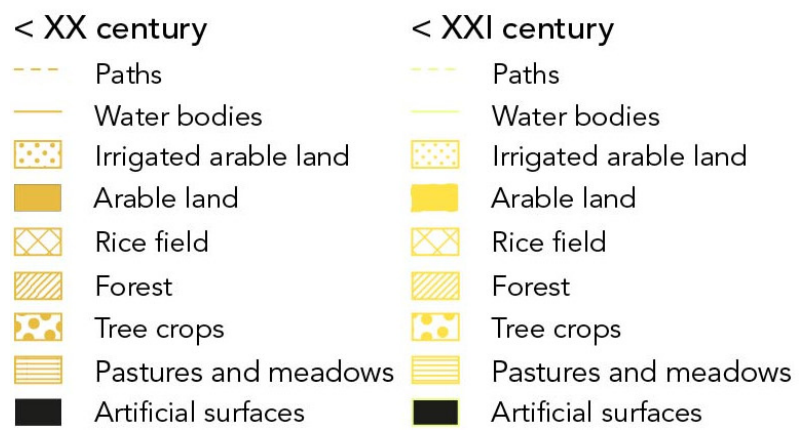

Figure 13: Synchronic Landscape Analysis.

\subsection{Results analysis}

VASA analysis offers good results with its construction of indexes and maps, thanks to this, it's easy to understand how much the landscape and the land use change. It's a quantitative analysis. But It's probably more useful by cropping the analysis area, to better understand dynamics and to make a more accurate and specific evaluation about. Doing this, it's clear how much the dynamics of land use tend to the intensification outside the Ticino Valley. It's easy to see how many crop fields (yellow shapes) replace pastures and meadows (in green), especially outside the Ticino Valley in the NorthEast (orange line) (Fig. 1). Even another important landscape element, rows of trees (Fig. 2), progressively disappear in the years outside the valley. Differences between the two areas emerge even with the next step of VASA: cross-tabulation tables and pie charts (Fig. 5) show in numbers and part how much the crops change. As shown in Figures $5 b$ and $5 c$, the percentage of fields that don't change land uses grows within the Ticino Valley, and fields converted for intensification use grow 
massively outside the valley. We need to make attention about pie charts: they should be illusory, especially for small areas; extensification changes (light blue) outside the valley have a relatively high percentage but it's referred to a real small area where crops kind change.

\section{Discussions}

\subsection{Permanencies' comprehension}

The LASHA methodology analyzes permanencies on a longer period of time. The longer timespan allowed to identify more meaningful permanencies: land uses, road connections and hydraulic artifacts testifying their resilience to historical, social, economic and technical changes. The final output (synchronic map) is more diversified and detailed as the data come from.

Concerning interpretation of landscape as a system, which include tangible and intangible heritage (Branduini, Laviscio, L'Erario, \& Toso, 2019), in the LASHA methodology, long time permanencies may be connected not only to physical aspects and may allow an easy detection of intangible permanencies related to long time developed and consolidated traditions and techniques (as in the case of the water meadow). This is possible thanks to the informations coming from more detailed maps (cadastral maps) and from a close scale (1.2000), so the diversification of data is carried along the whole comparison process. This is not possible in the VASA were the differences between the agricultural practises are not detectable due to the homogenisation of data as also Varotto states (2019). Clearly in the case of tradition and techniques their identification is not directly observable from the maps. However, cross verifying maps, archive sources (as witnesses of the past) and interviews (for the present) is possible to detect intangible values of the area.

For what concern clarity of the changes, the VASA methodology is presenting a large and clear set of land use change maps that allows an immediate comprehension of the main land use changes occurring in between the two periods of analysis (e.g., anthropization, deforestation, river changes, etc.). This map can be generated since the VASA carries out a pairwise comparison: in the case of a multi-epoch analysis like in the LASHA methodology, such visualization cannot be created and it is replaced by the synchronic multi-temporal map. The VASA methodology computes also a historical index, $\mathrm{HI}$, that allows assessing the degree of emergency or the risk of disappearance for each use of the land (Reterurale, 2021).

\subsection{Digital data availability}

The VASA methodology uses material that exists and is accessible throughout the Italian territory. The LaSHA instead uses cadastral maps that change from territory to territory, from region to region. The material does not have the same quality in all Italian areas and is not available with certainty.

Regarding the interpretation of the data, VASA analysis is based on the interpretation of an image which, depending on the quality, reveals more or less information. The choice of a black and white image to define land use should be contradictory, even if GAl images are the very first ones that cover almost the entire Italy country. It should be impossible to identify different kinds of crops. This downside remains also with current land use and images.

While the LaSHA is based on reliable data written in land registers. However, both are seeking integrations, therefore both try to use additional maps, written and oral information and surveys in the field that can enrich and give solidity to the description. A campaign on situ to verify current land use seems necessary to be sure to define the correct kind of crops.

In addition, VASA analysis prefers quantitative index to understand how the landscape changes in years, but some of those as the historical index for example can return unexpected results that do not represent well the real land use modifications. This index does not work for land uses that don't exist in one of the analysis periods. But it should offer good results to understand which kind of crops or lands have a persistence, even if it doesn't express their extensions. At the level of data collected, the LaSHA often presents more in-depth characterization, especially about land uses, having the ability to trace the information transcribed in the land registers.

For the greater amount of data to be tracked, the difficulty of georeferencing, the higher number of information analyzed and the periods studied, the LASHA analysis takes longer. Finally, the VASA analysis has a greater speed of execution due to the use of GIS software to obtain the overlap of the data and implement the required calculations.

\section{Conclusions and future development}

As discussed, the evaluation of landscape integrity is a complex issue due to the identification of key elements and the definition of proper analysis for the evaluation of them. The availability of digital and editable sources is fundamental for any typology of evaluation. More specifically the use of GIS tools is of paramount importance to combine different data sources (e.g., maps, archive information, interviews, etc.) and create a common data infrastructure for any typology of analysis. In addition, GIS tools can be fruitfully used to carry out different typologies of numerical and statistical analysis as well as for creation of maps and visualization of results. In this paper we have compared two different methodologies: VASA and LaSHA. Both of them strongly rely on GIS for analysis and visualization of the results. The comparison showed a complementarity of the two methods: land use change map of VASA methodology can be applied in the LaSHA too when identifying changes in two consecutive epochs. Conversely, when a comparison from different periods is needed, LaSHA synchronic analysis is more suitable, because it allows a quick look to old permanencies thanks to the colour gradient.

Looking at the final users of the methodologies, as the landscape committees, the synchronic map allows them to read and assess easily the main important permanencies in the landscape in order to attribute values and preserve traces and meaning. This investigation can be useful to those who have to manage the transformation of the landscape and preserve the historical characters. It is useful to recognise permanencies and to assess the state of integrity. At the national level, it can be useful for 
the delegates from the Ministry of Cultural heritage (architect and archaeologist) that are in charge of evaluating landscape transformations (in Italy) and to the Municipal and Park landscape Commissions in charge to understand the degree of historical permanencies in the landscape. At an international level, the suitability of the proposed methods is conditioned to the availability of maps of the local territory, it can be useful for evaluating landscape transformation projects in order to recognize material traces and intangible meanings and assess whether the proposed transformations respect or damage them.

The results presented in this work are derived from a first analysis and comparison of the two methods. In our future works we are planning to deepen our study in two directions: i) enlarge the analysis to other municipalities in the nearby of the Ticino river and to different areas characterized by different landscape to understand the flexibility of the two methods at a territorial scale, ii) test the use of both final output map to different end users, in order to check the clarity, ease of understanding and practicality in the everyday evaluation work.

\section{Acknowledgements}

The authors would like to acknowledge Martina Motti Sparacio for grammar check and proofreading.

\section{References}

Agnoletti, M. (2006). The Conservation of Cultural Landscapes. CABI. Cambridge. https://doi.org/10.1079/9781845930745.A

Agnoletti, M. (2007). The degradation of traditional landscape in a mountain area of Tuscany during the $19^{\text {th }}$ and $20^{\text {th }}$ centuries: Implications for biodiversity and sustainable management. Forest Ecology and Management. https://doi.org/10.1016/j.foreco.2007.05.032

Agnoletti, M., \& Tempesta, T. (2016). Linee guida per il dossier di candidatura all'osservatorio nazionale del paesaggio rurale. ISMEA. Retrieved March 15, 2021, from www.reterurale.it

Branduini, P., Laviscio, R., L'Erario, A., \& Toso, F., C. (2019). Mapping evolving historical landscape systems. The International Archives of the Photogrammetry, Remote Sensing and Spatial Information Sciences, Volume XLII2/W11. https://doi.org/10.5194/isprs-archives-XLII-2-W11-277-2019

Brovelli, M.A., \& Minghini, M. (2012). Georeferencing old maps: a polynomial-based approach for Como historical cadastres. e-Perimetron 7(3). 97-110.

Gullino, P., \& Larcher, F. (2013). Integrity in UNESCO World Heritage Sites. A comparative study for rural landscapes. Journal of Cultural Heritage 14, 389-395. https://doi.org/10.1016/j.culher.2012.10.005

ICOMOS. (2017). Principles concerning Rural Landscapes as Heritage. ICOMOS-IFLA. Retrieved March 15, 2021, from https://www.icomos.org/images/DOCUMENTS/Charters/GA2017_6-3-1_RuralLandscapesPrinciples_EN_adopted15122017.pdf

Krakow Charter. (2000). The Krakow Charter. Principles for conservation and restoration of built heritage. The International Conference of Conservation, Krakow

Mitchell, N. (2008). Considering the Authenticity of Cultural Landscapes. APT Bulletin. The Journal of Preservation Technology, 39(2/3), 25-31. Retrieved November 3, 2020 from http://www.jstor.org/stable/25433948

Previtali, M., \& Latre, M., Á. (2018). A brokered Virtual Hub approach for the generation of web applications based on historical maps. Applied Geomatics, 10(4), 453-472. https://doi.org/10.1007/s12518-018-0235-1

Reterurale. 2021. Criteri di ammissibilità e tempistiche per le candidature delle aree nel Registro Nazionale del Paesaggio $\begin{array}{llll}\text { rurale storico. } & \text { Retrieved } 2021, \quad \text { February } & \text { from }\end{array}$ https://www.reterurale.it/flex/cm/pages/ServeBLOB.php/L/IT/IDPagina/13826

Scazzosi, L., \& Branduini, P. (2014). Paesaggio e fabbricati rurali. Suggerimenti per la progettazione e la valutazione paesaggistica, Ministero dei Beni e delle Attività Culturali e del Turismo, Maggioli.

Scazzosi, L. (2004). Reading and assessing the landscape as cultural and historical heritage. Landscape Research, 29, 335-355

Scazzosi, L. (2011). Lombardia. In M. Agnoletti. Paesaggi Rurali Storici. Per un catalogo nazionale/Historical Rural Landscape. For a National Register, 204-206. Laterza.

Scazzosi, L. (2018a). Rural landscape as heritage: Reasons for and implications of 'Principles Concerning Rural Landscapes as Heritage ICOMOS-IFLA 2017'. Built Heritage 2, 39-52. https://doi.org/10.1186/BF03545709

Scazzosi, L. (2018b). Landscape as systems of tangible and intangible relationships. Small theoretical and methodological introduction to read and evaluate Rural Landscape as Heritage. In E. Rosina \& L. Scazzosi (Eds.), The conservation and enhancement of built and landscape heritage, 19-40. PoliScript.

UNESCO. (1972). World Heritage Convention. UNESCO. Retrieved March 15, 2021, from https://whc.unesco.org/archive/convention-en.pdf

Varotto, M. (2019). Oltre la vetrina: i paesaggi rurali storici come strumento per una ruralità sostenibile e multifunzionale 
in Salvatori, F. (2017). L' apporto della geografia tra rivoluzioni e riforme. Programma e abstract. $32^{\circ}$ Congresso geografico italiano (Roma, 7-10 giugno 2017). A. Ge.I. Roma.

Venice Charter. (1964). International Charter for the Conservation and Restoration of Monuments and Sites. The Venice Charter. ICOMOS. Venice

Yang, C., \& Han, F. (2020). A digital information system for cultural landscapes: the case of Slender West Lake scenic area in Yangzhou. China. Built Heritage 4(1). 1-14. https://doi.org/10.1186/s43238-020-00004-8 


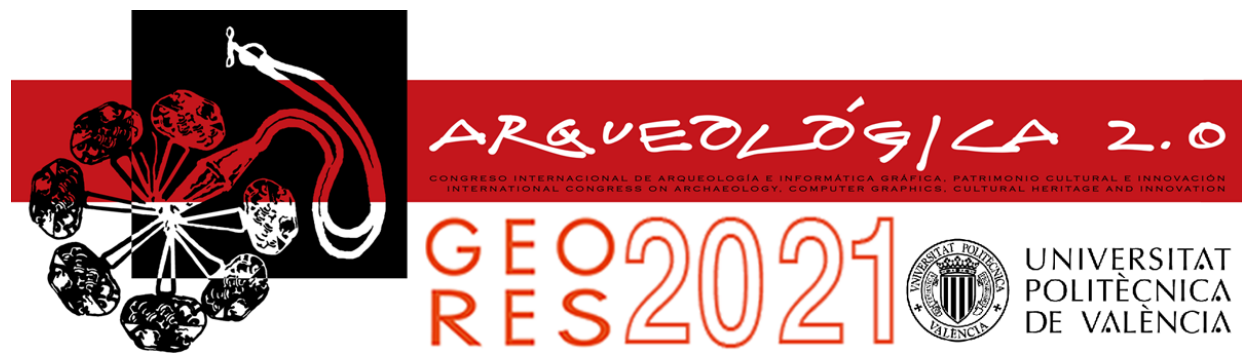

\title{
PARAMETRIC GENERATION IN HBIM WORKFLOWS FOR SLAM-BASED DATA: DISCUSSING EXPECTATIONS ON SUITABILITY AND ACCURACY
}

\author{
Giulia Sammartano ${ }^{a, b,}{ }^{,}$, Mattia Previtalic, Fabrizio Banfic \\ a Department of Architecture and Design (DAD), Politecnico di Torino, Viale Mattioli 39, 10125 Torino, Italy. giulia.sammartano@polito.it \\ ${ }^{b}$ Future Urban Legacy Lab (FULL), Politecnico di Torino, Toolbox coworking, Via Agostino da Montefeltro 2, 10125 Torino, Italy. \\ c LAB Gicarus, Department of Architecture, Built Environment and Construction Engineering (ABC), Politecnico di Milano, Via G. Ponzio \\ 31, 20133 Milano, Italy. fabrizio.banfi@polimi.it; mattia.previtali@polimi.it
}

\begin{abstract}
:
In the wide framework of Scan-to-BIM 3D modelling procedures, the complexity of the architectural heritage and its components is evidencing a gap of best practices and specification in the HBIM-modelling and thus it is requiring important considerations about the modelling strategies and protocols between the requested level of detail (LOD), the expected accuracy and above all the actual user-oriented requirements. Several works are largely focusing on developing modelling workflows for traditional static LiDAR scanning sensors. The amount of starting data is as much an asset when a bottleneck. In fact, the chance to benefit from on-site faster data acquisition is needful at times, and data collection procedures are directing toward rapid mapping 3D approaches, evolving from traditional static scanning toward MMS (Mobile Mapping Systems) based on SLAM technology (Simultaneous Localization and Mapping) implemented in portable devices. The potential derived from these solutions can contribute to increasing massive cost-effective documentation, and also in view of BIM-HBIM models generation, and this needs further researches. At the same time, the descriptive capabilities of this class of portable scanners do not reach the precision of static solutions. Many considerations towards the analysis of geometry, grade of generation (GOG) and details can be thus conducted, especially under the point of view of time-cost balance. This paper aims to presents the entire modelling workflow (from raw data acquisition up to parametric modelling) based on a first comparison between TLS (Faro Focus 3D) and hand-held scanner Zeb Revo (by GeoSLAM), focusing on the Bramante's Canonica Court in the Basilica of Sant'Ambrogio. First, the two raw data are compared, considering geometric features (data density, precision, possibility to detect edges, details and accurate curvature). Then, some wellestablished modelling procedures developed for TLS data, as triangulation mesh and NURBS generation, are applied to MMS point cloud to assess their suitability, identifying limits and potential. Different elements belonging to the architectural structure hierarchy are considered in a multi-scale perspective: the vaulted system of the porch, the columns and the arches of the porch with their different architectural elements.
\end{abstract}

Keywords: SLAM, MMS, grade of accuracy, grade of generation, HBIM, TLS, model accuracy, model scales

\section{Introduction}

In the last decade, great attention was paid to the topic of defining clear and reliable workflows for incorporating 3D laser scanning and photogrammetric point cloud information within a BIM environment (Oreni et al., 2014; Rocha, Mateus, Fernández, \& Ferreira, 2020; Yang, Lu, Murtiyoso, Koehl, \& Grussenmeyer, 2019). Indeed, in recent times two different trends have been observed: on the one side the noticeable emergence of technology supporting the integration of rich data within architectural models in the framework of building information modelling (BIM) and on the other side the rapid expansion on surveying technologies (e.g., 3D laser scanning and photogrammetry) that allowed fast and reliable digitization of large and complex architectures. The adoption of BIM paradigm proved to be revolutionary in many applications like design (Wong \& Fan, 2013), construction site management (Kumar \& Cheng, 2015) and maintenance (Motawa \& Almarshad, 2013) among others. The BIM concept shows great potentialities also in the case of Historical buildings (HBIM) where well-established and shared concepts within building and materials conservation can be associated with specific building objects that may be characterized by complex and irregular geometries. Here the potential of scanning technologies (active or passive) to record the existing built environment is clear: complex shapes, irregular geometries and geometrical anomalies that characterize historical building can be easily recorder with level of accuracy which was not feasible even a couple of decades years ago. Even if the cross-connection between BIM and $3 \mathrm{D}$ scanning is evident, the development of a

*Corresponding Author: Giulia Sammartano, giulia.sammartano@polito.it 
workflow for effective and efficient integration of laser scan data within a BIM environment has required an indepth study and several types of research are focusing on this issue (Dore \& Murphy, 2013; Hichri, Stefani, De Luca, Veron, \& Hamon, 2013; Oreni et al., 2014; Rocha, Mateus, Fernández, \& Ferreira, 2020; Yang, Lu, Murtiyoso, Koehl, \& Grussenmeyer, 2019). Indeed, even if it is possible to import point clouds within BIM software, in order to make the best use of the highly accurate and often massive data, a certain amount of postprocessing (filtering, smoothing, subsampling, etc.) is strictly required. The amount of acquired data is as much an asset when a bottleneck. In addition, modelling strategies should be adopted and often adapted to transform a point cloud into parametric objects. The different Level of Geometry (LOG) that are connected with the different Level of Development (LOD) can be obtained by using different strategies. In particular, the possibility offered by different Grades of Generation (GOG) and the possibility to use NURBS (GOG 9-10) proved to be successful to accurately represent complex geometries in BIM applications (Banfi, 2017). On the other hand, solid parametrization modelling and GOG 1-8 can be successfully used for LOG and LOD characterized by a lower level of details and wherever high accuracy is not required. Nowadays consolidated workflows have been developed for Scan-to-BIM and are efficiently used in several projects. The issue on the treatment of the starting massive data remains open.

\subsection{Motivation}

Reality-based modelling is highly benefitting from scanning data in the so-called as-built modelling. Even if point clouds can be directly used for the production of BIM objects (e.g., GOG 9-10) the amount of data really used for the modelling is much lower with respect to the one acquired (Fig. 1). Point clouds are highly subsampled and only a small fraction of the original data is used: often less than $1 / 10$. Due to this aspect, a high percentage of the points is not directly used in surface generation making them unused in the case of parametric modelling. This leads to a contradiction: on the one side highly density point clouds are collected in the surveying stage (in order also to guarantee the required precision in scan registration) on the other hand the majority of those points is not used in the surface generation and modelling workflow. As a consequence of that, the survey with traditional static Terrestrial Laser Scanning (TLS) may be considered by then as not the optimal data source and survey method for all applications. Indeed, even if a TLS survey is much faster than traditional survey techniques and allows to capture structures that are well outside the physical reach of the surveyors, a TLS campaign may be quite a time expensive, some hours to few days according to the extent of the area, especially in the case of complex structures to avoid occlusions and high completeness with homogeneity of points distribution.

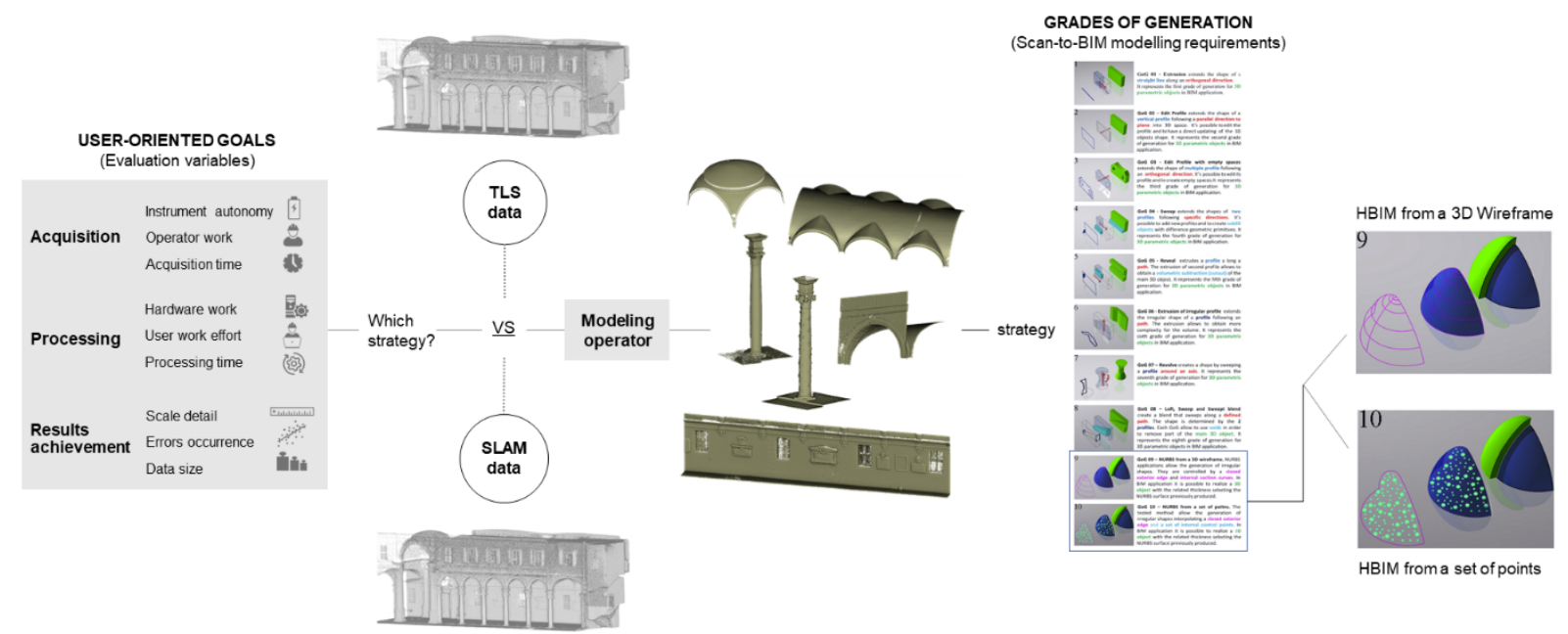

Figure 1: The diagram indicates the research demand, through the investigation of suitable strategies. The established HBIM parametric modelling is applied to SLAM-based data according to a series of user-oriented variables. The investigated generation approaches are the GOG9 and GOG10.

In the last years, the availability of Mobile Mapping Systems (MMS) proved to be an interesting alternative to TLS for a large set of applications, especially if portable as handheld or backpack tools, like: rapid mapping after earthquakes and extreme events (Sammartano, 2018), the survey of industrial sites, quarries and mines (Dewez, Yart, Thuon, Pannet, \& Plat, 2017), narrow spaces (Zlot \& Bosse, 2014) and heritage and archaeological sites (di Filippo et al., 2018; Sammartano \& Spanò, 2018; Spanò, 2019; Zlot et al., 2014). The main advantage of those instruments is the "scan-while-walking", making the survey of large areas more efficient with respect to the traditional TLS survey, in terms of time-saving. In a general way, a handheld Indoor Mobile Mapping system is composed by a $2 \mathrm{D}$ infrared laser scanner profilometer generally coupled with an IMU sensor. The laser profilometer continuously provides the range measurement, while the IMU sensor, generally triaxial gyros and accelerometers, which is firmly mounted close to the laser, provides measurements of angular velocities and accelerations. The IMU sensor and the scanned 2D profile data are used to estimate the sensor position and progressively the trajectory. The $2 \mathrm{D}$ laser profiles acquired by the profilometer are continuously aligned by using 3D SLAM (simultaneous localization and mapping) approach (Riisgaard \& Blas, 2005), estimating the six degrees of freedom of the sensor motion, and generates the $3 \mathrm{D}$ point cloud of the scene. The more the scanned environment is rich in detail with no recurring elements, 
the more the SLAM algorithms benefits from the geometric features extracted during the operating.

The main drawbacks of MMS compared with TLS are: i) lower point density and ii) lower precision in point measurement. Indeed, LiDAR mounted on MMS are characterized by single-point measurements precision of some centimetres $(1-3 \mathrm{~cm})$. An extensive review of MMS and comparison of MMS and TLS data is out of the scope of the presented work, for more details the reader is addressed to (Nocerino, Menna, Remondino, Toschi, \& Rodríguez-Gonzálvez, 2017; Sammartano \& Spanò, 2018; Tucci, Visintini, Bonora, \& Parisi, 2018).

This paper aims to investigate, from an end-user perspective, the possibility of using MMS data for modelling specific architectural elements that can be interoperable with BIM objects and not customary in the current application. The main purpose of the work is to verify the possibility to use a more time-cost efficient workflow related to end-user's requirements in terms of requested accuracies, level of details and expected scale. In particular, the main question we would like to address can be summarized as follows: "Which are the main differences in the TLS/MMS data acquisition and processing workflows? Which are the differences in terms of data density, precision, possibility to detect details and curvature between TLS and MMS? Which accuracy and level of details can be obtained in the parametric modelling? The modelling strategies (GOG) used for TLS can be adopted also for MMS?"

\section{Multi-scale architectural elements modelling strategies}

The reality-based modelling from point clouds, as introduced, is essentially based on a continuous geometry reconstruction, with or without semantic information association, from processes of understanding, simplification, approximation and interpolation of the starting 3D data. The modelling pipeline cannot be completely separated from human interaction and interpretative intervention. Uniqueness, richness, complexity and anomalies of architectural elements are the crucial issues to be featured in their geometric, radiometric and semantic dimensions' definition for a pre-determined scope for which the informative model is designed and expected. But they don't always have all the same weight: the end-useroriented requirements are the constraints on which to base the modelling organization ex-ante (Banfi, 2017). For this reason, the pure modelling based on NURBS, solid volumes and shapes from scratch generation, which proves not to be very flexible and adaptive to the specificities of existing heritage shapes, is usually set aside to make way for point-cloud based modelling, aroused from the as-built modelling. The polygonal mesh model Figure $2 a$ is a first-step solution of transformation from unorganized points set via interpolation of a continuous surface made of triangles or quadrangles (Remondino, 2003). In this case, the solution leads to a continuous surface and not solid object, often with radiometric content deriving from textures, even with very impressive photorealistic visualization effects, generated by photogrammetric approaches but not semantically organized.
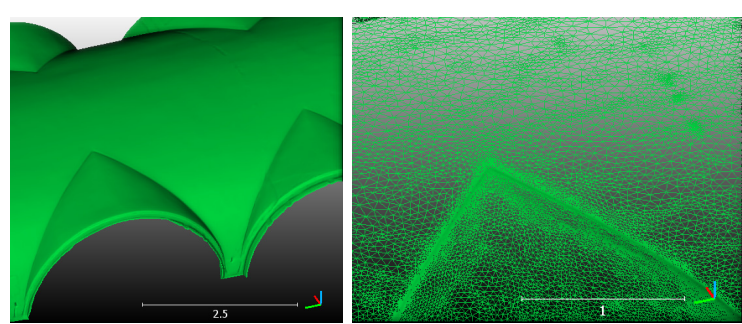

(a)
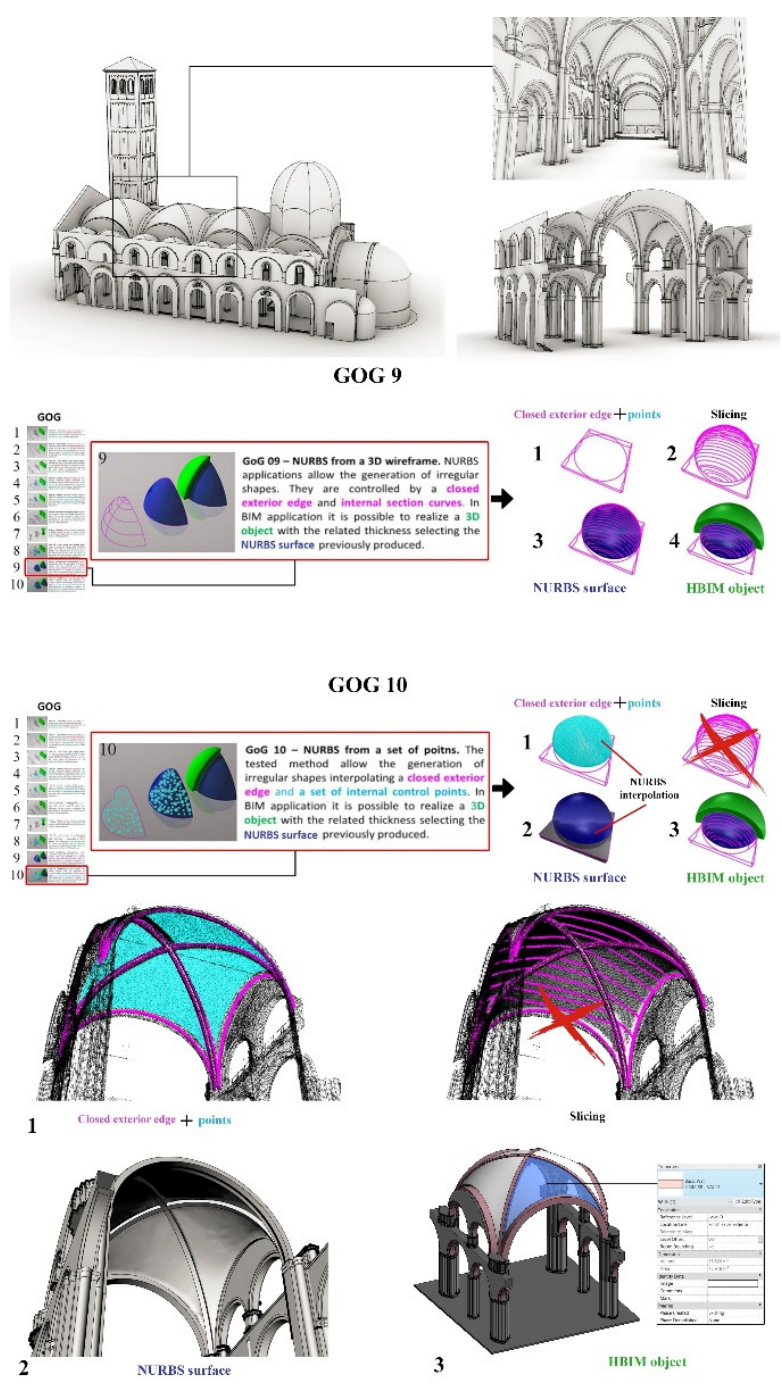

(b)

Figure 2: The 3-types modelling step, based on point cloud data operated in the vaulted system of the porch in the case study, the Bramante Canonica court: (a) the triangulated mesh; (b) a GOG9 based on extracted primitives and edges and a GOG10 based on external edge and interpolation of a points sample.

Contrariwise, the so-called scan-to-BIM approach is characterized, as well known, by the possibility to involve the parametrization procedures rules in the generation of $3 \mathrm{D}$ objects and not only interpolated surfaces. The modelling is therefore constrained based on generative geometries and 3D transformation or combination of them, that are more or less complex and articulated in their hierarchy or Grade of Generation, as developed in (Banfi, 2019) and represented in Figure 2b. GOG are 
dependent on many variables but, first of all, the selection of a starting 3D data is one of the crucial factors affecting the result. It could therefore be said that there is an exante connection between GOG of models and LOD of points models. Afterwards, the needs of explicit geometry generation require different parametric modelling approaches, less or deeply connected with the point cloud detail Figure $2 \mathrm{~b}$, or with specific 3D profiles primitives and edges extracted from it Figure $2 \mathrm{~b}$. As a consequence of recent research developments in the framework of parametric modelling, many operative solutions have been implemented to lead advanced modelling tools in order to extract, extrude, revolve, swipe etc... It can therefore be summarized that the more complex the shape and the LOD is required for the informative model for user-oriented purposes, the more the GOG must be chosen and applied to solve the geometric definition of architectural elements at the proper scale. For this reason, traditionally LiDAR point clouds have always been connected to as-built modelling, for their ability to provide support in the modelling stage with different LODs and GOGs. In this particular context, the degrees of generation and the 3D survey tools are also decisive for exponentially reducing the time and costs related to the creation of as-found models. So Therefore in the presented research, architectural and structural elements have been selected that are able to outline a scan-to-BIM workflow, allowing the authors to compare the application of generation grades 9 and 10 beyond the point clouds (TLS and MMS), the last identified and developed to support the generation of complex elements from point clouds.

The main consistent difference is that the GOG9 (HBIM object from wireframe model) is based on the extraction of profiles and geometric primitives from a point cloud while the GOG 10 automatically transforms a selection of points corresponding to an architectural element into a parametric object Figure 2. However, to achieve an appropriate generation with both of them, it is necessary to identify the 3D edges of the element to be created. For this reason, the identification of the wireframe models corresponding to vaults, walls, columns, arches are determined if the process is based on reliable data. For the GOGs and the scan-to-bim process in general, point clouds are considered primary data sources. Consequently, the more precise a 3D survey is, the more precise the creation of as found models will be. GOGs depend solely on two factors: (i) the accuracy of point clouds and (ii) the user's ability to correctly interpret the construction logic of the surveyed building and the 3D survey data, dividing them into architectural and structural elements (semantic decomposition). Furthermore, at this level, the economic impact linked to the reduction of the number of hours dedicated to every single architectural element is difficult to identify. Many factors within the process need to be considered. On the other hand, in (Banfi, 2020) the generative times associated with GOG 9 and GOG10 have been identified. It was found that the morphology of the element, its semantic breakdown, the information to be associated are the main factors that influence the realization. Consequently, as mentioned in various studies, national regulations and various LODs should consider studies and methods capable of properly explaining the holistic value of HBIM models and the scan-to-BIM process. Different disciplines such as geomatics, representation and restoration now merge into a single digital project. The value of precision of $3 D$ survey, the scale of representation, GOGs and LOD become interconnected. There is not always accurate data like a point cloud coming from TLS or digital photogrammetry. Sometimes, for different project objectives and for non-architectural scales, it is possible to use the integration of other tools. In particular cases, furthermore, within a single HBIM project there may be different LODs, LOIs obtained in turn from 10 different GOGs.

In this context, MMS has been compared to TLS in order to highlight their behaviour in the $3 \mathrm{D}$ mapping of the substantial differences between objects that characterize historical buildings for the most part. Vaults, columns, and arches were detected with both tools and in turn, generated using both GOG9 and GOG10. The final goal indeed is not only to determine what is better tout court but, based on the project objectives and pre-determined LOD, which values derived from TLS or MMS data can be considered the most suitable in terms of precision and accuracy. In other terms, where the use of MMS clouds, due to their competitiveness in terms of time-cost ratio, can support, the achievement of an expected LOD, using 2 different GOGs. Some issues arise based on the employed tools and GOG used to generate the objects. They are reported below in order to clarify the starting point of the study proposed in this article.

If we circumscribe the scale expected from some types of 3D surveys for which the expert user must have an HBIM information model available, can a LOD be satisfied starting from a low precision and high-efficiency point cloud? With what accuracy? The research toward the positive answer must necessarily pass through the control of the GOA of the generated models that can validate the use of such source data.

\section{The case study}

The historical and architectural framework of the $\mathrm{S}$. Ambrogio Basilica particularly stratified site in which the research is conducted leads us to operate on the Bramante's enlargement intervention on the Canonica arcades (portico) of the S. Ambrogio Basilica in Milano dated back to $15^{\text {th }}$ century (Gatti Perer, 1995; Lusuardi Siena, 1997; Marucci, R. A., Negri, M., Rastelli, A. Romaniello, 2004) Figure 3a. The whole remarkable architectural work of Bramante today arrives us after the war damages and the restoration by architect Reggiori in the $20^{\text {th }}$ century. However, the harmonious and cadenced proportions of the arcades of the portico, the classical entasis of columns and finely worked capitals, separated from the arches by pulvini, the columns with gnarled protuberances (laboratas ad tronchonos) still remain (LombardiaBeniCulturali, 2016). They required a tailored approach to their documentation in past years as well as today. Recent researches have dealt extensively with scan-to-bim modelling for the creation of the HBIM information model for various purposes Figure $3 \mathrm{~b}$ (Banfi, Previtali, Stanga, \& Brumana, 2019; Banfi, Brumana, \& Stanga, 2019b; Stanga et al., 2017).

\subsection{Data acquisition \& processing}

The data acquisition belong to different phases. Particularly for the TLS dataset (2014-2015), a great effort has been spent during the last years for the generation of a complete and enriched 3D HBIM model of the whole 
complex of St. Ambrogio, its historical stratification, materials and construction techniques. In 2019, in the occasion of the GEORES Conference and the Young Researcher Workshop event, experimentation of a SLAM-based mapping has been proposed and performed. For the experiment proposed here, the south area of the portico was selected adjacent to the basilica and the bell tower, and the Canonica rooms above Figure 3. A series of considerations will be proposed regarding the different nature of the acquisition and processing pipelines, starting from survey planning, post-processing and cloud optimization. The covered area is almost 2000 $\mathrm{m}^{2}$ on the ground floor and the first floor, for an overall outside and inside volume of $2500 \mathrm{~m}^{3}$.

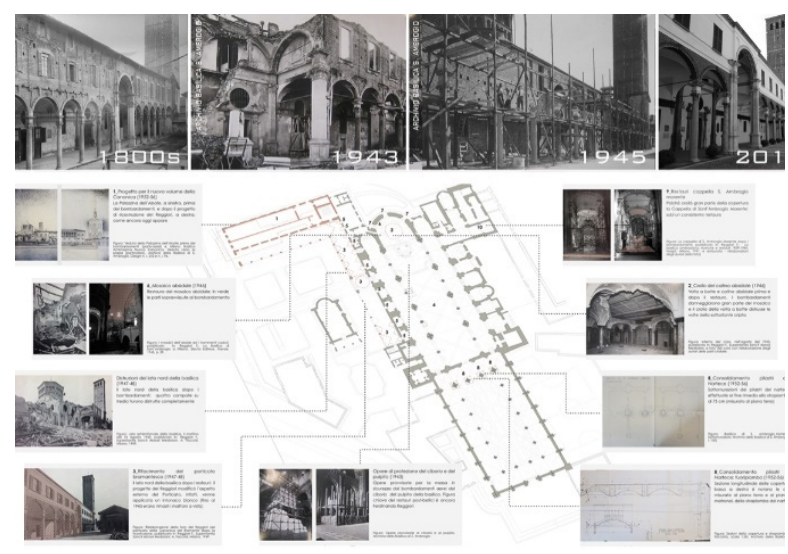

(a)

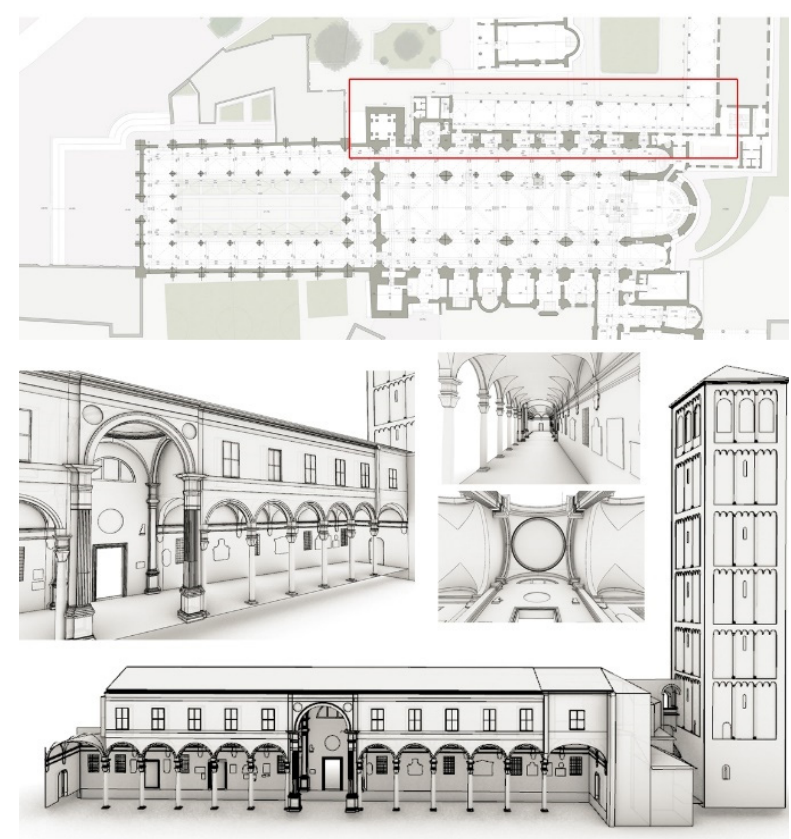

(b)

Figure 3: The case study: the Bramante's Canonica porch in Basilica of Sant'Ambrogio (MI). (a) the history of the building XX cent. across bombing and reconstruction; (b) the architectural drawings generated with the HBIM model recently generated.

\subsubsection{LiDAR points model}

The dataset of $n^{\circ} 20$ scans referred to the Canonica court and upstairs rooms are distributed in the area of the arcade and the first floor designed to cover the visible surfaces, as visible in Figure 4. Supporting the whole 3D metric survey, a geodetic network has been materialized and measured with Total Station Leica TS30. In this network, a set of control points in the form of black \& white target have been measured for the scan's registration and accuracy control. The static laser Faro Focus 3D was employed in different survey phases. The 3D scans were registered with an average precision of $\pm 3.0 \mathrm{~mm}$ by using targets, topographic measures and with additional scanto-scan correspondence (spherical targets) (Banfi, Brumana, \& Stanga, 2019a). The fieldwork required almost 3 hours work for scanning and 40 min for the topographic measures supporting the LiDAR survey (considering already measured topographic network vertices, and only detail survey execution on them), and this is, as usual, a time-consuming procedure. Three expert operators were involved. The average weight of the scans is $800 \mathrm{Mb}$ for coloured scans and $100 \mathrm{Mb}$ for grayscale scans. The time for registration was approximately 4 hours and the derived point model has been cleaned and filtered of about $10 \%$.

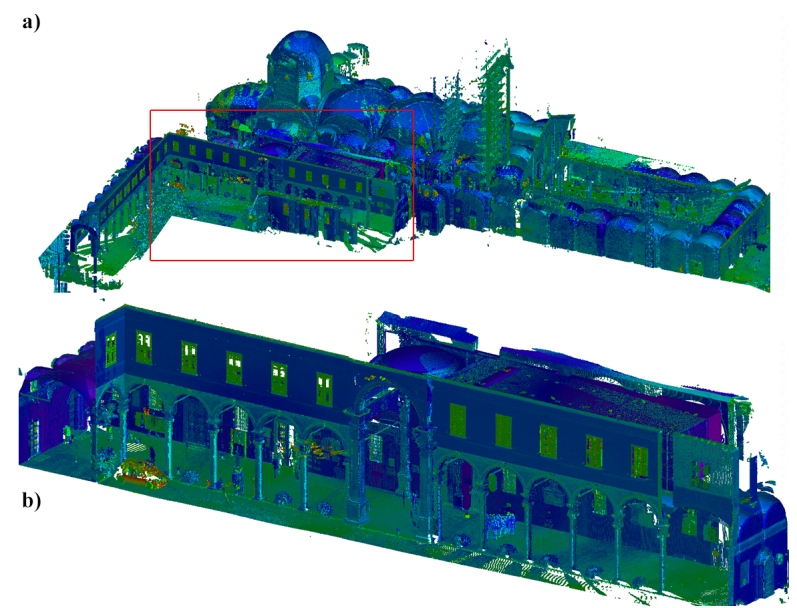

Figure 4: View of the global 3D point cloud from static TLS acquisition on the Basilica (a) and on the Canonica porch (b).

\subsubsection{SLAM-based mapping}

The SLAM acquisition (Fig. 5) was performed using ZEB Revo-RT handheld scanner by GeomSLAM, by $n^{\circ} 1$ expert operator walking almost for $15-20 \mathrm{~min} / \mathrm{scan}$, with the coincidence of starting-ending point. The two clouds, covering the whole area of the arcades and the first-floor rooms were acquired along a trajectory of almost $600 \mathrm{~m}$ roundtrip: $40,7 \mathrm{mln}$ points $+21 \mathrm{mln}$ points, for an entire weight of $970 \mathrm{Mb}$ data. After the acquisition, a first step reprocessing the SLAM algorithm is performed according to a set of parameters and with a non-rigid co-registration of the two scans supporting each other based on 3D features reconstruction (Sammartano \& Spanò, 2018) and finally, the derived point model has been cleaned and filtered of about $20 \%$. The overall amount of time for firststep data re-processing and second step non-rigid coregistration is almost $30+20 \mathrm{~min}$, and in any case less than 1 hour. The third step of manual segmentation and semi-automatic filtering is conducted in almost 2 hours. 


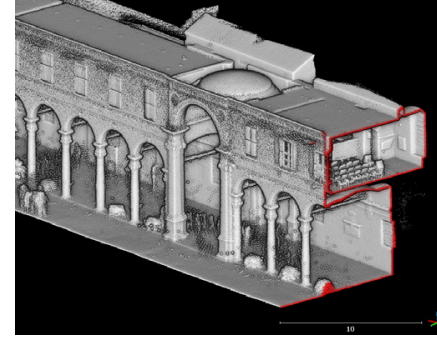

(a)

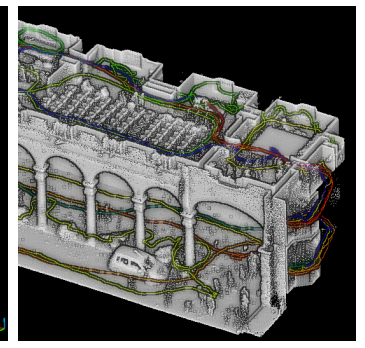

(b)
Figure 5: The SLAM-based point cloud acquired in the two floors levels of the Bramante's Canonica: in a section view (a), with the visualization of the time-marked trajectory (b).

\section{Evaluating SLAM-based points clouds for parametric modelling strategies}

\subsection{Point cloud analysis}

After the first step comparison introduced, related to acquisition procedures of SLAM-based data parallel to traditional static scanners, a second analytic phase is conducted on the points models' quality for parametric modelling and their descriptive capabilities. This phase begins with the metric analysis of the two initial point cloud data and then some specific geometric features are hierarchically considered according to a requirements sequence. Particularly the SLAM-based point clouds are analysed in order to support GOG modelling strategies, according to modelling choices and requirements conducted by the operator during the modelling: GOG 9 based on characterising polylines/break lines, belonging to the objects surfaces, and GOG 10, based on point cloud interpolation and external edge profiles (Banfi, 2019).

Firstly, a global and a local analysis should be considered in terms of accuracy in the case of SLAM acquisition, due to the 3D space reconstruction strictly connected to the trajectory behaviour, as recent researches demonstrated (Nocerino, Menna, Remondino, Toschi, \& RodríguezGonzálvez, 2017; Sammartano \& Spanò, 2018; Tucci, Visintini, Bonora, \& Parisi, 2018). In fact, if generally, the local performance of 3D surface reconstruction of SLAM scanner is suitable for medium-high detail with good continuity of the surface digitization (despite the lower precision of the static Lidar sensor) it is not uncommon that the global accuracy is often affected by drift errors on long distances.

The global accuracy analysis is conducted with TLS scan as a reference, and with SLAM data aligned with a rigid roto-translation fixed in $n^{\circ} 10$ points located closer to the position of the scans start (room adjacent to the side of the stair). The mean deviation error results (Table 1) of the ten points-based alignments is $2,4 \mathrm{~cm}$, with st.dev = $1.3 \mathrm{~cm}$, in line with the results already obtained for this type of verification. In particular, the main error direction is along the $Y$ axe, that is the longitudinal axe, as expected, underlining the influence of scan trajectory direction in the error propagation.

Instead, the global measurement of the drift error far from the starting point and in levels, indicates a deviation error distribution according to both the longitudinal and cross direction of the arcades proportionally to the distance from starting point. In particular, as shown in Figure 6 a horizontal deviation error of SLAM data from TLS data at the ground floor has been identified from $2 \mathrm{~cm}$ up to $4 \mathrm{~cm}$ in the central part and more than $4 \mathrm{~cm}$ in the farthest part from of the porch. The lower error in the horizontal direction is upstairs, and it is validated due to the nearest position from the trajectory starting point. In the vertical direction, a deviation error is recognized using vertical section profiles along the building sleeve of only $2 \mathrm{~cm}$ also in the central vaulted module; about $2 \mathrm{~cm}$ in the thickness of the floor of the overlying room, and up to $4 \mathrm{~cm}$ in the higher and farthest part or the large room above. This is generally due to the lack of a vertical closure of the scanning trajectory also in the northern part of the building, and in the SLAM algorithm processing the constraints deriving from the intersection of common vertical and planar paths are thus missing. For this reason, the room above behaves cantilevered without a constraint in $\mathrm{Z}$.

Table 1: The deviation error in the control points used as rigid roto-translation. The vector value is split into the axes component.

\begin{tabular}{c|c|c|c|c} 
& $X(m)$ & $Y(m)$ & $Z(m)$ & Dist $(m)$ \\
\hline mean & 0.012 & 0.020 & 0.012 & 0.024 \\
st.dev & 0.013 & 0.029 & 0.007 & 0.013
\end{tabular}

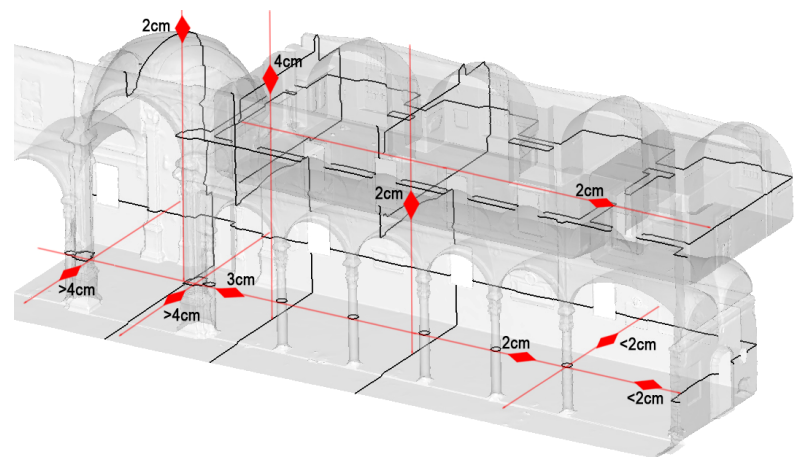

Figure 6: Drift error along the SLAM scan measured in deviation error between TLS and SLAM data.

The analysis related to geometric features of the point cloud data from a local point of view considers now the quality of objects reconstruction finalized to GOG9 and GOG10 and starts from the planarity, the density, the roughness, the curvature.

The perimetral wall of the Canonica portico is considered for planarity analysis to verify the ability of the two different point cloud, using region growing algorithm (Besl \& Jain, 1988; Vo, Truong-Hong, Laefer, \& Bertolotto, 2015) identifying points with similar characteristics of planarity starting from featuring seed points. This allows a comparison between SLAM data e TLS data to be intercepted by a fitting plan extracted and in Figure 7 is visible the result for the SLAM point cloud deviation map in scalar colours. The graph shows the distribution for both the dataset and displays that only $36 \%$ of points fits in $\pm 1 \mathrm{~cm}$ form the plan for SLAM, and $53 \%$ for the TLS data, but for both cases almost the $84 \%$ of points is within $\pm 3 \mathrm{~cm}$ from the plan. This implies, as expected for TLS sensors data and also for SLAM-based point cloud, an effortless recognition and extraction of plans for smoothed and generally regular areas as the single- 
curvature surfaces and walls, for their possibility to be parameterized in the model.
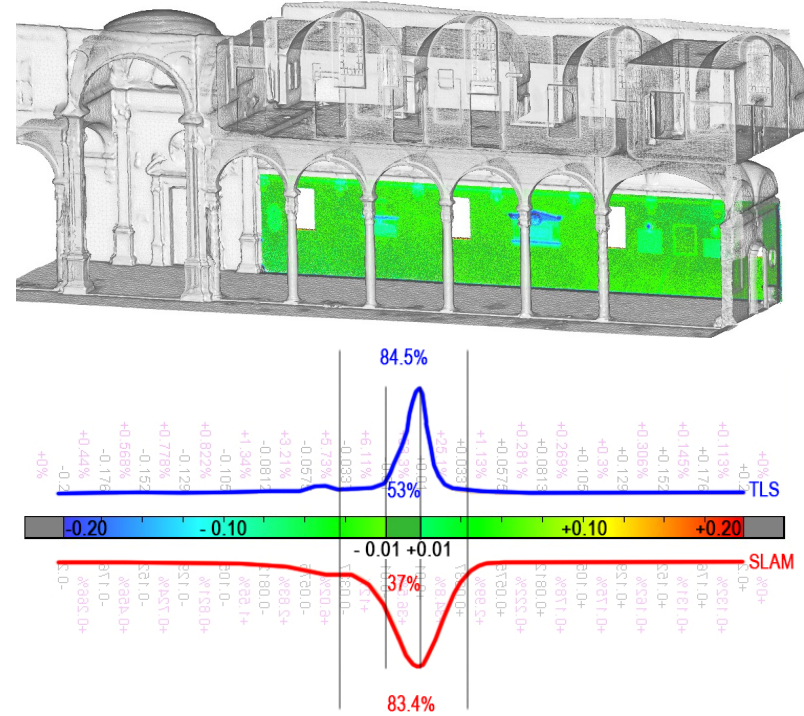

Figure 7: Plane fitting on points model from SLAM-based acquisition. In the related graph, the points distribution within \pm 1 $\mathrm{cm}$ for red SLAM, $37 \%<1 \mathrm{~cm}$; blue TLS, $53 \%<1 \mathrm{~cm}$.

\subsubsection{Density of data: between acquisition planning and post-processing optimization}

The concept of density of data is a crucial issue and is strictly related to the effectiveness of usage, both in the data acquisition planning and in data optimization for modelling procedures, whether these are based on triangulation modelling, or benefits from parametric geometry rules. Moreover, the density slightly changes implication and shows us different matters, if considered from the local and global point of view. In fact, the concept of density of information, from a global point of view concerns also the concept of continuity and completeness of data, as well as the quality of that.

In the case of SLAM-based 3D mapping, the distribution and overlapping of data are connected to typical operator walking point-of-view and the differences in density depending on the trajectory trend. In Figure $8 a$ the density gradient map of ZEB Revo system represented in the 3D environment along the trajectory, expressed with the number of neighbours in a pre-determined sphere (Algorithm implemented in CloudCompare [CC] software interface). It is the representation of the number of points contained in a local neighbourhood of a sphere with a $0.05 \mathrm{~m}$ radius (CloudCompare, 2015). Blue areas contain on average less than 100points in $0.05 \mathrm{~m}$ radius sphere (r.sph.), and denser areas are located at operator height. If the porch floor is digitized with almost 50 pts $/ 0.05 \mathrm{~m}$ r.sph., the topmost part of the façade in the connection with the moldings contains only 5 points. The point density in the $1^{\text {st }}$ floor rooms is almost $100-200$ pts $/ 0.05 \mathrm{~m}$ r.sph. and the values exceed the 300 pts only where the operator came very close to surfaces (red). The uniformity, as in Figure $8 \mathrm{~b}$, is however guaranteed, opposite to the static TLS, by the possibility for the operator to cover all the accessible spaces even with the extension of arms or supporting tools, and so this decreases considerably with the height.

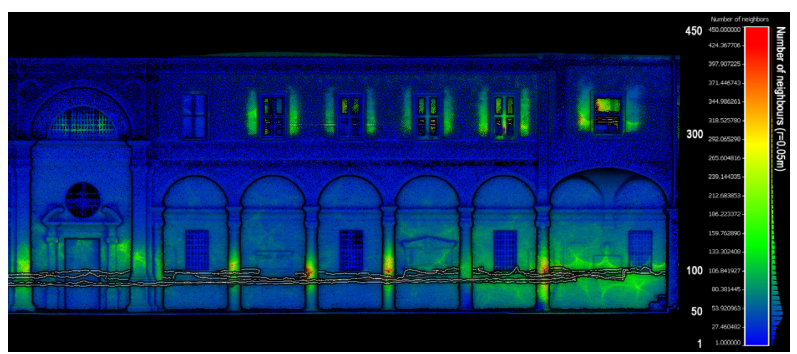

(a)

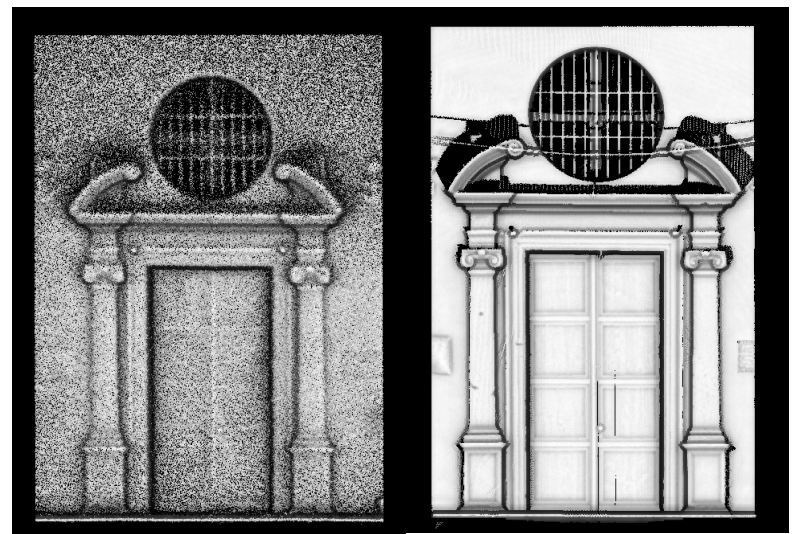

(b)

Figure 8: (a) Density distribution with ZEB Revo acquisition along the trajectory (white line), with typical operator-point-ofview. (b) Comparison between shadow areas in static TLS and continuity in SLAM dataset.

The major local density of TLS point clouds is featured by a general non-uniformity of points distribution depending on overlapping areas between scans. It frequently causes a lack of data if shadow areas occur in Figure 8b. They are above the frames or in the presence of interposed objects that cause shadow areas, which are only covered by the correct planning of other scan positions. Given the bottleneck of the LiDAR data weight for traditional TLS scans (up to $1 \mathrm{~Gb} / \mathrm{scan}$ with colour value), if on one hand, the increase of scan positions guarantees a greater coverage and density uniformity for the scanned surfaces, on the other hand, it increases exponentially the amount of data, negatively affecting the manageability of the scans project. In Figure 9 the final optimal distribution of the scans necessary in the ground floor for the indoor/outdoor surfaces, with a simulation carried out by using the methodology presented in (Díaz-Vilariño, Frías, Previtali, Scaioni, \& Balado, 2019) and develop in Par.5.

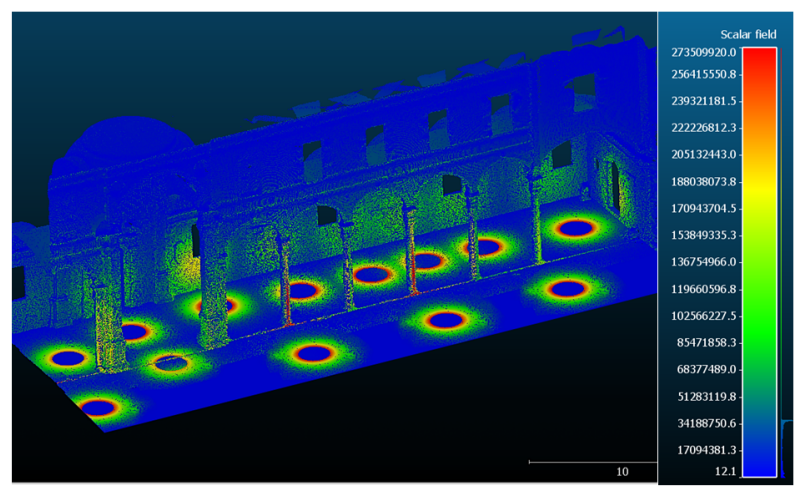

Figure 9: Optimized distribution of scans ensuring maximum uniform overlapping and minimum number of acquisitions. 


\subsubsection{Details and precision of point clouds}

In order to evaluate the Level of Detail that the digitization methodology can satisfy using the two scanning solutions, a specific analysis should be conducted, typically for architectural elements as the ones of the Canonica arcades of Bramante. The analysis is based on the 3D features that commonly define geometric description of point cloud surfaces, helping the possibility of their segmentation and classification (Grilli, Menna, \& Remondino, 2017; Paiva, Cogima, Dezen-Kempter, \& Carvalho, 2020). They are not only the values from density computation methods but also the curvature analysis of points surface, roughness of points distribution in order to evaluate the optimal semi- or automatic recognition of continuous surfaces, of edges and break lines.

The local density analysis (Fig. 10) focused on the upper part of the column shaft and the capital underlines the remarkable difference in detail definition for data (a) and (b) with a 3:1 ration for density mean value magnitude.
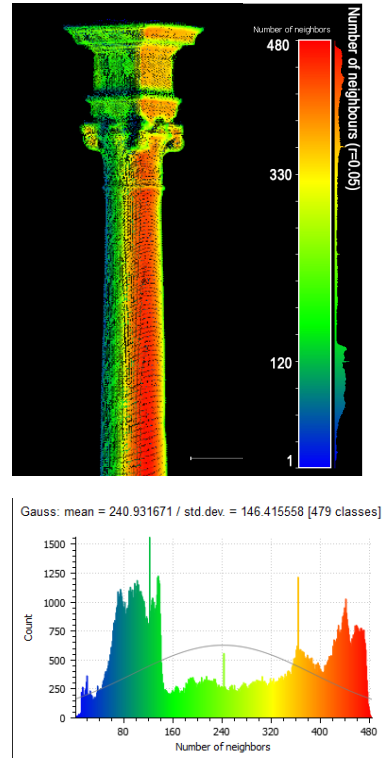

(a)
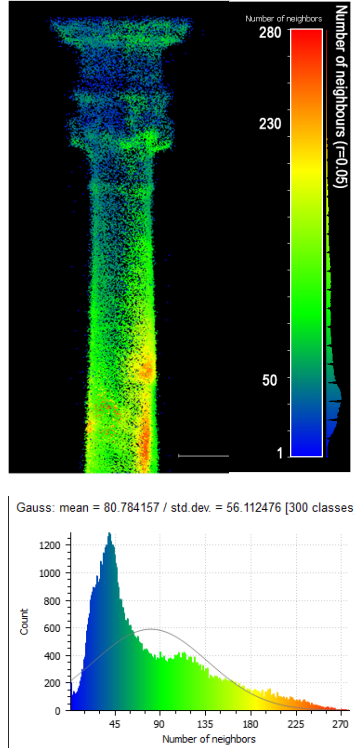

(b)
Figure 10: Analysis of details content in the column element Density comparison by number of neighbours [CC] $(r=0.05 \mathrm{~m})$ for TLS (a) and SLAM (b).

The curvature analysis is able to highlight, in the other side, the surface detail trend in a 'kernel' size, that is the radius of a sphere inside which the neighbours are extracted (around each point) and evaluated for the curvature. This computation is very sensitive to noise and outliers' values ([CC], 2015). In fact, as stressed in the assessment of Figure 11, if a $3 \mathrm{~cm}$ kernel radius is able to fit the centimetric detail of the capital, a kernel radius of $15 \mathrm{~cm}$ is rather necessary for emphasize the architectural order details for the abacus and pulvino.

Therefore, the two surfaces radically differ due to the noise errors typically affecting the SLAM point cloud generation. It could be specifically evaluated with roughness analysis that is able to establish, according to a local neighbourhood defined as a sphere, the accepted points and outliers' values according to a distance (CloudCompare, 2015).
In Figure 12, the statistical distribution of points according to roughness method applied with a radius equal to $5 \mathrm{~cm}$ kernel size, clearly points out the homogeneity of TLS Lidar points precision (a), related to violet point color (outlier values only localized in corners description) and, in (b) the wider distribution of the curve, related to a greater distribution on the surface of noise points (green and yellow). This implies, when calculating a triangulated mesh surface, and/or in case of manual or semi-automatic extraction of edges and representative polylines and breaklines, a greater effort in obtaining a smooth surface and simplified lines.

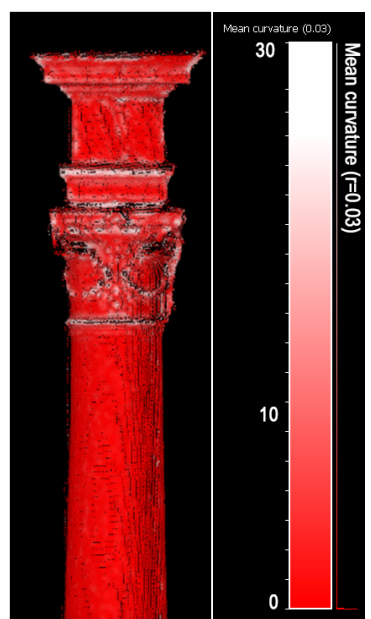

(a)

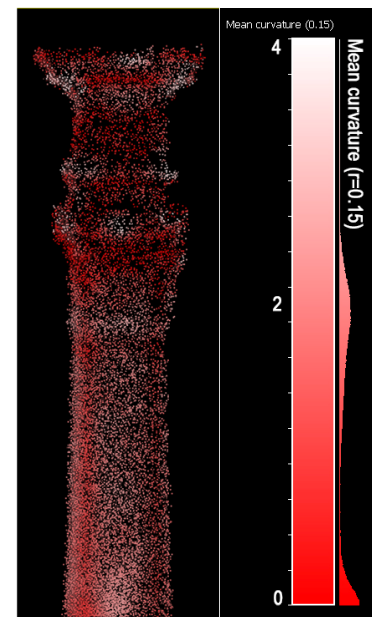

(b)
Figure 11: Curvature analysis highlighting detail elements with 0.03 kernel sphere for TLS data (a) and with 0.15 kernel sphere for SLAM point cloud (b)
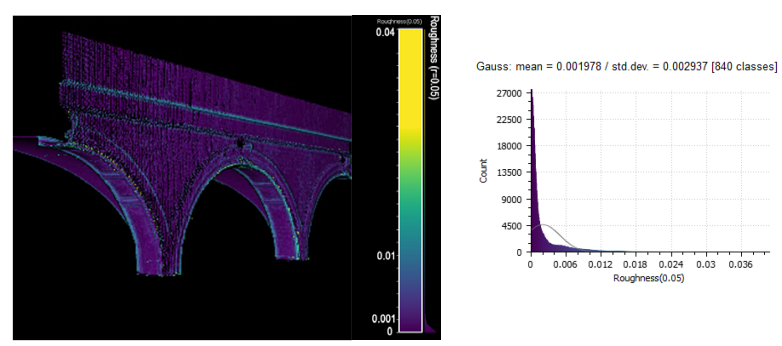

(a)
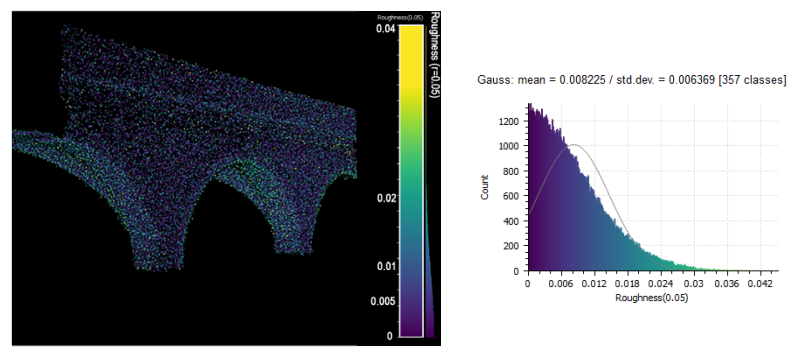

(b)

Figure 12: Noise error evaluation using roughness analysis with kernel sphere $(r=0.05 \mathrm{~m})$ for TLS $(a)$ and SLAM $(b)$.

\subsubsection{The vaulted surface representation}

Considering the single or double curvature surfaces, they generally require, according to the expect LOD, an interpolated surface that could be able to describe accurately not only the generative geometry but also even 
local irregularities or structural deformation from original shape. Beyond the pure triangulation modelling based on the optimized point cloud, a GOG10 is thus the proper generation solution based on points sample interpolation within an exterior closed edge. Sometimes probably the GOG9 is also admitted, starting from a set of polylines in the form of extracted profiles and even isolines to represent the local irregularity, within the closed edge.

The use of extracted profiles and sub-samples of dense points is almost established by recent application in researches based on the use of static LiDAR data. But what happens if a lower precision point cloud as an initial data takes over, as the SLAM-based here? In the research here presented, it was explained how the geometric features are radically different and also the designated modelling strategy could change. The SLAMbased point cloud, as shown in Figure 13 is featured by inherent variability in points distribution in comparison with TLS data. However, it could be stated that in the case of the circular vault sample in the central module of the porch, $90 \%$ of the points are comprised within $2 \mathrm{~cm}$ error, and only $57 \%$ has a deviation of almost $1 \mathrm{~cm}$.
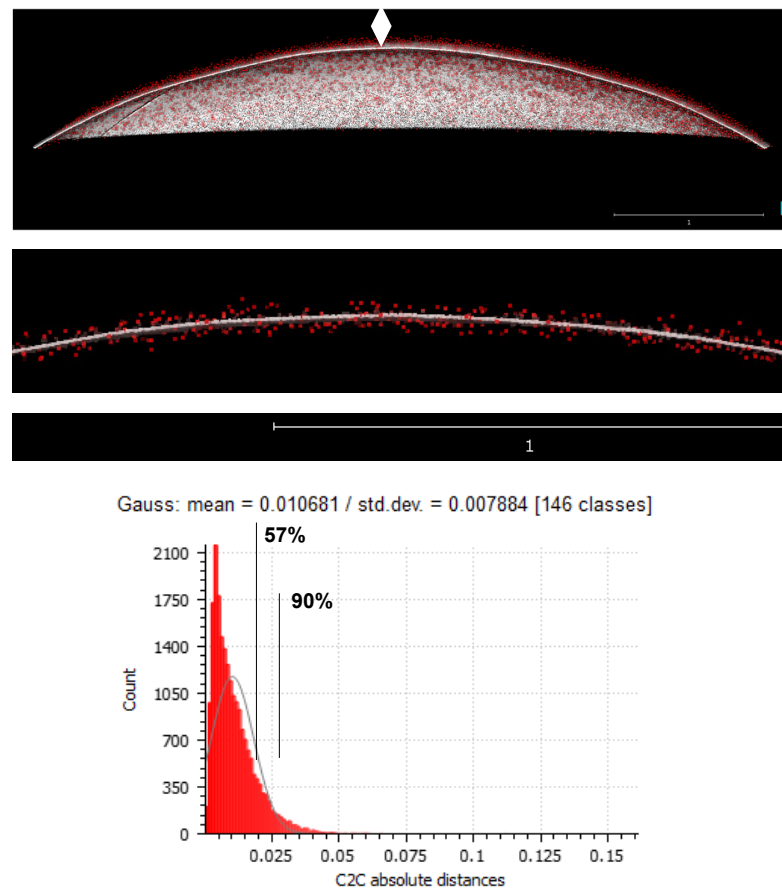

Figure 13: Surface deviation analysis Cloud to Cloud [C2C] between TLS surface and SLAM-based data, and the distribution of the distance on the related graph.

As expected, and as it will be demonstrated in the next paragraph, this noise badly influences the direct parametric generation in the case of NURBs interpolation by GOG 10 and so GOG 9 approach is parallelly presented. Structure isolines and eventually isolines are convenient in the GOG9 pipeline. In the case of SLAMbased data, the proposed procedure must go through the calculation of a triangulated surface.

For this reason, and generally, if a mesh model is required as the first step of modelling procedure for independent use, the triangulated surface of the vaulted elements is presented (already introduced in Figure 2, the groin lunette vault). From the calculation of mesh model, both for TLS data (3.736.984 points; 404.657 triangles; tot. 15 min time) and SLAM-based data (396.241 points; 55.342 triangles; tot. 10 min time) a set of internal section curves and a set of isolines has been extracted with $0.05 \mathrm{~m}$ steps. In Figure 14 the isolines only are represented together for TLS data (blue) and SLAM-based data (red). Considering this vaults reconstruction, the test of isolines comparison emphasized a lack of detail up to $7-8 \mathrm{~cm}$ in the diagonal rib detail. This could be admitted if the assumptions in the planning phase of the parametric modelling generation are related to such LOD and scale.

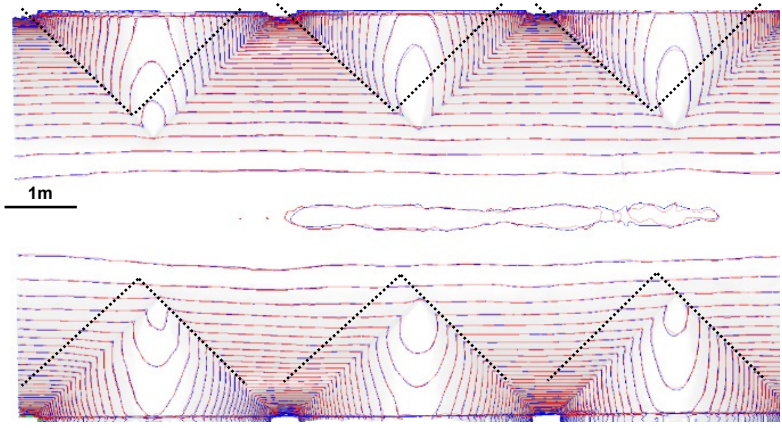

LiDAR data SLAM-based data

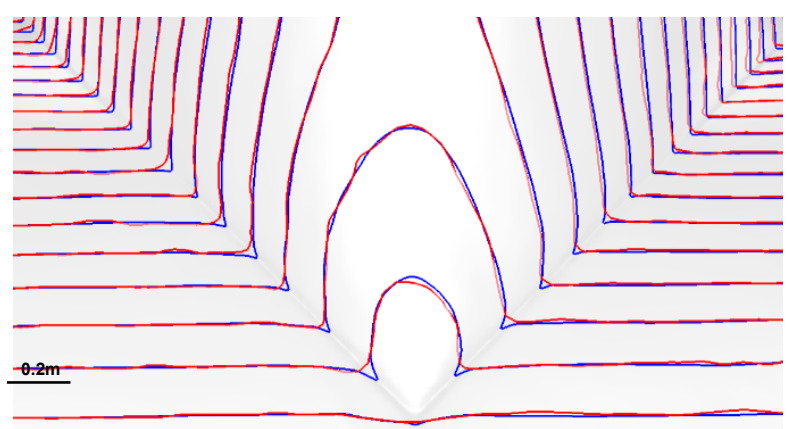

Figure 14: Extraction of isolines profiles ( $0.05 \mathrm{~m}$ step) and an indication of the diagonal ribs directions.

\subsection{Oriented parametric modelling generation}

Starting from the optimized point clouds originated from the two different scanning methods, and wherever necessary the 3D wireframe polylines extracted from the 3 samples considered for the analysis, the following workflow has been implemented. The samples are:

a) The circular vault in the central higher module of the arcades.

b) A column-type of the porch.

c) An arch-type connecting the columns of the porch.

From the cleaned and filtered point cloud, a set of primitives and edges have been extracted from the 3D point cloud (3D mesh model for SLAM data). The NURBS models have been calculated with GOG9 for A, B, C, and GOG10 for A. For the parametric NURBS models results the GOA was analysed and verified (Banfi, 2020) according to the starting point data.

\subsubsection{The circular vault}

For the parametric modelling of the circular vault with SLAM data, the GOG9 and GOG10 were implemented and evaluated. The NURBS models based on TLS data are the reference ground truth (around 700.000 points for 
the circular vault). The GOG10 was executed using two sub-sampled point clouds: a first-step filtering sample of points (35000 points) and an onerous sub-sampling of about $1 / 30$ points (Table 2 ). The GOG9 was tested with an external edge and isolines with $0.10 \mathrm{~m}$ and $0.20 \mathrm{~m}$ step. In order to verify data accuracy, the four parametric surfaces, are measured with their GOA and st. dev. compared with the original TLS points dataset. In Table 2 the results are expressed in terms of the percentage of points within $1 \mathrm{~cm}$ and $5 \mathrm{~mm}$. In the end, no substantial difference in the final surfaces emerged, and in any case not largely exceeding $1 \mathrm{~cm}$.

Table 2: The GOG parametric modeling applied to the central vault based on SLAM-data.

\begin{tabular}{|c|c|c|c|}
\hline \multicolumn{3}{|c|}{ GOG - Grade of Generation tests } & \multirow{2}{*}{$\begin{array}{c}\begin{array}{c}\text { GOA (points } \\
\text { deviation) }\end{array} \\
86,7 \% \pm 0.5 \mathrm{~cm}\end{array}$} \\
\hline GOG10 & 10.1 & 35.600 points & \\
\hline & & & $94,1 \% \pm 1 \mathrm{~cm}$ \\
\hline & 10.2 & 1.360 points & $49,4 \% \pm 0.5 \mathrm{~cm}$ \\
\hline & & & $79,3 \% \pm 1 \mathrm{~cm}$ \\
\hline \multirow[t]{4}{*}{ GOG9 } & 9.1 & $0.10 \mathrm{~m}$ step isolines & $87,4 \% \pm 0.5 \mathrm{~cm}$ \\
\hline & & & $97,7 \% \pm 1 \mathrm{~cm}$ \\
\hline & 9.2 & $0.20 \mathrm{~m}$ step isolines & $55,9 \% \pm 0.5 \mathrm{~cm}$ \\
\hline & & & $82 \% \pm 1 \mathrm{~cm}$ \\
\hline
\end{tabular}

A further analysis was conducted on the parametric surfaces generated with the presented GOG. The choice was to use the RANSAC algorithm (implemented in CC interface) allowing the recognition and extraction of an adaptive spheric shape, firstly based on the starting points clouds and then on the generated NURBS. The extracted sphere dimension was around radius equal to $4.8 \mathrm{~m}$. For TLS point cloud, the $92 \%$ points fits within $\pm 1 \mathrm{~cm}$ in the sphere extraction, instead for SLAM points dataset, they are the $52 \%$. Applying the same algorithm to the parametric NURB surface with GOG9 and GOG10, that is an already approximated interpolation (verified with GOA yet), the RANSAC is able to extract the sphere almost with the $80 \%$ of surface both for TLS and SLAM NURBS. In particular, Figure 15 shows the GOG10.2 with the few point sample superimposed on the sphere and on the points dataset (black dots).

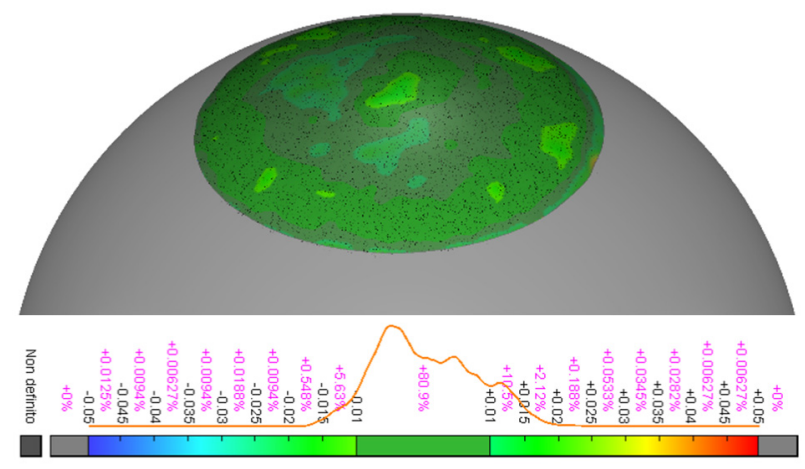

Figure 15: Deviation analysis between the reference sphere surface recognized with RANSAC. and the NURB derived from GOG10.2 applied to SLAM-data.

However, from the comparisons of the two GOG 10 it emerges that the lower precision of the SLAM data with the intrinsic irregularity, even with filtering the data, causes a non-smoothed surface for extended curved areas as vaults. The interpolation at step $20 \mathrm{~cm}$ can be added as the example in Figure 16 in comparison with the TLS surface where we consider the simplification in areas between curves, but we can define them however within the centimetres tolerance limits.
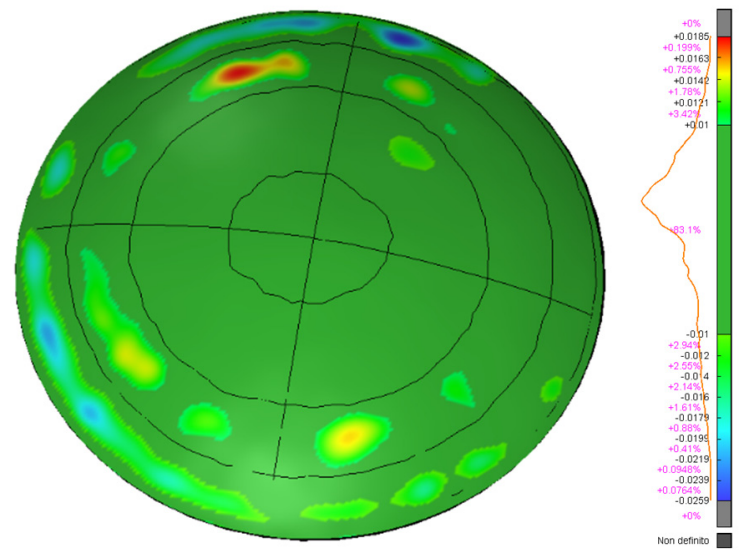

Figure 16: Deviation analysis between GOG10 applied to TLS (reference, higher detail expected) and GOG9.2 with $20 \mathrm{~cm}$ step profiles, applied to SLAM data (the poorest expected).

\subsubsection{The column}

In the case of GOG application for punctual elements as columns, it is well recognized the parametric approach based on GOG7-GOG9, or rather the binary swipe along the extracted profile. For the column generation based on the point cloud, the generatrixes and directrices extracted by parallel cutting planes applied to the 3D mesh model calculated on the SLAM data could be used: they can be employed as increasing constraints especially is required for the LOD, of if eventual anomalies of the geometry occurred. The test evidences the impossibility to use parametric as-built GOG to generate specific detail for basements and capitals as well. For them, focused modelling is required, and SLAM data does not support high level of detail for decorative apparatus as visible in next paragraph too (Fig. 17). Considering the column shaft and the entasis representation, for which the GOG9 is implemented here, the combined use of profiles as increasing constraints using the swipe method, as Figure 18 , could offer a solution according to the expected detail.

According to Figure 18, the (a) solution was employed in the generation of the parametric modelling from SLAM data, in comparison with NURBS generated with TLS reference data. In the GOA verification system, the GOG9 (a) results with $6.4 \%$ points with $\pm 1 \mathrm{~cm}$ deviation error from original point cloud data, and almost $90 \%$ with $\pm 2 \mathrm{~cm}$ deviation error, against $\pm 0.5 \mathrm{~cm}$ for TLS data. The major errors are positioned in the topmost and lowest area of the column entasis.

\subsubsection{The portal/arch}

In the case of the arch, the difficulty of the choice of GOG concerned the selection and construction of the 3D wireframe structure of the featuring polylines. The two parallel edge elements defining the arch between two columns are extracted semi-automatically from the mesh model calculated on SLAM data, necessary to recognize clearly edges due to noise affecting the surface (Fig. 12), 
and used to generate the parametric surface. After the GOA verification, the derived result from the comparison with the original point cloud declares that almost $57 \%$ of points are belonging to the new surface within $\pm 1 \mathrm{~cm}$, and in any case, almost $93 \%$ fits between $\pm 3 \mathrm{~cm}$. The use of an increased number of polylines constraints with the double swipe-based method along the external-internal edges, allows solving the problem of the lack of detail specifically located in the arch moulding modelling (Fig. 19).
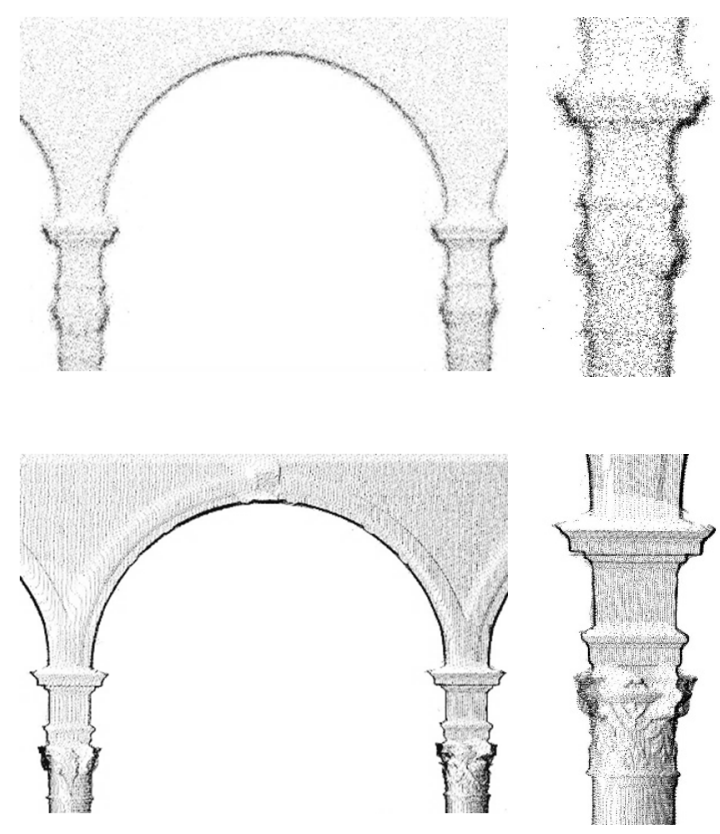

(a)
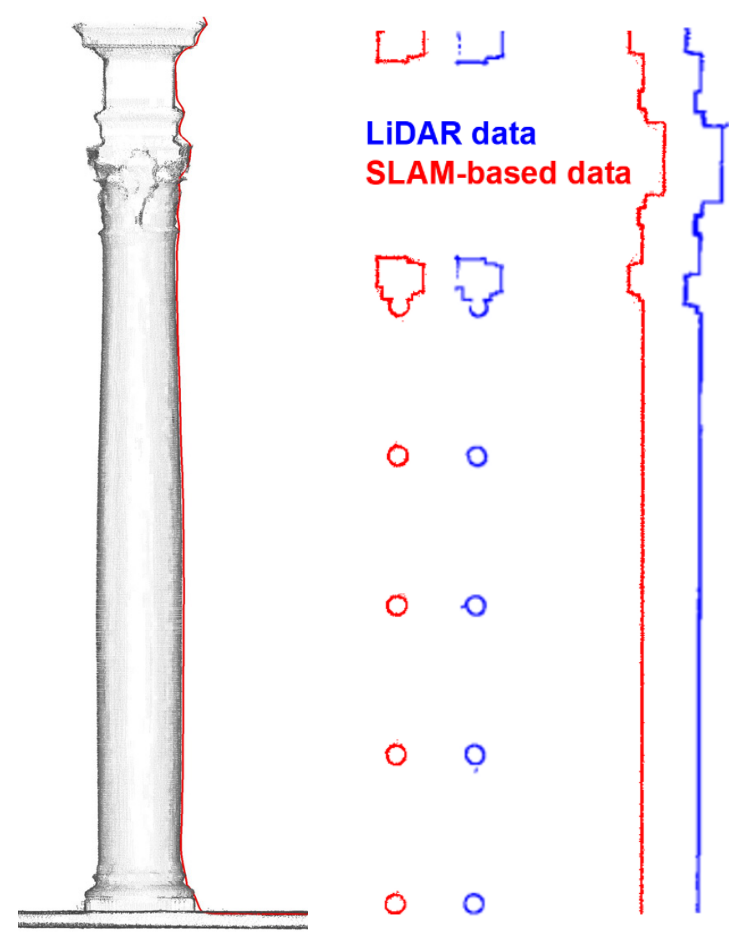

(b)

Figure 17: Data comparison between static TLS and SLAM data. (a) for façade digitization; (b) for profile extraction and digitization in vertical section and planar sections.

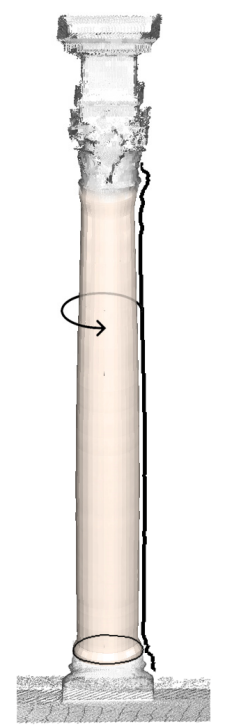

(a)

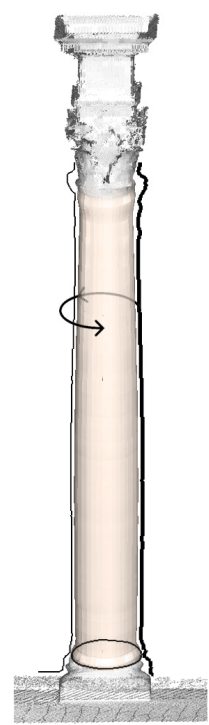

(b)

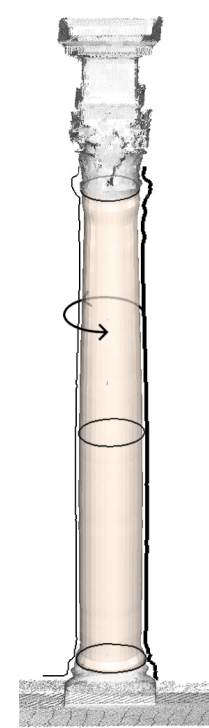

(c)
Figure 18: GOG9 swipe profile extracted from the column model. 1horiz/1vert. 1horiz/2vert. 3horiz/2vert.
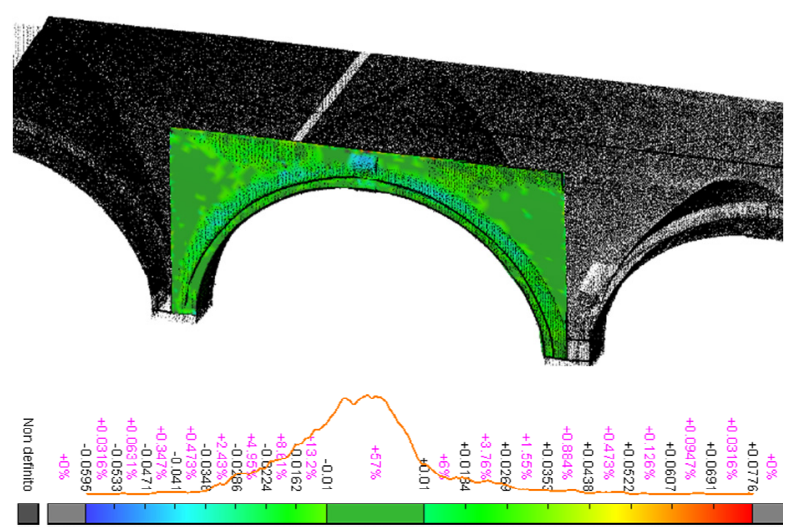

Figure 19: Deviation analysis GOA <between GOG9 applied to SLAM (higher detail expected) and original SLAM data

\section{Discussion}

The generation of parametric objects based on point cloud data it is part of a very well-established panorama as has been discussed in this work. The research demand, at the beginning of the validation analysis proposed and related to the test on the architectural elements of the S. Ambrogio Canonica court and arcades, is about the role of SLAM-based data in the HBIM modelling process. Due to the anticipated initial contradiction, the main goal is to establish how and when it is possible to place at the base of the consolidated scanto-HBIM pipeline a source data of a different nature, with lower density and precision, but with undoubted advantages in terms of efficiency of data acquisition and management times. The ZEB Revo point clouds are native with a lower level of detail $(<5-10 \mathrm{~cm})$ and for scales not greater than 1:100 (corresponding to the admitted error tolerance). But they can, in many cases, replace extensive and time-consuming use of static LiDAR for the generation of objects by BIM modelling or triangulated mesh models. This emerging portable digitization solution could be operationally suitable for 
many more survey purposes and applications than those for which the tool is commonly currently employed.

Table 3 tries to summarize the comparison analysis between the alternative existing approaches according to a set of variables introduced in the diagram.

Table 3: Preliminary comparison for the overall workflow for the two measurement systems

\begin{tabular}{c|c|c} 
& Static TLS & SLAM \\
\hline Data acquisition time & $* * *$ & $*$ \\
Data processing time & $* * *$ & $* *$ \\
Hardware-user work & $*$ effort & $*$ \\
Metric quality & $1: 20-1: 50$ & $1: 100-$ \\
& $1: 200$ \\
Precision & Edge and corners & Diffuse \\
noise & noise \\
Profile extraction & Point cloud & Mesh \\
Parametric generation & GOG9-10 & GOG9 \\
Triangulation mesh & $* * *$ & $* *$ \\
modelling & $* * *$ & $*$ \\
Data size & &
\end{tabular}

Specifically, for the individual nature of the point cloud data, as previously observed, it could be identified one of the main differences between LiDAR and MMS approach, which is the data acquisition planning and the quality of captured data. The two main variables are: efficient time to obtain a uniform and homogenous coverage in terms of point cloud densities. In fact, in order to have an estimation of the ideal number of TLS scans and consequently the optimum acquisition time necessary to achieve the same coverage of the acquisition with the MMS, a simulation was proposed in a second phase and here discussed. The simulation, as introduced in Par.4.1.1, was carried out by using the methodology presented in (Díaz-Vilariño, Frías, Previtali, Scaioni, \& Balado, 2019). This methodology is divided into three steps: (i) 2D optimisation of the scanning position according to a minimum point density threshold (ii) 3D simulation of the scan to verify the data completeness, (iii) re-computation of the scanning positions if the density threshold is not met somewhere. In this case, the threshold data density was the one derived from the MMS point cloud (average value of 10000pts/m2) and no predefined overlap is set among point clouds. Under these constraints, the final simulation foresees 12 scans for the porch and the outer façade and 8 scans for the first floor. The simulation was carried out considering as static TLS a Faro Focus X 130 laser scanner and as scanning time 1/5 (i.e., 28 million points). In terms of the requested time of acquisition, this turns in approximately 60 minutes of scanning time. Nevertheless, taking into account scanner movements for repositioning by operators, approximately 90 minutes can be estimated and without forgetting target placing and topographic measurements, 120 minutes for a reliable overall value. On the contrary, for the execution of the acquisition only by operator walking handling SLAM-based scanner, 20 minutes totally are consumed. Considering also possible failed SLAM scans, which not only occasionally happen in the initialization phase, an overall value of $30-45$ minutes can be spent for the SLAM-based mapping in such a large environment $\left(2500 \mathrm{~m}^{3}\right)$.

These considerations allow providing a framework of SLAM point clouds distinctive behaviour in meeting those requirements typical of the HBIM parametric modelling with Grades of Generation that we establish at the beginning as a pipeline well consolidated with TLS data. In particular, from one side, it has been demonstrated that the scan-to-HBIM pipeline and the modelling strategies (GOG) used for TLS can be generally adopted also for MMS data, with real advantages in terms of data acquisition and processing. In the other side, a distinction should be defined in the case of GOG9 and GOG10 applicability. The final performance of the test on GOG10 NURBS based on SLAM source datasets (after a firststep of cleaning and optimization), does not allow considering the SLAM point cloud, equally efficacious both for the GOG9 and GOG10 application. Since GOG10 has been created to support the generation of complex architectural elements from points model, the point cloud surface noisiness is a bottleneck for SLAM data to retrieve smoothed and accurate NURBS surfaces. In the time-cost evaluation, nonetheless, the time expense for the generation of the simplified mesh from SLAM data play a key role because, on the other hand, the profiles and edges for the GOG9 application are necessary to be extracted. As visible in Figure 17, in the case of 2D/3D digitization using SLAM-based point clouds, the operator is asked to apply a higher interpretative effort than the LiDAR data, and in any case, the different density and noise of the surface do not allow the achievement of the same scale and LOD. On the other hand, it is important to consider that the use of SLAM-based data proves to be easily manageable, as introduced, also in the generation of a first-step of modelling with a triangulated mesh (contrary to costly mesh generation on TLS, according to optimization time and the number of triangles). In Figure 20 an example of a triangulated model calculated after a point cloud optimization (20 min time expense, 1,41 mln triangles), of the whole volume of the Canonica related to the presented test. As a fist-step on modelling, the generation of a mesh from this kind of MMS dataset results more adaptable, easily manageable and texturizable with high-definition data (Sammartano, Spanò, \& Teppati Losè, 2019), in those cases where a continuous light model is required for virtual navigation, web application and data enrichment.

If we consider the generation of rapid and manageable points clouds as an efficient alternative to static methods, the use of SLAM-based data can be also proficiently employed in independent targets: ortho-projection and rasterization for $2 \mathrm{D}$ drawing and plotting of sections and façades Figure 17a, and also triangulated mesh modelling allowing to derive precise extracted profiles.

\section{Conclusion and future perspectives}

We are aware that more and more parameters come into play, from a user-oriented perspective, in the crucial moment in which the 3D survey is planned and specific techniques are adopted. This is usually established to gain expected results in the 3D reality-based model's generation. The premise of the research is based on the well-known bottlenecks referring to static TLS data and the required postprocessing phases leading to the filtering of a significant percentage of the acquired massive data. 
In fact, the long-time applications using consolidated TLS digitization, providing a plentiful source of data for HBIM modelling, with huge efforts of procedural time and waste of collected points, justify nowadays the research in the direction of a worthwhile alternative, using different kinds of clouds, as the MMS-derived, that already born lighter than about 1:10 and therefore do not necessitate to undergo processes of simplification and massive decimation. An evaluation of the required LOG and LOD is however always necessary in these cases where the use of portable scanners is competitive. The aim pursued in the point cloud processing and management, especially for this kind of SLAM datasets, is to be able to extract and focus the semantic content of objects and elements, supporting the segmentation and the modelling phase. The possibility to generate effortless BIM models through more fluid processes, must not make us forget the BIM space as a complex database of information. In this perspective, the research can investigate interesting application in the integration of direct radiometric information useful in HBIM models enrichment for knowledge and interpretation of architectural objects. This direct data augmentation could be based on the fusion of active/passive data simultaneously captured by integrated portable systems, or co-registered from different times, in a multi-temporal perspective aimed at information monitoring and updating.

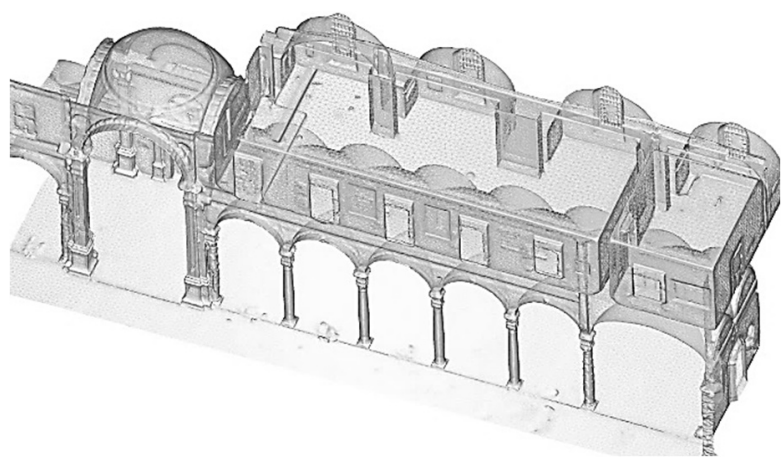

(a)

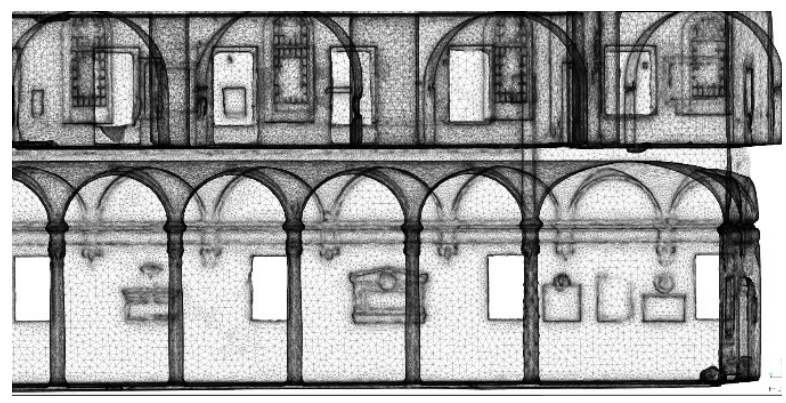

(b)

Figure 20: A low detail mesh model generated from the SLAM based data of the southern side or the Canonica porch $(70 \mathrm{Mb}$ ${ }^{*}$.obj data, without texture, for $2500 \mathrm{~m}^{3}$ of digitized space).

\section{References}

Banfi, F. (2017). BIM orientation: grades of generation and information for different type of analysis and management process. International Archives of the Photogrammetry, Remote Sensing and Spatial Information Sciences, XLII2/W5, 57-64. https://doi.org/10.5194/isprs-archives-XLII-2-W5-57-2017

Banfi, F. (2019). HBIM generation: extending geometric primitives and BIM modelling tools for heritage structures and complex vaulted systems. International Archives of the Photogrammetry, Remote Sensing and Spatial Information Sciences, XLII-2/W15, 139-148. https://doi.org/10.5194/isprs-archives-XLII-2-W15-139-2019

Banfi, F. (2020). HBIM, 3D drawing and virtual reality for archaeological sites and ancient ruins. Virtual Archaeology Review, 11(23), 16. https://doi.org/10.4995/var.2020.12416

Banfi, F., Brumana, R., \& Stanga, C. (2019a). A content-based immersive experience of Basilica of Sant'AMbrogio in Milan: from 3D survey to virtual reality. International Archives of the Photogrammetry, Remote Sensing and Spatial Information Sciences, XLII-2/W11, 159-166. https://doi.org/10.5194/isprs-archives-XLII-2-W11-159-2019

Banfi, F., Brumana, R., \& Stanga, C. (2019b). Extended reality and informative models for the architectural heritage: from scan-to-BIM process to virtual and augmented reality. Virtual Archaeology Review, 10(21), 14. https://doi.org/10.4995/var.2019.11923

Banfi, F., Previtali, M., Stanga, C., \& Brumana, R. (2019). A layered-web interface based on HBIM and 360 panoramas for historical, material and geometric analysis. International Archives of the Photogrammetry, Remote Sensing and Spatial Information Sciences, XLII-2/W9, 73-80. https://doi.org/10.5194/isprs-archives-XLII-2-W9-73-2019

Besl, P. J., \& Jain, R. C. (1988). Segmentation through variable-order surface fitting. IEEE Transactions on Pattern Analysis and Machine Intelligence, 10(2), 167-192. https://doi.org/10.1109/34.3881

Dewez, T. J. B., Yart, S., Thuon, Y., Pannet, P., \& Plat, E. (2017). Towards cavity-collapse hazard maps with Zeb-Revo handheld laser scanner point clouds. The Photogrammetric Record, 32(160), 354-376. https://doi.org/10.1111/phor.12223

Di Filippo, A., Sánchez-Aparicio, L., Barba, S., Martín-Jiménez, J., Mora, R., \& González Aguilera, D. (2018). Use of a Wearable Mobile Laser System in Seamless Indoor 3D Mapping of a Complex Historical Site. Remote Sensing, 10(12), 1897. https://doi.org/10.3390/rs10121897

Díaz-Vilariño, L., Frías, E., Previtali, M., Scaioni, M., \& Balado, J. (2019). Scan planning optimization for outdoor archaeological sites. International Archives of the Photogrammetry, Remote Sensing and Spatial Information 
Sciences, XLII-2/W11, 489-494. https://doi.org/10.5194/isprs-archives-XLII-2-W11-489-2019

Dore, C., \& Murphy, M. (2013). Semi-Automatic Modelling of Building Façades with Shape Grammars Using Historic Building Information Modelling. Proceedings of the International Archives of the Photogrammetry, Remote Sensing and Spatial Information Sciences - 3D Virtual Reconstruction and Visualization of Complex Architectures, XL(February), 57-64. https://doi.org/10.5194/isprsarchives-XL-5-W1-57-2013

Gatti Perer, M. L. (1995). La basilica di S. Ambrogio: il tempio ininterrotto (Vita e Pen).

Grilli, E., Menna, F., \& Remondino, F. (2017). A review of point clouds segmentation and classification algorithms. International Archives of the Photogrammetry, Remote Sensing and Spatial Information Sciences, XLII-2/W3, 339344. https://doi.org/10.5194/isprs-archives-XLII-2-W3-339-2017

Hichri, N., Stefani, C., De Luca, L., Veron, P., \& Hamon, G. (2013). From point cloud to BIM: a survey of existing approaches. International Archives of the Photogrammetry, Remote Sensing and Spatial Information Sciences, XL5/W2(SEPTEMBER), 343-348. https://doi.org/10.5194/isprsarchives-XL-5-W2-343-2013

Kumar, S. S., \& Cheng, J. C. P. (2015). A BIM-based automated site layout planning framework for congested construction sites. Automation in Construction, 59, 24-37. https://doi.org/10.1016/j.autcon.2015.07.008

Lusuardi Siena, S. (1997). Ambrogio, il costruttore sapiente. In M. Marco Rizzi, Cesare Pasini \& P. Rossignani (Eds.), La città e la sua memoria: Milano e la tradizione di Sant'Ambrogio (pp. 34-35). Electa.

Marucci, R. A., Negri, M., Rastelli, A. Romaniello, L. (2004). Bombe sulla città: Milano in guerra 1942-44 (Skira (ed.)).

Motawa, I., \& Almarshad, A. (2013). A knowledge-based BIM system for building maintenance. Automation in Construction, 29, 173-182. https://doi.org/10.1016/j.autcon.2012.09.008

Nocerino, E., Menna, F., Remondino, F., Toschi, I., \& Rodríguez-Gonzálvez, P. (2017). Investigation of indoor and outdoor performance of two portable mobile mapping systems. In F. Remondino \& M. R. Shortis (Eds.), Videometrics, Range Imaging, and Applications XIV, edited, SPIE 2017 (p. 103320I). https://doi.org/10.1117/12.2270761

Oreni, D., Brumana, R., Della Torre, S., Banfi, F., Barazzetti, L., \& Previtali, M. (2014). Survey turned into HBIM: the restoration and the work involved concerning the Basilica di Collemaggio after the earthquake (L'Aquila). ISPRS Annals of Photogrammetry, Remote Sensing and Spatial Information Sciences, II-5(June), 267-273. https://doi.org/10.5194/isprsannals-II-5-267-2014

Paiva, P. V. V., Cogima, C. K., Dezen-Kempter, E., \& Carvalho, M. A. G. (2020). Historical building point cloud segmentation combining hierarchical watershed transform and curvature analysis. Pattern Recognition Letters, 135, 114-121. https://doi.org/10.1016/j.patrec.2020.04.010

Remondino, F. (2003). From point cloud to surface: the modeling and visualization problem. International Archives of Photogrammetry, Remote Sensing and Spatial Information Sciences Remote Sensing, 34.

Rocha, G., Mateus, L., Fernández, J., \& Ferreira, V. (2020). A Scan-to-BIM Methodology Applied to Heritage Buildings. Heritage, 3(1), 47-67. https://doi.org/10.3390/heritage3010004

Sammartano, G. (2018). Optimization of Three-Dimensional (3D) Multi-Sensor Models For Damage Assessment in Emergency Context: Rapid Mapping Experiences in the 2016 Italian Earthquake. In F. Remondino, A. Georgopoulos, D. Gonzalez-Aguilera, \& P. Agrafiotis (Eds.), Latest Developments in Reality-Based 3D Surveying and Modelling (pp. 141-168). MDPI. https://doi.org/10.3390/books978-3-03842-685-1-7

Sammartano, G., \& Spanò, A. (2018). Point clouds by SLAM-based mobile mapping systems: accuracy and geometric content validation in multisensor survey and stand-alone acquisition. Applied Geomatics, 10(4), 317-339. https://doi.org/10.1007/s12518-018-0221-7

Sammartano, G., Spanò, A., \& Teppati Losè, L. (2019). A fusion-based workflow for turning slam point clouds and fisheye data into texture-enhanced 3D models. International Archives of the Photogrammetry, Remote Sensing and Spatial Information Sciences, XLII-2/W17(December), 295-302. https://doi.org/10.5194/isprs-archives-XLII-2-W17-2952019

Riisgaard, S., \& Blas M-R.. (2005). SLAM for Dummies. A Tutorial Approach to Simultaneous Localization and Mapping. MIT OCW.

Spanò, A. (2019). Rapid Mapping methods for archaeological sites. 2019 IMEKO TC4 International Conference on Metrology for Archaeology and Cultural Heritage, MetroArchaeo 2019, 25-30.

Stanga, C., Spinelli, C., Brumana, R., Oreni, D., Valente, R., \& Banfi, F. (2017). A N-D virtual notebook about the Basilica of S. Ambrogio in Milan: information modeling for the communication of historical phases subtraction process. International Archives of the Photogrammetry, Remote Sensing and Spatial Information Sciences, XLII-2/W5, 653660. https://doi.org/10.5194/isprs-archives-XLII-2-W5-653-2017

Tucci, G., Visintini, D., Bonora, V., \& Parisi, E. (2018). Examination of Indoor Mobile Mapping Systems in a Diversified Internal/External Test Field. Applied Sciences, 8(3), 401. https://doi.org/10.3390/app8030401

Vo, A.-V., Truong-Hong, L., Laefer, D. F., \& Bertolotto, M. (2015). Octree-based region growing for point cloud 
segmentation. ISPRS Journal of Photogrammetry and Remote Sensing, 104, 88-100. https://doi.org/10.1016/j.isprsjprs.2015.01.011

Wong, K., \& Fan, Q. (2013). Building information modelling (BIM) for sustainable building design. Facilities, 31(3/4), 138157. https://doi.org/10.1108/02632771311299412

Yang, X., Lu, Y.-C., Murtiyoso, A., Koehl, M., \& Grussenmeyer, P. (2019). HBIM Modeling from the Surface Mesh and Its Extended Capability of Knowledge Representation. ISPRS International Journal of Geo-Information, 8(7), 301. https://doi.org/10.3390/ijgi8070301

Zlot, R., \& Bosse, M. (2014). Efficient Large-scale Three-dimensional Mobile Mapping for Underground Mines. Journal of Field Robotics, 31(5), 758-779. https://doi.org/10.1002/rob.21504

Zlot, R., Bosse, M., Greenop, K., Jarzab, Z., Juckes, E., \& Roberts, J. (2014). Efficiently capturing large, complex cultural heritage sites with a handheld mobile 3D laser mapping system. Journal of Cultural Heritage, 15(6), 670-678. https://doi.org/10.1016/j.culher.2013.11.009 


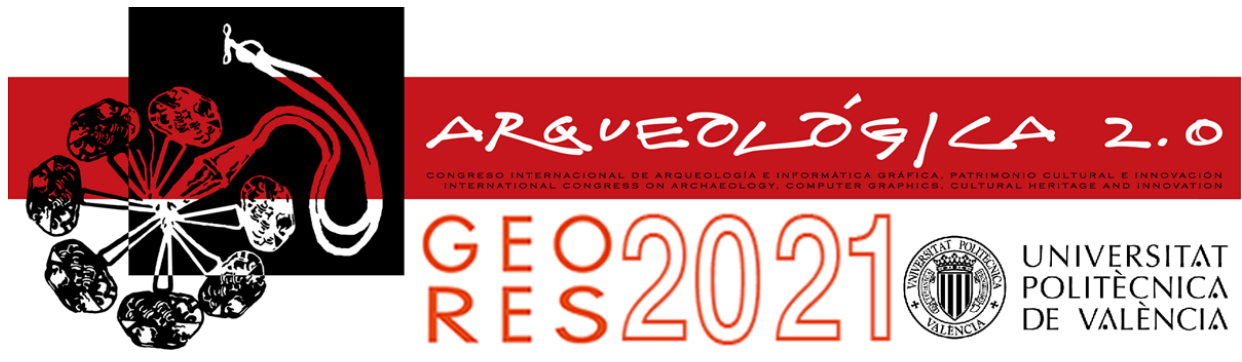

Proceedings of the joint international event $9^{\text {th }}$ ARQUEOLÓGICA

$2.0 \& 3^{\text {rd }}$ GEORES

Valencia (Spain).

26-28 April 2021

\title{
TOWARDS AN INTEGRATED DESIGN METHODOLOGY FOR H-BIM
}

\author{
Eugenio Pellis a, ${ }^{a}$, Andrea Masiero ${ }^{a}$, Grazia Tuccia ${ }^{a}$, Michele Bettia, Pierre Grussenmeyer ${ }^{b}$ \\ a Department of Civil and Environmental Engineering, University of Florence, Via di Santa Marta 3, 50139 Florence, Italy. \\ eugenio.pellis@unifi.it; andrea.masiero@unifi.it; grazia.tucci@unifi.it; michele.betti@unifi.it \\ ${ }^{b}$ Photogrammetry and Geomatics Group, ICube Laboratory UMR 7357, INSA Strasbourg, University of Strasbourg, France. \\ pierre.grussenmeyer@insa-strasbourg.fr
}

\begin{abstract}
:
In recent years, the numerous advantages introduced by Building Information Modelling (BIM) have led to its application on the heritage environment and giving birth to the concept of H-BIM (Heritage BIM). The resulting demand in heritage survey data processing has focused this research on the development of strategies and methods to improve the construction of three-dimensional and informative models starting from 3D point clouds. The implementation of an automated procedure is fundamental for easing and speeding up the survey data processing and one of the most challenging tasks to achieve this purpose is the problem of semantic segmentation. The research presented in this paper aims at testing already existing methods and exploring new strategies for 3D point cloud semantic segmentation on heritage scenarios focusing on deep learning and neural network techniques.
\end{abstract}

Keywords: H-BIM, cultural heritage, 3D point clouds, semantic segmentation, deep learning

\section{Introduction}

Over the last few decades three-dimensional (3D) modelling, in particular, the Building Information Modelling (BIM), has become a standard design approach in the Architecture, Engineering and Construction (AEC) sector (Azhar, 2011; Azhar, Khalfan \& Maqsood, 2012). While for new buildings the design methodologies are quite well defined, the BIM platforms still have serious issues to represent historical buildings and cultural heritage. From a geometrical point of view, heritage elements, due to their uniqueness, irregularity, and shape complexity, require careful modelling. From an informative aspect, a proper comprehension and description of heritage buildings requires heterogeneous information like images, drawings, report, information from previous surveys, etc. As a matter of facts, given such a complex set of information to be properly integrated, regular software and databases are not suitable for dealing with this kind of application (Oreni, 2013; Khalil \& Stravoravdis, 2019; Dore \& Murphy, 2017).

These challenges lead to the need for the development of an ad hoc approach for historical buildings and to the concept of Heritage Building Information Modelling $(\mathrm{H}$ BIM) (Murphy, McGovern \& Pavia, 2009). Over the last few years, the growing interest for H-BIM turns out from the numerous advantages of this type of modelling, and it goes along with the growing necessity of protection, conservation, restoration, and dissemination of cultural heritage (López et at., 2018; Volk, Stengel \& Schultmann,
2014). A well-established approach for the construction of an as-built model starts from data acquisition, the processing of point clouds, up to the construction of a three-dimensional (3D) and informative model (Fig. 1). This workflow is commonly called Scan-To-BIM (Rocha, Mateus, Fernández, \& Ferreira, 2020; Laing, Leon, Isaacs, \& Georgiev, 2015). Nowadays, the high levels of detail and automation achieved by 3D laser scanning and photogrammetry technologies allow to collect of a large amount of data in a short time (Grussenmeyer, Landes, Voegtle, \& Ringle, 2008), but properly processing such data is still a quite long procedure, requiring a time consuming manual intervention by a specialized operator, aiming at the definition of a 3D parametric model of the building of interest suitable for standard BIM software. (Rodriguez-Moreno et al., 2016; Tang, Huber, Akinci, Lipman, \& Lytle, 2010).

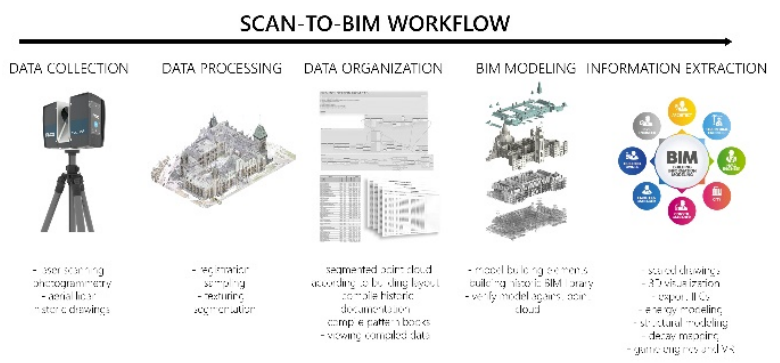

Figure 1: Scan-To-BIM workflow. 
One of the key points to enable automatic data processing in the above-mentioned procedure, is the development of a proper automatic semantic segmentation procedure (Macher, Landes \& Grussenmeyer, 2015). Semantic segmentation is the process of classifying each pixel in an image or each point in a 3D point could into classes or categories that share similar feature characteristics (Fig. 2). In practice, it can be considered as a fundamental step in the machine automatic comprehension of the considered data, and hence it plays a central role in a wide range of applications such as scene understanding, robotic perception, autonomous driving, augmented reality, and many others. The continuously increasing number of applications employing semantic segmentation makes it a very active research field, with several segmentation approaches already proposed in the literature (Yu et al., 2018; Nguyen \& Le, 2013).

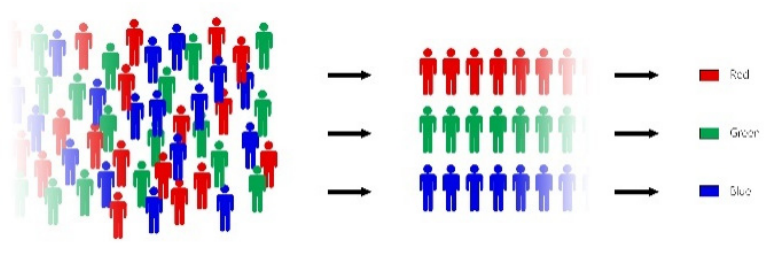

Figure 2: The concept of semantic segmentation.

Given the demand for automatic data analysis and modelling that emerged during the last decade also in the Architecture, Engineering and Construction (AEC) sector, many studies have explored strategies to apply semantic segmentation to the AEC problems as well. However, in particular for historical buildings, there is still a lack of standard procedures and methodologies to manage such complex data, and currently, the results are still not sufficiently accurate to fully understand heritage scenes and automatize the creation of detailed three-dimensional models (Grilli \& Remondino, 2019; Grilli, Menna \& Remondino, 2017).

The research presented in this article aims at partially reducing the above-mentioned lack, testing already existing methods, and exploring new strategies and methods for point cloud semantic segmentation in heritage and historical scenarios. Furthermore, this research also contributes to the generation of a database to be used as a benchmark for comparing different heritage building segmentation approaches: such database can be considered both as integration of certain already existing ones, and as a new one, providing the possibility of investigating point cloud segmentation methods and multi-view based ones as well.

\section{Semantic segmentation review}

3D point cloud semantic segmentation (PCSS) is attracting an increasing interest due to its applicability in a wide range of different applications (Xie, Tian \& Zha, 2020). Despite the term semantic segmentation is widely used in computer vision, in photogrammetry and remote sensing applications, the following nomenclature is also often used for similar purposes: "point cloud classification" or "point labelling" (Boulch, Le Saux \& Audebert, 2017).

Given a point cloud, the goal of semantic segmentation is to separate it into several subsets according to the semantic meaning of the points. Artificial Intelligence (Al), in particular the branch of machine learning, has become the basic building block for these tasks and nowadays PCSS is usually realized by supervised learning methods, including "regular" supervised machine learning and deep learning (Guo et al., 2020).

\subsection{Regular Supervised Machine Learning}

Regular supervised machine learning methods for semantic segmentation of point clouds can be divided into two main groups (Weinmann et at., 2015):

1) Individual PCSS methods, which classify each point based only on its individual features. Four stages can usually be identified in these methods: neighbouring selection, feature extraction, feature selection, and semantic segmentation. These methods are usually computationally efficient, but their results are often affected by a significant level of noise. The most important methods in this category are Random Forest, AdaBoost, Support Vector Machine, Maximum Likelihood.

2) Methods based on statistical contextual models, which focus on point cloud statistic and relational information over different scales. Differently from individual PCSS they take into account contextual features. The most widely used model in this category is Conditional Random Fields (CRF) (Weinmann, Jutzi, Hinz, \& Mallet, 2015; Vosselman, Coenen \& Rottensteiner, 2017).

\subsection{Deep learning}

Deep learning has been recently successfully used on several 2D vision problems, becoming more and more popular during the last five years, in particular after the introduction of Convolutional Neural Networks (CNN) (He, Zhang, Ren, \& Sun, 2016), and nowadays it can be considered as a predominating technique in Al.

Given the typical high performance of deep learningbased solutions, there is an increasing interest of the civil engineering sector in the extension of the use of such techniques also to data related to construction and building models. For instance, they may be used to extract information from 3D point clouds, for 3D Shape classification, 3D Object Detection, 3D Object Tracking, and 3D Point Cloud Segmentation (Zhu et al., 2017; Long, Shelhamer \& Darrell, 2015).

Three-dimensional data provide richer spatial and geometrical information compared to two-dimensional data and could better characterize complex scenes. However, the use of deep learning methods on point clouds still faces several significant challenges, due for instance to:

- The large data size, which implies long computing time,

- The unstructured nature of 3D point clouds, which complicates the use of network architectures commonly used for 2D data,

- The unavailability of large shared datasets, which makes the results of the training process hard to be exportable to scenarios different from the one that motivated the network realization. 
According to the literature, semantic segmentation methods for $3 \mathrm{D}$ point cloud can be divided into two groups: a) projection-based methods and b) point-based methods (Zhang, Zhao, Chen, \& Lu, 2019), which are going to be described in the following.

\subsubsection{Projection-based methods}

The main issues to be solved for using standard neural networks, such as Convolutional Neural Networks (CNNs) or Fully Connected Layers (FCs), are the unstructured nature of point clouds and the presence of orderless data. To this aim, projection-based methods first apply a transformation to convert 3D point clouds on a data with a regular structure, then they perform the semantic segmentation task by applying standard approaches, and finally, they re-project the extracted features on the starting shape or point cloud (Lawin at al., 2017). The advantage of projection-based methods is that they leverage well-established networks. However, any kind of transformation and intermediate representation involves inevitably a loss of information, in particular geometrical and spatial. Depending on the type of used representation, it is possible to distinguish four categories among these methods: multi-view, volumetric, spherical, and lattice.

\subsubsection{Multi-view representation}

These methods first project the 3D shape into multiple views, then apply $2 \mathrm{D}$ image segmentation methods to extract information from each image. The results obtained on such images are compared and analysed, and eventually re-projected on the original scene to obtain a semantically segmented point cloud. How to aggregate the multiple views in a global representation is still a key challenge for this method.

MVCNN (Su et al., 2015) is a pioneering work, which proposed the use of Convolutional Neural Networks (CNN) with multiple perspectives of the $3 \mathrm{D}$ object. It is suitable for an individual object rather than complex scenes because it ignores the spatial relationship between objects. Another important work is SnapNet (Boulch, Guerry, Le Saux, \& Audebert, 2018), that, in order to address the problem of information losing, it selects some snapshots of the point clouds to generate RGB and depth images, and then it uses the marked points to project the segmentation on the $3 \mathrm{D}$ cloud. The more recent SnapNet-R improves the process of image generation and the overall accuracy. These networks ensure excellent image segmentation results, but the transposition of such results on the 3D cloud entails a large loss of spatial and geometrical information.

\subsubsection{Volumetric representation}

Volumetric representation or voxelization of point clouds consists in the transformation of the unstructured 3D cloud into a regular spatial grid, and then the information distributed on such a regular grid is exploited to train a quite standard neural network to properly perform the segmentation task. VoxNet (Maturana \& Scherer, 2015) converts the $3 \mathrm{D}$ clouds into a grid in which CNN operations can be applied and use CNN to predict the classes directly on the order grid. PointGrid uses the same transformation of VoxNet, but it addresses the problem of information loss and change of scale, and it has less memory requirements. SEGCloud (Tchapmi, Choy, Armeni, Gwak, \& Savarese, 2017), to reduce the computational cost has introduced the methods of spatial partition such as K-d tree or Octree. In conclusion, the mentioned methods and others like OctNet (Riegler, Ulusoy, \& Geiger, 2017), VV-Net (Meng, Gao, Lai, \& Manocha, 2018), ScanComplete (Dai et al., 2017) ensure the achievement of a reasonable segmentation of nonstructured relatively small point clouds. Unfortunately, they are still unsuitable for the semantic segmentation of complex scenarios.

\subsubsection{Spherical representation}

These types of representation, compared with the multiview representation, retain more geometrical and spatial information. However, they have some issues such as discretization errors and occlusion. The most important works are SqueezeNet (landola et al., 2017) and RangeNet++ (Milioto, Vizzo, Behley, \& Stachniss, 2019) for real-time LiDAR data semantic segmentation.

\subsubsection{Lattice representation}

Volumetric representation is naturally sparse, and it is inefficient to apply dense convolutional neural networks (DCNN) on spatially sparse data. Lattice representation converts a point cloud into discrete representation such as sparse permutohedral lattice. This method can control the sparsity of the extracted features and reduces memory requirements and computational costs reducing the convolution output. One of the main works is SPLATNet (Su et al., 2018). It interpolates a raw point cloud to a sparse lattice and then a Bilateral Convolutional Layers (BCL) is applied to convolve on occupied parts of lattice. Other works are LatticeNet (Rosu, Schutt, Quenzel, \& Behnke, 2017), which achieves efficient processing of large point clouds, and MinkowskiNet (Choy, Gwak \& Savarese, 2018), a 4D spatio-temporal convolutional neural network for $3 \mathrm{D}$ video perception.

\subsubsection{Point-based methods}

Point-based methods, or direct methods, work directly with point clouds and they do not introduce explicit information loss with intermediate representations. This direct approach leverage on the full use of the characteristic of the raw point cloud data and consider all the geometrical and spatial information. Despite pointbased methods are still in development, they seem the most promising in the future and a series of networks have been proposed recently. Overall, these methods can be divided into four categories: pointwise MLP methods, convolution methods, RNN-based methods and graphbased methods.

\subsubsection{Pointwise methods}

These methods usually use shared Multi-Layer Perceptron (MLP) as the basic unit in their network. The pioneering work for this method is PointNet (Qi, Su, Mo, \& Guibas, 2017), it learns per-point features using shared MLPs and global features using symmetrical polling functions. However, MLP cannot capture local geometry in the mutual interaction between points. In order to capture wider context and learn more local structures, a lot of network-based on PointNet have been developed recently. These methods are based on neighbouring 
feature pooling such as PointNet++ (Qi, Yi, Su, \& Guibas, 2017), PointSIFT, PointWeb, RandLA-Neton attentionbased aggregation such as Gumbel Subset Sampling (GSS) or Local Spatial Aware (LSA), and on local-global concatenation such as EdgeConv and NetVLAD.

\subsubsection{Convolution methods}

These methods tend to propose effective convolution operators for point clouds (Hua, Tran \& Yeung, 2018). PointCNN (Wang et al., 2018) is a network-based on parametric continuous convolution layers and the kernel function of this layer is parametrized by MLPs. KP-FCNN is based on Kernel Point Convolution (KPConv), and the convolution weights are determined by the Euclidean distances to kernel points, and the number of kernel point is not fixed. ConvPoint proposed a point-wise convolution operator, where the neighbouring points are binned into kernel cells and then convolved with kernel weights.

\subsubsection{RNN-based methods}

Recently Recurrent Neural Network (RNN) have been used for semantic segmentation, in particular, to capture inherent context features from point clouds. $\mathrm{G}+\mathrm{RCU}$ first transformed a block of points into multi-scale blocks and grid blocks to obtain input-level context. Then, the blockwise features extracted by PointNet are sequentially fed into Consolidation Units (CU) or Recurrent Consolidation Units (RCU) to obtain output-level context. 3DCNN-RNN (Liu et al., 2017) first learns spatial distribution and colour features using a 3D CNN, and then the final concatenated feature vector is fed into a residual RNN to obtain the final segmentation. However, these methods lose geometric features and density distribution from point clouds when aggregating the local neighbouring features with global structures.

\subsubsection{Graph-based methods}

To improve the results and capture richer geometrical structures several methods leverage graph networks. Graph Neural Network (GNN) is a type of Neural Network which directly operates on the Graph structure. The most important works are DGCNN (Wang et al., 2018), PyramNet based on Graph Embedding Module (GEM), and GACNet.

Finally, a summary of the main network architectures with their typology, year, and accuracy (mloU) on the ModelNet40 dataset (Fig. 3).

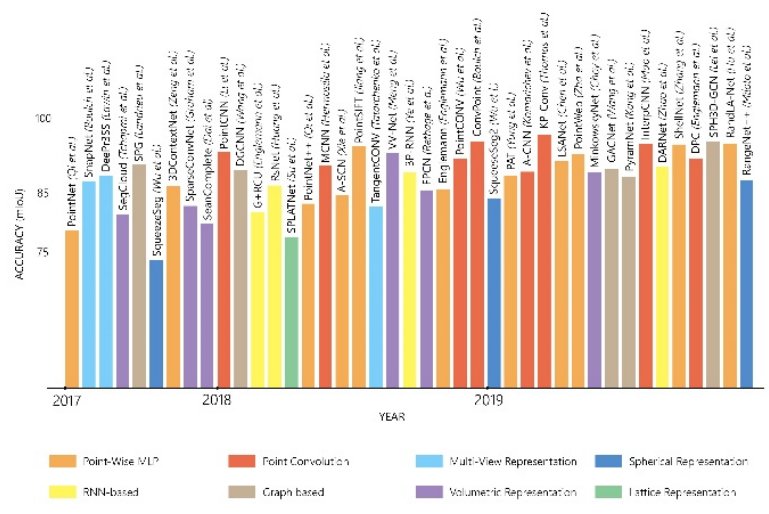

Figure 3: Summary of the main networks for 3D point cloud semantic segmentation.

\section{Research goals}

According to many studies, the problem of managing and processing $3 \mathrm{D}$ point cloud data is still a challenging task, in particular 3D complex data such as the historic and heritage ones. The main aim of this research is to develop strategies and methods to improve the automatization of 3D point cloud data processing and further the construction of three-dimensional models. As mentioned above, one of the key points for these purposes is $3 D$ point cloud semantic segmentation and this research has the purpose to investigate methods and techniques to improve segmentation on heritage 3D point clouds. Among all the methodologies describe previously, the research is focused on Deep Learning and Neural Networks techniques.

The choice of these typologies is motivated by their growing use in various applications, the great number of different algorithms and the continuous spread of new techniques, that could be adapted and tested on heritage 3D data. Despite the algorithm, results are improved every year, and new methods are proposed to improve their accuracy and reliability, there are few works that are focused on the use of Deep Learning on heritage data (Llamas, M. Lerones, Medina, Zalama, \& Gómez-GarcíaBermejo, 2017; Matrone et al., 2020a; Heipke \& Rotternsteiner, 2020).

This work aims at investigating two different approaches:

- Multi-view approach, based on image semantic segmentation and then on the re-projection of the extracted features on the point cloud,

- Point-based approach, that works directly with the raw point cloud.

The multi-view approach is being investigated first, mostly motivated by the greater simplicity and clarity of image-based algorithms and by the strong and solid results obtained recently on image segmentation (Minaee et al., 2020; Ulku \& Akagunduz, 2020). In addition, at this time, a multi-view approach for semantic segmentation on heritage data has never been tested and it is reasonable to also explore this direction. However, the results with point-based methods are improving rapidly and, in our future research work, this approach will be tested as well. The construction and the development of a specific network for heritage segmentation needs necessarily of a dedicated dataset for training and validation step and currently there are not available datasets for this purpose. The creation of a good dataset is a long and timeconsuming procedure, but this effort is motivated by the possibility of using it for comparing a) various network architectures and b) point-based and multi-view approaches, c) for possible integration with point-based methods, and hence for the development of a hybrid image-point based method that may improve performance, accuracy and reliability of the existing methods.

To recap, the main goals of the first phase of this research are two: a) the construction of a dedicated dataset for semantic segmentation of heritage buildings and $b$ ) the testing and tuning of image segmentation algorithms on this specific dataset. 


\section{Dataset creation}

Datasets play an indispensable role during the model training, and a large number of datasets have been created to evaluate the performance of deep learning algorithms for different applications.

In the context of 3D point cloud semantic segmentation, the most used and complete datasets are Paris-Lille-3D, ScanNet, Semantic3D (Hackel et al., 2017), SemanticKITTI, DALES (Varney, Asari, \& Graehling, 2020). In the specific context of heritage and historical environment, only two datasets are available. The first is Architectural Heritage Elements Dataset (AHE_dataset), a collection of 10,000 images classified in 10 types of architectural elements for the task of images classification. The second is ARCH_dataset (Matrone et al., 2020b), a benchmark for large-scale heritage point cloud semantic segmentation, composed of 17 annotated scenes in 10 categories.

The new dataset will be structured following the categories and the guidelines of $\mathrm{ARCH}$ dataset. The images will be a label with 10 classes including wall, floor, roof, column, moulding, vault, arch, stair, window/door and others, corresponding with the BIM standard constructive elements. An example of a segmented image according to ARCHdataset is shown below (Fig. 4). This choice, in addition to the possibility to compare the progress and the obtained results, allows a possible collaboration with the $\mathrm{ARCH}$ dataset. On one hand, introducing different scenes and increasing the number and the typologies of the labelled buildings. On the other hand, introducing the possibility of integration with photogrammetry images that are often paired with LiDAR data. This would entail the creation of a richer and more complete dataset, improving the generalization and the learning capability and the possibility to develop new algorithms and improve the existing ones.

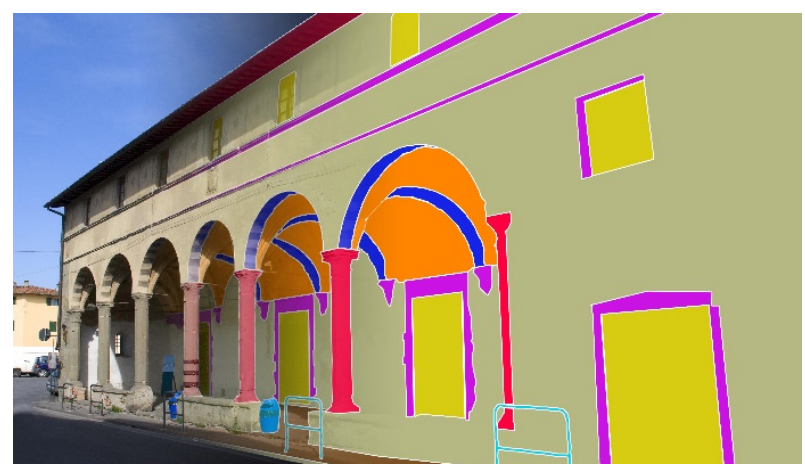

Figure 4: Example of a segmented image according to ARCHdataset.

Initially, the dataset will be composed of 9 partial scenes of heritage buildings from different historical period and architectural styles. The survey data were collected in research and didactical context by GECO Laboratory. GECO, affiliated with the Department of Civil and Environmental Engineering of Florence (DICEA), is a Geomatics and Conservation laboratory, headed by prof. Grazia Tucci. Its activities are mainly focused on documentation, protection, and enhancement of Cultural Heritage with innovative technologies. For all these buildings the laboratory has already available the LiDAR data that will be integrated, for the creation of the dataset, with terrestrial photogrammetry images. Due to the limitations of the latter, the scenes will be probably incomplete: they will mostly include façades and loggia.

The presence of the two data types allows to exchange of features and information between photogrammetry and LiDAR clouds, facilitate and semi-automatize the segmentation operation to obtain the ground truth and speed up the creation of the dataset. Further, both point clouds could be used with a point-based network.

A list and the images (Fig. 5) of the nine buildings that will be used for the creation of the dataset is reported below.

1) Spedale di Sant' Antonio, Lastra a Signa

2) Ospedale del Ceppo, Pistoia

3) Palazzo Pitti, Firenze

4) Basilica della Santissima Annunziata, Firenze

5) Ca' Granda, Milano

6) Galleria dell' Accademia, Firenze

7) Certosa del Galluzzo, Firenze

8) Cappella Buontalenti, Firenze

9) Palazzo Vecchio, Firenze
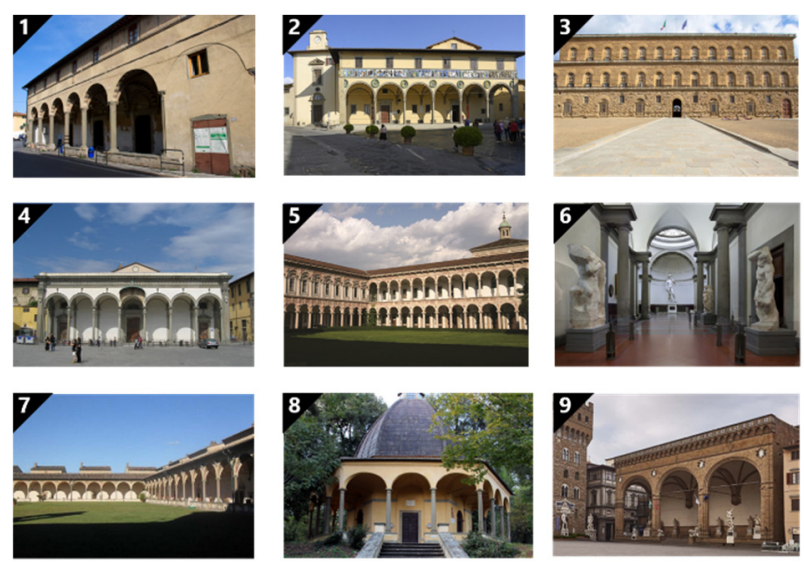

Figure 5: The nine buildings of the dataset.

A good and functional image-based dataset should be composed of thousands of images and a semiautomatized procedure is crucial to obtain results in a reasonable time. As shown below a possible solution tested with the façade of SS Annunziata case study is reported. Starting from survey images (1), with the standard software tools a dense point cloud was built (2). After pre-processing operations such as cleaning, sampling and alignment with the LiDAR cloud, the point cloud was manually segmented (3). Finally, with the last step, the features were reprojected on the initial images obtaining all the images segmented (4) (Fig. 6).

The longest and most challenging step is the third, but a semi-automatize process will be developed and tested. However, the effort could be justified by three reasons: (i) the obtained clouds could be used to quickly project the features also on LiDAR clouds, (ii) through only one cloud it is possible to project the segmentation to hundredsthousands of images and (iii) both could be used also as inputs of point-based networks.

Once the procedure will be performed on all the proposed buildings, the initial number of the labelled images in the dataset will be around 5000-7000 images. Although the many images are just enough for the initial tuning of the network and the size of the dataset will be probably not 
enough to train from scratch a network for a complex task such as semantic segmentation. In addition, to increase the number of the study case, two methods can be used to face this problem: (i) data augmentation, that allows increasing the number of the image just mirroring, cutting and filtering the images, and (ii) synthetic data generation, that allows to automatically create new data starting from a data source.
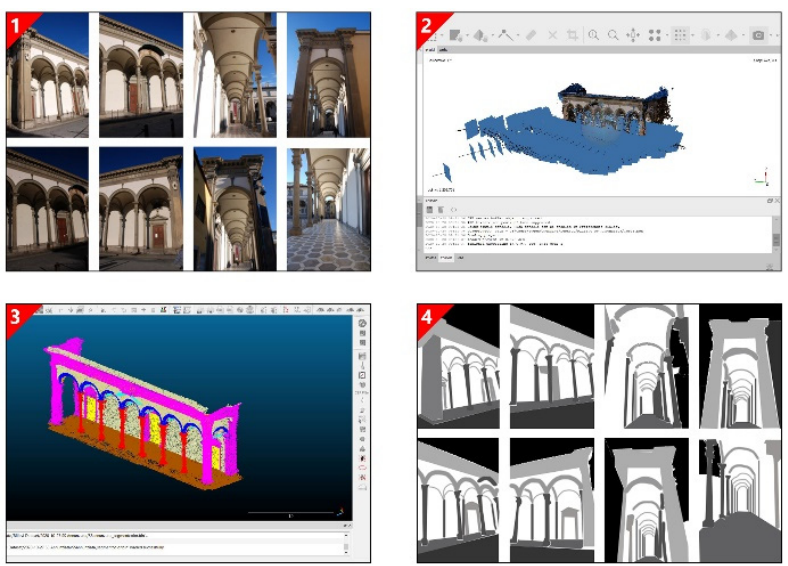

Figure 6: Four steps for dataset creation.

\section{Semantic segmentation methods}

Once the dataset will be created, the research will focus on the implementation and testing of various existing neural network architectures for image semantic segmentation on the new data. Numerous algorithms have been developed in the literature for this task, like region-growing (Nock \& Nielsen, 2004), K-means clustering (Dhanachandra, Manglem, \& Chanu, 2015), sparsity-based methods (Minaee \& Wang, 2019) and others. Over the last past few years deep learning networks, usually Convolutional Neural Networks (CNNs), have reached remarkable performance, surpassing other approaches by a large margin in terms of accuracy and efficiency (Garcia-Garcia et al., 2018).

The task of semantic segmentation is the natural extension of simpler problems: at first classification, which consists of making a prediction of a whole input, and then localization or detection, which regard the spatial location of the objects. The next step of semantic segmentation is to make a dense prediction inferring labels for every pixel. For this reason, common networks approach for classification are often used as building blocks for many semantic segmentation architectures, like AlexNet (Krizhevsky, Sutskever \& Hinton, 2012), VGG (Simonyan \& Zisserman, 2014), GoogleNet (Szegedy et al., 2015), ResNet (He, Zhang, Ren, \& Sun, 2016).

Currently, the most successful state-of-art deep learning techniques stem from a common forerunner: the Fully Convolution Network (FCN) (Long, Shelhamer \& Darrell, 2015). They transform the existing and well-known classification models into FCN replacing the fully connected layers with convolutional ones to output spatial maps with per-pixel labelling instead of classification scores. Despite its popularity and flexibility, FCN has some limitations. It is not fast enough, it does not take into account useful global context information and it is not well suited for unstructured data. To address these problems other methods and architecture have been proposed.
Among Fully Convolution-based methods, ParseNet (Liu, Rabinovich, \& Berg, 2015) adds global context by using the average feature for a layer to augment the feature at each location. Some popular deep models are based on encoder-decoder architecture. Two popular works are SegNet (Badrinarayanan, Kendall, \& Cipolla, 2015) and U-Net (Ronnenberg, Fisher \& Brox, 2015). SegNet is composed by a set of upsampling and convolutional layers which are at last followed by a softmax classifier to predict pixel-wise labels. U-Net was initially proposed for biomedical image and then used also for aerial images. It consists of a contracting path (downsampling) that captures context and a symmetrical expanding path (upsampling) that enables precise localization. Dilated or "atrous" convolution-based methods allow efficient dense feature extraction on any resolution. The most important works include DeepLab family (Chen, Papandreou, Kokkinos, Murphy, \& Yuille, 2017), Multi-scale Context Aggregation (Yu \& Koltun, 2015) and ENet (Paszke, Chaurasia, Kim, \& Culurciello, 2015). Recently also RNNs based models were proposed. Using RNNs, pixels may be linked together and processed sequentially to model global contexts and improve semantic segmentation. Two important works that leverage this architecture are ReSeg (Visin et al., 2016), based on the classification network ResNet, and LSTM-CF (Li, et al., 2016), which use two different data sources, RGB and depth.

Between the most popular state-of-the-art techniques the research will be focus on the implementations of two networks: (i) U-Net and (ii) DeepLabv3+. The choice of these architectures is motivated by their remarkable results on different data sources and by their popularity, which makes documentations and shared implementations easily available. In a first step, the dataset will be split in a training and a validation set. Secondly, according with the training and validation results, the network will be improved tuning the hyperparameters, trying to prevent overfitting or underfitting, and possibly changing some building blocks of the network to make it fit with the new data. Depending on the obtained results, other networks may be tested.

Training a deep neural network from scratch is often unfeasible for various reasons: a dataset of sufficient size is required and reaching convergence can take too long for the initial tuning of a network. For these reasons two techniques will be used to test the performance on the new data: (i) transfer learning and (ii) data augmentation.

Transfer learning is a technique that allows to grab a model trained on a certain task and dataset, and employ it on a different task. As a consequence of such re-use of the original network, the learning procedure for the new one starts with pre-trained weights instead of randomly initialized ones. Fine-tuning the weights of a pre-trained network by continuing with the training process is one of the major transfer learning scenarios. In the context of semantic segmentation, the difficult of gathering and creating per-pixel labelled datasets that make their scale not large and the learning procedure from scratch difficult, enhances transfer learning a standard procedure. The most popular and largest dataset for semantic segmentation is ImageNet, and due to its size and completeness it is often use to pre-train new networks.

Data augmentation is a common technique used for training machine learning models and consists of applying a set of transformations in the training data such as 
translation, rotation, warping, mirroring, scaling, crops, colour shifts etc. The aim of these transformations is to increase the number of the images and to create a larger dataset. Thanks to augmentation, which is especially helpful when the available dataset is small, it is possible to partially prevent overfitting, increase generalization capabilities, regularize the model, balance the classes, and speed up the convergence. For instance, augmenting a dataset of 1000 images with four rotations, four new scales, and four gamma variations, it is possible to generate a new dataset of 13000 training images.

\section{Conclusions}

This paper has shown the motivations and purposes of my $\mathrm{PhD}$ research, focused on the problem of 3D semantic segmentation of heritage scenarios. Starting from a multi- view approach up to point-based methods, the aim of this research is to test existing deep learning algorithms on heritage survey data. Actually, the main goals are two. First, the creation of a dedicated dataset for image semantic segmentation of heritage buildings with a semiautomatic approach. Second, the implementation of existing network architecture and the testing on the new data source. Currently a semi-automatic procedure for the creation of the dataset was created and based on next test, it will be improved. The future goals of the research are to integrate the new dataset with the existing ones, creating a benchmark with more generalization capabilities based both on images and points, and the exploration and development of point-image based networks that could increase the overall performance on heritage scenarios.

\section{References}

Azhar, S. (2011). Building Information Modeling (BIM): Trends, Benefits, Risks, and Challenges for the AEC Industry. Leadership and Management. Engineering, 11(3), 241-252. https://doi.org/10.1061/(ASCE)LM.1943-5630.0000127.

Azhar, S., Khalfan, M., \& Maqsood, T. (2012). Building information modelling (BIM): now and beyond. Australasian Journal of Construction Economics and Building, 12(4), 15-28. https://doi.org/10.5130/AJCEB.v12i4.3032.

Badrinarayanan,V., Kendall, A., \& Cipolla, R. (2015). Segnet: a deep convolutionalencoder-decoder architecture for scene segmentation. IEEE Trans. PatternAnal. Mach. Intell., $39 \quad$ (12), 2481-2495. https://doi.org/10.1109/TPAMI.2016.2644615

Boulch, A., Le Saux, B., \& Audebert, N. (2017). Unstructured point cloud semantic labeling using deep segmentation networks. 3DOR. http://dx.doi.org/10.2312/3dor.20171047

Boulch, A., Guerry, J., Le Saux, B., \& Audebert, N. (2018). Snapnet: 3d point cloud semantic labeling with 2d deep segmentation networks. Computers \& Graphics, 71, 189-198. https://doi.org/10.1016/j.cag.2017.11.010

Chen, L. C., Papandreou, G., Kokkinos, I., Murphy, K., \& Yuille, A. L. (2017). Deeplab: Semantic image segmentation with deep convolutional nets, atrous convolution, and fully connected crfs. IEEE transactions on pattern analysis and machine intelligence, 40(4), pp. 834-848. arXiv:1606.00915

Choy, C., Gwak, J., \& Savarese, S. (2018). 4D spatio-temporal convnets: Minkowski convolutional neural networks. CVPR.

Dai, A., Chang, A. X., Savva, M., Halber, M., Funkhouser, T., \& Nießner, M. (2017). Scannet: Richly-annotated 3d reconstructions of indoor scenes. Proceedings of the IEEE Conference on Computer Vision and Pattern Recognition, pp. 5828-5839. arXiv:1702.04405

Dhanachandra, N., Manglem, K., \& Chanu, Y. J. (2015). Image segmentation using k-means clustering algorithm and subtractive clustering algorithm. Procedia Computer Science, 54, pp. 764-771. https://doi.org/10.1016/j.procs.2015.06.090

Dore, C., \& Murphy, M. (2017). Current state of the art of historical building information modelling. The International Archives of the Photogrammetry, Remote Sensing and Spatial Information Sciences, XLII-2/W5(5), $185-192$. https://doi.org/10.5194/isprsarchives-XLII-2-W5-185-2017.

Grilli, E., \& Remondino, F. (2019). Classification of 3D Digital Heritage. Remote Sensing, $11(7), 847$. https://doi.org/10.3390/rs11070847

Grilli, E., Menna, F., \& Remondino, F. (2017). A review of point cloud segmentation and classification algorithms. Int. Arch. Ph. Remote Sens. Spatial Inf. Sci., XLII-2/W3, 339-344. https://doi.org/10.5194/isprs-archives-XLII-2-W3-339-2017

Grussenmeyer, P., Landes, T., Voegtle, T., \& Ringle, K. (2008). Comparison Methods of Terrestrial Laser Scanning, Photogrammetry and Tacheometry Data for Recording of Cultural Heritage Buildings. International Archives of Photogrammetry, Remote Sensing and Spatial Information Sciences. 37.

Guo, Y., Wang, H., Hu, Q., Liu, H., Liu, L., \& Bennamoun, M. (2020). Deep Learning for 3D Point Clouds: A Survey. IEEE transactions on pattern analysis and machine intelligence. arXiv:1912.12033

Hackel, T., Savinov, N., Ladicky, L., Wegner, J., Schindler, K., \& Pollefeys, M. (2017). Semantic3d. net: a new large-scale point cloud classification benchmark. ISPRS Annals of Photogrammetry, Remote Sensing and Spatial Information Sciences, pp. 91-98. arXiv:1704.03847

He, K., Zhang, X., Ren, S., \& Sun, J. (2016). Deep residual learning for image recognition. Proceedings of the IEEE conference on computer vision and pattern recognition, 770-778. arXiv:1512.03385 
Heipke, C., \& Rottensteiner, F. (2020). Deep learning for geometric and semantic task in photogrammetry and remore sensing. Geo-spatial Information Science, 23(1), 10-19. https://doi.org/10.1080/10095020.2020.1718003

Hu, Q., Yang, B., Xie, L., Rosa, S., Guo, Y., Wang, Z., Trigoni, N., \& Markham, A. (2020). RandLA-Net: Efficient semantic segmentation of large-scale point clouds. CVPR. arXiv:1911.11236

Hua, B. S., Tran, M. K., \& Yeung, S. K. (2018). Pointwise convolutional neural networks. CVPR. arXiv:1712.05245

landola, F. N., Han, S., Moskewicz, M. W., Ashraf, K., Dally, W. J., \& Keutzer, K. (2016). SqueezeNet: Alexnet-level accuracy with 50x fewer parameters and < $0.5 \mathrm{MB}$ model size," ICLR. arXiv:1602.07360

Khalil, A., \& Stravoravdis, S. (2019). H-BIM and the domains of data investigations of heritage buildings current state of art. International Archives of the Photogrammetry, Remote Sensing \& Spatial Information Sciences, XLII-2/W11, 661-667. https://doi.org/10.5194/isprs-archives-XLII-2-W11-661-2019.

Krizhevsky, A., Sutskever, I., \& Hinton, G. E. (2012) ImageNet classification with deepconvolutional neural networks. Advances in Neural InformationProcessing Systems, 2012, pp. 1097-1105. https://doi.org/10.1145/3065386

Laing, R., Leon, M., Isaacs, J., \& Georgiev, D. (2015). Scan to BIM: the development of a clear workflow for the incorporation of point clouds within a BIM environment. WIT Transactions on The Built Environment, 149, 279-288. https://doi.org/10.2495/BIM150241. https://doi.org/10.2495/BIM150241

Llamas, J., M. Lerones, P., Medina, R., Zalama, E., \& Gómez-García-Bermejo, J. (2017). Classification of Architectural Heritage Images Using Deep Learning Techniques. Appl. Sci., 7, 992. https://doi.org/10.3390/APP7100992

Lawin, F. J., Danelljan, M., Tosteberg, P., Bhat, G., Khan, F. S., \& Felsberg, M. (2017). Deep projective 3D semantic segmentation. CAIP. arXiv:1705.03428

Li, Z., Gan, Y., Liang, X., Yu, Y., Cheng, H., \& Lin, L. (2016). LSTM-CF: Unifying Context Modeling and Fusion with LSTMs for RGB-D Scene Labeling. Springer International Publishing, Cham, pp. 541-557. arXiv:1604.05000

Liu, F., Li, S., Zhang, L., Zhou, C., Ye, R., Wang, Y., \& Lu, J. (2017). 3DCNN-DQN-RNN: A deep reinforcement learning framework for semantic parsing of large-scale 3D point clouds. ICCV. arXiv:1707.06783

Liu, W., Rabinovich, A., \& Berg, A. C. (2015). Parsenet: Looking Wider to See Better. arXiv:1506.04579.

Long, J., Shelhamer, E., \& Darrell, T. (2015). Fully convolutional networks for semantic segmentation. Proceedings of the IEEE conference on computer vision and pattern recognition, 3431-3440. arXiv:1411.4038

López, F.J., Lerones, P.M., Llamas, J., Gómez-García-Bermejo, J., \& Zalama, E. (2018). A Review of Heritage Building Information Modeling (H-BIM). Multimodal Technologies and Interaction, 2, 21. https://doi.org/ 10.3390/mti2020021.

Macher, H., Landes, T., \& Grussenmeyer, P. (2015). Point clouds segmentation as a base for as-built BIM creation. ISPRS Annals of the Photogrammetry, Remote Sensing and Spatial Information Sciences, Volume II-5/W3.

Matrone, F.; Grilli, E.; Martini, M.; Paolanti, M.; Pierdicca, R.; \& Remondino, F. (2020a). Comparing Machine and Deep Learning Methods for Large 3D Heritage Semantic Segmentation. ISPRS Int. J. Geo-Inf., 9, 535.

Matrone, F., Lingua, A., Pierdicca, R., Malinverni, E., Paolanti, M., Grilli, E., Remondino, F., Murtiyoso, A., \& Landes, T. (2020b). A benchmark for large-scale heritage point cloud semantic segmentation. ISPRS - International Archives of the Photogrammetry, Remote Sensing and Spatial Information Sciences. XLIII-B2. 1419-1426. https://doi.org/10.5194/isprs-archives-XLIII-B2-2020-1419-2020.

Maturana, D., \& Scherer, S. (2015). Voxnet: A 3d convolutional neural network for real-time object recognition. IEEE/RSJ International Conference on Intelligent Robots and Systems (IROS), pp. 922-928. https://doi.org/10.1109/IROS.2015.7353481

Meng, H. Y., Gao, L., Lai, Y., \& Manocha, D. (2018). Vv-net: Voxel vae net with group convolutions for point cloud segmentation. arXiv preprintarXiv:1811.04337.

Milioto, A., Vizzo, I., Behley, J., \& Stachniss, C. (2019). RangeNet++: Fast and accurate lidar semantic segmentation. IROS.

Minaee, S., Boykov, Y., Porikli, F., Plaza, A.J., Kehtarnavaz, N., \& Terzopoulos, D. (2020). Image Segmentation Using Deep Learning: A Survey. ArXiv, abs/2001.05566.

Minaee S., \& Wang, Y. (2019). An admm approach to masked signal decomposition using subspace representation. IEEE Transactions on Image Processing, 28, no. 7, pp. 3192-3204. arXiv:1704.07711v2

Murphy, M., Mcgovern, E., \& Pavia, S. (2009). Historic building information modelling (HBIM). Structural Survey, 27(4), 311-327. https://doi.org/10.1108/02630800910985108.

Nguyen, A., \& Le, B. (2013). 3D point cloud segmentation: A survey. 6th IEEE conference on robotics, automation and mechatronics(RAM), 225-230. https://doi.org/10.1109/RAM.2013.6758588

Nock, R., \& Nielsen, F. (2004). Statistical region merging. IEEE Transactions on pattern analysis and machine intelligence, 26(11), pp. 1452-1458. https://doi.org/10.1109/TPAMI.2004.110 
Oreni, D. (2013). From 3D content models to H-BIM for conservation and management of built heritage. Computational science and its applications. ICCSA 2013. lecture notes in computer science, 7974 . https://doi.org/10.1007/978-3642-39649

Paszke, A., Chaurasia, A., Kim, S., \& Culurciello, E. (2015). Enet: A Deep Neural Network Architecture for Real-Time Semantic Segmentation. arXiv:1606.02147.

Qi, C. R., Su, H. Mo, K., \& Guibas, L. J. (2017). PointNet: Deep learning on point sets for 3D classification and segmentation. CVPR. arXiv:1612.00593

Qi, C. R., Yi, L., Su, H., \& Guibas, L. J. (2017). PointNet++: Deep hierarchical feature learning on point sets in a metric space. NeurlPS. arXiv:1706.02413

Riegler, G., Osman Ulusoy, A., \& Geiger, A. (2017). Octnet: Learning deep 3d representations at high resolutions. Proceedings of the IEEE Conference on Computer Vision and Pattern Recognition, pp. 3577-3586.

Rocha, G., Mateus, L., Fernández, J., \& Ferreira, V. (2020). A Scan-to-BIM Methodology Applied to Heritage Buildings. Heritage, 3(1), 47-67. https://doi.org/10.3390/heritage3010004.

Rodriguez, C., Reinoso, J. F., Rivas-Lopez, E., Gomez-Blanco, A., Ariza-Lopez F., \& Ariza, I. (2016). From point cloud to BIM : an integrated workflow for documentation, research and modelling of architectural heritage. Survey Review, 50(360), 1-20. https://doi.org/10.1080/00396265.2016.1259719.

Ronneberger, O., Fischer, P., \& Brox, T. (2015). U-Net: convolutional networks forbiomedical image segmentation. Medical Image Computing andComputer-Assisted Intervention (MICCAl), 9351 of LNCS, pp. 234-241.

Rosu, R. A., Schutt, P., Quenzel, J., \& Behnke, S. (2019). LatticeNet: Fast point cloud segmentation using permutohedral lattices. arXiv preprint arXiv:1912.05905. arXiv:1409.1556

Simonyan, K., \& Zisserman, A. (2014). Very Deep Convolutional Networks forLarge-Scale Image Recognition. arXiv:1409.1556.

Su, H., Maji, S., Kalogerakis, E., \& Learned-Miller, E. (2015). Multi-viewconvolutional neural networks for 3d shape recognition. Proceedings on the IEEE international conference on computer vision, 945-953.

Su, H., Jampani, V., Sun, D., Maji, S., Kalogerakis, E., Yang, M. H., \& Kautz, J. (2018). SplatNet: Sparse lattice networks for point cloud processing. CVPR. arXiv:1802.08275

Szegedy, C., Liu, W., Jia, Y., Sermanet, P., Reed, S., Anguelov, D., Erhan, D., Vanhoucke, V., \& Rabinovich, A. (2015). Going deeper with convolutions, Proceedings of the IEEE Conference on Computer Vision and Pattern Recognition 1-9. arXiv:1409.4842

Tang, P., Huber, D., Akinci, B., Lipman, R., \& Lytle, A. (2010). Automatic reconstruction of as-built building information models from laserscanned point clouds: A review of related techniques. Automation in construction, 19(7), 829-843.

Tchapmi, L., Choy, C., Armeni, I., Gwak, J., \& Savarese, S. (2017). Segcloud: Semantic segmentation of 3d point clouds. 2017 International Conference on 3D Vision (3DV), pp. 537-547, IEEE. arXiv:1710.07563

Ulku, I., \& Akagunduz, E. (2019). A Survey on Deep Learning-based Architectures for Semantic Segmentation on 2D images. Computer Vision and Pattern Recognition. arXiv:1912.10230

Varney, N., Asari, V. K., \& Graehling, Q. (2020). Dales: A large-scale aerial lidar data set for semantic segmentation," arXiv preprintarXiv:2004.11985.

Volk, R., Stengel, J., \& Schultmann, F. (2014). Building Information Modelling (BIM) for existing buildings - Literature review and future needs. Automation in Construction. Elsevier B.V., 38, 109-127. https://doi.org/10.1016/j.autcon.2013.10.023.

Vosselman, G., Coenen, M., \& Rottensteiner, F. (2017). Contextual segmentbased classification of airborne laser scanner data. ISPRS journal of photogrammetry and remote sensing, $128,354-371$. https://doi.org/10.1016/j.isprsjprs.2017.03.010

Weinmann, M., Jutzi, B., Hinz, S., \& Mallet, C. (2015). Semantic point cloud interpretation based on optimal neighborhoods, relevant features and efficient classifiers. ISPRS Journal of Photogrammetry and Remote Sensing, 105, $286-304$.

Weinmann, M., Schmidt, A., Mallet, C., Hinz, S., Rottensteiner, F., \& Jutzi, B. (2015). Contextual classification of point cloud data by exploiting individual 3d neigbourhoods. ISPRS Annals of the Photogrammetry, Remote Sensing and Spatial Information Sciences II-3, 4(2), 271-278. https://doi.org/10.5194/isprsannals-II-3-W4-271-2015

Wang Y., Sun, Y., Liu, Z., Sarma, S. E., Bronstein, M. M., \& Solomon, J. M. (2018). Dynamic graph cnn for learning on point clouds. arXivpreprint arXiv:1801.07829.

Wang, S., Suo, S., Ma, W. C., Pokrovsky, A., \& Urtasun, R. (2018). Deep parametric continuous convolutional neural networks. CVPR. arXiv:2101.06742

Xie, Y., Tian, J. \& Zhu, X. (2020). Linking Points with Labels in 3D: A Review of Point Cloud Semantic Segmentation. IEEE Geoscience and Remote Sensing Magazine. https://doi.org/10.1109/MGRS.2019.2937630. 
Yu, H., Tan, Y., Wang, L., Yaonan, S., Sun, W., Mi, \& Yandong, M. T. (2018). Methods and Datasets on Semantic Segmentation: A review. Neurocomputing, 304. https://doi.org/10.1016/j.neucom.2018.03.037.

Zhang, J., Zhao, X., Chen, Z., \& Lu, Z. (2019). A Review of Deep Learning-Based Semantic Segmentation for Point Cloud. IEEE Access, 7, pp. 179118-179133. doi: 10.1109/ACCESS.2019.2958671.

Zhu, X., Tuia, D., Mou, T., Xia, G. S., Zhang, L., Xu, F., \& Fraundorfer, F. (2017). Deep learning in remote sensing: A comprehensive review and list of resources. IEEE Geoscience and Remote Sensing Magazine, 5(4), 8-12 


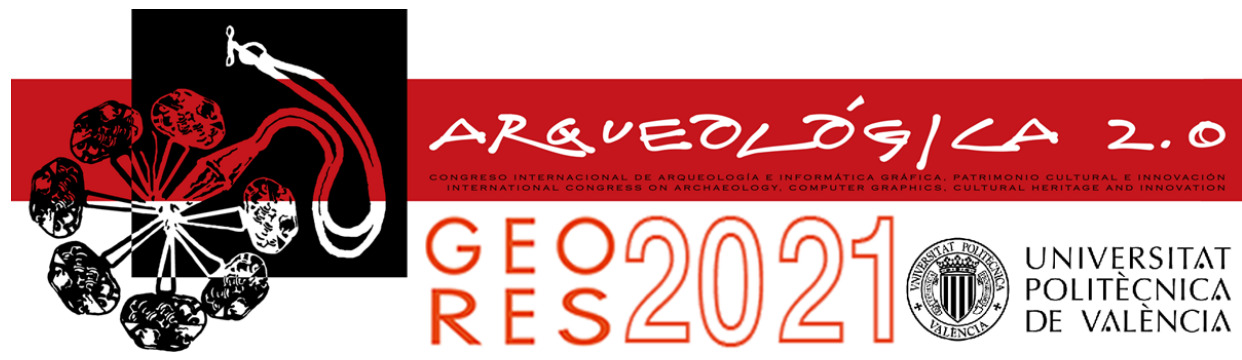

Proceedings of the joint international event $9^{\text {th }}$ ARQUEOLÓGICA

$2.0 \& 3^{\text {rd }}$ GEORES

Valencia (Spain).

26-28 April 2021

\title{
RESTORATION, REPRESENTATION, PROJECT: A DIALOGUE-LIKE APPROACH FOR THE COMPSA PALIMPSEST
}

\author{
Bianca Gioia Marino*, Raffaele Catuogno, Rossella Marena \\ DiARC Department of Architecture, University of Studies Federico II, Via Toledo 402, 80134 Naples, Italy. bianca.marino@unina.it; \\ raffaele.catuogno@unina.it; rossellamarena@gmail.com
}

\begin{abstract}
:
Compsa is the name of the ancient town of Conza della Campania, situated on a hill in the oriental part of Irpinia, Italy. The hill dominates the valley of the Ofanto River, on the border between Campania and Basilicata, in a high seismic risk area. After the 1980 earthquake, which almost completely destroyed the town, it was re-built in a new site in the valley. The ruins of the old town have been protected since 2004 by the establishment of the Archaeological and Historical Park, which has left intact the surviving urban fabric. The destruction of Conza Cathedral has brought out the remains of the Samnite, Roman and medieval Compsa. The discovered structures, as documented by important archaeological studies, testify to one of the most stratified settlements in Irpinia. An extensive study over the entire urban area founded on the dialogue between the examples of the restoration project and the potential to represent it through innovative, instrumental researchprojects has revealed not only unedited historical data which have enriched our knowledge as regards the site, but also significant traces to elaborate on the proposed project so as to re-evaluate such a unique archaeological park. The extreme complexity of the theme, which involves the urban and panoramic dimensions as well as the architectural one includes also the need for the re-evaluation of the archaeological park and the extraordinary co-presence of ancient evidence where the remains of the town are made up of rubble.
\end{abstract}

Keywords: Compsa, archaeological park, restoration, cultural heritage, documentation

\section{Registering the architectural reality of the "unexpected"}

In the understanding of reality, Salvatore Veca refers to the "unexpected" as an element and a willingness to accept dimensions without dividing the field of knowledge. What the scholar then emphasises with regard to the horizons of reading things seems to be the set of 'equipment' of method and approach with which the project to reuse and preserve an urban area destroyed by the earthquake was approached.

The case in question is the present-day Historical Archaeological Park in Compsa, the name of the ancient site of Conza della Campania, in Irpinia, Italy, situated on a hill that dominates the valley of the Ofanto River, in an extraordinary high-ground position (Fig. 1). After it had been almost completely destroyed following the earthquake and with the re-building/building of the new site in the valley, the ruins of the old town have been looked after through the setting-up of the Archaeological Park in 2004. Nevertheless, at the same time, the urban texture as well as the surviving buildings have been left intact. By demolishing and evacuating the parts which had collapsed, the remains of Compsa came to the fore. This was the ancient Sannite and Roman town which through the centuries had stratified the place until the destructive, catastrophic 1980 event. This study project, which involved the restoration disciplines along with the possibility for the development of a degree thesis, has experimented with an approach which aimed at cultivating, as regards the site, "una certa umiltà nell'ascolto [...] un buon grado di attenzione nei confronti di altre fisionomie, di altre voci, di altre grammatiche» (Veca, 2017), while trying to gather together all those things that the site could suggest on searching for solutions regarding its reasons for existing and being. Thus this was a reference point for the inhabitants, but not only, whose aim was to re-evaluate the archaeological park with its problems and its critical fruition elements. Therefore this was a multi-level research-project, which involved on an archaeological scale, urban lacunae and contextual and natural particularities which, even today, interact with the dimension of the ruins which are found throughout the entire area. The bottom line choice was thus a reception one which, while it never lost sight of the urban background which was still visible and could be traced back to the remains of an interrupted daily history, nonetheless it was sensitive to the archaeological strata and the material entities of the dismantled forms of architecture as well as to what had survived. With the aim of re-evaluating the Archaeological Park and following on from the methodology of the restoration project, a conscious and representative plan was set out. However 
this was not only limited to the archaeological evidence, and this is thanks to the campaigns which have been carried out and those which are still up and running.

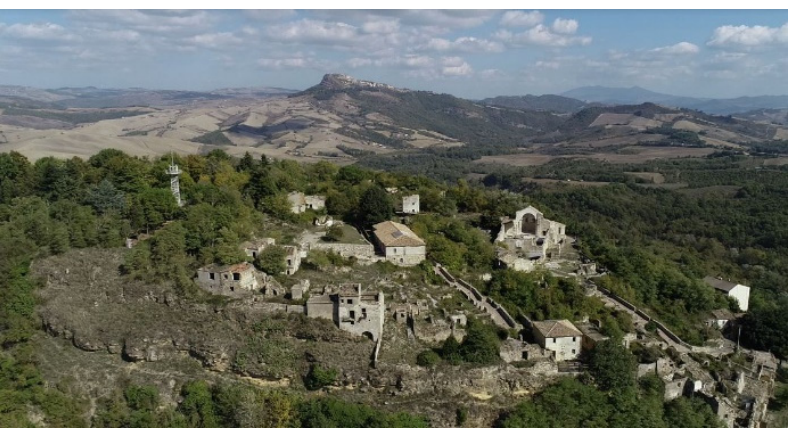

Figure 1: Aerial view of the Compsa Hill, video photogram by the Architect Marco Facchini, October 2019.

\section{The discovery of Compsa: the arrangement and the progression of the archaeological remains}

Immediately after the earthquake, the archaeological exploration carried out by Werner Johannowsky, led to one of the major research projects in Irpinia. Its aim was to be of immense relevance regarding the knowledge of the Sannite, Roman and medieval town (Johannowsky, 1982; Rea, 1982). A profitable season of studies started, even before, in the '70s, by G. C. Pescatori, G. Bailo Modesti and O. Onorato, whose studies set the basis for the knowledge of the archaic culture of the valley of Ofanto (Colucci Pescatori, 1988).

The area of the ancient city shows how carefully it had been chosen. The site occupies, indeed, a group of two hills, from which the entire valley is dominated. At least initially the coming of Romanization took over the preexisting Sannite structure where the original population had remained. This area was endowed with its own political and religious order, as well as its own usages and customs. Also the urban arrangement is a witness to such a stratification. It became a politically functioning administrative centre in the ancient Conza «coesistono, giustapposte al vecchio assetto topografico e sociale che ha resistito fino ai processi di municipalizzazione posteriori alla fine della guerra sociale e fino al I secolo, tutti quegli edifici pubblici che rappresentano le funzionalità della città romana: il foro, l'anfiteatro e le terme» (Di Giovanni, 2015).

In the urban texture, which even up to 1980 seemed to be based on the Roman one, it is possible to identify a plot of various axes which define the insulae. At least three decumans can be hypothesized which cross the city from east to west and two cardines, along the lines indicating the maximum incline of the hill (Fig. 2). The urban plan, which follows a terraced set of rules, adapts itself to the slope in the hill, with modest gains in height towards the south-east. On the plateau of the 'arce', the highest part of the hill, there is the amphitheatre, on the median terrace instead, there is the forum, while the thermal baths are in the lower part.

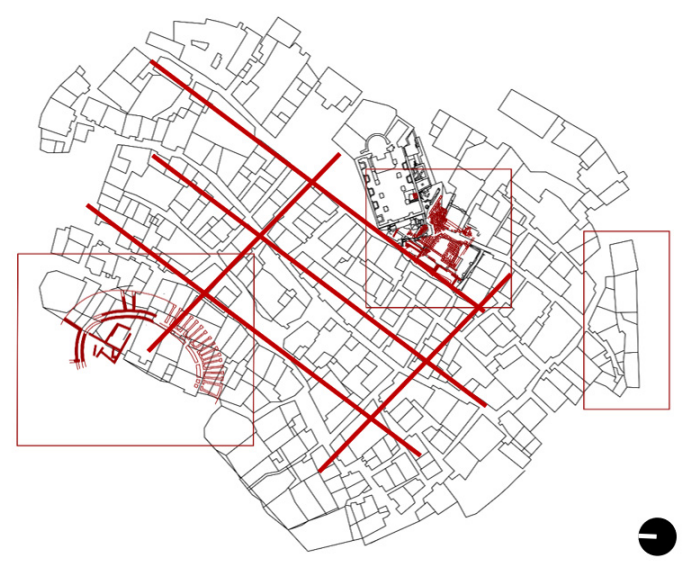

Figure 2: Conza della Campania (Compsa), plan of the modern city.

\subsection{Reading the historical layers. The archaeological flowerings in the urban context}

On the structure of the Thermal Baths, situated at the southern end of the park, is located one of the few building complexes which have survived the 1980 earthquake (Fig. 3). This one, in particular, presents a complex building stratification which encompasses internally mural structures, with a opus caementicium nucleus and an external-facing in opus latericium belonging to a thermal building which can be dated back to the $2^{\text {nd }}$ century A.D. The sac foundations of this walled structure seem to indicate the probable course of the city's mural defences which was firstly Irpinian and then Roman. They were probably demolished in the late-medieval period (Johannowsky, 1994). The facade is marked by successive adaptations as well as elements belonging to ancient manufactures (Fig. 4).

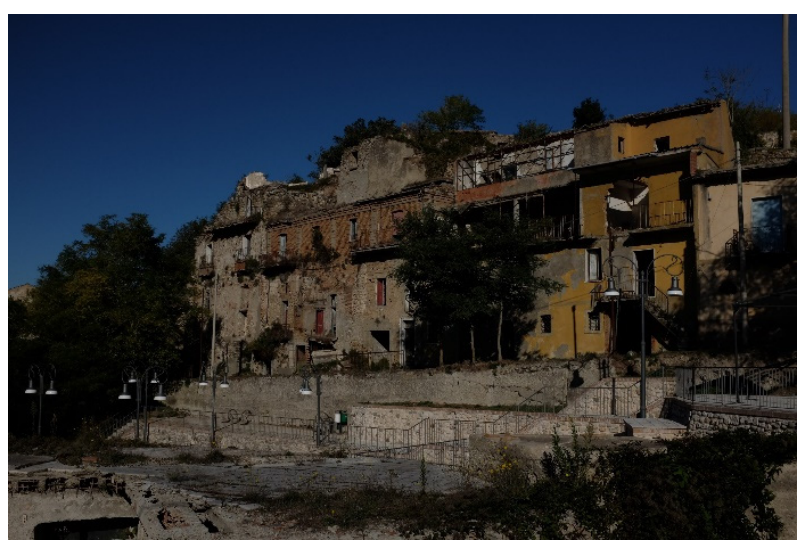

Figure 3: View of the building complex of the Thermal Baths ( $R$. Marena, October 2019).

The area corresponding to the Roman Forum, before 1980 , was completely taken up by private houses and its presence and positioning had already been set apart in the 1930s by Italo Sgobbo. A part of the podium of a temple, belonging to the northern side of the forum, and part of the calcareous canal set in front of it were, in fact, visible in a basement in a modern building. Besides part of the quadrangular slab pavement of the forum area in its median part, still in situ, was seen and used as a roadbed (Sgobbo, 1938). From the end of the ' 90 's systematic excavations, carried out by the Archaeological 
Superintendent of Salerno and Avellino, have investigated in various phases, the remaining part of the forum, giving back completely, at least for what still remains of it, the public monument in its planimetric development (Fig. 5).

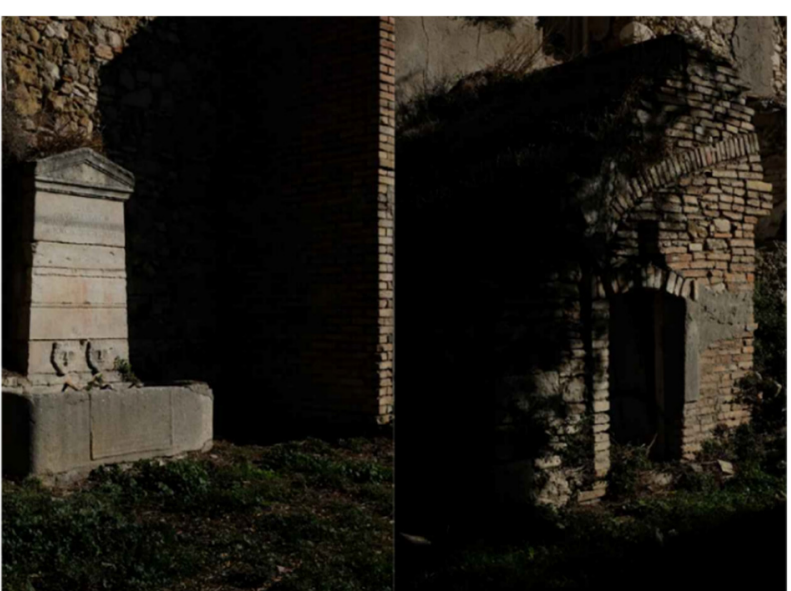

Figure 4: The Thermal Baths Complex. A particular of the stone facing and a detail of the sarcophagus in calcareous stone from the 4th century (R. Marena, October 2019).

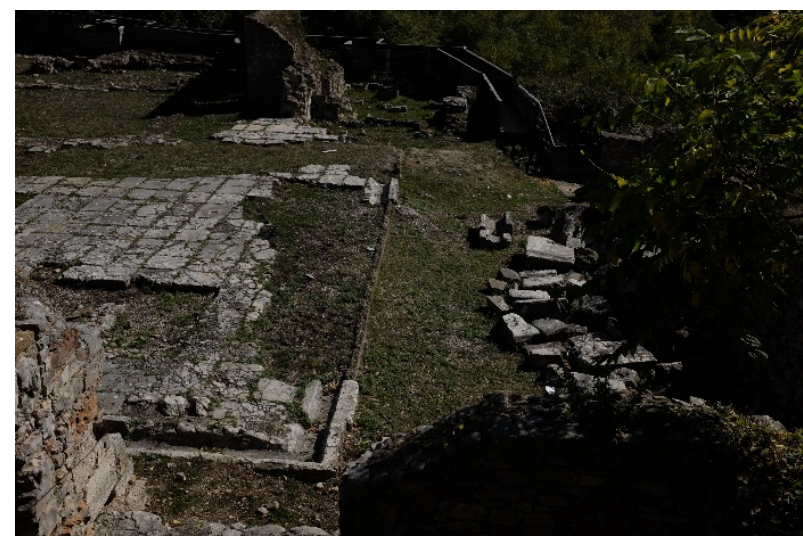

Figure 5: View of the Forum area (R. Marena, October 2019).

The cathedral was inserted in the Forum square from the Roman period, on a more elevated position with respect to the height of the ancient plan following an orientation that is different to it. The shots taken by drones have highlighted the wide rotation compared to the urban arrangement, placing itself outside the axis as regards the forum one and the rest of the installation which instead follows the orientation of the city (Fig. 6). It is not possible to date its foundation precisely. It definitely came after the Byzantine victory in 555 A.D. which led to a significant reorganization of the forum area and the re-use of a part of its structures as a cemetery. It was quoted for the first time in Concilium Romanum del 743. Many scholars are inclined to date the first cathedral to the 6 th or 7 th centuries.

Of the original structure, completely destroyed by the earthquake of 990 , some traces remain in the crypt. In its perimeter is preserved the layout of the right apse (Fig. 7 ), consisting of an irregular stone facing and an arch in opus vittatum formed by a succession of bricks and stones. Moreover, a frescoed, datable between the 12th and 13th centuries, is visible at its base. The covering of the crypt with cross vaults, uses supports obtained from the recovery of architectural elements of the previous construction. The interior is also characterized by the presence of classical elements of recovery such as bases and shafts of columns and epigraphs (Fig. 8).

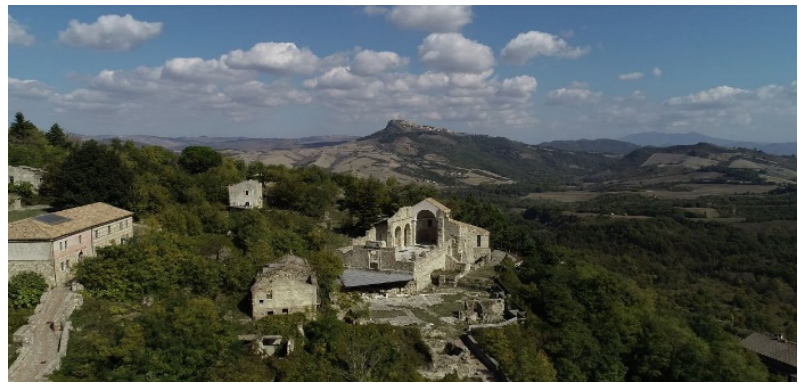

Figure 6: An aerial view of the forum area and the cathedral, photogram from a video by the Architect Marco Facchini, October 2019
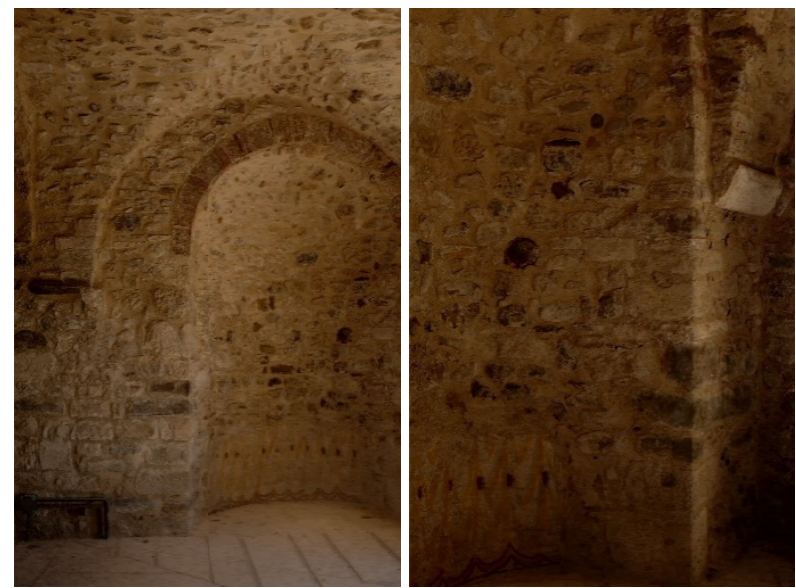

Figure 7: Crypt. The affrescoed at the base of the apse ( $R$. Marena, October 2019).

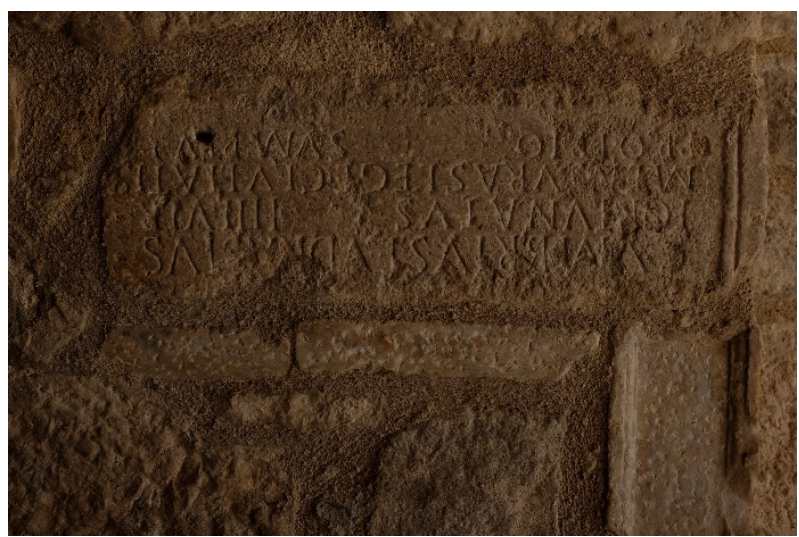

Figure 8: A particular of the epigraph found in the right-sided pillar of the arch of the crypt (R. Marena, October 2019).

The architectural layout of the cathedral, which is still visible, goes back to its last reconstruction in 1736 and, although it has inherited some features of medieval construction, is characterized by its recourse to an 18th century style, evident in the internal re-working and stucco-work in the central nave and in the new chapels in the side aisles (Fig. 9). The collapse caused by the 1980 earthquake have brought to light some pre-existing structures (in the south-west corner masonry structures from the Roman period), as well as the levels of the 
original floor and various tombstone-like elements sculpted in the $12^{\text {th }}$ century. A rich stratification, evidence of the continuous reconstructions on-site and the reuse of materials coming from the ancient constructions.

In the upper part of the town (Fig. 10), in the area used as a garden since the beginning of the 1900s, there was the Castle of the Gastaldi family and the Counts of Conza dating back to the $7^{\text {th }}$ century (Gargano, 1935; Acocella, 1927-1928). The remains, which were still visible in the 1950s, were completely demolished in 1957 to give way to the levelling work which was carried out, at that time, so that a football pitch could be built. In 1951, in the same area, during the building work on the water reservoir which was to be used by the town, further remains of an evidently medieval building were discovered and cuniculi and two underground roads, which probably led from the upper part of the castle to a building below, were also found.
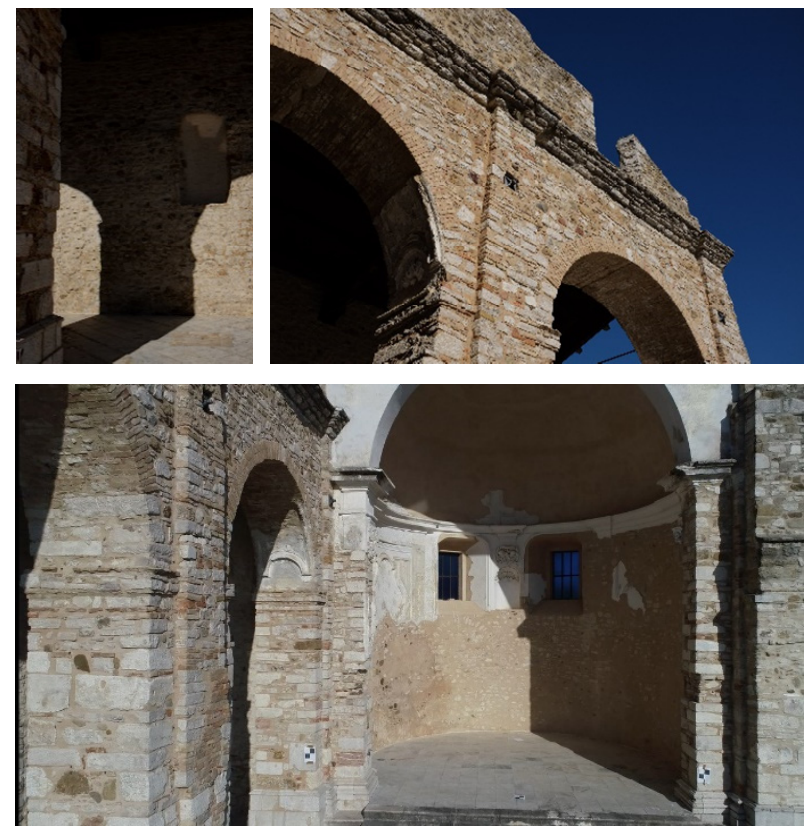

Figure 9: Internal views of the cathedral (R. Marena, October 2019).

Next to this area is the Compsa Amphitheatre, discovered only partially by an excavation campaign in 1997 . Situated next to the gardens, it is in a north-west south-east direction and dates back to between the $1^{\text {st }}$ century B.C. and the $1^{\text {st }}$ century A.D. In the eastern part of the excavation there emerged the wide hemicycle of the amphitheatre, limited behind by the first ring of the gallery of the lower ambulatory and covered by a barrel vault and some radial septa, probably the perimeter walls of the entrances to the bleachers, the vomitoria (Fig.11). The investigation, also, led to the discovery of layering of structures that can be dated back to between the late ancient period and the 17 th and $18^{\text {th }}$ centuries, and which are built directly on the trampling floor of the arena.

Currently, the ruins of the modern city, the archaeological evidence and the few restored buildings (for example the museum and seismological centre), constitute isolated segments in an urban continuum that today appears fragmented (Figs. 12 and 13). The area of the Historical Archaeological Park includes, indeed, the existence of numerous areas in which the excavations of the past have left in sight important archaeological complexes that coexist with the palimpsest of the earthquake (AA.VV. 1982; Mazzoleni, \& Sepe, 2005).
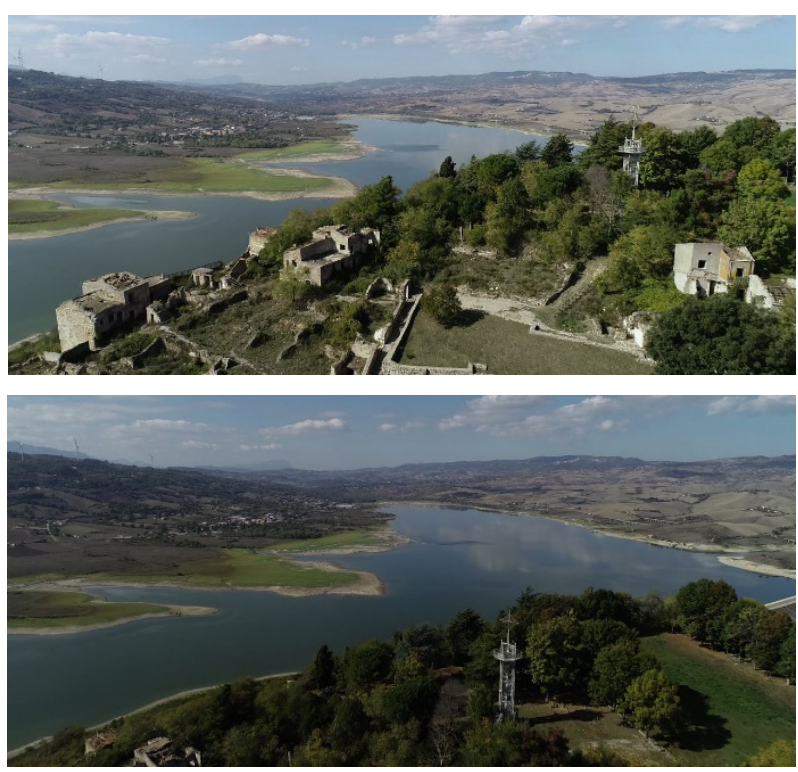

Figure 10: Panoramic views of the garden towards Lake Conza, photogram from a video by the Architect Marco Facchini, October 2019.

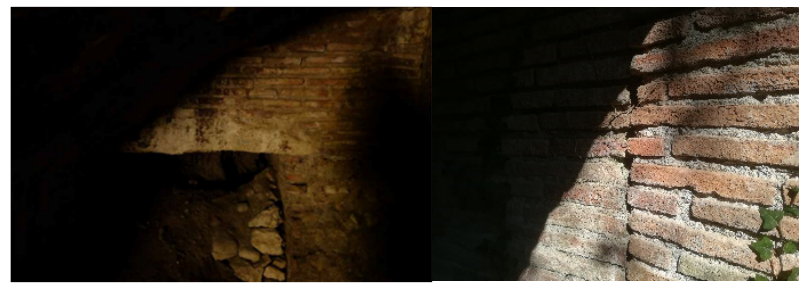

Figure 11: Lower ambulatory of the Amphitheatre. Internal views (R. Marena, October 2019).

\subsection{Continued acquisition of the data for a complex description of the artefact}

The state of the Park's documentation, where the operation was started, was lacking. The archaeological campaigns, over the years, had produced a valid collection of drawings, where only some of them had been digitally produced, but they concentrated on the individual areas of the excavations and on the main archaeological structures, an overall survey was missing.

Along with conducting planimetric surveys of the entire site, detailed forms of the survey were carried out on some technical reference units with the aim of reporting every relevant piece of information as regards the dimensional, material and typological characteristics, and even on the level of the conservation of the structures themselves. It was decided to use forms of technology that allowed us to give a precise and implementable datum when dealing with future projects which in turn could be used for the conservation and restoration projects (Marino et al., 2019; Chiabrando et al., 2019). The former operation sequences took advantage of the aerial photogrammetry and led to the integral survey of the Compsa Hill (Fig. 14 and 15) while the latter involved using, at the same time, the aerial photogrammetry and the Laser scanning 3D technology, and dealt with the area of the Forum and the cathedral (Fig. 16). 

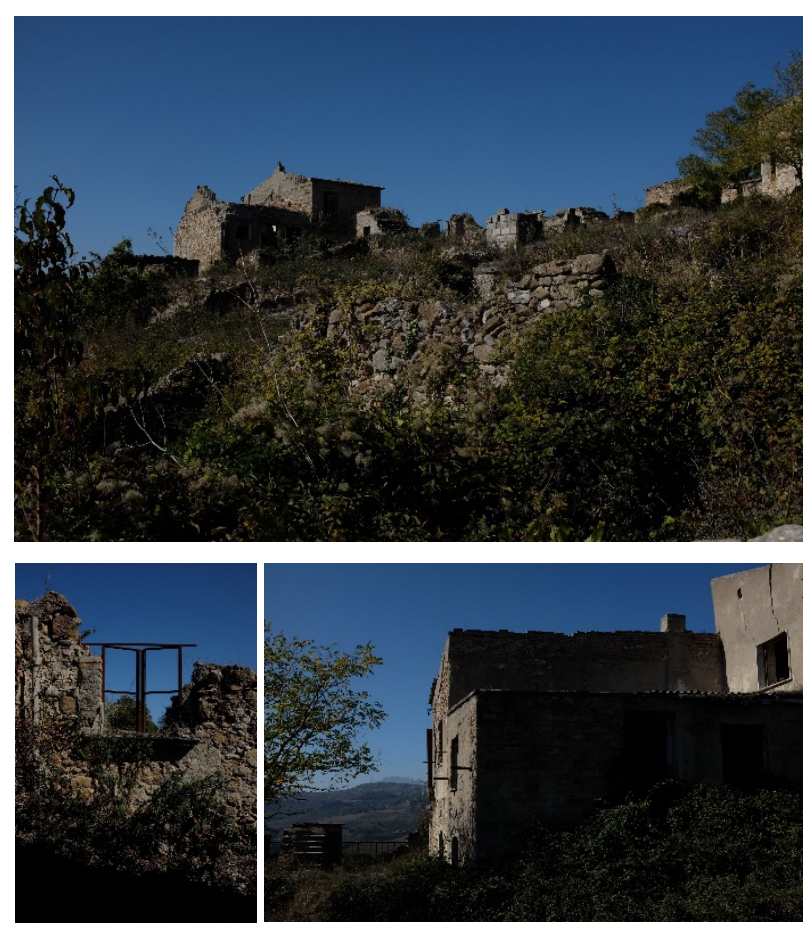

Figure 12: Views of the Manufacturer's house in via S. Michele and the remains of the buildings on the western side of the Buldo Mastroberti house (R. Marena, October 2019).
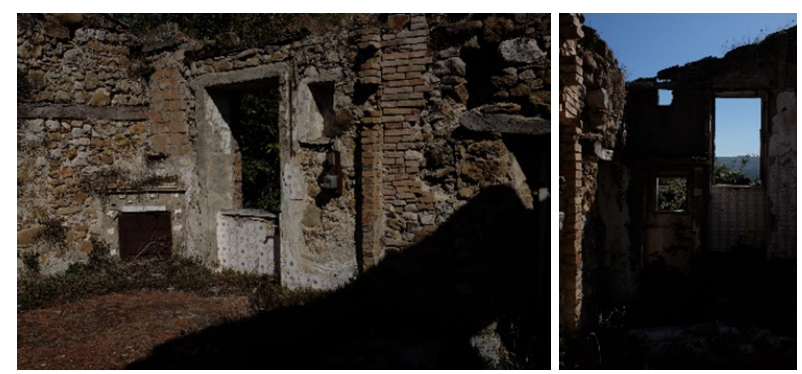

Figure 13: Internal views of the buildings which look out over the square of the Forum (R. Marena, October 2019).

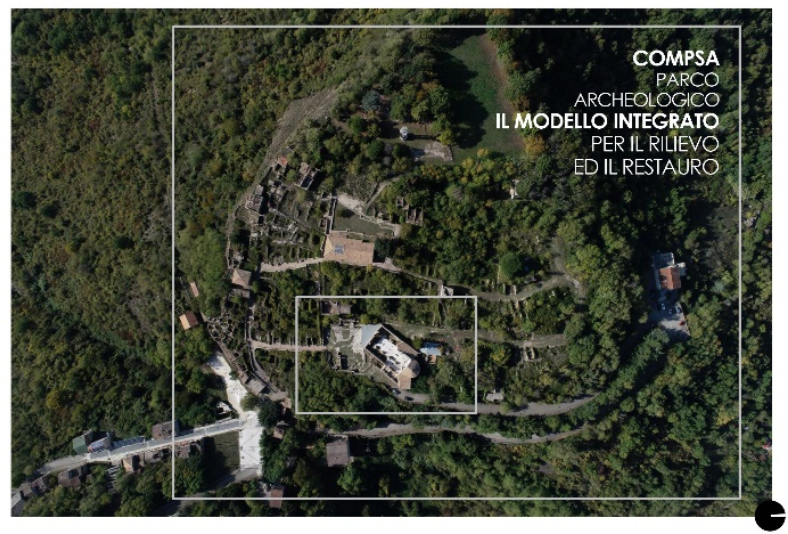

Figure 14: An aerial photo of Compsa Hill by the Architect Marco Facchini, October 2019.

Starting from the orthoprojections of the point clouds which were obtained, a map of the macro-areas relative to the materials and building techniques and the level of degradation associated with them was elaborated on. Besides, it was possible to pick out the articulated transformation of the artefact, which led to conspicuous material integrations (Fig. 17).
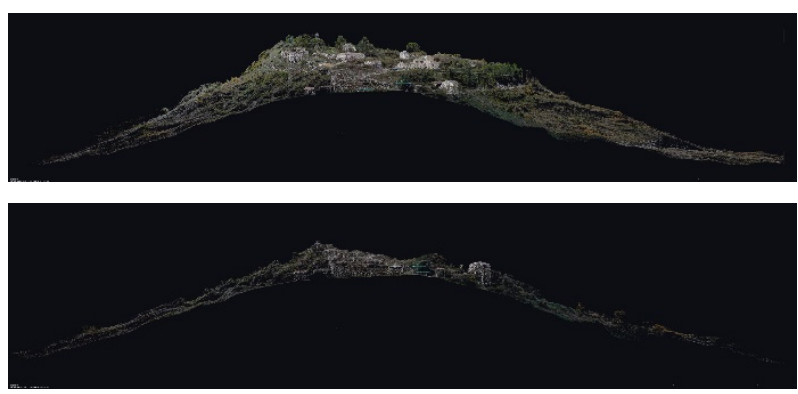

Figure 15: A visualization of the point clouds of Compsa Hill.
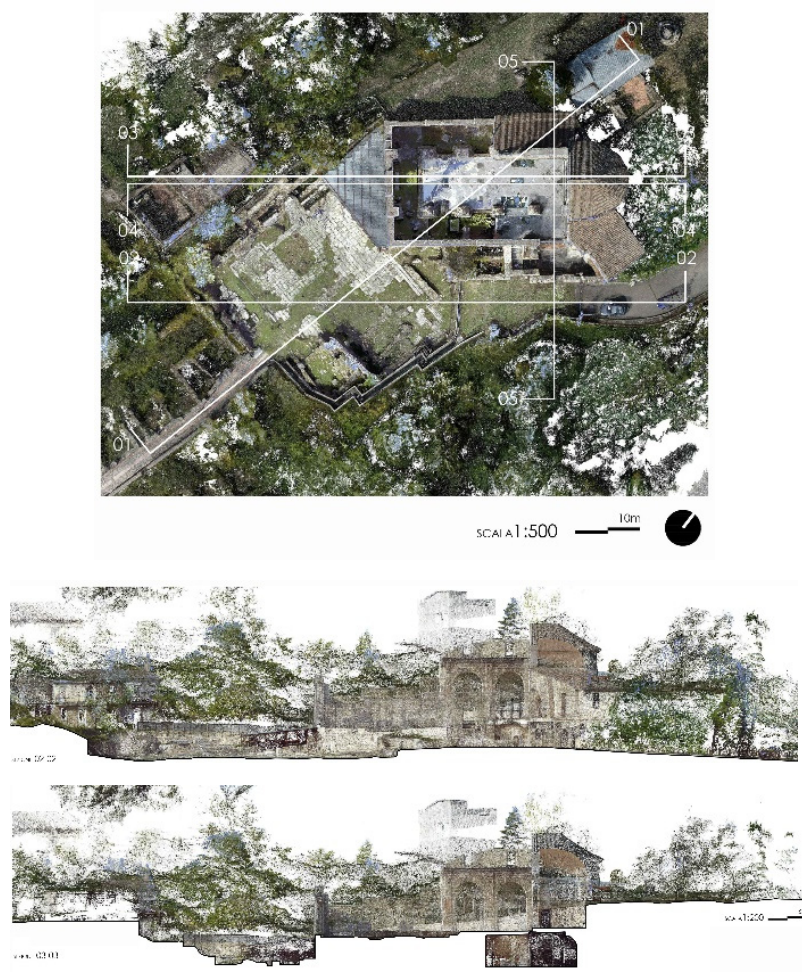

Figure 16: The final drawing of the survey operations carried out in the Historic Archaeological Park in Compsa, October 2019. Map and longitudinal sections along the area of the forum and the cathedral.
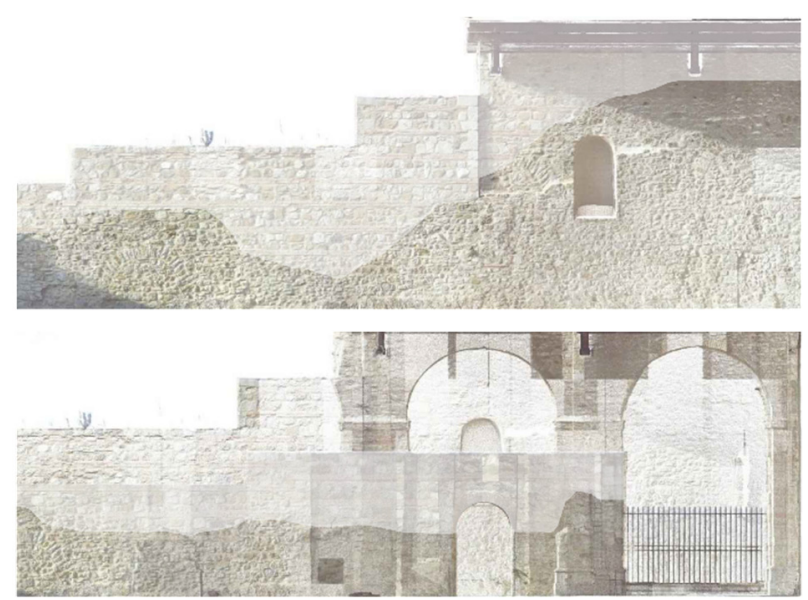

Figure 17: Orthophoto. Masonry details of the left-sided aisle of the cathedral. The re-building interventions are in white (SAABS, 2004-2006) 
The surfaces which were elaborated on, starting from the point clouds allowed us, indeed, to describe not only geometrically and dimensionally the surveyed elements, but also to describe in detail their material consistency. This made the stratifications legible, as well as the degradation of the materials and the lesions. This complied with the need to produce a support model for the restoration and conservation activities (Marino, 2017). This material allowed us to build up a data-base relative to the historical masonry typologies and the variants used during the restoration work which took place afterwards (Fig. 18).
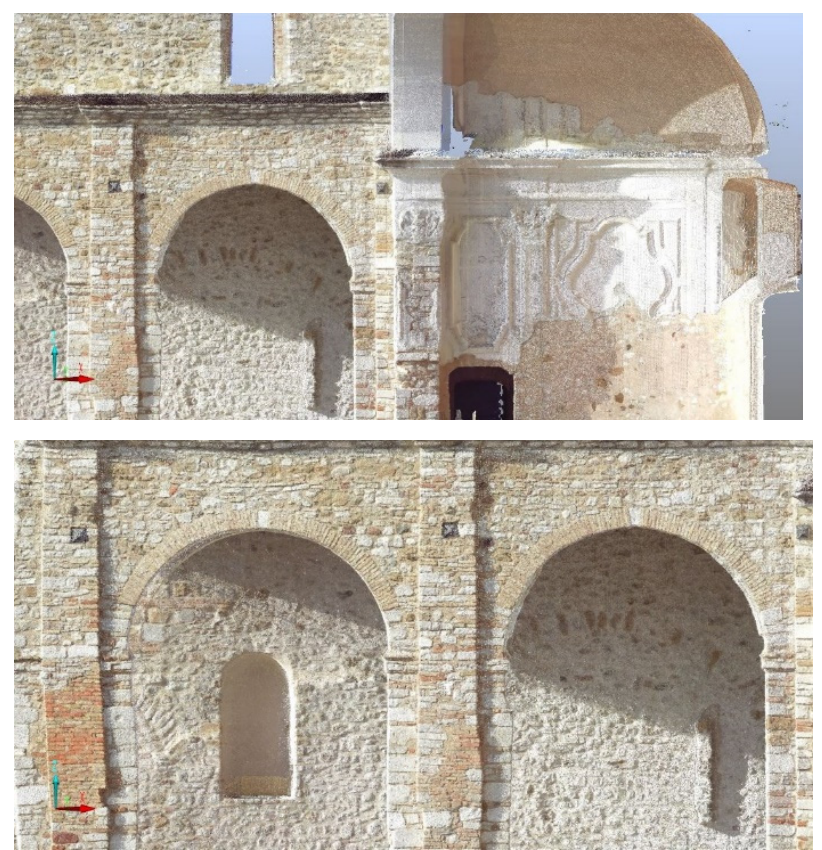

Figure 18: Masonry details of the cathedral. Orthoprojections of the surveyed point clouds.

The survey methodology adopted had double usefulness. On one hand, it allowed to obtain metric forms of survey and accurate graphic representations and on the other, it provided support for an integrated reading which attempted to link the interpretation of the evolutionary dynamics of the site to the material stratifications of the artefact and their level of conservation (Aveta, Marino, \& Amore, 2017).

\section{Instrumentation, data and representation}

The particular orography of the places led to the use of two survey techniques which helped give back the morphometric consistency of the archaeological area. The principal aim of the survey campaign was to build a model through which we could explore the morphology and the relationship between the parts, as well as draw up and elaborate on efficient representations to enrich both the technical and scientific documentation. From the acquisition work, those structure surveys which did not allow us to work in a safe way were excluded. The survey operations were carried out in two phases, the first in November 2018, with the survey of the whole hill and we used the photogrammetry, whereas the second took place in October 2019, and we used an integrated survey with the help of the photogrammetry and the laser scanning 3D technology. This involved the area which included the Forum and the Cathedral.

\subsection{Operative Methodology. Image-based and Range-based}

In the first survey campaign the acquisition through UAV (Unnamed Aerial Vehicle) was carried out. This involved aerial images which were both of a nadir type and various angle-shots of the entire archaeological complex. The resulting dataset was made up of 740 photograms which had been taken by a drone, a DJI Phantom 4 at a height of 95 metres with a $70 \%$ overlapping (overlap and sidelap) and we obtained orthoprojections with a GSD (ground sample distance) of $3.19 \mathrm{~cm} / \mathrm{px}$ (Fig. 19). and this was elaborated on with the help of an Agisoft Photoscan photogrammetric modelling software system. This process allowed us to re-build the current state by creating a three-dimensional model, which was used as a research instrument to create orthographic planes and sections of the site.

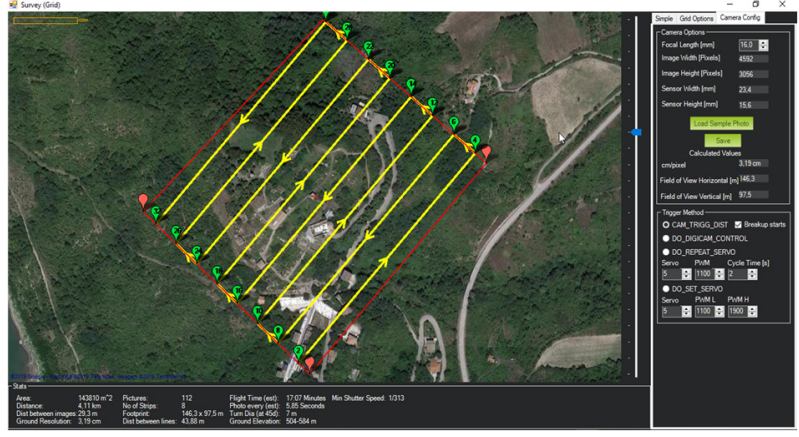

Figure 19: Preliminary flight planning. November 2018.

In the second survey campaign, we continued with the integrated survey of the area which includes the Forum and the Cathedral through the use of the UAV and a scanner laser. The dataset was made up of 366 photograms which were taken by the drone at a height of 33.5 metres with a $70 \%$ overlapping and the orthoprojections were obtained with a $0.85 \mathrm{~cm} / \mathrm{px}$ GSD (Fig. 20).

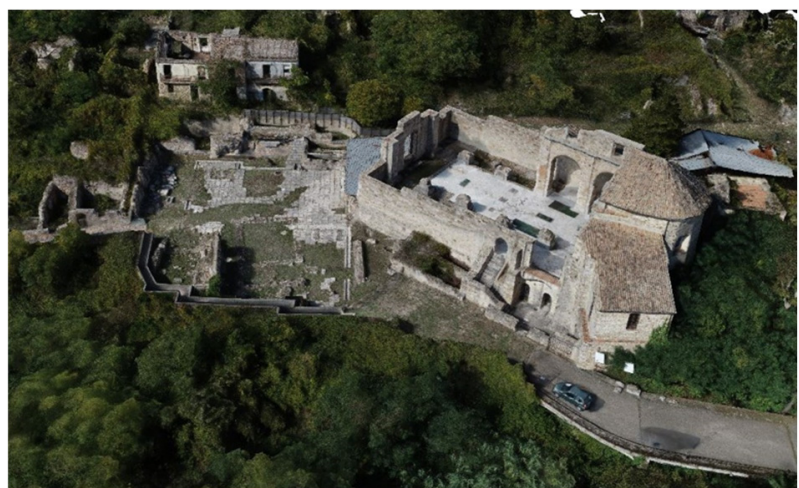

Figure 20: Dense point clouds of the Cathedral and the Forum.

The photographic acquisition made by the UAV needed a preliminary shot project, based on the map of the area in question with the help of Mission Planner. This software allows the creation of flight paths through the creation of waypoints that set out the route, the number of shots, and the value of the ground resolution. The operating and 
environmental factors which could influence the reconstruction so as to ensure the maximum coverage of the zone to be surveyed were taken into account.

Regarding the survey when using the laser instrumentation on the site and acquiring the morphometric characteristics of the Forum and the Church of Assunta, a TLS (Terrestrial Laser Scanner) phase modulated (phase shift) of the CAM2/Faro, the Focus 3D X330 model. This type of instrumentation allowed us to acquire information that was useful in defining the typology of those parts of the complex which could not be reached by any other instrument or survey technique. (Wei, Chin, Majid, \& Setan 2010) For the alignment of the scans, two methods were essentially used, i.e. natural points and artificial targets. With the aim of operating efficiently, particular attention was paid to the positioning of the zoned targets which were necessary to join the point clouds and because of which there was a constant verification for the pairs of consecutive takes.

In reference to the survey of the area of the Forum and the Cathedral of the Assunta, 44 scannings were carried out, choosing appropriate station points which presented to a lesser extent possible occlusion. The resolution was 6.136 millimetres and was measured on a plain 10 metres from the emitter, with a $3 X$ quality, the time used for any scan was 7 minutes (Fig. 21). The clouds which were acquired were alignment through the collimation of the artificial targets while for some of the parts which could not be reached directly the cloud to cloud was used. After pre-processing, was proceeded with the alignment phase of the individual scans by establishing the starting scan and aligning all the others to it, applying the rototranslation matrices between the different internal local systems in order to put them into a global reference.

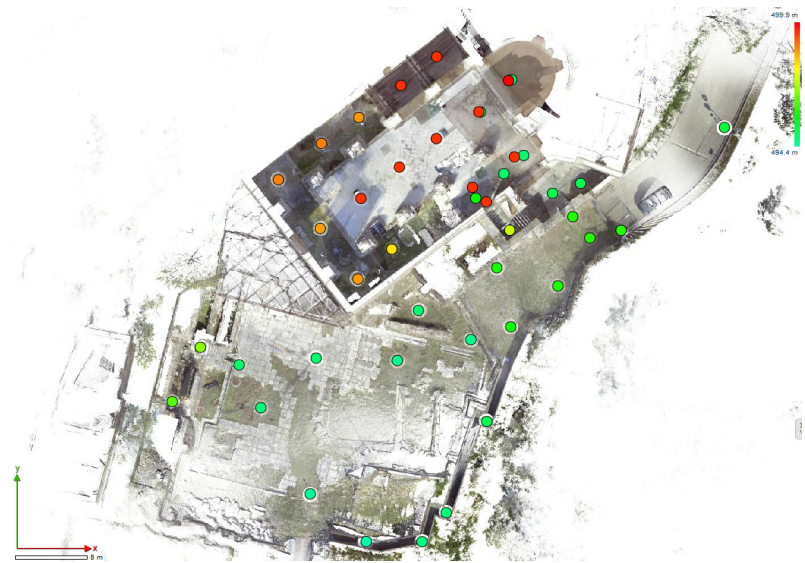

Figure 21: Orthoprojection with the position of the station points of the laser scanner.

This allowed them to be referenced to the reference system through the coordinates in common with the targets, and the successful union of the individual point clouds in a unique three-dimensional model. The data obtained through the laser scanner allowed us to give back dimensional values, generate orthophotos, elaborate on the three-dimensional models, extract textures and produce spherical photos. The choice of technology with active sensors like the laser scanner allowed us to operate also in environments with little lighting like the crypt positioned under the apse of the cathedral, thus giving to it reflectance values. This particular factor allowed us to re-build its geometry.

\subsection{The integrated survey}

With the aim of obtaining a single model from the two point clouds, both in the first and in the second survey campaigns, there were positioned some GCP (Ground Control Points) which materialized through the checkerboard targets and RAD (Ringed automatically detected) targets (Parente, Chandler, \& Dixon 2019). These were visible from the UAV and can be individualized in the point clouds obtained with the help of the laser scanner (Fig. 22). The network of the control points guaranteed the topographical support to alignment both models (the photogrammetric and the laser ones) until the empty spaces present in both the clouds were compensated for. The survey campaigns have, thus, made up an interesting integration application with different forms of technology, whose outcome, in this initial stage of the research-project, can be considered more than successful.

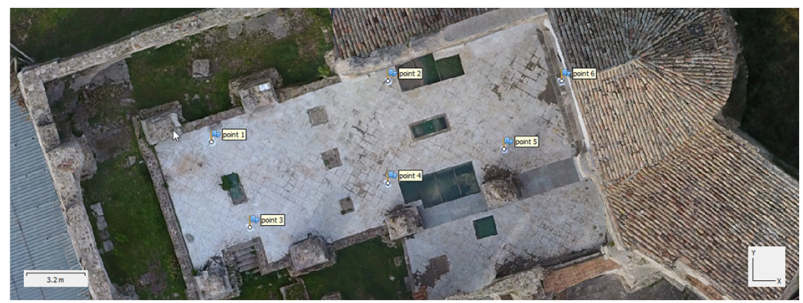

Figure 22: Ground control points materialized with the automatic RAD recognition target. November 2019.

The three-dimensional visualization of the given model proved to be extremely useful for the rapid exploration of the entire complex, allowing us to read the altimetric relationships between the parts and to carry out an initial examination on the three-dimensional configuration of the object (Fig. 23).

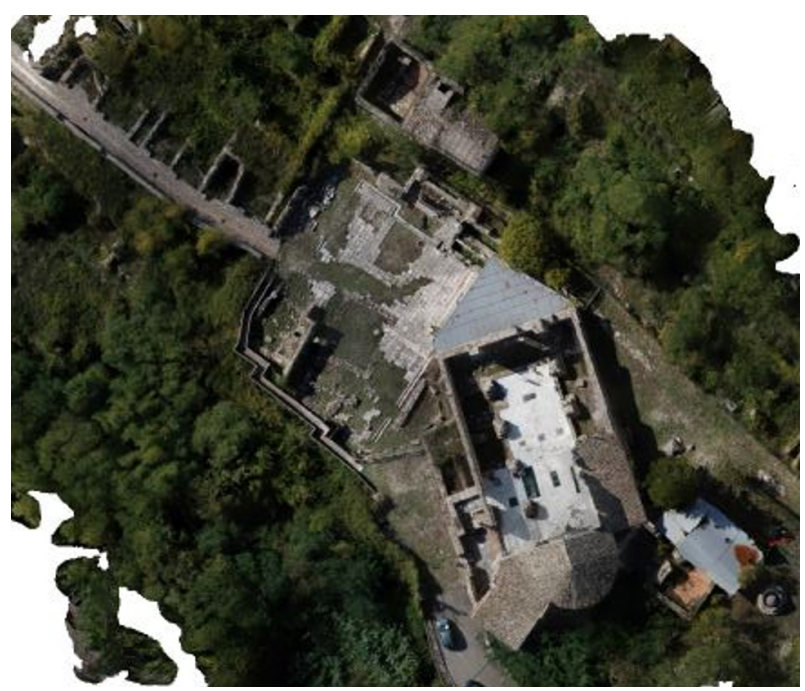

Figure 23: Orthoprojection of the area of the Forum and the Cathedral.

The point clouds allowed us to analyse on various occasions the existing one, operating comparisons and interrogations, also through its on-line fruition. The applicative Scene2Go of the Faro had, in fact, been predisposed on the Apache server.

The configuration of the web server (Faro Scene2Go) allowed us to visualize the data and the virtual fruition of 
the projected space, having archived the various scanning to get access to it from the remote. The system which was used allowed us to interrogate and visit virtually the enjoyable environments through immersive photos (Panoramic Views) and maps (Overview Maps). It is possible to carry out on these products, besides the verification and control procedures, also measurement operations, thus configuring itself as an information archive that can be used for further research-projects. Side-by-side with the traditional orthoprojected representatives, new methods of the visualizing of projected data have been experimented with which can efficiently give back the complexity of the site, such as the articulation and the careful cataloguing of the parameters. Besides, the use of an on-line platform gave us the chance to verify the informative potentialities of the immersive shots, with the aim of singling out new modalities as regards knowledge and fruition.

\section{The dialogue approach for the project and some concluding considerations}

The cognitive field-work of the investigative survey of the above-mentioned survey campaign was carried out by means of numerous on-site visits and choices made in order to deepen, through instrumental recordings, certain aspects of the object of investigation. A rigorous analysis of the conditions and the potential contexts for the re-use and re-launching of the archaeological park at Compsa were also used.

The study of the still existing volumes, their criticalities, the typology and the degree of 'ruin' of the buildings which still allow us to read the layout and the street pattern of the village swept away by the seismic event have contributed to the construction of hypotheses for a likely possibility of sustainable reuse. A wide-ranging mapping of the existing facilities, enabled us to measure its 'pulse' with regard to the attractiveness of the site, while a community survey on the perception of the abandoned site as a place of collective memory provided significant data to support the project proposals (Carbonara, 2017). The perception of the scenery and the physical and immaterial relationships with the new Conza allowed us to hit upon the strategies and destinations to be used, which are both compatible and auspicious. Some basic functions have been provided (a bookshop, a snack bar, and so on) and different 'cultural devices' which could be the start of a widespread, intercounty, developmental process, along with other possibilities. In particular, the Laboratories (visual anthropological ones, an active memory one, a spontaneous theatre, a rural design one, an immaterial patrimony one and a start-up laboratory for the various urban projects) would transform, in the planning forecast, the park into an active and propulsive site. Recuperating the urban-natural pathways, through a planned project, would lead to the fruition of the site and ruins which would be inserted along with the archaeological data of the re-emerged destroyed past, would become the material headquarters for an active memory with regard to its collective re-use.

The 'waiting' behaviour - referred to at the beginning of this contribution - with regard to the process of marking down the data and their processing thus represent one part of the methodological process of the project proposal. The very same thematic representation that relating to materials and construction techniques and degradation, basic steps in the methodology of the restoration project, supported by the indispensable and preliminary historicalcritical study, was therefore enriched with new interpretative in-put. Among these, there are: the flagrancy of the material, the presence of cast-off materials, as well as hypogean parts, the micro-histories impressed on the surfaces of the surviving internal parts, or even the hidden pathways which, back in the day, built up a visual relationship with an urban interior or with the Irpinian scenery or even the individualization of 'archaeologically fertile' areas. These are points that a specific instrumental campaign, through deep, critical reading, could bring to light. The restoration approach has thus revealed a project that is sensitive to what exists, in fruitful interaction with the instrumental survey. This interaction attentive to the preservation of contemporary meanings, with the aim of transformation to enhance them and, finally, the recovery of a social and physical fracture, which even nowadays can be perceived, between the new Conza and the people from Conza with a still painful past (Marino, Rispoli, \& Vitale, 2016; Marino, 2020).

Comparison and dialogue between disciplines, therefore, between "other interpretative grammars" can give rise to proposals and horizons for the life of a building or a site, with an operative approach based on the genius loci and the questions that pre-existence inevitably poses. These are topics that, if grasped in their complexity and seen through different reading filters, can offer appropriate solutions to the multiform values of the heritage.

\section{Acknowledgements}

This work was supported by Prof.ssa Arch. Bianca Gioia Marino, Prof. Arch. Riccardo Florio, Prof. Arch. Raffaele Catuogno, Coll.: Arch. Marco Facchini and explains the results in the thesis study by arch. Rossella Marena. (Department of Architecture, University of Naples Federico II, a.a. 2018-2019).

\section{References}

AA.VV. (1982). Campania oltre il terremoto: verso il recupero dei valori architettonici, Catalogo della mostra "Campania oltre il terremoto", Arte tipografica, Napoli.

Acocella, V. (1927-1928). Storia di Conza, I, Il gastaldato e la contea fino alla caduta della monarchia sveva, estratto dagli "Atti della Società Storica del Sannio", Benevento 1927-1928 F.Barbagallo, Sviluppo e sottosviluppo agli inizi del Novecento, in Id. (a cura di), Storia della Campania.

Aveta, A., Marino, B.G., \& Amore, R. (2017). Materia e realtà storica. Catturare la trasformazione: un approccio transdisciplinare alla conservazione. In 'ANANKH, Numero speciale novembre 2017, 30-36.

Carbonara, G. (2017). II restauro fra conservazione e modificazione. Principi e problemi attuali, artpaparoedizioni, Napoli. 
Chiabrando, F., Marino, B.G., Fissore, F., Lingua, A.M., Masiero, A., \& Vettore, A. (2019). UAV Photogrammetric Model of Girifalco Fortress, in Marino, B.G. (ed.), Across the Stones. Images, landscapes and memory. The interdisciplinary knowledge for the conservation and enhancement of the Girifalco Fortress, Collana frequenze_conservazione/restauro, artstudiopaparo, Roma.

Colucci Pescatori, G. (1988). Conza della Campania, l'Attività Archeologica nelle Province di Salerno, Avellino e Benevento. In Atti del XXVII Convegno di Studi sulla Magna Grecia (Taranto-Paestum, 9-15 ottobre 1987), Taranto.

Di Giovanni, V. (2015). Compsa tra Irpini e Romani, Tesi di dottorato in Storia Romana, Università degli Studi di Napoli "Federico II". Dipartimento di Studi Umanistici, Scuola di Dottorato di Storia (XXVII ciclo), Prof.ssa A. Storchi Marino, Coordinatore Prof.ssa A. M. Rao.

Gargano, G. (1934). Ricerche storiche su Conza antica, Avellino (Ristampa anastatica Calitri 2011).

Johannowsky, W. (1982). Risultati e prospettive della ricerca archeologica irpina, in AA. VV., Conza alla ricerca del passato. Atti dell'incontro- dibattito tenuto a Conza l'11 agosto 1979, Calitri.

Johannowsky, W. (1994). Conza (Compsa), in EAA, II, supplemento, Roma, 262-263.

Marino, B.G., Rispoli, F., \& Vitale, F. (2016). Memorie dalla città a venire. Decostruzione e conservazione, artpaparoedizioni, Napoli.

Marino, B.G. (2017). La complessità della rappresentazione come potenzialità della conservazione,. In 'ANANKH, numero speciale GeoRes novembre 2017, 11-12.

Marino, B.G. (2019). Data Optimization for the 3D Modeling and analysis of a Fortress Architecture. In «Geomatic \& Restoration. Cultural Heritage: challenges, new perspectives and technology innovation. Towards informative content models and beyond» re (Milan, 8th-10th May 2019).

Marino, B.G. (2020). Patrimoni e memorie in dissolvenza: dinamiche di trasformazione e di abbandono dei centri dell'Alta Irpinia tra distruzione e ri-costruzione. In A.M. Oteri, G. Scamardì (a cura di), Un paese ci vuole. Studi e prospettive per i centri abbandonati e in via di spopolamento, «ArcHistor» Extra, 7 (supplemento di «ArcHistoR» 13/2020).

Mazzoleni, D., \& Sepe, M. (2005). Rischio sismico, paesaggio, architettura: Irpinia, contributi per un progetto. Centro Regionale di Competenza Analisi e Monitoraggio del Rischio Ambientale, Università degli Studi di Napoli Federico II - CRdC-AMRA.

Wei, O. C., Chin, C. S., Majid, Z., \& Setan, H. (2010). 3D documentation and preservation of historical monument using terrestrial laser scanning. Geoinformation Science Journal, 10(1), 73-90. http://eprints.utm.my/id/eprint/27787/1/ZulkepliMajid2010_3DDocumentationandPreservationofHistorical.pdf

Rea, R. (1982). Primi risultati della ricognizione archeologica nel territorio di Conza, in AA. VV. Conza alla ricerca del passato. Atti dell'incontro-dibattito tenuto a Conza l'11 agosto 1979, Conza della Campania.

Sgobbo, I. (1938). Ricerche topografiche dell'antica Compsa. In Atti della Reale Accademia Nazionale dei Lincei, Notizie degli Scavi di antichità, vol. XIV, serie VI, Roma.

Parente, L., Chandler, J. H., \& Dixon, N. (2019). Optimising the quality of an SfM-MVS slope monitoring system using fixed cameras. The Photogrammetric Record, 34(168), 408-427. https://doi.org/10.1111/phor.12288.

Veca, S. (2017). Non c'è due senza tre, in Terza Cultura. Idee per un futuro sostenibile. A cura di V. Lingiardi e N. Vassallo. 


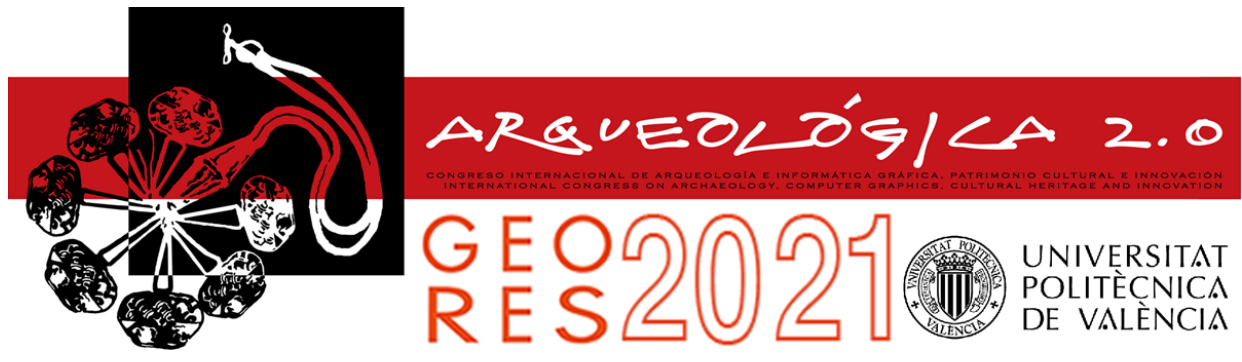

Proceedings of the joint international event $9^{\text {th }}$ ARQUEOLÓGICA

$2.0 \& 3^{\text {rd }}$ GEORES

Valencia (Spain).

26-28 April 2021

\title{
THE COMPLEX OF SANTA CROCE IN RAVENNA AS A CASE STUDY: INTEGRATION OF 3D TECHNIQUES FOR SURVEYING AND MONITORING OF A HISTORICAL SITE
}

\author{
Gabriele Bitellia,b, ${ }^{*}$, Ester Barbieri ${ }^{\mathrm{b}}$, Valentina Alena Girellia,b, Alessandro Lambertinia ${ }^{a}$, Emanuele \\ Mandanicia , Eleonora Melandri ${ }^{b}$, Domenico Simone Roggio ${ }^{b}$, Angela Santangelo ${ }^{\mathrm{b}, \mathrm{c}}$, Maria \\ Alessandra Tinia , Simona Tondellib,c, Andrea Ugolinib,c \\ a DICAM, Department of Civil, Chemical, Environmental and Materials Engineering, Alma Mater Studiorum, University of Bologna, Viale \\ Risorgimento 2, 40136 Bologna, Italy.gabriele.bitelli@unibo.it; valentina.girelli@unibo.it; alessandro.lambertini@unibo.it; \\ emanuele.mandanici@unibo.it; mariaalessandra.tini@unibo.it \\ b Interdepartmental Centre for Industrial Research in Building and Construction, Alma Mater Studiorum, University of Bologna, Via del \\ Lazzaretto 15/5, 40131 Bologna, Italy. ester.barbieri2@unibo.it; eleonora.melandri3@unibo.it; simone.roggio@unibo.it \\ ${ }^{\mathrm{c}}$ Department of Architecture (DA), Alma Mater Studiorum, University of Bologna, Viale Risorgimento 2, 40136 Bologna, Italy. \\ angela.santangelo@unibo.it; simona.tondelli@unibo.it; a.ugolini@unibo.it
}

\begin{abstract}
:
Over the last decades, climate change has brought more and more challenges to managers of cultural heritage and researchers. The increasing effects of natural hazards on assets have required the development of a new protocol of techniques and methodologies for the monitoring of Cultural Heritage and the adoption of management plans adapted to the new challenges at every stage of risk management. The work here presented aims at providing an insight of the work undertaken under the framework of the H2020 SHELTER project, to showcase the first steps of the multi-disciplinary research conducted in one of the project's case studies, the complex of Santa Croce in Ravenna, Italy. The paper provides the presentation of the case study and the description of the surveying activities with some first results, to provide a preliminary assessment of the site criticalities to be addressed in the future activities in the area, in line with the EU project expected outcomes.
\end{abstract}

Keywords: 3D surveying, 3D modelling, digital archaeology, cultural heritage, natural hazards, climate change

\section{Introduction}

In recent times, Cultural and Archaeological Heritage has been increasingly threatened by the growing relevance of events related to natural hazards due to the effects of climate change.

The complex of Santa Croce, in Ravenna, once a unique building with the Mausoleum of Galla Placidia, is affected by the recurring hazards encountered in the wide monumental heritage of the city: subsidence and flooding. The area was chosen as a case study of the H2020 SHELTER (Sustainable Historic Environments holistic reconstruction through Technological Enhancement and community-based Resilience) project, which aims at addressing, with a holistic approach, the impacts of climate change on cultural heritage, developing plans for disaster risk management along with protocols and methodologies to enhance the resilience of these areas.

The University of Bologna, a partner of the project, brings together researchers from different fields of expertise that will carry out the activities in the area with an interdisciplinary approach. The work here presented describes the surveying activities that are being undertaken in the archaeological area, showing some first results. The chosen methodology, already successfully applied in other similar case studies by the Geomatics group of the Department of Civil, Chemical, Environmental and Materials Engineering (DICAM), sees the application of different surveying techniques used in integration, with the aim to realize the complete and accurate characterization of all the aspects of the object of interest: geometry, materials, structural behaviour, damaged areas, etc. Geomatics nowadays can offer many techniques devoted to the digitalization, the documentation and the management of objects related to archaeology and built heritage (e.g. loannides \& Quak, 2014; Tucci, Bonora, Conti, \& Fiorini, 2017; Balletti, Bertellini, Gottardi, \& Guerra, 2019; Bitelli et al., 2019; Girelli, Tini, Dellapasqua, \& Bitelli, 2019) and the management of these data inside interdisciplinary researches is of increasing interest. 
In this case study, terrestrial laser scanning and digital photogrammetry, both close-range and aerial by drones, were chosen as they are able to respond to the various and complex requirements of 3D surveying in the field of Cultural Heritage, as for example the high geometric accuracy together with colour fidelity and photorealism. GNSS observations and classical topography by Total Station, on the other hand, provided the georeferencing of all the collected data in the same absolute coordinate system. In addition, thermal images analysis was performed on the interior walls, to investigate and highlight the occurrence of problems related to hygrothermal alterations, which are an often encountered problem on Cultural Heritage (Bitelli, Girelli, Vannucci, \& Pigozzi, 2020).

The final goal of the workflow is the creation of a georeferenced 3D model of the complex system related to the whole area, integrated with other products in support of the multi-disciplinary studies carried out in the framework of the SHELTER project. The collected data will be useful for different purposes: documentation, preservation, restoration, structural health monitoring, GIS and HBIM establishment, touristic exploration (Bitelli, Dellapasqua, Girelli, Sanchini, \& Tini, 2017; Girelli et al, 2019).

\section{The complex of Santa Croce: the Church and the archaeological area}

\subsection{Looking back on the history}

The Santa Croce complex (Fig. 1), located in the historic area of Ravenna, is characterized by the coexistence of different architectures that over time have been layering in the area: the early $17^{\text {th }}$ century Church, the remains of the late-antique Placidian Church and the structures of a Roman domus with part of its mosaics. The Roman remains were attributed to a luxurious residence, coherently with others identified in the surroundings. The studies were undertaken in the area date the domus back to the turn of the $3^{\text {rd }}$ and $4^{\text {th }}$ century $A D$ (Sericola, Agostinelli, \& Ugolini, 2019).

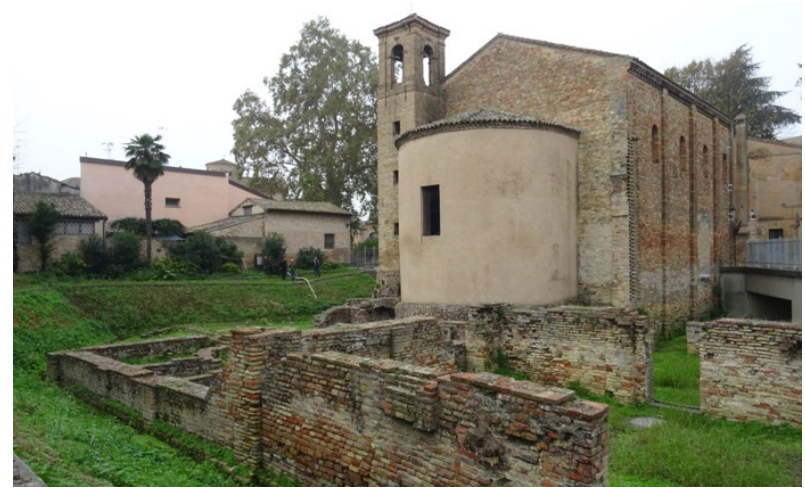

Figure 1: General outer view of the complex of Santa Croce: the Church and the archaeological area.

The late-antique Church, erected between the 424 and the 432 A.D., was built on orders of the Empress Galla Placidia. A narthex completed the single Latin cross nave of the church and shortly afterwards, among other interventions, a sacellum at the South end was added, currently known as the Mausoleum of Galla Placidia. This phase of the Church, in the configuration of a unique building with the Mausoleum, corresponds to its period of greatest magnificence, thanks both to the dimensions of the complex and the presence of the finely decorated mosaic floors (Cassanelli et al., 2013).

Since medieval times, the area has been the subject of several architectural interventions. The current configuration of the Church dates to the $17^{\text {th }}$ century, when several modifications affected what was left of the original structures. The narthex was demolished and the construction of a street separated the southern sacellum from the Mausoleum, consequently requiring the construction of a new facade for the church. In addition, the crosshead and the rectilinear apse were removed, and a new Church with a semi-circular apse flanked by a bell tower was built, corresponding to the last and current architectural configuration of the building.

The archaeological investigations in the area, started in the $20^{\text {th }}$ century, revealed the structures and the different floor levels of the ancient configurations, and continued with several studies and attempts of interventions in the area. Nowadays, the complex, closed to the public, encompasses the Church, whose walls display the different phases of the building, the structures of the first Latin cross plan of the ancient church and the remains of the wall structures and marbles of the domus.

\subsection{Site criticalities}

Among the main potential risks to which the complex of Santa Croce is exposed to, hydrogeological and waterrelated risks are probably those that most affect the archaeological assets. The first excavations undertaken in the area resulted in giving the site a basin configuration. Later, in 1984, to manage the groundwater in the area a pumping system was installed. The intervention, however, worsened the situation of the site, since the pumps drained not only water, but also soil debris, altering the altitude of the archaeological remains and causing loss of stability on the structures (Sericola, Agostinelli, \& Ugolini, 2019).

The area, as well as the rest of the city of Ravenna, is affected by the subsidence phenomena, and results exposed to several water-related risks (Marino, 2019). This major risk factor is linked to the intrinsic characteristic of the wider area around the city and its geomorphological features. The progressive sinking of the soil together with the aquifer proximity to the ground entails a high hydrogeological natural risk for Santa Croce and the surrounding monuments, consequently posing the assets also under flooding risk (Simonini, Ceccato, \& Tosi, 2017).

The flooding hazard is even more relevant as, seen the configuration of the archaeological area, also rainwater and stagnant water constitute a relevant potential risk for the site. Currently, the presence of water is only managed with manually controlled pumps conveying the groundwater into the city sewerage system. However, no early warning system is active in the area, a situation that hiders an immediate response when anomalous situations occur. As happened both in 2016 and 2019, a malfunction of the water pumping system caused sudden flooding of the archaeological area (Fig. 2).

The lack of adequate alarm systems caused a delay in intervention in the area. In addition, as there are currently no well-established and validated emergency management protocols between the managers and 
owners of the area, the implementation of field operations was slow, subjecting the assets to a high risk of loss in case of an abnormal event.

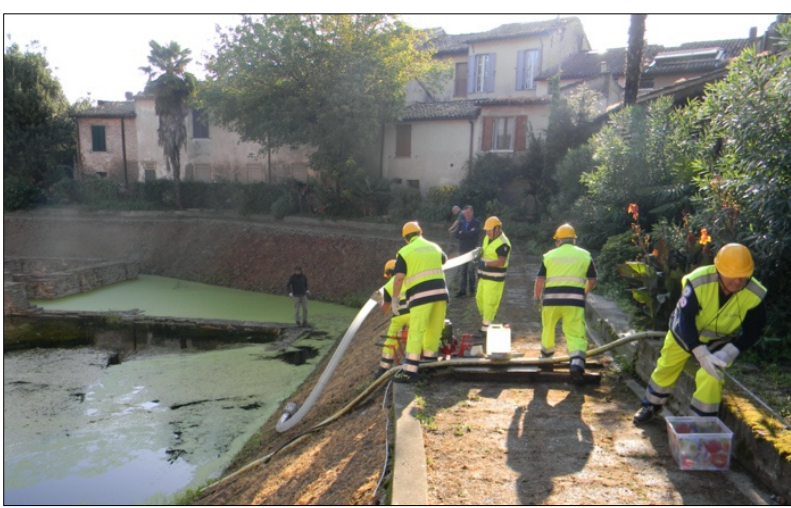

Figure 2: Draining operations of the area after the flooding event in August 2019.

\subsection{SHELTER Project and Ravenna Open}

Lab

The main objective of the SHELTER project (https://www.shelter-project.com) is to provide public authorities and institutions consolidated tools and methodologies for adaptive planning, governance and management of Cultural Heritage, which will be validated during the project lifetime in 5 European Open Labs. The chosen case studies are characterized by different territorial scales, from the cross-regional level to the single building one, and by the different natural hazards to which they are exposed to. The tools and methodologies developed in SHELTER project will be tested and validated in these sites.

The Santa Croce complex has been chosen as one of the five Open Labs of the project, specifically addressing subsidence, flooding and earthquake hazards, and consequently the challenges that are posed to the conservation of the archaeological site. The area will be studied, and methodologies, tools and protocols developed for enhancing the resilience and mitigating the impacts of these hazards.

The first step to achieve these objectives is the global understanding of the risks, natural and non-natural, that affect the assets and the state of conservation of the sites. The University of Bologna cooperates in the project activities with the different institutions involved in a matter of cultural heritage and disaster risk management at a local level, as the local Superintendence, the Diocese and the Municipality of Ravenna, and others at the regional level, as ArpaER (Regional Agency for Prevention, Environment and Energy of Emilia-Romagna). The University fielded diverse expertise placing, thanks to the activities of the project, the study of the complex at the level of European scientific interest.

The first activity that was undertaken, with the aim of documenting the site, reaching a deep understanding of its criticalities and supporting the diagnostic and restoration consequent phases, was the surveying of the area, which allowed the 3D reconstruction of the assets. The work is described in the following paragraph, showing some first results.

\section{Geomatics surveying activities: description and first results}

The surveying operations involved the integration of different techniques: GNSS observations, classical topography with Total Station, Terrestrial Laser Scanning, aerial (by UAV) and close-range digital photogrammetry, thermal images analysis. A careful planning of all the activities allowed the design and the realization of a network for the absolute geo-localization of the acquired data (Fig. 3).
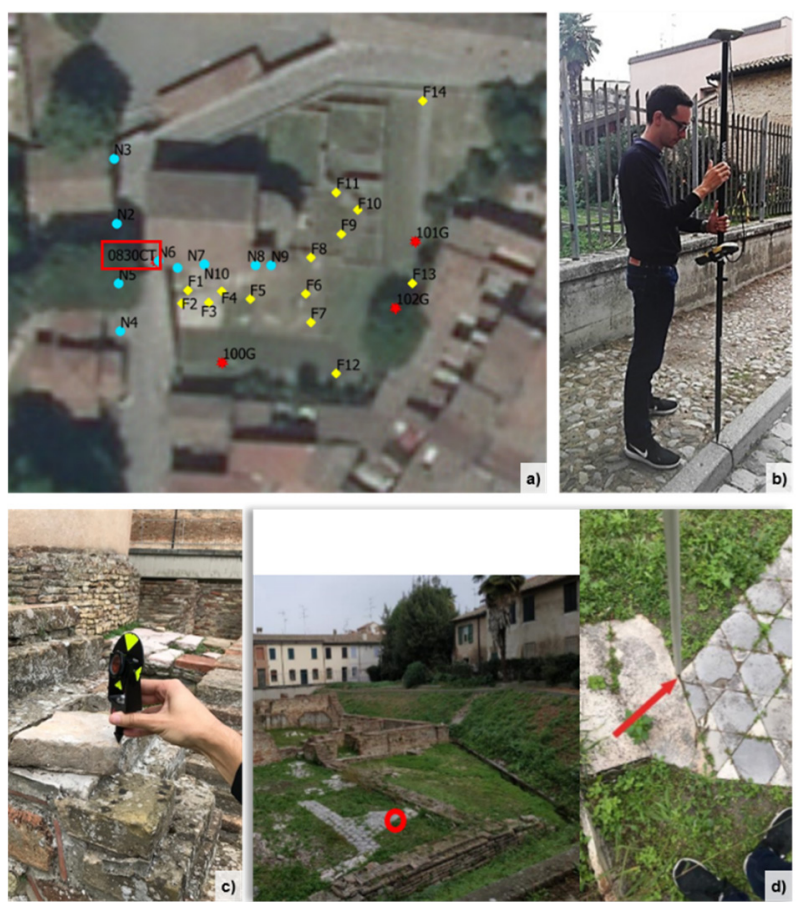

Figure 3: Surveying operations: a) Topographic network; the red stars indicate the GNSS stations, with in the red box the benchmark of the municipal levelling network; cyan and yellow squares indicate respectively targets and natural points used for geo-referencing laser scanning and photogrammetric data; b) a phase of the GNSS survey; in c) and d) two natural control points in the archaeological area.

GNSS observations in NRTK mode were performed for the planimetric network absolute georeferencing, through the survey of three vertices in the area (red stars in Fig. 3). The GRS-1 receiver by Topcon, with PGA-1 antenna, was used and it was connected to NetGEO, the NRTK commercial service provided by the manufacturer. For the altimetric network referencing, the orthometric height of a benchmark of the existing municipal levelling network was used. The position of the benchmark is indicated in Figure 3 by a red rectangle.

The topographic network was surveyed using the firstclass motorized Leica TS30 Total Station $( \pm 0,5$ " angular error, $\pm(0,6 \mathrm{~mm}+1 \mathrm{ppm})$ distance error $)$. Overall, 25 points were measured, both targets and natural points, used as ground control points for geo-referencing laser scanning and photogrammetric data (respectively cyan and yellow squares in Figure 3). The target coordinates were obtained by a least-square adjustment with minimal constraints. 
Figure 4 shows the planimetric drawing of the topographic network. The error ellipses evidenced an uncertainty of 2$3 \mathrm{~mm}$ on the calculated positions.

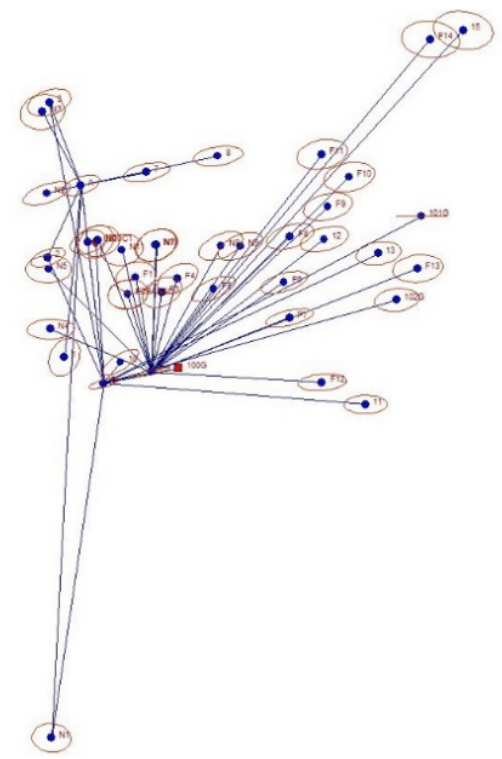

Figure 4: Topographic network drawing; the error ellipses, in red, show uncertainty of 2-3 $\mathrm{mm}$ on the calculated positions (exaggeration factor of 500).

The laser scanner survey of the complex was realized using the time-of-flight (TOF) Riegl VZ400 (declared accuracy $5 \mathrm{~mm}$, precision $3 \mathrm{~mm}$, measurement speed 122000 points/sec) coupled with a Nikon D90 reflex camera. The acquisitions were performed by 15 scanpositions, 7 for the interior, 8 for the exterior (Fig. 5). The number of the measured points is significant: more than 410 million points overall.

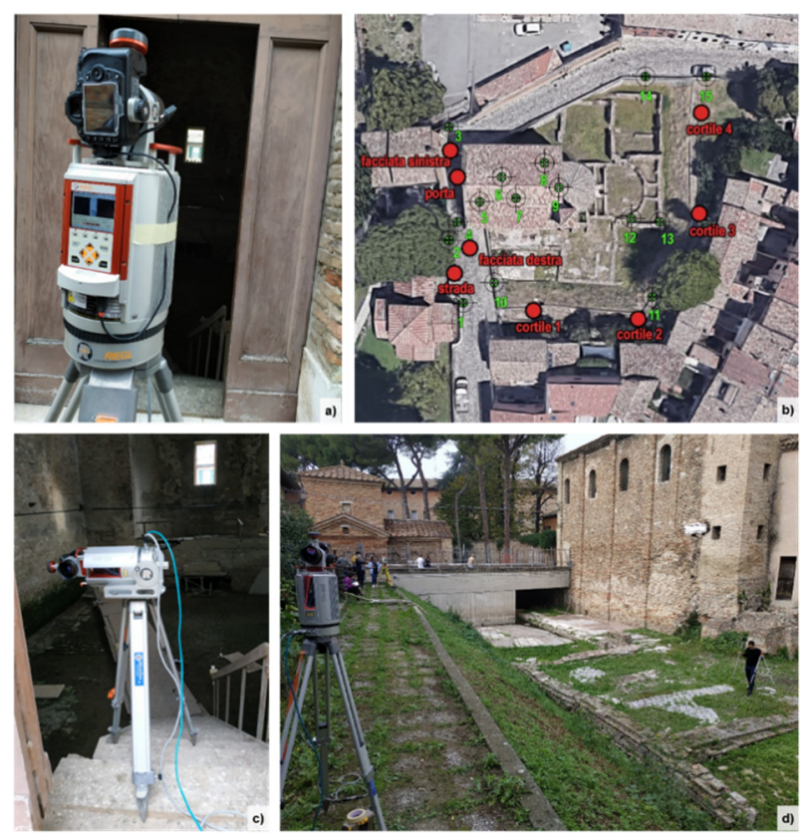

Figure 5: Laser scanning surveys: a) Riegl TOF system; b) scheme of the scan-positions performed for the exterior survey (red circles); c) acquisition of the church ceiling, with the laser tilted horizontally; d) acquisition of the south wall.

In particular, some hidden parts in the archaeological area and the north wall of the church, undetectable by laser scanning due to the fence, were acquired by a closerange photogrammetric survey, whereas in the interior of the church, especially for the apse and the upper part of the truss in the ceiling, an aerial photogrammetric flight by UAV was performed.

In the first case, more than 600 images were acquired using a full-frame DSLR camera, then processed by MultiView Structure-from-Motion approach. The achieved average error was in the order of 1-2 pixel and the obtained point cloud consists of 3.5 million points. Inside the church, two flights with UAV were realized to obtain a detailed model of the apse and a point cloud of the whole interior, especially of the ceiling (Fig. 6). The UAV was a DJI Spark, equipped with FC1102 camera (sensor size $6.17 \times 4.56 \mathrm{~mm}$, resolution $3968 \times 2976$ pixel, pixel size $1.57 \mu \mathrm{m}$, focal length $4.4 \mathrm{~mm}$ ).
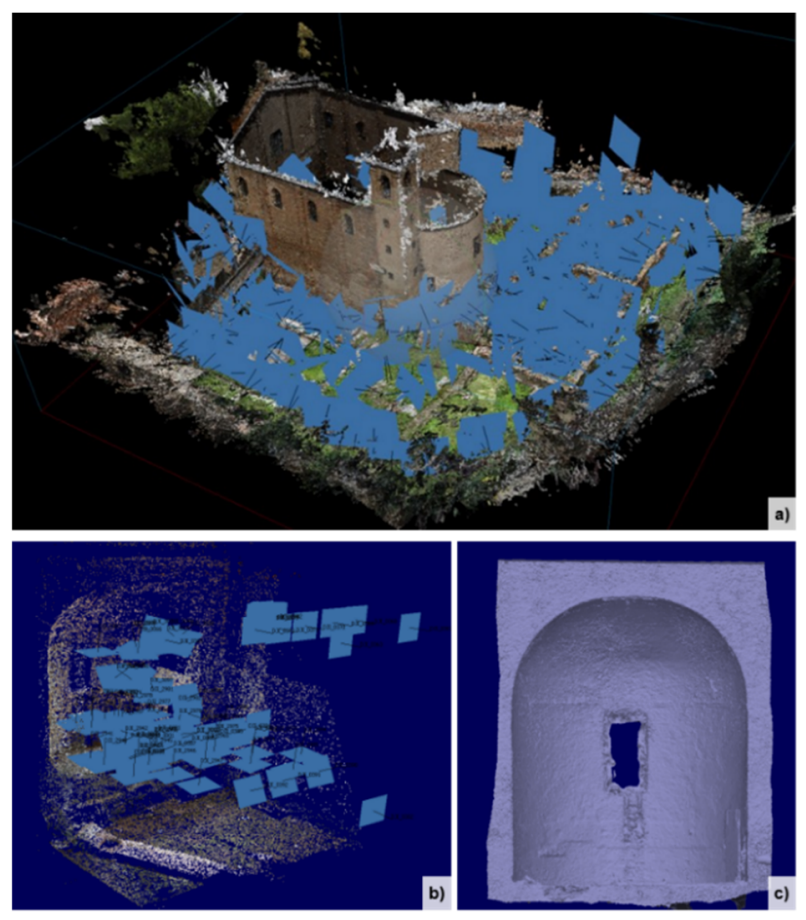

Figure 6: Photogrammetric surveys: a) close-range in the exterior; b) and by drone in the interior; c) the detailed 3D model of the church apse.

All the point clouds obtained by the different techniques were aligned in the absolute reference system established by GNSS and topographic surveys. In particular, the alignment of each TLS point clouds to the reference system adopted, performed by means of the 3D targets, always provided root means square of less than $5 \mathrm{~mm}$. The clouds were then cleaned, fused and filtered. The processing, due to the area complexity and the huge amount of data, required an accurate manual intervention. The alignment between photogrammetric and TLS clouds was realized in two steps: firstly, a coarse registration using manually collimated homologous points and then a fine registration by ICP procedure. The filtering of the outliers was done mostly manually. The TLS model was integrated with data by photogrammetry only where it was lacking, trying to limit the overlapping areas. After the fusion, an automatic resampling was applied, by imposing an average point spacing of $5 \mathrm{~mm}$ (Fig. 7). Considering the integration with the photogrammetric data, the overall reliability of the final model can be evaluated at about $1 \mathrm{~cm}$. 


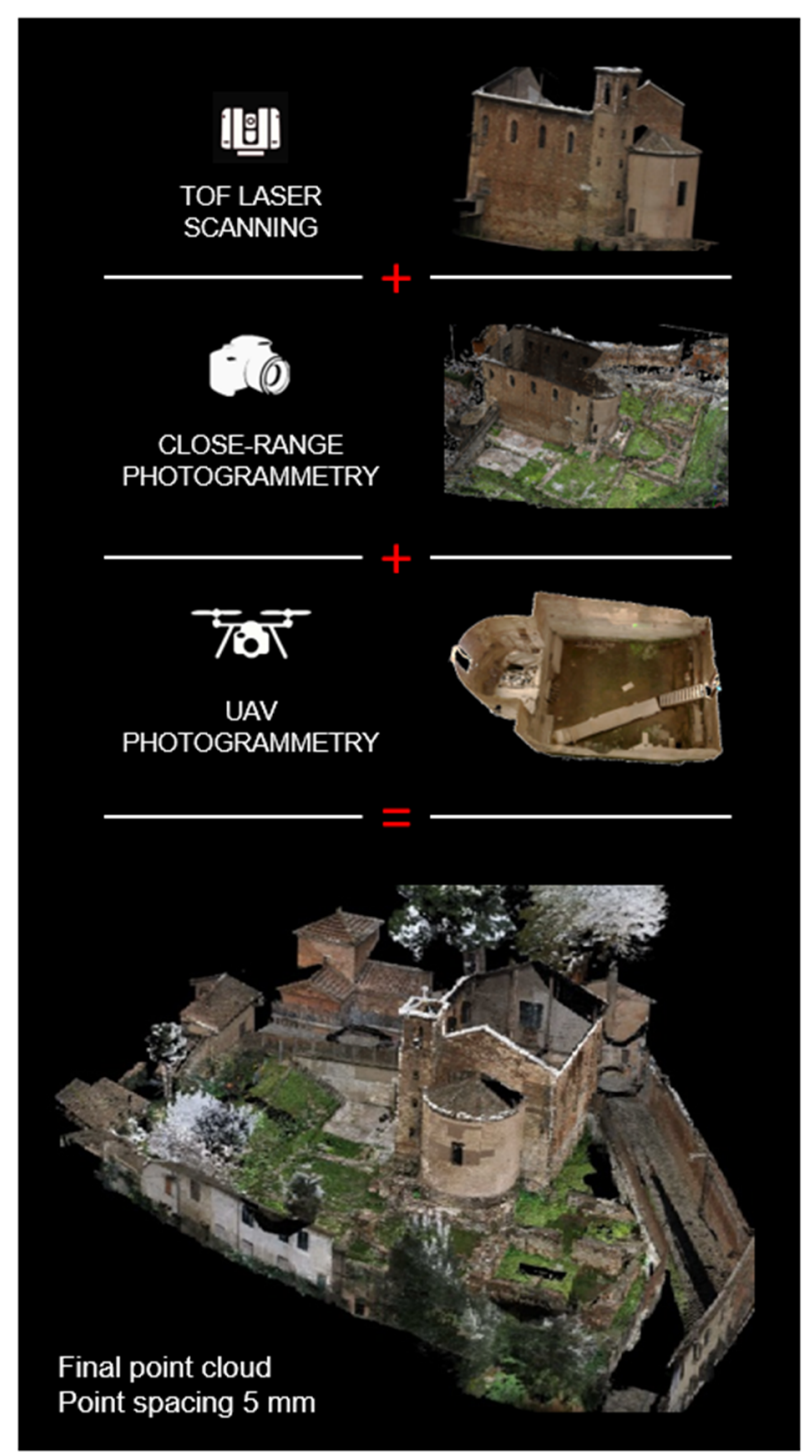

Figure 7: The final point cloud of the complex, obtained fusing together all the acquired data.

Starting from the final point cloud, a simplified BIM model of the Church of Santa Croce was produced (Fig. 8). The BIM model, generated according to an HBIM approach, can represent further support for the knowledge of the current state and its preservation and conservation (Brumana et al., 2020).

As said before, also a diagnostic analysis by thermal imaging (Adamopoulos, Bovero, \& Rinaudo, 2020) was experimented in the interior. The used thermal camera was a FLIR P620, which has a spectral range between $7.5 \mu \mathrm{m}$ and $13 \mu \mathrm{m}, 640 \times 800$ resolution; the camera was equipped with the standard $24^{\circ}$ lens. During the survey, 56 thermal images were acquired. In order to facilitate the focus of the camera and to identify points during postprocessing phase, artificial targets were placed on the masonry. The images were later processed with FLIR software, producing 32-bit tiff files without loss of quality. Thermal images were then edited for easier reading by using a false-colour, to highlight small temperature differences between 17 and $21{ }^{\circ} \mathrm{C}$. Figure 9 shows an example of the acquired thermal images.

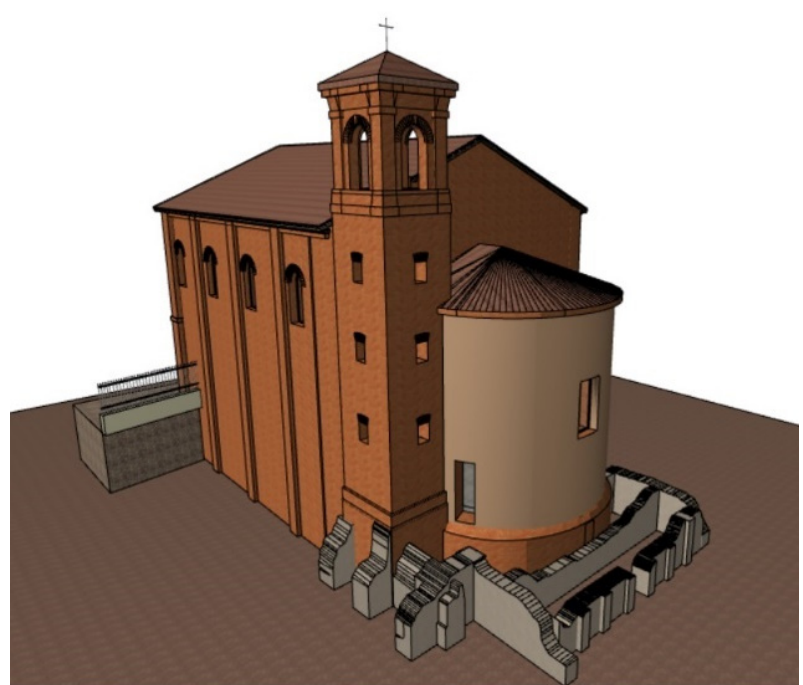

Figure 8: Simplified model of the Church obtained by the HBIM approach.

Some areas remain still incomplete. In the next future, a new survey by UAV will be realized in the exterior, to acquire the roof and to fill some gaps in the archaeological area.

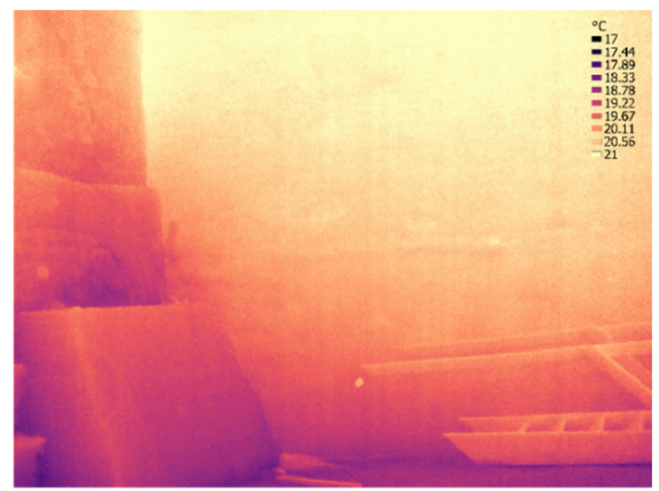

Figure 9: Thermal image of the interior south wall.

\section{Conclusions}

In the framework of the SHELTER project, a highly detailed 3D model of the complex of Santa Croce in Ravenna was produced by the integration of different Geomatics techniques. The acquired data are georeferenced in absolute coordinates and are directly usable in GIS environment, even in large scale analysis. The model and the other generated products will support the many activities involved in the different areas of intervention considered in the project, in a modern multidisciplinary approach.

The creation of the 3D model required important manual editing and harmonization effort, choosing the most appropriate processing methods and approaches according to the peculiarities of the object and the requirements of the project.

By the final point cloud, a simplified model of the church was created using an HBIM approach. The main purpose of this model is not linked to the production of a 3D model strictly reflecting the geometric characteristics of the building but is oriented to integrate the geometric component, with a series of information indispensable for 
the characterization of the existing historical heritage and for the evaluation and design of future recovery and restoration interventions. It is also possible to integrate data from the surveys with different predictive diagnosis tools, through a flow of information of which the BIM model represents the graphic and management interface. Working in a BIM environment also represents an objective advantage, because it is a method that can be used during the entire life cycle of the building or infrastructure, and therefore also includes its management and maintenance phases.

Thanks to the access to the detailed information contained in the model, all the maintenance interventions can be drawn up in a simpler and more intuitive way, facilitating the communication between the various stakeholders involved in the project, simplifying the analysis and design processing phases and optimizing the resources.

\section{Acknowledgements}

This research has received funding from the European Union's Horizon 2020 Research and Innovation Programme under grant agreement no. 821282. This paper reflects only the author's views and neither Agency nor the Commission are responsible for any use that may be made of the information contained therein. Acknowledgements to Superintendence of Archaeology, Fine Arts and Landscape (SABAP) of Ravenna, to the Diocese of Ravenna and the Municipality of Ravenna.

\section{References}

Adamopoulos, E., Bovero, A., \& Rinaudo, F. (2020). Image-based metric heritage modeling in the near-infrared spectrum. Heritage Science, 8, 1-12. https://doi.org/10.1186/s40494-020-00397-w.

Balletti, C., Bertellini, B., Gottardi, C., \& Guerra, F. (2019). Geomatics techniques for the enhancement and preservation of cultural heritage. ISPRS Annals of the Photogramm., Remote Sens. and Spatial Inf. Sci., 42 (2/W11), 133-140. https://doi.org/10.5194/isprs-archives-XLII-2-W11-133-2019

Bitelli, G., Dellapasqua, M., Girelli, V.A., Sanchini, E., \& Tini, M.A. (2017). 3D Geomatics techniques for an integrated approach to Cultural Heritage knowledge: The case of San Michele in Acerboli's church in Santarcangelo di Romagna. Int. Arch. Photogramm. Remote Sens. Spatial Inf. Sci., 42-5/W1, 291-296. https://doi.org/10.5194/isprsarchives-XLII-5-W1-291-2017

Bitelli, G.; Balletti, C.; Brumana, R.; Barazzetti, L.; D'Urso, M.G.; Rinaudo, F.; \& Tucci, G. (2019). The GAMHer Research Project for Metric Documentation of Cultural Heritage: Current Developments. Int. Arch. Photogramm. Remote Sens. Spatial Inf. Sci., 42-2N11, 239-246. https://doi.org/10.5194/isprs-archives-XLII-2-W11-239-2019

Bitelli, G., Girelli, V.A., Vannucci, G., \& Pigozzi, M. (2020). Geomatics as a knowledge base propaedeutic to the restoration of an extended fresco wall. Proc. 2020 IMEKO TC-4 International Conference on Metrology for Archaeology and Cultural Heritage, 22-24 October 2020, Trento, Italy.

Brumana, R., Oreni, D., Barazzetti, L., Cuca, B., Previtali, M., \& Banfi, F. (2020). Survey and Scan to BIM Model for the Knowledge of Built Heritage and the Management of Conservation Activities. In: Daniotti B., Gianinetto M., Della Torre S. eds.: Digital Transformation of the Design, Construction and Management Processes of the Built Environment, pp. 391-400, Springer. https://doi.org/10.1007/978-3-030-33570-0_35

Cassanelli, R., Cirelli, E., Crociati, E., Civiletti, J.P., David, M., Fiorini, A., Jäggi, C., Pasquini, L., \& Scaini, R. (2013). La Basilica di Santa Croce. Nuovi contributi per Ravenna tardoantica. ISSN 1722-1374. Edizioni del Girasole.

Girelli, V. A., Tini, M. A., Dellapasqua, M., \& Bitelli, G. (2019). High resolution 3D acquisition and modelling in Cultural Heritage knowledge and restoration projects: the survey of the Fountain of Neptune in Bologna. Int. Arch. Photogramm. Remote Sens. Spatial Inf. Sci., XLII-2/W11, 573-578. https://doi.org/10.5194/isprs-archives-XLII-2W11-573-2019

loannides, M., \& Quak, E., (2014). 3D Research Challenges in Cultural Heritage. A Roadmap in Digital Heritage Preservation. Springer-Verlag Berlin Heidelberg. https://doi.org/10.1007/978-3-662-44630-0

Marino, L. (2019). II restauro di siti archeologici e manufatti edili allo stato di rudere. Italy, Firenze: Dida Press.

Sericola, M., Agostinelli, E., \& Ugolini, A. (2019). L'area archeologica di Santa Croce. Rischio e degrado come elementi per pianificare il futuro di un sito. Monitoring and maintenance of archaeological areas. Climate change, hydrogeological imbalance, environmental and chemical degradation. International Study Conference. Rome, 20-21 March 2019.

Simonini, P., Ceccato, F., \& Tosi, L. (2017). Effetti della subsidenza sul patrimonio edilizio e infrastrutturale. XXVI National Conference of Geotechnics. 20-22 June 2017, Roma, Italy.

Tucci, G., Bonora, V., Conti, A., \& Fiorini, L. (2017). High-quality 3D models and their use in a cultural heritage conservation project. Int. Arch. Photogramm. Remote Sens. Spatial Inf. Sci., Vol. XLII-2N55, 687-693. https://doi.org/10.5194/isprs-archives-XLII-2-W5-687-2017

UNESCO, ICCROM, ICOMOS, \& IUCN (2010). Managing Disaster Risks for World Heritage. ISBN 978-92-3-104165-5. 


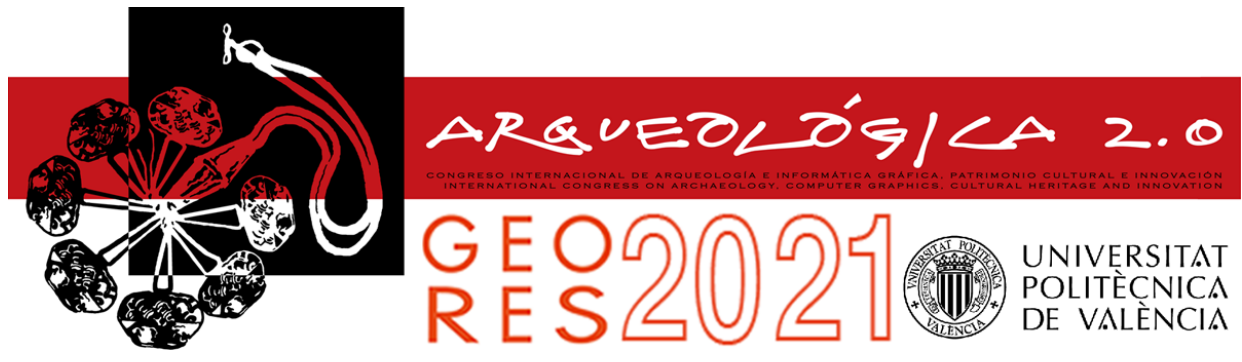

Proceedings of the joint international event $9^{\text {th }}$ ARQUEOLÓGICA

$2.0 \& 3^{\text {rd }}$ GEORES

Valencia (Spain).

26-28 April 2021

Received: 05/12/2020

Accepted: 01/04/2021

DOI: https://doi.org/10.4995/Arqueologica9.2021.12165

\title{
CARE OF ANCIENT HUMAN REMAINS. CONSERVATION AND MANAGEMENT WITH 3D MODELING AND DBMS
}

\author{
Elena Dellù*, Angela Sciatti \\ Physical Anthropology Laboratory, Superintendence of Archaeology, Fine Arts and Landscape for the metropolitan city of Bari, Strada \\ Lamberti 1, Bari 70122, Italy. elena.dellu@beniculturali.it; angelasciatti6@gmail.com
}

\begin{abstract}
:
The interaction between humanities and scientific disciplines is a slow and recent process, which is still standing influencing more and more frequently the reconstruction of our history. Ancient human remains are a significant part of our heritage, both from a cultural and biological point of view. They keep track of our evolution at a macroscopic and genetic level; for this reason, they must be adequately protected. Since 2018, the Superintendence of Archaeology, Fine Arts and Landscape for the metropolitan city of Bari (Ministry of Culture of Italy) has launched a specific protocol for the management of physical anthropological finds, with the aim of protecting, knowing and enhancing them. The use of new technologies, such as 3D modelling of the finds and the management of all archaeological and anthropological data through DBMS, will allow us to carry out long-term protection. This will be the basis for achieving new studies and enhancement activities on ancient human remains, without increasing their degradation.
\end{abstract}

Keywords: cultural heritage, physical anthropology, ethic, digital anthropology, 3D reconstruction, DBMS

\section{Introduction}

Over the last two centuries, the archaeological and speleological investigations carried out in Apulia, in southern Italy, have documented an exceptional quantity of human remains.

The Physical Anthropology Laboratory of the Superintendence of Archaeology, Fine Arts and Landscape for the metropolitan city of Bari deals with the protection and knowledge of this territorial sector. Here are preserved biological testimonies among the most significant in the world, such as Homo Neanderthalensis of Altamura, the oldest and most complete Neanderthal still known in the world (Di Vincenzo et. al., 2019; Lari et. al., 2015) (Fig. 1).

The sites with the discovery of human remains are more than a hundred; these attest to a frequentation starting from the Middle Palaeolithic. Numerous individuals have been identified - still being defined thanks to the ongoing project - which are chronologically framed between the most ancient ages, up to the most recent ones: Neolithic, Eneolithic, Bronze Age, Classical-Hellenistic period, Roman and Middle Ages.

The protection and knowledge activities launched by the Laboratory - starting from 2018 - aim to better and ethically manage human remains, as unique and unrepeatable evidence of our biological history. The goal is to:
- Define the total number of individual differentiated by chronological age / epoch;

- Reconstruct the biological profile of each individual;

- Monitor the state of decay and stabilize it;

- Implement long-term conservation procedures;

- Produce 3D models for better management, conservation, knowledge, enhancement and training purposes;

- Create a DBMS useful for the overall and multivariate management of the various information.

\section{State of art for Physical Anthropological Heritage in Italy}

Anthropological and Paleoanthropological findings are important biological evidence of pre-protohistoric and historical populations. They constitute a little known part of the cultural heritage and are protected by Italian law through the Code of Cultural Heritage and Landscape (D.Lgs. 42/2004) and the Mortuary Police Regulations (D.P.R. 285/90). Human remains preserve the biological and social history of the individuals to which they are related, both at macroscopic, microscopic and genetic levels. They constitute unique and unrepeatable osteobiographies that allow us to reconstruct the

`Corresponding Author: Elena Dellù, elena.dellu@beniculturali.it 
evolution of our species in its morphological, genetic and social components.

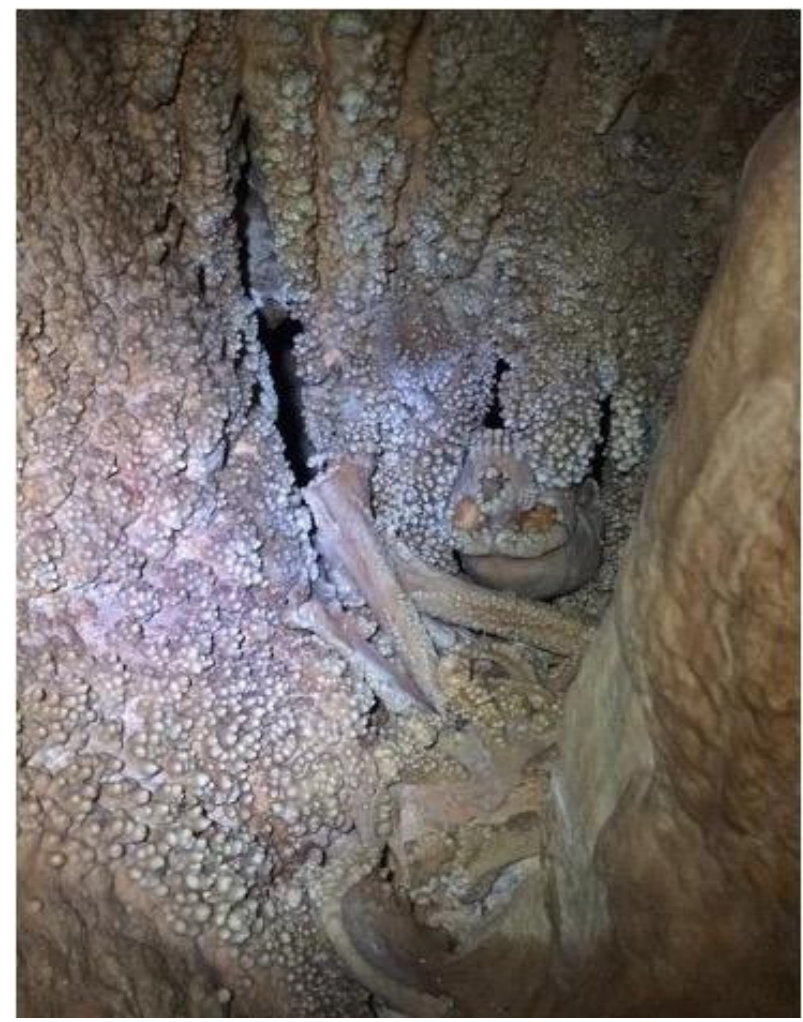

Figure 1: Altamura (BARI), Cave of Lamalunga. Homo Neanderthalensis.

For too long the informative potential of these remains has not been fully expressed, due to the marginalization and discrimination of anthropological data. Consequently, a gap was created in the methodological approach: the contribution of scientific disciplines was considered an appendix to the interpretative reconstruction of the sociocultural processes of past eras, produced almost exclusively by theoretical elaborations by the humanities sector (Perry, 2007; Earle, 2008; Knüsel, 2010; Šlaus, Petaros \& Adamić, 2015; Larsen, 2017; Dellù, 2020). This has generated a reversal of priorities and perspectives, whereby the investigation starts from the products of human actions excluding (in part or in whole) bodies of the people, who instead record first and 'into the bones' personal and social history of their time (Goldstein, 1976; Larson, 1971; Peebles, 1971; Saxe, 1970; Tainter, 1978; Rothschild, 1975; Ubelaker \& Guttenplan Grant, 1989).

In addition to archaeological research, colonial dominations, ethnographic missions and the medicallegal field have allowed the establishment of anthropological collections. Especially in recent decades, the management of human remains is leading to the emergence of ethical problems, at an international and national level.

This part of cultural heritage is defined as "sensitive materials", as explained in the ICOM Code of Ethics for Museums (art. 2.5): "collections of human remains or objects that have a sacred meaning must be acquired only if they can be placed in a safe place and treated with respect. This must be done in accordance with professional standards and with the beliefs and interests, if known, of the members of the communities, ethnic or religious groups from which the objects come".

\section{Ethics of human remains management}

Since these are testimonies of individuals who have actually lived and assumed that, over time, their identity has taken on a different value for the various communities (Ubelaker \& Guttenplan Grant, 1989), Physical Anthropological Heritages are to be considered "sensitive materials" precisely in relation to the different perception of their physical component and at the same time symbolic aspect.

In Italy this sensitivity and awareness is hardly emerging (ICOM Code of Ethics for Museums, 2009; Monza, 2014), while in the Anglo-Saxon world the issue is much more debated; all this because of the recriminations expressed by ethnic or religious communities who have seen themselves deprived of a sensitive part of their past and of the sacred and cultural sphere of their heritage (Mc Gowan \& LaRoche, 1996; Turner, 2005; Turner, Wagner \& Cabana, 2017; Ubelaker \& Guttenplan Grant, 1989).

In this case, the concept of "Cultural Heritage" is fundamental, as it goes to protect a type of finds that has contributed to the construction of the collective memory of a community, with whom it is necessary to establish a dignified and respectful dialogue of its customs and beliefs.

In the past, due to the requisitions carried out by colonial dominations and ethnographic missions, even archaeological research has not been well accepted by the "expropriated" communities. These were judged as acts of racism and violation of the sacred sites, where the remains of their ancestors are deposited; for these reasons, repatriation was requested (Ubelaker \& Guttenplan Grant, 1989; White \& Falkens, 2005, pp. 25 28; Documento sulla questione della richiesta, 2011; Monza, 2014; Monza, 2015; Turner, 2005; Turner, Wagner \& Cabana, 2017)

For example, the strong pressure carried out by Native Americans in the 1990s led to the approval, by President Bush, of the Public Law 101-601, Native American Graves Protection and Repatriation Act (NAGPRA): a protocol for laboratories and museums that provided for the return of the deceased (Mc Gowan \& LaRoche, 1996; Rose, Green \& Green, 1996; White \& Falkens, 2005; Documento sulla questione della richiesta, 2011; Turner, Wagner \& Cabana, 2017). All this did not take into account the conservation issues that would have compromised the physicochemical nature of the finds and actually caused an impoverishment of biological and physical anthropological collections worldwide.

Recently in Italy, this problem is starting to be addressed, as emerges from conferences such as Human Remains. Ethics, conservation, Display (Naples-Pompeii 20-21 May 2019, Turin 30 September-1 October 2019) carried out by the Archaeological Park of Pompei and the Egyptian Museum of Turin; Eticamente sapiens. Dallo scavo alla valorizzazione dei resti umani / Ethically Sapiens. From excavation to the enhancement of human remains (Bari, 17-18 June 2020) by the Superintendence ABAP for the metropolitan city of Bari and the University of Bari; Etica e resti umani. Linee guida e codici etici tra ricerca, documentazione, protezione e valorizzazione / Ethics and 
human remains in the archaeological field. Guidelines and ethical codes between research, documentation, protection and enhancement (Webinar, 10-11 November 2020) by CNR Ethics.

\section{Material and methods}

Starting from October 2018, the Superintendence of Archaeology, Fine Arts and Landscape for the metropolitan city of Bari has been equipped with personnel adequately trained in the physical anthropological field.

This made it possible to start a project entirely dedicated to the management of ancient human remains of the aforementioned territorial sector, also benefiting from the collaboration of trainees and anthropologists / archaeoanthropologists / bioarchaeologists operating on the regional territory and more generally in a national/international context (Fig. 2).

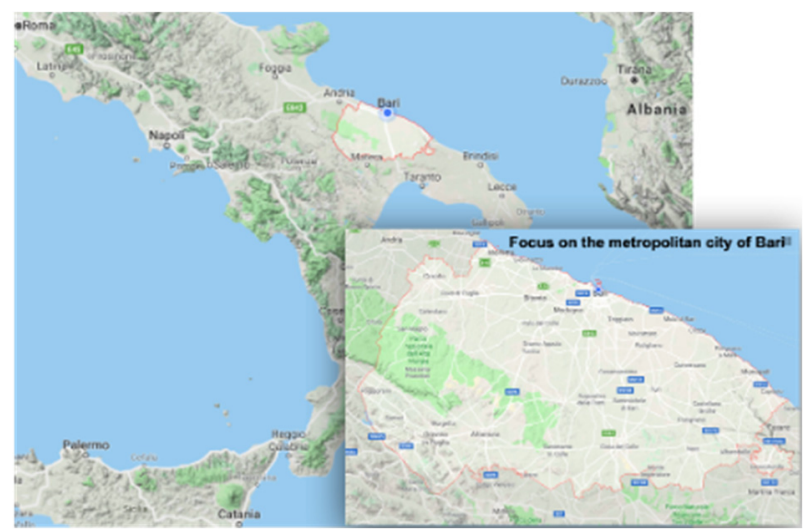

Figure 2: General and particular view of the territorial boundaries of the metropolitan city of Bari.

From a first survey carried out in the deposits of the structure and at the same time the vision of the archive or published documentation, it was possible to arrange a first screening of the archaeological and paleontological sites in which anthropological remains have been identified over the past two centuries. This was the basis on which to set up a multi-year work of managing a type of complex and sensitive cultural heritage.

The human remains available come from different environmental contexts: from karst areas overlooking the coast, to multi-layered urban areas, to hilly complexes of the Alta Murgia Barese. For these reasons, the soils in which the bones have been deposited for millennia were of a different nature and produced diversified diagenetic and taphonomic processes (Canci \& Minozzi, 2015; Duday, 2006; White \& Falkens, 2005). In some cases, they represent isolated testimonies of depositional practices, but in the majority, they constitute funerary areas with tens to a few hundred graves.

It was therefore decided to start a systematic study on two chronological periods, for which a greater number of information was available, such as individuals of the Neolithic age and those of the Middle Ages (Fig. 3). In both cases, there were good conditions of conservation and cleanliness, ease of retrieval in the deposits, preliminary cataloguing of biological profiles, archaeological studies of the contexts and relative dating (often also obtained through ${ }^{14} \mathrm{C}$ analyzes) and, for the most recent investigations, also 3D modelling carried out during excavation.

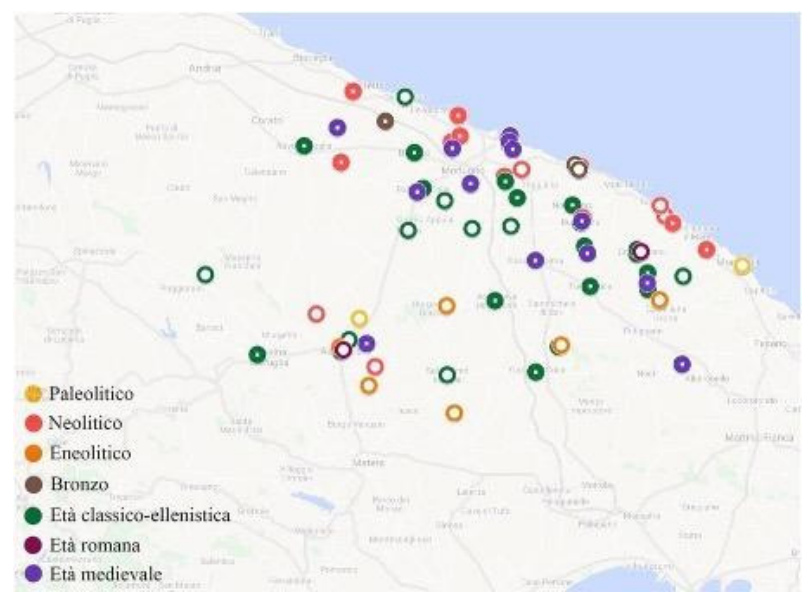

Figure 3: Metropolitan city of Bari. Distribution of archaeological and paleontological sites with the discovery of human remains.

\section{Data acquisition}

\subsection{Archaeological Data}

The archaeological contexts data were identified through a composite research that initially involved the paper and digital archives of the Superintendency. In this way, extrapolated data were available from excavation reports, from stratigraphic unit cards, from topographic surveys and from 3D models obtained through Close Range Photogrammetry (Thanaphattarapornchai, 2012).

This was following by the use of complex cataloguing system with web-based use, designed and continuously implemented by the ICCD-MiC (Central Institute for Catalogue and Documentation), such as the SIGECweb (General Information System of the Catalogue) (www.sigecweb.beniculturali.it). This manages the entire project of Italian Cultural Heritage cataloguing, the production and dissemination of cataloguing standards, in addition to the assignment of the unique catalogue codes and the online publication of the catalogue cards for users. For this reason it was possible to have data referable to many archaeological excavations inherent to the project.

\subsection{Anthropological data and scientific analyses}

Similarly to what was done for the recovery of archaeological data, also for anthropological materials the first step was to identify the existing documentation relating to the human remains in question. Therefore, study reports, Depositional Stratigraphic Unit Cards, AT Cards of Anthropological Findings, reports of scientific analyses and diagnostic investigations $\left({ }^{14} \mathrm{C}\right.$, aDNA, isotope analyses, microscopy analyses, confocal microscopy analyses, X-rays, CT scans, etc.) were identified.

The Lab is also carrying out new targeted studies on each individual based on standard and experimental anthropological methods used in science (Canci \& Minozzi, 2015; White \& Falkens, 2005). The aim is to define the state of conservation and the completely biological profile (sex, age, height, pathologies, 
biomechanical stress, etc.). Since archaeological excavations are destructive activities and at the same time human remains easily degradable and fragmentable, it was decided to integrate data from the previous documentation with the new acquisitions. Given the absence of normalized biological profile cards by $\mathrm{MiC}$, a new complex data storage prototype has been created, based on excel worksheets for use by the Lab and which is extending over the entire Apulian territory. This became fundamental to have a system of standards, where cataloguing tools and rules were based on homogeneous criteria to be used in contexts referable to an extended territory and to different chronological arcs (Fig. 4).

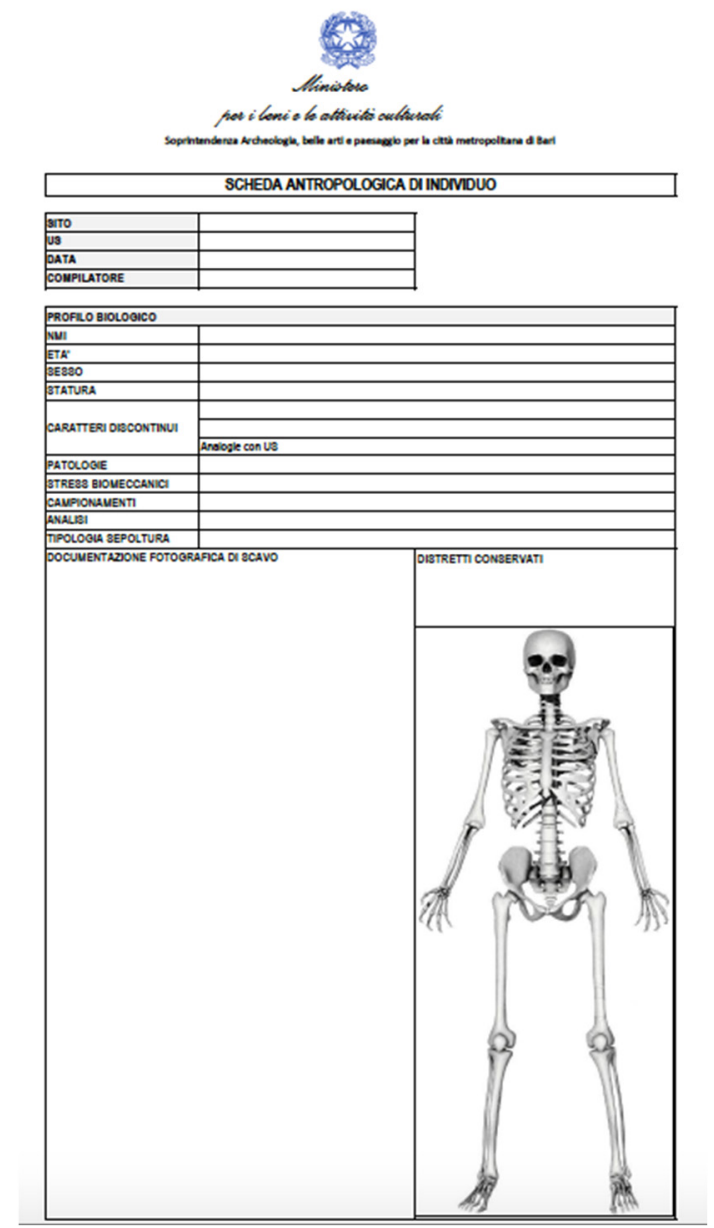

Figure 4: Superintendence of Archaeology, Fine Arts and Landscape for the metropolitan city of Bari, Physical Anthropological Laboratory. First pages of the new normalized anthropological profile cards.

Hand in hand with what has been inserted more extensively on the biological profile sheets of each individual, the AT (Anthropological Finds) and MINP (Asset Value Inventory Form) catalogue sheets are being placed on SIGECweb so that all data are available to the community.

\subsection{Conservative incoming monitoring}

The anthropological finds submitted to the protection of the Lab come from different environmental and chronological contexts. Most of them are located in the deposits of the Superintendency, but in some limited cases they are still preserved in the place of discovery, like the Homo Neanderthalensis of Altamura (Di Vincenzo et. al., 2019; Lari et. al., 2015) (Figs. 5 and 6).

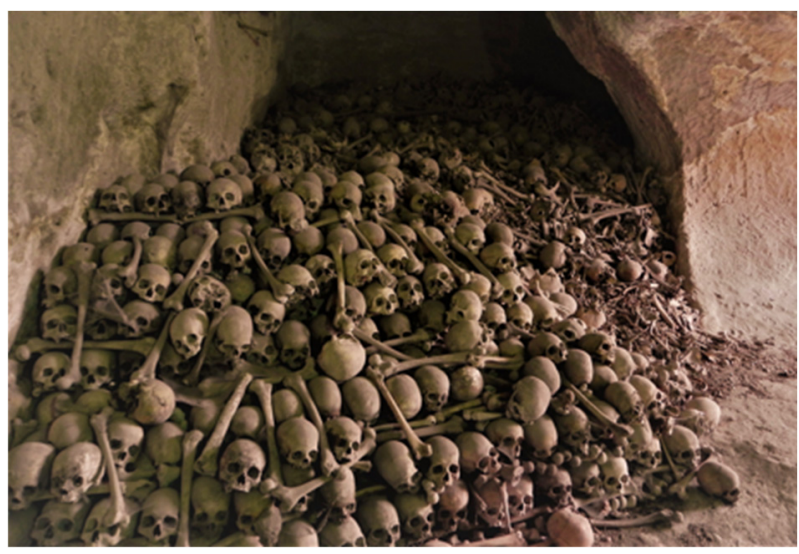

Figure 5: Rock Church of Saint Michael, Gravina in Puglia (Metropolitan city of Bari). Particular conditions of identification and current position of skeletonized human remains.

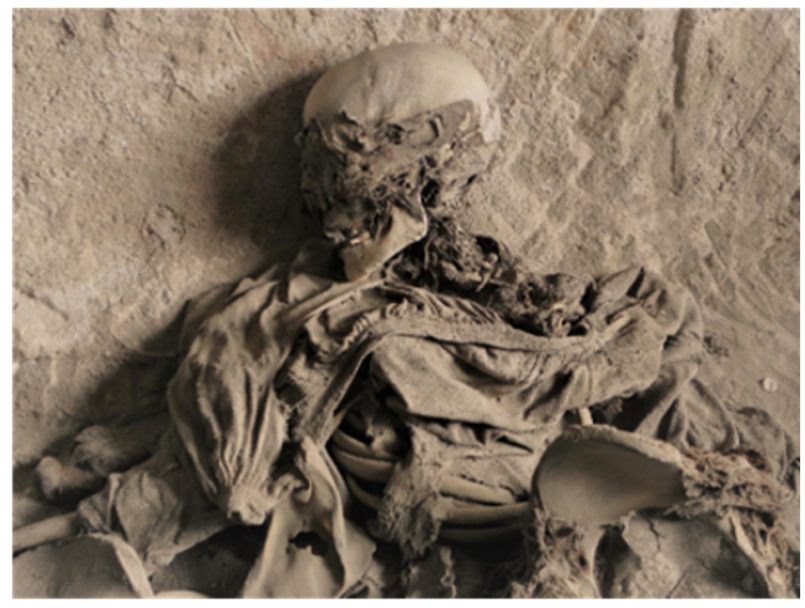

Figure 6: Rock Church of Saint Michael, Gravina in Puglia (Metropolitan city of Bari). Particular conditions of identification and current position of mummified human remains.

There are different diagenetic and taphonomic conditions to which human remains have been subjected over the millennia. At the same time, the moment of their discovery led to changes in the chemical-physical stability that they had reached during the laying (Cassman, Odegaard \& Powell, 2006; Beaubien, 2019; Freiwald \& Miller Wolf K. A., 2019). For these reasons, from the moment of their identification and subsequent extraction by archaeologists and anthropologists, the finds have undergone new changes depending on the new conditions.

At present in Italy there are no monitoring and conservation procedures entirely dedicated and tested on human remains, with the exception of mummified individuals (Samadelli, Zink, Roselli, Gabrielli, Tabandeh \& Fernicola, 2019). For this reason, a new model of conservation data sheet was drafted at the Lab, formulated on the basis of the emergency data sheets prepared by the MiC-Central Institute for Restoration in the context of the management of artworks from the areas affected by the earthquake of L'Aquila in 2009 and Emilia Romagna in 2012 (http://www.icr. beniculturali.it/pagina.cfm?usz=5\&uid=47 3). 
The datasheet was designed to carry out the initial and incoming/long-term monitoring of human remains at the $\mathrm{Lab}$, in order to normalize the information of each find (Fig. 7).

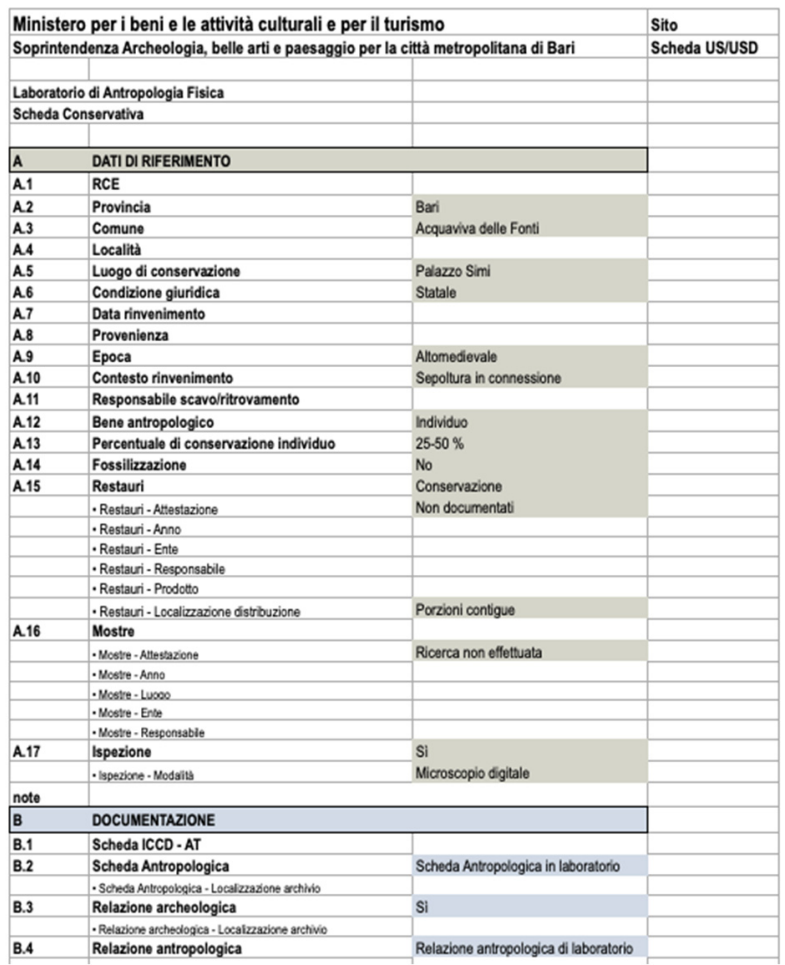

Figure 7: Superintendence of Archaeology, Fine Arts and Landscape for the metropolitan city of Bari, Physical Anthropological Laboratory. First pages of the new normalized Anthropological Conservation Data Sheet.

This was created with excel worksheets and can then be inserted into the DBMS. The structure includes fields with closed answers, in order to normalize the information as much as possible, and is divided into three sections:

- Reference data of the find (place and date of discovery; place of current conservation; epoch; percentage of conservation of the individual; fossilization processes; restorations; samplings; scientific analyses; exhibitions; inspections; etc.) (Fig. 8);

- Documentation (AT sheet; technical sheet of the biological profile; photographic documentation; 2D and 3D graphic documentation; bibliography; etc.);

- Current location conditions (air conditioning, exposure to heat sources, type of container; risks from exposure, mould, humidity, vibrations; safety; etc.) (Fig. 9);

- Technical data and state of conservation (quantitative and qualitative degree of preservation of the individual; degree of compactness of lamellar bone; taphonomicdiagenetic deformations; decohesion; friability; fracturing; chromatic variations; concretions; demineralization; etc.).

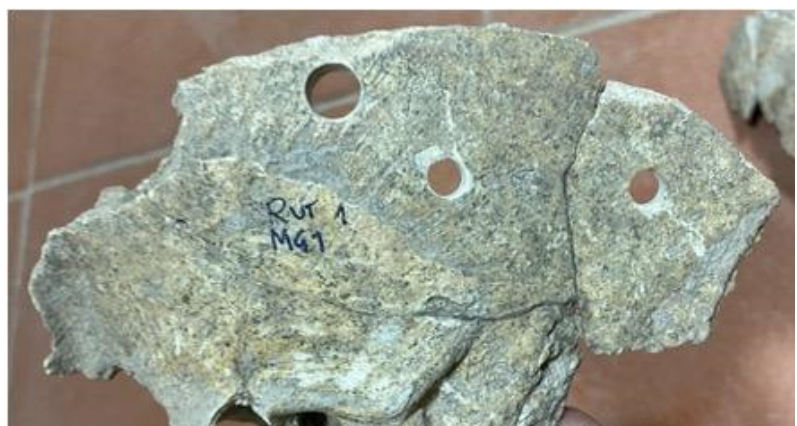

Figure 8: Superintendence of Archaeology, Fine Arts and Landscape for the metropolitan city of Bari, Physical Anthropological Laboratory. Parietal bone of a Neolithic individual with numerous traces of sampling for scientific analysis.

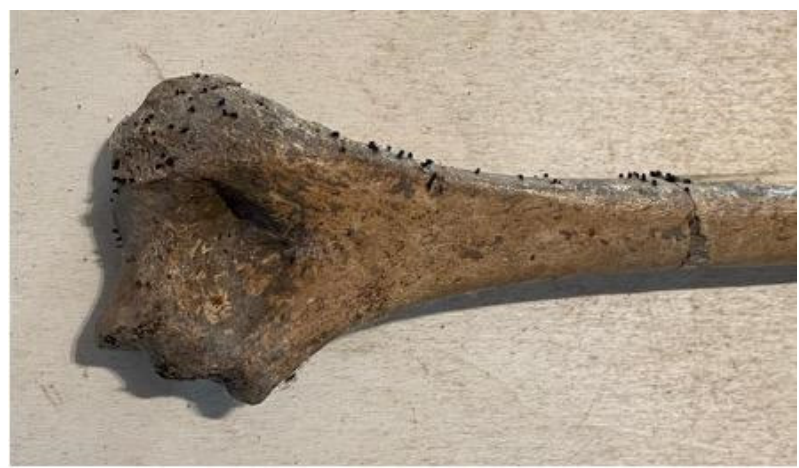

Figure 9: Superintendence of Archaeology, Fine Arts and Landscape for the metropolitan city of Bari, Physical Anthropological Laboratory. Humerus of a Neolithic individual with proliferation of insects.

\subsection{D modelling}

In order to ensure the long-term conservation of ancient human remains, the Lab has launched digital procedures through tridimensional modelling of anthropological finds.

These new technologies allow to conduct a digital anthropological and anthropometric study (Brzobohatá, Prokop, Horák, Jančárek \& Velemínská, 2012; Di Vincenzo, Profico, Tafuri \& Manzi, 2016; Robedizo, 2016; Petarosa et al 2017; Rmoutilová et al, 2018; Wrobel, Biggs \& Hair, 2019); at the same time, they are useful for educational purposes (Serrano, Jiménez Arenas \& Esquivel, 2016). Only recently researchers have begun to utilize 3D digital data to quantitatively evaluate sexual skeletal traits, reducing errors and simplifying statistical analysis for a variety of fields of study, such as clinical, biomedical, forensic, biological and anthropological ones. The latter, in fact, can be carried out correctly: for example, several studies compared the measurements on bones elaborated from digital techniques to real bones. The result was that the virtual models are highly accurate (Decker, Ford, Hoegstrom \& Hilbelink, 2008).

Moreover, supported by computer tomography (CT) scans, 3D output allows to have accurate acquisition data about human bones, that can be also useful to a palaeopathological research (Stull, Tise, Ali \& Fowler, 2014; Urbanová, Hejna \& Jurda, 2015). In fact, the application of CT scan allows for better contrast resolution that results in more detailed images of bones and offers a rapid processing time. 
From a conservative point of view, 3D modelling is aimed to preserve real skeletal remains: it allows a digital study of them that does not require manipulation, without compromising the physical and chemical nature of the material. Then it also preserves numerically constrained fragile skeletal and dental material in paleoanthropological collections (Fiorenza et al., 2018).

For these reasons, the Lab has launched a digitization plan of archaeological and anthropological heritage, under its own protection. Close-range photogrammetry (Thanaphattarapornchai, 2012) - and also Laser Scanning (Karadimas, Kotsopoulos, Papastamatiou, Spyropoulos \&Tsergoulas, 2010) - are useful tools from the excavation phase yet. They provide accurate digital surface models and photo-realistic outputs, optimizing time, for example during operations of preventive archaeology. They also allow to collect information in detail compared to traditional techniques of graphic documentation, so in retrospect, it is possible to review and understand information collected also by those who were not physically on the field.

Thanks to the economy and functionality of the method, through a well-studied photogrammetric survey it is possible to collect materials for elaboration of a 3D model referred to an object or a whole archaeological context.

So ancient human remains collected by Superintendence have undergone the following operations: once placed the object of interest on support, many photos have been taken at $360^{\circ}$ under monitored light conditions (Fig. 10). Then the frames captured in sequence were uploaded to specific software (such as Agisoft Photoscan and Metashape Professional). After aligning points, we have been able to build a dense cloud and a mesh and so elaborate an output which errors were fixed postproduction. The final digital output has been a 3D mesh, known as a polygonal model, representing the morphology of the scanned object. The texture has given the virtual model a realistic appearance with colour and other optical qualities (Kotulanová, Chalás \& Urbanová, 2014). Finally, according to the needs, the file has been exported in various formats.

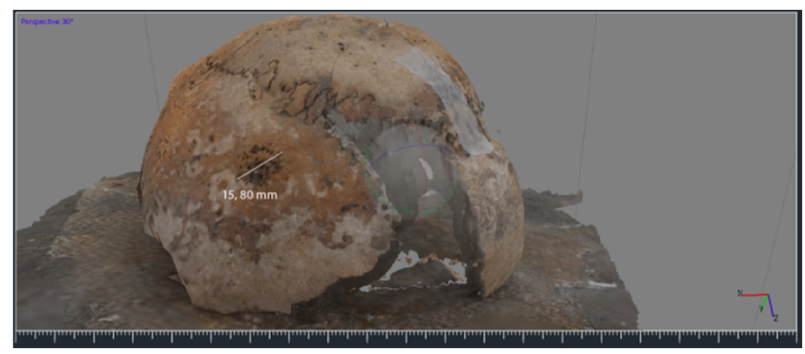

Figure 10: Superintendence of Archaeology, Fine Arts and Landscape for the metropolitan city of Bari, Physical Anthropological Laboratory. 3D model of a medieval skull characterized by pathological circular lesions (metastatic carcinoma vs. multiple myeloma). Method: Photogrammetry; software Agisoft Photoscan, author A. Sciatti.

For the purposes of suitable anthropological documentation, aimed at the morphological, morphometric, palaeopathological and biomechanical study of individual bone remains, there was a need for the calibration of the photographic instrumentation with high resolution, that is, able to guarantee a high accuracy of the anatomical details. At the same time, in the phase of elaboration of the polygonal/three-dimensional model (Reverse Modeling) particular attention was paid to the editing phase (Chibunichev, Knyaz, Zhuravlev \& Kurkov, 2018; Seguchi \& Dudzik 2019). This is because software or non-specialized operators in the anthropological field could correct the various geometries by adopting parameters connected with the aesthetic rendering of the 3D product, effectively homogenizing the surfaces, decimating the meshes and closing the gaps. All this can compromise a correct reading of the finding and lead to an incorrect interpretation of the data.

3D models will prove particularly useful for recreating the original volumes of the bodies of the deceased. On them, it will be possible to rework - through post-processing phases - the biomasses (formulated on the basis of anthropological studies) that have degraded during the course of post-mortem taphonomic events (Cabo, Dirkmaat, Adovasio \& Rozas, 2012).

At the same time products are useful for the learning of students of all levels; useful, in this perspective, is the virtual collection edited by the Smithsonian Institution's Human Evolution Center, in Washington D.C., which has created an extensive online database of primate and hominin fossils available for viewing online and free of charge (https://humanorigins.si.edu/evidence/3dcollection).

In this way, new virtual exhibitions will be able to take advantage of $3 \mathrm{D}$ models to be shown in multimedia products (Barceló, 2000); at the same time, these could be used for new accessibility plans with the adoption of tactile sensory experiences through 3D prints (EvelynWright, Dickinson \& Zakrewski, 2020).

3D modelling results in a functional and sensible tool that softens visitors' effects and creates new approaches to customer experience, for example through augmented reality (Barceló, 2000). It is also useful for scientific needs, as demonstrated by AR experience offered by Field Museum of Chicago which reproduces a funerary context that can be looked through in order to understand archaeological steps of mummy deposition.

Ultimately, from a 3D model, it is possible to operate a face reconstruction of an individual that, if it is well-made (Lee, Yoon, Song, Wilkinson \& Shin 2014; Suppersberger Hamre, Ersland, Daux, Parson \& Wilkinson, 2017) can be an educational tool of enhancement for visitors and so an important instrument of public archaeology (Allen, 2014).

\section{Results}

\subsection{Database Management System}

The aim of Physical Anthropology Laboratory by Superintendence of Archaeology, Fine Arts and Landscape for the metropolitan city of Bari is to promote not only physical and chemical conservation, but also digital one for the consistent anthropological heritage under its own protection. This by virtue of the particular nature of anthropological finds that, in comparison to others, is composed of biological material and so it is at higher conservative risk. At the same time, a digital approach is aimed to support a circular, free and democratic sharing of current knowledge. 
Ethical, sociocultural and emotional implications related to sharing information or images about ancient human remains, and generally, the archaeology of the dead, are sometimes a restriction on scientific research (Manacorda, 2014; Volpe, 2019).

However human remains are not objects to study on the verge of reification, but subjects with their own dignity and they must be managed in a dualistic perspective between ethical and professional deontology (Colleter, 2019). So, this sensible approach is necessary to ensure respectful management of biological evidence that effectively belongs to our cultural heritage.

Due to the digital revolution, the acquisition of archaeological data has changed more than before. The digitization of information has allowed a faster, more efficient and standardized data recording, that facilitates the synthesis work required by the discipline.

In order to encourage the use of advanced technological procedures that are effective, efficient, ergonomic and open-source, testing for the establishment of a preliminary Database Management System is taking place at Physical Anthropology Lab. The main purpose is to allow to store, save, edit, sort and query information about the knowledge of physical anthropological heritage (Nagar, 2011) and so to create an open data and opensource system (Cook, 2018) for a "public bioarchaeology" that is sustainable, stimulating, free and democratic (McGimsey, 1972; Skeates, McDavid \& Carman, 2012; Bonacchi, 2014; Moshenska, 2017; Valenti, 2017; Volpe, 2020).

The requirement is shown for a large amount of material surveyed. Therefore, to ensure consistency of work and an easier finding of information, it was necessary to suggest systematic procedures for data storage, from the acquisition on archaeological sites. This approach will optimise the recording of human bones from the context of finding yet and it configures as a management tool able to manage large quantities of human skeletal remains, count and locate them.

In this way we focus on the elaboration of a real mapping of physical anthropology collection finding in the area of metropolitan city of Bari: so the digitization should interact also in GIS software (Ruda, 2016), considering the List of Apulian Cultural Heritage (CartAPULIA, Progetto finanziato dal P.O. 2007-2013 - Linea 4.2).

At a preliminary step, data collection starts from the information currently known and inserted in the SigecWeb cataloguing system of the Ministry of Culture; therefore a revision of previous documentation is a prerequisite.

Such operations require a rather elaborate time of analysis and design of the structure that will be configured as a real repository (Polly \& Stringer, 2011).

Already from the beginning, it is necessary to define the degree of analyticity to record information within the DB (Valenti, 1998; Fronza, 2001).

Normalizing language is indispensable to give synthetic and direct information, to homogenize incoming data in order to ensure sustainability in terms of costs and time, not sacrificing archaeological and anthropological research
At present, the implementation of such systems is offered by various software, as Microsoft Access 2013, created for the management of relational databases (RDBMS) that exploits the Microsoft Jet Database Engine and which integrates with itself a module for rapid application development (Rapid Application Development). The saving structure follows the relational table model, which allows storage and manages data in tables composed of a large number of records. Each one contains data separated by fields and it is possible to create direct relationships between records.

Because it is a work still in progress, testing of different solutions is legitimate: so we can identify the one that best suits our needs. The purpose is to design an open and implementable DBMS, including not only archaeological information (on the model of ICCD classification), anthropological data (as results from laboratory analysis) and conservative one, but also interacting with other sources, for example as historical ones, with a section of literature in order to ensure a bioinformatics reconstruction as complete as possible (Nielsen, Paul, Albrechtsen \& Song Y. S., 2011; Korneliussen, Albrechtsen \& Nielsen 2014; Ehler, Novotńy, Juras, Chylénski, Moravčík, \& Pačes, 2019).

Moreover, for this purpose, it is necessary to include photographic and eventually 3D documentation, which computer weight may compromise DBMS efficiency. To avoid the problem, the use of QR code seems efficient: users are directed to the web link of the 3D model, as it is possible with Sketchfab platform (Zechini, Holmstrom, Voas \& Killgrove, 2016).

For the aims pursued by the Laboratory, the use of opensource software HumanOs has proved very useful (Colletter, Romain \& Barreau, 2020): it is a practical tool for archaeologists and anthropologists for data acquisition in an ergonomic and sustainable way, open-source and without internet connection.

Skeleton is a key element of DBMS, accompanied by localization and context references and archaeological, taphonomic, conservative, anthropological and biological information.

Some features could be improved, such as the possibility to insert excavation and lab images or to create $3 \mathrm{D}$ models useful for educational and scientific purposes.

So digital recording allows real-time processing of one or more samples, its comparison between different contexts and reduces the occurrence of errors for incoming data.

\subsection{Conservative long-term monitoring}

With "preventive conservation" we identify «all measures and actions aimed at avoiding and minimizing future deterioration or loss. They are carried out within the context or on the surroundings of an item, but more often a group of items, whatever their age and condition. These measures and actions are indirect - they do not interfere with the materials and structures of the items. They do not modify their appearance» (ICOM Terminology to characterize the conservation of tangible cultural heritage, 2010).

In Italy, the idea of "preventive conservation" is closely related to the monitoring of archaeological and artistic assets in museum spaces or for exhibition (Giannini, 
2010; Bonvicini, 2010). But guidelines on the conservation of anthropological heritage are hardly defined.

As already shown by conservative incoming monitoring, Physical Anthropology Laboratory is trying to adopt a management and conservation protocol also with longterm monitoring, in order to minimise the damage caused by the inevitable degradation of organic material (Michalski \& Pedersoli, 2016) (Fig. 11).

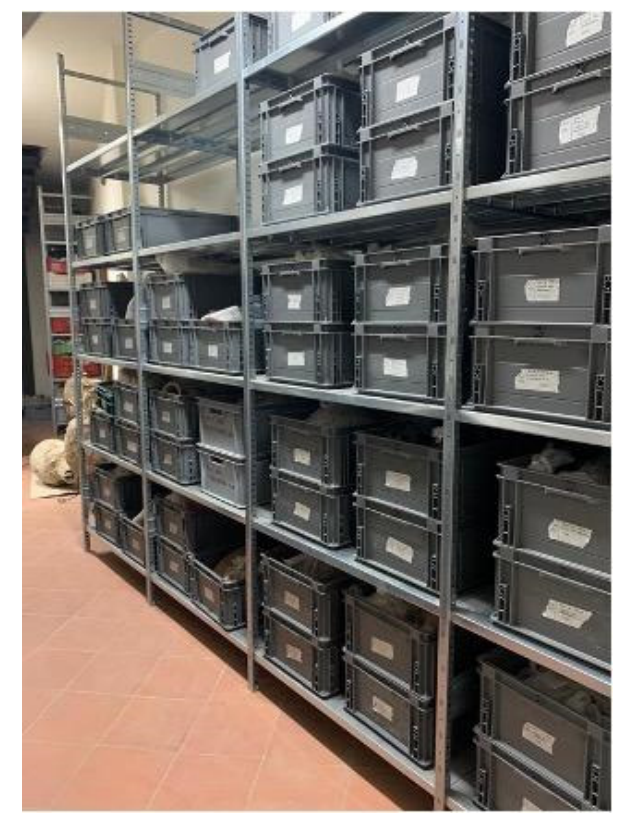

Figure 11: Superintendence of Archaeology, Fine Arts and Landscape for the metropolitan city of Bari. New staging of the archaeological and anthropological deposits of the structure of Palazzo Simi.

So in conjunction with the first attempts on national territory (ch. 3), Lab is moving on the model of Emergency cards in use at the MiC-Central Institute for Restoration (http://www.icr.beniculturali.it/).

These measures are intended to ensure the integrity and identity of anthropological remains over time (Pedersoli, Altomarchi \& Michalski, 2016) and they can be summarised in: conservation, handling, emergency and legislative plan, microclimatic and environmental monitoring (light, humidity, contamination and proliferation of mould and parasites), storage regulation (Marquardt, Montet-White \& Scholtz 1982), use of inert material for housing remains (Cassman \& Odegaard, 2004), staff training, collaboration with other specialists, relationships with potential stakeholders, best practices for public education.

In summary, the Lab is promoting action of deposits adjustment and storage conditions ensuring an entomological control (Matè, Adamo, Cotellessa, De Francesco \& Trematerra, 2016), monitoring spaces, packaging and assessing over time probable changes in the conservation state of anthropological remains (Matè \& Palazzi, 2017).

\subsection{Fruition and enhancement}

As declared by the Convention on the Value of Cultural Heritage for Society, «rights relating to cultural heritage are inherent in the right to participate in cultural life, as defined in the Universal Declaration of Human Rights» (art. 1a, Faro Convention, 2005) and «the conservation of cultural heritage and its sustainable use have human development and quality of life as their goal» (art. 1c, Faro Convention, 2005). If we consider that «a heritage community [...] wish, within the framework of public action, to sustain and transmit [cultural heritage] to future generations» (art. 2b, Faro Convention, 2005), it is clear that these principles can be implemented only through innovative forms of preservation and enhancement.

But in practice, it is not always that easy. Because of wrong conservative conditions and carelessness due to lack of human and economic resources, cultural heritage, and especially ancient human remains, goes toward a progressive deterioration of physical and chemical conditions; so its knowledge is in danger for future generations.

Therefore, modern technologies such as photogrammetry, 3D modelling and printing are necessarily useful to ensure suitable conservation and at the same time enhancement and training purposes. In this way, real ancient human remains are not affected and they are handled as little as possible. So there is a new way to satisfy the needs of scientific research and to ensure an educational and respectful tool that replaces real skeletal remains (Petarosa et al 2017).

This aspect is important also for the communication of Bioarchaeology: because of the nature of this sensible cultural heritage, it is necessary to consider the different impact that his view can generate and the segmentary of the public.

The choice of displaying ancient human remains is not insignificant (Redfern \& Bekvalac, 2013) because, just as in the past, it represents an intimate and symbolic moment for the visitor, which directly seems not to belong to the same community of the deceased, but it really offers a cathartic experience that the sight of skeletal remains produces. The elaboration of death is a human stage with ancestral roots: therefore the museum exhibition takes on not only a didactic value, but also an intimate meaning, depending on viewer sensibility. Hence the doubts about the museum choice of displaying or not the infant skeletal remains.

The potential offered by modern technologies is still unexplored. For example, never as today because of the crisis situation due to the Covid pandemic, we have tested the impossibility to reclaim our rights relating to cultural heritage. Only through virtual experience with social platforms, we have compensated for this human and cultural deprivation, shortening the physical distance and discovering new ways of interaction.

At the same time, this situation brought out the socioeconomic gap that kept many people from the fruition of cultural heritage.

In the first phase, many museums and institutions dealing with cultural heritage have produced an excessive quantity of digital products proposed on social platforms (Mandarano, 2019), almost like a desperate scream by the culture that claims its place in the world and human beings' lives.

But, as Umberto Eco said, «we risk being overwhelmed by an excess of information, and the difference between 
silence and too much noise is really minimal». We must not forget that the progress of knowledge needs a real human identity and the virtual experience shall be designed as an auxiliary tool, and not as a substitute one.

In that sense, the Physical Anthropology Laboratory has reflected on best practices for anthropological remains enhancement in many ways.

From a scientific point of view, it has encouraged archaeoanthropological research publishing and a preliminary elaboration of visual tridimensional content that will be inserted in DBMS, useful to the digital study of ancient remains.

With the aim of promoting knowledge of sensitive heritage, the Laboratory is also opened to the wider public: on these occasions, we offer an overview of archaeoanthropologists work and the potential of the study of ancient human remains (Fig. 12). At the same time, a sociological survey was launched through the drafting of a questionnaire submitted to visitors: so we can understand how they perceive visiting and seeing the experience of ancient human remains. In this way, consumers can give feedback useful to improve customer experience in terms of the museum economy and take part in a new model of sensitive education.

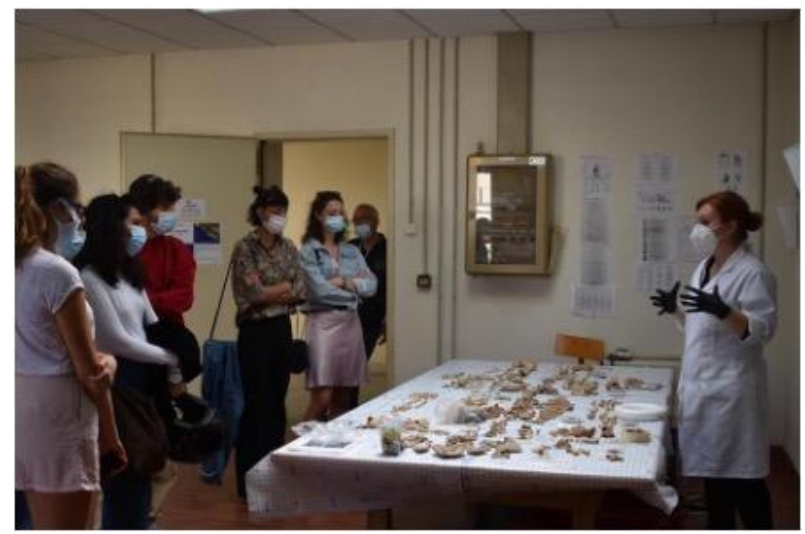

Figure 12: Superintendence of Archaeology, Fine Arts and Landscape for the metropolitan city of Bari, Physical

Anthropological Laboratory. Public communication activities carried out during the European Heritage Days 2020.

Death is a cathartic experience and the seeing of ancient human remains can arouse different feelings depending on the different degree of sensitivity. It is necessary for education and sensibilization of anthropological heritage and before that an accurate analysis of the public, not ever adequately prepared to tolerate a similar impact.

Only with this respectful approach, it is possible to present the potentiality of the study of ancient human remains also to non-experts, with which it is necessary to establish a constructive relationship in order to increase the sense of belonging to the heritage community (art. 2b, Faro Convention, 2005).
Our humble effort represents a contribution to the definition of the best practices to ensure the preservation and the knowledge of cultural heritage (Elfadaly \& Lasaponara 2019).

\section{Discussion}

If until 2018 the human remains found in the territory of the metropolitan city of Bari had not been managed at a conservative level by personnel specialized in the anthropological field, subsequently it was possible to implement a new methodological approach.

The Superintendence of Archaeology, Fine Arts and Landscape for the metropolitan city of Bari has created a new Laboratory of Physical Anthropology, the only structure of MiC for the whole Apulia, thanks to which an interdisciplinary and complex management project of ancient human remains has been launched.

The new practices involve aspects of macro-microscopic and genetic conservation, scientific knowledge, enhancement and training purposes. The management protocols aim to adopt an ethical approach that takes into consideration the respect for these 'sensitive materials' (as people), their long-term conservation and their public knowledge through new ways of dialogue.

The modern methods of 3D model and at the same time the use of DBMS (for the overall management of information) are proving extremely useful to avoid an increasing degradation of this type of biological finds, which are easily perishable. If up to now the experimentation has been taking place on anthropological assets attributable to the Neolithic and medieval age, it is hoped to extend this type of approach to all the biological collections of the Superintendence of Archeology, Fine Arts and Landscape for the metropolitan city of Bari.

\section{Acknowledgements}

Funding: This research was fully funded by the Italian Ministry of Culture.

We would like to acknowledge the numerous archaeologists, anthropologists, archaeoanthropologists, conservative restorers of MIC, MIUR and free professionals who, over the years, have worked in the territory of the metropolitan city of Bari providing useful data for the current project. In particular L. La Rocca, F. Radina, M. R. De Palo, M. Corrente, A.M. Tunzi, S. Cicala, V. Scattarella, S. Sublimi Saponetti, G. Manzi, M. Cuccovillo, P. D'Onghia, G. Panzarino, L. Lamanna, S. Sivilli.

We also acknowledge the architect M. Piccarreta, director of the Superintendence ABAP for the metropolitan city of Bari and all the staff of the institution; the professors D. Nuzzo, director of the School of specialization in archaeological heritage of Bari (University of Bari - Aldo Moro), and G. Volpe.

\section{References}

Allen, H. (2014). Handing the Past to the Present: The Impact of 3D Printing on Public Archaeology. Pennsylvania Archaeologist, 84(1), 9-13.

Beaubien, F.H. (2019). Field Conservation of Skeletal Remains: Stabilization Treatment Techniques and Implications for Future Analysis. Advances in Archaeological Practice, 7, 23-29. https://doi.org/10.1017/aap.2018.36 
Bonvicini, C. (2010). La conservazione preventiva nel contesto degli standard museali italiani, in Complesso Museale Santa Maria della Scala (Ed.) Conservazione preventiva e controllo microclimatico nel contesto degli standard museali, Siena (pp. 19-27).

Brzobohatá, H., Prokop, J., Horák, M., Jančárek, A., \& Velemínská, J. (2012). Accuracy and benefits of 3D bone surface modelling: a comparison of two methods of surface data acquisition reconstructed by laser scanning and computed tomography outputs. Collegium antropologicum, 36/3, 801-806.

Cabo, L.L., Dirkmaat, D.C., Adovasio, J.M., \& Rozas, V.C. (2012). Archaeology, mass graves, and resolving commingling issues through spatial analysis. In D. C. Dirkmaat (eds), A Companion to Forensic Anthropology, Hoboken-New Jersey, pp. 175-196. https://doi.org/10.1002/9781118255377.ch9

Canci, A., Minozzi, S. (2015). Archeologia dei resti umani. Dallo scavo al laboratorio, Roma.

Cassman, V., \& Odegaard, N. (2004). Human Remains and the Conservator's Role. Studies in Conservation, 49(4), 271282. https://doi.org/10.2307/25487703

Cassman, V., Odegaard, N., \& Powell, J. (2006), Human Remains: Guide for Museums And Academic Institutions, Lanham. https://doi.org/10.1525/aa.2007.109.3.551

Chibunichev, A., Knyaz, V., Zhuravlev, D., \& Kurkov, V. (2018). Photogrammetry for Archaeology: Collecting Pieces Together. ISPRS - International Archives of the Photogrammetry, Remote Sensing and Spatial Information Sciences. XLII-2, 235-240. https://doi.org/10.5194/isprs-archives-XLII-2-235-2018

Colleter, R. (2019). Les restes humains archéologiques en France: entre objets de science et sujets de droit. Canadian Journal of Bioethics, 2/3, 97-108. https://doi.org/10.7202/1066467ar

Colletter, R., Romain, J. B., \& Barreau, J. B. (2020). Humanos: an open source nomadic software database. Virtual Archaeology Review, 11(23), 94-105. https://doi.org/10.4995/var.2020.13422

Convention on the Value of Cultural Heritage for Society, Faro (2005).

Cook, K. (2018). Open Data as Public Archaeology: The Monumental Archive Project. Online Journal in Public Archaeology Special, 3, 177-194. http://dx.doi.org/10.23914/ap.v8i2.152

Bonacchi, C. (2014). Understanding the Public Experience in the UK and Italy: A Call for a Sociological Movement of Public Archaeology. European Journal of Post-Classical Archaeologies, 4, 377-400.

Decker, S., Ford, J., Hoegstrom, E., \& Hilbelink, D. (2008). Virtual skull Anatomy: Three-Dimensional Computer Modeling and Measurement of Human Cranial Anatomy. Proceedings of the American Academy of Forensic Sciences, 14, 312.

Decker, S. J., Davy-Jow, S. L., Ford, J. M., \& Hilbelink, D. R. (2011). Virtual Determination of Sex: Metric andNonmetric Traits of the Adult Pelvis from 3D Computed Tomography Models. Journal of Forensic Science, 56(5), 1107-1114. https://doi.org/10.1111/j.1556-4029.2011.01803.

Dellù, E. (2020). Antropologia e Archeologia. Un approccio bioculturale per la ricostruzione delle popolazioni storiche, in G. Castiglia \& Ph. Pergola (eds.), Instrumentum Domesticum. Archeologia cristiana, temi, metodologia e cultura materiale della tarda antichità e dell'alto medioevo, Città del Vaticano (pp. 233-258).

Di Vincenzo, F., Churcill, S.E, Buzi, C., Profico, A., Tafuri, M.A., Micheli, M., Caramelli, D., \& Manzi, G. (2019). Distinct among Neanderthals: The scapula of the skeleton from Altamura, Italy. Quaternary Science Reviews, 217, 76-88. https://doi.org/10.1016/j.quascirev.2018.11.023

Di Vincenzo, F., Profico, A., Tafuri, M. A., \& Manzi, G. (2016). The cranium of the Altamura Neanderthal (Puglia, Italy): virtual extraction, digital restoration and morphological notes, Poster Conference EHSE - 6th Annual Meeting (Madrid, 24-28 September 2016), 80.

Documento sulla questione della richiesta, 2011 = Documento sulla questione della richiesta, presentata dal Governo Australiano, di restituzione di resti scheletrici umani provenienti dal territorio Australiano conservati presso la Sezione di Antropologia ed Etnologia del Museo di Storia Naturale dell'Università di Firenze, Museologia Scientifica, Nuova serie, $5,11-21$.

Duday, H. (2006). Lezioni di Archeotanatologia. Archeologia funeraria e antropologia sul campo, Roma.

Earle, T. (2008). Anthropology Must Have Archaeology. Archaeological Papers of the American Anthropological association, 2008, 17-26. https://doi.org/10.1525/ap3a.2003.13.1.17

Ehler, E., Novotńy, J., Juras, A., Chylénski, M., Moravčík, O., \& Pačes, J. (2019). AmtDB: a database of ancient human mitochondrial genomes. Nucleic Acids Research, 47, D29-D32. https://doi.org/10.1093/nar/gky843; https://amtdb.org/

Elfadaly, A., \& Lasaponara, R. (2019). On the Use of Satellite Imagery and GIS Tools to Detect and Characterize the Urbanization around Heritage Sites: The Case Studies of the Catacombs of Mustafa Kamel in Alexandria, Egypt and the Aragonese Castle in Baia, Italy. Sustainability, 11, 2110, 1-18. https://doi.org/10.3390/su11072110 
Evelyn-Wright, S., Dickinson, A., \& Zakrewski, S. (2020). Getting to grips with 3D printed bones: Using 3D models as 'diagrams' to improve accessibility of palaeopathological data. Papers from the Institute of Archaeology, 29(1), 1-10.

Fiorenza, L., Yong, R., Ranjitkar, S., Hughes, S., Quayle, M., McMenamin, P. G., Kaidonis, J., Townsend, G. C., \& Adams, J. W. (2018). Technical note: The use of 3D printing in dental anthropology collections. American Journal of Physical Anthropology, 167(2), 400-406. https://doi.org/10.1002/ajpa.23640

Freiwald, C., \& Miller Wolf, K. A. (2019). Considering Conservation of Human Skeletal Remains in Archaeological Contexts. Advances in Archaeological Practice, 7 (1), 3-9.

Fronza, V. (2001). Il sistema degli archivi nella gestione di un cantiere di scavo e la sua integrazione in un sistema globale (l'esperienza senese). Workshop Soluzioni GIS nell'informatizzazione dello scavo archeologico (Siena, 9 giugno 2001), 25-34

Giannini, C. (2010). Dizionario del restauro. Tecniche, diagnostica, conservazione, Firenze.

Goldstein, L.G. (1976). Spatial Structure and Social Organization: Regional Manifestations of Mississippian Society, Unpublished Ph.D. Dissertation, Northwestern University.

ICOM Code of Ethics for Museums. (2009).

ICOM Terminology to characterize the conservation of tangible cultural heritage (2010).

Karadimas, N., Kotsopoulos, K., Papastamatiou, N., Spyropoulos, A., \& Tsergoulas, K. (2010). Combination of Cost Effective 3D scanning techniques for the development of web virtual museums, Conference: ICCOM'10 Proceedings of the 14th WSEAS International Conference on Communications (Corfu Island, Greece - July 2010). https://doi.org/10.13140/2.1.4102.9443

Knüsel, C.J. (2010). Bioarchaeology: a synthetic approach. Bull. Mém. Soc. Anthropol. Paris, 22, $62-73$. https://doi.org/10.1007/s13219-010-0003-1

Korneliussen, T. S., Albrechtsen A., \& Nielsen R., (2014). ANGSD: Analysis of Next Generation Sequencing Data. BMC Bioinformatics, 15, 356. https://doi.org/10.1186/s12859-014-0356-4

Kotulanová, K., Chalás, I., \& Urbanová, P. (2014). 3D Virtual Model Database of Human Faces: Applications in Anthropology and Forensic Sciences. Dolní Věstonice Studies, 20 (Mikulov Conference Anthropology Meeting 2014), 177-180.

Lari, M., Di Vincenzo, F., Borsato, A., Ghirotto, S., Micheli, M., Balsamo, C., Collina, C., De Bellis, G., Frisia, S., Giacobini, G., Gigli, E., Hellstrom, J.C., Lannino, A., Modi, A., Pietrelli, A., Pilli, E., Profico, A., Ramirez, O., Rizzi, E., Vai, S., Venturo, D., Piperno, M., Lalueza-Fox, C., Barbujani, G., Caramelli, D., \& Manzi, G. (2015). The Neanderthal in the karst: first dating, morphometric, and paleogenetic data on the fossil skeleton from Altamura (Italy). Journal of Human Evolution, 82, 88-94. https://doi.org/10.1016/j.jhevol.2015.02.007

Larsen, C.S. (2017). Bioarchaeology in perspective: from classifications of the dead to conditions of the living. American Journal of Physical Anthropology, 165, 865-878. https://doi.org/10.1002/ajpa.23322

Larson, L.H. Jr. (1971). Archaeological implications of social stratification at the Etowah Site, Georgia, in J.A. Brown (Ed.), Approaches to the Social Dimensions of Mortuary Practices, «Am. Antiquit.», 36 (pp. 58-67).

Lee, W. J., Yoon, A. Y., Song, M. K., Wilkinson, C. M., \& Shin, D. H. (2014). The archaeological contribution of forensic craniofacial reconstruction to a portrait drawing of a Korean historical figure. Journal of Archaeological Science, 49, 228-236. https://doi.org/10.1016/j.jas.2014.05.022

Manacorda, D. (2014). L'Italia agli italiani. Istruzioni ed ostruzioni per il patrimonio culturale, Bari.

Mandarano, N. (2019), Musei e media digitali, Roma.

Marquardt, W. H., Montet-White A., \& Scholtz, S. C. (1982). Resolving the Crisis in Archaeological Collections Curation. American Antiquity, 47(2), 409-418. https://doi.org/10.1017/S0002731600061308

Matè, D., Adamo, M., Cotellessa, G., De Francesco, M., \& Trematerra, P. (2016). Azione dei Blattoidei su "stampe a colori": fotografiche, fotomeccaniche e digitali, Poster Sessione XI - Entomologia merceologica e urbana (Merceologica), Atti XXV Congresso Nazionale Italiano di Entomologia (Padova, 24-25 giugno 2016), 344.

McGimsey, C. R. (1972). Public Archaeology, New York.

Mc Gowan, G.S., \& LaRoche C.J. (1996). The Ethical Dilemma Facing Conservation: Care and Treatment of Human Skeletal Remains and Mortuary Objects. Journal of the American Institute for Conservation, 35/2, 109-121. https://doi.org/10.1179/019713696806124548

Michalski, S., \& Pedersoli, J. L. (2016). The ABC Method: a risk management approach to the preservation of cultural heritage, Ottawa.

Monza, F. (2014). Esporre I resti umani: un problema tra ricerca, etica e comunicazione. II caso britannico. Museologica Scientifica Memorie, 11, 241-244. 
Monza, F. (2015). Un approccio multidisciplinare alla gestione dei resti umani nei musei, Poster XXI Congresso degli Antropologi Italiani (Bologna/Ravenna, 3-5 settembre 2015).

Moshenska, G. (2017). Key Concepts in Public Archaeology, London.

Nagar, Y. (2011). Human osteological database at the Israel Antiquities Authority Overview and some examples of use. Bioarchaeology of the Near East, 5, 1-18.

Nielsen, R., Paul, J. S., Albrechtsen A., \& Song Y. S. (2011). Genotype and SNP calling from next-generation sequencing data. Nat Rev Genet, 12(6), 443-451. https://doi.org/10.1038/nrg2986

Pedersoli, J. L., Altomarchi, C., \& Michalski, S. (2016). A Guide to Risk Management of Cultural Heritage, Ottawa.

Peebles, C.S. (1971). Moundville and surrounding sites: Some structural considerations of mortuary practices, in J.A. Brown (Ed.), Approaches to the Social Dimensions of Mortuary Practices, Am. Antiquit., 36 (pp. 68-91). https://doi.org/10.1017/S0081130000002550

Perry, M.A. (2007). Is bioarchaeology a handmaiden to history? Developing a historical bioarchaeology. Journal of Anthropological Archaeology, 26, 486-515. https://doi.org/10.1016/j.jaa.2007.02.002

Petarosa, A., Garvinc, H. M., Sholtse, S. B., Schlagerf, S., Sebastian, K.T.S., \& Wärmländer, S. K. T. S. (2017). Sexual dimorphism and regional variation in human frontal bone inclination measured via digital 3D models. Legal Medicine, 29, 53-61. http://dx.doi.org/10.1016/j.legalmed.2017.10.001

Polly, P. D., \& Stringer, C. (2011). The Ancient Human Occupation of Britain (AHOB) Database, in R. Macchiarelli, G. C. Weninger (eds.) Pleistocene Databases: Acquisition, Storing, Sharing, Mettmann (pp. 51-60).

Redfern, R., \& Bekvalac, J. (2013). The Museum of London: An Overview of Policies and Practice, in M. Giesen (Ed.

Curating Human Remains. Caring for the Dead in the United Kingdom, Newcastle University, (pp. 87-98).

Rmoutilová, R., Guyomarc'h, P., Velemínský, P., Šefčáková, A., Samsel, M., Santos, F., Maureille, B., \& Brůžek, J. (2018). Virtual reconstruction of the Upper Palaeolithic skull from ZlatyÂ Kůn̆, Czech Republic: Sex assessment and morphological affinity. PLoS ONE 13(8): e0201431. https://doi.org/10.1371/journal.Pone.0201431

Rose, J.C., Green, T.J., \& Green, V.D. (1996). Nagpra is forever: Osteology and the Repatriation of Skeletons. Annual Review of Anthropology, 25, 81-103.

Rothschild, N.A. (1975). Age and Sex, Status and Role, in Prehistoric Societies of Eastern North America, Ph.D. Dissertation, University of New York.

Ruda, A. (2016). Exploring Tourism Possibilities Using GIS-based Spatial Association Methods. Geographia Technica, 11(2), 87-101. https://doi: 10.21163/GT_2016.112.09

Samadelli, M., Zink, A., Roselli, G., Gabrielli, S., Tabandeh, S., \& Fernicola, C. (2019). Development of passive controlled atmosphere display cases for the conservation of cultural assets. Journal of Cultural Heritage, 35, 145-153. https://doi.org/10.1016/j.culher.2018.05.005

Saxe, A.A. (1970). Social Dimensions of Mortuary Practices, Ph.D. Dissertation, University of Michigan.

Seguchi, N., \& Dudzik, B. (2019). 3D Data Acquisition for Bioarchaeology, Forensic Anthropology and Archaeology. Cambridge, Massachusetts: Academic Press. https://doi.org/10.1016/C2017-0-02320-0

Serrano, A., Jiménez Arenas, J. M., \& Esquivel, J. A. (2016). Evolución humana y antropología virtual: una propuesta para la docencia y la investigación. Revista Otarq Otras arqueologías, 1, $267-283$. http://dx.doi.org/10.23914/otarq.v0i1.98

Skeates, R., McDavid, C., \& Carman, J. (Eds.) (2012). The Oxford Handbook of Public Archaeology, Oxford.

Šlaus, M., Petaros, A., \& Adamić, A. (2015). Bioarchaeology. A discipline that encompasses the past, present and future of mankind. Periodicum Biologorum, 117/1, 27-34. https://hrcak.srce.hr/139483

Stull, K. E., Tise, M. L., , Ali, Z., \& Fowler, D. L. (2014). Accuracy and reliability of measurements obtained from computed tomography 3D volume rendered images. Forensic Science International, 238, $133-140$. https://doi.org/10.1016/j.forsciint.2014.03.005

Suppersberger Hamre, S., Ersland, G. A., Daux, V., Parson, W., \& Wilkinson, C. (2017). Three individuals, three stories, three burials from medieval Trondheim, Norway. PLoS ONE 12(7), 1-26. https://doi.org/10.1371/journal.pone.0180277

Tainter, J.A. (1978). Mortuary practices and the study of prehistoric social systems, in M. Schiffer (Ed.), Archaeological Advances in Method and Theory, 1 (pp. 105-141).

Thanaphattarapornchai, M. (2012). Close-Range Photogrammetry for 3D Archaeological Documentation: Digital Human Remains, Poster Finearts Department, Thailand 2012.

Turner, T.R. (Ed.) (2005). Biological Anthropology and Ethics: From Repatriation to Genetic Identity, New York. 
Turner, T.R., Wagner, J.K., \& Cabana, G.S. (2018). Ethics in biological anthropology. American Journal of Physical Anthropology, 165, 939-951. https://doi.org/10.1002/ajpa.23367

Ubelaker, D.H., \& Guttenplan Grant. L., (1989). Human Skeletal Remains: Preservation or Reburial ?. Yearbook of Physical Anthropology, 32, 249-287.

UNI 10829 (1999). Works of art of historical importance - Ambient conditions or the conservation - Measurement and analysis.

UNI EN 15757 (2010). Conservation of Cultural Property - Specifications for temperature and relative humidity to limit climate-induced mechanical damage in organic hygroscopic materials.

Urbanová, P., Hejna, P., \& Jurda, M. (2015).Three-dimensional Body Surface Documentation in Forensic Pathology, Poster Conference: AAFS 67th Annual Scientific Meeting, Florida USA.

Valenti, M. (1998). La gestione informatica del dato; percorsi ed evoluzioni nell'attività della cattedra di Archeologia Medievale del Dipartimento di Archeologia e Storia delle Arti-Sezione Archeologica dell'Università di Siena. Archeologia e Calcolatori, 9, 305-329.

Valenti, M. (2017). Appunti, grezzi, per un'agenda di Archeologia Pubblica in Italia, in J. Moreland, J. Mitchell, B. Leal (eds.) Encounters, Excavations and Argosies: Essays for Richard Hodges, Oxford (pp. 314-328).

Volpe, G. (2019). Il bene nostro. Un impegno per il patrimonio culturale, Bari.

Volpe, G. (2020). Archeologia Pubblica. Metodi, tecniche, esperienze, Roma.

White, T.D., Falkens, P.A. (Eds.). (2005). The Human Bone manual, USA.

Wrobel, G.D., Biggs, J.A., \& Hair, A.L. (2019). Digital Modeling for Bioarchaeologists. Advances in Archaeological Practice, 7, 47-54. https://doi.org/10.1017/aap.2018.47

Zechini, M. E., Holmstrom, J., Voas, M., \& Killgrove, K. (2016). Digitizing ROGeR: Creating a Recommended Osteology Guide for e-Readers, Poster University of Florida 2016. 


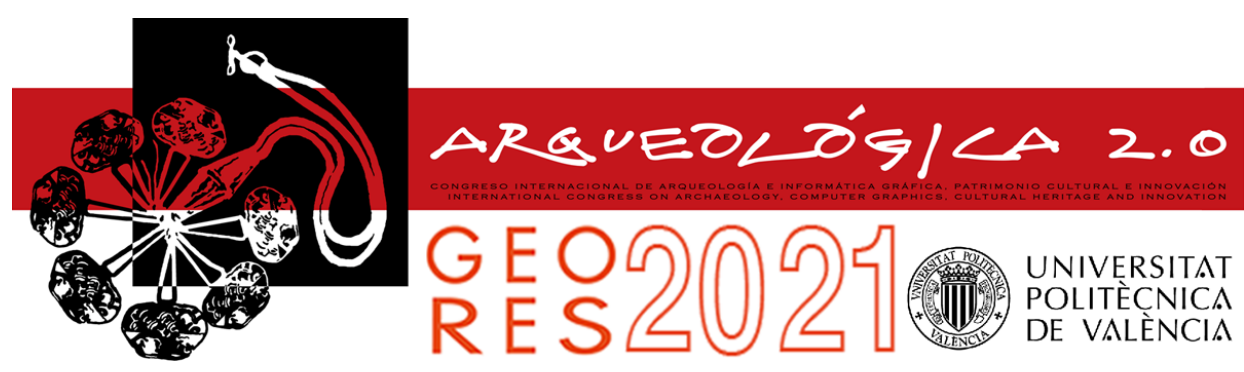

Proceedings of the joint international event $9^{\text {th }}$ ARQUEOLÓGICA

$2.0 \& 3^{\text {rd }}$ GEORES

Valencia (Spain).

26-28 April 2021

\title{
THE TAORMINA THEATER: THE DIGITAL SURVEY SYSTEM OF KNOWLEDGE OPEN IN TIME
}

\author{
Giuseppe Di Gregorio \\ Dipartimento di Ingegneria Civile e Architettura, Università degli Studi di Catania, Via Santa Sofia 64, 95125 Catania, Italy. \\ giuseppe.digregorio@unict.it
}

\begin{abstract}
:
In Sicily, there are 19 show venues including ancient theaters and theatrical architectures. Many of these structures are fully functional and subject to visitor flows such as the theater of Syracuse and that of Taormina. They are object of interest and curiosity, revealed in the eighteenth century during the Grand Tour by travelers and landscape painters, in the last twenty years they have become reasons for study in various scientific areas as from acoustics to archeology, always passing through digital surveying. Studied through classical photogrammetry, structure from motion (SFM), 3D laser scanner, their representation as well as by increasingly refined and detailed two-dimensional graphics, makes use of 3D representations and techniques of virtual reality (VR) and augmented reality (AR). Due to their particular geometry, the need for studies and researches is considering essential to deepen the methods of the surveys and plan their developments. Examples and problems for the archaeological survey are reporting with the aim of critically evaluating the current state of the art of 3D survey, the potential and possible future developments. The present study shows the results obtained for the survey of the Taormina Theater (ME) and an in-depth analysis of the versura environments.
\end{abstract}

Keywords: digital archaeology, cultural heritage, digital survey, 3D reconstruction, photogrammetry, drawing

\section{Introduction}

The Taormina Theater (Fig. 1) has a diameter of the cavea equal to about $109 \mathrm{~m}$, that of the orchestra equal to about $35 \mathrm{~m}$, the current number of seats is 4,500 , the plant is about $50 \mathrm{~m}$ in width and $120 \mathrm{~m}$ in length, for height it develops for about $20 \mathrm{~m}$. Slightly smaller than that of Syracuse in size, it exceeds it in terms of the number of visitors equal to 888,353 in 2019 , against the 692,186 of the Syracuse Theater, contending in alternate periods for the primacy for Sicily with the archaeological area of the valley of the temples in Agrigento, which counts 954,988 visitors in 2019. If you think that in 2010 the number of visitors was 592,468 , we understand that the trend is constantly growing, but it should also be observing that it is for all the archaeological museum sites of Sicily Island. These considerations make us understand the growth of an increasingly culturally evolved tourism, from which the importance in both directions derives, on the one hand, the need for increasingly in-depth scientific studies (Benedetti, Gaiani, \& Remondino, 2010), on the other of dissemination and fruition products such as virtual reality (VR) and augmented reality (AR). This study gives the results of the survey carried out for the Greek-Roman theater of Taormina and the in-depth study for the development of the versura environments. For these two environments, different softwares was used, both for acquisitions with active sensors, and via SFM for terrestrial images with known problems, such as initial filtering, cloud decimation, elimination of external and internal noise, saturation of holes, removal of points of low quality, etc.

\section{Digital survey, variants and invariants}

The definition of analogical indicates the comparison between operations based on their describability through logical similarities, defining the imperfect correspondence between phenomenon and model, often referred to as relations of formal, figurative or material mimesis. The image contained in a photograph intended as a representation of an object is always analog: its support can be digital or analogical. Structure From Motion (SFM) and dense Matching, Multi-View Stereo (MVS) multiimage photogrammetry transform two-dimensional analog models (photographs) into a continuous 3D digital model. The exponential acceleration of the last ten years has seen the evolution in different directions of studies concerning digital technologies. The need to safeguard the heritage of artistic, architectural and archaeological heritage has led to the development of increasingly innovative research systems, suitable for documentation, knowledge and survey, intended as a basic prerequisite for cataloging, study and protection. The tower of Babel of the many management, processing, post processing, $3 \mathrm{D}$ creation software, with their interchange formats that are sometimes mutually compatible and others not, constitutes a universe in continuous evolution. The direction taken by a single study depends on the objectives to achieve, but essentially everything can be traced back to two directions, the first is based on 
knowledge and envisages a scientific or cultural result for specialists as an objective, the second goes in the direction of dissemination and fruition. In the process of representing the Cultural heritage, there are variants and invariants. The survey, the measurements, the laser scanning, the graphic representation are invariant over time. The software, the applications for clouds post processing, for thinning, the software for photogrammetry single image, multi-image, SFM, MVS, for the creation of VR and AR are variants. More generally, the measurement data constitute primitives that describe the object at time to of the survey, certainly invariable, if the meaning has changed over time, it must sought in the dynamic analysis of the object. More simply, a drawing or a dated 3D Laser scan retains its validity: a current laser scanner, although faster than the first generations, will obtain the same metric data. What varies is the finally result through the post processing routines, creation of $3 D$ environments, semantic segmentation, pipelines, solutions, algorithms (Grilli, \& Remondino, 2019). Emphasis is increasingly on the studies innovation, but it is believed that with the speed of development of digital applications, studies on the variable aspects of the representation process, that is post processing, of the digital data of the Cultural Heritage it is constantly renewed. Essentially the results of $3 D$ representation, modeling and VR of a few years ago need to be rework. It should also observed that in the process of creating virtual VR environments a distinction must made between visualization and interaction.

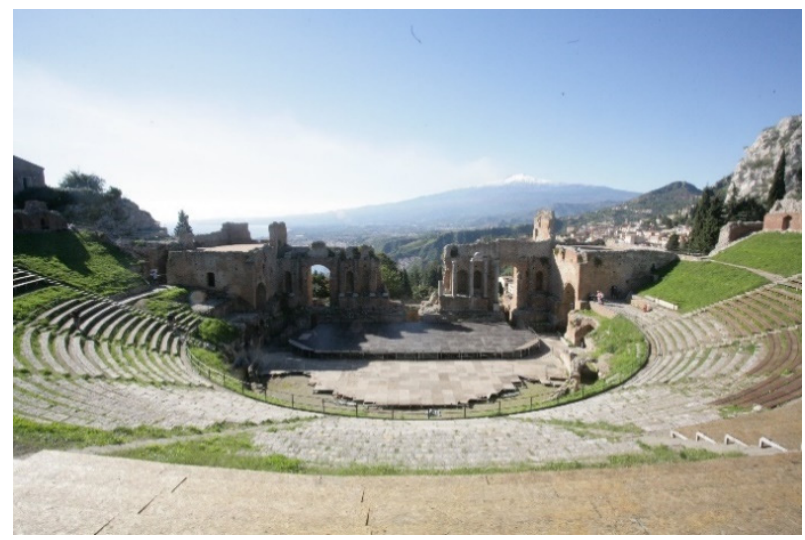

Figure 1: The Taormina Theater, in the background the Etna volcano and the sea.

\section{Brief diachronic notes on the theatre}

Here are some diachronic information, with the sole purpose of framing the evolution of the various parts. The theater stands on the slope of monte Tauro, in the eastern part of the city, on the site that was originally occupied by the agorà. According to the most authoritative sources, the birth of the theater dates back to the third century b.C. in the hellenistic period by Hieron II of Syracuse. The origin is documented by the remains of the blocks of Greek origin under the current scene and by some Greek inscriptions on the steps where the name of Philistis, wife of Hieron II, is engraved. Three phases have been hypothesized, to the first theatrical system is attributable a theater smaller than the current one, enriched in the top of the cavea of a small temple (of which today there are only a few remains) and a scene (skené) rotated due to an about three degrees of the axis with respect to the Roman structures. The second theatrical system is attributable to an early Roman phase. It sees the introduction of the new front scene (scaenae frons), with a hypothetical rectangular plan, consisting of three archways (two hospitalia and a valvae regiae) and two side walls, to delimit the length of the scene (pulpitum). The two walls that intersect the analemmata walls delimit the two parascaeni, without cover at this stage, which allowed the passage to the orchestra area through the paradoi. Finally the expansion of the cavea led to the introduction of intermediate accesses that led to the respective precinctions (praecinctio) in a total number of three. The third theatrical installation, from the second Roman phase, brings transformations and new introductions. Among the transformations the enriched scene, the enlargement of the scene and on the sides the covering with large barrel vaults of the parascaenia giving life to the so-called versura, among the new introductions are the creation of a portico behind the scene (porticus postscaenium) and two large semicircular corridors crowning the cavea. The cavea has maintained the horseshoe shape, with the two external wings extended towards the scene, originally it was organized in nine wedges interspersed with eight stairs and the ambulatory divided it horizontally into two sections, the upper part closes with a hemicycle crowning, consisting of a double arcaded gallery occupied by wooden steps. On the internal front towards the cavea, there are eight entrances (vomitoria) in correspondence with the stairs that allow access to the cavea, the central wedge is maintained on the axis of symmetry according to the Greek manner. In the late imperial age, to allow the orchestra (conistra) to be transformed into an arena, the scene was suppressed, the first orders of seats removed and an annular cryptoporticus was created. The circumference that inscribes the orchestra is separated from the front of the scene at one third of the radius, the underground corridor coming from the scene building is arranged on the central axis of symmetry. The scene building is the only one present in Sicilian theaters, althought largely incomplete. It has a front scene consisting of 3 orders originally decorated with niches, statues and Corinthian columns, supporting the architraves. The lower order remains partially preserved, the building currently represents one of the favorite destinations of visitors with archaeological knowledge (Gallo, 1773).

Regarding the materials were used local limestone and brick. With an act of 1465 , the viceroy of Sicily Lope Ximénez, in the name of King John II of Aragon, granted Guglielmo Zumbo the ancient theater of Taormina, referred to as: "quoddam hedificium anticum et dirutum [...] vulgariter appellatum Iu goliseu alias Iu palazu", with permission to build inside but without damaging the monument (Muscolino, 2020). The first historical images belong to the period of the Grand Tour, and they see two opposing groups of protagonists. On the one hand landscape interpreters of the ruins who have given us drawings of an epic state of affairs of their time like LouisJaean Desprez and Louis Francois Cassas, on the other, artists such as Jean-Pierre Houël (Houel, 1977) and Andrea Gallo (1773) with the drawings of their reconstruction hypotheses (Fig. 2). 


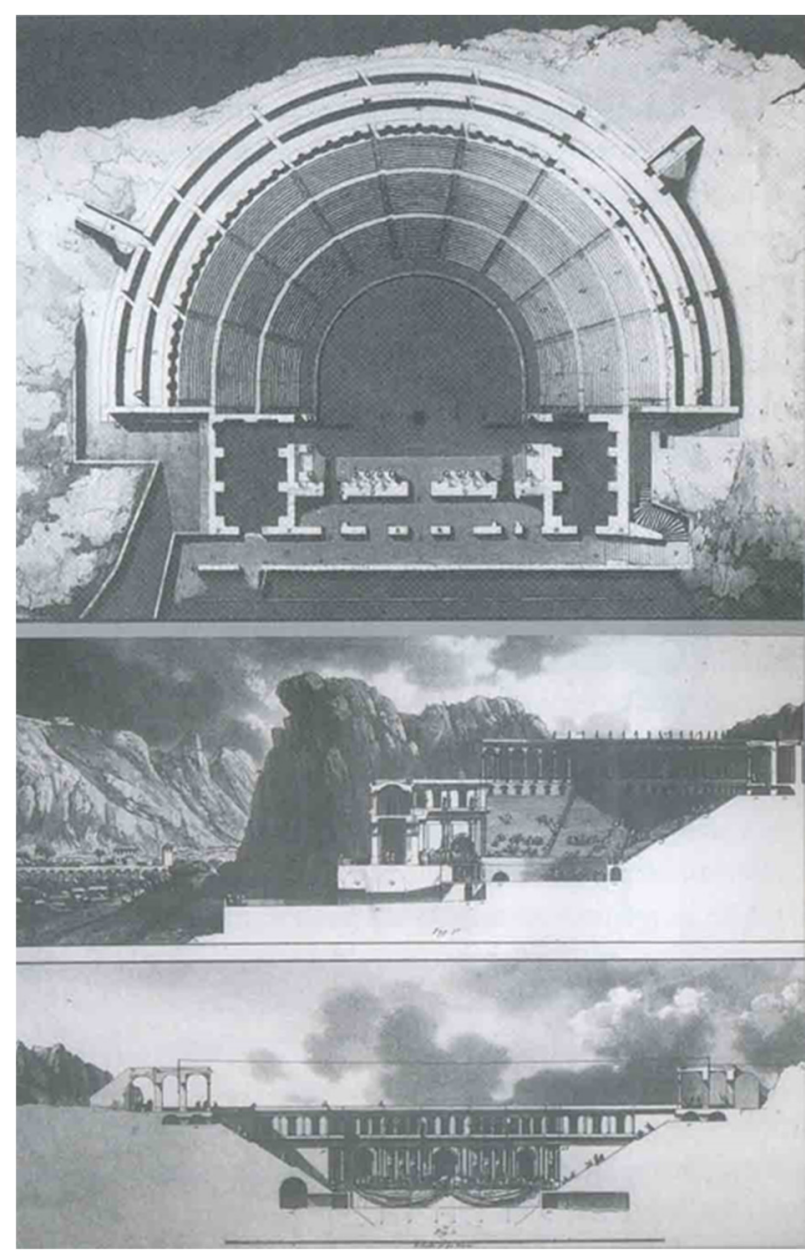

Figure 2: Plan and section of the theater according to the hypothesis of $\mathrm{J}$. Houel.

\section{The versurae}

In the Greek period the spectators accessed the seats on the steps by means of the parodoi, openings located between the stage and the stalls. The stage and the proscenium were separated from the stalls: two independent bodies from each other, of these lateral spaces free today nothing remains. The romans were not particularly fond of dramatic performances, famous and flourishing in the Hellenistic period, so at the end of the $2^{\text {nd }}$ century a.C. the orchestra was thus reduced and transformed into an arena for gladiator games and pits were dug, while the lateral parodoi were covered with large vaulted structures and transformed into vomitoria. Later were also suppressed the vomitoria, the scene wall and the covered corridor behind them were connected to the great Roman vaults with large internal walls. The new constructions, called versurae (or more commonly called porticoes or hallways), formed at the two corners of the theater, effectively welded the scene to the stalls (cavea) (Lo Faso, 1842). Definitively abolishing the trace of the two Greek parodoi and the Roman vomitoria that they tried to preserve, in part, the original structure, both in form and in the function of accompanying the public inside the theater. At the time when the theater underwent this further transformation, all accesses were transferred to the upper part of the building and connected, at the lower level, by means of stairs and new floors supported by the vaults of the two versurae (Rizzo, 1983).
On the north-west side, the insertion of new structures has almost closed an opening of the theater period, in the south-east side, the restructuring coincided perfectly with the original plan. The main staircase, which rises to the side of the east entrance hall, still today has three turns that all end with a door that leads into the auditorium or terrace above the versura. The staircase ends in the external corridor of the second portico, from which, through the first, one came directly to the cavea. Next to the outer wall of the west side there is another staircase, which gives access to the terrace placed as an extrados above the vault that formed the vomitoria. In both terraces, the plebs found their place during the games.

The versurae are not only an element of discontinuity with the architecture of the past, but they represent the radical change in Roman society of the vision of the theater: from an introspective and certainly cultural place in the time of the Greeks, it becomes in the roman times an arena for bloody games and shows sumptuous.

The versurae were never for the public: their new function was to bring together and host the actors who therefore used them as a dressing room and storage for stage tools. The northern walls of the versurae were the limit of the stalls on which the spectators sat and they were been entirely closed, as was their external wall, which had no opening. Their insertion in the terminal part of the auditorium alters the reading of the analemma wall, an element of differentiation between the two types of theater. According to the tradition, the inhabited part of the theater, relating to the concession of 1465 , coincides with the two versurae and part of the scenic building.

\section{The survey methodology}

The choice for the survey was been based on a mixed methodology integrated with TLS (Terrestrial Laser Scanner) instrumentation and photogrammetry, in order to have both quality survey data based on active sensors and dense clouds based on photogrammetric data. For the most extensive parts of the survey, it was preferred to use only the TLS active sensor instrumentation, such as the laser scanner in order to have structured metric data. For the smaller objects, both the previous one and the multi-image photogrammetric technique were been used, to compare and integrate the results. Thus for the internal parts of the versurae, so as the remains of the annular barrel vault of the hemicycle both the Structure from Motion (SFM) and the TLS methodology were used, for the cavea, the orchestra, the scene, the versurae. A total of twenty-seven stations were performed (Fig. 3), some with multiple scans, of which eleven in the upper corridor (Figs. 4-6), four in the west, three internal and one external, five in the east, three internal and two external, two along the south side of the scene, four along the stage, one in the center of the orchestra (Fig. 7). The instrument used is a Leica Geosystem HDS laser scanner, with a range of $300 \mathrm{~m}$, and a scanning field of $270^{\circ}$ vertically and $360^{\circ}$ horizontally. The entire model was merged using the Cyclone software from Leica Geosystem (Fig. 8), but for the graphic restitutions (Fig. 9) of the various parts, single scans were used or only the clouds necessary to define the parts, as in the case of the versurae (Fig. 10) or of the scene. The reason for this choice is due to the considerable size of the data file. The automatic decimation procedures of the Cyclone software by Leica and JRC 3D Reconstructor by Gexcel (Scarciotta 
2009; Raimondo G. F. 2009) were used separately, other attempts were made with Cloud compare. In the archaeological heritage sector, the procedures for decimation and automatic thinning of point clouds, must be used with particular caution, since along the vertical, horizontal and curved surfaces even the most modest variation of the order of a few centimeters can be a reason for interest and investigation for the research and cultural and scientific dialogue (Malinverni et al., 2019).

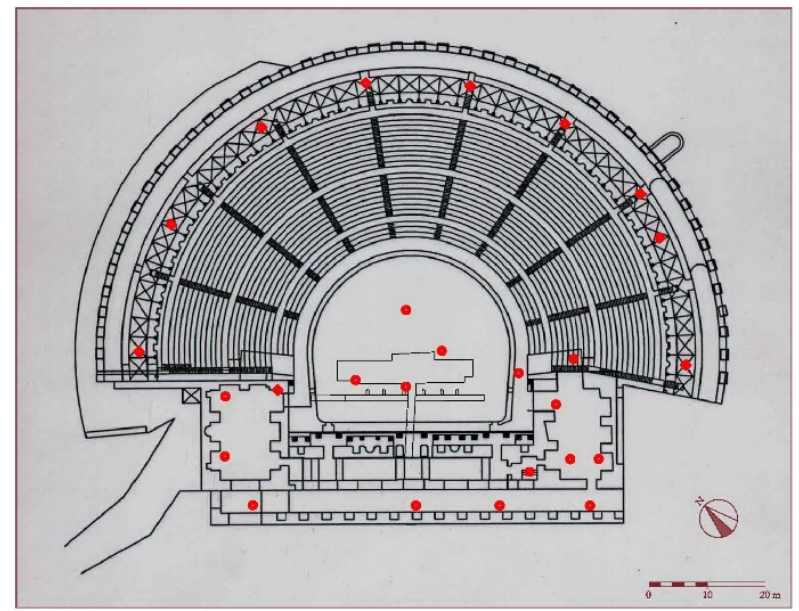

Figure 3: Position of the 28 stations performed with the laser scanner.

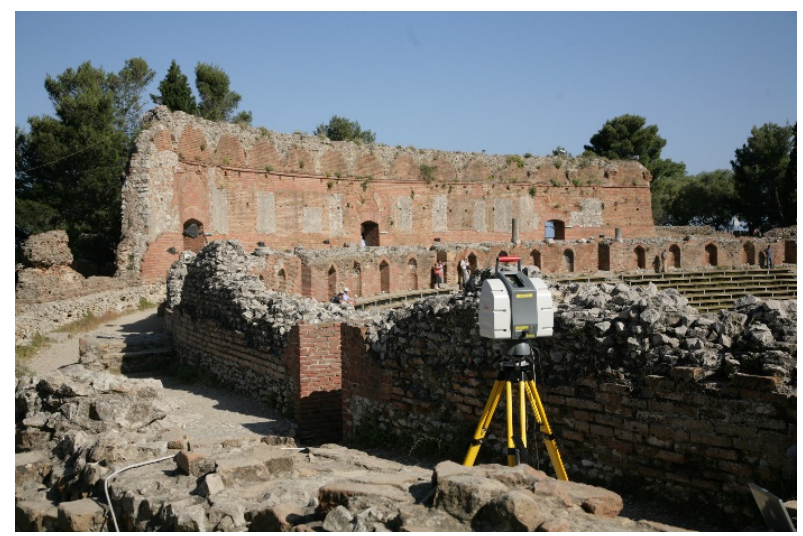

Figure 4: Station from the upper corridor.

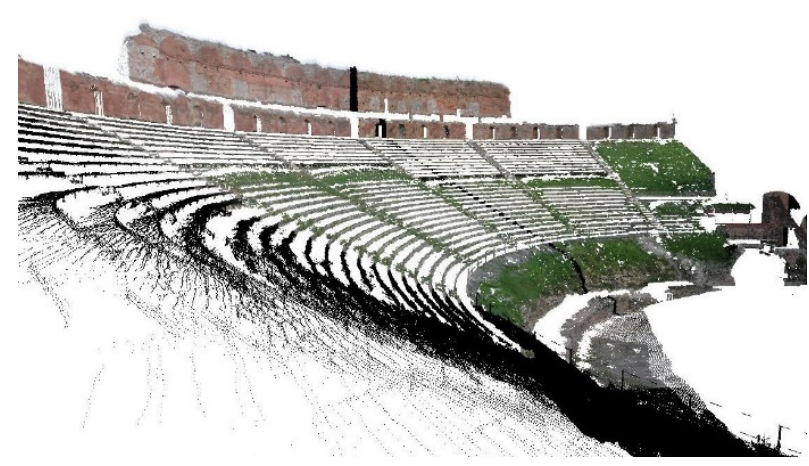

Figure 5: Scans of the upper zone.

The situation is different for the processing of continuous $3 \mathrm{D}, \mathrm{VR}$ and AR models, where the processing must be managed by multiscale hierarchical levels. In the archaeological survey, unlike the architectural one, there are no fundamental geometric references (horizontality, verticality, symmetries, parallelisms), which guide the restitution of a survey. As far as survey is concerned, the new methodologies are based on the use of $3 \mathrm{D}$ laser scans that combine high precision and versatility ensuring high quality detection and optimization of working times. The possibility of creating, starting from the point cloud, high-precision digital three-dimensional models, allows the monitoring of complex organisms, the creation of virtual museums, restoration. The many possibilities offered by this new technology for archaeological surveying, have not been exploited fully yet. Archaeological artefacts, are often characterized by irregular, discontinuous geometries and these make it difficult to identify specific reference elements for a geometric and material survey (Farella, Remondino, \& Torresani, 2019).

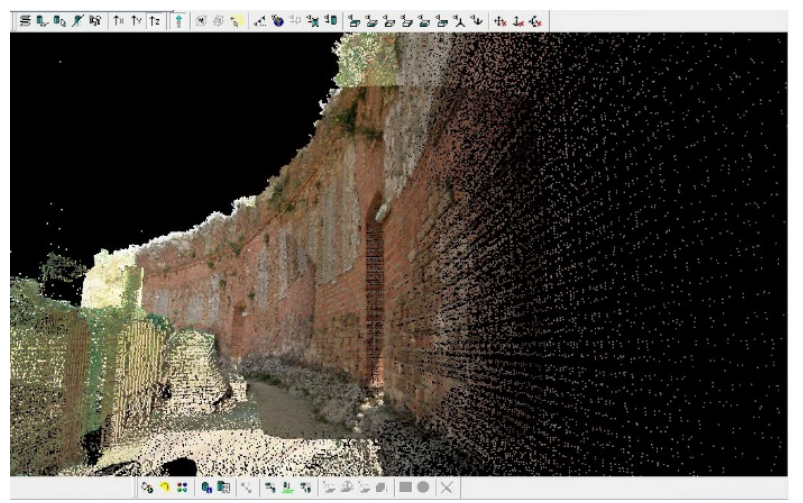

Figure 6: Scans of the upper corridor.

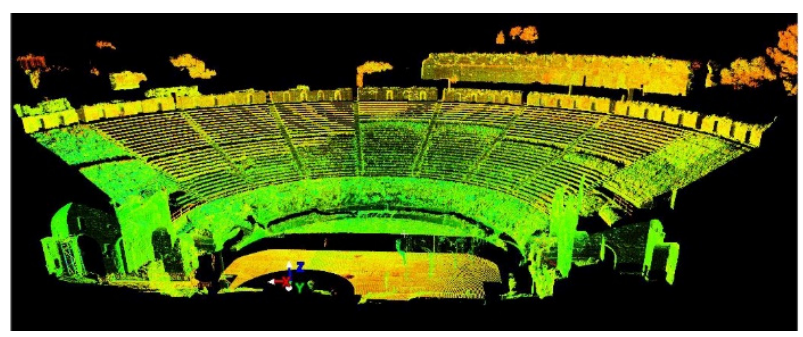

Figure 7: The scans of the cavea.
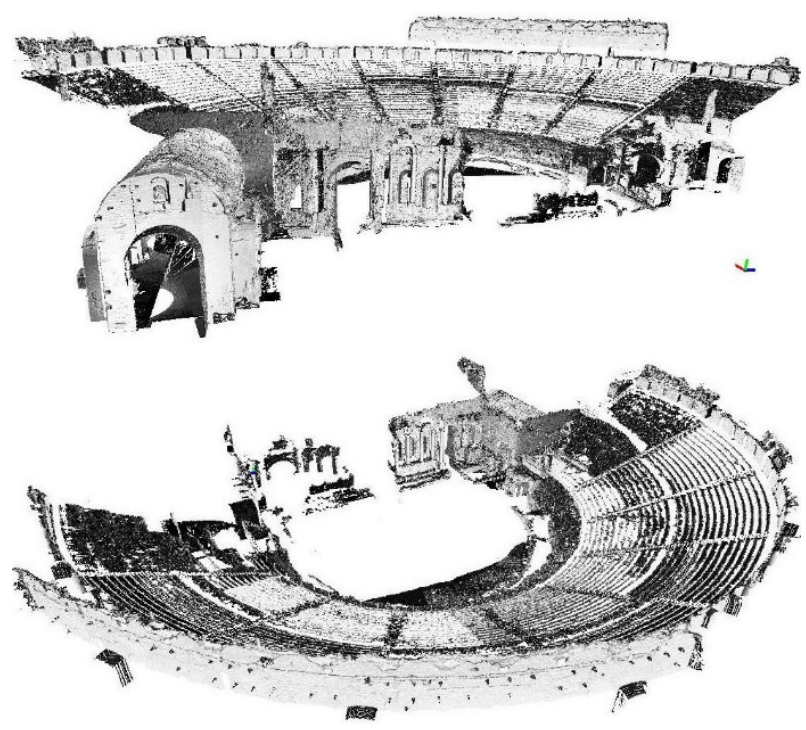

Figure 8: The union of the clouds, the cavea with the northwest side, from two different views. 


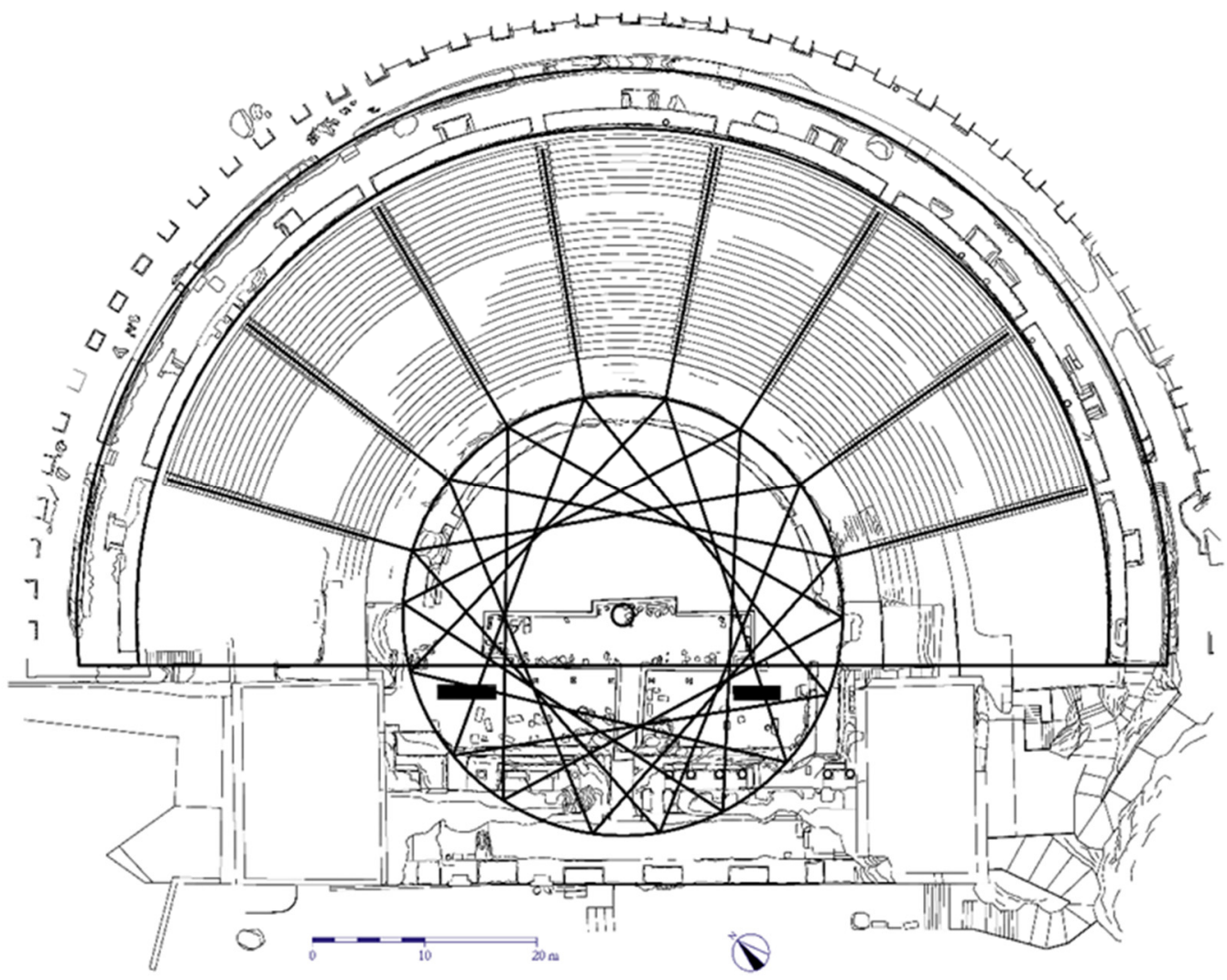

Figure 9: Theater plan and the geometric hypotheses of Vitruvius.

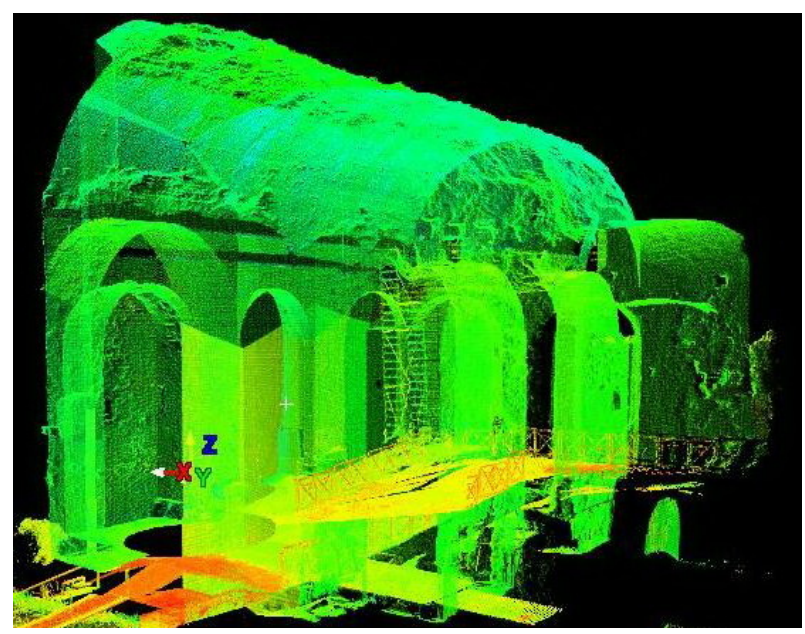

Figure 10: The point cloud of the northwest versura.

\section{The versurae}

The studies performed on the versurae (Fig. 11) have allowed us to find some results on their geometric conformation and the processing of 3D models. With reference to the southeastern side, the difference in size between the niches of the eastern and western walls is immediately evident. The modular searches have resulted that the one facing south-east is been modulated according to the ancient Greek foot unit, equal to $30.8 \mathrm{~cm}$ each niche is equal to 10 feet, also defined as kalamos or akaina that is about $3.08 \mathrm{~m}$. The projection separating the niches is equal to half of the module. On the opposite wall, the openings are wider and for the two equal there is a modulation equal to 12 times the roman foot, defined in the ratio of $29 \mathrm{~cm}$, therefore a total of $3.48 \mathrm{~m}$. The septum that divides them is about half, the third arc, which see the scene, is equal to about 13 times the Greek foot. The width of the versura equal to about $7.00 \mathrm{~m}$ is set on the roman module. The results obtained lead to various hypotheses, but the simplest is the definition of the Greek and Roman parts. The eastern wall with its niches already existed in the Greek period from which also the shorter length derives, probably arriving at the border with the analemma wall, then in the Roman phase, the wall was incorporated into the environment dimensioned with the "new" units of measurement. There is no symmetry between the two versures, nor correspondence between the dimensions, it should been observed that in the other versura, the north-west one, the north wall is occluded and separated from the rest.

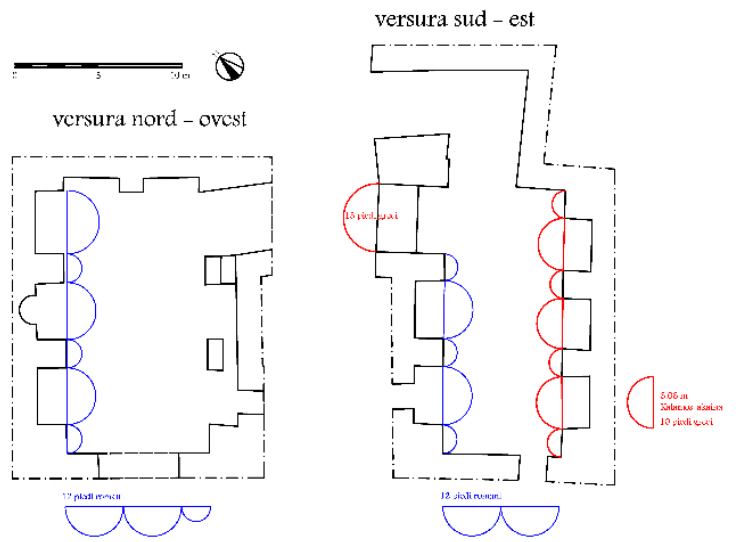

Figure 11: Modulation according to the ancient units of measurement. 
The studies carried out have shown dimensional matrices for the north-west side that can been traced back to the Roman period only. We do not know if any transformations place by the Zumbo family, following the concession of 1465 . Some aspects were been processed from the clouds obtained with TLS active sensors, including automatic decimation, without losing significant information, segmentation attempts and extraction of profiles with automatic procedures (Matrone et al., 2020). Through the software Cloud Compare, the qualitative data between the clouds obtained with photogrammetric methods (SFM) and those with laser scanners were been compared. The extraction of the profiles (Figs. 12 and 13) made it possible to verify and measure some degradations present in the barrel vault of the north-west versura. The extraction of the cloud with the SFM photogrammetric method with the Metashape software allowed to obtain about 50 million points with mediumhigh settings of the processing parameters, the initial photographic set included 113 images of which 109 aligned, with processing with Zephyr of 3DFlow 105 of 127 images were aligned, the Ground Sample Distance (GSD) was calculated for both alignments for a significant sample of photos. Taking into account the parameters of the photographic sensor equal to $25.8 \times 23.9 \mathrm{~mm}$, the GSD was equal to $2.3 \mathrm{~mm} / \mathrm{pixel}$ which for average object distances of about $7.5 \mathrm{~m}$ means an average image coverage of $10,88 \mathrm{~m}$ wide and $7.05 \mathrm{~m}$ high, valid values for the survey purposes and compatible with the quality of the 3D laser scanner survey. The resulting dense clouds were processed with mesh and texture (Figs. 14 and 15). The laser scanner cloud recorded 18 million points. The two point clouds were then evaluated with the Cloud Compare software. The restitution results are showed in Figures 16 and 17.

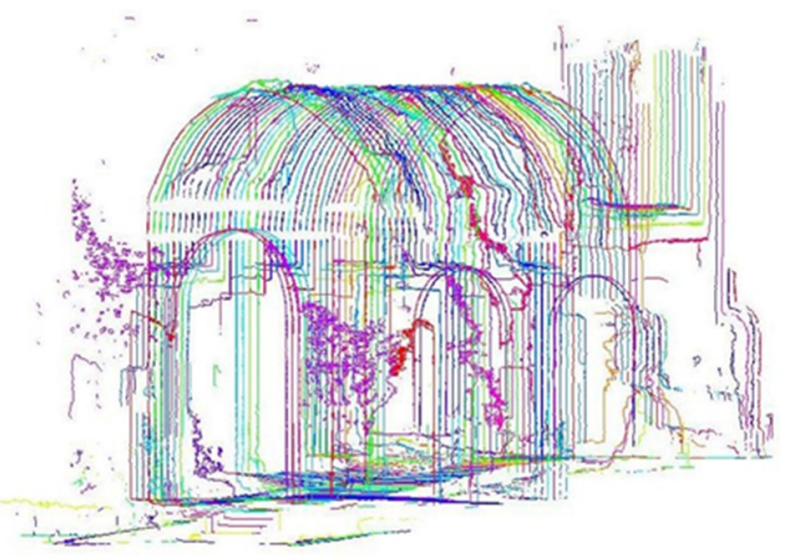

Figure 12: the north-west versura automatic extraction of profiles.

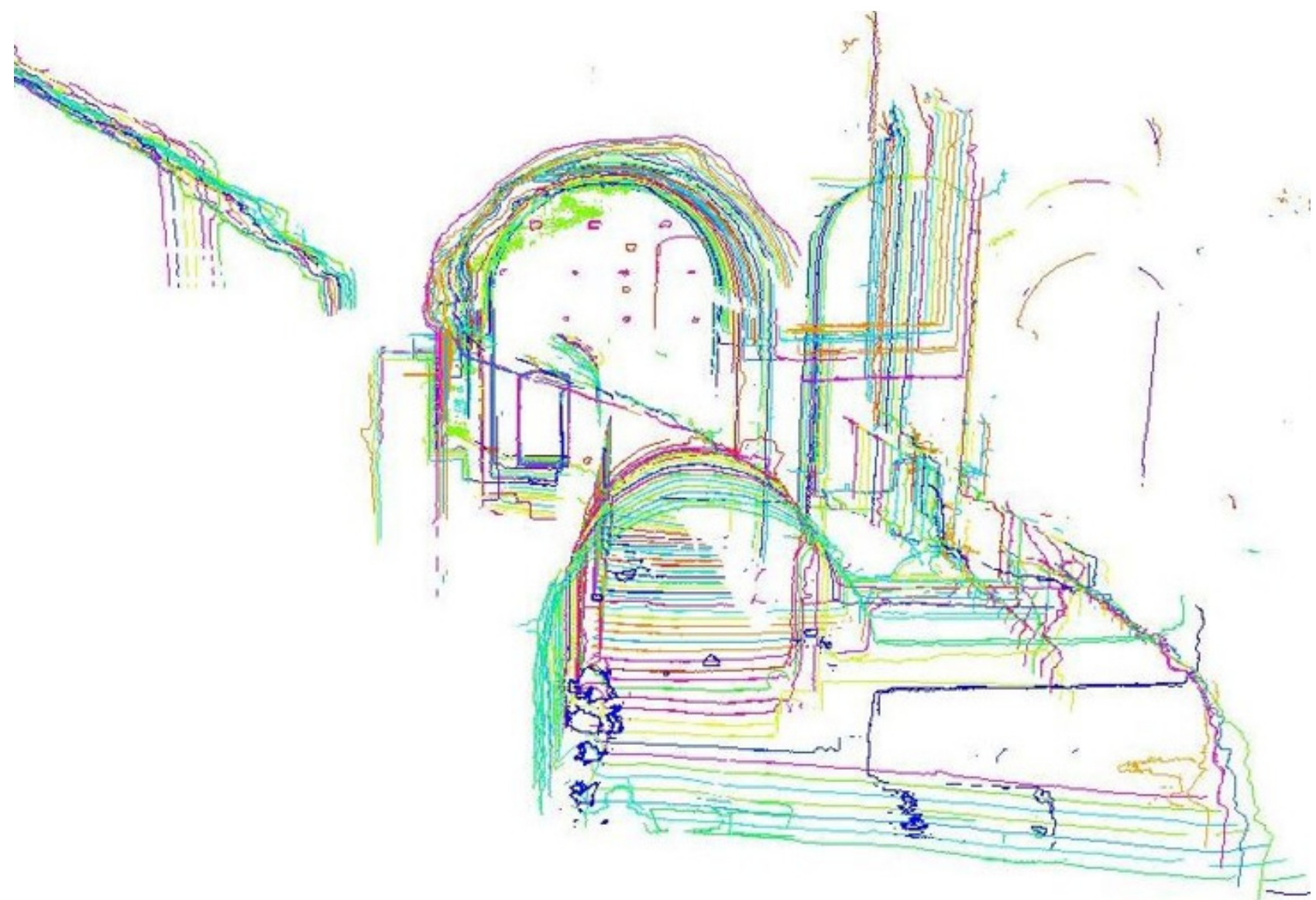

Figure 13: South - east versura, automatic extraction of profiles. 

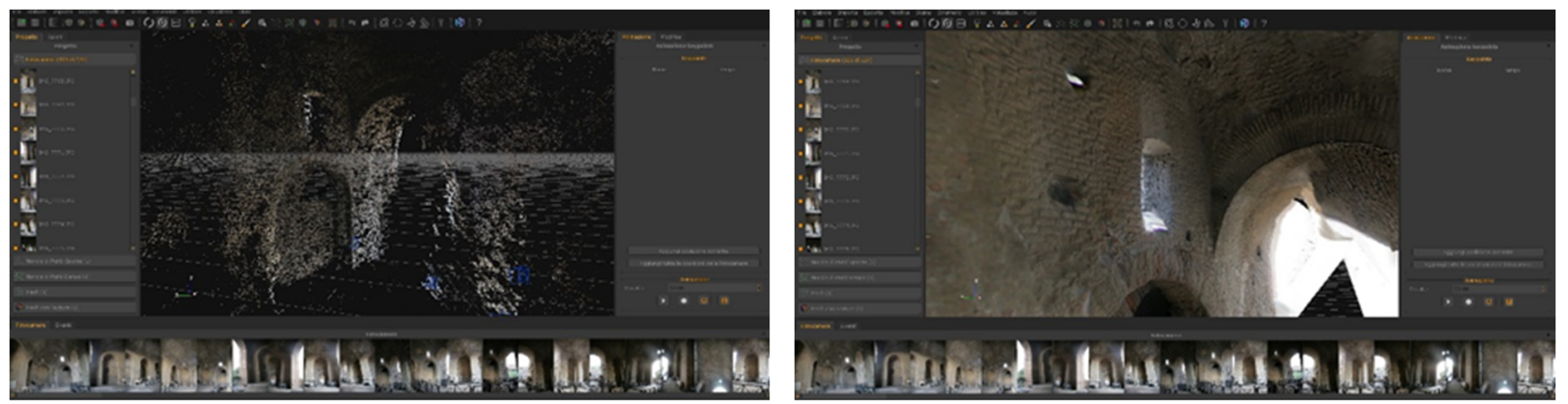

Figure 14: Northwest versura, SFM processing with Zephyr.

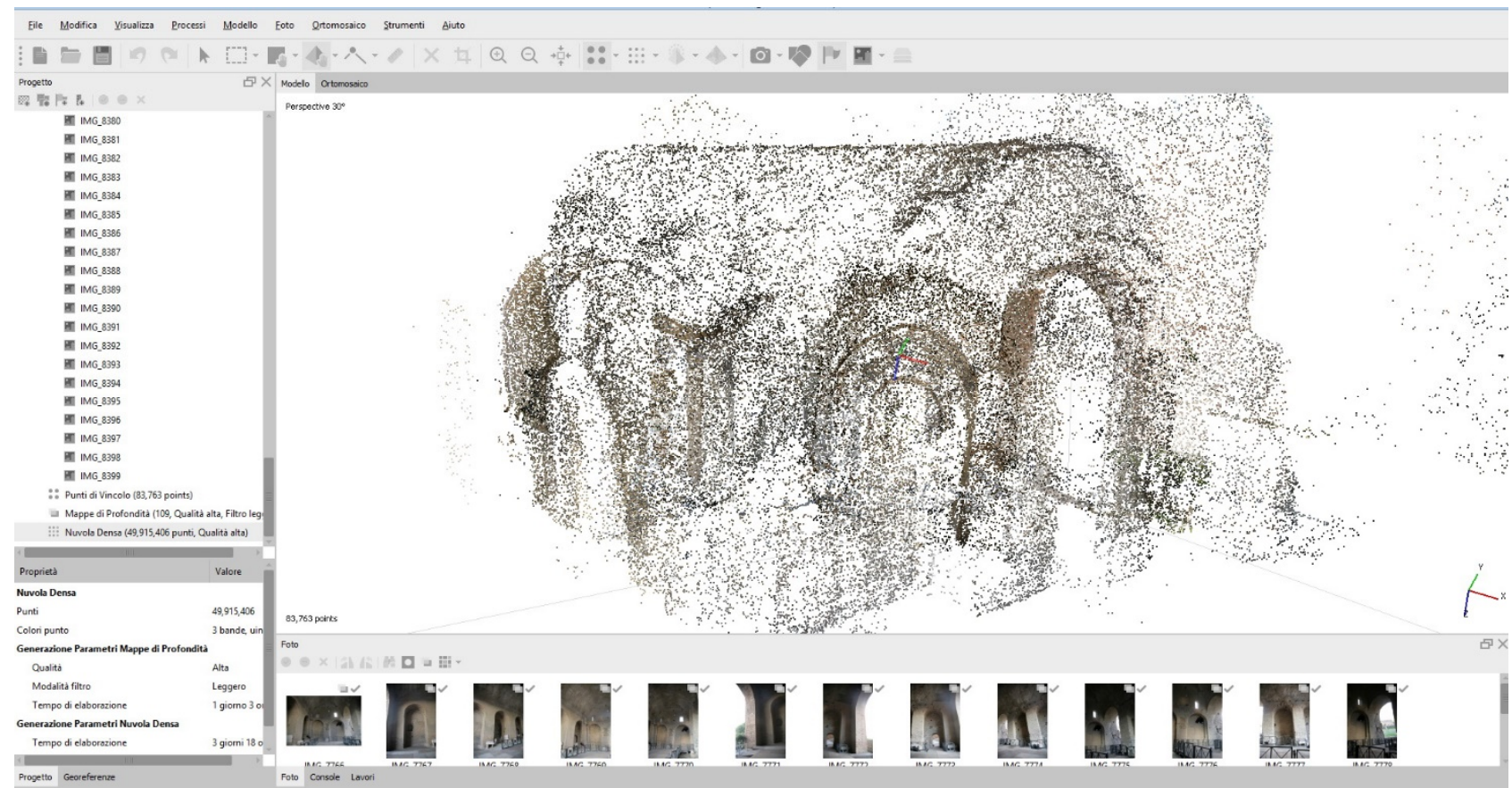

Figure 15: Northwest versura, SFM processing with Metashape.

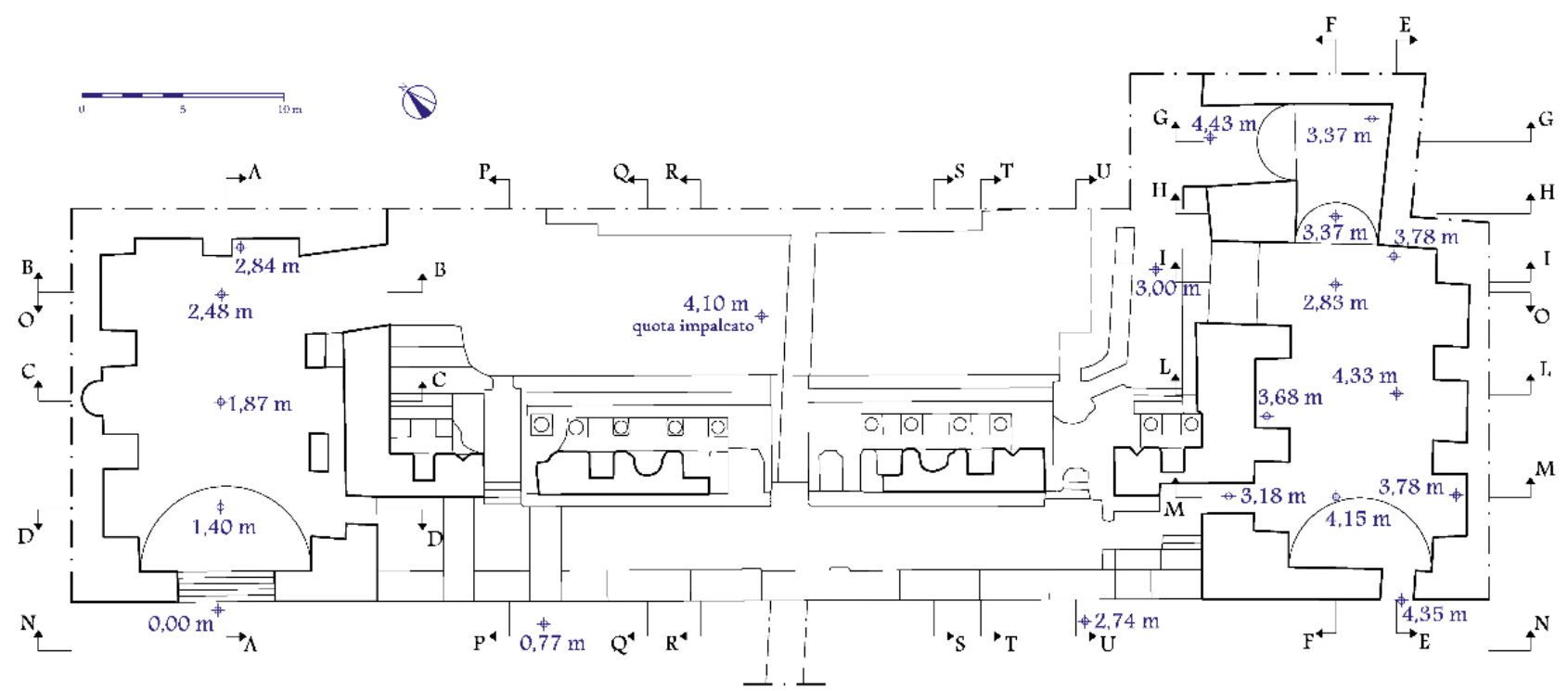

Figure 16: Plan of the scene and the two versurae. 


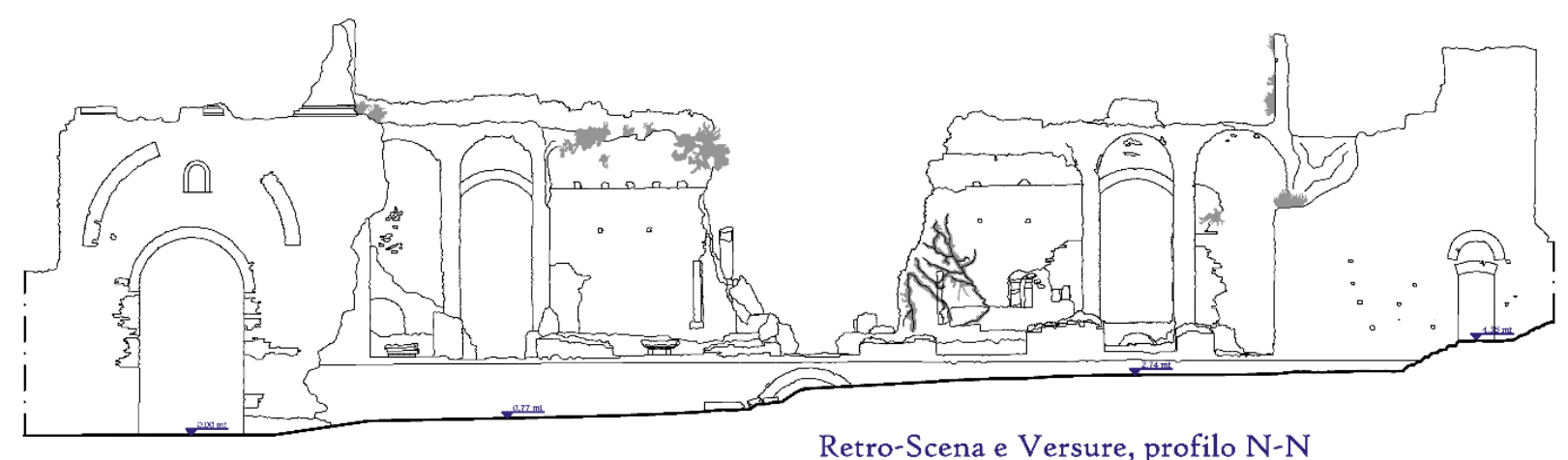

Retro-Scena e Versure, profilo N-N

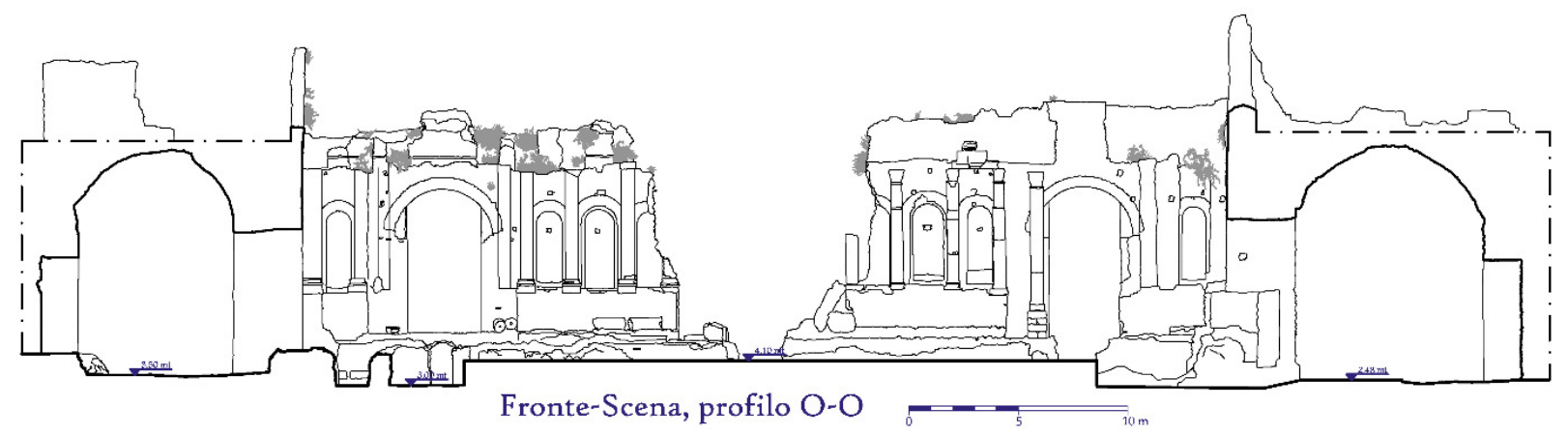

Figure 17: Restitution of the scene from both sides.

\section{Conclusions}

The digital survey that underlies the knowledge and interpretation of this work of man, 3D model and virtual reality is a system of knowledge open over time. Starting from the metric data, from the registered numerical model, the studies can be many and varied, always finding a topic for both cultural and informative study. The development of automatic procedures for the 3D classification of Cultural Heritage it is demanding in architecture and even more so in archeology. Modulations, proportions, signs, drawings, 3D models, virtual reality (VR), augmented reality (AR), are opportunities to deepen the knowledge of this place of entertainment, in that continuous call between the two Latin and Greek cultures, in a continuous research for the key to reading them, for all the things that have been. This site reveals the chosen place for cultural, social exchanges and relations between men and civilizations. A work of man that has survived time and is used today still for the same purposes for which it was intended.

\section{Acknowledgements}

This work was supported by the project "Creazione di una rete regionale per l'erogazione di servizi innovativi basati su tecnologie avanzate di visualizzazione" (3DLabSicilia), Grant No. 08CT4669990220, funded by Operational Program 2014-2020 of the European Regional Development Fund (ERDF) of the Sicilian Region.

\section{References}

Benedetti, B., Gaiani, M., \& Remondino, F. (2010). Modelli digitali 3D in archeologia: il caso di Pompei. Editore Scuola Normale Superiore, Edizioni Pisa, EAN: 9788876423536, ISBN 978-88-7642-353-6.

Farella, E. M., Torresani, A., \& Remondino, F. (2019). Quality Features for integration of and UAV Images. Int. Arch. Photogramm. Remote Sens. Spatial Inf. Sci., XLII-2/W9, 339-346. https://doi.org/10.5194/isprs-archives-XLII-2-W9339-2019

Gallo, A. (1773). Descrizione istorica, ed antiquaria dell'antico teatro di Tavormina.

Grilli, E., \& Remondino, F. (2019). Classification of 3D Digital Heritage. Remote Sens., $11,847$. https://doi.org/10.3390/rs11070847

Houel, J. P. L. (1977). Viaggio in Sicilia e a Malta, "Storia di Napoli e della Sicilia". Società Editrice.

Lo Faso Pietrasanta, D. (1842). Le antichità della Sicilia esposte ed illustrate, presso la reale stamperia, Palermo.

Malinverni, E. S., Pierdicca, R., Paolanti, M., Martini, M., Morbidoni, C., Matrone, F., \& Lingua, A. (2019). Deep learning for semantic segmentation of 3D point cloud. Int. Arch. Photogramm. Remote Sens. Spatial Inf. Sci., XLII-2/W15, 735-742. https://doi.org/10.5194/isprs-archives-XLII-2-W15-735-2019

Matrone, F., Grilli, E., Martini, M., Paolanti, M., Pierdicca, R., \& Remondino, F. (2020). Comparing Machine and Deep Learning Methods for Large 3D Heritage Semantic Segmentation. ISPRS Int. J. Geo-Inf. 2020, $9,535$. 
https://doi.org/10.3390/ijgi9090535

Muscolino, F. (2020). Taormina 1465: la concessione del teatro antico (lu Goliseu alias lu Palazu) come residenza signorile e altri casi di riuso di monumenti antichi nella Sicilia del XV secolo. Mélanges de l'École française de Rome - Moyen Âge. https://doi.org/10.4000/mefrm.6772

Raimondo, G. F. (2009). Rilievo e rappresentazione del Teatro Antico di Taormina tramite Laser Scanner 3D. Tesi di Laurea, Università degli Studi di Catania.

Rizzo, P. (1983). Tauromenion. Salvatore Sciascia editore, Caltanissetta, Roma.

Scarciotta, R. (2009). Rilievo e rappresentazione del Teatro Antico di Taormina tramite Laser Scanner 3D. Tesi di Laurea, Università degli Studi di Catania. 


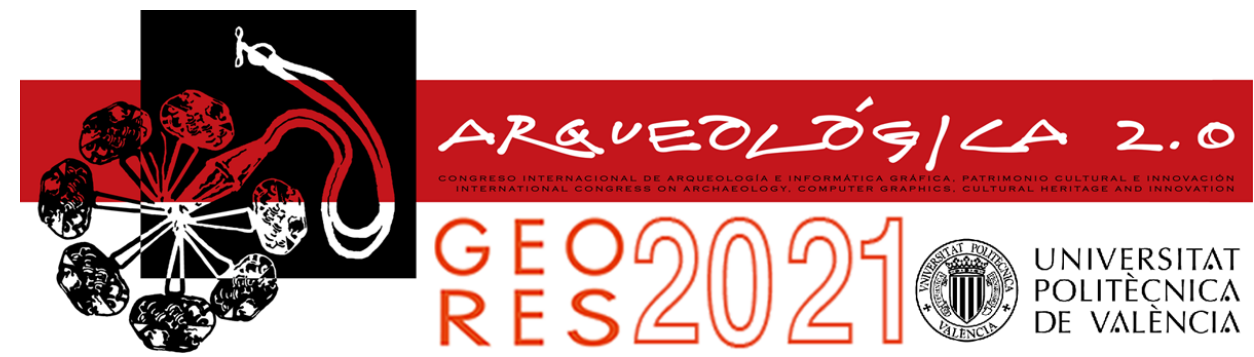

Proceedings of the joint international event $9^{\text {th }}$ ARQUEOLÓGICA 2.0 \& $3^{r d}$ GEORES Valencia (Spain). 26-28 April 2021

\title{
HOW WERE THE TAPESTRIES IN THE SALA DI SATURNO OF PITTI PALACE ARRANGED? GEOMATICS AND VIRTUAL REALITY FOR ART CURATORS
}

\author{
Grazia Tucci”, Valentina Bonora, Alessandro Conti, Lidia Fiorini
}

GeCO Lab, Dipartimento di Ingegneria Civile e Ambientale, Università degli Studi di Firenze, Via di Santa Marta 3, 50139 Florence, Italy.grazia.tucci@unifi.it; valentina.bonora@unifi.it; alessandro.conti@unifi.it; lidia.fiorini@unifi.it

\begin{abstract}
:
Three-dimensional acquisition techniques, reality-based modelling and virtual reality are tools used in Digital Humanities prevalently for displaying the results of a study, but they can also suggest new methods of investigation to humanities scholars. In a case study regarding art history, these techniques made it possible to recreate the layout of the Sala di Saturno in Pitti Palace (Florence) in the $17^{\text {th }}$ century, based on information obtained from archive documents on the tapestries designed for that hall and a 3D model expressly elaborated with geomatic techniques. The results were summarised in a video showed in 2019 during the exhibition on tapestries dedicated to Cosimo I de' Medici. A tool was also developed to assist exhibition and museum curators in their work. Through virtual reality, they can design temporary exhibitions or modify the display of the works of art in a museum in a realistic way, using visually and metrically accurate models of the pieces and exhibition rooms.
\end{abstract}

Keywords: 3D modelling, virtual reality, digital humanities, curatorship, tapestries, sala di Saturno

\section{Introduction}

The research methodologies that involve computing technologies to perform or support traditional humanities methods are now widely diffused.

The expression Digital Humanities was born mainly in relation to text-based disciplines. In such a context, disciplines in which imprecision, qualitative information and individual interpretations are traditionally the norm, had to deal with precision, quantitative measurement, and accuracy.

The Spatial (Gregory \& Murrieta-Flores, 2016) and Visual Digital Humanities (Münster \& Terras, 2019). have been even more successful and have renewed methods for comparing data, integrating sources, and presenting research results in many disciplines.

Among the different ways of using visual resources, the use of 3D models for reconstructions and simulations has strongly emerged with the diffusion of digital technologies among the wider public, perhaps not expert in Cultural Heritage $(\mathrm{CH})$ but already aware of the digital graphics language, assimilated by movies or videogames (Münster, Friedrichs, \& Hegel, 2018; Mandelli et al., 2019; Fazio \& Lo Brutto, 2020).

The consequence is that the $3 \mathrm{D}$ tools and the various declinations of eXtended Reality (XR), like Augmented Reality (AR), Mixed Reality (MR) and Virtual Reality
(VR), were initially conceived by humanistic scholars, in particular museum and exhibition curators, for communication to the public, especially to the younger generations or to people considered less interested in traditional exhibitions (Gifreu-Castells, 2019; Huaman, Aceituno \& Sharhorodska, 2019; Eliseu, Lopes, Ribeiro. \& Oliveira, 2020)

The possibility of virtually accessing places of culture is particularly highlighted during the current COVID-19 pandemic when many museums are using virtual tools to maintain and consolidate their dialogue with the public. (Greco \& Della Torre, 2020; NEMECH, 2020; NEMO, 2020).

Actually, the digital revolution has so radically transformed our cognitive approach (Greco, 2019) that the starting point for new research often stems from the feasibility of digitally investigating and representing their results (Tucci, Bonora, Conti \& Fiorini, 2017).

It is not merely about adapting to a trend, digitisation is reconfiguring the role of those who produce and manage art (such as museums) and new, consolidated business models are also emerged (Lazzeretti \& Sartori, 2016).

The aim of this article is to show the benefits of geomatic surveying techniques and $3 \mathrm{D}$ modelling in the field of Digital Humanities, in particular:

- By fostering new investigations in art history; 
- by developing new tools for the curatorship of art exhibitions;

- By improving the comprehensive management of museums.

Experiences concerning the Sala di Saturno of Pitti Palace (Florence) are presented. After a brief historical overview (part 2), a case study concerning the tapestries designed for this hall in the $17^{\text {th }}$ century is illustrated (part 3). The methods of acquisition and the investigations that led to the reconstruction of the original arrangement of the tapestries are then explained (part 4). An application for the design and management of museum exhibitions in VR is also outlined (part 5).

\section{Historic background}

Pitti Palace is the largest palace in Florence (Fig. 1) and was one of the great Italian royal palaces, inhabited by the dynasties of the Grand Dukes of Tuscany (Medici and Hapsburg-Lorraine) and, after the unification of Italy, by the Savoia royal family for five years (Bertelli, 2002). It currently houses four museums that are part of the Uffizi Galleries complex.

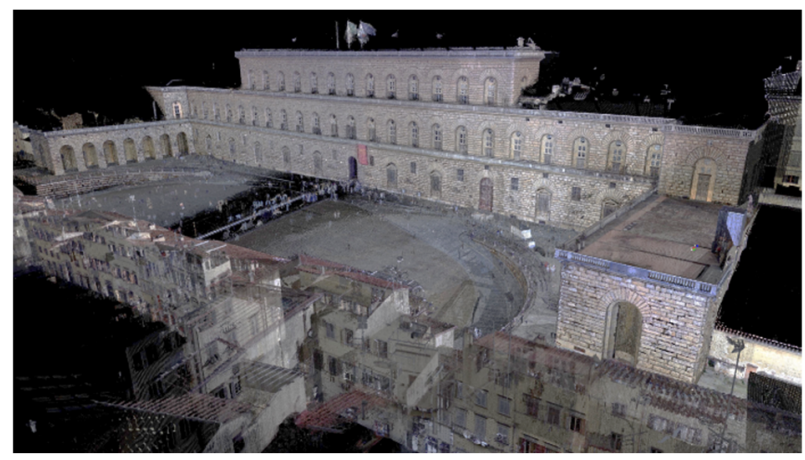

Figure 1: General view of the main façade of Pitti Palace (point cloud obtained by laser scanner survey).

The original core takes its name from the Pitti family who built it in the middle of the $14^{\text {th }}$ century. In 1550 it was bought by Eleonora di Toledo, wife of Cosimo de' Medici, who in 1569 became the first Grand Duke of Tuscany.

The palace was enlarged several times, in the $17^{\text {th }}$ century the façade was increased by adding eight windows on each side. The expansion on the left side of the piano nobile consists of a suite of staterooms connected with the Grand Duke's apartment. These rooms, in which guests were progressively admitted according to their rank, are called the Planetary Rooms because they are entitled to the gods associated with the Ptolemaic planets, in homage to Galileo, who had just dedicated the discovery of Jupiter's satellites to Grand Duke Cosimo II (Bandini, Felici; Lanfranchi \& Mariotti, 2009).

The decoration of the rooms was based on complex allegories linking the deities of classical mythology, the cardinal virtues, and the astrological influences of the planets on the phases of the sovereign's life. The Sala di Saturno (dedicated to the attainment of the wisdom that leads to eternal fame) was the last of the sequel. It was already a part of the Grand Duke's private apartment and secret hearings were held there.
The ceiling had a very rich decoration in stuccoes and paintings designed by the Italian Baroque master Pietro Berrettini (also known as Pietro da Cortona) and executed in 1665 by his pupil Ciro Ferri. Instead, the walls were originally unadorned, as the main floor was used as a winter residence and therefore were intended to be covered with tapestries which, in addition to being a decorative element, also performed a thermoinsulating effect.

Ferdinando II wanted some of the tapestries dedicated to the works of his ancestor Cosimo I to be placed in the Sala di Saturno, the Golden Age deity. The tapestries, designed by famous painters and woven in the Florentine Tapestry Manufactory directed by Pietro Févère, thus celebrated the Grand Duchy as new golden age (Griffo \& Meoni, 2019).

\section{The tapestries of the Sala di Saturno}

In 2019, the exhibition "Weaving a Biography. The tapestries in honour of Cosimo I" was held at Pitti Palace. In the exhibition, curated by the art historians Alessandra Griffo and Lucia Meoni, once again displayed the tapestries as a tribute to the first Grand Duke on the fifth centenary of his birth. Tapestries are particularly vulnerable works of art that can only be exhibited for short periods.

La Sala di Saturno is currently part of the Palatine Galleries and it would not have been possible to remove the paintings that are housed there for a temporary exhibition, which was therefore set up in the Sala Bianca. This is a very large room, and the tapestries could be comfortably admired by a large audience, but visitors lost the feeling of the context for which they were designed, so much so that the majestic tapestries appeared even larger than the Sala di Saturno (Fig. 2).

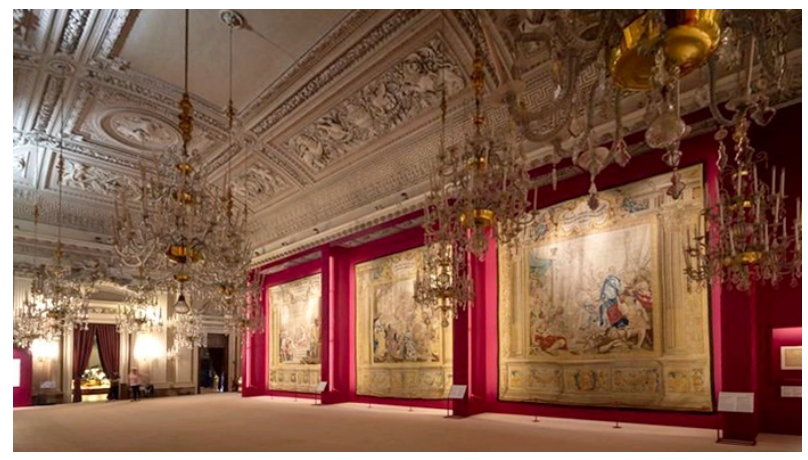

Figure 2: The tapestries dedicated to Cosimo I exhibited in the Sala Bianca of Pitti Palace.

An inventory of Pitti Palace dating back to 1688-96 reports that in the Sala di Saturno there were six tapestries of the series dedicated to Cosimo I, indicating their measurements but not the subjects and their disposition on the walls. The curators wanted to recreate the original appearance of the room starting from the dimensions of the tapestries, never compared so far with the actual size of the hall.

It is remarkable that this research, although also possible in the past with traditional manual measurements and drawings, has been conceived only now, when the use of spatial digitization, 3D models and digital reconstructions has become so widespread to be 
considered even by scholars who are not experts in these techniques.

The curators, therefore, required not to have a mere visual suggestion of the tapestries in the room, but to make accurate 3D models in real size of the room and the tapestries. So, they would empirically try to rearrange the tapestries in the room to study the most likely original disposition. It was also necessary that the model had a high visual quality for the communication project aimed at the visitors of the exhibition.

With respect to $3 \mathrm{D}$ digitizing techniques, in the Sala $d i$ Saturno there are currently many challenging objects and materials, among others gilding, frescoes and oil paintings, upholstery, marbles, furniture and many lamps and light sources. Considering that the study concerned only one room, it was initially planned to survey it both with laser scanning and photogrammetry and to select the best data acquired with the two techniques (Angheluță \& Rădvan, 2020).

\section{3D acquisitions}

The laser scanner survey was performed with a $Z+F$ 5010C scanner, also acquiring RGB values. Considering the complex geometry of the room and especially the vault, which has highly three-dimensional decorations, six scans were done in the hall (one in the centre, four in the corners and one in the splay of the window) and another two in the adjacent halls to show the relationship with the surrounding rooms (Fig. 3). For the best visual quality, scans were carried out under different conditions of natural and artificial lighting.

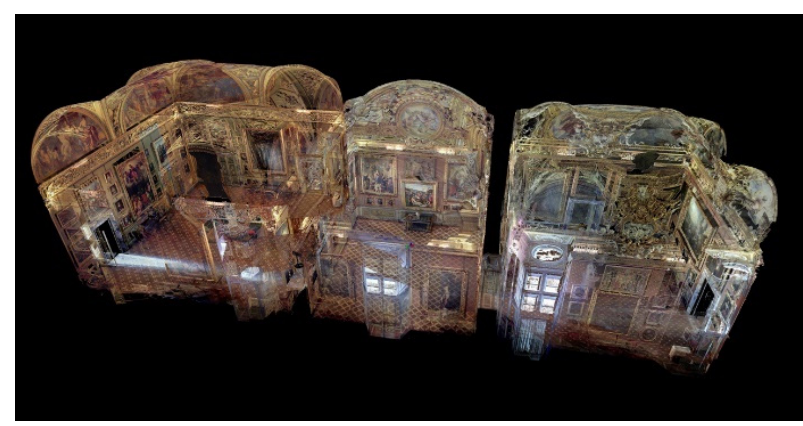

Figure 3: Laser scanner survey of the Sala di Saturno ( $\mathrm{n}$ the middle), between the Sala di Giove (on the right) and the Sala dell'lliade (on the left).

The images for the photogrammetric project were done with a Nikon D700 camera and Nikkor $50 \mathrm{~mm}$ f1.4 lens. To have the evenest illumination possible, all photos were taken with the windows closed and the museum lighting switched off, using instead a lighting balloon (Airstar, 2021) placed in the centre of the room which gives an intense and even illumination. Both orthogonal and convergent photos were taken towards the walls and the vault and around the corners between the surfaces, for a total of 842 images (Fig.4).

It was not possible to take tiered images, but as the room and its decorations were designed to be seen at eye level, it has been considered that some small gaps above the cornice or behind the sculptures on the vault were not significant for the aim of this project. It resulted that the photogrammetric model had a high geometric and visual quality, so the scans were used exclusively to determine the coordinates of the points used for scaling (Luhmann et al., 2019).

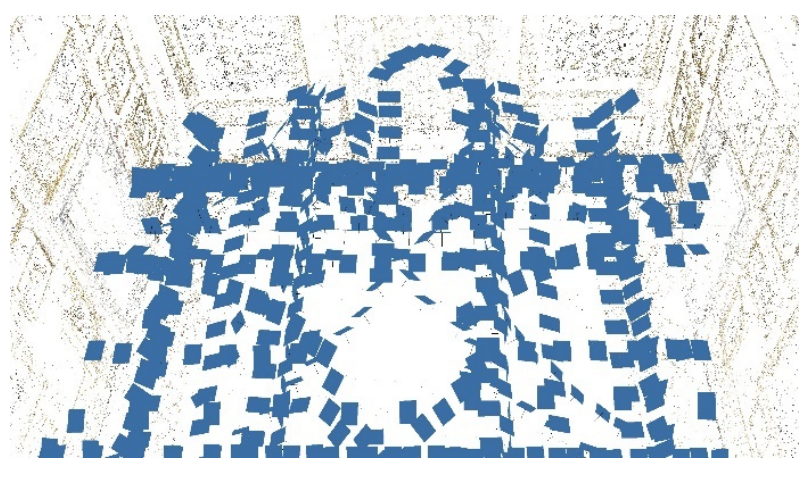

Figure 4: A visualization of the tie points of the photogrammetric model, also showing the estimated camera positions.

\section{The ancient layout of the hall}

Starting from the 3D model of the current state, a reconstruction of the Sala di Saturno in the $17^{\text {th }}$ century was carried out, removing all the paintings and furnishings present today (Fig. 5). Real-size models of the tapestries have also been created by applying highresolution images as textures.

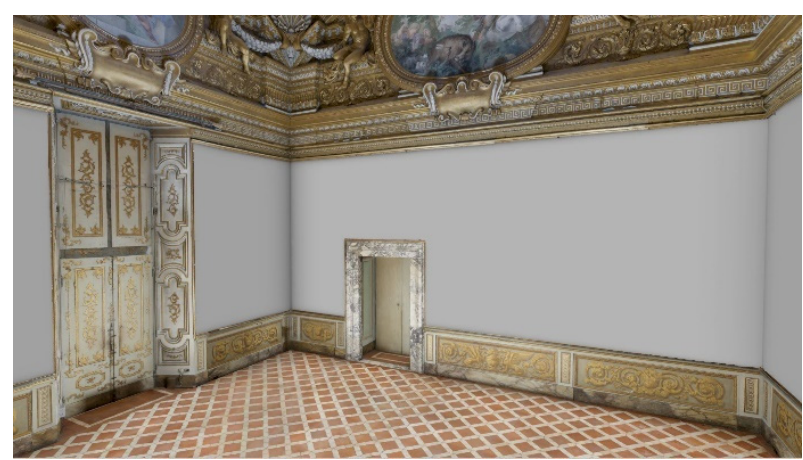

Figure 5: Reconstruction of the layout of the Sala di Saturno before its conversion into a picture gallery, used to study the disposition of the tapestries in the $17^{\text {th }}$ century.

Together with the curators, the arrangement of the tapestries listed in the inventory was then discussed. Each of the tapestries in the series has a central figure inserted into a frame, as if they were paintings set in an architectural order, with a socle, a column and a pilaster on both sides and an entablature at the top.

The approximately constant height of the tapestries corresponds to the distance between the floor and the moulding at the base of the vault, where it has been found a series of hooks from which the tapestries were presumably hung. In this way, the socle depicted in the tapestries corresponds to the simpler wainscoting at the base of the walls. The lengths of the tapestries, however, are considerably different, but there was no correspondence between the measure of the tapestries and the empty spaces of the walls. Rather, the total length of the tapestries was greater than the perimeter of the room, therefore it was not possible that they could simply be placed next to each other.

The curators were aware, however, that the tapestries could be partially overlapped, as they also had the function of protecting against the cold. Therefore, 
several attempts were made, considering that the bands with columns and pilasters on the sides of the tapestries could be paired to represent simple or coupled columns.

Given the constraints of the doors and windows and assuming that the tapestries were placed according to the chronological order of the Cosimo's life, the only possible layout is that the door to the Grand Duke's bedroom (currently hidden by a modern tapestry) should be opened and, on the other hand, the door that now leads to the next room (the Sala dell'lliade, not yet completed in those years) had to be covered by the tapestries (Fig. 6).

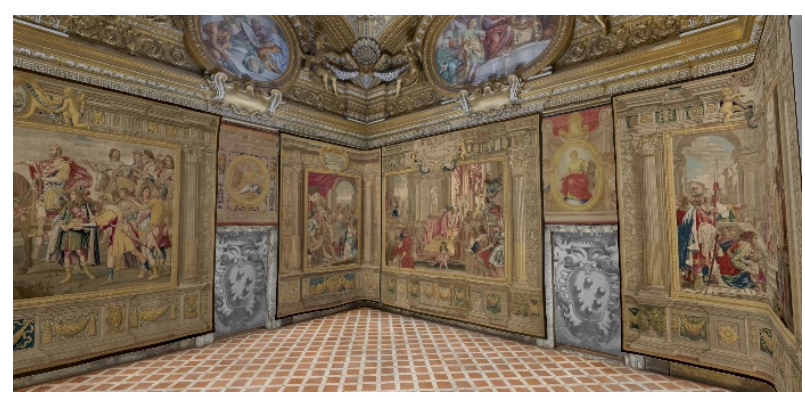

Figure 6: Reconstruction of the arrangement of the tapestries in the Sala di Saturno. The door on the left side is now covered by modern tapestry.

Some tapestries should also be folded at some corners. A possible confirmation of this reconstruction is that in some cases the figures are divided into two groups. If the tapestries were folded, the figures seemed to be face to face, and the perspective of the scene is accentuated. Other, smaller tapestries were placed above doors and as a door covering (Fig. 7).

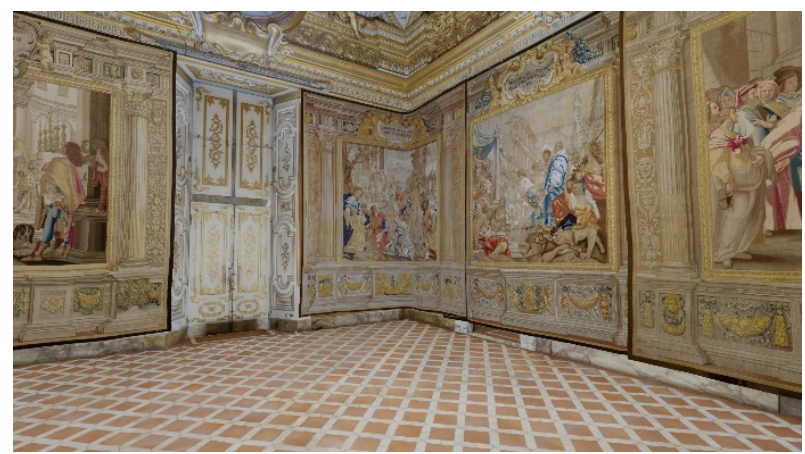

Figure 7: An example of the tapestries overlapped and folded in the corners. On the right wall, the door that now leads to the next room is covered, because the Sala dell'lliade was completed some years later.

\section{A video for communication}

On the communication side, the results of the study have been presented to the public by the Uffizi Galleries and GeCO Lab in a short video (LaboratorioGeCO, 2020). To summarize the function and position of the Rooms of the Planets in the palace, some already acquired pointclouds of the square were reused, in the spirit of the 'Open Data Directive' (2019) for the re-use of digital data. The video then illustrates the visitors' path to the Sala di Saturno, showing at first the photogrammetric model of the current layout, then a reconstruction of the architecture without the paintings. Afterwards, it is explained how the doors were modified and, finally, the supposed arrangement of the tapestries is shown.

\section{Virtual reality for curators}

The digital models of the room and the tapestries enabled the curators to carry out their research, but they always needed the assistance of a 3D expert and modifications could not be made and displayed in realtime.

Previous research has already shown how the management of museums can benefit from visually structured databases (Tucci et al., 2019a; Tucci et al., 2019b). BIM models (or H-BIM, in the case of museums in historic buildings) including data and 3D representation of works of art help museum managers in decision making by correlating information about the collections and the spaces in which they are located.

In this case, it was preferred to exploit virtual reality and allowing curators to personally manipulate and arrange the works of art within a realistic and metrically correct representation of the exhibition space. The creation of virtual environments essentially uses graphic engines born for developing videogames and therefore exploits the efforts made in this field for sufficiently intuitive interaction with the environment and the different assets. (Bekele, Pierdicca, Frontoni, Malinverni \& Gain, 2018) So even though virtual reality is not yet a widespread technology, even beginners can easily learn its use once the virtual environment has been correctly designed and built.

In this case, the virtual environment was built with the Unity graphic engine (Unity Technologies, 2021) starting from the 3D model in 3DS file format and not from a BIM model, which would have not been very meaningful regarding the mere geometry of a single room only. Both BIM and other 3D models must be converted in FBX file format before being imported into Unity, therefore many procedures are valid in both cases, even if with differences and limitations (Banfi, 2020).

By imagining the use of a curator, 3D models of the paintings currently on display in the Sala di Saturno were also created. For smooth interaction, all 3D models with a high number of polygons (high poly) were converted applying retopology and texture baking techniques into models with a low number of polygons (low poly) but maintaining a high visual quality (Fig. 8).

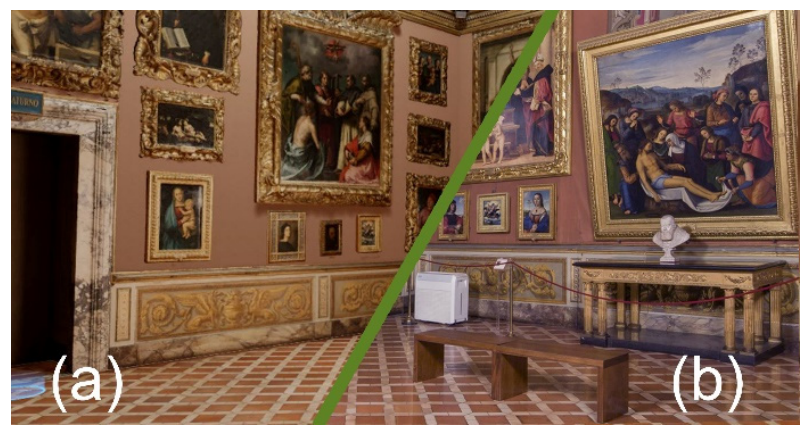

Figure 8: A comparison between the actual Sala di Saturno (a) and the VR model (b). 
The metadata of the works of art from the inventory records has been re-associated to the $3 \mathrm{D}$ models, so that they can also be browsed in the gaming engine.

The immersive virtual environment allows the user to visualize the life-size art assets by selecting (with several search keys) from a catalogue and placing them on the walls of the exhibition room. Therefore, the curator can study different layouts in real-time and record the various results (Fig. 9). There is also a "time machine" function for displaying how the layout of the works of art is changed over time.

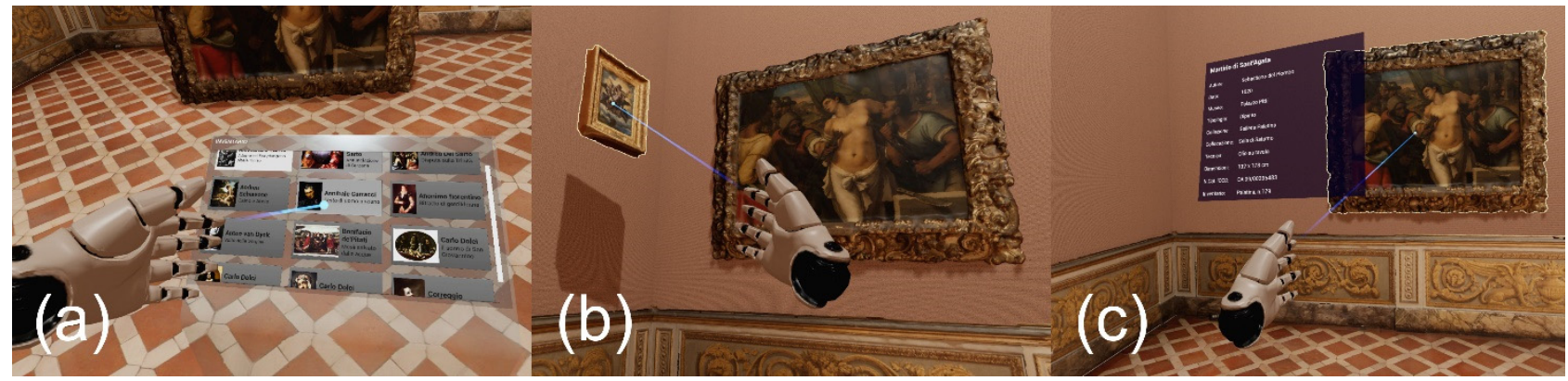

Figure 9: Some examples of the use of the virtual reality solution for museums and exhibitions. Selection of a work from a catalogue (a), arrangement of a painting on a wall (b), consultation of inventory data (c).

This can be used in different scenarios:

- For designing a display or a temporary exhibition, even without being in person at the exhibition site;

- For the pre-visualization of the spatial relationships of the works of art in a real space;

- For designing site-specific works of art;

- $\quad$ for archiving the sequence of the displays in a museum (in Italy this is requested by D.M. 113 2018);

- For creating virtual exhibitions in a realistic setting, according to thematic criteria or customised routes for visitors.

\section{Conclusions}

In the cultural heritage field, geomatic techniques for the acquisition of spatial data, 3D modelling and XR are not only tools used for recording and cataloguing or for visualisation, but also offer to Digital Humanities scholars a range of professional applications. The experience presented, concerning a room in Pitti Palace, has shown:

- The advantages provided by the use of 3D models in the study of the layout of the tapestries in the Sala di Saturno of Pitti Palace in the $17^{\text {th }}$ century;

- How 3D models and VR can be used by museum curators and managers for their professional activities;

- How the same models can be re-used for possible more traditional applications, like for communication projects and virtual exhibitions.

Extended reality technology could be applied to the virtual reconstruction of the ancient layout of the Sala di
Saturno to enable an even more immersive experience than with a video. The existing model can be easily adapted to see the reconstruction beyond the duration of the exhibition, either by allowing visitors to view it in augmented reality on-site or remotely using virtual reality devices.

The experience of art management would obviously be much more interesting if extended to the whole building and including non-visible works of art in the storage rooms also.

These applications are enabled using 3D models produced using geomatic techniques and therefore accurate from both metric and visual points of view. This stresses once again the relevance of proper digital metric documentation of cultural heritage and museum buildings.

The digitisation process of a large building is a challenging and time-consuming process, this effort must therefore be used for multiple purposes. In a museum, great attention is obviously paid to the collections, but the experiences presented show the close connection between the historical building and its content. In this direction, a digital survey of the entire Pitti Palace is currently underway, which will lead to a global model of this important architectural heritage, useful both for deeper knowledge and for improving its management.

\section{Acknowledgements}

We thank Dr Eike Schimdt, director of Le Gallerie degli Uffizi. We also thank the curators of the exhibition "Weaving a Biography. The tapestries in honour of Cosimo I", Dr Alessandra Griffo and Dr Lucia Meoni, together with Dr Cinzia Nenci, whose enquires led to this research. We also finally thank arch. Gabriele Tori for his contribution to the making of the video and the virtual reality project.

\section{References}

Airstar. (2021). Airstar lighting balloons: World leader, inventor and manufacturer. Retrieved November 27, 2020, from http://www.airstar-light.com/en/ 
Angheluță, L.M. \& Rădvan, R., (2020). 3D Digitization of translucid materials in Cultural Heritage objects: a comparative study between laser scanning and photogrammetry. Romanian Journal of Physics 65(7-8 (906)):1. Retrieved November 27, 2020, from http://www.nipne.ro/rjp/2020_65_7-8/RomJPhys.65.906.pdf

Bandini, F., Felici, A., Lanfranchi, M. \& Mariotti, P. (2009). II restauro dei soffitti delle tre Sale dei Pianeti in Pitti Palace a Firenze. OPD Restauro, (21), 145-160. Retrieved November 27, 2020, from http://www.jstor.org/stable/24395673 (27.11.2020)

Banfi, F. (2020). HBIM, 3D drawing and virtual reality for archaeological sites and ancient ruins. Virtual Archaeology Review, 11(23), 16-33. https://doi.org/10.4995/var.2020.12416

Bekele, M. K., Pierdicca, R., Frontoni, E., Malinverni, E. S. \& Gain, J. (2018). A survey of augmented, virtual, and mixed reality for cultural heritage. Journal on Computing and Cultural Heritage, 11(2), 1-36. https://doi.org/10.1145/3145534

Bertelli, S. (2002). Palazzo Pitti dai Medici ai Savoia.. In Bellinazzi, A. (Ed.) La Corte di Toscana dai Medici ai Lorena. Atti. Firenze 1997. Pubblicazioni degli Archivi di Stato: Saggi, 71, 11-109. Roma, Italy: Ministero dei Beni Culturali

D.M. 113 (2018). Adozione dei livelli minimi uniformi di qualita' per i musei e i luoghi della cultura di appartenenza pubblica e attivazione del Sistema museale nazionale. Ministerial Decree. Gazzetta Ufficiale della Repubblica Italiana Serie Generale 78, 04-04-2018. Retrieved November 27, 2020, from https://www.gazzettaufficiale.it/eli/id/2018/04/04/18A02353/sg

Eliseu S., Lopes M. M., Ribeiro J.P. \& Oliveira F. (2020). Learning and Creativity Through a Curatorial Practice Using Virtual Reality. In Stephanidis C. et al. (Eds) HCl International 2020 - Late Breaking Papers: Cognition, Learning and Games. HCII 2020. Lecture Notes in Computer Science, vol 12425. Cham, Germany: Springer. https://doi.org/10.1007/978-3-030-60128-7_28

Fazio, L. \& Lo Brutto, M. (2020). 3D survey for the archaeological study and virtual reconstruction of the "Sanctuary of Isis" in the ancient Lilybaeum (Italy). Virtual Archaeology Review, 11(22), 1-14. https://doi.org/10.4995/var.2020.11928

LaboratorioGeCO. (2020). Weaving a Biography: $17^{\text {th }}$ century tapestries in honour of Cosimo I. [Video file]. Retrieved November 27, 2020, from https://youtu.be/3406gZFWMX8

Gifreu-Castells, A. (2019). Approach to the Curatorship of Virtual Reality Exhibitions. In Buckley B. \& Conomos J. (Eds.) A Companion to Curation. Hoboken, NJ: Wiley. https://doi.org/10.1002/9781119206880.ch19

Greco, C. (2019). Keynote: The biography of objects. International Archives of the Photogrammetry, Remote Sensing and Spatial Information Sciences. XLII-2/W11, 5-10. https://doi.org/10.5194/isprs-archives-XLII-2-W11-5-2019

Greco, C., Rossi, C. \& Della Torre,S. (2020). Digitalizzazione e patrimonio culturale tra crisi e opportunità: l'esperienza del Museo Egizio di Torino / Digitalization and Cultural Heritage between Crisis and Opportunities: the Experience of the Egyptian Museum in Turin. II capitale culturale. Studies on the Value of Cultural Heritage, Suppl.11, 197212. https://doi.org/10.13138/2039-2362/2532

Gregory, I. \& Murrieta-Flores, P. (2016). Geographical information systems as a tool for exploring the spatial humanities. In C. Crompton, R. Lane, \& R. Siemens (Eds.), Doing Digital Humanities: Practice, Training, Research. Oxford, United Kingdom: Routledge

Griffo, A., \& Meoni, L. (2019). Una biografia tessuta: gli arazzi seicenteschi in onore di Cosimo I. Livorno, Italy: Sillabe

Huaman E.M.R., Aceituno R.G.A. \& Sharhorodska O. (2019). Application of Virtual Reality and Gamification in the Teaching of Art History. In Zaphiris P., loannou A. (Eds) Learning and Collaboration Technologies. Ubiquitous and Virtual Environments for Learning and Collaboration. HCII 2019. Lecture Notes in Computer Science, vol 11591. Cham, Germany: Springer. https://doi.org/10.1007/978-3-030-21817-1_17

Lazzeretti, L. \& Sartori, A. (2016). Digitisation of Cultural Heritage and Business Model Innovation: The Case of the Uffizi Gallery in Florence. II capitale culturale. Studies on the Value of Cultural Heritage, 14. http://doi.org/10.13138/2039-2362/1436

Luhmann, T., Chizhova, M., Gorkovchuk, D., Hastedt, H., Chachava, N. \& Lekveishvili, N. (2019). Combination of Terrestrial Laserscanning, Uav and Close-Range Photogrammetry for 3d Reconstruction of Complex Churches in Georgia. International Archives of the Photogrammetry, Remote Sensing and Spatial Information Sciences, XLII2/W11, 753-761. https://doi.org/10.5194/isprs-archives-XLII-2-W11-753-2019

Mandelli, A., Perfetti, L., Fiorillo, F., Fassi, F., Rossi, C. \& Greco, C.. (2019). The digitalization of ancient Egyptian coffins: a discussion over different techniques for recording fine details. International Archives of the Photogrammetry, Remote Sensing and Spatial Information Sciences. XLII-2/W15. 743-750. https://doi.org/10.5194/isprs-archivesXLII-2-W15-743-2019

Münster, S., Friedrichs, K. \& Hegel, W. (2018). 3D Reconstruction Techniques as a Cultural Shift in Art History?. International Journal for Digital Art History, 3. https://doi.org/10.11588/dah.2018.3.32473

Münster, S. \& Terras, M. (2019). The visual side of digital humanities: A survey on topics, researchers, and epistemic 
cultures. Digital Scholarship in the Humanities, 35(22), 366-389. https://doi.org/10.1093/llc/fqz022

NEMECH (2020). MuseiEmotivi e motivi post_Covid-19. Ascoltare i partecipanti. Retrieved November 27, 2020, from http://nemech.unifi.it/MuseiEmotivi_reports/MUSEIEMOTIVI_e_motivi_post_Covid_19.pdf

NEMO (2020). Survey on the impact of the COVID-19 situation on museums in Europe. Retrieved November 27, 2020, from https://www.ne-mo.org/fileadmin/Dateien/public/NEMO_documents/NEMO_COVID19_Report_12.05.2020.pdf

Open Data Directive (2019). Directive (EU) 2019/1024 of the European Parliament and of the Council of 20 June 2019 on open data and the re-use of public sector information. Official Journal of the European Union, English edition $L$ 172, 26 June 2019. Retrieved November 27, 2020, from https://eur-lex.europa.eu/eli/dir/2019/1024/oj

Tucci, G., Betti, M., Conti, A., Corongiu, M., Fiorini, L., Matta, C., Kovačević, C., Borri, C. \& Hollberg, C. (2019a). BIM for Museums: An Integrated Approach from the Building to the Collections. International Archives of the Photogrammetry, Remote Sensing and Spatial Information Sciences, 4211, 1089-1096. https://doi.org/10.5194/ISPRS-ARCHIVES-XLII-2-W11-1089-2019

Tucci, G., Bonora, V., Conti, A. \& Fiorini, L. (2017). High-quality 3D models and their use in a cultural heritage conservation project. International Archives of the Photogrammetry, Remote Sensing and Spatial Information Sciences, XLII-2/W5, 687-693. https://doi.org/10.5194/isprs-archives-XLII-2-W5-687-2017

Tucci, G., Conti, A., Fiorini, L., Corongiu, M., Valdambrini, N. \& Matta, C. (2019b). M-BIM: a new tool for the Galleria dell'Accademia di Firenze. Virtual Archaeology Review, 10(21), 40-55. https://doi.org/10.4995/var.2019.11943

Unity Technologies (2021). Unity Technologies. Unity Real-Time Development Platform | 3D, 2D VR \& AR Engine. Retrieved November 27, 2020, from https://unity.com/ 


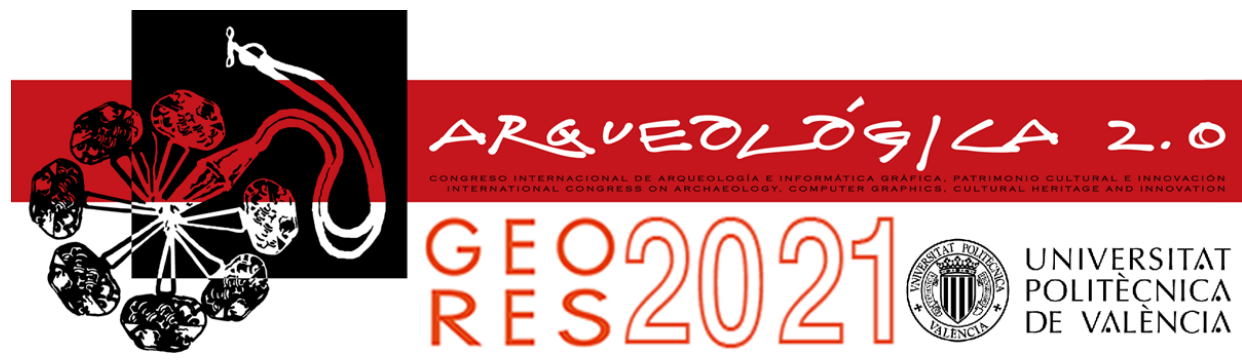

Proceedings of the joint international event $9^{\text {th }}$ ARQUEOLÓGICA

$2.0 \& 3^{\text {rd }}$ GEORES

Valencia (Spain).

26-28 April 2021

\title{
INTEGRATING LASER SCANNING AND GEO-MECHANICAL SURVEY IN CONSERVATIVE RESTORATION; THE CASE OF FIRST WORLD WAR'S CIMA GRAPPA MILITARY SHRINE, ITALY
}

\author{
Francesco Mugnaia, ${ }^{a}$, Paolo Farina ${ }^{b}$, Grazia Tucci ${ }^{a}$ \\ ${ }^{a}$ Department of Civil and Environmental Engineering, University of Florence, Via di S.Marta 3,50139 Firenze, Italy. \\ francesco.mugnai@unifi.it; grazia.tucci@unifi.it \\ b Geoapp s.r.I.,Viale Spartaco Lavagnini 70-72, 50129 Firenze, Italy. paolo.farina@geoapp.it
}

\begin{abstract}
:
The work presents results obtained performing a survey campaign specifically designed to formulate an effective restoration project in a critical context. Within the remarkable project, promoted and financed by the Italian Presidency of the Council of the Ministers, and the Italian Ministry of Defence, for designing the conservative restoration plan of the Military Shrine in Cima Grappa (Italy), the assessment of the overall tunnels' stability and a report of the state of conservation of the underground area has been produced. Exploiting the most advanced laser scanning survey technique, and some specific algorithms for point cloud analysis, several outputs have been generated, in particular a detailed geometrical 3D reconstructions of man-made and natural tunnels coating materials, geo-mechanical survey of rock mass, map of rock collapses and cinematic analysis of instability processes. The integration of the laser scanning technique with the most commonly used Scan-line survey for rock-mass characterization and architectural surveys, allowed to perform advanced analysis even in a high-risk study area as the one considered in the restoration project, which is represented by a predominant subterranean development. Most of the tunnels and underground spaces, displayed rock collapses and diffuse active instability processes that certainly could have drastically slowed down surveys and analysis. The adopted techniques allowed to rapidly proceed in acquiring data end to deliver sound outputs. This paper aims to report both a general description of the project, spending some words on the historical value of the place and describing the complex environment of work, and a detailed depiction of the performed survey activities with particular attention in showing laser scanning survey and the obtained results.
\end{abstract}

Keywords: laser scanning, conservative restoration, kinematic analysis, 3D digital model, segmentation

\section{Introduction}

Some authors reveal that the politization of the fallen could be the true objective of the monumental ossuaries that Fascist Leadership built after the first world war (Malone, 2017).

In addition to its historical value and the noticeable cultural and architectural heritage, sometimes old witnesses, even when the told story concerns war, suffering, death and poverty, need to be remembered, if only to prevent certain events from happening again.

However, it undisputed how the project of conservative restoration of the Cima Grappa Military Shrine and of the revival of the annexed buildings, of the former NATO base and of the related neighbouring areas, assumes extraordinary importance not only for the complexity and heterogeneity of the envisaged interventions, but also for the historical and programmatic legislative framework of which the Cima Grappa complex is a central and strategic part.

Promoted and financed by the Italian Presidency of the Council of the Ministers, and the Italian Ministry of Defence, the restoration project insists on a mountain area on the top of Monte Grappa (also called "Cima del Grappa"), in particular the municipal area of Crespano del Grappa, Borso del Grappa and Paderno del Grappa in the Province of Treviso, Cismon del Grappa in the Province of Vicenza and Seren del Grappa in the Province of Belluno, in the geographic area of the Venetian Prealps. The intervention area can be conveniently divided into two sectors:

- The south area, consisting of the Shrine and the surrounding monumental complex, which in turn includes other celebratory elements (the Via Eroica and the Porta Roma, the Observatory, the Sacello della Madonnina) and defence and fortification works carried out during the First

“Corresponding Author: Francesco Mugnai, francesco.mugnai@unifi.it 
World War (the Vittorio Emanuele III Gallery and the Milan Barracks);

- The north area (Fig. 1), which host the site of the former NATO base and the relevant military perimeter

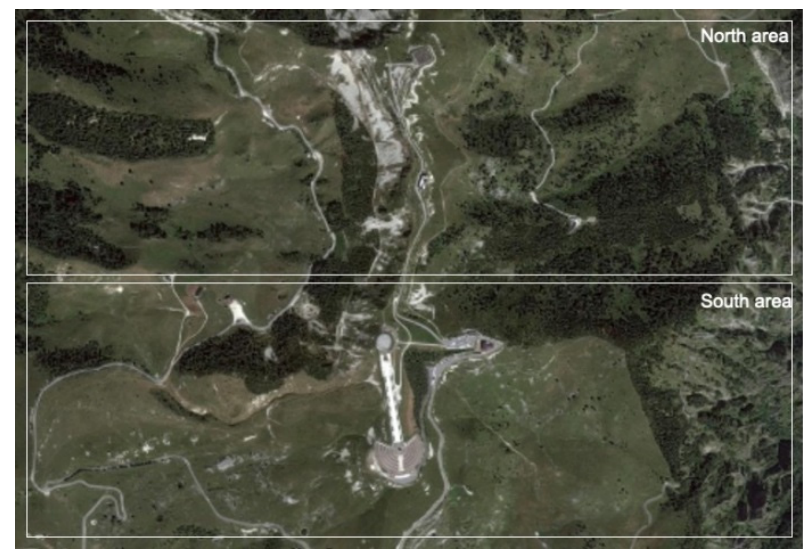

Figure 1: Aerial Orthophoto of the studied area.

The restoration project has driven by a quite extensive program that involved the various sections of the monumental complex.

Figure 2 shows the locations of the various rooms and sections in which the interventions have planned. In particular 1) Preventive environmental restoration works; 2) Scientific conservative restoration of the Shrine including Italian Ossuary, Via Eroica, Rome Portal and Austro-Hungarian ossuary as well as the observatory located in the EX NATO area; 3) Restructuring and transformation into an equipped museum of the Milan Barracks, connection restoration pedestrian staircase from the Austro-Hungarian cemetery to Piazza Cadorna; 4) Underground connection between the Milan Barracks and the former underground infirmary, with related securing of the infirmary itself; 5) Restoration of the Vittorio Emanuele III tunnel up to the connection with the underground ossuary; 6) Demolition of closing diaphragms of the underground ossuary and scientific restoration of the same; 7) Reconstruction of rainwater storage tank; 8) Demolition of former NATO barracks, garage building and pump room, and construction of green furniture areas; 9) Connection of the new storage tank to the autoclave and distribution of the water supply pipes along the Vicentina shoulder (south-east side) of the Cima del Grappa, in order to connect the Bassano Refuge to today in operation and prepare the water supply for possible other building interventions in the area.

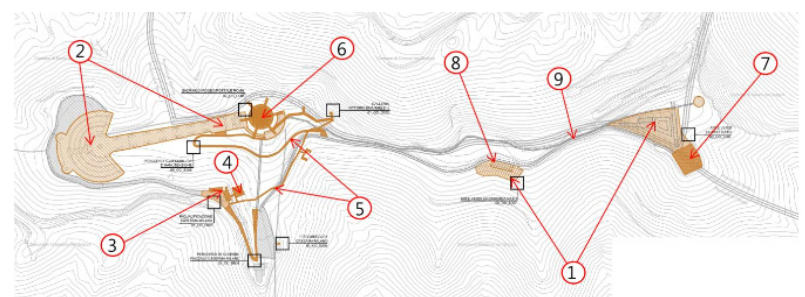

Figure 2: Map of restoration interventions.

The paper focuses in particular on the intervention number 4 , especially on securing the former infirmary room and tunnels to access this and the other main gallery named Galleria Vittorio Emanuele. Other than serving as linking path to access the other areas of the site, the ex-infirmary is one of the main highlights, an "archaeological" path of war in the mountain heart.

The area of interest, mainly represented by underground tulles (Fig. 3 ) is strongly affected by a generally poor state of conservation, as a matter of facts, several rock collapses have occurred in the underground infirmary environment and the access tunnels during the last few years (Fig. 4).
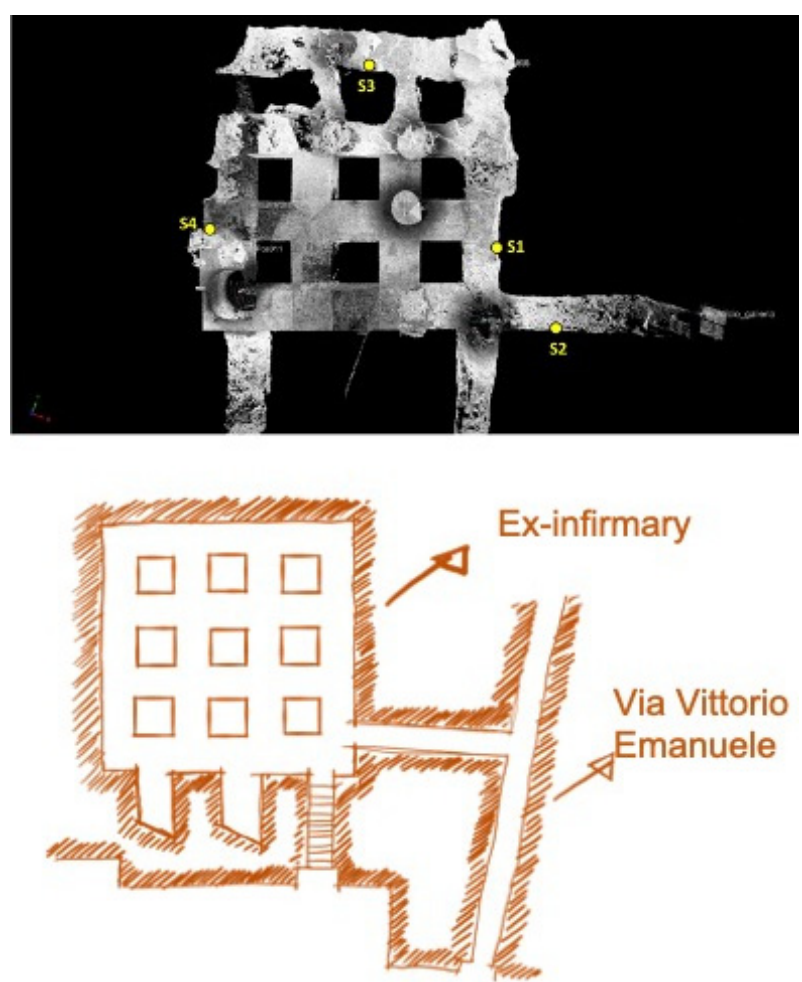

Figure 3: Top view of the Infirmary from 3D Point Cloud. S from 1 to 4 are scanning positions. The sketch on the right shows the position of Via Vittorio Emanuele.

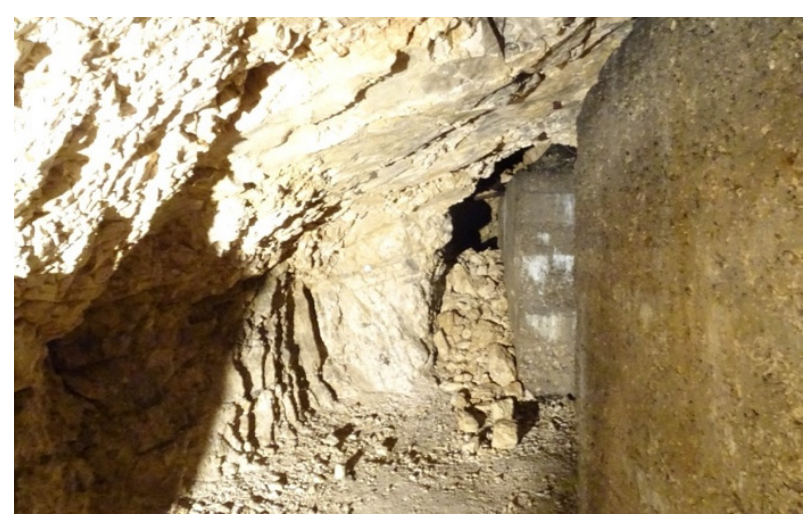

Figure 4: View of vault collapse within the infirmary tunnel.

This paper follows a well-established path (Bonora, Chieli, Spanò, Testa, \& Tucci, 2003; Bitelli et al., 2017; Castagnetti, Bertacchini, Capra, \& Dubbini, 2012; Grussenmeyer et al., 2012; Chías, Abad, Echeverría, De Miguel, \& Llorente, 2017; Lo Brutto, Sciortino, \& Garraffa, 2017), of using remote sensing and 3D surveys techniques (Thiel, \& Wehr, 2004; Wagner, Ullrich, Ducic, Melzer, \& Studnicka, 2006; Varady, Facello, \& Terek, 
2007; Remondino et al., 2011; Remondino, 2011; Tucci, Bonora, Fiorini, \& Conti, 2016; Chías, Abad, Echeverría De Miguel, \& Llorente, 2017) to support out of the ordinary conservative restoration projects in a complex work environment (Gallay et al., 2015, Gigli, Mugnai, Leoni, \& Casagli, 2009, Roncella, Forlani, \& Remondino, 2005, Gracchi, Lotti, \& Saccorotti, 2017).

A detailed geo-mechanical characterization of the former infirmary underground area has been therefore necessary in order to properly plan specific consolidating interventions. For this purpose, a) a high-resolution laser scan survey has been performed (Mucchi et al., 2018; Mugnai, Ridolfi, Bianchi, Franchi, \& Tucci, 2019) and b) 3D meshes of the area have been extracted. By automatically extracting rock-mass characteristics (surface orientation, number of cracks, spacing, frequency of cracks) the traditional geo-mechanical survey has been improved and extended to the whole exinfirmary area, including spaces and surfaces not completely accessible by technicians, and with an associated high-risk of rock collapse.

With such a dataset, the traditional geo-mechanical survey can be improved with information automatically extracted from the point clouds produced by the laser scanner.

\section{Methods}

In order to obtain the mechanical properties of the rock mass a geo-mechanical survey (Priest, 1993; Priest, \& Hudson, 1976) of the calcareous rock mass surfacing in the infirmary rooms, dug under the Cima Grappa, near the Milan barracks, was carried out. It consisted in some steps, in particular:

1) Geo-mechanical characterization of intact rock;

2) Geo-mechanical characterization of discontinuities;

3) Geo-mechanical characterization of the Rock Mass.

A laser scanning survey has been used to extract geometries. The Laser Scanner model is a Riegl LMSZ420i ground-based in Table 1.

Table 1: Laser Scanner hardware parameters.

\begin{tabular}{c|c} 
Parameter & Value \\
\hline Measurement Range & $0.2-1000 \mathrm{~m}$ \\
Accuracy & $10 \mathrm{~mm}$ \\
Laser class 1 & 1 \\
Minimum angle step-width & $0.004^{\circ}$
\end{tabular}

\subsection{Integration of classic geo-mechanical scan line survey}

In correspondence of not accessible areas, or in correspondence of areas prone to collapsing events, the classic geo-mechanical survey (scan-line detection method. citation) of the rock mass has been substituted with measures obtained from Laser Scanning datasets. In particular, the results of the geo-mechanical analysis thus obtained were combined with the results of the analysis of the point clouds acquired by the laser scanner. For the geo-mechanical characterization of the intact rock, tests were also carried out in the laboratory on samples of irregular shape taken on-site, however, as the paper focuses on Laser Scanning and analysis related to the acquired dataset.

\subsection{Acquisition Campaign}

A Riegl LMS-Z420i laser scanner model has been employed to perform the acquisition campaign (Fig. 5). The thirteens Scan Positions allowed to cover the entire areas of the ex-infirmary, adjacent to the Milan Barracks.

In order to obtain a comprehensive acquisition of both the tunnel vertical flanks and of the vaults, the laser scanner instrument has been deployed both in a vertical and horizontal configuration. The horizontal configuration has been mostly adopted in correspondence with the main collapses. For each shooting position, low-resolution framing scans and detail scans were acquired. A total of over 40 million points were thus acquired, one point $/ \mathrm{cm}^{2}$ is the average point cloud density of the processed point clouds after optimisation and unification. Before proceeding with laser scanning acquisition, some targets/reflectors were positioned within the scene.

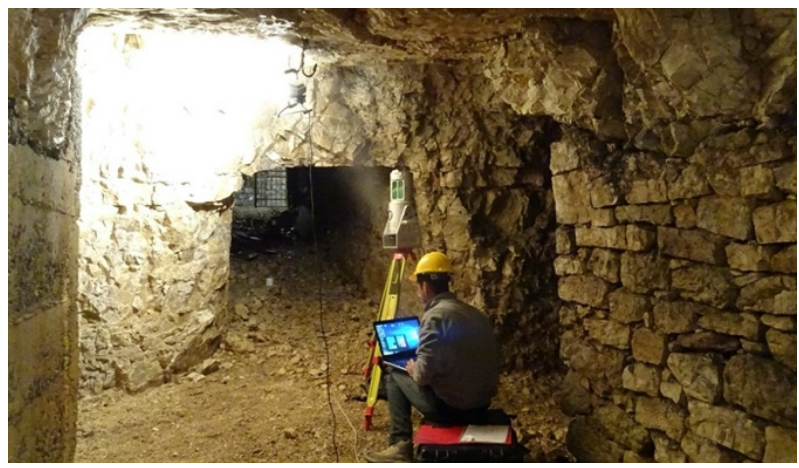

Figure 5: Tunnel area, Scan position $n^{\circ} 3$.

The use of reflectors is linked to the possibility for the acquisition software to recognize the same in the various scans in order to then combine them into a single cloud of points, minimizing the problems related to the presence of shaded areas.

\section{Data Analysis}

The accuracy in the alignment procedure of the scans has been improved by applying the Multi-Station Adjustment algorithm, (MSA) developed by Riegl (RIEGL, 2004), based on the recognition of homologous plans materialized for each scan (which therefore require portions of scanned surfaces in common between them) and their iterative alignment, up to minimizing the position differences (Fig. 6).

Due to the impossibility of acquiring the coordinates of the reflectors placed outside with acceptable accuracy via GPS (for lack of GPRS / UMTS coverage), the point clouds were oriented using as reference the walls of the Milan barracks, whose orientation was measured by compass and verified by georeferenced aerial photos.

Four traditional geo-mechanical surveys were carried out with the scanline method (scanline survey) at the main outcrop portions of the limestone rock mass inside the hospital wing, plus a series of random measures to complete the sample. in areas where the extension of the outcrops is more limited. The traditional geo-mechanical 
survey (Hoek, 1999) is however highly limited if the area to be investigated is inaccessible or unreachable, or, as in the case in question, very articulated and intensely fractured.

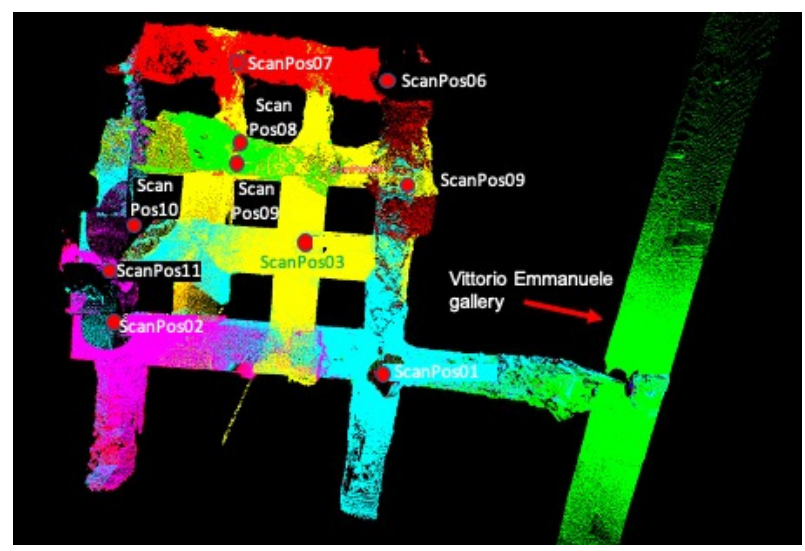

Figure 6: Top view of the Infirmary from the total point cloud. Each point clouds is showed with a different colour. Red dots represent Scan Positions.

Fortunately, by exploiting advanced techniques, it is possible to obtain effective data, even if the adopted technique has not been specifically designed for the selected application (Olsen, Kuester, Chang, \& Hutchinson, 2013; Mugnai, Ridolfi, Bianchi, Franchi, \& Tucci, 2019; Pesci, Teza, \& Boschi, 2015). In these cases, thanks to the high spatial resolution of the laser scanning data, it is possible to use point clouds to integrate the data of the traditional survey and obtain information on the geometry of the rock mass remotely.

In the specific case, a calculation algorithm was applied to the point clouds to extract accurate geometric information, useful for the reconstruction and characterization of the rock mass. In particular, through the use of a tool developed in the Matlab environment called DiAna (Gigli \& Casagli, 2011), the discontinuity plans were identified semi-automatically and their spatial orientations were calculated.

The analysis was carried out in correspondence with the main outcrop areas of the limestone rock mass and allowed to extract 2761 discontinuous surfaces. It is however possible that a surface of discontinuity that is not perfectly planar and with high persistence is fragmented into a certain number of "sub-surfaces", with the result that the number of discontinuities extracted is overestimated.

\section{Results}

Thanks to the performed survey campaigns a huge amount of the 3D data of the underground spaces have been obtained and a series of elaborations have been processed capitalizing on the high-resolution point clouds acquired by laser scanning. The elaborations were specifically aimed at:

a) Providing detailed geometric reconstruction of the natural and anthropic outcropping materials in the underground rooms;

b) Extracting a digital model of the detailed soil of the outcrop portions of the limestone rock-mass; c) Integrating the traditional geo-mechanical survey by identifying the main discontinuities affecting the rock mass and dividing them into families;

d) Providing detailed geometric reconstruction of the collapse events that occurred;

e) Identifying main failure mechanisms (Barton, \& Choubey, 1977; Barton, Lien, \& Lunde, 1974; Bieniawski, 1989) of the rock mass in correspondence of the tunnels and underground spaces (Kinematic Analysis).

\section{Discussions}

By applying point clouds segmentation, remotely extracted orientations of planes have been measured. Orientations of joint families modal plans have been identified (BG: $13^{\circ} / 245^{\circ}$, JN1: $76^{\circ} / 069^{\circ}$, JN2: $76^{\circ} / 001^{\circ}$, JN3: $75^{\circ} / 125^{\circ}$ ) and a stereographic projection has been populated.

From the comparison between the stereographic projections, a good correspondence between the joint families measured by scan line survey and the ones extracted applying the semi-automatic method is noticeable. Considering joint families' setting and rockmass characteristic, in terms of material and joints orientation, restoration interventions will be designed and to avoid further collapse events.

The reduction of operators' time exposure to risk-prone areas and the capability to acquire valuable data from inaccessible spaces completes the benefits list.

To survey the whole area, a group of 3 operators spent more than three days. Considering the relatively small extension, the long time spent appears to have resulted from the highly complex surface's morphology and the cramped spaces. Although static TLS is an appropriate technique for this kind of environment, a mobile and presumably remoted operating system, e.g. a TLS mounted on a robotised platform, would have performed the same in less time.

\section{Conclusions}

Point clouds obtained from the high-resolution laser scanning survey, which has been specifically carried out in the underground area, former infirmary, have been exploited to create a detailed 3D model of the area and to integrate traditional geo-mechanical survey with information automatically extracted from the point clouds. The results of the geo-mechanical analysis of the rock mass thus obtained were used to perform a 3D kinematic analysis aimed at assessing the propensity to failure for the various plausible breaking mechanisms in the tunnel sectors analysed.

Finally, a detailed 3D kinematic analysis was carried out on the hypogeum portions where the rock mass emerged, using the discontinuities detected and the mesh obtained from the clouds of laser scanner points as input data. This analysis made it possible to identify which sectors of the infirmary have an adverse orientation in relation to the main kinematic mechanisms of instability (planar sliding, wedge sliding, overturning, free fall), according to the orientation of the discontinuity planes that pervade the rock mass. 
The discontinuity families identified are characterized by decimetric spacing values and mostly have a high degree of alteration and low roughness; these divide the rock mass into small (decimetric) blocks.

Consequently, the general geo-mechanical behaviour of the cluster based on the main classification systems was found to be a material with poor characteristics.

The phenomena of instability observed concern the portions in which the rock mass is directly outcropping and consist more frequently in the detachment of single blocks of decimetric size and secondly, in the detachment of portions of rock mass with a maximum volume of a few m3. In accordance with what emerged from the kinematic analysis, the most observed failure mechanisms are the sliding of wedges and secondly the planar sliding and the free fall.

In particular, it is observed that these phenomena are mainly located in correspondence with some bands of weakness that cross the rock mass parallel to two of the main discontinuity families, or in the intersection areas between tunnels.

\section{Acknowledgements}

The authors want to thank: 1] Italian Ministry of Defence and the Presidency of the Ministry Council for having founded this study, 2] Dr. Geol. Pietro Accolti of Politecnica and Architettura, main promoting company of the temporary grouping of professionals (consortium) for designing, together with: 3] ACPV studio, 4 ]Parallelo and Bit Movies, 5] Architect Gianfranco Tedeschi as Project Manager, 6] Engineer Fabio Camorani as Structural and Geotecnical design, and 7] engineer Francesco Frassineti, 8] Massimo Cavazzuti and 9] Claudio Pongolini for the technical project harmonization. 10] GEOAPP s.r.I. for technical support and outstanding technical experience in managing such a sensitive and complex survey project.

\section{References}

Barton, N. R., \& Choubey, V. (1977). The shear strength of rock joints in theory and practice. Rock Mech., $10,1-54$.

Barton, N. R., Lien, R., \& Lunde, J., (1974). Engineering classification of rock masses for the design of tunnel support. Rock Mech., 6(4), pp. 189-239.

Bieniawski, Z.T. (1989). Engineering Rock Mass classification. Wiley, New York. 251 pages.

Bitelli, G., Balletti, C., Brumana, R., Barazzetti, L., D'Urso, M.G., Rinaudo, F., \& Tucci, G., (2017). Metric documentation of cultural heritage: Research directions from the Italian gamher project (2017) International Archives of the Photogrammetry, Remote Sensing and Spatial Information Sciences, 42 (2W5), pp. 83-90. https://doi.org/10.5194/isprs-archivesXLII-2-W5-83-2017

Bonora, V., Chieli, A., Spanò, A., Testa, P., \& Tucci, G. (2003). 3D Metric-modelling for knowledge and documentation of architectural structures (royal palace in Turin). International Archives of the Photogrammetry, Remote Sensing and Spatial Information Sciences, 34 (5W12), 60-65.

Castagnetti, C., Bertacchini, E,. Capra, A., \& Dubbini, A. (2012). Terrestrial laser scanning for preserving cultural heritage: analysis of geometric anomalies for ancient structures. In: FIG Working Week 2012 - Knowing to Manage the Territory, Protect the Environment, Evaluate the Cultural Heritage, Rome, Italy.

Chías, P., Abad, T., Echeverría, E., De Miguel, M., \& Llorente, P. (2017). Underground surveying: $16^{\text {th }}$ century cellar vaults in the Gallería de Convalecienties, monastery of san Lorenzo del Ecorial. In: International Archives of the Photogrammetry, Remote Sensing and Spatial Information Sciences, XLII2/W3, $179-186$. https://doi.org/10.5194/isprs-archives-XLII-2-W3-283-2017

Gallay, M., Kaňuk, J., Hochmuth, Z., Meneely, J. D., Hofierka, J. \& Sedlák, V., (2015). Large-scale and high-resolution 3D cave mapping by terrestrial laser scanning: a case study of the Domica Cave, Slovakia. International Journal of Speleology, 44(3), 277-291.

Gigli, G., \& Casagli, N., (2011). Semi-automatic extraction of rock mass structural data from high resolution LIDAR point clouds. International Journal of Rock Mechanics \& Mining Sciences, 48(2011): 187-198.

Gigli, G., Mugnai, F., Leoni, L., \& Casagli, N., (2009). Brief communication "Analysis of deformations in historic urban areas using terrestrial laser scanning". Nat. Hazards Earth Syst. Sci., 9, 1759-1761. https://doi.org/10.5194/nhess-9-17592009, 2009

Gracchi, T., Lotti, A., \& Saccorotti, G., (2017). A method for locating rockfall impacts using signals recorded by a microseismic network. Geoenviron Disasters 4, 26. https://doi.org/10.1186/s40677-017-0091-z

Grussenmeyer, P., Alby, E., Landes, T., Koehl, M., Guillemin, S., Hullo, J. F., Assali, P., \& Smigiel, E., (2012). Recording approach of heritage sites based on merging point clouds from high resolution photogrammetry and terrestrial laser scanning, Int. Arch. Photogramm. Remote Sens. Spatial Inf. Sci., XXXIXB5, 553-558. https://doi.org/10.5194/isprsarchives-XXXIX-B5-553- 2012

Hoek, E.; Bray, J.W., (1981) Rock Slope Engineering. Revised 3rd Edition, The Institution of Mining and Metallurgy, London, 341-351.

Malone, H., (2017). Fascist Italy's Ossuaries of the First World War: Objects or Symbols? RIHA Journal 0166,27 June 2017. http://www.riha- journal.org/articles/2017/0150-0176-special-issue-war-graves/0166-malone 
Lo Brutto, M., Sciortino, R., \& Garraffa, A., (2017). RPAS and TLS techniques for archaeological survey: the case study of the archaeological site of Eraclea Minoa (ITALY). International Archives of the Photogrammetry, Remote Sensing and Spatial Information Sciences, Vol. XLII-2/W3, 433-438. https://doi.org/10.5194/isprs-archives-XLII-2-W3-4332017

Mucchi, L., Jayousi, S., Martinelli, A., Caputo, S., Intrieri, E., Gigli, G., Gracchi, T., Mugnai, F., Favalli, M., Fornaciai, A., \& Nannipieri, L. A., (2018). Flexible Wireless Sensor Network Based on Ultra-Wide Band Technology for Ground Instability Monitoring. Sensors, 18, 2948.

Mugnai, F., Lombardi, L., Tucci, G., Nocentini, M., Gigli, G., \& Fanti, R. (2019). Geomatics in bridge structural health monitoring, integrating terrestrial laser scanning techniques and geotechnical inspections on a high value cultural heritage. Int. Arch. Photogramm. Remote Sens. Spatial Inf. Sci., XLII-2/W11, 895-900. https://doi.org/10.5194/isprsarchives-XLII-2-W11-895-2019

Mugnai, F., Ridolfi, A., Bianchi, M., Franchi, M., \& Tucci, G., (2019). Developing affordable bathymetric analysis techniques using non-conventional payload for cultural heritage inspections. Int. Arch. Photogramm. Remote Sens. Spatial Inf. Sci., XLII-2/W15, 807-811. https://doi.org/10.5194/isprs-archives-XLII-2-W15-807-2019

Olsen, M., Kuester, M., Chang, B., \& Hutchinson, T., (2010). Terrestrial laser scanning-base structural damage assessment. Comput Civil Eng, 24(3), 264-272. https://doi.org/10.1061/(ASCE)CP.1943-5487.0000028

Pesci, A., Teza, G., \& Boschi, E. (2015). Laser scanning-based detection of morphological changes of a historical building occurred during a seismic sequence: Method and Case study. International Journal of Geomatics and Geosciences, 5(3) 427-447.

Priest, S. D., \& Hudson, J.A., (1976). Discontinuity spacings in rocks. Int. Journ. Rock Mech. Min. Sci. \& Geomech. Abstracts, 13, 135-148.

Priest, S. D., (1993). Discontinuity analysis for rock engineering. London: Chapman \& Hall.

RIEGL Laser Measurement Systems GmbH, (2004). RIEGL - RIEGL Laser Measurement Systems. Technical data Retrieved March 15, 2021, from www.riegl.com.

Remondino, F., Rizzi, A., Jimenez, B., Agugiaro, G., Baratti, G., \& Amicis, R., (2011). The Etruscans in 3D: From Space to Underground. Geoinformatics FCE CTU, 6, pp. 283-290. https://doi.org/10.14311/gi.6.35.

Remondino, F., (2011). Heritage recording and 3D modeling with photogrammetry and 3D scanning. Remote Sensing, 3, pp. 1104-1138.

Roncella, R., Forlani, G., \& Remondino, F. (2005). Photogrammetry for geological applications: automatic retrieval of discontinuity orientation in rock slopes. In: Videometrics IX, electronic imaging, IS\&T/SPIE, Proceedings of the 17th annual symposium (pp. 17-27).

Thiel, K.H., \& Wehr, A., (2004). Performance Capabilities of Laser-Scanners - An Overview and Measurement Principle Analysis. International Archives of Photogrammetry, Remote Sensing and Spatial Information Sciences 36 (Part 8/W2), 14-18.

Varady,T., Facello, M.A., \& Terek, Z., (2007). Automatic extraction of surface structures in digital shape reconstruction. Comput Aided Des, 39(5), 379-388. https://doi.org/10.1016/j.cad.2007.02.011

Tucci, G., Bonora, V., Fiorini, L., \& Conti, A., (2016). The Florence baptistery: 3-D Survey as a knowledge tool for historical and structural investigations. International Archives of the Photogrammetry, Remote Sensing and Spatial Information Sciences, 41, 977-984. https://doi.org/10.5194/isprsarchives-XLI-B5-977-2016

Wagner, W., Ullrich, A., Ducic, V., Melzer, T., \& Studnicka, N., (2006). Gaussian Decomposition and Calibration of a Novel Small- Footprint Full-Waveform Digitising Airborne Laser Scanner. ISPRS Journal of Photogrammetry \& Remote Sensing, 60(2): 100-112. 


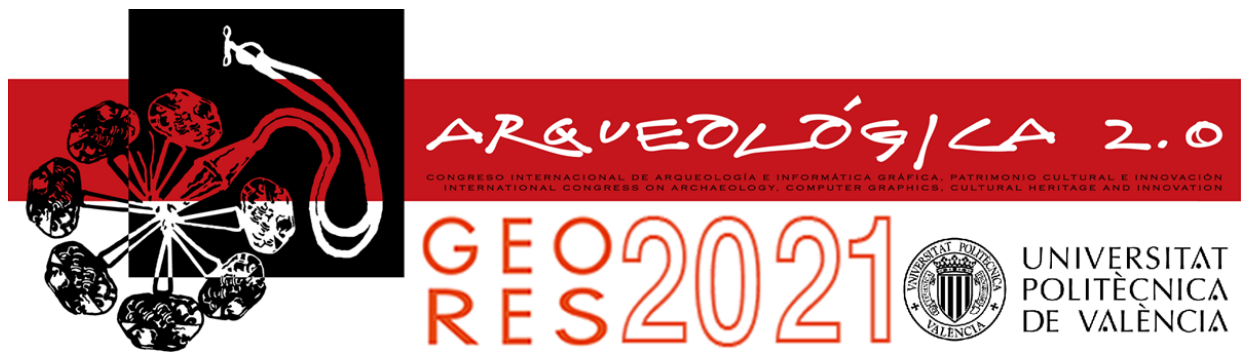

Proceedings of the joint international event $9^{\text {th }}$ ARQUEOLÓGICA

$2.0 \& 3^{\text {rd }}$ GEORES

Valencia (Spain).

26-28 April 2021

\title{
FRESCO PHOTOGRAMMETRY: DOCUMENTING THE IMPERIAL CULT CHAMBER AT LUXOR TEMPLE
}

\author{
Owen Murray \\ Owen Murray, Oriental Institute, University of Chicago, 1155 East 58th Street, Chicago Illinois, USA. omurray@ommphoto.ca
}

\begin{abstract}
:
This paper discusses the photogrammetric and epigraphic documentation of the late-Roman frescoes in the Imperial Cult Chamber at Luxor Temple by the University of Chicago's Oriental Institute, Epigraphic Survey Project. It presents a brief history of the room and an overview of research related to it, while relaying the epigraphic documentation technique and methodology employed, and the use of photogrammetry to achieve those objectives. Due to the nature, and timing, of the project, this paper explores the intersection of traditional epigraphic documentation methods with more recent digital trends and how these toolsets have been adapted and adopted into a print publication workflow by the Survey. Of note is the relationship of GSD to specific scale reproduction ratios and print resolutions for traditional 2D publications, as well as how this translates into the number of points $\mathrm{per} / \mathrm{m}^{2}$ in a 3D dense cloud.
\end{abstract}

Keywords: Luxor temple, imperial cult chamber, fresco, photogrammetry, digital epigraphy, cultural heritage

\section{Introduction}

The Luxor Temple complex (Fig. 1) is located on the East bank of the Nile River in what was ancient Thebes (modern-day Luxor). Constructed during the late Bronze Age (New Kingdom) between the $14^{\text {th }}$ and $13^{\text {th }}$ centuries BCE, like many of the major temple complexes throughout Egypt, it has stood witness to history ever since - through several phases of subsequent Pharaonic expansion, then Greek, Roman, early Christian, Coptic and Islamic additions and modifications. Considered a tourist attraction even in antiquity, now, at the beginning of the Anthropocene, the site finds itself both benefactor and victim of mass tourism, with guides that oft neglect and/or confuse its rich and varied past.

Perhaps the best example of this can be found in the Imperial Cult Chamber, (also called the Emperor's Chambers or King's Room), located at the heart of the temple between the Portico of Amenhotep III (A III) and the Barque Shrine (Fig. 2).

As part of an $18^{\text {th }}$ Dynasty addition by Amenhotep III, the room was originally a sanctuary devoted to the divine Pharaoh - the eight papyrus-bundle columns within supporting abaci, sandstone architraves and flat sandstone roof blocks. As its current name suggests, the room went through a significant transformation during the late-Roman reformations of Diocletian, finding itself altered to occupy the Principia position of standard Roman fortifications. Roman builders converted the room by removing the columns, blocking the original doorway leading to the barque shrine and rooms beyond, and installing a niche. A canopy supported by four granite Corinthian columns was placed directly in front of the niche, thereby drawing attention to it and centering it as a focal point not only in the room, but along axial fault lines of the temple complex at large (Fig. 3).

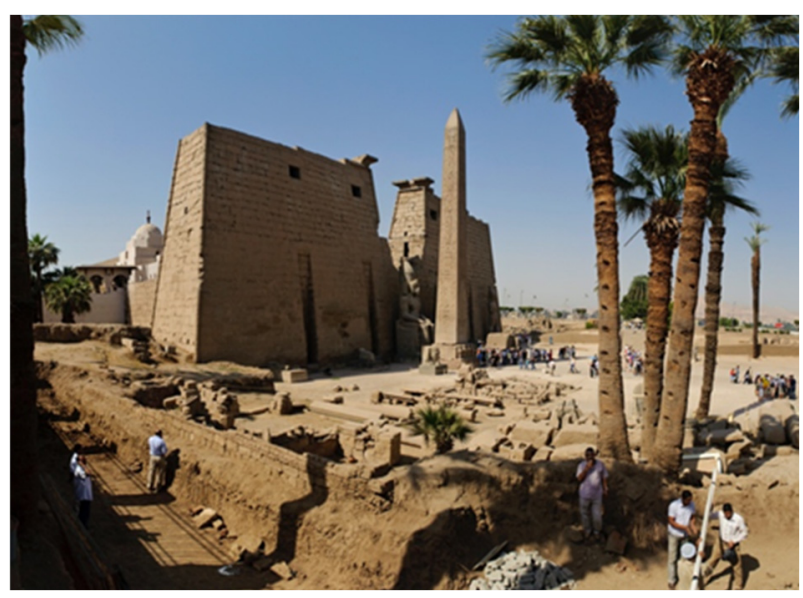

Figure 1: Luxor Temple. General view of Luxor Temple from the North East. Murray/ARCE 2009.

In addition to height modifications of the walls themselves, the A III $18^{\text {th }}$ Dynasty wall reliefs in the room were covered entirely with plaster and then decorated with Roman frescoes celebrating the imperial cult of the first four lateRoman rulers (tetrarchs). The niche was painted with a dado upon which the four tetrarchs, depicted in imperial purple mantles, float in nebulous semi-divinity - Diocletian himself represented with the attributes of Jupiter, holding a spear in his raised right hand while cradling a globus in his left. Between the two more senior and central Augusti, a floating bust of Jupiter was most likely painted, while in the semi-dome directly above them references to Jupiter ensue with a zoomorphic representation - an eagle with 
outstretched wings clutches a gilded and bejeweled oak corona (see Fig. 23).

As such, these frescoes are the only example of monumental paintings from the tetrarch era remaining in situ, and perhaps the finest preserved Roman paintings in Egypt.

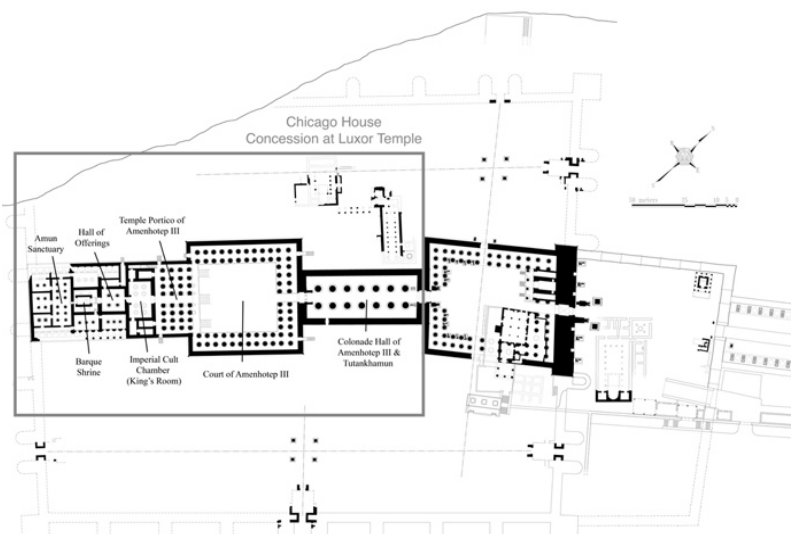

Figure 2: Luxor Temple Plan. Location of the Imperial Cult Chamber (in red). Heidel/The Epigraphic Survey 2015.

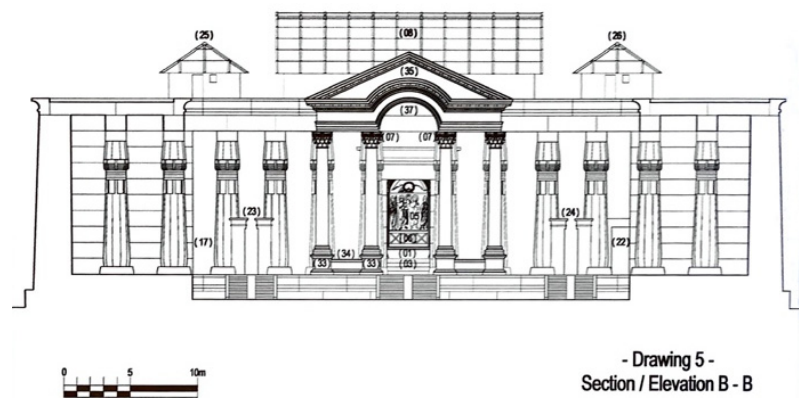

Figure 3: Hypothetical Elevation. View of Imperial Cult Chamber apse through the Alll Portico Facade; after Heidel 2015, fig 3.11 .

\section{Background}

Covered in debris along with the rest of the temple complex, the Imperial Cult Chamber was most likely excavated during the winter of $1853-1854$ by Victor Gustave Maurnier, a French photographer and antiquities dealer whom also served as the unofficial French consul in Luxor. Watercolours from two different sources (George de Sausmarez, 1855 \& John Gardner Wilkinson, 1856) provide glimpses of the room shortly thereafter (Fig. 4 ), as well as rare colour information, however a definitive set of tracings that were supposedly completed by Urbain Bouriant have never come to light.

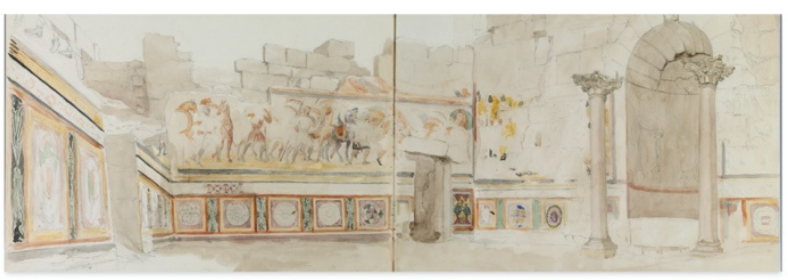

Figure 4: J.G. Wilkinson Watercolour. View of Imperial Cult Chamber shortly after excavation from Wilkinson's sketchbook 25V \& 26R, after Jones 2015, fig A.1.
Slowly, over the following century, more was learnt about the paintings and their origins, and confusion over their provenance - early Christian church vs. Iate Roman tetrarchy - definitively established (Monneret de Villard, 1953). But despite such knowledge, the quality of artisanship, and the relevance of the frescoes, it wasn't until the 1970's that detailed conservation efforts took place under a team led by J.G. Deckers. Indeed, it is due largely to his reframing and presentation of the Imperial Cult Chamber within a modern archeological context (Fig. 5 ) that led to American Research Center in Egypt (ARCE) conservation efforts (Jones, 2015), and it is in turn from this project, that the photogrammetric and epigraphic documentation methods detailed below, follow.

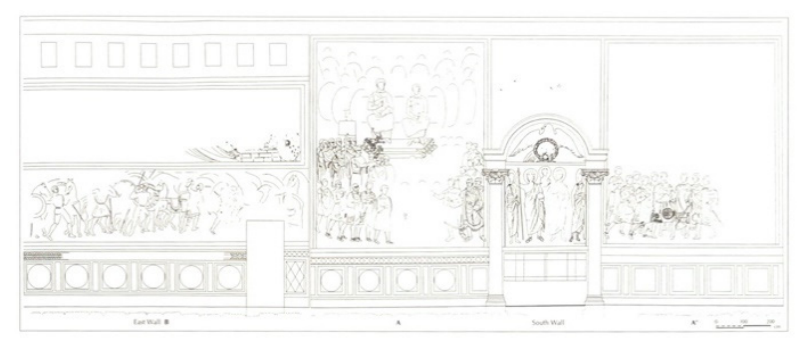

Figure 5: Deckers Reconstruction. Reconstruction of the Imperial Cult Chamber frescoes, after Deckers 1979, Fig. 34.

From 2005 - 2008 an ARCE conservation project led by Michael Jones involved a team of Italian wall painting conservators working in conjunction with the Epigraphic Survey of the Oriental Institute, University of Chicago, towards the project's objectives: cleaning, recording and documenting the frescoes in situ, followed by publication. The Epigraphic Survey provided large format colour film as well as digital photography before, during and after conservation, and these photographs, paired with chemical analysis from the Italian conservators, provided an invaluable record of the frescoes and understanding of pigment makeup at a molecular level. In 2015, Art of Empire (Jones \& McFadden eds. 2015) was published and stands as the exemplar work of scholarship on the frescoes; tying together multiple disciplines and perspectives and honouring the Imperial Cult Chamber by chronicling its history and interlocutors from antiquity until the present moment. In line with Deckers' publication of the state of conservation as of 1979 (Fig. 6), the Italian conservators on the ARCE project made detailed drawings outlining areas of extant plaster and paint layers (Fig. 7), as well as multiple conservation records of visual impediment, detachment, cavity filling and overall cleaning.

These works complement one another and are interesting comparisons. Although the former appears slightly more nuanced in execution to the latter, it is clear what areas of the fresco suffered degradation during the quarter century between them. It should be noted that although both sets of drawings are 'to scale', they are best considered approximations, as their dimensions neither match one another, nor the actual dimensions of the wall itself. This is especially clear in the ARCE documentation of the unraveled, perspective corrected niche whose doorway remains the same width as the uncorrected one as seen in situ, a fact that is as implausible as it is inaccurate (Fig. 8) That said, insofar as providing a snapshot of conservation state both perform their job admirably, and in Deckers publication, provided the base upon which his 
reconstruction of the painted frescoes was informed (see Fig. 5, above).
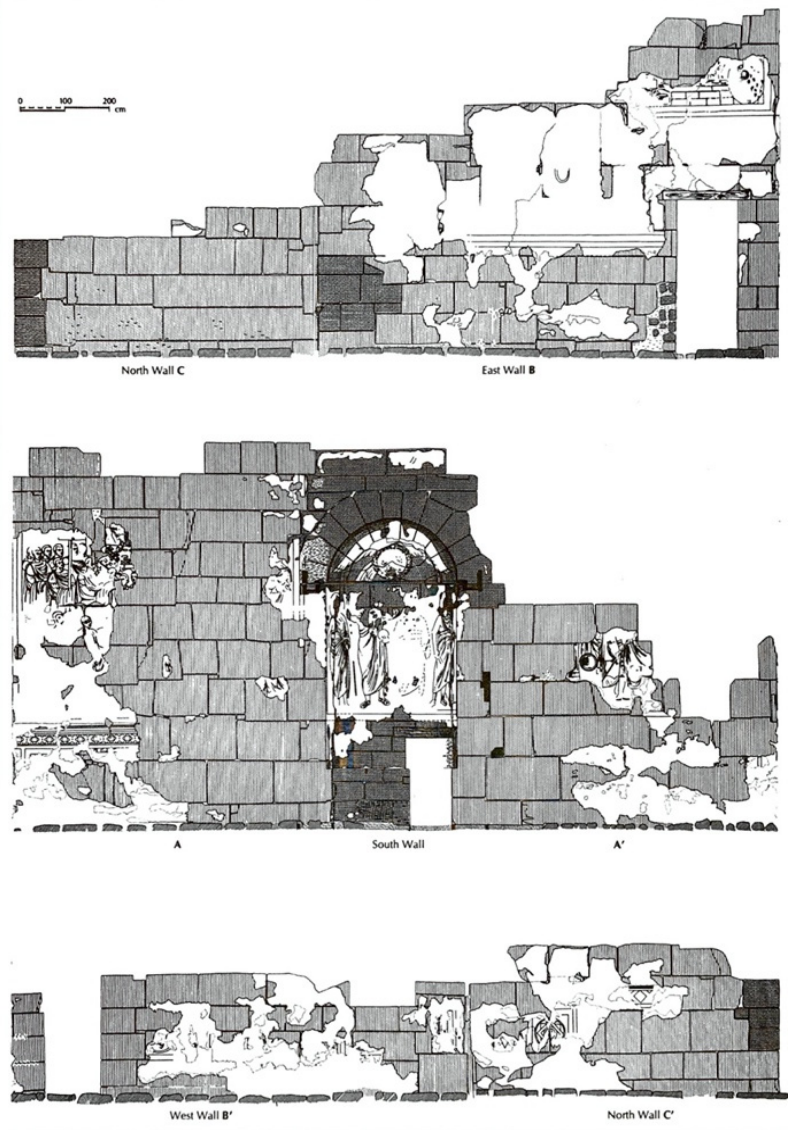

Figure 6: Conservation State. Deckers' publication of the state of conservation of the Imperial Cult Chamber as of 1979, after Deckers 1979, fig. 33.

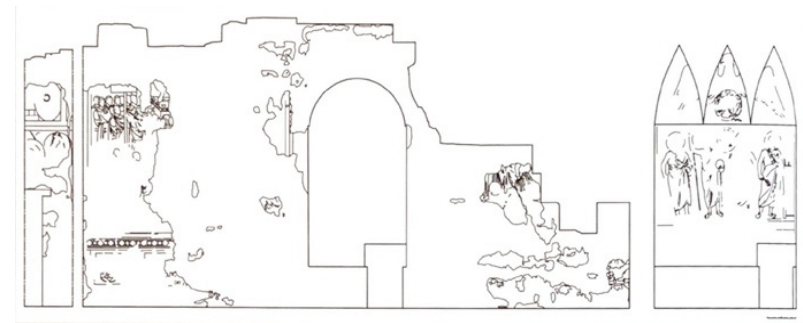

Figure 7: Conservation State. ARCE publication of the state of conservation on the south wall of the Imperial Cult Chamber as of 2005, after De Cesaris, Sucato \& Ricchi 2015, fig. 5.2.
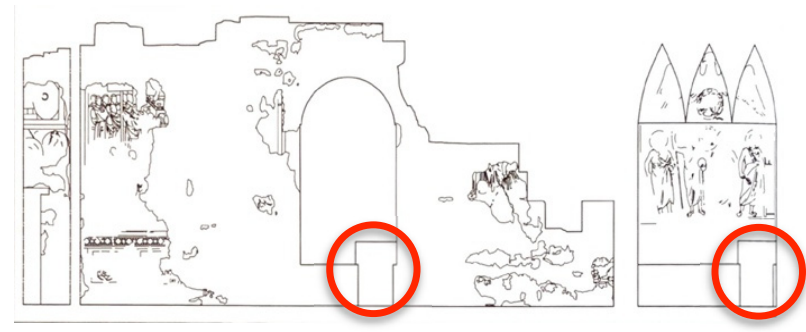

Figure 8: Conservation State. ARCE publication of the state of conservation on the south wall as of 2005; (problematic perspective corrected niche doorway in red), after De Cesaris, Sucato \& Ricchi 2015, fig. 5.2.
In 2013, Epigraphic Survey documentation efforts furthering Deckers' invaluable archaeological contextualization began. Following the tried-and-true scientific methodology for epigraphy devised by James Henry Breasted at the inception of the project in 1924, this documentation relied on a multidisciplinary approach underpinned by rectified large format photography, onsite observation and drawing by skilled artists, and a series of checks of the facsimile line drawing against the original carried out by specialized philologists. As Breasted realized early on in his quest for an accurate epigraphic documentation technique - although film photography purported to be an ideal one-stop documentation solution, its impartial nature placed equal emphasis on all surface elements thereby highlighting none. Paired with directional lighting concerns, but even more so - the illusion of reality - he came to realize there was no replacement for rectified photography paired with the skilled hand of artist and keen observation of a specialized Egyptologist in front of the source material. Understood as the gold standard of documentation in epigraphy circles, this technique has come to be known as the Chicago House Method (McClain, 2020). In light of the ever-increasing use, and reliance on SfM documentation techniques, many of the same problems that Breasted encountered with the medium of photography and are applicable to photogrammetry today, only compounded, as the illusion has sidled into the third dimension. Virtually real, or really virtual? (Huggett, 2019). As Breasted surmised nearly 100 years ago, Epigraphic Survey Assistant Director Brett McClain (2020) states categorically today: there is no substitute for taking the time to make multiple examinations of the wall, with multiple collations of the copy against the original.

In the case of the frescoes, although a plethora of film and digital photographs were taken from 2005 - 2008, their dimensions paired with the sheer volume of work required to maintain high quality results proved challenging for both the Survey photographer and artist involved. This was due in part to technological constraints: mainly, the Epigraphic Survey's reliance on large format film photography and an inability to unravel and "flatten" the niche, thus providing a standard, suitable photographic enlargement from which the traditional Chicago House Method (McClain, 2020) could unfurl.

\section{Documentation Technique \& Methodology}

Despite first class conservation efforts, a closer look at the frescoes revealed the ravages of time multiplied by exposure to the elements; much of the top layer of painting containing the bulk of details was gone. Occasionally, only paint scars were preserved, with very little pigment remaining on the surface. In some instances, the traces did not form any recognizable features, thus the main goal of the epigraphic recording was to isolate the visible pigment and synthesize the data detectable on the surface. It was clear that by reducing the traces to mere line drawing, as both Deckers and the Italian conservators had done, that one could not register all of the remaining traces of paint on the wall, not to mention accurately capture the style of the original artisanship. Since extensive colour photographs taken before, during and after the 2005 - 2008 conservation provided a complete record of every preserved shade, 
hue and tint of the paintings, the epigraphic drawing method focused on the strict clarification of all detectable features on the walls, in grey scale. After numerous trials to test out different styles of representation, it was determined that outline drawings paired with pigment texture in various combinations produced a suitable solution that balanced original painting style with an accurate recording of the fresco conservation state postcleaning (Fig. 9 \& Fig. 10) (Vértes, 2019).
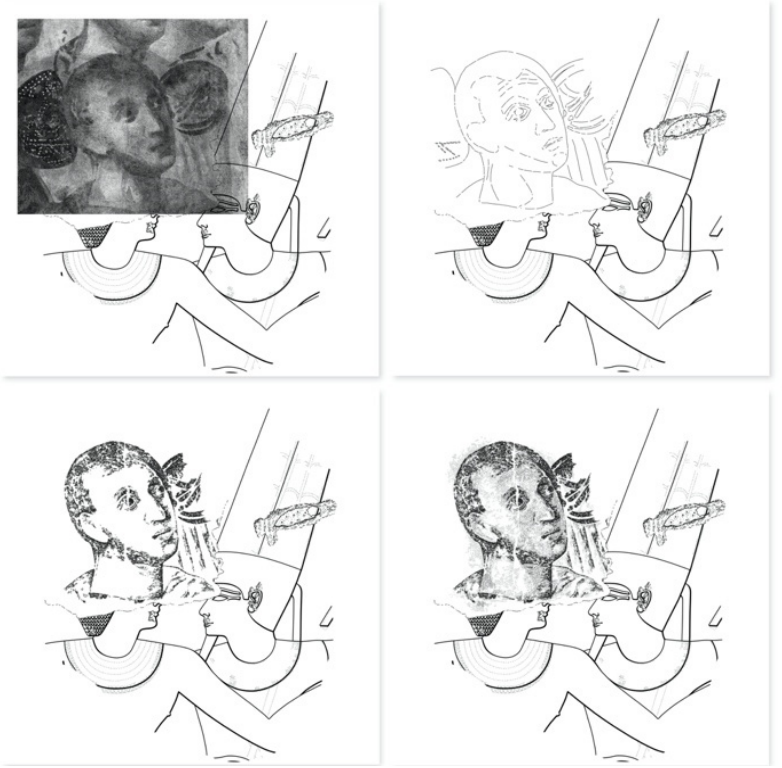

Figure 9: Epigraphic Drawing Trial. Mock up area used to test different epigraphic representations. Vértes 2019.

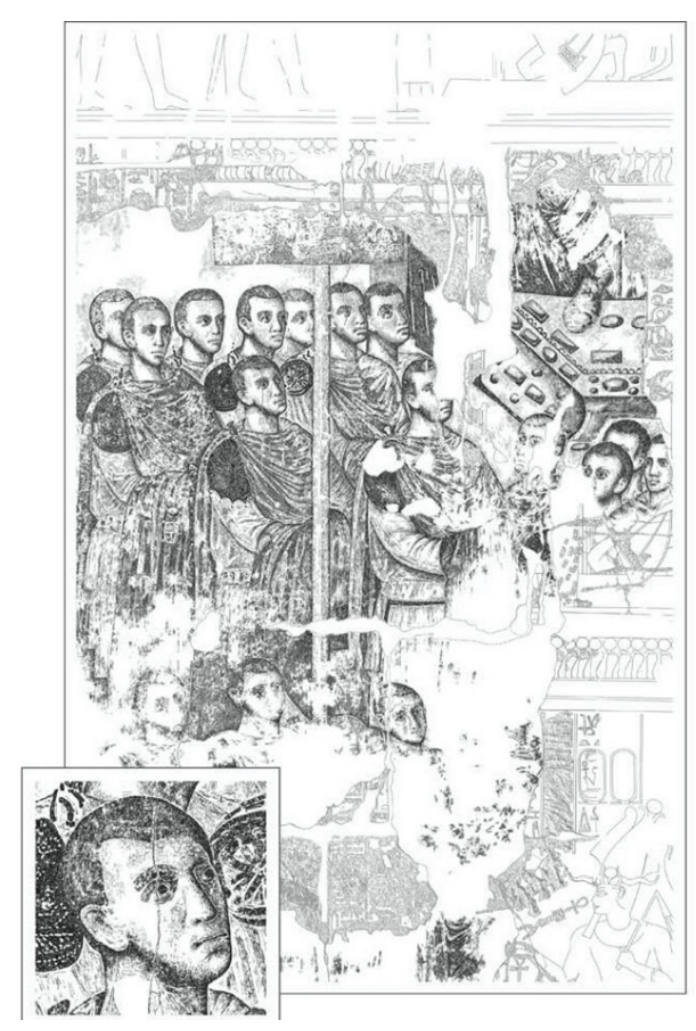

Figure 10: Epigraphic Drawing Sample \& Detail.

Representation of the late Roman frescoes on the south east wall in the Imperial Cult Chamber, courtesy of the Oriental Institute of the University of Chicago; after Vértes 2020, fig III.7.4).
As the sole artist involved in this epigraphic documentation, and with a case study required to adapt digital documentation workflows, Krisztián Vértes developed a hybrid approach, blending the Epigraphic Survey's tried-and-true traditional methods with more recent digital trends.

The bulk of in situ documentation on the east wall as well as the south wall to the east of the niche followed the traditional Chicago House Method outlined briefly below.

Large format 1:4 scale black and white film negatives of the walls were printed by Survey photographer Yarko Kobylecky, which Vértes verified as accurate through a series of comparison measurements. Then, observing the wall carefully, he began mechanically penciling texture directly on top of the photograph, employing a hand held light shone from multiple directions on the wall to ensure veracity of what was being recorded. A crosshatched texturing technique was adopted to represent the graphical impression of the scenes - already in-and-ofitself a departure from the traditional outline drawing applied to Pharaonic relief. Vértes reinforced every discernible trace of pigment by adding pencil marks with variable strength, slowly forming a textural impression of the paintings on paper (Fig. 11).
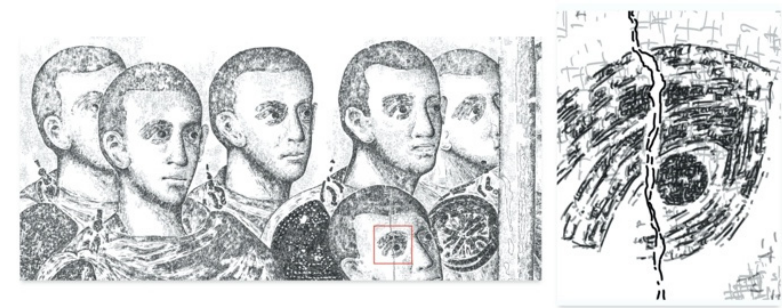

Figure 11: Crosshatch Texturing Technique. Textural impression of paintings on paper using pencil marks with variable strength. Vértes 2019.

While effective and manageable in small sections, applying the technique wholesale to over $60 \mathrm{~m}^{2}$ encompassing the east and eastern portion of the south wall became overly time consuming and problematic, not only for Vértes but also Kobylecky, as each penciled enlargement subsequently needed to be immersed in an iodine solution causing the photographic emulsion to dissolve, leaving only the pencil drawing of pigment texture on photo paper. This bleached drawing then needed to be scanned in high resolution before receiving final studio treatment.

In 2015, experiments with an iPad Pro opened up new possibilities for onsite recording. Although Vertés had experimented with lugging a laptop and Wacom Cintiq into the field since 2013, drawing in Photoshop proved cumbersome and unwieldy, plagued by concerns with external power, file size and the resulting lag between stylus/cintiq and the laptop running Photoshop. The first generation of iPad Pros, and accompanying Apple Pen paired with the ProCreate app realized an experience much closer to drawing on paper by hand. Its portability, lack of external power issues, and stylus hand pressure sensitivity and responsiveness opened up the first real possibilities of drawing digitally onsite. However, despite this much welcomed possibility, the first-generation iPad Pros didn't have enough processing power to be able to handle the amount of information the frescoes held at 1:4 @ 1200ppi. Indeed, the maximum file size on the 
ProCreate App was (and remains) 8K, which in turn dictates the maximum tile size that can be handled in the field. Viewed strictly in terms of pixel count, the maximum number of pixels a ProCreate file can handle is $+/-67 \mathrm{M}$ px; the number of pixels in just $1 \mathrm{~m}^{2} @ 1200$ ppi is $+/-2.2 \mathrm{~B}$ px. The entire frescoes cover approximately $160 \mathrm{~m}^{2}$, and Vertés was employing a crosshatch technique building up layers of information resulting in large file sizes, rather than a traditional line drawing, which generates smaller files when saved.

Rather than get bogged down in cross hatching minutiae, Vertés put the iPad Pro to use recording the original $18^{\text {th }}$ dynasty A III wall reliefs upon which the frescoes were plastered, and that in turn, were required to provide context. To keep the process as close to a physical pencilon-enlargement method as possible, these line drawings were done in the Procreate app. This required careful planning beforehand, with the division of large master orthomosaic files on a more powerful studio computer done first, before parceling smaller, downscaled sections suitable for transfer to the iPad for drawing onsite.

The creation of these large master orthomosaics was done photogrammetrically and begun by the author during the 2016-2017 field season (Fig 12). The north east, north west, west and south west walls of the Imperial Cult Chamber were photographed in such a manner for fresco documentation, while in turn, doubling as backgrounds for the $18^{\text {th }}$ Dynasty Pharaonic reliefs (Fig. 13) An added bonus of these high resolution photogrammetric orthomosaics was the colour information included (not to mention the 3D datasets from which they were derived!).

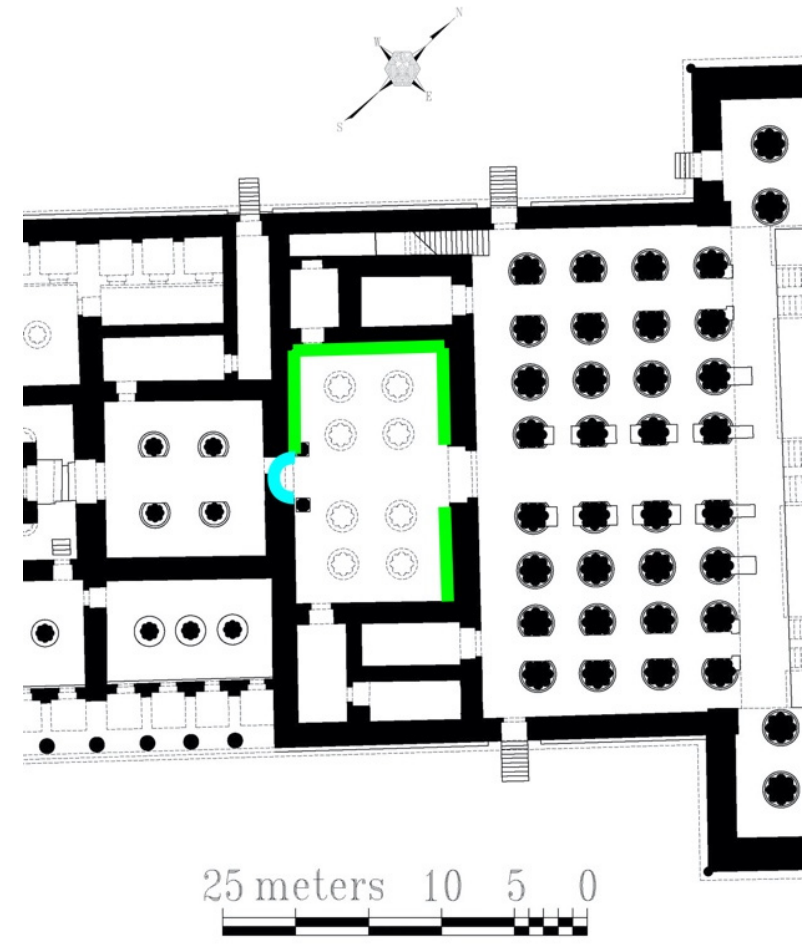

Figure 12: Areas Documented using Photogrammetry. Areas documented using photogrammetry; 2016-2017 field season in green, 2017-2018 field season in blue. Murray/The Epigraphic Survey 2017.

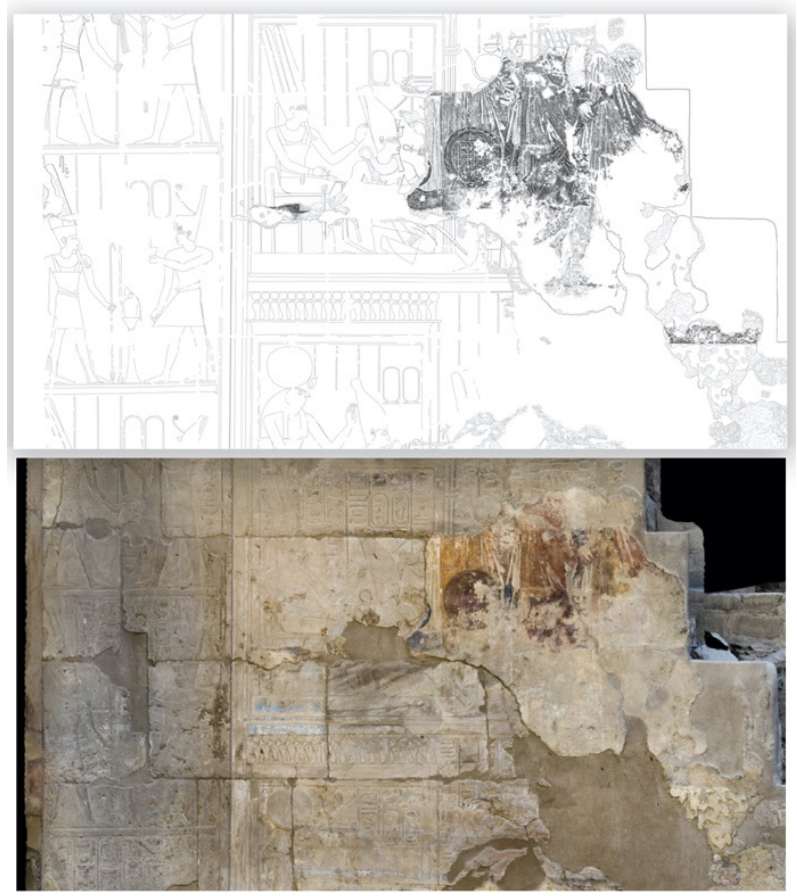

Figure 13: Drawing from Photogrammetry. Sample of drawing (top) from photogrammetric orthomosaic (bottom) on the south west wall, used for fresco documentation as well as inscribed Alll Pharaonic material behind. Vértes, Murray/The Epigraphic Survey 2017, 2018.

This was a first in the Survey's epigraphic operations and further negated the need for separate colour film negative documentation post black and white drawing enlargement, as well as providing a robust set of 3D information and measurements hitherto unimaginable.

\section{Fresco photogrammetry}

In order to meet the requirements of the Survey's digital inking and large folio print publication standards, any digital drawing enlargements or orthomosaics need to be produced at a 1:4 scale @ 1200ppi. In photogrammetric terms this involves a correlation between the Ground Sampling Distance (GSD) - formulaic in nature, depending on the sensor size, lens used and distance to/from the object - with the print resolution and desired scale required for publication, which can be tricky as the photogrammetric application used to process the datasets, Agisoft PhotoScan (now Metashape), renders orthomosaic results as 1:1@72ppi. This means that results will always adhere to the actual dimensions of the subject at hand (given a series of controlled measurements are taken and equipment has been properly calibrated), regardless of the size of the sensor used to achieve it. So, what is in question is not the veracity of the results in terms of accuracy and precision, but its resolution in terms of the number of pixels that represent any given real-world dimension. 10px may represent $1 \mathrm{~m}$ or $1000 \mathrm{px}$ may represent $1 \mathrm{~m}$, or $10000 \mathrm{px}$ may represent $1 \mathrm{~m}$; the result with the highest degree of fidelity in terms of measurement on screen is inevitably the image with the highest number of pixels, especially as most screens now are capable of more than the classic 72ppi and work anywhere in a range of between 200 500 ppi. Going forward, display resolution capabilities will only increase, both in physical dimension and number of 
pixels. In print, although there is often a misconstrued relationship between ppi and dpi, an image with a higher pixel count will inevitably give the printer more information to work with regardless of its dpi capabilities. The default print resolution for most inkjet printers is between 300 $600 \mathrm{dpi}$, while high end printing presses are upwards of 1000 dpi. Regardless of interpolation and smart upscaling algorithms, printed at a scale of $1: 1$, the result with the highest degree of fidelity to its real-world companion will be the image with the highest pixel count per any given real-world dimension. This point is oft neglected as most print publications do not need to reproduce, nor concern themselves with reproducing, results at 1:1 - however, for a digital twin cable of producing a physical facsimile at various scales, the point cannot be overstated enough.

In order to realize the aforementioned 1:4 scale @ $1200 p p i$ a $0.0845 \mathrm{~mm} / \mathrm{px}$ ratio is required. However, due to processing limitations of the first-generation iPad Pros and the aforementioned file size restrictions of the Procreate app, Vértes requested the drawing enlargements for the fresco documentation at 1:4 @ 400 ppi $\left(1 \mathrm{~m}^{2}=+/-250 \mathrm{M} \mathrm{px}\right)$. This requires a $0.254 \mathrm{~mm} / \mathrm{px}$ ratio. To obtain this, a Mamiya RZ67 Pro IID and MamiyaSekor Z $50 \mathrm{~mm}$ f/4.5 (prime/fixed lens) mounted with a Hasselblad CFV-50C digital back were used for photography. Images were shot handheld from a distance of 1.5 - 2m, RAW at 1/125@ $\mathrm{f} / 8.5-16$ and ISO 100-800 (the 2.5 stop aperture difference was used to make incremental adjustments as required while onsite; ISO 100 was used for direct sunlight; ISO 800 for shadow) (Fig. 14). Scaffolding was used to achieve the right vertical ( $Z$ ) height, and a series of coded targets were placed in corner positions with long horizontal, vertical, and diagonal measurements taken to accurately scale the results.

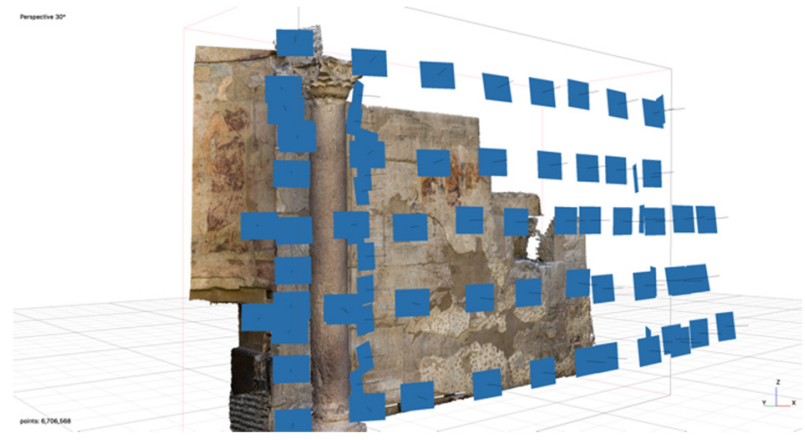

Figure 14: Camera Positions on the SW Wall. Screenshot of the camera positions on the south west wall of the Imperial Cult Chamber. Murray/The Epigraphic Survey 2017.

The method of data acquisition followed standard photogrammetric overlap rules of $2 / 3$ rds (Chandelier, Egels, Héno \& Schelstraete, 2013) in all directions and in most cases erred higher. Because the frescoes were relatively flat and uncomplicated in their architecture, save for the apse, only one pass from the $1.5-2 \mathrm{~m}$ distance was needed. The exception to this was the remaining Corinthian column on the south west wall, next to the apse. Because of the limited distance between column and wall $(+/-0.65 \mathrm{~m})$ two sets of photos were shot from either side on an angle as close to perpendicular to the wall as possible (Fig. 15). This allowed a result both with, and without, the column to be produced (Fig. 16).

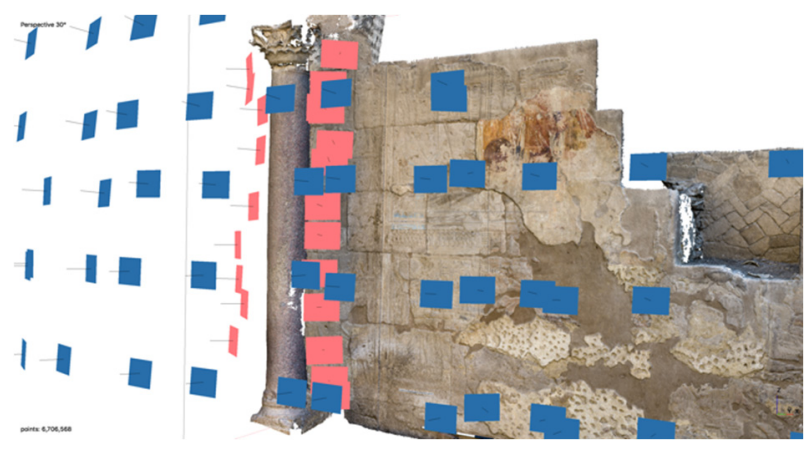

Figure 15: Corinthian Column Camera Positions. Screen shot of the camera positions used to photograph behind the column on the south west wall of the Imperial Cult Chamber. Murray/The Epigraphic Survey 2017.

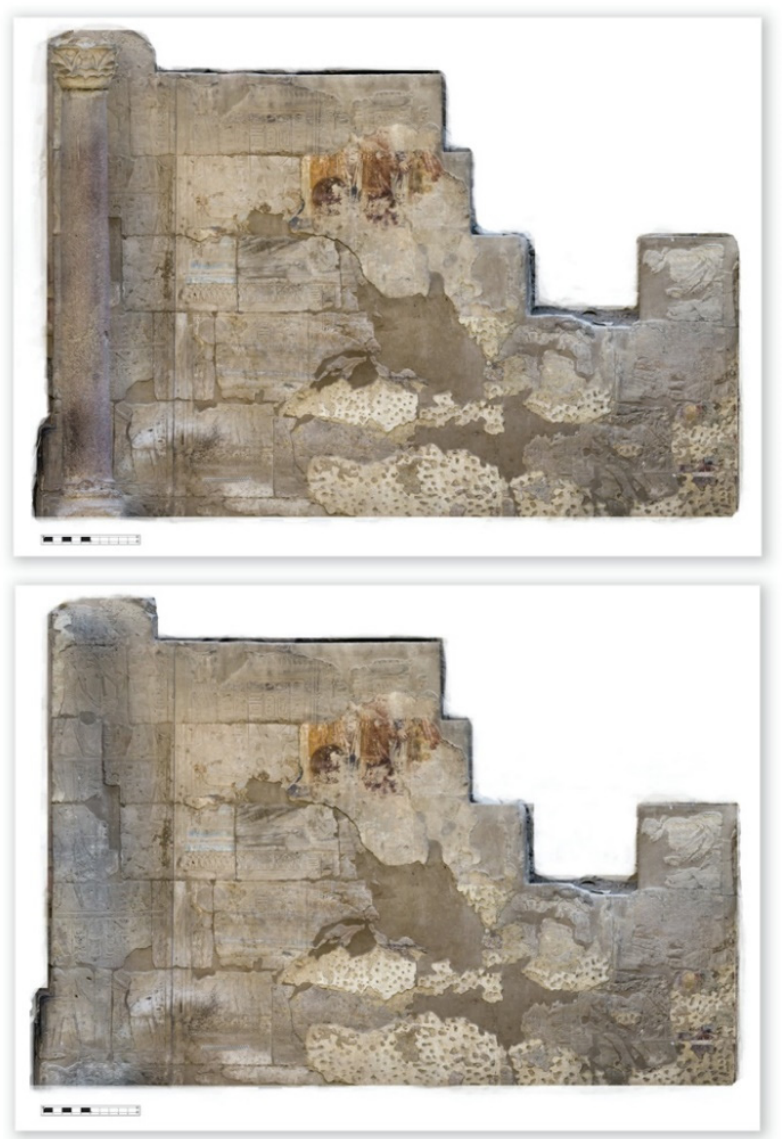

Figure 16: SW Wall With and Without Column. The south west wall of the Imperial Cult Chamber with (top) and without (bottom) the column, shot in diffused indirect ambient sunlight. Murray/The Epigraphic Survey 2017.

All of the photographs were shot using natural sun light, timed to specific periods of the day in order to obtain the desired result. The north walls were shot in the morning in direct, raking sunlight from the east (Fig. 17), and the south west wall was shot in the early afternoon while in shadow in diffused indirect ambient sunlight (see Fig. 16). The west wall was shot twice as requested by Vértes; both at midday, in direct raking sunlight from the south, as well as later in the afternoon while in shadow in diffused indirect ambient light (Fig. 18). 

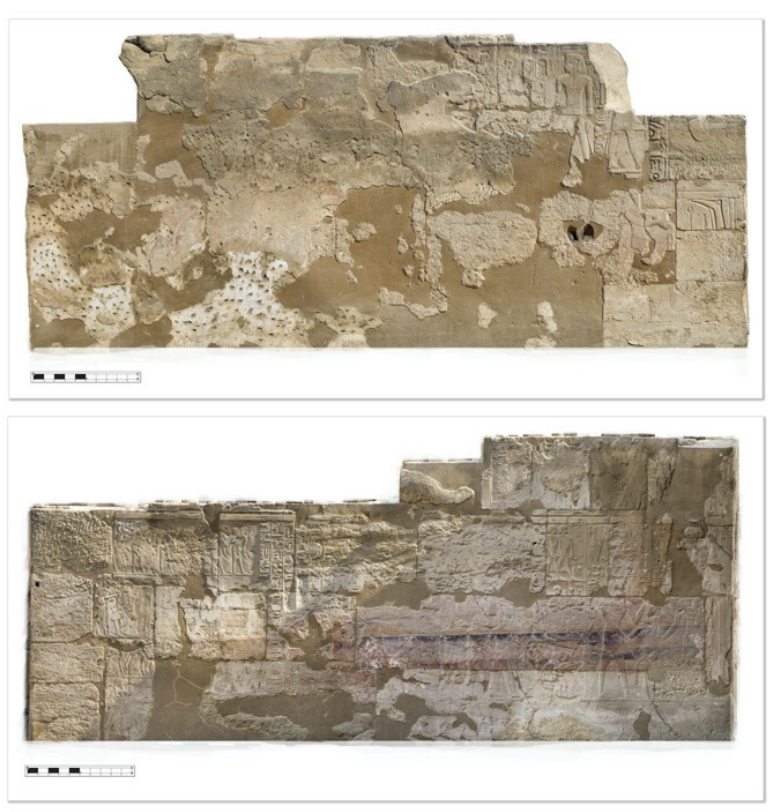

Figure 17: NW \& NW Walls. The north west (top) and north east (bottom) walls of the Imperial Cult Chamber. Murray/The Epigraphic Survey 2017.

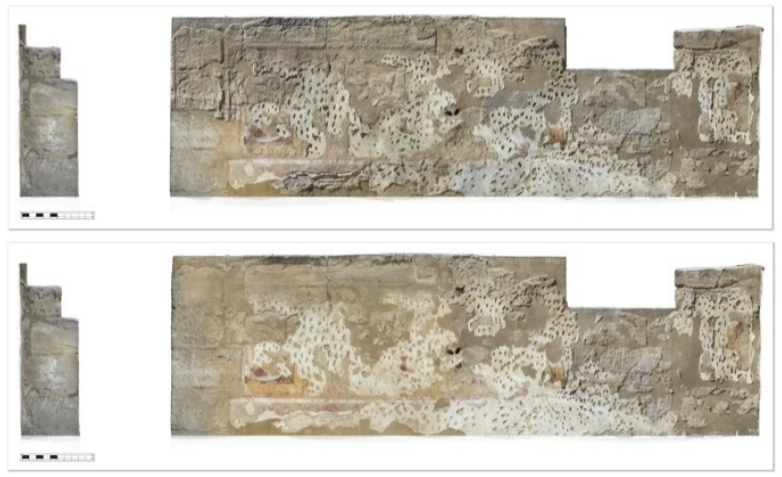

Figure 18: The West Wall. The west wall in direct raking sunlight (top) and diffused indirect ambient sunlight (bottom). Murray/The Epigraphic Survey 2017.

\section{Niche Documentation}

During the winter of 2017-2018, the author worked with Vertes to produce an unravelled, flattened view of the niche apse from which epigraphic documentation in the chamber could be finally completed. This documentation objective was realized in 2019 (Fig. 19).

In order to achieve this result, and with an understanding that photogrammetric documentation efforts would be expanded upon in future seasons throughout the Survey's temple concession, the author implemented a local coordinate survey with the assistance of master stone mason, Frank Helmholz. Though the survey coordinates and origin point were new, the physical baseline points used pre-existing iron survey markers hammered into place by an Egyptian Military engineering team some 30 years previous during an overhaul and reconstruction of the A III Court. It is hoped that the choice of these established permanent markers will allow the more recently implemented local coordinate system to integrate with previous surveys if-and-when these datasets are made available, as well as shift to global coordinates as needed. In consultation with colleagues Yves Egels (ENSG) and Emmanuel Laroze (CNRS-UMR 8167) the best target positions in order to unravel the apse were determined and then measured (Fig. 20). These measurements when integrated with the photogrammetric dataset and overall $0.634 \mathrm{px}$ target accuracy returned averaged error margins of $1.4 \mathrm{~mm}$.

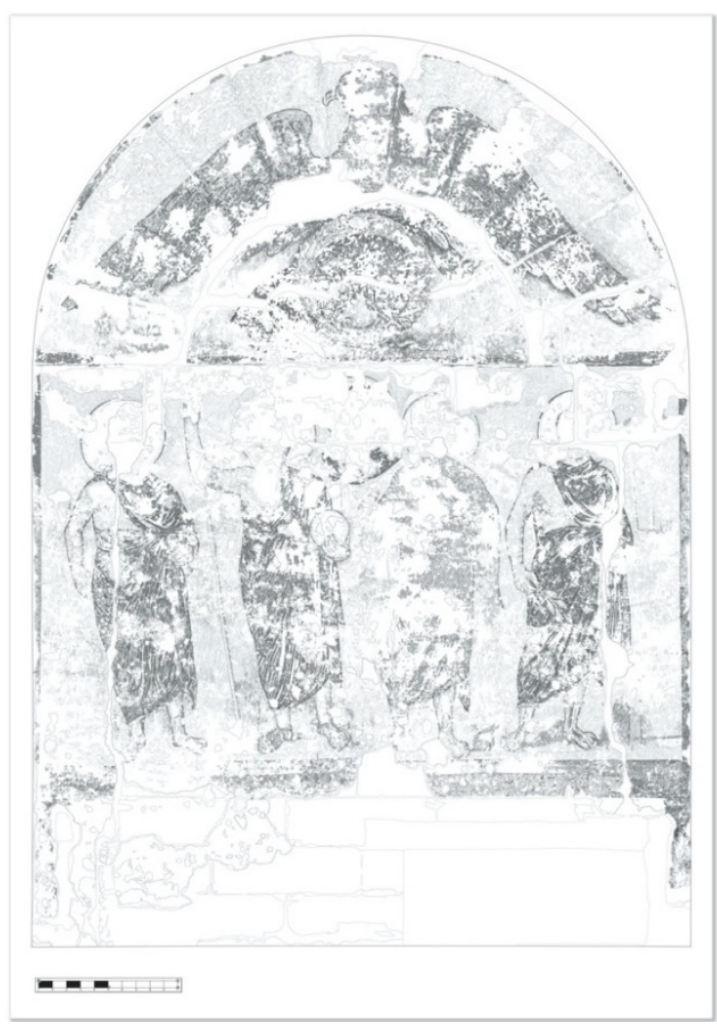

Figure 19: The Niche Apse. Representation of the late Roman frescoes in the niche in the south wall of the Imperial Cult Chamber. Vértes/The Epigraphic Survey 2019.

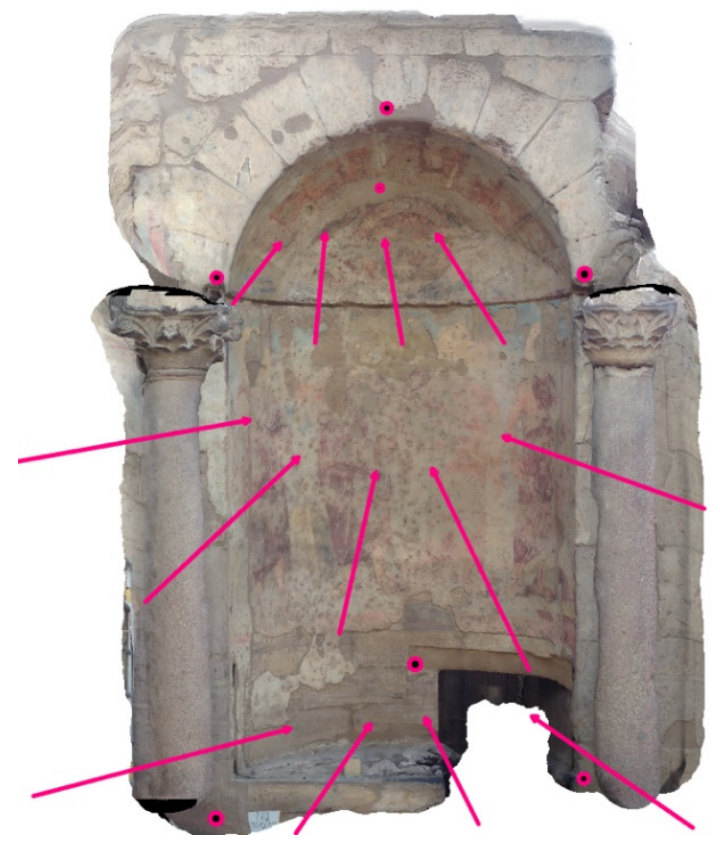

Figure 20: Niche Apse Trial. Mock up model indicating the optimal target positions (pink circles with black dots) for measuring the niche apse; a total of 7 targets. Egels 2017. 
A sturdy yet easily moved set of scaffolding was set up by the Survey's raise (foreman) Bedaowy Abd' Alaa and Ahmed Abdou, and this was used to achieve the right vertical $(Z)$ height within the apse. The scaffolding was set up in three different footprint positions that allowed the author to maintain a $1.5-2 \mathrm{~m}$ distance as perpendicular as possible to the curve of the niche in any given position and at any given height. Photos were shot from bottom to top during lulls in tourist activity, from a series of 14 levels in approximately $1 / 2 \mathrm{~m}$ increments resulting in a 250 -photo dataset (Fig. 21). Nine of these 250 photos were taken as a control set from a distance of $+/-11 \mathrm{~m}$ in order to consolidate and strengthen the sparse cloud tie points.

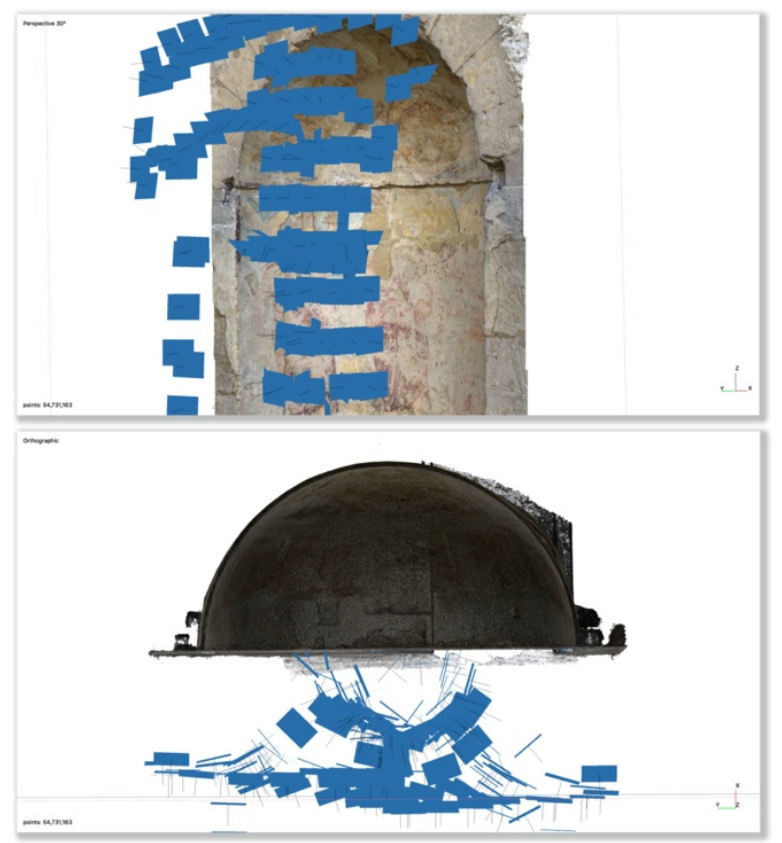

Figure 21: Apse Camera Positions. Two screen shots of the camera positions used for the niche photogrammetry; a dataset of 250 images. Murray/The Epigraphic Survey 2018.

As with the south west wall, the apse was photographed in the early afternoon while in shadow in indirect ambient sunlight, and as with the north, west and south west walls, an X-rite colour checker was photographed and used to maintain correct colour calibration in post process. Hasselblad's proprietary RAW files were imported into Adobe Lightroom, adjusted with a lens profile specifically made for the Mamiya-Sekor Z 50mm f/4.5 then colour corrected and fine-tuned for exposure, shadow and highlights before being exported as high-resolution JPEGS with the least amount of compression. Agisoft PhotoScan/Metacshape was used to build the model at medium resulting in a $54.7 \mathrm{M}$ points, extrapolated to a mesh of $3.6 \mathrm{M}$ triangles, and textured at $36 \mathrm{~K}$.

This PhotoScan model was exported as a .PLY and imported into Yves Egels' Cumulus software (Cumulus, 2014) and the apse was unravelled twice: once using a spherical projection for the semidome portion containing the representation of Jupiter in the form of an eagle, and once using a cylindrical projection for the remaining lower portion containing the four tetrarchs (Fig. 22). Cumulus relies on the GeoTIFF format to accurately unravel texture in conjunction with mesh. These two results were aligned and combined in Adobe Photoshop to produce the final result at the requested scale of 1:4@ 400ppi (Fig. 23).
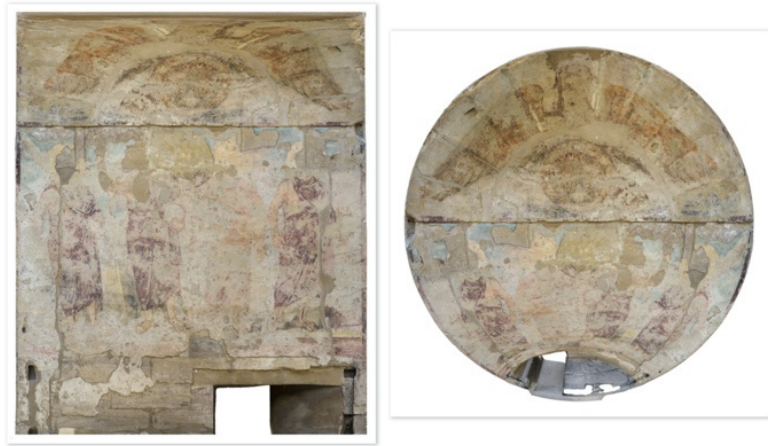

Figure 22: Apse Projections. The cylindrical (left) and spherical (right) projections used to unravel and flatten the apse niche for epigraphic documentation. Murray/The Epigraphic Survey 2018.

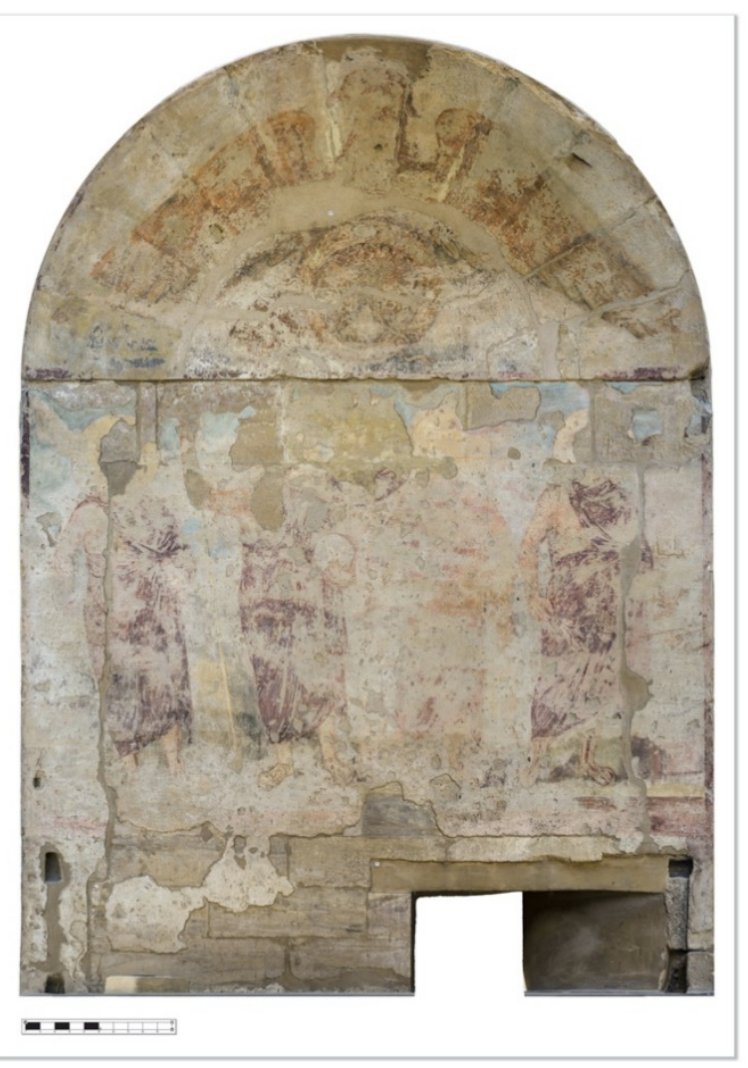

Figure 23: The Unravelled Apse. The overall perspective corrected (flattened) niche in the south wall of the Imperial Cult Chamber. Murray/The Epigraphic Survey 2018.

\section{Conclusions}

The resulting epigraphic fresco documentation stands unparalleled (Fig. 24) and as mentioned by Jones \& McFadden (2015) regarding the 2005-2008 conservation efforts in Art of Empire, becomes yet one more piece in the cultural biography of the Chamber itself, inevitably influencing how future generations will perceive the frescoes, and in so doing, becoming part of the ever evolving physical and intellectual landscape in which they exist. 


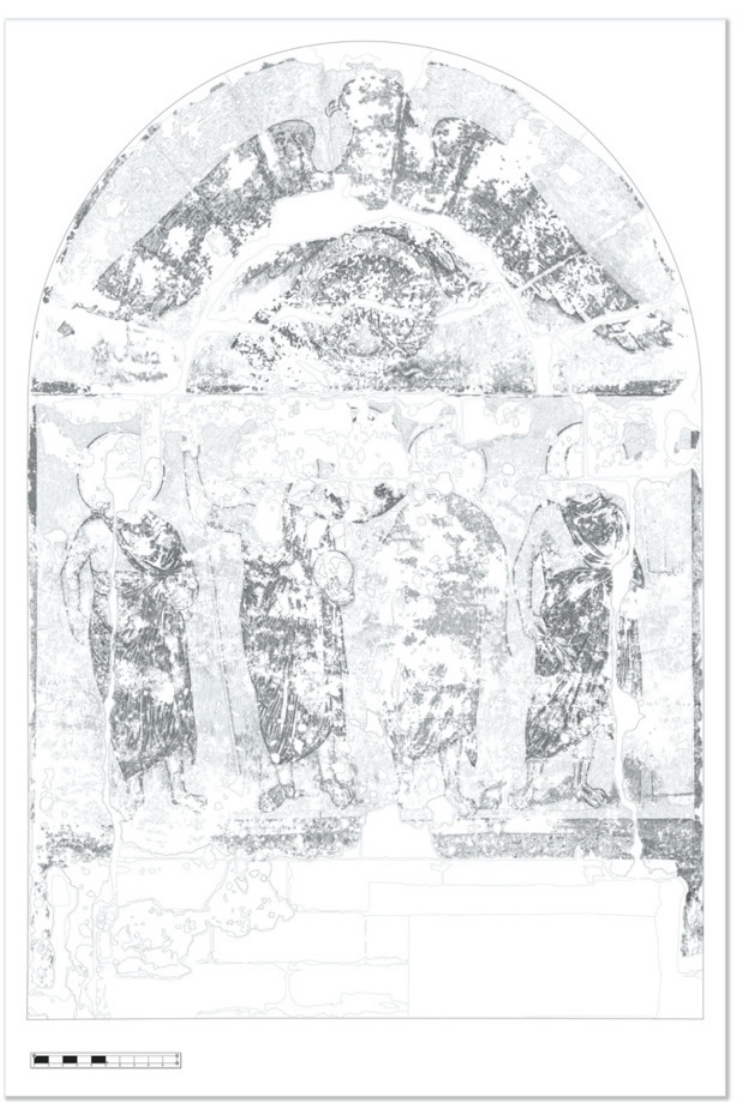

Figure 24: Luxor Temple Roman Wall Paintings.

Representation of the late Roman frescoes in relation to 18th Dynasty reliefs; original at 1:4 @ 400ppi. Vértes/The Epigraphic Survey 2019.

As the objectives for this project were two dimensional in nature and focused predominately on texture, medium settings were used for the modelling, however it should be noted that the aforementioned $0.0845 \mathrm{~mm} / \mathrm{px}$ ratio run on the high setting in Metashape delivers a dense point cloud of $43 \mathrm{M}$ points $\mathrm{per} / \mathrm{m}^{2}$, while on the ultra-high setting, delivers $193 \mathrm{M}$ points per $/ \mathrm{m}^{2}$. Though the high setting falls short, the ultra-high setting delivers well over the 100M points per/m $\mathrm{m}^{2}$ established by Factum Arte (2020) for routing physical facsimile reproductions in the Valley of the Kings (Factum Foundation, 2014), and in terms of the desired capabilities and outputs of a digital twin, is worth noting.
In the 2018-2019 field season the Imperial Cult Chamber was laser scanned from 24 different positions using a Leica BLK 360 by Alexis Pantos with assistance from the author. Along with the photogrammetry described above, the goal is to combine and optimize these datasets for eventual game engine and web browser display. It is hoped that along with 2D printed materials, Vértes' epigraphic fresco documentation will be presented in a georeferenced 3D virtual environment similar to the efforts of the Swedish Pompeii Project (Dell'Unto et al, 2016) (Fig. 25).

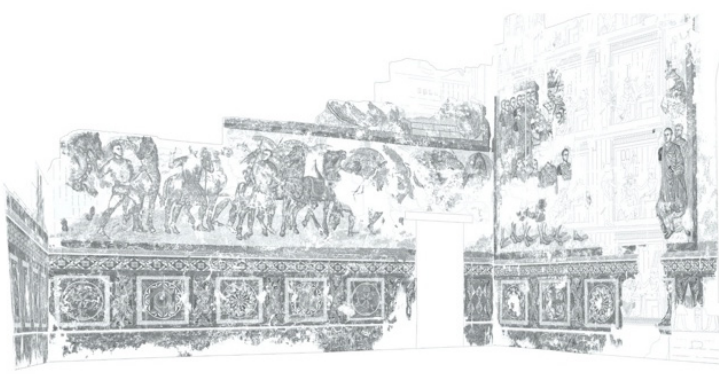

Figure 25: Roman Wall Painting Reconstruction. A reconstruction of the Roman Wall paintings in the Imperial Cult Chamber combining rectified archival material with current epigraphic documentation. View based on Wilkinson's sketchbook. Vértes 2019.

Ultimately, an augmented reality app that allows a user to experience the fresco documentation along with the Epigraphic Survey's past and future documentation efforts, while onsite, would be of great help not only to interested colleagues and researchers, but the visiting public at large.

\section{Acknowledgements}

The illustrations and photographs (orthomosaics) presented in this article acknowledged as 'Surname/The Epigraphic Survey 20XX' are courtesy of the Oriental Institute of the University of Chicago and forthcoming in the Epigraphic Survey's Luxor Temple Series, Volume III.

Many thanks are due to the editors and authors of Art of Empire: Jones, McFadden, Ruffini, Heidel \& Johnson, De Cesaris, Sucato and Ricchi, without whom the introduction and background in this paper would have been neither succinct nor so well informed.

\section{References}

Cumulus. (2014). Yves Egels freeware. Retrieved October 30, 2016, from http://yves.egels.free.fr/Soft/telecharger.html

Chandelier, L., Egels, Y., Héno, R. \& Schelstraete, D. (2013). Prise de Vue Photogrammatrique. Ecole Nationale des Sciences Géographiques, Département Imagerie Aérienne et Spatiale: Photogrammétrie Rapprochée, V.3 (41-48).

De Cesaris, L., Sucato, A., \& Ricchi, E. (2015). Conservation of the Fragments of Roman Wall Paintings in the Imperial Cult Chamber of Luxor Temple. In M. Jones \& S. McFadden (Eds.), Art of Empire: The Roman Frescoes and Imperial Cult Chamber in Luxor Temple. (Chapter 5, pp. 89-103) ISBN 978-0-300-16912-6.

Deckers, J. G. (1979). Die Wandmalerei im Kaiserkultraum von Luxor. Iahrbuch des Kaiserlich Deutschen Archäologischen Instituts, 94, 600-652.

Dell'Unto, N., Landeschi, G., Leander Touati, A.-M., Dellepiane, M., Callieri, M., \& Ferdani, M. (2016). Experiencing Ancient Buildings from a 3D GIS Perspective: a Case Drawn from the Swedish Pompeii Project. Journal of Archaeological Method and Theory, 23, 73-94. https://doi.org/10.1007/s10816-014-9226-7

Huggett, J. (2019). Virtually Real, or Really Virtual: Towards a Heritage Metaverse? Studies in Digital Heritage, 4, 1 (1-15). https://doi.org/10.14434/sdh.v4i1.26218 
Heidel, J. B. \& Johnson, W. R. (2015). The Tetrarchic Architectural Renovation of Luxor Temple: Context, Significance and the Amun Cult. In M. Jones \& S. McFadden (Eds.), Art of Empire: The Roman Frescoes and Imperial Cult Chamber in Luxor Temple. (Chapter 3, pp. 39-59) ISBN 978-0-300-16912-6.

Jones, M. \& McFadden, S. (2015). Introduction. In M. Jones \& S. McFadden (Eds.), Art of Empire: The Roman Frescoes and Imperial Cult Chamber in Luxor Temple. (pp. 1-11) ISBN 978-0-300-16912-6.

Jones, M. (2015). From Ruins in a Landscape to a Monument on Display: A Conservation History of the Imperial Cult Chamber and Its Paintings. In M. Jones \& S. McFadden (Eds.), Art of Empire: The Roman Frescoes and Imperial Cult Chamber in Luxor Temple. (Chapter 4, pp. 61-87) ISBN 978-0-300-16912-6.

Jones, M. (2015). Appendix: John Gardner Wilkinson's Documentation of the Imperial Cult Chamber and Frescoes. In M. Jones \& S. McFadden (Eds.), Art of Empire: The Roman Frescoes and Imperial Cult Chamber in Luxor Temple. (Appendix, pp. 154-168) ISBN 978-0-300-16912-6.

McClain, J. B. (2020). The Chicago House Method. In V. Davies \& D. Laboury (Eds.), The Oxford Handbook of Egyptian Epigraphy And Palaeography. (Chapter III .4, pp. https://doi.org/10.1093/oxfordhb/9780190604653.001.0001

McFadden, S. (2015). The Luxor Temple Paintings in Context: Roman Visual Culture in Late Antiquity. In M. Jones \& S. McFadden (Eds.), Art of Empire: The Roman Frescoes and Imperial Cult Chamber in Luxor Temple. (Chapter 6, pp. 105-133) ISBN 978-0-300-16912-6.

Monneret de Villard, U. (1953). The Temple of the Imperial Cult at Luxor. Archaeologia of Miscellaneous Tracts Relating to Antiquity, c. 1 v.95 (85-105).

Recording with the Lucida 3D Scanner. (2020). Factum Arte. Retrieved October 26, 2020, from http://www.factumarte.com/pag/1552/recording-with-the-lucida-3d-scanner

The Facsimile of Tutankhamun's Tomb: Overview. (2014). Factum Foundation. Retrieved October 26, 2020, from https://www.factumfoundation.org/pag/1548/the-facsimile-of-tutankhamuns-tomb-overview

Vértes, K. (2019). Documenting and Reconstructing the Late Roman Murals in the Roman Vestibule at Luxor Temple. XII ICE Cairo, Forthcoming. Cairo, Egypt.

Vértes, K. (2020). Tradition and Innovation in Digital Epigraphy. In V. Davies \& D. Laboury (Eds.), The Oxford Handbook of Egyptian Epigraphy And Palaeography. (Chapter III .7, pp. 624-650). https://doi.org/10.1093/oxfordhb/9780190604653.001.0001

Wilkinson, J. G. (1852-6). Oxford, Bodleian Libraries, MS. Wilkinson dep. d. 34. Sketchbook, Retrieved November 30 , 2020, from https://archives.bodleian.ox.ac.uk/repositories/2/archival_objects/85379 


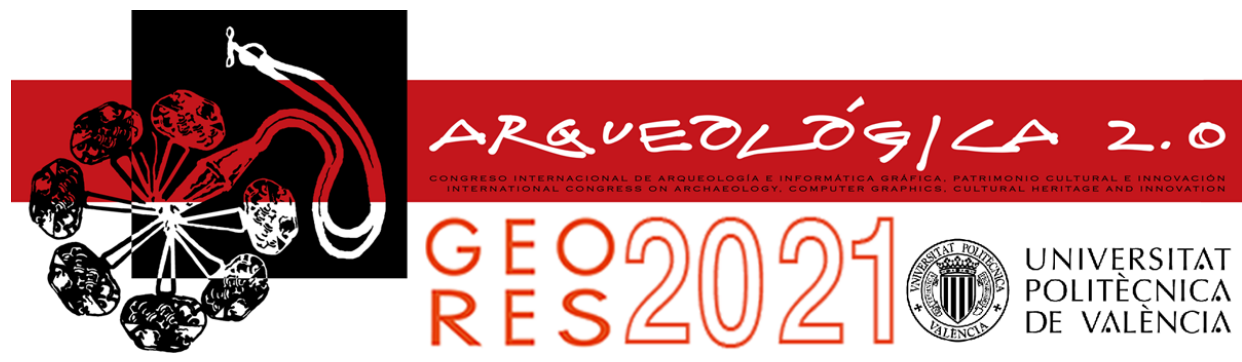

Proceedings of the joint international event $9^{\text {th }}$ ARQUEOLÓGICA

$2.0 \& 3^{\text {rd }}$ GEORES

Valencia (Spain).

26-28 April 2021

\title{
COPERNICUS EARTH OBSERVATION FOR CULTURAL HERITAGE
}

\author{
Athos Agapiou ${ }^{a, b,{ }^{*},}$ Vasiliki Lysandrou ${ }^{a, b}$, Branka Cucac \\ a Department of Civil Engineering and Geomatics, Faculty of Engineering and Technology, Cyprus University of Technology, Saripolou \\ 2-8, 3036 Limassol, Cyprus. athos.agapiou@cut.ac.cy; vasiliki.lysandrou@cut.ac.cy \\ ${ }^{b}$ Eratosthenes Centre of Excellence, Saripolou 2-8, 3036 Limassol, Cyprus.
}

${ }^{\mathrm{c}}$ Department of Architecture, Built Environment and Construction Engineering, Politecnico di Milano, Piazza Leonardo da Vinci 32, 20133 Milan, Italy. branka.cuca@polimi.it

\begin{abstract}
:
This article summarises the European Union's Earth Observation Copernicus Programme's contribution and other satellitebased platforms for cultural heritage applications. It highlights the results of some national and European projects conducted in this domain. Even though the Copernicus Programme has recently been introduced for cultural heritage use (i.e., after the second half of this decade), the full, free, and open data policy, known as FFO, has increased the number of relevant applications. Since then, several studies dedicated to cultural heritage monitoring, management, etc., have been presented in the literature. Despite the medium spatial resolution of the radar and optical Sentinel sensors, their hightemporal revisit time combined with other legacy space programmes (e.g., the Landsat space programme) can provide useful information to local and regional stakeholders, and other national agencies. New developments in the domain of image processing like the use of big-data earth observation cloud platforms already showcased the potentials for dedicated space-based cultural heritage services. However, this technological shift remains still within the scientific and theoretical research domain. Therefore, much effort is still needed for the implementation of national policies.
\end{abstract}

Keywords: Copernicus Programme, cultural heritage, Sentinel sensors, remote sensing, satellite observation, heritage management

\section{The Copernicus Programme}

European Union's Earth Observation Copernicus Programme is coordinated and managed by the European Commission (EC) with the support of the European Space Agency (ESA), the European Union's Member States and European Union's Agencies (Copernicus, 2020). The scope of this multi-billion spacebased programme is to provide various digital geospatial information services and datasets, systematically acquired from satellite sensors. With almost global coverage, these calibrated datasets can be integrated with other relevant ground-based, airborne, and seaborne measurements and remotely-sensed datasets.

Today, the Copernicus Programme is composed of different segments, including the space infrastructure and the ground segment. Besides, satellite-based services are provided through the exploitation of these datasets (Satellite Components, 2020).

The Copernicus Earth observation satellites are divided into two groups of missions. The Copernicus space infrastructure is built upon a family of satellites and instruments called "Sentinels" (Sentinel Overview, 2020). This study focuses on the first two instruments, namely the Sentinel-1 (2020) and the Sentinel-2 (2020) sensors. These sensors can provide radar and optical images systematically. Both sensors were employed in the recent past for different cultural heritage applications and heritage management purposes.

Beyond the Sentinel sensors, the Contributing Missions which are operated by National, European, or International organisations - provide a series of other supportive data, which can further integrate the various Copernicus services. Contributing Missions data are important for quite a few satellite-based applications as these sensors usually provide higher spatial resolution images, a key parameter for particular case-studies.

The ground Copernicus segment is delivered by international agencies (ESA and EUMETSAT) and national public and private facilities. It provides the "mission control", that turns the Sentinel satellites and facilities data into Copernicus Services products.

Currently, six different thematic Copernicus-based services can be found. These are the marine, atmosphere, land, climate change, emergency, and security (Copernicus Services, 2020). Copernicus services are operational since 2014 and support, among others, policies such as environment, transport, energy, 
agriculture and forestry, migration, border security, maritime safety, disaster management, urban planning, development, energy, and fight against climate change.

Access to the Copernicus datasets and services is of fundamental importance for any exploitation concerning cultural heritage. A particular aspect of the Copernicus Programme relies on its FFO policy (full, free, and open policy) (European Comission, 2018). Therefore, Copernicus data and products are freely and openly accessible to end-users, with the possibility to use and reuse these data and information for addressing specific needs.

At the same time, the FFO policy ensures the most comprehensive re-use of these datasets. Open data drives growth by stimulating the creation of firms that reuse such data in innovative ways.

The current paper presents technological shifts that have observed in the last years in the domain of earth observation for documentation, mapping and monitoring of cultural heritage environments, including big-data cloud platforms. The paper presents an overview of the contribution of the Copernicus Programme to cultural heritage, through the results of two on-going research projects, namely the "Copernicus Earth Observation Big Data for Cultural Heritage" (in short NAVIGATOR http://web.cut.ac.cy/navigator/), and the "Portal for heritage buildings integration into the contemporary built environment" (in short PERISCOPE https://uperiscope.cyi.ac.cy/). Both projects are cofinanced by the European Regional Development Fund and the Republic of Cyprus through the Research \& Innovation Foundation. Also, gaps observed for targeted earth observation geo-services related to the European and national policies are discussed. The paper ends with remarks dealing with the potential use of these geoservices for heritage management.

\section{Earth Observation Technological Shift}

Recent developments regarding big-data processing, have shifted the traditional applications of singlecomputer based earth observation to cloud-based. In this direction, the European Commission has funded the socalled Data and Information Access Services (DIAS) cloud-based platforms (Data and Information Access Services (DIAS, 2020), providing thus cloud access to the Copernicus data.

The DIAS platforms are developed when other private commercial entities have showcased the tremendous advantages of big-data cloud services for the end-users. The Google Earth Engine (GEE) is considered one widely known earth observation big-data cloud platform, whereas, different satellite data, can be processed online.

The Google Earth Engine@ (2015) is "a platform for petabyte-scale scientific analysis and visualisation of geospatial datasets". The engine is acting as a computing platform that runs on top of the Google's infrastructure, allowing end-users to access petabytes of earthobservation datasets, including the Copernicus data, around the globe (Fig. 1).

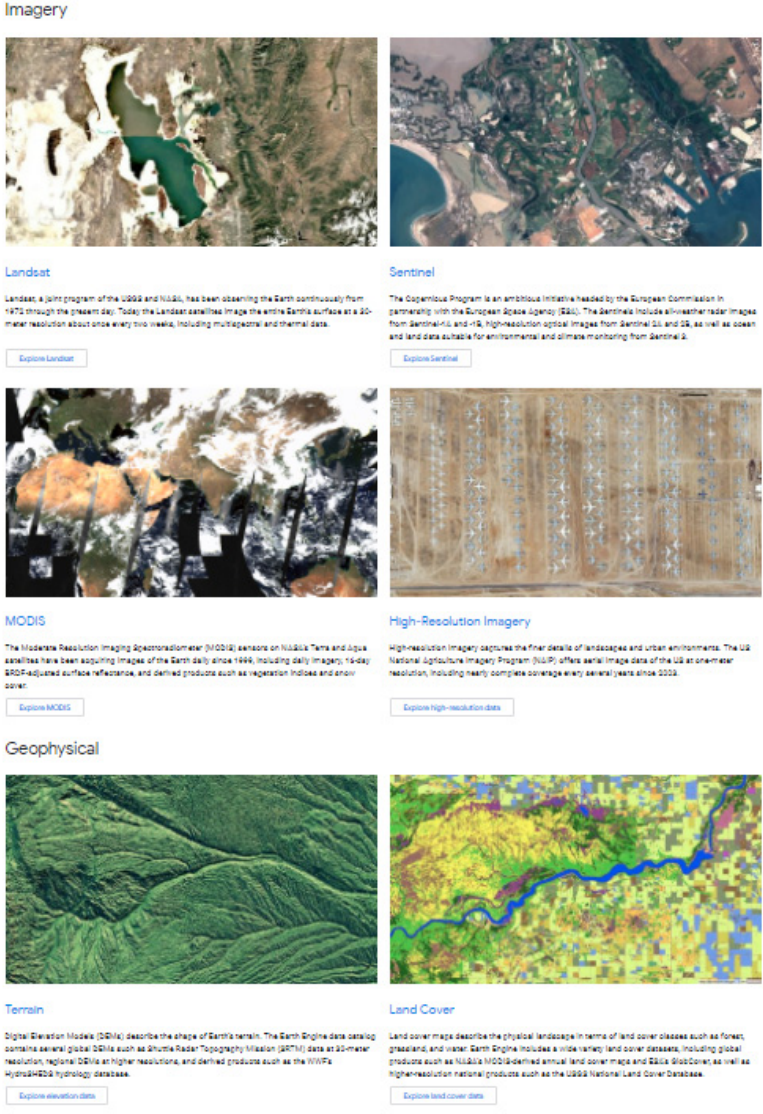

Figure 1: Screenshot from the Google Earth Engine data access (@Google).

The Google Earth Engine( $)$ includes various earth observation data and images before launching the first Sentinel sensors. The databased includes the Landsat series, while the end-users can upload other highresolution datasets for further processing.

The platform is expandable so that end-users can input (?) customised applications (e.g., image processing routines). The platform's access can be carried out in two ways: using the Core Editor or the Explorer. Explorer interface is a web access point to the platform that does not require any prior programming skills, while the Core Editor interface is more suitable for complex geospatial workflows (Fig. 2).

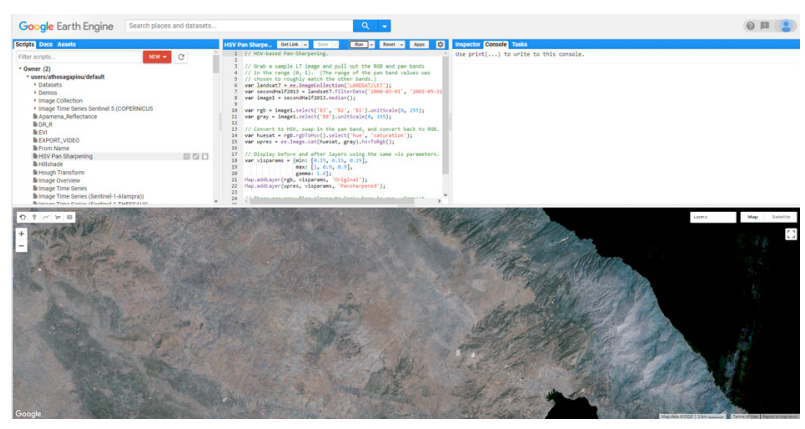

Figure 2: Screenshot from the Google Earth Engine Core Editor.

Similarly, other relevant cloud-based platforms are currently running to the Google Earth Engines, like the Amazon Web Services (2020). It should be mentioned 
that these cloud-based services explore machine and deep learning approaches, increasing thus the overall performance of image processing.

\section{Copernicus Services in Support of Cultural Heritage}

Very recently, in 2019, the European Commission has released the "Copernicus services in support to Cultural Heritage" report (Copernicus services in support to Cultural Heritage, 2020), that summarises the prospective implementation of the Copernicus Programme to cultural heritage applications. This report provides a European scale investigation, whereas several inputs from national agencies and other interested parties were reported. Even though cultural heritage is not directly linked to any of the existing Copernicus core services, the Copernicus related datasets can support some cultural heritage user requirements (see more in the next section).

The analysis of that report emphasised that only a small percentage $(7.5 \%)$ of the cultural heritage user requirements are already fully covered by Copernicus core services products. An additional $19.0 \%$ of user requirements have mentioned that are partially covered by existing Copernicus core services products without adaptation.

Adding to the Copernicus the Contributing Missions capabilities, these numbers increased by $50 \%$ of the user requirements (for fully covered), while an additional $14 \%$ could be partially covered. Therefore, half of the endusers requirements could be potentially supported by the downstream industry with access to very high-resolution data and/or very high revisiting time imagery, not available in the pool of Copernicus Contributing Missions. Overall, by using all Copernicus capabilities (core services products, Sentinels and Contributing Missions), $64 \%$ of cultural heritage end-user requirements could be covered.

Nonetheless, $36 \%$ of the end-user requirements, could not be covered by the Copernicus programme (Contributing Missions included). From this percentage, $7 \%$ cannot be covered due to the spatial or temporal limitations of the existing Copernicus Programme. In comparison, another $13 \%$ remains uncovered due to unfulfilled needs (i.e., sensors and/or wavelengths - such as hyperspectral, lidar - not available in the Copernicus Programme. Finally, $16 \%$ of the cultural heritage user requirements cannot be covered by satellite-based imagery at all. These needs require precise in-situ measurements and surveys (Ground Penetrating Radar (GPR), bathymetric surveys, etc.) or other complex valueadded products (e.g., assessment of sites frequentation pattern).

Concerning the monitoring of heritage sites from either natural or anthropogenic hazards, the report specifies that the existing Copernicus services focus mostly on cultural heritage rather than natural heritage sites. Hazard-related actions from the Copernicus Programme includes: (a) the hazard risk mapping of heritage sites that can be subjected to damage in cases of extreme meteorological events like floods or natural disasters such as earthquakes; (b) hazard early warning related to heritage sites that may be impacted/damaged by a geo-hazard; (c) hazard monitoring heritage sites for specific geo-hazards to support damage mitigation and damage assessment; and (d) hazard damage assessment of heritage sites due to a specific geo-hazard.

The capacity for performing these four categories of activities is critical for protecting and safeguarding heritage sites in Europe and worldwide. Commonly, when a geo-hazard occurs, civil protection agencies in charge of emergency response and mitigation focus first on human life protection and damage prevention on land use (e.g., critical infrastructure, farms, industries, etc.). In general, the safeguarding of cultural heritage is usually a secondary concern for civil protection agencies. However, some best practices have been introduced on a national level. In Italy for example, after major earthquakes that have hit the central part of the country in 2009 and 2016, a specialised body called "Funzione Beni Culturali" has been formed for securing the movable and immovable heritage. The two main representatives of this body are MiBACT (Italian Ministry of Cultural Heritage and Activities and Tourism) and Civil Protection. Such initiative declares a significant public commitment that can set the ground for a more extensive intervention framework on built Cultural Heritage in periods of hazards (Brazzetti \& Cuca, 2020).

\section{Cultural Heritage Applications: A Literature Review}

A literature review analysis, though the Scopus engine was performed in relation to the Copernicus programme and its contribution to cultural heritage. Scopus is the largest abstract and citation database of peer-reviewed literature: scientific journals, books, and conference proceedings.

The following search criteria were input in the Scopus database: "Copernicus AND archaeology"; "Copernicus AND cultural AND heritage"; "Sentinel AND archaeology" and "Sentinel AND cultural AND heritage". These keywords were selected to be found either in the title, the abstract, or the scientific journals' keywords within the Scopus database. This analysis's results are visualised in the figure below (Fig. 3), where a gradual increase in publications is observed, with an ever-increasing tendency from 2017 onwards. The use of Copernicus for cultural heritage was published in several scientific journals such as the "Remote Sensing MDPI", "Natural Hazards and Earth System Sciences", "Proceedings of SPIE" etc. Other findings, like documents by the author, documents by country or territory, and documents by funding sponsor are also shown in Figure 3.

Moreover, various risks that can affect cultural heritage, such as fires, earthquakes, landslides, soil erosion, floods, urbanisation, war conflicts or looting, have also been searched in the Scopus engine. Beyond the type of risk, the word "Satellite" was added, from 2010 to 2020. Figure 4 depicts the publications for the last decade (2010-2020). As shown, floods and earthquakes risks were by far the topic that attracted researchers' interest with 5162 and 5296 publications, followed by soil erosion, fires, and urbanisation (3587, 3206, and 2538 articles respectively). War conflicts and looting using satellite observation raised limited studies with only 39 articles in total. Also, a query for "Sentinel-1" and "Sentinel 2" has revealed a total number of more than 12000 articles indicating a significant wealth of research in exploiting the specific Copernicus sensors. 


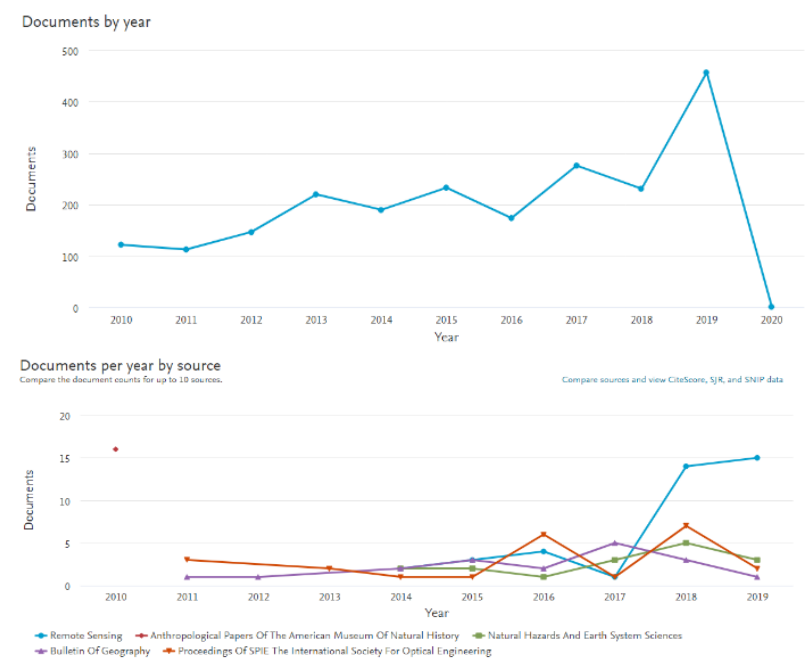

Figure 3: Scopus engine query results concerning the use of Copernicus and cultural heritage since 2010. Documents per year are shown on top while documents per year by source are visualised below-analysis for the NAVIGATOR project.

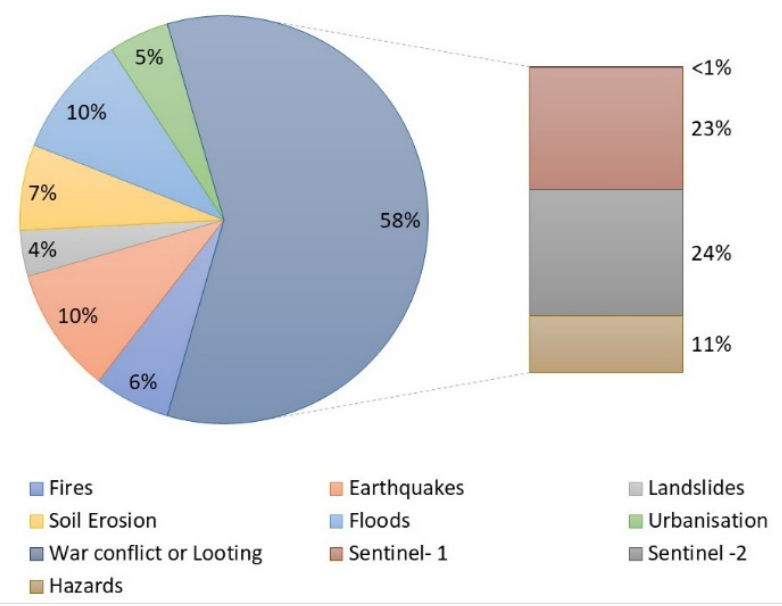

Figure 4: Total number of articles related to the study of various hazards with the support of satellite and space-based observations for the last decade (2010-2020) (results from Scopus engine database). Analysis of the NAVIGATOR project.

Specific queries at the Scopus engine such as "Looting and Earth Observation" or "Looting and Remote Sensing" and the "Earthquakes and Earth Observation" or "Earthquakes and Remote Sensing" have also been performed. The Scopus engine's literature review was then extracted and imported in the VOSviewer a software tool for creating maps based on network data, as shown in Figure 5 for looting and earthquakes risks, respectively. The different colours of this visual representation stand for a different thematic cluster, based on the keywords data of all articles found in the search engine. The size of each circle represents each cluster's size (i.e., how many times the specific term has been used). The links between each cluster are also visualised.

This desk-based analysis's overall results outlined the recent evolution of Earth Observation for applications related to cultural heritage.

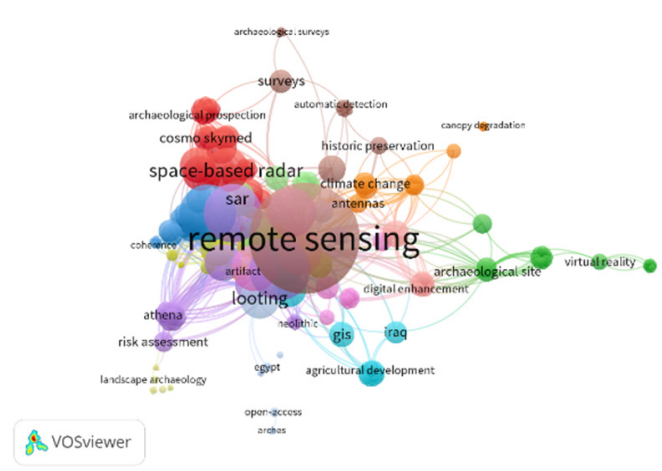

Figure 5: Visualisation of the scientific literature for looting. The database was extracted from the Scopus engine and visualised in the VOSviewer software. Analysis of the NAVIGATOR project.

\section{Earth Observation-based Applications}

In the past, remote sensing applications for cultural heritage have been populated in the scientific literature (Luo et al., 2019; Agapiou \& Lysandrou, 2015). The recent capabilities of the big-earth data cloud platforms have been already presented as well (Orengo et al., 2020). Several other studies have also used Copernicus radar and optical data for heritage management and risk assessment (Howland, Jones, Najjar, \& Levy, 2018; Agapiou et al., 2015; Cuca \& Agapiou, 2018).

In this section, we provide some of these examples, mainly focused on using the Copernicus Programme and other legacy data like the Landsat series. A recent example is Sentinel-1 images from monitoring land displacements after an earthquake event that occurred in the western part of Cyprus in 2015 (ref). The hightemporal revisit time of the Sentinel-1 images provides the opportunity to process images before and after an earthquake event. We can then blend this information with other geographical data using Geographical Information Systems to perform deformation analysis. Such damage proxy maps are critical for heritage management, especially after natural or man-made catastrophic events.

Figure 6 shows the coherence map as derived from the Sentinel-1 SAR images in ascending orbit and descending orbit using two pairs of Sentinel-1 images taken before and after the earthquake event. Figure 7 shows the unwrapped interferogram (Fig. 7a), the vertical displacement (Fig. 7b) and the coherence map (Fig. 7c) in the surroundings of a UNESCO World Heritage site in the western part of Cyprus (Agapiou \& Lysandrou, 2020).

Similarly, we can also explore the optical Sentinel-2 images for detecting urban areas in the vicinity of archaeological sites. Classification analysis of the multispectral optical data can be used to map the urban areas for extended regions. Using archive information like the Corine Land Use Land Cover program, the trend and the overall change in archaeological sites' vicinity can be estimated. In Figure 8 the red colour indicates the urban sprawl over the archaeological site of "Nea Paphos" and "Tombs of the Kings" in Paphos district, Cyprus (see yellow rectangles in Figure 8 left). The classification accuracy was estimated to be more than $86 \%$ using the random forest classifier. 

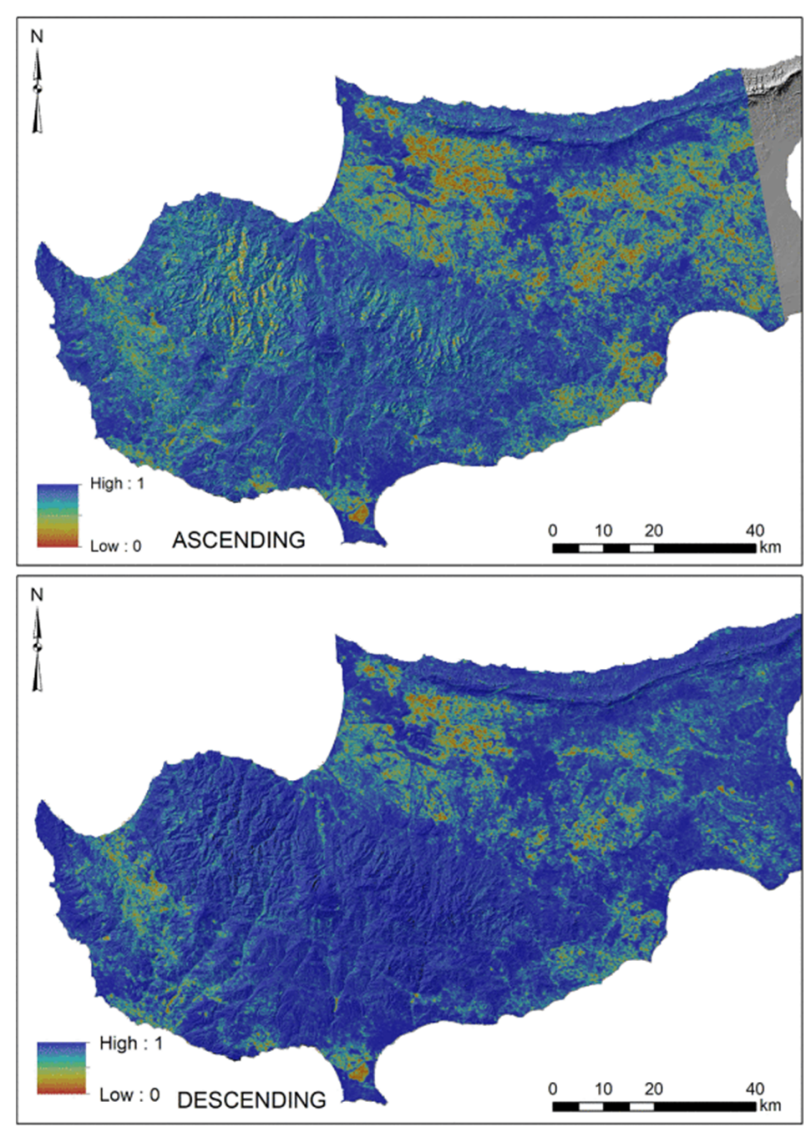

Figure 6: Coherence map as derived from the Sentinel-1 SAR images in ascending orbit and descending orbit. Analysis of the NAVIGATOR project (Agapiou \& Lysandrou, 2020).
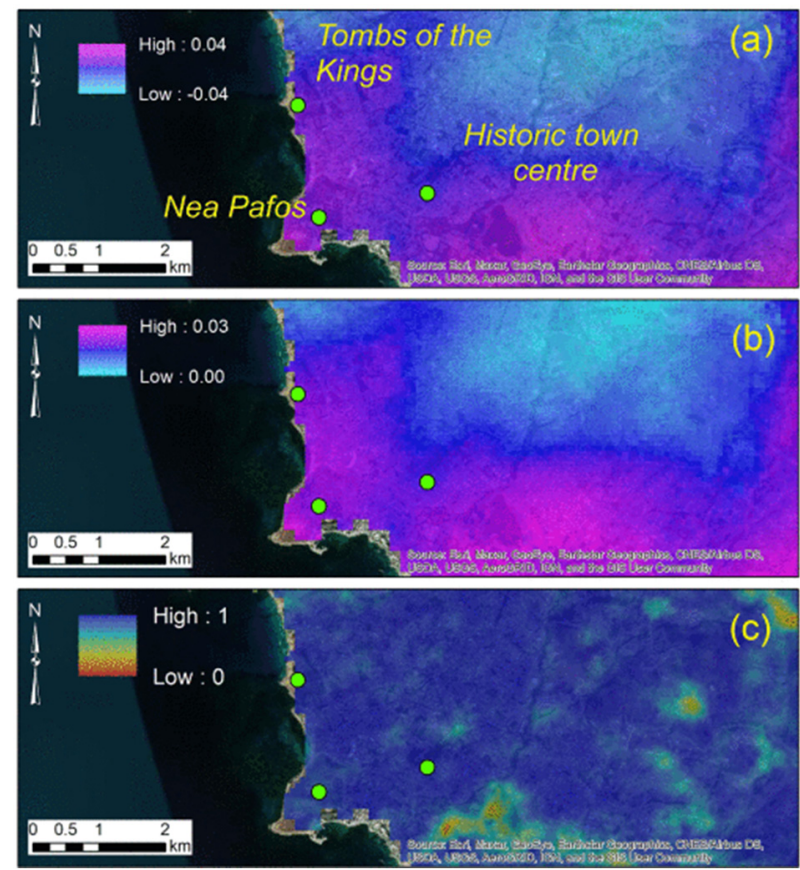

Figure 7: UNESCO World Heritage site in the western part of Cyprus (Agapiou \& Lysandrou, 2020): a) Unwrapped interferogram; b) Vertical displacements; c) Coherence map.

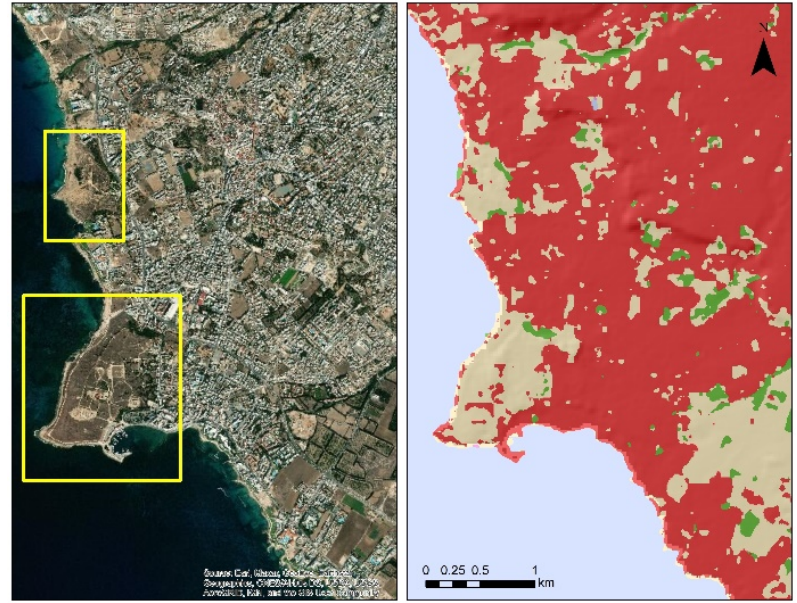

Figure 8: Classification results of a Sentinel-2 optical image over the Paphos town, western part of Cyprus (right). Urban areas are shown with red colour. On the left, two UNESCO World Heritage properties, namely the "Nea Paphos" and the "Tombs of the Kings" are shown with a yellow rectangle. Analysis for the NAVIGATOR project.

Other legacy satellite data, like those of the Landsat programme, can be explored to analyse historic buildings' thermal conditions. For this multi-temporal analysis, the macro-scale thermal anomalies can be further enhanced with higher spatial resolution and ground data, as shown in Figure 9. In the micro-scale level of observation ground sensors and observations on individual historic buildings can also be used as validation and calibration inputs of the satellite-based observations. The mean temperature over the municipality of Strovolos and Limassol, Cyprus, for a period covering from 2013-2020 are shown in Figures 10 and 11 , respectively.

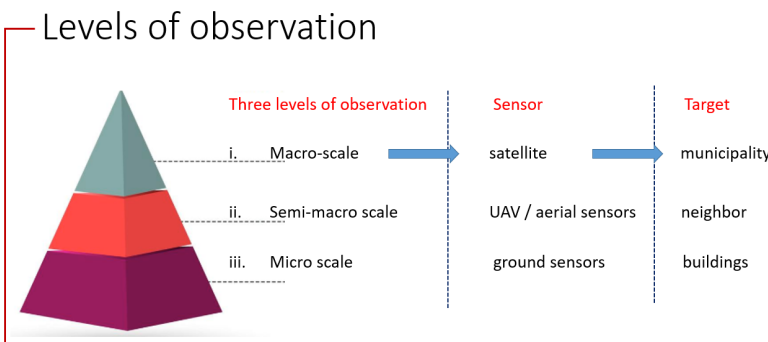

Figure 9: Observation levels for monitoring the thermal conditions of historic buildings. Analysis for the PERISCOPE project.

To better understand how earth observation and specific the Copernicus Programme can support cultural heritage, we should investigate cultural heritage needs. Figure 12 shows the disaster risk management (DRM) cycle, composed of six steps starting from the context, the identification of risk, the analysis, the evaluation and treatment and the monitoring phase (Agapiou, Lysandrou, \& Hadjimitsis, 2020). These steps are also known as preparedness and response phases and the recovery and mitigation actions. 


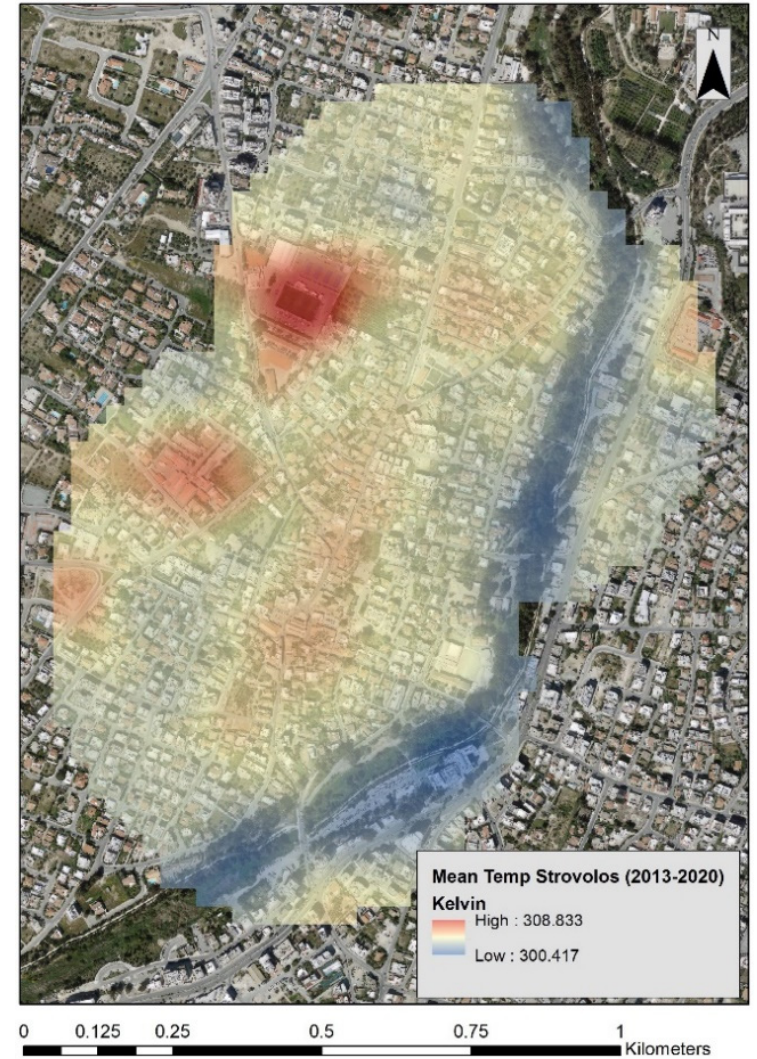

Figure 10: Mean temperature over Strovolos' municipality for a period from 2013-2020 using Landsat thermal images. Analysis of the PERISCOPE project.

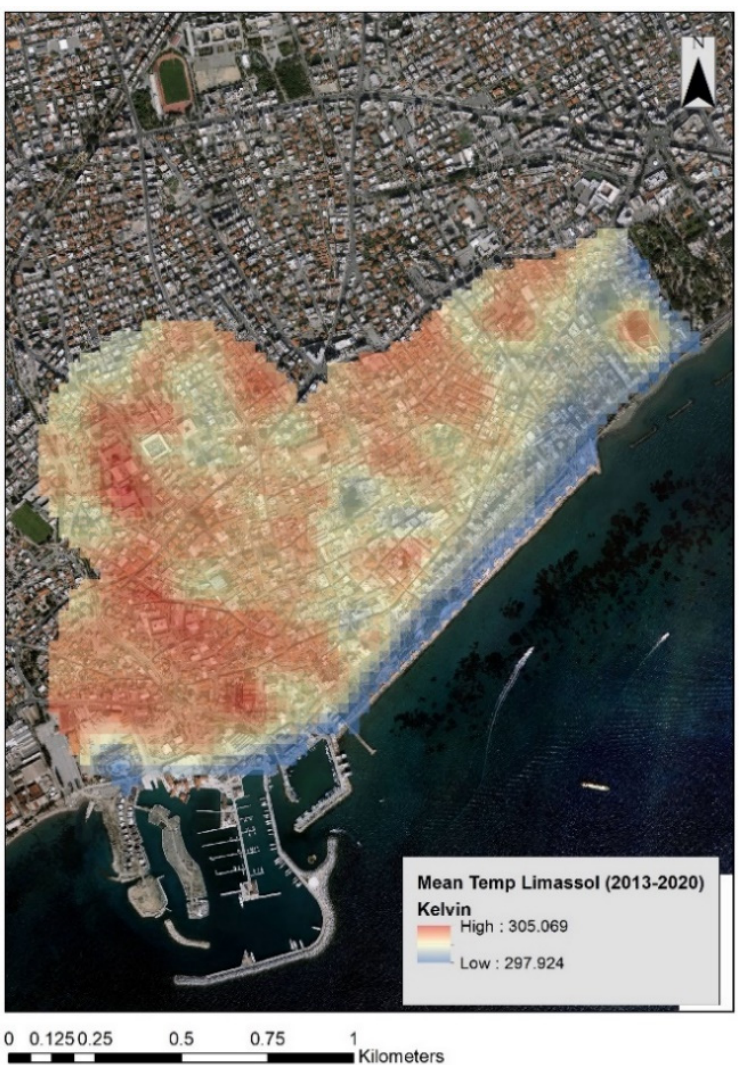

Figure 11: Mean temperature over the municipality of Limassol for a period from 2013-2020 using Landsat thermal images. Analysis of the PERISCOPE project.

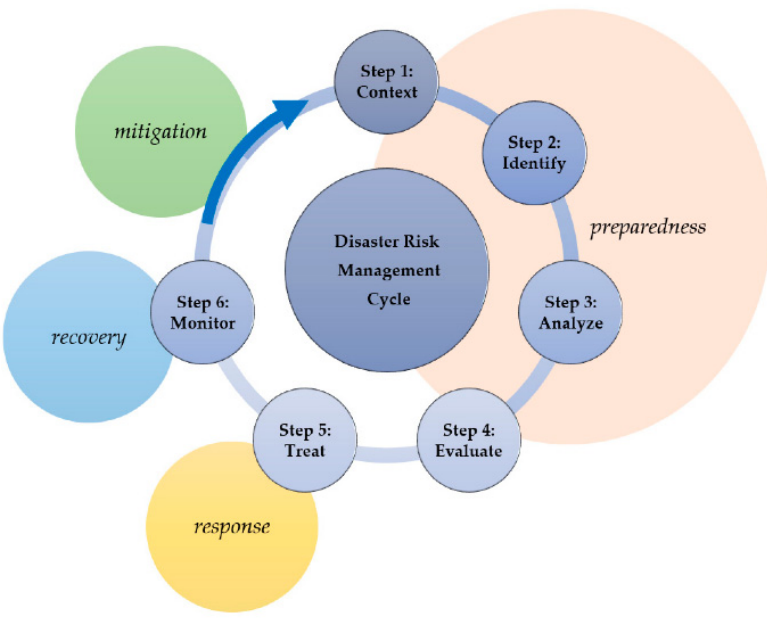

Figure 12: Disaster risk management (DRM) cycle for cultural heritage applications (Agapiou, Lysandrou, \& Hadjimitsis, 2020). Analysis of the NAVIGATOR project.

Earth observation can support the DRM cycle in various ways as this was also reported in (Agapiou, Lysandrou, \& Hadjimitsis, 2020). Figure 13 shows with green colour the potential contributions of the Copernicus Programme to DRM cycle in each of the six-steps:

Step 1. Understanding the context: Context information includes among others the physical environment of a site or monument. Such kind of information can be retrieved from the use of time-series satellite-based observations

Step 2. Identify risks: Agents of deterioration and loss, the various layers of enclosures, as well as the risk occurrence are defined. The use of earth observation images and image processing can be very important as satellite sensors can cover an extensive area and therefore oversee not only the archaeological site itself but also the surrounding area.

Step 3. Analyzing risks: this step quantifies the potential impact of all considered risks and any potential uncertainties of the analysis.

Step 4. Evaluation of risks: At this step, earth observation images can be used as inputs in the various models to evaluate the risks.

Step 5. Treating risks: Earth observation can be used as input layers of information for treating risks and provide systematic input to local stakeholders.

Step 6. Monitoring: Earth observation systematic monitoring may be used as a systematic tool of observation and monitoring purposes.

These steps are interconnected, and therefore any assumptions and uncertainties at any stage might influence the subsequent stages of the DRM cycle. The design and conceptualisation of a DRM cycle plan is a collective effort made by several parties that can provide specific information with local value, scientific knowledge for better characterisation of a site, and technological understanding. 


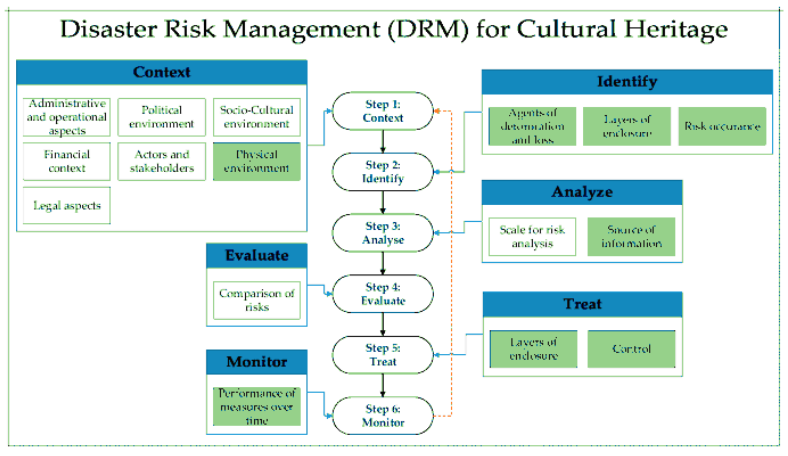

Figure 13: The potential contribution of satellite observation within the various steps of the risk management plan proposed by the International Centre for the Study of the Preservation and Restoration of Cultural Property (ICCROM) is highlighted in the green rectangle (Agapiou, Lysandrou, \& Hadjimitsis, 2020). Analysis of the NAVIGATOR project.

\section{Space-Based Applications for $\mathrm{CH}$ as a part of geospatial data policies}

Despite the increase of applications and case studies dealing with the Copernicus programme for cultural heritage, a gap is observed concerning adopting these methods as a systematic observation tool. National and regional authorities are pursuing a step forward through local INSPIRE Geo-portals, including Copernicus imagery and some specifically derived information supporting targeted actions. National and regional geo-portals are a product of coordinated European action to create a legal framework. This framework is used for the exchange, sharing, and access of interoperable (geo) spatial data and spatial data services, across different sectors and different levels of public authorities (European Parliament (EP), Directive 2007/2/EC, 2021). To include Sentinel imagery and derived products in such portals can be seen as an attempt to systematise geospatial information deriving from Earth Observation technologies. In this sense, the road for Cultural Heritage sites management could already be deemed as "paved" if the Theme "Protected sites" is considered. A specific INSPIRE theme dedicated to Cultural and Natural heritage could indeed serve not only for purposes of geo-location of specific monuments or areas under protection. It can also monitor their current state, vulnerability and potential threats that could be detected using integrated remote sensing technologies, including satellite imagery and products.

\section{Conclusions}

This paper presented some potentials of using earth observation (EO) sensors, including the Copernicus Programme data, with a focus on cultural heritage applications. The increased employment of space-based observations for monitoring purposes and risk assessment are some of these applications. The new technological shift observed in terms of image processing and cloud computing will impact the traditional way of EO implementations.

Earth observation can play an important role in the disaster risk management cycle (DRM) supporting local stakeholders and responsible agencies with tailoredmade products and different management phases. However, today, a gap still exists regarding the adoption of space-based sensors by national agencies to monitor cultural sites and monuments systematically.

One way of bridging this gap is to rely on organised and systematically updated infrastructures of open geospatial data where satellite-based data and services, like the Copernicus Sentinels, can provide timely and targeted products. These infrastructures can support cultural heritage preservation and management.

\section{Acknowledgements}

The paper is submitted under the NAVIGATOR project. The project is being co-funded by the Republic of Cyprus and the European Union's Structural Funds in Cyprus under the Research and Innovation Foundation grant agreement EXCELLENCE/0918/0052 (Copernicus Earth Observation Big Data for Cultural Heritage). Results related to the Landsat thermal analysis are part of the "Portal for heritage buildings integration into the contemporary built environment", in short PERISCOPE, co-financed by the European Regional Development Fund and the Republic of Cyprus through the Research \& Innovation Foundation. Grant Agreement INTEGRATED/0918/0034.

\section{References}

Agapiou, A., Lysandrou, V. \& Hadjimitsis, D. G. (2020). Earth Observation Contribution to Cultural Heritage Disaster Risk Management: Case Study of Eastern Mediterranean Open Air Archaeological Monuments and Sites. Remote Sens., 12, 1330. https://doi.org/10.3390/rs12081330

Agapiou, A., \& Lysandrou, V. (2020). Detecting Displacements Within Archaeological Sites in Cyprus After a 5.6 Magnitude Scale Earthquake Event Through the Hybrid Pluggable Processing Pipeline (HyP3) Cloud-Based System and Sentinel-1 Interferometric Synthetic Aperture Radar (InSAR) Analysis. IEEE Journal of Selected Topics in Applied Earth Observations and Remote Sensing, 13, 6115-6123. doi: 10.1109/JSTARS.2020.3028272

Agapiou, A., \& Lysandrou, V. (2015). Remote Sensing Archaeology: Tracking and mapping evolution in scientific literature from 1999-2015. J. Archaeol. Sci. Rep., 4, 192-200. https://doi.org/10.1016/j.jasrep.2015.09.010.

Agapiou, A., Alexakis, D. D., Lysandrou, V., Sarris, A., Cuca, B., Themistocleous, K., \& Hadjimitsis, D. G. (2015). Impact of Urban Sprawl to archaeological research: The case study of Paphos area in Cyprus. J. Cult. Herit., 16, 671-680. doi:10.1016/J.CULHER.2014.12.006

Amazon WebServices (2020). AWS | Cloud Computing - Servicios de informática en la nube. Retrieved January 27, 2021 from https://aws.amazon.com

Brazzetti, L., \& Cuca, B. (2020). Identification of Buildings Damaged by Natural Hazards Using Very High-Resolution Satellite Images: The Case of Earthquake in L'Aquila, Italy. In Hadjimitsis et al. (Eds), Remote Sensing for 
Archaeology and Cultural Landscapes (pp. pp 139-151). https://doi.org/10.1007/978-3-030-10979-0_9

Copernicus. (2020). Retrieved January 27, 2021 from https://www.copernicus.eu/en

Copernicus Services. (2020). Retrieved January 27, 2021 from https://www.copernicus.eu/en/copernicus-services

Copernicus services in support to Cultural Heritage (2020). Retrieved January 27, 2021 from https://www.copernicus.eu/sites/default/files/2019-06/Copernicus_services_in_support_to_Cultural_heritage.pdf

Cuca, B., \& Agapiou, A. (2018). Impact of land use change and soil erosion on cultural landscapes: The case of cultural paths and sites in Paphos district, Cyprus. Appl. Geomat., 10, 51. https://doi.org/10.1007/s12518-018-0237-z

Data and Information Access Services (DIAS) (2020). Retrieved January 27, 2021 from https://www.copernicus.eu/en/access-data/dias

European Parliament (EP), Directive 2007/2/EC: Establishing an Infrastructure for Spatial Information in the European Community (INSPIRE), last accessed Jan 2021 EUR-Lex - 32007L0002 - EN - EUR-Lex (europa.eu)

European Comission (2018). COM(2018) 447 final. Retrieved January 27, 2021 from https://eur-lex.europa.eu/legalcontent/EN/TXT/?uri=COM\%3A2018\%3A447\%3AFIN

Google Earth Engine Team. (2015). Google Earth Engine: A planetary-scale geospatial analysis platform. Retrieved January 27, 2021 from https://earthengine.google.com

Howland, M.D., Jones, I.W.N., Najjar, M., \& Levy, E.T. (2018).Quantifying the effects of erosion on archaeological sites with low-Altitude aerial photography, structure from motion, and GIS: A case study from southern Jordan. J. Archaeol. Sci., 90, 62-70. https://doi.org/10.1016/j.jas.2017.12.008

Luo, L., Wang, X., Guo, H., Lasaponara, R., Zong, X., Masini, N., Wang, G., Shi, P., Khatteli, H., Chen, F. (2019). Airborne and spaceborne remote sensing for archaeological and cultural heritage applications: A review of the century (19072017). Remote Sens. Environ., 232, 111280. https://doi.org/10.1016/j.rse.2019.111280

Orengo, A. H., Conesa, C. F., Garcia-Molsosa, A., Lobo, A., Green, S. A., Madella, M., \& Petrie, A. C. (2020). Automated detection of archaeological mounds using machine-learning classification of multisensor and multitemporal satellite data. Proceedings of the National Academy of Sciences Aug, 117(31) 18240-18250. https://doi.org/10.1073/pnas.2005583117

Satellites components. (2020). Satellites component | Copernicus. Retrieved January 27, 2021 from https://www.copernicus.eu/en/about-copernicus/infrastructure/satellites-component

Sentinel Overview. (2020). Missions - Sentinel Online. Retrieved January 27, 2021 from https://sentinel.esa.int/web/sentinel/missions

Sentinel-1. (2020). Missions - Sentinel Online. Retrieved January 27, 2021 from https://sentinel.esa.int/web/sentinel/missions/sentinel-1

Sentinel-2. (2020). Missions - Sentinel Online. Retrieved January 27, 2021 from https://sentinel.esa.int/web/sentinel/missions/sentinel-2 


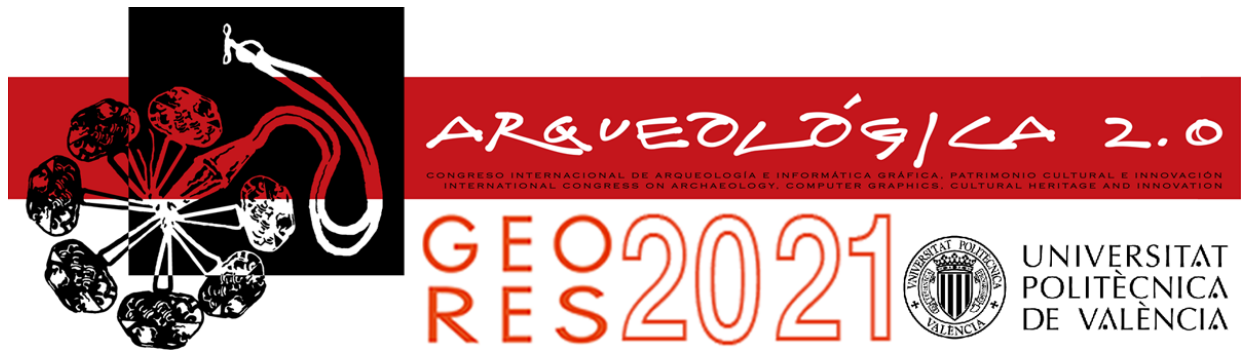

Proceedings of the joint international event $9^{\text {th }}$ ARQUEOLÓGICA

$2.0 \& 3^{\text {rd }}$ GEORES

Valencia (Spain).

26-28 April 2021

\title{
SPACE-BASED APPLICATIONS FOR BUILT CULTURAL HERITAGE: EXPERIENCE OF COPERNICUS4REGIONS PUBLICATION
}

\author{
Branka Cuca*, Raffaella Brumana \\ Department of Architecture, Built Environment and Construction Engineering, Politecnico di Milano, Piazza Leonardo da Vinci 32, 20133 \\ Milan, Italy. banka.cuca@polimi.it; raffaella.brumana@polimi.it
}

\begin{abstract}
:
NEREUS is a Network of Regions Using Space Technologies established in Brussels in 2007. The need of this network emerged out of the conviction that the regions are the key users and procurers of space-based applications, products and services. For more than a decade, the mission of the Network has been to raise awareness of the benefits that space technologies can offer to the citizens, especially in a regional context, for public services and public policies. Within this framework, and with support by the European Commission and European Space Agency, NEREUS has developed several publications that have promoted different Earth Observation applications such as "The growing uses of Copernicus across Europe's Regions" (2012) and the latest one "The Ever Growing Use of Copernicus across Europe's Regions" (2018). Politecnico di Milano was in charge of Publication management of this last use-cases collection. The paper here presented illustrates and discusses the result of the Publication with a specific focus on space-based applications and Copernicus Programme for Cultural Heritage.
\end{abstract}

Keywords: cultural heritage, earth observation, Copernicus programme, Copernicus services, space-based applications, NEREUS, ESA

\section{Importance of regional dimension to EU policies and "Copernicus4Regions" initiative}

"Copernicus4Regions" is a joint initiative of European Commission (EC), European Space Agency (ESA) and NEREUS that explores how regions in Europe have managed to tackle common challenges, shows the benefits of the Copernicus programme and invites more regions to be involved in the ecosystem of the European Earth Observation (EO) Programme called Copernicus. The Programme is composed of the space infrastructure segment and the ground segment. The space infrastructure is based on a constellation of satellites called "Sentinels" that provide a timely and systematic earth coverage for numerous applications in the domain of environmental monitoring (Copernicus, 2020).

The regional dimension in the European Union (EU) is of great importance - on an institutional level, for example, it is represented by the body called European Committee of the Regions (CoR) with a mission to represent opinions of local and regional legislations and to provide opinions and advises on new EU laws that have an impact on the life of the citizens. (Committee of the Regions - CoR, 2020). For instance, a tool called "Territorial Impact Assessments (TIAs)" is used in order to provide CoR's rapporteurs with an analysis of the potential territorial impact of different EU legislative proposals. (CoR, 2015).

As far as the Cultural Heritage and Cultural Landscape is regarded, the regional dimension has already been recognised by the Florence Landscape Convention that with Art. 5 calls for each (signatory) party "to integrate landscape into its regional and town planning policies and in its cultural, environmental, agricultural, social and economic policies, as well as in any other policies with possible direct or indirect impact on landscape" (CoE, 2000).

A more recent document on emerging issues regarding impacts and mitigation of climate change called "European Climate Pact" states that "the Climate Pact will bring together 'regions, local communities, civil society, industry and schools. Together they will design and commit to a set of pledges to bring about a change in behaviour, from the individual to the largest multinational."” (EC, 2020).

Hence, it could be argued that the regions have been recognised as one of the main actors to implement policies of interest for local management, as a direct link with the citizen and as a possible facilitator of their behavioural change.

The initiative "'CCopernicus4Regions'”' has been brought forward by NEREUS - a Network of Regions Using Space

"Corresponding Author: Branka Cuca, banka.cuca@polimi.it 
Technologies established in Brussels in 2007. The need for this network emerged out of the conviction that the regions are the key users and procurers of space-based applications, products and services. Since more than a decade, the mission of NEREUS has been to raise awareness of the benefits that space technologies can offer to the citizens.

The initiative "Copernicus4Regions", and more specifically the results of the Publication here discussed, fully recognise the importance of the regional dimension: the publication aims to highlight the best practices of space-based solutions and applications that have been put in place by regional public authorities and local players to tackle some specific challenges that affect the lives of European citizens.

The paper here presented will illustrate and discuss the result of the publication with a specific focus on spacebased applications and Copernicus Programme for Cultural Heritage.

\section{99 user stories by local and regional authorities: publication structure and discussion of results}

The publication entitled "The Ever Growing Use of Copernicus across Europe's Regions" is the result of the most recent survey on space-based applications for European regions, conducted in 2018 within "Copernicus4Regions" initiative. The selection of 99 user stories presents an insight on how public administrations across Europe are using Copernicus data and services to address their challenges and how this is positively impacting the lives of citizens.

In order to emphasise the link of EO applications and services with the specific territorial challenges, the collection procedure required for European regions (and not academies or research bodies) to be proponents of specific user stories. The selection was based on a double peer-review process, with expert reviewers selected all over European Union. The topics considered by this collection have been structured into eight (8) themes:

(i) Agriculture, Food, Forestry and Fisheries;

(ii) Biodiversity and Environmental Protection;

(iii) Climate, Water and Energy;

(iv) Territorial management and Urban Planning;

(v) Civil Protection;

(vi) Transport, Civil Infrastructure and Safety;

(vii) Public Health;

(viii) Cultural heritage, Tourism and Leisure.

The results show that almost two-thirds of the papers describe applications falling in three themes: "Agriculture, Food, Forestry and Fisheries" (32 papers), "Biodiversity and Environmental Protection" (17 papers) and "Climate, Water and Energy" (16 papers). Figure 1 illustrates the results for all topics in a pie chart.

Although the themes "Public Health" and "Cultural Heritage" have received respectively one and two publications, these results have been considered significant for two reasons: (i) EO applications in these fields have not yet reached the levels of maturity comparable to more traditional fields of applications such as agriculture or environmental monitoring and (ii) these domains were not within the original objectives of the Copernicus Programme (Copernicus, 2020). Hence, the resonance of the EO potential within the fields so apparently distant from the initial purpose of the European space programme, could already be considered a significant achievement.

\section{Track 1. Transports, Civil Infrastructure and Safety \\ \rack 2. Cultural Heritage, Tourism and Leisure \\ 园 Track 3. Biodiversity and Environmental Protection \\ Track 4. Territorial Management and Urban Planning \\ a Track 5. Public Health \\ a Track 6. Civil Protection \\ Track 7. Agriculture, Food, Forestry and Fisheries \\ Track 8. Climate, Water and Energy}

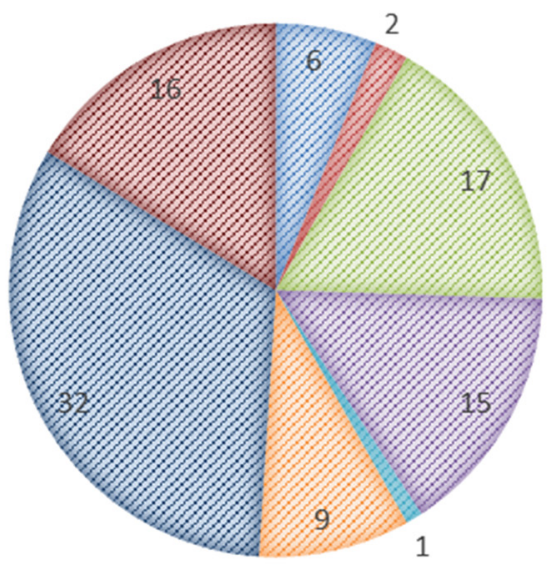

Figure 1: Distribution of the Copernicus User Stories by thematic area. Source: "Copernicus4Regions" | Second Review Panel Report.

The survey conducted has regarded four specific aspects:

(i) the challenge tackled by the application;

(ii) the space-based solution;

(iii) benefits to the citizens and

(iv) outlook to the future.

More specifically, in the space-based solution section the authors were required to refer to type of Sentinel (and/or to contributing missions) data used and to self-asses the User Maturity Level (UML) of their application. As far as the use of Sentinels are considered, use of S-2 has been recorder as highest (74 cases), which can be explained by the fact that this high-resolution optical imagery can be of effective use to LRAs in territorial management.

Regarding the UML, these have been defined by "Copernicus4Regions" initiative in following manner: UML 1- Explorer; UML 2 - Ad-hoc user; UML - 3 Pilot/ Experimental tester; UML 4 - Early Adopter and UML 5 Operational user. As a result, almost half of the publication cases identify in the definition "Pilot/Experimental tester" (UML 3, 43 use cases), while circa $15 \%$ of applications declare to be at the Operational user level (UML 5). 
It is also interesting to mention that geographical distribution of cases was highly significant: the use case have arrived from 72 different European regions and municipalities distributed across 24 Copernicus countries. Figure 2 shows a distribution of articles across countries per affiliation.

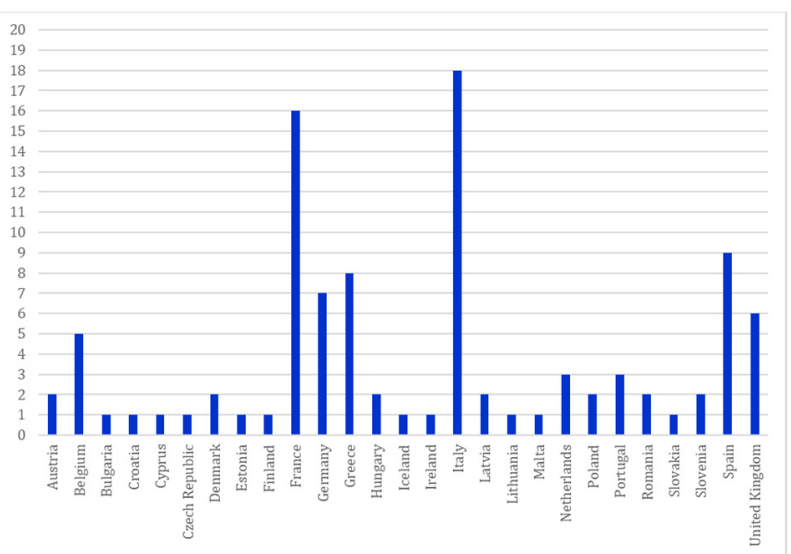

Figure 2: Distribution of articles (in numbers) across the Copernicus countries per affiliation (origin as declared by the main author). Source: "Copernicus4Regions" | Second Review Panel Report, statistics.

\section{Copernicus Services: opportunities for Cultural Heritage communities}

Scientific activities and research regarding the application of EO technologies in the domain of built Cultural Heritage has already been extensively reviewed (Lasaponara \& Masini, 2011; Giardino, 2011; Agapiou \& Lysandoru. 2015; Cuca \& Hadjimitsis 2017; Agapiou, Lysandrou, \& Hadjimitsis, 2020). However, Cultural Heritage was not a domain considered to be initially strategic for Copernicus Programme. Successively to Sentinels launch, an active response by the scientific community, but also some dramatic events involving destruction of heritage sites of world-wide importance, have put the employment of satellite-based technologies for purposes of monitoring and preservation of built heritage higher up in the political agendas. For instance, in the document "Towards an EU strategy for international cultural relations" (European Commission, 2016), EC expresses the will to share with UNESCO "satellite imagery of cultural heritage sites at risk in order to evaluate the damage and plan possible reconstruction".

Most recently in 2019, EC has released a study on "Copernicus services in support to Cultural Heritage" that has been conducted with an aim to "support the European Commission in its assessment on the possibility of initiating an institutional action for promoting the use of Copernicus data for Cultural Heritage preservation, monitoring and management" (Copernicus services in support to Cultural Heritage, 2020).

This Report, together with an broad analysis of user requirements, provides an extensive list of Copernicus capabilities in response to these needs. In particular, specific capabilities offered by the Copernicus programme are tackled by two already existing Copernicus services: (a) Copernicus Security Service and (b) Copernicus Emergency Service (CEMS). In particular: a) The EU Satellite Centre (SatCen), in charge of the Copernicus Security service in support of EU External Action (Copernicus SEA), can provide a twofold action for purposes of tangible Cultural Heritage monitoring: (i) Damage assessment: change detection products, available on-demand; (ii) Activity analysis: EO-based products analysing pre and post-human activity over Cultural Heritage sites, available on-demand and/or for monitoring activities.

b) The Joint Research Centre (JRC), on the other side, is in charge of CEMS and provides information for disaster risk and recovery as well as for emergency response related to natural disasters, extreme meteorological events and accidental man-made disasters. The Copernicus EMS targets authorised users from civil protection agencies as well as UN agencies and international NGOs and provides: (i) On-demand mapping: provision of rapid maps for emergency response, and risk and recovery maps for prevention and planning; (ii) Early warning and monitoring system: provision of geo-hazard forecast and monitoring to support situational awareness, and decision-making for prevention and preparedness purposes.

\section{Advantages and difficulties in using Sentinel imagery: a brief overview}

As described, the paper focuses on a specific experience with an attempt to highlight the results of a public survey conducted specifically among Public Authorities (PAs) at the local and regional level. That is to say that the paper refers not so much to the scientific advancement of the Copernicus programme products and services but rather to those examples that have been proposed as a concrete uptake in the practice of heritage documentation and site management.

It is, however, appropriate to mention some main advantages and possible difficulties for wider use and a better uptake of Sentinel imagery. The main advantage of Copernicus is that this space programme in general relies on a free, full and open (FFO) data policy (European Parliament, 2018). This means that data provided by the programme are open to all end-users and are available for use and possibly re-use. Hence, Sentinel data, in addition to the educational and scientific use, can be employed for developing concrete commercial solutions, hence stimulating the private sector uptake as well.

From a more technological perspective, benefits in using Sentinels regard their high temporal resolution: in case of Sentinel-1 Constellation the coverage frequency refers to 6 -days for countries of the European union and 12 days for the rest of the world, while Sentinel-2 Constellation provides a revisit time of 5 days at the equator in cloudfree conditions. In particular, Sentinel-2 swath width is $290 \mathrm{~km}$ (in comparison to Landsat 5 TM of $185 \mathrm{~km}$, and the swath width of SPOT- 5 is $120 \mathrm{~km}$ ). Sentinel-2 data are acquired with a Multi Spectral Instrument (MSI) at three spatial resolutions $(10,20$ and $60 \mathrm{~m})$, with a resolution of $10 \mathrm{~m}$ in Red, Green, Blue and NIR bands (ESA, 2020). Availability of this kind of optical multi-spectral imagery free of charge is highly stimulating also for the cultural 
heritage community that in the past has extensively relied on Landsat missions (at $30 \mathrm{~m}$ resolution in the abovementioned bands).

This paper does not specifically tackle the disadvantages of the use of Sentinel data, but some difficulties could be mentioned when dealing with satellite imagery in general. Aspects that come to mind more specifically for the "nontraditional" fields of application (such as cultural heritage domain) is a wider user-uptake of Sentinel data opportunities, often limited due to knowledge and expertise gaps. Another problem could regard the methodology frequently applied on satellite imagery in cultural heritage domain i.e. visual (and manual) investigation that could be time-consuming and potentially influenced by subjectivity of the operators. In fact, the authors of the Cases examined recognise these drawbacks and suggest some concrete solutions for the future, possibly within a larger collaboration framework of institutions and scientific disciplines (see Table 1).

Table 1: A summary of issues per section of the Publication for Case 1 and Case 2.

\begin{tabular}{|c|c|c|}
\hline Analysis per section & Case 1 & Case 2 \\
\hline Challenge tackled & $\begin{array}{l}\text { To provide PAs with a possibility to: (i) } \\
\text { monitor the condition of heritage; (ii) } \\
\text { repeat the assessment; (iii) perform timely } \\
\text { checks in case specific events of damage } \\
\text { occur. }\end{array}$ & $\begin{array}{c}\text { To analyse threats to } \mathrm{CH} \text { assets induced } \\
\text { by natural hazards or extreme } \\
\text { meteorological events as effects of } \\
\text { climate change; } \\
\text { To provide an overview of capabilities of } \\
\text { space-based solutions for monitoring geo- } \\
\text { hazards on the UNESCO WHL in Europe. }\end{array}$ \\
\hline $\begin{array}{l}\text { Space-based solution (use of Copernicus } \\
\text { data) }\end{array}$ & Sentinel-2 & Sentinel-1 \\
\hline $\begin{array}{l}\text { Usage Maturity Level (UML, as stated by } \\
\text { the authors) }\end{array}$ & $1-3$ & 3 \\
\hline Benefits to the citizens & $\begin{array}{l}\text { Assessing and monitoring of heritage at } \\
\text { risk; } \\
\text { Strengthen disaster preparedness. }\end{array}$ & $\begin{array}{c}\text { Enhancement of management practices; } \\
\text { Strengthen disaster preparedness. }\end{array}$ \\
\hline Outlook to the future & $\begin{array}{l}\text { Automation (e.g. automatic processing } \\
\text { chain); } \\
\text { Capacity building for better user uptake. }\end{array}$ & $\begin{array}{l}\text { An agreement among European } \\
\text { institutions on the use of satellite services } \\
\text { for monitoring hazards affecting } \mathrm{CH} \text {. }\end{array}$ \\
\hline
\end{tabular}

\section{Cultural Heritage use cases in "Copernicus4Regions": an overview and discussion on results}

Although the cases received on Cultural Heritage topic by the Publication were few, the paper intends to provide an illustration of these cases in order to highlight the possibilities for further advancements to the more operational phase of space-based applications in this domain.

The two use cases received on the $\mathrm{CH}$ theme will be briefly discussed here and they will be referred to as:

Case 1: an experience heritage sites at risk in the Middle East and North Africa entitled "Monitoring Heritage at Risk", presented by Italian Space Agency - ASI, (Tapete \& Cigna, 2018), the case illustrated in Figure 3.

Case 2: an experience from a project funded by a Joint Programming Imitative on Cultural Heritage and Global Change (JPI-CH) entitled "Protection of European Cultural Heritage from Geo-hazards", presented by a consortium of PROTHEGO project (Bee et al., 2018), case illustrated in Figure 4.

\subsection{The challenge}

The section of the use-cases that was dedicated to "The challenge" had as a purpose to set up a context in which a space-based application has been inserted in order to meet specific requirements of public authorities. In the two cases Authors describe two different challenges: while Case 1 focuses on risks caused by man-action, Case 2 sets the priority on monitoring of threats and damages caused by mainly natural hazards. It could be argued that, in light of Section 3 of this paper, Case 1 is closer to the topics tackled by the Copernicus Security Service while Case 2 could rely on products of Copernicus Emergency Service.

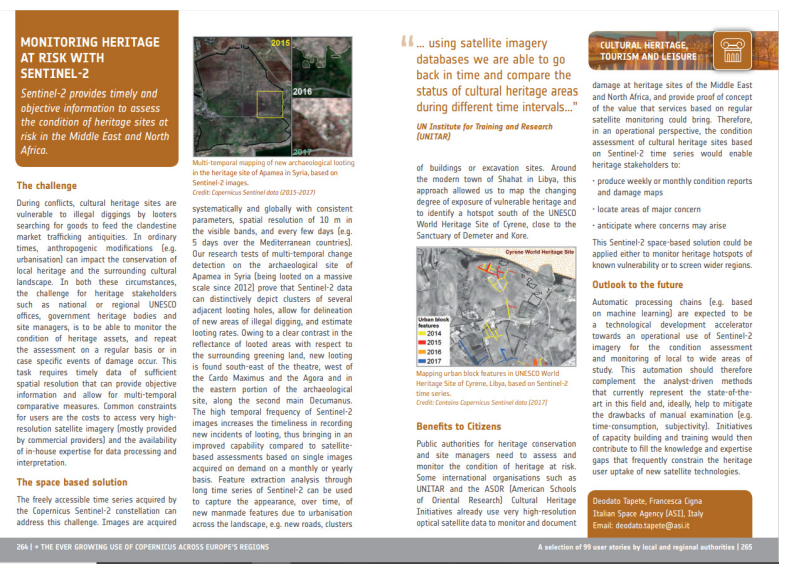

Figure 3: Case-study 1: "Monitoring Heritage at risk with Sentinel-2", pages 264-265 extracted from the publication "The Ever Growing Use of Copernicus across Europe's Regions" () NEREUS-ESA-EC. 


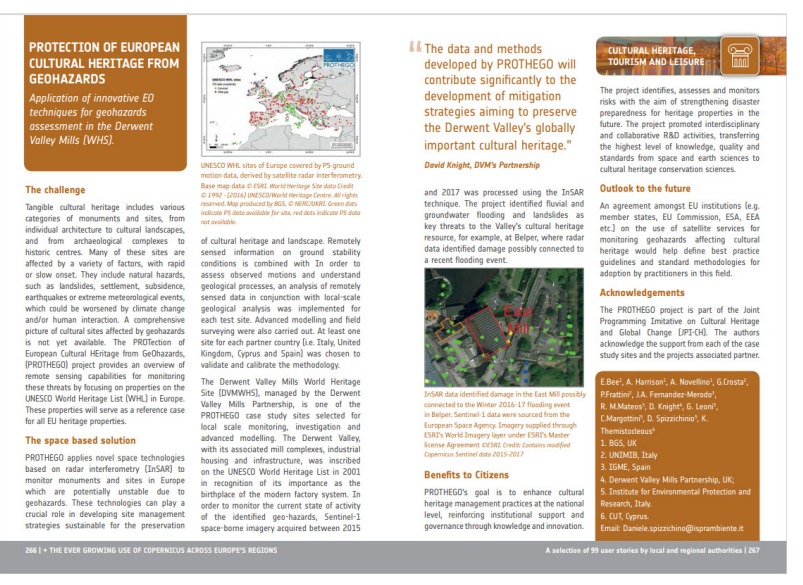

Figure 4: Case-study 2: "Protection of European Cultural Heritage from Geohazards", pages 266-267 extracted from the publication "The Ever Growing Use of Copernicus across Europe's Regions" C NEREUS-ESA-EC.

In more detail, the challenge in Case 1 has been identified as a need to provide PAs with a possibility of (i) monitoring the condition of heritage assets; (ii) repeating the assessment on a regular basis; (iii) performing timely checks in case specific events of damage occur, specifically in areas affected by armed conflicts that are under high risk of heritage looting. In particular, two specific obstacles for PA identified are "the costs to access very high resolution satellite imagery (mostly provided by commercial providers) and the availability of in-house expertise for data processing and interpretation".

Case 2 focuses on threats to Cultural Heritage assets induced by natural hazards, such as landslides, settlement, subsidence, earthquakes or extreme meteorological events caused by (or that could be worsened by) effects of climate change. The challenge of the solution was also to provide an overview of the capabilities of space-based solutions for monitoring these threats regarding the properties on the UNESCO World Heritage List (WHL) in Europe. Such first exercise should then serve as a reference case for all EU heritage properties.

\subsection{Space based solution}

Case 1 presents the work based on multi-temporal change detection on the archaeological sites in order to identify (i) single episodes of extensive looting over the past few years on a case study in Middle East (Apamea in Syria) and (ii) to map the vulnerability and exposure to other man-made threats such as unplanned urbanisation (case study in North Africa, the modern town of Shahat in Libya). The tests use systematically and globally acquired imagery with consistent parameters, the spatial resolution of $10 \mathrm{~m}$ in the visible bands, and every few days (e.g. 5 days over the Mediterranean countries). Authors state that the added value of Copernicus Programme in this case regards the high temporal frequency of Sentinel-2 images i.e. every few days. This aspect has enabled scientists to improve their observation in terms of timelines of a space-based application (specifically regarding extensive looting).

On the other side, the objective of Case 2 space-based solution was to monitor monuments and sites in Europe potentially unstable due to geo-hazards, using radar interferometry (InSAR). In this example, the processed Sentinel-1 imagery allowed the scientists to identified fluvial and groundwater flooding and landslides as a major threat to one of the use-cases (The Derwent Valley Mills World Heritage Site, UK). Such procedure has identified damage possibly connected to a contemporary flooding event (i.e. a flood in Belper, UK, 2016-2017).

The cases here identify an added value of Sentinel- 1 and Sentinel-2 for both (i) man-made damages and (ii) naturally-induced hazards. In addition, Cases illustrate how Copernicus data has been useful for damage estimation of both (i) events that happen suddenly and proceed rapidly such as earthquakes, floods or even looting episodes and (ii) those events hazardous events more consistent over time (e.g. soil erosion).

\subsection{Benefits to citizens: site managers and concerned communities}

The cases of Cultural Heritage applications are not fully operational yet as the authors identify as Usage Maturity Level (UML) 3 for both applications i.e. the level of "Pilot/ Experimental tester" for which the Local Regional Authority has already used the Copernicus-based solution in one or more trials and is concretely considering its integration within its standard practices.

At the moment of issue of the publication, both applications underline the need for an improved management of Cultural Heritage monuments and sites: as stated in Case 1: "Public authorities [...] need to assess and monitor the condition of heritage at risk", while the authors of Case 2 argue than management practices need to be enhanced by "reinforcing institutional support and governance through knowledge and innovation".

Both cases propose solutions to identify, assess and monitor threats to the heritage sites in order to strengthen disaster preparedness. In particular, from operational perspective Case 1 proposes as useful a series of concrete products such as: (i) production of weekly or monthly condition reports and damage maps; (ii) rapid location areas of major concern and (iii) simulation of possible future threats.

\section{Discussion}

Cultural Heritage and Cultural Landscapes are of importance to European regions not only for their intrinsic cultural and identity values. As largely studied in relevant European research, the investment in culture has an impact on the local economy (CHCfE, 2015). In addition, a study "World Heritage and Tourism in a Changing Climate" gave an insight on the impact of climate change effects on tourism, a specific economic sector related to built environment and traditionally linked to heritage. The report states that in the period of 1979 till 2013 a specific factor identified as one negatively affecting the outstanding universal value of the property was "Management system/management plan": In Europe and North America this number accounts for a highest number of cases i.e. $58 \%$ of investigates sites (Markham, Osipova, Lafrenz Samuels, \& Caldas, 2016). These results suggest that, in case of emergency the concrete threat could be given by the hazardous event itself; in case of ordinary administration, however, the threat 
seems to be a "hazardous attitude" towards cultural assets that could lead to inadequate maintenance and thus to a risk of an improper management of Cultural Heritage sites (as discussed in Cuca, 2017).

It is worth mentioning that in both Cases 1 and 2 of the Publication the experiences refer to UNESCO World Heritage Sites (WHS) of great importance for both scientific communities as well as humanity in general. These examples could be examined as a reference for implementation of EO technologies and space-based applications in a more systematic manner also for sites and monuments widely spread across European regions that do not yet enjoy the status of "outstanding value" but are of major importance for the culture, identity and economy of local and regional realities.

\section{Conclusions}

The paper presents a brief overview of the statistical results of the publication "The Ever Growing Use of Copernicus across Europe's Regions. A selection of 99 user stories by local and regional authorities", issued in 2018. The focus of the paper is specifically an illustration and comparison of the two space-based applications that have been received on the topic "Cultural heritage, Tourism and Leisure". Although not an initial priority of the Copernicus, the domain of Cultural Heritage and archaeology has resulted as extremely interesting, thanks to the novel capabilities offered by the programme.

The Cases here illustrated identify as significant added value the fact that Sentinel data are open and available free of charge, underlining thus the importance of the FFO data policy of the programme. Also, the Cases remind the importance of significant temporal resolution of acquired data and the possibility for frequent inspections, often of high relevance when it comes to monitoring unexpected events and damages caused by either anthropologic actions or by natural phenomena.

As Copernicus Programme is achieving its operational maturity, the future regarding its capabilities to full-fill the needs of Cultural Heritage community remain to be decided. From the cases by the "Copernicus4Regions" publication it is clear that Copernicus enabled spacebased applications are already capable of modernising the public sector and providing more efficient public services. A great technological potential of illustrated solutions (and of many more present in scientific literature) could make a substantial difference if employed systematically in practice of built Cultural Heritage monitoring, management and preservation.

\section{Acknowledgements}

This paper refers to "Copernicus4Regions" initiative that is managed by the Network of European Regions Using Space Technologies (NEREUS), under a contract from the European Space Agency and funding from the European Union, in collaboration with NEREUS. The Editorial Committee of the Publication was composed by Roya Ayazi (NEREUS), Ilaria d'Auria (NEREUS), Alessandra Tassa (European Space Agency) and Julien Turpin (European Commission). The work presented by this paper is a result of the activities conducted within a contract between NEREUS Network and Politecnico di Milano.

\section{References}

Agapiou, A., \& Lysandrou, V. (2015). Remote sensing archaeology: tracking and mapping evolution in European scientific literature from 1999 to 2015. J. Archaeol. Sci. Rep. 4, 192-200. ISSN 2352-409X. http://dx.doi.org/10.1016/j.jasrep.2015.09.010.

Agapiou, A., Lysandrou, V., \& Hadjimitsis, D. G. (2020). Earth Observation Contribution to Cultural Heritage Disaster Risk Management: Case Study of Eastern Mediterranean Open Air Archaeological Monuments and Sites. Remote Sens., $12,1330$.

CHCfE Consortium. (2015). Cultural Heritage Counts for Europe. Full report. Retrieved March 15, 2021, from http://blogs.encatc.org/culturalheritagecountsforeurope/outcomes/

Bee, E., Harrison, A., Novellino, A., Crosta, G., Frattini, P., Fernandez-Merodo, J. A., Mateos, R. M., Knight, D., Leoni, G., Margottini, C., Spizzichinio, D., \& Themistocleous, K. (2018). Protection of European Cultural Heritage from Geohazards. In NEREUS/ ESA/EC “The Ever Growing use of Copernicus across Europe's Regions", pages 266267.

Copernicus. (2020). Retrieved March 15, 2021, from https://www.copernicus.eu/en

Committee of the Regions. (2020). Retrieved March 15, 2021, from https://cor.europa.eu/en

Committee of the Regions (CoR). (2015). Renewed Territorial Impact Assessment Strategy of 2015. Retrieved March 15, 2021, from https://cor.europa.eu/en/our-work/Pages/Territorial-Impact-Assessment.aspx

Copernicus services in support to Cultural Heritage. (2020). Publications Office of the European Union, 2019. Retrieved March 15, 2021, from https://www.copernicus.eu/sites/default/files/201906/Copernicus_services_in_support_to_Cultural_heritage.pdf

Council of Europe (CoE). (2000). European Landscape Convention. Retrieved March 15, 2021, from https://www.coe.int/en/web/conventions/full-list/-/conventions/treaty/176

Cuca, B. (2017). The contribution of Earth Observation technologies to monitoring strategies of Cultural Landscapes and Sites. Int. Arch. Photogramm. Remote Sens. Spatial Inf. Sci., XLII-2NW5, 135-140. https://doi.org/10.5194/isprsarchives-XLII-2-W5-135-2017, 2017. 
Cuca, B., \& Hadjimitsis, D. G. (2017). Space technology meets policy: An overview of Earth Observation sensors for monitoring of cultural landscapes within policy framework for Cultural Heritage. Journal of Archaeological Science: Reports (JASPER), 14, 727-733, ISSN: 2352-409X. https://doi.org/10.1016/j.jasrep.2017.05.001

European Commission (EC). (2020). Joint Communication to the European Parliament and the Council "European Climate Pact”. Retrieved March 15, 2021, from https://europa.eu/climate-pact/system/files/202012/20201209\%20European\%20Climate\%20Pact\%20Communication.pdf

European Commission, (EC). (2016). Joint Communication to the European Parliament and the Council "Towards an EU strategy for international cultural relations". Retrieved March 15, 2021, from https://eur-lex.europa.eu/legalcontent/EN/TXT/?uri=JOIN\%3A2016\%3A29\%3AFIN

European Parliament (EP). (2018). Regulation on establishing the space programme of the Union and the European Union Agency for the Space Programme and repealing Regulations, COM(2018) 447 final. Retrieved March 15, 2021, from https://eur-lex.europa.eu/legal-content/EN/TXT/?uri=COM\%3A2018\%3A447\%3AFIN

ESA, Sentinel Overview. (2020). Retrieved March 15, 2021, from https://sentinel.esa.int/web/sentinel/missions

ESA, Sentinel-1. (2020). Retrieved March 15, 2021, from https://sentinel.esa.int/web/sentinel/missions/sentinel-1

ESA, Sentinel-2. (2020). Retrieved March 15, 2021, from https://sentinel.esa.int/web/sentinel/missions/sentinel-2

Giardino, M. J. (2011). A history of NASA remote sensing contributions to archaeology. J. Archaeol. Sci. 38(9), 2003-2009. September 2011. ISSN 0305-4403. http://dx.doi.org/10.1016/j.jas.2010.09.017.

Lasaponara, R., \& Masini, N. (2011). Satellite remote sensing in archaeology: past, present and future perspectives. J. Archaeol. Sci. 38(9, September 2011), 1995-2002. ISSN, 0305-4403. http://dx.doi.org/10.1016/j.jas.2011.02.002.

Markham, A., Osipova, E., Lafrenz Samuels, K., \& Caldas, A. (2016). World Heritage and Tourism in a Changing Climate. United Nations Environment Programme, Nairobi, Kenya and United Nations Educational, Scientific and Cultural Organization, Paris, France.

NEREUS, European Space Agency and European Commission. (2018). "The Ever Growing use of Copernicus across Europe's Regions: a selection of 99 user stories by local and regional authorities”, 277 pages.

Tapete D., \& Cigna F. (2018). Monitoring Heritage at risk with Sentinel-2. In NEREUS/ ESA/EC "The Ever Growing use of Copernicus across Europe's Regions", 264-265. 


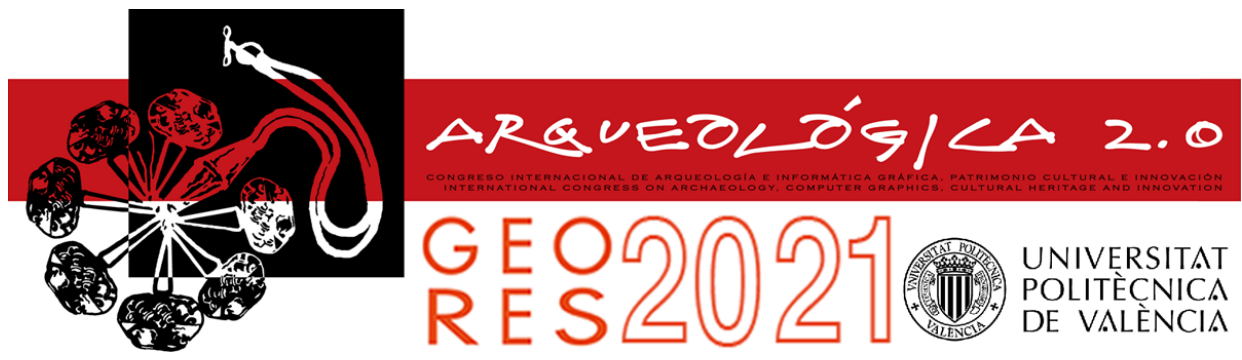

Proceedings of the joint international event $9^{\text {th }}$ ARQUEOLÓGICA

$2.0 \& 3^{\text {rd }}$ GEORES

Valencia (Spain).

26-28 April 2021

\title{
SANTA MARIA NOVA (VIA APPIA ANTICA, ROME), II - XX A.D. ARCHAEOLOGY OF ARCHITECTURE OF A LONGLIFE BUILDING
}

\author{
Luigi Oliva, Francesca Romana Paolillo, Stefano Roascio* \\ Parco Archeologico dell'Appia Antica, MiBACT, Piazza delle Finanze 1, 00185 Rome, Italy. luigi.oliva@beniculturali.it; \\ francescaromana.paolillo@beniculturali.it; stefano.roascio@beniculturali.it
}

\begin{abstract}
:
The historical complex of Santa Maria Nova, located in the heart of the Parco Archeologico dell'Appia Antica in Rome, is a real monumental "palimpsest" that has been developed from the second century A.D. until the last restorations, which have transformed it into an exhibition centre of the via Appia Antica, within an archaeological, monumental and landscape context unique in the world. The introductory paragraph summarizes the archaeological and topographical characteristics of the Santa Maria Nova complex, which was part of the Quintili villa in Roman times. It was transformed into an agricultural estate in the early Middle Ages, with a fortified farmhouse, the object of this research. Therefore, the paper illustrates the results of the stratigraphic analysis of the structures, comments on photogrammetric surveys' role in the study of complex buildings, and 3D models in communicating the results. A further paragraph is dedicated to the description of the functional transformations of the interior spaces. In conclusion, after presenting the Casale di Santa Maria Nova's current use, open problems and future research perspectives are set out.
\end{abstract}

Keywords: archaeology of architecture, cultural heritage, documentation, 3D reconstruction, stratigraphic analysis

\section{The archaeological context}

The archaeological and monumental site known from the Middle Ages as Tenuta di Santa Maria Nova (Coppi, 1855; Tomassetti, 1975; Asor Rosa \& Munzi, 2003; Frontoni, 2012; Humar, 2014; Paris, Frontoni, \& Galli, 2019), is located to the east of the ancient Via Appia, just beyond the fifth milestone, at the junction with an unnamed paved secondary street which probably reached the Via Latina (Fig. 1)

In this area, a pavilion was built during the first half of the II century A.D., belonging to the monumental Villa dei Quintili, a suburban residence owned by the two famous Quintili brothers, who together held the consulship in the year 151 A.D. (De Franceschini, 2005; Rotondi et al., 2006; Angelelli, 2016; Paris, Frontoni, \& Galli, 2019).

The enormous Villa consists of many building units occupying a large plateau, at the same altitude as the ancient Via Appia, with a spectacular view towards the Fosso Statuario and the Via Latina (Fig. 2).

The Santa Maria Nova pavilion was close to the Via Appia and independent from the other Villa buildings; the plan is organized around uncovered courtyards, surrounded by residential and service rooms. The topographical location and morphological characteristics have suggested a possible receptive function for special guests (Paris, Frontoni, \& Galli 2019). Since its construction, the complex has had dedicated thermal baths.

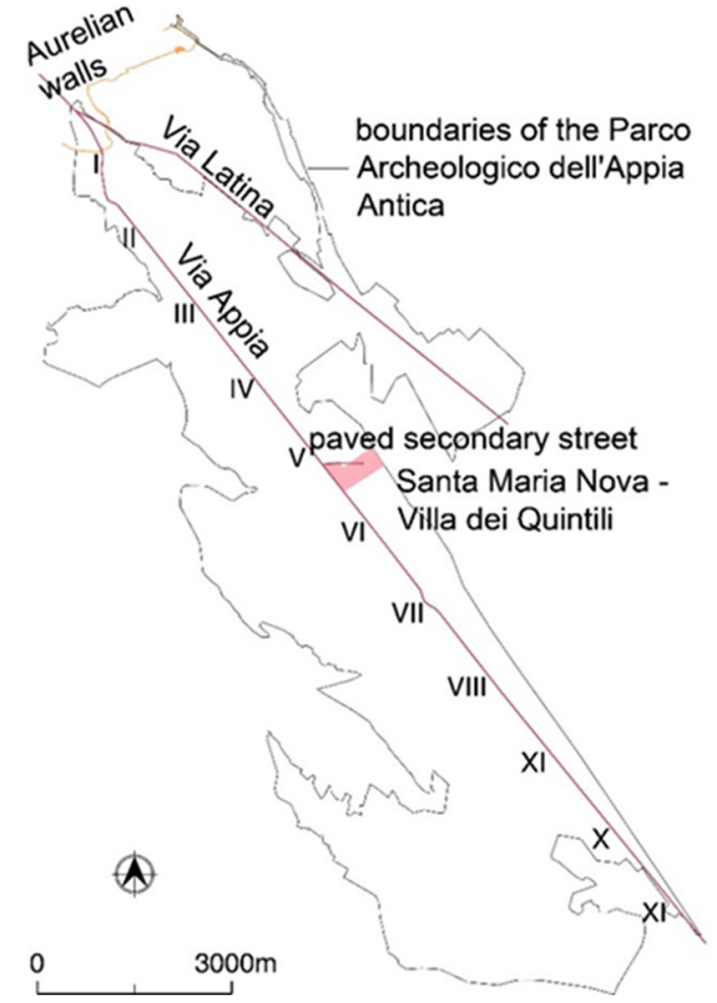

Figure 1: Position of the site in relation to the Via Appia and the boundaries of the Parco Archeologico dell'Appia Antica. 


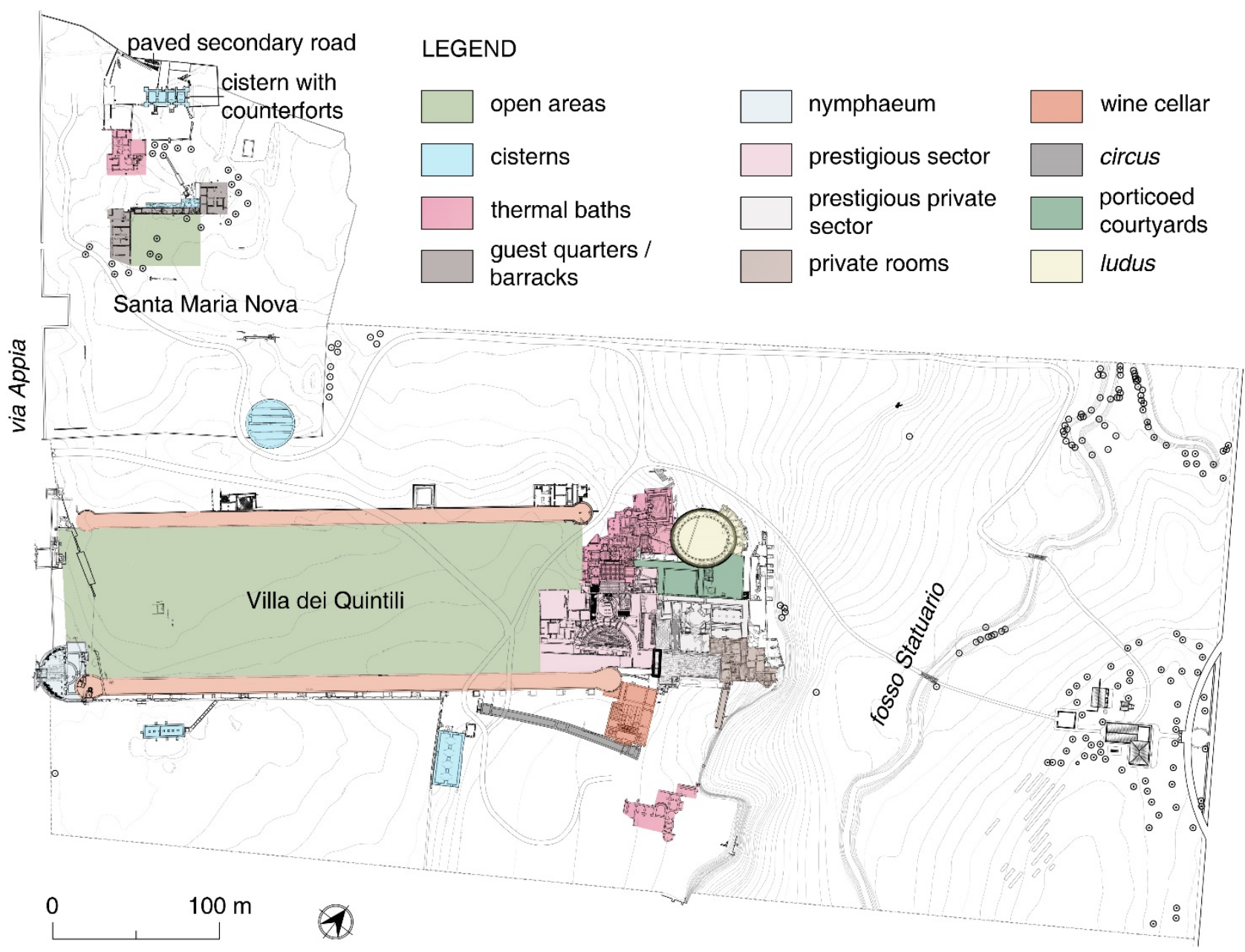

Figure 2: General plan of the site of Santa Maria Nova - Villa dei Quintili (re-elaboration from Paris, Frontoni, \& Galli 2019).

The water supply was ensured through a semiunderground cistern located in the central part of the area; perhaps, through a large circular cistern - which, due to its location and size, was to serve a large part of the building nuclei of the Villa dei Quintili - located to the southeast and at a higher altitude than Santa Maria Nova; and, at least in the design intentions, through a large rectangular cistern above ground, supported by counterforts, which will provide a basis for the Casale (Fig. 3), the main building of the medieval farming estate.

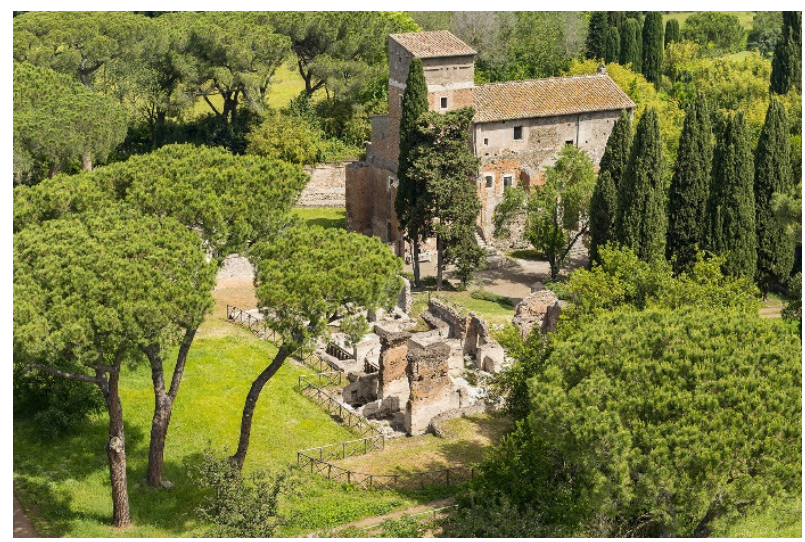

Figure 3: General view of the Casale di Santa Maria Nova and the II century A.D. thermal bath (S. Castellani).
The sudden entry of the property into the imperial estate, the day after the killing of the Quintili brothers by the will of Emperor Commodus, occurred in 182/183 AD, determines new and different needs. The pavilion of Santa Maria Nova, placed in a strategic point for the control of the viability system, was probably converted to accommodate the imperial guard (Paris, Frontoni, \& Galli 2019).

The new use of the complex determines a significant functional reconsideration of the sizeable rectangular cistern with counterforts, which was probably still under construction at the time of the change of ownership, as the absence of any cocciopesto suggests. The structure, close to the Via Appia diverticulum, is probably reconverted for the use of the Pretorian guards.

The medieval history of the complex sees the transformation of the imperial villa into an agricultural and productive estate, with its typical elements (the farmhouse with tower and cloisters, the redimen: Del Lungo, 2004), acquired at the end of the fourteenth century by the Benedictine Congregation of Santa Maria di Monte Oliveto, which will keep it for over five centuries until the liquidation of the Church's land properties, which took place in 1873. After that, the complex remained in private ownership until 2006, when the Italian state bought it. 


\section{3D model and masonry stratigraphic analysis}

The Casale di Santa Maria Nova is the first extremely complex building in the Parco Archeologico dell'Appia Antica to have been subjected to a systematic stratigraphic analysis of the masonry, which, however, has followed the restoration activity, ended in 2018.

Up to that point, in fact, the whole area had been investigated through a documentary study, with the examination of the available cartographic and iconographic sources. The stratigraphic analysis of the numerous construction phases of the building, the complexity of which scholars reported (De Rossi, 1969; Tomassetti, 1975), had yet to be addressed in detail.

Before starting the restoration works, ortho-photographic surveys were made of all the external elevations (Figs. 4 \& 5), characterized by a remarkably high degree of precision and resolution. In fact, the use of digital photogrammetry makes it possible to conduct the process of knowledge optimizing working times and maximizing results (Frigieri, \& Gasparri, 2019).

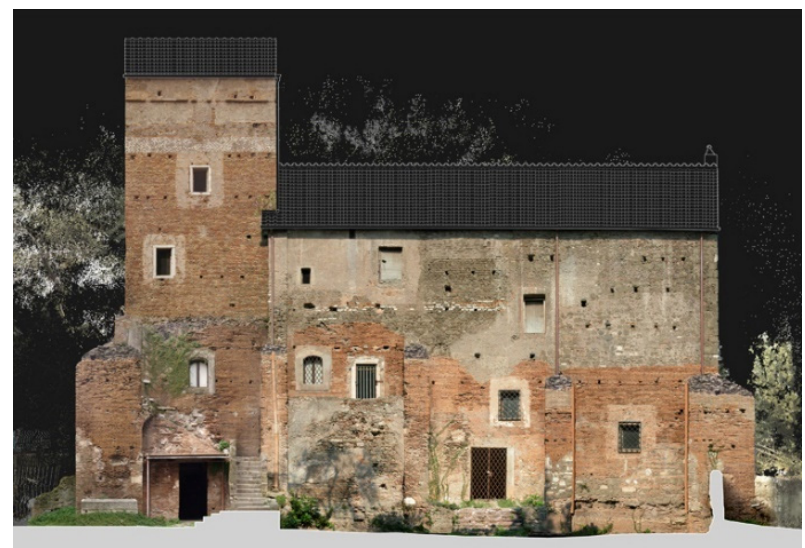

Figure 4: Orthoimage of the southern façade (M. Cola).

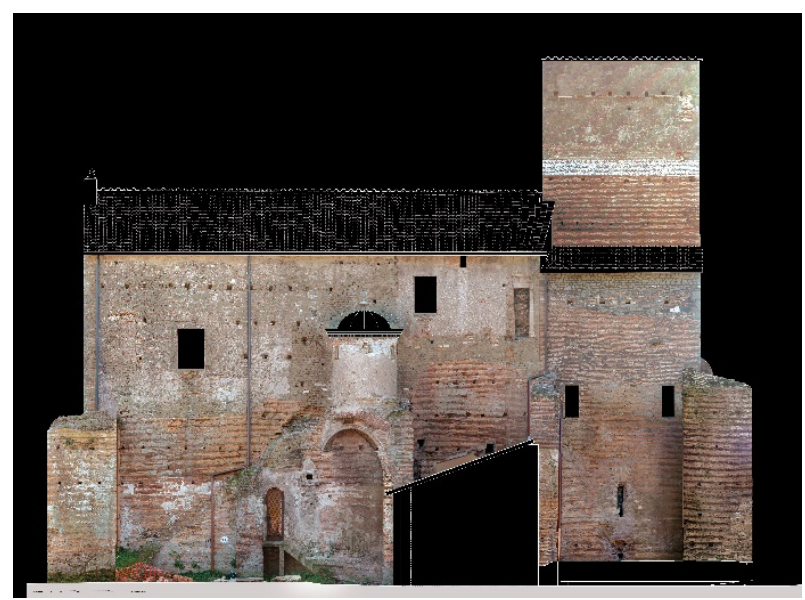

Figure 5: Orthoimage of the northern façade (M. Cola).

The availability of images that are highly faithful to reality, manageable, and measurable remotely in the CAD environment, was, in this case, crucial for performing the ex-post stratigraphic reading of the structures and the analysis of the constituent materials. Being able to control the images as a whole from a personal computer can also allow us to grasp, on the walls, characteristics, and phenomena that are difficult to understand with the naked eye. All the more so for the fact that it is a monumental structure with high elevations that extend up to almost 20 meters from the country level. For this reason, it is essential to assist the autoptic analysis with the use of orthophotographic surveys, which are faster and considerably more precise than hand-operated drawings, without, however, going beyond the direct approach that must necessarily characterize the phase of knowledge of the ancient structures.

A crucial perspective for the monument in question is the repetition of ortho-photographic surveys over time to monitor the variations in degradation over the years, using photogrammetry as a pre-diagnosis tool on the building's state of health and as a form of non-destructive investigation, suitable for orienting conservative strategies (Genin, 2019).

The stratigraphic analysis of the structures was conducted with the methodologies and the diacritical and descriptive marks of the stratigraphic relations established in the discipline manuals (already in Boato (2008) and further refined in Brogiolo, \& Cagnana, 2012).

It was decided to use the prints of the ortho-photographic images of the walls as a basis for the field survey, which helped to have realistic representations of the Masonry Stratigraphic Units' surface.

This choice allows immediate recognition between what was examined in the field, observing the monument, and identifying the edges of the various Masonry Stratigraphic Units and their relative stratigraphic relations, and the reading's transposition on the survey (Brandt, 2020). For the higher portions of the monument, hardly visible from the ground, the photogrammetric surveys' onscreen enlargements were beneficial. They are essential for defining the wall covering stratigraphic units' surface refinement and the so-called Post-Depositional Units (Brogiolo, \& Cagnana, 2012). For this last aspect, examining the historical photos helped to date to a sub contemporary era the actions of lowering the ground level on the southern side of the structure, which led to a change in the layout of the entrances, with the addition of stairs, that would have been difficult to understand otherwise.

The analysis of the stratigraphic relations between the Masonry Stratigraphic Units led to the structural construction sequences, transposed with the standard diacritical marks on the relief for the Units' physical connections and a stratigraphic matrix.

The absolute chronology for the various phases is mainly based on the construction techniques typical of the different periods and, for the Roman age, on brick stamps from the Hadrian period. It remains to better define the period from late antiquity to the early Middle Ages, for which absolute archaeometric analyzes will be appropriate (infra).

The results are summarized below.

Roman age: the first configuration of the building seems to belong to a massive above-ground rectangular-shaped cistern. The building has multiple chambers on at least two overlapping floors and is supported by strong counterforts to counteract the water pressure. The external dimensions on plan are $27 \times 12 \mathrm{~m}$; the internal dimensions are $21,92 \times 6,44 \mathrm{~m}$. The containing chambers 
are 4,08 to $4,90 \mathrm{~m}$ high. The masonry is in opus latericium, with overall good workmanship, made with bricks from the same furnace, put in place in an extremely regular manner (average brick sizes $28 \times 3.5 \mathrm{~cm}$, height of the mortar joints $1.9 \mathrm{~cm}$ ), which dates the phase to the Hadrian or post Hadrian age. Some brick stamps dating back to the consulship of Apronianus and Paetinus (123 A.D.) provide the construction of a terminus post quem. An embrasure placed on the north-western wall, certainly belonging to the first construction stage, seems incompatible with the water containment function. The cistern's original function must have been subjected to an ongoing rethinking in favor of military use. The embrasure appears to be connected to the secondary street perpendicular to the via Appia, found by archaeological excavations about 12 meters from the Casale.

Late antiquity: the military function that can be identified in the original foundation seems to be confirmed during the late antiquity, when a squat rectangular tower $(6 \times 5$ meters) is installed on the imperial structures, once again on the north-western vertex, to control the road axles. The masonry, once again in opus latericium, is in this phase made up of reused material. The attention in putting the bricks in place indicates that the workers were probably still referring to the late Roman culture and construction practice (Spera dates the tower to the IV - V century A.D.; Spera, 2019); although a date to the period of the greekgothic war cannot be excluded (VI century A.D.; Humar, 2014). Because of the lack of precisely dating architectural elements, radiocarbon analysis of the mortar clumps is in progress for precise chronological attribution.

Middle Ages: probably during the thirteenth century, the structure undergoes extensive transformations. The building is raised and equipped with a redimen, an enclosure typical of the medieval country houses (Carocci, \& Vendittelli, 2004). The masonry is made with small tufa blocks, laid on regular horizontal courses (average height $8 \mathrm{~cm}$ ). This technique spread between the twelfth and fourteenth centuries and testifies to a strong standardization of the construction yards and the workers' skills.

The white and red checkerboard decoration of the walls of the tower's main room (Fig. 6), belonging to this stage, could have been inspired by the coat of arms of the Sanguigni family, who owned the building until the second half of the fourteenth century.

Modern age: probably between the fifteenth and sixteenth centuries, the structure, now a farmhouse belonging to the Olivetan Monks, undergoes further transformations that consist of the elevation of the tower and the enlargement of the building. The enclosed area of the estate is enlarged at the same time. This construction phase presents the typical "bricklayer masonry", characterized by the laying of heterogeneous stone material and fragments of inhomogeneous bricks, as the irregularity of the wall is partially covered by plaster (Brogiolo, \& Cagnana, 2012).

Sub-contemporary age: between the nineteenth and the first half of the twelfth century, the building underwent further interventions to transform it into a prestigious residence. The external ground level is heavily lowered, and the entrances to the building are modified simultaneously. In this phase, the restoration walls are embellished with various marble and ceramic inserts, according to the antiquarian taste of this period.

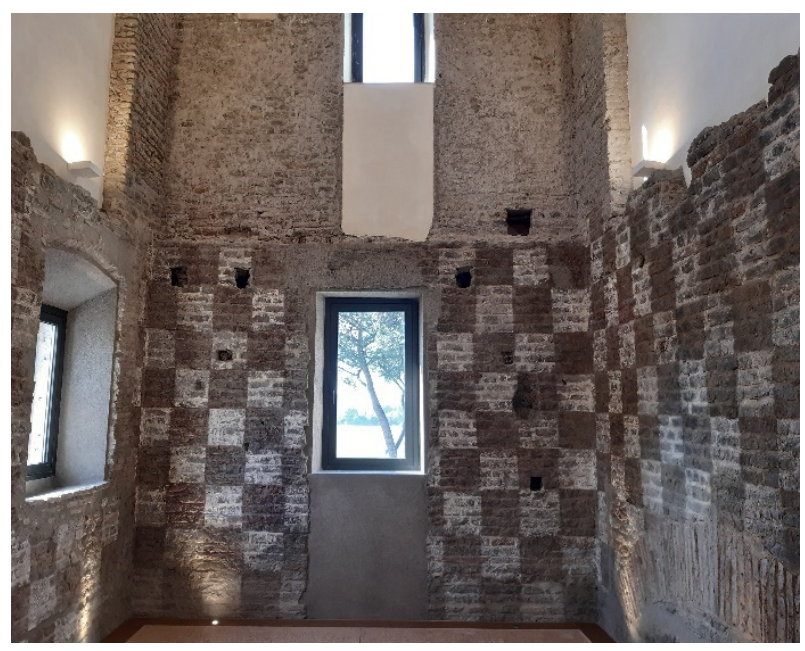

Figure 6: The white and red checkerboard decoration in the main room of the tower.

After the stratigraphic analysis of all the walls, the data was transposed onto a 3D model (Figs. $7 \& 8$ ) based on the structures' photogrammetric surveys mounted on the building plan.

Therefore, the three-dimensional modeling has made it possible to display the various construction phases in a clear and intelligible way, treated with differentiated colors.

The surfaces' characterization was made on a schematic relief, extrapolated from the photogrammetries, to avoid the overlapping of photographic images and colors and information redundancy in the restitution phase.

The transposition of the stratigraphic analysis on a 3D model does not only constitute a persuasive communication, effective and suitable for the general public concerning the analytical readings that underlie it (Gabellone, 2020). It also implements a contribution from the point of from a scientific point of view. It constitutes an overcoming of the only two-dimensional approach in the analysis of architectures. It provides proper support for the analysis not only of the surfaces but also of the volumes inside the buildings, their specific uses, and in general, the spatial relationships of the buildings (Cardaci, Gallina, \& Versaci, 2013; Brandt, 2012).

Today the $3 D$ survey and the relative reading of the construction phases constitute a part of the multimedia educational preparation of Santa Maria Nova, dedicated to the same monument and the surrounding area.

A video is also available on the youtube channel of the Parco Archeologico dell'Appia Antica (https://www.youtube.com/watch?reload=9\&v=SF2rO 7 wbQ4). 


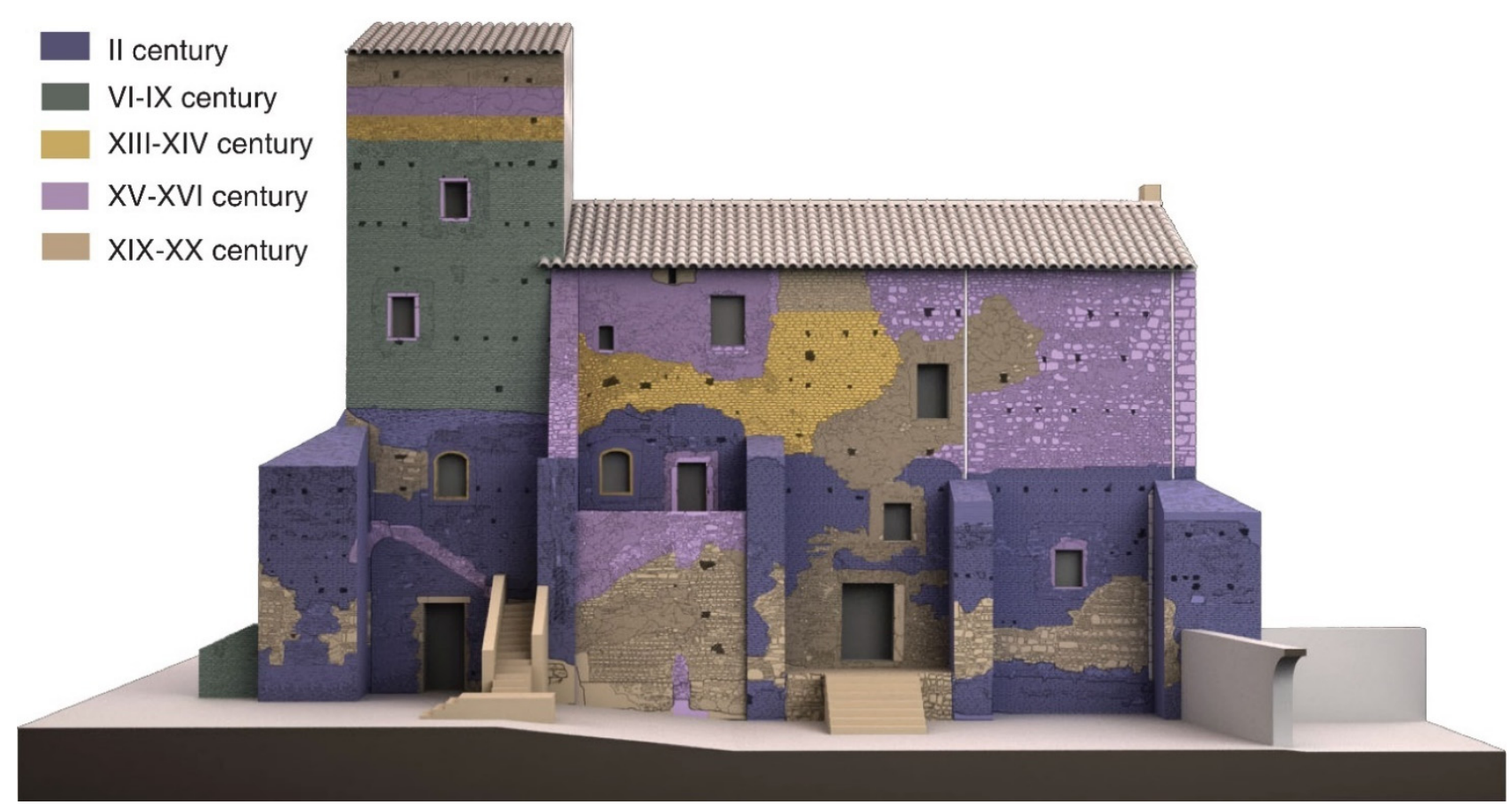

Figure 7: Stratigraphic analysis of the masonry on the 3D model of the Casale di Santa Maria Nova, southern façade.

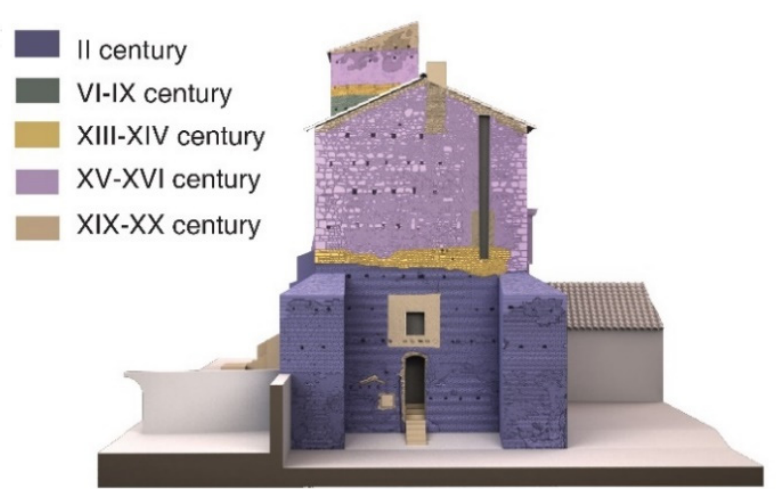

Figure 8: Stratigraphic analysis of the masonry of the Casale di Santa Maria Nova, eastern façade. The narrow and elongated vertical window on the building's upper floor is one of the recognizable interventions of architect Luigi Moretti.

\section{Spatial and functional transformations}

Soon after its construction, since the $2^{\text {nd }}$ century $A D$, the imposing building reinforced with buttresses built as a parallel chambers cistern has been adapted to serve as hospitium for the imperial garrison (Paris, Frontoni, \& Galli, 2019). The evidence of this transformation is visible in the shooting slit that opens on the north-west front of the southern chamber and, probably, in the trace of the external staircase on the same front of the northern chambers. The roman layout influenced the early medieval reconfiguration, in which the south-west front facing the Appian Way got strengthened with the construction of the tower and an adjacent room (Fig. 9).

Since the late Middle Ages, new portions of masonry have been added above the remaining rooms of the original cistern. The upper rooms were probably still accessible via the external staircase which was still in use. The construction of the walled enclosure (redimen) on the northern side also dates back to this period. The distribution system was conceived to give access to upper floors from a protected area, separating the accesses to the various levels for safety reasons. The aforementioned red and white checkered dealbatio, which can be admired in the second level of the tower, also belongs to the same period (Paris, Frontoni, \& Galli, 2019). If, on the one hand, this pictorial decoration is attested for several centuries in religious buildings, on the other hand, it recalls a peculiar element of the late medieval castle and court contexts. Its presence allows identifying the master's rooms, perched above the Roman remains.

Since the early modern age, the building has been further raised, introducing new elements that affect its external appearance. An additional level raises the tower, connected with the ones below by a lost internal wooden staircase. The northern room on the first level was probably of considerable size and internal height, as it seems to be attested by both the absence of windows on the upper parts and traces of intermediate floors. Such a volume could have been used to keep products or other goods protected from looting or natural agents of degradation. This hypothesis is confirmed by the absence of a fireplace in this construction phase. There is a small semicircular niche on the north-west side of this room, protruding from the front and resting on the landing of the disused ancient staircase (Fig. 5). Its location at the wall of the renclaustrum; the arrangement of the splayed windows, inadequate to illuminate even such a small space and in contrast with any decorative elements; the absence of traces of furnishings or interior decorations, are all evidences that suggest its original use as a sentry box, placed to guard the north-western front.

The battlements represented in the engraving by Labruzzi dating to the late Eighteenth century (Ustrinum right corner of the Via Appia, Vat. Lat. 14930/55 / I), are probably of the same fortification program of the farmhouse, from a functional or symbolic point of view (Esposito, 2005; Cosenza, 2017). 
The main building does not seem to undergo major transformations in the Nineteenth century if we exclude the construction of the external bodies intended for stables and storage.

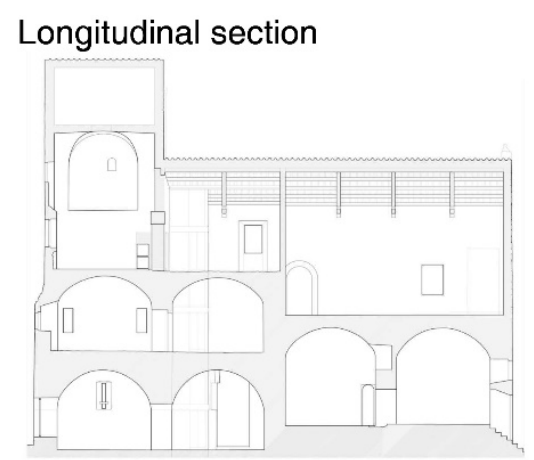

Ground floor plan
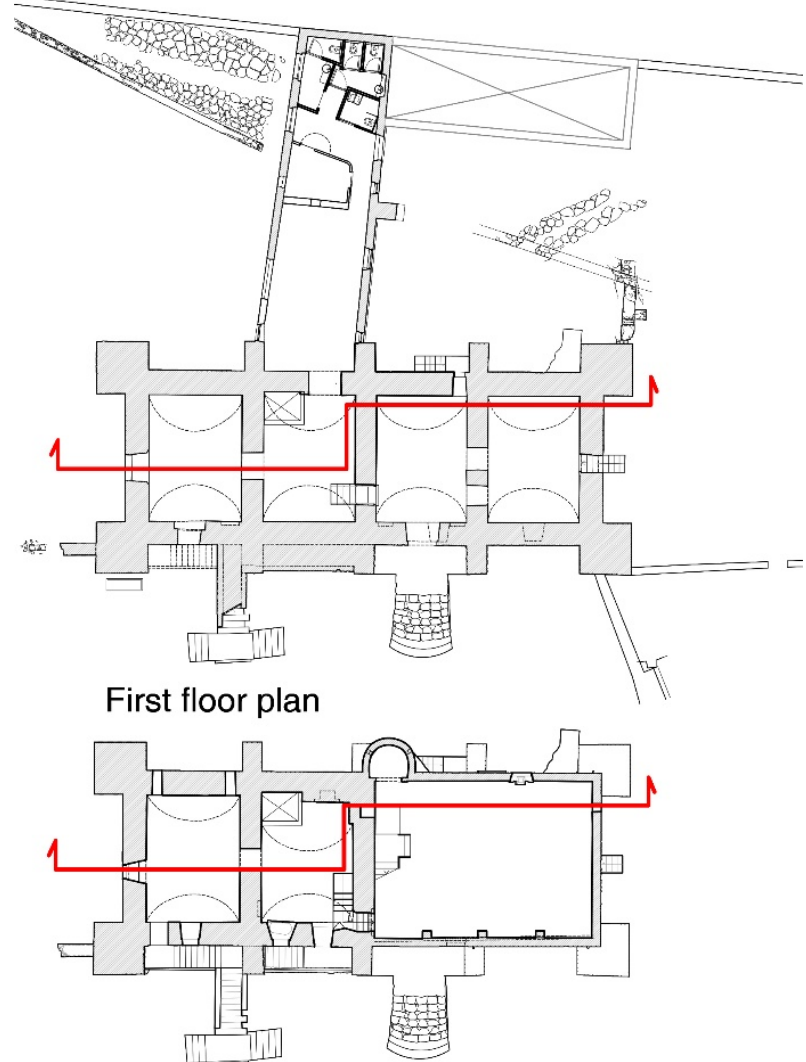

Second floor plan

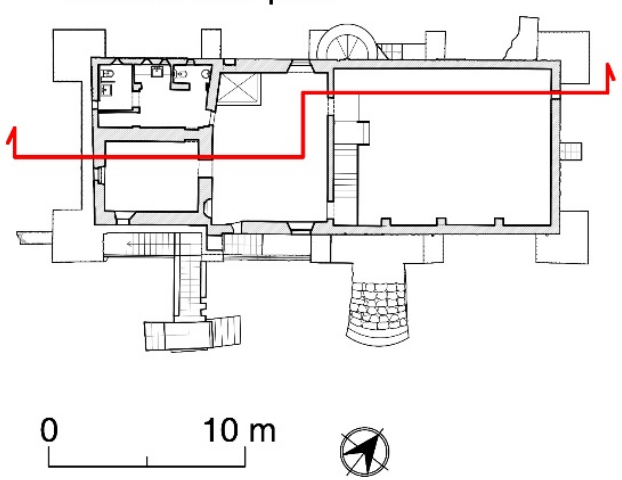

Figure 9: Architectural drawings of the Casale di Santa Maria Nova.
During the last restoration, almost all the contemporary superfetations have been removed, many of which were introduced in the 1950s by the famous architect Luigi Moretti (Fig. 8) in order to adapt the building to a luxurious residence. The results of this subtractive process, together with the defunctionalization of the spaces aimed at the new museum use, highlighted both the discontinuity between the different levels and the disconnection between the internal environments in distributive and chronological terms.

\section{The current phase of the life of the Casale di Santa Maria Nova}

Having outlined the many phases of life of the Casale di Santa Maria Nova - a monumental water cistern in the initial design intentions, a defensive structure for the Emperor's property in the imperial age and for the agricultural estate in the early Middle Ages, a fortified farmhouse in the late Middle Ages and in the modern age, and a private residence surrounded by splendid grounds in the sub-contemporary age - it remains to mention the current function of the building, which, after the restoration and the complete re-functionalization, welcomes visitors to the Parco Archeologico dell'Appia Antica with an educational section dedicated to the history of the monumental complex and its territory, and continuously hosts temporary exhibitions (Figs. 10, \& 11).

So today, the monument is not only a prestigious container for valorization activities but is also a permanent exhibition of its multi-layered building phases.

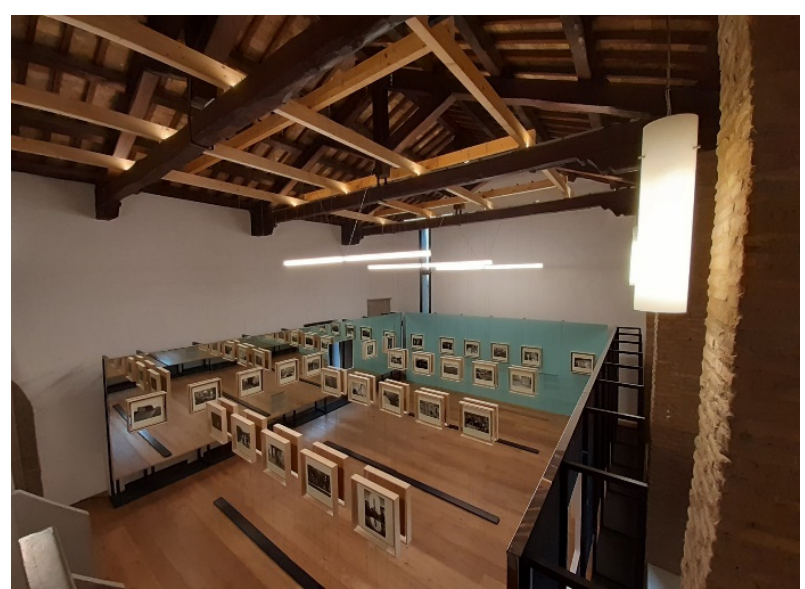

Figure 10: View of the hall on the first floor of the Casale di Santa Maria Nova, during the exhibition "Gianni Berengo Gardin. Roma"

\section{Conclusions}

The study on Santa Maria Nova helped integrate literary and iconographic sources data with information from the material traces displayed in the constructive stratigraphy.

The careful approach to the material data in its diachronic development has allowed us to recognize significant factors for understanding the monument and its use over the centuries. For example, a deep embrasure was identified on the Roman cistern, indeed in phase with the first construction, which does not seem compatible with water containment. Moreover, it appears to have been created concerning the control of a nearby road diverticulum perpendicular to the Appia. 
The reading of the archaeological evidence combined with the written and iconographic sources has also offered some actual results for the post-classical phases. The red and white checkered decoration in one room of the tower has been traced back to the heraldic coat of arms of the Sanguigni, who were owners of the farmhouse until the second half of the fourteenth century (Coppi, 1855).

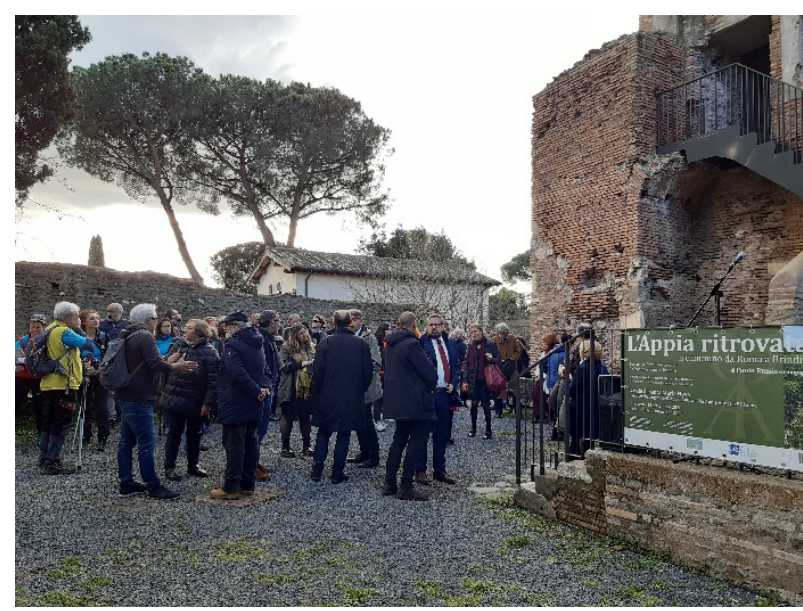

Figure 11: View of the area outside the Casale di Santa Maria Nova, during the opening of the exhibition "L'Appia Ritrovata".

On the other hand, we found no clear traces of the late medieval fortified aspect, with a tower and sloping roof surrounded by battlements represented by Carlo Labruzzi, which was remarkably faithful in describing the state of the places.

This fact highlights the essential need to integrate and combine the available data, with particular regard to historical iconography, to understand a complex monument.

It is also clear that the iconographic sources have to go through careful critical evaluation. For example, the representation of the building made by Piranesi (Fig. 12) seems to tend towards a hypothetical reconstruction of the Roman cistern and fails to document the evidence of the Casale, which certainly already existed at the time he drew up the image.

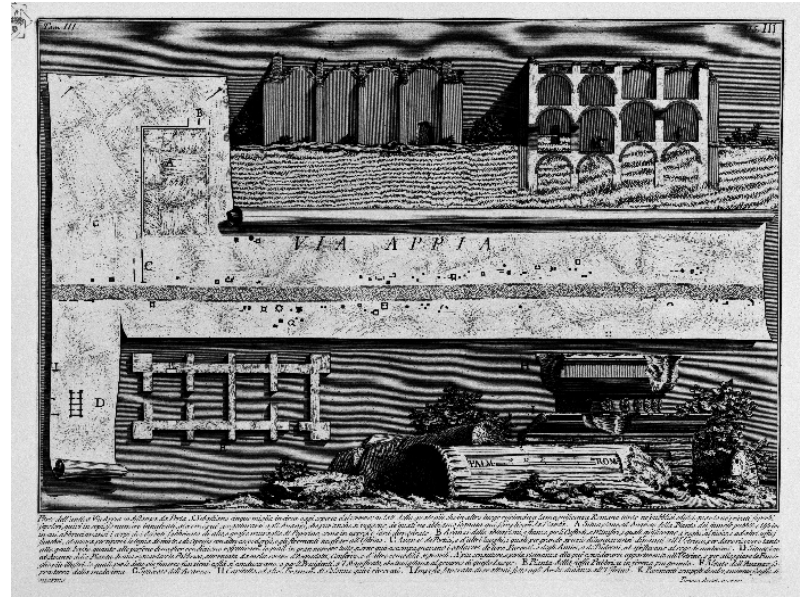

Figure 12: The roman structures of the Casale di Santa Maria Nova (Giovanni Battista Piranesi. Le antichità romane, Roma, 1784 , vol. III, tav. III).

The study has also made it evident that in many cases, it is not possible to disregard radiocarbon analyzes on the lime lumps of the mortar to define the absolute chronology of some building phases (Vecchiattini, 2019). This is, in particular, the case of the first installation of the tower, for which, at the moment, only the relative stratigraphic sequence is available, between the phase of the II and that of the XIII century AD.

A building such as the Casale di Santa Maria Nova, an excellent testimony of the historical stratification, undoubtedly deserves the continuation of a scientific path to increase and disseminate knowledge, starting from the material data and investigating the many possibilities that new technologies applied to cultural heritage offer us: from virtual restoration (Gabellone, 2020), with the threedimensional reconstructions of the possible appearance of the monument in the various phases identified, to virtual archaeology, with the reconstructions of the extraordinary multi-layered landscape contexts and environments in which the monument has developed and changed throughout history.

We intend to explore these paths in the future, enhancing the information potential of an extraordinary monument.

\section{References}

Angelelli, C. (2016). Le ville del suburbio di Roma tra età repubblicana e tarda antichità: integrazioni e aggiornamenti attraverso l'analisi dei contesti pavimentali. Amoenitas, 5, 9-153.

Asor Rosa, L., \& Munzi, M. (2003). Villa dei Quintili, In Le Pera Buranelli, S., \& Turchetti, R. (Eds.), Sulla Via Appia da Roma a Brindisi: le fotografie di Thomas Ashby: 1891-1925 (pp. 56-74). Roma: "L’Erma" di Bretshneider.

Boato, A. (2008). L'archeologia in architettura. Misurazioni, stratigrafie, datazioni, restauro. Venezia: Marsilio Editori.

Brandt, O. (2012). Battisteri oltre la pianta. Gli alzati di nove battisteri paleocristiani in Italia. Città del Vaticano: Pontificio istituto di archeologia cristiana.

Brandt, O. (2020). Archeologia del costruito. In Castiglia G., Pergola Ph. (Eds.), Instrumentum domesticum. Archeologia cristiana, temi, mtodologie e cultura materiale della tarda antichità e dell'alto medioevo: Vol. 1 (pp. 345-364). Città del Vaticano: Pontificio Istituto di archeologia cristiana, 2020.

Brogiolo, G. P., \& Cagnana, A. (2012). Archeologia dell'architettura. Metodi e interpretazioni. Firenze: All'Insegna del Giglio.

Cardaci, A., Gallina, D., \& Versaci, A. (2013). Laser scanner 3D per lo studio e la catalogazione dell'archeologia medievale: la chiesa di Santa Croce in Bergamo. Archeologia e Calcolatori, 24, 209-229. 
Carocci, S., \& Vendittelli, M. (2004). L'origine della Campagna Romana. Casali, castelli e villaggi nel XII e XIII secolo. Roma: Società Romana Storia Patria, Miscellanea.

Coppi, A. (1855). Memorie relative ad alcune tenute dell'agro romano adiacenti alla Via Appia. Dissertazioni della Pontificia Accademia romana di Archeologia, 23, 443-450.

Cosenza, F. (2017). II sistema dei casali della campagna romana: problemi e metodologia d'indagine. In III Ciclo di Studi Medievali, Atti del Convegno, Firenze, 8-10 settembre 2017 (pp. 189-203). Monza: EBS Print.

De Franceschini, M. (2005). Ville dell'agro romano. Roma: “L’Erma” di Bretshneider.

De Rossi, G. B. (1969). Torri e castelli medievali della campagna romana. Roma: De Luca.

Del Lungo, S. (2004). Ricognizioni topografiche ed archeologiche nella campagna romana. Archeologia Medievale, 31 , 21-51.

Esposito, D. (2005). Architettura e costruzione dei casali della campagna romana fra XII e XIV secolo. Roma, Società Romana Storia Patria, Miscellanea.

Frigieri, C., \& Gasparri, P. (2019). La conoscenza del patrimonio culturale attraverso l'uso della tecnologia:obiettivi e metodologie. In P. Fiore, E. D'Andra (Eds.), I centri minori.. da problema a risorsa - Small towns... from problem to resource (pp. 317-326). Milano: Franco Angeli, 2019.

Frontoni, R., \& Lugari, A. (2009). Nuovi mosaici con scene di spettacolo da un edificio termale sull'Appia Antica in località S. Maria Nova, Villa dei Quintili (Roma). In Atti del XIV Colloquio dell'Associazione Italiana per lo Studio e la Conservazione del Mosaico, Spoleto 2008 (pp. 603-615). Tivoli: Scripta Manent Edizioni

Frontoni, R. (2012). Santa Maria Nova. Forma Urbis, 2, 45-46.

Gabellone, F. (2020). Archeologia Virtuale. Teoria, tecniche e casi di studio (2nd ed.). Bari: Edizioni Grifo.

Genin, S. M. (2019). Photogrammetry: methods of survey and applications on restoration works. Int. Arch. Photogramm. Remote Sens. Spatial Inf. Sci., XLII-2N11 (pp. 557-564). https://doi.org/10.5194/isprs-archives-XLII-2-W11-5572019, 2019

Humar, M. (2014). La tenuta di Santa Maria Nova amplia il patrimonio archeologico dell'Appia Antica. Vespertilla, 11, 5, 66-80.

Paris, R., Frontoni, R., \& Galli, G. (2019). Via Appia. Villa dei Quintili. Santa Maria Nova. Milano: Electa.

Rotondi, A., Pettinau, B., Bevilacqua, G., Frontoni, R., Galli, G., \& Lalli, C. (2006). Quintiliorum praedium, In Lexicon Topographicum Urbis Romae: Vol. 4 (pp. 279-294). Roma: Quasar.

Spera, L. (2019). Roma, il suburbio e gli imperatori nel V secolo. Archeologia di un ritorno. Archeologia Classica, 70, 455498.

Tomassetti, G. (1975). La campagna romana antica, medioevale e moderna. Nuova edizione aggiornata a cura di Chiumenti, L., e Bilancia, F., 2, via Appia, Ardeatina e Aurelia, Roma: Banco di Roma.

Vecchiattini, R. (2019). L'applicazione del metodo di datazione del radiocarbonio alle malte della fortificazione. In De Meglio P. (ed.), Un paesaggio medievale tra Piemonte e Liguria. II sito di Santa Giulitta e l'Alta Val Tanaro, (pp. 85-94). Firenze: All'Insegna del Giglio. 


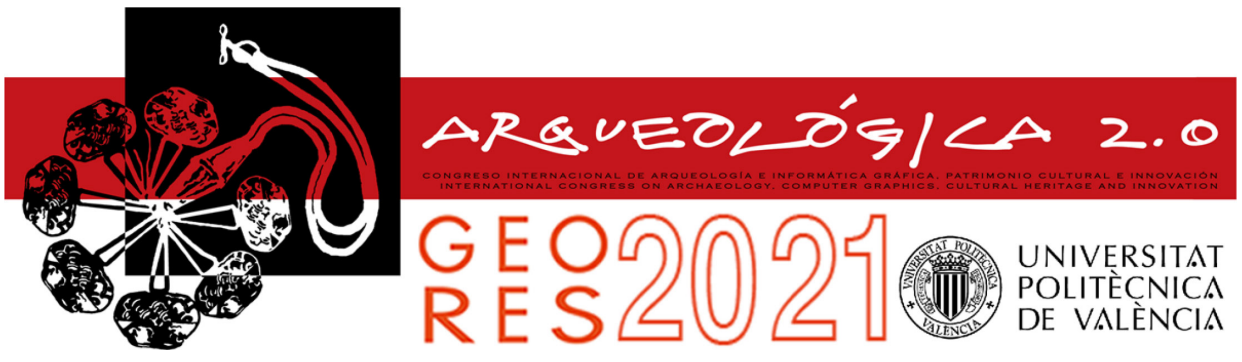

Proceedings of the joint international event $9^{\text {th }}$ ARQUEOLÓGICA $2.0 \& 3^{\text {rd }}$ GEORES, Valencia (Spain). 26-28 April 2021

\section{Works in progress}




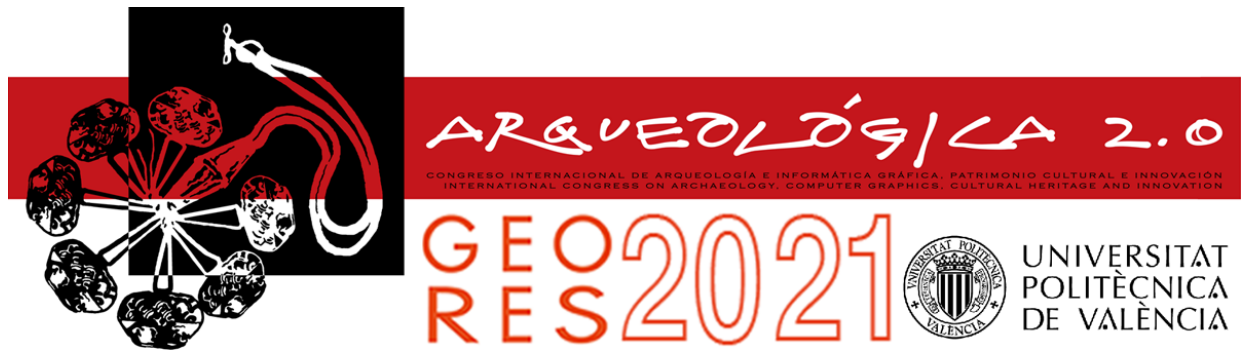

\title{
DOCUMENT MANAGEMENT FOR ARCHITECTURAL HERITAGE RESTORATION AND ITS APPLICATION IN THE MONASTERY OF SAN MILLÁN DE LA COGOLLA (LA RIOJA)
}

\author{
Jaione Korro a, ${ }^{\star}$, Pilar Acosta ${ }^{b}$, Francisco Pintoc, José Manuel Vallea ${ }^{a}$ Ainara Zornoza-Indart ${ }^{\mathrm{d}}$ \\ a Laboratorio de Documentación Geométrica del Patrimonio, University of the Basque Country (UPV/EHU), C/ Justo Vélez de Elorriaga \\ 1 (Edificio Micaela Portilla, 2.01), 01006 Vitoria-Gasteiz, Spain. mirenjaione.korro@ehu.eus; jm.valle@ehu.eus \\ ${ }^{b}$ Instituto Andaluz de Patrimonio Histórico (IAPH), Av. Camino de los Descubrimientos s/n (Monasterio de la Cartuja), 41092 Sevilla, \\ Spain. pilar.acosta@juntadeandalucia.es \\ c Institute of Architecture and Building Science (IUACC), University of Seville, Av. Reina Mercedes, 2, 41012 Seville, Spain. fspp@us.es \\ d Department of Painting, Faculty of Fine Arts, University of the Basque Country (UPV/EHU), Leioa, Spain. ainara.zornoza@ehu.eus
}

\begin{abstract}
:
The presented work is part of a PhD project aimed at the development of a methodological proposal on the generation, preservation and use of the documentation concerning the restoration event. During the research, various work systems and strategies carried out in cultural institutions and research institutes are being analysed, with emphasis on the conceptual aspect; in particular, the present text analyses the procedures implemented in the Andalusian Institute of Historical Heritage (IAPH), the results that are being obtained and the degrees of compliance and satisfaction regarding the information on architectural heritage restoration. Furthermore, developments from other fields - such as the databases linked to 3D models (HBIM), technological and regulatory contexts concerning "open data", criteria for semantic description and so on- will be also explored and included; as well as some aspects related to the normalization and standardization of information on restoration processes - to which they will provide greater accessibility, traceability and completeness. All this knowledge and ways of work will be applied to a case study: the monastery of San Millán de la Cogolla in La Rioja (Spain)
\end{abstract}

Keywords: documentation, restoration, architectural heritage, HBIM, archives

\section{Introduction}

Many works have stressed the interest -as well as the complexity - of documenting and preserving heritage also digitally (e.g. Remondino \& Rizzi, 2010). This awareness not only covers the creation of digital information regarding the processes involved in heritage interventions, but also its recovery, preservation, and maintenance (Acosta, 2019).

Historical buildings require the discipline of Restoration to slow down damage and increase durability; in addition, information is essential to understand the heritage item, to make correct diagnoses and to mandate suitable interventions, with the ultimate aim of achieving the pursued conservation. Presently, cultural heritage elements are no longer considered as static but in permanent evolution; therefore, restorations cannot be seen as simply actions that - to a greater or lesser degree- "affect" these assets, they have to be integrated into the history of the monuments and become part of their nature, as well as part of the scientific basis that will support the intervention actions. However, restoration has historically been a poorly documented discipline (Culubret, Dávila, Moreno, \& Pérez, 2016) and this lack of information has led to significant inefficiencies in several architectural interventions. Nevertheless, there is a growing concern on the preservation of the documents about interventions and their accessibility to the public (Acosta \& Alanís, 2019); as for example the Andalusian Institute of Historical Heritage (IAPH), that has begun to collect, classify and offer access to its heritage datasets through a network of open institutional repositories (IAPH, 2016; García, 2018).

Conservation implies manifold operations: upkeep of the environmental context, in situ treatments prevention, safeguarding and maintenance through preventive conservation. It can be established that conservation and preservation are inseparable notions, just as restoration is linked to -and preceded by-conservation (Macarrón, Calvo, \& Gil, 2019). For that reason professionals dealing with interventions in cultural heritage have been interested in innovative tools for managing and visualizing the associate information and, thus, tools such as the HBIM have worked their way into the field of conservation 
and restoration of heritage (Jordan-Palomar, Tzortzopoulos, García-Valldecabres, \& Pellicer, 2018; Bruno \& Roncella, 2019; Trizio, Savini, Giannangeli, Boccabella, \& Petrucci, 2019), including some pioneering initiatives to apply the HBIM to preventive conservation (Oreni, Brumana, Georgopoulos, \& Cuca, 2013; Angulo, Castellano, \& Pinto, 2019).

From this starting point, this study wants to deepen in this relationship between the information management and the restoration action itself, since it is a key point for the correct development of the Intervention projects and, consequently, the objective is to evaluate whether an interoperable information system (accessible to companies, professionals and public institutions) may substantially improve the selection of the best courses of action.

\section{Objectives}

The aim pursued in this work is to merge the strategies followed by a reference centre for the collection and management of the cultural heritage information (in particular, the aforementioned IAPH) and integrate them with the technical possibilities provided by the HBIM systems, using for its implementation the case study of the monastery of San Millán de la Cogolla (UNESCO World Heritage site) (Fig. 1). Due to the large size of the monastery, the application will be focused on an area selected by its appropriate features, in particular the cloister of this monument. This cloister was built on successive occasions during the $16^{\text {th }}$ century, with the result of a combination of different styles and is located in the south of the church and has a quadrangular floor plan with slightly uneven sides of around 38 metres long.

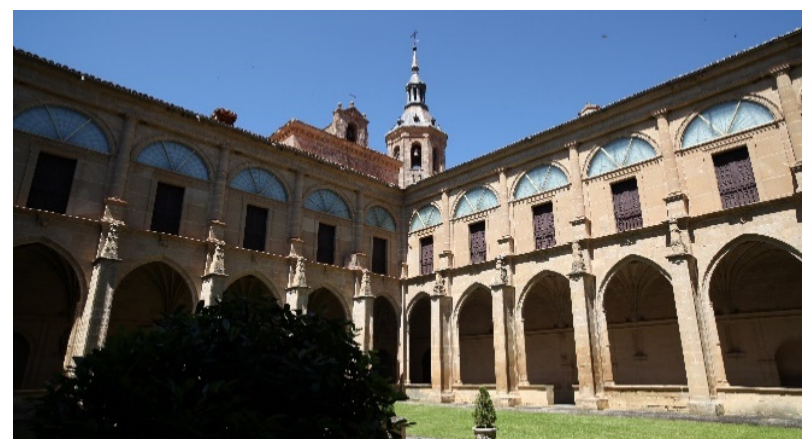

Figure 1: View of the cloister of the Monastery of Yuso, San Millán de la Cogolla (La Rioja, Spain).

The selection of a section of the Monastery of San Millán de la Cogolla as a testbed is supported by several reasons: firstly, due to the undeniable cultural significance of the monument, secondly, because of the complexity of its management and, finally, owing to the existence of a huge amount of heterogeneous documentation of diverse origin related to interventions which have not yet been systematized. Summing up, the features that this monumental group offers from all perspectives of heritage management guarantees that the conclusions of the case study can be extrapolated to other buildings.

The declaration of San Millán de la Cogolla as a World Heritage site in December 1997 served to renew interest in the architectural complex and to fill the significant historiographical gaps that have been noted in the course of numerous investigations (Arrúe \& Martínez, 1997).
The objectives can be described in more detail as follows:

- Carry out an analysis of the formal aspects of information management on conservationrestoration interventions (documentary typologies on heritage interventions, databases and their internal structure used) stored in the $\mathrm{IAPH}$, in collaboration with the Department of Projects and Archives, and study the alternatives of implementation, identify good practices and study how to implement them in the case of study.

- Develop with the collaboration of the Heritage Knowledge Strategies - ECP research group of the University of Seville-, a digital HBIM model of the cloister of the monastery of San Millán de la Cogolla.

- Analyse the potential of the HBIM for the potential of documents management of the different restoration works undertaken on the aforesaid cloister.

\section{Methodology and preliminary results}

Based on what has been described above, two simultaneous and, eventually, intersecting lines of work have been established. On the one hand, the acquisition of the geometric and material information of the actual state of the monument, by the creation of a digital model, by means of the combination of classical surveying, photogrammetry and laser scanning techniques (Figs. 2 and 3).

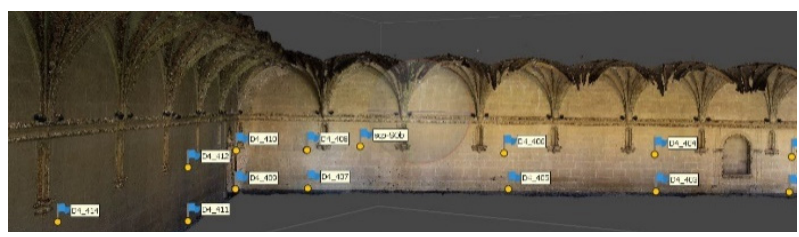

Figure 2: Half of the south elevation inside the cloister (dense point cloud with markers).

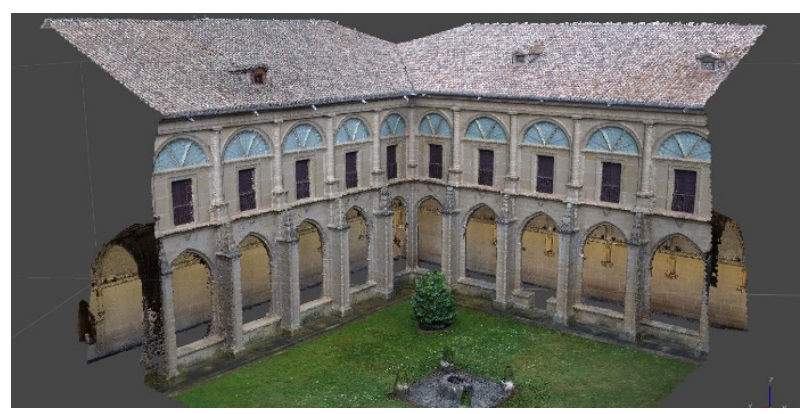

Figure 3: Point cloud of two walls of the cloister from the outside.

Besides, a cognitive phase, consisting of the systematic collection of the information about the restorations (archival documents, restoration projects, photographs, sketches and so on) and the association of this information to a database will be developed. In order to carry out good documentary practices and implement them in the case study in a correct way, the formal aspects of the information management carried out by the 
IAPH will be analysed, taking into account: the typology of the projects that arise from the conservation plan and the documentary contexts that define the documentary corpus of the intervention.

Both lines of work will ultimately converge into the digital reconstruction phase, which consists of the creation of the HBIM model. Modelling is going to be carried out in parallel to the analysis, reconstructing the main construction phases of the most important environments of the cloister from its origins to date as well as adding the information regarding the conservation / restoration interventions carried out. This analysis will offer valuable keys to generate the model, meanwhile the modelling process could reveal unapparent relationships that would enable new readings of the information sources.

\section{Conclusions}

Due to the importance that the documentation of the restoration acquires for the correct conservation of architectural heritage, the combination of good documentation and current technologies will permit an approach for viewing and interacting with information, allowing to achieve new developments in information management. Moreover, users will be also able to turn the graphical object into an information model and associate all the related documents and data to it, including those that exist now and any others that may appear in the future. Restoration and conservation will benefit from all these achievements regarding 3D HBIM model and hybrid data models, to preserve the information. Therefore, the available information can be, on the one hand, preserved associated with the object and, on the other hand, make it accessible to researchers in the future.

HBIM is only one of the options for the generation of a model. Modelling alternatives with lower levels of accuracy may also be acceptable depending on the objectives of the model, such as conservation, restoration, and preventive actions. The realization of this fact is a fundamental issue in conservation practice, which must lead to the definition of documental standards. In addition, the proposed model will also be open to any reviews, corrections or additional contributions that will emerge in the future.

\section{Acknowledgements}

This research is supported by the Basque Government through grants for doctoral studies of the call 2019-2020, and the collaboration of the IAPH and ECP research group (University of Sevilla).

\section{References}

Acosta, P. (2019). Documenting knowledge: Document management of intervention projects on immovable heritage. In Science and Digital Technology for Cultural Heritage-Interdisciplinary Approach to Diagnosis, Vulnerability, Risk Assessment and Graphic Information Models: Proceedings of the 4th International Congress Science and Technology for the Conservation of Cultural Heritage (TechnoHeritage 2019), March 26-30, 2019, Sevilla, Spain (p. 176). CRC Press.

Acosta, P., \& Alanís, A. (2019). La gestión documental como estrategia para la transferencia del conocimiento: Implementación en el proyecto_re-HABITAR. In re-HABITAR el Carmen: Un proyecto sobre patrimonio contemporáneo (pp. 134-141). Consejería de Cultura y Patrimonio Histórico.

Angulo, R., Castellano, M., \& Pinto, F. (2019). Pilot experience of HBIM modelling on the Renaissance quadrant façade of the Cathedral of Seville to support its preventive conservation. In Science and Digital Technology for Cultural Heritage-Interdisciplinary Approach to Diagnosis, Vulnerability, Risk Assessment and Graphic Information Models: Proceedings of the 4th International Congress Science and Technology for the Conservation of Cultural Heritage (TechnoHeritage 2019), March 26-30, 2019, Sevilla, Spain (p. 122). CRC Press.

Arrúe, B., \& Martínez, E. (1997). Valoración del Patrimonio arquitectónico del Monasterio de San Millán de la Cogolla de Yuso (La Rioja). Berceo, 133, 111-140.

Bruno, N., \& Roncella, R. (2019). HBIM for Conservation: A New Proposal for Information Modeling. Remote Sensing, 11 (15). https://doi.org/10.3390/rs11151751

Culubret, B., Dávila, C., Moreno, M. A., \& Pérez, M. (2017). Documentando la restauración... pasado, presente y futuro. Boletín del Museo Arqueológico Nacional, 36, 387-404.

García, J. J. (2018). Los repositorios en acceso abierto como elemento central en la transferencia de conocimiento entre los profesionales del patrimonio. In Las profesiones del patrimonio cultural. Competencias, formación y transferencia del conocimiento: reflexiones y retos en el Año Europeo del Patrimonio Cultural 2018 (pp. 474- 481).

IAPH, (2016). ReA, el Repositorio de Activos Digitales del IAPH, disponible en su web. Revista PH, 89, 22-23.

Jordan-Palomar, I., Tzortzopoulos, P., García-Valldecabres, J., \& Pellicer, E. (2018). Protocol to manage heritage-building interventions using heritage building information modelling (HBIM). Sustainability, 10(4), 908. https://doi.org/10.3390/su10040908

Macarrón, A., Calvo, A., \& Gil, R. (2019). Criterios y normativas en la conservación y restauración del patrimonio cultural y natural. Editorial síntesis. Madrid.

Oreni, D., Brumana, R., Georgopoulos, A., \& Cuca, B. (2013). HBIM for conservation and management of built heritage: towards a library of vaults and wooden bean floors. ISPRS Ann. Photogramm. Remote Sens. Spatial Inf. Sci., II5/W1, 215-221. https://doi.org/10.5194/isprsannals-II-5-W1-215-2013 
Remondino, F., \& Rizzi, A. (2010). Reality-based 3D documentation of natural and cultural heritage sites-techniques, problems, and examples. Applied Geomatics 2(3), 85-100. https://doi.org/10.1007/s12518-010-0025-x

Trizio, I., Savini, F., Giannangeli, A., Boccabella, R., \& Petrucci, G. (2019). The Archaeological Analysis of Masonry for the Restoration Project in HBIM. Int. Arch. Photogramm. Remote Sens. Spatial Inf. Sci., XLII-2/W9, 715-722. https://doi.org/10.5194/isprs-archives-XLII-2-W9-715-2019 


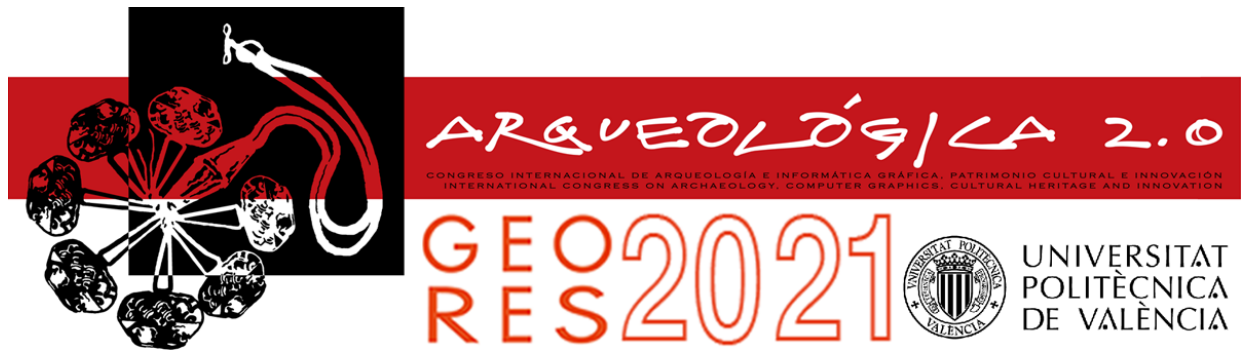

Proceedings of the joint international event $9^{\text {th }}$ ARQUEOLÓGICA

$2.0 \& 3^{\text {rd }}$ GEORES

Valencia (Spain).

26-28 April 2021

\title{
TOWARDS ONLINE 3D ARCHIVE OF HISTORICAL SITE: THE TURIN 1911 WORLD'S FAIR
}

\author{
Alessandra Spreafico ${ }^{a,}$, , Cristina Della Coletta ${ }^{b}$ \\ a Department of Architecture and Design (DAD), Politecnico di Torino, Viale Mattioli 39, 10125 Torino, Italy. \\ alessandra.spreafico@polito.it \\ ${ }^{\mathrm{b}}$ Division of Arts and Humanities (DAH), UCSD, University of California San Diego, 9500 Gilman Dr. La Jolla, 92093 California, USA. \\ cdellacoletta@ucsd.edu
}

\begin{abstract}
:
Digital technologies as online virtual experiences are more and more emerging and widespread as dissemination tool of culture and education, recreating the past of historical sites and enabling the 'unreal' visualization of no more visible configuration. The present paper illustrates the topic, aims and first analysis related to the first year of research, in the context of the 'Turin 1911' international project. The recreation of a virtual world dedicated to the first World's Fair held in Italy in 1911 is based on digital technologies exploited by Geomatics; the development of an up-to-date online platform containing original textual and graphical documentation aims to support the diffusion of a human-drive technoculture. Firstly the Turin 1911 project mission and vision, related researches and already achieved results are reported. Secondly, the core of the paper explores the preliminary investigations about historical research and geodatabase development related to the Turin 1911 project, finally interesting perspectives are considered.
\end{abstract}

Keywords: geodatabase, WebGIS, cultural heritage, technoculture, international exhibitions, long-term preservation

\section{Introduction}

Nowadays, digital technologies and web communication play a crucial role, especially in time of emergency like pandemic during while institutions suffer from closing or restrictions and people are confined at home. Especially in this situation, digital tools are more and more available to everyone and can be an intuitive communication tool by facilitating and stimulating curiosity and knowledge. In this framework, the world culture embodies a primary element, related explicitly to heritage as material and immaterial proof of this common culture belonging to all humankind. Recently the development of digital solution to create online archive of historical sites is becoming a fundamental task to provide data access to experts and public (Münster et al., 2020). Large scale initiatives to collect big data related to the past like Time Machine project (Time Machine Organisation, 2021) encounter different expertise and train a new generation of experts in Cultural Heritage and Digital Humanities (Münster et al., 2019). Today the Time Machine Organization (TMO) - founded in the 2019-2020 as fruitful result of the Time Machine project - constitutes a milestone for the entire Europe. In fact, the European Parliament's Committee on Culture and Education (CULT) has recognized the Time Machine Project relevance for the application of Artificial Intelligence and Information Technologies in the framework of culture and education (CULT, 2020). The use of advanced digital technologies unites documentation stored and preserved in archives, libraries and also museums, custodians of a fragmented history of places. In this way, digital solutions applied to documentation and sites give meaning to a global past aiming to recreate the cultural and economic history of Europe. Given the above, promising techniques and methods in the Geomatics field applied to cultural heritage can support the widespread communication of the culture and good practise, as tested in the case of the 'Turin 1911 ' project.

\section{2. 'Turin 1911' project}

'Turin 1911 ' is a joint research project led by University of California San Diego (UCSD) and Politecnico di Torino where the encounter between ancient and digital worlds constitutes the core of a multidisciplinary and international investigation devoted to the Turin 1911 World's Fair on Industry and Labour. The Fair has been held in occasion of the $50^{\text {th }}$ anniversary of the Italian Unity in the fabulous stage of the Valentino Park in Turin, the first Italian capital city. The leading idea of the digital project (Della Coletta, 2012) is to support a technoculture developed in a human direction fostering users' imagination and critical thinking. The immersive digital world of the 1911 Fair will constitute reality in a second degree that means the virtual reconstruction of an imaginary construction, in fact, the Exposition was itself a representation of the real world. In this context creativity technologies constitute a source of

"Corresponding Author: Alessandra Spreafico, alessandra.spreafico@polito.it 
freedom, pushing the actual fairgoer to reflect about potentiality of emerging digital world from one side, and allowing to explore not real world exploiting multimedia as tool of leisure, but also with critical interpretation on the other side. In detail, the project aims to explore the recreated 3D virtual world of the 1911 Fair as tool of knowledge and visualization of both the actual and the no more surviving places, mixing the real and the not real world. The integration between traditional research methods and digital innovations facilitates and implements processes related to past events as: longterm preservation of original and fragile documentation, integration with newest studies and discoveries, comparison and query between heterogeneous elements and concepts.

\subsection{Previous researches and results}

'Turin 1911: The World's Fair in Italy' is the first digital project solely dedicated to this International Exposition; an entire webpage (see University of California, 2018) aims to collect, organize, disseminate and study primary and secondary sources in a systematic way exploiting digital technologies. In the last decades, different researches focused on various topics about the Turin 1911 Fair; a selection of the main studies is here reported. First of all, the Italy's role in the World's Fair Exhibitions as a phenomenon emerging during the XIX and XX centuries is discussed in Della Coletta (2006); in particular, the relevance of the Turin 1911 Fair itself is affirmed considering it the first international fair in Italy and the last before the First World War; then the role of Turin in creating the sense of national identity in an international context is deepen examined overturning the scholars' point of view about Italy's role in the political, social and economic world context. Secondly, for the $100^{\text {th }}$ anniversary of the Turin 1911 Fair two books have been published (Bassignana, 2011; Balocco, 2011) providing a general overview of a complex phenomenon; traces of which are only represented by postcards, black and white photos, few drawings and videos, guide books, newspapers, journals and narratives. In fact, about 100 temporary structures were built for this gorgeous moment lasting only 7 months but requiring years of planning. Recently, the interdisciplinary team of UCSD and Politecnico di Torino has considered different topics related to the integration between history and Geomatics as the challenging survey and modelling of the few remaining structures in the Valentino Park (Chiabrando, Sammartano, Spanò, \& Spreafico, 2019), and the 3D digital modelling and visualization of the no more existing pavilions starting from a combination of original drawing and photos.

\section{Main}

The aforementioned relevance of the Turin 1911 Fair pushes researchers to search, collect and compare old and new discovered documentation hold by private and public archives and libraries, mostly spread in Piedmont region. The creation of a dedicated and interactive website, where all data is collected in a unique online tool open to the public, constitutes a promising solution. In this way the Turin Exposition can be explored in a new way boosting the critical analysis for experts, but also showing digital 2D and 3D environments for non-scholars.

\subsection{Preliminary researches}

In the planning of the entire Exposition, an exciting role has been played by one of the three main 'architects' responsible of the general design of the fair, the engineer Stefano Molli (Gli Architetti dell'Esposizione, 1910). He was depicted as a humble man, in fact only few friends were aware of his projects and also other colleagues ignored part of his work (Reycend, 1916). Maybe for this reason the huge collection of technical drawings dedicated to the Turin 1911 World's Fair remained unstudied for about a century, but well preserved by Fondazione Marazza of Borgomanero (Italy), Molli's hometown. The documentation consists of 588 sheets subdivided in folder and subfolder, varying in size from a letter up to 1 or 3 meters for side and drawing scale from $1: 2000$ up to $1: 10$ (Fig. 1). A pre-inventory of this important documentation has been created and the drawings are currently under digitization process performed by Politecnico di Torino.

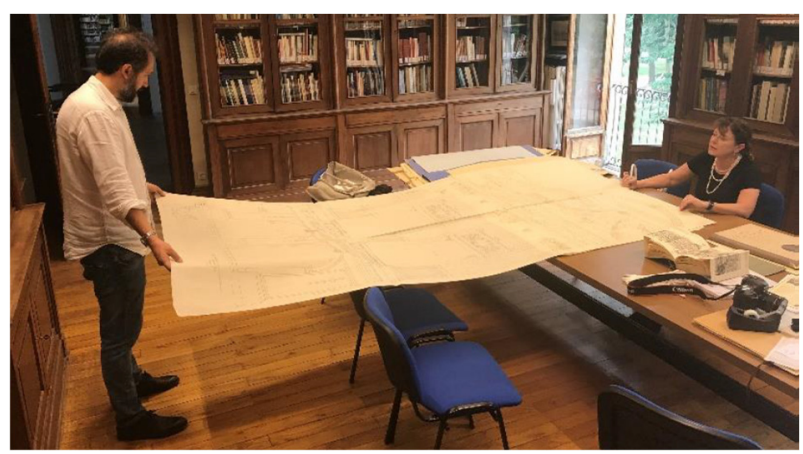

Figure 1: Stefano Molli's large format drawing at Fondazione Marazza of Borgomanero.

\subsection{Geodatabase development}

Currently, the website dedicated to the 1911 Fair is based on a database continuously updated by UCSD. The UCSD relational database has an articulated schema consisting of 54 entities and containing information about structures, media object, sources, people and places. This database lacks the geospatial data; therefore tests have been performed to create a geodatabase in GIS environment (ArcGIS Pro) starting from the objectrelational database system (PostgreSQL) and the related management tool (PgAdmin). A lot of tests have been performed to solve technical issues related to the development of a non-native geodatabase starting from an already existing relational database. As first attempt a UCSD database backup file has been created in PgAdmin, this provided data constitute the starting point. Then it has been analysed and optimized for the database connection to ArcGIS Pro and then to enable it as a geodatabase. At the moment only structures and media object entities have been considered to connect them to the corresponding geometry in ArcGIS Pro, generated starting from a 1911 general plan of the Fair. Geographic information allows association between spatial content added by Politecnico di Torino - and textual and graphical information - already contained in the UCSD database. Currently, in ArcGis Pro starting from the query of a single geometry, as a pavilion, it is possible to retrieve a pop-up containing a selection of information (i.e. the name of the structure, a brief description, the architect and style of the structure) and all the images contained in media objects 
such as photos and postcards (Fig. 2) thanks to the recreation of the relationships. A lot of complications have been tackled during the development of the geodatabase starting from the UCSD database (i.e. managements of: pre-existing entities before the geodatabase enabling, relationships between entities not automatically recognized in ArcGis Pro but existing in the UCSD database, media object in GIS environment), especially due to compatibility issues between PostgreSQL and ArcGIS Pro, and solved adopting manual solutions as registering the entities in the geodatabase and at the moment recrearting only the relationships needed. In only one year three version of ArcGIS Pro and two of PostgreSQL have been employed; from one side the updating to the last version of ArcGIS Pro has provided benefits, but also further problems related to compatibility between different versions of both softwares.

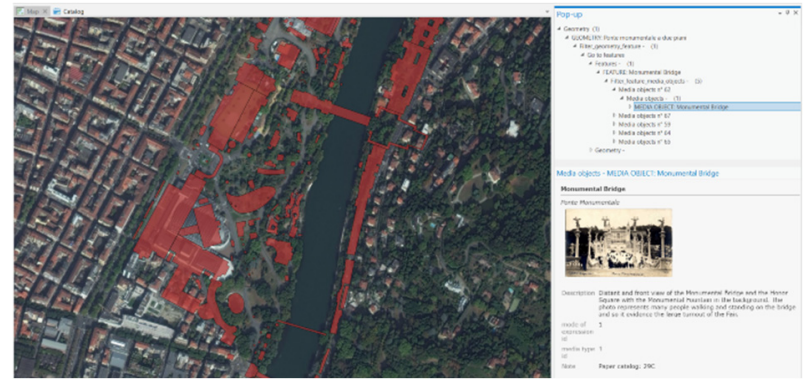

Figure 2: Visualization of a configured pop-up in the geodatabase with images related to the selected geometry.

\section{Conclusion}

Turin 1911 World's Fair represents a complex phenomenon, therefore it can be considered a challenging case study for the creation of ad-hoc WebGis starting from an already existing relational database missing of spatial content.
As regard archival research, unknown original drawings have been discovered in the Fondazione Marazza, increasing the available documentation of the Turin 1911 Wold's Fair. This material requires to be inserted in the geodatabase according to cataloguing standards for architectural drawings and providing metadata. Concerning the geodatabase, only a few issues have been solved. The development of a WebGis dedicated to the Turin 1911 Fair requires further studies, also considering to extend the connection between spatial content and related videos and 3D models for visualization in a medium-term period - as partially tested at this stage of the research (Fig. 3) - and the possibility of exchange and integration between systems, such as GIS and BIM, in a long-term period.

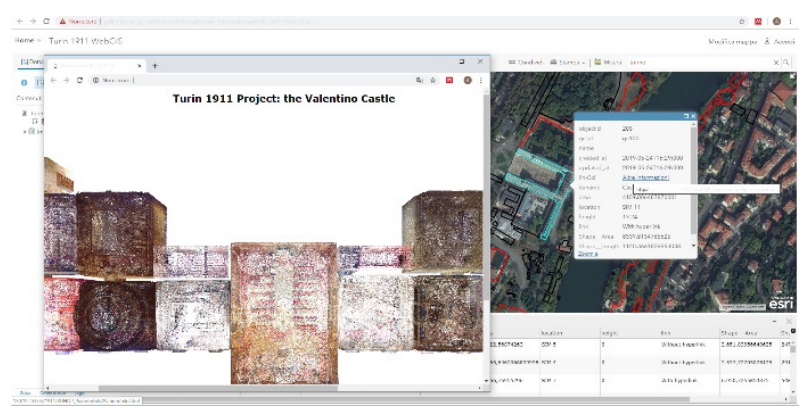

Figure 3: Visualization of the connection between 3D model and the selected geometry in the WebGis test.

\section{Acknowledgements}

The work here presented is part of the 'Turin 1911' joint research project led by University of California San Diego and Politecnico di Torino. The authors thanks: Fondazione Marazza of Borgomanero, Cynthia Lee and Miki Urban of University of California San Diego for provided data, Elisabetta Colucci and Fabio Giulio Tonolo of Politecnico di Torino for assitance, and Filiberto Chiabrando of Politecnico di Torino for proofreading.

\section{References}

Balocco, P. (2011). L'Esposizione internazionale di Torino del 1911. Torino: Graphot.

Bassignana P. L. (2011). Torino 1861-2011 Storia di una città attraverso le esposizioni. Torino: Edizioni del Capricorno.

Chiabrando, F., Sammartano, G., Spanò, A., \& Spreafico, A. (2019). Hybrid 3D Models: When Geomatics Innovations Meet Extensive Built Heritage Complexes. ISPRS International Journal of Geo-Information, 8(3), 124. https://doi.org/10.3390/ijgi8030124

CULT. (2020). European Parliament's Committee on Culture and Education. Draft report on artificial intelligence in education, culture and the audiovisual sector, Committee on Culture and Education. Available at: https://www.europarl.europa.eu/doceo/document/CULT-PR-655862_EN.pdf

Della Coletta, C. (2006). World's Fairs Italian-Style: The Great Exhibitions in Turin and Their Narratives, 1860-1915. Toronto Italian Studies. Toronto, University of Toronto Press, $351 \mathrm{pp}$

Della Coletta, C. (2012). Of Work and Leisure: Digital World's Fairs and the Active Fairgoer. PMLA, 127(4), pp.939-946.

Gli Architetti dell'Esposizione. (1910). L'Esposizione di Torino 1911: giornale ufficiale illustrato dell'Esposizione internazionale delle industrie e del lavoro 1911, 1, Torino: Stabilimento tipografico Momo.

Münster, S., Apollonio, F. I., Bell, P., Kuroczynski, P., Di Lenardo, I., Rinaudo, F., \& Tamborrino R. (2019). Digital Cultural Heritage meets Digital Humanities, Int. Arch. Photogramm. Remote Sens. Spatial Inf. Sci., XLII-2/W15, 813-820. https://doi.org/10.5194/isprs-archives-XLII-2-W15-813-2019

Münster, S., Niebling, F., Bruschke, J., Barthel, K., Friedrichs, K., Kröber, C., \& Maiwald, F. (2020). Urban History Research and Discovery in the Age of Digital Repositories. A Report About Users and Requirements. In H. Kremers (Eds.), Digital Cultural Heritage, (pp. 63-84). https://doi.org/10.1007/978-3-030-15200-0_5 
Reycend, G. A. (1916). L'ingegnere Stefano Molli e la sua opera di architetto: commemorazione tenuta alla sede della Società degli ingegneri e degli architetti di Torino nella sera del 30 giugno 1916. Torino: Edizioni d'arte E. Calenza.

Time Machine Organisation. (2021). Time Machine Europe. Retrieved March 15, 2021, from https://www.timemachine.eu

University of California. (2018). A World's Fair in Italy: Turin 1911. Retrieved March 15, 2021, from http://www.italyworldsfairs.org/ 


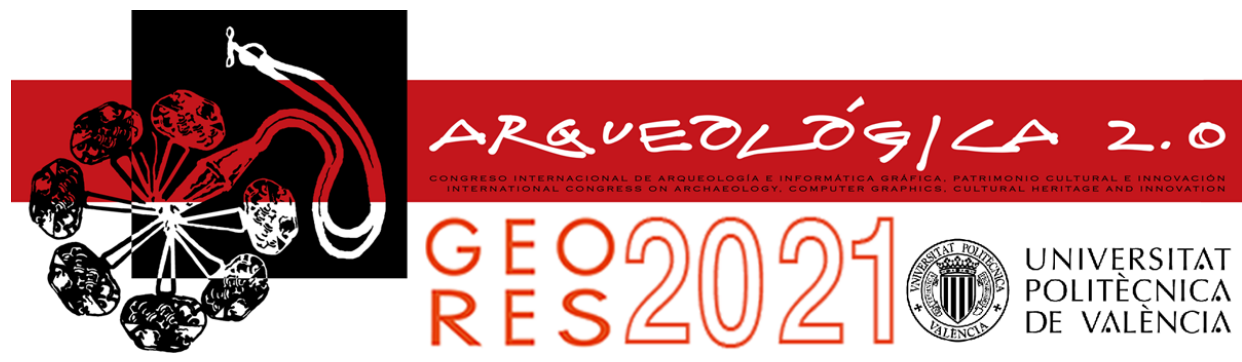

\title{
CLOUD DATA SHARING AND EXCHANGE OF HBIM PROJECTS FOR ARCHAEOLOGY: POSSIBLE SOLUTIONS AND PROPOSALS
}

\author{
Filippo Diara*, Fulvio Rinaudo \\ Department of Architecture and Design (DAD), Politecnico di Torino, Viale Mattioli 39, 10129 Torino, Italy. filippo.diara@polito.it; \\ fulvio.rinaudo@polito.it
}

\begin{abstract}
:
Nowadays, archaeological research requires safe and stable digital platforms for ensuring data protection and exchange. For this reason, the creation of anonymous 3D models is no longer enough if semantic information is not dynamically included. Historic Building Information Modelling (HBIM) has proved to be one of the most suitable solutions in order to preserve historical and semantic information concerning archaeology and Cultural Heritage in general, realizing a real breakthrough and avoiding data fragmentation of digital humanities studies. However, the other fundamental goal of this informative system, apart from being a secure 3D DBMS (DataBase Management System) for data documentation and analysis, is to be a dynamic platform designed for data exchange and online dissemination for spreading collaboration and interoperability processes. In this regard, the actual panorama is characterised by different commercial and open source solutions based essentially on a 3D space for model visualization coupled with an integrated basic or advanced DBMS for managing data through analyses, queries, reviews and validations. However, how can these solutions adapt to archaeology purposes? This work in progress is focusing on a quick analysis of possible solutions for online data sharing and exchange of archaeological studies through actual cloud-based platforms also proposing an ideal online HBIM platform suitable for the archaeological domain.
\end{abstract}

Keywords: archaeology, cloud-BIM, data exchange, dissemination, HBIM, server-BIM

\section{Introduction}

Data publication and communication is crucial for sharing data at the end of archaeological analyses. This data and information exchange have to be planned in suitable ways to satisfy user needs, because dissemination is the dialogue moment between who contributed to the research and who is getting the final data for analyses and revisions. Since dissemination and data exchange issues referred to traditional archaeological and humanities studies have become more emphasised especially in the last digital age, Historic Building Information Modelling (HBIM) methodology has achieved more and more attention especially for avoiding data fragmentation, allowing and encouraging the correct data management and consequently the right data exchange.

For this reason, the creation of bare three-dimensional models of archaeological sites and structures is no longer enough in the actual research panorama: digital twins make sense only if semantic data are included and dynamically linked to models, allowing to extract desired information via ad-hoc queries (Diara \& Rinaudo, 2020).

Moreover, studies carried out via BIM methodology require a smart data exchange and dissemination for guarantee a multidisciplinary and open approach, and cloud-based platforms are fundamental for this reason.
This work in progress is based on a quick analysis of actual cloud-based BIM solutions for online data sharing, trying to understand whether their architecture could adapt to archaeological information, also proposing an ideal solution for this data.

\section{Data sharing and exchange}

The online dissemination of BIM projects is essentially based on consulting and managing IFC (Industry Foundation Classes) files and related data derived from AEC (Architecture, Engineering \& Construction) projects. For this purpose, third-part solutions, as web-servers and advanced online viewers, are fundamental instruments in order to ensure an open and collaborative approach to BIM projects. Integrated DBMSs semantically linked to 3D parametric models constitute the essential backbone of these software (which are characterised by a clean and more intuitive graphic interface than BIM client software) in order to extract information from IFC files through relational queries for data validation.

This accessibility proves to be fundamental for archaeology and in general for Heritage assets, both for new projects (e.g. for risk assessment) and to make available past Cultural Heritage researches. In this case, the collection and management of DBMSs or paperbased datasheets could be considered the most crucial 
step of this process before the dissemination and data exchange. Fragmented data, derived from past studies, should become crucial connections that hold the HBIM project up.

\section{Cloud-BIM solutions and proposal}

\subsection{Cloud platforms}

Existing cloud platforms panorama consist of suitable stand-alone solutions for sharing IFC objects and their information, in addition to the integrated cloud solutions of popular commercial software.

Actual cloud-based BIM software is essentially based on a 3D space and a basic or advanced DBMS for managing data in a collaborative environment (Logothetis, Karachaliou, Valari, \& Stylianidis, 2018).

BIMData Platform (2020) is a smart web platform for sharing BIM projects through the upload of IFC files and related data. This web solution is based on XEOKIT, which is an open source programming toolkit developed by XEOLAB for BIM and AEC graphics. XEOKIT source code is available through XEOKIT SDK distribution for the purpose of allowing customization of the main structure. Inside BIMData platform the project manager can easily handle files, users and workflow in a user-friendly environment. IFC files visualization is guaranteed by the $3 \mathrm{D}$ viewer (based on HTML and JavaScript) which allows the exploration and investigation of the IFC structure and objects properties, also allowing attributes modification (up to stable version 0.8.26). Inside the viewer, IFC objects can be easily reviewed by selecting BCF (BIM Collaboration Format) option which allows to report issues and revised version of the project. Apart from IFC files, BIMData platform can host any file type associated to digital models: images, PDFs, datasheets (CSV, XLSX, MySQL and others) can be consulted and updated inside the web environment.

Another solution to take into account is represented by BIMserver.center package (BIMserver.center, 2020). It is a cross-platform for data exchange of BIM projects (IFC models), accessible from every device. It is also composed by an important store that includes standalone apps and plugins to make the project usable on the web platform, allowing several analyses. Another important feature is related to the possibility to access the project in a VR (Virtual Reality) and AR (Augmented Reality) environments, giving fundamental support to accessible and immersive analyses.

An open source solution is characterized by BIMServer web platform (see GitHub, Inc, 2021), accessible via JavaScript server app. It allows sharing (by using an online server or by localhost) BIM projects and related IFC objects (Logothetis, Karachaliou, Valari, \& Stylianidis, 2018; Diara \& Rinaudo, 2018): it is essentially based on the investigation and revision of parametric models belonged to AEC families and these analyses could be performed both on 3D space and semantic data.

\subsection{A proposal solution for archaeology}

Regarding archaeological documentation and analysis, there is no purely dedicated software both for HBIM design and sharing processes. This issue is due to AEC inclination of BIM. Other applications could be considered methodological adaptations not only referred to the main workflow but also to the instrument itself, acting directly on BIM software. The dynamic adaptation of open source solutions to specific HBIM purposes has been proved through the custom exploitation and utilization of FreeCAD (Diara \& Rinaudo, 2020). At the same time, for cloud-based platforms the goal should always be their adaptation towards archaeological data.

Like the already mentioned solutions, an ideal cloud-BIM platform for archaeology should have three types of users (Fig. 1): a project manager; invited users; public users. The first one should be in charge of the project design, data management, revisions, updates and validations processes (apart from analyses and queries).

The project manager invites selected users for collaborations and for a multidisciplinary approach, as they would be delegates for analyses, queries, revisions and updates; at the end, the project should be available to public users for data analyses and queries, in order to spread knowledge and offer the possibility to interact with it.

For the purpose of integrating archaeological data into online platforms, DBMS storage management should be planned and organised to collect different types of data (Fig. 1): Archaeological stratigraphy; Stratigraphic analysis; Chronological interpretation via Matrix; 2D graphic drawings; Photographic details; Iconographic references; Bibliographic references.

Cloud-based BIM solutions for archaeology should integrate and must be able to investigate this kind of sensitive data (Fig. 1), from alphanumerical data (stratigraphic analysis DBMS) to 2D drawings and photos, from material analyses to relational schemes (Matrix), and actual platforms can hardly host and query these data.

Moreover, the correct implementation of archaeological research into BIM workflows and related online platforms must take into account the exceeding of a strict IFC semantic classification for 3D objects, designed only for the $A E C$, of which a proper classification for Heritage assets will be hardly obtained.

The main goal should be mainly the stability of the project and then ensuring data sharing via online solutions, to fulfil the fundamental role of BIM methodology: data dissemination for a collaborative approach. Pathways, workflows, and software typology should be put in the background.

Another fundamental aspect is concerning the portability and accessibility of information. Mobile devices play an important role for the portability and easiness of managing HBIM semantic data (Balletti, Bertellini, Gottardi, \& Guerra, 2019), especially when laptops could be considered both desktop and mobile machines. In this way, DBMSs and 3D spaces should be consultable in every place and every moment, avoiding having to carry out analyses in specific places with particular instruments, for example laboratories and dedicated computers.

HBIM projects, designed for the knowledge of historic contexts, should be guaranteed to public use through adhoc platforms, as well as accessible with ad-hoc solutions in order to involve different types of audience. For example, online BIM solution via mobile devices coupled with AR or VR could offer excellent support for information access (Banfi, Brumana, \& Stanga, 2019; Banfi, 2020). 


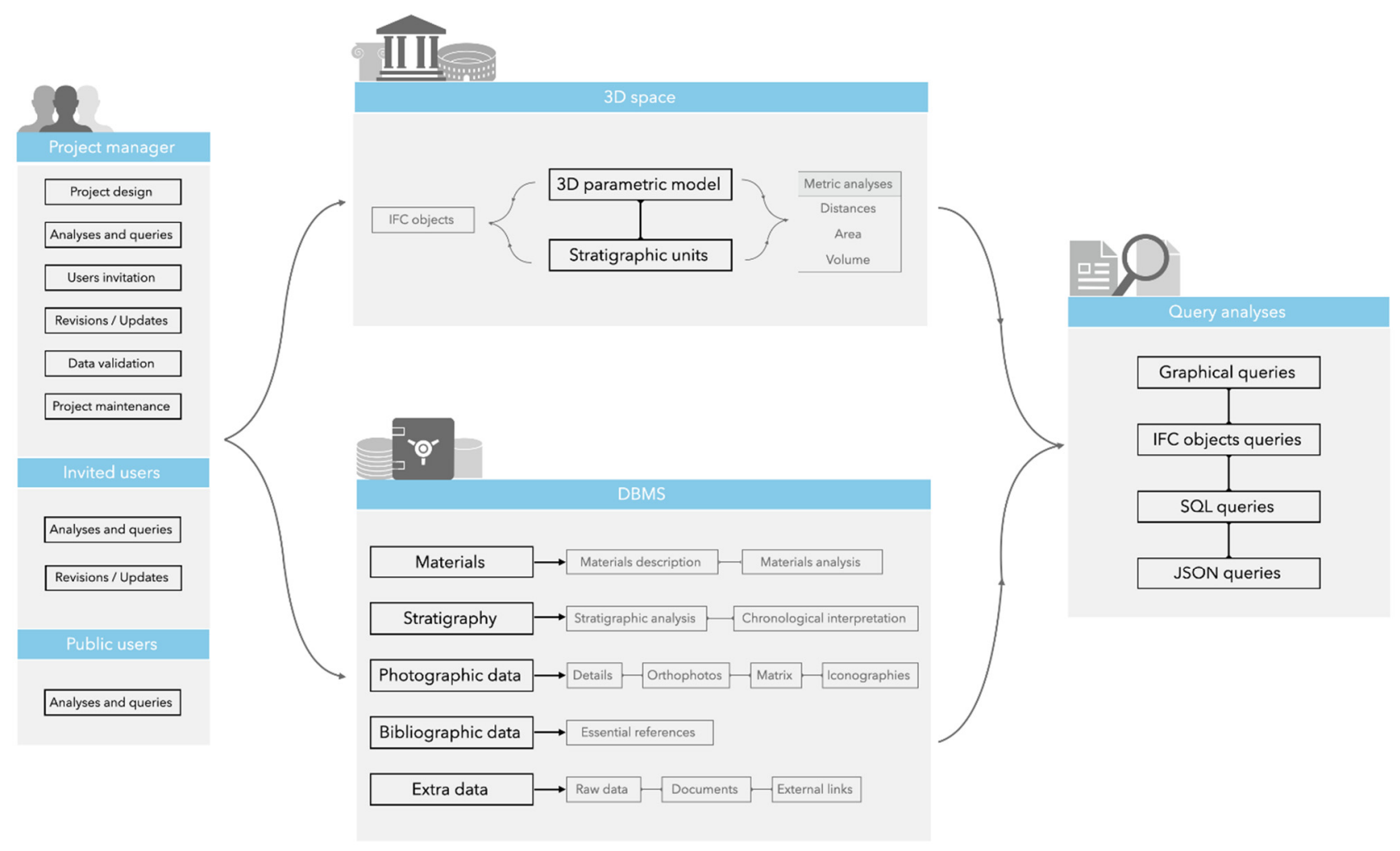

Figure 1: Ideal cloud-based BIM platform for archaeology.

Online data sharing is apparently the last moment of traditional scan-to-BIM workflows for Cultural Heritage assets: from knowledge processes (mostly characterized by surveys) to data management, from the design of the BIM platform to data sharing (Fig. 2). Regarding archaeological studies, data sharing moment must initiate required revisions and validation processes, apart from pure data sharing for public users.

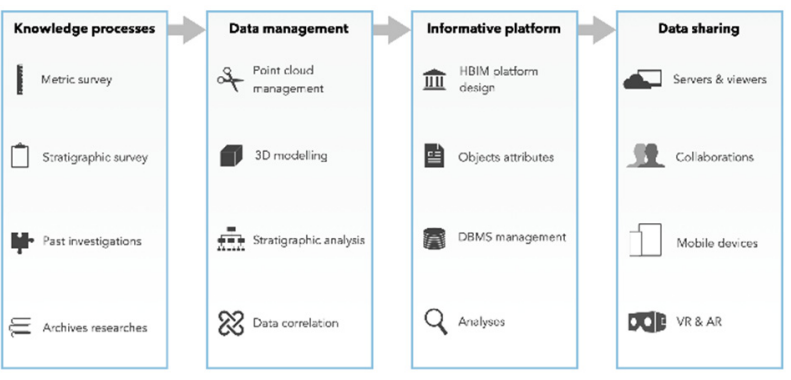

Figure 2: Main steps from knowledge processes to data sharing via BIM methodology for archaeological contexts.

Looking at the actual solutions mentioned before, BIMData.io platform might be the most flexible and customizable online solution for archaeology, especially if accompanied by a proper development process through other open source packages (XEOKIT - XEOGL ThreeJS).

\section{Conclusions}

The individuation of a suitable and smart solution for the online publication of archaeological researches based on BIM methodology has been the initial reflection that has led and will lead this work in-progress research.
Cloud-based platforms as web-servers and advanced online viewers have a big responsibility in order to ensure a collaborative, open and stable approach with different kind of users especially since the online dissemination has proved to be essential in these challenging times, where remote accessibility is often revealed the only possibility to carry out and update researches and analyses.

However, the sharing moment should not be considered the final step of analyses but it must be seen also as a new beginning to review and update researches. For this reason, the entire BIM and HBIM workflow can be considered a cyclical process (Fig. 3) and mobile access should serve as a guide to online sharing.

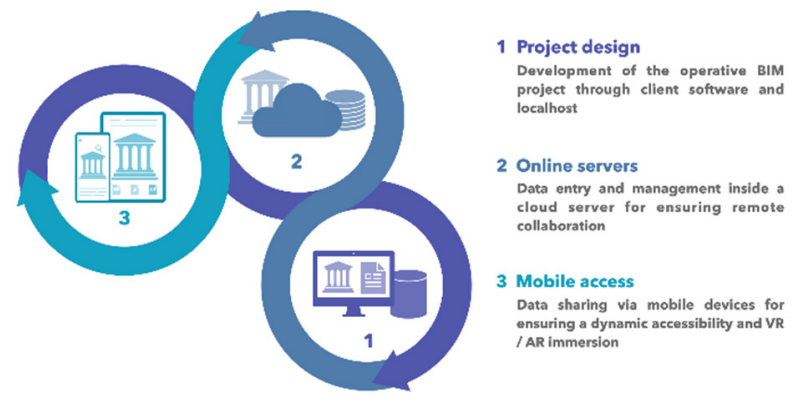

Figure 3: From project design to mobile access for HBIM.

Experimentations and customization of BIMData.io platform may be the focus of future research, also trying to develop a proper FOSS online solution for archaeology. 


\section{Acknowledgements}

This project is supported and funded by the GAMHer project (Geomatics data Acquisition and Management for landscape and built Heritage in a European perspective), a 3 years project financed under the Italian PRIN 2015 framework (Progetti di Ricerca di Rilevante Interesse Nazionale).

\section{References}

Balletti, C., Bertellini, B., Gottardi, C., \& Guerra, C. (2019). Geomatics techniques for the enhancement and preservation of Cultural Heritage. Int. Arch. Photogramm. Remote Sens. Spatial Inf. Sci., XLII-2/W11, $133-140$. https://doi.org/10.5194/isprs-archives-XLII-2-W11-133-2019

Banfi, F., Brumana, R., \& Stanga, C. (2019). Extended reality and informative models for the architectural heritage: from scan-to-BIM process to virtual and augmented reality. Virtual Archaeology Review, 10(21), 14-30. https://doi.org/10.4995/var.2019.11923

Banfi, F. (2020). HBIM, 3D drawing and virtual reality for archaeological sites and ancient ruins. Virtual Archaeology Review, 11(23), 16-33. https://doi.org/10.4995/var.2020.12416

Diara, F., \& Rinaudo, F. (2018). Open source HBIM for Cultural Heritage: a project proposal. Int. Arch. Photogramm. Remote Sens. Spatial Inf. Sci., XLII-2, 303-309. https://doi.org/10.5194/isprs-archives-XLII-2-303-2018

Diara, F., \& Rinaudo, F. (2020). Building archaeology documentation and analysis through open source HBIM solutions via NURBS modelling. Int. Arch. Photogramm. Remote Sens. Spatial Inf. Sci., XLIII-B2-2020, 1381-1388. https://doi.org/10.5194/isprs-archives-XLIII-B2-2020-1381-2020

BIMData Platform. (2020). The BIM collaborative platform of BIMDATA.IO. Retrieved March 15, 2021, from https://bimdata.io/

BIMserver.center. (2020). BIM en la nube de CYPE Ingenieros, S.A. Retrieved March 15, 2021, from https://bimserver.center/es

GitHub, Inc. (2021). GitHub: Where the world builds software · GitHub. Retrieved March 15, 2021, from https://github.com/

Logothetis, S., Karachaliou, E., Valari, E., \& Stylianidis, E. (2018). Open source cloud-based technologies for BIM. Int. Arch. Photogramm. Remote Sens. Spatial Inf. Sci., XLII-2, 607-614. https://doi.org/10.5194/isprs-archives-XLII-2607-2018 


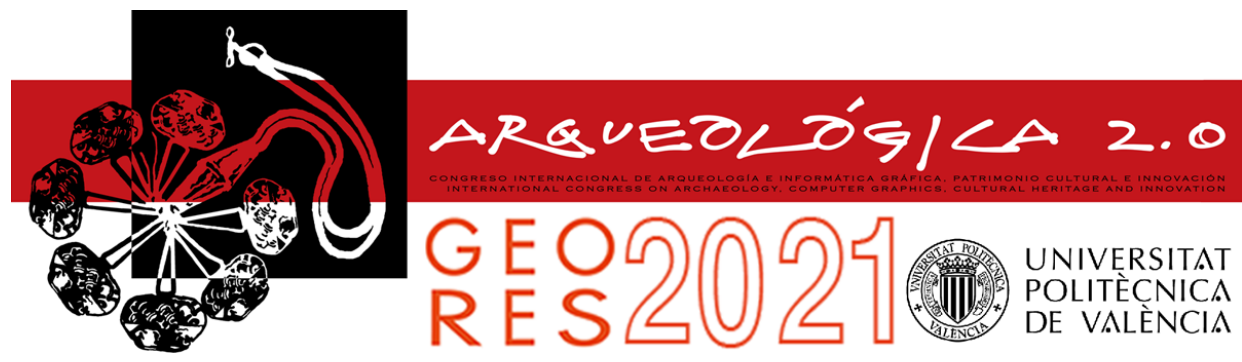

\title{
ARTIFICIAL INTELLIGENCE APPLIED TO MULTISPECTRAL IMAGERY FOR FLUVIAL MACROPLASTICS DETECTION
}

\author{
Irene Cortesi \\ Department of Civil and Environmental Engineering, University of Florence, Via di S. Marta 3, 50121 Florence, Italy. \\ irene.cortesi@unifi.it
}

\begin{abstract}
:
The research treats the detection of macroplastics in fluvial environments with multispectral images obtained by means of UAV proximity sensor. Further it will be developed an automatic classification methodology through Artificial Intelligence, machine learning and deep learning algorithms. The final goal of the project is to build a cheap methodology to be used for the periodic monitoring and create a digital georeferenced cartography to be updated and easily usable from local administrations and communities. Thanks to an efficient cleaning of riverfront, consequently it is possible to have an urban and social redevelopment of this fundamental area for the cities.
\end{abstract}

Keywords: plastic waste, river ecosystem, macroplastic, multispectral proximity sensor, artificial intelligence, machine learning

\section{Introduction}

Plastic is the third world's most produced material by industry, after concrete and steel (Lavers \& Bond, 2017). In the last fifty years it has been recorded a significant growth of production thanks to its high resistance to deterioration and versatility in use. Today people recycle only $9 \%$ of plastic they have used. The other parts are burned and accumulated in landfills or in the environment (Geyer, Jambeck, \& Law, 2017). Consequently, plastic pollution has become one of the major global environmental emergencies (United Nations Environment Programme, 2016), with a significant impact on many terrestrial and aquatic ecosystems.

Depending on size (linear dimensions), plastic litter are divided in three different categories: macroplastics ( $>5$ $\mathrm{mm}$ ), microplastics (between $5 \mathrm{~mm}$ and $0.1 \mu \mathrm{m}$ ) and nanoplastics $(0.1-0.001 \mu \mathrm{m})$ (Bråte et al., 2017). Macroplastics fragmentation produces microplastics. Macroplastics are present in greater quantities than microplastics in rivers and in other aquatic environments. The majority of plastic litter in seas and oceans comes from rivers (Lebreton et al., 2017). Consequently, the study of fluvial distribution and transportation mechanism is important because in these habitats macroplastics can be detected and recovered before they reach marine environments. However, only $20 \%$ of global studies about rivers concerns the problems related to macroplastics (Blettler \& Wantzen, 2019).

Moreover, the mouth of the river and the riverfront will get more attention during this research because they are the most critical sections of the river where every waste flow into. In fact, the river basin is a closed system with a constant flow that runs from mountain to valley. In many cities the riverfront is an identity part of the place and often tells somethings of the past. In the last years, some big towns have started the regeneration process of the riverfront, for their cultural identity like Hamburg, London (Schubert, 2010) or Detroit (Detroit Riverfront Conservancy, 2021). For these reasons the detection of macroplastics in the river is not only an environmental topic but also urban.

\section{State of art}

The plastic pollution is a topic studied in many different disciplines, in particular remote sensing technologies have provided effective methods for the identification of plastic waste in aquatic environments. Most of the surveys for the detection of plastic waste use only Infrared bands (from $900 \mathrm{~nm}$ to $1700 \mathrm{~nm}$ of electromagnetic spectrum on), in particular NIR (Near InfraRed) and SWIR (Short-Wave InfraRed) because this part of electromagnetic spectrum is not influenced by the colour of objects (Salzer \& Siesler, 2014), and satellite imagery for remote detection of large accumulations of floating plastics in natural seawater (Topouzelis, Papakonstantinou, \& Garaba, 2019). It is important to consider that remote sensing from satellites returns multispectral images with a spatial resolution that varies from half a metre to some kilometres and high-resolution data are often not freely available. Other researchers have proposed an automated system for identification and separation of plastic resins based on NIR reflectance spectroscopy (Masoumi, Safavi, \& Khani, 2012).

An alternative methodology has been developed by the author during the research work for her master's degree thesis based on the use of proximity sensors (i.e., MAIAWV2 made by SAL Engineering and EOPTIS) (SAL Engineering and EOPTISSAL Engineering, 2018) 
combined with the Decision Tree algorithm (a multistage classifier based on binary decisions) for the detection and classification of macroplastics in fluvial ecosystems. An important step of this study was the analysis of the spectral signatures of plastic waste. In the NIR bands radiance values of plastic samples are higher than the other elements of environment but the VIS bands showed greater variations due to the different colour, as presented in Figure 1. Thanks to this knowledge it was possible to build the expressions and the rules to implement the decision tree algorithm (De Giglio et al., 2020). This method has some limits which will be probably overcome through Artificial Intelligence.

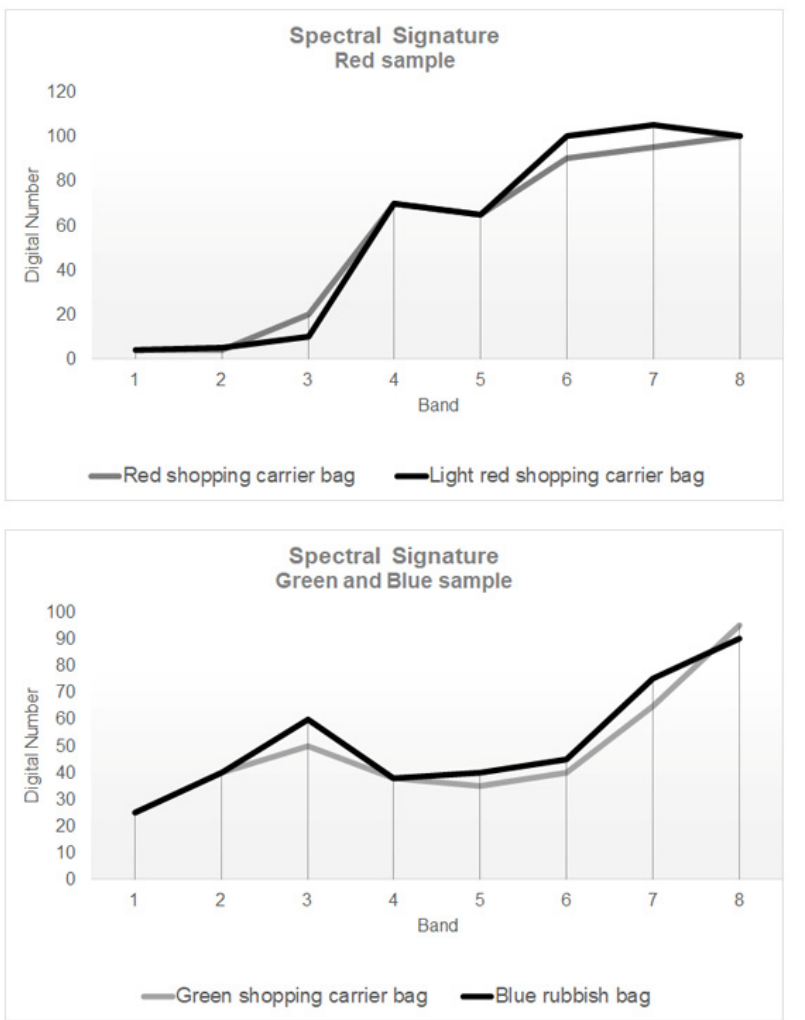

Figure 1: Spectral signature of plastic samples with a different colour.

\section{Body section}

This project aims to improve the previously developed procedure by using a machine learning approach. The use of Artificial Intelligence and Artificial Neural Networks (Anderson \& McNeill, 1992) should provide effective tools to tackle the issues related to dealing with the large amount of information provided by multispectral sensors, and lead to an automatic and optimized plastic detection procedure.

Several machine learning based methods of classification will be investigated to determine the most suitable approach in the considered problem, ranging from the Random Forest algorithm, that creates sets of independent decision tree which share the same destination classes (Akar \& Güngör, 2012), to advanced deep learning methodologies which implies a learning process through hierarchical multiple levels (Huang, Zhao, \& Song, 2018). It considers worthwhile to apply a classification that combines multispectral image and spectral indices, in particular Plastic Index (PI) (Themistocleous, Papoutsa, Michaelides, \& Hadjimitsis, 2020) and Normalised Difference Water Index 2 (NDWI) (Page et al., 2020). Machine learning methods should improve the accuracy of classification in respect to the previous result obtained by the Decision Tree method. In particular, the Random Forest method is known for its capabilities of reducing the overfitting issue (Segal, 2004) of the learning process of the Decision Tree.

One of the most distinctive characteristics of deep learning versus the machine learning technique, is the ability to automatically extract the best features from the input data to obtain the desired classification target (Aggarwal, 2018). Given the excellent results obtained by means of these tools in the classification field during the last decade (Belgiu \& Drăguţ, 2016), their usage is expected to lead to noticeable improvement of findings in this project too.

The acquisition of various and numerous data sets is a sine qua non condition for the use of machine learning and deep learning technics (Kelleher, Mac Namee, \& D'Arcy, 2015). Data collection campaigns will be carried out by using the multispectral sensor MAIA with the same spectral bands as the WorldView-2 satellite (from $395 \mathrm{~nm}$ to $950 \mathrm{~nm}$ of the electromagnetic spectrum). This sensor is characterized by reduced overall dimensions and weight (99x128x46 $\mathrm{mm}^{3}$ and $\left.400 \mathrm{~g}\right)$, being easily installed on UAV platforms (SAL Engineering and EOPTIS, 2018). It will be required to define a detailed flight plan through a dedicated software and to repeat the acquisitions periodically to have both a spatial and temporal data monitoring. A highly accurate georeferencing of the collected multispectral images will be performed through the measure of Ground Control Points (points of control distributed on the ground and measured by topography of GNSS methods) positioned before each UAV flight (Martin et al., 2018).

Finally, the obtained datasets will be shared online for free in order to promote the collaboration between different research teams, making future studies on these topics easier and providing shared data suitable to test different approaches.

\section{Conclusions}

The final goal of the whole project is to build a userfriendly and cheap methodology to be used for periodic monitoring of medium size areas.

Georeferenced images and classifications would allow setting up a digital cartography which can also be updated by crowdsourcing approaches, for example by using smartphones inputs of common citizens. This tool would provide live information on the position of plastic waste and on its transit sections for the development of related, efficient, systematic, and fast collection systems. Public administrations may take advantage of this tool both for developing prevention actions in the most impacted areas and for efficient and specific cleaning of fluvial areas.

The organisation of cleaning events of the Riverfront could be a way to requalify the area not just from environmental point of view but also urban and social purposes. 


\section{References}

Aggarwal, C. C. (2018). Neural Networks and Deep Learning. Springer, 10, 978-3. https://doi.org/10.1007/978-3-31994463-0

Anderson, D., \& McNeill, G. (1992). Artificial neural networks technology. Kaman Sciences Corporation, 258(6), 1-83.

Akar, Ö., \& Güngör, O. (2012). Classification of multispectral images using Random Forest algorithm. Journal of Geodesy and Geoinformation, 1(2), 105-112. https://doi.org/10.9733/jgg.241212.1

Belgiu, M., \& Drăguţ, L. (2016). Random forest in remote sensing: A review of applications and future directions. ISPRS Journal of Photogrammetry and Remote Sensing, 114, 24-31. https://doi.org/10.1016/j.isprsjprs.2016.01.011

Blettler, M. C., \& Wantzen, K. M. (2019). Threats underestimated in freshwater plastic pollution: mini-review. Water, Air, \& Soil Pollution, 230(7), 1-11. https://doi.org/10.1007/s11270-019-4220-z

Bråte, I. L. N., Huwer, B., Thomas, K. V., Eidsvoll, D. P., Halsband, C., Almroth, B. C., \& Lusher, A. (2017). Micro-and macro-plastics in marine species from Nordic waters. Nordic Council of Ministers. Copenhagen, Denmark.

De Giglio, M., Dubbini, M., Cortesi, I., Maraviglia, M., Parisi, E. I., \& Tucci, G. (2020). Plastics waste identification in river ecosystems by multispectral proximal sensing: a preliminary methodology study. Water and Environment Journal, 1-11. https://doi.org/10.1111/wej.12652

Detroit Riverfront Conservancy (2021). Retrieved January 1, 2020, from https://detroitriverfront.org

Geyer, R., Jambeck, J. R., \& Law, K. L. (2017). Production, use, and fate of all plastics ever made. Science advances, 3(7), e1700782. https://doi.org/10.1126/sciadv.1700782

Huang, B., Zhao, B., \& Song, Y. (2018). Urban land-use mapping using a deep convolutional neural network with high spatial resolution multispectral remote sensing imagery. Remote Sensing of Environment, 214, 73-86. https://doi.org/10.1016/j.rse.2018.04.050

Kelleher, J. D., Mac Namee, B., \& D'Arcy, A. (2015). Fundamentals of Machine Learning for Predictive Data Analytics: Algorithms. Worked Examples, and Case Studies. MIT press.

Lavers, J. L., \& Bond, A. L. (2017). Exceptional and rapid accumulation of anthropogenic debris on one of the world's most remote and pristine islands. Proceedings of the National Academy of Sciences, 114(23), 6052-6055. https://doi.org/10.1073/pnas.1619818114

Lebreton, L. C., Van Der Zwet, J., Damsteeg, J. W., Slat, B., Andrady, A., \& Reisser, J. (2017). River plastic emissions to the world's oceans. Nature communications, 8, 15611. https://doi.org/10.6084/m9.figshare.4725541

Martin, C., Parkes, S., Zhang, Q., Zhang, X., McCabe, M. F., \& Duarte, C. M. (2018). Use of unmanned aerial vehicles for efficient beach litter monitoring. Marine pollution bulletin, 131, $662-673$. https://doi.org/10.1016/j.marpolbul.2018.04.045

Masoumi, H., Safavi, S. M., \& Khani, Z. (2012). Identification and classification of plastic resins using near infrared reflectance. International Journal of Mechanical and Industrial Engineering, 6, 213-20.

Page, R., Lavender, S., Thomas, D., Berry, K., Stevens, S., Haq, M., Udugbezi, E., Fowler, G., Best, J., \& Brockie, I. (2020). Identification of Tyre and Plastic Waste from Combined Copernicus Sentinel-1 and-2 Data. Remote Sensing, 12(17), 2824. https://doi.org/10.3390/rs12172824

SAL Engineering and EOPTIS (2018). MAIA - the multispectral camera. Retrieved January 18, 2020, from https://www.spectralcam.com/maia-tech/

Salzer, R., \& Siesler, H. W. (Eds.). (2014). Infrared and Raman spectroscopic imaging. John Wiley \& Sons.

Segal, M. R. (2004). Machine learning benchmarks and random forest regression. UCSF: Center for Bioinformatics and Molecular Biostatistics.

Schubert, D. (2010). Waterfront revitalizations: from a local to a regional perspective in London, Barcelona, Rotterdam, and Hamburg. In Transforming Urban Waterfronts (pp. 90-114). Routledge.

Themistocleous, K., Papoutsa, C., Michaelides, S., \& Hadjimitsis, D. (2020). Investigating Detection of Floating Plastic Litter from Space Using Sentinel-2 Imagery. Remote Sensing, 12(16), 2648. https://doi.org/10.3390/rs12162648

Topouzelis, K., Papakonstantinou, A., \& Garaba, S. P. (2019). Detection of floating plastics from satellite and unmanned aerial systems (Plastic Litter Project 2018). International Journal of Applied Earth Observation and Geoinformation, 79, 175-183. https://doi.org/10.1016/j.jag.2019.03.011

United Nations Environment Programme (UNEP) (2016). Inputs to the Secretary-General's Report on Marine Debris, Plastics and Microplastics. Retrieved Janury 18, 2020, from https://www.un.org/depts/los/general_assembly/contributions_2016/UNEP_Contribution_to_ICP_on_marine_debris .pdf 


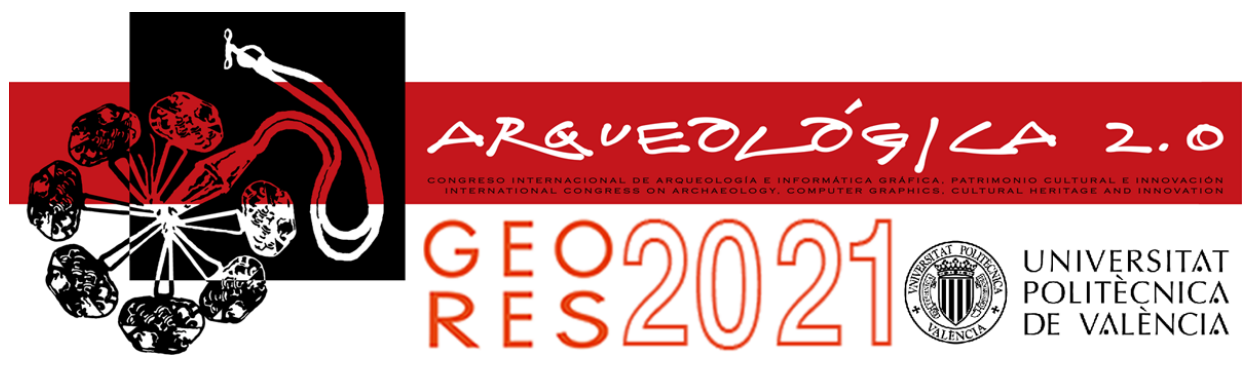

\title{
ENGINEERING THE ARCHAEOLOGICAL RESEARCH: SUBMILLIMETRIC CT SCAN OF ANCIENT EGYPTIAN ARTIFACTS
}

\author{
Simone Galli \\ Department of Architecture, Built Environment and Construction Engineering, Politecnico di Milano, Via G. Ponzio 31, Milan, Italy. \\ simone.galli@polimi.it
}

\begin{abstract}
:
The aim of this ongoing research is to test the contribution of new technologies on the archaeological research, in particular on the study of metal and hard stone artefacts. In order to achieve this goal, the production of submillimetric 3D models of objects made of metal and hard stone contained inside a fully wrapped ancient Egyptian mummy was chosen as a case study. This paper describes the ongoing decision-making process that will eventually lead to the choice of the instrument, of its parameters and of the type of object to be examined in order to perform a preliminary test, to be followed by an analysis of the dose to be provided to the mummy, designed to minimize the effects of ionization on the ancient DNA molecules. Thanks to the definition and the future implementation of this test, it will be possible to obtain 3D models of high-density archaeological finds not visible by eye. This will lead to new and more detailed information on the material culture of ancient Egypt, thus significantly contributing to the archaeological research.
\end{abstract}

Keywords: Egyptian mummies, Egyptology, archaeometry, tomography, image analysis

\section{Introduction}

The aim of this work is to investigate how archaeometric techniques can contribute to the archaeological research by opening new directions of research. In particular, this research focuses on the study of fully wrapped ancient Egyptian mummies and on the possibility of obtaining detailed information on the objects wrapped together with the body.

Computed tomography (CT) is one of the most important investigation techniques in the study of mummies. It has been used since 1977, when Lewin and Harwood-Nash performed the first tomographic scan on an ancient Egyptian mummy (Lewin \& Harwood-Nash, 1977). In fact, CT allows to obtain 3D models of the internal composition of an object starting from a series of planar images (Bradley \& Creagh, 2006). Since then, several works related to the tomographic study of mummies have been published (for a summary see Cox, 2015). The mummies of Kha and Merit, located at the Museo Egizio in Turin, represent a significant example of the importance of this kind of analyses (Museo Egizio di Torino, 2019). They underwent radiological investigations in 1966 (traditional radiographic analysis), in 2001 (tomographic analysis by MDCT multidetector spiral computerized tomograph), in 2013/2014 (radiographic analysis by mobile digital instrument) and in 2017 (tomographic analysis by CT Trailer). These analyses allowed to investigate in detail the anatomical structures of the bodies and the characteristics of the embalming process (Ferraris et al., 2017). They also offered a progressively more defined glimpse of some artifacts associated to the mummies (Fig. 1), but the final resolution of the models was not sufficient to read the hieroglyphs engraved on the finds visible.

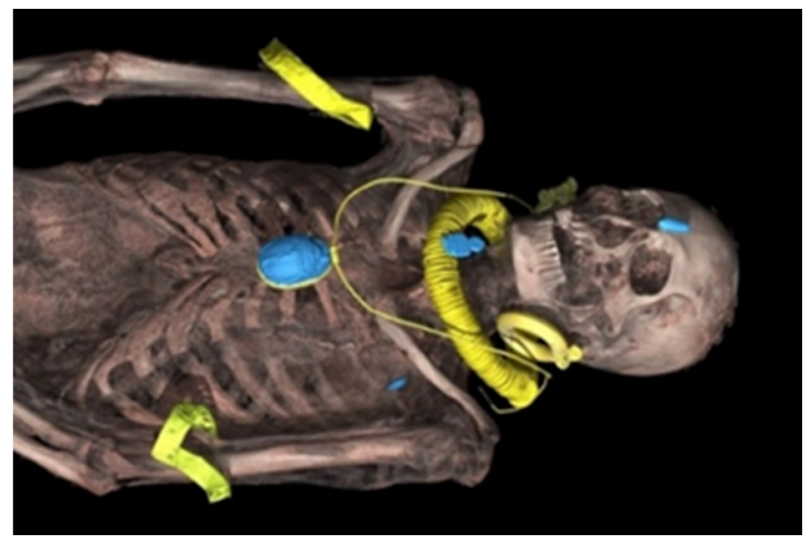

Figure 1: Skeleton and jewels of the mummy of Kha (Museo Egizio di Torino, 2019).

The main reason of the diffusion of this technology is the belief that tomography is a non-destructive technique for the tissue of mummified bodies. Recently, DNA analysis of the mummified remains has been growing in popularity (Ikram, 2017), and this assumption has been challenged. There are still only a few studies on the effect of X-rays on ancient DNA and they detect significant damage for dose values up to 200 Gy (Hall, Sherlock, \& Sykes, 2015; Immel, Cabec, Bonazzi, \& Krause 2016).

In order to show the importance that a technology like tomography can have for archaeological research, a study was started to verify the possibility to obtain a 
submillimetric 3D model of the jewels (made of hard stone and metal) contained inside fully wrapped mummies, taking as a theoretical case-study that of Kha. Such a study would have the double outcome of identifying the criteria to be adopted and to obtain more detailed information on the material culture of ancient Egypt. To verify the feasibility of such $3 \mathrm{D}$ models, a preliminary test should be performed. This paper describes the decisionmaking processes that will lead to the preparation of this test.

\section{Methods and Materials}

In order to perform a CT scan of the finds contained in a fully wrapped ancient Egyptian mummy, a simulation test should be carried out. To start with, it will be important to decide how to simulate the mummy and choose the right type of tomograph.

\subsection{The Mummy}

In order to simulate the mummy and its jewels, the best procedure would be to replicate them using materials with similar densities. In fact, the absorption of X-ray radiation, on which the principle of tomography is based, is mainly influenced by the density of the analyzed object. The plan is to test the effect of the CT scan on three separate materials chosen to represent the three main components (human remains, bandages and metal artefacts) and then on a composition of them.

\subsection{The Computed Tomograph}

The computed tomograph consists of an X-ray emitter that moves or rotates around an object and a detector on the opposite side that collects the image of a section of the object from multiple points (Carmignato, Dewulf \& Leach, 2018). During the scan, the detector measures the attenuation of the X-ray beam that is caused by the irradiated object. The tomographs used in the medical and industrial fields are generally different (Du Plessis, Yadroitsava, \& Yadroitsev, 2020). In fact, only the socalled "Industrial $x$-ray computed tomography" can reach resolutions in the micrometer range (up to $5 \mu \mathrm{m}$ ) in the analysis of very dense elements. This is due to the fact that, in order to safeguard the patient's health, the settable parameters of the medical Computerized Axial Tomography (CAT) are much more limited (only 140kV can be reached while in the industrial $X$-ray tubes, high voltages up to $450 \mathrm{kV}$ can be set) (Faggioni, Paolicchi, \& Neri, 2010; De Chiffre, Carmignato, Kruth, Schmitt, \& Weckenmann, 2014). Moreover, generally, industrial tomographs are characterized by a small working chamber. Medical CT scans, on the other hand, have a gantry structure, designed for a human body, in which the source-detector group rotates. As the object to be examined is a mummy, it follows that the most suitable structure and analysis technique is the Spiral CT in the multi-slice CT configuration. The choice of multiple rows of detectors will improve the spatial resolution given by the tomograph structure. By combining this type of structure with an industrial X-ray tube it is possible to achieve the maximum resolution offered by the technology. In addition, by controlling the advance time and the rotation speed of the scan, it will be easy to manage the X-ray dose provided to the mummy.
Once the instrument and its characteristics have been decided, it will be important to define the parameters to set. The potential difference applied to the tube determines the energy of the X-ray beam emitted. As the voltage increases, X-rays have a higher penetration power and the Signal to Noise Ratio and the absorbed dose are increased. However, the contrast of the image decreases. Since high-density objects will have to be examined, it will be set a range of $160-240 \mathrm{kV}$, as recommended for large rocks and heavy metals (Du Plessis, Broeckhoven, Guelpa, \& Le Roux, 2017). Increasing the $\mathrm{mA}$ value, the number of photons emitted by the X-ray tube increases. It will result in a decrease in noise and in an increase in contrast resolution. Many photons will be absorbed by the metal because of the high density, then values around $80 \mathrm{~mA}$ will be used as a starting point. However, it is possible that it will be necessary to use several hundreds of $\mathrm{mA}$. In order to evaluate the dose given to the mummy, as defined by the CEI EN 61223-2-6 standard (International Electrotechnical Committee, 2004), Ionization Chambers and Imaging Phantoms can be used (Fig. 2). They are used to evaluate the Absorbed Dose D (Brady, Mirro, Moore, \& Kaufman, 2015), which is the amount of energy $E$ absorbed per unit of mass $m$ of the material as in Eq. (1):

$D=\frac{d E}{d m}[G y]$

\subsection{The Test}

This test will be used in order to understand if the choices that have been made are correct or if it is necessary to change some of them. Working on a phantom is a crucial step of the research that must take place before taking into account real mummies. In this way, all the necessary experiments on the instrument parameters and on the absorbed dose will be carried out in advance without involving the archaeological remains. If the images or the dose amount are not satisfactory, the test can be repeated with new parameters in an iterative manner. Of course, laboratory activities have their own costs and therefore carefully planning in advance all the details of the tests on the phantom represents an important preliminary step to be addressed in advance.

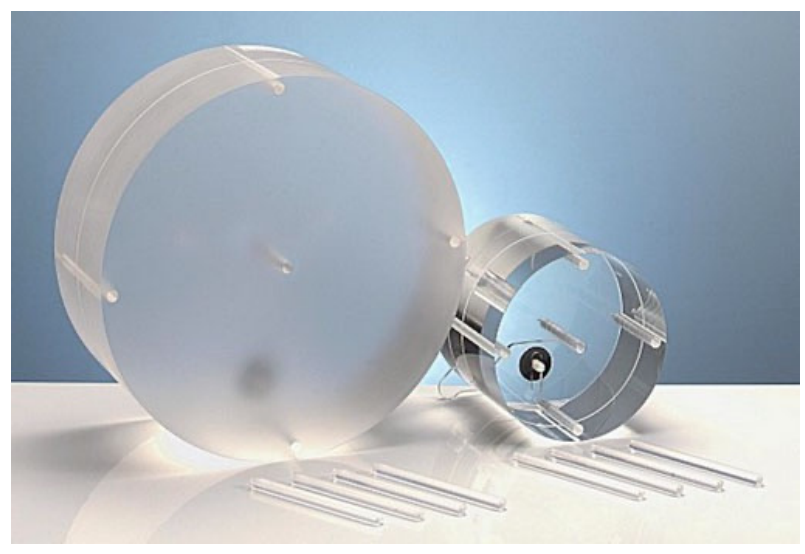

Figure 2: Cylindrical polymethylmethacrylate phantoms of 320 and $160 \mathrm{~mm}$ diameter with accommodations for the ionization chambers (Faggioni, Paolicchi, \& Neri, 2010). 


\section{Results}

The results obtained from the test will consist of a series of sections of the analyzed object that will compose its 3D model. In addition, it will provide information on the dose administered to the analyzed sample. The images of the sections may be sharp and characterized by a satisfactory resolution or may present 'artefacts', that is, small defects in the results. The dose that will be identified during the test on the phantom may be very close to that provided in the medical field. Bearing in mind that this dose must remain below the limit of $200 \mathrm{~Gy}$, it will be possible to experiment slightly higher values in comparison with the medical dose.

\section{Discussion}

Once the 3D models of the examined objects have been obtained from the test and the supplied dose has been evaluated, it will be possible to decide whether to accept the result or to repeat the test with new parameters. It is reasonable to expect that the doses given to the studied object will be in the order of some $\mathrm{mGy}$, anyway significantly lower than 200 Gy. However, it should be considered that over the last forty years, tomographic scans have been performed on mummies several times, without worrying about the effects on DNA. This will result in an increase in the total dose to which the mummy has been exposed. A mummy does not have the regenerative mechanisms characteristic of living beings and therefore the effects of the absorbed doses will accumulate. This aspect, in particular, is being thoroughly investigated.

\section{Conclusion}

Once the different parameters have been optimized, it will be possible to repeat this scan on a real mummy. In addition, this analysis will allow to grasp new details of the objects wrapped together with the body. Thanks to this technology, it will also be possible to read the inscriptions on the hidden objects. Finally, by increasing the level of detail, it will also be possible to investigate the internal part of the detected artefacts, study the marks left by their production process and obtain fresh information on some ancient Egyptian manufacturing techniques.

\section{Acknowledgements}

Thanks to Prof. Corinna Rossi and Prof. Michele Ezio Ruggero Maria Carboni (Politecnico di Milano), supervisor and co-supervisor of this research project. Thanks to Dr. Christian Greco, Director of Museo Egizio, Torino, for the access to the material related to the CT scan of the mummy of Kha. This paper represents an outcome of the project LIFE (Living In a Fringe Environment), funded by the ERC CoGrant 681673.

\section{References}

Bradley, D., \& Creagh, D. (Eds.) (2006). Physical Techniques in the Study of Art, Archaeology and Cultural Heritage, Volume 1. Amsterdam, Elsevier Science.

Brady, S. L., Mirro, A. E., Moore, B. M., \& Kaufman, R. A. (2015). How to Appropriately Calculate Effective Dose for CT Using Either Size-Specific Dose Estimates or Dose-Length Product. American Journal of Roentgenology, 204(5), 953-958. https://doi.org/10.2214/AJR.14.13317

Carmignato, S., Dewulf, W., \& Leach, R. (Eds.) (2018). Industrial X-Ray Computed Tomography. Cham: Springer International Publishing

Cox, S. L. (2015). A Critical Look at Mummy CT Scanning. The Anatomical Record, 298(6), 1099-1110. https://doi.org/10.1002/ar.23149

De Chiffre, L., Carmignato, S., Kruth, J. P., Schmitt, R., \& Weckenmann, A. (2014). Industrial applications of computed tomography. CIRP Annals, 63(2), 655-677. https://doi.org/10.1016/j.cirp.2014.05.011

Du Plessis, A., Broeckhoven, C., Guelpa, A., \& Le Roux, S. G. (2017). Laboratory x-ray micro-computed tomography: a user guideline for biological samples. GigaScience, 6(6), 1-11. https://doi.org/10.1093/gigascience/gix027

Du Plessis, A., Yadroitsava, I., \& Yadroitsev, I. (2020). Effects of defects on mechanical properties in metal additive manufacturing: A review focusing on X-ray tomography insights. Materials \& Design, 187. https://doi.org/10.1016/j.matdes.2019.108385

Faggioni, L., Paolicchi, F., \& Neri, E. (Eds.) (2010). Elementi di tomografia computerizzata. Milano: Springer.

Ferraris, E., Boano, R., Cesaroni, F., Gandini, G., Marochetti, E. F., \& Martina, M. C. (2017). Deir el-Medina e la tomba di Kha e Merit. In Moiso, B., Del Vesco, P., Missione Egitto 19031920 (p. 257-269). Torino: Franco Cosimo Panini.

Hall, A. C., Sherlock, E., \& Sykes, D. (2015). Does Micro-CT scanning damage DNA in museum specimens? Journal of Natural Science Collections, 2, 22-28.

Immel, A., Cabec, A. L., Bonazzi, M., \& Krause, J. (2016). Effect of X-ray irradiation on ancient DNA in sub-fossil bones Guidelines for safe X-ray imaging. Scientific Reports, 6(32969). https://doi.org/10.1038/srep32969

International Electrotechnical Committee (2004). IEC 61223-3-5. International Electrotechnical Committee.

Ikram, S. (2017). Morte e Sepoltura nell'Antico Egitto. Trofarello: Kemet Edizioni. Torino, Italy

Lewin, P.K., \& Harwood-Nash, D.C. (1977). Computerized axial tomography in medical archeology. Paleopathology newsletter, 17, 8-9.

Museo Egizio di Torino (2019). Archeologia Invisibile. Modena: Franco Cosimo Panini. 


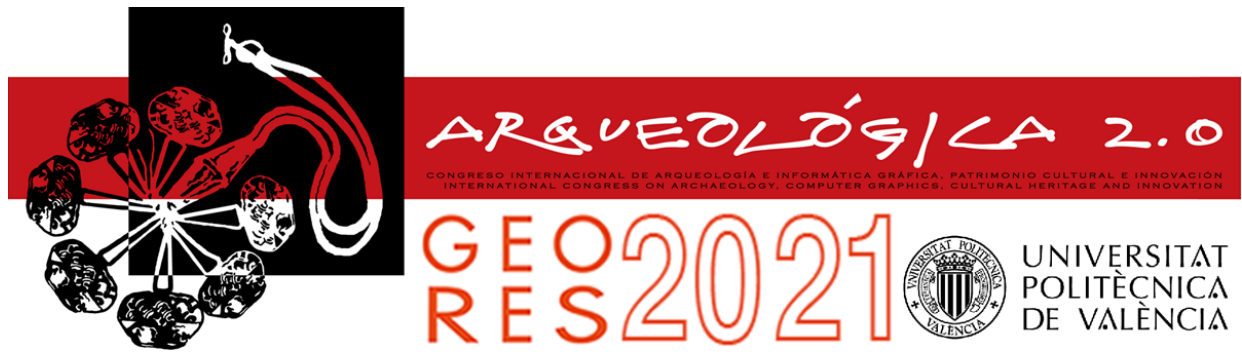

\title{
ANALYSIS OF HISTORICAL EVOLUTION AND PRESENT STATE OF CONSERVATION OF REGIO VII, INSULA 14 IN POMPEII
}

\author{
Alice Capobianco ${ }^{a}$, Sara Gagliolob, ${ }^{\text {, }}$, Silvia Pallecchia, Domenico Sguerso ${ }^{b}$ \\ a Department of Antiquity, Philosophy and History, University of Genoa, Via Balbi 4, 16126 Genoa, Italy. alicecapobianco@ymail.com; \\ silvia.pallecchi@unige.it \\ ${ }^{\mathrm{b}}$ Laboratory of Geodesy, Geomatics and GIS, Department of Civil, Chemical and Environmental Engineering, University of Genoa, Via \\ Montallegro 1, 16145 Genoa, Italy. sara.gagliolo@edu.unige.it; domenico.sguerso@unige.it
}

\begin{abstract}
:
The present work is intended to provide preliminary results about the ongoing collaboration in the study of a site located in the Archaeological Park of Pompeii, the Regio VII, Insula 14. The research group include experts in archaeology, geomatics and structural engineering disciplines belonging to the University of Genoa. The aim of this cooperative work is twofold: on the one hand, to deepen the designated use that rooms had in the past and their spatial layout, examining the surviving hints about what is no longer visible; on the other hand, to analyse the state-of-the-art in terms of structural behaviour, checking the eventual necessity of urgent retrofitting interventions. In this scenario, there is the necessity of high-quality surveying, geometrically and thematically reliable, in order to allow further studies basing on the 3D representation of the entire "insula" and 2D projection of each wall. A description of the site of interest is reported, then information about the survey campaign performed in September 2020 employing Photogrammetry, Terrestrial Laser Scanner (TLS), Total Station (TS) and Global Navigation Satellite System (GNSS) techniques follows. A brief excursus about the survey operations and the ongoing post-processing is shown, with a mention to the expectations about the final results.
\end{abstract}

Keywords: cultural heritage, documentation, walls' stratigraphy, 3D reconstruction, survey integration and accuracy, 3D virtual analysis

\section{Introduction}

In the last years, the application of Geomatics techniques to the context of Cultural Heritage is increasingly a consolidated practice. In facts, the acquisition of reliable metrical and thematic information of an object is extremely important in view of its physical and testimonial preservation and study.

The present work, born from the cooperation of archaeologists and engineers, is intended to describe the preliminary results of the ongoing study about the Regio VII, Insula 14 site in the eminent scenario of the Archaeological Park of Pompeii (Capobianco, 2019; Pallecchi \& Santoro, 2019; Pallecchi, 2018). Concerning the applied techniques, an integrated approach has been planned for the survey (Gagliolo et al., 2018a; Gagliolo et al., 2018b; Casella, Chiabrando, Franzini, \& Manzino, 2019), in order to exploit all the features of the available instrumentation, consisting in Unmanned Aerial Vehicle (UAV) and terrestrial Photogrammetry, Terrestrial Laser Scanner (TLS), Total Station (TS) and Global Navigation Satellite System (GNSS).

The territory of the Archaeological Park of Pompeii has been recently the scene of several integrated surveys, as described e.g. in Francolini, Girelli, \& Bitelli (2020), Verde (2020), Monego, Menin, Fabris, \& Achilli (2019).

In the analysed scenario, the survey of the area is mandatory to support further studies from the archaeological and structural points of view, based on reliable metrical knowledge of the site. Hence, the two aims are: on the one hand, to investigate the destination of use that each space had in the past and the reciprocal relationship among rooms, deepening the surviving hints about what is no longer visible; on the other hand, to analyse the state-of-the-art in terms of structural behaviour, to check the eventual need of retrofitting urgent interventions.

The dissertation is organized as follows: section 2 contains a description of the site; section 3 regards the survey campaign carried out in September 2020, with a brief report of the operational steps and the employed instrumentation; section 4 concerns the ongoing postprocessing phase, mentioning its criteria. Conclusions and future perspectives complete the paper.

\section{Regio VII, Insula 14: site description}

The Regio VII, Insula 14 is a district of about $(60 \times 35) \mathrm{m}$, located in the western part of Pompeii: it faces south on 
the most important road artery of the city, Via dell'Abbondanza, and is bordered westward by Vico della Maschera, northward by Vico dello Scheletro and eastward by Vico del Lupanare. The area of interest is located close to some of the most important monuments of Pompeii, including the Civil Forum, the Stabian Baths, the Triangular Forum and the Theater District, confirming its importance in the urban development framework.

The insula is composed by three houses and 12 shops, divided among 20 entrances located on all four sides of the district. In the northern part of the complex, in correspondence with the boundary of houses VII, 14, 9 and 15 , a masonry structure made up of large blocks of soft lava is visible (De Simone et al., 2008). Dating back to the 6th century $\mathrm{BC}$, it can be considered a proof of the antiquity of this area of Pompeii within the urban fabric.

The building on which the survey activity has been focused (Domus VII, 14, 5) is a large dwelling $\left(656 \mathrm{~m}^{2}\right)$ which occupies almost the entire western sector: it is an atrium domus, composed of 27 rooms, whose life stages are connected with those of the adjacent shops.

The activities of the University of Genoa, started in 2016 and still ongoing (Permission DDG 553 34.31.07/246.7 of 26 January 2016 and renewal 34.31.07/3.4.7/2018 of 9 April 2019), have the aim to reconstruct a detailed picture of the history of this district of Pompeii, outlining its evolution over time, its phases of life, its relationship with the rest of the city, the function of the shops facing the street. Parallel to the excavation activity, which led to important results regarding the history and the function of the shops, a stratigraphic analysis of the walls was carried out, involving all the structures of the district. The aim of this activity is to outline the construction events of the insula and its changes from a structural point of view, proposing a reconstruction of its appearance in some phases: traces of secondary elements (stairs, regular rows of holes in the walls, drain pipes) may suggest the presence of one or more upper floors. The survey and the structural analysis activities could confirm the hypotheses proposed by the stratigraphic analysis.

In particular, the activities of archaeological investigation and wall analysis have been concentrated in recent years in the western portion of the insula, which includes the Domus VII, 14, 5 and the shops $1-4,6-7$, managing to reconstruct the evolution and the succession of phases ranging from the late Samnite period (III-II century $\mathrm{BC}$ ) to the eruption of 79 AD.

\section{Survey campaign}

A survey campaign has been performed in the period $22^{\text {nd }}-24^{\text {th }}$ September 2020 , using UAV and terrestrial Photogrammetry, TLS, TS and GNSS techniques. A preliminary inspection has been achieved onsite on $18^{\text {th }}$ July 2020 , in order to define the aims with the reunited research team, consisting in three groups expert in archaeology, geomatics and structural engineering.

Concerning the employed instrumentation, the UAV photogrammetric survey has been achieved by means of the drone DJI Mavic 2 PRO, with an embedded Hasselblad L1D-20c camera. The focal length is $10 \mathrm{~mm}$, while the 20 MP sensor is a CMOS whit a size of 1 ". Four datasets have been acquired, including two nadiral (Fig. 1) from different flight heights Above Ground Level (AGL),
$40 \mathrm{~m}$ and $15 \mathrm{~m}$ respectively, and two tilted $\left(45^{\circ}\right)$ taken from two concentric paths looking towards the internal and the external of the perimeter at $15 \mathrm{~m} \mathrm{AGL}$. The resulting Ground Sample Distance (GSD) at $15 \mathrm{~m}$ is about $4 \mathrm{~mm}$, sufficiently precise to obtain a reliable overview of the whole site; instead, the GSD at $40 \mathrm{~m}$ is about $10 \mathrm{~mm}$, allowing a general framework of the area. The total amount of frames is about 1400 .

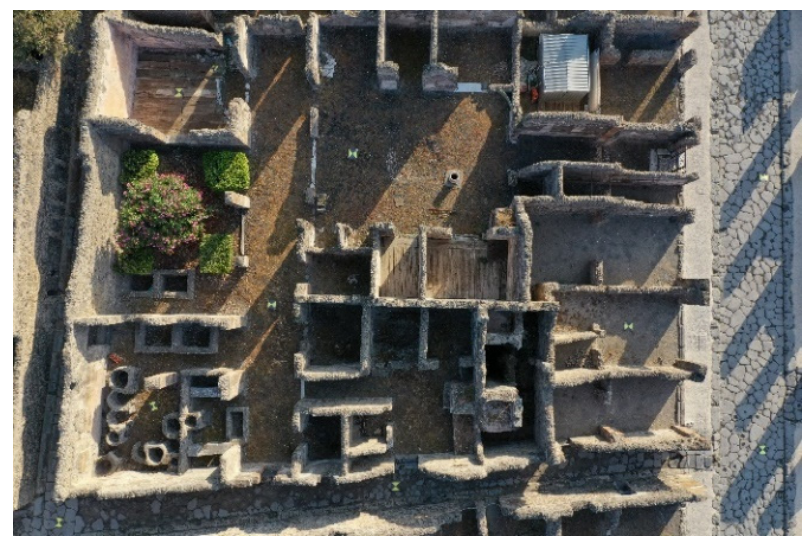

Figure 1: Aerial view of the Domus 5 and close workshops.

The Ground Control Points (GCPs) and Check Points (CPs), 21 in total, have been identified by means of flexible PVC supports coloured with a cross-pattern of alternated black and yellow triangles. Their coordinates have been acquired by means of the TS Leica TCR703, located on 13 station points.

The TLS has been employed in order to acquire more in details the specific areas of interest, in particular the rooms of Domus 5. A total amount of 26 scans have been performed in the likewise spaces of the building by means of the $\mathrm{Z}+\mathrm{F} 5006 \mathrm{~h}$ scanner, setting super high resolution corresponding to 20000 points on $360^{\circ}$. Considering an approximate distance from the walls up to 5 meters, the resulting spacing between points is maximum $1.6 \mathrm{~mm}$. Each scan is focused on a single room, typically closed on three sides. In order to avoid the excessive increase of the number of scans needed, the reciprocal overlapping of points for the registering operation has been disregarded, favouring the alignment with the survey coming from UAV Photogrammetry. The GNSS Network Real Time Kinematic (NRTK) survey, in connection with the Regional positioning Service of Campania, has been applied also to the GCPs if no obstructions were in the line of sight of satellites direction.

The use of a couple of clearly identifiable points for each scan, represented by nails and acquired by means of GNSS, has been adopted for the registration in a global Reference Frame (RF), obtaining an approximate reciprocal positioning and orientation of the scans themselves.

The terrestrial photogrammetric survey, acquired by means of the Canon Eos 40D camera with a focal length of $17 \mathrm{~mm}$, has been planned in order to maintain a maximum distance from the walls of 5 meters, obtaining a GSD of $1.7 \mathrm{~mm}$. Nevertheless, for a further enhancement of the level of detail, the distance onsite has been maintained around 2 meters, corresponding to a GSD of $0.7 \mathrm{~mm}$. About 7000 images have been collected. 


\section{Ongoing post-processing operations}

The ongoing post-processing operations are based on the same abovementioned criterion used to collect data: a different level of detail is distinguished for the whole Insula or for the specific parts of interest in Domus 5.

Concerning the photogrammetric post-processing, the software packages that will be employed are Agisoft Metashape $\odot$ and MicMac: the former will be used for the reconstruction of the 3D model of the entire Insula by means of the aerial images, while the latter will be used to treat data from terrestrial photogrammetry. The aim is to use the latter dataset in order to produce high-reliable orthophotos with an adequate resolution to perform both archaeological studies and structural analysis.

The TS and the GNSS dataset will be used to attribute a local or global RS, respectively, to $3 \mathrm{D}$ and $2 \mathrm{D}$ products. Finally, the TLS scans will be reciprocally registered, to have a unique high-resolution model of the Domus 5 .

\section{Conclusions and future perspectives}

The present work concerns the preliminary results of synergic cooperation among three research groups of the University of Genoa, experts in archaeology, geomatics and structural engineering, in the analysis of the Regio VII, Insula 14 site within the Archaeological Park of Pompeii. The aim is twofold: starting from a reliable 3D reconstruction of the area, archaeological and structural analysis will be performed to investigate the past and the present condition of the site. The interest is focused on the one hand on the past destination of use of the rooms and their spatial layout, inferable from what still present nowadays, on the other hand on the state-of-the-art in terms of structural behaviour, to recognize eventual risks.

The eminent context is absolutely stimulating and worthy, as well as the cooperative work, which allows to further appreciate the value of the different skills.

The future perspectives consist in: first, the conclusion of the post-processing operations related to the survey, then the achievement of archaeological and structural analyses to both recognize the historical evolution of the site and the present state of conservation.

\section{Acknowledgements}

The authors wish to thank:

- the directorate of the Parco Archeologico di Pompei, for the release of the authorisations and the support;

- Prof. Stefano Podestà and his collaborators of Yellow Room Engineering for the contribution they will offer in the structural analysis;

- Ce.Dro., University of Genoa, for the realization of the UAV photogrammetric survey;

- Scuola Droni Genova and Eurodrone Flight Systems for the cooperation.

\section{References}

Capobianco, A. (2019). Pompei. Regio VII, Insula 14. Analisi stratigrafica degli elevati del settore occidentale. Master Degree Thesis, University of Genoa, Italy.

Casella, V., Chiabrando, F., Franzini, M., \& Manzino, A. (2019). Accuracy Assessment of a Photogrammetric UAV Block by using Different Software and Adopting Diverse Processing Strategies. In Proceedings of the 5th International Conference on Geographical Information Systems Theory, Applications and Management - Volume 1: GISTAM, 7787, Heraklion, Crete, Greece. https://doi.org/10.5220/0007710800770087

De Simone, A., Lubrano, M., Cannella, R., Caprio, L., Carannante, S., Grazioso, M. R., De Luca, M., \& Franciosi, V. (2008). Pompei, Regio VII, Insula 14. In M.P. Guidobaldi \& P.G. Guzzo (Eds.), Nuove ricerche archeologiche nell'area vesuviana (Scavi 2003-2006). Atti del Convegno internazionale, Roma 1-3 febbraio 2007 (pp. 283-292).

Francolini, C., Girelli, V. A., \& Bitelli, G. (2020). 3D image-based surveying of the Safe of the Obellio Firmo Domus in Pompeii. Int. Arch. Photogramm. Remote Sens. Spatial Inf. Sci., XLIII-B2-2020, 1389-1394. https://doi.org/10.5194/isprs-archives-XLIII-B2-2020-1389-2020

Gagliolo, S., Ausonio, E., Federici, B., Ferrando, I., Passoni, D., \& Sguerso, D. (2018a). 3D cultural heritage documentation: A comparison between different photogrammetric software and their products. Int. Arch. Photogramm. Remote Sens. Spatial Inf. Sci., XLII-2, 347-354. https://doi.org/10.5194/isprs-archives-XLII-2-347-2018

Gagliolo, S., Fagandini, R., Passoni, D., Federici, B., Ferrando, I., Pagliari, D., Pinto, L., \& Sguerso, D. (2018b). Parameter optimization for creating reliable photogrammetric models in emergency scenarios. Applied Geomatics, 10(4), 501514. https://doi.org/10.1007/s12518-018-0224-4

Monego, M., Menin, A., Fabris, M., \& Achilli, V. (2019). 3D survey of Sarno Baths (Pompeii) by integrated geomatic methodologies. Journal of Cultural Heritage, 40, 240-246. https://doi.org/10.1016/j.culher.2019.04.013

Pallecchi, S. (2018). Pompei: indagini archeologiche nelle botteghe della Regio VII. Campagna 2016 (VII, 14,1-3). The Journal of Fasti Online, FOLD\&R.

Pallecchi, S., \& Santoro, E. (2019). Pompei: indagini archeologiche nelle botteghe della Regio VII. Campagne 2017-2018 (VII, 14, 1-7). The Journal of Fasti Online, FOLD\&R.

Verde, D. (2020). Vaulted Structures in The Archaeological Park of Pompeii: 3D Survey And Monitoring. Int. Arch. Photogramm. Remote Sens. Spatial Inf. Sci., XLIV-M-1-2020, 303-309. https://doi.org/10.5194/isprs-archives-XLIVM-1-2020-303-2020 


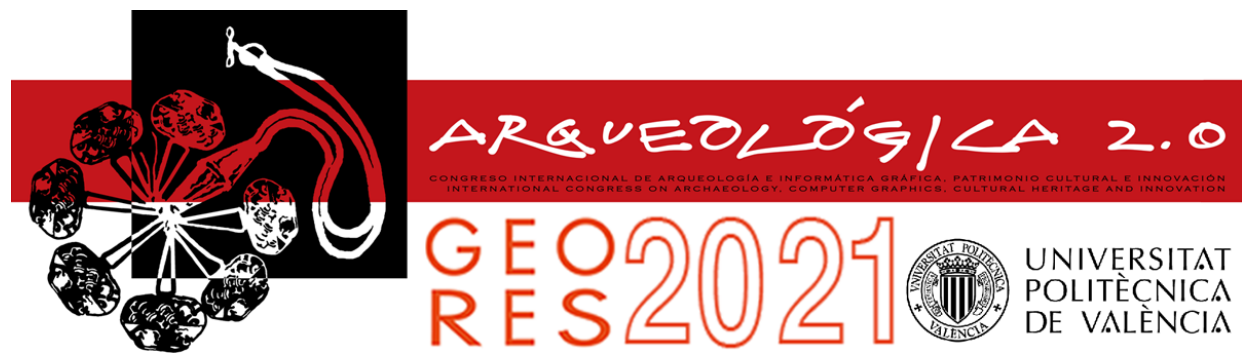

\title{
3D TECHNOLOGIES IN CYPRIOT PREHISTORIC ARCHAEOLOGY AND HERITAGE: THE ERIMI USER EXPERIENCE
}

\author{
Francesca Dolcettia, ${ }^{,}$, Luca Bombardieri ${ }^{\mathrm{b}}$ \\ a Department of Archaeology, University of York, King's Manor, York, YO1 7EP, UK. francesca.dolcetti@gmail.com \\ b Dipartimento DFCLAM, Università di Siena, Palazzo S. Niccolò, Via Roma 56, 53100 Siena, Italy. Iuca.bombardieri@unisi.it
}

\begin{abstract}
:
The use of digital technologies is deeply affecting our engagement with the archaeological record and reshaping cultural heritage encounters. However, the creation of digital resources for specialists and non-specialists alike is rarely informed by design theory and practices, even though design is deeply embedded in archaeological practices and in the way archaeologists and heritage professionals produce and share knowledge. By not engaging with core design epistemologies and audiences we are missing meaningful opportunities in terms of alignment of project goals with user outcomes and the creation of more impactful archaeology. This paper discusses the application of 3D technologies within the Erimi Archaeological Project and the creation of 3D models and interactive digital media for research and public engagement, through an iterative process of User Experience Design (UXD), evaluation and implementation or redesign based on users' feedback and insights gained through each iteration.
\end{abstract}

Keywords: digital archaeology, digital cultural heritage, 3D modelling, museum experience design, Erimi, Cyprus

\section{Introduction}

In the past few decades, the use of 3D technologies has become ubiquitous within the archaeological and heritage sectors, changing how the archaeological evidence is collected, interpreted, shared and communicated.

Three-dimensional models of stratigraphy and structural remains are a valuable tool for the interpretation of stratigraphic sequences and the analysis of spatial relationships. As such, more and more excavations have implemented 3D documentation workflows using laser scanning and photogrammetric techniques to generate 3D models at the trowel's edge (Dell'Unto, Landeschi, Apel, \& Poggi, 2017; Opitz, 2018).

Moreover, museums have been increasingly adopting digital technologies as part of their efforts to democratise their practices and transform what is usually a passive learning process into a more active performance. Virtual and augmented reality installations, 3D prints, mobile apps and other interactive digital media have become a meaningful medium for museums and exhibitions, since they offer a wide range of possibilities for a more dynamic, interactive and emotionally engaging experience. (Simon, 2010; Di Franco, Camporesi, Galeazzi, \& Kallmann, 2015; Economou, 2015).

Using the case study of the Middle Bronze Age site of Erimi-Laonin tou Porakou (Limassol, Cyprus), this paper discusses the application of $3 D$ technologies as a research tool and a medium for public communication, by presenting the iterative design journey from a standalone interactive 3D model to a multimedia museum visiting experience (work undertaken as part of Dolcetti PhD research).

\section{Prehistoric Erimi in context}

The development of the Middle Bronze Age community at Erimi (2000/1950-1650 BC) in the southern coastal region of the island, takes place on the verge of the origin of the urban society in Cyprus.

Thanks to a wide-ranging and multi-scalar analysis of the archaeological evidence, the Italian research team has identified three major occupational areas different in use and functions, where the Prehistoric community had decided to organize its space for living, working, gathering or burying and commemorating the dead. On the top of the hill we locate the central complex with the main function of a workshop (Area A). On the large natural terrace extending southward the workshop complex, the lower city extends with its dense framework of housing units belonging to the residential area (Areas B and T): it is surrounded and protected by an imposing circuit wall that separates the settlement from the funerary areas (Area E). Here large chamber tombs and smaller pit tombs were excavated into the limestone bedrock terraces.

The processing structures and storage spaces, together with the residual artefacts and raw materials from the central workshop complex, are evidence of a complete

*Corresponding Author: Francesca Dolcetti, francesca.dolcetti@gmail.com 
textile chaîne opératoire, consisting of the diversified activities of spinning, weaving and dyeing. The great ideological significance that this community ascribed to textile craftsmanship is reflected in the increasing efforts to secure and monumentalize the workshop complex; and, on a broader perspective, the success in trade exchanges accelerates the emergence of elements of social differentiation based on the prestige of some family groups or clans (Bombardieri, 2017).

Erimi offers an emblematic case study as the nature of its interpretation addresses many of the issues present in the field of 3D visualisation of archaeological sites. Its poor state of preservation (due to erosion, bioturbation and grazing) is problematic for achieving a comprehensive interpretation of the site's architecture and more broadly in terms of communication to academic and public audiences. Erimi in fact, like many other archaeological sites, in its present state does not have features that are easily recognisable and understandable by people outside a restricted circle of experts, thus making their 3D visualisation extremely valuable for public engagement.

\section{From field to museum}

The first design iteration was carried out between 2015 and 2016 and resulted in an interactive 3D model of the workshop complex, presenting the area in its actual state and the hypothetical reconstruction of the built environment, modelled according to several interpretive hypotheses made over the years by the Erimi research team (Dolcetti, Bonora, Fiorini, Conti, \& Tucci, 2017).

The model was then imported in Unity (Unity Technologies, 2021), to create a graphic user interface (GUI) that allows to explore the 3D model, while retrieving information through interactive hotspots, and also provides a first-person navigation via avatars (luminous silhouettes) (Fig. 1).

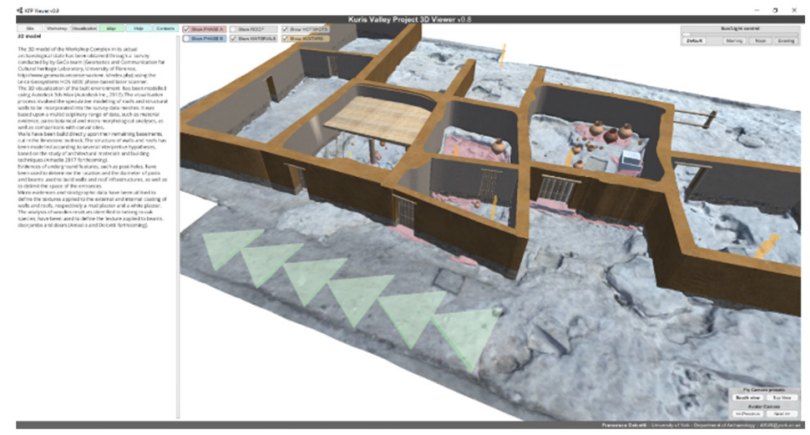

Figure 1: Erimi interactive 3D model (credit: Francesca Dolcetti).

The GUI was subjected to peer review and assessed through a series of interviews and focus groups conducted with members of the Erimi research team. Feedback from participants highlighted how the interaction with the 3D model heightened their comprehension of the built space, seen as more tangible, while also fostering new interpretive issues regarding accessibility and the different use of spaces.

Moreover, the interface was evaluated by different user groups (experts, non-experts and students) outside the Erimi research team. Feedback gathered through a multistage survey was used to assess different audiences' responses to the interactive $3 \mathrm{D}$ model and subsequently integrated within the redesign and improvement of the GUI during the second design iteration (Dolcetti, 2021 in prep).

In 2018, the Erimi research team started a collaboration with the Musei Reali in Turin to develop the exhibition "Cipro. Crocevia delle Civiltà", aimed at presenting the history and art of Cyprus across millennia in its paradigmatic role within cultural exchanges in the Mediterranean. As part of the exhibition, the thematic session "Turin in Cyprus. From fieldwork to virtual reconstruction: 3D models and immersive experiences", was designed with the purpose of providing a multimedia immersive experience of Erimi and enhancing visitors' engagement with ancient material culture through different interactive media. In order to do so, the pathway was designed as a journey into the archaeological site through the stories and lives of three artefacts selected from the Erimi assemblage (a goat-shaped askos, a comb-shaped pendant and a decorated spindle whorl), while presenting archaeologists' interpretation of the symbolic meaning embedded in these artefacts and their significance for the Prehistoric community at Erimi.

Here, the original $3 \mathrm{D}$ model, designed as a computerbased standalone feature, was refined and enhanced using users' feedback gathered during the previous iteration. Some components of the GUI, for example, were criticised in terms of usability and comprehensibility of text descriptions. Users reported the feeling of disorientation while interacting with the model and suggested the adoption of a story as a recommended path of exploration. Users also advocated the use of less academic jargon to ensure readability. Moreover, users' feedback registered a negative reaction to the choice of using avatars as neutral silhouettes.

To overcome these issues, the following improvements were undertaken. Firstly, the exploration mode was redesigned, providing a predefined exploration path to avoid the sense of disorientation. As for information, content was revised and layered so it can be accessed if desired, without being overwhelming or disruptive of the visitor experience (Fig. 2).

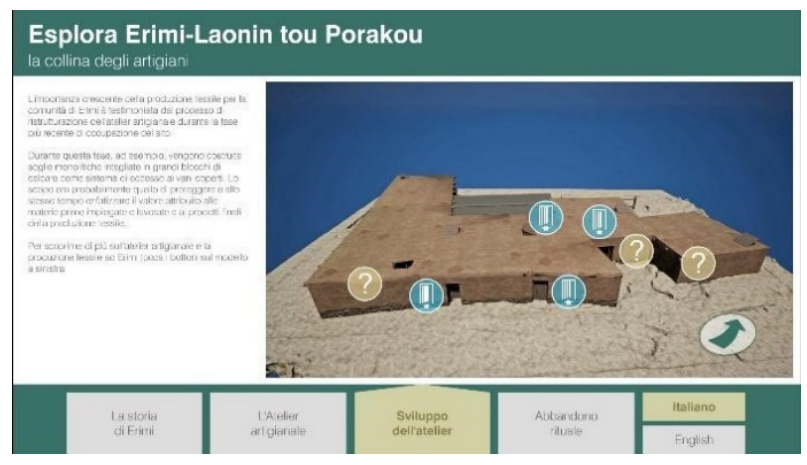

Figure 2: Exhibition touchscreen app (credit: Francesca Dolcetti).

Secondly, a narration was developed to make the visitor experience more engaging (Perry, 2019). The story of the artefacts from Erimi, interpreted as common-use objects and ornaments embedded with symbolic value in relation to textile activities, introduces a narrative on how textile productions were pivotal to the local economy and performed by a large number of the community members. It also presents one of the interpretations about the 
abandonment of the settlement and how these artefacts, along with other objects found in the workshop complex, were left behind on purpose as a part of a ritual practice involving the burning of significant structures, to physically and symbolically 'seal off' a place that was an integral part of the community identity (Amadio \& Bombardieri, 2018).

Finally, to convey the sense of an inhabited place and provide a multi-sensorial experience, the 3D model was populated with animated characters, performing working activities supposedly conducted at Erimi, and complemented by a natural and human soundscape (Dolcetti, 2021 in prep).

The visitors' pathway also presents 3D printed replicas of the three artefacts associated with interactive tablets to offer visitors a tactile and embodied experience with the objects, while retrieving more contextualised information on their function (Fig. 3).

The overall aim is to encourage visitors to reflect on the cultural significance of these artefacts and what they can tell us about the identity of the community who made them.

\section{Discussion and conclusions}

In this paper, we presented how 3D technologies have been integrated within the Erimi Archeological project as aids for archaeological interpretation and as a means of public engagement. By adopting an iterative design process the initial interactive 3D model has been refined and implemented as part of a multisensory museum experience to enable a more reflective and critical engagement with the archaeological record. Further evaluation during the exhibition, currently on hold due to the COVID-19 pandemic, will provide a deeper understanding of the impact of digitally enhanced museum visiting experiences on a wide and variegated audience.

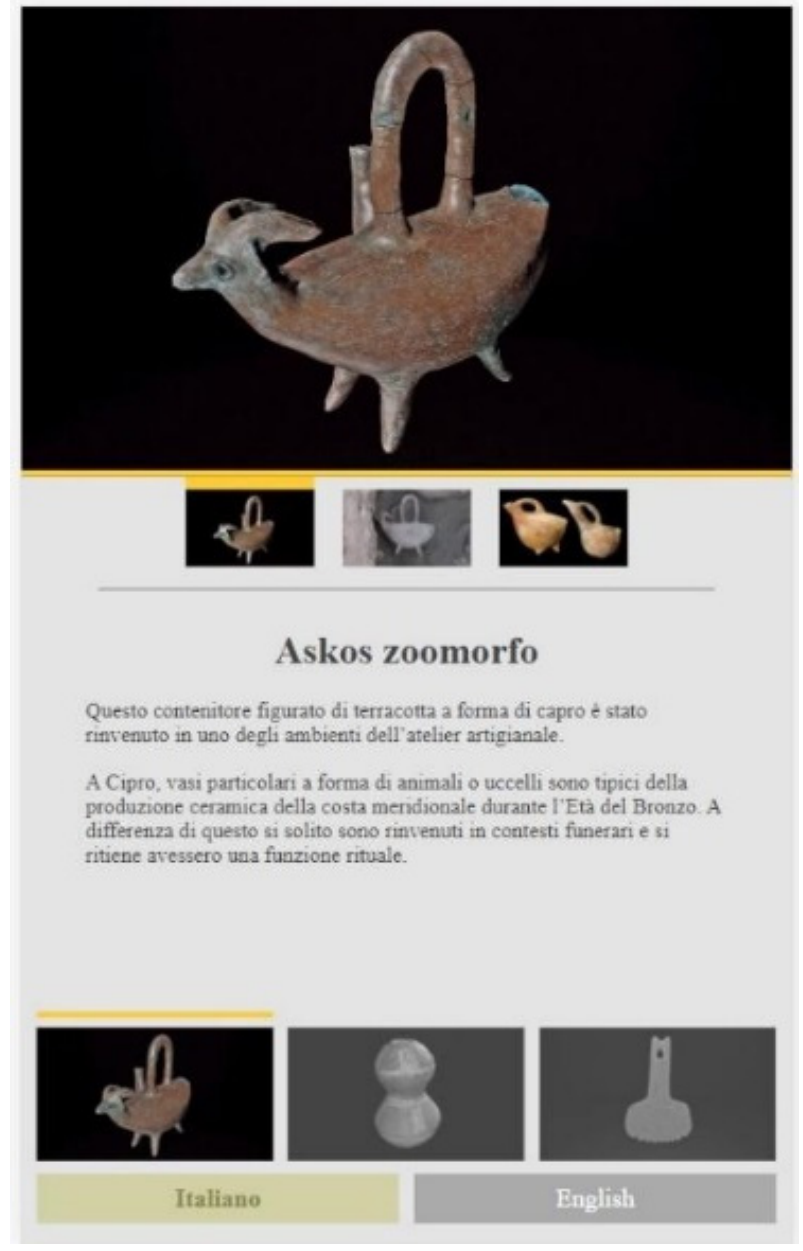

Figure 3: Exhibition tablet app (credit: Francesca Dolcetti).

\section{Acknowledgements}

This work was supported by the Università di Torino, the Italian Ministry of Foreign Affairs and the Ente CRT (Grant 2019.0470. ArcheoTech to ArcheoTeach) Thanks are also due to the University of York, the Department of Antiquities of Cyprus and the Erimi team.

\section{References}

Amadio, M., \& Bombardieri, L. (2018). Abandonment processes at Middle Bronze Age Erimi: A multi-scalar approach. Antiquity, 93(368), 1-7. https://doi.org/10.15184/aqy.2019.29

Bombardieri, L. (2017). Erimi-Laonin tou Porakou. A Middle Bronze Age Community in Cyprus. Excavations $2008-2014$. Studies in Mediterranean Archaeology Vol. 145. Uppsala, Sweden: Paul Åströms Förlag.

Dell'Unto, N., Landeschi, G., Apel, J., \& Poggi, G. (2017). 4D recording at the trowel's edge: Using three-dimensional simulation platforms to support field interpretation. Journal of Archaeological Science: Reports, 12, $632-645$. https://doi.org/10.1016/j.jasrep.2017.03.011

Di Franco, P. D. G., Camporesi, C., Galeazzi, F., \& Kallmann, M. (2015). 3D Printing and Immersive Visualization for Improved Perception of Ancient Artifacts. Presence: Teleoperators and Virtual Environments, 24(3), $243-264$. https://doi.org/10.1162/PRES_a_00229

Dolcetti, F. (2021). Designing digital experiences in archaeology: integrating participatory processes into archaeological practice. PhD Thesis. York, UK: University of York. Manuscript in preparation.

Dolcetti, F., Bonora, V., Fiorini, L., Conti, A., \& Tucci, G. (2017). 3D modelling and architectural visualisation. In: L. Bombardieri, Erimi Laonin tou Porakou. A Middle Bronze Age Community in Cyprus. Excavations 2008-2014 (pp. 327-334). Studies in Mediterranean Archaeology Vol. 145. Uppsala, Sweden: Paul Åströms Förlag.

Economou, M. (2015). Heritage in the Digital Age. In: W. Logan, M.N. Craith \& U. Kockel (Eds.), A Companion to Heritage 
Studies, 15 (pp. 215-228). Hoboken, USA: John Wiley \& Sons, Inc. https://doi.org/10.1002/9781118486634.ch15

Opitz, R. (2018). Publishing Archaeological Excavations at the Digital Turn. Journal of Field Archaeology, 43(1), 68-82. https://doi.org/10.1080/00934690.2018.1505409

Perry, S. (2019). The Enchantment of the Archaeological Record. European Journal of Archaeology, 22(3), 354-371. https://doi.org/10.1017/eaa.2019.24

Simon, N. (2010). The participatory museum. Santa Cruz, USA: Museum 2.0.

Unity Technologies (2021). Unity Real-Time Development Platform | 3D, 2D VR \& AR Engine. Retrieved February 2, 2021, from https://unity.com/ 


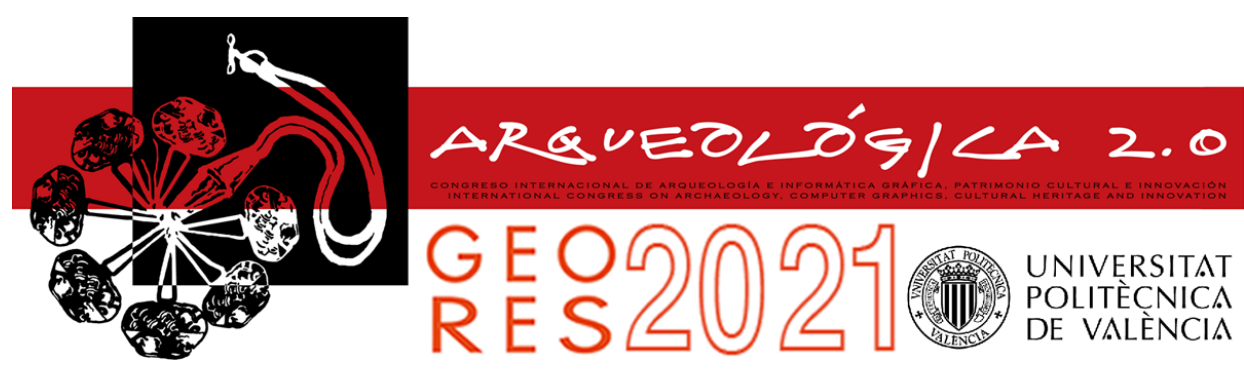

Proceedings of the joint international event $9^{\text {th }}$ ARQUEOLÓGICA

$2.0 \& 3^{\text {rd }}$ GEORES

Valencia (Spain).

26-28 April 2021

Received: 23/11/2020

Accepted: $27 / 02 / 2021$

\title{
ALGORITHMIC MODELLING PROCESSES IN SCAN-TO-BIM WORKFLOWS
}

\author{
Raffaele Argiolas \\ Department of Civil and Environmental Engineering and Architecture, University of Cagliari, Via Marengo 2, 09123 Cagliari, Italy. \\ raffaele.argiolas@hotmail.com
}

\begin{abstract}
:
The benefits brought by the application of the BIM philosophy to built heritage are now widely recognised, so much so that a closely related methodology, Heritage BIM. The HBIM finds practical confirmation in the so-called Scan-to-BIM processes; the data of architectural organisms, in the form of point clouds, are the basis on which the modelling of information is developed, to arrive at geometric models within which all the information necessary for the reading and interpretation of the architectural artefact as well as for its preservation and management is collected. In the paper some of the problems that arise from the application of the Scan-to-BIM processes to complex historical elements are analysed, particularly related to the phases of creation of three-dimensional models. In addition, a reasoning is made about how such problems can be solved or at least mitigated, thanks to the use of algorithmic modelling; the aim is to parameterise the generative process of the models, when the model itself cannot be parametric. In order to do this, a classic typology of historical architecture was examined: late-gothic vaulted systems.
\end{abstract}

Keywords: HBIM, algorithmic modelling, scan-to-BIM, geometric rules, late-gothic vaults

\section{Introduction}

In the Scan-to-BIM workflows, at the base of HBIM methodology (Murphy, McGovern \& Pavia, 2009), we can identify as the main purpose the transition from survey data to 3D models (Fig. 1); these models must be suitable to be enriched with the multidimensional information characteristic of the BIM philosophy. The main criticalities can be detected especially in the interpretation phase of the survey data, almost always represented by point clouds, and in their transposition into three-dimensional models. The management and processing of point clouds is still a highly time-consuming and resource-intensive process, as evidenced by the numerous studies aimed at the automation of these steps (Liu, 2016; Amano \& Lou, 2016). But while in some cases, for elements with relatively simple geometries, the results obtained by the algorithms for recognising architectural components have given excellent results (Macher, Landes, Grussenmeyer, \& Alby, 2014), in the case of particularly complex geometries the process proves to be much more difficult (Andriasyan, Moyano, Nieto-Julián, \& Antón, 2020). This can be attributed not only to the geometric complexity of the elements, but also to their enormous variety of declinations; this makes it more problematic to identify characteristics that allow precise recognition of shapes. The same factors influence the modelling phases, since complex historical elements often represent unicum that are difficult to reuse in different case studies or contexts; among the causes we can identify the excessive rigidity of the tools for parameterization and modelling of objects within BIM environment. If it is possible to obtain sufficiently complex models, this would in any case require excessive processing time (Aubin, 2014). Therefore, the use of modelling tools external to BIM environments is often necessary. Finally, it should be remembered that the identification of the components in the segmentation phases of the point cloud and modelling is essential to preserve the hierarchy of architectural elements. This is particularly important for the understanding of the architectural organism, both as regards its spatial organisation and construction techniques. The final model must therefore maintain the subdivision but also the correlations of the various components.

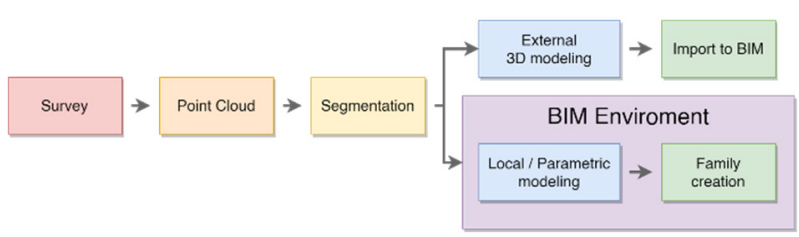

Figure 1: Standard Scan-to-BIM workflow.

\section{Methodology}

Algorithmic modelling is a technique of generating 3D models by executing an instruction algorithm; specifically, the Dynamo extension of Autodesk Revit software has been used. Dynamo use a visual programming language (VPL) that allows the development of algorithms through a flowchart structure and/or a dedicated scripting language (DesignScript). The advantages offered by this type of tools is, in addition to the possibility of keeping the 
entire process within the BIM environment, to allow parameterization upstream of model generation.

This means that, unlike standard parametric modelling, a model is not offered with parameters associated with it for subsequent modification, but the parameters are changed before the model is generated. For greater clarity, imagine that it is necessary to adapt a family (how variants of a typology are called in Revit) to a specific case study; this family will offer a predetermined number and type of parameters imposed according to a "basic" model, and therefore cannot be modified except by acting on the model of the family itself. Moreover, the parameterisation tools offered by the BIM environment often do not allow excessive nesting of parameters. If, for example, you want to create a series of $n$ objects, if $n$ is variable, the objects must all be the same; if, on the other hand, you want different objects, their number must be known and fixed in advance. In algorithmic modelling, the initial number of parameters itself becomes a variable; the simple parsing of a string, for example, allows the input of an unfixed number of variables. In addition, the automatic repetition of the entire process each time the parameters are changed makes the nesting of the parameters executable without any problem. Finally, it should not be forgotten that geometric modelling is only a part of the operations that can be performed from the VPL environment, which also include information modelling tools, as well as the possibility of interacting and modifying elements already present in the BIM project, or managing the dialogue with external software and data sources.

Though, since the generative flow is based on an algorithm, it is essential to identify instructions, geometric rules, which lead to the creation of the desired model. The hypothesis underlying the research is that such rules can be deduced from historical treatises, by virtue of the enormous importance that the so-called "geometric rule" has had in the history of construction (Capone \& Lanzara, 2019). These rules are evidently linked to the category of elements analysed and not to the single object or context; consequently, the characteristic of reusability of the algorithm, as provided for by the BIM methodology, becomes evident. A single algorithm can, when the initial parameters deriving from the survey vary, generate multiple models, automating a large part of the process. Moreover, the algorithm, developed on the same "instructions" historically used for the definition of shapes, allows not only to preserve the hierarchy of the elements but also the rules: it becomes in fact metadata of the model itself, as it describes its geometric genesis.

It is interesting to note that such an approach to modelling offers interesting perspectives also regarding the phase of extrapolation of information from the point cloud. If in the classical methodology the segmentation of the point cloud is necessary from the beginning for the definition of the shapes to model, starting from the identification of the type and therefore of the geometrical rules that govern it, it is possible to hypothesize a more targeted extraction of the information. If the geometric rule establishes an arc is monocentric, and this is reflected in a wide range of cases, then it is sufficient to derive a few points from the cloud to determine this arc and no longer the whole profile. Furthermore, if the model thus obtained proves capable of representing the real object with a small and stable margin of error, then it can be thought that the model itself becomes an aid to segmentation; segmentation that once performed makes the analysis of the point cloud easier, more easily automated and more specific.

A typology of common historic elements not natively managed by the most BIM software, but strongly linked to geometric rules, is that of turned systems. The research examines vaulted systems belonging to the so-called late Mediterranean Gothic, a category with a rich historical treatment and with many suggestions on which to work for the definition of geometric rules. In this phase, the research focused on the development of modelling algorithms regarding panels only; as extended elements, panels allow a wide representation of geometries and a greater possibility of error verification. Given the vastness of available treatises, it has been decided to begin the development of the algorithm with what is universally recognised as one of the earliest examples of an attempt to define a geometric rule related to Gothic vaults: Villard de Honnecourt's Rule of the Three Arches (1230).

\section{Method application and early results}

The method described has been applied to several case studies concerning some churches in the city of Cagliari. The paper presents two particularly significant cases: the vault covering the presbytery in the Church of "Santa Lucia" and the system on the main nave of the Church of "La Speranza" (Fig. 2).

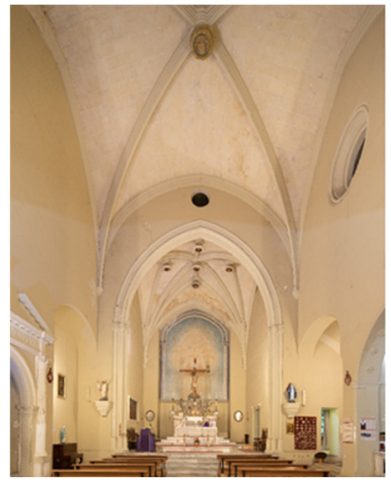

(a)

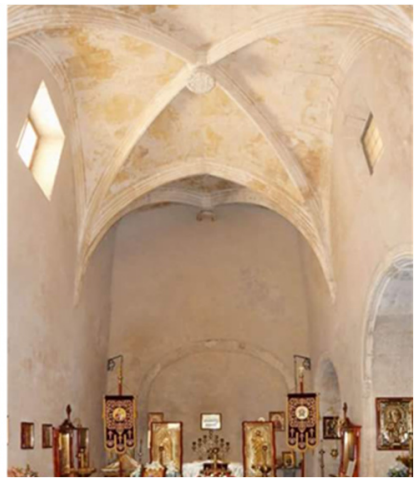

(b)
Figure 2: The case studies: a) Church of "Santa Lucia"; b) Church of "La Speranza"

The vaulted systems studied present two types of complexity: geometric or configuration. The geometrical complexity is that found in the systems of five gemstone vaults, typical of the late Gothic period; the complexity of configuration is instead determined by the presence of cross vaults flanked by further portions of cross vaults, specifically a system composed of a cross vault flanked by two half-vaults.

The first step was to develop an algorithm strictly conforming to the "ideal" model obtained from the treatises. As already said for the first phase of development, it was decided to follow Villard's three arches rule (Fig. 3).

In all the case studies the same workflow was followed, which can be summarised in the following steps:

- Identification of the case study and the type of element to be analysed; 
- Survey by laser scanner and obtaining the relative point cloud;

- Cleaning and first segmentation of the clouds;

- Geometric analysis and identification of the references / minimum parameters necessary for the application of the geometric rules derived from the treatises;

- Development or implementation of the modelling algorithm, according to the variants found on a case-by-case basis, so that all the declinations can be managed by a single algorithm;

- Generation of models and their validation by computation of model - cloud distances through CloudCompare software.

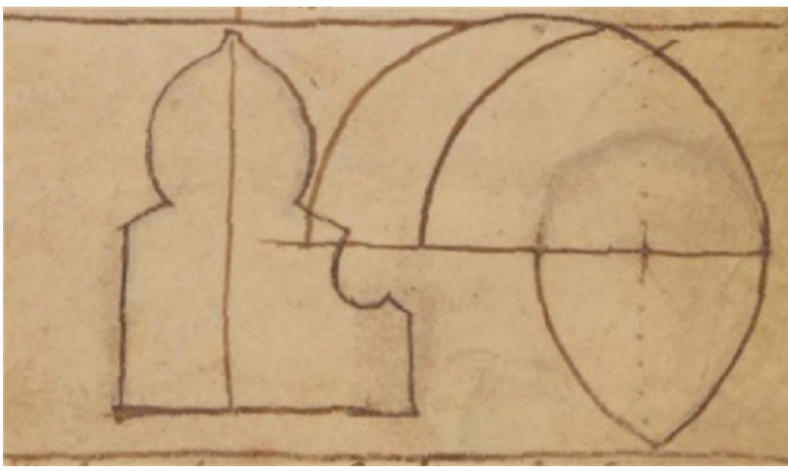

Figure 3: Villard de Honnecourt, the three arcs rule (1235).

Validation is necessary because it is essential to verify the correspondence of the model with the real object, but also to be able to quantify the order of magnitude of the error in the various cases.

The distance computations result for the stellar vault in the Church of "Santa Lucia" are shown in Figure 4. As we can see from the results, already from the application of relatively simple geometric rules such as the one proposed by Villard, the errors for the modelled components are particularly small, generally below a few centimetres.
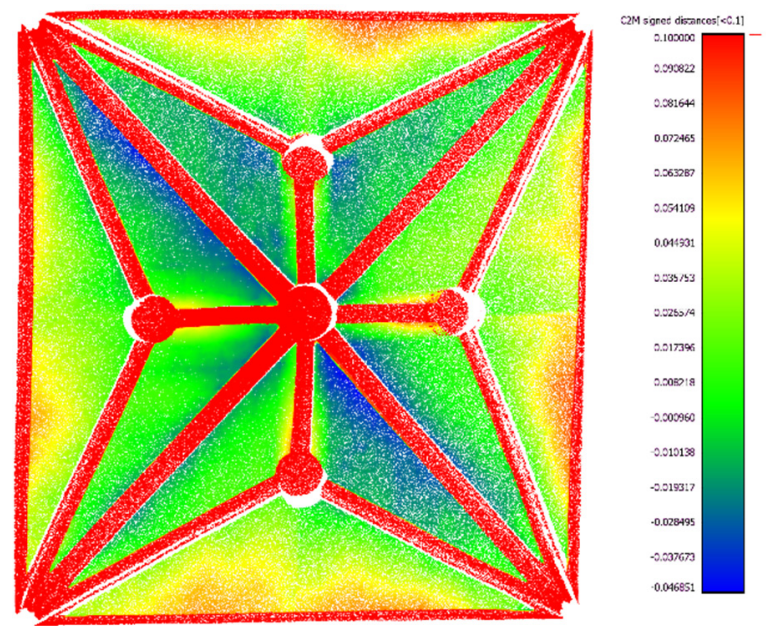

Figure 4: Model - cloud distances computation.

What has been obtained so far therefore seems to confirm the help that the proposed method can provide in the extraction of data from point clouds and their transposition into three-dimensional models.

The future phases foresee a widening of the cases analysed for a better definition of the algorithm; it may also be interesting to apply the same method basing the algorithm on more complex geometric rules, such as those suggested by Curioni in his "L'Arte di Fabbricare" (1865).

Finally, the algorithm is currently being completed for the implementation of the remaining main components of the vaults: the ribs and the bosses.

\section{References}

Amano, K., \& Lou, E. (2016). BIM for existing facilities: feasibility of spectral image integration to 3D point cloud data. MATEC Web Conf., 66, 00024. https://doi.org/10.1051/matecconf/20166600024

Andriasyan, M., Moyano, J., Nieto-Julián, J. E., \& Antón, D. (2020). From Point Cloud Data to Building Information Modelling: An Automatic Parametric Workflow for Heritage. Remote Sensing, 12(7), 1094. https://doi.org/10.3390/rs12071094

Aubin, P. F. (2014). Renaissance Revit: creating classical architecture with modern solfware. G3B Press.

Capone, M., \& Lanzara, E. (2019). Scan-to-BIM vs 3D ideal model HBIM: parametric tools to study domes geometry. Int. Arch. Photogramm. Remote Sens. Spatial Inf. Sci., XLII-2/W9, 219-226. https://doi.org/10.5194/isprs-archives-xlii-2w9-219-2019

Curioni, G. (1869). L'arte di fabbricare: Geometria pratica applicata all'arte del costruttore, lavoro ad uso degl'ingegneri, degli architetti, dei periti in costruzione e di quanti si trovano applicati alla direzione ed alla sorveglianza di costruzioni civili, stradali ed idrauliche, utile agli studenti delle scuole di applicazione per gl'ingegneri e dei corsi tecnici pei periti in costruzione. Negro, A. F. (Ed.). Torino, Italy

Honnecourt, V. D. (1230). Livre de portraiture. Paris National Library.

Liu, Y. (2016). Robust segmentation of raw point clouds into consistent surfaces. Science China Technological Sciences, 59(8), 1156-1166. https://doi.org/10.1007/s11431-016-6072-8

Macher, H., Landes, T., Grussenmeyer, P., \& Alby, E. (2014). Semi-automatic Segmentation and Modelling from Point Clouds towards Historical Building Information Modelling. In: Ioannides M., Magnenat-Thalmann N., Fink E., Žarnić R., Yen AY., Quak E. (Eds) Digital Heritage. Progress in Cultural Heritage: Documentation, Preservation, and Protection. EuroMed 2014. Lecture Notes in Computer Science, vol 8740. Springer, Cham. 
https://doi.org/10.1007/978-3-319-13695-0_11

Murphy, M., McGovern, E., \& Pavia, S. (2009). Historic building information modelling (HBIM). Structural Survey, 27(4), 311-327. https://doi.org/10.1108/02630800910985108 


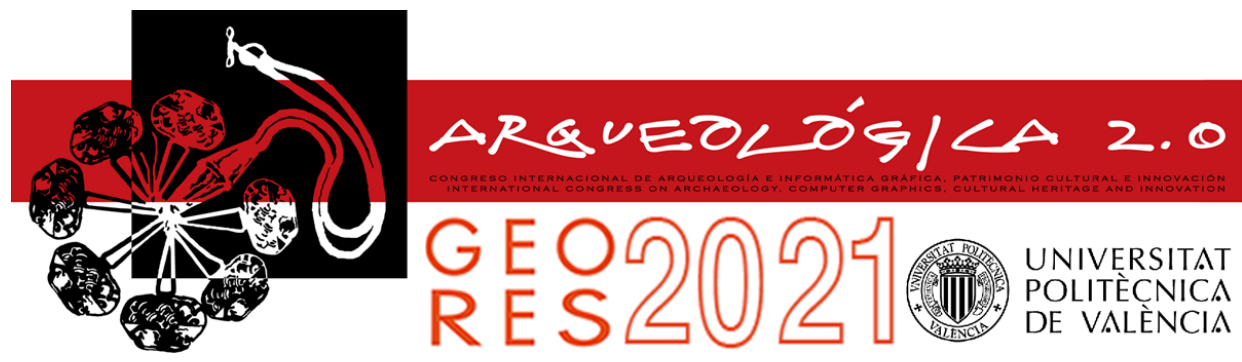

\title{
PRE- AND SELF-CALIBRATION OF UNDERWATER CAMERAS FOR PHOTOGRAMMETRIC DOCUMENTATION OF ARCHAEOLOGICAL SITES
}

\author{
Alessio Calantropio ${ }^{a,}$, Dominique Rissolo ${ }^{b}$, Evan Kovacs ${ }^{c}$ \\ a Laboratory of Geomatics for Cultural Heritage (LabG4CH), Department of Architecture and Design (DAD), Polytechnic University of \\ Turin, Viale Pier Andrea Mattioli, 39, 10125 Torino, Italy. alessio.calantropio@polito.it \\ ${ }^{b}$ Center of Interdisciplinary Science for Art, Architecture, and Archaeology (CISA3), University of California, San Diego (UCSD), USA. \\ drissolo@ucsd.edu \\ ${ }^{\mathrm{c}}$ Marine Imaging Technologies, USA. evan@marineimagingtech.com
}

\begin{abstract}
:
Underwater photogrammetry has become one of the most affordable and adopted methods for the documentation and the 3D reconstruction of submerged archaeological assets. In digital photogrammetry, images are captured to exploit (using computer vision-based procedures) their intrinsic metric contents. To preserve the metric consistency and to obtain reliable 3D metric products, this process must be followed according to photogrammetric principles that are even more important in underwater photogrammetry. The wide diffusion of low-cost and non-metric sensors requires that some attention be given to proper geometric calibration of the employed cameras. Via calibration, it is possible to opportunely describe geometric distortions that are observable on final images due to lens shapes and construction characteristics of the cameras and the optics used in the survey operations. This research addresses the importance of pre-calibration in underwater cameras, and for this purpose, three calibration datasets are acquired and compared: the first $(A)$ where the camera is pre-calibrated without any addition (flat or dome ports); the second (B) in which the camera is used in combination with a dome port; and the third $(C)$ where the camera setup has been employed in an underwater environment. For both scenarios (dry and wet), self-calibration and pre-calibration procedures are compared. Moreover, is possible to notice how the use of the right camera and lens combinations, specifically designed for underwater survey purposes, are functional to lower the distortion of the images and consequently improve the accuracy of the final 3D products. Different tests have been performed, and preliminary results are presented and discussed in this work-in-progress paper.
\end{abstract}

Keywords: underwater photogrammetry, digital archaeology, cultural heritage, 3D reconstruction, camera calibration, radial distortion

\section{Introduction}

Calibration of digital cameras for photogrammetric purposes is a well-known practice (Remondino \& Fraser, 2006) and is an essential preliminary step for a correct 3D object reconstruction. Via camera calibration, it is possible to obtain intrinsic camera parameters ( $f, c_{x}, c_{y}, k_{1}, k_{2}, k_{3}$, $b_{1}, b_{2}, p_{1}, p_{2}$ ) that allow for describing the interior orientation and the lens distortion. Knowing these parameters is essential as they can be used for generating undistorted images to be used for metric purposes.

There are, however, different methods and strategies for calibrating digital cameras. The most commonly available photogrammetric suites that use computer vision algorithms allows performing the so-called self-calibration of the camera (Fraser, 1997). In this standard approach, it is possible to reach accuracy improvements up to a factor of 3 (Gruen \& Beyer, 2001) compared to a situation where no camera calibration is performed. This approach proved to be effective even in the case of non-metric and non-conventional Low-Cost photogrammetric sensors (Perfetti, Polari, \& Fassi, 2018).

In situations where the conditions do not significantly change between the calibration and the survey phases, it is possible to pursue a pre-calibration strategy. In precalibration, the camera is calibrated in a controlled environment (using a calibration polygon) or with ad-hoc procedures (employing calibration panels with checkerboard or dot patterns) in order to obtain a set of intrinsic parameters to be used as an initial guess during the self-calibration phase performed before or during the BBA (Bundle Block Adjustment) in a typical photogrammetric workflow.

While the first option is the most common in data acquisition situations, especially in archaeology (Rodríguez-Martín \& Rodríguez-Gonzálvez, 2020), it is still possible to observe a consistent gain in the accuracy of the survey whenever a robust self-calibration 
procedure is conducted; when correctly performed this will pay back in lower reprojection errors. This aspect is essential mostly when a photogrammetric survey is conducted in underwater environments (Fryer \& Fraser, 1986), as additional distortions are introduced due to the different refractive indexes of the two mediums (the water and the air), and due to the geometric characteristics of the flat or dome port that could be used (Menna, Nocerino, \& Remondino, 2017).

This research aims to investigate the pros and cons of pre- and self-calibration approaches when underwater cameras are used in combination with dome ports, both in subaerial and in submerged situations. At first, the materials and methods adopted in this research are introduced. Then results with a comparison of different camera configurations are presented, and the observable gain in accuracy is discussed. In the end, conclusions and future perspectives of this work-in-progress paper are outlined.

\section{Materials and methods}

The material used in this paper is related to three datasets of images acquired using a Nikon Z7 mirrorless camera (sensor diagonal 43,13 mm; Pixel size 4,34 $\mu \mathrm{m}$ ), equipped with a $14 \mathrm{~mm}$ Rokinon Cine DS lens. The camera was used in combination with a zen $230 \mathrm{~mm}$ glass dome port, to enhance the quality of images along the edges. This setup has been previously used in combination with other two identical cameras mounted on the SeaArray; a diver operated photogrammetric system designed by Marine Imaging Technologies (Calantropio et al., 2020; Wright, Conlin, \& Shope, 2020).

The three datasets are comprised of images acquired to produce a geometric calibration of the sensors using a calibration checkerboard (Fig. 1) of $120 \times 65 \mathrm{~cm}$ (with each square $5 \mathrm{~cm}$ in size). The acquisitions have been divided into three datasets:

- (A) Camera: Nikon Z7 with 14 mm Rokinon Cine DS lens: 42 images;

- (B) Camera + Dome port: As (A) with a zen 230 $\mathrm{mm}$ glass dome port: 41 images;

- (C) Camera + Dome Port Underwater: Same setup of (B) but employed in underwater condition: 83 images.

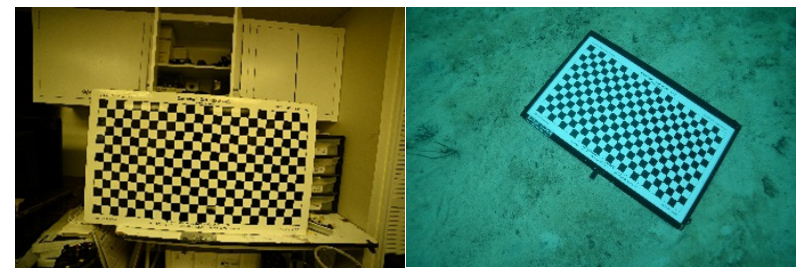

Figure 1: The calibration panel employed in the acquisition of the dataset $(A)$ and $(B)$ on the left; and the dataset $(C)$ on the right.

\section{Results and discussions}

After the data acquisition, camera calibration was performed for the three datasets using the Single Camera Calibrator App of the Camera Calibration Toolbox for Matlab (Fetić, Jurić, \& Osmanković, 2012). The results of this self-calibration procedure, based on (Heikkila \&
Silven, 1997), explicitly aimed at obtaining the values of the polynomial radial distortion coefficients, that are summarized in the following Table 1.

Table 1: Values of polynomial radial distortion coefficients and focal length (in pixels) for each of the three camera configurations employed.

\begin{tabular}{c|c|c|c|c}
$\begin{array}{c}\text { Camera } \\
\text { Configuration }\end{array}$ & $K_{1}$ (pix) & $K_{2}$ (pix) & $K_{3}$ (pix) & $f($ pix) \\
\hline $\begin{array}{c}\text { (A) Camera } \\
\text { (B) Camera }\end{array}$ & -0.1257 & 0.0586 & -0.0096 & 3328.63 \\
+ dome port & & 0.0731 & -0.0093 & 3365.25 \\
$\begin{array}{c}\text { (C) Camera } \\
+ \text { dome port } \\
\text { Underwater }\end{array}$ & -0.1081 & 0.0650 & -0.0128 & 3678.33 \\
\hline
\end{tabular}

In order to make a more straightforward comparison of the obtained parameters, the curves of the radial distortions have been graphed for the three datasets in the same diagram using MS Excel, as presented in Figure 2. The curves of radial distortion are described as a function of the radial distance from the centre of the sensor (Brown, 1971; Krauss, 1997), as presented in Eq. (1):

$\delta r=k 1 \rho 3+k 2 \rho 5+k 3 \rho 7$

where:

- $\rho=$ distance from the centre of the sensor

- $\quad \mathrm{k} 1, \mathrm{k} 2, \mathrm{k} 3$ = polynomial coefficients of the radial distortions

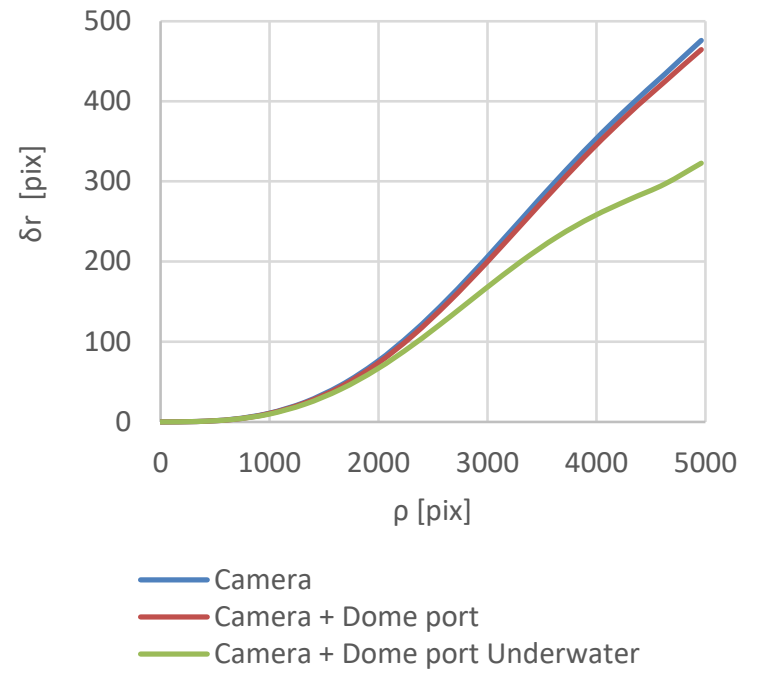

Figure 2: Radial distortion curves for the three camera configurations: in blue, the configuration $(A)$, in red $(B)$ and in green (C).

To also investigate how a pre-calibration approach can positively affect the quality of the survey, pre-calibration has been performed for the dataset $(B)$ and $(C)$. In doing so, the calibration certificate obtained from the selfcalibration of $(A)$ has been used as an initial guess for the pre-calibration of (B). Following the same principle, the calibration certificate obtained from the self-calibration of (B) has been used as an initial guess for the precalibration of $(\mathrm{C})$. The comparison of the reprojection error when self-calibration or pre-calibration are performed, are shown in the following Figure 3. 


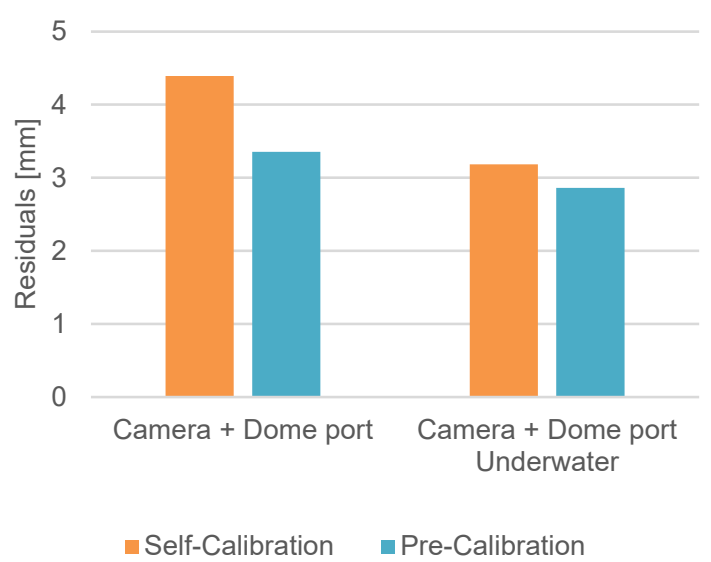

Figure 3: Comparison of the reprojection errors based on the values of the residuals, expressed in millimetres, for the datasets (B) and (C) both when self-calibration and precalibration are performed.

In this case, it is possible to observe how the use of a precalibration approach can further improve the quality of the survey, reducing the residual reprojection error of the selfcalibration in a consistent way.

\section{Conclusions}

This paper focuses on the importance of the geometric calibration of a camera in underwater photogrammetric surveys for archaeological purposes. It is also presented how the adoption of pre-calibration strategies could increase survey accuracy, reducing the reprojection errors. It is also essential to underscore how calibration itself is undoubtedly an important step, but the proper use of specific cameras must accompany it. Underwater cameras and dome ports, specifically made for marine environments, are essential for lowering errors related to the presence of two mediums. Future research will be aimed at deepening these aspects.

\section{Acknowledgements}

The authors would like to thank Brett Seymour and Dave Conlin of the Submerged Resources Center (SRC) of the US National Park Service (NPS), for their availability and support in carrying out part of this research. The authors also appreciate the support of Eric Lo, Falko Kuester and Vid Petrovic of the University of California, San Diego (UCSD). Last but not least, thanks also to Filiberto Chiabrando of the Polytechnic University of Turin for his useful hints during all the phases of this research project.

\section{References}

Brown, D. C. (1971). Close-range camera calibration. Photogramm. Eng, 37(8), 855-866.

Calantropio, A., Chiabrando, F., Seymour, B., Kovacs, E., Lo, E., \& Rissolo, D. (2020). Image Pre-Processing Strategies for Enhancing Photogrammetric 3d Reconstruction of Underwater Shipwreck Datasets. Int. Arch. Photogramm. Remote Sens. Spatial Inf. Sci., XLIII-B2-2020, 941-948. http://dx.doi.org/10.5194/isprs-archives-XLIII-B2-2020-9412020

Fetić, A., Jurić, D., \& Osmanković, D. (2012). The procedure of a camera calibration using Camera Calibration Toolbox for MATLAB. In 2012 Proceedings of the 35th International Convention MIPRO (pp. 1752-1757). IEEE

Fraser, C. S. (1997). Digital camera self-calibration. ISPRS Journal of Photogrammetry and Remote Sensing, 52(4), 149159. https://doi.org/10.1016/S0924-2716(97)00005-1

Fryer, J. G., \& Fraser, C. S. (1986). On the calibration of underwater cameras. The Photogrammetric Record, 12(67), 7385.

Gruen A., Beyer H.A. (2001). System Calibration Through Self-Calibration. In: Gruen A., Huang T.S. (eds) Calibration and Orientation of Cameras in Computer Vision. Springer Series in Information Sciences, vol 34. Springer, Berlin, Heidelberg. https://doi.org/10.1007/978-3-662-04567-1_7

Heikkila, J., \& Silven, O. (1997). A four-step camera calibration procedure with implicit image correction. In Proceedings of ieee computer society conference on computer vision and pattern recognition (pp. 1106-1112). IEEE.

Krauss, K. (1997). Photogrammetry, Volume 2: Advanced Methods and Applications.

Menna, F., Nocerino, E., \& Remondino, F. (2017). Flat versus hemispherical dome ports in underwater photogrammetry. Int. Arch. Photogramm. Remote Sens. Spatial Inf. Sci., XLII-2MW3, 481-487. https://doi.org/10.5194/isprs-archivesXLII-2-W3-481-2017

Perfetti, L., Polari, C., \& Fassi, F. (2018). Fisheye multi-camera system calibration for surveying narrow and complex architectures. Int. Arch. Photogramm. Remote Sens. Spatial Inf. Sci., XLII-2, 877-883. https://doi.org/10.5194/isprsarchives-XLII-2-877-2018, 2018.

Remondino, F., \& Fraser, C. (2006). Digital camera calibration methods: considerations and comparisons. International Archives of the Photogrammetry, Remote Sensing and Spatial Information Sciences, 36(5), 266-272.

Rodríguez-Martín, M., \& Rodríguez-Gonzálvez, P. (2020). Suitability of Automatic Photogrammetric Reconstruction Configurations for Small Archaeological Remains. Sensors, 20(10), 2936. https://doi.org/10.3390/s20102936

Wright, A. E., Conlin, D. L., \& Shope, S. M. (2020). Assessing the Accuracy of Underwater Photogrammetry for Archaeology: A Comparison of Structure from Motion Photogrammetry and Real Time Kinematic Survey at the East Key Construction Wreck. Journal of Marine Science and Engineering, 8(11), 849. https://doi.org/10.3390/jmse8110849 


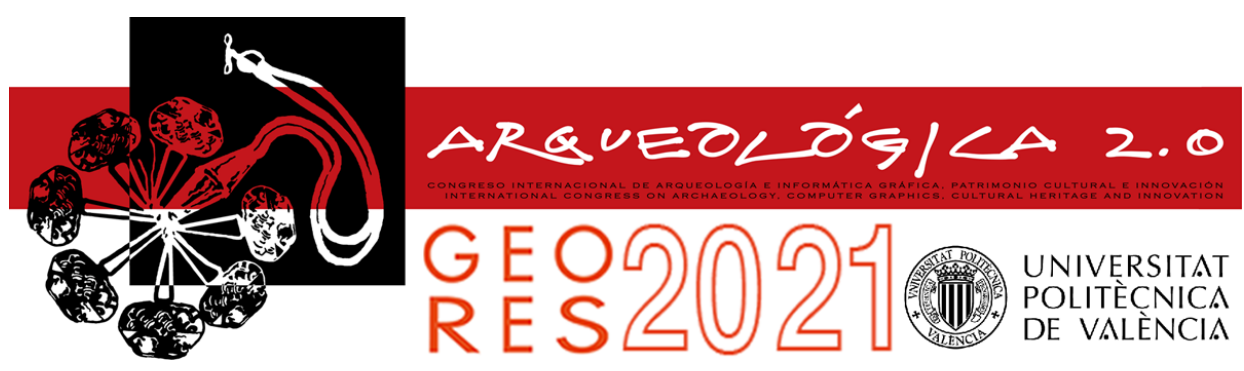

\title{
MYTHOPOIESIS AND COLLECTIVE IMAGINATION IN VIDEOGAMES
}

\author{
Andrea Piano ${ }^{a,{ }^{*}}$, Emiliano llardia, Alessio Ceccherellib \\ a Department of Pedagogy, Psychology, and Philosophy, University of Cagliari, Via Is Mirrionis 1, 09123 Cagliari, Italy. \\ andrea.piano@unica.it; ilardi@unica.it \\ b Department of Enterprise Engineering, University of Rome "Tor Vergata”, Via del Politecnico 1, 00133 Rome, Italy. \\ alessio.ceccherelli@uniroma2.it
}

\begin{abstract}
:
As videogames become more and more popular, their ability to generate and communicate mythologies (mythopoiesis) appears clearer. Pokémon, The Legend of Zelda, and Halo are just a few of the specific transmedial storyworlds created through (relatively few) years of reiteration. At the same time, recent examples of massively diffused products also picture remediations of heritage, folk tales, architecture, and other cultural elements, reaching users of any background. Franchises like Assassin's Creed, God of War, or Final Fantasy take large inspiration from various cultural heritages. By doing so, video-ludic remediations add to previously shared imaginary some peculiar interactive (ergodic) features: since video games have specific features that imply interaction by (and with) the user, the remediated cultural elements acquire properties that were not present in any previous representation. The interest of this study is to enlighten how it is possible for blockbuster videogames to build over previous archetypes and imaginaries, creating common knowledge about certain cultural objects, myths, and figures, among players on a global scale. The main focus of this research will be Japanese cultural heritage representation in recent popular videogames such as Nioh, Ghost of Tsushima, and Sekiro: Shadows Die Twice. In a comparative analysis of these products, the study will try to underline the common elements of blockbuster remediations, while exploring the emerging interactive (ergodic) features that the mentioned videogames add to previously shared imaginary of portrayed cultural elements. Any emerging evidence will then serve to build a tentative framework or method to remediate and represent any given cultural element in future videogame projects that aim to properly communicate heritage on a large scale such as the global digital game market
\end{abstract}

Keywords: cultural heritage, digital games, game studies, mythology, representation, communication

\section{Introduction}

Videogames have nowadays become products of mass consumption. Such massive diffusion creates the right conditions to study them as a worldwide cultural process, a phenomenon that involves and permeates contemporary society in many ways.

From a Sociology of Culture perspective, videogames can be considered as processes of remediation (Bolter \& Grusin, 1996) and representation (Salen \& Zimmermann, 2004) able to reflect the cultural values of their authors, while incorporating a very specific set of own values (Barr, Noble, \& Biddle, 2007). These elements combined make videogames multi-cultural objects, that can be understood by people from different backgrounds and, at the same time, massively convey images, cultural elements, and messages of any kind.

It has also been observed (Bogost, 2007) how videogames influence players' cognitive processes to some extent, through the repetition of behaviours or patterns and through audiovisual communication (Squire, 2006). Studies on the effects of videogames on players are numerous, and the results point to both positive and negative effects (Ceccherelli, 2012). In both cases, however, it is now generally accepted that there is an influence of video games on players. On the other hand, it is quite obvious that every medium necessarily has positive and negative aspects, stimulating abilities and behaviours (De Kerckhove, 1991) that can also be contradictory: when you use a medium, something is lost and something is gained, and a lot depends on the particularity of the people involved.

Such potential, alongside a massive diffusion, raises legitimate questions on how videogames concur in forging a shared cultural imagination on a global scale; we aim to investigate that process with specific attention to folk heritage, mythology, and related cultural elements.

\section{Mythopoiesis in videogames}

Collective imagination can be defined as a symbolically and socially shared configuration of meaning (Ragone, 2016), constituted on a cycle of constant reformulation of collective memory. This definition assumes that collective identity consists of a pattern of behaviour, values, and

"Corresponding Author: Andrea Piano, andrea.piano@unica.it 
relationships based on the sharing of a set of narratives and metaphors, or "fictions of humanity" (Le Goff, 1979), learned and processed through primary (family and living environment), secondary (educational, religious, labour, political institutions, etc.) and tertiary (mainly consumption and media) experience (Morin, 1962). Through remediation and reiteration of stories, figures, places, characters, and structures from collective memory, collective imagination is continuously reconfigured.

Remediation has been defined by Bolter and Grusin (1996) as "the way in which one medium is seen by our culture as reforming or improving upon another". Cultural elements are constantly reformed in remediative processes: from oral tradition to visual arts, or from cinema to digital games.

Mythopoiesis, as the process in which mythologies are forged, follows the same pattern: countless narratives repeated and re-enacted concur in the creation of recognizable images (the Greek Pantheon, the Star Trek narrative universe, Lovecraftian stories, etc.). In a recent work, Ortoleva (2019) separates high-intensity myths from low-intensity myths. The former are those that date back to more archaic historical periods and are more closely connected to sacred and religious/metaphysical dimensions (Greek myths, Middle Eastern myths, Nordic myths, etc.). The latter, on the other hand, have appeared more recently, in the last two centuries or so, and have characteristics that place them in human time and practices. They depend very much on the medium through which they are told, and are internalized through continuous exposure to these stories, in politics, advertising, literature, cinema, television, comics. Also in videogames, of course, where such mythopoetic ability is reflected allowing the renovation of already existing mythologies (Fig. 1), while creating new ones (the Pokémon world, The Legend of Zelda shared multiverse, etc.).

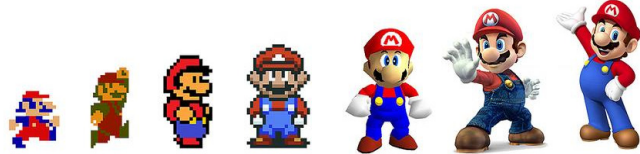

Figure 1: The recognizable character of Super Mario as reiterated in multiple instalments during the years.

Every remediation of myths, figures, or other cultural elements contributes to a transformation in the collective imagination, adding from time to time some features to the previously existing idea (Fauconnier \& Turner, 2010). The result of this process, in blockbuster and entertainment videogames, is certainly conditioned by the necessities of a global market. Nevertheless, every remediation of massively diffused games becomes part of a wider panorama of collective knowledge, between extremely vast and diverse social groups.

However, each re-functionalization in videogames presupposes a set of characteristics that are not merely audiovisual, unlike in literature or cinema. The specific involvement model of the medium (Calleja, 2011) makes it necessary that represented and remediated cultural elements acquire recognizable interactive properties. Take, for example, the figure of the vampire as remediated from Bram Stoker's Dracula onwards: the knowledge, for videogame players, that such creatures are weak to garlic or daily light, allows them to face the medium's typical problem-solving process with varying degrees of effectiveness. These typical elements of the character in the collective imagination have, over the course of many representations, taken on the dimension of stereotype. If writers and scriptwriters work on stereotypes to play with the expectations of readers and spectators, in video games these characteristics can also be pre-interpreted as interactive elements.

It is possible to define this specificity as ergodic characterization (Vandewalle \& Malliet, 2020): an audiovisual representation equipped with recognizable interactive properties that contribute to a re-modulation of the collective imagination through reiterated remediations. The definition is currently under development and based on the concept of ergodic literature, as a form of literature where a nontrivial effort is required to traverse the text (Aarseth, 1997). In this kind of literature, the reader is called upon to play an active role in the unfolding of the story. Pre-digital examples are the literary experiments of the 1960s and 1970s, such as Queneau's Cent Mille Milliards de Poèmes, and Cortázar's Rayuela; but also the gamebooks of the 1980s; up to the cybertextual experiments and electronic literature of the 1990s and 2000s, such as Danielewski's House of Leaves or Multi-User Dungeons (MUDs). Obviously, with video games, the potential for action for the reader/player expands considerably.

Through these mythopoetic dynamics, videogames contribute to the creation of an always growing cultural imagination of mythology, altering its collective perception while adding the medium's peculiar features to already existing configurations of meaning. This implies that knowledge and diffusion of any given heritage becomes a mass process in which remediated and represented cultural objects are constantly modified. An Ifrit is no longer a figure of Arabian mythology: it is part of a larger pantheon of figures that belong to videogames' collective imagination. A Yuki-Onna (Fig. 2) is not anymore a myth known just by Japanese folks or scholars, it is a recognizable element in a given game due to its icerelated features.

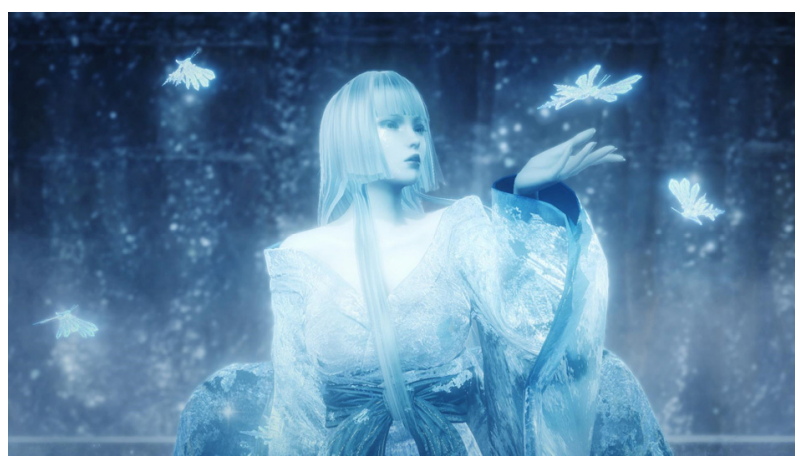

Figure 2: A Yuki-Onna as portrayed in Nioh (Team Ninja Studio, 2017).

There are the premises for an articulated study of this phenomenon, of its impact and consequences. In particular, it would be interesting to underline a modus 
operandi of how it actually works, and a design framework that could be applied to any given cultural object (mythological figure, architecture, etc.); a process of conscious ergodic remediation that could lay the foundations for more accurate communication of cultural heritage on a global scale.

\section{Case studies}

The connection between classical antiquity, cultural heritage, and videogames is a field that recently has seen a growing interest in scholars (Christesen, \& Machado, 2010; Rollinger, 2020). However, it has been noted that studies of antiquity in videogames approached the topic from a limited number of perspectives so far. The interest of scholars mostly revolves around the accuracy of historical and cultural representation, the way historical processes are simulated, and the learning potential of games applied to teaching.

This project is still at a very early stage. So far, it has focused on the analysis of existing media and literature, making a comparison between a few possible case studies. The next step of our study will focus on the reasons why cultural heritage, with a focus on mythology, is represented as it is in blockbuster and diffused videogames. It will also try to underline the most common methods used in the process of remediation, and see how much cultural backgrounds influence game designers in their choices. Lastly, it would be interesting to see if given a peculiar cultural heritage - it is possible to replicate the effects of already successful products in communicating and remediating myths, figures, and places.

To do so we will use a storyworld approach (Paprocki, 2020), where cultural heritages are seen as flexible transmedial constellations of narratives about gods, myths, and places. Hopefully, this will help us in observing how cultural objects are being represented and refuncionalized in modern videogames, and consequently how these elements are perceived by the users.

This study also aims to examine the potential of popular videogames in communicating and representing cultural heritage, with a focus on ancient mythological figures (creatures, gods, etc.). Building over the "ergodic characterization methodological framework" currently under development by Vandewalle \& Malliet (2020), the research will observe how certain aspects of Japanese cultural heritage have been represented and remediated in recent times. In order to do so, a brief list of case studies of the most diffused and distributed games will be taken into account: the Nioh saga (Team Ninja Studio, 2017; 2020), Sekiro: Shadows Die Twice (FromSoftware, 2019), and Ghost of Tsushima (Sucker Punch Productions, 2020) will be the primary focuses of observation.

\section{Discussion}

These products depict Japanese cultural heritage in very different ways, but all show certain common (ergodic) elements. Historical figures such as Oda Nobunaga and Hattori Hanzo, or mythological creatures like the already mentioned Yuki-Onna and the legendary Yamata no Orochi (Fig. 3) acquire some recognizable interactive (ergodic) features that allow the player to properly interact with them. For example, Hattori Hanzo i usually portrayed as a legendary swordsmith, hence aquiring a specific role in any digital environment in which he appears. With regards to mythological figures, as mentioned, the interactive propertires (and the ability to recognize them by the player) are crucial to overcome the problem-solving structure of videogames: so, the legendary serpent Yamata no Orochi perfectly fits the role of "final boss" in Ninja Studio's Nioh (2017), by having also certain features that the player already should know, or could know from previous remediations (the many heads of the serpent must be all cut to defeat it).

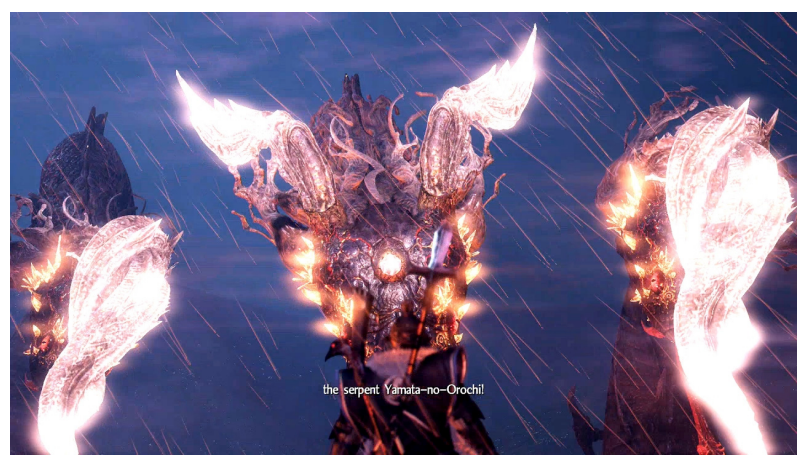

Figure 3: The serpent Yamata no Orochi as portrayed in Nioh (Team Ninja Studio, 2017).

We will also investigate the influence of local cultural heritage in videogames deveolped by Japanese studios (Team Ninja Studio, FromSoftware) and compare the representation of cultural elements with games set in Japan, yet made by multi-cultural teams (suchas Sucker Punch Productions).

\section{References}

Aarseth, E. J. (1997). Cybertext: Perspectives on ergodic literature. Baltimore, MD, US: Johns Hopkins University Press.

Barr, P., Noble, J., \& Biddle, R. (2007). Video game values: Human-computer interaction and games. Interacting with Computers, 19(2), 180-195. https://doi.org/10.1016/j.intcom.2006.08.008

Bogost, I. (2007). Procedural rhetoric. In Persuasive games: The expressive power of videogames, 1-64. Cambridge, MA, US: MIT Press.

Bolter, J. D., \& Grusin, R. A. (1996). Remediation. Configurations, 4(3), 311-358. Cambridge, MA, US: MIT Press.

Christesen, P., \& Machado, D. (2010). Video Games and Classical Antiquity. Classical World 104(1), 107-110. Available at: https://www.muse.jhu.edu/article/406986

Calleja, G. (2011). In-game: From immersion to incorporation. Cambridge, MA, US: MIT Press.

Ceccherelli, A. (2012). Videogiochi e apprendimento tra medium e messaggio. Considerazioni sull'uso didattico dei 
videogiochi. Rivista Scuola laD, 6. Available at: http://rivista.scuolaiad.it/n06-2012/videogiochi-e-apprendimento-tramedium-e-messaggio-considerazioni-sull'uso-didattico-dei-videogiochi

De Kerckhove, D. (1991). Brainframes. Technology, mind and business. Utrecht, Netherlands: BSO/Origin.

Fauconnier, G., \& Turner, M. (2010). The way we think: Conceptual blending and the mind's hidden complexities. New York, US: Basic Books.

FromSoftware. (2019). Sekiro: Shadows Die Twice [Play Station 4]. Digital game directed by Hidetaka Miyazaki and Kazuhiro Hamatani, published by Activision.

Le Goff, J. (1979). Memoria. In Enciclopedia, vol. VIII. Torino: Einaudi.

Morin, E. (1962). L'Esprit du temps. Essai sur la culture de masse, vol. 1. Paris: Grasset.

Ortoleva, P. (2019). Miti a bassa intensità. Racconti, media, vita quotidiana. Torino: Einaudi.

Paprocki, M. (2020). Mortal Immortals: Deicide of Greek gods in Apotheon and its role in the Greek mythic storyworld. In C. Rollinger (Ed.), Classical antiquity in video games: Playing with the ancient world, 193-204. London, UK: Bloomsbury Academic.

Ragone, G. (2016). Storytelling, immaginari, heritage. In S. Calabrese \& G. Ragone (Ed.), Transluoghi: Storytelling, beni culturali, turismo esperienziale, 41-60. Napoli, Italy: Liguori editore.

Rollinger, C. (Ed.) (2020). Classical antiquity in video games: Playing with the ancient world. London, UK: Bloomsbury Academic.

Salen, K. \& Zimmerman, E. (2004). Rules of play: Game design fundamentals. Cambridge, US: MIT press.

Squire, K. (2006). From Content to Context: Videogames as Designed Experience. Educational Researcher, 35(8), 1929. https://doi.org/10.3102/0013189X035008019

Sucker Punch Productions. (2020). Ghost of Tsushima [Play Station 4]. Digital game directed by Nate Fox and Jason Connell, published by Sony Interactive Entertainment.

Team Ninja. (2017). Nioh [Play Station 4]. Digital game directed by Fumihiko Yasuda and Yosuke Hayashi, published by Sony Interactive Entertainment.

Team Ninja. (2020). Nioh 2 [Play Station 4]. Digital game directed by Fumihiko Yasuda, published by Sony Interactive Entertainment.

Vandewalle, A., \& Malliet, S. (2020). Ergodic characterization: A methodological framework for analyzing games set in classical antiquity. In DiGRA '20 - Proceedings of the 2020 DiGRA International Conference: Play Everywhere. http://www.digra.org/wp-content/uploads/digital-library/DiGRA_2020_paper_317.pdf 


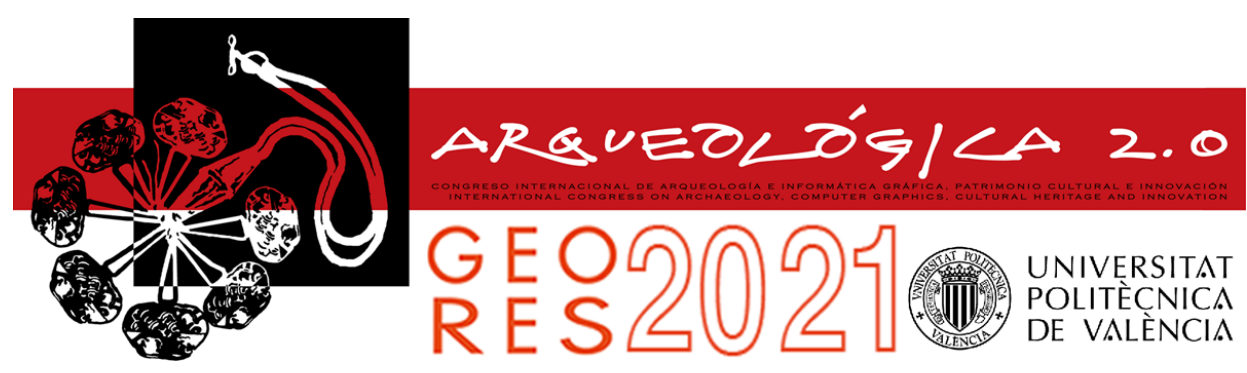

Proceedings of the joint international event $9^{\text {th }}$ ARQUEOLÓGICA

$2.0 \& 3^{\text {rd }}$ GEORES

Valencia (Spain).

26-28 April 2021

\title{
POINT CLOUD PROCESSING FOR URBAN ACCESSIBILITY MANAGEMENT IN HISTORIC CONTEXT
}

\author{
Daniele Treccania, ${ }^{*}$, Andrea Adamia, Lucía Díaz-Vilariño ${ }^{b}$ \\ ${ }^{a}$ Department of Architecture, Built Environment and Construction Engineering (ABC), Politecnico di Milano, 20133 Milan, Italy. \\ daniele.treccani@polimi.it; andrea.adami@polimi.it \\ b Universidade de Vigo, CINTECX, GeoTECH group, 36310 Vigo, Spain. lucia@uvigo.es
}

\begin{abstract}
:
Accessibility management in historic urban areas is a crucial topic which can benefit from technological advancements in information technology. Relating it to Geomatics, point cloud semantic segmentation represents a possible answer. The purpose of this task, in fact, is to subdivide the geometric survey into classes, applying semantic labels. The purpose of the research work presented in this paper is to perform a segmentation of a historic urban environment, the challenging aspect of the work is that historic urban items and their configurations are not standardized. The case study, on which tests will be made, is the UNESCO site of Sabbioneta. The first step of the research is a geometric survey, done by implementing mobile mapping technologies. Then the segmentation algorithms are developed both basing on existing literature and implementing new ones; possibilities given by machine learning techniques will also be investigated. The extracted data can then be implemented and used for several purposes by different users (public administrators, citizens, tourists). Those data can be a basis to address accessibility issues, to detect criticalities, to develop urban plans and 2,5D or 3D GIS maps.
\end{abstract}

Keywords: point cloud processing, semantic segmentation, mobile mapping, urban environment, accessibility management, cultural heritage

\section{Introduction}

\subsection{Motivation of the research}

The importance of accessibility and the evaluation of possible architectural barrier is considered in the European Union regulations, in particular through several key actions aimed at improving the social and economic situation of persons with disabilities (EU, 2020). This topic is also addressed by the United Nations through the Department of Economic and Social Affairs (UN, 2020). Within the topic of accessibility and inclusion in cultural heritage environments, information technologies play a crucial role for inclusive cultural heritage sites (Marconcini \& Pracchi, 2019).

\subsection{The research context}

In the Cultural Heritage field, the most popular survey techniques are photogrammetry and terrestrial laser scanning (Barsanti, Remondino, \& Visintini, 2012), however, mobile mapping technologies represent an interesting approach, whose spatial resolution is more suitable for an urban environment. Mobile mapping systems have been used in the latest years in several applications and they can be grouped depending on their use: mounted on vehicles, or portable systems like backpacks, handheld, and trolley (Nocerino, Rodríguez-
Gonzálvez, \& Menna, 2019). Plus, portable mobile mapping systems are either suitable for indoor and outdoor mapping.

Point cloud semantic segmentation, also known as point cloud classification, can be defined as the job of linking each point of the point cloud to a specific semantic label (Xie, Tian, \& Zhu, 2020). This process, ideally as automatic as possible, gives the possibility of adding significant attributes to 3D data. Semantic segmentation can be broken down into segmentation and classification. Segmentation refers to clustering and grouping points depending on their geometric and radiometric characteristics, while the classification task is related to allocate specific groups to classes or labels (Grilli, Menna, \& Remondino, 2017). Semantic segmentation can be achieved following two approaches (Nguyen \& Le, 2013). The first one implements mathematical models, geometric logic thinking, and statistical rules. The main results of this procedure are regions that contain similar points, depending on custom-made geometric constraints. These results do not have semantic information and require further steps to apply a label. The second approach, instead, is based on supervised machine learning and deep learning techniques, where the computer learns from classified datasets (training data) and is able to classify new data. 
In the literature, referring to point cloud processing, the topic of accessibility in urban environments is investigated basing on the detection of possible barriers and obstacles for wheelchairs. Some authors focuses on curbs and ramps detection (Ishikawa, Kubo, \& Amano, 2018; Serna \& Marcotegui, 2013), others on path planning or building entrances (Balado, Díaz-Vilariño, Arias, \& Garrido). Existing studies are mostly related to standardized urban scenes where, for example, curbs are always present and sidewalks are always made by a smooth material.

\section{The research project}

\subsection{Purpose of the research}

Point cloud semantic segmentation is nowadays increasingly important and is a challenging task. The objects of the survey, if semantically segmented, provide more significance and effectiveness to the survey itself. Detected features and classes can potentially represent anything.

In historic urban areas, accessibility management can be enforced by information technology and can take benefit from new technologies, such as point cloud segmentation methods. The term urban accessibility, broadly speaking, can be referred not only to people with disabilities but also to impaired people, families with small children in need of baby carriages, elderly people with mobility problems.

This research intends to perform a semantic segmentation that is not generalized but focused on one specific category of objects: urban accessibility items. The results of the segmentation will include a classified point cloud where all points of specific urban features are labelled together. Plus, the analysis focuses on a historic urban environment. The choice of the historic environment is related to the challenging aim of dealing with urban configurations that are not standardized. In fact, historic urban environments present several specific stratifications and peculiarities (on the materials used and also on the technical solutions implemented to cope with historical constraints).

To test the approaches, we selected a historic city as a case study. The selected city is Sabbioneta, located near Mantova, in Northern Italy. It was built in the 16th century as a fortified city, following the "ideal city" principle. Since 2008 it is a UNESCO site.

\subsection{Materials and methods}

The first step of the research consists of geometric data acquisition. The focus of the survey is on the ground portion of the city, composed by, among the others: sidewalks, roads, pathways. Considering the required accuracy and the object of the survey, the selected instrument is a mobile mapping system.

The segmentation method used in this research follows, implements, and upgrades existing methodologies proposed in the literature. The historic urban context requires a change, an adaptation, and an improvement of the existing approaches because it is not a standardized solution. During the research, also possibilities given by machine learning and deep learning techniques will be evaluated.
The research will be developed into several interconnected macro-blocks. The results of the previous one will be used to feed the following one. The idea is to extract useful data from the point clouds at some different levels in each block. Then the results of all the previous blocks will be conveyed to the last block, which will be used to give meaningfulness to all the work, by presenting all the gathered accessibility-related features in a comprehensive way.

A summary of the methodology is presented in Figure 1.

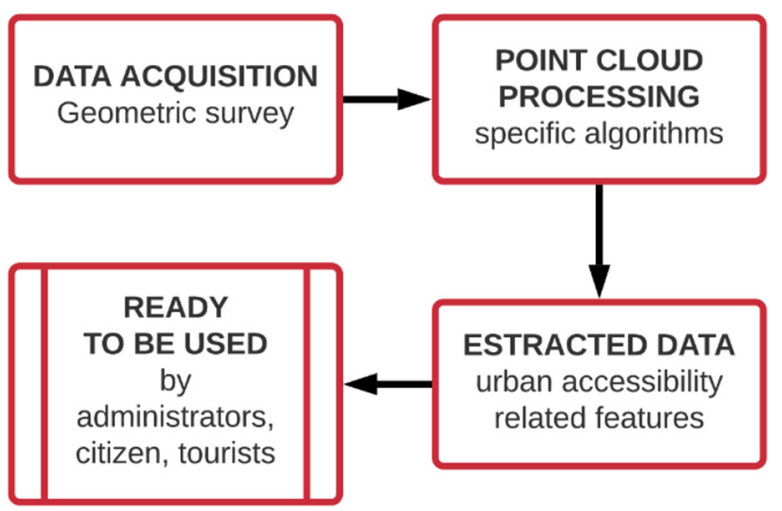

Figure 1: Flowchart describing the project workflow.

More in deep, the blocks will focus on the following jobs: detect and segment sidewalks from the geometric survey, basing on geometrical and topological features; detect the presence of manholes on the navigable ground for pedestrians; detect and characterize shaded areas; use previous data to update existing cartography.

The research will be tested and developed on a specific case study, but all the procedures will be evaluated and their effectiveness and scalability will be proved on other datasets of similar characteristics (i.e. on other historic urban environments).

\subsection{First advancements}

The first step of the research consists of a geometric survey of the case study proposed. We surveyed a portion of the city with Leica Pegasus:Two, a mobile mapping system with a declared accuracy of 0.020 metres in horizontal and 0.015 metres in vertical. After one hour of acquisitions, we were able to acquire almost the entire city, including the fortified walls. Figure 2 shows a top view of the resulting point cloud. A portion fo the acquired data will be used for the research project tests.

\section{Expected results}

The main result of this research is a procedure, a workflow that can provide more significance to a geometric survey of an urban environment. The second expected result is a set of classified points that can be used at different levels and for several purposes, dealing with the accessibility of historic urban environments. More in specific, those data can be used by administrators, citizens, and tourists; those pieces of information can be crucial to produce several deliverables in different formats $(2 \mathrm{D}, 3 \mathrm{D})$ and can also be used to update existing cartographic data. 


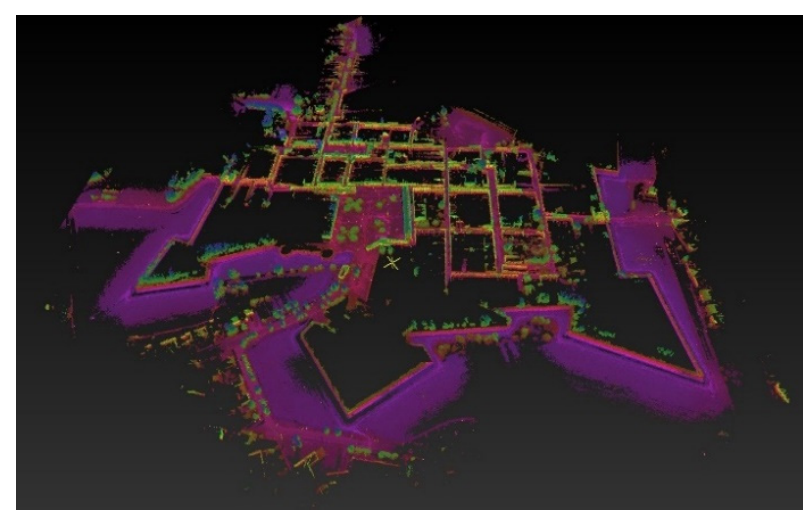

Figure 2: Point clouds of Sabbioneta, acquired with Leica Pegasus: Two

For example, classified point clouds could be helpful to be a support for public administrations to develop Safety and Security analysis. It can also be a starting point to detect critical issues and to plan interventions (e.g. the Italian PEBA, Architectural Barriers Elimination Plan). The segmented point cloud can be used to help the modelling stage in $3 d$ city modelling. The point cloud can be a basis for making pathfinding simulations. The point cloud can be used directly as a 3D informative model by linking information to each segment. Interactive maps with accessibility issues and paths to help the visit of the historical city. Many strategies can be implemented to reach this purpose: through algorithms that produce lists and implementing them in BIM, modelling software, GIS environments.

\section{Conclusions}

The presented research project brings together accessibility and urban management, survey techniques, point cloud processing, and information technology. The method of this research is based on semantic segmentation of point clouds. In particular the semantic is related to urban and accessibility elements of a historic environment. The method proposes to use the proper algorithm to reach the purpose.

The scalability of the project is a key element, it is tested on a specific case study, but the developed methodology can be used also in other similar historic contexts. The social benefits provided by this project can be related to better urban management and better usability of the city.

\section{Acknowledgements}

The authors wish to thank Leica Geosystem Italy for the support provided during the test with instrument Leica Pegasus: Two.

\section{References}

Balado, J., Díaz-Vilariño, L., Arias, P., \& Garrido, I. (2017). Point clouds to indoor/outdoor accessibility diagnosis. ISPRS Ann. Photogramm. Remote Sens. Spatial Inf. Sci., IV-2/W4, 287-293. https://doi.org/10.5194/isprs-annals-IV-2-W4287-2017

Barsanti, S. G., Remondino, F., \& Visintini, D. (2012). Photogrammetry and laser scanning for archaeological site 3D modeling - Some critical issues. CEUR Workshop Proceedings, 948(January).

EU. (2020). European Union Employment, Social Affairs \& Inclusion. Persons with disabilities. Retrieved November 10, 2020, from https://ec.europa.eu/social/main.jsp?catld=1137\&langld=en

Grilli, E., Menna, F., \& Remondino, F. (2017). A review of point clouds segmentation and classification algorithms. Int. Arch. Photogramm. Remote Sens. Spatial Inf. Sci., XLII-2/W3, 339-344. https://doi.org/10.5194/isprs-archives-XLII2-W3-339-2017

Ishikawa, K., Kubo, D., \& Amano, Y. (2018). Curb detection and accessibility evaluation from low-density mobile mapping point cloud data. International Journal of Automation Technology, 12(3), 376-385. https://doi.org/10.20965/ijat.2018.p0376

Marconcini, S., \& Pracchi, V. (2019). Inclusive Cultural Heritage Sites: Ict As A Tool to Support the Design Process and Share Knowledge. Int. Arch. Photogramm. Remote Sens. Spatial Inf. Sci., XLII-2/W11, 793-800. https://doi.org/10.5194/isprs-archives-XLII-2-W11-793-2019

Nguyen, A., \& Le, B. (2013). 3D Point Cloud Segmentation. A survey. In 2013 th IEEE conference on robotics, automation and mechatronics (RAM) (pp. 225-230). https://doi.org/10.1109/RAM.2013.6758588

Nocerino, E., Rodríguez-Gonzálvez, P., \& Menna, F. (2019). Introduction to mobile mapping with portable systems. In B. Riveiro \& R. Lindenbergh (Eds.), Laser Scanning. CRC Press. https://doi.org/10.1201/9781351018869

Serna, A., \& Marcotegui, B. (2013). Urban accessibility diagnosis from mobile laser scanning data. ISPRS Journal of Photogrammetry and Remote Sensing, 84, 23-32. https://doi.org/10.1016/j.isprsjprs.2013.07.001

UN. (2020). United Nations Department of Economic and Social Affairs Disability. Retrieved November 10, 2020, from https://www.un.org/development/desa/disabilities/

Xie, Y., Tian, J., \& Zhu, X. (2020). Linking Points With Labels in 3D: A Review of Point Cloud Semantic Segmentation. IEEE Geoscience and Remote Sensing Magazine, 8(4), 38-59. https://doi.org/10.1109/MGRS.2019.2937630 


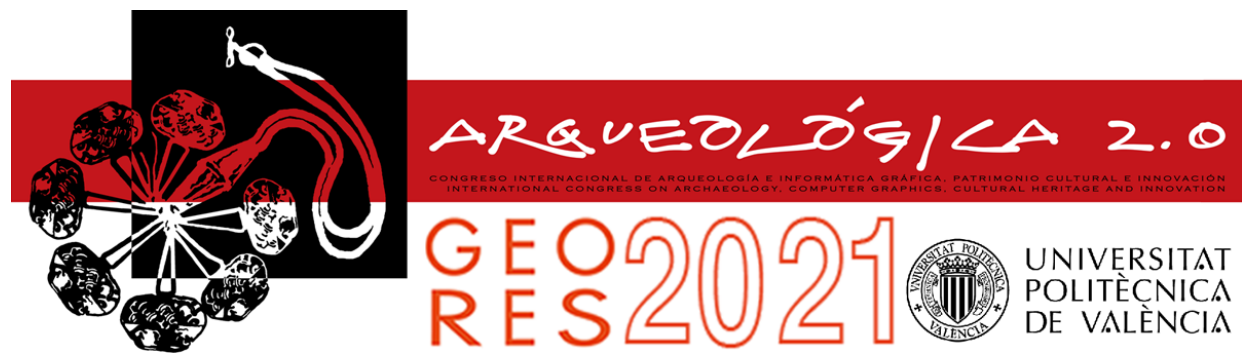

\title{
THE ARCH OF AUGUSTUS IN AOSTA: DATA AND ANALYSIS REUSE FOR A CONSERVATION PROJECT
}

\author{
Andrea Adamia, ${ }^{a}$, Lorenzo Appolonia ${ }^{b}$, Barbara Scalac \\ a Department of Architecture, Built Environment and Construction Engineering (ABC), Politecnico di Milano, Mantua Campus, Piazza \\ d'Arco 3, 46100 Mantova, Italy. andrea.adami@polimi.it

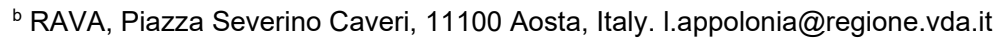 \\ c DICATAM, Università degli studi di Brescia, Via Branze 43, 25123 Brescia, Italy. barbara.scala@unibs.it
}

\begin{abstract}
:
The paper proposes a path for the management of the Arch of Augustus in Aosta to exploit the potential of Historic Building Information Modelling (HBIM). The HBIM system acts both as a place where to georeference the available data and as a tool for the elaboration of the conservation project in all its aspects. The system deals with different data from the survey of geometries to that of materials and alterations, up to the conservation project (mainly focused on the surfaces, with the aim of traceability of the events that the monument has lived, lives, and will live). The challenges in this research concern several aspects. First, it will be necessary to adapt the regular geometry of the BIM approach to the complex shapes necessary for the reproduction of surface alterations in the Puddinga stone. In addition, even more important, the ability to manage the monitoring data distributed at different times, comparing and making them available to current and future restorers (and other operators involved in the preservation). These tasks will be fixed by drawing up a dynamic conservation project, i.e. one that can make use of the available data at any time and all those that will become available during the work. Attempts of data digitization to give a shared value to the conservation activities had already been proposed in the past. The new research now starts from the reconnaissance of the weaknesses of the previous proposals, mainly related to the use of tailor-made systems (software) that are difficult to maintain, to implement and use in a very heterogeneous team of operators (architects, archaeologists, engineers, topographers, chemists, historians...)
\end{abstract}

Keywords: digital architecture, cultural heritage, documentation, HBIM model, conservation project

\section{Introduction}

As part of its asset management activities, the Soprintendenza della Valle d'Aosta has decided to set up a work protocol with Politecnico di Milano, Mantua Campus and Università degli Studi di Brescia, in order to identify a system that would guarantee the management of the numerous analysis and knowledge data carried out and processed over the years for the Arch of Augustus, as well as preparing the operational basis for future conservation interventions.

The need to identify a new way to manage data arises from the problem of having a summary of a large amount of information. This can also allow preventing the risk of data dispersion, especially when they are no longer shared by those who, in the past, have activated research and enriched the knowledge about the monument. The idea is to create, through new technologies, tools more and more capable of transmitting collected data to other users, overcoming the close link with historical memory and providing that context of traceability necessary for any good conservation practice.
The proposal concerns the possibility of adapting new technologies for architectural design (Building Information Modelling systems) to Heritage conservation and linking the potential of information systems in order to allow the comparison of information through a geo-referenced and dynamically accessible structure (Leon-Robles, ReinosoGordo, \& Gonzalez-Quinones, 2019).

The experimentation will be carried out on one of the main monuments of Aosta: the Arch of Augustus. The Arch has always stimulated the interest in researchers, historians, and architects of the past because of the architecture, the materials, and the related problems. For all these reasons, including the sum of technical-scientific data available, the monument proves to be particularly suitable to test the HBIM (Historic BIM) approach, which does not want to be identified as a simple container of information, but needs to become a useful tool for the design of current and future interventions.

\section{Previous researches}

For the position and importance of the monument, the superintendency has always paid particular attention to 
the Arch of Augustus in Aosta as part of the process of protection and enhancement (Appolonia, Migliorini, Idone, \& Piccirillo, 2007).

The Soprintendenza della Regione Aosta is provided with an internal analysis laboratory, which aims to document the regional heritage and carry out diagnostic investigations and monitoring to analyze the state of conservation of the various assets of competence. Thanks to this fortunate coincidence, the Roman arch has been the subject of numerous in-depth surveys and campaigns to acquire climatic-environmental data over time.

Among these, the most significant analyses were carried out in the period 2007-2010. In those tests, the arch's microclimatic conditions and its surroundings were evaluated according to the exposure and dust deposition studies (Ponziani, Ferrero, Appolonia, \& Migliorini, 2012). We point out especially the chemical-physical study of Puddinga stone, the primary "material" of the arch. That investigation is essential for understanding the current state of conservation of the arch and the definition of the mechanisms of alteration.

Among the various activities that have concerned the arch, we finally mention the mapping of the alterations that had two functions: monitoring the state of conservation over time and preparing all the documentation for the drafting of the conservation project. The intense study and analysis activity has also been accompanied by numerous attempts to organize and manage data, aware that this is the fundamental activity for a good conservation project. The most relevant is the attempt, innovative for its time, to manage all the information of the alterations through a GIS approach. The arch's two-dimensional representations have been used as the "territory" on which the information systems map the different phenomena (Fig. 1) in the ARKIS Architecture Recovery Knowledge In formation System applied also on the Roman Theater of Aosta (Salonia, 2003).

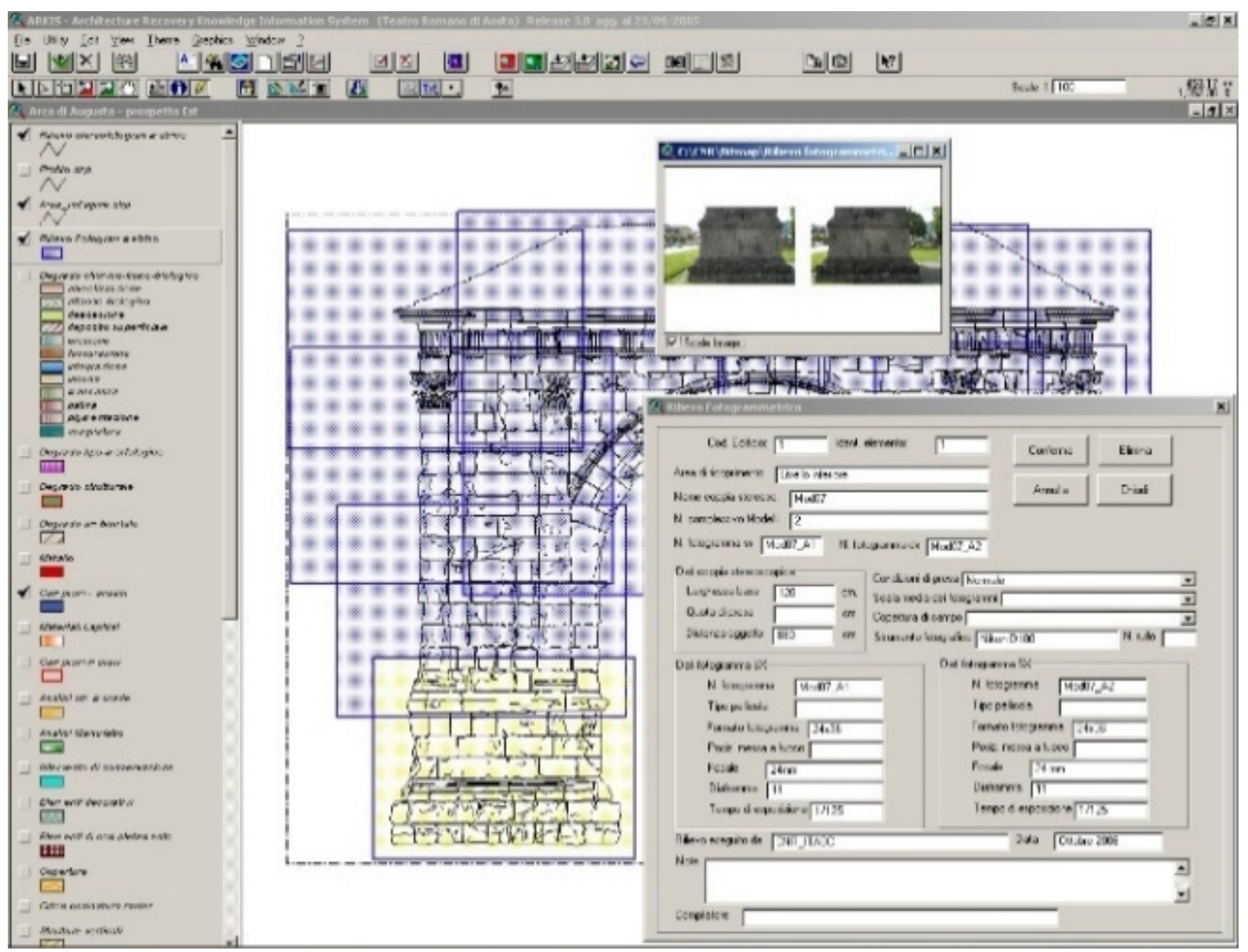

Figure 1: Screenshot of Arkis system for the management of data in a GIS environment.

All these activities developed around the Arch of Augustus have bequeathed a heritage of massive data and decisive in preparing a planned restoration and conservation intervention. However, these actions have also highlighted some aspects that are common in applied research. Among these, the difficulty of finding suitable tools for the management of the existing heritage and the subsequent attempt to adapt software, systems and processes, created for other applications to the conservation needs of the Augustus Arch. We must also reiterate the difficulty in managing projects carried out with excellent tools designed explicitly for this purpose, which, however, show the major critical issues in updating the systems and their sharing among the various actors of the conservation process.

\section{New management tools}

Attempts of data systematization, until now conducted, were born from the necessity of an objective and precognitive conduction. Common to other regional monuments, this need brought to the development of instruments to keep under control the widespread heritage on the territory. 
When carried out, the usual management has long been based on methodologies developed at the national level, with systems such as the Carta del Rischio (Accardo, Cacace, \& Rinaldi, 2005) or the SICAR method (Siotto, Baracchini, Santamaria, \& Scopigno, 2016), tested by some Superintendencies in Italy. However, the value of these systems is affected by the costs necessary to repeat the assessments (not always accessible or traceable).

These problems make these systems too "static", rigid and unsuitable for planned conservation programs or the preparation of conservation and restoration projects.

For these reasons, most of the management activities still occur with more or less continuous analysis and inspections, which was also the case at the Arch of Augustus until the beginning of the study campaign. The inspection value remains one of the limits of the asset control method, although often the most accessible. The inspection, however, presents several problems that cannot be solved.

The main one concerns the training of inspection operators. In fact, the restorer should define the evaluation of the state of alteration; but even in this case, we should take into account some variables. First of all, the ability of objective reading. The reading of the alterations is easily linked to a perceptibility factor, i.e. the state of knowledge and sensations that the reader has at the precise moment of the evaluation. These conditions can vary over time, also depending on data interpretation capabilities and data memory, especially when it is necessary to establish a link between one inspection and the other. It is evident that a further degree of variability can occur if the reader changes, as well as if the $t$ inspections are carried out in different environmental conditions. Even the light and the point of view can influence the evaluation. It should also be taken into account the difficulty of proper verification and evaluation for large monuments, such as the Arch of Augustus.

From this list, we can understand the complexities of managing a monument and how informative systems are fundamental. However, it is necessary to add the possibility of repeatable evaluations to have an objective but economical, synthesis framework.

\section{The research project}

This paper describes the research project involving Soprintendenza di Aosta, the Università degli Studi di Brescia and the Politecnico di Milano. The research aims to identify effective systems for the management of data for conservation.

For this reason, we have proposed the use of informative systems, which must be adapted to the needs and have different characteristics suitable to facilitate the preservation of the asset through interoperability and integration of different knowledge (Bruno \& Roncella,
2019). First of all, the proposed system should work with very different data (by nature, origin, period, and time of acquisition), progressively integrating them into a single environment. Secondly, it is fundamental to be able to manage data in a dynamic and shared way; allowing their continuous updating, making them accessible, according to certain rules and degrees of interest, to the different operators involved in the process.

The proposed project, also aware of the technical difficulties related to the implementation and management of dedicated software, aims to test BIM systems' adaptability in a preservation approach. Such system starts from the concept of the informative model. They allow to manage very different data, using the threedimensional model, at different levels of complexity, like an index, a starting point from which to access all the data (Adami et al., 2019). To enrich the model, a first step is the collection of information and its systematization according to linear, sequential, and complete criteria. In particular, it is necessary to proceed to the abstraction of information in order to identify the best method to find it easily in the model. Furthermore, the definition of a ID that identifies uniquely the object to which data are conneted (semantic classification), in order to set the biunivocal relationship between information level and representative geometry (Adami, Bruno, Rosignoli, \& Scala, 2018). These steps must occur with a close synergy between those who realize the model, those who know the data's contents and quality, and those who manage the asset. The comparison between these three managers of the model allows deciding the level of information to be reached.

The informative model, synthesis of geometric content and information, plays the role of the index and works to facilitate design choices. All data (reports, diagnostic analysis, etc.) must be immediately understandable to the designers to become useful materials for the elaboration of the intervention. This phase appears quite complicated because the operations planned on the Arch of Augustus mainly concern actions for the conservation of surfaces, since from a structural point of view there are no emergencies. The challenge is to exploit the model's utilities, representing the time sequences of the planned actions and/or the multidirectional paths that can be predicted according to the architecture's responses to the proposed solutions.

Finally, maintaining one of the characteristics of BIM, i.e. the management of the entire life cycle of the building, the system is an effective tool to set up systems suitable for planned conservation. This allows to project and schedule the necessary conservation interventions in the fourth dimension (time), but also to record all future events that affect the architecture itself (through reports of maintenance interventions, updating data and photographic collections over time), thus enriching the monument database.

\section{References}

Accardo, G., Cacace, C., \& Rinaldi, R. (2015). II Sistema Informativo Territoriale della "Carta del Rischio". In ARKOS Scienza e Restauro dell'Architettura Nardini Editore Anno VI - Nuova Serie- Aprile/giugno 2005 Della Torre S. (2014), Oltre il restauro, oltre la manutenzione. In S. Della Torre (Ed.), I.C.T. per il miglioramento del processo conservativo, Proceedings of the International Conference Preventive and Planned Conservation, Monza-Mantova, 5-9 Maggio 2014, Nardini Editore, Florence. 
Adami, A., Fregonese, L., Lattanzi, D., Mazzeri, A., Rossignoli, O., \& Scala, B. (2019). A Multidisciplinary Conservation Project for the Cavallerizza Courtyard, Palazzo Ducale di Mantova. Heritage, 2, 1441-1459. https://doi.org/10.3390/heritage2020091

Adami, A., Bruno, N., Rosignoli, O., \& Scala, B. (2018). HBIM for Planned Conservation: A New Approach to Information Management. In W. Börner, S. Uhlirz (Ed.), Proceedings of the Visual Heritage, Vienna, 12-15 Novembre 2018

Appolonia, L., Migliorini, S., Idone, A., \& Piccirillo, A. (2007). L'Arco di Augusto in Aosta: un esempio di percorso programmato tra progettazione e diagnostica. In Bollettino della Soprintendenza per i beni e le attività culturali, 4, pp 215-228

Bruno, N., \& Roncella, R. (2019) HBIM for Conservation: A New Proposal for Information Modeling. Remote Sens., 11, 1751. https://doi.org/10.3390/rs11151751

Leon-Robles, C. A., Reinoso-Gordo, J. F., \& Gonzalez-Quinones, J. J. (2019). Heritage Building Information Modeling (HBIM) Applied to A Stone Bridge. International Journal of Geo-Information, 8(3), 121. https://doi.org/10.3390/ijgi8030121

Ponziani, D., Ferrero, E., Appolonia, L., \& Migliorini, S. (2012). Effects of temperature and humidity excursions and wind exposure on the arch of Augustus in Aosta. Journal of Cultural Heritage, 13(4), $462-468$. https://doi.org/10.1016/j.culher.2012.01.005

Siotto, E., Baracchini, C., Santamaria, U., \& Scopigno, R. (2016). Sperimentazione del Sistema Ministeriale SICaR w/b per la gestione e consultazione informatizzata dei dati sulla policromia. Archeologia e Calcolatori, 27, 131-151

Salonia, P. (2003) Strumenti informatici innovativi di ausilio allac conservazione del patrimonio storico-architettonico: problema di organizzazione, diffusione e gestione dei dati. In Rossi M., Salonia P., Comunicazione multimediale per i beni culturali, Addison Wesley, Milano, pp 25-52. 


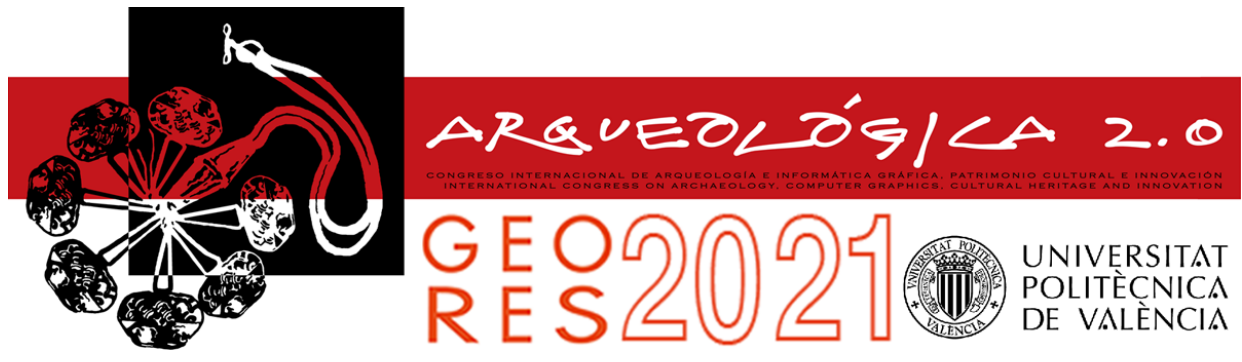

\title{
MANAGEMENT OF ARCHAEOLOGICAL HERITAGE THROUGH TICS IN MUSEUMS. THE CASE OF THE ARCHAEOLOGICAL MUSEUM OF BURRIANA (CASTELLÓN)
}

\author{
José Manuel Melchor-Monserrata, ${ }^{a,}, J^{*}$ José Martínez-Uso ${ }^{b}$, Jorge Alcaide-Marzalc \\ a Burriana Municipal Archaeological Museum, Plaza de la Merce s/n, 12530 Burriana, Spain. museu.arqueologic@burriana.es \\ ${ }^{b}$ Cologne Game Lab, Technische hoschschule Köln, University of Technology, Arts, Sciences, Claudiusstr. 1, 50678 Köln, Germany. \\ jose.martinez_uso@smail.th-koeln.de \\ ${ }^{c}$ Institute for Research and Innovation in Bioengineering (i3B), Universitat Politècnica de València, Camino de Vera s/n, 46022 \\ Valencia, Spaiin. jalcaide@dpi.upv.es
}

\begin{abstract}
:
This article is a summarized presentation of the project that is being developed with the aim of creating a platform for managing the digital documentation of archaeological heritage using new technologies. The aim of this platform is to provide a common space for heritage management through a museum network. The results presented are based on the collaboration between the Archaeological Museum of Burriana and the Universitat Politècnica de València. As a result, a significant number of archaeological pieces have been digitized using 3D scanning and photogrammetry techniques. These high resolution models are suitable for 3D printing as well as for their geometric analysis. They also allow obtaining lowresolution models by retopologization to export them to interactive virtual environments such as video game engines and virtual environments based on OpenGL 2.0 and DirectX technology. Then, virtual and augmented reality interaction libraries were implemented, allowing recreations or reproductions for scientific, informative and didactic purposes, for subsequent use by visitors or specialists in the proposed networks. The proposed platform has a double social aspect, on the one hand through web technology, allow greater interoperability between cultural centres as well as individual users, being able to share information about digitized pieces. On the other hand, virtual and augmented reality technology enhances interactivity and greater immersion, since all these features can be accessed from any mobile device at no additional cost.
\end{abstract}

Keywords: virtual archaeology, digital archaeology, 3D reconstruction, museum, web, mobile

\section{Antecedents}

Since 2016 the Project Engineering Department of the Polytechnic University of Valencia has been collaborating with the Archaeological Museum of Burriana (Castellón). As a result of this collaboration, several projects of digitization and modelling of archaeological and historical artifacts have been carried out. Being reflected not only in the museography of the entity, but also in several publications and research projects (Melchor, Martinez, Bonafe, \& Cabrera, 2016; Melchor, Cabrera, \& Martínez, 2018).

This dynamic that continues nowadays has made arise the need for unifying procedures and translating them into a single digital management platform.

\section{Objectives}

The constant technological advances, specially focused on the development of mobile and web applications, enable the development of a global online platform hosting strategic documentation provided by a network of museums and heritage dissemination centers.

This platform is based on native web technology, using modern development frameworks such as React.js which allow easy cross-platform communication while optimizing the performance of the app. This opens the possibility of developments with greater graphic load such as the virtual reconstruction of interactive online 3D parts in VR and AR; GIS positioning of the museum and archaeological sites from which the exhibited pieces come; and the exclusive generation of virtual tours of areas to visit, being possible to develop personalized tours from the mobile device itself.

All these objectives would be structured within a gamification context. The information would first be displayed in a simplified way for a friendly approach to the potential visitors, who would always have the freedom to explore and choose the contents, expanding and deepening them according to their interest. 


\section{The museum space as a reference}

One of the challenges that this platform faces is to keep the museum space as a reference for the visitor. The use of TICs as a communication channel favors a decontextualization with respect to the historical heritage. If the digital representation of the object is too far away from the original, the visitor may not value adequately the importance of archaeological materials.

Therefore, we have chosen using the physical space of the museum as the center of this project in two main aspects: On one hand, bringing to the museum space elements that could never be physically exhibited, such as archaeological sites, large pieces, buildings, elements already disappeared, etc. On the other, displaying pieces and artifacts as they could not be done physically, using digital restoration, 3D motion graphics or virtual recreations.

These concepts are proposed bidirectionally. In the museum, every digital intervention is contextualized with the proximity of the original object. In the digital platform, constant references are made to the museum as a container space of the originals or as a managing element of the archaeological assets.

\section{Current results}

Frequently, museums are aware of the possibilities that new technologies offer them in the form of new communication channels. The problem lies in the lack of material or economic means to carry out such actions. That is why institutional collaboration between Museums and Universities is presented as an essential vehicle in this process.

The collaboration between the Archaeological Museum of Burriana and the UPV began in 2017 as an experience of mutual exchange, in which the Museum provided original work material and the University offered the result of that work. Thanks to this collaboration, numerous pieces have been 3D scanned, and their digital files have been used in various ways (Fig. 1). Just to cite some examples:

- 3D scanning and printing of a set of pieces for International Museum Day 2019 (Fig. 2).

- Creation of a holographic representation for exhibition in the room, with the possibility of adaptation to different pieces.

- Digital reconstruction of an anthropomorphic pre-Columbian terracotta.

It is also worth noting that the Museum, in collaboration with other UPV professors, has developed specific interactive applications in the field of dissemination and virtual reconstruction of heritage, such as the virtualization of the "Torre del Mar", the "Torre de Carabona" and the development of interactive 3D viewers specialized in virtual and augmented reality.

The relevance of these actions is that they are a starting point for further actions. Once the Museum has a digital format of its heritage, the range of options of use for this material is enormous, ultimately enabling comprehensive management of the digital heritage through a web platform. Some other researchers have proposed similar frameworks (Apollonio et al., 2018; Meyer,
Grussenmeyer, Perrin, Durand, \& Drap, 2007; RojasSola, Castro-García, \& Carranza-Cañadas, 2011).

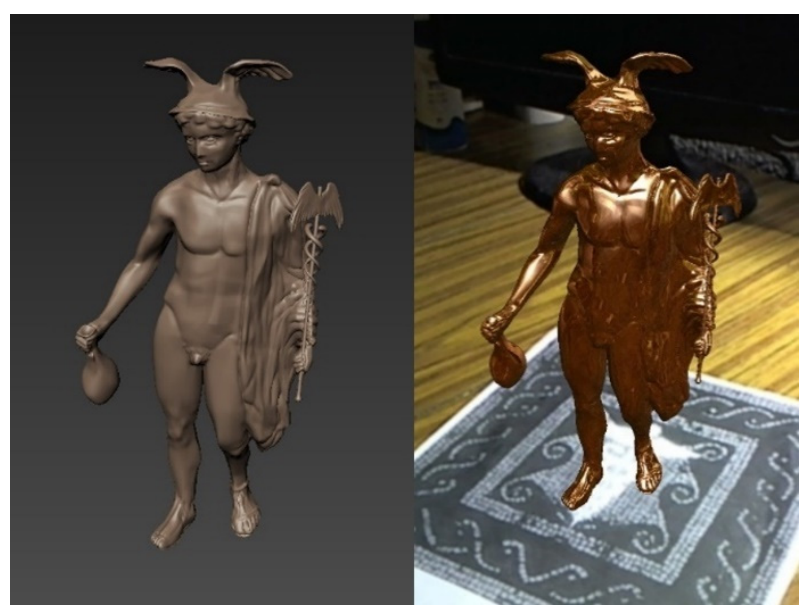

Figure 1: Hermes sculpture augmented reality restoration. Reproduction from the Archaeological Museum of Burriana heritage.

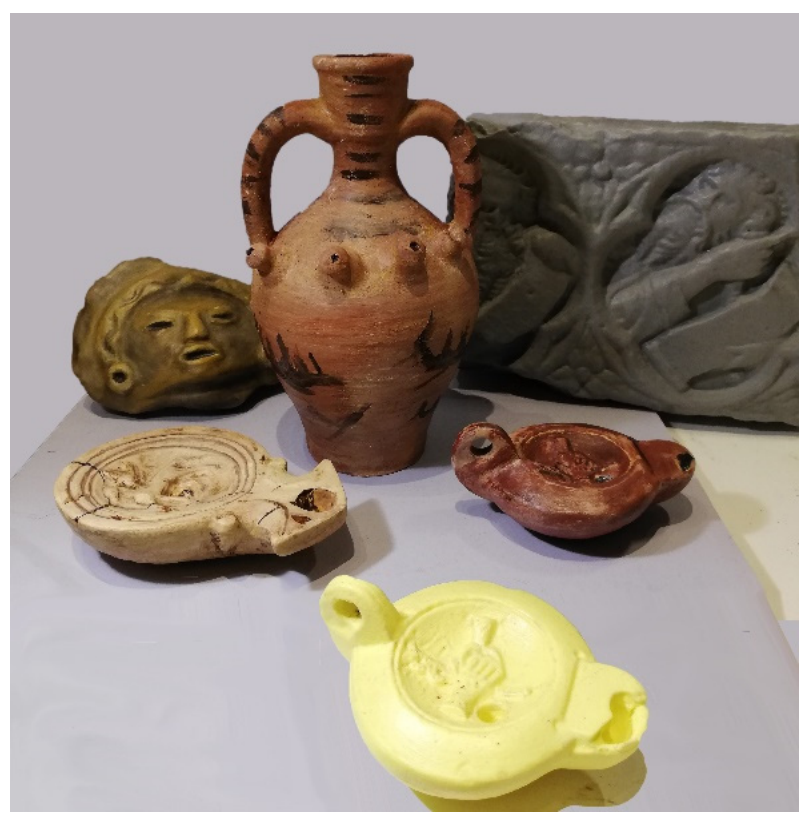

Figure 2: Several 3D printed and hand-painted pieces.

Reproductions from the Archaeological Museum of Burriana heritage.

\section{A global project and the integration of current results}

The strategy for developing a global network of museums must lay on the existing actions to the moment. All of them are encompassed within the concept of digitization and virtualization. Digitization as the ability to store information persistently and securely, and virtualization as the way to interact with this transformed information from a physical environment to a virtual one.

Current techniques for achieving this digitization process focus on developing cross-platform accessible no-SQL databases, which enable greater user interconnectivity and better compatibility between programming languages. In addition, they are easily scalable allowing potential network growth. 
With these databases, you can interact in various virtual ways. As stated, access is cross-platform, which gives the ability to nurture AR-VR applications with database information. Currently, low-cost developments such as Google Cardboards are already being used in the Archaeological Museum of Burriana. Other solutions such as the use of Oculus Rift allows, at an average cost, generating high-definition environments.

Another example is native augmented reality-generating Android applications, and an important qualitative step could be made with the acquisition of specialized hardware such as Hololens, although its price remains high and its scalability is relative compared to current mobile-based augmented reality applications.

The digitization of pieces of heritage will allow their geolocation and the communication between different digital platforms, thus being possible to integrate this information into the current existing platforms such as Google Maps and GVsig.

This proposal pursues to provide the user with a unitary experience. In addition, a gamification criteria approach will allow the visitors to decide to what extent they want to deepen the virtual experience, ranging from a purely graphic simple visit to an interactive/immersive highly detailed and explained one. To achieve this, the creation of a "serious game" is proposed where users are presented with a series of cultural milestones to overcome as they progress with the knowledge of the museum heritage.

\section{Future prospects}

The use of advanced technologies to increase the visitor experience of a museum is not something new. A lot of scientific work points to a paradigm shift in the way the visitor interacts with the museum (Vermeeren et al., 2018).

Although this change seems to be clearly driven/forced by the digitization of society (Komarac, 2014), other authors suggest that there are causal factors that have been present for some time and that, while the demands of a museum visitor have not changed so much, what has done so is how museums can respond (Vermeeren et al., 2018).

Technologies related to 3D scanning are expected to continue to improve in terms of process and portability. Currently, the most basic photogrammetry technique, using mobile cameras, already produces results of some quality for medium-size parts, and reconstruction algorithms have been improving year after year. Something similar happens with the use of RGB-D (Kinect) or LiDAR (Apple LiDAR Scanner) based sensors. Reaching a certain level of scanning quality, the low acquisition value and portability of such devices will allow any museum to have at its fingertips the ability to scan its pieces in a simple and intuitive way.

In the particular case of the Archaeological Museum of Burriana, all these advances could contribute to further develop the initiative already taken. At this stage, the Museum is preparing the creation of a unique platform providing tools to manage technologies and content for archaeology museums.

The creation of this platform, in addition to providing a self-guided visit to museums, will also allow two-way communication between the entity and visitors. Users will be able to choose the scope and level of the visit, within a wide spectrum of artifacts and ICT, and their choices will undoubtedly provide important information to the entity about the interests and preferences of the public.

The usefulness of the platform is not only limited to teaching or informative aspects (based on resources such as digital documentation or virtual recreation); it will also reinforce a research field related to the creation of these products: digital restoration of pieces and virtual recreation of historical relevant contexts where pieces can interact. Moreover, enabling the accessibility to this information to all groups is also an important benefit.

Although the proposed approach of the platform is the archaeological museum heritage, it is very likely that its application will spread among other fields of cultural heritage.

\section{References}

Apollonio, F. I., Basilissi, V., Callieri, M., Dellepiane, M., Gaiani, M., Ponchio, F., Rizzo, F., Rubino, A. R., Scopigno, R., \& Sobra, G. (2018). A 3D-centered information system for the documentation of a complex restoration intervention. Journal of Cultural Heritage, 29, 89-99. https://doi.org/10.1016/j.culher.2017.07.010

Melchor, J. M., Cabrera, A., \&Martínez, J. (2018). Realidad Aumentada y didáctica del patrimonio: El ejemplo del Museo de Burriana. In Jornades d'Arqueologia de la Comunitat Valenciana: 2013-2015, pp. 513-517. Conselleria d'Educació, Investigació, Cultura i Esport.

Melchor, J., Martinez, J., Bonafe, C., \& Cabrera, A. (2016). La virtualización en el Museo Arqueológico de Burriana (Castellón-España). In8th International congress on archaeology, computer graphics, cultural heritage and innovation, pp. 78-84. Editorial Universitat Politècnica de València. https://doi.org/10.4995/arqueologica8.2016.3036

Meyer, É., Grussenmeyer, P., Perrin, J. P., Durand, A., \& Drap, P. (2007). A web information system for the management and the dissemination of Cultural Heritage data. Journal of Cultural Heritage, 8(4), $396-411$. https://doi.org/10.1016/j.culher.2007.07.003

Rojas-Sola, J. I., Castro-García, M., \& Carranza-Cañadas, M. del P. (2011). Content management system incorporated in a virtual museum hosting. Journal of Cultural Heritage, 12(1), 74-81. https://doi.org/10.1016/j.culher.2010.10.004

Komarac, T. (2014). A new world for museum marketing? Facing the old dilemmas while challenging new market opportunities. Market-Tržište, 26(2), 199-214. 
Vermeeren, A. P. O. S., Calvi, L., Sabiescu, A., Trocchianesi, R., Stuedahl, D., Giaccardi, E., \& Radice, S. (2018). Future Museum Experience Design: Crowds, Ecosystems and Novel Technologies. In: Vermeeren A., Calvi L., Sabiescu A. (Eds.) Museum Experience Design. Springer Series on Cultural Computing. Springer, Cham. https://doi.org/10.1007/978-3-319-58550-5_1 


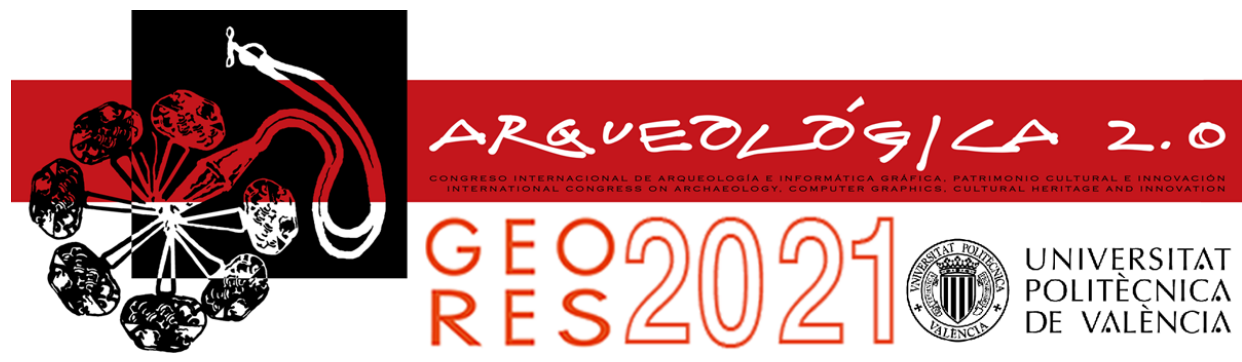

\title{
FROM THE DOCUMENT'S LIFE CYCLE TO THE MONUMENT'S LIFE CYCLE: THE CASE OF THE DE MURTAS BARRACK IN CAGLIARI
}

\author{
Alice Agus*, Donatella Rita Fiorino \\ Department of Civil-Environmental Engineering and Architecture (DICAAR), University of Cagliari, Via Santa Croce 59, floor 3, 09124 \\ Cagliari, Italy. alice.agus@unica.it; donatella.fiorino@unica.it
}

\begin{abstract}
:
The paper illustrates the first results of interdisciplinary research aimed at investigating the role of documentary sources in the process of conservation, protection, and sustainable use of military historical heritage. In particular, the study deals with the possibility of enhancing the quality of the Monument's Life Cycle Management through an innovative Document's Life Cycle Management; the meticulous analysis of the artefact, as well as the monitoring and documentation of the changes that have occurred over time, are meant to be the basis of this process. The research specifically focuses on the 'military inventory', a tool used to give a constantly updated image of the heritage. The inventory structure has remained almost unchanged over time: thanks to the possibility of carrying out a consequential reading of the updates, it represents today the key instrument for understanding defensive historical architectures, finding an interesting parallel in the Raumbuch - undoubtedly its direct descendant. The transposition of the inventory/Raumbuch into a digital device, based on HBIM technologies, can innovatively support the governance of the Monument's Life Cycle, by designing an effectual archiving system for the obtained information, whose storage and traceability depend on an appropriate set of metadata. The case study is the De Murtas Barrack, an ancient Jesuit Novitiate converted in XIX century in a military hospital, site of great complexity in terms of historical stratification and documentary consistency. As part of the research, the historical inventories and an important iconographic fund related to the monument were identified and digitized, followed by the definition of a specific metadata set. The systematization of the data coming from these different types of documents, compared with those coming from the direct analysis of the building, has led to a detailed knowledge of the monument: the updating of this preparatory database for BIM modelling is the instrument for monitoring the transformations, and for developing future informed restoration projects.
\end{abstract}

Keywords: digital archives, digitization, restoration, cultural heritage, life cycle management, planned maintenance

\section{Introduction}

In the context of the Italian cultural heritage, historical military architecture is generally little investigated. Despite a vast and heterogeneous panorama of prestigious architectures, several factors make this field a difficult object of study: first of all, the limited access to the related documents for security reasons. It must also be emphasized that the military archives are only partially digitized and not yet adequately catalogued, in particular, according to the architectural aspects. This creates difficulties and slowness in the enhancement processes, which are hindered, and limits the possibilities of an informed restoration.

The work illustrated in this paper is part of the AIDforINFO research project, which in turn is part of wider research carried out under the agreement between the University of Cagliari and the Ministry of Defence, signed in September 2018. The collaboration focuses on the rehabilitation of Sardinian military areas and for scientific aspects is coordinated by Professor Donatella Rita Fiorino. During the first two years of activities, the
University of Cagliari carried out several research programmes on single architecture in Cagliari and La Maddalena, but also scientific studies on methodologies and tool for documenting historical buildings and for monitoring their transformation due to restoration worksites (Fiorino, lannotti, \& Mellano, 2019).

Specifically, AIDforINFO project focuses on the investigation of the military documentary sources and their inclusion into an interoperable digital environment. Moreover, the project also considers a new interpretation of the documentary contents, together with the reorganization of the archives. The research relies on the assumption that archives represent an irreplaceable source of information for a deep understanding of construction history. This knowledge is the theoretical and operational basis for the recognition of the material and immaterial values, typical of this architectural heritage. The cognitive process necessarily passes through the analysis of the documents, whose projection in the digital environment opens new possibilities of an operational nature. The methodology has been tested on the Former Military Hospital of Cagliari, now the Military Department 
of Forensic Medicine, located at the De Murtas Barrack in the heart of the historic centre of Cagliari.

\section{Research and methodology (DRF)}

Among the different typologies of documents produced in the contest of the historical building management, the research has identified as the main topic of investigation, the 'military inventory' (Fig. 1). It is a type of document used since the beginning of the twentieth century by military engineering corps for the management of all their infrastructures. The current model follows the GEN-G-001 Regulation (Ministero della Difesa, 2014) issued by the Ministry of Defence, but the framework has remained almost unchanged over time.

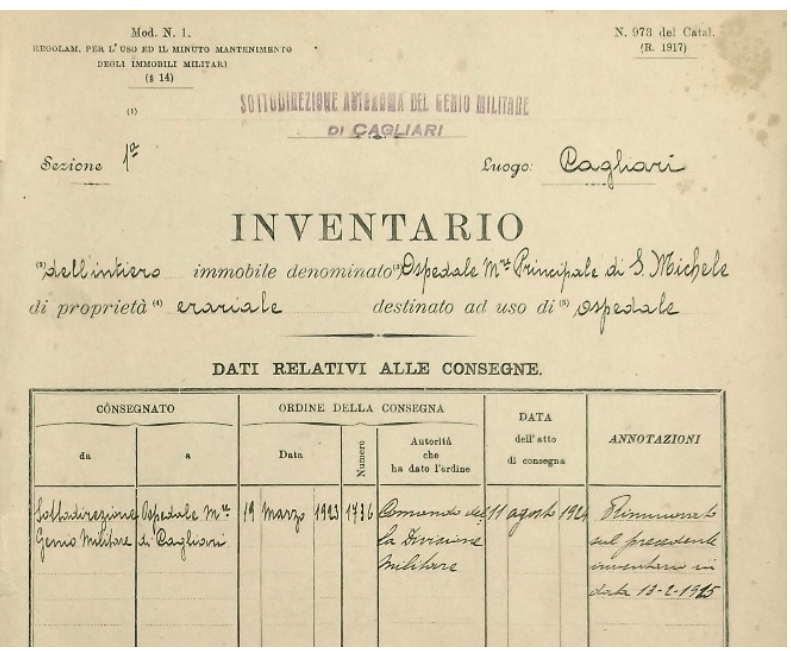

Figure 1: Title page of the inventory dated 19 March 1923, delivered on 11 August 1924. This is the oldest document found in the archive, drawn up by the Autonomous Subdirection of the Military Engineers on the basis of the previous inventory, dated 1915. It describes, room by room, the entire building called the Main Military Hospital of San Michele, referring to the model provided by the Regulations for the use and minute maintenance of military buildings updated to 1917.

In detail, the document illustrates the consistency of each room of every single building. For each level, a distinctive number is associated to every room, based on a reference map where this number is indicated. Every working and living space are described with a brief text as well as a set of information including dimension, current use, technical features - floors, windows, plasters, decorations, etc. - and service equipment.

Comparing the inventories drawn up over time for the same building, it is possible to trace the changing in the building features, often related to the several changes of use. For this reason, a systematic analysis of these documents allows the dating of every single constructive element and the reconstruction of the building morphology during the time (Fig. 2).

The large flow of heterogeneous information belonging from this investigation needs the set-up of a database, whose framework must be strictly related to the original document. The connection between the document and the database can be achieved through the assignment of a specific metadata set associated during the process of the dematerialization of the documentation (Pigliapoco, 2016).

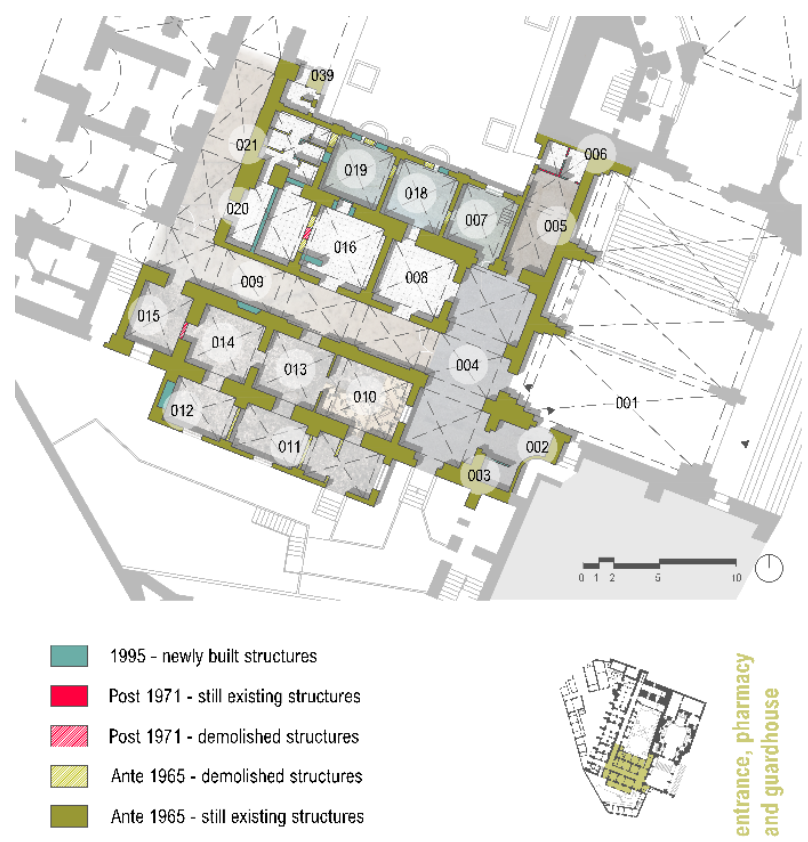

Figure 2: The south wing of the historic building of the complex, highlighting the construction chronologies and the vaulted ceilings. (c) 2021, A. Agus.

AIDforINFO works on the definition of these metadata. Starting from the standard titling in line with the Dublin Core, the research aims at generating a new set of metadata, functional for the traceability of information concerning the architectural matter. With this purpose, metadata will record not only the information about the document, but also the reference to its contents and, as a consequence, a set of useful data about the building itself.

The challenge is, at this point, to link metadata and database to the elements they refer to. The traditional methodology of monitoring the military assets by the inventory has been used as an operative tool for practising maintenance and for keeping updated the state of its consistency. The legacy of this practice can be found in the Raumbuch (literally "the book of rooms"), adopted in the last two decades in the conservation field as an effective knowledge tool, particularly useful to orienting design choices. The University of Cagliari has developed some examples of information system structured as a Raumbuch, able to connect 3D models to technical and historical data, using HBIM techniques. Starting from this background AIDforINFO aims at the definition of the archival metadata as the interoperable date for implementing HBIM model, using the efficient framework of the Raumbuch for extracting and reordering data from the inventories. This affinity between the Raumbuch and the structure of the military inventory opens towards a transdisciplinary interpretation of information (Fiorino, Grillo, Quaquero, \& Pilia, 2017).

This common digital environment makes it possible to compare a different kind of information and opens new perspectives towards IoT tools and predictive model (machine learning) to support scheduled maintenance and management activities.

Currently, the research is dealing with the crucial set of the metadata definition, following the digitization of a 
remarkable corpus of historical documents including maps and drawings.

\section{Case study and current state of the research (AA)}

The case study analyzed is the Former Military Hospital of Cagliari, now Military Department of Forensic Medicine, located at the De Murtas Barrack in the heart of the historic centre of Cagliari (Fig. 3).

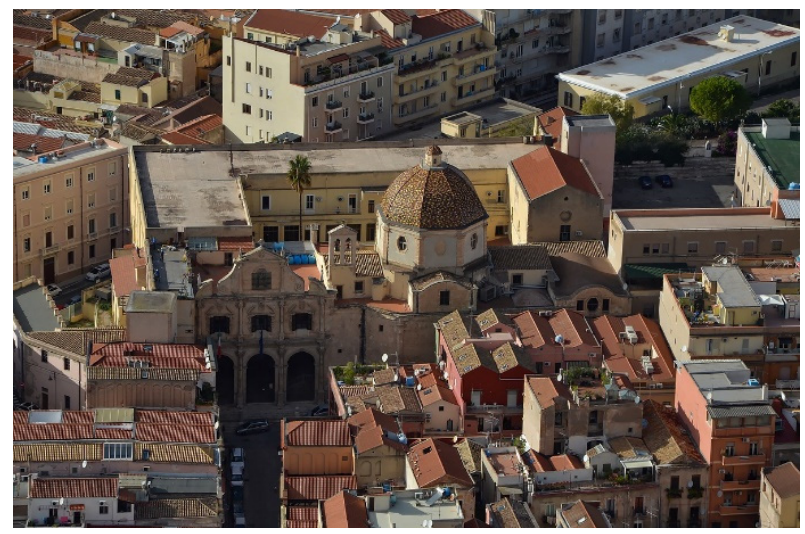

Figure 3: Aerial photograph of the De Murtas Barracks complex in the historic centre of Cagliari.

The building, designed at the end of the 17th century by architect Francesco Lagomaggiore to house the Jesuit Novitiate, is now a heterogeneous architectural complex consisting of eight buildings annexed to the San Michele Church. Despite the several adaptations it has undergone over time, especially concerning the new hospital function, the fabric still retains its original architectural conformation.

The research started with the reconnaissance of the archival funds belonging to the XIV Department of Infrastructures, in the premises of the Riva Villasanta Barrack in Cagliari. The most significant inventories, coinciding with those of 1923, 1965, 1989 and 1995, were then recognized and analyzed, in order to transpose them into a digital environment. The constant structure of the military inventory made it possible to easily and uniquely identify each space, immediately showing whether it, in its current configuration, is the result of a merger or division of several rooms, or if the nature of the cladding has been changed and when.

The main difficulty encountered during the creation of this database coincided with the absence of plans associated with the older inventories. The Drawings Archive of the XIV Department of Infrastructures, in which the historical iconographies relating to the case study are kept, therefore constitutes the knowledge base for obtaining further information about the fabric. The goal is to overlap the historical plans, with the specific aim of combining the information thus obtained to the data coming from the inventory collection.

The difficulties linked to the physicality of the supports, such as a wide variety of formats, the poor conservation state of some drawings, and the intrinsic impossibility to generate an overall view, were further confirmation of the need to digitalize the management system. Part of the research work, therefore, consisted on the selection and digitization of the historical drawings at the CEDECU,
Unique Defence Dematerialization and Conservation Center, based in Gaeta (LT); at the end of the process, 93 PDF/A-1a files were obtained.

The assignment of a specially designed metadata set to the produced digital documents, the central phase of the research, was then conducted starting from the Dublin Core model. The fifteen metadata of the Simple Dublin Core Metadata Set were first associated to each file, allowing to generate simple descriptions and to improve the quality of the management process (Rovella, lelpo, \& Caruso, 2016). Each series was therefore implemented by introducing specific qualifiers, aimed at expanding its meaning: for example, the Subject, about the category Identification and primary characteristics, was enriched through the extensions of 'building' - further specified into 'current denomination' and 'historical denominations' -, 'level', 'representation' and 'scale of representation'. This branching gives the possibility to perform reverse searches, starting from any available data - a toponym used historically - or from specific needs - drawings representing the elevations of the building -.

This set of metadata, currently under development, focuses on the relationship between the life cycle of the monument and the life cycle of the associated records. The intention is to create an operational correspondence between the transformations undergone by the building over time - from construction to disposals, restoration projects, demolitions - and the documentary reference, observed in the light of the related record management process. Structurally modelled as the Raumbuch, the database lays the foundations for the management of the interventions and the updated control of maintenance, which cannot be separated from the creation of a proposal for the selection and conservation of the associated funds. The set, therefore, includes geometric and material information, defining construction systems and techniques. Particularly relevant is the field relating to the 'purpose of the drawing', for which a specific vocabulary is being built.

These descriptors will constitute the structure of a web portal for historic defence architectures and must allow both targeted consultation and implementation, through the inclusion of any information source. Its aim is not only to provide a constantly updated control system of the structures but also to ensure the success of monitoring, management, routine maintenance and informed restoration projects (Santana Quintero, Blake, \& Eppich, 2007).

\section{Conclusions and perspectives}

The proposed research looks at the archive as the place of production of information, recognizing, in fact, its 'industrial dimension' for the management of the processes of analysis, reorganization, conservation, access and traceability of the contents of documentary sources. This vision, for the benefit of understanding the values and protecting military architecture, consists even first in a real awareness of the information transversality offered by these fields, in the kaleidoscopic range of opportunities for using and interpreting their contents. In particular, it intends to contribute to the interconnection between different document systems, as well as between main management applications, such as maintenance, conversion, capitalization and disposals, joining the 
debate on long-term preservation - one of the most complex and insidious aspects of the electronic document management (Marzano, 2011).

The guidelines and the process documents resulting from the experimentation are therefore proposed as a potential best practice, with possible methodological extensions to other geographical areas and different categories of artefacts.

\section{References}

Fiorino, D. R., Grillo, S. M., Quaquero, E., \& Pilia, E. (2017). Methods and processes of critic assessment for the historical military heritage: integrated use of raumbuch and HBIM for the reuse of the Cascino barrack in Cagliari. In Fiorino, D.R. Military Landscapes. A future for military heritage. Proceedings of the international conference. Milan, Italy: Skira Editore (pp. 369-370).

Fiorino, D. R., lannotti, P., \& Mellano, P. (2019). II riuso delle aree militari in Italia: esperienze di ricerca e didattica per le caserme di Bolzano e Cagliari. In II patrimonio culturale in mutamento. Le sfide dell'uso, $35^{\circ}$ Convegno Internazionale Scienza e Beni Culturali, Biscontin, G. \& Driussi, G. Atti delle Giornate di studi internazionali, Bressanone, Italy, 1-5 july. Collana Scienza e Beni Culturali. Venice, Italy: Edizioni Arcadia Ricerche.

Marzano, G. (2011). Conservare il digitale. Metodi, norme, tecnologie. Milan, Italy: Editrice Bibliografica.

Ministero della Difesa. (2014). GEN - G - 001, Direzione dei Lavori e del Demanio. Available at: https://www.difesa.it/SGDDNA/Staff/DT/GENIODIFE/Circolari/Documents/gen-g-001-2014/GEN_G_001_2014_0035932_2014-10-15.pdf

Pigliapoco, S. (2016). Progetto archivio digitale. Metodologia, sistemi, professionalità. Torre del Lago Puccini, Italy: Civita Editoriale.

Rovella, A., lelpo, N., \& Caruso, A. (2016). Using DC Metadata in preservation content: the case of the Italian "Protocollo Informatico", Dcmi Global Meetings \& Conferences, Dc-2016, Copenhagen, Denmark, 13-16 October. Proceeding Int'l Conference on Dublin Core and Metadata Applications, paper $n$. 479 . Available at: http://dcevents.dublincore.org/IntConf/dc-2016/paper/view/427/479.

Santana Quintero, M., Blake, B., \& Eppich, R. (2007). Conservation of Architectural Heritage. The role of digital documentation tools: the need for appropriate teaching material. International journal of architectural computing, 5(2), 239-253. https://doi.org/10.1260/1478-0771.5.2.240 


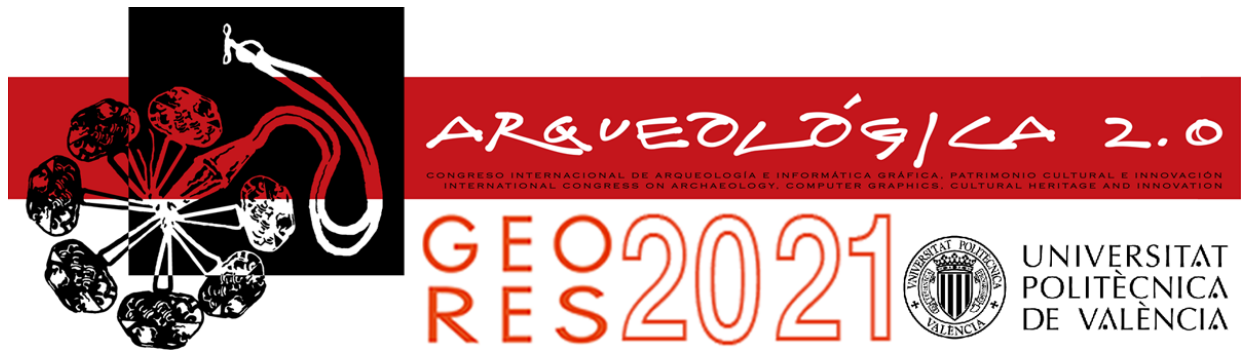

Proceedings of the joint international event $9^{\text {th }}$ ARQUEOLÓGICA

$2.0 \& 3^{\text {rd }}$ GEORES

Valencia (Spain).

26-28 April 2021

\title{
USE OF A NOVEL, LOW-COST 3D CT-SCAN VIEWER BY THE HOYO NEGRO PROJECT, QUINTANA ROO, MEXICO
}

\author{
James C. Chattersa, William O. Adams Jr. ${ }^{b}$, Diana Arano Recioc, Dominique Rissolod, ${ }^{\mathrm{d}}$, Helena \\ Barba Meineke \\ ${ }^{a}$ Applied Paleoscience, Bothell, Washington, USA. paleosci@gmail.com \\ ${ }^{\text {b } M e d V i z i, ~ L L C, ~ S a l t ~ L a k e ~ C i t y, ~ U t a h, ~ U S A . ~ b i l l . a d a m s @ m e d v i z i . c o m ~}$ \\ c Delegación Campeche, Instituto Nacional de Antropología e Historia, Mexico. darano.camp@inah.gob.mx \\ ${ }^{d}$ Center of Interdisciplinary Science for Art, Architecture, and Archaeology, University of California, San Diego, USA. drissolo@ucsd.edu \\ e Subdirección de Arqueología Subacuática, Instituto Nacional de Antropología e Historia, Mexico. helenabarbamei@gmail.com
}

\begin{abstract}
:
Computed tomography (CT) scanning technology has become an invaluable tool for archaeological and paleontological research, particularly in the study of ancient human skeletons. Once CT scans have been obtained, however, viewing and analyzing the results typically has high entry-costs in terms of hardware and software. Here we report a new, low-cost app for exploring CT scans in 3D, called MedVizi ${ }^{\mathrm{TM}}$. We briefly discuss its application to the study of Naia, the late Pleistocene human skeleton from Hoyo Negro, Quintana Roo, Mexico.
\end{abstract}

Keywords: CT scanning, 3D visualization, bioarchaeology, Mexico

\section{Introduction}

Radiological imaging is an increasingly important tool for bioarchaeological, paleoanthropological, and paleontological research and conservation. In paleontology and paleoanthropology, X-rays and particularly computed tomography (CT) scans have been used to investigate matrix-enclosed fossils, aiding in extraction planning and 3D visualization of as-yet unexposed bones and giving access to internal structures, including brains (Müller, Ferreira, Pretto, Bronzati, \& Kerber, 2020). It is almost impossible to publish findings on such skeletal features without accompanying radiographic evidence.

While CT scanning has become essential in paleoosteological research, it is far from universally accessible. High entry costs create insurmountable barriers for many researchers, particularly faculty, students, and staff of smaller colleges and individuals at resource-challenged institutions. CT scan equipment used in hospitals, dental offices, and industrial settings costs $\sim \$ 250,000 \rightarrow$ $\$ 1,000,000$ USD. It is typically necessary to develop alliances with hospitals, medical schools, and colleagues with substantial grant funding to obtain the initial data. This can be the easy part. Once a specimen is scanned, software to investigate large $3 \mathrm{D}$ volumes can cost upwards of $\$ 15,000$ USD and require a specialized workstation which is equally expensive. The new
MedVizi ${ }^{\mathrm{TM}}$ mobile viewer allows specimens to be explored offline, without being connected to these expensive systems.

The MedVizi ${ }^{\mathrm{TM}}$ mobile viewer is developed by MedVizi, LLC of Salt Lake City, Utah. It can be used to explore and manipulate $\mathrm{CT}$ scans and $3 \mathrm{D}$ volumes of specimens on iPhone $^{\circledR}$ and iPad ${ }^{\circledR}$. Digital Imaging and Communications in Medicine (DICOM) files generated by the medical CT scanner and TIFF files produced by microCT systems are sent to MedVizi ${ }^{\mathrm{TM}}$ and for $\$ 150$ USD are converted directly into $3 \mathrm{D}$ volumetric studies. Studies are configured to be rotated or peeled in the sagittal, coronal, or axial plane with density threshold manipulation. In addition, MedVizi ${ }^{\mathrm{TM}}$ can apply color to enhance density, simplifying illustration of skeletal features of interest. This represents functionality typically only found on expensive systems like those that accompany CT scanners (Christiansen, Shorti, Smith, Prows, \& Bishoff, 2018). Once uploaded to the MedVizi ${ }^{\mathrm{TM}}$ website, these studies can be downloaded multiple times to numerous mobile devices and explored in real time in the office, laboratory, or even in the field without being connected to expensive, non-portable systems. Cost of the mobile viewer is \$0.99 USD.

\section{Hoyo Negro Case Study}

Hoyo Negro is an immense collapse chamber located deep within the submerged Sac Actun cave system of eastern Quintana Roo state, Mexico (Chatters et al., 
2017). In that chamber, at depths between 39-50 m below sea level, our research team led by the Subdirección de Arqueología Subacuática of the Instituto Nacional de Antropología e Historia has documented the remains of over 50 mammals of 18 species, including a human. The human skeleton, an adolescent female known as Naia, has been dated by radiocarbon and uranium-thorium methods to between 13,000 and 12,000 cal BP (Chatters et al., 2014). Missing only a few ribs and vertebrae, along with most bones of the feet, Naia is the most complete of the earliest skeletons from the Western Hemisphere. As such, she provides an unequaled opportunity to explore the life of a young female among the earliest Americans.

To document and obtain a record of the bones, should they disintegrate upon contact with air, the remains were first CT scanned while in water-filled collection containers at the Hospital de Especialidades in Campeche, Mexico. Thereafter, numerous additional scans were conducted, including dental and microCT scanning at the Universidad Autónoma de Yucatán. MicroCT images were also obtained using Nikon Metrology X Ray CT XTH225ST at the Facultad de Odontología, Universidad Nacional Autónoma de México (UNAM), Mexico City and a Zeiss Xradia Versa 510 at the Geosciences Center, UNAM Querétaro. The problem we faced, despite this extensive, detailed record, was the lack of systems and expertise for viewing and manipulating these detailed datasets.

MedVizi ${ }^{\mathrm{TM}}$ contacted the senior author in summer, 2020, offering the viewer and service to the Hoyo Negro Project. We have since used it to explore Naia's skeleton, and for the first time are able to work through high resolution microCT and medical CT DICOMs to explore the endocranial cavity (Fig. 1), investigate anomalies in the teeth (Fig. 2), inspect detailed growth anomalies in the long bones (Fig. 3), and validate limb fractures (Fig. 4), among other studies.

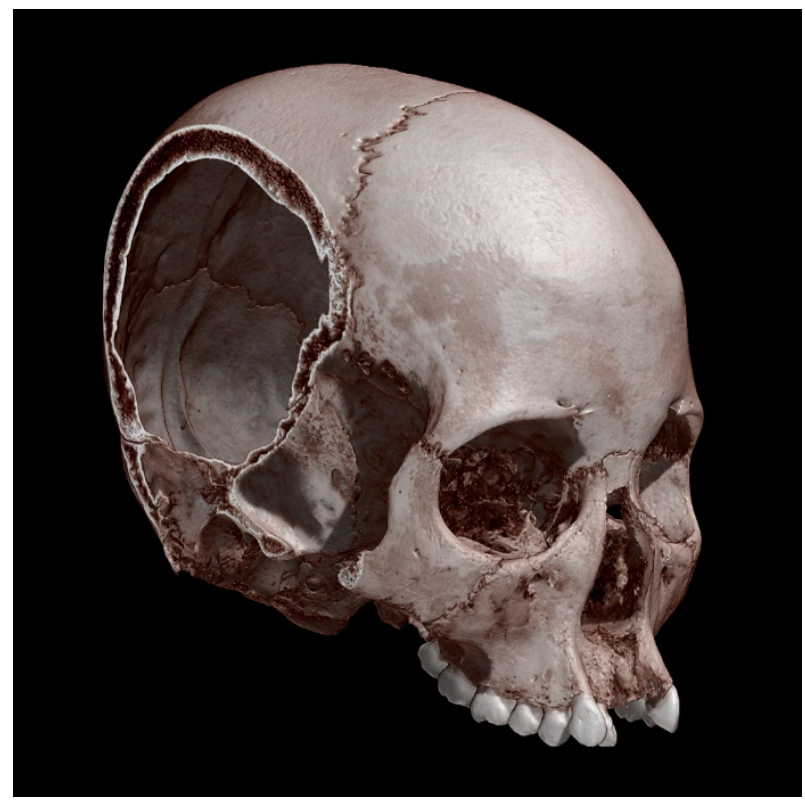

Figure 1: An image from the MedVizi app, in the process of sagitally "peeling" the skull to expose the endocranial cavity of Naia from Hoyo Negro.

In the teeth, for the first time, we were able to work through microCT slices to determine tooth root number, investigate the extent and severity of caries, and map the extent and severity of diagenesis. With these findings, we were able to more selectively sample one of the teeth for radiocarbon dating while avoiding contaminated tissues in the diagenetically altered dentine.

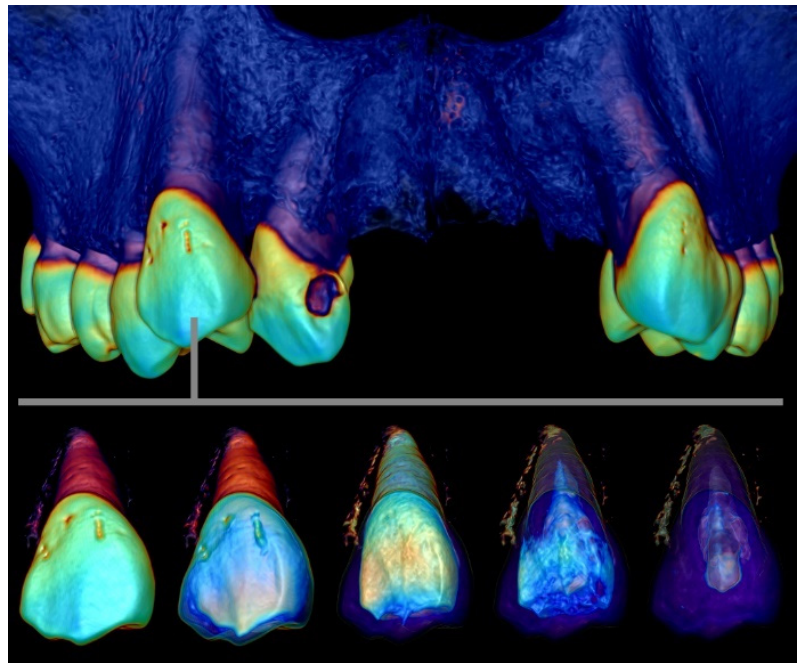

Figure 2: A composite of images produced by MedVizi, including a volumetric model of the maxilla (above) showing a large carious lesion in a second incisor, and a series of images of the right canine, extracted from the maxilla and highlighting high density tissues at left progressing to emphasis of low density on the right.

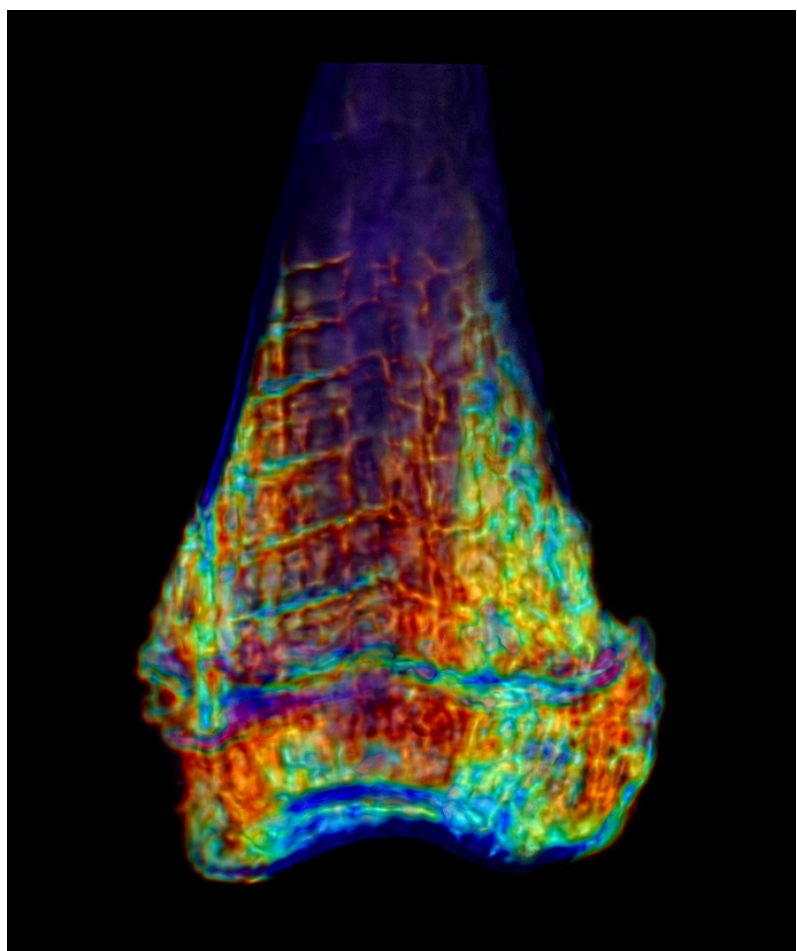

Figure 3: Naia's left femur, peeled to expose bright Harris lines transverse to the bone's long axis.

In the long bones, it was possible to scroll through the partially deteriorated trabecular bone to visualize, count, and quantify the severity of multiple episodes of growth interruption indicative of severe protein deficiency or abrupt surges in protein availability. This takes us a significant step toward understanding this young woman's mode of subsistence. 
Manipulating density in the left radius, we could better visualize and confirm a healed spiral fracture, indicating a possible episode of abuse in her young life.

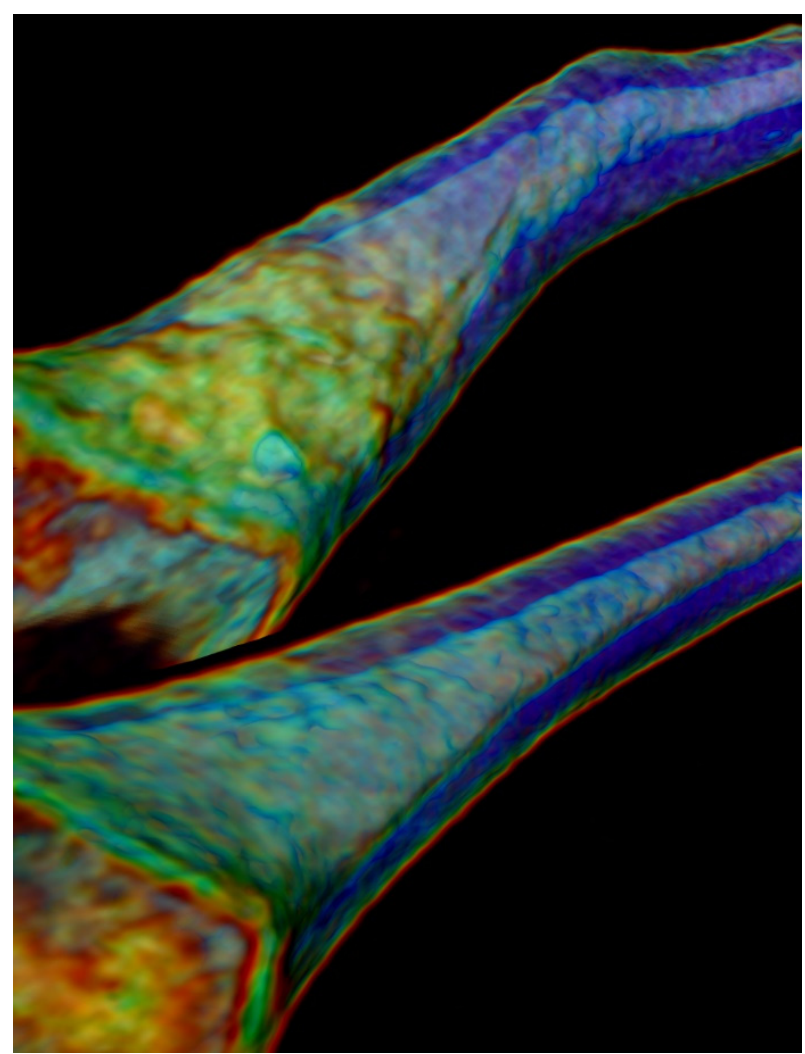

Figure 4: Sections of the diaphyses of Naia's radii, manipulating density to show the normal right (lower) and the healed spiral fracture in the left (above), which appears as a shaded green line.

\section{Tools and Methods}

In addition to the "hollow geometry surfaces" used in 3D printing, light scans and VR, it is desirable to explore both the interior and surface densities of a specimen CT scan using 3D pixels called "voxels." Two free tools helpful for viewing voxels and organizing CT scans are 3DSlicer and Horos $^{\mathrm{TM}}$ desktop viewer for Mac. Both have 2D grayscale and basic $3 \mathrm{D}$ rendering. Horos ${ }^{\mathrm{TM}}$ also offers a mobile viewer with $2 \mathrm{D}$ grayscale and limited $3 \mathrm{D}$ rendering. 3DSlicer does not offer a mobile viewer. Unlike most other mobile viewers, neither the Horos ${ }^{\mathrm{TM}}$ nor MedVizi ${ }^{\mathrm{TM}}$ mobile viewer suffer from remote-render lag or 15 viewer perserver limitations. In addition to 2D grayscale, MedVizi ${ }^{\mathrm{TM}}$ Mobile renders cinematic 3D reconstructions in real time while rotating or changing density and peeling in axial, sagittal and coronal planes. Medical CT DICOM and microCT TIFF files sent to MedVizi are reconstructed into voxels in MedVizi ${ }^{\mathrm{TM}}$ Workstation. Voxel density changes are stored as opacity, color, surface and lighting in studies shared via the cloud. On iPhone ${ }^{\circledR}$ or iPad ${ }^{\circledR}$, tapping a MedVizi ${ }^{\mathrm{TM}}$ link in text or email prompts "install" or "study download." Once downloaded, 2D and cinematic 3D reconstructions from multi-gigabyte CT scans open instantly and can be explored in real time, even in the field.

\section{Concluding Statement}

MedVizi ${ }^{\mathrm{TM}}$ is an inexpensive alternative to high-priced 3D systems for CT that effectively makes this important analysis, visualization, and documentation technique much more readily available to archaeological, paleontological, and paleoanthropological practitioners. Needing only an iPhone ${ }^{\circledR}$ and access to the Internet during download, it will be particularly valuable for researchers who do not have access to more costly software solutions.

\section{Acknowledgements}

This research is a project of the Subdirección de Arqueología Subacuática of the Instituto Nacional de Antropología e Historia (INAH), Mexico, directed by Roberto Junco. Field research was conducted under the supervision Adriana Velázquez Morlet and Margarito Molina of Centro INAH Quintana Roo. Funding for the recovery of human skeletal remains was provided by the National Geographic Society, with field activities facilitated by CINDAQ. Specific to the research presented here, we thank Leopoldo Ruiz, Dante Arteaga, and Norman H. Gellada. The following individuals have been integral to the success of the Hoyo Negro Project: Alejandro Alvarez, Joaquín Arroyo-Cabrales, Franco Attolini, José Balam, Patricia Beddows, Susan Bird, Roberto Chávez Arce, Andrea Cucina, Danylo Drohobytsky, Falko Kuester, Eric Lo, Robert Lourie, Sam Meacham, Alberto Nava Blank, Vid Petrovic, Eduard Reinhardt, Blaine Schubert, Brian Strauss, Vera Tiesler, and always Pilar Luna Erreguerena.

\section{References}

Chatters, J. C., Kennett, D. J., Asmerom, Y., Kemp, B. M., Polyak, V., Nava Blank, A., Beddows, P. A., Reinhardt, E., Arroyo-Cabrales, J., Bolnick, D. A., Malhi, R. S., Culleton, B. J., Luna Erreguerena, P., Rissolo, D., Morell-Hart, S., \& Stafford, T.W., Jr. (2014). Late Pleistocene Human Skeleton and mtDNA Link Paleoamericans and Modern Native Americans. Science, 334(6185), 750-754. https://doi.org/10.1126/science.1252619

Chatters, J. C., Rissolo, D., Arroyo-Cabrales, J., Stafford, T. W., Jr., Kemp, B. M., Alvarez, A., Nava Blank, A., Attolini, F., Beddows, P. A., Reinhardt, E., Kovacs, S., Collins, S., Morell-Hart, S., Chávez-Arce, R., Bird, S., \& Luna Erreguerena, P., (2017). Hoyo Negro: Tapping the Paleoanthropological and Paleoecological Potential of a Deeply Submerged, Underground Chamber on the Yucatan Peninsula, Mexico. In P.B. Campbell (Ed.), The Archaeology of Underwater Caves (pp. 119-129). Southampton: Highfield Press.

Christiansen, A. R, Shorti, R. M., Smith, C. D., Prows, W. C., \& Bishoff, J. T., (2018). Intraoperative utilization of advanced imaging modalities in a complex kidney stone case: a pilot case study. World Journal of Urology, 36(5), 733-743. https://doi.org/10.1007/s00345-018-2260-4

Müller, R. T., Ferreira, J. D., Pretto, F. A., Bronzati, M., \& Kerber, L., (2020). The endocranial anatomy of Buriolestes 
schultzi (Dinosauria: Saurischia) and the early evolution of brain tissues in sauropodomorph dinosaurs. Journal of Anatomy, 238, 809-827. https://doi.org/10.1111/joa.13350 


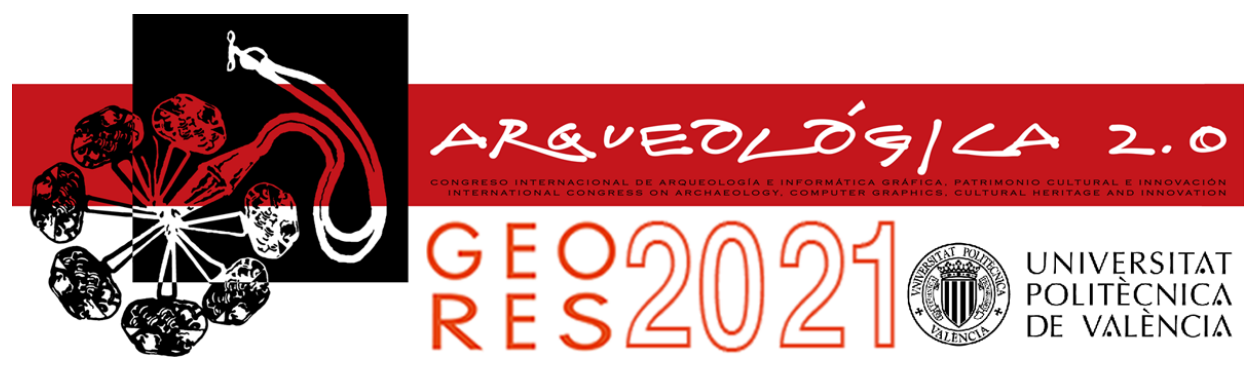

\title{
MIXED REALITY FOR THE MONUMENTAL HERITAGE. A FIRST TEST
}

\author{
Simone Teruggi ${ }^{\star}$, Francesco Fassi \\ 3D Survey Group, ABC Lab, Politecnico di Milano, Via Ponzio 31, 20133 Milano, Italy. simone.teruggi@polimi.it; \\ francesco.fassi@polimi.it
}

\begin{abstract}
:
This short paper presents the first results obtained in developing a Mixed Reality application to support maintenance and inspection activities performed in Milan Cathedral building site. Up to now Cultural Heritage applications have been relegated to tourism, leisure, and virtual museums activities, but as it is happening in many other fields, MR could improve building inspectors' workflow allowing for cost reduction and timesaving. Milan Cathedral constitutes an excellent case study, a top example for its periodic maintenance and inspection interventions. MR could potentially give an enormous contribution in terms of exchange and dissemination of information among the many practitioners working on the Cathedral yard. On this line, a prototype is currently being developed to support Milan Cathedral yard activities with some initial positive results.
\end{abstract}

Keywords: HoloLens, Mixed Reality (MR), cultural heritage, point cloud, industry 4.0

\section{Introduction}

At the industrial level, the need to have information at disposal in real-time and directly at the production line is spreading the development of technologies related to "smart factories". This need is reshaping how the production process has been intended. Integration among the physical and virtual world, together with widespread connectivity are key points in factories of the future (Culot, Nassimbeni, Orzes, \& Sartor, 2020). Augmented Reality $(A R)$ and Mixed Reality (MR) are the leading enabling technologies for this new way of intending the production process inside the new "industry 4.0". They give the possibility to see in the real world all the virtual information related to different aspects of the fabrication process.

This short paper presents some impressive initial results related to the first steps moved toward the use of MR in support of maintenance work inside Milan Cathedral building sites.

\section{What is MR}

During the last years, the distinction among the terms AR and MR, usually used as synonym of Holographic AR, has become increasingly blurry. The difference between the two words lays in how the augmented content is perceived in relation to real objects. In MR, 3D virtual objects are shown as holograms. These are objects made of light that are displayed and sensed as part of the environment through head-mounted displays (HMD) that can project these holograms into the real world. They enable the user to interact with the holograms using gaze, gestures, and voice commands. Contrary to a standard
AR application, it is possible to directly manipulate the 3D virtual objects as well as real objects. A movement through the real world corresponds to the same motion in the digital one (Fig. 1). This blend mixes capabilities of Virtual Reality with those of AR producing an environment where physical and digital coexist (Pedersen, Gale, Mirza-Babaei, \& Reid, 2017).

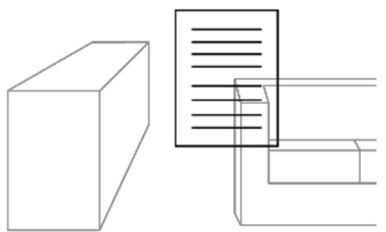

AR

(a)

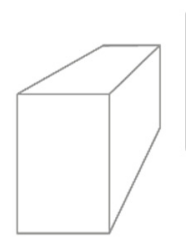

MR

(b)
Figure 1: Virtual object perception difference: a) AR where the virtual content is projected onto the real world; b) MR, real object and virtual ones coexists.

\subsection{MR in Cultural Heritage}

MR in Cultural Heritage could potentially give an enormous contribution in terms of exchange and dissemination of information among the many practitioners working on a particular case study, from restorers to site managers.

However, nowadays, the uses of $A R$ and $M R$ are relegated mostly to tourism, education and virtual museum (Bekele, Pierdicca, Frontoni, Malinverni, \& Gain, 2018) with no example of the use of this technology for

*Corresponding Author: Simone Teruggi, simone.teruggi@polimi.it 
more professional activities. This could be due to two main reasons: an intrinsic delay of $\mathrm{CH}$ in accepting and using new technologies in the daily practice and, the difficulties in producing $\mathrm{CH} 3 \mathrm{D}$ models, a mandatory task for a MR system. Some interesting experiments demonstrated improvements in $\mathrm{CH}$ dissemination allowing broader access to knowledge (when physical access is constrained) as well as visitor experience enhancement through exhibition enrichment with virtual content (Andrade \& Dias, 2020; Hammady, Ma, \& Strathearn, 2020).

However, looking at $\mathrm{CH}$ substantial necessities for maintenance and restoration planning and interventions, it is possible to see that in many cases the building site of a monumental heritage architecture is as alive as that of new construction and although different, some needs are similar for the two worlds even those that can be solved with dedicated Mixed Reality systems. For example, the combination of BIM (Building Information Modelling) and MR can improve building inspectors' workflow allowing for cost reduction and time savings. Overlaying the architectural model to the real world, filling the inspection form and assigning damage reports with attached photographs and audio record proved successful in building an effective workflow (Brito, Alves, Magalhaes, \& Guevara, 2019). MR can allow for multi-dimensional exploration of technical documents projecting them directly on the reality, visualizing hidden objects and details, wall thicknesses, allowing to check planarity and verticality, to count objects (e.g. statutes or marble blocks) and to inspect far and near objects at the highest resolution (Pratt et al., 2018). Furthermore, the possibility to share info in a real-time multiuser experience is another essential feature of the system that could facilitate the exchange of information between actors in the maintenance process (Brun et al., 2019) as in the new construction design activities.

\section{From Survey to Holograms: the Milan Cathedral prototype}

Milan Cathedral can be an exceptional case study concerning this topic for its periodic maintenance and inspection activities, for the number of different actors working for its conservation that need to access and share all different type of data, and the amount of technical and historical documents that constitute the cognitive patrimony of the whole cathedral. A MR system could help under so many aspects of the Cathedral activity. Moreover, thanks to previous research activities, there is at disposal the complete point cloud model of the cathedral. It is "only" a matter of solving the problem of how to model a complex and extensive monument like this or better to choose what kind of model is possible to be used to speed up the process, minimize costs and maintain a high degree of metric accuracy. A realitybased 3D surface or parametric model of complex $\mathrm{CH}$ usually is not easy to be produced, and to be used in real conservation activities. The modelling phase is timeconsuming, uneconomical, introducing an unsupervised degree of subjectivity and lowering the initial metric content of the survey. For all these reasons, the main research idea aims at using the $3 \mathrm{D}$ point cloud models (produced during survey activities) directly, skipping this unproductive modelling phase. This can be done preparing the point cloud to use it as a real $3 \mathrm{D}$ model segmented in its constitutive parts, assigning semantics and structure to the whole model. Milan Cathedral pointcloud dataset has been classified at different resolutions, following the procedure presented in (Teruggi, Grilli, Russo, Fassi, \& Remondino, 2020) and finally used as 3D on which to build the Mixed Reality System.

\subsection{The prototype}

The prototype is being developed for HoloLens 2 (Microsoft, 2020), a Head-Mounted Display (HMD) that through a pair of transparent glasses allows the user to see and manipulate 3D models as holograms in the real world. The software environment is Unity 3D (Unity3D, 2020) using the MRTK v2 (MRTK, 2020) package as the interface that allows communicating with the physical device.

However powerful, it is essential to remember that the HoloLens 2 is a portable device and, therefore, it has computational as well as battery life limits to be considered. To cope with these problems, it is necessary to use different resolution point models: the same that were used during the classification process (Teruggi, Grilli, Russo, Fassi, \& Remondino, 2020). Lower resolution $3 \mathrm{D}$ point models can correctly display objects seen from a bigger distance retaining a good visualization quality: the resolution increase as the distance from the object decreases. Full resolution point models $(0.5 \mathrm{~cm})$ are used only to display single instances of detail objects (e.g. statues, ornaments). This is necessary to ease the computational requirements to which the device is subjected, thus increasing battery life, and keeping the application above 60 frames per seconds (necessary to display the holograms correctly).

The HoloLens 2 device works on the possibility to recognize hand gestures as well as gaze direction and voice inputs. When device's cameras detect a hand present inside the rendering area, a white dashed line is projected in the direction to which the hand is pointing. Four primary types of hand gestures are used to interact with holograms: hand ray or touch for far and near interaction, air tap to select and air tap and hold to grab and drag holograms. These gestures have been used ad hoc to give the user the possibility to navigate through the structured point cloud. It can be orbited, navigated, moved, and scaled depending on user necessities.

A first ad-hoc application was developed to test the point cloud visualization on a MR system and the use in the real vast environment of the Milan cathedral interiors. Starting the app, the device presents the spectator with the lowresolution point cloud $(10 \mathrm{~cm})$ of the concerned sector. Due to the low resolution, the model is zoomed out so that it is wholly contained in the HoloLens 2 field of view. Side by side with the model, there is a small navigation menu that allows performing some operations on the object. The model is divided into its constituent architectonic macroelements (e.g. pillars, vaults) only touching the holographic "split" button on the main menu. At this stage point cloud resolution does not change since all elements are still contemporary visible. Through the hand ray gesture, it is possible to highlight distinct elements that, when touched, will be selected and isolated displaying the correspondent higher resolution version $(5 \mathrm{~cm})$ with all related information attached. Iteratively the user could split through the corresponding menu button the isolated macro element in its constituting architectural elements. 
These objects can be highlighted and touched as well as isolated and displayed at a higher resolution $(2 \mathrm{~cm})$.

The last step is to split the architectural element in objects (e.g. statues, decoration) that highlighted and isolated will be displayed at full resolution $(0.5 \mathrm{~cm})$ or in their 3D mesh model version in those situations where a modelling
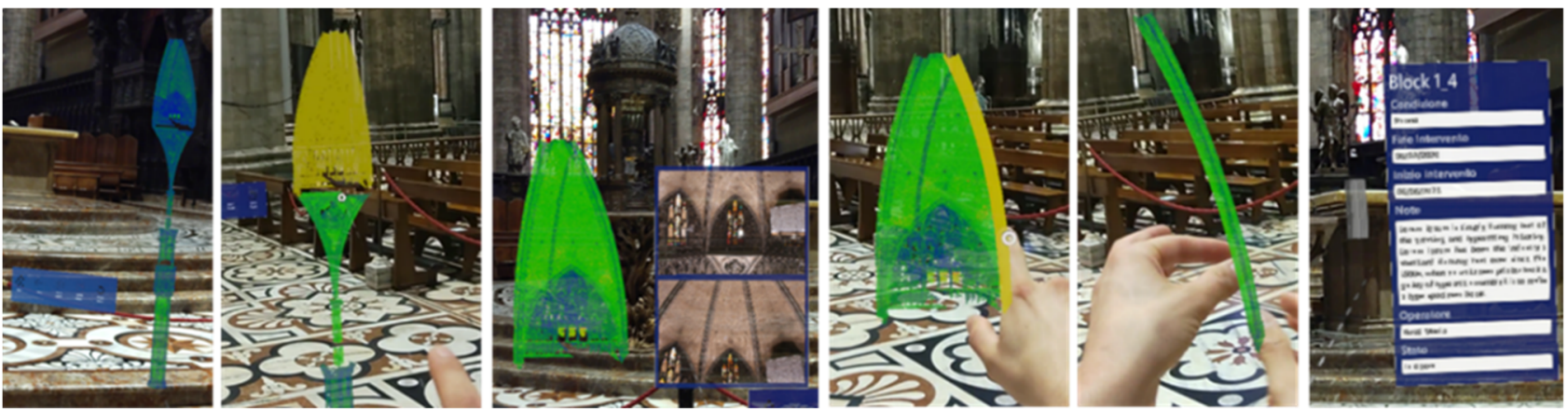

Figure 2: MR point cloud model interaction example. From the first low resolution point cloud it is possible to navigate through sequential increasing resolution point clouds reaching the 3D model of the marble block. Information could be attached at each step.

Finally, the first test of superimposition of the point model at $1: 1$ scale to the real object has been performed. Holograms have been placed manually, but the visualization quality and their spatial persistence have proved satisfactory (see Teruggi, S., \& Fassi, F. 2020).

\section{Conclusions}

A first MR prototype that uses a vast point cloud model of a very complex monumental heritage has been presented. Through the dedicated developed application, it is possible to navigate the 3D point model of one portion of the crossing of Milan Cathedral. The manual modelling phase has been totally avoided since different resolution phase is still mandatory (e.g. marble blocks) (Fig. 2). The possibility to display different types of models is useful to complement already existing 3D mesh models with those parts too complex to model speeding up the implementation process without wasting energy on the modelling phase itself. point clouds are used depending on the dimension of the visualized element as well as on the detail to be displayed on these elements.

Many are aspects that need further research: from the automatic superimposition of virtual content on the real object to database connection and real-time retrieval of stored information to the possibility in updating this information from the building site to the capability of having real-time multiuser experiences. So, the road to a truly usable system during construction activities is still very long; nonetheless, the prototype assessed the feasibility of the research project and showed positive initial results.

\section{References}

Andrade, J. G., \& Dias, P. (2020). A Phygital Approach to Cultural heritage: Augmented Reality at Regaleira. Virtual Archaeology Review, 11(22), 15-25. https://doi.org/10.4995/var.2020.11663

Bekele, M. K., Pierdicca, R., Frontoni, E., Malinverni, E. S., \& Gain, J. (2018). A survey of augmented, virtual, and mixed reality for cultural heritage. Journal on Computing and Cultural Heritage, 11(2). https://doi.org/10.1145/3145534

Brito, C., Alves, N., Magalhaes, L., \& Guevara, M. (2019). Bim mixed reality tool for the inspection of heritage buildings. ISPRS Ann. Photogramm. Remote Sens. Spatial Inf. Sci., IV-2/W6, 25-29, https://doi.org/10.5194/isprs-annals-IV2-W6-25-2019. https://doi.org/10.5194/isprs-annals-IV-2-W6-25-2019

Brun, H., Bugge, R. A. B., Suther, L. K. R., Birkeland, S., Kumar, R., Pelanis, E., \& Elle, O. J. (2019). Mixed reality holograms for heart surgery planning: First user experience in congenital heart disease. European Heart Journal Cardiovascular Imaging, 20(8), 883-888. https://doi.org/10.1093/ehjci/jey184

Culot, G., Nassimbeni, G., Orzes, G., \& Sartor, M. (2020). Behind the definition of Industry 4.0: Analysis and open questions. International Journal of Production Economics. https://doi.org/10.1016/j.ijpe.2020.107617

Hammady, R., Ma, M., \& Strathearn, C. (2020). Ambient Information Visualisation and Visitors Technology Acceptance of Mixed Reality in Museums. Journal on Computing and Cultural Heritage, 13(2). https://doi.org/10.1145/3359590

Microsoft. (2020). HoloLens 2: overview, funzionalità e specifiche. Retrieved November 25, 2020, from https://www.microsoft.com/it-it/hololens/hardware

MRTK. (2020). GitHub - microsoft MixedRealityToolkit-Unity. Retrieved November 25, 2020, from https://github.com/microsoft/MixedRealityToolkit-Unity

Pedersen, I., Gale, N., Mirza-Babaei, P., \& Reid, S. (2017). More than Meets the Eye: The Benefits of Augmented Reality and Holographic Displays for Digital Cultural Heritage. ACM Journal on Computing and Cultural Heritage, 10(2), Article 11. http://dx.doi.org/10.1145/3051480

Pratt, P., Ives, M., Lawton, G., Simmons, J., Radev, N., Spyropoulou, L., \& Amiras, D. (2018). Through the HoloLensTM 
looking glass: augmented reality for extremity reconstruction surgery using 3D vascular models with perforating vessels. European Radiology Experimental, 2(1), 0-6. https://doi.org/10.1186/s41747-017-0033-2

Teruggi, S., \& Fassi, F. (2020). FAPER - OneDrive (sharepoint.com). Retrieved March 15, 2021, from https://polimi365my.sharepoint.com/:f:/g/personal/10323083_polimi_it/EhYS8zRzYmBPi6td4HZxJ6YB0hPp8o4wFNfb9Pbxp9HV0Q $? \mathrm{e}=\mathrm{Vs}$ JilG

Teruggi, S., Grilli, E., Russo, M., Fassi, F., \& Remondino, F. (2020). A hierarchical machine learning approach for multilevel and multi-resolution 3D point cloud classification. Remote Sensing, 12(16). https://doi.org/10.3390/RS12162598

Unity3D. (2020). Unity Real-Time Development Platform. Retrieved November 25, 2020, from https://unity.com/ 


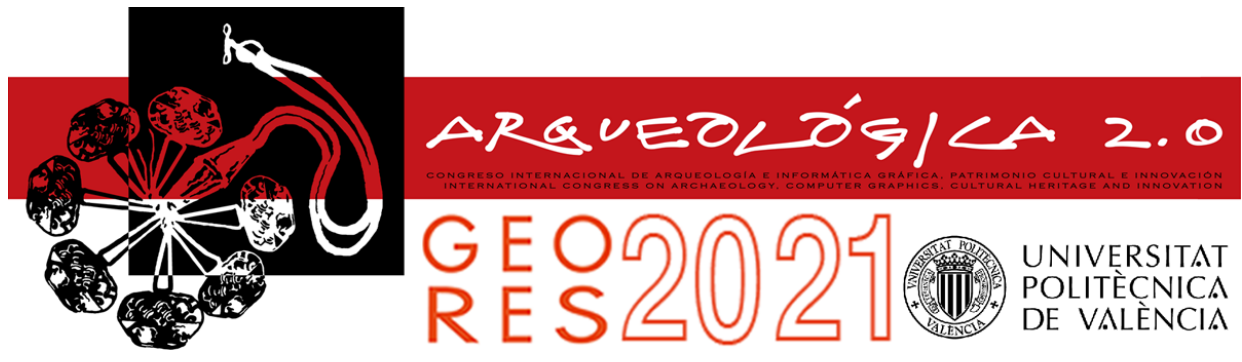

Proceedings of the joint international event $9^{\text {th }}$ ARQUEOLÓGICA

$2.0 \& 3^{\text {rd }}$ GEORES

Valencia (Spain).

26-28 April 2021

Received: 27/11/2020

Accepted: 26/02/2021

\title{
AN EXPERIMENTAL WORKFLOW FOR THE VIRTUAL RECONSTRUCTION OF ANCIENT STATUES
}

\author{
Leonarda Fazio ${ }^{a,{ }^{*}}$, Mauro Lo Brutto ${ }^{b}$ \\ a Department Cultures and Societies, University of Palermo, Viale delle Scienze, Ed. 15, 90128 Palermo, Italy. leonarda.fazio@unipa.it \\ ${ }^{b}$ Department of Engineering, University of Palermo, Viale delle Scienze, Ed. 8, 90128 Palermo, Italy. mauro.lobrutto@unipa
}

\begin{abstract}
:
The work aims to investigate the main steps of a virtual reconstruction process of ancient statues, inspecting theoretical and technical approaches. Two fragmentary Roman statues from the "Sanctuary of Isis", inside the Archaeological Park of Lilibeo-Marsala (Italy), were chosen as a case study. Trying to preserve the original artwork authenticity and the transparency of the reconstruction method, a workflow was developed following three steps: 1) 3D survey and realitybased model production; 2) evaluation of reconstruction hypotheses based on a rigorous selection of reference sources; 3) 3D modelling and source-based model creation. Three models for multiple visualization purposes were carried out: a high-resolution reality-based model for documentation and detailed specialist analyses, a real-integrated model for scientific purposes in which it is possible to visually distinguish the surviving fragments from the modelled ones through a partial texture and an ideal model useful for dissemination aims with a uniform texture that simulates hypothetical original state of the sculptures.
\end{abstract}

Keywords: virtual reconstruction, Roman statues, 3D survey, 3D organic modelling, source-based model

\section{Virtual reconstruction of ancient statues}

Technological progress in 3D survey and computer graphics have opened new scenarios for cultural heritage enhancement. Among these, the virtual reconstructions (VR) of archaeological buildings and artefacts offers a strategical opportunity for knowledge dissemination.

The London Charter (2009) and The Seville Principles (2011), which define the scientific principles for cultural heritage visualization in virtual environment, provide general guidelines but no prescriptions or standards to guide the VR practitioners. To fill the gap especially in the well-established scientific field of architectural VR, different codes and standards were developed taking inspiration from museum standard (Kuroczyński, 2017), physical restoration or archaeological practice (Demetrescu, 2015).

Developed methods and guidelines highlight the transparency of a reconstruction process and the use of reliable information sources as essential scientific values to minimize arbitrariness in a VR process. Most of the archaeological monuments or artefacts, in fact, come to us lacking. In these cases, interpretation and consequently reconstruction (physical or virtual) must make use of sources of information - e.g. descriptions, drawings, or comparisons with similar specimens - to recreate their original state. Often, sources are also lacking, involving a greater inventiveness effort, for example, to recreate a complex building as it was in historical reality starting from poor archaeological remains.

A particular case of VR concerns ancient sculptures. For Greco-Roman statuary, the reconstruction may take advantage of a detailed sample of iconographic models and variants for multiple purposes. Specimens' comparison allows formulating more scientifically reliable hypotheses on VR of fragmentary statues. At the same time, different documents (photos, drawings or 3D models) can be used as references to support the 3D modelling.

A 3D product of a reconstructed statue can achieve a very high level of realistic representation, re-creating the space, shapes and colours to simulate and emphasize the visual experience. VR of statues was employed for scientific or educational purposes, in diagnostics and restoration (Bagnéris et al., 2017), for knowledge and dissemination aims, producing physical (Fregonese et al., 2019) or digital models (Bennoui-Ladraa, Chennaoui, \& Ainouche, 2020) following reconstruction approaches and methodologies formulated for each specific study case. However, without effective sources of information to support VR and using an arbitrary reconstruction process, the final model could be very different from the historical reality of an artwork. Variables such as shape, size, colour can suffer significant changes during different steps, 
compromising the transparency, as well as the scientific value of virtual reconstruction.

The work aims to investigate the main phases of a VR process for ancient statues, evaluating theoretical and technical aspects in order to assess a suitable workflow for different aims and levels of visualization, trying to preserve the authenticity of the original artwork and its surviving fragments.

\section{The case study: Aesculapius and Hygeia statues from Lilybaeum}

The "Sanctuary of Isis" is the only one known sacred area of the ancient Hellenistic-Roman city of Lilybaeum, today's city of Marsala (Italy). Archaeological excavations conducted in 1988 and 2008 have brought to light a temple stands inside a sacred space. Two main phases of the building are known: the first ( $2^{\text {nd }}$ century BC), of which few traces are survived, and the second $\left(2^{\text {nd }}-4^{\text {th }}\right.$ century $A D$ ), best preserved, with the main room decorated by a polychrome mosaic with geometrical motifs. Few archaeological evidence suggests that the temple was dedicated to Isis, as proves a small column with a dedication to the myrionimos (thousand names), epithet of the Alexandrian goddess (Giglio Cerniglia, Palazzo, Vecchio, \& Canzonieri, 2012).

One of the main goals of the researches promoted by the University of Palermo inside the archaeological Park of Lilybaeum, aims to increase site attractiveness and the study of the sacred area through VR approaches. Until now, activities have produced detailed documentation of the preserved architectural remains integrating rangebased and image-based techniques (Ebolese, Lo Brutto, \& Dardanelli, 2019) and a 3D partially reconstruction of the building (Lo Brutto \& Fazio, 2020). A significant rule in the project is the interior design reconstruction, with stucco frames decorations on the roof, polychrome marble on the walls, ornamental columns and several sculptures specimens survived fragmentarily. Among the fragments recently exhibited in the Archeological Museum of Lilibeo, two life-size statues stand out, whose iconographies correspond to Aesculapius and Hygieia (Fig. 1), medical and healing deities of the Greek and Roman world. Based on the excavation data, both statues should be placed in the mosaic paved room, probably on top of a small podium.

\section{Workflow}

The main steps of the VR workflow are (Fig. 2):

1) 3D survey and reality-based model creation;

2) Evaluation of reconstruction hypotheses and selection of sources/references;

3) 3D modelling and source-based model creation.

As in restoration practice, VR process should use tools and techniques that do not physically alter the structure of an object, preserving its authenticity. State of conservation of the monument, dimensions and type of material, ambient lighting conditions, are thus all aspects that must be taken into account choosing the right technique of survey.

Different 3D survey methods (range-based and imagebased techniques) were adopted for step 1 (reality-based model creation). Generally, laser scanners allow good geometric accuracy, but a low-quality texture, unlike photogrammetric ones. For this reason, two techniques were integrated.

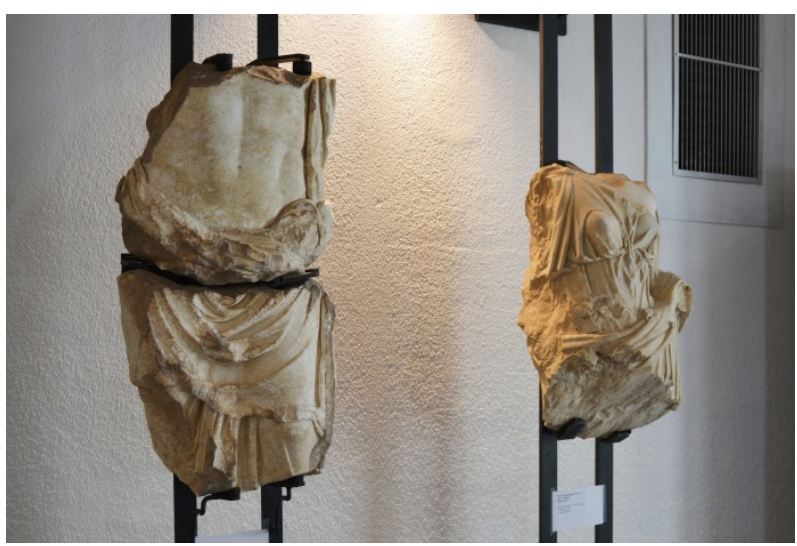

Figure 1: The fragments of the statues of Aesculapius and Hygieia/Salus.

Firstly, the Stonex F6 portable 3D laser scanner was used. The instrument enables to capture medium-large objects 3D models in dynamic motion. 3D scans of Aesculapius and Hygeia statues and further smaller fragments were acquired. The survey was conducted in a controlled indoor environment, monitoring every acquisition step in real-time through a tablet. Echo software was used for noise removal, editing, registration corrections and meshing of the 3D data, obtaining 3D models with a mesh of about 850,000 faces for the Aesculapius's statue and about 940,000 faces for Hygieia. Data checking highlighted low output quality texture, especially for smaller fragments.

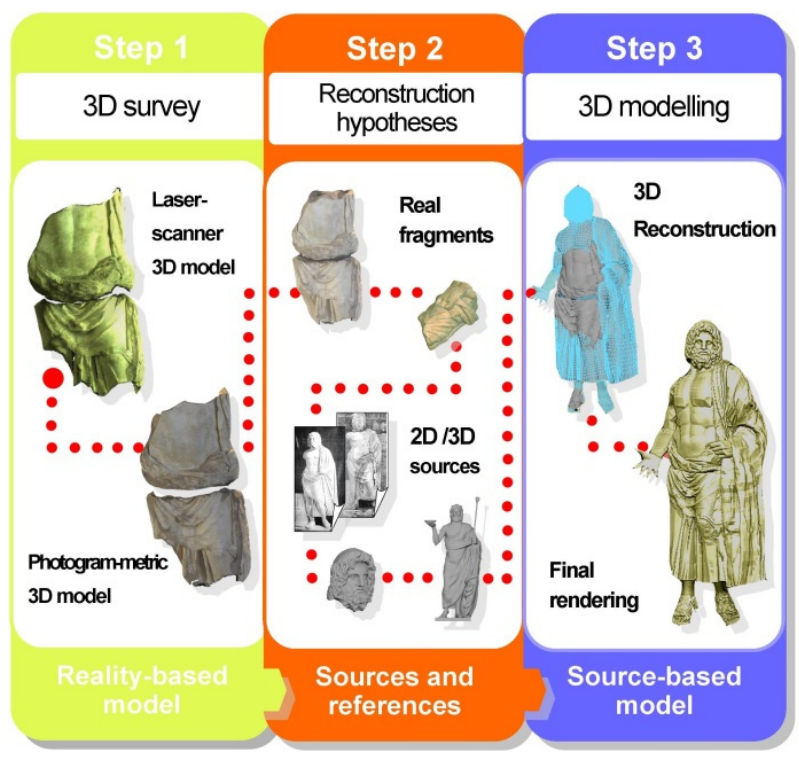

Figure 2: Workflow of Aesculapius statue VR.

Then, a close-range photogrammetric survey was carried out on the same fragments. Images were acquired with a Nikon D5200 digital camera, equipped with $24-55 \mathrm{~mm}$ lenses and a resolution of $6000 \times 4000$ (pixel size $4.05 \times$ $4.05 \mu \mathrm{m})$. For the statues of Aesculapius and Hygieia, a total of 55 images and 48 images respectively were taken. Images were processed with Agisoft-Metashape version 1.5.0. Image orientation was automatically computed by 
the software; a dense point cloud and a textured mesh were generated.

In order to obtain a correct overlap between laser scanner and photogrammetric 3D models, the photogrammetric one was scaled according to the size of laser scanner model (Fig. 3); a unique reference system was then assigned to both 3D models.

Currently, steps 2 and 3 were only performed for the statue of Aesculapius.

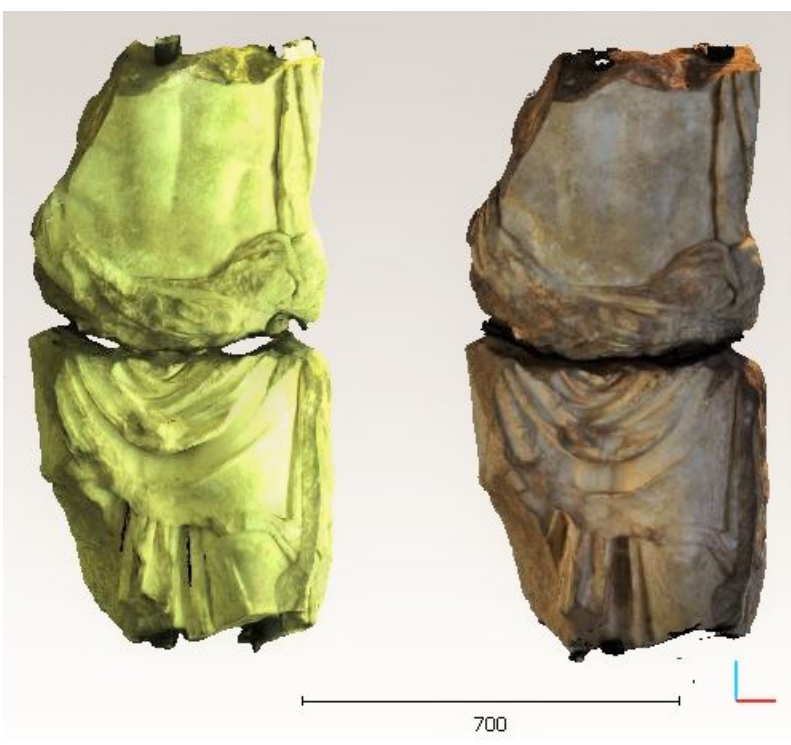

Figure 3: Laser-scanner 3D model (left) and photogrammetric 3D model (right) of the Aesculapius statue.
The second step of the workflow concerns sources and the assessment of reconstructive hypotheses on the missing parts. In order to define the whole 3D geometry of the statue, its $3 \mathrm{D}$ reality-based model was compared to a set of typologically similar statues of the same period; one of these was chosen as reference in the modelling phase.

In the third step, the reality-based model was first imported into the virtual workspace of Autodesk-Maya and then modelled integrating missing anatomical parts according to the information obtained by the image reference (2D source). In addition, a small fragment of the foot belonging to the statue, previously surveyed, was integrated. Further 3D sources (such as the 3D model of a Serapis head) were used to recreate some problematic elements in organic modelling. The obtained sourcebased model was finally refined in Pixologic-ZBrush, which allows a more realistic rendering for visualization purposes.

Further processing will be performed on the Hygieia statue, improving and verifying the experimental workflow, and developing an infrastructure for the AR / VR visualization of models.

\section{Acknowledgements}

The authors would like to thank the "Lilibeo-Marsala Archaeological Park" for permission to the 3D survey and Stonex for carrying out the laser scanner acquisition.

\section{References}

Bagnéris, M., Cherblanc, F., Bromblet, P., Gattet, E., Gügi, L., Nony, N., Mercurio, V. \& Pamarta, A. (2017). A complete methodology for the mechanical diagnosis of statue provided by innovative uses of 3D model. Application to the imperial marble statue of Alba-la-Romaine (France). Journal of Cultural Heritage, 28, $109-116$. http://dx.doi.org/10.1016/j.culher.2017.05.002

Bennoui-Ladraa, B., Chennaoui, Y. \& Ainouche, H. (2020). The virtual archaeology and interpretative process: Case study of the virtual reconstitution of a Hercules marble statue from the nameless temple of Tipasa. Digital Applications in Archaeology and Cultural Heritage, 19, 1-10. https://doi.org/10.1016/j.daach.2020.e00163

Demetrescu, E. (2015). Archaeological Stratigraphy as a Formal Language for Virtual Reconstruction. Theory and Practice. Journal of Archaeological Science, 57, 42-55. https://doi.org/10.1016/j.jas.2015.02.004

Ebolese, D. Lo Brutto, M. \& Dardanelli, G. (2019). UAV Survey for the Archaeological Map of Lilybaeum (Marsala, Italy). Int. Arch. Photogramm. Remote Sens. Spatial Inf. Sci., XLII-2/W11, 495-502. https://doi.org/10.5194/isprs-archivesXLII-2-W11-495-2019

Fregonese, L., Giordani, N., Adami, A., Bachinsky, G., Taffurelli, L., Rosignoli, O. \& Helder, J. (2019). Physical and virtual reconstruction for an integrated archeological model: 3D print and maquette. Int. Arch. Photogramm. Remote Sens. Spatial Inf. Sci., XLII-2/W15, 481-487. https://doi.org/10.5194/isprs-archives-XLII-2-W15-481-2019

Giglio Cerniglia, R., Palazzo, P., Vecchio, P., \& Canzonieri, E. (2012). Lilibeo (Marsala). Risultati della campagna 2008. In C. Ampolo (Ed.), Sicilia occidentale. Studi, Rassegne, Ricerche: Erice, 12-15 October 2009, II, (pp. 225-238). Pisa: Scuola Normale Superiore.

Lo Brutto, M., \& Fazio, L. (2020). 3D survey for the archaeological study and virtual reconstruction of the "Sanctuary of Isis" in the ancient Lilybaeum (Italy). Virtual Archaeology Review, 11(22), 1-14. https://doi.org/10.4995/var.2020.11928

Kuroczyński, P. (2017). Virtual research environment for digital 3D reconstructions: standards, thresholds, and prospects. Studies in Digital Heritage, 1(2), 456-476. https://doi.org/10.14434/sdh.v1i2.23330

The London Charter. (2009). For the computer-based visualisation of cultural heritage. Retrieved March 15, 2021, from http://www.londoncharter.org/ 
The Seville Principles. (2011). International Principles of Virtual Archaeology. Retrieved March 15, 2021, from http://smartheritage.com/seville-principles/seville-principles 


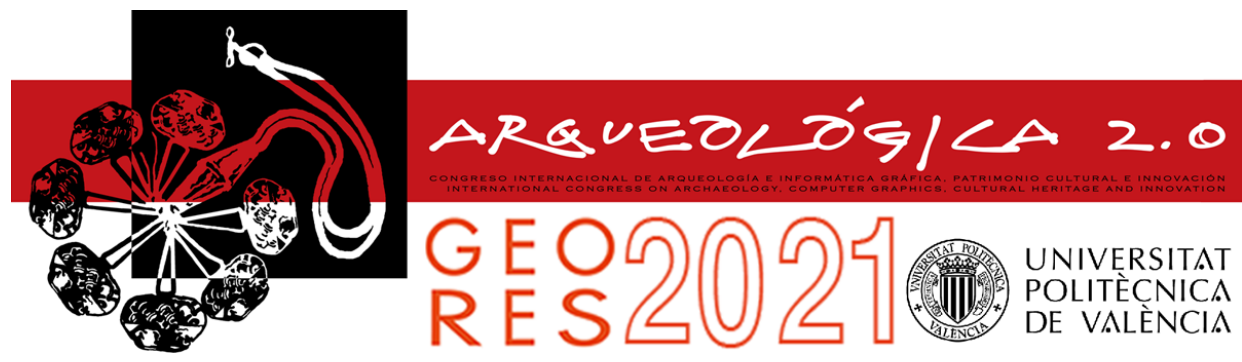

\title{
INTEGRATION OF DIGITAL ACQUISITION TECHNIQUES FOR THE MANAGEMENT OF CULTURAL HERITAGE: THE ARCHAEOLOGICAL PARK OF THE VIA LATINA AND VIA APPIA ANTICA TOMBS
}

\author{
Santino Alessandro Cugnoa, Filippo Fantinib ${ }^{\mathrm{b}}$,Francisco Juan-Vidalc, Simona Rinaldib,c, \\ a Parco Archeologico dell'Appia Antica, MIBACT, Piazza delle Finanze 1, 00185 Roma, Italy. santinoalessandro.cugno@beniculturali.it \\ ${ }^{\text {b }}$ Dipartimento di Architettura, Università di Bologna, Viale del Risorgimento 2, 4013 Bologna, Italy. filippo.fantini2@unibo.it; \\ simona.rinaldi5@unibo.it
}

` Departamento de Expresión Gráfica Arquitectónica, Universitat Politècnica de València, Camino de Vera s/n, 46022 Valencia, Spain. fjuan@ega.upv.es

\begin{abstract}
:
This study, still in its initial phase, aims to develop the knowledge of the ancient Tombs, through digital models of a selection of case studies belonging to the archaeological area of the Archaeological Park of the Tombs of Via Latina in Rome. A crucial role of the on-going research is the integration of current surveying technologies in combination with the interdisciplinary exchange of information with the managers of the archaeological site. This site - belonging to the Archaeological Park of the Appia Antica (MIBACT) - hosts one of the most important funerary complexes which currently presents an intact view of traditional features of the ancient Roman landscape. In addition to this, the complex preserves, along the cobbled road between the $3^{\text {rd }}$ and $4^{\text {th }}$ mile, the remains of the Via Latina which once connected the city of Rome with Capua (Rea, 1999; Montella, 2005; Cugno, 2020). Currently, in a stretch of about 450 meters, there are numerous tombs of various types, built between the Republican age and the early Middle Ages (Tazzi, 1998). The synergy resulting from the relationship between these converging landscape/architectural/archaeological components can be defined as "a synthesis of the visual element that insists on the space included in a single turn of the horizon" (Biasutti, 1962). The challenge of this project is to document and "represent" this specific case: the Landscape of the ancient Via Latina, with its complex reality of interrelation between the tombs, the archaeological areas (the so-called "mansio"; the early Christian basilica of S. Stefano Protomartire), the biotic elements, the historical center and the urban suburban network composed of the old roads that must coexist with the continuous expansion of the contemporary ones.
\end{abstract}

Keywords: 3D digital models, Via Latina, Imperial Roman Architecture, tombs, digital archaeology, cultural landscape, surveying

\section{Introduction}

The multifaceted system of the Ager Romanus and the cultural site of the Via Latina/Via Appia Antica is comparable to a living and dynamic structure and as such should be analysed. The key aspects that the research wants to address are those of digitization and documentation of Cultural Heritage. In fact, historical sites and monuments cannot be maintained only by using them passively, but by activating all the protection and conservation operations through direct and indirect interventions such as the use of the most advanced architectural survey techniques (laser scanner and photogrammetry) and the detailed study of their state of conservation. Therefore, careful digital documentation becomes a priority and the main objective is to develop an accurate three-dimensional documentation method able to record the current state and facilitating the original morphological aspect of this ensemble, as well as the planimetric organization and the archaeological remains that constitute the apparently most significant value. The problem of transposing in digital form the characteristics of the territory, urban sediments and details of archaeological relevance is not simple (Benedetti, Gaiani, \& Remondino, 2010); previous studies aimed at creating innovative systems of acquisition have in fact deepened the theme of the representation of Cultural Heritage by developing a high level of knowledge both theoretical and practical. The on-going research, currently under development, is part of a $\mathrm{PhD}$ program in Survey, Management and Development of the Cultural Heritage of the Via Latina/Via Appia Antica (Rome) carried out in collaboration with the UPV (UniversitatPolitècnica de València) and UNIBO (Alma Mater Studiorum - University of Bologna), in collaboration with the Archaeological Park of the Appia Antica (MIBACT) and the Soprintendenza Capitolina ai Monumenti. The global Cultural Heritage is in fact what distinguishes and characterizes each single 
country (in this case Italy), in which it reflects itself and the whole community (Riegl, 2011). It is the concrete task of local and non-local communities to protect its historical, artistic, archaeological and landscape heritage, as well as to promote the widest possible dissemination of its history and knowledge; it is also a common duty to make every effort to accustom citizens to frequent the "Places of Culture" assiduously, in order to achieve civil and social growth. The Tombs of the Archaeological Park of the Via Latina (Fig. 1) (Rea, 1999; Montella, 2005; Cugno, 2020) are set in a landscape, cultural and urban context of great importance, the result of complex interactions between man and the natural environment (Ager Romanus), through which local communities self-represent themselves. Specifically, the cultural landscape of the Roman Campagna and the Via Latina must be studied starting from the value offered by their territorial structure and the analysis of the transformation of the urban context that surrounds them, so as not to neglect a double aspect: environmental on one side and historical/archaeological on the other. Indispensable, in such a delicate balance of elements, becomes the contribution of innovative methodologies for the diffusion and fruition of the knowledge of Cultural Heritage, such as the use of advanced digital tools (metric data acquisition), information technologies and modern information transmission channels for a correct communication and valorization of Digital Cultural Heritage (through Virtual Reality and Augmented Reality technologies). The study to be conducted therefore starts from the technological examination to understand the effects on the interpretation of a "set" carrying hybrid values, testing the limits of graphic production codes (2D and 3D) in the reproduction of entire portions of territory that allow total analysis in digital environments (Gaiani \& Apollonio, 2015).

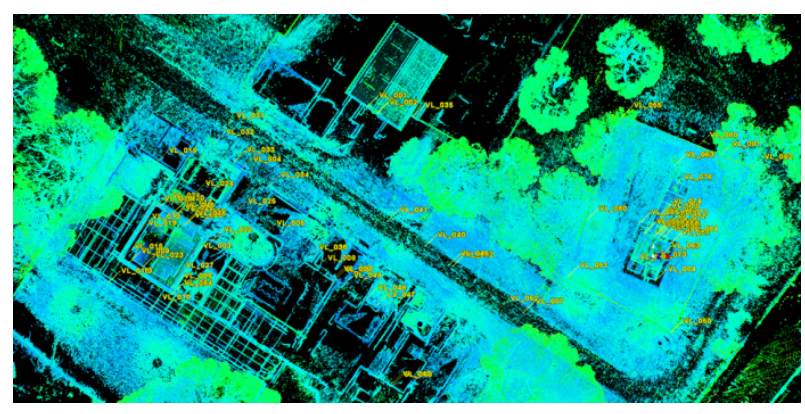

Figure 1: The Latin Tombs: plan view - point cloud.

\section{Territorial and historical context}

The Roman Campagna, in its general and more common meaning, does not correspond only to Ager Romanus nor to the Lazio Region, as it extends in the territories that historically belonged to the Etruscans. Its name does not derive from that of ancient Campania, which corresponds to the region of "Terra di Lavoro", but, as Tomassetti \& Tomassetti (1910) remind us, from the rural state of this large portion of territory surrounding Rome. Historically, the Suburbium included a peripheral strip characterized by the presence of vines and vegetable gardens, beyond which the estates and farmhouses of the Ager Romanus developed: a marshy and unhealthy countryside, which remained, for a long period of time, very difficult to frame due to its extension and complexity. In addition to the geographical aspects of the Ager Romanus, of fundamental importance are the history and the infrastructural development of the two ancient and main roads: Via Latina and Via Appia Antica. In particular, the Via Latina was one of the oldest of the great suburban roads, thanks to which the Romans were able to exercise their political, military and commercial activity. Remembered by Strabone and Tito Livio as the link used between Rome and Casilinum during the first Republican Age, it was travelled by Hannibal in the Punic wars between Rome and Carthage. The Via Appia Antica intersects with the previous one in the road development, presenting similar construction characteristics, but it differs both in history and in the place of arrival (Brindisi). The testimonies of how the Romans faced death are still offered to us by the tombs thanks to which it is possible to understand the philosophy, uses and customs connected to the cult of death and the dead and which play a role of fundamental importance for the impact that this it was a subject in ancient society.

\section{Tombs and the first survey}

The first documentation campaign was carried out during August 2020 on tombs of the imperial age of the Via Latina (specifically the Calpurni and Valeri) and the Cenotaph of Annia Regilla (located in the Caffarella Park, between the $2^{\text {nd }}$ and $3^{\text {rd }}$ mile of the Via Appia Antica). Planned activities include further steps, in addition to the first documentation activity carried out by means of a Terrestrial Laser Scanner (Faro Focus $X$ 130, measurement range between $0.6-130 \mathrm{~m}, 3 \mathrm{D}$ point accuracy of $\pm 2 \mathrm{~mm}$ at $10 \mathrm{~m}$ ). Once the situation allows it, a photogrammetric survey campaign is planned for the mapping of the facades, as well as the interiors of the buildings to be carried out with SLR Cameras and a campaign with UAV for the documentation of the roofs (Fig. 2). The digital modelling of these architectures allows morphological, constructive and structural understanding as it facilitates their complete and fluid exploration of various aspects. The pipeline (Guidi, Russo, \& Beraldin, 2010) for the construction of reliable, optimized mesh models are split into the following stages:

1) Range map alignment in Leica Cyclone 9;

2) High definition $3 D$ model construction through meshing in 3D System Geomagic;

3) Photogrammetric model construction and referencing with TLS data;

4) Mesh integration and optimization (quad-dominant re-meshing, parameterization, baking);

5) Texturing by means of frames re-projection onto parameterized mesh.

In this way a three-dimensional model was obtained that could then be used in the most flexible ways in the field of representation in a digital environment (Stylianidis, \& Remondino, 2016). High definition models (Master models, high-poly models) will facilitate the achievement of a better knowledge of the site and of specific design features (2D and 3D) of buildings by means of reverse modelling techniques (Van Genechten, 2009). The aim of this phase is to obtain 2D-3D outputs such as the generation of orthographic images, sections, profiles, contour lines and finally the export through interactive visualization (such as $3 \mathrm{dhop}$ ). The extraction of reliable vectorial drawings are supposed to facilitate the dialogue 
with other professionals working on the site (archaeologists, restorers, etc.).

\section{Discussion}

In the framework of a complex reality that characterizes the survey of Cultural Heritage, the support of current analysis software in a digital environment is often considered a powerful tool available to operators because it allows versatility and interconnections with numerous information that can be obtained from architectures. The purpose of this section is twofold: firstly, to review the state of this field, discussing and characterizing different approaches to manage information on geometric models; secondly, to present in detail an innovative analysis proposed and evaluated in the framework of the Cultural Heritage applications of the Archaeological Park of Via Latina Tombs. At present, Digital Cultural Heritage is increasingly influencing the field of Cultural Heritage and the research/restitution of data concerning Architectural Heritage is undergoing a rapid transformation; moreover, the use of three-dimensional models, fundamental for restoration professionals and Public Administration bodies, allows the fast and multiple collections of metric information, the easy sharing of contents among users and their immediate reading (Apollonio, Gaiani, \& Bertacchi, 2019).

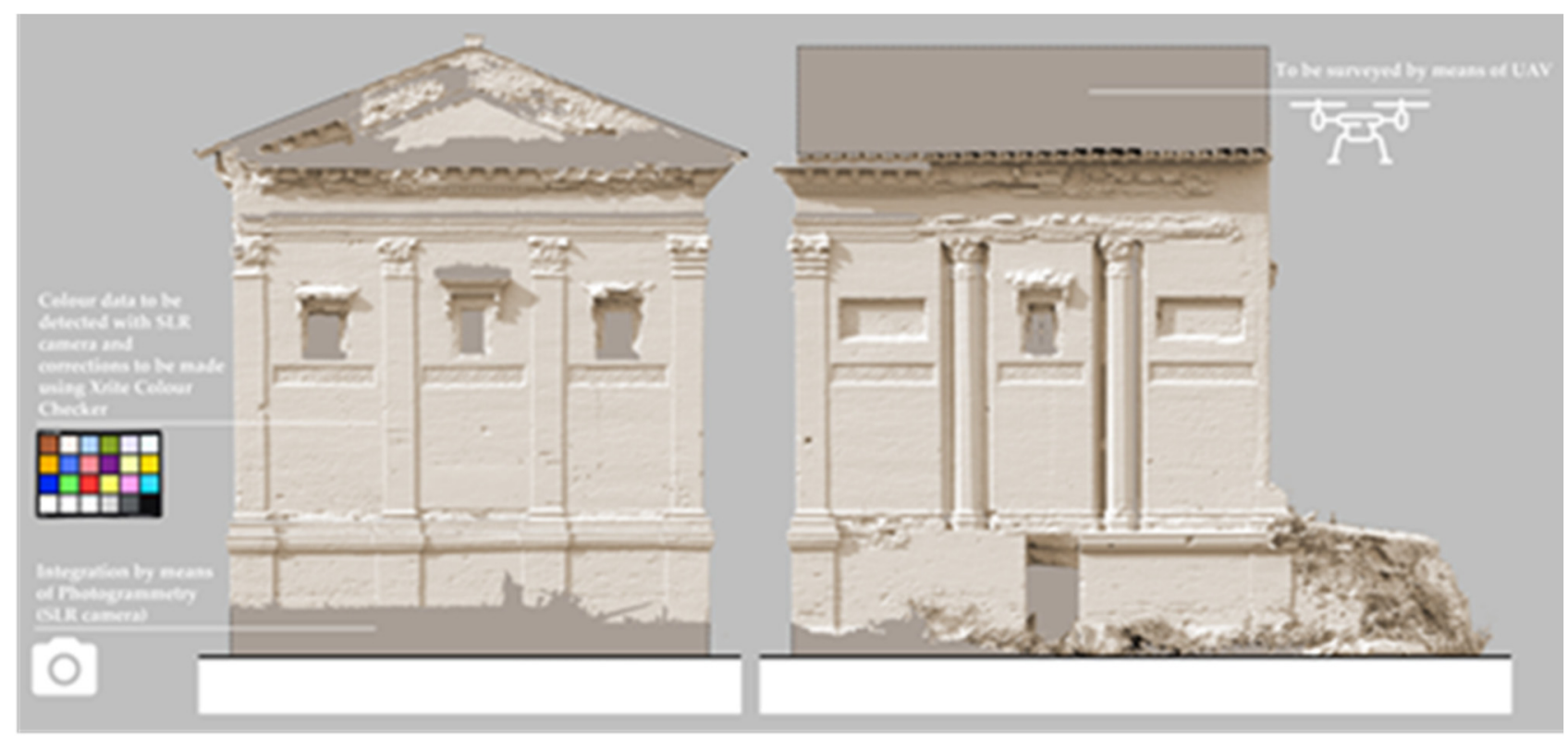

Figure 2: Annia Regilla's Cenotaph: front rendering.

\section{Conclusions}

Thanks to the potential offered, technological innovation in the field of Cultural Heritage surveying can lead to their intelligent management and use, with the aim of transforming them into Smart Cultural Objects. This workflow could become a means to quickly and efficiently unite and share knowledge between public and private users, thus becoming an integrated method of analysis, interpretation, detection and archiving at the service of the protection, management and enhancement of the historical, artistic and archaeological heritage (by obtaining advanced data that take an active role in the restitution of the Via Latina Tombs). This analysis therefore starts from a recovery of those representation abilities that once synthesized the historical, topographical, morphological and chromatic knowledge of an environment and the surrounding territory such as the Via Latina and Appia Antica and their original qualities.

\section{Acknowledgements}

We thank the Director of the Archaeological Park of the Appia Antica arch. Simone Quilici, the Director of the Capitoline Superintendence for Cultural Heritage Dr. Maria Vitoria Marini Clarelli and the functionary Dr. Ersilia Maria Loreti.

\section{References}

Apollonio, F., Gaiani, M., \& Bertacchi, S. (2019). Managing Cultural Heritage With Integrated Services Platform. Int. Arch. Photogramm. Remote Sens. Spatial Inf. Sci., XLII-2/W11, 91-98. https://doi.org/10.5194/isprs-archives-XLII-2-W1191-2019

Benedetti, B., Gaiani, M., \& Remondino F., (2010). Modelli digitali 3D in archeologia: il caso di Pompei. Edizioni della Normale, Pisa.

Biasutti, R. (1962). II paesaggio terrestre. Torino: Unione tipografico-editrice torinese.

Cugno, S. A. (2020). Pirro Ligorio e le tombe della Via Latina. In I. Sgarbozza (a cura di), La lezione di Raffaello. Le antichità romane, Roma, pp. 158-167. 
Gaiani, M., \& Apollonio, F. (2015). I portici di Bologna: architettura, modelli 3D e ricerche tecnologiche. Bologna: Bononia University Press.

Guidi, G., Russo, M., \& Beraldin, J. (2010). Acquisizione 3D e modellazione poligonale. Milano: McGraw-Hill Education.

Montella, F. (2005). Latina Via. III miglio. In A. La Regina (a cura di), Lexicon topographicum urbis Romae: Suburbium, III, Roma, pp. 155-170.

Rea, R. (1999). II parco archeologico della via Latina. "Forma Urbis", IV, pp. 4-15.

Riegl, A. (2011). Il culto moderno dei monumenti: il suo carattere e i suoi inizi. Milano: Abscondita.

Tazzi, A. M. (1998). Le strade dell'antica Roma: dal 4. secolo a.C. al 5. secolo d.C. in Europa, Asia e Africa. Roma: Librerie Dedalo.

Tomassetti, G, \& Tomassetti F. (1910). 1: La campagna romana in genere. Roma: E. Loescher \& C.

Stylianidis, E., \& Remondino, F. (Eds.). (2016). 3D Recording, Documentation and Management of Cultural Heritage. Caithness, UK: Whittles Publishing.

Van Genechten, B. (2009). Creating Built Heritage Orthophotographs from Laser Scan. Katholieke Universiteit Leuven. 


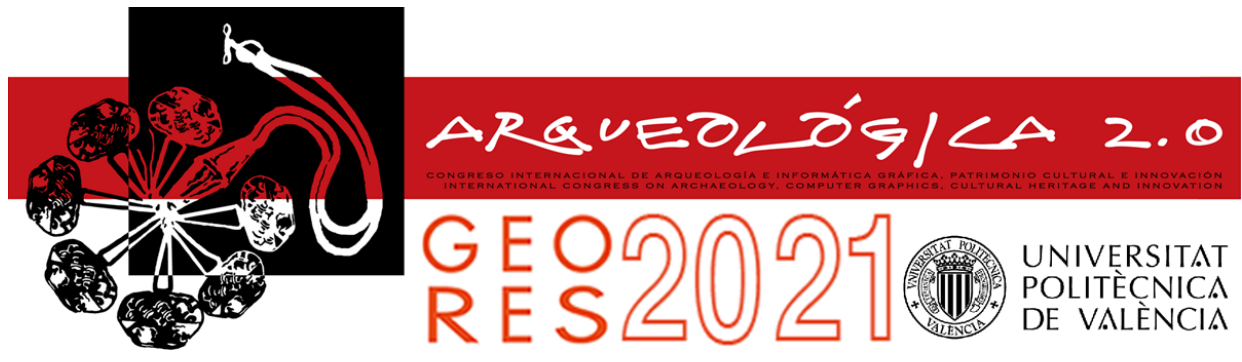

Proceedings of the joint international event $9^{\text {th }}$ ARQUEOLÓGICA

$2.0 \& 3^{\text {rd }}$ GEORES

Valencia (Spain).

26-28 April 2021

\title{
DIGITIZING TO RE-DISCOVER: THE CASE STUDY OF THE ROMAN CITY-GATE IN ALTINUM, ITALY
}

\author{
Caterina Ballettia , Eleonora Delpozzo b, \\ a Università luav di Venezia, S. Croce 191, 30135 Venezia, Italy. balletti@iuav.it \\ b Department of Humanities, Università Ca' Foscari di Venezia, Dorsoduro 3484/D, 30123, Venezia, Italy. eleonora.delpozzo@unive.it
}

\begin{abstract}
:
Graphic documentation in archaeology has always been a primary tool for scholars, used to record, publish and compare data. The vast majority of it, however, is still bi-dimensional, i.e. plans and sections, mostly because it was produced in the last century. Nowadays, sophisticated recording techniques are diffused and regularly utilized by researchers, and they have proven to be relevant to better record and understand an archaeological context. The case-study of the Roman citygate in Altinum is exemplary in this regard: a site that has been dug between 1972 and 1994 and has been exposed to the public since. Recently, a research project, carried out by Ca' Foscari and luav Universities, aims to further re-think and investigate the architectural and urbanistic aspects of the Roman city using digital tools. Because of this, it was possible to conduct a 3D survey of the archaeological areas, including the one where the city-gate is located, and to ensure the preservation of the data in the future. Preliminary elaborations, aimed at comparing the legacy data available on this site with the point clouds from the digitization campaign, show the potential of these tools, even more when studying contexts that are already known and published.
\end{abstract}

Keywords: Roman archaeology, digital archaeology, cultural heritage, documentation, 3D digitization

\section{Introduction}

The current work is part of a more extensive research project that involves both Ca' Foscari and luav Universities, which aims to reassess and examine indepth, with the aid of digital technologies, the urban and architectural history of the ancient city of Altinum, located at the north-eastern margin of the Venice Lagoon.

Amongst the initial steps of this project was the 3D digitization of the archaeological areas open to the public. Documenting the actual state of the structures is crucial in order to obtain an accurate reality-based model for further analysis, but also to preserve its current status for the future.

The digitization of the remains of the ancient city-gate, in particular, offered an occasion to reflect on the practice of archaeological documentation, which is still mostly limited to bi-dimensional representations such as plans and sections. On the other hand, 3D recording techniques are now widespread and used in many excavations all over the world (Russo, Remondino, \& Guidi, 2011). While there are extremely sophisticated projects that use $3 \mathrm{D}$ data to create complex visualization tools for a more efficient interpretation of the sites (Lercari, Shiferaw, Forte, \& Kopper, 2018), it is also common practise to use this data to obtain only 2D outputs (e.g. orthophotos).
In Italy many important excavation campaigns were carried out in the past century; for this reason, the legacy data regarding these sites is often restricted to paper documentation, including technical drawings and photographs.

\subsection{The city of Altinum: history and state of research}

Today, the territory of Altinum belongs to the municipality of Quarto d'Altino (province of Venice), located near Venice Marco Polo Airport, where its geomorphological setting consists of a complex network of rivers and canals and a central mound formed by archaeological deposits (Mozzi et al., 2016).

Archaeological finds in the area are attested from the Mesolithic; the first permanent settlement originated during the eighth century $\mathrm{BC}$ and flourished in the following centuries, becoming an important centre of trade for the Veneti, the pre-Roman population that lived in the area during the Iron Age (Gambacurta, 2011).

At the beginning of the second century $\mathrm{BC}$, the expansion of Roman control in the Italian peninsula started the process known as "romanization" and this territory was consequently integrated into the larger network of roads and sea routes, notably the Via Annia that connected the main northern Adriatic cities from Adria to Aquileia, the Latin colony founded in 183 BC (Tirelli, 1999). 
During the first century $\mathrm{BC}$, the city was affected by a systematic re-organization of its natural and hydraulic framework, along with an extensive monumentalization of the urban centre. Altinum maintained its key role of port city (emporium), as proven by many archaeological finds related to trade and commerce (Cresci \& Tirelli, 2003). The municipium flourished significantly during the Roman Empire, but it was abandoned around the seventh century $A D$, when different factors led to movements of people from the inland to the nearby islands of the lagoon (Tirelli, 2011).

The area remained uninhabited for centuries and was reclaimed only in the 19 th century. Up to this day the main features of the landscape are open fields and farms. This means most of the archaeological deposit is still buried and "frozen" at the time of the abandonment.

Archaeological research during the 20th century mostly focused on the funerary areas and monuments located along the main roads connecting the city to other centres of the region. Only few extensive excavations contributed to shed light on the urban centre, revealing a conspicuous part of the new neighbourhood expanded during the Augustan period, comprised of several domus and a section of the decumanus, and the city-gate which marked the northern limit of the city, used also as landing point (Scarfi \& Tombolani, 1985).

In 2007 a major breakthrough occurred in the research, when a remote sensing campaign of the University of Padua produced a set of visible and near-infrared aerial photographs of the territory of Altinum, which showed conspicuous and detailed cropmarks related to the urban structures buried underground (Fig. 1). Thanks to these images and further research, it was possible to identify the monumental sector of the city, including the central forum, its shops, the theatre, an odeion, the amphitheatre, large buildings with apses, walls, gates, roads and canals (Ninfo, Fontana, Mozzi, \& Ferrarese, 2009; Mozzi et al., 2016).

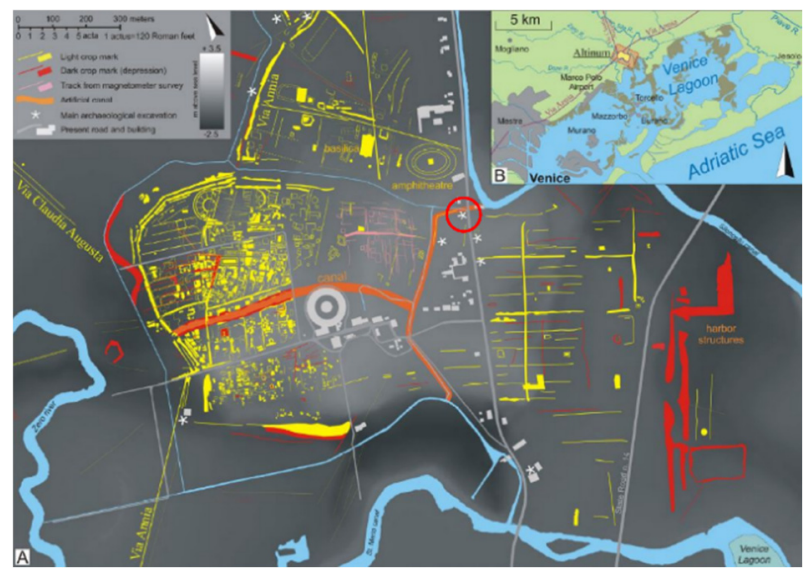

Figure 1: Map of Altinum as visible from the aerial photographs; in the red circle the location of the city-gate (Ninfo, Fontana, Mozzi, \& Ferrarese, 2009; modified by the authors).

After this pivotal moment, there was a renewed interest in the urbanization and development of the city, aimed at better understand the complex set of data provided by the aerial photographs. In particular, since 2012 a research group of Ca' Foscari University is investigating the dynamics related to a vast sector of the city known as "località Ghiacciaia" (Sperti, Cipriano, Paveggio, \& Delpozzo, 2017).

\subsection{The Roman city-gate}

The city-gate previously mentioned is one of the bestpreserved archaeological contexts in Altinum, and it is open to the public (Fig. 2).

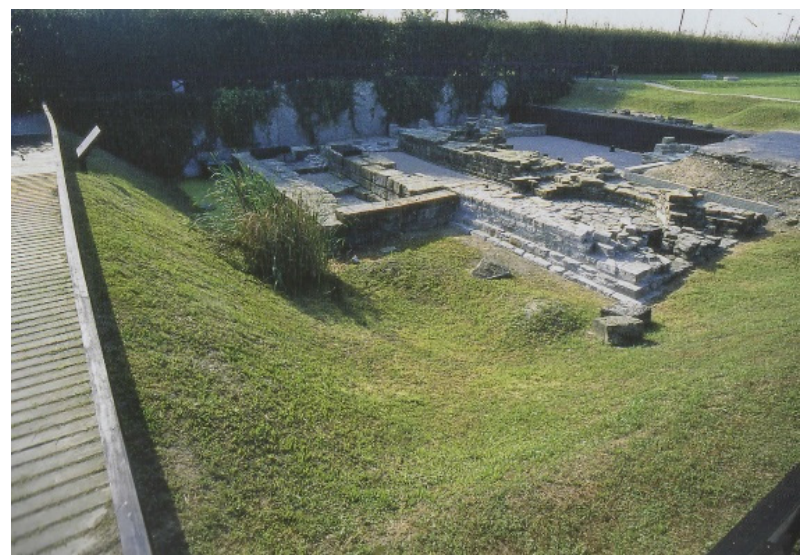

Figure 2: Site of the city-gate (Tirelli, 2011).

The excavations in the area began in 1972, then proceeded between 1980 and 1985, and resumed in 1991 until 1994, to conclude the works necessary to include this sector in the archaeological itinerary for tourists.

The architectural structure, dating to the first half of the 1st century $\mathrm{BC}$, is formed by two square-plan towers, round inside, and a central cavedium, with foundations made of sandstone blocks resting on massive wooden poles. The western tower was preserved entirely and measures $7.40 \mathrm{~m}$ on each side.

On the northern part of the building, the archaeologists identified the foundations of an avant-corps, added later to the structure and slightly offset from it to north-east, interpreted as the southern sector of a bridge: this side of the city-gate, in fact, overlooked a canal, and, because of this, had also the function of landing place. On the opposite side, south to the building, a stone paved road was found, probably the kardo maximus of the city. The main structure was conceivably constituted of bricks, as was its architectural decoration consisting in terracotta elements (Scarfi \& Tombolani, 1985; Tombolani, 1987; Gambacurta, 1992; Tirelli, 1999; Cipriano, 1999).

Furthermore, in the stratigraphic units attributed to the construction phase, the archaeologists recovered a set of finds interpreted as a ritual deposit related to the foundation of the building, consisting of animal bones, bronzes, and pottery sherds, some of which had dedicatory inscriptions in Venetic, Greek, and Latin (Tirelli, 2011).

It appears that the city-gate had not a defensive function per se, but represented a significant landmark, symbolizing the pomerium, the limit between the city and the suburbs (Tombolani, 1987).

\section{3D digitization: tools and methodology}

In the summer of 2020 , the team of the Laboratory of Photogrammetry of the IUAV University of Venice realized the digitization of the area, using an integration of different 
techniques proven to be effective especially for archaeological contexts (Balletti, Guerra, Scocca, \& Gottardi, 2015).

A suitable topographical net was set up with a total station, in order to create a local reference system. After setting up the targets, it was possible to acquire seven scans of the area with a terrestrial laser scanner, located in different positions in order to cover the entire area without obstacles. This final point cloud consists of $208,150,760$ points.

The area was then covered with a detailed photogrammetric survey using UAVs. The flights were planned based on the scheme most appropriate for each case, essentially sequences of linear strips. Using a DJI Mavic2Pro, a first set of 167 photographs of the city-gate was acquired and then it was decided to implement the survey with two flights covering both archaeological areas, resulting in 336 photographs overall.

Since the eastern part of the remains pertaining to the ancient city-gate is protected by a covering, it was not possible to acquire the geometry underneath with general flights of the area. For this reason, it became necessary to use a smaller drone, able to fit in the narrow space under the covering (Fig. 3). In this case, a DJI MavicMini was used, taking a total of 138 photographs.

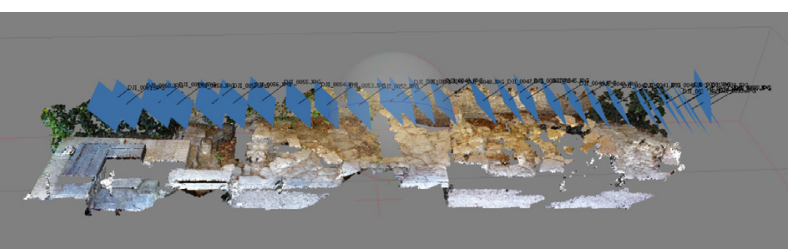

Figure 3: An example of how it was possible to do close-range photogrammetry with a smaller UAV in a narrow space.

After processing the photographs in Agisoft Metashape and georeferencing the models on the targets, selected sets of the point clouds were integrated and merged.

The data were later integrated with the scans obtained with the terrestrial laser scanner, allowing a more complete representation of the geometry of the city-gate.

\section{Elaborations and preliminary results}

Although the substantial work is still in progress, it was still possible to make some observations about the potential of 3D recording in re-discovering and studying archaeological sites that have been excavated, and therefore documented, decades ago.

Primarily, three-dimensional models, whether point clouds or polygon meshes, allow to instantly extract every measure needed. These metric data are more accurate and precise than the ones in the physical drawings. On the models it is also possible to measure parts of the structure not reachable in person and, besides, having a digital copy of the site allows to generate sections as required, without having to come back to the site every time to extract the data.

Moreover, as mentioned above, the cityscape of Altinum has a peculiar topographical configuration, consisting of higher areas and a complex system of canals (Calaon, 2006), which is why the accurate recording of elevation data is crucial for its study. In this regard, the 3D models offer a significant contribution to the history of the research and they represent a key asset, especially when integrated with stratigraphic and chronological data from other archaeological excavations (Fig. 4).

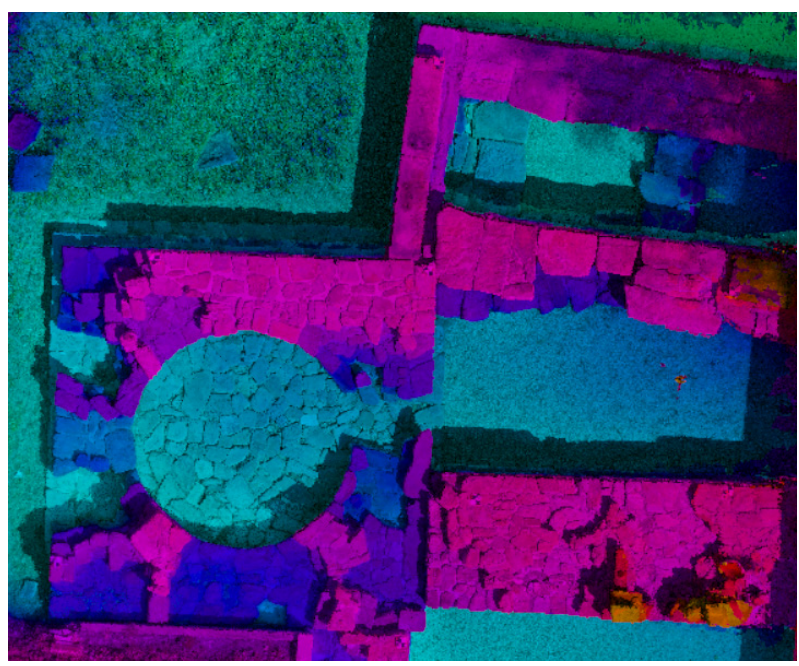

Figure 4: The photogrammetric point clouds combined, with a height shader to accentuate the different elevations of the structures preserved.

Ultimately, the preliminary comparisons between the data acquired on site with digital techniques and the bidimensional representations of the city-gate, as manually recorded during the excavations, show a significant error in the measurements (Fig. 5). Integrating different types of documentation representing the same object permits, on one side, to correct the original, handmade plans and sections; on the other side, these can also be used to recover information regarding the conservation status of the building and how it changed from the moment when the drawing was realized to the present day. These plans and sections, moreover, often include details and data which have been lost after the years.

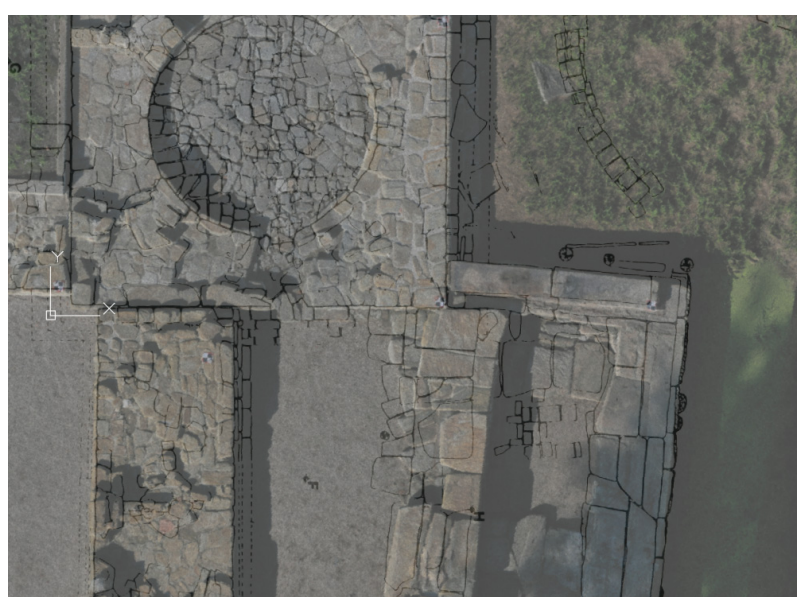

Figure 5: Orthophoto extracted from the photogrammetric survey, overlapping the original plan of the excavation (Gambacurta, 1992).

\section{Conclusions and future work}

These first results show that modern techniques of digitization can be a significant asset when studying archaeological contexts, including the ones for which the 
documentation available is not recent and was realized with traditional methods, i.e. handmade drawings.

One of the main goals for the future is to integrate the 3D models within the 2D GIS system that manages all the data related to the archaeological deposit in Altinum, in order to increase the knowledge base available. Further 3D data are expected to be included as well, such as a high resolution DEM of the territory obtained with a LiDAR survey, which has proven to be a powerful tool in understanding and investigating the landscape (Masini, Coluzzi, \& Lasaponara, 2011).

In future developments of the project, the main objective is to implement a BIM system for the semantic annotation of these models. BIM applications for Cultural Heritage have grown exponentially during the past years, offering remarkable case studies and results regarding archaeological heritage as well (Diara \& Rinaudo, 2020; Moyano et al., 2020). This solution, integrated with the GIS system previously mentioned, would permit a multiscale approach, capable of managing all the different information regarding the site (Rechichi, 2020); moreover, it could prove useful to manage and monitor any operation on the archaeological site, such as restoration and maintenance.

\section{Acknowledgements}

The project, still in progress, is made possible thanks to the collaboration with the Soprintendenza Archeologia, belle arti e paesaggio per il Comune di Venezia e Laguna and the National Archaeological Museum of Altinum.

\section{References}

Balletti, C., Guerra, F., Scocca, V., \& Gottardi, C. (2015). 3D Integrated Methodologies for the documentation and the virtual reconstruction of an archaeological site. Int. Arch. Photogramm. Remote Sens. Spatial Inf. Sci., XL-5/W4, 215-222. https://doi.org/10.5194/isprsarchives-XL-5-W4-215-2015

Calaon, D. (2006). Altino (VE). Strumenti diagnostici (GIS e DTM) per l'analisi delle fasi tardoantiche ed altomedievali. In Ruggiu, A. Z. (Ed.), Le Missioni archeologiche dell'Università Ca' Foscari. V giornata di studio, (pp. 143-158). Università Ca' Foscari di Venezia, Italy.

Cipriano, S. (1999). L'abitato di Altino in età tardo-repubblicana: i dati archeologici. In G. Cresci Marrone \& M. Tirelli (Eds.), Vigilia di romanizzazione. Altino e il Veneto orientale tra II e I sec. a.C. (pp. 33-65). Rome, Italy: Quasar.

Cresci, G., \& Tirelli, M. (2003). Altino da porto dei Veneti a mercato romano. In G. Cresci Marrone \& M. Tirelli (Eds.), Produzioni, merci e commerci in Altino preromana e romana, (pp. 7-25). Rome, Italy: Quasar.

Diara, F., \& Rinaudo, F. (2020). Building archaeology documentation and analysis through Open Source HBIM solutions via NURBS modelling. Int. Arch. Photogramm. Remote Sens. Spatial Inf. Sci., XLIII-B2-2020, 1381-1388. https://doi.org/10.5194/isprs-archives-XLIII-B2-2020-1381-2020

Gambacurta, G. (1992). Altino, area a nord del Museo, lettura della sezione relativa alla porta urbica. Quaderni di Archeologia del Veneto, 8, 70-78.

Gambacurta, G. (2011). Altino preromana (VIII-IV secolo a.C.). In M. Tirelli (Ed.), Altino antica. Dai Veneti a Venezia (pp. 54-61). Venezia, italy.

Lercari, N., Shiferaw, E., Forte, M., \& Kopper, R. (2018). Immersive Visualization and Curation of Archaeological Heritage Data: Çatalhöyük and the Dig@IT App. Journal of Archaeological Method and Theory, 25, $368-392$. https://doi.org/10.1007/s10816-017-9340-4

Masini, N., Coluzzi, R., \& Lasaponara, R. (2011). On the Airborne Lidar Contribution in Archaeology: from Site Identification to Landscape Investigation. In Wang, C. C. (Ed.), Laser Scanning, Theory and Applications (pp. 263-290). IntechOpen. https://doi.org/10.5772/14655

Moyano, J., Odriozola, C. P., Nieto-Julián, J. E., Vargas, J. M., Barrera, J. A., \& León, J. (2020). Bringing BIM to archaeological heritage: Interdisciplinary method/strategy and accuracy applied to a megalithic monument of the Copper Age. Journal of Cultural Heritage, 45, 303-314. https://doi.org/10.1016/j.culher.2020.03.010

Mozzi, P., Fontana, A., Ferrarese, F., Ninfo, A., Campana, S., \& Francese R. (2016). The Roman City of Altinum, Venice Lagoon, from Remote Sensing and Geophysical Prospection. Archaeological Prospection, 23, $27-44$. https://doi.org/10.1002/arp.1520

Ninfo, A., Fontana, A., Mozzi, P., \& Ferrarese, F. (2009). The Map of Altinum, Ancestor of Venice. Science, 325(5940), 577-577. https://doi.org/10.1126/science.1174206

Rechichi, F. (2020). Chimera: a BIM+GIS system for Cultural Heritage. Int. Arch. Photogramm. Remote Sens. Spatial Inf. Sci., XLIII-B4-2020, 493-500. https://doi.org/10.5194/isprs-archives-XLIII-B4-2020-493-2020

Russo, M., Remondino, F., \& Guidi, G. (2011). Principali tecniche e strumenti per il rilievo tridimensionale in ambito archeologico. Archeologia e Calcolatori, 22, 169-198.

Scarfi, B. M., \& Tombolani, M. (1985). Altino preromana e romana. Musile di Piave, Italy: Tipolitografia Adriatica.

Sperti, L., Cipriano, S., Paveggio, A. \& Delpozzo, E. (2017). Altinum: discovering a hidden municipium through GIS, historical research and new excavations. In E. Livieratos (Ed.), Proceedings 12th ICA Conference Digital Approaches 
to Cartographic Heritage (pp. 310-323).

Tirelli, M. (1999). La romanizzazione ad Altinum e nel Veneto orientale: pianificazione territoriale e interventi urbanistici. In G. Cresci Marrone \& M. Tirelli (Eds.), Vigilia di romanizzazione. Altino e il Veneto orientale tra I/ e I sec. a.C. (pp. 531). Rome, Italy: Quasar.

Tirelli, M. (Ed.) (2011). Altino antica. Dai Veneti a Venezia. Venice, Italy: Marsilio.

Tombolani, M. (1987). Altino. In G. Cavalieri Manasse (Ed.), // Veneto nell'età romana, /l (pp. 311-485). Verona, Italy: Banca popolare di Verona. 


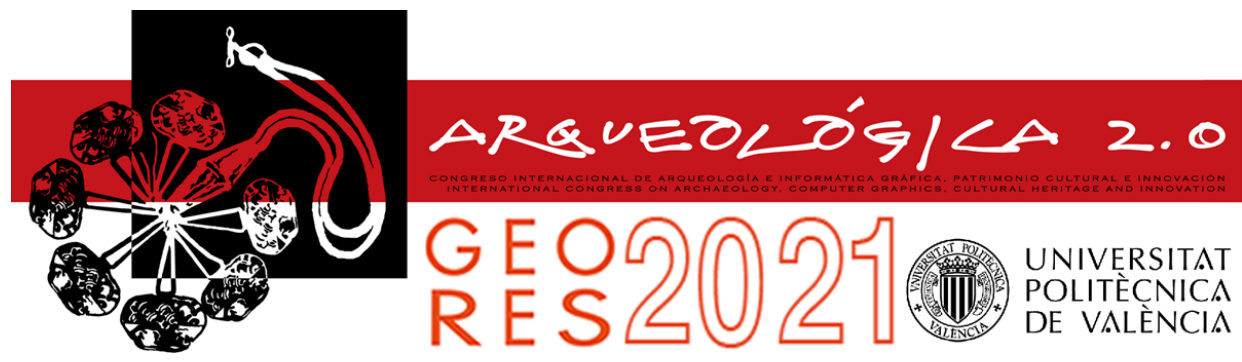

\title{
MAPPING MONUMENTS' STONE WEATHERING USING LOW-COST MULTISPECTRAL TECHNOLOGIES AND IMAGE PROCESSING
}

\author{
Efstathios Adamopoulos a, ${ }^{a}$, Fulvio Rinaudo \\ a Dipartimento di Informatica, Università degli Studi di Torino, Corso Svizzera 185, 10149 Torino, Italy. efstathios.adamopoulos@unito.it \\ b Dipartimento di Architettura e Design, Politecnico di Torino, Viale Pier Andrea Mattioli 39, 10125 Torino, Italy. fulvio.rinaudo@polito.it
}

\begin{abstract}
:
Mapping and analyzing stone monuments' surface condition and time-induced deterioration are necessary for the decision making on conservation measures. Since the assessment of architectural facades and elements is often conducted manually, there is significant value in investigating automatic weathering mapping procedures. This short paper aims to discuss how the combination of multispectral imaging, computational visualistics, and geomatics techniques can costeffectively assist in evaluating the state of preservation of monumental heritage through the use of low-cost sensors. The conducted experiments employ a medium-format camera modified for spectral imaging, mobile sensors, free and low-cost software. The Presented results concern three important archaeological sites in ancient Elis and Arcadia (Greece).
\end{abstract}

Keywords: multispectral imaging, photogrammetry, decay mapping, image processing, low-cost sensors, stone heritage

\section{Introduction}

Monuments made of stone represent a substantial part of the word's heritage. They possess essential values tied to culture, religion, construction techniques, and aesthetics of the period during which they were built. The importance of conserving them stems from the need to preserve these values and from the sense of continuity and identity historic buildings provide for future generations (Baer, \& Snethlage, 1997). However, building stones are subjected to continuous weathering, which imposes significant challenges to ensuring the stone monuments' preservation. Weathering results from physicochemical interactions between the stones and the environment (climate, biosphere, pollution) and leads to gradual deterioration (Siegesmund, Weiss, \& Vollbrecht, 2002).

The diagnosis of deterioration constitutes the basis for successful decision-making and effective implementation of conservation measures; therefore, documentation and monitoring of weathering forms is essential for safeguarding stone monuments' sustainability (Fitzner, 2016). Weathering documentation through mapping methods has been established as a non-destructive technique for recording and evaluating lithotypes and deterioration patterns (Fitzner, 2004). Maps of weathering are obtained through photographic documentation, onsite observations, graphic mapping-often conducted manually-and facilitate the identification of mechanisms of the genesis and progress of decay (D' Agostino, 2010; Adamopoulos et al., 2017).

In the last years, digital image processing has been widely used in the field of stone heritage conservation for studying decay indicators, such as black crusts and salt efflorescences (Moropoulou, Labropoulos, Delegou, Karoglou, \& Bakolas, 2013; Vázquez, Galán, Guerrero, \& Ortiz, 2011). Furthermore, the employment of multi-band imaging has proven the ability to contribute to more accurate mapping results due to different radiometric signatures that historical materials, decay forms, and moisture content levels show, especially at the nearinfrared (NIR) and thermal infrared (TIR) spectra (Lerma, Cabrelles, Akasheh, \& Haddad, 2012; Rahrig, Drewello, \& Lazzeri, 2018). The combination with photogrammetric techniques (Del Pozo et al., 2015; Themistocleous, Evagorou, Mettas, Prodromou, \& Hadjimitsis, 2020) and low-cost sensors (Adamopoulos, Rinaudo, \& Bovero, 2019; Russo, Giugliano, \& Asciutti, 2019) provides an additional potential towards increasing the automatization and cost-effectiveness of weathering mapping procedures.

Based on the above rationale, the presented work aims to investigate the application of low-cost multispectral sensing techniques and simple digital image processing procedures to record stone weathering on the remains of monumental structures. This combination serves to facilitate the rapid preliminary evaluation of heritage assets, by identifying regions of interest for more in-depth diagnostic investigations (invasive and non-invasive).

\section{Materials and Methods}

The techniques implemented in this work involved three sensors for capturing imagery at different spectra. A Canon Rebel-SL1 digital camera (with resolution of 5184

“Corresponding Author: Efstathios Adamopoulos, efstathios.adamopoulos@unito.it 
x 3456 pixels) was used to acquire the NIR images. A Huawei P30 smartphone (Sony IMX650 sensor) was used to acquire the visible spectrum images, and a FLIR ONE Pro TIR camera (with resolution of $160 \times 120$ pixels) was used to acquire long-wavelength infrared images.

Captured visible-spectrum and NIR photos were exported in raw image format, then undistorted, denoised, and devignetted (Del Pozo et al., 2015). RGB images were additionally color-balanced. The band-specific images of all sources (visible-spectrum, NIR, and TIR) were coregistered-using feature based-matching, and affine transform and cubic interpolation for the resampling - and fused to create multispectral images and pseudo-color composites in the HyperCube free software. For some of the investigated surfaces, partial three-dimensional (3D) models were constructed in a standard photogrammetric procedure, while the processing and the classification of multispectral images and mesh textures were also conducted in HyperCube. Visualization and exploitation of the 3D meshes were executed in CloudCompare.

\section{Results and Discussion}

The first case study used to showcase the considerable value of the implemented technologies was the temple of Apollo Epikourios at Bassae (Greece), a World Heritage List inscribed monument degraded from acid rain and extreme weather conditions, sheltered since 1987.

Multispectral images of the naos (Fig. 1a) were analyzed utilizing principal component analysis (PCA) to construct maps of the preservation state (Fig. $1 \mathrm{~b}$ ), revealing not only the level of weathering (grayscale) but also the locations of past restoration interventions (white-colored). The NIR images' histogram was adjusted appropriately to derive a map of the extensive cracks (Fig. 1c).

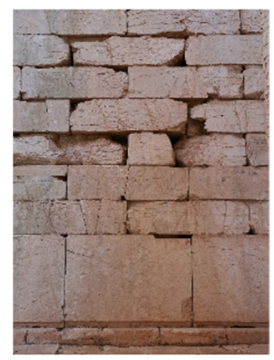

(a)

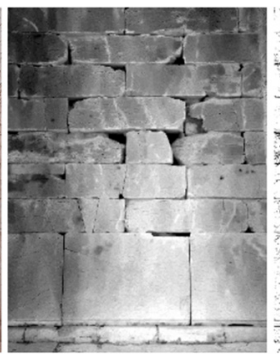

(b)

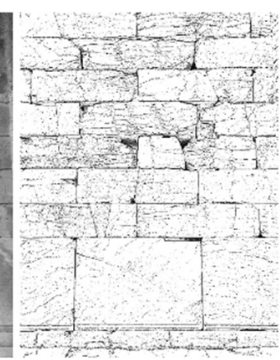

(c)
Figure 1: Weathering mapping for the temple of Epicourios Apollo at Bassae: a) visible image; b) map of weathering stages; c) map of cracks.

The second case study was the temple of Athena and Zeus Sotiros at ancient Phigalia (Greece). Unsupervised k-means segmentation-based classification of NIR-RedGreen composites (based on the number of observable types of deterioration) gave a representative mapping of the crusts (Fig. 2b; brown) and lichens (blue-colored).

The cubic stone pedestal surfaces of the worshiping statue from the cella (Fig. 3a) were digitally 3D modeled using a NIR photogrammetric dataset. The model was segmented in 3D (Fig. 3b) according to the near-infrared intensities. As evident, the white segmented areas represent surface parts covered with lichens, while the gray areas represent the scales of weathering, and specifically the development of black crusts.

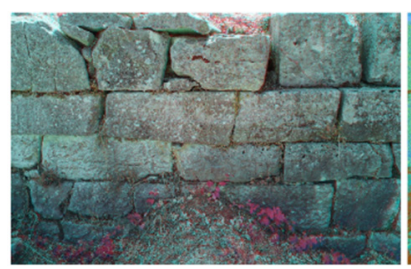

(a)

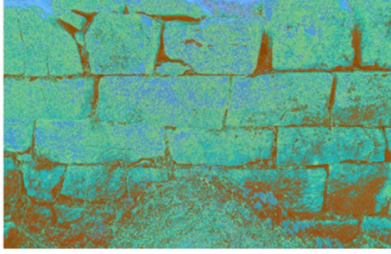

(b)
Figure 2: The temple of Athena and Zeus Sotiros: a) NIR-RedGreen composite; b) weathering mapping.

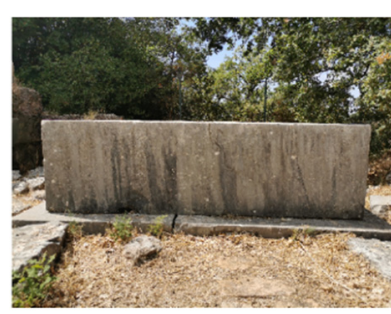

(a)

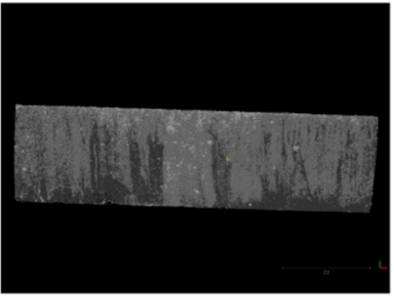

(b)
Figure 3: Ancient pedestal of the worshiping statue from the cella: a) visible-spectrum image; b) 3D classification of the surface weathering by texture segmentation.

The last case study was the remains of the ancient walls at the archaeological site of Lepreum (Greece). Part of the walls was modeled using visible-spectrum imagery and image-based modeling (Fig. 4a). A workflow including orientation of optical images from the ONE Pro camera at the same photogrammetric dataset as the RGB images from the P30 camera, and subsequent replacement of RGB images with the thermal images (after necessary geometric transformations were applied) was implemented to additionally map the model with thermal information (Adamopoulos, Volinia, Girotto, \& Rinaudo, 2020) (Fig. 4b). Both models were segmented, revealing the covering of historical surfaces by different alteration and damage types (Fig. 4c) and the approximate distribution of moisture content (Fig.4d). (a)

(b)

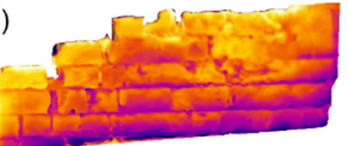

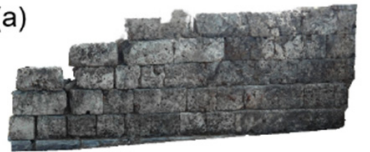
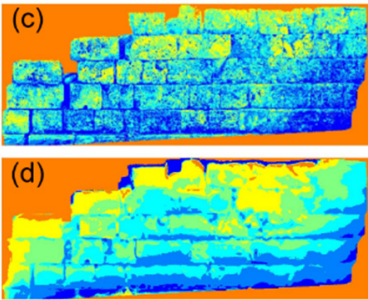

Figure 4: Weathering mapping for the ancient walls at Lepreum: a) 3D model textured with visible-spectrum imagery; b) 3D model textured with thermal imagery; c) classification of surface decay; d) classification of moisture content levels.

\section{Conclusions}

This short paper presented the authors' progress in involving low-cost sensors for rapid, cost-effective, and automatized generation of maps of the weathering of heritage remains, which can serve as the basis for detailed and accurate non-destructive diagnosis. The results showcase how inexpensive techniques can provide crucial results for the state of preservation assessment that is required for every decision making process regarding essential heritage assets. In particular, 
near-infrared and thermal-infrared sensors' employment contributed significantly to the results, while weathering indices and different deterioration typologies were successfully identified.

\section{Acknowledgements}

This project (part of the Technologies for Cultural Heritage doctoral program at the University of Turin) has received funding from the European Union's Framework Program for Research and Innovation Horizon 2020 (2014 - 2020) under the H2020-Marie-Skłodowska Curie ActionsCOFUND scheme (Grant Agreement No 754511) and by the banking foundation Compagnia di San Paolo.
The authors acknowledge the Hellenic Ministry of Culture and Sports/Archaeological Resources Fund. The authors acknowledge that all rights to the depicted monuments belong to the Hellenic Ministry of Culture and Sports (I.3028/2002). The authors extend their gratitude to the Ephorate of Antiquities of Ilia (Ef.A. Ilias) for granting the permission to capture, reproduce and disseminate to the public the images of archaeological content regarding the Temple of Apollo Epikourios (Archaeological Site at Bassae of Phigaleia), the Temple of Athena and Zeus Sotiros (Archaeological Site of Phigaleia), and the ancient walls at the Archaeological Site of Lepreum. All depicted monuments fall within the competence of Ef.A. Ilias.

\section{References}

Adamopoulos, E., Rinaudo, F., \& Bovero, A. (2019). First assessments on heritage science oriented image-based modeling using low-cost modified and mobile cameras. Int. Arch. Photogramm. Remote Sens. Spatial Inf. Sci., XLII-2/W17, 23-30. https://doi.org/10.5194/isprs-archives-XLII-2-W17-23-2019

Adamopoulos, E., Tsilimantou, E., Keramidas, V., Apostolopoulou, M., Karoglou, M., Tapinaki, S., Ioannidis, C., Georgopoulos, A., \& Moropoulou, A. (2017). Multi-Sensor Documentation of Metric and Qualitative Information of Historic Stone Structures. ISPRS Ann. Photogramm. Remote Sens. Spatial Inf. Sci., IV-2/W2, 1-8. https://doi.org/10.5194/isprs-annals-IV-2-W2-1-2017

Adamopoulos, E., Volinia, M., Girotto, M., \& Rinaudo, F. (2020). Three-dimensional thermal mapping from IRT images for rapid architectural heritage NDT. Buildings, 10(10), 187. https://doi.org/10.3390/buildings10100187

Baer, N. S., \& Snethlage, R. (Eds.). (1997). Saving our architectural heritage: The conservation of historic stone structures. Chichester (NY), USA: J. Wiley \& Sons.

D' Agostino, D. (2010). A methodology of damage assessment in cultural heritage: Graphic decay mapping. ICAMS 2010 - 3rd International Conference on Advanced Materials and Systems, 433-438. Bucharest, Romania.

Del Pozo, S., Herrero-Pascual, J., Felipe-García, B., Hernández-López, D., Rodríguez-Gonzálvez, P., \& GonzálezAguilera, D. (2015). Multi-spectral radiometric study to detect pathologies in historical buildings. Int. Arch. Photogramm. Remote Sens. Spatial Inf. Sci., XL-5/W4, 193-200. https://doi.org/10.5194/isprsarchives-XL-5-W4193-2015

Fitzner, B. (2004). Documentation and evaluation of stone damage on monuments. $10^{\text {th }}$ International Congress on Deterioration and Conservation of Stone, 27, 677-690. Stockholm, Sweden.

Fitzner, B. (2016). Investigation of weathering damage on stone monuments. Geonomos, 24(2), 1-15. https://doi.org/10.18285/geonomos.v24i2.835

Lerma, J. L., Cabrelles, M., Akasheh, T. S., \& Haddad, N. A. (2012). Documentation of Weathered Architectural Heritage with Visible, Near Infrared, Thermal and Laser Scanning Data. International Journal of Heritage in the Digital Era, 1(2), 251-275. https://doi.org/10.1260/2047-4970.1.2.251

Moropoulou, A., Labropoulos, K. C., Delegou, E. T., Karoglou, M., \& Bakolas, A. (2013). Non-destructive techniques as a tool for the protection of built cultural heritage. Construction and Building Materials, 48, $1222-1239$. https://doi.org/10.1016/j.conbuildmat.2013.03.044

Rahrig, M., Drewello, R., \& Lazzeri, A. (2018). Opto-technical monitoring-A standardized methodology to assess the treatment of historical stone surfaces. Int. Arch. Photogramm. Remote Sens. Spatial Inf. Sci., XLII-2, 945-952. https://doi.org/10.5194/isprs-archives-XLII-2-945-2018

Russo, M., Giugliano, A. M., \& Asciutti, M. (2019). Mobile phone mapping for CH façade modelling. Int. Arch. Photogramm. Remote Sens. Spatial Inf. Sci., XLII-2/W17, 287-294. https://doi.org/10.5194/isprs-archives-XLII-2-W17-287-2019

Siegesmund, S., Weiss, T., \& Vollbrecht, A. (Eds.). (2002). Natural stone, weathering phenomena, conservation strategies and case studies. Bath, UK: The Geological Society Publishing House.

Themistocleous, K., Evagorou, E., Mettas, C., Prodromou, M., \& Hadjimitsis, D. G. (2020). The documentation of cultural heritage sites in Cyprus using integrated techniques: The case study of the Church of Agios Athanasios and Kyrillos. In K. Themistocleous, S. Michaelides, V. Ambrosia, D. G. Hadjimitsis, \& G. Papadavid (Eds.), Eighth International Conference on Remote Sensing and Geoinformation of the Environment (RSCy2020) (115240A). Paphos, Cyprus: SPIE. https://doi.org/10.1117/12.2571640

Vázquez, M. A., Galán, E., Guerrero, M. A., \& Ortiz, P. (2011). Digital image processing of weathered stone caused by efflorescences: A tool for mapping and evaluation of stone decay. Construction and Building Materials, 25(4), 16031611. https://doi.org/10.1016/j.conbuildmat.2010.10.003 


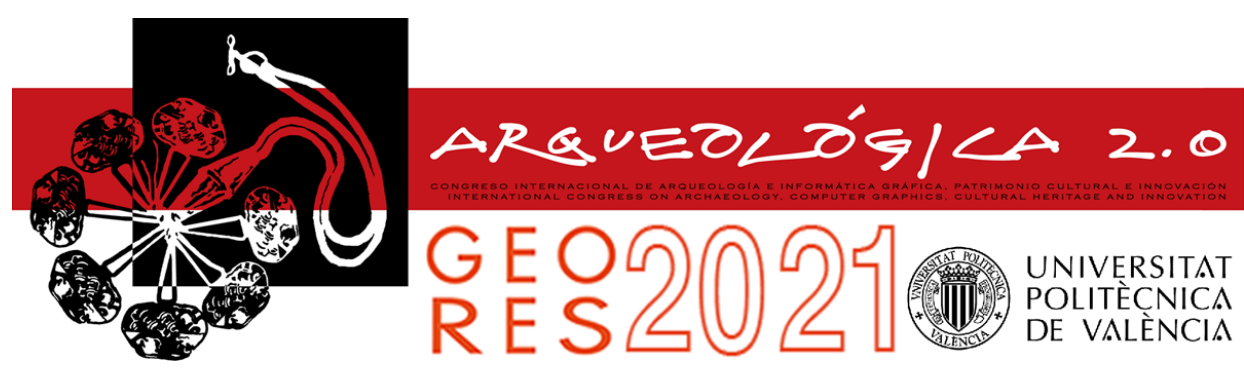

Proceedings of the joint international event $9^{\text {th }}$ ARQUEOLÓGICA

$2.0 \& 3^{\text {rd }}$ GEORES

Valencia (Spain).

26-28 April 2021

Received: 27/11/2020

Accepted: 05/03/2021

\title{
HBIM AND WORKSITE SIMULATION: FIRST EXPERIMENTS
}

\author{
Olga Rosignoli \\ Department of Architecture, Built Environment and Construction Engineering (DABC), Politecnico di Milano, Piazza Leonardo da Vinci \\ 32, 20133 Milan, Italy. olga.rosignoli@polimi.it
}

\begin{abstract}
:
Numerous HBIM (Historic Building Information Modelling) projects are being developed globally at an incremental pace. As results of steady improvements in the scan-to-BIM processes, as well as of the digital survey technologies available, increasingly accurate representations of heritage assets (and their attached information) are being obtained. Less often, and because of the efforts and resources necessary to explore such phases of the process, a further temporal evolution analysis is carried on, despite having tools that come from the commercial world which could be suitable to that use. This article narrates the attempt of an analysis alike on the case study of the Duomo of Mantova HBIM, where digital instruments were bent to construct the simulation of a refurbishment worksite as a separated actor in the federated model. Accordingly, the possibility of adding a temporal dimension (regarding the sequence of refurbishments) tasks was explored: some seminal 4D simulations were the results. What began as a mean of checking the dimensions and the footprint of a refurbishment worksite and its equipment, became more: the HBIM acted as a decision-making helper, a project management tool and a risk management device.
\end{abstract}

Keywords: HBIM, cultural heritage, 4D scheduling, worksite simulation

\section{Introduction}

In 2018 the Diocese of Mantova required the realization of an experimental BIM model of one of its most valuable and articulated assets, the Duomo of San Pietro; the final product (already available to the stakeholders) represents the as-built situation of the building recorded through an extensive and integrated survey combining laser scanning, photogrammetry and topographic techniques (Adami et al., 2019). The model effectively constitutes an example of Historic Building Information Model, or 'HBIM' (Murphy, McGovern, \& Pavia, 2009); it was commissioned for assisting planned conservation of the asset. The complexity and the scale of the Duomo determined the breakdown of its model into smaller portions, which refer to different disciplines. The different portions exist together in the 'federated' version of the model (Fig. 1) a solution commonly adopted with large projects (Solihin, Eastman, \& Lee, 2016); in the federated model the different parts, originally drafted with Autodesk Revit@ software, interact through their shared 'spatial colocation'. Additionally, the possibility of adding a temporal dimension (Castellano-Román \& Pinto-Puerto, 2019), conventionally called '4D' regarding time sequencing of the refurbishments tasks was settled; the reason is manifold: the knowledge obtained when including the fourth dimension in BIM environments can be of great assistance in planned conservation projects. Moreover, a thorough understanding of the past temporal evolution of architecture can help predict its future developments and avoid further damages, thus becoming a recommendable procedure for those who work in heritage conservation. In the immediate term, it also helped manage the settlement of a worksite in a difficult context.

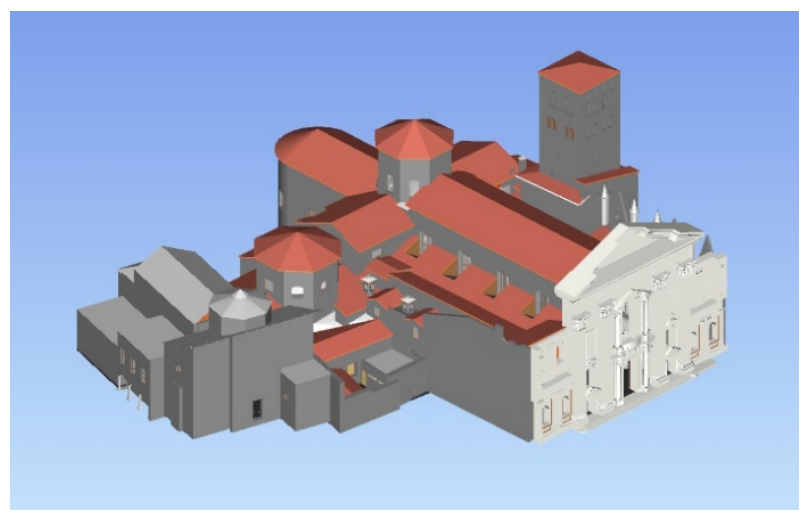

Figure 1: The HBIM original federated model (i)

\section{The roof refurbishment project}

For evident reasons, it is particularly important to register the 'maintenance and restoration works made over time, keep track of past actions and plan the future ones' in heritage assets. (Bruno \& Roncella, 2019). HBIM environments can contain information about historic phases in an integrated way (Jordan-Palomar, Tzortzopoulos, García-Valldecabres, \& Pellicer, 2018) or in external stand-alone databases that complement them (Bruno \& Roncella, 2019). For the case object of the study, understanding the succession of past restoration worksites during model drafting helped determine the overall historic phases and assign them to the objects within the model. The refurbishment of the roofing above 
some of the naves of the Duomo in the second half of 2020 was included in the wake of this temporal insight and enriched the historical record that is being produced thus.

\subsection{The worksite model}

As already stated, the HBIM models referring to the architecture and other disciplines, had already been produced at the time of these experiments. With the refurbishment of the roofing, arose the opportunity to exploit furtherly what already created: a separate virtual model of the worksite was plotted according to the asbuilt one, to obtain a 'design of the intervention' (Nieto, Moyano, Rico Delgado, \& Antón García, 2016). A series of objects composing the worksite were drafted, including a crane (to transport material onto the roofs), several scaffoldings, means of transport and equipment.

Risk management was the objective firstly: as usual for these contexts (historic city centres), space was crammed and with limited manoeuvre options (Lucarelli, Laurini, \& De Berardinis, 2019). Important measurements for decisions regarding the equipment (height and type of the crane, length of scaffoldings, loading zones, to name some) were derived from the original HBIM model elements and were double-checked with the point-cloud upon which the model had been plotted.

Planning of the construction site operations was developed by the commission in a traditional way, with a Gantt chart. The limited scale of the intervention meant that all operations required reduced personnel and were dedicated to a specific area, therefore no overlapping between them was predicted by the chart.

\subsection{Clash detection and simulation}

After having acquired information by the mandatory 'Piano di Sicurezza', the Italian security management plan (Italian Government, 2008), and by observing the development of the construction site, an environment on where all this information could be combined had to be selected: along with the example of some other similar experiences recorded in literature, Autodesk Navisworks $\bigodot$ was chosen (Fai, Graham, Duckworth,
Wood, \& Attar, 2011; Bruno, Musicco, Fatiguso, \& Dell'Osso, 2019).

The software strengths are two: clash detection and 4D simulation. Its clash detection capability was used to combine and see the interaction between: the generic architectural model (i) and the model of the construction site (ii), which for the first time existed together in the Navisworks environment (Fig. 2). The 4D simulation, although limited, was the tool used to place this intervention along a timeline, and to check the movement of equipment. The results of the clash showed only minor collisions between the worksite objects and the as-built model, of which an example is shown in Figure 3.

\section{Discussion}

The federated model interoperability solution was explored after noticing that the architectural BIM model on its own could not collect all the information necessary for the worksite operations. Instead of implementing the construction site objects (crane, scaffolding etc.) into the architectural model, it was preferred to plot the objects in another new (equally georeferenced) model (Fig. 4). It appeared more immediate for clash detection purposes and for avoiding the increased weight of an already substantial Revit file. Paradoxically, having an active construction site, which is native for BIM, compared to the exhausted ones of the past, posed a new issue: the presence of several objects not functional for conservation activities schedule, that could be eliminated. On second thought, having drafted the worksite model separately (even though always loadable in the federate environment) resulted convenient: all the objects temporarily necessary for simulating the worksite but not significant for the lifecycle heritage of asset information have not unnecessarily occupied and weighted the model.

Nevertheless, the set-up interoperability allows retrieving this information, which is conveniently stored when not used. Moreover, future interventions and the documentation related, could be, in the same way, drafted and stored accordingly, thus creating a historical record of those objects not strictly necessary for planned conservation.
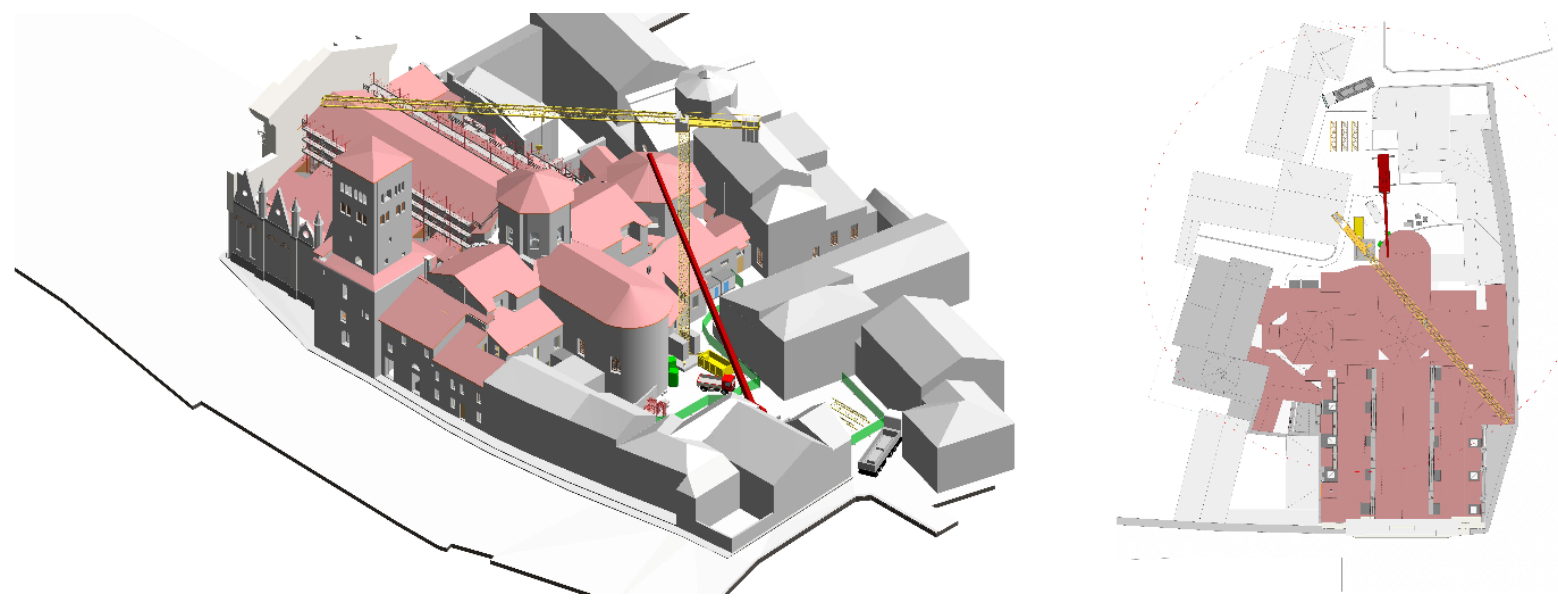

Figure 2: The two models (i,ii) coexisting and interacting in Navisworks: check of the operating range of the crane. 


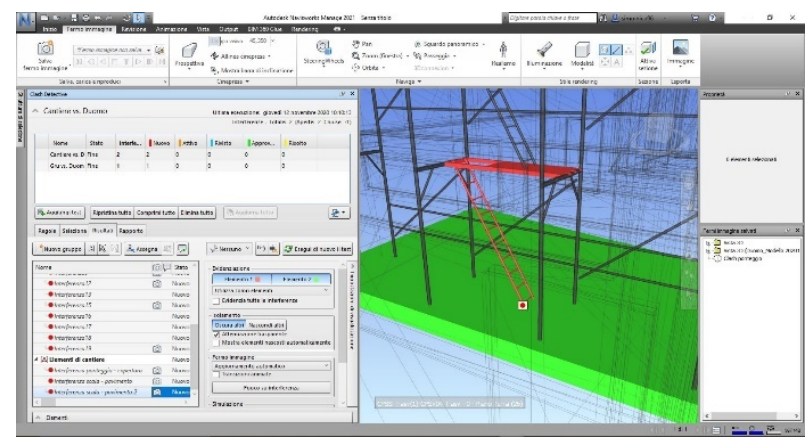

Figure 3: Example of a clash in correspondence of which Navisworks detected an unwanted interaction between the worksite scaffolding and the as-built model.

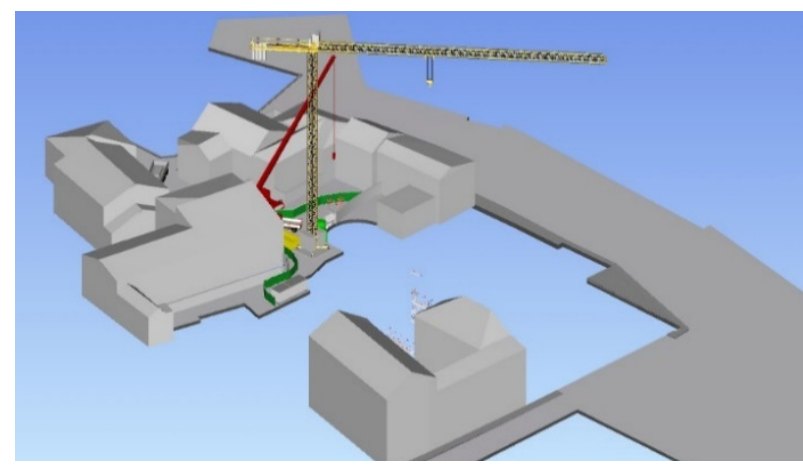

Figure 4: The model of the construction site (ii); parts of the surroundings of the Duomo had to be added because important to define the construction site.

\section{Conclusions and future works}

The host Autodesk Navisworks project is going to collect the timeline of interventions, the ones already carried out as well as the future ones. It is demonstrated that temporal analyses and reconstructions, when coupled with reality-based models, can enhance decisions related to conservation interventions. Introducing the temporal dimension into three-dimensional geometric objects is beneficial: the several advantages that derive from these representations and their potential use for heritage conservation should be explored; the Duomo HBIM project is an occasion to act on such premises.

\section{References}

Adami, A., Fregonese, L., Rosignoli, O., Scala, B., Taffurelli, L., \& Treccani, D. (2019). Geometric survey data and historical sources interpretation for HBIM process: the case of Mantua cathedral façade. Int. Arch. Photogramm. Remote Sens. Spatial Inf. Sci., XLII-2/W11, 29-35. https://doi.org/10.5194/isprs-archives-XLII-2-W11-29-2019

Bruno, N., \& Roncella, R. (2019). HBIM for conservation: A new proposal for information modeling. Remote Sensing, 11(15). https://doi.org/10.3390/rs11151751

Bruno, S., Musicco, A., Fatiguso, F., \& Dell'Osso, G. R. (2019). The role of 4D Historic Building Information Modelling and Management in the analysis of constructive evolution and decay condition within the refurbishment process. International Journal of Architectural Heritage, 1-17. https://doi.org/10.1080/15583058.2019.1668494

Castellano-Román, M., \& Pinto-Puerto, F. (2019). Dimensions and Levels of Knowledge in Heritage Building Information Modelling, HBIM: The model of the Charterhouse of Jerez (Cádiz, Spain). Digital Applications in Archaeology and Cultural Heritage, 14. https://doi.org/10.1016/j.daach.2019.e00110

Fai, S., Graham, K., Duckworth, T., Wood, N., \& Attar, R. (2011). Building Information Modelling and heritage documentation. In Proceedings of the 23rd International Symposium, International Scientific Committee for Documentation of Cultural Heritage (CIPA), Prague, Czech Republic (pp. 12-16).

Italian Government. (2008). D.Igs. 9 aprile 2008, n. 81. Testo unico sulla salute e sicurezza sul lavoro. Available at: https://www.lavoro.gov.it/documenti-e-norme/

Jordan-Palomar, I., Tzortzopoulos, P., García-Valldecabres, J., \& Pellicer, E. (2018). Protocol to manage Heritage-Building interventions using Heritage Building Information Modelling (HBIM). Sustainability, 10(4), 908. https://doi.org/10.3390/su10040908

Lucarelli, M., Laurini, E., \& De Berardinis, P. (2019). 3D and 4D modelling in building site working control. Int. Arch. Photogramm. Remote Sens. Spatial Inf. Sci., XLII-2/W9, 441-446. https://doi.org/10.5194/isprs-archives-XLII-2-W9441-2019

Murphy, M., McGovern, E., \& Pavia, S. (2009). Historic building information modelling (HBIM). Structural Survey, 27(4), 311-327. https://doi.org/10.1108/02630800910985108

Nieto, J. E., Moyano, J. J., Rico Delgado, F., \& Antón García, D. (2016). Management of built heritage via HBIM Project: A case of study of flooring and tiling. Virtual Archaeology Review, 7(14), 1-12. 
https://doi.org/http://dx.doi.org/10.4995/var.2016.4349

Solihin, W., Eastman, C., \& Lee, Y. C. (2016). A framework for fully integrated building information models in a federated environment. Advanced Engineering Informatics, 30(2), 168-189. https://doi.org/10.1016/j.aei.2016.02.007 


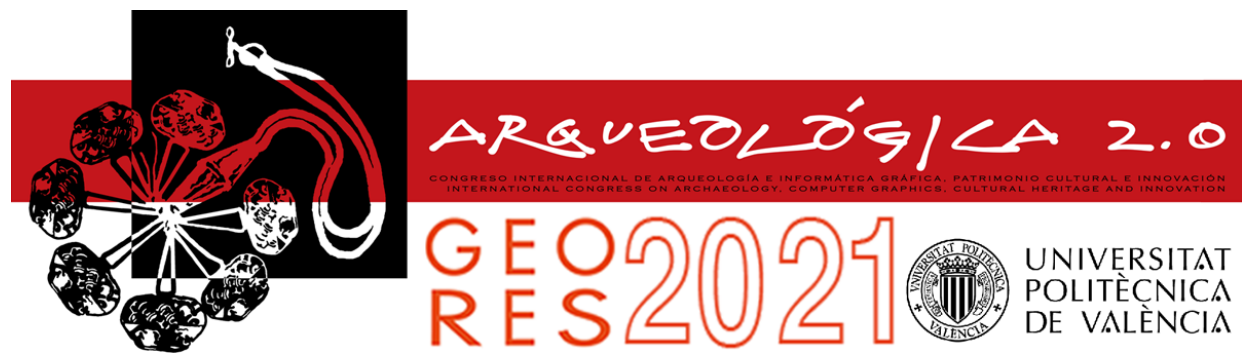

\title{
A HERITAGE INFORMATION SYSTEM FOR MULTISCALE ANALYSIS FOR THE WORLD HERITAGE SITE OF CUENCA, ECUADOR
}

\author{
Verónica Heras*, Paúl Ochoa, Andrés Delgado \\ Facultad de Diseño, Arquitectura y Arte, Universidad del Azuay, Av. 24 de Mayo 7-77, Cuenca, Ecuador. vheras@uazuay.edu.ec; \\ pochoa@uazuay.edu.ec; adelgado@uazuay.edu.ec
}

\begin{abstract}
:
The Historic Center of Santa Ana de los Ríos de Cuenca is a World Heritage Site since 1999. The outstanding universal value of the city is more related to urban features, nevertheless, the decision over the heritage site is mainly linked to single monuments. In this context, this ongoing research aims to settle a geographic information system based on heritage data (Heritage GIS) that allows analysis at different scales. The system started by establishing management decisions and a monitoring process, lately the existing and missing data were identified, for the non-existent data a documentation process was executed using photogrammetry and Unmanned Aircraft System (UAS). The preliminary results show different possibilities to monitor and heritage data analysis at different scales. Currently, the gathered data has been linked to an SDI (Spatial Data Infrastructure) which will allow the dissemination, use, and motoring of the heritage information.
\end{abstract}

Keywords: heritage information system, decision making, UAS, photogrammetry

\section{Introduction}

Humanity is losing cultural heritage faster than it can be documented, preserved, and disseminated. There is a huge concern about the preservation and safeguard of cultural heritage, but resources are limited (Lerma, Heras, Mora-Navarro, Rodas, \& Matute, 2019). In this context, digital technologies for cultural heritage documentation in the last years has developed very fast. However, the heritage documentation field still faces limitations related to:

- Management of Large Scale Data. An important attribute of cultural heritage projects is the use of information from previous research, which often contains different data formats. Researchers have to load objects using proper tools for visualization and manually link and maintain its related files.

- $\quad$ Lack of Analysis and Evaluation Methods. Most digital technologies focus on data gathering and data visualization but are poor in information display and analysis, which play indispensable roles in cultural heritage research.

- Documentation and Sharing. Most digital analyses tools fail to provide platforms for researchers to share the results. In most cases, researchers use digital technologies only to visualize data and they have to turn to other software for documentation, which can be shared and propagated conveniently.

Even if the described problems are common for different heritage sites, they are more evident in sites that are part of developing countries, where the economic resources are limited. In the World Heritage Site of Cuenca for many years' different researches have been focused on the study of single buildings, such as the last city heritage inventory in which different heritage value categories were established. In this campaign, more than 9.200 built structures were identified, and from them, 3.250 buildings have a heritage value. Even if these efforts are important, the management decision making in Cuenca are made at the urban scale level (Heras, 2017). It shows the importance of developing, gather, and use heritage data at different scales. Among the previously mentioned problems and in the current scenario, this working project established a Heritage Information System (HIS) that will be part of a Geo Portal as a thematic layer. In the following paragraphs the main contributions are described:

- Cultural Heritage Database and graphic structure. The cultural heritage database is introduced as the basic container of information about cultural heritage. The defined database can efficiently maintain and manage all the objects and their related files.

- Heritage documentation system. It provides a clear overview of the existing data and recording technique that was used or could be used to gather non existing data. 
- The decision-making system. The system will be allowed to make different analyses, especially at the urban scale.

- Automatic Report Generation. Provides functions to generate a research report in pdf format, which can summarize the project information clearly and efficiently.

\section{Methodology}

As part of the developed methodology the research project is organized in three main phases:

1) Cultural Heritage Database and graphic structure. The proposed database aims to structure and gives the opportunity to integrate different types of data and city scales. The structure of the database is also linked with the management decisions and periodic monitoring requirements of a World Heritage City.
2) Documentation system. The documentation structure has been identified as a clue aspect of the whole system. It facilitates the integration of the existing data but also aims to guide future documentation processes, as they need to be linked to the developed HIS.

For this purpose, between 2013 and 2015, twodimensional photogrammetric surveys of 50 facades of heritage buildings were obtained. In 2019, for the 2D - 3D models tools like photogrammetry and unmanned Aircraft System were used to capture heritage data. Therefore, a series of photos of a single building were collected. Elements related to the context, the building geometry, distance to the object, among others were taken into account before the field work. Figure 1 illustrates the documentation process and the decisions that were taken, which constitutes an important research contribution for the particularities of this WHS.
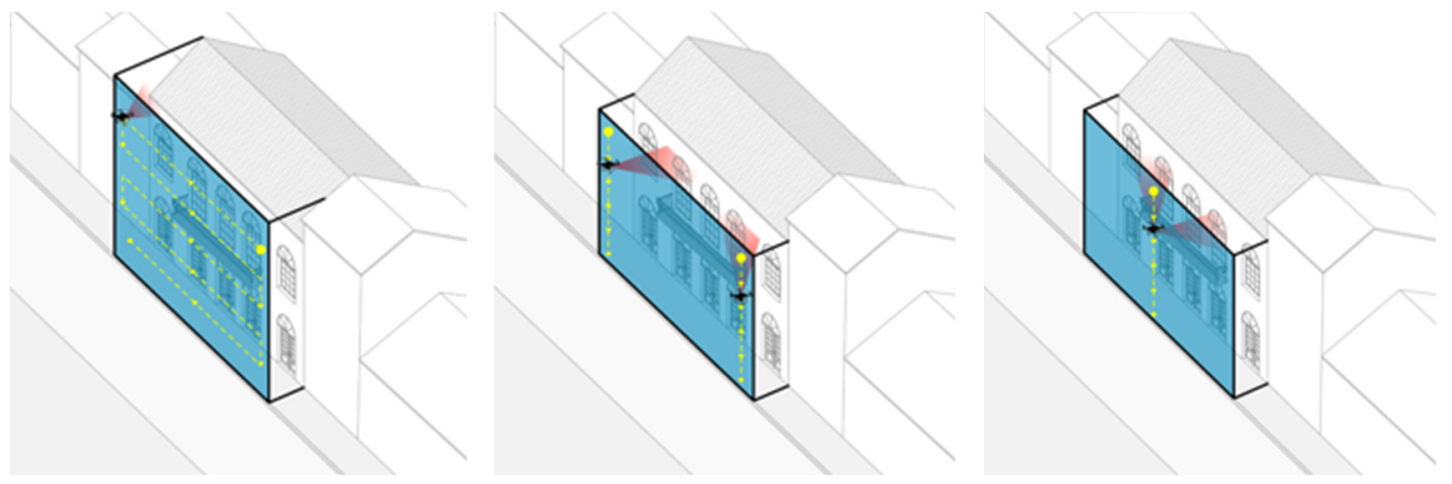

Figure 1: Documentation process executed in 3 stages, that started taking photos from left to right every 2 meters, then the camera is located at the edges of the façade and at the final stage a photo series is done from top to the ground of the façade.

3) The decision-making structure. For the decision making phase, the project started with the identification of the main heritage decisions that are needed in order to preserve the city's heritage. Therefore, in Table 1, there are some examples of the explored possibilities.

Table 1: Decision making phase at different scales.

\begin{tabular}{|c|c|c|c|}
\hline $\begin{array}{l}\text { Heritage } \\
\text { feature }\end{array}$ & $\begin{array}{l}\text { Data } \\
\text { type }\end{array}$ & $\begin{array}{c}\text { Documentation } \\
\text { tool }\end{array}$ & $\begin{array}{l}\text { Proposed } \\
\text { analysis }\end{array}$ \\
\hline $\begin{array}{l}\text { Height of } \\
\text { the building }\end{array}$ & $\begin{array}{l}2.5 \mathrm{D} \\
/ 3 \mathrm{D}\end{array}$ & DTM & $\begin{array}{l}\text { Building block } \\
\text { height average }\end{array}$ \\
\hline $\begin{array}{l}\text { Aesthetic } \\
\text { features }\end{array}$ & $\begin{array}{l}0 \mathrm{D} \\
12 \mathrm{D}\end{array}$ & $\begin{array}{c}\text { Factsheet } \\
\text { /Photography }\end{array}$ & $\begin{array}{c}\text { Color /Land use } \\
\text { /Rhythm } \\
\text { /Symmetry } \\
\text { /Aesthetic style }\end{array}$ \\
\hline $\begin{array}{l}\text { Height of } \\
\text { mezzanine }\end{array}$ & $2 \mathrm{D}$ & $\begin{array}{c}\text { Factsheet } \\
\text { Photography } \\
\text { /Photogrammetry }\end{array}$ & $\begin{array}{l}\text { Monitoring of } \\
\text { heritage } \\
\text { features }\end{array}$ \\
\hline $\begin{array}{l}\text { Building } \\
\text { typologies }\end{array}$ & $\begin{array}{l}2 \mathrm{D} \\
13 \mathrm{D}\end{array}$ & $\begin{array}{c}\text { Factsheet } \\
\text { Photography } \\
\text { /Photogrammetry }\end{array}$ & $\begin{array}{c}\text { State of } \\
\text { conservation }\end{array}$ \\
\hline Damages & $2 \mathrm{D}$ & Thermic camera & $\begin{array}{l}\text { State of } \\
\text { conservation } \\
\text { /Threats }\end{array}$ \\
\hline
\end{tabular}

Once the possible decisions were defined, the type of data needed, and the analysis are also recognized. From this data, $2 \mathrm{D}$ and $3 \mathrm{D}$ models were generated, that are aimed to be monitored over time. Then the required analysis is executed in the GIS platform. Nevertheless, it is important to recognize that the output information helps the heritage manager to take an informed decision. The system will never pretend to replace human perception.

4) Report. In order to accomplish with the objective of publishing and sharing heritage information. The HIS will give us an important output the automatic report generation, which will summarize the output of an executed analysis. In this scenario, the report could include information related to a studied building or a city's building block. The metadata for each object reveals the information of raw data based on the data format such as resolutions.

As part of the sharing process, the research has the opportunity to be part of a territorial platform developed for the region in which the heritage data will appear as another layer (see Universidad de Azuay, 2019).

\section{Discussion and preliminary results}

In relation to the preliminary results, the system structures and keeps different layers of information. It gives the opportunity to compare and make the historical analysis 
at different scales. Figure 2 shows an urban level analysis (facades of one building block) that aims to understand and control the height homogeneity of the buildings. The buildings stretch (Fig. 2a), clearly shows buildings that have different heights, they have also different façade colors, materials, and façade rhythms. These results differ from the buildings stretch (Fig. 2b), which shows more height homogeneity between its buildings. From the examples, both types of analysis executed at a building or building block levels are important for decision making.

In these cases, the heritage manager could have different layers of information and not only compare the visual changes of a single building, but also understanding the relation of a building heritage value and its aesthetic features such as the façade rhythm or the height homogeneity. In any case, the HIS aims to become a tool for a site manager and will never replace the human perception, on the contrary, this research recognizes the importance of participatory management dynamics that allows the sustainability of the initiatives, as expressed in the works of (Asmal, 2019; Siguencia, Vintimilla, \& Auquilla, 2018), since the conception of the object of work includes the population, so that it results in a comprehensive improvement based on the potentialities of each community as expressed by Alfredo Conti (2016), and supported by several authors who highlight the necessary interaction between the physical and human component of the city (Carofilis \& García, 2015).

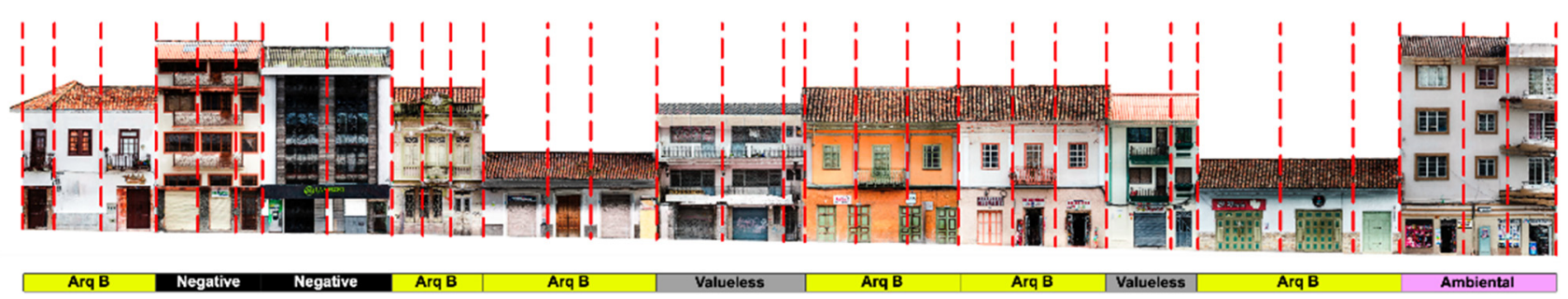

(a)

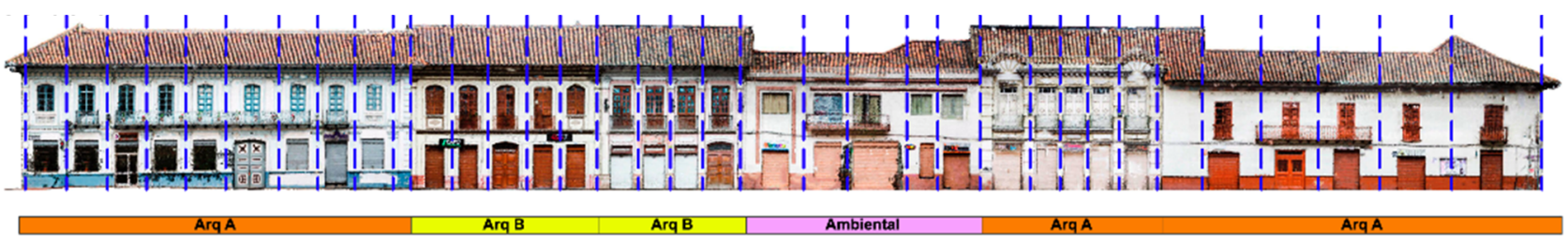

(b)

Figure 2: Rhythm and Height homogeneity of the building blocks: a) Non-Uniform façade rhythm by Mariscal Lamar; b) Uniform façade rhythm by Luis Cordero

\section{Conclusions}

The project aims to generate an SDI (Spatial Data Infrastructure), in which a distribution of responsibilities could be proposed and executed between different institutions. Therefore, the Patrimonial IDE model starts by establishing interoperability as one of the main attributes. Furthermore, the system allows the integration of information with other databases, projects a possibility of continuity as it becomes one more gear of the information system for territorial management.

\section{References}

Asmal, D. (2019). Modelo de gestión del patrimonio cultural edificado basado en la participación ciudadana para la ciudad de Cuenca. Tesis de Maestría en Conservación y Gestión del Patrimonio Cultural Edificado. Universidad de Cuenca. Cuenca, Ecuador.

Carofilis, N., \& García, G. (2015). El patrimonio como recurso: el cambio de paradigmas en la conservación urbana desde una perspectiva internacional. Estoa. Revista De La Facultad De Arquitectura Y Urbanismo De La Universidad De Cuenca, 4(6), 69-80. https://do i.org/10.18537/est.v004.n006.12

Conti, A. (2016). Paisajes históricos urbanos: nuevos paradigmas en conservación urbana. MEC-EDUPAZ, 2(10), 1-12. Available at: https://bit.ly/3grcAnh.

Heras, V. (2017). Cuenca, quince años como patrimonio mundial: evaluación de los procesos de documentación y monitoreo. Estoa. Revista De La Facultad De Arquitectura Y Urbanismo De La Universidad De Cuenca, 4(6), 27-35. https://doi.org/10.18537/est.v004.n006.06

Lerma, J. L., Heras, V., Mora-Navarro, G., Rodas, P., \& Matute, F. (2020). Geoportal Proposal for the inventory of cultural heritage in Nabón (Ecuador). Int. Arch. Photogramm. Remote Sens. Spatial Inf. Sci., XLIII-B2-2020, 1415-1418. https://doi.org/10.5194/isprs-archives-XLIII-B2-2020-1415-2020

Siguencia, M. E., Vintimilla, S. \& Auquilla, S. (2018). El paisaje en la perspectiva de la comunidad, identificando Patrimonio en Cuenca-Ecuador. ASRI: Arte y sociedad. Revista de investigación, 14, 236-253. Available at: https://bit.ly/3j9fajn. 
Universidad de Azuay. (2019). Información territorial: Azuay (uazuay.edu.ec). Retrieved March 15, 2021, from http://gis.uazuay.edu.ec/proyectos/pr_cob/\#13/-2.8848/-78.9781 


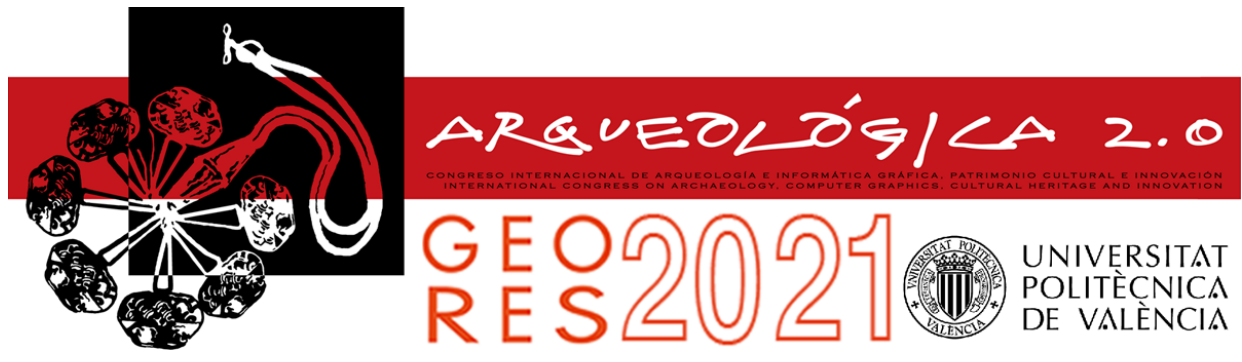

Proceedings of the joint international event $9^{\text {th }}$ ARQUEOLÓGICA

$2.0 \& 3^{\text {rd }}$ GEORES

Valencia (Spain).

26-28 April 2021

Received: $13 / 12 / 2020$

Accepted: 05/03/2021

\title{
CANTÓN NABÓN CULTURAL HERITAGE GEOPORTAL IMPLEMENTATION: FIRST STEPS
}

\author{
Angel Colladoa, ${ }^{*}$, Gaspar Mora-Navarroa, Paula Rodas ${ }^{b},{ }^{a}$ Verónica Heras ${ }^{c}$, José Luis Lerma ${ }^{a}$ \\ ${ }^{a}$ Department of Cartographic Engineering, Geodesy and Photogrammetry, GIFLE, Universitat Politècnica de València, Camino de Vera \\ s/n, 46022 Valencia, Spain. acolmur@topo.upv.es; joamona@cgf.upv.es; jllerma@cgf.upv.es \\ b Instituto Nacional de Patrimonio (INPC), Ecuador. paula.rodas@patrimoniocultural.gob.ec \\ c Facultad de Diseño, Arquitectura y Arte, Universidad del Azuay, Av. 24 de Mayo 7-77, Cuenca, Ecuador. vheras@uazuay.edu.ec
}

\begin{abstract}
:
The world is losing its architectural and archaeological cultural heritage faster than it can be documented, preserved and disseminated. We have a moral obligation to preserve the past filled with history, culture, the advancement of arts and technology as an insight into our present and as part of our future. We can do this by proposing the creation of an archival resource, insurance against change or loss of heritage places due to a combination of natural and human actions that are heavily affecting our present. Knowing the benefits of heritage recording are countless, and this paper presents the progress of the international cooperation proposal already initiated for strengthening efforts to protect and safeguard the world's cultural and natural heritage. This proposal is being achieved through the creation of a geoportal with the Arches platform for the inventory of tangible and intangible cultural heritage in Cantón Nabón, in the Azuay province, in Ecuador, following the suggestions of local institutions, custodians and inhabitants that aims to preserve their cultural expressions. In this sense, this project integrates existing and gathered information, as well as documentation that will be collected in the future.
\end{abstract}

Keywords: cultural documentation, tangible and intangible heritage, Sustainable Development Goals, international cooperation, Arches, geoinformation, heritage cycle

\section{Introduction}

A combination of natural and human actions such as longterm climate change, vandalism, war, pollution and natural hazards such as floods, volcanic activity and earthquakes are affecting natural architectural features and archaeological cultural heritage. Due to these factors, the world is losing its heritage faster than it can be documented, preserved and disseminated.

We have a moral obligation to make the past part of our future and the way to achieve this is by preserving and safeguarding the cultural heritage, thus creating insurance against change to or loss of heritage places. But resources are usually scarce and/or limited, and consequently reducing the potential development of appropriate measures and actions.

The 2030 Agenda for Sustainable Development was adopted by the United Nations in 2015 (United Nations, 2015) includes 17 Sustainable Development Goals (SDGs). In particular, SDG 11.4 seeks to strengthen efforts to protect and safeguard the world's cultural and natural heritage.

In addition, the present cooperation project in Ecuador, focused on a rural village called Nabón, aims to contribute and strengthen collaboration in documenting the area's cultural and natural heritage. Furthermore, this project is aligned with the National Ecuadorian Constitution (COOTAD, 2010), which in different articles mention the importance of heritage identification, documentation and conservation for the country identity.

Nabón was recognized as an Ecuadorian national heritage in 2005 due to its natural and cultural features which are well-preserved. This project focus on contributing to management decisions by implementing the Heritage Cycle (Thurley, 2005) that is understanding, valuing, caring and enjoying cultural heritage through building a geospatial-based website following the suggestions of the local inhabitants and carried out by local, regional and international experts (Lerma, Heras, Mora-Navarro, Rodas, \& Matute, 2020).

The SIPCE (Information System of the Ecuadorian Cultural Heritage) is the official inventory platform established as mandatory in 2010. Nabón has never been able to have an updated and digital inventory that should be part of SIPCE. Therefore, this cooperation project aspires to reverse this situation.

`Corresponding Author: Angel Collado, acolmur@topo.upv.es 


\section{Gathered Information}

All the gathered information, from historical records, old photographs, architectural and archaeological surveys, in combination with state-of-the-art photogrammetric documentation surveys, will integrate the new geoportal.

Being more specific, the available data that are likely to be part of the geoportal are the following:

- The last real state inventory, executed by the Instituto Nacional de Patrimonio Cultural (INPC) in 2005, consists of 141 records in PDF format, and with images in black and white.

- $\quad$ An inventory produced by INPC since 2008 in advance, consisting of 464 files in PDF format with the real state, 134 with movable assets, 19 with archaeological sites, 47 with intangible assets, and 15 with documents and archives.

- An updated inventory will take place in the first months of 2021. The data that will be gathered should be considered in terms of future monitoring.

- $\quad$ Several DWG files (CAD), that define the blocks of the town, and some shapefiles (GIS) with the geolocation of the real estate, archaeological sites and places of natural interest expressed in UTM 17S coordinates (WGS84).

- High-resolution satellite images of the area will be useful for background maps.

- The PDYOT (Development and Territorial Ordering Plan) with alphanumeric information on urbanism and territory, as well as society, economic and institutional data.

\section{Geoportal implementation}

In this scenario, after exploring the existing heritage systems, the Arches heritage inventory and management system (Myers, Dalgity, \& Avramides, 2016) has been choosing as one of the best existing systems for the development of the cooperation project.

The Arches geoportal is based on a three-tier architecture. Geoportals are a great way to allow nontechnical users access to spatial information (Blower et al., 2015; Ganning, Coffin, McCall, \& Carson, 2014; Resch \& Zimmer, 2013). These three layers are: the logic tier, the data tier, and the presentation tier.

The data tier is the database. The presentation tier is the web portal, while the logic tier is the code that gets the data from the database and sends it to the presentation tier by the internet, to be shown to the user. The logic tier also follows the other way round getting the user data from the presentation tier, and storing it into the data tier.

In addition, Arches makes available a mobile app, Arches Collector, that allows, in a synchronized way, to collaborate on an active data acquisition project. Work is currently underway to put it into operation.

\subsection{Database model}

Arches has some default database models (Arches, 2020). In our case, we have used the Heritage Resource
Model as a template for the reason that this resource model describes heritage resources, which includes monuments and buildings. The Arches Designer exists to facilitate the creation and customization of resource models. In that sense, Arches is a flexible and powerful platform.

From the chosen model, we have selected those attributes, or 'branches' in Arches, that are of interest to this project, as presented in Table 1, among others.

Table 1: Branches used in Cantón Nabón Arches Project

\begin{tabular}{|c|c|}
\hline Branch & Definition \\
\hline Name & The name of a resource \\
\hline Place 1 & $\begin{array}{c}\text { Describes the physical location of a } \\
\text { heritage resource }\end{array}$ \\
\hline $\begin{array}{l}\text { Resource Type } \\
\text { Classification }\end{array}$ & Describes the type of resource \\
\hline Description & $\begin{array}{l}\text { Generic branch for capturing free-form } \\
\text { written descriptive information }\end{array}$ \\
\hline Existence & Starting date for resources \\
\hline $\begin{array}{l}\text { Condition } \\
\text { Assessment }\end{array}$ & $\begin{array}{l}\text { Describes the conditions, threats, and } \\
\text { disturbances affecting a Heritage } \\
\text { Resource. Additional information may } \\
\text { include a management recommendation }\end{array}$ \\
\hline Component & Physical thing on a heritage resource \\
\hline
\end{tabular}

These branches follow the CIDOC Conceptual Reference Model (CRM), a reference ontology for the interchange of cultural heritage information. Since 2014 it can be found at ISO 21127:2014 (CIDOC-CRM, 2020).

\subsection{Presentation layer}

At this moment, we have already functional Arches for our project in the next URL of our server: https://patrimoniocantonnabon.tk.

There, you can see how Arches presents the data on the map as point entities, and the information associated with those points (Fig. 1).

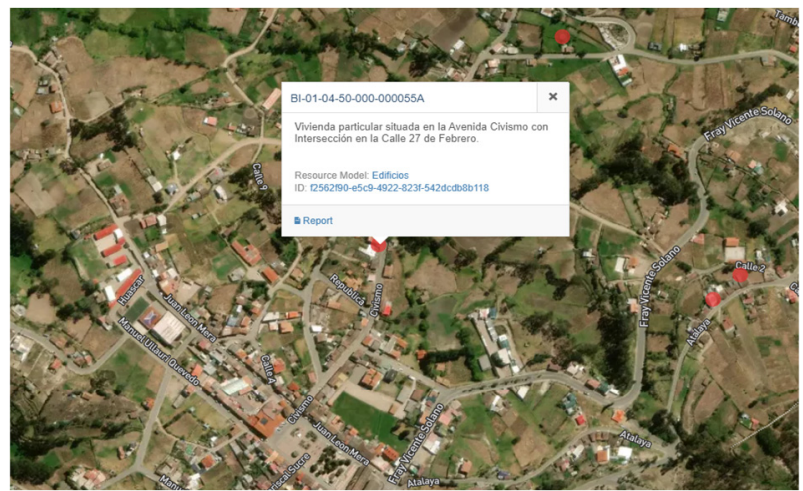

Figure 1: Example of map data visualization in the Arches platform.

In addition, it can also be observed and generated as a report with all the data that is part of the element (Fig. 2). Apart from photographs, you can also add PDF documents and links to websites containing any resources such as 3D models or historical information. 


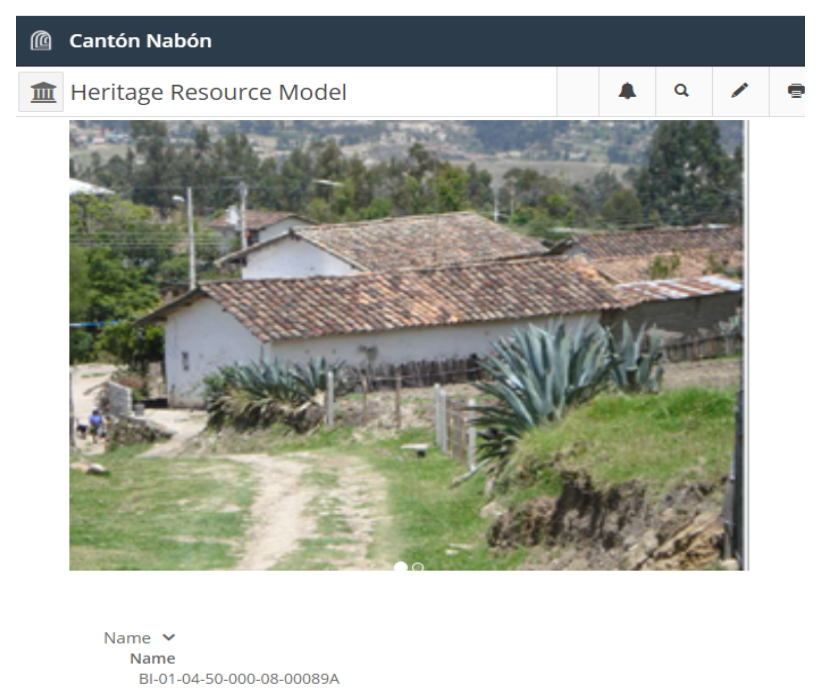

Figure 2: Part of the report that can be generated.

Arches has good enough default functionalities to setup a heritage project. For each project, you have available options to make a different configuration that fits the requirements of the project to be implemented.

Other aspects as the aesthetics of the main page or symbolism and visualization should be done by computer programming. In this project, the default design will be used.

\section{Conclusions}

This paper has presented the first steps undertaken to set up a robust and open-source geoportal in Cantón Nabón. Our project is gradually progressing in the right way and we are sure that at the time of its completion, the valuable cultural heritage of Cantón Nabón will be efficiently managed, displayed and disseminated, empowering the society with their resources.

There is a big amount of digitized information about cultural heritage in Cantón Nabón (images, PDF files, old maps, and urban planning). Our goal is to complete that information and make it easily accessible for users and managers through the Arches platform. Work is underway to make this happen by demonstrating a promising implementation, able to link, enrich and integrate, if it is required, with other geoportals in the region such as the SIPCE (INPC) and IERSE UDA.

\section{Acknowledgements}

The authors acknowledge the support by the Centro de Cooperación al Desarrollo, Universitat Politècnica de València (Research Programme MERIDESCOOPERACIÓN-2020).

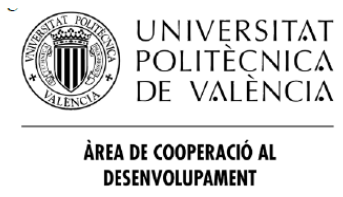

\section{References}

Arches. (2020). An open source data management platform for the heritage field. Arches Project Cultural Heritage Inventory and Management Software. Retrieved March 15, 2021, from https://www.archesproject.org/

Blower, J. D., Maso, J., Diaz, D., Roberts, C. J., Griffiths, G. H., Lewis, J. P., Yang, X., \& Pons, X. (2015). Communicating Thematic Data Quality with Web Map Services. ISPRS International Journal of Geo-Information, 4(4), 1965-1981. https://doi.org/10.3390/ijgi4041965

CIDOC-CRM. (2020). CIDOC Conceptual Reference Model. Retrieved December 10, 2020, from http://www.cidoc-crm.org/

COOTAD. (2010). Código orgánico de organización territorial, autonomía y descentralización. Registro Oficial Suplemento 303 de 19 octubre de 2010

Ganning, J. P., Coffin, S. L., McCall, B., \& Carson, K. (2014). Goals, Challenges, and Capacity of Regional Data Portals in the United States: An Updated Understanding of Long-Standing Discussions. Journal of Urban Technology, 21(4), 125-139. https://doi.org/10.1080/10630732.2014.942168

Lerma, J.L., Heras, V., Mora-Navarro, G., Rodas, P., \& Matute, F. (2020). Geoportal proposal for the inventory of cultural heritage in Nabón (Ecuador). The International Archives of the Photogrammetry, Remote Sensing and Spatial Information Sciences, XLIII-B2-2020, 1415-1418. https://doi.org/10.5194/isprs-archives-XLIII-B2-2020-1415-2020

Myers, D., Dalgity, A., \& Avramides, I., (2016). The Arches heritage inventory and management system: a platform for the heritage field. Journal of Cultural Heritage Management and Sustainable Development, 6(2), $213-224$. https://doi.org/10.1108/JCHMSD-02-2016-0010

Resch, B., \& Zimmer, B. (2013). User Experience Design in Professional Map-Based Geo-Portals. ISPRS International Journal of Geo-Information, 2(4), 1015-1037. https://doi.org/10.3390/ijgi2041015

Thurley, S. (2005). Making the past Part of Our Future: English Heritage Strategy 2005-2010. Retrieved March 15, 2021, from https://historicengland.org.uk/images-books/publications/eh-strategy-2005-2010/making-past-part-of-ourfuture

United Nations. (2015). Transforming our world: The 2030 Agenda for Sustainable Development. A/RES/70/1, pp. 1-41. Retrieved March 15, 2021, from https://sdgs.un.org/ 


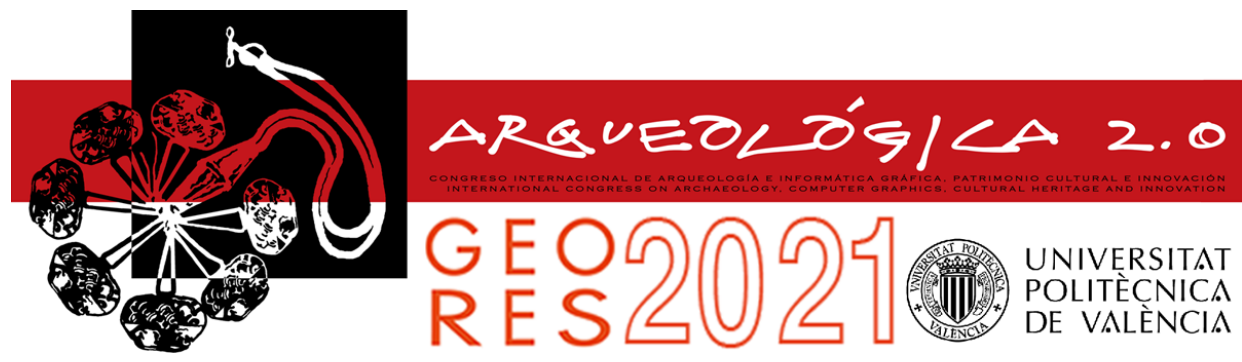

\title{
DIGITAL SURVEY AND RECEPTION STRUCTURES FOR A VIRTUAL FRUITION: THE CASE STUDY OF THE HYPOGEUM OF CALAFORNO (RAGUSA)
}

\author{
Graziana D’Agostinoa, ${ }^{a},{ }^{*}$ Marianna Figuerab ${ }^{\text {, Gianluca Rodonòa }}$ \\ ${ }^{a}$ Department of Civil Engineering and Architecture, University of Catania, Via Santa Sofia 64, 95125 Catania, Italy. \\ graziana.dagostino@unict.it; gianluca.rodono@unict.it
}

${ }^{\mathrm{b}}$ Department of Human Sciences, University of Catania, Via Biblioteca 4, 95124 Catania, Italy. marianna.figuera@unict.it

\begin{abstract}
:
This contribution offers the initial results of an on-going multidisciplinary project aimed at exploring digital approaches to overcoming the complexities associated with certain archaeological monuments, such as the Hypogeum of Calaforno, one of the most interesting prehistoric monuments in Sicily. It is a unique sample of rock-cut architecture in terms of size and architectural features, in comparison with the Sicilian territory and the entire Mediterranean context. In addition to the usually rock-cut architecture characteristics, as the narrow spaces and the lack of light, the hypogeum also presents some practical problems due to the serpentine route of the rooms and the presence of water in some spaces. This case study highlights the need to pursue the development of digital products which have a clearly scientific value and can also improve the dissemination aspects. The paper also shows the development and experimentation of workflows to obtain viable 3D digital twin models through the use of low-cost techniques for the photogrammetric surveying of archaeological sites characterized by the presence of narrow and complex spaces. Thanks to the comparison with the laser scanner point cloud of a previous survey, it was possible to verify the accuracy of the photogrammetric model. This has been obtained through the use of the action cam GoPro Black Hero 6. This cam proved to be a highly useful instrument, with lenses offering fields of view somewhere between those of fisheye lenses and of traditional lenses. The aim of this work is the communication of cultural content to the public through immersive virtual experiences that can enhance real visits to stimulate public interest and improve understanding of the monument with the help of unique reception and observation structures based on innovative enabling technologies. The construction system is designed to integrate analogue and digital apparatus and allow the creation of privileged observation points to experience 3D reconstructions of the site.
\end{abstract}

Keywords: archaeology, virtual fruition, narrow spaces, digital survey, photogrammetry, GoPro

\section{Introduction}

The work presented here is part of an on-going project focused on improving public appreciation of sites that are not readily accessible, through the development of digital twin environments that offer virtual access as an effective instrument of cultural transmission. The work is part of the wider eWAS project aimed at the precautionary conservation of Cultural Heritage assets before they are lost or compromised due to unforeseen calamities.

The test site is the Hypogeum of Calaforno (province of Ragusa, Sicily), chosen by the eWAS project for its high historical, archaeological and cultural significance, as well as for its intrinsic fragility and criticality associated with hydrogeological and seismic factors. The site is also characterized by access difficulties and resides in a remote location away from tourist circuits, generating communication issues and a general lack of sufficient support to allow visitors to fully appreciate the structural and functional significance of the hypogeum.
The project includes plans to render 3D tours possible on location through structures in the vicinity using specific technologies that will ensure flexibility, reversibility, and low environmental impact. The ultimate goal of the project is to therefore improve and heighten public awareness of the hypogeum through virtual experiences made possible by integrated digital survey methodologies such as Laser Scanner (LS) and Structure from Motion (SfM).

\section{The Hypogeum of Calaforno}

The Hypogeum of Calaforno is one of the most interesting prehistoric monuments in Sicily in terms of size and its unique representation of rock-cut architecture (Figuera, 2018).

The hypogeum was identified in the 1970s by Lorenzo Guzzardi (1980) but, notwithstanding its peculiarity, did not undergo systematic investigation until 2013, when archaeological research under the direction of Pietro Militello (University of Catania) allowed a more profound

‘Corresponding Author: Graziana D’Agostino, graziana.dagostino@unict.it 
understanding of its chronology, architecture and function (Militello \& Di Stefano, 2015; Militello, 2021). Since 2016, the Superintendence BB.CC.AA. of Ragusa has been leading excavations around the main entrance of the monument (Militello, Sammito, \& Scerra, 2018).

The hypogeum (Fig. 1) is carved into a layer of soft marl lying beneath a harder limestone layer. It includes a wide entrance room (ca. $12 \times 4 \mathrm{~m}$ ), and 35 circular rooms forming an irregular route (ca. $100 \mathrm{~m}$ long). The rooms have a diameter ranging from 1.5 to $3 \mathrm{~m}$, and range in height between 1.6 and $1.8 \mathrm{~m}$; concave floors and walls curve slightly up to the ceiling, which is perfectly flat. A second entrance was added in the vicinity of room 17 .

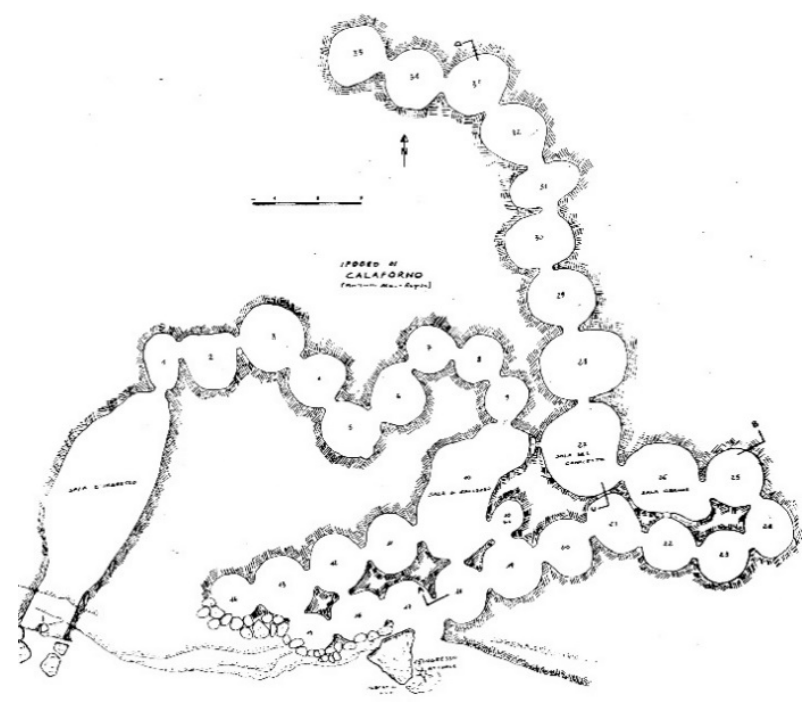

Figure 1: Calaforno Hypogeum (Guzzardi, 1980).

Construction spanned a long period, from the Late Copper Age (ca. 2700-2200 BC) to the Early and Middle Bronze Age (ca. 2200-1250 BC). It was initially used as a burial site until it became a ritual area in honour of the ancestors between 1000 and 700 BC. After a period of abandonment (excluding the immediate external area, which continued to be frequented), it was partially reoccupied as a cemetery (ca. 300-500 AD), and as an industrial and stockage area or an animal shelter (ca. 8001050 AD), until the final collapse of the entrance.

The features of the Calaforno Hypogeum do not lend themselves to straightforward survey: in addition to the lack of relevant points of discontinuity and the difficult identification of section planes necessary for identifying the layout, there are practical problems due to the narrow spaces, the serpentine route of the rooms, the lack of light and the presence of water in some spaces (Figuera, in press).

An initial solution to these problems came in the form of a laser scanning survey performed in 2017-19, culminating in a final 3D model consisting of approximately 25 million points and additional data, such as a coloured view based on the reflectivity of the materials detected by the instrument (Fig. 2). The technique proved fundamental for the resolution of many scientific problems caused by various technical issues that riddled the first survey (Guzzardi, 1980), as well as for identifying previously undiscovered architectural elements and recording the current state of preservation in enough detail to be able to adequately monitor any future degradation.

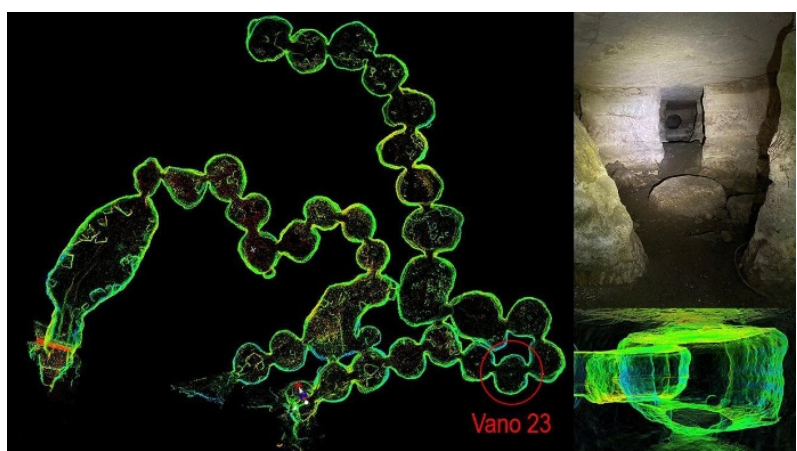

Figure 2: The laser scanner point cloud.

This case study highlights the need to pursue the development of digital products which, besides having a clearly scientific value, can also vastly improve communication aspects associated with sharing and disseminating information regarding heritage sites from local to supralocal scales (Salerno, 2017).

\section{The Structure from Motion survey: from point cloud to 3D model}

In recent years, several studies have been conducted on photogrammetric survey using fisheye or wide-angle lenses, together with necessary comparisons with other methods of digital acquisition (e.g., laser scanning), to verify the accuracy of acquired data and the reliability of derived models (Mandelli, Fassi, Perfetti, \& Polari, 2017). Our interdisciplinary research group addressed the matter by successfully deploying a GoPro action cam to survey tall and narrow environments in poor lighting conditions (Aiello et al., 2019), in addition to the laser scanning survey technique. The GoPro proved to be a highly useful instrument, with lenses offering fields of view somewhere between those of fisheye lenses and of traditional lenses. The experimentation carried out on the Calaforno Hypogeum, however, presented new challenges in terms of morphological and environmental complexity, with no lighting and very narrow rooms connected by small passageways.

Current research is aimed at developing and experimenting workflows to obtain viable $3 \mathrm{D}$ digital twin models featuring high quality and highly realistic chromatic data through low cost survey techniques. The first step of the SfM survey involved the acquisition of a single room (Room 23) to determine the most appropriate instrumentation and processes, before proceeding to acquire the entire site. The selected room is one of the smallest in the hypogeum and is part of a group of four rooms arranged in a ring shape around Room 26 . The room was subject to renovation work during its history, so its original shape remains undetermined. A serendipitous outcome of this detailed 3D survey is the identification of previously unseen geological features like traces due to water infiltration, especially in the ceiling, while realistic colour rendering on the slightly curved walls also revealed numerous geological stratifications.

The advantages of using the GoPro action cam instrumentation for capturing very tight environments include its small size (L: $62.3 \mathrm{~mm}$., H: $44.9 \mathrm{~mm}$., D: 32.0 mm.; Weight: 118 g.), high manoeuvrability and wide field of view (FoV), which allow greater area to be captured. The $130^{\circ}$ FoV implemented produces a fisheye aspect, 
especially at the scene edges, which simplifies the entire surveying phase by reducing the number of images needed to acquire the whole site and reducing the processing time with more manageable data.

Lighting was introduced with a LED lamp (24 LEDs, 0.5 W, 220 Lm; L: 73 mm., H: 250 mm., D: 165 mm.; Weight: 640 g.), configured to deliver neutral white light (4000$5000 \mathrm{~K})$ in order to derive realistic 3D model chromaticism. In addition, a portable lamp was employed to follow the shooting path of the dataset and to facilitate movement in narrow spaces.

The photographic dataset collected (35 images at $4000 \mathrm{x}$ 3000 resolution) was processed using the Agisoft Metashape photogrammetric software to generate a point cloud of about 23 million points and a polygonal model of about 5 million faces.
CloudCompare was used to compare the accuracy of the photogrammetric data with the more accurate laser scanning metric information. The GoPro point cloud was georeferenced in Metashape by assigning the coordinates of 7 recognizable markers from the laser scanner point cloud to corresponding points in the photogrammetric model (Fig. 3).

The deviation between the two models is shown in a Blue/Red scalar field. The calculation range was set between 0.00-0.01 m (Fig. 4).

With the reliability of the model to some extent verified, we believe that this research can contribute to the formulation of new protocols governing the archaeological survey of sites characterized by irregular surfaces, narrow spaces, specific chromatic features, scarce or total absence of illumination, and physical obstacles.

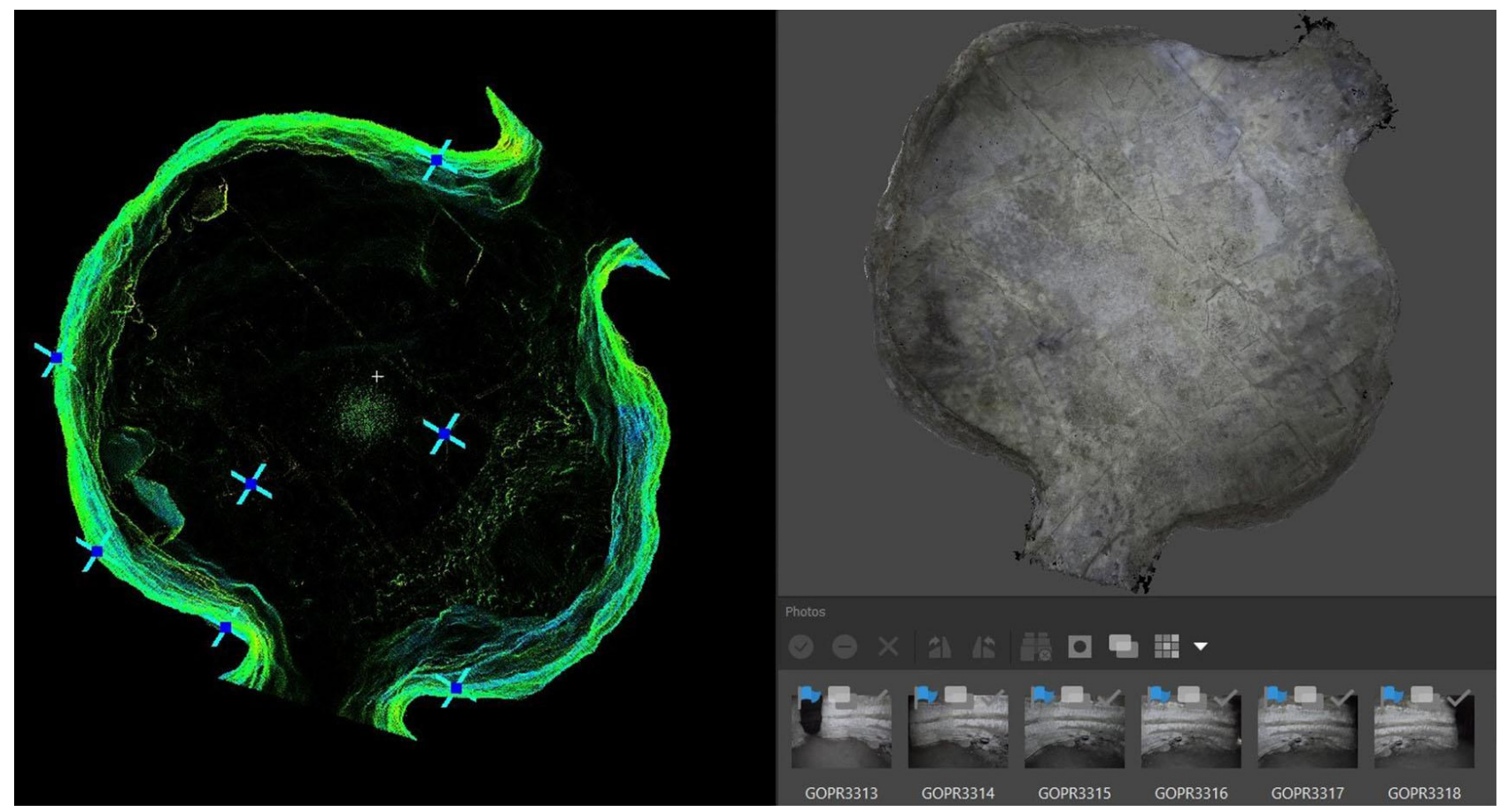

Figure 3: On left, top view of laser scanner point cloud with control points; on right, top view of GoPro polygonal model.

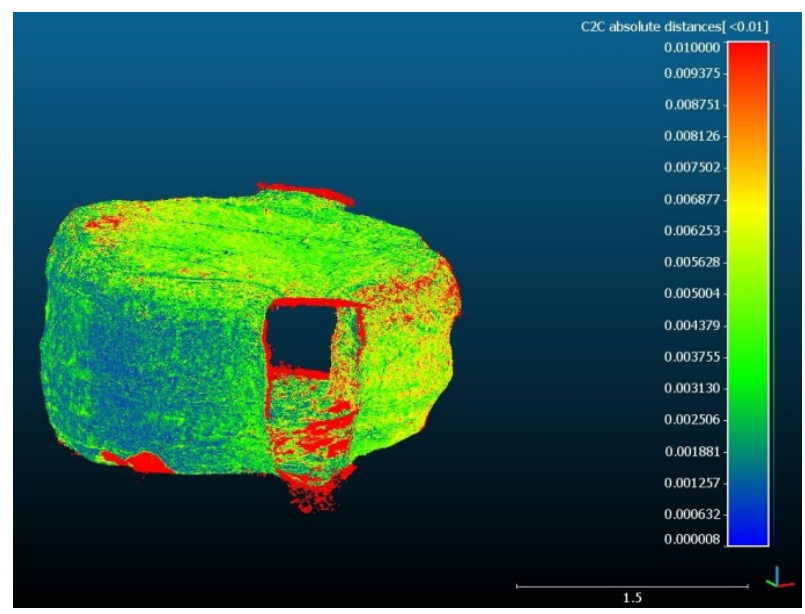

Figure 4: Comparison between the laser scanner and GoPro point clouds.

\section{The reception structures}

The intrinsic complexity of the Calaforno site renders the need to implement small pavilions and other micro service infrastructure particularly relevant in order to adequately communicate the knowledge acquired from past, current and subsequent research.

The construction of architectural volumes in sensitive areas demanding minimal and non-invasive interventions has inspired, within the scope of the eWAS project, experimentation with innovative technologies that, beyond the aforementioned requirements, also account for difficulties associated with access and supply of energy that often characterize sensitive areas. Any viable architectural objects must therefore be characteristically lightweight, easy to assemble and disassemble, and have minimal impact on the underlying terrain. A modular system was therefore conceived, involving a prefabricated timber frame with corrugated cardboard boxes inside. 
These materials offer low cost, rapid assembly and installation due to their low specific weight and complete recyclability (Distefano, Rodonò \& Sapienza, 2016).

The construction system is designed to integrate analogue and digital apparatus (periscopes and camera equipment), and allow the creation of privileged observation points to experience $3 \mathrm{D}$ reconstructions of the site in its original configuration. Flexible and envelope integrated photovoltaic cells shall complete the design to ensure off-grid energy independence.

\section{Conclusions and future developments}

$3 \mathrm{D}$ digital technologies can be instrumental research and documentation tools, as well as providing innovative communication channels. They should not, however, represent substitutes for real visits, but rather encourage them by stimulating public interest. For this reason, the on-location fruition of acquired digital information through flexible reception structures is integral to this project. The structures are intended to allow virtual consumption of immersive and realistic digital twins in order to enhance the overall experience of interested visitors and academics alike. The former, by overcoming any inconveniences associated with less accessible areas, and the latter, by providing realistic morphologic and chromatic data, with levels of resolution and detail that will allow focus and investigation of particular aspects of the monument. To this end, the 3D model shall be enriched with semantic content providing detailed information surrounding the hypogeum, including architectural features, chronological and functional aspects, and so on.

\section{Acknowledgements}

The research was partly funded by the project PON ARS01_00926 eWAS - An Early Warning System for Cultural Heritage - PNR 2015-2020. The scientific director is prof. Vincenzo Sapienza (Department of Civil Engineering and Architecture, University of Catania), responsible for on-site research activities is prof. Pietro Militello (Department of Human Sciences, University of Catania).

Excavation activities were conducted under Project Mneme, Costruzione del passato e pratiche della memoria nel Mediterraneo, Bando Prometeo Linea 3, University of Catania.

The laser scanning activities were performed in trying conditions with the technical contribution of Antonio and Salvatore Garro (3D Dimension Company, Catania, Italy).

\section{References}

Aiello, D., Buscemi, F., D'Agostino, G., Galizia, M., Militello, P., \& Santagati, C. (2019). Low cost techniques for the digital survey of a Minoan architecture in the archeological site of Phaistos (Crete). Int. Arch. Photogramm. Remote Sens. Spatial Inf. Sci., XLII-2N17, 31-38. https://doi.org/10.5194/isprs-archives-XLII-2-W17-31-2019

Distefano, D.L, Rodonò, G, \& Sapienza, V. (2016). Le nuove frontiere dell'architettura di cartone. II progetto sostenibile, 38, 112-119.

Figuera, M. (2018). Patrimonio diffuso, comunità locali. La "riscoperta": per una ipotesi di valorizzazione innovativa dell'ipogeo di Calaforno. Archivio Storico per la Sicilia Orientale, 2018(1), 5-23. https://doi.org/10.3280/ASSO2018001001

Figuera, M. (in press). Sicilian Landscape and A-structural Architecture from Survey to Virtual Reconstruction: the case of the Calaforno Hypogeum. In D. Panagiotopoulos \& P.M. Militello (Eds.), Modelling Archaeological Landscapes.

Guzzardi, L. (1980). Un ipogeo preistorico a Calaforno e il suo contesto topografico. Sicilia Archeologica, 42, 67-94.

Mandelli, A., Fassi, F., Perfetti, L., \& Polari, C. (2017). Testing different survey techniques to model architectonic narrow spaces. Int. Arch. Photogramm. Remote Sens. Spatial Inf. Sci., XLII-2/W5, 505-511. https://doi.org/10.5194/isprsarchives-XLII-2-W5-505-2017

Militello, P.M. (2021). Calaforno I. Le indagini 2013-2017. Oxford.

Militello, P.M., \& Di Stefano, G. (2015). Calaforno (Giarratana, Prov. di Ragusa). Indagini 2013-2014. Notiziario di Preistoria e Protostoria, 2(II), 63-65.

Militello, P.M., Sammito A.M., \& Scerra, S. (2018). Calaforno (Giarratana, RG). Notiziario di Preistoria e Protostoria, 5(II), 90-93.

Salerno, R. (2017). Digital Technologies for "Minor" Cultural Landscapes Knowledge: Sharing Values in Heritage and Tourism Perspective. In A. Ippolito \& M. Cigola (Eds.), Handbook of Research on Emerging Technologies for Digital Preservation and Information Modeling (pp. 510-535). https://doi.org/10.4018/978-1-5225-0680-5.ch019 


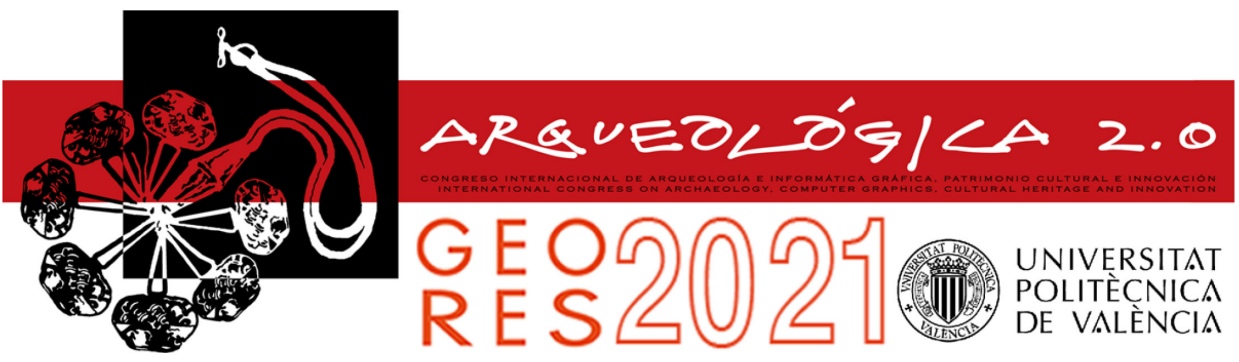

Proceedings of the joint international event $9^{\text {th }}$ ARQUEOLÓGICA $2.0 \& 3^{\text {rd }}$ GEORES, Valencia (Spain). 26-28 April 2021

\section{Extended Abstracts}




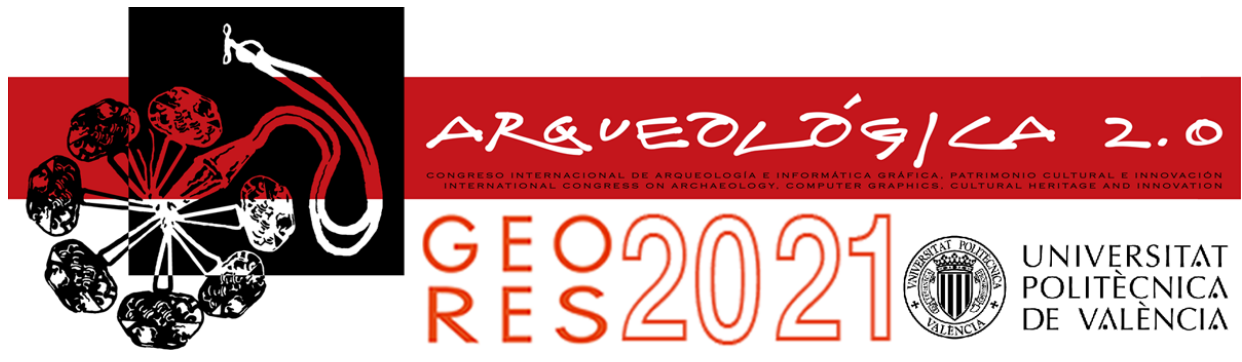

\title{
SIMULATION OF PAST PROCESSES THROUGH LINEAR PROGRAMMING. THE CASE OF THE DISTRIBUTION OF SUPPLIES DURING THE SIEGE OF BILBAO IN 1874
}

\author{
Álvaro Rodríguez Mirandaa,b, ${ }^{\mathrm{*}}$, Patricia Ferreira-Lopesc ${ }^{\mathrm{c}}$, Gorka Martín ${ }^{\mathrm{a}}$, Jaione Korro ${ }^{\mathrm{a}}$ \\ a GPAC - Built Heritage Research Group, University of the Basque Country (UPV/EHU), C/ Justo Vélez de Elorriaga, 1 (edificio Micaela \\ Portilla, 2.01), 01006 Vitoria-Gasteiz, Spain. alvaro.rodriguezm@ehu.eus; gorka.martin@ehu.eus; mirenjaione.korro@ehu.eus \\ ${ }^{\mathrm{b}}$ Department of Applied Mathematics, University of the Basque Country (UPV/EHU), Faculty of Engineering of Vitoria-Gasteiz, Spain. \\ c Instituto Andaluz de Patrimonio Histórico (IAPH), Monasterio de la Cartuja, Av. Camino de los Descubrimientos s/n, 41092 Sevilla, \\ Spain. patricia.ferreira@juntadeandalucia.es
}

\begin{abstract}
:
This work analyses the applicability of "linear programming" - a mathematical methodology for modelling, by means of (in)equations, and optimizing systems - to the simulation of past events and uses, as a case study, the allocation of artillery pieces and bombs during the siege of Bilbao in 1874, a key episode of the Third Carlist War (1872-1876) in Spain. Although, as many other conflicts at the turn of the $19^{\text {th }}$ century, the historiography concerning the Carlist Wars seems firmly settled on an important number of historic sources, such as operational debriefings, telegrams, plans and sketches of the fortifications, biographies of the main protagonists and descriptions of relevant battles... it is also true that some significant knowledge gaps remain and, in addition, there are important concerns about the uncertain and biased nature of the sources. In order to deal with this context, we can resort to different complementary approaches: on the one hand, the archaeology of the battlefields can provide new direct insights about the episodes; on the other hand, digital technologies such as the Geographic Information Systems (GIS) or the scientific simulation enable the virtual recreation of the events. In order to show this, the present study develops two complementary models for a particular occurrence (the siege of Bilbao) which try to visualize the strategies used by the attacking and the defending armies. These models follow the rules of the linear programming and are iteratively scaled on the basis of the textual information about the events; besides, for illustrative purposes, both models are fully formulated and solved in the text. The study demonstrates that the models may be useful not only to display already known facts but also as a way of understanding them and testing alternative hypotheses. Nevertheless, we must consider that the representativeness of the models usually encompasses the general dynamics of the events and that they can hardly be effective to reproduce each step in detail. Indeed, the historical truth is extremely complex and the grounds of a victory or a defeat cannot be simply extracted from a set of equations, regardless their extension. Indeed, we cannot pretend to be aware of all the causes, conditions and nuances which influenced the decision-making and the development of the events... but we can definitely use these models to peer at the historical events and gain knowledge about them. On a different note, the models are also useful as an instrument for discussion between archaeologist/historians and computer scientists/mathematicians: on the one hand, the pieces of historical information need to be expressed in the model and, on the other hand, every mathematical solution need to be translated and interpreted in textual mode.
\end{abstract}

Summing up, linear programming is a flexible option for creating a mathematical model from a textual context, a set of hypothesis and constraints; in addition, the calculation procedure is well established and affordable with limited computational resources and the variation of the results due to changes of the initial data can be also estimated. With regard to all these considerations it can be said that linear programming is an interesting tool for including reasoning and improving the geographical analysis for historical purposes.

Keywords: archaeology of conflict, battlefield archaeology, cyber-archaeology, GIS, linear programming, $19^{\text {th }}$ C. war

\footnotetext{
${ }^{1}$ Please check its full version at the Virtual Archaeology Review: LINEAR PROGRAMMING FOR THE ANALYSIS AND VIRTUAL RECREATION OF HISTORICAL EVENTS. APPLIANCE TO THE ALLOCATION OF THE ARTILLERY DURING THE SIEGE OF BILBAO IN 1874. https://polipapers.upv.es/index.php/var/article/view/15278.
}

*Corresponding Author: Álvaro Rodríguez Miranda, alvaro.rodriguezm@ehu.eus 


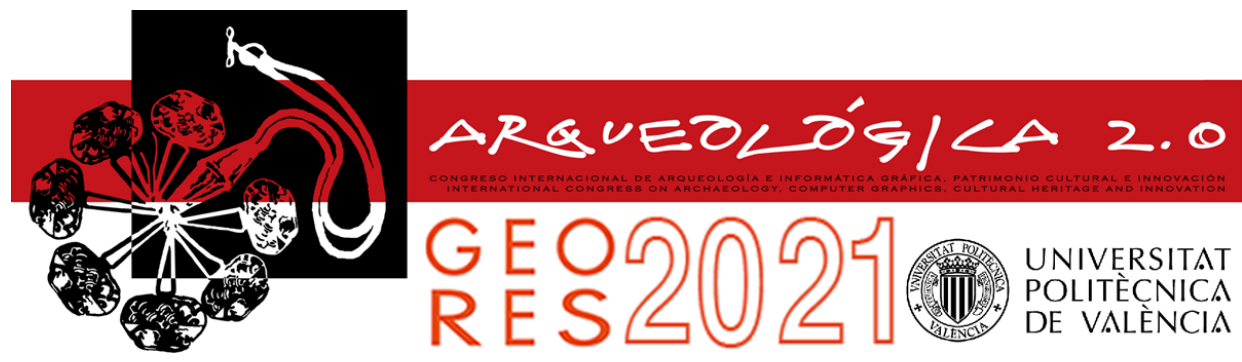

\title{
A WEB APPLICATION TO GEOLOCATE THE CURRENT CITY OF SAN CRISTOBAL DE LA LAGUNA IN A XVI CENTURY MAP ${ }^{1}$
}

\author{
Fernando Pérez-Navaa, ${ }^{a}$, Isabel Sánchez-Berriela ${ }^{a}$ Alejandro Pérez-Navaa, Virginia Gutiérrez- \\ Rodríguez ${ }^{b}$, Jesús Pérez-Morera ${ }^{c}$ \\ a Departamento de Ingeniería Informática y Sistemas, Escuela Superior de Ingeniería y Tecnología, 38203 La Laguna, Spain. \\ fdoperez@ull.edu.es; isanchez@ull.edu.es; aperez@ull.edu.es \\ b Departamento de Psicología, Facultad de Psicología, 38200 La Laguna, Spain. vgutier@ull.edu.es
}

c Departamento de Historia del Arte y Filosofía, Facultad de Humanidades, 38200 La Laguna, Spain. jperezmo@ull.edu.es

\begin{abstract}
:
The increasing interest in the conservation of historical cities has been an important aspect of urban development throughout recent history. To protect the cultural significance of a city we need to preserve its memory so that it can become part of our collective knowledge and thereby endure over time. In this paper, we present an approach to promote the knowledge of the World Heritage city of San Cristóbal de La Laguna in Spain. Founded in 1496, it has a unique value due to the original conception of its urban planning. It is an urban system in a grid, outlined by straight streets that form blocks of houses with a rectangular shape. Its layout is the first case of an unfortified colonial city with a regular plan. In this work, we present a web application that allows a user to locate places of the current city in the first map of San Cristóbal de La Laguna by Leonardo Torriani in the $16^{\text {th }}$ century. The first step to build this application is the georeferencing process that allows the internal coordinate system of the map to be related to a georeferenced coordinate system. The georeferencing process follows the identification of homologous ground control points (GCPs) in the coordinate systems of two elements of different origin. A set of $221 \mathrm{GCPs}$ have been defined through the map and several parametric transforms have been studied: similarity, affine and polynomials of degree two and three. Since the identification of homologous of the GCPS is prone to errors we have used the robust M-estimator sample consensus (MSAC) to obtain the param of the transforms and their associated fitting errors. The mean error ranged from $8.3 \mathrm{~m}$ for the similarity transform to $6.1 \mathrm{~m}$ for a polynomial of degree 3 transform. To obtain more precise results, the non-parametric natural transform interpolation has also been studied. This method finds the closest subset of input samples to a query point and applies weights to them based on proportionate areas to interpolate its value; global mean error of $3.2 \mathrm{~m}$ in the historical centre. This leads to a precise localization in the ancient map. The outliers of the transform have been identified and their location corresponds to the borders and exterior of the city. Their substitution is difficult, since there are no matching points in the map outside the city because Torriani represents there generic fields and the lagoon in the map was desiccated in 1839. The benefit of using geographical or projective coordinates has also been discussed finding no appreciable difference. To provide a satisfactory response to the user in the application, the computational impact of the natural transform has been considered and a technique to precompute it offline is presented. This is done by decomposing the transformation with natural interpolation between the modern cartography and the old map in two steps: 1) global similarity transform; 2) predicting the points in the old map using these transformed points using natural interpolation. The advantage of this decomposition relies on the fact that the second step can be stored as two precomputed images for row and column coordinates. These images are used by the web application. It has a simple front end where the user fills the current city address in a form. This activates a query in the back end to obtain the geographical coordinates of the address that are transformed to map coordinates using the precomputed natural transform. These map coordinates are used by a map viewer in the front end to locate the user address in the ancient map. To test the performance of the web application the behaviour of a typical internet user was studied and the load of the system has been analysed obtaining a latency of $1.4 \mathrm{~s}$ for 50 concurrent users. Results show that the web application provides accurate results in the historical centre while providing satisfactory response times.
\end{abstract}

Keywords: historical maps, cultural heritage, georeferencing, geoportal, geolocation

${ }^{1}$ Please check its full version at the Virtual Archaeology Review: PROMOTING THE HERITAGE OF THE CITY OF SAN CRISTOBAL DE LA LAGUNA THROUGH A TEMPORAL LINK WITH A $16^{\text {th }}$ CENTURY MAP. https://polipapers.upv.es/index.php/var/article/view/15322

*Corresponding Author: Fernando Pérez Nava, fdoperez@ull.edu.es 


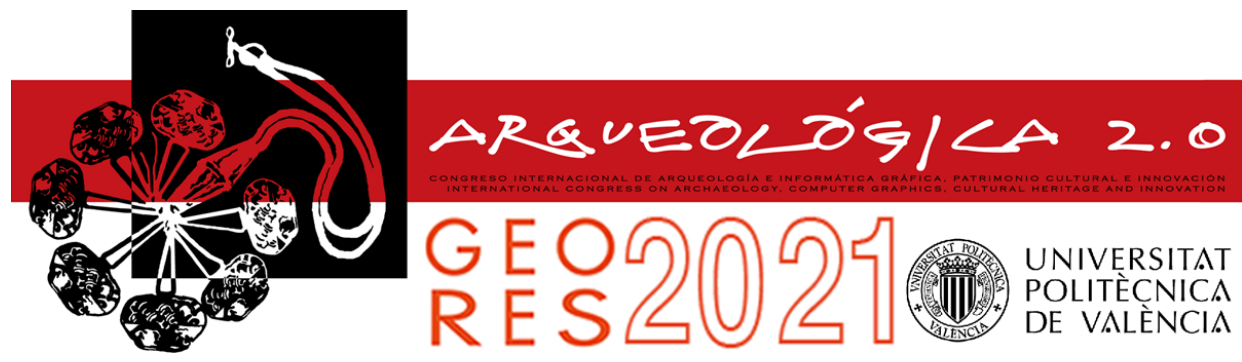

Proceedings of the joint international event $9^{\text {th }}$ ARQUEOLÓGICA

$2.0 \& 3^{\text {rd }}$ GEORES

Valencia (Spain).

26-28 April 2021

\title{
PARAMETRIC APPROACH TO THE RECONSTRUCTION OF TIMBER STRUCTURES IN CAMPANIAN ROMAN HOUSES ${ }^{1}$
}

\author{
Luca Sbrogiò \\ Department of Cultural Heritage, University of Padova, Pizza Capitaniato 7, 35139 Padova, Italy. luca.sbrogio@unipd.it
}

\begin{abstract}
:
The virtual reconstruction of ancient architecture aims at describing the 'original' elevation and volume of a disappeared building. The feeble archaeological traces, often limited to their foundations, left by houses impair the reinstating of their image, in contrast to that which is made possible by the massive structures of public buildings. The extensive use of perishable materials, like timber, for horizontal structures (e.g. floors and roofs) rather than masonry vaults or domes, contributes to the scarce preservation of domestic contexts. Timber elements played an important role in traditional masonry buildings, since a) their availability on the construction site determined the maximum structural spans allowed to a building, and $b$ ) their diaphragm effect granted the mutual structural connection among walls. Consequently, a twofold problem arises when dealing with timber structures during a reconstruction procedure, according to the scale considered. At the local scale of the individual beam (e.g. joists or rafters), a beam's cross-section depends on its span; at the overall scale, the shape of a building results from that which its structures allowed it to be. Ancient written sources give to present reconstruction tasks just hints, since they are partly obscure to our comprehension, especially about technical jargon, partly lack specific details, as their encyclopaedic nature prevent them to focus on technical aspects. To some extent, timber construction in the Middle Age and Early Modern era may fill in major gaps in the general framework, although it cannot enable a precise understanding of empiric design criteria. Conversely, modern treatises seem too 'scientific' to be applicable also to Antiquity. Specific information may come from peculiar cases, like Herculaneum and Pompeii in Italy; notwithstanding the archaeological evidence they offer is often incomplete and tampered with since the time of their rediscovery and therefore require an additional interpretation.
\end{abstract}

This work proposes a procedure to deal with the 'local' problem, i.e. the definition of a beam's cross-section from its span, starting from those partial data which may be commonly found in reconstruction tasks. To that end, a simplified, parametric structural model was created. The available bits of information were organized into inputs, parameters and outputs of an analytical problem by matching each information to a structural quantity (load, cross-section, spacing, etc.). Two mathematical relationships among them were proposed, which express two equally possible dimensioning criteria, basing either on joists' strength or deformability. To choose which of them was adopted in which context (i.e. floors or roofs) a parametrical analysis and the comparison with archaeological findings in Herculaneum were carried out. It seemed that the joist's strength was the option for lightly loaded joists, as in roofs, or tightly spaced floor frames; conversely, heavily loaded joists conformed to the deformability criterion. Both dimensioning procedures were translated into a visual algorithm in Grasshopper, a plugin for Rhinoceros 3D modelling software, which enabled the parametric definition of the problem. The dimensioning algorithm the parametric definition of a floor's frame as a part of the required input. Loads are also parametrically defined, picking their values from a room's usage and architectural details, as acknowledged in previous studies. Another plugin, Karamba 3D was entrusted of the translation of the geometrical model into an analytical one, in which structural quantities could be computed. As a result, the input phase was completely parametrized. Outputs, represented by joists' cross-section and another mechanical descriptors, such as bending moments and deformations, were updated in real-time, as input values changed. Structural data were useful to control the overall soundness of the reconstruction proposal. Finally, the proposed procedure was tentatively applied to the reconstruction of floor and roof frames that covered the Domus on top of the Sarno Baths in Pompeii (Regio VIII, Insula II, 18-21), whose superstructures completely disappeared in the $79 \mathrm{CE}$ eruption. The parametric algorithm automatically picked the suitable dimensioning criteria in relation to each frame's span and hypothesized loading conditions and determined their joists' orientation and minimum cross-sections. The obtained floor frames, with their sensible structural conditions, will be adopted in an overall virtual reconstruction proposal of the ruins, based on the analytical evaluation of masonry structures.

Keywords: timber structures, reconstruction, parametric modelling, Roman house, Pompeii, Sarno Bath

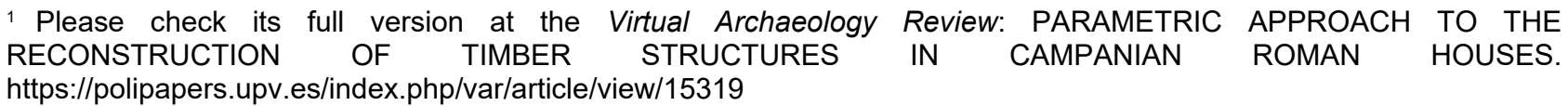




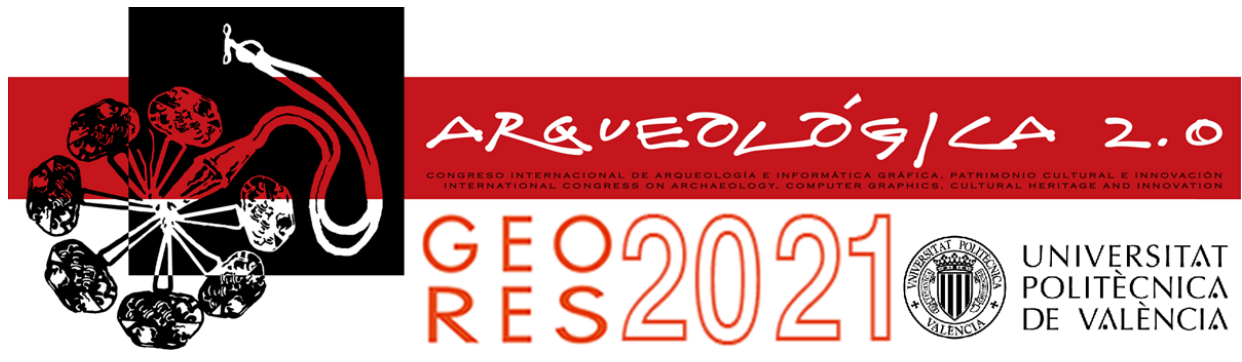

\title{
DOCUMENTATION AND ENHANCEMENT OF A ROMAN WATERMILL WITH ALL ITS STRUCTURAL ELEMENTS ${ }^{1}$
}

\author{
Josefina García-León*, Jesús A. González-García, Pedro E. Collado-Espejo \\ Department of Architecture and Building Technology, Technical University of Cartagena, Calle Real 3, 30201 Cartagena, Spain. \\ josefina.leon@upct.es; jesusagel93@hotmail.es; pedroe.collado@upct.es
}

\begin{abstract}
:
The accurate graphic survey of an archaeological site is fundamental to its analysis and research. Furthermore, if this site is to be covered by a building and will not be accessible or visible, its documentation is essential, not only to continue with the research, but also to disseminate and enhance the relevant discoveries. An example of this is the archaeological site "Hoya de los Molinos" in Caravaca de la Cruz (Region of Murcia, Spain). In this archaeological site, the first trace of the wheel of a Roman vertical mill has been found that preserves all its structural elements in the lberian Peninsula. This fact is fundamental because remains of vertical-wheeled watermills Romans had been found across the Mediterranean but not in the Iberian Peninsula. The watermill was moved by water to grind the cereal grain, a basic component of the human diet, for this reason, it has played a fundamental role in the development of rural areas of the world. To understand its dimensions and to be able to make a virtual recreation of the operation of the watermill, it is necessary to graphically document it. Due to all the foregoing, it is essential to disseminate this discovery, so that it can be recognized and considered as archaeological and cultural heritage. We have determined that the waterwheel radius was $1 \mathrm{~m}$ long, that the blades would be radial or quasi-radial (not buckets), that the water flow reached a medium height, the paddles would be flat and radial rather than inclined and that the waterwheel would rotate. The paddles would not project beyond the shrouds. From the end of the waterwheel to the base of the box, there is a $45 \mathrm{~cm}$ gap. The waterwheel box was rectangular: 4.13 $\mathrm{m}$ long, $0.55 \mathrm{~m}$ wide and $0.98 \mathrm{~m}$ deep. Water would fall down on the blades driving the waterwheel. The reconstruction of the watermill gears and the rotation of the wheel until it drives the millstones have been determined according to the drawings made by Professor Dr Robert Spain, who visited the site and provided his valuable notes.
\end{abstract}

After having analysed the elements of the watermill, we have designed the hypothetical building protecting the gears. This building has been made light and transparent, to give an idea of the original volumes. This is a two-storey building, with its roof sloped towards the waterwheel, in order to take advantage of rainwater as well. Covered gears would be located on the ground floor. And the millstones, hoppers and grain to be ground would be located on the upper floor. Access to the upper floor would be gained by using a stair. We have also animated the various elements of the watermill. To that end, we have prepared the 3D model with Rhinoceros and, subsequently, each gear has been animated with the Bongo plugin. This animation starts from the rotation of the waterwheel on its main axis. This rotation is transferred to the first gear at the same speed. To that end, we replicate the animation of the waterwheel for the gear. Finally, the last element rotates on the X-axis, contrary to the previous pieces that rotated on the Z-axis and at a higher speed. That is why we apply the ratio between both gears when assigning the speed. The necessary supports have also been modelled to make it possible. To see the result in motion, please visit the video at https://youtu.be/ODzOleeESmg. Furthermore, two reproductions have been created: 1) scaled of the archaeological site with a 3D printer; and 2) the hypothetical structure of the Roman watermill. Printouts and the final video will be exhibited at the Archaeological Museum of Caravaca de la Cruz. Videos contain music and descriptions of the elements and are easily accessible to any person interested in this matter. The intention is to guarantee their universal accessibility and to make all documents inclusive. This graphic documentation is essential to future studies of the archaeological site, since it is currently beneath a new building. The hypotheses presented may be subject to modification as the research progresses; however, they are a useful tool to understand, enhance and disseminate the discoveries made in the archaeological site "Hoya de los Molinos". To that end historians, archaeologists and engineers have collaborated to achieve this result, which enables, in an inclusive manner, not only its proper dissemination, but also its accurate documentation, so that it can be studied and recognized as an integral part of the Cultural Heritage.

Keywords: virtual archaeology, digital archaeology, cultural heritage, documentation, 3D reconstruction

1 Please check its full version at the Virtual Archaeology Review: DOCUMENTATION AND MODELLING OF A
HYPOTHETICAL RECONSTRUCTION OF THE FIRST ROMAN WATERMILL IN HISPANIA. https://polipapers.upv.es/index.php/var/article/view/15316

*Corresponding Author: Josefina García-León, josefina.leon@upct.es 


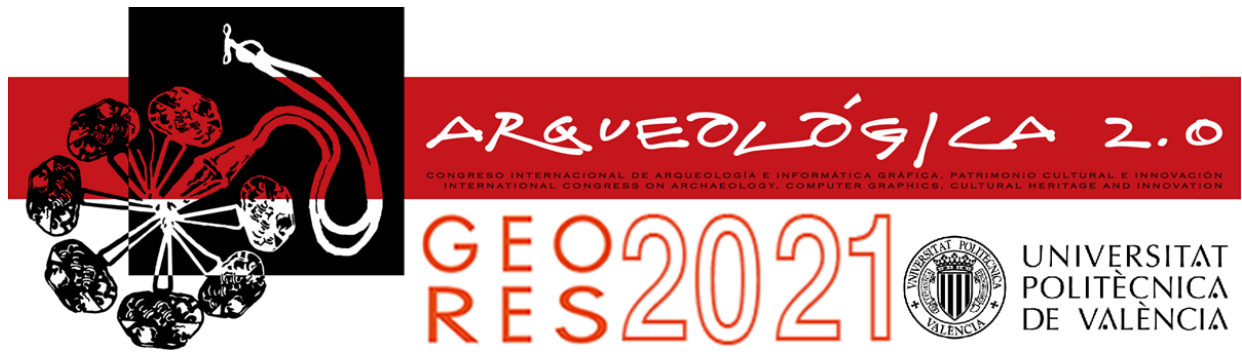

\title{
DIGITAL EARTHQUAKE-DAMAGED BUILDING USING HBIM, COMMON DATA ENVIRONMENT(CDE) AND EXTENDED REALITY (XR): THE CHURCH OF SAN FRANCESCO IN ARQUATA DEL TRONTO'
}

\author{
Fabrizio Banfia, ${ }^{*}$, Raffaella Brumanaa , Angelo Giuseppe Landib, Mattia Previtalia, Fabio Roncoronia, \\ Chiara Stangab \\ a Department of Architecture, Built Environment and Construction Engineering (DABC), Politecnico di Milano, Via Giuseppe Ponzio 31, \\ 20133 Milan, Italy. fabrizio.banfi@polimi.it; raffaella.brumana@polimi.it; mattia.previtali@polimi.it \\ ${ }^{b}$ Department of Architecture and Urban Studies (DAStU), Politecnico di Milano, Via Edoardo Bonardi 3, 20133 Milan, Italy. \\ angelogiuseppe.landi@polimi.it; chiara.stanga@polimi.it
}

\begin{abstract}
:
The central of Italy, on 24 August 2016, was hit by a 6.0 magnitude earthquake that devastated Arquata del Tronto, Amatrice, Norcia and Accumuli (Ascoli Piceno). On October 30th, the strongest quake of magnitude 6.5 in Norcia razed to the ground the hamlet of Arquata, collapsing houses and causing serious damage to one of the most representative buildings of the local community: the church of San Francesco. In this tragic context, the municipality commissioned the research to support the preliminary restoration phase. The methodological approach flows into a research and development phase supported by the latest generation tools and methods for sharing data in interactive and digital form such as 3D survey (terrestrial and mobile laser scanning, terrestrial and UAV photogrammetry), heritage building information modelling (HBIM), virtual and augmented reality (VR-AR). The integrated approach between advanced 3D survey techniques and digital information models (HBIM) has made it possible to define digital data flows capable of communicating a large amount of content, from material and decay analyses to the identification of historical phases of the main wall partitions. The digitization and management process envisaged the application of four distinct phases correlated with each other by a gradual morphological - typological deepening. The first step involved a phase of 3D data collection.

Thanks to the integrated use of laser scanners (terrestrial and mobile), total station and photogrammetry (terrestrial and UAV) it was possible to define an environment characterized by a large number of point clouds (primary data sources) able to describe through points the internal and external geometry of the church. The next step involved the semantic enrichment of 3D parametric objects (information mapping). The historical and material analyzes have been reported and linked within the HBIM project to communicate not only geometric values but specific characteristics capable of supporting the choices for the preliminary conservation plan. In particular, the material analyses were represented volumetrically where it was possible with the aim of communicating not only a two-dimensional representation but also 3D objects capable of appropriately representing and sharing the quantities relating to the different materials and construction technique. The three-dimensional representation of the analysis carried out through the building archaeology highlights cognitive uncertainties. When the stratigraphic units of the 2D drawings "are transformed" into HBIM objects, along with geometrical data, two aspects are particularly significant since they can be embedded in the model: i) material and constructive techniques; ii) chronological data. Finally, through a common data environment (CDE) and new levels of interactivity, it was possible to lay the foundations for new eXtended reality (XR) environments capable to share a huge amount of complex data sets to support the preliminary design phase of the restoration and conservation process.
\end{abstract}

Keywords: 3D survey, scan-to-BIM, HBIM, building archaeology, common data environment (CDE), eXtended reality (XR)

1 Please check its full version at the Virtual Archaeology Review: BUILDING ARCHAEOLOGY INFORMATIVE
MODELLING TURNED INTO 3D VOLUME STRATIGRAPHY AND EXTENDED REALITY TIME-LAPSE COMMUNICATION. https://polipapers.upv.es/index.php/var/article/view/15313

*Corresponding Author: Fabrizio Banfi, fabrizio.banfi@polimi.it 


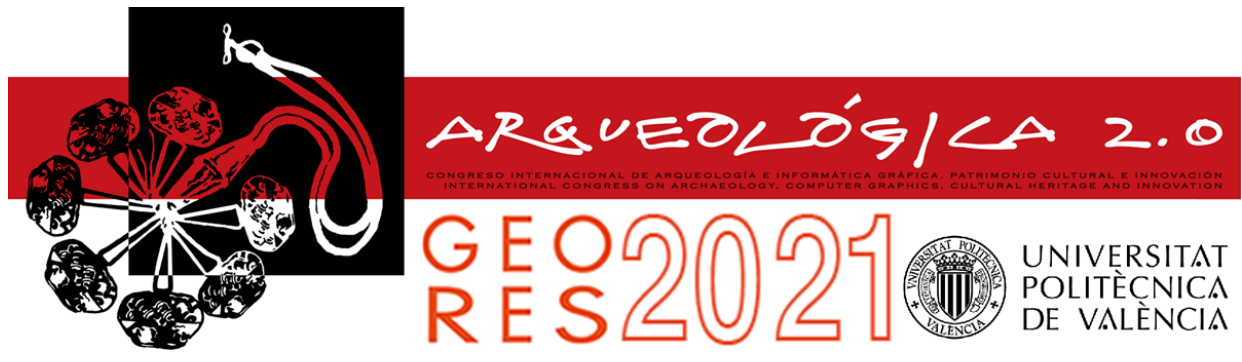

\title{
AUTOMATIC MASKS GENERATION FOR THE DIGITIZATION OF A WOODEN COLLECTION OF MAQUETTES USING DEEP LEARNING ${ }^{1}$
}

\author{
Giacomo Patrucco a, ${ }^{a}$, Francesco Setragno ${ }^{b}$ \\ a Laboratory of Geomatics for Cultural Heritage (G4CH Lab), Department of Architecture and Design (DAD), Politecnico di Torino, Viale \\ Mattioli 39, 10125 Torino, Italy. giacomo.patrucco@polito.it \\ b Volta@ A.I., Via Roberto Lepetit 34, 21040 Gerenzano VA, Italy. francesco@volta.ai
}

\begin{abstract}
:
In the last few years, a new challenge for the researchers operating in the framework of 3D metric survey and modelling has been represented by the possibility to develop new strategies to digitize the artwork objects and the historical artefacts stored in our museums. The achievable 3D models can be used for many applications and they can effectively contribute to the management of the collections, to the dissemination and the sharing projects based on online 3D viewers. This appears evident in the historical period we are experiencing: due to the global pandemic limiting access to the places of culture, digital technologies can provide some valid alternatives to access heritage, improving the accessibility of these movable assets. Among the many technologies and techniques for the digitization of heritage objects, digital photogrammetry (usually based on Structure-from-Motion algorithms) can represent an efficient, effective, and relatively low-cost solution, since it allows to achieve high resolution 3D models with photographic textures characterised by high radiometric resolution. However, many procedures are still very repetitive and time-spending, requiring many resources from the operator in order to be fulfilled. Nowadays, deep learning can be a valuable instrument to improve the efficiency of these operations with a high degree of accuracy. The acquisition of the data used during the presented research has been carried out in the framework of the B.A.C.K. TO T.H.E. F.U.T.U.RE. project started in 2017, during which a collection of wooden maquettes representing Egyptian architectures has been digitized. For each of the 26 pieces, a complete photogrammetric survey has been performed using a fixed camera and a rotating platform. In order to process the images and to generate a texturized 3D model, an exclusion mask has been generated for each image (to exclude the background). This procedure was very time-consuming and, one of the main aims of this research was to establish an alternative workflow characterized by higher automatism.
\end{abstract}

A dataset of 3000 images (and corresponding exclusion masks) has been used to train the Neural Network. The images have been downsized due to their very high resolution ( $8688 \times 5792$ pixels) and augmentation strategies (random rotation; random cropping; horizontal and vertical flipping; random brightness change; random occlusions) have been applied, in order to increase the diversity of the dataset. $90 \%$ of the images have been used as a training set, while the remaining $10 \%$ has been used as a validation set (to verify the performance of the model during the training). After the training of the model, a post-processing phase has been designed to fix some topological errors produced by the segmentation process. Both 1-class scenario and 2-class scenario have been considered during this experience (using properly labelled dataset): in the first case, the Neural Network has been trained to recognize only the object of interest (the maquette), while in the second case it has been trained to perform a semantic segmentation and to classify the maquette as Class 1 and the metric bars (placed on the acquisition stage in order to provide metric reference during the photogrammetric process) as Class 2. As regards both scenarios Accuracy, loU (Intersection over Union) and F1 score have been considered and evaluated. Starting from the segmented images, it was also possible to perform the 2-Class segmentation also on the 3D point cloud (each point has been labelled with the value of the corresponding Class) and the final result was characterised by an adequate level of accuracy. The obtained results have been presented and discussed (both quantitatively and qualitatively). In addition, in the conclusions, the next steps of the current research have been discussed and they will focus on improving the generalization capability of the model and on the possibility to use texturized 3D models to create an artificial dataset as an augmentation strategy for Neural Network training.

Keywords: close-range photogrammetry, deep learning, semantic segmentation, automatic masking, movable heritage

${ }^{1}$ Please check its full version at the Virtual Archaeology Review: MULTICLASS SEMANTIC SEGMENTATION FOR
DIGITISATION OF MOVABLE HERITAGE USING DEEP LEARNING TECHNIQUES. https://polipapers.upv.es/index.php/var/article/view/15329

*Corresponding Author: Giacomo Patrucco, giacomo.patrucco@polito.it 


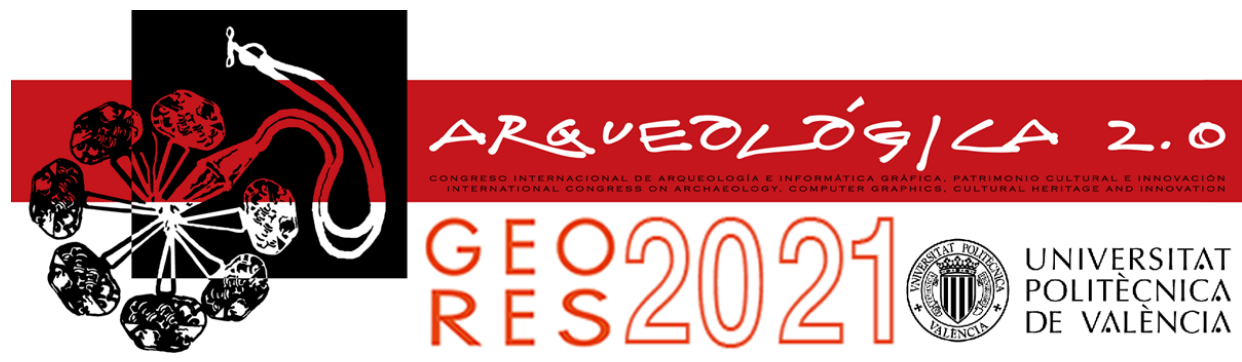

\title{
FINE TUNING AND DATA AUGMENTATION TECHNIQUES FOR SEMANTIC SEGMENTATION OF HERITAGE POINT CLOUDS ${ }^{1}$
}

\author{
Francesca Matrone ${ }^{a,{ }^{*}}$, Massimo Martini ${ }^{b}$ \\ a Department of Land and Infrastructure Engineering (DIATI), Politecnico di Torino, Corso Duca degli Abruzzi 24, 10129 Torino, Italy. \\ francesca.matrone@polito.it \\ ${ }^{\mathrm{b}}$ Department of Information Engineering (DII), Università Politecnica delle Marche, Via Brecce Bianche 12, 60100 Ancona, Italy. \\ m.martini@pm.univpm.it
}

\begin{abstract}
:
This topic of this contribution falls within the broader debate on Digital Humanities. Experiencing and testing an approach that combines geomatics and its production of three-dimensional data of the built cultural heritage $(\mathrm{CH})$ with information technology is the core point. In the digital $\mathrm{CH}$ domain, the ever-increasing availability of three-dimensional data, provides the opportunity to rapidly generate detailed 3D scenes to support restoration and conservation activities of built heritage. Concurrently, the recent research trends in geomatics are facing the issue of managing these heritage data to enrich the geometrical representation of the asset, creating a complete informative data collector. HBIM (Historical Building Information Modeling) constitutes a reference, and they typically rely on point clouds to perform the scan-to-BIM processes. These processes are still mostly manually carried out by domain experts, making the workflow very time-consuming, not fully exploiting the potential of point clouds and wasting an uncountable amount of data. In fact, parametric objects can be described through a few relevant points or contours. The use of Artificial Intelligence algorithms, in particular Deep Learning (DL) techniques, for the automatic recognition of architectural elements from point clouds can therefore provide valuable support through the semantic segmentation task. A proposal to tackle this framework was outlined in previous works, and the methodology here proposed constitutes a development of their results. Starting from those former tests obtained with the Dynamic Graph Convolutional Neural Network (DGCNN), close attention is paid to: i) transfer learning techniques, ii) the combination with external classifiers, such as Random Forest (RF), iii) the evaluation of data augmentation techniques on a domain-specific dataset (ArCH dataset). Besides, an investigation on how to make the whole workflow more functional and "friendly" for external users is carried out too. With regard to transfer learning techniques, the fine-tuning approach is proposed to understand if, also in the $\mathrm{CH}$ domain, it can lead to performances improvement, introducing a new scene in a pre-trained network. In fact, the peculiarities of each scene do not guarantee certain and definite results, as for other domains. This section is divided into two subsections: a classic fine-tuning and a fine-tuning with the addition of the RF in the final part of the prediction. In the latter case, the choice of adding the RF is due to the results obtained in some stateof-the-art works, where this classifier provides excellent results in a short time and even in the presence of relatively limited data. In this hybrid approach, the network weights are employed as well as in the classic fine-tuning technique. Then, the final part of the DGCNN performing the segmentation of the points is excluded, leading the network to be used as a feature extractor method; afterwards, a scene of the dataset never seen by the network is chosen and divided into one part for training and one for the test. Finally, the features of both parts are extracted, using the feature extractor, and exploited as input for training the RF classifier. Tests conducted on data augmentation show that it does not significantly affect overall performances, but still provide proper support for those categories with fewer points. On the other side, the tests on the fine-tuning have given rise to manifold considerations. Firstly, the standard fine-tuning can achieve performances almost equal to those where only the DGCNN is used, considerably improving some categories. Thus, they confirm that, once the DNN is pre-trained, data processing and prediction times can be significantly reduced (from ca. 48 to $0.5 \mathrm{~h}$ ), in the case of heritage point clouds too. Then, performances similar to the reference tests are obtained also with the use of the DGCNN as a feature extractor and the RF as a classifier, demonstrating that the final classifier does not affect the prediction.
\end{abstract}

Keywords: built heritage, semantic segmentation, deep learning, artificial neural networks, point clouds

\footnotetext{
${ }^{1}$ Please check its full version at the Virtual Archaeology Review: TRANSFER LEARNING AND PERFORMANCE ENHANCEMENT TECHNIQUES FOR DEEP SEMANTIC SEGMENTATION OF BUILT HERITAGE POINT CLOUDS. https://polipapers.upv.es/index.php/var/article/view/15318
}

*Corresponding Author: Francesca Matrone, francesca.matrone@polito.it 


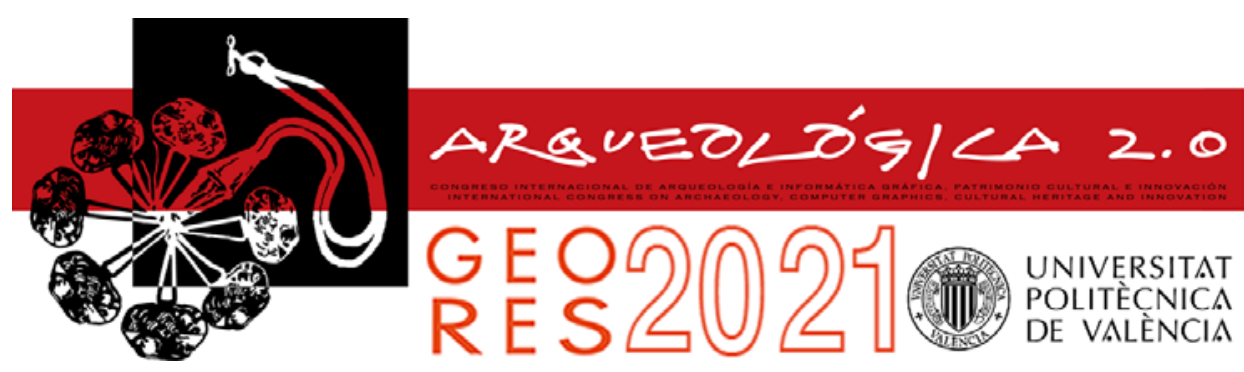

Proceedings of the joint international event $9^{\text {th }}$ ARQUEOLÓGICA

$2.0 \& 3^{\text {rd }}$ GEORES

Valencia (Spain).

26-28 April 2021

Received: 15/12/2020

Accepted: 09/04/2021

\title{
LOST GEOMETRIES - A METHODOLOGY FOR THE DIGITAL RECONSTRUCTION OF HISTORIC ARCHITECTURAL RUINS ${ }^{1}$
}

\author{
Simone Fallica*, Raissa Garozzo, Cettina Santagati \\ Department of Civil Engineering and Architecture, University of Catania, Via Santa Sofia 64, 95123 Catania, Italy. \\ simone.fallica93@gmail.com; raissa.garozzo@unict.it; cettina.santagati@unict.it
}

\begin{abstract}
:
The present study aims to define a digital reconstruction methodology for ancient architectural ruins. The research has been applied to the six Mannerist altars and the main portal of the church of Santa Maria de Monasterio Albo, located in the ancient village of Misterbianco (Sicily). These artefacts partially destroyed during the 1669 eruption of Mount Etna and brought to light after various excavation campaigns conducted in the 2000s, represent a rare example of Mannerist art in eastern Sicily.
\end{abstract}

To document their extraordinary artistic value, the researchers digitally reconstructed the altars and the main entrance portal, ideally bringing them back before the eruption. This goal was achieved through a workflow that started from a cognitive phase, consisting of harvesting the documentation and data to support the reconstruction process. Then, the following steps were followed: in-depth archival research (focused mainly on archival documents dating back to the years between 1300 and 1666); an analysis of Classic and Renaissance treatises, useful to understand the geometric rules underlying the proportions of the architectural orders; two integrated digital survey campaigns (laser scans and SFM photogrammetry) aimed at acquiring the configuration of the ruins and the photogrammetric textured models of 28 isolated fragments belonging to the decorative apparatus.

The 3D digital reconstruction of the altars and the portal, carried out after the cognitive/interpretative phase, was characterized by the ethical principles of transparency of the intervention, recognition of non-original additions and distinction between evidence and hypothesis (according to the London Charter and the Seville Principles). The base of the virtual reconstruction is represented by the seven photogrammetric meshes of the ruins (re-topologized by means of ZBrush 2019 software). In general, the 3D digital reconstruction was carried out using the following criteria: 1) The ruins of the altars and the portal, which survived in their original location, were re-proposed in the form of photogrammetric meshes; 2) 15 of the 28 isolated fragments have been located into the $3 D$ reconstruction as photogrammetric meshes and have been reassembled in their original likely location by means of a virtual anastylosis. Specifically, the researchers identified: contiguous fragments separated by a sharp crack; fragments that are contiguous but whose contact surface has been eroded; and, finally, fragments that belong to the same artefact (altar or portal) but are not contiguous; and 3) The elements no longer existing or no longer recognizable have been 3D modelled as NURBS surfaces based on Classical and Renaissance treatises (which provided information on the correct proportioning of the architectural orders) or in analogy with other coeval altars and portals, which are supposed to be similar to the ones to be reconstructed.

This methodology has proven its remarkable potential in the documentation, conservation and promotion of cultural heritage. In this regard, for the first time, it was possible to elaborate reliable theories on the dating of the altars and the portal, and to get an idea of the original configuration of the entire decorative apparatus. The virtual reconstruction also allowed a more precise classification of isolated fragments whose original location was not accurately hypothesized so far. These new hypotheses can consequently provide valid support for possible restoration interventions, partial anastylosis or new museum exhibitions. Finally, the collected information allows for developing a digital archive of the site, with free access to all the sources used for the virtual reconstruction, thus making explicit the arguments at the base of 3D modelling and the different levels of accuracy of the reconstruction itself.

Keywords: architectural ruins, documentation, 3D reconstruction, digital cultural heritage, digital photogrammetry, architectural treatises, virtual anastylosis

\footnotetext{
1 Please check its full version at the Virtual Archaeology Review: RETRACED MEMORIES - VIRTUAL RECONSTRUCTION OF AN ARCHITECTURAL LANDMARK. https://polipapers.upv.es/index.php/var/article/view/15302

*Corresponding Author: Simone Fallica, simone.fallica93@gmail.com
} 